

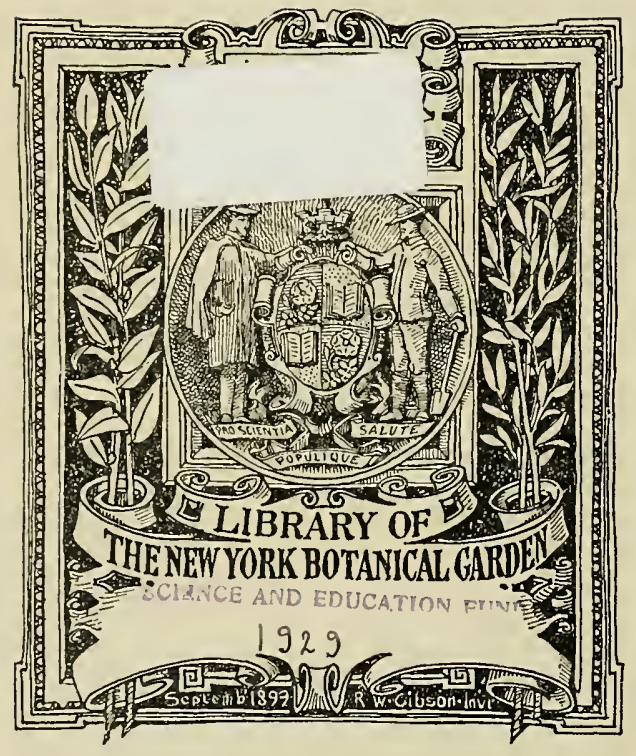


$+4$ 







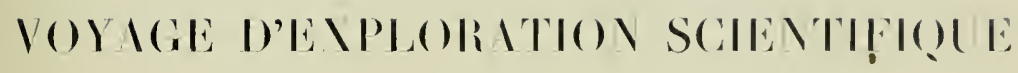

LN COLOMBIE 



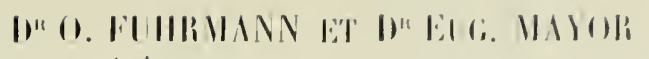

\section{VOYAGE D'EXPLORATION}

SCIENTIFIOUE

\section{EN COLOMBIE}

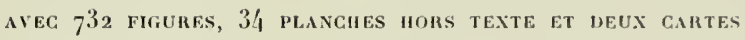

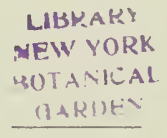

Volume $V$ des "Mémoires de la Société neuchiteloise des Sciences nalurelles".

NEUCHATEL

ATTINGER FRÉRES, ÉDITEURS

1914 


$$
\begin{gathered}
Q+21 \\
=8+ \\
1910
\end{gathered}
$$




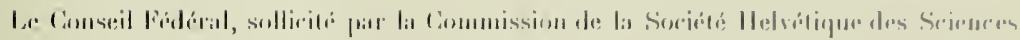

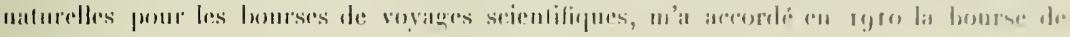

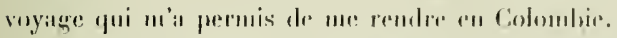

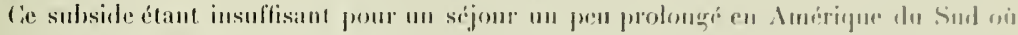

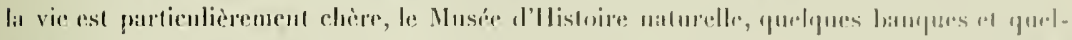

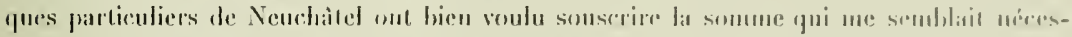
silire juor la réussite de mes projets de voyatgere

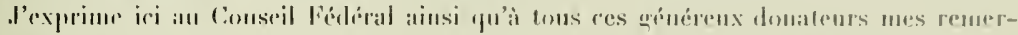

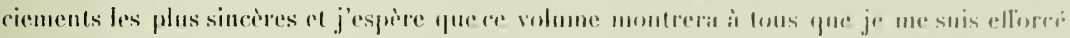

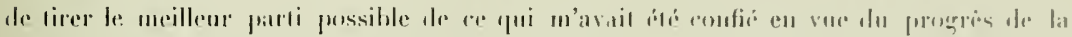
seience.

$$
\text { 1) 0. Finnsisis. }
$$

Ciest avec le plus vif plaisir que f’ai acreflé la projusition de mon ami .I. I. 1) Professeur Fulumann de l'acenumagner, en Colombie, à litre privé.

Qu’il me soit permis d'exprimer ici ma plus profonde recomaissance à mes parputs qui mont facilité la réalisation de ce sufrerbe voyage et de feur témoigner toute ma gratitude pour l'intérèt el l'affection dont ils mont toujours entouré.

I) Eug. M.1ron. 



\section{LIHUAKY \\ VF:W Y()RZ \\ (1) INICAL \\ IASIUN}

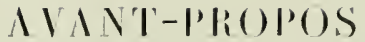

Avant de commencer le récit de nos explorations en Colombic et de donner les rúsullats scientifigues de mos recherclies, nous tenons a exprimer notre profonde reconnaissance à tous ceux qui, d'une maniore ou d'une autre, ont facilité la réussite de molre voyage dans ce pays loinlain.

M. Comlesse, à cette époque chef du Département politique de la Confédération Suisup, a bien roulu faire les démarches nécessaires pour nous recomminder an Ministre lhísident d'Xllemagne à Bogoti - puisqu'il n'y avait pas ì cetle époque de représentants oflicicls suisses en Colombie - et hii demaniler de nons faciliter, dans la mesure du porsible, la réalisatiou du but scientifique de notre voyage.

Son Excellence M. S. Perez Triana, ministre plénipotentiaire de Culombie, en résidence à Londres, a eu la grande obligeance de nous faire remeltre par l'intermédiaire de M. le Dr John Mac Call, ministre de Tasmanie à Londres, plusieurs leltres de recommindation qui nous ont élé fort précicuses.

11. le Professeur Ernest Rülhlisberger, de Berne, professeur honoraire à l'Ĺniversilí de Bogota, nous a donné un certain nombre de lettres d'introduction pour des compatriotes et des notahilités de Bogota.

M. Maurice Borel, le distingué cartographe de Neuchàtel, a bien voulu compulser les diverses cartes à très petite échelle que l’on a de la Colombie, et dessiner, à une échelle pratique, nne carte des régions que nous nous proposions de parcourir. Gràce à lui, nons avous eu ainsi entre les mains la meilleure carte du pays, carte d'ailleurs très incomplète encore el qui demanderait à ètre remaniée pour correspondre exactement à la topographie de ces régions.

II. Karl Bimberg, consul d'. Illemagne à Medellin, a droit ì notre plus profonde reconnaissance. Arec une complaisance inlassable et une inépuisable amabilite, il $n^{\circ}$ a cesse de nous guider de ses précieux conseils. Pendant plusieurs semaines, il a mis à notre dis- 
position, non seulement si propriété La Camelia, où nous avons pu fate de trés riches récoltes, mais encore son mumbrenx personnel at les mules dont nous avions hesuin; anssi le succès de notre royage dans les Andes centrales lui est-il dù en grande partie ef n'oublierons-mous jambis lout ce qu'il a fail pour nous.

M. Robert Beck, consul suisse à Bogota depuis 191t, s'est entierement mis ì notre disposition pendant notre trope court séjour dans la capitale el a fait tout ce qui dépendait de lui pour quu nous puissions retirer de notre voyage dans les Andes orientales le plus de profit possible.

Nous ne pourons mentionner ici pour les remercier comme ils te miriteraient tous nos compatriotes, ni toutes les familles colombiennes chez lesquels nous arons trouri une charmante hospitaliti; leurs noms se trouveront phus loin.

Arant notre départ, M. Carl Russ-Suchard de Serrières a eu l'ubligeance de nous envoyer du cacio et du cliocolat qui nous ont été de la flus grande utilite, surtout pendant notre síjour prolongé daus la région du Cauca.

La maison Magrgi a mis à notre disposition une ahondante variété de ses excellents froduits que nous avons savourés en route et qui complétaient avantageusement la nourrilure seuvent détestable que nous avions.

La fabrique suisse de produits de Iait à Châtel-St-Denis nous a donné une grande quantité de boites de lait en poudre dont nous avons pu apprécice lous les avantages.

Les nombreux et riches matériaux que nous avons récoltés ont ététudir's par une série de spécialistes distingués anxquels nous tenons ì exprimer toute notre gratitude pour leurs travaux importants et désintéressés.

Ce sont :

MII. I. C.tra, Genève (Diploporles).

Eug. de Danar, Budapest (Nematodes).

Iug. Forel, Yrorne (Fon'mis).

Th. Defachatx. Neuchattel (Poleries).

F. llersis, Bâle (Fitume des Mousses).

A. Iruscher, Berlin (Mousses).

P'. KR.epelis, Ilambourg (Scorpious et Pedipalpes).

F. LeGmaxdiox, Nencluatel (Ofservations allimélriques).

fi. Laxbat, Berlin (Lichens).

f. VÉnes, Budapest (Ostratrodess).

IV. Mcherses, Hambourg (Oligurhetes).

E. Pexiro, Genéve (Rhizopodes).

M.-G. Peraces, Turin (Amphibiens et Reptiles).

J. Pinget, Neuchâtel (Mollusques).

E. Piguet, Neuthatel (oiseaux).

11. Rubsut, Toulonse (Chioloporles).
MM. C.-Lrr. Rinewer, Bremen (Opilionicles).

E. Rosexstorik, fotha (P'éridophytes).

II. Ricunusox, Washington (Isopodes).

11. Sicnellenbeifi, Berliu (Phimérogames).

II. Scums, Zurich (Phanérogames).

11. Sınпот, Leipzig (Mollusigues).

Th. Sringesis, Olten (Gladocères).

E. Strand, Berlin (Iraiquées).

$1 /$ el P. Sroow, Berlin (Clormpignons, cxepplé les Urédiures).

A. Thellonge, Zurich (Plamírogames).

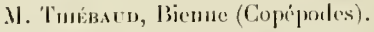

C. Wátẹr, Bâle (Hyilracluniles).

II. Weben, Neuchàtel (Ilirudinéces).

G.-S. WEst, Birmingham (Ngues d'cau (dunce).

C. Ziмmer, Breslau (Decapoles d'eau (louce). 


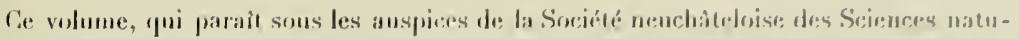

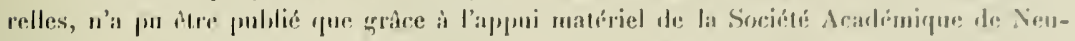

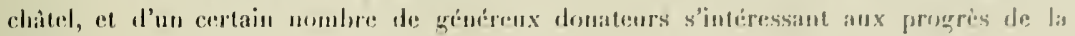
Science.

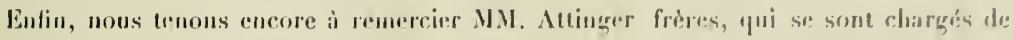
f'impression et de l'élition dre ce volume, at à les féliciter de la manicre distinguée dont ils se sont acquittés de ce travail et du soin qui a été apporté à l'impression el a l'illustration. 

PREMIERE PARTIE

QUELQUES MOIS EN COLOMBIE 



\section{CHAPITRE PREMIER}

\section{La traversée.}

Tous ceux qui s'intéressent d'une manière ou d'une autre auxsciences naturelles, ont eu certainement le désir de visiter une fois les itelmirables tropiques 'de l’Amérique du Surl, ou la végritation est si merveilleuse et la faune si richement representé. Nous avons eu pendant quelques mois le bonhenr de voyiger en Colombie et nons mapportons de ce trop court síjour là-las des sonvenirs ineflagalules que nous voudrious faire revive dans ces quelques notes de voyage.

Le 20 juin 1910, nous quiltons Ncuchâtel pour ц̧agner Anvers oủ nous arrivons le 22, apri:un court arret it Bruxelles pour jeter un rapide eoup d'o.il sur l'Exposition universelle. Yous espérions aller, le lendemain, faire connaissance aver le navire qui doit nous emmener, mais, four iles raisons que nous ne comprenons pas tout de suite, le hatean avait deux jonrs de retard et ne devait partir que le 25 au matio. Dans la soirée du $2 / 4$, nous apprenons que le schwarshury était arrivé à quai et qu'il"nous fallait monter ishord, car le départ devait avoir lien dans la nuit.

Nous nous attendions à être en présence d'un navire moderne, propre, bien aménagé, confortahle et élégant, mais au licu de cela, nous voyons un tout petit lrateau, sale et encombré de marchandises. Pour arriver sur le pont, on est ohligé d'utiliser une simple planche qui tenait lieu de passerelle et sur laquelle on était tant bien que mal en équilibre. Sommétoute, la première impression est deplorahle et ue nous présage rien de bon pour l'avenir : mais, comme nous n'avons pas le choix, il nous faut hien monter à bord de cette vieille carcasse qui n'était en réalité qu un bateau marchand. En eflet, il ne contenait que "luit cahines à deux lits, placécs, pour comble te malheur. i l'arricre, juste au-dessus de l'hélice. Toute la nuit, les grues et les cabestans; font un vacarme assourdissant et ce n'est qu'à unc heure du matin que le chargement est terminć; nou sculement les cales, mais une partie du pont sont remplies de marchandises.

Généralement, une foule nombreuse assiste au départ_des transatlantiques et salue une dernicre fois les passagers en leur souhaitant une heurcusc traversee, mais à une heure et demie du matin personne n'est sur le quai'quand les amarres sont levées; nous partons lentement et tristement dans la nuit.

A quelque distance du port on stoppe, et nous comprenons quelle est la cause de notre retard actuel et de nos retards futurs. On charge en effet goo caisses de dynamite. destinée aux mines d'or de Colombie, et 6 caisses de cartouches de fulminate, qui rendaient tout particulièrement "inquiétante cette peu agréable marchandise, d'autant plus qu'à chaque escale il faudra décharger le tout en dehors du port. A midi, après avoir attendu la maréc haute, nous partons enfin et descendons 
Ientement l'liseaut aver deux pilotes à bord. 14 heures, nous passons au large de Flessingue et sommes en pleine mer.

Par un curieux hasard, sur les linit passagers du Schuarsburg. cing partaient, comme nous, pour la Colomhie, en vue dexplorations diverses. Les Drs Neumann et lBultmann, Allemands, se rendaient dans la rigion de l'Itrato et du Rio San Juan pour y explorer les mines d'or et de platine si mal conutes malore leur granle tichesse. N. Ulisch, forestier autrichien, allait it la recherche de bois de construction el de mines d'or dans la region du Choco, en passant par Buenaventura, sur le Pacifique. Les autres passagers étaient des négociants; deux d'entre eux allaient en Colombie, à Bucaramanga

Les preniers jours, la mer est très agitée el de grosses averses sont chassées par un vent violent. 1 lapproche des Içores, le ciel se déharrasse de ses nuages, le temps se calme et reste superhe

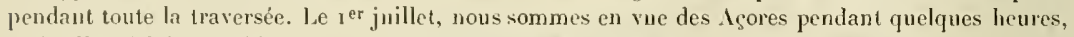
mais elles sóloignent bientit et nous nous trouvons au milien de l'immensité de l'Océan. $\Lambda$ mesure yu'on approche des tropiques, nous ponvons admirer, la nuit venue, la phosphorescence de la mer, particulièrement belle aux deux extrémités du navire, oi l'on croyait voir un véritable leu d'artifice. Pendant la journée, la monotonie de la traversíe est parfois interrompue par les gracieuses ¿volutions de bandes de dauphins ou par des vols de poissons-volants qui s'enfuient à notre approche.

Le 4 juillet, par $31^{\circ} 41^{\prime}$ de latitude nord et $39^{\circ} 49^{\prime}$ de lougritude ouest, on entre dans la zone des Sargasses [Sargassum bacciferum (Tonx) J. $\mathbf{A g}$.] qui seront de plus en plus abondantes les jours suivants. Ce qui frappe surtout les voyageurs, c'est la disposition très caractéristique de ces alones Hottantes. Elles lorment des lignes étroites, parallèles, à peu de distance les unes des autres et toujours orientées Est-Ouest, lien que le vent souffle souvent suivant une direction perpendiculaire.

Malğré l'intérêt que présente la traversée, il nous tardait de voir la terre el surtout d'ahandonner pour quelques heures notre maison flottante si peu confortable. Comme nous l'avons déjà dit, les huit cabines, étroiles et sales. étaient à l'arrière sur le pont, à côté d'une toute petite salle à mangerer très hasse, servant en même temps de salon, de fumoir et de salle de réunion. Au dessus se trouvait le pont réservé aux passagers, il avait hien 15 pas de long et 10 de large! C'était tout l'espace dont nous pouvions disposer, tout le reste étant encombré de marchandises. Les voyageurs n'avaient aucune espèce de confort ou d'agréments, pas même les plaisirs te la table; il lallait réellement avoir l'appétit féroce que prorluit l'air marin pour se contenter des menus impossibles qu'ou nous servait et dont voici un échantillon: Soupe aux myrtilles - Canards lareis avec on ne sait quoi et servis avec de la confiture - Pudding avec encore de la confiture, le tout arrosé de bière chaude, car on manquait de glace! Lorsqu'on mangeait de la viande fraiche, tuée à bord, on était sûr d'avoir ì chaque repas la mème espéce de viande jusqu'à ce que la provision soit épuisée. Nous nous consolons, en pensant que c'est là une execllente préparation à notre vie dans les Andes.

Le ro juillet, à notre réveil, nous constatons avec un vif plaisir que nous sommes en vue des Petites Antilles. Ce sont d'ahord quelques rochers uus, stériles et iuhabités qui émergent des flots bleus; puis le bateau longe de plus grands îlots et nous arrivons enfin à l'île San-Thomas, possession danoise, où nous devons laire notre premiere escale à la eapitale Charlotte- $\Lambda$ malia. La ville est située au fond d'une baie tranquille, au pied d'une colline, sur le flane de laquelle se distinguent quelques villas. Les maisons aux toits rouges et aux murs blanchis à la chaux ainsi que de nombreux groupes de cocotiers, donnent à la ville un aspect riant qui contraste agréablement avec l'aridité des environs.

Le navire aborde au dépôt de charbon de la Compagnie (Hamburg-Amerika-Linie), situésur un petit îlot à l'intérieur de la rade. On hisse deux grands disques blancs ì un mât(signe que nous devons faire du charbon), et aussitôt de nombreuses petites embarcations partent de la ville, chargées de 


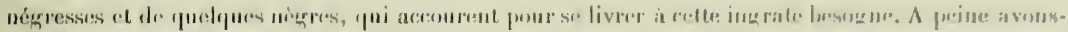

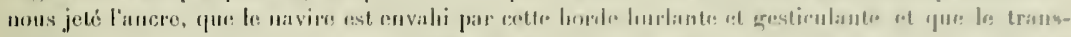

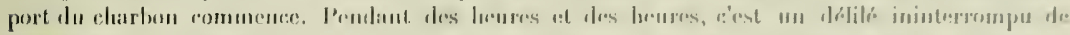

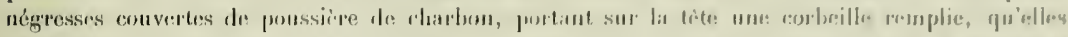

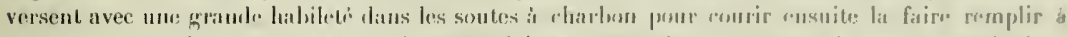

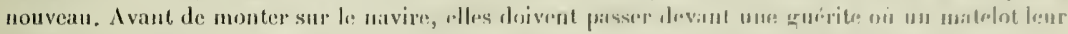

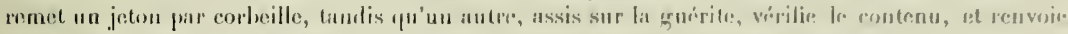
impitoyablement les porteuses dont la quantité de chatron est jugrér insuflisinton.

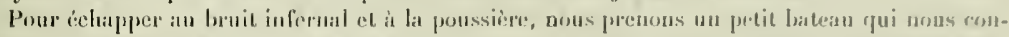

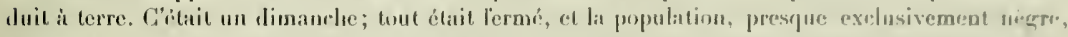

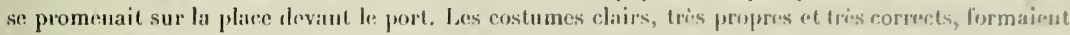
un contriste liappant avec to noir des visages et rles lias.

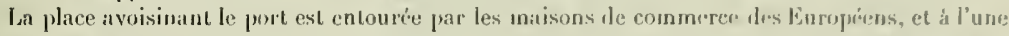
des extrémités se tronve unc ancienno forteresse, actuellencut caserne at prison. Les nigres bal,itent la périphérie de rette ville de 8000 anmes, dans de petites maisonnetles do brois comprenant

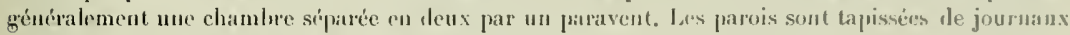
illustrés de toutes provenances, amenés par les marins qui ont fait escale. Tontes les luuttes sont baties sur pilutis afin d'échapper aux inondations causées par les orages.

Nous sortons de la ville pour gravir la colline pui la lomine el pour prendre contact aver la nature tropicale. Pas une qoutte d'ean n'était tombée depuis plusieurs semaines, aussi tout était grillé par le soleil. Nous nous attentions a rencontrer une vingétition luxuriante, mais au lieu de cela, nous voyous de petits arbustes, les uns grarnis d'aiguillons acéris, fus autres (en trínéral dees

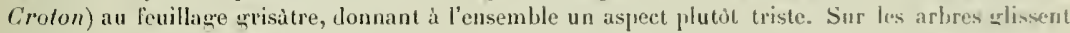
de nombreux lizards (Anolis cristutellus) yue nous cherchous à attraper, mais re u'est pas cluse facile, vu leur qranle agilité. Lorsque les mâles sont irrilés, la peau de leur cour se sonfle et prend de superhes teintes irisées, vert, hlen, jaune on brun-ronge. Nous voyons aussi deux ravissants colibris, suçant le nectar d'une Scrophulariacée; ils étaient d'un bleu-noir aux reflets métalliques ct leur têtétait surmontée d'uae huppe d'un brillant vert-émeraude.

$\mathrm{Au}$ cours de notre promenade, deux jeunes nègres nous aident dans nos recherehes et sortent de profonds trous, sous les racines des arbres, de superbes Parures (Coenolita diogrnes) avant élu domicile dans de grosses coquilles de Trochus. Tette trouvaille nous étonne considérablement, car nous ne nous attendions pas à trouver ces animaux essentiellement marins aussi loin de la mer et dans un milieu aussi see. Ces Pagures, clont la maison ne suit pas la croissance, sont obligés de descendre périouliquement à la mer pour abandonner leur coquille ét en reprendre une plus graule quils trausportent póniblement dans leurs terriers, situés sur le flanc de la colline. Nos négrillons semblaient avoir nn saint respect de ces Pagures, armés de pinces formidables : pour éviter d'être pincés, ils introduisaient dans les terriers une bağuette à laquelle l'animal se cramponnait si hien qu'on n'avait plus qu’à le tirer à l'extérienr.

Iprès avoir pris dans un des hótels de la ville un repas un peu plus convenable que cenx que nous avious à bord, nous regagnons notre Schwarzburg tout en admirant la phosphorescence merveilleuse de la rade. Aussitut qu une rame plongeait, des éclats de lumière jaillissaient tout autour et des multitudes de poissons s'enfuyaient, semhlahles à des éclairs d'argent. Si l'on trempait la main dans l'eau, elle laissait derrière elle une lonģue traînée lumineuse.

Le lendemain, ne devant partir que dans l'après-mili, nous faisons encore une petite excursion à terre. Nous longeous la cote, et après avoir traversé des bouquets de cocotiers qui faisaient l'elfet d'une petite forêt, nous arrivons à Mosquito bay, où se trouve un hameau habité exclusivement par des blancs. C'est une petite colonie de picheurs, d'origine franģaise, parlant francais, 
Etablie dans cette rérion depuis plusieurs grénérations et ne se mélangeant pats au reste de la population. Nous vovons en passaut une quantité de plantes intéressantes, telles yue l'Acajon, l'/hrmaloxylon campechianum donnant le bis de Campòche, des Acacia, des dlimosit et antres Lègumineuses, des Polygonées arborescentes (Coccoloba nvifera). des Euphorbiacées, de très nombreuses Broméliacées épiphytes sur les arbres dont elles recouvrent partois entièrement les branches, des Mangifera indica, des Héliotropes, des Lantana, des Solanées, ete., etc.

L'après-midi, arant de partir, par une chaleur de $34^{\circ}$, nous visitons l'îlot anquel est amaré notre navire. La végétation est assez différente de colle de l'île; en effet, ici dominent les Opuntin, les Cereus gigantesques se dressant dans les airs comme de véritables cierges, les Agaves et une loule d'arbustes épineux reliés entre eux par des lianes, ce qui rend ces bosquets impénétrables. Là aussi, nous remarquons de nombreuses Broméliacées épiphỵ tes même sur les Cereus.

14 heures, la sirène donne le signal du départ pour la Jamaïque. Pendant quelque temps, le. bateau est suivi par une troupe de goëlands sur lesquels l'un de nous exerce ses talents de chasseur. Deux victimes tombent à la mer; aussitòt les autres oiseaux nous abandonnent et entourent les cadavres eu poussant de grands cris, non de tristesse comme on pourrait le croire, mais de joie a la perspective d'un bon repas.

Après deux jours de navigation sur la mer des Caräbes, toujours agitée, nous arrivons, le 14 juillet, en vae de la Jamaïque dont les Montagnes Bleues $(2230 \mathrm{~m}$.) se profilent au loin. Bien avant le jour, nous avions pris à bord un pilote nègre, venu à notre rencontre pour faire entrer le navire dans la rade de lïingston A partir de ce moment, et pour notre malheur, c’est lui qui sera responsable de la marche du navire, jusqu'au moment ou nous quitterons les eaux de la Jamaïque.

La baie de Kingston est séparée de la mer par une étroite presqu'ìle, à l'extrémité de laquelle se trouve un phare. L'entrée de la rade est rendue très difficile par des récifs et des bas-fonds très nombreux, aussi la route à suivre est-elle indiquée, pendant plusieurs kilomètres, par des bouées afiu d’éviter les échouements, du moins dans la mesure du possible. Nous passons près des épaves de deux grands navires ayant appartenu à notre compagnie: le Prinz Waldemar et la Prinzes$\sin$ Victoria-Luise. L'un des deux a échoué sur la côte au moment du grand tremblement de terre de 1906 , parce que tous les ploares étaient éteints; l'autre, grâce au bronillard, vint sombrer juste à côté du premier.

A l'entrée de la rade, le bateau est forcé de s'arrêter pour décharger nos goo caisses de dynamite sur un chaland qu'on éloigne de la route suivie par les navires. Vers une beure, nous touchons à Kingston, près d'un croiseur anglais placé là pour tenir en respect la population noire de cette île, car les blanes y sont en très petit nombre $(2,5 \%)$.

La ville, de 40,00o hab., n'a rien de particulièrement intéressaut; nous y voyons encore, surtout aux environs du port, des ruines du tremblement de terre de igo6. Les rues, larges et bien entretenues, sont parcourues par des tramways électriques; nous terminons notre visite en allant au Jardin Botanique de Hope Gardens, qui sert de station d'essais. G'est une bonne préparation pour nous que de voir toutes les plantes des différentes régions équatoriales réunies dans ce jardir.

Pendant toute la nuit, on décharge une foule de marchandises, parmi lesquelles nous voyons avec plaisir des centaines de caisses de farine Nestlé. Le lendemain, le bateau part en se faufilant avec peine entre les nombreux navires ancrés dans le port. Comme il faut recharger notre dynamite avant de sortir de la baie, nous ne ponvons plus traverser, de jour, la zone dangereuse; en effet, il est minuit lorsqu'on se met en route.

Le bateau contourne sans encombre la presqu'île, lorsque tout à coup, nous sentons une violente secousse. Nous sautons hors de nos lits, allons sur le pont, et constatous que le pilote nègre nous a conduit contre un rocher sur lequel notre bateau reste fixé, à peu de distance des deux navires dont il a déjà été parlé. En vain l'hélice fait-elle machine arrière, nous restons toujours à la même 


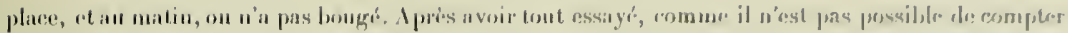

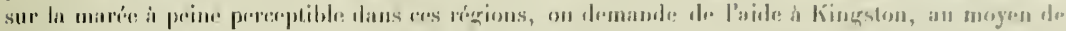

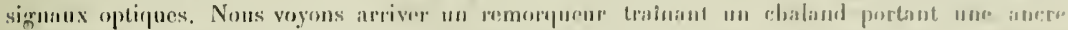

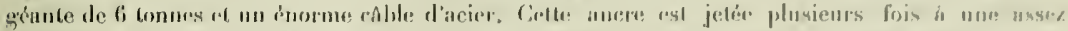

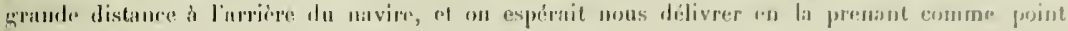

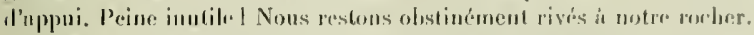

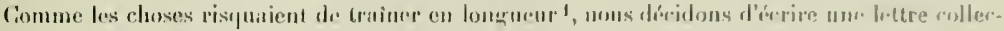

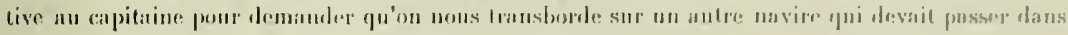

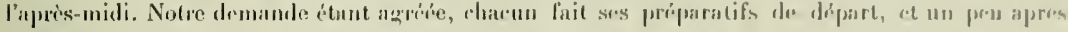

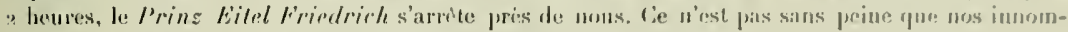

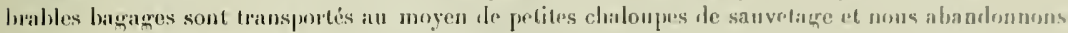
sins aucun regret notre vipeur mardanul, pour monter entin sur un nivire moderne, confortable

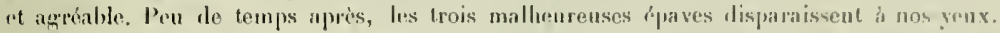

he 7 juillet, nous sommes en vue des cotes de Haiti, la druxirme des Antilles cromme suprerti-

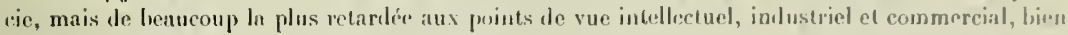
qu'elle soit la plus privilégriée en l'ait de richesses naturelles. Nous alprochons de l'île qui mst anti-

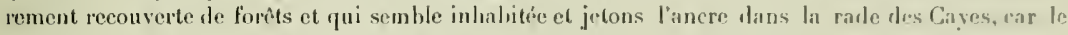
peu de profondenr de la mer ne permet pits d'arriver ì quai.

De loin, la ville a l'air pauve et miseralule, el cethe premire impression s'accentue lorsque nous descentous it lerre. A part quelgues maisous de commere, les halititions sont de simples lutles dont l'interieur est des plus sales el des plus primitifs; cel aspect frappe d'autant plus que nous venons de voir les maisons im ligines de St-Thomas et de la damaïrue. les rues sont, en vérits. fort larges, mais souvent couvertes d'herbes et de déchets de tonles sortes; on marche sur du sable fin qui se trausforme en bourbier dés qu'il plent. Des pores noirs et squelettiques, des vaches, des chiens, portant au cou une sorte de grand triangle de bois, destiné vraisemblablement à les empécher de pénétrer dans les cultures, eireulent lihrement diuns les rues et même dans les maisons.

A part quelques malheureux négociants, la population est forme exelusivement par des niegres. Nous sommes un dimanche aux Cayes ; malgrré cela, lit correction dans la tenue des liabitants laisse beaucoup à désirer, surtont au point de vue de lit propreté. Alors que les néres de St-Thomas sont counus pour etre de bons travillleurs el qu'on les recherche pour cela, ceux de 1laiti, au contraire, brillent par leur fainéantise et leur vanité. Ils sont persuadés qu'ancune des républiques de la terre ne viut la leur.

Malheureusement nous sommes arrivés trop tard pour assister it la pararle militaire qui a lieu. parait-il, chaque dimanche el qui est remarquable par le grotesque de la tenue, des uniformes et par la varićté des armes. Nous avons du reste l'occasion de voir des représentants de cetle sinculière armée dans divers postes répartis en ville, et sommes fort surpris d'ètre accostís par tles soldats et même par des sous-officiers à nombreux qalons, qui nous demandaient l'aumùne.

Nous avions hatte de sortir de cette jẹu intéressante ville dont les maisons, vers la périphérie. ne sont plus que des huttes eu bamlıus recouvertes de feuillage. Nous longeons un petit ruisseau aux eaux noiritres, emportant ì la mer une partie des déchets de lis ville, el ì un tournant, nous nous trouvons en présence d'une troupe de négresses preuant leurs éhats dans ces caux fangeuses. A notre demande pourquoi elles ne préférent pas l'eau claire de la mer situce a peu de listance. elles répondent (en franģais de Haïti) que cette cau est particulièrement bonne pour le sang et qu'elle augmente la sécrétion du lait chez les femmes qui allaitent! La population de Haĭli parle français,

1 Le navire dut ètre entièrement dechargé et arriva à Puerto Colombia avec trois semaines de retard! nous dit-on plus tard. 
mais un français qui ressemble fort peu ì celui de l'Acudémie et qui devient souvent parfaitement incompréhensible.

Ce qui est l'rappant, c’est que les environs le la ville ne présentent que de très maigres cnltures. Cela domerait probablement trop de peine de les entretenir. D'antre part, les droits d'exportation sont si élevés, qu'on ne pent songrer à une culture intensive et lucrative; les Haïtiens se coutentent de caltiver juste ce dont ils ont hesoin jour eux-mêmes. Près du rivage, nous voyons les ruines d'une forteresse, et les restes d'un cimetiere frangais dont les pierres tombales se dressent dans les cultures ou au milien des taillis. Ce sont les derniers vestiges de l'occupation française qui, malhenreusement pour cette ile si riche, prit fin en 1 So4 après des luttes acharnées et sanglantes. Depuis cette époque, Haïti est libre et les nègres y sont maitres chez eux ; bien que leurs iustitutions politiques imitent, au moins en théorie, celles de la France, l'insécurité y est perpétuelte et les révolutions continuelles paralysent tout développement dans tous les domaines.

Pour caractériser les mœurs de cette peu intéressante population, il nous sulfira de mentionner quelques anecdotes que nous tenons de première main.

Il arrive parfois qu'à l'arrivée d'un navire, l'inspecteur de la douane, de connivence avec le chef de la police, fait enfermer tous les débardeurs et ne leur rend la liberté pour décharger les marchandises, que lorsque le capitaine a consenti à remettre une certaine somme d'argent à ce liant fonctionnaire.

Lor's dı tremblement de terre qui ravagea la Jamaïque en igo6, toutes les rations firent parvenir des seconrs à l'île. Les Haïtiens ne voulurent pas rester en arrière; ils décidèrent d'envoyer une assez forte somme d'argent, et des vivres. Lorsqu'il s'agit de partir, aucun des nombreux amiraux de la république ne voulut se charger de conduire le navire à kingston qui n'est qu'à vingtquatre heures de là. On s'adressa à l'un des officiers d'un des navires ctrangers en rade de Port au Prince; il ne put accepter, aussi les délégués haïtiens furent-ils obligés de partir seuls. Ils perdirent la direction el abordèrent à Cuba où on les remit dans la bonne voie; ils arrivèrent enfin à la Jamaïque, mais sur la côte nord-est, d'où un pêchenr les conduisit enfin à lïngston. En cours de route, une partie de l'argent avait disparu; aussi décidèrent-ils de se partager le reste, jugeant que c'était trop minime à ofirir !

Les généranx on officiers supérieurs fourmillent à Haïti il y en a autant, sinon plus, que de simples soldats. Mais leur position sociale n'est pas toujours très relevée; on en trouve qui sout débardenrs, et l'un d'entre eux. qui se présenta à nons comme général, avec nn superbe képi galonné, était vêtu de lıaillons et ressemblait beancoup plus à un mendiant qu'à un officier supérienr.

C'est avec un soupir de soulagement que nous quittons la république nègre de Haïti qui nous semble être un défi jeté à la civilisation, surtout quand on pense que ce pays est situé en Amérique. C'est pour nous nne démonstration frappante de ce que penvent faire les nègres, abandonnés à euxmêmes et responsables de leurs actes.

Le 20 juillet, à l'aube, on vient nous réveiller en nous disant qu'on arrive en vue de la Colombie. En effet, nous voyons dans le lointain les sommets couverts de neige de la Sierra Nevada de Santa Marta (plus de $5000 \mathrm{~m}$.), étincelant au soleil dn matin. Plus loin, c'est la vaste plaine d'allıvions formée par le delta du Magdalena, qui se présente comme un océan de verdure. Au premicr plan s'élèvent de petites collines convertes d'nne maigre végétation el au pied desquelles, an hord de la mer, se trouve le village de Puerto Colombia.

Enfin, après une traversée longue et passablement mouvementée, nous allons mettre le jied sur le sol de cette Amérique tropicale si ardemment désirée. 


\section{CIINITTLE II}

\section{Considérations générales.}

La Colombie, dont les rôtes atlintiques ont été déconvertes pul $1 / 99$, a me surface de 1.1 $27.37^{2} \mathrm{~km}^{2}$; elle a'est habitie que par 4.978 .000 habitants (chillre ofliciel pour 1911 ) en comptant les 3on.000 ludiens sauvages qui vivent cncore retirís dans les forits vierges. Le pays est donc environ vingt-sept lois plus grand que la Suisse, mais il compte à peine $1,000.000$ d'labbitants ile plus.

L'aspeet plyysique de la Colombie est des plus variés; on y trouve des plaines fertiles et des

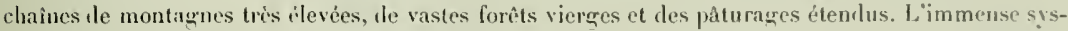
time montagnenx des Andes couvre le ticrs de la république, les deux autres tiers sont ocrupés par les llanos.

Les deux chaines des Ambis, la Cordillère occulentale et la Comdillère orientale, qui, depuis l'Équatenr pénètrent en Colombie, se divisent en quatre chaines. Ce sont, en allant de l'Onest à l'Est: la Cortillère eotien alı Choco, relativement basse et peu étendue; la Cordillíre occidentale au delà Iu Rio San Iuan et du Rio Atrato avec des sommets atteiguant 3 亿00 m.; la Cordillere centrale entre le Cauca et le Magdaleua (Huila, 57 ro $\mathrm{m}$., Tolima, $5525 \mathrm{~m}$., Ruiz, $5600 \mathrm{~m}$.) avec le massif détachi le la Sierra Nevada de Santa Marta dont les sommets arrivent jusqu'à $5100 \mathrm{~m}$., puis enfin, à l'Est. la Cordillère orientale ou Cordillère de Bogota qui se prolonge dans le Vénéznela et qui, dans Ir Cocui, atteint prìs de $5000 \mathrm{~m}$. Toutes ces chatines sont séparées par sles flenves importants: l'itrato. le Canea et le Magdalena qui coulent du Sul an Nord.

L'Arrato qui, comme le Rio San Juan, oceupe la depression entre la Cordillie citicire ef la Cordillere oceidentale, a une longueur de $60.5 \mathrm{~km}$. Le Canca prend sa source au Paramo d. las Papras. comme le Magdalena; il suit une direction norilest entre la Cordillère occidentale et la Cordillere centrale, et apres un cours de $1350 \mathrm{~km}$ se jette dins le Magulalena entre Magangue et El Banco. Le Maşlalena, le plus srand fleuve de la Colombie, profondément encaissẻ entre la Cordillère centrale et la Corditlere orientale, a une longueur d'environ $1700 \mathrm{~km}$. (d'après Vergara et roule

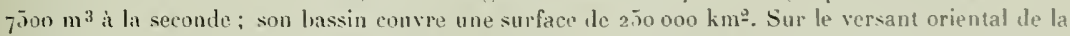
Cordillere de bogota, naissent les aftuents de l'Orénoque et de l'Imazone. Les principaux sont.

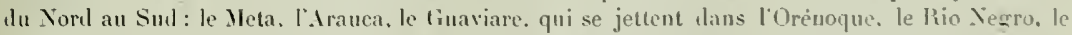
Caqueta ef le Pulumayo, afthents de l'Imazone; tous ces tleuves traversent les llanos. Ja Colombie n’a plus de geands laes dout la profondeur soil queline peu considérahıle. Les deux hassins lacustres les plus qrands ot les plus profonds sont le lace de Coeha dans le nepul de Pasto altiute

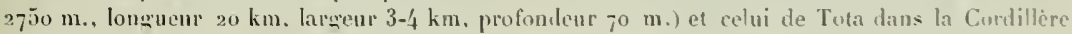
orientale, qui est de la grandeur du lac de Thoume (altitude $3000 \mathrm{~m}$.. surface $45 \mathrm{~km}$. profondenr 
maximale 5i m.). Eu dehors de ces deux bassins lacustres, il y a plus de 3oo lianures, souvent très étemlues, mais loujours peu profoules. Elles sont situies le long des rrands llewes et sur les hauts plateatux; ce sont presque toujours des restes d'anciens lacs, jadis heancoup plus élendus el plus profonds.

Les montagnes qui séparent les grands sistèmes fluvianx sont de composition très différente. La Cordillère côtiere, peu connue. semble étre composér de terrains sédimentaires très jeunes, de gries et de schistes recouverts d'importants dépóts d'alluvions riches en métaux précieux. La Cordillère occidentale, dont le versant pacifique est à peine exploré, est formée de roches éruptives, de schistes et de sédiments crélaciques et tertiaires. La Cordillère centrale est surtont constituée par des schistes cristallius et par des roches éruptives, granites, syénites et liabases, recouvertes par places par des conglomérats de grè̀s, de caleaires et d'argites crétaciques. C'est senlement dans cette chinine que se trouvent, sur le territoire de la Colombie, quelques volcans éteints dont seul le Tolima, ct d'après certains atuteurs te Ruiz, aurait eu une éruption importante en 1595 . La Cordillère orientale, ligne de partage des eaux entre les bassins du Magdałena, de l'Orénoque et de l'A mazone, a une largeur de $200 \mathrm{~km}$. à la hauteur de Bogota. Ses nombreuses chaines renferment des hauts plateaux fort intéressants, anciens bassins lacustres. Cet important șrsteme de chaines comprend surtont des roches crétaciques et tertiaires reposant sur une base formée de schistes cristallins préerétaciques fortement plissés. Dans la région dı Cocui, la Cordillere orientale, se divise en deux: la sierra de Perija et la Sierra de Verida. La première forme la frontière entre la Colombie et le Vénézuéla ; elle est très peu conuuc : sa hase est formée de mélaphyres, de porplyyres, de brèches et de tuff, sur lesquels, en discordance, repose le crétacique. La Sierra de Nerida est entièrcment sur territoire vénézuélien. La Sierra Nevada de Santa Marta, situce au bord de la mer, entre le Magdalena et le golfe de Naracaïho, n'est pas, comme certains auteurs le diseut, un massif à part : c'est la continuation de la Cordillère centrale dont elle est séparée par un vaste champ d'effondrement.

L'histoire géologique de la Colombie est fort intéressante, mais rełativement peu comue; d'après les recherches de II. Stillet, clle peut se résumer de la manière suivante: Le sédiment le plus ancien des Andes colombiennes dont on puisse établir l'âge est le Hauterivien; toutes les roches sur lesquelles le Crétacique repose en discordance sont des roches cristallines d’âge précrétacique, des schistes plyylitiques fortement plissés et traversés par des roches éruptives dont il est impossible de déterminer l'àge. Le plissement des terrains précrélaciques remonte-t-il, comme en Bolivie, au P'érou et en .Irgentine, à l'époque prémésozoïque? Un fait semble alsolument certain, c'est que la périok crétacique fut précédée d'une longne période contineutale, et l'érénement le plus important dans le passé géologique de la Colombie est une transqression formidable frar la mer crétacique, ainsi que I. témoignent les couches de conglomérats souvent d'une épaisseur de plusieurs centaines de mètres. qui forment la lase du Crétacique. Cette transqression a introduit l'époque crétacięue pendant liquelle des sédiments d'une épaisseur considérahle ( $6000 \mathrm{~m}$. envirou) se déposèrent. Comme il n'existe en Colombie aucune diseordance daus cette majestueuse suite de sédiments, on pent en conclure que pendant toute cette période, il n'y a eu aucun plissement de l'écorce terrestre colombienne. Des. mouvements tectoniques s'étalulirent seulement après le dépót des couches de Guaduas et avant la lormation des sédiments de Honda. Doue, à la fin de la périox̧e crétacique et au commencement de l'époque tertiaire, il y eut un très fort plissement accompagné d'une forte intrusion et éruption de roches voleaniques. C'est done à cette époque que s'élevèrent les Indes qui sout déjà par places trìs fortement diminuées par l'érosion. Le relief actuel de lit région du Wagralena et de la Cordillere orientale — régions les mieux connues actuellement - est dû avant tout au phénomène tectonique

11. Strlue, Geologische Studien im Gebiele des Rio thagdalenr., "Festschrift zum siebzigsten Geburtstage von $A$, von firnen. Igo7". 


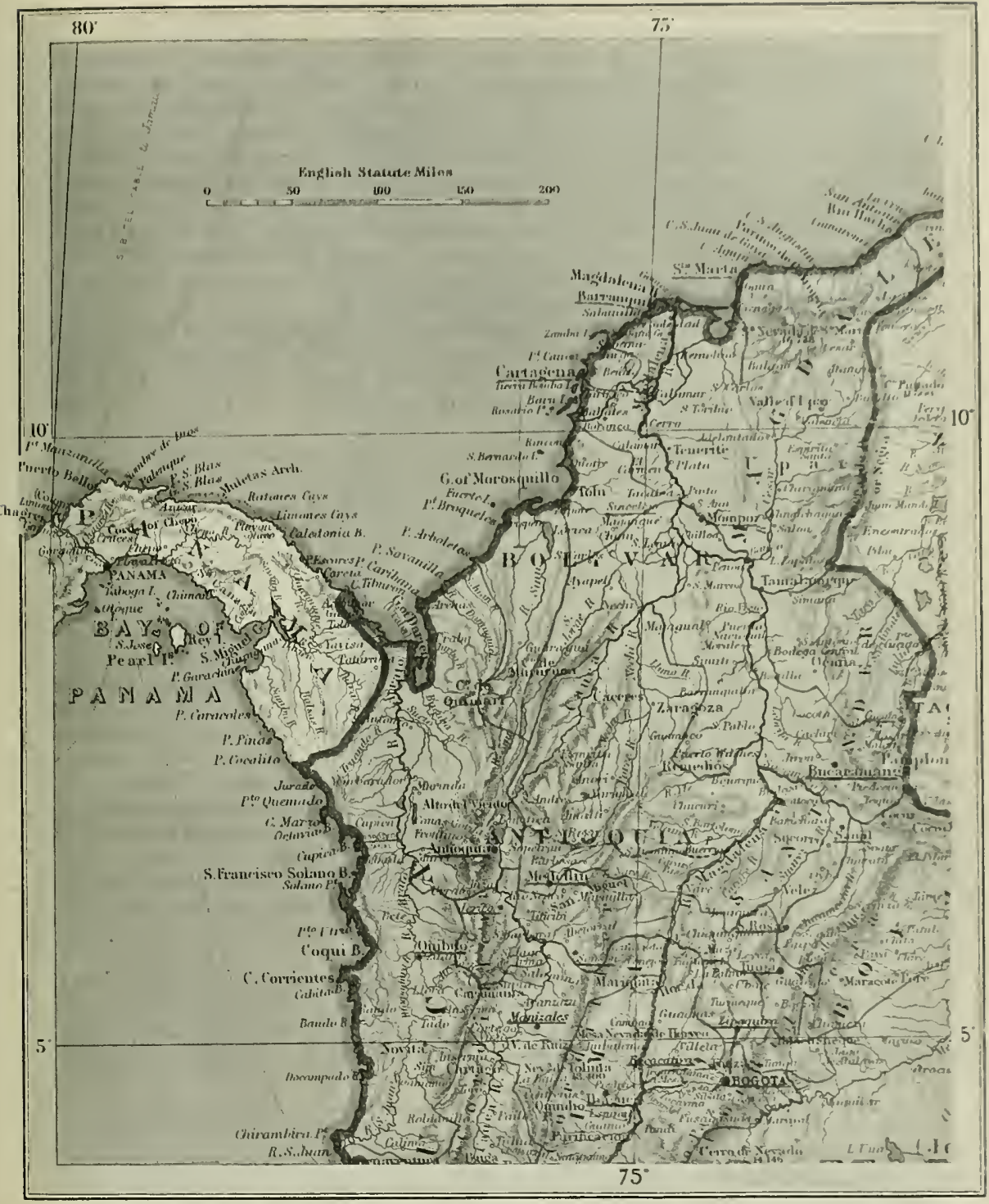

CARTE DE TORD DE LA COLONBIE 
le la période du Tertiaire supérieur. Le phénomène le plus frappant est justement la formation de la vallée du Mlagdalena, fossé l'affaissement zarandiose de près de $1000 \mathrm{~km}$, de long. Cette valléce ressemble á celle du Rhin depuis Bàle : elle a la mème direction et présente la même disposition tectonique. La large séplaration entre la Cordillère centrale et la Cordillère orientale est done ilue à la formatiun de ee fossé d'atlaissement. Aussi la Cordillère orientale n'est pas, comme le veulent Ilettner it d'autres géologues, un srstème de montagues comparable an dura, mais elle est formée de long's ¿raclius séparís par des lailles plus ou moins verticales et plus ou moins profondes. C'est un sistème l'énormes gradins descendant vers la dépression interandine du Magdalena. Sous ces assises crétaciques se trouve le systìme des schistes fortement plissís et traversés par des roches éruptives. Peutêtre a-t-on dans la vallée du Cauca les mêmes phénomènes. Stilleadmet que le grand fossé d'atfaissement passe entre la Sierra de Périja et la Sierra de Santa Marta.

La Colombie, situće entre le $5^{e}$ legré de latitude sud et le $13^{\text {e }}$ degré de latitude nord, baignée sur une grande étendue par le Pacifique et l'Allantique et traversée par de hautes chaines de montagnes couvertes de neiges éternelles, offre par conséquent les climats les plus divers. Le célèbre naturaliste colombien Caldas a pu dire qu iil sulfisait de descendre "de 12 à 14 lienes pour passer les neiges éternelles aux chaleurs du Sénégal ».

Au point de vue du climat, on distingue 3 régions: la "tierra caliente ", région chaude allant de o à $1000 \mathrm{~m}$. d'altitude, la "tierra templada » ou région tempérée de 1000 à $2300 \mathrm{~m}$, la " tierra fria ", le pays froil avec l'intéressante région des Paramos, de 2300 à $4500 \mathrm{~m}$.

Les terres cliaudes qui comprennent les cótes, les plaines et les vallées des grands fleuves, ont une température moyenne de 20 à $30^{\circ} \mathrm{C}$; c'est la zone des vastes forêts vierges et des llanos. La zone tempérée comprend les hautes vallées et les pentes des Cordillères; la température moyenne y est de 17 à $23^{\circ}$; ce climat, semblable à celui de l'Italie, est très sain et la végétation y est très riche. Si l'on monte plus haut, on arrive dans la zone froide dans laquelle, à partir de $3000 \mathrm{~m}$., commence la région particulière des Paramos. Tandis qu'entre 2000 et $3000 \mathrm{~m}$., la température moyenne est environ de $15^{\circ} \mathrm{C}$, dans la région des Paramos elle oscille autour de $5^{\circ}$. La zone froide in férieure possède un climat de printemps éternel ; là prospèrent nos céréales et autres graminées, ainsi que uos arbres fruitiers; c'est le pays d'origine de la pomme de terre, qui fut transportée en Europe en 1563. Les Paramos sont, par contre, des régions glacées où il pleut et neigre fréquemment; dans ces espaces déserts, enveloppés de nuages épais, seules par places des forêts de chênes peuvent encore subsister.

11 u'y a pas en Colombie de saisons proprement dites; mais on y donne le nom d'ćté à la saison sèche et d'luiver à l'époque des pluies. Já chute de pluie varie de 600 à $6000 \mathrm{~mm}$ suivant les régions : c'est la région du Choco qui est la plus humide. Au nord du pays, il n'y a qu'une saison des pluies, mais deux daris le sud. Dans la Cordillere de Bogota, les saisons des pluies durent de mars à mai et le fin septembre au commencement de lécembre, tandis que dans l'Antioquia c'est d'avril à la mi-juin et de la mi-août à la mi-septembre; sur la côte nord, la saison des pluies s'étend de la mi-mai à la mi-novembre.

Presque toute la population de la Colombie est fixée dans la partie occidentale du pays, dans les Cordillères au climat tempéré et liroid. C'est là que sont surtout concentrés les $497^{8}$ ooo habitants, sur une sulace l'environ $300000 \mathrm{~km}^{2}$; la moyenne est done de 12 à 14 hab. par km", tandis que si l'on comptait la superficie totale du pays, la moyenne de la population ne serait que de 4.4 hal., par $\mathrm{km}^{2}$.

A l'époque de la conquête, les indigènes étaient groupés en nombreuses tribus indépendantes, parmi lesquelles celles des Chilıchas et des Quimbayas étaient les plus civilisées. Cette population l'environ 8000000 d'habitants fut décimée avec une barbarie dont l'histoire offre peu d'exemples.

Il y a actuellement en Colombie trois races différentes. Les Indiens, de beaucoup les plus nomhreux (30 à $55 \%$ ), habitent surtout les lauts plateaux; ils sont civilisés, à part certaines tribus qui 


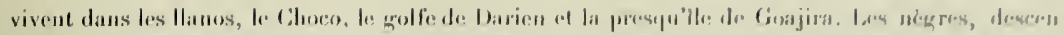

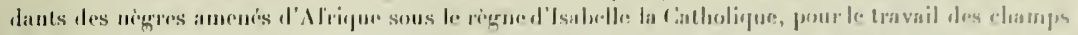

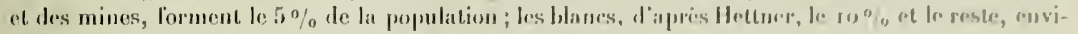
ron 50 $1 / 0$, sont des Mestizos, des Mulatres ot des Zamlus.

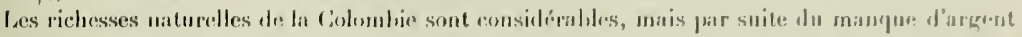

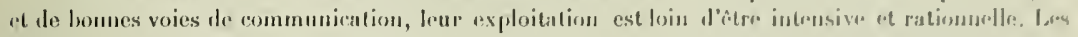

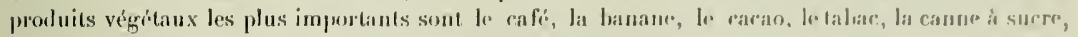
l'ivoire végétnl et le caoulchoure.

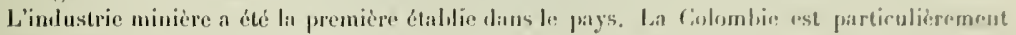

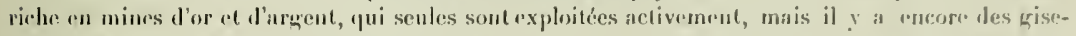
ments tres riches de platine, de euivre, de plomb, de fer at de houille; do plus, las mines d'émrritudes de Mu\%o sont Ir'ès élelbres. 


\section{CHAPITRE III}

\section{Le Magdalena. - De Barranquilla à Puerto Berrio.}

Puerto Colombia n'est qu'un misćrable hameau de quelques huttes à côté de villas situées au bord de la mer et ou les riches habitants de Barranquilla viennent passer quelques semaines ì l'épo-

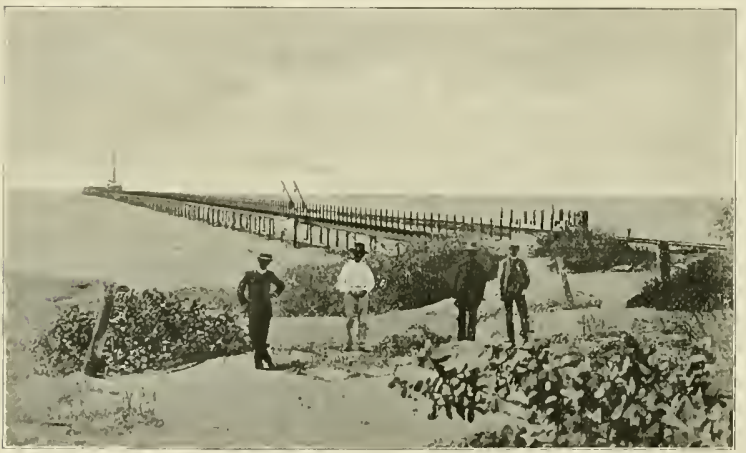

La jetée de Puerto Colombia. que des grandes chaleurs. Le véritable porl est Barranquilla, relié à la côte par une ligne de cliemin de fer de $28 \mathrm{~km}$. C'est lì que s'acenmulent toutes les marchandises à l'arrivée et an départ, là aussi que sont les négociants el les représentants des maisons de 1:ommerce itrangères.

Les navires accostent a' l'extrémité de la jetée longue de $1 \mathrm{~km}$., construite en 18,93 par la compagnic du chemin de fer de Balranquilla. Cette jetée a contribué pour beaucoup au développement de la ville, car, avant sa construction, on ne pouvait alteindre la côte qu'an moyen de petits bateaux, ce qui n'était guère favorable au commerce.

Après quelques heures d'attente, le train part en longeant d'aborl la mer, puis des marais dans lesquels nous pouvons observer l'intéressante végétation des palétuviers, ces arbres étranges qui ont l'air d'être perchés sur des échasses. Une quantité d'oiseaux évoluent dans ces marais: nous voyons des Jacana qui courent sur les plantes aquatiques, des hérons et autres échassiers, des rapaces et une foule de passereaux aux couleurs éclatantes.

A midi, nous arrivons à Barranquilla el nous uous mettons à la recherche d'un hotel. Nous avons de la peine à trouver de la place, car on célèbre le premier centenaire de l'indépendance colombienne, anniversaire qui tombe sur le 20 juillet. La ville est en fête el cncombrée par les personnes venues des environs pour assister à toutes les cérémonies préparées. Pendant toute une semaine, la vie publique est interrompue, la poste, le télégraphe, les banques et les magasins sont 


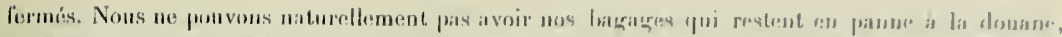

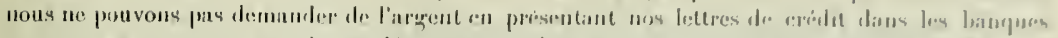

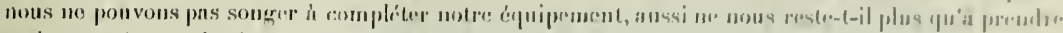

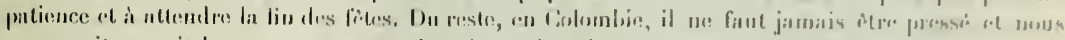

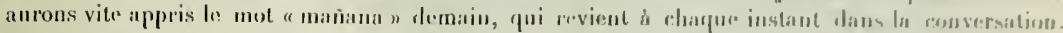

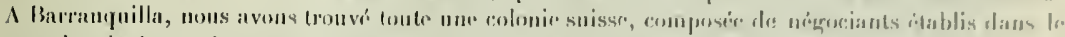

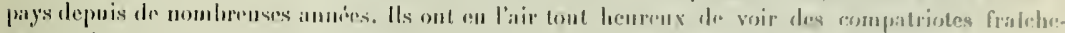

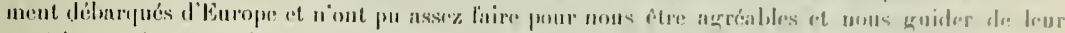

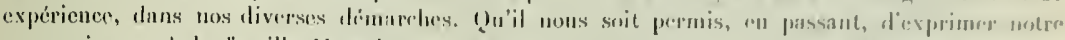

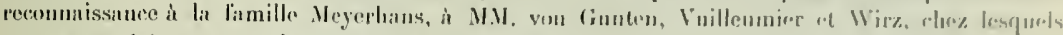

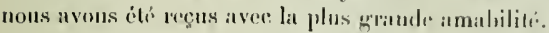

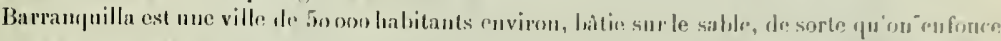
dans les rues par un temps sec et que ces rues deviennent de vrais torrents dis yu'il pleut. Les trottoirs sont souvent très élevés à canse decela, et les pictons sont obligés, pour y acećder, de faire parfois de vraies ascensions. Dans les faubourgs, on trouve surlout des huttes tres primitives, le plus souvent reconvertes de fenilles de palmiers; en ville, les maisons, construites en briques ou en terre, se romposent le plussouvent d'un

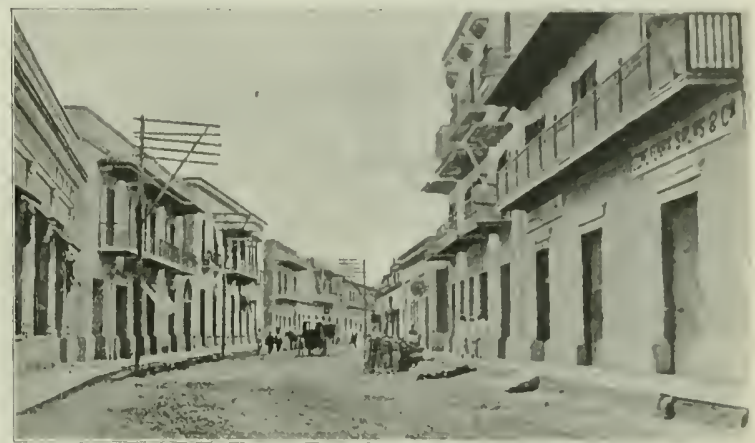

Line rue de Barranquilia. simple rez-ile-chaussée re. couvert d'un toit plat. Les fenctres, très grandes, sont urrillagées à la mole espagnole el l'on aperçoit lien souveut, par les interstices, les figures aimables et gracieuses de charmantes Colombiennes qui regardent les passants. Le soir, pour cherdher un peu de fracheur, les familles süinstallent le plus souvent sur les trottoirs. On cause tout en se balançant diuns des fautcuils á bascule, on se raconte les menus faits du jour, on potine aussi un peu... ou bien on chantecesromares tristes et monotoues si chìres aux Colombiens, et qu' aceompigne la musique énervante de la maudoline ou de la gruilare.

C'est l'élément nére et mulàtre qui forme la majeure partic de la population ; la race blanche est représentée par les Colombiens et par la colonie étrangère oi les. Mllemands dominent: ers derniers ont entre les mains une grande partie du commerce d'importation.

Barranquilla est située prés du Magdalena, la srante artère colombienne. Uis quartier de la ville est longé par un canal qui rejoint le flenve et au bord lungel se trouve un marché convert. Chaque jour, ure quantité de bateaux indiens de tous modèles. apportent des fruits et des poissons pour laalimentation de la ville. Dins ce marehé, on rencontre quelyues hazars loués à des Tures ou à des Syriens; ces négociants orientaux font un tort énorme au commerce local, aussi dans certains pars, le Vénézuela par exemple, le permis d’élablissement leur est-il refusé.

En nous promenant dans lesenvirons de la ville, nousavous pu soir de pres les hutles primitives, oi grouillont des masses d'enfants; ils sont de races tries mélangées; on en voit parfois avec des 
cheveux blonds. Cesenfants, tout nus, présentent souvent un ahdomen très proéninent et disproportionné à leur ìge. D’après le peu que nous avons pu observer, ce doit ctre le produit de lésions du foie et de la rate. causées par la malaria. La malaria est une des plaies de Barranquilla, comme du reste de toutes les régions torrides de la Colombie, et nous aurons trop souvent l'occasion de faire connaissance avec les moustiques qui la propagent.

Le soir venu, toute la campagne s'illumine de mille feux follets. Ce sont les lucioles qui voltigent ì la surface du sol ou qui s'élancent dans les airs jusqu'au sommet des plus grands arbres. Elles ont, comme nos vers luisants, l'abdomen phosphorescent qui répand une lueur blafarde, tandis que le "cocuyo ", qu'on ne rencontre que dans les rémions très chaudes, porte sur le thorax, de chaque cóté de la tête, deux fovers lumineux beaucoup plus brillants. La nuit tropicale, éclairée de ces mille feux, est troublée par les cris stridents des Cicades qui, dans les buissons et sur les arbres,

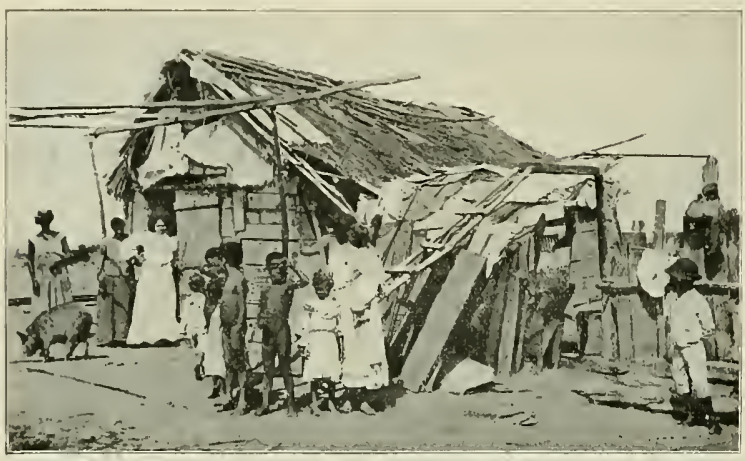

Hutte dans les faubourors de Barranquilla. font entendre sans discontinuer leur note, toujours la même.

Les hôtels colomniens, du moins ce qui porte ce nom, ne rappellent en rien ceux d'Europe; ils sont remarquables par leur manque de confort et leur saleté. La chambre que nous occupons à l' «Hòtel Colombia " possède comme mobilier deux lits, une table buiteuse et deux chaises, dont l'une sert à fermer la porte sans serrure donnant sur un soi-disant salon. Comme ustensiles de toilette, une cuvette microscopique sur un trépied, un pol à eau contenantà peine un litre d'eau et une glace incapable de refléter quoi que ce soit. Le plancher, qui fut propre une fois ou l'autre, est maculé de crachats en partie dlesséchés, et dans un angle, une large fente nous permet de suivre tous les faits et gestes des gens qui boivent dans un har situé au-rlessous. Comme les chambres sont situées au premier étage, le plafond est formé par la charpente du toit; l'air peut ainsi librement circuler, ce qui est un grand avantage, mais les inconvénients de ce système sont plus grands encore. Les cloisons qui séparent les chambres ne vont pas jusqu'au toit, de sorte que toutes les pièces communiquent par le haut et chacun peut entendre tout ce qui se dit et se fait dans tout l'étage. De plus, ces cloisons sont percées de trous plus ou moins grands qui permettent aux indiscrets bien des observations intéressantes. Tel est le confort ollert par la plupart des hôtels colombiens.

Au cours de notre voyage sur mer, nous n'avions guère été gâtés sous le rapport de la nourriture; malgré cela, nous avous bien de la peine à nous faire aux menus colombiens, toujours les mêmes. A cliaque repas, on voit invariablement apparaitre des bananes préparées d'une manière ou d'une autre, du riz ou du maïs; comme viande, toujours du bœul dur comme du cuir. Le repas se termine par une minuscule tasse de café ou de cacao brut, accompagnée d'un petit morceau de fromage et de "dulce», sorte de confiture ultra sucrée, faite avec toutes sortes de fruits et servie sur une soucoupe qui en renferme deux cuillerées! 


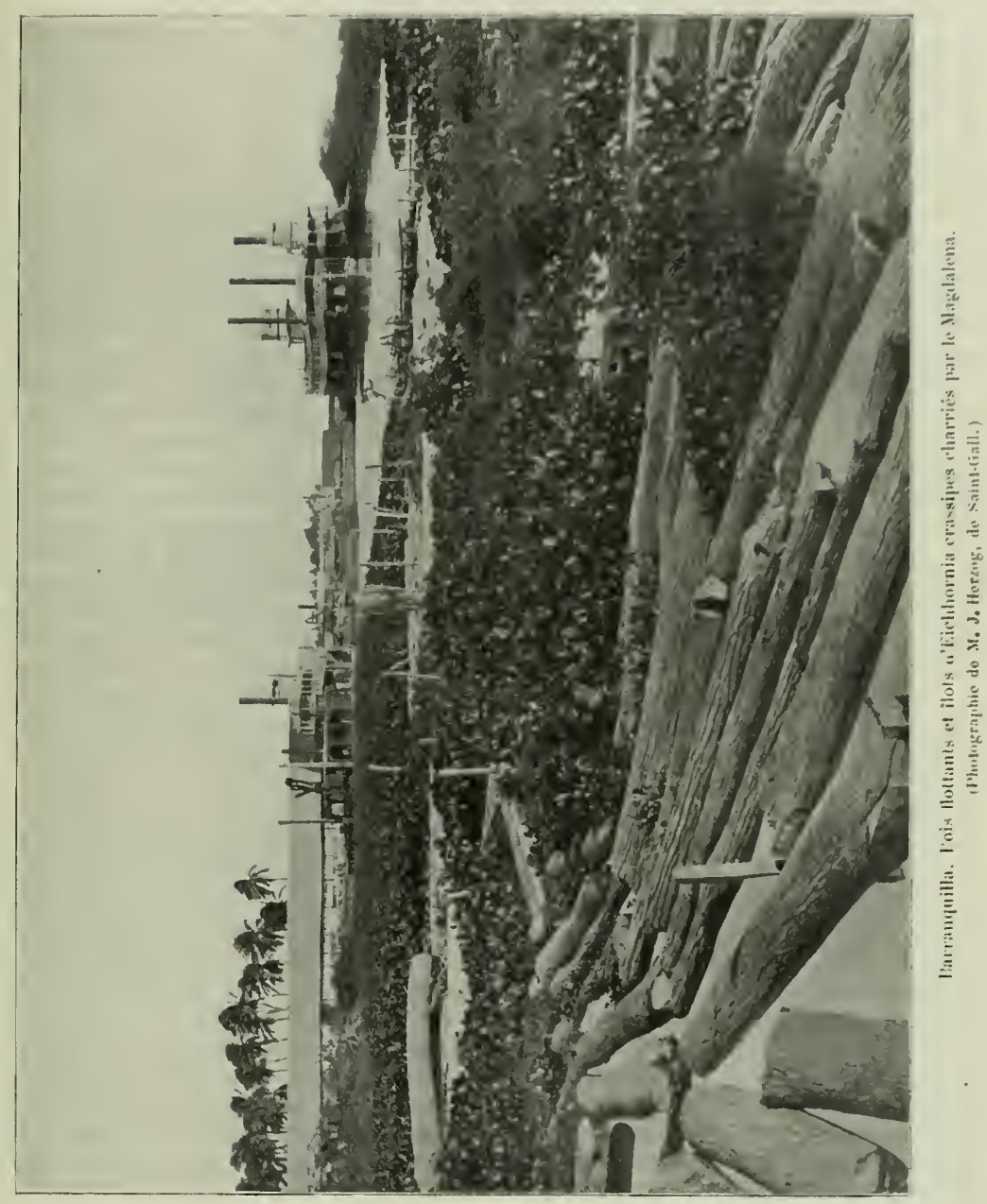


Comme nous l'avons dit, la Colombie est en lète, et le drapenu national Hotte sur les maisons, surtout aux environs du "Camellon", sorte de Corso ou nous assistons à une parade militaire, qui nous produit une excellente impression. Depuis quelques amées, l'armée colombienne a lait de şrands progrès, gràce à des instructeurs chiliens, élèves des. Illemands. Liuniforme rappelle celui du solelat allenand avec sin qunique particulière et sat casquette conique. Aux accents de l'hymue uational, les solılats défilent au pas cadencé, devant le club de Barranquilla, sur la galerie duquel se tiennent les antorités de la ville et les ol'ficiers supérieurs, trís élégants, que nous prenons tout d'abord pour des ofliciers allemands, ì cause de leurs casques à pointe.

Dans la soirée du 20 juillet, nous allons écouter une série de discours patriotiques que prononcent des politiciens sur la place de la cathédrale. Daus tous ces discours délirants de patriotisme, on sentait une haine impuissante contre l'I méricain du Nord qui s'est emparé du Panama. Tout le beau monde de Barranquilla était réuni dans le parc près de la cathédrale, pour entendre la musique et les discours; des agents ıle police postés aux entıées, surveillaient les pieds des arrivants et repoussaient impitoyablement cenx qui n'avaient pas de chaussures convenables ou qui n'en avaient point.

Lorsque les fétes lurent terninées, graice à une lettre de recommandation du Mlinistre plénipotentiaire de Colombie à Londıes, II. S. Perez Triana, et grâce à l'appui de nos aimables compatriotes, nous pourons enfin retirer de la douane nos inuombrables bagages, sans qu'on les ouvre et sans rieu débourser, ce qui est extrêmement avantageux, car nous avons plus de $600 \mathrm{~kg}$. Or, cu eutrant ea Colombie, chaque kilogramme de bagage en plus des 150 de franchise accordés à claque vovageur, doit payer fr. 7.50 de donane, quelle que soit la nature de la marchandise importée.

Les banques ctant de nouveau ouvertes, nous pouvons retirer de l'argent avec notre lettre de crédit. Si nous parlons de ce fait banal cntre tous, c’est que nous pouvons juger immédiatement de l'état économique du payss. En demandant $500 \mathrm{fr}$. à la banque, nous recevons 50.000 fr. en billets colombiens! En effel, un billet de 100 pesos (valeur nominale $500 \mathrm{fr}$.) vaut actuellement environ $5 \mathrm{fr}$. Ceci provient du fait que le cours du change oscille perpétuellement cntre q,00o et $10,000 \%$. Cet état de choses, unique dans le monde, remonte à la dernièe révolution de rgoo et caractérise suffisamment la misère économique actuelle de la Colombie, pour éviter de longs développements à ce sujet. En 1900 , au début de la révolution, le taux du change monta subitement à $9^{62} \%$, en r $9^{\circ 1}$, il était à $2640 \%$, en 1902 à $7191 \%$ et en octobre 1902 , à $18900 \%$ !

Bien que la Colombie posside des mines d'or, d'argent et même de platine, et des richesses végétales immenses, il n'existe aucune pièce monuayée colombienne en or ou en argent; toutes les transactions se font au moyen de billets de banque, a l'aspect souvent repoussant. Ceux que l'on rencontre le plus fréquemment ont une valeur réelle de $5 \mathrm{cts.,}$, $0 \mathrm{cts.,} 25 \mathrm{cts.,} 50 \mathrm{cts}$, et $5 \mathrm{fr}$.; très rares sont ceuri de 500 et r 000 pesos $(25$ et $50 \mathrm{fr}$.). Cette diltérence considérable entre la valeur réelle et la valeur nominale des billets caıse au début à des novices, tels que nous, un embarras perpétuel.

Le peu de temps dont nous disposions ne nous a pas permis de visiter une région assez voisine de Barranquilla el trís inıportante au point de vue économique; nous voulons parler de Santa-Marta $\mathrm{et}$ de ses plantations de bananiers. C'est en 18 go que commencèrent les premières exportations de bananeset, depuis cette époque, la culture a été poussée tries activement, sauf pendant les années de révolutions 1893 - 1903 . En 1892 , l'exportation annuelle était de 171,891 régimes; en 1900, de 269,077 régimes; en 1905 , de 863,750 ; en 1907 , de $1,980,419$; en 1909 , de 3 , 39,307 , pour arriver en $\mathbf{1 9 1 0}$ au chillie de 3,844,319 régimes. Les derniers chiflres que nous avons sous les yeux, ceux de Igı, indiquent 4.90 r, 894 régimes. On estime que l'augmentation annuelle sera par la suite de plus de joo,00o régimes; la banane est devenue un des produits d'exportation les plus importants de la Colombie. 


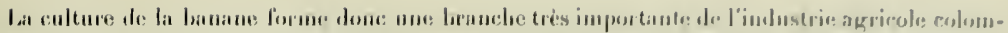

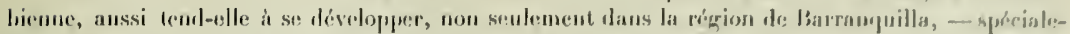

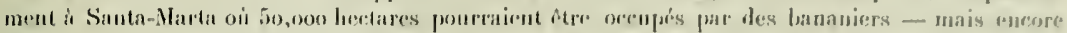

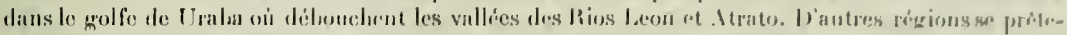

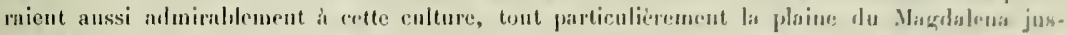

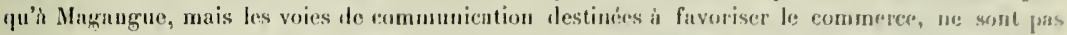

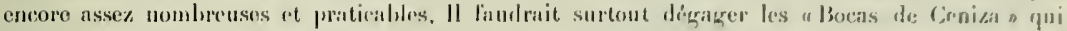
ferment le delta du Magdalema pour permettre aux mavies do remontar jusquanx plantations. La culture de la lanaure est une source de revenus considérabless; deux on trois ans sufficrnt

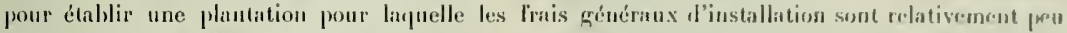

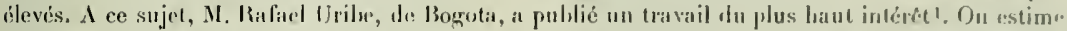

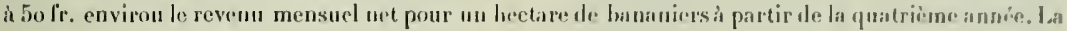
production dure longtemps et si, à coté de cette plante, on cultive le cacao ou le caoutchouc comme arlores protecteurs, le rendement de la plantation atteint des proportions suryrenantes. Tout los marché do la hanane, mou seulement de la Colombie, mais aussi des pays limitrophes, est entre les mains d'une compagnie américaine qui paie en moyenne l'r. 1,12 le trígime de 25 ou $30 \mathrm{kgr}$. On estime qu'un heetare contenant 1000 plantes, produit annuellement 25 it iso,oon ky, de bananes.

La veille de notre départ, nous sommes très aimablement iuvités à passer la soirée clıez les MI. von Gunten avec d'autres compatriotes. Cette dernière réunion, avant de nous lancer dans linconnu, fut aussi charmante qu'agréahle, et pour nous laisser un meilleur souvenir, nos luites eurent l'aimable attention de nous ofl'rir quelyues bouteilles d'un délicieux vin de leuclaatel.

Le lenlemain matin, nous sommes brusquement réveilles par un coup de canon, tiré en l’honneur de l'anniversaire de Bolivar, le libérateur de la Nouvelle Grenade. Nous nous liatons de faire nos deruiers préparatil's de départ et de règler notre note d'Intel qui, pour ces quatre jours, se monte pour les deux à fr, 10,370! Nous allons ensuite prendre notre passage sur le hatcau qui doit nous conduire le long du Magdalena et pour chacun, nous payons fr. 12,000, en pa piers colom liens!

Nous sommes agréablement surpris en constatant que notre vapeur, le Lopez Penhu, ne correspond pas à la description pessimiste que nous avions lue dans l'un ou l'autre des récits de voyage en Colombie. Il est vrai de dire qu'en cours de route, uous en avons croisé quelques-uns semblables au nitre, mais beaucoup moins confortables. Les lateaux du Nagdalena sont d'un trpe tris particulier; leur fond plat et leur tris laible tirant d'eau leur permettent de circuler sur les bas-fonds. Ils sont actionnés par une immense roue presque aussi haute qu'cux, située à l'arriére, pour être ainsi protígée contre les banes de sable et les trones d'arbres que charrie le fleuve. Ils ont deux étages surmontés d'une petite guérite où se tient le pilote avec le gouvernail. Presque à lleur d'cau se trouve l'entrepont, ouvert de tous les cotés, qui renferme, à l'avant les chaudières, à l'arrière les machines; entre deux sont entassées, pêle-mèle, les marchandises qui serviront de lits pour les passagers de $3^{0}$ classe et l'équipage; de chaque cùté des chaudières est empilé le hois qui remplace lat houille dout les gisements sont trop éłoignés.

Un escalier, plus ou moins élégant suivant les hateaux, conduit au p étage oủ sont les cabines de re $^{\text {re }}$ classe, disposées sur deux rangées; le large espace lihre qui les ś́prare sert de salle à manger. A l'avant se trowve une plateforme couverte où les voyareurs se tiennent peodant la journée et qui, bien souvent, se transforme, le soir, en dortoir; à l'arrière sont les cuisines, l'office et les diverses dépendances. L'étage supérieur est résewé au capitaine qui y a ses appartements particu-

1 Revista de la Sociedad de agricultores de Colombia. Monografia del banano, por el Dr Rafael CribeCribe, Bogota, Mayo igos. 
liers, la situation du gouvermail, tout au-dessus du hateau, permet au pilote d'iviter plus facilement les trones darbres et les las-fonds dont lat situation extrenmement changeante rend la navigation trés dangereuse. Toute carte est inutile et, a chaque voyage, le pilote doit chercher sa ronte.

Une fois partis, nous prenons possession de notre calhine dont le mobilier comprend deux lits formés d'une sangle tendue sur un cadre de hois sontenu par deux chevalets, deux chaises, une toute petite grlace très mauvaise où l'on voit juste sa tîte, et une minuseule curette supportéc par un trèpied. Yos lits de camp paritissant plus confortahles que ceur qu'on nous oflire, nous les installons à leur place et nous nous hàtons de quitter la cabine oì la chaleur est ditoullante, pour aller sur' les confortables lauteuils à lascule de l'avant, admirer le splendide paysage qui se cléroule

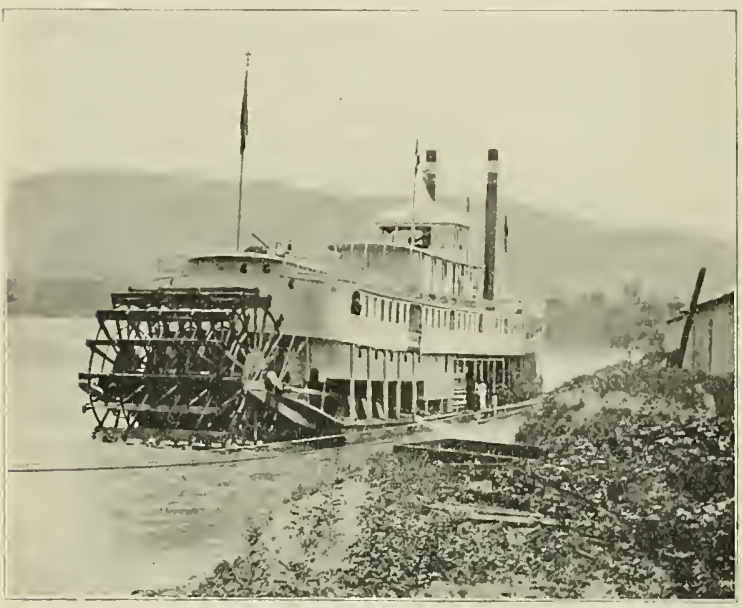

Bateau du Magdalena. à nos yeux.

Les eatux dlu Magdalena, ce fleuve immense, le quatrième le l'A mérique du Sud, comme importance, ne sont pas claires et limpirides; elles sont boueuses et jaunâtres et charrient une quantité énorme de bois et de végétaux. Ce sont parlois de véritables îlots flottants arrachés au rivage, ou des groupes de I'istia stratiotes el d'Eichhornia crassipes avec leurs grappes de fleur's d'un bleu violacé, qui descendent lentement vers la mer. Dans son cours inlérieur, le fleuve, parfois large de $2 \mathrm{~km}$. et profond de 8 : 16 mitres, roule un volume d'eau de $7500\left\{\mathrm{~m}^{3}\right.$ par seconde, en moyenne; il est sujet à des variations de niveau très considérables, suivant les conditions 'atmosphériques. Par un heurenx lasard, nous sommes à une époque où le fleuve est relativement haut, et nous n'avons pas á redouter des échouements assez l'réquents quand les eaux sont basses, et dont quelques compatriotes qui restèrent deux et trois semaines rivés à des banes de salıle, en attendant une crue, nous parlèrent eo termes fort peu enthousiastes. Grâce aux hautes eaux également, nous n'aurons pas trop à soullirir des "zancudos » ou moustiques qui rendent le voyage si redoutable pour ceux qui pénètrent par cette voje dans l'intérieur du pays.

La première journée sur le lleuve est de beaucoup la moins intéressante; le pays est absolument plat; on ne distingue aucune montagne à l'horizon. Le paysage est monotone : à perte de vie, ce sout des prairies avec de nombreux troupeaux, des cultures de maïs, de canne à sucre, de banane, et ici et lì, de petits bosquets de cocotiers dressant dans les airs leurs gracieux mouchets de palmes. De gigantesques Cereus, sur la rive droite, rompent un moment cette monotonie. Sur les rives, c'est une laune nombreuse: des Jacana, des hérons gris à tîte noire, la l'ameuse "Garza real ", l'aigrette blanche tant pourchassée, et des passereaux en foule, avec leur plumage éclatant. Les habitations sont peu nombreuses, misćrables et primitives; elles sont occupées par des nègres, des" Indiens ou 


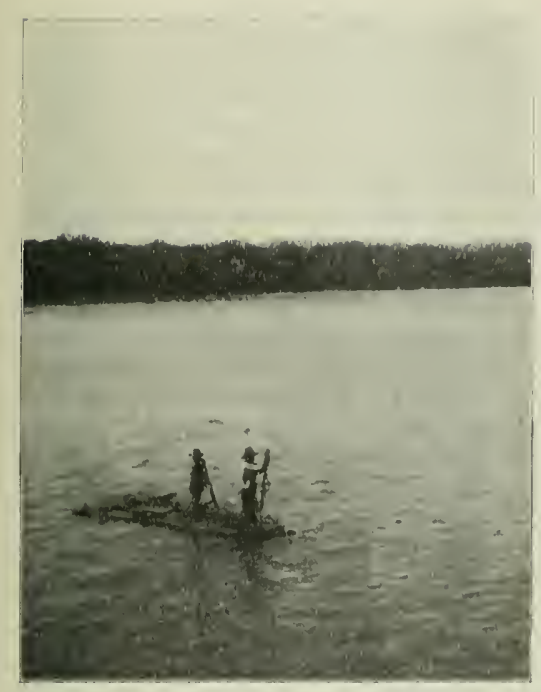

Lin rateau sur le Magdatena.

(r. 3.. $)^{\prime}$

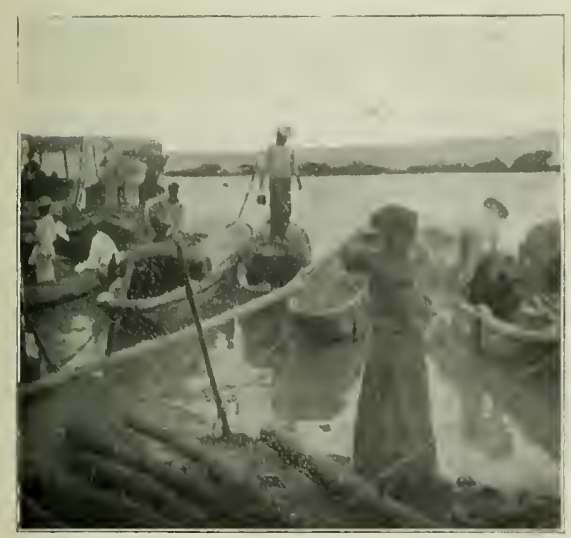

Pirogues amarécs au hord du fleuve à Magangue. (F. x.)

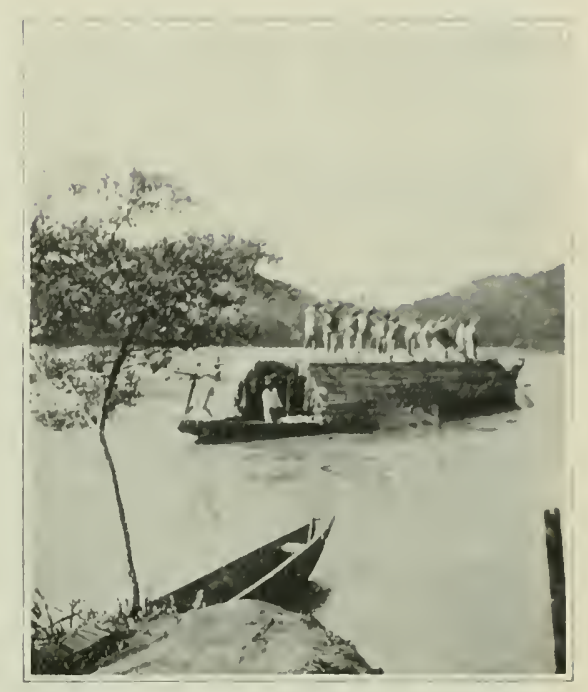

l'irugue "t Champan remontant le leure.

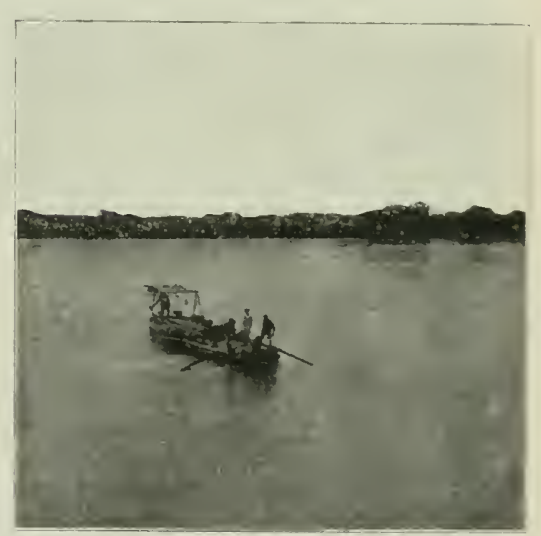

Grante pirogue traversant le Maģdalena près de Magangue. F, w.

- Les photographies suivies des lettres F. Ml. ont été faites par les auteurs. 
des Zambos (eroisement de l'lndien et du nègre), dont les enfants nus jouent au bord du Heuve.

Vers dix heures du soir, nous laisons escale à Calamar, petite ville formant le point terminus d'une ligne de chemin de fer, de construction récente, qui conduit à Carthagena. Autrefois, on arrivait it cette ville par un canal appelé Dignue, actuellement inutilisé à cause de l'ensablement.

$\Lambda$ près une mauvaise nuit causée par la chaleur $\left(30^{\circ} 5\right)$, et par le bruit du chargement des marchandises, nous allons le lendemain, de bonne heure, renouveler la provision de combustible, puis nous partons, en remorquant deux chalands chargés de matériaux pour un jont métallique. La place réservée aux marchandises étant presque toujours insuffisante, on ajoute souvent de chaque coté de la pointe un ponton métallique sur lequel on entasse les marehandises et parfois aussi les bestiaux, ce qui donne aux bateaux, déjà étranges, un aspect plus étrange encore.

Le parsage est intiniment plus varié que la veille; les prairies monotones ont fait place ì des forêts dans iesquelles on remarque de grands arbres au feuillage clair, en forme de parasol, et qui sont vraisemblablement des Coprifera officinalis; les indigènes les nomment "Campanos». Les palmiers ne se voient guère quanx abords des halitations, ce qui indiquerait qu'ils ont été plantés. Peu ì peu le cocotier (Cocos nucifera) disparail, et nous ne voyons plus quo les palma real ou palma de vino (Cocos bntyracea) que nous trouverons tout le long du fleuve. Pour la première fois, nous rencontrons des crocodiles, ces hideux animaux vautrés sur le salule ou sur les herges du fleuve, la gueule largement ouverte. A notre approche. ils sortent de leur torpeur et disparaissent dans les eaux houeuses. Il s'agit du Crocodilus aculus que les indigènes appellent Caïman.

A quatre heures de l'après-midi, le ciel s'obscurcit et un formidable orage éclate, accompagné de roulements de tonnerre, d'une pluie torrentielle, d'un vent violent et d'une chute de la température des plus agréables. Au bout d'une demi-Leure, l'orage cesse, le ciel se découvre et le soleil brille de nouveau pour se cacher peu après. Nous assistons alors à l'un de ces merveilleux couchers de soleil, comme on n'en voit que sous les tropiques, et qui vous laissent un souvenir inetlaçable.

Les eaux étant hautes, nous pouvons continuer notre voyage pendant la nuit, et le lendemain matin, nous arrivons à la petite ville de Magangue dont l'aspect est très pittoresque. Toutes les maisons situées au bord du fleuve sont bâties sur pilotis, afin d'éviter les inondations; cette précaution est cependant insuffisante parfois, puisque nous voyons plusieurs de ces cases à demi-détruites. La plupart des rues sont inondées et transformées en canaux et on y circule en pirogue; à l'usage des piétons, on a installé des sortes de passerelles, an-dessus du niveau des eaux. Ces passerelles sont très fragiles; elles sont formées de tiges de bambous juxtaposées et l'on s'y tient tant bien que mal en équilibre. Comme c'est jour de marché, il y a foule sur le bord du fleuve à notre arrivée, et nous avons l'oceasion de voir des_modèles de toutes les embareations utilisées sur le Magdalena.

Ce sont d'ahord les "Bongos" ou "Champan », bateaux étroits et très allongés atteignant jusqu’à dix mètres de long et plus, recouverts sur presque toute leur longueur par une sorte de dòme en tiges de bambous. Sur le toit de cet abri se tiennent les bateliers qui font avancer le bateau au moyen de longues gaffes. Avant la navigation à vapeur, il n'y avait pas d'autre moyen de locomotion pour pénétrer dans l'intérieur, aussi se représente-t-on-aisément la longueur des voyages et les désagréments de toutes sortes auxquels on était exposé. Puis ce sont les pirogues, longues et étroites, creusées tout simplement dans un trone d'arbre. Ces embarcations, qui peuvent contenir une dizaine de personnes assises les unes derrière les autres, sont fort peu stables. Les Indiens les conduisent au moyen de pagaies en forme de raquettes et ils arrivent à une très grande lrabileté, mème lorsque le courant est très rapide. Le moyen de navigation le plus primitil est le radeau, dont on se sert pour transporter les fruits ou autres marchandises, et sur lequel s'installent des familles entic̀res. 


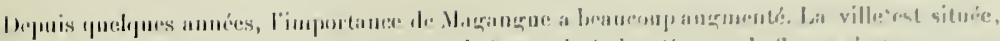

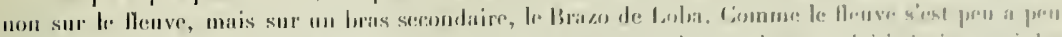

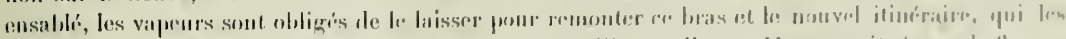

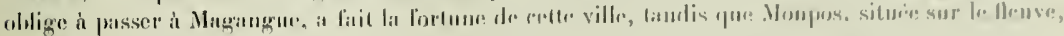
ne resse do délinir.

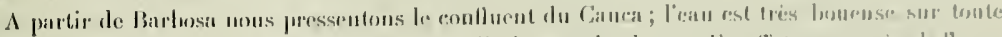

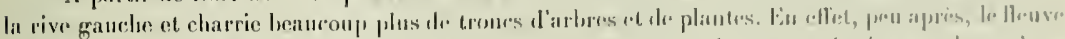

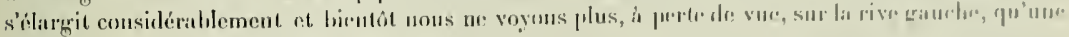
immense choulue d'ear, parsermére d'îlots. C"est

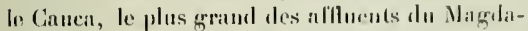
lrua, presqur aussi important que lui, qui se prícipite imprótueusementalans ses eaux relativement calmes.

Au-dessus du coulluent des deux arands llemves, nous nous artotons four faire une nouvelle: provision de bois. Celle oprération, qui se fait régulièrement deux on trois fors par jour, nous prosure presque tonjonrs l'occision ale descendre it terre et ile pousser une pointe dans les lameaux ou dans la forêt viergre. Là, nous sommes toujours aretés après quelques pas par lis barricre infranchissable que forment les?plantes les phus diverses, garnies d'aiguillons acérés et enchevetrées les unes dans les autres. I chacun de nos arrets, nous admirons les aborlages qui ont souvent lieu de nuit, sans aucune aide, sans lumicre et sans débarcadère. Les pilotes sont d'une hahileté consommée pour diriger ces lourds hatenux massifs a fond plat sur le fleuve encomhré d'obstacles de toutes sortes.

A Pinillos, on nous nous arrétons, il fait dejà nuit et c'est à la lneur de torches que les matelots transportent à horl les buches mesurées et empilées soigneusement sur la herge Ce tra-

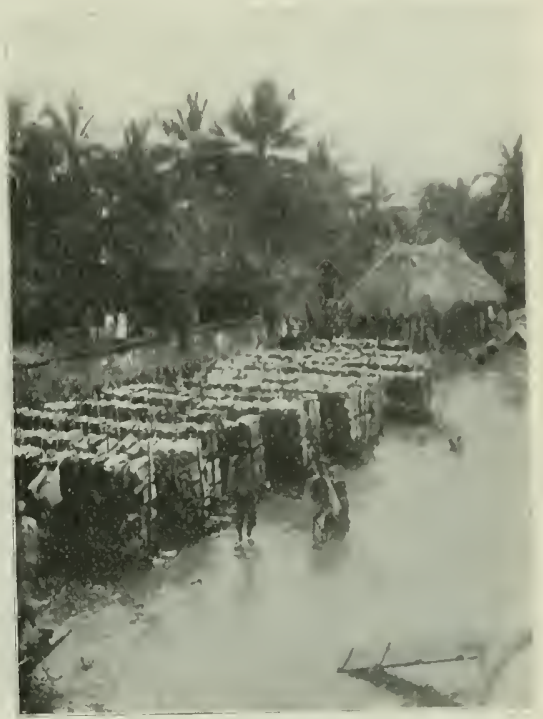

Dépöt de bois préparé pour lez bateaux. (F. \& vail est rendu plus pénible que d'hahilude, parce que les tas de bois sont dans leau et que les porteurs enfoncent jusqu'i mi-jambe lans une vase gluante avant de pouvoir prendre jied sur une petite passerelle formée d'une simple planclie jetéc sur le pont du bateau. Apres le bois, on hisse encore a bord, par les cornes, quatre crínisses, comme provisions de voyage, puis nous rejartons dans la nuit.

Tout le long du tleuve, soit près des hameaux, soit devant les huttes isolées dans la forét vierge, on voit de ces piles de hois préparés pour les hateaux. Lorsqu'un grand espace a rité déboisé, les indigènes transportent leurs hutles un peu plus loin. Le moment ou lion clarer le hois est une honne aubaine pour le zoologiste, car entre les buclses se trouvent une quantiti d ausimaux: des énormes crapauds (Bufo marinus). des iguanes, des serpents, des scorpions. des scolopendres. etc. Nous nous empressons de les saisir et de les plonger dans des flacons d'alceol, au grand chahissement de l'equipage et des Indiens qui ont une ripulsion profonde pour tous ces animanx.

Le lendemain. nous quittons le Brazo de Loba pour suive le cours du fleuve et nous arrivons j 
a El Banco, sur la rive droite, petite ville groupée autour d'une très jolie église, et situce sur la herure assez élevée à cet endroit, C'était jour de marehé, aussi la place était-elle recouverte d'oljets hétéroctites, parmi lesquels, à cùté d'ustensiles de ménage en terre cuite, sont ctalées des nattes tissees qu'on emploie comme matelas.

Depuis le matin, on distingue, à gauche, des chaines de montagnes peu élevées, anx sommels arrondis et entièrement recouvertes de forćls: ce sont les Andes orientales. A la hauteur de Gloria, on a, à droite, les premier's chainons des Andes centrales, que nous gravirons beaucoup plus au sucl dans quelques jours.

Nous naviquions tranquillement dans l'obscurité, lorsque, vers huit heures du soir, des cra-

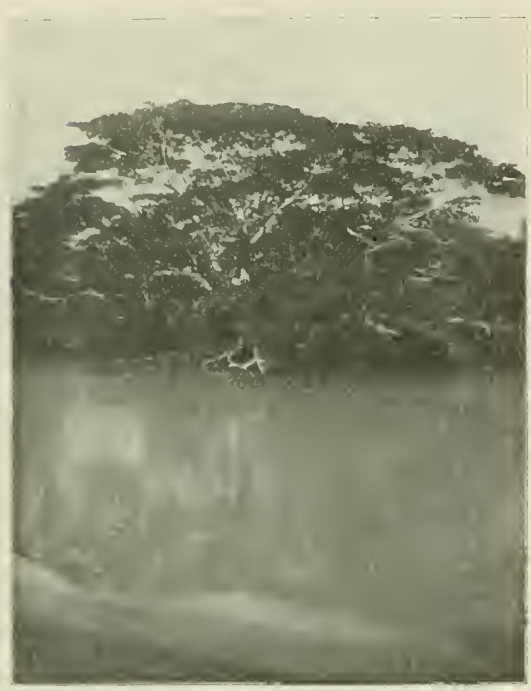

La forêt tropicale près de Bodega Central. (1, ı. quements se font entendre, comme si le bateau allait se désarticuler. Nous venions de rencontrer un banc de sable on un tronc d'arbre immergé: après un moment d'anxiété, le bateau réussit à se dégager et nous continuons notre route sans incident. A partir de ce jour-là, la navigation ne se fait plus pendant la nuit, à cause des nombreux obstacles dangercux que l'on risifue de rencontrer.

C'est à partir d'El Banco surtout que nous pouvous nous rendre compte de ce qu'est réellement la nature tropicale, dont il est impossilule de se faire une représentation exacte aussi longtemps qu'on ne l'a pas vue. Aucune plume ne saurait rendre le charme, la variété et l'imposante majesté de la forêt tropicale dans son exuhérance et son luxe de végélation. Combien nos lorêts semblent petites el monotones à còté de ces forêts vierges immenses qui couvrent toute la plaine du Nagdalena et qui viennent mourir au bord du fleuve! Quel spectacle imposant que ces arbres gigantesques dont les branches s'inclinent jusqu'au niveau des eaux dans lesquelles elles baignent souventen donnant au paysage un charme tout particulier! Ce qui nous frappe surtout, c'est la grande variété des espèces qui forment la forêt vierge; il n'y a pas comme chez nous une ou quelques essences seulement sur un espace restreint, mais des centaines et des milliers. Aussi ces arbres immenses, au feuillage aussi varié de couleur que de lorme, constiluent-ils des tableaux admirables et laissent-ils un souvenir inellaģable à ceux qui les ont contemplés. La beauté de la forêt est encore augmentée par les sous-bois épais, par les lianes et les plantes grimpantes, s'enlaçant les unes aux autres, passant d'un arbre à l'autre, pour venir étaler leurs feuilles et leurs grappes de fleurs de toutes couleurs jusqu'au sommet des plus grands arbres. Sur les troncs, sur les liranches, c'est la flore épiphyte si riche el si curieuse, où nous voyons des Fougères, des Aracées, des Broméliacées, des Cactées et surtout ces merveilleuses Orchidées, l'une des richesses et l'une des gloires de l'A mérique tropicale et de li Colombie en particulier.

Au milieu de cette végétation luxuriante comme leuillage, mais plutôt pauvre en lleurs, nous relevons la présence de magnitiques palmiers aux feuilles pennées ou en forme d'éventail; certaines espèces, les Astrocaryum, sont armées d'aiguillons longs et acérés, d'autres, du genre Phy- 


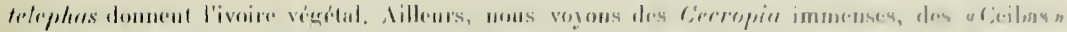

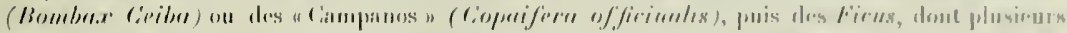

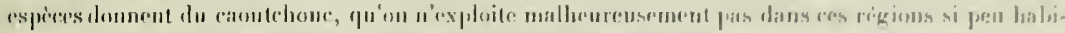

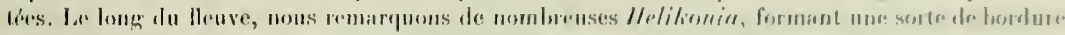

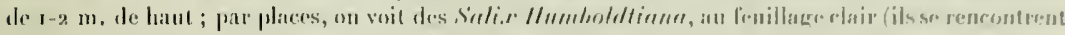

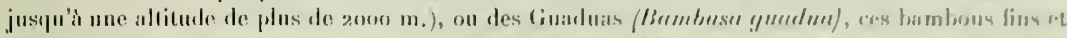

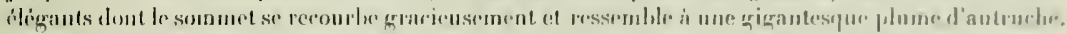

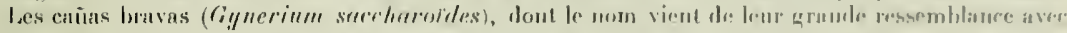

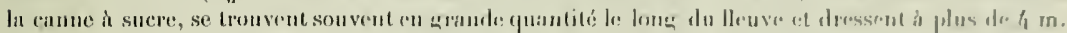

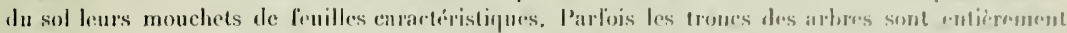

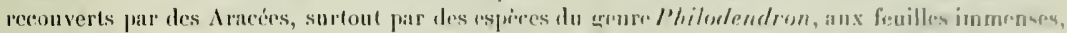

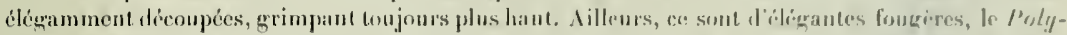

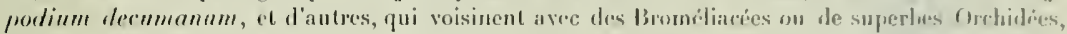

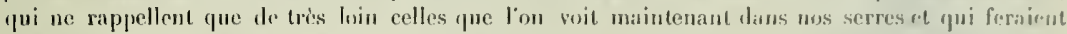
triste figure à coté de leurs saurs vivant ì l'état sauvage. Il laudrait encore citcr les ldécumineuses,

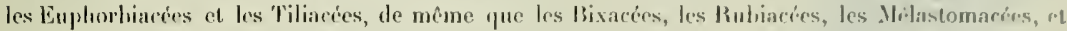

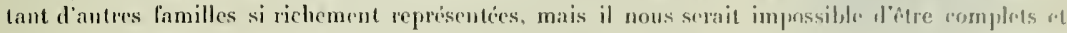
relte sìclı́ énumération nous conduirait trop loin.

On s'imagine souvent que l'exulcirante forct vicrge que nous venons de tricrire sommairrmint fourmille d'animaux : il n'en est rien. La lorêt vierge est silencicuse el pauve cu animanx, maispar contre la lisière, surtont lorsqu'elle est située an bord d'un lleuve comme le Mauglalena, possèdo une laune extrômement riche. Depuis le bateau, nous te pouvons naturellement olserver que les siserux ut les reptiles; ; les mammifères, trìs sauvages, s'enfuient à notre approche et nous n’avons v'u qu'une

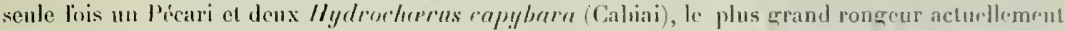
vivant. 1 Chucuri, nous arrivons au moment on l'on venait de tuer un singe fort interesant (. 1teles lermaphroditus), appartenant au groupe des singes it quene prenante si carartivisliques de l'Imérique du Sud et lort nombreux au bord ein Magdalena. Le dagnar, le P'uma, l'Ocelot, le daguarumdi ot autres carnivores sont invisibles et ne viennent que de nuit s'abrewrer an bord du lleuve.

Si les mammiferes sont ares, les oiseaux sont d'autaut plus nombreux et varies. Sichmarda dit avee raison: "Dans l'avifaune de l'A mérique du Sul règne une variéte de forme, de couleur, de

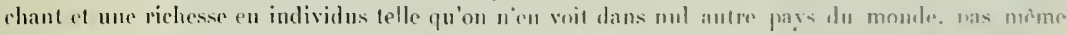

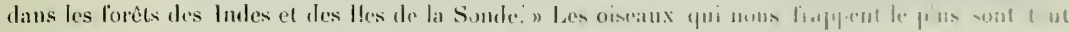

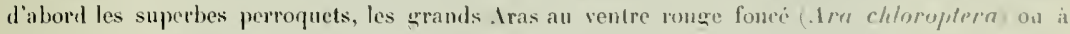
face ventrale lileue (A ten merno), qui traversent souvent le lleuve par paires, en jarissint. Dans les arbres, des perroquets verts of des petiles perruches attirent l'attention par leur's ris assourdissants. Nous votons des Passereaux multicolores, des Toucans au hec énormr. des Tyranuides. des Tanagrides, des letérides et des Turpiales. Ces derniers, a l'imitation des oiseax lisscrands d'. Irique, construisent des nids en forme de massite, l'une longueur de $1 \mathrm{~m}$. ou plus, que nous voyous souvent se halancer légèrement it l'extrémite des branches. In burd de l'ean, sur un arbunle, "puelques Phalacrocorax vigua gueltent des poissons; plus loin, une dizaine de Sarcoramphus papa. grands et superlyes viseaux rapaces, s'acharnem autour d'un crocolite mort. Sur lis lai nes

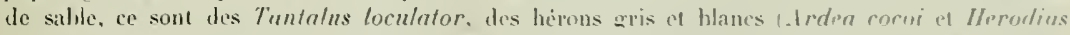
eqrefta), des Spatules (Platatea ajaja), des this el des Pluviers. Tout ce monte aile ne semble pas intimidé pau les groupes de crocotiles, qui. par 2 ou 3. souvent par to ou par 25. sont vautrés sur le sable, leur queule hideuse largement ouverte montrant leurs lnngues dents acérées. Ces monstres de 3 a $4 \mathrm{~m}$. de long ne hronchent pas quamil le bateau passe; ils contiument leur sieste sous le 
soleil ardent; seul un coup de feu, ou un coup de silliat strident les met en mouvenent; malatroitement. ils se jettent à louu et disparaissent dans les flots jaunàtres.

E.- Les Iguanes verts (Iymuna luberruluta) el les grandes tortues aqquatiques (Podocnemis) sont heancoup plus crantifs. In pen arant Puerto Berro, nous voyons un graul serpent haverser le Heuve it la nage. Nous passons sous silence les nombreuses formes d'amphiliens, craprauds on grenouilles, dont nous entendons les cris peu hamonienx dans le concert nocturne, tandis que notre hateau. altaché à l’un des géants de lia forêt, attend le lever du jour pour reprendre sal roule. Nous ne parlerons pas non plus des poissons si nombreux, aux formes bizarres, recouverts d'une carapace ef appartenant surtout à la famille des Silurides, si richement représentée dans l'Amérípue du Sud.

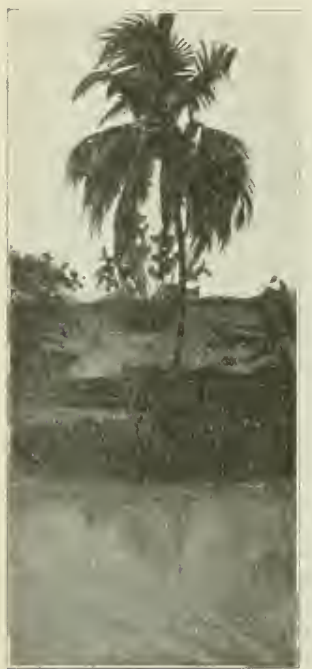

Au bord du Atagratena. ( $F, M$ Les eaux dtaient si hautes qu'il ne nous a malheurcusement pas été possible de linire des péches quelque peu línctueuses.

Le 28 juillet, de très bonne beure, nous arrivons it Botega Central, village situé à l'embouchure du Rio Lebrija, oủ nous quitteut les deux négociants danois, MII. Klausen et liofert, avec lesquels nous avions fait route, et qui se lirigent vers Bucaramanga.

Bucaramanga, chef-lieu du département de ce nom, est une ville de 20 ooo habitants, située it $9^{25} \mathrm{~m}$. d'altitude dans les Andes orieutales ; elle est assez importante, mais isolée jusqu'it maintenant clu monde extérieur, et d'un accés lifficile. Pour y arriver, ces Nessieurs devaient pendant so heures prendre un petit vapeur inconfortable: ils avaient ensuite en perspective 2 à 3 jours de pirogue et 2 jours à dos de mule.

A la nuit, nous sommes à Cañabetal où nous faisons du bois, et le lendemain, nous arrivons à Puerto Wilches, endroit qui comprend actuellement une seule maison. Plus tard, il pourra y avoir lit un centre important au point de vue économique et commercial. Ce sera en ellet le point d'arrive du chemin de fer de Bogota à Bucarananga et au bord du Magdalena. De ce demier tronçon de $115 \mathrm{~km}$., une vingtaine seulement sont construits. Il est étonnant qu'on se décide si tard à construire cette voie lerrée el que les travaux avancent si lentement, car toute la région de Bucaramanga est particulièrement intéressće à cette construction, à cause de ses plantations de café et de ses riches mines d'or, d'argent et de cuivre encore inexploitées, vu le manque de voies de communication.

Le soir, nous nous arrêtons à Chucuri. petit hameau habité par des pêcheurs et des chasseurs. II se compose, comme tous cenx que nous avons rencontrés, de huttes en terre ou en bambous recouvertes de chaume. Autour du village s'étendent quelques cultures de cacao, de mais, de canne ì sucre et de banane; près des maisons s'élèvent des bouquets de palmiersélégants, ainsi que des Mrangifera indica. Un arbre éminemmentutile ct qui se trouve près de toute agglomération, est le Lagenarinvulgaris, dont les fruits, attcignant souvent de grandes dimensions sont appelés calabas et servent à la falrrication de tous les ustensiles de ménage (bols, tasses, assiettes, cuillers, etc.). Comme à Barranquilla, la population, surtout Ja population inlantile, est décimée par la malaria, contre laquelle on essaye de lutter avec la quinine qui est importée, bien que les quinquinas soient originaires de l'Amérique équatoriale.

Pendant l'occupation espagnole, l'exploitation de ces arbres si précieux a été faite d'une manière si peu rationnelle, qu'ils ont été détruits et qu'on ne les trouve plus guère maintenant que dans des 


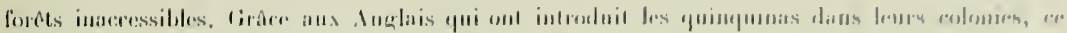

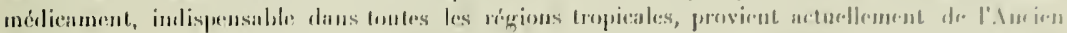
Monde.

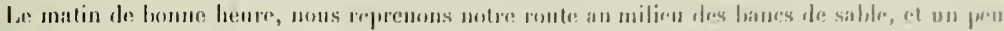

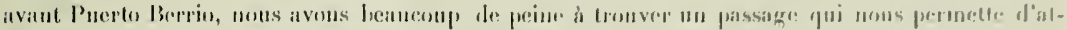

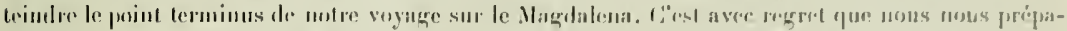

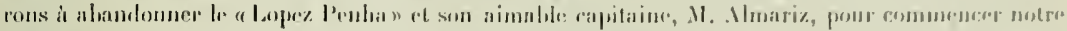

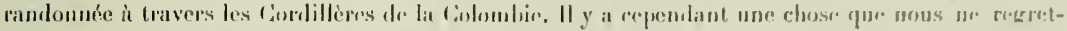

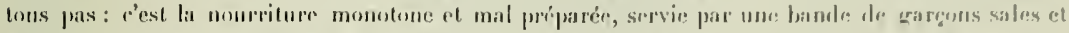

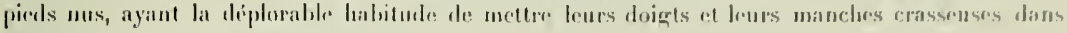

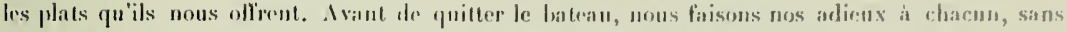

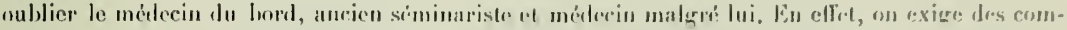

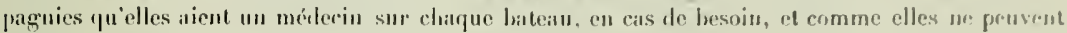
se payer le luxe d'un mélecin ayan litit des études, elles engagent n'importe qui, pour remplir cette lonction.

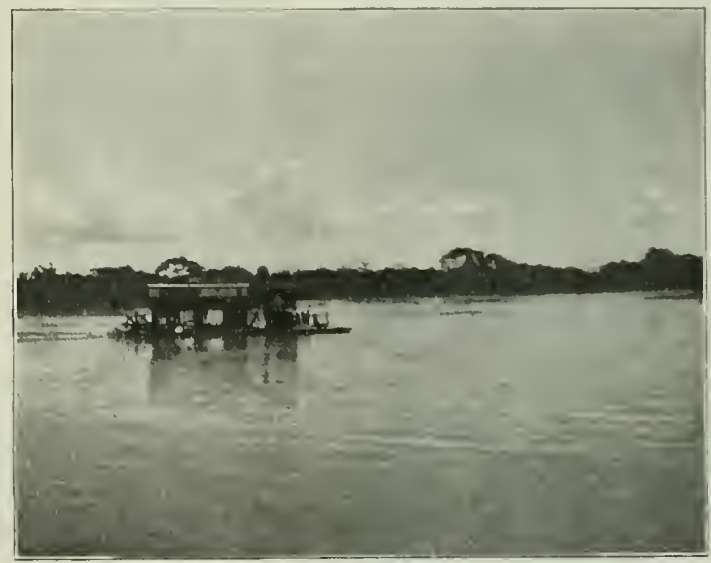

Le batean du Rin Lelrija. 


\section{CHAPITLE, IT}

\section{De Puerto Berrio à Medellin.}

Puerto Rerrio (ait. $143 \mathrm{~m}$.) est un village qui n'a d'importance que parce qu'il est le point terminus du chemin de fer qui aloutira un jour à Nedellin. Comme dans toute la vallće du

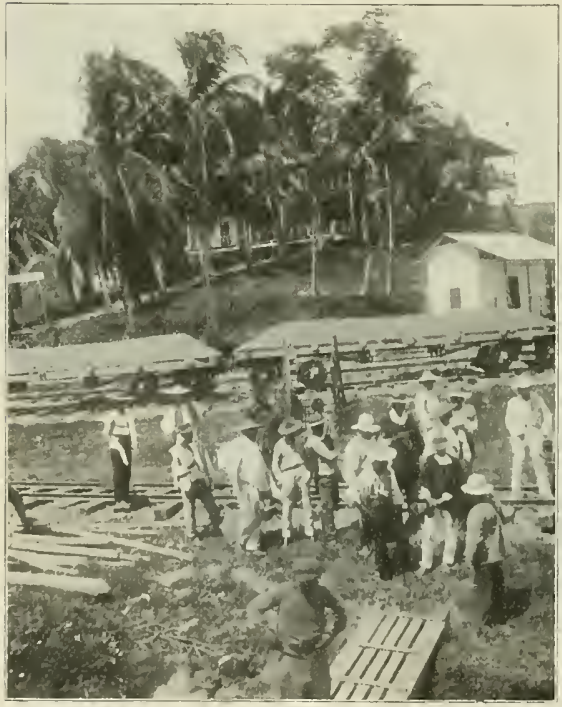

P'uerto Berrio. Gare et débareadère. Magdalena, la population comprend ici des Nigres, des lndiens et des Zambos. En arrivant à Puerto Berrio, on est frappé par l'aspect des lndiens qu'on rencontre: c'est le type autioquien dont nous reparlerons et qui differe de celui des Andes orientales.

Le chemin de ler de l'Antioquia, commencé en 8778 , a aujourd'hui $105 \mathrm{~km}$, d'iehevés, ce qui représente la moitić environ de la tongueur de la ligne. La partie la plus difficile reste à laire, e'est celle qui traverse une des ramifications des Andes centrales, séparant la vallée du Rio Nus de celle du Porce où se trouve Medellin, la ville la plus importante de l'Autioquia Insqu'i maintenant, la Colombie ne posside que quinze lignes de chemin de fer, d'une longueur tolale de $9^{50} \mathrm{~km}$. Ces lignes, dont la longueur varie de it à $100 \mathrm{~km}$., sont relativement peu importantes, parce qu'elles ne sont pas reliées les unes aux autres.

I l'hemre exacte, chose a noter, le train quitte Puerto Berrio pour gagner les Andes centrales. Tout d'alord, la ligne traverse la vallée du Magdalena, avee ses étangs et ses marécages qui donnèrent tant de fil à retordre aux ingénieurs lors de la construetion de la voie lerrée, et remonte la vallée du Rio Malena jusqu’à Pavas. Ce trajet est remarquable par les forêts superbes que nous traversons; les atbres géants sont recouverts d'une riche végétation épiphyte. Sur les grosses branches, près du trone, on voit souvent des nids 


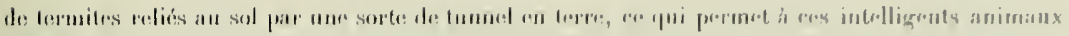

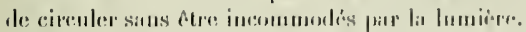

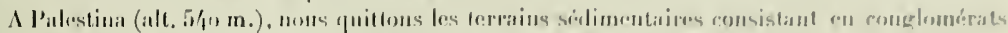

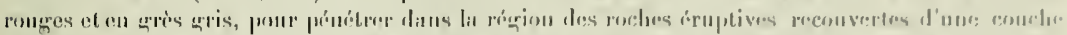

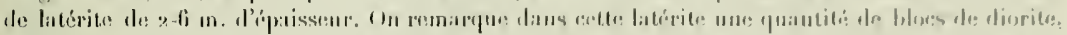

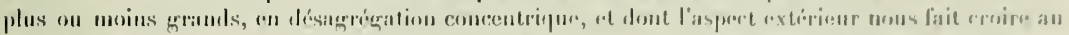

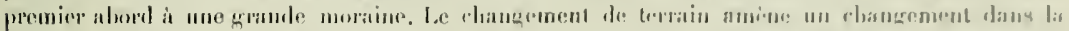

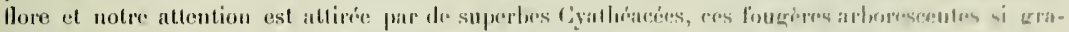

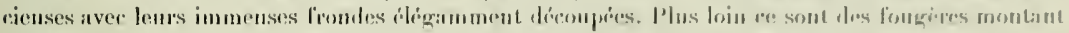

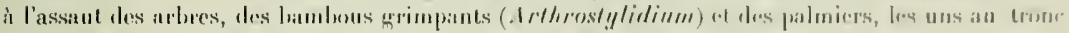

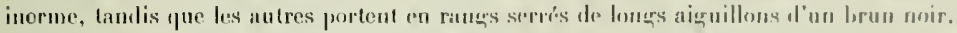

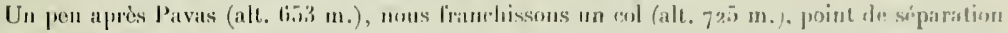

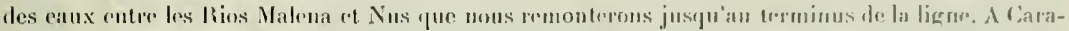

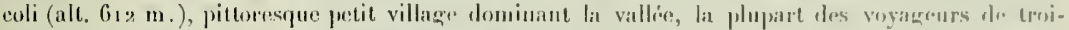

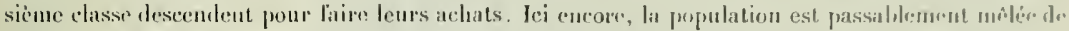

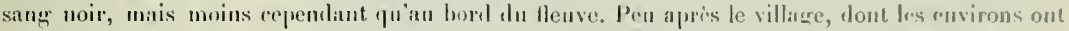

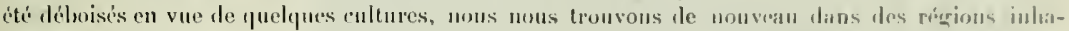

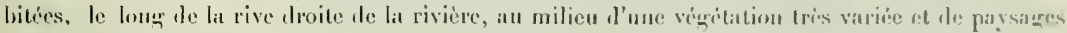
tris pittoresques.

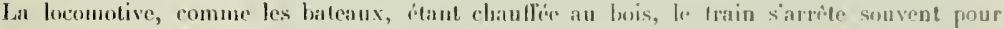
renouveler liı provision de combustible. Confortablement iuslallés dians notre joli wagon de premiere

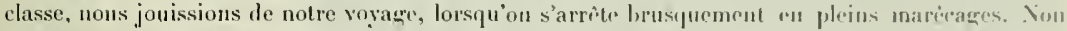
sans peine, nous parvenons it comprende qu'un acrident "st survenu ct qu'il fant transhoriler. En destendiut du train, nous constatons que le talus de lit voie ferrée a été enlevé is deux placess sur une assez grande longueur, a la suite d'un violent orage ; cet accident se prodnit asse\% frequemment et prouve la sécurité de la ligne. I quelque distance, nous voyons en ellet un tritin de secours at nous nous mettons, non sans peine, a transhorder avec nos nombrenx colis. Il nous faut circuler sur les rails et les traverses suspendus dians le vide, an-tessus des eaux fandeuses de la riviere lébordée, dins laquelle on so serait in lailliblement noyé en cas de chute. Lintin, nous arrivons saim et satulis de l'autre coilé de ce pout d'une stahilité plutôt douteuse et nous installons tant bien qun mal sur des wagonnets de ballist en prenant nos lagages comme sièges. Pendant les if $\mathrm{km}$. quil reste it franchir, nous rotissons sous un soleil de feu el sommes aveuglés par la fumce de la locomotive et les charbons ardents qu'elle crache. Le jeune ingénicur qui conduit la machine: semble avoir mis son point d'honucur à marcher aussi vite que possible et le train file à une allure quelque peu inquiétante. Enfin, nous arrivons ì Cisneros (alt. troo m.), situé au piest d'une thaine de montagnes assez élevées qui séparent la vallée du Rio Nus de relle du Rio Porce. Lit se termine atucllement (et prohahlement pour longtempsencore) le chemin de fer de Medellin. Le village se compose de quelquues maisous et de lépòts cle marchandises; cest lit qu'arrivent tous les produits d'exportation de l'Antioquia el les articles d'importation, en particulier les materianx pour la construction de la voie fercée à laquelle on travaille activement de l'autre coité de la montagne.

A notre arrivée en gare, étant les seuls étrangers, nous sommes assaillis par des muletiers on " arrieros " qui nous ollirent leursservices. A force de peine et surtout de gestes. nous parvenons à nous entendre avec eux, à fixer le nombre de mules nécessaires et l'heure du départ. Après un très fru. gal diner, nous en fourchons nos mules et quittons Cisneros pour gravir la montagne, escortẻs de trois arrieros et de huit mules de charge pour nos vingl-deux colis. Lentement, le chemin séblève sur la rive droite du Rio Nus, et arrive au col de la Quiebra (all. $1.584 \mathrm{~m}$.) ou nous devons passer la nuit. Sur ce versant, la végétation est très paurre: la montagne est entièrement déhoisie. on n'y voil que 
quelques taillis et de maigres paturages on patissent quelques bestiaux. L'aulrerge dans laquelle nous nous arrêtons nous fait l'ellet d'un coupe-gorge et ne nous inspire qu'une confiance très limite. Nous y trouvons trois hruyants prospecteurs qui, avec force gestes et un tlot de paroles, essaient de nous expliquer leurs louts faits; nons n'y comprenons pas grand'chose, mais nous admirons leur Taconde et leur volubilité. Après un repas antioquien où les inévitables frisoles (lieves noires) apparaissent, nous gagnons notre réduit d'une propreté des plus relatives el nous nous empressons de remplacer par nos lits de camp ceux qui s'y trouvaient et qui renfermaient sans nul doute une innombrable vermine.

Ivant le jour, nos "peons" sont déjà sur pied pour capturer dans le " potrero » (enclos dans lequel on laisse paître les animaux) nos dix mules et les anener, non sans peine el avec force jurons, it la porte de l'auberge. Après le déjeuner, nous assistons aux préparatif's longs et pénibles ilu chargement des mules, source d'ennuis et de retards considérables. En effet, il laut soupeser ehaque colis et tàcher de l'équilibrer, aussi bien que possible, sur les flancs de l'animal, avec un autre colis. Cette opération délicate terminée, on fixe le tout au moyen de lanières de cuir ou de cordes en fibres d'Agave. Nos bagages étant passablement hétéroclites. le ehargement est tres difficile, et pendant les premières heures, les peons sont constamment obligés d'arrêter les bêtes pour équilibrer et ficeler à nouveau les malles et caisses. Pour que la mule, ainsi arrêtée, ne suive pas la caravane, on lui met sur les yeux une bande de toile que les arrieros portent toujours avee eux.

Avant de quitter La Quiebra, nous allons encore jeter un coup d'oil sur le magnifique panorama qui se déroule à nos pieds. A l’est s’étend la vallée supérieure du Rio Nus, tandis qu'à l'ouest nous pouvons suivre les méandres du Porce jusqu’à l'horizon, linité par les chaines parallèles des Andes centrales, recouvertes jusqu'a leurs sommets arrondis par d'immenses forêts.

A 6 heures et demie, nous sommes enfin prêts à partir et nous descendons une petite vallée qui aboutit à celle du Porce. Suivant les conseils qui nous avaient été donnés, nous nous mettons en queue de la caravane afin de surveiller nos bagages, et nous pouvons ainsi à loisir examiner nos peons, Ce sont de superbes gaillards, forts et robustes, dont nous aurons à plus d'une reprise l'oceasion d'arlmirer l'endurance. Ils portent fièrement, du còté gauche, le traditionnel "Machete », sorte de long couteau à deux tranchants et à lame très large. Au moyen d'une bretelle en cuir souvent recouverte de broderies, ils portent en bandoulière le "Carriel», sacoche à soufflet et à compartiments multiples renfermant les objets les plus divers. Leur vêtement se compose d'un pantalon, auquel des picces nombreuses, en étoffes de toutes les couleurs, donnent un aspect des plus pittoresques et d'une eliemise courte s'arrêtantà la ceinture, par dessus laquelle ils mettent une sorte de tablier en toile blanche grossière, qui descend jusqu'aux genoux et protegge leurs vêtements. Ils marchent nu-pieds et ont comme coiffure un chapeau de paille à larges hords.

Le chemin qui conduit au fond de la vallée étant très bon, voire même carrossable, tout se passe normalement, mais, dans l'après-midi, nous faisons connaissance avee les fameux "Pantanos m, la terreur des voyageurs non initiés aux chemins colombiens.

En Colombie, il n'y a généralement pas de routes le long des fleuves, dans le fond de la vallée. Les chemins que l'on doit suivre écharpent la montagne, souvent à une grande hauteur. Lorsqu'ils arrivent à un vallon formé par un affluent, au lieu de s'enfoncer dans le vallon pour chercher un passage à peu près à la même hauteur, les chemins descendent presque verticalement jusqu'au ruisseau, le traversent à gué ou sur un pont rustique et remontent non moins verticalement sur la rive opposée de tout ce qui a été descendu. C'est en général dans ces rapides descentes que se trouvent les fameuses fondrières qui constituent les pantanos. Le cliemin, au lieu d'être plat et uni, ressemble à un champ labouré avee ses nombreux sillons transversaux formés par le passage des mules, qui posent toujours leurs pieds à la même place et finissent ainsi par former, à intervalles réguliers, de profonds creux remplis d'une boue liquide et gluante. Par places, les creux sont si 


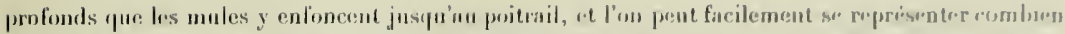

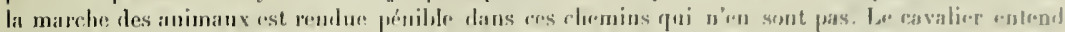

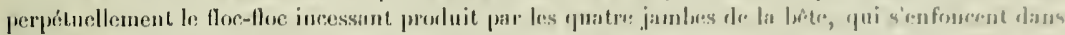

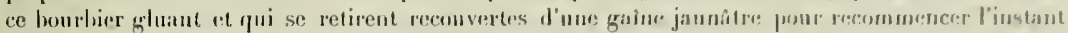

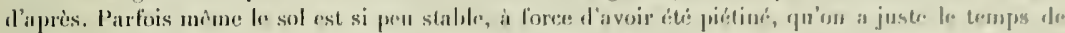

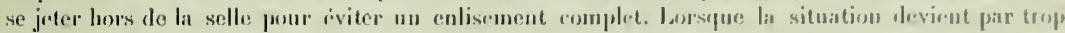

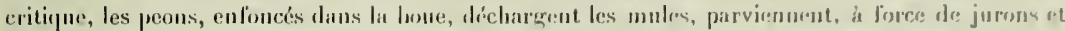

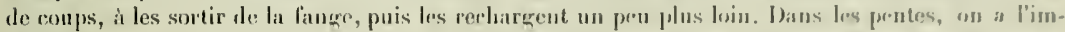

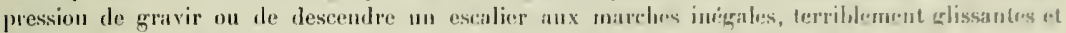

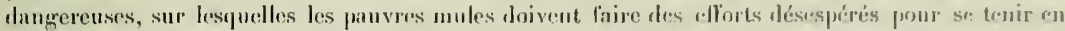
épuilibre et ne pas dre précipitées dans le vile aveo lenr charere. Sons noublierons jamais une de nos mules, ifui avait glissé et était tombée la tête la première dans la boue, d'ou elle ne pouvait se sortir, tandis fuc ses jambes de derrière s'agitaient désespérément en l'air.

ll est étonnant de penser que ces chemins, si l'on peut baptiser de ce nom ces atlireuses londricres, sont les seules voies de communication dans l'intérieur de la Colombic el l'on comprend quel olsstacle ils opjosent au développement du mouvement rommercial.

Apres avoir pataugé

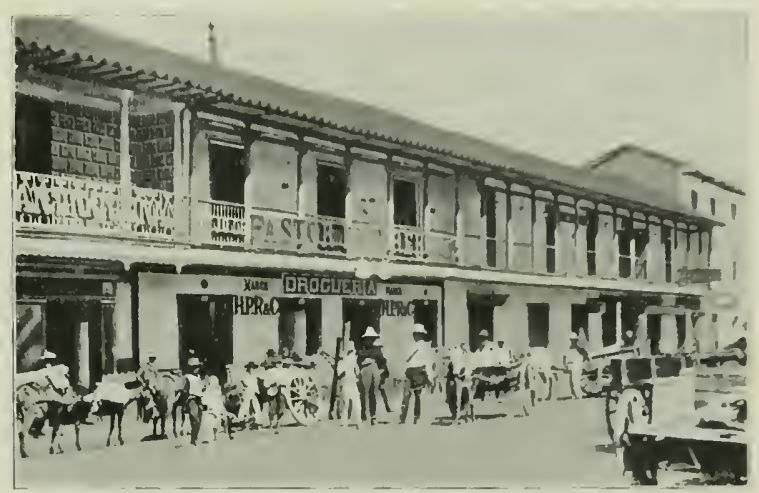

L.a Pace de Medellin.

pendant des heures, nous arrivons à Varumito (alt. $1308 \mathrm{~m}$.), au bord du Porce. Un y travaill. activement à la construction de la voie ferrée daus la direction de Medellin et nous avons du reste rencontré, en cours de route, ıles caravanes de mules et de chevaux portaut péniblement les matériaux nécessaires. Le lendemain, 2 aout, nous remontons la vallée du Porce et nous retrouvons des pantanos jusqu'à Barbosil. Heureusement. à partir de ce village. le chemin s'améliore de plus en plus et devieot une mauvaise route carrossable à partir de Girardota jusqu'à Medellin, ce qui nous permet d'avancer rapidement.

La vallée du Porce, quoique assez monotone, est cependant riante et surtout très fertile: presque partout, les forêts ont été complètement abattues et sont remplacées par des taillis, des pàturaģes ou des cultures diverses aux environs des agglomérations assez distantes les unes des autres. Sur le borl de la rivière, dont les alluvions sont riches en or, nous voyons plusieurs installations primitives oủ l'on se livre au lavage des sahles aurifères. I Copacabaua, nous franchissons le Porce sur un pont en fer el nous suivons sa rive ganche jusque près de Medellin.

Medelliu (alt. $1524 \mathrm{~m}$.) est une ville de 60.000 habitants environ, construite au pied et sur le penchant d'une des chaines des Cordillères ceutrales. C'est la capitale de la province d'Antioquia et la ville commerciale la plus importante de la Colombie. Elle a été fondée par le conquistador Robledo et forme le point d'arrivée de tous les chemins des régions du Cauca. du Magdalena et des 
provinces du Sud, Cest là qu'arrivent l'or des montagnes, le café et le cacao, de méme que tous les produits d'importation.

La ville elle-mème ne présente rien de bien intéressint; elle ressemble à toutes les autres villes de la Colombie. Les maisons n'ont le plus souvent qu'un rez-de-chaussée construit autour l'une cour intérieure ou "patio », entourée d'une galerie sur laquelle s'ouvrent toutes les chambres. Les labitations sont toutes en terre battue, sanf quelques exceptions, et les murs sont blanchis it la chaux: leur construction ne nécessite pas les talents l'un architecte distingué. On fait une sorte de mule en planches. ayant $1 \mathrm{~m}$. 50 de haut sur $2 \mathrm{~m}$. 50 ou $3 \mathrm{~m}$. de large; on dome aux denx parois llu moule l'écartement correspondant à l'épaissenr du mur que l'on désire; on remplit cet espace vile de terve, on la pile au moves de pilons et on la laisse sécher, puis on enlève le moule et l'opération recommence un peu plus loin. Ce mode de construction donne aux murailles un

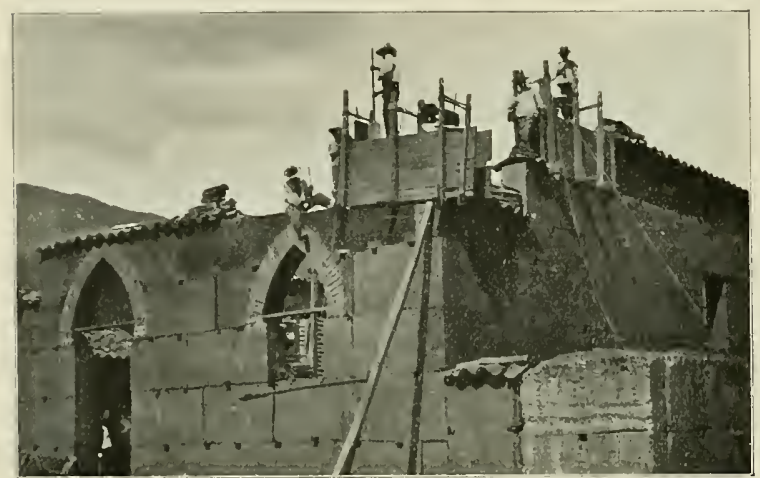

Construction diune maison en terre battue. aspect très particulier; elles ont l'air d'être faites avec le grandes dalles régulières en terre battue, posées te champ les unes à coté des autres. On comprend que ces murs soient d'une solidité relative; une bonne pluie les aurait vite détériorés; aussi, pendant la construction, les protège-ton en posant de larges tuiles sur ce qui forme momentanément leur face supérieure. (Voir figure cicontre.) Les toits avancent passablement pour protéger les murailles qui sont toujours blanchies à la chaux, ce qui forme une sorte de couche protectrice. Dans les campagnes et les faubourgs des villes, les murs des habitations ont une sorte de squelette fait de poutrelles ou de tiges de bambons dans les interstices desquelles on tasse de la terre.

La population de la vallée du Porce, comme de tontes les régions tempérées de l'Antioquia, comprend quelques étrangers, des créoles, et surtout des métis et des Indiens; les nègres sont heureusement en assez petit nombre. Le goût inné des Antioquiens pour le commerce, leur habileté dans ce domaine et leur aspect extérieur, semble confirmer la légende prétendant qu'ils descendent d'anciennes colonies juives transportées manu militari dans le Nouveau Monde après la conquête. Elles auraient eu la chance ou l'habileté de s'établir dans cette riche contrée ou elles auraient créé la puissante race actuelle. L'Antioquien est très intelligent et travailleur, très économe, ce qui fait que l'Antioquia est de beaucoup la province la plus riche et la plus développée aux points de vue commercial et agricole; aux points de vuc scientifique et littéraire, elle reste en arrière de Bogota, qui a été, à juste titre, appelée l'Athènes de l'Amérique du Sud. L'Antioquia est une des provinces les plus peuplées de la Colombie; les familles de $10,12,15,18$ enfants y sont communes. Quand le nombre des enfants est de 24 , on commence sculement à s'intéresser; nous avons même vu à Zancudo, près de Titiribi, un ménage de mineurs à la tête de 33 enfants de la même mère! 


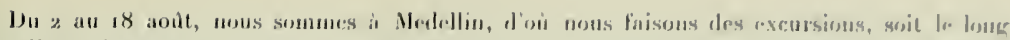

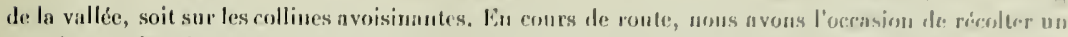

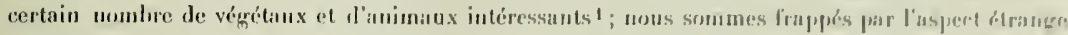

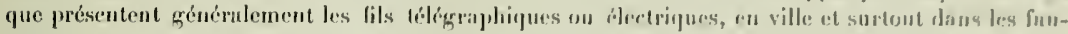

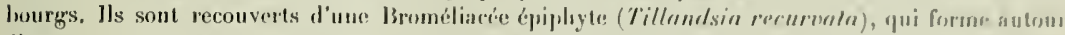

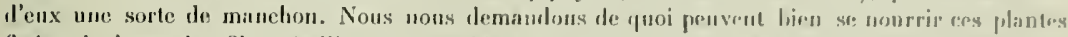
fixées ainsi sur des fils métalliques; ciest hien la démonstation évirlontro qure, sous los tropiques, les végétaux peuvent présenter les adaplations les plus inatendurs anx plus extraordinabres gonres de vie.

Avant de puitter Merlellin, nous avons eu l'oreasion dr visiter les luelles collections d'amtipui-

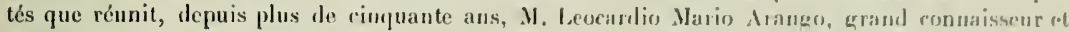
collectionneur daus l'ame. Sous la conduite alu vénérable vieillard, nous pouvons tout admirer à loisip en recueillant de sa bouche les rensciguements les plus intéressants. Ces antiquités proviennent surtout de la vallée du Cauca, plus spécialement des provinces d'Antioquia et du Cauca, et forment une collection très riche en poteries et en objets d'or de l'époque préespagnole. Les poteries, au nombre de plusieurs centaines, sont presque toutes en terre noire, décorées de dessins à l'ocre. Elles représentent surtout des animaux, en particu-

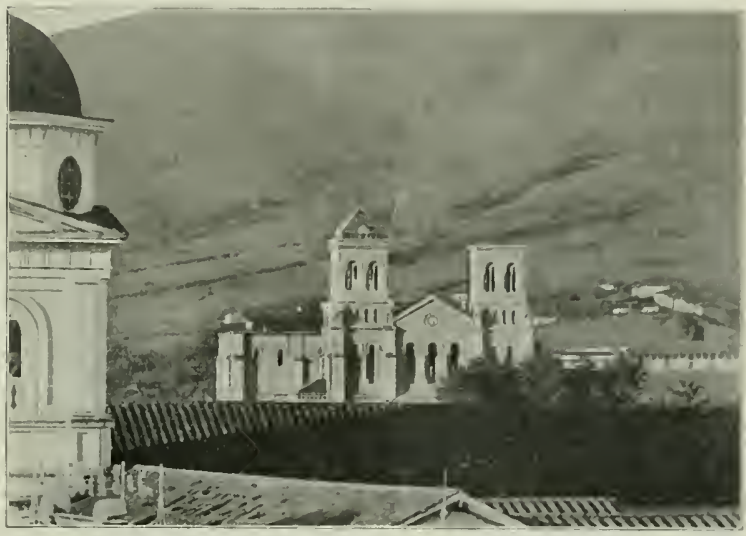

La cathẻilrale de Medellin. (F.M.) lier des grenouilles, sala(Vue prise an téléphot Vaubierı.

mandres et serpents, parfois aussi des singes, ours, tapirs, etc. Nous sommes frappés par quelrures vases ayant la forme de véritables bétes apocalyptiques et rappelant les gravures quelque pru fantaisistes des zoologistes du $x_{v} y^{\circ}$ siecle. Nombreuses sont les poteries à ligrure humaine au type mongol très nettement marqué. I] y a aussi des vases présentant une ou deux ouvertures permeltant de scen

1 Espèces végétales nouvelles recueillies à Itedellin el aux environs: foratorema lenerrima; Cosmarium anlıarniense; Closterium columbianum; Cylindrospermum minimum; Stauras/rum .Vayori; Tri. chostomum norogranatense; Dicranella . Hayorii; Cromyces Rulsi-nrticifolii, porcensis, columbianns: Puceinia Coneolvulareuram, Hyptilis-mulabilis, medellinensis, enpaloritcola, Enpalorvi-colnmbirmi, Baceharidis-rhexioidis, Wealeliae, spilanthicoln; Lredinopsis , Mayoriana ; Aeculinm medellinense; Lredn

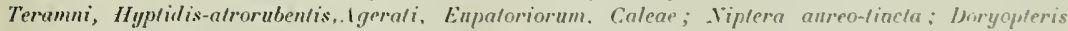
Iayoris; Gymnogramme fumarioüdes; Stachys . Vuyorii el Eupatorimn columbianmm.

Especes animales nouvelles: Greoplana ron Gunteni, IJ enleu colmmhiana, Dichogas'er medellini. Canthocamplus fuhrmanni, Cypridopsis fuhrmunni, llla mesonotalis n. var. fulirmanni, Dulicherleprs schulsi n. var. columbica, Vacrobiolus fuhrmanni, Taranlula medellinu, Epinanmulene errilis, E. mgr' In. 
servir comme siftlets, des cruches dont le bord supérieur, très finement travaillé, parfois mème ajouré, ne permettrait jas qu'ou s'en serve pour boire. Pour parer à cet inconvénient, l'artiste a placé à la partie supéricure un embout, d'où part un tuyau en terre cuite, qui descend jusqu'au fond tu vase; on peut ainsi le viler completement en aspirant simplement; c'est du moins l'explication très plansible que nous donne notre aimable guide. Nous voyons aussi des rouleaux et des plaques en terre cuite décorés de gracieux motifs d'ornementation, et qui servaient probablement it imprimer les toiles. Ayant eu l'occasion de nous procurer un certain nombre de poteries, nous arons eu la chance de pouroir les comparer avec celles de cette ancienne collection, unique en son genre, et de constater lenr similitude parfaite, comme maticre el comme travail. $\perp$ coté de ces innombrables poteries, dénotant une fantaisie el une imagination aussi féconte qu'artistique, nous en voyons d'autres plus simples et moins décoratives en terre rouge-brique. Ce qui fait aussi la grande valeur de cette riche collection, ce sont les objets en or. Nous voyons les insignes dont se revètaient les caciques: les pectoraux, les frontaux, les brassards, les cnémides et les sceptres d'or; tout cela est simple et en or massif. Il y a aussi des colliers, des bracclets, des anneaux pour le nez, des aiguilles, des épingles à cheveux et d'autres menus objets dont on ne se représente pas lien l'utilité. Dans un petit coffret nous pouvons voir, dans plus de 8 ao tubes, des échantillons de pépites l'or provenant des différentes mines de l'Intioquia. Enfin, daus une petite salle, se trouve une très helle collection d'oiseanx el d'insectes du bassin du Cauca.

Nous avons été très heurenx de pouvoir visiter cette remarquable collection trop peu connue, et c'est grâce à MI. Karl Bimberg, consul d'Allemagne à Medellin, que nous avons pu le faire. M. Bimberg avait été prévenu de notre arrivée en Colombie par son gouvernement, auquel nous étions recommandés par le Conseil fédéral. M. Bimberg ne s'est pas seulement contenté de nous donner tous les renseignements qui pouvaient nous être utiles; il a encore mis à notre disposition une maison dans sa vaste plantation de eafé, non loin du Cauca, sur les flanes abrupts de la vallée du Rio Amaga. Grâce à lui, nous avons pu faire un séjour de quelques semaines dans une région extrêmement riche en animaux et en végétaux nouveaux pour la science. Qu'il nous soit permis de lui renouveler ici l'expression de toute notre gratitude. 


\section{GIIAPITRE I}

\section{Séjour à La Camelia.}

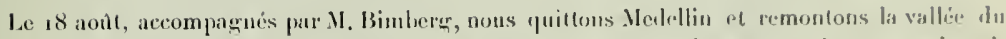

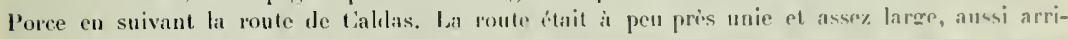
vons-nous ripilement à ltaigrui. Ce village est mallienreusement envali par les termites el nous voyons en passant des poutres entièrment vidées par ces terribl's iusectes. Peu apre's, nous prenous un manvais sentier ahoutissant à Estrella (alt. $1506 \mathrm{~m}$.$) , situé au pied te$ l'Alto Romeral, que nous eomurngons a gravir lentement. Le chenin, passable au début, devient le jlus en plus mauvais, puis impraticable tant il a été raviné par les pluies antérieures; nous devous même l"abantomner

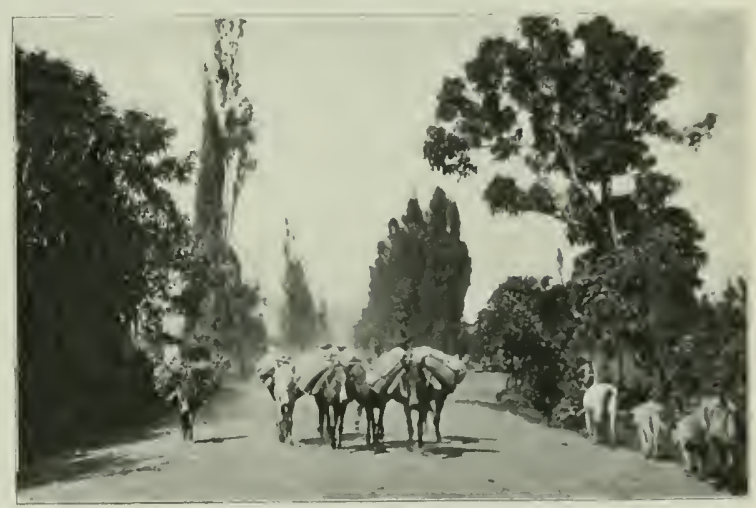

Chemin the Mtedellin à Itagui. pour un autre qui ne vaut

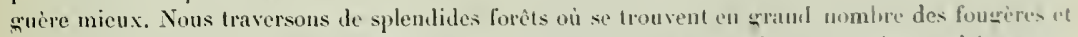
des (hehidées, puis nous arricons pénilhlement ì une petite lagune (alt. 1779 m.). perchée sur un replat de la montagne, mais dont ha faue est des plus paures. Le chemin, trés abrupt.entrecoupio de pantanos profonds, longe un vallon encaissé el nous permet de voir par échappes la riante vallice du Porce, tundis qu'i nos pieds, nous arons souvent un abime profond, recouvert de forêts vierges. Enlin le sentier atteint un col (alt. 287 h m.). d'où nous jonissons d'un magnifique panorama. I lest et au norel s'étend la riche vallec du Poree, dont les méandres étiucellent au soleil; dans le lointain. ou apergoit Medellin el ses maisous hanches. L,horizon est fermé par les chaines des Cordilleres centrales, qui s'abaissent graduellement jusqu'au Magdalena. Ce qui nous frappe surtont, cest hat quantité innombrable de vallées plus ou moins profondes qui donnent à la région un relief des plus viries. Les montagues de celte rigion, formées de roches éruplives. présentent tonjours une crête 
arrondie d'ou se détachent perpendiculairement une infinité d'arêtes secondaires qui se subdivisent elles-mêmes et donnent naissance à de nouveaux chaînons perpendiculaires. Ces détails topographiques très caractéristiques du relief des Andes centrales sont à peine et très mal indiqués sur les carles, même les meilleures de cette région. Si nous tournons nos regards vers l'ouest, nous avons devant nous quelques chaines des Andes centrales, puis au delà de la profonde dépression où l'on devine, sans le voir, le grand affluent du Magdalena, le Cauca, on distingue dans le lointain les premiers contreforts des Andes occidentales. A près avoir admiré ce merveilleux panorama, nous reprenons notre route. Le chemin descend rapidement les pentes de l'Alto Romeral et traverse ou longe de magnifiques forêts aus arbres géants, recouverts de plantes épiphytes, Aracćes (surtout de superbes Philodendrone), Broméliacées ou Orchidées, et réunis par un inextricable fouillis de plantes grimpantes et de liaues. Vers le bas de la descente, le chemin est si étroit et si encaissé, que nous ne savons plus que faire de nos jambes qui, à chaque instant, risquent d'être arrachées. Nous sommes obligés de nous transformer en acrobates et de nous tenir en équilibre sur nos selles, les pieds appuyés sur le cou de la mule; par places même nous devons nous décider à descendre de nos montures. A mesure que l'on approche

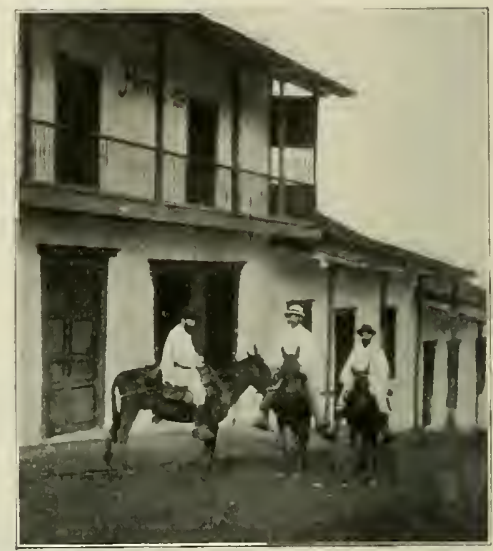

Estretla.

(Au milieu, M. Bimberg). d'Angelopolis, le ehemin devient de plus en plus mavvais et les pantanos se multiplient d'une manière désespérante. Angelopolis (alt. ${ }_{19} 69 \mathrm{~m}$.) se trouve au haut d'un petit vallon, sur un terrain sédimentaire, qui renferme dans les couches crétaciques des dépôts nombreux de charbon et de sel. Par des chemins épouvantables, coupés de pantanos, nous gravissons la pente orientale de l'Alto Don Elias, recouverte d'une maigre végétation. Du sommet (alt. $2130 \mathrm{~m}$.) nous pouvons embrasser

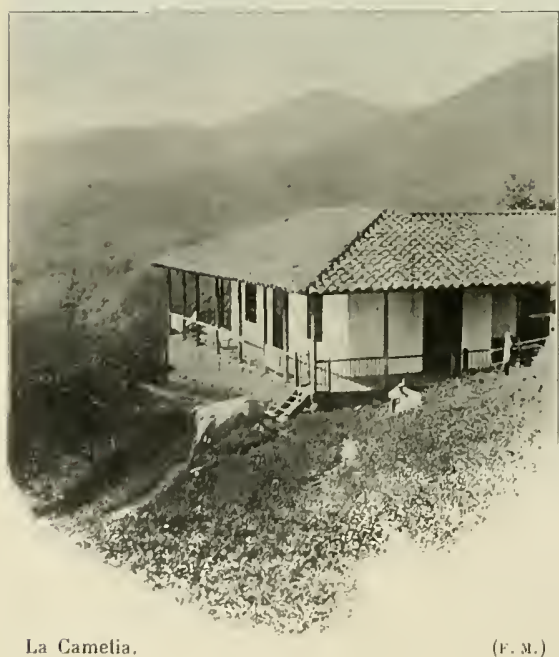
toute la région que nous venons de pascourir, alors que devant nous s'étend la vallée profonde du Rio Amaga, sur le flanc de laquelle se trouve la riche el vaste plantation de café de M. Bimberg; dans le lointain, nous distinguons à peine la maison qui va devenir, pour quelques semaines, notre quartier général. Par en sentier très rapide, mais relativement bon en comparaison de ceux que nous avons suivis, nous dévalons la montagne et, à la nuit, harassés de fatigue après neul heures passées en selle, nous arrivons à La Camelia (nom de cette partie de la plantation), et nous mettons pied à terre devant la maison que M. Bimberg met gracieusement à notre disposition, tandis qu'il continue son clremin pour se rendre à son hacienda, assez éloignée de la nótre. 


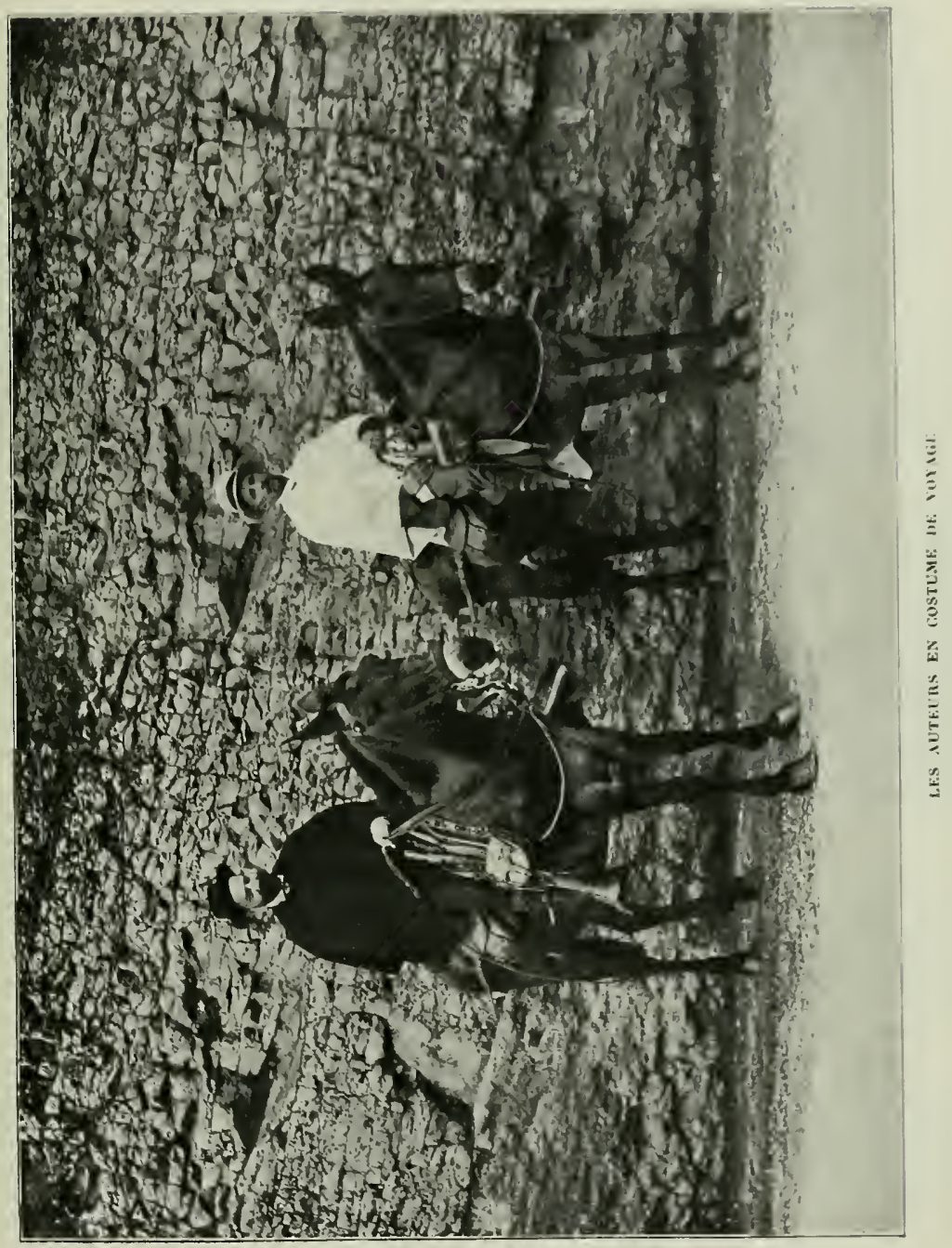


Le lendemain 19 aotit, itprès une excellente unit, nous uous rendons compte de la topographie de l'endroit où nous sommes. La maison est à $1830 \mathrm{~m}$. d'altitude. I l'est, l'horizon est horré par l'Alto Don Elias, tandis qu’à l'ouest s'étendent les chanes des Andes. I nos pieds se trouve le vallon de l'. Imagadiente qui débouche dans l'ítroite et profonde vallée du Rio Amaga, un des aftluents du Canca. De notre observatoire, nous distiuguons nettement trois chaines de montagnes parallèles coupées par la riviere au courant trés rapide. Au deli de la première chaine, nous pouvons voir une partie de l'importante localité minière de Zancudo, dont nous reparderons, tandis que nous ne laisons que deviner les usines de Citio Viejo et la petite ville de Titiribi. Les montagnes sont générilement dénudées et recouvertes de maigres pâturages ou de taillis, les grandes forêts ont disparı ct ne subsistent que dans le fond de la vallée encaissée du Rio Amaga. Dans le lointain, se devine la profonde dépression oì coule le Cauca, et an delà on voit très nettement les deux premières chaines des Cordillères occidentales.

La maison de La Camelia avait été vidée à notre intention, aussi nous pouvons nous installer à notre aise dans toutes les chambres. Comme les maisons colombiennes, celle-ci est en terre battue, entourée d'une galerie d'oin, le jour, nous admirons le paysage et, la nuit, les mille feux follets des lucioles on le clair de lune admirable, donnant un aspect féerique à tonte la vallée. Un soir mème, nous avous eu le spectacle rare et imposant d'un arc-en-ciel de lune formant un immense pont vaporeux et multicolore an dessus de la vallée. Derrière nous, la montagne est reconverte de forèts; à nos pieds s'étend la plantation de café, le "Cafetal ". Il nous suftic d'explorer les alıords immédiats de la maison pour faire de trés riches récolles zoologiques et hotaniques '; c’est ee que nous faisons les premiers jours, réservant pour plus tard les excursions plus lointaines. Dans ce vallon de l'. Imagadiente, que nous avons exploré en tous sens, nous avons passé des semaines inoululiables, grâce à la large hospitalitè de M. Bimberg et à son inlassable complaisance it nous donner de précieux renseignements.

Comme nous nous trouvons dans une riche plantation de café cultivée d'après les données scientifiques modernes, nous pouvons facilement étudier cette intéressante culture, si importante au point de vue économique : le café étant avec la banane le principal produit d'exportation de la Colombie. Le caféier (Coffea arabica) se cultive en Colombie, entre 600 et $2200 \mathrm{~m}$. d'altitudc.

1 Espèees nouvelles recueillies à La Camelia et aux environs. - I. Végétaux nouveaux: Scemlesmus qurAricauda var. rectangularis; Trichostomum Raapii; Iromyces antiorquiensis, Phtirusne, Rubi-ur/irifolii Crucheli, columbianus; Puccinia Marisci, Borconiae, dubia, Sirlne-rhombifoliae. Conuolvulucenrum, Hyptidis-mutabilis, medellinensis, Sarachne, Vernonine-mollis, Vayerhnnsi, Wedeliae, Bimbergi. spelanthicola, Oyedaene, Liabi; Coleosporium Fischeri; Uredinopsis Mayoriunn; Milesina Denustaedline: Aecidium amagense, Adenariae, hantanae, Vernoniae-mollis, Inrliopsidis, Liabi; Iredo Cameliae, amagensis, Hymenaeae, Myrcine, Nandevillae, Salviarum, Hyptidis-alrorubeulis, Vernonine, Calear: Werliola Lanlanne; Mycosphaerella Drymariae; Didymella Penniseti; Cercospora Liabi; Illosporillm Monorit; Liriden Hayori; Polypodium angustifolium var. heterolepis; Paspalum Fournierianum var. maximum; Dichromena polystachys; Physurus Mayoriona; Stachys Moyorii et Eupalorium columbirmum.

II. Animaux nouvenux: Planarin cameliae, fieoplana cameliae, G. colambiana, G. amagensis, $G$. bimbergi, G. muyori, Pelmatoplana graffi. Rhynchodemus enmeliae, Blanclurd iella cameliae, Rhinolrilus cameliae, Rh. birolor, Cinuhocomplus fuhrmanni, Epiloborern fuhrmutuni, Pseudothetphusa monticula, Heteropoda comelin, Stygnomma fuhrmanui, Cranuus culcur, Cumelianus fuhrmanni, Priomostemmn "llimanum, Newportia fuhrmanni, Siphaophora fuhrmanni, s. columbiann, Epinamuolene fuhrmanni, Virrospirobolns muyori, Jh, fuhrmunni, Rhinacricus brevipes, Slemmaloculus debilis, St. hortensis, St. mayor, Spirotreplus ruralis, Sp. inconstans, Leplorlemus angustus, Tilyns fulurmanni, T. parrulus, Chactas reticulatas, Peripalus bimbergi, P. mullipoles, Isomaria oreas, nov. var. parrula, Lalıgrinlhus angelopoliles, Philon!yrus columbiomus, Vuginula prismulim, 1: rnfeseens, 15. minula, Limphis psemlirobella. 


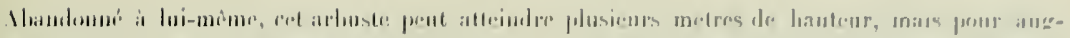

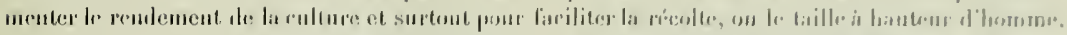

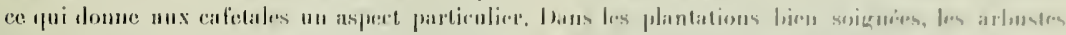

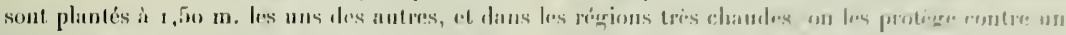

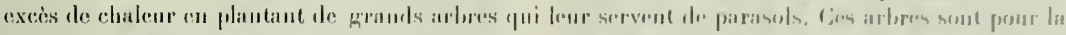

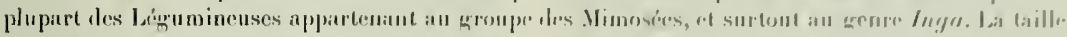

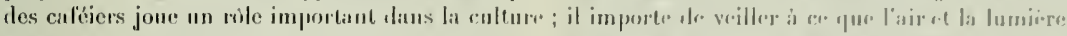

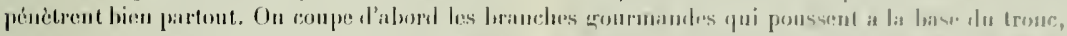

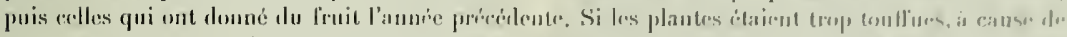

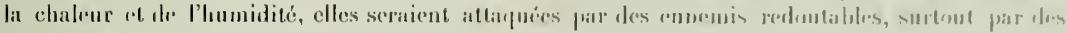
clampionous qui compromettraient nou senlement la plante envahie, mais la plantation tout entiere. Lientretion ales carletales cist minuticux et asse\% conteux, car il laut tiiller les arbustes avec discernement et, deux fois par au au moins, arracher les mavaises lart'bes qui se développent et se propagent tress rapidement. I La Camelia, comme partout en Colombic, la récolte se lait toute l'annice, mais elle est particulicrement importante an printemps, et il est singulier de voir sur un mème arbre, sur une même branclie, ì la fois des boutons, des fleurs, des jeunes liruits et des fruits murs de la grosseur d'une petite cerise entourés d'une enveloppe charnue de couleur rouge. Ces fruits renlerment toujours deux graines et ce sont ces graines que l'on consomme.

Au moment de la récolte, les peons, hommes et lemmes, recueillent un a an les fruits dans de petits paniers contenant $5 \mathrm{~kg}$. Pour

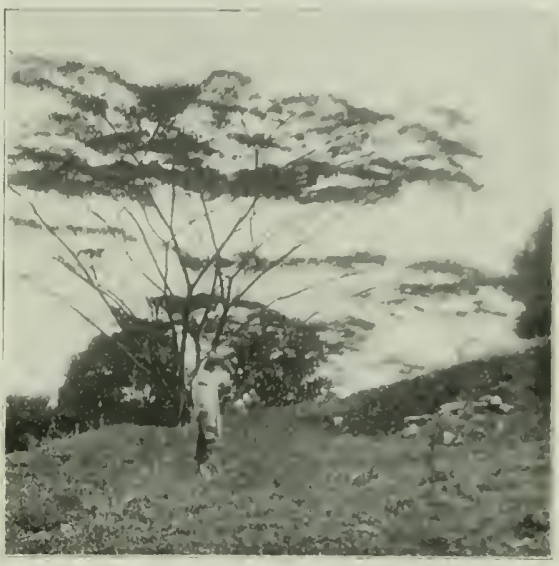

Irbe parasut dans un cafetal. chaque panier plein, ils reçoivent un jeton qu'on leur change ensuite contre du papier-monnaie. Utu bon peon, logé et nourri par son patron, peut gagner de 20 a 30 pesos (fr. I-fr. 1,50 ) par jour. Les fruits récoltés sont mis dins de grands sacs et portés à dos de mules jusqu'aux machines, toujours actionnes par l'eatı, qui sćparent les graines de leurs enveloppes. Nous avonsété forl étonnés de voir combien les installations pour la préparation du café sont compliquées et combien cette graine doit subir de manipulations avant d'ètre livréc au commerce. De plus, comme toutes les machines nécessaires, fourdes et encombrantes, ont dì ètre transportées à dos de mules dans des régions éloignées des principales voies de communication, nous nous représentons sans peine combien de telles instaflations doivent étre couteuses. Le fruit est d'abord sépitrí de son enveloppe charnue, an moyen d'appareils assez, semblables à ceux qui servent à fonler le raisin. Les graines qui restent sont lavées, séchées au soleil dans de grands séchoirs, puis passées dans de grands cylindres oú circule de l'air chaud qui achève la dessiccation. La graine est encore entourée de deux enveloppes, l'une argentie, l'autre parcheminée, qui sont enlevées, soit à la main, soit à la machine. Enlin, les graines sont trices, presque toujours mécaniquement d'apres leur grosseur: alor's sculement te cal'é est prèt à ètre exporté. Comme toutes les cultures, le calëier doil ètre renouvelé périodiquement, car après un certaiu nombre d'années, le rendement diminne considerablement. (In 


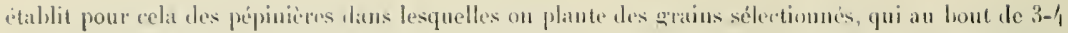
semaines commencent à lever ; lorspue les plantes ont ",in ì 1 m. de haut, on les transplante et elles commeneent a porter du fruit deux on trois ans apris. M. Bimberg nous donna des renseignements fort intéressints sur le rendement des plantations. Il y a dans le département d'Intioquia, environ

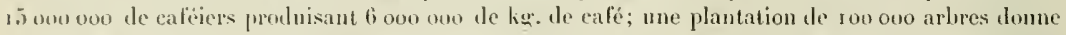
anunellement en movenne $40000 \mathrm{k}$. de calé. Le calcé de Colombie est de première qualité et très apprécié it l'étranger; il se vend lort cher, et en 1912, il a ćté acheté aux plantations, Pr. 1.40 le lign.

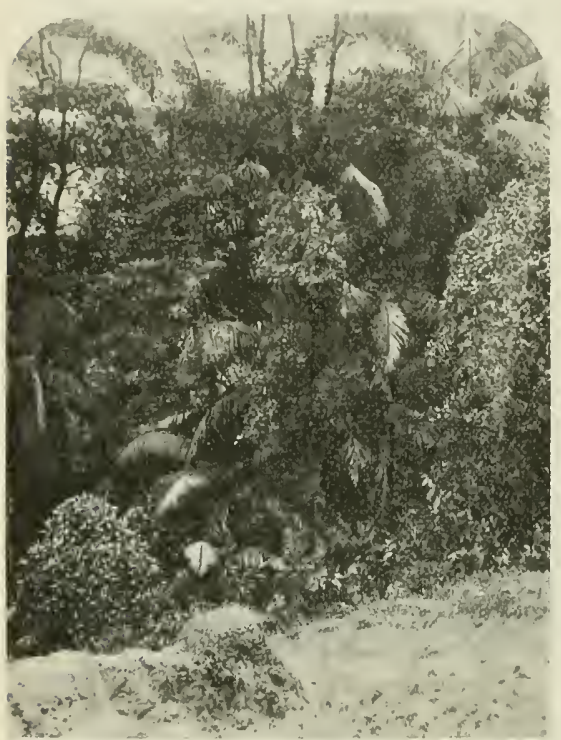

Forêt près de liuaca.

Dans atte région se trouvent aussi des plautations de milis pour les usiges domestiques et des plantations de cinne à sucre. Cette dernière graminćc (Saccharum of ficinarum) est des plus utiles et d'un rendement exeellent; un kilogramme de sucre hrut (panela) se vend sur place 10 pesos (5o cent.); on la cultive daus les régions chandes et humides. La plante se reprodnit par houtures el produit déji la premiere année; on coupe les tiges environ tous les six mois, et on n'en utilise que la partie inferrienre, sur ane longueur maximum de $1 \mathrm{~m}$. Lorsque les cannes à sucre sont mùres, les tiges prennent une couleur janne-brun très caractéristique; on les coupe et on les transporte à dos de mules, daus les moulins à sucre. Elles y sont écrasées entre deux cylinlres métalliques et le liquede qui s'échappe ist recueilli daus de gramdes cuves en cuivre placées sur un brasier. On fait évaporer jusqu'à consistance pâteuse et on laisse relroidir; le sucre brut brun se solidifie et on en fait des pains que l'on vend tels quels.

Notre centre d'opérations est situé sur le borl d'un grand bassin de terrains sédimentaires, appartenant surtont à l'époque crétacique; il est entonré à l'tist el à l'Onest par thes roches éruptives. Tonte cette contrée est, it juste titre, réputée pour ses richesses mincirates, et nous avons eu l'occasion de voir, au cours de nos nombreuses courses dans les environs, des mines d'or, d'argent, de charbon et de sel.

Une de nos plus intéressantes excursions lut celle à Gnaca (Éliconia) où se trouvent des mines de charbon el d'importantes salines. Quittant Lat Camelia de bonne heure, nous commencons par patanger daus les innombrables pantanos du Ilanc oriental de l'Alto Don Elias, et surtout dans cenx plus éponvantables encore, qui se trouvent à l'entrée du village d'Angelopolis, situé sur un grè̀s gris qui se désagrìze très facilement, ce qui explique l'état déplorable des chemins. Depuis Angelopolis, nous faisons un crochet pour descendre dans un petit vallon an fond duquel se trouve la Laguna Santa Rita (alt. $1720 \mathrm{~m}$.) oi nons recneillons quelqnes plantes et animaux intéressiuts. Nous visitons en passant une mine de charbon (alt. $1803 \mathrm{~m}$.), coustituće par une coucle de $2 \mathrm{~m}$. it $2 \mathrm{~m} .50$ d'épaisseur entre des couches de calcaire. L'exploitation est des plus primitives; ce sont de simples galeries, sans revêtement aucun, au lond desquelles, à coups de pioche, on enlive le charbon, 


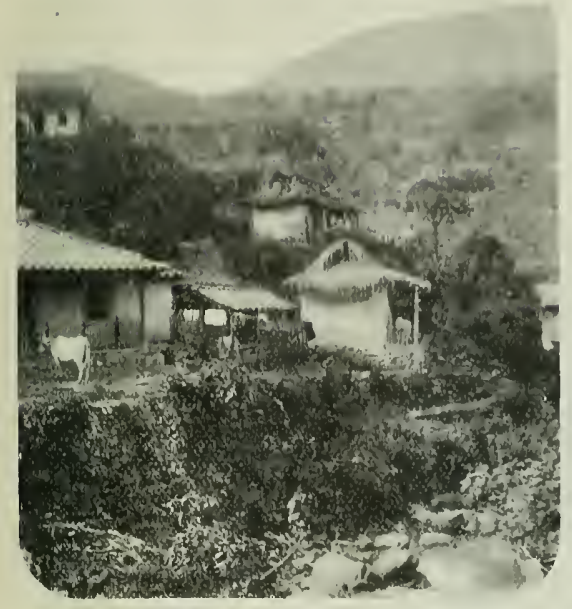

liliacit.

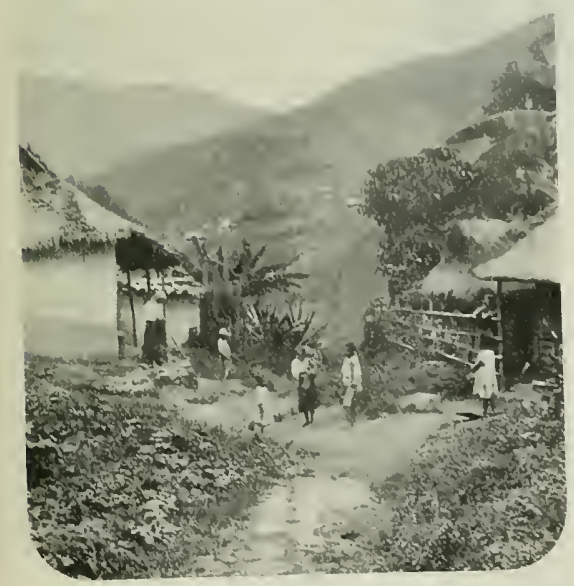

fillicit.

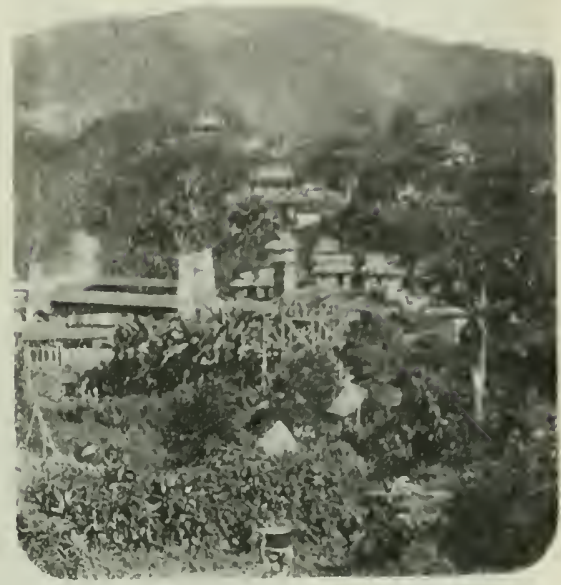

Silimes di. Guscis.

1.

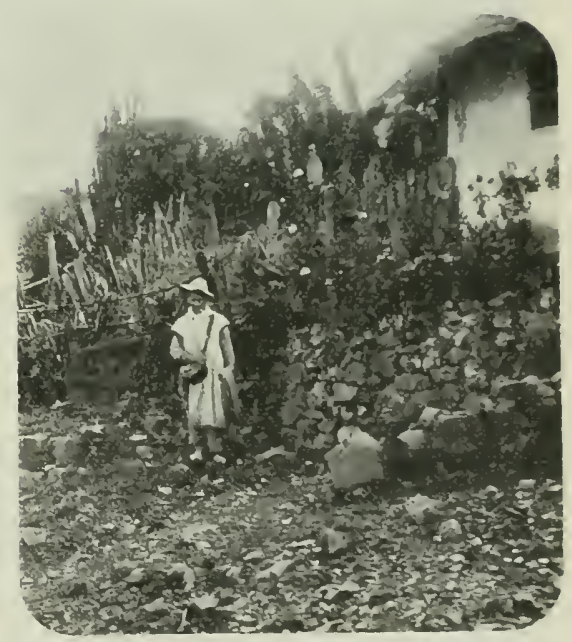

I'ris ale Guaca. Sutre arriero devant nn* haie te Ceruns. $r$, w. 
à la lueur vacillante de simples chandelles. Eu descendant i la Laguna par des sentiers détrempés et des prairies marécagenses, l'un de nous longeait un petit marais lorsyre, brusquement, le chemin s'éboule, et la mule. perdant pied, roule avec son cavalier en las un talus. Il n'? a heureusement ancun aceident à déplorer. mais la mule va s'enliser dans un hourbier où elle s'enfonce jusqu'au cou. Tous les efforts pour sortir li malheureuse bète de ce mauvais pas restent vains, aussi notre peon est-il obligé d'entrer daus ce hourlier infect pour enlever lia selle; la lète pent enfin se remettre sur pied el sortir de cette firchense situation. nou sans avoir suli une volée de cuups accompagnés de nombreux jurous. De l'aventure, notre belle selle colombienne, toute newe et pimpante, est entierement recouverte de hone et conservera toujours, malgré de fréquents nettoyages, des traces de cet accident qui aurait pu avoir des consiquences très graves. D'aprés notre carte, nous persions avoir a longer depuis Angelopo-

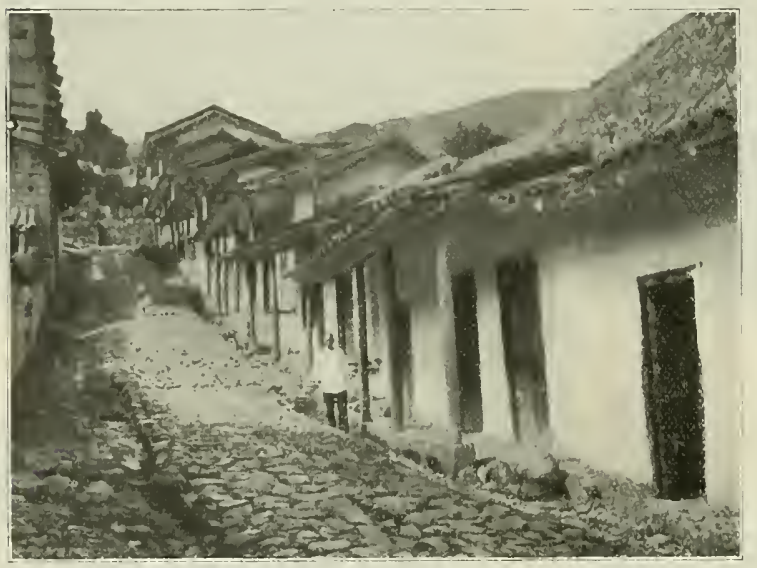

La rue principale de Guaca.

lis un vallon peu accidenté, mais, à notre grande surprise, nous avons à franchip quatre chaines de montagues séparées par de profondes dépressions. Au déluut, le eliemin était relativement bien marqué, mais à mesure que nous avangons, il devient de plus en plus indistinct et finit par disparaitre tout à fait, ce qui nous oblige à nous en frayer un tant bien que mal. Dans ces régions écartées, la forêt reprend ses Jroits, surtout le long des torrents, aussi avons-nous sous les yeux une végétation d'une richesse extraordinaire. Les fongères arborescentes de très grandes dimensions alternent avec des arlıres immenses et des palmiers élégants au trone grêle terminé par un mouchet de longues palmes pennées. Souvent des arbres entiers disparaissent sous une luxuriante végétation épiphyte ou parasite composće de plusieurs espèces d'Aracées, Broméliacées, Pipéracées, Orchidées, Cactées (Phyllocactus dont les tiges de plusieurs mètres pendent aux branches des arbres), etc. Enfin, nous arrivons au petil hameau de Pueblito, situé sur le chemin de Medellin à Armenia, et peu après, nous débouchons dans la vallée de Guaca.

Près de l'entrée du village de Guaca (alt. $1458 \mathrm{~m}$.), le chemin a complètement disparu et nous sommes obligés de suivre le lit de la rivière qui est heureusement peu profonde. $\Lambda$ l'entrée mème du village, les pantanos rendaicnt le chemin alssolument impraticable, et c'est par un sentier très raide que nous arrivons, par un dẻtour, sur la place principale. Nous nous mettons aussitôt à la recherche d'un hòtel, et le seul que nous trouvons est d'un primitif quelque peu exagéré. La seule chambre mise í la disposition des voyageurs est un réduit sans fenêtre dont le plancher est remplacé par la terre battue. On y entre par une ouverture que ne lerme aucune porte, aussi pour empêcher les nombreux curieux de nous importuner par trop, nous nous barricadons avec une vieille chaise boiteuse! Notre peon se couche dans le séul lit de la chambre, tandis que nous dressons à cóté nos deux lits de camp 


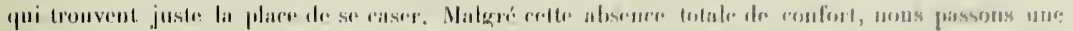

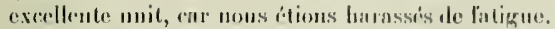

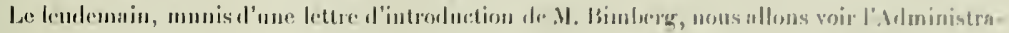

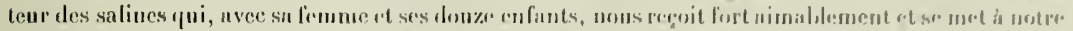

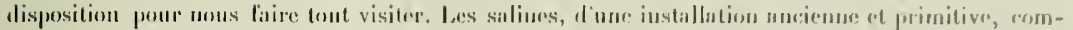

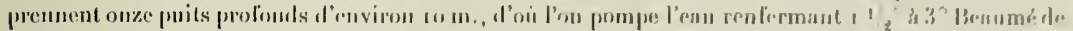

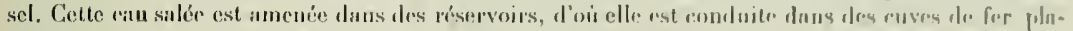

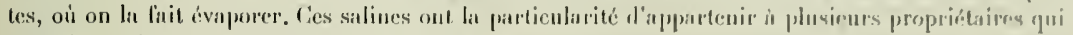
possident chacun un nombro dillírent do parts de chaque source. Il en risulte une tres gramble romplication prom la répartition de l'eau dans les euves d'évipuntution, rar charue série de euves ( 7 cuves forment um sćrie) n'úvajore que la part d'un seul proprićlatire el se trouve dans des harraquements dilferents. lien n'est plus rurieux que de voir l'embroit ou se fait la répurtition proportionuelle le l'eau. On voit sortir du réservoir, qui parfois reçoit l'eatu de trois sources de degric de roncentration lifle. rente, une quantité de tuyaux de diamitres dillients suivant les parts des proprietaires.

Le sel, une fois séché, est placé dans un petit sac en feuilles de "caña brava ) et expédié dans cet emballage rostique jusqu'i Medellin et alans les environs. Ces silines pouraient rapporter beaucoup plus si l'iustallation était plus simple, mais jusqu'it maintenant, malgré toutes les propositions laites, les iutéressés ont refusé de chauger leur méthode d'exploitation et de répartition. L'exploitation de ces sillines n'est possible que parce qu'il existe tout pres de

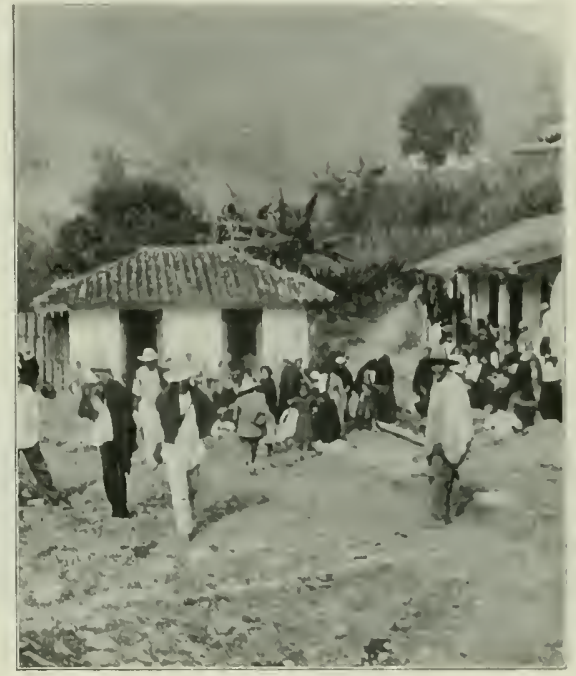

Le marchei de fiuaca. la un important gisement de charbon permettant d'extraire à peu de frais la faible quantile de sel que renferment ces sources. Bieu 'jue la production du sel soit un monopole de l'Etat. les salines particulieres de Guaca peuvent exister. par le fait que le degré de concentration des soures est inférieur au minimum imposé par l'État ponr qu'il dirige lui-mème l'exploitation. Après cette visite, nous faisons dans les cmvirons une excursion au cours de laquelle nous avons la chance de tecueillir quelques animaux intéressants et noureaux ${ }^{1}$, en particulier une rainetle (Hỵln Fuhrmanni) qui comme Hyla Göldi porte ses cufs sur le dos. Sur celle que nous trouvons, nous distinguons, à travers les membrancs ovulaires, les petises grenouilles complètement développées ; tans cette espèce, comme chez quelques autres trís rares, le stade de têtard fait défaut. Nous mettons également la matin sur un certain nombre de plantes fort intéressantes et nourelles .

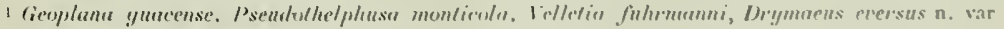
alula, n. val'. subula, Hyla fuhrmanni.

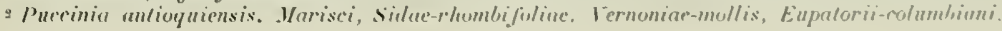


In retour de cette interessante excursion, nous trouvons devant laulieren M. Luis Gomez

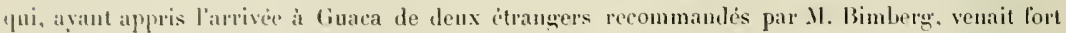
aimalilement nous tirer de uotre honge et uous oflrir l'hospitalite dans sa helle hacienda El Tirol alt. $1685 \mathrm{~m}$.). situéc ì y heure au-dessus du village. Nous te nous laisons pas prier pour accepter cefte clarmante invitation et nous partons apres avoir réplé notre note, 22.5o fr. en papiers colombiens pour une nuit et deux maigres repas! La propriété de $\mathrm{Ml}$. Comez se trouve an milieu d'une plantation de eafé on nous admirons de mignifiques arlores-parasols du plus gracienx elfet. I la tombce de la nuit, nous sommes accueillis fort aimablement par la nombreuse famille de M. tiome\%.

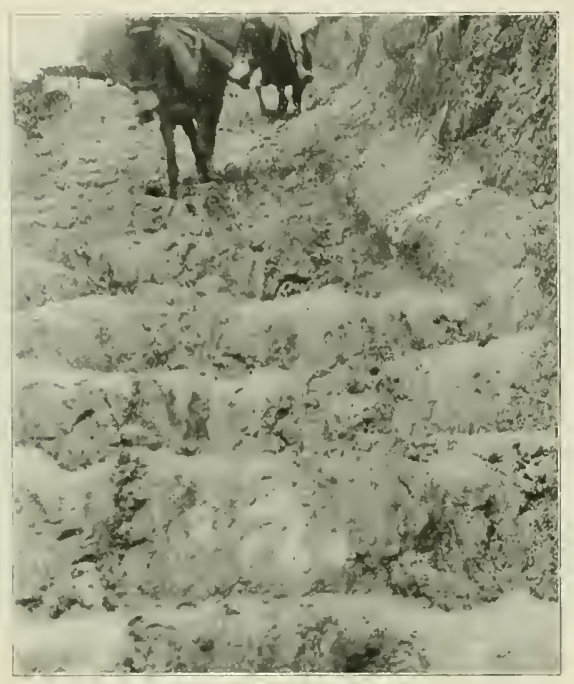

Pantanos pues ale Pueblito. Notre soirée se passe ì causer en lianģais et en anglais et, pour la première fois depuis bien des semaines, nous avons le plaisir de coucher dans des lits confortables el matleux. Le lendemain, nous prenons congé de nos hutes qui nous ont montré ce qu'est la large hospitalité colombienne et nous repartons pour La Camelia, accompagués de .l. Gomez qui a encore l'extrême ollligeance de nous mettre dans le hon chemin. Un orage lormidable avait éclaté pendant la nuit et les sentiers étiient encore moins praticables que la veille. En descendaut les pantanos de Pueblito, une de nos mules de selle tombe la tête la première dans le bourbier, en entrainant son cavalier qui n'a que le temps de se jeter liors de la selle. Plus loin, l'un de nous est désurçonné parl' une branche qu'il n'avait pas vue; occupé qu'il était à surveiller le chemin; enfin ailleurs, au moment de se laisser dévaler daus un sentier encaissé, étroit et rapide, les pieds du cavalier restent accrochés aux talus, tandis que la mule continue seule sa glissade en se raidissant sur ses quatre jambes. Le soir, après avoir traversé par une pluie battanto les terribles pantanos al'. Ingelopolis, nous arrivons exténués et couverts de boue at La Camelia.

Ipres claque excursion, nous sommes ol,ligés de rester quelques jours au logis pour mettre en ordre nos nombreuses el riches récoltes. ce qui nous permet de voir de près les gens et les choses. En dehors du caleetal de .1 . Bimberw, les habitations de cette région éloignée de tonte eivilisation sont rles plus primitives, généralement en bambous, à claire-voie et couvertes de claumes. L'intírieur comprend une seule piece, tris rarement deux; la cuisine se fait presque toujours sous m abri à còté de la maison. Le mobilier n'existe pas, les gens couchent sur des grabats en feuilles de maïs; le plus sonvent, le seul meuble que l'on reneontre est une malle en cuir hrut contenant les richesses de lat limille. Nous vivons tres frugalement à la mode du pays, et nos menus se composent invarialılement de potages. Maggri et de lait en poudre qui nous avaient été aimablement ollerts 


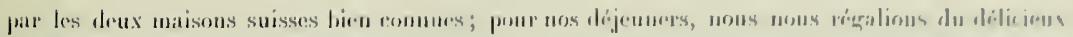

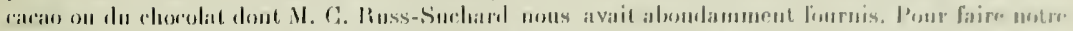

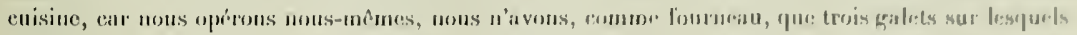

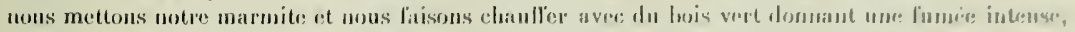

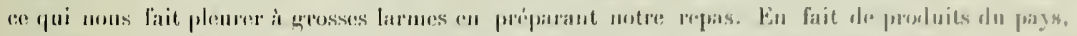

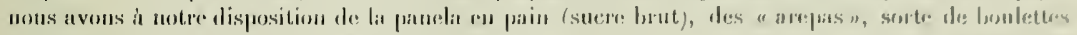

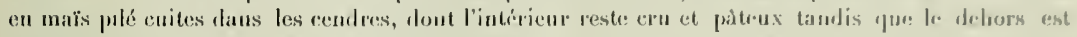

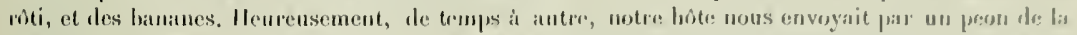

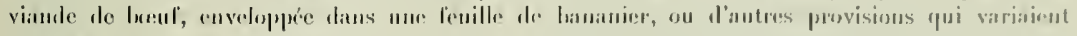
agrenblement notre orrlinatire.

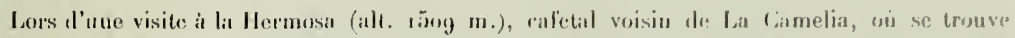

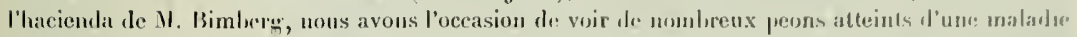

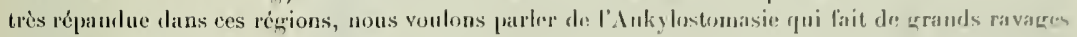
daus la population ouvrière res régions chaudes et tempéries de la Colombie. Celte alfedion est due ¿t un ver intestinal dı gronpe des Nématoales (Veralor americanus). Les malades présentent une ancmic profonde avee décoloration de la pean et des muqueuses, accompagnée de liablesse ginérale, de vagues doulenrs articulaires surtout aux genoux, de céplatlées, de palpitations avee bruits anormaux du caruret des vaisseaux et hico souvent d'une diarthée prol'use. L'inaptitude an travail suivi est un des symptomes caractéristiques et cause aux propricitaires de plantations des pertes sensilses, car leur persomel doit être augmenté pour foumir le

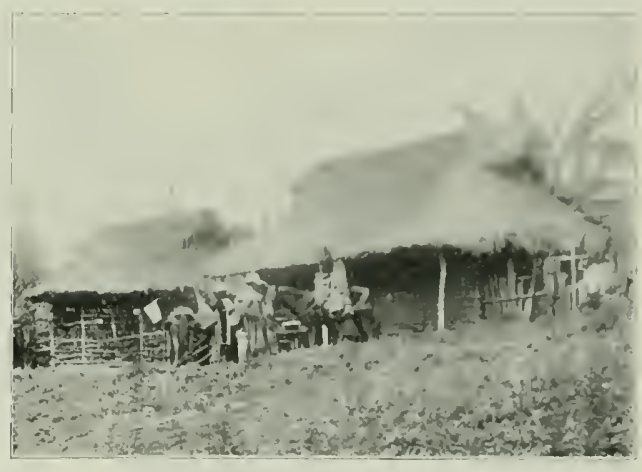

Mutles an summet de lidto de los Mpes. mine travail. Le "tuntun», comme on appelle cette maladie en Colomhic, ou tont an moins dans l'Intioquia, púnćtre daus le corps de l'homme par la voie buccale ou par la voie cutance. Chez les peous, cette lernière vore d'infection est de heaucoup la plus fréqueute, car ils marchent toujours un-pieds sur la terre humide: les larve. du parasite qui s'y trouvent penetrent lacilement daus l'organisme par les "candelillas n. erevasses nomlreuses ct souvent très profondes. De ces plaies superficielles, le parasite passe dans la circulaLion, arrive dans le couc droit et de la aux poumons. La larve quitte le systeme circulatoire, pénètre dans les bronehes, remonte la trachée pour descendre par l'usophage dans le tube digestif ou elle se fixe, (ie voyage très compliqué dure cuviron douze semaines, daprès les olservations récentes. Les Aukylostomes se nourrissent de sang et provoqquent sur la muqueuse intestinale de multiples saignées qui, répétées, déterminent cette anémie prolonde pouvant amener la mort si les parasites sont en trop grand nombre. D'apres les données de l'Institut Rockeleller, de Washington, on estime que $9^{\circ}{ }^{\circ}$ des ouviers de eampagne des zones chaudes de la Colombe sont atteints d'Anlyylostomasie, et l'on comprend qu'elle constitue un grave prohleme qui préoccupe ou devrait prcoecuper les gouvertuments des pays tropicaux et suh-tropicaux de l'. I mérique à cause de ses ravages. Ifin

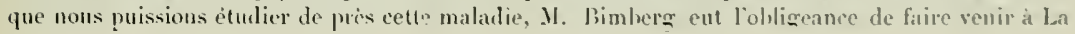


Camelia trois ouvriers malades. Après avoir examiné les divers strmptòmes de cette alfection, nous l'arons traitée en administrant du thymol et un purgatif énergique. Nos gens ayaut été prévenus du but que nous poursuivions, tirent leurs éliminations fécales sur les leuilles de bananiers où, tout à loisir, la loupe et la pince ì la main. nous avons pu reeueillir en grand nombre le Vecalor americanus, ce ver long de quelques millimètres et qui cause cette endémie si terrible.

Pendant notre séjour à La Camelia, nous faisons une excursion d'une semaire aux mines d'or de Zancudo et au bord du Canca. Pour arriver à Zancudo, dont nous vovons les huttes dans le loin-

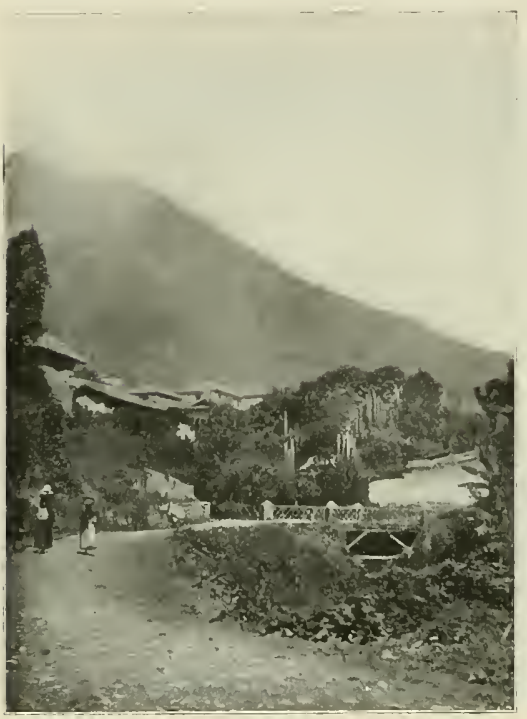

Entrée de Titirili. tain, nous sommes obligés de descendre jusqu'aı fond de la profonde vallée de l'A maga qui coule à nos pieds, et de franchir à gué cette rivière (alt. I $800 \mathrm{~m}$.) sur laquelle il n'y a pas de pont. Les eaux étaient très hautes, par suite des fortes pluies de la nuit, et lorsque nous arrivons an bord de la rivière, nous voyons qu'elle est infranchissable à cause de la rapidité du courant. Nous sommes obligés d'attendre patiemment - cela arrive souvent en Colombie - que l'Amaga devienne moins tumultueuse. Après quelques heures, nous cherchons un endroit favorable et nous traversons sans accident, tandis que nos peons s'accrochent à la queue de nos mules pour ne pas étre entrainés par le courant. Nous gravissons ensuite une colline aride pour arriver ì l'Alto de los Alpes (alt. $1782 \mathrm{~m}$.) d'oni l'on jouit d'une très belle vue. Derrière nous s'élève la chaine de l'Alto Don Elias, sur le flane abrupt duquel est perchée La Camelia; devant neus, nous voyons le vallon où se trouvent la petite ville de Titiribi, les mines de Zancudo et les hauts fourneaux de Gitio Viejo.

Titiribi (alt. s $584 \mathrm{~m}$.) ressemble à tonte les villes colombiernes et présente, comme seule particularité, de jolis bosquets de bananiers et de magnifiques Cereus qui se dressent dans les airs

a plusieurs metres de haut. Comme il se fait tard, nous ne pouvons aller plus loin et nous cherchons une auberge pour y passer la nuit. Celle où nous descendons est primitive, mais relativement confortable, malgré la vermine qui nous dévore. Au moment où nous allons nous coucher, l'hôtesse vient nous dire que toutes ses chambres disponibles sont occupées et nous demande si nous consentirions à avoir "una señora muy estimada" dans le troisième lit de notre chambre! A la dernière minute, les dispositions furent changées et nous n'avons pas, comme beancoup d'autres voyageurs, l'honneur d'avoir une compagne de chambre! Le lendemain, nous ne disposons prour notre toilette que d'une toute petite cuvette d'émail et d'un minuseule pot à eau commun à tous les voyageurs. Cet ustensile, un linge de toilette et une brosse à dents se trouvent dans un coin du corridor à la disposition de chacun!

Nous réservons pour notre retour la visite des mines d'or, et nous partons pour les bords du Cauca. Le chemin descend rapidement en écharpant la partie inférieure de la vallée de l'A maga et lorsque nous sommes à $800 \mathrm{~m}$. d'altitude, nous constatous un changement de végétation très marqué; nous sommes 


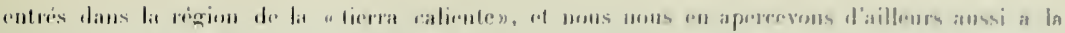

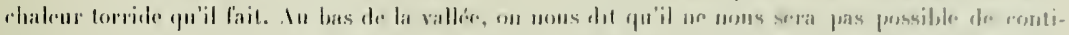

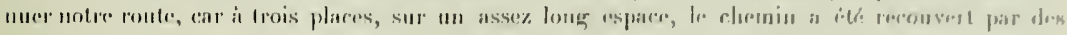

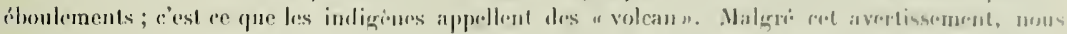

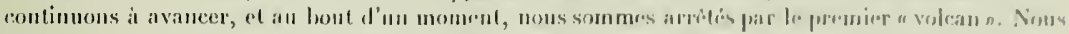

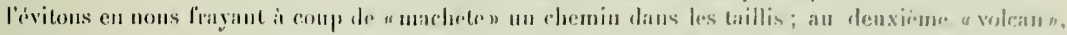

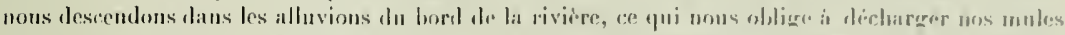

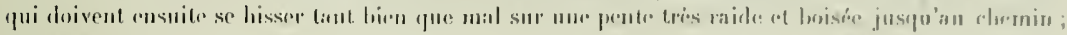

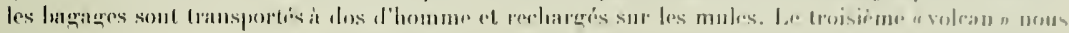

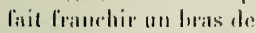
la rivione gue mous deroms relraverser ensuite pous eprendre nulde rouke. I lone de prine, nous arrivons all Paso de linucordia au hord du Canca, re graud aflluent du Magdalena. Ses eaux sont jimues et houeuses el la ripidité du courant le resul impraticable ì la navigation, sauf daus reytaines parties de son cours.

Nous traversous le fleuve a hord d'un grand bac sur lequel s'entassent gens et bites, pour débarquer à Puerto de Los Pohres

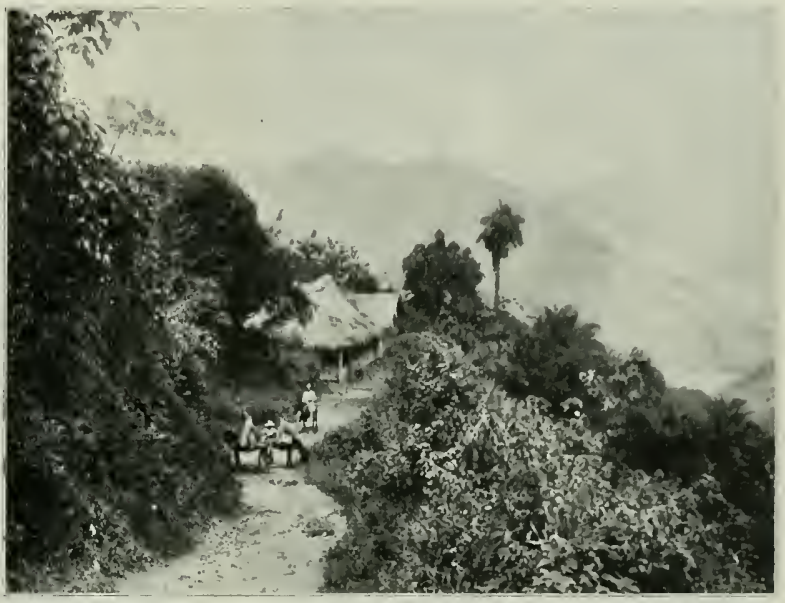

La vallée du Cauen, vue de celle de l'Imaga. (alt. 673 m.), où se trouve une auberge. Cette tocaliti se compose seulement de quelques luttes au pied de la premiere elaine des Cordilleres occidentales. Dins l'auberge se trouve un petil bar où sarrétent les caritvanes de passage pour se rafraichir avec de l' aguardiente" ou "anisado" (eau-de-vie renfermant de l’anis) ou du "gुurapon " (breuvage à l'aspect boueux ohtenu par la fermentation du jus de la canne à stere). Giace à une lette d'introduction de M. Bimbers, nous sommes tries aimablement resus par l'auhergiste, Mexandro Mejia, qui met sa propre chambre à notre disposilion et va s"installer avee sa femme dans un riduit roisin.

Pendant quelques jours, nous explorons les rives du Canea et parcourons quelque peu les grandes forèts vierges qui hordent le lleuve; nous y retrouvons la mine vegutation exubérante que nous avions admire le long du Magdalena. Sur les arbres immenses se développent ces lianes flexiWles, parmi lesqueltes nous remarquons une magnifique Jalpighiacée (Banisleria argentea) dont les feuilles argenties et les grappes de fleurs roses s̈épanouissent au somnet des arbres. el toute ectte flore épiplỵte si riche et si variée. Ce sont les fougères surtout le heau Polypodium decnmanmm), les Pipéracies (Peperomia), les Aricées Plyllodendron). les Broméliacées surtout les Tillnurlsia), lessuperhes Cactées (Cerens brirnnirmsis el Philloraclus spec.), dont les tiges recou- 


\section{- in -}

vertes de grandes fleurs d'un rouge échtaut pendent de plusieurs mètres aux branches des arlores. Nous voyons aussi de merveilleuses Grchidées, aux lleurs élaurges comme forme el comme coulenr. Quand la foret riest pas trop tonflue, nous rencontrous des Solanum, des Moracées (Dorsteniu controjererr). des Tiliacées, des Pi péracées, de gigantesques Cerrus, des Urticacées, des Boragimies

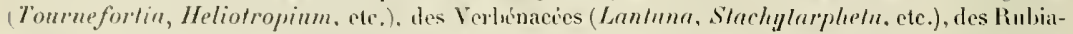
cíves, les tionvolvulacées, etc., sans parler des innombrahles lićgumineuses et Composies, des Palmiers en grand nomlire dans les régions détooisées on dans les tailfis, et des (iuaduas (Bumbusa (inadua). nombreux le long du flenve. Dans la forêt, le long du fleuve, nous arons l'orcasion de
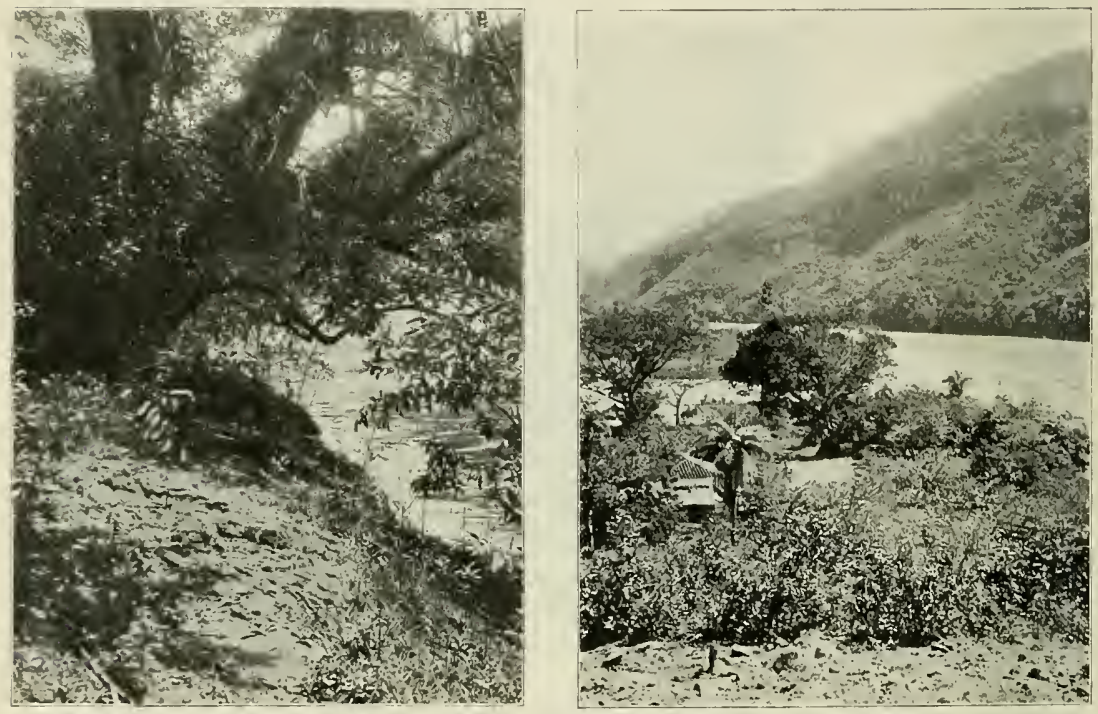

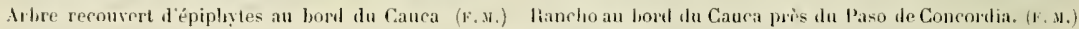

récolter un fort joli clampignon appartenaut aux Gastéromyciles, Gerasler cf. saccalus (esperce étudiée et déterminće par M. le I)" prof. Eul. Fischer, de Bernej. I

La richesse de la faune ne correspond pas it celle de la llore, exception faite pour l'avifaune très brillante et très variée, ainsi que pour les papillons représentés par une foule d'espéces aux couleurs les plus éclatantes, particulièrement un Papilio d'un blen d'azur merveilleux ayant environ $20 \mathrm{~cm}$. d'envergure, véritable géant de ce groupe.

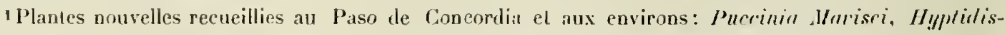
mutabilis, Baccharirlis-rhe.rinirlis; Coleosporium Fissheri; Peperomia marentricha.

Animaux nouveaux: Geoplana cancensis, Rhinotrilus bicolor, Rhizomyrmn fuhrmami, Rubution fuhrmanni, Spirostrepius ruralis, Sp. ineonstans, Stemmaloculus horlensis, thinorricus semiplumbens, Cametiunus fuhrmanni, Conulus fahrmanni, Scolotonla santonainsis n, var. depressa, Leplinatio cancensis. Leiostrarns studeri n. var. iris. 


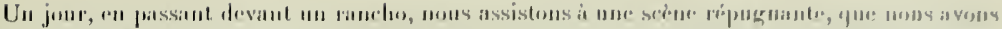

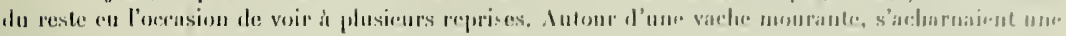

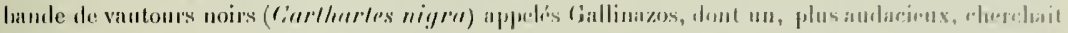

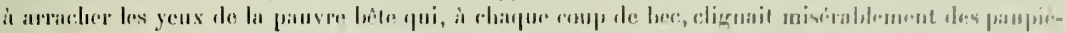

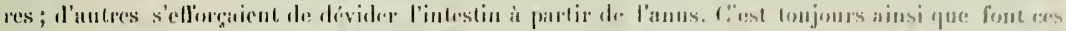

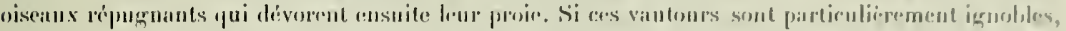

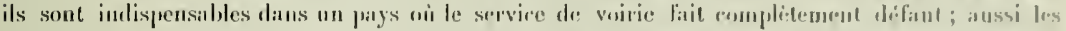

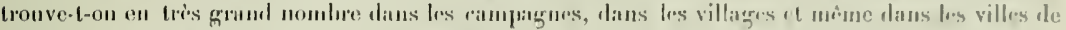
lonte la Colomblie. Comme leurs servicess sont estimés ì leur juste valeur, ils sont protégés par les habitants et deviennent prespue des animanx domestipues el "pprivoisés.

Dans celle vallée du Cauca, profondément encaissce entre denx hautes chaines de montagnes, la nuit vient plus tot et plus rapidement que dans les autres eulroits situés à lin mene latitude. Le soir, assis sur de hautes chaises dout on appuic le dossier aus murailles des maisons, nous nous balamgons comme les labitants du pays et nous admirous les lucioles et les "cocuyos", lanulis que les cigales ne cessent de remplir l'air de leurs cris stridents et que le fleuse coule lentement en murmurant ì nos pieds. Un soir, un indigine, inspiré par la benuté de cette muit tropicale, commence it improviser un hymne patriotique entlammé et clélirant qu'il déclame d'une voix tonitruante pendaut plus d'une heure.

Malgré la lreauté de ces licux, nous n'y prolongeons pats notre séjour, parce que nos récoltes n'y sont pas des plus fiuctueuses ; nous repartons pour 'Titiribi, en suivant to même chemin qǚ̀ l'aller. En traversant le Heuve, nous voyous le eadave d'une vache

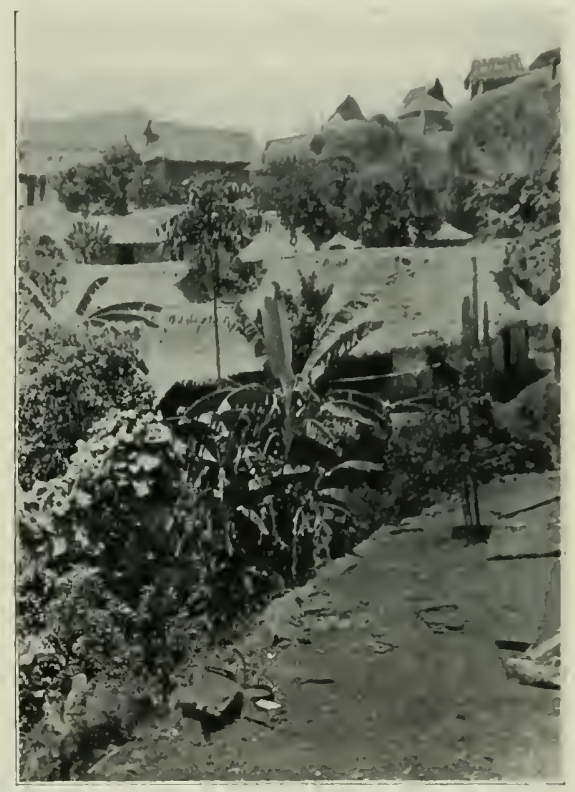

Zancudo. entraiué par le courant; deux gallinazos, installés sur la bête, dévoraient consciencieusement leur proie malodorante, en se laissant allor au fil de l'eau. Nous nous arrotons à Titiribi dout nous voulons visiter les mines d'or et l'argent et nous protitons des quelques heures qui nous restent avant la nuit, pour aller voir le doeteur Calle qui nous regoit fort aimahlement et nous donne des details interessants sur letat sanitaire de la région. Nous avous l'oceasion d'examiner une maladie très curieuse, particuliẻre a la Colombie où elle est très fréqueute: le Carate. Cette maladie de la peau. qui s'attaque surtout au visage, aux maius et aux pieds, est produite par un champignon du groupe des Aspergillns et se présente sous des aspects diflírents. Chez les uns, la peau devient grise, chez d'autres, violette. bleue, rougre ou noire, mais le Carate bleu est de beaueoup le plus fréquent. La maladie en ellemème n'est pas dangereuse, mais clle est pour le moment rebelle à tout traitement el elle donne aux 
malades un aspect très partieulier, voire mème risihle on grolesfuc. Actuellement les recherehes sont trop peu nombreuses, pour que l'on siche si les divers larate sont dus it un seul et mème parasite. Quant à l'étiologie de cette maladie qui, d'après Montoga ot Uribe, atteint le $4 \%$ de la population ourrière colombienne, elle est encore inconnue ; cependint ces auteurs estiment que les puces, punaises et autres parasites du corps humain, sur lesquels ils ont pu observer quelques lormes ispergillaires, Joivent jouer un röle dans sa transmission.

Le lendemain, nous descendons a Zancudo, afin de visiter les mines d'or les plus connues de la Colombie, exploitées depuis plus de cent ans par une compagnie exclusivement colombienuc. Les galeries sont trìs nombreuses et forment un réseau souterrain, de $7^{5} \mathrm{~km}$. de long. Le minerai se trouve dans des schistes fortenent inclinés, reposant sur la roche íruptive. Par ci, par lá, des

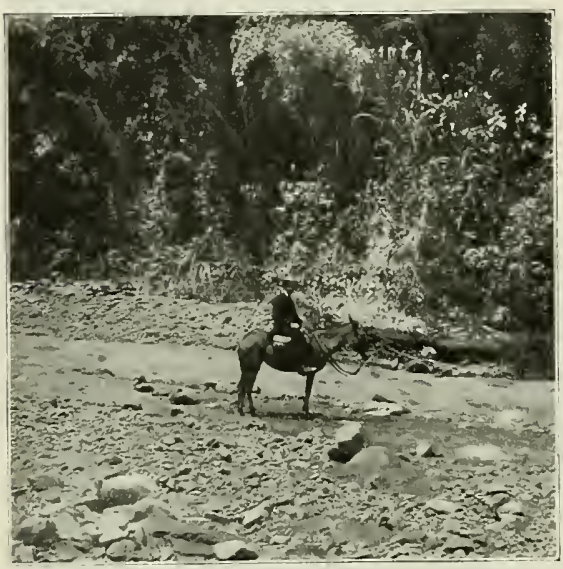

Au bord de limaga. Lisiẻre de la forêt asec des Guaduas et Conos bravos. rannifications du filon pénètrent daus des conglomérats qui reposent sur des schistes; it d'autres endroits, comme à la mine Altos Chorros, au-dessus de Zancudo, le congloméral aurifère se trouve directement sur la roche cruptive. On extrail par mois 1500 tonnes de minerai, dans lequel la proportion entre l'or et l'argent est généralement de 1 is 10 . Ce minerai est conduit dans $1 / 4$ moulins autioquieus avec 120 pilons et 2 moulins californiens simplifiés avec 54 pilons. Les moulins californiens étant très conuus, nous nous bornerons à parler des moulins antioquiens très caractéristiques. Ils sont entièrement en bois et actionnés par l'eau qui fait tourner une grande roue. L'arbre de couche est muni de dents en bois qui soulevent des pilons en bois dont l'extrémité inféricure est revêtue d'un fort manchon de fer. Un ouvrier pousse continuellement sous ces pilons le minerai qui, au bout d'un certain temps, est devenu une fine poudre qu'un faible courant d'eau entraine sur un plan fortement incliné, recouvert de nattes en tissu à longs poils. L'or se dépose sur ces nattes, tanlis que le reste continue à descendre vers la vivière qui coule au fond de la vallée. De temps à autre, on secoue les nattes dans une cuve en bois remplie d'eau. Le sable très fin et très riche en or se dépose an fond de la cuve; on le lave ensuite sur la battce, sorte d'assiette en bois ou l'on met le sable avec une petite quantité d'eau. Par des mouvements rythmugues, on élimince peu à peu le sable et il ne reste plus que l'or. C'est de cette manière, plutôt primitive, qu'on exploite presque toutes les mines de Colombie. A Zancudo, une partie du minerai, qui renferme des sulfates, doit subir des manipulations spéciales et assez compliquées. On le conduit a dos de mules, et par des sentiers épouvantables. a Citio Viejo, ou se trouvent des hauts fourneaux et des installations de. cyanuration organisėes par un ingénieur suisse, le Dr Zïrrcher, actuellement á Medellin. Le charbon nécessaire pour les hauts fourneaux se rencontre en trés grande abondance à $500 \mathrm{~m}$. à peine de là, sur le versant occidental de l'Alto de los Alpes. Entin, comme surcroit de conditions favorables, tout près de Zancudo se trouvent les graphites et la terre utilisée pour la construction des hauts fourneaux. Malgré ces conditions d'exploitation avantageuses. malgré la richesse du minerai - on 


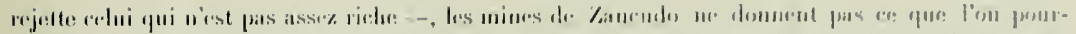

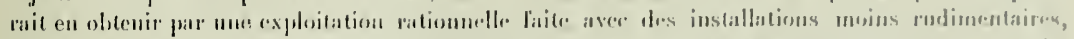

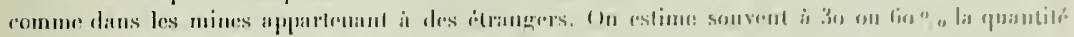

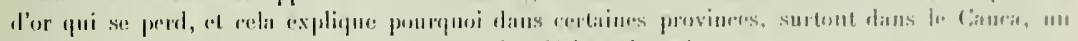

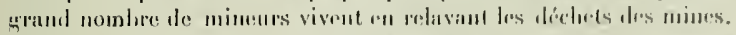

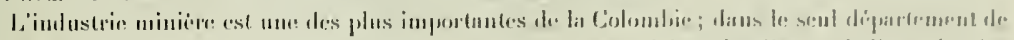

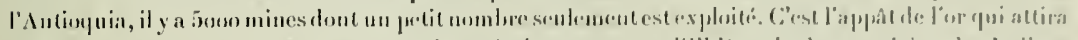

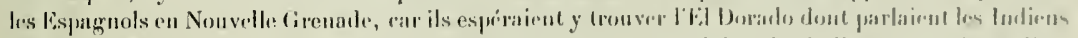

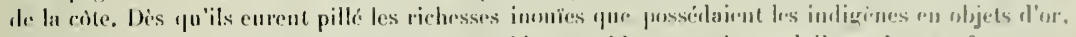

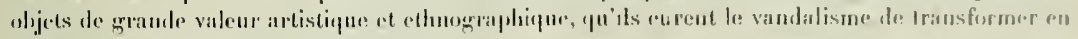
limgots, ils se mirent it exploiter les mines. Cor sont les provinees d'Intiuguia, du Citura, da Choce, de Santander et du Tolimat qui fommirent et qui fomrnissent eneme ir plus d'ur el d'argent. Malerri les révolutions liéyuentes qui artionent continuellement le developpement des mines, lis production est toujours restéc consibéralile et, avaut la découverte des mines de Californie et d'dusunalic, la Colombie daic le pays le plus riche en or. Hn estime à fr. 3 goo ono oon la production antiliere alepuis lit conquite; actucllement, la production annuclle est de lix. r 5 i 20000 on'. La Colombie redeviendra sans donte une seconde Californie lorsque lexploitation des mines seru plus importante, grâce au capital étranger et à la consturuction de voies de communication plus rationnelles ef maticables. C'est la rigion du Choco qui renferme les plus riches placers d'or, diargent el de platine; daus les alluvions du Rio

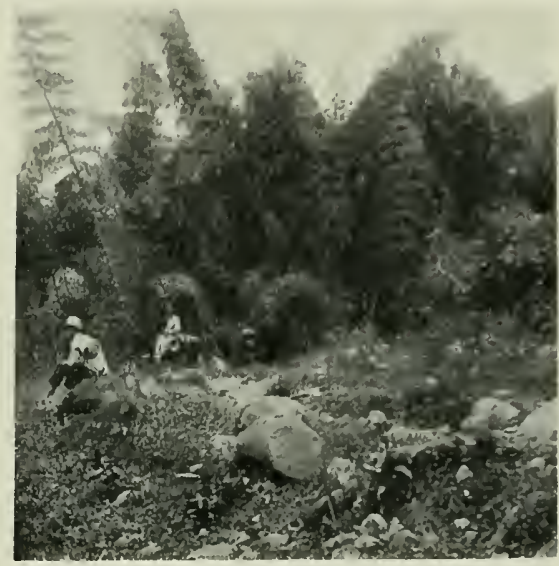

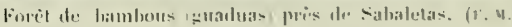
Tamana et dı Rio San Juau, on trouve des pépites de platine pesant de 200 a 300 err. el valant de bur a gou lir. Irtuellement, fresque tout le platine nous vient de l'oural, et comme si valeur est le louble de relle de l'or, on rompremil sans peine l'importince que prendrait cette exploitation.

Iprès avoir visité cu détail toutes les installations des mines, nous regagnons Titirili en traversint les quarticus hahités par les ouvriers. Ce sont surtout des mulàtres. décimés par l'antirlostomasie et la luberculose. Par le mème chemin, nous arrivons à La Camclia, apris avoir traversé sans encombre l'Imaga dont les eaux ćtaient relativement lrasses.

Quelques jours avant de quitter La Cimmelia, nous allons visiter. en compagnie d'un de nos compatriotes, M. Bachmann, unc plantation de café qu'il possède avec M. Heiniger et qu'il a appelée La Suiza. Ce cafetal est situé au sul de Titiribi. Nous derons d'abord alteindre l'I maga, ce que nous faisons en nous laissant dévaler, à dos de mules, le lonģ l'une pente très rapide. dépourvue de sentiers et en nous frayant un passage d coups de "machete ", dans les taillis qui bordent un tor. rent tributaire de la rivière. Nous traversons à gué le Rio Inaga à plusieurs reprises. cherchant le

I Ilenry Jalux. La République de Colombie. Bruxelles, jq̣og. 
ehemin qui nous conduira a Salualetas. Sahaletas eut une période de prospérité, au moment où il possédait les installations dans lesquelles on traitait le minerai de Zancudo. Ce village est situé sur les mèmes terrains sćtlimentaires que Titiribi et Guaca et on y trouve en abondance le charbon nicessaire aux hauts fonrneaux; depuis que ceux-ci ont été transportés à Citio Viejo, Sahaletas est abandonné et u'est plus qu’un misérable hameau. $A$ une heure de là, nous pénétrons dansle cafetal la Suiza. Cette plantation suisse passe, à juste titre, pour ètre une des plus belles, si ce n’est mime la plus lielle de l'Intioquia. Nous constatons avec grand plaisir l'état excellent dans lequel se trouvent la plantation et toutes ses installations. Ce qui nous frappe le plus, e'est d'y voir de tres bons chemins, ce qui pronve qu'avee du savoir-faire et de la honne volonté, on peut avoir, mème en Colombie, des voies de communication convenables. Après un repas l'rugal, nous montons au-dessus de la plantation, d'où nous jouissons d'une

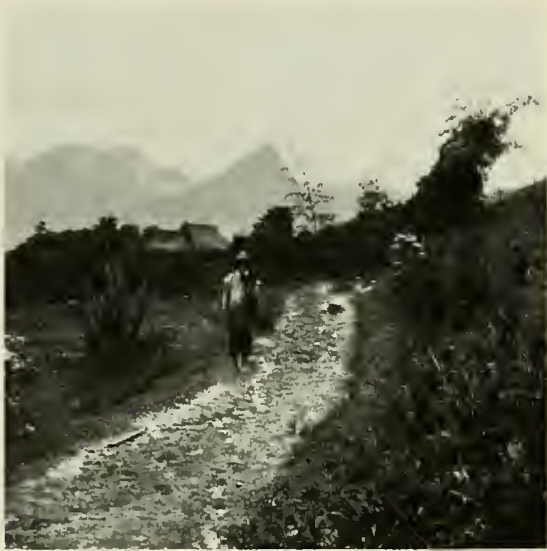

Près de Siabaletas.

Dins le lond le Cerro Bravo et le Cerro Tusa. (r. . . vue magnifique. A nos pieds s'étendent la plantation, puis les “tierras calientes» de la vallée du Rio Sinifana, au dela de laquelle se dressent le Cerro Tusa et le Cerro Bravo, deux montagnes pyramidales, les premières que nous voyons ne pas avoir un sommet arrondi. A notre droite scintillent les méandres du Cauca que nous traverserons dans quelques jours pour gagner Manizales. Après une nuit passce dans une hacienta voisine du eafetal, nous nous dirigeons vers Titiribi pour rentrer i La Camelia.

Malbeureusement, notre sćjour i La Camelia touche a sa fin, et nous devons songer it continuer notre voyage du còté de Bogota. Gràce à $\mathrm{M}$. Bimberg, qui a mis à notre disposition, non seulement une habitation, mais encore plusieurs de ses peons pour nous aiter dans uos recherches et les mules nécessaires à nos excursions, nos récoltes en animaux et en plantes de cette riche contrée ont été très abondantes. Le soir, les peons apportaient dans des tubes ou dans des boites prêtées ou simplenent dans des feuilles de bananiers, le produit de leurs chasses. Nous y trouvons une foule d'espèces du plus haut intérêt, parmi lesquelles nous citerons des Péripates, des Planaires terrestres et une quantité de Myriapodes et Scorpions. Ceux 'jui nous apportaient des Mygales, ces énormes araignées poilues, aux longues pattes poilues aussi et aux mandibules acérées, les amenajent attachées ì un brin d'herbe $\mathrm{ct}$ avec d'infinies précautions, pour éviter leurs morsures qui peuvent être dangereuses.

Le 20 septembre, après avoir emballé les nombrenses caisses renfermant nos précieuses collections, nous quittons La Camelia où nous avons passé de si belles semaines et nous regagnons Medellin par le mème chemin que celui que nous avions suivi à l'aller. En gravissant les pentes de l'Alto Romeral, nous pouvons voir jusqu'où va l'entêtement d'une mule. $\Lambda$ peine avons-nous fait qquelques mètres que l'une de nos mules de selle commenee à s'arrêter tous les dix pas el ne se remet en route qu'après avoir eu le tlanc labouré de coups d'éperons. Bientôt, elle refuse de mareher el ni les injures ni les coups distribués à profusion, ne lui font faire un pas en avant. Foree est donc au cavalier de descendre et de suivre à pied. Une fois déchargé, l'animal marche pendant quelques mètres, 


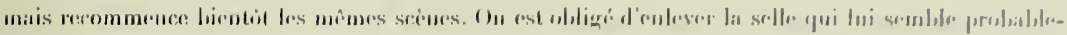
ment trop lourde a

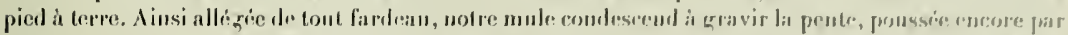

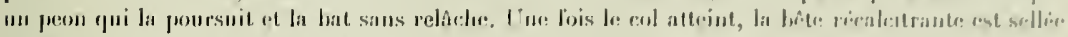

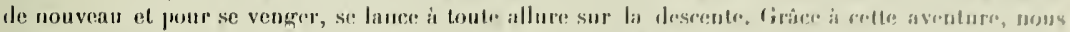
perdons quelques leures et mons n'arrivoms que de unit is . Veedellin. 


\section{CHAPITLE VII}

\section{De Medellin à Bogota.}

Du 21 au 25 septembre, nous restons à Medellin pour faire nos derniers préparatil's eu vue de eontinuer notre vayage sur Manizales et Bogata. Pour diminuer nos bagages, nous expédions directement à la còte toutes les caisses contenant nos collections et nous ne gardons avec nous que le strict nécessaire, aussi nous n'avons plus besoin que de quatre mules de charge. Le 26 . nous quittons Medellin après avoir lait nos adieux à nos compatriotes, et tout particulièrement à M. Bimberg, qui pousse encore l'amabilité jusqu'à nous donner plusieurs lettres d’introduction qui, dans la snite, nous seront d'une très grande utilité.

Naus suivons d'ahord la même route que pour aller à La Camelia, nous repassous à ltagui, puis, laissant à notre droite le village d'Estrella, nous prenons le chemin qui, au fond de la vallée, suit tous les méandres de la rivière. Inn peu avant Caldas, petite localité à laquelle on a douné le nom du célébre naturialiste colombien décapité par les Espagnols lors des guerres de l'Indépendance, la vallée est ferméc par un chaînon transversal, reliant les deux versants et au travers duquel le Porce a clì se fraver un étroit passage. Sans doute, il existait jadis au-dessus de ce chainon un bassin lacustre qui a dì se vider en formant une cascade dont la hauteur diminıait à mesure que l'érosion rreusait plus profundément les roches.

I Primavera (alt. $1860 \mathrm{~m}$.), nous retrouvons nos bagages, et le lendemain matin, à cinq heures et demie, nous sommes déjà en selle et nous commençons à gravir en zig-zag l'Alto San Miguel où le Porce prend ses sources. 'Tout d'abord, nous traversons de maigres pâturages, puis nous alteignons la forêt; a vant l'y pénétrer, nous jetons un dernier regard sur le Porce qui étincelle aux rayons du soleil et qui traverse une vallée riche et fertile alors que le sommet des hautes chaines des Andes centrales est occupé par de grandes forêts. $A$ io h. du matin, nous atteignons un col (alt. 2/78 m.), d'où malheureusement nous n'avons pas une vue très étendue, puis nots commençons la descente après une petite halte. Nous traversons le hameau de Versailles (alt. 2284 m.), qui ne ressemlile guère ¿ la ville du grand roi, car il ne se compose que de misérables luntles dont plusieurs sont en construction. Nous voyons de près la manière de procéder dont nous avons déjà parlé, et ì côté de chaque lutte, nous remarquons un trou p'us on moins profond d'ou l'on extrail à mesure la terre nícessaire it la construction des murs. l'ar des chemins relativement hons, is travers un pays tries accidenti et malgré cela monotone, nous arrivons ì Santa Barhara (alt. $1928 \mathrm{~m}$.), petite localité située sur les derniers contreforts des Andes centrales et d'où la vue sur la vallée du Cauca et les Andes occidentales est très étenduc. Nous nous arrêtons pour manger dans la seule auberge de l'endroit et nous y sounmes servis par un gramin qui n'avait certainement pas vu d'eau depuis plusicurs semaines. Ivant notre repas, comme uous désirons faire un peu de toilelle, ou nous introduit dans une chambre sur 


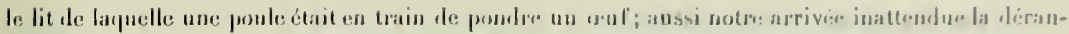

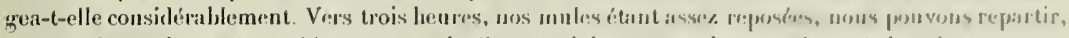

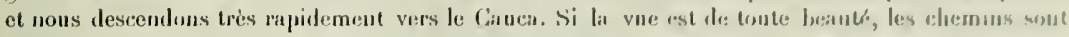

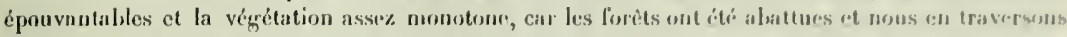
seulement quelques-unes qui deviennent de plus en plus imposanles à mesure que nous descemulom vers la "tierra ealienten. Un jeu a vant d'atteindre libtape du soir, nous rencontrons un caravan. de mules littéralénent convertes do boue des pierls in la tête. Carci nons laisse suppouser que le chemin ne doit pas ctre exrellent; en effet, quand nous demandous a l'un des peenrs quel est l'blat do scrotiur, il nous répond ces mots, que nous ne connaissons, hélas! que trop hien : «. Muy malo, Surueres o. A peine avous-nous eroisé la caravinc, qu une de nos mules de charage s'culise si profondément inass la

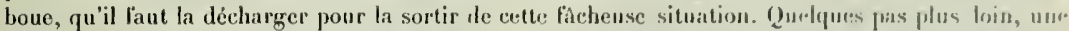

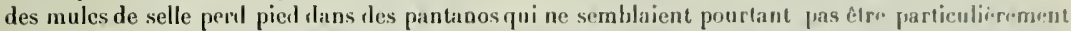
manvais, et s'enfonce si brusquement, que le cavalier est projete hors du la sille dians lat hour cruantu. Pen après ces incidents, nous atteignons, à la tombéc de la nuit, un refuge situé tlans la forêt "t nous décidons d'y passer la muit. Cet enciroit ne porte pas de unm; sur la prorte de lia maismon ast catte seule inscription : " $\mathrm{El} g^{3}$ " (alt. $845 \mathrm{~m}$.).

Nous nous trouvons dans cette auberge avec unc earavane transportant du talac. Ninus jassons la soirée en compagnie des peons avec lesquels nous nous efforgens de eauscr. Nous tlistribuuns des cigares aux hommes et aux femmes, et, à notre demande, ils se mettent à chercher sur eux des " niguas", ces fameuses puces pénétrantes des régions tropicales. La femelle a la déploralile hillitude de se loger sous les ongles des orteils oủ elle produit des démangeaions insupportables. Péu à peu, l'abdomen de l'animal se gonfle démesurément par suitc du développement des a'ufs et peut atteindre la grosseur d'un petit pois. La présence de ce parasite devient dangerense si, en so grattant, on écrase l'animal, car cela peut amener une infection accompagnée de suppuration et parfois même d'infection généralisée pouvant devenir mortelle. Il faut done extraire ees animaux sans les blesser ; c'est ce que savent très bien faire les peons qui marchent toujours pieds nus, et surtout certaines Indiennes, dont c'est la spécialité. Elles passent leurs journées à inspecter les orteils et à les débarrasser de ces parasites; une fois l'opération terminće, en guise d'antiseptique, elles crachent sur la plaie!

Avant de regagner ce qui nous servira de chambreà coucher, nousadmirons longuement la beauté de la nuit tropicale, si calme, illuminée par les lucioles et animée par le cri des cicades. Lorsque nous nous couchons, quelques chauves-souris tournoient silencieusement autour de nos têtes. Au bout d'un moment éclate un orage formidable. comme on n'en voit que sous les tropiques, accompragnè d'une pluie diluvienne, qui nous fait prévoir que, le lendemain, nous aurons à nous débattre au milicu de pantanos plus terribles encore que ceux de la veille. Le 28 septembre an matin, nous quittons ces lieux enclsanteurs, entourés de superbes forêts, où nous admirons de qrands et aracieux palniers aux immenses grappes de fruits ronges et de nombreux groupes de bambous presque aussi hants qu eux, se balançant doucement au gré du vent Nous rencontrons de granıls arbres, aux braches desquels pendent de nombreux nids d'oiseaux tisseurs ; un peu plus has, nous pénétrons daus une immense forêt, au travers de layuelle on a frayé un chemin detustab!e, mais des plus pittoresques. Vuus retrouvons la flore épiphyte dans toute sa variété et sa beauté, les Orthidée merveilleuses quo'on ne se lasse pas d'admirer, parfois par centaines et par milliers, sur les troncs ei les branches des arbres et dont les inflorescences dépassent souvent $\mathrm{I} \mathrm{m}$. de long. Ailleurs. nous chevauchons sous un dome formé par les branches des Guaduas qui bordent le chemin ; ils sont souvent recouverts par une Léģumineuse grimpante qui laisse pendre à l'extrémité de longs fils de $2 \mathrm{~m}$. ou plus de longueur, soit ses inflorescences ombelliformes, soit ses fruits longs de $20-30 \mathrm{~cm}$., et qui, semblables à des pendules, se balancent dans les airs. 
Dans ces régions, l'avifaune est très riche: ce sont de magnifiques Passereaux aux couleurs éclatantes, de bruyants Perroquets, des Toucans, de gros oiseaux au plumage brun-noir, probablement des Gallinacées, qui, au sommet des plus grands arbres, poussent des cris rappelant le croassement des corbeaux; lout autour de nous voltigent de superbes colibris et des papillons souvent plus grands qu’eux. A to h. du matin nous arrivons au bord clu Cauca. Au point de vue géologique, celte région est très différente de la vallée du Porce que nous venons de quitter et qui est creusée dans les roches éruptives. A près avoir franchi l'Alto San Miguel, nous sommes entrés dans les terrains sédimentaires formés par un Précrétacique très plissé dont les banes sont fortement inclinés dans la direction du Cauca. Près du fleuve, ces roches sont remplacées par des conglomérats qui semblent appartenir à la base du Crétacique.

Arrivés au bord dn fleuve, nous sommes très surpris de voir, au milieu de cette région à peine habitée, un beau pont métallique suspendu. L'impression produite est d'autant plus grande que

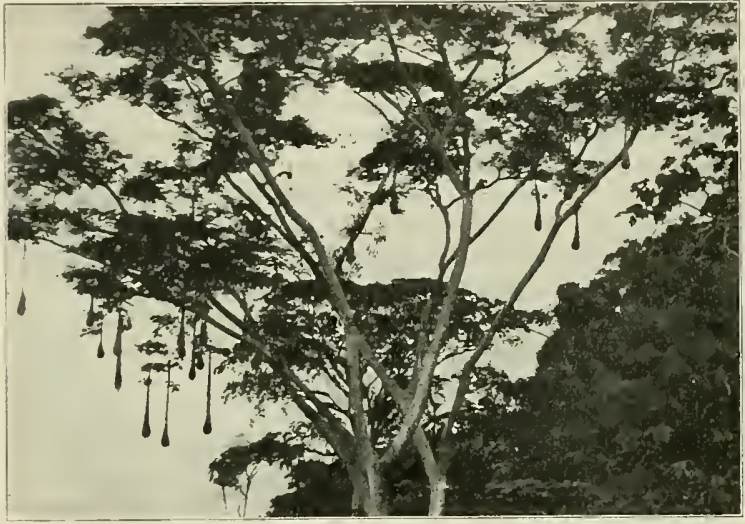

Nids d'oiseaux tisseurs. (Vue prise an téléphot Vautier) les chemins qui y conduisent sont d'affreux sentiers díloncés. Après a voir righle le droit de péage: 250 lir. (soit 2 fr. 5̄o ou 50 pesos), nous traversoins le Cauca et nous gravissons les premiers contreforts des Cordilleres occidentales, que nous longerons pendant trois jours.

Nous commençons par traverser des pàturages marécageux, puis nons atteignons bientót une magnifique forèt ressemblant, quoique moins grandiose, à celles que nous venons de voir sur la rive droite du fleuve. Nous remarquons de très nombreux nids d'oiseaux tisseurs suspendus aux branches; un seul arbre en portant jusqu'à 20. Puis nous sommes dans un terrain déboisé et des plus accidentés; enfin, nous arrivons à Valparaiso, notre étape. C'est avec un soupir de soulagement que uous mettons pied à terre, car nous n'avons fait aucune laalte pendant la journée et notre estomac crie famine; depuis le matin, nous n’avons rien trouvé à manger ou à boire, et nous avions négligé de prendre des provisions de route. Valparaiso (alt. $1384 \mathrm{~m}$.), situé sur la rive droite de la Quebrada Sabaletas, est un petit village séparé du Cauca par une chaîne de montagnes relativement peu élevées. Nous descendons dans la seule auberge de l'endroit, qui nous olfre un confort très relatil'. Le réduit où nous logeons n'a pas de fenêtre et la seule ouverture est la porte, donnant directement sur la rue, aussi sommes-nous assaillis par une foule de curieux qui viennent voir quels originaux se sont égarés volontairement dans ces parages. Pendant que nous prenons notre repas du soir, nous voyons, dans une pièce voisine, quelques Indiennes occupées à rouler sur leurs cuisses de gros cigares se vendant dans tout le pays 5 pesos ( 25 cent.) les 32 pièces. Tout près de nous, une fillette de cinq ans nous dévisage curieusement en fumant un de ces gros cigares dont elle chasse la fumée par le nez, comme le fumeur le plus expérimenté! En effiet, chacun fume en Colombie, les 


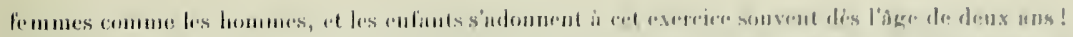

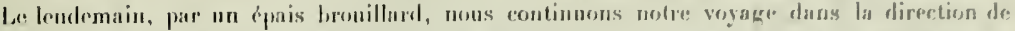

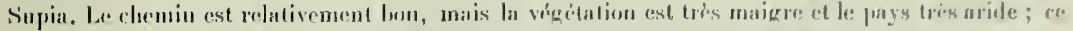

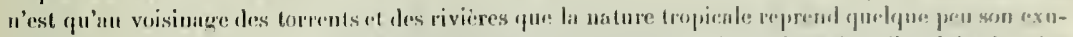

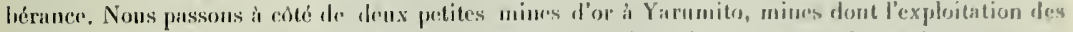
plus sommaires est munice simplement d'un monliu antiongien. Vers a lurures du matin, nous som-

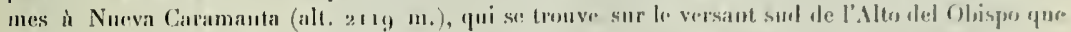

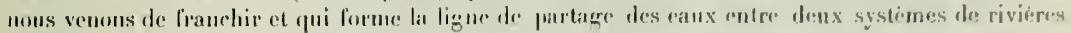

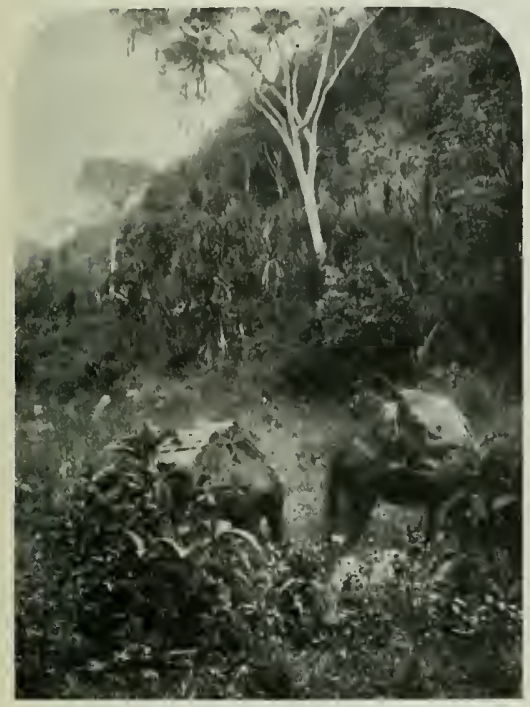

Forèt au pied des Cordilleres oreidentates. Sur un Cecropia des nids d'oiseaux lisseurs el au pied des Canas bravas. (r. 3.)

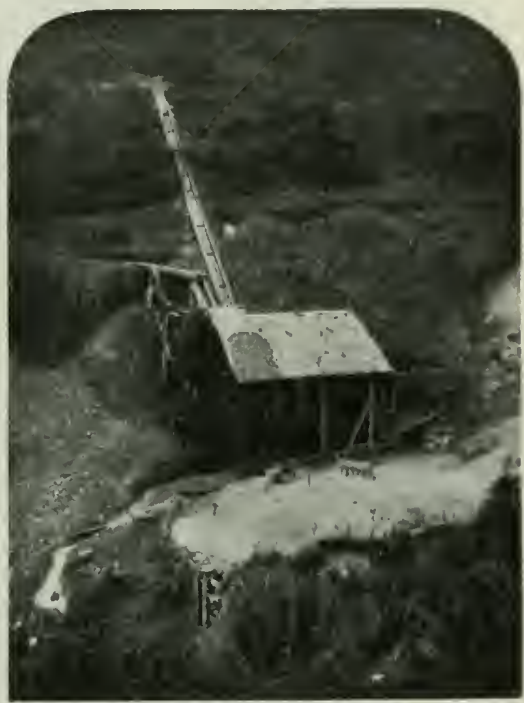

Mine d"or de larumito

(F. x. Moutin antioquien.

trihutaires du Cauca. Curamanta, située dans le voisıage de nines d'or et de grandes plantations de café, est une localité assez importante. Pour passer de l'autre còté de la vallée du Rio Arquia. qui coule profondément encaissé an-dessous de Caramanta, nous devons, par de grands contours, franchir tons les petits afluents de celte rivicre, ce qui nous doune parfois descehappées magnifiques sur cette vallée dont la région moyenne seule est cultivée, tandis que le fond et le sommet sont ahandonnés à la nature. Par places, nous distinguons de arandes cascades qui se détachent comme des rubaus d'argent sur le lond sombe de la végétation. A Taiza. nous quittons la vallẻe de l'Arquia pour franchir un col et passer laus celle de Supia. Nous nous eufonçons dans une forêt profonde par un chemin détestahle oủ les prutanos se suivent sans interruption et semblent être, par places, infranchissables. Une magnifique vue vers le sud nous dédomnage de ce mauvais pas, car, une fois hors de la forèt, nous dominons la riante vallée de Supia qui s'étend à nos pieds. A notre gauche, 
s'élèvent de hautes montagnes pyramidales, derrière lesquelles se trouvent les importantes mines d'or de .larmato, apprartenant à unc compagnie anglaise. Devant nous, c'est la vallée qui, de loin, semble être bien cultivée, mais qui l'est en réalité fort peu; dans le lointain, nous distinguons deux grandes taches vert pale que nous prenons d'abord pour de petites lagunes, mais qui, vues a la lorgnette, sont des cultures de mais et de canne à sucre ; tout au fond se devinent les premières maisons de Supia au delà desquelles les collines se relèvent pour fermer la vallée hordée, à notre droite, par de hautes montagnes. Nous descendons de notre observatoire par un chemin en zigg-zag, très rapide, et is la tombée de la nuit, nons arrirons à Supia (alt. $1226 \mathrm{~m}$.). C'est nn endroit fort pen

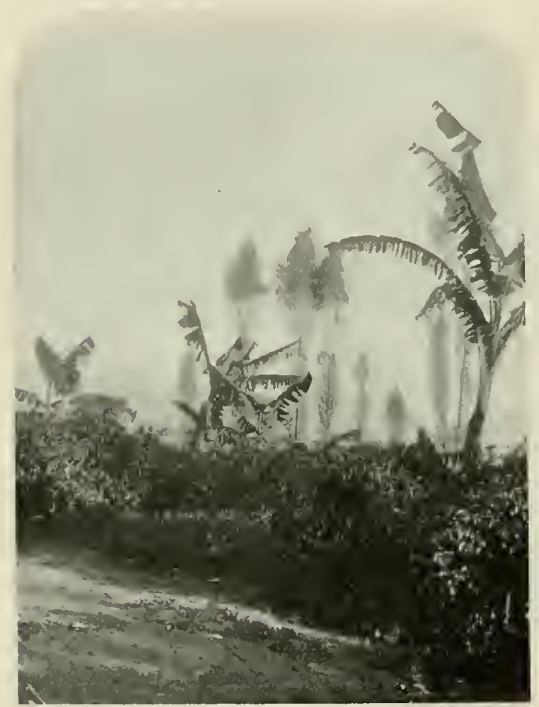

Hantation de café près de Filardelfia. (r., u.) intéressant; il est habité presque exclusivement par des nìgres et des mulâtres, aussi sommesnous très heureux d'en repartir le lendemain 3o septembre au matin.

Celte région, comme du reste tout le département du Cauca, dans lequel nous avons pénétré à Caramanta, forme un contraste frappant avec I Antioquia. Les cultures y sont beancoup moins nombreuses et surtont beaucoup moins bien soignées; la poprulation, oì domiue l'élément nègre, est praressense el prélère au travail un "dolce Farmiente ). Num traversuns d'abord la vallee tu Rio Supia pour gravir les montagnes qui la séparent du Rio Sucio. Toutc cette région est très arcideutée, mais très monotone, car la végétation est maigre et rabougrie sur tous ces vallonnements arides. Depuis le fond de la vallée du Rio Sucio (alt. $879 \mathrm{~m}$.), par un solcil de plomb, nous gravissons péniblement les flancs de l'Alto Chaquero (alt. $127.3 \mathrm{~m}$.), d'où le panorama est magnifique. Tandis que derrière nous s'étend celte région aride et dénudée que nous venons de traverser, à nos pieds, ce sont les riches forêts des régions chaudes et le Cauca, profondément encaissé entre les montagnes recouvertes d'une abondante végétation. $\Lambda$ midi, nous arrivons an bord du flenve (alt. $81.4 \mathrm{~m}$.) et nons faisons halte dans une auberge pour nous reposer et laisser reposer nos mules. Là, le fleuve est extrêmement rapide, mais nous parvenons cependant à tronver un endroit où nous pouvons prendre un bain rafraichissant et faire nne toilette quelque peu sérieuse et très nécessaire, car nons ronstatons qu'on s'babitue facilement à vivre dans la saleté du milieu ambiant.

Dans cette contrée, les conglomérats ne présentent rien de particulier, contrairement à ce que nous avons vu au Paso de Concordia. Durant loute la jonrnée, nous avons traversé des régions éruptives, tandis que de l'autre côté dı fleuve, nous rencontrerons des schistes micacés fortement plissés d'un bleu verdâtre. Nous franchissons lc Canca sur un pont suspendı où les mules ne penvent passer que deux à la fois pour éviter de trop forts balancements. Nous nous trouvons de nouveau au pied des $A$ ndes centrales et nous remontons pendant quelque temps une étroite vallée que nous quittons pour gagner Filadelfia (alt. $1589 \mathrm{~m}$.). Nons arrivons de nuit au village et nous nous lébattons avec peine dans les eflroyables pantanos qui en forment l'entrée. 


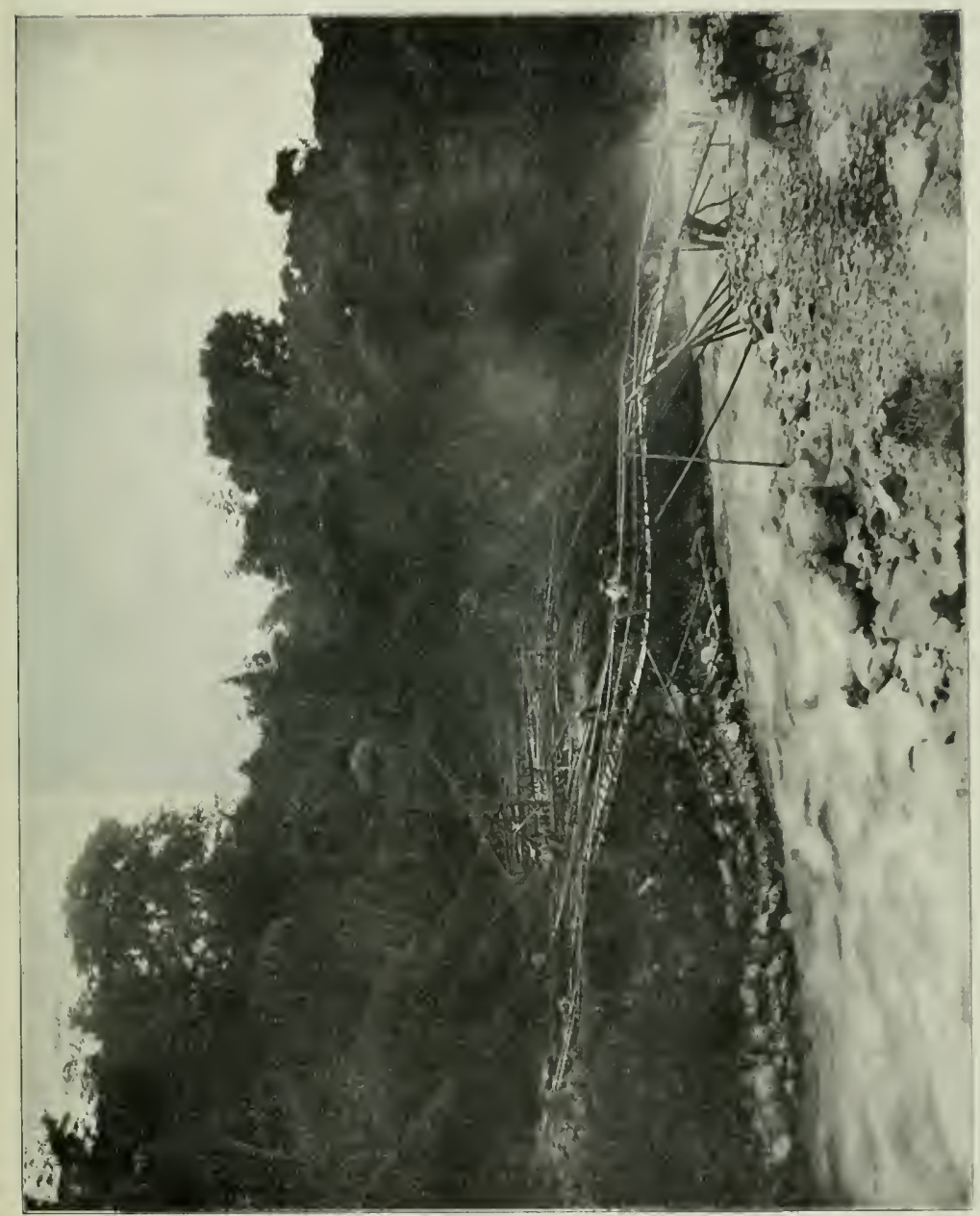

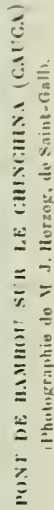


Le lendemain, avant de repartir. nous faisons le tour de la plate el nous voyous plusieurs cnfants prendre de l'eau à la fontaine et lit transporter dans des tiges de bambous. Ces tiges ont une longueur de 2 à 6 entre-nœuds, et pour que l'eau ne s'écoule pas pendant le trajet, on applique un petit morceau de toile sur l'ouverture. Dans toute cette région, on transporte l'eau dans ces cruches d'un nowveau grenre que l'on porte, soit sons le bras, soit sur l'épaule.

Nous partons à 7 heures du matin et nous prenons la montagne en échinge en longeant des plantations de café. Près d'un col, nous voyous quelques huttes construites en bambous et it clairevoie, atux parois formées par cles tiges de bambous fendues et ouvertes, ce qui leur donne l'aspect de lattes très étroites. A còté des huttes se trouve le poulailler traditionnel, consistant en unc perche verticale portant à 2 ou 3 mètres du sol des traverses horizontales sur lesquelles vient se poser, le soir, la gent ailée qui est ainsi à l'abri des quadrupèdes carnassiers. Le long des chemins, nous croisons souvent des indigènes portant au marché, qui se tient toujours le dimanche, des volailles attachées par les pattes aux deux extrémilés d'un bàton posé sur l'épaule. Ces animaux n'ont pas l'air d'être incommodés par ce genre de locomotion; nous avons entendu un coq chanter à gorge téployée, malgré cette position anormale.

Nous descendons dans une vallée assez profonde en traversant plusieurs "Quebradas " le long desquelles la végétation est particulièrement luxuriante. $A$ un contour du chemin, nous ne sommes pas peu surpris de rencontrer huit hommes transportant un piano suspendu à des cordes; nous nous arrêtons un

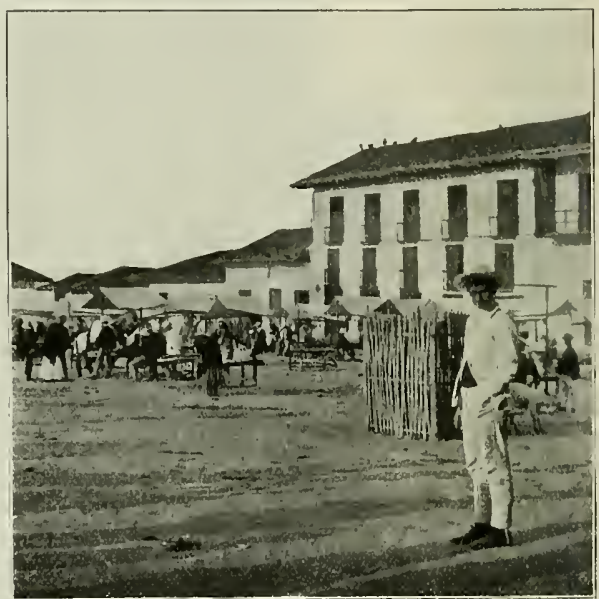

Marché de Neira. moment pour voir au prix de quelles difficultés cet instrument est calıoté au milieu des pantanos. On se représente sans peine le pria élevé que doit coûter un piano transporté ainsi à dos d'hommes depuis le Magdalena jusque dans l'intérieur, et l'état dans lequel il arrive souvent à destination. Peu après avoir croisé ce convoi bizarre, nous trouvons le chemin tout à coup interrompn; il a été emporté par les eaux quelques jours auparavant. Nous devons descendre dans la Quebrada Sardina, que nous suivons pendant $2 \mathrm{~km}$. environ. S'il ne nous est pas toujours très facile de nous l'rayer un passage au milieu des galets de la rivière, par contre, la nature qui nous entoure est admirable. Au-dessus de nos têtes s'arrondit un dòme de verdure formé par des arbres gigantesques et d'élégants Guaduas, tandis que des plantes épiphytes qui s'en détachent, se balancent mollement au-dessus des eaux qui les reflètent. Arrivés au confluent de la rivière avec le Tarea (alt. $1274 \mathrm{~m}$.), nous traversons ce dernier à gué et nous montons rapidement dans la direction de l'Alto Cantadelicia (alt. $\mathrm{g}^{3} 9 \mathrm{~m}$.) où nous rejoignons le chemin de Salamina ; toute celte région, entièrement déboisée, n'offre aucun intérêt. Depuis le hameau de Cantadelicia, nous montons encore pendant près d'une demi-heure pour arriver à Neira (alt. $199^{2} \mathrm{~m}$.). Sur ce chemin, qui est la grande voie de communication entre Yedellin et le centre minier de Nanizales, nous nous trouvons en nombreuse compagnic. 
C"est dimanche, jour de marché par conséruent, et la lyaza est encombriede grons venus pour

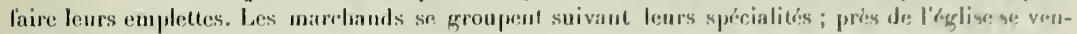

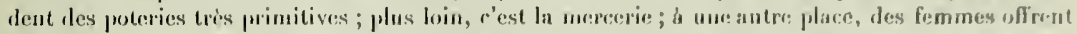

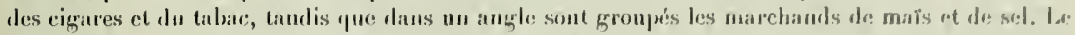

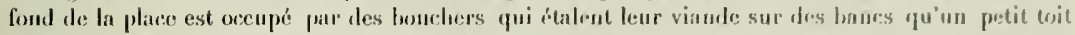

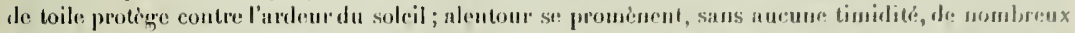

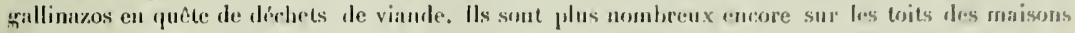

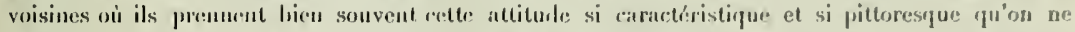

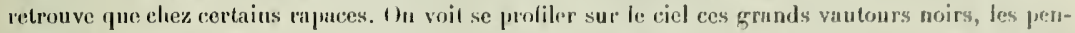
nes de lem's ailes étendues ed railies, bizares ou liératiques, semblables aux aigles inpróriales dest blasons ou des monnaies.

Coume nous ne pouvous arriver le soic mome ì Manizales, nous passons la nuit à Neirn, et le lendemain z octobre, nous nous mettons en route pour cetfr ville importante. Is: chomin que nous

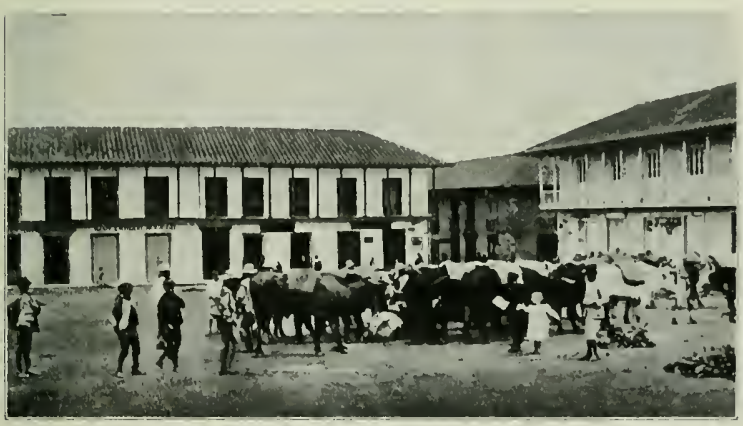

La Plaza de Manjzales avee un tronpean do bont's de chauge. suivons est très fréquenté borle de cultures. I'ries des ciny Ouebralas que nous traversons, la végétation devient intéressante: partout ailleurs, la montagne est denudée dans la zone voisine du chemiu.

I I heures $1 / 2$ du matin, nous arrivons is Manizales; nous traversons la ville pour alescembre à l'hotel Internacional qui nous offre un confort relatif, mais suffisant pour les deux jours que nous passons à nous reposer. Yon seulement, nous avous besoiu de repos après une semaine de chevauchées ininterrompues dans un pays très accidenté et par des chemius exécrables, mais nos mules boitent et sont à bout de forces. Sur leur dos, on voit de larges plaies produites par le frottement continuel du hat ou de la selle sur la peau. Aussi sommes-nous obligés de changer de mules, car les notres devraient se reposer trop longtemps avant de pouvoir se remettre en route.

Grace à une lettre de recommandation de M. Bimberg, nous trouvons facilement les mules nécessaires, ce que nous aurions eu de la peine à faire dans une ville aussi attairée que Manizales. Nous réussissons aussi à mettre la main sur un excellent peon qui nous accompagnera jusqu à la fin de notre voyage et nous rendra de précieux services. Jose Maria Soto est un Antioquien typique, fort. vigoureux, bien musclé, intelligent. travailleur et chercheur infatigable, ce qui nous aidera plus d'une fois. Contrairement à beaucoup de voyageurs qui ne cessent de se plaindre de leurs peons, nous n'avons jamais eu le moindre ennui avec lui, sauf une fois ou deux où le beau sexe exerga sur lui une attraction trop forte!

Manizales (alt. $2 \operatorname{rog} \mathrm{m}$.) est une ville de 30000 hab. située au cour des Andes centrales et perchée comme un nid d’aigle sur un plateau, adossé d'un còté au massif du Ruiz tandis que les trois autres còtés sont en pente très inclinée. La situation est celle d'une forteresse de montagne, et Manizales est considérie avee raison comme la clé de la province de l'Antioquia. La ville fut fondée 
un 1848 par l'Antioquien Palacios qui avait explorẻ la rérion oì il espérait trouver de l'or. Depuis sa fondation, el malyré des arrêts momentinés dus asux tremblements de terre de 1875 et 1878 , la ville n’a pas cessé de s'accroitre. Actuellement elle est la troisième ville importante de Colombie au point de vue commercial. Manizales doil sa prospérité et son développenent rapide à ses nombreuses mines d'or et à sa situation à la frontière des États de l'Autioquia et du Cauca; tous les produits d'exportation et d'importation passent par là pour arriver soit au Mlagdalena, soit au Cauca. De plus, comne les commerģants antioquiens n'aiment guère sortir de leur département, its anèent daus cette ville tes marchandises que les habitaots du Cauca viennent y chereher. Enfiu, sur une longrueur de plus de $50 \mathrm{kin}$. vers le sud, les Cordillères sont infranchissables, a cause des massif́s gigantesques du Ruiz et du Tolima, recouverts de neiges éteruelles, et c'est de Manizales que partent tous les passages importants conduisant à Ambalema et à Honda sur le Magdalena. La contrée étant très souvent ravagéc par des tremblements de terre causés par le voisinage du Ruiz dont le rratère est éteint depuis longtemps, les habitations sont construites très légèrement; elles sont souvent même en bambous sculement. Les deux grandes églises de Manizales elles-mêmes, sont en bois mais recouvertes d'une sorte de carapace en plaques de tỏle peintes à l'huile. La couleur claire de ces édifices leur donne un aspect très particulier et les fait ressembler bien plus à des pièces montées qu'à des églises. La ville est comme toutes les autres, avec cette différence qu'il y règne une activité considérable; malgré son

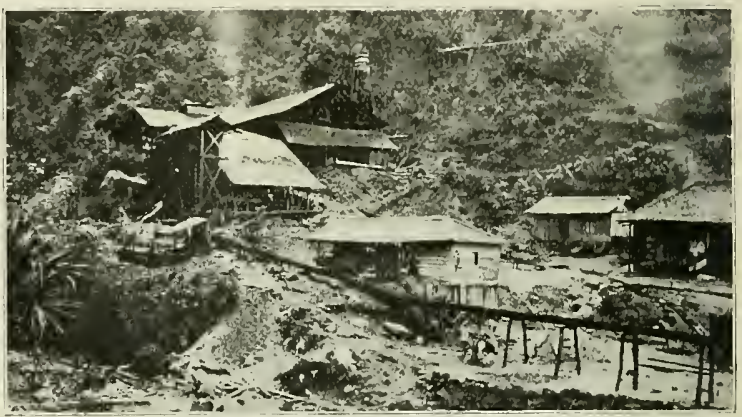

Yue de la mine d'or La Cascarla. importance, elle n'est reliée au monde extérieur que par des chemins épouvantables, entrecoupés d'horribles pantanos, terreur des voyageurs pendant la saison des pluies ; parfois même, ces chemins deviennent tcllement impraticables que Manizales peut être isolée pendant quelques jours de tous les centres voisins.

Nous avons la chance de rencontrer à Manizales deu. Français, représentants de maisons de commerce, et qui, très au courant des conditions économiques, ont pu nous donner une quantité de renseignements intéressants. Aucun négociant étranger n'est établi dans celte grande ville, car il serait soumis à des tracasseries continuelles de la part des néguciants indigènes. La fièvre de l'or et des spéculations minières plus ou moins honnêtes fait rage dans ce centre minier; comme beancoup d'autres voyageurs, nous sommes souvent accostés dans la rue ou poursuivis jusqu'à l'hôtel par des gens qui nous exhibaient des minerais d'or ou nous offraient des mines à des prix fantaisistes. Le nombre des mines déclarées dans cette région est très grand et augmente presque chaque jour; mais deux seutement semblent êlre particulièrement riches et exploitées rationnellement: La Cascada et La Union.

Conduits par M. Gregori, un négociant de la ville auquel nous étions recommandés par M. Bimberg, nous faisons une petite excursion aux environs immédiats de Manizales, au bord du contrefort sur lequel la ville est batie. De là nous avons la chance d'admirer partiellement les sommets neigeux du Ruiz, ce géant des Andes qui se dresse à $5590 \mathrm{~m}$. et qui est le plus souvent 


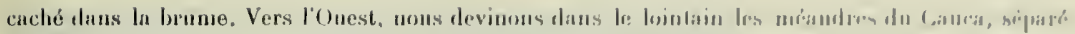

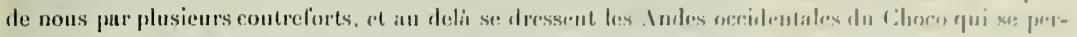

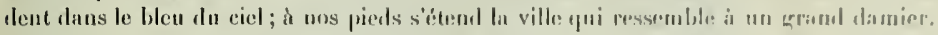

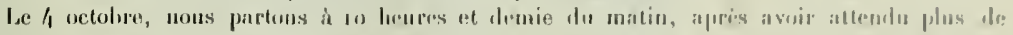

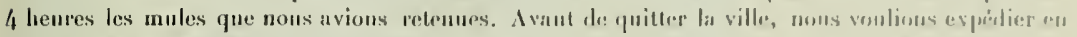

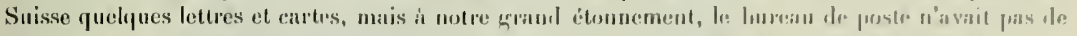

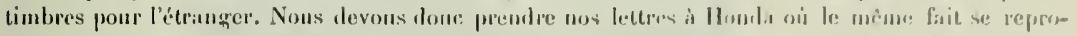

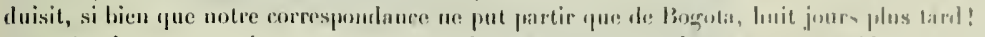

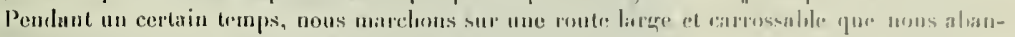

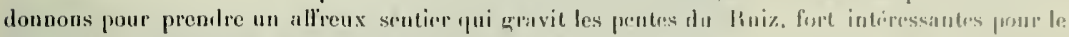

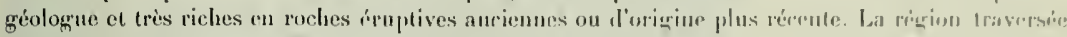

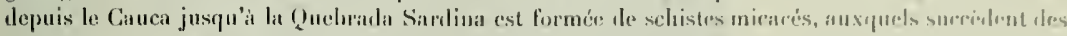
conglomérats rouges plus ou moins inclines. bepuis le coufluent des rivieres Sindina ut Tarea, ons pénètre dans une région de sélimeuts calcaires renfermant par places de's hatues de charbon, puis on passe daus la zone des roches éruprives fortement rlécomposies.

Au moment oú nous eutrous dans la forêt, la phric se met à tomber avec violence, et pendant 3 heures et demic, nous pataugeons dans des pantanos ctrroyables, les plus terribles et les plus intermiuables que nous ayons ren-

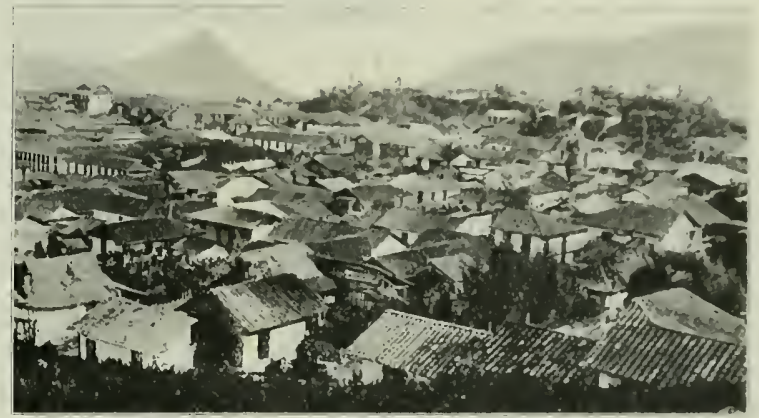

lue générale te Manizales. contrés jusquà maintenant. Dans un des plus nauvais passages, une fles mules marche sur ur carlavre culisé el caché par la boue et aussitòt une odeur si nausíaboule se répand que nos bètes intrépiles reculent. Un peu plus loin, nous voyons un malheureux cheval abandonné, tout tremblint, qui henuit d"une façon lugubre, a bout de forces et couvert de houe jusiju aux oreilles, prèt à sieflondrer. Au-dessus de lui, des Gallinazos décrivent de grands cercles dans les airs, atlendant le moment on l'animal s'aflaissera pour se précipiter sur lui, l'éventrer el le dévorec. (Plus haut, nous ne rencontrerous plus ces vautours noirs quion voit partout, depuis lo bord de la mer juspü í $3000 \mathrm{~ns}$. d'altitude.) Tout le long de la route conduisant au col du Ruiz et sur l'autre versant. les cadivres et les squelettes de mules et de boufs sont très mombremx et uous prourcut que les chemins sont redoutables. Du reste, en Colombic, on rencontre assez souveut, soit au milieu des chemins. soit sur les bords, des cadavres d'animanx en décomposition ou des squelettes depecés par les vautours et sur lesquels on est obligé ıle passer: ce sont les paurres bètes de somme, enlisies dans les pantanos ou ayant succombé sous les coups et qu'on abandonne ainsi à une mort lente et. terrible.

A mesure que nous montons, la végétation change de caractère; peu à peu. les fougères arborescentes et les palmiers font place à des arbres qu'on ne trouve que dans la régrion des paramos andins qui commenceut à partir de $2800 \mathrm{~m}$. daltitule. La-lıaut, il pleut presque tous les jours; les 
arbres se recouvent dinnombralies épiphytes, ou de mousses of lichens, tandis qu'à terre el sur les trones rroissent d'élégantes fougères linement découpées.

141, heures, nous arrivons a lilto Elvira (alt. $3678 \mathrm{~m}$.) (l'oì nous prenons un mawritis sentier qui nous conduit à la mine d'or Union (alt. 35 g5 m.) que nous atteignons à la tombee de la nuit, harassés de latigue et couverts de bour, après une chevauliee ininterrompue

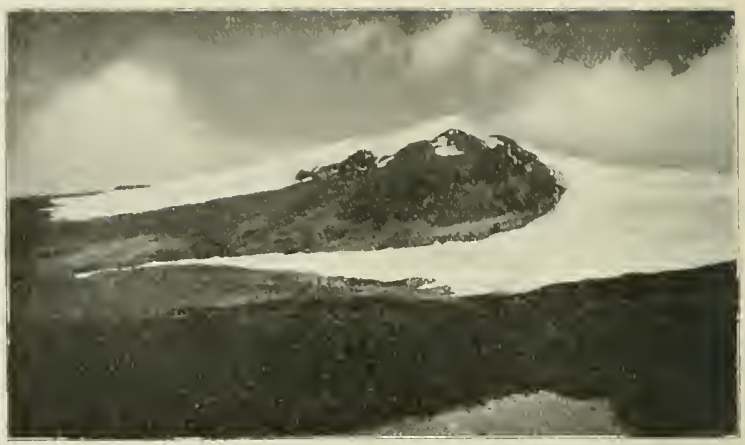

Sommet itu Riuiz. de $81 / 2$ lieures par des chemins iudescriptibles. Nous présentons à l'Administrateur une lettre dintrotuction que la direction nous avait tris aimablement remise a Manizales et yui nous vaut un accucil chaleureux. C'est avec le plus grand plaisir que nous acceptons le frugal repas des mineurs qui nous réchaufle, car nous sommes transis el à demimorts de faim, nayant rien pris de toute la journéc. Après avoir posé bien des questions

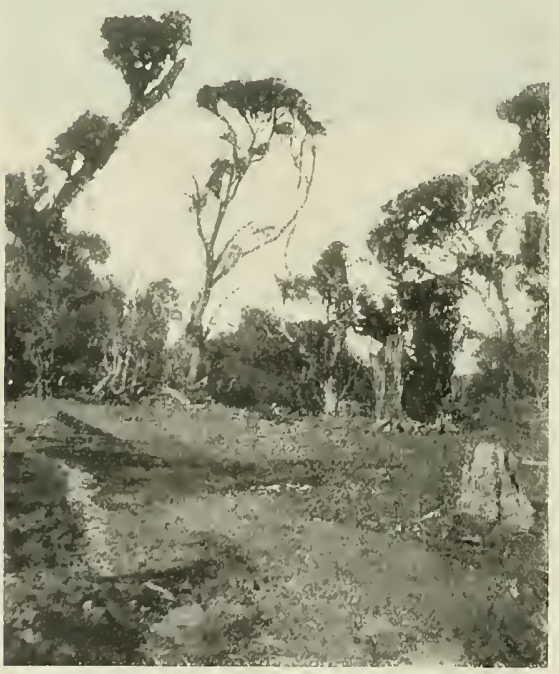

Aspect des arbres dans les Paramos du Ruiz. au sujet de la mine que nous visiterons le lendemain, nous nous retirons daus les chambres mises à notre disposition et nous nous couvrons de tout ce que nous pouvons, car le froid est très vif.

Le lendemain matin, nous sommes réveillés en sursaut par la cloche qui appelle les mineurs au travail. Nous nous levons rapidement et, depuis la véranda, nous admirons le lever du soleil derrière les cimes neigenses du Ruiz. Nous avons en eflet le rare bonheur de jouir d'une vue superbe sur ce massif ģéant aux neiges éternelles qui se dresse devant nous, imposant et majestueux. Longtemps nous restons là, ne pouvant nous arracher au spectacle grandiose de celte montitgno: étincelante de blancheur sous les rayons du soleil, spectacle d'autant plus frappant que sous cette latitıde de $5^{\circ}$, les neiges éternelles ne commencent qu'à partir de l'altitude du Mont Blane!

1) ne lait pas chaud, $4 \frac{1}{2}{ }^{\circ}$ seulement, ef c'est avec plaisir que nous nous réchaufions (F.,.) avec une tasse d'un excellent cacao bouillant, 


\section{- $7^{n-1}-$}

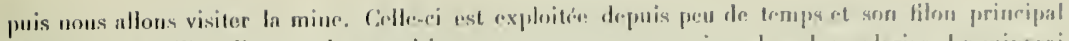

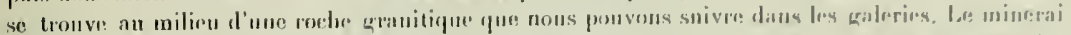

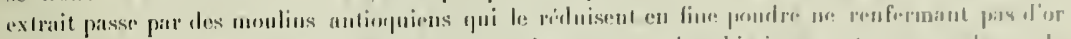

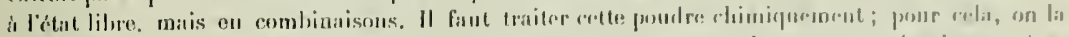

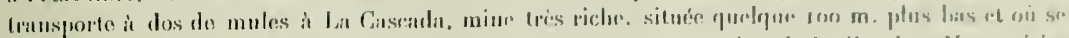

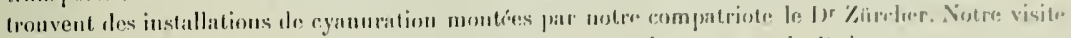
terminée, nous cufourchous nos mules et mous partous pour les paramos du liuiz.

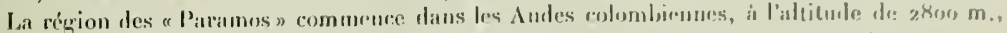

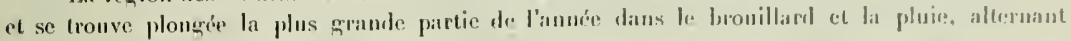

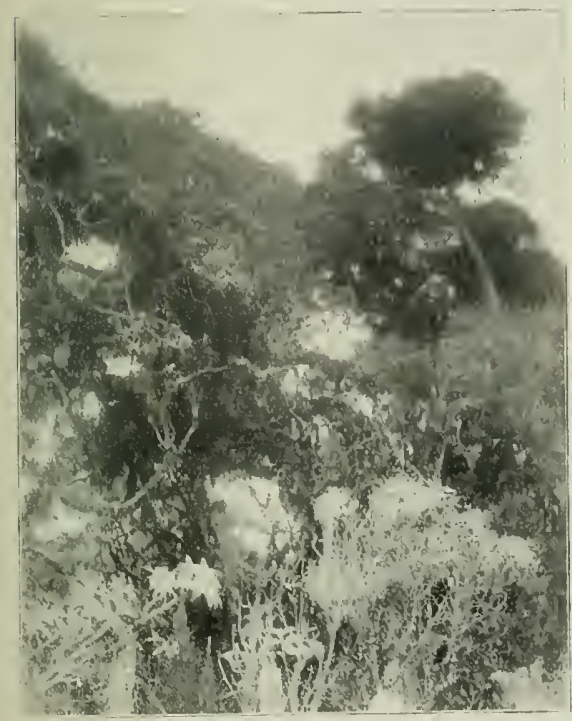

Piramos du liuiz. Forèts avec leur revètement de monsser, de lichens et de plantes épiphytes. (F.M.)

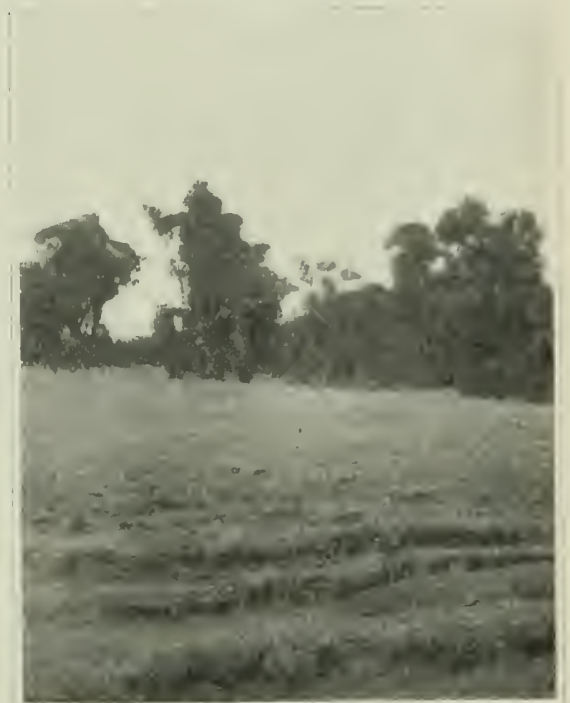

Paramos du Ruiz.

Chènes à la lisière de la forêt. $\quad(F$, M.

avec des ouragans et de formidables orages. C"est d'ailleurs aussi sous une pluie fine et froide que nous avons traversé cette intéressante zone d'une uature toute partieulière. Nous commençons par rencontrer une forêt étrange à l'aspect chaotique, ou les arbres, aux formes hizarres, sont recouverts llépiphrtes, surtont de fougieres et d'Orchidées. Des mousses et des lichens śaccrochent anx troncs, aux branches et aux plus petits rameaux, les relient entre eux en formant des sorles de grands rideaux d'un vert sombre plus ou moius nuiràtre qui peuvent masquer parfois les frondaisons. Les formes bizarres des arbres sont dues soit aux vents qui les tordent et les decharnent. soit aux orages et ì la foudre. Certains n'ont plus que quelques maigres rameaux à l'extrémité de branches déłulcées; d'autres sont à moitié morts, d'autres ont été reuversés et gisent à terre en voic de décomposition; par places se dressent des fragnents de troncs qui se reconvrent rapidement 
d'une riche végétation. Dans cette étrangre nature, le sol est détrempé, l'eau dégoutte des arbres et le passage est très diflieile; les animaux mème ne peuvent s'écarter du chemin frayé. A coté de nombrenx Fnchsia (F. ampliata el quindiuensis) et Calceolaria perfoliata, nous voyons avec surprise de magnifiques graples d'Orchidées du grenre Odontoglossum qui, malgré le froid très vif des nuits, atteignent cependant de grames dimensions. Dans cette région si humide, le sol est tellement détrempé quaprès chaque pluie dinnombrables ruisselets se creusent un lit dans les prairies el obliznent ainsi le voyagent à traverser toute une série de rigoles plus ou moins larges.

A cơté des forèts s’étendent de vastes prairies recouvertes d'un maigre gazon oi se développent en foule, par endroits, des IIyperirum ligneux (II. acerosum, aciculare, laricifolium et caracasanum), pressés les uns coutre les autres, et surtout des Espeletia (E.grandiflora) qui se dressent espacés, tels des candélabres géants dans ces contrées désolées. Les Espeletia, plantes caractéristiques des paramos andins sont des Composées; leur tige pent atteindre $3 \mathrm{~m}$. de hauteur, elle est souvent de l'épaisseur d'un bras et se ternine par une rosette de feuilles argentées au milieu de laquelle se développent de petites grappes de fleur's d'un jaune d'or.

Notre vulgaire Trifolium repens, aux fleurs d'un blanc un peu rosé, forme par place un vrai tapis; ailleurs sont en quantité : Senecio ledifolius, Cotula minnta, Gnaphalium spicatum et stachydifolium, Leontopodium graphalioides, Gentiana corymbosa, Bartsia laticrenata, Oreomyrrhis andicola, Epilobium meridense, des Alchémilles (A. nivalis, orbiculata et tripartita), des Peperomia (P. blanda et IIartweginna), des Salvia, Satureia, etc. pour ne pas prolongुer une sèche énumération de tout ce que nous avons eu l'occasion de voir et de recueillir. 1

La faune de ces régions élevées est paure ; à peine voyons-nous quelques oiseaux aux couleurs ternes (pies, merles et pinsons), contrastant avec les plumages éclatants de ceux des terres chaudes. Par contre, nous sommes très étonnés de rencuntrer à ces altitudes de nombreux colibris dont les cris stridents troublent seuls le silence. Si la faume apparente est pauvre, plus riche est la faune cachée sous le bois mort et sous les trones d'arbres en voie de pourriture. ${ }^{2}$ Vers midi, nous faisons une petite halte dans une hutte appelée Letras (alt. $367_{1} \mathrm{~m}$.), située un peu au-dessous du point culminant de notre chemin. Nous nous y restaurons, puis nous gagnons le col situé à $3820 \mathrm{~m}$. d'altitude. Il serait intéressant de parler ici de la distribution verticale des plantes et animaux les plus intéressants de la Culombie. Pour éviter de longs développements, nous donnons ci-après trois tableaux qui permettent une comparaison facile de l'altitude à laquelle apparaissent ou disparaissent les divers groupes de plantes et animaux. Ces données sont tirées de Bürğer et Vergara et ont été corrigées et complétées d'après nos observations personnelles. ${ }^{3}$ (Voir graphiques ci-après.)

Depuis un moment, la pluie a cessé de tomber, et lorsque nous nous engageons sur la pente orientale des paramos. par un heurenx hasard, le ciel se débarrasse de ses nuages épais et pendant quelques instants, nous jouissons d'une vue maguifique $\Lambda$ notre droite se dresse le Ruiz avec ses neiges étincelantes et son petit glacier, tandis que devant nous se distinguent les Cordillères orientales vers lesquelles nous allons et dont les teintes bleues se confondent peu à peu a vec le bleu du ciel.

Notre chemin desıend rapidement en longeant ou en traversant de petits cañons creusés dans la roche éruptive décomposée. et au fond desquels coulent de petits ruisseaux. Par places, la roche à nu présente très nettement des traces d'un ancien glacier, et cette intéressante question se pose à

' Espèces nouvelles recupillies dans les Paramos du Ruiz: Breutelia falcatula, Puccinia ruizensis et paramensis ; Polypodium Mrnyoris.

2 Espèets numvell's recueillies dans les Paramos du Ruiz: Auliodrilus ruizanus, Blanchardiella paramensis, Macrobiella columbiensis, Vaginula fulirmanni, Scytodes ruizensis.

3 Otro Bünger, Rrisen eines Nalurforschers in tropischen Südumerila. Leipzig, igoo. - VergaraVelasco. Nueva Geografia de Columbia. Boggota, igui-igoz. 


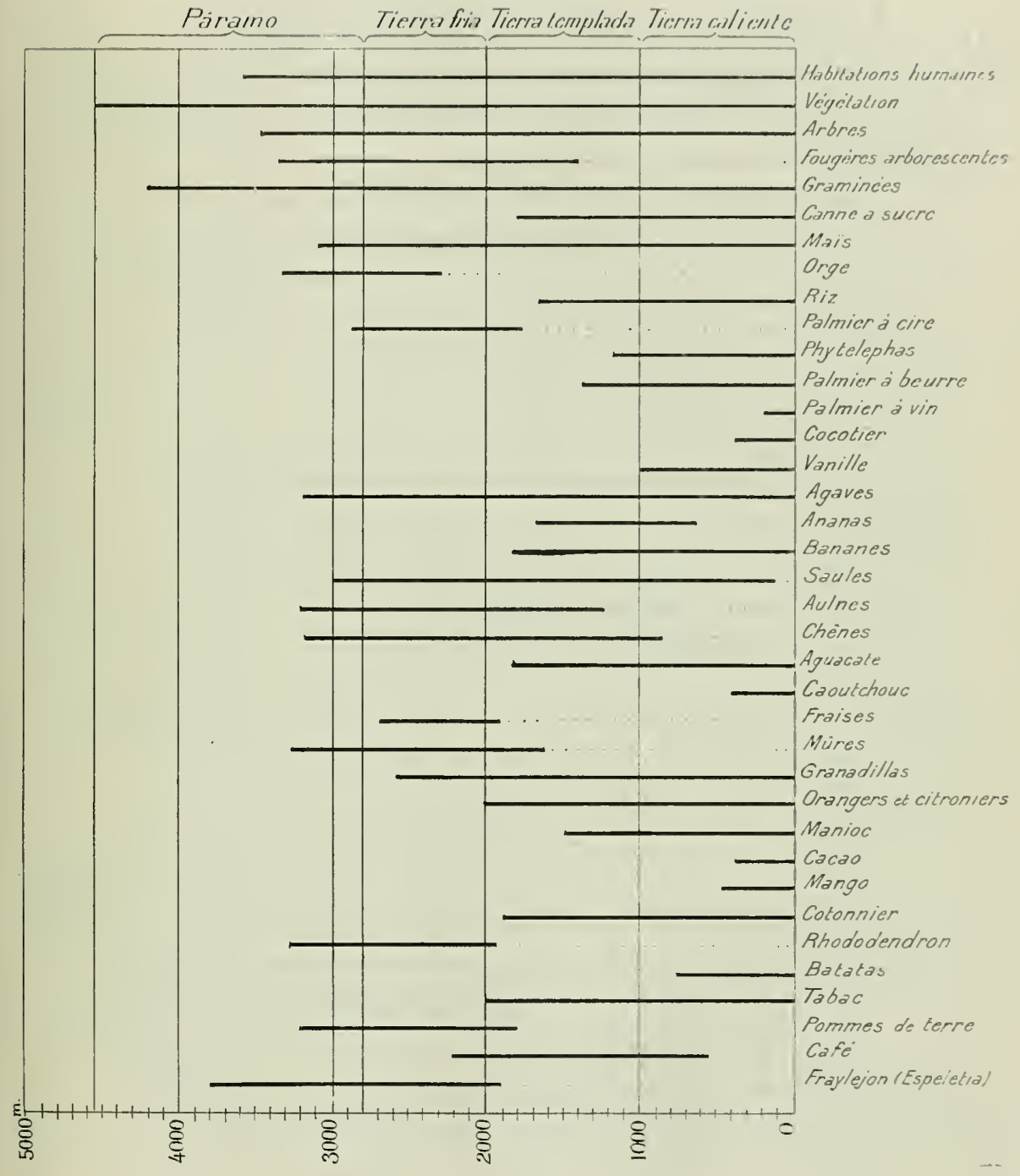




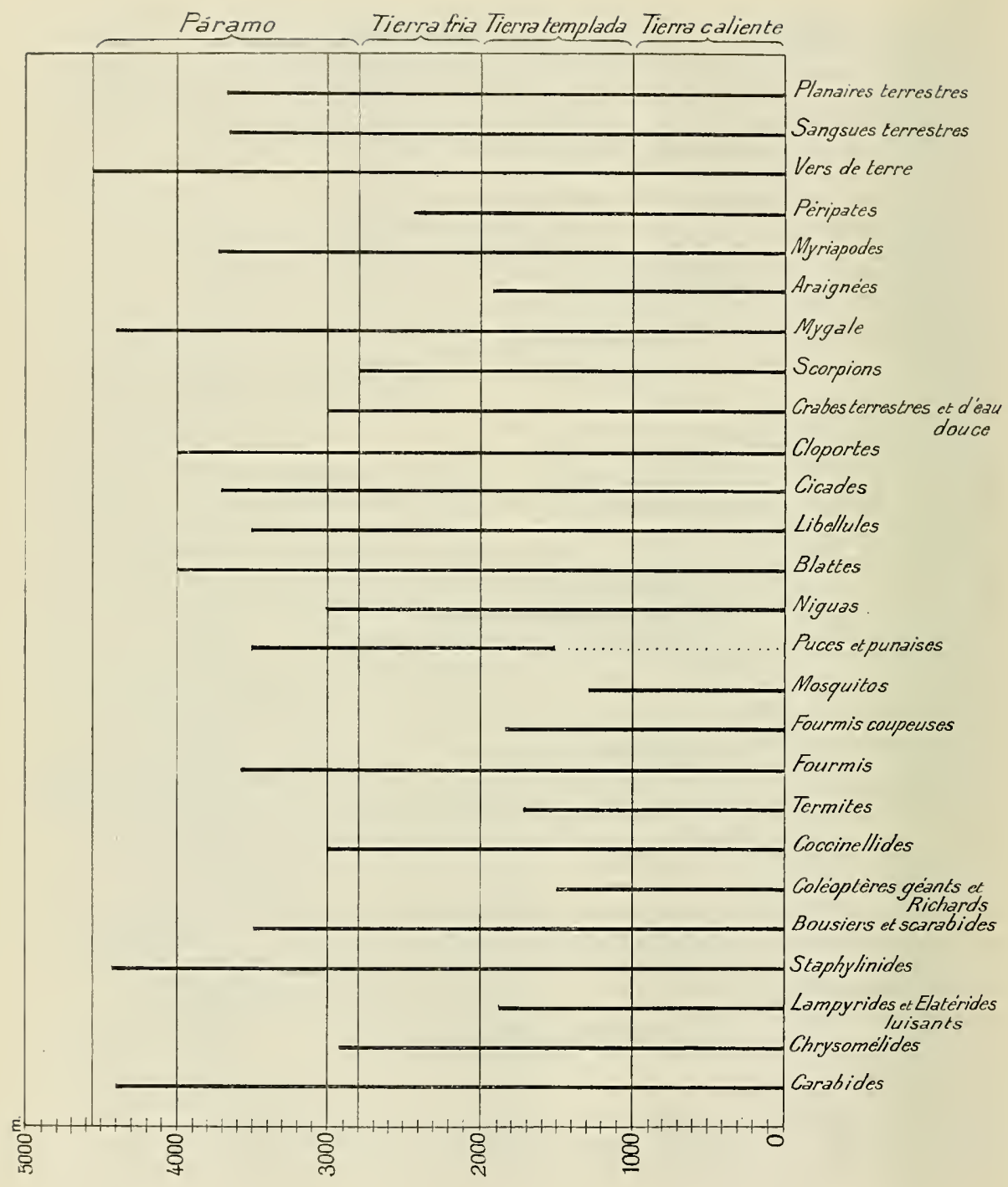




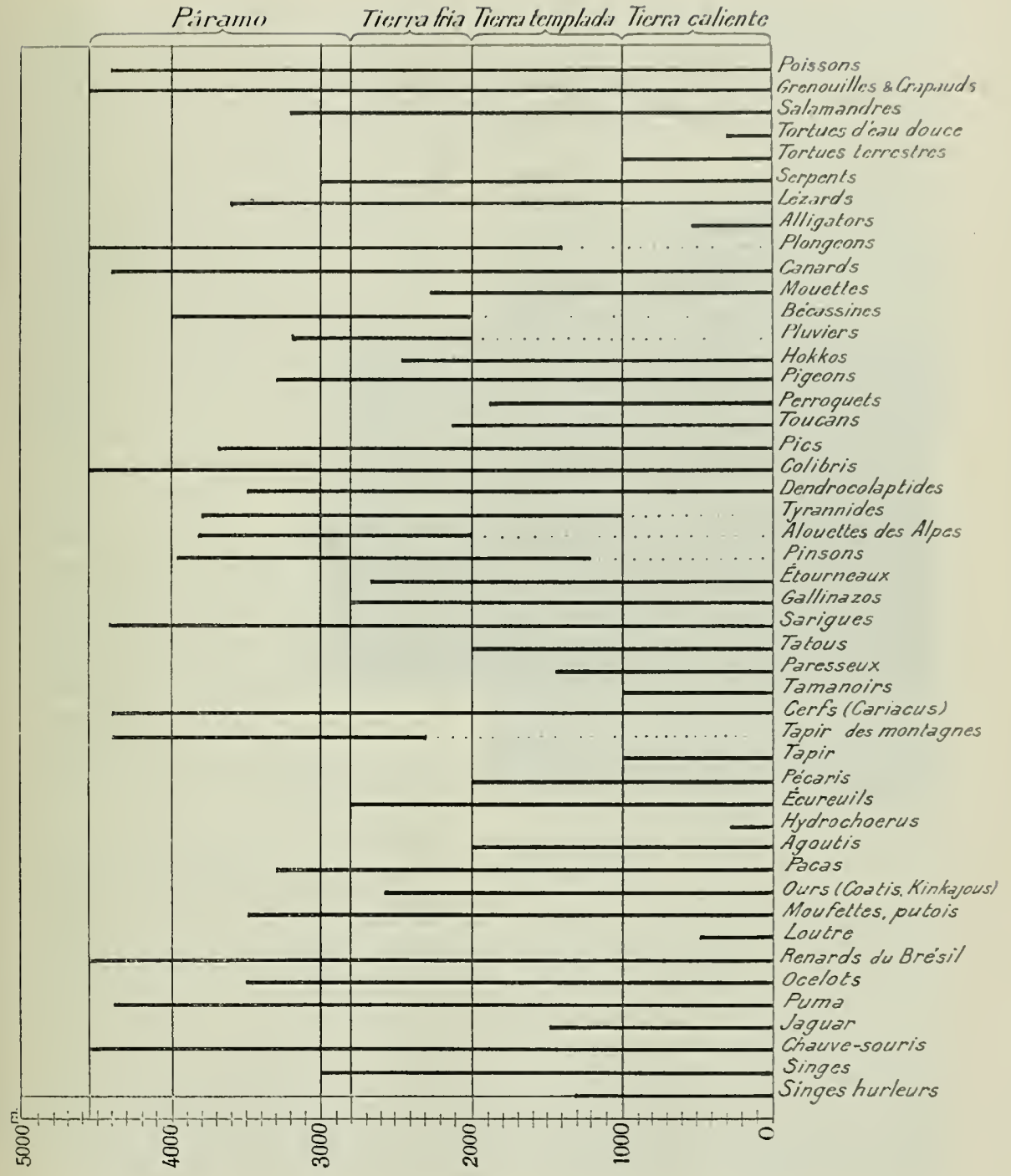


nous: I a-t-il eu dans les Andes tropicales, près le l'Équateur (nous sommes par $5^{\circ}$ de lat. nord) une époque glaciaire?

La limite les neiges éternelles se trouve au Tolima et au Ruiz, à une altitude supérieure à celle des plus hauts sommets de nos Alpes; de ces cimes, les grlaciers sont-ils aussi descendus dans les vallees ahontissant au Cauca et au Magdalena? Ilbert Heim, le géologue bien connu de l'Université de Zurich, écrivait encore en 188.5 : "Dans la zone tropicale de notre terre, il n'y a pas trace d'une énoque glaciaire. " Vu la difficulté d'atteindre les bautes montagnes de la régrion tropicale, les observations quion a pu faire dans ce domaine sont le date récente. Pour ne citer que celles qui ont été faites diuns la région voisine de celle oǹ nous nous trouvous, Hans Meyer, qui étudia les géantr des Corlillives situés sous l’équateur, ohserva que la limite inférieure les glaeiers, qui était julis a 3700 on $3800 \mathrm{~m}$., est aujuurthui a 4500 ou $4600 \mathrm{~m}$, e qui donne une dillérence de niveau de goo m. En Culombie, Hettner et Regel observaient des polis glaciaires dans le Coeui,

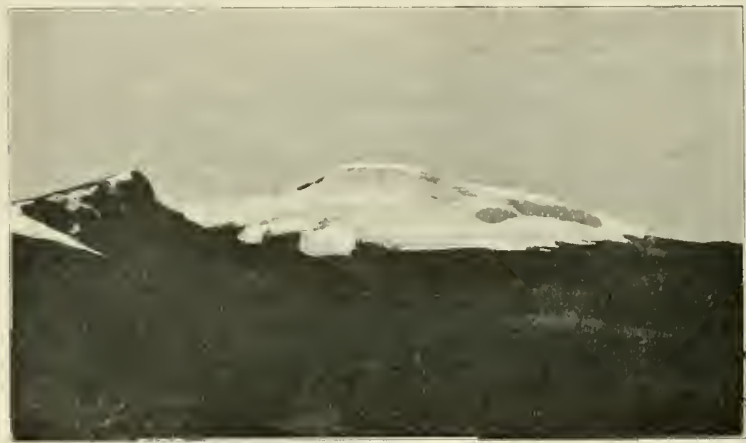

Sommet du Ruiz. ì $4000 \mathrm{~m}$., et dans la régrion lu Tolima, it $3600 \mathrm{~m}$. En descendant des paramos du Ruiz, rous avons vu di deux reprises des polis glaciaires a des altitudes beaucoup plus faibles : 350 I m. et $3309 \mathrm{~m}$.

Donc sur le versant oriental des Cordilleres centrales, oi le climat est et était plus humide que sur le versant occidental, les glaciers seraient descendus beaucoup plus bas que ne lindiquent les observations précédentes et la différence de niveau serait, d'après nos olservations, d'environ $1200 \mathrm{~m}$. Ces résultats coinncident parfaitement avec ceux de l'expéditiou Steimmann, Ifoeck et Bistram en Bolivie, qui constatèrent que sur le versant oriental, les traces glaciaires deseendent jusqu’à $2600 \mathrm{~m}$.

En résumé, il résulte des études faites, que les hautes montagnes des tropiques, en Amérique et en Ifrique, présentent deux périodes glaciaires séparées par une période interglaciaire bien marquée. Pendant la première, comme en Europe, le recouvrement par la neige et la glace était plus consiclérable que pendant la seconde. Mais ce qui est surtout intéressant, e’est que ces deux époques glaciaires comespondent aux deux deruieres des trois ou quatre époques glaciaires de l'Amérique du Nord et de l'Europe. Actuellement. comme ehez nous, la limite des neiges et des glaciers recule. La concordance parlaite sur tout le grlube, de l'oscillation des limites des neiges et des glaciers actuels et de la période diluvienne, est fort intéressante et a une portée théorique qui ne peut se liscuter ici.

Nous étions en train d'examiner de près les polis glaciaires, lorsque le passage d'une nombreuse caravane de boufs pesamment charģés nous arracha à nos olservations. La traversée de la Cordillère centrale dans cette région est particulièrement dilficile et pénible à cause de l'état déplorahle des chemins, aussi transporte-t-on de préférence les marchandises à l'aide de boufs. Ces animaux peuvent porter des charıres plus lourdes que les mules, ils ont le pas plus sûr, probablement à cause de la conformation de leurs pieds, ce qui compense l'extrème lenteur de leur marche. Sou- 


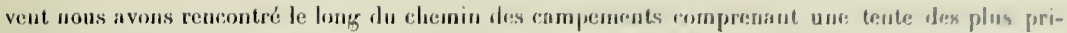

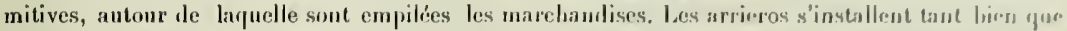
mal sous cet abri pour laire leur cuisine et flormir, taurlis que les animaux, livres a tax-mones, we

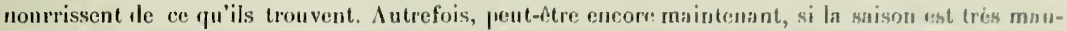
vaise, les breul's servaicut d'animnux do selle jerm franchir les passages dangereux.

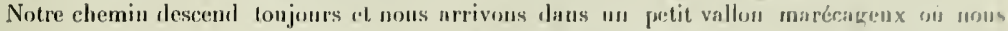
voyons de nombreux firaylejon (nom espagnol des Esspelelia), puis nous remontons juspu'h un. petite crete (alt. $3 / 181 \mathrm{~m}$.) ou nous assistons. à notre étonnement, à un clangement complet et tris larusque de la végétation, comme si eette crete formait une barrière. Derrièe nous s'étendent les paramos dans tout ce qu'ils ont de plus caractéristique, tandis que levant nous commence la forct des terres froides avec ses lougères arborescentes (Cyathea Mellenii var. cracann, plus las $1 /$ sophila armata) et plus loin ses palmiers (Oreodoxa spec.). Nous descendons très rapidement le versant oriental des Andes cen. trales en traversant de grandes forêts. Vers 4 heures, nous sommes au-dessus d'une sorte de paroi de rochers, au pied de laquelle nons voyons nos mules de charge qui nous attendent; elles nous ont précédés penłiınt la traversée des paramos que nous avons faite très lentement pour y recueillir force olservations et collections. Comme la descente se fait par des esealiers formés de dalles de granit glissant, nous mettons pied à terre, pour éviter tout accident.

L'endroit oủ nous devons passer la nuit s'appelle Morron (alt. 26 ig m.) et se compose de trois maisons on nous trouvons un gite primitif. Les gुens ne sont pas habitués à recevoir des voyageurs, aussi ont-ils de la peine à trouver de quoi apaiser notre faim,

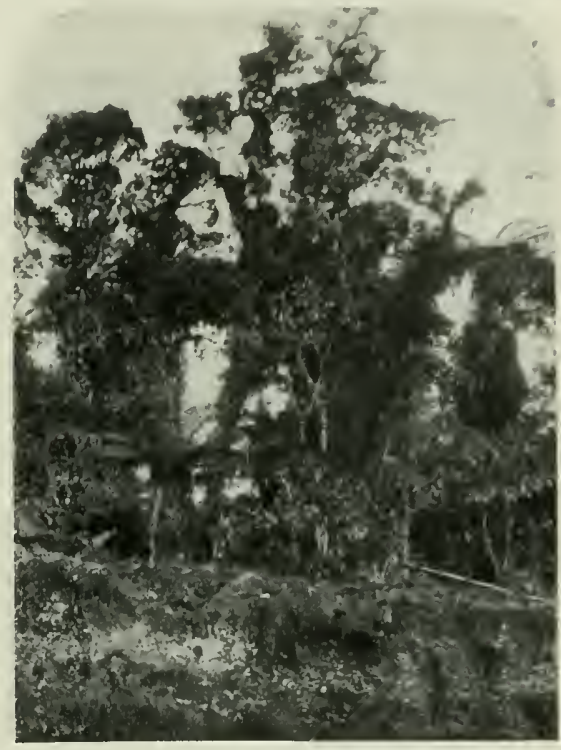

Forêt, versant oriental du Ruiz, près de la limile inférieure des paramos. A gauche, une fougère arborescente (Alsophila armatal.

(F. 3.) et, faute de mieux, nous sommes obligés de nous contenter de quelques aufs et de cacao. Morron est situé sur la croupe dénudée d'une montagne, de chaque còté de laquelle se trouvent les profondes vallées de deux affluents du Guali ; dans ces vallées, surtout à notre droite, la végétation est riche et abondante.

Le lendemain matin, nous partons pour Soledad, et depuis une petite éminence, non loin de Morron, nous voyons pour la dernière fois, dans toute sa splendeur matinale, le Ruiz complètement découvert. La colline oú nous sommes n'est plus formée de roches éruptives, mais de schistes. Jusqu'à Soledad le chemin est assez monotone et peu accidenté ; nous suivons la crète d'une montagne qui se détache perpendiculairement du massif du Ruiz. Le villagge de Soledad (alt. 2310 m.). que nous atteignons à midi, est un misèrable endroit oì nous ne trourons à nous restaurer que chez un particulier. Il est situé à l'extrémité de la crêteque nous avons longée toute la matinée: de lá, on 
plonge sur la vallée profondément encaissée du Rio Aguacatal. Par un mauvais sentier en zig-zag, trés rapide, nous arrivons au fond de la vallée où la végétation est d'une rare exubérance. $A$ la hauteur de Soledad, le Rio Aguacatal fait un coude brusque, coupant transversalement la chaine que nous suivons depuis Morron. Il passe par un étroit défilé anquel aboutit notre sentier qui lranchit la rivière sur un pont de bois couvert (alt. $1440 \mathrm{~m}$.), long d'une quinzaine de mitres seulement. Sous nos pieds, la rivière coule impétueusement, resserrée entre deux parois de rochers presque perpendiculaires formés de schistes précrétaciques.

Il nous faut attendre assez lorigtemps avant te traverser le pont où passe une grande caravane de boufs transportant des matériaux destinés à des machines pour les mines de la région de Mani-

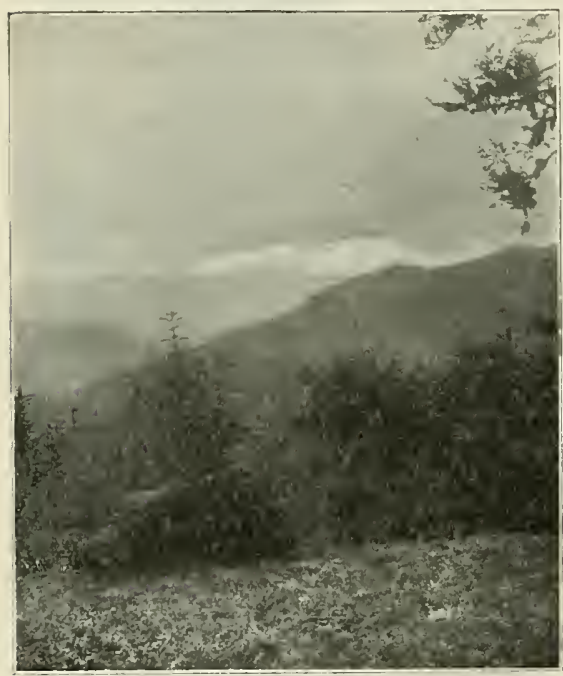

Sommet du Ruiz.

Vue prise des environs de Morron.) zales. Une fois le pont franchi, nous gravissons l'autre versant de la vallée en nous efforçant d'éviter la rencontre des retardataires de la caravane. En effet, ces animaux, comme les mules, vont toujours droit devant eux, sans se détourner de leur chemin et sans s'oecuper des gens ou des bêtes qu'ils peuvent croiser.

Au haut de la montée (alt. $2267 \mathrm{~m}$.) et vis-í-vis de Soledad se trouve le village de Guarumo (alt, $2159 \mathrm{~m}$.), dont toutes les maisons sont construites en planches et couvertes de toits de bardeaux. Un peu plus loin, au hameau de Partida, nous rejoignons le ehemin qui, par Salamina, traverse les Andes centrales plus au nord. Depuis le matin, nous allions dans la direction du nord, mais nous commençons enfin it nous diriger vers l'Est en descendint (tout en remontant bien sot1vent 1!) vers Fresno (alt. $1474 \mathrm{~m}$.) où nous arrivons is 7 heures el demie du soir. Nous trouvons à nous loger dans une auberge où nous jouissons d'un confort relativement grand, et le lendemain matin nous continuons notre route. Pour sortir du village, nous devons faire un grand détour, car le chemin labituel est défoncé et impraticable depuis plusieurs jours.

Durant toute la journée, nous longeons la croupe ondulée d'un chainon qui s'alaisse de plus en plus jusqu’à la plaine de Mariquita. Cette région est assez habitée et surtout très fréquentée ; les forêts ont à peu près disparu, aussi le sol est-il aride et la végétation, de même que le paysage, sontils peu intéressants.

Après Fresno, nous voyons d'abord des terrains formés de minces couches de terre glaise colorée en rouge, en jaune et en bleu, puis nous pénétrons dans une région de conglomérats inclinés dans la direction de l'Ouest. Ces conglomérats renferment par places des blocs arrondis de roches éruptives ayant jusqu't̀ $1 \mathrm{~m}$. de diamètre. Ce sont ces conglomérats qui, plus bas, forment ces nombreuses mines d'or d'alluvions que nous rencontrons au bord du chemin et qui eurent jadis un si grand renom. A tous moments nous longeons ou nous croisons de grandes conduites amenant l'eau nécessaire aux machines hydrauliques des mines. 


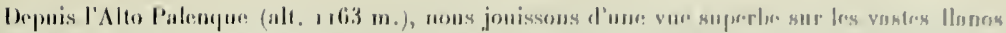

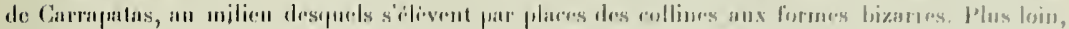

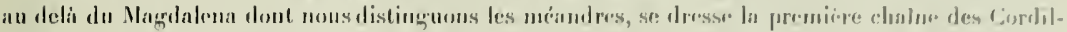
leres orientiles.

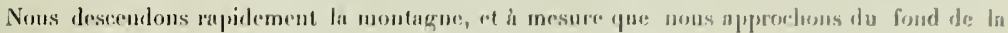

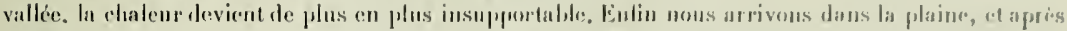

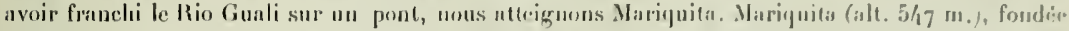
en 5550 , lint jadjs le principal centre minier de toute cette région. Ce n'ast plus maintenant qu'ura misérable village qui n'a d'iutres restes de son ancienue importane: que quelquass vicilles maisons

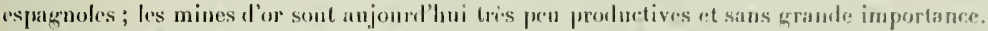

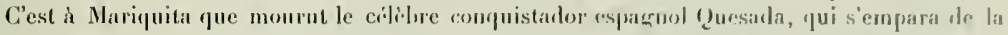
Savane de Bogrota al laquelle il donna le nom de "Valle de los Alrazales " w fonda liogrota, la rapitale du vice-royaume de Nouvelle (Brenade. Apres avoir citabli solidement la domiration apagnolu

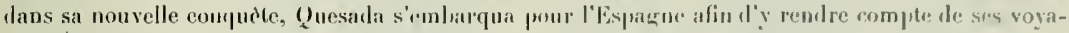
gese. Il fut disgracié pour s'ìtre présenté richement vîtu it lit cour qui portait le deuil de la rein: Isabelle; it rentrit en Colombie et cet homme, qui avait connu les honueurs princiers et qui s'atait emparé de richesses immenses, mourut misérahlement de la lipre à Mariquiti.

A Mariquiti, nous abandonnous nos mules fourbues et lilessées et nous nous dirigeons vers la grare pour prendre le train qui uous couduira à Honda. La ligne traverse dans toute leur longueur les llauos, vastes plaines couvertes d'une herre maigre et desséchée par un soleil de feu (on n'est plus qu'à $220 \mathrm{~m}$. d'altitude) et de quelques arlorisseaux. Aux environs de Honda se dressent des cullines peu élevées, aux formes hizarres, modelées par l'érosion dans une cipaisse conche de unf qui ruronvrait tous les llanos à l'époque tertiaire ou tuatermaire et qui devail provenir de la région éruptive du Ruiz. Il ue reste plus, comme lémoins de ces formidalıles éruptions, que res quelques collines de tul' voleauique au bord du Magdalena prés de Honda.

Vers 5 heures, nous arrivons à Ilonda et descendons it l'hòtel Santanter oi nous trouvous uxe joic un preu de confort. A jeine étions-nous arrivés, que nous avons la visite al'un fournisseur de mules qui, ayant été préveuu de notre arrivée par M. Gregori, de Manizales, venait se mettre a notre disposition. Ce peu serupuleux personnage devait du reste abuser de notre qualité détrangers et ne nous amener le lendemain que des bittes étiques et fourbues, an lien des animaux robustes qu'il nous avail promis.

Ilonda, la Profomle (all. 21 : m.). est situce sur la rive gauche du Magdalena, encaissee entre les montagnes; elle a une lempérature moyenne de $29^{\circ}$. C'est une ville de 4000 habitants. trés importante, car elle est le point terminus de la uavigation sur le Haut et sur le Bas Magdalena. Elle est aussi le licu de passage obligatoire du commerce d'importation et d'exportation du centre de la Colombie et de Bogota en particulier; ćest de là que nous pénétrerons dans les Cordillères orientalés avec leurs curicux hants plateaux, ou fut fondé en 1538 l'ancien vice-royaume de Youvelle Grenade avec sa eapitale Santa-Fé-de Bogota.

Nous avons de la peine à nous habituer à la chaleur torride qui rè̀ne à Honda. car nous venons d'une altitude de près de $4000 \mathrm{~m}$. où la température nocturne était voisine de $0^{\circ}$, aussi ne sommes-nous pas fächés de quitter eette ville le 8 octobre pour gravir les Indes orientales. Pour atteindre le pont suspendu qui traverse le Jlagdalena, nous sommes obligés de franchir à ģue une rivic̀re assez large. mais peu prolonde; une fois sur la rive droite du lleuve, apres avoir paré un fort droit de peage. nous commençons à monter. Nous chevauchons maintenant sur le "Camino real " qui relie directement Honda it Bogotit en esciladant trois des Cordillires orientales. Ce chemin ra de roval que le nom ; en réalité, c’est l'aucien sentier trace prar les Indiens et il n'est guère meilleur actuellement quautrefois. Alors qu'il eût été si facile de construire une route carrossable éu évitant de faire trois 
ascensions, ainsi que le proposait un ingénieur français, on a préféré consacrer des sommes énormes à mal entretenir celle voie très fréquentée qui était, il y a peu de temps, encore, la seule qui reliait Bogota avec le monde extérieur. Si les fondrières sont relativement peu nombreuses, le chemiu n’en est pas meilleur pour cela ; il est pavé par places, mais de telle manière que les mules préfèrent marcher à còté, car elles risquent soit de glisser, soil d'engager leurs sabots dans l'intervalle séparant les pierres.

Nous vorons avec étonnement, au - bord du chemin, une locomotive toute rouillée, enfouie au milieu d'une riche végétation : e'est tout ce qui reste d'un commencement de ligne de chemin de fer qui devait relier Honda à Bogota. Cette ligne fut commencée il y a une trentaine d'années; mais à peine 4 ou $5 \mathrm{~km}$. étaient-ils construits que la compagnie fit une faillite frauduleuse, en engloutissant d'importantes subventions de l'Etat. Comme cela arrive trop souvent en Colombie, dès les premiers coups de pioche, on avait fait venir à grands frais de l'étranger des locomotives et des wagons qui ne furent jamais utilisés et dont nous voyons les carcasses exposées it toutes les intempéries le long de la route.

L'ascension de la première Cordillère nous déçoit passablement à cause de la pauvreté de la végétation qui ne rappelle que de très loin celle des bords du Bas Magdalena; les forèts et les cultures manquent et l'on ne voit guère que des taillis ou des régions dénudées. Sur ce célèbre "Camino real ", pous rencontrons et dépassons des caravanes de mules lourdement chargées, conduites par des peons criant et jurant sans cesse; elles apportent à Bogota, isolée sur les Hauts plateaux. les produits des terres chaudes et les marchandises d'outre-mer. D'autres troupes de mules descendent à vide et nous pouvons voir les corps de ces pauvres bêtes couverts de grosses plaies que personne ne songe à soigner. Ce qui nous frappe le plus, c'est de rencontrer des Indiens isolés ou en famille, portant sur le dos, comme des bêtes de somme, de lourdes charges retenues par un ruban qui passe sur le front. Nous remarquons avec étonnement que ces indigènes du Cundinamarca présentent un type mongol très prononcé qui semble accuser une parenté asiatique indubitable des plus curieuses. Tous ces Indiens ont les vêtements en lambeaux, un air misérable et une expression d'indicible tristesse. Ce sout là les descendants des glorieux Chibchas qui régnaient jadis sur les Hauts plateaux et qui avaient une eivilisation très développée, civilisation que les Espagnols s'acharnèrent à détruire par des procédés atroces. Les pauvres descendants de cette race supérieure vivent aujourd'hui dans une ignorance crasse et n'ont plus aucun souvenir ni de leurs dieux, ni de leurs traditions, ni de leur langue.

Un peu au-dessus de Consuelo (alt. I $340 \mathrm{~m}$.), nous arrivons au sommet de la première Cordillère (alt. $1423 \mathrm{~m}$.), d'où nous jouissons d'une vue merveilleuse. Devant nous, c'est le flanc de la montagne abrupte qui descend jusqu'au Magdalena dont les méandres étincelants ressemblent à un gigantesque ruban d'argent. Au delà des vastes llanos de Carrapatas se dressent les Cordillères centrales, au milieu desquelles nous devinons le Ruiz que nous avions vu de si près quelques jours auparavant. Derrière nous, s'élève la seconde chaîne des Cordillères orientales dont nous sépare une vallée assez profonde, au fond de laquelle se trouve Guaduas (alt. $1015 \mathrm{~m}$.). Nous atteignons ce petit village à la tombée de la nuit et nous logeons dans une maison qui fut certainement jadis la muison de campagne d'un riche Espagnol.

Le lendemain matin nous partons de bonne heure, pour gravir la seconde chaîne de montagnes, dont le sommet est à $1949 \mathrm{~m}$. d'altitude; de là-haut, on domine la profonde vallée du Rio Negro, où se trouve la petite ville de Villeta (alt, $858 \mathrm{~m}$.). Comme nous sommes un dimanche, nous pensions trouver les habitants propres et endimanchés ainsi que nous l'avions toujours vu. Mais au lieu de cela, nous ne voyons que des gens misérables avec des vêtements en loques et dont l'aspect extérieur seul montre déjà leur infériorité vis-à-vis des $\Lambda n$ tioquiens, infériorité qui se manifeste par heaucoup d'autres signes encore. Après un repas réconfortant pendant lequel nos mules peuvent se 
reposer, nous commengons in gravir la troisième ct dernirie chaine qui nous sépare de la Satana de: Bogota. Le chemin écharpe la montague au milien d'une uature aride ct dénudée, trés prou intéren-

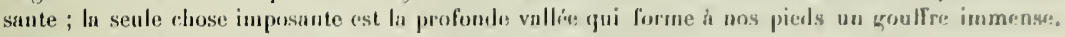

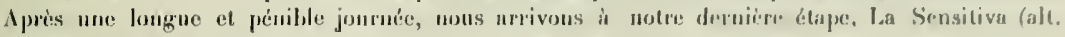
$19^{3} 3 \mathrm{~m}$.), auherge très conlortahle où nous pouvons passer la muit. 1

Le lendemain matio, nous partons avaut 6 heures pour Agua Larga ou le chemin, detestable jusqu'alors, devient une mute carrossable. Nous voyous en eflit de nombrenx clars ht deux rones,

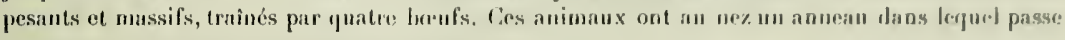

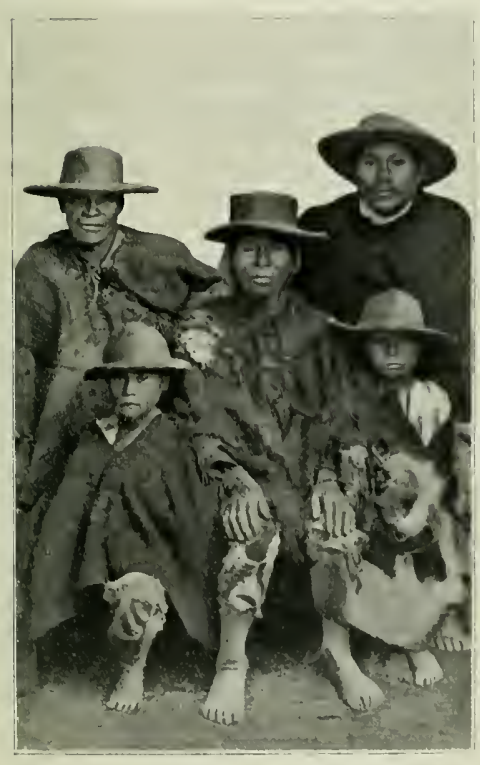

Chibchas du Cunlinamatea.

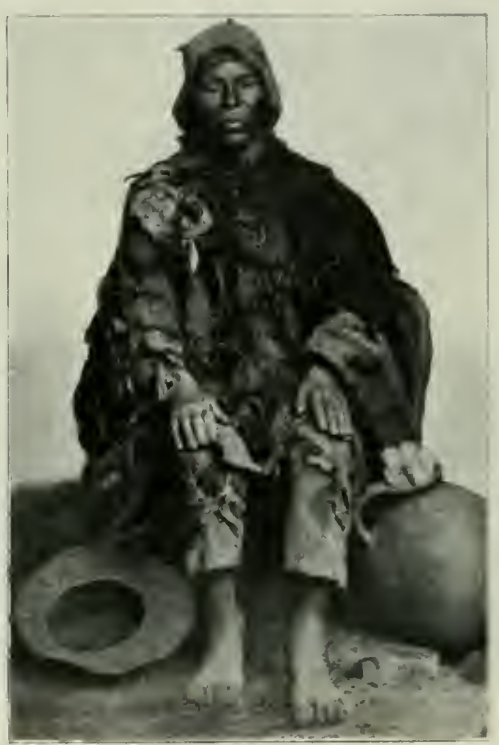

IChiheha du Cundinamarea.

une lanière de cuir qui sert it les diriger; le eonducteur, armé d'une longue perche dont lextremité porte uno mollette métallique molile et aux dents acérées, harcèle continnellement res pauvres animaux.

Peu à peu, la végétation change d'aspect el devient beaucoup plus intéressante. Yous voyons de nombreux Digitalis purpurea, des Fuchsia, des Calceolaria. el toute une flore bien différente

1 Espèces nouvelles régétales et animales recueillies entre Honda et la Sałana de Bogota :

1. Plantes nouvelles : Pnccinia Sarache et solanicola: Coleosporium Fischeri: I redo Cyalhulu. el Baccharidis anomala'.

11. Animaux uouveaux: Geoplana bilineatu, l'seutolhelphusn dispar, Peripalus bimbergi, Ribaulin fahrmanni, Cranaus calcat, Rhinocricus instabilts. 
de celle que nous venons de quitter et qui était remarquable surtout par sa paurreté. Vers 8 heures du matin, nous arrivons au sommet de la terniere Cordillère et nous voyons devant nous, à perte de vue, une immense plaine, la fameuse "Sabana de Bogota".

Ce haut platean. de $1000 \mathrm{~km}^{2}$ de superficie, fut jadis sans aucun doute un grand bassin lacustre dont le niveau s'ahaissa progressivement, a mesure que l'ćcoulement au bord sud se creusait jusqu'au fond du lac, niveau de la Sabana d'aujourd'luui. Les seuls vestiges qui restent encore de cette époque lointaine sont de nombreuses lagunes et des marais peu profonds. Cette vaste plaine, grace à son origine, a de tout tempsété très fertile; avant la conquête espagnole, elle était habitée et culti-
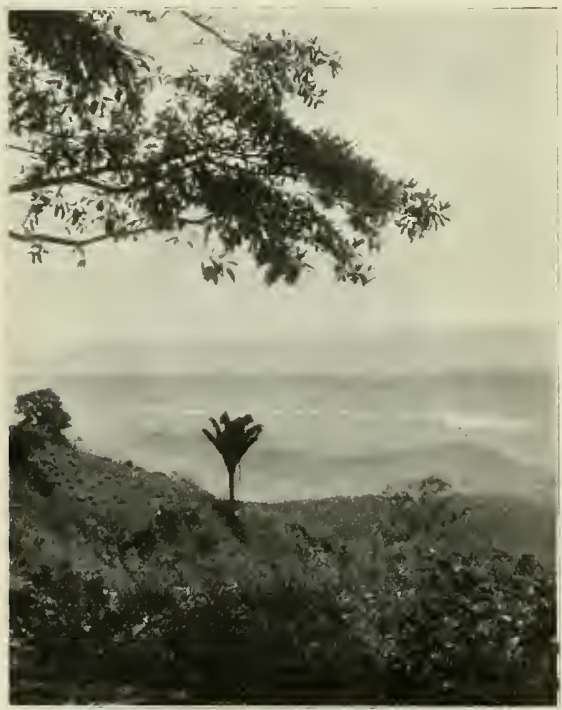

Lat plaine du Magdalena (Vue prise de Consuelo). vée par les Chibchas, lont la civilisation était presque aussi avancée que celle des Incas et des Aztéques.

L'interprétation des géologues qui fout de la savane le fond d'un ancien lac se retrouve dans les légendes des Chibchas. Ils racontent "qu'au temps des amours du demidieu Bochica et de la déesse Witaca, celle-ci, pour se venger des infidélités de son mari, fit d'un seul coup mourir tous ses fils, les Hom. mes, par une l'ormidable inondation du Funza. Ils furent tous engloutis sous les vagues furieuses du Grand Lac. Mais le dieurenvoya son épouse ahominable, renversa d'un coup de pied la barrière des Andes, donnant ainsi naissance à la chute de Tequendama, et il remplaça cette mer agitée et maudite par une riche mer de moissons: la savane de Bogota n. 1

Nons admirons longuement cette perspective imposante, puis nous nous dirigeons vers Facatativa (alt. $2505 \mathrm{~m}$.), que nous voyons à quelques kilomètres et où nous trouvons le chemin de fer qui traverse toute la Sabana pour aboutir à Bogota.

Un peu après I heure et demie, nons partons avec un assez grand retard dù à un déraillement de la locomotive pendant la formation du train. Le matériel roulant est très joli et très confortable et c'est avec délices que nous échangeons le dos de nos mules contre des sièges plus stables et plus rembourrés. On file à tonte vitesse pour rattraper le temps perdu et nous admirons le paysage qui s'enfuit rapidement. Tout d'un coup, nous remarquons que la vitesse diminue sensiblement et que nous nous arrêtons; en regardant par la portière, nous constatons avec peu de plaisir que notre wagon s'est détaché du convoi et reste en panne, tandis qu’à un contour de la voie, nous apercevons la queue du train qui disparaît à toute allure. Tout le monde se met à pousser des cris de détresse pour attirer l'attention et nous voyons heureusement au bout d'un moment le train faire machine arrière pour venir nous chercher. Nous profitons de cette balte inattendue pour recueillir quelques plantes, parmi lesquelles l'une se trouve être particulièrement intéressante, Chrysocelis

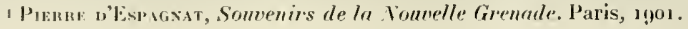




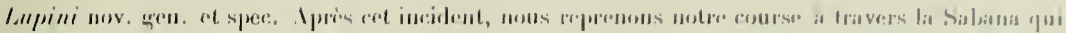

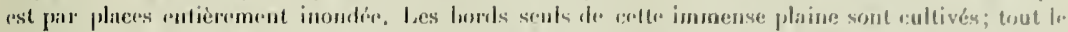

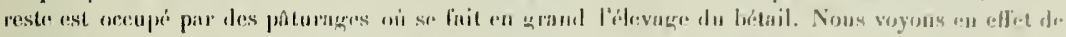

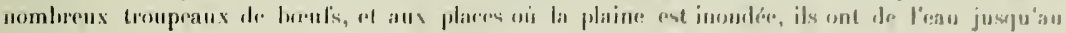
poitrail.

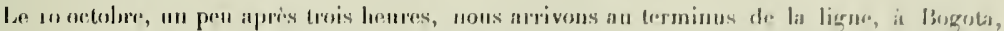
enpitale de la Colombie. Ce lajet, accompli en une heure et demie, represonte le ticess environ de la

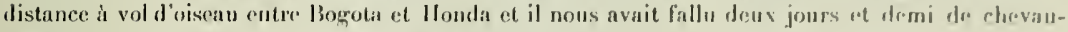
clées ininterrompues pour pareourir les denx autros tiors !

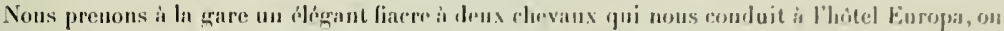
nous trouvons pour la premire fuis, depuis notre arrive con Colombie, tout le confort moderor. Ceela

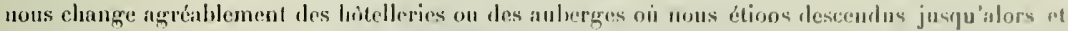
qui brillaient par lenr simpliciti, leur manque de confort ot souvent par lour malpropreti. 


\section{CHAPITRE VIII}

\section{Bogota et ses environs.}

Bogota (alt. $2626 \mathrm{~m}$.) est une ville de 13000 habitants environ, batie au pied des Monts Guadeloupe et Montserrate, dans les Cordillères orientales, à l'extrémité est de la vaste savane de Bogota. "Cette ville, capitale de l'ancienne Présidence, de l'ancien Vice-Royaume de Nouvelle-Grenade et de la première grande République de Colombie, fut fondée le 6 août 1538 par Gonzalo Jimenes de Quesada. Elle fut construite sur l'emplacement du village indien Tensaquillo (aujourd'hui Fontibon), séjour de plaisance du souverain chibcha détròné, et reecut le nom de Santa-Fé de Bogota. Le nom de Santa-Fé fut douné en mémoire du camp retranché établi par Ferdinand et Isabelle devant Grenade, celui de Bogota rappelle celui de Bacata, la capitale des Muyscas, distante de $20 \mathrm{~km}$. Un décret du 17 décembre 1819 retrancha les mots de Santa-Fé du nom de la capitale qui s'appela désormais Bogota. $)^{1}$

A peine étions-nous arrivés à l'hôtel, que nous recevons la visite de M. Robert Beck, consul suisse à Bogota, qui avait été prévenu de notre arrivée par MI. Bimberg, de Mcdellin. C'est avec le plus grand plaisir que nous faisons la connaissance de ce compatriote actif, énergique et influent, qui vient fort aimablement se mettre à notre disposition et nous indiquer comment nous pouvons le mieux employer le peu temps dont nous disposons. Avec lui, pas d'hésitations ni de tergiversations; le soir de notre arrivée, tous nos projets d'excursions étaient dèjà faits, aussi ne saurions-nous lui ètre assez reconnaissants de tout ce qu'il a fait pour nous rendre facile et agréable le séjour dans la capitale et ses environs. Accompagnés par M. Beck, nous allons voir quelques notabilités de la ville pour lesquelles M. le professeur Röthlisberger, de Berne, anciennement professeur à l'Université de Bogota, nous avait remis des lettres d'introduction, avant notre départ de Suisse. C'est ainsi que nous faisons la connaissance des divers membres des familles Samper et Ancizar, chez lesquelles nous trouvons le plus chaleureux accueil.

Bogota, que nous avons le loisir de visiter en détail, ressemble aux villes espagnoles par l'aspect des maisons, et à toutes les villes américaines par ses rues qui se coupentà angle droit; elle est éclairée à l'électricité et possède un réseau de tramways électriques. Les monuments les plus importanis se trouvent sur la grande place d'où l'on a une vue superbe sur les deux montagnes qui dominent la ville et au sommet desquelles sont deux chapelles. La cathédrale, lourde et massive, est le type des anciennes églises de style jésuite; elle passe pour être une des plus belles de l'Amérique latine. Le Capitole, de style grec et d'ordre ionique, destiné au Parlement, est très imposant, mais pas encore achevé; sa construction fut cependant commencée en 1840 , mais en Colombie, il ne faut

1 Henry Jums, Ln Aépubliqu" de Colombie. Bruxelies, rygg. 


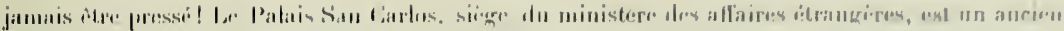

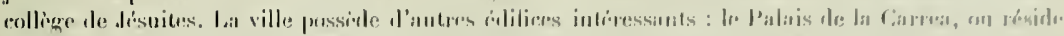

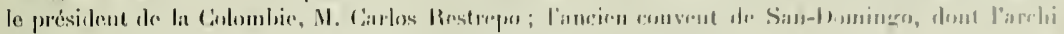

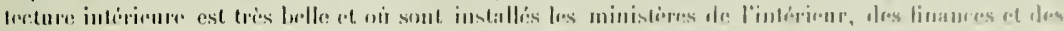

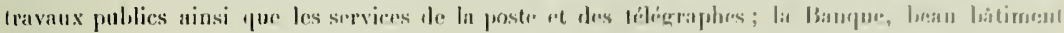
molerne tres bien aménarié, itc.

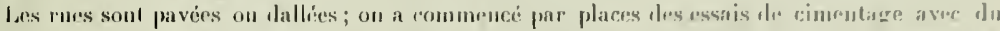

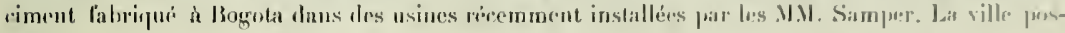

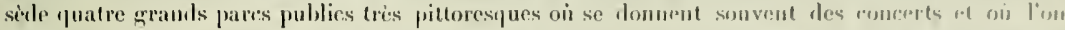

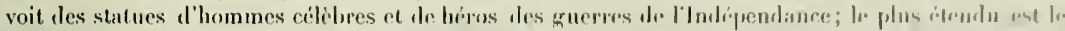

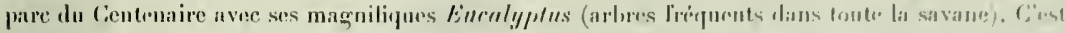

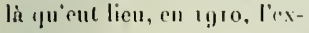
position mationale at lorension des leses du centenaire de l'Indejemance colomlienme. A notre arrives, relte intéressante maniliestation lu développement de la Colombie etait malheureusement terminée, et nous n'avous pu voir que les hàtiments villes, mais tries beanx exférieurement. La ville est traversée par quatre torrents: les Rios funza, San Agustin, San Francisco et del Arzohispo qui sont. suivant la saison, torrentueux ou desséchés. La distrilution d'ean potable est

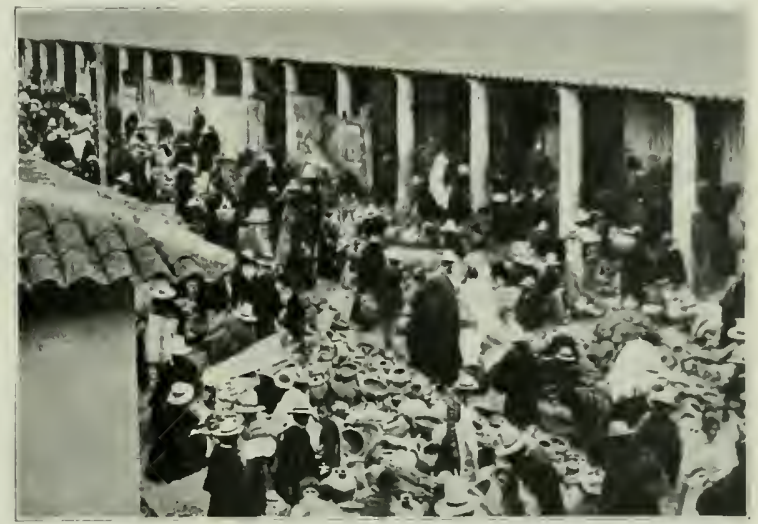

L.e marche de logola. Le coin des puteries. très délectueuse à Bogota: les concuites sont mal installées et lon est obligé de boullir ou de liltrer l'eau avaul de la hoire,

Les Bogotains sont très intelligents, charmants el d'une élucation parfaile: ils soot de plus poètes et orateurs nés. Leur esprit est naturellemeut porté vers l’étulle et śassimile facilemınt les. sciences les plus diverses; aussi la culture intellectuelle est-elle très développée il Bogola, "I'Athines de l'Imérique du Sud n. Les Bogotaines sont remarquahles par leur beauti, leur gràce, leur savoir-vive parfait et leur distioction naturelle. Les jeunes filles ont de iris boune heure nne personnalití très accusée; à partir de treize ans, elles sont dejà lemmes et président avec aisance aux invitations, tandis que leurs saurs d'Europe sont encore dans l'àge ingrat. Elles sont toutes-puissantes dans la famille ou chacun se range à leurs moiadres volontés, et dans le mariage, pour lequel on s’incline toujours devaut leur décision, elles trouvent une vie oủ leur autorité est égale ì celle de celui qu'elles ont choisi comme époux. Elles sout de très bonne heure éponses ct mères. mais leur beauté passe vite; elles conservent cependant toujours un charme tout particulier lorsqu'on les voit passer, enveloppées de la mantille nationale, ce costume si bien en harmonie avec le milicu, mais qui tend malheureusement à disparaitre de plıs en plus devant la mode de Paris. Les Bogotaines sont pieuses, souvent même dévoles, aussi les cérémonies religrieuses se déroulent-elles dan- toutes les églises de la ville avec baneoup de faste au milieu d"une assistance tres nombrense et recueillip. II 
semble mème qu’il reste à Bogota quelque chose de Vantique lanatisme religicux du temps da la conquète esparnole.

Le 12 octobre, nous partons pour une excursion à la célebre chute du Tequendama (alt. $2210 \mathrm{~m}$.) par laquelle s'écoulent les eaux de la Sabana de Bogota. Nous prenons le chemin de fer jusqu'di la station Tequendama sur la ligne de Sibate. A la gare, nous trouvons laimable ingénieur. II. J.-II. Samper qui tient à nous faire lui-même les honneurs de cette merveille dont les Bogotains sont si fiers, et à juste titre, et à nous faire visiter ses usines électriques situées an Charquito, à $2 \mathrm{~km}$, en amont. Quatre chevaux fougueux nous attendent et nous partons au galop vers la gorge

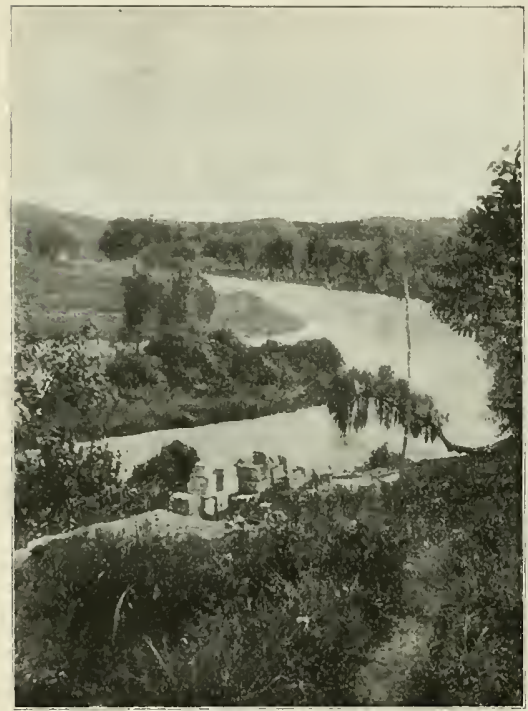

Le Rio Funza dans la Savane. (F. x.)

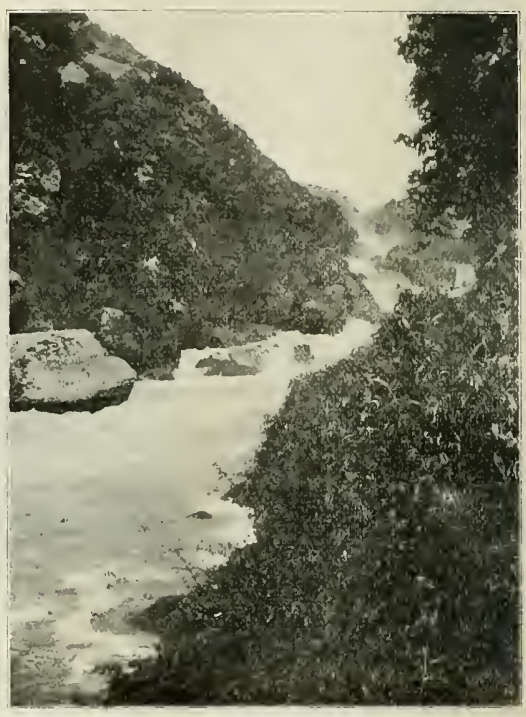

Les gorges du Rio Funæa en amont du Charquilo. (Г. ..)

creusée dans les rochers par la rivière. Nous longeons le Rio Funza, calme et paisible, coulant lentement, en formant de nombreux méandres, jusqu'au bord de la savane. A l'entrée des gorges, la rivière prend brusquement un courant rapide et se précipite en bouillonnant, par des cascades successives, jusqu'aux usines du Charquito; puis, elle reprend son cours paisible et les rapides cessent à peu près jusqu'au bord de la chute. Cette chute s'annonce de loin par un grondement semblable à celui du tonnerre et par des nuages de vapeur qui s’élèvent incessamment au-dessus d'elle.

Nous arrivons enfin et nous restons saisis d'admiration devant cette calaracte de $145 \mathrm{~m}$. de haut qui roule un volume d'eau considérable. Perchés sur un promontoire surplombant la chute, nous jouissons, par une chance exceptionnelle, sans aucune trace de brouillard, du spectacle grandiose de cetle cascade qui se précipite dans le gouffre avec un vacarme assourdissant et qui rejaillit en vapeur. Quand le soleil brille, ce sont des myriades d'arcs-en-ciel se succédant, s'entrecroisant, se 


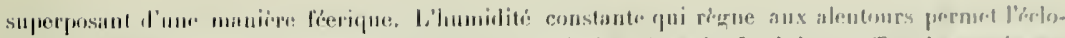

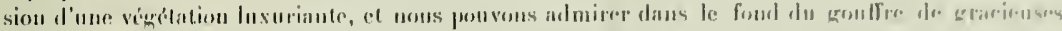

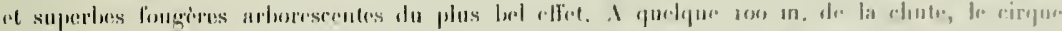

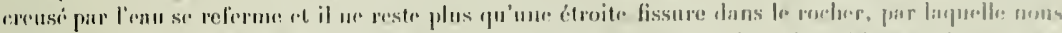

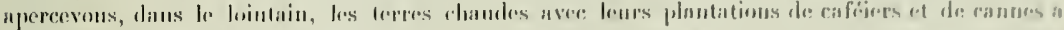

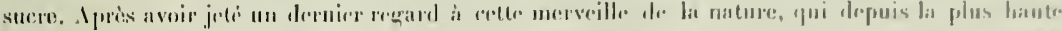

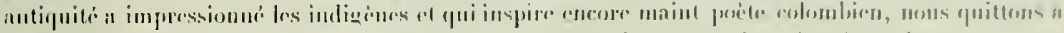

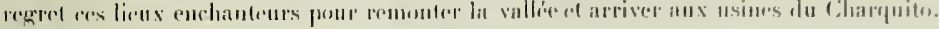

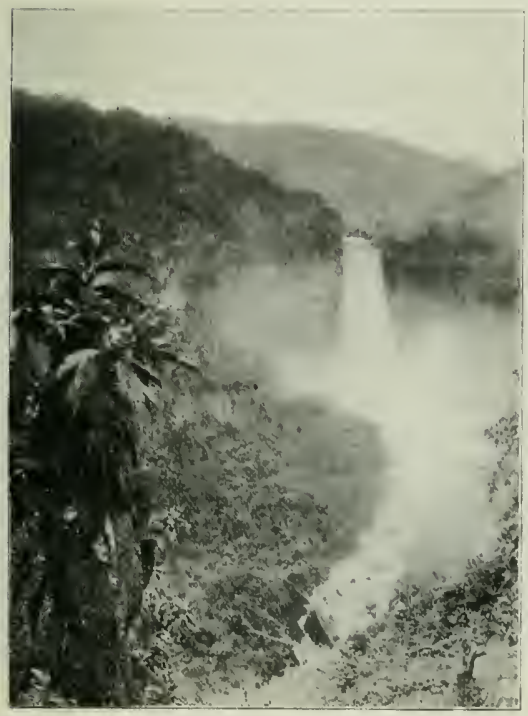

La chute du Tequendama.

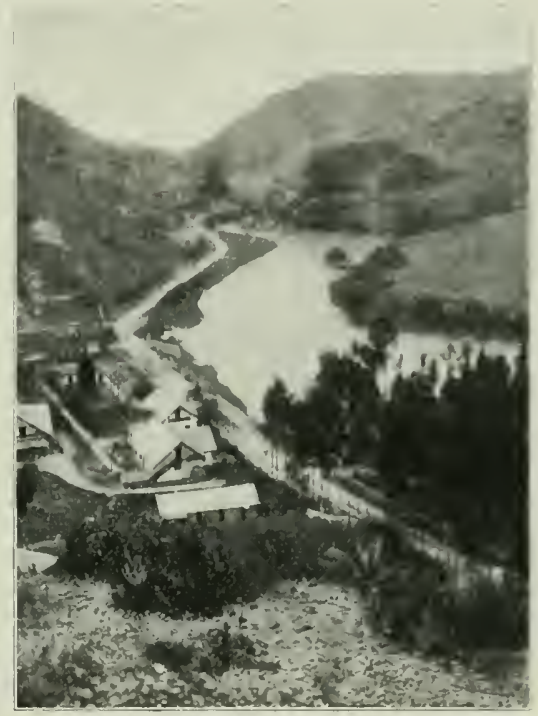

Charquito.

Sons laimible conduite de M. Samper, directeur de l'usine of l'un de ses fondateurs. nous visitons en détail toutes les instailations destinées it fournir le courant électrique à lBoguta. Chose interessante, ce sont des maisons suisses qui ont fourni tontes les machines: les turhines. action-

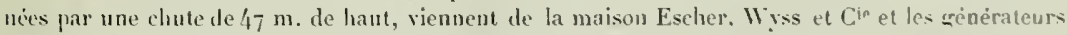
sont de l'usine d'Oerlikon ( 4 dinamos, 3 de 450 chevaux, 1 de 1200 ). Lors de notre visite, on traraillait à l'agrandissement de l'usine qui fournira, une fois terminée, le double de force. Par $27 \mathrm{~km}$. de cảlules sonterrains, le courant est conduit à Bogota, oi il est transformé et utilisé pour l'échirage (36 ooo lampes) ou pour l'industrie (imprimeries. moulins à blé ou à maïs, etc.). L'usine. très coquette. est situèe au milieu d'un grrand pare, plantẻ de superbes Eucalyptıs, qui contribuent it embellir le paysage; au moins lit-bas cette installation n'culaidit pas les environs. comme c'est malheurensement trop souvent le cas chez nous. C'est avec un véritable regret que nous voyons 
arriver l"leure du depart el pue nous remontons en selle. 1 . Iu retour, nous admirons encore les grorges du Rio funza et ses cascades en amont du Charquito. puis, une lois dans la Sabana, nous regagnons au salop la trare pour rentres à Bogota, toujours accompagués par Mt. Samuer. Qu’ıl nous soit permis de lui réitier jei, de mène quà sa lamille. l'expression de toute notre reconuaissance. Nous avous p'u constater que l'amabilite colombienne r'est pas un vaiu mol, car la l'amille Samper a finit pour deux itrangers auxquels elle ne devait rien, bien plus qu'on ne l'ait sonvent pour ses amis.

De retour en ville, M. Samper a encore l'olligeance de nous conduire daus la fahrique de ciment qu'il vient d'iustaller avec quelques membres de sa famille. Cette usine, qui ctait encore en construction, est appelée à une grande prospérité, car jusqu’à maintenant, tout le ciment était importí à grands frais de l'ćtranger. Les installations sont très bien comprises et les laboratoires possèdent tous les appareils molernes. Depuis quelques années, l’industrie se développe à Bogota d'une manière réjouissante. A còté de ces usines que nous venons de visiter, nous pouvous citer plusieurs fubriques de pates alimentaires, de chocolat, d'allumettes, de grands moulius, etc., n'oublions pas les brasseries, dont la plus importante est celle de M. Kopp, qui nous la fit visiter en détail et nous Ionna à léguster ses excellents produits.

Parmi les nombrenses excursions que nous avons faites aux environs de Bogota d'après les indications de X. Beck, la plus intéressante fut certainement celle au lac d'Ubaque. Partis de Bogota le 14 octobre au matin, nous gagnons le village San Cristobal, après avoir traversé la rivière du mème nom; de là, nous commengons à monter el nous pénétrons presque immédiatement dans la régrion des paramos qui, là aussi, est caractérisće par la présence de nombreux Espeletia. Par un chemin caillouteux ou pavé, mais sans pantanos, ce qui nous change de nos randonnées antérieures, nous gravissons lentement le paramo Cruz Verde, et à 2 heures nous atteignons le col de l'. Ilto Cruz Verde, à $366_{2} 6 \mathrm{~m}$. d'altitude. Le paramo que nous traversons ditlère considérablement de ceux que nous avons vus dans le massif du Ruiz. lei, plus de lorêts aux arbres tordus par la tempite, mais de vastes prairies arides, très humides avec, de place en place, quelques arbustes ne dépassant guér I m. 5o de haut, des Iypericum ligneux (les mêmes que ceux des paramos du Ruiz), de petites fougèes arborescentes (Blechnum linealum et loxense) et des Fuchsia. On rencontre en foule des Sphagnum, des Digitulis purpurea, des Geranium (G. diffusum et mulliceps), A zorella crenala. Eryngium slellalum, Gentiana corymbosn, Bartsia santolinifolia, Senecin crepidifolius et une quantité d'autres Composées, des Paepalanlhus (P. rolumbiensis, ensifolius et pilosus), des Espeletia (E. corymbosa el argenteu), moins hauts que ceux du Ruiz, et une foule d'autres plantes fort interessantes?. En cours de route, nous avons également l'oceasion de recueillir toute une sirie l'animaux du plus haut intérêt".

Du sommel du col, nous avons une vue d'ensemble de ce paramo el de ceux qui l'enton'rut. Ils lorment un suite ininterrompue de vallonnements arides et dénudés, toujours pareils,

1 Lispieces nouvelfes recueillies près des usines du Charquito et de la chute du Tequendama:

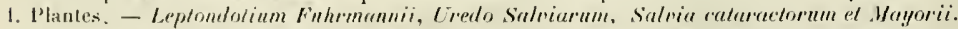

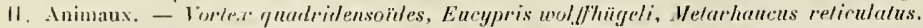

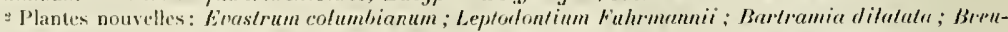

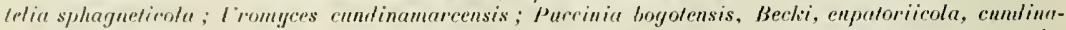

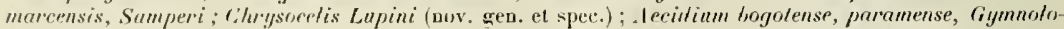

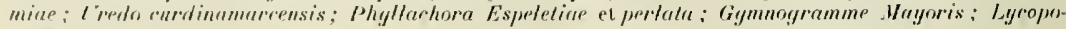
dium Mrayoris.

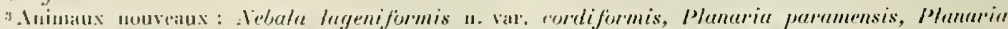
polyorrhis, firmplumu ortizi, tmblyplana monloyae, Blanchardiella paramensis, Bl. fuhrmanni, Periscolex fuhrmanni, Stemmulucutus logolensis, Eurytus surrinoides n. var. intermerlia, Vaginula allicolu. Iylodes fuhrmanni. 


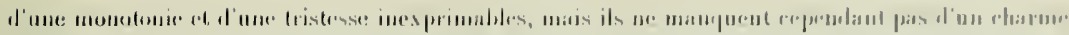
particulier.

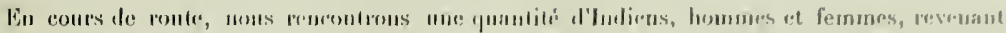

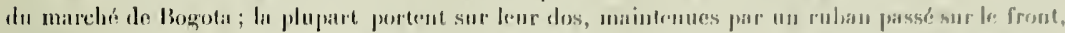

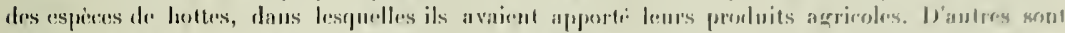

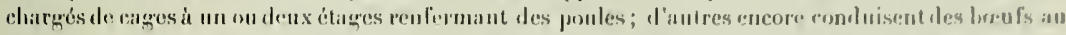

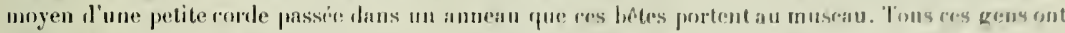

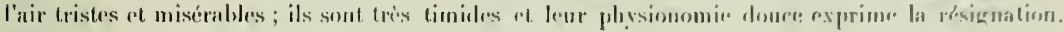
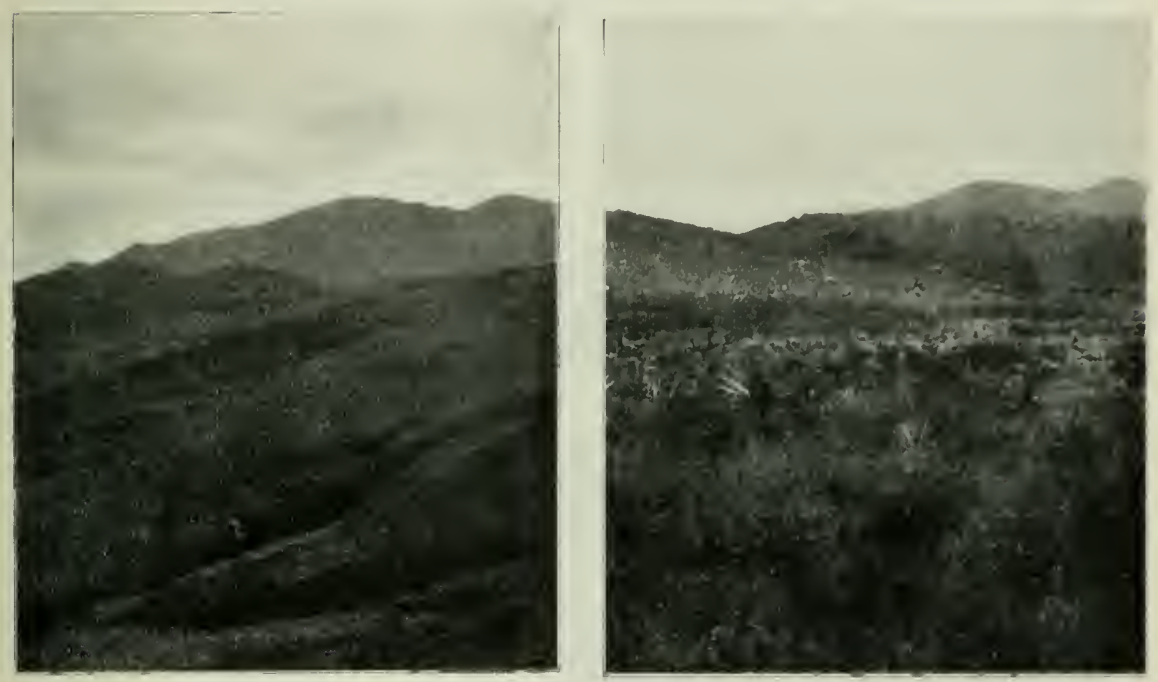

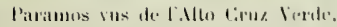

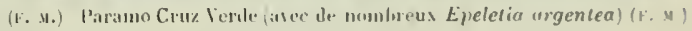

Ipres avoir admiré ce enrieurl parsige, si diflirent de tont de que nous avons vu, nous de-

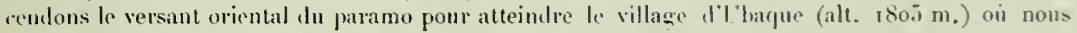
arrivons a la nuit ef ai nous eherehons en vain un gite. I force de peine, nous trouvons asile dans une "assistenciaria n, plus que primitive, a l'estrémite du village. les chambres quon nous offre n'ont pas de lits, et comme nous ne nous soucions guere de encher sur la terre liatlue, nos hites mous installent leurs propres lits dans un reduit borgue.

Le Iendemain matin de bome heure, nous allons visiter le petit lac situe an-dessus du village. sur un plateau, au pied d'une paroi de rochers. Celte lagune (alt. $2112 \mathrm{~m}$.), perchée sur le flanc de la montagne, est du plus riant effet aree ses eanx calmes el tranquilles: malheureusement, on ne peut pas s'approcher de la rive, car sur un certain esprace. le lord est maricageux el occupé par une quantiki de Cypéracées et autres plantes aquatiques, et par une bordure d'un vert émeraude un petu brunâtre, forméc par des milliers d'Azolln filiculoides. ravissantes petites fougeres aquatịues. Nínnmoins, c'est dans cette zone littorale que nous faisons les pêches les plus fructueuses de 
lout notre vorage, si ce nest au point de vue du nombre des especes, du moins au point de vue de la dispersion géographique. ${ }^{1}$ De tons cótés de hantes chaines de montagnes nous environnent et donnent un charme particulier à ce ravissant endroit. A l'Est se trouve la chaine du paramo de Chingasa, la dernière des Cordillères orientales, au delà de layuelle s’étendent les llanos, ces inmmenses plaines brûlées par le soleil, et dont les eaux sont tributaires de l'Orénoque. D'ailleurs, nous sommes déjà sur le versant oriental des Cordilleres, car la rivière qui sort de la Laquana de Ubaque est un aftluent du Rio Negro qui se jette dans le Meta.

On comprend que le charme et la beauté de ce lac aient frappé limagination des ludieus primitifs qui en firent un de leur's lacs sacrés où s'accomplissaient des cérémonies religieuses très curienses et malheureusement encore légendaires on mỵstérienses. Des cérémonies analogues avaicnt anssi

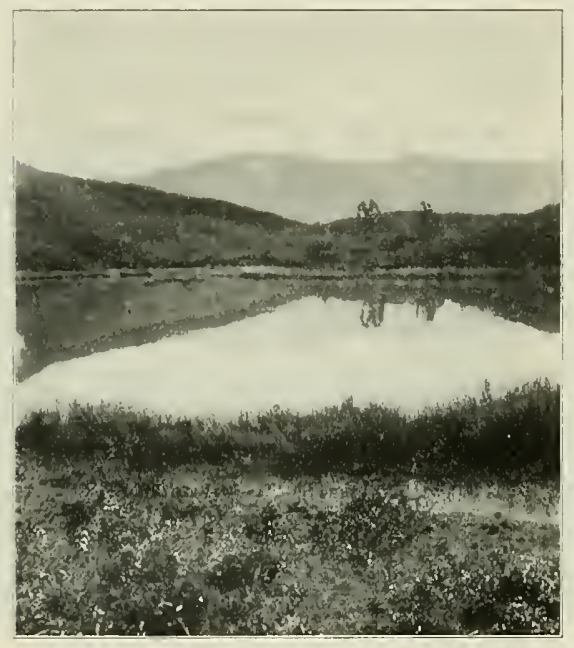

Laguma de tbaque. lieu chaque année aux lacs de Guatavita et de Siecha, et ce sont ces manifestations qui donuèrent naissance à la légende de l'El Doralo.

"Le jour du couronement de l'Empereur, tous les Indiens du Cundinamarca se reunissaient autour de lui, au bord du lac Guatavila, dans les montaques derrière la savane. Le roi se dévêtait puis, le corps enduit d'une mince couche de miel, il se roulait diuns de la poudre d'or et apparaissait comme une idole étincelante aux yeux de son peuple. Mlais les barques sacrées l'attendaient; il prenait place sur l'une d'entre elles; ses proches et les hauts dignitaires montaient dans les autres et le cortège se dirigeait vers le milien du lac. Là, le roi adorail le soleil reflété dans les eaux calmes et lui ollrail en libations tout l'or de ses cotlres, tous ses bijoux et ses joyaux. Quand tout avait disparu au fond des eanx, le monarque s'y plongeait à son tour pour en ressortir déprouillé de son élincelante parure, chétil comme l'un de ses sujets. Aiusi, après s'être humilié devaut le Dieu qui l'avait reconun, il était consacré par ce Dieu même aux yeux de tout son peuple. Ainsi naquit la légende de l'El Dorado, à cause de laquelle tant de eonquistadors se mirent en route à la recherche du royanme gouverné par le Roi Doré. q "

Ce que l'on erut pendant longtemps n’être qu'une légeude se trouve ètre une réalité historique. En efiet, depuis longtemps on eherchait à vider ces lacs sacrés afin d'en retirer les pierres prérieuses et les bijoux des Caciques, mais on n'avait obtenu que de maigres résultats. Cependant, des Iragages ont iamené un certain nombre d'objets en or, fort intéressants, et en particulier le fameux larleau de l'El Worado, retiré du lac de Siecha. Ces dernicres années, des travaux plus importants

1 Espèces nouvelles reeueillies a la Laguna de Lbaque et aux environs: t. Plantes: Anlistrodesmus

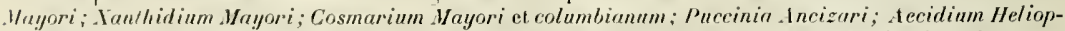
sidis. - I1. Inintaux : Plannria longistriala. Dunhevedin oflomloplar, n. var. columbiensis. Dirplomus

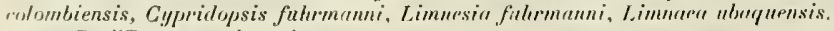

: P. d'Espigivit, lor. ril. 


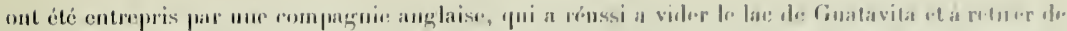

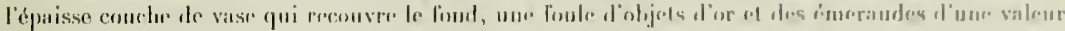

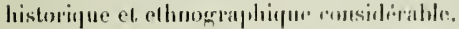

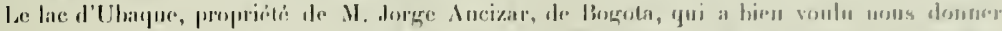

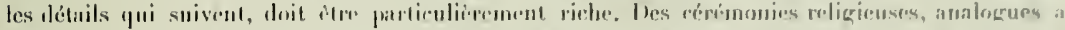

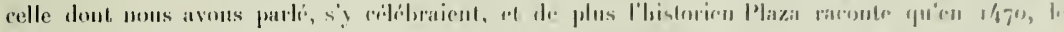

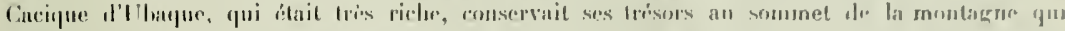

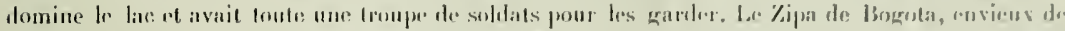

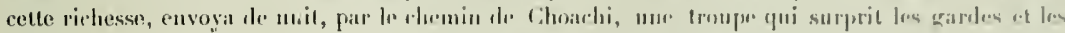

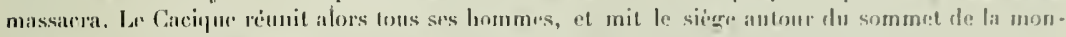

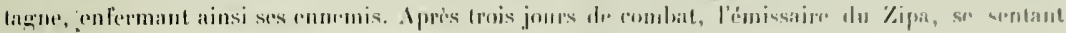

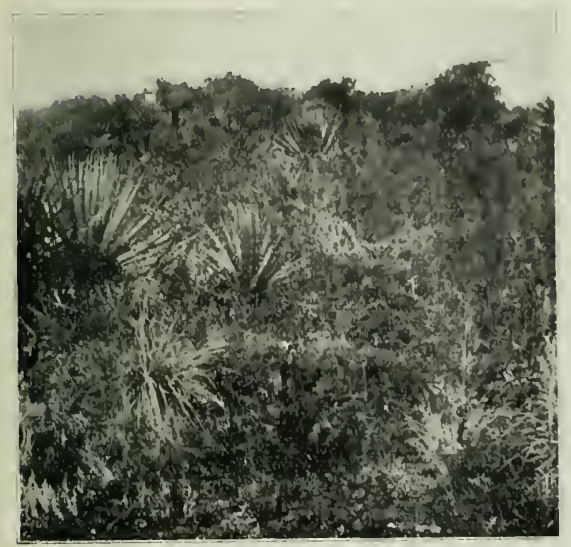

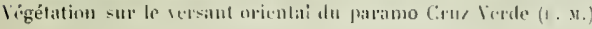

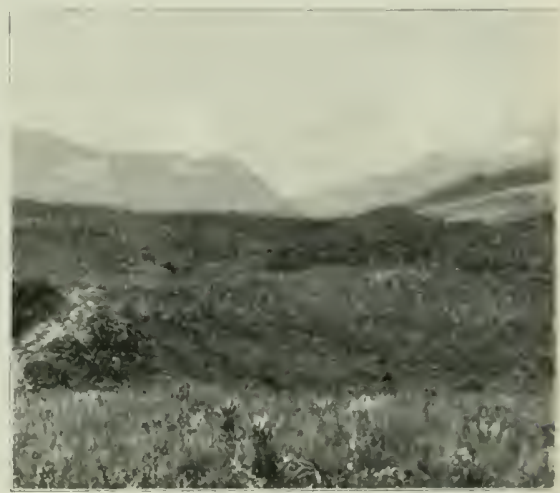

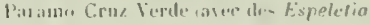

perilu, precipita dans le lac tous les trésors dout it venait de semparer et réussit a so fraser un passage it travers lis rangs ennemis it it regagner Bogota, mais en laissant presque tous ses bonmes sur te eliam] de bafaille.

Toutes ces ligendes nous revenaient à lesput tandis que nous rentrions à Bogota par le mème clemin qu'i l'aller, en faisunt en cours de route des obserwations baromcitriques pour déterminer l'altitude à laquelle apparaissent ou disparaissent les plantes les plus Iypiques du paramo.'

1 A lialtitude de $2477 \mathrm{m.,}$ nous remarquons les premiers Pupultanthus (P. ensifolzus) qui deviendront cosuitc plus abondants: jusqü $2634 \mathrm{~m}$., nons rencontrons en phus ou moins grand nombre les précicus Agare americana, qui disparaissent i partir de eetle altitude. A 2 (t65 m., nous entrons dans la region du piramo typique, alors quen dessons it y avait eneore un milange de la Hore de la a tierra fria s. Les Digitalis purpurea, en petit nombre, deviennent de plus en plus ahondints et nombreux. el à partir de l'altitude de $2762 \mathrm{~m}$. on les rencontre par milliers. eqayant le paramo de leurs eorolles pourprees. A 2030 mi.. nous ubservons lapparition de nombreux Fuchsia, el surtout de ces petites fougères arboreseentes que nous n'avons vues qu' au paramo Cruz Verdo (Blechnmm strialmm et Invense) enfin les Espelelia (E. argenlen ef corymbosa) apparisisent en foule et en nombre de plus eu plus grand à mesure que uous montons. 
1 peine etions-nous de retour à l'hòtel, qu'éclata un epouvantahle orage, comme nous n'eu avions pas encore v'u. . Iu tonnerre et aux éclairs qui se succédaient sans interruption, s'ajouta une véritable trombe qui transforma en un instant toutes les rues de la ville cn torrents impétueux; lepuis des mois et peut-être mème des années, nous dit-on, on n'avail eu un orage pareil. Nous comprenons mieux encore l'utilité des rues pavées ou dallées qui seraient sans cela constamment défoncies par ces orages.

Entre deux exeursions, nous allons visiter l'Université de Bogota. Les laboratoires et les anditoires domnent sur une cour centrale entourée de galeries. Les étudiants s'y promènent bruyamment, liscutant avec force gestes ou lisant à haute roix leurs manuels, presque tous français, sans songer quils peuvent gêner les professeurs qui donnent leurs cours. Les laboratoires nous ont semblé assez primitifs, car ils manquent d'appareils el surtoú de collections pour démonstrations : cela s’explique par le fait que leurs erédits sont trés limités.

L'Université comprend quatre facultés: droit et seiences politiques avee 232 étudiants, médeciue ct sciences naturelles, 202 étudiants, mathématiques et école d'ingénieurs, 58 éludiants, érole dentaire, 44 étudiantst. II y a une soixantaine de professeurs parmi lesquels plusieurs ont lait des ¿ludes très soignées à l'étranger. Ils reçoiven des traitements dérisoires, à peine supérieurs ì fr. 1 aon, ce qui les empêche de consacrer tout leur temps à l'enseignement, car ils sont obligés d'avoir une autre occupation plus rémunératrice. Il est à espérer que le gouvernement. comprenant l'importance de cet établissement d'enseignement supérieur, s'cfforcera de nodifier cet état de choses déplorables. Depuis les gquerres de l'Indépendance, l'instruction s'est de plus en plus développée. Suivant l'historien Restrepo, la généraliti des Colombiens resta plongée dans la plus profonde ignorance sous la domination espagnole, puisqu'au commencement du xix sičcle, le roi Charles IV refusa l'autorisation de fonder une université à Merida, sous prétexte que l'instruetion ne convenait pas aux Américains! Aujourdhui, à cóté de l'université de Bogota, il y en a nne á Popayan, à Carthagine. à Pasto, ainsi qu'ì Medellin qui possède en outre une École des Mines, La bibliotheque, fort bien aménagée, nous a semblé surtout riche en livres théologiques, tandis que les ouvrages de sciences naturelles sont peu nombreux et généralement très anciens. $\lambda$ côté se trouve le Musée national, qui renferme des tableaux ou des gravures représentant tous les hommes ayant joú un rôle dans l'histoire de la Colombie. Par contre, les collections ethnographiques et zoologiques, qui devraient être très importantes dans un pays aussi riche et intéressant, brillent par leur pauvreté. Ici encore les crédits ne sont pas suffisants pour permettre de développer cette institution qui servirait à l'instruction de chacun. En 19,3 , le budget prevoyait pour l'instruction publique dans toute la Colombic la modeste somme de $\$ 782.509$, tandis qu'on aflectait an budgel de la guerre $\$ 3.300 .632 ?$

1 Chittres donnés pour ig12.

- A titre de renseignenients, nous donnons le budget prévu pour 1913.

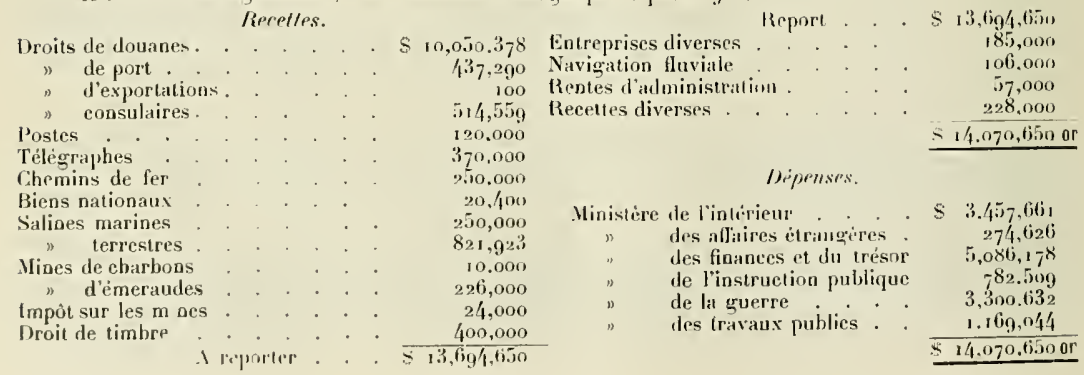


Les $18 \mathrm{et}$ ig octobre, nous faisons des excursions dinns les montugnes al l'ouest de la navaum, en comprignie d'un do nos compatriotes, M. Haggenmacher. Pour cela, nous prousus los rebernirs dos ler de Facatativa jusqu'a Madrid; hì, mous trouvons des chevaux retenus a notro intention et nous

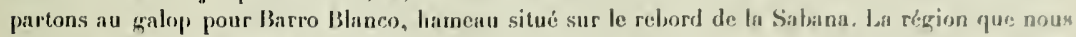
traversons est très marécageuse el de nombreux palmipèdes prennent lours b́bats sur loss lagurnes et les étaugs. Pour attuper ces oiseaux, très méliants de nature, les Indirus ont unr: rurieuse maniore de procéder. $\Lambda$ près avoir jeté leur dévolu sur un itang particulièrement riche, ils préparent lrur pièrge, en jetant ì la surface de l'eau de grosses calebasses. An bout de quelqques jours, les oiseaux sont habitues a ce voisiuage et ne se mélient plus de ce qui les avait elTrayés au déluat. la cluasseur arrive alors, entre dans l'eau en se dissimulant daus les hatutes plantes arjuatiques et mot sur sa tiue une calelasse munie de trous pour lui permettre d'olıserver sa proic. Aiusi maspué, il attend la venur. du gibier qui ne tarde pas ì se poser untour de fui. Lindien saisit alors les volatiles par lees pattos et les tire vivement sous l'eau oì elles sont vite étoulfées. Les autres oiseaux ne s'effarouchent pas, car ils ont l'labitude de plonger de temps à autre, et la chasse pent ctre ainsi trè fructueuse en jeu de temps.

$\Lambda$ Barro Blanco, nous rencoutrons une quantité de mules clıargées de "miel n, liquide analogue à la mélasse, et qu'on retire de la came à sucre; on le transporte dans de grandes poches de euir suspendues des deux cotés du bat. De nombreux attelages de breufs conduisent à Bogota et dans la Sabana les marchandises apportées jusque là à dos de mules depuis Girardot.

Peu après le hamcau, une échancruse dans la montagne, Boca del Wonte, forme unc barrière très nette entre deux zones de végétation très différentes. En effet, derrière nous s'étend la Sabana dont lo rebord nu et aride contraste avec le reste de la plaine riche et fertile, et en dessous de nous, c'est la végétation luxuriaute des terres froides. Le sentier descenıl rapidement; nos chevaux hésitent et font des faux pas, ce qui nous fait amèrement regretter les mules au pas sily et ferme, animaux indispeusables lorsqu'on voyage dans les montagnes de Colombic. Vers 2 heures, nous arrivons à l'auberge de Tambo (alt. $1679 \mathrm{~m}$.), non loin du village de Tena oi nous devons passer la nuit Aprés quelques instants de repos, nous nous mettons enroute sous une pluie battante pour aller au petit lac Pedropalo (alt. $2010 \mathrm{~m}$.); le lac est extrèmement pittoresque, car il est entouré de graniles forêts et les branches des arbres plongent dans ses eaux paisibles. Malheureusement la pluie nous tient trop filtèlement compagnie et nous ne pouvons songer à parcourir les environs. Aussi, après avoir fait quelques pêches et ramassé quelques plantes intéressantes, nous prenons le chemin du retour et nous arrivons à Tambo.' L'auberge on nous descendons présente un confort rare en Colombie : elle est éclairée à l'électricité, de mème que le village de Tena dont les lumières scintillent dans la nuit. Le soir, dans une chambre voisine de la nòtre, deus ravissantes señoritas font de la musique. et nous nous endormons au son de la "tiple» et des romances monotones, mélancoliques et plaintives si chères aux Colombiens.

Notre dernière excursion nous conduit à Zipaquira (alt. $2630 \mathrm{~m}$.), petite ville située sur le rebord septentrional de la Sabana, sur la rive droite du Rio Tibite, aftluent du Rio Funza. Nous faisons cette course sous l'aimable conduite de M. Beck, qui veut bien nous faire visiter luimême les salines. Zipaquira est en effet très célèbre par ses mines de sel gemme, étudiẻes autrefois

1 Espèces nouvelles recueillies au cours de l'excursion à Barro Blanco, Tambo el à la Laguna Pedropalo. - I. Plantes, Lromyces Mayorii; Uredo Agerali.

11. Aninaux. - Planaria longisiriata, Geoplana Iamboensis, G. nigrocephala, G. becki, Helobdella fuhmanni, $H$. hemisphaerica, $H$. columbiensis, Blanchardiella tamboensis, Candona ubaquensis, Pseudothelphusa dispar. Peripatus bouvieri, Rhinocricus instabilis, Rh. i. n. subsp. adolesceas, Stemmatoculus fuhrmanni, Tamboicus fuhrmanni, Pararhancus marmoratus, Uctarhancus reficulatus, Cynorta culcarapicolis, Limnesia fuhrnanni, trrhenurus fuhrmanni, Iaginula varians, I". montana. 
par Alexandre de Humboldt, qui fut chargé par le vice-roi de faire une expertise et d'indiquer les meilleur's procidés d'exploitation. Le sel se trouve seulement dans une colline peu élerée, de quelques kilomìtres de long et de large. I l'ouest de la ville, ces dépôts très ancieus, d'orighine crítacique, sont enveloppés et traversés par des couches d'argile, de g.pse et d'anlı̣ilrite, qui les protigent eontre les agents atmosphériques. L'exploitation en est trè facile, car les galeries sont horizontales. Gràce à MI. Beck, nous obtenons très facilement l'autorisation de pénétrer dans la mine et de tout visiter. Nous montons sur des wagonnets et nous admirons en passant les parois qui, lépourvues de boisages, étincellent à la lumière des torches des mineurs. Par places, les galeries

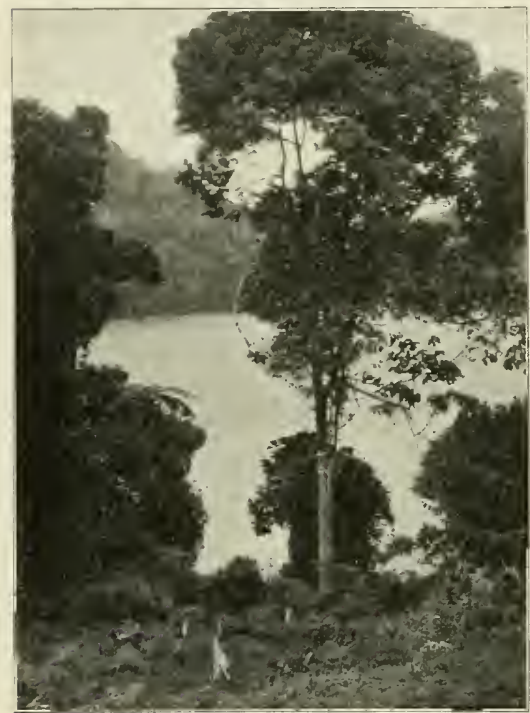

Le lac Pedropalo. s'blargissent, formant de vastes cavernes dont la partie supérieure, taillée en dòme, scintille aux lumières des ouvriers occupés à l'extraction. Le sel est extrait soit à la pioche, soit it l'aide de perforatrices à nain; les bloes retirés sont formés soit de sel pur, soit de sel mélangé à de l'argile. Les premiers sont vendus tels quels, les autres doivent itre purifiés dans des falrriques munies d'installations très simples. MI. Beck étant intéressé dans une de ces fabriques, nous pouvons la visiter en détail.

Au milien d'un grand réservoir rempli d'eau, se trouve un axe te bois mobile, portant des traverses de bois disposées comme les rayons d'une rone. On suspend à ces traverses des paniers renfermant le sel mélangé d'argile. Par suite du mouvement rotatoire, la dissolution du sel est activée, l'argite reste en partie dans les paniers et ce qui en sort tombe au fond du réselvoir et s'y dépose. Lorsque la solution est sulfisamment concentrée, on la laisse s'écouler sur un filtre d'où elle passe dans des cuves hémisphériques où on la fait évaporer. L'installation que nous avons visitée renfermait 40 de ces cuves et produisait r8oo quintaux de sel par mois ( 15000 arohas). Ges salines sont la propriété de l'État et produisent annuellement une moyenne de 1 r ooo tonnes de sel. Les salines terrestres de Colombie rapportent à l'Etat plus de 4 millions par an. Ce qui permet d'exploiter ces mines à peu de frais relativement, e'est qu'à proximité immédiate on trouve, comme du reste sur tout le rebord de la Sabana, des gisements d'un charbon ressemblant à la houille.

Toute cette région est renommée par ses pâturages très lertiles où l'on fait en grand l'élevage du bétail; elle est encore riche en gisements de fer, de plomb, de cuivre et de houille non exploités.

Notre intention était de pousser jusqu’à Muzo, malheureusement notre temps était trop limité et nous avons dû renoncer à visiter ses mines d'émeraudes. C'est en etfet là que se trouvent d'importants gisements de ces pierres précieuses, peut-être même les plus importants du monde; ces mines appartiennent à l'État et sont exploitées depuis trois siècles. La région de Muzo est particulièrement riche en papillons; l'un d'eux (Morpho cypris), aux ailes d'un beau bleu métallique, est particulièrement rare et recherché par les collectionneurs. 


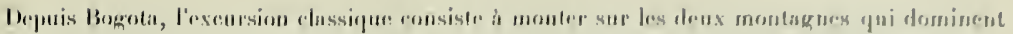

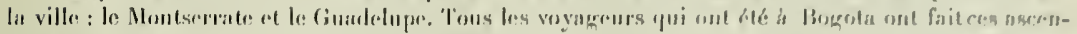

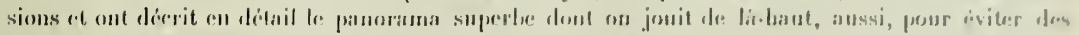

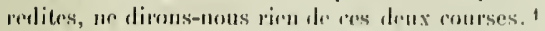

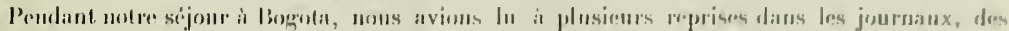

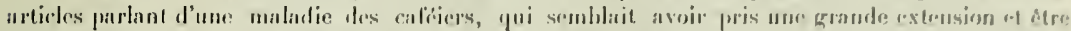

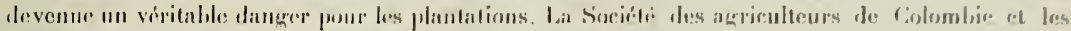

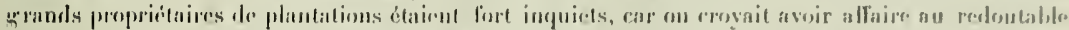

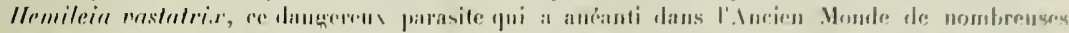

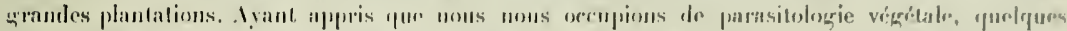

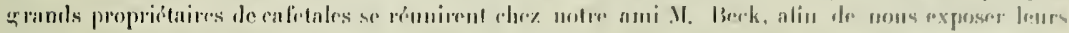

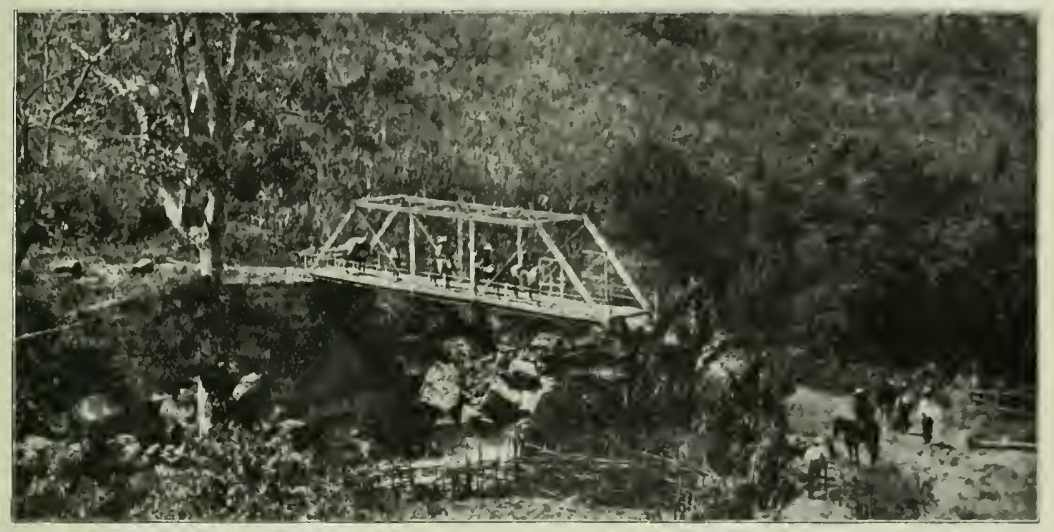

Pont de bois an bord de la sabana de Bogota.

(1)hotographie de .I. I. Ilerzog, de Sainl-Gall.)

doléances. Nous eûmes lì une série de causeries du plus haut intérêt et nous avons pu tranquilliser ces Messieurs en leur affirmant que le parasite en question n'était pas le fameux Ilemilein. Comme il ne nous était pas possihle de nous prononcer sur cette maladie qu'ils appelaicnt la a mancha n, en examinant seulement des échautillons desséchés ou mal conservés, nous décidons d’aller étudier sur place le parasile. Linsi, au lieu de regagner directement le Magdalena par le chemin de: Bogutir.

1 Espices nouvelles recueillies au cours de nos excursions anx environs de Bogrota et dans la Sabana

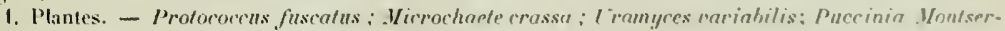
rates of Incisuri; Chrysocelis Lupini (nov. gen. et spec.).

11. Inimaux. - Geoplana beckit, G. nigrocephala, G. mullipunelaln, G. ucellaht, Rhynchodenus samperi. Vortex complirutus, Blunchardiella octocnlata, Bl. bogatensis, Candana annae. C. colmmbiensis, Cypridopsis dadagi. t. fuhrmunni, Conthneamptus fuhrmanni, Stemmaloculus fuhrmanni, Rhinocricus instabilis, Rh. i. n. subsp. allalescens, Metarhaur'us albilineatus, Eylais columbiensis, Englandina fuhrmanni, E. gadeti, Taginula colmmbiana, thactus fuhrmanni. 
de fer de Girardot, qui du reste ne marchait pas ì ce moment, nous sommes invités très aimablement à visiter les cafetales de la vallée de Viota, sous la conduite de trois membres de la Société des agriculteurs, et eux-mêmes propriétaires de cafetales. Cette chevanchée est celle qui nons laissera peut-être les plus beaux souvenirs, car nous avons traversé des contrées extrêmement pittoresques et des forêts idéalement belles dans la plus agréable des compagnies.

Avant notre départ fixé au 22 octobre, nous allons prendre congé des aimables Bogotains chez lesquels nous avons été si bien accueillis. et de la famille Beck que nous tenons à remercier d'une manière toute particulière. Notre ami nous apprend qu'il a pu obtenir pour nous de la Compagnie de navigation sur le Magdalena des billets de faveur, nous permettant de faire gratuitement le long voyage de Girardot à Barranquilla. Cette nouvelle preuve d'intérêt et d'amabilité que nous donne y. Beck nous remplit de reconnaissance. Nous ne savons comment le remercier de tout ce qu'il a fait pour nous, de tous les renseignements de toute nature qu'il nous a donnés sur la Colombie. Bogota et ses environs (renseignements dont nous nous sommes servis ci-dessus), aussi conserveronsnous toujours un sonvenir particnlièrement reconnaissant de ce digne représentant de la Suisse. C'est un véritable ami que nous laissons là-bas, et un ami qui n'a jamais craint de se donner de la peine pour nous, transformant ainsi complètement et embellissant singulièrement notre séjour dans la capitale colombienne. 


\section{CIINPITLE IX}

\section{Visite aux Cafetales de la vallée de Viota.}

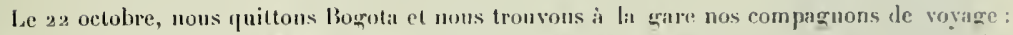
MM. Rurique Gonzalez, Luis Montoya ot Giabriel Ortiz. Nons prenons le: train pour Silate, point terminus de la ligne que nous avions suivie quelques jours an paravant pour aller au Tequendama. Sibate (alt. $2585 \mathrm{~m}$.) est à peine un hameau situé près tu hord sud-nuest de la savane de Bogoti.

Nous logeons diuns une tris belle maison de campagne, mise a notre disposition par un des Messieurs Samper, ce qui nous est fort agréable, car nous aurions du, sans cela, nous installer dans l'auberge voisine où uous allons souper. Cette auberge n'abrite pas seulement les woyageurs de passage, elle renferme aussi une "chicheria". On appelle ainsi les cabarets oi le peuple dn Cundinamarea vient s'alcooliser avec de la "chicha ", le breuvage national cher déji aux anciens Indiens. Ce liquide, fort peu appétissant, se fabrique avec de la farine de maiss et du jus de canneà sucre quo on laisse fermenter; on le boit en pleine fermentation. Dans un réduit sale et obscur, heureusement! nous voyous de granles cures dans lesquelles bout ce liquide de couleur indécise. Dans certains villages, le mais n'est pas réduit en farine par des pilons, mais par les dents de vieilles Indiennes, ce qui contribue peut-être à donner à la chicha une saveur plus agréable! De temps à autre, des aides viennent puiser dans ces cuves le liquide qu'on porte ensuite au comptoir. Comme nous sommes un samedi, la chicheria est remplie d'hommes, de fenmes et d'enfants qui boivent en quelques heures la plus grande partic de leur salaire hebdomadaire. Ce n'est d'ailleurs pas ici sculement que nous faisons cette observation, mais partout aux environs de Bogota oủ le peuple s'adonne démesurément it l'alcool. En Antioquia, le peuple est infiniment plus sobre; ici, la race est décrénérée, plus on moius abrutie, conséquence probable de cette funeste passion. Pour ces geas, la chicha est en quelque sorte l'essence de la vie; ils en hoivent des quantités énormes, ce qui leur tient souvent lieu de nourriture, car elle renferme des principes nutritifs.

Le lendemain matin, nous nous mettons en route avec un assez fort retard causć par l'orcanisation de notre caravane. Nous sommes six cavaliers et nous avons six mules de charge et six de rechange. Ce nombre important de bêtes de rechange nous laisse rèveurs et nous permet de supposer que les chemins que nous allons suivre ne doivent pas être des voies de communications interuationales $! \Lambda$ còté de notre peo $\mathrm{I}$, il $y$ en a une dizaine d'autres pour surveiller les bètes de charce. C'est done une véritable caravane qui part de Sibate à 8 heures du matin.

Nous commençons à gravir une petite colline, l'Alto Puerto Chirriadora (alt. 2786 m.), d'oi nous descendons dans un petit vallon inculte et marécageux appelé Angarillo (alt. $2707 \mathrm{~m}$.). 
Apres un court arret pour attendre les mules de charge, nous reprenons notre route et nous escaladons les pentes rapides le l'Alto Angarillo (all. $3084 \mathrm{~m}$.) en nous lirayant un passage dans les rochers et les taillis. Au sommet, le chemin cesse presque d'exister, et ce qui reste est si défoncé que nous devous l'abandonner el lescendre la pente assez rapide à travers une forcht ćpaisse, sur un sol si détrempé que nos bêtes enfoncent profondément à chaque pas. Par places, c'est à grand'peine que nous passons sous des branches qui risquent de nous désargonner; nous devons escalaker de gros troncs d'arbres ou en éviter d'autres, tout pourris et cachés sous un tapis de mousses trom-

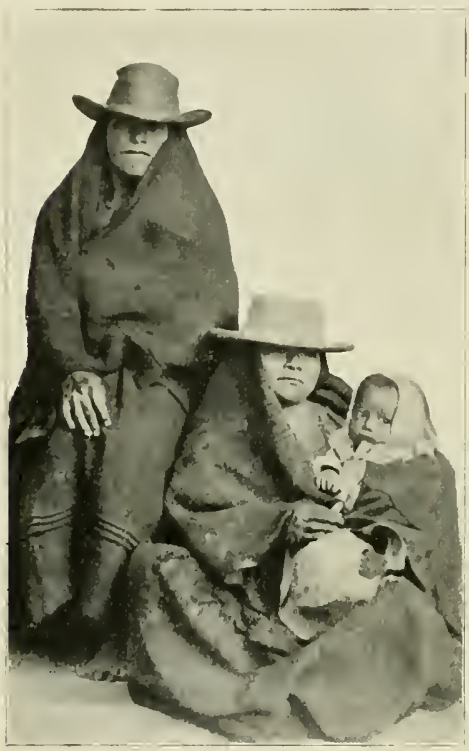

Indiens du Cundinamarea. peur. Enfin, non saus peine, nous letrouvons te chemin, mais il est plus épouvantable eucore et plus dangereux qu'avant. En effet, par suite de l'humidité perpétnelléqui rògne dans cette région, les chemins seraient impratirables; on pare à cet inconvénient d'me manie fort peu banale. Sur une listance de plusicurs kilomitres, on a placé còte à côte cl transversalement de grosses traverses de bois formées de rulgaires billons bruts. II n'est pas dilficile de comprendre combien un tel chemin est inconfortable et dangereux avec ces traverses arrondies, sonvent mobiles et écartées les unes des autres. Aussi les mules cheminent-elles avec une lenteur extrême pour éviter de glisser ou de prendre leurs pieds dans l'intervalle plus ou moins grand qui sépare les poutres. Bien souvent aussi, grâce aux intempéries, les traverses se pourrissent et deviennent un véritable danger pour les animaux qui posent leurs sabots sur les parties attaquées et enfoncent brusquement en risquant de se casser les membres on de perdre pied. Nous chevauchons ainsi pendant des heures sur ce chemin épouvantable, nous demandant presque à chaque pas si nous n'allons pas culbuter et être précipités dans la boue noire et malodorante en nous cassant quelque membre. Comme ficlie de consolation, nous avons tout autour de nous une végétation magnifique, au milieu de laquelle nous revoyons avec plaisir les gracieux palmiers portés sur un tronc long et mince (Oreodoxa spec.) et de nombreuses fougères arborescentes (.Ilsophila armata). A l'Alto San Carlos (alt. $2625 \mathrm{~m}$.), où nous nous arrêtons pour diner, la végétation est tout particulièrement dense, et c'est par centaines et par milliers que nous voyons des bambous grimpants (Arthrostylidium aff. sarmentosum) recouvrant des taillis ou des arbustes en formant un enchevêtrement inextricable. A l'endroit où nous nous arrêtons se trouve une hutte des plus primitives, construite avec les troncs de fougères arborescentes dont le bois est à peu près imputrescible. La hutte se compose de deux pièces; nous nous installons dans l'une d'elles, au grand ébahissement des propriétaires, qui ne comprennent pas ce que tant de citadins viennent faire dans ces régions éloignées de toute voie de communıcation. Gràce à la quantité considérable de vivres que nous trausportions, nous faisons un diner plantureux où rien ne manqua, depuis les bors-d'œuvre jusqu'an dessert, le tout arrosé de bière, d'un excellent vin français et de cognac. Pour diner, nous sommes assis par terre, loin de rester silencieux, sans faire attention ì une corde que nous avions consciencieuse- 


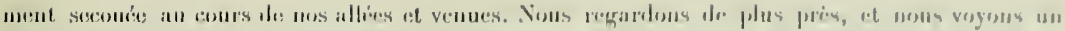

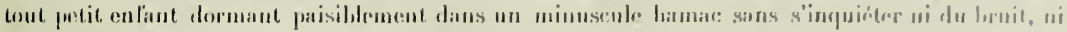
des seconsses intrmpestives qu'un lui avail fait suliir!

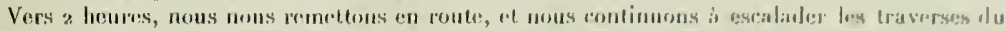

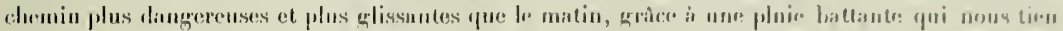

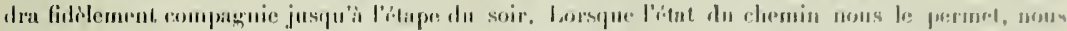

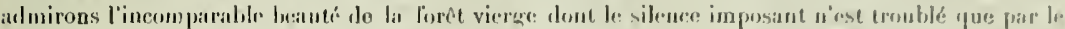

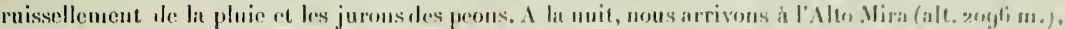

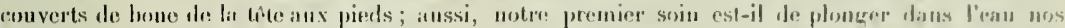

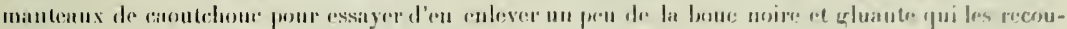
vo. las forets immensins de tonte eette région sont exploitées parplaces romme bois de construclion el l'on prent se demantire comment et dans quel etat arrivent jusifun is Bogotal les poutres et les planches coupres ilats les scieries primitives installées en pleine loret. A l'Alto Mins se trouve une le ces scieries, in colté al'une très jolie maisom le cimpagne, appartenint at the commassance de nos compragnons de roule et oi nous pousons logrer. Apres un repas aussi plantureux que le précélent et mue excellente muit, noms nous sentons ì peu près reposés, l,e lemelemain 2/, ortobre, comme la pluic tombait toujours avec nue extrime violence, nous ne nous mettons en route qu'ì 8 heures ilu matin, par un temps assez beau rt quelque peu éclairci. Nous traversons des forêts splentirles, plus belles encore, si possible, que celles de la veille. C'est avec peine que nous suivous le sentier très étroit où une mule a tout juste la place de passer, tandis que le cavalier doit souvent se coucher sur le dos de sa bite pour éviter les branches qui forment un dome épais au-dessus de nos têtes. A droite et à gatuche, c'est l'inex-

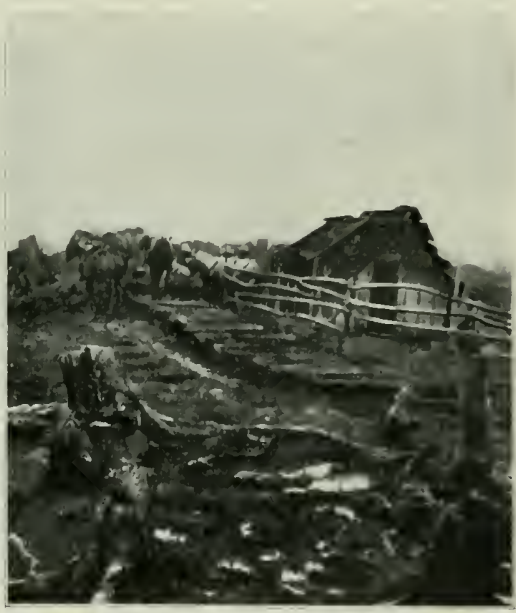

Chemin formé de troncs diarbres et hulle indienne à lilto san Carlos

tricable fouillis de la forèt vierge dans toute son

exubérance et sa beauté, et, sans descendre de nos mules, nous pouvons recucillir une quantité de plantes tris intéressantes, dont plusieurs sont nouvelles', ainsi que quelques animaux (Rotifer' yuadrangularis, Habrotrocha fuhrmanni).

Le chemin est d'abord fangeux, et l'on pourrait se croire par places dans un marais: de temps à autre, il est compé par des troncs d'arbres couchés en travers et que nous devons escalader ou contourner. Nous arrivons enfin sur le flanc des Cordillères de Subia. ou le chemin change d'aspeet. Nous prenons en eltet la montagne en écharpe, et pendant plus d'une henre, nous marchons sur une paroi de rochers inclinée souvent de $45^{\circ}$. Nos mules nont aucune difficulté à suivre ce chemin vertigineux; elles grimpent comme des chèvres, sans faire un seul faux-pas; elles passent mẻme d'un pas tris sùr sur des rochers polis. rendus très olissauls par un petit torrent. Enfin, non sans

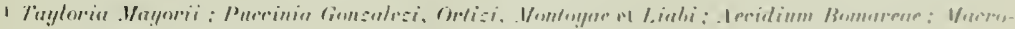
phermm Symberlernthi. 
a voir éprouvé une certaine angoisse, car nous nous demandions à chaque instant si nous n'allious pas être précipités dans le vide, nous arrivons au Boqueron de Guachuni (alt. 2447 m.). C'est un col d'où l'on jouit d'une vne magnifique, d'un còté sur la région de Fusagasuga, malheureusement masquée par le lrouillard, de l'autre sur la vallée du Rio Bogota et les eatétales de la région de Viota. La Cordillère de Subia est la dernière des grandes chaìnes des Andes orientales, aussi lorsque le temps est clair, peut-an distinguer dans le lointain la plaine du Magdalena. Nous nous arrêtons (longuement, tant pour admirer la vue que pour nous reposer un peu. Sur les rocliers qui nous entourent se dressent des centaines de petites croix de bois que les Indiens ont l'habitude de dresser en quise d'ex-voto pour' que te passage de ce col dangereux s'accomplisse sans encombre. Les Indiens font cela dans tous les cols, mais ici, les croix sont particulièrement nombreuses, car [le danger est aussi particulièrement grand. Nous nous figurions naïvement

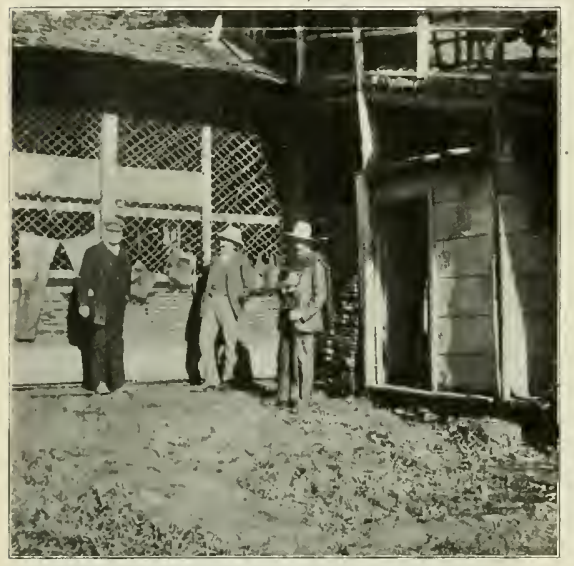

MII. Montoya, Gonzales et Orti\%. (Vue prise au cafetal Argelia.) que nous étions au bout de nos peines; il n’en était rien, car le plus périlleux restait encore à faire. En effet, en nous avançant sur le bord du rocher, nous voyons le vide, et tout au fond, adossée à la montagne, la plantation de café où nous nous rendiuns. Pour y arriver, nous devons nous laisser glisser dans une fente de rochers, couloir presque à pic et vertigineux. Nous descendous en zig-zag au milieu d'éboulis mobiles que l'eau qui suinte et ruisselle de tous còtés déplace constamment. Dans de pareils passages, le mieux est de s'abandonner ì la sagesse de sa mule et de ne pas vouloir lui donner de conseils; aussi lâchons-nous les rênes, ayant déjà plus que sulfisamment a faire pour nous maintenir en équilibre et ne pas être projetés dans le vide à chaque pas. Là plus que partout ailleurs on devient fataliste ! A mesure que le danger augmente, notre admiration pour nos mules augmente aussi; après avoir escaladé des rochers comme des chèvres, elles descendent des couloirs à pic sans faire le moindre faux-pas en se raidissant sur leurs jambes lorsque le sol mouvant glisse sous elles. On ne comprend pas comment ces animaux réussissent à garder leur équilibre et à conduire leur cavalier sain et sauf. Plus encore que les mules de selle, les mules de charge excitent notre admiration, car il la ut avoir vu de ses yeux les efforts inoüs qu'elles font pour conserver leur équilibre el ne pasêtre entraînées dans l'abìme par leur charge, pour les apprécier à leur juste valeur. On pense bien que e'est avec un gros soupir de soulagement que nous arrivons au bas de la paroi de rochers. En regardant en arrière, nous nous demandons comment il nous a été possible de faire cette descente vertigineuse à dos de mule, alors qu'à pied elle eût été déjà des plus dangereuses. Nous sommes séparés de la plantation de café Argelia, appartenant à M. Louis Montoya, par une étroite bande de forêt vierge que nous traversons rapidement. Le chemin qui, quelques jours avant, nous aurait semblé détestable, nous apparaît comme une route nationale en comparaison de ce que nous venons de voir! Au commencement de l'après-midi, nous arrivons au cafetal où nous sommes heureux de mettre pied à terre après les émotions de la journée.

Au cafetal Argelia (alt. 182 I m.) nous trouvons la plus gracieuse hospitalité chez M. Montoya 


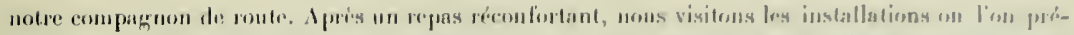

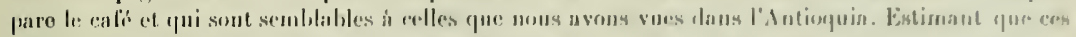

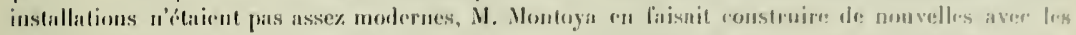

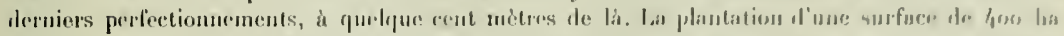

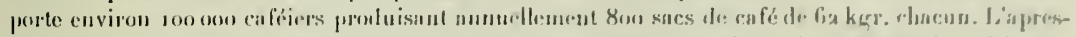

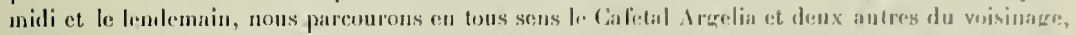

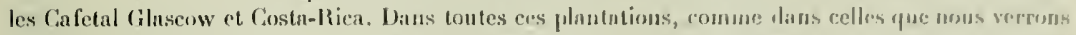

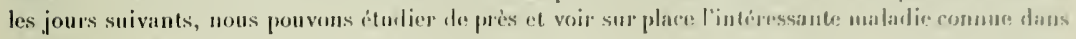
le pays sous le mom de amanchis n.

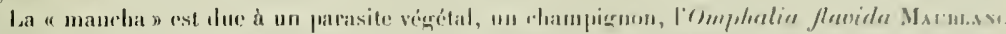

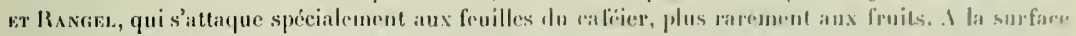

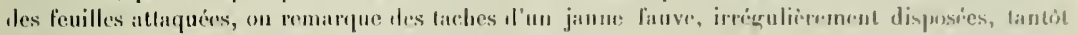

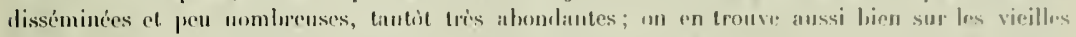

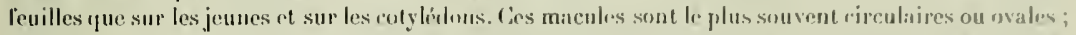

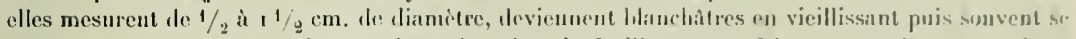
débachent et tombent en laissant ì leur place daus la feuille un tron fait comme à l'emprorte-puicen. Sur les deux faces des faches, soil seulement sur l'une on l’autre, an comstate la présence floreranes

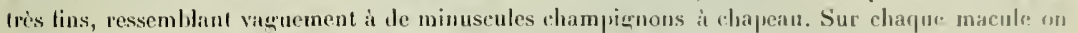
olsserve le petites tiges jaunatres terminces par une tête de móme couleur et attignaut à prine I mm. Ces organes qui sont plus ou moins nombrex - il peut y en avoir plus de ro sug la mème tarhe - tombent fris facilement et sont très délicats; ceci explinge pourquoi nous n’avous pas pu ère, à Bogota, exactement fixé sur l’identité du parasite tui nous élait toujours apporté dépourvo do ses tiges et tites. Sur les fruits, le champignon présentr le mème asject, et fait rapidement sicher tous cenx yui sont attaqués.

Nous avons eu l'ocension de voir ce parasite en très errande quantilé daus certaines plantations, et lorsque les conditions sont favoralıles it son développement, il s'atlaque en masse à preque toutps les feuilles des plantes qui ne tarlent pats à souffrir de eet envahissement.

la "mancha " est connue depuis fort longtemps; elle sévit, non seulement en Colombie. mais encore dans toute l'Amérique tropicale et subtropicale. D’apres Des.nros, ce parasite fut olservé pour la premiere fois vers 1876 par SAEN\%, professeur at l'université de Bogota, mais il fut confondu avec l'Iemileia vastalrix. Ce fut l'ëminent mycologue anglais Cooke qui. le premier, en 1880 , l'étudia scientiliquement et l'appela Stilbum firovidum. Jusqu'à maintenant. la place exacte à assigner à ce parasite laus la classification lotanique était douteuse, car on n'en connaissait pas la forme parfaite de reprodurtion, mais seulement la forme stérile dont il est parlé plus liant.

Tout dervièrement, dans une communication faite il l'Académie des Sciences de Paris par l'intermédiaire de M. Prillieux, MM. A. Maublaxc et E. Risige ' annoncent qu'à la suite d'expériences. ils sont arrivés à la conclusion ferme que le Stilbum flavidum est une forme avorlie et stérile d'un Basidiomycète, c'est-it-dire d'un champignon à chapeau appartenant au genre Omphalin et qu'ili appellent Omphalia flavida. Ce champignon ne se développe pas uniquement sur le cafëier. mais sur une grande quantité d'autres plantes. pour peu que les conditions de milieu soient favorahles. Expérimentatement, les deux auteurs sont arrivés ab obtenir toutes les formes intermédiaires entre le Stilbum flavidum stérile et leur Omphalia fluvida, type entiẻremont développe. daus lequel ils

- Le Stilbum flavidum Cookr, parasite du caférer et sa place daus la classifiention. Tote de M.M. A. Muzu.ixc el E. Rivgec, présentée par M E. Prillieltx. Comples realus hebdomadaires des seances de l"Académie des Sciences, Paris. Tome 157. No 1! (10 novembre 1913), p. sis. 
retrouvent tous les éléments microscopiques trés caractéristiques du Stilbum, Ils arrivent aux deux importantes conclusions suivantes que nous citons textuellement:

" ı. Le Stilbum flavidum, loin d'être un parasite spécial du caféier, est une espèce qui croît sur les plantes les plus varićes de la forêt et s'est attaquée au caféier dans les localités où elle a trouvé les conditions de chaleur lıumide nécessaires à son développement;

2. Le Stilbum flavidum est un état avorté et stérile d'un Basidiomycète, l'Omplaalia flavida n. sp. : ce dernier, par suite des conditions d'humidité qu'il exige, ne doit se produire qu'exceptionnellement dans la nature; mais, gràce au retour à l'état végétatif des têtes stériles du Stilbum, l'apparition de la forme parfaite fertile n'est pas indispensable pour assurer la reproduction et l'extension du parasite. "

Si la "mancha " ne tue que rarement les plantes attaquées, par contre les caféiers malades sont moins vigoureux que les autres, et si l'infection s'étend encore aux l'ruits, le rendement d'une

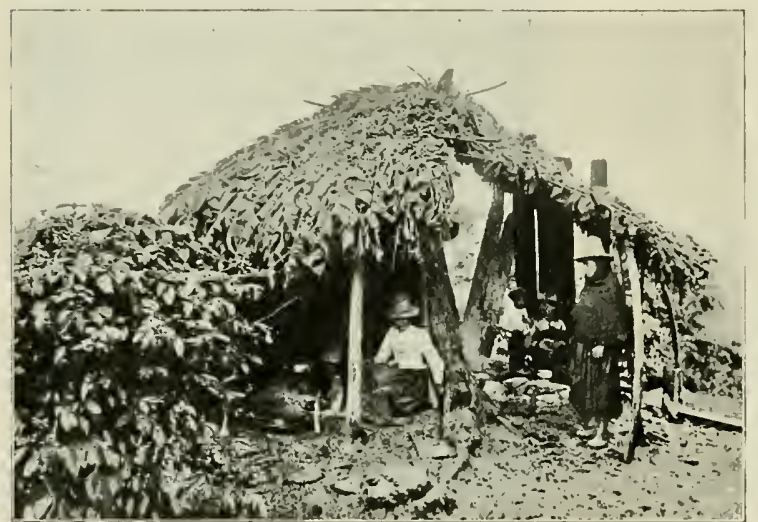

Hutte indienne dans une plantation de café. plantation diminue beaucoup. On comprend que les cultivateurs se soient émus en présence de cette maladie qui, depuis quelques années, semble devenir plus envahissante.

En nous basant sur ce que nous avions pu observer dans les plantations de la région de Viota, nous avons pu donner aux intéressés quelques couseils sur les mesures prophylactiques à prendre. L'humidité favorisant le développement des parasites, il faudra drainer judicieusement les plantations, tailler les arbres trop loutfus et planter, comme arbres protecteurs du soleil, ceux qui seront le mieux appropriés à l'altitude. Il va sans dire yue pour obtenir de bons résultats, il faut que tous les propriétaires d'une même région prennent les mêmes précautions, sans cela, loute tentative reste inutile.

Pendant notre visite dans les caletales, on a attiré notre attention sur une autre maladie des caléiers, "l'amarillamiento ", qui, bien que moins répandue que la " mancha ", n’est pas moins dangereuse, car elle tue rapidement les arbres attaquès. A première vue, nous ne trouvons rien qui explique cette maladie, car si les feuilles jaunissent, sèchent et tombent, elles ne présentent aucune altération due à un parasite animal ou végétal ; les tiges et la partie supérieure des trones ne présentent rien de spécial. Nous avons alors l'idée de faire arracher un des arlires morts ou languissants, et en examinant de près la base du tronc, nous remarquons que l'écorce est en partie tombée et qu'à sa place, il y a de grandes taches noires. En sciant transversalement ce trone, nous sommes trés étonnés de voir que l'écorce et le bois sont eriblés d'une infinité de petits points noirs ; une coupe longitudinale nous montre des sortes de galeries comme en font les larves d'insectes, aussi nous demandons-nous, si nous ne sommes pas en présence d'un parasite animal plutot que 
végótal. Nous ne pouvons, sur place, arriver h̀ une couclusion, aussi remettons-nous la solution du

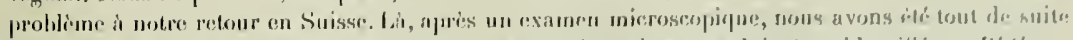

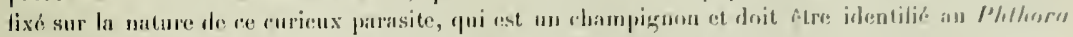

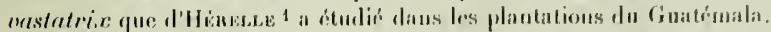

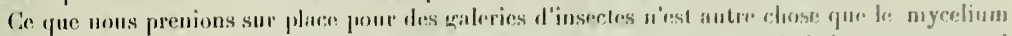

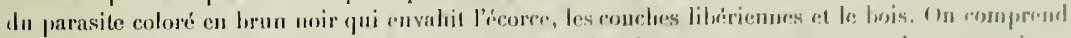

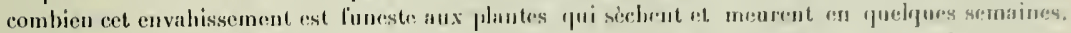
Dans les plantations que nous avons visités, nous avous souvent remarque ces taclars formbes frar

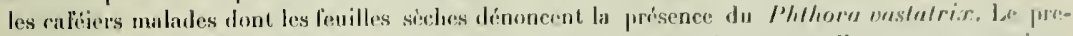
mier symptome apprarent est un soulivement de l'ícorce a la base du tronc; clle se crevasse puis so

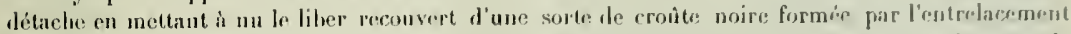
des filaments da myeclium. La maladie sévit unipuement a la hase du trone, sur un biuteur de

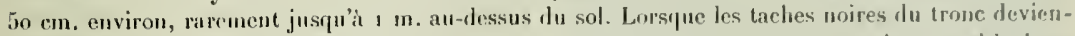
uent visihles, il est trop tard pour somger à sauver lialue voué a une mort certaine, anssi la lutto contre ce dangereux parasite est-elle à jeu pres impossible, puisfuton ne possede ancun sizne indiquant le début de l'inlection. Pour le moment, le seul traitement consiste à arracher et it brîler immédiatement les arbres envahis pour empecher la proparation do la maladie.

D'après les renscignements qui nous ont été donnés, a l'amarillanniento n sévit daus toutes les plantations du Cundinamarea. Comme les ravages ne sont pas encore trés errands, il faudrait, lo plus vite possible, prendre des mesures énerqiques pour enraver la maladie et empécher qu'elle ne s'implante définitivement. Le Phthora vastatrix pent devenir un fléan redoutable pour les rultures, aussi dangerenx que l'Irmilein uastatrix.

Le 25 octolre, nous quittons le Cafetal Argelia pour descendre par des chemins tres pittoresques au Cafetal Magdalena, propriet' de M. Gabriel Ortiz-Williamson, notre aimable compagnon de route, directeur de la "Revista Nacional de Agriculura ), l'organe de la grande Société des agriculteurs de Colombie. Ce Cafetal (alt. $1003 \mathrm{~m}$.) a une surface de 500 fanegadas (400 lia.) et produit annuellement 1000 sacs de café. Comme l'altitude est beaucoup plus basse, la chaleur est phus intense et nous revoyons avee plaisir aux alentours du Cafetal la végétation des terres cliaudes. La maison de maitre ou nous logeons, tapissée de plantes grimpantes, est entonrée d'un fort joli jarilin, ou nous remarquons des palmiers, des cacaoyers et des vanilles passant d'un arhre

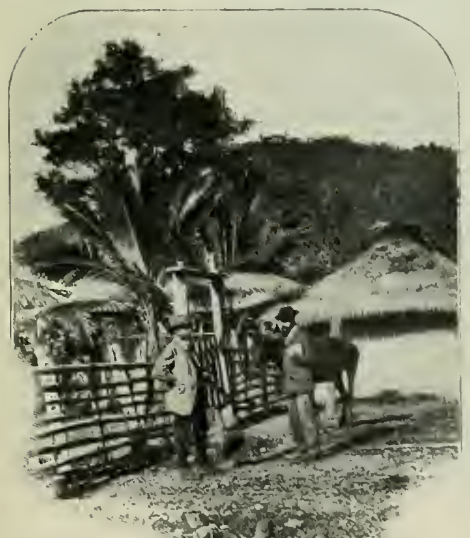
il l'autre.

Pendant que nous sommes établis devant la maison, notre attention est attire par les allées el venues continuelles d'un ravissant petit colibri, an plumage d'un vert métallique. Ponssés par la curiosité, nous le suivons des yeux et nous le voyons se diriger vers un petit palmier à quelques mètres de nous. En nous approchant, nous voyons à la base d'une feuille un charmant nid minuscule dans lequel la femelle couvait denx reufs. Les maisons des ouvricrs forment une sorte de petit hameau autour duquel sont quelques cultures. Nous vorons un champ de cannes a suere dont la plupart sont en flcurs et agitent leur panache blanc arrenté du plus bel effet; jusqualors, nous

i F.-H. d'Hérelte. Maladie du cafëier au Gualemala. Bull, Soc. Ifycof. de Franre. T. XXI, igog.

Vue prise an cafetal binenavista, par M. G. Ortiz. 
n'avious vu que quelques plantes isolées en pleine floraison; c’était la première fois que nous en vovions autant en tleurs ensemble.

Le 26 octobre an matin, nous contimons notre voyage à travers les plantations de café et nous nous dirigeons vers le Cafetal Arabia dont la surface est de r 200 ha. Nous sommes très aimablement reçus par le gérant, qui nous offre une collation sur lat véranda de sa maison d'où l'on jouit l'une vue superbe, d'un còté sur la plaine du Rio Bogota, de l'autre sur les Cordillères de Subia et le fameux Boqueron de Guachuni. Cette haciendia est situće sur un point stratégique important; elle servit de refuge et de forteresse aux belligérants, lors de la dernière révolution colombienne, et ses murs portent encore la trace des balles. An sortir du Cafetal Arabia, nous pénétrons dans la plantation la plus vaste de la régrion, la dernière que nous visiterons: le Cafetal Buenavista, appartenant à MII. Jorge et Carlos Crane. Cette propriété, d'une superficie de 4200 la., esten grande partie recouvertede forits immenses sétendant jusqu'aux Cordillères de Subia; le reste est planté eu calëiers et en cannes à sucre. $\Lambda$ notre entrée dans la plantation, nous trouvons un des propriétaires qui est venu très aimablement à notre rencontre et nous offre la plus cordiale hospitalité dans sa belle maison. Pour y arriver, nous traversons tantôt des cultures de café, tantót des endroits boisés et des forèts superhes. Nous sommes maintenant à une altitude de $988 \mathrm{~m}$. et partout où l'on ne cultive pas, la forêt tropicale des terres chaudes reprend ses droits. 1

Le 27 , nous quittons les Cafetales pour gagner la grande plaine et le Mlagdalena; c'est notre dernière journée à dos de mule; le lendemain nous naviguerons sur le fleuve pour atteindre rapidement la còte. Nous partons assez tòt, car nous ne savons pas à quelle heure nous devons prendre le train a Portillo. Nous descendons rapidemeut la vallée qui aboutit à Viota (alt. $598 \mathrm{~m}$.) ; lat, M. Crane, qui a lien voulu nous accompagner, nous quitte en nous souhaitant un heureux retour. Sons un soleil de feu, nous montons sur une petite colline d'où nous redescendons dans un vallon que nous suivons jusqu'à Portillo. Cette vallée est parcourue par une rivière au courant très faible, qui se prélasse en nombreux et gracieux méandres. Notre chemin en ligne droite, suivant la coutume do pays, la traverse plus de vingt fois à gué, car les ponts sont inconnus dans cette région. Accablés par la chaleur, nous faisons halte de temps à autre pour remplacer le liquide que nous perdons en d'abondantes transpirations; nous buvons d'ailleurs ce que boivent les indigènes, du guarapo ou de la chicha, ce breuvage qui nons aurait profondément légoûtés en toute autre circonstance.

Un peu avant d'arriver sur le bord du liio Bogota, nous tombons dans un vol de sauterelles, ces terribles animaux qui, en quelques heures, a néantissent les plus belles récoltes. C'est par millions qu'elles tourbillonnent autour de nous et se posent ensuite sur le sol où il ne reste plus rien après leur passage. Nous atteignons enfin le Rio Bogota, qui est ici un large fleuve aux thots noirs et au courant très rapide. Dans la Savane de Bogota, nous l'avions déjà vu rivière calme et paisible et au Tequendama, nous l'avions admiré se précipiter dans l'abîme comme un torrent impétueux. Nous le traversons sur un pont métallique ct nous mettons pied à terre sur l'autre rive, à Portillo(alt.435 m.), une des stations de la ligne de Bogota à Girardot.

La voie avait été coupée et on ne peut nous dire à la gare ni si le train passera, ni à quelle heure; nous nous décidons à dìner en attendant les événements. $A$ peine sommes-nous á l'auberghe, qu'on entend le ronflement d'une locomotive ; nous nous précipitons à la gare, mais ce n'est pas encore notre train; c'est un convoi de soldats qui passe sans s'arrêter. Un quart d'heure après, nouvelle alerte. Cette fois, c'est le train transportant le courrier de Bogota, qui s'arrête juste le temps

1 Espèces nouvelles recueillies dans la région des cafetales de la vallée de Viota.

1. Plantes, - Puccinin Marisci, Sarachre et solanicolr.

11. Animaux. - Pseatolhelplusa dispar, P. monlicola, Sphaeroniscus frontalis, Camelianus fuhrmanni, Chondrodesmus dorsovilaths, Ch.cartonarins, Rhinocricus instablis, Microspirobolus fuhrmanni, Siphonophora gracilicarnis, Lycosa fastosa n. var. vioba, Vaginulu cordillerce, Alraclus werneri. 


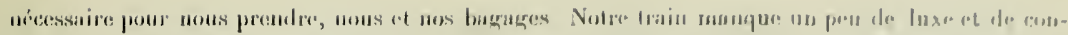

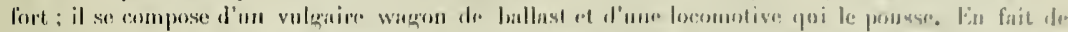

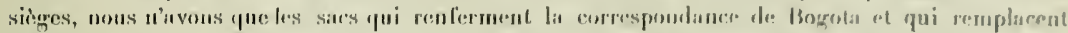

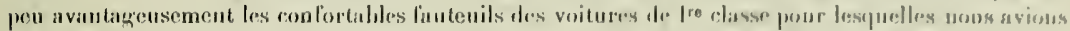
nos billets!

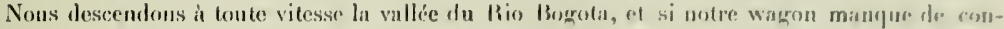

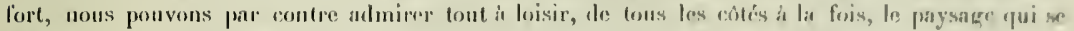

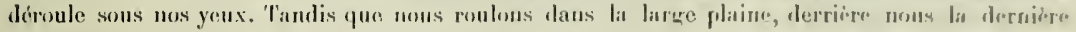
chaine des Andes orientales, la Cordillere de Subin, disparait peu à peu dans le loimtain. A '́ocaima, nons mattrapens le convoi de soldiats que nous avous vil passer devant nous et nous fouvons dejit nous rendre compte de l'aspeet étrange de ce corps de troupe dont nous reparterons plus loin. Apris mon assez long arret, on se remet en mute et l'on continue is descendre la vallée converte presque entièrement de vastes paturages oit se lait en grand l'élevage du bétail. Pitr ci par lit seulement, on voit quelques taillis el surtout des groupes de superhes it élérants palmiers, l'alma de vino, qui rompeut lit monotunie de cette grande plaine. Nous sentons que nous sommes de nouveau dans les régions torrides (alt. environ $400 \mathrm{~m}$.), car la chaleur est suffocante. Bien que nous filions à toute vitesse sur la voie en ligne droite, la température jurise au thermonctre froude est de $33^{\circ}$, tandis que nos siiges primitifs sont surrhauffies it $199^{\circ}, \overline{5}$ !

A la tombic de la nuit, nous arrivons it Girardot (alt. $371 \mathrm{~m}$.), oin nous destendons dans le premier hôtel de l'endroit qui brille par son état primitif. Accallés par une chaleur torride, nous nous trainons dans les rues, pour nous rendre aux bureaux de la Compagnie de navigation

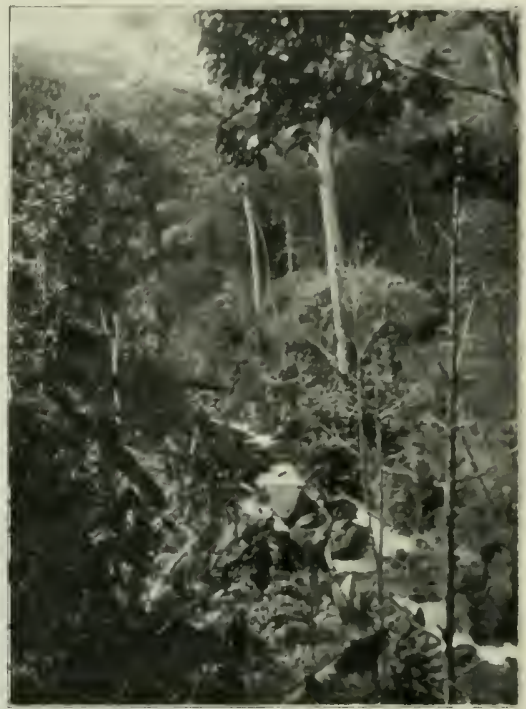

foret près du caretal Magdalena. ou, gràce aux recommandations de M. Beck, on nous fait le meilleur accueil et ou l'on nous remet notre lillet comportant deux cabines de premiere classe et un libre passage pour notre peon. Le soir. nous sommes invitís à visiter de trés vastes et helles installations destinces à enlever les enveloppes parcheminées des graines de cafí. Les propribtaires de plantations de celte région ne possèdent généralement pas les installations nécessaires el envoient leur café à Girardot pour qüil r subisse cette manipulation.

Il est tard quand nous nous glissons sous nos monstiquaires, pour essayer de nous rejoser un peu; mais la chaleur est si accablante, que nous passons une tris mauvaise nuit. Iu point du jour. nous sommes debout et nous sortons dans la cour intérieure, où nous vovons couchés à terre on sous les tables, tous les domestiques qui prélèrent passer la unuit dehors que dans une pièce étouffante. En sortant dans les rues, nous trouvons, étendus sur les trottoirs, des gens qui, cux aussi, ont préféré passer la muit au grand air, cmroulés dans leur "ruana " et que la police fait deguerpir de luon matin à coups de pied. 
Après un déjeuner rapide, nous allons vers les berges sablonneuses du Magdalena où est amarié le petit vapeur sur lequel nous descembrous le fleuve jusqu'a Beltran. Il s"appelle le "Caribe " et présente le mème aspect particulier que celui qui nous a conduits de Barranquilla à Puerto-Berrio.

Au bord du fleuve salignent de nombreuses barques, des radeaux, des "champan " et des pirogues ; partout grouillent, nus comme des vers, des enfants qui prennent leurs ébats dans le Magdalena. Enfin, au milieu de ce va-et-vient, nous voyons des caravanes de petits anons, portant deux tonnelets qu'on remplit d'eau, car les fontaines sont inconnues eu ville, de même que la distribıtious d'eau potable à domicile.

Nos trois aimables cicerone nous accompagnent jusqu'au bateau, malgré l'heure matinale. Nous nons séparons d'eux avec le plus vil' regrel, car c'est avec enx que nous avons fait le voyage qui nous laissera peut-être le souvenir le plus durable, grâce à toutes les choses intéressantes que nous avons pu observer et à la merveilleuse nature que nous avons ene sous les yeux. Nais, hélas! les plns belles choses ont une fin, et à $\mathbf{6}$ heures du matin, notre vapeur démarre et nous ne pouvons plus faire que des signes d'adieu et de remerciements à MM. Ortiz, Montoya et Gonzales.

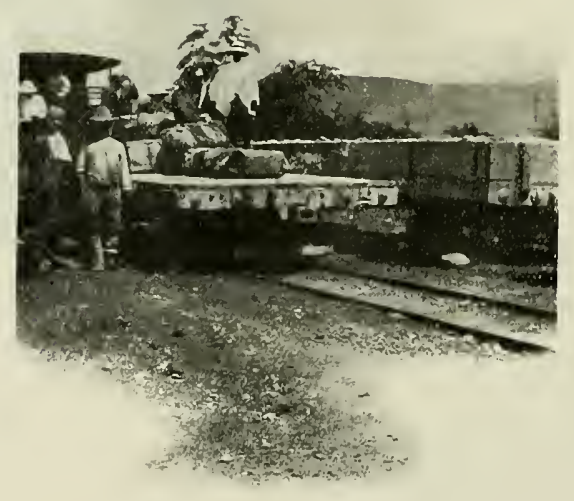

Notre train en gare de T'ocaima.

(Vue prise par .V. G. Ortiz.) 


\section{CHAPITRE X}

\section{Le retour.}

Le courant rapide du Haut Magdalena nous entraine à une grande vitesse, mais le paysage qui se déroule à nos yeux nous désillusionne autant que crux du Bas et du Moyen Magdalena nous avaient enchantés. Ce n'est plus ici cette végétation riche et exubérante qui, de toutes parts, vient is l'assaut du tleuve, mais une maigre végétation, sans aucun intérêt, soit d'immenses prairies oi l'ou élive le bétail. Seules les montignes donnent un pru de charme à ce paysage monotone. Des denx cortés, nous voyons les croupes arrondies des dirniers contreforts des Andes centrales et des Andes orientales qui s'abaissent jusqu'an fleuve.

Nous avons heureusement a bord quelques sujets de distraction, en plus des crocodiles que l'on rencontre de temps à autre. Le batean transporte, en effet, les soldats que nous avions déja vus la veille, et nous nous amusons it les ohserver de press. 1

Nous arons à bord 200 soldats et 37 femmes, sans compter les petits enfants et les officiers dont un colonel et plusieurs eapitaines. Cette tronje vient de l'intérieur, des llanos du Rio Meta, ct se dirige vers la frontière de Panama, ce qui explique pourquoi la troupe n'a pas l'air pimpant qui nous avait frappé elez les soldats à Barranquilla, Hedellin el Bogota. L'uniforme est des plus variés: à cóté de quelques soldats en tenue d'ordonnance, nous en royons en kakiousimplement en civil, ayant comme conve-chef la easquette conique allemande ou le kipji franģais ou plus simplement un chapeau de paille ou de feutre. Les armes sont aussi disparateśque les costumes. L’àge de ces soldats est des plus variables; à còté d'enfants pouvant à peine porter leur fusil, on voit de vieux soldats blanchis sous les armes. La plupart sont des Indiens du Cundinamarca avec leur type mongol si accentué: il y a aussi des métis et quelques mulätres. La discipline semble être assez élastique, el des officiers prussiens auraient fort à faire pour maintenir l'ordre et le silence, car ce ne sont que conversations bruyantes sans fin, auxquelles les officiers assistent sans mot dire.

Hélangée à cette troupe se trouve celle des Juanas, femmes ou compagnes des soldats; elles sont d'une très grande utilité vu le manque complet des services d'administration et d'iutendance. Aux

1 En Colombie, larmée aetive comprend en tout 2 divisions de 12 régiments d'infanterie, un régiment de eavalerie de 4 escadrons, un régiment d'artillerie comprenant 9 batteries de 4 pièces, un bataillon de géaie et un du train. En temps de paix, larmée colombienne eompte 6000 hommes, dont 35 r officiers et 218 musieiens. En tenips de guerre, la Colombie peut mettre sur pied 300.000 bommes au maximum. Il existe à Bogota 3 écoles militaires: a Escuela Militar ". "Escuela de applicacion » et a Escuela superior de gruerra ». Comme armements. l'infanterie a des fusils Mauser (modéle $1906-1908$ de $7 \mathrm{~mm}$.), la cavalerie a la carabine Mauser du mème modéle et la lanee, l'artillerie possède des canons de montague Krupp, modẻle tg12, et les artilleurportent la mème carabine que la eavaleric. Le budgret de la guerre pour rg13 était de fr. 16.503 .000$. 
étapes, elles réquisitionneut et préparent la nourriture de la troupe. Elles portent une partie des provisions et la batterie de cuisine en plus des enfants qu elles ont sur le dos et qui sont soumis, dès leur naissance, à une existence triste el malheureuse.

En cours de route, nous apprenons par le colonel que nous aurons le plaisir' (si c'en est un) de voyager avec la troupe jusqu'id Barranquilla. Nous touchons quelques villages et nous admirons it nouveau l'habileté avec laquelle le pilote conduit son bateau informe et la facilité avec laquelle il aborde. lci aussi, personne pour donner un coup de main au moment de l'abordage; dès que l'on s'arrète, un matelot saute à l'eau et gagne la rive à la nage en tenant dans sa bouche une corde qu'il se hàte de fixer sans nul souci de sa nudité presque complète. Le seul endroit important où nous nous arrêtons est Ambalema (alt. $245 \mathrm{~m} .1$ ), célèbre par ses tabacs. Peu après, uous sommes ì Beltran. du moins à la station du chemin de fer, car le village est situé sur l'autre rive. Le point terminus de la voie ferrée de Honda se trouve aiısi à $2 \mathrm{~km}$. et demi de Ambalema, en pleine campagne et isolé de tout. Il est inconcevable que la voie n'ait pas été continuée jusqu’à Ambalema qui deviendrait une petite ville très importante et prospère, tandis qu'actuellement, elle semble déeliner qrrâce à son isolement.

Nous partons à i henre et demie pour Honda et nous traversons de vastes llanos où paisseut en quantité de lort beaux bestiaux. Peu à peu, la voie ferrée quitte le lleuve et se dirige dı côté des Indes centrales dont nous longeons le pied pour arriver à Mariquita, où nous étions quelques semaines auparavant en descendant du Ruiz. De là nous traversons les llanos de Carrapatas et ì 5 leures nous arrivons à Honda, où nous retrouvons fort heureusement les bagages qui nous avaient été expédiés directement de Bogota par Villeta.

Le 29 octobre au matin, le train nous emporte vers La Dorada, it quelques kilomètres de Honda, endroit où le Magdalena redevient navigable jusqu'à Barranquilla. $\Lambda$ peine sortis de l'étouffante Honda, nous pénétrons dans de splendides forêts où la végétation est de toute beauté. Par places, nous roulons au milieu de palmiers de tout âge et de toute grandeur, d'un aspect vraiment léerique. Jusqu’à La Dorada, nous sommes accompagnés par uotre fidèle et dévoué peon qui surveille une dernière fois le transport de nos nombreux bagages et veille à ce qu'ils soient bien placés. Il nous aide encore à déballer ce dont nous aurons besoin dans notre cabine, puis il prend congé de nous et nous le voyons partir it regret; de son côté, il semble réellement ému et il ue quitte le bord du fleuve que lorsque notre bateau disparait à ses yeux au prochain contour du Magrdalend.

Les soldats sont de nouveau avec nous, aussi notre bateau, le "Bogota", est.il rempli. Malgré cela, nos deux cabines sont retenues; chacun de nous se prélasse dans la sienne, tandis que les offiriers sont trois ou quatre ensemble; ce voisinage manque quelque peu de charme, car ils ne sout pas tous d'une distinetion parfaite. Par contre la vie de la troupe à bord est infiniment plus intéressante, et nous occupons nos nombreux loisirs i examiner les soldats du haut de notre pont. lls n'ont pu trouver tous de la place dans l'entrepont, aussi a-t-on fixé à droite et à gauche du bateau deux grands poutons sur lesquels ils se sont établis; c'est là aussi que se fait la cuisine. L'installation, des plus primitives, consiste en deux tables de bois reconvertes de terre sur lesquelles on fait le fen; les marmites sont placées directement sur les lutches, dans un équilibre fort instable. Ce sont les lemmes qui font cuire les rations que leur apportent les soldats après la distribution. $\Lambda$ claque arrêt, elles se précipitent à terre pour aller à la recherche d'œufs on d'autres petits extras destinés à compléter l'ordinaire. Lorsqu'on passe devant un village, les six clairons se massent à l'avant du bateau et jouent toujours le même air, qui attire invariablement sur le rivage toute la population qui se demande peut-être si c'est le prélude d'une révolution nouvelle.

1 Toutes les altitudes indiquèes dans ce récit de voyage ont été ealculćes d'après nos observations barométriques faites avec un anèroïde de précision Goldschmid contròlè à plusieurs reprises avec l'hypsomètre. 


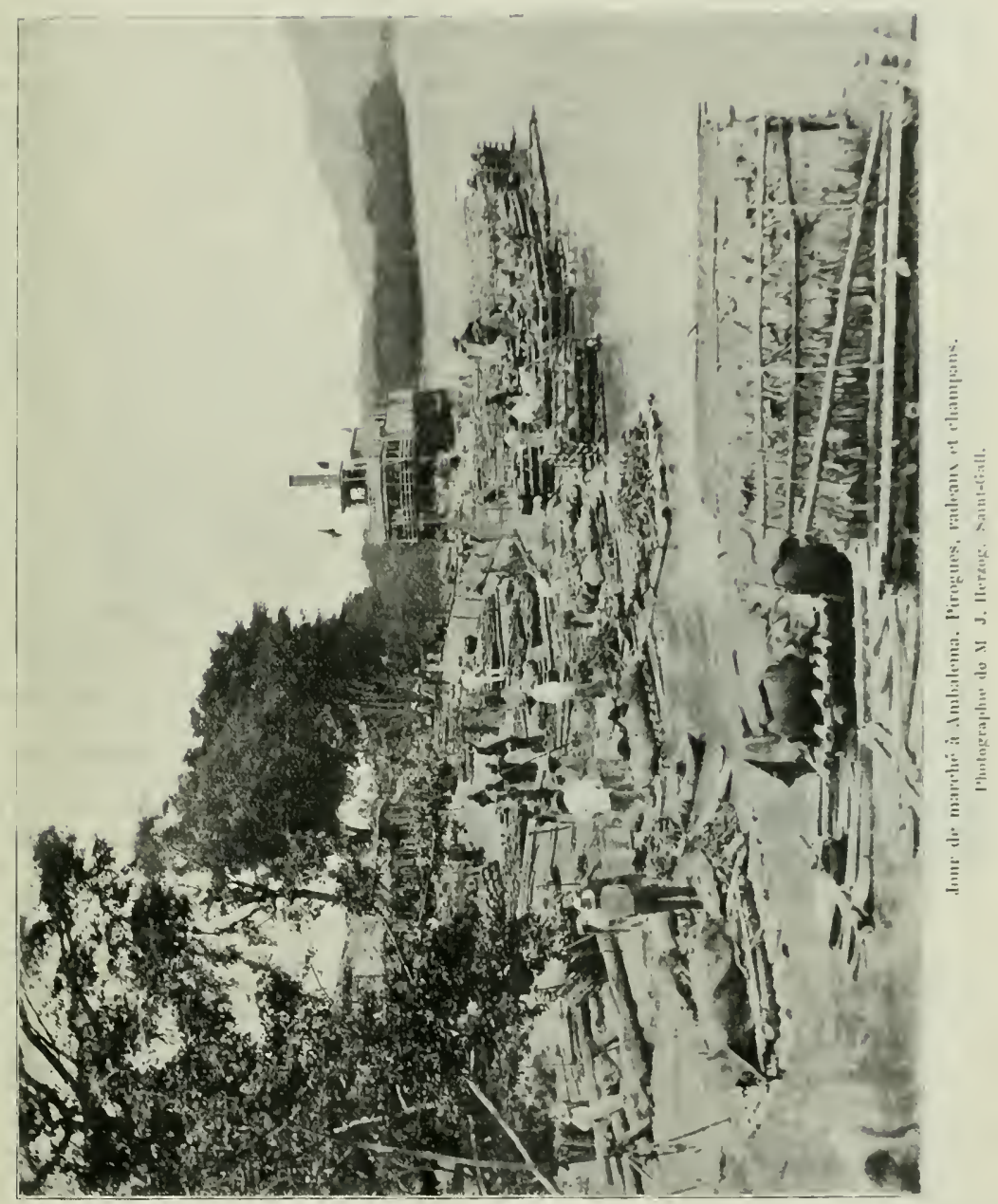


Le suir veru, hommes et femmes se couchent pête-méle sur les pontons, enroulés daus une couverture. Le matin. les hommes, accroupis tout mus an hord du hateau, font leurs ablutions en s'aspergeant le corps au moven de grandes "calabas ". I citc, les femmes, drapies pudiquement taus de longues chemises, prennent aussi leur latin et se changent avec une «rande habileté, sans latisser voir un brit de leur corps. Yous assistons souvent ì tes scènes pittolesques; les mères nourrissant leursenfauts, les femmes épouillant leur licn-aimé ; parfois ce sont des querelles de ménage ui la jalousie jouc le plus grand ròle. Somme toute, cette troupe nous a vivement intéressés et nous atvons été surtout liappés de la propreti de ces geens dont la grande occupation eonsistait à boire, it

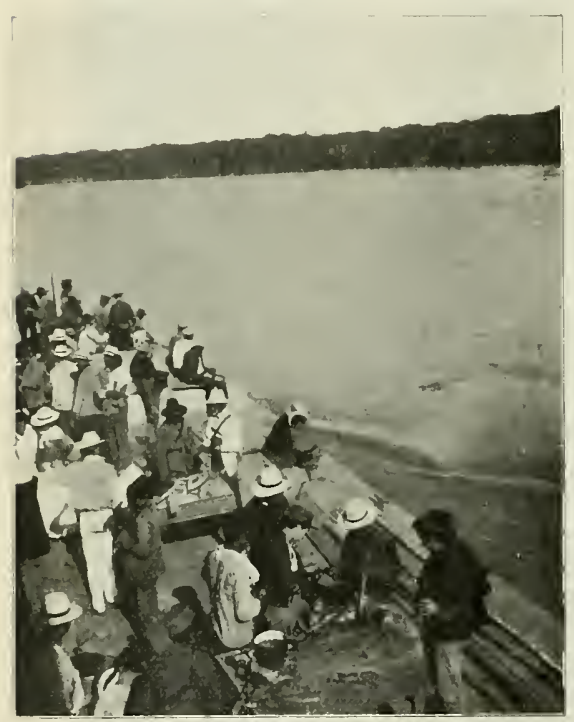

Soldats à bort du Brignter.

(Au milien la cuisine.) manger, it dormir, à se lisver ou ì laver leur linige.

Pendant ciny jours nous naviguons sur le tleuve, emportés rapielement par les hattes eaux. La chateur est étouflante et très prubible pendant les baltes; heureusement, les moustiques manquent presque complètement it l'appel! Nous revoyons avec admira(iion cette végétation luxuriante dont nous avons déjà parlé, la superbe avifaune, si brillante et si variée. de même que ces bancs de sible oi s"étalent les crocodiles it la grueule largement ouverte. Nous distinguons aussi de grandes tortues ou des iguanes parés des plus belles couleurs. Les villages si pittoresques que nous voyons sont pour la plupart entierement sous l'eau, car la saison des pluics bat son plein. Les haltes que nous faisons pour reprendre du combustible sont si courtes que nous ne pouvons descendre à terre; du reste les piles de bois sont alignées dans l'eau même. Le 29, nous touchions à PuertoBerrio où, trois mois auparavant, nous étions descendus pour pénétrer dans les Andes cen. trales. Nous revoyons aussi Puerto Wilches, Bodega Central et Mangangue, qui est très animé, car ćest jour de marché et les mar-

chandises sont étalées jusqu'au bord du fleuve. Nous touchons enfin à Calamar, et le s novembre, nous arrivons à Baranquilla, linissant ainsi notre voyage sur le Magilalena.

Après avoir déposé nos bagages à la Pension Inglesa, nous allons voir MM. von Gunten et lleverhans. qui nous reroivent d'une manière charmante. Notre départ était fixé an 5 novenbre et mous employons le peu de temps qui nous reste à laire nos deruiers préparatil's el à emballer nos dernières récoltes.

Le 4 novembre au soir, toute la petite colonie suisse est réunic en notre houneur chez les MM. von Gunten et nous passons là une délicieuse soirće, la dernière de nos soirées en Colombie! Le 5 al matin, nous partons pour Puerto Colombia où se trouve déjà la "Normandie " de la Compagnie transatlantique. $\Lambda$ I heure, nous prenons congé de $\lambda$. von Gunten, qui a bien voulu nous accompagner jusqu'au hateau, puis nous levons l'ancre et partons pour les cótes du Vénézuéla.

Nous passons en vue du delta du Magdalena, nous voyons de loin le massil imposant de la 


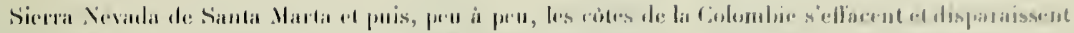

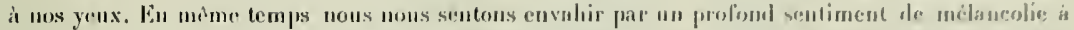

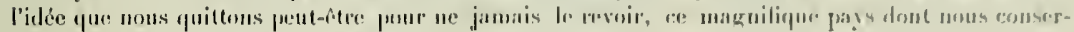
verons toujumrs un somvenir inellagahls'.

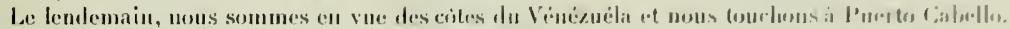

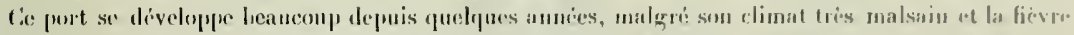

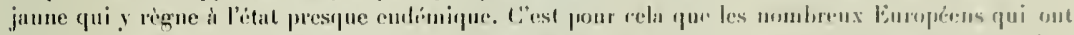

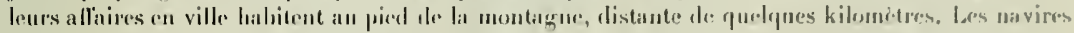

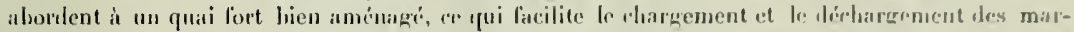

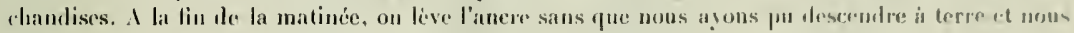

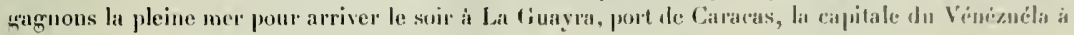

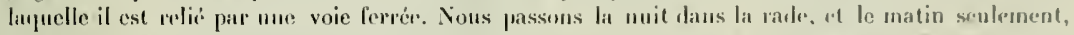

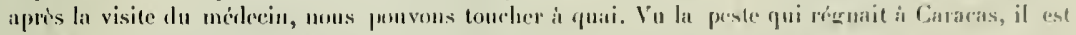

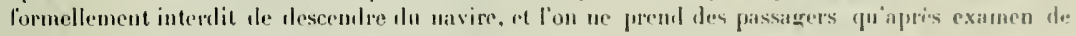
rertilicats de vaccination anti-pesteuse.

La fillaym est uno petite ville assez impurtante en tant que prort de la rapitale. Fille cest situie

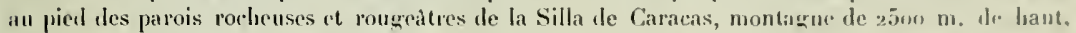
yui domiue directement la mer la ville est batie en graulins sur le llane de la montagne et on dislingue vagruement des maisonnctles quisatres it toits plats, ressemblant it des nils d’hirondelles appliqués contre les rochers. Dans rette ville règne une rlıaleur étoulfante; c'est d'ailleurs un rles endroits les plus chauls de la cote; ceei explique peut-ctre pourquoi la région est aussi arisle; c'est à peine si sur le flaue de la montagne on distingue par places une ties maigre viegétation.

Le 8 novembre, nous levons l'ancre et nous partons pour les Intilles françaises. La côte de l'Aucrique du Sud s'eloigne rapidement, puis clle disparait à l'horizon; mais hous esivivos encore Ie distinguer au loin le continent qui f'uit el nous quittons défuntivement et non sins regret les inlmirables tropinges de l'. Imeripue du Sud.

Toute la journce du g novembe, unus naviguous daus la mer des labrïles, i.t le soir. nous arrivons en vue des Petites . Intilles. Le sout d'ibord quelques iluts it fleur al'eau ou de simples rochers qui émergent des Jots, puis des ilots plus grands et enliu nous atteignons la .llartinique. Nous abordons à fiort-ele-France ou nous levons renouveler notre provision de cliarbon avant d'entreprendre la traversée de l'Océan. A peine sommes-nous arrivés que nous assistons à nouveau, comme à San-Thomas, au défilé ininterrompu des négresses porteuses de charbon.

Le lendemaii nous descendons à terre pour visiter rapidement la ville et ses environs immédiats ; en passant dans les rues, nous avons pu nous rendre compte que la réputation de beautẻ des Martiniquaises n'est pas usurpée. Fort-de-France est une petite ville assez propre, qui ne prisente rien de lien particulier, sauf le marché cowvert ou se vendent une loule de fruits et de lérumes tropicaux et des poissons variés. Sur une grande place, entre le port marchand et la ville, s'èlève un monument à limpératrice Joséphine environné de palmiers superbes. Le palais du gouverneur, au milicu de magnifiques jablins, est un pen en dehors de la ville, comme aussi de nombreuses ct lielles villas.

A i heur's da soir le chargement de charbon (1000 tomes) est lermine et nous continuons wotre route en longeant la cóte occidentale de la Martinique. A la tombée de la nuit, nous sommes en vue de la trop célebre Montagne Pelée et de la malheureuse ville de Saiut-Pierre, qui fut anéantie le

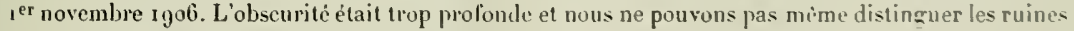
de lancienue capitale de l'ile.

Iu milieu de la nuil, nous arrirons ì la Guadeloupe, a Basse-Terre. el le matin de bonue lreure nous faisons notre demiere escale at Pointe-it-Pitre, oi nous ne restons que quelques heures. san. 
pouroir aller it terre. L'ile est moins accideutée que la Martinique et les montagnes y sunt scusiblement moins élevées. I 1 heures, nous quittons la Guadeloupe, nous longeons encore quelques iles. puis nous gagnons la pleine mer. Peu à peu la terre disparait et nous ne voyons plus que l'Océau infiai, d'un bleu splendide.

Pendant onze jours, nous sommes en pleine mer et nous avons un temps superbe pendant tonte la traversée. De nonveau recommencent ces longues journées oủ les seules occupations consistent à manger, boire et dormir et oủ l'on peut se distraire en regardant les animaux marins et en contemplant les effets de lumière sur l'Océan toujours blen. Fnfin le 21 novembre 19 ro, nous sommes en vue des cotes de France et nous arrivons à Saint-Nazaire, point terminus de notre voyage. I notre départ d'Europe, notre bateau portait un drapeau rouge, indiquant qu'il transportait des matières explosibles, au retour on avait arboré le drapeau jaune, signe que nous venions de pays contaminés par la peste.

Nous voici donc de retour dans la vieille Europe eivilisée. Nous somınes tont de suite frappés par l'absence d'horizons infinis; le regard est arrêté par des clòtures et des limites, par des maisons et des villages. Nous nous retrouvons dans la vie civilisće avee tous ses avantages, mais malgré tout, nous ne pouvons nous empêcher de regretter ces pays immenses que nous venons de traverser, oii la nature, livrée à elle-mẻme, se présente dans toute sa magnificence anx yeux des vovageurs imerveillés. 
Mémoires de la $\mathrm{S}^{\text {té }}$ Neuchâteloise des Sci

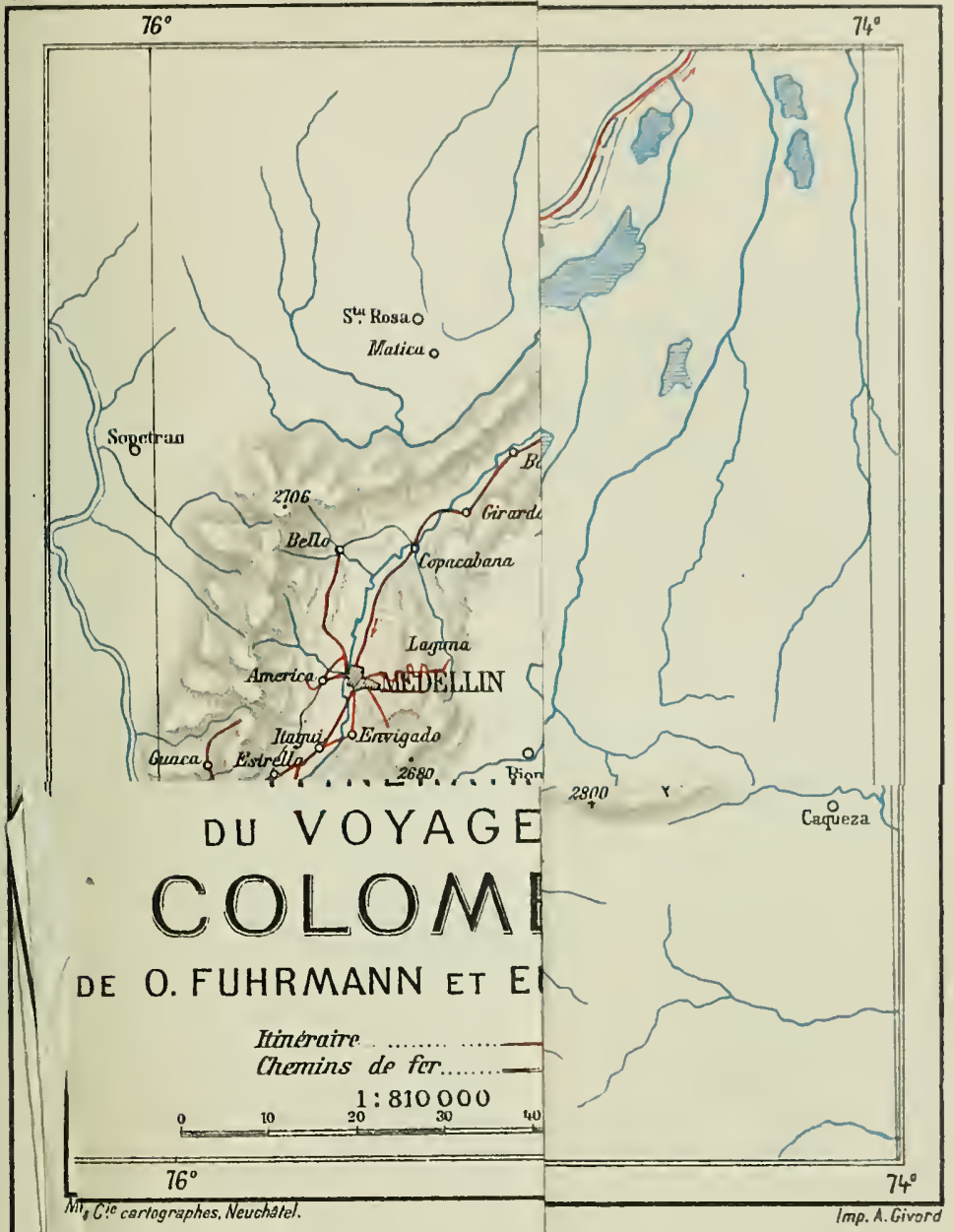




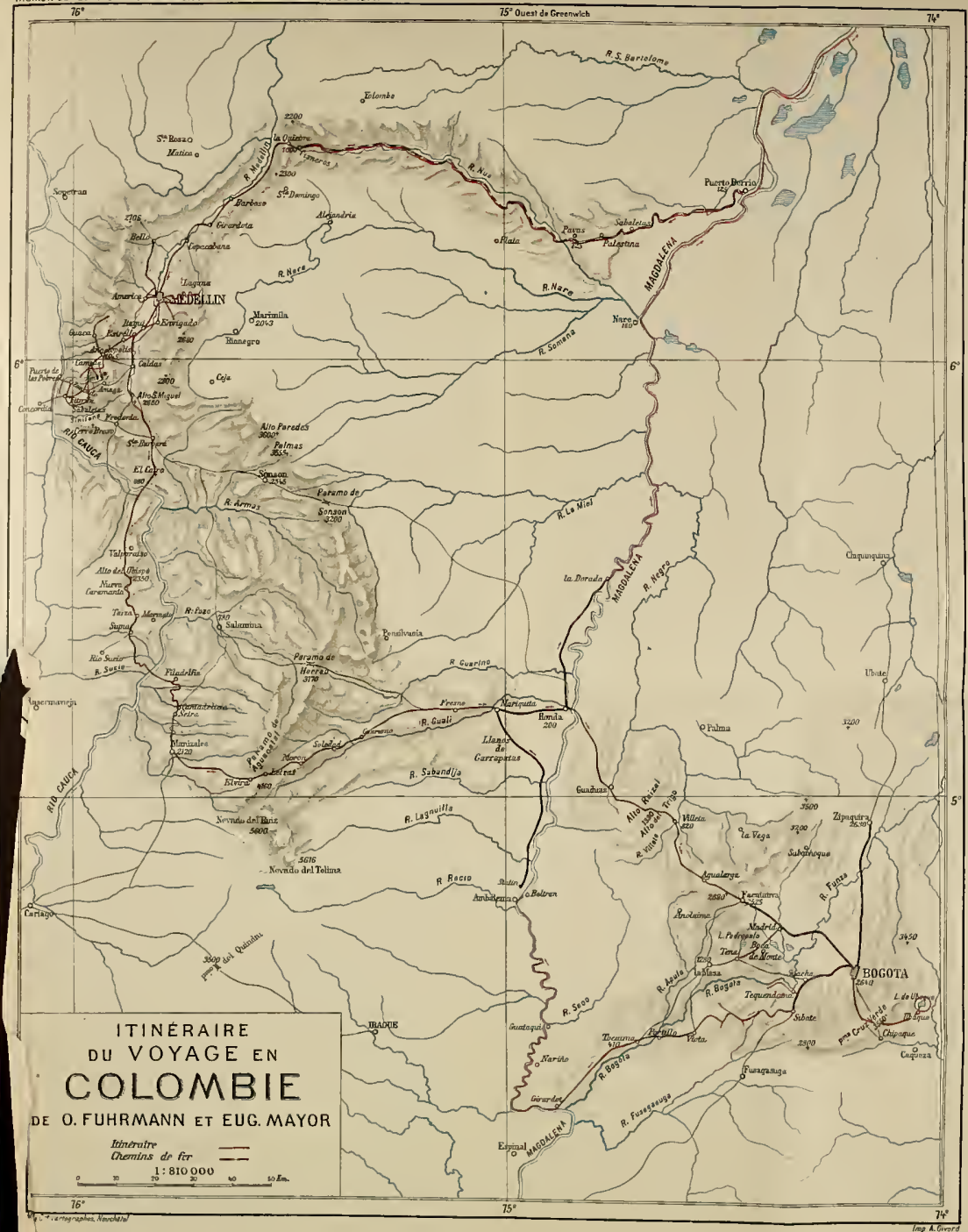


SECONDE PIRTIE

TRIVIUX SCIESTIFIQUES 



\section{B E I'TR A G}

Z116 KENTISS Mils

\section{Süsswasserdekapoden Kolumbiens}

$\operatorname{lin}$

PROF. Dr C. ZIMMER, BRESLAU

Die von Prolessor Fuhrmanu gesammelten Süsswasserdekapoden verteilen sich auf 4 Familien, 5 Gattungen und 7 Arten.

Von diesen gehörten 4 Arten neuen Species an.

Im folgenden gebe ich eine Liste der Fundorte und der an don einzelnen stellen erbentelen Arten :

1. Antillen. Sux Cayes, Iläti : Uca vocator (II Enвsт);

2. Antillen. St. Thomas: Coenobita diogenes LATr.;

3. Barranquilla am Magdalena : Trichodactylus quinquedentatus Rатнв.;

4. Calectal Camelia bei Ingelopolis, $1800 \mathrm{~m}$. : Epilobocera fuhrmanni n. sp.:

5. Zwischen Guaca und Angelopolis, $1600 \mathrm{~m}$.: Pseudothelphusa monticola n. sp.:

6. Guara 1200 m. ; Pseudothelphusa monticola n. sp.;

7. Zwischen Gnadnas und Sensitiva $1000 \mathrm{~m}$ : Pseudothelphusa dispar n. sp.;

8. Zwischen Guadnas und Hondil 800 m. ; Pseudothelphusa dispar n. sp.:

9. Tambo unterhalb Boca del Monte $2000 \mathrm{~m}$. : Pseudothelphusa dispar n. sp.;

10. Cafetal Argelia 1600 m. : Pseudothelphusa sp.;

11. Cafetal Buenarista $1200 \mathrm{~m}$. : Pseudothelphusa dispar n. sp. : Pseudothelphusa monticola n. sp. 


\section{Familie Potamonidæ}

\section{Gattung Pseudothelphusa Saussure}

\section{Pseudothelphusa dispar n. sp. \\ (Textlig. 1-5, Tab. 1 Fig. I et 2)}

Yon dieser An war nehen einer Anzahl grosser, mittelgrosser mol liner Weibehen nur ein Männchen rorhanden, das an Dimensionen beträchtlich hinter den qrössten Weibehen zurrüekblieb, dabei aber doch schon einen wohl entwiekelten Penis besass.

Beschrebuxg : Der Carapax ist etwa $3 / 5$ so lang wie breit. In beiden Riehtungen ist

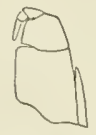

Fig. 1: dritter Maxillipes Verg. ca. $3 \mathrm{mal}$

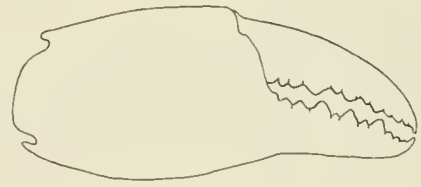

Fig. $2: \delta$ grössere Scheere, Vero. ca. 2 mal

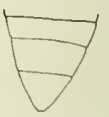

Fig. 3 : O letzte Abdominalsegmente Verg. ca. 3 mal

er mässig gewölbt. Seine Oberlläehe zeigt eine microscopiseb feine Granulierung und ist mit Nadelstielıen übersäht.

Die Seitenäste der Cervikalfurehe sind breit und haben einen annähernd gradlinigen Verlauf.

Der obere Stirnrand ist mit selır wenig entwickelten Körnehen besetzt. Eine mediane Längsfurche ist vorhanden, bei den grösseren Exemplaren deutlicher ausgebildet als bei den kleineren. Der obere Stirmrand ist von oben fast

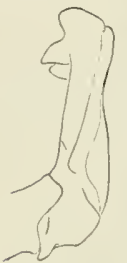

Fig. 4: 8 Penis, Ansicht der Unterseite Verg.ca. $8 \mathrm{mal}$ gar nieht sichtbar. Von vorn gesehen, ist er jederseits sehwach ausgebuchtet, und dadureh undentlich dreilappig.

Die Orbitie sind viereekig und ziemlich hoch in Verhältnis zur Breite. Die Granulierung der Ränder zeigt sieh besonders hei den grösseren Exemplaren nur ausserordentlich schwach entwiekelt. Die obere äussere Ecke ist bei den grösseren Exemplaren nicht einmal durch einen Tuberkel markiert. Ein Ausschnitt im Rande ist nieht vorhanden. Die Zähnelung am vorderen Seitenrande des Carapax ist nur schwach entwickelt.

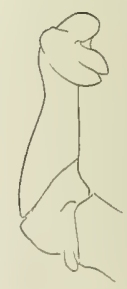

Fig. 5: Penis, Ansicht der Oberseite Verg. ca. $8 \mathrm{mal}$

Das letzle Abdominalsegment des Männchens ist dreieckig, etwa $3 / 5$ so lang wie breit. Am dritten Maxillipes ist der Aussenrand des Mecopoditen eckig. Der Exopodit ist 


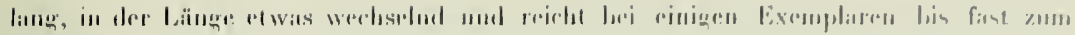
Eirde des Meropoditeri.

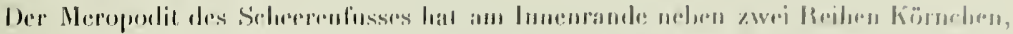

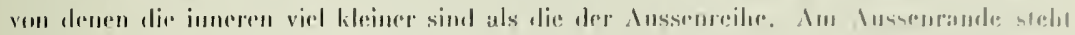

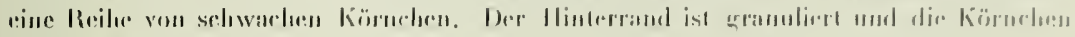

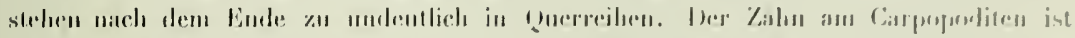

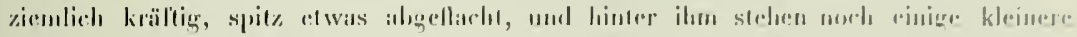

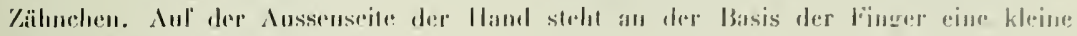
Busle. Dire Finger klaflion nichte.

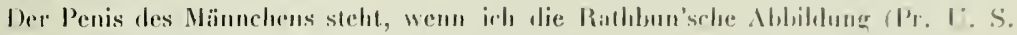

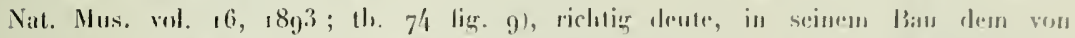

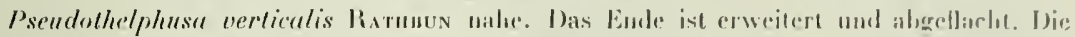

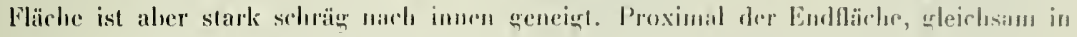
ihrer spiraligen fortsetzung liegend, sind zwei dreieckige nach innen z.n frerichtete Lappen vorhanden.

Masse (in mun) tles of und fles qrö̈sceren o

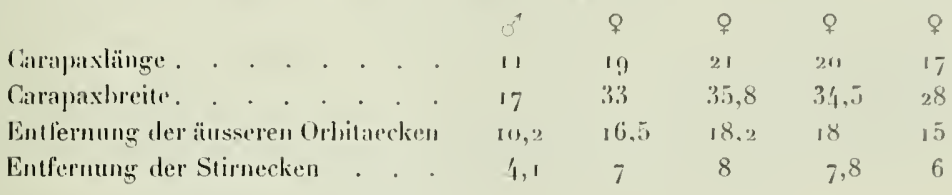

\section{Fundorte:}

Zwischen Guaduas und IIonda, 800 m., Zwisehen Guaduas und Sensiliva, $1000 \mathrm{~m}$, Cadetal Bucnavista bei Viota $1020 \mathrm{~m}$. In kleinen Bächen und an ilıren L'fern. Alte Arei Fundorte sind in der Ostkordillere spelegren.

\section{Pseudothelphusa monticola n. sp.}

(Textlig. (i-10, Tab. , Fig. 3 et f)

Manncuen: Der Carapax ist efwat $3 / 5$ so laner wie breit. Seine Wöllung ist nur schwach, sowohl in der Längs- wie in der Qucerrichtung. Die Oherlläche zeigl microseopisel feine limmeln mnd ist mit Nadelstichen ïhersïhı.

Die Seiten:iste der Cervicallurche sind breit, und sie werden nur nahe dem liörperrande linienförmig. Ihr lerlauf ist fast grerade.

Der obere stirrand ist infolge des starken. Whalles der Vorderstirn trut ausageprägt. aber weder grekich noch mit Tulverkeln heselzl, sondern glatt. In der Vilte ist er durch eine krätige Längslurde geteilt. Die Stirn ist niedrig. Der untere Stirnsand ist won oben nicht sichbat, ron rorn gresehen ist er jederseite ansuebuchtet und erscheint so dreilappig. Die Orbilie sind viereckig. Die Ränder mit dusnahme des oberen Innenrandes sind 
schwach granuliet, der olvere Innenrand ist mur mit Nadelstichen versehem, sonst aber glatt. Die ohere Iusenecke ist nur durch einen starken Tuberkel markicrt. Unterhalbs von ihm ist an Iussentande der Orbita eine Ausschnitt vorhanden. Die Zähnelung am vorderen Inssenrande des Carapax ist verluälnismässig gul entwicklet.

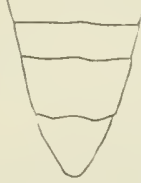

Fig. 6: Letzle Abdominalsegmente Verg. ca. $3 \mathrm{mal}$

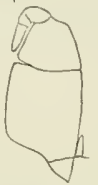

Fig. 7 :

Dritter Maxillipes Verg. ca. $3 \mathrm{mal}$

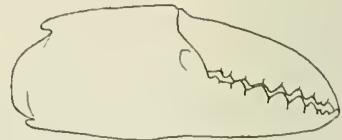

Fig. 8:

Grössere Scheere, Verg. ca. 2 mal

Das letzte Mbdominalsegment ist dreieckig, an der Spitze etwas gerundet, etwa $7 / 10$ so lang, wie breit. Das vorletzte Abdominalsegment ist etwas über halb so lang, wie am Hinterrande breit.

Am drillen Maxillipes ist der Aussenrand des Meropoditen mit einer Ecke versehen. Der Exopodit ist selır kurz.

Der Meropodit des Scheerenfusses ist am Innenrande und Aussenrande mit je einer Reihe Tuberkeln besetzt, und der Hinterrand ist unregelmässigg granuliert. Der Dorn am Carpopoditen zeiğt mittlere Grösse. Auf der Aussenseite der Palma sitzt am Grunde der Finger eine nicht besonders stark entwickelte Beule. Die Finger der Scheeren klaffen nichı.

Fig. 9: Penisspitze von oben Verg. ca. $9 \mathrm{mal}$

Nach der Ausbildung des Penis gehört die vorliegende Art zur Gruppe 8 Ratruuns (Pr. U. S. Nat. Mus. v. 2r, 1899 , р. 5r3). Wenn wir von der etwas abweichenden Pseudolhelphusa lindigiana Ratubur absehen, die Rutubun sellssl später in ihrer Nonographie ans der Nähe der anderen entfernt hat, so ist der Penis bei den einzehen Arten selır ähulich. Der vorliegenden Art unterscheidet sich von den anderen dadurch, dass aul' dem abgestutzten Ende des Penis ein kleines Zähnchen sitzt. Von Psendothelphusa bonvievi Rathus und $P$. conradi Ratmon ist die Arl ducch den

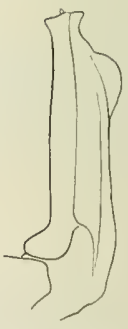

Fig. 10: Penis von unten Verg. ca. 9 mal glatten, weder kiellörmig ausgebildeten, noch granulierten Stirurand unterschieden. Auch bei Psendothelphnsa cequatoriulis On'tmann ist der obere Stirurand viel markanter entwickelt, als bei der vorliegenden $\Lambda \mathrm{rt}$ : Wie die Prüfung eines zum Verógleich aus dem Strassburrer Zoologischen Museum eutlichenen Originalexemplares ergab, ist anch hei dieser Art der obere Stirnrand nicht einfach als abgerundete Kante ausgebildel, sondern ziemlich kräftig wulstförmig, so dass man ihn fast gekielı nemnen könnte. 


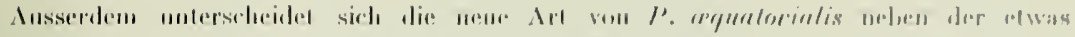

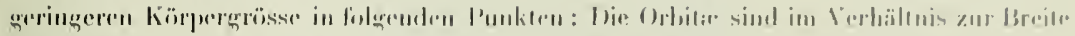

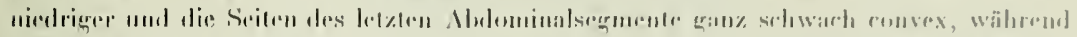

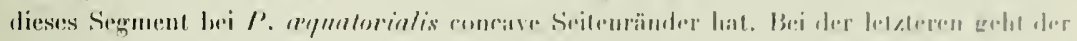

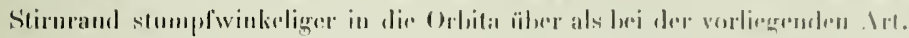

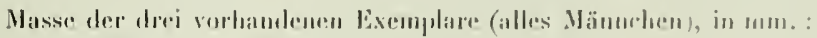

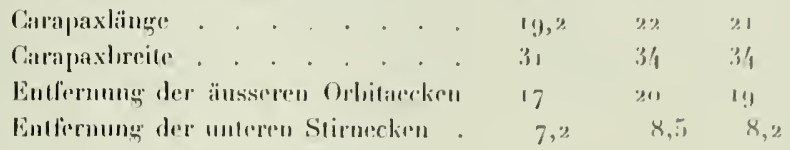

Finulorle :

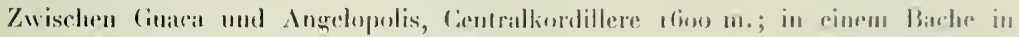

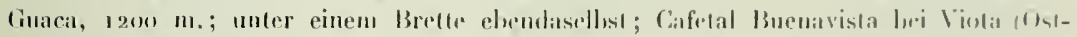
kintillere), $1020 \mathrm{~m}$.

\section{Pseudothelphusa sp.}

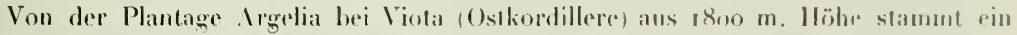
erwachsenes Weibchen, das mil keriner der beschriebenen Irlen genau ühereinstimmt. Bri der Bedealung jectoch, die qurade der Bau des Penis für die Stystenatik dieser schwierigen Cirmpe von krehsen hal, will ich es nicht mormolumen, eine neus Art cintach anle ein Weibehen hin anfzustellen.

\section{Gattung Epilobocera Stimpson}

Der Autor der Gallung Epilobocera Strmpsox, wiebl ils ihr Characterislicuma an, dass der innere Augenlippen an den Stimrand anstösst. Dieses . Jerkmal komme aber nicht allen Ingehörigen des Genus zu; Rıтnвux nimm als Lnterscheidungsmerkmale gegen Psendothelphusa an: den Exopoditen am dritten Maxillipes, der his zur spitze des Iehiums oder noch darüher heraus reicht, die zalınfömige Aushildung des liandes der Aemöfhnung, die stärkere Bedornung des Daclylopoditen und dic starke Liranulicrung der Subcervikalfurche.

Bei Psemblothelphusa macropa kommt (nach R.tтuBtw) eine eben so starke Bedornung der Dactypopiten vor. Auch der Zahn ium Rande der Alemöfinmer fintel sich hei manchen Angehörigen der Gallung Psendolhelphusen. Bei etlichen Arten dieses Gemus reicht auch der Exopodit wenigstens his annähernel an das Ende des Ischiums. Lnd her der unten beschriebenen nenen Art ist die subervikalfurche nicht arranuliert. Nach alledem erscheint mir Epilobocera höchstem den Wirt eine Lntergatlung ron Pseudothelphasn zol label.. 


\section{Epilobocera fuhrmanni n. sp.}

(Textfig. 11-to. Tab. 1 Fig. 5 et 6 )

Der Carapax ist etwa 3/5 so lang wie breit. Sowohl in der Lünge, wie in der Breite ist er wenig gewölht, wenn er auch nicht so abgeflacht erscheint, wie der Carapax von Epilobocera sinualifrons (1. Muxe Eowands), oler E. haytensis Ratubun. Seine Oherfläche zeigt im vorderen Teile hei kleinen Exemplaren eine feine Granulierung, die

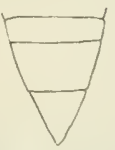

lig. $11: 0$ Ende des Abdomens Yerg. ca. $3 \mathrm{mal}$

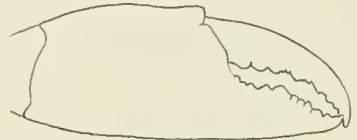

Fig. 12: $\delta$

Scheere, Verg. ca. $2 \mathrm{mal}$ aber bei grösseren Tieren fast völlig verschwunden ist. Die Seitenäste der Cervicalfurche sind fast gerade.

Ein oherer Stirnrand aus Tuberkeln bestehend, ist, rorhanden, jedoch nicht so stark entwickelt, dass es zur Ausbil-

dung eines vorspringenden Kieles käme. Von oben gesehen sowohl, wie von vorn gesehen zeigt der Rand eine fası gleichmässige Biegung. Eine mittlere Längsfurche ist nicht vorhanden.

Der untere Stirnrand ist in der Ansicht vou olen fast völig verdeckt; von vorn gesehen, hat er jederseits eine Ausbuchtung und erscheint dadurch dreilappig.

Die Orbite zeigen die Form eines Rechteckes. Hhr Oberrand, Aussenrand und Unterrand

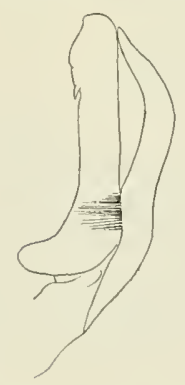

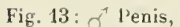
von der Unter'seite Verg. ca. 8 mal

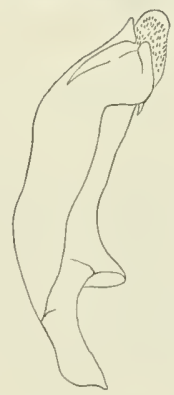

Fig. 14: $\gamma^{-1}$ Penis von der Innenseite Verg. ca. $8 \mathrm{mal}$

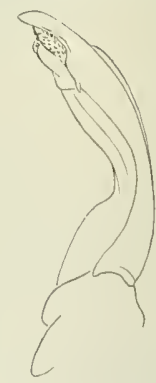

Fig. 15: o Penis von der Uberseite Verg. ea. $8 \mathrm{mal}$

ist granuliert. Die obere Aussenecke ist nur bei kleineren Exemplaren schwach zahnartig entwickelt während sie bei grösseren Exemplaren sich als abgestumpft erweisı. Unterhalb der Ecke findet sich ein Ausschnit, älmlich wie bei Epilobocera sinuratifrons, jedoch schwächer entwickell unt vor allem durch das Fehlen der Granulierung angedeutet. 


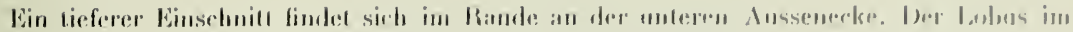
Inurnwinkel reichl nichl bis zor Stirn.

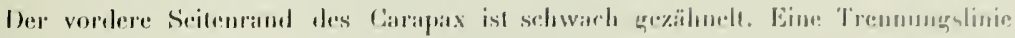

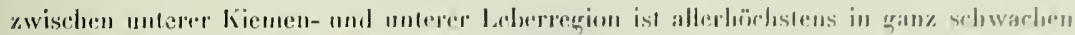
Andentungen vorlanden.

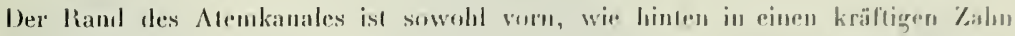

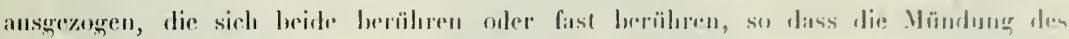
Kanales ganz oder fast gan\% ueselilussion erscheint.

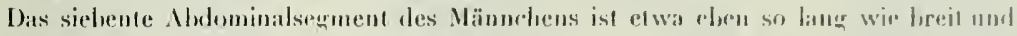

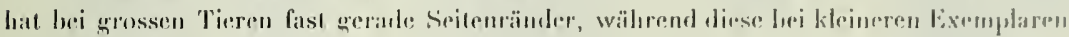
selowach convex sind.

Der Meropodit des driten Maxillipeden ist zirmlich srhmat. Sirin Inssmoramd int

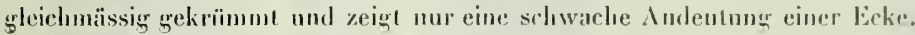

Im Meropoditen des Scheerenfusses ist der Innenrand mit pinigen slirkiren Tuherkeln nach dem Ende zu hesetz. An Aussenrande steht eime rinzelne Reilue friurer Tuberkeln, und dic stumpfo Hinterkante ist unregelmässig eranulierl. Der Dern an Carpopoditen ist verhälunsmässigr klein mol meh oder weniger abgestumpef. IBei Weihehen und kleineren Männchen schliessen die Scheeren heilte, wïhrent hei grössorm Männchen die starke Scheere klalli. Ueber den Bau des sehr komplizierten Panis vergleiche Fig. I 3-15.

Masse bei einger der grösseren Exemplare (in $13 m$ ).

Carapaxlänge . . . . . . . 20

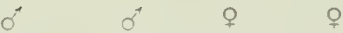

Carapaxbreife . . . . . . . 1

Entfermung der äusseren Orhitaecken

Entlernung der unteren Stimecken . 6,5

$24,5 \quad 26 \quad 27$

$14.8 \quad 15,5 \quad 16$

$15 \quad 15 \quad 1.1$

i, $5,8 \quad$ (i)

Fundorte :

Cafetal Camelia des deutschen Consuls bri Angrelopolis (Central kurdillere 1820 m.. in kleinen Bächen und an ihrem Rande. Zahlieiche grosse und kleine Exemplare.

\section{Trichodactylus quinquedentatus Rathbun.}

Zwei Exemplare, ein kleineres Weibehen und ein grösseres Männchen von Barranguilla am Magdalena, terrestrisch am Lfer lrbend. Während bei dem Weibchen der vierte und fünfte Zahn slumpf ist, zeigł sich bei den Männchen, einem Tiere von etwa I6 mm. Länge insofern eine kleine Differenz gegen die Originalheschreihung. als dor füntle Zahn links und der vierte und fünfle rechte eine deutliche Spize haben. 


\section{Familie Ocypodidæ \\ Gattung Uca Leach}

6. Uca vocator (Herbst).

Mehrere Exemplare aus Hä̈t, aux Cayes, in Erdlöchern eines Baches.

\section{Familie Conobitidæ \\ Gattung Conobita Latr.}

\section{Conobita diogenes Latr.}

Mehrere Exemplare aus St. Thomas, wo sie in tiefen Erdlöchern am Abhange des hinter der Stadt gelegenen Hügels gefunden wurden. Steckte man den Stock in die Löcher, so bissen sie sich fest und konnten herausgezogen werden. 
PI.ANCHE I
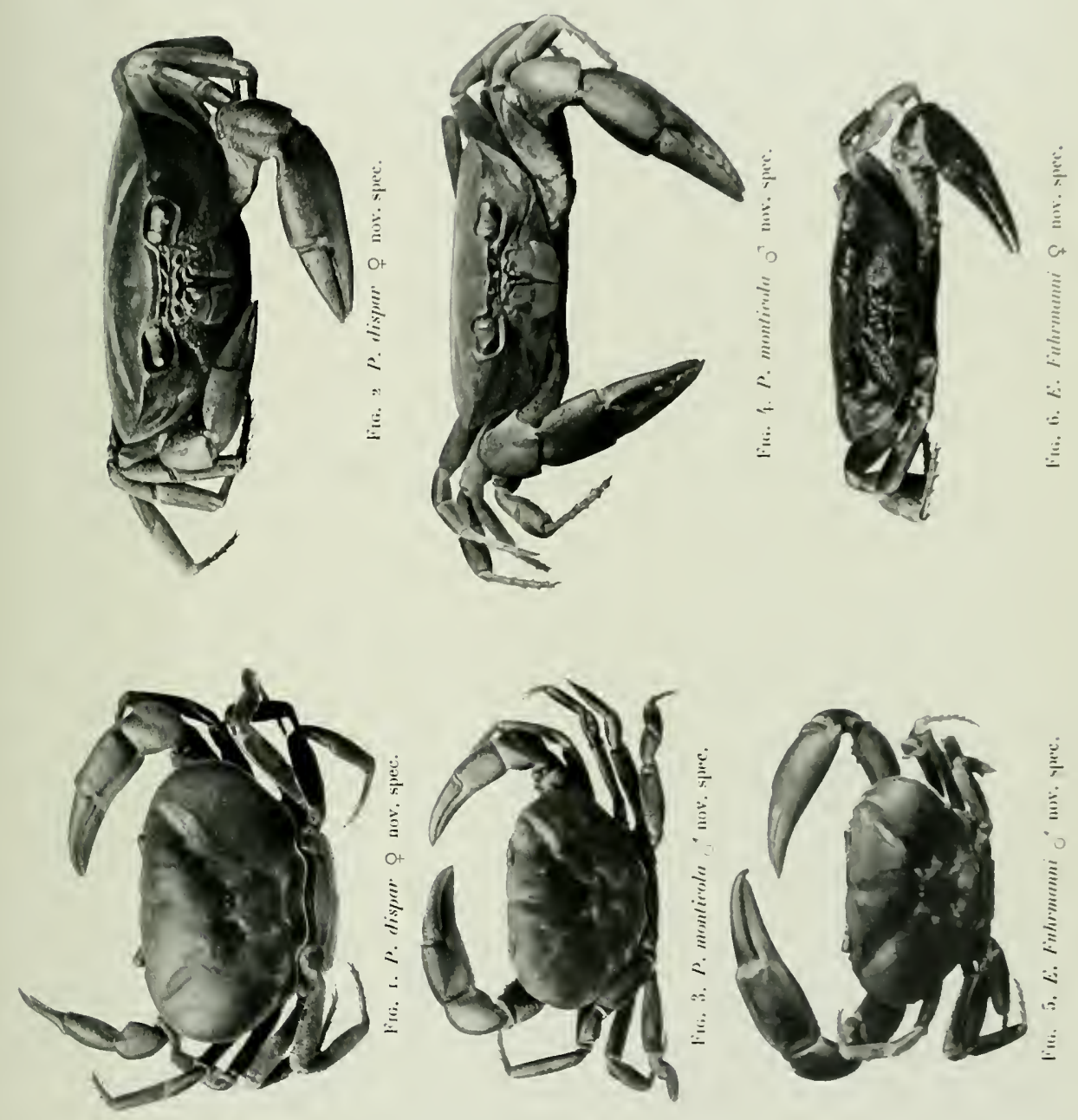



\section{Quelques fourmis de Colombie}

1יA1

\section{A. FOREL}

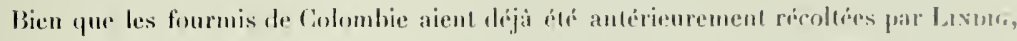

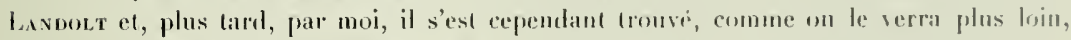

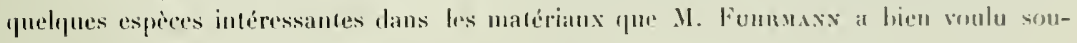
metle à mon examen.

\section{Subf Ponerinae Lep.}

I. Odontomachus haematodes L. subsp. erythrocephalus Ex. \& \&. Bello près Melellin (C. e." Dep. Antioquia, al1. 1547 m.); Cafelal Camelia pries Angelopolis (C. c. Dip. Antioquia, alt. $18 \mathrm{ig} \mathrm{m.}$.)

2. Odontomachus haematodes L. var, rugisfuama Fonel. Pherto de los Puhres, hords du Canca (Dép. Antioquia, alı. ca. $720 \mathrm{~m}$.). Entre Honda el Finaduas (C. or. Dip. Cundinamarea, alt. 950 m.). Lbaque (C. or. Dép. Cundinamarea, alt. 18.3 m.).

3. Odontomachus chelifer Larr. $q$. Bello près Medellin (C. c. Dep. Antioquia. all. 1547 m.) ; (ruaca (C. c. Dép. Antioguia, alt. r.joo m.) ; Cafetal Argelia (C. or. Dép. Cundinamarcar, alt. r6oo m.).

4. Ectatomma tuberculatum Latr. O Pnerto de los Polıres, Camea (Dép. Intioquia. alt. $720 \mathrm{~m}$.) el Cafetal Camelia près Angelopolis (C. e. Dép. Intioquia, alt. $1820 \mathrm{~m}$.). Espèce très commune dans toute limérique tropicale.

5. Ectatomma ruidum Rog. o. . Calamar (sur le Maızdalena. Dép. Magdalena, alt. 50 m.) : Bello près Medellin (C. c. Dép. Antioquia, alt. 1547 m.). Espiece tris commune en Colombie.

1 C. $\mathrm{c}$. = Cordillères centritles, C. or. - Corditleres orientales. 


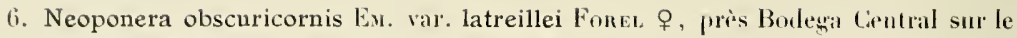
Magdalena (Dip. Magdalena, alt. ca. $70 \mathrm{~m}$.).

7. Neoponera foetida Ous. \& . Bodega Central sur le Magdalena.

8. Pachycondyla fuscoatra Rog. subsp. transversa Ex. 우 우. Cafetal Camelia pris Angrelopolis (C. c. Dép. Intioguia, alt. 1819 m.).

\section{Subf. Dorylinae Leach.}

9. Eciton coecum Latr ㅇ. Caletal Camelia près Angelopolis (C. c. 18 I9 m.); Puerto de los Pubres; bords du Canca (Dép. Antiequia, alt. ca. 720 m.). Espice très commune dans toute I'Amérique Iropicale.

ı. Cheliomyrmex andicola Emery. ․ Cafetal Camelia près Angelopolis (C. c. $18 \mathrm{r} 9 \mathrm{~m}$.). Aquacatal (C. c. Dép. Tolima, alt. $15.5 \mathrm{~m}$.). Facatativa (C. or. Dép. Cundinamarea, alt. $2588 \mathrm{~m}$.).

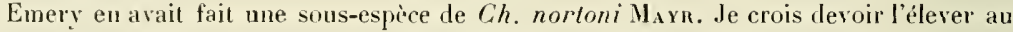
rang d'espèce. Aux caractìres déjà indiqués par Emery, il faut ajouter en effet que tous les articles du funicule sont bien plus longs qu'épais (art. 8 el 9 , souvent mème 5 à 9 , uı peu plus épais que longs chez Ch. nortoni).

Il est intéressant de retrouver en Colombie cette espèce du Péron.

\section{Subf. Myrmicinae Lep.}

II. Atta cephalotes L. v. opaca Foré . Cafetal Magdalena (C. or. Dép. Cundinamarca, alt. $1053 \mathrm{~m}$.) ; Bello près Medellin (C. c. Dép. Antioquia, alt. $1547 \mathrm{~m}$.). Une des espèces bien connues qui sèment et jardinent un champignon (Rhozites gongylophora MöLter) sur les feuilles qu'elles coupent et apportent dans leur nid après les aroir triturées. M. le Prof. Fuhrmann a observé, comme d'autres, que souvent 2 on 3 petites Atta (I'onvière est très polymorphe) se laissent porter par leurs compagnes en se perchant sur la feuille coupée que celles-ci portent.

12. Atta columbica Guérix o. Entre Guaduas et Sensitiva (C. or. Dép. Cundinanarca, alı. goo à $1000 \mathrm{~m}$.). J'ai déjà observé moi-même en Colombie que cette espèce vit dans les parages inférieurs chauds (tierra caliente), tandis que la précédente se trouve plutót sur les hauteurs, I 200 à $2000 \mathrm{~m}$.

13. Atta (Acromyrmex) mesonotalis Ex. v. fuhrmanni n. var. ㅇ L. 3,5 à 5 mill. Abdomen entièrement brun, comme le reste du corps. Ce n'est pas l'épine postoculaire qui est bifide, comme chez le type, mais l'épine du vertex, en avant de l'épine occipitale. Correspond du reste bien à la description d'Emery, mais plus petite.

Prìs de la Laquna au-dessus de Medellin (C. c. Dép. Antioquia, alt. $2300 \mathrm{~m}$.). Les épines oecipitales sont courbées et l'extrémité de toutes les longues épines lissr et jannàtre, comme l'indique Emery, el comme chez l'A. mölleri Foret. 


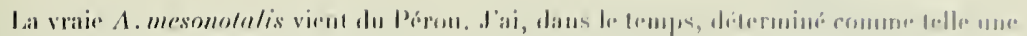

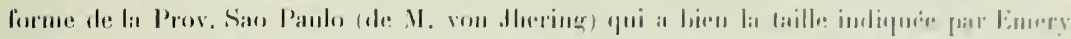

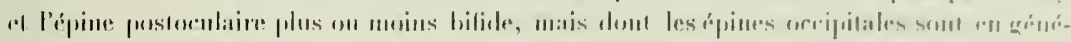

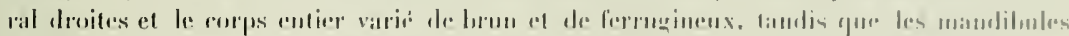

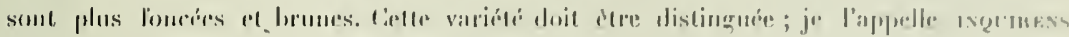
II. var.

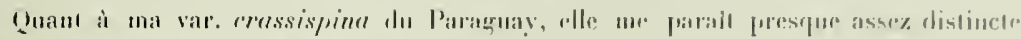
pour constiluer une sums-aspire.

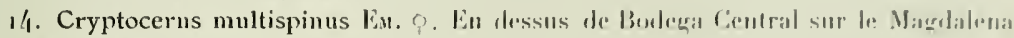

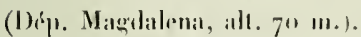

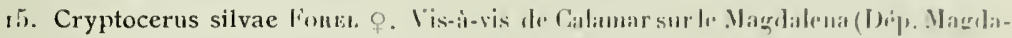

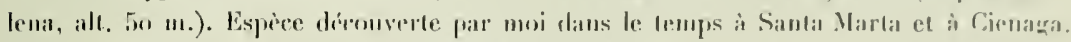

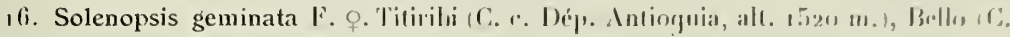

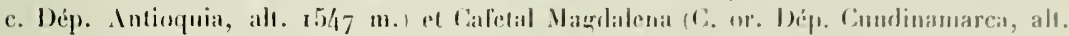

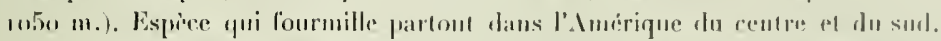

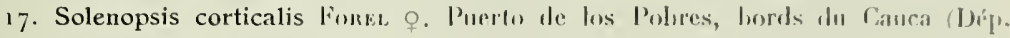
Autioquia, alt. car. 720113.$)$.

18. Cremastogaster brevispinosa Mar o. Medellin (C. c. Dép. Antiognuia, alt. 15/7 i1.), presifue aussi commune que S. geminnalı li.

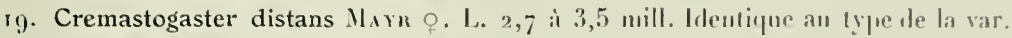
corticicola Mark, mas d'un brun noir, aver l'ablomen noir, la base fles funicules, l'ex-

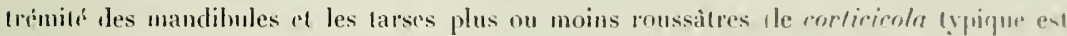
d'un roux jaunitre, avec l'ablomen et les membres hrunsi. L'ipinotum int encore un peu plus large que che\% le corlicirola, une fois el demic plus large que le promisumotum. Ce dernier très bossu. Tète aussi lisse que chez le ygpe de la subsp. el épines plutrit phus longues.

Bello près Medellin (C. c. Dép. Antioquia, alt. 1547 m.).

La subsp. puraensis Foneu est moins bossue, a le promesonoum anssi large que l'épinotum et l'épine plus courte, mais la mène couleur foncée.

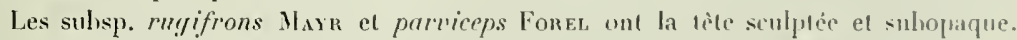

It est difticile d'aftimer que c'est exactement te type colombien de . Hayr, car l'auteur me semble avoir confondu an moins deux on lrois varictis dans sa description. Il p-1 inadmissible que toutes les différences quil indique se trousent dans la mème fourmilicre. Les exemplaires du Prof. Fuhrmam out le secont noud faiblement et largement chancré, l'abdomen assez lisse, l'épinotum aussi, le premier noud large ol sulcarré (comme chez corticicolu), nullement cordiforme. le mésonotum avec un sillon longitudinal, la tèle lisse.

Pour simplifier la question, le type de l'espèce nayant pas éli retrowé depuis a 8 je propose de considérer comme typique celle forme qui correspond bien à l'une des varitlés mentionnies ex arquo par Mayr dans sa tescription oit il fait une synthése avec des 
"ou \# - et de domer un nom de variété à la forme à premier norud cordiforme ( $v$. Condixod. 11. var.) - érentuellement à d'autres - si eltes se retrouvent.

20. Pheidole flavens Rog. subsp. navigans For. ㅇ. Medellin (C. c. Drip. Intioquia, alt. I彷 $\mathrm{j}$.).

21. Pheidole guilelmi mülleri Fokel, subs]' bucculenta Fonel, var. socrus n. var. Q. L. 2,7 à 3 mill. Toute semblable an tỵe de la sous-espèce, avec l'épinotum mutique et la mème tète allongée, mais l'occiput ot le vertex ont les mèmes grosses rides transversales quion roit chez les subsp. avin For. et injuncta For., du reste tout à fait dillirentes à d'autres égards.

Cafetal Camelia près Angelopolis (C. c. Dép. Antioquia, alt. ı820 m.).

\section{Subf. Dolichoderinae Forel.}

22. Dolichoderus bispinosus Otıx. ㅇ. Entre Ilonda ef Fuaduas (C. or. Dép. Cundinamarea, alt. $950 \mathrm{~m}$. ).

23. Dolichoderus schulzi Ey. var. columbica n. var. ㅇ. L. 3,7 à 4,3 mill. La tète cordiforne est beaucoup plus élargie derrière, avec les còtés beaucoup plus convexes que cliez le type de l'espèce qui est le Para : elle a 1 mill, de long et de large (plus longue que large chez le type de l'esprice qui est bien plus petit et n'a que 3 à 3,3 mill.). Angles antérieurs du pronotum presque droits, pas on à peine dentiformes, quoique fort acérés (dentiformes chez le type; dent plate et triangulaire). L'ícaille est au contraire plus fortement acuminée que chez le schulzi typique, avec une pointe plus aiguë, dirigie en liaul et en arrière, an sommet. Mésonotum plus long, moins transversal, à peine une fois et demie plus large que long, et plus arrondi derrière (presque deux fois plus large que long chez le type de l'espice) ; suture mésoćpinotale plus profonde. Pattes. antennes et mandihules d'un roux un peu jaunàtre (brunàtres chez le schulzi typique); Epinotum plus élargi derrière.

Du reste identique au type de l'espèce, en particulier la sculpure et la pilosité, ainsi que la forme pour tout le reste.

Medellin (C. e. Dép. Antioquia, alt. 1547 m.).

24. Dorymyrmex pyramicus Rog. v. nigra Peng. o. Bello près Medellin (C. c. Dép. Antioquia, alt. $1547 \mathrm{~m}$.)

25. Irydomyrmex humilis Marr o. Aguacatal (C. e. Dép. Tolima, alt. 1515 m.).

\section{Subf. Camponotinae Forel.}

26. Rhizomyrma fuhrmanni n. sp. of L. 1,7 à 1,9 mill. Très voisine de l'exsangnis Wheeler, mais les mandibules ont 4 dents, un bord terminal assez distinct, et elles sont plus élargies vers ce dernier. Tête distinctement un pen plus longue que large, un peu plus large devant, rectangulaire. Yeux bien plus distincts que cliez l'exsanguis, situés à 


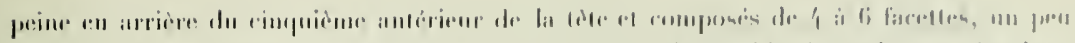

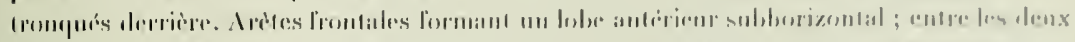

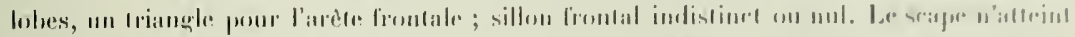

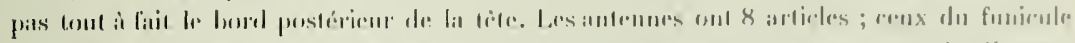

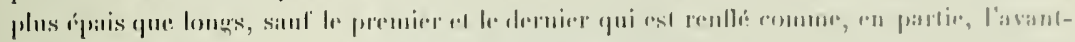

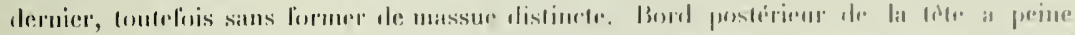

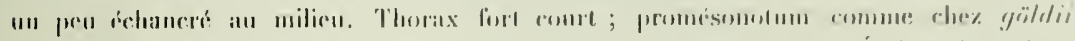

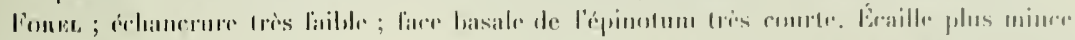

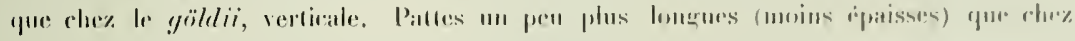
leexsanguis.

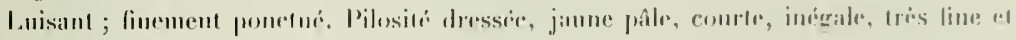

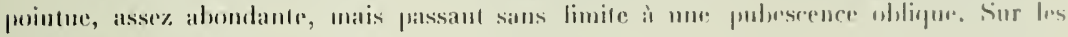

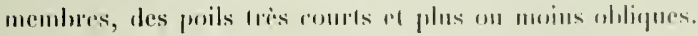

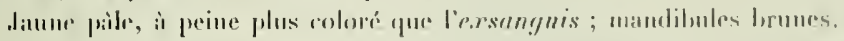

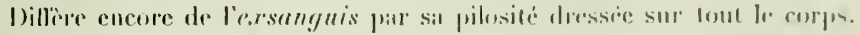

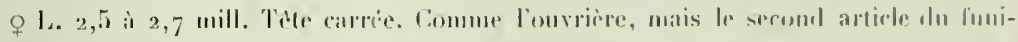

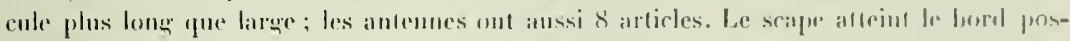
tericur de lis tìle.

I) vertex d'un brum un peu jaumatre.

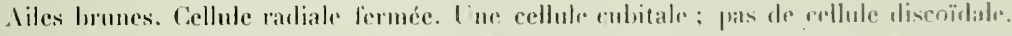

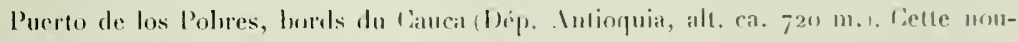

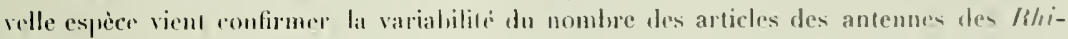

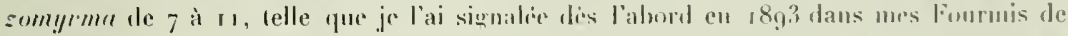

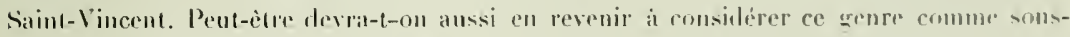
genre d'Acropyga, ainsi que je l'avais fail au déhul.

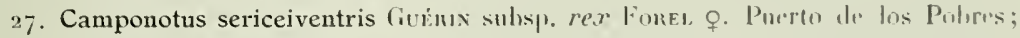
loords ilu Carica (Dép. Intioquia, all. ca. 7201 m.).

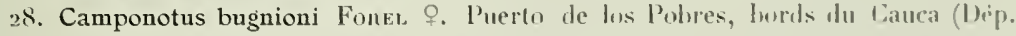

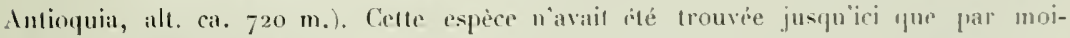
mème, de Santa Marta à Dihubla. an pied de la Sierra Vevada de Sitlla Masta en Colombic.

29). Camponotus abdominalis $l i$ vas. costaricensis Forke. O. Vin-a-lis de falamar sur le Magdalena (Dép. Ma gुelatena, all. 5o m.1.

Ma subsp. ustulatus n'est qu'unc variéti do la subsp. alriceps sm. plu- ranire qur lit var. costuricousis et avec les maudibules matrs, densément sculpules.

30. Camponotus melanoticus Ex., var. substituta Ex. O. Entre llumla el linaduas (C. c. Dép. Cundinamarca, alt. ca. gōo m. ı.

31. Camponotus maculatus F. subsje. indianus FoneL O. Cafetal Camedial press Ingelopolis (C. c. Dép. Anlioquia, alt. 1s20 m.). 
32. Camponotus nitens Marn o. En dessus de Bogotia (C. or. Dép. Cundinamarea, ill. ca. 30oo m.). Espèce typique ponr la région de Bogola, la seule où on l'int tronvée jusqu’ici. - Exemplaires foncés el grands, de 5 ì 7,5 mill.

33. Camponotus crassus Marr sulisp. Brishliensis Marn o. Uhaque (C. or. Dép. Cundimarca, alt. 1833 m.) et Paramo Cruz Verde (C. or. Dép. Cundinamarea, ałt. 3500 m.). Navail été trouvé jusqu’ici que bien plus au sud.

34. Camponotus trapezoideus Marn o. Medellin (C. c. Dép. Antioquia, alt, 1547 In.). 


\section{BEITRA G}

ZUII liNNTNIS MEI

\section{Skorpione und Pedipalpen Columbiens}

VON

\section{KARL KRAEPELIN}

Von Herrn 1) O. Fuhrmann ist mir das von ihm in Columbien gesammelte Material von Skorpionen und Pedipalpen zur Bearbeitung anvertraut worden; es ist nirht sehr reich, griebt aber trotzdem ein ziemlich qutes Bilal der in Columbien vertretenen Furmen dieser Gruppen. Von Skorpionen waren bisher ans Columbien mit Sicherheit efwa 18 Arten hekannt, die, mit alleinigrer Ausnahme des den sonst ganz altwoliliehen Ischrnrinen angrehörigen Opisthacanthus elatus, sich ausschliesslich anf die tiamilien der Centruriden (mit den Gattungen Tityus und Centruroides) und der Chactiden (mit den Gattungen Chactos und Broteochactus) verteilen. Von diesen is Arten ist nur ein Drittel in der Coll. Funumas vertreten; dazu kommen dann aber noch eine bisher nicht ans Colnmbien bekannte, sowie drei für die Wissensehaft neue Arten. Von Pedipalpen kenut man aus Columbien bisher drei sichere Arten, von denen zwei erbentet wurden.

\section{A. Scorpiones.}

\section{Gattung Tilyus C. L. Koch.}

Aas der sehr artenreichen, auf Südamerika und Westindien heschrïnkten Gatung Tityus sind bisher in Columbien neun, zum Tril allerdings wohl nur als Varietäten aufzufassende. Irten beobachtet worden. Von diesen gaehören acht. nämlich $T$. magnimanus. 


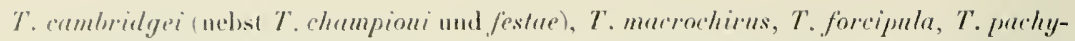
uras (melset $T$. engelliei), der Gruppe der grossen, meist einfarbig roblamuen formen an, deren of dureh blasige Erweiterung der Kammgrumllamelle chatacterisiert sind (combridgpi-firuppe), während die Gruppe der kleinen, meist schachbrettartig gefleckten Formen olne solche Kanmgrundblase beim of (columbianns-Gruppe) allein durh den $T$. columbiumus vertreten ist. Das ron Herro Dr Fun maxx gesammelte Material mulasst im Canzen sechs Arten, von denen aber nur vier mit bishor beschriebruen formen idenlisch sind, während zwei sich als neu erwiesen.

\section{Tityus macrochirus Poc.}

1897 Tityns macrochirns Pocock in: Nm. Mag. Nat. IIist. (6) NIX, p. 512.

Diese Art ist in erster Linie kenntlich durch die dicht mit kürzeren weissen und längeren rotbraumen, aus gröberen Punktgruben hervorragenden Borsten besetzte Blase, die zudem, im Gegensatz zu allen verwandten Formen, bei alten Exemplaren völlig glatt und olıne Andeutung einer lörnelung ist. Bei jungen Individuen ist dagegen eine ziemlich deutliche Reihenkörnelung nachzuweisen. Die Geschlechtsuntersehiede zwischen ơ und o sind gering, indem dic Canda des ot nach hinten nur wenig vertreitert ist (1. Caudalsegment $4 \mathrm{~mm}$, 5. Candalsegment $5 \mathrm{~mm}$ breit), die Hand des $\sigma^{1}$ an Dicke den Unterarm nur wenig übertriff und der bewegliche Finger nur einen schwachen Lobus am Grunde besitzl. Die Kiele der Iland sind ziemlich obsolet, die Flächen mehr oder weniger gekïrnt, die Zahıl der Schrägreihen des Fingers beträgt 15. Die Bauchplatten des Truncus sind sämtlich gekörnt, das Mittelfeld des 4. Segments aber ziemlich obsolet gekörnt. Die 3. Baurhplatte trägt in der Hitte des Hinterrandes cinen grossen glänzenden DreiecksHeck; ein älılicher, aber matterer, ist auch anf der ersten Banchplatte erkennbar. Dir Zahıl der Kammzälıne beträgt für gewöhnlich 15 oder 16 , doch wurden an dem vorliegenden Material auch mehrere Male nur 14, einmal i 7 Kammzähne beobachtet.

Fundort: Ubaque (Ostkordillere) in 1850 Neter Hölıe. 1 o $\sigma^{4} 7$ ㅇ.

\section{Tityus pachyurus Poc.}

${ }_{1} 8, y 7$ Tityns pachyurus Pocock in: Mnn. Mag. Nat. Ilist. (6) XIX, p. 314.

Ein in der Ausbeute befindliches jugendliches Exemplar erlıärtel aufs neue die nir lereits vom T. cambridgei her bekannte Tatsache, dass die ludividuen vieler TityusIrten im Laufe ihrer Entwicklung einen sehr auffallenden Farbenwechsel durchlaulen. Während die alten Exemplare in Truncus, Cauda, Beinen einfarbig dumkelbraun erscheinen und nur etwas mehr ins Rotbraune fallende. Arme und Hämle (mit schwarzen Fingrern) besitzen, ist der Truncusrücken der jungen Individuen hell ledergelb und nur am Hinterrande der Segmente mit schwarzen Vierecksllecken marmoriert; die Cauda ist im 1.-4. Segment gelbrot, unterseits selıwarz gelleckt, im 5. Segment nebst der Blase dunkel, 

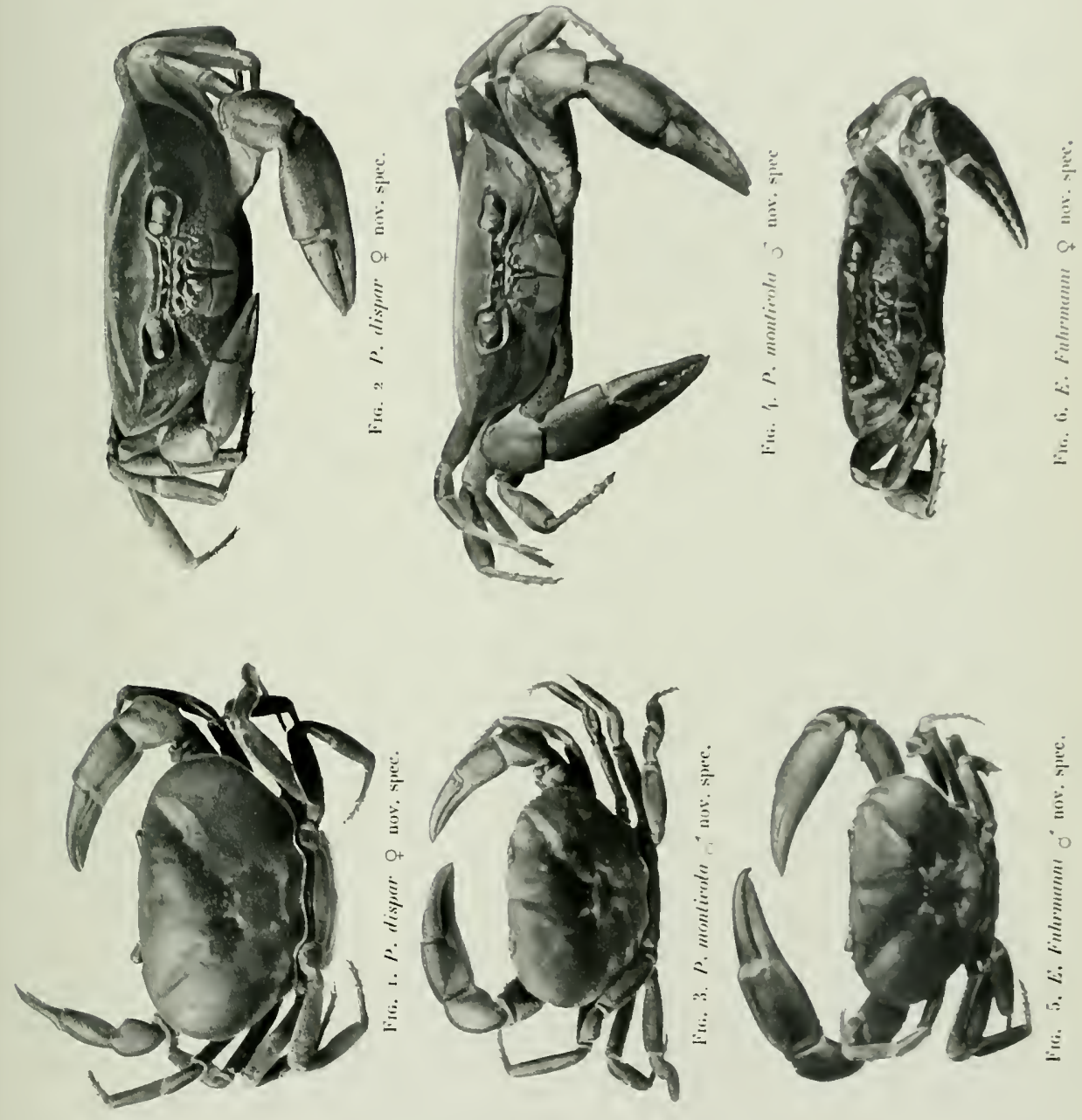



\section{Quelques fourmis de Colombie}

PAII

\section{A. FOREL}

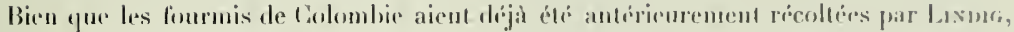

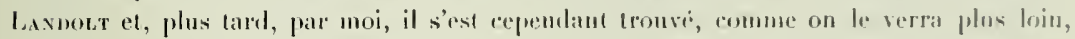

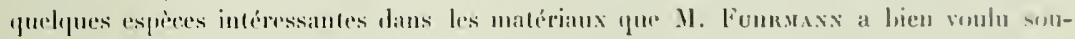
mettre a men examen.

\section{Subf Ponerinae Lep.}

1. Odontomachus haematodes L. subsp. erythrocephalus Ex. $q$ Q. Belln prims Merlellin (C. e. ${ }^{1}$ Dep. Antioquia, alt. 15/7 Mi.); Cafelal Camelia près . Inerelopolis (C. c. Dép. Intioguia, alt. 1819 m.).

2. Odontomachus haematodes L. var. rugisinuma Fonel. Puerto de los Pulures, bords du Canca (Dép. Antioquia, att. cat. 720 m.). Entre Honda el Guaduas (C. or. Dip). Cundiumarea, alt. $9^{50} \mathrm{~m}$.). Thaque (C. or. Dép. Cundinamarca, alt. $1830 \mathrm{~m}$.)

3. Odontomachus chelifer Latr. $\&$ $ᄋ$. Bello pres Iledellin (C. c. Dip. Antimpuia, alt. 1547 m.) ; Guaca (C. c. Dép. Antiuquia, alt. 1500 m.) ; Cafetal Argelia (C. or. Dép. Cimndinamarca, alı. $1600 \mathrm{~m}$.).

4. Ectatomma tuberculatum Latn. Q Puerto de los Pohres, Canca (Dép. Intionjuia. alt. $720 \mathrm{~m}$.) el Cafetal Camelia près Ingelopolis /C. c. Dép. Intiopula, alı. I $820 \mathrm{~m}$. - Espèce très commune dans toute l'Amérinue tropicale.

5. Ectatomma ruidum Rog. Q. Calamar (sur le Jaglalena, Dép. Yagdalena, alt. 50 m.): Bello près Mededlin (C. c. Dép. Antioguia, alt. 154 ; m.). Espece très commune en Colombie.

${ }^{1}$ C. . c. $=$ Cordilleres centrales, C. or. = Cordilleres orientales. 
6. Neoponera obscuricornis Ey. var. latreillei foked of, près Bodegal Cientral sur le Magdalena (Dip. Magdalena, alt. ca. 70 m.).

7. Neoponera foetida OLIV. \&. Bodega Central sur le Magdalena.

8. Pachycondyla fuscoatra Rog. subsp. transversa E.. ㅇ ㅇ. Calletil Camelia près Angelopolis (C. c. Dép. Intioquia, alt. 1819 11t.).

\section{Subf. Dorylinae Leach.}

9. Eciton coecum Latı ㅇ. Caletal Camelia près Angelopolis (C. c. 18$\lrcorner 9$ in.); Puerto de los Pobres; bords du Canca (Dép. Antiequia, alt. ca. 720 m.). Espèce très commune dans toute l'Imérique tropicale.

ro. Cheliomyrmex andicola Emerx. F. Cafetal Camelia près Angelopolis (C. c. 1819 m.). Aquacatal (C. c. Dép. Tolima, alt. 1515 m.). Facatativa (C. or. Dép. Cundinamarca, alt. $2588 \mathrm{~m}$.).

Emery en avait fait une sous-espèce de Ch, nortoni Mar. Je crois devoir l'élever au rang d'espèce. Aux caractìres déjà indiqués par Emery, il faut ajouter en ellet que tous les articles du funicule sont bien plus longs qu'épais (art. 8 et 9 , souvent mème 5 à 9 , un pen plus épais que longs chez Ch. nortoni).

Il est intéressant de retrouver en Colombie cette espèce du Pérou.

\section{Subf. Myrmicinae Lep.}

Ir. Atta cephalotes L. v. opaca Forel ㅇ. . Cafetal Magdalena (C. or. Dép. Cundinamarca, alt. ro53 11.) ; Bello prìs Medellin (C. c. Dép. Antioquia, alt. 1547 m.). Une des espèces bien connues quj sèment et jardinent un champignon (Rhoziles gongylophora MüLcen) sur les feuilles qu'elles coupent et apporteut dans leur nid après les avoir triturées. M. le Prof. Fuhrmann a observé, comme d'autres, que souvent 2 ou 3 petites Atta (l'onvière est très polymorphe) se laissent porter par leurs compagnes en se perchant sur la feuille coupéc que celles-ci portent.

12. Atta columbica Gub́rux o. Entre Guaduas el Sensitiva (C. or. Dép. Cundinamarca, alt. goo ì $1000 \mathrm{~m}$.). J'ai déjì olsservé moi-même en Colomhie que cette espèce vit daus les parages inférieurs chauds (tierra caliente), tandis que la précédente se trouve plutòt sur les hauteurs, r 200 à $2000 \mathrm{ml}$.

13. Atta (Acromyrmex) mesonotalis Ex. v. fuhrmanni n. var. $ᄋ$ L. 3,5 à 5 mill. Abdomen entièrement brun, comme le reste du corps. Ce n'est pas l'épine postoculaire qui est bifide, comme chez le type, mais l'épine du vertex, en avant de l'épine occipitale. Correspond dı reste bien à la description d'Emery, mais plus petite.

Prìs de la Laguna au-dessus de Medellin (C. c. Dép. Antioquia, alt. 2300 m.). Les épines occipitales sont courbées et l'extrémité de toutes les longues épines lisse et jannàtre, coụme l'indique Emery, et comme chez l'A. mölleri l'onel. 


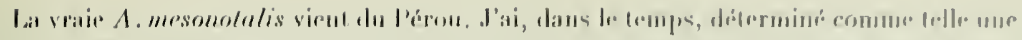

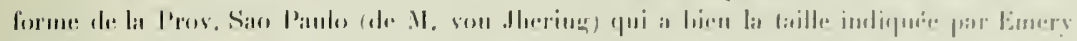

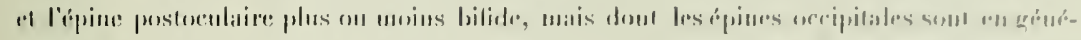

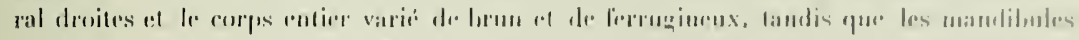

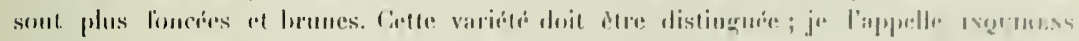
II. var.

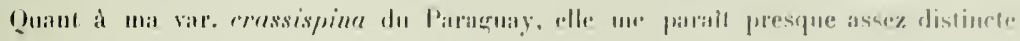
pour constiluer une semsisesprere.

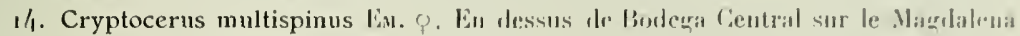
(1)ep. Misditiliti, alt. 7n m.).

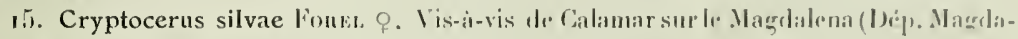

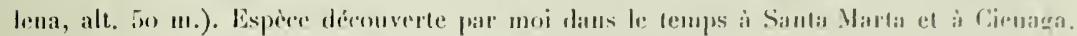

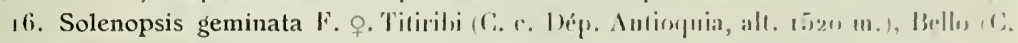

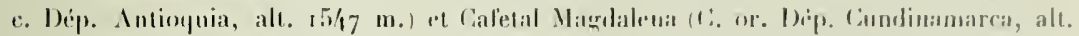

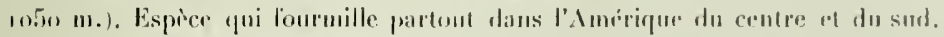

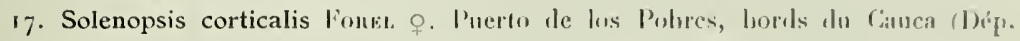
Antioujuia, ilt. car. $720 \mathrm{~m}$. .

18. Cremastogaster brevispinosa Marn o. Medilliu (C. r. I)ip. Intimpuia, alt. 15/7 II.), prestfur aussi commune qu S. geminata F.

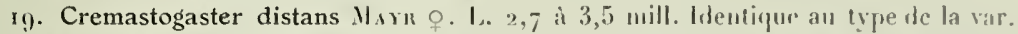

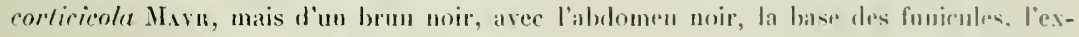

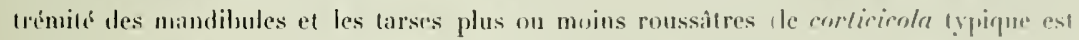

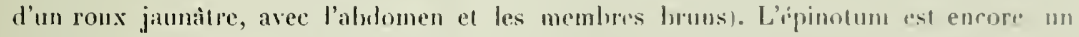
peu plus large que chez le corticirola, un fois el demie plus liarge quir le pronrisonotum. Ce dernier très bossu. Tète aussi lisse que chez le yye te la subsp. el ipines plutit plus longues.

Bello près Medellin (C. c. Dép. Antioquia, alt. 1547 m.).

La subsp. paraensis forel est moins bossue, a le promésonotum aussi large que l'épinolum el l'épine plus courte, mais la mème conleur foncée.

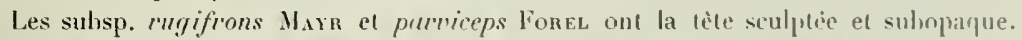

II est difficile d'affirmer que c'est exactement le type colombien de Mayr, car l'autemr me semble avoir confondu au moins deux ou trois varictés dans sa description. II eat inadmissible que toutes les différences qu'il indique se trouvent dans lis mème fourmilìre. Les exemplaires dı Prof. Fuhrmann ont le second noul faiblement et lircement ichancré, l'abdomen assez lisse, l'épinotum aussi, le premier neuil larae et mbcarri (comme chez corticicola), nullement cordiforme, le misonotum avec un sillon longitudinal, la tète lisse.

Pont simplifier la question, le ype de lespece nayan pas éte retrouri depuis r8jo, je propose de considerer comme yppique celle forme qui currespond bien à l'une des varietís mentionnes ex cequo par Mayr dans sa lescription ou il fail me syndhese avee des 
"ou" - et de dommer un nom de variété it la forme ì premier nurud cortiforme (v. Condixodn n. var.) - eventuellement ì d'autres - si elles se retrouvent.

20. Pheidole flavens Rog. subsp. navigans Fon. O. Medellin (C. c. Dép. Intioquia, alt. 1547 m.).

2I. Pheidole guilelmi mülleri fonel, subsp. bucculenta fones, var, socrus $\mathbf{n}$. var. O. L. 2,7 i 3 mill. Toute semblable au type de la sous-espèce, avec l'épinolum mutique et la même tète allongée, mais locciput el le vertex ont les mèmes grosses rides transversales quion voit chez les subsp. avia For. et injuncta Fon., du reste tout à fait dilférentes à d'autres égards.

Cafetal Camelia près Angelopolis (C. e. Dép. Antioquia, alt. i 820 m.).

\section{Subf. Dolichoderinae Forel.}

22. Dolichoderus bispinosus Otuv. Q. Entre Honda et Guaduas (C. or. Dép. Cundinamarca, ali. $950 \mathrm{~m}$.).

23. Dolichoderus schulzi Eм. var. columbica n. var. ․ L. 3,7 à 4,3 mill. La tète cordiforme est beaucoup plus élargie derrière, avec les còtés beaucoup plus convexes que chez Ir type de l'espèce qui est de Para; elle a 1 mill. de long et de large (plus longue que large chez le type de l'espèce qui est bien plus petit et n’a que 3 à 3.3 mill.). Angles antérieurs du pronotum presque droits, pas ou à peine dentiformes, quoique fort acérés (dentiformes chez le type ; dent plate et triangulaire). L'écaille est au contraire plus fortement acuminée que chez le schulzi ypique, avec une pointe plus aiguë, dirigre en haul et en arrière, au sommet. Mésonotum plus long, moins transversal, à peine une fois et demie plus large que long, et plus arrondi derrière (presque deux fois plus large que long chez le type de l'espiece); suture mésoépinolale plus profonde. Pattes. anteunes et mandibules d'un roux un peu jaunàtre (brunàtres clıez le schulzi lypique) ; Epinotum plus élarģi derrière.

Du reste identique au type de lespèce, en particulier la sculpture el la pilosité, ainsi que la forme pour tout le reste.

Medellin (C. c. Dép. Antioquia, alt. 1547 m.).

24. Dorymyrmex pyramicus Rog. I. nigra PellG. o. Bello près Medellin (C. c. Dép. Antioquia, alt. $1547 \mathrm{~m}$.)

25. Irydomyrmex humilis Marn o. Aguacatal (C. c. Dép. Tolima, alt. 1515 m.).

\section{Subf. Camponotinae Forel.}

26. Rhizomyrma fuhrmanni n. sp. o L. I,7 à I,9 mill. Très voisine de l'exsanguis Wheeler, mais les mandibules ont 4 dents, un hord terminal assez distinct, et elles sont plus élargies vers ce dernier. Tête distinctement un peu plus longue que large, un peu plus large devant, rectangulaire. Yeux bien plus distincts que chez l'exsanguis, situés à 


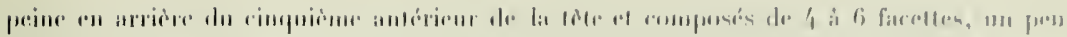

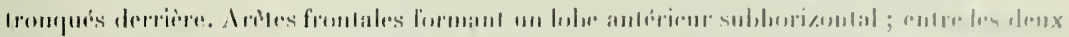

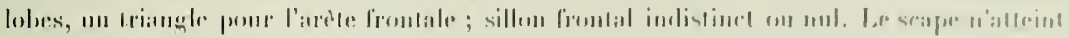

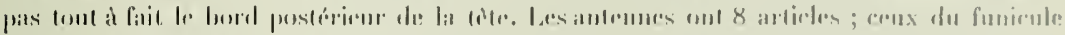

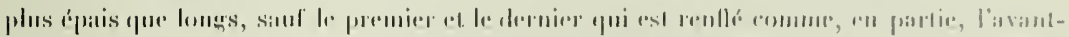

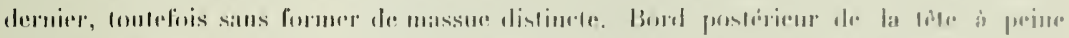

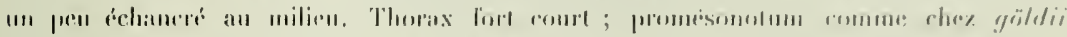

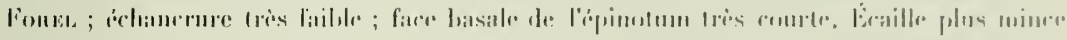

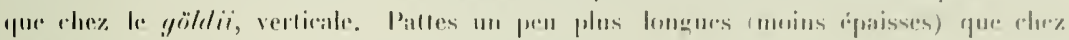
l'exsengmis.

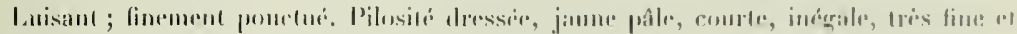

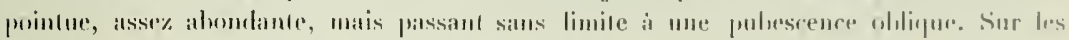
membres, des poils tres courts et plus an moins obligues.

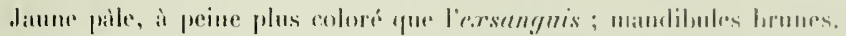

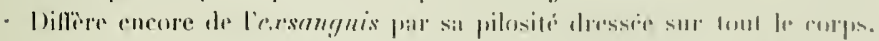

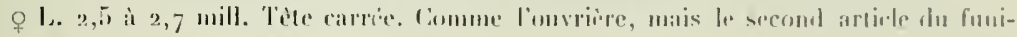

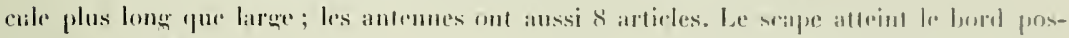
terieur de la tite.

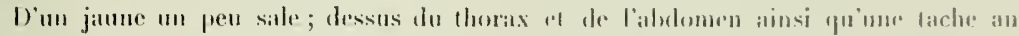
vertex d'un brun un peu jitunatre.

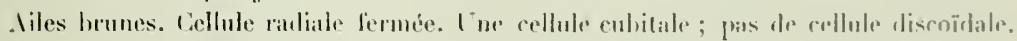

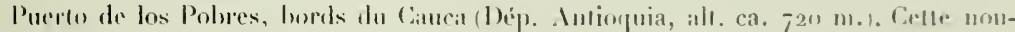
velle esperer vient confirmer la variabilite du nombere des articles des antennes des lihi-

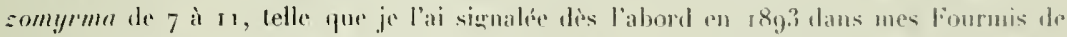

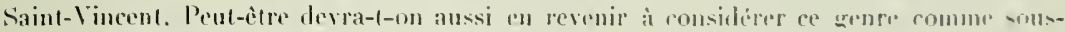
genre d'Acropyga, aninsi que je l'avais fait an lébul.

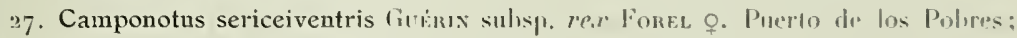
bords du Cauca (Dép. Inlinquia, all. ca. $7201 \mathrm{m.}$.

28. Camponotus bugnioni Forez o. Puerte de los Pobres, lords lu Canra (1)ip.

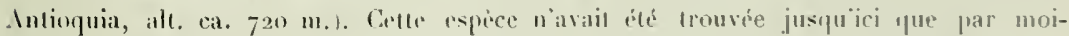
meme, de Sanla Marla à Dilubla, au pied de la Sierra Nevidla de Santa Marta en Colomlice.

29. Camponotus abdominalis F. rar. costaricensis Fonel $\mathrm{O}$. Vin-à-vis de Calimar sur le Magdalena (Dép. Magqdalena, all, 5o m.).

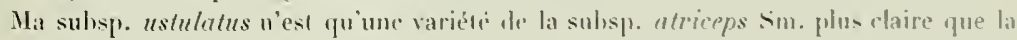
var. costaricensis el avee les mamdibules mates, densément soulptés.

30. Camponotus melanoticus Ex, var. substituta Ex. O. Enlwr Hondla el fillduas (C. c. Dép. Cundinamarea, alt. ca. 9) 50 m.

31. Camponotus maculatus $F$. subsp. indianns Forel Q. Ciafetal liamelia prés Angelopolis (C. c. Dép. Intioquia, alt. 1820 m.). 
32. Camponotus nitens Maxи o. En dessus de Bogota (C. or. Dép. Cumlinamarca, alt. ca. $3000 \mathrm{~m}$. . Espéce typipue pour la région de Bogota, la senle on on l'ait trouvéc jusqu’ici. - Exemplaires foncés et quands, de 5 à 7,5 mill.

33. Camponotus crassus Mayn subsp. Brasturexsis Maxk q. Chaque (C. ol. Dép. Cundimarca, alt. $1833 \mathrm{~m}$.) el Paramo Cruz Véde (C. or. Déje. Cundinamarca, alt. $3.500 \mathrm{~m} .1$. N'avait élé trouvé jusqu’ici que bien plus an sud.

34. Camponotus trapezoideus Mayn o. Medellin (C. e. Mép. Antioguia, alt. 1547 m.). 


\title{
BEITRAG
}

Z1) KENNTIS HR

\section{Skorpione und Pedipalpen Columbiens}

\author{
ViN
}

\author{
KARL KRAEPELIN
}

Von Mlerra Dr O. Fuhrmanu ist mir das von ihu in Columbien gresanmelte. Matlerial von Skorpionen and Pedipalpen zur Bearheitung anvertrant worten; es ist nicht ache reich, qieht aber trotzden ein zirmlich wutes Bilal der in Columbieu virtretenen formen dieser Gruppra. Von Skorpionen waren hisher ans Cohmblen mit Sirherheit elwa

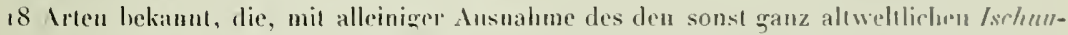
rinen ingehörigen Opisthreauthus elatus, sich ansschliesslich anf dir Fantien dor Centruriden (mit den Galtungen Tityus und Cientruroides) mul der Chactiden amit den Gattungen Chactas und Broteochactust verteilen. Von diesen is Arten ist nur ein I)rittel in der Coll. Fumuans vertreten; dazu kommen daun aber noch eine bisher nicht ans Columbicu hekanute, sowie drei für die Wissenschaft nene Arten. Von Pedipatpen kenut man aus Columbien bisher drei sichere Arten, won denen zwei erheutet wurlen.

\section{A. Scorpiones.}

\section{Gattung Tilyus C. L. Koch.}

Ins der selur artenreichen, aul' Südamerika und Westindicn beschränkten Gattuner Tityus sind bisher in Columbien neun, zum Teil allerdings wohl mur als Varietäten aufzufassende. Irten beobachtet worden. Von diesen gehören acht, nämliclı T. magnimanus, 
T. cambridgei nebst T. chumpioni und festue), T. murrochirus, T. forcipula, T. puchyurus (nehs T. engelkei), der Gruppe der grossen, mejs einfarbig rothramen Formen an, deren o durch blasige Erweiterung der kammgrundlamelle characterisiert sind (cumbridypi-Girupe), während die Gruppe der kleinen, meist schachbrellartig gelleckten Formen ohne solche Kammgrunlblase beim of (columbiamus-Gruppe) allain durch den $T$. columbianus vertreten ist. Dats von llerrn Dr Furnaxy gesammelte Material mmfasst im Ganzen sechs Arten, von denen aber nur vier mit bisher beschriebenen formen idenlisch sind, wälırend zwei sich als nen erwiesen.

\section{Tityus macrochirus Poc.}

1897 Tilyus meacrochirus Pocock in: Ann. Mag. Nat. llist. (6) NIX, p. 512.

Diese Art ist in erster Linie kenntlich durch die dicht mit kürzeren weissen und längeren rotbraunen, aus gröberen P’unktgruben hervorragenden Borsten besetzte Blase, die zudem, im Gegensatz zu allen verwandten formen, bei alten Exemplaren völlig glatı und ohne Andeutung einer Körnelung ist. Bei jungen Individuen ist dagegen eine ziemlich deutliche Reihenkörnehng nachzuweisen. Die Geschlechtsuntersthiede zwisehen ô und o sind gering, indem die Cauda des nach hinten nur wenig verbreitert ist (r. Caudalsegment $4 \mathrm{~mm}$, 5. Caudalsegment $5 \mathrm{~mm}$ breit), die Hand des ot Dirke den Unterarm nur wenig ühertritlı umd der hewegliche Finger nur einen schwachen Lobus am Grunde besitzt. Die Kiele der Hand sind ziemlich olssolet, die Flächen melsr oder weniquer grekörut, die Zahl der Schrägreihen des Fingers beträgt 15. Die Bauchplatten des Truncus sind sämtlich gekürnt, das Mittetfeld des 1. Segments aber ziemlich obsolet gekörnt. Die 3. Bauchplatte trägı in der Mitte des Hinterrandes einen grossen glänzenden Dreieckslleck; ein ähnlicher, aber matterer, ist auch auf der ersten Batuchplatte erkennlar. Dic Zahıl der Kammzälıne beträgt für gewähnlich 15 oder 16 , doch wurden an dem vorliegenden Material auch mehrere Male nur 14, einmal 17 Kammzähne beobachtel.

Fundort: Ubaque (Ostkordillere) in 1850 Meter Höhe. 1 u. 7 .

\section{Tityus pachyurus Poc.}

1897 Tityus pachyurus Pocock in: Amn. Mag. Nat. Hist. (6) XIX, p. 314.

Ein in der Ausbeute befindliches jugendliches Exemplar erhärtet aufs neue die mir lereits rom $T$. cambridgei her bekannte Tatsache, dass die lndividuen vieler TityusIrten im Laufe ihrer Entwicklung einen sehr anfallenden Farbenwechsel durchlaufen. Während die alten Exemplare in Truneus, Cauda, Beinen einfarbig dunkellsaun erscheinen und nur etwas mehr ins Rotbraune fallende Arme und Hände (mit schwarzen Fin„rern) besizen, ist der Truncusrücken der jungen lndividuen hell ledergelb und nur am Hinterrande der Segmente mit schwarzen Vierecksllecken marmoriert; die Cauda ist im 1.-4. Segment gelbrot, unterseits schwarz getleckt, im 5. Segment nebst der Blase dunkel, 


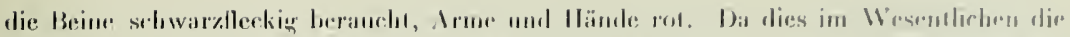

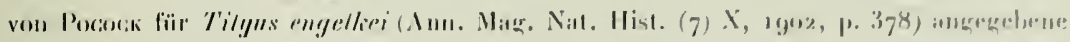

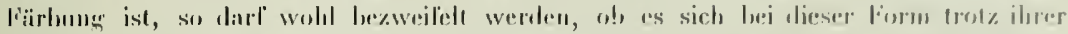

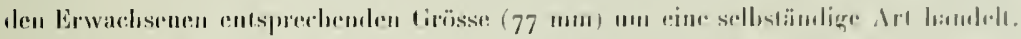

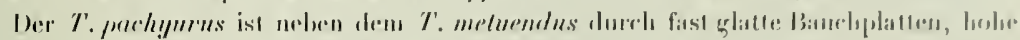

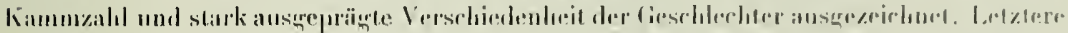

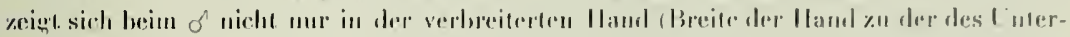

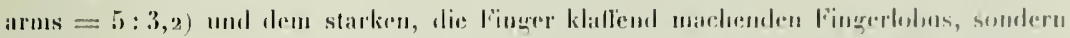

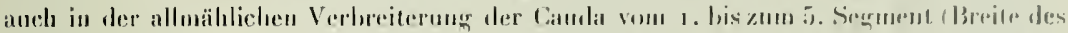

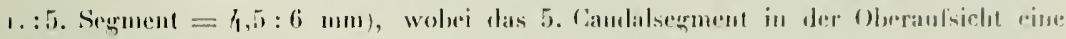

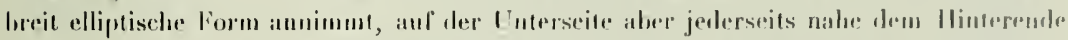

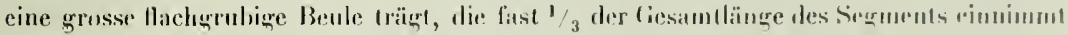

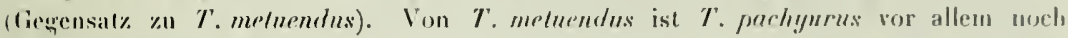

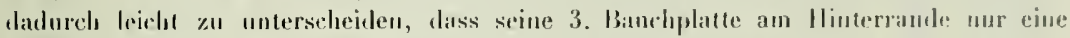

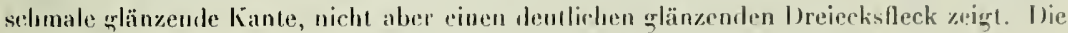
Zahlıl der Kamnzälune wirl von Poкокк aul' ig angegeben. Die mir vorliegenden Lxemplare besizen sämtlich 22-24 kammzähne, dorh glaube ich nicht, dass hierin rin spezifischor Unterschied zu crblicken ist.

Fundort: Zwisehen Ilonda und (iunduas (Ostkordillere) und zwischen 5oo und 8on m llöle. Nur 1 q ad. 11.1 q juv.

\section{Tityus Fuhrmanni n. sp.}

Zur cambridlgei-Gruppe wehörig.

Färbung des Truncus, der Canda und der Beine bei Erwachsenen chunkelrothraun

his dunkelbraun, letzle Caudalsegmente schwarzhraun. Irme und Hände meist ein wenig heller rotbrann, Finger schwar\%. Bauchplatten dunkelrotbraun, die vorderen etwas heller, mit heller Mediannaht. Stamm der Kämme und Grundblase hell lederbraun. Junge Individuen sind auf der Oberseite des Truncus hell lederhraun, mit schmaler dunkler Mittelbinde und je einer breiteren dunklen Seitenbinde. Die Arme und Iānde sind bei ganz jungen Exemplaren marmoriert gelleckt, bei etwas äloren fast einfarhig urelhrot. Dic Cauda ist dorsal cinfarbig gellorot, unterseits hesonders am Vorder- und Hinterrande der Segmente schwarzlleckig, das 5. Sigment fast ganz dunkelbrann, die Blase etwas lieller; Beine schwarzlleckig marmoriert.

Cephalothorax und Rüeken des Abdomens ziemlich grob gekörnt. wie bei den verwandten Arten. Bauchplatten des Ahdomens sämblich dicht und ziemlich grols gekörnt. so namentlich auch das Mittelfeld des 4. Serments his zum Hinterrande a ähnlich $T$. forcipula und liraepelini, Gegensatz zu T. macrochirus), während das 3. Segment einen schublen grlänzenden, in der Mitte zu einem äusserst winzigen Dreieck sich erweiternden Ifinterrand zeigt. 
Cauda robust, heim o von 1.-3. Segment gleich breil $(3,5$ bis 4 mm), im 4. Segment und noch deutlicher im 5. Segment meist etwas an Breite abnehurend (Fig. ra), hein 1 rom 1.-3. Sexment deutlich an Breite zumehmend (von 5 mm zu 6,2 mm), dann deutlich verschmilert, so dass das 5 . Segment nur eine Breite ron 4,2 mm gegen $6,2 \mathrm{~mm}$ des 3. Sequnents besitzl (Fig. 1h). Caudalkiele im 1.-4. Segment körnig entwiekelt, nur die

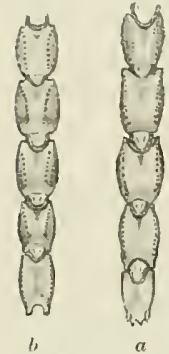

Fig. 1:

Tityus Fuhrmanni n. sp., 1-5. Caudalsegment von oben. $a !+, b) \delta$ oheren Lateralkiele tes 4. Segments beim of fast ohsolet. Die Dorsilkiete in r.-3 Segment ron gewöhnliches, llach convex-bogiger Form, aber mit starken Enddorn, namentlich im 3. segment. Dorsalkiele des 4. Caudalsegments beim o geradlinig (Fig. 2a), beim $\sigma^{1}-\mathrm{im}$ Gegensatz zu allen bekannten Arten - ausgesprochen concau-bogig verlaufend (Fig. 2b), an Ende bei beiden Gieschlechtern mit ausserordentlich starkem Enddorn, dem noch eine grössere, spitz aufragende Dornzacke auf dem hinteren Absturz des Dorsalkiels folgt. Die: Körnelung des Dorsalkiels in dem ConcavBogen des $\sigma^{-1}$ ist flach und ziemlich obsolet. Ebenso treten die unteren Caudalkiele des 5 . Segments bei of und $q$ nur wenig hervor. Die
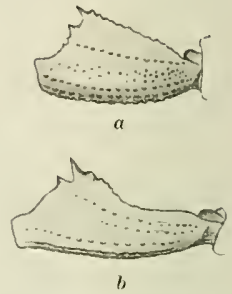

Fig. 2: Tityus Fuhrmanni n. sp. 4. Caudalsegment von der Seite. a) 9, b) $\sigma^{1}$ Caudallächen sind in r.-3. Segment ziemlich dicht feinkörnig, in den lreiden Endsegmenten gröber, aber mehr obsolet ggekörnt. Die Blase ist ziemliclı hreit, ınterseits beim o elwas abgeflacht, nur sparsam mit kurzen, meist weissen Borsten hesetzt und an den Seiten meist mit Andeutung von Körnelung. Der Dorn unter dem Stachel ist stumpf, mit nur schwachen Spuren dorsaler IIöckerchen und der Stachelhasis sehr genähert; seine Unterkante geht schwachbogig in den Mediankiel der Blase über.

Die Hand ist auch beim of nur so hreit wie die Tibia (2,5-3 mm); sic trägt drei durchgehende und einen abgekürzten äusseren perlkörnigen Handkiel. Finger bei $\delta$ und o ohne Lohns, iı ganzer Länge zusammenschliessend, mit 14 bis r 5 Schrägreihen. Das Verhältnis der Hinterhandlänge zur Fingerlänge beim $q=4: 8 \mathrm{~mm}$, beim $\sigma$ 4: $10 \mathrm{rmm}$.

Zahl der Kammzähne meist s6-I7, seltener r5 oder 18 , einmal einerseits nur 13 , einmal einerseits s 9 . Grundlamelle des kammes beim o erweitert, aber nicht blasigr rundlich, sondern oblong, hell lederbraun wie der Kammstamm.

Endtarsen der Beine unterseits nur mit lockerer Reihe kurzer Borsten besetzt, nicht dicht bürstenhaarig wie bei den verwandten Arten.

Körperlänge der ○ $60 \mathrm{~mm}$ (Truncus zur. Cauda $=26: 34 \mathrm{~mm}$ ), des of $70 \mathrm{~mm}$ (Truncus zur Cauda $=24: 46 \mathrm{~mm}$ ).

Fundort: Angelopolis (Centralkordillere), in $1820 \mathrm{~m}$ llöhe. 6 o und r5 9 .

Die vorstehend beschriebene $\Lambda \mathrm{rt}$ ist durch eine ganze Reihe von Merkmaten charak- 


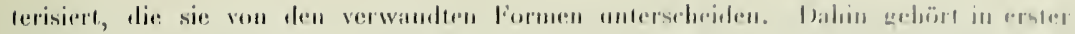

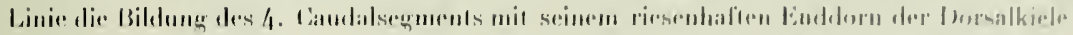

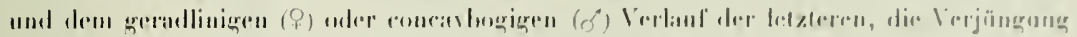

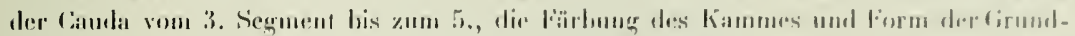

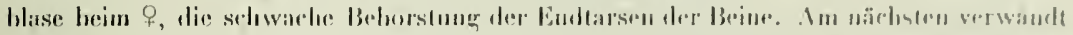

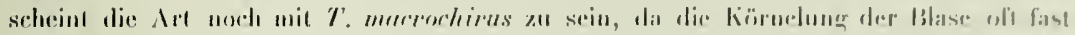

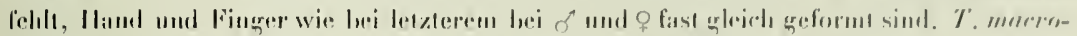

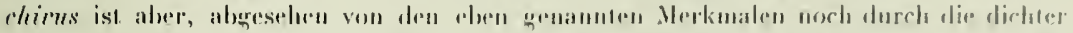

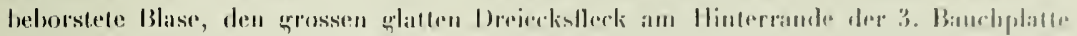

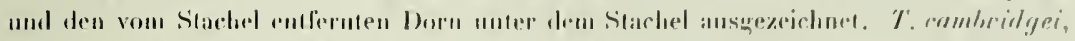

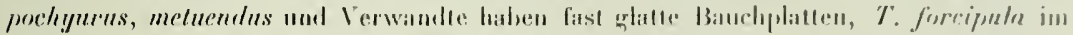

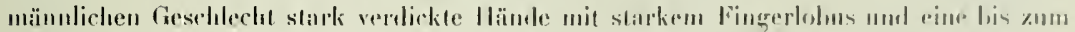

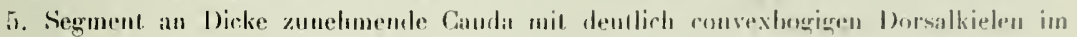

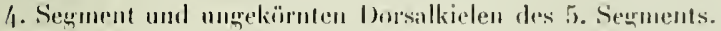

\section{Tityus columbianus (Thor).}

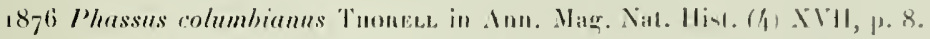

Die vorliegenden zahtreichen Exemplare lassen in der lïirhung des Truncus ziemlich erhebliche Unterschiede erkennen. Manclie erscheinen olserseits fist wan\% schwarz, indem

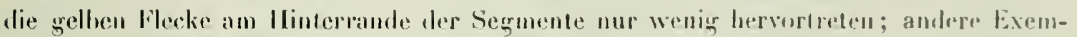

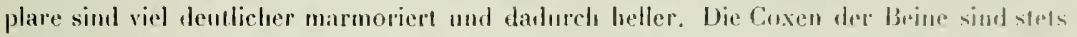

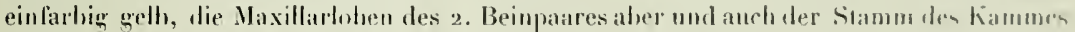
sind nicht selten schwärzlich heraucht. Inf den schwärzlich herawhten, drollich feinkörnigen Bauchplatlen trilt in jedrom Sequment eine schmate, nicht pigmentierte und nichl qekörnto Ilache Depression auf, die die Vorderhälfte jecles Segmens in der Unere durchzieht, dann aber jederseits hogig gegen den Hinterrand des Sesments verlänft. Die 3. Bauchplatle zeigh an Ilinterande einen kleinen, aher deutlichen glänzenden I)rejerkinlleck, die 1. nichı; die 4. hesilzt zwei abgekiurale qukörnte keile. I ntersehiode der Grschlechter sind mil Sicherheil nicht nachamweisen. Die Zahl der Kimmzähne schwinnkte bei allen Exemplaren zwischen r umd 13; dir Zahl der Schrïgreilsen des hewerlichen Fingers heträgt 1.3. Der Mediankiel der Blase ist bis zur Spilze des Stacheldorns zackigkïrnig.

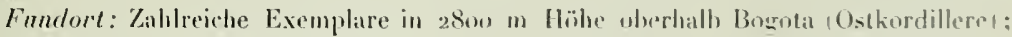
3 Exemplire von Uhaque (Ostkondillere) in $1850 \mathrm{~m}$ Höhe.

\section{Tityus parvulus n. sp.}

Von lewarassu in Nordbrasilien is von Pocon:k rine Tilrusant henchrieben worden. die sich von den vewanden formen ( $T$. colmmbiamns, rhthratus. silvestris, atriventer 


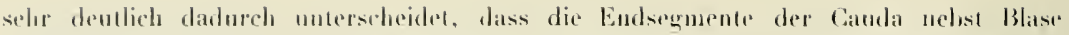
nicht dunkler gefärbt sind als die vorderen Caudalsegmente, sondem rhenfalls rine gelbrote Färbung mit schwarzen Flecken besitzen. Eine nahe verwandte form findet sich nun auch in der vorliegenden Collection. Soweit die Beschreibung Pococks ein Crrteil znlässt, bestcht der wesentlichste Intersthied zwischen den T. pusillus l'oc. und der nenen Art in ler Zahl der liammzälne, die bei ersterem bein 9 16, 17, bein o 17,18 betrïgl, wälırend die beiten mir vorliegenden Exemplare des $T$. parvulus nur r2, 13 Kimmzähne besitzen. In Lebrigen ist die Ueherrinstimmung lueider Formen eine ziemlich grosse, wie mir auch Herr Hunst-London bestätigt, dem ich ein Exemplar des T. paruulus znm Vergleich mil dem Typus des T' pusillus Poc. ïber'sandte.

Die Färbung des Truncus ist oberseits gell, und schwarz marnoriert, ähnlich wie bei T. columbianus und pusillus, doch ist nahe dem Aussenrande des Abdomens jederseits eine dentliche, ununterhrochene schwarze Längsbinde erkemubar, die bei den ebengenannten Arten felılt. Dic Cauda ist in ganzer Länge gelb bis gelbrot, schwarz gelleckt, die Endglieder sind nicht dunkler; Beine und Arme sind marmoriert. Die Hände sind gelb, etwas schwarz gelleckt, die Finger kaum dunkler. Bauchplitten sämtlich schwarz gelleckt. Kämme, Coxen der Beine und Maxillarloben einfarbig gelb, unberancht, nur die Spitze der Maxillarloben des 1. Beinpaares mit schwarzem Fleck.

Truncus oberseits gekörıt. Bauchplatten sämtlich feinkörnig, olıne deutliche Ausprägung der hei T.columbianus beschriebenen glatten Querdepression in der Mitte jedes Segments. 3. Bauchplatte am Hinterrande mit deutlichem glatten Dreieckslleck, chenso die erste Bauchplatte; 4. Bauchplatte mit 2 kurzen Kielen. Nach Hunst's brieflieher Mitteilung fehlt bei $T$. pusillus der glatte Dreieckslleck im 1. Segment, und die Kiele des 4. Segments sind fast ganz rudimentär.

Canda schlank und dünn, nach hinten nicht verbreitert, das 5. Segment über doppelt so lang wie breit $(4: 1,7 \mathrm{~mm})$, selbst in der Mitte kaum hölıer als breit (Gegensatz zu den Formen mit hochgewölbtem 5. Caudalsegment). Caudalkiele sämtlich körnig, die dorsalen auch im 3. und 4. Segment mit kaum merklich stärkesem Enddorn. Candal1lächen fein gekörnt; die Nebencriste im 2. Segınent in ganzer Länge erkennbar; die Seitenllächen des 3. Segments gleichmässig körnig. Blase nur undeullich gekörnt, der untere Mediankiel fast glalt, kaum geschweift in die Unterkante des vom Stachelgrunde entferuten, dicken und wenig zusammengedrückten Dorns übergchend.

Hände nicht verdickt, mit drei durchgehenden, gekörnten Kielen. Fingrer ohne Lobus, mit 14 Schrägreihen. Länge der Hinterhand zu der des Fingers $=2,7: 4,6$.

Zahl der Kammzähne 12, г3.

Körperlänge bis $31 \mathrm{~mm}$ (Truncus: Cauda $=12: 19 \mathrm{~nm})$.

Fundort: Bei Angelopolis (Centralkordillere) in 1820 m Höhe. 2 Exemplare.

Ob der $T$. parvulus nicht doch durch Uebergänge mit T. pusillus zusammenhängt, lässt sich ersl durch ein reicheres Matcrial entscheiden. - Auch T. parä̈nsis besitzt eine 


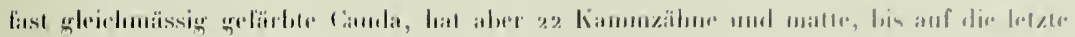
ungekïrnte Banchplallen.

\section{Tityus intermedius Bor.}

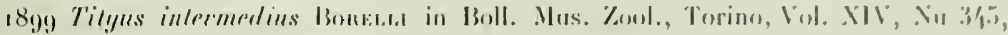
1. 8.

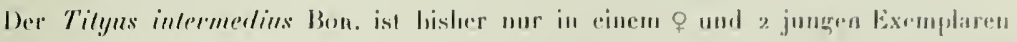

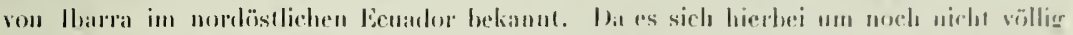

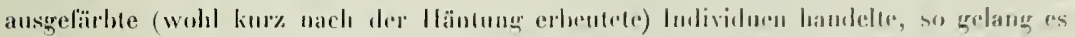

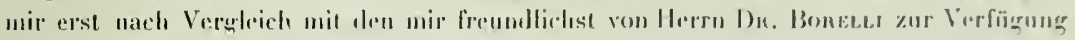

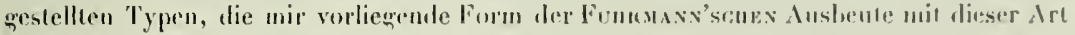
zu identifizieren.

Ahweichend von den formen dere rigentlichen columbianns-fimpun ist der $T$. inter-

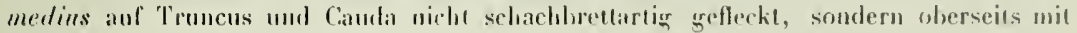

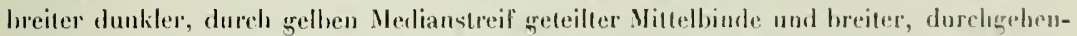
der Seitenbinde jederseits ansgestattet, worlurels er sich dem erst kürzlich (.Mt. Mus. Hann-

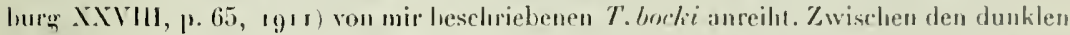
Längshinden ist der Truncus gell). Dic Caudit ist gelb lis gellorot, zeigh alber unterseits romelımlich am Vorder- und Ilintermule jedes Segnients rinen enrösseren, unregelmässig gezackten lileck, dazu meist cinen schwarzen, nelzigen Verlindungsstreifon zwischen den unteren Mediankieten. Sehr anlfillend ist das fast ann\% dunkellorame, nur einire kleime rundliche gelbe Jlecke tragende 5. Caudalsegmont. Anch dic Blase ist dunkelliraun, alser mit hellgellum Stachel. Die Beine sind schwarzleckin marmoriert, ebenso der Oberarm und meist auch der Lnterarm. Die Hände sind gelb, etwas schwarzgeliechi, die finger schwarz. Die Bauchplatten des Ibdomens sind in Wiltelfelde dunkel Inrauch, meist auch die Coxen der Beine, nicht aber die Kämme und die Maxillarloben.

Die Batrehplitten sind in den ersten 3 Semmenten matl, aher ohne erkennhare Förnelung ; der Hinterrand des 3. Segments ist etwas glänzend, aber ohne scharf abgesetzten Dreieckslleck (wie iln Bonelu zu crkennen glanbte). Die Endtarsen der Beine sind unterseits nur mit i Par Borstenhaten zerstreut besetzt.

Im Uelurigen stimmen die vorliegenden Exemplare durchaus mit der Beschreibung Bonet.1s. Die nur y mm breite Hand hat Finger ron doppelter Länge der Hinterhand $(2,2: 1$, I $13 m)$, die Finger mit 14 Scluägreihen, ohne Lobus. Die Zilıl der Kammzähne hetriggt meist 16 oder 17, einmal 15, 15, eimmal 17, 18. Die hasale Mittellamelle des Kammes springl etwas winklign vor. Körperlänge bis $22 \mathrm{~mm}$ (Truncus zur Canda $=10,5: 11,5)$. Es ist wohl die kleinste Tityns-.Irt.

Fundor: La Camelia bei Angelopolis (Centralkordillere) in $1820 \mathrm{~m}$ Höhe. 5 Exemplare.

T. bocki ron Bolivien ist $40 \mathrm{~mm}$ lang. hat qelbe Blase und Finger. deutliche 
Kammgrundlamelle heim o, schlankere Blase und schlankeres 5. Candalsegment (dreimal länger als brei(); die Endtarsen der Beine sind unterseits mit zalbreichen Borstenparen beselzl.

\section{Galtung Centruroides Poc.}

Die im südlichen Nordamerika, in Centralameriki und auf den westindischen Inseln verbreitete Gattung Centruroides greift mur mit wenigen Arten anf das südamerikanische Festlant äber, so namentlich nit der Lutergattung Rhopalurks, von welcher der Rh. laticanda auch aus Columbien bekannt ist. Von echten Centruroides bat sich nur eine centralamerikanische Ant entlang der Andenkette durch Columbien und Ecuador bis nach Chile ausgebreitet, nämlich der

\section{Centruroides margaritatus (Gerv.)}

Von dieser Art enthält die Sammlung Funnaxx nur ein junges Exemplar aus einem Weidenstrunk am Porce bei Medellin (Centralkordillere). Höhe $1547 \mathrm{~m}$.

\section{Gattung Opisthacanthus Ptrs.}

Die fast ausschliesslich afrikanische Gattung Opisthacanthus (Süd- und Centralafirica bis zum dequator) ist bekanntlich in einer Art auch in Amerika vertreten, und diese von den afıikanischen Formen recht gut unterschiedene, wenn auch nicht, wie Pocock will, generisch zu trenuende Art ist sogar der einzige Vertreter der ganzen Subfamilie der Ischnurinae in Amerika.

\section{Opisthacanthus elatus (Gerv.)}

Als Heimat dieses Skorpions hat wohl das centrale Amerika, hesonders dessen südlicher Teil (Panama), wie ein Teil der Intillen (Haïti, St. Thomas, St. Joseph) zu gelten. Gleich dem Centrmroides margaritalus ist er dann von der Panama-Landenge weiter in das Innere Columliens eingedrungen.

Exemplare des Festlandes und von Haïti lassen bei genauerer Betrachtung kleine Luterschiede erkennen, die leidlich konstant zu sein scheinen und es ermöglichen, die Provenienz eines Stückes mit ziemlicher Sicherheit festzustellen. Zu articher Trennung alser halte ich diese in der Bedornung der Tarsen, der Sculptur und Beborstung rles Unterarmes etc. auftretenden Verschiedenheiten nicht für ausreichend.

Die Sammlung fummaxn enthält 3 q von Bodega central an Magdalena in $60 \mathrm{~m}$ Höhe. 


\section{Gattung Chactas Gerv.}

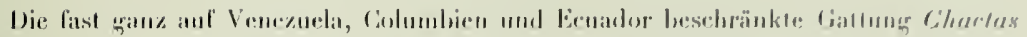

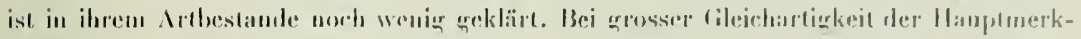

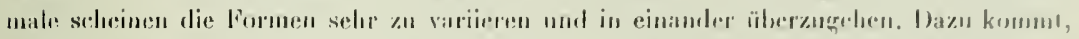
dass of und of oft stark von einander abweichen, und dass lisher kanm iruend romem

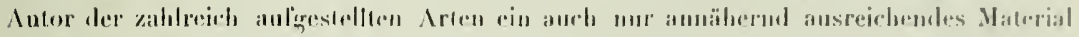

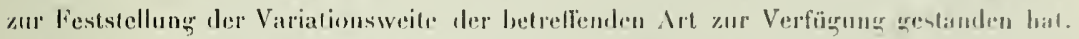
Fist ansschliesslich htundelt es sich um Beschreilunge einzolner ludividuen, die daun - boi

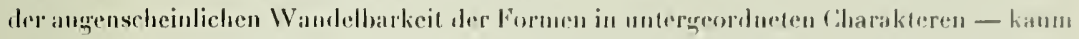
jemals gatuz anf ein anderes, zor Bestimmung forliegrendes ludividum passen will. Nur

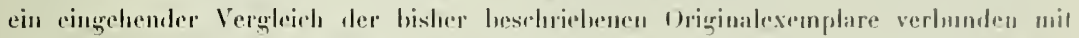

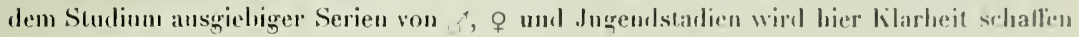
kïnnen.

Die l'unnass'sclue Iusbeute enthält von den 4 oder 5 bishor ans Columbien

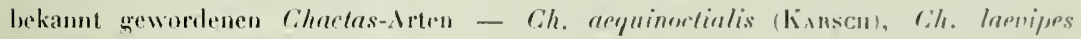

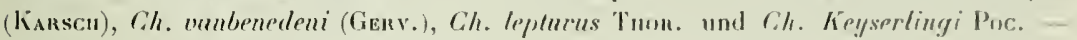
nur eine Art, dancben aber noch eine zweite, bisher nicht heschriebene, heide in einer ausreichendeu Zahl vou Individun, und beide aus jener Gruppe, die durch grlatte. glänzende Oberseite des Truncus (wenigstens beim of), wie durch die fatst völligre lïicllosigkei der grlatten, nlänzenden Unterseite der vier ersten Candalsermente charaktorisiert ist. Ish glaube die beiden Arten als Ch. leplurns Tror. und C.h. reficulntns n. sp. bezeichnen zi sollen.

\section{Chactas lepturus Thor.}

In meiner Bearbeilung der Galtung Chactas im "Tierrich " ISkorpinne, p. 189) hahe ich Ch. lepturus Tnor. als Synonym zu Ch. vanbenedeni (ienv. grestellt. Erst das vollegende reiche Material lässt mich dies als lrrtum erkennen, und die lergleichung mit dem Originalexemplar Tronelss, die mir Ilerr Prof. Susöstedt-Stockholm freundlichst ermöglichte, lehrt, dass die von Ilerrn Dr. Fun waxix gesimmelten Exemplare dieser Species sich anschliessen, wenngleich sie gewisse Abweichungen zeigen, denen aber nur der Wert ron Rassenmerkmalen zuzugestehen sein dïrfe. Weniger Gewicht möchte ich hierbei darauf legen, dass das Originalexemplar TฬовеLls aulfallend hellbraune Beine und Abdominal-Rückenplatten hesilzl, gegenüher der mehr tief pechlıraunen Färbung der Funruax'schen Exemplare, da dieser L'nterschied augenscheinlich auf eine erst kurz vorher überstandene Häutung des Originalexemplars zurückzuführen ist (wie auch einige dunklere Wolken an den hellen Beinen eine Xachfärhung andeuten). Wesenticher erscheint, dass das Tronel'sche Originalexemplar nur 5, 6 Kammzähne trägg gegen $7-9$ 
der Funmaxx schen Exemplare, und dass die Seiten des 5. Caudalsegments bei jenem völligg glatt und ungekörnt, bei diesen aher in allen fï̈llen ziemlich reich mit zerstreuten Körnchen besetzt sind. Diss es sich hei diesen Unterschieden nicht um eine individuelle Aberration oder um Jugendmerkmale des schwerlich ausgewachsenen Originalexemplars hamlelt, konnte ich an einer mir gु̈̈tigst von Herrn E. Sımos-Paris zur Verlügung gestellten Chactiden-Collection feststellen, in der sich auch ein Dutzend Exemplare Ch. lepturns: befanden, die, alıgesehen von der auch bei ihnen pechbramen Färbung der Abdominalrückenplatten und der Beine, völlig dem Thonels'scher Originalexemplar entsprechen. Auch bei ihnen sind die Seitenltäehen des 5. Caudalsegments beim o ungekörnt, und die Zahl der hammzähne beträgt in 9 Fällen 6,6 , in nur 3 Fällen 6, 7 . Die Grösse dieser Tiere dürfte nicht über $47 \mathrm{~mm}$ hinausgehen (Truncus zur Cauda etwa $26: 21$ ). teh bezeichne diese Form als Ch. leptnrus typicus. Ihr gegenüber stehen die Exemplare der Funrmavs'schen Collektion mit mindestens 7, 7 (bis 9, 9) Kammzähnen und deutlich gekörnten Seitenllächen des 5. Caudalsegments auch beim 오. Auch dieses im Ganzen 27 Exemplare umfassende Material lässt noch wieder, entsprechend den zwei weit von einander entfernten Hauptfundpunkten, eine Scheidung in a Formenkreise zu, die ebenfalls namentlich durch verschiedene Zahl der Kammzähne, aber auch in einigen weiteren morphologischen Merkinalen von einander abweichen; sie mögen als Ch. lepturus intermedius n. $r$. und Gh. lepturas major n. v. unterschieden werden. Als eine vierte Varietät des Ch. lepturas betrachte ich, wie der Vollständigkeit halher betnerliı werden mag, den Ch. heyserlingi Poc., über dessen Beziehungen zu den mir vorliegenden lepturus. Formen Herr Hirst-London nach Vergleich mit dem Pocock'schen Originalexemplar mich freundlichst unterrichtete. Die von mir angenommene Gliederung des Formenkreises des Ch. lepturıs Tиов, dürfte am besten aus folgender Tabelle ersichtlich sein :

A) Obere Lateralflächen (zwischen Dorsal- und oberen Lateralkielen) im r.-4. Caudalsegment grobkörnig. Blase unten und an den Seiten grobkörnig. Zahl der Kammzähne 7,7 . Fundort: "Columbien. "

Ch. lepturus keyserlingi Poc.

B) Obere Lateraltlächen im t.-4. Caudalsequent ungekörnt oder nur mit einzelnen wenigen körnchen besetzt. Blase fast glatt oder nur obsolet zerstreut gekörnt. 1. Zahl der Kammzähne meist 6, 6 (bei 13 Exemplare neummal 6, 6, dreimal 6, 7, einmal 5, 6). Scitenllächen des 5. Caudalsegments beim ㅇ ungekörnt; nur der Nelıenkiel in der Grundhälfte als fast glatter Längswulst entwickelt (beim ơ dieser Wulst körnelig und auch die Fläche mit einigen zerstreuten körnchen). Hand des of nicht gestreckt parallelseitig, nur wenig sehmäler als die des 우 und erheblich breiter als der Unterarm. Körperlänge bis $47 \mathrm{~mm}$. Fundort : "Columbien " (Thonell), Neu Granada (Рососк).

Ch. leplurus typicus Tror.

II. Zahl der Kammzähne zum mindestens 7,7 , oft lis 9, 9. Seitenllächen des 5. Caudalsegments beim 우 zers1reut grobkörnig; der Nebenkiel meist nicht 


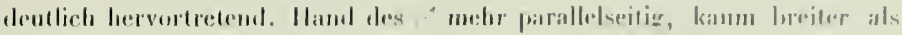
ler Untrorarm.

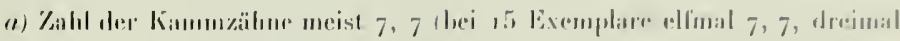

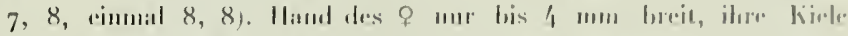

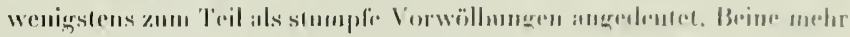

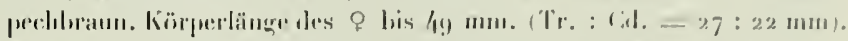

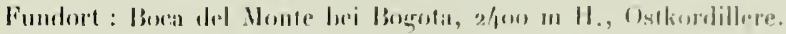

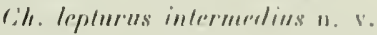

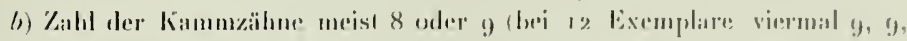

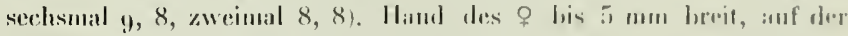

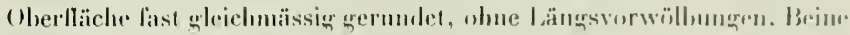

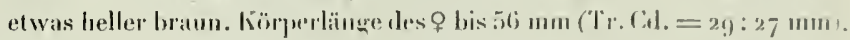
Fundort : Anegelopolis, 1820 m, Centralkordillere. Vin Exemplar anurh von Ciuaduas, Ostkorilillere, gion in II. Ch. Ioplums major n,

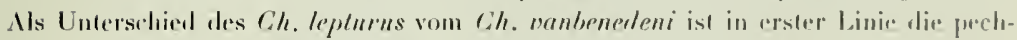

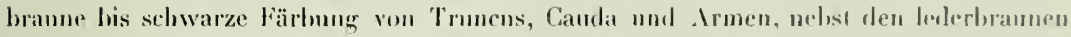
his dunkelpechbraunen Beinen zu nennen, gregen̈̈ber der rothranen Värbung des körpers und den ziemlich hell ledergelben Beinen von Ch. vanbenerleni. Anch sind dic unterin Flïchen des 1-4. Caudalsegments bei letaterer Art durchaus enleichmässigr trerumdet, wiilırend hei Ch. lepturus zum mindesten schon im 3. Caudalsegment das Mlittelfeld der Unterlläche durch eine deutliche Längsdepression am frrunde des Seginents ron den Seitenflächen alggegliedet ist. Die Darlegung weiterer Lnterschiede dieser suthr nahe verwandten Formen und ilıre Abgliederung ron dem durch untere Borstenreihe an den Endtarsen der Beine (am Stelle der Dörnchenreihe) ausqezeichneten Ch. Karschi Poc. hehalte ich mir für eine monographische Bearbeitung der Gattung Chactes vor.

\section{Chactas reticulatus $\mathbf{n}$. sp.}

Diese neue Art gehört, gleich der vorstehenden, zur vanbenedini-Gruppe.

Färbung : Truncus und Cauda dunkel pechbraun. Blase und Beine fast ledergelh.

Weibchen: Stirmand in der Nitte kaum ansgerandet. Stirnlolen etwas frin runzelig, aber nicht nadelstichig; Seitenllächen feinkörnig; Hinterecken mats, fein chagriniert. Rückenplatten des Abdomens glatl und glänzend, letzte in den IInterecken feinkörnig. Bauchplatten gुlatt, gुlänzend, nichıt nadelstichig.

Dorsalkiele im r. Candalsegment nur durch einen Endhöcker antredeutet, im 2. und 3. Segment etwas rugos, im 4. deullicher körnigg. Dorsalflïchen im 1.-4. Segrment äusserst fein matt chagriniert, im 5. Semment älnlich an den Seiten, mit qlattem Mittelstreif. Obere Lateralkiele im r. Segment eine fast glatte, kielige Kante. die des 2.-4. Segments zum Teil etwas feinkörnig rumzelig; obere Laterallächen im r. und 2. Segmenı mit einzelnen zerstreuten Körnchen, im 3. und 4. Segment fast glatt. I'ntere Vediankiele 
im 1. und 3. Sexment lehlent, aher im 3. cund anch wohl sehon im 2.) Segment dureh eine thatre kleine Benle in der Medianlinir am Grunde des Serments angedeuter; im 4. Segment ist diese Beule aestreckter, und die sie begrenzenden Wulste (Mediankiele) zeigen spuren von Kö̈nchnng. Die unteren Lateralkiele sinıl in ähnlicher Weise clurch flache Längstepressionen in 3. und besonders in 4. Segment vom Mlltelledde abgenliedert und erscheinen im 4. Sesment etwas könnig. Untere Lateral- und Merlianllächen im

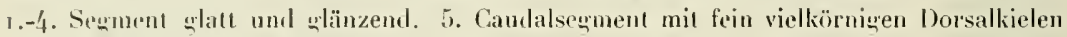
und zackig urobkümpigen Ventralkielen. Die Ventralllächen mit einzelnen groben Körnchen, die Sidinnllächen fast glalt, mit schwach erhabenem, etwas körneligem Nebenkiel. Blase fast głalt, nur nach dem Ende elwas obsolet feinkörniæ.

Oberarm bis auf das äusserste, an den Unterarm stossende qlatte, qlänzende Ende matt, lein grekörnt und dazı chagriniert; unterseits in der Grundhälfte deutlich körnigr, der Rest ehagriniert. Unterarm dorsal am Vorderrande etwas grob gekörnt, die filäche fein netzkörnį; Unterfläche ebenfalls fein netzį qnekörnt. Oberer Grundhöcker der Vorderlläche des Unterarms von mässiger Ausbildung, elwa so gross oder etwas grösser als der an der Lnterkante. Hand ziemlich breit (Verhältuis von Handhreite zur Länge der Hinterhand und zum beweqlichen Finger wie $5: 8: 8 \mathrm{~mm}$ ), dic Ilandkiele alle 3 in der Fläche liegend und nur als äusserst feinkörnige längsstreifen angedeutcl. Das Mittelfeld der Oberhand netziø feinkörnig, qegen den Innenrand gröber netzis-körneliø, aher nicht isoliert-körnig; ähnlich gegen den Aussenrand. Letzterer kielig-kerbig. Die 2 Trichobothrien auf der Fläche der Oberhand in der Körnelung nur wenier hervortretend. Aussenfläche der Unterhand netzig feinkörnig, Innenfläche zerstreut spitzkörnig. Unbewegticher Finger auf der Schneide mit 7 kaum vorspringenden Zälınen besetzl, deren qrundständiger nur wenig grösser ist als die übrigen.

Femur und Tibia der Beine glatt. Endtarsen mit Reilıe kurzer Dörnclien unterseits.

M exnchex. Die Stirnloben sind feinkörnig, die Rü̈kenplatten des Ablomens malt, feinkörnig chagriniert. Cauda wie beim 올 aber die Dorsalfläche viel gröber chagriniert, untere Lateralkiele schon im 2. Segment etwas feinkörnig, Ventralfiäche an Hinterrande des 3. und noch deutlicher im 4. Segment gekörnt. Nebenkiel im 5. Segment mehr hervortretend, fein vielkörnig. Blase deutlich gekörnt. Handbreite etwa halb so gross wic die Länge ter Hinterhand (z. B. 3,6:7,5 mm); letztere etwas länger als der beweghlich Finger (z. B. $7,5: 6 \mathrm{~mm}$ ). Von den drei durch dichte, feine Körnelung gekennzeichneten Handkeilen trill der zweite sehr stark über die Fläche hervor. Das Mittelleld der Fläche schwach netzig gekörnt, gegen den Innenrand kurze Querreihen feiner Körnchen, gegen den Aussenrand mehr längsgerichtete. Sonst wie $q$.

Zahl der Kammzähne 6 oder 7 , und zwar wurden bei 18 Individuen zehnmal 7,7 , zweimal 7,6 , fünfmal 6,6 und einmal 6,5 Kammzähne beobaclıtel.

Fundort: Angelopolis (Centralkorditlere) in $1820 \mathrm{~m}$ Höhe, zusammen mit Ch. lepturus major. Wie bei allen Chactas-Arten, so sind auch bei dieser dic o angenscheinlich sehr viel häufiger als die $\delta$, da neben 16 o nur 2 orbeutet wurden. 


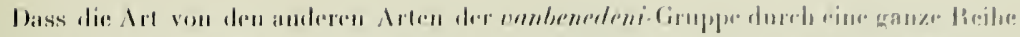

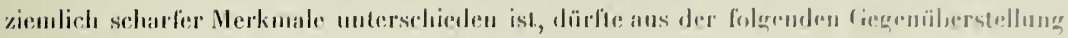
genügend erlerllen.

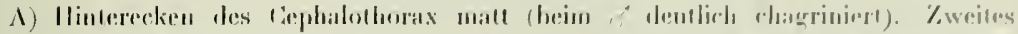

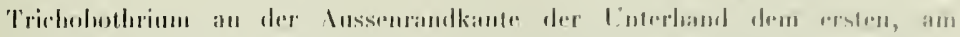

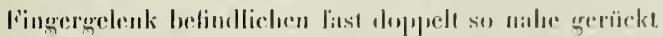

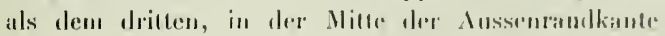

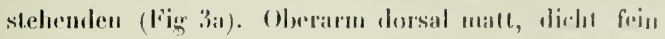

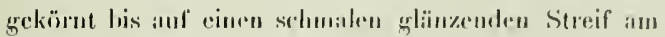
Unterarmgelenk; ilublich ventral. Lulararm dorsal

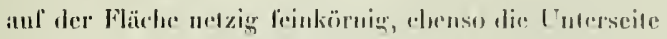

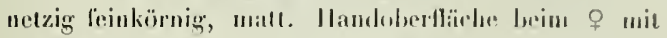
dree dentlichen, in aler lä̈he liegenden, durch feine Körnelung markierten Längsstreilen als Ausdrurk der liele (beim of 3 erhabeme, durch leime lï̈rnelung

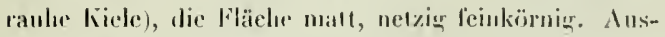

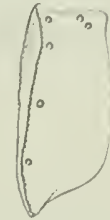

$\alpha$

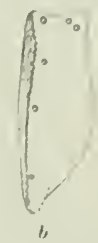

Fig. 3: Aussontlache der I'nlerhand. al von Chaclas reliculaug n. 8fs. b) von Ch. lepturus.

senflärhe der Unterhand netzig l'einkërnig. Dorsalllïlien der Canda in r.-4. Segment matt, beim of sehe fein, hein of deutlicher chagriniert. Brim a anch dic Untrrläelsen in 3. und 4. Candalsegment deutlich clatgriniert, elsenso die Rïekrnplatten.

Ch. reticulntus n. sp.

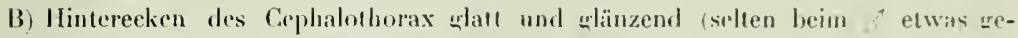
körnt). Zweites Trichobothrium an der Anssenrantkante der Interhand dem ersten, an Fingergelenk hedindliclıen nur wenig näher als dem driften, in der Mitte der Aussenrandkante stehenden ( Vïg 3b). Oherarn dorsal und rentral glïnzend, nur im Mitfelfedd zerstreut gekörnt. Unterarm glänzend, slant orler etwas qrobkïmig, aber nichl nelzig, rentral glall oder zerslreut feinkörnier. Handoberfläche beim of fast ungekielt, die Kiele hö̈lssteus durch schwache Linnasvorwölbungen angedeutet, beim mit glatten linntenkielen, die libche qlatt uder etwas runzelig körnig, nicht netzig. Aussentläche der Lutcrhand statt oder zorstrent isoliert leinkïrnig, nidı netzkürniщ. Dorsalllächen der Cauda im 1.-1. Sermenl glatt, glünzend, höchstens an den Sciten mit rinizen groben Buckelkörnchen. Beim g die Unterlläclen der Cauda im 1.-4. Serment wall und ulänzend, selıen in der Endlälfte de's 4. Segments atwas körnig. 1.-4 Rückenplatle des. Aludomens beim $\sigma^{+}$glall und whänzend.

Ch. unbenedeni und Veru'andte. 


\section{B. Pedipalpi.}

Aus der Ordnmm der Pedipalpen ist nur die Gruppe der Pliryniden in Columbien vertreten und auch diese nur in. wenigen Arten aus den Galtungen Tarantula und Admetus. Die Ausbente enthält nur zwei Arten.

\section{Tarantula palmata barbadensis Poc.}

Diese ron Poсоск als selbständige Art betrachtete und ziemlich gut charakterisierte Form ist, yleich der llauptform, üher Ecuador, Columbien, Venezuela und die kleinen Antillen weit verloreitet. Die Collection Funruax enthïlt 4 Exemplare von Bodega central am Magdalena und ein Exemplar von Calamar am Magdalena.

\section{Admetus pumilio C. L. Koch.}

Dass der Name Admetns C. L. Kocı für diese Gattung zu Recht besteht und nicht der von Pocock neu geschaffene Helerophrynus, habe ich im Zoolou. Anzeiger, Bd. 28, p. 203, rgo4 dargelegt. Ton der Richtigkeit der Ansicht Pococks, der an Stelle dieser Art ein volles halbes Dutzend Irten beschreibt, halse ich mich bisher nich überzeugen kömnen. Es ist ja nicht ausqeschlossen, dass der Formenkreis die Gliederung in eine Reihe von Arten oder doch Unterarten erheischt; zur Zeit ałer ist das Material in den Museen viel zu dürftig, ım über die Constanz der von Pocock nach einem oder wenigen Exemplaren konstruierten Unterschiede ein Urteil zu ermöglichen.

Die Sammlung Furrmans enthält 2 Exemplare der Art von Angełopolis (Centralkordillere) aus $\mathrm{s} 820$ in Höhe; sie unterscheiden sich von dem von Pocock allein lür Columbien angegebenen $A$. cervinus (Poc.) sowohl durch die Färbung (lehımfarben unit gelbroten Maxillarpalpen) wie durch die ungekörnte, glatte Oberhand, wohingegen die Bedorung von Femur und Tibia des Maxillarpalpus mit jenem übereinstimmı. 


\title{
Terrestrial Tsopods of Colombia
}

\author{
II Y
}

\author{
HARRIET RICHARDSON
}

The following report is of the Isopods collected in Colombia by I)r (oto Finhruamu during his recent scieutific expedition to that country.

\section{Family Oniscidæ}

\section{Porcellio scaber (Latr.)}

Porcellio scaber Latreileg, Hist. Crust. Ins., VIl, 1804, p. 45. - Leach, Edlinl. Encycl., VIl, 1814, p. 406.

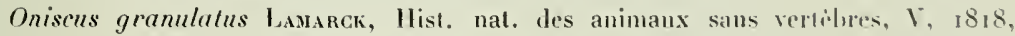
p. 154 .

Porcellio nigrn SA, Journ. Phil. Acad. Nat. Sc., J, 1818, P. 432.

Poreellio scaber Desmarest, Consid. Crust., $18_{25}$, p. 321 . - Brandt and Ratzehure. Med. Zool., II, 1830-1834, p. 77, Jl. XII, figs. I-4 and A-B. - Brandt, Bull. Soc. Imp. de Naturalistes de Moscou, VI, 1833, P. 14.

Porcellio brundlii Mune Enwaros. Hist. Nat. Crust., III, 184n, p. 1 tis.

Porcellio granululus Mune Edwards, IIist. Nat. Crust., HI, I840, p. $169, \mathrm{pl}$. xxxil, fig. 21 .

Porcellio scaber Mrune Eowand, Curier, Reg. An., r849, pl. Lxxi-Lxxi his. Koch, Deutschlands Crust., 1835-1844, p. 34.

Porcellio dubius Kocn. Dentschlands Crust., 1835-1844, P. 34.

Porcellio gemmulatus Daxa. Cinst., U. S. Expl. Exp., NIV. 1853, p. 725, pl. NI,VII. 
Porcpllio seaber Bate and Westwond, Brit. Sess-eved Crust., II, 1868 , p. 47\%. Budde-Lund, Crust. Isop. Terrestria, 1885, P1'. I20-131. - Sars, Crust. Norway, II, 1899 , pp. ז76-177, pl. Lxxris. - Clibton. Trans. Linn. Soc. London (2), V111, 1901, Pt. 4. P. I 39 .

Localities. Euvirons de Bogota (2600 m.); dans une Quebrada au-dessus de Bogota (C. or. $27.50 \mathrm{~m}$.) ; près de la clute du Tequendama (C. or. $2210 \mathrm{~m}$.); Zipaquira (C. or. $2600 \mathrm{m.}$ ) ; entre Boca del Ionte et Tambo (C. or. 1800 m.).

Porcellio scaber var. marmoratis Brandt and Ratzeburg and Porcellio scaber var. marginatus Brandt and Ratzeburg were also collected from the above localities.

\section{Procellionides pruinosus (Brandt).}

Porcellio pruinosus Brandt, Bull. Soc. Imp. Naturalistes de Moscou, VI, i 833 , P. 19 .

Porcellio truncalus Milne Ebward, Hist. Nat. Crust., Ill, i 840, p. I 7 I.

Porcellio maculicornis Kocı, Deutschl. Crust., 1835-144, p. 34.

Metoponorthus pruinosus Budde-Lund, Crust. Isop. Terrestria, I885, pp. I6y-171; Entom. Ieddelel., IV, $1893-94$, p. I 8 . - Sars, Crust. Norway, 11, 1899 , pp. 184-185, pl. LXXX, fig. 2. - Chilton, Trans. Limn. Soc. Lond. (2), V1II, 190I, 1. 141.

Procellionides pruinosus Stebbing, Records of the Indian Nluseum, VI, Pt. 4, I9I I, p. 189 .

Localities. - Sur le Porce (rivière) dans un tronc de sanle avec des fourmis près Medellin (C. c. 1547 m.); Cafetal Camelia près Angelopolis (C. c. $1820 \mathrm{~m}$. ); près du Ruiz (C. c. $3700 \mathrm{~m}$.).

\section{Philoscia variegata Dollfus.}

Philoscia variegata Dolbfus, Anm. Soc. Entomologique de France, 18g3, LXII, p. 343, pl. X, fig. io.

Localities. - Bellio près Medellin vallée du Porce (C. c. 1547 m.); plantation de café Camelia près d'Angelopolis (C. c. 1820 m.); Alto San Miguel (C. c. $2200 \mathrm{~m}$.); près du Ruiz (C. c. $3700 \mathrm{~m}$.) ; entre Guaduas et Sensitiva (C. or. $1600 \mathrm{~m}$.); entre Honda el (iuaduas (C. or. $1200 \mathrm{~m}$.) ; environs de Bogota (C. or. $2700 \mathrm{~m}$.); près de la chute du Tequendama (C. or. $2210 \mathrm{~m}$.); Zipaquira (2600 m.); entre Boca del Monte et Tambo (C. or. 1800 m.); Paramo Cruz Verde (C. or. $3600 \mathrm{~m}$. .).

In the male the first three pairs of legs have the propodus dilated as shown in the figure by Dollfus. In the female the propodus of the first three pairs of llegs is not dilated and the first article of the flagellum of the second antemne is not as long as in the male. 


\section{Alloniscus papillosus Budde-Lund.}

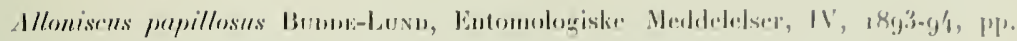
$123-12 / 4$.

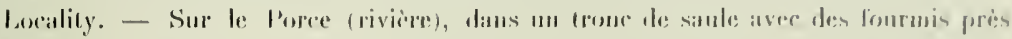
Merlellin (1: e. $15 / 17$ m.).

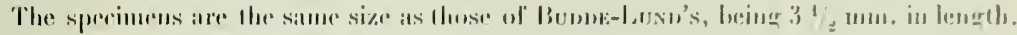

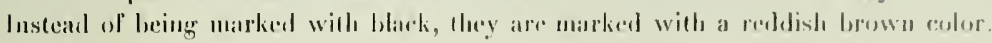

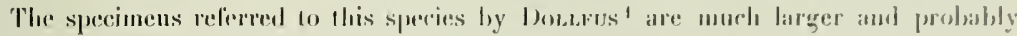
represent a difterent speries. Almot twenty specimens were collected.

\section{Family Armadillididæ}

\section{Cubaris grenadensis (Budde-Lund).}

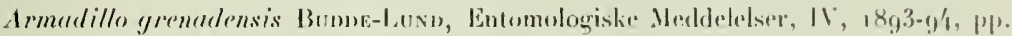

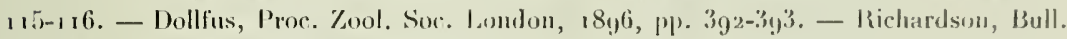
U. S. Nat. Museum, No. 54,1905, p. 651 .

Locality. - Calamar sur le Magdelena.

\section{Sphæroniscus flavomaculatus Gerstäcker.}

Spharoniscus flawomacululus tienstacker, Entomolog. Zeit., 1854, Pl. 31.-315,

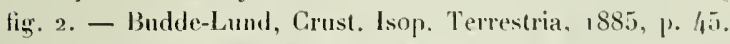

Locality. - Entre Boca del Monte et Tambo (C. or. 1800 m.).

\section{Sphæroniscus granulatus Dollfus.}

Spharoniscus gramnlutus Doblfus, Ann. Sioc. Entomologique de France, LxIl. 18 i) 3 , p. 341 .

Locality. - Sur le Cauca, Puerto de los Pobres (C. c. Soo m.).

Two specinens measuring $5 \mathrm{~mm}$. in length. The imner branch of the uropodit does not quite reach the tip of the outer branch.

\section{Sphæroniscus frontalis $\mathbf{s p . ~ n o v . ~}$}

This species is very elose to Sphoroniscus flavomacnlalus. Lierst.ecker, but differs in not baving the epistome produced a wreat distince beyond the frontal margin of the

1 Anu, Soc, Eutomologique de France, 62, $18,3$. p. 342, pl. 10, tig. y. 
head; in having the first segment of the thorax with the lateral margin not rolled back so much and not so wide as in $S$. flavomaculatus and in not having the lateral margins of the segments fighter in color.

Six specimens were collecled al the plantalion of eafé, Argelia (1800 m.) near Viota (C. or.) a uniform orange brown colur, with light wavy lines of yellow on either side of the median line.

(The speeimen from the plantalion of the café Buenavista (1020 m.) near Viota (C. or.), is dark gray, with way lines of yellow on either side of the median line.

\section{LIST OF REFERENCES}

Budne-Lund, G. Crustacea lsopoda Terrestria, 1885, IJaunia.

Landisopoder Ira Venezuela, indsamlede af' Dr. Fr. Meinert. Entomologiske Meddelelser, IV, $1893-94, \mathrm{Pp}, 111-129$. Kjobenhavn.

Dollfus, Adnien. Sur quelques Isopodes du Musie de Leyde. Notes from the Leyden Museum, XI, r88y, pp. 9r-94, pl. v. fig. 2, Leyden.

- Voyage de II. E. Simon au Veneznela (Décembre 1887 -Avril 1888). Isopodes teriestres. Ann. Soc. Entomologique de France, LXII. $189^{3}$, pp. 339-345. pls, y-10, Paris.

40o, London.

On West Indian Ierrestriat Isopod Crustaceans. Proc. Zool. Soe. London, 1896, pp. 338-

Gerst.ecker, A. Ueber eine neue Myriapoden-und Isopoden-Gattung. Entomolog. Zeitung, XV, 1854, pp. 314$3 \mathrm{t} 5$, fig. 2, Stettin.

Sirs, G.-O. An aceount of the Crnstacea of Norway, II, 1899 , pp. $169^{-1} 9^{2}$, pls. LXXY-LXXXIII, Bergen. 


\section{CONTRIBUTION}

\section{à l'étude des Ptéridophyles de Colombie}

PAII

\section{Dr E. ROSENSTOCK, de GOTHA}

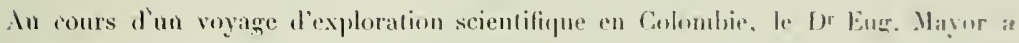

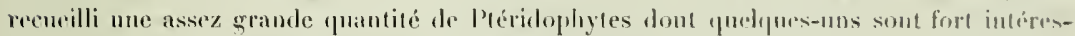

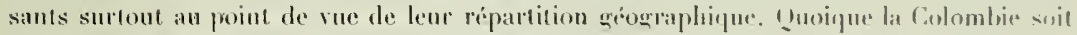

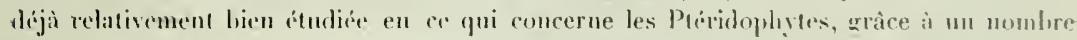
assez considérable de trivanx parus sur ce sujet, il s'est cependant trouse dans celte cul-

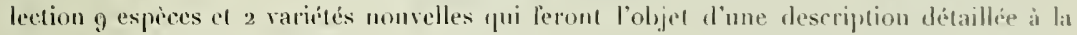
suite du calalogne ci-dessoms.

\section{Gleicheniaceae}

\section{Genre Gleichenia. Sm.}

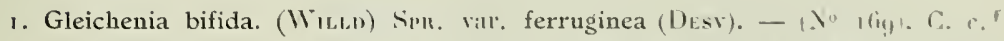
Ripandu dans les cultures, it la lisiore des taillis el des forès anx emvirons du cafetal La

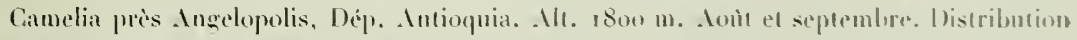
géngraphique: Amerique tropicale.

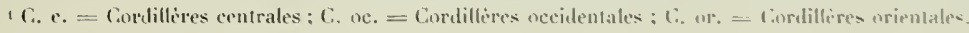
5 


\section{Cyatheaceae}

\section{Genre Hemitelia R. Br.}

2. Hemitelia horrida. (L.) R. BR. - (No 6o). C. oc. Environs du village de Vajparaiso. Dép. Caucat. Alt. environ rquo m. 28 septembre. - C. or. Environs des cafetales Magdalena et Bnenavista près de Viota. Dép. Cundinamarca. Nlt, environ $1100 \mathrm{~m} .25$ et 26 octobre. Distribntion géographique : Indes occidentales, Guatemala, Équateur.

3. Hemitelia Lindigii. Bak. - $\left(\mathrm{N}^{0} 102\right)$. C. c. Chemin de Inonda ì Fresno, sur les dernieres collines dominant le village de Mariquita. Dép. Tolima. Alt. environ goo m. 7 octohre. Distribution géographique : Colombie.

\section{Genre Alsophila. R. Br.}

4. Alsophila armata. (Sw.) Pr. - ( $\left.N^{\circ} 125\right)$. C. c. Taillis, cafetal I a Moka, près Angelopolis. Dép. Antioquia. Alt. $1800 \mathrm{m.} 2$ septembre. - (No 87). C. c. Forìts de l'Nto Romeral entre Angelopolis et Estrella dans la vallée du Porce. Dép. Antioquia. Al. environ $2700 \mathrm{~m} .20$ septembre. $-\left(N^{0 s} 7^{5}\right.$ et $\left.9^{6}\right)$ C. c. Forêts entre le village de Soledad et Ie versant oriental des Paramos du Ruiz. Dép. Tolima. Alt. environ $2400 \mathrm{~m}$. 6 octobre. - ( No 52). C. or. Forèts au bord du lac Pedropalo. Dép. Cundinamarca. Alt. environ $2000 \mathrm{~m} .18$ octobre. Distribution géographique : Amérique tropicale.

5. Alsophila coriacea. Nov. spec. - (No 86). C. oc. Forcts entre Valparaiso et Supia. Dép. Canca. Alt. environ 1500 m. 29 septembre.

6. Alsophila quadripinnata. Gimel. - $\left(\mathrm{N}^{0} 9^{2}\right)$. C. c. Forêts de l'Alto Romeral entre Angelopolis et Estrella dans la vallée du Porce. Dép. Antioquia. Alt. environ $2700 \mathrm{~m}$. 20 septembre. - (No 80$)$. C. c. Forèts de l'Alto San Miguel, haut de la vallíe du Porce. Dép. Antioquia. Alt. environ 2300 m. 26 septembre. Distribution géographique : Amérique tropicale et sul,tropicale.

\section{Genre Cyalhea Sm.}

7. Cyathea Mettenii. Larst, var. caucana. Hieron. - (No 94$)$. C. c. Forèts, versants occidental et oriental du Ruiz. Dép. Antioquia et Tolima. Nlt. remonte jusqu’à $3350 \mathrm{~m}$. 5 octobre. Distribution gréographique : Colomlie.

8. Cyathea spec. (sterilis). - ( $\left(N^{\circ} \mathrm{I} 0\right)$. C. or. Forêts de l'Alto San Carlos, près du liogueron de Guachuni. Dép. Cundinamarca. Alt. 2650 m. 23 octobre. 


\section{Genre Balantium Kaulf.}

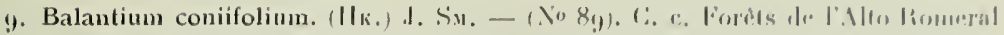

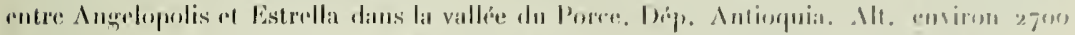

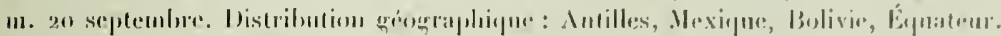

\section{Hymenophyllaceae}

\section{Genre Hymenophyllum. Sm.}

16. Hymenophyllum elegantulum. v. n. B. - (N"79). C. c. Forits, versilut orientil du

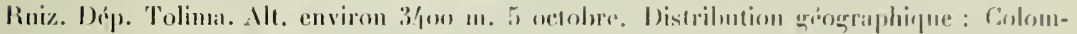
lie, lifualenr.

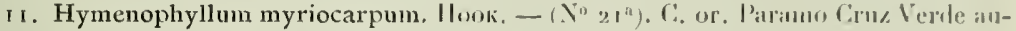

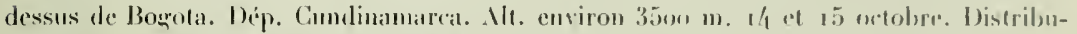
(ion mógraphique : Andes amrírienines.

12. Hymenophyllum polyanthos. Sw. - (No $\left.21^{h}\right)$. C. or. Paramn Cruz Verdis an-

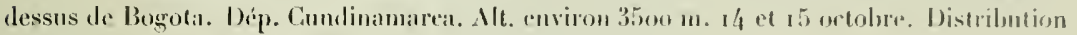
géographingue : Régions tropieales.

\section{Polypodiaceae}

\section{Genre Dennstædtia Bernh.}

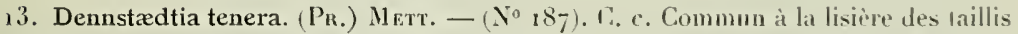
et des forèts et daus les terrains non rultivés dims le voisinatre des cafetales Yoka el Camelia, près Angelopolis. Dép. Antioquia. Alt. 1500-20no m. Aott ct septembre. Distribution géographicque: Amérique tropicale.

14. Dennstædtia rubiginosa. (Kavlf.) Moore. (No 85). C. oc. Environs le la paraiso, sur le chemin de Supia. Dép. Cauca. Alt. environ r foo m. 29) septembre. Distribution géographique : Amérique tropicale.

\section{Genre Lindsaya Dry.}

15. Lindsaya stricta. Dns. - (No 104). C. or. Chemin de Honda à Bogota, près du village de Guaduas. Dip. Cundinamarea. Alt. environ 1000 m. 9 octolire. Distribution gréographique : Amérique tropicale. 


\section{Genre Adiantum. $L$.}

16. Adiantum grossum. Metт. - (No 93). C. or. Chemin de Ilonda à Boguba, près de

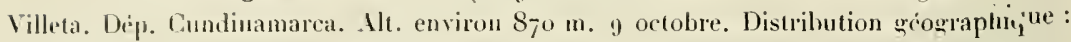
Colombie.

17. Adiantum latifolium. Las. (A. Kaulfussii. Kze.). - ( $\left.\mathrm{N}^{\circ} \mathrm{1} 24\right)$. Bord du Cauca au Pasu de Concordia pris de Puerto de los Pobres. Cauca el Autioquia. Alt. $720 \mathrm{~m}$. fi septembre. Distribution géographique : Imérique tropicale.

18. Adiantum tetraphyllum. WiLfo. - $\left(\mathrm{N}^{\circ}, 52\right)$. C. c. Forèts près de El Poblado sur Medellin. Dép. Antioquia. Alt. environ roo m. 14 aoult. Distribution géographique : Anérique tropicale.

19. Adiantum tetraphyllum. WiLld. var. obtusa. Kunx. - (N0 123$)$. Forêts le long du Canca an Paso de Concordia, près de Puerto de los Pobres. Dép. Cauca el Antioquia. Alt. 720 n. 6 septembre. Distribution géographique: Amérique tropicale.

20. Adiantum tinctum. Moore. - ( $\mathrm{N}^{\prime}$ I 49). C. c. Forèts près de El Poblado sur Medellin. Dép. Antioquia. Alt. esviron r $700 \mathrm{~m}$. 14 aoùt. - (No 340$)$. C. c. Endroits humides et ombragés près de Guaca. Dép. Antioquia. Alı. environ 1400 m. 12 septembre. $-\left(N^{0} 22\right)$. C. or. Au-dessus de Lbaque, le long du chemin de Bogota. Dép. Cundinamarca. Alt. environ $2000 \mathrm{mt} .15$ octobre. Distribution géographique: Costa-Rica, Bolivie.

\section{Genre Cheilanthes. Sto.}

2i. Cheilanthes myriophylla. Desv. - $\left(N^{\circ} 47\right)$. C. or. Bois entre Boca del Monte près de Marlid dans la Savane de Bogota et l'auberge de Tambo près du village de Tena. Dép. Cundinamarca. Alt. environ $2200 \mathrm{~m}$. 18 et 19 octobre. - (No 5 $\mathrm{J}$ ). C. or. Nurs entre Boca del Monte et Madrid dans la Savane de Bogota. Dép. Cundinamarca. Nlt. 250o$2600 \mathrm{~m} .19$ octobre. Distribution géographique: Mexique. Chili.

22. Cheilanthes elegans. Desv. - $\left(\mathrm{N}^{0} 176\right)$. C. C. Haies et murs aux environs de la

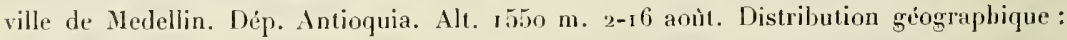
Mexique, Chili.

23. Cheilanthes lendigera. (Cav.) Sw. - ( No 33). C. or. Au-dessus de Cbaque, le long du chemin de Bogota. Dép. Cundinamarca. Nlt. environ $2300 \mathrm{~m}$. 15 aoùt. Distrihution géographique: Mexique, Chili.

24. Cheilanthes marginata. H. B. K. - ( Nos 24 et 61). C. or. Au-dessus de Ulbaque, le long du chemin de Bugota. Dép. Cundinamarca. Nlt. environ $2300 \mathrm{~m}$. i 5 octobre. Distribution géographliqque: Amérique centrale et australe (Audes). 


\section{$-.37-$ \\ Genre Hypolepis. Bernh.}

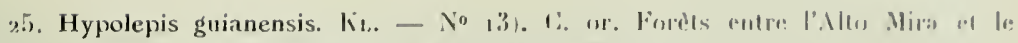

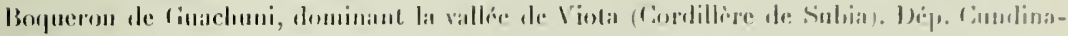

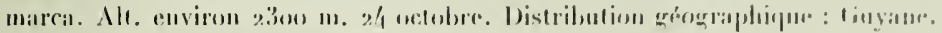

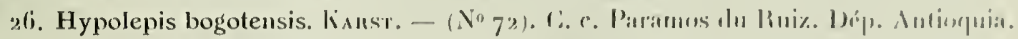

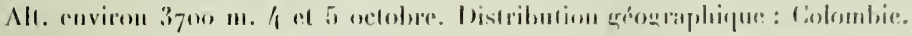

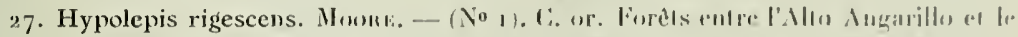

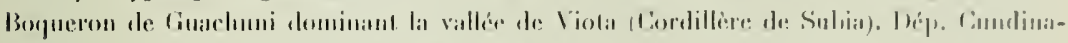

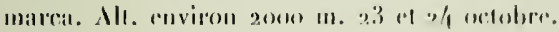

\section{Genre Doryopleris. Sm.}

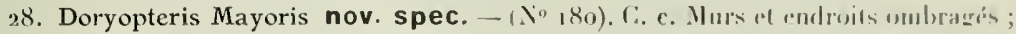

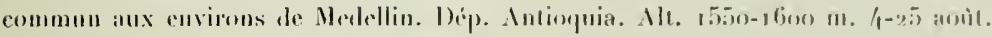

29. Doryopteris patula. Fíe. - (No $9^{8}$. C. c. Buissons près da Maripuita. I híp.

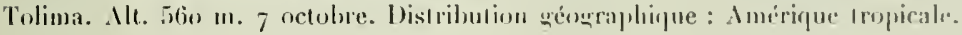

\section{Genre Pellax. Lk.}

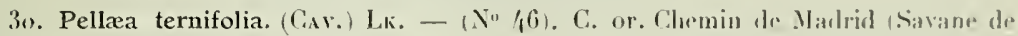
Bongola) à Tena, près de l'auberqe de Tambo. Dép. Cundinamarca. .lı. environ $220 \mathrm{~m}$. 18 achobre. Distribution grographique: Mexiq̨ue, Chili.

\section{Genre Pteris. L.}

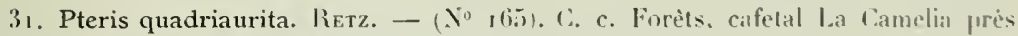

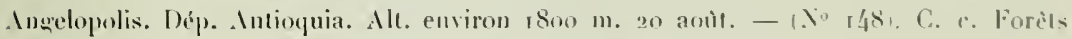

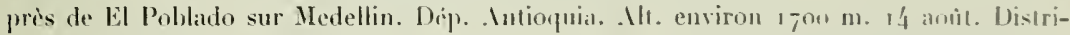
bution géographique : espèce pantropicale.

32. Pteris pungens. Willd, var. Shimekii, nov, var. $-\left(N^{\circ} 101\right.$. C. c. Chrmin de Fresno, près de Mariquita. Dép. Tolima. Mlı. environ $600 \mathrm{~m}$. T octohre.

33. Pteris muricata. Hook. - $\left(N^{0} 6\right)$. C. or. Pente du Monserrate atl-desins de

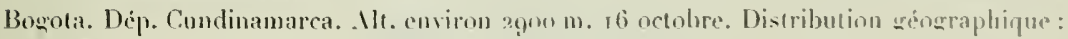
Custa-Rica, Bolivie.

34. Pteris grandifolia. L. - ( No $1-7)$. C. c. Cafual La Moka près Incelopolis. Dép.

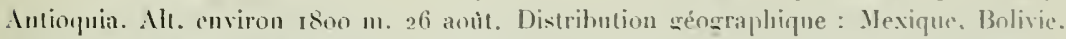

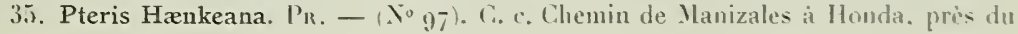


village de Soledat. Dip. Tolima. Mlt. environ $2400 \mathrm{~m}$. 6 octobre. Distribution géngratphique: Guatemalil, Bolivir.

36. Pteris. Spec, now., prope. P. sericeam. Fí. (?), sed fronde subtus papillosohirta. Sprecinen ad deseriptionem insufficiens. - ( $\mathrm{N}^{\circ} 8$ ). C. or. Forèt entre l'Mlto Mira et le Boyuerous de tiuachuni dominant la vallée de Viota (Cordillère de Subia). Dép. Cundinamarca. If, environ $2300 \mathrm{~m} .24$ octobre.

37. Pteris orizabx. M. et Gat. - ( No 12r). Forèts le long du Cauca iu Paso de Concordia, près de Puesto de los Pubres. Dép. Antioguia et Cauca. Alt. $720 \mathrm{~m}$. 7 septembre. Distribution griograplique: Colombie, Mexique.

38. Pteris Kunzeana. Aci. - $\left(\mathrm{N}^{\circ}, 54\right)$. C. c. Forèts près de El Poblado sur Metlellin. Dip. Intioqua. Alt. environ $5700 \mathrm{~m}$. I4 aoùt. Distribution géographique: Amérique Iropicale el subtropicale.

39. Pteris podophylla. Sw. - $\left(N_{0} \quad 7.3\right)$. C. C. Forèts, environs du caletal La Camelia, près Ingelopolis. Dép. Intioquia. Alt. $1800 \mathrm{~m} .27$ aorit. Distribution géographique: Imírique tropicale el subtropicale.

40. Pteris podophylla. Sw. var. rufo-pubescens. IIser. - (No r55). C. c. Forèts près de El Polslado sur Medellin. Dép. Intioqua. Alt. environ $1700 \mathrm{~m} .14$ aoùt. Distribution gíographique: Colombic, Équateur.

\section{Genre Histiopteris. J. Sm.}

43. Histiopteris incisa. (Thвя.) J. Sy. - (No 5). C. or. Forèts entre bogola et Ubarue, 15 octobre; chemin entre Boca del Monte pris Madrid et Tena, 19 octobre; entre l'Nlto Ingarillo et les cafetales de la vallée de Viota, 23 el 24 octolre. Dép. Cundinamarca. Alt. $2000-2300 \mathrm{~m}$. Distribution géographique : Régions tropicales, subtropicales et antarctiques.

\section{Genre Pteridium. Gled.}

42. Pteridium aquilinum. (L.) liuns. - $\left(\mathrm{N}^{\circ}, 86\right)$. C. c. Commun au bord des bois et dans les cultures jusqu'à l'altitude de $2000 \mathrm{~m}$. environ. Dép. Antioquia. Loût el septembre. Distribution géographique : Régions tempérćes et tropicales.

\section{Genre Prsia. St. Hil.}

43. Prsia viscosa. St. Hı. - (No go). C. c. Forèts de l'Alto Romeral entre Angrelopolis et Estrella dans la valléc du Porce. Dép. Antioquia. Nlt. environ $2700 \mathrm{~m}$. 20 septembre. Distribution quégraphique: Antilles, Amérique centrale, Brésil. 


\section{Genre Blechnum. $L$.}

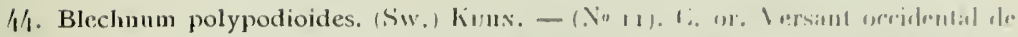

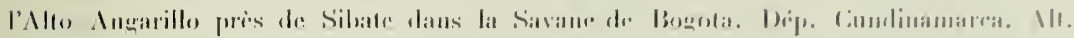

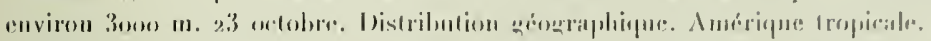

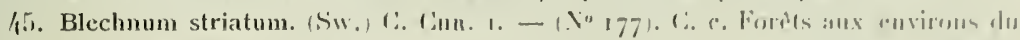

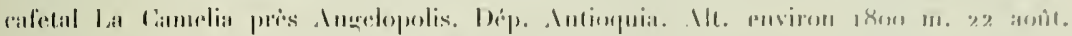

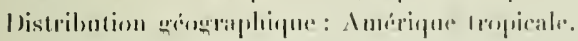

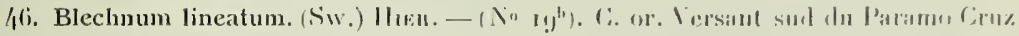

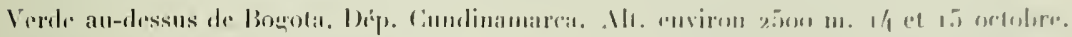

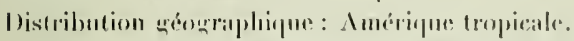

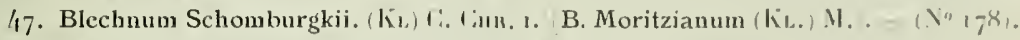

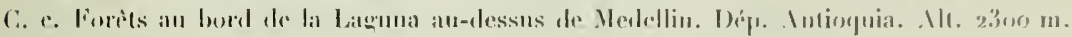
8 aont. Distribution grogriplaipur : Amiripue tropisale.

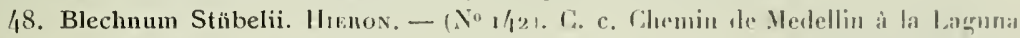

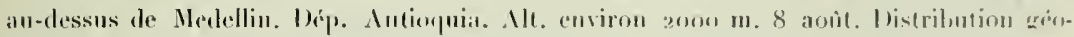
graphligue : Colombie, Equateur.

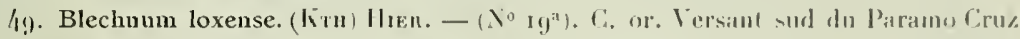

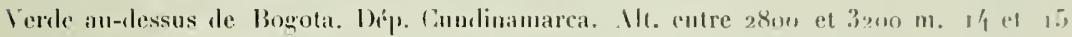

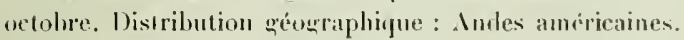

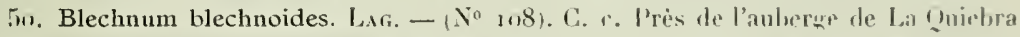
an-dessus de Cisneros, sur le chemin de Medellin. Dip. Antiognia. .1t, 1470) 111. 31 juillet. Distrihution géographique: Amirique tropicale.

is. Blechnum occidentale. L. - $\left(N^{0} 185\right)$. C. c. Riprandu partont dans le diprartement de l'Antioquia entre 1500 et $2000 \mathrm{~m}$. d'altilude. Ant et septembre. Distribution géographique : Amérique tropicale.

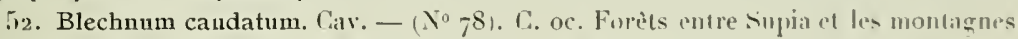

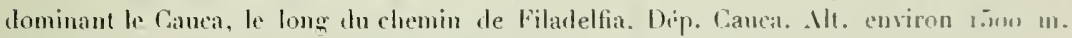
in septembre. Distribution géographique : Amérique tropicale.

53. Blechum volubile. KLf. - (No r26i). C. C. A plusienrs androits le long du chemin al'Angelopolis à Guaca: Dép. Antioquia. Alı. environ $1600 \mathrm{~m}$. 11 septemlire. -

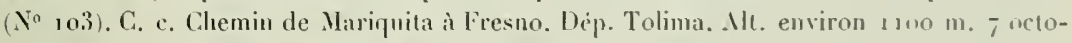
lure. Distrihulion géographique : Amerique tropicale.

\section{Genre Asplenium $L$.}

54. Asplenium monanthes. L. - (Xn 64). C. or. Pente du Monserrate au-dessus de Bogota. Dép. Cundinamarca. Alt. environ $2900 \mathrm{~m}$. 16 octobre. Distrilution géographique : Amérique tropicale. 
55.) Asplenium sessilifolium. Desr, rar, columbiensis. Нгек, - $\left(\mathrm{N}^{\circ} 12\right)$. C. or. Vallon Angarillo prís du village de Sibate dans la Savane de Bogota. Dép. Cundinamarca. Mlt. $2720 \mathrm{~m}$. 23 octohre. Distribution grographique: Guatemala, Bolivie.

56. Asplenium auritum. Sw. var. sulcatum (JAM). - ( $\left.X^{0} 7\right)$. C. or. Forèts entre l'Alto Angarillo et le Boqueron de Guachnni, dominant la vallée de Viota (Cordilline de Suhia). Dép. Cundinamarea. Ilt, environ 2300 m. 23 et 24 octobre. Distribution géographique: Amérique tropicale.

57. Asplenium auritum. Sw. var. macilentum (KzE). - (No 158$)$. C. c. Forèls près de E) Poblado sur Medeltin. Dép. Intioquia. Att. environ $1700 \mathrm{~m}$. 14 aont. Distribution géograpliqque : Imérique tropicale.

58. Asplenium praemorsum. Sw. - (No38). C. or. Cliemin entre Agua Larga el Facatativa dans la Savane de Bogota. Dép. Cundinamarea. Alt. environ $2500 \mathrm{~m}$. 10 octobre. - ( No $\left._{7} 3\right)$. C. c. Paramos des rersants occidental et oriental du Ruiz. Dép. Antioquia et Tolima. Att. entre 2500 et $3000 \mathrm{~m}$. 4 et 5 octobre. Distribution géographique: Amérique tropicale.

59. Asplenium praemorsum. Sw, var. angustisecta. Rosenst. - (No.35). C. or. Entre le village de Uhaque et le versant sud du Paramo Cruz Verde au-dessus de Bogota. Dép. Cundinamarea. Nit. environ 2300 m. 15 octobre. Distribution giographique: Amérique tropicale.

6o. Asplenium dimidiatum. Sw. $-\left(N^{0} \times 47\right)$. C. c. Commun aux environs de la ville de Medellin : haies, murs, lisière de bois. Dép. Antioquia. Ntt. ı550-ı600 m. 10 aoǹt. Distribution géographique: Imérique tropicale, Afrique occidentale, Asie orientale.

61. Asplenium theciferum. (11. 13. K.), Metr. - (No36). C. or. Chemin de Villela à Facalativa près de l'auberge La Sensitiva. Dép. Cundinamarca. Alt. environ zooo m. 1o ociohre. Distribution géographique : Imérique tropicale, Afrique tropicale el australe.

\section{Genre Diplazium. Sw.}

62. Diplazium Mayoris. nov. spec. - $\left(\mathrm{N}^{\circ} 67\right)$. C. c. Chemin de Mariquita à Fresto. 1)eip. Tolima. Ilt. environ roo m. 6 octobre.

63. Diplazium angelopolitanum. nov. spec. $-\left(\boldsymbol{N}^{0} 174\right)$. Forèts aux enviruns du cafetal La Canclia près Anggelopolis. Dép. Antioquia. Alt. 1800 m. 20 aoùt.

\section{Genre Cyclopeltis. J. Sm.}

64. Cyclopeltis semicordata. J. Sм. - ( N"122). Foréts le long du Canca au Paso de Concordia, prés de Puerto de los Polsres. Dép. Canca et Antioquia. Nit. $7^{20}$ m. 7 et 8 septembre. Distribution géograplirque : Amérique tropicale. 


\section{Genre Polystichum Rolh.}

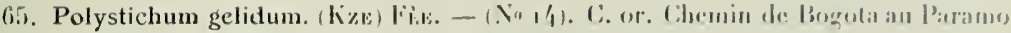

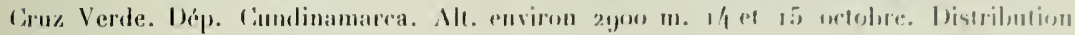

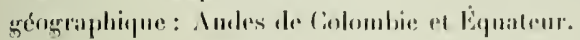

\section{Genre Dryopteris. Adans.}

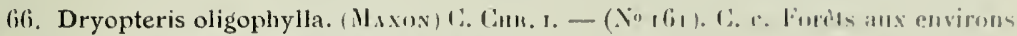

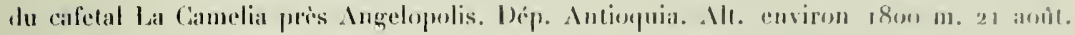
Distribution urographiepue : Indes ocriblentales if. Iypican).

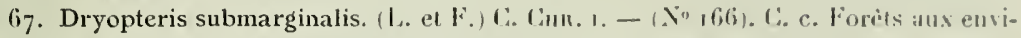

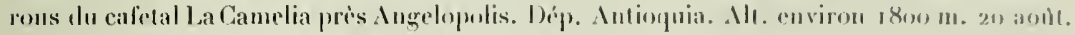
Distribution géographique: Amŕriqur tropicale.

68. Dryopteris tristis. (Kze) U. Kтуе. - (No 123). Forêts le long du Cancii an l'asto de Concordia, pris de Puerto de los Pobres. Dép. Catuca el Antiopuia. Mlt. $720 \mathrm{~m}$. 7 el 8 septembre. Distrihution géographique : Amérique tropicale.

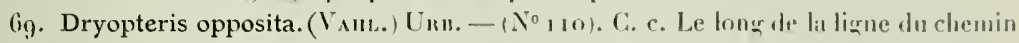
de fer entre Caracoli et Cisneros (elemin de Medollin. Dép. Antiojuia. Nlte environ $800 \mathrm{~m} .31$ juiltet. - (Nos 160 et 167$)$. C. . Forèts el lisières de hois anx environs du cafetal La Camelia pròs Angelopolis. Dép. Antioquia. Alt. environ 1800 m. 21 anout. DisIribution ereographique : Amérique tropicale.

70. Dryopteris concinna. (WiLbo) C. Ank. 1. - $\mathbb{N}^{\circ} 23$ ). C. or. Au-dessus de Lbaque. culre te villige el le versant sud du Paramo Cruz Verde an-dessus de Bogota. Dép. Cundinamarea. Alt. cuviron $2300 \mathrm{~m}$. 14 el 15 octubre. Distribution giographipue : Inúrique Iropicale.

71. Dryopteris columbiana. C. Cur. - (No rio). C. c. Forèts prís de El Poblidu sur Medellin. Dép. Antioquia. Alt. environ $1700 \mathrm{~m}, 16$ aoù. Distribution tréngraphique : Colombie, Vénéznela, Trinidad.

72. Dryopteris navarrensis. Cunıst. $-\left(\mathrm{N}_{0}, 63\right)$. C. C. Forèls aux enviruns du cafulal La Camelia pres Angelopolis. Dép. Antioquia. Alt environ $1800 \mathrm{~m} .20$ aoù. Distribution gुégraphique : Colombie, Coslit-Ricil.

73. Dryopteris pterifolia. Nutr) O. Litze. - (No r 28 . C. c. Le long du chemin de Angelopolis à Guaca. Dép. Antioquia. Alt. environ 1600 m. I2 septemhre. Distribution gुégraphique : Colombie, Bolivie.

74. Dryopteris Filix mas. L. vil, parallelogramma (Kze). - (.0 321 . C. or. Versant sud du Paramo Cruz Verde au-dessus de Bogota. Dép. Cundinamarca. Mlt. environ $2900 \mathrm{~m} .15$ octobre. Distribution gréographique : Amirique centrale.

75. Dryopteris parasitica. (L.) O). Krze. - (No 1531. C. c. Forets pris de El Poblado (i) 
sur Vedellin. Dép. Antioquia. Alt. emviron $1700 \mathrm{~m}$. 14 atont. Distribution qúographique: espice pantropicale.

76. Dryepteris rudis. (lize) C. Cun. I. - (

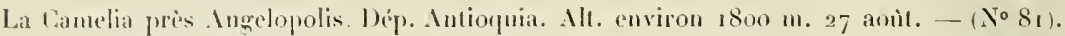
C. c. Forèts te l: Blto San Miguel près de Caldas, haut de la vallée du Poree. Dép. Antioquia. Nl. environ 2300 m. 26 septembre. - (No gis). C. c. Forits du versant oriental du Ruiz, non hin dn village de Soledad. Dép. Tolima. Alt. environ $2300 \mathrm{~m} .6$ octolore. Distribution géngraphiqué: Amérique tropicale.

77. Dryopteris pteroidea. (KL.) C. Cun. I. - (Nos 3 et 4). C. or. Forèts cutre l'Alto Angarillo of le Boqueron de Guachuni dominant la vallée de Viota (Cordillère de Subia). Dép. Cundinamarca. Alt. coviron $2200 \mathrm{~m} .23$ el 24 octobre. Distribution géograpliçue : Colomlie, Équateur, Brésil.

78. Dryopteris (Phegopteris) spee nova ex affinitate D. caudatae (Rinuoi); rhachibus asperis, rufo-rillosis, laminis subcoriaceis, subus pilis longis alhidis flaccidis vestitis. Limine frars superior modo exstans, ad descriptionem non sufficiens. - ( $\left.\mathrm{N}^{0} 9\right)$. C. or. Forèts entre l'Alto Mira et le Boqueron de Guachuni, dominant la vallée de liota (Cordilliere de Subia). Dép. Cundinamarca. Alt. environ 2200 m. 24 octolıre.

79. Dryopteris punctata. (ТнвG) C. Cun. 1. - ( $\mathrm{N}^{\circ}$ I 70). C. c. Forèts aux environs du caletal La Camelia près Angelopolis. Dép. Antioquia. Alt. environ 1800 m. 27 aonit. Distribution géographique: espèce pantropicale.

8o. Dryopteris sorbifolia. (Jace) Hier. - (No 100). C. c. Près de Mariquita, sur te chemin de fresno. Dép. Tolima. Alt. environ $1000 \mathrm{~m} .7$ octobre. Distribution géographique: Anérique tropicale.

\section{Genre Nephrolepis. Schott.}

81. Nephrolepis pendula. Ravdr. - ( $\left.\mathrm{N}^{\circ} 1_{27}\right)$. C. c. Endroits humides et ombragés des forèts entre Angelopolis et Guaca. Dép. Antioquia. Alt. environ $1400-1600 \mathrm{~m}$. 11 septembre. - $\left(N^{\circ} 146\right)$. C. c. Commun aux environs de la ville de Medellin dans les endroits ombragés et sur les murs. Dép. Antioquia. Alt. 1550-1600 m. Aoùt. Distribution géographique: Amérirue tropicale et subtropicale.

\section{Genre Polypodium. L.}

82. Polypodium marginellum. Sw. - ( No 88). C. c. Forìts de l'Nlto Romeral entre Angelopolis et Estrella dans la vallée du Porce. Dép. Antioquia. Alt. euviron $2500 \mathrm{~m}$. 20) septembre. Distribution géographique: Amérique tropicale, Infles occidentales et Porlynésie.

83. Polypodium pilosissimum. M. at GaL. - $\left(\mathrm{N}^{\circ} 136\right)$. C. c. Environs du cafetal La 


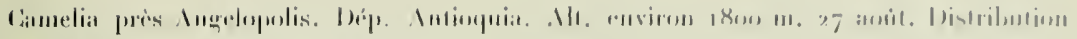

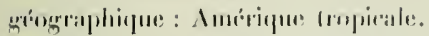

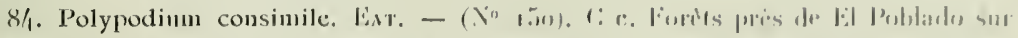

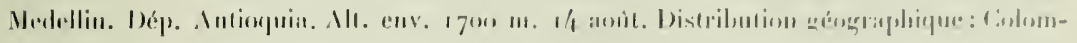
bice, Amérique rentrale.

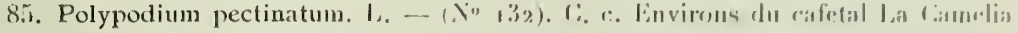

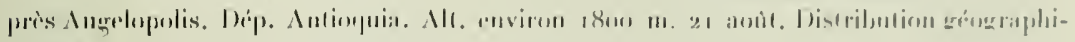
que: Amśrique: Iropricale.

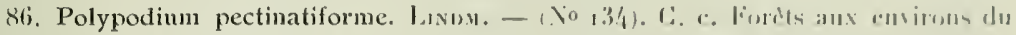

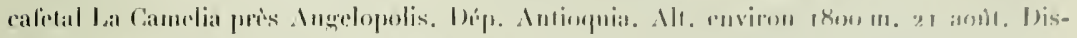

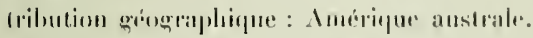

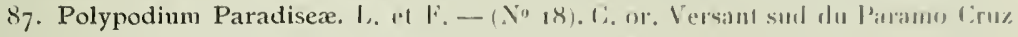

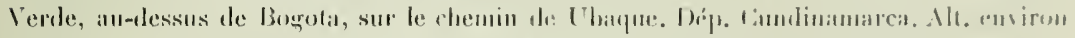

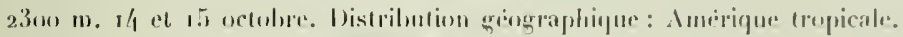

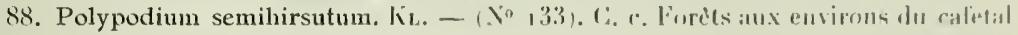

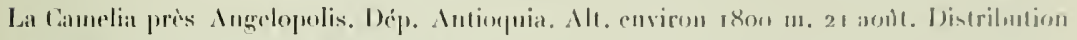
qéngraphique: Antilles, Imérique contrale el auslratu.

89. Polypodium Mayoris. Nov. spec. - 1 \% 69). C. c. P'alamus du liniz, versint occilental. Dép. Antioguia. Alt. emiron 37un m. is actubre.

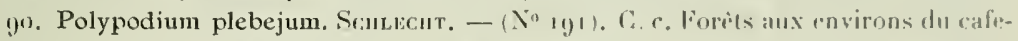
tal La Camelia pris Angelopolis. Dép. Antioquia. Alt. envirun $1800 \mathrm{~m}$. 15 strumbre. Distribution gromraphique: Mexigur, Bolivier, Brísil.

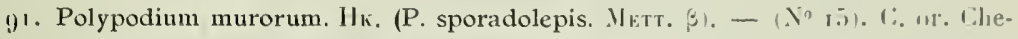
min de Bogotin au Paramo Cruz Verde. Dép. Cumlinamarca. Ale, environ 33om m. 14 el 15 octobre. Distribution géographlique: Colombie, Bolivie.

9\%. Polypodium murorum. IK. f. integra. Rusexst. - ( ${ }_{0} 37$ ). C. or. Enlre Aeria Lallgar el liacatativa dans la savane de Bogota. Dép. Cundinamarca. Alı. environ z3an m. 10 octohre. - (No 34). C. or. An-dessus de I baque, entre le village et le Paramo Cruz Verde alt-dessus de Bogoti. Dép. Cundinamarca. Alt. environ 2300 m. rá uctubre. Distribution grographique: Amérique anstrale (Andes).

93. Polypodium monosorum. Desr. - ( $\left.N^{0} 71\right)$. C. c. Paramos da Ruiz, versant ueci-

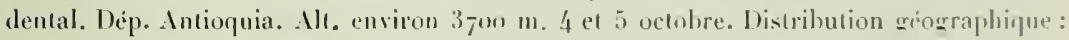
Colombie, Bolivie.

94. Polypodium fraxinifolium. Jace. - (Nos 12!) el 190). C. c. Forits aux mirums du cafetal La Camelia pris Angelopolis. Dep. Antioquia. Alt. env. 180010 . Aolt el seplembre. Distribution géographique: Imérique tropicale.

95. Polypodinm lepidopteris. Wu, - - (No 66). C. c. pris du village de Fresno. sur le chemin de Mariquita. Dip. Tolima. Mlt. envion 130 m. 7 octobre. Distribution géographique: Imerique tropicale.

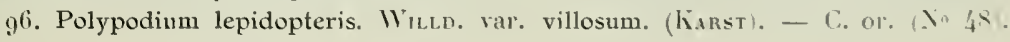


Forèts entre Boca del Monte prés de Madrid dans la Savane de Bogota el l'auberge dr Tambo près du village de Tena. Dép. Cundinamarea. Alt. environ $2200 \mathrm{~m}$. 18 el 19 octobre. - (No 53). C. or. liorèts au bord du lac Pedropalo près du village de Tena. Dép. Cundinanarea. Alt. 2000 111. 18 octobre. Distribution géographique: Amérique tropicale.

97. Polypodium thyssanolepis. A. Br. - (No 156). C. c. Colline aux environs de America près de Medellin. Défr. Antioquia. Alt. cnviron $1700 \mathrm{~m}$. 15 aoùt. $-\left(\mathrm{N}^{0}{ }_{2} 5\right)$. C. or. Sur des murs entre le village de Ubaque et le Paramo Cruz Verde au-dessus de Bogota. Dép. Cundinamarca. Alt. euviron $2300 \mathrm{~m}$. 15 octobre. Distribution géographique: Antilles, Amérique centrale et australe.

98. Polypodium areolatum. H. B. W. - $\left(\mathrm{N}^{0} 26\right)$. C. or. Sur des murs et des rochers entre Lbaque et le Paramo Cruz Verde au-dessus de Bogota. Dép. Cundinamarca. Alt. euviron $2300 \mathrm{M} .14$ et 15 octobre. Distribution géographique : Amérique tropicale.

99. Polypodium decumanum. Willo. - ( $\left.\mathrm{N}_{0} \mathbf{1}_{2}\right)$. Bord du Magdalena, dans les forèts près de El Banco. Dép. Magdalena. Alt. $110 \mathrm{~m} .27$ juillet. - ( No 16 ). Forèts au bord du Cauca an Paso de Concordia, près de Puerto de los Pobres. Dép. Cauca et Antioquia. Alt. $7^{20} \mathrm{~m} .6$ et 7 septembre. Distribution géograplique : Amérique tropicale.

100. Polypodium augustifolium. Sw. - (No 84). C. oc. Forèts entre Valparaiso et Supia. Dép. Cauca. Alt. environ $2000 \mathrm{~m} .29$ septembre. - ( $\left.\mathrm{N}^{\circ} 50\right)$. C. or. Forèts entre Boca del Monte près de Madrid dans la Savane de Bogota et l'auberge de Tambo prìs de Tena. Dép. Cundinamarca. Alt. environ $2000 \mathrm{~m}$. i 8 et ig septembre. Distribution géographique: Amérique tropicale et subtropicalc.

101. Polypodium angustifolium. Sw. var. heterolepis. nov. var. $-\left(\mathrm{N}^{\circ}\right.$ I 40$)$. C. c. Forèts aux environs du cafetal La Camelia près Angelopolis. Dép. Antioquia. Alt. environ 1800 m. 20 août.

102. Polypodium Phyllitidis. L. var. (prope P. Lorentzii. Hienon), - ( $\left.\mathrm{N}_{0} \mathrm{I}_{3}{ }_{7}\right)$. C. c. Près du Rio Amaga, au-dessous du cafetal La Camelia près Angelopolis. Dép. Antioquia. Alt. environ r roo $\mathrm{m} .26$ aoùt. - ( $\mathrm{N}^{0} 1$ 1 9 ). Forèts le long du Cauca au Paso de Concordia, près de Puerto de los Pobres. Dép. Cauca et Antioquia. Alt. 720 m. 7 et 8 septembre. Distribution géographique : Amérique tropicale et subtropicale.

103. Polypodium latum. Moore. - ( $\mathrm{N}$ I 35). C. c. Forèts aux environs du cafetal La Camelia près Angelopolis. Dép. Antioquia. Alt. environ $1800 \mathrm{~m} .2$ I août. Distribution ¿éographique: Amérique tropicale et subtropicale.

I04. Polypodium percussum. Cav, - $\left(\mathrm{N}^{0}{ }_{1} 5_{7}\right)$. C. c. Forèts le long de la Quebrada Sinta Elena aurdessus de Medellin. Dép. Antioquia. Alt. environ $1700 \mathrm{~m}$. 6 aoùt. $\left(\mathrm{N}^{\circ}{ }_{\mathrm{I}} \mathrm{H}_{1}\right) \mathrm{C}$. c. Forêts aux environs du caletal La Camelia près Angelopolis. Dép. Antioquiia. Alt. environ r $800 \mathrm{~m}$. 2 I août. - ( $\left.\mathrm{N}^{\circ} 59\right)$. C. or. Chemin de Honda à Bogota, entre (iuaduas et Villeta. Dép. Cundinamarca. Nit. environ $\mathbf{3} 300 \mathrm{~m}$. 9 octobre. Distribution géographique: Amérique tropicale.

105. Polypodium lanceolatum. L. - (No r 30). C. c. Forêts aux environs du cafetal 


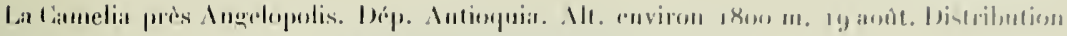

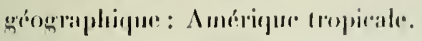

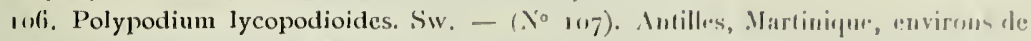

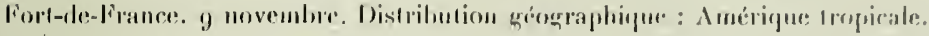

167. Polypodium crassifolium. 1.. I'. angustissima. Rosevst, Ifoliis pralongis, vix ultra

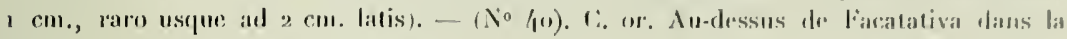

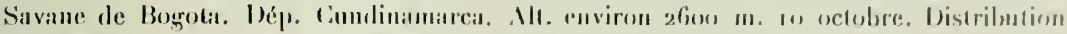
grasographinge: Améringe tropicale. (f. typica)

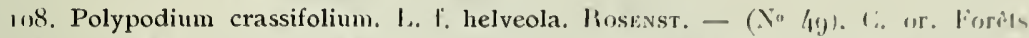

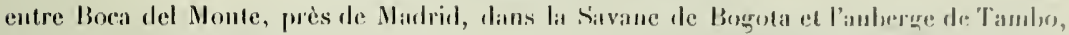
près du village de Tena. Dáp. Cumlinamarea. Alt. environ 2300 m. 18 ef ryoutubre. Distribution grographique : Amérique tropicale (t. Lypica).

\section{Genre Nolochlana. R. Br.}

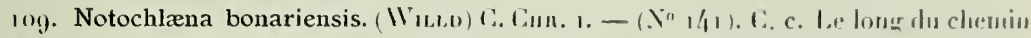
de Medellin à Bello. Dép. Antioquia. Alt. $1500 \mathrm{~m}$. / aoult. - (No 27). C. or. IBurıl dı chemin encre Ubaque el le Paramo Cruz Verde, au-dessus de Bogota. Dép. Candinamarca. All. envirun 2200 m. 15 octobre. Distribution géographique : Vexique, Chili.

\section{Genre Gymnogramme. Desv.}

110. Gymnogramme antioquiana. nov. spec. $-\left(\begin{array}{l}N^{0} \\ 82\end{array}\right)$. C. c. Foréts de l'Alto Sau Miguel au-dessus de Caldas (lıaut de la vallée du Porce). Dép. Antioquia. Alı. cuviron $2300 \mathrm{~m} .26$ septembre.

॥ा. Gymnogramme flexuosa. Desv. - $\left(N^{0} 91\right)$. C. c. Forèts de l'.llto Romeral, cutre Angelopolis et Estrella, dans la valléc du Porce. Dép. Antioquia. Alt. environ $2700 \mathrm{~m}$. 20 septembre. - $\left(\mathrm{N}^{0} 2\right)$. C. or. Forèts près du Boqueroh de Guachuni, dominant la vallíe de Viota (Cordillère de Subia). Dép. Cundimamarca. Alt. environ $24001 \mathrm{~m}$. 24 octobre. Distribution géographique: Costa-Rica, Bolivie.

1\%. Gymogramme flexuosa. Desr. var. hirsuta. - (No $\left.144^{2}\right)$. C. c. Foréts pris de la Laquna au-dessus de Medellin. Dép. Antioquia. Mll. environ $2300 \mathrm{~m} .8$ aoùt.

113. Gymnogramme fumarioides. nov. spec. - (No 144). C. C. Forèls près de lal Laguna au-dessus de Nedellin. Dép. Intioquia. Nlt. environ $2300 \mathrm{~m}, 8$ aoìt.

14. Gymnogramme (Jamesonia) imbricata. (C.Av) HK. el GREv. - (No 68). C. с. Paramos du Ruiz, versant occidental. Dép. Antioquia. Alt. environ 37on m. 5 octobre. Distrihution géographique : Colombie, Pirou.

15. Gymnogramme (Jamesonia). Mayoris. nov. spec. - (No 74 . Paramo Cruz Verde au-dessus de Bogota. Dép. Cundinamarca. Alt. 3500 m. r 5 ochohre. 


\section{Genre Gymnopteris. Bernh.}

116. Gymnopteris rufa. (L.) Benxu. - (No 118$)$. Forrits au hord du Cauca au Paso de Concordia, prés de Puerto de los Pohres. Dép. Cauca et Antioquia. Mlt. 720 m. 7 el 8 septembre. Distribution géographique : Amérique tropicale.

\section{Genre Ceropleris. Lk.}

117. Ceropteris calomelanos. (L.) Lxv. - (No 159$)$. C. c. Forèts et lisières de bois aux environs du cafectal La Camelia près Ingelopolis. Dép. Intioquia. Alı. environ s $800 \mathrm{~m}$. 21 aonic. - (N०41). C. or. Taillis près de la chute du Tequendama. Dép. Cundinamarca. 1lt. $2200 \mathrm{~m}$. 12 octobre. Distribution géographique : Amérique tropicale.

18. Ceropteris tartarea. Lk. - $\left(\mathrm{N}^{\circ} 181\right)$. C. c. Forèts près de El Poblado, sur Medellin. Dip. Antioquia. Alt. environ $1700 \mathrm{~m}, 14$ aoùt. - (No $\left.181^{a}\right)$. C. c. Forèts aux cuvirons du cafetal La Camelia près Angelopolis. Dẹp. Antioquia. Alt. environ a 8 ro m. 2 ] aont. Distribution géographique: Amériłue tropicale.

\section{Genre Trismeria. Fée.}

I 19. Trismeria trifoliata. (L.) Diels. - ( $\left.\mathrm{N}^{0} 179\right)$. C. c. Dans le sable et les graviers, au bord du Rio Amaga, au-dessous du cafetal La Camelia près Angelopolis. Dép. Antioquia. Alt. environ rooo m. 26 aoùt. - ( $\left(\mathrm{N}^{\circ} \mathrm{r} 79^{\mathrm{a}}\right)$. Daus le sable et les graviers au bord du Rio Amaga, près de son embouchure dans le Cauca el le long du Cauca au Paso de Concordia près de Puerto de los Pobres. Dép. Antioquia. Nh. 720 m. 5 à 9 septembre. Distribution giographique: Amérique tropicale et subtropicale.

\section{Genre Antrophyum. KIf.}

120. Antrophyum lineatum. KLF. -- (No, 64$)$. C. c. Forèts anx envirous du cafetal La Camelia près Ingelopolis. Dép. Antiơuia. Alt. environ $1800 \mathrm{~m} .20$ aoùt. Distribution géographique: Amérique tropicale.

\section{Genre Eschatogramme. Trevis.}

121. Eschatogramme furcata. (L.) C. Chr. I. - (No 99). C. c. Sur les Lranches d'un Calabas, non loin de Mariquita, sur le chemin de Fresno. Dép. Tolima. Nlt. environ $12(16) \mathrm{m} .7$ octohre. Distrilution géographique : Amérique tropicale. 


\section{Genre Hemionilis. 2 .}

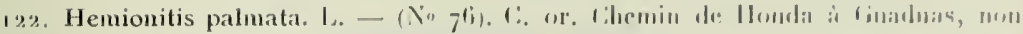

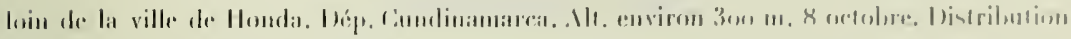

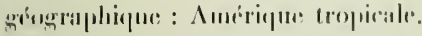

\section{Genre Elaphoglossum. Schott.}

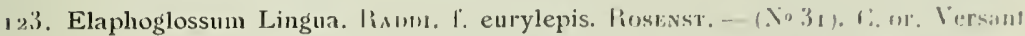

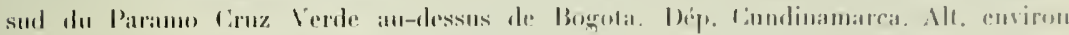

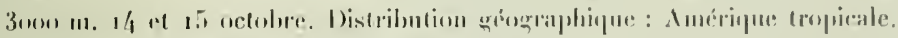

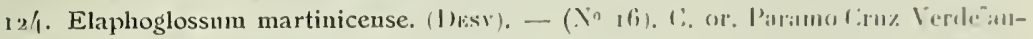

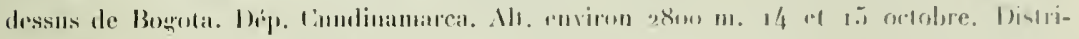

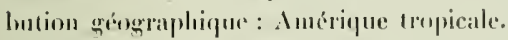

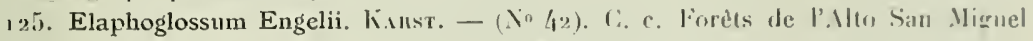

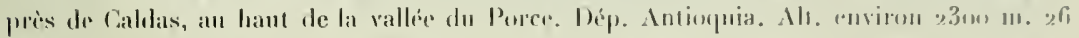

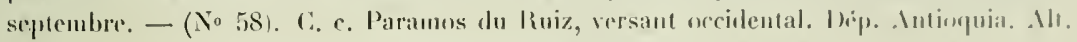

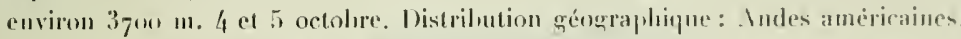

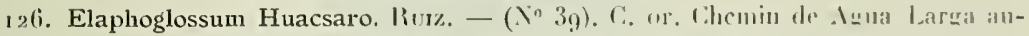
dessus de Facatativa dans la Savane de Bogota. Dép. Candinamarca. Mt environ atum m. 10 octobre. Distribution góographique : Colombie, Pérou, Antilles.

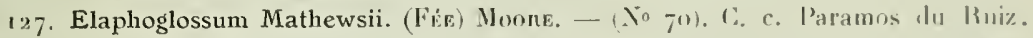

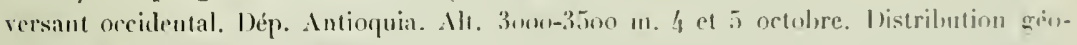
eraplinjue: Andes américaines.

\section{Genre Polybotrya. Humb. et Bonpl.}

128. Polybotrya Kalbreyeri. C. Cur. 1. - (. (2) 65). C.. e. Forèts, pentes de la derniere Cordillère dominant le village de Mariquita, sur le chemin de Fresmo. Dép. Tolima. Ma. environ 1100 m. 7 octobre. Distribution géographique: Colombie, Costa-Rica.

\section{Genre Acrostichum. L.}

120. Acrostichum aureum. L. - $\left(\Upsilon^{\circ}, 89\right)$. Endroils marécaqenx an boril de la mer. Fort-de-France, Martinique. Antilles. 10 novembre. Distribution géngraphique E-perere pautropicale. 


\section{Schizaeaceae}

\section{Genre Aneimia. Sw.}

130. Aneimia hirsuta. Sw. - $\left(\mathrm{N}_{0}{ }_{1} 8_{2}\right)$. C. c. Endroits boisés aux environs de Bello près de Medellin. Dép. Antioquia. Alt. $5500 \mathrm{~m}$. 4 aoǹt. Distribution géographique : Imérique tropicale.

131. Aneimia flexuosa. Sw. var. villosa. Prit. - ( No 184). C. c. Forèts le long de la Quebrada Santa Elena an-dessus de Nedellin. Dép. Antioquia. Alt. environ $1700 \mathrm{~m}$. 6 aoùt. Distribution géographique: Imérique tropicale.

132. Aneimia Phyllitidis. (L.). Sw. - ( $\mathrm{N}^{\circ}$ 188). C. c. Bord du cheniu de Medellin à Imerica. Dép. Intioquia. Alt. $1600 \mathrm{~m}$. 10 aoùt. - (No I83). C. c. Bas de la vallée de l'Amagna forèts le long du chemin de Titiribi au Cauca. Dép. Antioquia. Mlt. environ 800 m. 5 septembre. - (No i I5). Forèts au bord dı Cauca, au Paso de Concordia, près de Puerto de los Pobres. Dep. Antioquia et Cauca. Alt. $720 \mathrm{~m}$. 6 à 8 septembre. Distribution géographique: Imérique tropicale.

\section{Genre Lygodium. Sw.}

133. Lygodium polymorphum. (Cav.). II. B. K. - ( $\mathrm{N}^{0}$ I I $\left.7^{\mathrm{a}}\right)$. Bord du Cauca au Paso de Concordia près de Puerto de los Pobres, à l'emboucluare du Rio Amaga. Dép. Antioquia. Alt. $720 \mathrm{~m} .7$ septembre. $-\left(\mathrm{N}_{0}\right.$ II 7$)$. C. c. Forèts le long du Rio Imaga au-dessous du cafetal La Hermosa, près Angelopolis. Dép. Antioquia. Alt. environ r $100 \mathrm{~m}$. g septembre. Distribution géographique : Amérique tropicale.

\section{Ophioglossaceæ}

\section{Genre Ophioglossum. L.}

I34. Ophioglossum reticulatum. L. - $\left(\mathrm{N}^{\circ}{ }_{1} 3_{9}\right)$. C. c. Dans les cultures, cafetal La Camelia près Ingelopolis. Dép. Antioquia. Alt. environ 1800 m. 21 aonit. Distribution géographique: Espice pantropicale. 


\section{Salviniaceæ}

\section{Genre Azolla. Lam.}

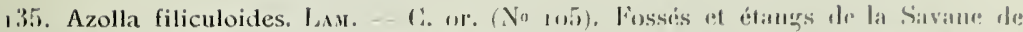

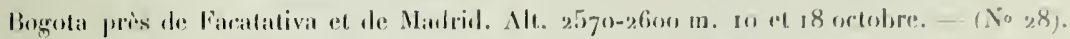

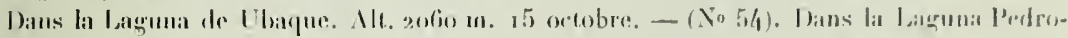

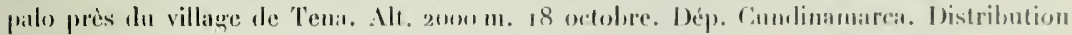
géographinge: Améripue tropicale et subropicale.

\section{Genre Salvinia. Adans.}

136. Salvinia auriculata. Aun. -- (No Iog). Environs de lit ville de Barranjuillit, dians les fussés, maréctures et cananx. Dep. Bolivar. 21 juillet. Distribution géographique : Amérique tropicale.

\section{Lycopodiaceæ}

\section{Genre Lycopodium. I.}

137. Lycopodium reflexum. Las. - (No57). C. c. Versants necidental el oriental du Ruiz. Dép. Antioquia el Tolima. Alt. environ 30 o m. 4 et 5 octobre. - ( No -7 ). Clemin de Sinta Barbara au bord du Cauca, près de l'auberge El Cairo. Dép. Antioquia. Mlt. environ $2000 \mathrm{~m} .28$ septembre. Distribution géographique : Amérique tropicale, Afrique. Malaisie.

138. Lycopodium reflexum, Las. var, minor, Sprisg. - (No 44). C. c. Forits, versant occidental du Ruiz, le long du chemin entre Manizales el la míne d'or La Union. Dép. Antioquia. Alt. entre 3e00-3500 m. 4 octobre. Distribution géographique: Amérique tropicale, Afrique, Malaisie.

ı39. Lycopodium cernuum. L. - (No I r.3). C. c. Le long dı chemin te Cisneros à Medellin. Dép. Antioquia. Alt. $1300-1600 \mathrm{~m}$. 3 r juillet à 2 aoule. Distribution géographique: Espece pantropicale.

I40. Lycopodium contiguum. Kí. - (. 29 29). C. or. Paramo Cruz Verde au-dessiss de Bogota. Dép. Cundinamarea. Alt. envirun 2 goo m. 14 octobre. Distribution géograplique: Colombie, Bolivie (Andes). 
141. Lycopodium Mayoris. nov. spec. - (No 17). C. or, Chemm de Bogota au Paramo Cruz Verde. Dép. Cundinamarca. Alt. environ 290 m. I 5 octobre.

142. Lycopodium clavatum. L. - $\left(\begin{array}{lll}N_{0} & 171\end{array}\right)$. C. c. Cultures et lisières de forèts, cafetal La Camelia près Angelopolis. Dép Antioquia. Alt. environ 1800 m. 27 aont. Distrilution géographique: Régions tempérées et tropicales.

143. Lycopodium clavatum. L. var. aristatum. (H. B. K.). - (No 1/5). C. c. Forêts près de la Laquna, au-dessus de Medellin. Dép. Antioquia. Alt. environ $3200 \mathrm{~m} .8$ aont. -. (No 56). C. or. Pente du Monserrate au-dessus de Bogota. Dép. Cundinamarca, Alt. environ $2900 \mathrm{~m}$. I 6 octobre. Distribution géographique : Andes américaines, Indes occidentales.

I44. Lycopodium complanatum. L. - (No r/43). C. c. Près de la Laguna, au-dessus de Medellin. Dép. Antioquia. Alt. environ 2300 m. 8 août. - (Nos 20 et 55). C. or. Pente du Monserrate au-dessus de Bogota et Paramo Cruz Verde. Dép. Cundinamarca. Alt. environ $2900 \mathrm{~m}$. 14, 15 et 16 octobre. Distribution géographique: Régions tempérées et tropicales.

145. Lycopodium Jussiaei. Desv. - (No 43). C. c. Paramos du Ruiz, versants occidental et oriental. Dép. Antioquia et Tolima. Alt. $3000-3500 \mathrm{~m} .5$ octobre. $-\left(\mathrm{N}^{\mathrm{os}} 30 \mathrm{et}\right.$ 63). C. or. Pente du Monserrate au-dessus de Bogota et Paramo Cruz Verde. Dép. Cundinamarca. Alt. environ $2900 \mathrm{~m} .14$, 15 et 16 octobre. Distribution géographique : Andes américaines, Brésil, Jamaïque.

146. Lycopodium spurium. IVILld. - ( $\left(\mathrm{N}_{\circ} 62\right)$. C. c. Versant occidental du Ruiz, chemin de Manizales à la mine d'or La Union. Alt. environ $3000 \mathrm{~m} .4$ octobre. Distribution géographique: Andes américaines, Brésil.

\section{Alsophila coriacea nov. spec.}

(Planche II, fig. 1)

Alsophila, foliis amplis, coriaceis, subglabris, in sicco livido-brunneis, bipinnatifidis ; pinnts c. $80 \mathrm{~cm}$ vel ultra longis, $30 \mathrm{~cm}$ latis, breviter petiolatis, lineari-lanceolatis, breviter acuminatis; pinnulis infra apicem pinnatifidum c. 3o utrinque, petiolis $3-4 \mathrm{~mm}$ longis instructis, alternis, patentibus, subdistantibus, lineari-lanceolatis, acuminatis, medialibus maximis c. $15 \mathrm{~cm}$ longis, $2 \frac{1}{2} \mathrm{~cm}$ vel paullo ultra latis (basalibus paullo minoribus, superioribus cito decrescentibus), profunde pinnatifidis ; segmentis numerosis, remotiusculis, linearibus, subfalcatis, apice obliquo acuto, sinubus latiusculis, acutis interstinctis, margine serratis, superioribus in dentes obliquos apicis cito transeuntibus; costis livido-brunneis, supra canaliculatis, apicem versus strigosis, ceterum glabris, infra teretibus et sparsim aculeolatis ; costnlis supra immersis, strigosis, subtus semiteretibus, parce verrucosis, paleolis brunneis, lanceolatis, fimbriatis venisque pilis brevibus simplicibus vel furcatis vel stellatis adspersis; venis supra distincte, subtus parum prominentibus, latera- 
PLANCHE II
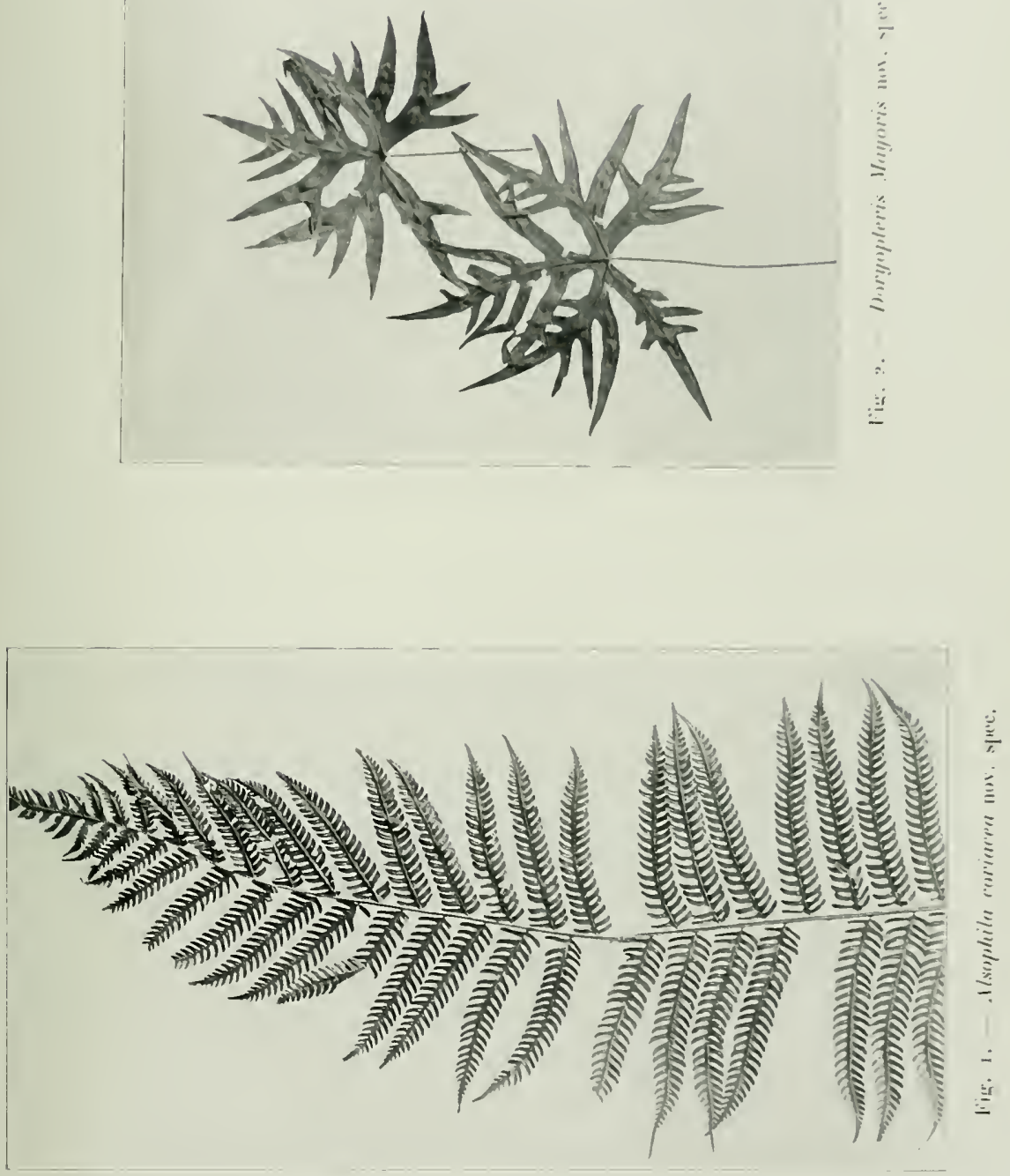



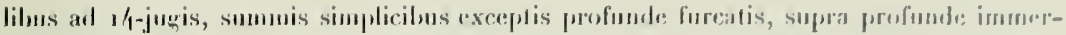

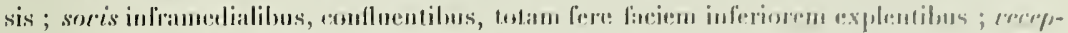

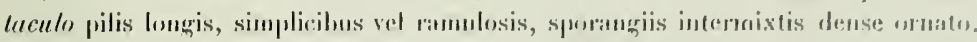

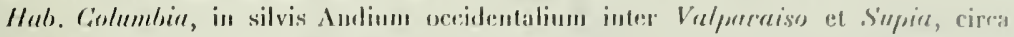

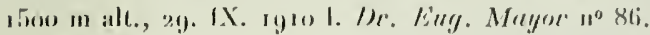

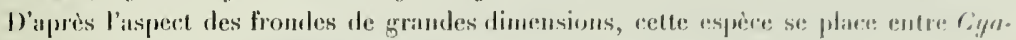

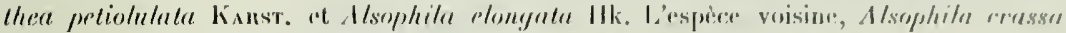

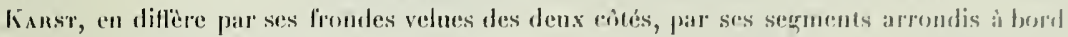
phus fortement dentelé ansi que par ses parapluyses plus courtes et simples. Par les proils Iongs et la plupart ramiliés da réreptacle, notre espore se distingue farcilement des antres especes analognes.

\section{Doryopteris Mayoris nov. spec.}

(1'linche 11, tig. 2)

Eudoryopteris, whizomute hreviter repente vel atsiendente, puleis lancerolatis atrobrumeis, pallide marginatis, c. 4 mm longis, $1 / 2 \mathrm{~mm}$ latis apice dense vestito; stipitilus fasciculatis, atropurpureis, antice parum applanatis et hreviter tomentosis, ceterum teretibus, glaberrinis, atidis, ad $25 \mathrm{~cm}$ longis, $11 \% \mathrm{~mm}$ medio crassis ; laminis a basi sul, cordata deltoideo-rotundatis, usque ad $18 \mathrm{~cm}$ longis, $20 \mathrm{~cm}$ latis, basi ggemniferis, sul,coriaceis, in sicco lutescentibus, glaberrimis, pinnato-pedatifidis seu trifidis ; seymentis basulibus latere anteriore plerumque integris, posteriore segmentis 2. ord. $2-4$ simplicilus vel infimis iterum pinnatifidis instructis, ala subconica $8-11, \mathrm{~mm}$ deorsum lati, sursum paullo dilatata cum segmento terminali conjunctis ; segmento terminali ad alan c. $1 \mathrm{~cm}$ latam pinnatifido, lobis lateralibus $1-3$-jugis, lineari-lanceolatis, integris, infimis rarissimı lobulo unico postice instructis; thachibus costisque supra immersis, subtus prominentibus, atropurpureis, nitidis ; nenis reticulatis, distincte conspicuis ; soris apice except" totum marginem linea continua eingentibus (laminis sterilibus non visis).

Hab. Columbin, in locis umbrosis Andium centralium prope Ledellin, $1550-16 m, 11$ alt., VIII. rgro I. Dr Eug. Mayor n ${ }^{\circ}$ iso.

Diffère de Doryopteris perlata J. Sx. par ses limbes moins fortement divises et proliférants à la base, dont la largeur est généralement plus grande que la longaueur. Doryonpleris palmata (Willo.) possède un pétiole jaune et non brun-pourpre; Doryopteris angularis FÉE a ses limbes moins fortement divisés.

\section{Pteris pungens Willd. var. Shimekii nov. var.}

(Planche 1II, fig. 3)

Varietas pinnis deorsum angustatis, ad alam brevem, c. $21 / 2 \mathrm{~mm}$ latam basi reduclis, venulis lateralibus infinis medio inter binas costulas e costu oriundibus a typo diversa. 
Ilab. Columbia, Andes centrales, inter Mariquita et Fresno, cirea $600 \mathrm{~m}$ alt., 7. X. 1910 1. Dr Eug. Mayor no ro1.

Celte variété est mentionnée comme forme de Pleris quadriaurita Retz. et en parlie représentée dans Shimel, Ferns of Nicaragua, Bull. Nat. IFist. L'niw. Jouer IV. r897, pag. 137, Pl. 11 , fig. 6.

\section{Diplazium Mayoris nov. spec.}

(Planche III, fig. 4)

Eudiplazium,.. laminis $7^{\circ} \mathrm{cm}$ vel ultra longis, $25 \mathrm{~cm}$ latis, lanceolatis, apice acuto, membranaceis, viridibus, glaberrimis, pinnatis apice pinnatifido ; pinuis alternis, breviter petiolatis (petiolis c. $1 / 2 \mathrm{~cm}$ longis), erecto-patentibus, e basi cuneata oblongo-lanceolatis, sensim acuminatis, margine leviter crenatis, crenis obscure undulato-crenulatis vel integerrimis, maximis c. $24 \mathrm{~cm}$ longis, $4 \mathrm{~cm}$ latis, inferioribus ejusdem lateris usque ad $7 \mathrm{~cm}$ vel magis inter se distantibus; rhachibns rufo-stramineis, supra sulcatis, infra teretibus, glabris; costis supra sulcatis, in sulco brevissime tomentosis, subtus teretibus, cum costulis renisque utrinque prominentibus; costulis vix $1 \mathrm{~cm}$ inter se distantibus, sub angulo $70^{\circ}$ e costa egredientibus, plerisque pinninerviis, venis utrinque 3 (4), omnibus liberis, marginem attingentibus, superioribus furcatis simplicibusve; soris linearibus, e basi venularum usque fere ad marginem extensis, basalibus anticis diplazioideis, 1 1/2 $\mathrm{cm}$ fere longis, ceteris simplicibus, brevioribus ; indusiis membranaceis, angustis, integerrimis.

IIab. Columbia, Andes centrales, inter Mariquita et Fresno, circa 1 roo in alt., 6. X. rgro I. Dr Eug. Mayor, $n^{0} 67$.

Cette espèce est voisine de Diplasium neglectum Karst., qui s'en distingue par sa structure plus ferme, ses costules et ses nervures velues, ses frondes plus profondément incisées, ainsi que ses sores plus courts.

\section{Diplazium angelopolitanum nov. spec.}

(Planche [V, fig. 5)

Eudiplazium..., laminis $75 \mathrm{~cm}$ vel ultra longis, $30 \mathrm{~cm}$ latis, ovali-lanceolatis, longe acuminatis, laete viridibus, membranaceis, glaberrimis, pinnatis, apice pinnatifido ; pinnis infra apicem pinnatifidum 20 vel pluribus in utroque latere, alternis, approximatis, sul)sessilibus, patentibus, e basi subtruncata lineari-lanceolatis, acuminatis, maximis $22 \mathrm{~cm}$ longis, $3 \mathrm{~cm}$ fere latis, margine ultra mediam inciso-lobatis, in apicem 3-4 cm longum, lineari-lanceolatum, serrulatum desinentibus, lobis ad 25-jugis, recte patentibus vel paullo obliquis, interstitiis anguste linearibus sejunctis, lineari-ligulatis, oltusis, serrato-dentatis ; rhachibns rufidulis, supra canaliculatis, infıa teretibus, sparse pilosis ; costis supra sulcatis in sulco furfuraceo-pilosis, ad basin costularum mutice denticula- 

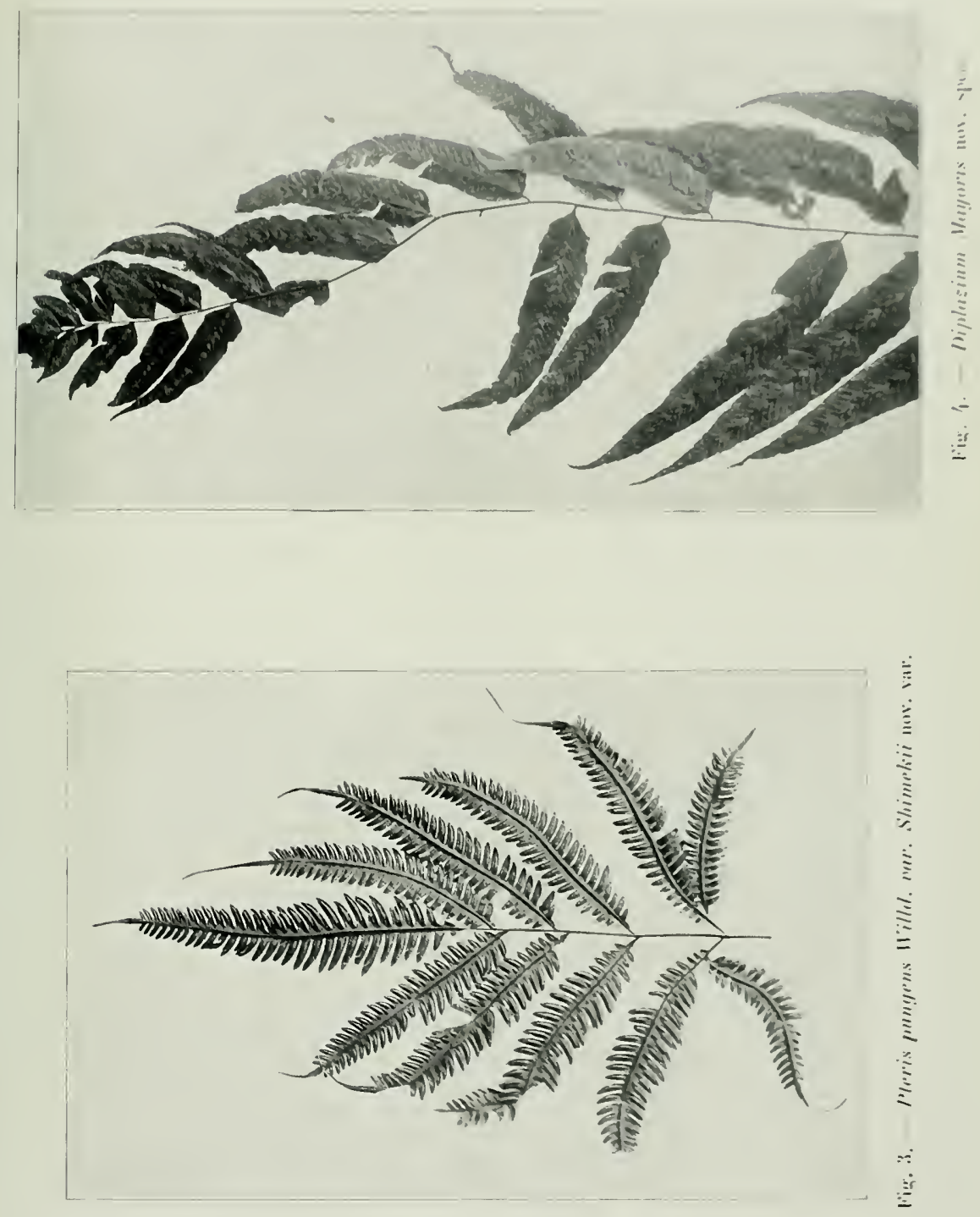



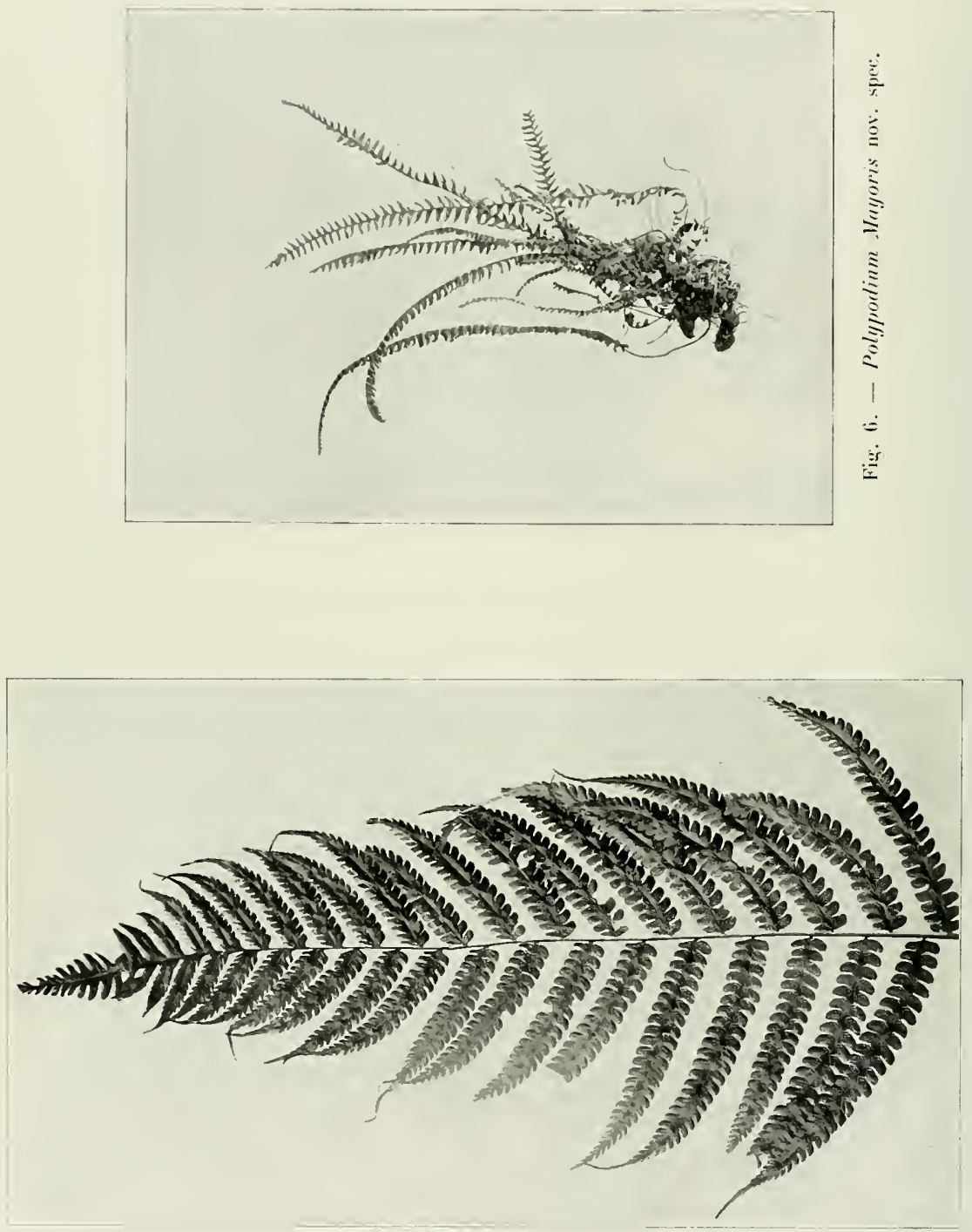


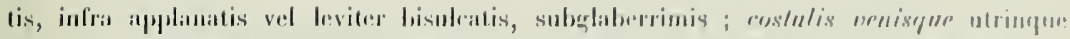

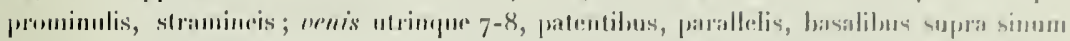

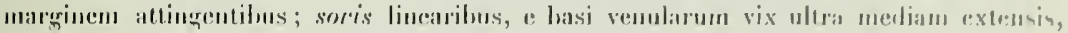
hasalibus anticis sape diplaziondeis exceptis simplicilus; indnsies magnis, lirmis, integerrimis.

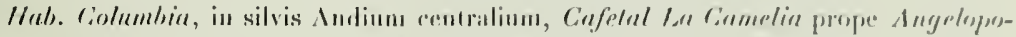

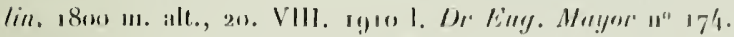

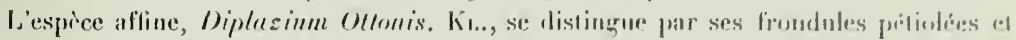
moins profondément incisies, par le nombre moins grand des nervares latérales, par son indusium plus faible ainsi que par ses costule's mon denties.

\section{Polypodium Mayoris nov. spec.}

(1'tancle $1 \mathrm{~V}$, lieg, 6)

Eupolypodinm, rhizomatr lreviter repente, ramoso, radiculoso, preleis rufudulis, lineari-lancolatis, longe acuminatis, pilis albidulis, patentibus, margine cilialis, forso parum pilosulis, 5-6 mm longis, $1 / 2$ mm latis dense vestito; frondilus numerosis, pendentibus; stipitibus dense lasciculatis, and $10 \mathrm{~cm}$ longis, llexnosis, sul, apice saepe treniculatis, pilis hrevilus, vix $1 / 2 \mathrm{~mm}$ longis, strictis, recte patentilus, hirto-lomentosis, pilisque aliis mollibus, longioribus (ad $21 / \mathrm{g}-3 \mathrm{~mm}$ longis) plus minusve dense hirsutis ; laminis e basi vix angustata lineari-lanceolatis, acuminatis, $20-25 \mathrm{~cm}$ longis, 2 cn latis, subcoriaceis, pilosis, llavescentibus, deorsum pinnatis, ceterun profundissime pinnatificlis; segmentis numerosis, alternis, subrecte patentibus, strictis vel ob marginem posteriorem in sicco sapissime revolutum) arcuato-incurvatis, sessililms, medialibus maximis c. I cm longis, $4 \mathrm{~mm}$ latis, c basi inatuali (superiore parum contracta, suhrolundala, inferior" dilatata, decurrente) linearibus, acutis vel obtusiusculis, margine subintegrerimis vel leviter crenatis, superioribus sensim decrescentibus; thachibus teretibus vel supra parenchymate tectis, utrinque pilosis; cos/is supra prominulis, suhtus plerumque immersis. cun venulis luce transmissa subconspicuis, glaberrimis; venulis lateralibus c. 6-jugis. omnibus e media vel paullo infra mediam furcatis, ramis late divergentibus, ramo anteriore abbreviato soriferis; soris supramedialibus, c. 5 in utroque latere.

Hab. Columbia, Andes centrales (Antioquia), Parano de Ruiz, circa 370u m. alt.. ad arborum truncos vefustos, 5. X. 1910 1. Dr". Eng. Mayor n" 6g.

L'espece très voisine, Polypodim semiadnatum $\mathrm{H}_{\mathrm{k}}$, se distingue par ses segments plus courts toujours nettement séparés et la plupart un peu décurrents, ainsi que par la villosité differente des pétioles. 


\section{Polypodium angustifolium $\mathrm{Sw}$. var. heterolepis nov. var.}

(Planche $v$, fig. 7 )

Varietas magna (foliis ad $80 \mathrm{~cm}$ longis, $2 \mathrm{~cm}$ latis), rhizomate valde ablireviato et incrassito, paleis qnam in typo c. 3-plo majorilus (7 mm longis, I $\mathrm{mm}$ basi latis), confertissimis, patentibus a typo diversa.

IIab. Columbia, Indes centrales, cafetal La Camelia prope urben Angelopolin. 20. VIII. rgio 1. Dr Eng. Mayor n ${ }^{0} 140$.

\section{Gymnogramme antioquiana nov. spec.}

(Planche V, fig. 8)

Eugymnogramme, rhizomate repente, abbreviato, pilis articulatis rufis dense vestito; stipitibus fasciculatis, basi curvatis, ad $4 \mathrm{~cm}$ longis, cum rhachibus rufo-fuseis, leviter rugulosis, furfuraceis pilisque articulatis, griseis, persistentibus dense velatis; laminis e basi ovata lanceolatis, versus apicem longe attenuatis, rigide membranaceis, utrinque hispidis, subbipinnato-pinnatifidis ; pinnis infra apicem pinnatifidum c. I5-20-jugis, contiguis, sepius imbricatis, suberectis, breviter petiolatis, ad $2 \mathrm{~cm}$ longis, $3 / 4 \mathrm{~cm}$ latis, oblongo-lanceolatis, obtusis, ad alam angustam pinnatifidis vel infra pinnatis; pinnulis seu segmentis pinnarum inferiorum 8-jugis, contiguis, ollongis, obtusis, pinnatifidis; lacinuis in utroque latere $2-3$, brevibus, linearibus, apice $\mathrm{x}-2$-ies inciso-erenatis, crenis emarginatis; venis pellucidis, marginem attingentibus; soris linearibus, ad venas longe decurrentibus, pilis paucis sporangiis intermixtis.

Ilab. Columbia, in silvis Andium centralium (Antioquia), Alto San?Miquel, eirea $2300 \mathrm{~m}$ alt., 26. IX. 19ro I. Dr Eug. Mayor $\mathrm{n}^{0} 82$.

Espèce voisine de Gymnogramne hirta KLF, mais plus petite et plus brièvement pétiolée en comparaison de la longueur des limbes; le pétiole et le rachis sont plus densément velus, le limbe est plus étroit et étiré en longue pointe ; elle est diviśe à un moindre degré et tous les segments sont plus denses.

\section{Gymnogramme fumarioïdes nov, spec.}

(Planche VI, fig. 10)

Eugymnogramme, rhizomate erecto, paleis e. $1 / 2 \mathrm{~cm}$. longis, $\mathrm{r} 1 / 2 \mathrm{~mm}$. basi latis, lanceolatis, integerrimis, llavidis, llaceidis apice vestito; stipitibus c. $35 \mathrm{~cm}$. longis, $2 \mathrm{~mm}$. crassis, ereetis, strictis, purpureo-castaneis, nitidis, glaberrimis, basi interdum albo-cereaceis; laminis elongato-ovatis, apice angustatis, membranaceis, olivaceo-viridibus, parce pilosulis, usque ad $45 \mathrm{~cm}$. longis, $25 \mathrm{~cm}$. latis, 5-pinnatis; pinnis $12-15$ 
PLANCHE V

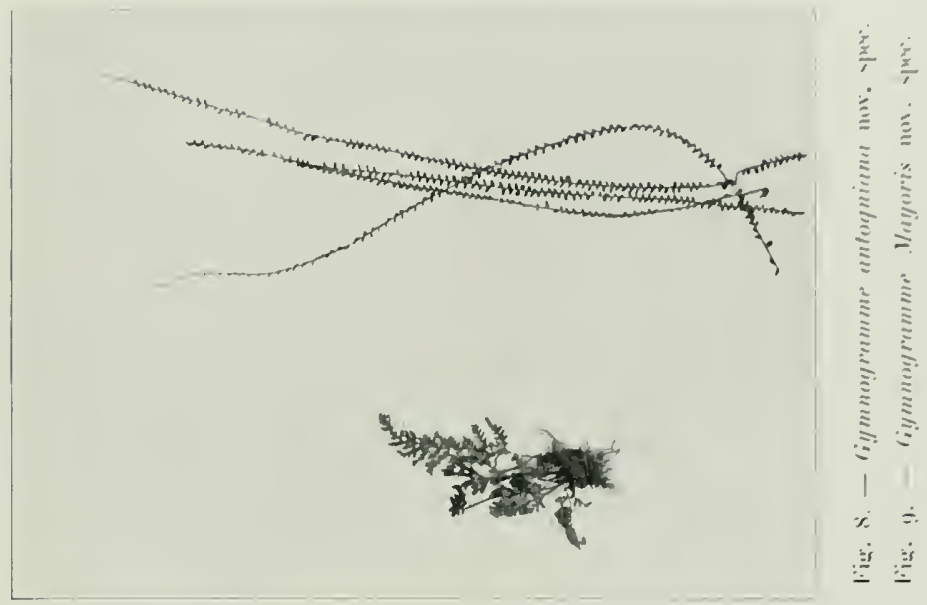

$\ddot{x}$

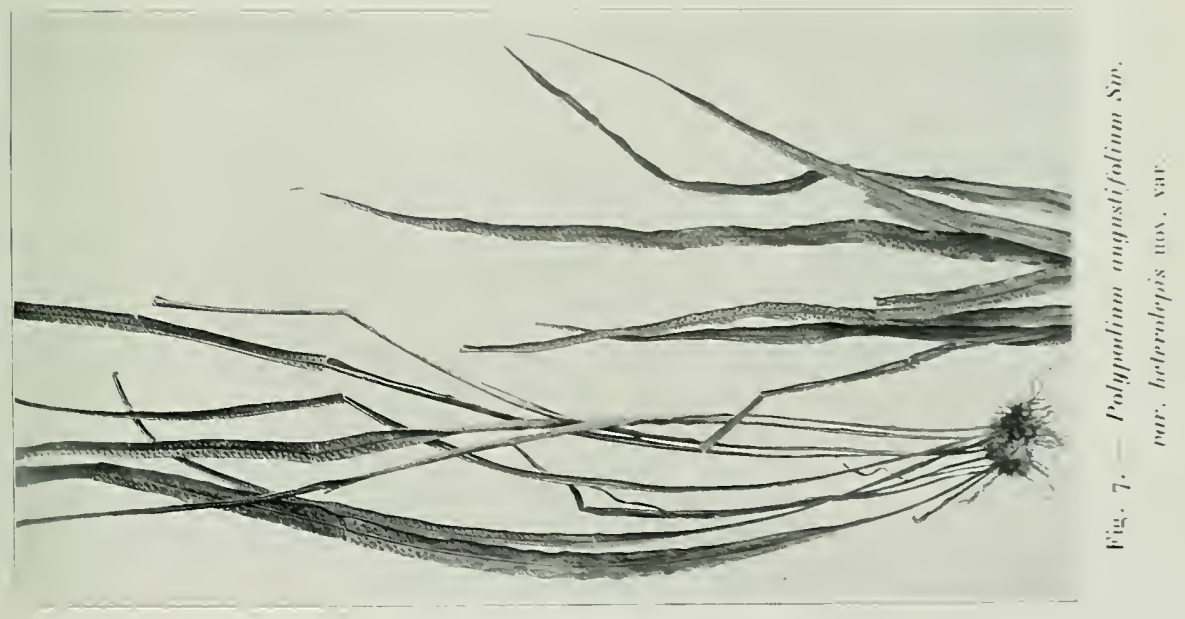





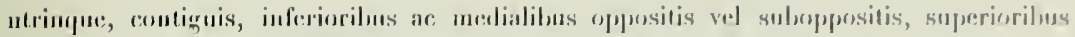

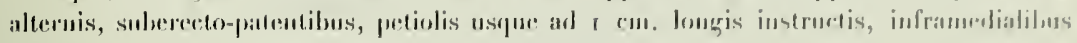

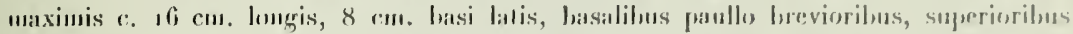
sensim diminutis, in apsicem angustato-lancenlatum, demum tobalum transemulilus;

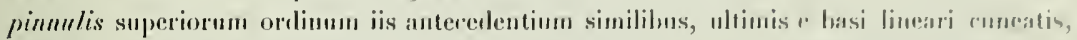

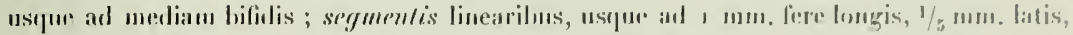

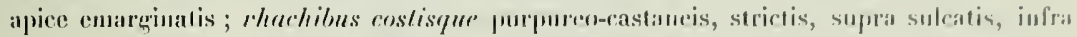
teretibus, apicem versus anguste margiualis, glaberrinis ; costulis superiornm oroliumm fotis anguste marginatis; vemnlis in segunentis ultmis solitariis; soris olylongic, lorevilus, paucis sporangiis compusitis.

IIal, Columbin, in Andilus centralilus, prope Lanuman infra Medillin sitan, circa 2300 m. alt., 8. VIII. чgro I. Dr. Eug. Mroyor No 1/1.

Espece inferméliaire eute G. schizophilla Bk., qui a la tige plus courte et la

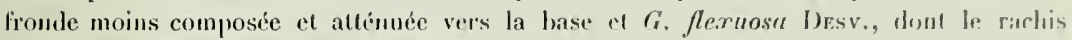
est Iroxueux et les lobes plus larges.

\section{Gymnogramme (Jamesonia) Mayoris nov. spec.}

(Planche V, tig. 9)

Jamesonia, whizomate repente, ramoso, pilis rufo-ferrugineis, articulitis, flexursis vestito ; stipitibns $2-8 \mathrm{~cm}$. longis, $1 / \mathrm{g} \mathrm{mm}$. crassis, Hexuosis, atropurpureis, sparse pilosis, mox glabrescentibus, nitidis; laminis anguste linearibus, basin versus sensim angustatis, apice revoluto, indefinito, maximis ad $60 \mathrm{~cm}$. longis, $1 / 2 \mathrm{~cm}$. latis, pinnatis ; pinnis numerosis (usque ad 200 vel ultra), subapproximatis (nec contiguis), alternis, breviter petiolatis, subdeflexis, coriaceis, olivaceo-viridibus, supra pliis brevibus, linearibus, unicellularibus, adpressis ornatis, subtus leviter tomentosis, marcine dentato, non attenuato, valde revoluto, inde concavis, c. $3 \frac{1}{2} \mathrm{~mm}$. longis. $2 \mathrm{~mm}$. vel paullo ultra latis ; rhachibns pilis articulatis, mollibus, ferrugineis supra densius, subtus minus dense restitis, subasperulis ; venis pinnatim dispositis, furcatis et simplicibus. ramis ro- 13 marginem attingentibus; soris confluentibus, pilis sporangiis intermixtis nullis.

Hab. Columbia, in Andibus orientalibus (bogolensibns), Paramo de Crnz lierde, $3500 \mathrm{~m}$. alt., ז5. X. г9ı I. Dr Eng. Mayor No 74.

Cette espèce est très roisine de Gymnogramme scalaris (lize), qui s'en distinque par son pseudoindusium fréquemment garni de glandes globuleuses et jaune d'or ì la face supérieure des frondes et à la face inférieure par des poils entremèlés aux sporanges. Gymnogramme glabra Hieron et $G$. glutinosa (Karst), ne possident pas de poils comme notre espèce, mais s'en distinguent entre autre par le rebord des frondes en forme d'indusium. 


\section{Lycopodium Mayoris nov. spec.}

(Planche VI, fig. 1 i)

Lycopodium, cruli longe repente, sparse foliaceo, 3 mm. vel ultra crasso, ramoso; ramis adscendentibus, ad $25 \mathrm{~cm}$. longis, inaqualiter 2-5 dichotomis ; ramulis curvatis, flexuosis, subdense foliosis ; foliis ollique verticillatis, 8-10-finris, late viridibus, rigidis, arcuato-adscendentibus, lineari-linceolatis, apice acuminato, pilifero (pilis deciduis), margrine integerimis, dorso olscure carinatis, basi longe decurrentibus; amentis sessilibus, simplicilus vel $x-2-$ dichotomis, $3-6 \mathrm{~cm}$. longis ; bracteis late deltoidcis, margine scarioso lacerato-denticulatis, breviter acuminatis.

Hab. Columbia, Andes orientales, Paramo de Cruz Verde, supra urbem Bogota, circa 2900 in. alt., 15. X. 1910 I. Dr Eug. Mayor No 17.

Diffère de Lycopodum clavatum L. par ses épis sessiles; de Lycopodium contiguum KL. par son port plus làche, le fait que ses rameaux ne sont pas dressés mais plus ou moins ixcurvés et llexueux, ainsi que par ses feuilles écartées. 




\title{
B E I'TRA G
}

7111

\section{Kenntnis der Flechten von Kolumbien}

\author{
VoI
}

\author{
PROF. Dr G. LINDAU, BERLIN
}

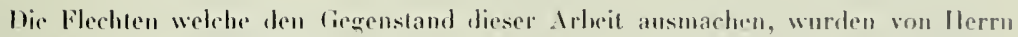
Dr Eug. Mron ant einer Reise in Kolmmbirn gesmmelt und mir fremullishst zur Brarberitung ïhergeben.

\section{Dermatocarpaceae.}

1. Dermatocarpon miniatum (L.) Maxx Lich. Bohem. (fi, - Id sixa eranilosa,

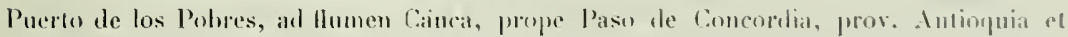
Catuca, alı. $720 \mathrm{~m}$. (No 100$), 6$. 1X. 1910.

\section{Sphærophoraceae.}

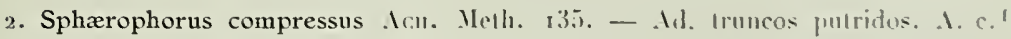

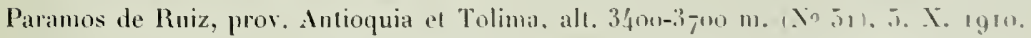

1. 1. c. = Anles centrales. - I. nr. - Indes orientales.

s 


\section{Diploschistacex.}

3. Diploschistes scruposus (L.) Nons. Conat. pram. 20. - Id teram. 1. c., Mlto Romeral inter Medellin et Ingedopolis, prov. Intioguia, alt. $2500-2800$ m. (No 27), 20. IX. rgar. - A. or. Ad Buca del Monte prope Madrid in Sabana de Boguta, prov. Cundinamarca, alt. 2600 in. (. . 37 ), 19. X. 1910.

\section{Lecideaceæ.}

4. Lecidea (Biatora) Mayori nov. spec. - Crusla alba, eflusa, tenuis, laevis vel subverrucosa, continua. Apothecia numerosa, ${ }^{3} 4^{-1}$ 1/4 mm. lata, juniora rubrofusca, margine thallodino albo, adulta nigrofusea, margine thathodino evanido, hiatorino obscuro, angusto, disco demum convexo. Asei apice rotundati 12-16 \%. crassi, 8 spori. Spora ellipsoider, siepe subirregulares, $13-15,5 \times 5,5-6 \mu$, hyalinie. Parapliyses lyalina, apice epithecium subfuscum formantes, tentes, filiformes, apice vix davate. Pycnidia non visa.

Ad terram et supra lapides in regione culta Cifetal La Canelia prope Angelopolis, prov. Antioquia, alt. $1800 \mathrm{~m}$. (No 78$), 2.1 \mathrm{X}, 1910$.

Der Thallus überzieht lehmige Erde und schmiegt sich allen Unregelmässigkeiten vollkommen an. Die last rein weisse Farbe macht ihn sehr aulfïllig. Je nach der Beschaffenlıeit des Untergrundes ist die Oberfläche glatt oder körnig oder warzig. Die Dicke ist ziemlich verschieden, an meinen Schnitten habe ich von 120-200 $\mu$. gemessen. Die Oberseite wird nicht durch eine feste Rindenschicht abgeschlossen, sondem das Hyphengewelse endet frei und zeigt oben höchstens Ansälze einer Verwitlerungsschicht. Das ganz farblose Plectenchym des Thallus zeigt sich selır feinmaschig, so dass es fast paraplectenchymatisch erscheint. Indessen sieht man an einzelnen Stellen auch melir strangartige Partieen. Die Dicke der Ilyphen schälze ist auf höchstens $1,5,0$. Die Gonidienschicht zejgt, wie bei den meisten krustenflechten, keine ganz regedmässige Lagerung, sondern weist Lïcken auf oder zicht sich nach olen oder unten weiter in den Thallus linein. Die grünen Pleurococcusgonidien erscheinen meist dichl gelagert, nur selten lockert sich das Gefü̈ge an den Ränder etwas.

Die Apothecien stehen ziemlich regelmässig, elwas in . Mbstäuden von $1-2 \mathrm{~mm}$. auf dem Thallus verteilt und treten als hellbräunliche bis dunklere Warzen hervor. Die jüngsten erkennharen Starlien stellen winzige Erhı̈hungen dar, in deren Mitte ein kleiner sternförmiger Riss auftritt. Der Riss erweitert sich und die vergrösserte Anlage lässt dann deutlich die Scheibe erkennen. Diese ist zuerst lıellyrann gefärbt und von einem ziemlich dicken weissen Lagerrand umgehen. Mit der Vergrösserung des Apothecimms 


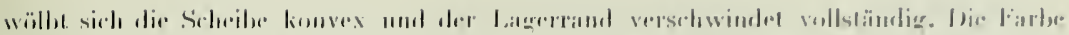

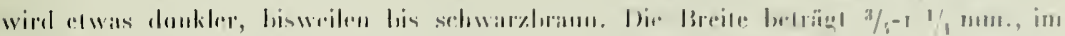

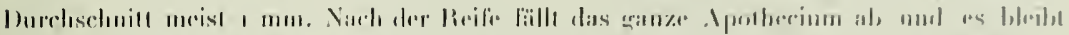

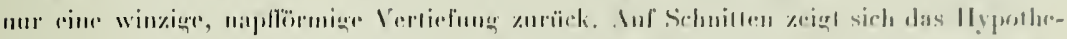

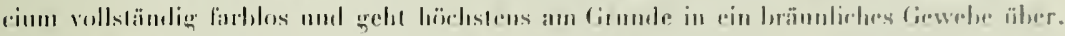

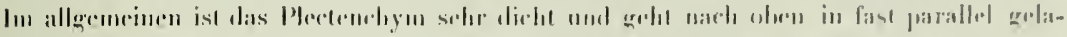

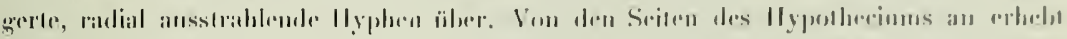

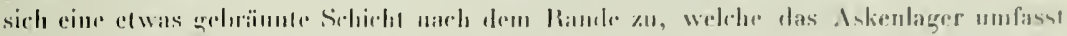

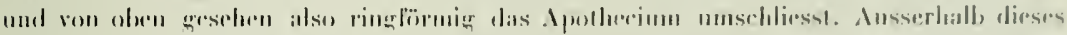

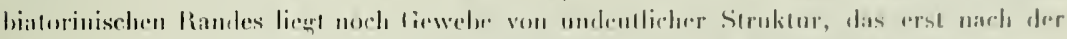

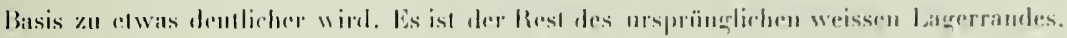

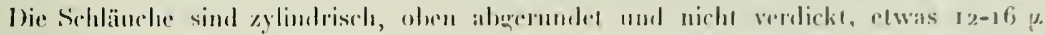

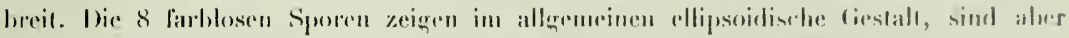

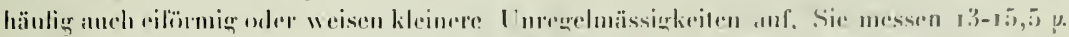

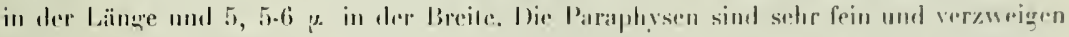

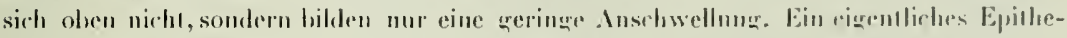

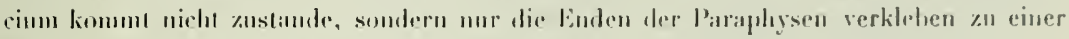
bräunlichen, durch Kali leich lrenubaren Sidhicht.

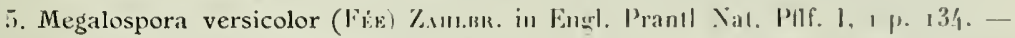

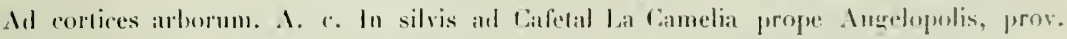

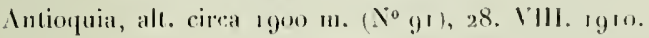

\section{Cladoniaceae.}

6. Bromyces roseus l'ens, in Lster. Ann. d. Bot. 111. 19. - Ad terram, .1. c. 1l1n

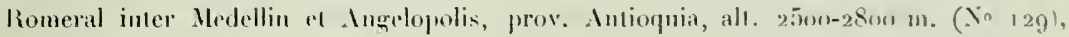
20. IX. 19 to.

7. Cladonia rangiferina (L.) Wels. in Wigr. Prim. Fl. Hols. 9o. - Mt terram calcarram. A. or. Paramo Cruz Virde supria Bugola, pros, Cundinamarca, all, circa $3300 \mathrm{~m}$. (No 41), 15. Х. 2910.

8. Cladonia pycnoclada (Favb.) Nrı. $x$ flavida WAs. Mon. Clad. I. 38. - Id

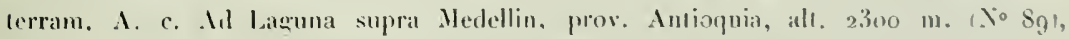
8. 1711. 1910.

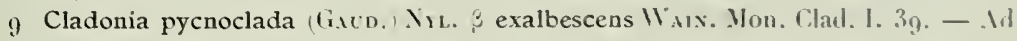

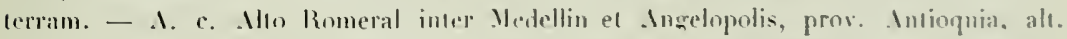
2500-2800 m. (No 120), 20. IX. 1910. - . . C. Ad Laguna supral Medellio. prov, Intioquia, aht. $2300 \mathrm{~m}$. (No 89$)$, \&. 1 1111. 1910.

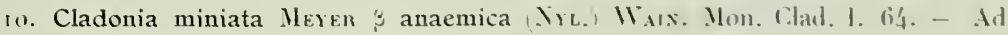


fertam calcarean. A. or. In parte oredentali Paramo de Alto Angarillo prope Silzate in Salbana de Bogota. prox. Cundinamarea, all. circa 3oro m. (No 3), 23. Х. 1910. - A. or. l'aramo Cruz Verde supra Bogota, prov. Cundinamarea, alt. cirea 3300 m. (No 4), 1.. X. 19)10. - A. c. Parmos de Ruiz, prox. Intioquia el Tolima, alı. 3000-37vo m. (No 30), 5. X. 1910. -- A. r. Alto Roncral inter Medellin et Angelopolis, prov. Antio-

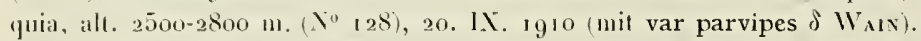

11. Cladonia miniata Meyen $\delta$ parvipes W WMN. Mon. Clad. I. 66. - Mil terram. A. c. In partem superiorem vallis lluv. Porce, ad meridiem versus Mlto San Mignel, prov.

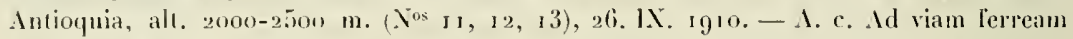

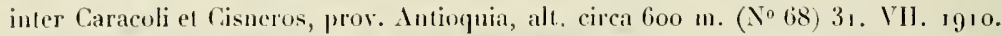

12. Cladonia miniata Mereu $\varepsilon$ secundana (Nir.) Was. Mon. Clad. 1. 67. $-\lambda d$ terram. A. c. In regione culta prope Cafelal La Camelia ad Angelopolis, prov. Antioquia, alt. 1800 m. (No 77), 2. IX. 19$) 10$.

13. Cladonia macilenta Hofrм. \& squamigera Was. Mon. Clad. I. 1og. - Ad terram et truncos putridos. A. c. Ad Laguna supra Medellin, prov. Antioquia, alt. $2300 \mathrm{~m}$. $\left(N_{0} 82\right), 8$. VIII. I910. - A. r. Nto Remeral inter Medellin el Angelopolis, prov. Antioquia, alt. $2500-2800 \mathrm{~m}$. (No 122$), 20.1 \mathrm{X} .1910$.

14. Cladonia reticulata (Russ.) W Wan. Mon. Clad. I. 280. - Id terram. 1 or. Paramo Cruz Verde supra Bogola, prov. Cundinamarca, alt. circa 3300 m. (No 34), I5. X. 1910 .

15. Cladonia squamosa (Scor.) Horru. muricella (Deq.) Wais. Mon. Clad. I. 43 j. - Ad terram. Puerto de los Pobres ad Ilumen Cauca, prope Paso de Concordia, prov. Antioquia el Cauca, alt. $720 \mathrm{~m}$. ( $\left.\mathrm{N}^{0} 75\right), 6$. L. $19^{10}$

16. Cladonia degenerans (F $F_{L K}$.) Sru. f. cladomorpha (AGH.) W Wun. Mon. Clad. II. 141. - Ad terram. A. c. Alto Romeral inter Medellin et Angelopolis, prov. Antioquia, alt. $2500-2800 \mathrm{~m}$. ( $\left(\mathrm{N}_{0} \mathrm{I}_{2} 3\right)$, 20. IX. 1910.

17. Cladonia degenerans (FLK.) SPR. f. phyllophora (Elıh.) Flot. Wainio Mon. Clad. II. 14r. - Ad truncos putridos el ad terram. A. c. Prope Laguna supra Medellin, prov. Intioquia, alt. $2300 \mathrm{~m}$. ( To $^{\text {8 }} 1$ ), 8. VIIl. 3910.

18. Cladonia verticillaris (RADD) Fr. Lich. eur. ref. 465 . - $\lambda$ d. terram et truncos putridos. A. c. Alto San Mignel in valle fluv. Porce, prov. Antioquia, alt. circa $2500 \mathrm{~m}$. (Nos 9, 48), 26. 1X. 1910. - - or. Boca del Monte prope Madrid in Sabana de Bogota, prov. Cundinamarca, alt. $2600 \mathrm{~m}$. (No 20), 19. X. 1910. - \. or. Paramo Gruz Verde supra Bogota, prov. Cundinanarca, alt. circa $3300 \mathrm{~m}$. (No 42), 15. X. I910. - A. c. Inter Angelopolis et firaca, prov. Antioquia, alt. circa $1400 \mathrm{~m}$. (No $\left.7^{2}\right)$, 11. IX. rg10. A. c. In silvis supra Caletal La Camelia prope Angelopolis, prov. Antioguia, alt. circa 2000 m. (No 95$), 2$ IX. Igro. - A. c. Ad saxa in pratis prope El Poblado supra Medellin, prov. Antioquia, alt. circa $1700 \mathrm{~m}$. (. $\left.\mathrm{N}^{\circ} 97\right)$, 14. VIII. 1910. - A. c. Alto Romeral inter Medellin et Angelopolis, pros. Antioquia, alt. $2500-2800 \mathrm{~m}$. (No 124), 20. IX. I910. 19. Cladonia pyxidata (L.) FI, $\alpha$ neglecta (FLK.) MAss. Sched. cril. 2. - Ad ler- 


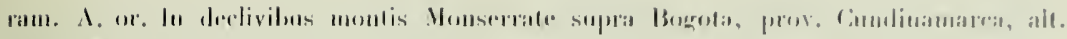

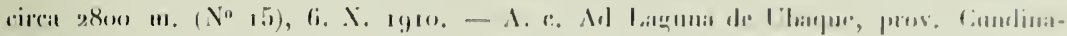

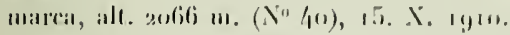

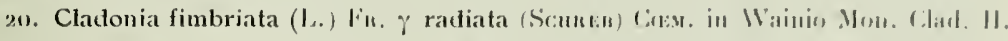

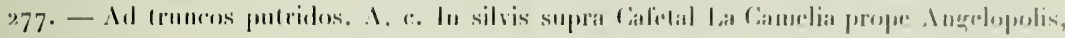

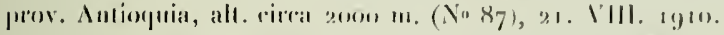

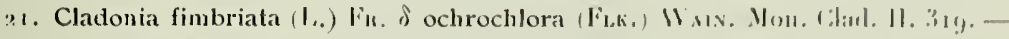

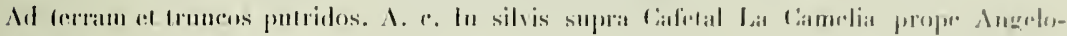

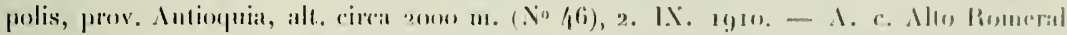

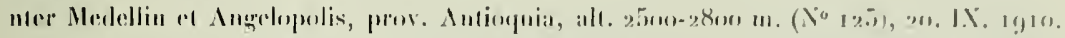

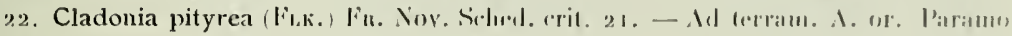

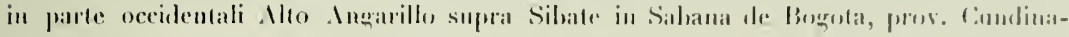

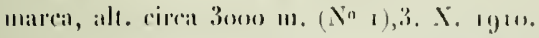

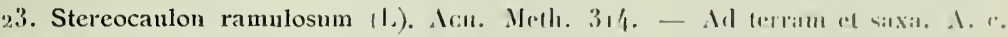

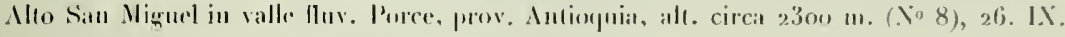

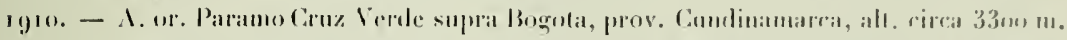

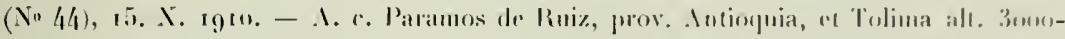

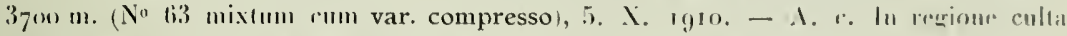

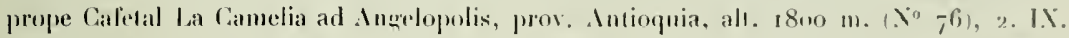

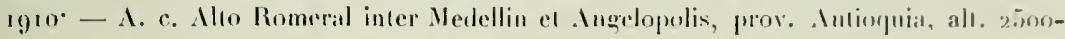
$2800 \mathrm{~m} .\left(\mathrm{N}^{\circ}+15\right), 20$. IX. 1910.

24. Stereocaulon ramulosum (L.) Acu. var. compressum Baн. Х. Keal. 3n. Ad terran et saxa. A. or. Paramo Cruz Verde supra Bugula, prov, Cundinamarea, alt. circa $3300\left(N^{\circ} 33\right) 15$, Х. 1910.

25. Stereocaulon violascens Mäll. Irg. in Rev. myc. I. 16\%. - Md terran calcalreau. А. or. Paramo Cruz Virde supra Bogota, pros. Cundinamarea, alr. circa $3300 \mathrm{~m}$. (No 43), 15. Х. 1910.

\section{Collemataceæ.}

26. Leptogium chloromelum (Sw.) Niz. Syn. I. 128. - Id truncos pulridos et saxa. A. or. Boqueron de Cinachuni smpra vallem Vioha, prox. Cumblinamarca, alt.

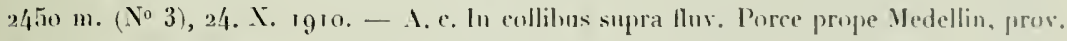

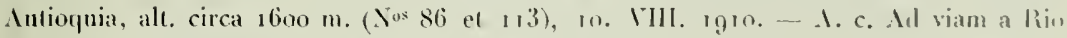
Amaga ad Cafctal La Hermosa prope Angelopolis, pros. Antioquia, alte circa inon m. (No 88), 26. V111. 1910.

27. Leptogium azureum (Sw.). Mont. Cub. 114. - Id sixa el truncos puntridos. A. or Prope Tequendama, prov. Cundinamarea, all, circa 230n m, 1.056, 32. 12. X.

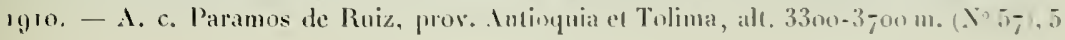


X. ıg10. - - . . Ad colles supra America prope Vedellin, prov. Antioquia, alt. rirea $1700111 .\left(N^{0} 80\right) .15 .1111 .1910 .-$ - A. c. In silvis supra Cafetal La Camelia jrope Ange-

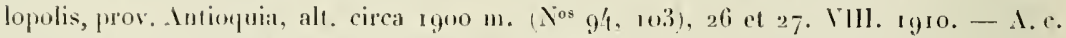
P’ope Laguna supra Medellin, prov. Antioguia, alt. 2300 m. (No r 17 ), 8. VIll. 1910.

\section{Pannariaceae.}

28. Coccocarpia pellita (Acır.) Müıt. Arg. Liclı. Beitr. \{21. - Id truncos arbołıu. A. c. In collibus supra llus. Porce prope Mectellin, prov. Antioquia, alt. cirea $1600 \mathrm{~m}$. (No 84$)$, 10. 1111. ig 10.

\section{Stictaceae.}

29. Lobaria Fendleri (Mont. et Tuck.) Liudau. - Ad truncos putridos. A. c. Paramos de Ruiz, prov. Antioquia el Tolima, alt. 3400-3700 m. (No 59a), 5. X. 19ro.

3o. Sticta aurata AcIr. Mellı. 277. - Ad terram, saxa truncosque. A. or. Paramo Cruz Verde supra Bogota, prox. Cundinamarca, alt. circa 2800 m. (No 23), 15. А. 1910. - A. c. In collibus supra America prope Medellin, prov. Antioquia, alt. circa $1700 \mathrm{~m}$. (N I02), 15. VIIJ. Igro. - A. c. In colle supra lluv. Porce prope Medellin, prov. Alltioquia, alt. circa $1600 \mathrm{~m}$. (No 114$), 10$. V1ll. 1910.

3ı. Sticta damicornis (Sw.) Acu. var. macrophylla Baв. New-Zeal. 15. - Ad unucos putridos. А. c. Paranos de Ruiz, prov. Antioquia et Tolima, alt. $3000-3700 \mathrm{~m}$. ( Nos $46,59,61), 5$. Х. 19 го.

32. Sticta damicornis (Sw.) Acrl. var. sinuosa (Pers.) Nrt. Syn. 1. 356. - Ad ramos arborum. А. c. Prope Laguna supra Medellin, prov. Antioquia, alt. $2300 \mathrm{~m}$.

16), 8. VIII. I910.

33. Sticta fuliginosa (Dicks.) Acı. Meth. 28ı. - Md terram, saxa lruncosque arborum frequens. $\Lambda$. or. Paramo Cruz Verde supra Bogota, prov. Cundinamarca, alt. $2700-$

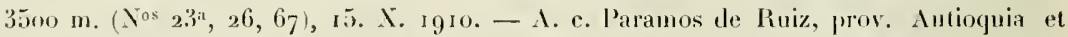
Tolima, alt. 3.300-3700 m. (Nos 56,62), 5. X. 19ro. - $\Lambda$ c. In collibus supra America prope Medellin, prov. Antioquia, alt. $1600-1800 \mathrm{~m}$. (Nos $69,7 \mathrm{r}, 83)$, 10 et r4. Vlll, r9ı. - I. c. In collilius supra fluv. Porce prope Medellin, prov. Antioguia, alt. circa i6oo m. (N 85), ro. VIll. I910. - A. C. In pratis prope El Poblado ad Nedellin, prov. Autioquia, alt. circa $1700 \mathrm{~m}$. ( $\left.\mathrm{N}^{0} 108\right)$, 14. V'lll. 1910. - A. c. In silvis supra Cafetal La Camelia prope Angelopolis, prov. Antioquia, alt. circa rgoo m. (No rï), 21. VIll. I910.

34. Sticta obvoluta Acu. Lich. univ. f.re. - Ad saxa el tmoncos arborum. A. c. Paramos de Ruiz, pror. Antioquia et Tolima, alt. 3300-3700 m. (No 58), 5. Х. 1910. 


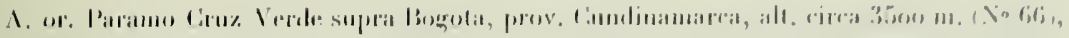

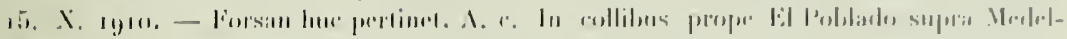

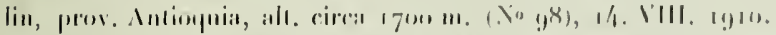

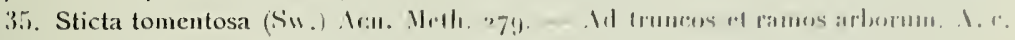

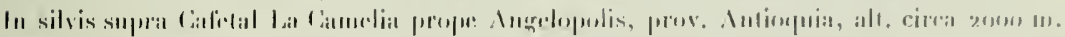

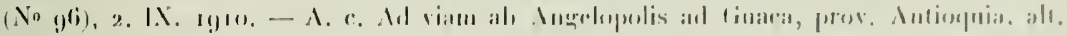

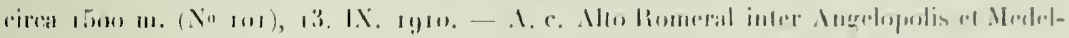

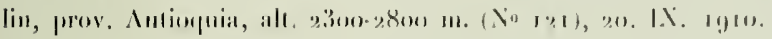

\section{Peltigeraceae.}

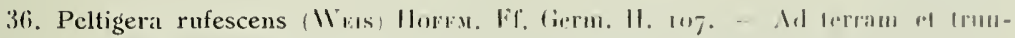

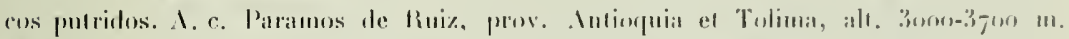

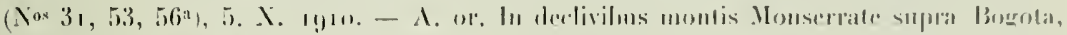

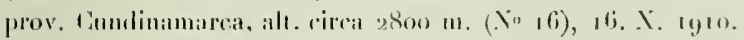

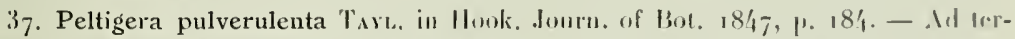

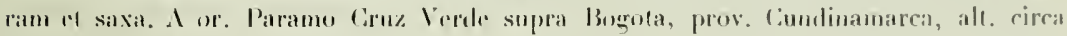
$3500 \mathrm{~m} .(N+35), 15$. . .1910.

\section{Parmeliaceae}

38. Parmelia kamtschadalis (Acır.) Escnw. Brasil, 202. - Wl terram et arloores. A. or. Boci del Monte prope Madrid in Salmani de Bogula, prov. Cumlinamarea, alt.

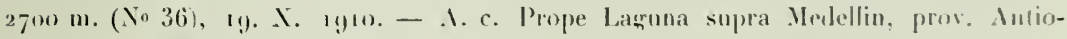

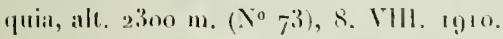

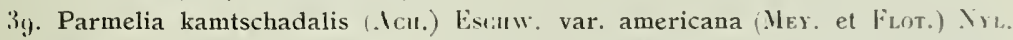
Sin. 1, 387. - M truncos el ramos. A. c. Mlo San Miguel, in superince valle flus. Porce, pros. Antioquia, alt. circal 270n III. (No in). 26. IX. 19to. - A. c. Paramos de

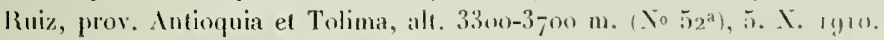

40. Parmelia cervicornis Tuck. in Nyl. Syn. I. 38.5. - M Iruncos el ramos. A. c.

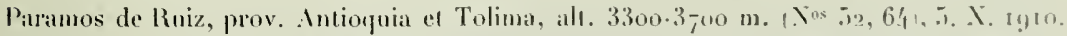
- A. or. Paramo Cruz Verde supra Boggota, pros. Condinamarca, als, circa 35ono un. (No 65), 15. Х. 1910.

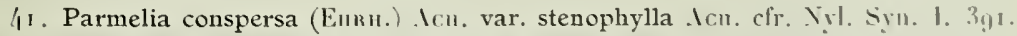
- Ne reram. A. or. Boca del Monte prope Madrial in Sabana de Bogota, pror. Cumdinamarea, alı. $2700 \mathrm{~m}$. ( No 19), 1!). X. 1 1)

42. Parmelia cetrata Acu. Sin. I!̣s. - Id terram. A. or. Bocil del Yonte prope 


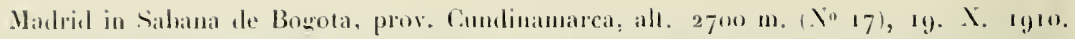

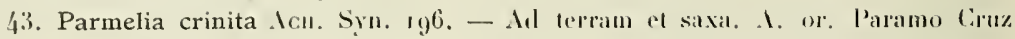

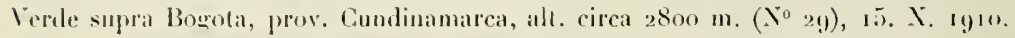

44. Parmelia acanthifolia l'ens. in tiaul. Voy. I ran. 197. - Ad terram el saxa. 1. or. Paramo Cruz Verte supra Bogota, prov. Cundinamarca, alt. circa $2800 \mathrm{~m}$. ( $\left.{ }^{0}{ }_{2} 5\right)$, 15. X. 19to. - A. or. Boca del Nonte prope Madrid in Sahana de Bogota, prov. Cundinamarea, all. $2700 \mathrm{~m}$. (No $18 \mathrm{8})$, r9. X. 1910.

4.). Parmelia revoluta Fek. Deutsch. Lich. n. 15. - Ad truncos arborum. A. c. lı collibus supra America prope Medellin, prov. Antioquia, alt. circa $1700 \mathrm{~m}$. ( $\left.\mathrm{N}^{\circ} 79\right)$, 15. 1III. 1910.

46. Parmelia caperata (L.) Acu. Mellı. 216. - Ad terram. A. or. Boca del Monte prope Madrid in Sabana de Bogota, frov. Cundinamarca, alt. 2700 m. (Nos 18, 38), 19. Х. 1910.

47. Parmelia ciliata. DC. Fl. Frans. II. 403. -- Ad Inucos arborum. A. c. Prope Laguud supra Medellin, prov. Intioquia, alt. 2300 m. (No 74), 8. YIII. 1910.

48. Parmelia perlata (L.) Icı. Metlı. 2 $16 .-$ Ad terram. A. or. Prope Laguna de Lbaque, prov. Cundinamarca, alt. 2066 m. ( \. 39), 15. Х. I 910.

49. Anzia tæniata (Nit.) Stizenb. in Flora r86ı, p. 393. - Ad terram, truncos ramospue. A. or. Paramo Cruz Verde supra Bogota, prov. Cundinamarca, ali. cirea $3500 \mathrm{~m} .\left(\mathrm{N}^{\circ} 45\right) \cdot 15$. Х. 1910.

\section{Usneaceae.}

5o. Alectoria bicolor (Ennн.) Nru. Prodr. 45. - Ad terram et truncos putridos. A. c. Paramos de Ruiz, pror. Antioquia et Tolima, alt. 3300-3700 m. (No 55), 5. X. 1910.

5r. Ramalina yemensis (Acu.) Nru var. Eckloni (SPr.) Wan. Lich. Brés. I. 20. Ad truncos et ramos. A. c. In valle tluv. Porce prope Medellin, prov. Antioquia, alt.

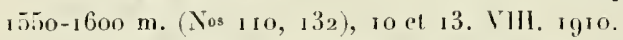

52. Usnea florida (L.) Hofrs. Pant. Lich. t. 3o, fig. 2. - Ad ramos el truneos. 1. c. Prope Laguna sujpra Medellin, prov. Antioquia, alt. 2300 m. (No $\left.118^{a}\right), 8$. 1111. 1910.

53. Usnea ceratina Acı. Lich. univ. 619. - Ad truncos et ramos. A. c. Parranos de Ruiz, prov. Antioquia et Tolima, alt. 3300-37vo m. (No 54), 5. X. 1910. - А. c. In collibus supra vallem lluv. Porce, prope Medellin, prov. Antioquia, alt. circa $1600 \mathrm{~m}$. ( $\left.\mathrm{N}^{0} \mathrm{1} 30\right)$, ro. VIll. Ig10.

54. Usnea articulata (L.) Hoffm. Fl. Germ. 135. - Ad iruncos putridos. A. c. Alto San Miguel, in superiore valle fluv. Porce, prov. Antioquia, alt. circa $2300 \mathrm{~m}$. ( No $\left.49^{\mathrm{i}}\right)$, 26. IX. 19ro. 


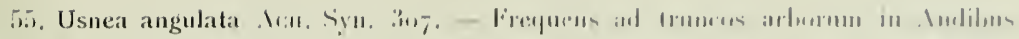

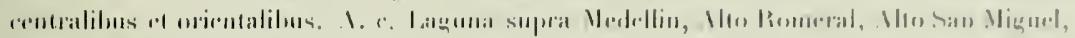

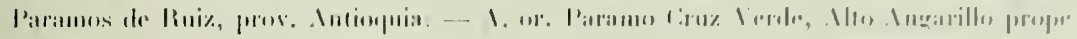

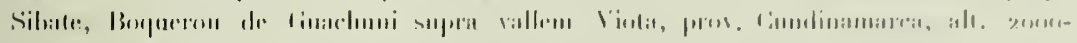
3 3ino in. $\left(\right.$ N $\left.^{0} 701\right)$.

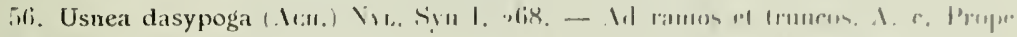

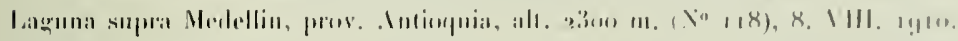

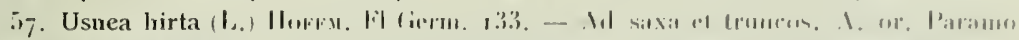

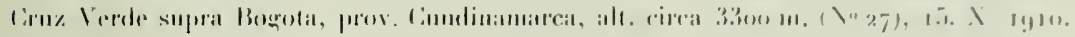

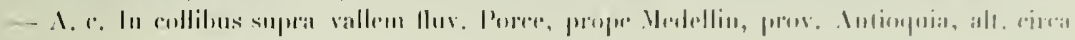

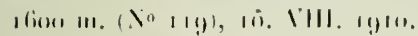

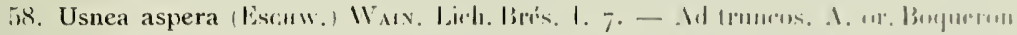

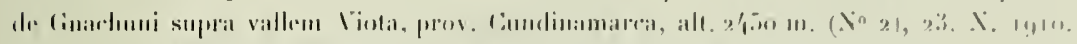

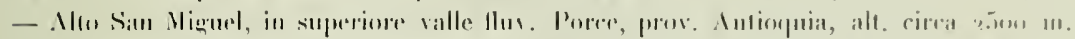

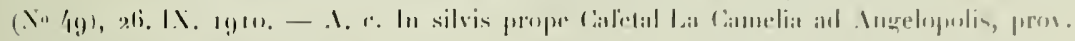

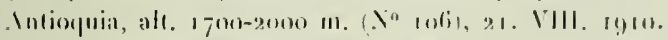

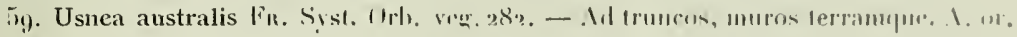

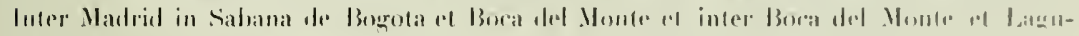

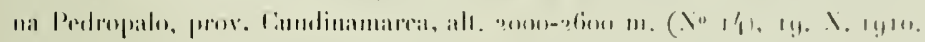

\section{Teloschistacæ.}

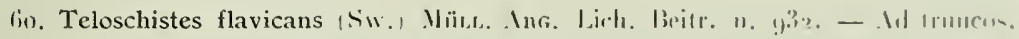

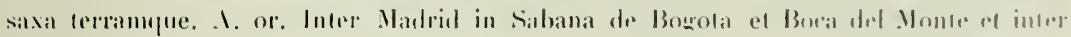

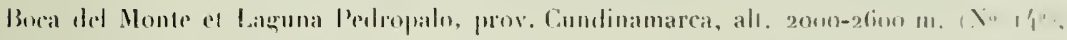

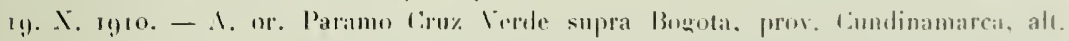
circil 2800 แ11. (.

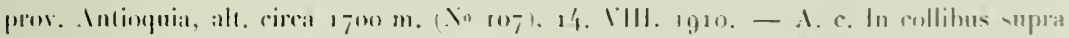

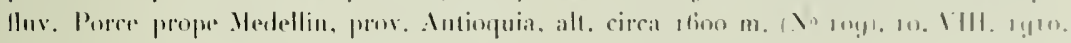

\section{Physciacæ.}

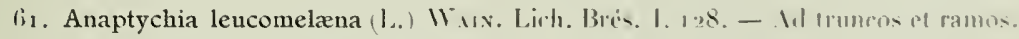

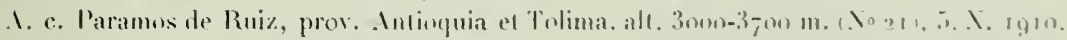

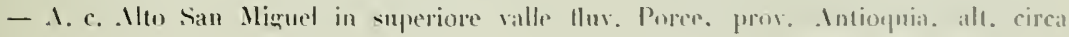

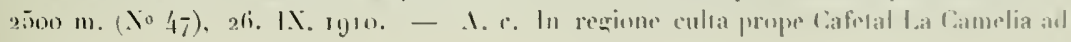




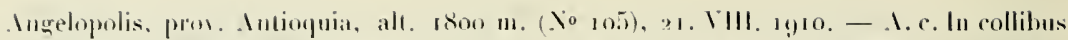

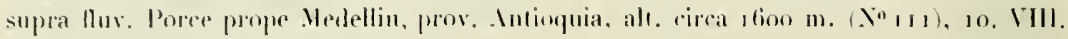
1!) 10.

(i2. Anaptychia comosa (Escuw.) Trev. Flora 18ti1. i2. - . I truncos arborum. 1. a. In collibus supra tluv: Poree prope Medellin, pros. Intionuia, alt. circa tion m.

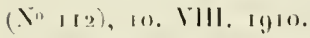

(i3.) Anaptychia speciosa (WULF, W.ux, Lich. Bris. 1, r.35) - Id lmuncos, ranos, silxa trreamque. I. c. In silvis prope Cafetal La Camelia ad Angelopolis, prox. Antioquia,

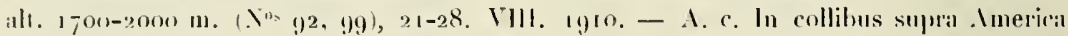

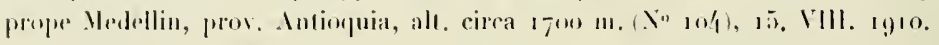

\section{Coraceæ.}

(i/. Cora pavonia (Wen.) Fr. Syst. Orb. veg. 3uo. - Nil lerram el Iruncos putrilos.

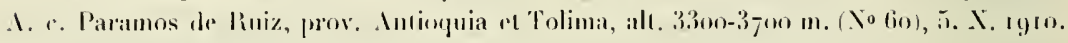




\title{
CON'TRIBU'TION
}

\section{à l'étude des Chilopodes de Colombie}

I'III

\author{
H. RIBAUT, professeur à I'Université de TOULOUSE
}

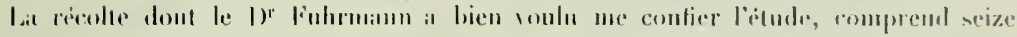

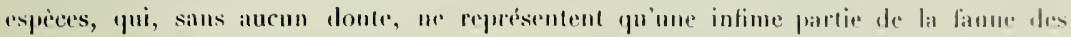

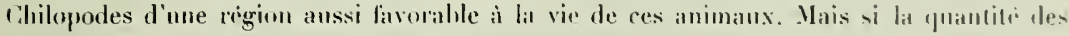

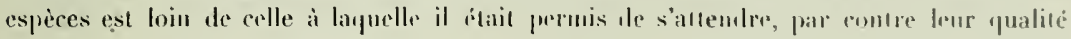
établir une large compensation.

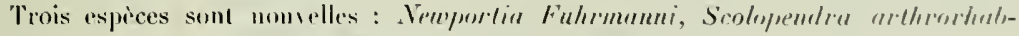

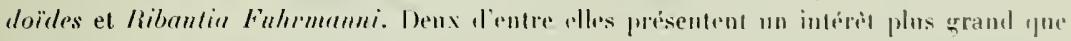
cedui de lemr numeanté:

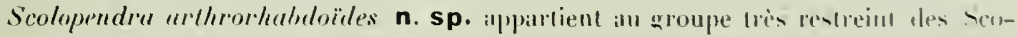

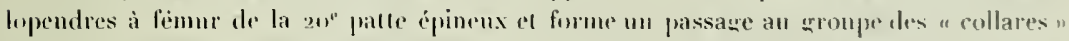

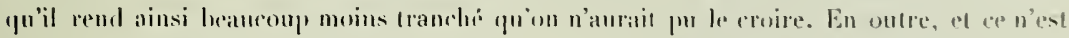

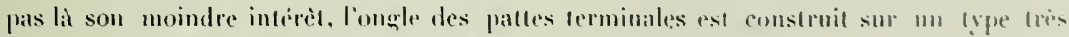
voisin de colui que loon rencontre dians le qenre Artherhabdus.

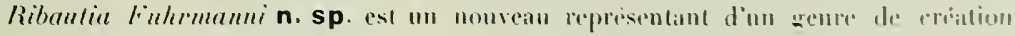
récente dont le maintien ponvait ètre discuti. La défonverte de crefle espèce apporte um argment de plus en faveur dn bien fonde de celle conpe grineripue. Elle ma fourni liscasion de mettre un pen d'ordre dans la sistemalique d'un gronpe d'especes reparties inconsidérément dans des gemres amagnels elles me devivent pas apprartenir.

Une antre espèce déjà conme, mais restéc mustériense à cims de l"insuftisance de

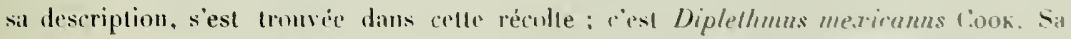

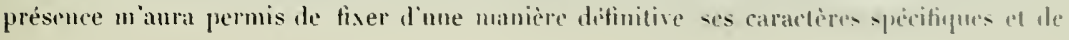




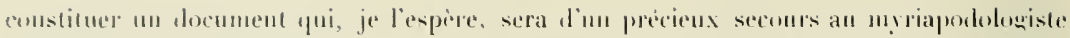

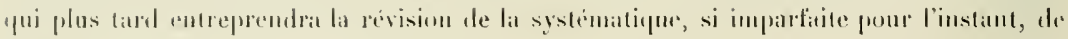
lil sums-fimille des Bullophilime.

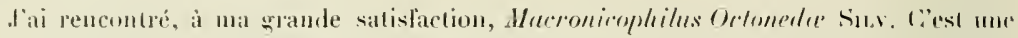

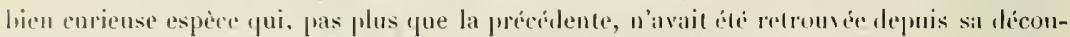
verte. Son auteur, hien qu'en ayant donné une description très driaillée, avait lassst daus

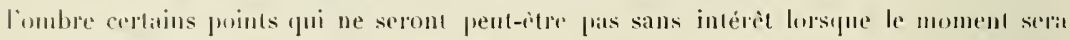
venu de lui assigner sat plare daus la classification des tirophilomorphes.

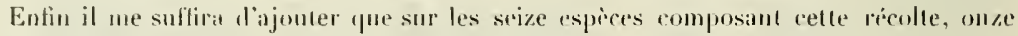
an moins sont nowelles pour la Colombie. Cie sunt:

Trigonocryptops /heringi Bü̈L.

Neuportin Stalli (Poc.).

") pusillum Poc.

" Fuhrmanni n. sp.

"monticole Poc.

Ohustigmuss inermis Por.

Ciupipes limerulus (Newr.).

Scolopendra arthrorhabdoïdes n. sp.

Ribautia Fuhrmanni n. sp.

Macronicoptrilus: Orfoneder Sus.

Diplethmus mexicanus linok.

Treize focalites ont fourni des Chilopodes ; elles sont siluées soil dans les Cordillères centrites, soit dans les Cordilleres oriontales.

\section{Combrlè̀res centrates (roches éruptives).}

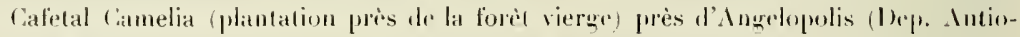
!(uia), $18211 \mathrm{~m}$.

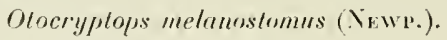

Nenportir pusillum Poc.

Newportia Fuhrmanni n. sp.

Voroporticr monticola Poc.

Olostigmus screbricandus: (11. el Sauss.).

") inermis Pok.

Cupipes linerrlus (NewP.).

Macronicoplitus Ortonedrr Silu.

Diplethmes mericanus Look.

Totiphilides Marcimilimin (II. et Sauss.).

Puerto de los Pobres (sul les loods du Canca) (Dep. Autionuia). 720 m.

Ribautia Fuhrmanni n. sp. 


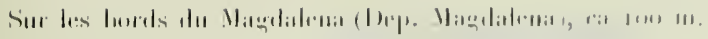

Ribaulia Fubrmammi n. sp.

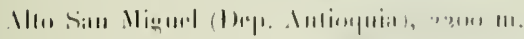

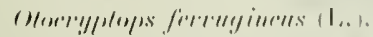

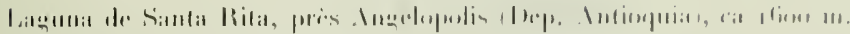

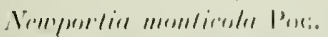

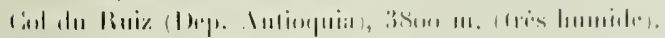

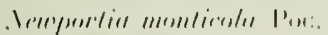

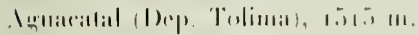

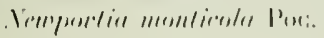

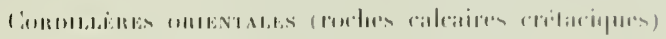

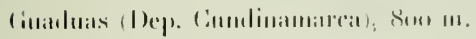

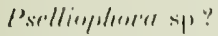

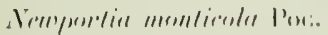

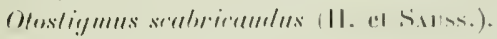

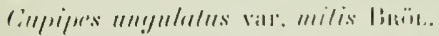

Scolopendra arthrorhabdoides n sp

Ribautia Fuhrmanui n. sp.

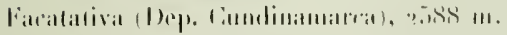

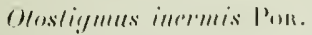

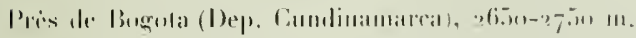

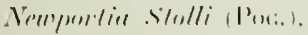

n) fmisillmm l'm:.

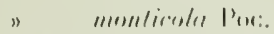

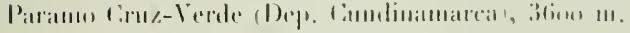

Semperlin fusillum Por.

") monlivelel l'ox:

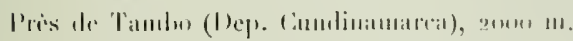

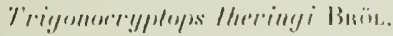

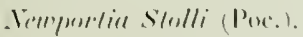

" pmsillmm Pox.

) mernlicolet Poxi.

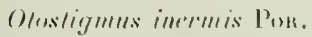

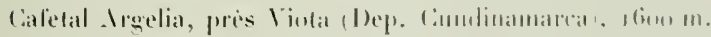

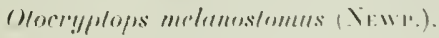

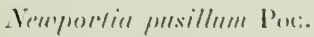

" montivele Pix:. 


\section{Notostigmophora.}

\section{Fam. Scutigeridx.}

\section{Pselliophora sp?}

Entre llonda el (inaluas ICord. or.) ; un seul exemplaire aupuel mampuent les antentes el prestue loutes les pattes. Les caltations lires de lit surfate des tergites ed des hàtonnets de l'orqane auditif permettent de rapporter cotte espree au qeuse Pselliophoru.

Le dos est noir violacé avec une large hande médiane blanche el quelques taches banches le long des bords externes de chaque torgite.

\section{Scolopendromorpha.}

\section{Fam. Cryptopidx.}

\section{Trigonocryptops Iheringi Bröl.}

P'rès de Tambo (Cord. or.), $2000 \mathrm{~m}$.

Un seul individu de $92 \mathrm{~mm}$. de long, anquel manque la $2 \mathrm{~J}^{\text {twe }}$ paire de patles. Je l'ai considéré comme étant un jeune le theringi malegr de nombreuses diffërences. Mais celles-ci peuvent itre attribuces à uı état de jennesse. La principale différence consisfe dans l'absence d'épines bien caratcrisées, sauf pent-ètre sur la zome palle. Partout on la présence d'épines a été indiquée on trouve seulement de longs poils plus robustes at plus colorés que leurs voisins. En outre, l'écusson eéphalique, au lien de recouvrir le bord antérieur du premier tergite, est an contraire recouvert prar lui. II n’y aurait rien d'étonnant à ce que l'on se trouve en présence d'une anomalie, que j’ai, du reste, observéc assec fréquemment chez une de nos especes frangaises Cryptops anomulans.

Les trois premiers tergites sont ilépourvus de stries et de sillons. Le /me an prisente que les deux sillons externes aryués. Du 5.'me an $18^{\text {me }}$, existent les sillons externes. arqués et les sillons internes au fond desyuels se trouve une strie. Le $18^{\text {me }}$ et le $19^{\text {me }}$ ont leurs sillons externes; les sillons internes ont disparu, mais la strie correspondante persiste. Le $20^{\text {me }}$ ne possède que les stries internes. L'espace compris entre les deux sillons externes est déprimé. Le sillon longitudinal des sternites n'existe nettement que dans la partie anterieure el s'arrète brusquement au sillon transierse ; eependant sur quelqurs sternites il se poursuit, mais tris vaguement, an arrière. Les $20^{\text {me }}$ et $21^{\text {mo }}$ sternites sout totalement dépourvus de sillons. Les coxoplenres sont glabres sur la majeure partie de leur surface; i l'angle interne seulement se tronvent quelques poils mbustes at loncés; les pores sont mombreux el sont loin d'atteindre le bord postérienr.

Tous les caracties 'pui onl servi à Vernoerf pour détinir son genre Trigunocryplops sont très nettement représentés chez ent individu. 


\section{Fam. Newportiida.}

\section{Newportia Stolli (Poc.).}

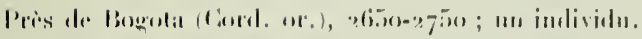

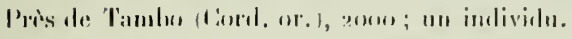

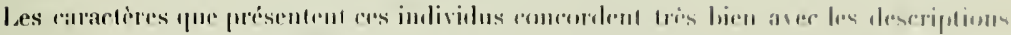

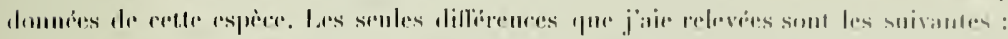

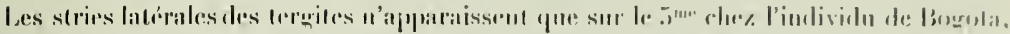

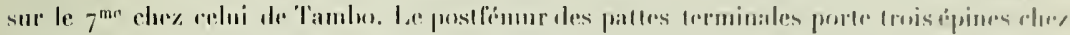

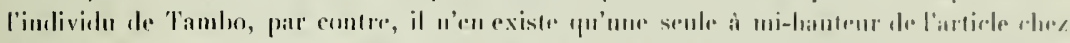

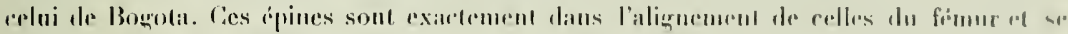

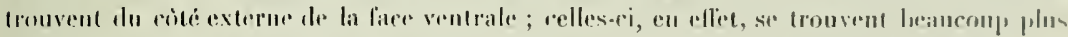

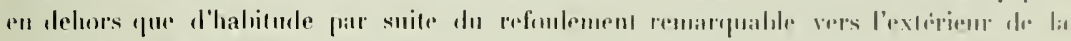
arine ventrala du fésnur.

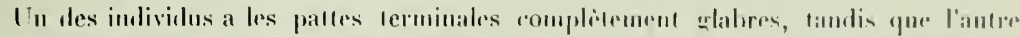

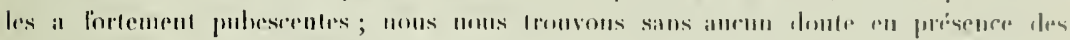
dens seses.

\section{Newportia pusillum Poc.}

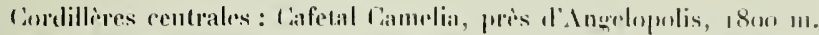

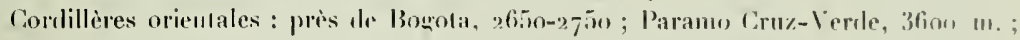

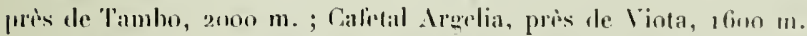

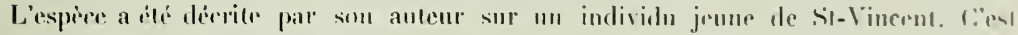

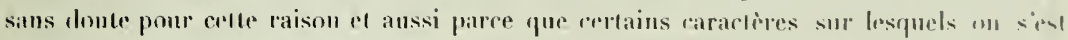

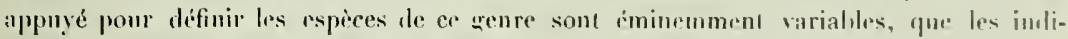
vidus de Colombir, dont il est question iri, ne concorent pas ahsolument aser lin less-

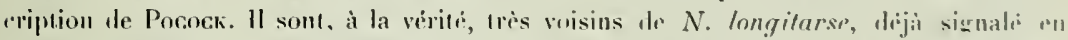

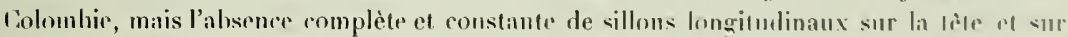

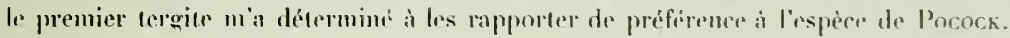

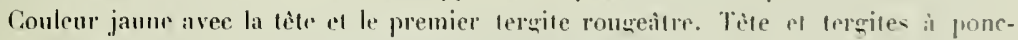

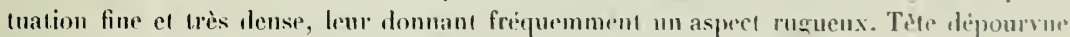
de stries longindinales; il nen existe meme pas de puliments at lis partir postrienur. Prensier tergite are une strie transwersale artpuie, mais sans trace de sfries longitudinales. Stries longitudiuales midian's romplites sur lo deuxieme terwite, mais génerale-

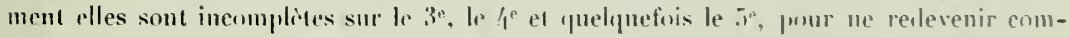

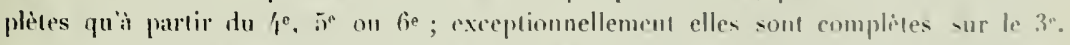
Le milieu du dos est sonlevi en une carène très prononece surtout dans la moitio posterieure du corps. Bord antrirur de coxosternum forcipulaire presplue droil aree ou sans 


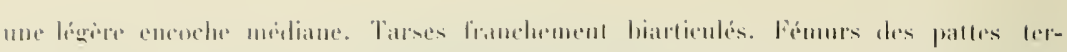

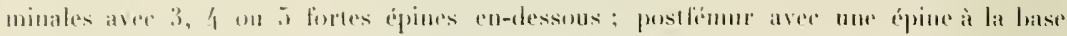

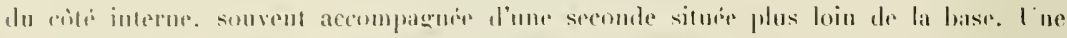

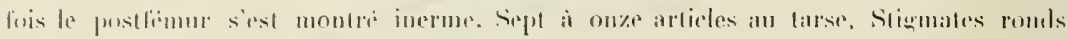

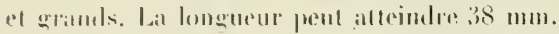

\section{Newportia Fuhrmanni n. sp.}

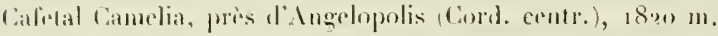

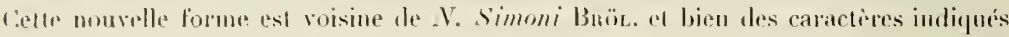

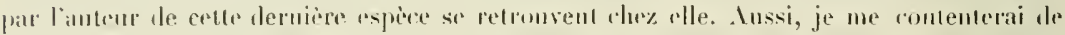

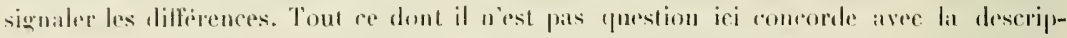
tion de brïgrevax.

Le bord antirienr du coxosternum forripulaire est fortement hilolé et très saillant en avant de l'angle interne de l'articulation coxofémorale; les lobes sont réguliopenent arromelis re leur horl libre est muni d’un fort bourelet, plus épais sur la partic médian do chaque lobe. Les sillons médians du denxiome tergite sont romplets. La

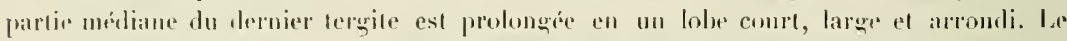
sillon undian des sternites est visible à partir du $2^{e}$; il est formé de deux truncons dont

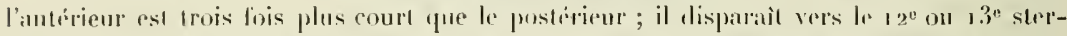

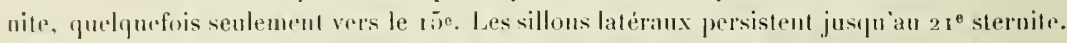
En arriòre du niveau des pattes, sur les trois ou quatre avant-derniers sternifus, se trouve nu. strie transversile qui coüncide avec un changement brusque d'inclinaison de leur surlace. Les épines du postfémur des pattrs terminales sont foutes deux situétes sur li lace iutrofe; l'un est à la base, l'autre est prís do l'extrímité, aux trois-quarts de la lavteur de l'atticle. La l'ómur porte quatre épines (une fois, trois d'un coth seulement). Le lorl disial de l'article basal du larse ast à peine oblique ; il col deux fois plus large que la base de l’arlinde suivant, qu’il déborle plus en dessous qu'en dessus; les antres

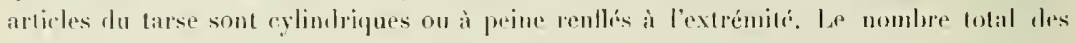
ardicles du larse varie de 5 is 8 .

\section{Newportia monticola Poc.}

Cordillères centrales : Cafetal Camelia, pris d'Angelopolis, i 830 m. ; Col du Ruiz,

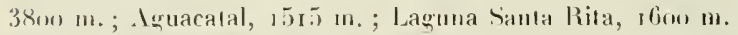

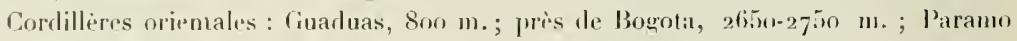

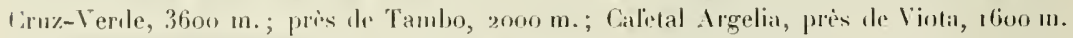

Les représentants de refle espore, an nombre d'me trentane environ, donnent une ilion de sit variabilité. 


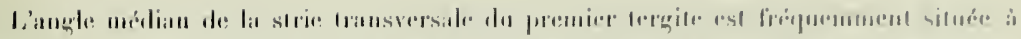

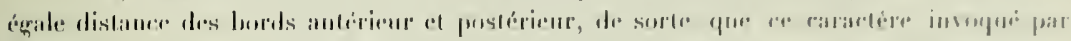

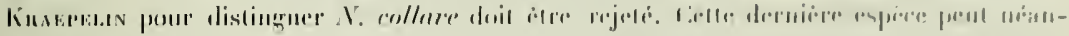

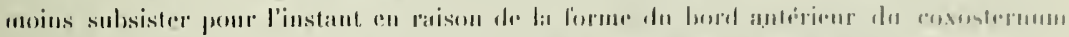

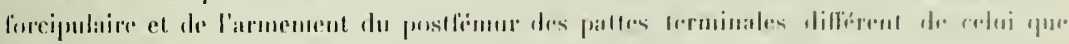

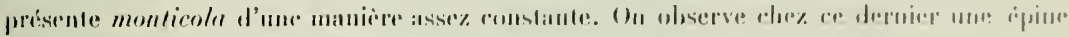

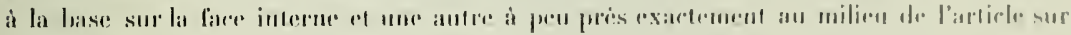

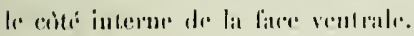

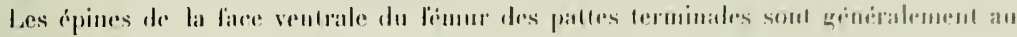

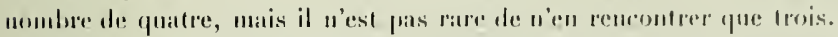

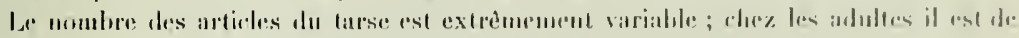

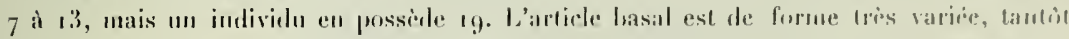

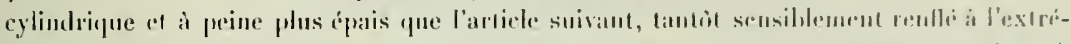

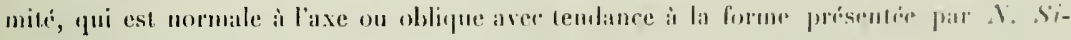
moni et collare.

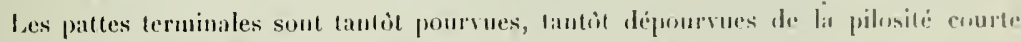
et dense, qui vraisemblablement est un apantage de l'un des sexes.

$\Lambda$ en juger par si description, $N$. liogersi Poc, ne ditfire en ancune façon de monlicola.

N. Bicegoi Bnör, peut àre conservér en raison de la forme du bord antórieur du coxosternum forcipulaire, de l'armement du postfémur des pattes terminales, quoinu’il prósente quelquefois la dispositon observe chez monticola, el, a la rigueur, du nombra normalement plus élevé des articles des tarses. Mais alors $\lambda$. collare doit se enufondre avec elle on lout au plus ètre considérín comme une variété; en effet, le caractire tiré de la position de la strie transversale du premier terónie el de la próminence de l'rstrémite de l'article basal du tarse, les seuls yai distinguent ces deux formes, sont varial,es rt, par suite, d'importance secondaire.

II me parait utile de donner ici une clef dichotomignue des espéces connues de len'portin dont les stries du premier tergite forment un $\mathbb{W}$. Elle s'inspire de celte de lisatPELIN, mais certains caractires, que je considere comme ne pouvant que troubler la marcle de la détermination, en ont été éliminis.

1. - Prenier tergite aree une stric Iransversale régutièrement arquée : en arricre de celle-ci pas de stries longitudinales ou, si elles existent, elles sont simples, parallèles ou légèrement divergentes en avant.

N. mexicanum Suuss, I. brewipes Poc., I Ernsti P'oc., I. Slolli Poc., N. Iongilurse Newr., I. dentutum Poc.

Premier tergite avec une strie transtersale plus ou moins angulense an milieu : en arricre de celle-ci deux stries hifurquées dont les branches externes divergent, tandis que les internes se rencontrent au milien; cette partie bifurquée dessine un $\mathrm{IV}$. 
2. - Extrémité du tibia des pattes ambulatoires avec une épine latérale et une épine ventrale. - Stries latérales des sternites doul,les. - Article batsal du tarse des pattes terminales anssi long et aussi cpais que le tibia. - Postfémur arec trois épines sur la lace ventrale. N. spinipes Poc.

Extrémité du tibia des pattes ambulatoires avec une épine latérale, mais sans épine ventrale. - Stries latérales des sternites simples. - Article basal du tarse des pattes terminales manilestement plus court et plus étroit que le tibia. - Postfémur inerme sur la face ventrale ou avec tout au plus deux épines.

3. - Premier tergite avec deux stries longitudinales en avant de la strie transversale, continuant les branches externes du $\mathrm{W}$.

Pas de stries longitudinales en avant de la transversale.

4. - Bord antérieur du coxosternum foreipulaire faiblement rebordé, sensiblement rectiligne, avec une légère encoche au milieu. - Face interne du postfémur des pattes terminales avec une seule épine à la base, sa face ven trale avee I à 2 épines. - Stries médianes des sternites visibles jusqu'au $19^{\circ}$.

N. Simoni BröL.

Bord antérieur du coxosternum foreipulaire bilobé et fortement rebordé. Face interne du postfémur des pattes terminales avec deux épines, l'une à la base, l'autre près de l'extrémité ; sa face ventrale inerme. - Stries médianes des sternites disparaissant au $12^{\mathrm{e}}$ on $13^{\mathrm{e}}$, exceptionnellement au I 5 e.

I. Fuhrmanni n. sp.

5. - Postfémur des paltes terminales inermes. - Article basal du tarse à peine différent des articles suivants.

N. Balzani Silv.

Postfémur des pattes terminales portant des épines soit sur la face interne, soit sur la face ventrale, soit sur les deux ì la fois. - Article basal du tarse nettement différent par ses dimensions des articles suivants.

6. - Bord du coxosternum foreipulaire indistinctement bilobé, presque droit. Postfémur des pattes terminales avec une épine à la base de la face interne et une autre à mi-hauteur de l'article, du còté interne de la face ventrale. - Tarse composé de 7 à 13 articles, exceptionnellement 19 .

$$
\text { N. monticola Poc. (= Rogersi Poc.) }
$$

Bord du coxosternum forcipulaire bilolse. - Postlémur des pattes terminales avec une épine à la base de la face interne et deux autres sur la face ventrale (exceptionnellement inerme sur la face interne ou avec une seule épine sur la face ventrale). - Tarse composé habituellement de 18 ì 25 articles.

N. Bicegoi Bröц. 
Article lassal do tarse des pattes torminates cylindrique.

X. Birrogri Burin.

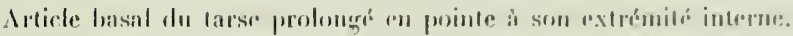

N. Biregroi var, colloris Kande.

Fam. Scolopocryplidx.

Otocryptops ferrugineus (L.).

Alto Sim Miguel (Corl. centr.) $2200 \mathrm{~m}$.

\section{Otocryptops melanostomus (Newp.)}

Caletal Camelia, pris al'Angalopolis (Cord. cantr.), $18 \% 0$ m., drux expmplaires jeunes.

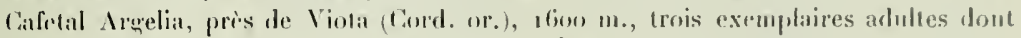
liun atleint $74 \mathrm{~mm}$. de long et 7 mm. de large, et ipuatre exemplaires jounes.

Dans la description domné par linapblas it esi dil que les pattes 20, 21,22 el 23 sont dépourvues d'epines tihiales ef tarsiles. lucun de nos exemplaires ue prósente re caractere. En géníral, la $20^{\mathrm{me}}$ patte possible une épine tibiale el un épinr larsale, la $21^{\text {mo }}$ est dépourvue d'épine tiliale et posside un épine tarsale, les $22^{\mathrm{mo}}$ et $23^{\mathrm{me}}$ n'ont $^{\mathrm{i}}$ épine libiale ni ípine tarsale.

Che\% quelques exemplaires jeunes on ohserve la modification suivante : $20^{\text {me }}$ fratte sans épine tiliale el arec unc épine larsale, $21^{\text {me }}$ sans épine tibiale et avec on sans épine tarsale, $22^{\text {mo }}$ el $23^{\text {mo }}$ sans épine tibiale et sans épine tarsale.

Les articles glabres des antennes sont au nombre de cinc].

\section{Otostigmus scabricaudus (H. et Sauss.)}

Cafetal Camelia, près d'Angelopolis (Cord. centr.), $1820 \mathrm{~m}$.

Guaduas (Cort. or.), $800 \mathrm{~m}$.

\section{Ostostigmus inermis Por.}

Cafelal Camelia, pris d'Angelopolis (Cord, centr.), $1820 \mathrm{~m}$.

Facatativa (Cord. or.), $2588 \mathrm{~m}$.

près de Tambo (Cord. or.), $2000 \mathrm{~m}$.

Les quatre individus provenant de Cafetal Camelia correspondent mieux ì la description de Brölemaxx (Voyage de M. E. Simon au Veneznela, p. 247), qu'à celle de hir.epelix (Revision der Scolopendriden, p. 12g) relativement ì la forme des dents du coxosternum forcipulaire et au nombre des pattes portant deux épines an tarse: mais les stries 
Iongitulinales des terqites existent, tandis que les exemplaires de Bü̈Lenaxs n'en portent aucune trace.

Ceux provenant de Facatativa et de Tambo ont aussi les dents du coxosternum comme lindique Bü̈Lемaxx at les stries longitudinales des tergites existent, mais le nombre des pattes munies de deux épines larsales se rapproche davantage de celui indiqué par Krafelis. Ils diffirent en outre des exemplaires de Camelia par les carenes dorsales heaucoup moins marequées et moins grannleuses.

Lir nombre des pattes munies de deux ćpines tarsales paraìt assez variable clez celte espece, comme en témoigneut les cliffres suivants:

Exemplaires de Brölemann.

$$
\text { de la récolte Fuhrinamn. }
$$

de Porat.

de la récolte Fulirmann.

)

)

)

\begin{tabular}{ll}
\multicolumn{1}{c}{ Provenance } & Nombre de puttes \\
Colonie Tovar (Venezuela) & $\mathrm{I}-4$ \\
Cafetal Camelia (Colombie) & $1-5,1-7,1-8$ \\
Buenos- Cires & $1-10$ \\
Tambo (Colombie) & $1-11, \mathrm{I}-\mathrm{I} 3$ \\
Facatativa (Colombie) & $1-16$ \\
& $\mathrm{I}-18$
\end{tabular}

Étant donné la variabilité de cette espèce en ce qui concerne les carines des tergites, il y aurait peut-être lieu de confondre avec elle $O$. occidentalis qui n'en diffère que par deux ou quatre articles de plus aux antennes et les carènes latérales nulles ou peu marquées.

\section{Fam. Scolopendridx.}

\section{Cupipes ungulatus var. mitis Bröl.}

Guaduas (Cord. or.), $800 \mathrm{~m}$.

Dents du coxosternum $3+4$. Épines du fémur des pattes terminales trìs rudimentaires, une à l'angle supero-interne, deux sur la face interne (une au milieu du bord postérieur, l'autre au quart postírieur du bord ventral). Pores des coxopleures subégaux.

Comme on le voit, cet individu constitue un passage de la variété au type.

\section{Cupipes lineatus (Newp.)}

Cafetal Camelia, près d'Angelopolis (Cord. centr.), $1820 \mathrm{~m}$.

\section{Scolopendra arthrorhabdoïdes n. sp.}

Giuaduas (Cord. or.), $800 \mathrm{~m}$.

Th individu de $42 \mathrm{~mm}$. de long.

Écusson céphalique recouvrant très largement le premier tergite, avec deux stries médianes divergentes. Antennes de 17 articles ; les cinq premiers sont glabres, les autres sont densément pileux sur toute leur surface. 


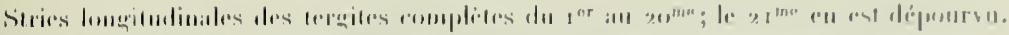

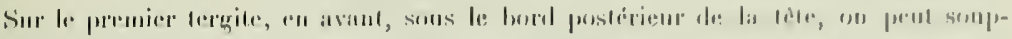

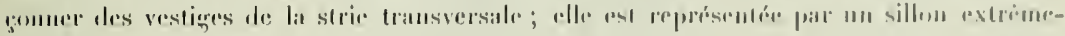

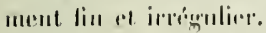

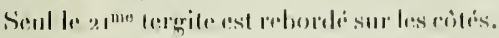

la coxostrermum lourcipulatire (liğ. 1) est

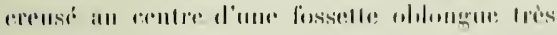
profonde qui s'afomel vers l'arriore soms forme d'un sillon. En avant de: la leosselle: se: trentro IIII: strie transversale tries forte, formant la base d'un triangle dont less revés sont lin'més par dews stries parallites an lond andiculanire du

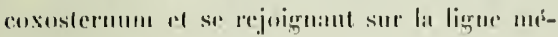

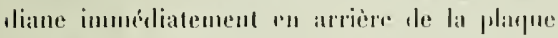
dentere. Ia surfiane de ce triangle est poncture

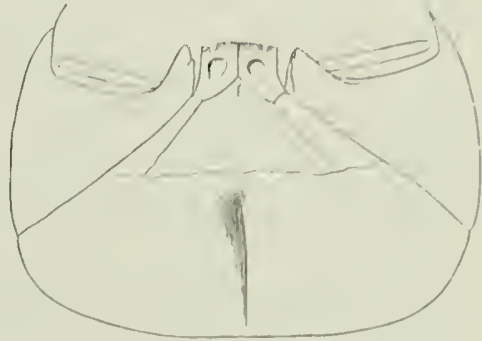

Fig. 1 : Scol, arthrorhabduders. - Coxostermum forcigulaire.

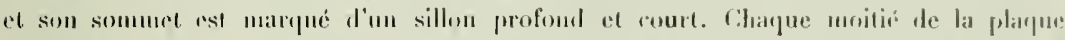

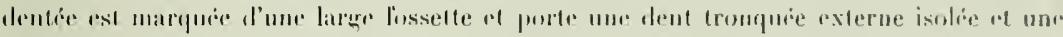
lanor interne risultant te la lusion d'un cerlain nombre de deuts, probablement trois.

Stries longitudinates des sternites complètes à partir du $5^{\text {rose }}$. Deruier sternite eu trapieze allongé.

P'remière palle avec demx cpines an premier tarse; pattes 2 iो 19

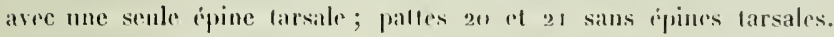
Thibia de wutes les pattes dépourva d'épines. Onghle de toutes les pattes aver deux épines à la hase : anx trminales, l'épine interne est heauroup moins diveloppie tgue l'exterme, sur me palte; sur l’antre, clle sist uulle.

límur el postfémur de la r $9^{\text {me }}$ patte sans épines.

Fémur de la $20^{\text {me }}$ palte avec une épine à l'angle dorsal interne -1 une antre sur la face ventrale. Pustrimur sans épines.

Coxnpleures du sezment terminal molérément prolongés en une pointe qui porte trois épines at son extremiti; une épine se trouve Également sur le hord postérieur, ì une petite distance de la commissure. Pores nombreux, comrant toute la surfice des coxopleures. saut le prolongement.

Fémur des patles terminales arec 7 à 8 epines sur sa face inférieure, en quatre rangés longitudinales $(?+2+1+2$ i 3$)$; hord

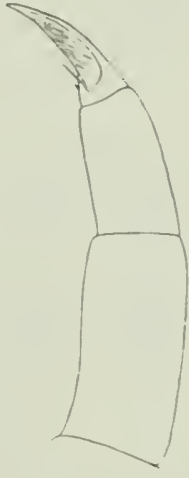

Fig. 2: Scol. arthro. Habcuides. - Eviremilé d"une palle terminale. supero-interue avec quatre épines, une atu quatt basal, lautre à la moitié, les deux autres conliguïs sur l'angle distal. Postfémur inerme. Ongle (fig. 2 ) à peine plus court que le demier larse, à concavité non chanfreince, tranchante: ce tranchant est finement crínclé. Cet ongle rappelle par sa furme celui d'Arthrorhabdus formosus. 
Couleur vert clair uniforme.

Cette espece se rapproche heaucoup de $S$. armalu linaep. dont elle diflere principalement: ${ }^{0}$ par lis strie transversate du premier tergite, qui, pour ainsi dire, n'existe pas; $2^{0}$ par les antennes qui sont pifenses en dessus comme en dessous sur les 12 premiers articles; $3^{\circ}$ par les stries longitudinales des tergites qui sont complètes à partir du prenier; $4^{\circ}$ par le rebord latéral tes tergites qui nexiste que sur le $21^{\text {me }} ; 5^{\circ}$ par la fossette mediane du coxosternum forcipulaire; $6^{\circ}$ par le développement de la strie transversale du coxosternum; $7^{\circ}$ par les stries longitudinales des sternites complètes à partir du $5^{\text {mo }}$;

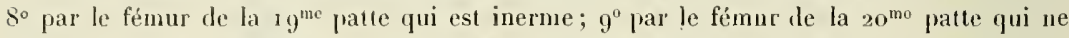
porte qu une épine en dessous ; $10^{\circ}$ par le postfímur des pattes terminales qui est inerme; $11^{0}$ prohablement aussi par la forme de longle des pattes tcrminales.

Elle se rapproche agalement de $S$. alternans Leacu dont elle dilfire: Io par la pubescence des antennes qui n'est pas alignée ; $2^{\circ}$ par le rebord des tergites limité an $21^{\text {me }}$; $3^{0}$ par le développement de la strie transversale du coxosternum foreipulaire ; $4^{\circ}$ par l'existence de la fossette centrale du coxosternum ; 5 par le fémur de la $20^{\text {mo }}$ patte qui ne porte en dessus qu'unr épine et qui, par contre, est épineux en dessous; 60 par le prolongrement des coxopleures qui ne porte que trois épines; $7^{\circ}$ par les faces interne et dorsale dn fémur des pattes terminales qui ne portent jue denx épines à leur rencontre; 8 o par l'angle dorsal interne du fémur de ces pattes qui est simplement biépineux mais non prolongé; $9^{\circ}$ par la forme et le diveloppenent de l'ongle des pattes terminales (chez alternans il est de forme normale, à face concave excavée, el sa longueur atteint à peine la moitie de celle du $2^{\text {me }}$ tarse).

S. arthrorhabdoüdes forme, au mème titre que S. alternans, un passage au groupe des a collares ». Elle forme aussi une transition intéressante au genre Arthrorhabdus par la forme de longle des pattes terminales.

En se servant du tableau dichotomique de Kiraepelin pour les espèces du genre Scolopendra, on sera renvoyé dès le commencement au paragraphie 13 , car la strie transversale du premier tergite sera toujours considérée comme négligeable. Ce paragraphe derra être modifié de la manière suivante :

13. - Femur des 20. Beinpaares dorsal am Ende mit 1-6 Dornzähnchen. Kopf mit 2 nach vorn divergierenden feinen Längsfurchen. Sternocoxalplatte vor der Mitte mit Querfurche. $\quad S$. alternans et $S$. arthrorhabdoürles.

Femur aller Beine dorsal am Ende ohne Dornzähnchen. Kopf ohne Längsfurchen. Sternocoxalplatte ohne Querfurche. Behaarung des Fühler nicht in deutlichen Längsreihen. 


\section{Geophilomorpha}

Fam. Geophilidx.

\section{Ribautia Fuhrmanni n. sp.}

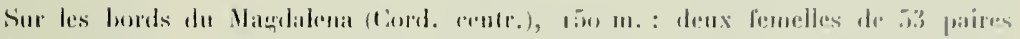
de: pittes.

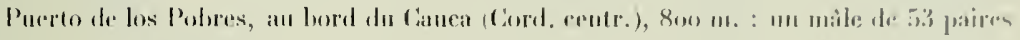
le palles.

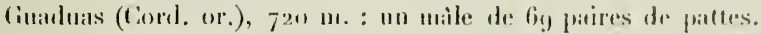

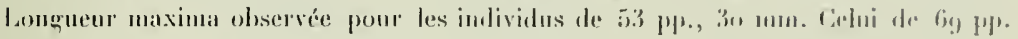
mesure 4/f mun. da long.

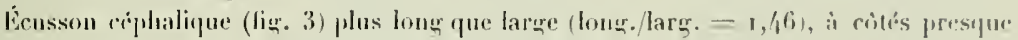

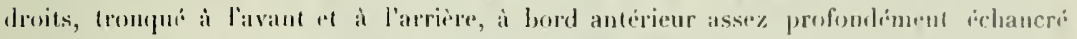
eutre les antennes. Il laisse il dérouvert une grande partie des plenres furcipulaires, la moitié externo do l'article basiline el la griffe an contier. Il est crusé d'un sillon profond et court inmédiatement an arriè du milien du borl frontal at de deux sillons loneritudinaux parallibes athut de la hase jusque vers le milieu, conx-ci peu maryués. Il porte des points infoncés assez espacés, plus deuses dans la moitié postérieure ou ils sont sériés longitudinalement. Front non sépare. Intennes ayant un peu plus de deux fois la fru-

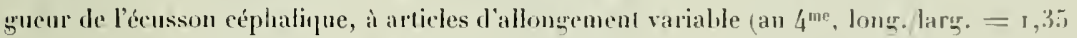
ì 1,65$)$. Écusson prébasal invisihle.

Zone prélabiale (tig. 4) plus large que longue (long./larg. = $=1,8$ ), porlant deux poils postantemnaires situćs dans une aire elypiale réticulée circulaire: un pen en arrière do cenx-ci, yuatre poils en ligne transtersale. Pas de poits contre le ladro. Pas de zone lisse enl avaut du labre.

Labre (fig. 5) composć de trois pièces bien distincles, la médiane siparant entièrement les latérales. Li partie superficielle des latérales semble avoir sqlissé sur la partie profonde à la fois vers le milien et vers l'avant pour former un repli qui recouvre les cirtés de la pièce midiane et une partie de la zone prélabiale. Le bord libre de la pièce médiane porte en son milieu une huitaine de dents tronquées et finement denticulies ì leur four sur la troncature. Le bord libre de la partir externe de la pièce médiane el llune partie intrme des pièces latérales est garni de franges à bords paratlèles qquelques-unes lorusquement épaissies à la base), à extrénité frangée. La limite, sur le hord libre, de la piècr médiane et des pirces laterales est difficile à préciser. La partie externe des pieces latérales est divisée en deux zones, lantérieure à un niveau plus dorsal que la postérieure. Le fulcrum s'appuie sur ces deux zones, sans pénétrer sous la pièce latérale, comme cela a lien, par exemple, chez les Schendylina. 

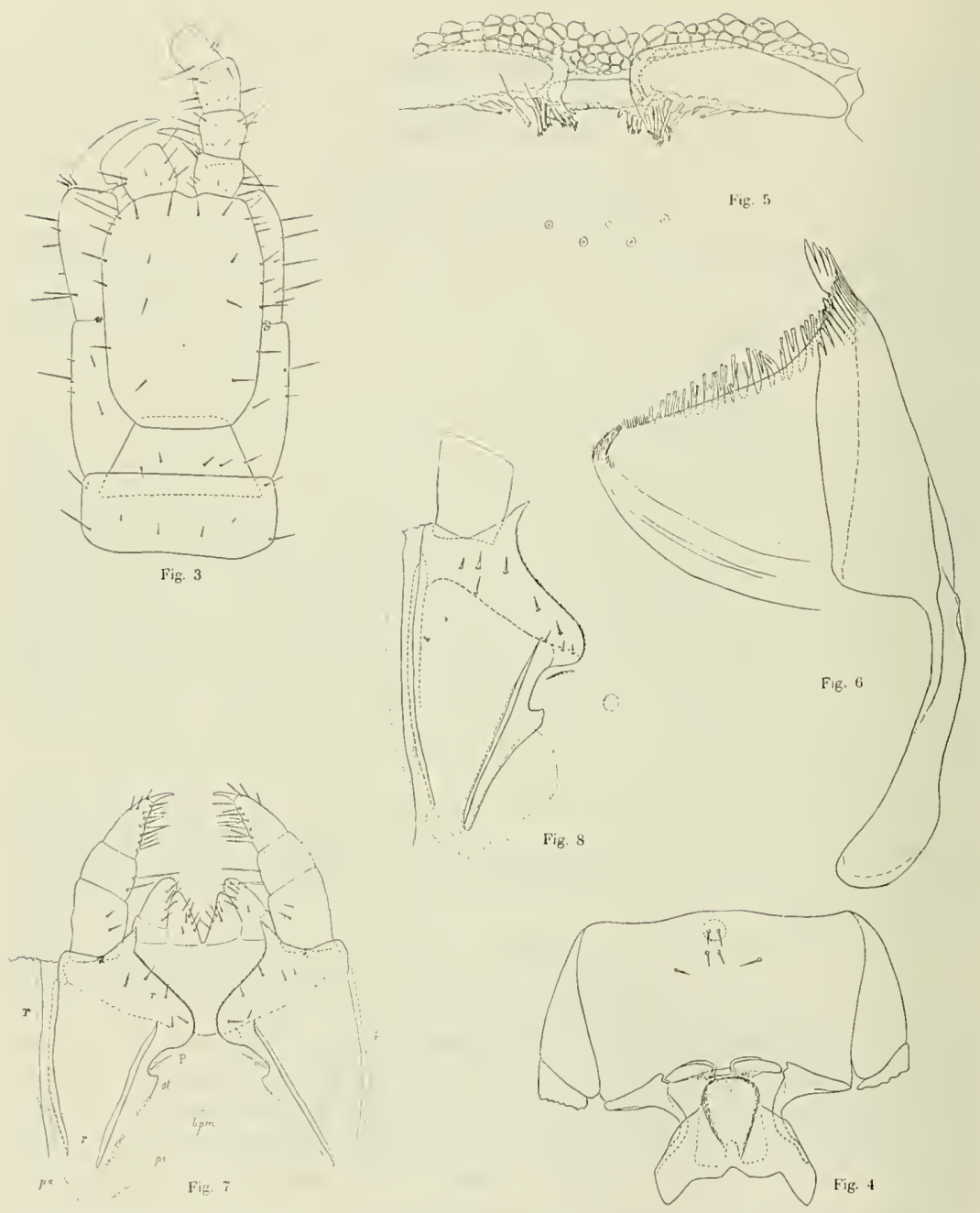

Ribautia Fuhmanni. - Fig. 3: Extrémité antérieure du corps, face dorsale. - Fig. i : Lixtrémité antérieure de la tête, face ventrale. - Fig. 5: Jabre, - Fig. 6: Mandibule droite. La ciliure de la crẻte n'a été dessinée que dans la partie sans lanières. - Fig. 7 : Première el deuxième mâchoires : $r$, parties réticulées, dont la limite est indiquée par une ligne pointiliée; $P$, pore métamérique; $b$, bord sous-membraneux; pe, pleurite externe; pi, pleurite interne; bpm, bipleurite médian; st, sternite. (Jndividu des bords du Magnale
Fig. 8: Moitié drnite du pleurocoxosternum de la deuxième mâchoire d'un autre individu (Guaduas). 

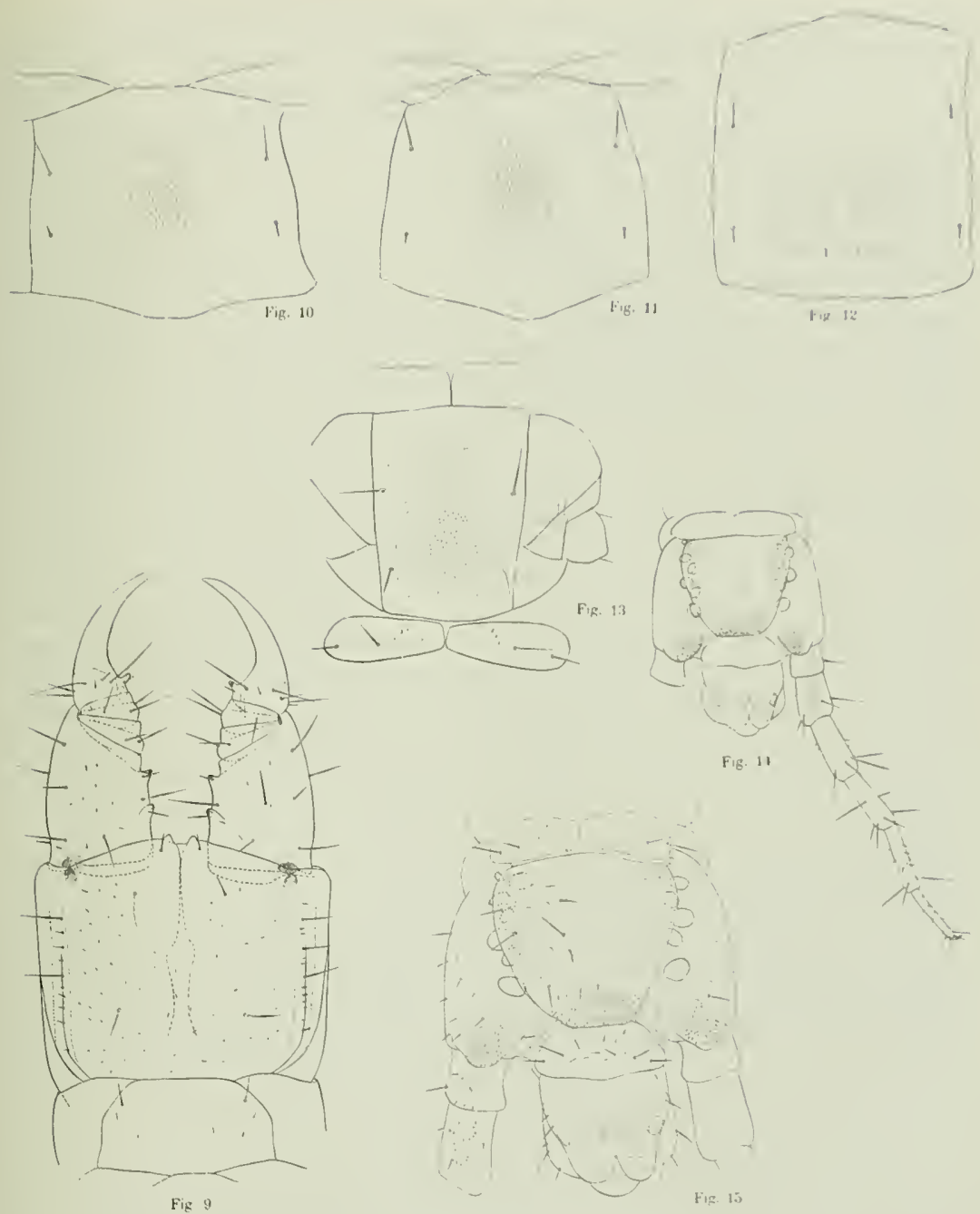

Ribautia Fuhrmanni. - Fig. 9: Forcipules. - Fig. 10: 2r sternite. Fig. 11: 10 sternite. - Fig. 12. 30' sternite. -

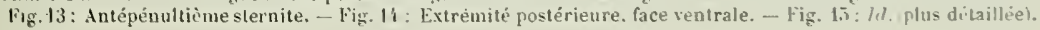


Mandibute (fig. 6) munie d'une lame pectinée noceupant que la moitié dorsale du bord. Du coté rentral. Ia fin du peigne est marque par un brusque retuat du hord de la mandilusle. Entre le peigne et liangle rentral, le bord est finement et densément cilie : il est en outre, muni de longues franges, généralement ramifiées, prenant naissance sur la face externe à une petite listance de lui. Face interne lisse, sans papilles ni spinules.

Premiève màchoire (fig. 7) sans palpes, à articles dh tílopodite et prolongement du coxosternum distincts. Coxosternum, glabre.

Télopodite de la deuxième màchoire (fig. 7 et 8) composé de trois articles, te hasal un pen plus long que larage, un peu plus large au sommet quà la base. Ongle simple. Pleurocoxosternum entièrement dissocié en deux parties symétriques. Son angle distal interne est fortement prolongé. La limite entre les parties stemale et coxale cst pen inclinée sur l'axe du corps et marquée par une hande complètement incolore. La partie sternale, surélevée par rapport à la coxale, tranche par sa forte chitinisation el sa coloration foncée; elle est largement échanerée en face du pore métamérique et se dilate progressivement depuis sa base jusqu'à l'échancrure, pour former immédiatement en artière de celle-ci un talon très accusé; elle est entièrement dépourve de réticulation. La partie pleurale se compose de deux parties nettement limitées, une partie interne uvalaire, située en dedans du sternite, empiétant légèrement sur lui et s'étendant depuis l'angle basal de la partie coxale jusqu'à l'échancrure du sternite; une partie externe d'átendue beanconp moins grande que la précédente, en forme de bande allongée, partant du niveau de l'angle hasal de la partie coxale et s'insinuant entre le bord externe de celle-ci el l'ćcusson cóplatlique. En ontre, entre les deux moitiés du pleurocoxosternum, en pleine membrane, se trouve un ilot circulaire réticulé de dimension variable. Les parties pleurales ainsi que l'angle hasal de la lanche et une bande au bord antérieur de celle-ci sont réticulés; le reste est lisse. Le bord antero-interne de la hanche est garni de spinules. Le bord externe libre sous-membraneux s'étend jusqu’̀ une faible distance de l'angle basal. Le long du bord de l'écusson céphalique se trouve une bande lisse.

Tergite forcipulaire (lig. 3) en trapèze à còtís fortement convergents, pas plus large à sa base que l'écusson céphalique, laissant entièrement ì déconvert le hord externe des pleures forcipulaires. Ensemble des pleures el du cososternum forcipulaires presque quadrangulaire (fig. 9). Lignes chitineuses fines, disparaissant vers le milien. Bords internes des hanches (vus par transparence) contigus en avint, puis s'écartant brusquemeut l'un de l'autre. Hanclues faisant fortement saillie au milieu sur le hord antérieur du coxosternum. Bord interne de l'article basilaire du tílopodite muni de deux dents vigoureuses, l'une, distale, au niveau du fond de la eavité articulaire, l'autre à mi-hauteur, dont la base se prolonge par une forte strie vers l'extérieur, marquant sans doute la limite entre deux articles dout la fusion aurait constitué l'article basilaice. Les denx articles suivants sont inermes; on observe senlement un retrait au niveau du fond de la cavité articulaire. La griffe est munic d'une forte dent à la base. Son trancliant est lisse. 


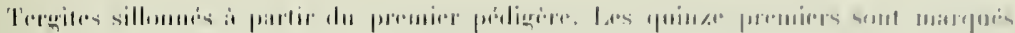

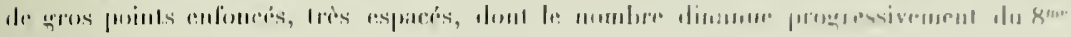

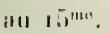

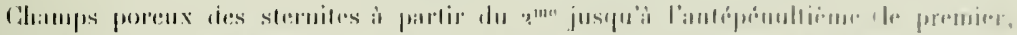

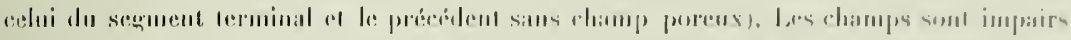

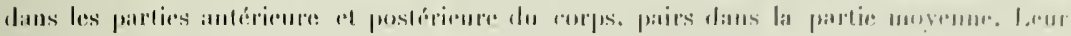

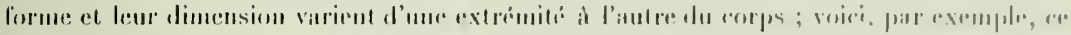

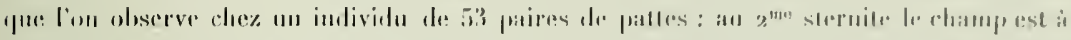

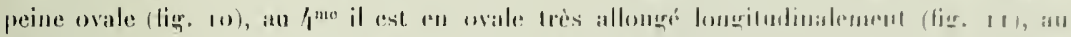

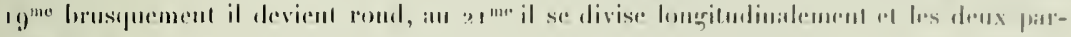

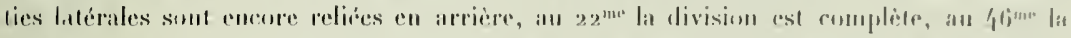

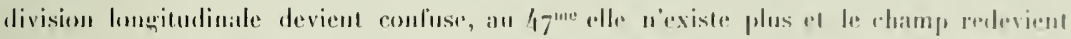

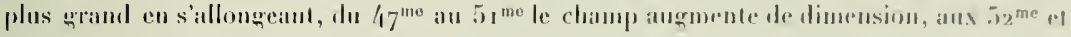
$53^{\text {mo }}$ il n'existr plus de clammp.

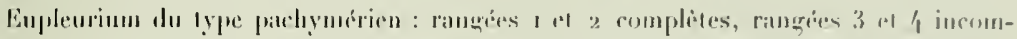

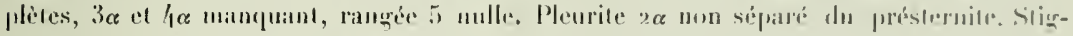
mates rouds. Dernier pleurite stigmatilère séparé du tergite correspundant.

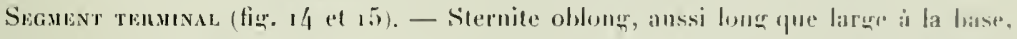

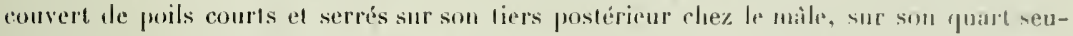
lement chez la fenelle. Pattes terminales à peine plus épaissies chez le màle qua chez la femelle, peu pileuses, munes d’un ongle. Manches portant dans les deux sexes, en desisus de teur extrémité postérieure, une protulérance garnie de poils courts el serrís. Porés coxaux de $5+5$ à $7+7$, localisés dians la gouttère sternocoxale, lionupudes du màle composes d'un seul article; gonopodes de la femelle mon distincts. 1)es pores anamx. P'als de pleurite contre lé dernier prétergite.

C’est de Ribantia Bomvieri Bü̈z. ef de Ril. repandum (.Ітт.) que Ril. Fuhrmanni se rapproche le plus. Elle differe de la premiere espece par l'absence de pores sur la face externe des hanches terminales et par le nombre relatif et la forme des champls purenx: de lir seconde par le mode de distribution el d'ourerlure des pores coximx.

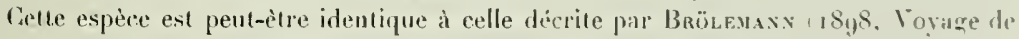
M. E. Simon au Tenezuela) sous le nom de Grophilus Iropicus. Mais lin description de celle-ci est complètement inutilisable à cause de son insuftisince.

\section{Le genre Ribautia et les genres voisins.}

Eu rgog, Atress créa le wenre P’olygonuren pour quatre especres apparténaul il sa

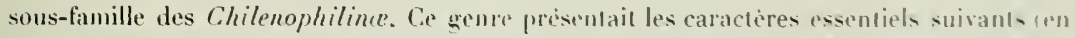
dehors des caracteres définissam la sous-famille) : Ungle des paltes teminales de forme normale, une aire clrpéale réticuléa, pièces latérales du labre séparées par la pièce 
médiane, angles internes de la deuxième nàchoire prolongés, sternites sans prolongement en lobe en avant du bord postérieur, sternite terminal farge.

Parmi ces qualre espéces, ume, apora, est dépourvue de champs poreux; aussi, daus une unte récente', l'ai-je exclue du genre Polygonarea et rangie dans le grenro Brarhygonurea, que jia crés pour alle.

l'resque au moment oi Aтrems faisait paraitre son nourat genre, Bhölemann publiait sous le nom de Riluntio n. g. Bonvieri n. sp. une esprice très voisine de celles comprises par Atrems dans le geme Polygonnen et la question pomait se poser de sivoir si

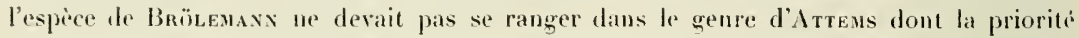
est imdisentable. Dans la note dont il a été question plus hant, jai cru devoir maintenir le genre Ribautiu en me hasant sur l'alssence complète de palpes à la premiere mâchoire chez Ributia Bonvieri, tandis que, an moius clez Polygonarea hroepelini el oligopus ces palpes sont très développés. Mais il fant bien reconnaitre que ce caractère unique pouvait ètre envisagé comme d'une valeur insuffisante. Depuis, si ce n'est la pullication, an moins la rédaction de ma note, trois nouvelles espèces ont été décrites par Artess sous le nom générique de Polygonarea. Ces nowelles formes constituent avec $R$. Bouvieri ct R. Fuhrmanni un ensemble des plus bomogènes qui apporte une excellente confirmation au maintien de la séparation des deux genres. En mème temps que l'absence de palpes, toutes ces espèces ont ceci de commun que les pores ventranx sont condensés en un champ médian (souvent divisé longitudinalement en deux parties), tandis que chez Pol. Krapelini el oligopus le degré de condensation est moins élevé, des pores se rencontrant également sur la partie antérieure des sternites. Des considérations d'ordre géographique s'ajoutent aux précédentes: Pol. Kraepelini et oligopus se rencontrent dans la Colonie du Cap, tandis que Jes especes que je rattache au genre Ribautia sont originaires du nord de l'Amérique du Sud ou de P'Australie.

L'espèce décrite par Silvestu sous le non de Eurytion centralis a été rangée par Atrexs dans le genre Polygonarea. Quoique nous ne sachions pas si elle posside des palpes, je n’hésite pas à la ranger daus le genre Ribautia, en raison de la condensation de ses pores ventraux et de son origine géographique. Je serais fort surpris si on constatait chez elle la présence de palpes.

La découverte par Atrexs des trois espèces récentes, qui sans aucun doute doivent se ranger dans les Ribautia, m’amène à abandonner comme caractère définissant les genres de la sous-tribu des Ribantiina, celui qui résulte du prolongement de l'angle distal externe du tibia de la deuxieme màchoire. En effet, deux de ces espices présentent ce prolongement tandis yu'il est absent chez les autres espèces de ce genre. It en résulte que, puur l'instant, le genre Brachygonarea se différencie seulement des autres genres Polygonarea et Ribautia par l'absence de champs poreux. Hais j'estime que ce caractère

1 limset, 11. Sur un gente nouveau de la sous-tribu des Ribautiina Bröl. Bult. te la Soc. d'hist. nat. cle Toulouse, 1910, Xill1, 105-126. 


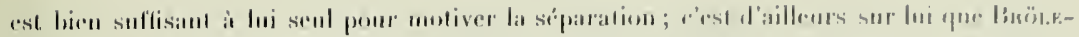

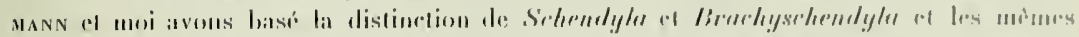

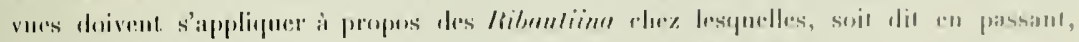

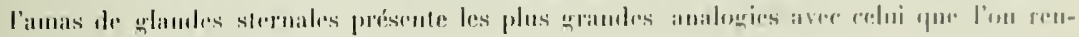
contre clue les s'ohemlylinu.

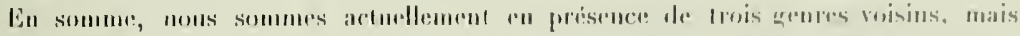

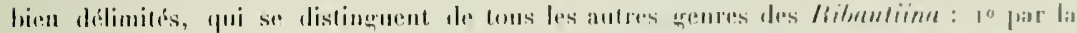

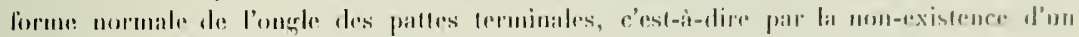

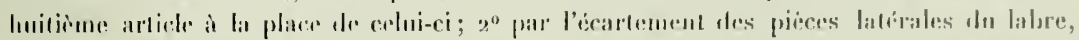

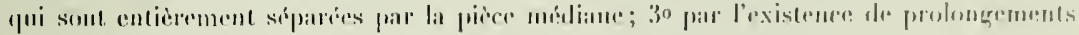

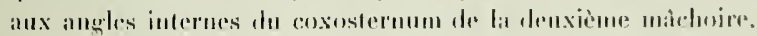

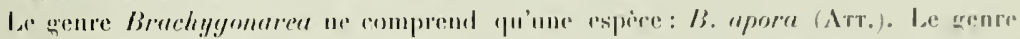

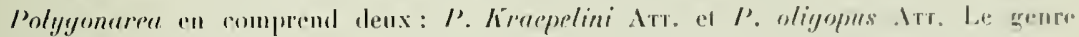

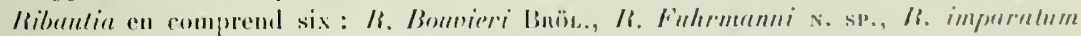

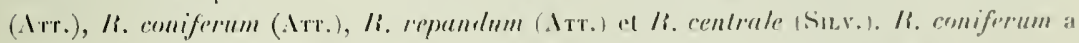

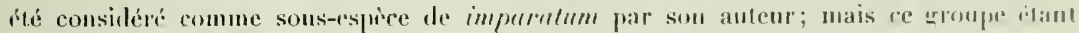
composé de formes très fixces, les caractères dillérentiels de romifermm sont suftisinument

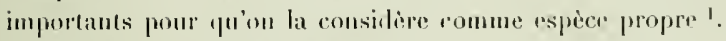

de domne ici une slef dichotominge qui prermettra de distinguer aisément les différentes espèces de Ribuntiu.

1. - Des fores sur la fiace externe des hatnches terminales.

Pores de la gontlière sternocoxale nniformáment ripartis. Ln champ prove sur le premier sternite. - Tibia de la deuxieme màchoire saus prolongement de l'angle distal externe. - Dent du fénur des forcipules forte, foncée. - Des pores ananx. - o $73 \mathrm{pP}$.

Pas de pores sur la face externe des hanches terminales.

2. - Pores de la gouttière sternocoxale des hanches terminales uniforminent ripartis.

Pas de champ poreux sur le premier sternite. - Tibia de la deuxième màchoire sans prolongement de l'angle distal externe. Dent du fémur des forcipules forte, foncée. - Des pores anaux, Angle interne du sternite de la deuxième michoire bien marque. - $0^{1}$ ㅇ 53-69 pp. R. Fuhrmunnix. sp.

Pores de la gouttière sternocosile des banches terminales condinsés en deux ou trois groupes: chicun de ces groupes est qéneralement silué au fond d'une poche.

1 Je ferai remarquer que je ne cite pas $R$. repandam mullipes (ATr.). Cetle denomination doit ère, en eflet, confondue avec $R$. repandum, les reghles de la terminologic exigeant que. lorsque une espice est autdivisce en sous-espèces, le nom de la sous-espéce typinue soit le mème que celui de l'espice. 
3. - Un damp porenx sur le premier sternite. - Dent du fémur des forcipules ruclimentaire, pas plus foncre que le reste du límur.

Tibia de la deuxieme michnire avec un prolongenemt de langhle distal externe. - Pas de pores anaux - o /45-í, 우 $17-5.5 \mathrm{pp}$.

li. imprarulum (. Itr.)

Pas de champ poreux sur le prenier sternite. - Dent du fémur des forcipules forte, plus foncée que le reste du fímur.

4. - Tibia de lis denxiome michoire avec un prolongenent de l'angle distal extente. Des pores anamx. - Angle interne du sternite de la deuxieme màclsoire indistinct. - o 61-71, ㅇ 63-73 Pp. R. conifernm (ATr.)

Tibia de la denxieme màchure sans prolongement de l'angle distal exterue. 5

5. - Des pores anaux. - Angle interne du sternite de la deuxième màchoire bien marqqui. - o 7 i-83, \& 77-85 p. R. repandum (Атт.)

Pas de pores anaux ${ }^{1}$. - Angle interne du sternite de la deuxième màchoire indistinct. R. centrale (SiLv.)

Liste des espèces des genres Ribautia, Brachygonarea et Polygonarea.

Ribaulia Bonnieri Brös.

Ribautia Fuhrmanni Ress.

Ribaslia imparalum (Атт.)

Polygonarea impuratu ItT.

Ribautia conifermm (. Iтт.)

Polygonarea imparala conifera AтT.

Riluntin repandum (Атт.)

Polygonarea repandr ArT.

Polygonarea repanda mullipess Aтr.

Ribantia centrale (Sisv.)

Enrylion centralis Sulv.

Polygounter centralis (Sicv.) Atr.

Brachygonared apora (Атт.) Ruв.

Polygonarea apora Атт.

Polygonaren oligopas Aтт.

Polygonarea hraepelini (Sus.) Atr.

Eurylion Krapelini Sus.
Ilaut-Carsévène

Colombie

Australie

Australie

Australie

Colombie

Colonic du Cap

Colonie du Carp

Colonie du Cap

1 D'après la figure donnee par Silvestri. 


\section{Macronicophilus Ortonedx Silv.}

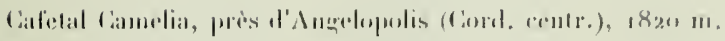

Trois miles de fir pairo's de palles.

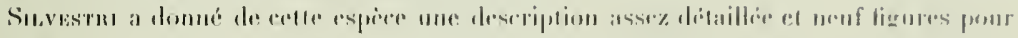

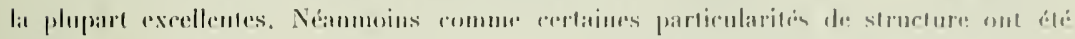

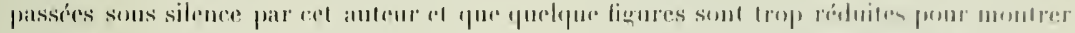

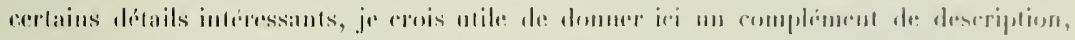

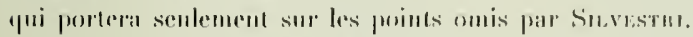

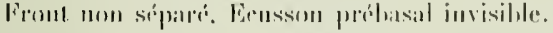

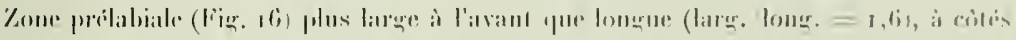

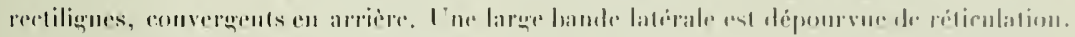

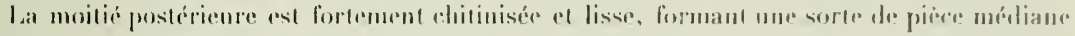

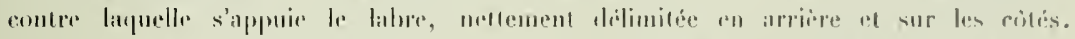

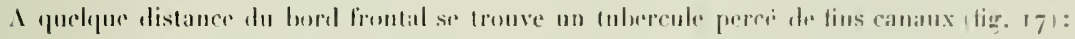

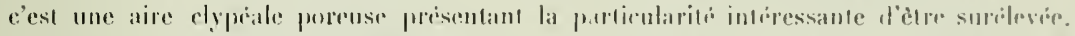

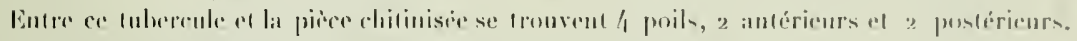

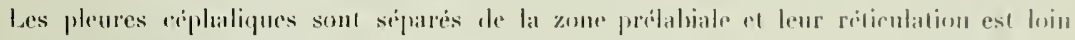
l'alleimlre lenr horel interme.

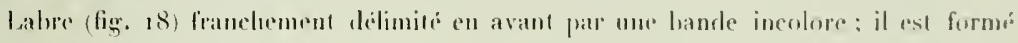

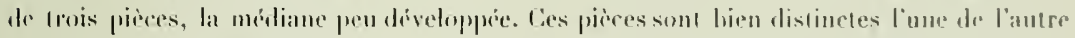

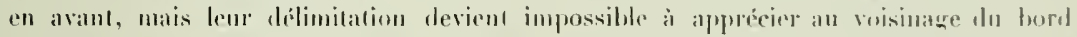

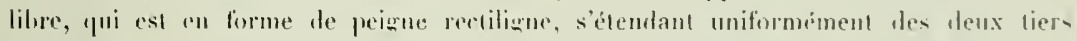

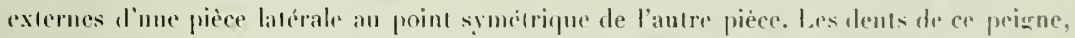
au nombre d'une suixantaine. sont alloneres el mousses, sauf dans les régins extermes

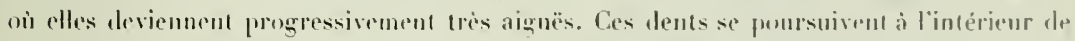

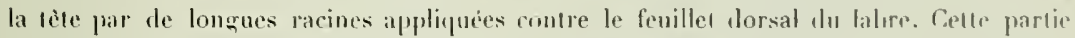

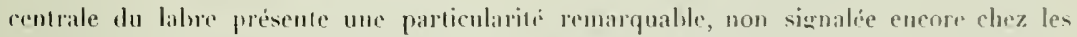

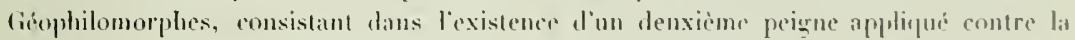
face dorsile alu premier; il est plus court que celui ci el ses dents som ceratement plus courtes, plus aiguës el plus momberuses go envirum), quoiqua létendur de ce denxiome peigne soil plus faible que celle du premier. Les fulerums ont leur parlie transiersale remarquablement conrte.

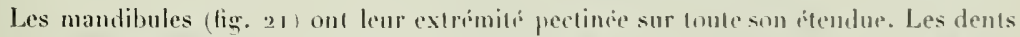
du peigne ne présentent pas l'aspeed habilucl; cllis sont comrles et lriangulaires, leur extrénite est fortement mucronéc par suite du probngement de lem parlie midiane plus

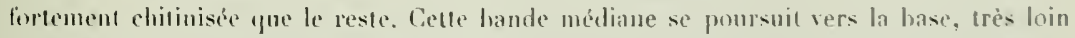
au delì du niveau des commissures des dents. Cefle slructure si particulière pent en rialité

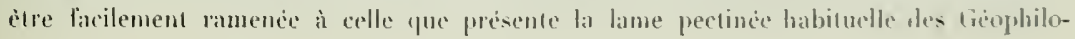



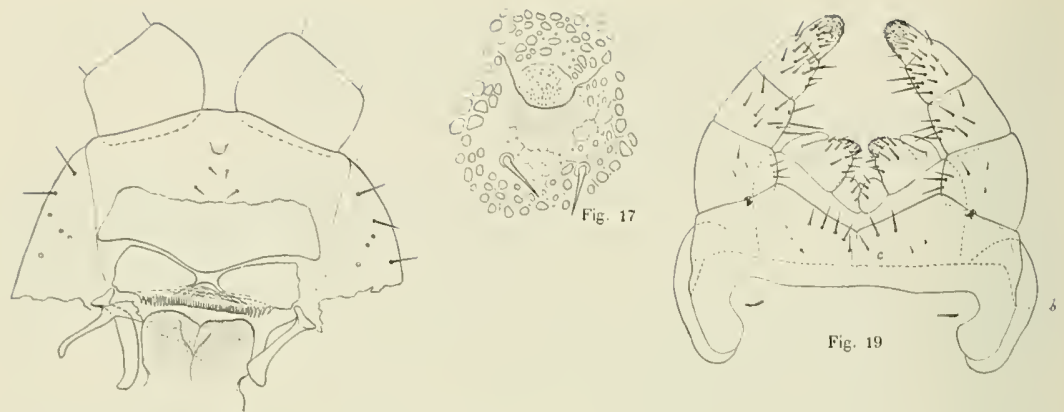

Fig. 16
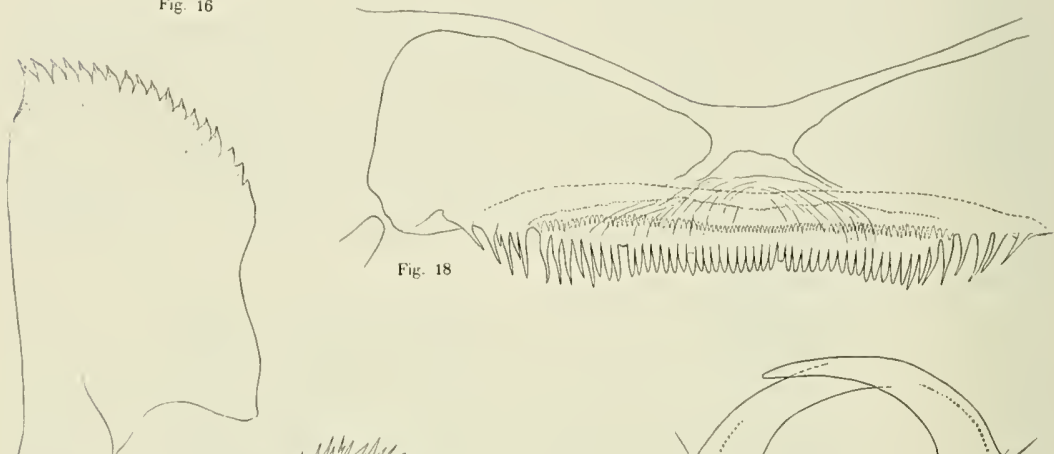

Fig. 21
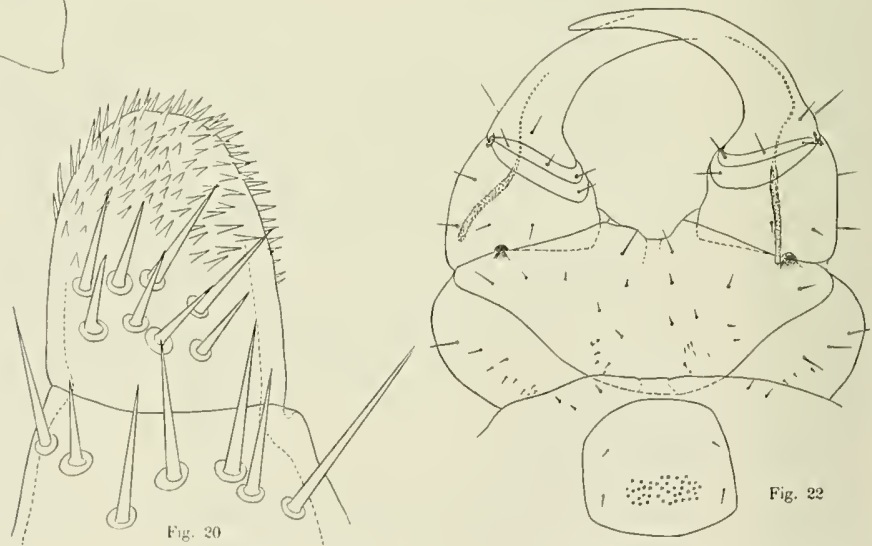

Yacronicophilus Grtonedx, - Fig. 16: Extrémité antérieure de la tête, lace ventrale. La tige de la mandibule droite est restée en place. - Fig. 17: Tubercule frontal. - Fiğ. 18: Labre. - Figg. 19: Première et deuxième mâchoires: $b$, bord sousmemhraneux; $c$, cloison médiane. - Fig. 20 : Article terminal d'un télopodite de la deuxieme uachoire. - Fig. 21: Mandibule. - Fig. 22: Forcipules el premier sternite. 


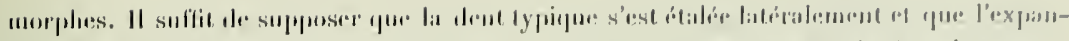

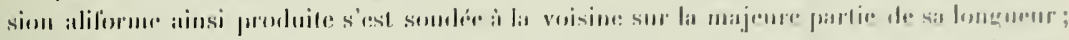

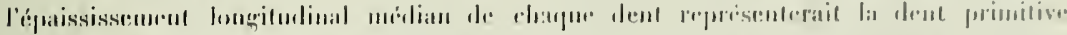

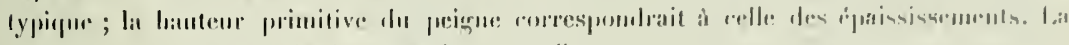

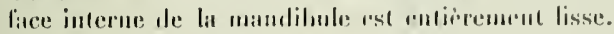
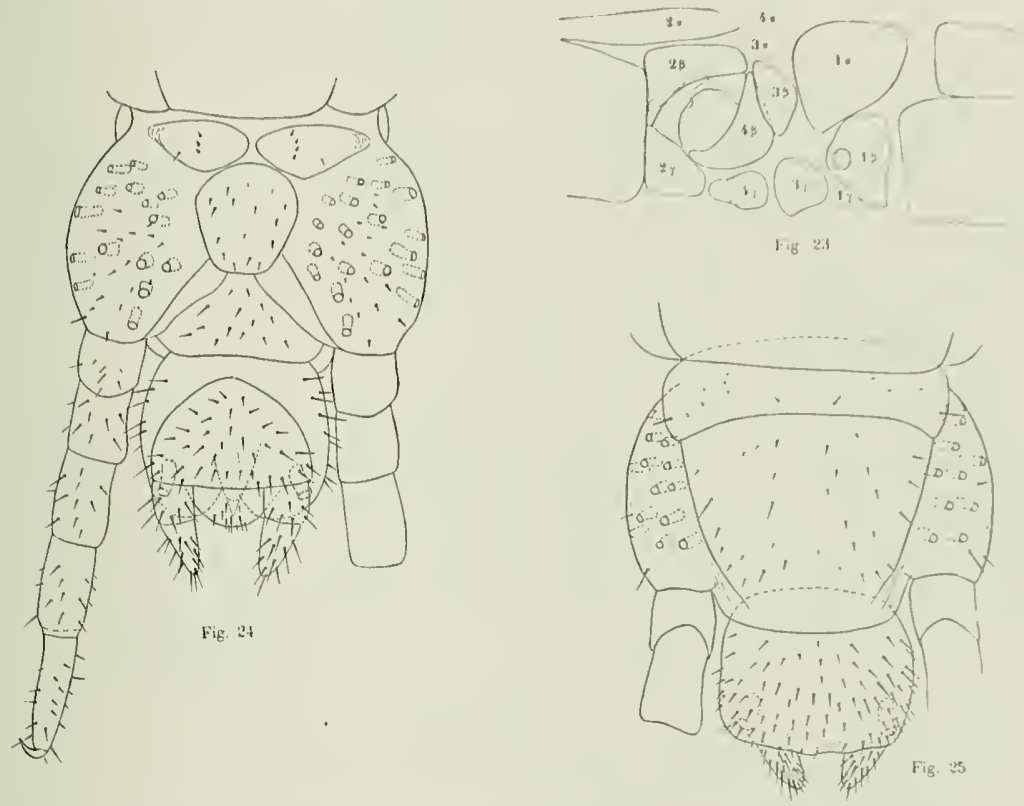

Macronicophilus Ortonedx. - Fig. 23: Pleures d'un segment de la région moyenne du corps. - Fig. 24: F.xırimité postérieure du corps, face ventrale. - Fig. 25 : Extrémilé postérieure du corps, face dorsale.

Hypopharyux semblable ì celui de Eucratonyx hamalus.

Première màchoire (figg. rg) à télopodite compusé d'un seul articlé résultant netfement de la fusion de deux, car l'emplacement du basal est maryui par la prisence d'un palpe trís développé. Coxostermum sans palpes.

Peurocoxostemum de la deuxieme michoire (figr. ig) duplicalure sur une longure étendue. Le bord externe libre (correspondant à la partie duplicaturee) descent jusçu au niveau du pore métamérique. Le bord externe sous-membraneux est extrèmement développé et au lieu de s'arrèter, en arant. au nireau de la duplicature, comme cela a lieu généralement, il se continue sur la face dorsale. La partie duplicaturée est cloisonnée 
wout le long de la ligne médiane ; elte reconve largement le coxosternum da lat premiere màchoire. Le bord anterieur est en forme de $l$ à angle postérieur frès accusc. Pas de dénarcation entre la partie coxale et la partie pleurate représentée vraisemblablement par le lohe lasal externe. Pores métamériques silués en pleine membrame, sans bourrelet chitineux, en forme de fente folroite à pen près prerpendiculaire à l'axe du corps.

Grille des forciputes (lig. 22) très aplatic, en lame de sabre, comme chey chalunder pinguis. Cul-de-sate poreux du canal de la ğlande venimeuse extrèmement allongé. Les pleures forcipulaires sont très díveloppés et fortement obliques 1.

Tergites très faiblement bisillonnés.

Champs poreux situés à peu près entièrement en avant des poils marginaux postérieurs. Ovales dans la partie antérieure du corps, ils tendent à devenir vagnement trianqulaires a partir de la partie moyenne. Sur les parties moyenne el postérieure ils sont très grands, leur limite postŕrieure est très rapprochée du bord postérieur du sternite et leur limite antérieure se trouve en avant du milieu du sternite; te champ poreux de l'avant-dernier segment est encore très grand.

Eupleuriun (fig. 23) compose de quatre rangées completes. Dans la rangée 1, $x$ et $\beta$ sont lien développées, mais $\gamma$ est tout à fait rudimentaire. Dans ha rangée 2 , tous les pleurites sont bien déreloppés, $2 \propto$ n’est pas séparé du présternite. Dans la rangée 3, $\beta$ el $\gamma$ sont bien développés, $\alpha$ est rudimentaire. Dans la rangée 4, $\alpha$ est rudimentaire et placé en avant de $3 \alpha$, est particulièrement et extraordinairement développé, ses limites sont très nettes et il s'élend depuis $2 \beta$ jusqu’à $2 \gamma ; 4 \gamma$ est divisé en deux parties. Stigmates ronds. Dernier pleurite stigmatifère séparé du terģite correspondant. Pas de pleurite contre le prétergite du segment terminal.

Gonopodes du màle biarticulés.

\section{Fam. Schendylidx.}

\section{Diplethmus mexicanus Cook.}

Cette espèce citée par son auteur comme type du genre Diplethmus (The Geophiloidea of the Florida Keys, Proc.ent. soc. Wash. 1899, IV, 306) n'a été jusqu'ici l'objet d'aucune description. Néanmoins, Соoк a accompagné sa citation de cinq bonnes figures qui, si elles ne suffisent pas à identifier l'espèce, ne permettent guère en tout cas d'en séparer un Batlophilien qui fait prartie de la récolte qui nous occupe. En réalité, on peut bien noter

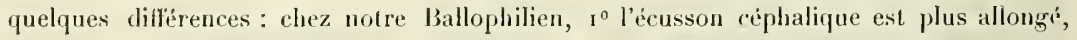
$2^{\circ}$ le sternite terminal est beaucoup plus court, $3^{\circ}$ les pores des champs poreux sont beaueoup plus nombreux. Mais il se pourrait fort bien que ces diflérences soient dues simplement soit à un âge diflérent, soit à ce que le sexe n'est pas le mème, soit encore à un

1 La limite interne des pleures a été omise dans la fig. 2 de Silvestri. 


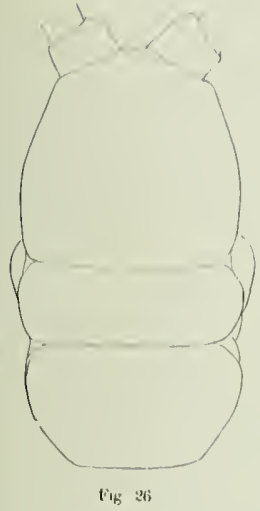

Fig. 27

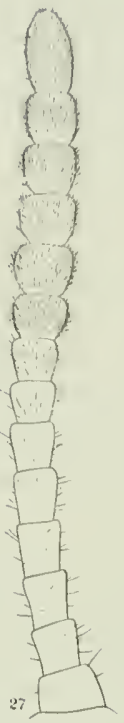

Fin. $2 \pi$

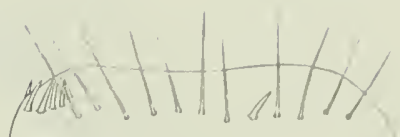

Fig.
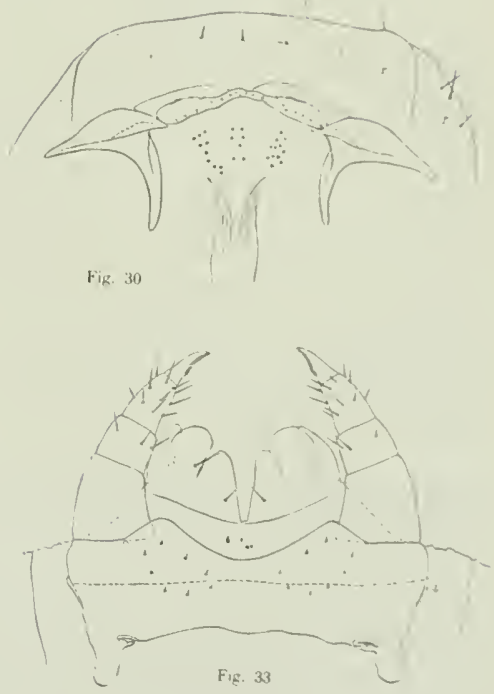

Hiplethmus Mexicams. - Fig. 26: Extrémite anterienre du corps, face dorsale, - Fig. 27: Intenne gauche, face dorsale. - Fig. 28: Lxtrénití du 9" article l'une antenne gauche, face dorsale. - Fig. 29: Exiremité du l3. ar. ticle d'une antenne droite, face ventrale. - Fig̣. 30: Extrémité antérieure de la tète, face ventrale: $r$. parties riticules. - Fig. 31 : Lixtrúmité le la mandibule gauche, face externe. - Fig. 32: Extrémité de la mandibule droite, fact interne. - Fig. 33 : Premie et denxime michoires : $h$, bord sous-membraneux. 
frat de contraction plus ou movius aceusé. Guoi qu’il en soit, it me parait sage pour l'instant de considérer que e'est à l'espèce de Соок que nous avous affaire.

Cafetal Camelia, pris d'Anelopolis (Cord. centr.), $1820 \mathrm{~m}$.

Jenx femelles : 77 paires de pattes, long. $50 \mathrm{~mm}$., larg. 1 mm. 1/3 ; 79 1p., long. 60 mm., larg. $111 \mathrm{~m}$. 1/g.

Couleur bleu-verditre varié de brim. La couleur brme est due aux sclériles, tandis

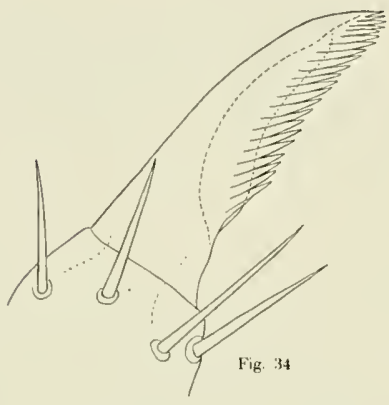

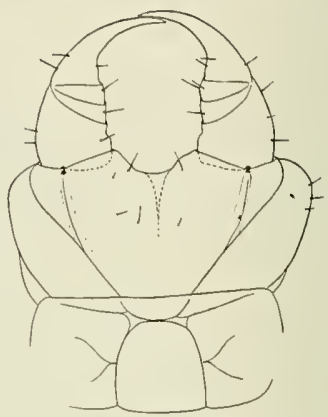

Fig. 36

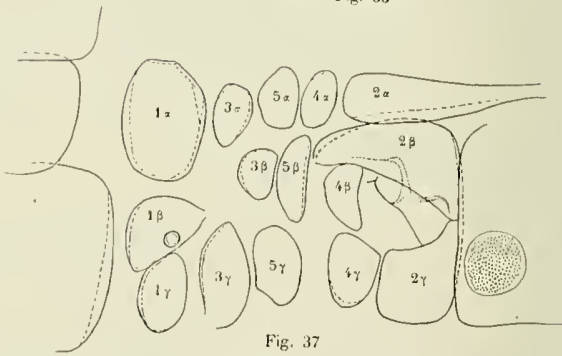

Diplethmus mexicanus. - Fig. 34: Ongle de la deuxième mâchoire, face ventrale. La ligne pointillée de droite indique l'extrémité des dents du peigne dorsal. - Fig. 35: Pores métamériques. - Fig. 36 : Forcipules, face ventrale. - Fig. 37 : Pleures et moitié droite du sternite d'un segment de la région moyenne du corps.

que la couleur bleue est due à la masse intérieure vue à travers les parties peu chitinisées des téguments. Corps très aminci en avant.

Écusson céphalique (fig. 26) sensiblement en demi-ellipse, aussi long que large ì lit base, couvrant entièrement les télopodites des forcipules.

Antennes (fig. 27, 28 et 29) allongées, ayant trois fois la longueur de l'écusson céphalique. Les six derniers artieles sont un peu plus larges que les autres, mais l'ispect claviforme de l'antenne est à peine marqué. Les articles de la massue ( 9 à 14 ) sont à 


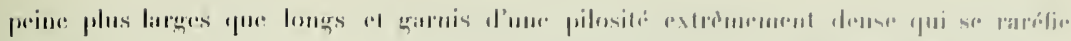

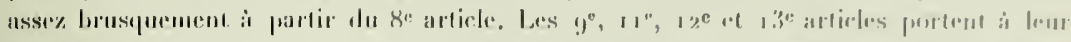

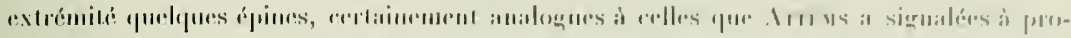

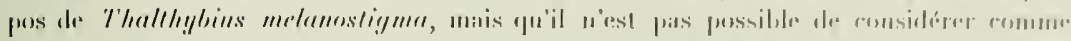

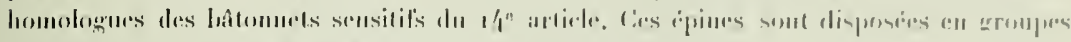

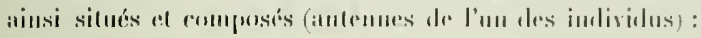

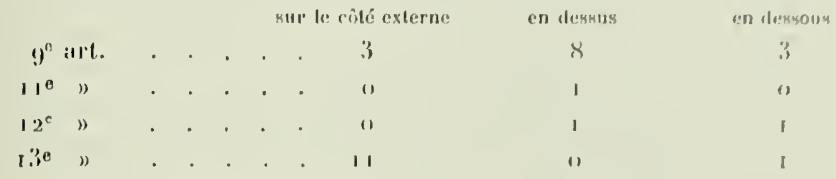

Érusson probusal invisible.

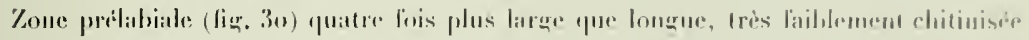

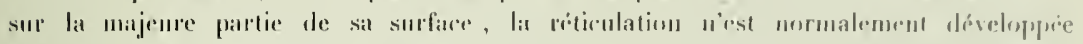

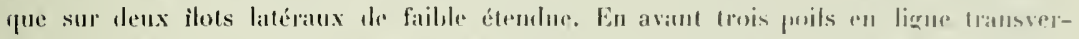

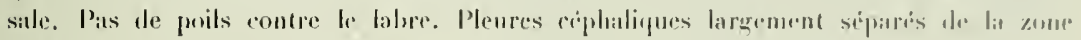
preilitsiale.

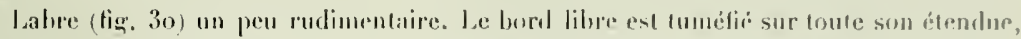
membramenx el incolore el porte quelques éciilles, rudiments de franges. Ein arant de ceth. lumefaction, se trouve une binde assez fortement chilinisce. interrompue an milicu:

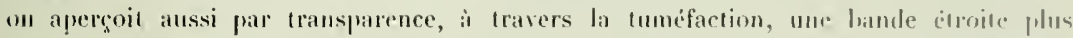
chitiniséc formant le feuillet dorsal du repli labial. Les fulcrums sont tris rohustom et

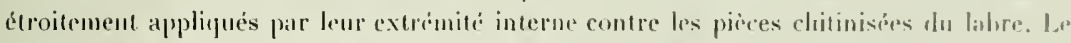
palais, tris finement piteux sur sa partie modiane, porte une trentaine de papilles réparties en trois groupes allonges.

Maudibule (tig. 31 et 32) munie d'un preigne composé de 25 à 35 dents el d'une lane dentée extrènement développée, empiritant sur le peigne par les deux tiers de snn élendue et dont les 4 a 5 dernières dents dorsales sout trininées pill un prolongement triangulaire lamelleux incolore.

Première machoire (tig. 33) is télopodite at prolongement sipares dlu coxosternum. Télopodite biarticulé. Palpe de lanticle intermédiaire tris déroppri, prestue ansi Inter que l'artiel terminal, eclui du cososternum rudimentaire. Lis poil sur le prolumerement coxal, un autre sur larticle terminal ; coxostermum orlahre.

Thlopodite de la deuxieme michoire (fig. 33) triarticulé. Ungle (fig. 34t pectime sur loute létendue de ses denx arètes. Coxosternum sans restiges de soudure au milien. lee pleurites sont représentes pall denx lobes relittrenent peu développés, silués anx argles le la base; il nexiste pas la moindre trace de dimarcation entre eux el la partie coxale. Pores metameripues tres doignes l'un de l'autre, entoures complitement par un lunrrelet

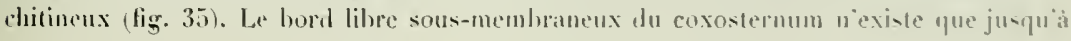


une faible distance de la duplieature de la hanche. La partie médiane du coxosternum empiète largenent sur celui de la premiere michoire.

Tergite loreipulaire (tig. 26 ) aussi large que la tète el que le tergite suivant, à coités arrondis, mon convergents. Les plemres foreipulates sont visililes en dessus, an niveau de l'encoche formie par la rencontre des ccités de l'écusson criplabique et du tergite forcipulaire. lorcipules (fig. 36) u'atteiguan pas de beaucoup le hord froutal. Téloprodites puadri-articules. Grille i tranchant lisse, inerme, ainsi que les autres articles; on olserve seulement sur le bord interne de l'article hasal un fort retrait de la partie correspondant à la cavité articulaire. Coxusternum à hord antérieur profondément et largement échancré, sans saillies coxales. Lignes dhithenses complètes, à extrémité antérieure venaut se fusionner avec le condyle. Pleures très développés, débordant d'une manière inusitíe le bord externe des télopolites, leur limite interne très oblique. La surface du coxosternum est liès déprimée sur la partie mérliane.

Tergites et prétergites non sillonnés longitudinalement, grossièrement gaufrés et granuleux, sauf sur une bande postérieure et sur les còtés qui sont fortement soulevés. Presque glalores sur la partie moyenne du corps, ils sont, au contraire, assez densément pileux dans les parties antérieure et postérieure.

Sternites gaufrés sur leur moitié antérieure. Du deuxième à l'antépénultième se tronvent deux champs poreux symétriques, parfaitement circulaires, siturs immédiatement en arriere du milieu du sternite, plus éloignés entre eux que du bord latéral, constitués par une surface lisse un peu surélevie dans layuelle se trouvent des pores en nombre considérable; ane zone périphérique de cette surface est dépourvue de pores. Masse glandulaire formant une tache bleu foncé.

Eupleurium (fig. 37 ) comprenant cinq rangées complètes. Le pleurite $3 \beta$ est entièrement en dehors de l'alignement de sa rangée. Le pleurite $2 \alpha$ u'est jas séparó du préstemite. Dernier pleurite stigmatifire séparé du tergite correspondant. Stigmates ronds.

Segment terminal. - Sternite en trapize plus large à la base que long $(10 / 7)$. Eupleurium róduit à deux sclérites: l'un contre le prétergite est très nettement $1 x$ car il occupe exactement la mème position et a la mème forme que ce sclérite dans les segments précédents; l'autre se truuve en avant de la hanche et fait aussi partie du présegment, mais il est plus grand que l'un quelconque des sclérites $3 \alpha, 4 \alpha$ ou $5 \alpha$ des segments précédents.; il représente vraisemblablement l'ensemble de ces derniers qui se seraient fusionnés. Pattes terminales fusiformes, tìs renllées ; la hanclie ne l'est pas proportionnellement plus que les autres articles. Elles sont couvertes l'une pubescence courte et très dense. Elles comprennent sept articles; le dernier est conique, un peu plus court quele précédent et complètement inerme. Deux qlandes coxales homogènes de chitque côti, s'ouvrant diacune par un pore ì demi-caché par le sternite.

Lionopodes de la lemelle courts, soudés entre cux, formant une plaque échancrée an milieu de son hord lilre. 


\section{Fam. Himanlariida.}

\section{Notiphilides Maximiliani (H. et Sauss.)}

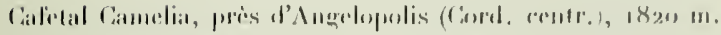

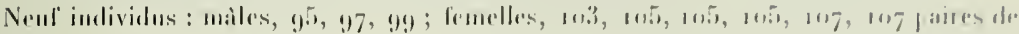
pilltes. 


\title{
Reptiles et Batraciens de Colombie
}

PAI

\author{
Dr M. G. PERACCA
}

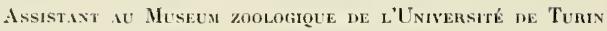

Les Reptiles et les Batraciens que le professeur Otto Fuhrmann a rapportés de son royage en Colombie et dont il a bien voulu me confier la détermination, appartiennent à 41 espèces, dout 4 (2 Ophidiens et 2 Batraciens) sont nouvelles.

\section{Reptilia}

\section{Lacertilia vera.}

\section{Geckonidx}

\section{Hemidactylus mabouia Mor.}

Boulenger (3) vol. I, p. I 22.

Un seul sujet provenant de Barranquilla (sur le Magdalena, près de la còte).

\section{Eublepharidx}

\section{Lepidoblepharis Festæ Peracca.}

Perafga (9) P. 2.

Quelques sujets du Cafetal Argelia (C. or. ${ }^{1}$ Dép. Cundinamarca, alt. $1600 \mathrm{~m}$.), identiques aux spécimens rapportés par le Dr Festa, de S. José Cuclipamba, dans l'Ecuador oriental.

1 C. c. = Cordillères centrales ; C. or. $=$ Cordillères orientales. 


\section{Iguanidx}

\section{Anolis stigmosus Bocourt.}

BOHLENGill (3) vol. 11, 1.87.

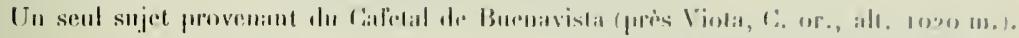

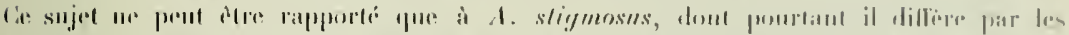

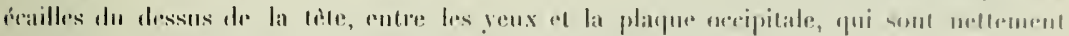

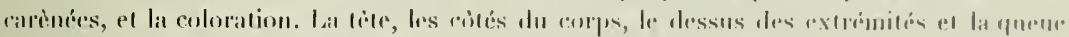

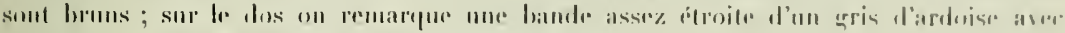

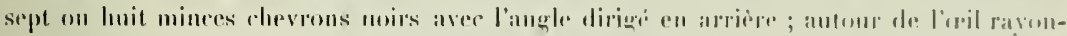

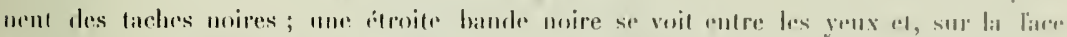

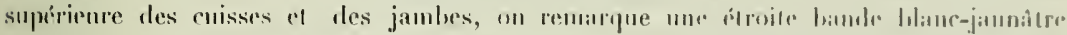

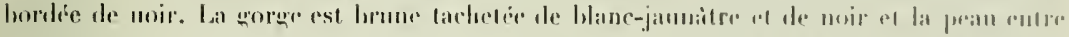

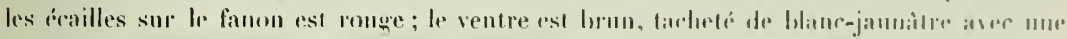

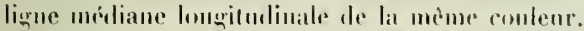

\section{Norops auratus Daud.}

BoUlengen (3) vol. 11, 1. 95.

Dewx sujets, dont un provenant du Cafetal Camelia, pres Angetonulis (r. e. liep

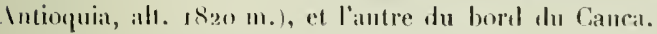

\section{Basiliscus americanus Laur.}

BOULENGE (3) rol. 11, p. rens.

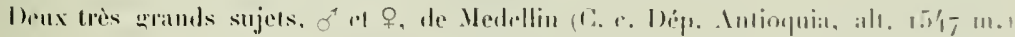

\section{Teiidx}

\section{Tupinambis nigropunctatus Spix.}

Botmengen (3) vol. II, p. 337.

Un seul sujet adulte, de moyenne laille, du Rio Matrdatena.

\section{Ameiva undulata Wiegm.}

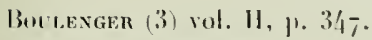

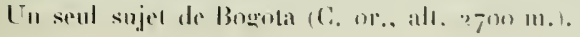


8. Anadia bogotensis Ptry.

Boulexgen (3) rol. II, p. fon.

Quelejues sujels de Bognota.

\section{Proctoporus unicolor Gray.}

Bovlentiel (3) vol. II, P. 413.

De nombreux sujets de Bugotis.

\section{Scincidx}

10. Mabuia agilis Raddi.

Bollengek (3) vol. III, p. igo.

Quelques sujets de Angelopolis (C. c. Dép. Antioquia, 2oro m.).

\section{Ophidia}

\section{Typhlopidx}

\section{Helmintophis flavoterminatus Ptrs.}

Boulenger (4) vol. I, p. 5.

Un seul sujet du Cafetal Camelia, près Angelopolis (C. c. Dép. Antioquia, alı. 18 ig m.).

\section{Boidx}

2. Boa imperator Daud.

Bovlexger (4) vol. I, J. I I g.

Un seul sujet de petite trille, de Barranguilla sur le Magdalena.

\section{Colubridx}

\section{(Aglypha)}

\section{Spilotes pullatus L.}

Boulenger (4) vol. II, P. 23.

In seul sujet de Filardelfia (près Janizales, C. c. Dép. Antioqquia, alt. ca. 16oor m.). 


\section{Coluber corais Boic.}

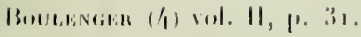

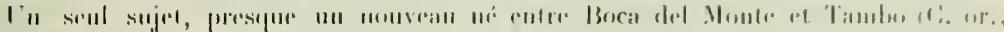
all. (i1. $18,1111$.$) .$

\section{Liophis typhlus L.}

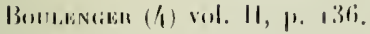

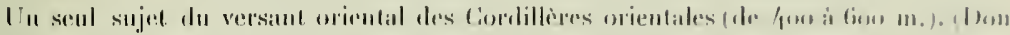

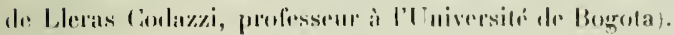

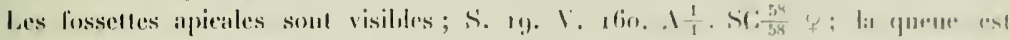

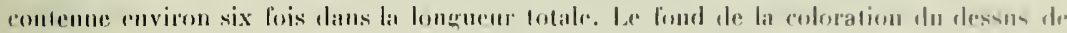

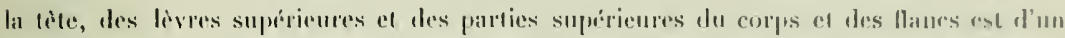

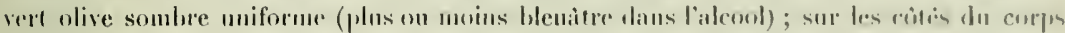

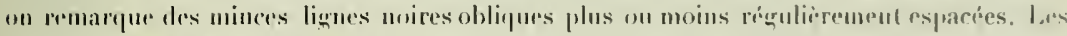

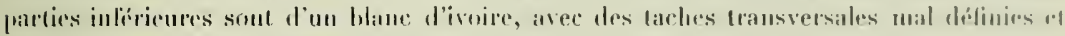
irmérulières d'un vert olive sombre.

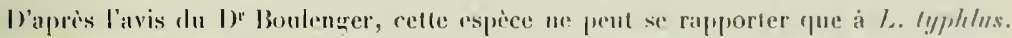

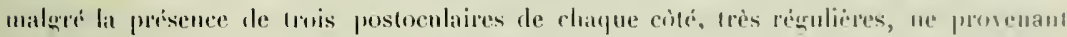
pas d'une division accielentelle des drux postoculares mormales de l'espree.

\section{Liophis pseudocobella $n$. sp.}

Celle nouvello espier reproduit d'une façon émnnante le facies el la ploblirlone de Rhadimuen cobella L. On pent tomlefois la recommitre aisement par la prosince des

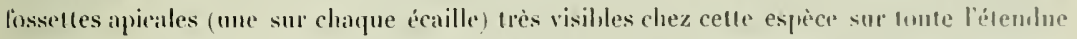
du corps, tandis que chez la plupart des especes du equre Limphis on ne les rencontre qu' sur la partie antíriemre du dos, roire mème seulement sur les icailles du con.

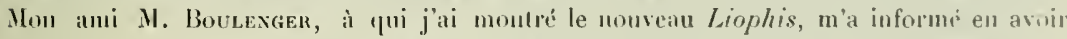
regu tout récemment trois individus provenant du l'ueblo Rico, Chaco Colnmbien. recueillis par M. M. G. Palmer. Ln de ces individus, conservés an British Muscum,

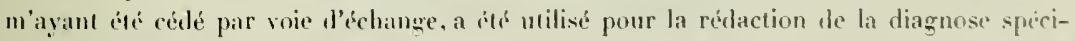
fique, dans laquelle j'ai aussi temu comple du numbre des pliques vemurales at caudales que m’a communiqué mon colligne An Brilish Musmm. La nouvelle espece, dapris mon ami Boulexgen, se rapproche de $l$. albirrntris dan.

Tèle assez diprimée, museau dibordan sur la leve inférieure, lrís obus, benuroup

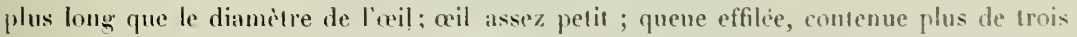
fois $\left(3 \frac{1}{3}\right.$ a $3 \frac{3}{4}$ a peu près) dans la longueur tolale.

Rostrale beaucuup plus large que haute (presque deux fois plus largere à prine visilitr" d'en laut; internasales un peu plus courtes que les préfromlales, aussi longues yue larses, 


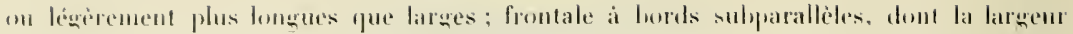

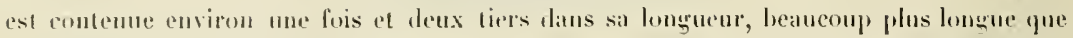
sal distance de l'extrénité du museau, plus courte que les pariétales; frenale aussi laute qü large; une prénculaire largement séparée de la frontale; deux postoculaires; tempo-

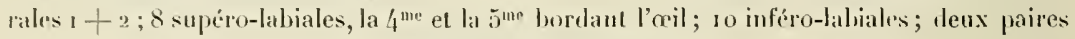
te sous-mandibulaires, subégales, dont celles de la première paire, séparées de la plarju. mentonnire, sont en contact avec les 4 w 5 premières labiales.

Ecailles tris lisses, luisantes, el pourvues sur toute l'álendue du corps, mème sur la 'queur, sur le sujet du prof. Fulirmann, d'une fossette apicale tres visible; S. 17. V. 145.

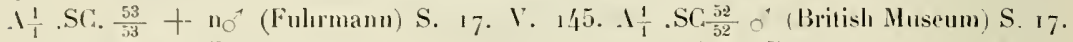

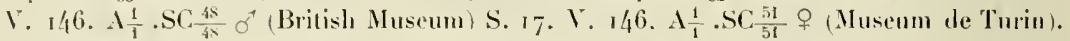

Les parties supérieures d'un moir brunatre, plus franchement noir sur la partie postéricure du corps el sur la queue. Lèvres supérieures, parties inférienres gorge, ventre, queuc) d'un jaune paille aree des bandes noires transversales (occupant 2 ou 3 gastrustignes) espacées, rappelant la disposition des taches veulrales chez certains sujets de Coronella girundica Dand. Parfois ces bandes sont interrompues sur le milieu du ventre ef ne correspondent pas exactement asec l'autre moitié de la bande noire qui se tronve déplacée en avant ou en arrière. Les écailles des côtés du cotps correspondant anx parties jaunes de la face ventrale, sont bordées de jaune, de façon à former des taches irrésulières sur les côtés du cor'js et des bandes plus claires plus ou moins visibles sur. le quart antérieur du corps el surtout sur le cou; les pariétales sont bordées de jaune sombre qui sétend en avant sur les temporales de la deuxione rangée. Chez le sujet de Puello Rico la tète et le dessus du corps sont d'un gris cendré avee des larges bandes noires transversales plus ou moins régulières descendant sur les flanes jusyu’à se foudr' avec les bandes noires du ventre. Les écailles des espaces entre les bandes noires transversales sont plus on moins régulièrement lordées de jaune, surtout sur la partie antérieure du corps. La première bande noire sur le cou (en arrière ef séparée des pariétales), we descendant pas sur la gorge, est reliée à l'œil par un trait noir.

Longueur totale $4 \mathrm{ro}$ mm.; queue $92 \mathrm{~mm}$.

Un seul sujet de Angrelopolis.

\section{Coronella micropholis Cope.}

Boulenger (4) vol. II, p. 203.

Un seul sujel du Cafetal Camelia près Angelopolis (C. c., ı8ı! m.).

\section{Atractus Fuhrmanni n. sp.}

Tète assez allıng̨éc; museau arrondi, denx fois aussi lonğ que le diamètre de l'reil ; tronc rohuste, mème un peu trapu, quene contenue un pen plus de douze fois dans la longuenr totale. Rostrale petite, un peu plus large que haute, à peu près invisible d'en haut; 


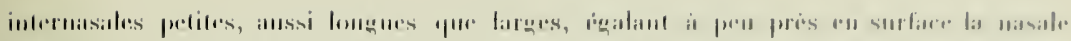

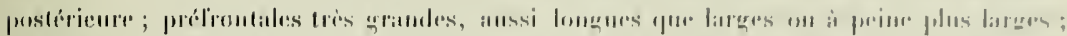

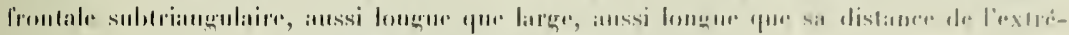

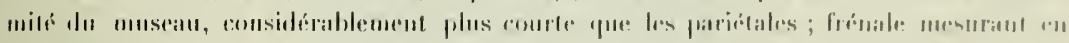

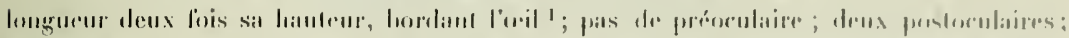

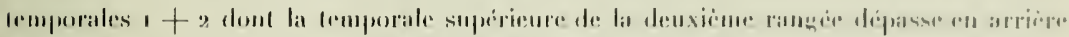

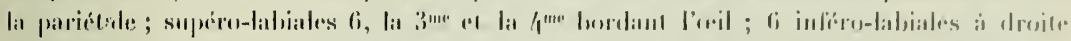

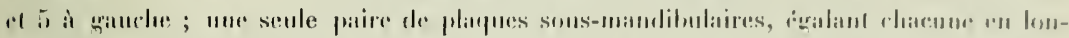

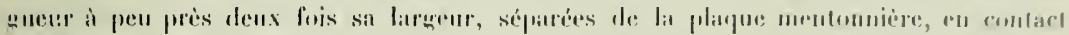

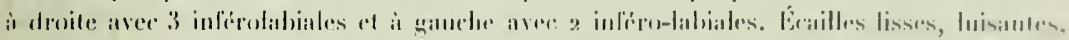

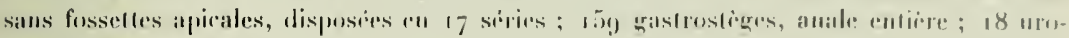
stimes toll dendlu sírie.

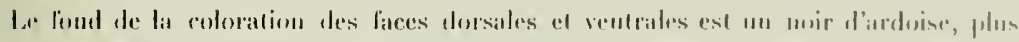

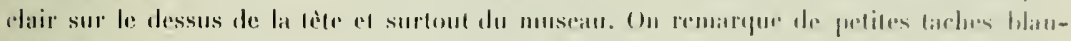

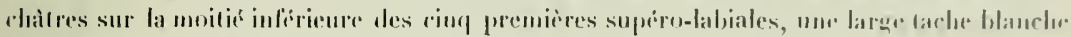

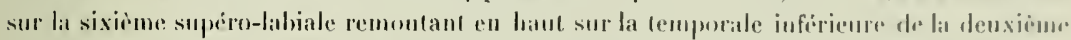

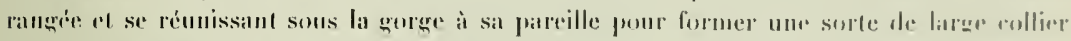

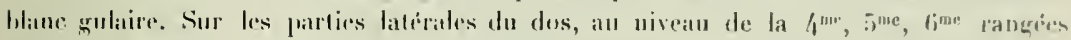

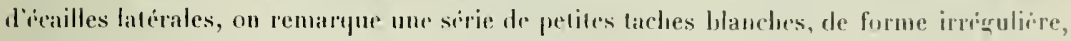

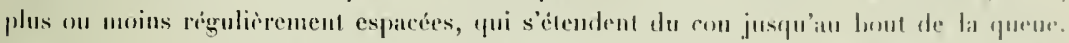

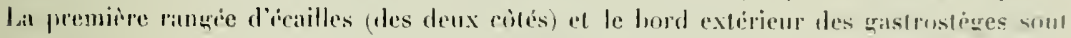

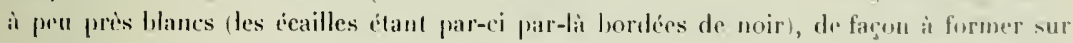

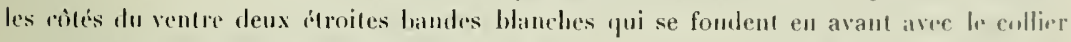
banc endaire. Sur le ventre, on remaryue des laches blanches mansversales irrésuliom. phes nombreuses vers la partic postirieure du corps. Les burds internes des infero-labialen sont muirs.

Lu seul sujet lemelle d'une Quehrada près de Bogrota, nesurant a $28 \mathrm{~mm}$. dunt is mum. représentent la longueur de la qurue.

\section{Atractus crassicaudatus D \& B.}

Boulengen (/) vol. II, p. 310.

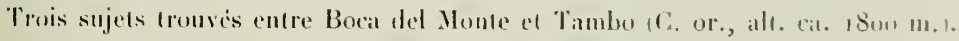

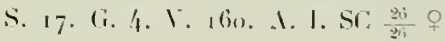

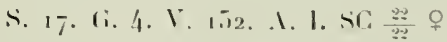

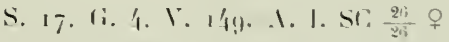

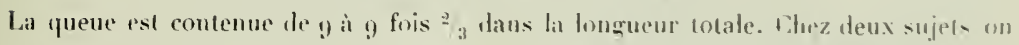

1 Divisec à droite par nue sulure verlicale en deux parties égales. 


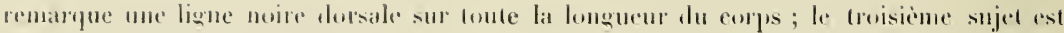

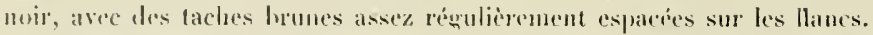

\section{Atractus Werneri n. sp.}

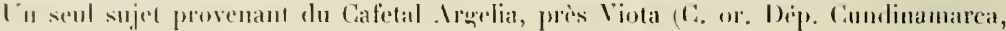
alt. $18: 3$ m.). Tète asse\% allongré, musean obtus, long un peu plus de derux lois le dia-

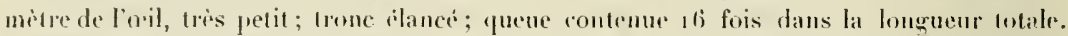
Rostrale petite, plus large que haule, invisible d'en haut; internasales petites, anssi longues que larges; prélirontales nellement plus longues que larges; frontale aussi longue que litrge, sulbriangulaire, aussi longue que sa distance de l'extrémité du musean, heancoup plus courte que les pariétales ; frinate mesurant en longueur deux fois sa hauteur, hordant l'oil; pas de préoculaire; une seule postoculaire: temporales $1+2$, dont la temporale supérieure de la deuxième rangèe dépasse en arriore les pariélales ; 7 supréro-

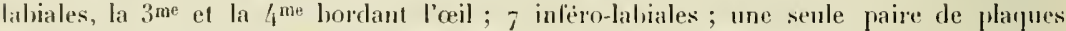
sons-mandihulaires égalant rlacune en longueur fleux fois sa largenr, en contact avec les trois premières inféro-labiales. Écailles lisses, luisantes, sans lossetles apieales, dispusies en 17 séries; 161 gastrostiges; anale entière ; 18 urostèges en double série.

En dessus el sur les Hancs, d'une couteur bistre uniforme, avec une ligne noire dorsale qui s'étend du cou à l'extrénilé de la quene. Les écailles, observées à la loupe, sont tinement sablées de noir. La série externe des écailles est d'un blane sale, de mème yur la face ventrale qui présente des taches noires transversales plus ou moins complites et irrrágulièrement disposées.

Le bord des premieres labiales est tache de blane sale. Longueur totale $245 \mathrm{~mm}$, dont 15 représentent la longueur de la quene. Cetle espèce est proche de A. crassicaudatns

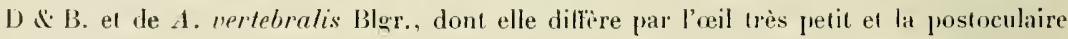
unique.

\section{Opisthoglpha}

\section{Oxyrhopus petolarius $\mathbf{L}$.}

BOULENGER (4) VOH. III, p. 101.

Ln seul sujet de Angelopolis (C. e., alı. ca, 1970 m.).

$$
\text { S. 19. V. } 205 . \text { 1. I. SC } \frac{98}{98} \text { \& }
$$

\section{Thamnodynastes Nattereri Spix.}

BuULENGEK (4) val. III, P. II6.

Ln seul sujet de Barranquilla sur le Magdalena. 


\section{Homalocranium melanocephatum L.}

Boumengen (/) vol. 111, p. 215.

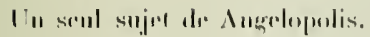

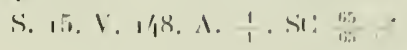

\section{Stenorhina Degenhardtii Berth.}

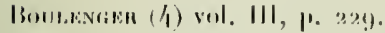

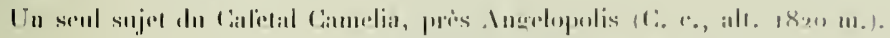

$$
\text { S. } 17.1 .1 / 7, \ldots .1 \% \text {. S1: } \frac{11}{11}=
$$

\section{Batrachia}

\section{Ecaudata}

(Firmisternia)

\section{Ranidae}

\section{Prostherapis subpunctatus Cope.}

Prostherapis subpunctatns Cope (6). 1. 6.

Prostherapis variabilis Werner $(7), 1 \% 4$.

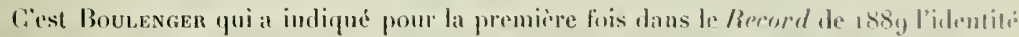
de Pr. andubilis Werner, awec Pr. subpunctotus Cope. En comparant les nombrenx

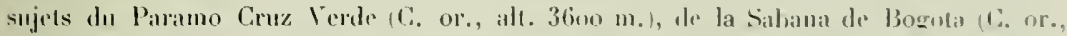
alt. 2650 m.), de Boca del Moute (C. 118., alt. 2400 m.), rapportés de Colombie par le prof. Fularmanu, je ne puis que confirmer la neressilé de rénnir les aleux espèces, qui

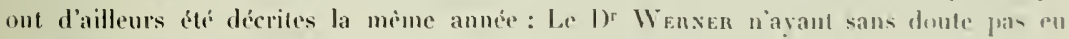
loccasion ou la possibilité de consulter la note du prof. Lope.

Dans da deseription de Cope, il s'est ponrtant enlissé un lapsens gui pourrait dímuler un naturaliste qui n'aurait pas sous les yeux la description hien plus complète et solugnó

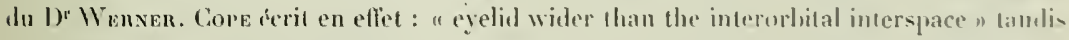

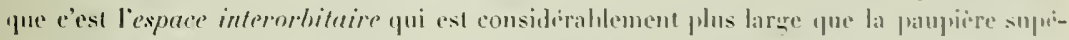

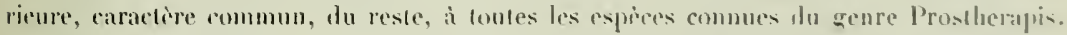

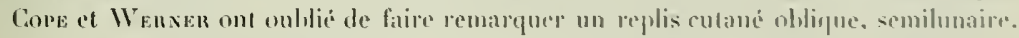

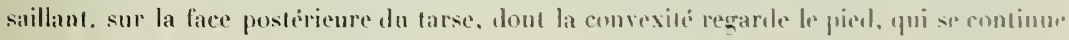

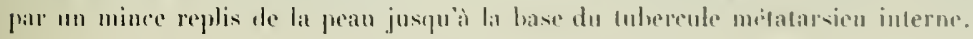




\section{Engystomatidae}

\section{Engystoma ovale Schn.}

Boulexger (t) p. i63.

Un seul sujet da Citetal Bnenavista, près Viola ( $\mathrm{C}$. or., alt. 1020 m.).

\section{Arcifera}

\section{Cystignathidae}

\section{Hylodes conspicillatus Gthr.}

Boulexger (1) p. 204.

De nombreux sujets des environs de Augelopolis.

\section{Hylodes bogotensis Ptrs.}

Bovlenger (I) P. 215.

De nombremx sujets de tous les àges, des montagnes des emirons di. Bownta (C. or., alt. $2800 \mathrm{~m}$.).

\section{Hylodes Fuhrmanni n. sp.}

Cint sujets, dont deux lemelles adultes et trois jennes, de taille différente, de Paramo Cruz Verde, montagnes it l'Est de Bogota (C. or., alt. 3000 it $3600 \mathrm{~m}$.).

Langue presque cordiforme, allongée, échancrée en arrìre. Dents vomériennes formant deux groupes obliques assez grands, en arrière d'une ligno réunissant le bord postérieur des choanes; museau anondi, don l'extrémité déhorde lígèremeni, mais visiblement, sur la live inférieure ', aussi long que le diamètre de l'ocil ; canthus rostralis distinct et saillant, la région frénale très oblique étant considérablement excavér; narin plus près de l'extrémilé du museau que des yeux ; espace interorbital consilérablemeut plus large que la paupière supérieure (pas tout à fait une fois et demie) ; fronto-pariétaux a bords non relevés, présentant toutefois une faible gouttière longitudinale; tympan très visible, dont le diamètre est un peu inférieur au demi-dianètre de l'ceil. Mains et pieds très rohustes, doights et orteils lourds, quoique assez longs, sans trace de palmure; les disques légèrement spatulés des doights dípassent modérément en largeur le diamètre dı doight, et les disques des orteils, à prine rétrécis à leur batse, à contour arrondi, égalent en largeur le diamètre des orteils; les doigrts et les orteils sont bordés de dratpue coté

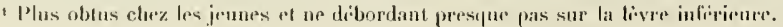




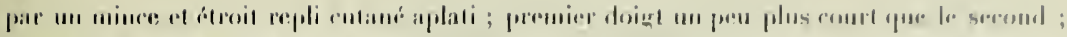

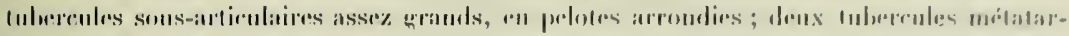

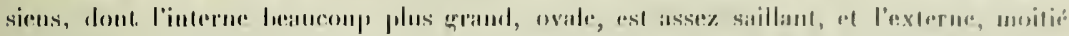

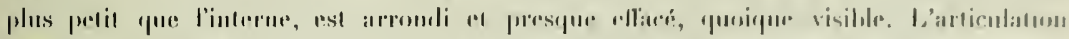

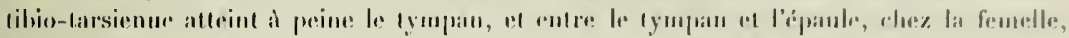

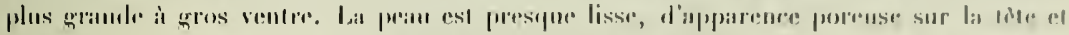

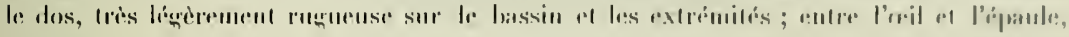

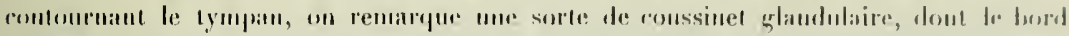

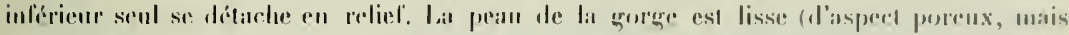

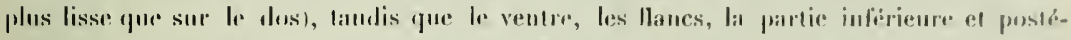

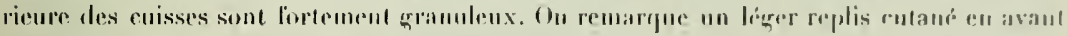
du ventere, rénnissant les aisselles, el un antre léger replis muins marqué qui, partant du

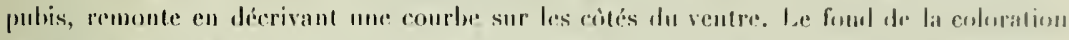

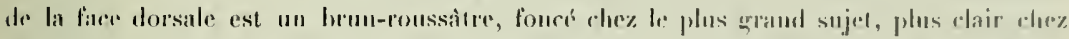
les antres, avee des laches lorunes plus sombres, dispusées de la façon suivanto : sur las

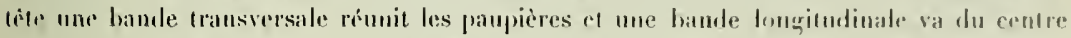
de la binde transversiale an hout du muscau ; une ligne va du loun du museau is lisil at de l'ail, ru contournant le tympan en haul, s’érend jusqu'à la raciur du membre antérienr;

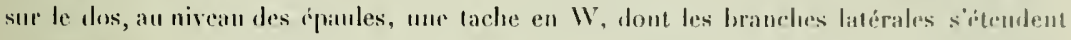

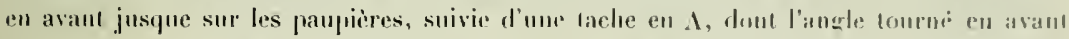
est plus on moins riguliorement redis aux branches latérales du $\mathrm{W}$ de facon à formor daus leur rusemble une lache en $X$; sur les llanes, m remarque des landes plus un moins régulières, parallèles anx barres de l'X. Les extrémilís sont harríes. Che\% un des sujets adultes, toutes les bandes lorunes sumt brisées a intermupmes, el chez l'autre sujel,

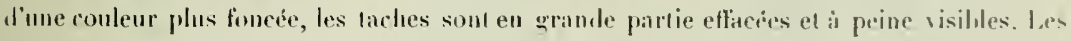
parties inféricures sont d'un hrun blanchitre, plus clair sur les régions palmaires el plinlaires at sur les cuisses. La gorge présente parfois des taches el des marbrures d'un brun foncé. la find de la coloration de la face dorsale, chez le sujel le plus jeune, est un gris clair a les parties infirieures son flun blane brunitre à peu près comme chez les adultes.

\section{Longuenr toliale}

Longurur de la lète

Laregrir de la títe.

Largeur espace interorbital .

Largeur paupière supérieure.

Diamerre de l'cil

Diamitre dı tympan

Lonquen extrénité antérieure

Longueur extrémilé postirioure

\begin{tabular}{|c|c|c|c|}
\hline & 0 & $\therefore$ &. \\
\hline $\mathrm{mm}$. & $41,-$ & $\{0,5$ & $27,-$ \\
\hline " & 13.5 & 14,- & !) \\
\hline " & $1, \pi, \overline{1}$ & $16 .-$ & 11. \\
\hline " & 4.5 & $4, \overline{7}$ & 3.5 \\
\hline " & 3.5 & 3.5 & $2, \overline{1}$ \\
\hline " & 4,5 & $4 . .5$ & $3, \pi$ \\
\hline " & וי, & ז & $1 . \pi$ \\
\hline " & $25 .-$ & 27. & 18,- \\
\hline$n$ & 洺, & $56 .-$ & $37 . .5$ \\
\hline
\end{tabular}




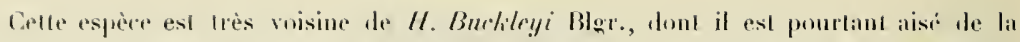
dislinguer par les dents vomériennes un peu moins en arrierr des choanes, par les hords

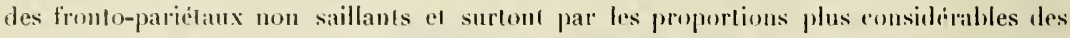
mains et des pirds. Les mains, les pieds, les larses, les doigts el les orleits sumt rraimenl lourds el massifs, comparés à ceux de // Buclileyi, qui sont beancoup plus élancés ; les disques des doigls et des ortrils sont aussi an proportion plus petits el surtout moins spalulés.

Pendant limpression de celle note, II. Despax, du Museum d'Histoire naturelle de Paris, a díerit (Reptiles et Batriciens de l'Équateur, recueillis par M. le Dr Rivet. - Extrait de: Mission dh Service Gégraphique de l'Armée pour la mesure d'un are du Méridien équatorial en Amérique du Sud. 189g-19ofi. Tome 9. Zoologie, fascicule 2. Reptiles, Poissons, Batraciens, Paris 1911) une nonvelle espèce d'Hylodes, Ilylodes Riveli, qui. quoijue différant par la eoloration, se rapproche tellement de mon H. Fubrminui, que je me suis décidé à soumettre à mon eollègue Despax un de mes types.

D’après M. Despax, il n'est pas douteux que ce soit là deux formes tris voisines; toutefois, il lui semble tque l'on peut les distinguer. Laissant de cóté la coloration, deux earactères lui paraissent les différeneier. Dabord la loogueur du pied (mesurée de l'articulation tibiotarsale au bout de l'orteil le plus long); elle est plus considérable ehez H. Fuhrmanni. Enfin l'aspect des téguments. A la face dorsale el partieulièrement dans la région saerée, ils sont heaueoup plus lisses ehez H. Fuhrmanni. A la fice ventrale, les granulations de ha peau sont plus irrégulières et oe sont pas distinctement divisées en area comme chez II. Kiveti, où elles rappellent un peu une mosaïque. A ceei, il faut ajouter que réellement les deux espèces différent par les rappor's différents des longueurs et largeurs des parties de leurs corps, ainsi qu'il résulte du tableau suivant dans lequel les mesmres absolues en millimètres sont réduites, d'après la méthode eonnue du prof. Camerano ${ }^{1}$, en $36 o^{m e s}$ de la longueur du eorps de l'animal, prise comme base et supposée divisée en 360 parties ehez tois les sujets que l'on veut comparer.

\begin{tabular}{|c|c|c|c|c|}
\hline \multicolumn{5}{|c|}{ Ilylodes Fuhrmanni } \\
\hline queur totale. . &.$\quad$. & $\mathrm{mm}$ & 40,5 & $=360$ \\
\hline de la tète? & & v & 14 & $=124.44$ \\
\hline Largeur de la tète. & . & . " & 16 & $=1 / 12,22$ \\
\hline Espace interorbital. & . & $"$ & 个,5 & $=40$ \\
\hline Largeur de la paupière & e supėr & r " & 3,5 & $=31,11$ \\
\hline Diamétre de l'ceil . & . . . & $"$ & 4,5 & $=40$ \\
\hline du tympan & . & " & 1.75 & $=15,55$ \\
\hline Extrénité antérieure . & . & . " & 27 & $=240$ \\
\hline Longueur de ta euisse & . & . $\quad "$ & 16 & $=142,22$ \\
\hline Loogueur de la jambe & . & $\cdot \quad \eta$ & 17 & $=151,11$ \\
\hline du pied. & . & - " & 28 & $=248,80$ \\
\hline
\end{tabular}

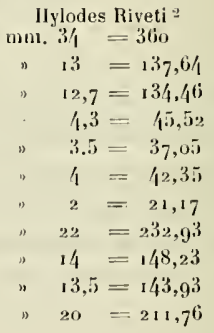

\section{Hylodes unistrigatus Gthr.}

BOUlenger (i) p. 217.

Deux sujets males pris entre Ilonda et Guarluas (C. or., alt. 30o-400 m.).

1 Camerano L. Lo studio quantitativo degli organismi ed il eoefficiente sonatico. Atti della Ra Accademia delle Scienze di Torino, vol. XXXY-rgoo e Bollettino dei Musei di Zoologia ed Inatnnia Comparata della Ra Universita di Torino. N. 375. vol. XV. ryon (Ristampa).

Z Mesures communiquées par M. Despax.

s Du baut du musean it l'nceiput. 


\section{Hylodes crucifer Blgr.}

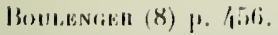

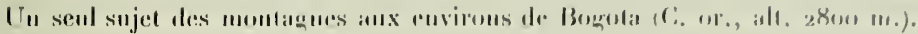

\section{Hylodes cornutus Espada.}

BoULANiBil (1) 1. 220.

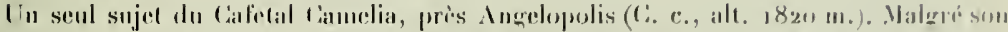

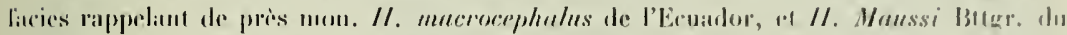

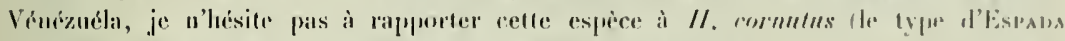

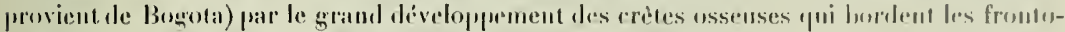

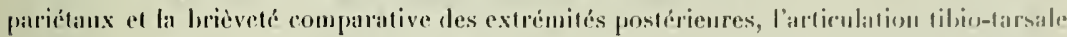

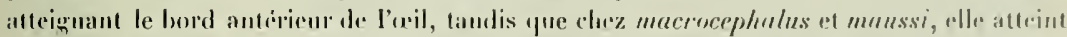
la printe dn musein. La langue, roude an subcordiforme, est légirement érlancrér sur son bord postérienr.

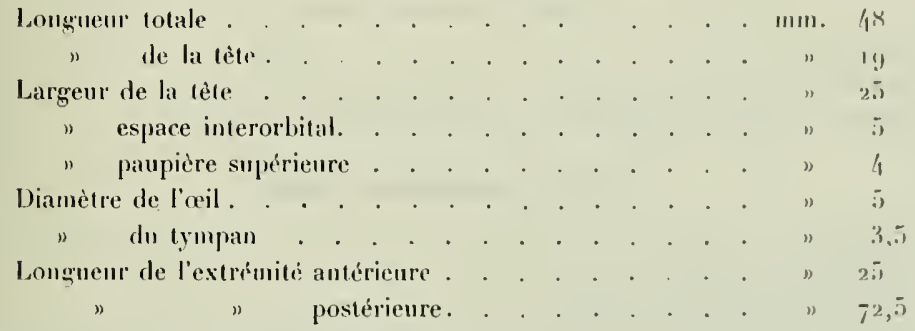

\section{Bufonidae}

\section{Eupemphix trinitatis Blgr.}

Ëupemphix trinitatis Boulengen (5) p. 307.

Bufo atrignlaris WЕНNEn (7) p. I2.

Denx sujots du Magdalena (Magangue et Bodega Central, alt. ca. Zo m.). Bnfn alrigularis de Werner (Trinitad) n'est autre que Eu. trimitatis Blgr., ainsi que Bunlexgen l'avait dejà fait remarquer dans le Record de 1899. Les sujets de Colombie correspondent parfaitement à la description de l'espéce. 


\section{Bufo marinus $\mathbf{L}$.}

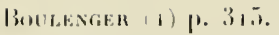

De nombreux sujels du Magdalena, du Cafinal Camelia (alt. 820 m.) el de l'Alto Don Elias (alt. ca. 2 roo m.).

\section{Bufo thyphonius $L$.}

Boulenger (1) p. 3i7.

Quelques sujets du Cafetal Magdalena pròs Viota (C. or., alt. $1200 \mathrm{~m}$. Dép. Cundinamarca) et Medellin (C...., alt. $1550 \mathrm{~m}$. Dép. Autionguia).

\section{Bufo sternosignatus Gthr.}

BOUleNger (1) P. 323.

Un seul sujel adulte dı Cafetal Camelia, près Angelopolis (C. c., alt. $1820 \mathrm{~m}$.).

\section{Hyla crepitans Wied.}

BOULENGER (1) P. 352.

In seul sujet du Rio Magdalena, Bodega Central (all. ca. 7o m.).

\section{Hyla wilsoniana Cope.}

IIyla wilsoniana Cope (6) p. 3.

IIyla creolica Wernen (7) P. 14.

Plusieurs sujets de facatativa (C. or., alt. $2580 \mathrm{~m}$.) et do Tequendama (C. or., alt. $2260 \mathrm{~m}$.). Cope et Werner ont décrit cetle espèce la mème année, el c'est Cope qui a la priorité. D'après Cope, les dents vomériennes sont disposies en deux séries transversales entre les choanes, et d'après Werner, elles seraient disposées en deux groupes elliptiques obliques. C'est Cope qui a raison. Pour ma part, je puis ajonter que ces groupes sont particulièrement, voire même extraordinairement, saillants sur le palais.

\section{Hyla Fuhrmanni n. sp.}

Espèce de grande taille, portant ses cufs sur le dos. Langue très qrande, subcirculaire, à peine échancrée fustérieurement, presque adlé́rente au plancher de la bouche. Dents vomériennes sur une rangée transversale, à peine interrompue au milieu, s'étendant sur les còtés jusqu'au delì des centres des choanes, dont l'ouverture est assez petite. Tète un peu plus longue que large, museau subaigu, oblus, aussi long que le diamètre 


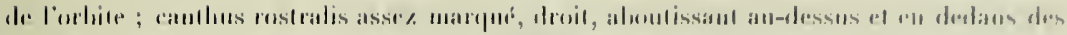

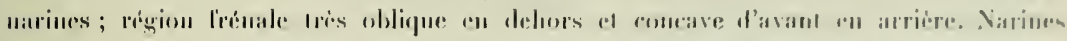

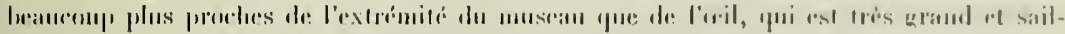

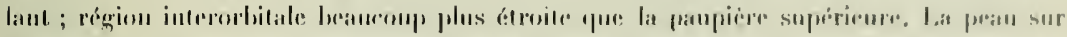

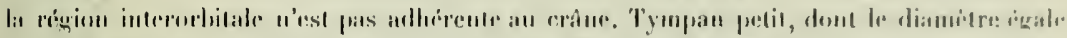

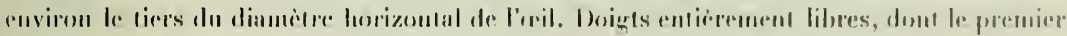

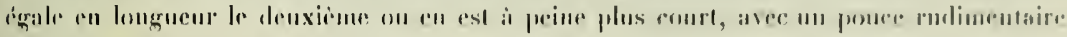

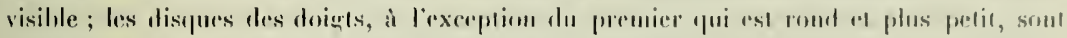

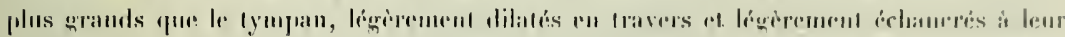

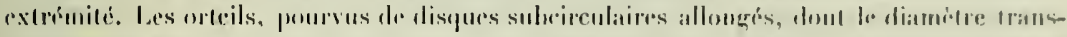

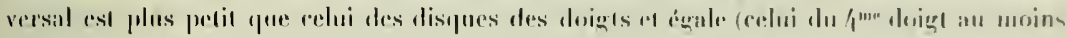

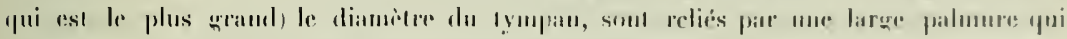

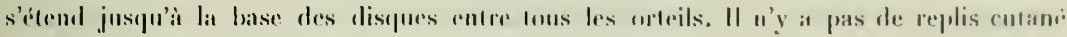

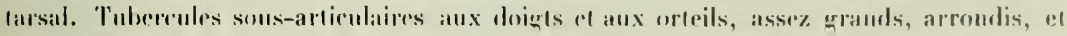

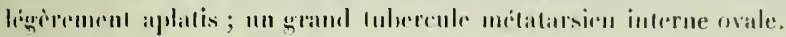

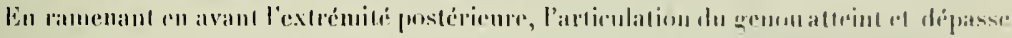

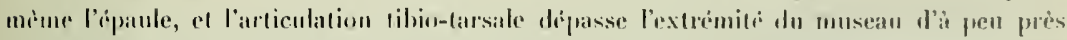

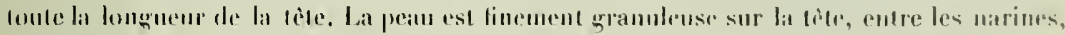

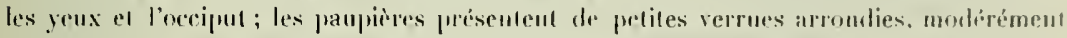

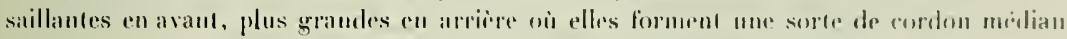

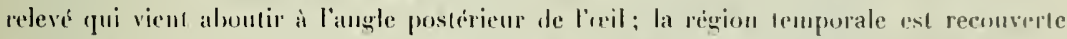

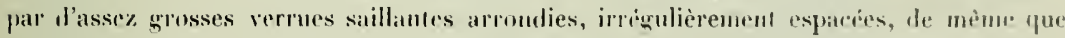
la pean en arrière el en dessous de la commissure do la houche : un remarpue un asiez fort replis culani qui s'clend de l'angle pustériem de l'acil à l'épanle, surmoutant le lympan ; la lève supérieure est parsemée de preties verrues arrondies et saillantes. La proun du dos, de la gorge el du ventre est grossièrement graunleuse, de mème qur vur los extrémilés incrnes des cuisses, soil sur leur liace postérieure, soil sur leur face infirinur. Partou ailleurs sur les cxtrénites antérieures et postérieures, la peiu est alsolument lisse.

L'unique spécimen rapporté par le prof'. Fummaxx est une femelle qui, à linstar d"

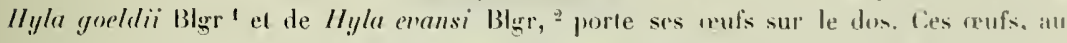
nombre de 33 , oceupent loute la rigion dorsale depuis locciput jusipu à la réerion sicrale ; elles ont en moyenne un dianc̀tre de 7 millimètres.

En soulevant les oufs de la rangée latriale, on remarque sums dhayue auf une légère dépression hémisphérique, oì la peau, grossièrement gramuleuse, paraì normale, sans moditication de structure en rapport avec l'incubation des ceufs; les atufs ne sont pas reliés a la pran par des vaisseam on ne semblem adhérer que par un sorfe de mucus.

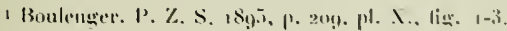

= Bunlenger. I'. Z. S. $190 \%$, p. roti, pl. 1. 
Dans rhagur aruf, cividemment à terme de sun developpement, on voit des petits completement formés, sans trace de queue, les jambes postérieures repliées sous le ventre, dont la paroi ent complètement fermée.

P'arties supérieures brunes avec des tacles d'un quis d'ardoise foncé. On remarque une qrande tache transionsile entre les yeux, empichant sur les paupières, mo tache en arant des yeux sur le museau el irois grandes taches sous l'oeil, dont la premiere et la dernière sont respectivement dirigées en avant el en arriere.

La région frénale est du mème gris sombre des laches. Les extrénités sont harrées de grris foncé. La grorge est grisatre, tachée de jaune sale ; la poilrine el le ventre, al'un lorun violacé très clair, présemtent des taches irrégulières d'un gris foncé el des marbrures plus marquées sur les tlancs. La fice inférieure des extrenités est d'un brun violacé assez chair, arec des laclies grises à peine visibles: la face intérteure et postéricure des cuisses est plutèt jaunatre avec des taches marbrées confluentes d'un gris d'ariloise sombre; les larses en dessous, de mène que les surfaces palmaires et plantaires sont d'un çris sombre uniforme.

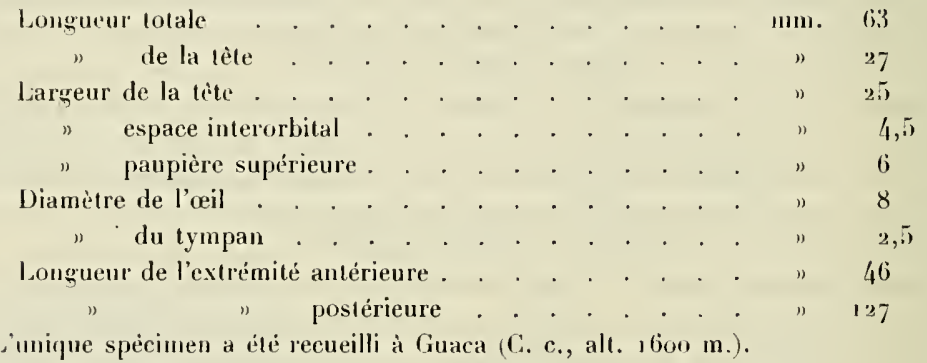

\section{Caudata}

\section{Plelbodontinae.}

\section{Spelerpes adspersus (Ptrs)}

Boulenger (2) 1). 7 "

De nombrens sujets de Bogota (alt, 2650 m.). 


\section{Apoda}

\section{1. 'Thyphlonectes natans Fischer.'}

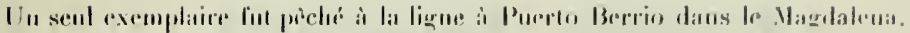

\section{BIII.IOGRA PHIE}

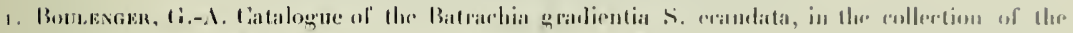
British Musenn (Natural History). Sorend mlition. 188\%.

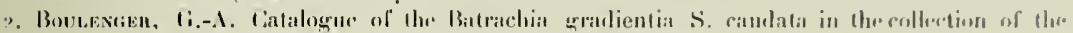

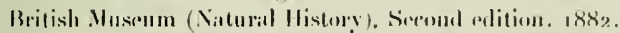

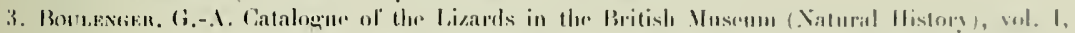
II, III.

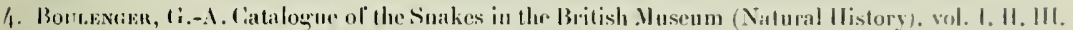

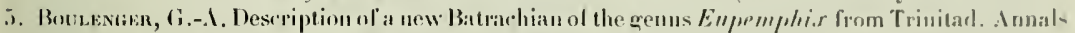
and Magazine ol Natural History (ii), III. I8sig).

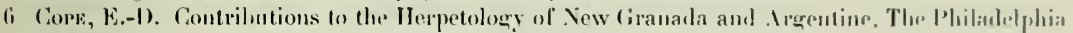
Museums S'cientifie Bulletin. No 1. May. 26. 1899.

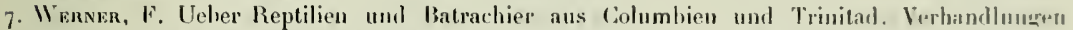
K. K. Zoologisch- Botanischen (iesellselaft in Wien. 3o Septemler. 1899.

8. Bom,enger, (i,-1. Descriptions of new Reptiles and Batrachians collected by ./r. P.-(). Simom in the Antes of Ecuador. Annals and Nagazine of Natural History (7) IV. ${ }_{1899}$.

(). Prascas M.-(i. Viaggio del Dott. Enrico Vesta nell' Ecuador e regioni vicine. IV. Bollettinn dei Musei di Zonlogia efl Inatomia Comparata della Ra Universita di Toriun. No $30 n$. 1897 . Vol. Xll.

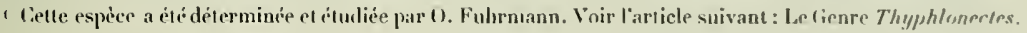




\title{
Le Genre Thyphlonectes \\ P.I IS
}

\author{
$D^{r}$ O. FUHRMANN, NEUCHATEL
}

Dans l'ordre des Apodes, le genre Thyphlonectes est ecrtainement un des groupes les plus intéressants; il dilfëre surtoul des autres par son genre đe vie. Tandis que tons les Apodes mènent une vie sonterraine semblable à eelle des vers de terre avee lesquels ils ont une certaine ressemblance extérieure, les représentants dı genre Thyphlonectes sont nettement aquatiques. Ce fait a dité souvent contesté et la plupart des anteurs, pen nombreux du reste, admettent que lors inème que tous les Thyplılonectes ont été trouvés dans l'ean, ils n’y séjournent très probablement que passagèrement. Mème les Sarasin ' dans leur magnifique onvrage sur /chllyophis glutinosus croient (p. 27) les observations rapportées par les collectionneurs non concluantes pour ee qui concerne la vie aquatique des Thyphlonectes. Dans un "Nachtrag" (loc. eit. p. 251 ), ayant lu le travail de J.-G. Fischer ${ }^{2}$, ils reviennent sur leur idée et admettent avee cet auteur la possibilité qüil existe de véritables Cerciliens aquatiques.

Xous allons voir dans les lignes qui suivent que ce genre de vie particulier pour des Aporles se confirme entièrement, non seulement par le fait que les Th!phlonectes ont tous flé trouvés dans l'eau et ont lenr corps plus on moins comprimé latíralement, à l'extrémité postérieure, mais eneore par certaines dispositions anatoniques, indiquant nettement que ces animanx doivent ètre exelusivement aquatiques.

En remontant le Magdalena, nous avons vo à Puerto-Berrio un Indien péchint ì la ligne sur le bord du fleuve à un endroil oi l'eau était très profonde et le bord abrupt. Tout d'un coup, il retire brusquement sa ligne de l'eau ell eriant: un serpent! un serpent! Je m’approche et j'arrive juste à temps pour recueillir l'animal que l'homme voulait

' Sumsis, P. 11. F. Zur lintwicklungsgeschichte und Analomir der ceylonesischen Blindwähle, Ichthyophis glutinosus. Wiesbaden, Kireidel’s Verlag i $887^{-1} 8$ tyo.

2 Fiscien. J. G. Vene Amphibien und Reptilien. Arch. l'. Naturg, ix8o. 


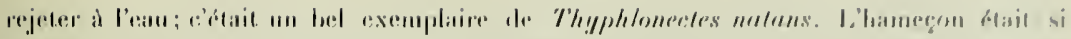

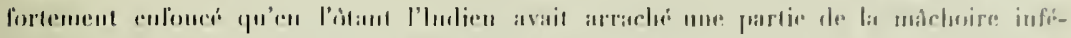

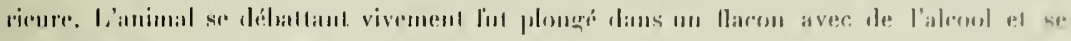

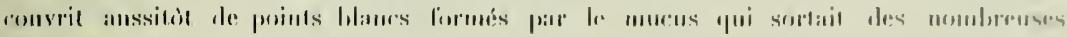
unlaurless rulaménes.

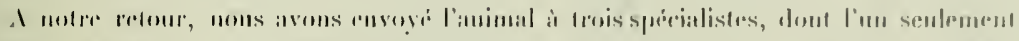

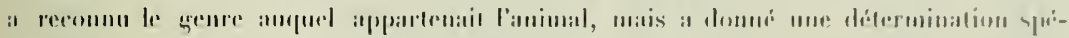

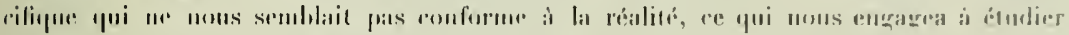

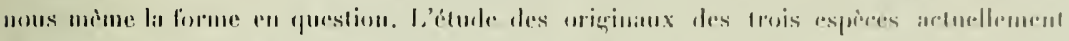

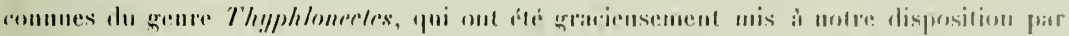

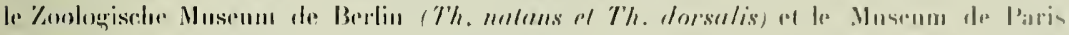

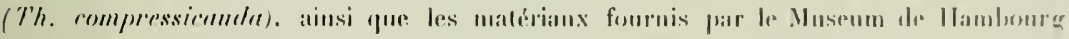

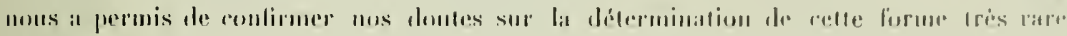
dians les collerlims.

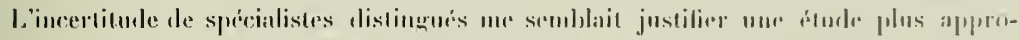
fondir des frois seules esprees bommes, élude qui se hase done sur les orighamx. Noms

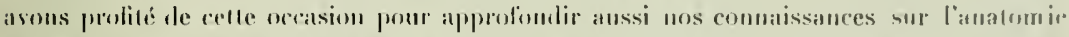

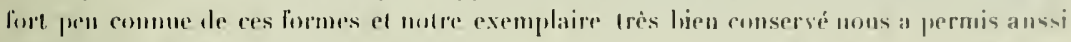

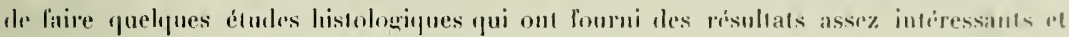
inillendus.

Nous commengons notre ílule ave le Th. noluns parce que, comme nousl'avms dejit

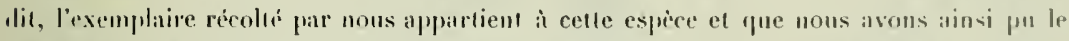
dissćpuer, ce qui naturellement n'a pu ilre fait avec les exemplaires des Musées. Pourtant le Musie de Berlin nous a autorisé à faire quelques incisions daus la face ventrale des exemplatires mis à notre disposition, incisions «ritr auxipuelles nous pourons donner des dítails anatomiques el les traits caractéristiques de l'mganisation interue de tous les mprisentiuts dlu gente.

\section{Thyphlonectes natans ( $F$ ischer).}

(Fim. 1-3.)

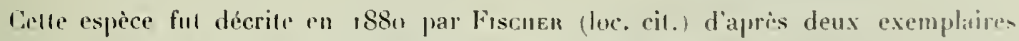
verant du Canca, aflurnt du Rio Magdalena. Daus le Magdalena mime, l'esprice fut trou-

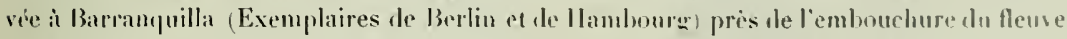
dans la mer, tandis que notre exemplaire fut recueilli bien en dessus de l'embouchure du Cauca dans le Magdalena, à Puerto Berrio. Les exemplaires types sont malloureusement très mal conservés et présentent une couleur bien différente de notre exemplaire ef de celui de llambourg qui sont beancoup plus fonces. En eftet, les quatre exemplaires de Berlin sont de couleur brun clair sur les critis el sur le dos, tandis que la face ventrale est d'un

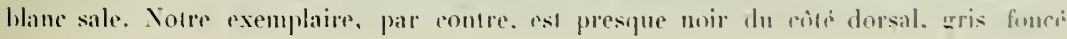




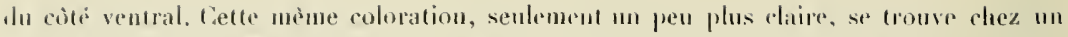

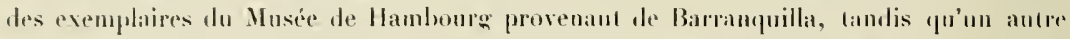
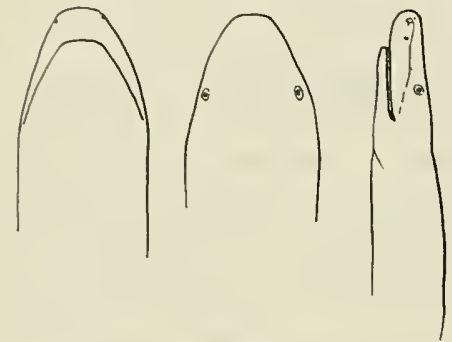

Fig 1 :

Th, natans Fischer. Type du Mlusée de Berlin. pris à Cáceres (aul Cauca) a la mème coulent que les exemplaires de Bertin. Celle différenes de couleur proviont sans doute de l'átat de conservation qui stail très bon chez notre exemplaire el celui de Hambouru, déficheux cliez les types.

La forma de la tete de Th. natans est tris earactéristique et permet de distingruer celle espece du premier coup de Th, compressirauda. En ellet, Th. uatuns a, contrairement it Th. compressicumbla, la tète trios fortement aplatic (voir fig. r el te lableau des mensulations, p. 125i). Las yeux sont facilement visibles sous la pean. l'urgane tentaculaire est plus distant de la narine yne chez Th. compressicanda et se tronve en arrière de celle-ci, sur une lignne qui va de la narine à l'angle de la bouche. Le corps des types (long de $44^{\prime} \mathrm{cm}$.) est très tlasque el maceré at ne permet pas de distinguer, aver
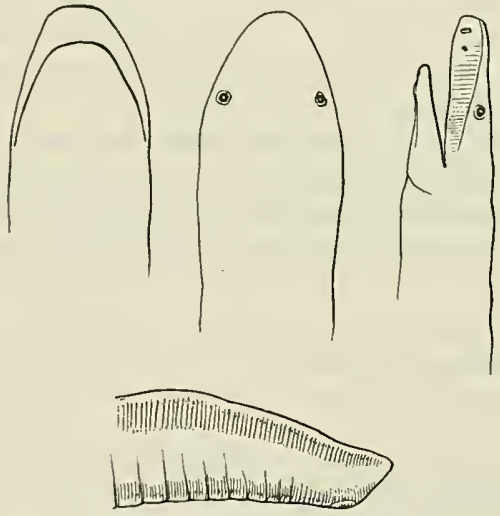

Fig. 2: Th. natans Fiscuer. Exemplaire du Musée de Neuchitel. certitude, le nombre des plis que Fisclier signale ètre très indistincts et pour lessquels Petens" indique : "Hantfalten an der Rü̈ckenseite verschwindend ungefälı. roo primäre und 86 secundäre. "II m'a été impossible de computer les plis pu question sur les types de Berlin; par contre notre exemplaire lien conservé, qui mesure $53 \mathrm{~cm}$. avec uII diamitre maximal de 17 à $19 \mathrm{~mm}$., montre neltement 95 plis primaires visibles sur la face ventrate et la partie infórieure des côtés latéraux, c'est-it-dire dans la région grise de l'animal. Sur le dos, ancune segmentation n'esı visible. Les plis secondaires, par contre, sont difficitment visibles et ue se montrent que sur une étroite bande de la face ventrale du corps; leur numbre semble ètre de 65. Les 9 à 10 premiers rt les vingt derniers segments du corps de Th. uatans ne présentent ancume subdivision

1 Peters, W. Uber die Eintheilung der Caecilien und insbesondere über die Gallung /hhimalrema um

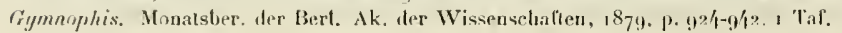




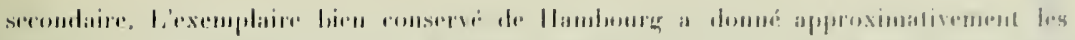

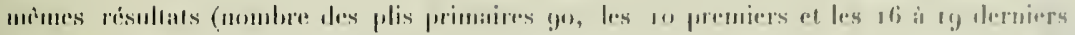

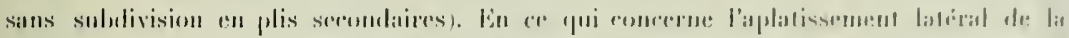

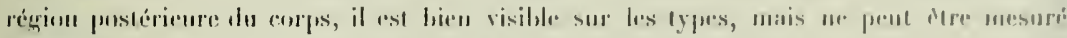

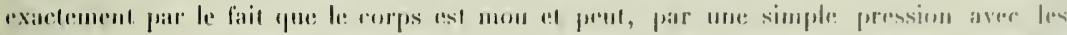

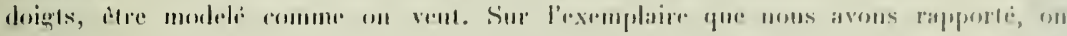

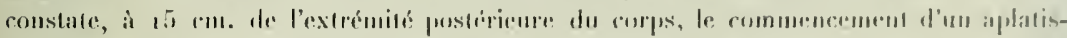

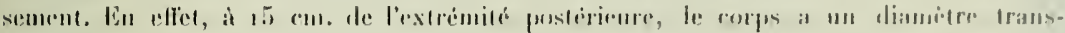

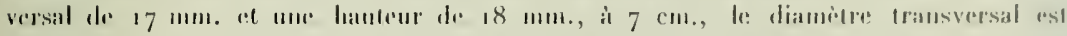

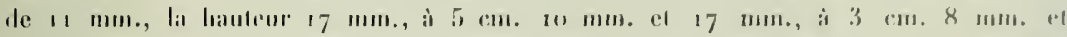
17 mm.

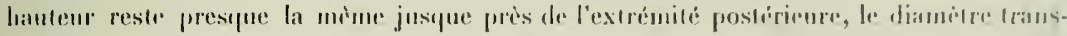

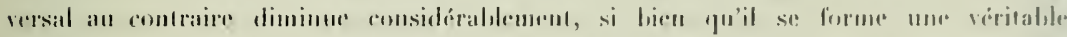

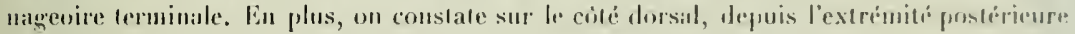

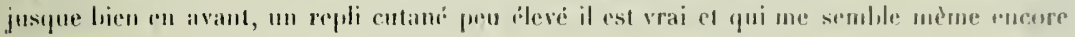

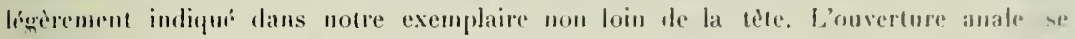

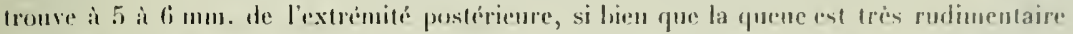

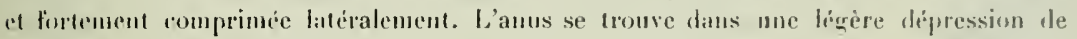
couleur latanclie et est entoure de replis lui domnint l'aspect d'une ventoust.

\section{Anatomie interne.}

de ne puis malheureusenent rien dire du squelete de ces animan; filan donnes leur rarcti, nous n'avons pu preparer un syurletle. le. fait que les Thyphlonectes sont des animax aqualiques, que leur organisation externe et interne montre certains traits primitil's, nous navons pu résister à la tentation de voir si le cràne de Thyphlonectes ne montremil pros non phus les dispositions primitives constaties par P. et F. Sirasix clicz

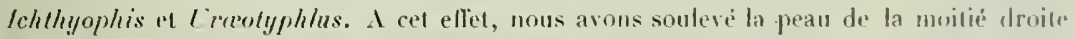
du arine de notre exemplaire de $T h$. natans, ce qui nous a permis de constater très nept'ment pue l'intermaxillaire, comme chez lchthyophis, Lropolhyphlus a Scolocomorphus, u'est jas soudé avec le nasal; quant au priefrontal, nous n'avons pu déterminur sa présence avec certitude. L̈̈ntermaxillaire semble ètre plus fortement dervoppé (hez Thyphlonectes que chez Ichthyophis glutinosus. Sirasix dil (p. 172 loc cit.) il

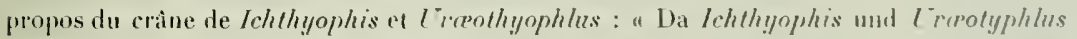
cinige linochen des Schädels getrennt zeigen welche bei anderen Formen verwachsen sind, so haben wir diese Gattungen, zunïchst wenigstens rüclisichtlich des Schäalels. als die ursprüngliclisten unter den lebenden Cueciliden aufzufassen. ". Iux trois genres cites, il fuut sans doute ajouter le rrenre Thyphlonectes dont les représentants se muntrent encore primitifs à d'autres points de vue. 


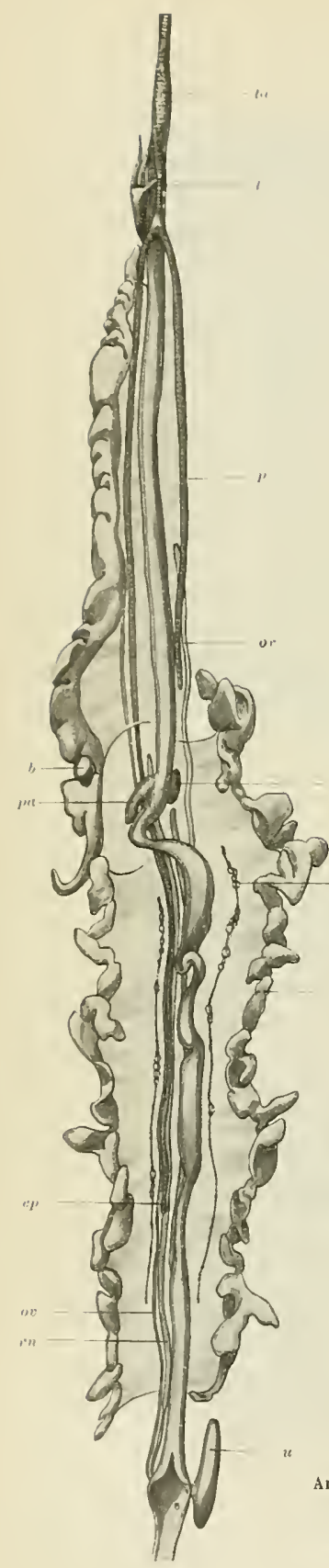

\section{Tube digestif et organes annexes.}

La dentition de Thyphlonectes matans est tris bien dévehpuner diens les màchoires supérienres et inférieures, nous trouvons denx ranqués de dents. Dans la rangíe antérieure de la michoire supéricur on compte de clacpue crite 22 it 23 dents. Dans la rangée interme 21 ì 22. Dans la màchoire inférienre, la rangre antírieure montre 16 à 17 dents, la rangée interne 5 à 6 dents de chanpe còtr. Les dents sont petites, sans pointe accessoire, et lésèrement courbées vers l'intérienr. La langue largement attachéce au plancher de la cavité buccale est peu musculense et probablement peu mobile. Le fait que les grandes de la cavité buccale, si richement différenciés che\% lchlhyophis ghutinosus et probablement chez toutes les formes terrestres sont très rudimentaires ou mème nulles thez $T$. natans est trìs intéressant (voir chappitre Histologie, p. I31). C'est sans doute une adaptation a la vie aquatique de ces animanx; ou serail-ce un caractire primitif?

Nous n’arons rien de hien intéressant ì remarquer an snjel du tule digestif lui-mime; il passe presque en ligme droite par la cavité du corpss el seul l'intestin grè̀le montre quelques légères courluures un pen en arrière du floie. La délimitation de l'osophage el de l'estomac, d'un còté, et de l'estomac et de l'intestin srèle de l'autre n'est pas possible sur notre exemplaire. Sur le type, par contre, on remarque que le pylore se trouve un peu en avant du pancréas. L'intestin "grèle est étroit dans celte région et sur une court' étendue, puis il s’élargit immédiatement en arrière du pancréas. La limite entre g’untestin grèle el le tectum est très maryuéc chez le type. En effet, l’infestin grè̀e étroit s’élargit hrusquement et passe en ligne droite en se rétrécissant lentement vers l'ouverture anale. Sur notre exemplaire dont lintestin est par place fortement contracté, le rectum est rétréci au début. puis il s'élargit vers l'extrémité postérieure. Notre individu ainsi que les types étant des femelles, le cloaque est relativement court, et la vessie urinaire attachée à la paroi du corpsi par une duplicaturs du mésentire débouche $2 \mathrm{~cm}$. en avant de l'anus dans le cloaque. Elle est étroite et longue de $3 \mathrm{~cm}$; la communication avec le claaque se lait $2 \mathrm{~cm}$. en arrière de l'extrúmité antéricure de la vessie, de sorte que le lobe postérieur tris marqué a une longueur de $1 \mathrm{~cm}$. chez notre exemplaire, landis que chez le type il semble ètre plus court.

Fig. 3: Th, natans l'ischer.

Anatomie : $\iota$ trachée, $t a$ organe respiratoire accessoire, $p$ poumon, ep exlrémité distale du poumon droit, $\zeta$ vésicule bilaire, pa pancrćas, $r$ rale, $r m$ rein. $u$, vessie urinaire, $o$ ovaire, $o v$ oviducle, $a$ glande adipeuse. 


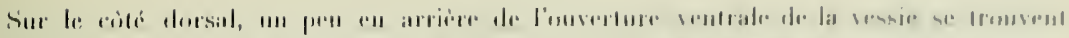

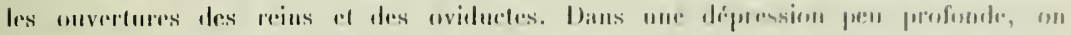

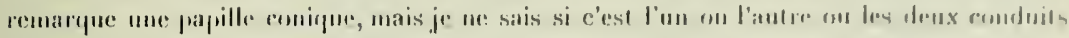

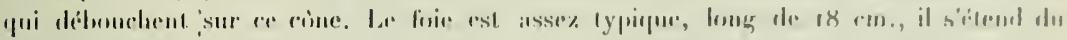

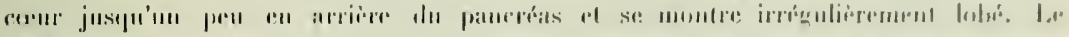

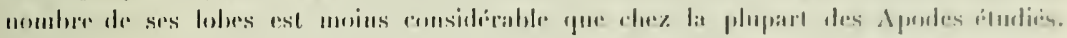

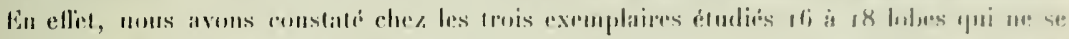

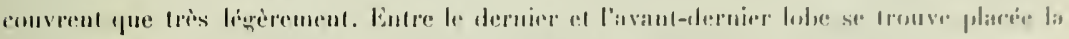

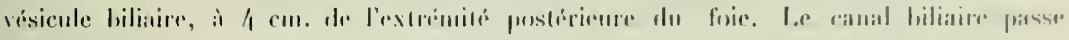

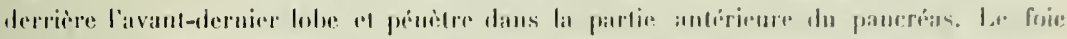

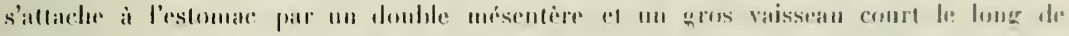

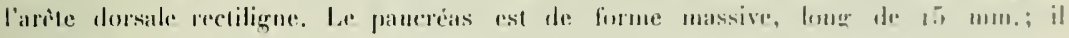

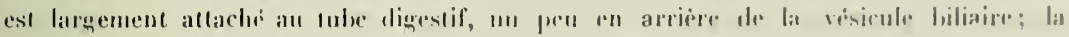

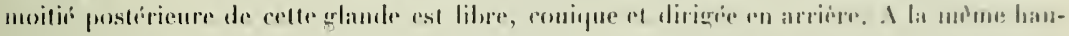

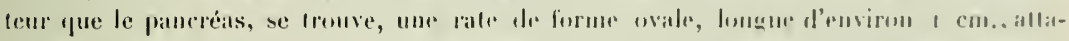

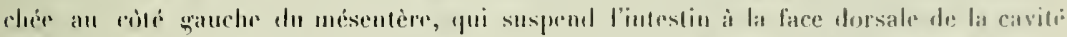

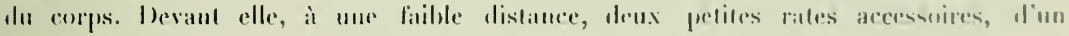

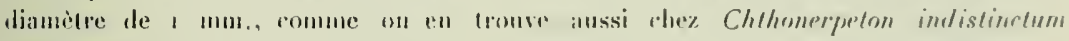
(Wnothshem ', fig. S/, i.

\section{Systeme respiratoire}

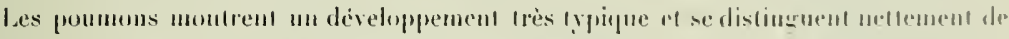

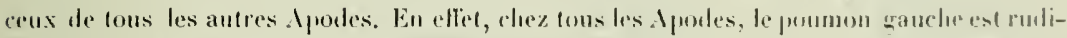
mentaire et souvent difficilement visihle, long de quelques mm. it preine, taudis que

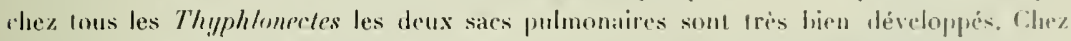
la plupart des Cieciliens, lextrémité postirieuse du pumon droit atteint le deraser tiers du foje el chez Chthomerpeton seulement il dépasse un pru la bongurm de cel organe. Chez Th, natans, par contre, le poumon droit alleint el depasse le commencemmut

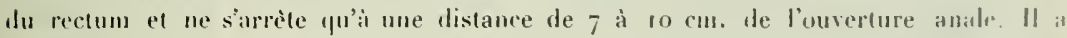
un diamètre de 2 mm. seulement el sil longueur est de $27 \mathrm{~cm}$.; si parui ne renferme pas de pigments el laisse facitement voir le systeme des alvéoles. Le promon gauche alleint al depasse meme la longueur du pumon droil des autres Ipodes; en elfet, thez

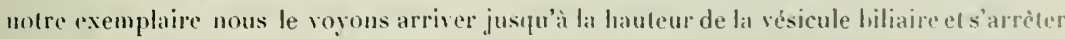
¿ 2 cur. en avant de cel organe. Chez l'un des ypes, le poumon gauch sarrète a i $\mathrm{cm}$. chez. l'autre, i $3 \mathrm{~cm}$. de la visicule hiliaire. Chez notre exemplaire, le poumon sauche a une longueur de ra cul., tandis que claez l'un des exemplaires lypes. il ne mesure que u $\mathrm{cm}$, diez l'autre seulement 8 à $9 \mathrm{~cm}$, c'est-à-dire un peu plus de lia Innerueur qu"in-

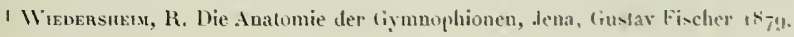




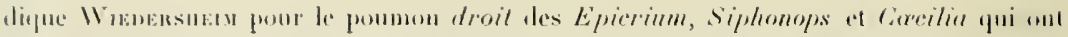

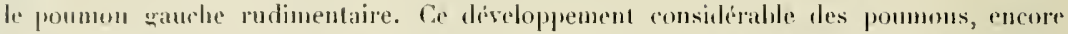
plus maryue chez Th, compressicandu, est saus doute con corrélation aver la vir aqualique de l'animal, il peut ainsi emunagasiner ume plus grande puantité d'air, ée qui lui permet un sijour prolongé sous l'eau. Le poumon est allaché par une tris élroite haude dans loute la région des organes sexuels, au mésentere qui porte l'wielute, lovaire et les grlandes adjpeuses. En avant, c'est au mésentère qui porte l'estomac que le poumon s'attache par une membrane, très étroite aussi (roir tig. 3). Less deux sacs pulmonaires sont tri's rapprochés de la ligne médiane et, vus depuis la face voulale, ils semblent courir le long du hord externe du rein. Les deux poumons se rémissent sous le ranr, d'où part la trachée longue el étroite. Ia trachée en opposition avec les Anoures et les Lrodè est très longue, elle mesure $8 \mathrm{~cm}$. chez notre exemplaire. En avaut du coeur, elle commence à se dilater en un orwane fusilorme, long d'environ 4 à 5 cm., avec un diamitre maximal de is mu.; en avant de cette dilatation, elle reprend le diamètre purinitif. La Irache presente tans sa paroi des anneaux cartilagineux incomplets qui existent aussi dans la partie dilatée ainsi que dans toute létendue du poumon. La région dilatée montre sons un faible grossissement une structure alvélaire el représente saus aucun dunte un organe respiratoire accessoire (roir chapitre llistologie, p. 135) comme nous n'en counaissons dans aucun groupe des vertéloés. Les anneanx cartilagineux sonı ouverts, nou pas sur le còté dorsal, comme dit Wieversuem (loc. cil., p. 84), mais sur le crité reutral, el c'est de ce cotrígalement que se trouve l'organe en question.

Nous n'avons pas pu éludier le larynx qui est sans doute très simple.

\section{Organes urogénitaux}

T'audis que les reins de la plupart des Aporles montent du cloatue jusquáa coeur, ceux de Th. natans commencent à $3 \mathrm{~cm}$. de l'ouverture des rains al organes sexuels dans le cloaque et atteignent seulement la hauteur du pancréas "l de la rate. Le rein droit mesure $18 \mathrm{~cm}$. de longueur, le rein gauche $16,5 \mathrm{~cm}$. Les deux reins se présentent sous forme de deux rubaus étroits $(2 \mathrm{~mm}$.) el sont séparés l’un de l'autre pau l'iorte el une veine.

Les trois exemplaires que nous avons pu dudier étaient des lemelles. Les ovaires el wiductes, ainsi que les ghlandes adjpenses, se trouvent fixés sur une bande mésentíringue large de $15 \mathrm{~mm}$. L’oviducte et l'ovaire se trouvent près de la ligne médiane, le prenier sur le côté interne du second. Au bord du ligament suspensenr se fixent d'inormes appendices graisseux, fortement lobés el de couleur jaunàtre. L'ovaire ganche $(12,5 \mathrm{~cm}$.) est un peu plus long que l'ovaire droit $(11 \mathrm{~cm}$.); l'oviducte se prolonge encore de $8 \mathrm{~cm}$. en avant te l'ovaire (longueur $27 \mathrm{~cm}$.). Ils sont droits et trés élroits. L'ovaire se prèsente sous forme d'une très ćtroite bande ne renfermant pas d'ceul's mùrs; les plus 


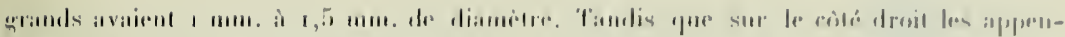

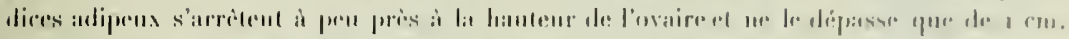

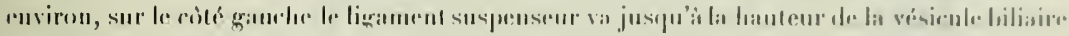

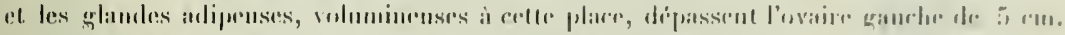

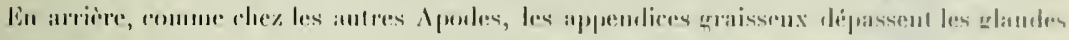

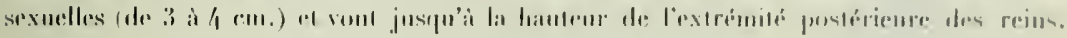

\section{Thyphlonectes compressicauda (Duméril et Bibron). \\ (liir i-fi.)}

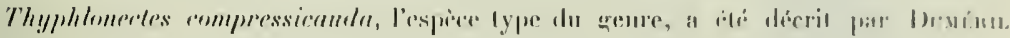
a) Bunun!.

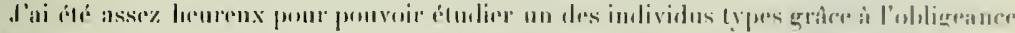

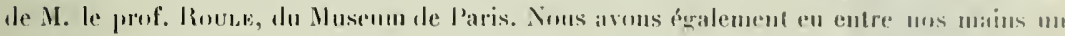

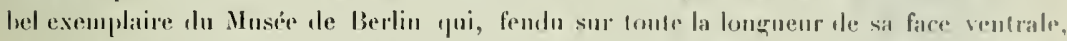

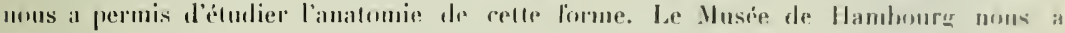
envoye un exemplaire, ypi mallerureusement, avait sans doute été des-

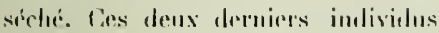
semblente appartenir à une varielsi

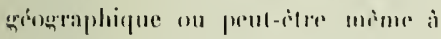
une espree nouvelle.

En outre, nons arous pu élurlicer drux embryous, dont l'un, prèt à ifre mis an monde, portail encore me forme lamelle branchiale inpaire ef dorsale (Muséc de Berlin; roir dessin de l'. el fi. Sarasin, loce cil., 1.26 ), randis que l'autre ne montrail plus que la cicatrice de la branchie combre.

La tète de Th. compressicumla
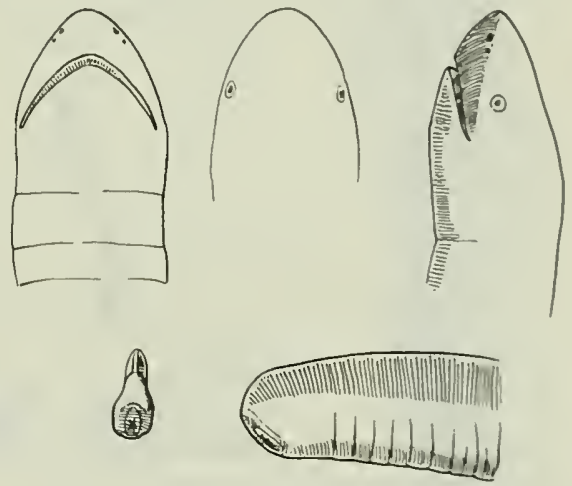

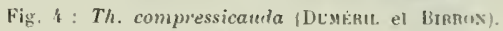
Type du Musée de Paris. st distingue nettement de celle de Th. natans. par le fait qu'elle est beaucoup plus hause et non pas aplatie comme cluez Th. muluns. L'n autre caraclère qui se remarque facilement, cest que le tentacule se trouve plus près (r mm.) de la narine el, comme chez Th. nalans. sur une ligne qui va de la narime a l'angle de la boucle. Le lablean des mensurations comparatives li. in ainsi qure les figures, indiqueront mieux qu une longue description la conformation de la

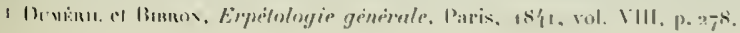


lète el les différemers qui semblent exister entre l'individn de Paris ef ceux de Borlin at

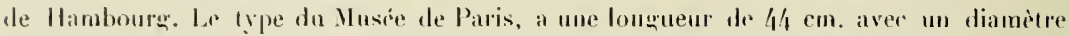

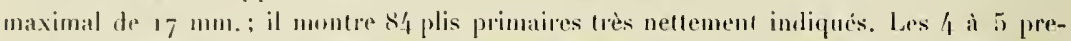
miers, ansi que les 8 à g derniers, ue sonf plus sublivisés; nous arons ainsi 70 à 72 plis secondiares, ce qui lait 152 à 157 plis, surtout bien marqués sur la fare ventrale. Lexemplaire de Berlin a également 作 com. de long, mais 22 mu. de dianètre maximal; le nombre des plis est de 04 ì gí, les 12 à 13 premiers et les 16 ì 17 dermirs ne som pas sulodivisés, de sorte que nous avons ainsi, malgré un plus grand nombre de plis primaires, it peu pris le mime nombre total de plis $(158-1$ bo). Les mèmes chillies se constatent pour l'exemplaire de Hambourg.

Duméril el Bubon indiguent 134 a 140 plis (la longueur est d'après ces mèmes auteurs $47^{\prime \prime}$, lo diamètre $2^{\prime \prime}$ ); par contre, Peters indique dans sa deserijution sommair d'apris l'exemplaire de Berlin que nous avons étudic, 97 plis primaires et 70 plis secondaires. Le corps est moins comprimí ì l'extrémité postérieure que chez l'espèce précídente. Liexemplaire tỵe montre ì $12 \mathrm{~cm}$. de l'extrémité postérieure, mu diamètre transversal de $17 \mathrm{~mm}$. avec une lauteur de $17 \mathrm{~mm}$. : à $7 \mathrm{~cm}$. de l'extrémité postérieure, $14 \mathrm{~mm}$. de diamilge transversal avec une lauteur de $17 \mathrm{~mm}$; à is cm., $11 \mathrm{~mm}$ et $17 \mathrm{~mm}$; ì $2 \mathrm{~cm}$., in $\mathrm{mm}$. el $17 \mathrm{~mm}$. La lanteur dı corps reste done la mème jusqu'à l'extrémité
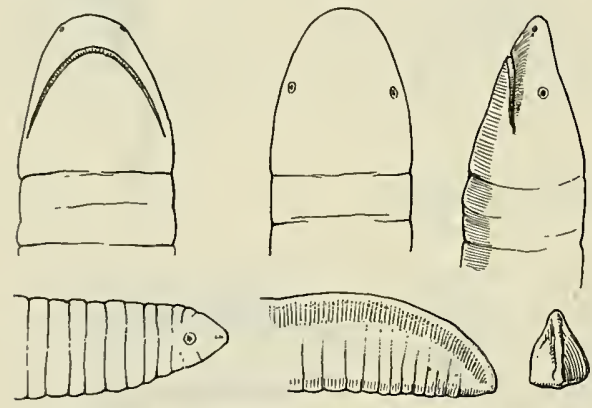

Fig. 5: Th. compressicauda (I). et F.) venezuelense nov, var. Type du Ilusée de Berlin. postérienre el seul le diamètre transversal diminue. Cette diminution est encore hien plus sensible si on mesure le diamètre transversal dans la partie dorsale et postéricure du corps qui est large de quelques millimètres seulement. Le dos dr l'animal est, comme le font déjì remarquer Dunéru, et Bıнın, nettrment lectiforme et offre une formo en toit très prononcée, qui est mème surmontée d'une légère crète descrndaul vers l'extrémité du corps (roir fig. 4). L'individu type, ainsi que l'exemplaire de llambourg, montrent sur le dos une coloration presque noire, d'un brun olivitre très foncé, qui ne s'éclaircil que triss peu sur la face ventrale. L'exemplaire de Berlin, par contre, est comme le type de Th. natuns, d'un brun clair, coloration due sans doute an mode de conservation on à la lumicre.

L'anus est presque terminal cliez le type (voir fig. 14) et se tronve à $7 \mathrm{~mm}$. de l'extrinité dı corps (voir fig. 万) chez l'exemplaire de Berlin.

Guant à la provenance des exemplaires, ceux de Paris proviennent de Calyenue, reux

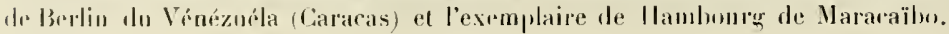




\section{Anatomie.}

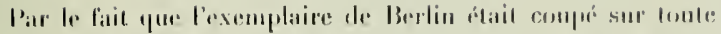

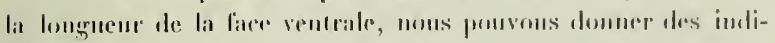

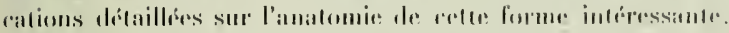

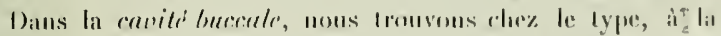

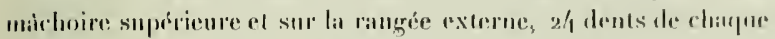

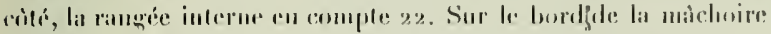

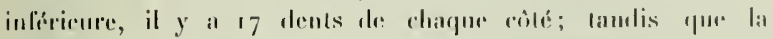

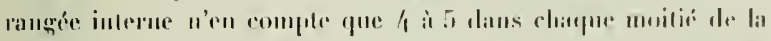

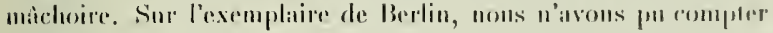

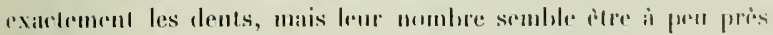
illentique it celui du lygre.

te tubre digestif montre des dispositims asse\% semblaldom a

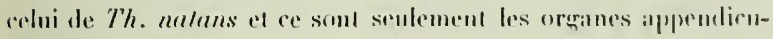

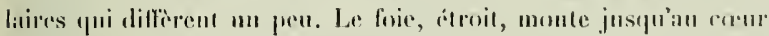
et mesure $10 \mathrm{~cm}$; il présente I loles irróguliers. La vésiculs biliaire se trone it $3 \mathrm{~cm}$, de l'extrémite postérienre du fuic. Le pancrisas a la mime formo que chez Th. naluns: par cuntur lit vessir urinaire diftere nellement de celle de l'espice précídente, parce qu'elle ne montre pas de lobe postérieur el consiste sivolrment en un simple sac citroit et long de 22 mm. La portion dirigre en arrière de l'murelure de la vessie, somvent si bien décelopréce chez les Apodes, est ici tout ì fail rudimentaire et it prine visible. Comme chez les antres. Ipodes, la vessie es fixio a la ligne médiane el ventrale par une bande mésentériqur.

Lat rate est un pen plus élroite el plus longue, mais sa position est la mème juo chez Th. untans. Je n'ai pas vin de rale arcessoire.

L'organe respiratoire est bien différent de cehin de $7 \mathrm{~h}$. $n$ mtans. En ellet, le sac pulmonaire droit a une longueur de $26 \mathrm{~cm}$, avec un diamètre de $2 \mathrm{~mm}$, il ra ici jusqu'i lextrémitr postérieure du corps el s'arrète seulement a $3 \mathrm{~cm}$. de l'anus; il se prolonge done jusquà l'extrémité postérieure du mésentìre

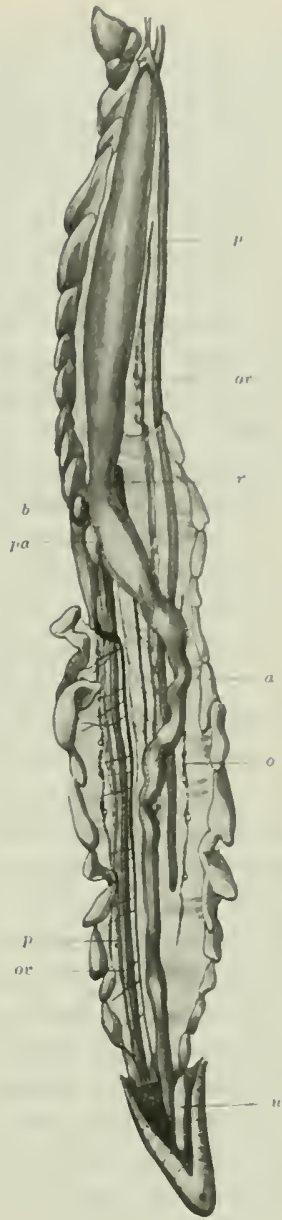

Fig. 6:

Th. compressicalida [D. el B. rar. venezuelense. Voir explication fig. 3 . suspenseur de lappareil urogenital, tandis que chez Th. nalans, c'est à ro cm. de l'anus que se trouve l'extrémilé du poumou druil. Dapres Pexers'. Pembryou de $7 \%$. compressicunda monle des poumons qui voul jusquan

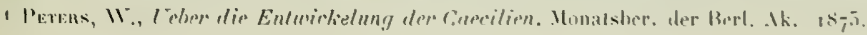




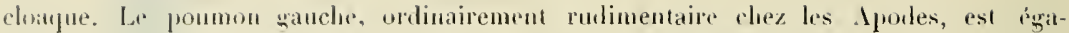
lement très développé el va exactenent jusqu'à lat lauteur du poumon droit de Th. nulans. Son extrémité postérienre n'est ainsi qu’à $8 \mathrm{~cm}$. de l'anus; sa longurur est le $20.5 \mathrm{~cm}$. Comme chez Th. natans, les poumons s'attachent ì leur extrémité antirienre far une très stroite bande an mésentère du tube digestif. Ditns la région de lappareil urogenital, ils se suspendent également très étroitement à la large bande qui porte l'viducte, l'ovare et les appendices graisseux. En avant comme en arrière, ils se trouvent, vu du còté ventral, rn dessus des oviduetes. Les deux poumons se réunissent au nivean du coeur et de lí prart la trachér qui, en avant du corur', se renlle et forme l'organe resjiratoire accessoire, dont nous avons déjà parlé chez Th. natans. Cet organe fusiforme est long de $5 \mathrm{~cm}$, avec un diametre maximal de $6 \mathrm{~mm}$, tandis que la trachico $n$ 'a près des poumons qu'un diamètre de $2 \mathrm{~mm}$. et en avant de $1,5 \mathrm{~mm}$. Cette dilatition fut également remarquée par Péters chez l'embryon de cette espèce, mais il ne l'étudia pas.

Le système circulatoire n’a pas été étulié spécialement; nons voulons seulement faire remarquer que les deux oreillettes, surtout la droite, sont bien plus grandes que le ventrieule. L'arète dorsale et rectiligne du foie est longée par un gros vaissean veineux, qui, à l'extrémité postérieure, quitte le foie en se dilatant sur une courte étendue pour courir ensuite dans la ligne médiane et dorsale, le long de la ligne d'attache des mésentères qui portent l'intestin et l'appareil urogénitał. Il reçoit de l'appareil urogénital el du tube digestif de très nombreux vaisseaux.

Appareil urogénital. - Les reins montrènt les wèmes dispositions que chez Th. zutans, de nème l'ovaice et les appendices graisseux yui vont ici igalement plus en avant sur le còté gauche que sur le còté droit. L'ovaire, trìs étroit, mesure à gauche $8 \mathrm{~cm}$., à droite $7,5 \mathrm{~cm}$. Les oviductes sont longs de $22 \mathrm{~cm}$. (droit) et $23,5 \mathrm{~cm}$ (ganche). L'oviducte est donc également 1 à $2 \mathrm{~cm}$. plus long à gauche qu'à droite; il va chez Th. compressicauda jusqu'i $4 \mathrm{~cm}$. du cacur. Sur toute sa Inngueur, on voit sur le còté interne de l'oviducte deux bandes dont la largeur correspond au diamètre du conduit sexuel femelle, formant une espèce de gouttière qui se termine à l'ustium ablominal. Peut-ètre est-elle tapissce de cellules vibratiles et destinée à conduire les teufs vers l'entonnoire de l'oviducte. Les plus grands oufs de l'ovaire avaient $2,5 \mathrm{~mm}$ de diamètre. La bande suspensoire de l'oviducte qui s'attache au rein est très étroite dans li moitié postérieure de la cavité du corps.

\section{Les embryons.}

Les Thyphlonectes sont vivipares. Nous avons en l'occasion d'éludier également deux individus très jeunes, dont l'un en tout cas était un embryon complètement développé et extraił de l'oviducte. Cet exemplaire, qui a été décrit par Peters ${ }^{1}$, mesure $1577 \mathrm{~mm}$.

1 Petens 1875, lor ril. 


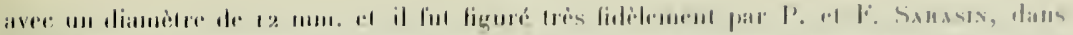

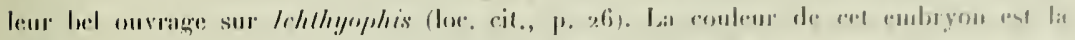

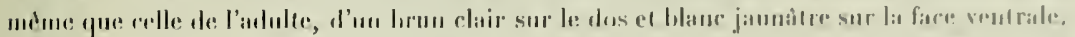

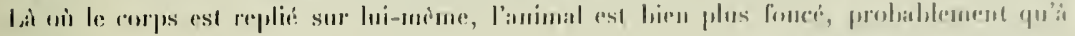

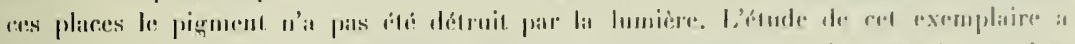

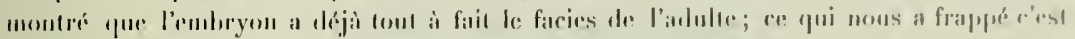

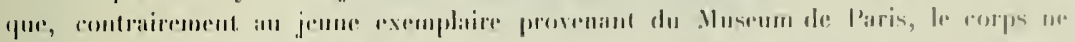

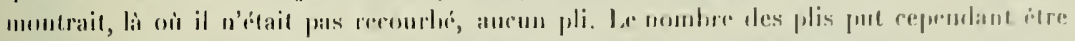

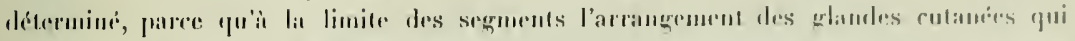

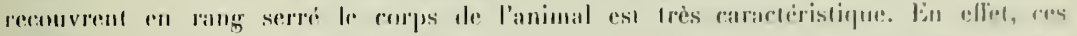

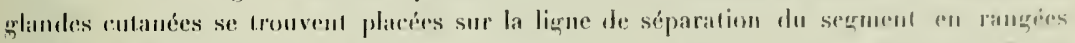

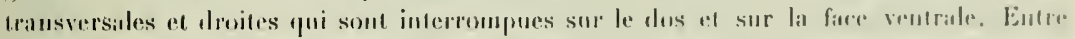

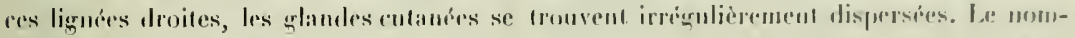

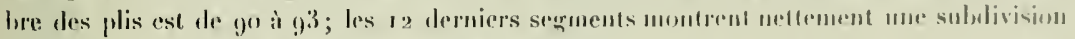

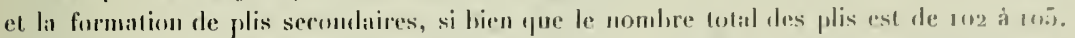

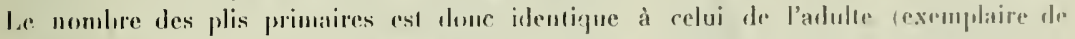

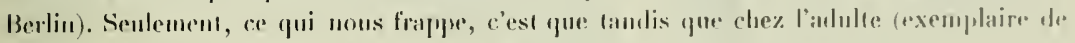

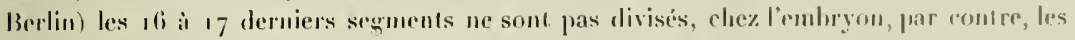

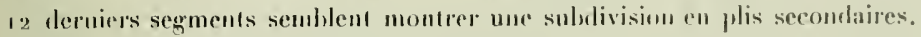

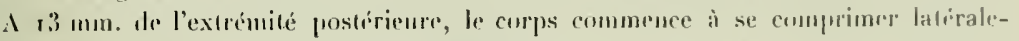
ment, ed dins cetle rigion il est, comme eluez l'adulte, lectiforme sur le dos.

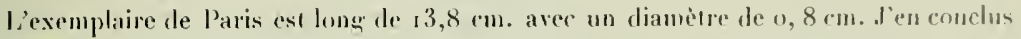
'jue in exemplaire est probablement aussi un embryou, peut-èlre un pen plus jeune que" le prósedent, bien que l'énorme lamelle branchiale dorsale n'existe julus. Cedfe dernière, tris délicatr, est saus doute tombée. La cicatrice dorsale de la branchie, larere de is mum.,

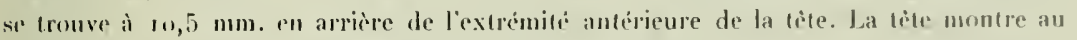
niveau des yeux une hauleur de 6,5 mu., dans la région de l'angle de la luouche une hauteur de 7,2 mm. Le nombre des plis marqués lris netlement est de 80 , et ce sont les 8 i 10 derniers qui montrent ici égulenent me subdivision en plis secontaires, si bien que l'ombryon posside en tout 88-9o plis. L'adulte de l'aris, comme nous avons dit plus haul, a 84 plis primaires, el les 8 i 9 derniers segments ne sout pas sublivisés frar des plis sccomblaires.

Le nombre de 93 a 95 plis primaires chez les abules, ainsi que chez l'emliryon. de Th. compressicanda de Berlin el de llambours, est supérienr de ro au nomfre ales plis constate cluez l'adulte el le jeme gye de l'aris. Ce fail, de mème que la provenance de régions différentes (V́neznéla el Cayemes), semble indiquer peut-ètre une différence sprestigur qui pourail soppuyer encore sur une dithérence peu marjuéc il est vrai dans

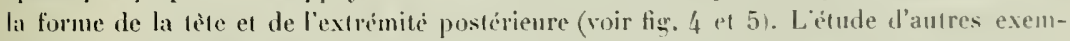
plaires el lamatomie sende pourmient trancher la question. mais les exemplaires eftant

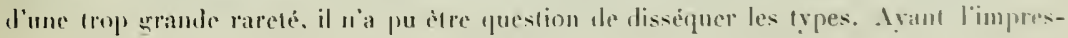


sion nefle d'une ditlérence spécitique entre les deus formes, mais diflicile à precisere je liens a créer jour les exemplaires de Berlin et de Hambourg donu la connasissance cest plus complite, ume varicté nouvelle, soil Thyphtonectes compressicanda (1). et B.) venezuelense, nov. var.

\section{Thyphlonectes dorsalis (Peters).}

(liig. 7.)

Cette intéressante espèce montre le mieux l'adaptation ì la vie ayuatique; con effel, le corjs est comprime latéralement sur presique toute sa longuenr.

Peters' a doméc une description sommaire de celte espèce trìs caractéristique d'apris un individu jeune, long de $26 \mathrm{~cm}$. seulement. Cet exemplaire, gue nous avons en entre les mains, est identique it la forme adulte que nous décrirons daus les lignes suivantes.
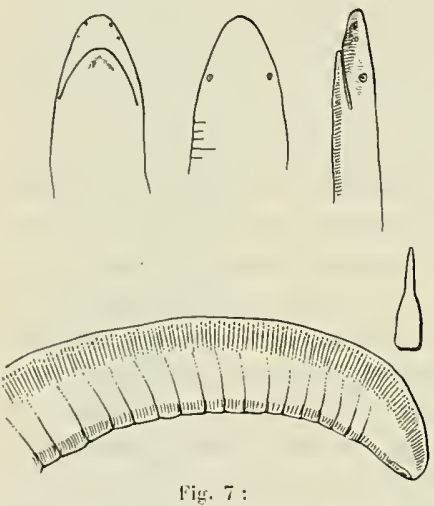

Th. dorsalis (Petens) du Susée de lerlin. Nous avons eu encore entre les mains deux exemplaires dı Musée de Hambourg, provenant également de lOOrénoque près de Ciudad Bolivar, łui élaient absolument identiques aux individus de Berlin,

Le second exemplaire du Musée de Berlin, beaucoup plus grand que le type, mesure 56 cm., avec un diamètre transversal maximal de $20 \mathrm{~mm}$. et une hauteur maximale de $24 \mathrm{~mm}$. La tète comparéc aux deux espèces prícédentes est très petite "t fortement aplatie, les yeux profondément cichés sous la peau sont à peine visibles (v. lig. 7 et tableau des mensurations, p. 125).

L'animal a une couleur générale d'un gris brun clair, qui est brun foncé sur un étroit espace des deux cótés de la ligne de siparation des segments. La ligne de séparation elle-mème est presque noire, anssi la segmentation du corps est-elle liès nette. Le grand exemplaire montre, comme te type, 99 plis primaires qui entourent tout le corps et sont seulement interrompus, rontrairement à ce que dit Perers sur la ligne médiane et dorsale oì se forme un épais repli longritudinal constituant une crète dorsale s'ilendant sur presque toute la longuens lu corps. Elle arrive en effet jusqu’̀̀ 4 à $5 \mathrm{~cm}$. de la tète. Sur l'exemplaire de Hambourg, le repli a une hauteur de $2 \mathrm{~mm}$. (chez le vivant, probablement plus haut); $10 \mathrm{~cm}$. en avant de l'extrémité postérieure, il mesure $3 \mathrm{~mm}$, et à 5 à $6 \mathrm{~cm}$. de l'extrémité, il atteint mème $5 \mathrm{~mm}$, de haut. Les plis secondaires manquent complètement.

\footnotetext{
1 Peters, Ueber die von llerrn P'rol. Dr Ki. Moehius 1874 aul' den Maskarenen und Seychelten, sowie über die von Herrn Dr Sachs in Venezuela gesammelten Amphibien. Monalsber. Berl. Akad., 1877, p. 45y.
} 


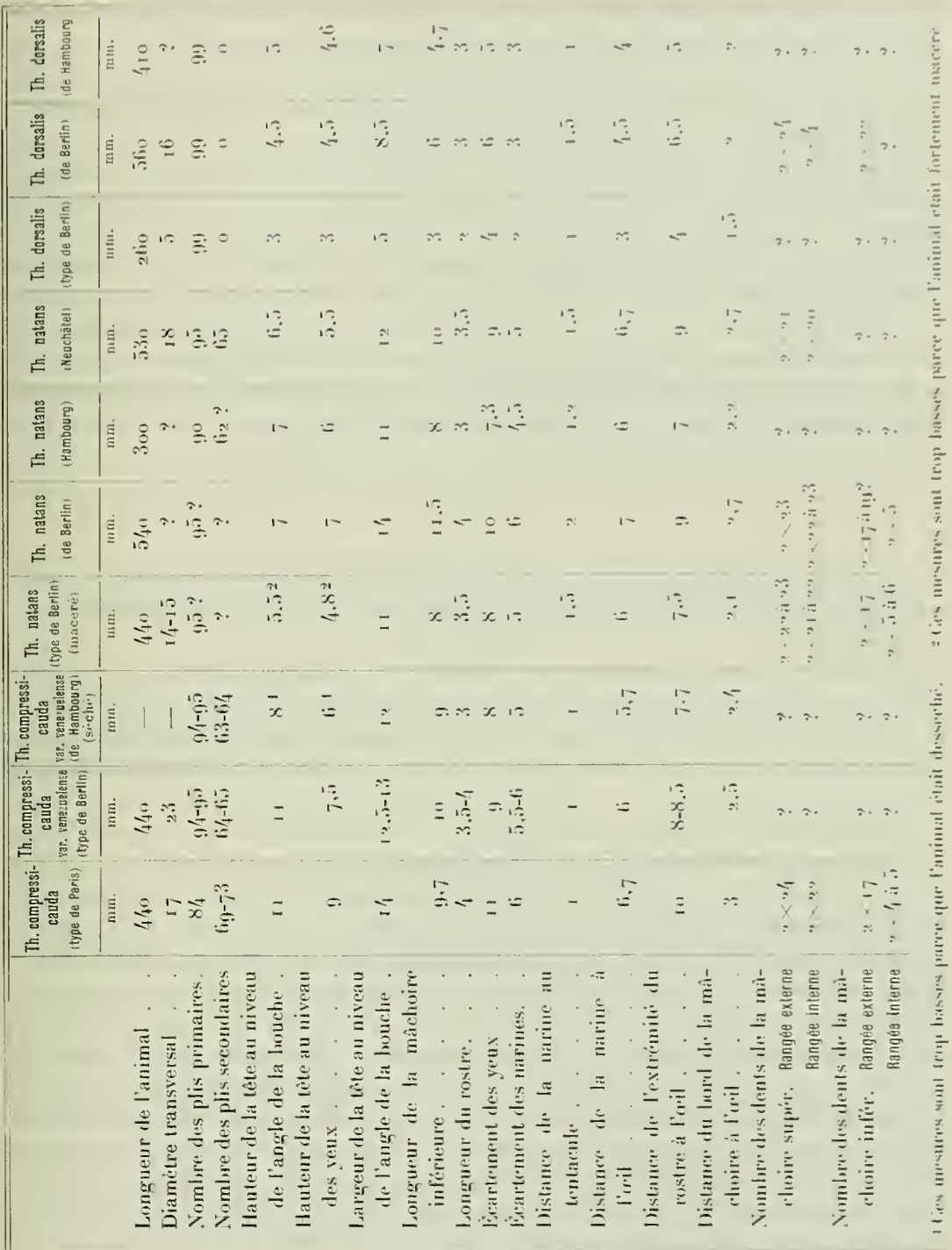


La compression laterale du corps commence déja tris an avant : a 3 con. derriche la lite, le corps a un diametre transversal de $11 \mathrm{~mm}$. el une hauteur de $8 \mathrm{~mm}$.; à 1 i $\mathrm{cm}$.,

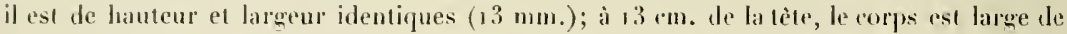
1.3 Imm. et haut de $20 \mathrm{~mm}$; à $28 \mathrm{~cm}$. de l'extrémité antériente, il est large de $20 \mathrm{~mm}$. et hant de $22 \mathrm{~mm}$; à $38 \mathrm{~cm}$. de l'extrémité antérieure, le thamitre transversal est de

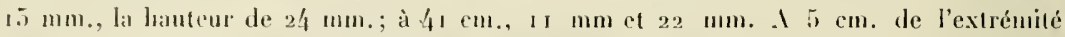
caudale, la largére n'est que de $8 \mathrm{~mm}$, la hauteur $18 \mathrm{~mm}$; a $3 \mathrm{~cm}$. de l'extrénité, la largeur est de $7,5 \mathrm{~mm}$, la hauteur $18 \mathrm{~mm}$, et à $1 \mathrm{rm}$. de l'extrémité postírieure, le diamétre transversal n'est plus que de 6 mm., taulis que la hauteur est de $12 \mathrm{~mm}$. La crète, lont je parlais plus haut, devient très prononcée vers l'extrémité postérieure, et ce n'est pas seulement comme chez Th. compressicanda un dos en forme de toil, mais une crete nataloire étroite et haute (fig. 7). Le corps aplati en avant, d'abord dorsoventralement, est comprimé latéralement sur presque toute sa longueur. L'animal doit nager tris labilement, et nous en arons une preuve dans le fait que nous avons trouvé dans l'estomac d'un des individus deux poissons, longs de 5 à $6 \mathrm{~cm}$.

\section{Anatomie.}

Comme nous n'avons pu faire que quelques incisions sur la face ventrale des individus, nous ne pouvons domer autant de détails anatomiques que chez les deux espèces précédentes.

Le tube digestif ne montre rien de particulier et ressemble beaucoup à celui des deux autres espices du genre. Dans la mâchoire supérieure, la rangée externe a 22 dents de clıaque côté. Les dents de la rangée interne n'ont pas pu ètre comptées exactement. La màchoire inférieure porte dans la rangée externe 24 dents et dans la rangée interne quatre dents de chaque còté.

L'csophage est très long, élant donné que le cour se trouve ì $14 \mathrm{~cm}$. en arrière de la tête et que c'est directement en arrière du cour que commence l'estomac qui a à peu près la longueur du foir. L’intestin est d'abord très étroit et s’álargit hrusiquement en arriere du pancréas. Ce dernier à peu près la mème forme que chez Th. natans el Th. compressicauda, seulement sa base atlachce à l'intestin est plus large el embrasse la moilié droite de l'intestin (longueur $17 \mathrm{~mm}$.). Le foie, long de $14,5 \mathrm{~cm}$., a un nomlire de lobes moins grand que cliez les espèces précédentes $(7$ à 8$)$; la vésicule biliaire est cachée entre le dernier lobe et l'extrémité nou lobée du foie. Son canal se dirige en arrière pour pénétrer dans la région antérieure du paucréas. La vessie urinaire étroite, placée comme chez lous les Apodes daus le seus de la longueur du curps, est longue de $17 \mathrm{~mm}$; conme rlez Th. compressicanda, elle ne posside pas de probongenent postéricur. La rate, dans le voisinage du pancréas, est très étroite et longue de 25 mm.; il semble exister devant elle whe petite rate accessoire.

L’anus se trouve ì $3 \mathrm{~mm}$. de l'extrénité du corps. Il débouche à l'extrémité pus- 


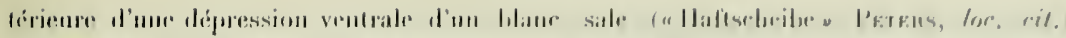

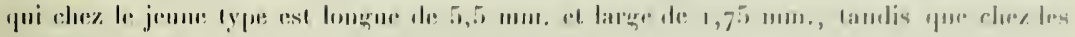

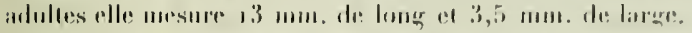

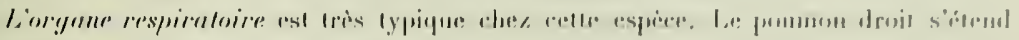

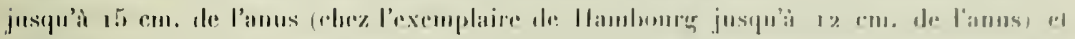

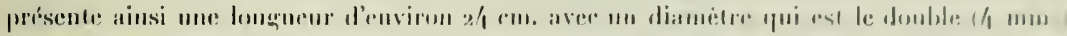

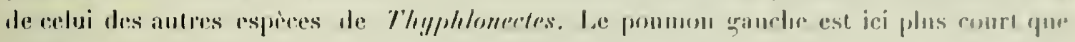

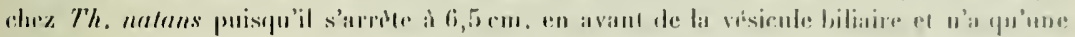

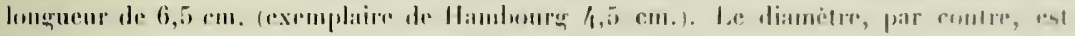

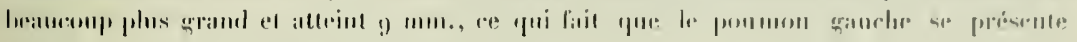
serts la furme d'un lange salc.

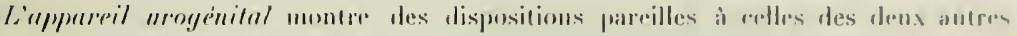

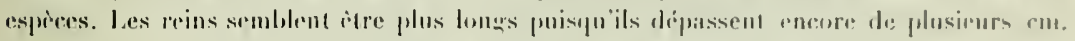

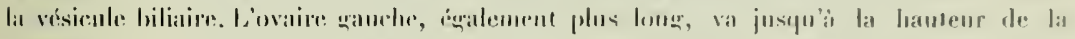

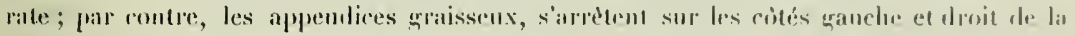

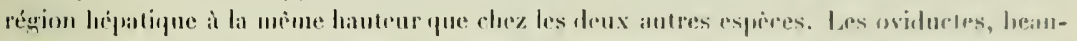
(oup plus longs, vonl jusqu'i 3 cou. du cormr.

\section{La structure histologique de quelques organes de Thyphlonectes natans et dorsalis.}

L'listologie des organes des Apodes ilant emrore assez mal romnue, il mons a semblé

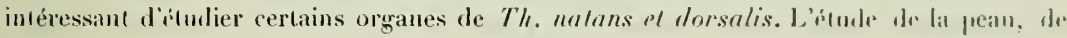

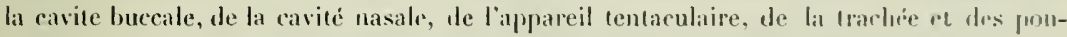

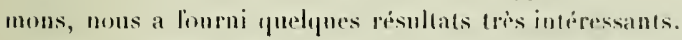

\section{La peau.}

La struchure de la peau des. Ipudes a ité efudiée res dernieres anmies, surtout par

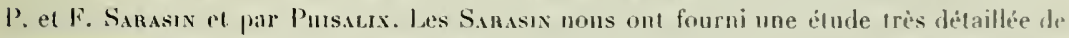
la peau de Ichlhyophis glutinosus landis yue Pussux a surtout indio da ripartition des prandes entances el leur localisation progressive en fonction de la disparition des ícailles.

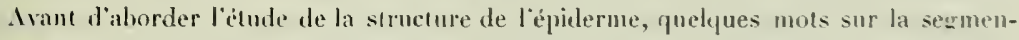
lation externe du corjs des Thyphlonectes. En opposition avec Ichlhyophis et d'autres Apodes à nombre de plis transversanx considerables, les plis primaires des Th!/phlonocles correspondent an nombre des Myotomes de l'animal el c'est la fixation sles Myocomalas an dermo le lanimal qui produit les plis visibles extérieurement. Les plis secondaires niont ancune relation arec les segments musculaires; ce snmt prohahlement

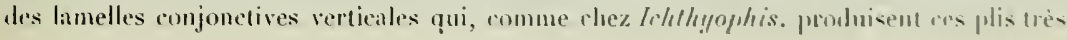


indistincls, ou manguant complètement chez Th. dorsalis. Xons avons pu observer clez. hehlhyophis, que sur 4 a i jolis, il y en a tuujours un qui est plus profond, et cést sans

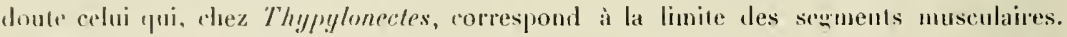

l:épiderm de Th. natums présente des particularités intéressantes; il est romposé, conme chaz la plupart des amphibiens, d'un nombre restreint de couches, 4 a 6 sur le corps, 8 à lo sur la lète. L'épaisseur de l'épiderme est de $13,0.3-0,0 / 4 \mathrm{~mm}$. sur le corps, tandis que sur la lète, dle est de $1,05 \mathrm{~mm}$. La couche externe, de mème que celle qui se trouve directement au-dessous sont légèrenrent cuticularisćes et formées de cellules très plates montrant encore les noraux. Ce's deux couches forment deux membranules nettemrnt délimitées, tandis que les autres couches sont formées de cellules non aplaties, de formur polyédrique el irrégulière.

Ce qui donne à l'épiderme un intérèt particulier, éest que sur les compes transversales el longitudinales, il semble itre interrompu ì des intervalles presque riguliers $\{60$ ì ron u.. $)$ \ ces places, il ne consiste qu'en deux couches superficielles cuticularisées, "paisses seulement de $1,008 \mathrm{~mm}$; sourent mème on wr voit que la ruticule superficielle. Ces dépressions internes de l'épiderme sont remplies par du lissu conjonctif sous jacent, et renferuenl des eapillaires vasculaires aceompagnés de ramifications des cellules pigmentaires du derme (fig. 9). Sur une compe horizontale trìs superticielle de l'épiderme, on voit les capillaires former un rístau inter-épidermique très serré et n’ayant d'analogue chez aucun Apode el mème chez aucun Amphilsien. La vascularisation de l'épiclerme manque sur toute la tète (fig. 8). Des vaisseaux capillaires inter-épithéliaux ont ité décrits chez les Lombricides el Hirudinées; Leidig ", dans son élurle "Vascularisirtes Epithel» el dans un travail antérieur "Die Hauldecke und Hautsinmesorgane "ler [rodelen", derit et figure chez un petil nombre d'Lrodibles² un épithólimu vascularisé, le mieux déreloppé, dit-il, chez Menopoma. Celle vascularisation consiste en petites anses vaseularisées qui pénétrent daus l'épiderme. La vascularisation de la peau de Thyphlonectes est poussée bien plus loin, puisque ce ne sont pas sentement de petites anses, mais un résean serré qui pénèlre dans l'épiderme el vient ainsi en contacl presifue direct avec le milieu ambiant.

Les Sarasin (lne. cil.) dans leur Monographie sur l'lehthyophis diseutent en détail la question des ramifications des eapillaires sanguins dans les espaces intercellulaires de l'ápiderme des larves. Ces canalicules très fins serviraient d'un còté ì la nutrition des cellıles épidermiques, d'un auire à la respiration cutanée. Ces canalicules à cause de leur étroitesse extrème (larges tle $0,004 \mathrm{~mm}$.), ne laissent pénétrer aucun corpuscule sanguin; ils s'ouvrent à la surlace de la peau, et ainsi l'ćchange des gaz dans le plasma sanguin serait considérablement facilité. Nous avons vu des canalicules semblables et

1 Archiv lür mikroskop. Anat. und Entwickl. Bd. 52, 18,8; Morpholourisches Jahrbuch, Bd. 2, 1876.

* Lobservation d'une vascularisation de la cavité buccale des grenouilles déerite par Maunen repose sur une erreur eomme l'a montré Joserp. En efiet, ee de sont pas des anses ou des réseaux vasculaires qu'on observe dans la murpeuse luxcale, mais de simples diverticules sacciformes provenant des capillaires souscipithéliaux. 


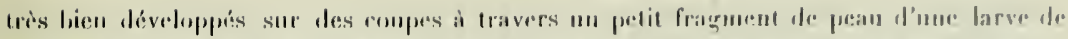

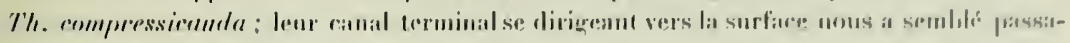

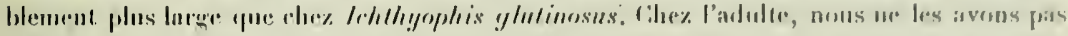

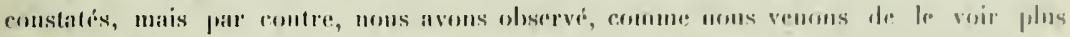

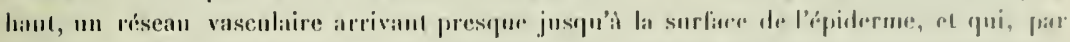

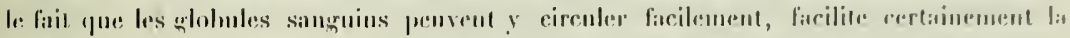

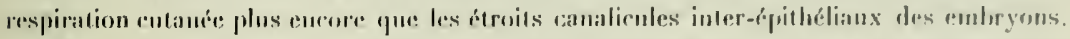

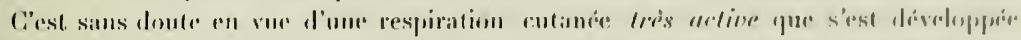

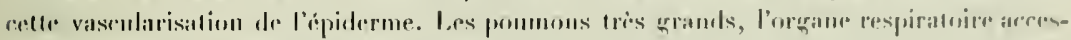

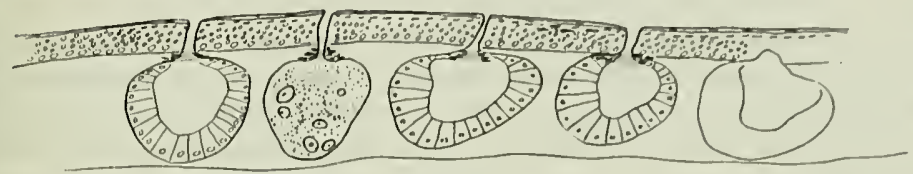

Fig. 8 .

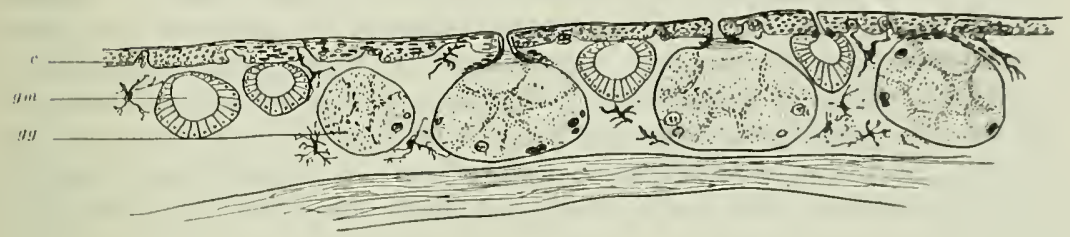

Fig. 9.

Fig. 8 et $9:$ Th. natans (Fiscier). Coupe transversale de la peau de la tile el du corps. c vaisseau capillaire de l'épiderme, $g m$ glande muyweuse, $g g$ glandes sranuleuses.

soire de la trachée, ainsi que la respiration cutane, permettent sans aucun doutr aux Thyphlonecles de restec très longtemps sous l'eau sans revenir à la surface.

En opposition arec la grande majorité des Apodes, les Thyplonectes ne possidlent aucune trace d'écailles dans leur derme. Les glandes cutanées ont ju ainsi se développer librement et on les trouve sorrées les unes contre les autres sur toute la surface du corps de l'animal.

Comme chez la plupart des. Imphihiens et chez tous les Apodes, nous trouvons deux catégories de glandes, les grandes muqueuses et los glandes granuleuses, dont la différence de taille est bien moins considérable que cliez la plupart dess Apodes. En elfet. les glandes granuleuses, de forme ovale comme les glandes mugueuses, ont un diamètre trinsversal de 0,24 à $0,4 \mathrm{~mm}$. et une hauteur de 0,16 à $0.22 \mathrm{~mm}$., tandis que les mesures pour les glandes muqueuses sont de 0,12 à 0,18 mm. pour la largeur et 0,08 à $0,12 \mathrm{~mm}$. pour la lauteur. Sur lia tiste. où les anlandes gramuleuses font presque rléfaut 
(il n’en rexiste qu’un nombre très restreint sur le crité dorsal et ventral), la dimension des glandes muqueuses est très égale et correspond au chiffre maximum indiqué pour ces ghlandes. Les quelques glandes granuleuses qui existent sont alors de mème taille que les glandes mnqueuses. La strueture de ces glandes correspond à la description détaillér quiont donnée les Sanasix, c'est pourquoi nous pouvons nous abstenir de ditails sur ces organes et renvover aux nombreuses figures de ces anteurs. La distribution de ces deux catégories de glandes est intíressante, paree qu'elle ne concorde pas arec l'exposé quien a donné Pussalix ${ }^{1}$ pour les Apodes étudiés par elle.

Sur le corps des Thyphlonectes, en opposition avec ce qu'on devait s'attendre à trouver d'après Phisalix, les glandes granulenses, comme les glandes muqueuses, se voient en aussi grand nombre sur la face ventrale que sur le còté dorsal du corpss. P'hisalix', en étudiant la distribution des glandes granuleuses chez Ichthyophis, Il!npogeophis, Caccilia, Herpele, Dermophis et Siphonops, a trouvé que les glandes granuleuses conservent leur développement uniforme et leur égale répartition sur chaque anneau, là où les écailles sont, au moins par place, bien développées tout autour du corps. La régression des écailles est suivie de celles des glandes granuleuses. C'est ainsi que chez Cacilia tentaculata, qui'n'a des écailles que sur le dos, le nombre et la grandeur des glandes diminuent sur le ventre et sur les flancs. La disparition des glandes de la face ventrale devient complète chez Dermophis, où écailles et glandes granuleuses ont la mème distribution dorsale. Chez Siphonops enfin, nous n'avons plus d'écailles et les glandes sont disposées seulement sur le dos comme chez Dernophis. Phisalix conclut de là que la localisation progressive des glandes granuleuses sur la face dorsalc dı corps des Apodes est fonction de la réduction graduelle des éeailles et non dı milieu qui est le mème pour tous.

Chez Thyphlonectes, en opposition avec les résultats de Phisalix, les glandes granuleuses sont régulièrement réparties sur tout le corps, aussi nombreuses sur la fact ventrale que sur la face dorsale. La disparition des écailles n'a donc eu aucune influence sur la disposition des glandes en question, à moins que les ancêtres de ces formes n'aient jamais eu d'écailles. Cette répartition des glandes granuleuses est en opposition avee celle de la grande majorité des Batraciens terrestres où les glandes granuleuses sont cantonnées surtout sur la face dorsale du corps. Comment expliquer ce fait? Cette distribution régulière des glandes granuleuses et venimeuses est-elle un caractère primitif ou est-elle une adaptation à la vie aquatique des Thyphlonectes? Comme ces glandes sont les organes de protection, il serait logique que chez l'Apode aquatique, ces appareils soient répartis sur toute la surface du corps, puisque plus encore que sur la terre toutes leurs faces sont accessibles aux attaques d'ennemis. Cette distribution égale des glandes, la vascularisation de l'épiderme et le développement considérable des pou-

1 Prisılix, M. Répartition des glandes cutanées et leur toealisation progressive, en fonetion do la disposition des éciilles che\% les Batraciens apodes. Verhandl. des VIll. internat. Zoologen-liongress, Gra\% г!) r2, p. (4): 


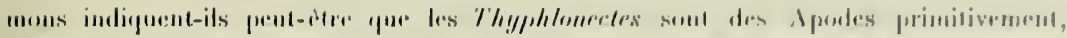

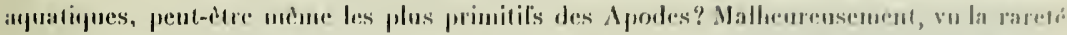

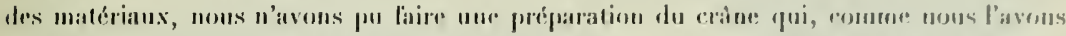

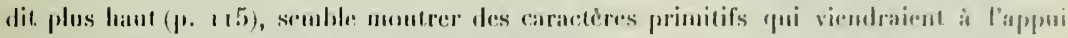
de motre manierte de voir.

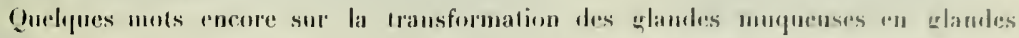
labiales. Chez tehthyophis, les glandes labiales sont extrimemont develuppres et

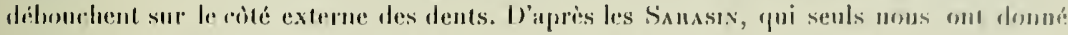

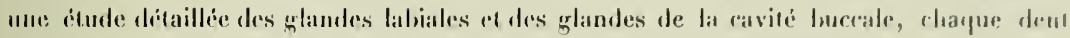

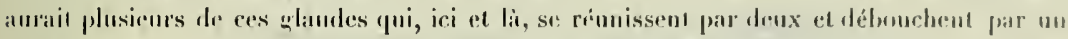

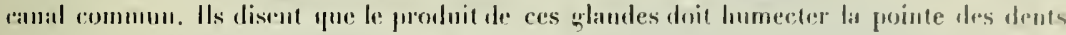
"t qu’il est possible que le produit ghandulaire de ees glandes ait une aretion loxigune.

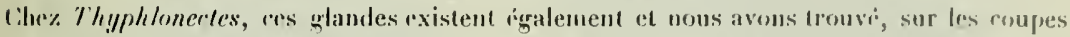
iransversales de la machoire inférieme, quelles sont toujours an nombro de denx at délonchent, comme chez Ichlhyophis par un canal commun. Jeeur nombre semble de moins considérable que chez lchthyophis, leur taille est un peu plus grande que celle des ghandes muqueuses de la tète, par contre leur structure est absolument identique; seul le canal excrétenr est beancoup plus long.

Lorsque l'épiderme passe dans li cavité buccale, son caractère est complintement chassá. fé nombre des couches est augmenté et, en opposition avec la pean, l'épildúlium esl alsolument dépourvo de glandes. Seules des cellules caliciformes, grlandes unicellulaires, se trument en assez grand nombre dans la muqueuse buccale. Sur la langue, entre les deux rangées de dents, comme sur le reste de la muqueuse du plancher de la caviti huceile, la struclure de la muqueuse reste la mème.

Le plafoud de la cavité buccale est lapissé d’un épithélium (épaisseur o, $1 \mathrm{~mm}$.) dans liquel se tronvent serrées les unes contre les autres des cellules caliciformes très allongées (longueur o,o6 mm.), dont le contenu se colore très vivement avec le Muscicarmin. Entre les dents maxillaires et la rangie de dents vomériennes, on croit roir, comme chez Ichthyophis (Sarasin, Taf. 24, fig. 117), une étroite bande de glandes. Étudiées de près, il nous semble que chez Thyphlonectes ces glandes ne sont que des cryples de la muqueuse, parce que l'épithélium qui les tapisse est en plusieurs couches et que la coloration avec le Muscicarmin révèle dans ces tubes de nombreuses cellules caliciformes comme celles dı reste de la muqueuse buccale. Le canal mẻme de ces tubes est rempli d'un mucus se colorant en rouge carmin comme la mucosité des cellules caliciformes. II nous semble donc que chez Thyphtonectes nous avons simplement affaire à des invaginations de la muqueuse buccale riche en cellules caliciformes. Ces cryptes sont souvent bifurquuces à leur extrémité, ceci surtout chez $T h$. dorsalis. Les víritables glandes du palais, si importantes chez lit plupart des Amphibiens, feraient défaut. Si notre interprélation est juste, il manquerait aux Thyphlnnectes les glandes buccales si richement développées sur le plancher et le plafond de la caviti huccale des Apodes et en particulier 


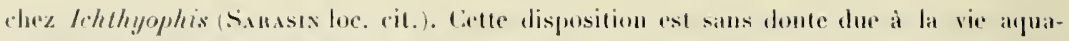
linue de ces animaux; ils ressemblent en cela à certains lehthyoüles et aux poissous. Ce qui nous frappe encore dans la cavité huceale, c’est la vaseularisation extrime. En efiel, suus l'epiderme du palais comme dans la langue, on ur voit que des lacumes el des vaisseaux boures de corpuscules sanguins, tandis que le tissus conjonetif, ainsi qur la museulature dans lat langoue, sont réluits au minimum. Tout semble indiquer qu’il y a, non seulement respiration pulmonaire et cutance, mais aussi respiration buccale chez les Thyphlonectes.

\section{La cavité nasale el l'organe tentaculaire.}

Cous avons pu ditudier sur une série de compes sagitlales d'un fragment de tìte de Th. dorsalis les dispositions intéressantes de la cavité nasale et de l'organe tentaculaire. Cette étude, ru le manque de matériel, est naturellement fragmentaire et nous nous contentons ici de décrire quelques coupes intéressantes dessinces toutes ì la mème échelle.

Nous commençons par les coupes sagittales passant par l'ouverture et toute la longueur de l'appareil tentaculaire (fig. 10 et is). La coupe fig. Io passe par l'ouverture de la poche de l'appareil tentaculaire qui conduit dans un petit vestibule (long de o,3 mm.) tapissé d’un épithélium tout à fait identique à celui de la peau. La porhe elle-mème a une longueur de $1,5 \mathrm{~mm}$. (longueur du cràne $\mathbf{~} \mathrm{cm}$.) et un diamètre maximal de $0,3 \mathrm{~mm}$. Le tentacule qui se tronve dans celle poche parait itre beaucoup plus simple que chez Ichthyophis, puisqu’il semble n'ètre qu'un épaississement de la face dorsale et latérale de: celte poche. Cet épaississement fusiforme, long de $0,8 \mathrm{~mm}$., se détache en avant et en arrière de la paroi du sac. Én avant, il en résulte une petite papille très courte (fig. 11), landis que l'extrémité postérieure semble plus libe. Le tentacule ne renferme que très peu de vaisseaux sanguins, contrairement à ce que les SARAsin décrivent pour l'Ichthyophis. Ce ne sont donc certainement pas les vaisseaux sanguins qui produisent ta turgescence de cet organe qui parait ítre peu protractil. Quant an muscle rétractenr, il ne semble pas non plus se fixer an tentacule, nais entourer l'extrénité interne de la poche tentaculaire. La paroi épithéliale de celte poche est garnie de très courts tubes, pentitre glandulailes, qui debouchent dans la cavité el paraissent manquer chez lchthyophis (v. fig. 10 d 11 ). Au lond de la poche, se léversent les glandes de Harder par plusieurs ouvertures. Cette glande, située derrière l'ceil rudimentaire, s'étend avec ses nombreux tubes glandulaires, jusqu'au muscle rétracteur el passe par-dessuscelui-ci pour se déverser dans la cavité tentaculaire. Sur la coupe sagittale, l'amas glandulaire est donc de forme allongée et entouré de la mème forte gaine conjonctive qui entoure aussi la poche renfermant le tentacule. Sur la coupe fig. 11 , on remaryne sous le sac tentaculaire, les parois d'un canal très large dont le diamètre est de $0,21 \mathrm{~mm}$. Il débouche, comme on pent également le voir sur la mème coupe, en avant, sur la face ventrale du vestibule de la 


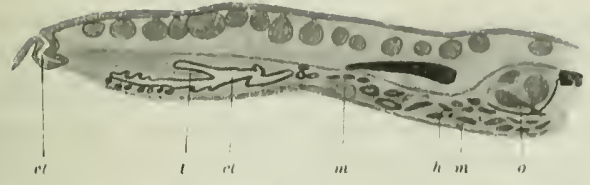

Fig. 10.

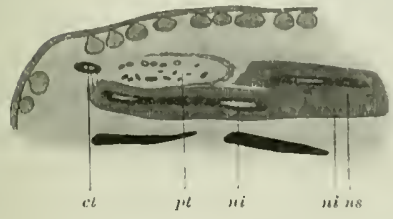

Fig. 12.

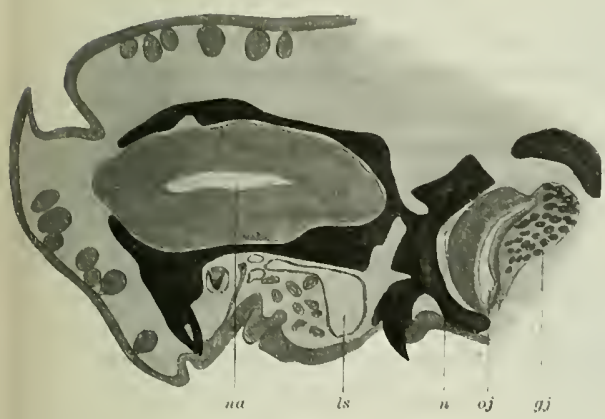

Pig. 14.

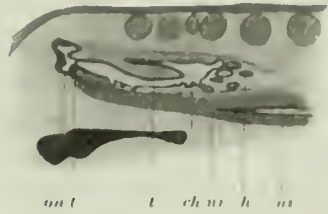

Fik. 11 .

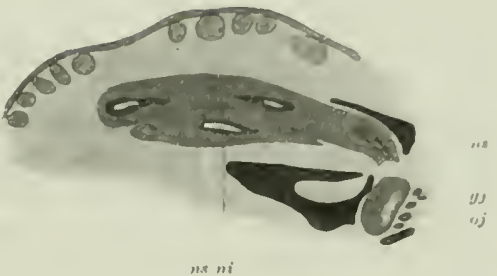

Fig. 13.

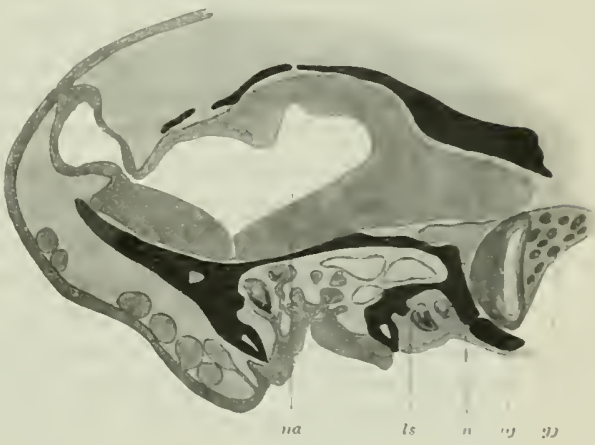

rig. 15.

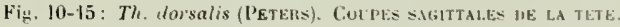

Toutes ces coupes ont été dessinées à la chambre claire el à la mẻme échelle. Coupe lỉg. IU passe par le còté latéral droil el coupe figs. 15 près de la ligne médiane.

"f restibule de la cavité lentaculaire, ct cavité lentaculaire. $/$ l poche tentaculaire, I tentacule, $/$ glandes de IIarder, $m$ muscle, ni canal naso-lacrymal inférieur avec forte qaine conjonctive, on onverture du canal nasulacrymal inférieur dans la cavité tentaculaire, ns canal naso-lacrymal stuérieur, oj organe de Jacobson, gi wlande de Jacobson. "a cavité nasale, $n$ nerf, ls lacune sanguine. 


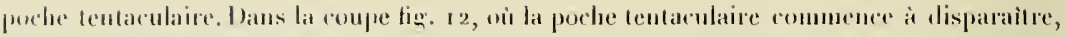
on voit en dessus du grand cantal et en arriere de la poche un second canal identique. les cantax sont enveloppés d'une gaine conjonctive très forte et le caual lui-mime est lapissé d’un épithélium. Dans la fign. 13 , le canal rentral disparait et on voit, par contre, le ranal dorsal s’étendrejusqu’à la hauteur du vestibule de la poche ientaculaire, où il déhouche (sur une autre conpe) comme le canal inférieur. Tandis que le canal ventral court le loner de la face ventrale de la poche tentaculaire, l'autre canal longe donc la face interne de celle mème poche el se trouve ainsi entre la poche tentaculaire al la cavité nasale. Ces deux canaux sont, comme l'ont montré les Sansin', les deux canaux naso-

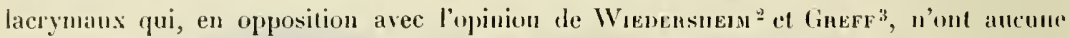
relation aver les glandes de l'organe de Jacobson, que ces deux auteurs interpritent comme des glandes de la poche tentaculaire. Ce qui ressort surtout très clairement de l'examen de nos coupes, c'est que les glandes de l'organe de Jacobson sont trés peu liveloppies, tandis que les canaux naso-lacrymaux sont énormes et présentent presque le mème diamètre que la poche tentaculaire; pour cette raison, ces deux organes, canaux naso-lacrymaux el glandes de Jacobson, ne peuvent ìtre en relation l'un avec l'autre. A l'extrémité interne, les deux canaux se courbent vers l'organe de Jacolsson où ils débouchent sans doute. Nous n'avons pas pu constater avec certitude leur relation arecl'urgane de Jacolsson, parce que les coupes sagittales à cette place étaient défectueuses.

Lorgane de Jacolsson apparait_sur les coupes sagillales bien avant que celles-ci tuuchent la cavité nasale; cet organe dépasse donc latéralement la cavité nasale. Dans la fig. ı3, où on voit encore le canal nasu-lacrymal dorsal, l'oryane de Jacobson présentc un diamètre vertical de $0,7 \mathrm{~mm}$. La partie antérieure de l'organe est pourvue d'un épithéliom sensoriel très puissant, tandis que la jaroi postérieure est beaucoup plus mince el montre derrière elle de nombreux tubes glandulaires, les glandes de Jaculison. Lil paroi latérale de la cavité nasale n'apparait que passablement vers la ligne médiane. L'organe de Jacobson a jci un diamètre vertical de $1,3 \mathrm{~mm}$. et mesure avec le coussinel rlandulaire, plus développé que précédemmeut, 1,2 $\mathrm{mm}$. (fig. 14).

Dans la fig. 14, on voit l'invagination du vestibule de la cavité nasale qui, dans la tig. 15, débouche dans la cavité nasale. Lorsque la conpe sagittale passe par toute la lungueur de la cavité nasale, l'organe de Jacobson est devenu plus petit el semble déhoncher, non pas dans la cavité nasale mais dans le "Choanenschleimbeutel ", poche

Note.,- Dans la tig. 30 , nous voyons sous le derme l'ueil très rudinentaire de Th. dersalis d'un dianuètre de $0,47 \mathrm{~mm}$. Les glandes muquenses de la peau, ainsi que le pigment sont à peine interrompus en dessus de l'ceil, aussi est-il peu visible depuis l'extérieur. Comme le montre la figure. la régression de l'organe visuel est poussée très loin, puisque le cristallin mème reste à un ètat embryonnaire présentant un dẻveloppement incomplet (diamètre $0,09 \mathrm{~mm}$.).

1 P. u. F. SArisin, loc. cit., p. 179.

2 Wiedersheim, Die Anatomie der Gymoophionen Jena, 1879 .

3 Gruers, R. l'eber Sijhonops Alomensis, Barboza du Bocaye. Sitzungsher. d. Ges. \%. Belörd. d. ges. Naturwiss, zu Marburg, 1884. 


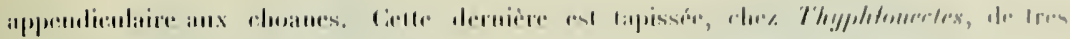
unulurenses cellules ralicifinmes.

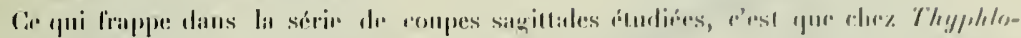

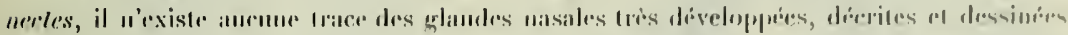

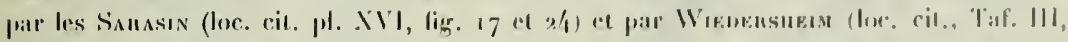

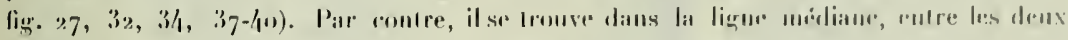

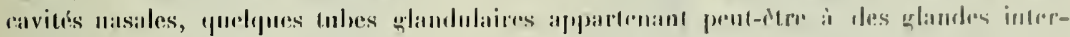

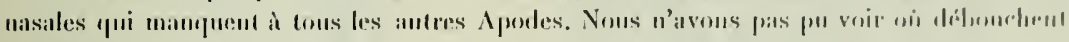
ins ghamdes.

\section{Les organes respiratoires.}

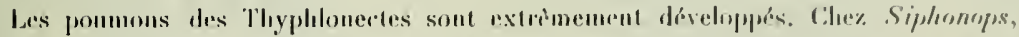

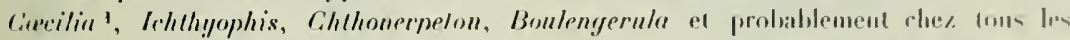

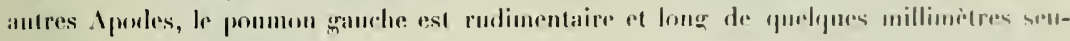
lement.

La longueur des poumons est la suivante chez les trois aspires du gente Thyphlue nietes: :

Th. compressicaula var. neuesuelense p. droit $26 \mathrm{~cm}$., p. wauche $20,5 \mathrm{~cm}$.

Th. naluns

p. droil $27 \mathrm{~cm}$., p. gauche $12 \mathrm{cul}$.

Th. dorsalis

p. droit $24 \mathrm{~cm}$., P. gauche $6,5 \mathrm{~cm}$.

Comme la trachése est trís longue, l'extrémité postérienre du poumon droit arrive trìs pris du cloayur, tandis que chez les antres Aporles, il dépasse rarement l'extrémiti juslérieure du foie.

La trache des Thyphlonectes présente une particulariti curieuse que nous a vons dejia relevée dans la description diss espices. Comme elle est très longue, allant du pluarynx jusque derrière le cour tris ćloigné de la tète, sit paroi renferme de nombreux anneanx cartilagineux qui, contrairement à ce que dit Wiedersuets (Joc. cit.), sont onverls sur le crite ventral et non sur le critédorsal, ceci non seulement chez Thyphlonecles, mais anssi clez lehthyophis glutinosus, etudie prar cet auteur. Sur la face ventrale de la trachée ve Iromv IIn singulier organe fusiforme, relativement trì volumineux.

Petens ${ }^{2}$ avait dejà remarqué cel orogane en dissiquant une larve de Th. compressiranslu. It dit : "Die Luftrïhre ist anfangs auf eine kurze Strecke $(3-4 \mathrm{~mm}$.) verengl um doulich ans Querringen zusaumen gesetzt. Darauf erweitert sie sich allmählich spindelfïrmig, zeirr keine Querringe, sondern ein netzförmiges Ansehen, bis sie sich an der Dorsalseile und

1. Joh. Müusn (1831) donne une figure (Fig. V11, Taf. 18) du situs de Careilin lumbrimiden on tes deux poumons sont de tongueur égale, it s'agit lì sans aueun doute d'un Thyplelonertes. puisque C. Inmhriorites a liapres Durkuxor, le poumon gauche rudimentaire.

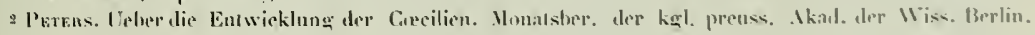
$187 . \pi$, p. 位. 


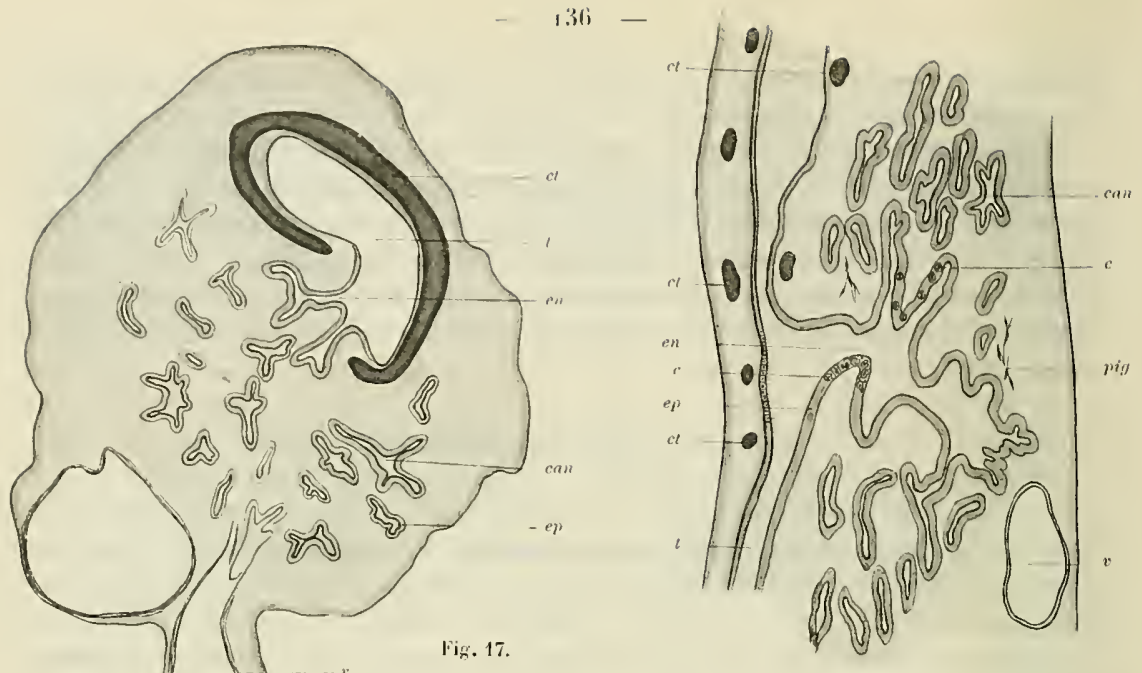

Fis. 17.

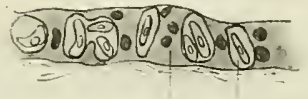

ef $\quad$ i.

Fig. 14 .

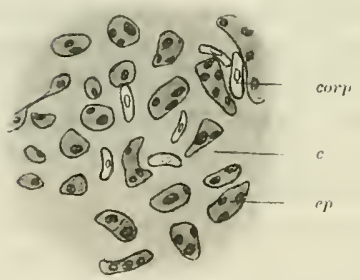

lig. 20.
Fig. I6.

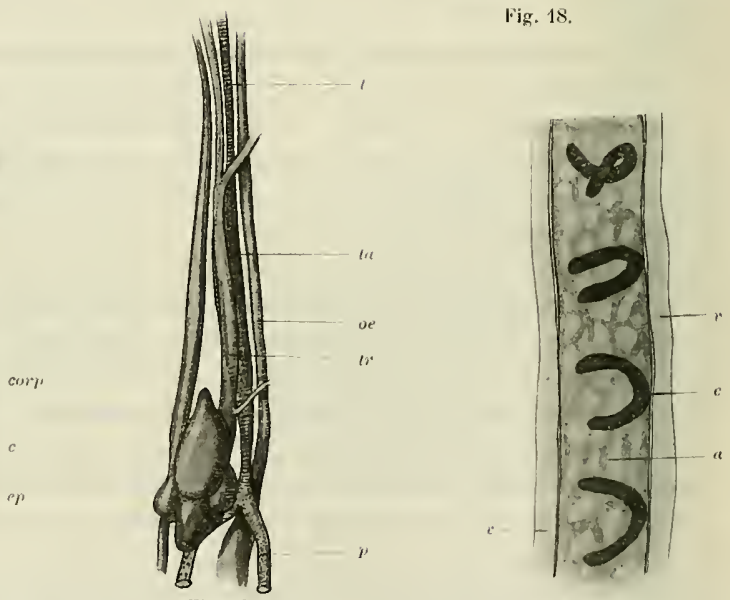

Fig. 18 ,

Fis. 21 .

Fig. 16: Th. compressicauda (D. et B.) et Fig. 17-21: Th. nalaus (Fischen). Organe hespiratoire.

Fig, 16: Th. compressicauda var. venezuelense. Région de la trachée, le cœur légèrement déplacé à gauche. 1 trachée, $t a$ organe respiratoire accessoire, $p$ poumon, oe osophage, $t$. Truncus. - Fig. 17: Coupe transversale de l'organe respiratoire accessoire de la tracheee, $t$ trachée, $c l$ cartilage annulaire de la trachée, en entrée des canaux de l'organe respiratoire accessoıre, can canal de l'organe respiratoire accessoire, ep épillıćlium vascularisé, "vaisseau sanguin. - Fig. 18: Coupe longitudiaale de l'organe respiratoire accessoire. Voir explication lig. 17 . c capillaires inter-épithéliaux, pig cellule pigmentaire. - Fig. 19: Coupe transversale de l'épithélium des cavaux de l'organe respiratoire accessoire de la trachée, ep épithélium, $c$ capillaire avec globule sanguin. - Fig. 20: Coupe horizontale de l'épithélium de l'organe respiratoire accessoire de la trachée. Montre le réseau des capillaires $c$ avec les globules sanguins comp (il n'en a été dessiné que quelques-uns), ep les îlots épithéliaux dans le réseau capillaire. - Fig. 21: Dessin d'après une préparation totale d'un fragment de l'extrémíté postérieure rlu poumon "roit. a alvéole pulmonaire. c' cartilage annulaire, " vaisseau sanguin gauche el droit. 


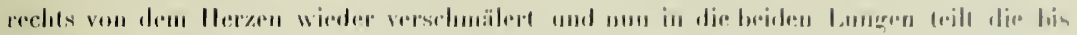

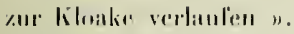

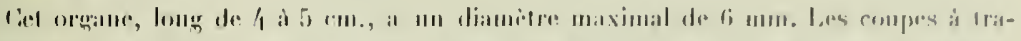

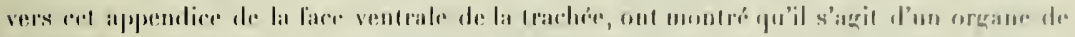

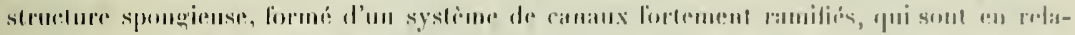

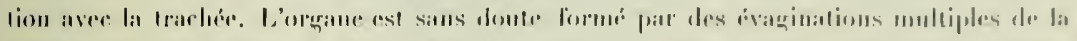

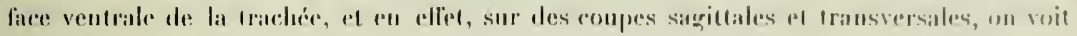

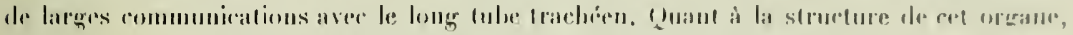

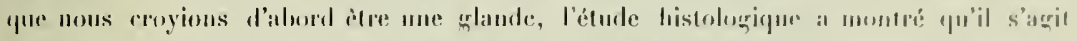

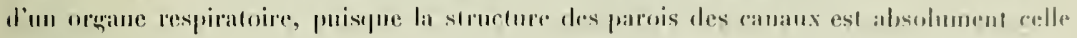

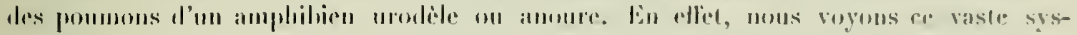

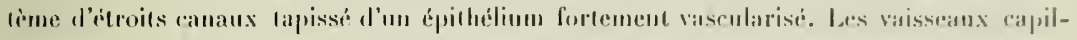

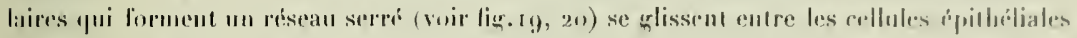

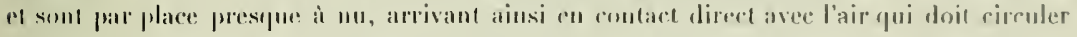

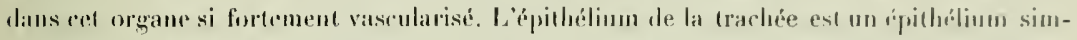

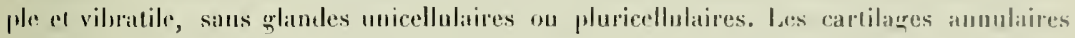

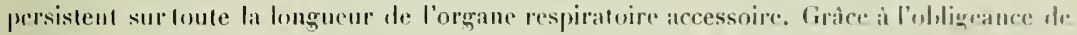
M. F. Samsin, nous avons pu dissequer et étudier l'anilomie de quedques exemplaires très

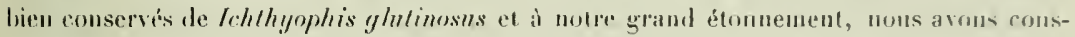

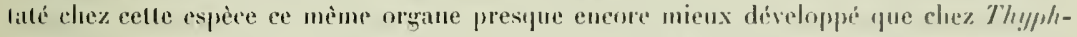
lomeress. Sur un exemplaire de $27 \mathrm{~cm}$. de long, lorgane situé sur le cotri ganclue du Trunrus et se whissant sous le curur par son extrémitc postirieure amincie, a une longueur de 3 o mm. aver un diametre maximal le $3 \mathrm{~mm}$. Le systime des cananx semble être un peu phus fortement ramific. La structure est la mèmo, seule la trachée moutre une diffirence assez notable avec celle des Thyphlonectes, puisque l'épithílium qui le tapisse semhle etre en phusienrs couches et surtout richement pourvu de cellules caliciforme, tont la contenu se colore vivement aver le Musciearmin. Le manyue de cellules grandulaires daus la trachie des Thyphlonectes est-il dù à la vie aquatique de ces animaux?

La structure du pumon est des plus curieuses. Il prẻsente cliez Th. nalans la forme d'un tube long el étroit, d'un diamètre de 2 mm. A gauche et ì droite, on remaryque un trìs gros vaissean sanghuin, qui envoie ses ramifications vers les alvéoles pulnumaires. Celles-ci sont très simples el l'épithélium qui les tapisse montre absolument la mènte structure que celui des poumons des amplabiens et de l'organe respiratoire accessoire de la trachée de Thyphlonectes. Cé qui fait la particularité du poumon, cest le fait qu'il existe dans toute sa longueur, jusquà l'extrémité qui se trouve prés du cloaque. des anneaux carlilagineux ourerts d’un còté. Ces anneaux cartilagineux sunt larges d'enviroll $13,2 \mathrm{~mm}$. el se trouvent distants de 1,1 à $1,6 \mathrm{~mm}$., si tien que le poumon droil de Th. nulans en renferme emviron 180 , tandis que le poumon gauche en montre environ so. Certains de ces anneaux présentent mème une légire ossifieation qui doil les rendre plus solides. Chez les Amphiliens on commait soulement dams la parlie? anterieure ot 
impare des poumons de Siren quelques anneaux cartiagineux mulimentaires. Quel pent ètre l'utilité de cette disposition curieuse, qui n’a été ohservée chez ancun amphitien?

Cetle armature cartilagineuse ne peut avoir un autre ròle que cehi qu'elle jone dans la trachée et les bronches des vertébrés supérieurs; elle doit sans doute tenir ouverte la cavité pulmonaire a la libre circulation de l'air. Cette cavité est si longue et si étroite cluez les Thyphlonectes que sans celte disposition intéressante, l'air ne pourrait jamais arriver jusqu'a l'extrémité distate du poumon, surtout lorsque l’intestin garui de nouriture, produit une pression el un aplatissement des étroits tubes pulmonaires.

Les représentants du genre Thyphlonectes que nous venons d'étudier nous montrent par la forme de leur corps, par l'organisation de leurs systimes respiratoires, par lo manque de glandes tlans la cavité buccale et dans la trachée ainsi que par leur nutritun (poissons) gu'ils sont des animaux nettement aquatiques. Ce gente de vie, la conformation de leur cràne, peut-ètre aussi la structure de leur peau, de l'épithélinun de leur cavití buccale et de leur système respiratoire semblent indiquer que nous avons affaire ì un groupe d'Apodes primitifs. N'ayant eu qu'un seul exemplaire à notre disposition, nous n’avons pu étudier en détail ni le crâne, ni le système circulatoire, si importants ponr less questions phylogénétiques. Nons espérons ponvoir combler celte lacune importante par une étude ultérieure sur de nouveaux matériaux qui nous montrera si les caractères signalés indiquent vraiment un groupe primitif ou s’ils ne sont que le résultat d'une adaptation secondaire ì la vie aquatique. 


\title{
BEITRAG
}

ZIII KENNTEIS HEll

\section{Weberknechle Kolumbiens}

vis

\author{
$D^{r}$ C.-FR. ROEWER, BREMEN
}

'liaf. VII

Die von Professor Fuhrmann gesammelten Welserknechte verteilen sich anf \& l'amilien, \& Subfamilien, an Gattungen und is Arten.

Von diesen sind 4 nene (iattungen und on nene Arten.

\section{Subord. A. Laniatores.}

Fam. T. Cosmetiden.

Sulyfum. a. Cosmetinen.

1. Cynorta calcar-apicalis $\mathbf{n}$. sp.

2. Pararhaucus marmoratus $\mathbf{n} . \mathbf{s p}$

3. Pararhaucus flavicinctus (Genvas sub Cosmetus).

4. Metarhaucus reticulatus $\mathbf{n}$. $\mathbf{s p}$.

5. Metarhaucus albilineatus $\mathbf{n}$. sp

Fam. TI. Gonyleptiden.

6. Phareus raptator (Genvis) Simon.

7. Metaphareus albimanum n. g. n. sp.

8. Camelianus fuhrmanni n. g. n. sp.

9. Cranaus calcar n. sp. 


\section{Fam. TIt. Phalangodiden.}

Sulifum. a. Mluchungolimen.

16. Stygnomma fuhrmanni n. g. n. sp.

\section{Subord. B Palpatores.}

Fam. IV. Phalangiiden.

Sulbam. ". Gagrellinen.

11. Prionostemma albimanum n. sp.

12. Tamboicus fuhrmanni n. g. n. sp.

Aus der Subord. der Palpatores warden aus der Fam. der Phalangiden wiedermu Formen gुefunden, welelıe den neuweltlichen Gagrellinen (Subfam.) angehören, wie sie aus Central- und Süd-Amerika zu erwarten sind. Es ist his heute noch nicht festgestellt, wie der geographische Zusammenhang in der Verbreitung der neuvelulichen und der alıeltlichen Gagrellinen (Südost-Asiens) sein mag; vielleicht mag die Brücke die Sul,fuı. Liobuninae der lam. Phalangidae sein, welche im gemïssigten und subtropischen NordAmerika wie auch in der gemässigten und suhtropischen Alten Welt gleichmässig wei verbreitet ist. Geselzt, dies ist der Fall und die Liobuninen bilden diese Brïcke, so müsste man zwei parallele (südliche) Ausstrahlungen der Entwicklung annehmen zu Formen der Gagrellinen, nämlich den Gagrellinen Central- und Süd-Imerikas einerseits und denen der ostasiatischen Inseh und Halbinseh (Indien und Sunda-Inseln bis Nen-Guinea) andererseits. Indere Zusammenhänge, besonders direkte geographisclie Beziehungen zwischen alt- und neuweltlichen Gagrellinen sind bis heute nicht hekanut.

Aus der Subord. der Laniatores finden sich in der vorliegenden Sammlung drui familien vertreten, von denen zwei ausschliesslich amerikanisch sind, und zwar vom sïdlichen Nord-Amerika an den Süden des ganzen Erdteils eigrentümlich sind : Fam. Cosmetiden und Fam. Gonyleptiden. Unter den Cosmetiden liegen hier Formen vor, wie sie aus den aequatorialen Gelirgsländern der Anden schon Simon 1879 beschrieben lıat, wemn es hier auch andere Arten sind. Diess Gebirgsformen hahen sämtlich rohuste lï̈per und Gliedmassen und zeigen extrem-ausgebildete sekundäre Geschlechtsmerkmale. Leber die Fam. Gonyleptiden lässt sich auch nach den in dieser Sammlung vorliegenden Formen bei der furchtharen Vervirrung, welche in deren System zur Zeit berrscht, geographisch ïber Verteilung und Verbreitung von Genera-Gruppen und Species-Gruppen schon garnichts sagen. - Im so meln von Wichtigkeit ist in der vorliegenden Sanmlung das Auffinden einer liorm, welche ich Stygnomma genanul habe, und welche 


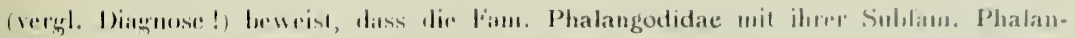

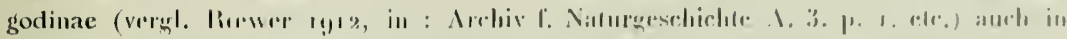

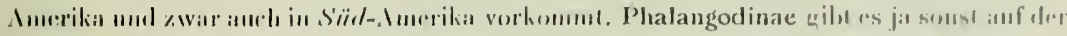

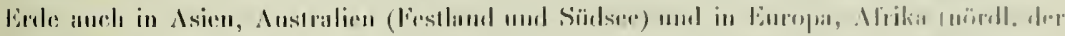

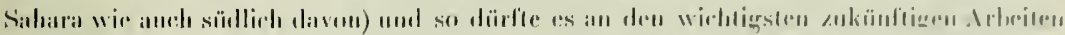

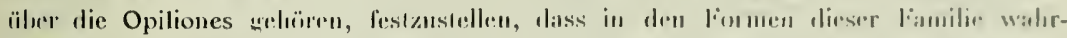

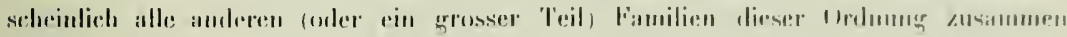

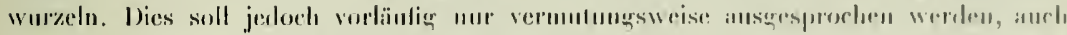

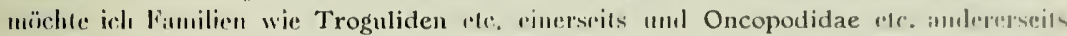

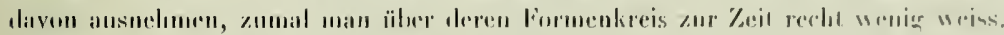

Die leier vorliegenden lomenen sind:

\section{Cynorta calcar-apicalis nov, sp.}

Länge des lï̈rpers 4,7 mm; I. des I. Beines $11 ; 11.21 ; 111.17 ; 11$. 18 mm.

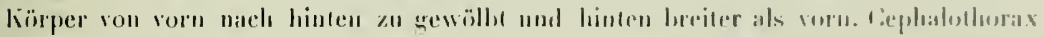

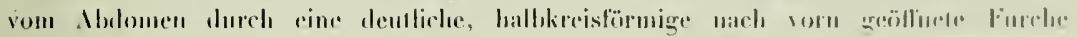

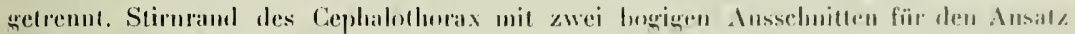

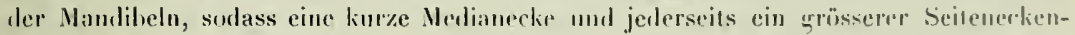

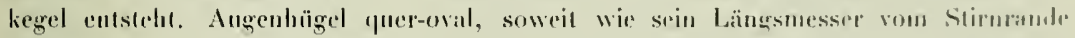

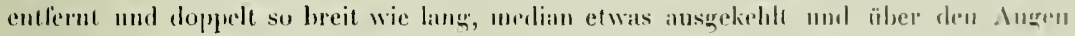

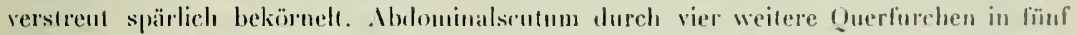
Arar geteill, deren erste ein miltleres Palar stumpfer, niedriger Tulwrkelu anfurist, deren zwejte und vierte unlsewehrt sind. desen drille ein medianes l'aldr helumeinander

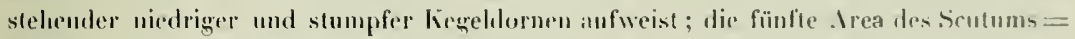
Himterand mit einer Querreihe winziger Kïmohen, wie anch auf jed'm der drei folgenden freien Dorsilsegmente. Seitenrand der Sculums, welehes rorn sehmal, neben der $\mathbb{W}$. Coxa nach anssen hogig erweitert unıl hiuter ler $\mathbb{W}^{\circ}$. Coxi werler plötzlich eingestüür und hinten reehtwiekelig ist, nieht durch eine dentliche finrche ahgesetzl und nur spärlich und winzir bekörnelt; Scutum sonst grleichnässig malt chagriniert. Freje Ventralsegmente mall chagrinierı, ohne Körnchenquerreihen. 1.-1II. Coxa klein, kurz, einander parallel. die IV. Coxa so breit wie die äbrigen zusammen und schräg nach hinten gerichtel. Spiracula deutlich sichıbar, möndchenlörmig. Mlle Cosen auf der Fläche matl glalt chąrriniert, ausserdem die I. Coxa an Vorderrand mit einer Reihe grober, stumpfer Ilëcherchen, dessrleichen eine etwas kleinere am Hinterrande der 11I. Coxa, die IV. Coxa am oburen vorderen Winkel mit einem srohen liegelhücker, der lateral ahsteht und unter slem Scutumseitenand hervorrang. Trochantere der Beine kur\%-walzig und I.-III. hasal-hinten, IV. apical hinten mit je ein stumplen Ilöelierchen brsetzl. Ille Beinre grleichstallk, nur I.

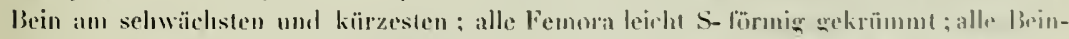

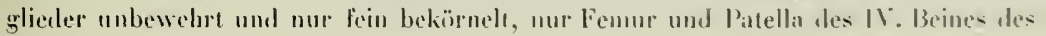


ahweichend gebaut: Fenur apical-ventral mil einer Reihe stumpfor liegelhäcker, von denen der ganz an der Spitze grelegene am dicksten und grö̈bsten ist, und Patella ventral innen an der Spitze mit einem grösseren stumpfen liegelhöcker besetzt; IV. Femur und Patellat leim o mbewehrt und normal. Tarsen der Beine: I. Tarsus 6-gliedrig; 1-3. Cilied dick und erweitert und gegen den 3- gliedrigen, sehr dümmen und knrzen Endabsehnitt deutlich ahgesetzt; 11. Tarsus ı.3- gliedrig nit 3 ghliedrigem Endabschnilt; 1H. Tarsus

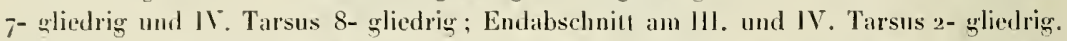
I. und II. Tarsus mil einfacher Endklane; III. und IV. Tarsus ohne Seopula, mit Pseudonychium und einfachen, nicht kammzähnigen Doppelklanen. Mandibehn bei beiden Geschlechtern gleich gebaut; 1. Glied wagerecht getragen, hasal schmal, mit deutlich abogesetztem dorsalen Apicalluckel, des auf' der Fläche wenig und winzig rauh hekörnelt ist und an seiner hinteren Kante eine Randreihe aus 4--5stumpfen Körnehen Irägl ; 11. Glied normal, ghlatt, umbewehrt und nicht mit seiner oberen Wölbung über das I. Gilied hinausragend. - Palpen flach frontal gegen die Mandibeln gedrückı, kurz und schmächtiş; Trochanter sehr dïnn, apical keulizg und veutral apical in einen schwachen Fortsatz auslaufend; Femur lateral stark zusammen enedrücki, dahıer dorsal und ventral seher scharf gekich und hier dorsal sehwächer, ventral in regelmässiger Reilıe stumpl'sägig bekïınelt; Patella kurz keulig, niclıt alggeflaclıt, nnbewehrt; Tilsia so lang wic der Femur, dorsalventral stark zusammengedrückt, daher lateral innen und aussen lamellenartig erweitert und scharf gekielt; die Kiele nur fein und kurz behaart; Tarsus kurz, hall, so lang wie die Tibia, nur basal wenig lateral erweitert, apical verjüngrt, unbewehrı, uur lıehaart; Tarsalklane sclıwach und nur halh so lang wie der Tarsus. Färbung des körpers und sämmtlicher Gliedmassen mehr oder weniger rostbraun, der Abdominalrücken am dunkelsten; das Seutum zeigt folmende weisse, seharf contrastierende Zcichunng: der Hinterrand des Cephalothorax ist durch eine breite V- Zeichnung umrahmt, die sich median aul dir 1. Area des Abdominalsentums fortsetzt, damı aber pötzlich aufhört; anl der II. Irea ein weisser sehmaler und nicht sehr scharler Medianstreif, ein gleichn anl der 1II. Irea zwischen den beiden liegelhöekern hindurch und hier verhmolen mit der vicrten Scutumpquerfurche, die scharf milch-weiss gezeichnet ist, die heiden Kegethöcker hinten bogig umrahmt und sich von hier ans quer bis zum äussersten Seitenrande fortsetzt.

Rio Magdalena vis-à-vis de Calamar ca. $80 \mathrm{~m}$ Mcereshöhe, $16^{1}+3$ q.

Zwischen Tambo und Boca del Monte, 1600-2/400 m Meereshöhe (Ost kiord., Dep. Cundinamarca), 3 우.

\section{Pararhaucus marmoratus nov. spec.}

(Taf. VIll, Fis. 1, 2 und 3.)

Länge des Körpers $6 \mathrm{~mm}$ \{ohır Nandilıhn).

Länge des 1 . Beinfemur is; II. $10 ; 111.7 ;$ IV. $9,5 \mathrm{~mm}$.

Länge des 1. Beines 16 ; 11. 36 ; 111. $22 ; 11$. 30 mm. 


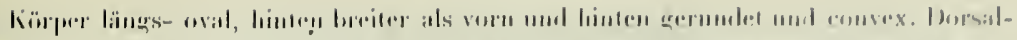

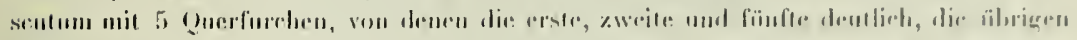

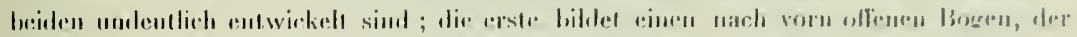

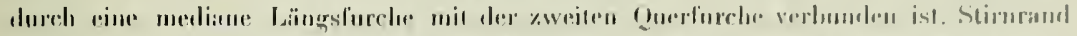

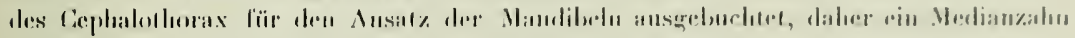

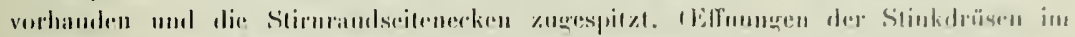

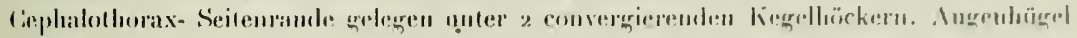

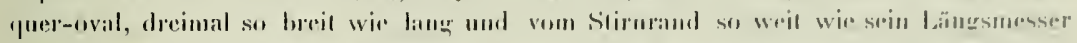

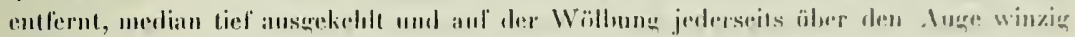

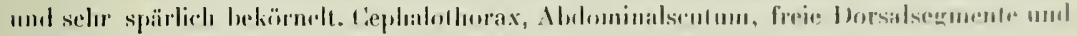

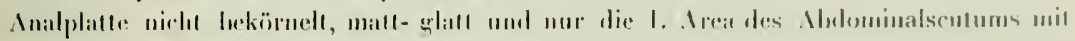

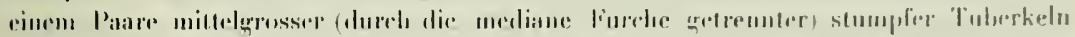

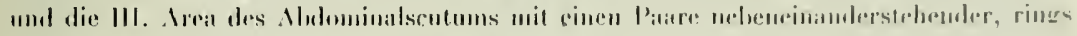

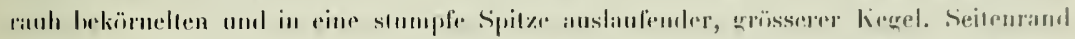

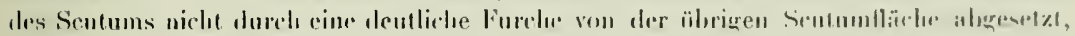

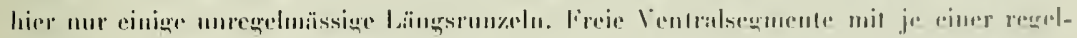

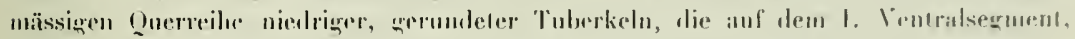

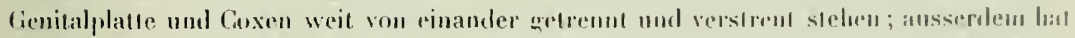

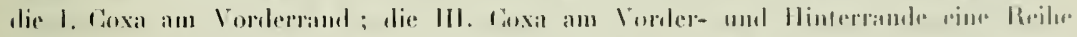

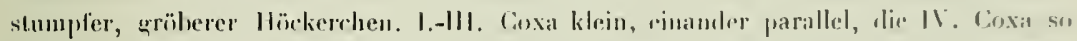

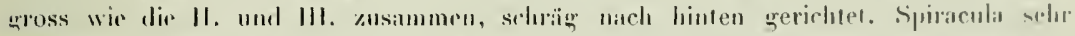

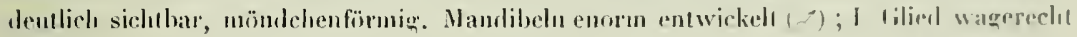

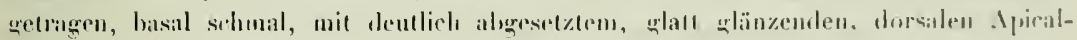

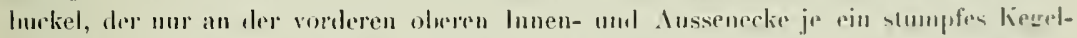

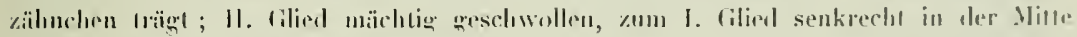

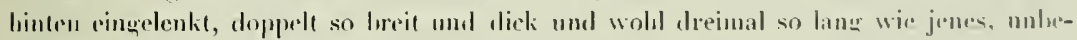

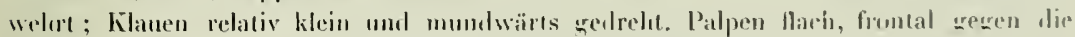

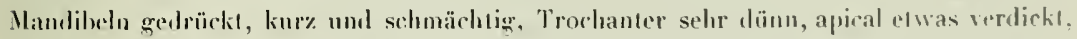
limur lateral stark zusimmenedrück1, daher dorsal mul rentral scharf gekiele und auf dirsen Kiclen besmulors ventral regelmässig mit ciner Sägereile stumpler hïrncheu besetzl ; Patella kurz, keuliz, nicht abgellachı, unbewehrt; Tilia so lang wie der Femur. dowal rentral zusimmengedrückt und apical lamellenartig verbroilert, dalur linteral- innen

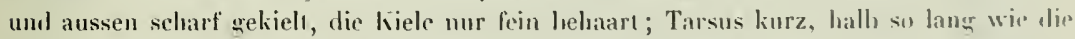

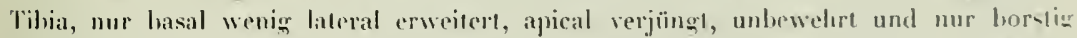

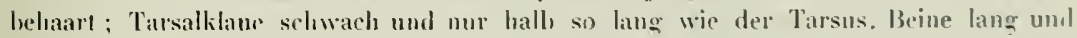
Itinn; III. und IV. Patir dentlich stärker als das I. und II. I.-II. Troclanter kurz Wal-

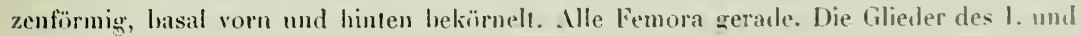
11. Beines mur ramb hohatest, somst unbewelent. Femur. Patella und Tibia des III. und

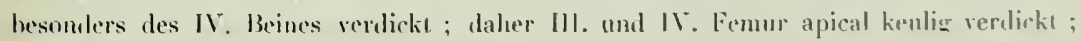

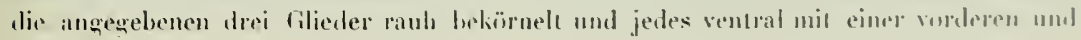




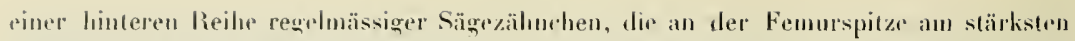

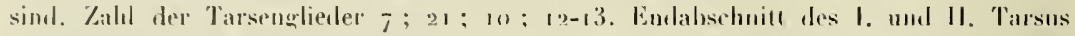

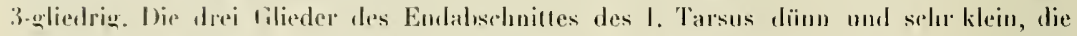
drei Cilieder des Basalalıschnilfes des I. Tarsus hreit sololenarlig emeiterl; die Tarsenglieder der ïlorigen Beine normal; 1. mul II. Tarsus mit Einzelklane, III. und IV. Tarsıs mit einfacben, nichı kammzälurigen Doppelklauen, deutlichen Psendonychium, ohne Sropula. Färlnng des Körpers und sämtlicher Gliedmassen rosthraun, die harten Chitinfrile des kïrpwes auch dunkirer angedaufen, nur die Trochantere der Brine bostgelb hreller. Der Räeken weist ausserden folgende Zeichnung anf : von Slirnrand bis anf die IV. Mrea des Abdoninalscutums läult jederseits in der Mitte zwisclsen Mediane und Scitenrand (also von diesem entfernt) eine Fleckentejhe ans b schwefelgelben, viereckigen, jedoch slark ausurzackten und (auf dem Cephalothorax) hraun punktierten Fleckin, von denen derjenige der II. Area lis zum Siculumreitenrande hin durchbricht. Diese beiden Fleckenreihen schliessen demnach einen breiten dunklen Medianstreif ein, der . Iugenhügel und die beiden grossen liegel der III. Area des Seutums enthälı. Scutumhinterrand und I. und II. lire Dorsalsegment des Ardomen jederseits im lateralen Drillel am Itinterrande schmal scluwrelgelb grestreilt.

Diese Form hat viel Aehulichkeit mit Erginus latesulfurens Simon, mil dessen Type aus dem Pariser. Museum ich die vorliegenden Formen vergleichen lionnte, unterscheidet sich aber ron ilım (der nach Cambridge auch zum Genus Pararhaucus gerechnel werden mïssle), durch Bewebrung des 1. Bliedes der Mandibehn, sie Bewehrung der 111. Tibia und besonders durch die Zeichnung des Rückens, die bei der Simon'schen For'm hinten convergiert und nicht so in einzelne Flecken anfgelïst ist, wie bei der vorliegrenden Form.

Zwischen Boca del Monte und Tambo, stbon-shoo m (Ost Kurd., Dep. Cundinamarea), $4 \delta^{1}$.

\section{Pararhaucus flavicinctus Gervais.}

$=$ Cosmelus flrueinctus, liervais 1842 , Mą. Zool. Arach. p. 4. 1. 5.

$=$ Cinsmetus flavicinctus, Gervais 1844, Walckenaer, Hist. Nat. Insect. Apt. III. 1. I 6. 1. 46. f. 50 .

Cafetal Argelia bei Viota, $1600 \mathrm{~m}$ (Ost Kord., Dep. Cundinamarea), $1+10 \cdot+$ Zwischen linaduas und Ilonda, $800 \mathrm{~m}$ (Ost liord.), 2 ㅇ․

Die vorliegeuden vier Exemplare komte ich nit den Typen fiervais' aus dem Parisev Museum veroleichen, mit denen sie vollständig übereinstimmen, nur lehlen den Pariser Typen die meisten Tarsenglieder. Die Zahl droelhen ist bei den vorliegenden Formen 7, 16-18; $10 ; 11-12$, wovon der Endabschnill des I. und II. Tarsus "3-ghliedrig ist und beim o der vier wliedrige Basalabschnill des I. Tarsus hreit sohleuförmig erweitert ist. Nach Cam-

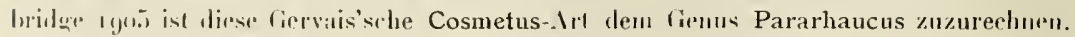




\title{
Metarhaucus reliculatus nov. spec.
}

\author{
('Iaf. V'II, fig. 亿).
}

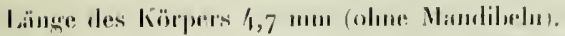

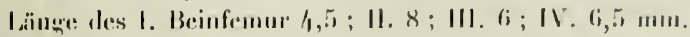

L.inge des I. Beimes $15 ; 11.27 ; 111.20 ; 11.251111$.

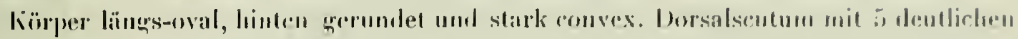

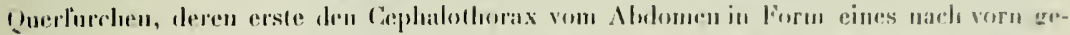

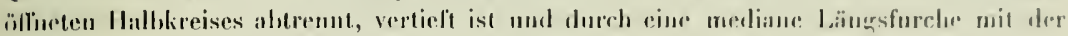

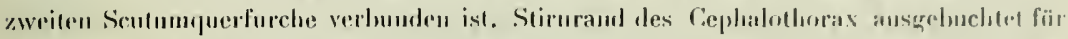

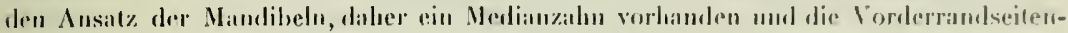

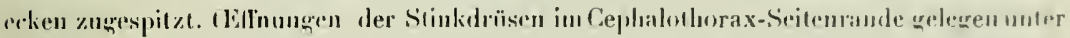

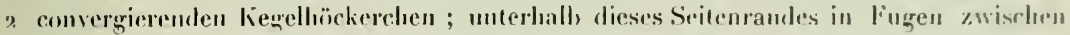

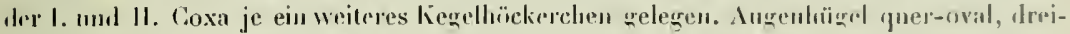
mal so breit wie lang, vom Stimand so weit wie sein Lïnesmesser entfernt, median tief ausgekehlt und anf der Wälbung jederseits äher dem Ange winzigr verstrent lekörnclt. Cephalothorax vor und seitlich vom Augenhügel mall-ghall, schräg seiflich von demsellurn einige winzigr Ilöckerhen verstrent und hinter demselhen mil rinem medianen l'aare

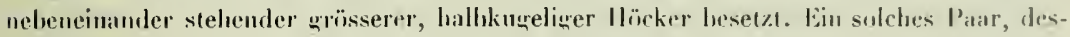
sen llöcker aher un die llälfte weiter von einumer antfernt sind, anch anf der 1. Area des Mblominalscutums, welche jederseits seitlich davon noch ein weiteres stumpfes, urriberes Ilöckerchen trïgl. It. Area doss Abdominalscutums mit einer Querreihe ans fo errö. beren, stumpfen IJöckem heselzt, zwischen denen kleinere llöckerchen verstreut siml, von denen din medianes Paar nahe nelkneinander stehender vor dem grösseren Medianparar dieser Area steht. Ausserdem ist die weissfleckige Seitengegend der I. und 11. Area dicht mit rundlichen, kleinen Ilöckerchen hestreut. Die III. Area des Arduminalscutume hat jederseits der Hachen Mediane einen allmählig ansteigenden, reich stump, hekörnelten und in eine arölnere stumpfe linpe endigenden llügel; in der Mediane dieser Area stelı vor diesen heiden grossen Hügeh ein Paar dicht neheneinander stehender kleinerer kinrnchen und seitlich dieser grösseren Hïgel jederseits 2 weitere grohe llöckerchen, nil dem medianen Ilöckerpaar eine Querreilıe bildend. Die W. Area hat eme Querreilur ans 4 qröberen Hï̈ckerchen. Die $\mathrm{V}$. Area = Sculumhinterrand wie auch jedes der drei folgenden Preien Dorsalsegmente mit ejner regelmässigen Querreilıe grober Häckerchen, mit je einem spitzenhärchen. Dorsale . Malplatte verstreut hehöckert. Freje Ventralsermente mi je einer regelmässigen Querreihe stumpfer llöckerchen besetzt, welche auf dem I. lentralsegment, der Genitalklappe und der ventralen Fläche aller vier Coxen verstreut stchen. Ausserdem hat die I. Coxa am Vorderrande, die III. Coxa am Hinterrante eine recrelmässige Ilöckerreihe. I.-III. Coxa klein und einander parallel, die II. Coxa so dick wir die drej ührigen zusammen, schrä̈r nach hinten gerichtet und lateral und hesonders literal-elorsal (nelen dem Scutumseitenrande) grobund dicht bebñckert, woraus vorn 
ohen eine warzenförmige Gruppe solcher Höekerchen mehr hervortritt und dorsal apieal ein stumpfer dicker Häcker äher dem Trochanter hinweuragt. Spiracula dentlich sicht-

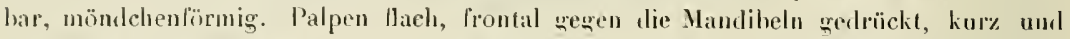
schuächtion: Trochanter selur dünn, apical kenlign verdickt, Femur lateral stark zusammengedrïcht, daher dorsal und rentral sehr scharf gekielt und hier dorsal schwächer und ventral in regelmässiger Reihe stumpfsïgig bekörnelt; Patellat kurz, keulig, nicht ahgellacht unbewehrt; Tibia so lang wic der Fenur, dorsal-rentral zusammengedrïckt, daher lateral innen und aussen lamellenartig erweitert und scharf qekielt, die Kiele nur fein und kur belaart; Tarsus kurz, halb so lang als die Tibia, nur basal wenig lateral erweitert, apical verjüngt, unbewehrt und nur belaart; Tarsalklaue schwach und nur halb so lang wie der Tarsus. Mandiheln und Beine (III. und IV.) mil ansyesprochenem Geschlechtsdimorphismus: Mandibeln des $\sigma$ : 1 . Glied klein, wagerecht getragen, basal schmal mit deutlich abgesetztem dorsalen Apicalbuckel, der lateral innen und aussen, wie auch hinten von cinem kranz stumpfer Zähnchen ungeben ist, in äbrigen unbewehrt; II. Glied mächtig entwickeh, zum I. Glied senkrecht gestellt und mit diesem in seiner hinterm Hitte eingelenkt, so dass eine mächtig gewölbte Kuppel die Körperlläche hoch ïberragt, dieses Il. Glied frontal schwach quergerunzelt; die klauen klein und schrä̈ einwärts gerichtet. - Mandibelı des $q$ : II. Gilied klein und normal gebaut, in seiner oberen Wölbung die k̈̈rpertläche nicht ïberragend. Beine lang und krältig, die beiclen binteren Paare besonders beim of viel stärker als die beiden vorderen, das erste am schwächsten und kürzesten: Trochantere lurz, walzig, 1.-111. bekörnelt und mit je einem basalhinteren quösseren Höckerchen, NT. lateral vorn und hinten apical mit einem grösseren Dïrnchen. 1. und II. Bein mit geraden Femora, welche wie die Patellen fein und winzi» hekörnelt sind; die ïbrigen Gliedes des 1. und II. Bein unbewehrt. III. Bein beim ot: Femur leicht S-förmig gekrümmt, schlank keulig, Patella dick, Tihia ılick geschwollen, diese Glierler allerseits stark rauh bekïrnelt und jedes mit einer ventral vorderen und hinteren Reihe stumpfer, prober Sagezähnchen, die übrigen Beinglieder unbewelırt; IV. Bein hein o wie das I11. gebaut und bewehrt, nur noch dicker und kräftiger bewelırt als das III. - III. und IV. Bein beim o wie beim of gebaut und bewelırt, also auch deutlich dicker als das 1. und II. Bein, aber bei weitem nicht so dick und stark bewehrt wie leim $\sigma^{7}$. - Zahl der Tausenglieder $6 ; 13 ; 9 ; 10$. Endabschnitt des I. und II. Tarsus ;ghliedrig; beim o die 3 Glieder des Basalabschnitts des I. Tarsus sohlenartig vorhreitert. I. und II. Tarsus mit Einzelklauen, III. und IV. Tarsus ohne Scopula, mit einem Psendonychium und einfachen, nicht kammzälınigen Doppelklauen. Färlung des Körpers und der Giliedmassen kalfeebraun, die harten Chitinteile oft dunkler angelaufen. Das Scutum weissyelb gezeichnet, und zwar beim of: am Seitenrande des Cephalothorax jederseits ein scharf begrenzter, alser unregelnässiger und vielfach ausgebuchteter gelber lileck, der teilweise in Zacken und Strichel aufgelöst crscheint und, schwarze, Tuberkelı eingestreut enthält, danelıen und dahinter einige viel kleincre, schwawe, wriss umrandete Tulukeln; ein solcher weissgelber Zackenlleck, fler aber viel grösser um reichlicher schwar\% 


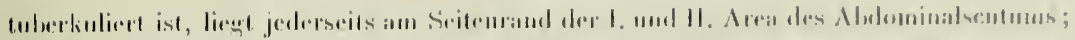

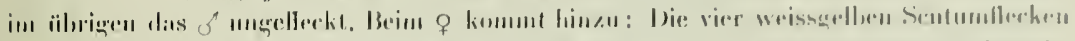

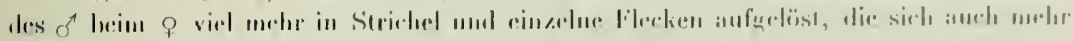

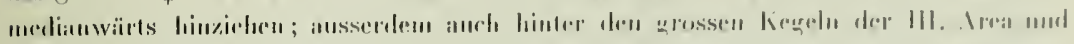

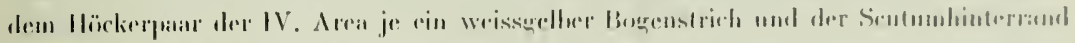

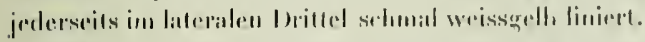

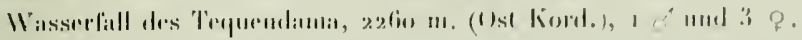

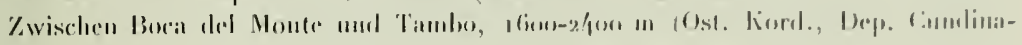
marria), 3 3 .

\section{Metarhaucus albilineatus nov. spec.}

(Tilf, vill, likg. 5 und fi.)

Lïnge des lïripers 7 mm (ohme Mandiluelı).

Länge des I. Beinfemur 3,$5 ; 11.6 ; 111.1$; IV. 7 mun.

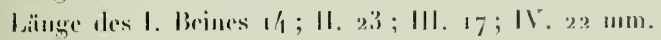

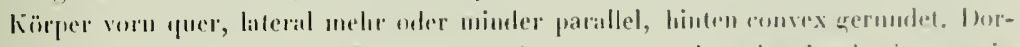

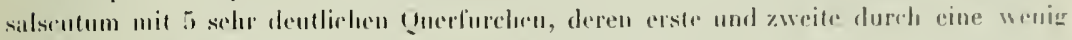

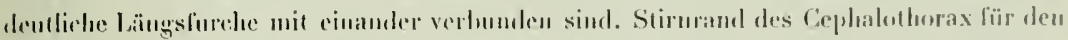

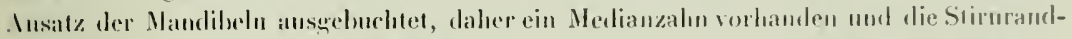

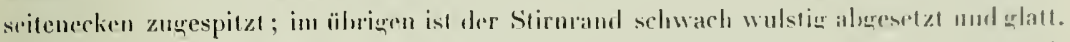

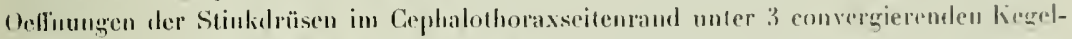

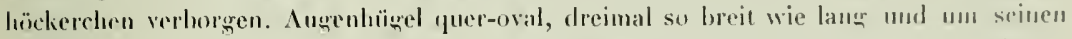
Längsmesser vou Stirnrande entfernt, median ausqekehlt und jederseits anf der oberen Angrowälbung groh und raub regellos hekïrnelt. Cephalothorax jederseits schrïg stilwärts hinter dem Augenhägel mit einigen groben Körnchen hestrent. Die dreate der Mhdominalscutums in wenigr regehnäsigen Qurreihen mit grösseren und kleineren, stumpfen, rumblichen llöckerehen besetzt, die auf der 1. unal II. Area je eine mehr reacelmitsige Querreihe aus je 6 grösseren Höckerchen, aus denen je ein mithleres Paiar niealrierr Tuberkehn deutlich hervortritt, erkennen lassen. Die III. Areal ausserden mit cinem medianen Pare nelseneinander stehender uroh behöckerter, in eine stumpfe Spitze endigender liegel besetzt. Die IV. Area nur mit cinen Paare groher Hächerdien hesotzt. die weiter von einander entfernt sind als die kegel der 111. Scutumseitenrand fast unlwwehrt. Die V. Area (= Scutumhinterrand) wie jedes der drei folgenden freien Dorsalsegmente mil einer Querreihe stumplor Höckerchen, welche auf der dorsalen Inalplatte verstreut stehen. I) freien Ventralsegmsnte mit wheichen, aber nicht so starken Guerreilien stumpfer Häckerchen, die anf aler Fläche der Coxen und der Genitalplatte spärlich verstrent stehen. Spiracula deutlich sichtbar und möndchenfïrmig. I.-111. Coxil

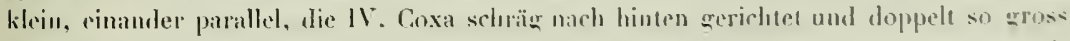
wis die III. Die I. Coxa an Vorkerande mil enrober Hëckerreihe; die III. Coxa mit

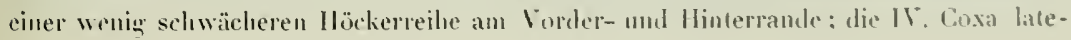


ral-dorsal (neben dem Scntumseitenrande) vorn mit erhohener Höckerwarze und hinten mit einer groben Kammreihe von stumpfen IJöckerchen, die ïber den Trochanterrand hinwegragen. Palpen tlach, frontal gegen die Handiheln gedrückl, kurz und schmächtig; Trochanter bissal selır dünn, apical verdickt und hier mit 2 ventralen Körncluen hesetzt; Femur lateral stark zusammengedrückt, lamellenartig, dorsal und ventral scharf quekielt, der dorsale und besonders der ventrale lïiel mit einer Sägereihe aus ca. 7-8 stumpfen lörnchen hesetzt; Patella kurz, keulig, dorsal spärlich bekörnelt; Tihia so lang wie der Femur, dorsal-ventual zusammen qedrüclit daher hateral scharf gekielt, apical verbreitert, stark lamellenartigr, unbewehrt, die lielränder nur fein hehaart nur jede Vorderecke nit leiner Borste; Tarsus nur labb so lang wie die Til,ia, dorsal gewölbt, ventral abgeflacht, basal nicht breiter wic apical, nicht lamellenarlig; der ventrale Innenrand mit 3, der ventrale Aussenrand mit 4-5 spitzen, aber kurzen Börstchen bewehrt; Tarsalklaue schwach und nur hall so lang wie der Tarsus. Mandibeln und Beine mit deutlichen Geschlechtsdimorphismus. Mandibeln : I. Glied wagerecht getragen, basat schmal, mit deutlich abgesetztem dorsaten Apicaluckel, der - auf der Fïche glall ghänzend - an seiner vorderen Innenecke r liegelzälınchen und lateral-alussen 3 solcher liegelzähnchen in einer Reihe hintereinander trägt; II. Glied beim ô mächtig verdickl und geschwollen, zum I. Glied senkrecht in der Mitte hinten eingelenkt, doppelt su hreit und dick und etwa dreimal solang wie dieses, unbewchrt; Klauen relativ klein und mundwärts gerichtet ; II. Glied beim o klein, normal gebaut und mit seiner olseren liniewölbung das I. Glied nicht überragend. Beine kräftig ; IH. und IV. Paar besouders bein o, aler auch beim of stärker und dicker als das 1. und II. Paar : I.-IV. Trochanter kurz walzig und allerseits ranh bekörnelt; I.-III. Femur gerade, IV. Femur schwach S-förmig gekrümmt; alle Femora, Patellen und Tibien raul beköruelt, die des III. und besonders des IV. Paares besonders stark und ventral mit vorderer und hinterer Längsreihe stumpfer Zähnchen, die apical an Grösse zunelımen. Die Beinlewelırung beim $\sigma^{7}$ vief stärker als heim 9. 1.-IV. Metatarsen und Tarsen unbewehrt, nur hehaart, sowohl beim of wie leeim . . Zaht der Tarsenglieder $6 ; 18 ; 8 ; 9$. Endabsclnnitt des I. und II. Tarsus 3- gtiedrig. Der dreigliedrige Basalabschnitt des I. Tarsus beim of stark sohlenartig verbreitert, gegen den dünnen Endabschnitl scharf abgesetzt. I. und II. Tarsen mit Einzel-EndkJauen; III. und IV. Tarsus mit einfachen, nicht kammzähnigen Doppelklauen, mit deutlichem Pseudonychium, ohne Scopula. Färbung des Körpes's und der Glieduassen rotbraun, die harten Chitinteile des Rücken dunkler angelaufen. Der Rücken weist ausserdem noch folgende Zeichnung auf : Cephalothorax schräg neben dem Augenhügel mit einem scharf gezeichneten weissen E-Ftecken, die Scutumfurchen scharf weiss und schmal linicrt, und zwar: I. Querfurche in Form eines medianen -, die 11. Querfurche in Form einer $\cdots$, die III. - $~$, die IV. $\smile$, die $\mathrm{V}$. in Form einer medianen $\smile$; ausserden ist der Hinterrand der V. Scutum-Area und der beiden ersten freien Dorsalsegmente des Alodomens jederseits im lateralen Drittel fein und schmal scharf weiss liniert.

Bogota, $2700-2800 \mathrm{~m}, 10+1$ 웅. 


\section{Phareus raptator (Gervais)}

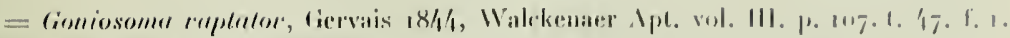

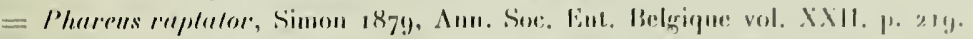

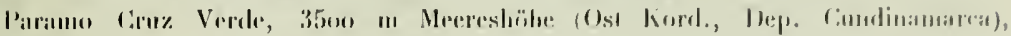
1 of 2 o.

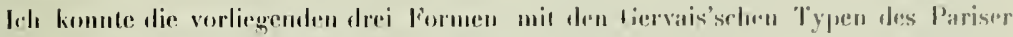
Musemus vergleichen mul deren Idrutitit lisststellen.

\section{Metaphareus nov. gen.}

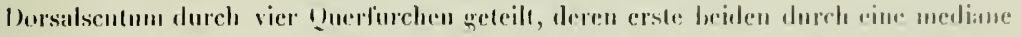

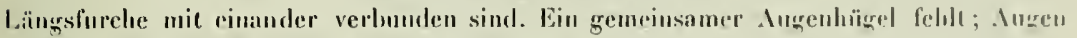
(jedes anf eigenem niedrigen Hïgel) dnppelt soweil wn cinander als vom Silimand ent fornt,

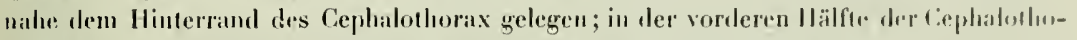
ma-Mrdiane ein quer-ovaler, breiter, deutlich abgesetzler, niedriger Ilügel, der in eine vordere stmmpfe Spitze ansläult. III. Area des Alolominatsculums mit einem l'atre selor lan-

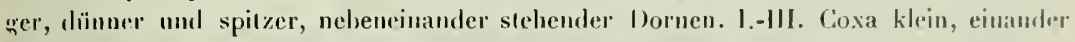
parallel, die IV. Cosa un die Ilälfte grösser als die N. und schräg nach hinten gerivlıtet. Spiracula deutlich sichthar, möndchenfërmig. Maudibeln kräftigg; I. Gilind mil dorsistem Apicalhuckel, II. Glied beim of nicht sonderlich geschwollen. Palpen selur lang, un die Ilälfte länger als der Körper: Coxa in Form eines dicken Stumpflegels weit umber de'u Stimmand vormagend, Trochanter mit Apicalbuckel, Femur lang und dïnn, unbewelırt; Patclla hall, so lang wie der Feumr, schlank mul dünn, apical rerdickt; Tibia und Tarsus sehr dick, längs-oval, dorsal gewölbt, ventral abgeflacht, die ventralen lianten lieshaclielt. Beine lang und dünn, hesonders des 1. und 11. Parres; hasale Glieder des III. mul besouders IV. Paires kräftiger und rauh bekörnelt. Endabschnitt des I. und II. Tarsus 3- gliedrig; III. und IV. Tarsen mit einfachen, nicht kammzïhnigen Doppelklanen und Pseudonyehium, olne Scopuli.

\section{Metaphareus albimanum nov. spec.}

(Tiaf. VIII, Fig 9.)

Körper $5,5 \mathrm{~mm}$ lang (olne Mandibeln).

Länge des I. Beinfemur $5 ; 11.7 ; 111.5,5 ; 11.6 \mathrm{~mm}$.

Länge des I. Beines 13,$5 ; 11.23 ; 111.18,5 ; 11.22 \mathrm{~mm}$.

Kïper vorn quer ahgestutzl, hier rechtechig, nach hinten verhreitert und hallskreisartig germulet. Dorsalscutum mit 4 dentichen Ouerfurchen, deren erste und zweite durch eine mediane Längsfurche mit einander rerbunden sind. Stirnrand des Cephilothorax oben wulstig abgesetzl, frontal mil 2 tiefen . Iusbuchtungen für den Insatz der Yandi- 


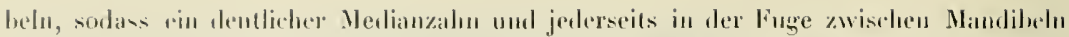
und Palpencoxin ein gleiches liegelzähneben vorbanden ist. Oeffunngen der Stinkdrüsen in Sicitenrande getergen. Augen doppelt so weit von einander ats vom Stimrande entfirm, uahe dem Ilinterrande des tephalothorax jedes auf eigenem, niedrigen, hekömelten Hü̈gel anelegen; taphalothorax zwischen den beiden Angen in der Mediane mit cinem scharlen, a)er kurzen Längseindruck, vor demselben ein furr-ovaler, breiter Ḧ̈gel, der rauh hekörnelt in eine stumple Spitze ausläult, gegen den Cephalothorax deutlich abgesetzt ist und frontal bis an die Stimrandfurehe reicht. Dieser wie anch die ührige Fläche des Cephalothorax spärliclı rauh bekörnelt. Die I. Area des Abdoninalscutums mit einem Medianpanre neheneinander stehender, nur durch die mediane Längsfurche gretrennter kleiuer Höckrrehen; die II. Area mit einer Querreihe ans 8 soleher Höckerchen, von denen das submediane Palar an Grösse nwvas liervortritt. Die 1II. Area mil einem Paare nebeneinander stehender sehr langer und sehr spitzer und schlanker Dornen, die so lang sind wie der Cephalothorax lireit. Diese Dornen sind glatt an der Basis und hahen jeder nur 2 kleine nebeneinander stehende spize Kegelzilhulien in der Mitte der Ilöhe an ihrer hiuteren flïche. Der Scotumseitenrand, der durch deusliche Furehen vom Scutum getrennt ist, und die IV. Area (= Srutumhintermand), sowie jedes der drei folgenden lraien Dorsalsegmente mit einer Gnerreihe stmmpler rundlicher Höckerchen, die auf dep dorsalen Inalplatte verstrent stehen. Veutrale Analplatte mallglatt, nicht behöckert; jedes der freien Vuntralsegmente mit einer Querreike stumpler Körnchen, die auf den Coxen qleichmässig verstreut stehen. Spiracula deutlich sichılsar, möndchenförmiær. I.-Ill. Coxa klein, einander parallel, die IV. Coxa schräg nach hinten gerichtet und fast doppelt so breiı wie die III. Coxa. Mandibeln kräftig; 1. Glied wagerecht getragen, loasal schmal, mit leutlich abgesetztem, kugelig-shlatten, dorsalen Apicalbuckel, der lateral-aussen und inuen cinige winzige Körnclıen trägt; Il. Glied dick, oval anfogetrieben, doch die obere Kniewölhung nicht viel lölser als das 1. Glied; H. Glied glat glänzend, mit kleinen, schräg mundwärls gerichteten Klauen. Palpen séhr lang und düm, um die llälfle läıger als der Körper. Coxa in Form eines glatten, dicken Stumplkegels weil unter dem Stimrande vorragend ; Trochanter basal sehr dünn, dorsal-aussen mil einem glatl-glänzenden, deutlich abgesetzten Apicalhuckel, Fenur sehr und dümı, apical liaum dicker als basal und rentral mit Spuren einiger llöckerchen; Patella schlank, halb so lang wie der Fensor, sehr dünn, apical keulich verdickt und unbewvelstt; Tibia und Tarsus doppelt so dick wic die Patella, längs-oval, dorsal gewölht, ventral abgetlacht, die ventralen Kanten bestachelt, uml zwar an der Tibia innen mit einer Reihe aus 4, aussen mit einer Reihe ans 5 Stacheln und Tarsns ventral jederseits mit einer Reihe aus 6 Stacheh bewelırt; Tarsalklaue lang sichelförmig, etwas länger wie der Tarsus und gegen diesen eingzeschlatren getragen. Beine lang; I. und II. Paat sehr dünn, III. und IV. Paar dicker; alle Trochantere slark rauh hekörneh, wie auch die Femora aller Paare; alle Femora und Tibien gerate und cylindrisch, der IV. Jenur an kräftigsten und randsten bekörnelt und dorsal-apical mit cinem über das P'atellargelenk hinweggeneigrten stumplen liegetdorn; dic 


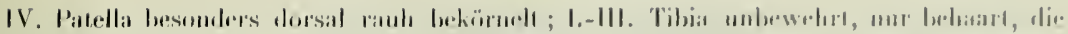

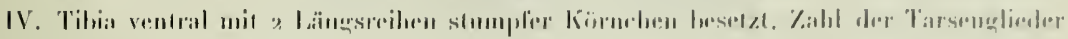

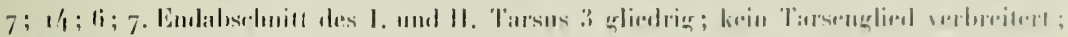

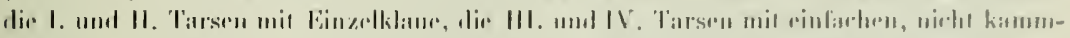

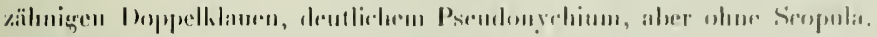

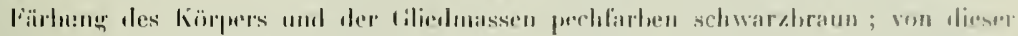

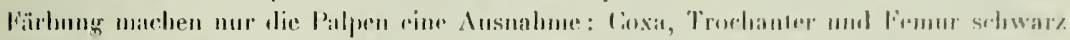

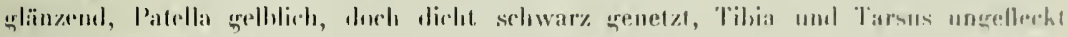

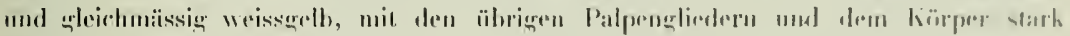
ionclastiereml.

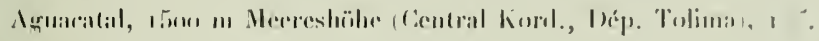

\section{Camelianus nov. gen.}

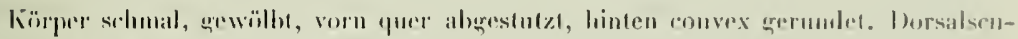

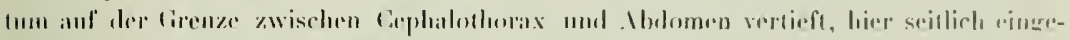

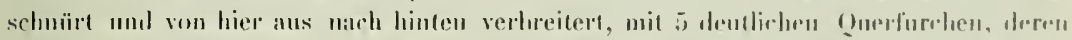
erste beiden dureh eine median Längsfurche mit rinander verlmulen sind. I ntorer Stirnmonl unbeweht bis anf ein Median-Zähnelen, oberer Stimrand an den Seitonechin

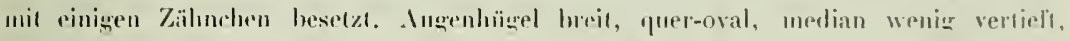

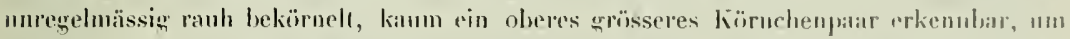

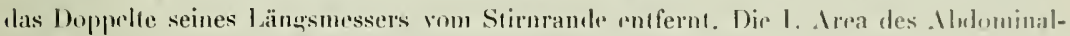

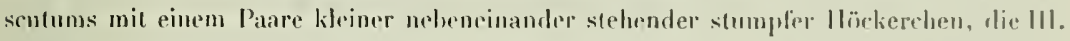

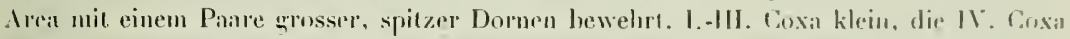
aufgetrieben, breit und dick, schrïg narb hinten gerichtet. Spriracula drullich sichular, möndehenfürmig. Mandiludn klein ; I. Glied basal schmal, mit dentlich alogesetztom, Ilorsalfou Apiealluckel. Palpen kriftig und dick, nicht apekreuzt getragen : lemur kurz. dirk, lateral elwas zusammengedrïclit, rentral kanm bewehr, apical-innen mit i schwachen Stachel hewehrt; Patella unhewehrt: Tibia nud Tarsus längs-oval, dorsal gewrilh, ventral alugetheht, die ventralen lianten bestachelı. Beine lang mol diün; Fanora nich

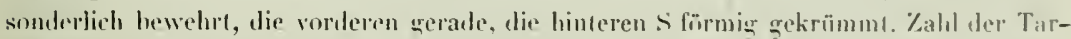

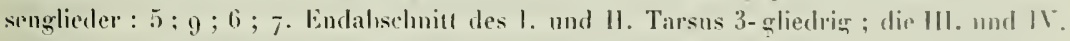
Tarsen ohne Scopula, mit deutichem Psendonyehim und einfachen, nicht kammzailınigen Doppelkanem. Beim ô sind die a Glieder des Basalalsschnitles des 1. Tarsus aulfällig dick geschwollen; weniere dick, doch anch dicker als die nihrigen sinel die 3 rilieder des Basalahschnittes des 111. Tiarsus. 


\section{Camelianus fuhrmanni nov. spec.}

(Tat. Vitt, Vign, 8.)

Längूe des lï̈rpers $4,5 \mathrm{~mm}$.

Liinge des I. Beines 6,5 ; II. 13,5; III. 9) ; 11 . $12 \mathrm{~mm}$.

К̈̈rper gewölbt, hinten gerundet, vorn quer abgestutzt, aut' der tirenze zwischrn Cephatothorax und Abdomen seitlich leicht eingeschuïrt, von hier aus nach hinten verbreitert. Dorsalscutum dureh 5 dentliche Qnerfurchen geteilt, deren erste und zweite durch eine ebenso deutliche mediane Längsfurche mit einander verbunden sind. Sitirnrand des Cephalothorax wulstartig (älnhlich wie der Seitenrand des Ścutums) von der Flïche des Cephalothorax ahgesetat und wie diese raul bekörnelt, doclı in der Mesliane zwisehen den Mandibeln mil s stumpfen Kegelzahn und auf seiner oberen Fläche an den oberen Seitenecken mit drei nebeneinander stehenden spitzen Dörnchen, deren mittleres das grüsste ist. Die 1. If. und III. Area des Abdominalscutums mit kleinen Kärnehen rauh bestreut, aus deren Menge auf der l. Area ein Paar nebeneinander steliender stumpfer, niedriger und glatter, grösserer llöcker hervorragt und auf der III. Area ein Paar nebeneinander stehender langer, schlanker und spitzer, divergierender und etwas nach lintengeneigter grosser Dornen emporragt. Die $\mathbb{W}$. Area sehr schmal, aher deutlich begrenzt und wie dir $V$. Area (= Sculumbinterrand) und die drei folgenden freien Dorsalsegmente mil je einer regelmässigen Querreihe kleiner liörnchen, die auch auf dem Scutunseitenrande in einer Längsreihe stehen. Dorsale Analplatte mit solchen kïrnchen regellos bestrent. Angenhügel quer-oval, median wenig gefurcht, doppeht so breit wie lanı, um das Doppelte seines Längsmessers vom Stirnrande entfernt und ïberall rauh mit kleinen Körnclıen bestreut, aus denen sieh oben ein wenig grösseres Paar abhebt. Freie Ventralsegmente mit je einer Körnclienquerreihe. Cosen der Beine auf der Flächı gleichmässig rauh kekörnelt; die 1.-111. Coxa klein, einander parallel, die IV. Coxa doppelt so breit und lang wie die III. und schräg nach hinten gerichtet, lateral anssen stärker und gröber bekörnelt und oben an der äusseren Spitzenecke mil einem schlanken, spitzen Dorn, der über das Trochantergetenk hinwegragt. Spiracula klein, möndchenfürmig und deuthich sichtbar. Mandibehn klein, I. Glied basal schmal, mit deutlich abgesetztem dorsalen Apicalhuckel, der am Hinterrand eine Reihe aus 4-5 kleinen Zähnchen trïg 1 und im übrigen glatt glänzend ist ; 11. Glied bei beiden Geschlechtern klein unr normal gebaut. Palpen kräftig und dick, niclıt gekreuzt getragen ; Trochanter kngelig, dorsal und ventral mit je 2 Körnchen besetzt; Femur dick, lateral wenig zusammengedrückt, daher dorsal etwas gewölbt, fast glatt, ventral nur mit Spuren je ein feines Här"hen tragender Ḧ̈ekerchen, jedoch imen-ajical mit einem deutlichen, schlanken Stachel bewelırt; Patella kurz keulig, unbewehırt; Tibia und Tarsus länggs-oval, dorsal gewölbt, ventral abgellacht, die ventralen Kanten an der Tibia aussen init 4, innen mit 5, am Tarsus jederseits mit :3 Stacheln hewelırt. Beine lang und dünn ; Trochantere kurz walzig, ranh hekörnelt, nur berin ơ der IV. Trochanter hintrn nit I schlanken Dïrnchen 


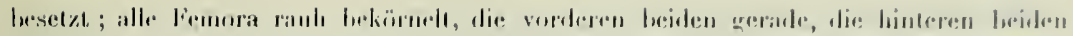

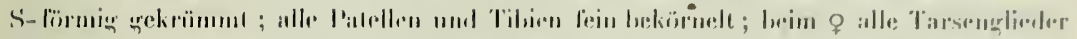

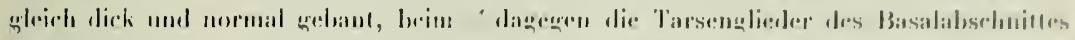

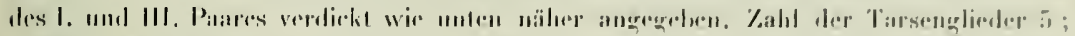

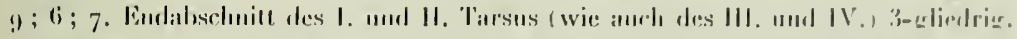

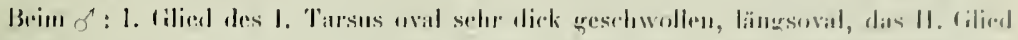

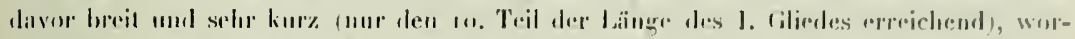

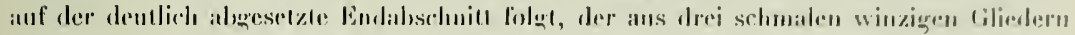

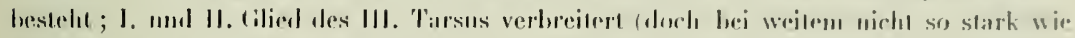

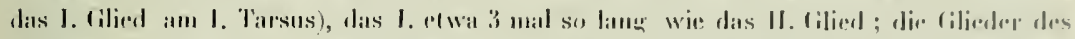

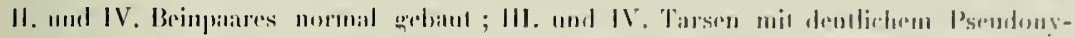

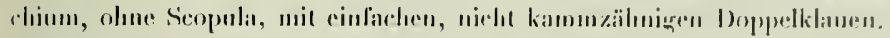

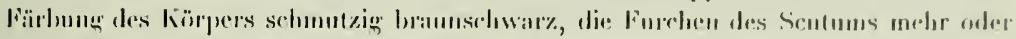

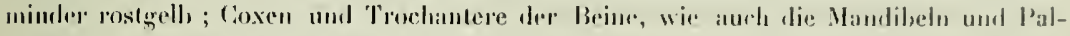

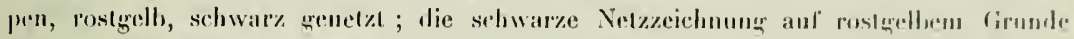

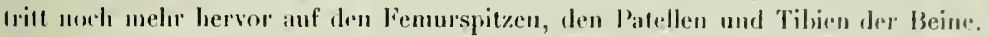

Calchal Camelia bei Angelopolis, $1800 \mathrm{~m}$ Meceshühe (Central Lord., Dep. Antio-

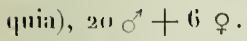

Puerto de los Pobres, Ufer des Cauca, $720 \mathrm{~m}$ Meereshöhe (Central Kord., Dep. Intiu-

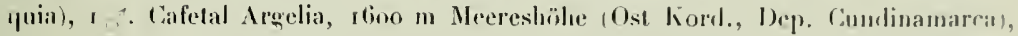
$10+1$ o. Ruel (?), 3\%.

\section{Cranaus calcar nov. spec.}

Lïuge des liörpers ir mm.

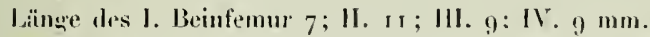

länge des I. Beines 22 ; II. 40; III. $29 ; 11.31$ nım.

Lïrper vor'n quer abgestutzl, an den Vorderand-Seitenecken abgerundet, his zur I. Sculmmquerfurche schmal, dam meben der IV. Coxa stark bogier verbeitert, an Sculumhintrande wieler schmaler, hinten mehr oder minder quer ahgestul zh beim o oval trernndet). Interer Stirmand des Cephalothorax mit 2 Ilachen Ausbuchlungen für den Ansal\% der Mandibeln; oberer Stimrand muewedort in der Mrdiane, an den Seitenrandecken mit einer Reihe aus je 5 legrelzïlneu. Augenhügel rom Stirurand phenso weit entfernt als von der I. Sculumquerlurclie, quel-oral, doppeh so breil wie lang, niedrig, median wenis ausgekehlt, äher den Augen jederseits mit je I nach vorn zeigenden liegreldärnchen und jederseits dahinter mit I sehr kurzen, stumpfen, orlatt glänzenden Höckerchen heselzı. Dorsalscutum mit 4 deulichen Querfurchen, deren erste tief nach hinten durchgehogen und mit der zweiten durch eine mediane Längrsfurche verbunden ist. Fläche des Cephillothorax und die L.-Ill. Area des Abdominalsculums sehr spärlich mil grohen Häckerchen hestrent, von denen? wenigan tirisse hervotretende rin laar auf der I. Irea des Iblo- 
minalscutums bilden. während auf der 111. Area 2 einander näher stehende grosse liegeldornen stelten. Seiten-mnd Ilinterrand $(=V$. Area) an den hinteren Seitenecken des Scutums etwas kielartign aulgewölbt, Seitenrand fast unhewehrt; Hinterrand des Scutums wir jedes der drei folgenden freien Dorsalsegmente des Abdomens mit einer regelmïssigen Querreihe groher Höckerchen besetzt, aus denen je ein Paar neheneinander stehender grrïsserer liegeldörnchen hervorragt, die aber ihrerseits wesentlich kleiner sind als die der 1II. Scutum-Area; diese Guerreihe auf' dem III. freien Dorsalsegment besonders grob; dorsale Analplatte auf die Banchseite hinahgerückt, viel breiter als die freien Dorsalsegmente, und vollständig glatt głänzend wie auch die breite, quergefurchte ventrale Analplatte. Die ührigen abdominalen Ventralsegmente, his auf das breite erste, sehr sclimat und zusammengeschoben (beim q durch breite weiche Gelenkhäute von cinander getrennt.) und jedes mit einer regelmässigen Querreihe stumpfer Körnchen; eine solche kräftige Querreihe findet sich auch am Hinterrande des l. Ventralsegments, das im äbrigen mattqlatt ist und nur die beiden sehr deutlichen, möndehenförmigen Spiracula aufweist. Coxen der Beine überall raulı und nur spärlich bekörnelt, besonders die IV. Coxa lateral-aussen, wo sie ausserdem apical-hinten einen breiten, langen und spitzen Kegeldorn trägt. 1.-III. Coxa klein und einander parallel; $\mathbb{N}$. Coxa dick geschwollen, schräg nach hinten gerichtet. Mandibeln heim o mächtig entwickelt beim \& kleiner, obwohl auch sehr kräftig; I. Glied basal schmal, mit deutlich abgesetztem, dorsalen, glatı glänzenden Apicalbuckel, der nur aı seinem Hinter-und Aussenrande einige Körnchen trägt; II. Glied beim $\sigma^{7}$ sehr breit und dick geschwollen, głatt glänzend, seine obere Wölbung jedoch das I. Glied nicht überragend; die beiden II. Glietler zusammen so breit wie die grössı Breite des Körpers; Kilanen kräftig, relativ kurz und schräg gegen den Mund gerichtet. Palpen kräftig und dick, nichı länger als der Körper, nicht gekreuzt getragen; Coxa kurz kegelförmig, ventral-apical mit schlankem Dornhaken; Trochanter kurz walzig, dorsal mit 2 Dörnchen, ventral mit einigen kleineren Körnchen und r kräftigen Apicaldorn bewehrt; Femur dick, etwas kenlig, rundlich, bewehrt mit einer dorsalen, einer dorsal-lateral-änsseren und einer ventralen regehmässigen Reihe kurzer liegelzähnchen, nur basal-ventral i spitzer länger Kegeldorn vorhanden; Patella kurz keulig, fast unbewehrt, nur dorsal mit rundlichen Höckerchen spärlich bestreut; Til,ia und Tarsus längs-oval, dorsal gewölbt, ventral abgellacht ; Tibia auf der dorsalen Wölbung rauh und stumpf behöckert, ihre ventralen Kanten mit je 4 Stacheln bewehrt, deren I. und III. doppelt so lang sind wie die übrigen; Tarsus dorsal glänzend-glatt, seine ventralen Kanten mit je 4 gleichgrössen Stacheln bewehrt; Tarsalklaue sichelförmig und so lang wie der Tarsus. Beine lang und dünn; alle Femora grerade; leim $q$ alle Beinglieder unbewehrt. Zahl der Tarsenglieder $7 ; 8-9 ; 7 ; 7$. Endalsschnitt des I. und II. Tarsus 3-gliedrig; die III. und IV. Tarsen mit deutlichen Pseudonychium, ohne Scopula, mit einfachen, nicht kammzähnigen Doppelklauen. Beim $\sigma^{\top}$ ausserdem : III. Femur ventral rauh bekörnelt; IV. Trochanter ventral-apical mit einigen grösseren stumpfen Kegehöckern; IV. Femur rauh bekörnelt, lateral-innen - genau in der läıgen-Mitte - mit ı spitzen, senkrecht abstehenden Döruchen und apical-aussen - um 


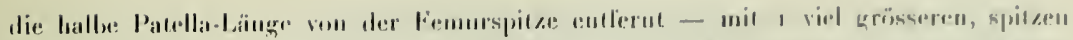

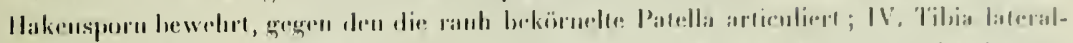

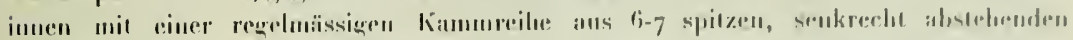
Diornchen hewelrirl.

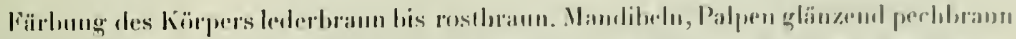

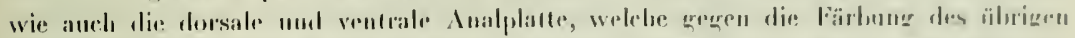

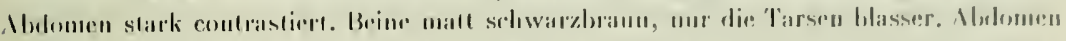

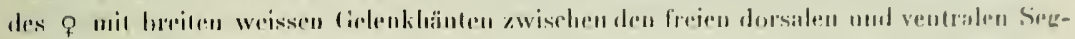
mente des $\backslash$ bidomens.

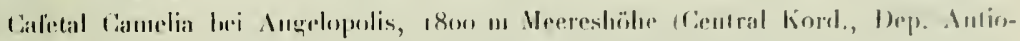

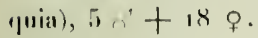

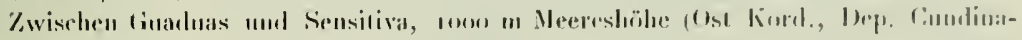

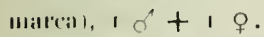

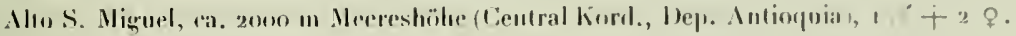

\section{Stygnomma nov. gen.}

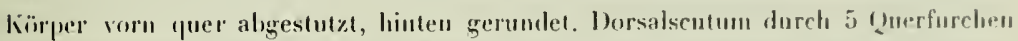
weteilt, die nicht durch eine menlian. Längsfurche mit einander verhunden sind; Sentum unhewehr und grössere Döınchempare weder auf den Areac des Mlıdouninalsoulums norlı anf den freien Dorsalsegmenten. Stimmand des Cephahothorax mil zwei ticfon Aushuch-

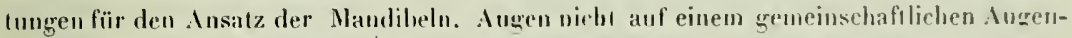
lı̈̈gel, sondern in der Ehene des Cephalothorax gुelegren, doppelt so weit won riunuder als vom Stimrand entfernt und mahe dem llinterramd des Cephahothorax grelegron. I.Wr. Coxa klein, die IV. Coxa lateral-aussen gowh hekëmelı. Spiracula in der Furche \%wischen der IV. Caxa und dem Abdomen deutlich sichthar, möndehenfürmig. Maxillarlohen der 11. Coxa durch eine deutliche Furche von der II. Coxa alsgetrennt, aber nicht frei hewegrlich. Mandibehn gross und kräftign; I. Glied cylindriselı und obue dorsalen ApicalInckel; II. Glied dick oval. Palpen selır lang und kräftign: Coxa in form eines schlauken Stumplkegels weit unter dem Simband vorragend und so lang wie rlas l. Glied der Mandihelı; Trochanter kugeliø; Fenum eyhdrisch mit piner ventralen Zähnchenreihe: Patella keulig, innen mit I Zahn hewehrt; Tilvia doppelt so lang wie der Tarsus, beide Glieder dorsil gewöllı, ventral abgeflacht, und an den ventralen Kanteu innen und aussen bestaclielt. Beine relativ kurz; 1.-1II. Femur grerabe, der 11 . S-fïrmig gelirümmt und alle f Fernora uil reselmässiger rentraler Zähnchenreilse. Zahıl der Tarsengrlieder 6, 9, 6. 7. Endahschuill des 1. Tarsus 2-, des II. 3- gliedrig; dic 111. und IV. Tarsen oline sicopula unul olne l'sendonychimm, mil cinfachen nicht kammzälnigen Doppelklauen. 


\section{Stygnomma fuhrmanni nov. spec.}

(Taf. VIII, Fig. 7.)

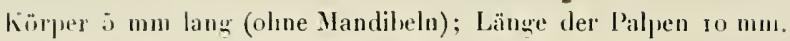

Länge des 1. Beines 10 ; II. 15; 111. 9,5; IV. $13 \mathrm{~mm}$.

Körper llach, kaum gूewälht, vorn quer abgestutzt, hinten gerundet. Dorsalscutum durch 5 Uarefurehen geteilt, die nicht durch eine mediane Längsfurche mit einander verhundeı sind und deren erste und fünfte scharf und deutlich, deren zweite, dritte und vierte jedoch nur angedeutet siud. Stirnrand des Cephalothorax mit zwei sehr tiefen Ausbuchtungen fï̈. den Ansatz der Mandibeln. Augen nicht auf einem gemeinschaftlichen Augeuhügel, sondern in der Eheme des Cephalothorax gelegen, doppelt so weit von einander entfernt als rom Stirnrand, nalıe dem Cephalohlırax-Hinterrand gelegen. Dorsalscutum auf der Gren\% zwisehen Alıdomen und Cephalothorax eingesehü̈t und mit deutlich abgesetztem Seitenrande, der wie der Scutumhinterrand eine regelmässige Reilıe stumpler Vürnchen trägt. Die liläche des Cephalothorax und jeder der ahdominalen Scutumsegmente und freien Nhlominalsegmente mit einem breiten Querstreif selır dicht stehender, winziger, mil feinem Spitzenhärchen vorsehener liörnchen; ebenso auch die freien Ventralsegmente hesetzt. Die Coxen der vier Beinpare überall gleichmässig mit runden Körnehen hestreut, mur die $\mathbb{W}$. lateral aussen mit längeren, stumpfen Dörnchen hesıreul; die vier Coxen untereinander grleich gross, die ersten beiden nach vorn gekrümmt, die dritte gerade querge-stellt, die $\mathbb{T}$. schräg nach hinten gerichtet, nur die III. Coxa an Vorder- und Ilinterrande mit dentlicher Körnchenreihe. Spiracula deutlich sichthar, nöndehenförmig. Maxillarloben der II. Coxa durch eine deutliche Furche von der II. Coxa abgetrennt, aber nicht frei beweglich. Mandibeln gross und kräftig; I. Glied lang und schmal, dreimal so lang wie breit, dorsal gewölbt, aber ohne Apicalbuckel, glatt glänzend, lateral innen mit 2 leenen Vlittelzähnchen und lateral aussen mit einer Längsreihe aus ea. to stumpfen Kürncheı liesetzt; II. Glied dick oval, glatt glänzend, im unteren Drittel froutal nit wenigen Körıeheu bestreut. Palpen sehr lang und kräftig: Coxa in Form eines schlanken Stumpfkegel weit unter dem Stirnrand vorragend, so lang wie das I. Glied der Nandihehn, allerseits mit kurzen kegelzähuchen bestreut, unter denen apical-innen ein grösseres steht; Trochanter kugelig, ventral mit 2 kurzen Höekerchen, dorsal mil 2 langen, divergierenden Dormen bewehrt ; lemur cylindrisch, walzenförmig, wenig gekrünmt, glatt glänzend und ventral ınit einer Längsreihe aus ca. I 2 stumpfen, spitzen borstigen Zähnchen beselzt; Patella dick, keulig kurz, apieal-innen mit I schlanken Dorn (nicht Stachel!) Jewehrt; Tibia etwas länger als der Femur, dorsal gleichmässig gewölht und glatt, ventral abgeflacht, die innere veutrale Kante mit 2 hintereinander, im Drittel der Tibialänge entfernten Abstande stehenden Stacheln, deren Sockel dick knollenartig hervortritt, die äussere ventrale liantemit einer Längsreihe aus ca. 12 schlanken grösseren und kleineren Staclıeln besetzı; Tarsus kurz, dorsal gewöllst, längs-oval, rmutral ahgeflacht, jede der ventralen Kanten mit 2 starken Stacheln bewehrt; Tarsalklane lang and slark, sichelförmig. Beine relativ kurz 


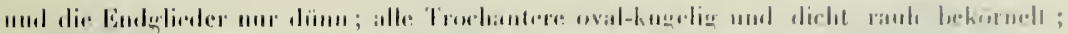

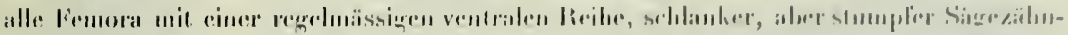

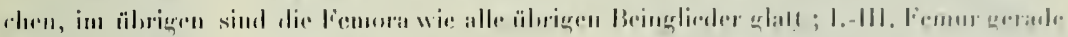

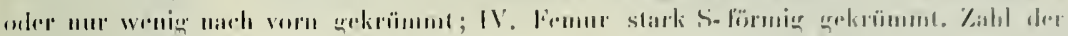

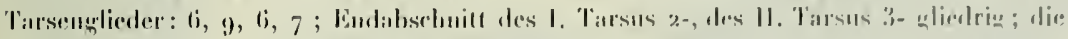

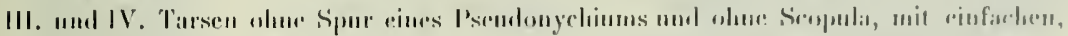

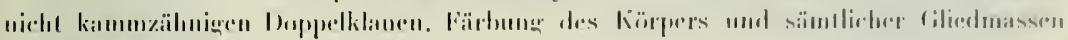

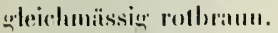

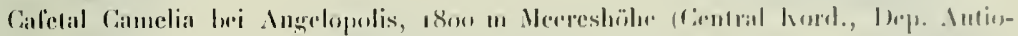

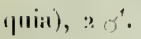

\section{Priosnostemma albimanum nov. spec.}

('all. V'111, Pigs. 10)

lailloge des kïrpers :3 min.

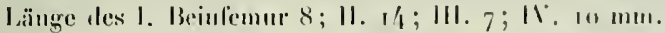

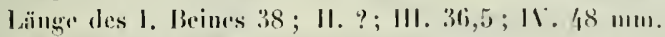

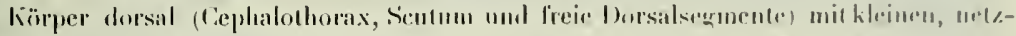

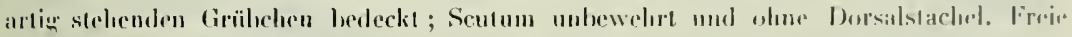

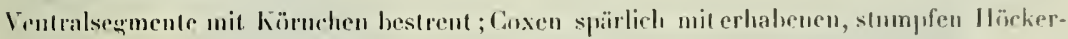
rhen hestrent; Coxenrandhöcker schintf vierspilzig. lugenhügel so lang wie breit lawh,

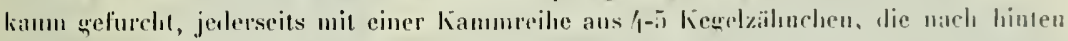
an Grösse zunchuen, hesctzl (hei dem einen kxamplar sind diese Zälunchen zirmlich ahgenutz1). Supramandihularlamellen deutlich spitz vorgestreckit und winzig luxzähnoll.

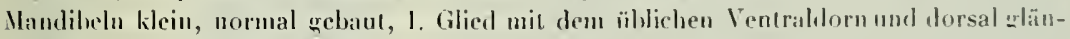
zend glatl. Palpen lang und dünn; Femur so lang wie Patellis + Tilhia, sn Lane wic der Tarsus ; Patella mil kurzer Innenapoplỵse; alle Palpengliedler liehaart, nur der Feunr rentral-basal mit feinen sägozälınchen hestrout; Tarsalplaue kammzälıniщ. Bein lanı und dünn, lemora fein hezälnelt; I. und III. Fenur ohne, IV. mil I, Il. Fonur mil ? Psendogelenken. Färhung des lïrpers dorsal schwarz einfarbig, cinschliesslich . Iugenhü̈еl, Supramandilularlamellen und Coxen, desgleichen die übrigen Beinglieder. Mandihelı

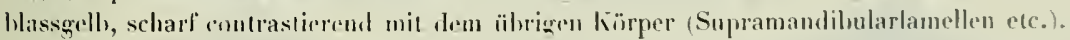
Palpen: Trochanter und fenur schwarz cinfarhig, die basale Hälfte der Tilia schwarz.

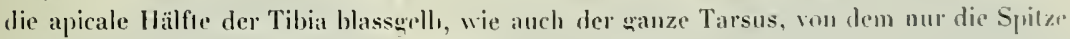
levelıt qebräunt ist.

Cafetal Camelia, $18 n 0$ m Meereshölse (Central Korrl., Dep. Intioguia), 2 Expl.

\section{Tamboicus nov. gen.}

Augenhägel längs gefurch, mi zwei melur mler minder regelmässigen Zülınchenkinmen

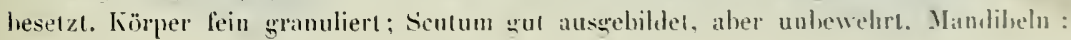


1. Lilied mit dem gewöhnliches Ventraldorn. Palpenpatella mit kurzer lunenapophyse; Tarsalklane der Palpen kammzähnig. Coxenrandhöcker aller 4 Beinpare scharf dreispitzig. Beine sehr langr und sehr dünn; der I. Femur mit I, II. mit 5, III. mit 2, IV. mit 3 Pseudogelenken.

\section{Tamboicus fuhrmanni nov. spec}

Länge des Kürpers 2, 5 mm.

Länge des I. Beinfemur $7 ; 11.11 ; 111.7 ; 11.9$ mm.

Länge des 1. Beines 27 ; 11. 41; 111. 27; IV. 39 mm.

Kïrper dorsal auf Cephalothorax und Seutumerhaben granuliert; Scutum unbewehrt. Freie Dorsal-und Ventralsegrmente des Abdomeus rauh bekörnelt. Augenhügel so lang wie breit wie hoch, schwach längsgefurcht, oben jederseits der Furche mit einer liammreilıe grober Körnchen besetzt. Coxen der Beine auf der Fläche rauh bekïrnelt ; die Hörker der Randreihen scharf dreispitzig. Supramandilularlamellen deutlich spitz vorgestreckt und winzig beköruelt. Mandibeln: I. Glied dorsal glatt, mit dem gewölınlichen Ventralspurn; II. Glied klein und normal gehaut. Palpen lang und düun; Femur so lang wie Patella ; Tihia so lang wie der Tarsus; Patella mit kurzer lmnenapoplyse ; Femur rentral dicht mit spitzen Zähnchen bestreut, Patella dorsal und Tibia ventral desgleichen; Tarsus unbewelı't, nur behaart, mit kammzähuiger Endklaue. Beine selır lang und sehır dünn ; die Femora rauh bekörnelt; I. Femur I, I]. 5; III. 2 ; IV. 3 Pseudogelenke aufweisend. Färbung des Ceplıalothorax, des Dorsalscutums und der freien dorsalen und ventralen Abrlominalsegmente rostfarben rotluann; der Augenhügel schwarz; Coxen der Beine dunkelbraun, jede mit schwach blassem Mittelfeck; Beine im übrigen dunkellıraun, ihre Femora an den Pseudogelenken scliwach blass geringelt. Mandibeln blass rostgell; Palpen einfarlig dunkellıraun.

Zwischen Boca del Monte und Tambo, 240o-1600 m Meereshöhe (Ost Kort., Dep. Condinamarea), r Expl. $(+2$ pull.).

\section{ERKL̈̈RUNG DER FIGUREN AUF TAFEL VII}

lig. I. Pararhaucus marmoratus n. sp. Dorsalansicht des lï̈rjers ohue Brine. lig. 2. desgl. Lateralansicht des K̈̈rpers ohne Beine.

Fig. 3. desgl. Tarsus des I. Beines beim of.

lïg. 4. Metarbaucus reticulatus n. sp. Dorsalausicht des körpers ohue Beine.

Fig. 5. Metarhaucus albilineatus n. sp. Dorsalansicht des kï̈rpers olıne Beine.

Fig. 6. desgl. Tarsus des I. Beines beim of. 
PLANCHE VII

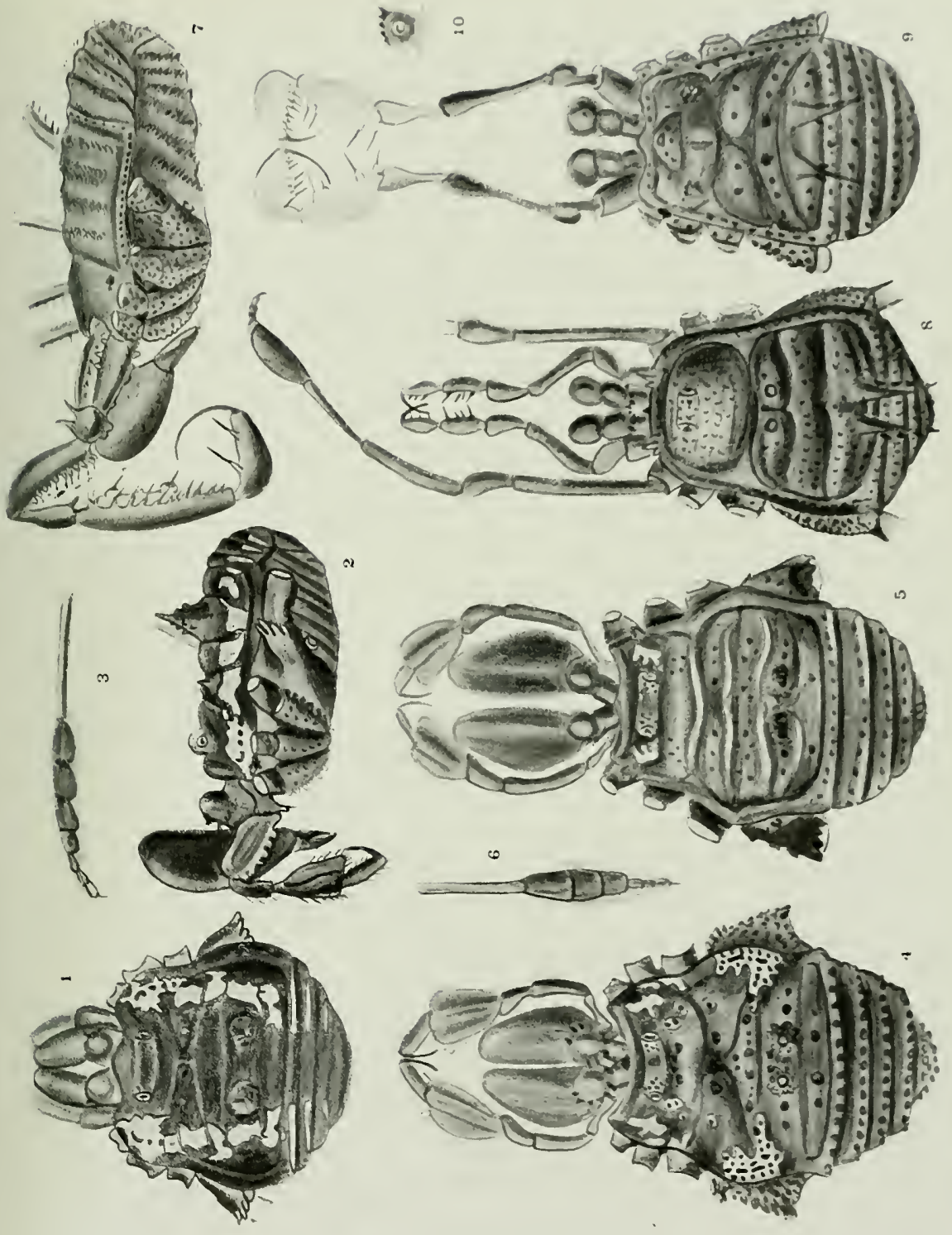





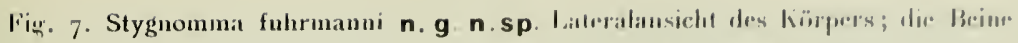

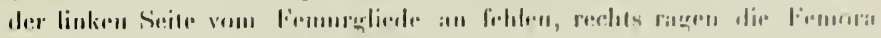

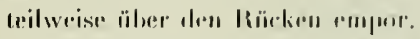

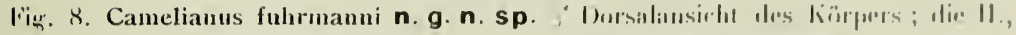

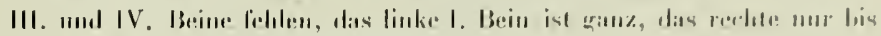
zur l'illelliı unèreliurl.

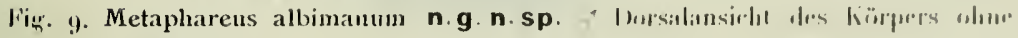
Briue.

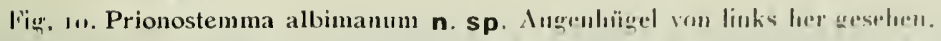




\section{Copépodes}

\section{de Colombie et des Cordillères de Mendoza}

PAlR

Dr M. THIÉBAUD, de Bienne.

L'historique de nos connaissances sur les Copépodes de l'Amérique du Sud se trouve résumé dans le grand ravail de Daday, sgo5, (Zoologiea) sur la faune d'au douce du Paraguay. I cette dat es recherches faunistiques de Lubboch, Poppe, Richard, Wierzejstii, Dahl, Dana, Mrazeli, Sars, Daday, avajent permis de constater en Amérique du Sud 55 espèces de Copépodes, à savoir : 25 Calanides, 22 Cyclopides et 8 llarpacticides. Depuis 1905, un seul travail, celui de van Domwe, 1911, sur les Copépodes du Brésil, est renu compléter nos connaissances el enrichir la liste de trois espèces nouvelles, Dirplomus gracilipes, Diaptomus aculeatus, et Canthocamptus laciniatus, ce qui porte le nombre de ces espèces à 58 , dont 38 sont spéciales à l’Amérique du Sud.

I remarquer que toutes ces espèces ont été constatées dans le sud du continent, au Brésil, Uruguay, Paruguay, République Argentine et Chili. Le matériel récolté par M. le professeur Fuhrmamn a d'autant plus de valeur, qu'il provient du nord du continent, de régions encore inexplorées à ce point de vue el de stations élevées situées entre $2000 \mathrm{~m}$. et $3600 \mathrm{~m}$. d'altitude. Fixé dans une solution au formol, ce matériel était très bien conservé et permettait un examen très minutieux. M. le professenr Fulurmann a eu l'obliggeance de me remettre, à titre de comparaison, 3 tubes renfermant des Copépodes récoltés par M. le Dr 1 olffhügel dans les environs de Mendoza (République Argentime) plus spécialement dans la Cordillère de Mendoza. L'étude de ce matériel aussi très bien conservé m'a permis de décrire une espece nouvelle el d'y retronver des formes identiques à celles de Colombie. Toici la liste des espèces de ces deux régions : 


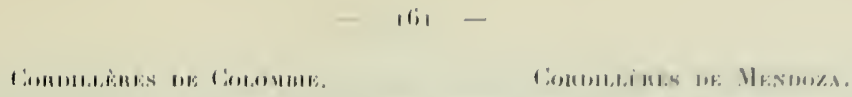

Cenlropagides.

1. Diaptomus colombiensis nov. spec. 1. Burrliella spere, jm!

Cyclopides.

2. Giyrlops atlhirlus.

3. Cigrlopse lenchiouli.

1. Cyclops lenckarti nov yar. longiseta. " Cyclops leuckarti nov var. longiseta.

5. Ciyclojs memlorinus.

$\therefore$ Ciyrlogss monlorimus.

(i. Cityr:lops sererululus.

1. Ciyclopse murrerurms.

7. Cigelopss fimbrimlles.

i. Cigrelopss fimlurioluss.

8. Ciyglopses phateroules.

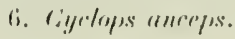

Harpacticides.

9. Canthocamptus Fuhrmanni nov. spec. 7. Canthocamptus aculeatus nov. spec. 11. Cirmlhocump/lus spere. jur.

\section{Centropagides.}

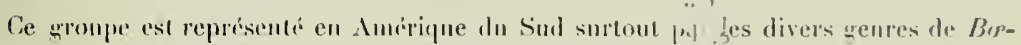

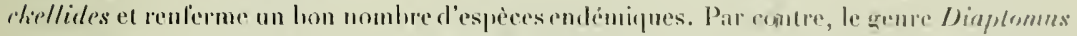

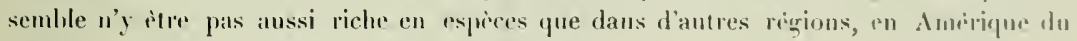
Norl par exemple; pourtant les travanx recents en angmentent peu it pen be nombre en dicrivant de nourelles espres; j'ai anssi eu l'occasion d'en trouver une dans le materipl de Colombie, en sorte quatuellement lo nombre des esprices de Diaptomus constaties en Amerique do Sud est de r3.

Le matériel récolti par M. le professeur Fuhrmann ne renfermait que Diaptomus rolombiensis, nov. spec. Cette pauretfi provient du fail, quensuite de circunstances défavorahles, des pèches púlaqiques nont pu ètre failes et que le matériel provienu sur-

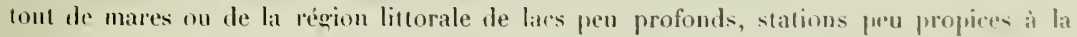
reolle des Centropagrides.

\section{Diaptomus colombiensis. nov. spec.}

(Fig. 1 i 5 )

Espece assez petite. Cephahothorax de la $q$ ayant sa plus grande lareseur an milien du :3me segment puis se rétrécissant insimsiblement. Dernier segment élareri en 2 ailes

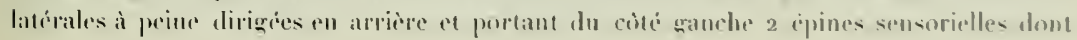




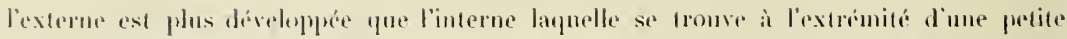

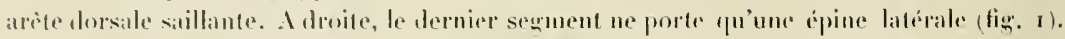

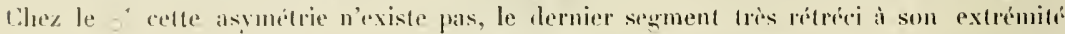
distale est laiblement prolongre en arrière el porte de chayue cotté une seule épinr (fieg. 2).

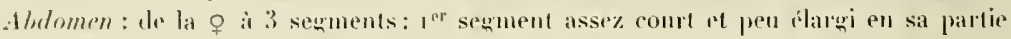

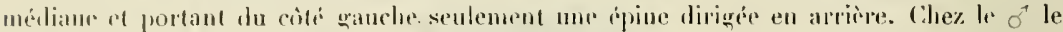

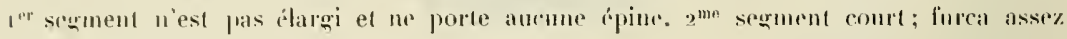
large or portant des soies relativment rourtes.

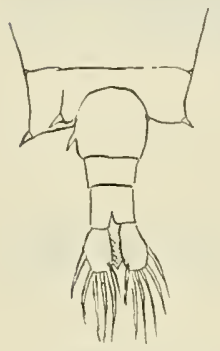

Fig. 1.

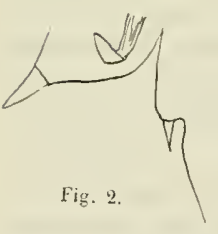

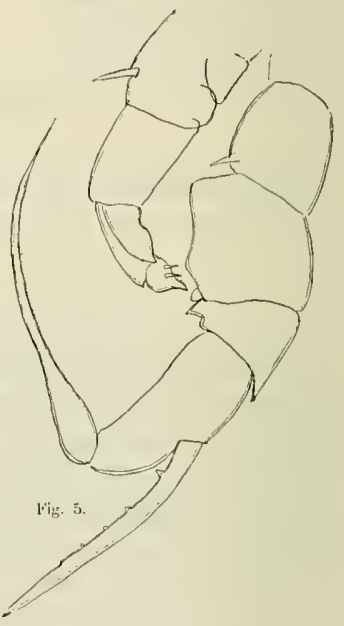

Fre antenne: atteint, rabattur, l'extrémité de la furca. L'antépróndlieme segnment de l'antenne préhensile sans dent ni prolongement quelconque.

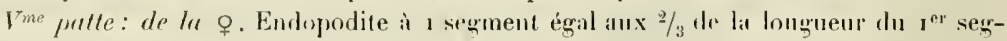
ment de l'exopodite; son extrémitr' régulièrement artondie porte 2 petitrs épines rogales, une médiane et me latérale, et colre denx une comronne de spinules.

Exopodite à 3 segments; $1^{\text {an }}$ segment à peu près 3 fois plus long que large, partout de la mème largenr, $2^{\text {me }}$ segment formant avee le $y^{\text {er }}$ un angle presque droit ot se pro-

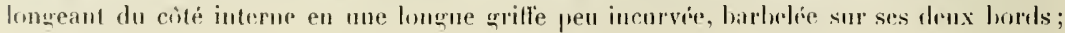




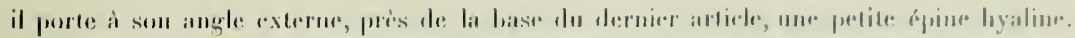

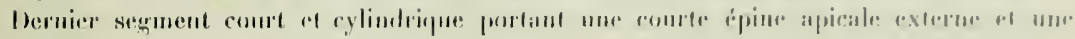

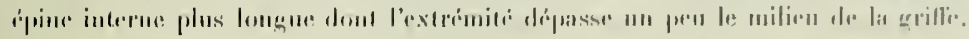

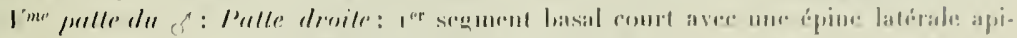

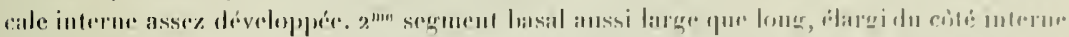

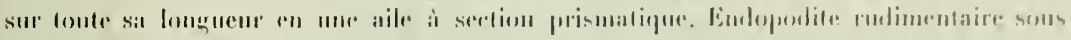

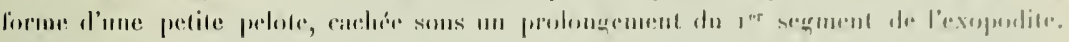

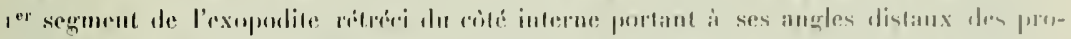

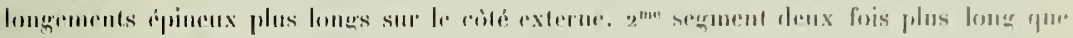

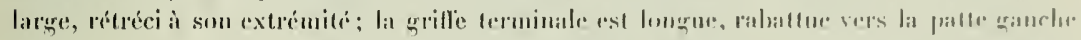

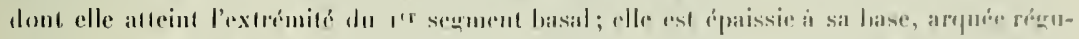

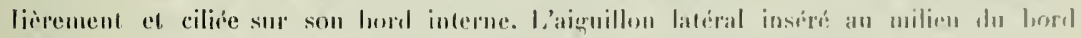

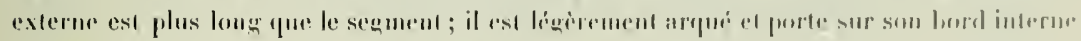

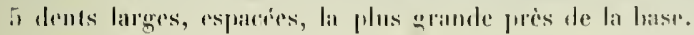

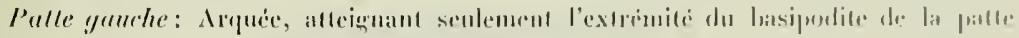

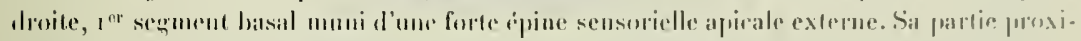

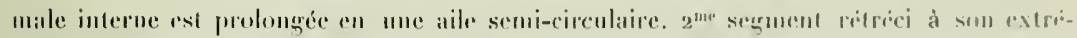

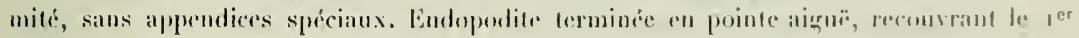

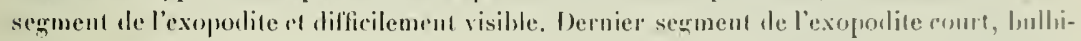
forme, terminé par me courte épine barlucle et portant sur son borl interne 2 ipines módianes assez conrtes.

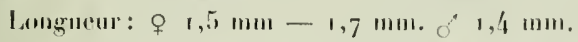

Ilabilal: Ciolombie: Plusieurs exemplaires of el provenant de la Lagmana de I Targue (38oo m.) C., or. ' (Collecion Fulumann).

\section{$2^{\circ}$ Boeckella. spec.}

Dans un tule de la collection Wollihn̈gel se trousairnt un eqand nombre de jeumeexcmplaires d'un Breckellide que je nai pu déterminer.

Ilabilul: Argentine: Laguna Hercones, Cordillere tle Menduza.

\section{Cyclopides.}

P'armi les \& espèces trouvées coll Colombic et en . Irementine, li se rencontrent aussi

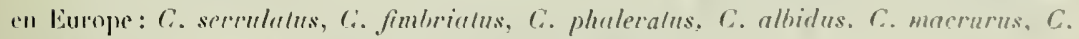
lendiarli). Les 2 antres especes, C. mernlocinus, Hiers al C. anreps, Rich. sont speciales. ¿ l'hémisphère sud, C. mentorimus n'ayant jusqu'a présent été constaté qu'en Amérique du Sul el dans lïle de Hä̈ti, C. anrepse conmu en ontre de Java, Sumatra, Siam i Dada!l

1 1. ur. Cordilleres orientales: 6 . e. Cordillere's centrites. 


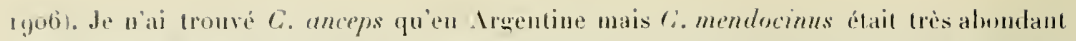

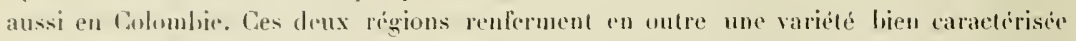
Iu C. lencliarti.

\section{Cyclops albidus Jurine.}

Espèce assez répanlue en Colombie mais sans jamais y àre bien ahondante. les exmplatres examinés ne prisentent pas de différence notable ave l'espice enropéenme.

Ilabital: Colombie: Laguna 1, près Madrid sur la Sabana de Bogota, 2640 m.; Laguna II, pres Nadrid sur la Sabana de Bogota C. or., 26/40 m. of et o wrigères; latqua Pedro Pablo, 24 no m. C. or.; Mares III et IV, mès Madrid sur la Sabana de Bogotia, C. ur., 2640 m.; Laguna de Estrelta, 250o m. C. c.

Counu en Inérique du Sud des contrées suivantes: Brésil (Richard): Chili (1) (reeli): Paraguay (Daday).

\section{Cyclops serrulatus, Fischer.}

Très alondant en quelques stations el repressenté surtout par des lormes assez petites $\left(0,88 \mathrm{~mm},-0,9^{6} \mathrm{~mm}\right.$.) correspondant à la variété de Lilljehorg, G. varius var. brachyjurns ì furca courte.

Ilabilal: Colombie: Laguna Cruz Verde, 3000 m. C. or.; Laguna II, 2640 m., près de Madrid sur la Sabana de Bogota, C. or; Mares III el IV, prés de Madrid sur la Sabana de Bogota, C. or., $2640 \mathrm{~m}$.; Laguna de Don Elias, $2100 \mathrm{~m}$., C. c.; étangs de l'Alto Don Elias, $2300 \mathrm{~m}$., C. c., très abondants, forme avec serra bien marquée; Etang au-dessus de Medellin C. c.; Laguna Santa-Rita, $1600 \mathrm{~m}$. C. c.

Conun en outre des contrées suivantes: Brésil, Chili (Richard). Argentine (Mrazek, Duday), Patagonie, Paraguay (Daday).

\section{Cyclops macrurus.}

te n'ai trouve que 3 exemplaires de celte espèce, toujours assez rare, daus la collection de .I. le Dr Wollihügel.

IIabital: Argentine: Station Espejo près de Mendoza, février ıyo8.

Connu des contrées suivantes: Argentine (Richard). Chili (Mrazeli). Paraguay (Daday).

\section{Cyclops fimbriatus Fischer.}

IIabital: Colombie: Laguna II, près de Madrisl sur la Saltana de Bogota, C. or., 2640 m.; Élang du Ruiz Pass, 3600 m., C. c., lris abondants of of ovigères de 0,9 - I mm, de longueur à furca plus large que dans l'espéce de sichmeil. 


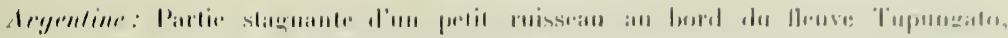

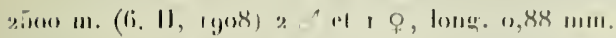

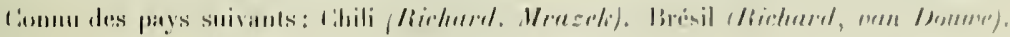

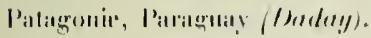

\section{Cyclops phateratus Koch.}

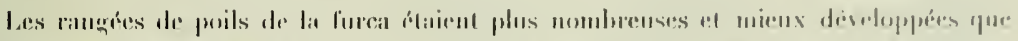

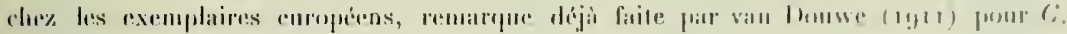

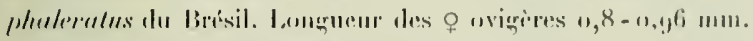

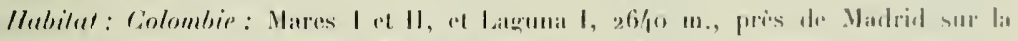

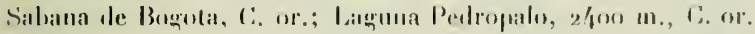

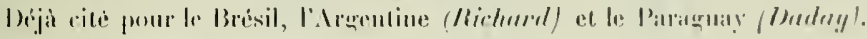

\section{Cyclops leuckarti Claus.}

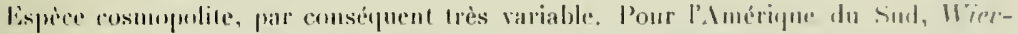

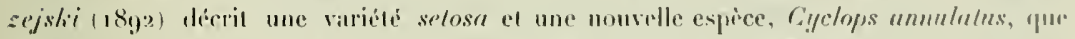

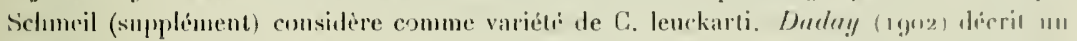

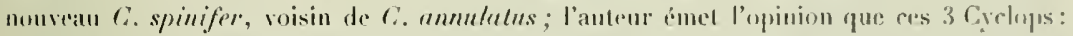

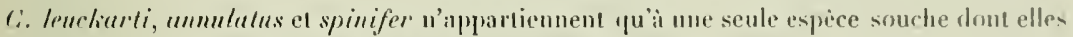
représentent diverses variélés extrèmes. Darluy (rgo6) fail connaitro un nouvean Cyclops:

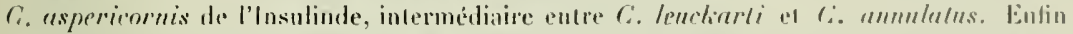

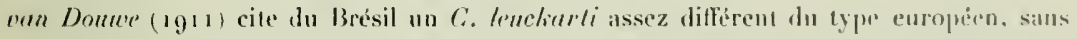
cependant en faire une rariéte distincte. Ces citations nous montrent lit trrande variabilitis dur Cyyclops lencliarli.

d’ai constaté l'espiór lype dans une seule station, dans la Lauruna de Santa-Rita, C. c.

Par contre, f’ai trouvé plusieurs individus que je crois devoir reprénenter une variété nouvelle:

\section{Cyclops leuckarti Claus nov, var. longiseta.}

(Fig. is à s)

Differe de l'espice lype (al'apris Schmeil) par les caraclères suivants :

$1^{\circ}$ Forme dn dernier seqment cephaholhoracique plus long et plus rétréci à sil partie proximale ;

$2^{0}$ Branches de la furca fatrallites et nou diverenentes à bord iuterne finement cilit:

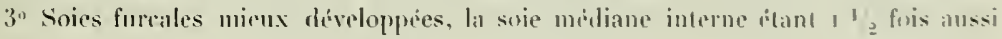
longur yur labelomen, an lieu de l'isaler simplement;

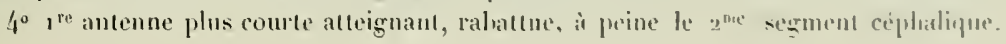


Jai lanselle du dernier segment présente une large incision et sa partic distale forme 2 alenk dirigeses en arriere;

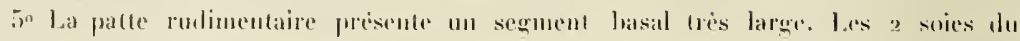

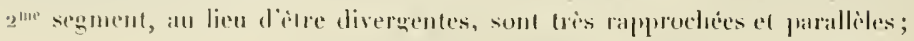

$6^{\circ}$ Le réceptactr siminal, en-

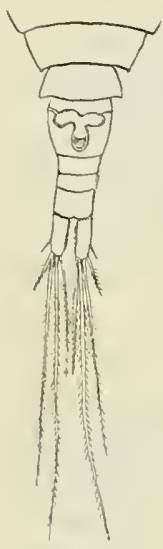

Fig 6.
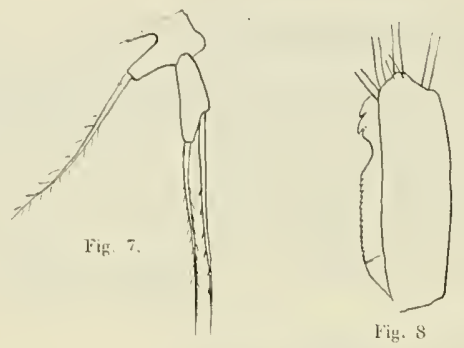
lin, rappelle heaneoup plus eehii de C.. Dyboustiti que exlui de C. lemelienti;

7" La couleute est d'un briun verdatre arec taclies violelles, sulltout aux extrémitis, couleur rajppelant aussi celle du C. Dybounstivi.

Celle varide ne semble ilre

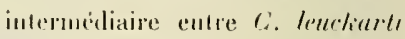
el C. Dyborestivi.

Ilabitut: Colombie: Etang an hord de la ronte, entre America et Mrdellin, $1540 \mathrm{m.,} \mathrm{C.} \mathrm{с.}$

Argentine: Mare à la station Espejo, pries de Nendoza, 6 long. $1,6-1,7 \mathrm{~mm}$.

\section{Cyclops anceps Rich.}

Espèce comme de lhémisphère sud seulement. J'en ai trouvé quelques exemplaires répondant très bien aux dessins el à la description qu'en doune Richard. Danss la collection Wollthügel seulement. Longrueur 1,2 mus.

Habitat: Argentine: Station Espejo, près le Mendozat. Partie stagnante d'un petit ruisseau sıI les rives du lleuve Tupmngato (Cordillères de Mendoza, z6oo m.).

Connu en ontre des payss suivants : Brésil /Richard), Patagonie (Mrazeli), Chili el Pallaguay (Dadey).

\section{Cyclops mendocinus. Wierzejski.}

I ne des espèces les plus communes de la Bolivie et répoudaut trés bien aux dessins Ifu'en donne Wierzejski. Le caractère le plus saillant est l'igaliti des a soies furcales médianes très courtes. I antenne à $\mathrm{r} 2$ segments n’atteignant pas l'extrémité du $1^{\text {er }}$ segment cephalothoracique. Conleur d'un blanc laiteux, oeufs rosés. Longucur 1,2-1,3 mm.

Habitat: Colombie: Nares 111 et $1 \mathrm{~V}$, pris de Madrid, sur la Sialnua de Bogota, zfifu m., C. or., trés alonrlant; Lagnuna Pedropalo 2/40o m. C. or.; Laguna SantaRita, Iljoo m. Ci. c. 


$$
117
$$

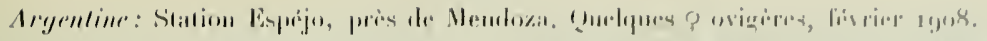

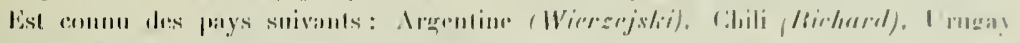

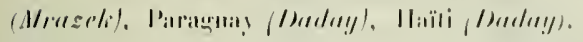

\section{Harpaclicides.}

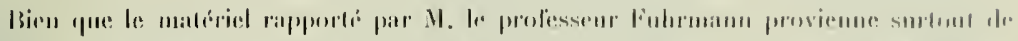

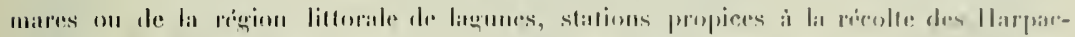

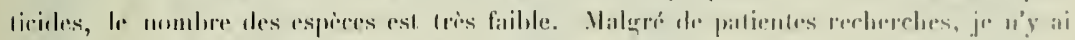

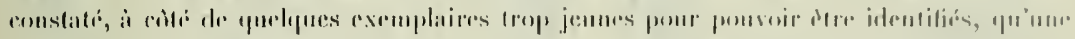

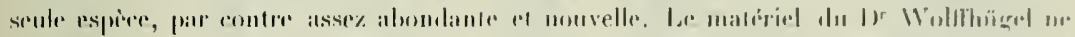

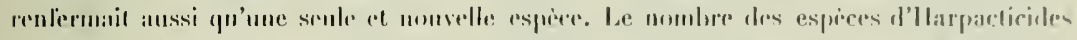

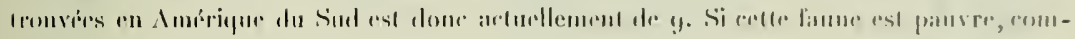

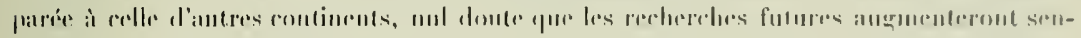
sildement la liste des espreses.

\section{Canthocamptus fuhrmanni nov. spec.}

(Viig. !) à 1 (i)

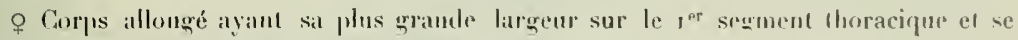

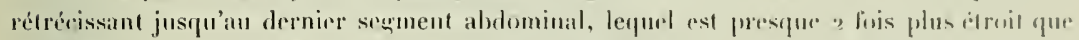
la partic la plus large. Bord postirionr des segments denté.

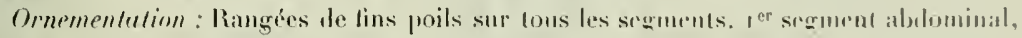
avec rangées latériles distales de 7 a 8 épines se prolongeant sur le coilé ventral, mais

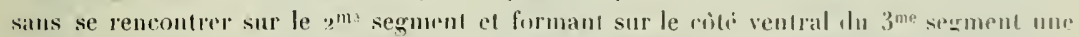
ranger continue de dents irréguliones. Dernier segment avee groupe de 3 ípines anx angles clistaux.

Opercule anal regulioment arromli, gami de nombreuses dents tris fines.

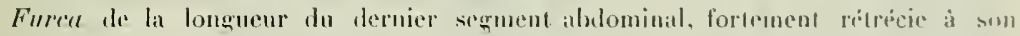

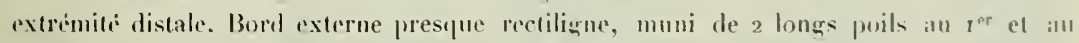
$2^{\text {me }}$ liers de la lungneur, lo proil inféricur arcompangé de a pelites épines lintérales. Burd interne courlé sans poil ni épine. Des 3 soies apirales, l’interne est si preu développée qu’il est très difficite de la constater, en sorte que la furca semble ne possider que 2 soies

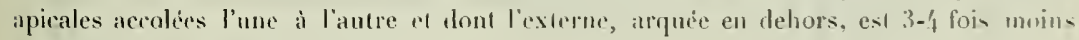
longue que fönterne épaissie à sa base el lichement cilice. Sur le crité dorsal de la furcal se trouve une soic assez longhe dirigée en dehors a inserrid assez hatul. Mu-dessus de

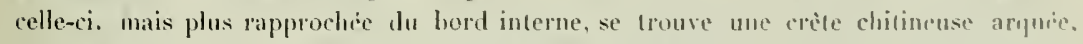

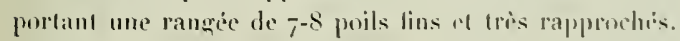



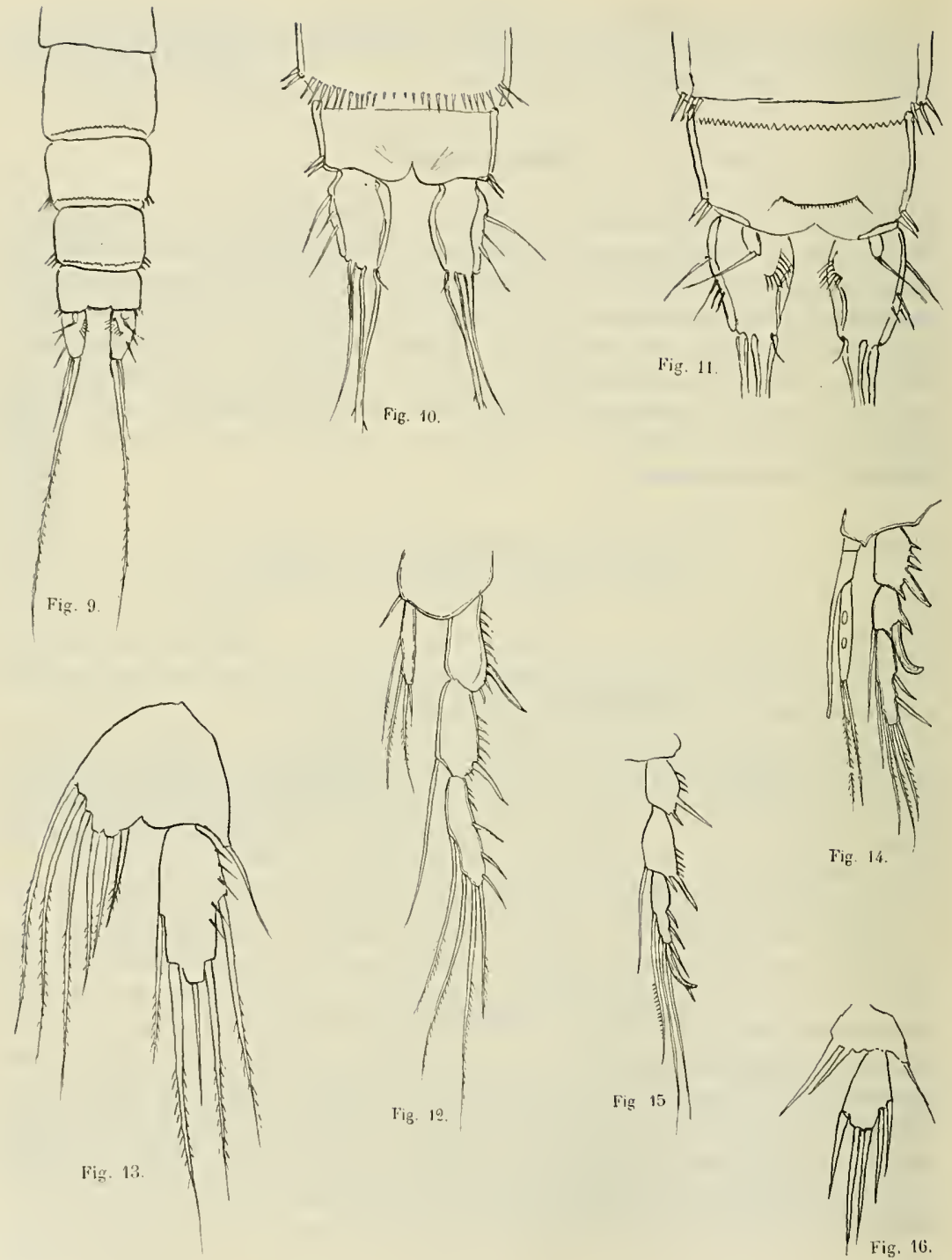

Fig. 14.

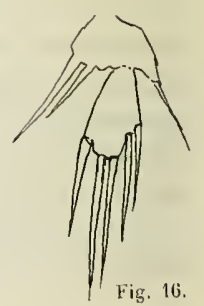




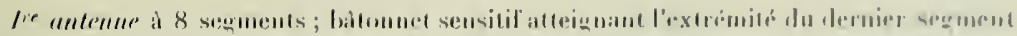

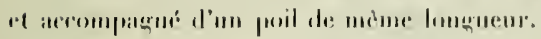

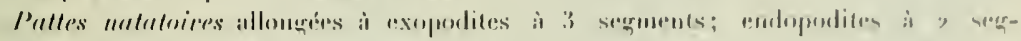

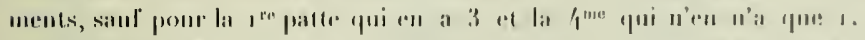

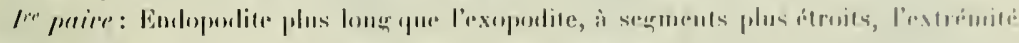

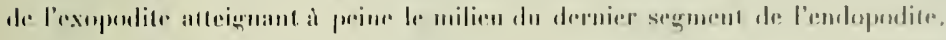

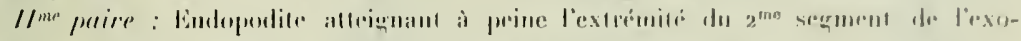

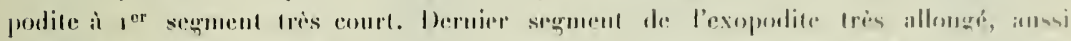

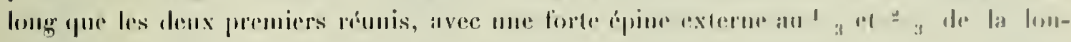

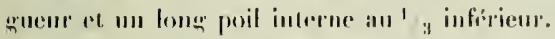

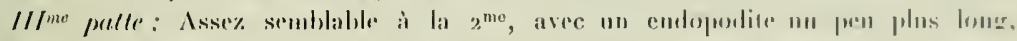

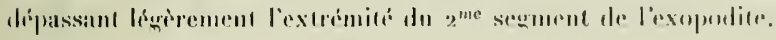

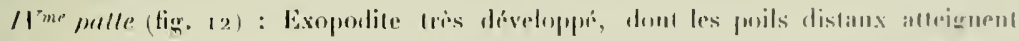

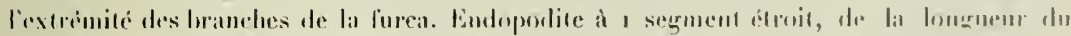
fer sement ile l'exopodite.

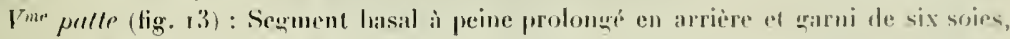
les 3 externes plus courtes qur les 3 iulemes, la $3^{\text {me }}$ ì pratir du borl interno élant

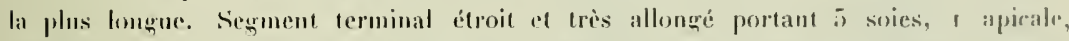
2 externes et 2 internes, insérées réciproyuement un pen an-dessous du milinu de la lon-

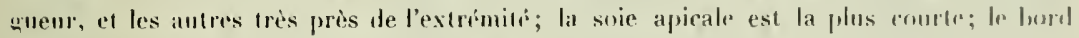
extrone est trami de quelyues lines fipines.

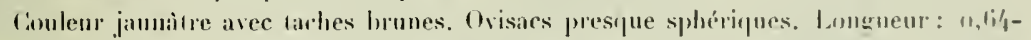
$0,7,5 \mathrm{~m}, \mathrm{~m}$.

$\sigma^{1}$ Copps plus large. $3^{\text {me }}, 4^{\text {me }}$ ef $5^{\text {me }}$ segments aldominanx, aver une rangrio

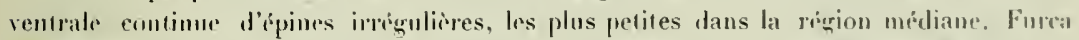
le mème conformation que chez ha o, rependan la soie apicale externe est flus longue.

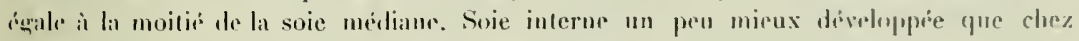
lit o quoingue more très petite.

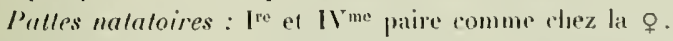

II/me paire (fig. 14) : Endopodite à 3 segments, alleignant la moitid du dernier stement de l'exopodite. $1^{\text {or }}$ segmont court; $2^{\text {me }}$ segment prolongi en son angle distal

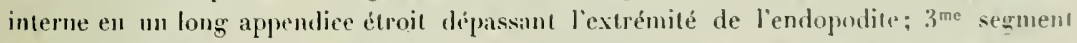
très allongé, portant 2 longues soies distales ciliées, égales. $2^{\text {me }}$ secrment de l'pxopoditr

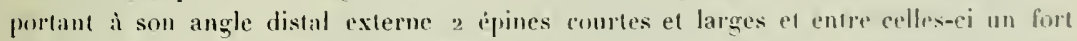
rrochet pen recourbé, à pointe dirigíe en dhors; dernier segrment plus étruit et amai tong que les a premiers réunis.

$1 V^{\text {me }}$ palle : Endopodite à 2 sewments: $1^{\text {er }}$ segment très court, $2^{\text {me }}$ plus long atteigrnant l'extrénité du $2^{\text {me }}$ segment de l'exopodite. Exopodite à 3 segments: $1^{\text {er }}$ et ame larges el dirgale longueur, munis, à leurs angles distaux externes do ? épines donites

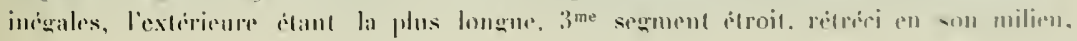


portant eutre tes 3 soies terminales, dont l̈̈nterne est la plus longue, un fort crochet recurbé en delors et hifite à son extrémité.

lime palle (fig. $\left.16^{\prime}\right)$ : Segment hasal portant it sa partie interme épines infogales dont linterne est la plus grande; segment terminal plus comt pue chez la of très rítrói

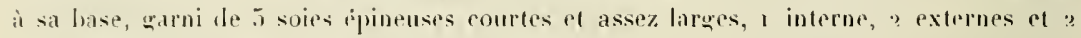
terminales égales, dant les plus longues.

Longuenr du $\sigma^{4}: 0,55 \mathrm{~mm}$.

Mubital. Colombie: Mares III et IV. près de Madrid sur la Sabana de Bogola, C. or., 2640 m. Laguna 11, près de Madriil sur la Sabana de Bogota, C. or., 2640 in.; Laguna Pedropalo, C. or., 2f,oo m.; Étang de l'.lto Don Elias, 2.3oo m., C. c.; Mare audessus de la Laguna de Medellin, 2300 m., C. c. Dans toutes ces stations, l'espéer n'est pas rare. Je me fais un plaisir de dédier cettr espèce à mon cher maitre, M. le professenr Fuhrmann.

\section{Canthocamptus aculeatus $\mathbf{n}$. sp.}

(Fin. $\left.17^{-9} .5\right)$

o Corps assez trapu. Rostre très faible.

Cephalolhornx ì segments, au bord postéricur dente, sans ornementalion, larges et courts.

Abdomen (tig. I8) : Segments larges et courts, se rútrécissant très pen vers la furca, garnis de nombrenses rangées de petites et fines épines. Bord postérieur de chaqur segment ararni de chaque còté d'une rangée d'épines se prolongeant sur le còté ventral sans y former une rangée continue, l'espace restant libre est plus grand sur le $3^{\text {me }}$ segment que sur les 2 premiers. Au-dessus de cette rangér d’épines, s'en trouve une autre, plus courte, mais formée d'épines plus grosses. Dernier seguent sans ormementation, sauf sur le còté ventral, 2 grosses dents situées de chaque cotté an-dessus de l'insertion des branches de la furca. Opercule anal arrondi sans dent.

Furca à branches courtes, à peine plus longues que larges. Bord externe, convexe, conrl, orné de 2 Iongs poils accompagnés chacum de 2 ípines el situés, l'un lrìs près de l'extrémité proximale, l'autre un peu au-dessous du milieu de la longueur. Borl interne muins arqué, prolongé à son angle apical par un poil pipineux dirigé en dedans. La soie dorsale est insérée très près dı bord interne. Soies apicales hien développées, appliquées l'une contre l'autre, la médiane étant 3 fois plus lonque que l'externe el garnie de cils rares et espacés ${ }^{2}$. Soie iuterne très courte, cachée sous la médiane.

1 Jutes Ricuard (1897) donne le dessin, page 276 , de fa 5 me patte d'un Canthoramplus of ressemblant beaucoup à celle du C. Fulumuni; mais ce seul caractire est insulfisant pour permettre d'identilior ces derux espèces.

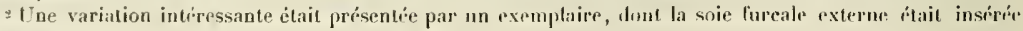
sur un large tourrelet bulliforme, rétrici à sa baste. 

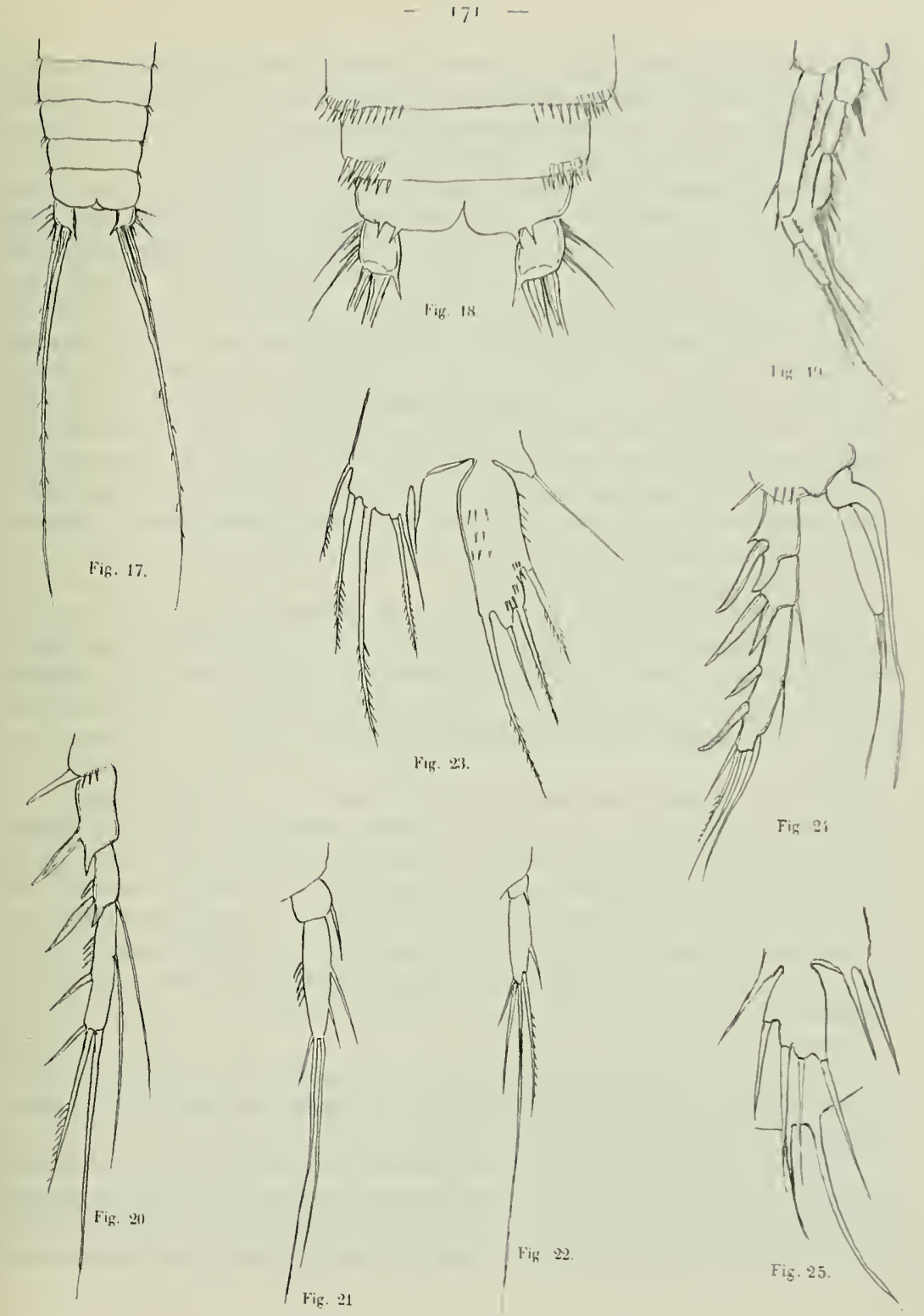


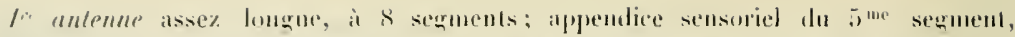
alteignant lextrimite de l'antenue. Branche accessoire de la sme antenne à 1 segment.

l'alles mataloires : Exopodites des 4 paires et entopodite de lat to paire it 3 serorments. Endoporlites des antres paires ì deux seqments.

Ire prire: Entopodite à 3 segments, dont le ter est très long, ainsi que l'exupodite muni sur son borl interne de deux épines courtes, l'une à l'extrémiti, l'antre au ${ }^{4}$ de la longrueur; $2^{\text {me }}$ segment plus court que le $3^{\text {me }}$ qui porte 3 soies lerminales dont la módiane est la phus longue. 1 $^{\text {er }}$ segment de l'exopodite plus large at plus rourt que les 2 antres (voir fig. 10).

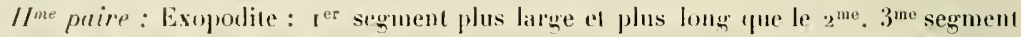
aussi lonğ que les deux premiers réunis. $1^{\text {er }}$ el $2^{\text {me }}$ segment avec une lorte épine externe subapicale el ì angle externe prolongí en appendice épineux. Bord externe du $3^{\text {me }}$ segment avec deux liotés épines insérées, l'une à l'extrémité, l'autre un peu au-dessous du milieu de la longuenr. Bord interne avec un long poil inséré an milien de la longueur.

Endoporlite à 2 segments dépassant un preu le $2^{\text {me }}$ segment de l'exopodile, le $2^{\text {tue }}$ segment 3 fois plus long que le $\mathrm{r}^{\mathrm{er}}$, avec une soie épincuse, courtc, subapical externe et deux longues soies apicales, l'externe un peu plus longne que l’interne.

III me paire ressemble beaucoup, à la $2^{\text {me }}$.

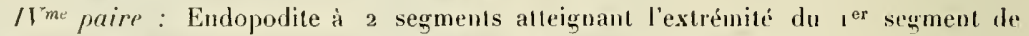
l'exopodite; ${ }^{\text {er }}$ segment très court, $2^{\text {me }}$ segment rétréci à sou extrénité et portant 3 soies apicales, dont l'interne est très longue et l'exterue bien plus courte en forme d'un poil épineux raide. Bord interne avec 2 soies, l'une courte, insérée un peu au-dessous Iu milieu de la longueur, l'autre subapicale plus longue, barbelée du còté interne seulement.

Vue putte: Segment hasal peu prolongé en arrière avec 6 poils disposís en 2 aroupes de 3, séparés par un espace vide, le groupe externe lormé de poils ípineux flus petits et plus serrés; le $3^{\text {me }}$ poil depuis le bord interne est le plus long et le $1^{\text {er }}$ externe le plas court. Segment terminal allongé, portant 4 poils, I terminal, phus qrèle et plus conrt que les autres, 2 subapicaux interne et externe inséres à la mème hauteur, l'mternc étant le plus long; le $4^{\text {me }}$ poil est inséré aux ${ }^{2}{ }_{3}$ de la longuenr du lonl externe. $A$ la base de ces poils el sur la surface du segment, près du bord interne, on conslale des groupes de petites épines assez larges.

Longueur : $0,7 \mathrm{~mm}$.

QPlus petit, peu différent de la $\$$, à ornementation plus accentuée. Branches de lat furca plus courtes, avec un poil apical externe plus développé que thez la $\$$. Les paltes ressemblent à celles de la of, sauf celles de la $3^{\text {me }}$ el de la $5^{\text {me }}$ paire.

II/me paire: Exopodite à pen près semblable à celui de la $o$, les probungements épincux apjorax externes, et les ipines subapicales lieacoup plus forts. Eudopodite a 2 segments dépasse l'extrémité du $2^{\text {ree }}$ segment de l'exopodite. Prolongrement tiliforme de l'angle interne du $1^{\text {er }}$ segment, large el coudé à sa base, juis s'anincissant, 


$$
17 \%
$$

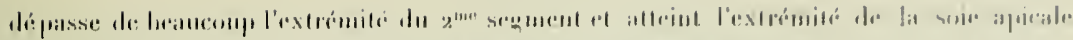

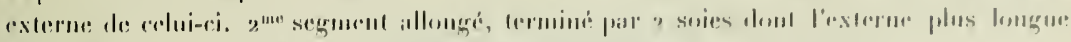

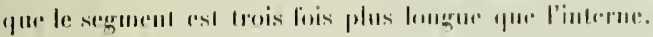

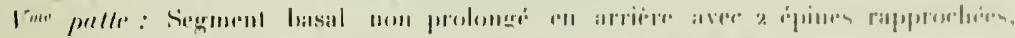

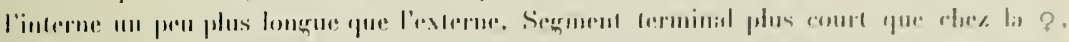

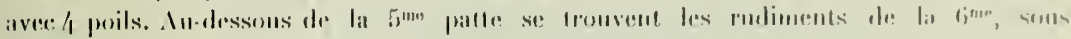

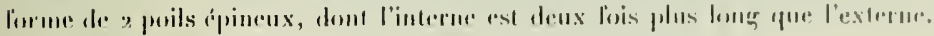

Longueur: : 1,6 mun.

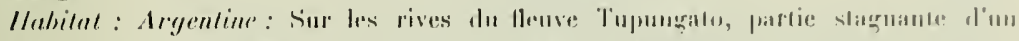

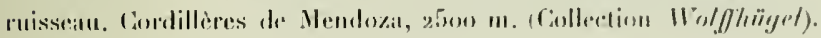

\section{Considérations générales.}

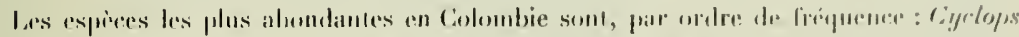

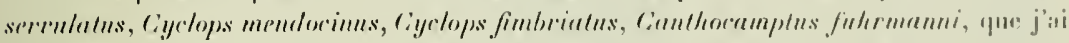

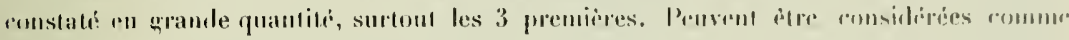

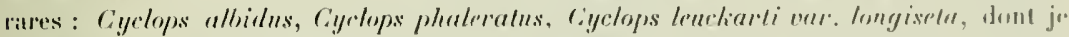
n'ili coustille yue 3 rximplaires.

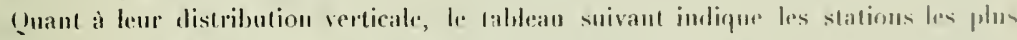

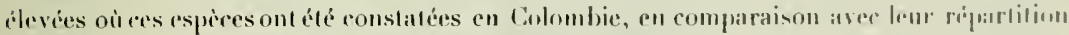

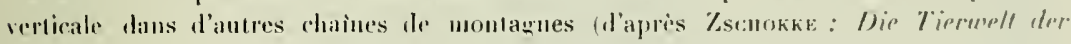
llochyebirgsseren).

$$
\text { Colombie (Cordilliers) Zselukke (1/pess suisson) }
$$

Diaplomus colombiensis $2800 \mathrm{~m}$.

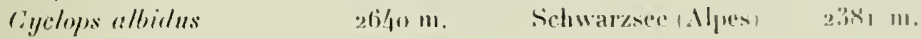

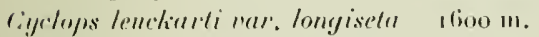
Ciyclops menulocinns: 20190 111.

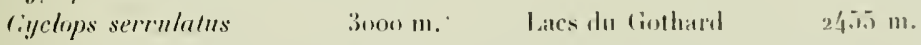

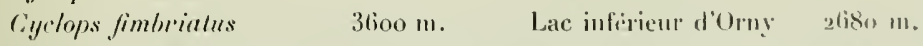

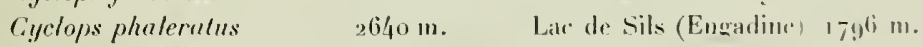

Cinnthoramplus fuhrmanni $2640 \mathrm{~m}$.

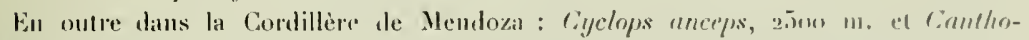
camplus aruleatus, $2500 \mathrm{~m}$.

Nous constatons donc que dians la Cordillère de Colombie. nous tromons a crite d'especes endémiques, des Cyychps, qui, en Europe, se rencontrent aussi dam les statims les plus élevées. Ce sont des espèces cosmopolites aussi bien dans leur are de distrilutim horizonlate que dams leur répartition rerticale. En Colombie. à quelques degrés de latitude, ces espèces montent plus hanl que dans les slations a littule plus arande. el

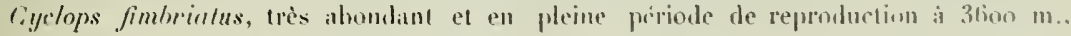
détient pour le moment le rerond de l'altiturle. 


\section{Explication des figures.}

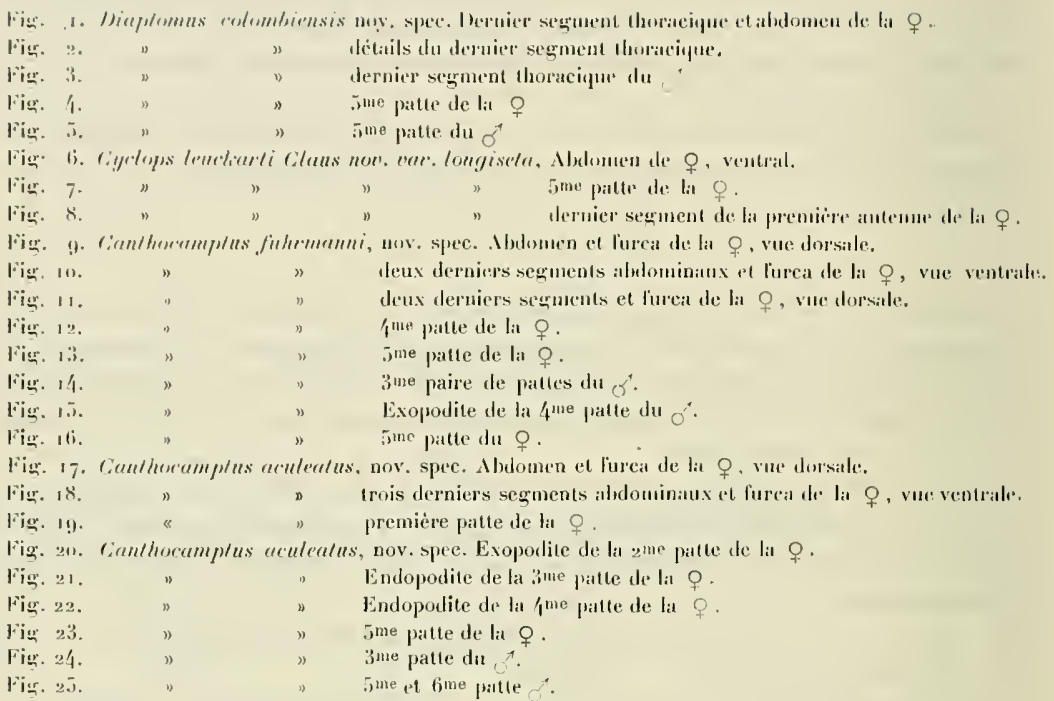

\section{Liste des principaux travaux concernant les Copépodes de l'Amérique du Sud.'}

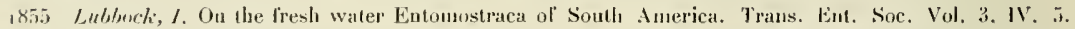
l'irl. VI,

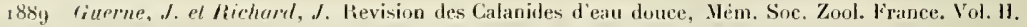

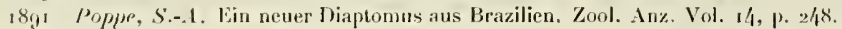

1892 Hierzejslit, A. Skorupiaki i wrotki (Rotatoria) slodkowodnie zebrane a Argentynie. Abls. Akad, Wiss. Krakau. math. naturw. Abtl. T. XXlY.

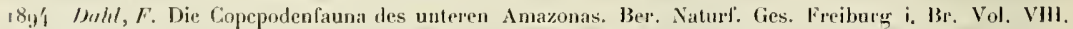

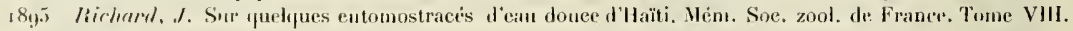

1 Lil liste complete se trouve dans Darlay, Igo.j. Nicroliana L'araguays. 


\section{1}

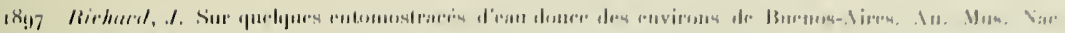

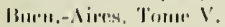

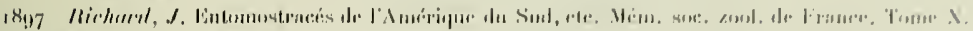

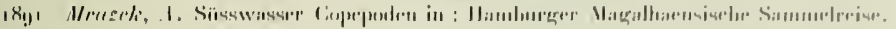

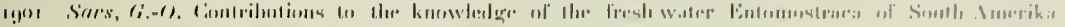

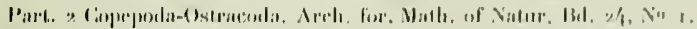

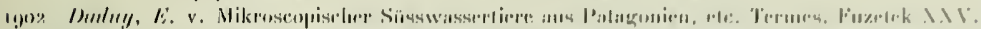

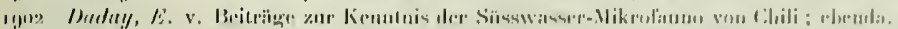

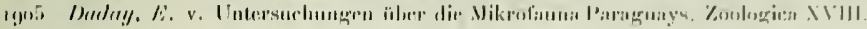

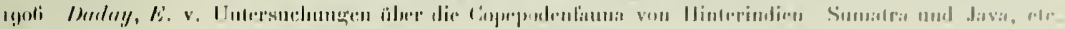

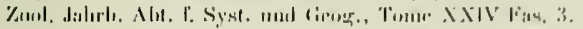

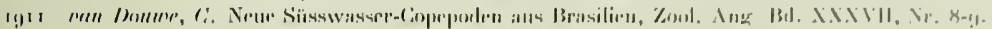

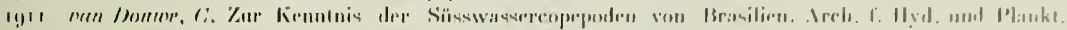
I3I. III, IIrit:". 


\title{
Quelques nouveaux Péripates américains
}

L.MII LN

\author{
Dr O. FUHRMANN
}

Nous arons rappoté, de notre voyage en Colombie, un riche matériel de Péripatrs, qui vient augmenter de trois espèces nouvelles les nombreux représentants de ce qroupe trouvés jusłpu’i maintenant dans les deux Amériques. En effel, nous connaissons déji 29 espèces de Péripates de la région néotropique, lıabitant la zone tropicale entre le $20^{\circ}$ de latitude nord et le $23^{\circ}$ de latitude sud.

Outre les 3 espèces nouvelles de Colombie, le Musée de Genève, ainsi que M. le prof. fï̈Lb, de Berne, ont en l'obligeance de nous soumettre 2 autres especes de Péripates, dont l'une, provenant de Costa Rica, est nouvelle, taudis que l'antre, du Rio Purrís du Brésil, est déjà décrite.

Le lieu d'origine du Péripate du Brésil, ainsi que les localités dans lesquelles nous avous trouvé nos Péripates, londeversent les idées zoogéographił jues que Bouvizı a ¿noncées dans sa belle monographie. Bouvier dit, en effet : "En dépit de leurs migrations ćrolutives, tous les Péripates andicoles, sans exception, sont localisés sur le versant pacifique du continent américain, dans la région équatoriale. Ils oecupent en ce poiut ilu globe l'étroite zone qui sépare la crète des Andes du littoral situé vers l'ouest, tantì atteignant les points élevés de la cliaine, tantôt rlescendant à de très faibles altituders." L" Per.iputus Bimbergi n. sp. a été trouvé dans les Cordillères centrales et orientales, dont les caux se jettent dans l'Atlantique; le P. multiporles n. sp. provient du versant atlantique des Indes. L’intéressante espèce cataibe $P$. Bouvieri $\mathbf{n}$. sp. lut récoltée par nous dans les Andes orientales, non loin de l'endroit oì nous avons aussi trouvé le P'éripate andicole P. Bimbergi; le Peripatus Éiseni Wheeler du Mexique, Péripate andicole très typique, a été tronvé au Brésil, dans une région qui ne devrait, d’aprìs Bouvien, lıéberger que des Péripates carä̈bes. Ces faits effacent la limite si bien tranchée entre les

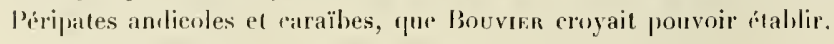




\section{Peripatus Bimbergi n. sp. \\ likg. i i li}

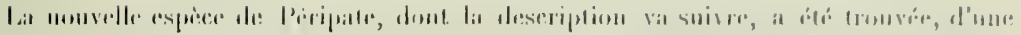

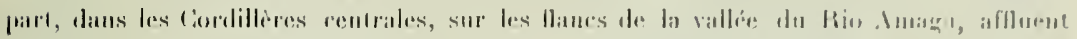

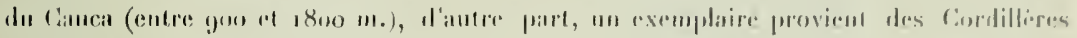

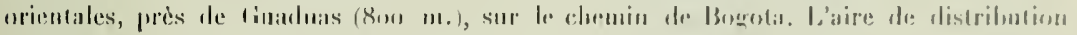

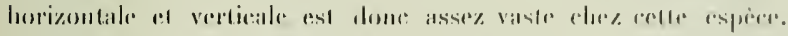

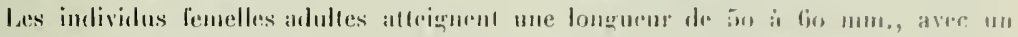

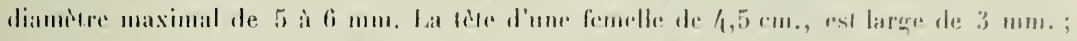

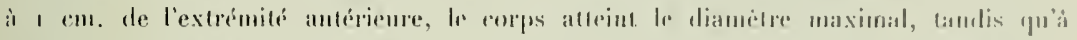

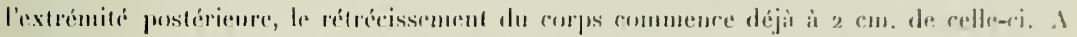
lextrémitc pustérienre, le diamctre transwersal est de z,

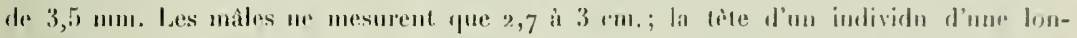

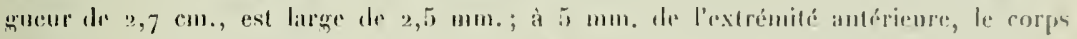

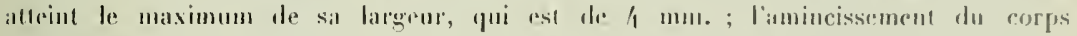

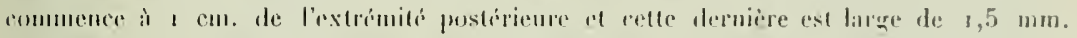
l'épaisscur du corps est te 2 mm. Lat colmation des nombreux axemplaires vivants que nous arons eu entre les mains, est la suivante: le corps ast frun foné sur le dos, avec une raie presque noire daus la ligne médiane; sur les tlanes ainsi que sur le cótí dorsial des pattes, la couleur de l'animal est d'un brun rouge. La pigmentation brun foncé lorme des losanges très réguliers, dont le nombre corresgond au nombre des paltes el dont laugh latéral an ive juste à 8 mm, en dessus de celles-ci. La teinte lirun rouge par

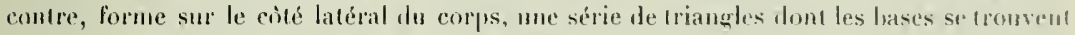
phaces entre les pattes. Arec une faible louje, on rembrqunit, des deux evites do la lienne médiane foncée, une rangée de prapilles claires, dont deux paires par segment daient prarticulierement visibles. Dans clatyue angle lateal des losanges, on voyait deux autres papilles claires situces l'me en dessus de l'aure; en plus, à la base de claquue triangle latéral brm rouge el situces entre les patles, on observe is à 6 papilles claires. La peau do lanimal vivant a $u$ aspect velouti avec un líger reflet verditre. La face ventrale est brun clair, de mème que la fare inféricure des palles ; loute celle face est parseméc de prapilles claires. An milieu de la face rentrale, entre chaque paire de patles se trouve une lache daire representant sans doute les organes ventranx. De celle tache claire partent. à ganclse a d droite, ainsi qu'en arrière, des traits de couleur brune.

Les animaux conservés ont coloré en brun le premier alcool; celui-ei. changé il y a deux ans, ne s'est plus coloré. Les spécimens conservés sont d'un brun foncé sur le dos

1 Je dédie cette espéce à M. Carl Bimberg. consul d'. Iltemagne à Medellin. Cést à ses précienx conseils el ì sa large hospitalité dans son vasle Catetal Camelia, près de Tilisibi, yoe nous devons en grande partie la réussite de notre voyige en Colombie.

23 


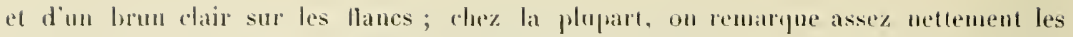
losanges decrits plus haut. Chez les individus un peu plus fortement dicolores, on voit

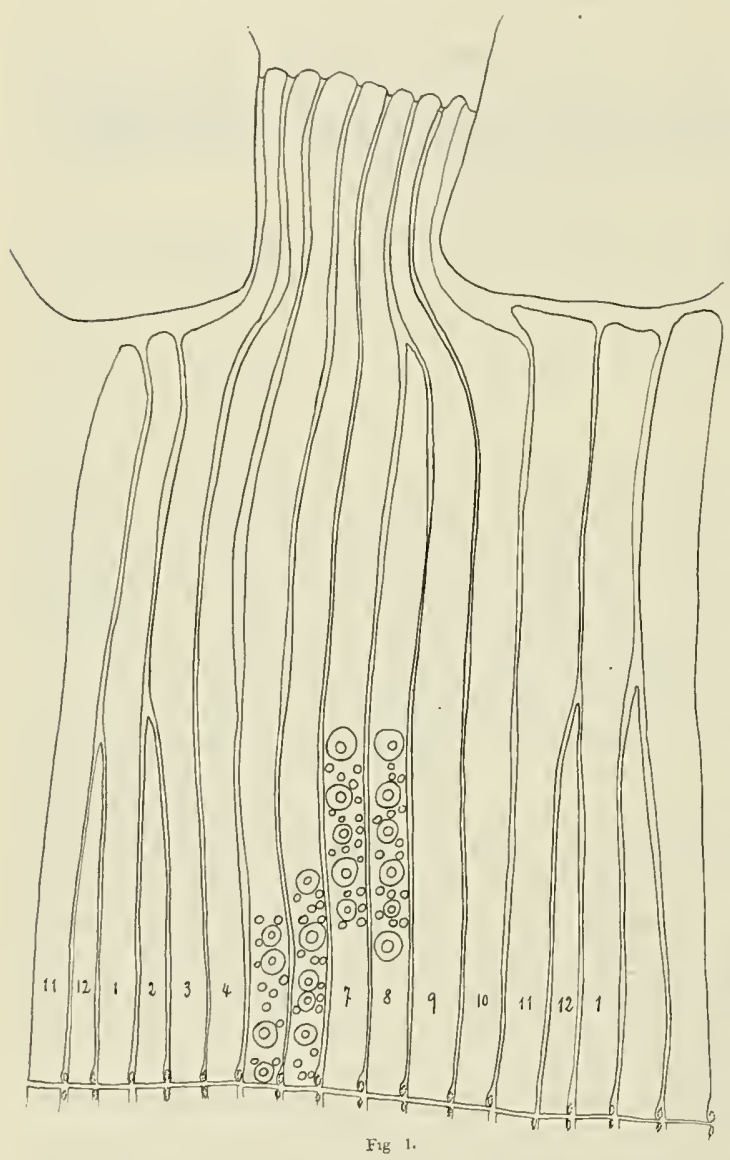
des denx coitris de la ligne mediane foncée et daus chaque segment, me paire de papilles claires. Les papilles claires assez urandes, se trouvant entre les pattes, sont en qúnéral sqalement bien visibles. If's pattes, chez beaucoup d'exemplaires, sont de nieme coulcur que la face ventrale de l'animal. Cette face ventrale est d'un brun rouge ou brun très clair. Les organes ventraux, ainsi que les trois lignes mentionnées plus haut, sont le plus souvent effacés chez les femelles, tandis que chez les mâles ils restent visibles sur tous les individus' conservés à l'alconl. Somme toute, chez la plupart des spécimens, la couleur et les dessins qu'on remarque sur l'animal vivant se voient encore sur les animaux conservés, et seul le velouté et les reflets verdàtres des téguments ont disparn complètement. Quant à la taille el à la forme des animanx, elles ont été relativement peu modifiées par la conservation dans l'alcool, seuls quelques rares exemplaires violenment contractés, se sont fortement raccourcis. L'opinion de II. Evans ${ }^{4}$, qui trouve qu'il est inntile de donner dans les descriptions des Péripates des indications détaillées sur la forme, les dimensions el la couleur des spécimens conservés, 


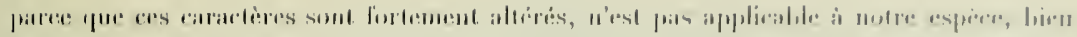

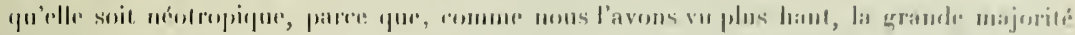

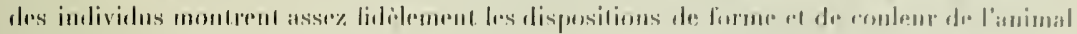
vivilll.

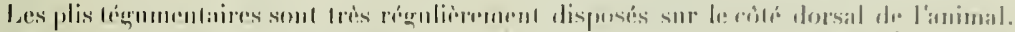

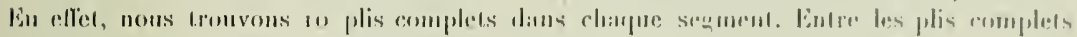

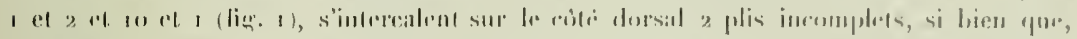

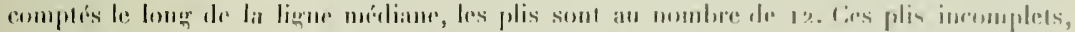

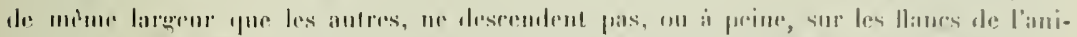

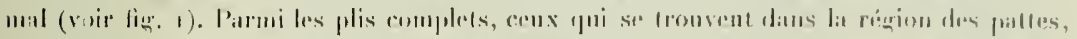

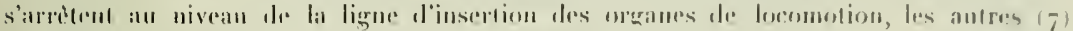

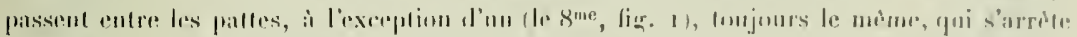

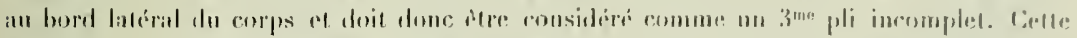

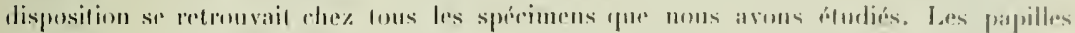

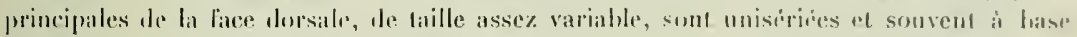

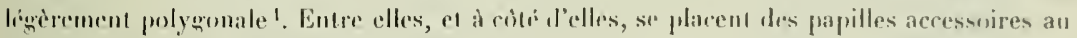

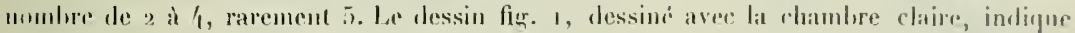

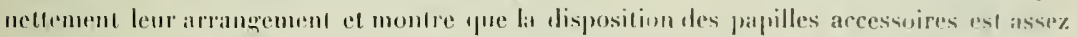

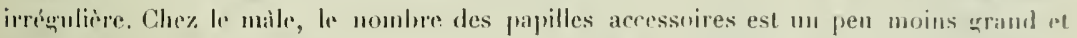
relles-ci sont somvent placres au nombre de 1 ì :3 entre les papilles principales.

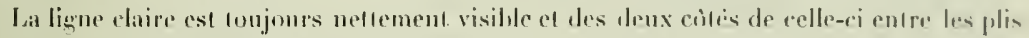

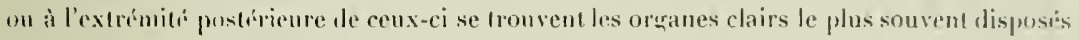
pał paires.

Sur la l'ace rentrale les papilles sont beaucoup plus pelites et les plis, a l'exirptim de"

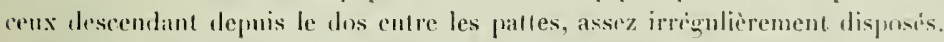

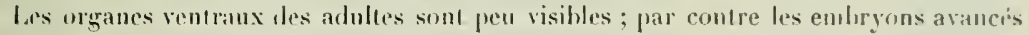
montrent des organes ventraux assez grands avec des organcs preventraux pen neflement dilimilís.

La tite porte deux antemes longues de 6 mm. que l'animal vivant fient lateralement lorspüil est an marche. Ces antemes se composent de 43 à 46 grands arceanx, doml les 7 i 8 derniers sont contigus ; is portent des papplltes le plus souvent assez distantes les mes des autres et leur nombre est de 12 it is par arceau. des arceaux intercalaires sont

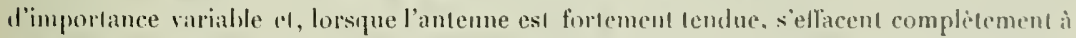
lextremiles antirieme.

(1) ne voit que sur une dizaine de ces arcemx increalaires appartenant an liers

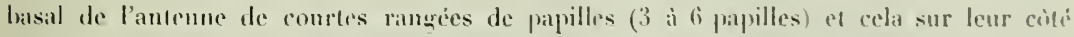

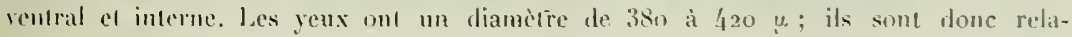

1 Toules ces papilles sont nellement coniques, arrondies an somunel ct maniosd un long cylindre lerminal aree soic. 
tivement tris grands, puisque, d'après Bonvier, l leur diamètre varie entre 200 et $300 \mathrm{u}$.

Je n'ai pas pu voir d'orwane froutal chez notre espèce.

Le nombre des pattes varie de 24 à 28 paires.

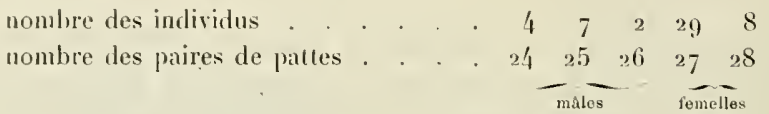

Les 3 a 4 premieres et les 3 it 4 dernières paires de pattes sont un peu plus pelites que les autres.

Les màles ont en général 24 ou 25 paires de pattes, tandis que les lemelles en portent le plus souvent 27 , rarement 28 (voir tableau).
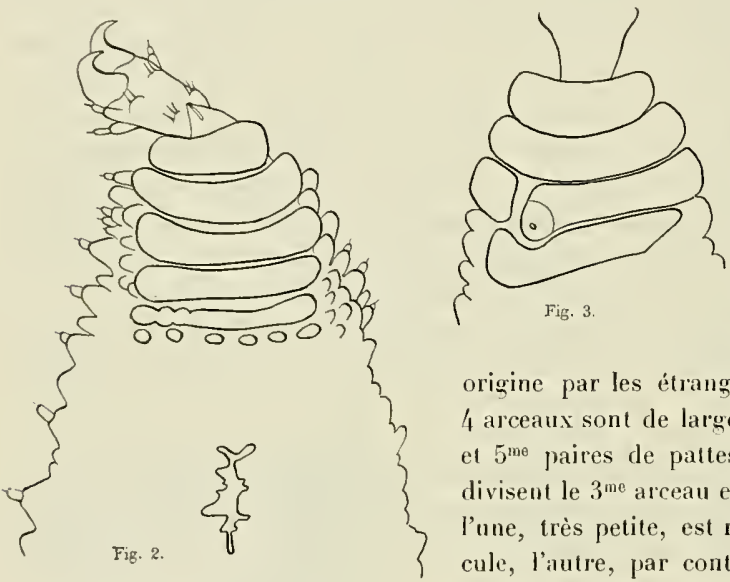

papilles pédieuses, prúsentent pour la plupart des soles de 4 arceaux; fréquemment il se mon1.re pourtant des ébauches d'un $5^{\mathrm{me}}$ arceau qui dans bien des cas est assez nettenent développé, bien que très étroit (Fig. 2) ef montrant encore son origine par les étranglements qu'il présente. Les 4 arceaux sont de largeur assez égale. Sur les $4^{\text {me }}$ et $5^{\text {me }}$ paires de pattes, les tubercules urinaires divisent le $3^{\text {me }}$ arceau en deux parties très inégales, l'une, très petite, est nettement séparée du tubercule, l'autre, par contre, en contact avec ce dernier. En opposition avec $P$. Gondoti qui est roisin de notre espèce à bien des points de vue, le tuhercule urinaire déplacé vers le hau, produit une assez forte échancrure dans le $4^{\text {me }}$ arceau et marque ainsi une tendance à se détacher du $3^{\text {me }}$ arcean. Sur les $4^{\text {mit }}$ et $5^{\text {me }}$ pattes, le $5^{\text {me }}$ arcean est toujours très peu marqué. La hampe du pied montre à sa base et sur sa face interne et ventrale un sillou relativement très long qui se prolonge mème un peu sur la face ventrale de l'animal. Dans ce sillon se trouve la fente coxale (Figr. 2). Je n'ai vu que sur deux exemplaires le plus grand nombre des vésicules coxales dévaginées. Leur dianètre n'était alors que de $0,4 \mathrm{~mm}$. Les papilles principales du pied sont très volumineuses et au nombre de 4; les saillies sétifères terminales montrent 2 soies, les saillies basilaires 2, le plus souvent 3 soies.

1 E. L. Bouvien, Monographie tes Onychophores. Annates de's se. nat. T. II Igo5, at '?, V. igo7. 


\section{Anatomie.}

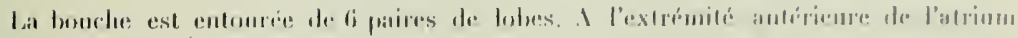

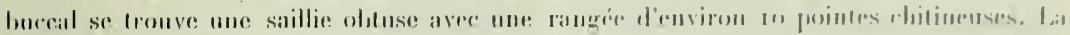

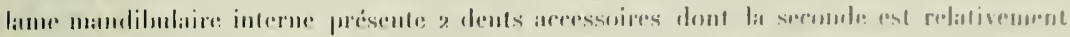

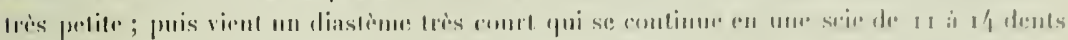

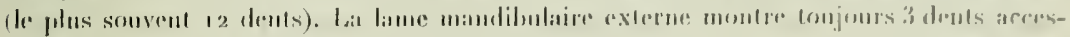

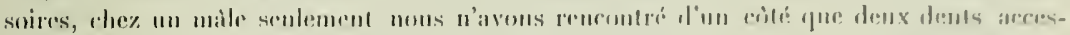
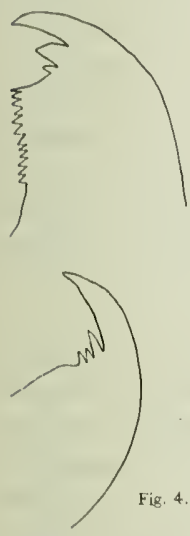

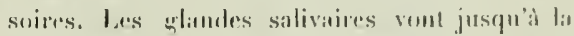

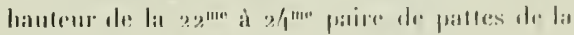

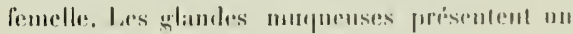
réservair long do 1,8 is 2 e'm. rhe\% les grameles

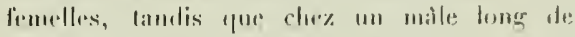

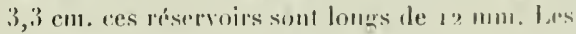

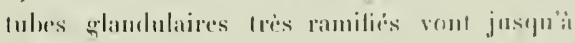
l'extrémitá prostériemre.

\section{Les organes sexuels femelles.}

L'oureture sexuclle se lrouve an nivean de l'avantelermice paire de patles. Les ulérus sont tris lengs, puisqu'ils mesurent clue un sporimen de $4,5 \mathrm{~cm}, 7 \mathrm{~cm}$. Les waires sont dépourvus de fumicule el de ce fait leur position n'est pas tris diterminese; en elled nous les avous tronves a pen pris entre la $12^{\text {me }}$ et la $16^{\text {me }}$ paire de palles, done a la moitic de la longueur du corps.

Les ovaires sonl longs de 0,9 iो 1,23 mm.; l'un est en général un peu plus comrt que l'autre. Lat litrgeur des ovaires sondies l'un à l'autre est de 0,2 à 0,26 mm. Less aufs ont nu diamètre de 0,04 it $0,1, f^{8} \mathrm{~mm}$. Le réceptacle ovulaire semble se terminer par un entomroir sourrant dans la cavití du corps. Dans me préparation nous voyons mine accolé ì lextérien de ce riceptacle un anf mir! Le réceptacle siminal oroüle a un diamirle de

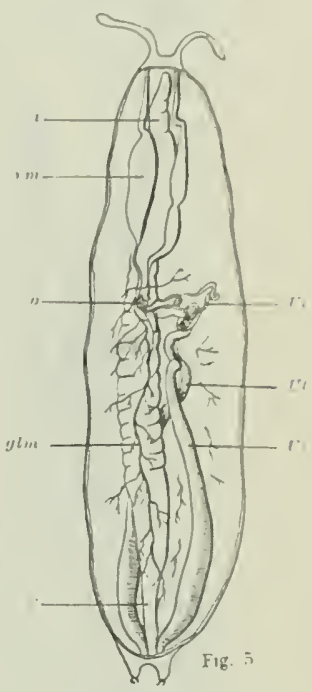

Peripatus Bimbergi n. sp.

duatomie diune remelle: $i$ inlestin. rreclum, glm glandes muqueuses. $r m$ réservoir dés glandes muqueuses, $a$ ovaires. 'I't ulérus.

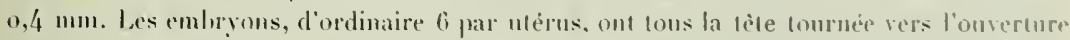
sexuelle. Les plus développés, situés dans la partie terminale el dilatée de liuterus, sont longs de $2,5 \mathrm{~cm}$. 


\section{Les organes sexuels mâles.}

Ils deburhent, comme les orgames femelles, entre lavant-dernière paire de palles, par une ourerture en forme de rroix. Sur les $1^{\text {re }}$ el $2^{\text {the }}$ paires de prattes prégénitaldes débouchent dis glandes crurales liliformes dont les antérieures sont tres divoloppers et allei-

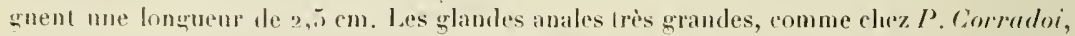

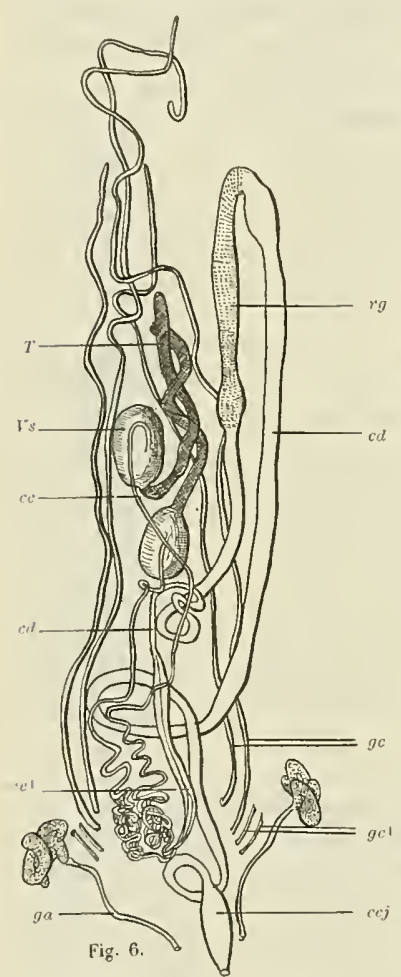

I'eripalus Bimbergi n. sp.

Appareil génital mâle : $T$ lesticule, $V s$ vésicule sèminale, ce canal ellérent, $c e l$ canaus elférents se soudant ensemble, cal canal déférent, rg région Glandulaire du canal déférent, cej conduit éjaculateur, $g c$ glandes crurales, $g c^{1}$ glantes crurales postérieures conpées, ga glande anale. sout également tubulaires, mais la partie ghlandulaire est assez forlemenl dilatíe el enroulíe. Le canal vecleur de la grande anale a une longueur de $2,8 \mathrm{~mm}$. avec diancitre de 0,09 i 0,1$]$ mm., tandis que la partie glandulatre enroula est longue de $7,6 \mathrm{~mm}$. alver un diamedre de 0,3 a $0,34 \mathrm{~mm}$. Les qlandes anales sont done fris fortement déreloppées chez I'. Bimbergi. Par leur' lorme, elles ressemblent beaucoup à celles que Bouvien (lne. eit. p. $\left.{ }^{8} 8-199\right)$ a dessinées pour Doperipatus insignis et Peripatoides orientalis, seulement chez ces espèces elles semblent ètre moins volumineuses et la partie glanilulaire pas ou peu contonrnée.

Les testieules sont tubuliformes, longs de 5 à $6,6 \mathrm{~mm}$. avec un diamètre de $0,47 \mathrm{~mm}$. Les vésicules séminales sont oviformes, longues de 2 mm, aver un diamitre de $\mathrm{r}, 1$ à 1,5 mm. Les canaux ellécents ne partent pas del'extrémité distale des vésicules séminales, mais à pen près au milieu de lem paroi latérale. Dans l'un des individus disséqués, les 2 canaux ellérents, légèrement ondulés, vont vers l'extrémité postérieure oì ils sont alor's lortement enroulés (voir Fig. 6); dans un autre exemplaire par contre, te canal effirent élait fortement ondulé dès sa sortie de la résicule séminale. Dans les denx cas, les canaux elférents se rémnisseut à l'extrémité postérieure de la cavité du corps d'oì le canal déférent se dirige en avaut. Il n’a semblé que les deux canaux sourlés ensemble restent séparés intérieurement sur me lonenent d'envirun $6 \mathrm{~mm}$. el e'est seulement alor's, dans le voisinage de la vésicule séminale posterieure que les denx manax efférents se rónnissent vaiment en un enduit imprair, le canal déférent, leaucoupplus átroit. Lat partie intérienrement donble du canal sóminal a un diamètre de 0,3 ì $0.4 \mathrm{~mm}$, laudis quaprès il ne mesure plus gue $0,59 \mathrm{~mm}$. 


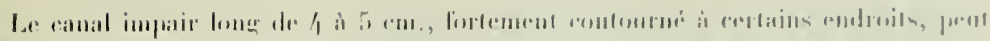

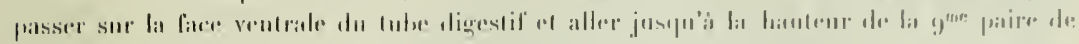

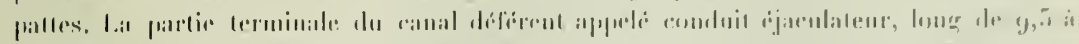

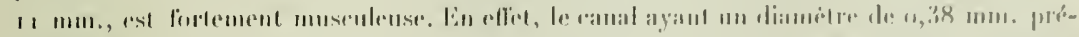

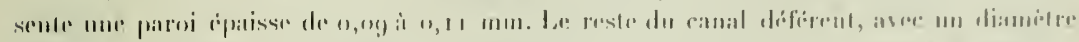

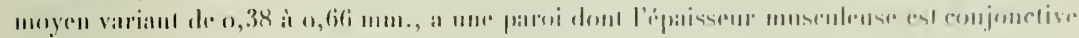

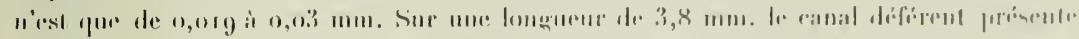

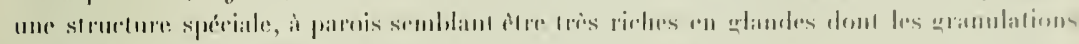

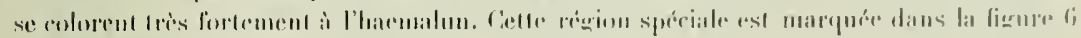
part lies juintillés.

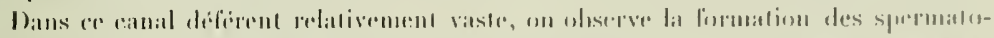

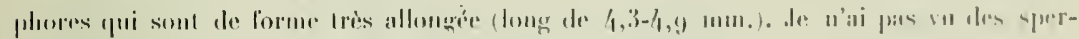

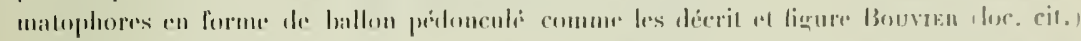

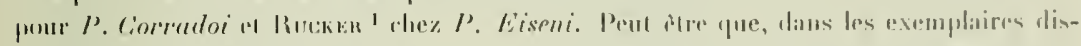

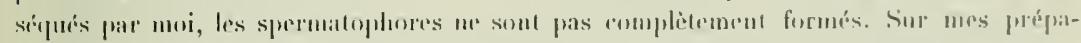

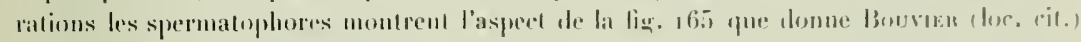
du caual décérent de Peripatopsis leonina P'ure.

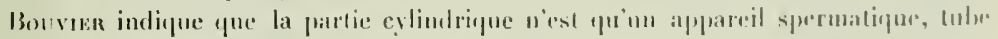
corne, rempli de spermalozö̈les à lextrémite distale dupuel se différenciend en séfa-

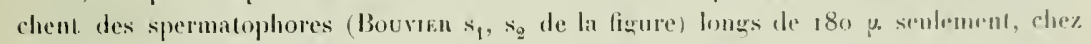
Periputes. Corredoi par contre les spermatophores smut longs d'environ I mu, de ne sais si l'interprétation do Burvien est juste el je erois plutot que l'ensemble de l'appareil qu il dessine représente un spermatophore, parer yur je vois dans le canal délérnul de motre $P$. Bimbergi 4 de ces appareils cyliudripues aver renflement distal à paroi très miner. el burré de sperme, situds les uns derriore les autres. Il se pent que ces tubes cylindriques longs d'environ $4.7 \mathrm{~mm}$. s'inrunlent dans la partic musculeuse du canal deférent et devienuent alors des spermatuphores semblables à ecux de $l$. Commoloi P. Eiseni.

La nowrelle espece de péripate que nous venous de décrire appartient au uronpe des péripates andicoles, avee plis incomplets segmentairement disposés (eroupe de $P$. Fondott, P. soratanus, P. Bulatmi et $P$. intermetiuss. Parmi les especes cilćes, cist de $P$. Coudoti que notre forme se rapproche le plus. En eflet, le nombre de pattes est identique dans les deux especes, de mènte la présence assez fréquente diun rudiment d'un 5ime areeau sur les soles pédieuses. Le funicule manque igalement dans les deux expèees.

Les diférences avec l'espèce mexicaine sont les suivantes : la laille est deux fois plus wrande dez notre forme. Larrangenent el le nombre des plis incomplets sont différents. Les papilles des plis semblent èlre diffiremuent disposées, surtunt en ce qui concerne les

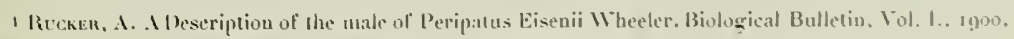
p. 251 . 
papilles accessoires. En opposition avec $/$. Cioudoli, les organes clairs sont très nets et les fusselles reutrales très peu distinctes. Contratrement ì $P$. Gondoli, les palles atteignent leur taille maximale dans le $4^{\text {me }}$ ou $5^{\text {me }}$ segment dejà (cluez P. Coudoti, dans le

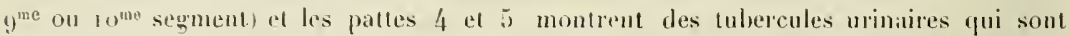
metlement déplacés vers le laat et produisent un fort étranglement dans le /m" arceau. Contrairement à ce qui existe cliez $P$. Gondoli, nons trouvons sur les saillies basilaires des pieds, nun pas 2 soies, mais 3 , et sur les saillies terminales non pas une, mais deux soies. La lame mandibulaire interne muntre une scie portant plus de denticules (1) à 14 an lieu de 11) ef ume lame mandilublaire externe ayant tonjours 3 el nou pas 2 dents accessoires; $P$. Bimbergi ressemble par ce dernier caractère à $P$. internedius.

\section{Peripatus multipodes n. sp.}

(Fig. $7-9)$ ).

Nous ne possídons de celte espèce intéressante qu'un seul exemplaire long de $2,4 \mathrm{~cm}$, arec une largeur maximale de $3 \mathrm{~mm}$. et une épaisseur de 2 mm. Il provient du Rio Amaga (Cordillères centrales). Le corps se rétrécit ggraduelfement en avant et en arrière. Le rétrécissement est plus fort à l'extrémité postérieure et s'étend sur une plus grande partie de la longueur du corps. L'animal est brun foncé sur le dos, s'éclaircissanı sur les llancs. La ligne médiane foncée est bien visible. La face ventrale est grise. De cliaque coité de la ligne noire, sur la face dorsale de l'animal, se trouvent arrangées 4 lignées régulieres de papilles blanches. Sur les llanes, les papilles blanches, plus nombreuses, sont moins régulièrement disposées.

Les plis segmentaires sont tous complets, a l'exception de deux par segment, toujours régulièrement disposés. Ces deux plis, correspondant comme position anx plis 6 et 8 du dessin de la peau de P. bimbergi (Fig. 1), arrivent jusqu'au niveau de la ligne d'insertion des pattes et sont donc beaucoup plus longs que ehez la plupart des espèces de péripates américains. Nous trouvons a 2 plis, dont to complets dans chaque segment. Ces pris, de mème largeur, montrent alternativement des papilles blanches qui sont done arrangées en lignées transversales et non seulement en lignées longitudinales. Il y a toujours un pli sans papilles claires, alternant avec un pli portant des papilles claires (6 it 8 ). Ces papilles sont un peu plus griandes que les autres qui sont également unisérićes et ne se touchent pas à leur base (Fig. 7). Les papilles blanches le sont depuis la base jusqu'au sommet, leur partie apicale est globulense, et sur les pattes senlement, elle est allongée et cylindrique. Les papilles brunes sont de structure très simple, coniques et arrondies au sommet. Elles se distinguent des papilles accessoires de P. Bimbergi par leur taille seulement. En effet, loutes ces papilles, à l'exception des rares papilles blanches, ne présentent aucune trace de portion apicale et sont done, malgré leur taille, à considérer 


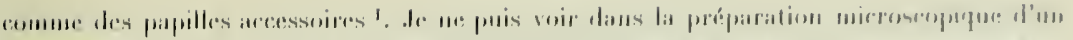

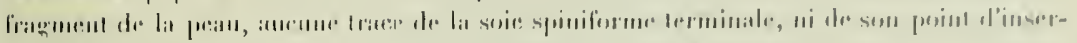

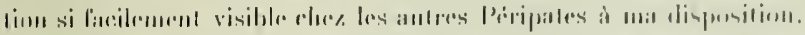

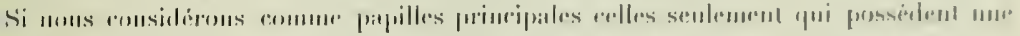

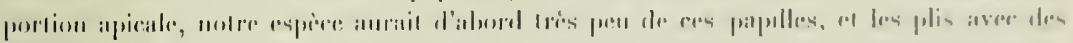

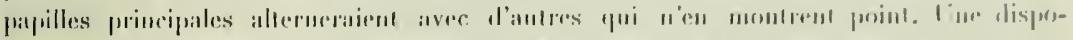

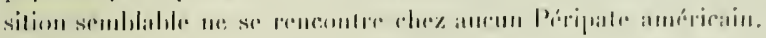

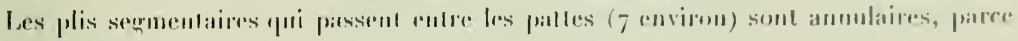
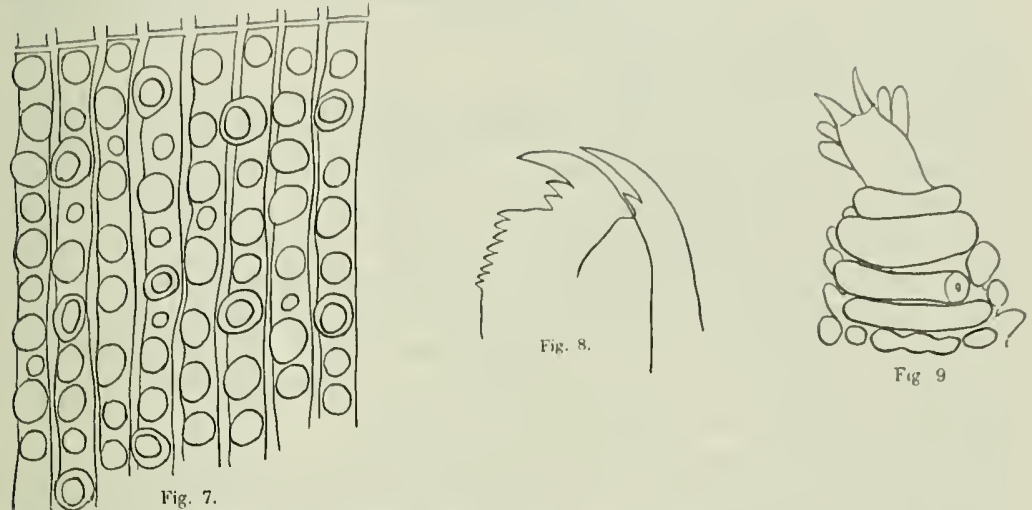

qu'ils passent sur la face ventrale sans se molifier. Ainsi l'arrangement des papilles ventrales est rigulier, el c'est seulenent daus l'ospace ventral buoil, compris entre les paires de patles que la dispusilion des papilles est irréguliere.

La ligne claire est forl nelle, par contre les organes clairs ne sont pas tries applarents. Les organes ventraux ne se voient quir vignement.

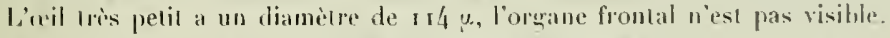

La lane interne des mandilumes a deux dents accessoires avec une scie portan 8 à 9) dents. La lame externe ne porle yu'une dent accessoire (Fig. 8i.

Chrz wore individu, qui est une femelle, dont le pore sexuel se trouve entre les paltes

1 Borren, dams sa Monographie (loc. cit.p. 15) et dans la deseription de certaines espéces ne caractérise pas assaz netiement ces deux sortes de papilles, qui jouent un ròle si capital dans la détermination des Péripates cariäbes surtout. Gest pour cette raison que nons avons longuement hésité dans la determination de certains l'éripates.

Ie crois qu'il taudrail appeler pappilles principales senlement celles qui possedent un cylindre terminal ou une portion appicale distincte de la base. Te sommet est toujours visible dans les preparations microscopiques de lit peru, mene lorsqu il est résracti. Toutes les autres papilles, quelle que soil leur grandeur. divivent. it notre aris, itre appelèes papillées accessoires.

2't 
de l'arant-ilernicre paire, les organes de locomotion se trouvent an nombre de 33 at

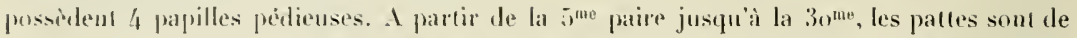
mime latille. Le $2^{\text {ma }}$ arcean des $4^{\text {me el }} 5^{\text {mer }}$ paires de paltes est un pen plus latrge que les

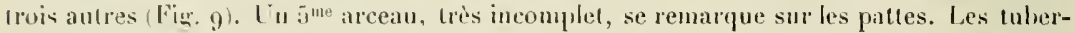
cules urinaires des patle's 4 at 5 se trourent totalement inclus dans le ?'ime arceau et ils le divisent en deux trongons très inégaux. Le petit trongon est absolument indépendant du wrand qui parte te tuberenle. Le pied porte 4 papilles volumineuses. Sur certines lentes coxales, on remarque une éragination plus ou moins complete de la vésicule.

le n'ai osć faire une dissection de l'unique exemplaire que je possède. Il est du reste sultisamment caractérisé par les caractires extérieur's pour ùdte confondu avec ancune espice andicole actuellement connue.

Si nous cherchons dans la belle monographie de Bouvier la place yue doit occuper notre espèce, nous trousons que c'est dans le second groupe des Péripates andicoles, dans le voisinage de $P$. Gondoti, $P$. soratanns et $P$. Bulsani et $P$. intermedius. Si tel est le eas, il faudra moditier un peu les caractères donnés dans le lableau dichotomique. Au lieu de dire nombre de pattes 26 à 32 paires, il faut dire 26 à 33 paires, el à la phrase: "plis incomplets segmentairenent disposés el commengant au voisinage du milieu des flancs ", il faudra ajouter que ces plis peuvent aussi aller jusqu'au bas des flancs. Pour ce qui concerne la longueur des plis incomplets, notre espèce rentrerait plutòt dans le groupe de $P$. Corradoi, $P$. Eiseni et $P$. Belli, avec celle différence pourtant, que les plis incomplets sont régulièrement disposés clez notre espìce.

Les mandibules de notre espèce ressemblent beaucoup à celles de P. Eiseni.

La disposition des papilles est telle qu'on peut distinguer deux catégories de plis légumentaires de mème largeur, mais dans l'une il existe des papilles principales, dans l'antre, celles-ci manquent. Basé sur ce caractère, on pourrait créer dans le groupe des Péripates andicoles, un groupe à part pour notre espèce, groupe qui viendrail s’intercaler entre les groupes I el II de Bouvier. Dans le groupe I, chez P. ecuadoriensis el P. Lubercalulus, on constate en effet aussi une différence entre les papilles des plis larges of celles des plis étroits, mais sur les deux existent des papilles principales.

\section{Peripatus Bouvieri n. sp.}

Fïgr. 1 is iो 13

Celle espice ${ }^{1}$ fut trouvée par nous, au nombre de deux individus femelles, en dessons de la Boca del Nonte, au bord occidental de la Sabana le Bogota, à une altitude de ston m. euviron. Bien que découverte dans les Andes orientales, l'espèce n’appartient pas an groupe des Píripates andieoles, mais est triss nettement un représentant des príripates caraïbes $(v, p, 176)$.

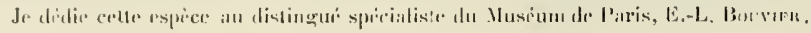




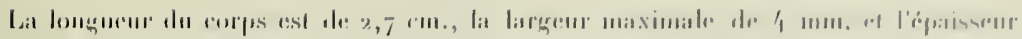

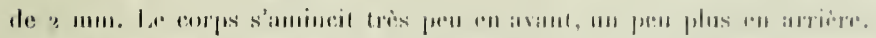

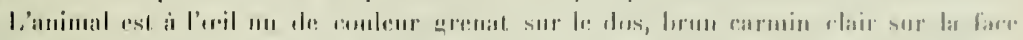

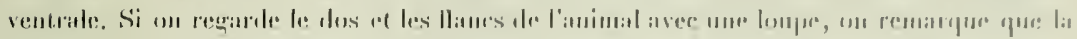

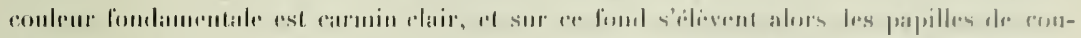

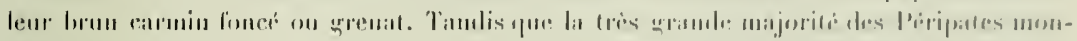

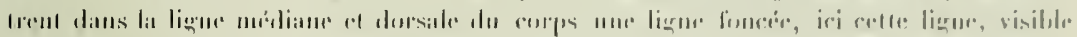
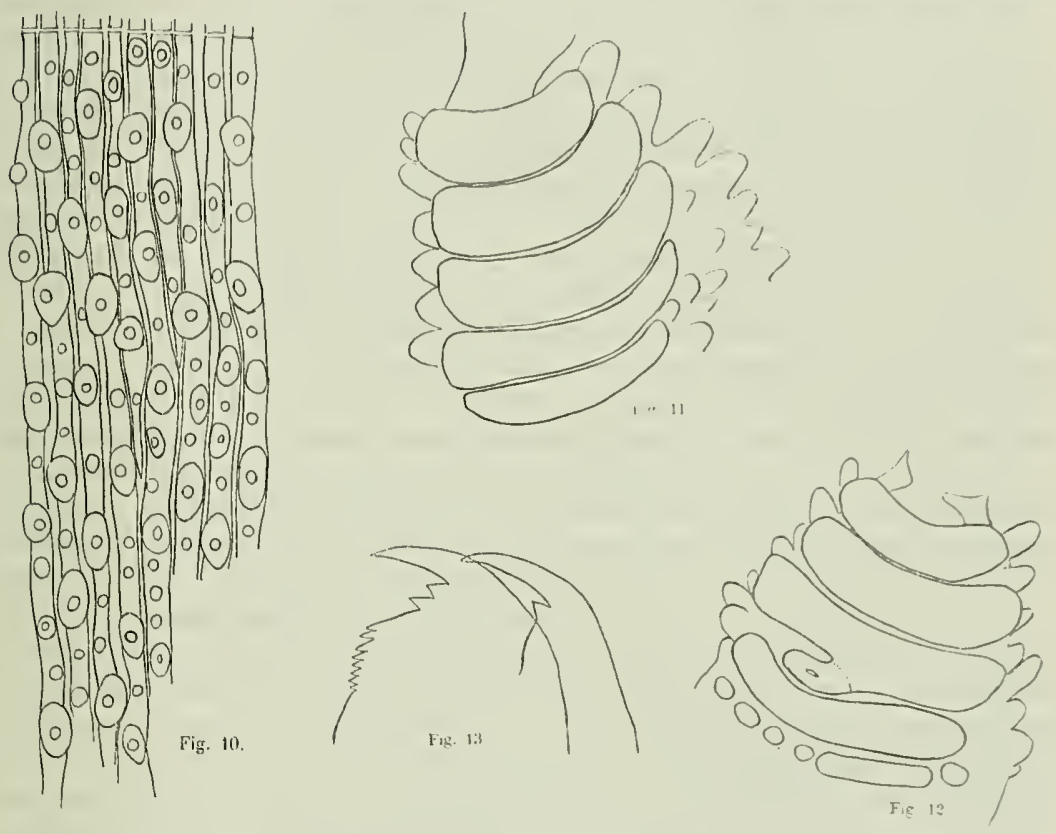

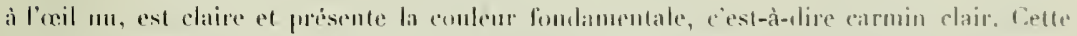

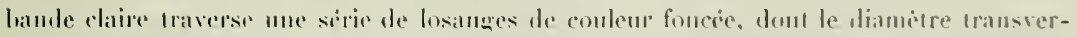

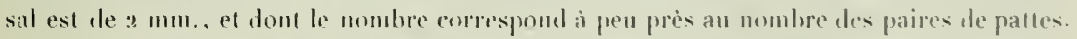

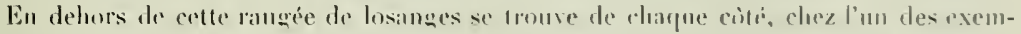

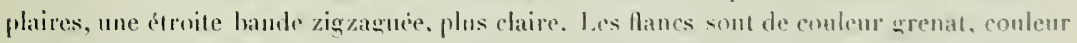

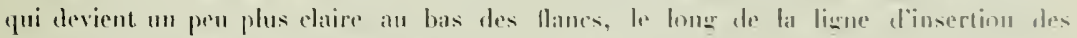
pattes el sur ces dernieres. La second exemplate, un peu plus fonce. ne montre qu" à

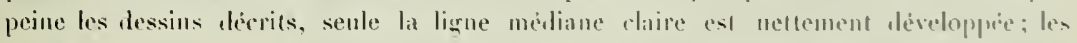

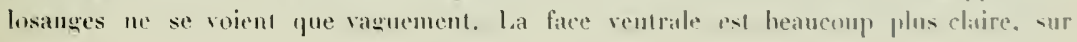


I'individu plus foncé, la pigmentation de la lace dorsale en latirale se continure un peu sur les plis segmentaires passant entre les pattes. Les plis segmentaires, an nombre de donze, sont toms complets, à l'exception de deax an nivau des patles. Les plis imomplets, s'intercalant entre deux plis complets successils, sont de longrneurs différontes et le plus lone descend a peine sur le lane de lanimal. Sur la face ventrate, les plise gui sont la continuation des plis dorsaux, c'est-i-dire cenx qui passent antre les pattes, sunt rexuliers et non bifurqués.

Les papilles principales sont très quandes ot de couleur foncée; entre clles s"intercalent I is 3 papilles heaucoup plus petites. Siil y a 3 perites papilles, celle du milieu est sourent du type des grandes, cest-à-dire ume papille principale de petite laille; les antres sont des papilles accessoires de taille relativement grande. Le diametre de la base des inrames papilles est de 0,08 à $0,1 \mathrm{~mm}$, la partie cylintrique courte el large s'clevaul sur la parlie basale conique est presque partoul rétraclée ; là où elle est léraginée, un constate quelle ert sans coloration. Le sommet cylindripue des grandes papilles principales doit done se frésenter sur l'animal vivant, vin avec une loupe, sous lorme d'une pretite tache hlanche située au centre de la papille de conleur grenat foncé. Cés points blancs se voient sur nos exemplaires presque exclusivement sur les papilles du las des llanes el sur le còté dorsal des pattes, parce que c'est la senlement que le cylindre ne s'est pas rétracti. Les papilles accessoires relativement grandes sont un peu moins fortenent prizmentées. Les papilles de la face ventrale sont beamoup phis petites el de conlenr claire.

Comme il existe dans la ligne médiane et dorsale une raie claire provenant de ce quil 1'y a pas de papilles principales, mais seulement de petites papilles accessoires claires; dans cette région, la ligne claire, et encore plus les urganes clairs, ne sont pas très nets bien quils existent. Les organes ventranx sont presque partoul peu apparents.

L'oeil a un diamètre de 228 u. il ne semble pas y avoir d'organe frontal.

Les pattes sont an nombre de 28 ou 29 paires. Elles possèdent 3 papilles pédieuses sentement et 5 arceaux dont le $4^{\text {me }}$ et le $5^{\text {me }}$ sont un pen moins larges et le $5^{\text {me }}$ un peu plus court que les autres. Ce $5^{\text {me }}$ arceau n'est qu'incomplètenent développí sur les pattes 4 et 5 (Fig. I1 et 12).

Le tubercule urinaire des pattes 4 et 5 est situe entre le $3^{\text {me }}$ et le $4^{\text {me }}$ arcean, produisant une dépression très marquée sur ce dernier. Comme clıez heaucoup de Péripates caraïbes, ce tubercule est largement relié au $3^{\text {me }}$ arcean mais sans le modifier dans sa largeur et sa forme. Le pied porte trois papilles, doul deux sont situces dorsalement; les saillies sétilères antérieures portent deux soies, les postérieures une soie. I, fé fentes coxales ne montrent nulle part les vésicules dévaginées.

La bouche est enlourée d'une couronue de lobes qui sont au nombre de six paires, portant presque tous 4 eppines ehitineuses dont les deux externes sont plus grandes.

I la face antérienre de l'atrium se trouve une saillie impare avec ciny un six pointes chitineuses seulement.

Les mandibules internes montrent deux dents acressoires et une scie avec sept it 


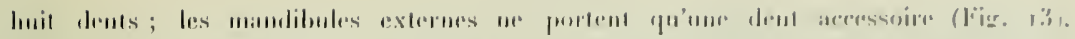

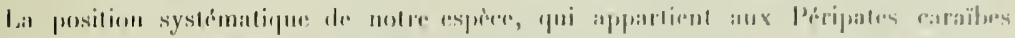

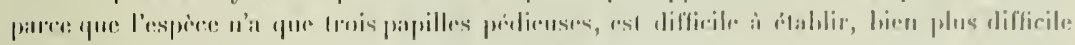

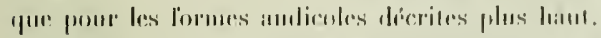

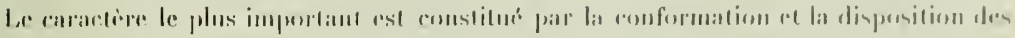

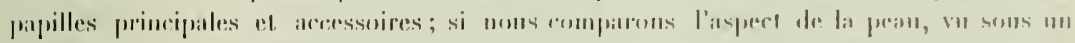

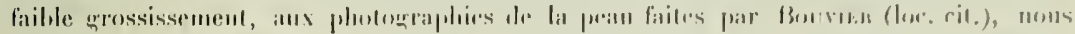

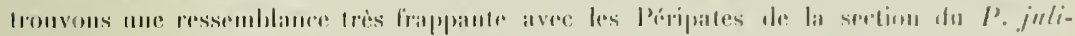

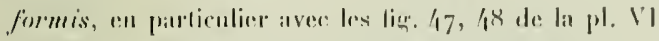

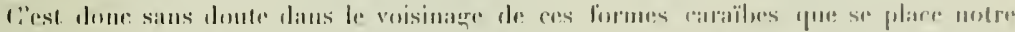

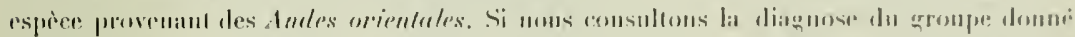

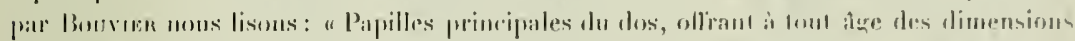

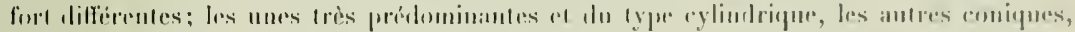

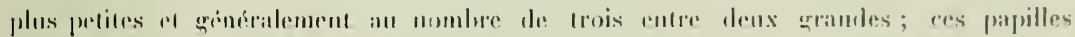

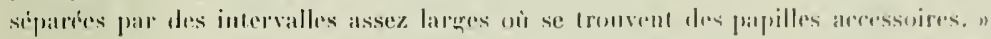

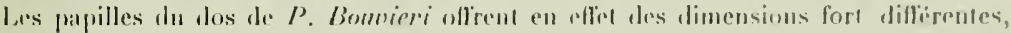

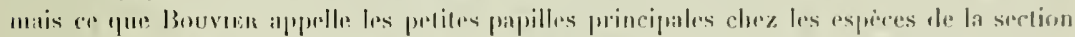

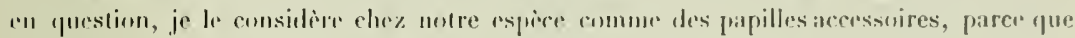

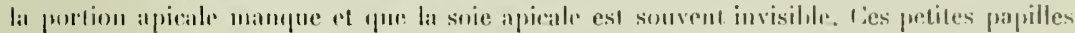

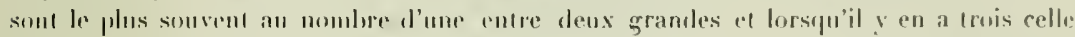

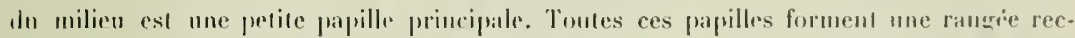

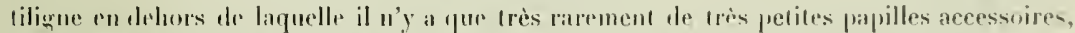

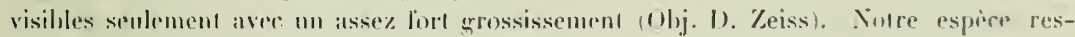
semble comme artangement des papilles à P. Sedguridi el P. Brölemanni; comme formes des papilles principale's ì l'. Brö̈lemanni.

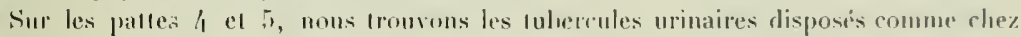

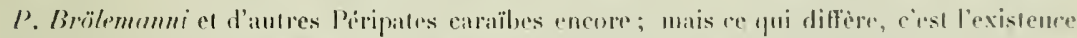

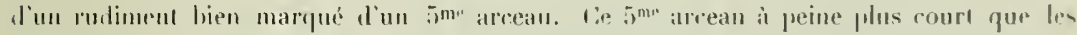

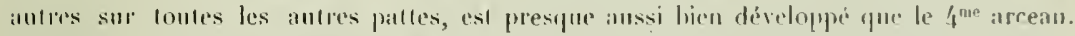

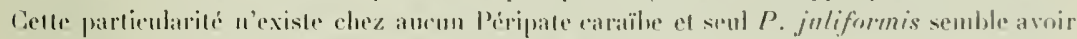
sur cortaines palles de pelits rudiments d'un jome areanu.

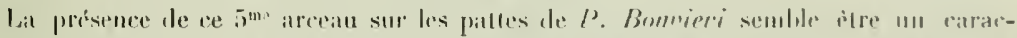

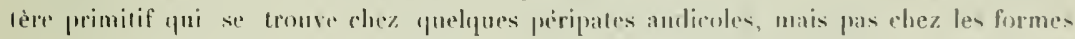

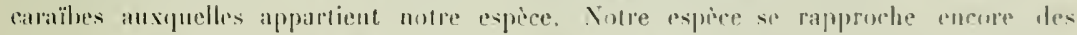
formes andicoles par l'existence de deux dents aceessures sur los manlibules internes. dispusition tres rare el exceptionnelle chez les propipates caräbes. les deux caracteres

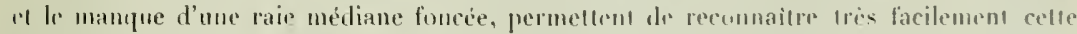
espece cariölos procenand des dudes. 


\section{$1911-$}

\section{Peripatus Eiseni Wheeler.}

Celle espèce nous fut envové par M. le professeur E.-1. (iöı, (Berne) qui l'avait reçue du Rio Purus, un des afflueuts supérieurs importants de la rive droite du lleuve des Amazones. Ses eanx ne vienuent pas des hautes chaines mèmes des Cordillères, mais des premiers pronontoires des Andes, conuus sous lo nom de Audes Comomanas. P. Eiseni est un Péripate andicole typique, trouve à Tepic, an Mexique, el it est fort intéressant de trouver cette espèce au Brisil (v. p. I 7 (j), dans une région on il ne devrait se trouver que des Péripates caraïbes. P. Eiseni est ainsi l'espèce qui a la plus gramle aire de dispersion, plus qrande que celle des formes caraïbes P. Edwardsi, P. Simoni et P. brasiliensis, qui semblent s’étendre du Brésil el de la Guyane, jusquanau Panama. Comme il n'y avait qu'un seul exemplaire, nous n'avous pu élulier que les caractires extérieurs de l'animal. Il est très décoloné, de teinte gris lorunàtre et a 29 paires de paltes. Les michoires ainsi que les luhercules urinaires sonl de mème conformation que chez les individns provenant du Mexique. La pean manque de plis incomplets régulierement disposés, et ceux-ci sont du reste rares.

\section{Peripatus ruber n. sp.}

Fig. 14 ì 16

Le Husce d'histoire naturelle de Genève a en Yobliquance de me soumettre mu Péripate collectionné par P. Bıoltex, én mars ı 890 , à Rancho Redondo (Costa-Rica) (6oo m. l'altitude). E.-L. Bouvier (loc cit.) a décrit du mème collectionneur et également de Costa-Rica le P. Biolleyi, espèce nellement différente de la nòtre mais rentrant également daus le groupe des Péripates carä̈bes.

Le seul exemplaire à notre disposition est long de 5,2 cm., large de $4 \mathrm{~mm}$., avec une épaisseur de $4 \mathrm{~mm}$. également. Le rétrécissement du corps en avant et en arrière est très peu important, puisque la tète et la région postérienre de l'animal sont larges de 3,2 mm. L'animal est de mème couleur sur le crité dorsal que sur le còté ventral, et sente la ligne médiane el dorsale est un peu plus foncée. Celte couleur est d'un gris brun clair, mais sur l'étiquette se trouve l'indication : couleur d'un rouge vif. Nous admettons done que la coloration de l'animal élail d'un rouge it peu press uniforme avec une ligne plus foncée sur le còté dorsal.

Les plis segmentaires 12 par segment) sont tous complets à l'exception de deux, régulièrement disposés à la liauteur des pattes. Ces plis incomplets, de lonģueurs diffërentes, aliernent régulièrement avec des plis complets, partant de la ligne médiane, ils sont longs de 1,3 à r,9 mm. el descendent dous jusqu'au milicu des llancs de l'animal. Le's papilles qui courrent les phlis sont les nnes de grande taille, el dominent les antres 


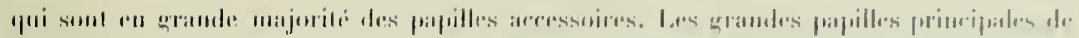

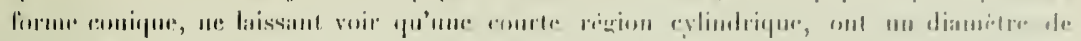

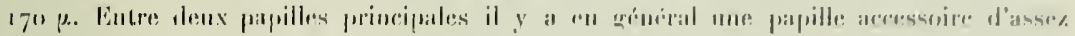

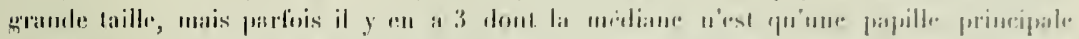

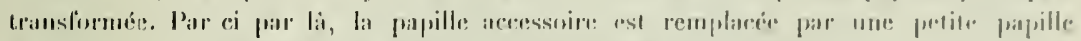

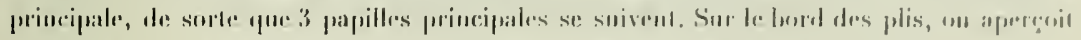

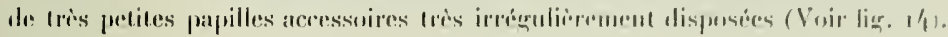
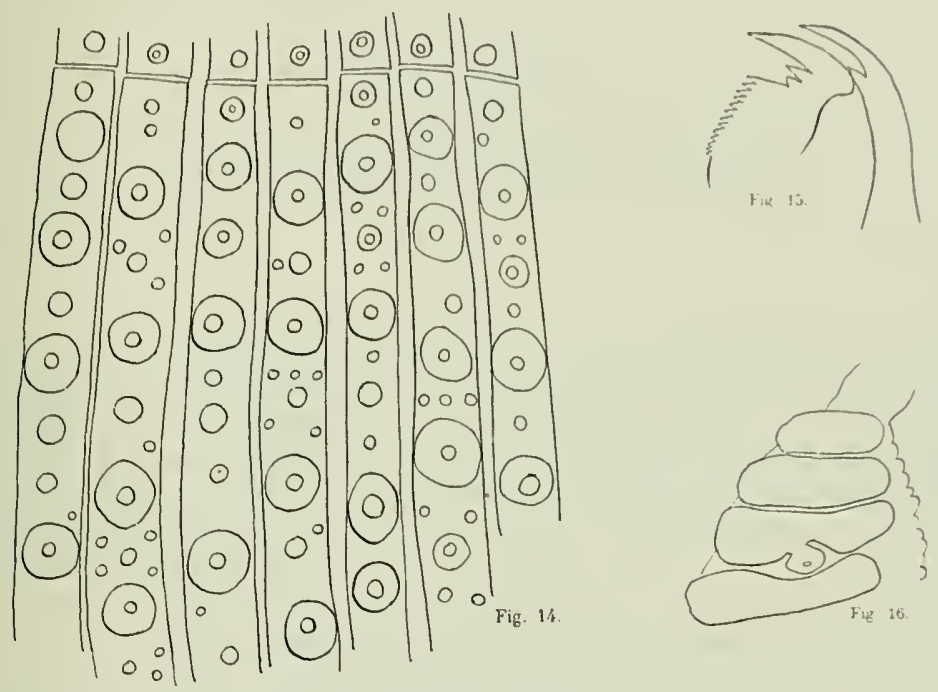

La face ventrale montre de triss mombrouses pajulles; sept des plis dursabx passent entre les pattes et tratersent la face ventrale; entre eux sintercalent de courts plis qui oflent par place l'arrangement sirie des papilles. Dans la rénion ventrale situce entre les palles, les papilles ne sont pals arrangées en sírie.

La ligne claire est peu nelte, et les organes clairs invisibles. Sur la face ventrale, il ne semble exister ancun organe ventral. L'teil a un diamitre te 228 .

La lame interne des mandibules a drux dents acessoires et me scie portant it it 3 dents. La lame exterme ne porte quime dent accessoire (Fig. r5).

Chez notre unique imlividu, le nombre des paires de patles pourves de Irois papilles pridieuses est de 30 . Toutes sont assez distantes les unes des autres, et seules les 3 promièr's paires et les 3 derniores sont nettement plus petites que les autres. Les tubercule-

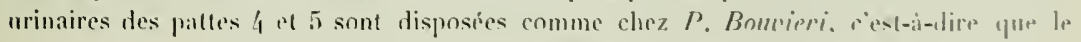




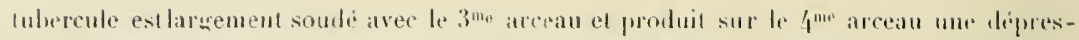
sion assez profonde. Contrairement à up qu nous trouvons chez l'espèce précédente, il

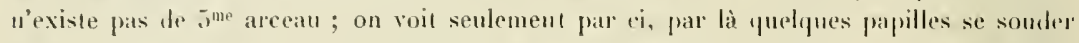

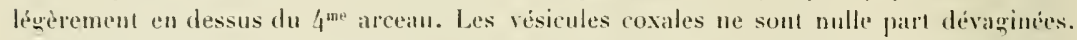
L'ouverture sexuefle de la femelle est située entre les paltes de l'avant-demidre paire.

Cette nouvelle espece rentre probablement dans la section du $P$, juliformis. 


\section{Hydracarina de Colombie.}

I.WH I, F:

Dr C. WALTER.

Institut zoologique de l'Université de BALE.

Les récoltes scientiliques faites par M. Le professenr O. Fumnaxs, en Colombie, contiennent une petite collection d'hydracariens clont l'étule nous a ditó confiée. Malgré lo nombre restreint d'esprèces différentes - nous en comptons quatre - nous pousons signaler des résultats d'une certaine valeur, car nos eonnaissances hydracarinologiques concernant l'Amérique du Sul sont encore si pen étondues que chaque contribution est d'aulant plus préciousr. Elles nous permettent de prévoir une faune sinon très variéce en genres, du moins riche en espèces.

Les espèces récoltís en Colombie appattienuent toutes à des gronres très répandus. Trois d'entri clles, Eylais columbiensis n. sp., Limnesia fuhrmanni n. sp. et Arrhenurus fuhrmanni n. sp., loivent ètre considriées comme nouvelles. La quitrième, Limnesia panciseta Ribaga, a déjà été signalée pour la faune de l'Arunentint. Il nous a itŕ possible de eompléter la diagnose donné par son anteur.

\section{Description des espèces.}

\section{Eylais columbiensis n. sp.}

Habitat: Lagune près de Madrid, Sabana de Bngota, $2650 \mathrm{~m}$., Cordillères orientales. Le sexe du seul exemplaire récolté n’a pu ètre déterminé. Cette espèce se range parmi les petites du genre, car la longueur du corps ne dípasse pas 2 mm. En largeur, il mesure $1,650 \mathrm{~mm}$. Son contour présente la forme d'un ovale rétréci antérieurement.

L'épiderme est assez grossièrement strié, et il montre en plus une granulation peu 25 


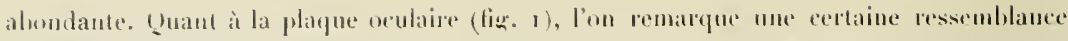

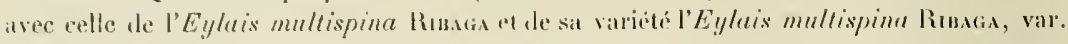
hrevipalpis Rusagi, les deux habitant l'Anérique du Sul. Le font interuculate est assez lange. Sou lord autiricur, it peine ondule, relie lout à fait en avant, les deux bords des capsules oculaires. Lon reconnail cepentant nur tris légère concavité mćdiane. Le hord postérieur du pont présente en son milien une découpure semi-circulaire qui, s’álargissant en arrière, se continue le long des capsules oculaires. Les points d'insertion des soies sensitives sont doignés de la ligne médiane el se tronvent adossés aux capsules oculaires.

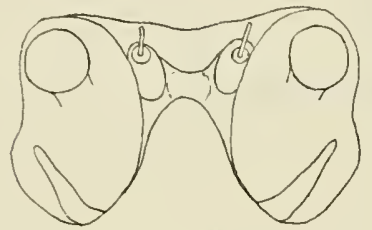

Fig. 1 .

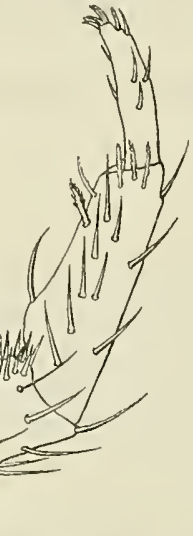

Fig. 2

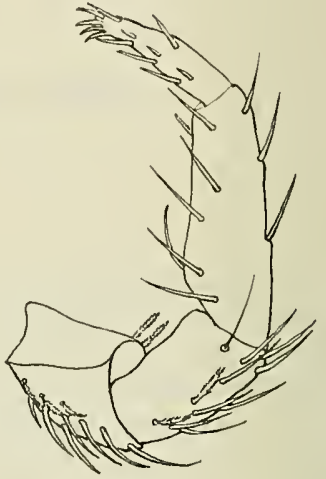

Fig. 3.

Fig. 1. - Eylais columbiensis n. sp. : plaque oculaire.

Fig. 2. - Eylais columbiensis n. sp. : palpe droit, face intérieure.

Fig. 3. - Eylais columbiensis n. sp. : palpe gauche, face extèrieure.

La plaque de fixation des muscles est située entre les points d'insertion susmentionnés, mais légèrement en recul, sans pourtant dépasser en arrière le hord dn pont. Les capsules oculaires sont réniformes et orientées parallèlement à l'axe longitudinal du corps. La structure de la chitine n'est pas très grossic̀rcment poreuse. Les lentilles de la première paire d'yeux sont de grandeur moyenne, circulaires et placées sur de conrts pédoncules. Celles de la seconde paire ont une forme très allongée, plus large dans leur partie intérieure qu'extérieurenent.

L'organe maxillaire, long de $0,465 \mathrm{~mm}$., pharyux y compris, n'a qu'une faible largeur $(0,270 \mathrm{~mm}$.). La plaque buccale, située assez ell avant, ne présente pas un contour absolument circulaire. Elle est un peu plus Jongue que large, tandis que la frange buccale est tout à fail ronde (dianc̀tre $0, \mathrm{to0} \mathrm{inm}$.). Le bord antérieur de l'organe maxillaire ne 


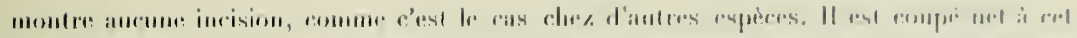

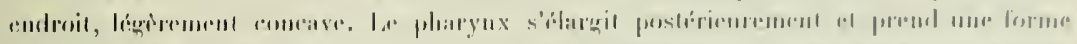

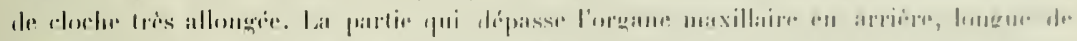

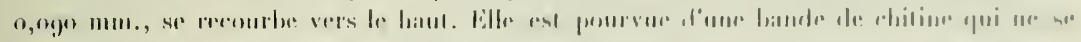

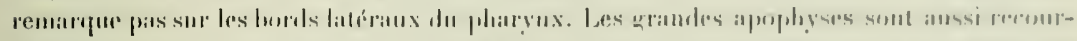

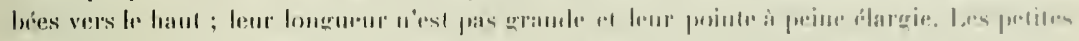

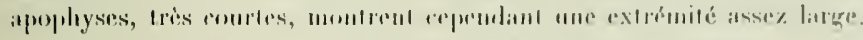

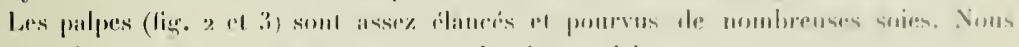

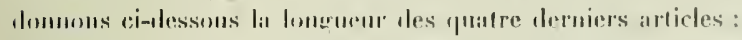

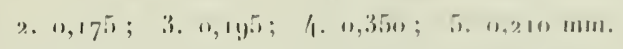

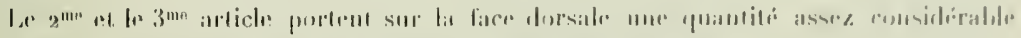

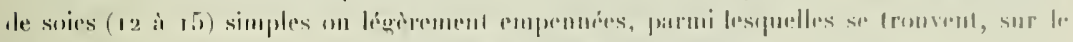

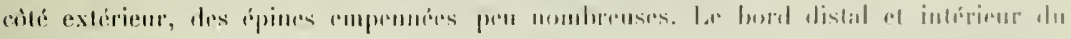

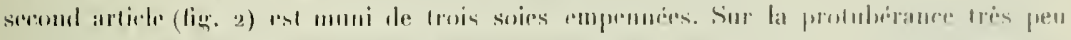

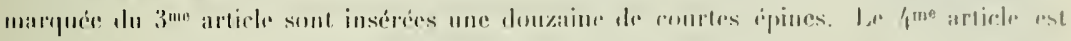

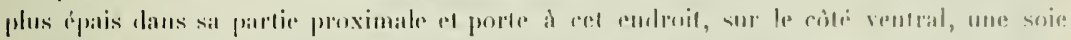

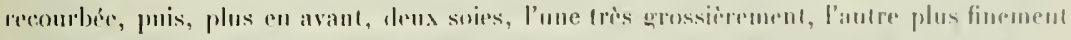

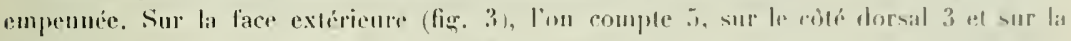

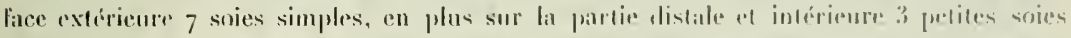

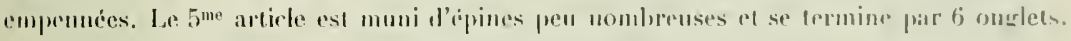

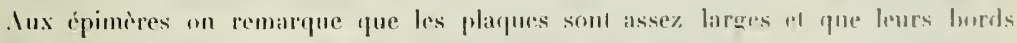

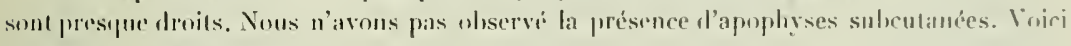
la longueur tles jambes:

$$
\text { I. } 1,800 ; \text { II. } 1,875 ; \text { III. } 2,100 ; 11.2,400 \mathrm{~mm} \text {. }
$$

\section{Limnesia pauciseta Ribaga.}

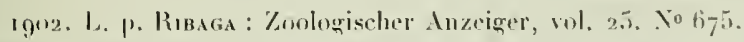

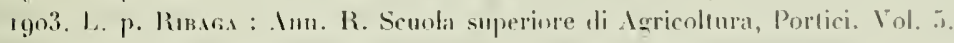

Habitul: Mlu Don Elias, 2100 m., matrais Cordillères centrales.

A l'aidr de lindivilu ricolté, il nous sera possible de compléter la diacruose ansez

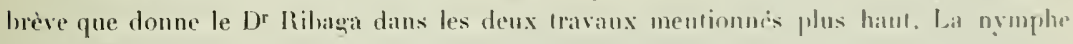
lia pas été clécritr jusqu ì ce jour :

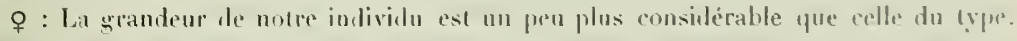
Rempli d'une grande quantifé de petits ceufs (diamitre $0,165 \mathrm{~mm}$.). le corps alteint unt longueur de $1,400 \mathrm{~mm}$. La largeur maximale est de 1,200 mm. Le contour du corps ressemble à une ellipse: lon remarque cependant que les cobés latiraux sunt lígèrement aplatis dans la région des geux. Les deux yeux de chaque cỏté. silués au lond, sunt trépetils a bien distinclement séparés. Lin distance entre les deux paires es rlo $0.40 .5 \mathrm{~mm}$ 1 l'etal conservé ba coloration parait diun heu verdatre. Lépiderme est lisse. 
L'organe maxillaire (longueur 0.280 mus possede un rostre court de forme conique. La mandibule atteint une longueur de $0,115 \mathrm{~mm}$. el est munie d'un crochet presque droit. I part quelques details peu importants, les palpes ne dithérent pas de ceux de ba forme trpe. Loun remarque en plus la présence de quelques soies sur les còtés latéraux des $2^{\text {me }}$ a $^{3 \text { me }}$ articles et d'une soie assez longue il l'extrémité distale et dorsale du 3 mo segment, et d'autre part, l'absence d'un troisième poil tactile sur la face ventrale du $4^{\text {me }}$ article. Voici la longueur des dilfirents articles :

1. 0,052 แmm.; 2. 0,209 mm.; 3. 0,125 mm.; 4. 0,286 mm.; 5. 1,066 mm.

Les deux premières paires de plaques épimérales sont reliées à la base des organes buecaux par une bande sulicutanée de chitine. Lenrs apophyses communes sont très peu distinctes et ne s'étendent pas très loin cu arrière. Le bord intérieur de la plaque formée par la $3^{\text {me }}$ et $4^{\text {tne }}$ épimère forme une ligne sinueuse, concave en son milieu.

Malheureusement il nous est im-

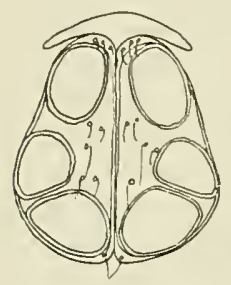

Fig. 4 .

Limnesia pauciseta Ribaga ㅇ.

Organe génital. possible de donner les mesures de la longueur des extrémitès, celles-ci ayant été cassées en partie, ni de parler du dernier article de la $4^{\text {me }}$ jambe. Nous avons cependant pu constater la présence de soies natatoires el observer la structure des ongles qui sont munis d'une petite dent accessoire extérieure et d'une plus grande à l'intérieur.

l'organe génital (tie. 4) de l'iı-

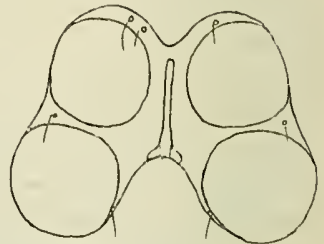

Fig. 5

Limmesia paucisela Ribaga. Organe génital de ta nymphe. dividu déerit par Ribaga ne semble

pas aroir été dans un état irréprochable. Les fentes que montrent les plaques gémitales ainsi que la concavité de leurs bords intérieurs ne doivent pas ètre normales. Les deux plaques de notre exemplaire ont ensemble la forme d'une poire (longneur $1,280 \mathrm{~mm}$., largeur prise dans la partie postérieure $0,245 \mathrm{~mm}$.). L'emplacement des disques esı le mème que chez le type. Les deux postérieurs de chaque plaque sont si rapprochés qu'ils s'aplatissent à l'endroit où ils se touchent.

\section{L'anus est situé très en arrière.}

Vymphe: Il nous a été possible d'étudier une nymphe de la mème provenance, et nous croyons pouvoir la décrire comme appartenant à cette espèce.

Le corps qui, en longueur mesure $0,600 \mathrm{~mm}$., en largeur $0,450 \mathrm{~mm}$., a une lorme ovale. Le bord antérieur est bien arrondi. Il porte de couttes soies antenniformes, légèrement recourbées en arrière. Une striation très tine caractérise l'épidernue.

Le $3^{\text {me }}$ article des palpes est assez fort, le $4^{\text {me }}$ élancé et de largeur à peu jrès égale sur toute son étendue. Les soies tactiles dı côté ventral sont insérées à un liers ou un quart de l'extrémité distale. Le dernier article, le forme élancée, est nuni de un à deux onglets. 


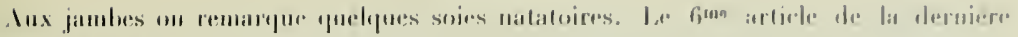
paire rest asse\% lomge.

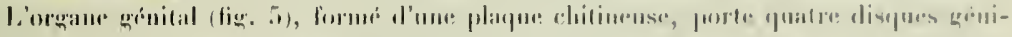

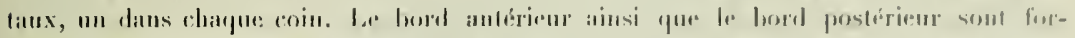

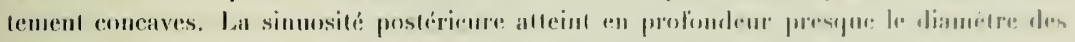

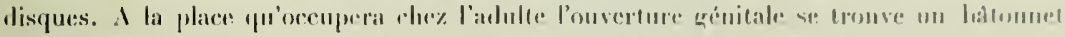

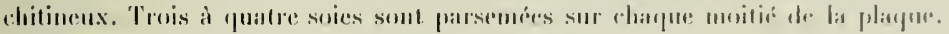

\section{Limnesia fuhrmanni $n$, sp.}

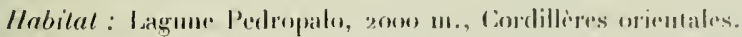

Lagume (Tbaque, zorio m., Cordilleres orientales.

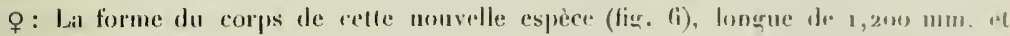

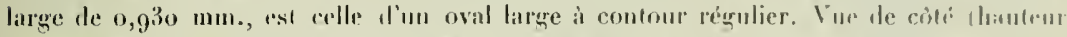
$0,750 \mathrm{~mm}$.) la partic postérieure présente une légerme dipression. Les denx paires d'yenx.

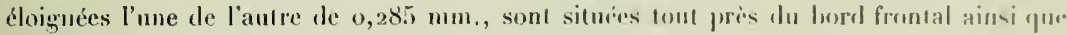
les soies antenniformes pui sont faibles et recourlues an arriere.

L'épiderme montre de petites rugosites, camsées tres probablement par lit conservation. A cet état, la coloration est d'un vert brun pour le corps, et verdàtre pusr les palpres et les jambes.

L'organe maxillaire se termine in $1 \mathrm{n}$ rostre très court. La mandilunle a mur fon-

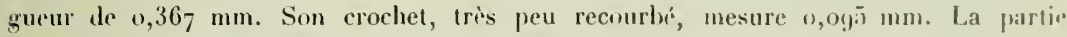
basale ne s'élargit que peu, pour s'effiler ensurte en forme de coun. Au milien de la face ventrale du second article palpaire (fig. 7), on trouve une pointe clitineuse fixée verticalement ou peu inclinée 'n avant, non sur m mamelon hasal, mais sur l'article luimème. Sur le côté dorsal, l'on compte 5 a ti soirs asse rourtes. Compraró à la limmesin volzi Piersig, l'avant-dernier article n'est pas épais, mais élancé. Dans lo tiers distal de la facr ventrale sont insírés, sur de petites protulnerances, les drux soies lactiles entourés de quelques soies très courtes. Le dernier arlicle est aussi plus ilance que chez la forme susmentionnée al se termine par derx onglets il peim perceptibles. I.ps articles des palpes ont la longueur suivante :

1. 0,035 mm.; 2. 0, 50 mm.; 3. 0,122 mm.; 4. 10,220 mun.; 5. n,063 mm.

Les épinceres (tig. 6) sont situces à quelque distance du herd anterieur du corps. Contrairement à limmesin volzi Prensig, les deux premières paires sont tris rapprochées l'une de lautre "r mème rliées par un ligament sous-cutane. Lapophrse chitineuse qui part de leur bord postérieur est dirigée fatiralement. C'ne distance de 0, $105 \mathrm{~mm}$. sépare les deux paires les $3^{\text {me }}$ el $4^{\text {mes }}$ épimères. Le bord extérieur de la $4^{\text {me }}$

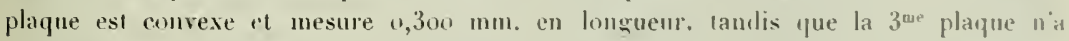
que o,ogo mm. de long. Le pore excrélem et ha soir qui l'avoisine sont placés comme chez d'iutres espèces du genre. 
Les jambes misurent :

I. 0.600 mm.: II. $0,765 \mathrm{~mm}$.: III. $6,810 \mathrm{~mm}$ : IV. 1, $125 \mathrm{~mm}$.

L'on tromer des suies natatoires sur les articles suivants: sur le fme de la seconde ; sur le $5^{\mathrm{mp}}$ de la troisiène quatrieme jamle porte, comme chez Limnesia volzi P’ansig, eing soies en une rangén et une soie terminale, longue de o, 098 mm.
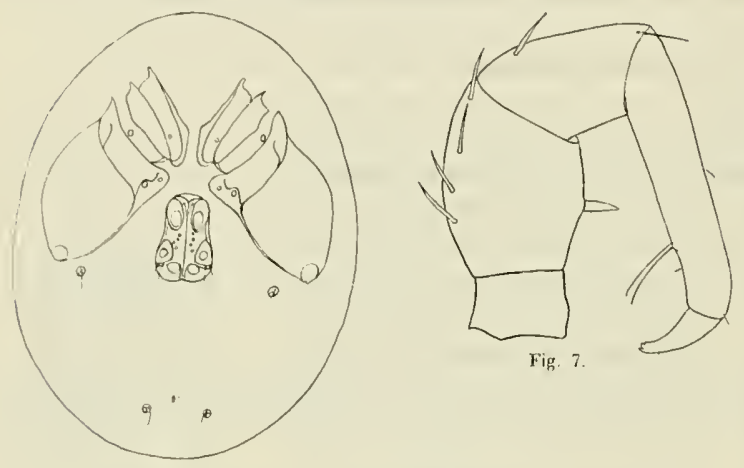

Fig. 6 .

Fig. 6. - Limnesia fuhmanni n. sp. 9 : face ventrale.

Fig. 7. - Limnesia fuhrmanni n. sp. 9 : palpe.
L'organe génital (fig. 6) mesure $0,240 \mathrm{~mm}$. de longueur. Sil largeur dans la partie postérieure est de o, r7o mm., dans la partie antérieure le $o$, r $35 \mathrm{~mm}$. La forme «st ì peu pròs pareille à l'organe de Limnesin fulgida C.-L. Коон, assez allongée avec les còtés concaves. En avant elle ne se rétrécit pas antant que chez Limnesia volsi Piensig. La position et la forme des disques génitanx sont

caractéristiques pour l'espèce. Le disque, silné tout ell avant, ressemble à un ovale rellversé. Il est le plus grand des trois $(0,087 \mathrm{~mm}$.), sur claque plaque. Le second est adossé au dernier, yıi, placé en traver's, occupe toute la largeur d'une plaque génitale. Entre les deux premiers disques, on compte quatre courtes soies sur chaque plaque et quelques-unes sur les bords.

L'ouverture anale se trouve dans le dernier tiers, entre l'organe génital et le bord postérieur du corps.

6: Le mâle est plus petit que la ㅇ $(0,750 \mathrm{~mm}$.), mais proportionnellement plus large $(\omega, 600 \mathrm{~mm}$.$) . La partie frontale surtont est moins pointue. Les pointes des pre-$ mières épimères la répassent eu avant. Les palpes aussi sont plus courtes.

Les articles mesurent:

1. 0,03 г $\mathrm{mm} . ; 2$. $0,126 \mathrm{~mm}$. ; 3. $0,070 \mathrm{~mm} . ; 4.0,157 \mathrm{~mm} . ; 5$. $0,045 \mathrm{~mm}$.

L'organe génital (longuenr a, $164 \mathrm{~mm}$., largeur $0,220 \mathrm{~mm}$ ) a la forme d'une pomme partagéc par le milieu (fig. 8). Son ouverture, longue de $0,122 \mathrm{~mm}$, est complètement entourée par les deux plaques génitales. Ces dernières ne se touchent cependant ni antérieurement, ni postérieurement. Les disques sont grands, leur disposilion sur cliaque plaque falciforme. Les deux premiers ne se touchent pas. Le second et lo troisiems: 


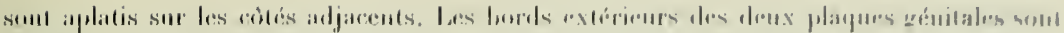

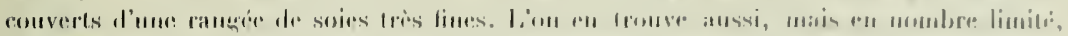
entro les distgurs.

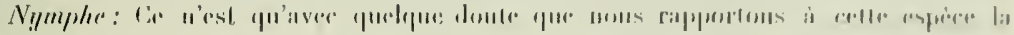

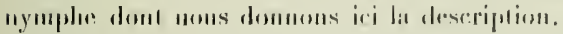

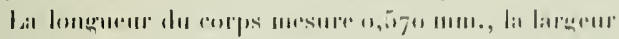

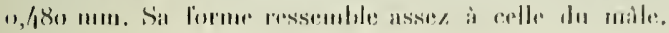

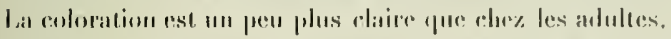
Le secomel article palpaire ne: pusside pas encore la dem

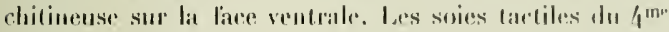
article se: Arouvent an milien de la fares ventrale, dome

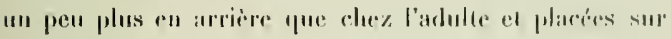
des probuhérances un pen plus prononées. A parlir de cet entroit, lo $4^{\text {me }}$ arlicle présinte une concavité se courbe légèrement vers le lias.

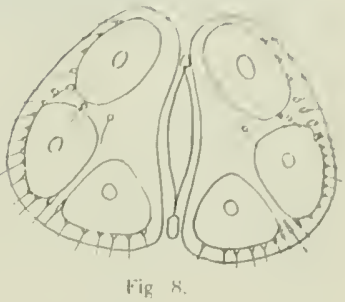

La plaqu acinitale (lig. 9) est munie de puatre disques. Son hord intérieur montre la forme olservít clies.

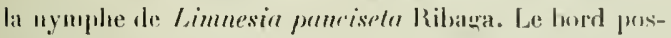
térieur rst presifur droit.

Les soies natatoires sont plus nombreuses que rhe\% la nymplie susmentionuce.

\section{Arrhenurus fuhrmanni n. sp.}

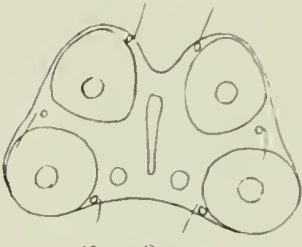

Fing. 9

Fig. 8.

Ilabitat: Lagune Pedropalo, $2000 \mathrm{~m}$. Cincillieres orientales.

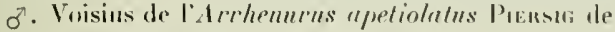
l'Amérique du Nord el de l'Arrhenurus ludificalor

hrmianni n. sp. $\sim$.

Fig. 9.

limnesia fuhmanni n. sp. : Nymphe. Organe génilal.

Kantke du Brésil, les individus récoltés présentent pourtant des différences assez considérables pour chahlir wae nouvelle espès.

Malqué la longueur du corps plus restreinte $(0,870$ is 0,9 s 5 mm.) que chez Arrhenurus: apetinlatus Punsug l'appendice est pourtant aussi lone que chez celte espiece $(0,420 \mathrm{~mm}$.). La largeur du corps est aussi moins gramle; elle ne mesure que 0,450 mm. Les hords des plaques génitales de claque còté de la hase de lappendice ne sont pas aussi visihles (fig. 10). L'appendice lui-mème esl plus élancé el il nr' s'élargit point postérieuremenı. Il est au contraire moins large qu'en arant ou se trouve un épaississement. Son bord postírieur se termine en deux pointes assez transparentes, siparées par une concavité semicirculaire. La papille mediane, qui, chez l'Arrhenurlas apeliolalns: Puersigr, se Iromve éloignéc du hord, n'existe pas chez notre espècr ; les deux latérales sont cependant repré- 
sentées. Vue de côté (fig. 11) la ligne torsale reste assez longrtemps parallèle à la ligne. ventrale, puis par une hrosque déclivitín alteint la hase de l'appendice. Ce dernier est de forme phus élancér. Ses lignes ventrale et dorsale sunt aussi parallètes et la partie postérieure se termine en forme de còne. la come, placís verticalement, est plus pointue et plus haute, limitée de lignes droites.

Les pointes des deux premières paires d'épimères ne sont pas autant pointues que chez l'A rrhenurus apelinlalus Piersigr el l'on trouve aussi des différences aux $3^{\text {mes }}$ et $4^{\text {mex }}$

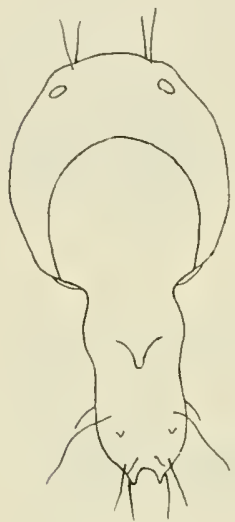

Fig. 10.

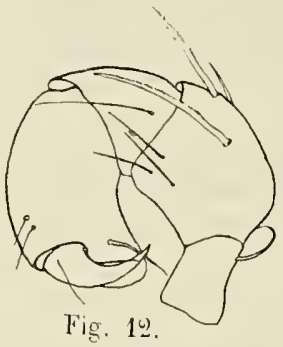

Fig. 12)

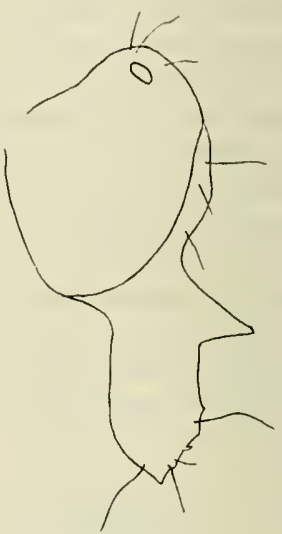

Fig. 11

Fig. 10. - Arrhenurus fuhrmanni n. sp. : vue dorsale.

Fig. 11. - Arrhenurus fuhrmanni n. sp. : vue lalérale.

Fig. 12. - Arrhenurus fuhrmanni n. sp. : palpe droit.

plaques épimérales. La distance entre les $3^{\text {mes }}$ épimères est plus considérable que celle cntre les $4^{\text {mes. }}$ L'espace qui sépare ces dernières s'agrandit cependant en avant. Le bord postérieur de la $4^{\text {me }}$ plaque montre une concavité plus profonde.

L'organe génital ressemble à celui de l'espèce de Prersif. Pourtant l'on remarque que l'ouverture génitale est large.

Les chiffres suivants donnent la longueur des articles des palpes:

$$
\text { 1. } 0,028 ; 2.0,062 ; 3.0,040 ; 4.0,068 ; 5.0,035 \mathrm{~mm} \text {. }
$$

Sur la face intérieure du second article (fig. 12), l'on trouve une très longue soie empennée el trois petites placées près du boirl distal et ventral. L'apophyse aplatie du $4^{\text {me }}$ article est munie d'une soie recourbée.

Nous donnons ci-dessous les mesures des jambes:

$$
\text { 1. } 0,450 ; \text { II. } 0,465 \text {; III. } 0,5 / 40 ; \text { IV. } 0,735 \mathrm{~mm} \text {. }
$$




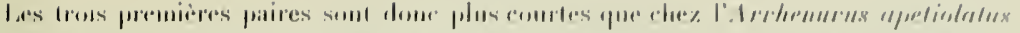

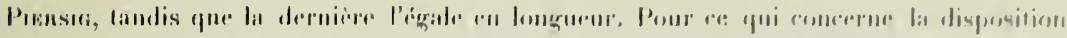

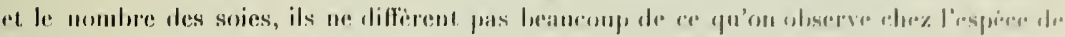

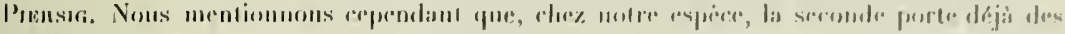

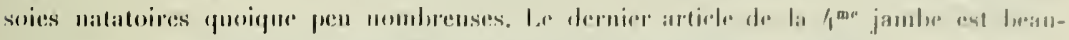

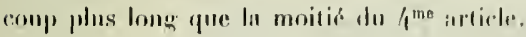




\title{
Die Oligochrten Columbias
}

\author{
VON \\ W. MICHAELSEN (HAMBURG)
}

(Mit einer Tafel und 2 Abbildungen im Text.)

Als ich die Bearbeitung der von Herrn Dr. O. Fuнruaxs in Columbia gesammelten Oligochäten übernahm, meinte ich geringe Mühe davon zu hahen. Ich glaubte nicht, dass diese Ausbeute erheblich von der aus denselben Distrikten Columbias stammenden, früher von nir bearbeiteten Bürger'schen Sammlung abweichen würde. Im Laufe der Durcharbeitung stellte sich jedoch mehr und mehr heraus, dass ich mich hierin geirrt hatte. Nur wenigge der Arten sind in beiden Ausbeuten vertreten; die neue Ausbeute hestand grösstenteils aus neuen oder bisher nicht in Columbia nachgewiesenen Arten. Worauf diese Verschiedenheit der beiden Ausbeuten zurückzuführen sein mag, bleiht mir fraglich. Dass sie auf Verschiedenheit der Sammelmethode heruht, wie Herr Prof. Funrmans vermutet ${ }^{4}$, will mir nicht recht einleuchten; dafür sehen sich die Ausbeuten habituell zu ähnlich ; beide enthalten Zwergformen, mittlere Grössen und Riesenformen; beide sind reich an endemischen Arten und weisen annähernd den gleichen Prozentsatz an peregrinen Formen auf. Die annehmlarste Erklärung scheint mir doch die zı sein, dass die Oligochätenfauna Columbias sehr reich und mannigfaltig ist, und dass die beiden Ausbeuten nur Stichproben derselben darstellen.

Unsere bisherigen Kenntnisse über die Oligochätenfauna Columbias beruhen hauptsächlich auf meiner Verölfentlichung über die Ausbente Prof. Bünger's (I. c. 19oo, II). Ausser dieser sind nur einige sporadische Angaben über colnmbianische Oligochäten veröffentlicht wordeı, wie sich aus den folgenden Literatur- and Faunen-Zusammenstellungen ersehen lässt.

1 Herr Prol. Funamaxs teilte mir mit, dass er seine Oligochäten nicht durch Ausgrabung erbeutet, sondern hauptsächlich unter gefattenen Baumstämmen gesanmelı habe. 


\section{Literatur über columbianische Oligochäten.}

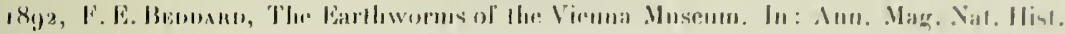
(i) $I X$.

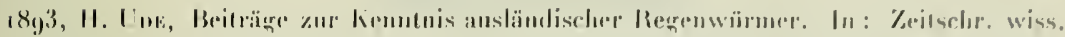
Zowl. I, I'll.

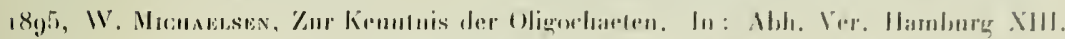

1897,

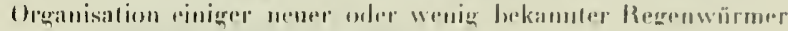

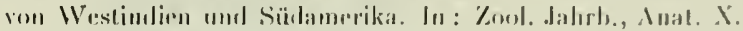

(g) (1) (1), -

$1900,111), \quad-$

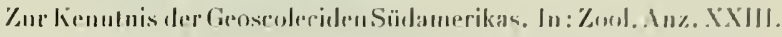

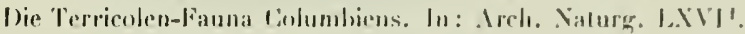

\section{Liste der Oligochäten Columbias}

cinschliesslich der unten anghrgehenen Arten.

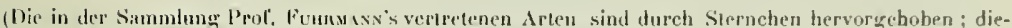
jenigen dersiben, die lär Colnmbiat neu sind, durch zwei Sternchens.

\section{Fam. Naididae.}

** Dero sp.

** Slavina appendiculata (I DE.K.).

** Pristima longiseta Euras. f. typica.

* - aequiseta Bourne, var.?

Fam. Enchytraeidae.

** Ilenlea columbiana n. sp.

Fam. Megascolecidae.

Subfam. Trigastrinae.

*Dichongster Modiglianii (Ros.).

* - Bolani (Micr.)

- "ffinis (Micu.) [1. c. Micmasasex squo (II) p. 234 : Benhamia a.

* _ - medellina n. sp. 
Subfam. Megascolecinae.

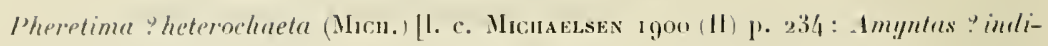
cus (Нокs)].

Subfam. Ocnerodrilinae.

** Ocnerodrilus (Ilyogenia) Calwoodi (Мсн.)

\section{Fam. Glossoscolecidae.}

\section{Subfam. Glossoscolecinae.}

Hesyeroseolex columbiunus (Micn.) I. c. Micnaelsen 1900 (II) P. 259 : Trichochuetu columbiana].

** Periscolex Fuhrmanni n. sp.

** - vialis $\mathrm{n}$. $\mathrm{sp}$.

** Pontoscolex corethrurus (Fк. MüLL.).

** Rhinodrilus (Thamnodrilus) Cameliae n. sp.

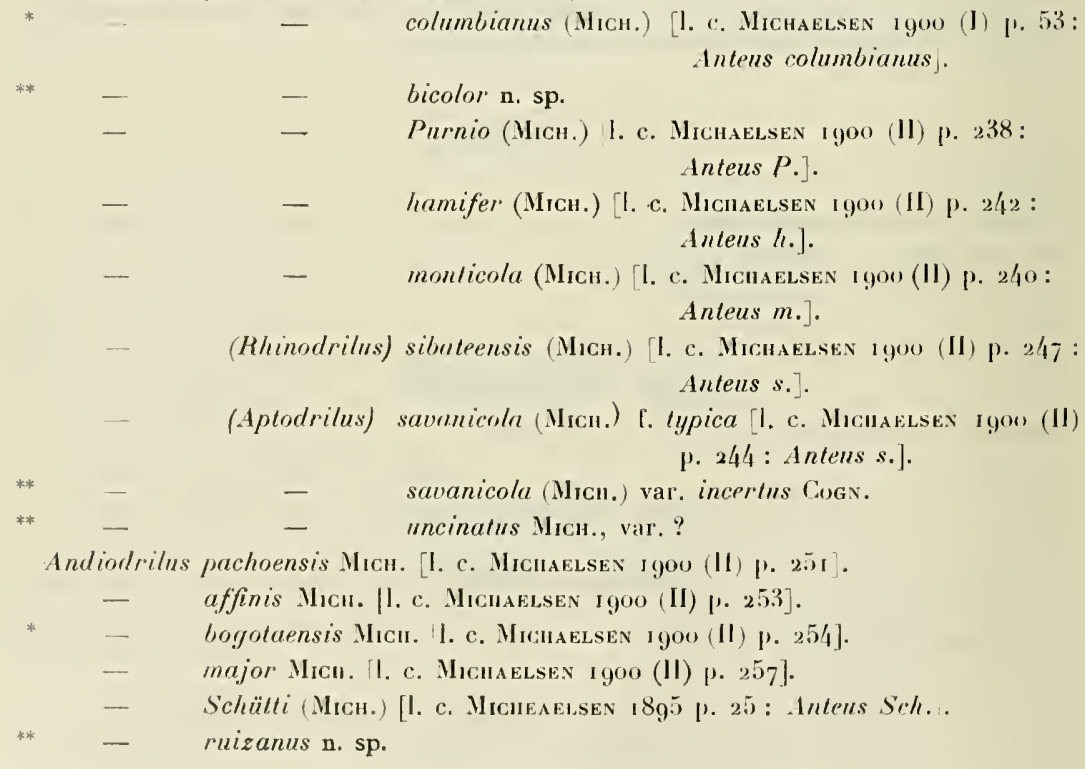




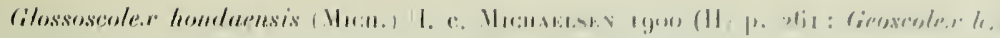

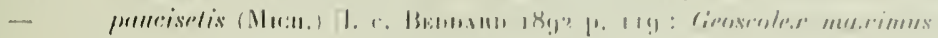

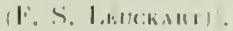

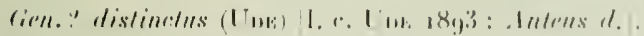

\section{Subfam. Criodrilinae.}

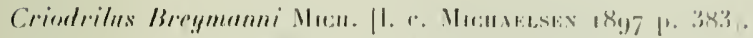

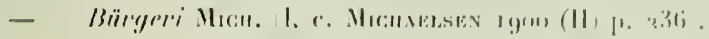

\section{Fam. Lumbricidae.}

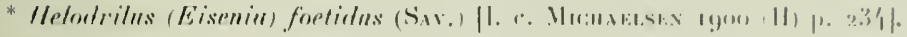

***

- - - moserse isivel.

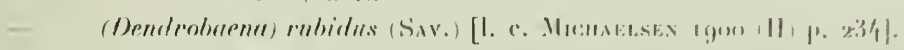

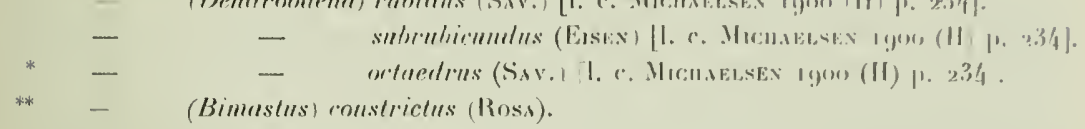

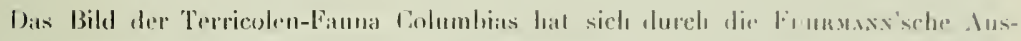

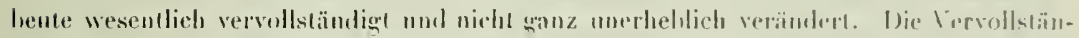

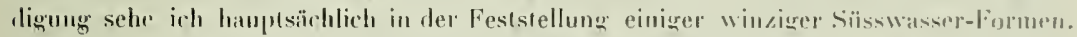

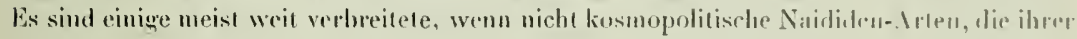

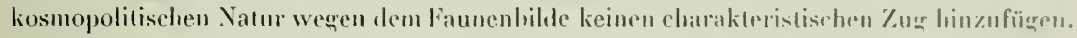

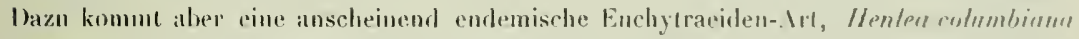

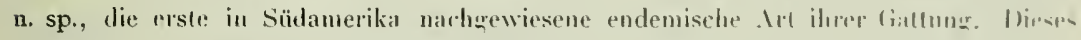
Vorkommen sehliessl sich eng an dir zentral-und nordanerikanischn linde endemisher Henleen, wie sie uns durch Essex's jüngsle Irbeil bekannt geworden sinel! an.

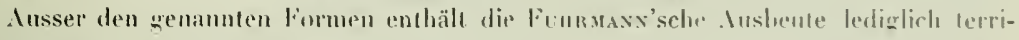
role Fomen. Enter diesen finden sich mehrere perentine, wahrscheinlich durch den

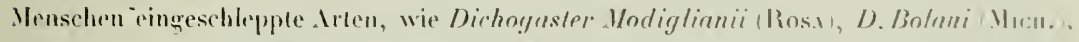

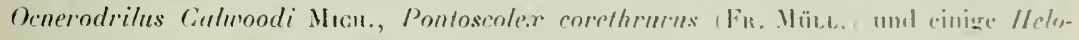
drilus-Arlen, die zur Charakterisierung der columbianischen Terricolen-fauna sollus diann

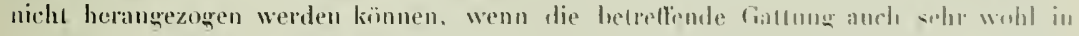

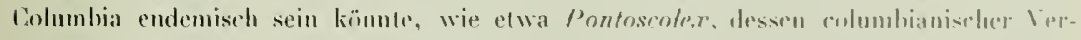

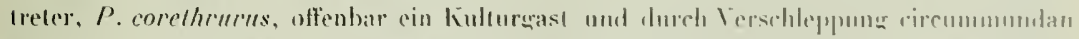

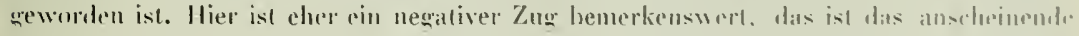

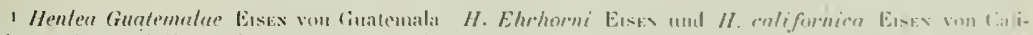

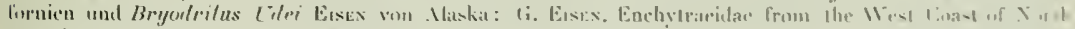
America. In: Marriman Exped. .Maska NII. p. pis u. i. 
Fehlen von Helodrilus (Allohohophora) caliginosus ( $\mathrm{S}_{\mathrm{A}} \mathrm{r}$.) in Columbia. Diese Art ist wohl die weitest verbreitete unter allen Obligochätan, die sownhl in den katten und gemässiglen, wie in den warmen und heissen Zonen sunst üherall da auflutl, wo sich der Europäer mit seiner Gartenkultur festgesetat hat. Von den meisten benachharten Ländern, von Mexico, Costa Rica, Ecuador. Peru und Bolivia, ist diese Art bekannt. In Columhia ist sie bis jetzt nieht nachgewiesen worden, trotzdem die beiden Haupt-Ausheuten von dor anch zahlreiche liulturgäste, darunter vicle eingeschleppte Lumbriciden, enthielten. Schon leei der Veröllentlichung der Büngkn schen Aushente machte ich auf dieso eigentümliehe Lücke in der Verhreitung dieser Arl aufnerksam (I. c. 1900 (II) p. 234).

Unter den endemischen Terricolen der ncuen Ausbente sind zunäclist zwei nene Periscolex-Irten hervorzuleben. Die Gallung Periscolex war hisher in der colmubianischen Fauna nicht vertreten; doch ist dieser Fund nicht überraschend. Columbia liegrt anl' dem Wege zwischen den bisher behannten Sondergebieten dieser Gallung, Ecuador und Darien. Bedeutsamer ist vielleicht noch der Nachweis einer oflenbar endemischen Dichoguster-Art in Columbla, ron wo diese äthiopisch-westindisch-zentralamerikanische Gattung hisher utr durch einige peregrine Arten bekannt war. Diese zu der Gruppe det zentralamerikanischen D. Guatemalue (EIsEx) gehörige A.l (D. medellina n. sp.) zeight ein Hineinragen der westindisch-zentralamerikanischen Fanna in den Nordwestwinkel des südamerikanisclien hontinents, ein liegenstück zu den Funde einzelner Glossoscoleciden in Zentralamerika, die ein Ilineinragen der tropiscls-südamerikanischen Fauna in das zentralamerikanische Terricolengehiel erweisen. Eine angeblich endemische Dirhogaster- Art, D. andina Cogn, soll mach Cognetri auch in Ecuador vorkommen. Es erscheint mir aber fraglich, ol as sich hier tatsïchich um ein endemisches Vorkommen handelt. Jedenfalls gehört $D$. andina nicht zu der typisch zentratamerikanisclıwestindischen Gruppe dieser Gallung.

Die älorigen, hier nicht weiter hervorgeholsenen entemischen drten der Fumnans' schen lusbeute gehören der Yypisch columbianischen Gatung Andiodrilus und der IYpisch tropisch- südamerikanischen Gallung lhinodrilus an.

Das Gesambild der endemischen Terricolen Columbias ist nunmehr folgendes: Abgesehen von einem sehr geringen Einschlag ans der zentralamerikanischen Fauna (Dichoyaster medellina n. sp.) erweist sich die columbianische Terricolenfauna als cin Teil der tropisch-südanerikanischen Terricolenfann:. In Spezielleren aber zeigt dieser rolumbianische Distrikt gewisse Besontlerheiten. Das ist vor allem dis Auftreten der Gattung Andiodrilus in melseren Arten, einer lattung, die schon in Ecuador anscheinend nicht melur rorkomml, amelerersets aber lis Costa Rica in Zentralamerikil vorWringet. Eins andere charakteristische Gruppe, die Lntergatung Aptodrilus, hat Columliat nur noch mit Ecnador gremein. Auch die Cidtungen Ilesperoscolex und Periscolex sinfl für den Nordwest-1Vinkel Südamerikas charakleristisch und greifen von hier in die ü̈rdlich sich daran inschliessenden Gebiete ïher. Bemerkenswert ist schliesslich noch die Spärlichkeit der l'nterqaltung Rhinodrilus (Rhinodrilus) in Culumbia, die hier nu 


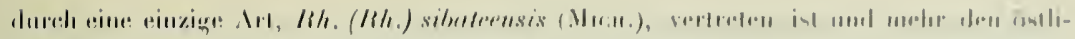

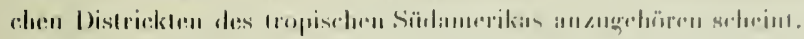

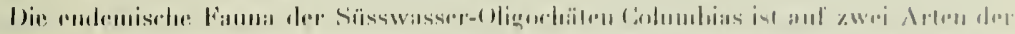

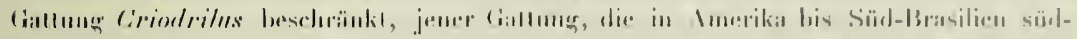

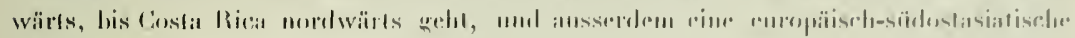
Art anliveist.

\section{Fam Naididx.}

\section{Dero sp.}

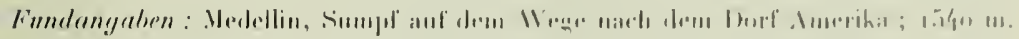

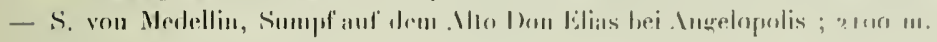

\section{Slavina appendiculata (d'Udek.)}

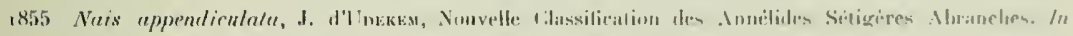

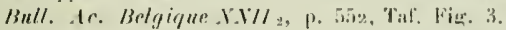

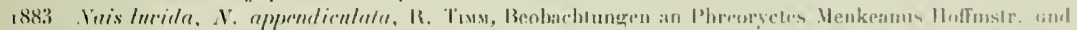

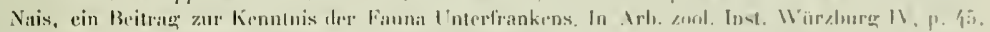
Taf. II ligig. 25.

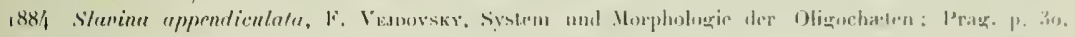
'Till. 111, lisis. $17-26$.

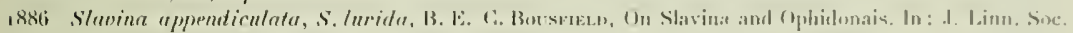

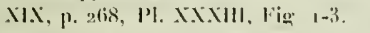

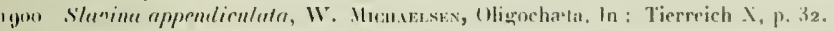

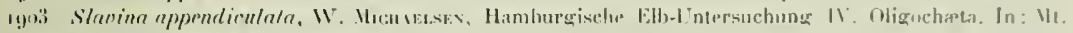
Mus. Hamburg .XI. p. Isi.

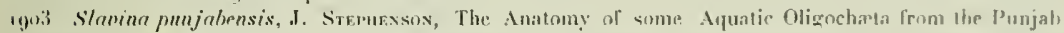

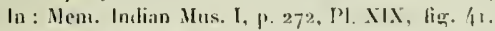

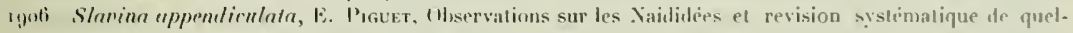

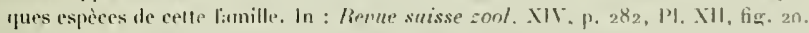

Fundangabe: O vou Bugolà, Sere vou l haxue, am Dsthang der Paramo Cruz Verde, 2200111.

Dieser sho charakterisliselu'n und leicht erkennbaren Art orlne ich ein Exemplar zu, Irolzdem ich die Gestalıung der dorsalen Borsten nicht feststellen konntr. Diese Borsten warn sämelich abgebrochen und bis auf ein kurzes Stümpfehen an riurm Segmente des Mitlelkörpers üherhaupt uicht rikenubar.

Mit Slawina appendiculata glaube ich auch S. pmighensis STEPHexsox (1. c. 1-272) vereinen zu sollen. Ils . Thweichungen qriebl Stephexsox für seine . Irl an : II den Besilz nur ciner einzigen Reihr von grossen Papillen per Segment anslatl zweier Reihen; 2) das Vorhandensein eines Gefässplexus anstall einfacher liommissuralgefässe, und 3/ vielleich eine geringere Zahl ron Borsten in dem seclisten dorsalen Bünlel (soll heissen in den dorsalen Bündelu des 6. Segments). Der dritte Punki, die Inzahl der dorsalen Borsten 


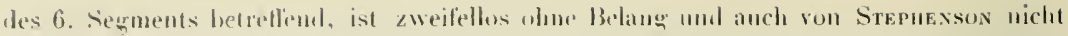

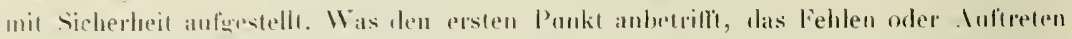
rines zweiten Ringels gronser Papillen an eintern Segment, so halle ich schon früher (I. c.

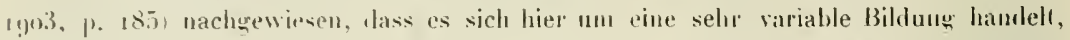

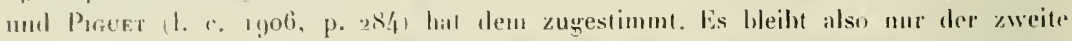

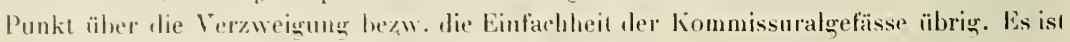
mun die Frane, wolrer hat Stepnexsox die Angahe, dass die Kommissuralgefässe hei $S$. appendiculata einfach sein sollen? Der . Iutor der Art, d'L DEnem, macht keine Angaben ïber den Verlauf der Kommissuralgefässe, ehenso venig Tims, Bousfiecd und Piguet. Dis Einzige, was ich hierïber finden konnte, lührte auf die von mir in "Tierreich " (I. c. $1900,1 \% .32$ ) aufgestellte Diagnose und auf Vejdorsky's (1. c. 1884, p. 3o) Besprechung ler . Irt zurïck, nud ich muss annehmen, dass Stephenson's Anschauung über $S$. appendiculula hieraut beruht. Meine Notiz in der Diagnose ron S. appendiculato: "Transversalgefässe sïmtlich einfach " heruht nicht auf eigener Untersuchung - mir war diese Art bis dahin nicht «u Gesicht gekommen, - sondern, wenn ich mich nicht irre, auf Uebernahme der Y'́dporsky' schen Angahe : "Das Gelässsystem verhält sich wie bei Nais elinquis ". Aus dieser Angabe durfte ich schliessen, dass nach VeJpovsky die Transversalgefässe bei S. appendiculntı wie bei Nais elinguis einfach seien. Erst die Beohachtung Śtepuensox's von verzweigten Transversalgefässen bei einer Slavina, die der S. appendiculata im übrigen gleicht, lässt mich zweifelhaft werden, oh die Angabe üher die Einfachleit der Transversalgefässe bei S. appendiculata zutreffend ist. Diese Art gehört zı1 denen, deren Blutgefässsystem schwer klarzustellen isı, der Undurchsichtigkeit der Haut wegen. Vejporskr's Angahe ist auch keine direkte, und aus der Abbildung (1. c. Taf. III, Fig. 18) ist lierüber nichts sicheres zu entnehmen. Verdächtig ist ferner, dass Vejporsky im allgemeinen Teil (1. c. p. 113) $S$. appendicnlata nicht unter den Formen mit einfaclıen Transversalgefässen aufführt. Er spricht hier nur von Dero obtusa, Stylaria lacustris, Nais elinguis, Pristina und Vaidium einerseits (mit einfachen Transversalgefässen), von Ophidonais serpentina, Bohemilla [jetzt V'ejdovshyella] und Nais Josinae. anderseits (mit verzweigten Transversalgefässen). Da erscheint es mir doch fraglich, ob VEsDorsky mit jenem allgemein gehaltenen Hinweis auf Nais elinguis tatsächlich auch die Einlachheit der Transversalgefässe von Slavina appendiculata feststellen wollte. Ich halte jedenfalls den direkten Nachweis für nötig. Solange dieser nicht erbracht ist, müssen wir annehmen, dass $S$. punjabensis mit $S$. appendiculatu identisch sei, und dass diese Art verzweigle Transversalgefässe hahe.

\section{Pristina longiseta Ehrbg. f. typica.}

ז!̣n, Pristina tongiseta f. Iypicu, W. Mchulsen. Die Oligochäten Dentsch-Oslafrikas. In : Zeitschr. wiss. Zool. LXXY.YII, p. 308.

Iguti, Pristina tongiseta, E. Ptguet, Observation sur les. Naididée: et revision systematique de rquetques espèces de cette lamille. In : Rev. suisse Zool. XIV. p. 209o. pl. X, fig. 22, 23, pl. XII, fig. $21,25$. 


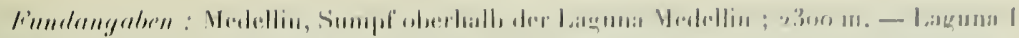

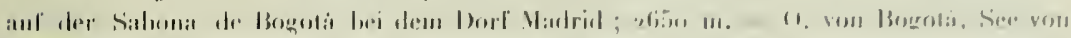

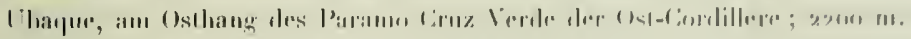

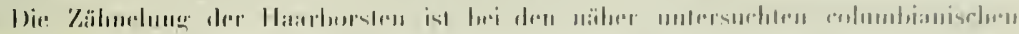

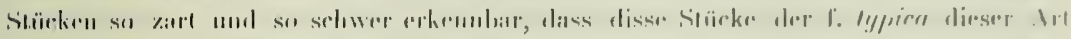
zuseurlarel wrolent miissen.

\section{Pristina requiseta Bourne, var.?}

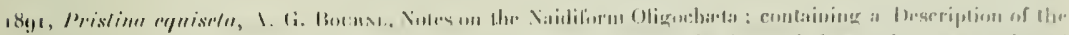

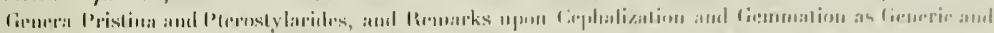

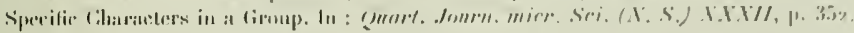

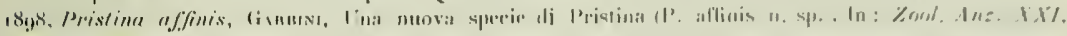
11. Itim, Tixxl. 1.

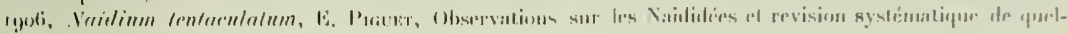

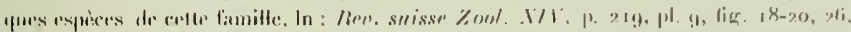

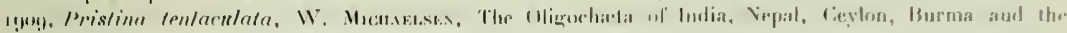

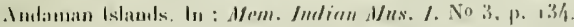

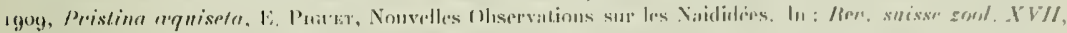
1. $21 \%$.

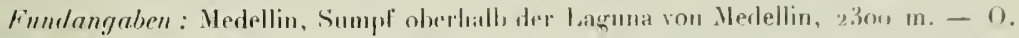

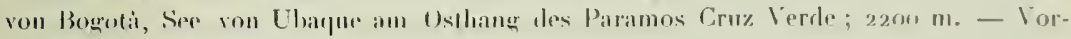
liegend mehrere geschlechlslose Exemplare.

Aensseres. Dimensiomm: Zwei ansclueinemd vollständiug ansegewachsen Einzeltiere waren 1,1 mul 1,2 mu lang mul bestamlen ans 19 lw\%w. 20 Sermenten plus einem

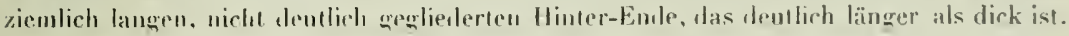

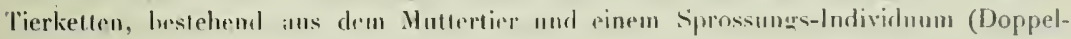
(iere odrer zweigliedrign liellen) waren $1,\{-2,1)$ mm lang, wovan ca. I, r mm auf das Muttertiel entfiel. Die Dicke beträgl im Maximum ea. o, I mm.

Sprossung : Die meisten Tiere hesassen dine anzige Sprossungszone, pinigo wenige waren rinfach, keines zeigla molır als pine Surossungszone. Die Zahl der Segmente vor

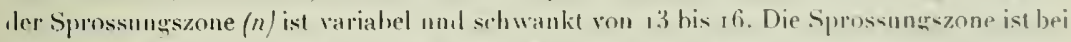

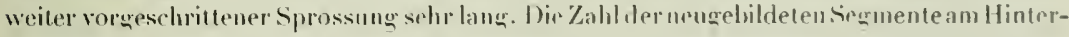
End. des Mullerlieres heträgl in zwei Fällen, wu sis schon annähernd zählhar warem, 7 , wemn nichl \&. Der neugehildere Kopflappen des Tuchurtiores ist manchmal annähernd

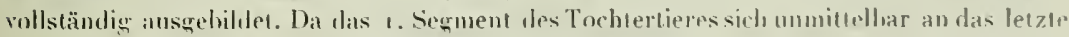
neugehildede Segrment des Multerlicres anschliesst, so erscheint der nengebildete liopt-

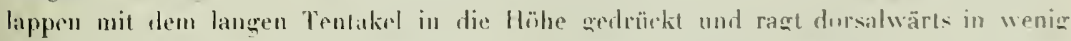
spitzem IVinkel von der Sprossmussone ab. Die Zahl der nengebilaleten virderen Segmente des Tochtertieres belrägl in eimen Falle, wo sie senan zählbar waren. - , in rinem zwoiten Falle, wo sic nicht mit voller Sicherheit zäl, har waren, anscheinend ehenfalls 7 . 
Färhung der konservierten Tiere gran; anscheinmol pigmenths.

Lopflappen vom 1. Segment scharf ahgesetzl, mit dickem Zwiebel- oder Kuppelförmigen Basalstück, das in cinen zi̊mlich langen, dünnen, mässig scharf alogesetzten Tamtakel ausgazogen ist. Das Basalstück des Lophlappens ist hinten meist deullich verengt, je nach dem kontraklionszustaml clwas dümner oder vipl dünner als das 1. Segment, im

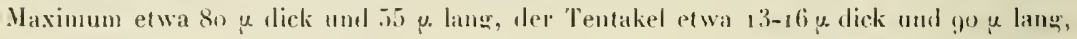
der ganzo liopliappen also elwa 145 u. lang. Der Tentakel entspringt nieht quenau aus tem vorderen Pol des Balsalstückes, somdern etwas unelur dorsal, so zwar, dass sein Unterratul in der Profillage noch ein sehr heringes oherhalb des vorderen Pols in das Basalstück ïhergeht. Augen sind nichı vorhanden.

Die Segnente sind mehr oder weniger deutlich aweiringlig, mit längerem die Borsten tragendem Vorderringel. Das 1. Segment ist wohl ansgehildet, nur wenigy kïrzer als das 2. Segnent, scharf von dem ledzteren abgesetzl und meist auch schon mit einer Andeulung von Zweiringeligkeil.

Borsten: Die am 2. Seqment beginnenden dorsalen Bündel enthatten meist z oder 3 llaarborsten, weniger häufig nur eine, und daueben mutmasstich ebenso virle Nudelhorsten. Die Haarhorsten sind meist dentlich länger als der Körper des Tieres dick, etwa

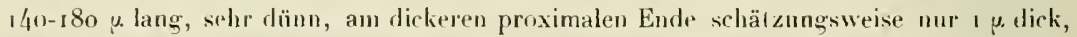
distal haarfein. Eine Zähnelung, wie sie bei deı meisten Pristina-Arten anftritt, konnte ich auch mit den stärksten mir zur Verfügung stehenden Objektiven an den IIarborsten nicht nachweisen. Vergrössirle Haarborsten kommen nicht vor. Die Haarhorsten eines Tieres sind im Allgemeinen annäherend gleich lang. Vielfach findet man allprdings, dass die Länge der Haarhorsten an den vordersten horstentragenden Segmenten etwas abnimmt; doch mag das nur ein WVachstumsstadium des erst nach Loslösung vom Muttertier voll auswachsenden Vorder- Endes des jüngeren Tieres sein. Nadebborsten konnte ich, zweifellos ilırer Feinheit wegen, nur in einzelneu dorsalen Bündeln nachweisen. Sie sind ungemein zart, etwa 35 u. lang und nur den Bruchteil eines $\mu$ dick. Sie sind ganz gerade gestreckt, anscheinend ohne Nodulus, und ihr distales Ende ragt nur etwa um $5 \mu$ über die Körperoberlläche hinaus. Hhr distales Ende ist für meine Hilfsmittel unmesshar fein. In rinem Falle glauhte ich bei günstiger Lage der Nadelborst? eine Gabelung des distalen Endes zu erkennen; doch lag das schon an der Grenze des für "mich sichtbaren. Die ventralen Bündel enthalten meist 6 oder 7 S-förmig gebogene, im Allgemeinen schlanke und zarte, ca. $50 \mu$ lange Gabelbor'sten. In einem Falle erkannte ich die ventralen Borsten des 5 . (nicht des 4.) Srumentes deullich vergrössert und dafür ihrer Anzahl nach reduziert (3 im Bündel). Die Ver'grösserung ist nicht so beträchlich, wie ich sie bei anderen Stäcken dieser Art won Ilamburg und von Vorderindien sah, und wie sie Piguet von dem Original seines Naidium tentaculatum schildert (1. c. Igo6, P. 220 und PJ. 9, fig. r8). Da ich diese vergrösserten Borsten nicht isolieren konnte das Stück sollte nicht lädiert werden - so kann ich leider keine genitue Grössenangabe machen. Der geringeren Vergrösserung entspricht übrigens die geringere Reduktion der 


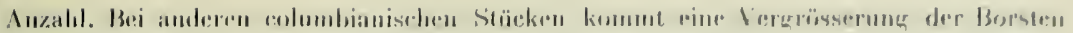

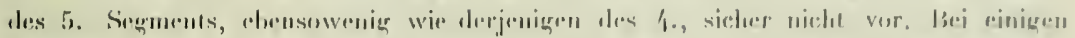

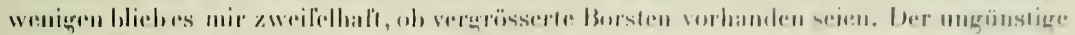

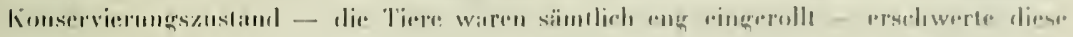

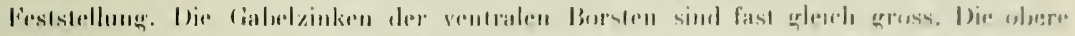

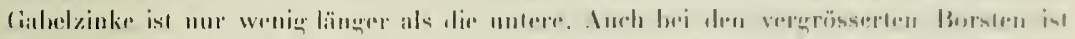

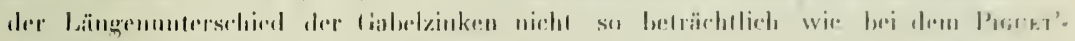

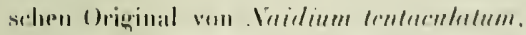

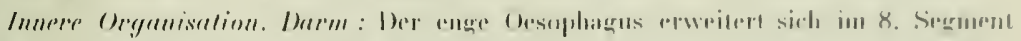

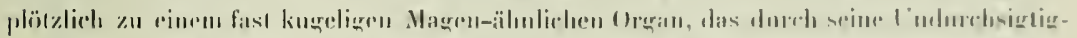

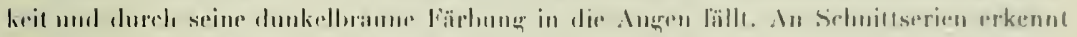

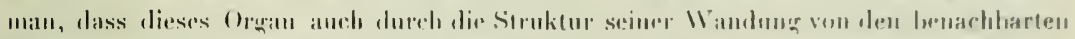

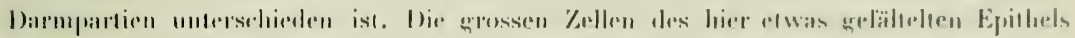

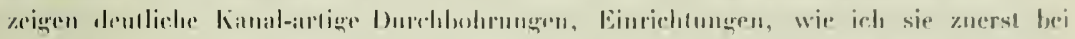

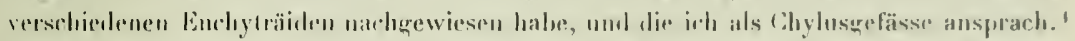

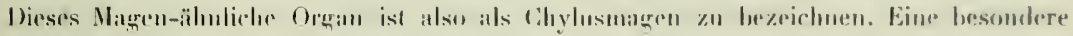

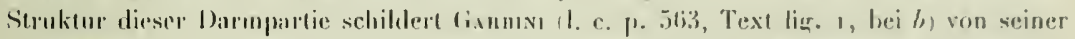
P. affinis, die wahlossheinlich mil $l$. aequiseln identisch ist. Mutmasslich sind die

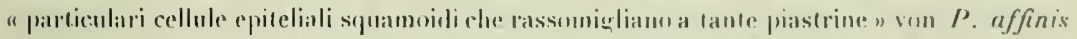

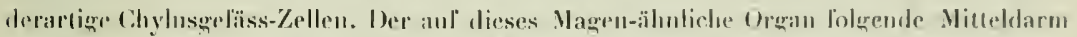

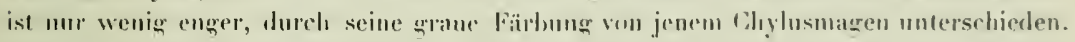

Geschlechlsoldgan sind bei keinem Stärk greschen worden.

Bemertiungen: Es ist mir nicht ganz klar, ob olie vorliegrnde fourm ohne Weiteres mil $P$. arequiselu zu vereinen ist, oder ob sie als Varictät ahgesomlert werden müsse. In der Ansstallung mil vergrösserten ventralen Bursten, die hier sicher nicht allgemein anftrilt, sondern nur bei einzelnen Individurn. Weicht sie von Paguet's Lntersichungsbljekten als. Bemerkenswert prscheint mir, lass anch Bockre boi stinen Stücken eine

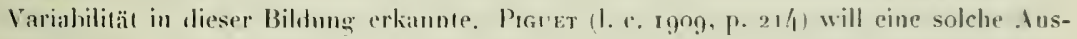
lequnn nicht grelten lissen, und meinl, diss Bounse zwei versehiedene Arten vor sich

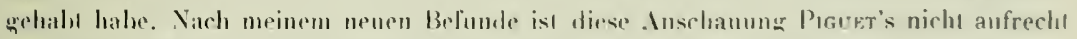

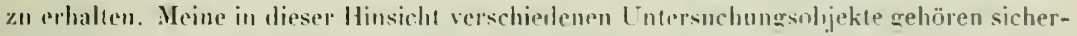
licls riner und derselben $\mathrm{Alt}$ an.

\section{Fam. Enchytraeidae.}

\section{Henlea columbiana $n$. sp.}

Fundangabe: Medellin, Lilguna von Medellin. am I'fer : $2000 \mathrm{~m}$.

Vorliegend einige wenige äberhältele Stücke, die nur eine unvollständige Lnter-

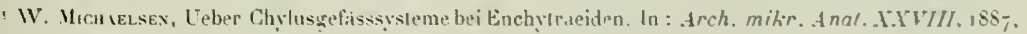
p. $29^{3}$ u. l. 
suchung und Beschreibung qestatten. Einiger besonder's interessanter Organisationsrer-

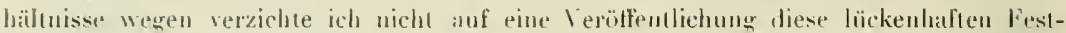
stellungers.

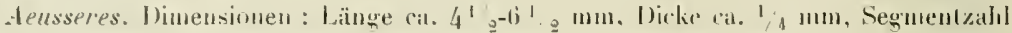
etwa $35-40$.

Koptlappen kurz, qresundet, kuppeltörmiæ.

loptporus nicht erkannl, wahrscheinlich winzig.

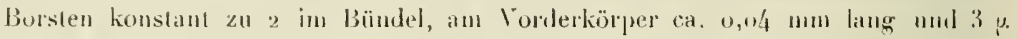
dick, in Allgeneinen gerate gestreck, distal einfach-spirzig und ciemlich plump.

liürtel saltelförmig. Helle und dunkle Drösenzellen des Gï̈rlel-Epilhels in Querschnit meist annähcrml quatratisch, in Guerreihen qestelf, unregelmässig Schachbrellartig angreordnet.

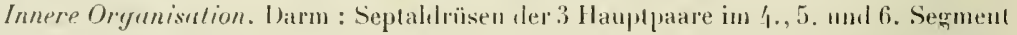

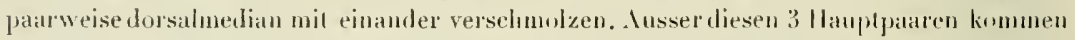
licke Velendrüsen an den Septaldrüsensträngen vor. Es sind fast die ganzen Septaldrüscnstränge mil Ausnahme ihrer vorderen Enden allseitig von diesen Vebendrüsmu bedeckl, so dass diese Stränge verdickt erscheinen. Hinten rehen liese Nebentrüsen (meist?) ohne dentichen Absalz in die Ilauptdrüsen äbes. Vorn im 1o. Segment weht Jer Uesopharas in den Mitteldarm über. Meist ist dieser lebergang duch einen deutlichen I bsats ausgezejchnet, zwar uicht durch eine beträchtiche Vesdickung des Umfanges, wohf abes durch eine deuthehe Enveiterung des Lumens. Bei einem Exemplar erschien dieser Absatz jedoch last qanz ausgeglichen; das Hinterende des Oesophagus, welches in der Regel leer erscheint - der Darminhalt scheint den Oesophagus schuell zu passieren, um erst in dem mejst von \nfang an gefülften Mittehdasm langsammer vorzurïcken enthielt bei diesem Exemplar ausnahmsweise Nahrmgsmassen und war infolgetessen erweitert.

Das Rückengefäss scheint vorn im 10. Segment, an Vorderende des Mitteldarms, aus dem Darmgefässplexus hervorzugeben; doch kann ich das nicht mit voller Sichesheil angeben. Der Verlauf der Blılgefässe war der ungünstigen Konservierung wegen nichl sicher festzusteljen.

Peptonephridien (?) : Im 7. - y. Segment liegt jerlerseits neben dem Oesophagus ein dicker, segmental aufgeblasener, intersegmental zwecks Durchselzung der Dissepimente verengter Schlauch, dessen Jünne IVandung unregelmässige und zarle, der Hauptsache nach ringelig verłaufende Fältelungen anfweist. Ich meinte an fangs dieses Schlanchpaar als Chylustaschen ansehen zu sollen; konnte jedoch trok anscheinend lüekenloser Schnillserien im 9. Segment, ebenso wenig wie im 8. und 7., rine Kommunikation dieser dicken Schläucle mil den Oesophagus finden. An ciner anderen darauf hin angefertigten Schnillserje grlaubte ich, daun rine enge, dünuschlauchförmige Verlängerung dieser dicken Schläuche nach vorn hin zu erkennen, und zu sehen, dass diese dünnen Schlüuche fast genau auf dem ghleichen Querschnill wie die Samentaschen, also im 5. Segment, 


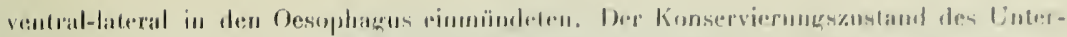

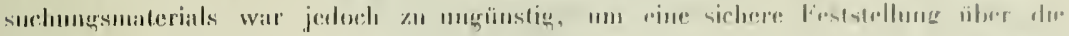

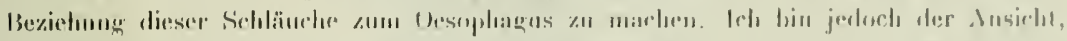

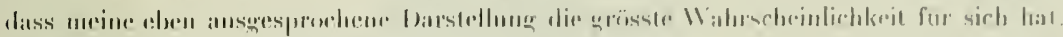

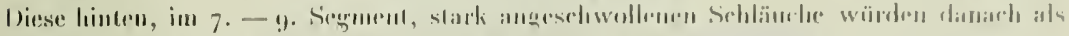

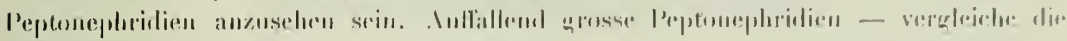

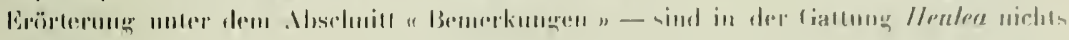
Vugewölunliche's.

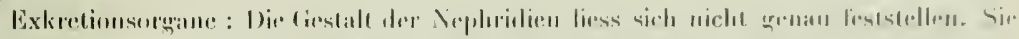

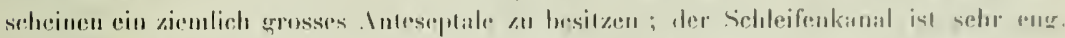

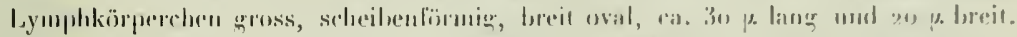

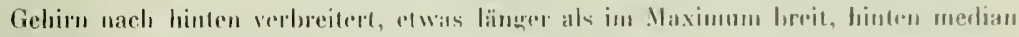
zienlich tiel aulugeschuitırn.

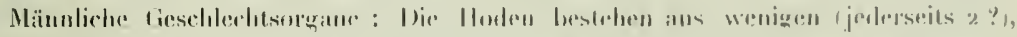

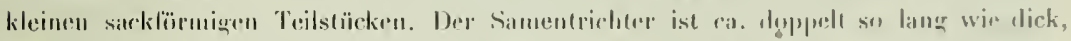

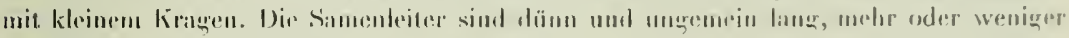
regelmässige eng schraubentö̈rmier anforewumben.

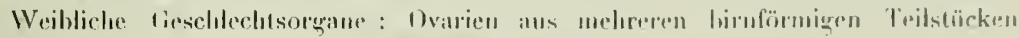

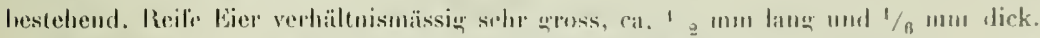

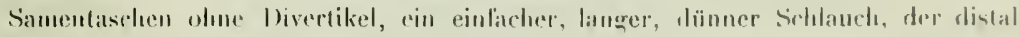

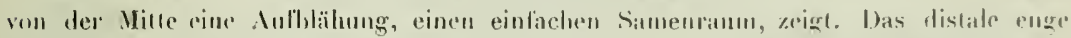

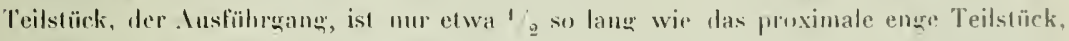
der proximale fortsatz der Ampulle, der tateral, weit entferut ron dem der fiegenseita, in den Oesophagus cimmündet. An der basis des. Insfïhronges der Samentaschen stehen uиr wenige Drïsenzellen.

Bemerlinngen: Die hervorstechendste Eigronheit dieser Art liegr in ten heiden anfge-

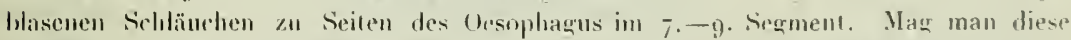

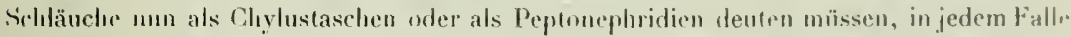
hilden sie einen bedeutsamen lusweis fär die IIentea-Xatur der fraglichen . Irt; denu niclat mur Lhylustaschen, sondern auch errosse Peptonephridien konne'n anch bei anderen Arten lieser Gallung vor. Eissix 1 grieht den Besilz grosser Peptonephridien sngar als eines der Hatupherkmale der Tattung Henleu (im Fiegensalz zu Bryodrilus) an. I)as ist allerdings nich angängig, denn IIrnlea nentriculosa (d'LDEk), eine échte IIenlea. weist un winzige Peptonephridien aut. Eigentümlich für Henteq und die nahe verwandu.

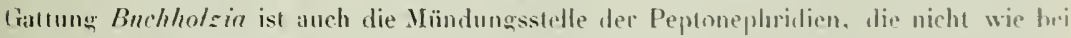
anderen Enchyträiden, z. B. Friedericin mul Enchytraens, dicht hinter tem Schlundkopf liegt, sondern weiter hinten, im 4. Segment (Buchholsion mbe gar im 5. Segmemt (die vorliegende $\mathrm{Irt}$ ). 


\section{Fam. Megascolecidae.}

\section{Subfam. Ocnerodrilinae.}

\section{Ocnerodrilus (Ilyogenia) Calwoodi Mich.}

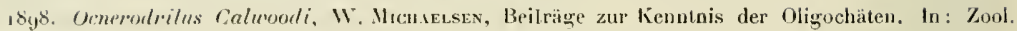
Jihrb., Syst., NII, p. ז3.

Fundanguben: S von Medellin, Cadelal Camelia bei Angelopolis, 1800 m. - SSO von Honda, auf dem Wege nach Guaduas; $800 \mathrm{~m}$.

Bemerlinngen. Vorliegend drei Exemplare, dic in allen wesentlichen Punkten mit den Typen ïbereinstimmen. Als fragliche Abweichung wäre nur zu crörtern die Dicke der Dissepimente des Vorderkörpers, die mir bei zwei nälıer untersuchten Stücken ron Columbia stärker (wenn vielleicht auch nicht antfallend dicker, so doch zäher und fester) ats bei den Typen vorkommen. Der Grad der Dissepimeut-Verdickung ist aher schwer festzustellen und die Festigkeit mag sehr von der Arl der Konservierung beeinllusst werden.

\section{Subfam. Trigastrinae.}

\section{Dichogaster Modiglianii (Rosa).}

Isyti, Benhamia Motiglianii, D. Rosit, I Lombrichi raccolti a Sumatra dal Dott. Elio Modigliani. In: Ann. Mus, Geoova XXXil, p. 510 , Tav. I, Fig. 1 a, 1 h.

Fundangabe : SIV von Medellin, Puerto de los Pobres bei Titiribi am Einfluss des Rio Amaga in den Cauca; $800 \mathrm{~m}$.

\section{Dichogaster Bolaui (Mich.)}

1!gon, Dichugaster Bolaui, W. Mch Ielsen, Oligochaeta. In: Tierreich X, p. 340.

Fundangaben : SSO von Honda, aul dem Wege nach Guaduas; $800 \mathrm{~m}$. - S W von Bogotà, Cátetal Buenavista bei Viota, nahe dem Rio Bogotà; rooom. -- Vorliegrend 4 Stücke.

Bemertiungen: Wälrend eines der 3 Exemplare vom Camino Real selır klein isl $115 \mathrm{~mm}$ lang und $1 \%$ mm dick) und die typische Zwergform dieser Arl (mit 3 Reilien llicronephridien jederseits) darstellı, sind die beiden anderen Stücke verhältnismässig gross (25 und $30 \mathrm{~mm}$ lang, $2 \frac{1}{2}$ bezw. $3 \mathrm{~mm}$ dick) und zeigen die cliarakteristischen Bildungen ler früher als Art order Varietät abgesonderten octonephra-Form (jederseits \& Reihen voı llikronephridien). Die Vergesellschaftung der beiden Formen dieser in Columbia zweifellos eingeschleppten und offenhar nur ganz sporadisch vorkommenden Art ist eine weitere Sıütze für meine Anschatıung, dass diese verschiedene Ausbildung nicht systematisch verwerthar ist, sondern dass man es hier nur mit verschiedenen Wachstumsformen (vielleicht Altersformen?) zu tun hat. 


\section{$-21 ;$ \\ Dichogaster medellina $n$. sp \\ Tillel VIII lïn. $7-$-).}

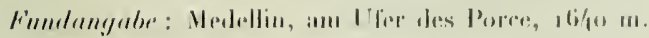

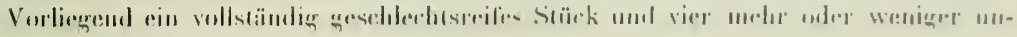
reile, anu Teil list reifie.

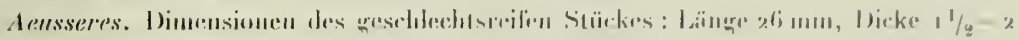
mun, Segmentzahl 110.

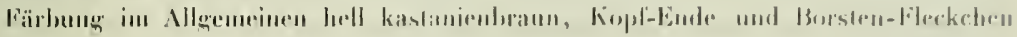
melur quars.

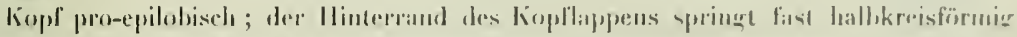
nach hinten in das 1. Segenent int.

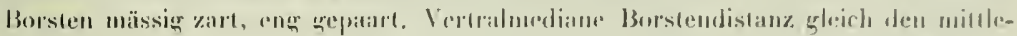

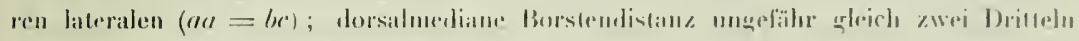

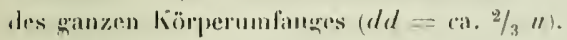

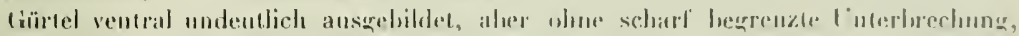
at11 13.-20, Segment (三8).

Prostata-Poren 2 Patar, am 7. und 19. Segment in den Borstenlinien al.

Simenrinnen in der Mille rerbreitert, Mondsichel-förmig, medial konvex.

Männliche und weihliche Poren nicht erkanme.

Samentaschen-Poren 2 Piar, auf Intersegmontalfurche $7 / 8$ und $8 / 9$, anscheinend in den Borstenlinien ab) (äusserdich nicht erkinnt, nur nash Beolachtung der auseinander-

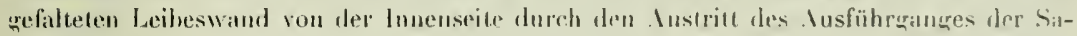
mentaschen annähernd festgestellt).

Innere Organisation Einige Dissepimente in der Region der vorderen männlichen Geschlechtsorquane $(9 / 10-12 / 13$ ? ) elwas werdickl.

Darm: Vor den vurderen mäurbichen fieschlechtsorganen 2 kurze, dicke, slark metallisch qü̈zzende Muskedmigen, die nicht durch eine denuliche dënnwandige Partie vou ciuander wrtrenut, sondern nur durch eine tiefe Ringrelfurche gesondert sind. Inch dir ewas angeschwollene Oesophanus-Partie vor dem vordersten Muskelmagen, der sogrnamnte kropl, gyänzt metallisch, ist also etwas stäslio muskuliis. Diese Partie këmule

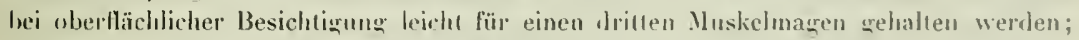
sie ist aber vicl dünnwandiger als die Yhuskelmagen. 3 Paar lialkdrüs'su linden sich im 15., r6. uml 17. Segment. Sie sind fast gleich gross, nur die vorderen rin Geringes kleiner. thre Gestalt ist flatt-nicrenfö̈mig oder Ohrmuschel-fïmig. Schon äusserlich kann man ihve lamellöse Struktur au der dichten Querstreifing (in Bezugnalume anf die Längsachse des ganzen Tieres: Längsstreifungi erkennen. Hor Rand ist dorch zwei Einkerhnngen in drei Teile greteilt. Der Mitleldarm trägt rine hreile, ziemlich niedrige Typhlosolis.

Blutgefässsystem: Räckmgefäss einfach. Letzle Herzen in 12. Segment. 
Exkretionsorqane: Im Miltelkörper funden sich jedrrseits fa. 6-8 Mikronephridien in einem Segment. Die drei oder vier obersten Mikronephrilien sim verhältnismässig gross und säckehentörmig, unregrelmässigg gnesteli, nichı in Längsseihen angeorduet. Din unteren oder ventral-medialen Mikronephridien sind vicl kleiner und nehmen mrdial nor/s mehr an Grösse ab; sie sind nicht zu einzehen Särkchen zusammengefasst mul nirla deutlich von einander gesonderl, so dass eine Angalue äher ilıre Kahl kaum IVert hat.

Vordere männliche Geschlechtsorgane: Zwei Par ziemlich grosse Smentrifhter anscheinend fri im 10. und ı. Segment. Zwei Paar kleine, rng gestieltr Samensäcke ragen ron Dissepiment 10/r und $11 / 12$ in das r 1 . bezw. 12. Segment hinein. Die Samensäckr des vorderen Paares im 11. Segment sind noeh kleiner als die tes hinferen l'ares im 12. Segment.

Prostaten auf' das Segment ihrer Ausmündung leschränkt, zur Seite und nach oben ragend, mit dickem und fast gerade gestrecktem, lö̈lsstens rinige wenige schwache umi undeutliche Schlängelungen beschreibendem J)rüscuteil und däınem Ausführgang.

Penialborsten (Tafel VIII Fig. 7 und 8) in dem näher untersuchten Penialborstensacli etwas verschieden; doch erseheint es mir fraglich, ob hier ein echter Dimorphismus vorliegt, wie er ja hei manchen Arten dieser Gattung vorkommt, oder ob es sich bei ler abweichenden Borstenform um eine zufällig etwas abgeänderte nder abnorıne Borste handelt: In dem Penialborsten-Apparat der einen Prostata fand ich 3 Penialborsten, von denen 2 die gleiche Gestalt batten. Sie waren ca. $1 / 2 \mathrm{~mm}$ langr und im Allgemeinen ra. $6 \mu$ dick, also fast gertenartig schlank, einfaclı gebogen. Giegen das distale Ende, und zwar elwa rom Ende des distalen Fünltels an, verjüngen sie sich bis auf eine Dicke von ca. $3 \mu$, um auch bei dieser Dicke, die an der distalen Spitze weder sich verringert noch zunimmt, in einfacher Rundung zu enden. Die Ornamentierung besteht ans kleinen undeutlichen, ziemlich weit zerstrenten Blattschuppen-fömigen Vorspröngen. Eine Regel der Anordnung dieser Ornamente liess sich nicht feststellen (Fig. 7). Die drilte, anscheinend in einem besonderen Borstensack steckende Penialhorste des näher untersuchten Prostaten-Apparats war deutlich kleiner als die der oben geschilderten Form, ca. 0,45 mm lang und im Allgemeinen ca. $5 \mu$ dick, gegen das distale Ende, und zwar schon ungefähı von der Mitte an, langsam bis auf eine Dicke von ea. 2 perjüngt, ebenfalls einfach gebogen. Thr distales Encle ist jedoch nicht einfach, sondern knopfartig angeschwollen, his auf eine Dicke von ca. $4 \frac{1}{2} \mu$ verdickt. Der Auschwellungsknopf ist nicht glatt, sondern zeigt unregelmässige Höcker. Eine weitere Ornamentiermug war an dieser Penialhorste nicht zı erkennen (Fig. 8). Sämtliche Peniallırsten sind wasserhell.

Samentaschen (Tafel V'III Fig. 9): Ampulle klein, dick birnförmig, Ausführgang nichı scharf von der Ampulle abgesetzl, laug und dünu, sehlauchförmig. In der Mitte des Ausführganges mündet ein zur Seite oder in die Höhe ragrendes Divertikel, das, an den Ausführgang angelegt, fast bis an die Ampulle reicht. Das Divertikel ist nässig schlank gestielı. Bei den vier Samentaschen des untersuchten Stückes besitzt nur eines einen einfachen Samenraum am Divertikel, der hier am hlinden Ende nur wenig angeschwollen ist; 


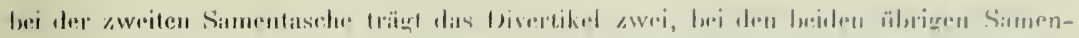

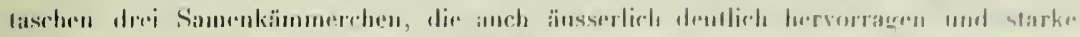

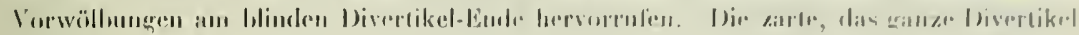

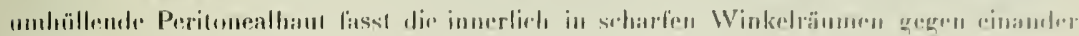

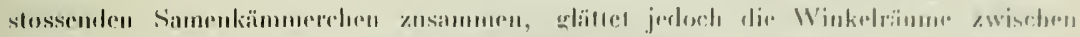
ihus:n nicht gan+ ans.

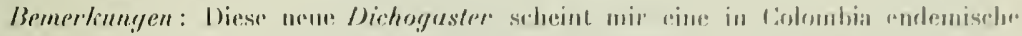

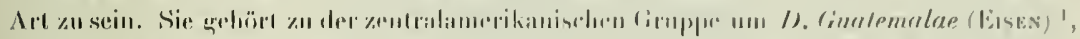

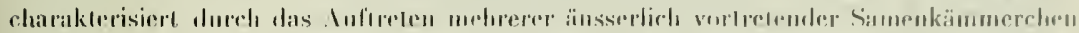

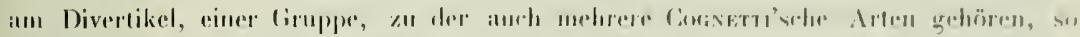

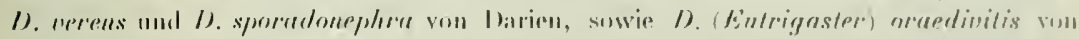

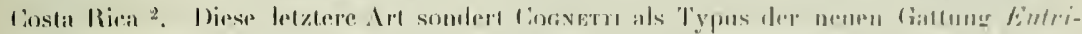

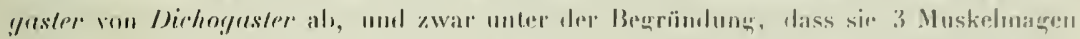

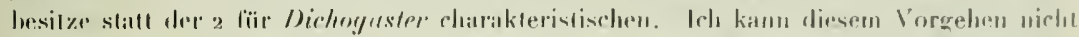

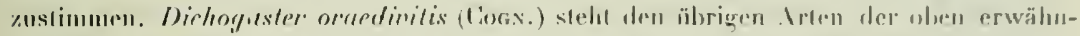

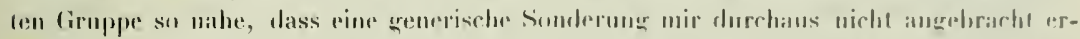

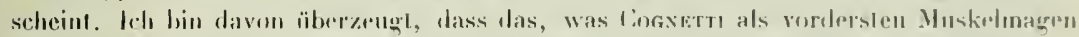

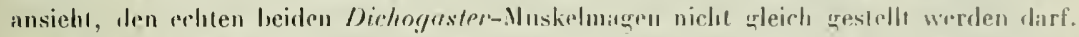

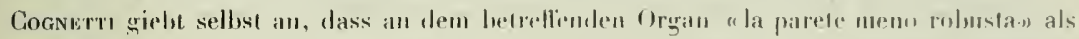
bei den typischen Dichogaster-.Muskelmagen ist. \%weifellus handelt es sich lior un eimen den Muskelmagen vorgelagenten Kmpt, dessen Muskelschicht etwas verslärkt ist, und Mer daher fast wie ein Muskelmagen aussieht, einem elensolchen liropf, wit ich ihn bei D. medellina fand (siehe ohen, 1.215!). Dass anch dieses Orzan innerlich unit mer Cuticula ausgekleidet ist, magr lïr die Entscheidung, ol Wuskelmagen ader nicht, hedeulungslos sein. Es besagf nichl mehr, als dass anch der Kropli mil einer Culicula ausgekleidel ist. Als derartiger "kropf" ist auch der angellich" vorderste. Muskelmagen ron Trigaster minima Friend anzasprerhen ("lhe loremust one was of quile a ditlerent texture from the other (wo) - - . c. p. 274). Es handell sich hier aweiffllos un eine kleine Dichogasler-Art, ührigens eine uspecies spurial n, denn die Beschreihung enthälı nicht ein einzige Herkmal, das zur l'eststellung der Art dienen könnte. Irh muss n̈brigens dir Nichtspezialisten ror der kritiklessen Inmahme der wenigen positiven Feststellungen in der Frueno'schen Besehreibung warnen. Die Angaben "The gizzards lity in semments 9) ro, 11 " (also anch in den Hoden-Segmenten!) und "The principal hearts liy in segments $(2-15)$, hesagen für einen Trigastrinen etwas so unglaubliches, dass meiner Ansicht narh ein grosser Mul dazu gehört, diese Behauplungen aufzustrillen, und das

1 Benhamiu Guatematue, G. Erses, Researches in American Oligochaela. with Especial Reference in

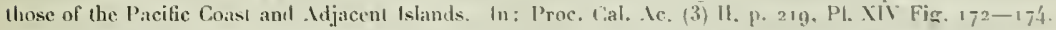

* L. Cogiettr, Gli Oligocheli detla Regione Keolropicale. In: Mem. Acc. Torino 2) 1. VI p. fri. Tav. I, Hig. 28 , 29 ; p. 43, Tav. I, Fig. $20-27 ;$ p. 36, Tav. 1, Fig. 11. 12.

3. Faend, New Annelids. In : Zoologist, London (4) XV, p. $27^{5}$.

28 
noch dazu, olne die verbhälemten Befunde an einer Schnitserie kontrolliert nud sichergestellt zu haben, Indiglich nach der hekinntlich leicht zu irrtümlichen Orienticrungen führeuden Betrachung des intakten durchscheinenden Tieres.

\section{Fam. Glossoscolecidae.}

\section{Subfam. Glossoscolecidae.}

\section{Periscolex Fuhrmanni n. sp.}

Fundangabe: SO vou Bogoti, Paramo Cruz Verde; $3600 \mathrm{~m}$.

Vorliegend einige wenige Exemplare einer neurn Periscolex-Art, dic Lauptsächlich ilıer Borstenverhältnisse wegen ausserordentlich imteressant ist. Sie zeigt nämlich deullich, wie in dieser Gatlung, der einzigen perichätinen Flossoscoleciden-Gattung, die erste Borstenvermehrung vor sich geht.

Aeussere Charalitere. Dimensionen: Länge 42-5 $\mathrm{I}$ mm, maximale Dicke an Gürtel $2^{1} 2 \mathrm{~mm}$, vor und hinter dem Gürtel $2-21 / 3 \mathrm{~mm}$, Dicke gegen das pfriemförmige Hinterende allmählich almehmend. Segmentzahl $109-148$.

Färbung : dorsal ziemlich dunkel grau mit selı schwachem bläulichen Ton, ventral hellgrau; Kopllappen und ז. Segment pigmentlos, hellgrau. Gürtel dorsal sehr hell grrau, rentral weisslich.

Kopflappen anscheinend klein, nicht rüsselförmig, bei den vorliegenden Stücken eingezogen. Erstes Segment meist ganz oder zun Teil eingezogen, stark netzarlig gefurcht. Segmente einfach oder undeullich zweiringlig, am Kopf-Ende manchmal mit fast kielförmig erhabener Borstenzone.

Borsten stark S-förmigg gebogen, distal hakenförmig, mit ziemlich dickem, aher unscharf begrenztem Nodulus proximal von der Nitte. Distales Ende gabelspitzig; obere Gabelzinke viel kürzer und deullich dünner als die untere, vielfach abgeschliffen und danu undeutlich. Borsten am Mittelkörper ungefähr 1/, mm lang und im Maximum $16 \mu$ dick. Borsten konstant zu 10 an jedem Segment vom 2. an. Borsten $a-d$ in regelmässigen Längslinien, getrenut. Im Allgemeinen sind die seitlichen Borstendistanzen annähernd ghteich gross oder die unteren wenig kleiner, die oberen wenig grösser als die mittleren, und die unteren um ein Drittel kleiner als die ventralmediane Borstendistanz $(c d \geqq b c \geqq$ $a b=2 / 3 a a)$. Dorsalınediane Distanz zwischen den obersten regelmässigren Borstenlinien etwas kleiner als der halhe Körperumfang $(d d=$ ca. " $/ 9$ " $)$. Gegen die Körper-Endeı, und zwar nur im Bereich einiger weniger Segmente, erweitern sich dic seillichen Borstendistanzen relativ, nicht aber absolut, da hier der ganze Körperumlang und damil die absolute Grösse der Borstendistanzen abnimnt. Diese relative Erweitsrung der seitlichen Borstendistanzen geschieht auf Kosten der ventralmedianen Borstendistanz, die schliesslich nicht grösser ist als die seitlichen (an den Körper-Enden $a a=a b=b c=c d$ ), und auf Kosten der dorsalen Borstendistanzen (an den Körper-Enden $d d=c{ }^{3} / 10 u$ ). Das Aufsteigen der 


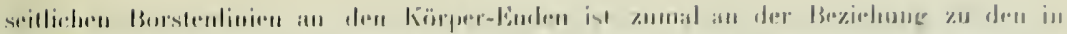

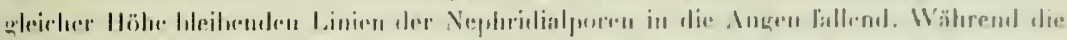

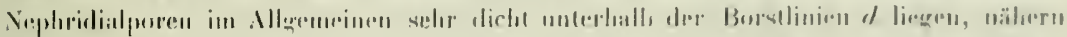

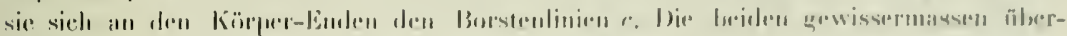

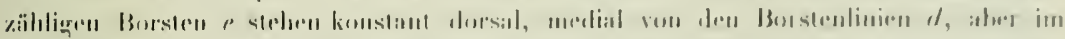

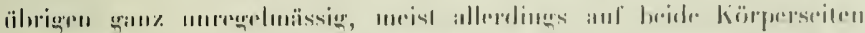

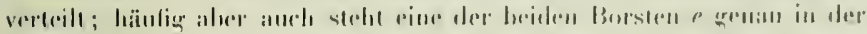

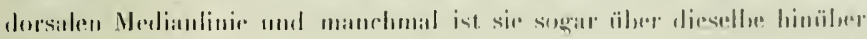

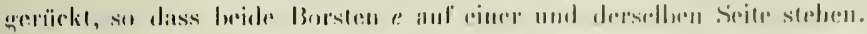

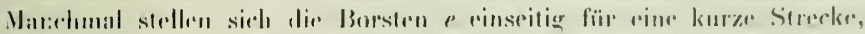

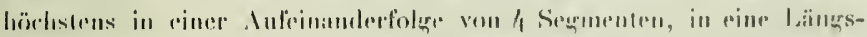

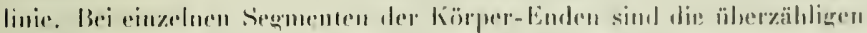

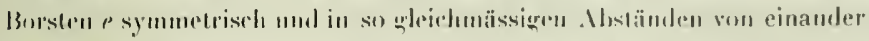

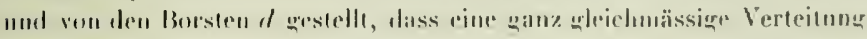

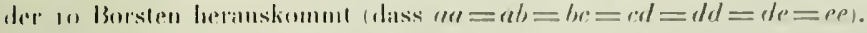

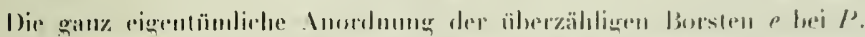

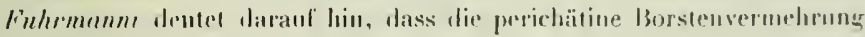

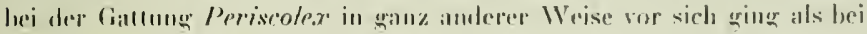

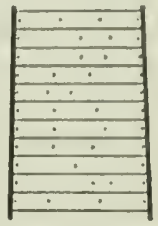

d e e d

Fig. I

Borstenanoriloung an der liückenseite des Mitlelkörpers von

Periscolex Fuhr. manni n. sp.

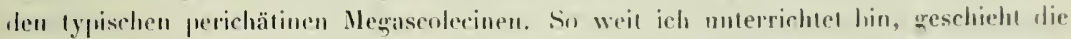

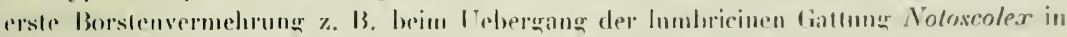

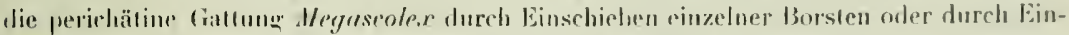
schichen von Borstenparen zwischen zwei ter ursprünglichen lumbricinen Borslen. Bri

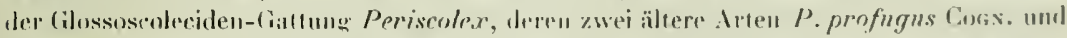

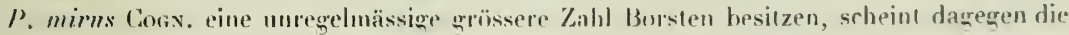

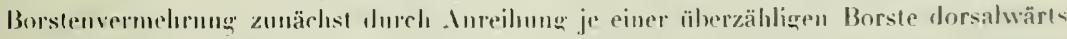
von den obersten der ursprünglichen 8 lumbricinen Borsten vor sich uregangen zu sein. In dieses P. Fmhrmnnni-Stadium swliessi sich dinn das Stadium der zweiten neuen Columbia-Ar, P. vialis (siehen mmen!), an. Bei dieser Art sind die lumbricinen Borsten

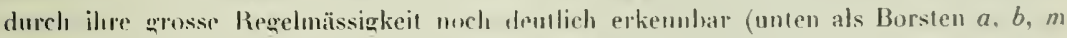
und $n$ bezeichnet). Zn diesen 8 lnmbricinen IBorsten kommen dann weitere üherzählige. und zwar nicht nur im Iorsilmedianen Raum awisiluen tlen Borsten of lrezw. $n$, wie bei P. Fnhrmami, sondern anch in den mittleren Bursteuräumen zwischen den Borstenlinien $b$ und $e$ bezw. m. Die Borstenäume der urspringlichen Borstenpaare, ab und col bezw. mn, bleiben hei $P$. vialis wis ancl hei $P$. Fnhrmanni ungeteilt, nicht mit cingescholenen Borsten besetz. Bei den hriden älteren Periscolex-Arten, P. profugus und P. mirns, scheinen die ursprüuplichen lumbricinen Borsten nicht mehr erkembar zu scin: Wenigstens geht aus den Antwaben Cogvetin's nirhts desgleichen hervor.

Besondere, modifizierte Geschlechtsborsten scheinen nicht gebildet zı werden.

Nephridialporen im Allgemeinen selır dicht unterhalh der Borstenlinien $d$, an wenigen Segrmenten der Körper-Enden den Borstenlinien c genähert. 
Gürlel stark erbaben, drüsig, ringtörnig, konstant an 14.-22. Segment $(=y)$, rorn und himlen schanf begrenzt, aber an 14 . Segment etwas schwächer answebildet als an den

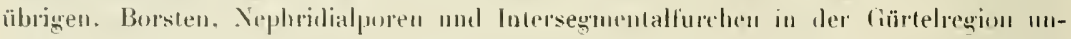
verändert deutlicls.

Ein Pan wenig erhabenc, parallelrandige Pulıchälswälle an 18.-22. Segment dich oberlalls der Borstenlinien c, olen nicht granz an die Borstenlinicon d heranreichend. Diese Pubertätswäll’ sind selı verschicden deutlich ausgebildel, aı wenigen Stöcke»

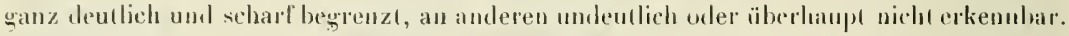

Mänulichu Poren dicht vor fotersegmentallurche 20/21, hinten an 20. Segment, an dem hinteren Mhlang, der die Einsenkmug der Intersegmentalfurche $2 \mathrm{~J} / 21$ bildet, etwas oberhalb der Borstenlinien $c$, d. i. aul' deı Puberlätswällen.

Weibliche Poren unscheinhar, auf lntersegmentalfurche $14 / 55$ in den Borstenlinien a, ganz in der Tiefe iler lntersegmentalfurch verborgen (nur an Sichnitserien erkannt!)

Samentaschen-Poren 3 Par, auf' Intersegmentalfurche $6 / 7,7,8$ und $8 / 9$ in den Borstenlinien $d$.

Innere Organisution. Dissepimente des Vorderkörpers abortiert. Das erste Dissepiment trennt anscheinend die Segmente 9. and ro. Sämtliche Dissepimente sebr zart.

Darm : Die Orientierung der vorderen Abschnitte des Darmes ist durch das Fehlen der vorderen Dissepimente sehr erschwert, wenn nicht unmöglich gemacht. In den ersten Segmenten liegt ein grosser Schlumlkopf, der mit zahlrcichen vielfach gelappten, traubigen Speicheldrüsen Lesetzt ist. Die Iraubigen Speicheldrüsennassinn ragen tris in die Region der. Samentaschen nach hinten. Seillich vom Schlunde liegen ein Paar hinten breit angeschwollene, nach vorn in einen langen, engen Ausführgang übergehende Peptonephridien, die noch etwas wejter nach hinten ragen als die Speicheldrüsen, und bei dem nälıer untersuchten Stück zahlreiche parasitisclse. Vimatoden beherhergten. Der Oesophagus modifizient sich im 6. Segment (?) zu einem grossen, dickwandigen, tonmenlörmigen Mnskelnıagen und hinter densellsen (im 7.-9. Seguent?) zu einem Paar anscheinend mehrteiligen Kalkdrïsen mit lanelliger Struktur der Wandungen. Die Kalkdrüsen sind ungeteilte seitliche Aussackungen des Oesophagrus, mit dessen zentraler Partie ihr Lumen in breiter Konmunikation steht. Sie sind durch tiefe Quereinschnitte in eine vordere (dem 7. Segment angehörige?) und eine hintere (dem 8. und 9. Segment angehörige?) Parlie gesondert. Die vordere Partie (in 7. Segment?) umfasst dorsal den Oesoplagus, ist jedoch in dieser medianen dorsalen Partie einfaclıer, nicht lamellös. Die hintere Partie (dem 8. und 9. Segment angehörig ?) ist durch eine undeutliche Querfurche wieder in zwei Teite geteilt, teren jeder vielleicht einem der beiden in Frage kommenden Segmente angehört. Es hat demnach den Anschein, als seien die Kalkdrüsen aus der Verschmelzung drejer Parre hervorgegangen; doch ist dies noch sehr fraglich.

Blutgefässsystem : Letzte Herzen inı I r. Segment.

Exkretionsorgant: Meganephridien ohne muskulösen Sphinkter ausmündenrl.

Männliche Geschlechtsorgane: Zivei Paar Hoden und Samentrichter ventral im 11. 


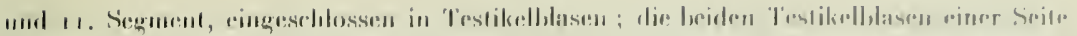

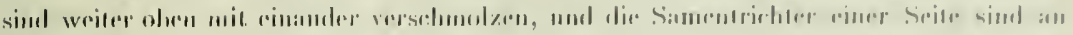

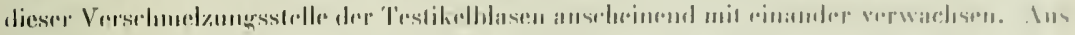

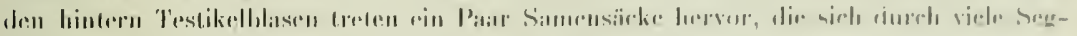

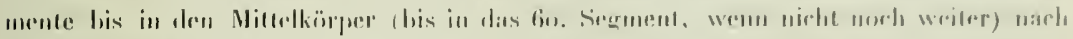

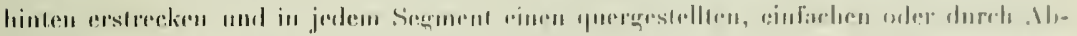

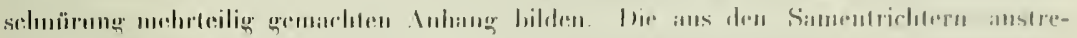

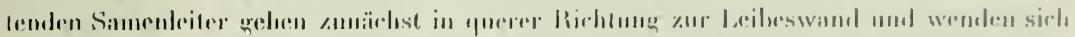

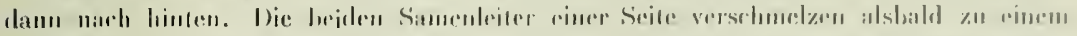

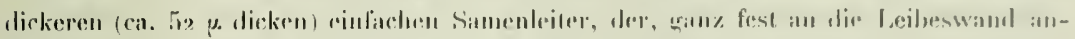

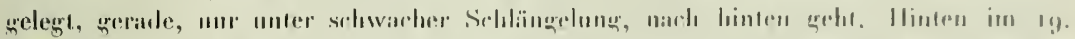

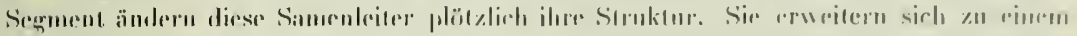

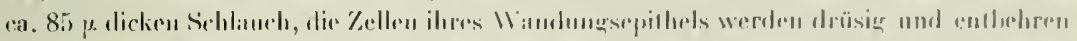

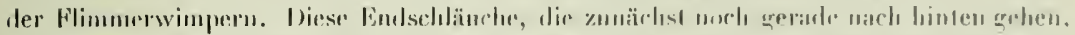

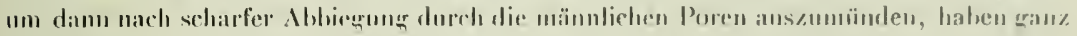

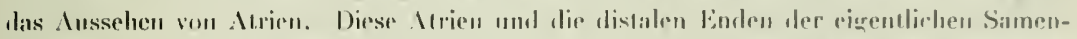

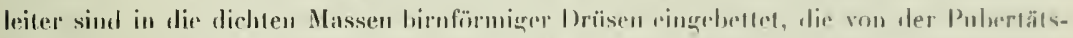

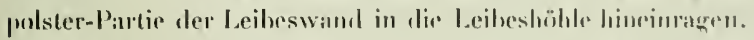

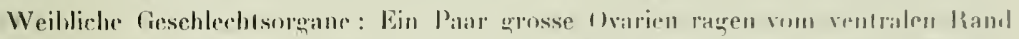

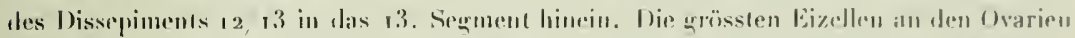

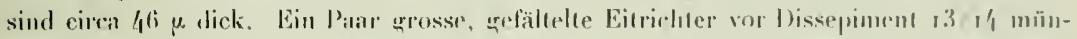
den durel je cincu enown, xiemlich kurzen bileiter aus.

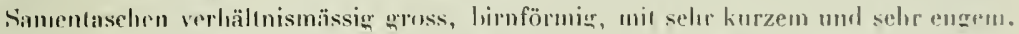

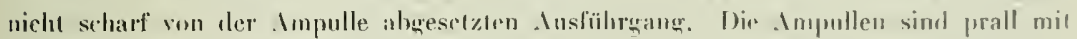
mmregrelmässigen Samemmassen gelïllı.

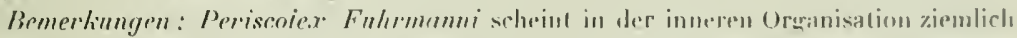

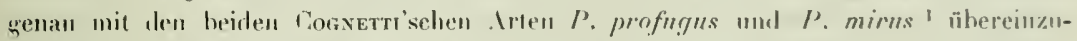

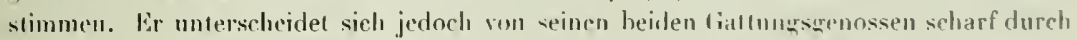
seine darakleristischen Borsten-Verhältnisse, zmmal leren treringe Zahl. ferner dureh dir 1)reizalıl der Samenlaschen-Patre.

\section{Periscolex vialis $\mathbf{n} . \mathbf{s p}$ \\ Tafel VIIl Fig. I.}

Fundangabe: Am Camino Roal, wwisclen Cimaduas mod Semsitiva, 1000 m.

Vorliegenul ein vollständiges Exemplar und die zerfetzlen Bruchsfücke eimes zweilen.

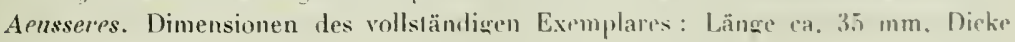
2-3 mm.. Segmenlzahl ca ı go.

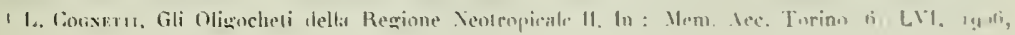
P. 1 (i), Tav. I Fig. 3 u. 4. und p. r63, Tar. I, Fig. 3 u. 6. 


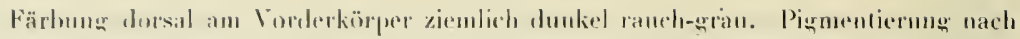

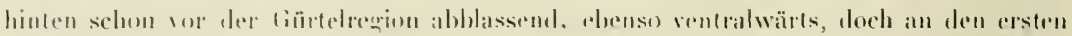

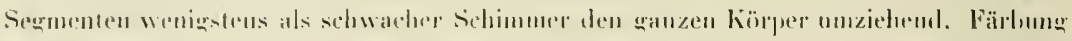
der nicht pigmentierten Hantpartien dorsal grau, rentral grelblich weiss.

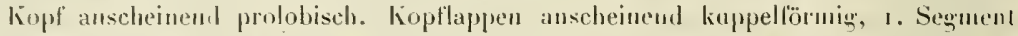
sehmal, durch eine nur sehr zarte Intersegmentalfurelue vom 2. Segment getrenut. Seurmente einfach.

Bursten zart, an Mittelliörper etwal $0,10-0,11 \mathrm{~mm}$ lang und $6-7$. dick, dorsal anscheineurl elwas zarter als ventral. stark S-förmig gebogen, mit undeulich begrenzteu Codulus distal ron der . Vitte, am distalen Ende gabelspitziيn, mit kürzerer, vielfach melır mber weniger ahgeschliflener oberer Gabelzinke, ohne weitere Ornamentiorung. Die Zahl der Borsten an den Segmenten des Miltelkörpers schwankl zwischen 20 und 25 (an g Segrmenten grenau gezälılt). Die Anordnung der Borsten ist rentral qanz charakteristisch, wemn auch gewissen Unregelmässigkeiten unterworfen. Hier zeigen die Borsten ganz. rntsehieden die Neigung zur Anordnung in reggednässigen Längsinien, die ihrerseits symmetrisch zur Mediane liegen. Eine sehr regehmässige Borstenlinie ( $n$ ) liegt jederseits "was oberhall, der Nephridialporen, eine ebenfalls sehr regelmässige Borstenlinie $(m)$ linut eine mässig acosse Strecke unterhalb der Nephridialporen. Fast ebenso regelmässim sind zwei Borstenlinien ( $a$ und $b$ jederseits nelsen der ventralen Medianlinie, so zwar, dass die mediale $(a)$ ungefähr in der Mitte zwischen der zweiten (b) und der ventralen Medianlinie liegt (alsu $a,=$ ca. $2 a b)$. Dazu kommen dann noch ventral-lateral jederseits rine Anzahl ( 2 this 4 ) Borsten, die aueh noelı die Neigung, sich in Längslinien zn stellen, zeigen, jedoch hei weitem nicht so ausgesprochen, wie die der Borstenlinien $\iota, b, m$ unl n. An den meisten Sèmenten beträgt die Zalı der ventral-lateralen Borsten 2 ( I Paar?), so dass man hier, algesehen von den dorsalen Borsten, jederseits 3 Paar in der ventralen hörperhälfte his etwas oberhalh der Nephridialporen erkennt. Vermehrt sich die Zahıl der ventral-lateralen Borsten (zwischen den Borstenlinien $b$ und $m$ ), so scheint es in jeden Fatle um \& (um I Patr?) zu sein; doch lässt sich aus den wenigen beobachteten Fälleı noch keine sichere Reget aufstellen. Auch die dorsalen Borsten stellen sich manclımal noch für sehr kurze Strecken in Längsinien; doch erscheinen sie meist ganz mnregelınässig gestellt. Eiı mässig breiter dorsalmedianer Raum ist meist frei von Borsten, doch rïeken an einzelnen Segmenten die obersten Borsten sehr nahe an die dorsale Nledianlinie heran, so dass von einer dorsalmedianen Unterbrechung der Borstenketten wohl nicbı gesprochen werden kann.

Nephridialporen selır dicht unterhalb der Borstenlinien $m$ (meist der sechısten, an einzelnen Segmenten der achten von der ventralen Medianlinie an gerechnet.

Gürtel ringförmig, am 14.-22. Segment $(=9)$, stark erhaben, ventral etwas abgeplattet.

Pubertätsbildungen : Sehr schwach ausgeprägłe schmale Pubertätswälle jederseits dicht unterhalh der Nephridialporen (in den Borstenlinien $m$ ) am r5._2 I. Segment (nur 


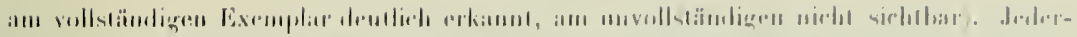

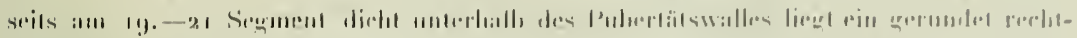

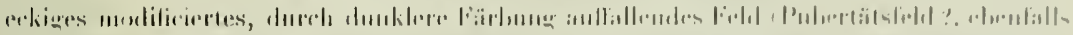
IIIr :

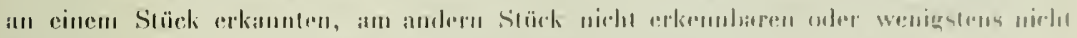

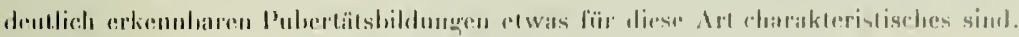

Mïnnlicle und weiluliche l'oren uichl erkannt.

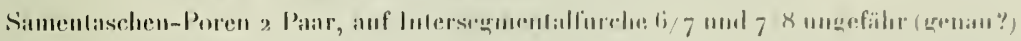
in den linien der Nephridialpuren.

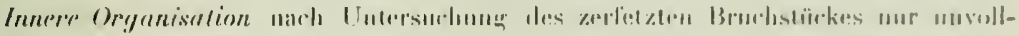

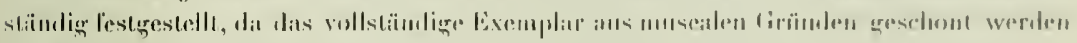
sollte.

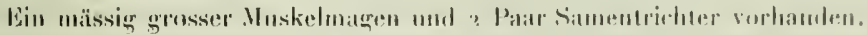

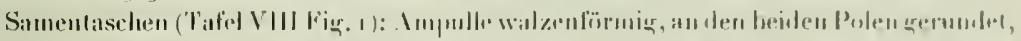

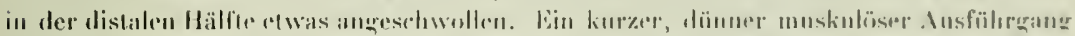

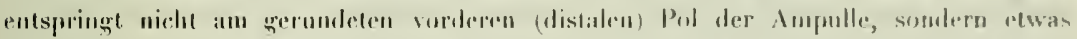

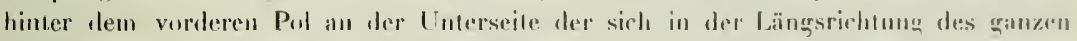

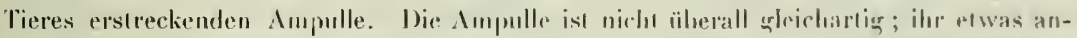
fresclıwollener vorderer Teil ist dïnnwandig und prall mit Sanenmassen grefüllı; ilır etwas engerer hinterer Teil besizt eine etwas dickere, drüsign IVandung und enthäl hauplsïchlich kömelige Drösensekrete, zwischen tenen sich allerdings anch kleinere Spermien-

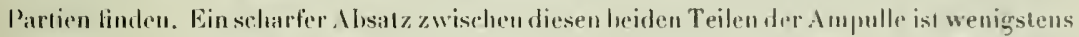

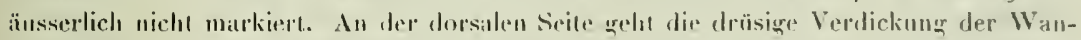
dung weiter nach rorn als an der Ventralseite. Diese hesondere Struktur der ImpullenWamlung ist wohl in Pillallele zu stellen mit jenen Bildungen bei den AndiodrilusArten und rinigen Thumnodrilus-drlen, lem denen sich der meist schon als Ausführganer lezeichnete distate Teil der . Mmpulle zu rimem Samenmagazin differenzierl und manchmal (\%. B. hei Andiodrilus bicolor n. sp. - sielı unten!) his zur Bildung woil Samenkäm-

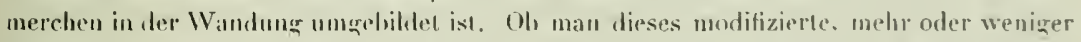

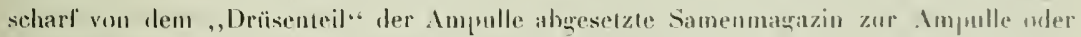
zum Ausfürang rechnet, ist wohl ziemlich belanglos.

Bemerkungen: Perisenter vialis 11. sp. steht seiner ganzen Organisation nach zwischen P. Fuhrmanni n. sp. (siehe oben!) und den heiden äleren Cogsetri'schen Irleu (1. c. 1go6, unter P. Fuhrmanni), und zwar ansheinend zunïchsi dem P profugns Cogs. Während die Zahl der Borsten an den Segmenten des Mittelkinpers leei P. rialis 20-25 hadränt, soll sie bei P. profugus ca. 26 sein, geuren 10 hei P. Fuhrmanni und 35-40 hei I'. mirns Cog.N. Oh die ventralen Borsten anch bei $P$. profngus in melır oder weniger regehmässigen Burstenlinien angeordnel sind, ist nnbekannt.

Auch in der Zahl der Samentaschen-Paare, ? lsei P'. cialis, steht diese nene Irt zwischen P. Fuhrmanni (3 P'aar) und den Cogxetri'schen Arten (1 Paar). 


\section{Pontoscolex corethrurus (Fr. Müll.)}

Fundangaben: Medellin, $1600 \mathrm{~m}$. - Zwischen Tuaduas und Seusitiva, rum m. Zwischen Guaduas und Honda, ion m.

\section{Rhinodrilus (Thamnodrilus) Cameliae n sp. \\ Tafel VIII Fing. 11-i4.}

Fundunguben: S. von Medellin, Cafetal Camelia bei Thitribi am Rio Anasa, Nebenlluss des liin) Cauca; $1800 \mathrm{~m}$.

Vorliegend awei Exemplare, die in dem Hahitat der Geschlechts-Charaktere stark von einander abweichen. Ich halte diese Abweichnngen joduch lïr unwesentlich, vielleichı nur darauf herubeud, dass das eine, mit eincm vollständign ausgebildeten Gürtol versehenc, also anscheinend vollständigg geschlechtsreife Stück in Hinsicht anf tie mäunlichen (Trgan. zurückgeblieben, und in Korrelation zu diesem partiellen Unreife-Zustand auch in gewissen äusseren Puhertätsbildungen rückständig ist. Das andere, in Ilinsicht anf die männlichen Organe vollständig ansgereifte Exemplar zeigt liese Pubertätsbildung in scharfer Ausbildung.

Aeusseres. Dimensioneu der anscheinend vollständigen Exemplarc: Länge no unc $65 \mathrm{~mm}$, Dicke $31 / 2-4$ bezw. $4 \mathrm{~mm}$, Segmentzahl $12 \mathrm{~s}$ bezw. 143 .

Färbung grau oder schmutzig graubraun. Keine deutlich ausgesprochene PigmentZeichnung.

Kopf mit einem dick-stummelförnigen, vorn gerundeten Rüssel, der wenig länger als dick ist. Bei einem Exemplar Kopf-Ende bis zum 2. Segment fast ganz eingezogen.

Borsten ventral am 5., lateral am 8. Segment beginnend (wenigstens habe ich sie weiter vorn nicht erkennen können), an den vorderen Segmenten ungemein zart, nach hinten allmählich an Grösse zunelımend, schoı dicht hiuter dem Gürtel ziemlich gross, nach hinten noch an Grösse zunehmend, so dass sie in der hinteren Köperhälfte, zumal am Hinter-Ende, als sehr gross hezeichnet werden küunen. Die vergrösserten Borsten des Hinter-Endles sind ungefähr y mm lang und im Maximum 65 u. dick. Während dir kleineren Borsten einfach und schlank S-förmig gebogen sind, sind die vergrösserten Borsten stärker S-förmig gebogen, am distalen Ende hakenförmig, so zwar, dass das äusserstı distale Ende quer zur allgemeineu Borstenrichtung gestellt ist. Die Ornamentierung der vergrösserten Borsten besteht aus einigen wenigen weitumfassenden, distalwärts etwas konkaven Narbenrändern an der Konkavseite cles gebogenen distalen Endes. Die Borsten sind gepaart, und zwar die lateralen ein wenig enger als die entsprechenden ventralen, und, entsprechend der Borstengrösse, die der vorderen Segmente enger als die der hinteren Segmente. Während die der vorderen Segmente ungemein eng gepaart sind, müssen die des Mittel- und Hinterkörpers als weit gepaart bezeichnet werden. Im Maximum, an den 


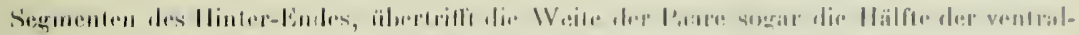

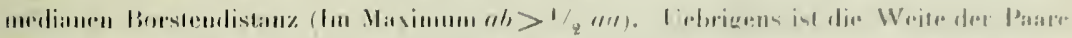

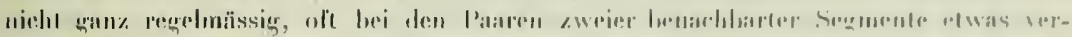

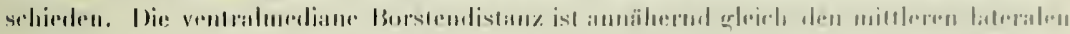

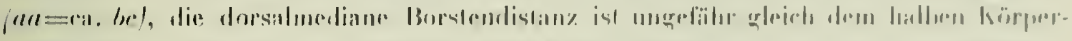

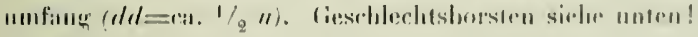

Nephridialfuren in den liorstrnlinimen ret.

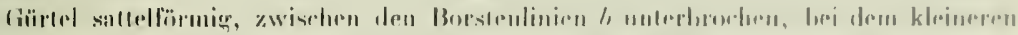

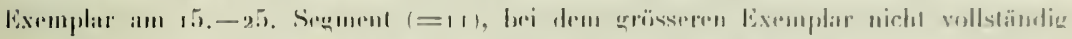

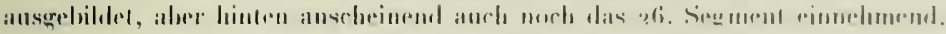

Mänulirle und weibliche l'oren nich erkaunl.

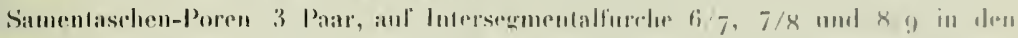
Borstenlinien $\mathrm{col}$.

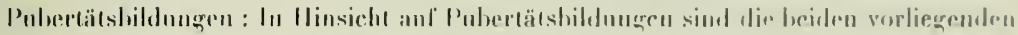

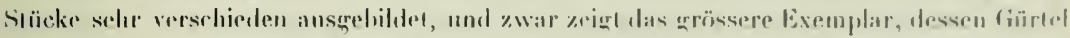

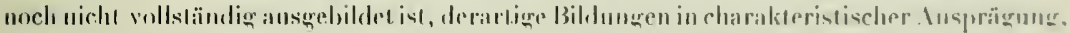

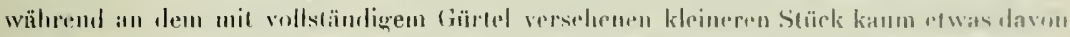

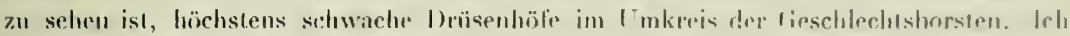

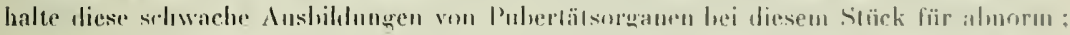

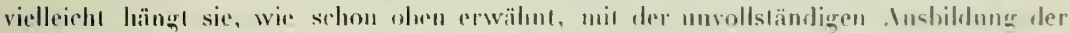

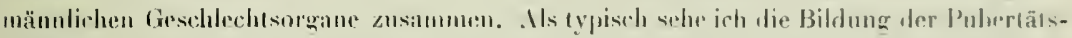

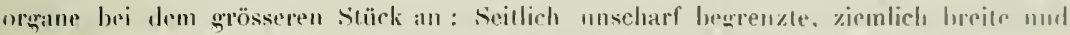

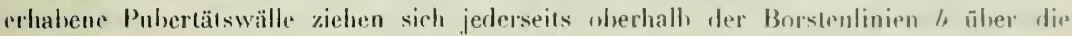
5 Segmente 20 bis 24 hin. Die ventralen Borstru dieser 5 Segmentr sind ron schwachen quer-ovalen, paarwerise aneinander s(ossenden und verschnelaralen 1)rïsenhöfen um-

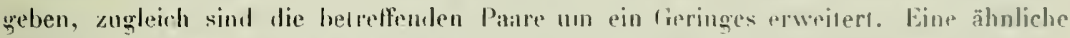
Bildung zeigl sirh in viel slärkerer Aushildmus an den wontralen Borsten der 3 segmente

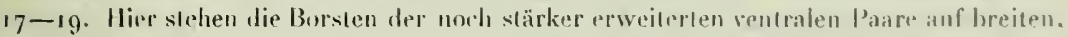
stark erhabenen Drüsenpulstern, tie dir ganze Ventralswite jlarer somente bis weil îher die Borstenlinien $b$ himaus rimnehmen und nur ventraluedian eine unvollständige [infer hrechung in tiestalt einer Längsfurche anfweisen. Pustrlitellial und in dem Bezirk der Samen-

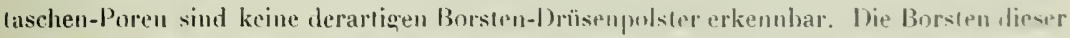
mit Drüsenpolstern oder Drüsenhölen ausgestatleton Patare sind zu Creschlechlshursten

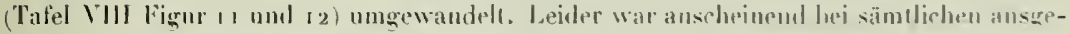
wachsenen Grsehlechtsborsten das distale Ende abgebrochen; dorlt setzl mich die lönter-

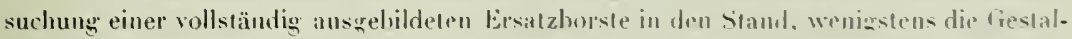

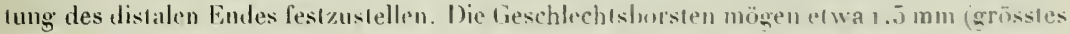
Bruchstück 1,2 mm) lang quewesen sein. Ihre maximale Dicke. elwa am Ende des proxi-

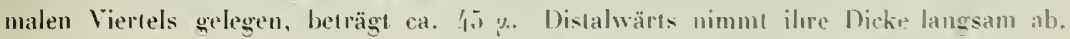
Sie sind nur am proximalen Ende etwas getogen, im lehrigen ganz gerade grestreckı. 
1)as äusserste distate Ende ist shlank Vogelschnalul-fömig, nicht eigendlich gebogen,

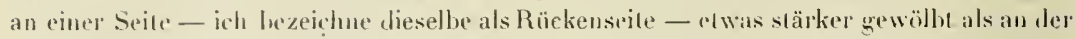
andern, die ichals Banchseite bezeichne. De distale llälfte der Geschlechtshorste zeigh cince sehr charaktoristische Unamentiernng, die von der anderer Rhinodrilus-Arten in bedentsames Weise aloweicht. Auch bei R. T.) Cameline hesteht die Ornamentierung, wie es für seine Gatlung charakleristisch ist, aus 4 Längsreilıen von liefen Xarben mil schärferem proximalen Rande; aler die Anmrlnung ist rime meines Wissens nngewölunliche. Es alternitren nämlich nicht die Naphen ron je zwei lemachbarten Reihen; sombern dic Tarben der beiden dorsalen Reihen stehen in glcieher IJöhe, ebenso wie: die Narlıen der beiden rentralen Reihen, und nur die beiden dorsalen. Narbenpaare alternieren in ilirer Stellung mil den ventralen Narbenpaaren. Die proximalen Ränder der Narben sind zienlich weil nmlassend, nur weng gehogen. In der dorsalen resp. in der ventralen Medianlinie der Borste stossen dir proximalen Ränder zweier neheneinander liegender dorsaler bezw, ventraler Varben list aneinander, und die heiden Narhenverljefungen sind nur durch einen dünnen, distalwär's niedriger werdenden Längskamm von einander getrenul. Da dieser die beiden zusammen gehörenden Narben trennende Längskamm nicht in jedrr Borstenlage deutlich zn sehen ist, so macht es manchnal den Eindruck, als seien nur zwej Längsreihen von Narben, eine dersale und eine ventrale, vorhanden, und in gewissir Lage scheint die Burste fast wellig konturiert zu sein. Die furch die Narben markierten Borstenglieder sind im Allgemeinen selır lang. Der Abstand zwischen zwei in einer Linie hintereinander liegenden Nirbeurändern ist ungefähr 4 mal so gross wie die Borstendicke. Dislalwärts werden alle Glieder etwas kürzer, bleiben aber bis ans Ende deutlich grösser als die Borstendicke. Die Zahl der Narben ist in den ventralen Längsreihen ewa um 2 grösser als in den dorsalen, da an der sog. ventralen Seite des Vogelschnabelähnlichen distalen Endes noch 2 Paar Narben stehen, wo die gegrenüber liegende gewölbte sog. dorsale Seile schon glatt und narbenlos isl. Die ahsolute Zahl der Narben in einer Längsreihe konnte ich leider nieht feststellen. Die unfertige Ersalzborste besast in den ventralen Längsreihen 7 , in den dorsalen 5 Narben; der grösste Stumpf der ausgewachsenen Geschlechtsborsten zeigte 5 Narhen in einer Längsreihe; doch zeigten die äussersten noch eine unverminderte Distanz zwischen sich, so dass sie noch nicht als die letaten dorsalen bezw. als die driltletzten ventralen angesehen werden können. Die Zahl der Narben war also mindestens un 2 grösser als bei der unausgebildeten Ersatzhorste. (Zahıl der Narben mindestens 9 in den ventralen, 7 in den dorsalen Längsreihen, vielleicht noch el was grösser).

Innere Organisution. Dissepiment $6 / 7$ bis ungefähr $13 / 14$ verdickt, $6 / 7-11 / 12$ mässig stark ( $7 / 8$ besonders stark?), die folgenden an Stärke abnehmend.

Darm: Ein ziemlich grosser Muskelmagen im 6. Segment. In den Segmenten 7-r.3 Irägt der Oesophagus je ein Paar Chylustaschen; es sind also deren 7 Paar vorhanden, wie bei $R$. (T.) savanicola Micn. ${ }^{1}$ und verwandten Formen. Die Chylustasehen der ver-

I W. Mrchaelsen, Die Terricolen-Fauna Columbiens. In : Arch. Naturg. LXV., 1900, 1, p. 244. 


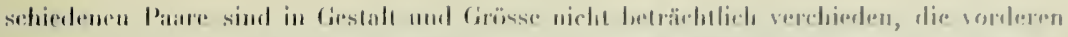

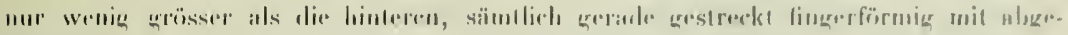

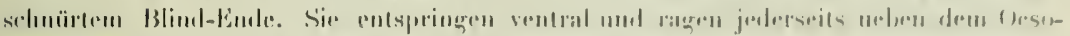

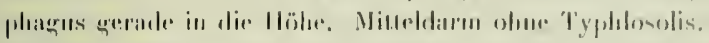

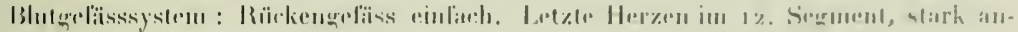

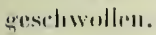

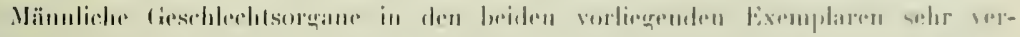

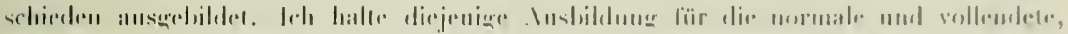

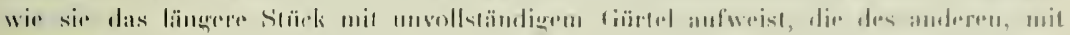

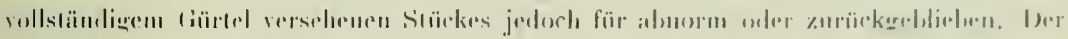

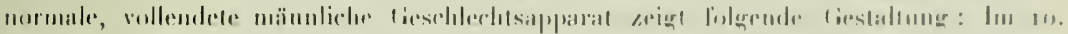

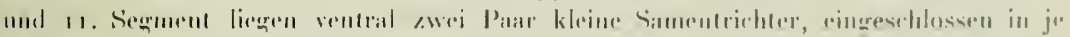

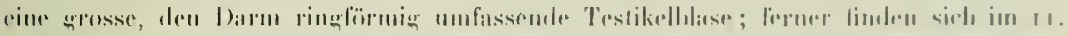

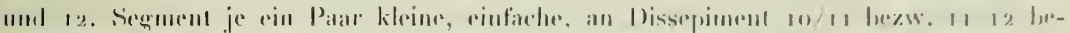

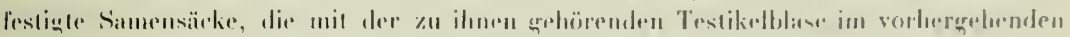

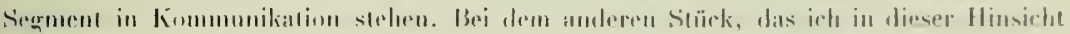

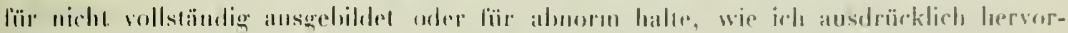

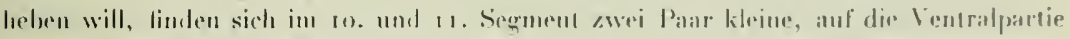

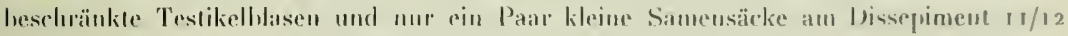

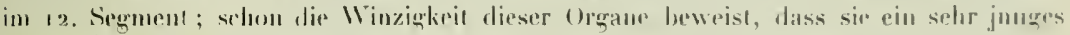
Stadiuni dastrillen.

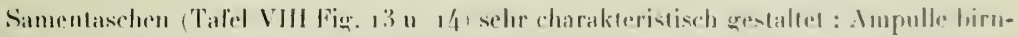

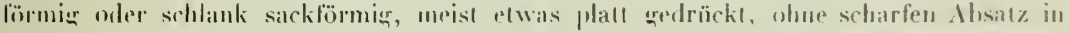
cinen ebenso hangen oler elwas kürzeren, im Ulgempinen schr dïnmen, schlanchförmieren

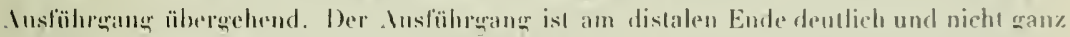

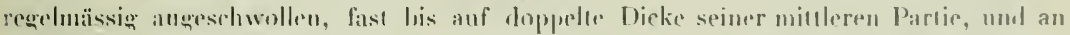
dem charakleristischen melallischen Gianz crkennt man schon bei änsserlicher Belrachlumg.

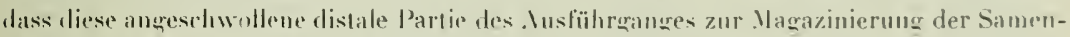
massen dient. In der Ampulle finden siclı digeuren keine Simenmassen. sondern mur zart-kïmelige Suhstanzen, anseheinemal Drïsensekpere. Das angeschwollena distale Ende

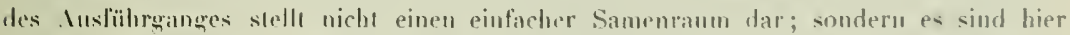

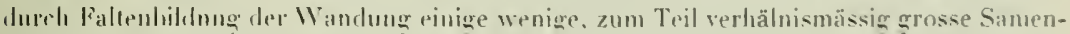
kämmerchen entslanden, die aher mil dem . Irhsiallumen des. Ausfülırganges in ziemlich

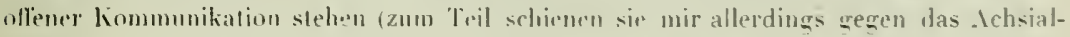
lumen mehr abgeschlossen zu sein). Die Samemmassen liegen nichl regellosi in desen (umonllständier abgeschlossenen ?) Simenkämmerchrn, sondern schopfarlig parallel milrimander, nml ansclseinemd mil den liopfspilzen an die Innenseife der SamenkämmerchenWindung angeselzt. Diese Eimbiohlung erinnert sehr andie änliche hei $R$. (T. I bicolor n. sp. (siche mnen!); doch ist hei diesem letzeren die Sanenhämmerchen-Bildung vollkommmon. R. (T.) Cameline steht in dieser Hinsicht in der Mitte zwischen $R$. (T.) en- 
Eonus Cors. und R.jT. bicolor "1. sp. (Vergleiche die Erörterung unter R. (T.) biculor,

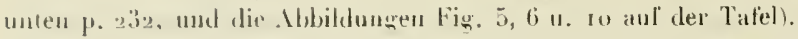

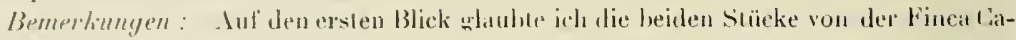

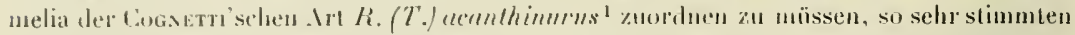
sie mil dieser Arl, the ich nach typisehen Stüelen vergheichen konnte, in den änsseren

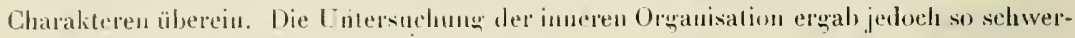
wiegende Interscherle, dass die Anfstellung einer nenen Art für diese beideu stücke notwendig wurde. Die hanptsächlichsien Unterschiede liegen in der Zahl der ChylustaschenPaare, in der selur charakteristischen Furm der Gesehtechtsborsten und in der Gestallungy der Samentaschen. Ieh halte eine eingehendere Vergleichung der beiden Arten l'ür angebraclit.

Dimensinuen: R. ( $T$.) Cinmoliae scheint beträchtlich kleiner zu sein als $R$. (T.) acanthinur'us.

Borsten: Des Ilauptsache nach, so in ter Anordnung, in der Gestaltung nud in den firössenverhältnissen (vergrösserte Borsten des Hinterkörpers) slimmen beide Arten überein; doch bewinnen die Borsten bei R. (T.) Cameliap anscheinend etwas weiter hinten (am 5. bezw. 8. Segment) als bei R. (T.) acanthinurks (am 3. Segment). Zu bemerken ist noch, dass ich die Lisweiterung der Padre an Hinter-Ende von R. (T.) acuuthinuras ebenso beträchtlich fand wie bei $R$. (T.) Camplice. Cognerro erwähnt das nichl; seine Angabe bezieht sich nus auf die Borstendistanzen an Mittelkörper.

ln der Erstreckung des Gürtels, dessen Länge un ein Segment schwanken kam, und der Pubertätswälle scheinen beirle Arten übereinzustimmen, ebenso in der Zahl und Lage der Samentaschen-Poren. Auch die Geschlechtsbursten-Drüsenpolster, deren Anordnung etwas schwanken kanı, zeigen in wesentlichen Uebereinstimmung.

Ein wesentlicher L'nterschied besteht in der Gestahtung der Geschlechlshorsten, die bei R. (T.) acanthimurns, wie ich bestätigen kann, die gुewöhuliche Ornamentierung der Rhinodrilus-Geschlechtsborsten aufweisen (Narben in 4 gleichnässig gesonderten Längsreihen, die der einander gegenüberliegenden Längsreilıen in gleicher Höhe, die zweier henachbarter Längsreihen regehmässig alternierend verschieden hoch), während bei R. (T.) Gameliae die weil abveichende, selır charakteristische Anordung und Geslaltung der Narben besteht, wie sie oben yeschildert.

lı der inneren Organisation bestebt ein sehr bedeutsamer Unterschied in der Zahl der Chylustaschen. Während R. (T.) acanthinurns wie die meisten Thamnodrilus-Arten deren 8 Paare in 7-14. Segment hesitzt, was ich bestätigen kann, finden sich bei R. (T.) Cinmeliae nur 7 Paare im 7.-13. Segment (die letzten Herzen im 12. Segment verlaufen, wie ich deutlich klarlegen konnte, hinter den Chylustaschen des vortetaten l'aares; im 14. Segment, das wie die ganze Darmstrecke vom 10.-16. Segment klar und intakt vor mir lag, sind keine Chylustasehen vorhanden).

1 L. Cognetr, Gli Oligocheli della Regione Neotropieale II. In : Mem. Acc. Torino (2) L, VI., Igot, P. 211 , Tay. I, Fig. $32-34$. 


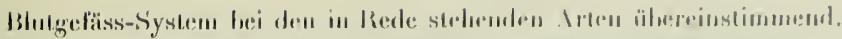

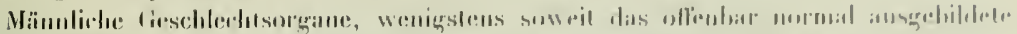

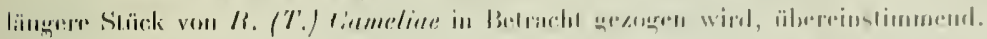

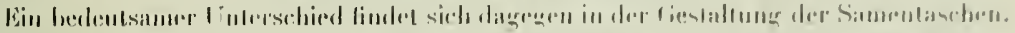

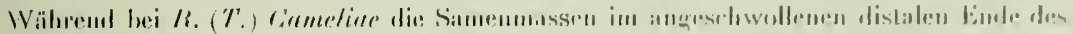

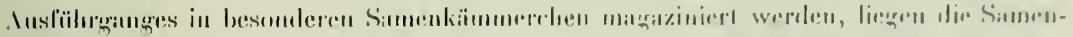

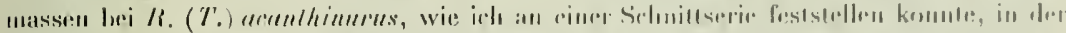

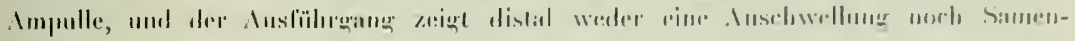
kïmmerchen.

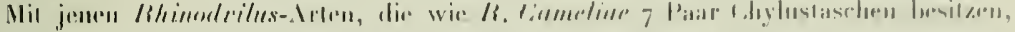

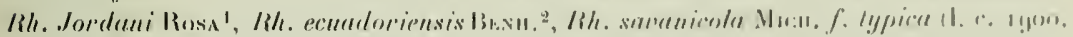

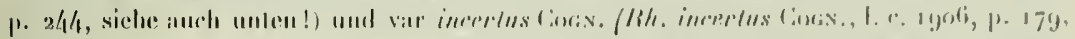

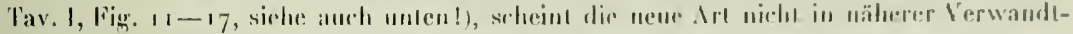

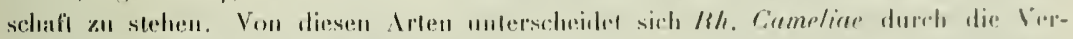

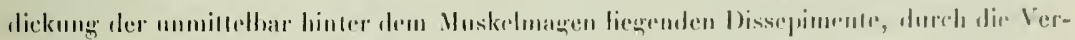

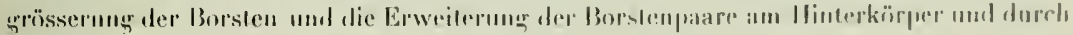

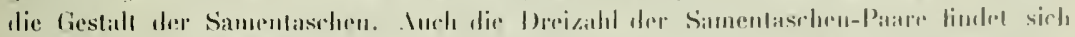

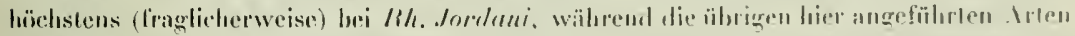

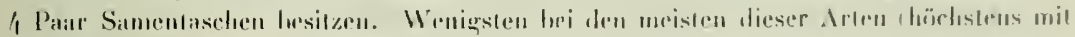

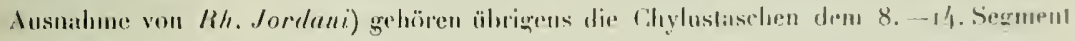
an (siehe minlen unter Rh. surnanicola!).

\section{Rhinodrilus ('Thamnodrilus) columbianus Mich.}

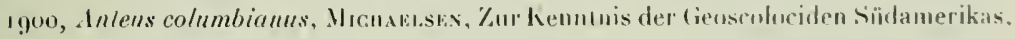
In: Zool. Anz. XXIII, p. 5i.3.

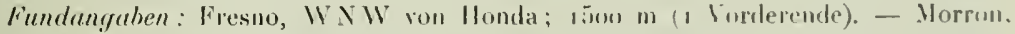

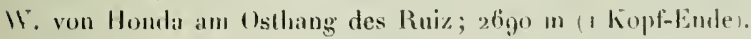

Vorliegend ein Vorder-Ende von $21-27 \mathrm{~mm}$ Dirke; dis vollständige Tier soll nach Inssage des Sammlers mindestens tion mu lang geweon soin. Es war also zwpifallos

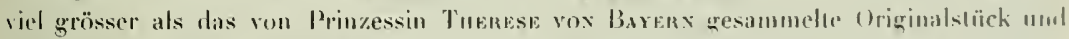

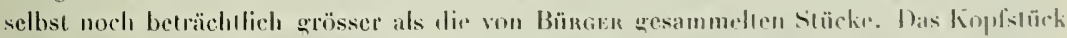
seheint rinem Exempliar von ähntichen Riesendimensionen anzehört zu haben.

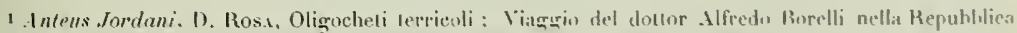

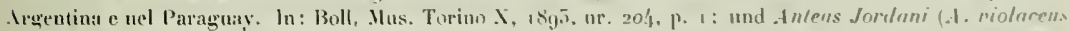

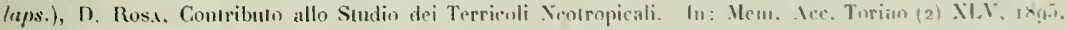
p. 100, 120. Tav. Fig. 8.

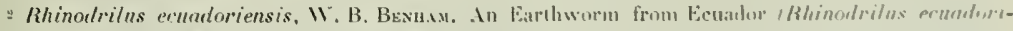

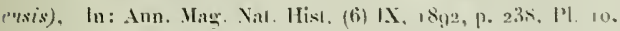




\section{Rhinodrilus (Thamnodrilus) bicolor $\mathbf{n} . \mathbf{s} \mathbf{p}$.}

Tatel Vill lïn. 5 11. 6, sumie Textlig, 11.

Fundanguben: SW ron Medellin, Puerto de los Polsres, lee Titiribi an Einfluss des Rio Amaga in ten Rio Cauça : $800 \mathrm{~m}$.

S ron Merlelliu, Cafetal Camedia bei Angelopolis ; $1800 \mathrm{~m}$.

Vinliegend zwei Exemplare, ein unvollstäudiges mit wohl ausgebildeten Gürtel und rin wolstïndiges, äülelloses, aber im ïhrigen geschlechtsreifes.

Aensseres. Dimensionen des vollständigen Sü̈ckes von Puerto de los Pobres : Längr (a) 220 mm, Dicke $4-6$ mm, Segmentzahl ca. 25 . Das unvollständige Stücke von der Finca Canelia scheint älntiche Dimensionen besessen zu haben; es ist in der Gürtelregion aher bis zu einer Dicke von $8 \mathrm{~mm}$ angeschwollen.

Färbung dorsal dunkel violett- his braun-schwarz (Stück von Puerto de los Pobres) orler dunkel rauch-grau (Sı̈̈ck von Finca Camelia); Bauchseite bräunlich oder graulich gelh. Die dorsale Pigmentierung ist in den Seitenlinien, den Linien der obersten Borsten (Borstenlinien d), sehr scharf gregen dir pigmentlose Ventralpartie abgesetzt.

Kopf-Ende: Das I. Seqment ist sehr kurz, bei den vollständigen Exemplar sam! deu Koptlappen (Rüssel) eingezoggen. Bei dem unvollständigen Stïck tagt ein dickstummelförmiger Rüssel aus der vorderen Körperöflnung hervor. Der Rässel ist nur wenig länger als dick.

Borsten vom 3 . Segment an vorhanden, überall eng gepaart, die ventralen ebenso eng wie dir lateralen. Die ventralmediane Borstendistanz im Allgemeinen gleich den mittleren lateralen $(a u=b c)$. Am Vorderkörper bis etwa zum 8. Segment siud die mittleren lateralen Borstendistanzen etwas verringert, so dass sie hier kleiner als die ventralmediane Borstendistanz sind (am Vorderkörper $a a>b c$ ). Dorsalmediane Borstendistanz annähernd gleich rlem lathen Körperumfang $\left(d d=\mathrm{ca} .{ }_{1 / 2}^{1} u\right)$. Die Borstendistanzen sind stellenweise dureh unregelmässige Aufblälıung des Körpers etwas verzert. Die normalen Borsteu des Vorder- und Mittelkörpers sind $0,9-1,0 \mathrm{~mm}$ lauğ, schlank S-förmig qrebogen, mit einem Nodulus etwas distal von ter Mitte ausgestattet; ihr distales Ende ist sclıvarh gebogen, einfach und schlank zugespitzt und ornamentiert. Die Ornamentierung liesteht aus 4 regelınässigen Längsreiben von je $6-8$ seichıen Narben, die proximal durch einen distalwärts konkaven scharfen Rand begrenzt sind. Die Entfernung zwischen zwei hintereinander liegenden Varbenrändern ist geringer als die Borstendicke. Diese Gestalıung der normalen Borsten wurde an einigen ventralen Borsten $(a$ und $b$ ) des 21 . Segments (hier hei dem vollständigen Stück keine Geschlechtsborsten, sondern normale Borsten!) und des 40. Segments festgestellt; die ausgewachsenen Borsten des 40. Segments hattin allerdings ihre distale Sitze verloren, doch konnte an den neben ihnen stehenden Ersatzborsten, bei denen audererseils das proximale Ente noch nicht ausgebildet war, die Vebereinstimmung in der Gestalt und Ornamentierung des distalen Endes mit dem der 


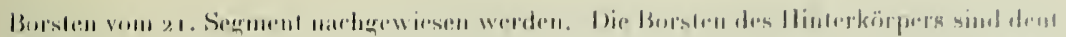

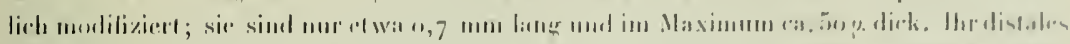

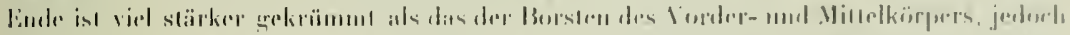

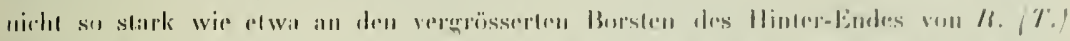

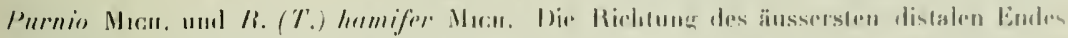

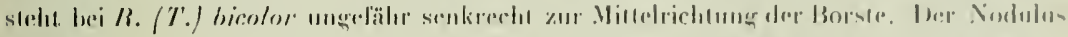

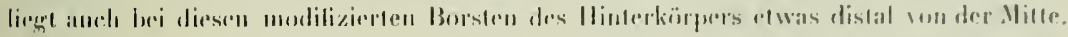

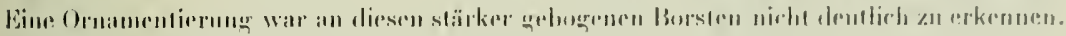

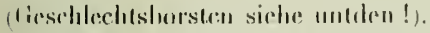

Nephridialporen in den Burstentinion ad.

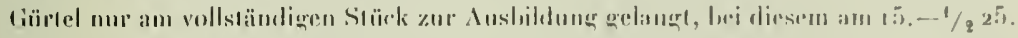

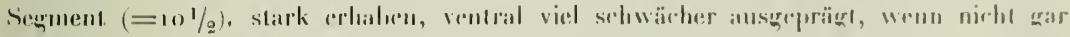
manz unterborochen.

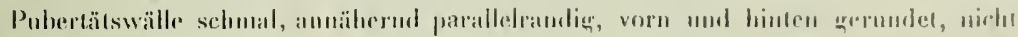

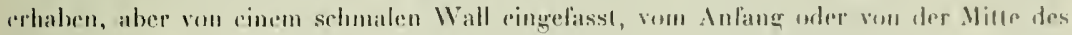
1). Segunents his eben auf dis 2 f. Scoment hinauf reschond.

Mämnliche und weihliche Poren nichl erkamm.

Samentaschen-Poren 3 Palar, aul Inlersegmentalfurche $6 / 7,7 / 8$ und $8 / 9$ in den Burstenlinien $\mathrm{cl}$.

Akzessorischr Pubertälshilhungen: Die Region emiger zu Geschlechtshorsten unwewablelter ventraler Borsten (ab) ist drüsig modifizicr, fast polslerförmig erhaben, wenn atuch nicht in scharfer I mrandung, und zwar lee dem Stück von Puerto de los

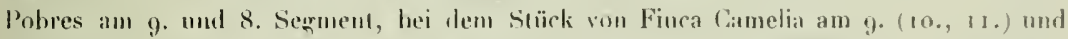
18. (und 20.) Sigment (an den Segmenten der eingeklammerten Nummern nur undentich).

Innere Organisation. Die ersten drei, weniwstens hei einem der heiden Exemplare deullich arkenubaren [tissegumente $6 / 7,7 / 8$ und $8 / 9$ sind ungemein zar. Dissepiment 9/10-r3 14 dentlich, wenn auch nicht sehr stark, verdickt, 9/10 und 13/14 noch etwan weniger slark als die dizwischen liegenelen, 14/15 umd die folgenden allmähliğ an Stärke abnelsmend, elwa $16 / 17$ und die lulgenden manz zarf.

Darm: Ein srosser, etwas schicfer (Konntraklions-Erscheinung?) Muskelmagen im 6. Segmeul. Der Oesophagus lrägl 8 Paar seillehe Chylustaschen, die des letzlen Paarm im 14. Segment, die 3 ersten Pare vor dem ersen verdickten Dissepiment, also zweifelles in den Segmenten 7,8 und g) (im Ganzen also die 8 Paare im $7 .-14$. Segment. wie po für die Untergatlung Thamnodrilns das Gewöhnliche ist). Dir Chylustaschen der ersten ca. 3 Parare sind etwas grösser als die hinteren. Die Chyhustaschen sind mehr oder weniger ahgeplatlet und in der Ebene der Abplathunঞ zu einer fast ohrförmigen Gestalt zusammen gehogen. Das gegen die Ursprungsstelle am Vesophagus hingebogene dislale Ende is durch eine scharfe, schmale liurche ron dem äbrigen Teil der Chylustasche abgeserzt und repräsentiert den sogenammten . Inhang der Chylustaschen. Der Anhang ist an seiner Basis fast ebenso breit wie die angrenzende Partie der eigentlichen Chỵlustasche. Seine Grōsse 


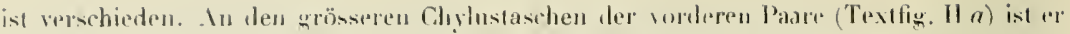

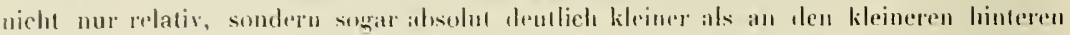

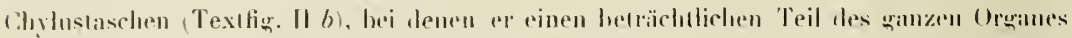
i’innimut, nämlich etwiı den sechstrn Teil.

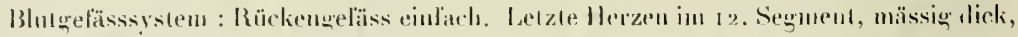

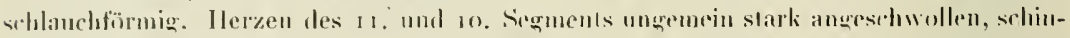
kentiormig, dorsal an dicksten.

Exkretionsorgane - Meganepluriedien.

Männliche Geschlechtsorgane: Zwei P’an mässig grosse, muregehüssig polyedrischu. Testikeflilasen rentral im 10. und at. Segment unterhath des Darmes.
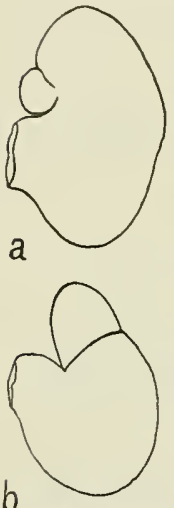

Fig. If

Umriss von Chylustaschen des 2. (a) und des 7. (b) Paares von Rh. (Th.) bienlor n. sp.; $12 / 1$. Die heirke Testikelblasen eines Paares sind entwoder durch einen sehr kurzon und engen medianen Quer-Schlauch mit einander verhunden orler (die des hinteren Paares bei ein'm der beiden Stücke) ventralmedian in ganzer länge mit einander rerwachsen. Die Testikelhlasen einer Seir sind vollständig von einander quetrennt. Zwei Paar flante, schildförmige Samensäcke sitzen mit einem seh kurzen, engen, exzentrisch aus ihrm. Vorterfläche entspringenden Stiel an der Hinterseite der Dissepimrnte 10/1 1 und I1/12 im ri. bezw, I 2 Segment. Hor Stiel setzl sich, das betretfende Dissepiment durchhohrend, in einem kurzen Schlauch forl, der in die zu dem Samensack gehörige Testikelblase eintritt. Die Samenleiter und ihre Ausmündungen sind nicht erkannt worden.

Samentasehen (Tafel VIII Fig. 5 u. 6.) des hintersten Paares hei einem Stück etwas grösser als die der beiden vorderen Paare, erstere im 9. letztere im 8. und 7. Segment gelegen. Ampulle plattgedrïckt hirufïrmig odes melır sackförmig, distal verengu. Die Impulle ist dünnwandig und scheint lediglich eine grannlierı, Eiweiss-ähnliche Substanz, keine Samenmassen, zu enthalten. Der Ausfïhrgang ist in der freien proximalen Partie und in ler dislalen, in der Leibeswand verborgenen Partir. verschieden gestaltel. Die freie, in Ier Leibeshöhle liegende proximalı Partie ist ungefähr so rlick wie lang, oder wenig länger als dick, in der Mitte manchmal schwach angesehwollen, am proximalen Ende so lick wie das distale Ende der Ampulle. Wenngleich dieser proximale Teil des Ausführganges nicht scharf von der Ampulle ahgesetzt ist, so unterscheidet er sich doch schon änsserlich von der letzteren, und zwar durch sein opak-ıeissliches Aussehen. Bei dem vollständigen noch gürtellosen Exemplar war diese weisslich-kreidige Färbung der proximalen Auslïhrgangspartie dureh rinige hellmetallisch glänzende lilecke modiliziert, zeigłe alue im Lebrigen krinertei Besonderheiten bei rein äusserlicher Betrachıtung. Ganz anders hei dem vollstängiپ şeschlechtsreifen Bruchstück: Bei diesem waren diese Flecke zugleich slark erhahen und ragten als mehr oder weniger starke, warzenförmige oder halbkugelig Protuberanzen ïher die allgemeine Oberfläche des Ausführoanges liervor, so dass man sie sehr wohl als Divertikel hezeichneı 


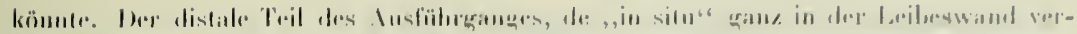

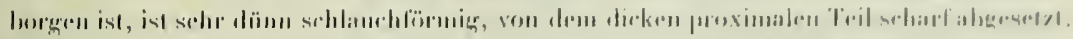

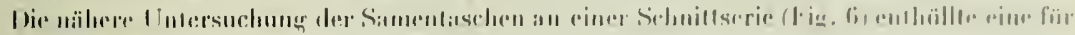

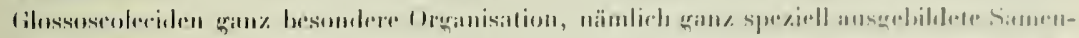

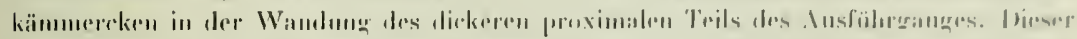

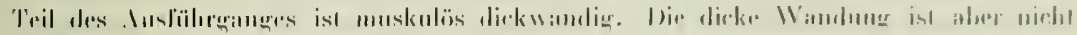

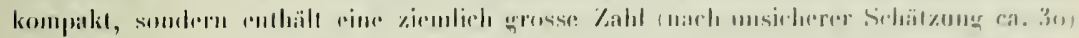

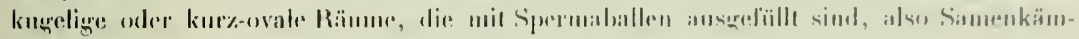

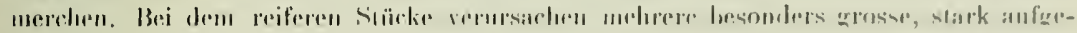

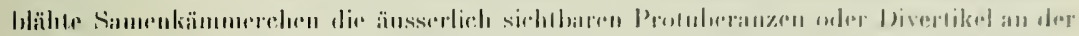

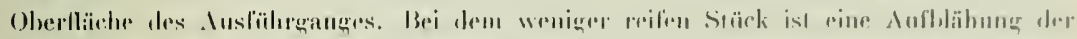

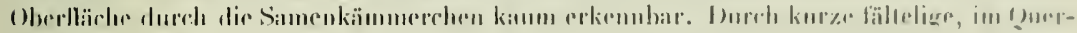

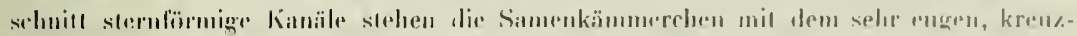

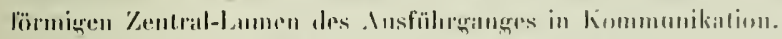

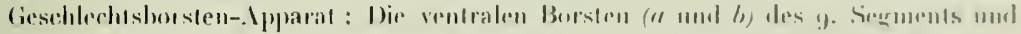

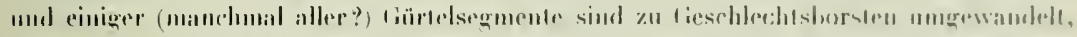

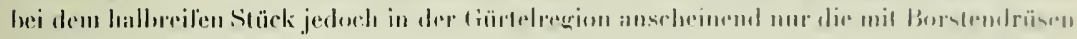

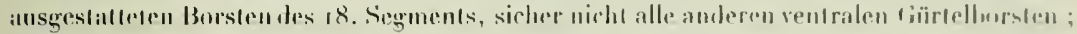

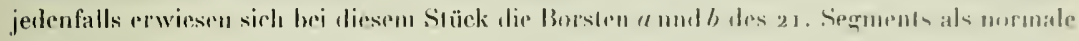

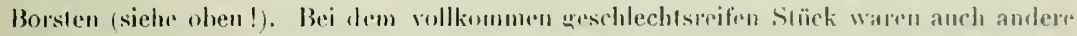

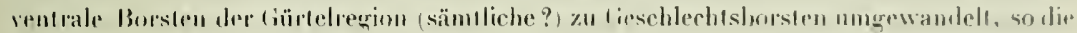

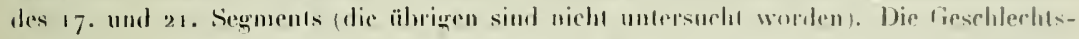

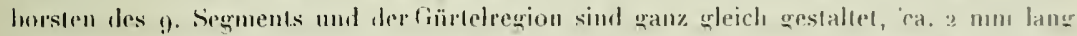
und in proximalen Tril 5n y. dick: geegen das disale Ende nehmen sie langsam und

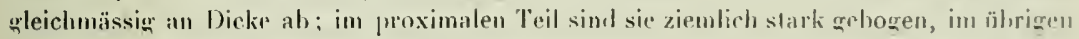
fast gerade gestreckl und nur am änssersten distalen Eude wirder was gebogen, aller-

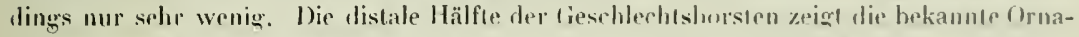
mentierung der Rhinodrilus-ficschlechlshorsten in scher scharfer .Insprïgune, jent vier längsteihen liefer, proximal in regelmässiger kinkavilïl scharf hegrenzler, distalwärts llach iuslaufender Narben; die Narben sind nur weng schmäler als die Borslenbreite; sie stehen w'a zu 16 his 20 in cimer Längsseihe, unıl zwar die Flankenuarben ziemlich

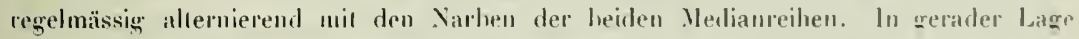
erscheint dir Borste infolgedessen selur regrelmässig gregliedert, mil läugeren distalen (iliedern (distate Glieder deutlich länger als die Borstenbreite) mod kürzeren, weniger scharf ausgeprägten proximalen Glicdern (ungefähr su lang wie hreil). Dils äusserste distale Endr ist schwarh grebogen, einfach und scharf zugespitzl mo jederseits mit winer Längskante versehen, im Ganzen von der Grestall rines schlanken Vugelschuabels. Die Grschlochtshorstenpare des q. Sequents simb mit einer blasenarligen, dick-linsenförmigen. vor ihnen stehenden Borstendrüse, die des 18 . Segrmens mil einer anscheinend meln kompakten, polsterförmigen Drüse ausğestattet. 
Bemertimngen: R. T.) bicolor n. sp. steht zweifellus dem R. (T.) enzonus Cogn. sehr nahe; um so mehr isl es zu verwundern, dassor in einem anscheinend ungemein sehwor-

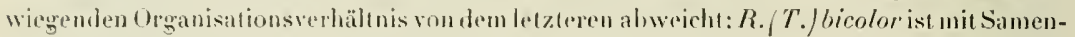
kämmerehen in . Insführgang der Samentasche, die selbst divertikel-artige Vorwölbungen rerursachen kömnen, versehen, R./T./ pnzonns nicht. leh meinte zunäehst, datss sich auch bei $R$. (T.) ellzonns. Samenkämmorehen mürsten finden lassen, und die äussere Gestalı der Samentaschen sprach auch dafür. Cog.verts mwähn rine Verdickung des Ausführganges

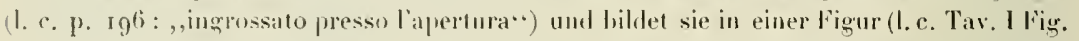
23 a) auch ah. Die Untersuchung ter Samentaschen eines nir ron Cognerro zur Verlïgung gestellten Originalstückes ergab jedoch, dass dieso Verdiekung nicht von besonderen Samenkämmerchen herrüht. Die Sanentasche von R./T.) enzonus hat nach meiner L̈ntersuchumg folgende innere Struklur (Tafel VIII Fig. 10): Die Ampulle ist dëmnwandig. Der Ausfülırgang, äusserlich nicht scharf von der Ampolle abgeselzt, isı innerlich

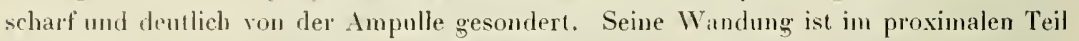
sehr dick, der Hauptsache nach von langen Drüsenzellen gebildet. Die innere Oberfläche dieses Drüsenepithels ist meben und fältelig und die proximale Mündıng des Ausführganges nach der Ampulle hin verengt. Distalwärts nimmt die Wandung des Ansführgranges bald an Dicke ah und verlierl zoggleich das drüsige Aussehen ihrer Epilhelschicht; sie ist hier sehr dünn, an ihrer inneren Oberfläche zwar nicht ganz glatt, aber doch nur mit schmalen und niedrigen Fältchen versehen, deren Zwischenräume durchaus nicht von dem sehr weiten Zentrallumen gesondert sinł. Diese nitclere dünmwandige Partie des Ausfülırganges ist etwas anfgebläh, und daher rührt die erwähnte Verlickung des Ausführganges. Die Muskelschicht dieser mittleren Partie des Ausführganges ist sehr dünn; sie wird erst am äussersten distalen Ende, am Ausmündungs-Ende, elwas beträchtlicher. Das kurze, dünne, mit sehr engen Lumen versehene Ansmündungs-Ende geht nicht gerade am vorderen Pol aus ver millteren, aufgeblähten Parlie des Auslührganges hervor, sondern etwas nach der Unterseite des mit des Längsachse dem ganzen Tierkörper annähernd parallel liegenden Organs. Vermullich war der bei dem Untersuchungsobjekt kurz abgerissene dünne Ausmündungsteil ursprünglich noch etwas länger, cntsprechend der Dicke der Leilseswaud, die er durchsetzen musste. Ganz anders als bei $R$. (T.) bicolor ist anch die Marazinierung der Samenmassen bei R. (T.) euzonus. Die magazinierten Samenmassen füllen die ganze anfgeblähı uncl sehr geräumige mittlere Partie des Ausführganges der Samentasche aus, aber nicht in regellosen Balten, sonderı als regelınässiger Besatz, mit den liopfspitzen an die innero Oberfläche der IVandung angeselzt und im übrigen wie lange, dichte Haalschöpte in das Lumen hineinragend. R. (T.) enzonus unterscheidet sich auch noch dadurch von dem oben besprochenen Ver-

1 L. Cogsetti, Gli Oligocheti delta Regione Neotropicale. II. In : Mem. Acc. Torino (2) LVI, rgot, p. 194, Tav. I Fig. $22,23 a$ u. $b$.

IV. Michaelsen, Sur rjuelques Oligochètes de l'Equateur. In: Miss mesure méridien èquat. Amer. S. (1899-1go6) IX, Zool. 3 (Mollusques; Innélides; Oligochètes 1910, p. C 131, Textfig. I, 2. 


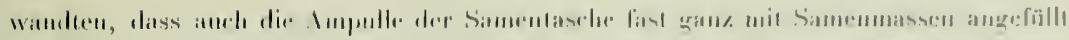

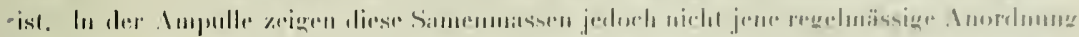

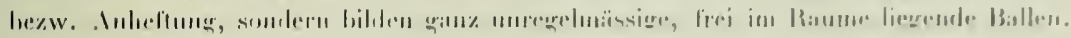

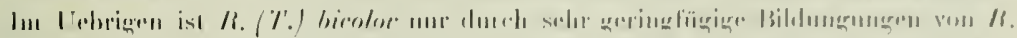

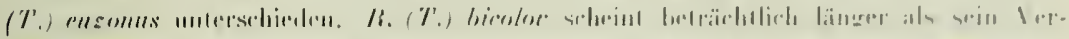

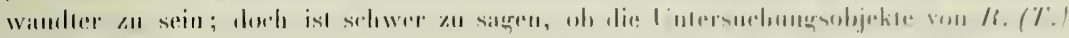

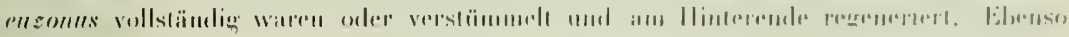

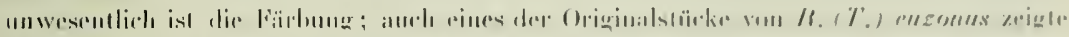

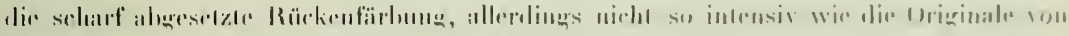

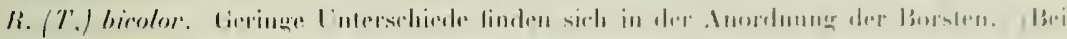

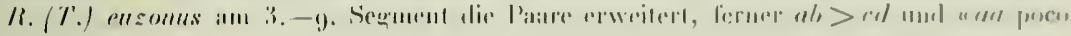

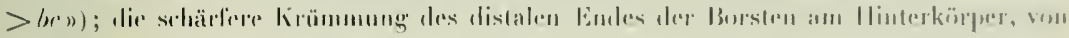

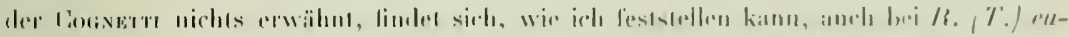

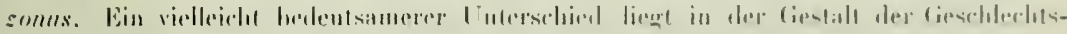

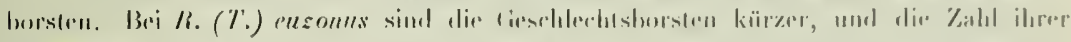

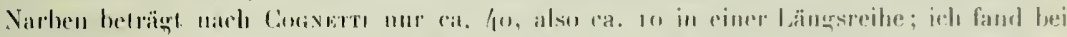

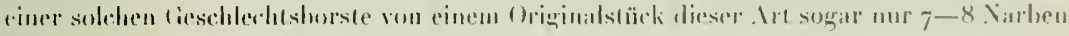

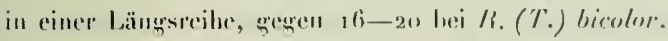

Bei R. (T.) ensonus sollen die Dissepimente $0 / 7,7 / 8$ und 8 a ganz folblen; bei /s.

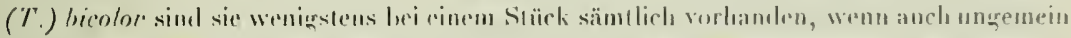

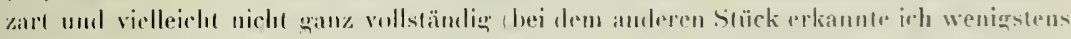
Reste des Dissepuments 8/9).

Die Chylustaschen zeigen bei R. (T.) bicolor pine ähuliche Virschierlenheil zwischen

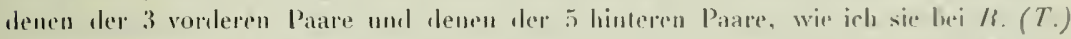

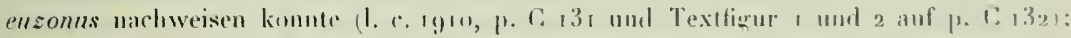

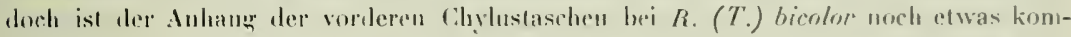

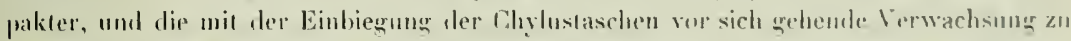

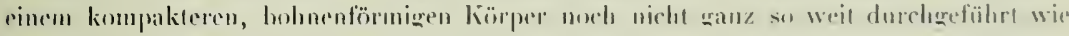

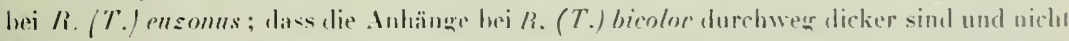
schlankrn, halsantigen Insalz zeigen. may eine besondere liontraklionserschrinun sein.

In der Trestaltung der Testikelblasen glejcht R. (T.) enzomus der neuen Irt. Wie iel nachweisen knnute, sind die Testikelbyasen rines Paares nicht "fra loro nellamente

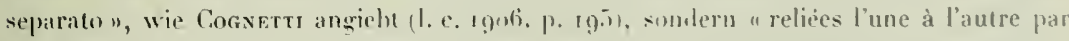
111 hoyau court el assez épais. dispose en lratrers " (I. c. C. 1910, p. 135), also so, wie im Illgemeinen hei R. (T.) hicolor. Diese Bildungr isl offenloar etwas variahel. denn bei rinem der beiden Eximplare von $R$. (T./ bicolor fand ich die Testikiblasen des hinteren Patares iuniger mit einamler verwachsen, etwa so, wie es für den sehr nahe stehenden R. (T.) Intus Cogxerti (1. c. 1906. p. 193: "fuse lungo la linea mediana longiturlinale" charakteristisch sein soll. 
Den hedeutsamen Cinterschired in der Gestaltumg der Samentaschen habe ich oben erörtert.

Den beiden hier erörterten Irten stehl noch $R$. T.) Inlus Cocinetr (1. e. Igof,

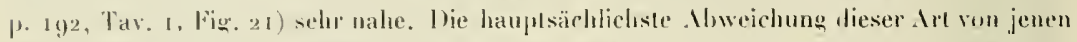
Verwanden liegt wohl in der lange der un eines Segmentes bänge nach hinten rer-

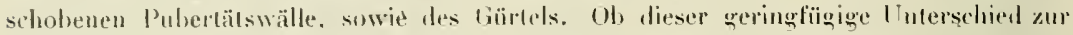
Somlerung genügl, erscheint mir l'aglich, denn selhst die leeiden Pubertälswälle eines und desselben Stückes sint nicht immer ganz gleich lang.

Wie sich R. T.) Inlus in Ilinsicht anf die Samentaschen verhäh, ob er hierin den R. T.) Pnzonus oder dem R. (T. bicolor giteicht, wher wh er von den beiden ahweicht, lässt sich aus der Cognetrr'schen Broschreihung und Abhildung (l. c. 1gu6, Tav. I., Fig. 2 I nicht ersehen.

\section{Rhinodrilus (Aptodrilus) savanicola (Mich.) var. incertus (Cogn.)}

1yoti. Rhinodrilus (Thamnodrilus) incer/us, L. Cocinerr, Git Otigocheli delli Regione Neotropicale. In Mem. Ace. Torino (2) LVT, p. 179. Tav. I, Fig. 11-13.

Funilangaben: S. von Honda, Puerto de las Pobres bei Tiliribi an Eintluss des Rio Amaga, Vebenfluss des Rio Cauca; 800 m.

S ron Medellin, Cafetal Camelia bei Angelopolis; $1800 \mathrm{~m}$.

SSW ron Honda, Camino Real zwischen Ilonda und Guarluas; $800 \mathrm{~m}$.

XW ron Bogotà, Camino Real zwischen Guaduas unil Sensitiva; 1 woo $\mathbf{m}$.

Vorliegend mehrese stücke einer Rhinordrilus-Art, die ich dem Rh. incer/us Coris. zuordnen muss, und die mich in ten Stand setzen, einige fragliche Organisationsverhälnisse lieser Arl infzuklären und ihre Beziehungen zu den nahe verwandten Formen,

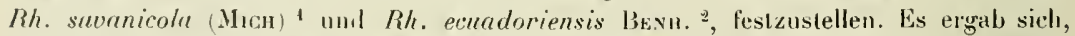
dass Rh. incertus mil Rh. samanicola vereint werden muss und höchstens als Varietäl dieser älteren . Irt gesondert erhalten bleiben kam. Diese Form ist demnach als Rh. sananicola (Мrси.) var. incertus (Cugix.) zu bezeichnen. Diesem Rh. savanicola s. I. steht der Bexнas'sche Rh. ecuadoriensis sehr nahe. Ob auch er mil Rh. savanicola vereinl werden müsste erscheint mir fraylich. Jedenfalls sprechen einige positive Feststellungen Bexнar's, die sich nicht anf Beobachtungs-lrrtümer zurückführen lassen, dagegen. Ichı knüpfe an die folgende Besehreibung des vorliegenden Materials von Rh. savanicola var. incerlus (der Einlachheit halher hier noch als Rh. incertus bezeichnet) vergleichemle Erörterungen über die f. Iypica vun Rh. savanicola (nach Revision der Originale) unf den nahe verwandten $R$ h. ecuadoriensis.

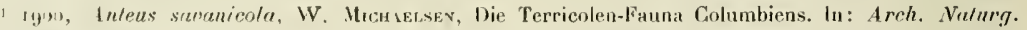
$L X V I, 1900 \mathrm{I}, \mathrm{P} \cdot 244$.

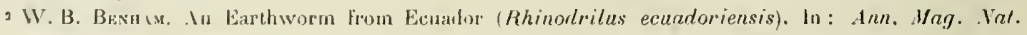
Hist. (6). IX, 1900, p. 238, P\&. 10, fig. 1-4. 


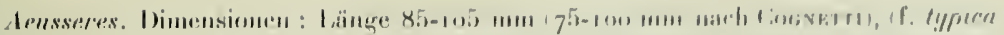

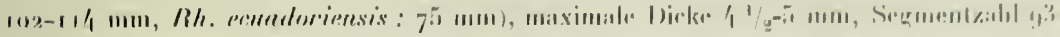

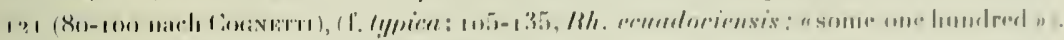

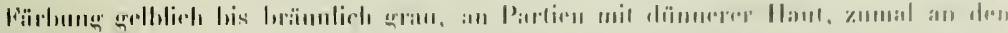

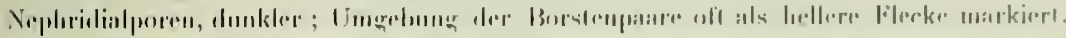

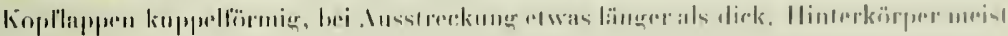

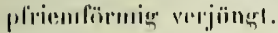

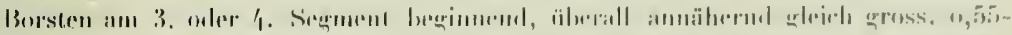

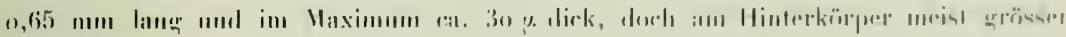

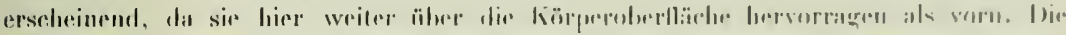

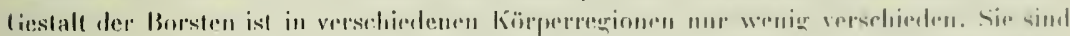

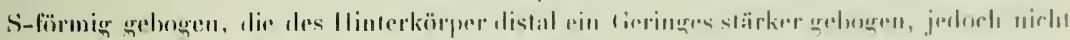

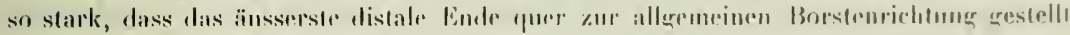

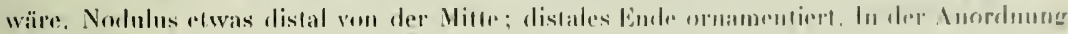

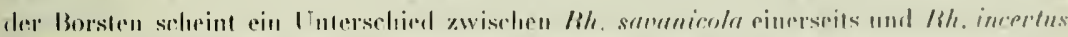

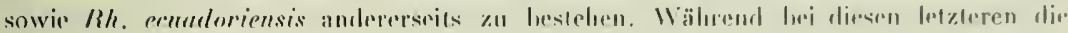

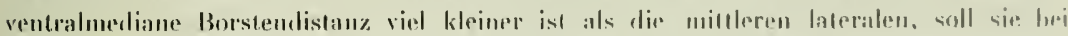

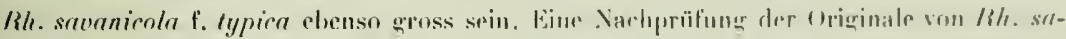

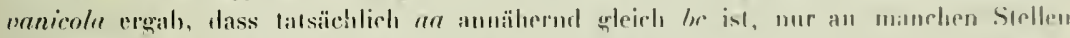

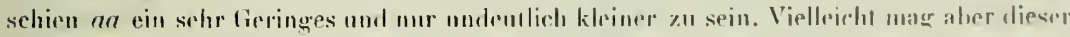

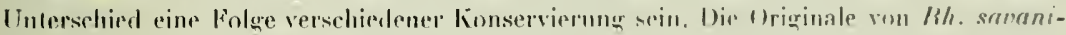

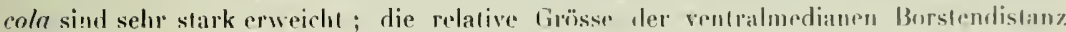

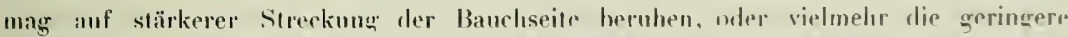

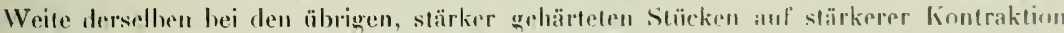

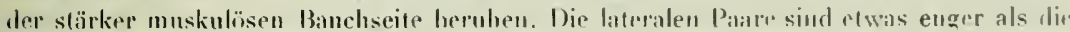
ventralen.

trïrtel sillelförnig mler ventral schwächer entwickelt, meist deullich am $15-24$. oder 25. Segument, seltener amch am 1// entwickell nder schon am 24. felilend. IBei

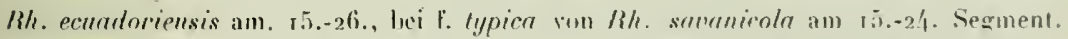

Puhertätswälle meist an 20.-27., sellener am 1/2 2t.-26. Segment hei f. lypica am

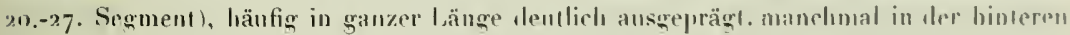
Partic umbentich. Auf' solcher undentlicheren Ausprägung, die ich auch an melıreren Stïcken meines neuen Matrials fanul, berulıt vielleichl die angebliche liñze der Puherlïtswälle: an dem Origrinal von Rh. ernadorimsis. bei dem sie sich mur von 21.-26. segment erstrecken sollen. Das Charakrerislische dieser Arl scheiul mir darin zu liegen, dase die Pubertätswäle den Grürtel hinten viberragen (heachte die diesben̈gliche Erörterung unter : Bemerkungen !)

Der wesentlichste Unterschied zwischen Rh. incerlus umb den ïhrigen Formen soll

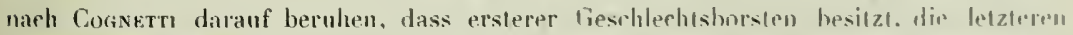

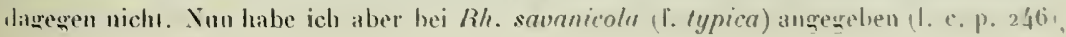


dass "die rentralen Borsten der Gürtelregion wher doch mehrere derselhen etwas stärker

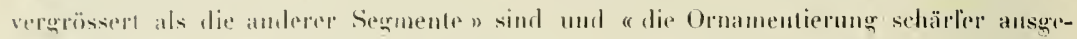

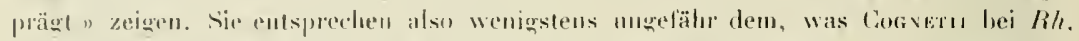

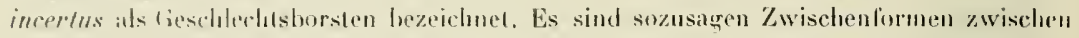
normalen Bursten und Grsehlechlshorsten, wie sie anch bei anderen Rhinodrilus-Arten anflraten. Bei den meisten Stäcken des neuen Materials, sowie bei dem Orighinalmaterial wn Rh. suranionlı (f. typica) komule ich keine anderen geschlechtslich modifizierten Borsten inftinden, hei cinem stück von lïnca Camelia jedoch erkannte ich echte, wollt ansogehildele lieschlechtshorsten, die viel typischer ausqehildet waren als ilie von Cognetw gefumlencen Giesthlichlsborsten, die fist noch der Zwischenform gleichen. Die typischen fieschlechtslursten des Stückes von der Finca Camelia sind 1,2 mm lang und in der Mill. ca. $42 \%$ dick (gegen 1, $7-0,87 \mathrm{~mm}$, bezw. $35 \mu$. bei dem Cognerríschen Stïck), nur an proximalen Ende slärker gebogen, im übrigen mit Ansnahme des schlank Vogelschnahelartigr ¿neshweifteu äussersten distalen Endes durchaus oder fast gerade (nach Cognetru: " insensibihnente sigmoili ", nach der Abbildung sehr schwach, aber deutlich S-förmig), nit grussen, liefen Narhen, die zu je 9-10 (uach Cognetri's: Narben nicht sehr gross unt (ief, zu jo 6 i) in 4 Länģsreihen stehen, und zwar die zweier henachbarter Längsreiben nicht oder nicht regelmässig alternierend. Die echten Geschlechtsborsten sind schon äusserlich durch lıetle kleine Drüsenhöfe markiert; es waren bei dem in Rede stehenden Stück von der Finca Camelia die beiden Borstenpaare ab des 10. und des 26. Segments suwie die rechlsseiligen Borsten ab des 16 . Segments. Wir schen also die Ausbildung der Gieschlechtshorsten bei den Stücken verschiedener Herkunft sehr varieren. Schwach inodilizierte (sogenanute Zwischenform) konmen wohl bei allen reifen Stücken vor. Slark morlifizierte, typisch ausgebildete Geschlechtshorsten fanden sich nur bei einem Stück (ron Fima Camelia); wälırend die?von Cognetrı geschilderte GeschlechıshorstenForm ein weiteres Zwischen-Stadium zwischen den schwach modifizierten und den typisch ausgebildeten darstellt. Schon das sehr sporadische Luftreten typischer Geschlechtsborsten (nur an ganz vercinzelten Segmenten und zum Teil auch nur einseitig) lässt ihr vollständiges Fehlen lxezw. ihre Erselzung durch schwächer modifizierte Zwischenformen als wenig belangreich erscheinen. Anf keinen Fall kann ich den von Cognetri anfgestellten Ciegensalz: "Speziali setole copulatrici assenti " bezw. "presenti " zwischen Rh. savanicoln und Rh. incertus als zu recht bestehend anerkennen, und auch die Verschiedenheir in der Stärke der geschlechllichen Modifikation der Borsten muss ich in diesem laalle als systematisch unwesentlich bewerten.

Samentaschen-Poren stets 4 Parr anf Intersegmentalfurche $57-8 / 9$ in den Borstenlinien $\mathrm{ed}$ iDie anscheinende. Abweichung von Benuar's R/t. ecuadoriensis berubt wahrscheinlich auf irrtümlicher Seurrnentzählung).

Innere Organisation. Die Dissepimente sind sämtlich sehr zart. Nach Cognerrı soll dis erste Dissepiment zwvischen dem 12. mol 13. Segment liegen. Ich fand an einer Schnill. serie einige wenige (2 oder 3) ungemein zarte und wahrscheinlich unvollständige Diss?. 


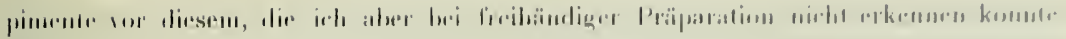

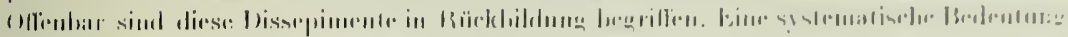

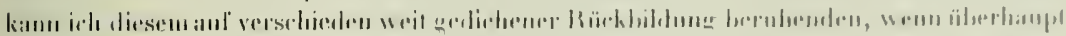

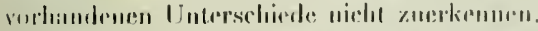

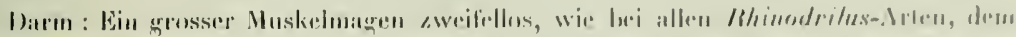

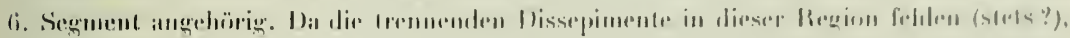

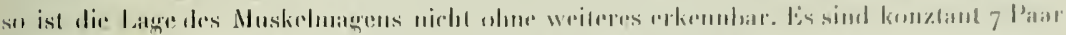

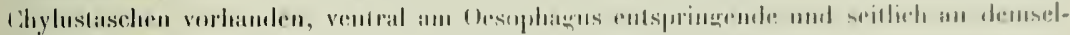

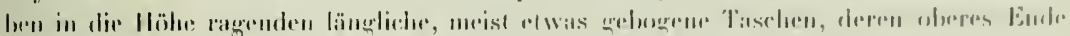

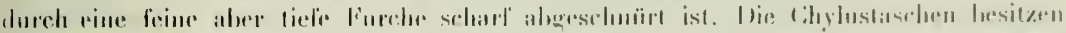

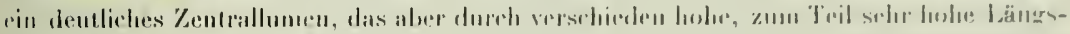

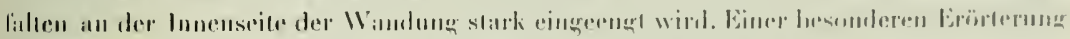

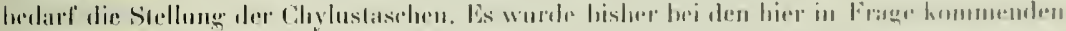

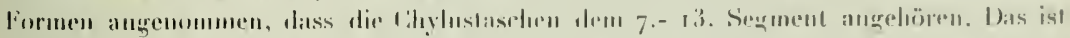

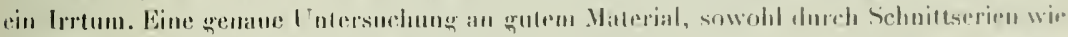

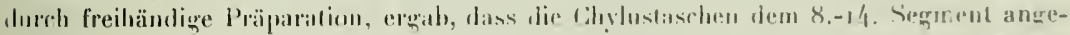

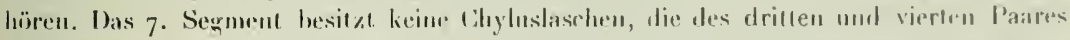

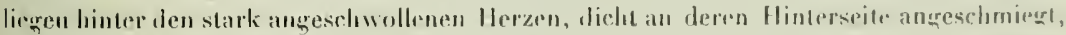

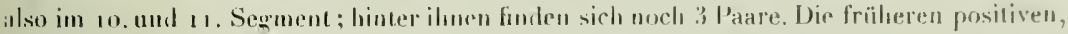
nicht lediglich aut Mutmassung heruhenten . Ingaben stehen meisl nich in Mirder-

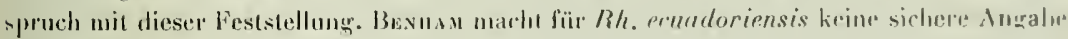

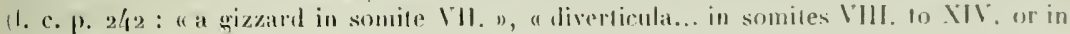
I. 10 XV ", d. I., wenn man seme nachweishar imämliche Zählung der inneren Segmente kurrigiert: Muskelmagen in 6., Chylustaschen in 7--13., wenn nicht im 8.-14. Tegenent I.

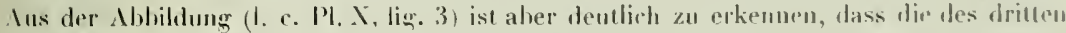
l'ares hinter den vorderen angeschwollenen Herzen, also im ro. Segment. liesen: danarh ist eine Velsereinstimmung mil meinem Belund so grut wie sicher, wenn auch die beilen

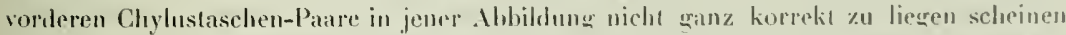
(hier zwei Paill Chyluslaschen zwischen den volderen angreschwollenen Herzen dess on. Seg-

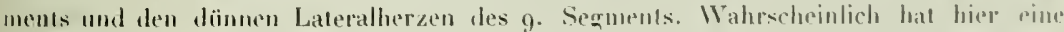
peringlügige Verzerung dieser Lateralherzen order eine parliello lerschiebung des Oeson-

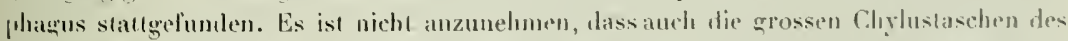
16. und 11. Segments an dieser Verschiehnng feilwenommen haben, denn sie schmieren sich tatsächlich eng an die Hinterseite der aneseschwollenen Helzen an, mal können nicht durch den engen Raum zwischen diesen Herzen und dem Tesophagus hindurdagezerre worden sein. Aus der etwas sehemalischen Zeichnung Bexwan's ist dis zwar nicht sn Jentlich ersichtlich ; hetrachtel man aher diese Grgine an einem Präpanat, so erkennt man cine solche Verlagerung der Chylustaschen des 11 . und 11 . Segments als unangängig. Auch für $R$ h. savanicola (I. typica) liegt kecine sichere Angabe vor (I. c. p. 246 : "Eiln tounentörmiger Muskelmagen mag dem 6. Segmente angehören : der Oesophagus trägl 
linter dem Muskehnagen, wohl in Segment 7.-13., 7 Pair schlanke Chylustuschen n). Mil

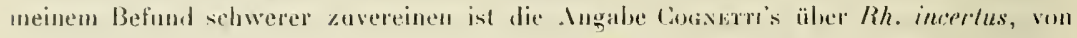

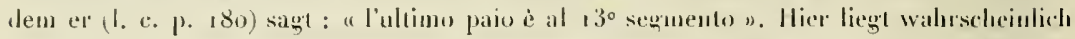
ein Irrtum vor; denn ich kann nir nicht denken, dass diese so schr mil meinem Matrial übereinstimmente form in einem soleh wesentlichen P'unkte von demsellen is heichen

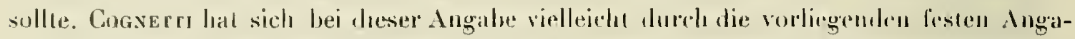
hen für die verwanden formen verteiten lassen, eine anscheinend sichere Varmulung als Tatsache hinzustellen, uml hierzu migg ich selbst die Teranlassung gewesen sein, als ich in der Zusammenstellung der Otigochäten- Diagnos'n' dir vorliegenden zweif'thaften Ingaben für Thumnodrilus stuvanicolu und Th. Peudoriensis als sichere leststellung in die Diagnosen aufuahm. (Ceher die subgemerische Bedrutung dieser Anordnung dar Chylustaschen siehe der Erörterung unter : Bemerkungen!) Bei meinen Untersuchungsmaterial, ebenso wie bei dem Cognetro's, und bei der f. Iypica, waren die Chylustaschen ler verschiedenen Paare fast gleich gross, hei Brsnan's Rh. ecuadoriensis sollen die mittleren viel grösser sein als die älrigen, unt zumal die des ersten und lelzten Paares sullen sehr klein sein. An der Richtigkeit dieser auch mit den Abhildungen deutlich ühereinstimmenden Angabe ist nicht zu zweifelı. IIier liegt offenbar ein Unterschied zwischen Rh. ecuadoriensis einerseits und R/t. savanicola I. lypica und var. incertus anderseits vor. Die Gestalt der Chylustaschen soll uach Bexнay hei seiner Form " kịdneyshaped " bis "hemispherical " sein ; sie waren wohl etwas stärlier angeschwolten als bei meinem und Cognetris Untersuchungsmaterial, bei den sie etwas melir gestreckt und, wenigstens hei meinem Material, zum Teil etwas gehogen, leicht konvex, waren. Dic Benнan'sche Bezeichnung "hemisphaerical " ist wohl nicht in strengen Sime aulzufassen. Nach der Mbbildung sind sämbliche Clyylustaschen länger als breit, könnten höchstens als "hemielliptical " bezeichnel werden. Auffallend ist, dass Bennam nichts von einer Abschnürung am oberen Pol erwähnt. Sollte seine Art wirklich in so wesentlichem Organisationsverhälınis von $R h$. savanicola abweichen? Möglich wäre ja immerhin, dass bei einer Zurëckbildung der Chylustaschen die ahgeschnürten Anhänge zuerst schwinden, und die geringe Grösse der vorderen und der hinteren Chylustaschen bei Rh. p.cuadoriensis könnte wohl als Zeichen von Rückbildung aufgefasst werden.

Blutgefässsystem : Intestinalherzen im 10. und ı. Segment stark angeschwollen, fast schinkenförmig, im 12. Segment sehr düın, manchmal ganz fehlend?

Männliche Geschlechtsorgane: 2 Paar Samentrichter im 10. und r. Segment, eingeschlossen in 2 Paar Testikelblasen, die im 16. und 11 . Segment unterlalb des Oesophagus liegen, die einer Seite mit einander verwachsen, die cines Segments von einander gesondert. Aus der Ilinterseite jeder Testikelblase geht ein grosser Samensack hervor. Die Samensäcke ragen nach Durchsetzung der zarten Dissepimente 10/1 hezw. 1 1/12 im 11. und 12. Segment seitlich vom Oesophayus in die Höhe, und die eines Paares stosseı

1 W. Micunelsen, Oligochata. In : Tierreich, $X$, igoo, p. 435, auch 436. 


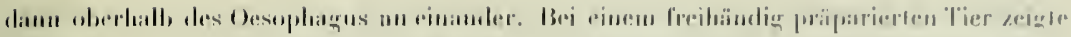

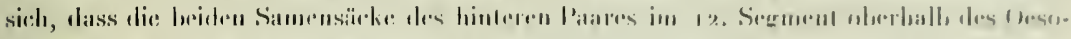

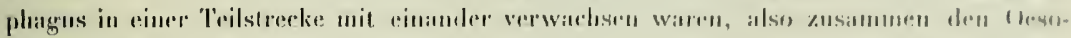

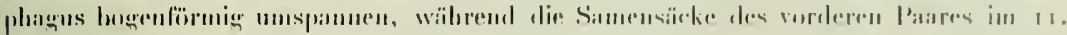

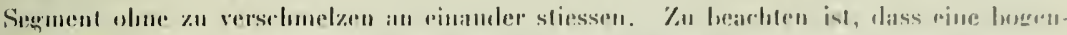

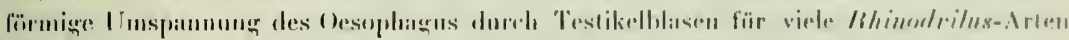

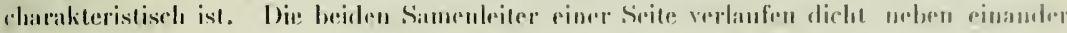

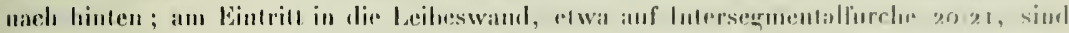

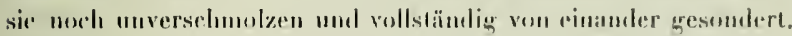

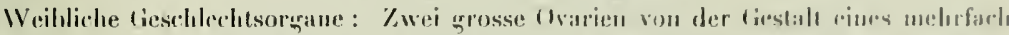

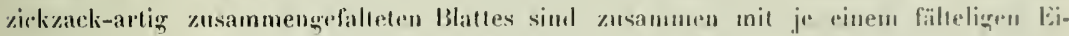

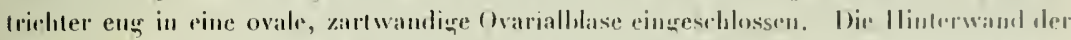

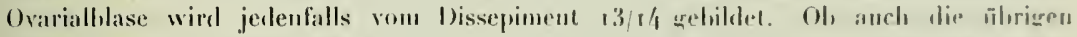

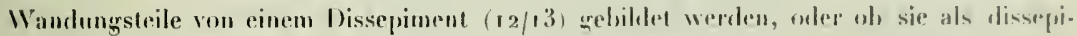

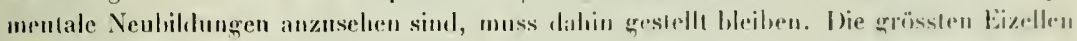
am Ovarium sind ungefähr 25 y. dick.

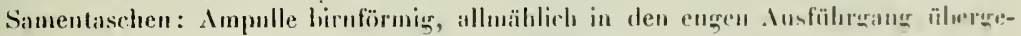
hend (bei /hh. eruadoriensis: "nearly grobular sae, will a narrow muscular duct, sharply separated from the sacn).

Bemerliungen: Die bedeutsamste lieststellung it der oligen Erörterung ist wobl ther

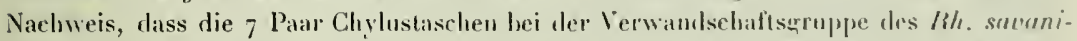
cola rem 8.-14. Sogment angehören, unl dass im 7. Segment keime liyplustaschen vorhanden sind, dass also die Maximal-.Iushildumer der Chylustaschen von Rhinodrilus

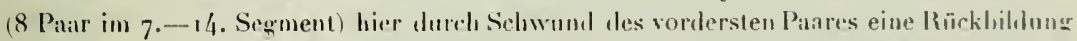

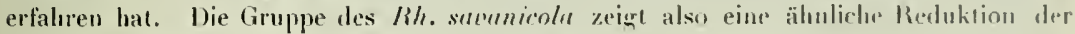
Chylustaschen-Zahl wie die Arten der Lnterwatung Aplodrilns Cogs. ', lie durde den Verhust der drei vordersten Chylustaschen-Paire charakterisiert ist. Dat der firad riner Rïckbildung meist von geringerem systematischen Belang ist, als die Tatsache ler Rinck-

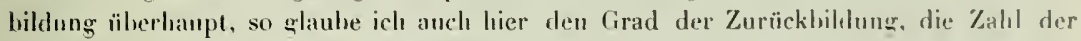
hereits ganz verschwondenen Chylustaschen, nicht als Irennendes Moment anselsen zu

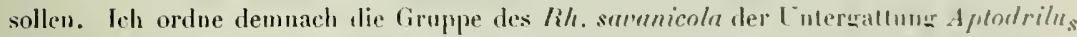
zu, deren Diagnose dementsprecheml zu erweilern isl. IChyluslaschen nicht unmittelhar in dem Segment hinter dem Gürtel heginnend, mindestens also das 7. Segment ohne

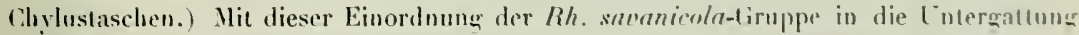
Aptodrilus steht cine andere Besonderheit dieser fruppe in voller Ilarmonie. d. i. las Veberwogragen der Puhertälswälle üher die hintero Grenze des Gürtels. Diese verhāltnismässign sebr seltene Bildung - meist enden ja dir Pubertätwälle schon eine deulliche

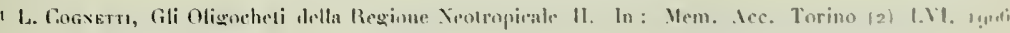
p. 226 . 
Strecke vor dem Hinterende des Gïrtels - thulet sich sowoh] bei der Rh, sananicolaGroppe, wie bei den Arten der Untergatung Aptodrilns im äleren Simne. Ich glauhe dieses Znsammentrelfen als Anzeichen einer näheren Virwandschaft ansehen zu sollen.

Fraglich erscheint es mir, ob noch andere Rhinodrilus-Arten mit reduzierter Chyluslaschen-Zahl der Untergatlung Aptodrilus zugeordnet werden müssen. Den Angahen nach sollen hei all diesen Formen dic vordersten Chylustaschen in 7. Segment liegen, die Reduktion also, wie es für die Untergattung Rhinodrilns besonder's charakteristisch ist, linten angreifen. In Frage kommen nur einige ältere Arten mit geringerer Reduktion (bei der Reduktion anf 3 Pare, Untergattung Rhinodrilns, ist ein Irrtum in der Stellung der Chylustaschen so gnt wie ausgeschlossen), Rhinodrilns Jordani (Rosa) mit 7 Paar Chylustaschen angeblich in 7.-13. Segment, sowie Rh. Gulielmi (Bedd.) und Rh. Tenliatei (Honst) mit 6 Paar Chylustaschen angeblich im 7.-12. Segment. Bevor eine Nachprüfung etwas Gegenteiliges erbringı, müssen wir die dieshezüglichın Angaben wohl als richtig ansehen, diese Arten also in der Untergattung Thamnodrilus stehen lassen. Die Betrachtung des oben (p. 226) beschriebenen Rh. (Thamnodrilns) Cameliae n. sp. zeigt, dass eine solche Anordnung der Chylustaschen wohl vorkommen kann, und zwar bei Formen, die typisch ansgebildeten Thamnodritus-Arten (mit 6 Paar Ghylustaschen im 7.-14. Segment) nahe stehen, also sicher zur Untergattung Thamnodrilus: gehören. Der früher zu Thamnodrilus mit 7 Paar Chylustaschen gesteltte Rh. heterostichon (Scus.) kommt hier nicht mehr mit in Betracht, da ich nachweisen konnte, dass er tatsächlich 8 Paar Chylustaschen besitzt ${ }^{1}$.

Was die Unterschiede zwischen den verschiedenen Formen der Rh. savanicolaGruppe, sowie ihre hauptsächlichsten Charaktere, anbetriff, so ınag die nehenstehende Tabelle eine Zusammen- und Gegenüberstellung derselben geben :

\section{Rhinodrilus (Aptodrilus) uncinatus Mich. var. ?}

Literatur der Art: 1910, Rhinodrilus (Aptodrilus) uncinatus: W. Muancsex. Oligoehètes de l'Equateur. In: Mission mesure méridien équator. Amer. S. IX, Zool. Fasc. 3, p. C. 135.

Fundangabe: S. von Medellin, Cafetal Camelia lei Angelopolis; $1800 \mathrm{~m}$.

Vorliegend mehrere Exemplare einer Form, die in den meisten wesentlichen Charakteren mit Rhinodrilus uncinatus Man. übereinstinmt, und die ich, wenn überhaupt, höclıstens als Varietät von clieser Art absondern kann.

Aensseres. Dimensionen: Längre $70-1,5 \mathrm{~mm}$, maxinale Dicke, von der Gürtel-Anschwellung abgesehen, 3-6 mm, Segmentzahl 9r-r20. Die Dimensionen sind also ziemlich variabel, zumal die Dicke. Die Originale der typischen Form sind noch beträchtlich dicker, aber nicht länger, als das grösste Stück der fraglichen Varietät.

1 W. Micmaelsex, Oligochäten von verschiedenen Gebieten. In: Mt. Mus. Ilamburg XXVII, p. 145 (naeh Votersuchung des Originals). 


\begin{tabular}{|c|c|c|c|}
\hline & 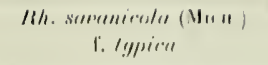 & 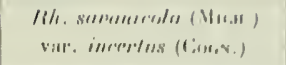 & 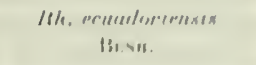 \\
\hline Isu'stertidistauz & $a n=m \cdot b r$ & an $\quad$ *a. $2, \mathrm{lnc}$ & $m$ c.s. $2, \mathrm{~lm}$. \\
\hline Giiirle! : an & 15. - $2 / 1 . \operatorname{singm.~}$ & 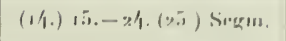 & 1.-26i. Sirkm. \\
\hline $\begin{array}{l}\text { P'ulerelïswaille: } \\
\text { allu }\end{array}$ & $201 . \quad 27$. Sirnaw. & 2u. $(1 / 2$ 20. $)-(3 t i) 27$. Sirk. & $21-2 k$. Singril. \\
\hline $\begin{array}{l}\text { Gerschlechts- } \\
\text { horsten }\end{array}$ & sehwach modilizian. & 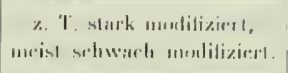 & nirblot monlitizirert. \\
\hline tihylustasehen & 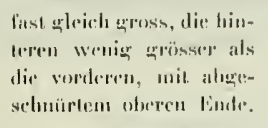 & 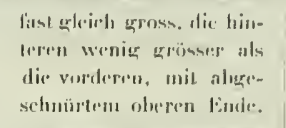 & 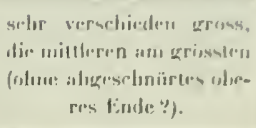 \\
\hline Samentaschen & 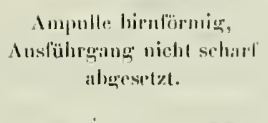 & $\begin{array}{c}\text { Ampulle birnförnig, } \\
\text { Auslührganer nicht schar } \\
\text { ahugesetzl. }\end{array}$ & $\begin{array}{l}\text { Amprulle fast kugraliz, } \\
\text { Ausfülırgange scharf } \\
\text { abgesetzt. }\end{array}$ \\
\hline
\end{tabular}

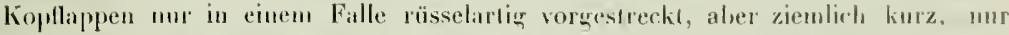
wenig länger als dick. meist kuppellärmig ausselend uder ganz eingezugen. Borstentzomen besonders der anteditellialen Sequmente manchmal wallfümign erliaben, in anderen Fällen gुanz ausgegrältel.

Borsten ventral am 3., Jateral am 4. Segmeul heginnend, an Vorderkörper selır zart. zumal dic lateralen, nach hinten allmählich grösier werhınd, am Hinterkörper sehr eross, ca. $0,8 \mathrm{~mm}$ lang und 40 p. dick, im übrigen genan wiv die der Yypischen Form gestaltel. Borsten am Vorderkörper selır eng gepaarı, zumal die lateralen; mit der Grössemzunahme der Borsten weiten sieh die Paare, jedoch nichı so selur wie lee der typiselı'n Form ; am Ilinterkörper Weite der Paare ea. 1/4 so gross wie die ventralnediane Borstendistanz. Ventralmediane Borstendistanz ein Geringes grösser als die mittleren lateralen $(a n=c a .6 / 5 b c)$. Dursalmediane Borstemlistanz am Vorderkirper ca. $2 / 3$. am Hinterkörper ca. ${ }_{9}^{5}$ des ganzen hörperumfanges betragend $d d={ }_{3}{ }_{3}^{5 / 9} 11$ ). Die fieschwindigkeil, mit der die Burstengrösse in der Rocihe der Segmente von vorn nach hinten zunimmt, ebenso wie die Regron der hauptsächlichsten Grässnzunahme, scheint etwas variabel zo sein. Bei einem Stücke waren die Borsten der Körpermitte schon beträchlich gross, während bei anderen die auffallendere Borstenverurösscrung erst im letzten Körperdritlel stalltindet.

Gürtel sattelfürmig, am 14. oder 15. bis 21. Oder ${ }^{1}$ 2 23. Segrment $(=7-81 / 2$ ). (Bei f. typica am 15 . his $1 / 222$ oder 22 . Segment $=7^{1}-8$.)

Pubertätswäle und Samentaschen-Poren koustant wie bei der lyjischen Form. 
Innere Organisntion. Dissepiment 6/7-9 10 ziemlich stark verdickt, 10 11 schwach verdickt, die folgenden zart.

Darm wie bei der (ypisclien Form.

Männliche Geschlechtsorgane: Zwei Par sehr kleine, ventralmedian in wanzem Limlange parmeise mit rinauder rerschmolzene Testikelblisen im m. und r. Segment. Dic Versclumelzung der Testikeblasen eines Paares ist so innig, dass man von zyei unparigen, lateral schwach erweiterten Testikelblasen reden könnte. 2 Paar grosse Samensïcke ron Dissepiment $10 / 11$ und $11 / 12$ nach hinten ragend. Während die Samensäcke des vorderen Paares ganz auf das 1 . Segment beschränkt sind, erstrecken sich, wrnigstens hei einem näher untersuchten Stück, die des linteren Pares, die trennenden Dissepinente durchsetzend, vom 12 . bis ins 16 . Srgment nach hinten. (Bei der f. typica sollen die Testikelthlasen ziemtich gross, und die Samensäclie des hinteren Paares auf das 12. Segment besclıränkt sein.)

Samentaschen wie bei f. Iypica.

lieschlechtsborsten-Apparat: Die ventralen Borstenpaare des 6.- ro. und des 18. Segments sind mit weisslichen, mehrteiligen, in die Leibeshöhle hineinragenden Dïusen ausgestattet. Am grö̈ssten sind die Geschlechtsborsten-Drüsen des 7.-9. Segments, kleiner die des 6 . und 10 . Segments und sehr klein die des r 8 . Segments. Die Borsten dieser ventralen Paare sind zu Geschlechtsborsten umgewandelt, die in Allgemeinen die Gestalt derjenigen der f. typica besitzen, vielleicht aber etwas kleiner sind. Eine näher untersnchte vollständige Geschlechtsborste (bei den meisten war das distale Ende abgebrochen) war $0,8 \mathrm{~mm}$ lang und $40 \mu$. dick (gegen r,oo $\mathrm{mm}$ und $50 \mu$ bei f. typica), fast gerarle grestreckt, nur distal etwas gebogen, und die Zahl der Narben, die wie bei f. typicu gestaltel und wie hier das distale Drittel der Borste einnehmen, beträgt 9 bis 10 in einer Längsreihe (ca. 8 bei f. typica). Ausser den lier geschilderten Geschlechtshorsten der allgemeinen Form fand ich noch eine Zwischenform zwischen diesen und den normalen Borstın, nämlich die Borsten $b$ des 18. Segments, deren Partner (Borsten $a$ ) vie die übrigen Geschlechtsborsten gestaltet waren. Diese Borsten $b$ des 18 . Segments waren wie die normalen S-förmig gebogen, aber etwas vergrössert, ca, o,6 mon lang und $30 \mu$. dick, und am distalen Ende mit der gleichen scharfen Ornamentierung versehen wic die lieschlechtshorsten spezieller Form. Es fanden sich bei dieser Zwischenform aber nur ca. 6 Narben in ciner Längsreilıe.

Bemerkungen: Ans den obigen Angaben ist ersichtlich, dass die vorliegende form "lem Lhinodrilus (Aptodrilus) uncinatus Hıcı. zugeordnet werden muss. Der einzige lecheutsame Unterschied liegt in der stärkeren Vergrösserung der Borsten des Ilinterkörpers und der zweifellos damit zusammenhängenden stärkeren Erweiterung der hetreffeuden Borstenpaare. Dieser Unterschied erscheint um so weniger helangreich, als die $\Lambda \mathrm{rt}$ und Weise der Grössenzunahme der Borste bei den zweifellos zusammen gebörenden Stücken von einem fundort schon Schwankungen zeigt. Vielleichıt hängt er auch mit den ollenbar ebenfalls variablen Dimensionen des ganzen Tierkörpers zusammen. 


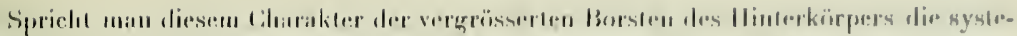

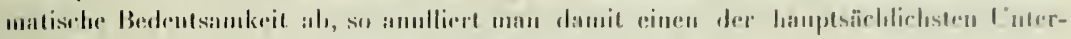

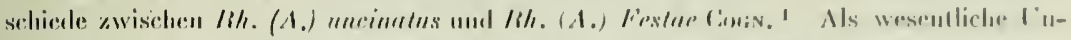

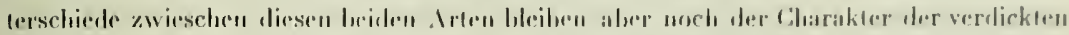

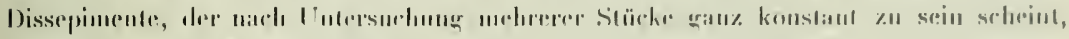
und die Lager der Puluertiilswïlle.

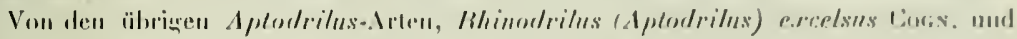

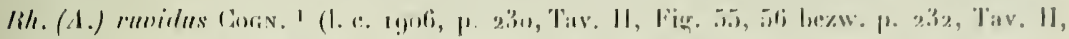

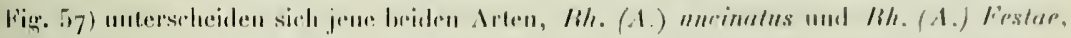

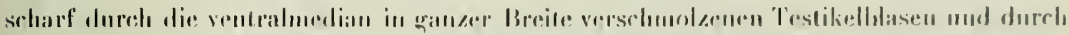

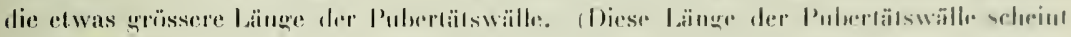

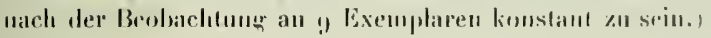

\section{Andiodrilus bogotaensis Mich.}

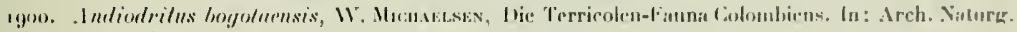
IXVI, 19001, p. 25/.

fintefrangaben: Umenegend vou Bugoti, 2800 m.

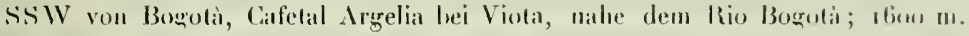

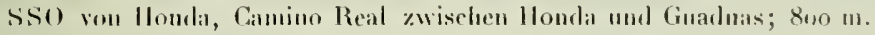

Bemerlinngen: De Cieschlechtsborsten-Papillen am medialen Ramde der Puhertäıswille zeismon nicht immer die in der Originalleschreibung geschilderte Anordnung; nichu immer sind alle Seghmentr der Pubertätswall-Region (20. - 25.) mit solehro Papillen ausenestateet, sondern manchmal nur die alternierenden Segmente 20, 22 und 24. In diesem lable zeigen die Papillen natürlich anch nicht die eigentïmliche Ineinanderlehnunar je zweier henachbarter (20-21, 22-23, 24-25) uml die dalurch enfolehende Iterzform der Drïseupolster. Da ich wcitere. Bhweichungen von den charalitrristisch ausgebildaten Originalen nich finden kamn, su ghabe ich von einer. Ibonderung dieser Formen ron 1. hogotn'nsis absehen zu sollen. Bemerken will ich ïlsrigens, dass sich auch nuter einigen Originalstïcken ein Exemplar der abweichenden form fand, wie anch beide Formen in dem wenen Material veruesellschaftet sind. Es lassen sich übrigens anch Leherqünge zwischen beiden formen crkennen; so waren bei einem stü̈k die Papilien des 30., 22. und 2/. Segments efwas nach himten verschoben, so diss sie die vorder Parlie ihres Segrments freiliessen und dafür die ihr Segment hinten begrenzende Intersegmentalfurche un cin Geringes äherschrilten. Der Lutcrschied zwischen heiden Formen leruhı demuach lodiglich auf' eimer Verschiebung der Drïsenwweherungs-\%entren um eines laalhen Segmentes Länge nach hinten, von Segment 20,22 und 24 (abweichende Form) auf

1 L. Colinetri, Gli Oligocheli della thegione Neotropicale II. In: Men. Ace. Torian (2) LII. 1got. 1.227. Tix. 11. Fig. 保- i4. 
Intersegmentalfurche $202 \mathrm{I}, 2223$ und $24 / 25$. An dieser Verschiebung nehmen auch die Pubertätswälle teil. An der hier erörterten sog. alweichenden form erstrecken sie sich über die 5 Segmente $20-24$, lrei der typischen Form dagegen über die Segmente 20-25. Trotzdem haben sie anch bei der typischen Form nur die Länge von 5 Segmenten; denn sie beginnen erst in der Mitte des 20 . Segments und enden schon in der Mitte des 25. was ich in der Originalbeschreibung zu erwähnen versäum habe. Die abweichende Forn ähnelt in Hinsicht dieser Pubertätsbildungen sehr dem A. pachoensis Mıн. (l. c. 1900, P. 252).

Dic männlichen Geschlechtsorogane zeigten bei einem näher untersuchten Stïck eine ähnliche Bildung, wie ieh sie weiter unten bei A. ruizanus n. sp. geschildert habe, nämlich einen grossen, alggeschnürten Xnhang linten an den Testikelblasen, also ein P'aa! Samensäcke. Dieselhen schienen aber bei A. bogotaensis mil den Testikelblasen zusammen im 10. Segment zu liegen.

\section{Andiodrilus ruizanus n. sp.}

Tafel Fig. 2-4.

Fundangabe: W S W von Honda, Zentral Cordillere, Pass des Ruiz, N. vom Massiv des Ruiz; 15 r.

Vorliegend ein einziges geschlechtsreifes Exemplar, das anscheinend vollständig ist.

Aeusseres. Dimensionen: Länge $9^{5} \mathrm{~mm}$, Dicke $3 \frac{1}{2}-5 \mathrm{~mm}$, Segmentzahl 119 .

Färhung gelblich - bis bräunlich grau, schmutzig-tleckig.

lopflappen dick kuppelförmigg? (zum Teil eingezogen?) 1. Segment nicht sichtbar (eingezogen?)

Borsten ventral am 5. oder 6 . Segment, lateral am 7. Segment beginnend, anteclitellial zart, postelitellial, zumal am Ilinterende, ziemlich gross. Eine Borste vom 3o. Segment èrwies sich als $0,6 \mathrm{~mm}$ lang und $30 \mu$ dick; die Borsten des Hinterkïrper's sind höchstens um ein Geringes grösser. Die normalen Borsten sind sämulich gleichartig gestaltet, S-förmig gebogen, distal nur schwach gebogen und einfach zugespitzt; ilır Nodulus liegt etwas distal von der Mitte; ilıre Ornamentierung besteht aus wenigen distalwärts konkaven Narbenrändern in zwei deutlichen Längsseilıen an der konkaven Seite der Krümmung des distalen Endes und in zwei weniger deutlichen Längsreihen an der konvexen Seite. In de॥ ventralen Reihen stehen höchștens 3 Narbenränder. Die normalen Borsten sind anteclitellial sehr eng gepaart. Postclitellial erweitern sich die Paare allmählich, entsprechend der zunelımenden Borstengrösse. Am Hinterende sind sie als ziemlich weit gepaart zu bezeichnen, ist hier doch die Weite der Paare gut halb so gross wie die ventralnediane Borstendistanz. Ein Unterschied in der Weite der ventralen und der lateralen Paare ist nirgends erkeunbar, ehenso wenig wie ein Unterschied in der Grösse der Borsten eines Segments. Die ventralmediane Borstendistanz ist deutlich kleiner als die mittleren 


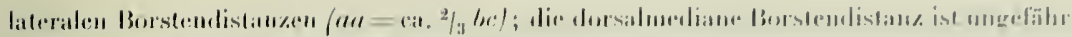

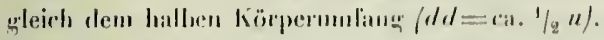

Nepluridialporen aviscluen den Borstenlinien a and d.

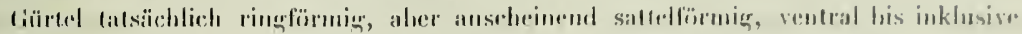

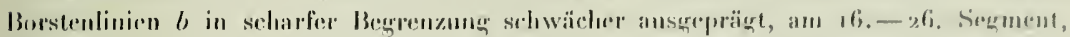

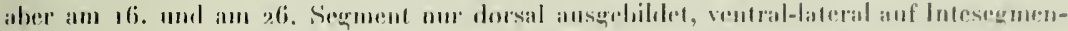

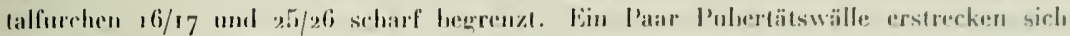

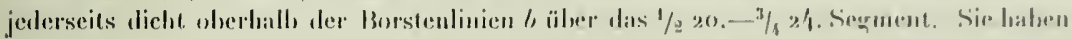
also die Länge von ungrefälır / Segmenten. Sir simd parallelrandier, vorn und hinben germulet, nur schwarb erhaben.

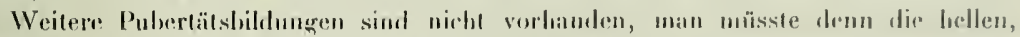
gelblich-weissen brösenhöfe gewisser (iesehlechtshorston hierher rechnen. Die ventralın Borsten a und b des 7., 8. und !). Segments siml weit anseinander gerïckt, so dass die? lintlemung zwischen ihnen sogar noch etwas grösser ist, als die ventralnediane bistan\% (am 7.-9. Segment $a(\ell<a b)$. Elwas erweilert, jedorh hei seiten niche in so hohem Gracle, sind die ventralen Borstenpante des 22., 23. und 24. Seaments. Scharf ansterprägte, wenn auch nicht sehr umfangreiche, gellılich-weisse Drüsenhöfr besitzen die Borsten $b$ dieser a Sermente, undeutlichere, kleinere Drüsenhöfe die Borsten a dieser Segunente. Diese Borsten, alser ausserdem auch die anteren ventralen Borsten der Gürtelregion, sowie einige laterale Borsten des 7. und 8. Segments, sind zn Geschlechtsborsten (siche unten!) umgewandelt.

Männliche und weihliche Poren nicht erkannt, jedenfalls unscheinhar.

3 Paar Samentaschen-Poren auf Intersegmentalfurche $6 / 7,7 / 8$ und 8/9, paarweise einander und der dorsalen Merlianlinie genïhert.

Innere Organisation. Die Dissepimente sind sämtlich als zart zu bezeichnen, wenngleich einige wenige hinter der Region der Testikelblasen (Dissepiment 11/12-13 14?) etwas dicker sind als die vorhergehenden und die folgenden. Die Dissepimente der Chylustasehen- und Testikelblasen-Region sind ungemein zart, anscheinend nicht voll ständig ansgebildet und vielleicht verschoben.

Darm : Ein wrosser Mnskelmagen im 6. Serment. 3 Paar Chylustaschen vor den Testikelhlasen, also zweifellos dem 7., 8. und q. Segment angehörig. Die TestikelblasenPaare sind einamder sehr nahe gertickt, wïhrend andererseits das zwischen ihnen und dem Muskelmagen liegende auhanglose Stïck des Oesophagus verhältnismässig sehr laug erscheint. Diese Verkïrzung des Oesuphagus im 8. und 9. Segment, sowie seine Verlängermg im 7. Sequment hängt wohl mit der Dissepiment-Verschicbung zusammen. Die Chylustaschen sind verhälınismässig sehr gross: sie sind schlank-hlallförmig, kurz und eng gestielı, am freien schmalen Ende mit einem hirnförmigen Anhang versehen: dieser Anhang ist dnrch cine halsförmige Verengung rom Hanptkörper der Chylustasche abgesetzt und ungefähr ' ! so lang wie der Hauptkörper.

Die männlichen Geschlechtsorgane (Tafel VIII Fig. 3) zeigen gan besondere Eigen- 
tümlichkeiten. Median unterhalh des Oesophagus liegt im to. Segment eine winzige, fast unpaare Blase ; ihre Gestalt ist länglich, hinten ist sie einfach und glatt gerundet, am Vorderende durch einen tiefen medianen Kerbschnitt in cin Paar glatte Verwölbungengeteilt. Diese paarigen Verwïlbungen künnen als der letzte Rest einer ursprünglichen Paarigkeit angeselten werden. Dicht hinter der.Mitte entspringt jederseits aus drrmmlianen Blase ein grosser, im . Nlgemeinen sackförmiger Inhang, die Testikelblasen. Diese beiden Testikelhlasen ïberragen die mediane Blase nach hinten und noch mehr nach vorn, und hesonders weit sehliesslich nach oben; seitlich am Oesophagus in die Höhte ragend und sich dorsal noch über den Oesophagus hinüber neigend, stossen sie oberhalb der Oesophagus dorsalmedian aneinander; sie umspannen also zusammen den Oesophagus, ohne jedoch dorsalmedian miteinander zu verschmelzen. Diese T'estikelblasen zeigen äusserlich eine weitmaschige Netzzeichnung, und dieser Netzzeichnung entspricht eine oberflächliche, aber doch tief ins Innere hineingehende Kammerung. Die Kammern stehen in ganzem Umfange mit dem Zentralraum der Testikelblasen in Kommunikation. An der Hinterseite jeder Testikelblase sitzl eine mässig grosse, obertlächlich glatte, ungeteilte, unregehnässig eiförmige, mit sich entwickehden Samenmassen gefüllte Blase, die ich als Samensack anspreelıen muss. Diese Samensäcke stehen mit den Testickelblasen durch einen sehr kurzen und engen Halsteil in Kommunikation. Ich glaubte am freihändig präparierten Objekt ein ungemein feines Häutclın aus dem Winkełraum zwischen Samensäeken und Testikelblasen hervorkommen zu sehen, mutmasslich das Dissepiment ıo/ı. Die Samentrichter waren bei dem untersuchten Stïck unsymmetrisch gelagert. Der der linken Seite lag ganz innerhalb der linksseitigen Testikelblase, und zwar im Basalteil desselben, unmittelbar neben der Stelle jhres Zusammenhanges mit der medianen Blase. Der Samentrichter der rechten Seite nahm den entsprechenden Raum in der rechtsseitigen Testikelblase cin, ragte aber mit einem beträchtlichen Teil ausserdem noch in die mediane Blase hinein, fast die ganze hintere Hälfte derselben ausfüllend. Die aus den Samentrichtern entspringenden Samenleiter treten dicht neben der Verbindungsstelle mit der medianen Blase aus der Unterseite der Testikelhlasen heraus. Als Hoden deute ich gewisse dünne und unregelmässige Zell-Lamellen, die in der vorderen Partie der Testikelblasen an der ventralen Wand sitzen und weit in das Lumen der Testikelblasen hineinragen, zum Teil die ganze Breite des Lumens äberspannend. In der medianen Blase sind keine Zellgruppen auffindbar, die als Hoden angesprochen werden könnten; sie ist ron dem medialen Teil des rechtsseitigen Samentrichters und ausserdem von losgelösten, in Entwickelung begrilfenen Samenmassen ganz ausgefülit. Es ist nun die Frage, als was wir diese fast unpaarige mediane Blase anzusehen haben. Fïr eine blosse Kommunikationsvorrichtung, wie sie sich wohl zwischen den Testikelblasen mancher Oligochäten bildet, erscheint sie zu selhständig gebildet und zu besonders geformt; zmmal die ollensichtliche Paarigkeit der Anlage, wie sie durch den tiefen medianen Einschnitt an VorderEnde der Blase markiert wird, spricht dafür, dass wir es hier mit dem Ueberrest eines besonderen, ursprünglich unpaarigen Organs zu tun hahen : Jeh halte diese mediane Blase für den Ueberrest eines zweiten, hinteren Paares von Testilichblasen. Es ist bei höheren 


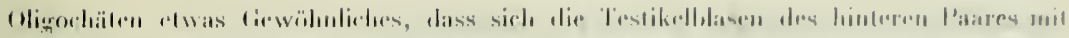

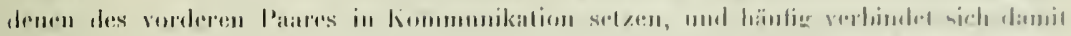

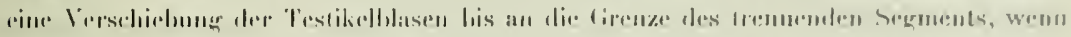

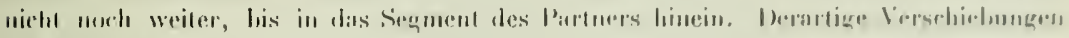

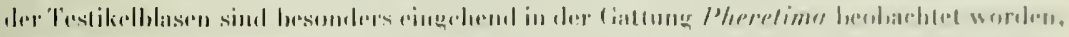

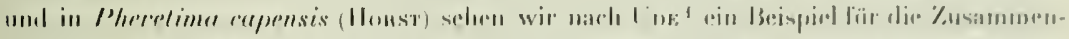

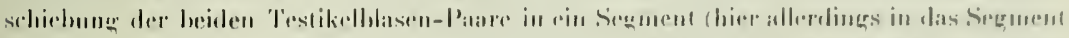

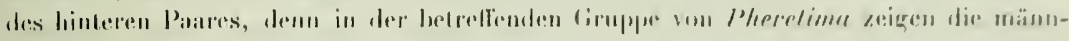

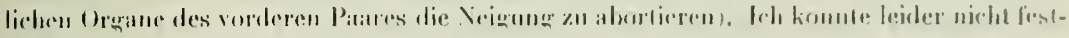

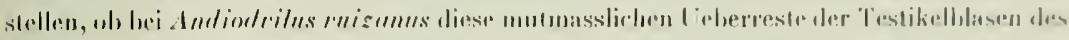

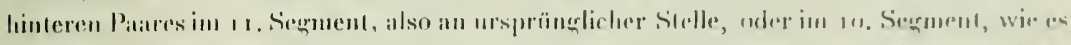

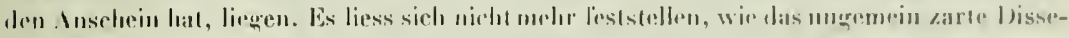

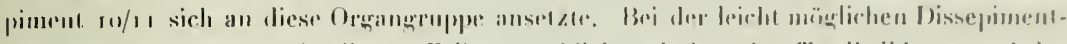

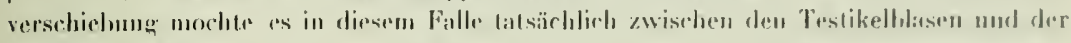

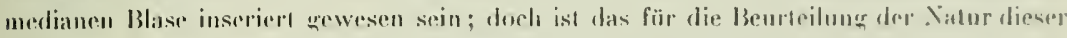

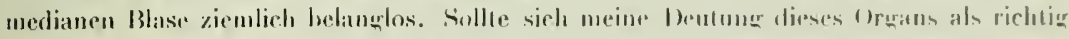

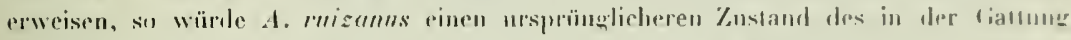

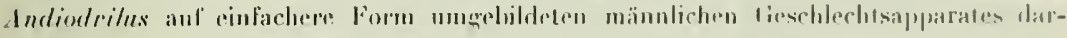
stellen, und damil wörde auch das Vorkommen der hei den anderen Irlen vollkoumen

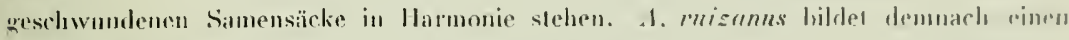

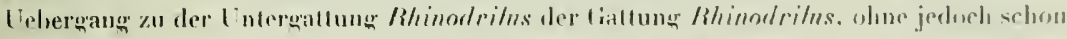
Zweifel an seiner Zugohöriskeil zu Alldiodrilus zu grestatten.

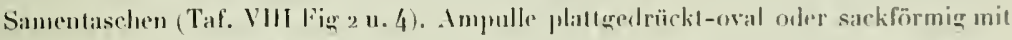
unregelmäsigen hlasigen Infheulungun. Insfïlırgang elwas kürzer nud selımäler als

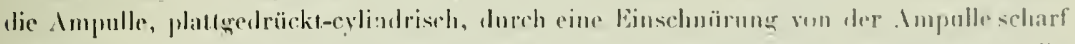

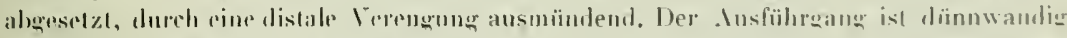

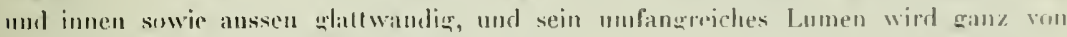

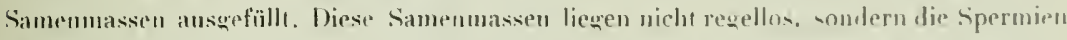

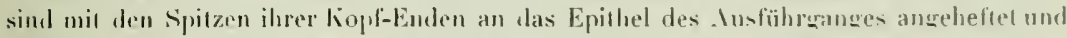

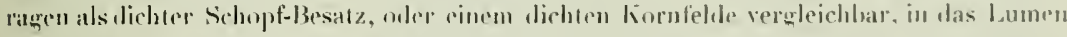

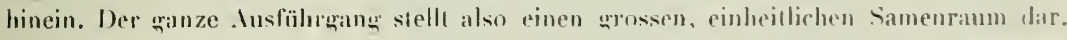
Die Ampulle enthäl keine Spermien, somelern mu wolkige Massen winziger, kugeligev mal polyedrischer Zellen von ca. 5u Durchmesser und feinste Körnermassen, dip am dem Zerfall jener hervoriregangen zu sein scheinen.

Geschlechtshorsten-. Ipparat: Dic ventralen Borsten a und $b$ des $7 .-9$. Serments und der Gürtelsegmente, sowio die lateralen Borsten des 7. und 8. ciesments, oder ein Tril der letzteren, sind zu Feschlechtshursten umgewandelı, und zwar zu lieschlechtshorslen

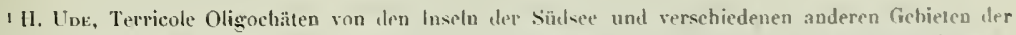

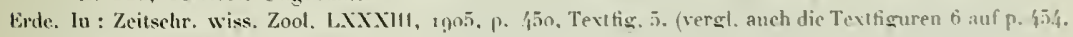
4 auf p. 197 und 3 auf p. 445). 
einerlei Form aber zweierlei Grösse. Die Geschlechtshursten des 8., 9., 22,, 23. und 24. Segments sind sehr gross, ea. $2 \frac{1}{2}$ mu lang und im Maximum, in der Mitte, 50 u. diek, Gegen das distate Ende nehmen sie langsam mol gleichmässig an Dicke ab. Sir sind in Algemeinen qanz grerade gestrecki, nur im proximalen Driltel chas gebogen. Ilır äusserstes distales Ende ist schlank Vogelschnabel-förmign, schwach quehogen, einfach zugespitzt, basal schwach rerdickt und dadurch etwas von dem eigenthehen Borstenkörper abgesetzt. Die dislaten zwei Drittel der Cieschlechlsborste mil Ansnatume des äussersten, Vogelschnabel-förmigen Endes zeigen eine schart ausgeprägle Ornamentirmug, hestehend aus 4 Läıgserilıen tiefer Narben, deren scharfer, distalwärls konkaver proximaler Rand die Narbenhöhlung mehr oder weniger üherragt, wenigstens bei den tieferen distalen und mittleren Narben. Die Breite der Narben ist nur wenig seringer als die Borstendicke. Dir Narben zweier benachbarter Längsreihen sind alternierend verschieden hoch gestellı, die zweier sich gegenüber liegender Reilın in gleichen Höhe. Die Zahlı der Narben ist bei dieser grossen Geschlechtsborstenform sehr gross, ca. 40 in jeder Reihe. Eine ebenso gestaltete, aber kleinere Geschlechtsborsten-Form wird durch die übrigen ventralen Borsten der Guirtelregion, sowie durch die lateralen und einzelne ventrale Borsten des 7. und 8. Segments dargestellt. Die Geschlechtsborsten der kleineren Form sind nur ca. I 1/2 mm lang, in der Nitte $30 \mu$ dick, und die Zahl der Narhen einer Längsreihe heträgt nur ca. 26. Eiı Teil der Geschlechtsborsten, und zwar besonders sämtliche der grossen Form, aber auch ein Teil der kleineren (sämtliche?) sind mit cinem Drüscuapparat versehen, bestehend aus mehreren (2-4?) wulstigen, lappigen oder zungenförmigen Drüsen, die im Umkreis der Borsten in die Leiheshöhle hineinragen. Die Drüsen der kleineren Geschlechısborsteı sind meist viel kleiner als die der grossen, manchmal aher ebenso gross. An einzelnen der kleineren Geschlechstborsten sieht man nut geringe Spuren dieses Drüsenapparats, hei vielen fehlen sie anscheinend ganz.

Bemerkungen: Andiodrilus ruizanus ist in mehrfacher Hinsicht interessant. Er bildet mit A. Schülti (Мıсн.) ${ }^{1}$ und A. major Мıсн. ${ }^{2}$ eine kleine Giruppe, die durch die Lage der Samentaschen-Poren dicht neben der dorsalen Medianlinie charakterisiert ist. Er unterscheidet sich von A. major unter anderem durch die Vergrössermng der Borsten und die Erweiterung der Borstenpaare am Hinlerkörper, von A. Schütti dadurch, dass diese Erweiternng die ventralen und lateralen Borstenpara gleicherweise betrifft und mässig ist. während hei A. Schütli nur die lateralen Pare erweitert sind, und zwar beträchtlich stärker, so dass die lateralen Paare ca. 4 mal so weit wie die ventralen sind.

Eine der bedeutsamsten Eigentümlichkeiten dieser Art liegt in der Gestaltung des männlichen Geschlechtsapparates, in dem, Vorkommen mutmasslicher Ueherreste einen hinteren Paares von Testikelblasen und in dem Vorbandensein echter Sameusäcke, welche

1.Anteus Schütti, WV. Mrchıeısev, Zur Kenntnis der Oligochaten. In : Abh. Ver. Hamburg XIII, I $89^{5}$ p. 25, Taf. Fig. 4-6.

2 IV. Mrchaelsen, Die Terricolen-Fauna Columbiens. In: Arch. Naturg. LXVI, 1900 I, p. 257. 


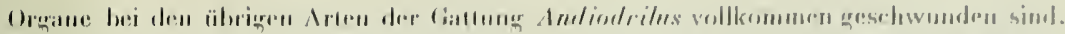

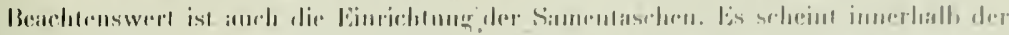

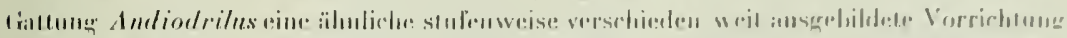

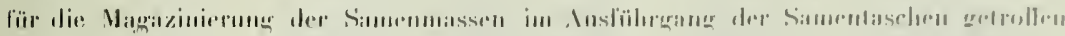

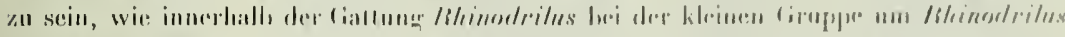

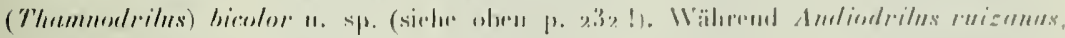

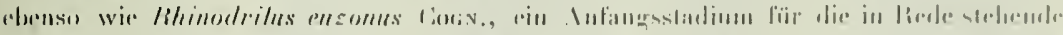

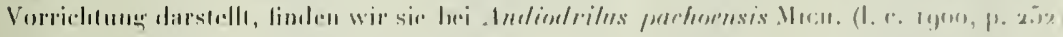

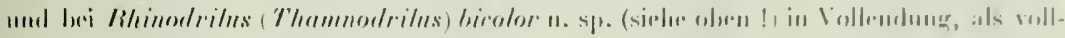

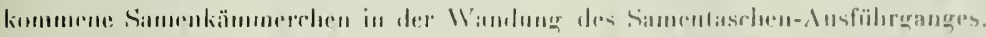

\section{Helodrilus (Eisenia) foetidus (Sav.)}

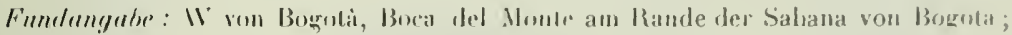
$2600 \mathrm{~m}$.

\section{Helodrilus (Eisenia) rosea (Sav.)}

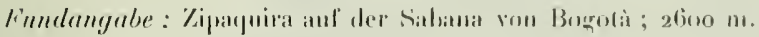

\section{Helodrilus (Dendrobaena) octaedrus (Sav.)}

fimudernguben: 1) von Medrllin, Mlto Sim Mignel; 2.30o m.

Zipaquira auf der Siahana vou Boguda; $2600 \mathrm{~m}$.

Umgegend von Bogoti ; $2800 \mathrm{~m}$.

\section{Helodrilus (Bimastus) constrictus (Rosa).}

Fundangaben: S von Malellin, Calcelal Camelia hei Anselopolis: $1800 \mathrm{~m}$.

O von Medellin, Mla San Miquil ; $2.300 \mathrm{~m}$.

II von Bogotà, Boca del Nonte; $2600 \mathrm{~m}$.

SO von Bogoli, Paramo Lruz Verde: $3600 \mathrm{~m}$.

$\mathrm{S}$ W von Bogotat, Calfetal Argelia bei Viota ; $1600 \mathrm{~m}$.

\section{TAFELERKL i R U N G}

\section{TAFEL VIII}

Fis. 1. Periscolex vialis n, sp. Längsschnill durch einc Samentasche: 10 n i.

Fin. 2. Andiodrilus mizanns n. sp Samentaschc. Fresambansicht : 25 r.

Fis. 3. " " " "ordere männliche Geschlechlsorsane von der Lalerseile: ;

Fiپ.. 4. " " Längsschnitl durch eine Samenlasche : 2.51 . 


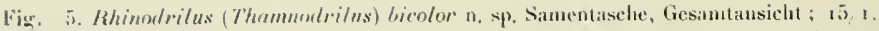

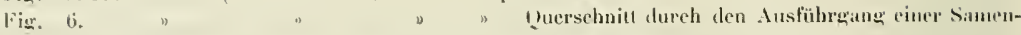
Lasebe; 100/1.

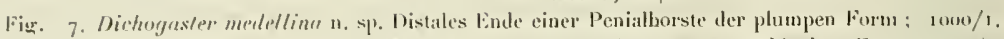

Fig. S. " " " "Distales lincle eitrer Penialborste der sehlanken Form; $1000,1$.

Fig. 4) " " "Simentasche, nach Iulbellung ; yo/1.

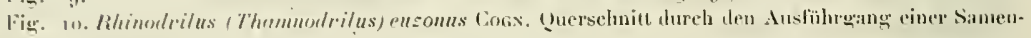

Fig. II.

Fig. 12.

Fig. 13.

Figr. 14. tasche: $100 / 1$.

Camelime n. sp. Stück einer Geschlechsborste, von vorn : 2 q0/t.

" "Stück ciner (ieschlechtsb., von eler Seite: 14011 .

$n$

- Längsehnitt durch den Ausführuang einer Samentascbe; $100 / \mathrm{r}$.

") Samentusehe, nach Authellung; $20 / 1$. 


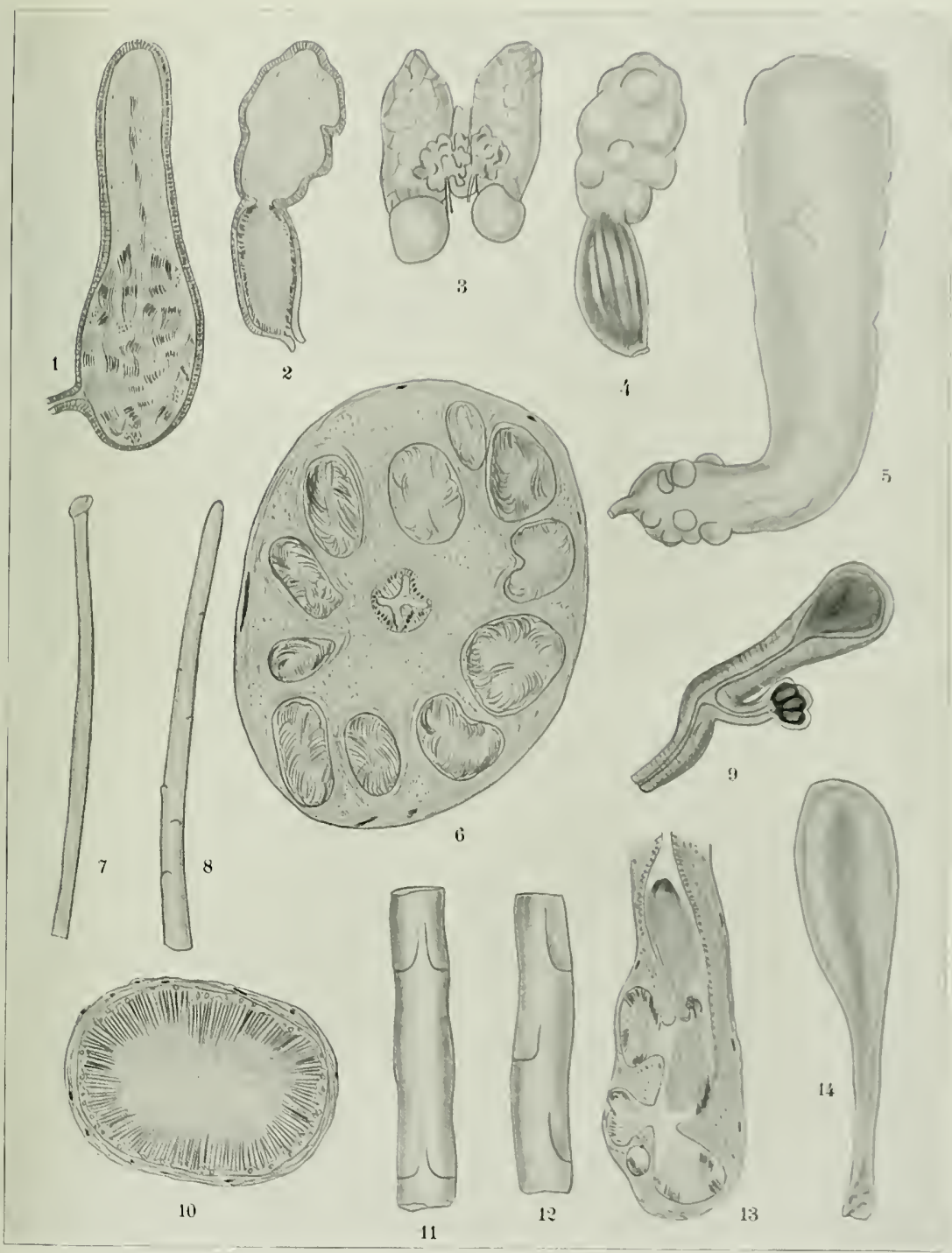





\section{Quelques Mollusques de Colombie}

\section{JEAN PIAGET}

Qu'on me permelle, avant toute chose, de monercier bien vivement M. le f)r

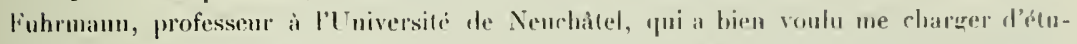
dier les mollusques testacis mpportis de sou exprolition de Colombir. Tous mes remerciements également à M. le prof. Brolol, directeur du Mlusée d'histoire naturelle de Gence, qui ma autorisé a consulter les importantes collections of la riche bibliotheque de son musce. de the fats mu devoir entin de rappeler yue mon cleer et vénéré naître, feu M. le D) Paul Godel, allait entreprendre ce travail, quand la maktalic l'a surperis.

La fanne malacologique de Colombie, bien connue dès te milien do dix-neuvième siicte, principalement par les travaux de Pfenfere, de Reeve et de Moussox, comprend environ 300 espèces terrestres el thuviatiles. L'éunme prédominance des espèces lunlimiformes (environ les $\frac{2}{3}$ ) est le principal fait qui la caracterise, ainsi que la présence d'un certain nombre de genres spécian, pour constituer la région colombienne, aver le Vínézucla, la Guyane el une partie de l'Équateur. Celte classification est déjà dhablie par Woopwand, en 1856 ; en $18 \overline{7}$, Sclaten fait rentrer ces pays dans sa région néntropicale, que Russel IValbage subrlivise en quatre sous-régions (18;6), donl la première renferme la Colombie (région brésilienne. comprenant tout le nord de l'Amérique du Sul). P. Frscher. en 1887 , reprend la région colombienne de $\mathbf{V o o d w a r d ~} 124^{\text {me }}$ région. la denxième de la zone néotropicale) en lui assignant les mèmes limites. I mesure que l'on avance dans l'ćtude des mollusques de ces pars, on observe un rapport toujours plus étroit entro l'Équateur, la Colombie et le Vénéznela, lapport bien évident dans les nonveaux matériaux recueillis par M. Fuhrmann : le Solaropsis Gibhoni est commun à l'Ëquateur ò à la Colombie, aiusi que le Borns Popelairianus el I'Orthaticus zelra: le Leptomerns 
cacticolus signalé d'ahord an Vénézuela a été trouvé anx environs d’Angelopolis, avec les Obeliscus riparius et cuneus, de l'Équateur; enfu la Subulina octona, tronvée à Supia, est signalée par le Dr Mnzen à l'Équateur.

11. Fulumann a rapporté de Colombie 27 espices alont me, toutc jeune, qu'il n'est pas possible de déterminer el une Rhodea, probablement Rh. Wallisianu qui provenait des environs de Titiribi et qui s'est perdue. Sur les 25 antres espices, 7 sont nonvelles, drux Glandinu, un Euconulus, un Labyrinthus, une Leptinaria, une Limnaen et un Ancylıs. J'ai aussi élahli $;$, nouvelles variétés en ute fondant sur des différences constantes et non individuelles, ou, quand l'exemplaire est unique, sur des dilférences assez importantes pour servir à caractériser des variétés. Je catalogue en outre deux espèces recueillies aux Antilles, un Thanmastus de Haïti et un Planorbis de Jamaïque.

Il résulte uaturellement un grand intérèt zoogéographique des provenances exactes, toujours soigneusement notées par M. Fulırmann, qui compléteront les données ordinairement trop vagues de la plupart des auteurs, sur les distributions horizontale el rerti cale de chaque esprice. Il est eu outre curieux de signaler ce fait que, malgré les quantités d'ean qui tombèrent chaque nuit et souvent pendant le jour, durant tout le voyage a travers la Colombie, les coquilles étaient extrèmement rares el que M. Fuhrmann n'a 'rouvé qu'un nombre restreint d'espèces, bien que le genre de recherches auquel il s'adonnait le plus le portàt à retourner tous les cailloux et les morceaux de bois humides et à étudier tous les endroits favorables aux mollusques.

Enfin, pour la bibliographie, je ne renvoie qu'aux onvrages originaux el aux manuels que j'ai consultés pour la détermination de l'espèce.

\section{Cl. Gastropoda}

\section{S. Cl. Pulmonata}

\section{Ord. Stylommatophora}

\section{Fam. Oleacinidæ}

Gen. Euglandina Cross. et Fisch.

\section{Euglandina Fuhrmanni nov. sp.}

Testa oblongo-subfusiformis, ventricosa, solidula, rubrofusca, unicolor, distincte striata et transverse striatula : spira curtu, ovato-eonica, apice obtuso, rubro; sutura angustissime albomarginata, erenulata; anfractus 6 convexiusculi, ultimus spiram 


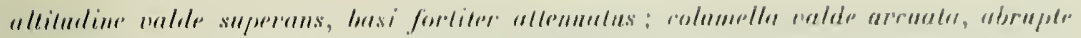

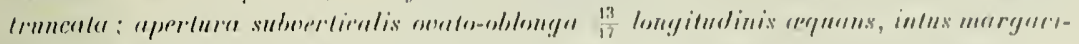

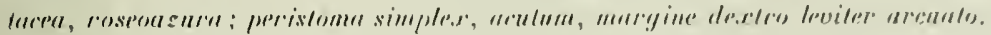

All. .

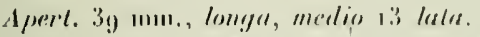

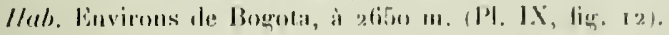

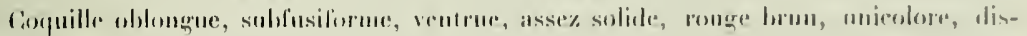

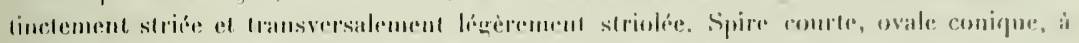

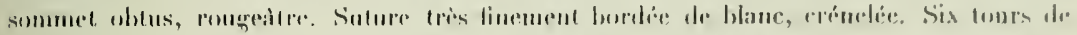
spire un pren rouvexes, le deruier dépassant de heancoup la spire en hantenr, passable-

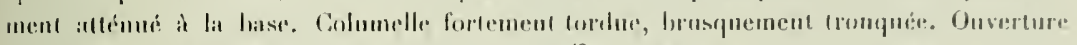

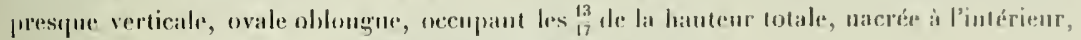

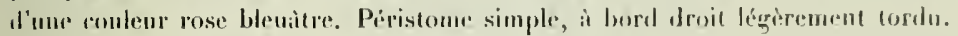

fo: n’ai trouvé ancune espèce qui lui soit très voisine.

\section{Euglandina Godeti nov. sp.}

Testa oblongo-fusiformis. solida. fusco-rosea, unicolor, distincto striala el trenssverse minntissime strialula; spira elongala, ronicu, oblusu, apire oltuso; suluru

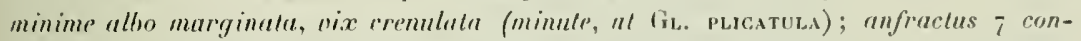
nexinsenli, ultimus , fere spiram requans; columella maxime arcuata, abruple truncala: apertura parum obliqua, acuminalo-sualis, basi ampla, intus roseo-nzura, margaritacea: peristoma simplex, acnlum, margine dextro leviter armato, basi expanso.

All. 47 , diam. $20 \mathrm{~mm}$.

Apert. $32 \mathrm{~mm}$., longa medin it latu.

Hab. Bogola, sub lapillibus, elc.. locis nvidis.

Coquille oblongue fusiforme, solide, brun rosé, unicolore, distinctement striée el transversalement très finement striolée. Spire allongée, conique, obtuse, à sommet obtus. Suture tress finement borlée de blanc, ì peine crénelée (comme la Gl. plicalula). Sept tours de spire peu convexes, le dernier égalant presque la spire en hanteur. Columelle fortement tordue et brusquement tronquée. Onserture trẻs peu oblique, ovale acuminée, ample vers la hase, rose bleuitre à l’intérieur, nacrie. Péristome simple, aigu, it bord droit légèrement épaissi, dilaté vers la hase.

Celle espèce se rapproche de l'Eugl. Irunculu (Turos et Prasbry, Man., II sér.. 19, pl. 21, l. 10-12) mais en differe par sa spire plus obtuse, par sa suture beaucoup plus finement marginée et ì peine crénelée, et surtout par son ouverture très dissemhlable: beancoup moins élevée, hien plus ample it la base et i columelle plus fordue. Elle est aussi voisine de l'Eugl. saceatu dont elle se distinque par les mèmes earactères de la suture et de l'ouverture ainsi que par sa columelle beancoup plus tordue. (PI. IX. tig. In et 11 .) 


\section{Var. dubia nov. var.}

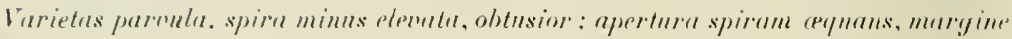
dextro attenuatiore.

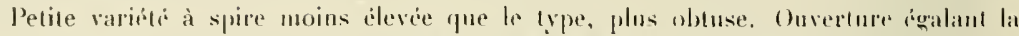

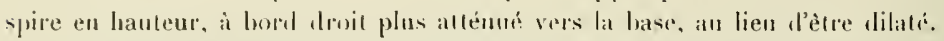

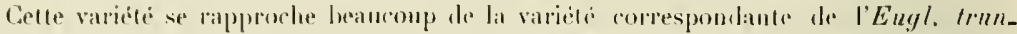

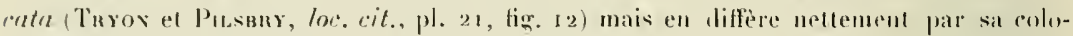
ration rouge brone et sil suture à peine cróneléde d'Engl, Godeti normale.

Hab. cmm typo. (PI. I.X, tig. 9.)

\section{Fam. Streptaxidæ}

Greı. Scolodonta Döring.

\section{Scolodonta (Happia) Santanaënsis}

Helir Santanaënsis PFn., Proc. Zool. Soe., 1854, P. 52.

- - Reve, Conch. ic., s1.1344, pl. 19!.

- - Pri., Mon. Hel., IT, p. 8\%.

Myalina - Tryos et Prussux, Man., Ser. 11, vol. 2, p. 165, pl. 52, fir. 57.

Scolodontı - Konelt, in Chemn., Streptaxida, p. 65, pl. 51, tig. 4.

\section{Var. depressa nov. var.}

Var. major, depressa.

Cette variété, dont M. Fuhrmam n’a trouvi qu'un exemplaire, est plus grande que ne l'indiquent Pfeiffer el Kobert (lexte: diam. 4, $5 \mathrm{~nm}$ ), mais, son diamètre correspomil à celur que donne Kohelt à sa fig. 4 (6 mm.); elle est bien plus déprinée.

Ce b'est pas la Scol. Thomasi, qui est plus grande el it une ouverture tris dillírente ("Apert. vix obliqua, subcircularis, morlice excisa").

Hab. vallée du Cauca, à l'embouchure du Rio Amaga. (Pl. X, fig. 7.)

\section{Fam. Vitrinidæ}

Gen. Conulus Filz.

\section{Conulus Fuhrmanni nov. sp.}

Testa imperforata, trochiformis, tenuis, glabra, nitida, corneo fulna, minutissime striatula: spira conoidea, apice subacuto: anfractus $5 \frac{1}{2}$ parum convexi, angusti, leniter crescentes, ultimus basi convexins: apertura transverse semilnnaris; peristoma 


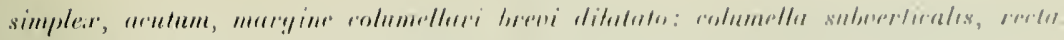

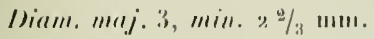

All. $29 / 10$ (11111.

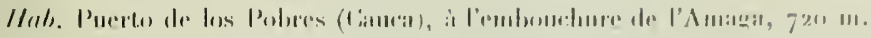

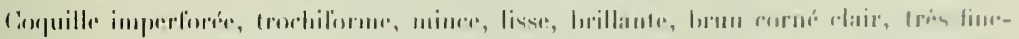

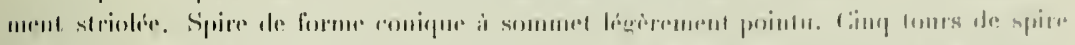

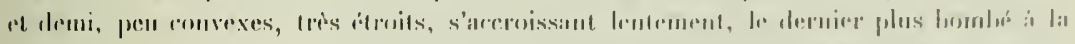

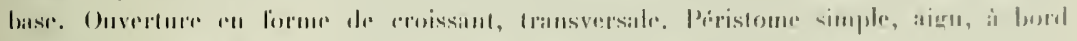

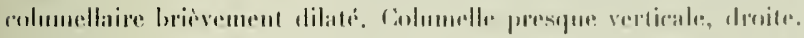

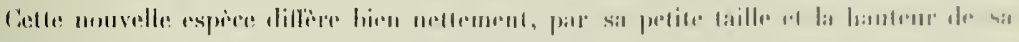

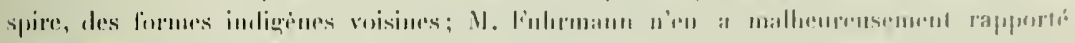
qu'un seml individu. (P). X, fig. 8-10.)

\section{Fam. Helicidæ}

Gen. Isomeria $\Lambda$ ll,.

\section{Isomeria Oreas.}

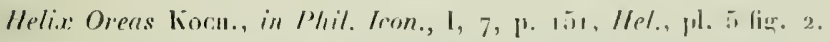

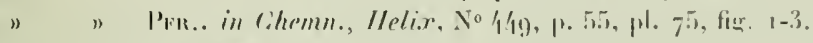

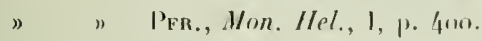

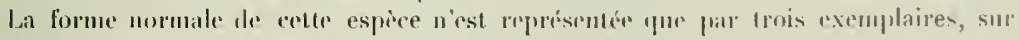

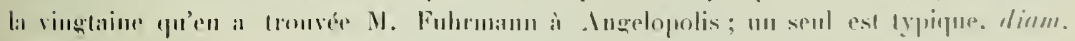
maj. 57, min. 46 ef alt. 27 mm.). Ies deux antres sont des:

f. elevata : diam. maj. 57, min. $46 ;$ all. 29 , 13 r $\mathrm{mm}$.

\section{Var. parvula nov, var.}

Als typo differt miunre testu et peristomule magis tenui.

Catte nouvelle variebé se distingur du type par sa taille plus petite el son péristume plus mince; la couteur est quentratement assez foncie. IP. IX, fiz. 8.

Diam. maj. 49-51 $11 m$, min. 41-42 mum.; all. 25 mm. Issoz variable:

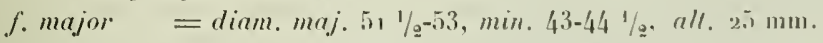

f. minor = " "47-48, " 4 $4{ }^{1} \mathrm{~g}-41 . " 24 \mathrm{~mm}$.

f. depress $=$ " " 49 " 41 " $423-24 \mathrm{~mm}$.

f. rotundata $="$ " $49 \quad$ " $43 \quad$ " $24 \mathrm{~mm}$.

f. tridentata $=\mathrm{LT}_{n}$ individu, sinun normal, presentant une proiminence dentiforme an bord supérieur de l'ouverture.

Hab. Angelopolis, près de Titirihi (prow. Intoquia) à 1970 m. 
(ien. Labyrinthus Beck.

\section{Labyrinthus Angelopolites. nov. sp.}

Testn late umbilirutu, lenliformis, acnle corimutu, irreguluriter striutu vel granulata, fusco corneas: spira obluse depressa, apice non mroeminente. pallidiorer: sutura fere planu; unfractus quinque, fere pluni: upertura sublorizontulis, plien minutu in pulato immersu preditu, intus cornea pallitlion: peristomu non in pariete solutum, olturse albo reflexum : margine parietali laminum erectam armutim introenutem emitlente; supero subexpanso anl carinam descendente camalem non formante : margine basali forliter bidentuto, sinn interposito, dente externo simplire. erecto, dente interno pliciformi sed ad extremum erecto, horizontuliter introenule, umbolms marginulibuss ; columelluri umbilicum sinuose invadente.

Diam. maj. 34, min. 29, alt. $11 \mathrm{~mm}$.

Hab. Angelopolis, près Titiribi, à $1970 \mathrm{~m}$. (2 exemplaires).

Coquille largement ombiliquie, lentiforme, fortement carénce (à carène très aignë), irrégulièrement striéce ou qranulée, brun corné assez foncre. Spire oblusément déprimée, à sommel non proéminent, plus pàle que le reste du test. Sulure presque plane de même que les tours de spire, qui sont au nombre de cinq. Ouverture subhorizontale, offrant un très petit pli fixé au bord supérieur, cornée à l'intérieur et de couleur plus pàle, présentant une lamelle acérée au hord pariélal; le bord supérienr ne lorme pas de canal en descendaut vers lit carène; le bord inférieur offre deux fortes dents séparćes entre elles, l'externe simple, dressée, l'interne en forme de pli mais relevée à son extrémilé, entrant horizontalement; le bord columellaire se replie dans l'ombilic en dicrivant une sinuosité.

Cetle nouvelle espèce ne peut se confundre qu'avec les /I. Taraponensis et bifurcata, dont elle diffère surtout par ses deux dents simples et non bifides. Par sat forme générale, elle se rapproche beaucoup de l'II. erectu Mouss. (II. subplanata Petit), bien différente par le canal de l'extrémité droite de l'ouverture. (PI. X, fig. I-6.)

Gen. Solaropsis Beck.

\section{Solaropsis Gibboni.}

Helix Gibboni Prr.. Syml., III, p. :37.

1) Prr., Mon. Hel. I, p. ${ }^{3} 7$ r.

") Pfr., in Chemn., Helix, p. 213, pl. 107, f. 10.

Un bel exemplaire provenant de la Sabana de Bogotil, de 64 nım. de grand diamètre. Ce nom de Gibbani n'est pas synonyme, commo le disent Pfarfar el Cuessin (Nom. het.) de l'llelix Amori Hidalg., qui a une taille lien plus grande. (Détermination de M. Paul Godet.) 


\section{Fam. Bulimidx}

(ien. Borus Nh.

\section{Borus Popelairianus.}

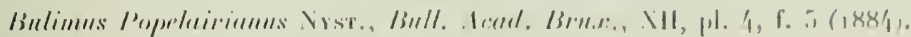

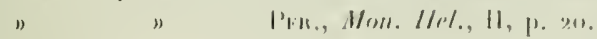

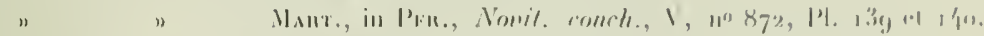

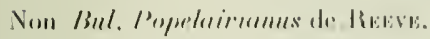

\section{Var. Thammianus.}

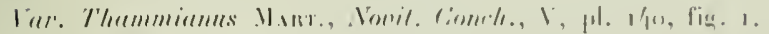

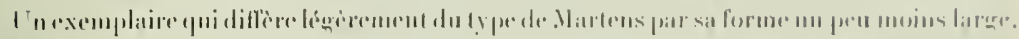

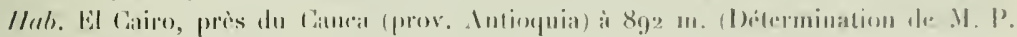
(iorlet).

lang. 135, li1rg. 70 mon.

Apert. lom 70 , larg. $18 \mathrm{smm}$. (rmm perist.)

\section{Var. connectens.}

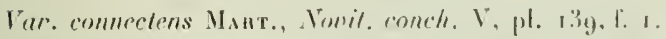

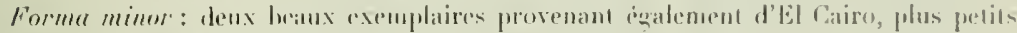
que le yye de Mardins.

L.omg. (a) 127 , b) 124 mms, ; lare. "1) 70, b) 68 mm.

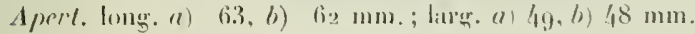

Gien. Plekocheilus Guild.

\section{Plekocheilus pulicarius.}

Bulimus pulicarius Reve, Conde. ie.. pl. 4?, sp. 2 (i).

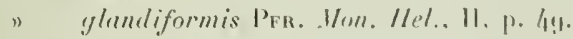

" pulicarius PFr., loe. cil. III, p. i32.

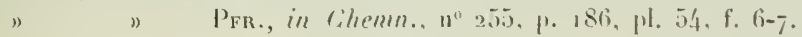

Cing exemplaires recueillis sur la Salbana de Bogrota, diterminés par M. (iodel, lous plus ou moins différents les uns des antres. Lal hauleur varie entre 31 el fo mm. of la larerenr entre $19 \mathrm{el} 35$; la spire est plus un mons allonere. louverture plus ou moins olluse, ele.

f. normalis $30-31 \mathrm{~mm}$. de hautenr el de $19-20$ de largeur.

f. gracilis $35 \mathrm{~mm}$. " "

f. major $37 \mathrm{~mm}$. " " $23-24$ "

f. maxima $40 \mathrm{~mm}$. " " 
(ien. Eurytus Alb.

\section{Eurytus succinoides.}

Bulimus succinoides Petrt, Reu. Zool., 1840, P. 75. Mag. Zool., 1841, pl. 31. Reve, Conch. ic., pl. 42, sp. 26 4.

PFr., Hon. Hel., II, p. 18.

Fér. el Desu., Hist. Moll., II, 1. 246 , pl. 145, figg. 19-21.

\section{Var. intermedia nov. var.}

Intermedia inter Eurytus latilabris et E. succinoides. Testa mugna, upertura latior.

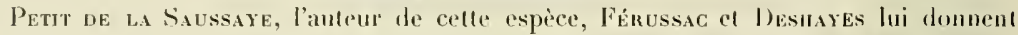
comme dimensions $32 \mathrm{~mm}$. de longuenr sur 18 de largeur (er 35 sur zo, dans Mag. Zool.); mais PFeiffer indique $39 \mathrm{~mm} . \times 19$ el une onverture de 3 i sm $18 \mathrm{~mm}$. D'aulre prarl, Iousson dans les Mrelek. Bl. (XXl, 873 , p. 7 ) parle d'une hauteur de 41 mum. Lunigue exemplaire trouvé par M. Fuhrmann au Paramo Cruz Verde (à l'est de Bogota, prov. Cundinamarca, alt. 360o m.) est remarquable par sa coloration très voisine de celle de l'Eurylus latilubris ainsi que par la laregenr de son ouverture et par sa grabde laille. II est cependant évident qu'il appartient à l' É. succinoides et je le désigne donc sous le nom de var. intermedia.

Alt. 41, diam. $23 \mathrm{~mm}$.

Apert. 3 y $1 / 2 \mathrm{~mm}$. alta, $20 \mathrm{~mm}$. latu. (PI. IX, lig. 7.)

\section{S. Fam. Bulimulinæ}

Gen. Bulimulus Leach.

\section{Bulimulus (Leptomerus) cacticolus.}

Bulimus cacticolus Reveve, Conch. ic., pl. LVIII, fiğ. 393.

$$
\text { " Prar., Mon. Hel., III, p. } 439 \text {. }
$$

Une douzaine d'individus récoltés aux environs d'Angelopolis (près Titrilit, prov. Intioquia, à l'alt. de $1970 \mathrm{~m}$.) absolument identiques aux individus vénézuéliens (coil. Brot à Genève).

GeI. Drymæus Alb.

\section{Drymæus eversus.}

Bulimus enersus Mouss. Mal. B/., I873, XXI, p. 11.

) Mouss., Pfr., Novil. conch., IV, 1. 136, pl. CXXX, fig. 9-ro.

" Per., Mon. hel., VIII, p. 50.

11. Fubrmann a recueilli à liuaca (près de Titiribi, frov. Antioguia, à f $600 \mathrm{~m}$.) une quinzarue d'exemplaires de celle espece, qui est assez variable. 


\section{Var. alata nov. var}

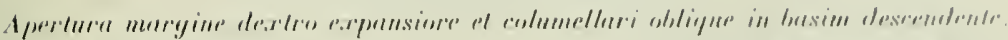

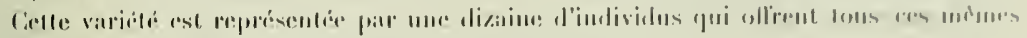

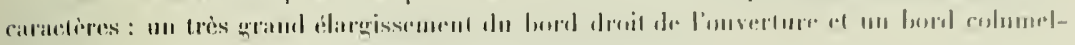

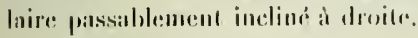
r. "lutu lypica

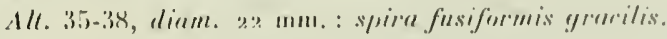
fi. mujor
$"$ 作
" $2 \% \mathrm{~mm}$.
fiminor ventricosu "3:3

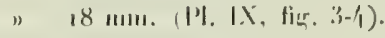

\section{Var. subula nov var.}

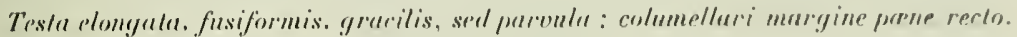
Alt. 33 , diem!. $15 \mathrm{~mm}$.

Apert. crum perist. 88 Inngu, 11 mun. lılı. (I'I. IX, tim. I-2).

Denx exemplaires.

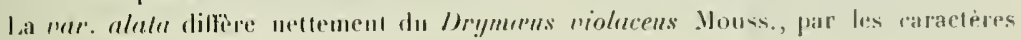
indiqués dans les Sonilates conch., N, p. 137 , de motme que le lype du Dr. eversas.

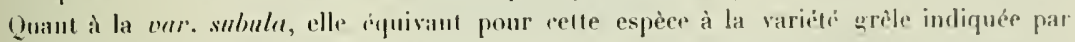

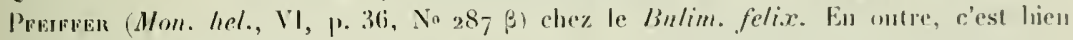
une variché du Dr. enersus amquel elle est reliée par plusieurs individus intermédiares, a alle n'a aucun rapport spécifique avee les Dr. hnorri el murrinns, voisins par leur forme élancée.

Gen. Leiostracus Alb.

\section{Leiostracus Studeri.}

Bulimus Studeri Pra., Proc. Zool. Soc., r846, p. I I2.

") Per., Mon. hel., II, P. 107.

$"$ et primula Reeve, Conch. ic. LVII, sp. 384 at 385.

\section{Var. iris nov. var.}

Varielas flauescens, columella alba, quinque fasciis fuscorubris cingulala, tribus inferinribus lutioribus el dnabus superioribus angustioribus. Apice fuscorubro.

Varicté jaune, à columclle blanche, à cinq fascies ronge brun: les trois infricieures. sunt plus larges et les deux supériemes plus titroites. Sommet rouge brun.

Cette jolie variété, roisine de la uar. primula de Reteve dont elle diffère par les fascies plus foncées et plus nombreuses, ainsi que par la couleur jaune du fond. a une laille tris légirement plus grande yue le type de Pferfaren: 
Alt. 26 , lat. if $\mathrm{mm}$.

1pert. alt. 12, lat. $7 \mathrm{~mm}$. (PI. IX, fig. 6).

Un liel exemplaire provenant d'El Cairo (près du Cauca, prov. Antioquia, à $892 \mathrm{~m}$.).

(ien. Thaumastus Ab.

\section{Thaumastus exilis.}

Ilelix exilis Gyen., Syst. nut., p. 3668, N. 252.

Bulimus exilis PFr., Mon. Hel., II, p. 223.

Bulimus exilis et Guadaloupensis, ReEve, Conch. ic., pl. XLVt, lig. 292, 29h a et h.

Ine vingtaine d'exemplaires recueillis aux Cayes (Haïti). Triss variables, ils sont pour la plupart, un peu plus petits que les spécimens de la Guadeloupe de la collection IEannenet (Musée de Teuchàtel), mais sont identiques aux individus de lläti de la collection Ввот à Genève.

\section{Var. trifasciata.}

Bulimus trifasciatus Leach.

Un ou deux individus; ils ont lı conleur du fond gris jaune et sont plus petits que Jes exemplaires types.

\section{Var. rubrifasciata.}

Brot, manuscr. in coll.

Variété à une ou deux larges lascies, rouge foncé. Celle variation est plus fréquente; un spécimen est mème complètement rouge brun, sauf le péristome, la suture et l'ombilic, qui sont blane sale.

\section{Var. concolor.}

Веот, manuscr, in coll.

Cne douzaine d'exemplaires sont d'un gris jaunâtre uniforme ailant jusquau bruı clair corné.

Enfin, quelques individus sont intermédiaires entre deux variétis, présentant soit deux larges bandes rouge brun el entre elles une mince ligne rouge, qui remplace la troisième fascie de la première variété, soit offrant des fascies extrìmement indistinctes, au nombre de deux ou de trois.

\section{S. Fam. Orthalicinæ}

Gen. ${ }_{c}^{8}$ Porphyrobaphe Shuttl.

15. Porphyrobaphe (Corona) Adamsoni.

Butimus Adamsonii Gray, Proc. Zool. Soc., 1833, p. 123. 


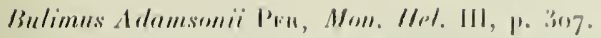

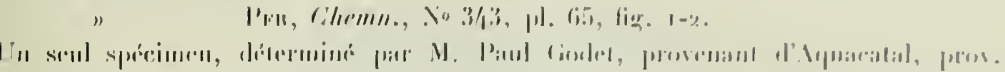

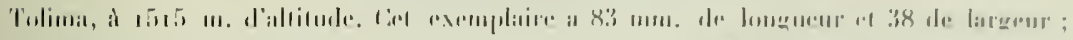

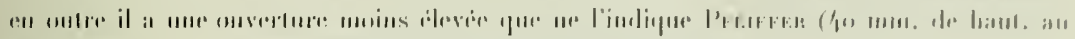

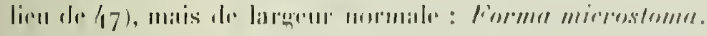

lien. Orthalicus IBreli.

\section{Orthalicus (Zebra) zebra.}

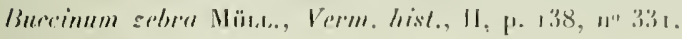

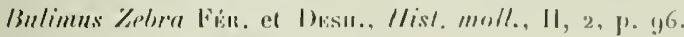

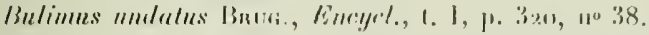

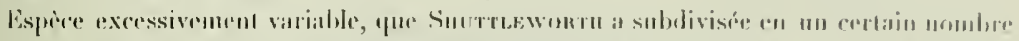

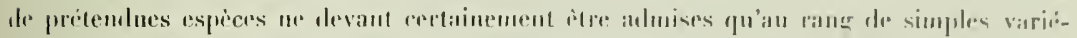

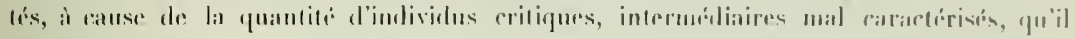
serait improssible de classel sùrement.

\section{Forma normalis.}

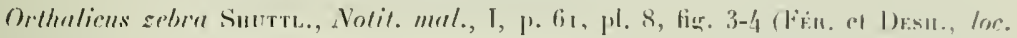
cit.. pl. 115, tig. 3 et 5).

Ciny spurimens licon raractérisés.

I/ut, albinu. Sept individus entièrement hanes, mais jeunes. M. Folumann a rafppotté en outre une quantité d'exmplaires jeunes et cinq spécimens fossiles.

\section{Var. obducta.}

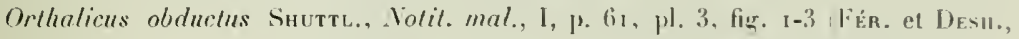
loc. cit., pl. I17, fig. 1).

Un exemplaire normal. M. Mrleer (Malak. BI., XXV, i8-8) signale avec donte celte variéti en Colomhie; clle existe à l'Équateur.

\section{Var. undata.}

Bulimus undalus Brug., Ior. cil., sec. Snutre., Volit. mal.. I. p. 63. pl. 3. lig. 4-5.

(Fér. el Desh., loc. cit., pl. 114, fig. 5-6, pl. I15, fieg. 1 el 4.

Deux spécimeus adultes el quelques jeunes.

Toutes ces variations ont été recueillies anx environs de Barranquilla. 


\section{Fam. Stenogyridæ.}

(ien. Stenogyra Shııtl,

\section{Stenogyra (Subulina) octona.}

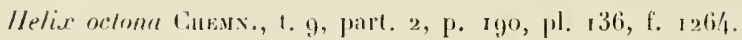

Achutina " P'Fr., Mon. Hel., II, p. 266, No6.).

" " PFr, in Chemn., Bul., p. 342, pl. 37, lig. 19-20, Ichal., No 73.

Quatre exemplatres dont deux jeunes, provenant de Supia (Cordilliores nccidentales, à $1263 \mathrm{~m}$. ; prov. Caucd ).

Gen. Obeliscus Beck.

\section{Obeliscus cuneus}

Bulimus cuneus PFr., in Chemn., P. 96, pl. 32, lig. I 1 et 12.

- - Pfr., Mon. hel., III, p. 39o.

\section{Var. minor}

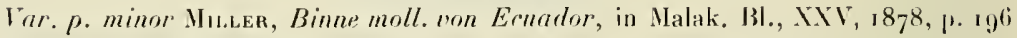
et XXVI, pl. III, fig. 3 b.

Forme assez variable, plus grêle que le type, beaucoup pluss petite et dont le dernier tour de spire est plus allongé, ainsi que l'ouverture, chez certains individıs. La columelle est rarement toute droite; elle est ordinairement plus ou moins tordue, en fonction de la hauteur de l'onverture. La couleur passe du jaune au vert foncé. Enfin la hauteur varie de 30 à $36 \mathrm{~mm}$. el la largeur de 8 à i $\mathrm{mm}$.

Cette curieuse forme, signalée par Miller dans le val de Pilaton, a élé trouvée par II. Fuhrmann à Angelopolis (près Titiribi, prov. Antioquia, à 1970 m.)

Une vingtaine d'exemplaires.

\section{Subsp. riparia}

Bulimus riparius PFr., in Chemn., p. 97, pl. 32, f. 13-14.

- - Prr., Mon. Hel., IJI, p. 391.

- cuneus var. riparia Tryon el Pilsbry, Man. conch., ser. II, XVIII, p. ${ }_{2} 52$ pl. 35 , fig. $61-62$.

\section{Var. minor}

Pfr., Mon. Hel., VI, p. 91. - Mrller, loc. cit., p. 197.

Huit spécimens recueillis également aux environs d'Angelopolis. 
(irn. Leptinaria lierk.

\section{Leptinaria Cattcensis nov. sp.}

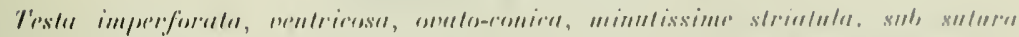

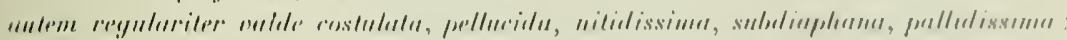

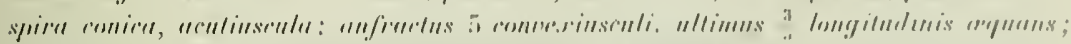

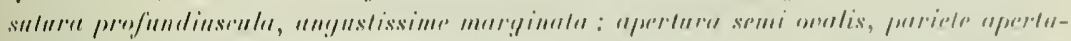

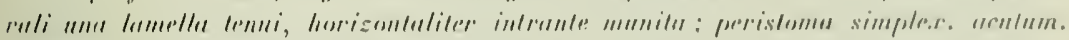

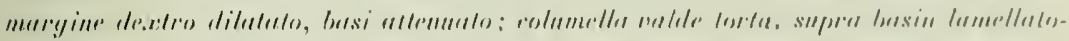

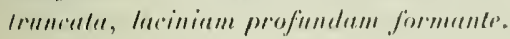

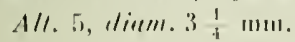

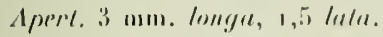

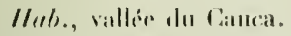

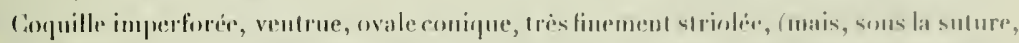

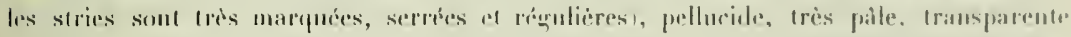

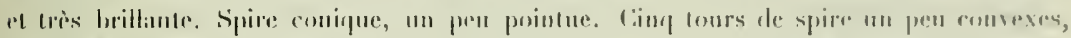

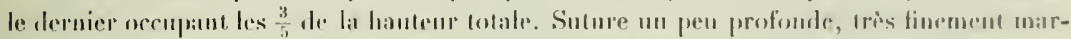

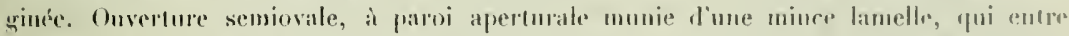

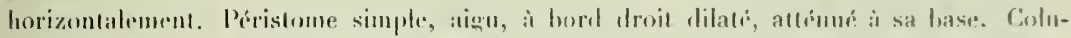

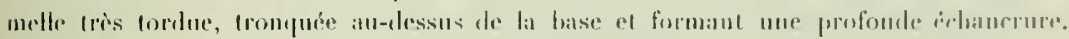
(1). I, lig. 11).

\section{Fam. Succineidæ}

(iris. Succinea Irip.

\section{Succinea (Tapada) Bogotensis}

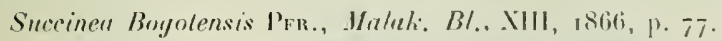

$$
\text { Prit., Mon. I/el. V, p. 37. }
$$

Un pretit spécimen, un pen jeme, provenant de Terquendama (pros. Cundinamarea, $220111 \mathrm{in}$.$) .$

\section{Succinea (Tapada) repanda}

Sureinen repautu. Pra., Pror. Zool. Sor.. 1854, p. r23.

$$
\text { PFr., Mon. IIel.. N, 1. 81.i. V. p. 3\%. }
$$

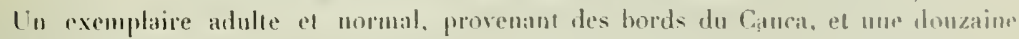
l'individus jemmes. 
Ord. II. Basommatophora

\section{Fam. Limnæidæ}

Lien. Limnæa Laur.

\section{Limnæa Ubaquensis nov. sp.}

Testu rimula, purva, onato-oblonga, solidulu, tenuisenlu, subtilissime striuta, oparen, fusea: spira bulde obinsa, brepis, irregulariter ronica: sutura impressa : anfractus

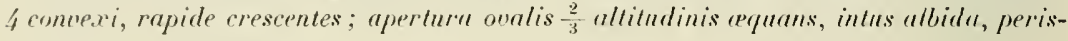
tomate recto, arcuato, margine columellari ualde torto.

All. 12 , diam. $7 \mathrm{~mm}$.

Apert. $8 \mathrm{~mm}$. longa, 5 lata.

Coquille indistinctement rime, de petite taille, ovale oblongue, assez solide, assez mince, très finement et irrégulièrement striée, opaque, brunàtre. Spire très oltuse, conrte, irrégulièrement conique, à suture peu profonde. Quatre tours de spire lombés, s'accroissant rapidement, les premiers courts, le dernier très quand, régulier, non dilaté. Ouverture ovale, atteignant les $\frac{2}{3}$ de la hauteur totale, blanchâtre ou un peu bleuâtre à l'irtérieur; l'angle formé au point d'insertion du bord droit est assez aigu mais il n'y a presque pas d'échancrure à l'insertion du bord columellaire. Péristome bien arqué, tranchant. Columelle fortement tordue, lien dilatée à sa partie supérieure puis s'amincissant.

Ilab. Laguna Ubaque, $2066 \mathrm{~m}$. (prov. Cundinamarca), sur le versant oriental de la Cordillere de Bogota.

Cette nouvelle espèce diff̈̈re bien nettement des L. Cousini et Ruphaelis, de l'Équateur: des deux espèces par la forme de sa spire, de la L. Raphaelis par sá columelle tordue et de la $L$. Comsini par sa forme générale el son ouverture. (PI. IX, fig. 5)

\section{Fam Planorbidæ}

(ien. Planorbis finetl.

\section{Planorbis (Helisoma) affinis}

Planorluis affinis C.-B. Inaus, Contrit). Conchol.. I, P. 44.

- Cuess., Chemn., Pliysa et Plan.. p. 132, pl. XX, tig. 5.

Une vingtaine d'exemplaires recueillis à Kingston (Jamaïque).

f. imajor. ı 6-17 mm. de grand diamètre.

f. depressa. Certains individus sont passablement plus aplatis que les autres relativement an diametre qui est mu peu plus grand.

[)iam. 16, alt. $5 \frac{1}{3}-6 \mathrm{~mm}$. 


\section{Fam. Ancylidx}

firu. Velletia firity.

\section{Velletia Fuhrmanni nov. sp.}

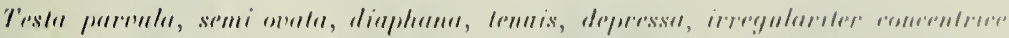

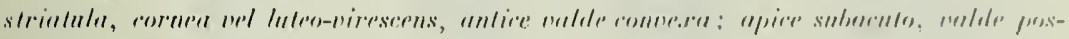

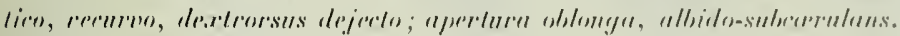

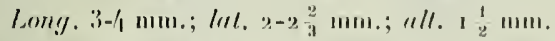

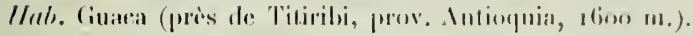

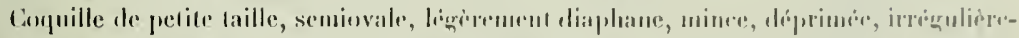

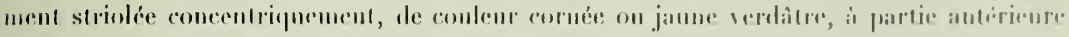

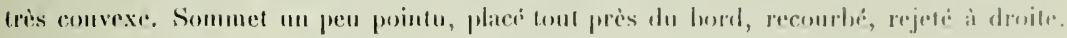

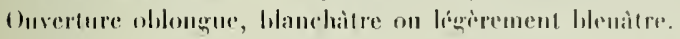

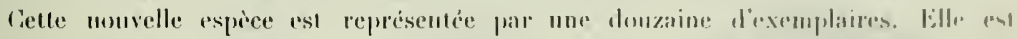

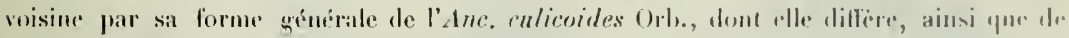

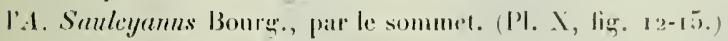

\section{S. Cl. Pneumopoma}

\section{Fam. Cyclophoridæ}

lien. Neocyclotus lisch. et firosice.

\section{Neocyclotus (Neocyclotus s. str.) cingulatus}

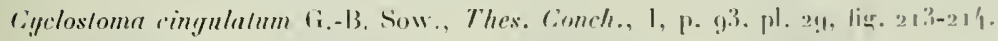

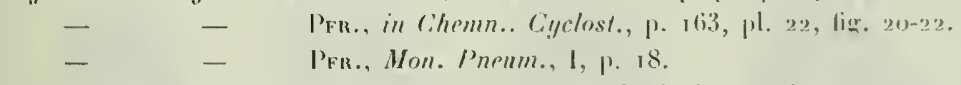

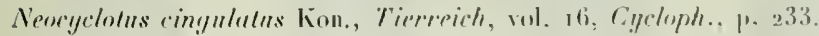

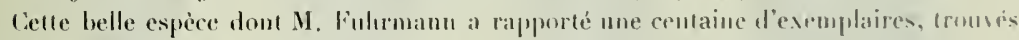
daus le Catfetal Camelia ( 820 m., prós Angelopulis, prov. Antioquia) est trés varialule.

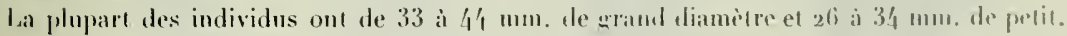

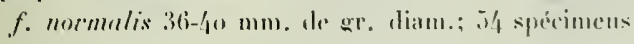

f. minor 4r-44

f. minor 33-35

$n$

is "1"

f. eleverlit

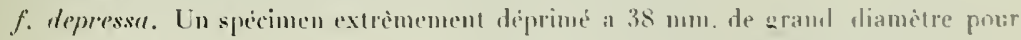
$18 \mathrm{~mm}$, de hasteur. 


\section{Var. Bogotensis}

C.yclostemu boyotense PFr., Proc. Zool. Soc., 1855, 1. 117.

Cyclotus bongotensis P'Fr., Mort. P'neum., II, 1. 17.

Veocyclotus boyolensis Kion., loc. cil., p. 232 .

11. Fuhrmann en a récolti. nn exemplaire adulte et lons jeunes, it P'merto de los Polnes (sur le Catuea, il l'embouchure de l'Xmaga, $720 \mathrm{~m}$.)

Celle forme ne me paraì pas assez distincte du $N$. cingululus pour ètre considérée conme une espèce différente: comme le dit Koвest, elle n'en diffère que par une titille moindre, une forme plus élevée et un ombilic plus étroitenent tordu. Or un grand nombre de cingulalus ì taille normale ont une spire plus on moins élevée, identique à celle du bogoteusis et d'autres ont une taille très petite, de sorte qu'il est facile de tromver une foule d'intermédiaires entre ces deux formes. Quant an caractère de l'opercule, il n'est pas constant et ne peut servir qu'à distinguer deux variétés.

\section{Var. gigantea}

Gyclostoma giganteum Reeve, Conch. syst., II, p. 99, pl. 184, 1. 17. - - Pfr., Chemn., Cyclost., p. 11, ph. 1, l.11-14.

Cyclotus giganteus PFr., Mon. Pneum., I, p. 16.

Yeocyclolus - Koв., loc. cil., p. 235.

M. Paul Godet qui avait encore śtudié l'exemplaire trouvé par M. Fuhrmann à Puerto de los Pobres, a inscrit sur son étiquette: "Neocyclolus cingulalus var. giganleus Reete ". Il est en effet évident, en considérant une centaine d'individus du $N$. cintgulalus, que le $N$. giganteus n'en est qu'une grande variété et que ses caractères ne sont pas assez concluants pour ètre considérés comme spécifiques, étant donnée la graude variabilité de ces espèces.

\section{Fam. Helicinidae}

Gen. Helicina Lam., senst stricto.

\section{Helicina concentrica}

Melicina concentrica Pfr., Proc. Zool. Soc.. 1848, [1. 129. Prв., in Ghemu., p. 6ı, pl. 7, fig. 28-29.

- - Pfr., Mon. P'neum., I, p. 400, pl. 8, fig. 18-19, oar B.

- - Wagnek, in Chemn., ed. nov., p. 282 , pl. 56, fig. $1-5$.

Un seul exemplaire trouvi pres du Cauca. 
PLANCHE IX
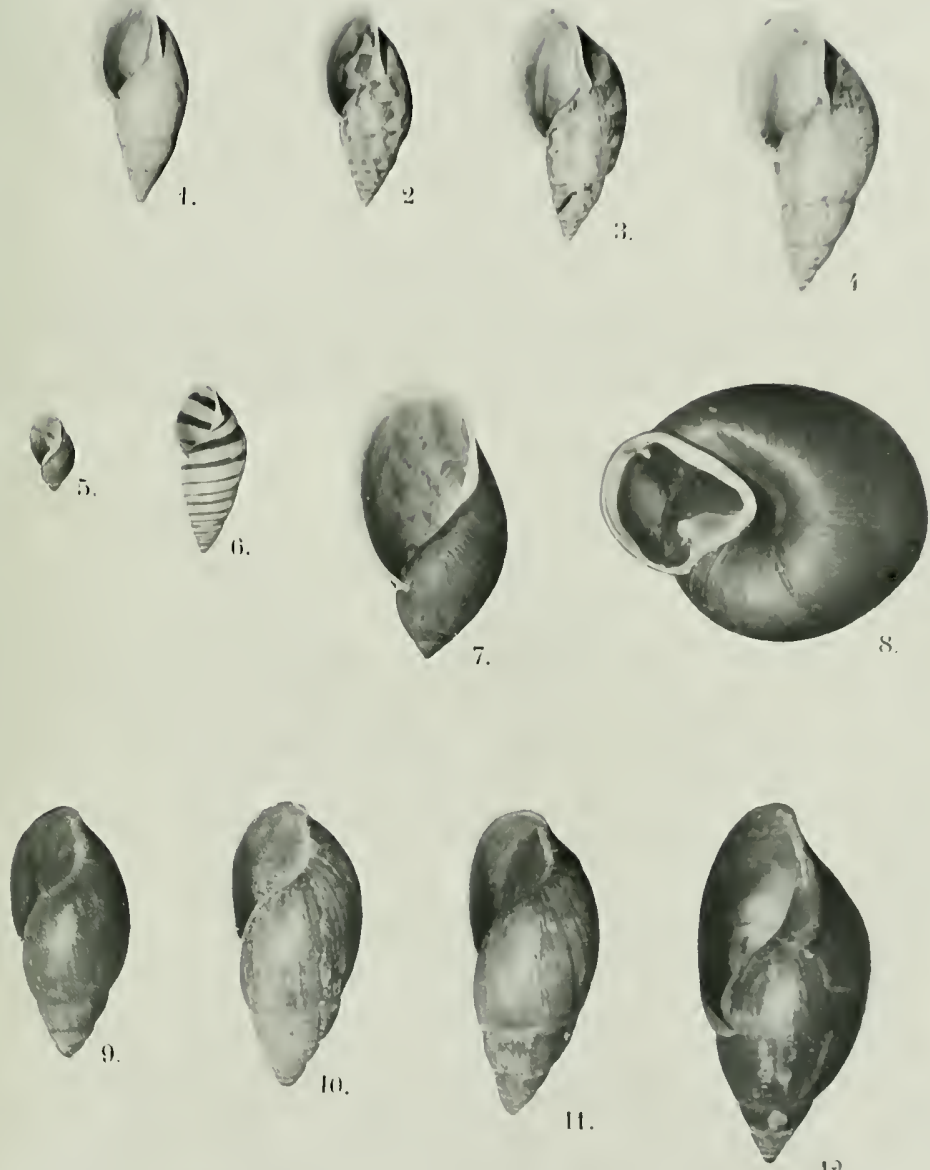

PLANCHE $X$
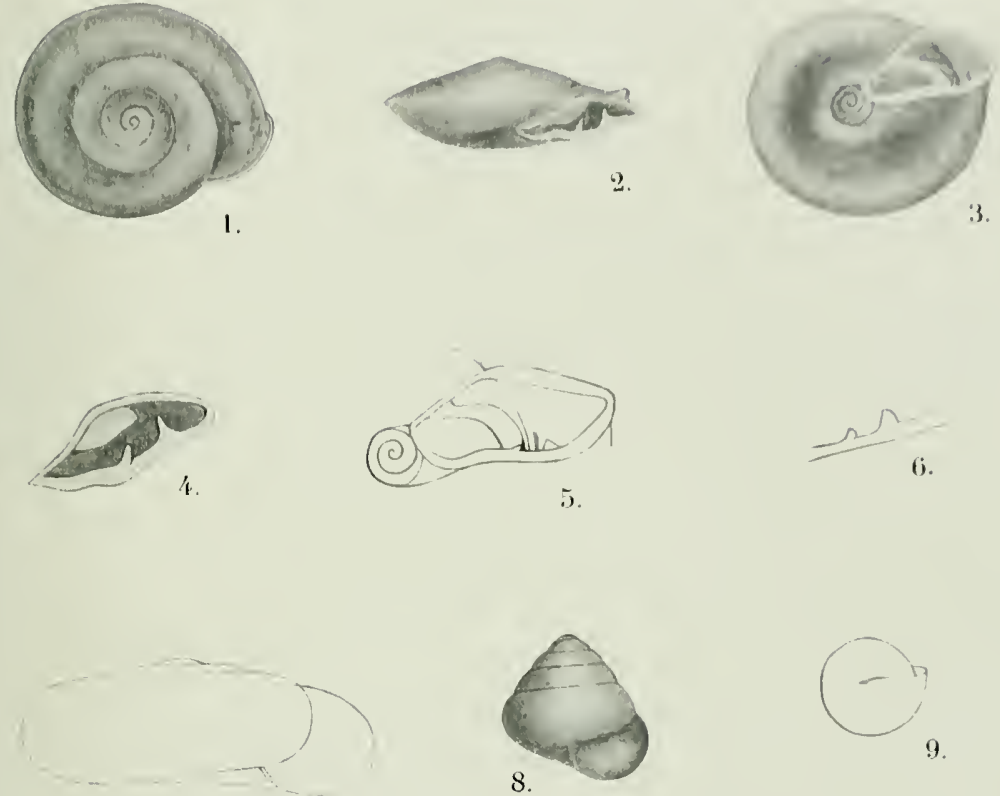

7.

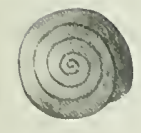

10.
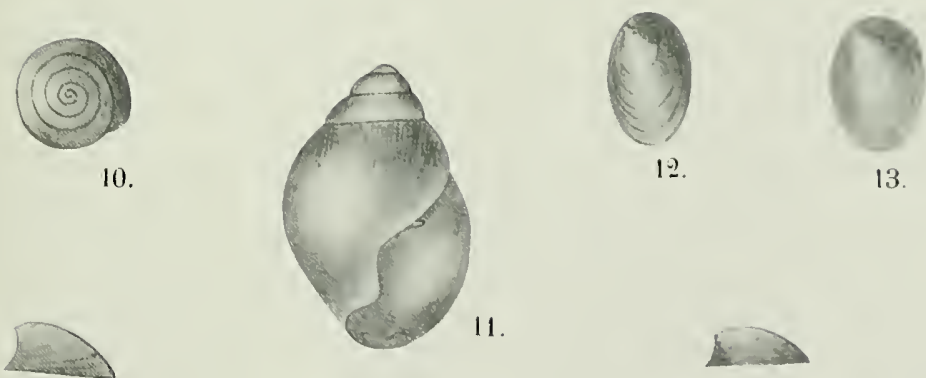

11.

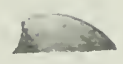

14. 



\section{S. Cl. Branchiala}

\section{Fam. Ampullaridae}

Givi. Ampullaria lam.

\section{Ampullaria reflexa}

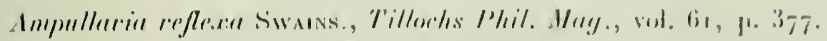

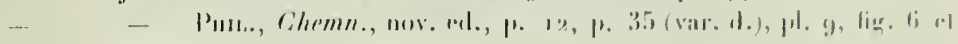
pl. 18, lig. 1 .

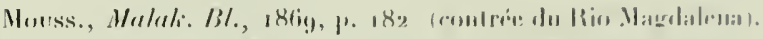

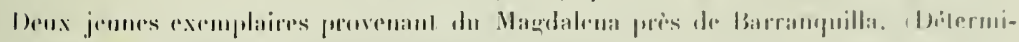
nalion de N. l'iul (indel.)

\section{FXPLICATION DES PLANCHES}

\section{P'L. IX}

lïg. 1-2. Drymuress mersus var, subutu P'iag. - Guaca.

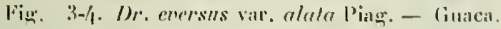

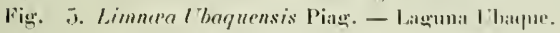

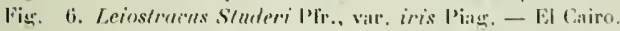

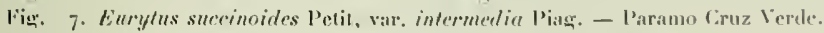

lïg. S. Lsomerin Oreas Koch, var. puruala l'iar. - Anselopolis.

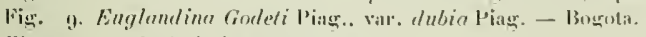

Fig. 10-11. E. Gorleli lype. - Bogota.

Fig. 12-13. E. Fuhrmanni Piacr. - Bognotis.

Figures ligèrenent plus petites que nature.

\section{P'L. X}

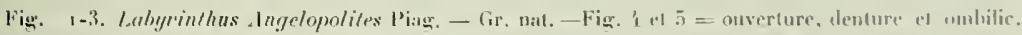
urossis. - Fig. $6=$ dents inféricures d'un autre exemplaire. grossies, - Ingelopolis.

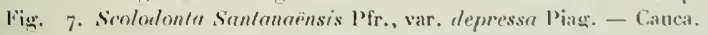

Fig. 8-10. Conulus Fuhrmanni Piag. - P'uerto de los Polures. (Tres srossi.)

Fug. 11. Leptinaria Cancensis L'iag. - Cauca. (Grossi environ \& fois.)

Fig. 12-15. Telledia Fuhrmanni l’iag. - Guaca. (l bifferentes formes arossies environ 6 fois.) 


\section{BEITRAG}

ZUR KENTNISS DER

\section{Nacktschnecken Columbiens}

ZUG!,EIGII EINL

\section{Uebersicht über die neotropische $\mathcal{N}$ acklschnecken-Fauna überhaupt}

Mit 4 Taleln und ciner Textligur

IIIN

PROF. SIMROTH

Das mir von Herru Prof. Funrmann anvertraute Material umfasst Angehörige der drei Siylomuatophoren- Familien : Limaciden, Arioniden s. 1. und Vaginuliden. Letztere sind am meisten vertreten. Ich komnte die Sammlung ergänzen durch die Nacktsclınecken, welche Herr Prof. Bürgen anf' dem gleichen Boden gesammelt und jch längst durch Herrı Gelıeimrat EnLens zur Bearbeitung erhalten hatte. Dazu kommt aber allerlei weiteres, die Formen, über die ich früber nach der Ausleute des Herrn Dr. Jondan in Paraguay eine vorläufige Mitteilung gab, eine Vaginulide von Hünner am Rio Branco erbeutet, eine Serie wahrer Riesen aus Brasilien, von IJerrn Prof. Braun, endlich allerlei Stücke aus dem Leipziger und Frankfurter Museum. Die Limaciden ergahen nichts neues, dic Arioniden eine geographische Erweiterung, die Vaginuliden, wie zu erwarten, eine Fïlle. 


\section{$-271-$ \\ Lissopode Slylommalophoren \\ Fam. Limacidae}

\section{Agriolimax laevis Müll.}

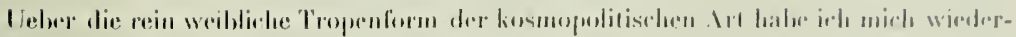

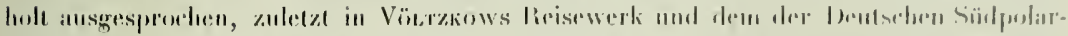

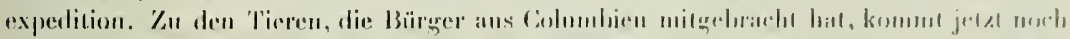

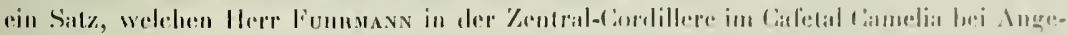

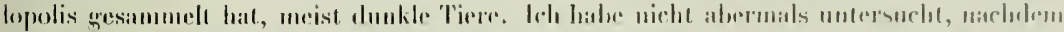

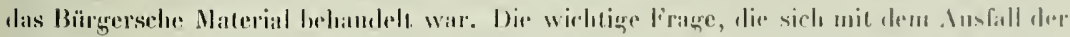

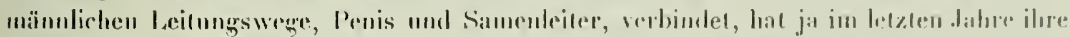

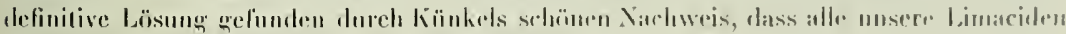

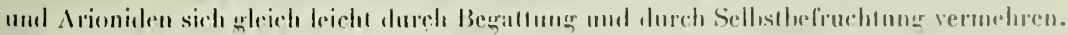

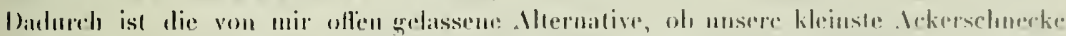

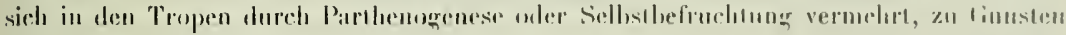

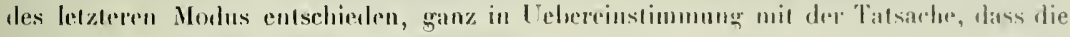

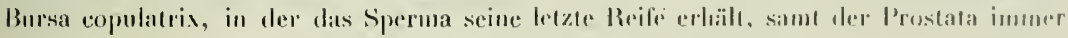

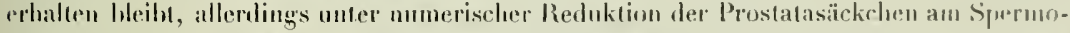
viduct. Durd diese Modification werden die L:hancen der Vermehrung verdoppelt, was recht wohl zar kosmopolitischen Verbreitung heigetragen haben, mag. Das Problem, dits

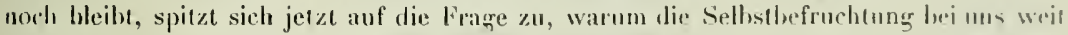

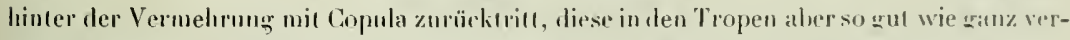
drïngt. Vielleicht kann das Experiment entscheiden, oh Wärme allein d.on Cmschlar auslïst

Ilieran kommen in Südamerika von weiteren Limarilen:

Ayriolimax agrestis, weit verbreitel.

Lima.r flavus, im Sïdwesteu.

Limux arbormm, bisher in nur rinem Exemplar vom Westen, und

Amalia gagates, im Westen his zu mehreren tausend Meter anstejgent.

Fïr rerschleppt halte ich in crster Linir Limax flavus; die ährigen kinnten wohl auf natürlichem Were ïber die Landhrürke zwischen Südleuropa und den Antillen einquewamlert sein.

\section{Familie Arionidae s. 1.}

\section{Philomycus Rafinesque.}

Unseren europaïschen Arioniden s. str. Arion und Gromalarus antspricht auf der pazifischen Erdhälfte. Philomycus mil seinem den ganzen Rücken ïherziehenten Mintel.

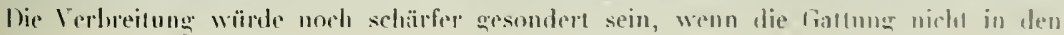


Vormingten Staten bis in den Osten vordränge und in Ilinterindien ein Vorstoss nach Westen erfolgte. Nlle übrigen Vorkommnisse liegen slreng anf pazilischer Seite, nämlich: lava, Celebes, China, Furmosa, Japan, Curea, Amuland, Sandwichinseln, Mexico, Guatemalı, Vicaragua, Costa-Rica, Chile.

In der Verbreitungr fällt die Verschiedenheit im Osten und Westen anf: im Osten hahen wir von den Tropen an einen zusammenhängenden Bogen von Java bis zum Amur, ohne wesentliche Luterbrechungen. Im Westen greift das Gebiet weit über die Tropen hinaus bis Chile, dalïr klalft eine weite Lücke zwischen Chite und Costa-lica. Dazu ein anderes. Im Osten beherbergt die Sïdspitze des Bogens, Java, die abweichende Form des Ph. strialıs, mil dem seharfen Courast zwischen den schwarzen Längshinden und dem Weissen Grunde, In Westen dagegen wird die chilenische Form cinfach als Ph. carolinensis: Bosc bezeichuet, also als identisch mit einer nordamerikanischen genommen. Das könnte den Verdacht der Verschleppung nahe legen. Nir sellsst zwar liegt er ganz fern, nicht aber einer vielfach verbreiteten Anschaung fler Zoogeographie, die woht in Mrchaelsen ihren schärfsten Vertreter findet, indem er hei jedem discontinuirlichen Auftreten eines Lumbriciden das eine Vorkommnis als peregrin hezeiclnet. Da ist es von Interesse, dass die klaffende Lücke jetzl durch die neue Aushente verkleinert wird, nämliclı durch

\section{Ph. columbianus n. sp.? n. f.?}

Columbia. Cafetal Camelia bei Angelopolis r820 M. (Central-Cordillere) Fubrmann leg. 20 Stïck.

Die Schwierigkeit der Bestimmung, ob Art oder Varietät, liegt in der Gattung überhaupt begrïndet, namenılich bei den amerikanischen Formen, die einer peiılichen Dureharheilung bedürfen. Vorläufig berulien die 13 heschriebenen IVest- $\Lambda$ rten nur auf der Schilderung des Aensseren. Ihnen mag sich die neue anschliessen.

Die Erwachsenen hahen cine Länge bis zu ry $\mathrm{mm}$, ein junges Stïck $6,5 \mathrm{~mm}$. Der Grundion des jungen Tieres ist röılichgran, darauf 2 dunkelgrane Längsbinden, die nach unten abklingen, der Rücken ist in der Mitte schwarzgrau angellogen und retikuliert. Von dieser Jugendzeichnung leitet sich die der alten ab in verschiedener Richtung. Manche behalten alles bei. Sonst wird der Grundton entweder lebhaft ockerig oder sellsst rol, einschliesslich der Sohle. Das grau steigert sich zu sehwarz, die schwarze Binde kanı sich schärfer abhehen, sodass unter Zurücktreten der übrigen Zeichmung ein Anklang an den javanischen Ph. striatus entsteht, ohne dessen scharfe Klarheit zu erreichen. Sonst wird das Schwarz meist gröber retikuliert, ein Netzwverk mit rundlichen Maschen von verschiedener Weite, das auf dem liücken am besten entwickelt ist und meist nur wenige Brücken bis zu den Binden hinüberschickt. Man könnte eine ganze Serie verschiedener Bikler entwerfen, doch alle verbunden. Der erwachsene Zustand der Tiere wird bezeugt durclı die auszestülpten Copulationswerkzeuge eines Stürkes. Aus gemeiusaner Basis 


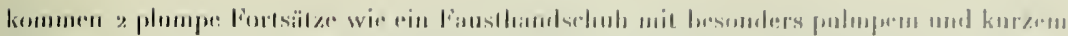

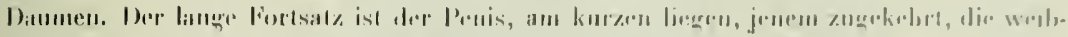

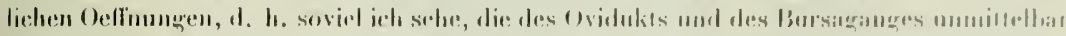

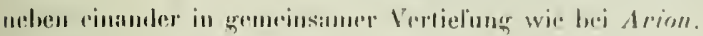

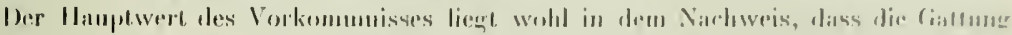

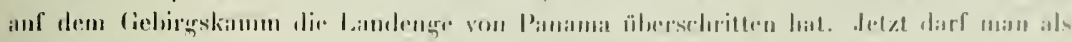

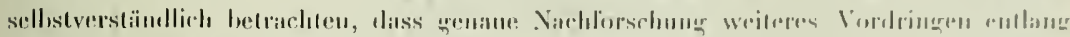
den Anden anfilerken wird.

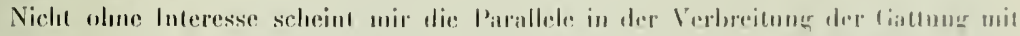

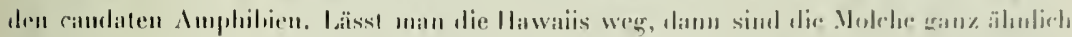

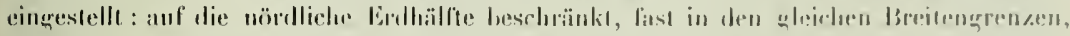

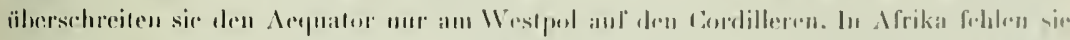

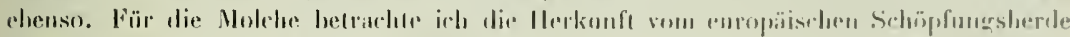

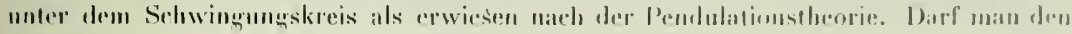

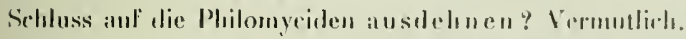

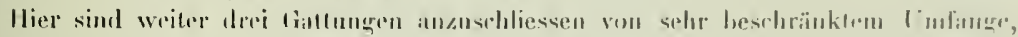

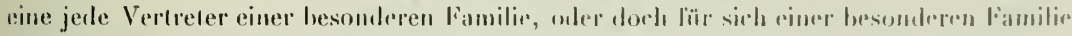
heschaller siylommatophoren anzurgerdern.

\section{Fam. Helicidae}

\section{Melostracon Pilsbry.}

Die kleine Nacktschnecke, in der Pilsbry einen Vertreter der Heliciden zu erkeunen

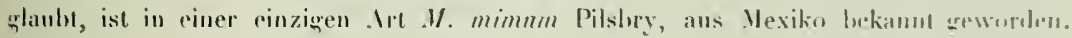

\section{Fam. Bulimulidae.}

Zu dieser rein neotropischen l'anilie gehïrt die Gallung

\section{Peltella Webb et van Beneden}

von der v. JuEm, den anatomischen Nachweis der Verwandschaft lieferte. Fischer griln als Ileimat an: Brasilien und Porto-Rico. Es fehlt noch an der veroleichemlen I Iarch.

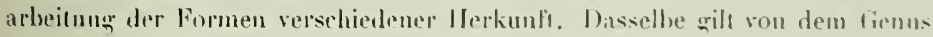

\section{Pellicula Fischer}

von den kleinen Antillen. 


\section{$-27 / 4-$}

\section{Fam. Succineidae.}

Währeml vermutlich dic vorhergehenden Erzengnisse des amerikanischen Bodens simb, ist die (iatlung

\section{Neohyalimax Simroth}

ron Rio Grande do Sul ein alter Rest, der seine nächsten, ehenso isolierten Verwandten aul den Mascarenen hat in den Vertretern der Crattung / Iyalimax. Man könnte die Gattungen recht wohl auf den Rang von Untergattungen herabdrücken, so gross ist die Achndichkeit. Dass die beiden so weit von einander getrennten Fundstellen genaur Symmetrielage haben zum Schwingungskreis, komute ich letzthin ansführen. Vou Süd-OstBrasilien ist wieder nur eine Art bekannt: Nerhyalimax brasiliensis Srth.

\section{Soleolifere Stylommatophoren.}

Vun den 3 Familien der Soleoliferen sind die Oncidiiden fast gänzlich amphibiotisch an den Meeresstrand gebunden. Die wenigen Vertreter, die noch rein terrestrich leben, sind auf das Ostpolgebiet beschränkt, ehenso die Rathouisiiden oder Atopiden. Nur die Vaginuliden gehen durch die Tropen der verschiedenen Erdteile hindurch. Sie kommen also allein fïr die neue Welt in Betracht.

Ich will mich nicht auf eine ansführliche Erörterung der Grönde einlassen, warum ich für die Hauptgaltung den Namen Vaginula leibehalte an Stelle des älteren Veronicella. Wenn es wahr ist, dass der ersten Beschreibung dieses Genus eine Schnecke mit Schale am IJinterende zu Grunde liegt, so hat man doch viel eher an eine Testacellide zu denken. Jedenfalls sehe ich gar keinen durchschlagenden Grund, diesen Namen au Stelle des sicher beglaubigten zu setzen.

\section{Vaginula (Férussac).}

Es ist woht überflüssig, die Schwierigkeiten ausführlich zı wiederholen, welche der spezifischen Determination der Vaginuliden sich entgegenstellen. Die meisten Beschreibungen sind nach dem Aeusseren gemacht. Bei dem aber sind wir ganz im Unklaren ïber die Variationsbreite. Es lässt sich leicht zeig̨en, dass manche Arten ausserordentlich zu Abänderungen neigen, wähırend andere desto konstanter sind. Bei den letzteren kommt es oft vor, dass sich unter derselhen oder fast dorselben äusseren Tracht wesentliche Artverschiedentreiten verbergen. Darf man so weit gehen, dass man nur die Spezies gelten lässt, dle anatomisch festgelegt sind? Das scheint mir der einzige IVeg, um allmählich zur klarheit zu gelangen. Aher er ist anderseits so radikal, dass wohl die grössere IIälfe 


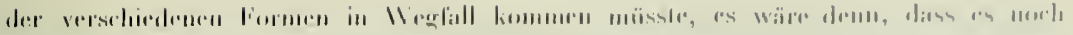

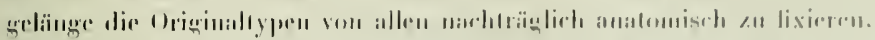

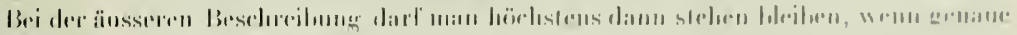

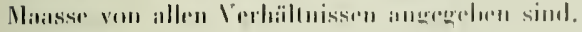

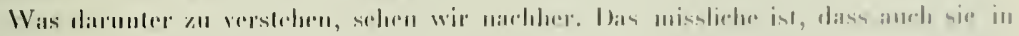

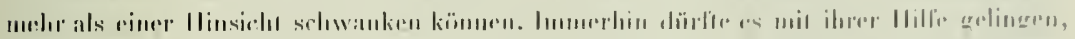

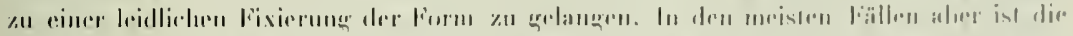

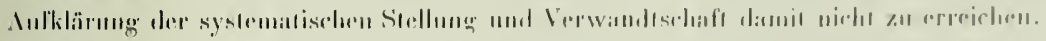

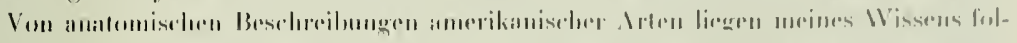

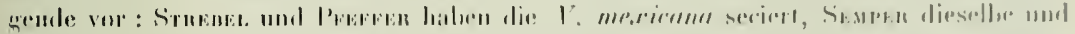

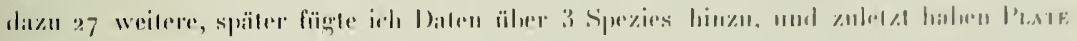

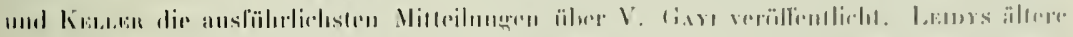

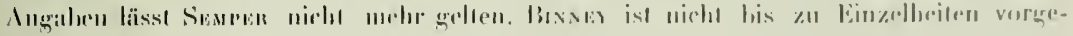

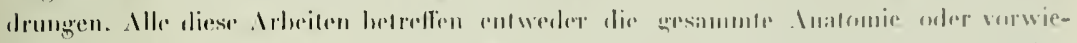

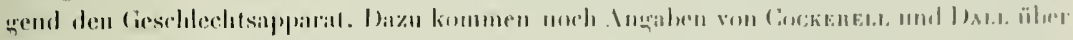

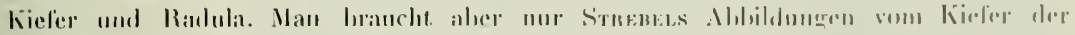

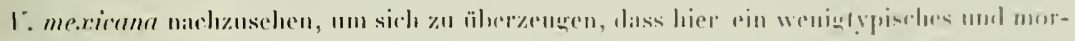

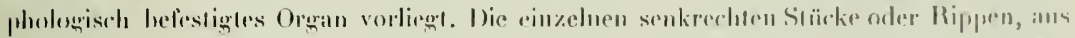

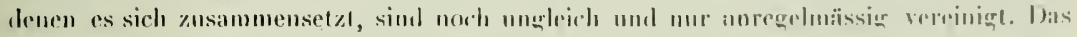

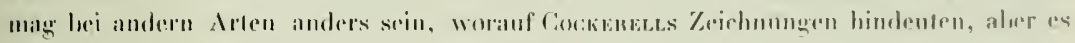

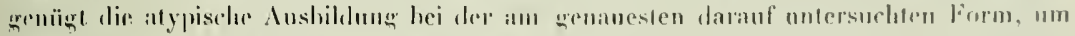

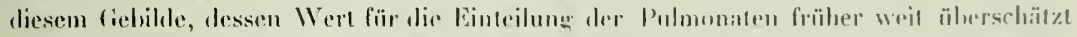

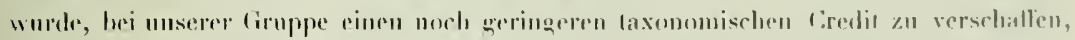

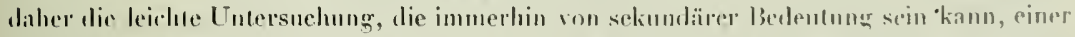

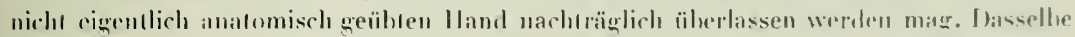

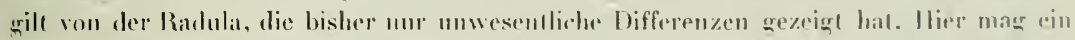

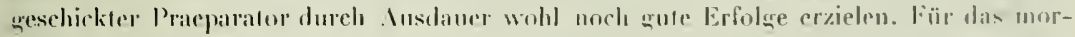

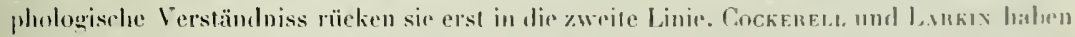

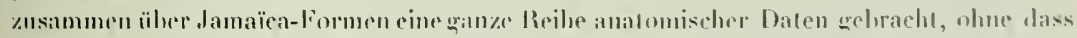

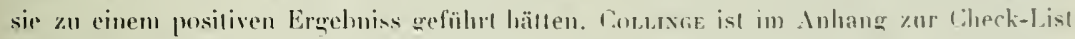

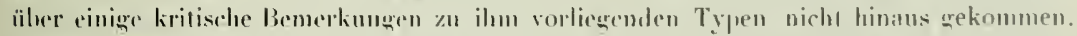

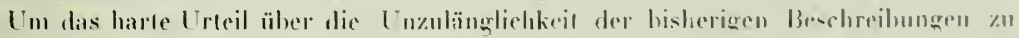

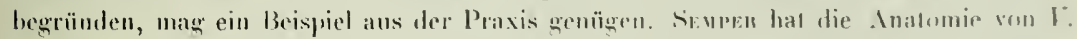

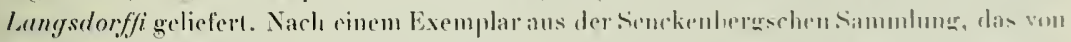

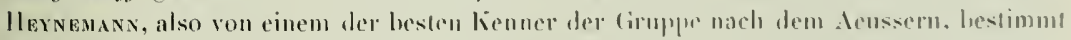

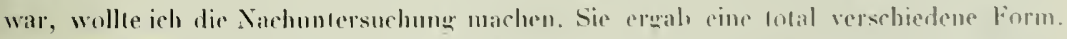

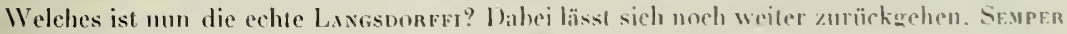

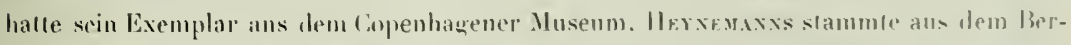

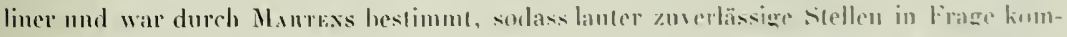

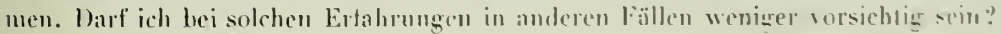




\section{Anatomische Merkmale.}

Ueber meine I.l zu abeiten kann die frühere Abhandlung über drei östliche liginularten Aulschluss quelon. Damals versuchte ich alle Organe möglichst gleichmässig zu berücksichtigen. Die ghleiche Methode erschien Angesichts des viel grösseren Malerials, dis mir vorliegl, untunlich aus Zeitmangel. Hätte ich rine vollkomneroc Anatomic einschliesslich der namentlich für das lntegument überaus wichtigen Histologrie anstreben wollen, wie es sich für die Vaginuliden gehört, dann hätte mir mindestensein Werk vorschweben müssen wie das L. v. Grafrs über die Turbellarien, allerwenigstens wie das äber die Landplanarien, nur dass die vielfach grossen und komplizierter gebauten Schnecken cinen entsprechend grösseren Umfang beansprucht hätten. Eine solche Lehensaufgrabe muss ich mir leider versagen, aus den verschiedensten (iründen. Meine Arbeiten können nur praeliminarisch sein.

Es kam also darauf an, wesentliches lïr die Lnterscheidung prägnanter Punkte herauszusuchen. Da bieten sich in erster Linie die Genitalorgane, solrald man wenigstens annähernd erwachsene Tiere vor sich hat. Ausser den männlichen Endwegen, die Sempen in den Vordergrund stellte, schien mir wichtig, auch die weihlichen, namentlich die wechselnde Verbindung zwischen Eileiter und Bursa copulatrix zu beachten, da hier möglicherweise morphologische Uebereiustimumug phylogenetische Verwandıschaft bedeutet. Allerdings erlebt man hier viele Fehlschläge je nach dem Niter unel Erhaltungszustand der Tiere. Bei harter conservierung kann oft das geduldigste Aufweichen brïckeligen Zerfall rerade der wesentlichen Feinheiten nicht verhindern.

Sodann wird der Darmkanal das Augenmerk auf sich lenken mehr nach seinen topographischen Alweichungen, die überhanpt in den Vordergrund zu stellen sind, als nach feineren Dilferenzen in der Structur, die höchstens bei den Speicheldrüsen häufiger sich bemerkbar machen.

Von grösserem Wert schien mir die Fussdrüse zu sein, die in dieser Pulmonaten- Fanilie das Maximum wechselnder Bildung zu erreichen scheint. Freilich wurde wieder nur das Makroskopische beachtet, Umriss, Länge und meist Zerlegung in zwei verschiedene Structurelemente, von denen sich das eine als hyalines Drüsengewebe kennzcichnet etwa rom Aussehen der Uterusmanschette, das andere dagegen, melır der Decke und der Mittellinie angehörig, schneeweiss, undurchsichtig und kreidig erscheint.

Alle andern Eirgenleiten, Dicke der Haut, deren Drüsen, Verlaul der Nerven, besonders der perlalen, Verteilung der Pigmente, mancherlei biologische Eigenheiten u. Ilergl. m. sind nelıensächslich behandelt, je nachidem etwas Auffälliges den Blick auf sich zog, ähnlich wie es Semper gemacht hat. Vielleicht ist es ein tiehler gewesen, und man bätle von Anfang nach einem bestimmten Schema auch solche Sachen gleichmässig beachten sollen. Vielleicht aber hat es seine gute Brogründung; einmal hemerkt man erst. im Laufe der Intersuchung, was alles abweichen kann und cutsprechend Aufnalume in 


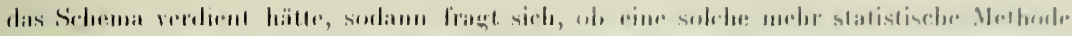

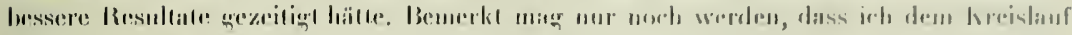

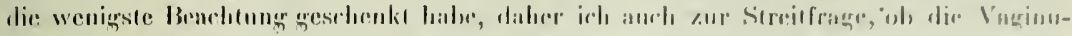

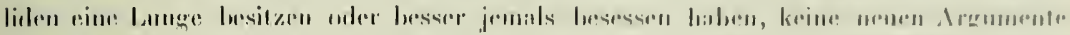

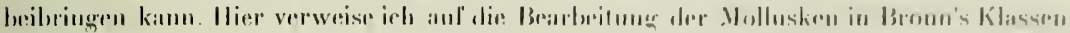

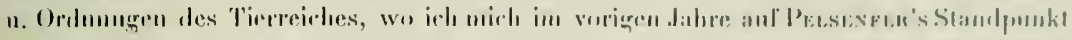

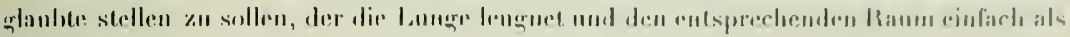

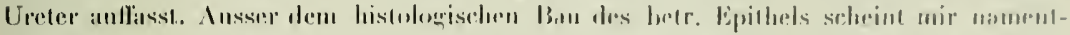

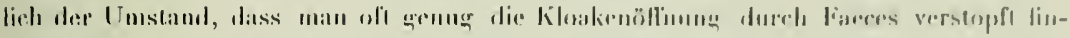

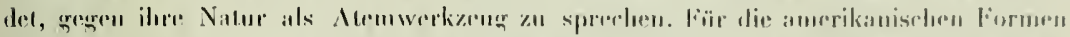

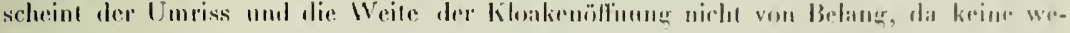
sentlichen Dillerenzen sorkomumen.

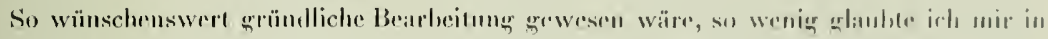

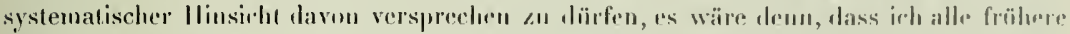

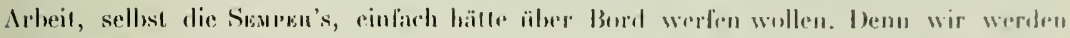

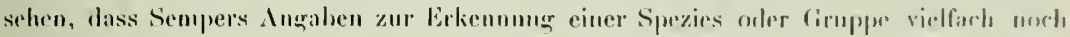

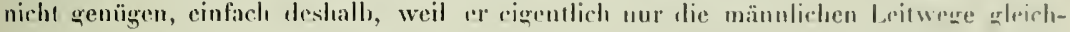

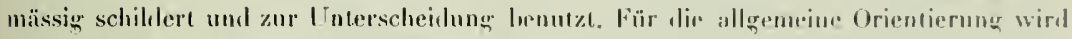
man mehr arebrauchen, aber doch, um uicht von vorne herein allo Cebersicht zen verlieren, in mässiger Beschränkung.

\section{Aeussere Kennzeichen.}

Bei aller Einförmigkeit lassen sich doch cinige tirumelformen in den l'mriswen nuterscheiden. Ist das Tier ausgestreckt - natürlich immer in konserviertem Zustand - dlann

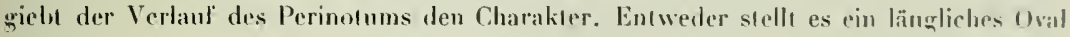
dar, oder die Seitemränder laufen paralled und sind nur vorn und hinten durch Bugenlinien verbuuden, wobei is nicht selten vorkomm, dass der hintere .1kschlusshogen nicht convex nach hinten schant, sondern entweder fuer abgestutzt oder selbst concav nach vorn eingebogen ist. Der letztere Typus verhindet sirl meist mit einer anderen Eigrenhreit, mit einem breitm und hohen Hyponolum. Die Seitenwände fallen viel steiler narh untron al, auch die Solıle ist vielfach schmäler. Das giebt einen anderen Typms, den man ten prismatischen nennen und dem ersten als onalem gegenüher stellen könnte. Früher habe ich darauf aufmerksam gemacht, dass die meisten. Irten beim Ahföten eine hestimmte Halung des Vorderendes annchmen, sodass sie den lopf enlweler ansgestreckl lassen uder zurückzichen, fast immer alle Individuen in gleicher Weise. Wird der liopf aranz relrahiem. dann kommt es olt genug zu einer Krömmung der Bauchserite, die concas wird, während der Rücken entsprechend convex sich wälb. Solche Eimsollung fällı ganz oder fast ganz fort hei der.prismatischen Gestalt, vermulich weil die steilen Wände des H!ponotums die Seiten hindernd versteifen. Die ovalen formen erhaten dadurch etwas Egelartizes. 
Hirndinales, und es passient öfter's, dass man mit Vaginuliden auch Landhlutegel und Landplanarien als ihresoleichen mit erhäh. Man kann also diesen dritten Typus recht wohl gelten lassen. Freilich muss man da aher gleich wieder leststellen, dass die drei Typen: der prismatische, der ovale und der egelbafte nur descriptive Bedeutumg haben mul keine systematische, denn sie gehen in verschiedenen, anatomisch zusammengehörigen Gruppen durcheinander. - Noch einige Worte üher die Naasse! Ich habe anf die Mbzählung der Breite der Soleohe verzichtet. Semper gilut meisl an, wieviel Qnerlinien auf ein cm knmmen. Aher man weiss nicht, ob er dabei nur die Furchen zwischen den Soleolae rechnet oder auch die feine Querlinie, die über jede Soleola entlang zieht von links mach rechts. Cockerezl gibt mit Rechl für eine $\lambda \mathrm{t}$ pro $\mathrm{cm} 36$ und 72 Furchen an, je nach der Zählung. Da meines Wissens dieses Maass bei der Determination kaum den Ausschlag gegeben hat, mag es wegbleiben. Die Länge bezieht sich stets auf die Mitlellinie des Mantels oder Notums. Die Breite kann man verschieden hestimmen, entweder als Querdurchmesser von einem Punkte des Perinotums zum gegenüberliegendeı, oder als wahres Rückenmaass in einer ebensolchen Linie, aher mit angelegtem Bandmaass, also als Bogenlinie. Die Differenz wird natürlich um so grösser, je gewölbter der Rücken ist; man kann aus ihr also den Grad der Wölbung ablesen. Ich habe sie in der Regel nur da beachtet, wo sie erheblich ist. Eine kleine Ungenauigkeit entsteht noch dann, wenn die Wölbung nicht gleichmässig verläuft, sondern sich seitlich abllacht, sodass das Perinotum gesimsartig rings herumläuft. Das Hyponotum wird in Allgemeinen nach der grössten Breite hestimmt. Han könnte sowohl für Notum wie Hyponotum melırere Messungen einführen, etwa in der Mitte sowie kurz hinter dem Kopf und vor den Schwanzende. Dadurclı wärde der allgemeine horizontale Umriss zum Ausdruck kommen. Doch hat er gelegentlich noch allerlej Eigenheiten, die man noch besser aus einer $\mathbf{A b}$ bildung entnimmt oder umschreibt. Für den Habitus mögen noch einige Verhältuisse bezeichnend sein. So kann man den Quotienten Länge durch Breite oder den Breitenindex bestimmen, ebenso das Verhälnniss zwischen Länge und Solılenhreite oder den Solhlenindex. Je grösser der erstere, um so gestreckter ist die Schnecke, je grösser der letztere, um so schmäler die Sohle. Lm nichı zu weitschweifig zu werden, beschränkt man wohl diese Angaben auf kritische Fälle, wo sie zur Bestinmung wertvoll werden können.

Endlich ist noch die Lage des weiblichen Porus wichlig. Ich bestimme seine Entferuung vom Vorder- und vom Hinterende des Notums, dazu aber seine Höhe am Hypnotum und zwar dadurch, dass ich seine Entfermung von der Fuss- (oder Mantel-) Rinne, welche die Sohle rings abgrenzt, in Bruchteilen der Breite des Hypnotums alsschätze. Kleine Ungenauigkeiten, die bej allen Messungen leicht unterlaıfen, halte iclı für unerheblich; denn sje bleiben hinter den Abweichungen zurück, welche sich aus der Art der Conservierung und der zufälligen Körperhaltung beim Al,töten mit Notwendigkeit ergeben.

Als wichtiges Ziel schwebte mir neben der Festlegung der Arten die Einteilung in Gruppen vor, aus denen künftigg Unterfamilien und Gattungen hervorgehen möchten. Denn es gebt unmögtich an, den grossen lïr die Tropenwelt so charakiteristischen 
Formenkreis, der von allen

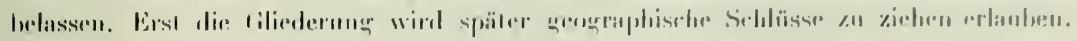

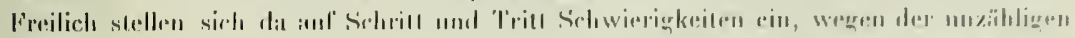

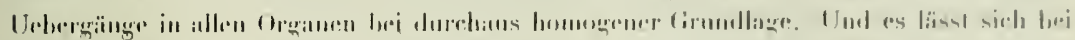

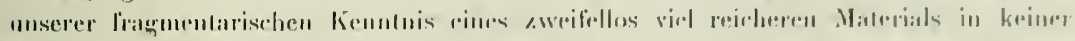

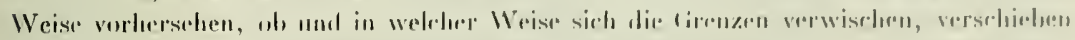

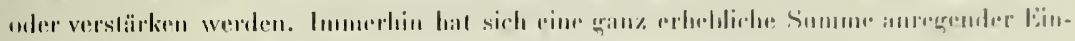

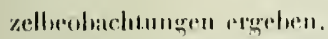

\section{Phyllocaulii. Blattruten.}

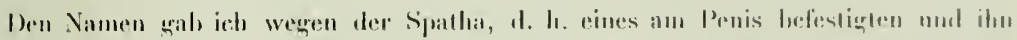

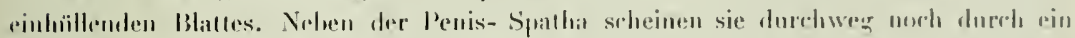
zweites, nur ihnen zonkummendes Merkmal charaklerisied, das ist die Thenmung der stelle,

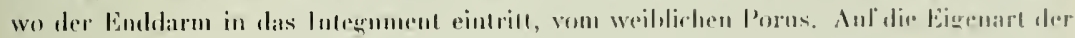
Zoichmung kemmmen wir anrïek.

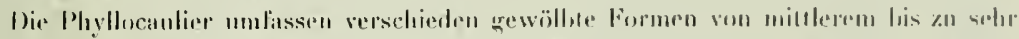

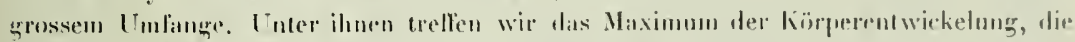

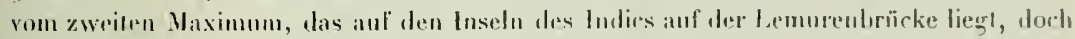

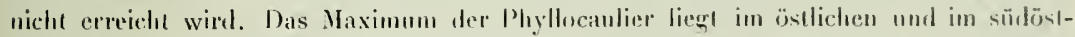
lichen Brasilien und greift in dic La Plata-Silaten üluer. Es dient wohl in hervorragenden Mansse zur Charakterisierung des Gobietes, das nach von duraxg's Lntersuchungen einst

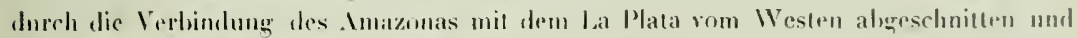
isoliert war. Ind so nelme ich zunïclsst

\section{die Ostformen.}

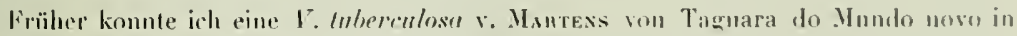
Südluasitien untersurhen, sir war $9,5 \mathrm{~cm}$ lang.

Anl' rine älunliche, ehenfalls als 1. Inbeprulose r. Mantexs bezeichnete Form hezieht

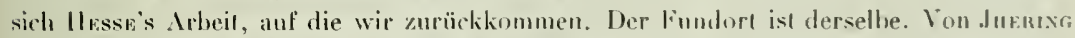
hat wohl reichliches Material in unsere Mnseen gehen lassen. Die Schnecke ist 7,2 cm lang.

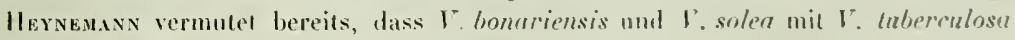
znsammenfallen. Mir liegen jelzl : I- solea Heynem. ans dem Frankfurtor Mnseum vor, ron gleichem fundorte, verschieden lang. SEaper hezeichnet fraglich eine 1: multicolor

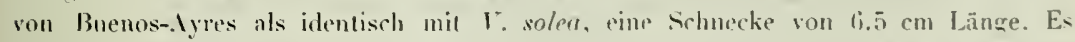

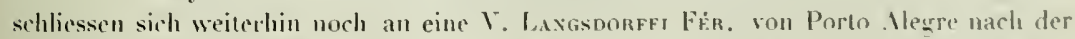

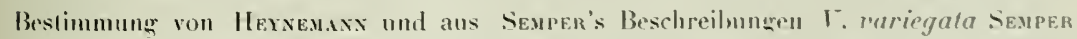
von Taulati in der Provinz S. Paulo von ti con Länge und charakterislischer Zcich-

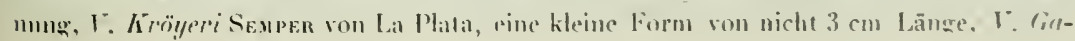


latheap Semper ron Montevideo und V. Galatheae var. SEupro von Corrientes von 4,5 und 3,3 cm Länge. Schon die Grösse schliesst die kleinen Südformen von der grossen $9,5 \mathrm{~cm}$ langen $\mathrm{V}$. Inberculosn aus. Jetzt kommen noch stattlichere dazu, die mir Prof. Braus zur Untersuchung überliess.

Mlan wird schwerlich irren, wenn man die grossen Tiere als

\section{Cruppe der V. tuberculosa Martens}

zusammenfasst. Die Scheidung in Arten bleibt unsicher, solange wir von der Biologic nichts kennen, nicht wissen, wie weit die anatomische Dillerenzierung zu grehen hat, um fruchtbare Begattung auszuschliessen. Ich ziehe es daher vor, die Verschiedenheiten durch Namen zn kennzeichnen und deren Wertschätzung, ob Art oder Varietät, der Zukunft zu überlassen. Alle die grossen Formen haben, sofern nicht ihr Notum einfarbig ist, einen Zeichnungscharakter gemeinsam, die Teilung des Rückens in drei Felder von annähesnd gleicher Breite. Das Mittelfeld bleibt heller, die Seitenfelder dunkeln namentlich gegen die Mitte hin, so den Kontrast verschäriend. Ueber dem Pericard hat das helle Mittelfeld, wie ich früher nachwies, eine annähernd halhkreisförmige Erweiterung nach rechts, was bei der Abhängigkeit der Zeichnung und Färbung von der Hautsculptur nicht weites auffällt. Allerdings mag bemerkt sein, dass ein Querschnitt durch das dicke Notum keinerlei Strukturwechsel olfenbarl; die Schichten streichen glatl über die Grenzen des Mittelfeldes hinweg, die düune Pigmentschicht unter dem Epithel, darunter die weisse Muskellage, zu unterst ein Lacunenschwamm. alle drei ineinander übergreilend. Es liegt wohl nahe, eine andere Ursache zu vermuten. Sarasins haben (im Celebeswerk) gezeigt, dass die zarte cuticulare Embryonalschale durch sejtlich hervorragende Mantelwälste abgeschoben wird. Es liegt nahe, den so vorbereiteten Medianstreif als die Stelle aufzufassen, wo die Wülste einander am nächsten kommen, um dann zu verstreichen. Man könnte daran denken, dass sie bei unserer Gruppe eher IIalt machten, so dass das breite Mittelfeld übrig bleibt. Doch stossen wir auch hier wieder auf Schwierigkeiten bei kleineren Arten (s. u.). Der Eindruck wird wenigstens durch die Forın dieses Feldes verstärkt, denn es begiunt vorn mit der normalen Breite höchstens ein wenig eingreengt, sodass es iı der Längsmitte am breitesten ist. Nach hinten abes spitzt sich's zu und hört so bereits vor dem Ende des Notums auf. Die Sejtenfelder erscheinen somit als das Bestimmende. In Hesse's Figus ist die hintere Zuspitzung kaum angedeutet. Bei den mir vorliegenden Formen läuft das Mittelfeld allmälılich in einen spitzen Zipfel aus; und damit zum Einzelnen:

\section{Vaginula solea d'Orb und Vaginula tuberculosa von Martens}

(Tatel I, Fig. I-7.)

lch habe früher ein Stïck von $9,5 \mathrm{~cm}$. Länge untersuch, das mit Heyuemanns Abbildung durchaus übereinstimmt. Es stammt von Taguara do Mundo novo in Südbrasilien. Auch Hesse's Figur passt hieher. Jetzt liegen mir 2 Stücke aus dem Sencken- 


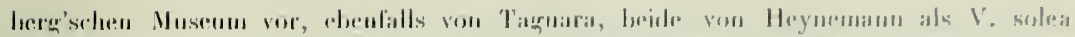

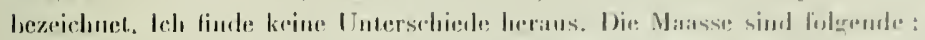

J.tunkn

Das urosse Stïck $10, "$ cm.

Das kleine [3weitu. Hypunotum

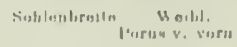

$3,6 j \quad 1,4$

1.9)

$(2,15)$
$1,1 \quad 1,8$

rechlits $0,0 \quad$ (1, !)

liuks ", 7 ì

个,7 it, li I i

$\%, 8,5 \quad 18$

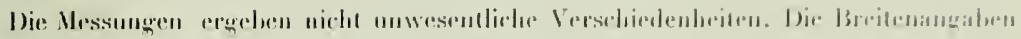

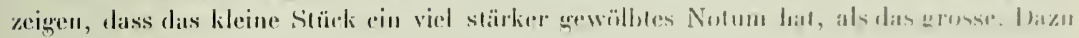

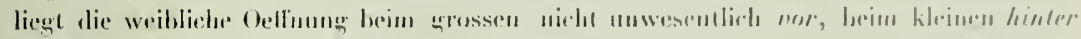

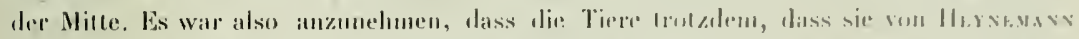

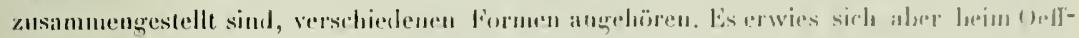

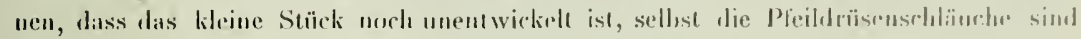

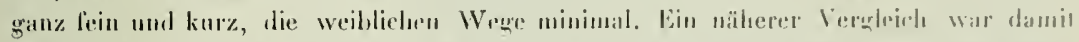

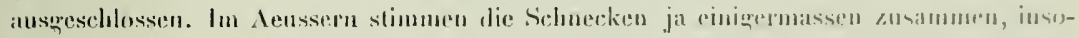

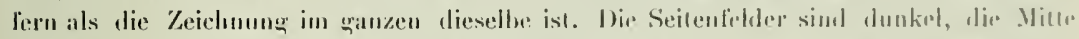

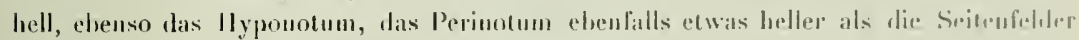

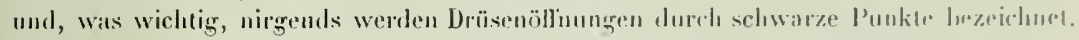

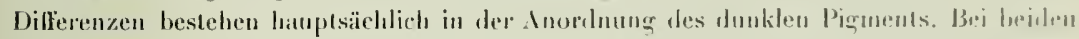
tritt es retikuliert auf, aber bei der grossin Foru viel dicker und foiner als luei ter klei-

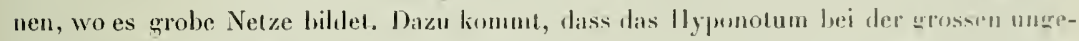
zeichnet ist, hei der kleinen aber ungefähr elensovied mit schwarz retikuliort mul funk-

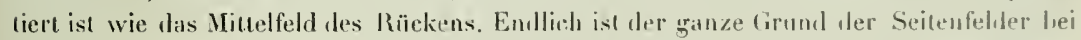

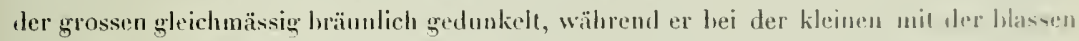
Grundfarbe des Mitlelfeldes äbereinstimme. Die Tuberkel, von denen der Sinno stanme, treten an Hyponotum der grossen denllich herror, wo sie als helle liuppen von Insektennadelknoplorrösse gleichmässig verstreut sind.

leh halte es für ansgeschlossen nach der Anlage der Genilalorgane, dass die kleine Form noch vicl weiter wachsen würde. Neue Namen mag ich lier nichl einlizhren. so

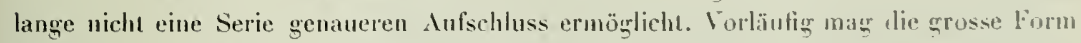
ais $r$. unberculosa, die kileine als $1^{\top}$. solea gelten.

Anatomisches. - Hier grele ich nur auf meine frülseren Angraben fïr eine grosse 1. tuberculosn ein mit Erläulerung durch ein Paar Zeichnumgen. Dic kurze Fusidrinse (Fig. 5) mündet mit breiter Sjalte. Sic bil,tet einen relativ weiten Site, der sich hinten verengert und zurückbiegt und schlängelt, um unter den pedalganglien an der Fussarterie zu enden. Die $\mathbf{W a n d u n g ~ e r s c h e i n t ~ g l e i e h m a ̈ s s i g ~ w i e ~ g e w o ̈ h n l i c h e s ~ S c h l e i m g e w e b e . ~ a h n e ~}$ weitere Ditlerenzierung.

l'är den Darmkanal mag die näthste Form Geltung haben (s. u.) 
Die Speicheldrüsen sind grobgelappte Tranhen. Die Pedalnerven in der ersten Ilälfte dicht nebeneinander, dann weit auseinandertretend.

Die mandelkernförmige Penisscheide mit kurzem, derbem Retractor. Die Pfeildrüse aus fast 3 Dutzent langen und zwar gleichlangen Schläuchen zusammengeselzt. Die Pfeilpapille klein und schlank. Um ihren Grund hat die Pfeilpapillenscheide auf der inneren Seite eine zierliche Blattrosette (Fig. 1), wie sie mir nirgends wieder vorgekommen ist, auch innerhalb unserer Gruppe nicht. Ihre Bedeutung ist ganz unklar, man müsste demn daran denken, dass die Entleerung gleichmässiger Schleimfäden zı einer ïleraus regelnässigen Ablagerung in der Pfeildrüsenscheide gefülırt und den zierlichen Ahdruck veranlasst habe. Die Vermutung basiert auf einer solchen Schleimanläufung (bei einer Form vom Indic), deren Oberlläche etwa del einer Grosshirnhemisphäre glich. Der Penis ist der typische der Phyllocaulier, insofern als ihn ein dickes derbes Blatt begleitet, überragt und zum grrossen Teil einhüllt (Fig. 2 und 3 ). An Blatt wie an Penis selbst je eine Bemerkung. Die Spatha trägt knorpelige, scharle Tuberkeln auf der konkaven Seite neben dem Penis, vermutlich aus Choudroidgewebe im Sinne Plates, weissliche harte Körper, die als Reizpapillen wirken mögen ; der Penis der die Nündungsspalte an der Spitze trägt, ist etwas abgelfacht mit einer abgesetzten Kante entlang jeder Seite. Von den Zwitterorganen, die stark entivickelt, ist alles typisch, am Zwittergang die Befruchtungstasche (Vesicula seminalis autt., Receptaculum seminis autt.), die grosse Eiweissdrüse, der als reichgewundener Spiralgang aufgeknäuelte Drïsenabschnitt des Oviducts oder Uterus und der abgellachte eigentliche Oviduct. Der Samenleiter mit der üblichen, derben, länglichen Prostata, unten gespalten. Der Canalis junctor tritt in eine dickwandige, spindelförmige Ausladung der Bursa copulatrix ein, welche dem Bursagang fast diametral gegenüber liegt und ilın etwa an Länge gleicht (Fig. 4). Namentlich diese Figur heischt Beachtung (s. u.).

Da die Formen verschieden sind, aber doch wohl, mindestens in deutschen Museen, unter den alten Namen stehen mögen, so schlage ich vor, keine Aenderung eintreten zu lassen, sondern die grosse als $V$. tuberculosa, die kleinere als $V$. solea zu führen, bis auf iveiteres. - -

Die Riesen von Sta, Catharina sind in I Exemplaren vertreten, die sich in zwei Richtungen differenziert haben, entweder in der Färbung oder in der Form. So entsteht auf der einen Seite eine verkürzte, gedrungene Gestalt mit derselben Zeichnung, oder die längere Form der $V$. tuberculosa bleibt erhalten, aber das Notum verliert seine Zeichnung. Mir scheint es angezeigt, die kurze Form auch auf anatomischer Grundlage abzutremuen, die übrigen aber nach wohl ausgeprägten Zeichnungsunterschieden in drei zu zerlegen. Die Verkürzung beträgt mehr als den dritten Teil der Länge. Gleichwohl werden die kurzen Tiere, erwaclisen, ebenso schwer und massig wie die langen, indem ihre Höhe entsprechend zunimmt. Beide erreichen, gehärtet wie sie sind, nach dem Abtrocknen ein Gewicht von nicht weniger als $45 \mathrm{gr}$. Bedenkt man, dass nach Fiscuen's Angaben eine Vaginnla im Kriechen etwa die doppelte Länge erreicht von der Ruhestel- 


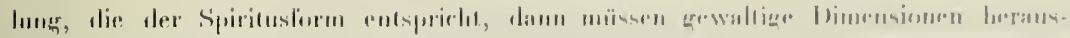

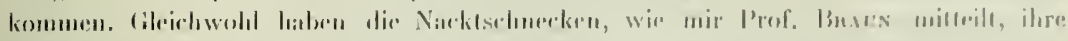

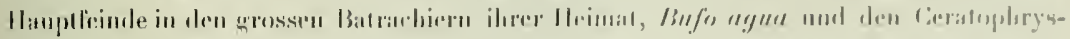

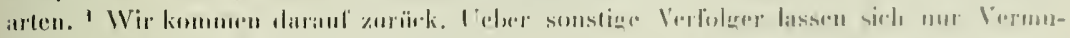

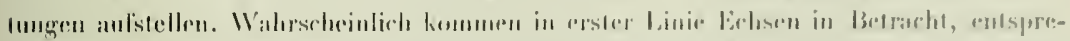

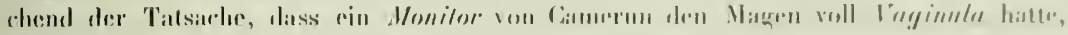

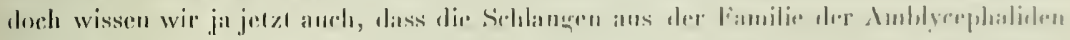

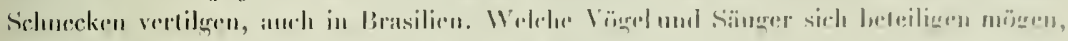

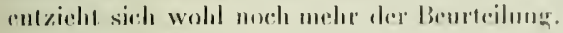

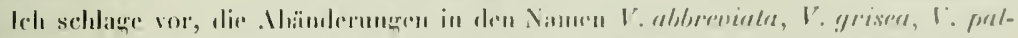

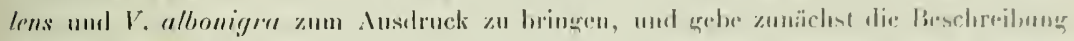
narh dem Aeusseren.

\section{Vaginula grisea $\mathbf{n} . \mathbf{s p}$.}

(Tisliv1 1, liin. 8.)

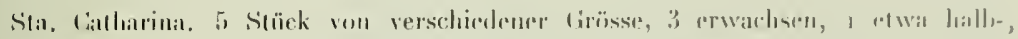

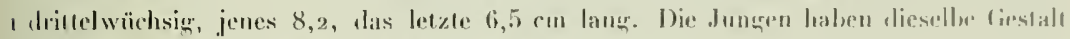
wie die alten. Von der einen gebe ich die Massse.

Liange 1,7 , Breite 4,4, Hyjonotum 1,7, Solle 1, fi, weiblicher Puras von vorn i,2, von hinten $6,5 \mathrm{~cm}$, von der Fussrinne $1 / 8$. Win Stück war noch 1 cm länger.

Zeichnung Bei allen hat der Rücken einen grleichuässign gratuen (irundun, in der Mille so gon wie auf den Sritenteilen; das grane weelself etwas in der Tiefo lois zum

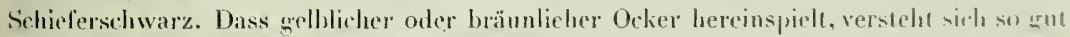
rou selbst, als Weiss hei unseren Nacktschnocken immer ein gelhliches ist. Freilich weiss man lui Spiritusexemplaren nicht, wieviel von diesin unreinen Ton auf olie brane Lodier an setzen ist, deren Extract rom Alkohol im Kïrper verbreitel wirl. Ein dunkles Stück lïsst moch die drei Fehler erkennen, indem an der Grenze ein unregelmässien durchlornchener schwarzer Strieh entlang zieht nit der Ausweituner ïber dem Ilerzbrutel. Das Schwarz kommt anch noch in rinzeluen rorwaschenen Flecken wor, ohne sich auf den Tulrerkeln zu concentrieren. Drei Stürke sind ganzeinfarbig. Das l'erinotum liellt sich efwas auf, noch mehr das Hyponotum und die Sohle. Die sama. Unterseite entheho jeder Zeichmung. Dir Tulierkel stehen ziemlich dicht und leben sich als hellere Flecken heraus. Dis alogebildefe Tier hat das Hyponotum am stäksten geren dis Perinotum geelunkelt. Ansserilem weist es ïher dem weillichen P'orus einen sehr starken Defekt aus. Es unterliew wohl keinem Zweifel, dass or auf dir Ratula-Täligheit des Partners beim Vorspiel zur Copula zu sehieben ist. Es ist der stïrkste substanzverhst dieser Art, den ich je greseluen habe, Beweis einer intensiven Erregung.

I Welehe Bissen diess Tiere mu hewilligen vermögen. wurte einst der deulschen zonh gisehen Gesellschalt in Zoologischen Garten zu Breslau vorgeführt. wo die cine liröle eine lehende Maus, die andre cinen lebenden Sperling rescheliang. 


\section{Vaginula pallens n. sp.}

(Talel 1. Fig. !r.)

I Stück. Sta. Katharina.

Das abgebildete Tier ist gleichmässig hellgrau ohen und unten, in Lehen wahscheinlich noch weit blasser. Dabei bteibt die Haut glatter, die Tuberkel treten zurück. Durch Schrumptung bei der liontraktion sind wellige, wlatte Wülste entstanden, die in der Figur hier und da quer herüberlanfen. Ton ihnen unterscheidet sich eine höchst sonderhare Strichzeichnung, die höchstens bei manchen Mtopos-Arten eine entfernte Parallele hat. So laufen vorn 4 parallele Striche schräg von dinks vorn nach rechts hinten ïher die Mitte. Hinter der Mitte geht einer besonders krältig bis auf die Liante des Peritonums. Einige beginnen mit einem rundlichen Fleck, wieder andere sind dreieckig u. dergl. m. lch habe versucht, sie möglichst nach ihrer Form und Verteilung und ihrem miltelgranen Ton darzustellen. Sollte diese Zeichnung wirklich angeboren sein? Bei Alopos sind ähnliche Schrägstreifen, wo sie vorkommen, doch weit regrelmässiger angeordnet. Ich habe eine andere Idee. Ich halte die Figuren für Narben, für Schmisse, die ron den mancherlei Atacken, die die Schnecke bestanden hat, ein beredtes Zeugnis ablegen würden. Einen Hinweis l'and ich in ciner ganz feinen Liniierung, welche das Gebicl der zuerst erwähnten 4 Parallelstreifen kreuzt, ungefähr von der Feinheit und Regelmässigkeit der Parallellinien an unseren Fingerspitzen. Die übrige Haut erscheint ganz glatt oder doch so dicht chagriniert wie ein recht feines Leder. Es muss also wohl eine locale Ursache gewirkt haben. Sollten das nicht die Zähne im Oberkiefer einer Ceratophrys gewesen sein? So mögen manche Zeichnungen auf Wunden deuten, die von Vogelschnäbehn herrühren. Zur Stütze meiner Ansicht verweise jch auf die Beschreibung, die die ich früher von einem kaukasischen Paramilax gab. 1 Hier war gleichfalls eine deutliche, noch im Relief sichtbare Narbe durch Pigmentierung ausgezeichnel. Es ist wohl auch anzunehmen, dass die Narben erst vor kurzem entstanden sind, da sie sich woch nicht verwischt hahen, mit anderen Worten, dass die Schnecke sie erst erworben hat, als sie schon gross trenug war, um so manchem Angriff stand zu halten. Die Proportionen sind dieselben wie bei $\mathrm{Y}$. grisea.

\section{Vaginula albonigra $n . \mathbf{s p}$.}

I Stück Sta. Catharina.

Die Schnecke, durch die klaffende weibliche Oeffnung als erwachsen gekennzeichnet, ist etwas kleiner als die vorigen, sonst von ähnlichem Habitus, nur vorn und hinten mehr verschmälert und abgerundet. Die Naasse sind die folgenden : Länge 9 , Breite 3,4, bez. 4,2, llyponotum links r,3, rechts 1,4, Sohle 1,5. Weiblicher Porus von vorn 4,8, von hinten 5,2 , von der Fussrinne $\mathrm{I} / 7$. Die verschiedenen Breitenzahlen zeigen eine ziemlich

${ }_{1}^{1}$ Simroth. Die Nacktschnecken des Russischen Reiches. 


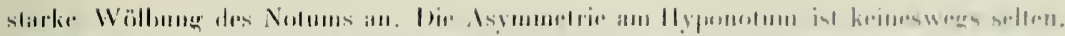

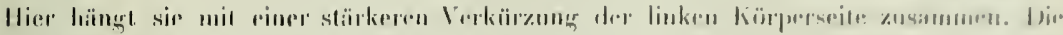

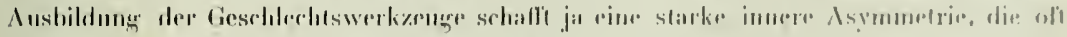

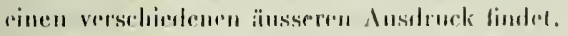

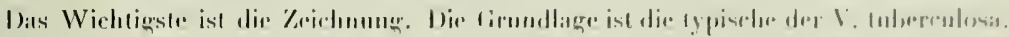

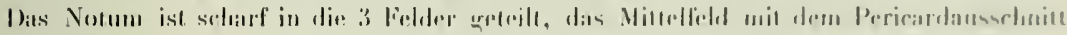

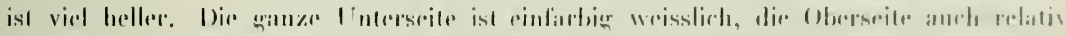

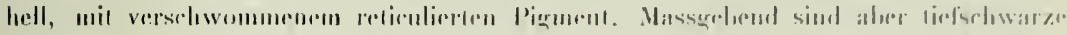

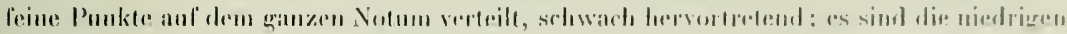

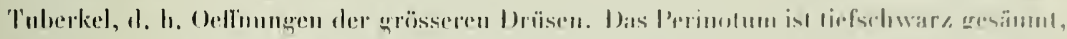

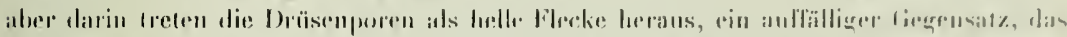

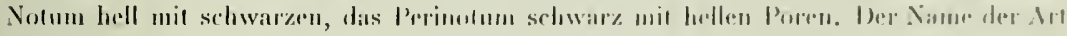

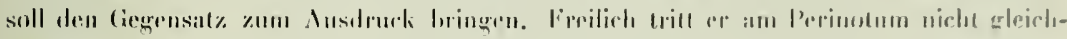
mïssige scharf hervor.

\section{Vaginula abbreviata n. sp.}

(Tialel 1, Fin. 10-15.)

3 Sitïck. Sita. Catharina.

Das längste mass 7,5, die anderen 5,0 und $5,2 \mathrm{~cm}$. Die P'ropurtionen sint dienellien. Das zweite Stück war in Copula erbentel und wurde seciert, es wal vollkummen entwickelt.

Die Maasse des grössten Stürkes simd:

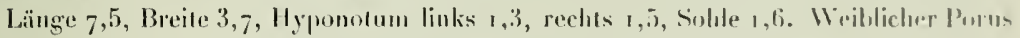
vou vorn 3,3, von hinten 3,65 cm, von der Fussrinue 1/8. Wenn dieses Stück su viel

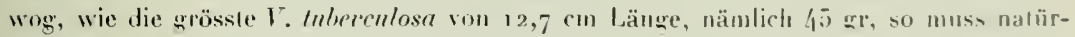
lich der Untersehied in der länge in inderer Richtung ausgenlichen werden. Der . Msghleich liegt in der IIöhe onler Dicke, wie die Abbildung zeigh.

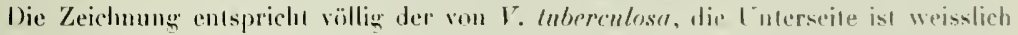
mil cingen Resten schwarzer Spritzllecken, die anch fehlen können. Das Conum isl selarf dreiteilig, und die Seitenfelder sind slark zedunkelt, das Milfelfeld mil demselhen bräunliehen Ocker. Die ganze Oberscite mit Schwarz grob reticuliert, die Tuhrerel auch hier vielfach schwarze Punkle, aber lange nicht so deutlich ahgeholien wie bei der vorigen Art. - -

Wir finden somit hei allen 4 Formen ganz ähntiche. Propurtionen, üherall liegr der weihliche Porus kurz vor der Milte, das Verhältnis von Länge und Breite dageren ver. schieht sich allmählich, die Zeichnung schatli weitere deurliche Linerschiedr.

Noch ist einer Eigenheir zu gedenken, welche alle diese Tiere auszeichnel, nämlich eine mediane flache Längsfurche, nuf der Milte der Sohle. Hat sie mil innerer Halbierung (durch ein Septum) zu tun? Wir haben Andentungen davon, z. B. bei Amalia. Näheres wissen wir nicht. 
Hie Drüsen des Mantels, d. h. des Totums, Perj- und Hyponotums sind so verteilt, dass an Perinotum die grössten stehen, die sich einsenken, demuächıs konmen die, welche auf den Tuberkeln münden, doch sind überall dazwischen noch feine und feinste Hörkerchen, mit entsprechend kleineren Poren. Wieweit die Drüsenbildung nach dieser unteren Grenze hinabgehı, wieweit Uebersänge oder Gegensälze vorhanden sind, müsste besonders untersucht werden 1.

\section{Anatomisches.}

Lim die Dillerenzen möglichst breit zu nehmen, wurde je ein Stück von 1. grisen und 1 . abbreviata geprüft.

Der Fussdrïsenschlauch ist auch diesem frischen Haterial noch gleichmässiger als bei 1 . tuberculosa, enger und ohne Differenzen in Secretionsgewebe.

Der Darmkanal, wiewohl in den allgemeinen Proportionen, emfachem Verlauf etc. übereinstimmend, zeigt doch wesentliche Utmbildungen in Parallele mit den äusseren. Bei 1 . grisea liegt ein Leberlappen vorn quer herüber und stellt das Vorderende des Intestinalsacks dar, wie bei allen Amerikanern. Bei $\mathrm{r}$. abbreviata dagegen ist er infolge der Verkïrzung nach links zur Seite gedrängt, und der zweite Darmschenkel begrenzt den Eingeweidesack. Wichtiger ist der Unstand, lass loei 1 . abbreviata der erste Darmschenkel sich in ganz nngewöhulicher Weise verkürzl hat (Fig. 12). Dafür ist der Magen entsprechend aufgetrieben, und zwar sein vorderer Teil, mit der Wandstruktur des Darms. Der Muskelhelag beschränkt sich auf seinen hinteren, verjüngten, alogesetzten Abschnitt, der die Hinterleber aufnimmt. Wenn ich für die Vorderleber zwischen $d_{1}$ und $d_{2}$ eine einfache Hündung angehe, im Gegensatz zu PLATE-Kellek, so ist das gleichgilitig, dat die Leher nur eine Ausstülpung des Darmes darstellt, wie Pelsexeer oben erwiesen hat. Die Wandstruktur greift auf den sich alshald verzweigenden Lehergang äber, und man kann die Grenzen zwisclsen Darm und Leber beliehig ansetzen. Der Schlund verhreitert sich etwas gegen das Hinterende, wo er in einer crenulierten Linie schart endigt. Der weitere liropt, der hier beginut, ist durch muskulöse Mesenchymbänder rechts und links an das Integument geheftet.

Ob die Differenzen in den Speicheldrüsen eine tirfere Bedeutung hahen, muss dahin gestellt bleiben. Bei V. grisea haben sie die Form einer Traube nit grossen, länglichen, festen Beeren, bei $Y$. abbreviata sind die Acini fein tubulös oder doch flach gedrückt und dicht gredrängıt.

Die Geschlechtswerkzeuge. V. grisea hatte 47, V. abbrevinta 36 lange Pfeildrüsenschläuche, dazwischen fanden sich in jedem falle noch 2 vder 3 ganz kurze, die schwerlich weiter auswachsen und den Unterschied nicht beeinträchtigen können. Das

1 In der Bearbeitung der afrikanischen Vaginuliden (tür Völtzkow's Heisewerk), welche nach der der amerikauischen durchugeführt wurde, bia ich zu einer veränderten Aulfassung der Tuberkel gekommen. Sie sind viellach ganz lirei von Drüsen, haben also im Grunde genommen mit der Sekretion nichts zu tun, bedeuten vietmehr eine Oberllichenvergrïsserung der Atemflïche, daher sie anch bei den grössten Formen besoniler's reich entwickelt sind. 


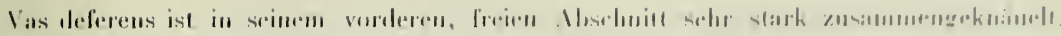

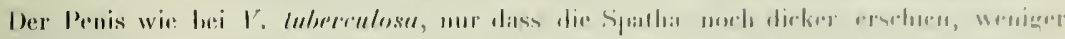

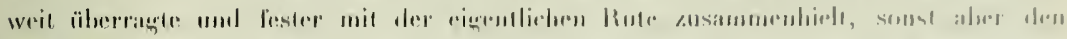

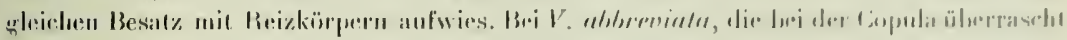

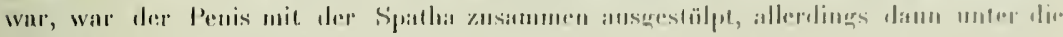

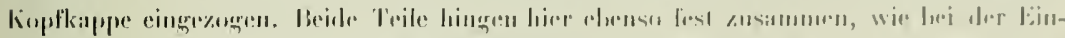

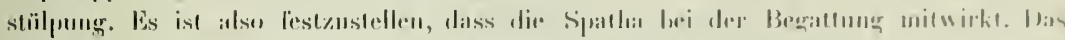

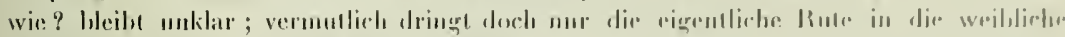

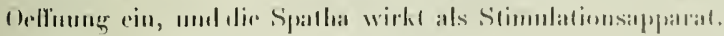

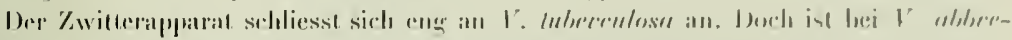

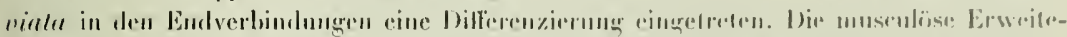

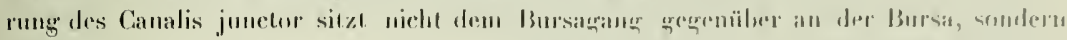

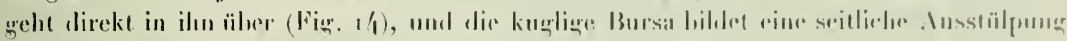

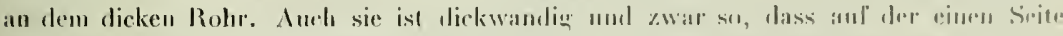

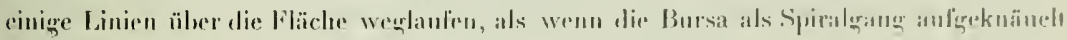

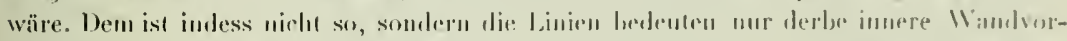

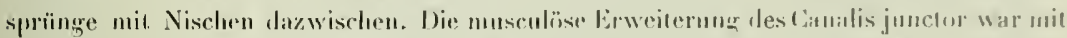

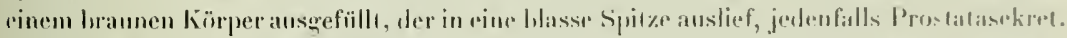

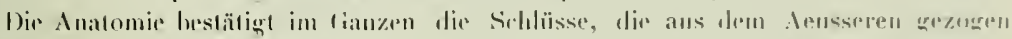

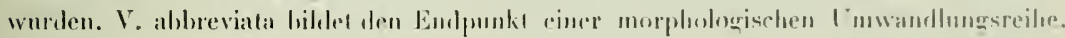

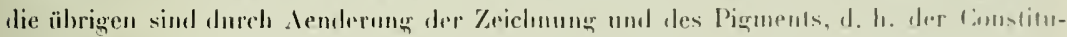
tion entstanten.

\section{Vaginula Heynemanni n. sp.}

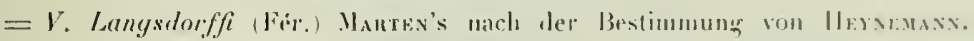

(Tiffel. 1, Fies. 17-22.)

2 Stück. Porto Nlegre. Museum Senckenlserg, Frankfurt.

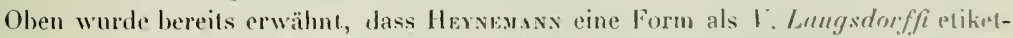

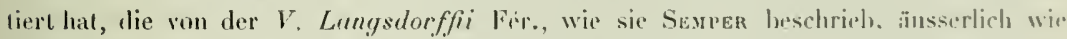
imberlich granz versehieden ist. Sie ist grösser und auf dem Rücken 3-feldrig, nicht mit einem Medianstreifen von 2 mm Breite versehen. Die Pfrildrïsen hei Sempler' Art sind kurz, bei Y. Heyuemanni üheraus lang, der l'enis ist ganz amlers etc. Fs bleibt mir mur ährio, die Irt nen zu benennen.

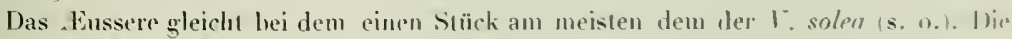
ganze Unterseite ist blass und pigmentfrei, tas Nolum in drei greich lireite Feldar geteill. alle drei sind schwarz reficuliert, das Mithelfohl mur wenig heller. Schwarze Flecke laäıfen sich namentlich gegen seine Grenzen an. Der Pericardansschnill fehlt oder ist inch ganz mdeutlich. Das efwas kleinere, aber anch ganz reife Exemplar hat die Zeichnnug verschwommener. 
Beide Tentakelpatare sind einfach qran, wie in der Gruppe allgemein.

Die Maasse sind folgende :

Länge 3,8, Breite r, I and 1,6 cm. also sehr gewölbt. Hyp. o,5-o,55. Sohle o,46, weibliche Oeffnung von vorn 1,95 , von hinten $1,5 \mathrm{~cm}$, von der Fussrinne 1/3. Die Lage des Porus hinter der Mitte ist bezeichnend.

\section{Anatomie.}

Die Fussdrüse bestelıt ans einem anf- und einem alsteigenden geraden Schenkel von yleicher Weite.

Der Eingeweidesack verhält sich wie bei $V$. abbreviata, insofern als auch hier der vordere Lcherlappen - und zwar durch die Pfeildrüse - nach links gedräng $\iota$ ist und der zweite Darmschenkel die Vordergrenze bildet.

Der Darm selbst ist wesentlich anders. Der erste Schenkel oder Kropf ist sehr lang und in verschiedene Abschnitte gegliedert. Der erste, der nur rechts an einem Mesenterialband hängt, ist dünnwandig und unregelmässig erweitert. Nachdem er siclı zu einem gewöhnlichen Darm verengert hat, schaltet sich in diesen abermals eine Erweiterung ein. Der Magen ist klein und auf den Muskelteil beschränkt, Unterschiede gegenüher der $\mathbf{I}$. abbreviata, wie sie in der Familie nicht stärker vorkommen. Der Eintritt des Enddarms ins Integument ist weit rom weiblichen Porus getrennt, also typisch für die Pliyllocaulier.

Die männlichen Urgane haben Pfeildrüsen- und Penisscheide von nahezu gleicher Gestalı und Grösse. Die erstere enthält eine ganz kurze Pfeilpapille. Sie trägt I 2 derbe Pfeildrüsenschläuche fast ron Körperlänge, also wahrhaft enorm, natürlich mannigfach zusammengelegt. Das freie Vas deferens ist zwar ziemlich lang, aber nicht aufgeknäuelt, sondern in einer Ebene unter der Pfeildrüse angeordnet. Der Penis ist länger als sein Blatt, das schmal und schlank bleibt und ihn keineswegs einhüllt. Er ist von ovalem Querschnitt ohne abgesetzte Seitenkante und trägt die Oelfunng nahe unter der Spitze. Der kurze Penisretraktor giebt einen schıankeren Zweig an die Pfeildrüsensclieide ab.

Von den Zwitterwegen ist der Canalis junctor charakteristisch. Ohne sich wesentlich zu erweitern, mündet er in den Fundus der nahezu kugligen Bursa. Der Bursagang sitzl etwas vom Porus entfernt am Eileiter, so dass eine kurze Vagina entsteht. Noch einen Blick auf den Uterus! Er ist sehr stark als Spiralgang entwickelt und quillt im Wasser auf ausser an der Spitze, an der IInschlagstelle der beiden Schenkel also ; beide bleiben auf eine kurze Strecke eng. Bedeutet das eine schärfere Grenze zwischen den proximalen auf- und dem distalen absteigenden Schenkel, so dass der erstere als Schalen-, der zweite als Nidamentaldrüse zu deuten wäre? Gewöhnlich grleichen beide Schenkel der Spermoviductmanschelte eines Stylommatophoren. Wir kommen auf die Deutung zurück.

Die Art ist sehr scharf gekennzeirhnel nach allen Richtungen. Man könnte vielleicht 


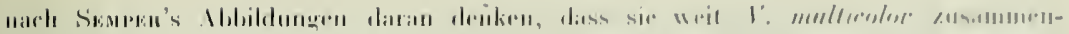

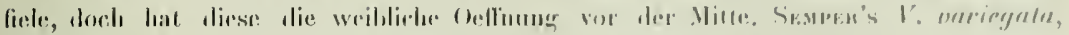

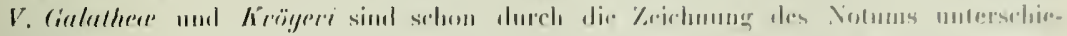

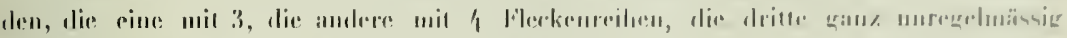

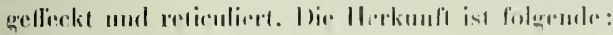

1. multicolor Sismon, Jarmus- Iyres,

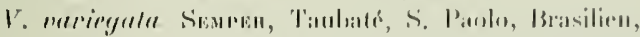

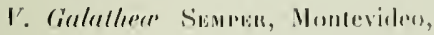
vale. Cimbrientes,

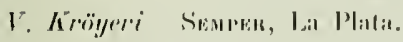

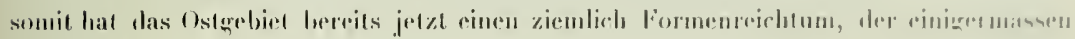
linstgeleat ist.

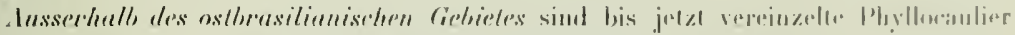

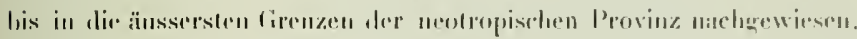

\section{Phyllocaulier von Chile.}

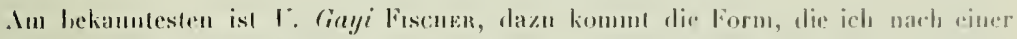

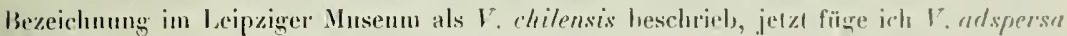

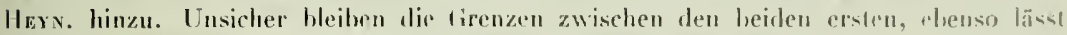

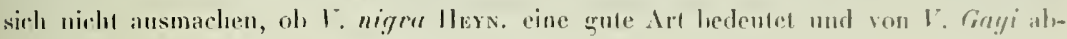
zutrenurn ist. Hexnemans selber hat sie zuletzl als syongm betrachtet.

\section{Vaginula Gayi Fischer und V. chilensis Srth.}

('Tafel I, Fig. 16.)

Wunderlich ist die lärbung der $V$. Conyi, ansser der fathlosen Suble im lechen pechschwar\%, im Alkohol olivengran von verschierlener lntensitä, das Pigment in schwarzen

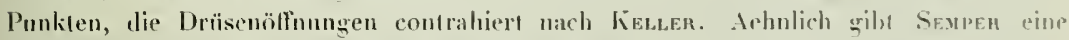

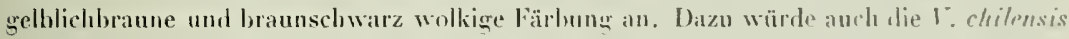
stimmen, d. h. die Färbung des Spirilusexemplars ist phenso nichtswageme. Man hat rich also nach anderen Merkmalen unzusehen. Ieh finde in mejnen Skizzen die Fusalläne schlauchförmig mit zuräckgeschlagenem Blindende. Dis fehth in Kequen's Zeichnung. Dafür hat er ein endständiges Inbulïses Organ angegrehen, welehes vielleicht meine Lmrisse vorgetäuschı haben könnte. Nolınen wir bei dieser Lusicherlwit die Maaser, so weit Vergleichungszahlen vorliegen.

$\begin{array}{lccccc} & \text { Länge } & \text { Breite } & \text { Solıle } & \text { Weill. Porns von vorn } & \text { von hinten } \\ \text { V. Gayi } & 5,1 & 1,8 & 0,7 & 2.2 & 2.9 \\ \text { V. chilensis } & 4,5 & 1,6 & 0,65 & 2,2 & 2.4\end{array}$

37 
Hiernach könnten die allgemeinen Umrisse stimmen. Mber die weibliche Oeffumng liegt doch bei 1: Conyi beträchllich weiter vor der Mille. Dieser Verogleich spricht schon stärker

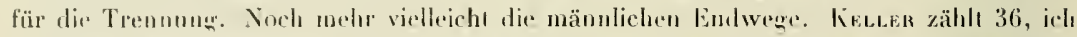
24 l’feidrüsenschläuche. Doch ist qerade dieses Homent hier wenig ansschlagrgehent, denn die Schläuche sind von verschiedener Länge, und KELLER hemerkl ausdräcklich, dass die Zahl bei kleineren Tieren stris geringer war. Auch die Pleildrösenpapille ist hei beiden auffallend kurz. Hier aber hat $V$. chilensis eine Besonderheit; denn die Papille liegr in einem anscheinend drïsigen Ringwall, von dem bei $V$. Gayi nichts angegelen

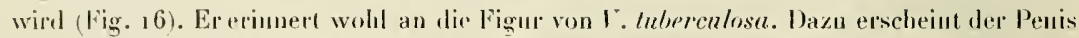
bei $r$. Luberculosa länger und mehrlach geknickt (hei Retraktion), auch die Spatha ganz besonders breit. IVer weiteres Material zur Verfügung hat, möge aul' diese Pnnlite achten! Vorläufig halte ich an der Existenz heider Arten nebeneinander fest.

\section{Vaginula decipiens Semper.}

Schon der Name soll die Schwierigkeit der Unterscheidung andenten; in grleicher Richtung deutet der Umstand, dass Semper ein Stück, das angeblich von Mexico stammte, von den chilenischen nicht unterscheiden konnte. Er giebt selbst an, lass die form der V. Gayi, sehr nahe steht und dass erst eine reichere Serie über die Selbständigkeit entscheiden könne. Die Massangaben, wonach bei einer Schnecke von 42 $\mathrm{mm}$ Länge die weibliche Oeffnung $4 \mathrm{~mm}$ vor der Mitte lag, deuten aut Trennung. Zum mindesten steht die Form der $V$. Gayi noch näher als der $V$. decipiens.

\section{Vaginula adspersa Heynem.}

(Tafel 11, Fig. 23-28.)

Chile. 2 Exemplare in Senckenberg'schen Museum.

Die Tiere sind stark gewölbt, mit ziemlich steilem Hyponotum. Folgende Maasse: Länge 5,3 , Breite $\mathrm{r}, 6(2, \mathbf{r})$. Hyponotum links 0,7 , rechts 0,8 bis 0,9 . Sohle 0,7 . Weilliche Oeffnung von vorn 2,6 , von hinten $2,9 \mathrm{~cm}$, von der Fussrinne $1 / 5$.

Die Färbung ist unten hell ohne Pigment, das Notum ähnlich schmutzig, mit tief schwarzem Farbstoff, der sich in runden Flecken, Strichen und Netzen grruppiert, hie und da schrär und parallel wie bei $V$. pallens, mil geringer Regelmässigkeil. IVesentlich ist seine Zusanmenulrängung gegen die Mille, wo er einen Medianslreifen frei lässt. Der aber ist merkwürdig unregelmässig, keineswegs mit parallelen Rändern der Länge nach, oder doch nur st reckenweise so, gelegentlich wolıl verdoppelt, indem sich eine schwarze Längslinie von einer Seite ein Stïck weit hereindrängt, nicht genan in der Medianlinie, sonderı mit ihr einen sehr spitzen Winkel bildend, in der Höhe des Pericards unregelmässig krans 11. dergl., kurz man hat nicht den typischen in der Ontogenie vermutlich begründeten (s. o.) Medianstreifen vor sich, sondern wohl eine sekundäre Zeiclınung, die anf das breite Nittelfeld der Phyllocaulier zurückgehen mag, wo die Grenzen der Seiten- 


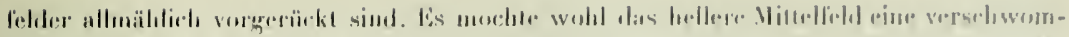

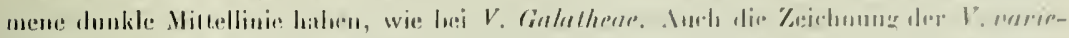

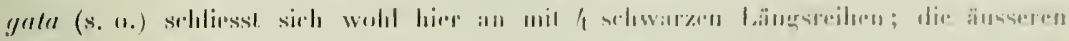

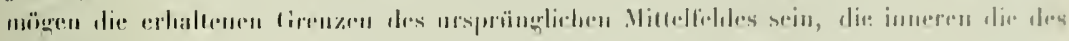
ringerengtest.

\section{Aluatomischess.}

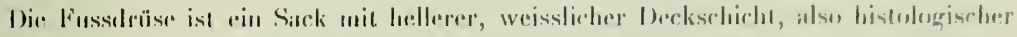

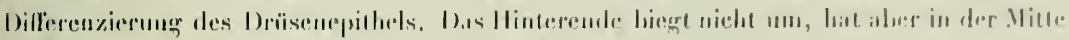

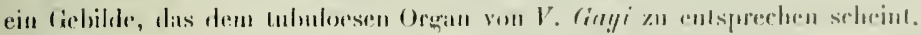

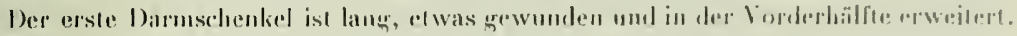

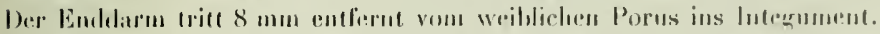

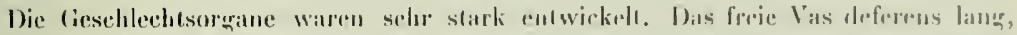

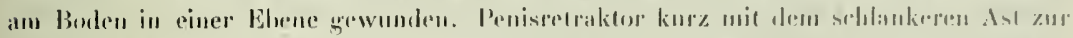

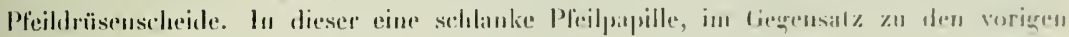

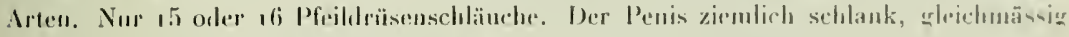

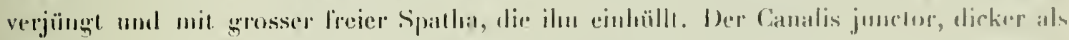

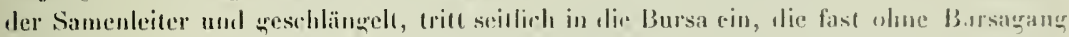
am Ovidukt ansitzt und dessen distales Eudr als Vagrina freri lässt.

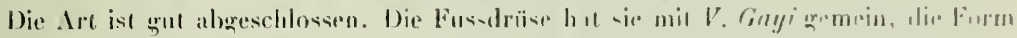
der grossen Spatha mil $V$. chilensis, die queringe Zahl der l'leildrüsen, die lenm der l'feilpapille und die Zeichunug hat sie fï̈r sich.

\section{Nordwestliche und nördliche Pbyllocaulier.}

Mit Sicherheit grehört zu den Phyllocauliern SExpen's mexicanische I: Strebelii (im Text als V. mexicana hezeichnet, I. C. S. 2433), ebenso nach dem Abstanele zwisehen dem weiblichen Porus und dem Eintrit des Enddarmes ins Integument, wie nach der Zeichnung des Notums, wo zwei Reihen schwarzer filecke wenigstens vorn an der Grenze zwischen Miltel- und Seitenteldern liegen, also solche wenigstens markieren. Bei der Beschreibun der Art vergleicht sie Semser mach der Anatomie mit r. limayana ron Ecuator, von der er indes keine hesondere Schilderung gibl. Sie dürfte wohl auch hierher zu rechnen sein. Nach der Beschreihung des Nomms, das durch Fleckenreihen 3 foldrig ist, möchte ich die mexikanische I. Moreleti Crosse et Fiscuen hierhershrllen, wiewohl die anatomische Prüfung ahzuwaren bleibı.

Zweilellafter wird die Auffussung hei der V. Sloanei Fẻr. von Cuha und damaĩca nach Senper's Beschreihung. Er fïhll sich sellsst in der Bestimmung unsicher und hal höchst walurscheinlich in dem einen hilase verschiedene Arten vor sich grehalu, mit und whe Medianstreifen. Zn Morelet's Sichilderung passt die 3-Felderung des Kolums durcy 2 Fleckenreihen. Eiggenartign ist aher die hreite Kloakenöflinug. die sonst mur der afri- 
kanischen Gruppre der 1. pleuroproctu zukommt. Der Penis ist von 2 Längstalten umsäumt, von denen die eine sehr schmale bis an die Spitze des Penis geht, während die andere als breites Blatt vorspringende weit hinter der Penisspitze plötzlich stumpf abgeschnitten endigt. "Der Enddarm setzt sich l'ast ganz neben dem Eileiter an die Ilaut an." Hier sind zwei Merkmale, die nicht mehr scharf zu den Plyyllocanliern passen. Die Figur rom Penis zwar wärte die Eigenart, das Blatt oder die Spatha, glatt ansdrücken, nichı aber die Beschreibung. Und beim Enddarm wird die Unsicherheit noch grösser. Es scheint, dass wir hier eine Zwischenform zwischen echten Phyllocauliern und dem übrigen

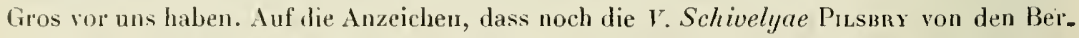
mudas und Bahamas zu den Blattruten gehört, kommen wir bei der nächsten Gruppe zurück.

Wenn es so weit gelıngen ist, eine Gruppe der Phyłlocaulier mit einiger Mühe in annälıernd befriedigender Umgrenzung herauszuschälen, so bleibt die Fortsetzung sch wicrig genug. Denn jede Anknü ?fung, die man nach einem Merkinal heraussucht, bringt neue Combinationen. Nach der Zeichnung schliesse ich an

\section{Vaginula mexicana Strebel und Pfeffer.}

(Tafet II, Fig. 29 und 3o.)

Mexiko. 2 Exemplare aus der Sexckenberg'schen Sammlung in Frankfurt.

Sie stammen aus dem Hanburger Nuseum, sodass über die sichere Bestimmung kein Zweifel aufkommen kann; die Anatomie liefert die Bestätigung. Die Zeichnung ist älınlich wie bei der V. Strebeli, die Semper ja zuerst als V. mexicana henannt hatte, also deutlichster Hinweis anf 3-Felderung des Notums, wie sie auch Streber's OriginalFigur zeigt.

\section{Anatomisches.}

Die Morphologie fällt zunächst aus dem Rahmen der Phyllocaulier ganz heraus, insofern als der Enddarm unmittelbar neben dem weiblichen Porus ins Integument eintritt.

Die Fussdrüse ist kurz, gerade gestreckt, ein Schlauch, der nach linten zu gleichmässig, doch unbedeutend anschwillt.

Der Geschlechtsapparat verlangt besondere Aufmerksamkeit, weil es nötig ist, auf Pғеғғек's Beschreibung genauer einzugehen. Penis und Pfeildrüsenscheide sind klein und kurz. Die 3n-33 Pfeildrüsenschläuche reichen, allerdings mit vielen Knicken, nichı über Pharynxlänge hinaus. Der freie Samenleiter schlängelt sich stark, olıne sich aufzuknäueln. Die Pfeilpapille konisch, von mittlerer Länge. Der Penis, von Senper und Pfeffer als ganz einfach angegeben, ist ein schwach gebogener Zylinder, der indes bei schärferem Zusehen eine Besonderheit zeigt. Auf der einen Seite verläuft seine Oberfläche ganz glatt, auf der anderen aber findet sich ein Absatz, eine verspringende Kante, sodass hier die distale Hälfte etwas schlanker erscheint als die proximale. Irre ich, wenn ich darin den Anfang der Spatha erbicke? Man brancht nur die Kante sich verlängern zu lassen, um das Blatt zu erhalten. 


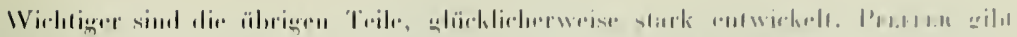

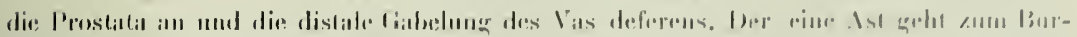

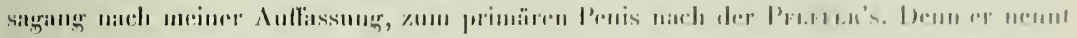

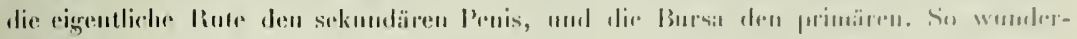

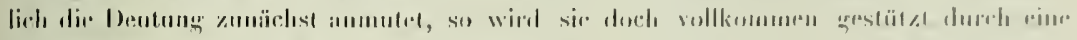

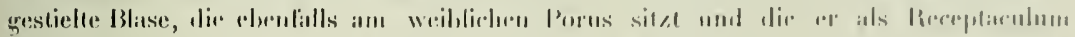

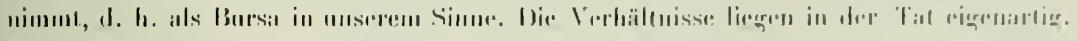

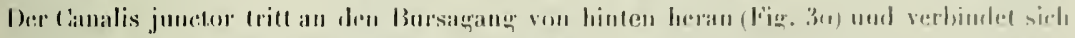

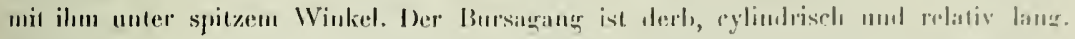

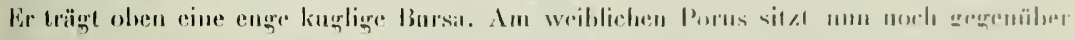

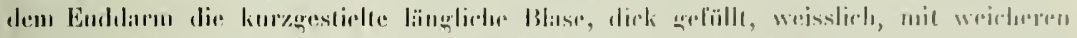

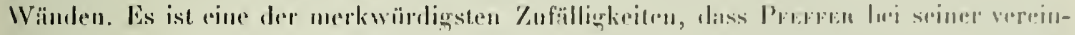

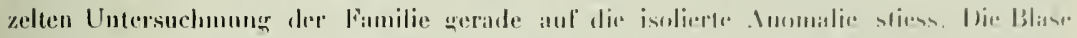

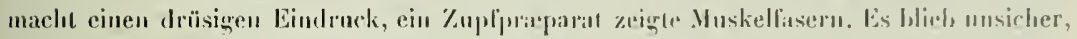

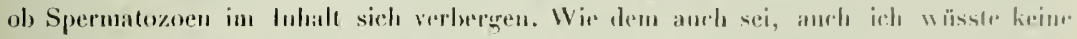

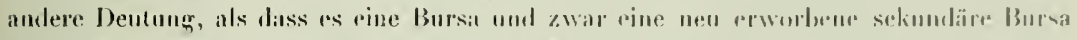

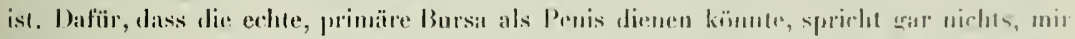
ist kein Fall von Andentung einer Ausstii]pung lsekinut, in Gomensalz anm wirklidien,

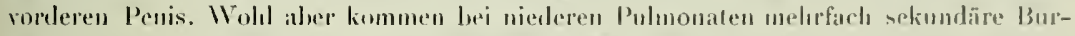

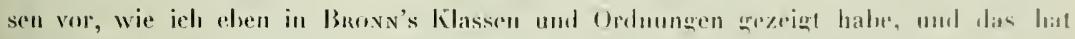

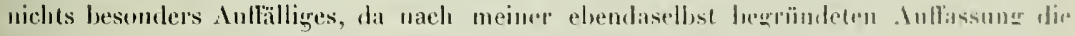
Entstehung der Bursa Jediglich als Einstiilpuner des lutegumentes an weiblichen Porm

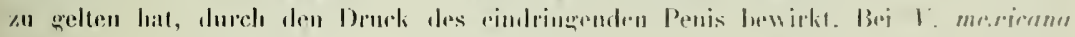

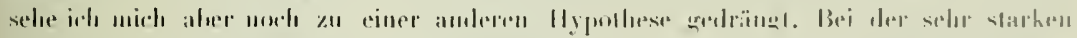

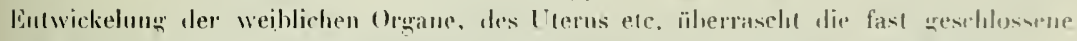
hugelform der eigentlichen primären Bursa. Sie macht durchaus nich den Eindruck, als wann sie bei einer vorausgehenden Begaltung zur. Iulnahme des Samens gulient hälle. Mit anderen Worten, hier scheint eine Arbeitsteilung vorzuliegen: Es ist einn npue

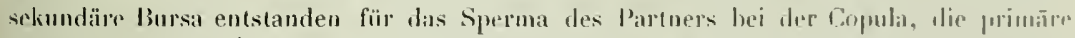

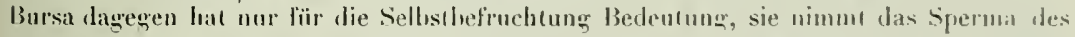

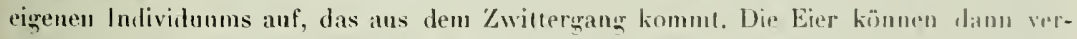
mulieh sowohl von der primären wie von der sekundären Bursa ans hefmelıtet werden. Dass die Einrichtung hei unserer Art völlig hefestigt ist, wird dureh dir I chwreinstinmung zwischen Pfeflers und meinen Befunden hewiesen. Iuf die Andenfung einer ïhnlichen Einrichtung hei einer anderer Form krmmen wir surück is. u.).

Noch habe ich einen troum Pferfer's klarzustellen. Er lengned die leplängerung des Samensleiters durch die Haut und behauplet, diss das Sperma durch eine äussirr. Samenrime nach vorn zum Pronis geführt wird. So weit Schnille Jurch dis allerdingu alte Material erkemen liessen, liegr der Samenleiter, wie zu erwarlen, im Integument. rerate ïher der rechten Wand der Sohle. 
Unter den anatomisch beglaubigten Irten ist $\mathrm{V}$. mexicana am weitesten nach Nordwesten vorgedrungen, autfallend genug, dass dem geographischen Vorstoss ein morphologischer entspricht. Die Eigenart, die in der Erwerbung der sekundären Bursa liegt, lheibt hestchen, auch wenn man den Anschluss an die Phyllocaulier nicht gelten lässt.

Möghicherweise gehör noch die Bermudas-Form, I. Schivelyor nar. bahamensis: hierher (s. 11.).

\section{Cylindrocauli, Walzen oder Schlankruten.}

ber Versuch, eine zweite Gruppe herauszuschälen, stössı auf grössere Schwierig keiten, namentlich aus dem Grunde, weil fremder Arbeil, d. h. der von Semper, uur ein. Merkmal zu entnehmen ist, die Form des Penis närmlich. Immerhin wird die Unannehmlichkeit dadurch gemildert, dass ich den cirka 6 Semperschen Formen etwa die doppelte Anzahl hinzufügen kann, die sich noch durch die gleichmässigen Beziehungen des Canalis junctor zusmmenhalten. Dazu kommen genug Einzelheiten, welche die Sonderstellung einzelner Arten oder Gruppen anzeigen, freilich ohne dass es müglich wäre, die Durcharbeitung bis zu voller Ueberzeugungskrafi zu treiben. Jedenfalls heischen sie Aufmerksamkeit.

Die gemeinsamen Merkmale der Gruppe sind namentlich diese : Kleine bis nittełgrosse Formen, jedenfalls niemals entfernt den Umfang der stattlichen Phyllocaulier erreichend. Die Tmrisse wechsehn zwischen schılank und gedrungen, flach und gewöibt. In der \%erichnung fehlt durchweg die 3. Felderung des Notums, meist auch der Mittelstreif.

Der Enddarm tritt unmittelbar am weiblichen Porus in das Integument.

Der Penis ist schlank und cylindrisch, hie und da etwas abgellacht, wobei sich die Kanten stärker ahheben köunen und in höchster Steigerung flügelförmige Verbreiterungen bilden.

Der Cumalis junctor verbindet sich mit dem Fundus der Bursa copulatrix, in conlinviertichem Uebergange, indem er sich, immer noch geschlängelt, gleichmässigg zur Bursa erweitert. Die Bursa ist gewissermassen nur eine allmähliche Erweiterung des Canalis.

Bei den Seмper'schen Arten fehlt natürlich das letztgenannte Kriterium. Ich stelle sie voraus, indem ich die zur Unterscheidung mir branchbar erscheinenden Elemente herausgreife. Um einen Anhalt zur Vergleichung zu gewinnen, habe ich den Längrenbreitenindex und den Längenindex der veiblichen Oeffnung, d. h. ihre Entfernung vom Vorderende des Notums in Prozenten der Notumlänge ausgedrückt, dazn seine Lağe im Hyponotun, ron der Fuss-orler Mantelimne aus, zusammengestellt. 


\section{Sempers Arten.}

\begin{tabular}{|c|c|c|c|c|c|}
\hline & Lange & 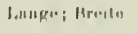 & 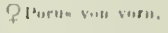 & vent der flu erinne & Mittenatsel \\
\hline 1. Tumfungi firr. & $\| 1111$ & 个, & 㐰"in & 18 & 11 \\
\hline 1. cosmeleseressis. & 5,1 (:II & $\because X$ & lit ", & 3,5 & () \\
\hline $\begin{array}{l}\text { 1. Bielembre!gist. } \\
\text { rur. }\end{array}$ & i1 1111 & 3,6 & 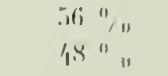 & I & $1+1$ \\
\hline - pmmelulissimm s'. & $\because, 8$ יוני & .1 & (31" 11 & 15 & $1+1$ \\
\hline . immineululu s'. & $\therefore, \bar{i} \times \mathbf{n}$ & $\because, \bar{t}$ & 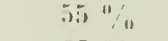 & 1,3 & $" 1$ \\
\hline 1. oseridentulis Ginilel. & 5,31011 & $\therefore, 8$ & $\overline{i .5} " 11$ & $1 ;$ & " \\
\hline
\end{tabular}

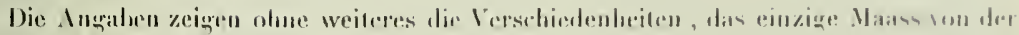

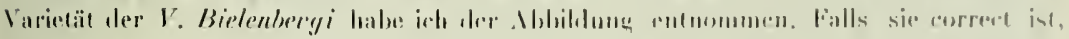

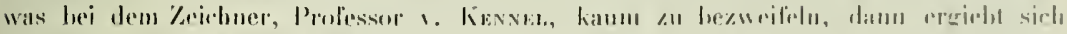

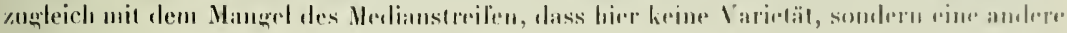

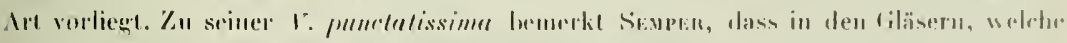

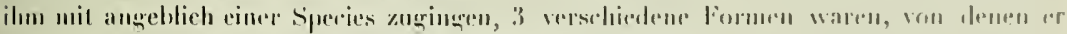

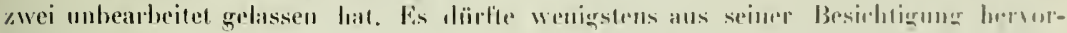

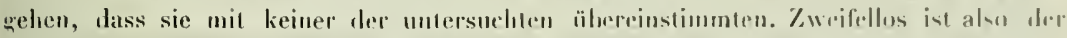
Artreichlum in dem Gehiet viel grösser. I unl damil das Geographisedur:
I. Tannayi : Brasilien (Rin de dincion)!
1. corrulexcerns: : Ciararis.

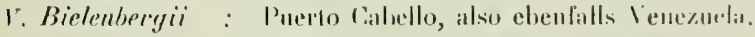
1. puncelulissimu : Porto Rico, sit. Thomas. Trinidad.
1. immuculale : Venezuela (Cialracas, P'uerto Cabello).
1. aecirlentalis: St. Thombas.

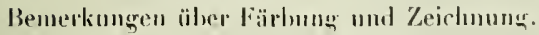

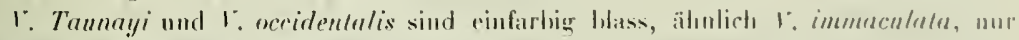

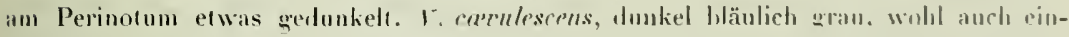

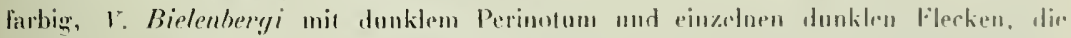

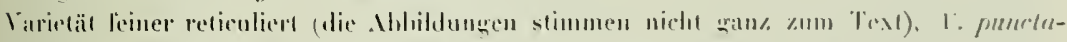
lissima endlich welhlicharan mit rewaschenen Flecken auf Xolum und Hyponotum, dazu aber auf dem Notum in regelrechter Verteilung scharfe, schwarze Punkte, offentar Drüsenöfunungen. Ẅir werden sie öfter antreffen. Da in allgrmenten grohe liörnelung der Haut kaum vorkommt, lasse ich den Charakter bei Seite.

\section{Anatomisches.}

As spezifisches Merkmal kann wieder der Xumerus der Pleildrïsen dirnen. je nachdem wechselud ron $\rightarrow$ bis 34 . dazu ihre serschiedene Läntre und die etwas wechselnde

- Ob die Vaginnla fusea von Rio de Janeiro. welche Heynemann nacl einem Exenłlar des Britischen Museum in seiner Weise beschrieb in diese oder eine andere Gruppe gehört. lässl sich ohne Autopsie und Sektion in keiner Weise entscheiden. 


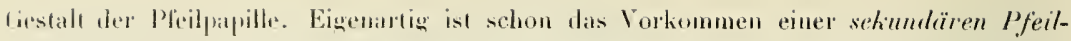
dräsenschede, d. h. ciner nesenterialen Cmbüllung der unteren Hälfte der l’feildrïsenschläuche. Sie wrelen mehr weniger fest zusammengehalten; auch der Pfeildrüsenretraktor fasst an dieser Scheide an. Senper leschreibt das Varkommuis bei 1 occilenlulis. Auch wir werden ihm wieder hegegnen. Leider scheint die Bildung wenig konstant, wenigstens in den Uehergangsformen, nach . Irt aller Mesenterialprodukle. Ich wurde erst auf einen extremen Fall aulmerksam. So viel ich sehe, beschränkt sich die Eigenlïmliclikeit anf einzoln. Gilieder der vorliegenden Gruppe und kömnte entspredhend vielleicht spekulativ verwand werden. Den Penis beschreilu SEmpen durchweg als schlank und cylindrisch, bei 1 . Tannuyi und 1 . rerulescens schraubig gedreht. Die Oelluung des Samenleilers liegl terminal oder subterminal unl dann unter einer Kappe, die charakleristisch ringeschnitten oder gelappt ist. Den Penis von r., accidentulis, der den 5. Tril der Krïperlänge misst, bezeichnet SEupen hereits als sehr lang.

\section{Eigne Untersuchungen.}

So viel ich sehe, stimmt keine Art ganz mit einer SEmpen'schen älerein. Das erlilärt sich oluse weileres aus der Verschiedenheil der Fundorte. Bei deu wenigen, wo die Herkunft die rgleiche ist, sind die Dillerenzen hesonders deutlich. Die zweifelhaften Fâtle werden zu beachten sein.

\section{V. olivacea Stearns.}

Tat. 11, Fig. .

Fuloon, Occillental-Departement, Nicaraguat. Senekexberg'sche Sanmlung, Frankfurt. 7 Stück.

Die schlanken Tiere sind hei ganz verschiedenem Unfange durchaus gleichförmig, worn und hiuten elwas zugespitzt gerundet, ïher und üher blass gelblich mit fein graver

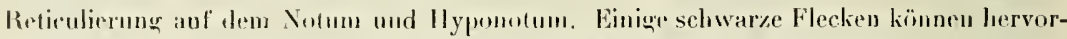
lreten, hesonders neten dem meist undeulichen Mittelstreif. Obere Tentakel dunkelgrau mit heller Calotte, untere blass. Im ganzen sind Zeiclınung und Färbung wenig charakteristisch. Die Maasse der grössten sind folgende: Länge 4,2 cm. Breite $1,2(1,3)$. Hyponotum 1,45 , Solite 1,38 , weibliche Oeffnung vou vorn 2,3 , von hinten 2 cu, von der liussrinne reichlich $1 / 5$.

\section{Anatomisches:}

Die Leher bildet das Torderende des Intestinalsackes wie bei allen folgenden. Die Speicheldrüsen sind grobblätterig gelappt.

Der erste Darmschenkel zerlegt sich in den dünnen Sclılund, ilın folgt der erweiterte Kropf, der sich nach hinten darmartig zuspitzt, um sich abermals in ähnlicher Weise zu erweitern und dann erst verjüngt in den Magen zu münden. 


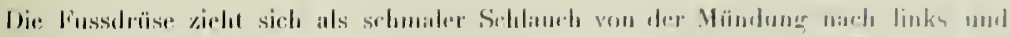

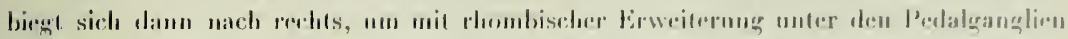

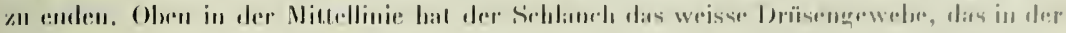

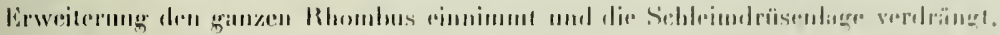

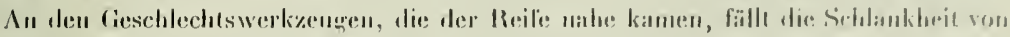

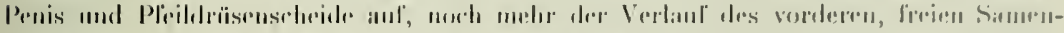

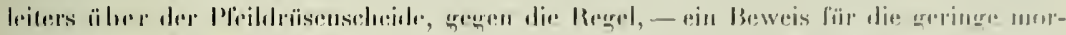

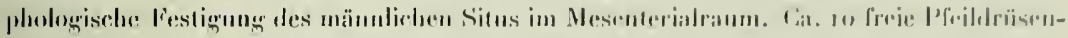

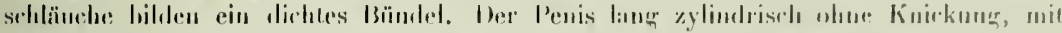

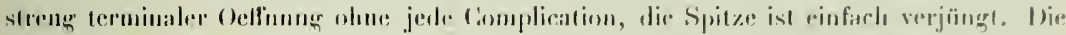

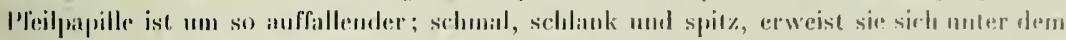

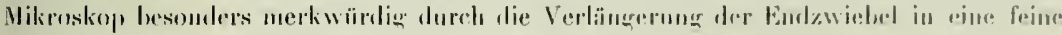
gevirïmme Conchinspita. Ls blich unentschioden, ob das letzte linte, das sich nicht

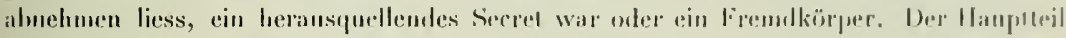

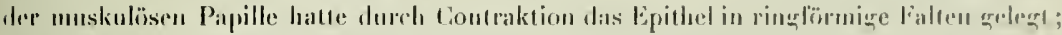

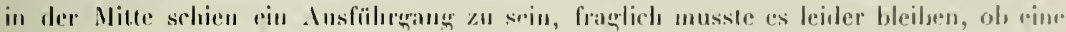
rumble helle Stelle nahe der Basis die wirkliche Drüsenölfnung ist. Jedenfalls machte es den lindruck, als ob die verschiedenen Pleildrüsen schliesslich durch einen gremeinsamen fiang mündeten, und ihrer lieinheit könute wohl das Conchinröhrchen entsprechen.

Die noch nicht ginz reifen weiblichen tienitalien zeigen den Canalis junctor in Iypipischer Form. Der Bursagang ist hirnförmig geschwollen und kräfrig muskulös. Di» Bedingungen scheinen gleich qut lïr Sellsthefruchtung und Begattung.

\section{V. nesiotis $\mathbf{n}$. sp.}

(Tal, It, Fi!n. 30-1/2.)

Kingston, Jamaïca. I Stück. Fuhrmann leg.

Auf den Intillen ist wohl mehr bei Gelegenheit kürzeren .Iufenthaltes ein einzelnes Exemplar aufgegriffen worden. Ich glauhte dasselbe so nehenher hehandelı zu dürfeı. Die genanere Einsicht machte jedoch mehr Ilühe, als zu erwarten schien, ohne zu bestinmtem Ergebuis zu führen. Die Beschreibung mag der Discussion roraufgehn.

Die Form ergielnt sich aus der ligur. Die Maisse sind :

Lïnge 3,5 cm. Breite I, I $(1,55)$, also stark gewölbt, Iyponotum 0,45, Sohle 0,4, weiblicher Porus von vorn 1,5, von hinten $1,9 \mathrm{~cm}$, von der Fussrinne $1 / 5$.

\section{Färbung und Zeichnung.}

Das Notum ist einfarbig dunkel bräunlich olive, ohne hervortretenden mitteren I ängsstreifen. Die liäche ist glatt, oder doch qanz fein granuliert. Die Lnterseite heller 
und namentich am Hyponotum weniger ockerig, mehr rein gran. Bezeichnend ist seine unrengehmässige, reticulierte Dunkelung in mittlerer Höhe, sorlass sowohl der obre Rand an Perinotum, wie der untere an der Fusstinne einfarbion hleiben, die Zwischenzone alner mit leinstem grau chagriniert ist, wobei die dunklere Zorehnung sich vorwiegend in der Transversilriehtung orientient.

Auf dem Nolum linden sich drei kleinere, scharf unschriehene Stellen mit Suhstanzverlusten, zwei gregen die längsmitte hin, die dritte an Perinotum ïber der weiblichen

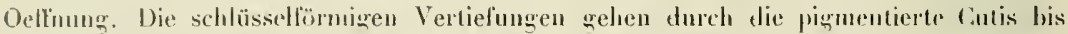
aut die weisse Muskellage. Sie rïhren offeubar wieder von Verletzmngen beim Vorspiel her, bewirkt threh die Radula des Partners. Das wurde bezengt durch das weissliche Ende des Penis, das noch ausgestälpt war und genau in der Mitte zwischen den mittelgratuen oberen und blasseren unteren Tentakeh herausschaute, von denen es sich hell und scharf abhob. Die Schnecke ist also nnmittelhar in oder nach der. Copula getötet.

Analomisches.

Leber- und Speicheldrüsen wie bei der vorigen.

Die Fusstrüse, in ihrer natürlichen Lage den Schhundkopf um den dritten Teil seiner Länge überragend, läuft zunächst schwach gebogen in der Medianlinie und lirümmt sich hinten unter Verdickung scharf nach links und zum Schluss wieder nach rechts, wo sie spitz austäuft (Fig. 37). Ihr vorderer Eingang ist engröhrenförmig, keine breite Spalte. Das Drüsengewebe von gleichnässigem, gewöhnlichem Aussehen, also wohł ohne besondere histologische Differenzierung.

Männliche Endorgane. — Pfeildrïsenscheide und Penisseheide von ähnlicher Gestalt nebeneinander, vorn verbunten (Fig. 38); die erstere trägt 12 Pfeildrüsenschläuche, von denen sich ciner hinten gabeh. Form und Länge dieser Dinge ergehen sich aus den Abbildungen, ebenso der Verlanf des vorderen Samenleiters in der Leibeshöhle unter der Pfeildrüsenseheide. Der Penis hat einen ganz kurzen, derben Retraktor, der einen düıneren an die Pfeildrüsenscheide abgibt. In letzterer liegt eine feine schlanke, etwas ahgeflachte Pfeilpapille. Der Penis ist in Anbetracht der Penissclieidenform von unerwarteter Länge, ein mehrfach zusammengeknicktes cylindrisches Rohr, an den Knickstelten entsprechend verengert, ohne irgendwelche Ausladungen oder Fortsätze seiner Wände. Nur oben an der Spitze entsteht eine Art Eichel, mit der Oeffnung subterminal unterhalh, eines kleinen Vorsprunges (Fig. 14). Diese Glans war es, die frei zwischen den Fühtern herausschaute und ahbrach (s. o.). Bei vorgestrecktem Kopf würde die letzte vordere Umbiegung des Penis wegfallen nod vielleicht auch die Einengung hinter der Głans, die wohl nur durch die Einschnürung in der männlichen Velfinung entstanden ist. Bei völliger Erektion hätte vermutlich der Penis einen gleichmässigen Zylinder gebildet. Auffallend bleibt dabei die kïrze der Penisscheide und des Penisretraktors, und man muss wohl annehmen, dass die eigene, innere Penisinusculatur genügt, um ihn nach der Copula hereinzuholen und zusammen zu brechen.

Die weiblichen Endwege wie bei der vorigen, höchstens der Bursagang el was kïrzer. 


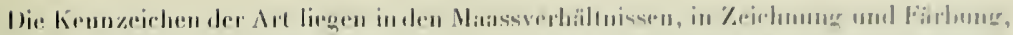

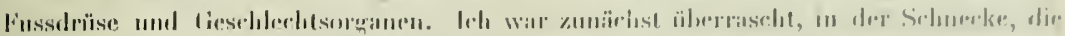

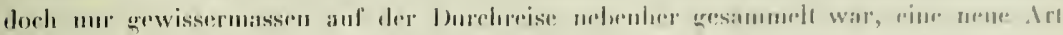

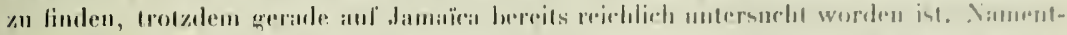

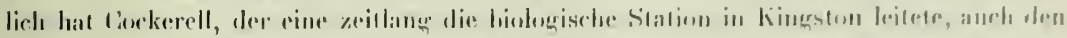

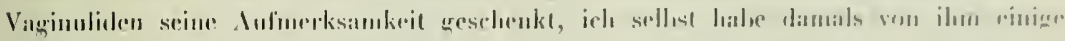

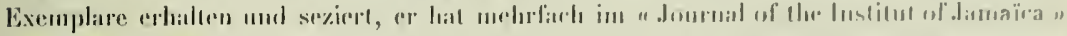

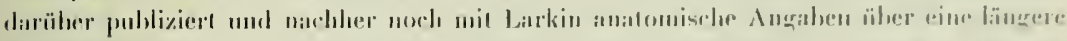

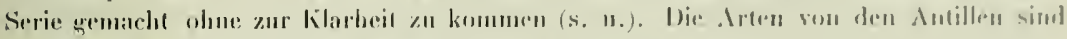

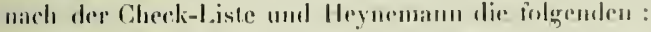

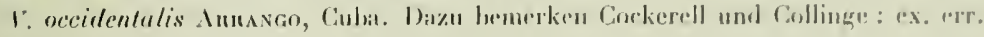

1:. Slomei Cuv., Cuba, damä̈ri.

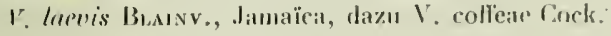

1. nirgale Саяк., damiäl':is.

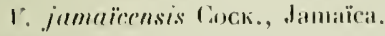

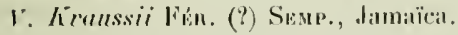

1. alissimilis Cock, Jamin̈ca.

1. porloricencis Sempen, Porlo-líico.

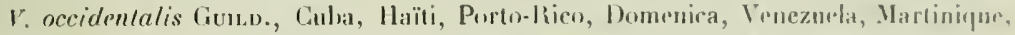

St. Vincent, Guadelonpe, Jamä̈ea, Trinislad und vielleicht St. Thomas.

1. punctulissima SEur., Porto-Rico, Si. Thomas, Trinidad.

1. dubir Semp., St. Thomas.

1. Marechii Semp., Guadeloupe. Yon Sempen allerdings als von liualeloup kamunend

hezeichnet und unter die afrikanisch-indischen Arten versetzt. Gieht's dort ein Guadeloupe?

1. Lnciar Cock., St. Jacques, St. Lncia.

Hierzu macht bereits Colunge anf die Unhaltharkeit der 1. occidentalis von Cuba aufmerksam, im Anhang zur Checklist; älnnlich in Bezug anf $r$. Slonnei. Was er sonst ron Anatomie heschreibt, reicht nicht aus, denn er greht nur auf den nichtssagenden Limriss der Penisscheide ein, nicht aber anf ten Penis sellost. Dasselhe grill von seiner Beschreibung der 1: Luciae. Dass Pferffer's Beselıreibung der 1: cubensis niclat groñgen kamu, versteht sich von selbst; denn hier musste der Scharfhlick des Conchybiohuren versagen. Somit bleibr die Terpllichtung, Semper's analomische Daten heranzuzielsen,

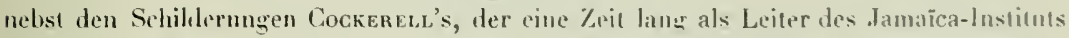
in Kingston die heste Gelegenheil hatte, die Fauni von Jamal̈ea zu studieren. Trulzelem

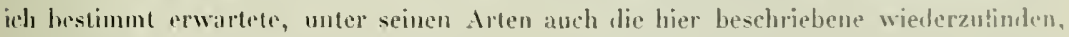
versagte genauere Einsichtnalime.

Coclierells Arten unn Jamaïn.

1. jumä̈ensis Cock. soll an Stelle von V. Kinussii fire treten. Cockerell beschreiht die Schnecke nur Alühlig nach dem Aensseren. Das Vorhandensein eines dentlichen 
Miltelstreifons erweist die Verschiedenheit von der worlegenlen I: nesiotis; weitere Inhaltspunkte sind nicht gegeben.

I. virgatu Cock. hat denselhen Nittelstreifen und den weiblichen Porus beträchtlich linter der Mitte, fällt also aus.

$\checkmark$. dissimilis Cock. hat ebenfalls den Medianstreifen, dazu 2 I lange und 8 kurze Pfuildrïsen, hat also ebenfalls mit Ir. nesiotis nichts zu tun.

Die lar. coffeae Cock. ist dadurch schon versehieden, dass sie nach Counngk die weibliche Oeffnumg ebenfalls hinter der Mitte hat.

Die von Sexper beschriebenen Species, die hier sämılich zur Diskussion kommen, scheiden aus, ebenso eine Form von $S$. Domingo, die ich nachlier noch zu beschreiben hahe (s. u.). Also bleibt nichts weiter tibrig als die $I$. nesiotis als $\mathbf{n}$. sp. getten zn lassen. Die Antillen belıerbergen somit sicher noch einen grossen Reichtum.

Ich möchte hier nur noch darauf hinweisen, dass das Frankfurter Museun noch ein Stück von Florida birgt unter der Etikette:

Tagiunla floridana von der Tampa-Bay, Floridix.

Es hat ungefähr die Grösse und die Umrisse der T. nesiotis, ist aber zu schlecht erhaten, um es zu secieren. Es scheint, dass auf Florida wie auf den Bermudas und Bahamas noch äusserlich ähnliche Arten vorkommen, deren lokale morphologische Ausbildung kïnttiger Arbeit festzustellen bleibt.

Einigen Anhalt gibt Dall's genane Schilderung nach dem Aeusseren. Er beschreibt von den Bahamas

I. Schivelyoe PrLsbry var. bahamensis $\mathbf{n}$.

als eine kräftige Sehnecke bis zu 6,3 cm Länge in Alkohol und betrachtet sie als Varietät der von Pıssbry aufgestellten Bermuda-Art. Dabei ist die Schilderurg der Jungen bemerkenswert: "The young are transheent white with two dark lines enclosing a broad, elongated area on the back which is pale and ontside of which the sides of the mantle are finely gray-dotted. "Die Mlen sollen ausser einem hellen Medianstreifen noch zwei verwaschene Bänder erkennen lassen als Reste der scharfen Jugendstreifen (die Abbildung nach Plotographie zeigt nichts davon). Solche 3-feldrigkeit des Rüickens wärde auf einen Phyllocaulier hindeuten, wofür bei $V$. floridana kein Anhalt gegehen ist.

\section{V. columbiana n. sp.}

(Taf. II, Fig. 43-45.)

a. Bürgen, 6 Stück. Peperital (Villavicendio) snoo m. Januar 1897.

b. Fuirruans, I Stück Bogota 2600-2700 m.

c. Micholitz, 1 Stüek Cohumbia.

Die Art ist schon durch ihre äıssere Giestalt scharf charakterisiert, schlank, aher gewölbt, unten steil abfallend, vorn abgestutzt gerundet, hinten noelı weit mehr abgestutzl, in den meisten Fällen sogar ausgerandet in einem nach hinten oflenen Hachen Bogen, was allein schon ein lypisches Merkmal wäre. Wenn auch Färbung und Zeich- 


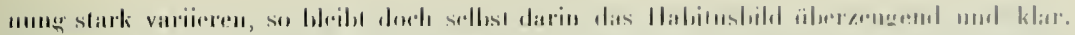

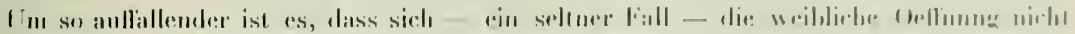

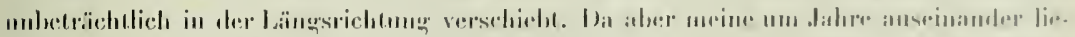

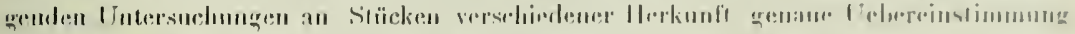

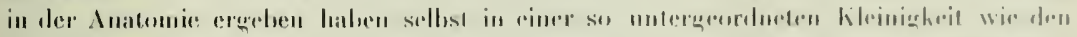

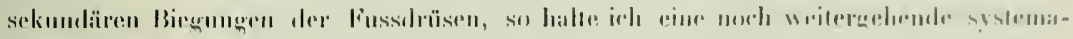
tische Zerlegung lï̈ ausegeschlossen.

Zanuälist die Matasse versehiedener Slürlie :

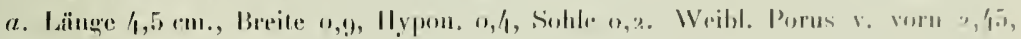
male der Fussrimme.

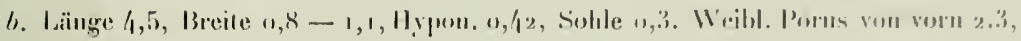
von hinten $2,25 \mathrm{an}$, von der linssrimer $1 / 3$.

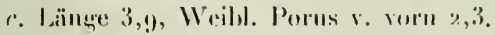

Dass giehl als Längenimdex för den weihlichen Porus

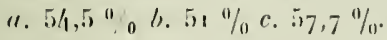

Dazu kommt noch ein Wechsel in ter Entfermug von der finsirimur.

Das algestutze ouler ausgeschniltene llinterende heruht anf der schumilheil de's

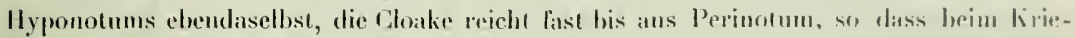

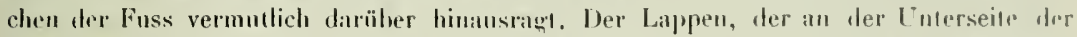

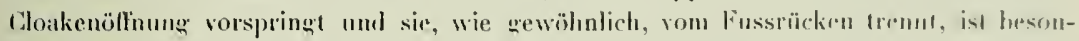

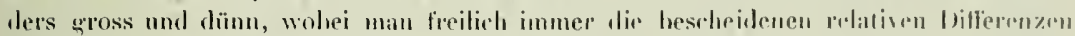
der Vaginuliden im Auge behalten muss.

Das lileichmass des Habitus wird noch rerstïlit durch dir Ilaltune des Vorderonles : alte Tiere haben den Kopf zurückgezogen, der Mund liegr weil zurück, das Vorlelende der sohte ist entsprechend weit umgebogen und cingezogen. Wenu irh früher versuchle, die Haltung des Kopfes im . Mkoholtod, - oh retrahiert oder ausgestrerkt muter die Species-Merkmale aufzunehmen, so hat sich das zwar meistens, alser nicht immer hewährt. Fïr l. colmmbiana triflt's scharf zu, was wohl zunächsi anf enlaprechende Beziehungen des Hautmuskelschlauchs und der kinfretractoren, die vermulich noch ein günstiges, ron mir vernachlässigtes limnzeichen ahgrehen wïrden, zurörkzılïhren ist. Man darf wohl annehmen, dass die Schnecke anch in Leben sich entsprechend verhät, d. h. den Kopf leicht zurückzich, überhaup schen und sensilus in. Das würde ich aus der Farbe der Fühler schliessen, denn die oheren Tontakel halu ich als hellgrau, die mutern als blass notier. Das steht im Gegensatz zur Intensitäl der ïbrigun Färbung und scheint zu heweisen, dass die Fühler relativ wenig vorgestreckl mul exponiert werden.

Fär Färhung und Zeichnung kann man zunächst eine allgemeine liegel aufstellen : Der ghleichmässige Grundion ist auf der Interseite blass, auf der Oherseite acteriz-

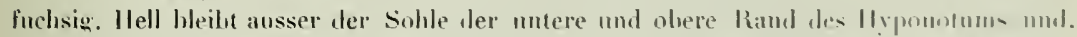

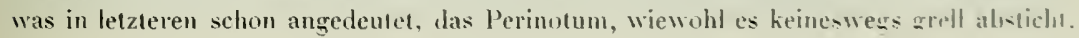


Dazn kommt nun als aweites Element ein derhes Schwar\%, zunächst in einzelnen Flekken und qroben Punkten anf dem Nolum, damn einen hellen Medianstreifen anssparend. Weiterhin werden aber die Flecke hand- oiler sternlörmig, und die Furtsätze communizieren mit einander, so dass nur helle lifecke bleiben und das Notum marmoriert rrscheint. Diese Zeichnung qreift schliesslich anch üher den Medianstreifen hinweg, dis Notum wird beinahe gleichmässig schwarz. Aelntich das Hyponotum, nur dass hier die Sterufiguren weniger deutlich sind. Dunkel wirl's immer, auch da wo das Notum fuchsrot hleilıt. Wass dabei ein unterer, hlasser Rand am Hyponolum ausgespart wirl, erwälnte ich hereits. Bei dem Exemplar b rerbreitel er sich im vorderen Drittel, so dass rechis wie links ein sichelförmiger heller Ausschnitt entsteht, also am Kopt wieder verengert. Man künnte l'arbenvarieläten aufstellen, was aber wohl überllüssig ist, del l ebergängæ wegen. Wichtiger erscheint mir eine andere Frage, die nach der Abhängigheil der Pigmente von der Exposition an die freie Amosphäre. Nach Fiscuen's Schilderung liegen die Vaginula in der Ruhe mit der ganzen Unterseite, also bis zum Perinotum, dem Boden auf. Ob das auch die steilen Formen tun? Jedenfalls darl man anuehmen, dass der starke Ocker des Notums der stärksten Exposition entsprich, also ant den Einfluss der Meteore zurückzuführen ist, eventuell als ein Saverstollülıertrïger hei der .lemung. Schwieriger ist das Schwarz zu heurteilen. Man könnte es auf die Wirkung der Kïlte, etwa in der Nacht zurückführen wollen. Das würde am hesten zı der Amalme stimmen, dass auch das Hyponolum bei der Steilform in der Ruhe etwas gelüpft, also exponiert bleibt. Nur die immer dem Boden anliegende Sohle blieb, farblos.

\section{Anatomisches.}

Jie grössten Stïcke sind voll mutwickelt, in den kleineren heginnt erst die weibliche Reifung. Darm wie liei der vorigen Art. Der Kropt zerfällt auch hier in zwei Erweiterungen, die durch ein kurzer Darmstück getrennt sind. Der Magen hat eine weite dünnwandige Abteilung mit $\mathrm{d}_{1}$ und $\mathrm{d}_{2}$, ihr sitzt die dickwandige mil der Hinterleher als schlankerer Schlauch an.

Speicheldrüsen aus llachen, blattarligen Icinis aufgebaut.

Die Fussdrïse beginnt mit breitem Mündungsspalt und zielıt erst nahezu gerale wach hinten, biegt dann scharf nach lizks vorn um und ebenso wieder zurück, um sich hinter dem linie allmählich nach hinten zı verjüngen. In ganzer Länge lıebt sich die Yitte der l)ecke als weisser Strang ab, der zum Schluss die ganze IVeite eimnimmt. Das Ende liegt nach dem ersten Viertel der körperlänge.

Bei a und b waren ir oder I2 Pfeildrüsenschläuche vorhanden. Mtit ihrer etwas weelıselnden Länge leginnen ferine Unterschiede zwischen den beiden Formen. Sie sind bei l, etwas kürzer, in der ersten Hälfte stark hin und her gewunden, d. h. durch eine sekundäre mesenteriale Bindegewebsscheide zusammengehalten, ohne dass ich's besonder's bemerkt hätte. Sie ist also nur schwach ausgebildet. Der freie Samenleiter war bei a kürzer und weniger geschlängelt als bei b, auch die Penisscheide war etwas kürzer. Das 


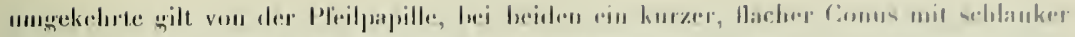

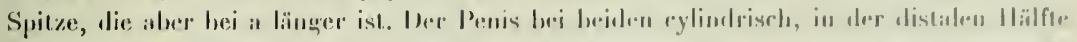

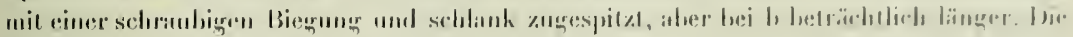

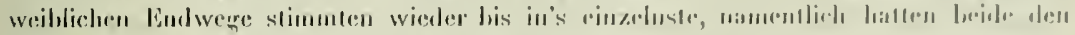

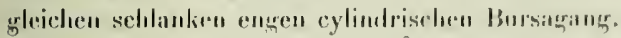

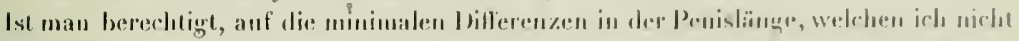

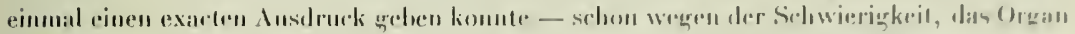

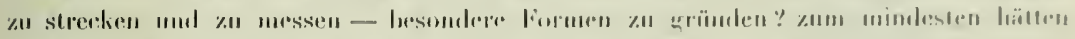

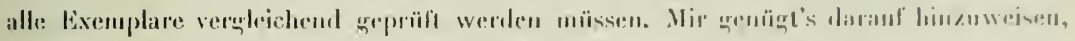

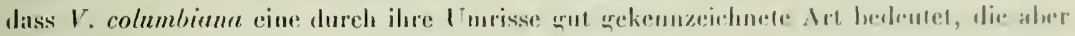

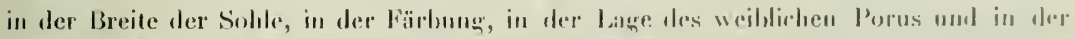
Liinge des Penis allerlei Schwankungen unterworfen ist. Amdeutungen lokaler Sondermun

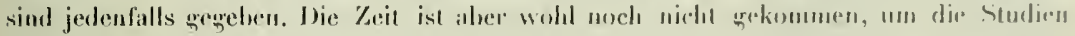

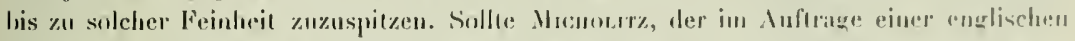

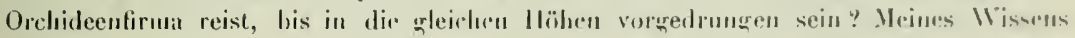

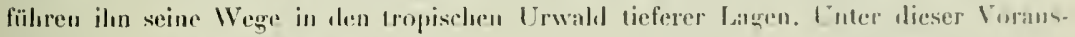

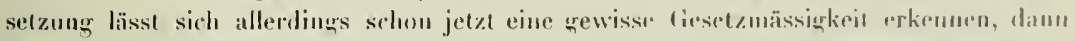

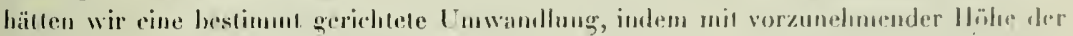

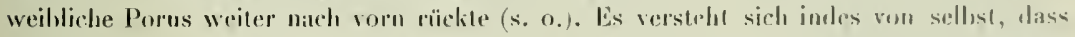

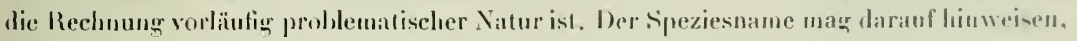
dass hirer sich nit dem Land ein tieleres J'rohlen rerknïpft.

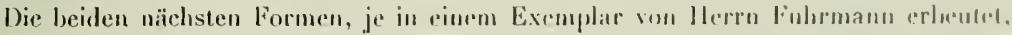
bilden wieder ane engere Gruppe, lrei der man äber die specifische Trenumer schwantion

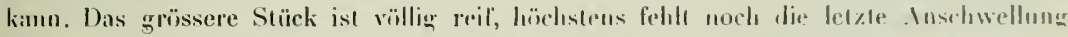
der weiblichen Drüsen, Uterus und Eiweissdrïse. Doch lësst sich am hl bej den kleineren Tieren alles wesentliche hereits freilegen. Da zeigrn sich immerhin einigge Difterenzon,

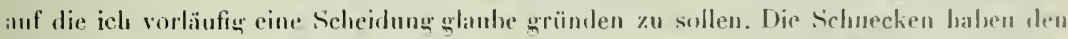

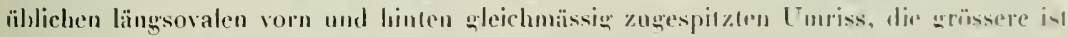

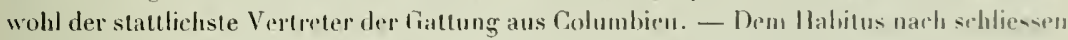
siclı weitere Formen eng an. Wir kommen darauf zurörk.

\section{V. cordillerae n. sp.}

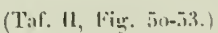

1. Stück. Columbia. Arrelia Citfetal. - Ostkordillere 1 (bou m. Funnux lear.

Die Maasse sind :

Länge 5,7 cm. Breite 1,7-1.8. Hypon, 6,9-1. Sohle knapp 6,6, weihlichere Porus von vorn 3,4, von himten $2,3 \mathrm{~cm}$, ron der Fussrinne reichlich $1 / 5$.

Der ganze Ton ist mit Ausnahme der hlassen Sohle schwärzlich chokoladenlıraun, durchaus cinfarhig, kaum dass das Perinotum eine Spur heller hleibl. Hie und da ist auf 
dem Notum eine hellere ockerige rundliche Stelle von höchstens a mm Durchmesser mit einem schwarzen P'unkt in der llitte, einem Drüsentuberkel. Sonst ohne Abzeichen. Die weit liereingezogenen Tentakel, zwischen denen die helle Penisspitze sichthar isı, lolmschwarz. Das Hyponotum, das vom Pigment his zur Grenze an der Fussrinne gleichmässig bedeckt ist, erscheint ganz feinkörnig. Ebenso das Notum, mur dass sich hier in regelmässigen Abständen von ca 1 num deutlich etwas grössere rundliche Körner erheben, die als dunkle P'unkte hervortreten, ohne doch tirl schwarz zu sein. Aus dem Hyponotum sind rechts hinten Stricke eler dunklen Hant herausgerissen, die gewöhnliche Erscheinung des Vorspieles.

l) liensseite ist vom äblichen Schleim überzogen. Sonst finden sich auf dem ginzen Notum und Hyponotum kleine weissliche Secretklümpchen, pilzartig, in der Hant anqeheftr. Fig. :3 stellt rins vom Hyponotum dar. Man sieht, wie ein zäher Schleim als einheitlicher Strang aus der Drüsenötlnung herausqequollen ist und sich ansserhalh aufgeknäuelt hat. Noch hält der Strang in der Drüsenölfnung fest. IVie das Vorkommen am Ilyponotum heweist, sind die ganz leinen, gleichmässior zerstrenten Drüsen dic Lieferanten. Ob die dunkleren, gröberen Körner des Notums ein besonderes Secret liefern, muss ich dahingestellt sein lassen.

Anatomisches.

Die derben Speicheldrüsen, von anderthalbfacher Pharynxlänge, bestehen aus groben Acinis. Der gestreckte, weite Kropf ist vorn rechts und links durch Mesenterialbänder ans lntegument befestigt.

Die Fussdrüse ist ein langgestreckter, nach hinten zugespitzter Sack mit enger Mündıng. Fast gerade gestreckt verläuft sie über das zweite Fünftel der Leilıeshöhe hinaus. Die Ĺnterseite gleichmässig schleimgrau, oben der weisse Mittelstrang, der, nach hinten zu Jurch eine Iedianlinie halbiert, schliesslich die ganze Breite des Sackes einnimmt.

An den männlichen Organen fällt zunächsı die starke Sekundärscheide auf, welche die 16 P’feildrüsenschäuche distal einlü̈llt und zusammenhält. Thr Retraktor gabelt sich in zwei scharf getrennte Aeste. Die gemeinsame Wurzel entspringt woll] mit dem Penisretraktor zusammen weit hinten, kurz $(5 \mathrm{~mm})$ vor dem weiblichen Porus, doch lässt sich eine gewisse Selbständigkeit deutliclı nachweisen. Die Retraktoren haben sich wohl unahlı̈ngig aus demselhen Mesenchymband entwickelt und liaben ihre Wurzeln nachträglicí verschmelzen lassen. Der lreie Sanenleiter ist stark gewunden, der Penis relativ lang, in ganz ungleiche Abschnitte geteilt, die kürzere schmälere Basis erweitert sich plötzlich, unter unregelmässigem Umriss (Fig. 5 i) zu dem Endcylinder, an dem die Oeffnung subterminal liegt. Der Penis hat wohl in unserer Gruppe durchweg eine ähnliche Basis.

Die weillichen Organe, gut entwickelt, geben zu einigen allgemeinen Bemerkungen Anlass. Die Eiweissdrüse, bei maximaler Ausdehnung gewölınlich ein einheitlicher Klumpen, war gerade auf dem Stadium, das den Bau am besten erkennen liess; der Ansfïlrganģ einseitig an der Otserfläche, daran die Drüsensäckchen in regelmässiger Gruppierung, von der anderen Seite sind sie noch deutlicher, da der verdeckende Gang fehlt. Mit anderen Worten, die Eiweissdrüse hat streng gefiederten Bau, wie ein Fiederblatt, dessen 


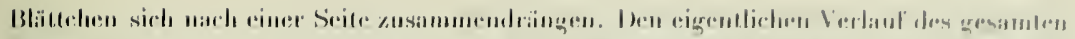

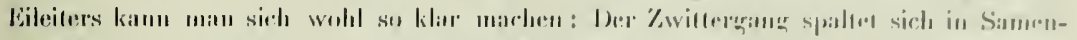

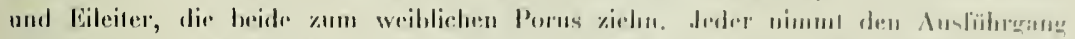

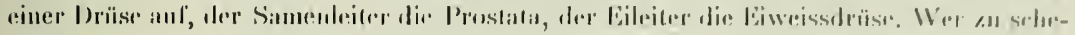

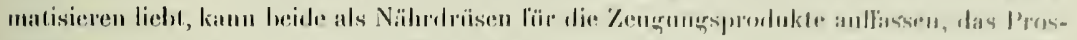

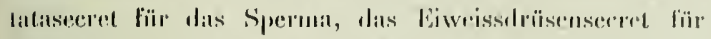

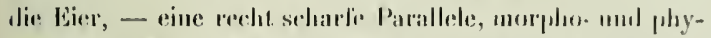

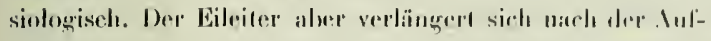
nahme der liweissdrïse, inden er die lïgur riner \& la-

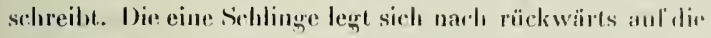
watehsende Biveissdrïse, wo sir unverïnlert verlanrt, man kïnute sie die Oherschlinge nemurn. Dir Untersshlinge

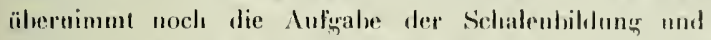
schwille zar Nielamentald löse an, wohei sire sirh verlïngert und zum sporralgang ader literus zusammenkuebelt. Die Oberschlinge bletbt, wie gesiset, hei den Vaginulirlen stets unverändert nnd ungequollen, wenn anch beträrhtlicls weiter, als der kura Eileiterteil zwischen Eiweissdrüse und Zwiltergang. Die Eicr scheinen hier Zeil zu brauchen, un sich mit Eiveiss zu umhüllen. Det aufsteigende Ast des Spiralyangrs ist dann vermutlieh die Schaten-, der ahsteigende die haichdrüse, beide wie zwei Korkziehn um riuander grewunden. Bei mserer Art nun zeight sich die distale Hälfte der Oberschlinge lebhaft graubraun gefïrh, bis zum Beginu der Unterschlinge oder des Spiralgangs, so zwar, dass ein feiner Randstreifen noch blass bleibt. Ich würde auf diese unscheinbare Kleinigkeit kein Gewicht legen, wenn sie nicht bei anderen Arten in grenau derselben Weise aufträte. Die Oberschlinge des Eileiter's zn Beginn der weiblichen Rejfe, d. h, nach der Copula, ist der einsige Ort im Vaginnlidenkörpes, wo Pigment anftritt (ausser

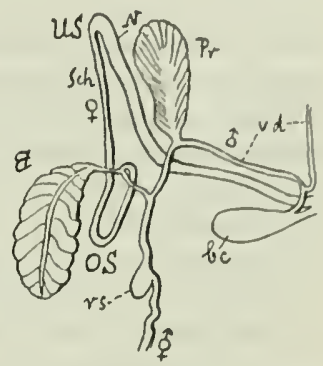

Schematisclie Darstellung dur Geschlechtswerkzeuge.

Der Zwittergang mit dem Receptaculum oder der liefruchtuagstasche (vs) spaltet sich in den mainnlichen und weiblichen Gang; dem männlichen sitzt die Prostata (Pr). dem weibliclıen die Eiweigsdruge ( $\mathrm{ki}$ an, die einander entsprechen. Iler weibliche Gang beschreibleine Uberschlinge (OS) und eine Unterschlinge (US). Die Oberschlinge liegt später unverändert der vergrússerten Eiweissdrüge auf, die Unterschlinge knebelt sich zum Spiralgang oder Lterus zusammen, dessen aufsteigender Schenkel als Schalendrüse (Sch), dessen absleigender als Nidamentaldrüse $(\mathbb{X})$ dient, während das Endstück den Eileiter bildet. b. c. leiter (vd) dentrix, die rom SamenBursa copula Canalis junctor erhält. den Farbstoffen der Hant oberball der Muskellage und denen der Verdaunngsdrüse). Diese Pigmentbildung im Infang des schwellenten Eileiters kann schwerlich etwas anderes sein, als ein mit dem Beginn der Schalenhildung verbumdenes Mbpaltungsprodukt. Gleichzeilig mit dieser (vorühergehrndent Pigmentierung ist die Befruchtungstasche stark und Lypisch entwickele, entsprechend dem Zusland zwischen Copula und Eiausbildung. Die Anmahme, dass das Sperma aus der Bursa durch den Oviduk, also den Spriralgaug elc, his in den Zwiltergang und desseu Befruchungstasche hinanfzusteigen habe, bedurf freilich noch der Nachuprüfung am hestem an reichlichem, frischem Materiale, d. h. vor Ort. 


\section{V. montana, n. sp. ? n. var?}

(Taf. Xit, Fig. 54-57.)

Columbia: Zwischen Boca del Monte und Tambo. Ostkordillere ca z/qoo m. FunitMans leg. I Stück.

Die vorliegende Schnecke gleicht der voligen in den Grössenverhältuissen vollkommen, nur ist das Hyponotum beträchtich heller, so dass seine Färbung, die sich gegen das Perinotum etwas aufklärt, zwischen dem dunkeln Ton des Notums und dem blassen der Sohle die Mitte hält mit einem Stich ins Rote. Die oberen Tentakel dunkel, die unteren hellgrau. Zwischen ihnen sah das Begattungswerkzeng hervor. lch würde die Form einfach als eine Varietät der vorigen betrachten, wenn nicht die Anatomie Anhalt zur Trennung böte.

Die Vaasse sind folgende:

Länge 4,25 cm. Breite 1,4. Hyponotum 1,7-1,8. Sohle 0,5 , weibl. Por'us von vorn 2,4, von hinten $\mathrm{I}, 9 \mathrm{~cm}$, von der Fussrinne reichlich $1 / 5$.

Am Perinotum bemerkt man in kurzen Distanzen gröbere Por'en, ausserdem aher ganz kurze, weissliche Härchen oder Borsten, die frei abstehen. Um ihre Natur zu erkennen, wurde wenigstens ein Tangentialschnitt gemacht (Fig. 57). Vorn zeigt sich ein blasses Epithel, unter demselben in feinster Reticulierung schwarzes Pigment. Zwischen den grossen Poren stehen kleine, in der Grösse scharf getrennt ohne Uebergänge, nicht so, wie es scheint, in der Funktion. Die grossen Poren sind erfültt mit einem gleichmässigen Secretpropf, die kleinen enthalten ebenso einen birnförmigen oben zugespitzten Propfen, allerdings blasser und stärker lichtbrechend. Ein prinzipieller Unterschied zwischen beiden scheint nicht zu bestehen. Das Secret ist offeubar noch fester als der zähe Schleim bei der $V$. cordillerae, der sich zusammenknäuelt. Der Unterschied ist also jedenfalls gegenüber dem Secret der $\boldsymbol{V}$. cordillerae grösser als zwischen der Abscheidung der kleinen und grossen Poren bei $V$. montana. Die der grösseren giebt die erwähnten, mit blossem Auge sichtbaren Borsten.

Bekanntlich hat Prate bei der V. Gayi gefunden, dass die Drüsen des Perinotums ein besonderes, brennend schmeckendes Secret liefern als Schreckmittel. Notumdrüsen von Oncidien liefern nach Semper feste Körner, die unter Druck herausgeschleudert werden können. Ich muss mich damit begnügen, bei den vorliegenden Arten Dilferenzen gezeigt zu haben, deren Bedeutung und Zähigkeit nur an lebendem Material geprüft werden können.

\section{Anatomisches.}

Die Speicheldrüsen dicht fein tubulös.

Die Pedalnerven, im ersten Viertel vereinigt, treten dann weit auseinander. Die Fussdrüse ist ein vollkommen gerade gestreckter schmaler Schlauch mit parallelen Wänden. Die Oberseite hat den weissen, durch eine Medianlinie halbierten Streifen. 


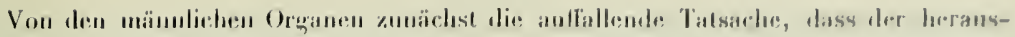

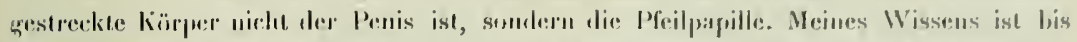

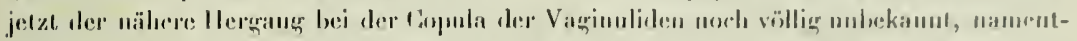

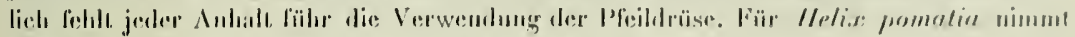

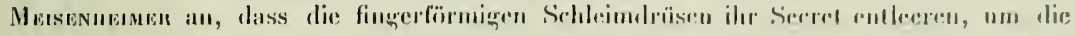

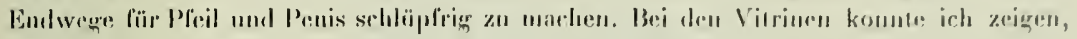
dass die Peilpapille volkummen narh aussen lacrvortrite. Bei V. olimaren dented die:

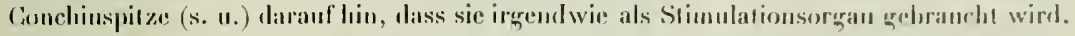

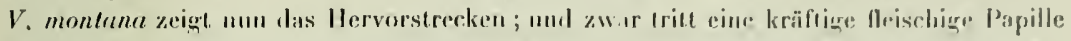
heraus, an der sich lerminal eine kleinere Papille wie cin feineres köpfoluen abluebe. Dire Bedentung des Pfrildrïsensecrets bleiht nach wie vor dunkel, wie äherall bei den Gas-

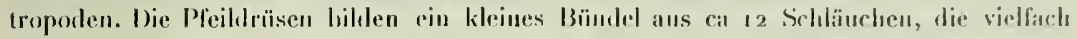
grewelle und geschläugelt sind, also wohıl mit secondlïrer Mesenchymseheide. Auscinander gelegrt, sind sie doch nicht länger, als die Pleilpappille. Der Penisredactor hat diesellor Länge wie bei ler vorigen Art, mit langem Ast lïr die Pfrildrüsenscheide. I)ie l’enisscheide ist in der proximalen IJälfte ausgelaurlu, dem der relativ lange cylindrisclee Penis ist in 3 Scheulsol zusammen gelegt, das freie Eude eiufach zugespilzt.

Die weiblichen Organe noch fast unentwickelt. Inunerhin liess sich die gleiche Anlige des Camalis junclor unI der Bursa erkennen, wie sie der Gruppe zukommu.

\section{Vaginula n. sp? n. var?}

(Taf. XII, Fig. 58.)

Columbia. Zwisehen Boca del Monte und Tambo, $2000 \mathrm{~m}$ ca. liunruaxi leg. 2 Stïck. Von demselben Fundort stammen 2 kleinere unter cinander ganz ïbereinstimmende Sclunecken mit demselluen IJabilus wie die elsen besprochenen, höchsteus dass das Perinotum etwas schärfer als Kante absteht Notum und llyponotum sind ghleichmāssig schieferschwar, dic Sohle mittelgran, mil einem Stich ins Grünliche, alle Tentakel dınkel. Eine Bestimmung nach der Sohlenfarbe ist wohl auszuschliessen, da es sich um Pigrmente aus der Nahrung handeln kann, welche durch den Alkohol gelöst und in die Hau gelıracht wurden. Die Maasse simd:

Lünge $3 \mathrm{~cm}$. Breite 0,9 . Hypon. o,45-o,5. Sohle 0,3 , weiblicher Porns ron vorn 1,05 , von hinten $1,35 \mathrm{~cm}$, von der liussrinne $1 / 4$.

Anatomisches.

Die Tiere sind so wenig entwickelt, dass ich anf eine Festlegung der Genitalien verzichten musste. Dass der erste Darmschenkel in zwei schlank-hirnförmigne Ahschnilte zerfällı, dass die Pedilnerven sich elsenso verhielten wie bei 1 . montana, würde nit der Färbung vielleicht für die Vereinigung mit $V$. cordillerae sprechen. Aher die Fussdrüse setzt einen bestimmten Unterschied. Sie ist ein langer Schlanch, hinten erweitert mit 
dem obern weissen secretstreifen, liegt aber nichtgerade in der Mittellinie, sondern wendet sich im Bogen scharf nach links.

Es mag grenügen darauf hinzuweisen, dass aus dieser Gruppe noch eine besondere Form in Columbien vorkommt, die später festgelegt werden mag.

\section{V. alticola n. sp? n. var?}

(Tal. . Nit, Fig. 59-6iz.)

Columbien. Paramo Cruz Verde. 3600 un. Fitunuas, leg. I Stück.

Dunkel chocoladenfarbig, das Hyponotum etwas blasser, die Sohle hell. Das Notum fein «rau reticuliert, überall heben sich in dichten Abständen ockerige Kreise ah mit einem schwarzen Tuberkel in der Mitte.

Die Mlaasse sind:

Länge 4 cm (in tler krümmung 4,3). Breite 1,4. Ilyponotum o,65-o,7. Sohle 0,4, weiblicher Porus von vorn 2, $\mathrm{I}$, von hinten $1,9 \mathrm{~cm}$, von der Fussrinne ca $1 / 3$.

Anatomisches.

Die Fussdrüse von reichlich I/3 Körperlänge, gerade gestreckı, nach hinten zu etwas erweitert mit dem weissen Streifen, schliesslich ein verschmälerter Blindsack mit dünnen Wänden.

Der erste Darmschenkel zerfällt in die beiden Abteilungen, aber sie sind ungleich, die vordere, vorn rechts durch ein Mesenterialband hefestigi, ist reichlich dreimal so lang, a]s die hintere, wegen der Länge mit einer Krümmung, nach hinten zu nicht verjüngt, sondern durch eine Einschnürung von der hintern Abteilung abgesetzt ; diese dagegen verjüngt sich und tritt als gewöhnlicher Darm in den Magen ein.

Die Fussnerven auf $\mathrm{r} / 4$ vereinigt, dann divergent.

ı6 dünne, kurze Pfeildrüsenschläuche von gleicher Länge. Pfeilpapille knrz und stumpf. Der Penisretractor lang, fast bis zum weiblichen Porus. Der Penis mit kurzer schmaler Basis, daun cylindrisch zugespitzt, von mässiger Länge, völlig gerarlegestreckt. Sind schon die männlichen Organe ziemlich schwach entwickelt, so erlauben die weibliclien gerade den charakteristischen Verlauf des Canalis junctor zu erkennen.

\section{V. punctata n. sp.? n. var.?}

(Taf. Nill, Fig. 63-65.)

- Columbia. La Omion-Chingasa. $11000-2 / 400 \mathrm{~m}$. danuar 1897 . Bünger leg. 6 Stück unter Baumstämmen.

Der Name mag an $V$. punctatissima Semper erinneru. Die Anatomie beweist, dass die Arten nicht zusammen gehören, denn SEMPER betont, dass im entwickelten Zustande Pfeil- und Penisscheide besonders klein waren. Die Tiere sind verschieden lang, sodass 


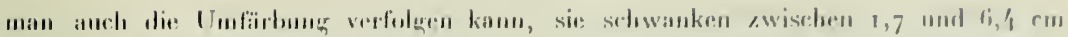
Jöinge. Die: Maisso des gröissten siml:

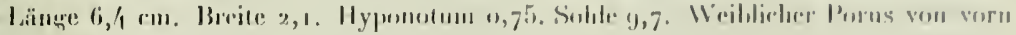
$3,35 \mathrm{~cm}, \mathrm{nahe}$ are linssinume.

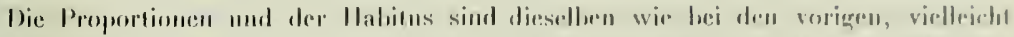

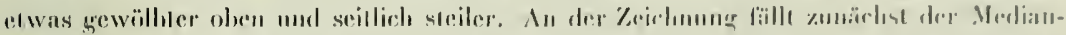

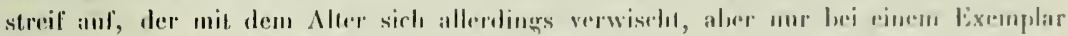

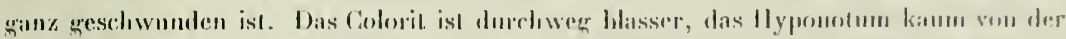

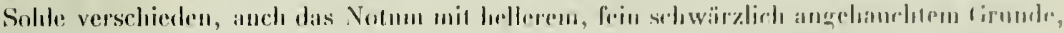

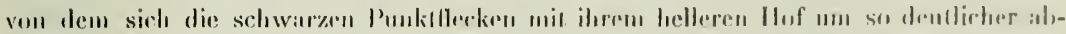

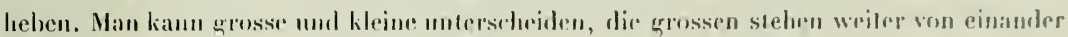

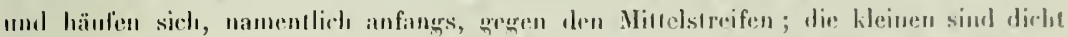

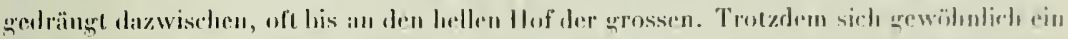

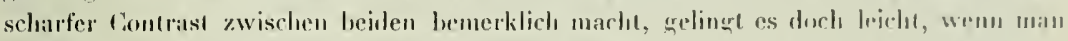
eine grössere l'läcle äbersieht, alle Zwischenstufen von deu allerkleinsten, kamm unch mil freiem lugr zu erkennonden an zu verfolegen. Ilier wird sicherlich nur ein gradueller linferschied in Seciet vorkonmen, schwerlich rin plyysiologisch-chenischer.

Antomisches.

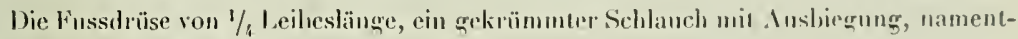
lich nach links. Weisser Serretstreifen in granzer Länge. Bei voller Enfwicklurng sind

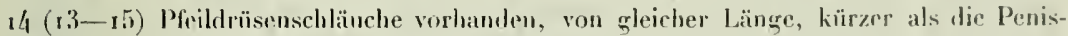
scheide. Die Pfeilpapille melı zyliudrisch als konisch. In der Penisscheide cin langer. nicht zusammengefalteter l'enis von zylimbrischer Form, aber mit zwei Längskanlen einander gegenïber, die Mündumg subterminal unler einem kleinen läppchen. Die kianten können den Lnfang von Flïgelhildung hedeuten. Man kann sie wohl als gutu Artumrkmale nelumen. Penis- und Pfeildrüsemelraktor sehr lang. Von den weiblichen Organon möchte ich dieselbe Pigmentahlagerung im Bewinn des Eileiters (in Her Oherschlinge) betonen, wir ich sie ohen ereschilder hahe. Der Canalis junctor stark ggeschlängrelı.

Mit diesen Tieren wurde ein Eihanfen gefunden, der an Schluss der folgenden l*orm berïcksichtigt werden soll (s. ı.).

\section{V. longicaulis $\mathbf{n} . \mathbf{s p} .{ }^{\prime}$}

Tat. N11, ligur bit-bo.

Columbia. Alto ron Sibate. 30. 12, 189 h. $2800 \mathrm{~m}$. Bürger leg. 2 Stïck. Inter morsehen Baumstïmmen.

In ilemselhen Gilas beland sich noch ein kleineres Stück, eine junge Sehnecke, die ieh nicht zu charaklerisieren weiss. Oben slark ahgedlachı, aranz dunkel, ohne Mediansireifen, das llyponolun dunkel sretleckt. die Sohle mit helleren . Mittelstreilen und ebensolehen händern, also mil zwei dunkleren. allerdingrs sehr

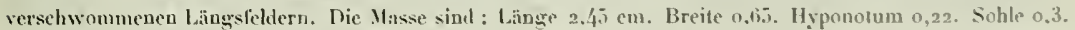
Weiblicher Porus von vorn 1,4. mumiltelbar nehen der Fussrinne. Die Schnecke ist schlank mil parallelen Rändern. Es isı ganz nuwahrscheiulieh. dass sie zu einer der vorliegenden Formen grehört. 
Die Maasse des einen Stückes sind :

Längne 4,5 cm. Brejte 1,9. Hyponotum o,65. Sohle o, 6. Weiblicher l'orus von vorn $2,5 \mathrm{~cm}, 13$ von der Fussrinne.

Die Proportionen wie bei den vorigen. Die Färbung verschieden. Die Oberseite ist nämlich blasser als the Unterseite. Das Notum ist schmuıig gelhgrau mit spärlichen dunklen Flecken, die zur gröhern. Drüsenform gehören, das Hyponotum dunkelşrau, verwaschen gefleckt. Es ist nicht ausgeschlossen, dass während der Untersuchung die Färbung etwas gebleieht ist.

Die Tiere sind in der Copnla grefangen, und bei dem cinen hängt der Penis heraus von mehr mehr als halher Körperlänge, bei weitem das Maximum imnerhalb der Familie. Ich nahm ibu, da er direkt aus dem Munde zu konmen schien, anfangs für eineu Regenwurm und glanbte schon einen Uebergang zur Fleischnahrung vor mir zn haben, was mich bewog auch die Mundwerkzeuge zu prüfen.

Anatomisches.

Der Kiefer ist breit, niedrig, schwarz, mit blasser Unterlage, die etwas unter dem freien Rande vorspringt, darauf sind die einzelnen Kieferplatten oder -rippen befestigt, von einander getrennt, meist schwarz, jede aus zwei verschmolzenen Hälften gehildet. Hier herrscht nicht viel mehr Regelmässigkeit als bei der Y. mexicana nach Strebez's und P'FefFer's Darstellung.

Die Rarlula fällt unter die übliche Form. Der Rhachiszahı ist ganz schmal, in Reduktion begriffer, die zahlreichen Lateralzähne kehren eine slumpfe Spitze der Medianlinie zu, die Marumalzähne sind meist cinfache Platten olıne alle Dentikel. Der Kropf ist in der .Hitte nur etwas eingeengt, sodass die beiden Abteilungen schwach geschieden sind.

Die Fussdrüse ist ein gerader, wenigstens nur ganz schwach gekrümmter Schlauch mit weiter Mündungsspalte, nach hinten unbedeutend erweitert, mit dem weissen Secretstreifen an der Deeke. Die Pfeildrüse setzte sich bei dem einen Exemplar aus i t kurzen Sehtäuchen von gleicher Länge, beim andern aus ı3 zusammen, von denen etwa die Hälfte merklich kürzer war, untereinander gleich lang. Die Pfeilpapille ist lang, koniseh, fein zugespitzl, das äusserste Ende nochmals als feiner Kegel ahgesetzt, doch ohne Conchinbewalfunng. Der Penis zerfällt in zwei gleich lange Hälften, die schmalere Basis oder den Sockeł und das zylindrisehe, fein geringelte Endstück. An der Basis zeigt die Haut stellemweise spiralige Faltung. Am Beginn des Endstïcks zieht eine Strecke weit eine Rinne entlang. Berleutet sie den Absatz ciner Kante? Die Oetlnung scheint subterminal unter einer kleinen Klappe zu liegen. Am Zwittergang ist die Befruchtungstasehe gut ahgresetzt. Bursa und Canalis junctor typisch, letzterer kaum gesehtängeht.

Etwa hierher, d. h. an die Gruppen der ovalen columbianischen Gylindroeaulier, sind vermulich 3 jugendliche Tiere zu setzen, welche Funвмann in der Centralcordillere im Cafetal Camelia bei Angelopolis erbeutete und mit der V. minnta (s. u.) zusammenwarf. Sie sicht ihr in der Tat ausserordentlich ähnlich, doeh zeigte sehon die Unauflindbarkeit 


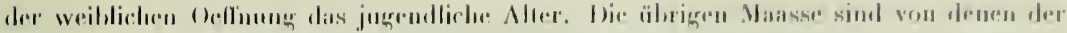

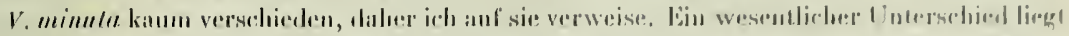

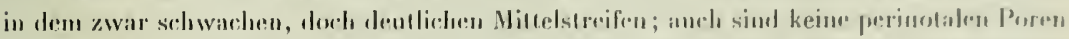

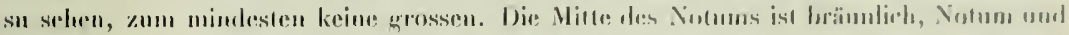

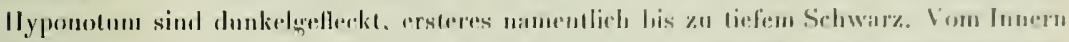

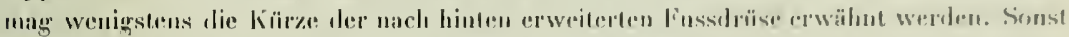

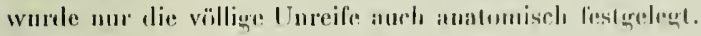

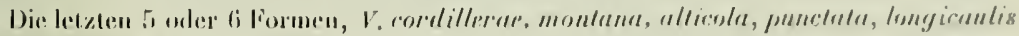

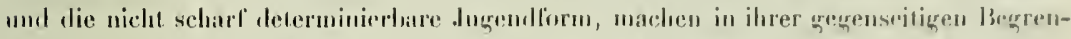

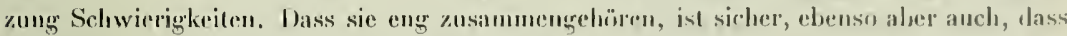

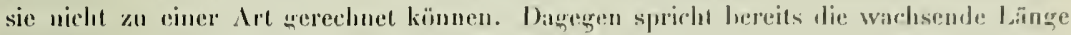
des Penis. Dazn kommen Untersehiede in der Zalul der P'feildrüsensihlänche in ilorer secundären Mesenchymscheide, in der Form der l'feilpapille, in der länge und Schlingुelung des Canalis junctor, in den Speichelılrüsen, in der schwächeren oder schürforen

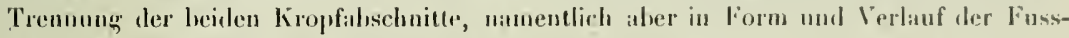
drüse. Soweit ich letztere lienne, zeigt sie innerhall, der Art kionstanz. Andererseits wird man nicht gencigt sein, auf dieses Merkmal, dass noch so wenig durchgreifende Beachtmog gefunden hat, ein System zu grünlen. Oh die Verschiedenheil in den Ilautabsonderungen auf zufälliger lionservierungr, temporärer Disposition oller derarl. berult, entzieht sich vorläıfig ganz dem Urteil. Vielleicht liegt gerade hierin ein wichtiges biologisches liriterium, das recht wohl gecignet sein ming, plyylogenetische Diveruenz zu hegränden. Ich hälle gerne schärfer eingeteilt und grruppiert in Arten und Aharten, sehe mich aber ausser Stande, mehr zu tun, als einen Complex beschreibend zusammenzufassen, der in der $V$. longicanlis seinen Höhejunkt zu erreichen scheint.

\section{Folgen von Parasitismus.}

Eine Schnecke, welche Funrmann im Cafelal Camelia bei Angelopolis erbeutete, setzte der Bestimmung grossen Widerstand entgegen, namentlich deshall, weil sie trotz reichlich $3 \mathrm{~cm}$ Länge den weiblichen Porus nicht auffinden liess. Der Ilabitus verwies sie unter vorstehende Gruppe. Die Matasse sind:

Länge $3,1 \mathrm{~cm}$. Breite $0,7(0,88)$. Hyponotum 0,3 . Sohle $0,25 \mathrm{~cm}$. Die Zeichnung: Notum mit hell ockerigem lirund und Mittelstreifen. Rein blassgrau reticuliert, hie und da etwas tiefer, fast schwïzlich. Feine Tulerkelpunkte sind überall zerstreut, auch gedunkelt, aher nicht schwarz, sondern höchstens dunhelgrau. Das Hyponotum feingran gesprenkelt und reticuliert.

Somit war die Schnecke keineswegs alhin, aber doch viel weniger energisch ausgeglichen, als bei denen, welche die gröheren Drüsenöffungen dunkel, und dann glänzend schwarz, herrotreten lassen. 
Beim Oeffnen ergab sich, dass der qanze Körper mit einem oder mehreren Fadenwärmern von stark wechselnder Dicke (Gordins:" Mermis") durclisetzt wat, bis in den linken Augenträge hinein, zwischen und un die Eingeweide, bis ans Hinterende. Der Schmarotzer äbertraf den Wirt an Länge jedenfalls un ein Vielfacles. Dieser starken Belastung entsprach die kleine und blasshräunliche Leber. Nlle Organe schienen gelitten zu haben. Der Wegfall der weiblichen Oeffnung hing uffenbar damit zusiunmen; immerhin scheint das antfïllig, weil der Porus bereits lange vor der Reife, schon auf jugendlichem Stadium sichtbar zu sein plfegt. Wird er durch Castration muterdrückt? Die Schwäche des Organismus schien in der zarteren Constitution, d. h. in der schwachen Pigmentiernug ihren äusseru Ausdruck zu finden.

Dass eine grenaue Determination ausgeschlossen war, versteht sich von selbst. -

Nematoden von $1 \mathrm{~cm}$. Länge ca., die bei zwei Arten vereinzelt festgestellt wurden, haben auf tie Organisation weiter keinen Einfluss sezeigt. Bei V. rufescens lag ein Wurm, zu einem Ringe zusammengeschlossen wie die ïlrigen, in einer Mesenchymcyste, die in der Leibeshöhle den Pedalıerven aufsass.

\section{Ueber den Laich von V. punctata.}

(Taf. XII, Fig. 46-49)

Es unterliegt wohl keinem Zweifel, dass die Schnur von io Eiern, die Buerger in demselben Mulm mit relativ zahılreichen Exemplaren der Schnecke fand, auch zu diesen gehört. Die Form stimmt zu bekannten Vaginula-Laichen, dazu war der Embryo bereits gut entwickelt und wohl dem Ausschlüpfen nahe.

Die länglichen Eier sind zu einer Kette verbunden, indem sich zwischen je zwei spitzen Polen eine gestreckte oder zusammengedrehte Schnur ausspannt, die in den Ueberzug der Eier übergeht. Dieser erscheint aulfallend ungleichmässig gestreift, indem abwechselnd undurchsichtig weisse seidenglänzende und durchscheinende Bänder von einem Pol zum andern laufen. Das Bild ändert sich, wenn man das Ei ins Wasser legt. Dann quilt die Aussenschicht auf und wird ganz und gar gallertig liyalin, wobei die weissen Streifen sich in die Kämme erhabener Längsrippen verwandelı. Das Mikroskop zeigt eine strukturlose Gallerte von derber Consistenz, beinahe bröcklig. Darunter folgt die glatte, ebenso strukturlose Eischale ohne jede Spur von Kalk- oder andern Einlagezungen oder von Schichtung. Das Ei ist in die Länge gestreckt und an beiden Polen glatt abgerundet. Im Innern sieht man den Embryo; einer zeigrte deutlichst die Augen. Zunächst aber liefs noch auf eine Täuschung hinaus, indem der Embryo parallel zu seinen Umriss von einer dicken Eiweisslage umhüllt war, durch die sie hindurchschienen. Am Kopfende liegen noch einige freie Dotterschollen, kuglig und länglich.

Auf entwicklungsgeschichtliche Studien kommt's hier nicht an. Wohl aber selrien die Verschiedenlıeit zwischen der Obertläche des Eies und des Laichs einen Anlıaltspunkt zu bieten zur Unterscheidung der Schalen- und der Laich- oder Nidamentaldrüse. Die 


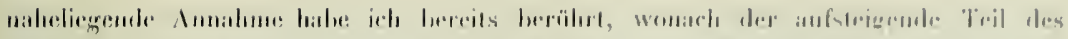

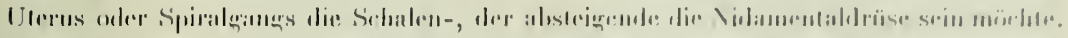

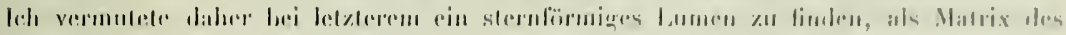

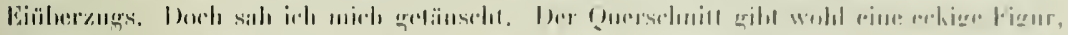

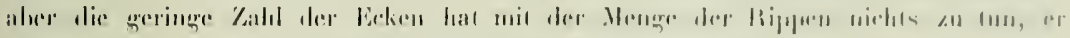

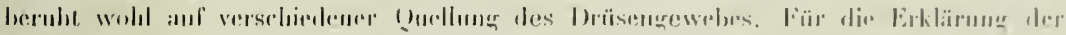

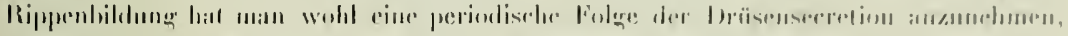

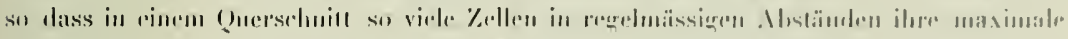

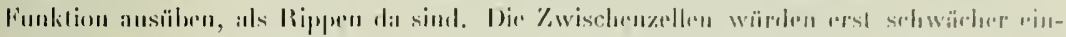
selzen, un daun das Maximum zu

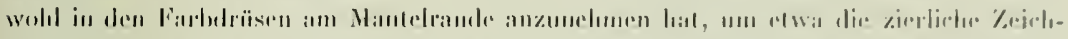

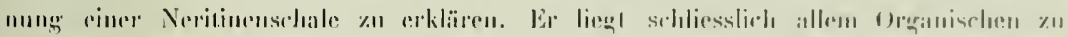

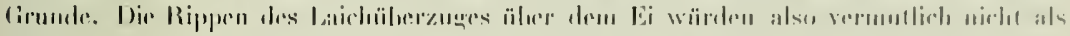

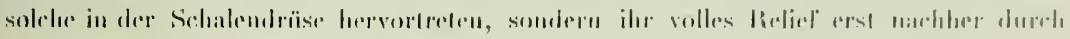
Aufipuellen whillen.

\section{Fuhrmanni n. sp}

(1'ill. XIII, rier. $7^{n-7 n .)}$

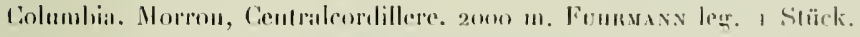

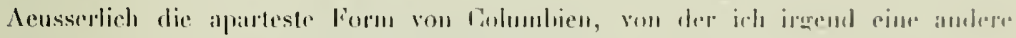

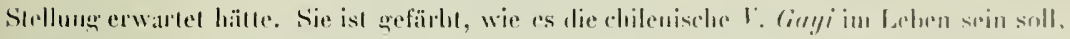

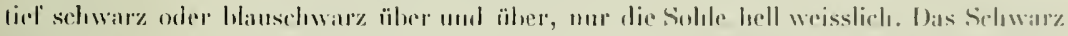
freht an Hyponotum seharf his an die unterste Grenze, so dass die finss- oder Mantelrime, I. I. die Medianseite des Hyponotums und Lalteralseile des Fusses weiss siml.

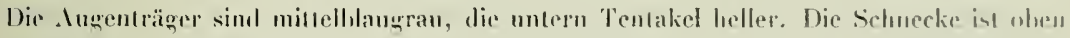
gewälb und lällt seitlich ziemlich steil al, das Perinolum libled eine slumpfe lianle. Dir

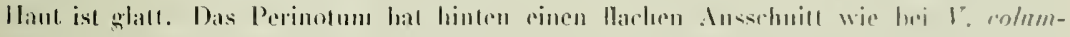
biuma (s. o.)

Die Mansse siml:

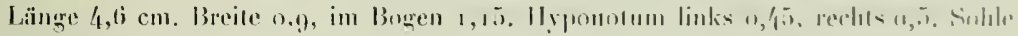

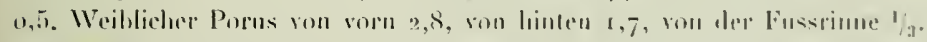

Anatomisches.

Ein Leberlappen begr quer vorn herrïler.

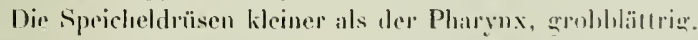

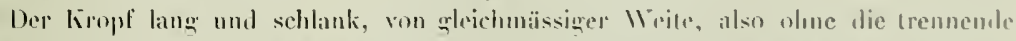

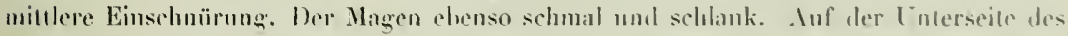
limplis, elwas mach rechls verschohen, verdanfen awei weisse Strifen, wnhl nustulise

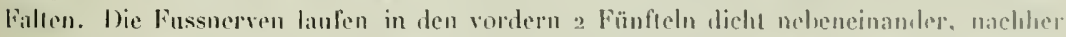

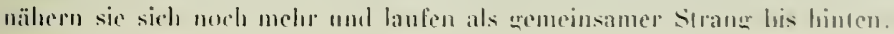




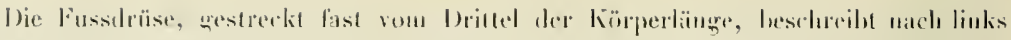
und recluts ein doppeltes linir. Weisser secrelstreifen when in ganzer bänge.

Die weibliche Reife ist voll erreicht. 13 Pfeildrüsensedalüuche von verschiedener

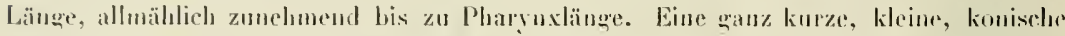
Plipilpapille. Der Penis, mit langem Retrakior, ist etwas länger als der Plaryux, gerstreckt

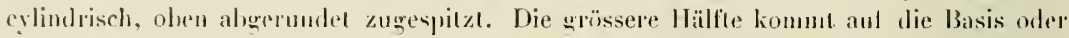
den Sockel, der mil ciner vorspringenden liante schliesst.

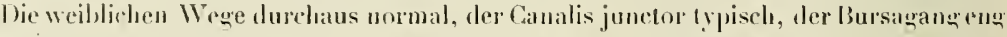
und lanw. Höchst antfällig aber ist eine kleine ovale Tasche, deren Wäule platl auleinander liegen, zwiscles Oviduct und Eudsarm, wohl nur als secundïre bursa ropulatrix zu deuten. der einzige Fall in der Familie nebn $V^{r}$. mexicana, bei welcher indess dats elwas lä̈grese und gestielte Aubïngsel auf der medialen Seite des Eileitrers liegt (s. o.).

Besondere Wandstrulituren marlsten sich micht bemerklich, ausser rundlichen Bläschen, die sich dicht drängten und wohl Drïsen sind.

Man möchte natürlich geneigh sein, der form eine Sonderstellung anzmwrisen, die lärbmug, der Kropf, die Fussnerven, die sekundäre Bursa geben lauter abweichemle Merkmale. Gleichwohl habe ich keine weitere systematische Aenderung vornehmon

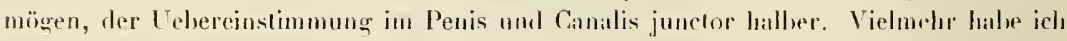
moch eine weitere Irt anzuschliessen:

\section{V. prismatica n. sp.}

(Tif, Xll1, Fig. $\left.7^{3-7} 7^{8 .}\right)$

Columbia. Cafetal Camelia bei Angelopolis, Centralcordillere 1800 m. Funumann leg. 2 Stïck.

Es gelang erst mil vieler Mühe, die neue Art ans zahbreichen Exemplaren der V. rufescens (s. 10.), mit denen ich sie in einem Glas erhalten und verwechselt hafte, lierauszufumlen. Die form ist ganz dieselhe, nur dass das Porinofum weniger als Kante vorspringt, also viehmehr dem von V. Fuhrmanni qleicht. Auch Zeichunng wud Fïbung waren durchaus ïhnlich, mit dem einzigen Unterschiede, dass der rote Grunden sich aul"s Notum beschräukte und ilem Hyponolum fehlte.

Die Schnecke sieht auf den ersten Blick fast schwarz aus mit weisser Sohle. Bei genauerem Zusehen argihs sieh eine feine Zeichmung. Das Notum hat in der Mitte einen

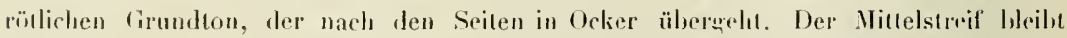
hell.

Dazu lommt eine graur Netzzeichunng, oft mehr in die Länge grezogen; ilır mischı sich vielfach Schwarz bei. Das Perinotum hleibt hell als feiner Strich. Das Iyponotum hat weisslichen Grund wie die Sohle, doch mit der grauschwarzen Zeichmung, die am Perinotum und hinten am intensivsten ist. Bei dem jungen Exemplar beiht, ausser an Ilinterende, die grössere untere llälfte des llypunotums weiss, hei dem erwathenen 


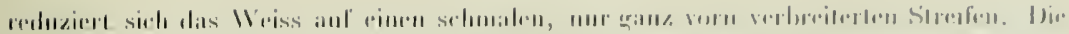

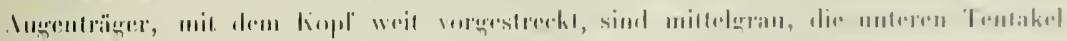

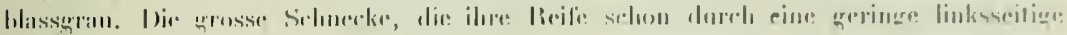

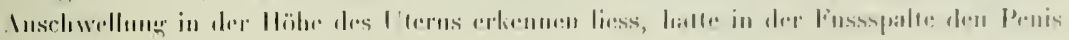
sichlbar vorgestrerlit.

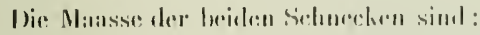

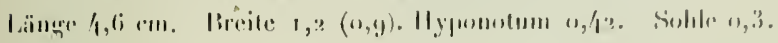

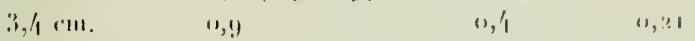

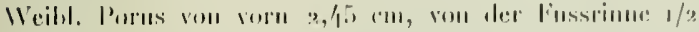

$$
1,1 \text { 1 } 111
$$

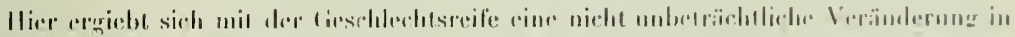

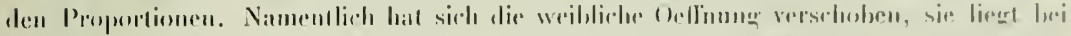

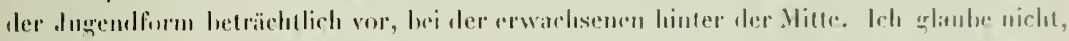

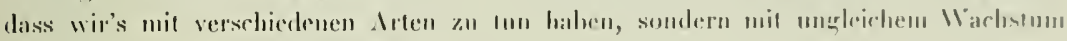

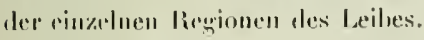

Inalomisthes.

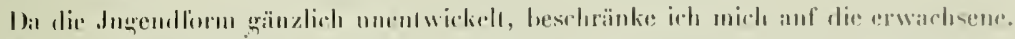

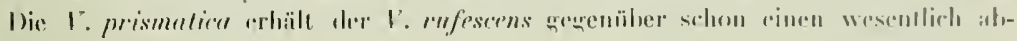

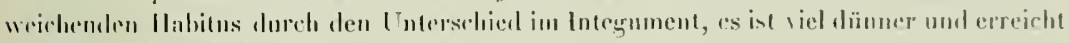
im Nolum kinum die Hälfte der Dicke.

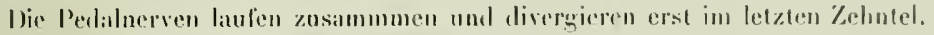

Die: Sipecicheldrösen ziemlich grobblïtrig.

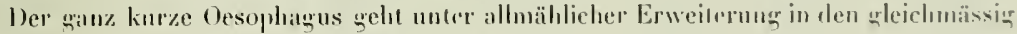
lingen kropt äber, dir noch hall gifülll war.

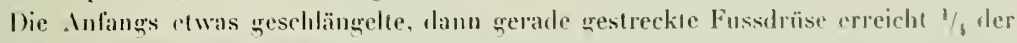
Körperlänze. Besondere lokate Differenzierung im Secret ist nicht wahrzunchmen, vielmehr ist dor ganze Schlanch weisslich, etwa eine Mittelstufe zwischen hyalinem Schleimund derh weissem Secretwewebe.

Die mä̈nnlichen Organe. 15 schmake Pfrildrüsensehläuche bilden ein dichtes Bändel von etwa doppeleer Länge als bei $\mathrm{V}$. Fuhrmenni. Eine secundäre Scheide un ihre Vorderhälfte ist hächstens angedeuted. Der lange Penisretrahtor gihl zwei schlanke Muskeln an

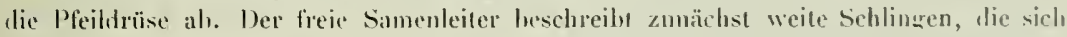
z. T, zwischen Pfeildrüsen und Penisscheiele einschiehen. Inf dicser Strecte ist er sohr weit. Plätich verengert er sich und dringt dann latd in den Penis ain. Der Penis int dem der V. Fuhrmanni durchaus ähnlich. Die Pfoilpapille dagregen ist viel länger, trestreckt konisch.

In den weiblichen Urwanen herrshot grosse Achulichkeil mit 1. Fuhrmanni. sie sind drenso qypisch, derselhe langeylundrische Bursagang etc. Höchstens kënnte man siluen, ditss der kurze, ungeschtängelte Canalis junctor plëtzlich, d. h. unter scharfem Msatz, sich mil der Bursal verbindet. Dir secundäre Bursa ist ebenso vorlanden, zwischen 


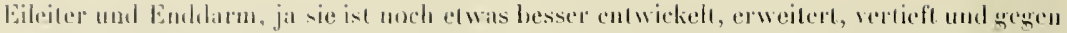
vie Mündung stielartign verengert.

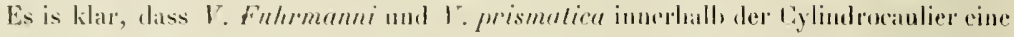
cuge, scharl' umgrenzle Gruppe liblen.

\section{V. pterocaulis $\mathbf{n}$. sp.}

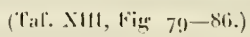

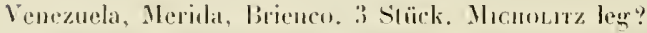

7wei groser, erwachsene, vermutlich in Copula erbentete Släcke, dazu ein viel kleineres, junges, das scheinbar nicht dazu gehört und doch beinalıe mit sicherlaeil dazu gerechned werden muss, nach den Manssen und der Analomie. Die qrossen haben im

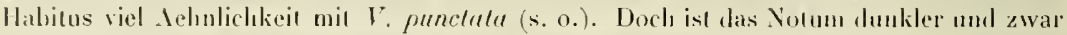
aus Dunkelinrau und Ocker marmoriert, so dass dieser helle Flecke aul' dem Grunde ansspart. Dazu kommen tiefschware Drësenpunkte, die hier nichts mit dem Ocker zu Inu hahen, sondern bald in hellem, bald in dunkeln Fehle stehen. Das dunkle Hyponolum olune die Punkte. Das Perinotum elwas blasser. Das kleine Exenplar älser und äber einlarbiz rolgrau, ohne Mhzeichen. Nlle mit Spuren eines helleren Medianstreifens. Dis kleine Stück hat die mediane Rinne anf der Sohle, wie wir sie hei Phyllocauliern häulieger antrifen.

Die Maasse eines grossen und des kleinen Slückes sind:

$\begin{array}{cccccc}\text { Länge } & \text { Breite } & \text { Hypon. } & \text { Sohle } & \text { Weiblicher Porus von vorn und von hinten } & \text { von der Fussrinne } \\ 5,5 \mathrm{~cm} & 1,85 & 0,65 & 0,65 & 2,55 \mathrm{~cm} & 1 / 4 \\ 3,1 \quad 11 & 1,15 & 0,35 & 0,35 & 1,7 \mathrm{~cm} & 1 / 4\end{array}$

Die Proportionen sind die greichen, namentich liegt die weibliche Oeflnumg bej beiden genau in der Mitte.

\section{Anatomisches.}

Fussdrüse ein Schlauch in der Medianlinie, in ler Milte durch eine nach links mul liuten ausbiegende Schleife unterbrochen. Ein weisser Medianstreif verläuft an der Decke res vorderen geraden Abschnittes und der Schleile, im lintern geraden, verschnälerten Blindende nimm er die gauze Breite ein. Bei dem kleiren Stück genau so, wieder eiu Beweis für die Konstanz dieses Merkmals.

Die Pfeildrüsenschläuche, I8 an der Zahl, sind hier von einer besonders deullichen secundären Mesenchymscheide umhüllt, imnerhalb deren sie in einer regelmässigen Spirale verlaufen. An ilı fasst der schlanke Muskel an, der sich vom langen und kräftigen Penisretraktor erst distal alyzweigt. Die Pfeilpapille ist ziemlich kurz und stumpf, etwas gekrimmt und abgellach. Die eine der yrossen Schnecken hatte den Kopf und Penis zuräckgezogen, die andere hatte beide ausgestreckt. Das erlaubt einige Formänderungen des Penis beim Gebranch festzustellen. Er zerfällt, von cinem kurzen Sockel abgesehı, 


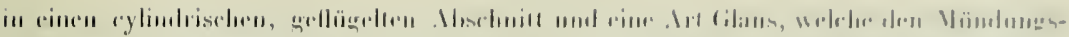

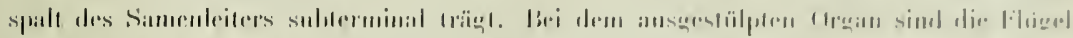

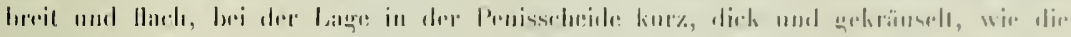

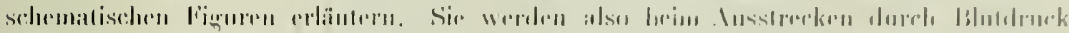

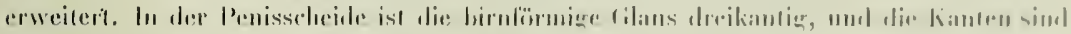

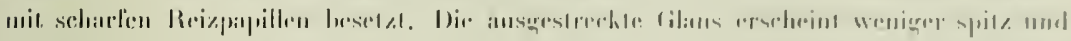

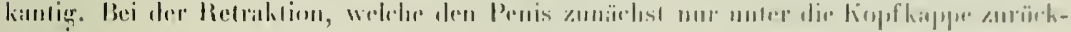

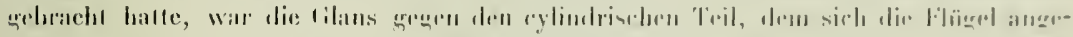

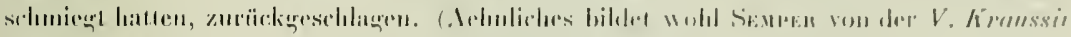

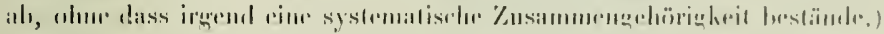

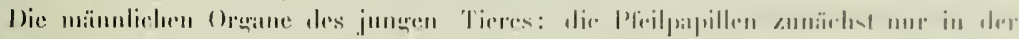

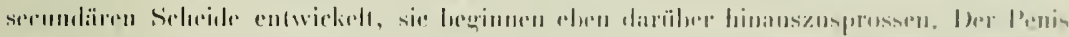

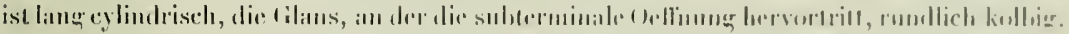

\section{Uebersicht über die Cylindrocaulier.}

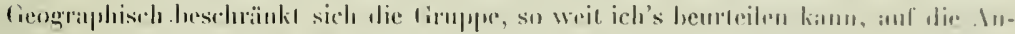

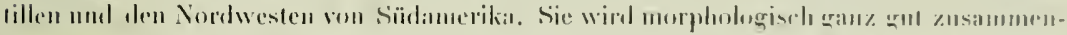

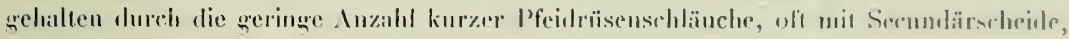

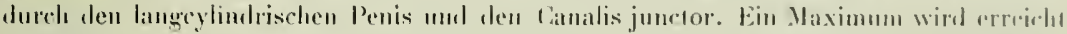

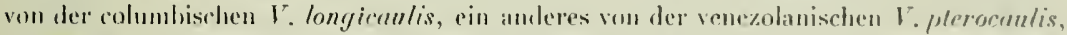

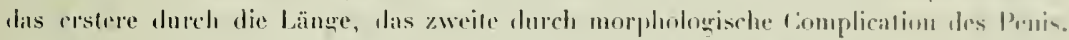

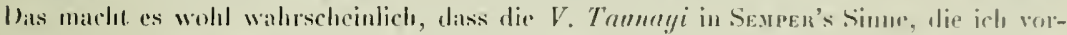
hin mit hergestellt hatte, zu Rochl hier steht. Man sollte irgend ein Extrem in der Penis-

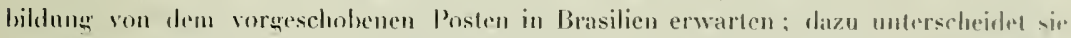
sich wesentlich durch ihre Crösse und die vordere Lage les weihlichen J'orus. Virrmulich wird ilı künftige genanere l'ntersuchung eine andere Stellung amweisen.

Wemn die übrigen Irten anatomisch ganz gुut alggeorenzt erscheinen. 1rotz. allerlei lilferenzen in Verlanf der Fussnerven, in der. Anshildung des liropfs u, dergh., so inōchle man wieder schwankend werken, wegen der helrächtlichn Verschiedenheit der änsseren Ciestalt. Die meisten haben den gewönlichen läugsovalen Limriss und krïmmen sich, Wä damil Hand in Iland zu gehen pHlegt, im Alkoholtude nach der Bauchseite ein, die somit concar wird. 1". columbiana dagegen. sellist wieder ein variahter, in der Imbilduner hegriffener formenkreis, isl sthlanker mit fast parallelen seitenrändern umb oft ciner

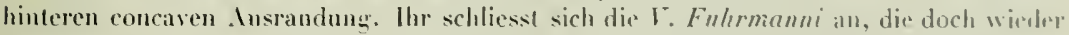
dureh die aullällige färbung sehart alssteht. Analomisch ist ihr dured den Verlanf der Pedalnerven, namentlich ahe dureh die secmudäre Bursa copulatrix ein besomberer Platz gesichert. Und so sieht man sich leider wieder zu dem Gestï̈dnis trezwungen, dars die Gruppe der Gylindrocaulier zwar durch dic Morphologie der Copulintouswerkzeuse 


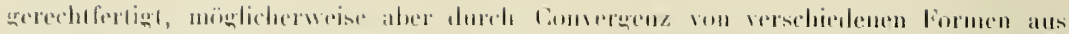
herrorgearamenn ist.

\section{Choanocaulier. Trichterruten.}

Ein P'alar alsonderliche keine Formen, die im Einzehen viol interessantes bielen, lansen sich wohl dureh die trichterartige Erweiterung des Penisendes an hesten als zus:ammengehöriz liennzeichnen.

\section{V. minuta n. sp.}

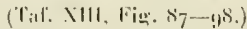

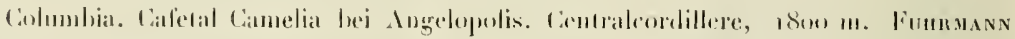
lew. 3 Silijck.

Zwei ziemlich schlanke Schnecken ron noch nicht anderthall, em. Lïnge ( 13 und $14 \mathrm{~mm}$ ), haben die Begattungsorgane ausgestreckt, sind also in Cepula gefingen. Sie reprïsentieren die kleinste Ar der Familir, denn alle bekannten bleiben über a cm, ïhertrellen dabei noch reichlich das grïssere dritte Stäck. Dessen Maasse sind: Länge 1,7 cm. breite o, 1 1. Hyponotum o, 2, Solsle o, 13-0,14. Weiblicher Porus von vorn 1, 15, von hinten 1, $5.5 \mathrm{~cm}$, von der Fussrinne fast 1/2. Der Rüeken hat einen blassgranen oder ockerigen tirund, je nach den Stücken. Ein Mittelstreif lehlt durchaus. Dichte dunkelgrane Flecken betecken den firund netzarligg, sie gehen vielfach in Sehwarz äber, mamentlich häult sich das Sichwarz nach der Mitte zu, bei einem Stück (Fig. gu) zu rinem elwas nach links verschobenen Längshalken, der sich nach vorn hin auflösl, bei den anderen requelrecht gesteigert nach der Jitte zu. Das Jyponotum ist blass und ähulich gelleckt. Das Perinotnm, ein hlasser Streifen, fällt durch seine Drüsen auf. Sie hilden eine liette hellerer Knoten, mehr als 20 jederseits. Das Schwarz drä̈gt sich von when und unton gegren sie heran, doch so, dass eine hellere Verbiudungsslinie am Rand frei bleiht. Wie Drösen treten mithin hier fast in embryonaler Gestalt auf, wie Simason's uns einesolche Reile hoim, Embryo kennen leluten; und man darf annehmen, dass die verschiedenen (iewebe mit der alsoder zumehmenden lï̈perürösse nicht goleichen Schrill halten; die Drïsen scheinen vielmehr ein gewisses absolutes Maass zu verlangen, unter das sie nichl heralssinken. Die interessante Frare, ob dieses Geselz nur für die Randdrïsen am Perinolum gilt, labu ich nicht weiter untersucht, da ich nicht mit Schnitten arbeitete. Die Lupe lässt weder auf arm Notum noch aul dem Perinotum weitese Poren erkennen, und so kommen für diese liächen, sovicl ich sche, viclleicht bur einzallige Drüsen in Betracht, also noch im Ejpithel ohne Einsenkung eines gemeinsamen llohlranms. Wie hei anderen Formen (unfer den Cydindrocanliern) ausqefïlut (s. o.), sind die lileinen Drüsen des Notums von den „2rossen anscheinend nur durch ibren Unlang verschieden, es finden sich alle Velverü̈nge. Ich ghaulse dalier, dass man für die Dribenentwielilung, the ja bei den Soleolifiren einen

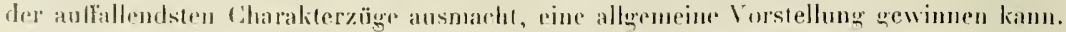
Ich würde sehliessen: 


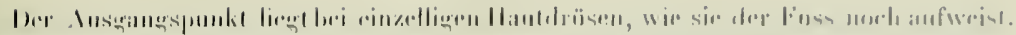

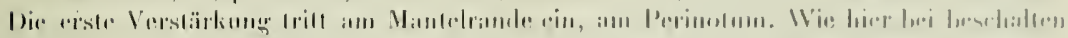

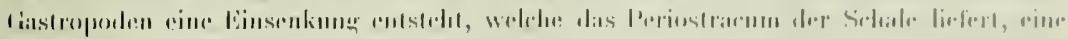

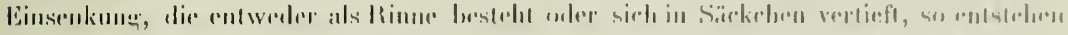

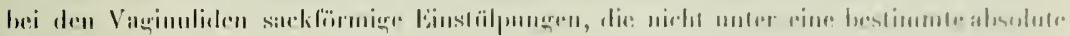

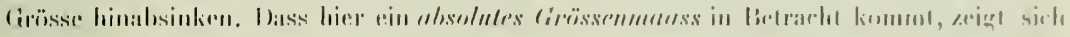

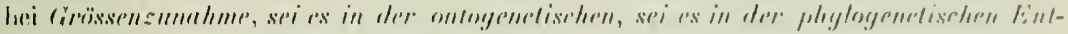

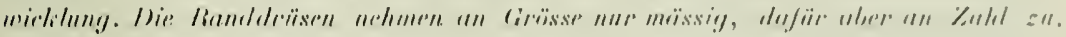

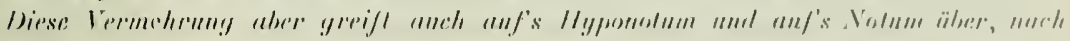

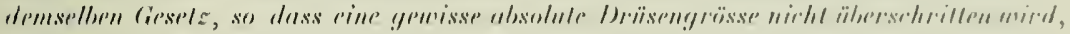

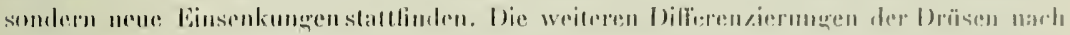

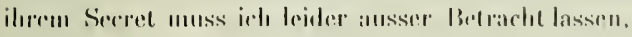

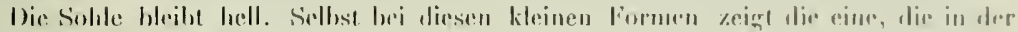

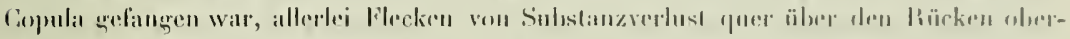

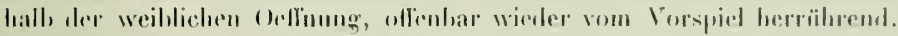

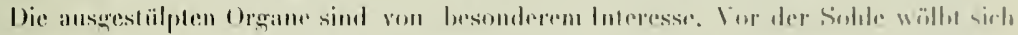

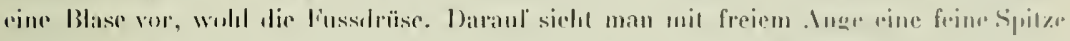

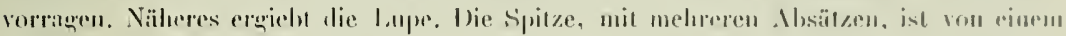

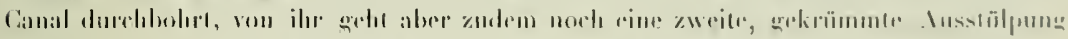

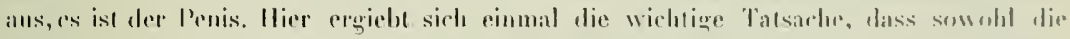

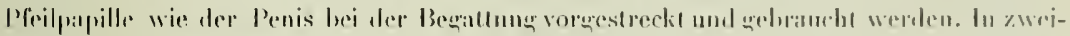

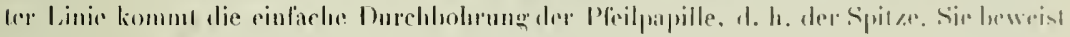
die vorleregegangene Versehmelzmng der Pleildrïsensehlïuche.

Inalomisrles.

Ein Leberlippen lingt auch hier yuer vor dem lutestinalsack.

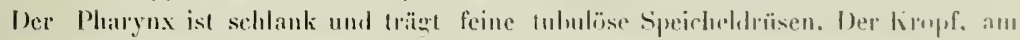

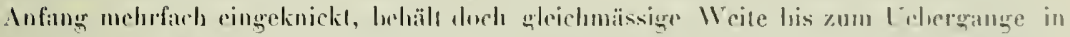

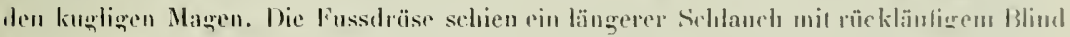
imele. Dorsal der weisse Secerelstreifen.

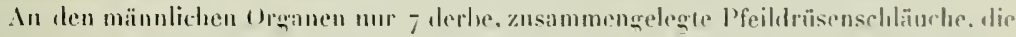

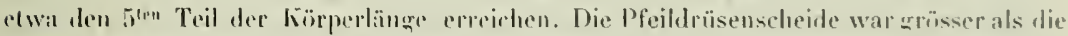
Penisscheide, die P'eilpapille schlank mit riner knopfarlig ahgestzten Embsjitze, dorsulhen, die beim Hervorstrecken weiter gereckt und verlïngent zu werden scheint. Der Penis

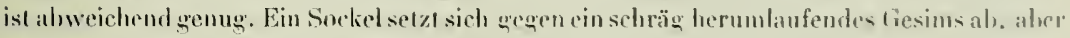

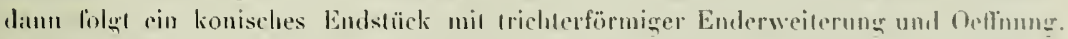

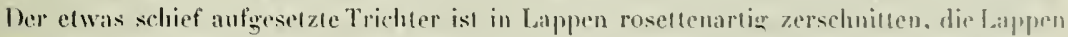

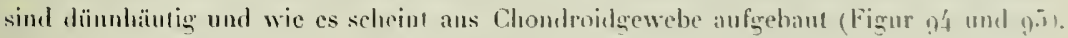
Brom Uphertragen in Glycerin schrumpften sie zu derleren Spifzen zusammen.

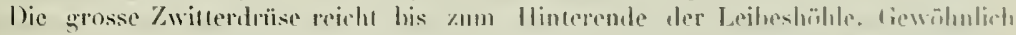

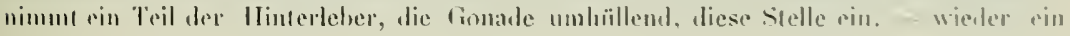




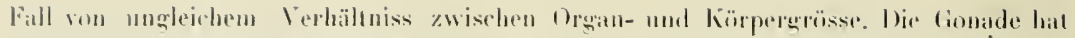

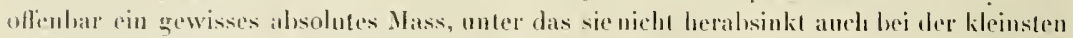
lorm. Die weiblichen Oregane, gut entwickelt, waren lypisch. Der stark anfqeknänelte

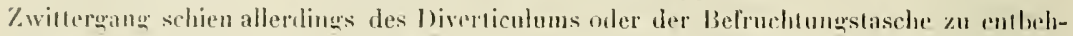

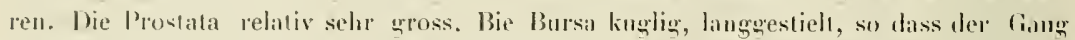

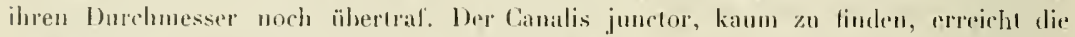

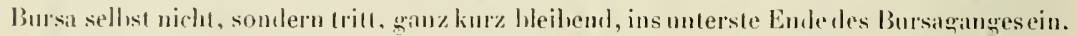

Der Endarm trilt unmitellar neben der weiblichen Oeffung ins Integument.

Die klene Sehnecke, wirwohl äusserlich von manchen Jugendformen kaum zu unterscheiden und von den Sammlern mit ihmen zusimmengestell, steht doch ganz isoliert, äusserdich durch die Drösen, immerdich durch die (restalt und Struktur des Penis. Die einzige Form, die man ans der literalur vielleicht zum Vergleich luranzinhen könnte, ist wohl Sempen's 1 . punclatissimu von den Antillen, wenigstens soll hier rin breiter, einereschnittener Lappen die spitze des ebenso knrzen Penis bilden. Doch finden sich, von der fast dreifarluen Länge abuesehı, so vied Differenzen in den Beschreihungen, dass an rim. nähere Verwandtschaft kaum zu denken ist. Der Hauptwert der V. mimula schrint

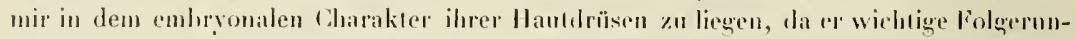
gen zu zichen erlaubl. Und dat lisst sirh wohl eine aul den ersten Blick ganz versidiedene Schnerke anknïpren, uämlich

\section{V. calcifera n. sp.}

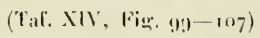

am Rio Branco. Husasen leg, 1896.1 Stück.

linyana nnel namentlich südlich davon das nördlichar Brasilien ist bisher hei den Virginuliden schwach vertreten ; um so erwänschter das vereinzelte Exemplar, freilich ohne genauere Bezeichung der Localitä, dem der Rio Branco ist lang.

Der Habitus ist granz anders als bei 1 . minnta, bej retriliestem liopf ventralzusammengekrümmt und durchaus rgellaft, dabei äber und äber einfarhig, dunkel ockiriģ, das Notum vielleich noch etwas dunkfer durch schattenhaft eingemischtes Schwarz. Sellist die Tentakel sind rein ockerig, so dass das Auge sehr kilar hervortritt. Teber das wahre Colorit lässt sich indes schlecht urteilen, weil der Alkohol von der Schnecke gehhbraun erefïrbt ist, ohne dass ich zu sagen wïsste, ob ein Hant-oder Leberpigment extrahiert wurde. Die Mitteldarmdrïse ist, wie gleich lemerkt worden may, besonders dunkel, was natürlich mil der gerade aufgenommenen Nahrung zusammenhängen mag. Das Perinolum ist stumpf, die Kante springt gar nicht vor. Zunächst die Maasse: Länge üher den Rä̈lien gemessen 4,3 cm, ohne Rücksicht auf die Krömmung r,7. Breile entsprechend $I, 9$ und 1,3. Hyponotum links o,5, rechts $n, 7,3$, also rechl unsymmetrisch. Solle 0,35,

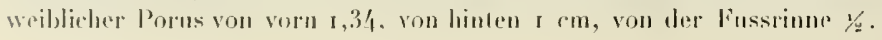




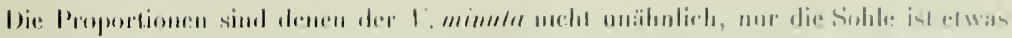

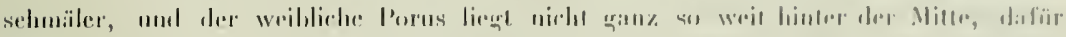

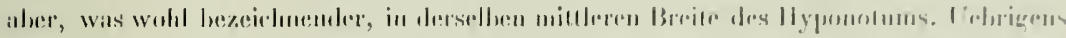

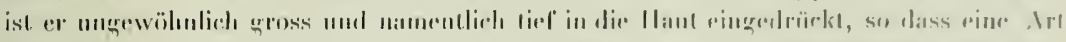

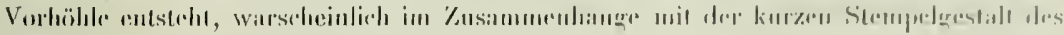
Penis (s. II.).

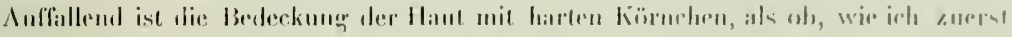

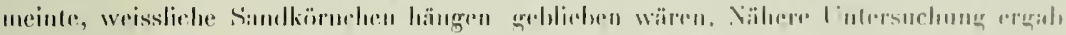

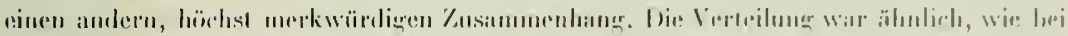

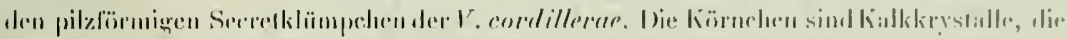

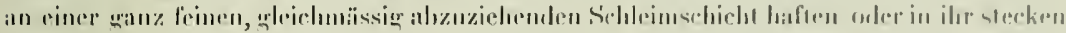

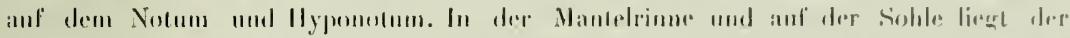

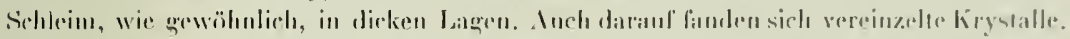

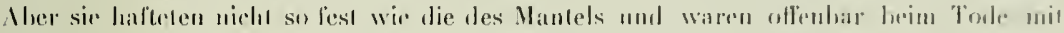

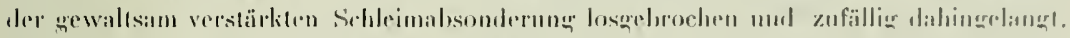

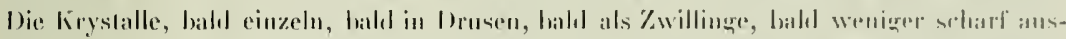

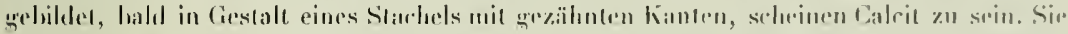

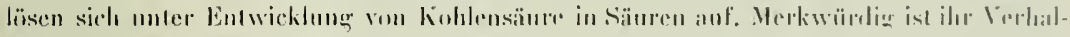

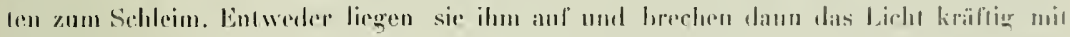

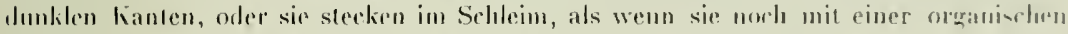
dirundage zusammengesehweisst wären. Narh der Enlkalkmug sieht man dan in dem durch die Säure slärker geronnen Schleim hasse Lücken von lirgstallform. Vereinzel

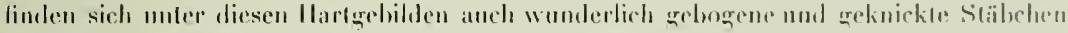

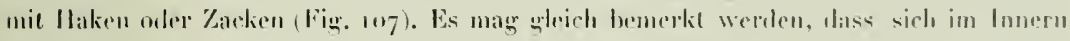

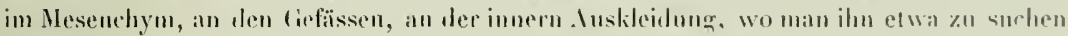
hälte, kein lialk find.

Die brscheinung ist an so anflälliger, als der Kilk unter den l'uhnomaten nirerends

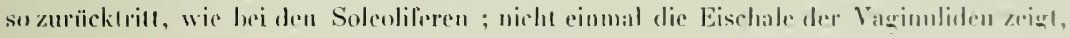

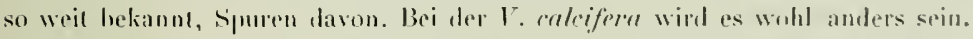

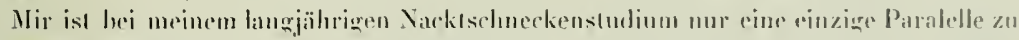

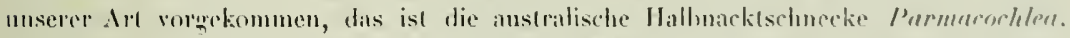
welche ganz älntiche Kalkikrstalle nicht nur an Mantel trïgt. sondern auch in der Conqudung anf den Seifen des Fusses. Ich habe sie Dermocatcite genannt. Im Cirumle senommen sind diese beiden bälle vermutlich von höchsler Bedentumer für dir llerkunft der P’ul.

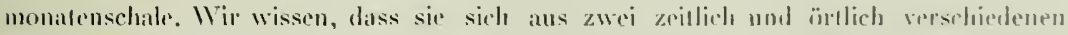
Moscheidungen aufhant, aus dem Periostracum, das vom äussersten Mantelrande wedilılol

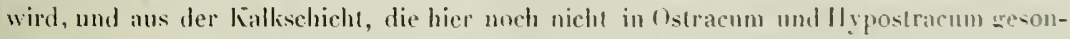
derl ist, so dass wenigstens nur in cinzehen Fällen das lelztere sich elwils perlmulteralligh abhebt, wie hei Zonites. Dann sind wohl dir Zollen, welche das Oslraeum liefern, lin-

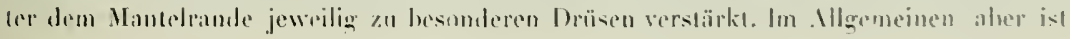




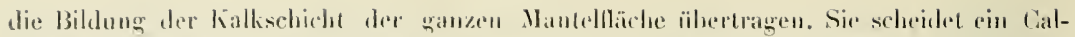
ciumalluminat ab, und erst nach der serretion zerlewt sich's in den krystallisieremden Kalk und in die Conehinhäutchen, welehe die Kislksehicht durehselzen. Die Kalkirystalle

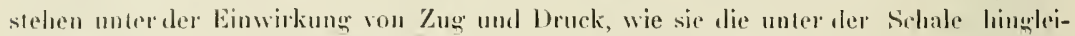
trode. Mantelthiche hedingl, sie orlnen sich zu entsprechenden Sisten wie die Trahekel in unseren Röhrenknochen. Wo das Periostracun fehlt, wite bei Schalenreparaturen

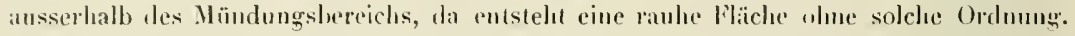
Parmacochlea nun und Vaginula calcifera sind die einzigen bekannten Pulmonalen, wo

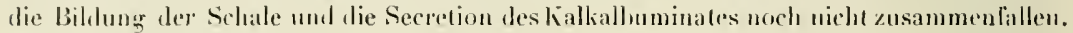

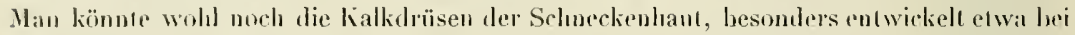

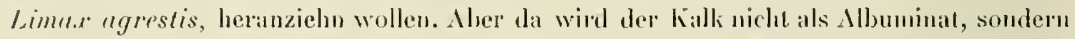
loreits im Inmern der Drüsen in Form von kïmchen abgeschieden. In weitern Sinne

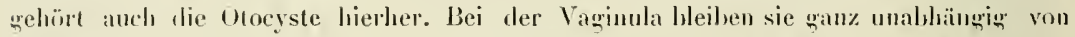
einander. Das Conchinschälehen wird bereits vom Embryo alogestossen. Nachlier setzl vermutich erst die Bildung der Dermocalcite ein.

Noch drängt sich eine Idee auf, die Konstintion unserer Schnecke betrellent. Es ist. doch höclıst sonderbar, dass das Pigment in der Hant so ganz zurïcktritl, sellsst in den Angentrïgern. Ist nicht der Kalk hier an seine Stelle getreten?

Die llaut erscheint anffallend l'ein und glatt, am Perinotum nur lassen sich einzehe Poren erkennen, so lass hier wolıl wieder Drüsen von besonderer Funktion liegen. Die Chälle zeigt sich besonders am Perinotum, das zwar gerunzelt erscheint, aber die Rumzeln folgen der Querrichtung, d. h. der Muskelordnung. Querschnitt ergeben die übliche' Mantelstruktur. Die Drüsen des Perinotums treten durch ilıre Grösse hervor, sie sind tief eingesenkl und bauchig erweitert. Notum und Hyponotum sind überall mil dicht gestellten Einsackungen bedeckt, meist nur mässig vertieft und da, wo sie sich tiefer einsenken, doch nur sclumal und eng. Es ist wohl eine Dillerenzierung anzunehmen, wobei die kleinen Drïsen den Kalk lielern werden. Ob die des Perinotums Wehrdrïsen sind, kam wohıl nur die Beohachlung der Lehenden entscheiden. Zu feinerm listologischen Sudimu genëğ die Conservierung leider nicht.

Die Solule zeigt auf eine Strecke regelrechte erhahene Querleisten, gewissermassen lixierte locomotorische Wellen. lede umfasst melırere Solcolar, wie ich's frïher von der lebenden Schnecke beschrieb. Die Entfernungen zwisclien den Wellen sind so, dass anf die wanze Sohle etwa 25 Wellen kommen würden, was den natïrlichen Verhältnissen entsprechen möchte. Gelegentlich sahı ich solche Fixation auch hei andern Arten. Berulıt sie anf der Fixierung der Muskelwelle oder der Blutschwellung? Wahtscheinlich in erster Linie auf letzterer. Zu heiden Seiten läuft ja über der Sohle ein starker Blutsinus, der durch Septen gekanmert ist. Ich wies zuerst bei Ltopos auf die Sphnucteren hin; Salzasiss beschrieben sie nachher auslührlicher. Sie treiben jedenfalls das Blut in die Sohle und zwar in der regelrediten Folge der Wellen. Monel,et gab bei Fiscuer (5. Lit. viez.) [an wunderlickes Bihl von einer kriechenden Vaginuk, wo die erhahenen Querwellen sich 


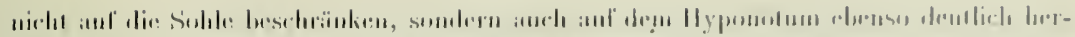

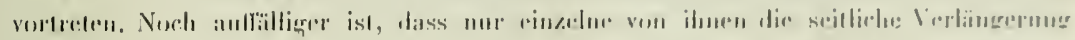

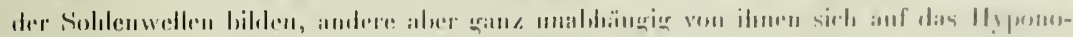

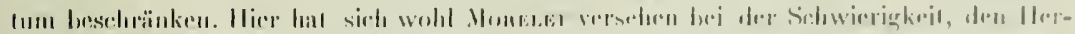

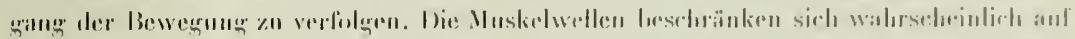

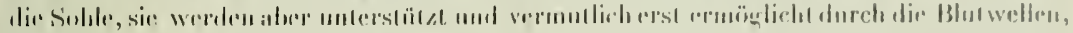

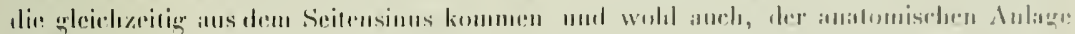

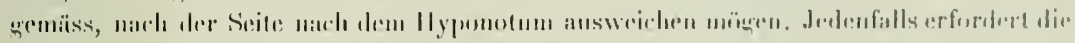

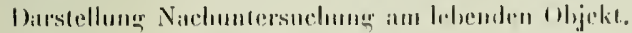

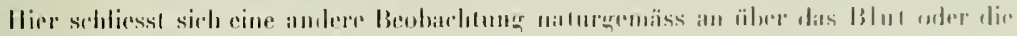

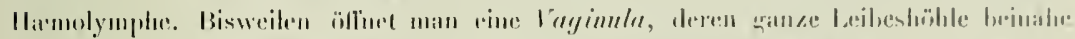

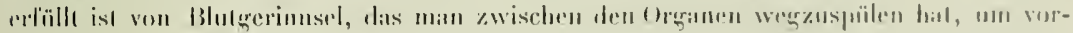

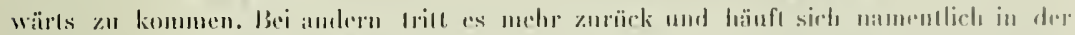

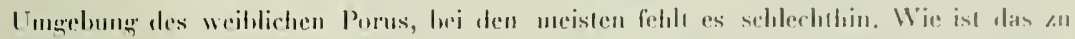

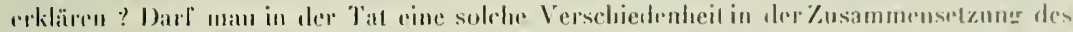

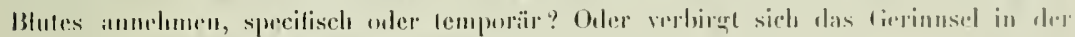

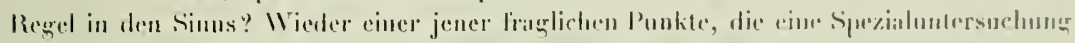

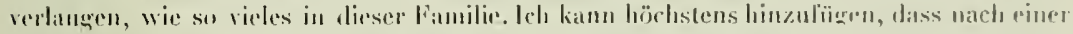

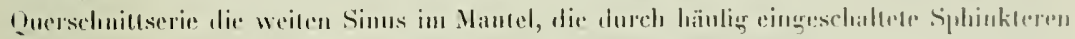

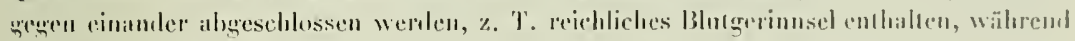
atulere leere simd.

lemtomisches.

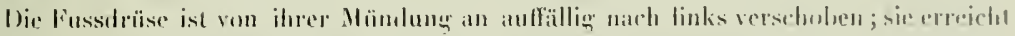

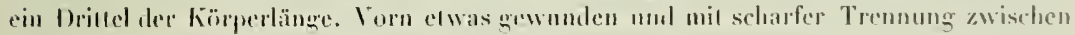
Schleim- umb horsilem weissen secregewerhe. Letzleres sehwill hinten zu cinem hreileren Silck in.

Vorn ein schmater lecherdiplen.

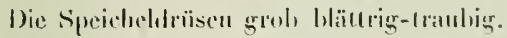

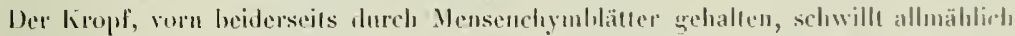
fweit an, um sich dam wieder zu verjüngen uml als enger Darm in den .lagen zı münden. Der trestedu ledighlielı aus dem lïnglichen ovalen Muskelmagen, olue dass es zu dem äblichen Vormagen käme. Die Ilinterleber sendet ihren schmalen Gianer von der Seite in ihu lerein kur\% vor seinem Ilinterende.

Die Schnecke war gut entwickett.

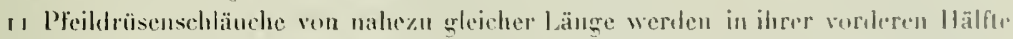
durch eine deulliche Secundärschride zusammengehalten, die einen. Ist rom kurzem Penis-

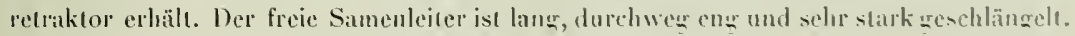
In der Pteildrïsenselucide sleckl eime krältigne am Ende umgehogene Pfeilpapille. Die kleinere Penisseheide enthält cinen kurzen P'enis, dessen cylindrischer Scltaft sich oben auffällig verbreiter. Es entsteht ein weiter Ring mit einigen vorspringenden Zipfeln, der 


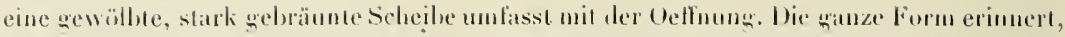
wemn man von dem Sinus absieht, an den Penis der V. minutu, der lions entspricht dem Trichter.

Die weiblichen Endwege gleiche'n denen der Zwergart noch mehr; denu der kurze tanalis junctor tritt ebenso in's mutere Ende des Bursaganges ein. Die Bursa ist elensu kuglig, der Endtarm trilt unmithelbar neben dem Porus in's lntegument ein.

Nimmt man dic Jage des weiblichen Porus in der mitteren Breite des Ilyponoums dazı, so werden die beiden Arten anatomisch andlallend eng verknüpft. Sie bilden wohl aine der primitiosten und interessantesten Gruppen der grossen Finilie.

\section{Angustipes-Gruppe. Brevicaulier, Kurzruten.}

As eine letzte Gruppe möchte ieh eine Anzahl miltelgrosser formen zusammenlissen, für die von älteren heglaubigten Arten die $V$. angustipes Hern, vorliegt. In der Tat scheinen alle einen niedrigen Sohlen-Coeffizienten zu haben, wenn er auch keineswegs durchweg unter die von schmalsohligen Arteu aus andern Gruppen herabzusinken hraucht. Es mag genügen, dass keine breitsohligen darunter sind. Die liörpergestalt schwankı wieder zwischen oval und prismatisch, die letztere wiegt vor. Das wesentliche Kennzeichen ist ein kurzer, Mach coniseher oder herzförmiger Penis und der Eintritt des Canilis junctor in den Bursagang oder in die Bursa unmiltelbar neben dem Gange.

llierher gehören $\%$. angustipes Heynem., die drei Arten, die ich früher von Paraguay beschricb, aher jetzt glaube in 4 zerlegen zu sollen, und 3 neue Species von Columbien, cine von Prof. Bürger, 2 von Pror. Funimaxs erbeutet. Um zunächst einen Anlalt für die Beurteilung der Körperproportionen zu gewimuen, stelle ich die Maasse voran.

\begin{tabular}{|c|c|c|c|c|c|c|c|c|c|c|c|}
\hline & & & \multirow[b]{2}{*}{ 志 } & \multirow[b]{2}{*}{ 站 } & \multirow[b]{2}{*}{$\begin{array}{l}\text { 톺 } \\
\text { 흘 } \\
\text { 호 }\end{array}$} & \multirow[b]{2}{*}{ 苇 } & \multirow[b]{2}{*}{ 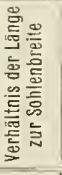 } & \multicolumn{4}{|c|}{ Weiblicher Purus } \\
\hline & & & & & & & & 总 & $\begin{array}{l}\text { 들 } \\
\text { 产 } \\
\text { 홍 }\end{array}$ & 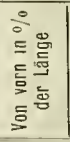 & 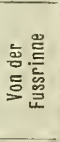 \\
\hline V. anguslipes & . . & . . . & $\begin{array}{l}\mathrm{cm} \\
3,3\end{array}$ & 0,9 & 0,46 & 0,15 & 21 & 1,9 & 1,2 & 59 & 34 \\
\hline V. parrayuensis. & . . & . . & 3,5 & 1,4 & $\mathrm{r}, 3$ & 0,3 & 13 & 2,15 & 1,4 & 68,3 & i) \\
\hline I. Tryylori. . & . . & . & 6,4 & 2,45 & 1,2 & 0,7 & $9, I$ & 2,8 & 2,3 & 55 & $2 ; 5$ \\
\hline V. Jordani. . & . . & . . & 4,5 & 1 & 0,45 & 0,2 & 22 & 2,2 & 2,5 & 47,2 & $3 / 5$ \\
\hline V. affinis n. sp. & . . & . & 4,4 & 1 & 0,4 & 0,2 & 22 & 1,8 & 2,6 & 43,2 & $1 / 2$ \\
\hline V. Bïrgeri n. sp. & . . & . & 2,2 & 0,7 & 0,3 & 0,2 & 11 & 1,3 & I & 54,3 & $1 / 10$ \\
\hline 1. rnfesseens n. sp. & . & . & 5,2 & $I(1,1)$ & $o, 6$ & 0,48 & II & 2,8 & 2,6 & 52 & ${ }^{1}, 6$ \\
\hline V. varians $\mathrm{n}$. sp. . & & . & 4,2 & $\mathrm{t}, \mathrm{I}$ & 0,38 & 0,5 & 8,4 & 2,2 & 2,5 & 47 & $1 / 4$ \\
\hline
\end{tabular}




\section{V. angustipes Heynen.}

(1:il: . II, lizg, $11+x-1,1)$,

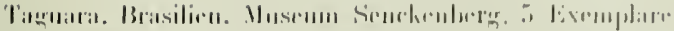

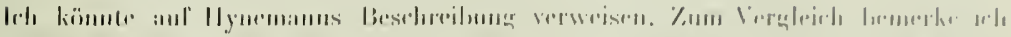

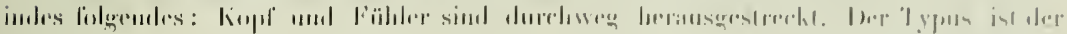

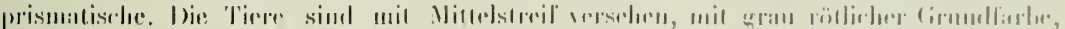

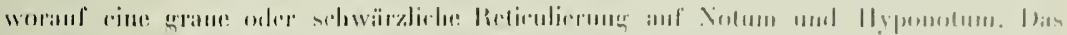

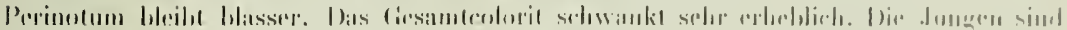

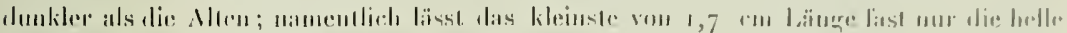

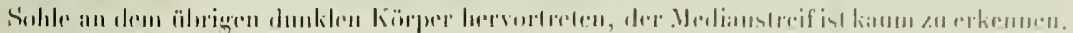

\section{Anotomisches.}

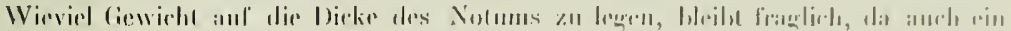

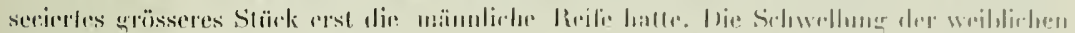

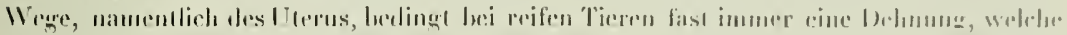

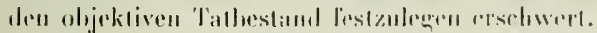

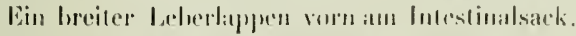

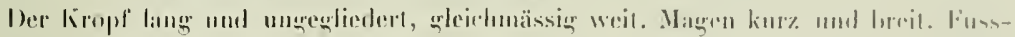

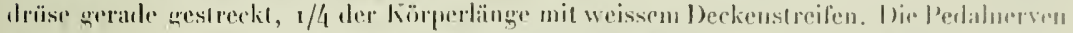
liewen vorn und hinten dicht zusiummen, nur in der Mille Ireten sie ctwas anseinander.

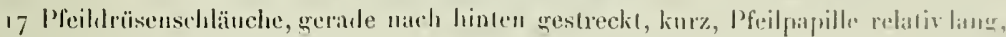

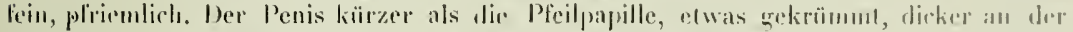
Basis. An den unentwickelnden weiblichen Endwerm liess sich dreh der wespulichn.

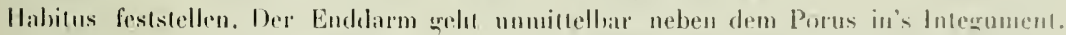

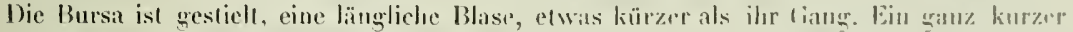
Cimalis junctor Irilt unten in den Bursigang ein.

\section{V. paraguensis Srth.}

(liaf. XII, liik. $111-113$.

P’araguay. Jemonas lew. 1 Stüek.

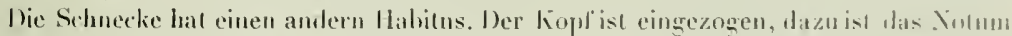
vorn und hinten etwas stärker zugespitzl, so dass mehr ein ovaler Tyjus heranstomme.

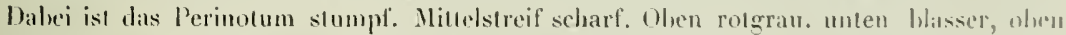
grau reticnliert mit seharfen, zerstreulen Fecken oder Punklen, von aanz verschiedener Cirüsse, wenigstens grösser, als dass sie Tuberkel und Drüs'nglfnungen berlenten kïnnten

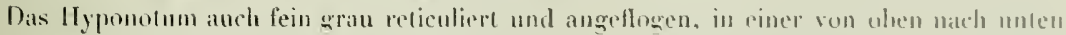
abmehmenden stäke. Das Perinolum hell. Die llant fein, fast glalt.

Anatomisches.

Ein Lelserlappen, breiter als bei den beiden nïchsten Arten, bildet elas Vorderende des Intestinalsacks, wie bei der ganzen Grupper. 


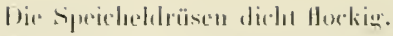

the Fussdrüse geralde anstreckt, ein schmaler Schlanch in der Miltellinie, mil zwei Abteilungen. In der vordern, die bis zu den Pedalgangrlen reieht, ist die Wand, wie es scheint, drüsenlos, sie ist cin einfacher Auslührgang. Der linntre, ctwas längere Aloschuilı hat dagegen die doppelte histologische Dillerenziesung in die Sehleimdrüse und den weisse'm Deckenstreif.

Auch dieses Tier war wenigr äber die männliche lieife hinausgrekonmen, die Zwit-

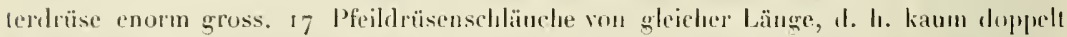

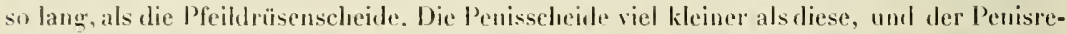
traktor elienfalls ziemlich kuz. Der P'enisscheide könute man allerdings noch cin cugeres cylindrisches Basalstück zurechnen, da der Samenleiter in den Redraktor lablowegs eintritt. Anch hier ist de gestreckt kunisehe Pleilpapille beträchllich länger als der kleine unerstenkornfürmige l'enis. Die weil,iehen Endwege schliessen sich wohl an die der vorigen Species an, loch war dic Bursa ganz ungestielt, das Vas deferens vertieft his zum Porus himunter, die 'Teilung liess sich noch nicht leststellen, es war kiar, dass der Catlitlis junctor, wenn vorhanden, nur kurz sein mol ganz unten eintreten kombe.

\section{Jordani Srth und}

\section{V. affinis n. sp.}

(Tall. NIV, lïg 118-120. Nigg. 121-123.)

Paraguay, Joundx leqr. Je I Exemplar.

Bei der Otiginalbeschreibung habe ich schon anl gewisse Lntersehiede der beiden Exemplare in der Färbung hingewiesen. Da jetzl anatomische Dillerenzen hinzutreten, so laalte ich's fïr nötig, zwei drten daraus zu machen. Sie lassen sich wohl schon durch die Maasse gut von einander trennen (s. o.). Gemeinsam ist beilen der Habitus, der cingrezogene Kopl', die selar schmale Solıle, der prismatiselue Typus.

V. Jorduni ist oben einfartig hellırau mit kaum durchdringemlem Medianstreifen 1. affinis lat eineu deulichen hellen Streifen, dazu schwames l'igment, fein gesprenkelt neben dem Streifen, ebenso gegendas Perinotum nach aussen zunchmend. Das Hyponotum ist bei beiden so hlass wie die Solıle.

\section{Anatomisches.}

Die Fussdrüse ist bei beiden ein langer schmaler Schlauch, vorn mil indifferentem Ausführgang, nachfier mit weissem Medianstreifen an der Decke. IVährent alier der

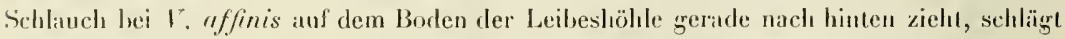
sich bei $V$. Jordani das letzle Viertel unter scharfer Biegung uach rechts und voru zurïck, nach den an der Familic gemachlen Erfahrungen ein wesentliches Moment.

Der vordere Leberlappen ist sclimal. 


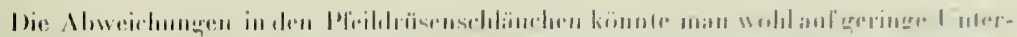

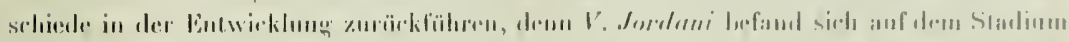

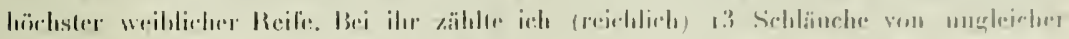

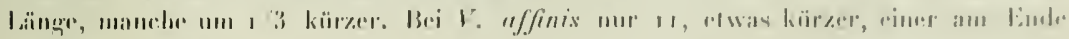

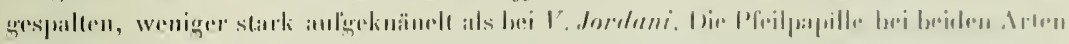

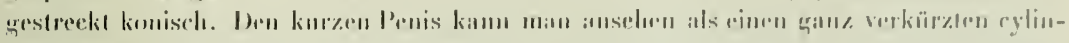

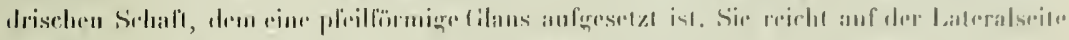

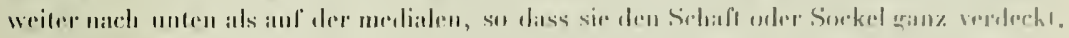

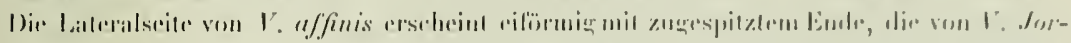

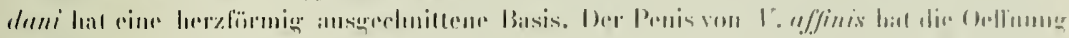

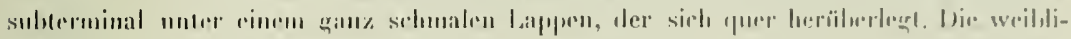

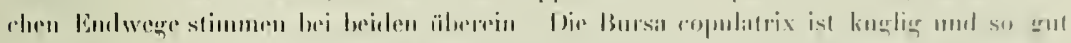

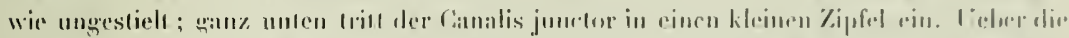

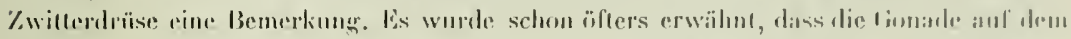

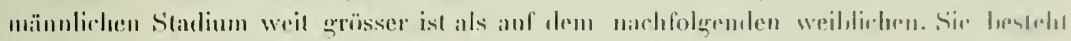

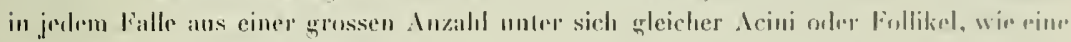

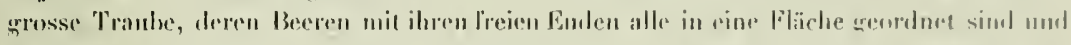

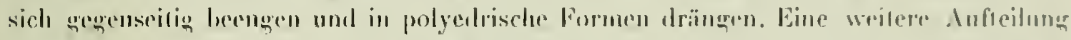

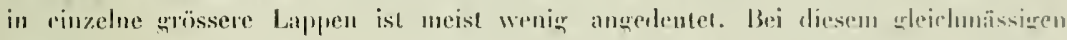
Ilathitus laillt as anf, dass dits kleiner weibliche Stadium moist grö̈ssere föllikel anfwrist, als dats umlangreichere männliche. lï̈r genanere Feststellung mïsste man wohl längere

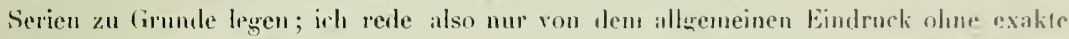
Basis, glanhe aher kanm zon irren. Wenn die Beobachtung slimm, so muss das spälore weibliche Starlium weit weniger Foltikel halven als das männliche, unch filuer den geschrumpflen Umfing linaus. Es müsste also entwedter eine grosse. Inzahl dep liullikel hei der weiblichen Reife zu Grunde gehen, oder die Reduktion beruht auf Verschmelzuner, die hei dem gleichmässigen Ausselun der Drüse jedesmal eine hestimmle Inzahl henichbachter Follikel zu einem vereinen würte. Mir scheint der letztere Modos der einzigre, der die Reduktion hinreichend erklärt. Nachalem die. Spermabildung im Inneru der Follikel sich erschöplt hat, widd dureh die Schwellung der peripherischen Eier, die ganze OtuerHäche aufgetrielsen, was recht wohl die Verschmelzung der Vachbarn herheiführen man.

\section{Taylori Srth.

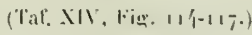

l'araguay. Jonoax leg. I Exemplare.

Die Form gehört nach dem Hahitus zu den bestgekennzeichneten der uanzen Familip.

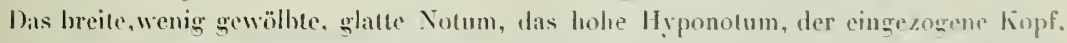
der dem Vorder- und Hinterende das gleiche Anssehn verleih, die kaum rorspringendo

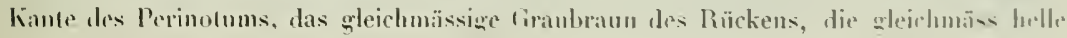


Lnterseite, die breite Alrumbung rom mul hinten schiffen eine rohuste, leicht an erkennende Schuecke. Man solle nach len Massen rein prismatischen Typus erwarten, anlfallenderweise krümmt sich die Ventralseite, wenn anch mïssig roncar ein so dass hier der prismatisehe Typus in den egelhalten ïhermeht.

\section{Inatomisches.}

Die Fussdrüse gerade gestrerkt, median, in ganzer Länge mil der grancn und weissen Differenzierung, mil kurzem engem Ausführgang.

Die Speichehdrïsen, hei den vorigen Arten dicht llockig, hier in Irache Blätter zerlallen.

Der vordere Leberlappen ist ïlnlich hreit wie bei $\mathrm{V}$. paraguensis.

Dre Muskelmagen litdel einen verkürzten derben Ring.

Da die weilsliche Reife noch nicht erreicht war, bildeten sowohl die mïnnlichen wie die weiblichen Organe je einen Complex ungefälır von Pharynxgrösse.

Dir Penisscheide grösser als die l’feildrüsenscheide. Wo sic sich vereinigen, machı sich ein kurzer Retraktor hemerkbar, der ganz vorn rechts zum lutegument herübersieht. Wiewohl weit verbreitet, habe ich ihn in den wenigsten fällen lreachlet und erwähnt. Der Penisretraktor ist ganz kurz, nur hallı so lang als bei den vorigen. 7 oter i 8 Pfeildrïsenschläuche. Dic Pfeilpapille kurz konisch mit umgebogener Spitze. Der Penis hier besonders kurz und breit, oben in eine kurze Spitze verjüngt. Auch hier dir Basis durch eine geschwungene Linie scharf von dem in dem kurzen Anfangsstïck bleibenden Sockel ahgeselzt, also eine Gilans. Ilı lroies Ende ist eigentïmlieh seharf durch eine gerade Wuerlinie abgesetzt. [n Canalis junctor erfordert hier besondere Beohachtung. Er trilt anch hier ganz unten, neben dem Porms gentalis in die Bursa ein, und diese ist ehenso wenig scharf rom Bursagang al)geselzt, wie bei den vorigen. Gleichwohl erinnem die Verhätnisse nahe an die der Cylindrocantier. Denn, wenn man an den Umrissen der Bursa dir lecilen orflunngen des Bursagangs und des Canalis junctor als Fixpunkte nimmt nud die Begrenzung lurch zwei zwischen diesen Punkten ausgespannte Kreishogen lezeichnet, die ziemlich eine ganze lireislinie ansmachen, so ist bei der 1'. Truylori der innere Bogen viel grösser, als bei 1. Jordani und 1. affinis. Man kann dic Reihe auch so von den Cylindrocanliern ableiten, dass man den Untersehied in der Struklur zuvischen Bursa und Bursaganon aufhelu und den gemeinsamen Ranm ghleichmässig schwellen lässt bis zur hugel. Dann stellt V. Taylori eine Zwischenstufe des Vurgangs dar, wälırend die andern beirlen das Ende bilden.

\section{Bürgeri n. sp.}

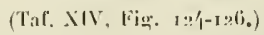

S. Domingo. Bünger leg .3 Stïck.

Die Maasse des qrössten Stïekess. o. Die andern sind wenig likeiner. Alle haben die Tentakel heranserestreckt, das kileinste am wenigsten. Die Tiere zedgen deudich den ova-

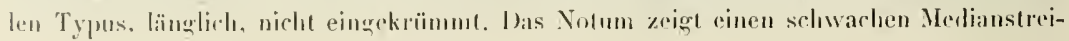




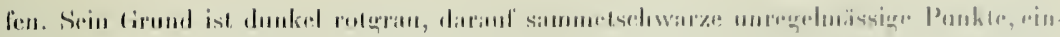

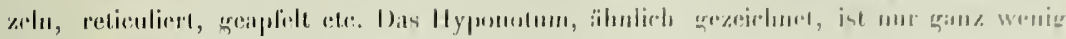

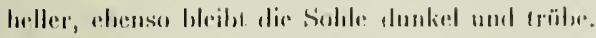

Anulomisc:hes.

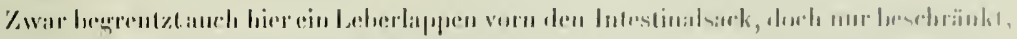

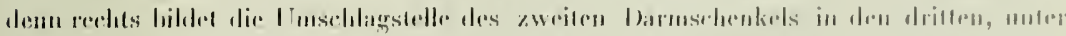

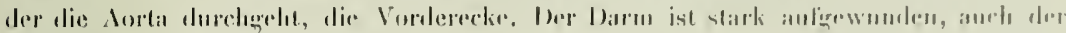

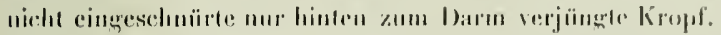

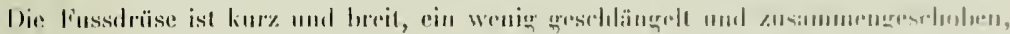

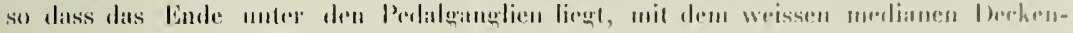
slrevilen.

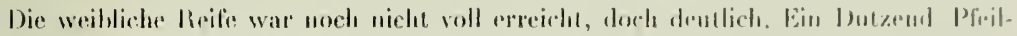

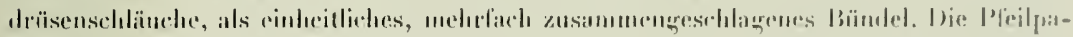

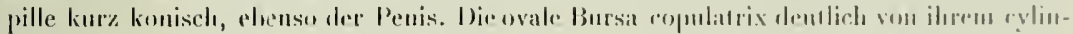

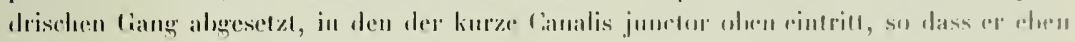
moch dir Bursal sellisi prejolit.

\section{V. rufescens n. sp.}

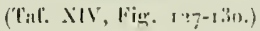

Columbia. Calebal Camedia brei Angelopolis. Centraleordillere.

liummann leg. 16 stück.

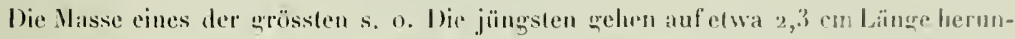

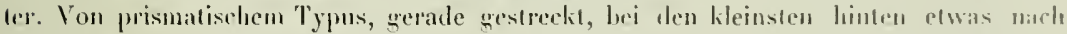
- unten gedongen. käpfe und frähler sind rorgestreckt, bei den kleinsten wenimstens dio Fïhlır, wieder ein Beispiel gleichmissign Verhaltens.

Das Nolum hat einen hellen, nicht inmer ganz klaren Medianstreifen; Sinren zeigan sich stets. Das Perinotum, das etwas als liante vorspringe, is denso hell. Ein räblichen Cirund, etwa Terma de Siena, lerrscht nicht nur anf dem Totum vor, somern anch anf dem Ilyponotum, wo er allmälılich nach unten abklingt. Dazu kommt anf dem dotum

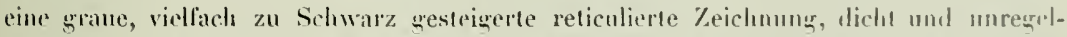

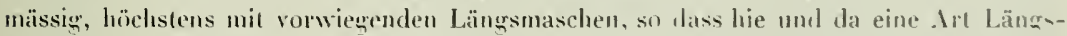
streifung entsteht, aher nie schart ausgeprägt. Das Notum ist feinkïrnig, im allenemeinen die Haut glatt. Auch bei dieser. Art zeigen qesehtechtsreifo Tiere rundliche Flectien

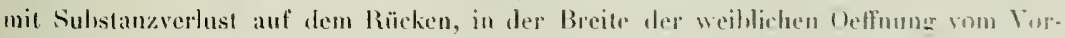
spiel her.

Inatomisches.

Ein Leberlappen quer vor dem Intestinalsack. Die Speicheldrïsen kleiu, rundlich acinoes, hie und da auch blätrign, und einzelne Blätler fein treältert, wic ein Baumblatl.

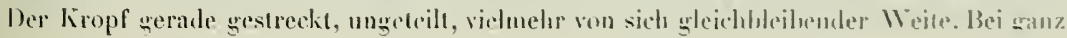


reifen Tieren ist ex ganz leer, wie bei andern Arten. Die Tiere fressen offenbar nichts wälırend der Latchperiode, ron dessen Dancr sich natiirlich nichts aussagen lässt.

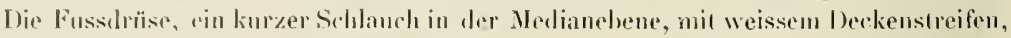
tocker, last llockig, elwas zusanmengeschohen, so datss in den mittleren Trilen hintere Absehnilte ïber vordere zu liegen liommen.

Die Pedalnerven halten auf ø/5 ilırer Längr zusamnen,

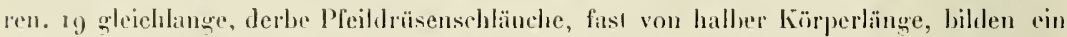
mehrlach znsammengesshlagenes Bündel, wohei die vorderen Trile sich dicht schlängehn, Hur dass sich eine Serumdärseheide prägrarieren liesse. Die Penisseheide kleiner als die

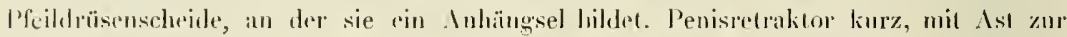
Pleildrïsenseheide. Der lreie Samenleiter dünn in missig write Sillingen gelegr. Die: Pleilpapille honisch, moist mil umgedegter Spitze, der Penis ähnlich, doel kleiner, alugeIlachl; aul der einen Seita hat er aine herzlörmig ausgeselunittene Basis, wo das Verhaillniss zwischen Glans und kïrzerem Sockel hervortritt. Ielo gathe eine auslïlndichere Figur wn einem stüek. Sie zeigte otwas von Spiralwinduny. Es scheint, dass der Simmoleitor im Innern rine Selalaubenlinie heschreilut.

An den weiblichen Endwegen ist wieder die Bursa das Wichtigste. Sie ist lenglig und ungestielt, oder doch mit minimalem Bursagang. Das Vas deferens schlägt sich über die Blase linweg und selickt seinen kurzen Canalis junctor zu ihrer Basis ganz nalue am Mlogange des Bursagangs.

\section{V. varians n. sp.}

(Tat. XIV, Fig. I31-131.)

Columbia. Zwischen Bora del Monte und Tambo. 2000 m. Funnano leg. 2 Exemplare.

Beide Tiere sind im ersten Beginn der weihlichen Reife und von demsellsen prisma(ischen Typus wie die vorige 1 . rufescens und wie 1 . prismalica, so dass ich alle drei erst allmählich unterscheiden lernte. Much hier sind die Kï̈pe ausgestreckt. Man kiann die Schmecken schon an der Haltung erkennen, denn an Stelle der eyelhaften Haltung mil concaver Sohle wirel hier der liëcken etwas concav, indem sich das Perinotum an beiden Enden schwach aulwärts krümmı. Wieder stimmen beide Stïcke in dem scheinbar ganz nebensächlichen Merkmal völlig älerein. Der Medianstreif fehlt. Die Färlomng ist zunächst ganz verschieden, denn das eine Stück hat einen lebhaft roten frundton ïher Nolum und Hyponotum, sogar bis anf die Sohle, das andere sieht üher mud über gुrau aus, mit der ïblichen blassen Sohle, sonst gleichnässig. Schliesslich bemerkt man, dass auch ihm ein farbiger, ockeriger Grundion zukommt, nur dass ein dunkleres, wohl schwarzes Pigment eine sehr dichte Netzzeichnung bildet in so feiner Verteilnng des Firdstoffes, dass er eigentlich nirgends sehwarz erscheint. Um so schärfer ist er bei dem ruten Stïck in allerlei unregelmässig zerstreuten, tief selıwarzen Flecken concentriert, 


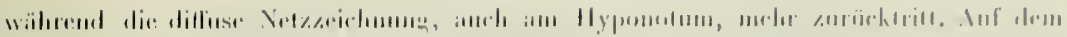

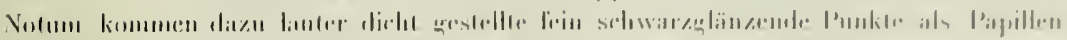

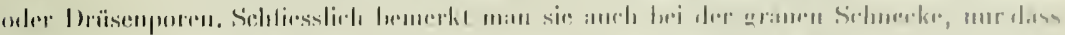

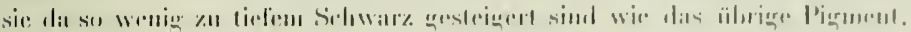

Anulomisishes.

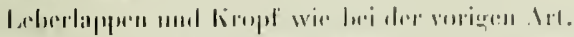

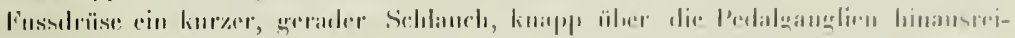

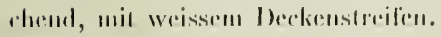

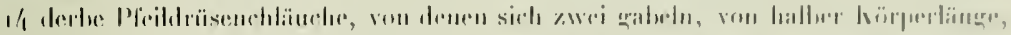

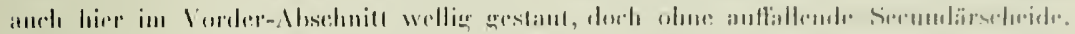

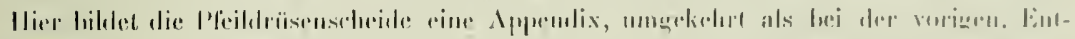

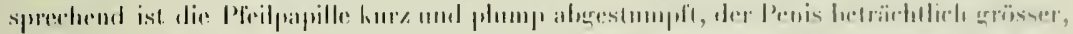

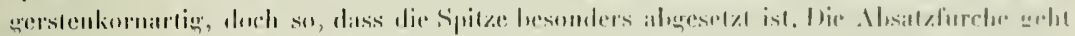

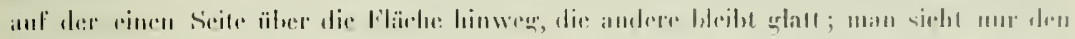

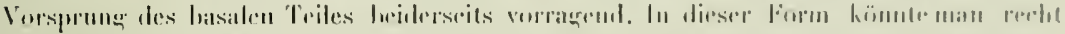

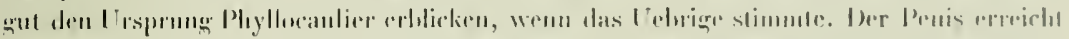

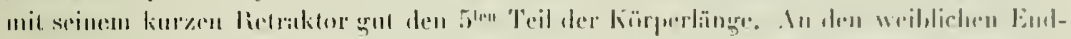

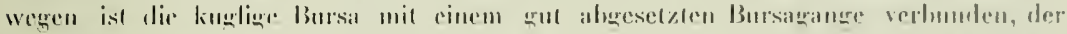

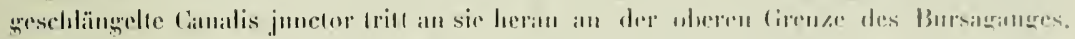

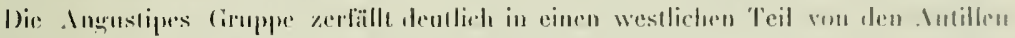

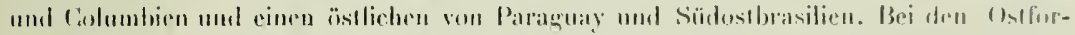

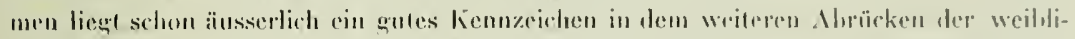

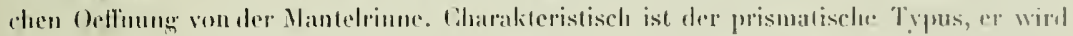

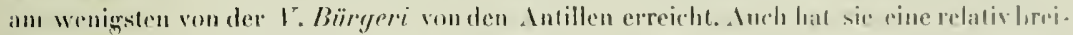

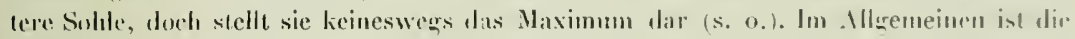

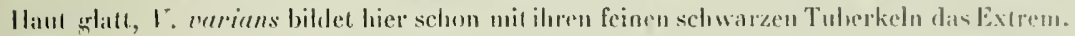

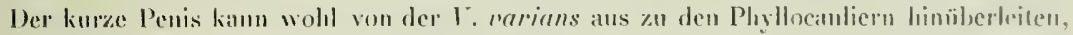
dic Art, wic der Canalis junctor sich mit der Busa verbindet, von 1: Taylori aus zu

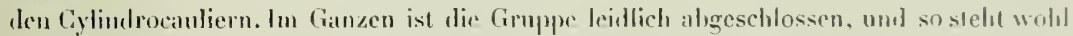
zu erwarten, dass die weite Lüclie zwischen dem Osl- und Wesllüred sich mil der \%eil moch schliessen wird, woranf wir shleich zurückionmen.

Morphologisch besteht allerdings noch eine Unsicherheit in Bezug auf alie Struktur des Penis. Schon Semper, der auf die Oellnung des Simenleiters hesonderes Gewicht leat, liemerkt gelegentlich, dass es ihm nichi geghekt sei, diesc leffnung zu finden. Und ivl kamn's weracle in der Gruppe der Brevicanlier am wenigsten sagen. Es wäre sellal möglich, dass sich der männliche Porus bei einigen an der Basis der Kappe verbirgl.

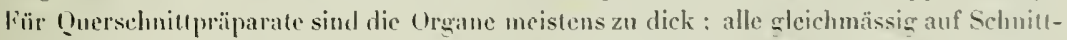
serien zu untersuchen, fehlı mil die Zeit umd has ulejehmässige Matcrial. Manche wcich conservierte Stäcke würden wohl versigen. Hier bleibl der Zukunftein reiches Feld offen. 


\section{Früher beschriebene Arten anderer Autoren.}

llass nur quanz sorgfältig heschriebene formen mit einiger Sicherheit identitiziert werelen können, branche ich kanm zu wieglerholen. Somit fallen alle ältern spezies weg. In erster Linie kommt natürlich SExpen's Arheit in Betracht. Es könute audfallen, dass ich so wenige von den mir rorliegenden Arten auf seine Beschreibungen bexiehen kanu; lats beweist aher wohl nul das Fragmentarische unserer lienntnisse. Es existieren offenlat weit mehr Arten, als bis jetzl lekannt sind. Machen wir wenigstens den Versuch, uns érigermassen über die Stellung der SEMPen'schen Species zu orientieren! Die Phyllocaulier und Cylindrocaulier wurden hereits beräcksichtigt. Ausscheiden müssen wohl 1. Arepideli, r. telescopium und r. roigti Semp. weil das Vaterland nicht bekannt ist. Wären sie Phyllocaulier, so künute man sie wenigstens mit Bestimmtheit nach Südanerika verweisen. Bei 1 . telescopium könnte vielleicht Verwandtschaft mit den Trichterruten in Betracht liommen. I. dubia Semp. von St. Tlomas hat am Penis heiderseits eine freic Falte, man könnte sie zu V. plerocaulis stellen, wenn die Falten nicht his zur Spitze liefen. Immerhin schliesst sie sich wohl an besten noch an die Cylindrocaulier an.

1. portoricensis Semp. ist ein typischer Brevicaulier, bei dem die männliche Oelfnung nicht aul'zufinden war. Die Schnecke scheint auch in Grösse und Färlunng die meisto. Aenlichkeit mit V. Bürgeri zu haben, die ja ebenfalls von den Antillen stammt. Doch sind klare Unterschiede vorhanden. Freilich mit den Maassangaben ist nicht recht auszukommen; Semper sagt, dass der weibliche Porus $4 \mathrm{~mm}$ hinter der Mitte liege, nach der Figur sind es aber kaum 1,5 mm; klarer ist schon die Lage am Iyponotum, bei V. Bürgeri weit näher an der Mantelrinne, als bei V. portoricensis. Nimmt man dazu, dass 1. Bürgeri 12, I: portoricensis abes 20 lange und 3 kurze Pfeildrüsenschläuche hat, tann springt der Interschied ohne weiteres in die Augen; er kann auch nicht durch die geringe Grössendifferenz, - V. Bürgeri ist 2, 2, V. portoricensis $2,5 \mathrm{~cm}$ lang —, erklärt werden. Sichertich würden sich bei unmiltelbarer Vergleichung noch weitcre Differenzen ergeben.

Bei der $v$. Langsdorfi Fér. nach SEMPER wage ich nicht zu eutscheiden, wh sie zu den Cylindro- oder zu den Brevicantiern gehört. Unter den ersten wörde sie wohl den kürzeste Penis haben. Man müsste die weiblichen Endwege kennen. Dass unter V. Langsdorfi der Museen sich verschiedenes verbergen kann, ist oben bei $V$. Ileynemanni gezeigt worden.

V. Böltgeri Semp. von S. Paulo ist wahrscheinlich ein Brevicaulier von der Ostgruppe, wofür auch die Entfernung des weiblichen Porus von der Fussrinne (1/2) spricht. Einc Besonderheit liegt wohl schon im Retraktor der l'feildrüse, der nnabhängig unı getrennt rom Penisretraktor entspringt und sich an einer Secundärscheide ansetzl. Dic 1. linguceformis Senp. von Ecuador (Guayaquil) ist durch die minimale Penisscheide neben der starken, kräftigen Pfeildrüse vollkommen charakterisiert. Die vorläufige Stellung wohl am besten hei den Brevicauliern. 


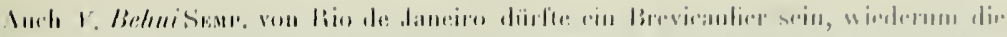

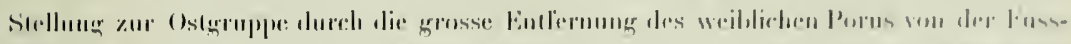

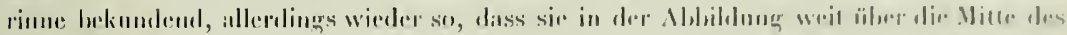

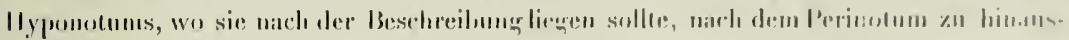
riiilil.

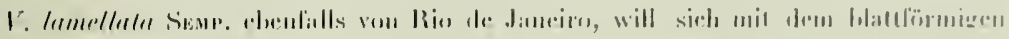

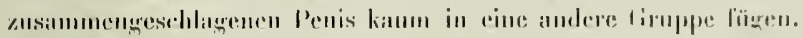

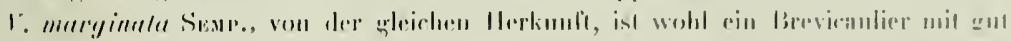

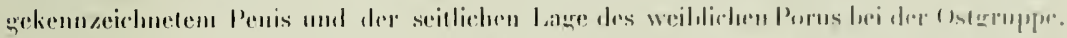

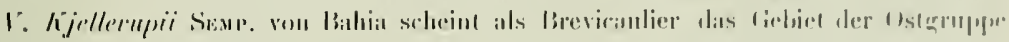
mordwärts zu erwoiler'ı.

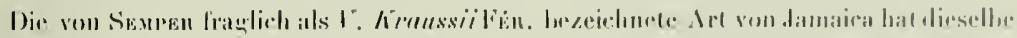

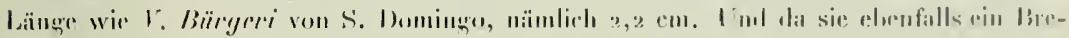

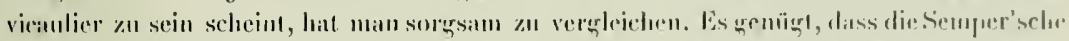

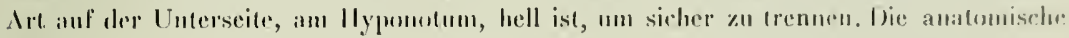

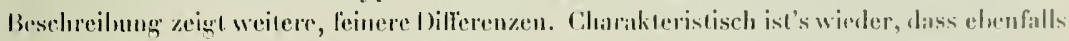

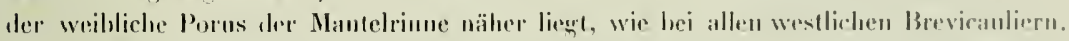

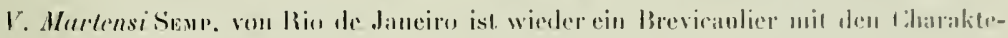
ren der (osigruppe.

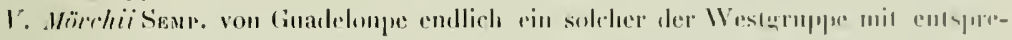

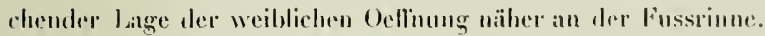

Formen, wie hei 1: Martensi, d. h. cin Brevicanlier mit wrlingerter Gilans ïber den

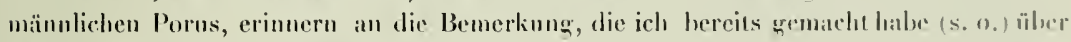
die Tnsielserheit der Penisform und -beurteilung innerhall, dieser firmpre. Sie marlı hier mehr Schwierigkeiten, als zumeist bei den afrikanischen und asiatisihen Arten. Wenn ich früher den Versuch matıe, die Familic nach dem Penis nur in Plyyllociulier. Acrucanlier und Pleurocanlier einauleilen, so ersehweren die letzlgenimnten geriele hei den neotropischen Arten die Abgrenzung gegen die Acrocaulier, die P'lỵlloraulier bleibrn als gut gekennzeichnete, rein amerikanische Gruppe hestehen.

Noch kemen wir nur wenig in Anbelrach des grossen Gebietes. Das imere Brasilien, die Ostahbänge der Anden, der ganze Nordrand östlich ron Venezmela sind reine terrae incognitae. Zwischen Columbien und Chile harrt ein weiter Raun der lütersuchung. Von Ecuador wenigstens ist etwas mehr beschrieben, namentlich durch MrLeEn, wozu Cousin und German $(9)$ weiteres gefügt haben. Hesse hat geglauht. die MhLer"schen Arten durch Znsammenlegen reduzieren zu sollen, und Hexsenaxs hat sich ihm angesthlossen. Dit Ilesse's Erfahrungen an der Familie anf der Sektion einer einzigen Art beruliten. war sein Standpunkt begreiflich. Jelzt wo wir anfangen, in de reiche Gliederung einigen Einblick zu erhalten, wird man Mrber in der Beachtung der feinen äusseren Unterschiede nur folgen müssen, und es wäre schr zu wünschen, dass seine Irlen anatomisch geprüft würden. Die grösste Species ist anscheinend 1. Marianitu Cotss : man 


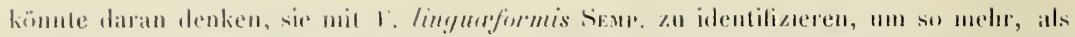

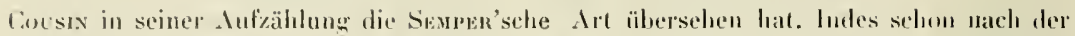
Beschreibung, so unvollkommen sie ist, kann man wohl Dilferenzen heraustiuden, so ist

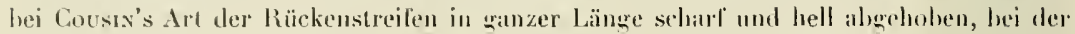

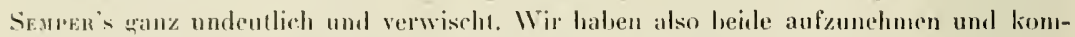
men auf I Species und wenn wir die beiden von Gisman zuletzt lesedrielsenen daza molıten, auf 13. Doch rwähnt Germatu nicht, oh er die seiner Vorgänger heachtet hat;

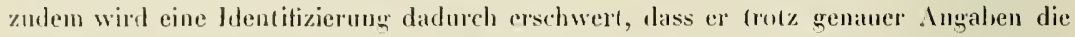
Lage des weiblichen Porus vernachlässigh hat.

1. ande'nsis MuLLer.

1. arenala MHLLER.

1. alropurnetule MILLEK.

1. Betzliesi MaLen.

1. complanuta Mu,Ler.

1. ceplaalophenra MuLen.

1. lima!yuna Lasson.

1. "quartrocularis MuLeks.

1. leves Mutcer

1. Marimilu Cousin.

1. Riureli liermain.

1. acquatorimusis lienumun.

1. lingureformis SEMrer.

Die einzige anatomisel beglaubigte ist die lelzte.

\section{Schlussbemerkungen}

leer Schwerpunkt der neotropisehen Nacktsehneckenfiuna liegt in den Vagrinuliden, dir an Artenzahl bei weitem die äbrigen übertreffen, trotzdem wir bis jetat nicht viel mehr kennen als die Randgebiete und diese noch movollständig genug.

Als die Hauptaufgabe nehen ter genauen Feststellung der Formen labe ielı die Zerlegung in Gruppen betrachtet ; denn es geht nicht an, die grosse, offenhar urafte und fïr die: gesamte Tropenwelt in höchstem Masse hezeichnende Gesellschaft, trotz aller Einförmigkeit, einfach in einer Gattung zu belassen ohne weitere Gliederung. (H) ich rechl daran getan habe, die Gieschlechtswerkzenge zum Einteilungsgrund zu nehmen und die Blatt-, Schlank-, Trichter-und kurzruten zu unterscheiden, muss dahingestellı bleiben. Ich fand wenigstens kein besseres Merkmal. Am besten sind wohl die Blattruten oder Phyllocanlier gekennzeichnet als eine streng neotropische Gruppe. Doch fehlt es nicht an der Möglichleit, die Form iłres Penis sowohl von der vereinzelter Schlank- als Kurzruten abzuleiten. Und die übriggen körperlichen Merkmale zeigen ähnliche Uebergänge. Am lästig- 


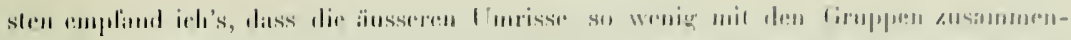

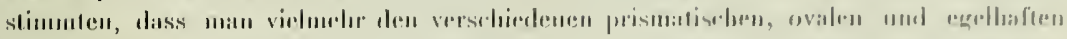

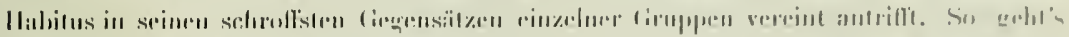

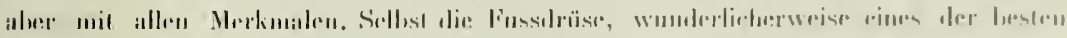

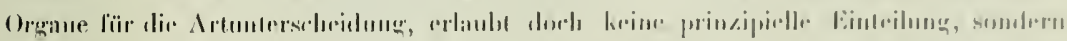

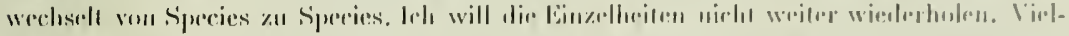

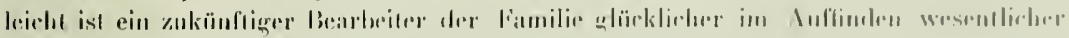
liesirhispounktie.

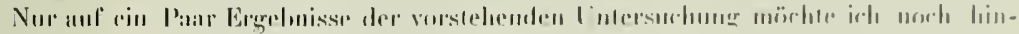

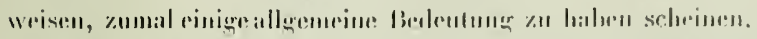

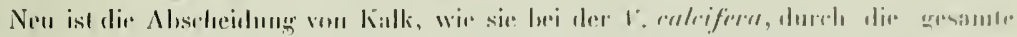

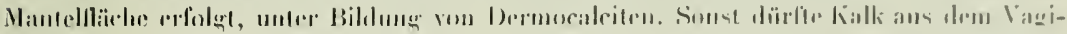

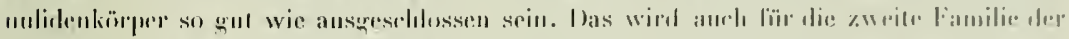

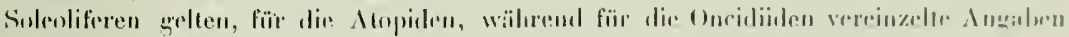

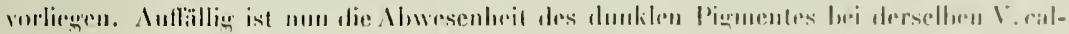
rilin'il.

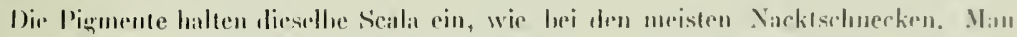

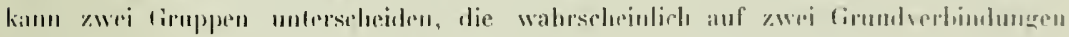

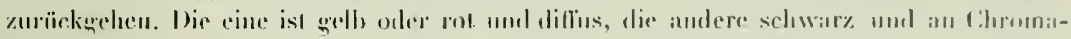

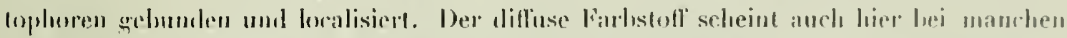

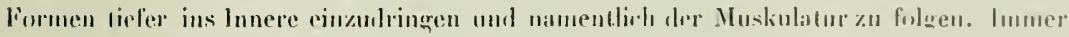
aher lat er seinen wesentlichen Sizz in den oberen Hantsehichten, auf die der schwarze

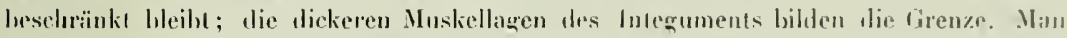
wirl anch hier schwerlich fehlgehen. Wom man dem diltusen Pigment rine besleuluner

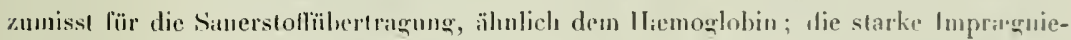
rung del obern Iantschichten wïrde der ilun vermutlich zufillenden respirilorisclsen Funktion durchaus entsprechen. Limgekelırt erhält man den Eindruck, dass der schwarze larbstoll ein Abfallprodukt darstell, das an Orten geringer gewehlicher Tätigkrit sich

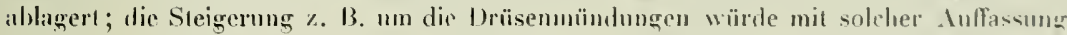

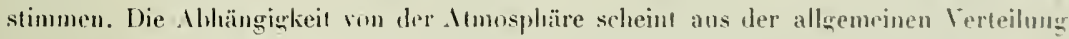
lervoryugehen ; das Notum ist am reichsten, das Iyponotum meist irmer, die Solule fast immer frer. Es scheint, dass der Grad Jer Färlung des Ilyponotums von seiner IJaltuner abhängr. Wïhrend es im Algemeinen hei der rulenden sichnecke dem Borlen aufliegen soll, bleibt doch noeh an der lebenden festzustellen, ob solche llaltung atuch bei dent

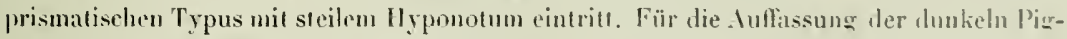
mentreilie als Neben- oder Mhfallsproulukte hein Stollwechsel lïss sich wohl die Latere der einzigen imnern Stelle, die coloriert ist, anführen, nämlich das dunkle Graubraun am Anfang des Utrus bei der weiblichen Reile.

Die llautdrïsen des Perinotums hahen eine bestimmte absolnte Vinimalgrös-e unter

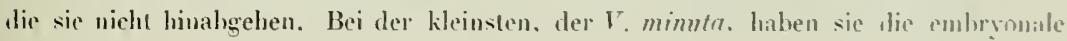


Inordmung behalten. Zunehmender Grösse der Irten entsprechen sie nicht durch proportionale Vergrösserung, sondern inrch Vermehrung ihrer Zahıl.

Ton alen Geschlechlswerkzeugen etwa folgemles:

Bein Vorspiel werden oft durch Belecken mit der Radula in der llaut des Parturers Substanzverluste crzeugt wie bei den Limaciden; sie nelımen anch relatir mil der hrösse der Art zu.

Bei der Copula wird sowohl die Pfeilpapille, wie der Penis herausgestreckt, zum mindesten bei cinigen Arten. Noch findet sich vereinzelt an der Pfeilpapille eine hohle Conchinspitze wie hei Vitrinen und andern. Die Pfeildrüsenschläuhe werden oft in ihrer distalen Hälfte von einer mesenterialen Secundärscheide zusammengehatten, an der sich der einfache oder gespaltene Pfeildrïsenretraktor ansetzt. In der Entwicklung legen sirlı die Schläuche zunächst innerhah der Scheide an, die wohl einen ernährenden Bhotranm darstellt; von ihr eingeengt, legen sie sich in welligen Biegungen zusammen, ähulich wie der kellenartige Zwiltergang. Späler wachsen die Enden riber die Secundärscheide hinaus. Zu systematischer Verwendung langt sie nichts, sporadischen Juftretens hallier. Wenig morphologische Bestimmthejt zeigr sich in der Lage des Pfeildrüsenbündels; meist liegt es über dem Schlund, oft aber auch darunter, ja es kommt bisweilen selbst mnter deu freien Samenleitor zu liegen, der sonst lie unmiltelbare Narbarschaft des Hautmuskelschlauchs heansprucht. Die besondere Eigenheil einiger neotropisclien Vaginuliden ist die Erwerbung einer secundären Bursa copulatrix. Entstand die normale Bursa, wie bei allen Ciastropoden, als Einstülpung unter dem Druck des eindringenden Penis nelien der weiblichen, durch einen Sphinkter verschlossenen Oetfnung, so erfolgte später, wie bei unseren Limaciden und Arioniden, die Neigung zur. Sellstlbefruchtung. Sie bewirkte dis Mbspaltung eines Zweiges vom Samenleiter und seinen Durchbruch zur Bursa als Canalis junctor. Sein durchıängiges Vorkommen beweist die Regelmässigkeit der innern Sellıstbefruchtung. Vermutlich verwehrt eine mit eigenem Sperma rom Canalis junctor aus gefüllte Bursa durch den Druck des muskulösen Bursagangs bei der nächsten Copula den fremden Penis den Eintritt, so dass es zur qewaltsamen Einstölpung einer secundïren Bursa konımt.

Leipzig-frautzsch, Septrmber 1912. 


\section{(athithe sillilltis}

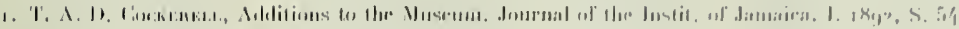

2. "Mnllusen ilicl. St. !fi.

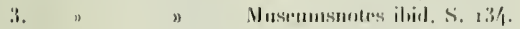

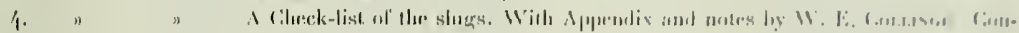
chulugist 11. 1 $8,9 \%$.

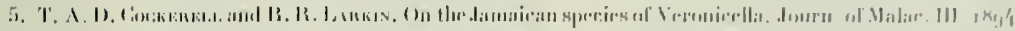

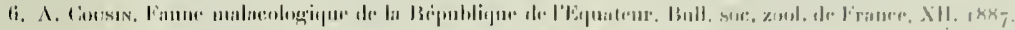

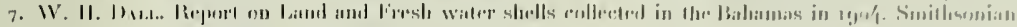
mise, coll, /7. 19!9?.

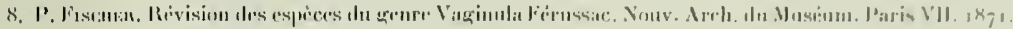

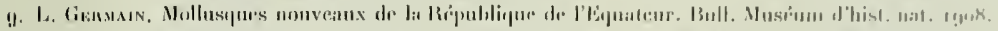

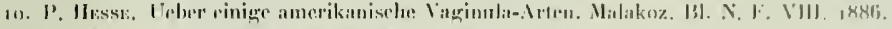

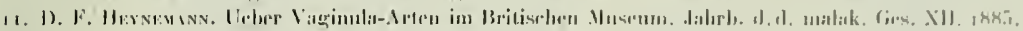

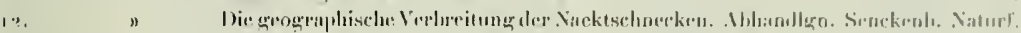
cies. 30. 190.\%.

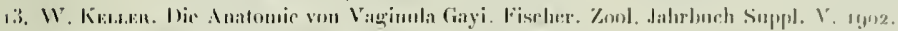

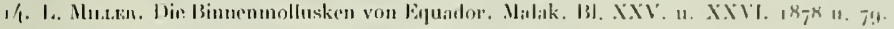

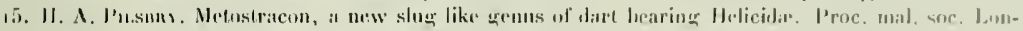
don 11.1 . 1 gos $/ 1$ (1)

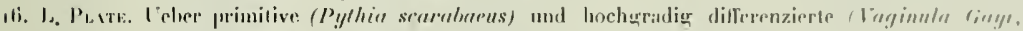

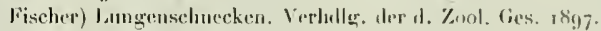

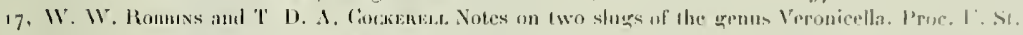
Nat. Mus. 3ti. 1!n!!.

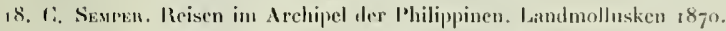

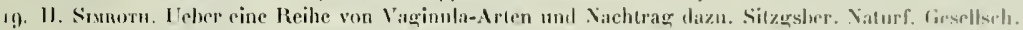
Iripzie. $1891 / 92$.

20.

On Nenhỵalimax hrasilicusis. I'roc. malac. Suc. Lonton II. 18 !11/97.

2.

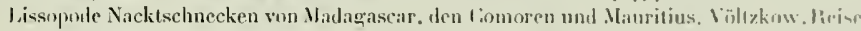
in Ostalrikir. 19t0.

$2 ! !, \quad$ (1)

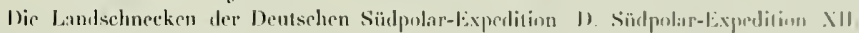
Zool. N. 1!) 11. 


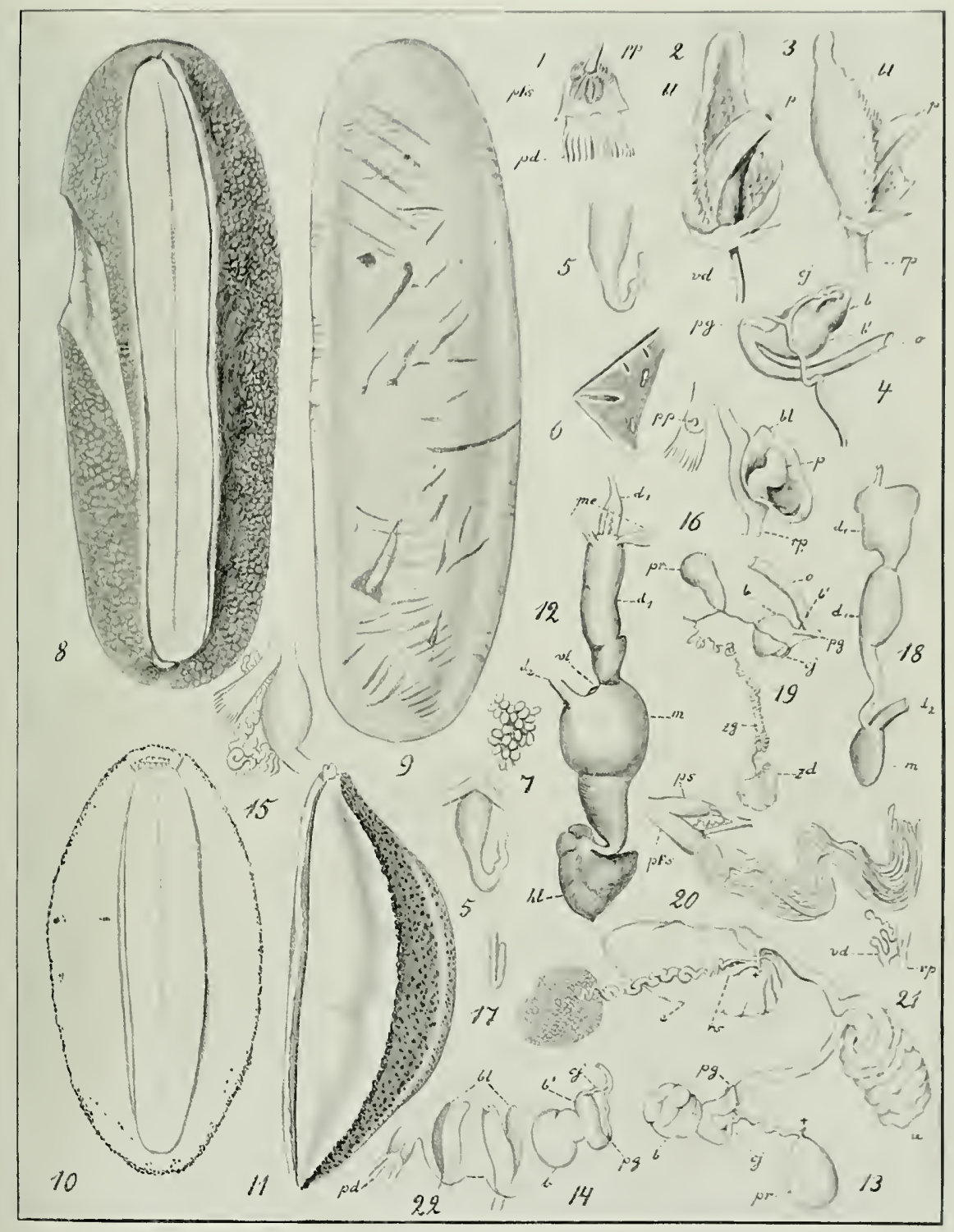






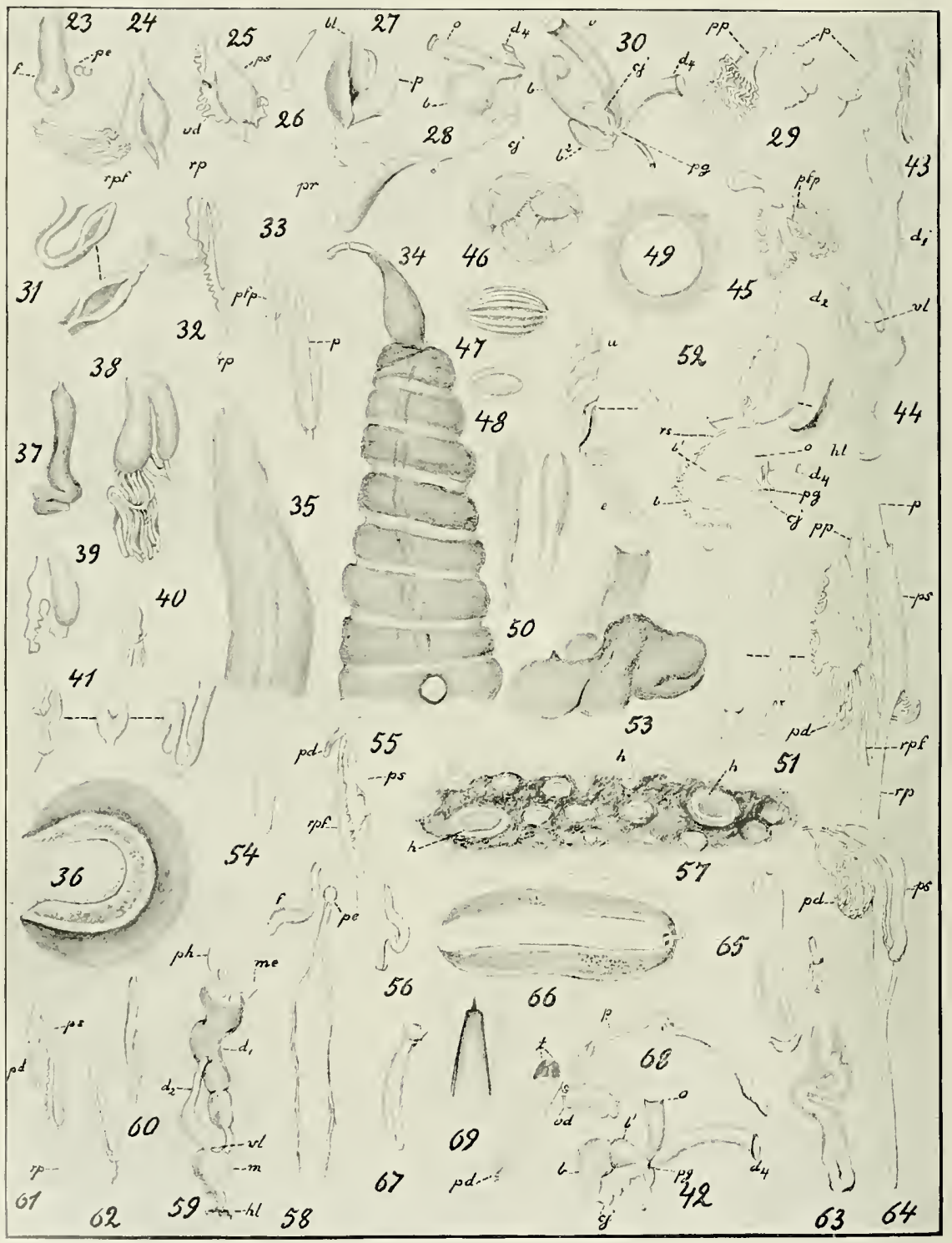


I AF, III.

Fig.

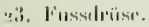

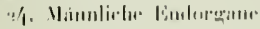

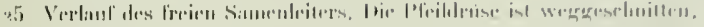

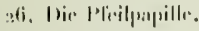

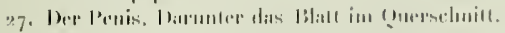

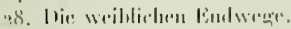

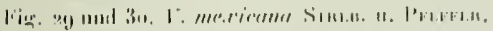

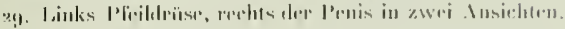

3a. Mir wriblishen binlwang.

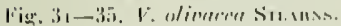

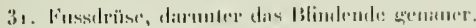

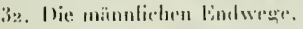

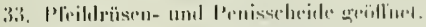

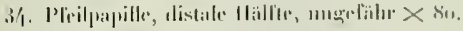

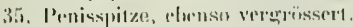

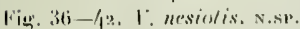

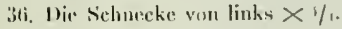

37. Fussdriust.

3.. Mäunliche linilwexte.

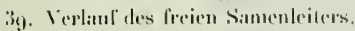

for. P'eildriase: mil Preilpaipille.

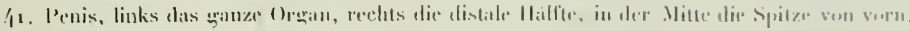

4?. Weiluliche Endwegy".

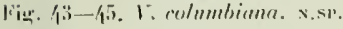

13. Lussilrïst'

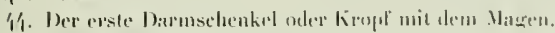

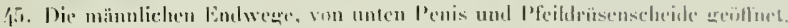

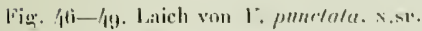

fi. Pischmur, $\times$ "s

17. linin rinzelues lii.

48. Dassellke olme Lachichülle.

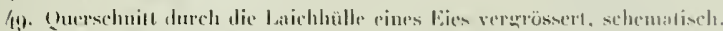

Fig. 50-53. 1: resedillerers $x \times 1$.

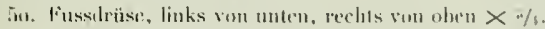

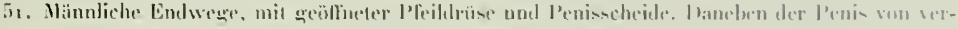
schirelenen sieiten.

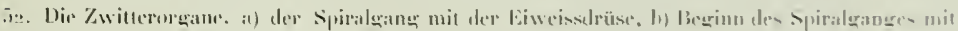
Pigmentalblangerung:

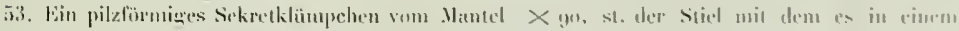
Drüsengange latlestigl ist.

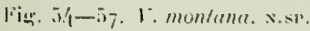

5 \%. Fusstrüse".

5i. Die männlichen Endwege.

ixi. Jer l'enis.

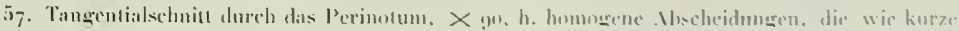
Haare hroussehen.

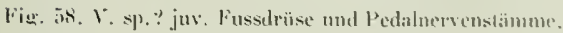




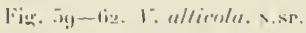

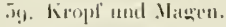

bo. Fussdrüse.

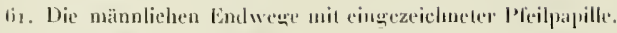

(i2. Penjsscheide mit P'enis.

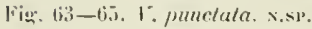

bi.). Fusslloüse.

6作. Männliche Endorgane.

6.5. P'enis, 65il, I'feilpapille.

lïg. titi-ling. 1: longlicaulis. x.ss.

ti6. Ein Tier mit ausgestrecktom Penis von unten.

iiz. Fussidrüse.

68. Männliche Endorane mit ausgestrecktem Penis.

by. Pfeilpapille in slärkerer Vergrösserung.

\section{Tafel IIII.}

Fig. 70-72. 1. Fuhrmanni. x.sp.

70. Fussdrüse.

71. Männliche Endwege.

72. Zwillerorgane.

lï. $73-78$. 1. prismatica. v.ss.

73. Vorderende mit herausstehendem Penis von unten.

74. Fussdrüse.

75. Die mänolichen Endorgane.

76. Deren Petraktoren.

77. Penis und Pfeilpapille.

78. Die weiblichen Endwege.

[igig. 7g-86. Y. pterocanlis. N.sP.

79. Fussdrüse.

8o. Männliehe Lindorgane.

81. Die Pfeildrüse mit der Sekundïrscheide lür sich.

82. Der Penis, mit dreikantiger, bedornter filans, aus der l'enischeide genommen.

83. Penis, hervorgestreckt.

84. Links Querschnitt durch, den retrahierten, rechts durch den heransgestreckten P'enis.

85. Weibliche Endwegre.

86. Die männlichen Endorgane eines jugendlichen Tieres $\times 50$ ungelähr.

Fig. $87-98$. V. minula. x.sr.

87. Schnecke mit ausgestrecktem Begattungsorgan, von unten, $\times 2$ beinalle.

88. Vorderende derselben stärker vergrössert

8y. Dissellye von links.

9o. Vorderende des Notums verürössert.

(1) Vorlerende mit herausgestreckten Copulationsorganen von links unul unted. Stärker vergu.

92. Ausgestreckte Pfeilpapille cines anderen Exumplares.

93. Männliche Endorgane.

94. Der Peais $x$ go.

95. Die l'enisspitze in elwas verinderter Ansicht.

96 . Die P feilpapille $\times$ go.

97. Die Zwilterorganc.

98. Kropl' und Magen. 


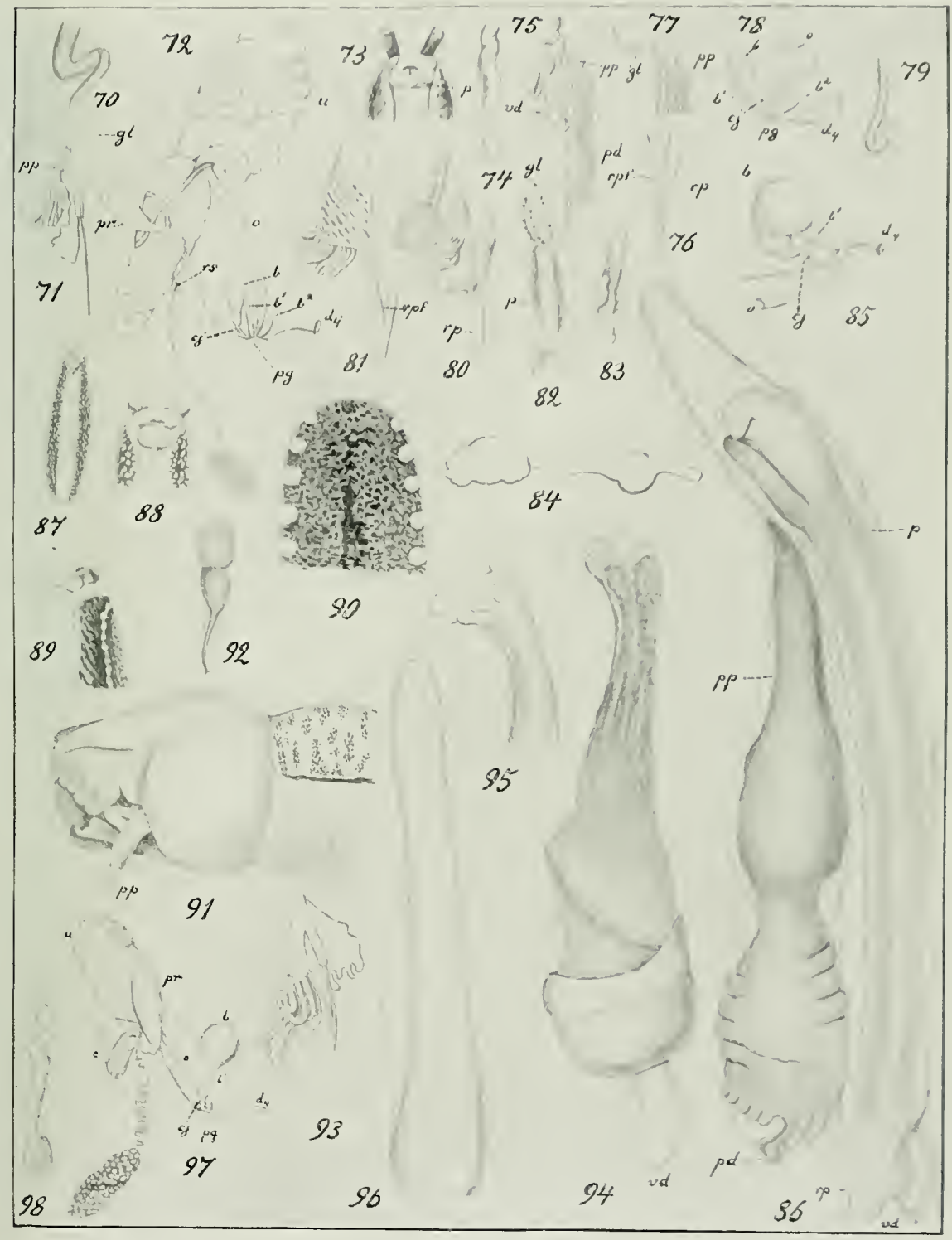






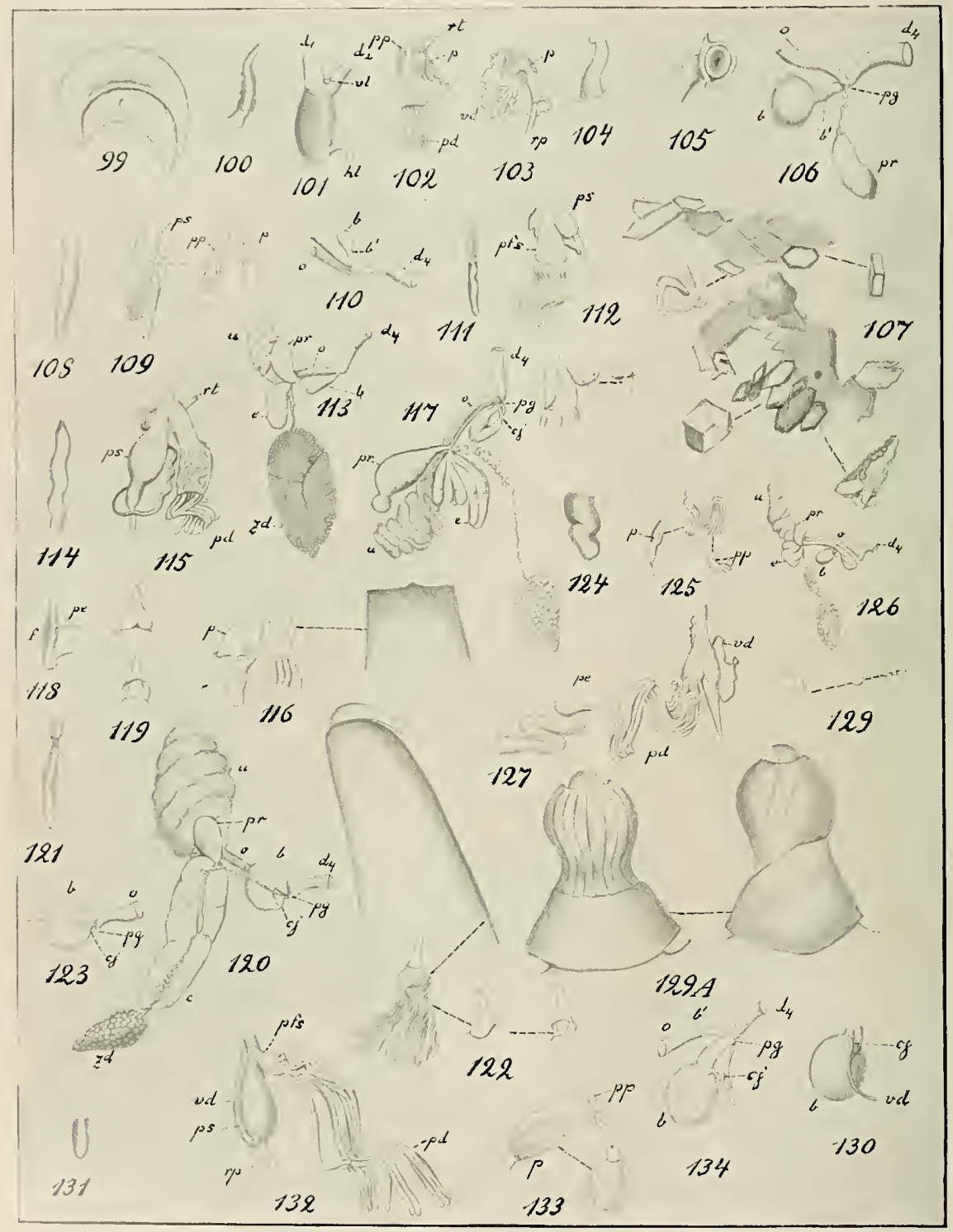


IAHT.T. IIS.

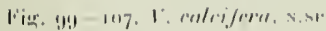

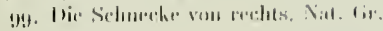

1в3. Vinssidriase.

111. Magen.

10\%. Nimnliche Binelwega".

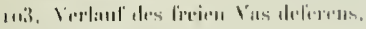

in/. Pleilp:ipille.

105.) I'ronis.

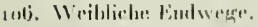

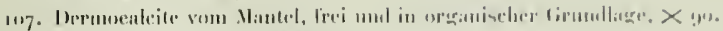

Fig, 1108-1111. 1: , In!

118. linsstrüsse.

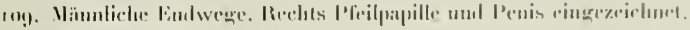

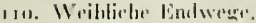

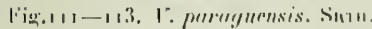

11, linssilrüise.

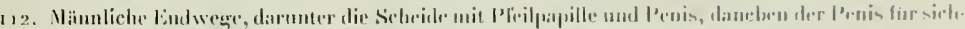

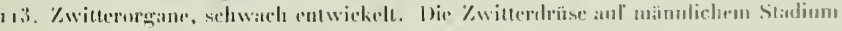

Fim.11/1-117. 1: Tinglowi. Sintr.

11/. liussilinise.

11.i. Minnliche Organe.

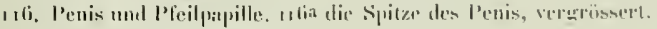

117. \%willerorgane in halker Reilie.

Fïg.118-120. 1\% Jordeni. Sintr.

118. Finsstriise.

119. I'enis von wersehichener Seite.

120. Die Zwitterorgane in volter weihticher lacile.

l"ïr. 121-123. 1'. "fflinis. N.s1.

121. Finssilrïse.

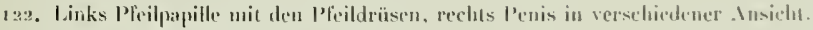

123. Samenteiler und Rirsia copulatrix.

lïin. 12,-126, 1. Bürgeri. 、...p.

12\%. Fusstrüse.

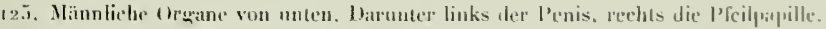

126. Dic Zwitterorgane, noch mitsig entwickelt, $\times 3$.

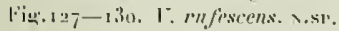

127. Fussdrïse von links. Darrülere die Pedalganghien.

128. Die minnlichen Mrome.

129. Links die Pleilpapille, rechts der P'onis in verschictener. Insicht. Izya der l'enis in ver-chir130. Samenteiter und bursil. dencer Insicht. Quetsclyprïparat, verencössert.

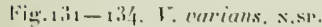

131. Fussiruise.

13. Männlicle Endweore.

133. Links P'enis und P'feilpinpille, reelats der l'enis von anderer serite.

13\%. Weillielte Endwege. 


\title{
BEITRÄGE
}

ZTR KENTIIS WF

\section{Flora von Kolumbien und Westindien}

\author{
lwarbeitet im botanischen Maseam der Universität Zïrich)
}

yol1

Dr. G. SCHELLENBERG-Berlin, Prof. Dr. Hans SCHINZ-Zürich und Dr. Albert THELLUNG-Zürich.

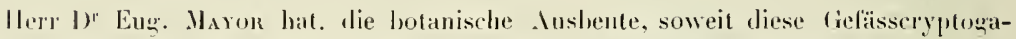
men (teilweise) und Phanerogamen hetriff, seiner wissenschaftlichen Reise in Kolumlien und Westindien dem botanischen Musenm unserer Cniversitäl zur Bearbeilungn äherwiesen und es haben sich an dieser die Herren I)' Schellenbeng, Prof. Dr Hans

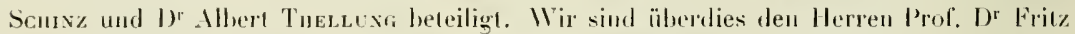

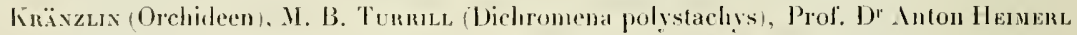
(Aychaginaceen), IF Cas. de Cindole (Pipreraceen), Prol. D" Alfeed Cogninux (Cucurbitit-

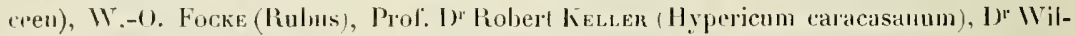

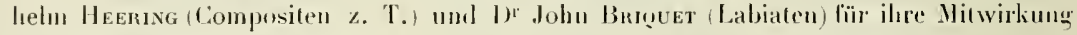
2.11 grrossem Danke verptlichtel.

Zürich, Botanisches Huseum der Universilät, Novemler 1912.

\section{Pteridophyta.}

\section{Salviniaceae.}

1. Azolla cf. filiculoides LA3. Encyel. I ( 1783$), 343$.

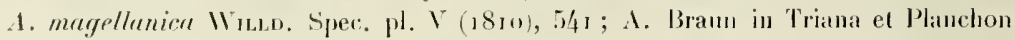
Prodr. 17. Novo-tiranat, in Amu. sc. nat, s̀" sér. Bot. III, 3 1t. 


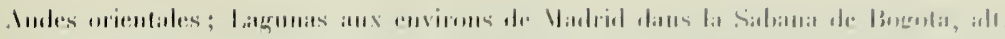

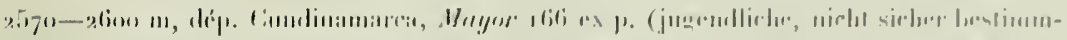

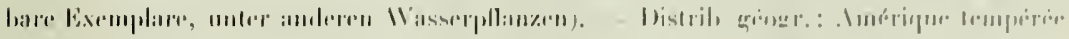

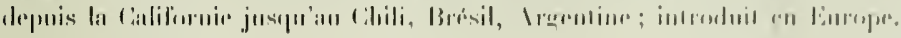

\section{Selaginellaceae.}

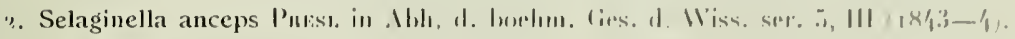

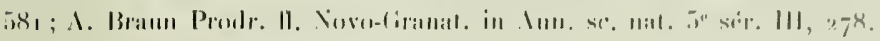

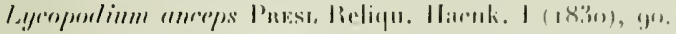

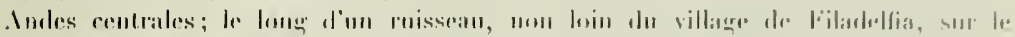

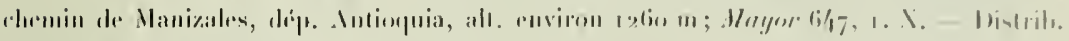

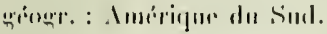

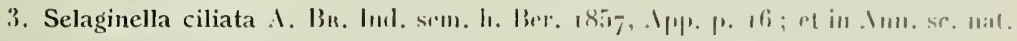

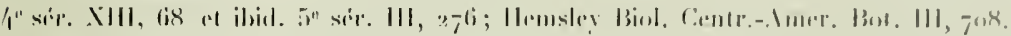

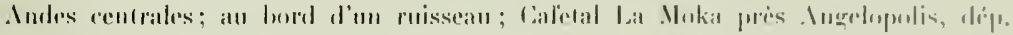

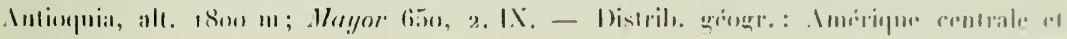
Amérityu dus Sull.

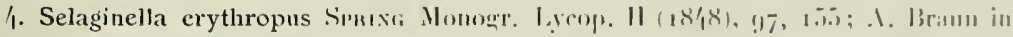

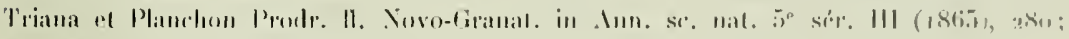
Htrusley Biol. Centr.-Am. Bot. HI, 7air.

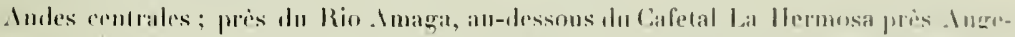

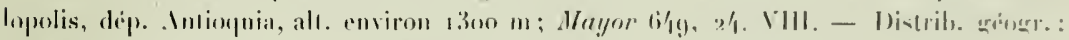
Amirique centrale. Amérique du Sud. Intilles.

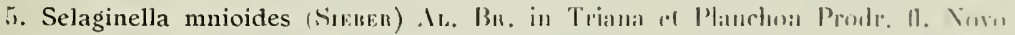

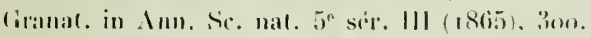

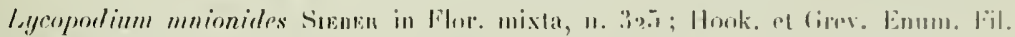
in 131). Miscell. II $(1831), 39$ 4.

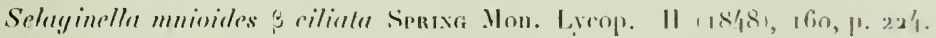

Audes centrales; endroils humides, Cafelat La Camolia pros Ingelopmlis, deip. In-

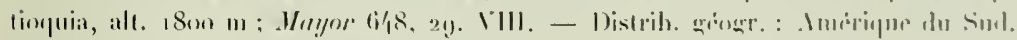

\section{Monocotyledones.}

\section{Gramineae.}

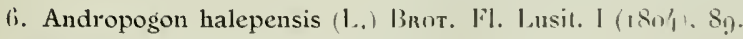

Holcus halepensis I. spec. pl. (17.53), 1047.

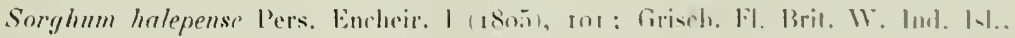
itin; Harkel in Marl. Nil. Brasil. I1, 3. 27\%. 


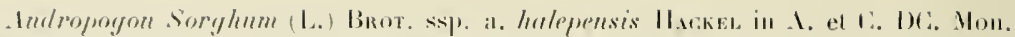

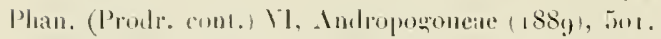

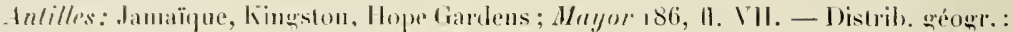
uriginaire de lontent, à l'útat cultivé el sub-spontani dans les contrées elundes du glolue.

7. Anthephora hermaphrodita (L.) O. Kuxtze Revis. gen. pl. I ( $89 \mathrm{~g}), 7.9)$.

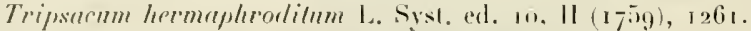

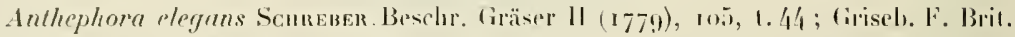
11. Ind. Isl., siti; Dïll in Mart. Fil. Brasil. I1, 2, :3.3.

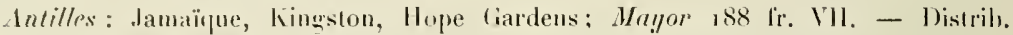
qéogr.: Amirique tropicalı.

8. Paspalum compressum (Sw.) Risp. in Ann. se. nat. sér. I, V (1825), 30r.

Milium rompressum Swantz Prodr. reg. Ind. occ. (1788), 2/4.

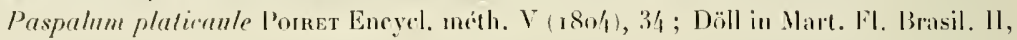
$\because$, wi (plalycrirlon).

Andes centrales; dreniu de Medellin à America, dép. Antioquia, alt. environ rtioo m; Ma! or 38., 11. VIll. Borl de la voie ferrée entre Pavas el Cisneros dép. Antioquia, alt. environ soo $\mathrm{m}$; Mayor 3 rq̣, II. VIIl. - Distrib. „éogr. : Amérique entière. Afriqur Iropicale?

9. Paspalum conjugatum Bekg in Act. Ilelv. VIl $(1772), 129$ 1. 8 ; Döll in Mart. Rl. Brasil. II, 2, 55.

Andes centrales; cultures, Cafetal La Camelia près Angelopolis, dép. Antioquia, alt. $1800 \mathrm{~m} ;$ Mayor 40\%, 11. VI11. - Distrib. géogr. : Amérique, Nfrique el Asie tropicales.

10. Paspalum fimbriatum B. B. K. Nor. qen. el spec. I $(\mathbf{8 1 5}), 93$ 1. 28 ; Döll iı Mart. Fl. Brasil. II, 2, 6.3; Griseb. Fl. Bril. W. Ind. Isl., 5/2.

Antilles: lamäque, lingston, Hope Gardens; Ma!jor 32r, 11. 1.3. V1l. 1910. Distrib. géogr.: Brésil, Antigua, Colombie.

i r. Paspalum Fournierianum Ricken ex exsicc. : Pringle Pl. Mexic. rgo/ n. 8761 ! var. (?) maximum ThflLung nov. var. : differt a planta mexicana statura vegetissima (ultra $2 \mathrm{~m}$ alta), foliis ad $3 \mathrm{~cm}$ latis, lantum in pagina superiore pilis e tubereulis ortis lirsutis, paniculae maximae ramis inferioribus iterum paniculato-ramosis. An mera forma e cullura orta?

Audes centrales ; cultures Cafetal I.a Camelia prís Angelopolis, dép. Antiopuia, alt. $1800 \mathrm{~m}$, plante en touffes, dépassant $2 \mathrm{~m}$ de hantenr ; Mayor 394, 11. VIII. - Audes centrales; Ia Primavera près Caldas, vallée dn Porce, dép. Antioquia, alı. 1870 m, dípartement Anloquia (Ciraminée cultivée pour la nourriture des mules, poussant en toulfes); Mayor Irg, fr. IX. - Distrih. géogr. : Mexique.

12. Eriochloa punctata (L.) Ilaniltox Prodr. pl. Ind. occ. (1825), 5.

Milium punctulum L. Syst. ed. 10, II (1759), 872.

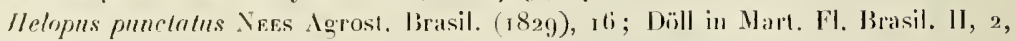
Paniceae, 125. 


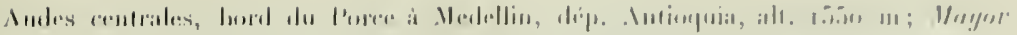

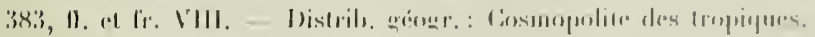

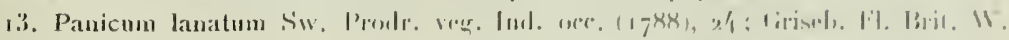
Iud. IsI., 5ir.

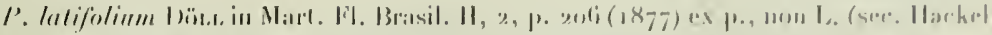

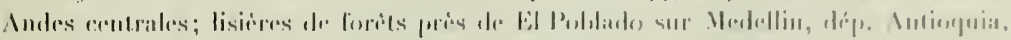

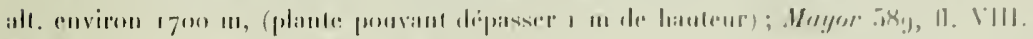

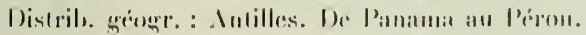

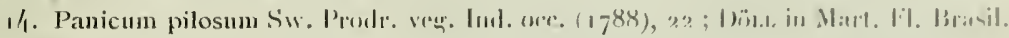
II, 2, P'ir1ir., 2111.

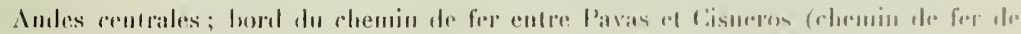

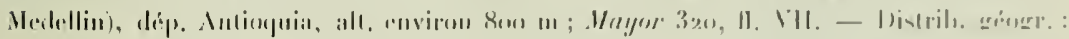
Amérique tropiciole.

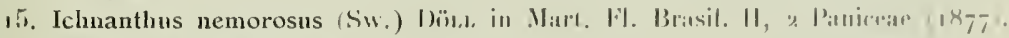

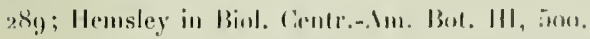

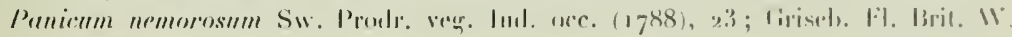
Int. IsI., 5.50.

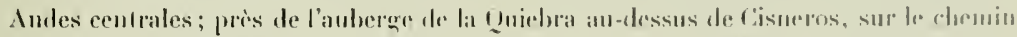

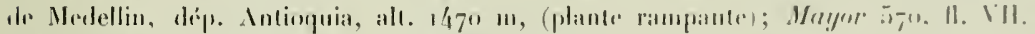

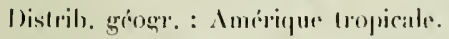

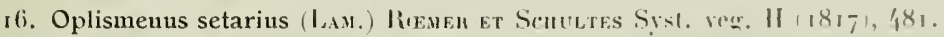

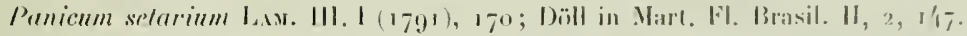

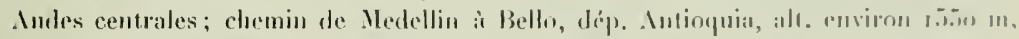

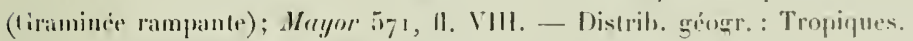

17. Setaria gracilis II. B. K. Now. qen. el spec. I (181,5), 10y).

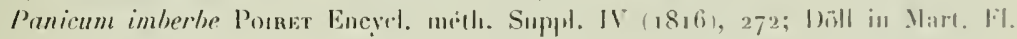
Brasil. II, 2, 156.

Selnvin imberbis Romen lit Schultes Syst. vergel. II (1817), 4!)1.

Andes centrales, commun dans les cultures el cafelates (La Nokia. La Ilermosa. Ia

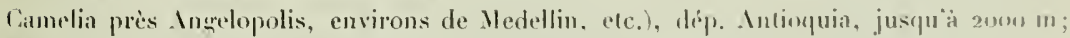

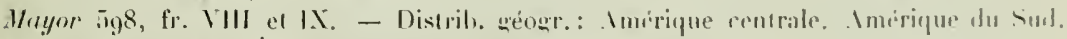
Ifrique équaloriale. Ifrique du Sud.

18. Setaria scandeus Scmuden in Sehult. Mant. II (1824), 279.

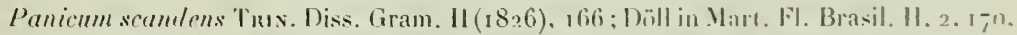

Indes centrales ; culures, Cafelal La Camelia, pris. Inegelopolis, dip. Inforpuia, alı.

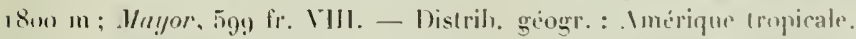

19. Cenchrus echinatus I. Spec. pl. (17-3), 10.m; Döll in Mart. FI. Brasil. II, ?, 3111011.43 !

Indes centrales: Bello pris Medellin, sur un mur, dep. Intinquia, all, anviron

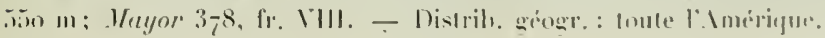




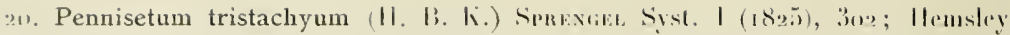
iil Bist. Cientr.-.111. Bol, 111, sog̣).

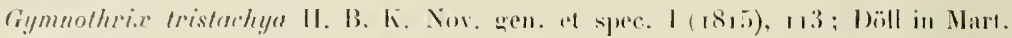
Fl. Brasil. 11, 2, 303, 1. 41!

Andes rentrales; cultures, Calctal La Cameliat pres . Ingelopolis, dep. Antioquia, all.

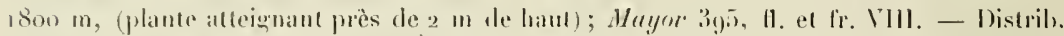
giongr.: Imérique tropicals.

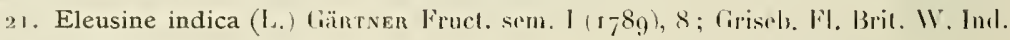
Isl. . iqu; Döll in Mart. Fl. Brasil. 11, 3, 86.

Gynosurns indicus L. Spec. pl. ( $1-5,3), 72$.

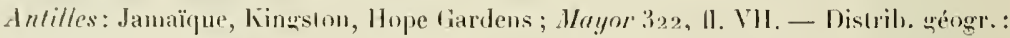
Cosmopolite des tropiques.

22. Arthrostylidium sp. (alf, A. sarmentosum PiLfiEr sec. Hackel).

Amles centrales, dep. Antioquia ; i beaucoup al'emdroits entre goo-1500 m; Bambusére grimprante en s'appnyant sur les plantes voisines, pouvant atteindre plusieurs mòlres de longueur et recouvir des arlurs el des arbustes; Mayor, 286 pl. sterilis.

\section{Cyperaceae.}

23. Cyperus diffusus VAm, Enum. II (1806), 321; C. 13. Clarke in Urban Symb. Intill. Il, I (1!)0u), 30.

Indes centrales; le long du chemin de leer endre Puerto Borro (sur le Magralena)

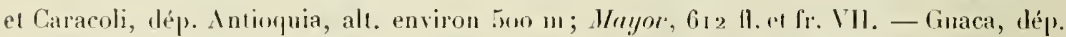

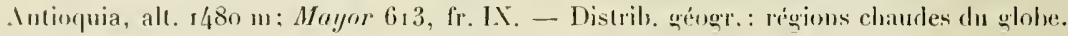

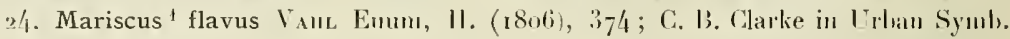
Intill. II, I, p. 4 i.

Cyperus flauns NeEs in Limnaea NIX (1847), 6g8 ; lonekelor in Limuaca XXXVI, 348 ex p. - non Prest.

Bored du Canca à Puerto de los Pobres, Paso de Concordia, fép. Antioquia, all. 720 m; Mayor bag, 1. fr. IX. - Disırib. grogre. : Commun depuis le Texas el le Mexique, jusqu'en Palagonie.

25.) Mariscus hermaphroditus (JAco.) Urвan Syml. Antill. II, I (1900), 165.

Carex hermaplirolita IAce. Collect. IV (1790), r74 a Ie. pl. rar. III, 1. 615!

1. Wuiscus im Sinne von Gartner Fruet. sem. 1 (1788), 11, Vahl Enum. II (1806), 372, C. B. Clarke nnd anderen neupreu Autoren. Dieser Gattungsname kann, wenn nan Mariscus übertaupt als Galtung aulrecht erhalten will, nieht beihehalten werden wegen der Existenz eines älteren, gülligen Homonyms: Mariscus [Haller 17/42] Lulwig Defin. gen. pl. (1760), 423 = Cladium [P. Browne 1756, nomen uudum] Schrader

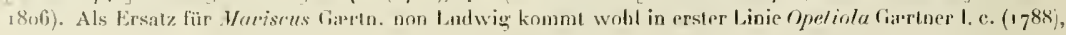
1' 1. in firage. 


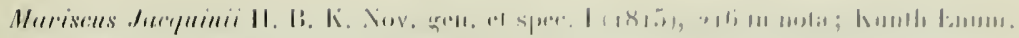

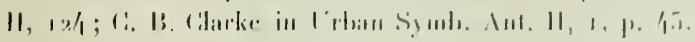

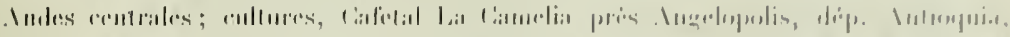

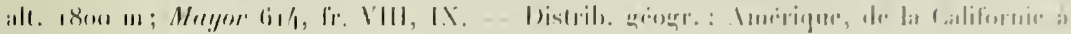

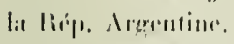

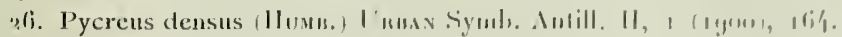

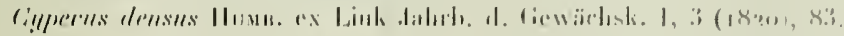

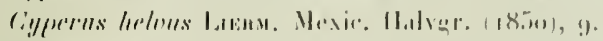

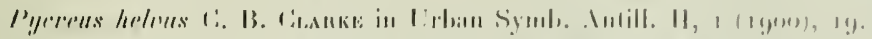

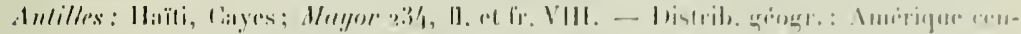
trals: Améripue du Sist. Intilles.

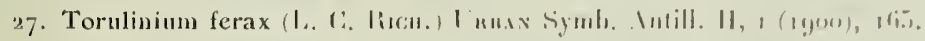

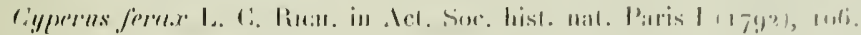

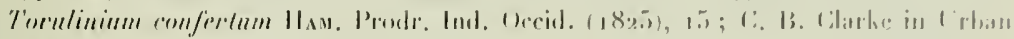
Symh. Intill. II, 1 (

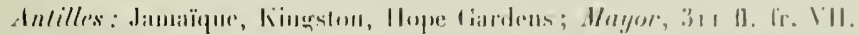

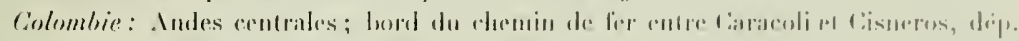

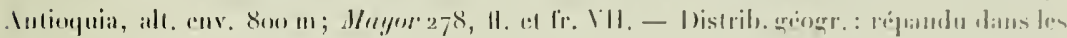
rimions rlaudes du ghtolue.

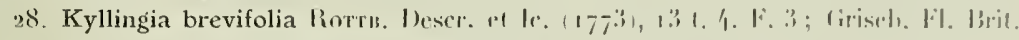

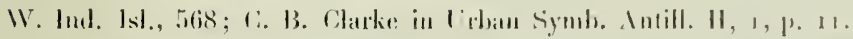

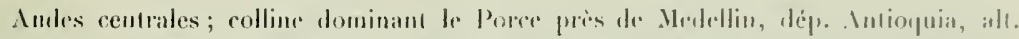

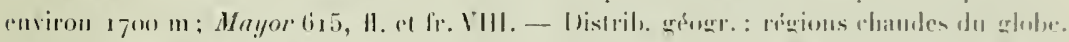

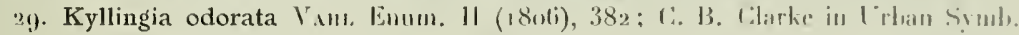
Antill. II, 1, 1. 1.3.

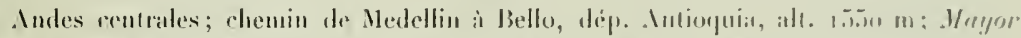

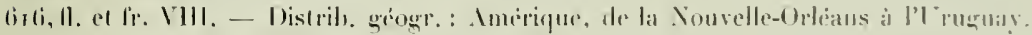

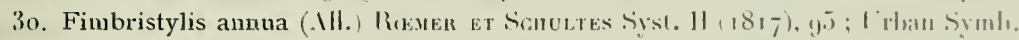
Intill. 11, 1, 1). I(i6.

Scirpas anmmis. ILL. Fl. P'edem II (1-85), 27 т.

Scirpus diphyllns lietz Ols. V. (178!)), ris.

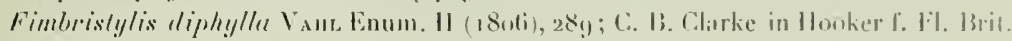
Ind. VI, ti36 in in Lrban Symh. Intill. II, 1, 1) 77 .

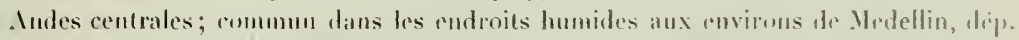

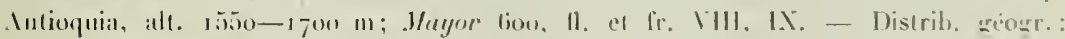

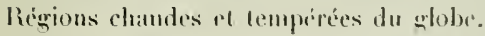

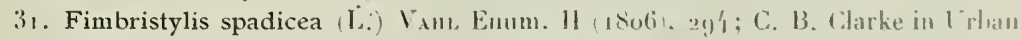
symb. Autill. 11, I p. 79.

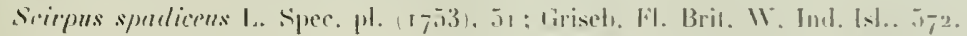

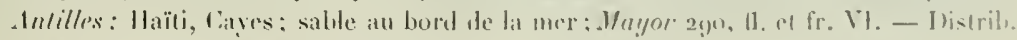
gécurr. : Amérique tropicale el rempérée. 
3:. Dichromena colorata (L.) Hurcut. P. Baham. (18,3), 141; LMan Symb. An(ill. 11,1 J. 1 liti.

Schernus coloratus 1.. Spere. pl. $(1,-53) .43$.

Schermus stellutus Lax. Encyed. 1 (1873), 741.

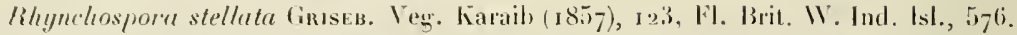

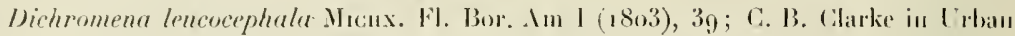
symls. Antill. II, I P. 99.

Allilles: Ilaïi, Canes, dans le sable.

Emvirons de Barranquilla, dép. Bolivar; Mayor 233 , fl. el fr. VIl. - Distrib. gréogr.: Imerique du Nord méridionale. Amérique centrale. Antilles.

33. Dichromena radicans Chм. et Schlecht, in Linnaea VI (1831), 38; C. 13. Clarke in Urban Symb. Intill. II, I p. ros.

Dichromena pubera et D. uereose Viul Enum. Il (I806), 241 ex p.

Rhynchospora Persoonima et Ril. Ilumboldtiana Grisers. Fl. Brit. W. ImL. IsI. $(1864), 577$.

Indes centrales; cultures, Cafetales La Moka el La Camelia près Angelopolis, dep. Intioquia ; condruts humides près du Porce ì Medellin, dép. Antioquia, alt. $1550-1800 \mathrm{~m}$; J/ayor 6r7, 11. el li. VIII-IX; chemin de Medellin, pres de l'auberge de la Quiebra, anlessus de Cisneros, dép. Intioquia, alt. 1470 m; Mayor 250 , 11. VIII. - Distrilı. géoggr.: Imérique centrale et tropicale.

34. 'Dichromena polystachys TukuL nov. spec. Radices librosac. Cnlmi ad 6 dm alti, caespitosi, apice excepto glabri, striati. Folia linearia, plana, acula, ad $30 \mathrm{~cm}$ longa, 4-6 mm lata, subrigida, pilosa vel leere glabrata, ciliata, nervis obscuris. Bracteae circiter 6 , ad $15 \mathrm{~cm}$ longae, foliis consimiles; caput $1-1,5 \mathrm{~cm}$ diametro, polystachyum; spiculae congestae, $6 \mathrm{~mm}$ longae, $4-5$ nucigerae. Glumae cuiusque spiculae 5-7, ovatolanceolatae, acutac, carinatae, 4-5 mm longae, 2 mm latae, glabrae, fusco-stramineac, nervis obscuris. Stamina 3, filamenta $5 \mathrm{~mm}$ longa; antherae lineares, $2,5 \mathrm{~mm}$ longat. Stylus (ramis inclusis) $4 \mathrm{~mm}$ longus; rami $2-2,5 \mathrm{~mm}$ longi. Nux anguste ohovoidei $1 \mathrm{~mm}$ lata, $1,7,5 \mathrm{~mm}$ diametro, sulcato-rugosa, cellulis extinis longitudinaliter oblongis, albostraminea nisi rostro nigro.

Indes centrales; taillis au-dessous du Cafetal La Canıdia près Ingelopolis, dép. Anlioguia, alt, emviron $1600 \mathrm{~m}$; Mayor 618, 11. el fr. IX.

The altinity of this plant is with D. ciliuta Vam, from which it diflers by the more robust habit, hy each head having many congested spikelets, and hy the smaller muts.

35. Rhynchospora cyperoides (Sw.) Marr. in Denkschr. Mkarl. Wiss. Münch. VI (1816-17), 149; Grisel. FI. Brit. W. Ind. Ist., 574.

Schrenus cyperoides Sw. J'rodr. veg. Ind. occ. (1788), 19.

Rynchospora cyperoides Britton in Trans. New York Acad. X1 (18y2), 84; C. B. Clarke in ITban Symb. Antill. II, I p. Iog.

1 Dèterminé par M. M. B. Turrill-kíw. 


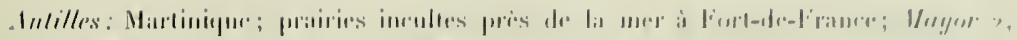

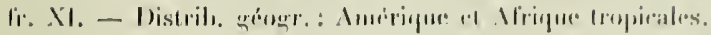

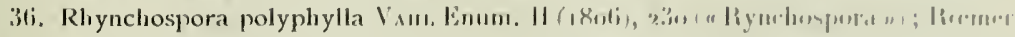

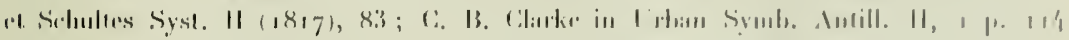
("liywd....").

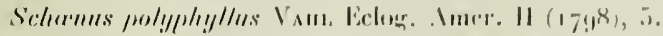

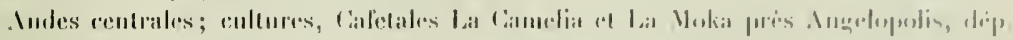

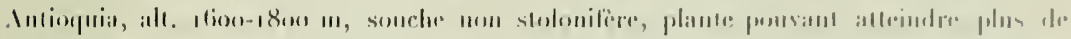

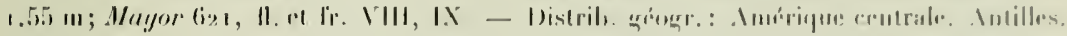
l'enrzuclis. Conloumbic.

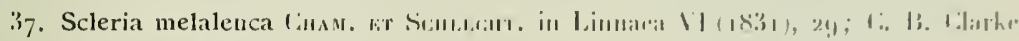
in I rlan Symh, Intill. II, 1, 1. Ifli.

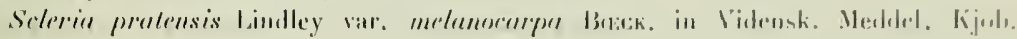
$(18(i)), 1,3.3$.

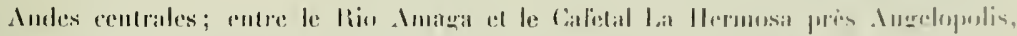

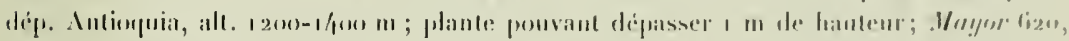

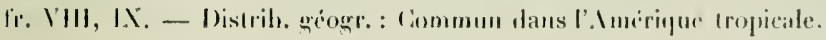

\section{Araceae.}

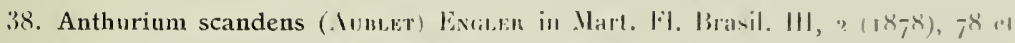

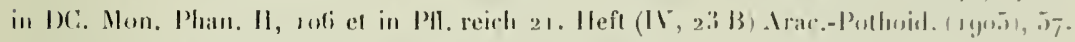

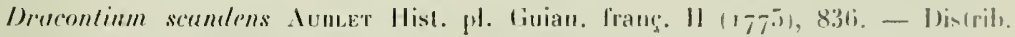
grogr.: Amérique tropicale.

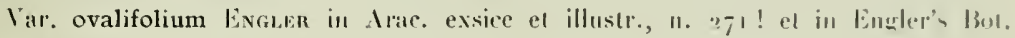
Ialul. XXY. (1898), $35 \mathrm{z}$ et in Pll. reich 1. c., ing

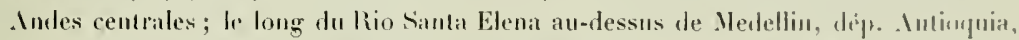

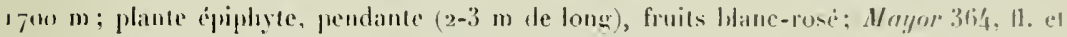
li. VIII. - Distrih, géogr. de la variste: Colombie.

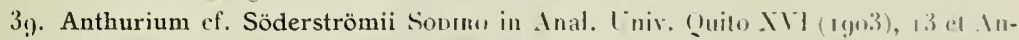
lurios equatorianos (rgo3), 7o; Engler in Engler's Pll. reich 2r. Ileft (11. 2.3 B) . Irac.Poth. (1905), 184.

Andes centrales ; forèts, environs du Cafetal Lal Camelia près . Ingelopolis, dép. I:nlimquia, alt. $1800 \mathrm{~m}$; Mayor 170, fr. IIIl. - Distrilı. géogr. : Équileur.

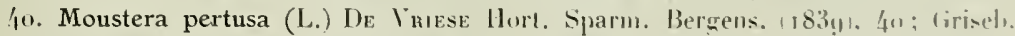
lil. Bril. W. Iud. Isl., Fog; Engler in Mar. II. Brasil. IH, 2, 1 13. 1. 20, 21 el in DI:

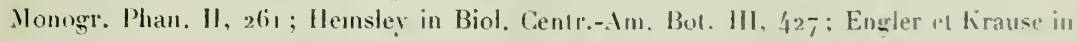
Engler's Pll. reich 37. Heft (II, 33 B), Arac. Monster. (rgos), ro.3 ("lypus polymm[1/us n). 


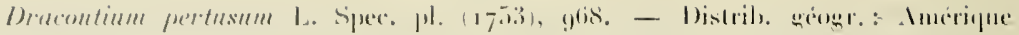
tropicale.

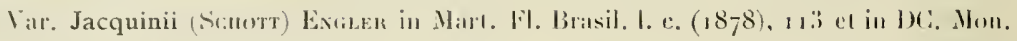

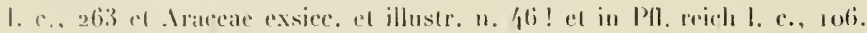

Drencontium pertusum Jaco. Hort. Sichurnhr. 11. (1797), 1. 184, 185.

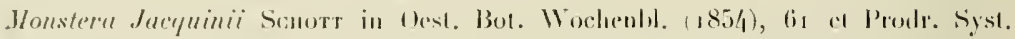
Aruil., $36 \mathrm{~s}$.

Audes centrales; lomets anx environs du Cafetal La Camelia prés Angelopolis, dip.

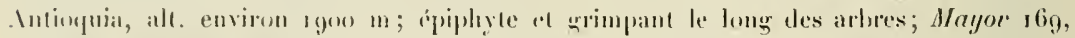
fr. 1111. - I)istrils, queorre de la variéte : Imerique tropicale.

11. Xanthosoma? spere.

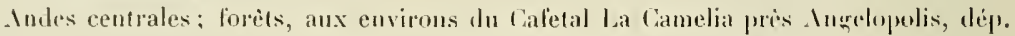

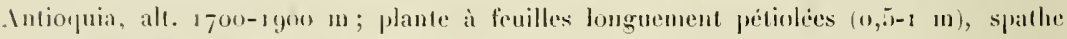
verte, jaune smperieurement; .Mayor 34!), 11. (?) VIII.

Blüton sind an dem getrockneten Material nichl zu rrkenmen. Die Bbattnervatur stimml wut mit derjenigen von lanthosoma ïlerein, doch passt die vollkommen alggerundel-slmmple Blaltspreite auf keine der von Engler in DC. Suites au Prodr. 11 (1879) beschriebenen Aren.

42. Pistia Stratiotes L. Spee. pl. (1753), g(73); Engler in DC. Mon. J'han. II, (i3/4 el in Engl. Prantl Nat. 1’l1, fam. 11, 3, p, r5z. - Mistrib, treggr.: Amérique tropicale et sult-tropicale. Ifrique el Asie tropicales.

Var. spathulata (Micnx.) Evgeen in Mart. Fl. Brasil. III, 2 ( 3878$), 214$ el in I)C. Mon. Phan. II, 634.

I'istiu spathulata Micux. Fl. Bor.-.m. II (1803), 162; Pursh I1. Am. sept. 1, 268.

Environs de Barranquilla, dans les cananx el fossés el le longr du Nagdalena jusquà Puerto Berrio; Mayor 66;, fol. V'll.

\section{Eriocaulaceae.}

4.3. Pæpalanthus columbiensis Ruhlatud in Engler's Pll. reich r.3. Ileft (1V, 3) Eriocianlaceate $(1903), 207$.

Indes orientales; $\lambda /$ (u) el Paramo Cruz Verde, au-dessus de Bogula, dép. Cundinamarca, alt. environ $3500 \mathrm{~m}$; lleurs lhane-jannàtre; Maygr, 3 1l. et fr. X. - Distrils. unéngr.: Colombie.

14. Pæpalanthus ensifolius (II. 13. K.) Kuntı Enum. pl. HI (18/1), 501 ; Körnicke

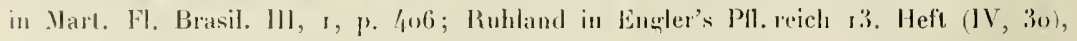
Eriocaulaceae (190.3), 208.

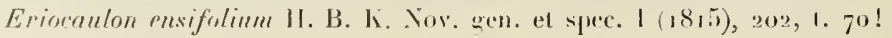




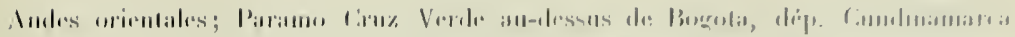

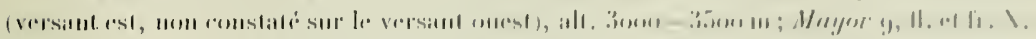

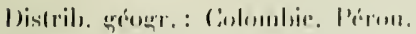

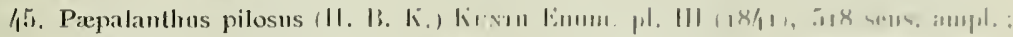

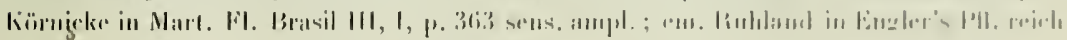

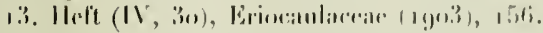

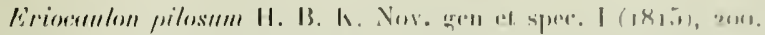

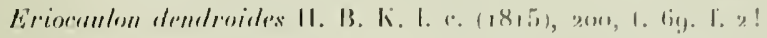

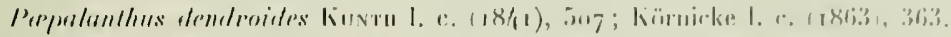

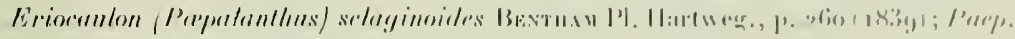

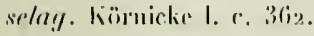

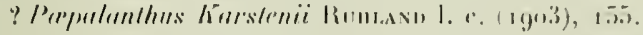

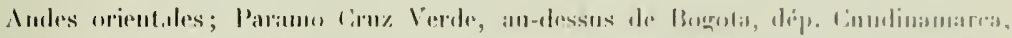

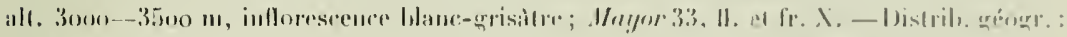
Colombire. Proms.

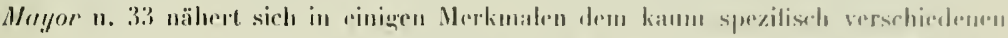

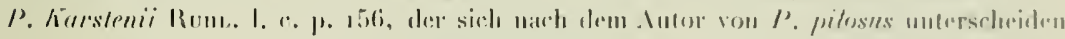

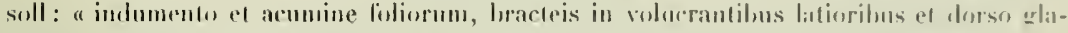

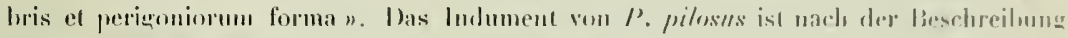

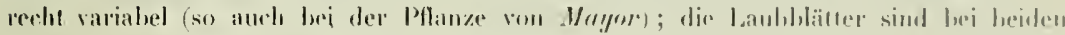

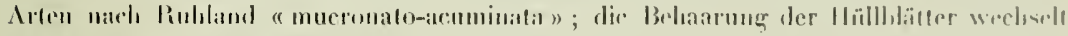

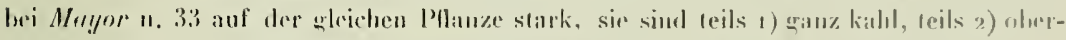

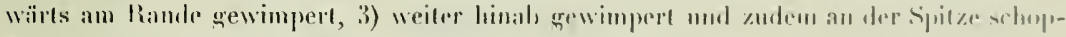

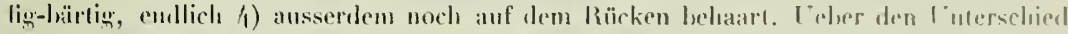

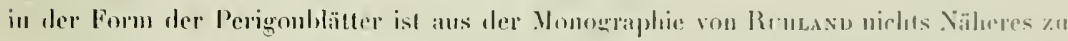

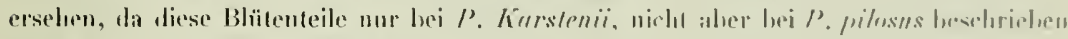

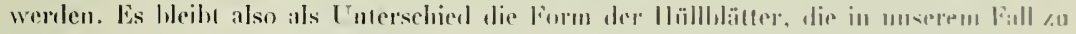
limsten vou I'. pilosus entsclieidet.

\section{Bromeliaceae.}

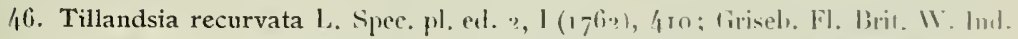

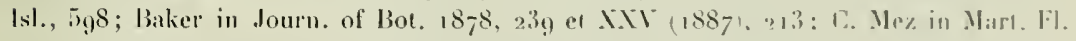
Brasil. 1II, 3, p. bog et in DC. Mon. Phan. .I, 8-2.

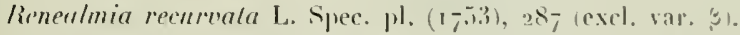

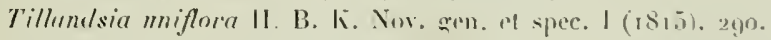

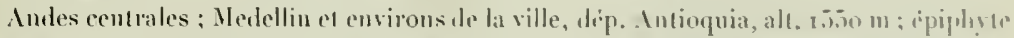

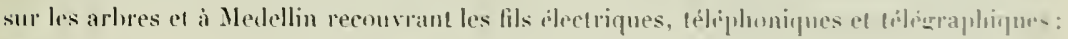

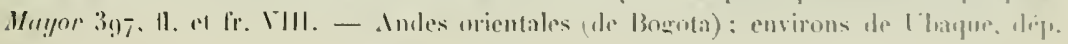




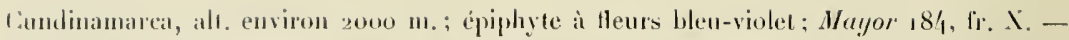
Distrib. giogr. : répandu dans les regions chaudes de l'Amérique.

47. Tillandsia usneoides L. Spee. pl. ed. 2, 1 (1762), 411; Griseh. Fl. Brit. IV. Ind. Isl., 5gs; Baker in Journ. of Bot. XXY (1887), 212 ; C. Mez in Martus W. Brasil. III, 3, P. 613 et in VI. Mon. Phan. Xl, 88r.

Reneulmiu usneoides L. Spee. $11 .,(1753), 287$.

Tillendsin trichoieles II. B. K. Nor. gen. et spec. I (1815), 290.

Antilles: Jamaïque, Kingston, llope Gardens; sur les arhres, plante pouvant alteintre phus de $2 \mathrm{~m}$; Mayor 187 , planta sterilis (VII).

Andes orientales (de Bogota); environs de Uhaque, lép. Cundinamarea, alt. environ snoo $\mathrm{m}$; plantes pendantes sur les arbres et les rochers, pouvant atteindre plus de 3 m de longueur; Mayor r 8. r (planta sterilis). - Distr. géogr. : régions chaudes de l'A mériqur.

48. Tillandsia utriculata L. Spec. pl. (1753), 286, ed. 2, I (1762), 409; (irisel. lil. Brit. W. Ind. Isl., 596; Baker in .lourn. of Bot. XXV1 (1888), 144; C. Mez in DC.. Mon. Phan. N1, 663.

Tillandsia flexnosa sw. Prod. veg. hod. oce. (1788), 60 et Fl. Ind. oce. I, 5oo; (iriseh. I. e. 596 .

Tillandsia flexusa var. pallida Lindeer Bot. Reg. IX (1823), 1. 749 !

Antilles: San Thomas; épiphyte sur divers arbres; Mayor 19", fr. VII. - Distrib. gíogr.: Fhoride. Mexique. Vénézuela. Antilles.

\section{Commelinaceae.}

4!). Commelina nudiflora L. Spec. pl. (1753), (iı; C. B. Clarke in DC. Mon. Phan. III, 144.

C. cayennensis Ricn. in Act. Soc. hist. nat. Par. 1 (1792), 105 ; Grisel. N1. Brit. WV. Ind. 1sl., 524 .

Antilles : Jamaïque, Kingston; plante phus ou moins rampante, à petites tlems hlenes; Mayor 323 ex p., fl. VIll. - Distrib. géogr. : régions chaudes des 2 hémisphères.

io. Commelina virginica L. Spec. pl. (1753), 6r ; C. B. Clarke in DC. Mon. Plıan. III, 182

C. elegans 11. B. K. Nov. gen. et spee. I (1815), 250; Seuhert in Mart. FI. Brasil, III, 1, 263 เ. 37 f. 2 ; Grisel. FI. Brit. W. Ind. Isl., 525.

- Antilles : Janaïque, Kingston; plante plus ou moins rampante, à petites fleurs blenes; Mayor 323 ex p., 11. VII. - Distrib. géogr. : régions chaudes de l'Amérique, du golfe dis Nexique au Paraguay.

51. Tradescantia elongata F. F. W. MeYer Fl. Essequih. (1818), 1/40; C. B. Clarke in [)C. Mon. Phan, III, 3o3.

T. Commelinn VELL. FI. Flum. III (18:7), 1. 15/. 


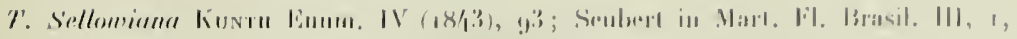
1. 2ixi.

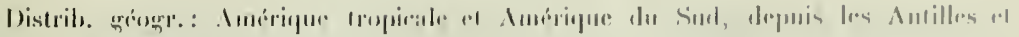

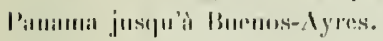

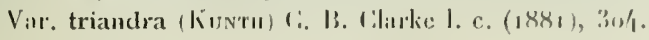

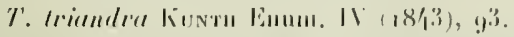

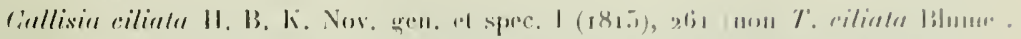

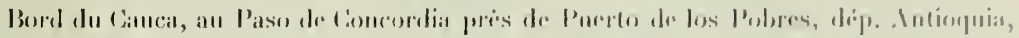

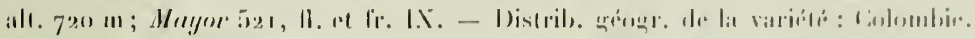

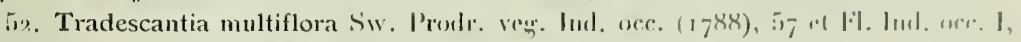

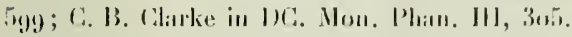

T. procumbens W11,1,. S'pure. pl. II (17!99), 1!).

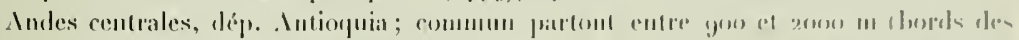

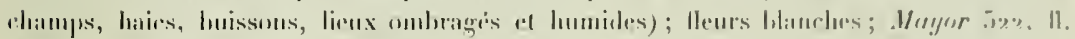

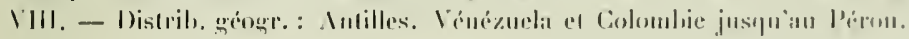

\section{Pontederiaceae.}

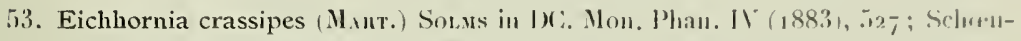
land in Engler-Prantl Nat. Pll. fatı. 11, 4, 1. 73 .

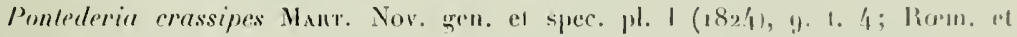
Schull. Syst. VII, 1137 .

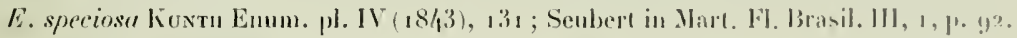

P. asurea НоoкEn Bol. Mag. 1. 29.3. ! (1829) non Sw.

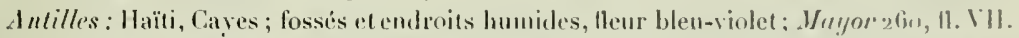

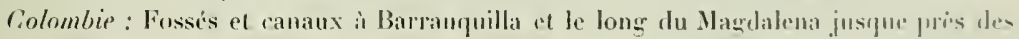
Purto Berrio. VIl. - Distrib. úógr. : Amérique tropirale pt suh-tropicale.

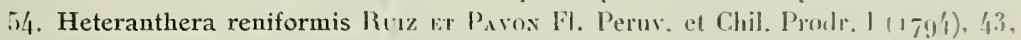
1. 71; Yahl Enum. II, 43; H. B. K. Nor. gen. el spec. I, 265; Senbert in Mart. H.

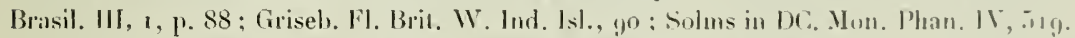

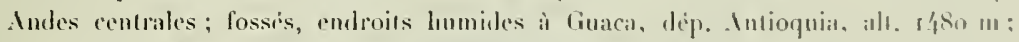

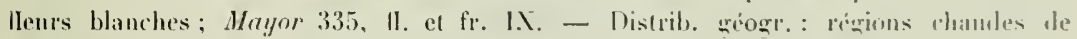
l'Amriqur.

\section{Liliaceae.}

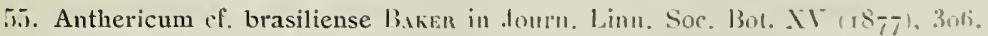

Andes centrales; forèts de l:Nlu Don Elias près Angalopolis, dip. Intinguia, alt.

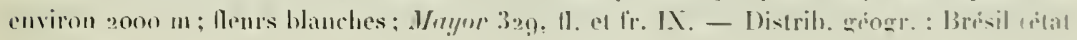
le. (iovaz).

45 


\section{Amaryllidaceae.}

56. Bomarea cl. Caldasii (II. B. K.) Witud. see. Pax in Engler-Prantl Nat. Pll. fam.

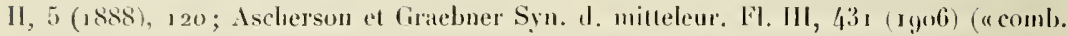
แ10., 1$)$.

Alstremeriu Caldasii II. B. K. Nov. gen. el spec. I ( 8 I5), 283 ; Bol. Mag. 1. 5/42.

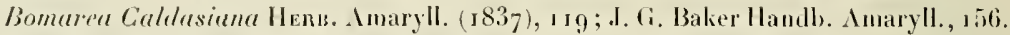
1/stremeria Caldusiana llessey in Biol. Centr.-Am. Bot. III (1882-(i), 336 iı. syu.

Antes orientiles (de Subia); forets entre l'Mlto Mira et El Boqueron de Guachuni dominant la valléc de Viota, le long du sentier el dans les taillis, dép. Cundinanarea, alı. $2400 \mathrm{~m}$; lleurs rouge-orange (plus petites que celles du $N^{n} 17$ ); plante rampante, pouvant devenir grimpante en s'appuyant sur les plantes voisines, el alleindre jusifu'it 2 m. de longuenr; Mayor r8, fr. X. - Da das vorliegende Exemplar sich im Fruchtstadium befindet, ist eine sichere Bestimmunğ nieht mögnlich. -- Distrib. qúogrr.: Andes dr. l'Equateur' el de Colombie. Costit-Rica?

57. Bomarea patacocensis Ilerв. Amaryll. (1837), 120 t. 14 f. 3; Bot. Migg. t. 66ge !; I. (i. Baker Handl). Amaryll., r57 ("patacoensis").

Indes centrales, dép. Antioquia et Tolima; chemin de Manizales à llonda, à plusienurs endroits, an-dessus de $1800 \mathrm{~m}$; lleurs ronges; Mayor 94, II. X. - Ambles orientales (de Subia), dép. Cunclinamarca; cutre l’Nlto Angarillo et les Cafetales de la vallée de Viota, forèts et lisieres de bois le long du sentier, alt. 2000-2500 m; Mayjor 17, II. X. Fleurs rouges; plante pouvant atteindre plusieurs mètres de longueur lor'siu'elle peut s'appuyer sur les plantes voisines comme support. - Distrib. géogr.: Andes de l'Équateur et de Colombie.

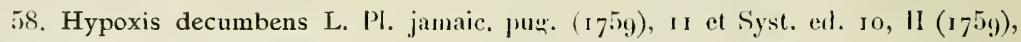
$9 \$ 6$; Seubert in Mart. FI. Brasil. III, 1, p. 51 at 1.7 f. 1 ! ; .I G. Baker Synops. Ilypox. in Journ. Limn. Soc. Bol. XVII, 107.

Andes centrales; cultures, Guaca, dép. Antioquia alt. $1480 \mathrm{~m}$; lleurs jaunes; Mayor 579 , fr. IX. - Distrilı, géogrr. : Amérique dı Sucl. Antilles.

\section{Tridaceae.}

59. Cipura paludosa Aubter Pl. Guian. 1 (1775), 38 t. 13; Klatt in Mart. Fl. Brasil. III, I, p. 513 1. 64!; Baker Handb. Irid., 105.

Marica palurlosa Willd. Spec. pl. I (1798), 246 ; Bot. Mag. L. 646 !

Gipura humilis et C. graminea H. B. K. Nov. gen. et spec. I (1815), 320.

Andes centrales; colline tominant le Rio Porce (rive lloite), près le Medellin, dép. Antioquia, alı. environ $1600 \mathrm{~m}$; Mayor 370, fr. VII; Henr violet-lilas. - Distril). géogr. : Imérípue centrale. Amérique du Sud. Antilles. 


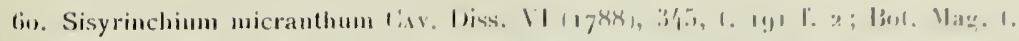

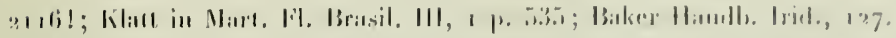

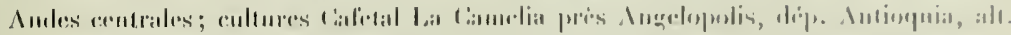

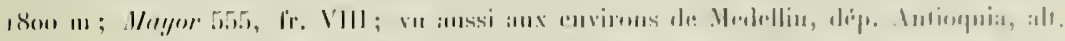

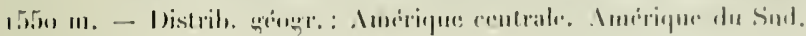

\section{Cannaceae.}

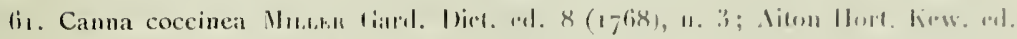

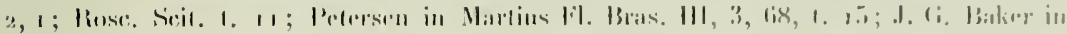

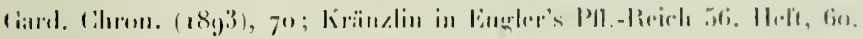

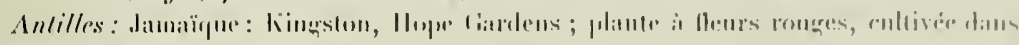

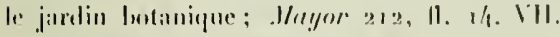

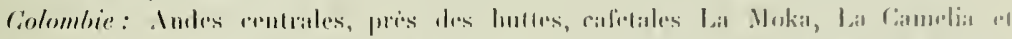

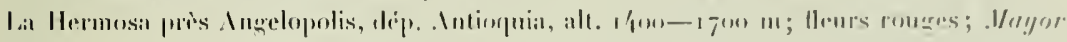

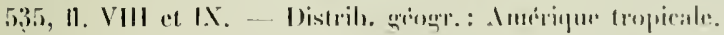

\section{Orchidaceae.}

Bustimmt ron l'rol'. IJ lirinaliu. Burlin.

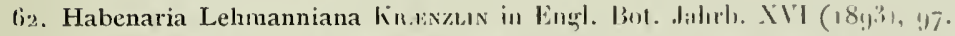

Andes centrales; entre Caldas ef les forrts de l'dlo San Mlinguel, hant de la vallow.

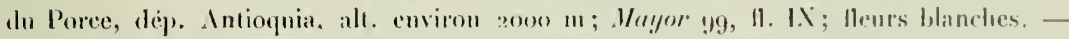
1)istrib. grogrr.: Colombic.

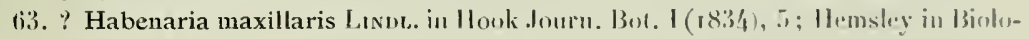
ghia Centr.-Amer. Bo1. III, 3o6; Krënzlin in Engl. Bot, dahrl, $11 \%$, 133.

Andes centrales; pentes lierheuses, rive droite de l'Amagadiente près din Cafotal lat

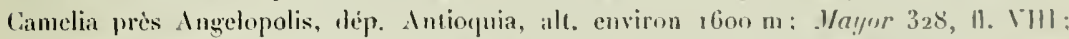
Meurs blanches. (Alle Blüten von einem Pilz zerstört.) - Distrih. eréogr. : Fuatémalin. Amirique du Sud.

64. Physurus Mayoriana Kinexzun nov. spec. - Chulis basi tantum repens, radices pro planta tenui longinsculae. Caulis cum inllorescentia ad 15 cm altus, tenuis, arl llores nsque boliatus. Foliorum vaginae breves, amplae, subito in petiolum brevem contractae, famine albo-punctatae, cordato-ovatae, acutae, 1.5 ad $3,5 \mathrm{~cm}$ longae, basi i as $1,2 \mathrm{~cm}$ latie, subtus 3-nerviac. Folia suprema inflorescentiam attingentia, scapus proprins mulus. Spica densinscula oviala panci-phurillora, bracteae ovatae, acuminatace oran ria non acguantes. Sepalum dorsale oratum acutum, cum petalis similibus arete conglutinatum ; sepala lateralia lation, oblonga, medio saepius paululum constricta, obtusa, omnia $7 \mathrm{~mm}$ longit. Lalelli hypochilium late ohlongum, profunde concavom, extus panlum incrassatum, intus lineis z crassiorilus munitum, cpichilium late obovatum: vo obcordatum. 
antice leviter cmarginatum, anteposito hobulo intermedio triangulo, aculo; calcar breve, sacaltum, valde ampliatum, a facie ad tergum compressum, subtus retusum, ovarium longe non aequans, hrevius quan cetera plyfla. Gynosteminn crassissimum pro llore magnum 23 sepalorum aequans. - Flores viridi alli. Floret exemute Augnsto.

Andes centrales; Entre le Cafetal La Cantelia près Argelopolis et le Rio Anaga, dép. Antioupuia, alt. r200-1400 $\mathrm{m} ;$ Mayor 327.

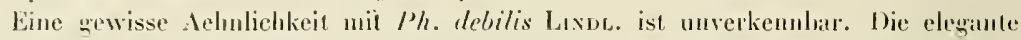
lileinc Pllanze hat aber so virl apartes, dass ich mich doch entschlossen habe, eine nov. sp. zn wagen. Das Labellum könnte streng genommen in ein epichilium, mesochilium und epichilinu geteilt werden, als letzterer den Teil gedach, den ich in der Diagnose etwas frei als "lobus intermedius" bezeichnet halse.

65. Cranichis ciliata Kuxrn Synops. 1 (1822), 324; Memsley in Biologgia Centr.Amer. Bol. 11I, 297 .

Andes orientales (de Bogota); forèts, près du lac d’lbaque, dép. Cundinauarca, all. $2000 \mathrm{~m}$; Mayor 6, 11. X., lleurs vertatres. - Wistril. géogr. : Guatémala. Améringe do sud (Colombie, Bolivie).

66. Prescottia spec.

Andes centrales: cultures, Caletal La Camelia pris Angelopolis, dép. Antioquia, alt. 180011 ; 111yor 400, 11. 20. VIII ; lleurs blanches.

67. Stelis spec.

Andes centrales; forèts de l'Alto San Mignel, haut de la vallic dn Porce, dcip. Anliorpuia, alt. emiron $2500 \mathrm{~m}$; Mayor 179 , Il. IX; Heurs jaune-verditre.

68. Restrepia spec.

Andes centrales; chemin de Angelopolis à Guaca, dép. Antioquia, alt. conviron stou in; Mayor I7, II. 13. IX; lleurs janne-vertitre.

69. Pleurothallis spec.

Andes centrales; forets de l'Nto Romeral, entre Angelopolis el Estrella dans la vallece du Porce, dép. Antioquia, alt. environ $2500 \mathrm{~m} ; \mathrm{Na}$ agr 174 ; lleurs d'un rose-lilas.

70. Epidendrum calyptratum Lens. ET KinenzLIN in Engl. Bot. Jilurb. XXVI $(1899), 47^{3}$.

Indes centrales; Paramos du Rniz, dép. Antioquia, alt. 3400-3700 m; Mayor 161, 11. 5. X. - Distrib, géogr.: Colombie.

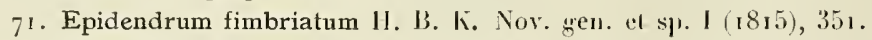

Andes centrales; environs de Medellin, dép. Antioquia, alt. 1550 m; Ma!yor :3y9, 11. VIIl. - Distril, géogr. : Colombie.

$7 \mathrm{I}^{\mathrm{a}}$. Epidendrum floribundum II. B. K. Nov. gen. el sp. I (1815), 353, 1. 86; Ilemsley in Biologia Centr.-Amer. Bot. III, 230.

Indes centrales; cliemin de Angelopolis it Guaca, dép. Antioguia, alt. environ $1500 \mathrm{~m}$; Mnyor I72, 11. I I. IX; Ileurs d'un janne-pâle et violet. - Distril. géogr.: Liosta-Rica. Vénézuéla. 


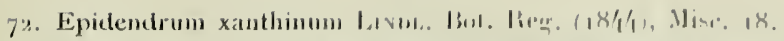

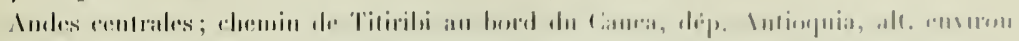

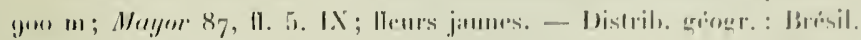

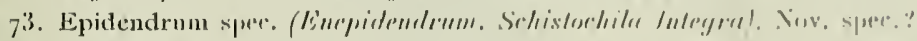

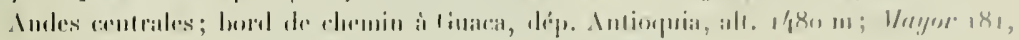

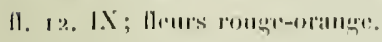

7/. Leptotes spret.

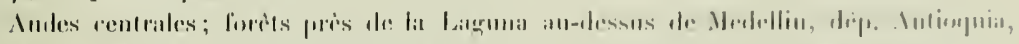

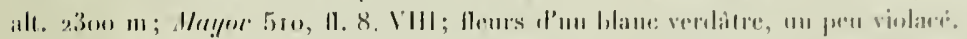

75. ? Rodriguezia sper. ?

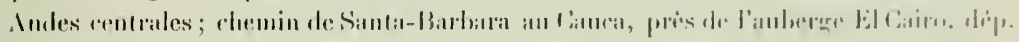

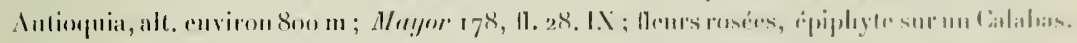

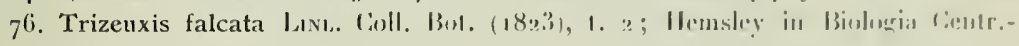
Imere. Bot. III, 2g!o.

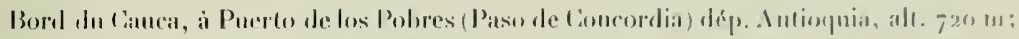

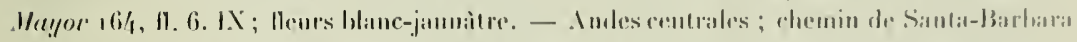

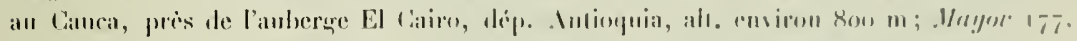

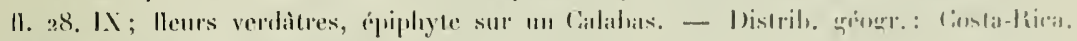
Vúmentar. Brésil. Ial Trinite.

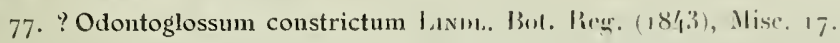

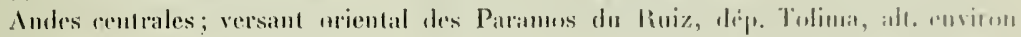

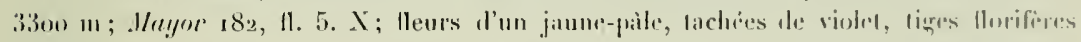

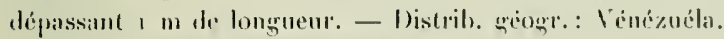

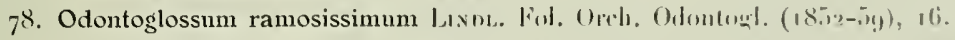

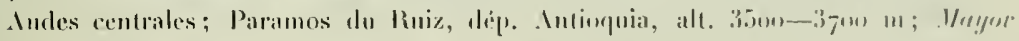

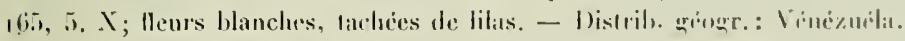

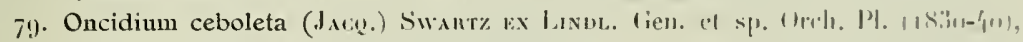
2u6; Ilemstey in Biologia Centr.-.lmer. Bol. III, 280.

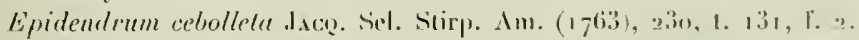

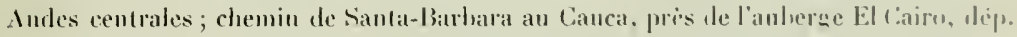

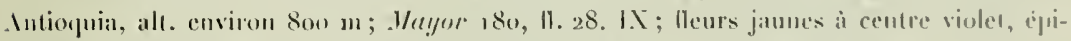
phyte sur un Calabas. - Distrib. géogr. : Nexique méridional. Imerique centrale. Iméripge do sud.

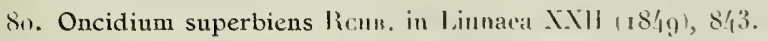

Andes orientales; Paramo Cruz Verde au-dessus de Bogota (versant urientali, dép.

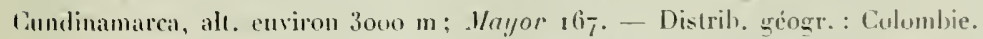

8ı. Pacliyphyllum Hartwegii licur. in Bonplaudia Ill (185i), 21!).

Andes orientales; Paramo Crou Verde au-dessus de Bogona, dép. Cundinamarca. all. 3500 m; Mayor r83, tl. 15. X: plance a lleurs vertes, dans les feules des ruchers. Distril., gु'ogrr. : Équatcur. 


\section{$-358-$ \\ Dicotyledones.}

\section{Piperaceae.}

Bestimmt von Dr. Cias. de Candolle. Genf.

82. Peperomia blanda (Jace.) II. B. K. Nor. gen. el. spec. I (I8,5), 67; C. I) C. in 1M: Prodr. XVT, 1, p. 458; Hemsley in Biol. Centr.-Am. Bot. 111, 58.

Piper blandum Jacu. Collect. III $(1-89)), 210$ et de. pl. 1ar. II $(1786-43), 1.218$.

Indes centrales; Paramos du Ruiz, dép. Antioquia, alt. 3500-3700 III épiplyyte;

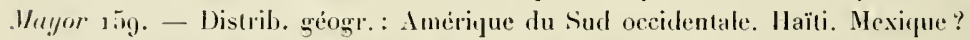

83. Peperomia Hartwegiana Mıg. in Hook. Loud. Journ. Bot. IV (1845), 425; C. IX.. in ICC. Prudr. NVI, 1, [1. 456.

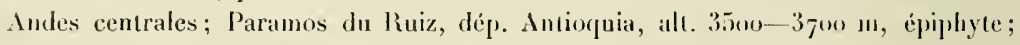

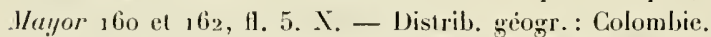

84. Peperomia macrotricha C. DC. nov. spec.

Foliis alternis longe petiolatis, limbis subreniformi-jolundis basi cordatis lolis conniventibus, utrinque Ienge pilosis, 9 -nervis; petiolis pedunculisque aequilongis longe pilosis; spicis glabris limbos aequantibus, tiliformibus, densilloris, bracteae pelta urbienlari centro pedicellata, antheris rotundatis; ovario emerso ovato superne subattemuto et summo apice stigmatifero, stigmate 2-Jobo lobis rotundatis; lacea gholosa sine pseudocupula, glandulis asperata.

Planta rhizomatica. Folia omnia e rhizomate orta. Limbi in siceo membranacei, creberrime pellucido-punctati, $5,5 \mathrm{~cm}$ longi, $6 \mathrm{~cm}$ lati, pilis $2 \mathrm{~mm}$ longis. Petioli circiter $8,5 \mathrm{~cm}$ longi. Spicae $1 \mathrm{~mm}$ crassae.

Bord du Cauca, Paso de Concordia (Puerto de los Pobres); dép. Antioquia alt. 720 m; Mayjor ı58, 11. 6. IX.

85. Peperomia obtusifolia (L.) A. Dietr. Spec. pl. I (1831), 154 ex p. ; Miq. Syst., I9' ex p. et in Mart. Fl. Brasil. fase. 11, $24 ;$ Griseb. FI. Brit. W. Ind. Isl., r66.

Piper oblusifolium L. Spec. pl. (1 753$)$, 30.

Piper magnoliaefolium JAce. Coll. III (1789), 210 et Ic. pl. rar. II (1786-93), 1. 213.

Peperomia magnoliaefolia A. Dietr. Spec. pl. I (1831), 153; C. DC. in DC. Prodr. XVI 1, p. 427; Hemsley in Biol. Centr.-Am. Bot. III, 62.

Andes centrales; chemin de Nedellin à Bello, dép. Antioquia, sur de vieux murs, alt. $550 \mathrm{~m}$; Mayor 642, 11. 4. VIII. - Distrib. gréogr.: Mexique méridional. Amériıue centrale. Nord de l'Amérique du Sud. Antilles.

86. Peperomia reflexa (L. f.) A. Diern. Spec. pl. I (1831), r80; C. DC. in DC. Prodr. XVI, ı, p. 位; Griseh. FI. Brit. W. Ind. Isl., ı68; Ilemsley in Biol. Centr.-Am. Bot. 111,64 ; 


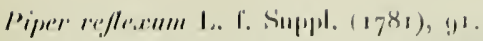

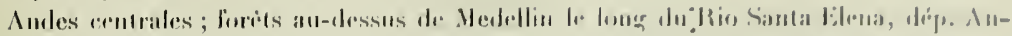

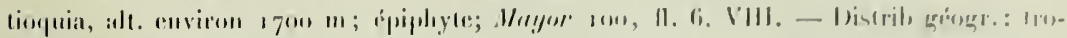

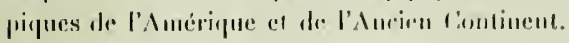

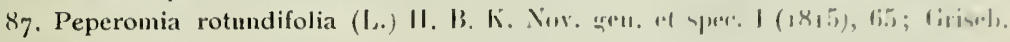
lil. Brit. W'. Ind. Ist., I6\}.

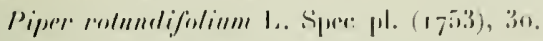

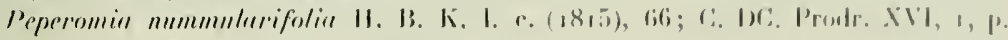

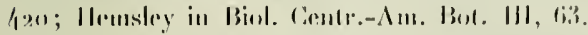

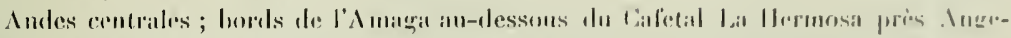

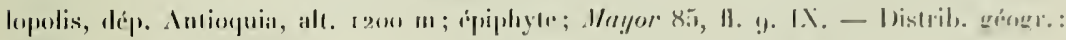

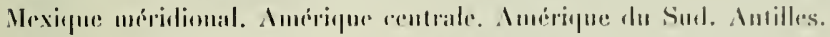

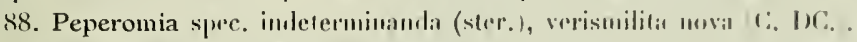

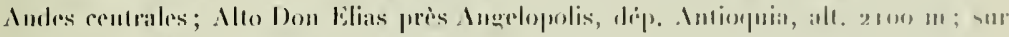

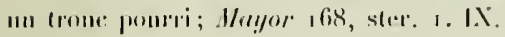

\section{Salicaceae.}

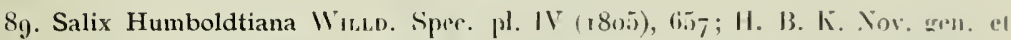
spee. II, 2.2, 1. 99 el 100 ; DC. Prodr. XVJ/2, 199; Hemsley in Biol. Centr.-Am. But. III, I $7 !)$.

Andes centrales, dip. Antioquia: commun partout jusqu’à l'altitude de $220 n$ un:

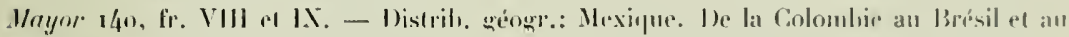
Chili. Antille's.

\section{Moraceae.}

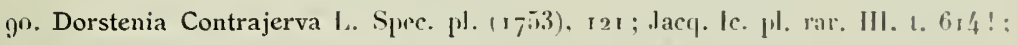

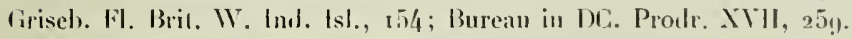

D. Conlrayferen Muten Gard. Dist. ed $8(r-68)$, n. 1.

Bord du Canca, forèts près du Paso de Concondia a Puerto de los Pohres, dép. Intioquia, alt. $720 \mathrm{~m}$; Mayor 66o: 11. fr. IX. - Distril), géogr. : Amirique tropicale, dı Mexique an Péron. Antilles.

Var. Houstoni (L.) Bureau l. c. $(18-3), 25 \%$.

D. Honstoni L. Spec. pl. ed. 2, I (1 762$)$, I 7 ; ; Bot. Mag. 1. $201-$ !

Audes orientales: chemin de Honda à Bogota, non loin de Honda, dép. Cundinanarca,

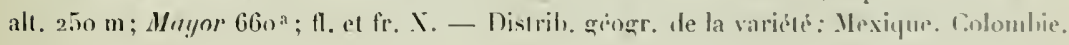
Péron. 


\section{Urticaceae.}

91. Pilea hirsuta (PAv.) Wedp. il AmI. sc. Hat. sir. 3, XVIII (1852), 220 (excl. var. (j) et in Dr. Proulr. XVI, 1, 1) 157.

l'rliea hirsuta Pavos mser. ex Wedl. I. c.

Andes contrales; chemin entre be Rio Amaga ef le Cafotal La Hermosa pres An-

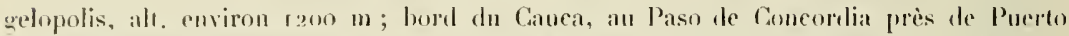

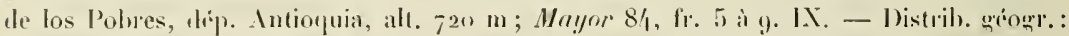
ciolombie.

92. Pilea microphylla (L.) Leпм. in Vidensk. Selsk. Skr. V, II (185i1), 303; Giriseb.

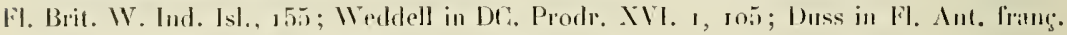
in . Inn. Mus. Colon. Marseille, vol. III $(1896), 161$.

Perrietaria microphy/la L. Spee. pl. (1753), 1492.

Irticn microphylla Sw. in Act. IIolm. (1787), 61.

Urtira callitrichoilles H. B. K. Nov. gen. . sper. Il $(1817)$, 40.

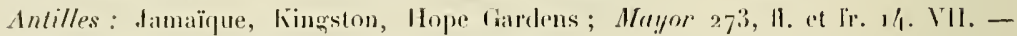
Distrib. gíogr.: Du Mexique au Pérou. Intilles.

\section{Loranthaceae.}

93. Loranthus spec.

Indes centrales; Paramos du liuiz, dép. Antioquia, alt. environ $3500 \mathrm{~m}$; Mạpor 2o, fr. 5. X. Exempl. sans lleurs! Plante à fleurs rouges, parasite sur les arbres.

94. cl. Phtirusa pyrifolia (H. B. K.) Eıchuen in Mart. Fl. Bras. V, 2, (1 868), p. 63, f. 7 .

Loranthus pyrifolius II. B. K. Nov, gen. et spec. Ill (1818), 44r ; DC. Prodr. IV, 29\%.

Indes centrales; Cafetal La Hermosa près Angelopolis, dép. Antioquia, alı. I800 m; parasite sur un arbre parasol, branches pouvant dépasser $2 \mathrm{~m}$ de longueur, feuilles se désarticulant par la dessiceation; Muyor 5og, fr. 24. VIII. - Distril. géogrt. : Amririque dis Sut tropicale. Colonibie.

\section{Aristolochiaceae.}

95. Aristolochia costaricensis Duginatre in DC. Protlr. XV, r (1864), 250 ; Hemsley in Biol. Centr.-Am. Bot. III, 41; Hieconymus in Engl. Bot. Jahrb. XX, Beibl. 49, 5.

Andes centrales; lisière de bois, Cafetal la Camelia près Augelopolis, dép. Antioquia, alt. $800 \mathrm{~m}$; Aristolochiće grimpante à lleurs verdàtres, lachies de brun; Ma!no :37.3, 11. 27. VIIl. - Distril, géogr. : Costa-Rica, Colombie.

(6). Aristolochia ringens VAlL Symb. bot. 111 (1794), 99; Duchartre in DC. Prots.

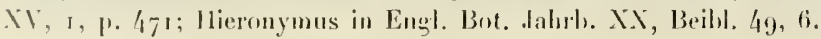




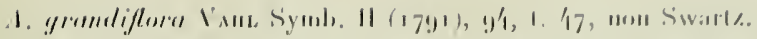

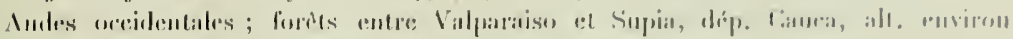

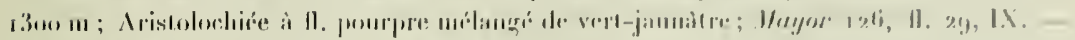

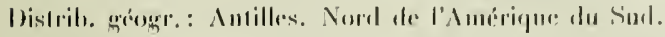

97. Aristolochia spee:

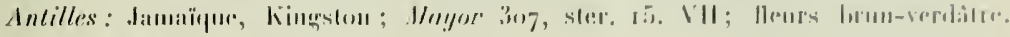
Lixemplate sans flemrs!

\section{Polygonaceae.}

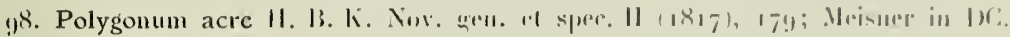
Prult. XIV, i, 1) I07.

Antilles: Hinti, Cayes; Ilaygm 28:3, II. VI.

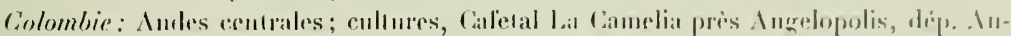

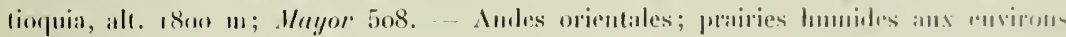

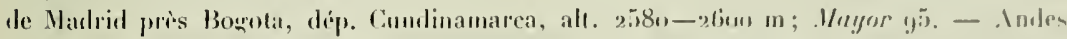

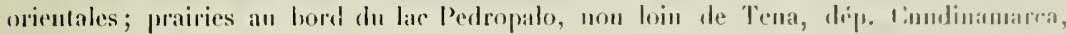

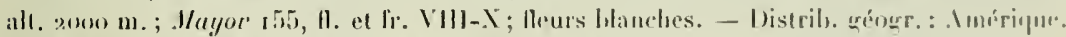
du Missouri ot de la Pensylvanie à Buemos-Ayres. Antilles.

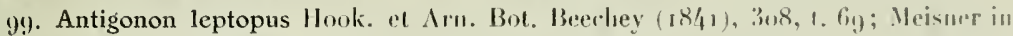
DC. Protr. XIV, 1, P. 184.

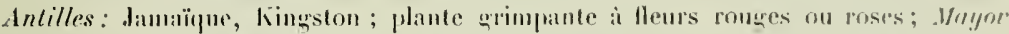

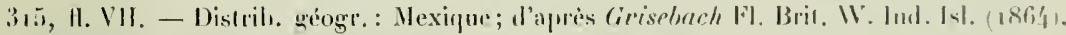
16 cultive seubment à la Jamaïque.

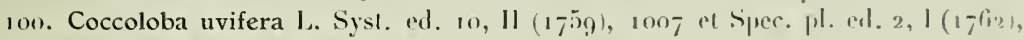

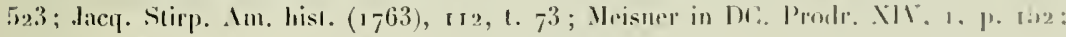
lindau in Enet. Bot. dahrl. XIII ( 1891$)$, 204.

Polygonum l'riferer L. Spee. pl. (1-533), 365.

Antilles: San Thomas; sable au hord de la mer, arbre alleignant plusienrs mitres

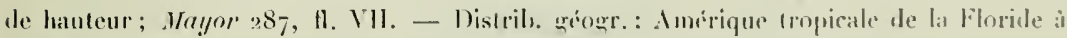
lis Guyane. Antilles.

\section{Amarantaceae.}

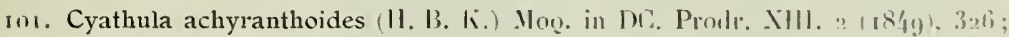
Seubert in Marlins Fl. Bras. V, ז, P. 231.

Desmochaelu achyranthoides H. B. K. Nor. gen. el spee. IV (1820), ? I0.

Andes centrales ; cultures, Cafetal La Camelia pres. Ingelopolis. dep. Inlioquia, alt.

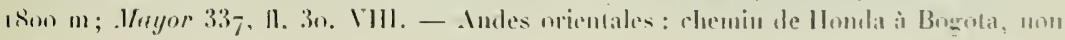
住 
boin de Honda, dép. Cundinamarèi, at. 5oo m; 1/uyor $9^{2}$, I1. 8. X. - Distrib. géogr.: Afrique. Imérique centrale. Imérique du sud.

102. Alternanthera polygonoides (L.) R. Bn. Irodr. N. Iloll. (1810), 416; Grisoly. F. Brit. W. Ind. Isl., 6iz.

Gomphreut polygonoides L. Spee. pl. (1753), ,25.

Illecebrum polygonoides L. Spec. pl. ed. 2, I (1762), 300.

Telanthera polygonoides Moo. in DC. Prorls. NIII, 2 (1849), 363 ; Scubert in Mart. lil. Brasil. I, r, p. 172 .

Antilles: Jamaïque, Kingston, Hope Gardens; Mnyor 235, II. VII. - Distrib.

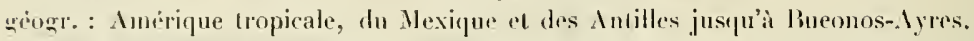

103. Iresine paniculata (L.) (). Kuntze Revisio gen. Plant. II ( $189 \mathbf{g})$, 5/12.

Celosin paniculalu 1. Spec. pl. (1753), 206.

Itesine celosioides L. Syst. ed. 10, II ( 759 ), 129 r ; Mog. in DC. Prodr. Xlll, 2, p. 347 .

Indes orientales : cultures, Cafelal Argelia, daus la vallée de Viọ̣a, dép. Comdinamarca, alı. $1850 \mathrm{~m}$; Mayor 524, H. 25. X. - Andes centrales el occidentales, dép. Antio-

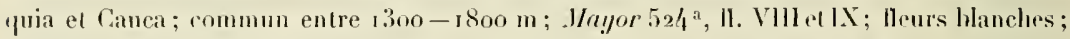

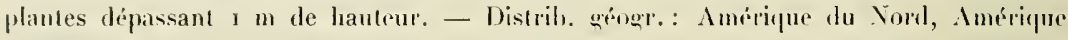
centrale. Ancirique du Surl.

so4. Iresine spec.

Indes centrales; chemin do Santa-liarbara i l'auberge El Cairo prìs du Cauca, dép. Intioquia, alt. environ $900 \mathrm{~m}$; Ma!jor r 28 , 11. 26 . IX. - Andes centrales; ford du

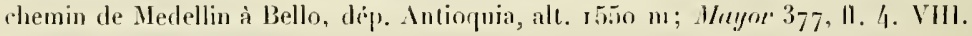

ro5. Iresine spec.

Andes orientales; forèts entre Boca del Monte, près de Madrid dans la Salrana de Bogota et l'auberge de Tambo, près de Tena, alt. environ $2200 \mathrm{~m}$; Maym ti8, 11.18 et 19. X. - Plante pouvant devenir grimpante en s'appnyant sur celles tu voisinage ef alors avoir une tige de plus de $2 \mathrm{~m}$ de longueur.

\section{Nyctaginaceae.}

Bestinmt ron Prol. Dr Heimert, Wien.

106. Boerhaavia erecta L. Spec. pl. ( 1753$), 3$; Clonisy in DC. Prod. XIII, 2, p. 450. Antilles : Jamaïque, Kingston; Hayor 209, II. 14. VII.

Colombie : environs de Barranquilla ; dép. Bolivar; Mayor 236 pr. J., fr. el Il. 2r. III. - Distril. géogr. : de la Géorgie au Nouveau-Mexique. Amérique centrale. Amérique du Sud. Antilles. Iles Galapayos.

ro7. Boerhaavia coccinea Mruten Fard. Dicl. edf. 8 (1768), I. 4; Ileimerl in Urban Syml. Antill. Ill (ry12), 2r\%. 


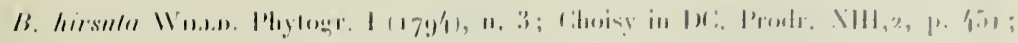

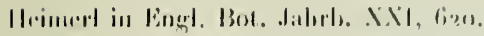

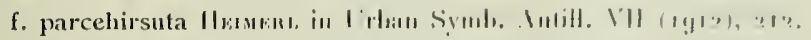

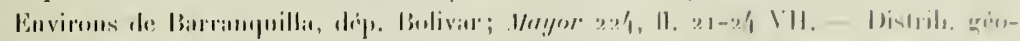

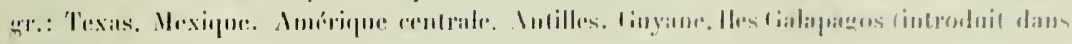
l'Amringe du sud probalilement).

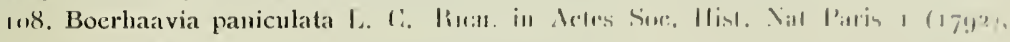

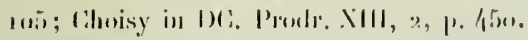

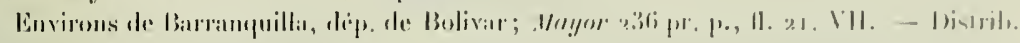

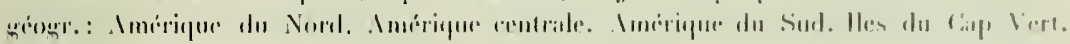

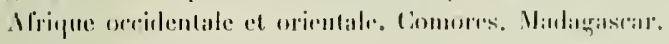

\section{Phytolaccaceae.}

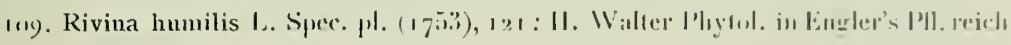
3 i. Heli (II. 83), 10.2.

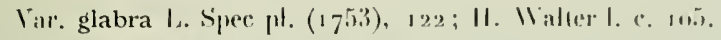

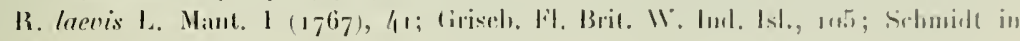
Mart. N1. Brasil. NIV, 2, 335.

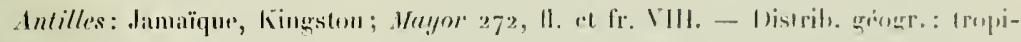
yue's des 2 hémisplières.

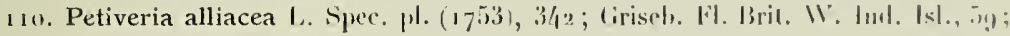
II. Waller Plytol. in Engler's P'll. reich :3y). Helt (1) 8.3), 118.

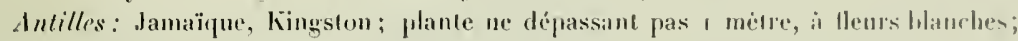
yayor 270 , II. VII. - Distrib. géogr.: Amirique tropicale.

\section{Aizoaceae.}

111. Sesuvium Portulacastrum L. Syst. ed. 10, $11(1,759)$, 1058 sems. Ial.; Rolırloach in Mart. HI. Brasil. NIT,2, p. 3ro.

Ilalimms Portnlacastrum O. Kuntze Revis. gar. pl. I (1891), z6.3.

Environs de Barranquilla, dép. Bolivar; dans le sable, lleurs rouges; . Va!yor 332. 11. el fr. VIl. - Distrib. géogr.: tropiques et sub-tropiques des 2 hémispheres, particulièrement au hord de la mer.

\section{Portulacaceae.}

112. Portulaca oleracea L. Sipec. pl. (17-53), 445; DC. Prodr. III (1828), 35.3: Rohrbach in Mart. Fl. Brasil. NIT, 2, p. 299.

Environs de Barranquilla, dép. Bolivar; dans le sahle, fleurs jamnes: Mayor 380. fr. VIl, - Distrib. géogr.: Cosmopolite. 
113. Portulaca pilosa 1. Speec. pl. (1753), 445 sens. ampl, ; em. Rohrbach in Mart. li). Brasil. .NT, 2, p. 303.

Environs de Barranquilla, dép. Bolivar; dans le suble, lleurs jaunes; Mayor 358, lr. VIl. - Indes orientales: chemin de Jlonda à Bogrotit, non foin de Ilonda, dép. Cundinamarea, alt. environ $350 \mathrm{~m}$; lleurs rouges; Mayor 163 , fr. X. - Distrib. géogr.: Inrique du Nord (sud-ovest). Antilles. Amérique du Sud, tropicale et extra-1ropicale.

\section{Caryophyllacae.}

114. Colobanthus quitensis (II. B. K.) BantL. in Presl Reliı. Haenk, II, I (1831), 1.3, 1. 49, 1. 2 !

Sagina quitensis II. B. K. Nov. uen. et spee. IT (18:3), 19; J)C. J'rodr. 1, 389; Triana et Planchon Prodr. It. Novo-Granat. in Ann. se. nat. 4c sér. 13ot. XVII, 149.

Andes centrales: Paramos du Ruiz, dép. Antioquia et Tolima, au-dessus de 3 ooo m ; 11. blanches; Mrıyor. 78 . - Distrib. géogr. : Andes de Colombie, de l'Équateur et jusqu'à la Patagonie.

115. Drymaria cordata (L.) WiLLD. ex lioemer el Sichultes Syst. V (1819), fo6; Rolırhach in Martius lil. Brasil. NT, 2, p. 259.

IOolosteum cordatum L. Spec. jl. (1 753$), 88$.

Indes centrales; cultures, Cafetal La Camelia près Angelopolis, dép. Antiounia, ał. $1800 \mathrm{~m}$. ; theurs blanches, plante rampante; Mayor 6or, ll. et fr. VIII. - Distrib. géogr. : tropiques et sub-tropiques de presque tout le globe.

\section{Ranunculaceae.}

116. Ranunculus pilosus H. B. K. nov. gen. et spec. V (1821), 45; DC. IProdr. I, 39.

Andes centrales; cultures, commun partout, Medellin; cafetales de la vallée de l' Dmaga, ete., dép. Antioquia, alt. $1500-2000 \mathrm{~m}$; Mayor 545 , ll. et fr. VIIl et.IX. - Distril). géogr. : Amérique du Sud.

Thalictrum podocarpum H. B. K. Nov, gen, et spec. V (1821), 31; DC. Prodr. I, 11.

Andes orientales; forèts, Boca del Monte près de Mardril, dans la Sabana de Bogota, lép. Cundinamarca, alt. $2500 \mathrm{~m}$; Mayor 67,18 et 19. X; 11 jaune-verdàtre. - Andes centrales; versants occídental et oriental du Ruiz, dép. Antioquia et Tolima, entre 2500 et 3ow $\mathbf{m}$ d’altitude; Mayor 138 ; Thalictrum à tleur violacé-jaunàtre; 11 . 4 et 5. X. Distrib. géogre. : Colombie.

\section{Menispermaceae.}

118. Cissampelos tropaeolifolia DC. Syst. I (1818), 532 et Prodr. I (1824), 100; Deless. Icon. select. I (1826) 26, 1. 98; Eichler in Fil. Brasil. XII, p. 191, 1. 4/; Diels in Engler's, Pfl.-Reich Heft 46, 299 . 


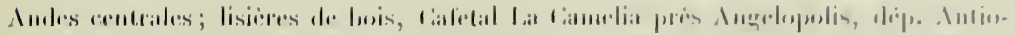

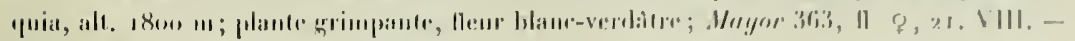

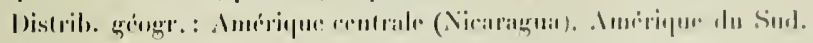

\section{Papaveraceae.}

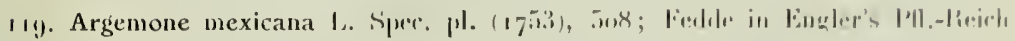
Ileli /11, 27\%.

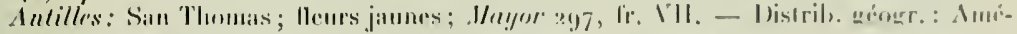

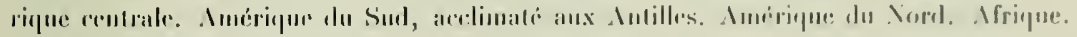
Asie midilionale, etr.

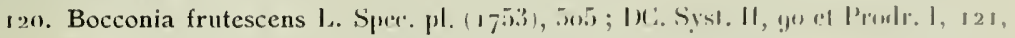
lierle in Eurl. I'll.-lieich llelt 190, 218.

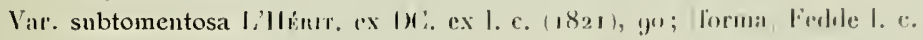

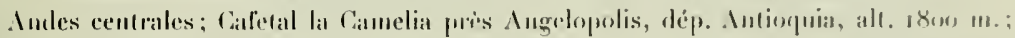

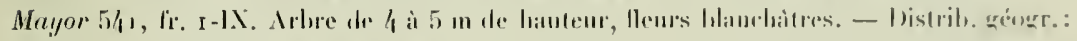
le type est répaudu daus l'Amérigue tropieale el aux Aurille's.

\section{Cruciferae.}

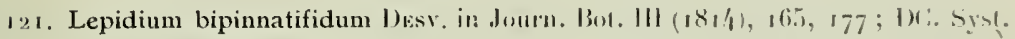
I1 $\left(1 \$_{21}\right)$, 544; Trima el Planchun Prodr. Il. Novo-Granal. in . Inn. sc. Mat. sér. 4. XVII

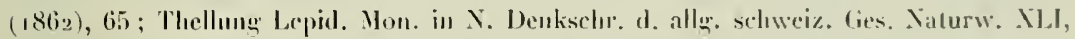
.11.h, I (1906), 241.

L. Inmboldtii DC. Syst. II (182 I), 532 non Hemstey in Bjol. Centr--In. But. I $(1879), 38$, quod $=$ L. reticulatum HoweLL.

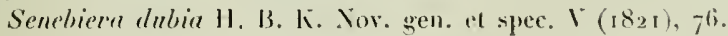

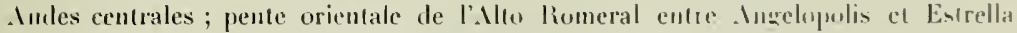

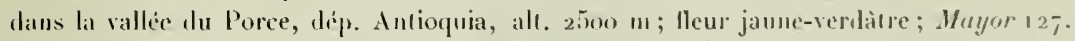

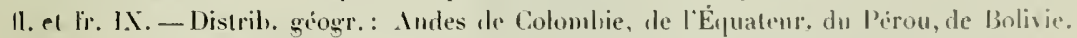

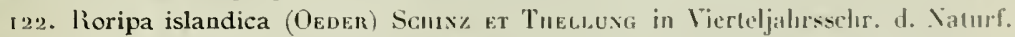
(ies. Zürich LIH ( 908$)$, Heft IV (1909), 538.

Sisymbrium islandicum Oeder Fl. Dan. HI, 7 ( $1-68)$, 8 1. CCCCIX.

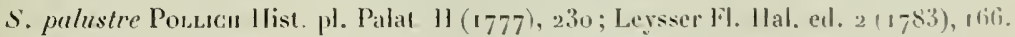
Nasturtium palustre DC. Syst. 11 (1821), 191: Triana ef Plunchon Prodr. 11. Novo-

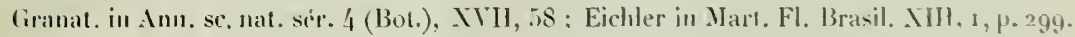
Andes centrales; cultures, Cafelal La Camelia près Angrelopolis, dép. Antiuquara, alı. 


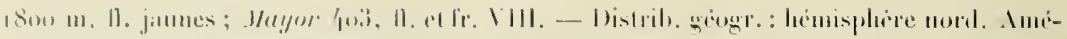
ripue du sud. I (Surinam. Colombie. Bréxil.) Australie.

\section{Capparidaceae.}

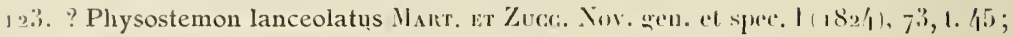

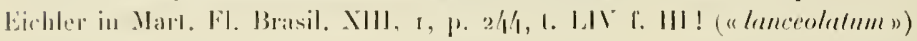

P. ambignum Boxe. in Bull. sc. Aciul. Sit. Peterst) I (1836), 115.

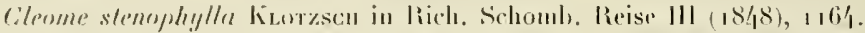

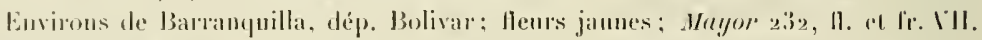

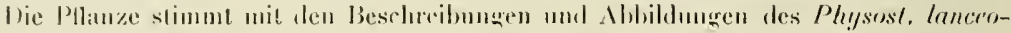

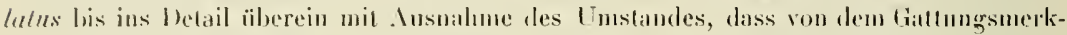
mal der unter der Anthere angeschwollenen filannente zweirr slanbbläller nichts zn bemerkin ist. - Distrib, giogr.: Anlilles. Imérique du Surl tropicale.

124. Cleome serrata JAco. Enum. pl. Carils. (1760), 26.

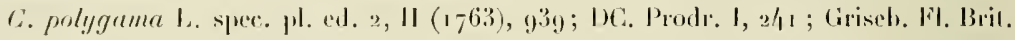
IV. Ind. Isl., I6.

Antilles: damaïque : Kinston; Mayor 21, I1. 14. VII. - Distrib, q̧égr. : Antilles. Amérique contrale. Colombie.

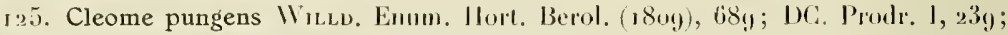
(irisclo. Fl. Brit. W. Inel. Ist., 15.

C. spinosa Swartz OHserv. (1791), 2iz - non Jicy.

Antilles: Jamaïque, lingston. - Colombie: le lougg du Magdalena et anx cuvirous de Barranquilla; Hayor 3o8, 1]. 20-30 Vl]. - Distril). géogr. : tropiques de l'Amérique (lı surl.

I26. Capparis Cynophallophora L. Spee. pl. ed. 2, I (1762), 721; Jaci. Am. select. $(1763), 1.98 ;$ DC. Prodle. 1, 249 ; Giriseb. Fl. Bril, W'. Ind. Isl., 18.

Antilles: San Thomas; Mayor 30o, 11. 11. VIl ; arbuste de a m de hauteur. Distrils, géogr.: Amérique du Sud tropicale. Amérique centrale. Antilles.

\section{Rosaceae.}

127. Rubus glaucus Bentı. Pl. Ilartw. (183y-57), 173 (ca. 1845).

Indes centrales et orientales, dép. . Intioquia, Tolima el Cundinamarca ; commun à porlée de 1300 in; Mayor 153, П. IX, X. liubus à tiges el petioles pruineux glancescents, lace inférieure des feuilles blanclue el velue, fleurs blanches. - Distrib. géogr. : Colombie.

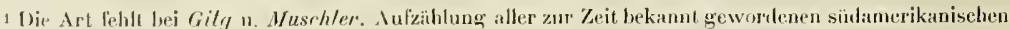
Cruciferen (Encler's lot. Jahrb. XLII [1909] $4377-187$ ).

- Déterminé par le Dr W. O. Focke, Bremen. 


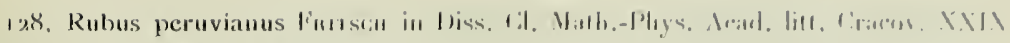
(18,g/), 220 vel forma arele altinis.

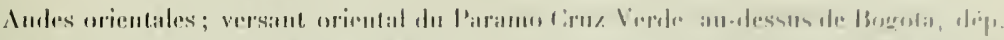

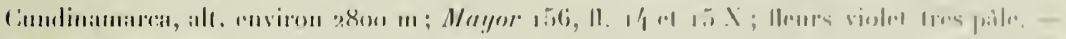

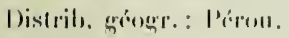

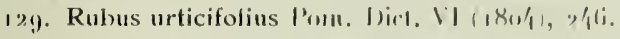

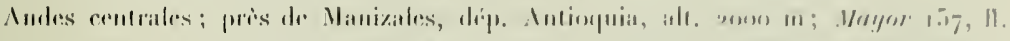

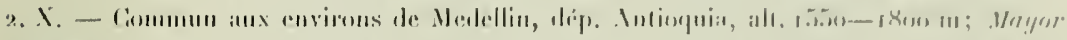

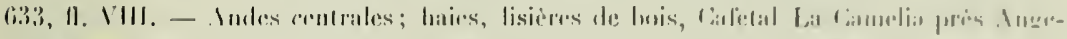

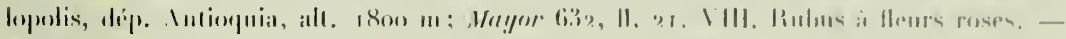

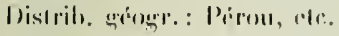

1.30. Rubus sprece.

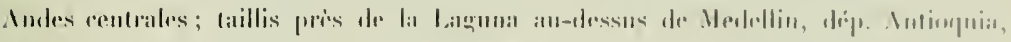

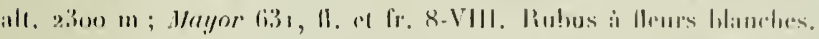

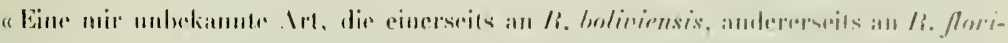

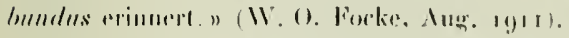

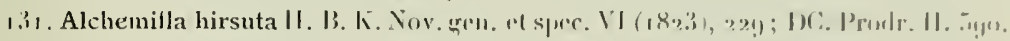

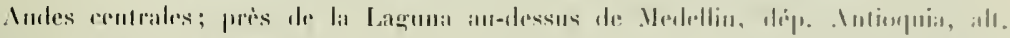

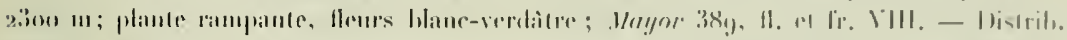

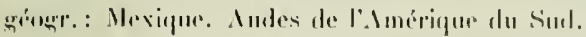

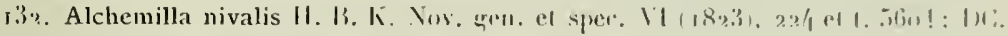
Prode. II, ingu.

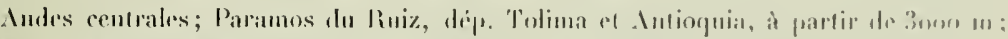

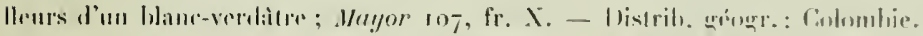

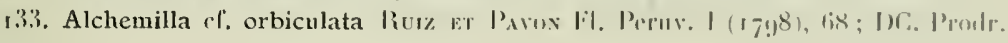
$11,5 g^{0}$.

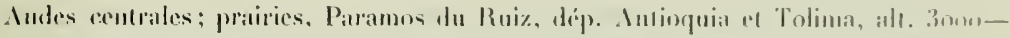

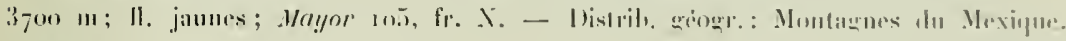
Audes de Colombie, du Prorou, ete.

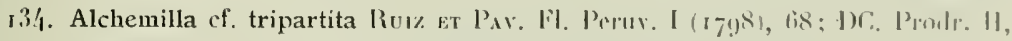
6yn; Ilemsley in Biol. Comm - - Im. Bol. 1, 377.

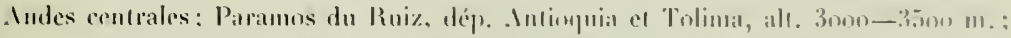

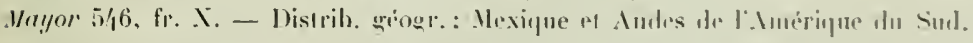

\section{Leguminosae.}

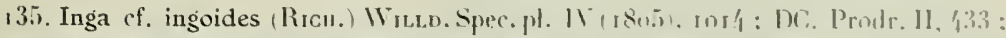

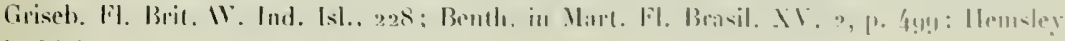
in Bint. Centr.-int. Bol, I, 3ti?. 


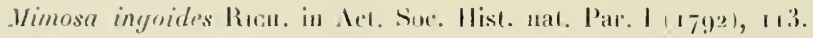

1. ormalu liustu Mlimos. (18ig-24), 46, 1. 14.

Indes centriles; priss du Porce an-dessous de lauberge de La Wuiebra près de Lisneros, rhemin de Cisneros à Medellin, dép. Antioquia, all. environ 1300 m; Mayor 31, fol I'11. - Indes centriles el occidentales, lép. Antioquia al Canca; assez commun jusqu ${ }^{\circ} 1800 \mathrm{~m}$; Hayor 638 , 11 . VIII el IX. Arbre de $6-7 \mathrm{~m}$ de hauteur; IIeurs hanches. Distrib, giogr.: Mexiegue, Antilles, Guyane. Colombir. Brésil.

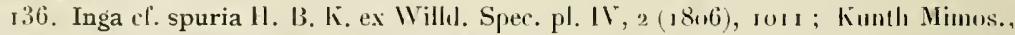

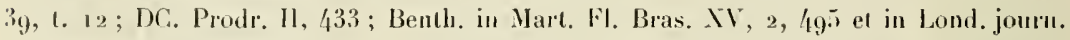
lot. 11, 615 et in Trans. Linn. Soc. XXX, ti28; Hemsley in Biol. Centr.-Am. Bot. 1, 36/.

Andes centrales el occidentales, dép. Antioquia el Cauca; assez commun jusqu'i I $800 \mathrm{~m}$., arhre de $6-7 \mathrm{~m}$ de haut, fleurs blanches; yayor 638, 11. VIII ei IX. Distril. géogr. : Colombie, Vénézućla, et probablement aussi Brósil (Prov. Bahia at Rio Janeiro); Nicaragua.

137. Pithecolobium ligustrinum (WiLld.) KLotzscu ex Bentlı. in Trans. Linu. Soc. XXX 1875$)$, 571; llemsley in Biol. Centr.-1m. Bol. 1, 360.

Inga ligustrina Wilco. Spec. pl. IV, $2(1806), 1007$; DC. Prodr. II, /37.

Environs de Barranquilla, dép. Bolivar; arbuste de $2 \mathrm{~m}$ de hauteur, fleurs hlanches; Mrnyor 264, 11. 21. V11. - Distrib. géogr.: Amérípue tropicale: Cayenne, Vénézućla, Colombie. Imérique centrale.

138. Acacia inacracantha Hun в. et Bonpl. in WILld. Spec. pl. IV, 2 (1806), 1080; Kuntl Mlim., 1. 28 ; Griseb. F. Brit. W.-Ind., 221 ; Benth. in Trans. Linn. Soc. XXX, 5oo; Hemsley in Biol. Centr.-Am. Bot. I, 354.

Antilles: Jamaïque, lïngston; arbre à fleurs jaunes; Wayor 291, 11. 14. 111. Distrib. géogr.: Amérique tropicale el suls-tropicale de Vera-Cruz à la Bolivie, surtout au voisinage de la mer.

139. Acacia tortuosa (L.) WuLld. Spec. pl. N, 2 (1806), 1083; Bentl. in Trans. Limn. Soc. XXX, 501 ; Griseb. Fl. Brit. W.-lud., 222; Hemsley in Biol. Centr.-Am. Bot. 1, 355.

Mimosa tortuosa L. Syst. ed. го, II (1759), г31».

Antilles: San Thomas; mimosée à 11 . jaunes, arbre dr $3-4 \mathrm{~m}$ de hauteur, très ípineux; Hayor 195, 11. el fr. immat. I I. VIl. - Distrib. géogr. : Amérique tropicale: damaïque. Antilles danoises. Vénézućla. Galapagos. Costa-Rica. Mexique.

140. Leucaena glauca (L.) Bentu. in Hook. Lond. Journ. Bot. IV (1842), 416 el in Trans. Limn. Soc. XXX, 443 et in Mart. MI. Brasil. XV, 2, p. 39.3; Hemsley in Biol. Centr.-Am. Bot. 1, 35i.

Nimosa glauca L. Spec. pl. (1753), 520.

Antilles: Jamäque, Kingston; arbre à fleurs blanches; Mayor 261, 11. I/4. VIII. Distrib. géogr. : cultivé dans tous les pays des tropinques, originaire probiblement d'Amérique. 


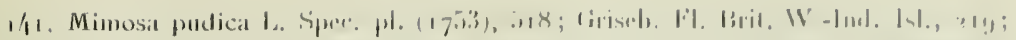

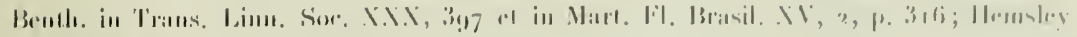

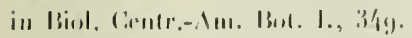

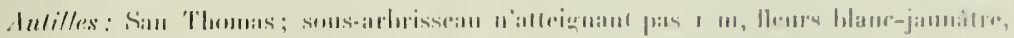

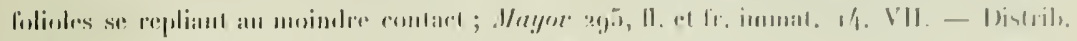

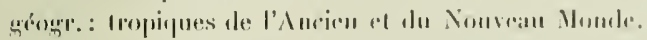

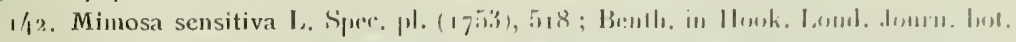

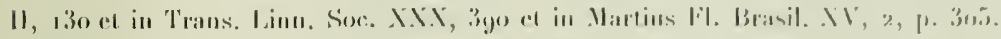

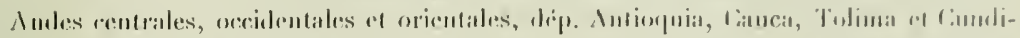

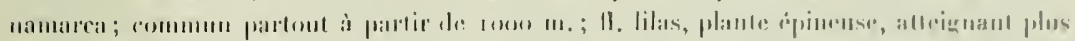

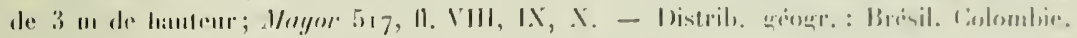
Costia-kiris.

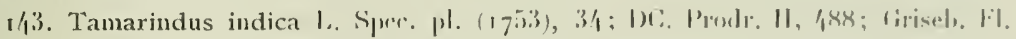

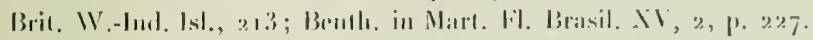

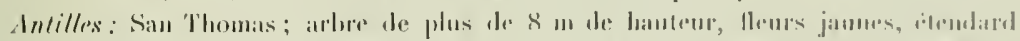

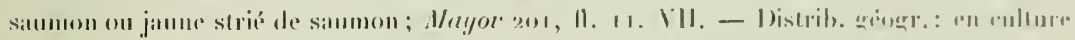

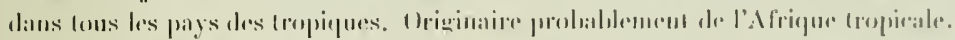

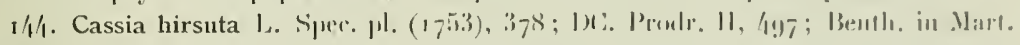

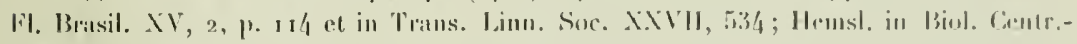
AIII. Bo1. 1, 331.

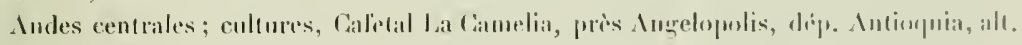

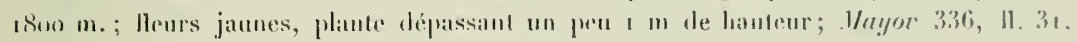
VIII. - Distrib. géogrt. : Amérique rmpiciale.

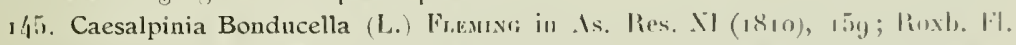

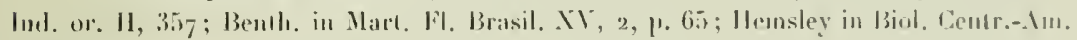
131) . 1, 324.

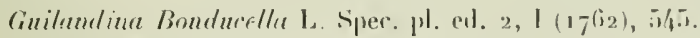

Intilles: : San Thomas ; plante grimpante (les exemplaires aver fleurs et liges se sont

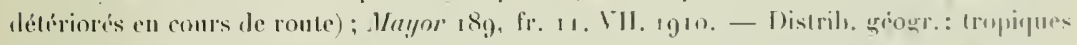

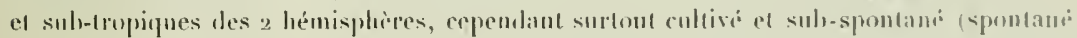
surlout sur les rivayes).

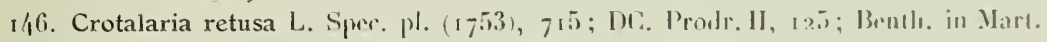

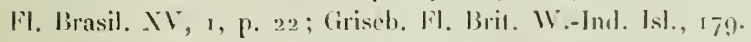

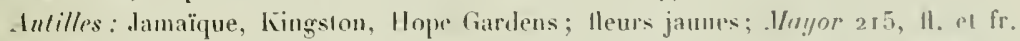

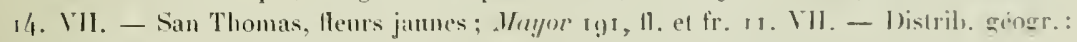
Iropiques des 2 hémisphères.

147. Lupinus spec.

Andes orientales : chemin de Agua Larega ì la Sarane de Bogola, non linin de Faralativa, dép. Cundinamarea, alt. environ $2600 \mathrm{~m} ; .1 /$ ayor 148, 11. 10. X. 47

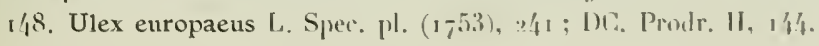


Indes centrales : prairies de l' Mlto San Miguel du latut de la vallée du Porce, dép. Intiogubil, alt. environ $2500 \mathrm{~m}$ : plante fratescente, pouvant dípasser \& $m$ de hauteus, it lleurs jumbe; , Mayor 125, 11. 26. IX. - Distrib. quéogr. : Région allantique de l'Europe, sub-spontané en Amérique du Sud.

149. Trifolium repens L. Spee. pl. ( $\left.7_{7} 53\right), 7_{67}$; Ser. in DC. Prodr. 11, 198; Brntl. in Mart. Fl. Brasil. XY, r, p. 35.

Andes rentrales; prairies Paramos du Ruiz, dép. 'Tolima el Antioquia, à partir dé $250 \% \mathrm{~m}$; Trifolinm rampant à tleurs blanches, parfois légèrement rosées; olsservé ì parlir de la mème altitude dans les Andes orientales de Bogota el de Subia dominant lir vallée de V̈inta, dép. "Cundinamarca ; Mayor 103, 11. 5. X. - Distrib, géngr. : Europre, cultivé et sub-spontané en Amérique du Nord et dans les hantes régions montagneuses des pays à climat chaud.

ז.̄o. Jndigofera Anil L. Mant. II ( 1771 ), 272 ; DC. Prodr. II, 225 ; Bentl. in Marl. FI. Brasil. XY, I, p. 4 ; ; Griseb. FI. Bril. W.-Ind. Isl., i81.

Antilles: San Thomas; Mayor 2/49, 11, et fr. 11. VIl. - Distrih. géogr.: Antilles. Caroline du Sud. Brésil. Introduit el acelimaté en Afrique tropicale, aux lndes el en Chine.

ris Dalea corulea (L. f.) Schinz et Tuelung comb. nov.

Galega coprulea L. f. Suppl. (г 781 ), 335.

Dalea Mutisii Kunth Mim. (1819[-24]), 161, 1. 47; II. B. K. Nov. gen. el spec. VI, 485 ; DG.' Prodr. 11, 247.

Andes orientales; Savane de Bogota, près de Facatativa, alt. $2600 \mathrm{n}$; lleurs violelles, plante ne dépassant pas $1 \mathrm{~m}$ de hauteur; Jayor 149, 11. 11. X. - Distrib. géoggr. : Colombie.

152. Pictetia aculeata (VAIL) Unbax Symb. Ant. II, 2, 294!1

Robinia aculeata VAнL in IVest St. Croix (1793), 30o; Juss. ex DC. Prodr. II, 314. P. squamata, aristata et Jussiaei DC. Prodr. I1 (1825), 314.

Antilles: San Thomas; arbuste de $\mathrm{r}-2 \mathrm{~m}$., folioles se détachant an moindre contaet par la dessiceation; Mayor 299, II. r/. III. r910. - Distril. géogr. : Antilles.

153. Stylosanthes guyanensis (Aúblet) Sw. in Vet. Acad. Handl. Stocklı. (1789), $29^{6}$; DC. Prodr. II, 318; Benth. in Nart. 1'. Brasil. XV, 1, 1. $9^{2}$; Taubert in Verh. Bot. Ver. Prov. Brandenb, XXXII (i89o), 25.

Trifolium Guianense Aublet Hisl. pl. Guian. II ( $\left.{ }^{7} 77^{5}\right), 77^{6}$, 1. 309.

Andes centrales; au-dessus de Medellin, cultures et pàturages le long du Rio Santa Elena, dép. Antioquia, alt. environ $1700 \mathrm{~m}$; Ileurs jaunes; Jhayor 373. 11. et fr. 6. VIll. - Distrib. géogr.: Amérique tropicale.

154. Zornia diphylla (L.) Pens. Encheir. II (1807), 318 ; Benth. in Fl. Brasil. XV, 1, p. 8o; Hemsley in Biol. Centr.-Am. Bot. I, 273.

Hedysarum diphyllum L. Spec. pl. (г753), 747. 


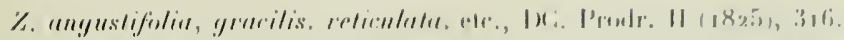

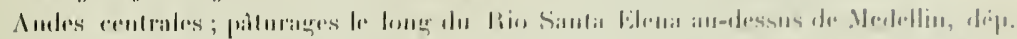

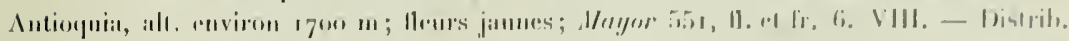

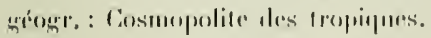

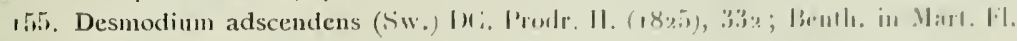
Brissil. XV, $1,1,97$.

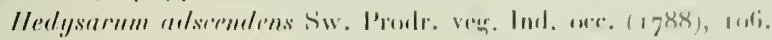

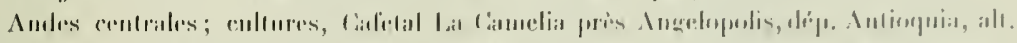

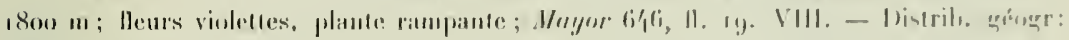
Amcripur centrale. Armiripur du Surl. Intilles.

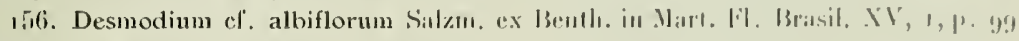

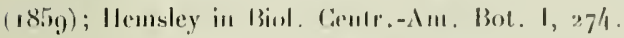

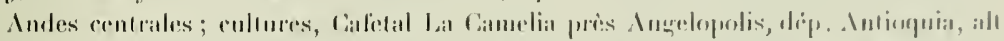

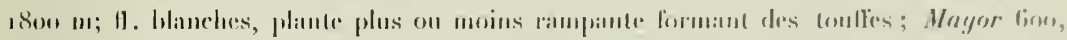
11. VIII. - Vistrils. genegre: Amérique du Surl. Imérique rentrate.

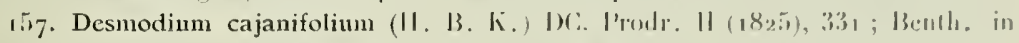

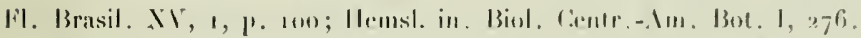

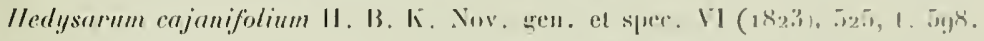

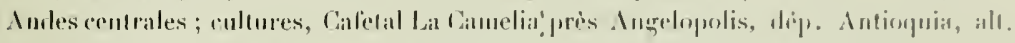

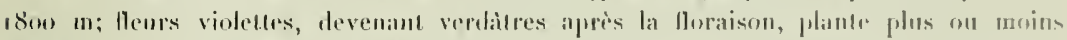
rampante, liormant des foulles; J/ayor 6o7, 11. 20. Vll1. - Indes rentrales; lured du

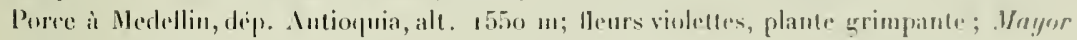
6os, 11. 9. VIII. - Distrilı gíogr. : Imerique rentrale. Amérique du Sud.

158. Desmodium canum (.I. F. limels) Scmiz ат Tueluif comb. nov.

Iledysarmm canmm I. F. (inel.1s Syst. (1791), 1124; Lunan Ilorl. Jamaic. I $(18,4), 305$.

11. canescens MILLen Gard. Dict. ed. 8 (1768), 11. 7 - non L. (1753) $=$ Desm. canescens DC.].

II. inranum Sw. Prodr. veg. Ind. necid. (1788), w7- non-Thunb. (1784).

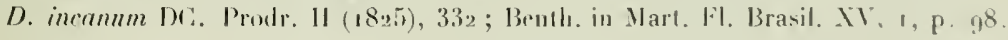

Indes centrales; (chemin de fer de Medellin) entre Carocoli el lisneros, dép. In-

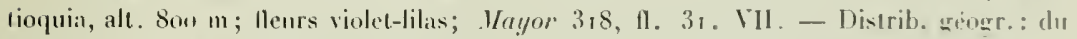
Mexique au Brésil. Intilles.

rign. Desmodium tortuosum (Sw.) DC. Prodr. II (1825), 33.32; Grisel. Fi. Brit. IV.-Ind. Isl., 188; Ilemsley in I3iol. Centr.-Am. Bot. I, 290.

Iledysarmm lortuosum sw. Prolle. reg. Ind. occ. (1788), 107.

Andes centrales; culures pres du Rio Amagra, au-dessins du Cafetal la Camelia près Angelopolis, dép. Antioquia, alt. environ $1400 \mathrm{~m}$; Il. violet-lilis, plante ne déprassant

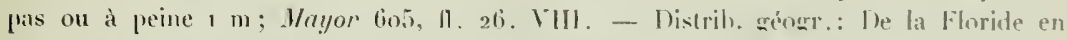
Colombir. Antilles. Sub-spontimi aux Indes. 
Itio. Aeschynomene americana L. Spee. pl. (1753), 713; I C. Prodr. 11, 320; Beuth. in Mart. Fl. Brisil. IV, 1, p. ti.

Bord du Canca a Puerto de los Pobres, Paso de Coneordia, depe. Antiorpuia, alt. $720 \mathrm{~m}$, Heurs janne-saumon; Mayor 594, 11. el fr. 6. IA. - Distrib. géogr.: répandu dans toutes les régions chaudes de l'Amérique.

Iti. Aeschynomene falcata (Porr.) I)C. Prodr. II (1825), 322; Benth. in Mart. il. Brasil. $\mathrm{NY}, 1, \mathrm{p} .67$.

Hedysarum falcalnm Pon. Encyel. 11 (1804), 448.

Andes centrales; Guaca, bord de chemin, dép. Antionguia, alt. 1500 m; lleurs

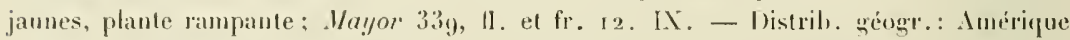
centrale. Imerifue du Sud. Intilles.

16. Aeschynomene sensitiva Sw. Fl. Ind, aecil. III (18006), 1256; I) ( Prodr. II, 330 ; Benth. in Fl. Brasil. . T , 1, p. 58.

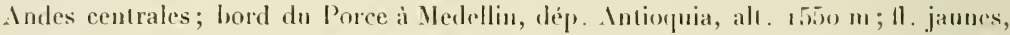

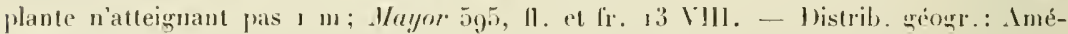
rique Iropicale.

163. Centrosema pubescens Bentu. in Inn. Mus. Vind. 11 (1838), $119 \mathrm{et} \mathrm{in} \mathrm{Mart.}$ F1. Brasil. XY, 1, 1. 131, tab. 34, fig. 2; Crisel, I1. Brit. IV.-Iml. Isl., r92.

Indes centrales; chemin de Titiribi au Cauca, dép. Intioquia, alt. environ $1506 \mathrm{~m}$; fleurs violettes, plante grimpante; Nayor 558, 11. et. fr. 8. IX. - Andes centrales; lisières de bois, Cafetal La Camelia près Angelopolis, dép. Autioquia, alt. r8oo m; plante grimpante pouvant atteindre plusieurs mètres, lleurs violet-lie de vin; Jlayor 396 , 11. et fr. 20. VIIl. - Distrilı. géogr.: Mexique. Amérique centrale. Amérique du Sud. Antilles.

164. Teramnus uncinatus (L.) Sw. Prodr. vegre. Ind. occ. ( 788 ), , 05 ; DC. Prodr. II, 382 ; Benth. in Mart. Fl. Brasil. XV, I, P. 138, tal,. 37 ; Griseb. Fl. Bril. W. -Ind. Isl., $19^{3}$.

Dolichos uncinalus L. Spec pl. ed, 2, II (1763), 1021

Andes centrales; haies et taillis au bord du Porce à Nedellin, lep. Antioquia, alt. 1550 ; papilionacée grimpante; Hayor 6ı I, fr. 9. VIll. - Distrib. quogr.: Amérique du Sud. Antilles. Mexique méridional.

165. Mucuna of. mollis (H. B. K.) DC. Prodr. II (1825), 405.

Negretiu mollis H. B. K. Nov. gen. et. spec. V1 (1823), 444.

Andes centrales el occidentales, dép. Intioquia, Tolima et Cauca; iu ì plusieurs endroits cutre 900 et $1500 \mathrm{~m}$; plante grimpante, pouvant alteindre plus de $10 \mathrm{~m}$ de longueur et pendant des arbres sur lesquels elle s'appuie, lleurs jaune-pàle un peu rosé; grappes de lleurs plus ou moins ombelliformes portées sur un longr pédoncule; M/ayor $36 \mathrm{r}$, 11. el fr. VIII. et IX. - Distrib. géogr.: Colombie.

166. Galactia dubia DC. Prodr. II (1825), 238 ; INban Syml. II, 2, P. 317.

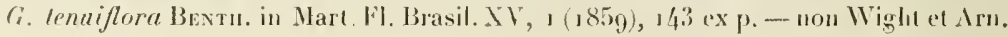




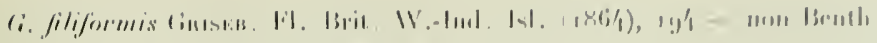

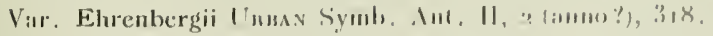

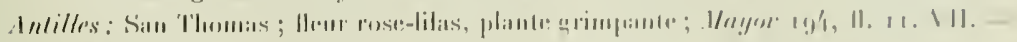

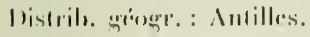

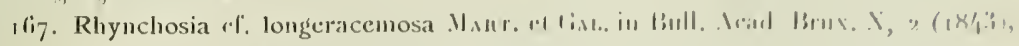

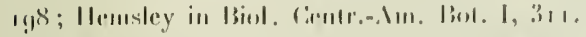

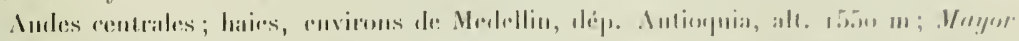

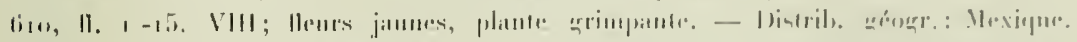

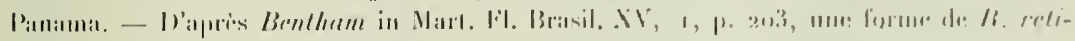
inlalı (Valil) I) :.

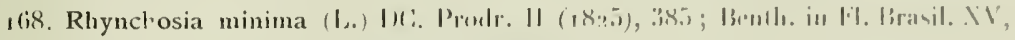

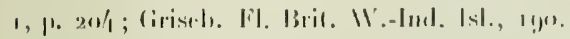

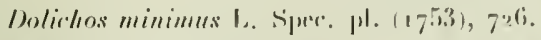

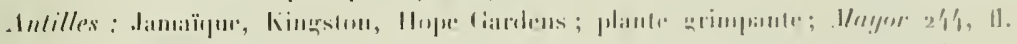

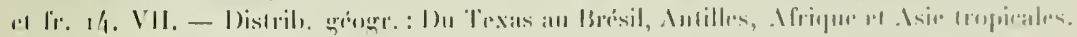

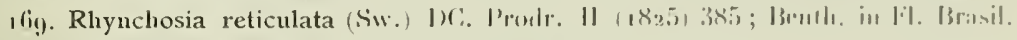

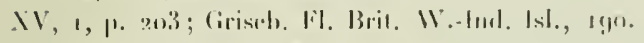

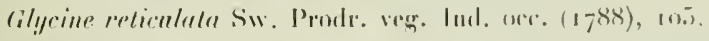

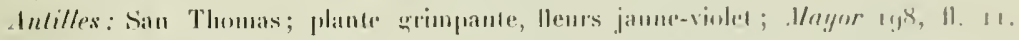
VII. - Distril, góngr.: Du Texas an Brisill ef an Prom. Intillex.

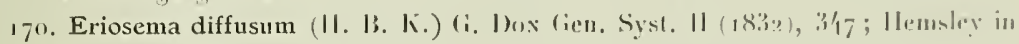
Biol. Conlr.-1m. Bot. I, 3 r\%.

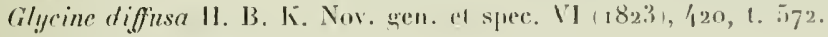

Rhynrhosiu diffusa DC. Prodr. II (1825), 388.

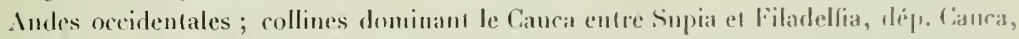

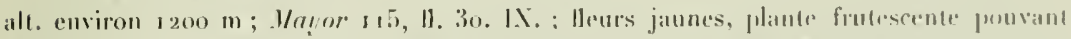
dipassor 1 m de hauteur. - Distrih. groger.: Amérinue contrale. Conlombie.

171. Eriosema aff. pulchellum (11. B. K.) (i. I)ox Iien. Sist. 11 1 18321, 348; Beulh.

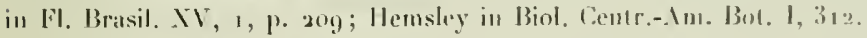

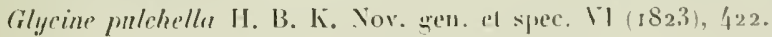

Rh!nrehosia pulchella I)C. Prodr. II ( $825 i)$, 38!).

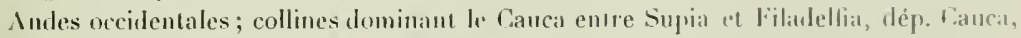

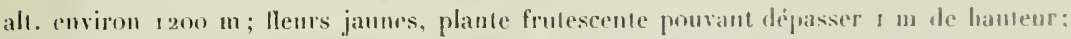

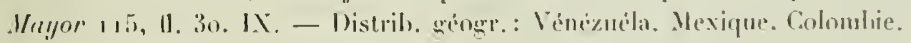

173. Phaseolus of peduncularis 11. B. K. Nor. gen. ef spec. II (1823), 447; DH:. l'rodr. II, 391; Bentl. in Mart. lil. Brasil. Xi, 1, 1. 194: Ilemsley in Biol. Centr.-Am. 1301. 1, 306.

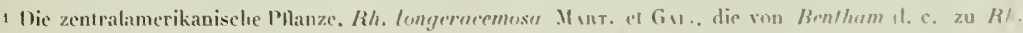
reliculala gezogen wird. isl nach Hemsley (I, c. 311) viue vigene $\mathrm{Irl}$. 
Bord du Magdalena i Puerto Wileles, dep. Santander; plante rampante, fleurs saumon ; Mnyor ${ }_{-77}, 11.29$. V111. - Distrib. géogr. : Intérique du Sud tropicale. Amérique centrale 1?).

173. Vigna luteola (JAco.) Bextu, in Mart. FI. Brisil. AV, 1, 1. 19/1 (1859), 1. 50, fig. 2 ; Ilrmsley in Biol. Centr.-Am. Bot. I, 30g.

Dulichos Inteolus dace. Hort. Vindulı. I ( $\left.777^{0}\right), 39$, 1. 90.

Ambes centrales; bords de ruisseaux aux environs de Medellin, dép. Antioquia, alt. 155o m; llens jaunes, plante grimpante; Mnyor bog, 11. 10. VIll. - Distrib. quegre: Régrions chandes de l’.lmérique.

\section{Geraniaceae.}

174. Geranium diffnsum 11. 13. K. Nov. gen. et spec. I (1831), 23 I ; I)C. Prodr. I, 63y); Triana el l'lanchon Protr. 11. Novo-Granal. in Aun. sc. nat. 5 e sér. Bot. XVII, 11 ; R. Knutl in Engler's Pll. reich 5i.). Heft (IV, 129), Cieran., p. 214.

Aules orientales; Paramo Cruz Verde au-dessus de Bugota, déj. Cundinamarca,

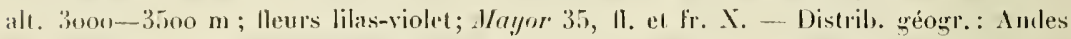
de Columbie, de l'Équateur et du Pérou.

17\%. Geranium mexicanum II. B K. Nov. gen. et spee. V (1821), 230; I) :. Prodr. 1, 641; R. Knuth 1. c. 196. - Distrils. quéogr.: Nontagnes du Mexique el du Guatémala, justu’à l'Équatem el au P'irou.

Var. macranthum (Bug.) R. lívти I. c. (1912), 197 .

G. Seemanni var. macranthum Bro. in Ann. Cons. et Iard. bot. Genève NI-ẌII ( 1908$), \quad 189$.

Andes orientales; pentes du Montserrate au-dessus de Bogota, dép. Cundinanarca, alt. environ $2 g 00 \mathrm{~m}$ : Heurs violettes, pétales de longueur double des séprales; Mayor qu, I1. 't lr. X. Das Exemplar nähert sich einigermassen dem von G. mexicamum wohl nicht spezifisch verschiedenen $G$. Kerberi R. Kívтu I. c. (гgr2), 200.

э $7^{6}$ Geranium multiceps Turcz. in Bull. Soc. Nal. Moseou XXX1 (1858), 2, 1. /17; Triana et Planclion Prodr. Al. Novo-Granat. in Ann. se. nat. $5^{\circ}$ sér. bot. XVll, 112 ; R. linuth I. c., ro5.

Andes orientales; Paramo Craz Verde, au-dessus de Bogota, dép. Cundinamarea; alt. 3ow-3500 m; lleur violet plus ou moins rouge; Mayor 46, II. X. - Distrilı. géogr. : Andes dn Ténézuéla et de Colombie.

\section{Oxalidaceae.}

177. Oxalis mollis H. B. K. Nov. gen. et spec. V (1821), 241 ; DC. Prodr. 1, 692,

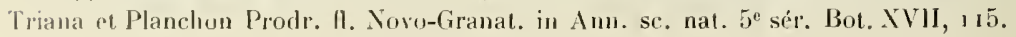




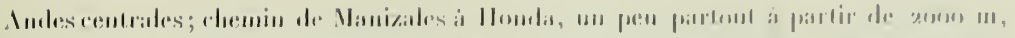

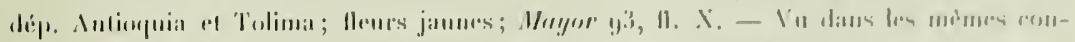

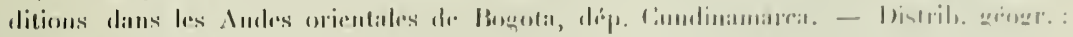
Audes da: Coulombire.

\section{Tropaeolaceae.}

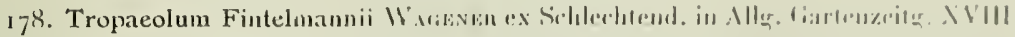

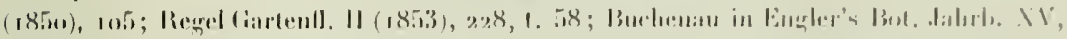

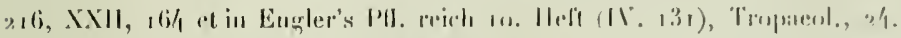

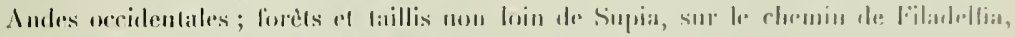

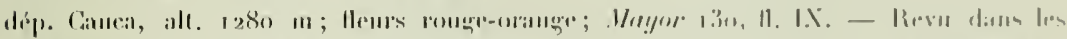

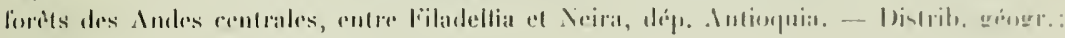
V'énézuéla. Columbire. Épuateur.

\section{Zygophyllaceae.}

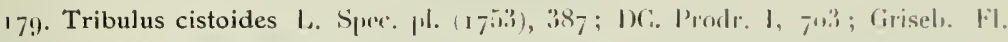

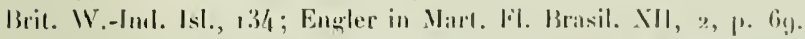

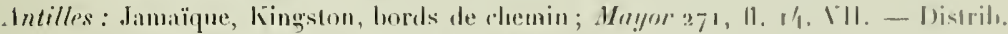

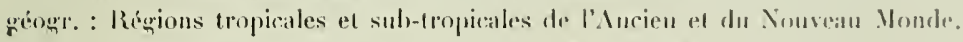

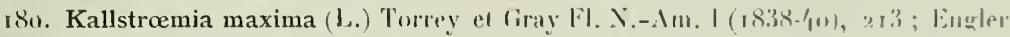
in Marl. Fl. Brasil. Xll, 2, p. 71.

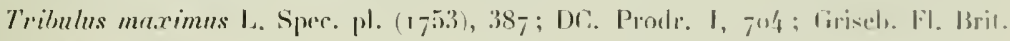
W.-Ind. 1sl., r.34.

Intilles: San Thomas; daus les culures; Muyor 266, 11. LII. Exemplare ohmo

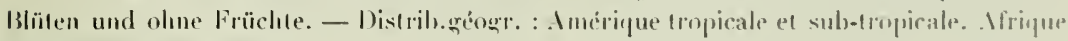
occidentale tropicale.

\section{Malpighiaceae.}

18ı. Banisteria argentea (H. B. K.) Spuevges ex .Idr. do .luss. in Irch. Mus. Par. 111 (1843), 3933 Walp. Rep. I, 225; Triana el Planchon Prodr. H. Nown-liranat. in AmI. se. nat. $4^{\text {e }}$ sér. Bot. XVIII, 321 .

Heteropterys argentea II. B. K. Nox. qen. el spec. I. (1821) 164. 1. 4in! ; D).. Prodr. 1, 59 r.

Bord du Cauca, an paso de Concordia, Puerlo de Ins Pobres, díp. Intioguia. alt. 720 m ; lleurs roses, plante grimpant jusqu'au sommet des grands arbres ui cipanouis. 


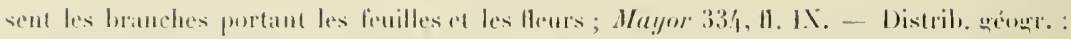
Pérou. Bolivie. folomblie. Panama. Costatkica.

I8. Stigmatophyllum spec.

Andes centrales : hord du Rio Amaga int-dessous du Cafelal La Camelia près Anerelopolis, dép. Antioquia, alt. environ $1200 \mathrm{~m}$; Mayor 5r2, 11. 26 . IIII ; plante grimpante ou rampante, a lieurs jaunes.

\section{Polygalaceae.}

183. Polygala paniculata L. Amoen. V (1-601), 402 lr. p.; I)C. Prollr. I. 329 ; Bril-

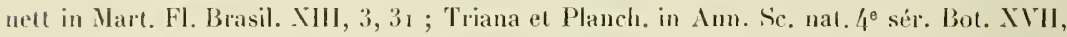
I.30; Hemsley in Biol. Centr.-Am. Bot. I, 61; Chodat Monogr. Polyg. II, 229

Andes centrales; culures, commun aux environs de Medelliu, dép. Autioquia, alt. $1550 \mathrm{~m}$; Hayor 552, 11. 4.-54. VIII. - Distrib. géogr. : Amérique du Sud tropieale. Antilles. Mexique.

\section{Euphorbiaceae.}

184. Phyllanthus diffusus Kíotzscin in Seem. Bot. Voy. Hrald $\left(185_{2}-57\right)$, ro5; Müll.-Arg. in DC. Prodr. $X V$, 2, 410; Hemsley in Biol. Centr.-Am. Bot. III, ro3; Miill.Arg. in Mart. Fl. Brasil. XI, 2, 55.

Andes centrales; cultures et pàturages le long du Rio Santa Elena au-dessus de

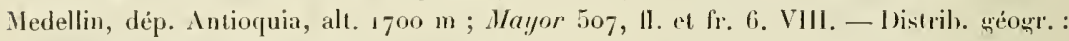
Amérique du Sud tropicale. Amérique centrale. Antilles.

I 85. Phyllanthus lathyroides H. B. K. Nov. ger. et spec. Il (1817), 110 ; Mäll.Ire. in DC. Prodr. XV, 2, 404; Ilemsley in Biol. Centr.-Am. Bot. III, ro/.

Andes centrales; cultures, Caletal La Camelia près Angelopolis, dép. Antirquia, alt. $1800 \mathrm{~m}$; Mayjor 5o6, fr. 23 . V1ll. - Distril. gérgre. : Amérique dı Sud tropicale. I 86 . Croton betulinus VAll Symb. II ( $179 \mathrm{r}), 9^{8} ;$ Müller- $\Lambda \mathrm{rg}$. in DC. Prodr. $\mathrm{XV}, 2$, p. 595 .

Antilles: San Thomas; arbrisseau de I in de hanteur; Mayor 206 , Il. el fr. VII - Distrib. géogr. : Antilles.

187. Croton glandulosus L. Amoen. V ( 759 ), 409 ; Mïll.-Arg. in DC. Prodr. XV, 2, 685 et in Fl. Brasil. XI, 2, 267, 706; Hemsley in Biol. Centr.-Am. Bot. III, I11.

Environs de Barranquilla, dép. Bolivar; Heurs blanches; Mayor 23 I, [1. ct fr. 21.-24. VII. - Distrib. géogr. : Amérique centrale. Amérique du Sud. Antilles.

188. Croton flavens L. Amoen. V (1759), 4I0; Müll.-Aig. in DC. Prodr. XV, 2, 61:3; Griseh. FI. Brit. W. - Ind. Isl., 38. 


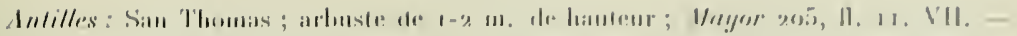
l)istrib. gureser. : Aurilles.

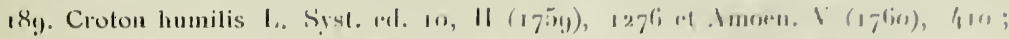

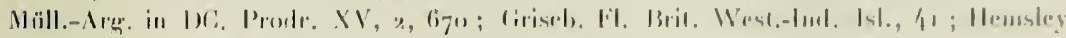

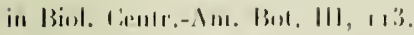

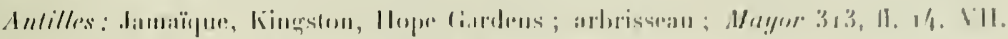

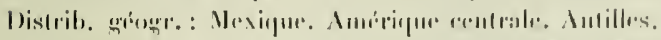

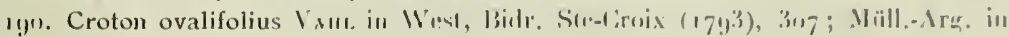

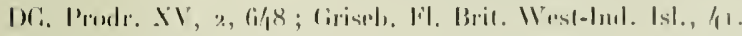

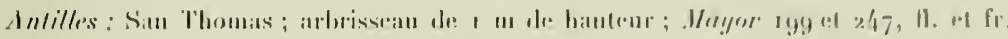

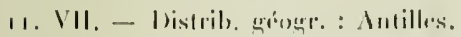

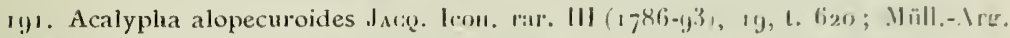

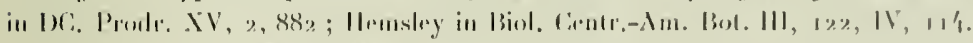

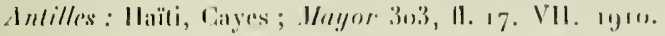

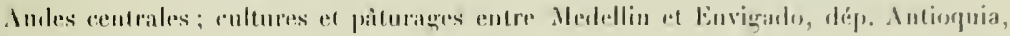

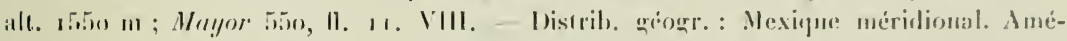
ripure reucrale. Vinezuila. Cuba.

1!)\%. Acalypha villosa Jace. Enum pl. Garih ( $17 f 0)$, 32 et Select. anner. stirp. hist.

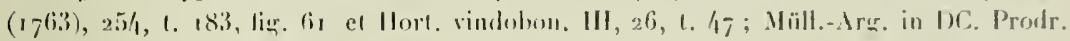

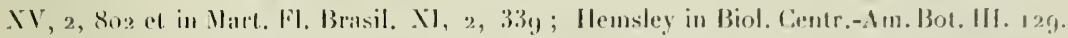

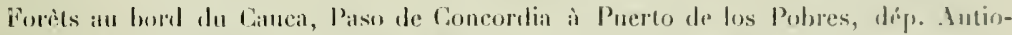

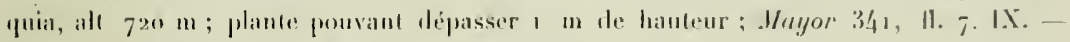
Distrib. griogr. : Amérigue do sul tropicale.

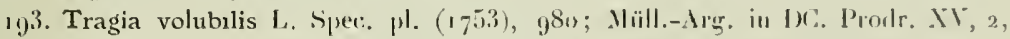
(9)30 an Mart. Iil. Brasil. NI, 2, 4r2; Griseb. Fl. Bril. West-Ind. Isl. 48; IJemsley in Bis). Centr.-An. Bot. IN, 114.

Antilles: San Thomas; plante plus ou moins grimpante en s'appuyant sur celles du

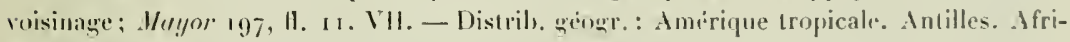
que occidemalie ropicale.

194. Jatropha gossypiifolia L. Spec, pl. (1-53), row6 var. staphysagriffolia Minll,Arg. in DC. Proulr. .T, 2 (1862-66), ro8jet in Mart. FI. Brasil. .I, 2. 4!) ; Hemsley in Biol. Centr.-Am. Bot. III, 107, II, 231 .

Lntilles: San Thomas; Jayor 2.3, I1. ro. VII. damaïque, Kingston. - Haïli, Cases.

Enviroms de Barmunuilla et le long du Magdalena; Mayor 54\%, M. VII. Fleurs brunes; plante ghtulineuse, alteignant jusqu'à $1 \mathrm{~m}$ de hanteur, se désarticulant par la dessiccation. - Distrib. géogr.: régrions chaudes de lMmérique. Afrique occidentiale.

195. Euphorbia buxifolia L.м. Encycl. II (1-86), 421 ; Boiss. in DC. Prodr. IV, 2.

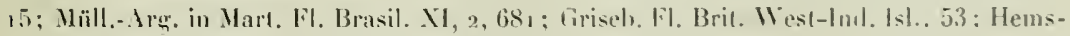
ley in Biol. 1.entr.-Am. Bot. 111, 91, 11, 11/. 
-1nlilles: San Thomas; sable an hord de la mer; Mayon 22.3 , It. el fr. Ir. V'll. Distrilı. qéogur. : Floricle. Honduras britannique. Amérique du Sud. Antilles.

197. Euphorbia cotinifolia L. Spec. pl.(1753), 453; Boiss. in 1)C. Prods. XV, 2 , iy, Grisel). W. Brit. West-lnd. Isl., 52; Hemsley in Biol. Centr.-Am. Bot. III, 92, 1V, 114.

1ulilles: San Thomas; plante ne dépassant pas a m de hauteur à latex blanchàtre; Yayor 196, 11. 11. VII. - Distrib. géogr.: Amérique centrale. Amérique du Sud. Antilles.

197. Euphorbia heterophylla L. Spec. pl. (1753), 45:3; Boiss. in DC. Prorlr. XV, 2,

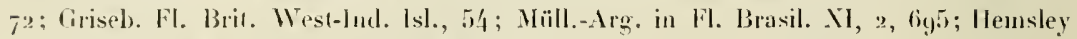
in Biol. Ceutr.-Am. Bot. 111, yii, 11, 108 .

1ntilles : damaïque, Kingston, Hope Liardens: Maym 268, fr. 14. V11.

Andes centrales; colline au-dessus de Aneriea près Medellin, dép. Antioquia, alt. э 700 $\mathrm{m}$; Luyor 393, fr. 15 . VIII. - Distrib). géogr. : de l'Illinois au Brésil el au P'́rou.

iys. Euphorbia nutans Lagasca Gen. et spec. nov. (18,6), 17.

Euphorbia Preslii Guss. Fl. Sic. Prodr. I (1829); Boiss, in 1)C. Prodr. NY, 2,23 .

Antilles: Hä̈t, Cayes; sables an hord de la mer; Mayor 304, 11. 17. VI1. - Distril. géogr. : Amérique, du Canada à l'Équateur, adventice et naturalisé dans l'lurope méridionale.

199. Euphorbia orbiculata H. B. K. Nov. gen. el spec. II (1817), 42; Boiss. in DC. Prodr. $\mathrm{XV}, 2,3$.

Andes orientales : Barro Blanco, près Madıid, dans la Savane de Bogota, dép. Cundi-

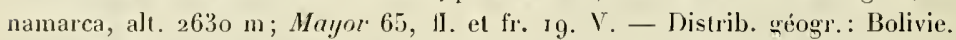

200. Euphorbia pilulifera L. Spec. pl. (1 753$)$, 454; Boiss. in DC. Prodr. XV, 2, 2I ; Griseb. Fl. Brit. West-Ind. Isl., 54; Müll.-Aro. in Mart. Fl. Brasil. Xl, 2, 684, 708 ; Hemsley in Biol. Centr.-Am. Bot. III, 98,11 , ro8, 14.

Antilles: Jamaïøue, Kingston; bord de chemins et cultures; Mayor 208, ll. "tr. li. I4. V11.

Andes centrales et orientales: dép. Antioquia et Cundinamarea; commun au bord des chemins entre goo et $1900 \mathrm{~m}$; Mayor 54o, 11. et fr. VIII., IX., X. - Distrib. géogr.: États du Sud de l'Amérique du Nord. Amérique tropicale el sub-tropicale. Antilles. Très répandu dans les régions chaudes de l'ancien continent.

201. Euphorbia elliptica Laм. Encycl. II (1786-...), 425 - non Thunb. 1800 (= nomen admissum, sed mutandum!).

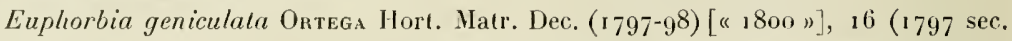
DC.); Boiss. in DC. Prodr. $\mathrm{XV}_{2}, 72$ : Hemsley in Biol. Centr.-Am. Bot. III, 94.

Euphorbia prunifolia Jace. Hort. Schönbr. IIl ( 1798$)$, tab. 277; Müll.-Arg. in Mart. Fl. Brasil. XI, 2, 694, 708.

Andes orientales: chemin de Honda à Bogota, non loin de Honda, dép. Cundinamarca, alt. $250 \mathrm{~m}$; lleurs rouges, plante dépassant $1 \mathrm{~m}$ de hauteur; Mayor r 76 , ll. et fr. 


\section{- $379 \div-$}

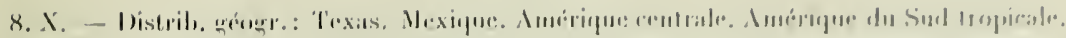
Autilles.

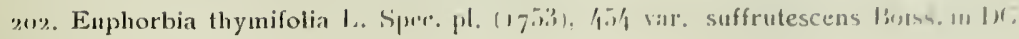
Proulr. XV, :, I $(17$ (i) $)$, 17.

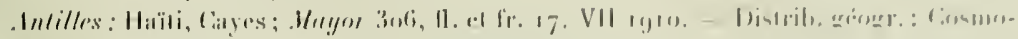
pulite des loppiques.

\section{Anacardiaceae.}

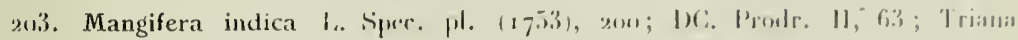

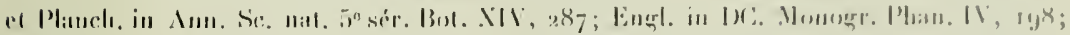

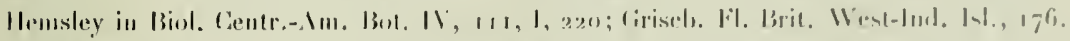

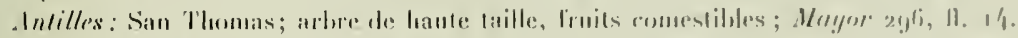

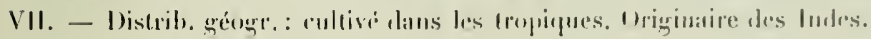

\section{Celastraceae.}

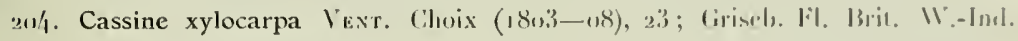
Isl., 145.

Élerodendron xylocarpam DC: P'rodr. II (182i), 11.

Anlilles: San Thomas; arbuste de 1.50 iो 2 m de latulewr, lieurs verditres; Mayor 298, II. ㅇ r4. Vul. - Distril). géogr.: Antilles.

\section{Sapindaceae.}

20\%. (?) Serjania spec.

Sians linit.

Andes contrates; chemin de Titirili au Canca, dip. Intioquala all, environ $1200 \mathrm{~m}$; Mayor $63_{9}$, fl. 8. IX. ; theurs bianches; plante errimpante.

\section{Ampelidaceae.}

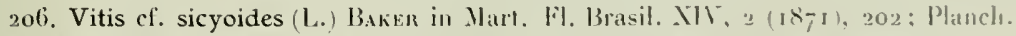
in 1)(. Nonogr. Phan. I, 521 ; Ilemsley in Biologia Centr.--1m. Bol. 11, 203.

Cissus sicyoides L. Syst. ed. ro, II (17-j9), 897; DC. Prodr. 1. 628.

Andes centrales; chemin de Medellin a Betho, dipe. Antioquia, ath. 17on m: Yayor

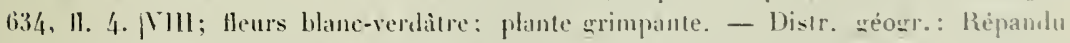
daus l'. Imérique tropicale el sub-tropicale el aux Antilltes.

207 . Vitis spec. 
Andes centrales; forits au-dessus du Canca, sur le chemin de Valparaiso, dép. Antiuquia, alt. $900 \mathrm{~m}:$. Mayor $143,38.1 \mathrm{X}$; plante grimpante à vrilles, lleurs petites, verditres. Exemplaire sans llour's el fruits.

\section{Tiliaceae.}

208. Triumfetta Lappula L. Spec. pl. (1753), 144; DC. Prodr. 1, 5o6i; Griseh. Fl. Brit. W.-lnd. Isl., 9.5.

Autilles : damaïque, Kingston, Hope Gardens; Maynor a 6 , fr. VII. - Distril, géogrr.: Amérique centrale, Antilles, Iles du Cap-liert.

209. Triumfetta mollissima H. B. K. Nov. gen. et spec. V (182 I), 345, 1. 488; DC. Prodr. I, 507, Triana el Planchon Prodr. 1l. Novo-Granat. in Ann. se. nat. $4^{\text {e }}$ ser. Bot., XV1], 35 r; Hemsley in Biol. Centr.-An. Bot. 1, 183.

Andes centrales; cultures el champs de maïs, Cafetal La Mokia pris Angelopolis, dép. Antioquia, alt. environ $1700 \mathrm{~m}$; plante pouvant dépasser i m de haut, ll. jaunes; Mayor 345, 11. et fr. V1ll. - Distrib. géogr.: Andes de Colombie.

210. Abutilon umbellatum (L.) Sweet Hort. Brit. ed. I (1827), 53 ; K. Schunann in Mart. Fl. Brasil. XIl, 3, 373.

Sida umbellata L. Syst. ed. 10, II ( 1759$)$, r I 45 ; DC. Prodr. 1, 469).

Abutilon cymosum Trana et Planghon Prodr. 11. Novo-Granal. in Ann. sc. nal. $4^{\mathrm{e}}$ sér., Bot. XVII (1862), 185 (N.-Granat.) vix specifice distinctum videtur.

Plaine du Magdalena à Beltran, prairies arides de long dn tleuve, dép. Tolima, alt. $260 \mathrm{~m}$; plante ne dépassant pas $60 \mathrm{~cm}$ de hauteur, à 11 . jaunes; Mayor 28, 29, fl. et fr. X. - Distrilı, géogr.: Nexique, Antilles, Colombie, Pérou.

211. Wissadula periplocifolia (L.) Press Reliq. Hank. Il (1835-6), 117; K. Sclumann in Mart. Fl. Bras. XII, 3, 441, t. L XXVII.

Sida periplocifolia L. Spec. pl. (1753), 684; DC. I'rodr. I, 467.

Wissadula zẹlanica. Mevikus liünstl. Gesch. d. Malrac. $(1787)$, 25; Triana el Planchon Prodr. ll. Novo-Granat. in Ann. sc. nat. 4e sér. Bot. ÄVll, 186.

Plaine du Magdalena a Beltran, prairies arides le long du fleuve, dép. Tolima, alt. $260 \mathrm{~m}$; plante ne dépassant pas $80 \mathrm{~cm}$ de hauteur, à fl. d'un brun un peu jaunàtre; Mayor 22, Il. el fr. X. - Environs de Barranquilla, dép. Bolivar; ll. jaunes; Mayor 225, 11. et fr. VII. - Distrib. géogr. : Mexique. Antilles. Colombie. Brésil. Indes. Malaisie.

212. Malvastrum coromandelianum (L.) Garcke in Bonplandia I (1857). 297; K. Schumann in Mları. F1. Brasil. XI1, 3, 268, t. 53 !

Malva coromandeliana L. Sprec. pl. (17.53), 687.

Malva gangetica L. Spec. pl. ed. 2, II (I 763$), 967$; DC. Prodı. I, 43 I.

Malva tricuspidata Aırox Hort. Kew. ed. 2, N (1812), 210 ; Triana et Planchon Prodr. fl. Novo-Granal. in Ann. se. nat. $4^{\ominus}$ sér., Bot. XVll, i 55. 


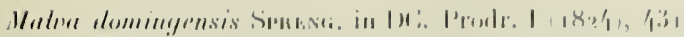

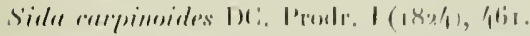

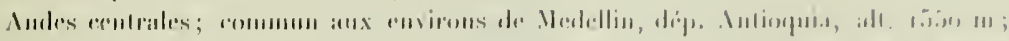

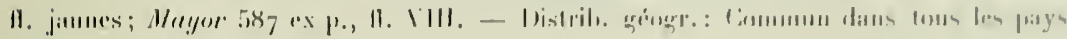
Iropicitus.

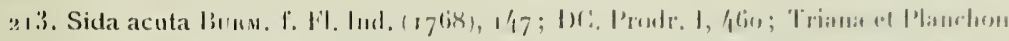

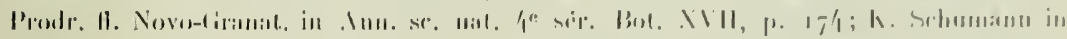

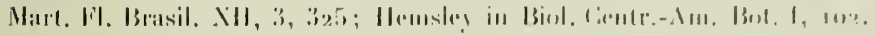

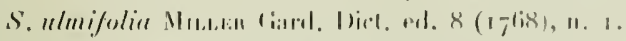

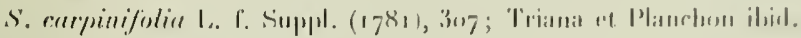

finruna (?) ranrpioliis sulumulicis.

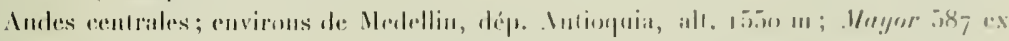
P., Il. et lir. IIII.

l'ar. stipulata $\{$ (a)

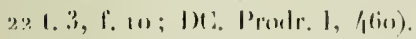

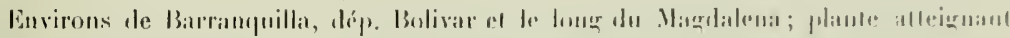

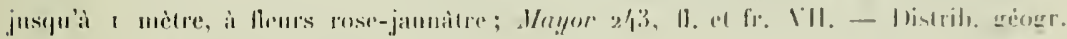
(speciei): Tropigues des derux himisphères.

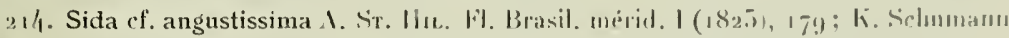
in Mitr. Fl. Brasil. N11, 3, 336.

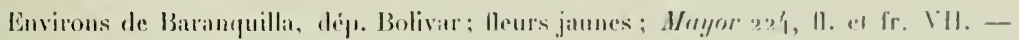
Distril, gyiogre. : Bresil. Coloulrie.

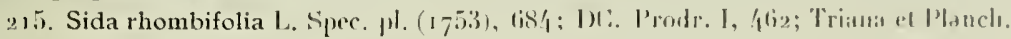

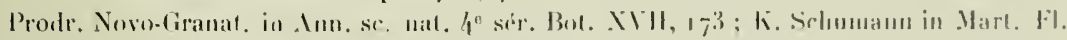
Brasil. N11, 3, 3377; Itemsley in Biol. Centr.-1m. But. 1, 1иti.

Var. ramis pilis simplicilus patentilus (practer lomentum hrevissimum) instruclis, carpidiorum rostris stellato-pubescentilus:

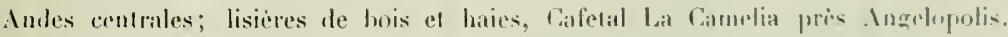

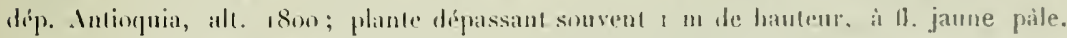

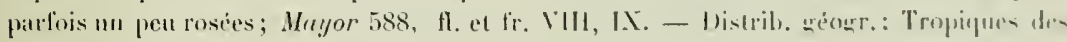
deux hémisphères.

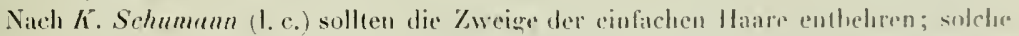
kommen jedoch anch an Exemplaren ron Costarica (Poletionsliy n. 218 !. Pillier el Durand 11. 23:30! 4r(i-7!, Tondu= 11. 7312!), wenngleich in kleinerer Menga, vor.

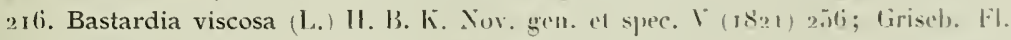

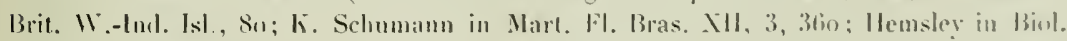
Centr.-1m. Bo1. 1, 107.

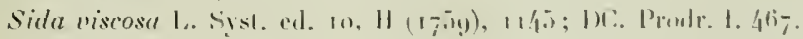

Sidn foetida Car. Diss. 11 (1788), 349): DR. I. c.

Antilles: San Thomas; Mayor 29.3, H. el fr. V11 ; lleurs jannes. 
Environs de Barranquilla, dep. Bolivar, Mayor 226 , 11. V11 (Henrs jaunes). - Plaine du Maghlalena a Behran (le long du llewve) dans les prairies arides, dep. Tolima, alt. $260 \mathrm{~m}$; plaute a lleurs jaunes, ligèement visquanse, ne dépassant pas 50 cm de hanteur; Mayoe 21, ll. et lir. X. - Distril. qéogre: Mexique. Antilles. Amerique du Sud jusqu'au Péroe ef an Brésil.

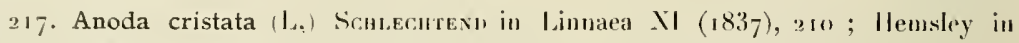
Biol. Centr.-Im. Bot. I, 101 .

Silla cristatu L. Spec. pl. (17:3), 685.

- tnoda triloba Cas: Diss. I ( 1785$)$, 34, 1. 10 f. 3 ! ; DC. Prodr. I, 458.

Inoda Dilleniunu Cav. 1. c. 40, 1. 11, f. 1 !; DC. P’rodr. I. c.

Andes centrales: chemin entre Neira et Manizales, dép. Antioquia, alt. environ $1900 \mathrm{~m}$; 11. violettes : Mryyor 142, 11. et lir. X.-Distrib. géogr. : Mexique. Guatémala.

218. Anoda hastata Ciy. Diss. I ( 7785$), 38$, 1. 11, f. 2 ! ; DC. Prodr. 1, 458; T'riana et Planchon Prodr. 11. Novo-Granat. in Anu. sc. nat. q $^{\mathrm{e}}$ sér. Bot. XVII, r $7^{2}$; Hemsley in Biol. Centr.-Am. Bot. 1, 101.

Sida hastata WiLLd. Spec. pl. 111, 1 (1801), 763.

Andes centrales; Medellin, partie baute de la ville, dép. Antioquia, alt. $1550 \mathrm{~m}$; 11. violettes; Mayor 568, fl. et fr. VIII. - Distrib. géogr. : Amérique centrale et tropiques de l'Amérique dı Sud.

2. 9. Pavonia paniculata CAv. Diss. III (1787), เ35, 1. 46, f. 2 !; DC. Prodr. 1, 444 ;

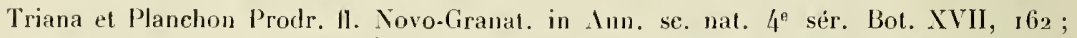
Hemsley in Biol. Centr.-Am. Bot. I, I16; Garcke in Mart. Fl. Brasil. XII, 3, 504, 1. 96, f. I!

Andes centrales et occidentales, dép. Antioquia, Tolima et Cauca : commun dans les régions chaudes entre 750 el $1800 \mathrm{~m}$; plante pouvant déprasser $\mathrm{I}$ m, à fleurs jaunes; Mayor 532, 11 e el fr. X.-Distrib. géogr.: Amérique centrale. Amérique du Sud. Intilles.

220. Gossypium ef. religiosum L. Syst. ed. 12, II ( 1767$)$, (i43; 1) C. Prodr. I, 156 ; (iarre in Mart. FI. Brasil. XII, 3, p. 583

G. herbaceum var. 1) religiosum K. Scuunans in Engler-Prantl Nat. Pfl. fam. Ill, 6 ( $18\left(y^{5}\right), 52$.

G. barbudense $\%$ vitifolium el acuminatum Truasa et Planchon Prodr. II. NovoGiranat. in Ann. sc. nat. $4^{\circ}$ sér. Bot. XYll (1862), 170, 171.

Audes centrales; cultures, Cafetal La Camelia près Angelopolis, dép. Antiorjuia, alt. environ 1 boo m; Mayor 539, ll. et fr. VIH, IX. Die Pflanze gehört vielleicht zu var. vilifolium subvar. peruviunum (Cav.) Triana et Planchon J. c. (I862), i 70, welche Form von den . Iutoren als in Columbien verwildert angegeben wird. - Distrib. géogr.: Cultivé dans les régions chandes de l'Amérique, rare dans les tropiques de l'Ancien Honde. 


\section{Slerculiaceae.}

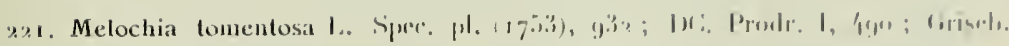

lit. Brit. W.-ludl. Isl., y,3.

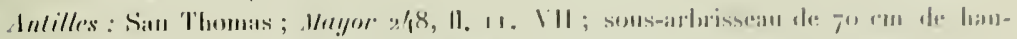

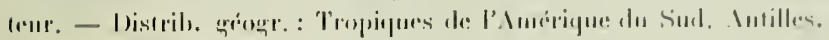

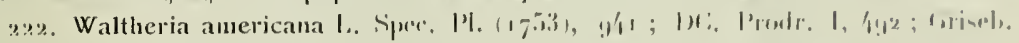

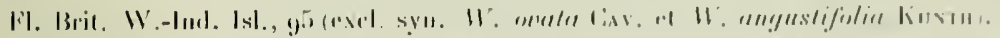

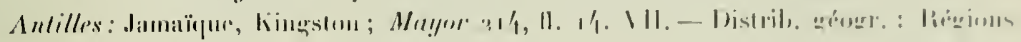

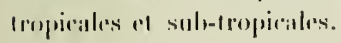

\section{Ochnaceae.}

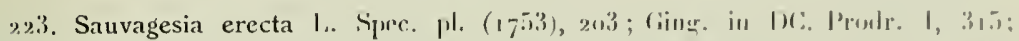

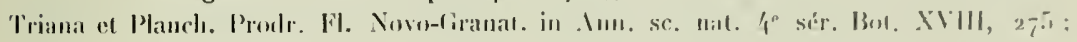

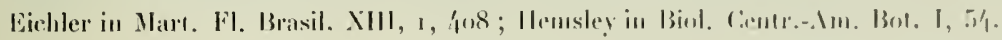

Sunungessin geminiflora DC. Prodr. I (182\%), 315.

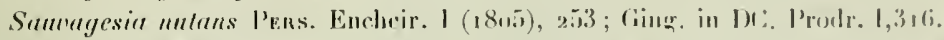

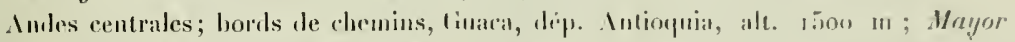
366, 11. 12. IX; Menrs blanches. - Distrils. wrogr. : Régious tropicales el subtropi-

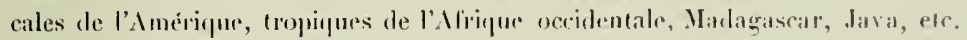

\section{Gutliferae.}

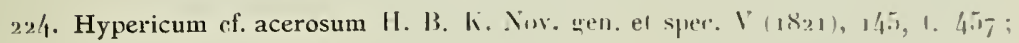
Choisy in DC. Prodr. I, 5ir.3.

Andes centrales; Paramos du Ruiz, dép. Antioquia et Tolima, alt. 3ooo$3700 \mathrm{~m}$; Mayor ır, 11. 5. X; arbrisseau à lleurs jaunes. Mème plante observèe au Paramo Cruz Verde sur Bogota, dép. Cundinamarca (Andes orientales, a partir de 3000 m. - Distrib. géogr. : Andes de Quito el de Bogrota.

IIypericum acerostm wird von Triana et Planchou (Prodr. Fl. Novo-Granat, in

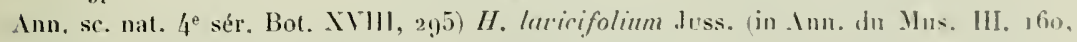
tah. I6, lig. 1) unterstellt.

225. Hypericum of. aciculare H. B. K. Nor. wet1. et sper, I , 18211. 1!̣o: DC. Prodr. I, 553.

Andes oricutates; pente du Montserrate an-dessus de Bognta, dipp. Comdinamarca, alt. environ $2000 \mathrm{~m}$; Mrayor $i^{2}$, 17. 14, 15, 1ti. X. - Indes centrales ; Paramos du liniz. dip. Antioquia et Tolima, alt. 3no:s-3-0n m. - Distrib. qungr. : Pérou. 


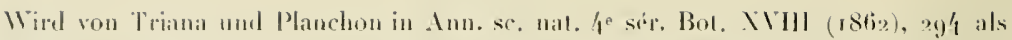

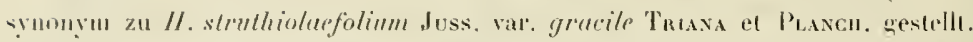

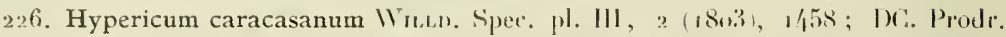
I. 454.

Indes orientales; pente du Moutserrate el Parano Crow Verde an-dessus de Bonota,

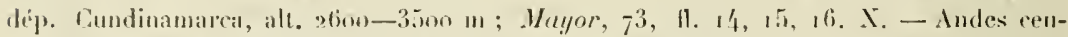

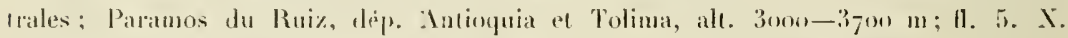
(. Notiz auf der Eliquette, ohne Belex.) - Distril. geogr. : Vinizuela.

227. Hypericum of. laricifolium duss in An11. Mus. Par. 111 (1804), 16, 1. 16. fig. 1; II. B. K. Vor. gen. et spec. I, 145; I)C. Prodr. I, 553 ; Triana et Planch. Prodr. H. Noro-Granat. in Anu. sc. nat. $4^{\mathrm{e}}$ sír. Bot. XYll1, $29^{5}$.

Andes orientales; pente du Montserrate et Pitramo Cruz Verde au-dessus de

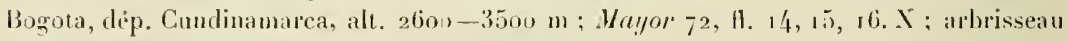
i lleurs jaunes.

Andes centrales ; Paramos du Ruiz, dép. Antioquia et Tolima, alt. 3’on-3700 m; Vayor 1o, 11. 5. X. 1910. Arbrisseau à lleurs jaunes. Hème plante observée au Paramo Cruz Verde sur Bogota. - Distrib. grogr. : Pérou.

Vergl. die Bemerkung bei II. acerosum H. B. K.

228. Hypericum struthiolifolium Juss. in Ann. du Mus. III (1804), Ifio, 1. 16, fig. ? a et b ; Clooisy in DC. Prodr. 1, 55:3; Triana et Planch. Prodt. Fl. Novo-liranat, in Amm. sc. nat. $4^{e}$ sér. Bot. XYIII, zg.3 vall. gracile Triana el Plaxcu. I. c. (1862), 294 tal. 16 fig. 2 b.

Mypericum struthiolaefolium Juss. var. minutum Cnossy in DC. Prodr. I (1824), 53.3.

Andes centrales; près de la Laguna au-dessus de Medellin, dép. Antinquia, alt. $2300 \mathrm{~m}$; Mayor 391, 11. 8. VIII ; Heurs jaunes, plante ne depassant pas $1 \mathrm{~m}$ de hant. - Distrib. géogre. : Pérou.

229. Hypericum thesiffolium H. B. K. Nor. gen. el spec. T (1821), 192; Triana et Planch. Prodr. Fl. Novo-liranat. in Aurr. Śe. nat. $4^{\circ}$ sér. Bot. XVHI, 290.

II. indecornm H. B. K. I. c. 19.3; Choisy in DC. Prodr. I, 5 iro.

II. uliginosum H. B. K. I. c. 194; Choisy I. c. 547 .

II. tarquense H. B. K. I. c. 103; Choisy 1. c. 550.

II. mulliflorum H. B. К. 1. c. I9/; Choisy 1. c. 5iro.

Indes centrales; cultures et pàturages près du Rio Santa Elena, au-dessus de Medellin, dép. Antioquia, alt. $1700 \mathrm{~m}$; Mayor 375, fl. el fr. 6. VIII ; lleurs jaunes.-Distrib. géogr.: Andes de Bogota el du (Uuindiu. - Ob von II. canadense I. specifisch verschieden? Cf. Choisy 1. c., 550.

23o. Hypericum thesiifolium 11. B. K. var.?

Andes centrates. P'àturages de l'Alto San Mignel, haul de la vallée dn Poree dép. Anlinguia, alt. 2 ñon m; Mayor 123, 11. 26. IX; Heur's jaumes. 


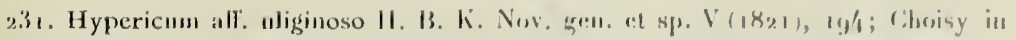
I): Prowle. I, $5 / 17$.

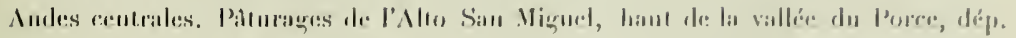

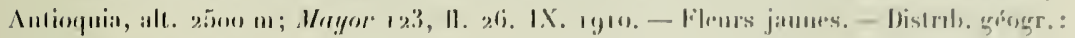
Mexirpur. Amsiripur du siml.

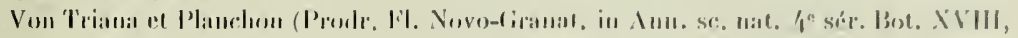

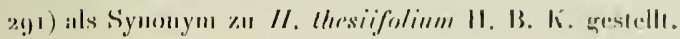

\section{Violaceae.}

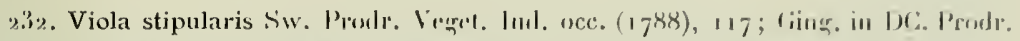

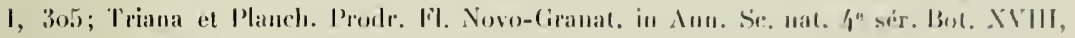
122 ; Bocker in Boilı. \%. Bot. Centralbl. XX, 2, 8ti.

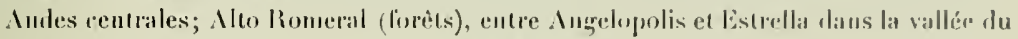

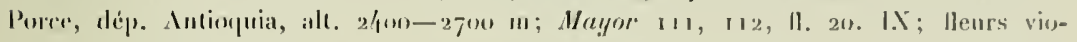

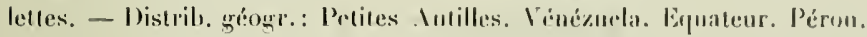

\section{Flacourliaceae.}

233. Casearia sylvestris Sw. FI. Ind. are. II (1800), 7512; I)C. I'rodr. II, 19); Giriseh. lil. Brit. W.-lnd. Isl., 23.

Intilles: Jamaïque, Hope Gardens; arbuste; Mn!yor 289 , 11. 14 . 1111. - Distril. greogr.: Antilles. Mexique. Amérique tropicale.

\section{Passifloraceae.}

234. Passiflora of. bogotensis Hevtray PI. Hartweg. (I839-57), 184: Triana et

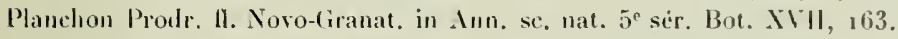

P. alnifolia Masters in Mart. Wl. Brasil. NIII, I, $519\left(r_{7} 2\right)$ ex p., non II. B. K. sec. Trianil et Pauchon l. c.

Arrles centrales; environs de Medellin, dép. Antioquia, alı. 1550 m; fleurs blanclies; Mayor 398 , li. et fr. WIIl. Die Pllanze scheint sich rom Typus der Benthamschen Art durch schwächere Belıarung und kleinere Blüten zu unterscheiden.-Distrih. urougr. : Colombie, (Antilles?).

235. Passiflora maliformis L. Spec. pl. ( 17.3$)$, g.56; Masters in Mart. Fl. Brasil. X111, I, 594; Triana et Planchon 1'rodr. 11. Yoro-(iranat. in .Inı. sce nat. 5e sér. Bot. IVII, 149.

I. ormate II. B. K. Nor. enen. et spee. II (1817), 120.

49 
bistril. quéogr. : Antilles, tropiqunes de l’. Imérique de Sul.

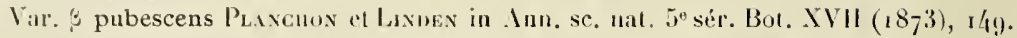

Indes centrales; chemin de Mcelellin à Bello, dép. Antioquia, ah. 1550 m; Heurs violelles; Mayor 3go, t1. VIll. - Distrih. géogrr. (var.): Colombie.

236. Passiflora vitifolia 11. B. K. Nor. gen. et spee. II (1817), э38; Masters in Mart. Fl. Brasil. XIII, 1, 6o7; Triana et Planehon Prodr. 11. Novo-Granat. in Ann. se. nat. $5^{\circ}$ sir. Bot. NV11, 143.

I'. punicen Ruzz el Ravon ex DC. Prodr. III (1828), 329.

Bord du Magdalena près de El Banco, dép. Magdalena, alt. yo m; lleurs rouģes; Mayor $2 \bar{j}^{5}$, 11. VI1. - Distrib. géogr.: Amérique centrale el tropiques de l'Amérique dı Sud.

237. Passiflora spec. nov. (?).

Audes centrales; laaies et taillis près du Cafetal La Camelia près Augelopolis, dép. Antioquia, alt. $1800 \mathrm{~m}$; lleurs violettes; Mayor 357 , 11. VIll.

\section{Begoniaceae.}

238. Begonia ferruginea L. fil. Suppl. $(1781), 419 ;$ II. B. K. Nov. gen. et spee. V'Il, 188 .

Casparya ferruginea $\mathrm{A}$. DC. P'rodr. $\mathrm{XV}^{\top}, 2$ (1864), 269.

Audes orientales; Alto Angarillo an-dessus de Sibaté, dans la Savane de Bogota, dép. Cundinamarea, alt. environ $3000 \mathrm{~m}$; plante à grandes fleurs rouges; Mayor 5, ll. $\left(\sigma^{*}\right)$ X. - Distrib. géogr.: Colombie.

239. Begonia hirtella Lisk Enum. I. Berol. 11. (1822), 396; А. DC. in Mart. Fl. Brasil. IV, 1, 345 et Prodr. XV, J, 299; O. E. Schulz in Urban Symb. Antill. VII, 1, 28. - Distrib. géogr. : Autilles, Brésil, Colombie, Pérou.

Var. nana (Walp.) A. DC. Prodr. XV, I (1864), 299.

B. diversifolia var. nana Walp. in Nov. Act. nat. cur. XIX, Suppl. I (1843), 408.

B. villosa var. nana et $B$. ciliala var. nana Ḱlotzsca ex A. DC. 1. c. in syn.

Andes centrales; ehemin de fer de Medellin entre Caracoli el Cisneros, dép. Antioquia, alı. environ $800 \mathrm{~m}$; plante à fleurs roses; Mayor 253, 11. et fr. V11. - Plaine du Magdalena, près de Mariquita, dép. Tolima, alt. $570 \mathrm{~m}$; plante à lleurs blanches; Mayor 97, fr. X. - Distril. géogr. [var.]: Brésil, Pérou.

240. Begonia tovarensis Kilotzsch in Monatsb. Berl. Akad. (Mäız 1854), I I2 sens. ampl.; A. DC. Prodr. XV, r, 3o3; Hemsley in Biul. Centr.-Am. Bot. 1, 500.

Audes centrales; haies et lisières de bois près du Cafetal La Camelia près Anggelopolis, dép. Antioquia, alt. 1800 in ; lleurs rose-ronge; Mayor 347 , l1. et fr. VIII. - Andes centrales, ehemiu de Angelopolis à Guaca, dép. Antioquia, alt. 1500 m; lleurs roses; Mayor 129, 11. et lir. IX. - Distrib. géogr.: Mexique. Vénézuela. Colombie. Guyane. 
2/1. Begonia Urticac 1. Lil. Suppl. (17 $\left.x_{1}\right)$, 位.

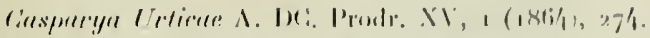

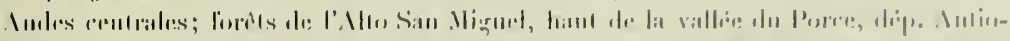

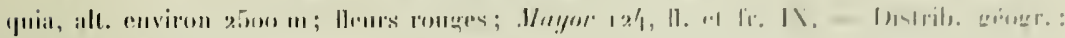

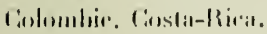

\section{Cactaceae.}

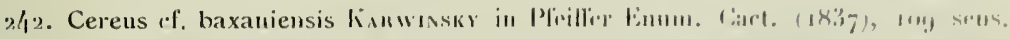

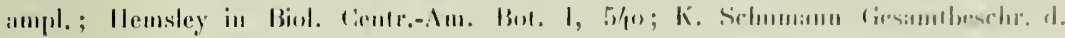
kinkt., , R. $^{8}$

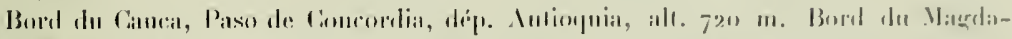

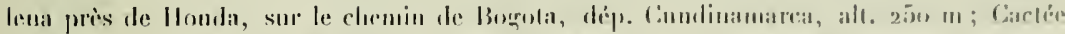

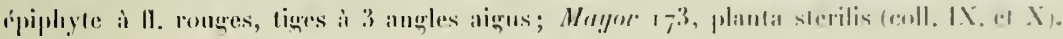

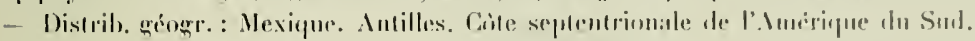

2/3.3. Phyllocactus sper:

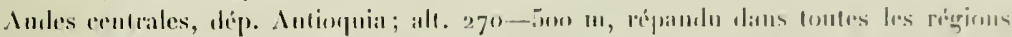

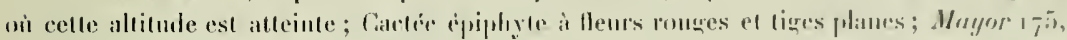
coll. IX (plintal sterilis).

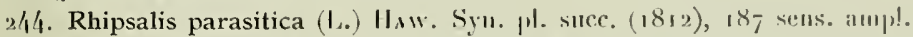

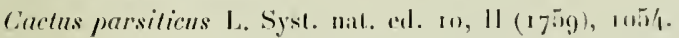

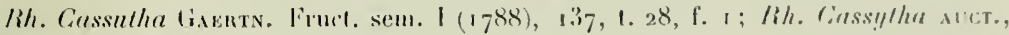

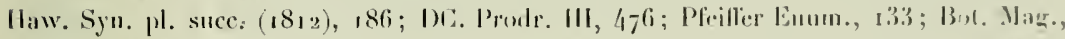

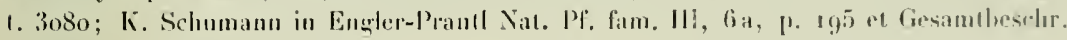
1. Kikk1., 622.

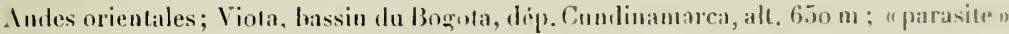

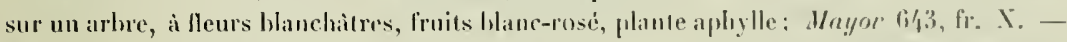
Andes centrales; Mariquita pres Homba dépr. Tolima, alt. 57u m; épiphyte; Mayor (ił4 (planta sterilis). - Distrib. quèngr. Antilles. Améringe centrale at Amerique do Sut. Alrique épualoriale. Maurice. Ceylan.

24.5. Opuntia triacantha (WtLb.) DC. Prodr. III (18:8), 4-3; Gristh. FI. Brit. W.-Ind. Isl., 302; K. Schumann Lesambesclır. d. Kinkt., 7 fon.

Antilles: San Thomas; Opmuta a llenrs jaun's, plante ne dipassant pas in $\mathrm{cm}$ de

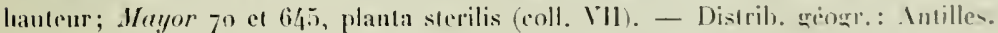

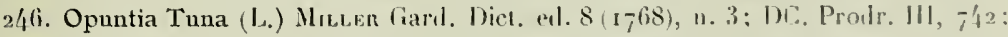
Grisel. Fl. Brit. W.-Ind. 1s1., 302; K. Schumann Gesambeschr. d. Kakiten $(1899)^{2}, 273$. Cactus Tuna C. Spece pl. $(1,-53), 4(i 8$.

Antilles: San Thomas; plante alleignant a m de hanteur el davautage: Mayor híg (plaula sterilis). - Distrib. géngr.: Intilles. Mexięue. Colombie. Porou. 


\section{Lythraceae.}

247. Cuphea dipetala (I. f.) Koenne in Engler's Bot. Jahrb. II (1882), 12? of in Engler's Pl.-Reich I7. Ileft (IV. 2, (i) Lythrac., P. $17 \%$.

Lythrum dipetalum L. f. Suppl. (1781), 250 ; DC. Prods. III, 83.

Guphea verticillata H. B. K. Nov. cene el spec. V1 (1823), 207, 1. 5i2; M. Prodr. III, 84; Koehne in Nart. Fl. Brasil. NIII, 2, 238.

Andes orientales; chenin entre Agua Larga et Facalativa, dép. Cundinamarca, alt. 2300 -260o m. - Paramo Cruz Verde au-dessus de Bogota et Laguna de l batye, dép. Cundinamarca, alt. $2000-3000 \mathrm{~m}$; arbuste de $2 \mathrm{~m}$ de hanteur it ll. violeltes, srlutinenses; Mayor 51, 11. et fr. X. - Distrib, géogr. : Colombie, Pérou.

248. Cuphea racemosa (L. f.) Sprexger Syst. II (i 825), 455; DC. Prodr. III, 86; Koelıne in Engler's Bot. Jahrb. I, 448 et in Engler's Pll.-Reich 17. Iteft (IV. 216 ) Lythrac, P. I04.

Lythrum racemosum L. f. Suppl. (1781), 250.

Cuphea spicata CAv. Icon. IV (I797), 56, t. 381!; DC. Prodr. III, 86; Kochure in Mart. Fl. Brasil. XlII, 2, $243,1.41$, f. 4 ! - Distrib. géogr.: Amérique centrale el Amérique du Sud. Antilles.

Var. extratropica (Сиa). ex Schlecnto. in Linnaca II | 18:7], 358, V [1830], 569) sub C. spicata) Koehne in Engler's Pll.-Reich I. c. (1903), 105.

Andes centrales, dép. Antioquia ; cultures et cafetales, Medellin, La Camelia, Guaca etc., commun jusqu'à $2000 \mathrm{~m}$; II. violet-lilas; Mayor 557, 11. el fr. VIII, IX. - Distril). géogr. (var.): Amérique du Sud.

249. Cuphea serpyllifolia H. B. K. Nov. gen. et spec. VI $(1823)$, 201, 1. 550! ; DC. Prodr. III, 87; Koehne in Mart. NI. Brasil. XIII, 2, 223, in Engler's Bot. Jahrb. II (188r), 14 I et in Engler's Pfl.-Reich 17. Heft (IV. 216), Lythrac., 1. 1 18; Hemsley in Biol. Centr.Am. Bot. I, 446 .

Andes centrales, dép. Antioquia; commun dans les cultures et au bord des chemins jusqu'à $2000 \mathrm{~m}$, fl. violet-lilas; Mayor 537, ll. et fr. VIII, IX. - Distrib. grégr.: Nexique (?). Colombie. Vénézuela.

250. Adenaria floribunda H. B. K. Nov. gen. et spec. II (1823), 188, 1. 549 et IC. Prodr. III, $9^{2}$ sens. ampliss.; Koehne in Mart. Fl. Brasil. XIII, 2, 2 Io et in Engler's Pll.Reich 17. Heft (IV. 216), 246. - Distrih. géogr.: Mexique. Amérique du Sud.

f. purpurata (H. B. K.) Koenne in Mart. Fl. Brasil. 1. c. (1877), 210 (pro var.) et in Engler's Bot. Jahrb. III ( 1882 ), 345 et in Engler's P(1.-Reich I. c. ( 1903 ), 247.

Adenaria purpurala II. B. K. I. c. (1823), 185 ; DC. I. c., 92.

Andes centrales et occidentales, dép. Intioquia et Cauca; un peu partout à partir de I $500 \mathrm{~m}$; arbre de 5-6 m de lauteur à lleurs verdàtres; Mayor 518 , ll. et fr. VIII et IX. - Distrib. géogr. (var.): Vénézuela. Colombie. Equateur. Pérou. Bolivie. Cuiabá. 


\section{$3 \times 4$}

\section{Combretaceae.}

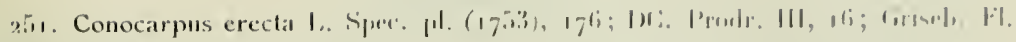
Bril. M.-Ind. Isl., 977 .

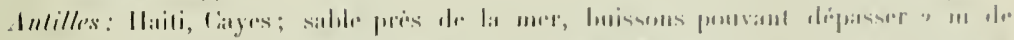

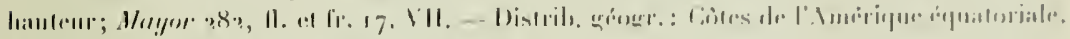

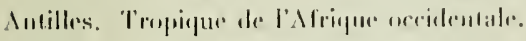

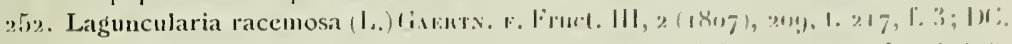

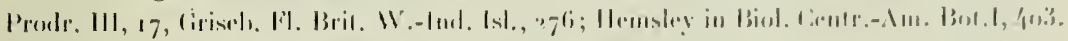

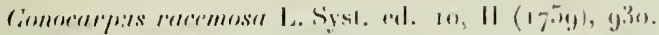

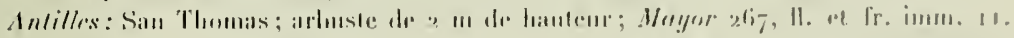

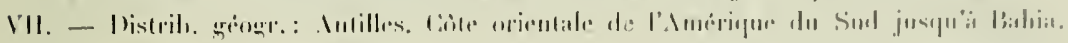

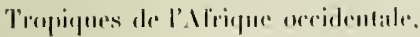

\section{Myrtaceae.}

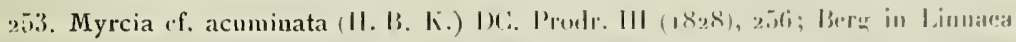

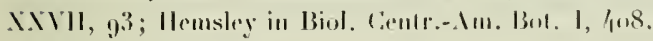

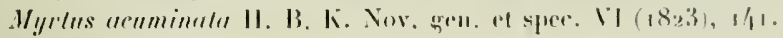

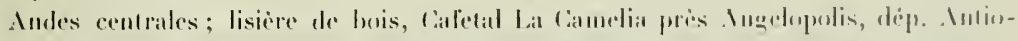

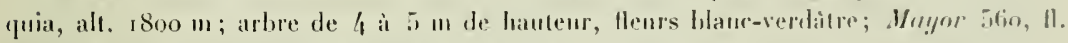
el fr. IIII, IX. - Tatllis et lisiores de hois prés de El Pohlades sur Medellin, dép.

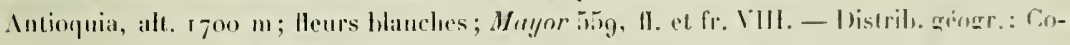
lombie. Vinezuelit. Pérou.

\section{Melastomalaceae'.}

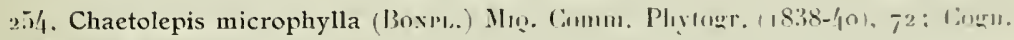
in I)(. Mon. Plian. VII, r jor.

Rhexia mierophyfle Boxw. Liliex (1823), 4, tah. 2.

Oshectiva microphylla D)C. Prodr. III (1828), 140.

Andes orientales; pente du Montserrate el Paramo Cmz Verde, au-dessus de Bogoha.

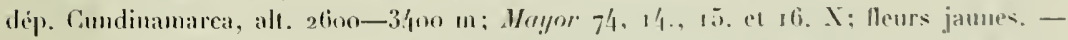

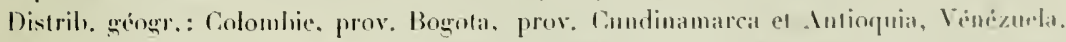

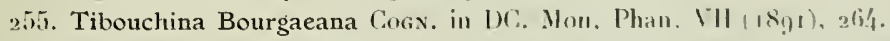

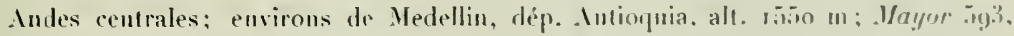

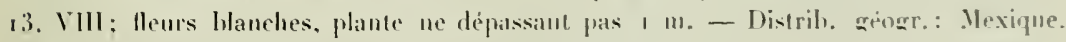
Cillatemala. Costa-Rica.

I Déterminies par M. A. Logniaux. 


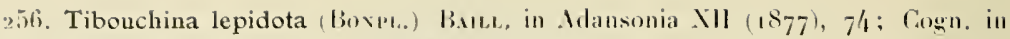
Mart. Fi. Bras. NIV, 3, 372 et in 1) Mon. Plian. YII, 2:37.

Rheriat lepidola Buxpe. Rhex (18.3), 38, lab. 15.

Chartogastra lepielota D)(: P'rodr. III (1828), 134 .

Andes centrales; chemin entre Medellin el la Latguna an-dessus de Medellin, depe.

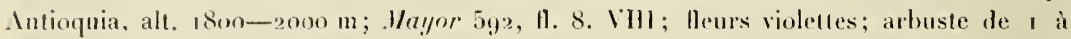
2 m de hauteur. - Distril. quegr.: Éfutitenr. Péron. Brésil.

2.57. Aciotis brachybotrya (1)C.) Tus.xa in Trans. Linn. Soc. XNVIll (1871), 5i; Cogniaux in llart. Fl. Bras. XIT, 3, 465 et in DC. Mon. Phan. V1l, 301.

Spennera brachybotrya DC. Prodr. IlJ (1828), 115.

Bord du chemin de fer entre Catracoli el Cisneros (chemin de Hedellin), dép. Antioquia, alt. environ $800 \mathrm{~m}$; Mayor 255, 11. 31. VIl; Heurs hlanches. - Distrib. géogr.: Brisil.

\section{Monochaetum Mayorii Cogs. nov. spec.}

Eumoxocnatum. Ramis junioribus petiolis pedunculisque breviter denseque plumosotomentosis; loliis parvis, breviter petiolatis, ovato-oblongis, acutis, basi rotundatis, 5plinerviis, utrinque setulis breviusculis subadpressis densiuscule vestitis; cymis majusculis, multilloris, laxiusculis, minute foliosis; floribus violaceis, rubro-striatis; calyce setis breviusenlis adpressis hasi leviter incrassatis sulsparse vestito, lobis triangulari-lanceolatis acuminatis, tuho vix brevioribus.

Frutex erectus, $2 \mathrm{~m}$ altus, ramis gracilibus, teretiusculis, cinereo-fuscis, satis ramulosis. Petiolus gracilis, 3-5 mm longus. Folia rigidiuscula, supra intense viridia, subtus cinereo-viridia, $1 \frac{1}{2}-3 \mathrm{~cm}$ longa, $8-1 / \frac{\mathrm{mm}}{\mathrm{m}}$ lata, nervis gracilibus, supra profundiuscule impressis, subtus leviter prominentibus. Flores longinscule pedicellati, minutissime bracteolati. Calycis tubus fuseo-viridis, anguste campanulatus, 4-5 $\mathrm{mm}$ longus; lobi primum erecti demum patuli, Hexuosi, $31 / \mathrm{g}-4 \mathrm{~mm}$ longi. Petala oblique obovata, apice vix ciliolata, $6-7 \mathrm{~mm}$ longa. Antherae majores purpureae, $4-5 \mathrm{~mm}$ longae, cauda rellexa, filiformi-spathulata; minores pallidae, $3 \mathrm{~mm}$ longae, cauda anguste cultriformi.

Celte espèce est voisine du $M$. pnlchrnm Degne., dont elle dillère surtout par ses rameaux notahlement plus grèles, ses feuilles heaucoup plus petites, ses inllorescences plus développées et multilłores, les lobes dı calice plus étroits, acuminés et relativenent plus longs.

Andes centrales; forèts de l'Alto Ronteral entre Angelopolis et Estrella dans la vallée du Porce, dép. Antioquia, alt. $2000-2500 \mathrm{~m}$; J/ayor ı 4 , fl. 20. IX; plante atteignant $2 \mathrm{~m}$ de hauteur, arlırisseau à 11 . violettes striées de rouge.

259. Miconia myrtillifolia Naúd. in Ann. se. nat. $3^{\text {e }}$ sér., Bot. XVI (1851), 198; Coguianx in DC. Mon. Phan. VII, 877.

Andes centrales; près de la Laguna au-dessus de Medellin, dép. Antioquia, alt. $2300 \mathrm{~m}$; Mayor 388, 11. 8. VHI; arbuste de $2 \mathrm{~m}$ au plus, lleurs blanches. - Distrib. «néngr.: Vénézuela. Costa-Rica. 


\section{Enolheraceae.}

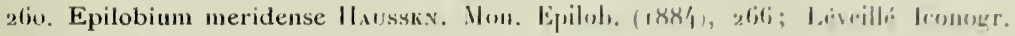

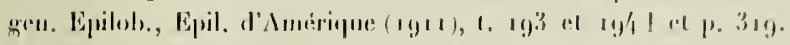

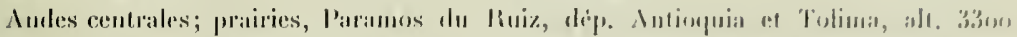

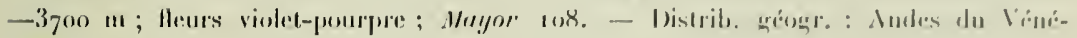
zoneli. Équatene. Péron. Chili.

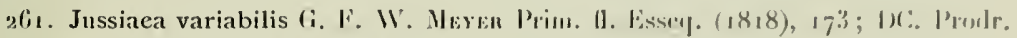
III, 53; Griseh. FI. Brit. W.-Iırl. Isl., 273.

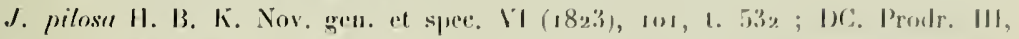

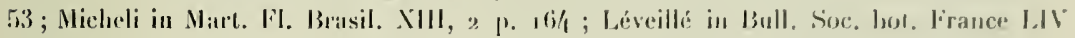
$(1907), 425$.

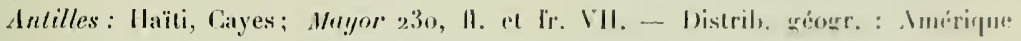
tropicale et sub-tropicale. Afrique tropicate.

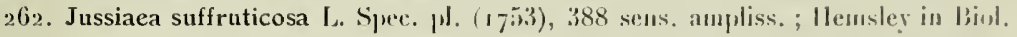

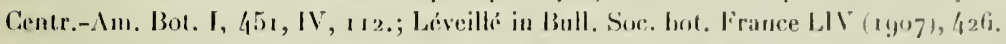

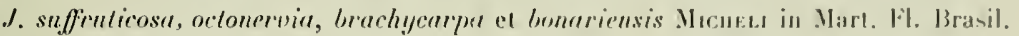
Xill, $2,1(9 y)-172$.

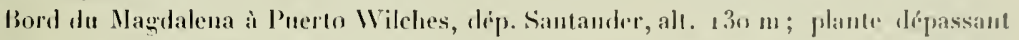
I m, ì lleurs jaunes; Mayjn 281, H. et fr. Vll. - I)istrib. géogr. : Régruns tropicales et sub-tropientes tes deux himisplieres.

263. Fuchsia el. ampliata Bentua Pl. Hartweg. (1839-57), 178.

Andes centrales; Paramos du Ruiz, dép. Antioquia, à parlir de 3oun m; vivan en épiphyte sur les trones d'arbres pourris, lleurs rongr-orange ; Wayor So, 11. X. Distrib. géogr. : Équatenr.

264. Fuchsia cf. quindiuensis II. B. K. Nov. zren. et spec. VI (1823), 104: I)C. Prodr. III, 38 ; cf. Hooker f. Bot. Mag. C.XI, sub. 1. 683y.

Audes centrales; Paramos du Ruiz, dép. Antioquia el Tolima, alı. à partir de

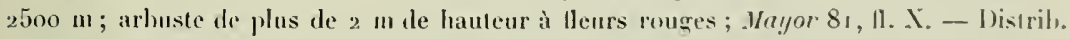
grégr. : Colombic.

265. Fuchsia venusta I1. B. K. Nov. qrell. el spec. VI (18\%3), 104; DC. Prind. III, 38.

Andes orientales; chemin de llonda à Bogota, entre Iquat Larga el Ficalativa dans la Savane de Bogota, dép. Cundinamarca, alt. $2200-2600 \mathrm{~m}$; huissons de $2-3 \mathrm{~m}$ de laanteur, à fleurs rouge-orange : Mayor 56, fl. X. - Bois entre Boca del Munte près de Madrid dans la Savane de Bugota et labuberece do Tambo pris de Tena, defr. Cundina-

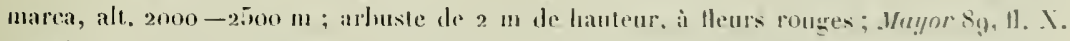
- Distrib. wéngr.: Colombie. 


\section{Umbelliferae.}

266. Hydrocotyle Bonplandi A. Ricu. Mon. Hydroc., P. 27 in Ann. Sc, pliys. IV (1820), 192, t. 54, f. 7 ; DC. Prodr. IT, 62 ; Lrhan in Mart. Pl. Brasil. X1, 1, 282 ; llemsley in Biol. Centl.-.In. Bol. I, 557.

Indes centrales; Paramos du Ruiz, dép. Intioquia et Tolima, alt. 3000-3500 m; plante rampante à llents blanches; Mayor 1,46, ll. et fr. X. - Distrib. géogr. : Cuatimala el Costit-Rica jusqu'au Chili.

267. Hydrocotyle leucocephala Casm. in Jinnatea I (1826), 364 (err. Yy|. 26/4); IC. Prodr. 11, 62 ; Urban in Mat. Fl. Brasil. Xl, 1, 278, tal. LXXVI, l. I!

II. minuta Poul in DC Prodr. IT (1830), 66.

II. humifusu PonL. I. c., 62 .

II. polyrrhiza DC. I. c., 65.

11. multicanlis Ponı 1. c., 64.

Andes centrales, dép. Antioquia; commun à tous les endroits ombragás et humides entre 900 el $2000 \mathrm{~m}$; plante rampante ì lleurs Hanches; Hayor $523 \mathrm{ex}$ p., ll. et fr. VIII, IX. - Andes orientales : Barro Blanco près de Madrid dans la Savane de Bogota, dép. Cundinamarca, alt. $2600 \mathrm{~m}$; plante rampante à fleurs blanclıatres ; Mayjor 147 , planta sterilis (coll. X). - Distrib. géogr. : Brésil et ailleurs dans l'Amérique tropicale.

268. Hydrocotyle quinqueloba Ruzz et Pavon Fl. Peruv. III (1802), 25, 1. 248 f'. b; DC. Prodr. IV, 6r, sens ampl, ; em. Urban in Mart. FI. Brasil. N1, I, p. 274.

II. Humboldtii A. Ricn. Mon. Hydrocol., 33 in Anı. Sc. phys. IV, i73, 1. 53, f. 6 ; DC. Prodr. IV, 60.

II. aconitifolia A. Ruch, ibiel. (1820), 35 (175), 1. 53, f. 5 ; DC. I. c. 61.-Distrib. géogr. : Brésil, Indes de l'Équateur el de Colonbie.

Yar. \& stella (Poirl) Urban in Mart. Fl. Brasil. Xl, r, 275 (1879), tab. LXXV f. p!

11. quinqueloba R. et P. I. c. sens strict.

II. stella Pонц in DC. Prodr. IV (1830), $6 \mathrm{i}$.

Andes centrales; versants occidental et oriental du Ruiz, dép. Antioquia el Tolima, entre 2500 et $3000 \mathrm{~m}$; plante rampante ì fleurs blanclies; Mayor $9^{6}$ ex p., fl. X.

Var. "द quinqueradiata $\mathrm{U}_{\text {нBA⿱ }}$ l. c. p. $275(1879)$ et L. LXXY, f. q!

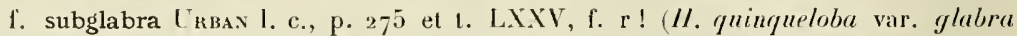
Gilax. in Linnaea VIII [1833], 329). Avec la variété précédente; Mayor $9^{6}$ ex p., fr. X.

269. Hydrocotyle umbellata L. Spec. pl. (1753), 234; DC. Prodr. 1V, 6o ; Torr. el Gray Fl. North. Am. I, 599 ; Grisel. Fl. Bit. W.-Ind. 1sl., 307 ; Urluan in Mart. Fl. Brasil. X1, 1, p. 269 .

Andes centrales, dép. Antioquia ; endroits ombragis et humides entre gou-2000 m;

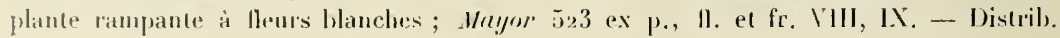




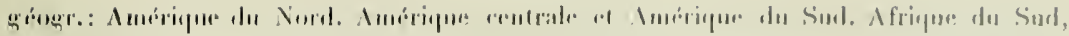
Marlacascare.

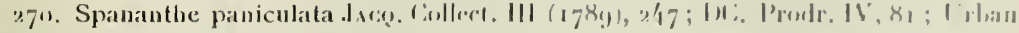

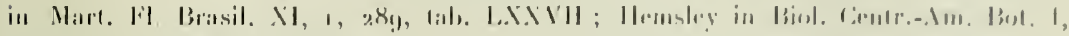

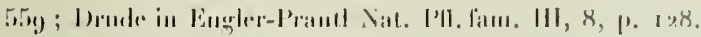

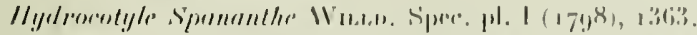

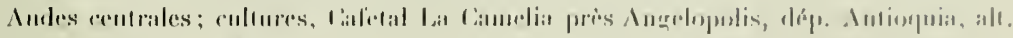

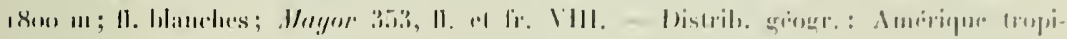

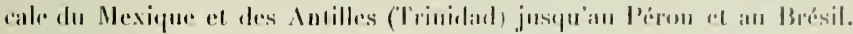

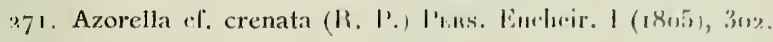

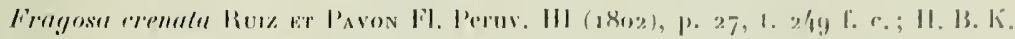

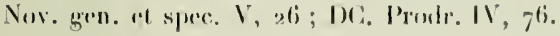

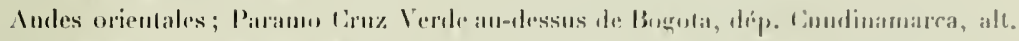

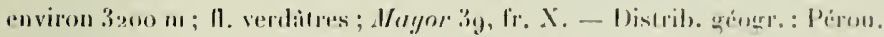

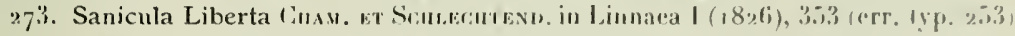

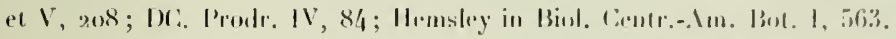

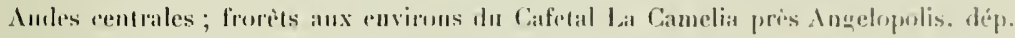

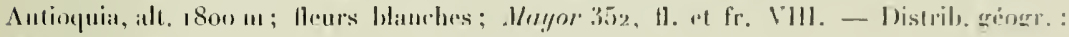
Mexique jusqua Chili.

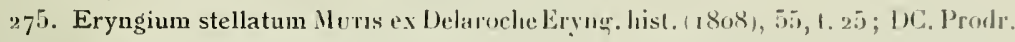
IV, 9.3; Hemsley in Biol. Centr.-.111. Bul. I, iliz.

Andes orientales; Paramo Cruz Terde au-elessus de Bogota, dép. Cumdiumarea, alt.

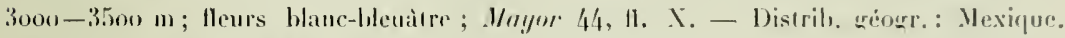

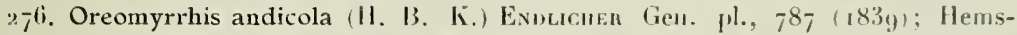
ley in 13iol. Centr.-Am. Bot. 1, 567; Hmule in Engler-Prantl Nat. Pfl. fam. III, R, p. $16 i 3$.

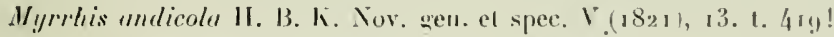

Caldasin andicola LAg. in 1)C. Coll. mén. V ( 829$)$, 6u et t. II, f. J I-3!); DC. Prorlr. $\left.1 T^{T}, 221\right)$.

Andes centrales; pàlurages, Paranos du Ruiz, dép. Ancioquia, alt. 37̈n m; 11. blanclies; Jnyor sog, fr. X. - Distril, gréogr. Andes du Vexique di Tucuman, en Argentine et aux iles Falkland; Australie, Tasmanie.

277. Apium ternatum (Willo.) Tueluung comb. nov. non Pallas ex Steudel I84o. quod $=$ Angelieae sjec., nec Selslecht. ex R. Seh. 1820 nec sielonld 1830, quod $=$ Lignstici spee.].

Lignsticmm termatum Wiblo. herh. ex Schlechtend. in Rumer el sichultes Sist. IVI $(1820), 555$.

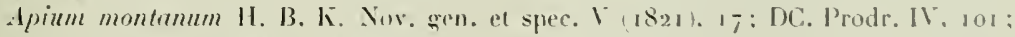

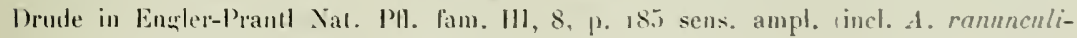

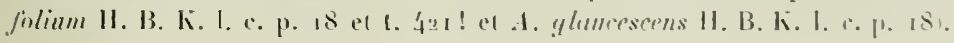




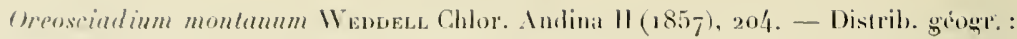
Colombie.

Var. ranunculifolium (II. B. K.) THellung comb. nov.

A. remunculifolium II. B. K. I. c.

A. montanum sulspls. Irmunculifolium DuUne 1. c. (1898).

Andes orientales: Parmono Cruz Verde au-dessus de Bugotia, dép. Camolinamarca, alt. $3500 \mathrm{~m}$; plante se trainant sur le sol, à Ilenrs blanches; Maygm 3/, fr. X.

Muyor's L'llanze hält etwa die Mitte zwisehen dem Typus des A. ternatum /montu$\mathrm{mmm}$ ) und der var. rrmunchlifolinm: die Pllanze ist selumächtiger its das von Kunth als $A$. ranunculifolium abgebildete Exemplar, die Laubblätter sind grösstenteils weniger zerteilt.

278. Daucus montanus IIvмв. Ex Boxpl. ex Willd. mse. in Schultes Syst. VI (1820), 482 ; Urban in FI. Brasil. AI, I, 350; Hemsley in Biol. Centr.-Am. Bot. I, 571.

D. toriloides DC. Prodr. IV (1830), 214.

Andes centrales; cultures, Cafetal La Camelia près Angelopolis, dép. Antioquia, alt. $1800 \mathrm{~m}$; plante à lleur's blanches; Mayor 354, 11. et lr. VIll. - Distrib. géogr.: Mexique, Vénézuela, Colombie jusqu’au Chili et Juan Fernandez.

\section{Ericaceae.}

279. Befaria coarctata Ilumb. et Bonpl. Pl. aequinoct. II (1809), 25, 1. 12 I! et Nor. gen. et spec. 111 (1818), 29I; DC. Prodr. VII, 731 .

Andes centrales; chemin de Medellin à la Laguna au-dessus de Medellin, dép. Antioquia, alt. 2000-2300 $\mathrm{m}$; arlmissean ne répassant pas z mètres, à lleurs rose violet; Mayor 386, 11. VIll. - Distrib. géogr.: Andes du Pírou.

280. Gaultheria anastomosans (L. F.) H. B. K. Nov. gen. el spec. III (I818), 285) ; DC. Prodr. VII, 5g3.

Andromeda anastomosans [Muris ex] L. f. Suppl. (1781), 830.

Indes centrales; taillis près de la Laguna au-dessus de Medellin, dép. Antioquia, alt. $2300 \mathrm{~m}$. - Forêts de l'Nlto Romeral entre Medellin et Angelopolis, dép. Antioquia, alt. 2500 ; fleurs blanc-rosé; Hrnyor 572 , 11. el fr. VIll, IX. - Distrih. géogr. : Colombic. 281. Sphyrospermum buxifolium Poeppig et Exdeicher Nov, gen. el spec. pl. Chil. I (1835), 4, 1. 8; DC. Prodr. V11, 794.

Andes centrales; chemin de Augelopolis à Guaca, dép. Autioquia, alt. euviron $1500 \mathrm{~m}$; épiphyte; Mruyor 86, 11. et fr. IX. - Distrib. wiogr. : Pérou.

282. Thibaudia ? spee.

Andes centrales; Paramos du Ruiz, dép. Antioquia, alt. $3300-3700 \mathrm{~m}$; épiphyte ì Heurs ronges; Nayor $61,11 . \mathcal{X}$. 


\section{Loganiaceae.}

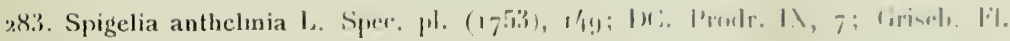
Brit. W.-lmil. Isl., 3i3.

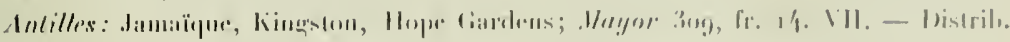

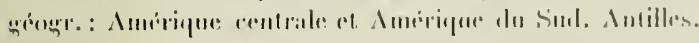

\section{Gentianaceae.}

38\%. Centaurium quitense (II. M K.) T'ut,uve comb. nov.

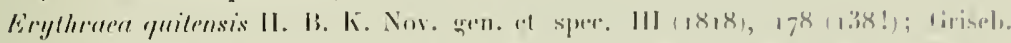

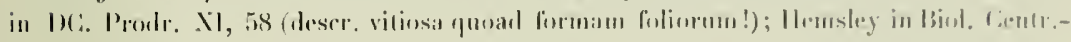
Am. But. II, 3, 36 .

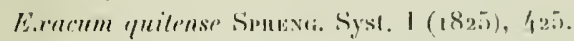

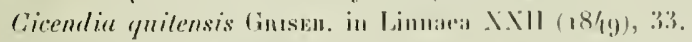

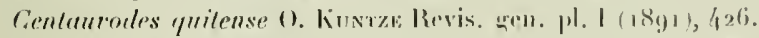

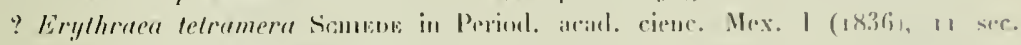
Sichlechtend. in Bot. Zeitung XIII (185i), $918-19$.

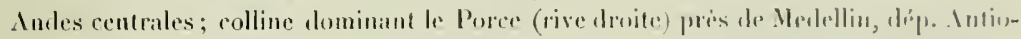

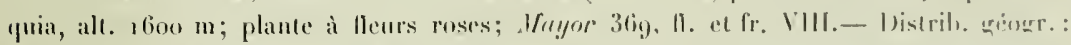
Andes de Costa-Rica! et Guatémala! jusqu'au l'bour E. Letramern: Mrexipue.

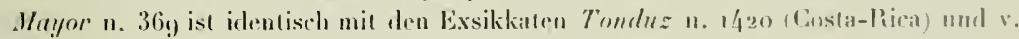

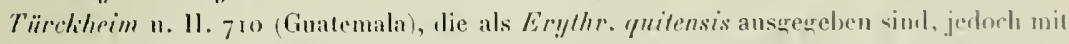

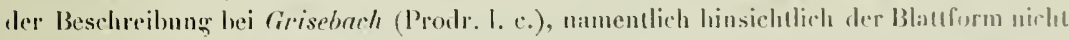

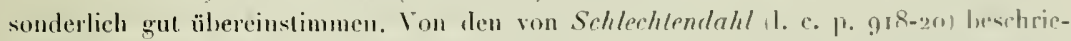
benen Schiedeschen und Schaffiner'schen Sivezies scheint am eliesten E. Ielramera in Betrachit zu kommen.

285. Gentiana corymbosa II. B. K. Nor. qen. el spec. III (1818), 1331. 224!; 1 iriset). in 1) C. Prodr. IX, 89 .

Audes orientales; Paramo Canz Verde au-elessus de Bogota, dip. Cumdinamarea, alt. $3000-3500 \mathrm{~m}$; lleurs blanches stries plus nu moins de violet; Mayor 42. 11 . et fr. x. - Constaté la meme plante aux Paramos cln Ruiz, dép. Antioquia ct Tolima, entre 3000 et $3700 \mathrm{~m}$. - Distrils. griogr.: Chili.

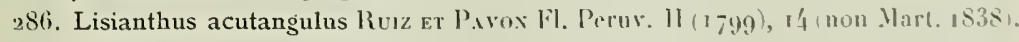

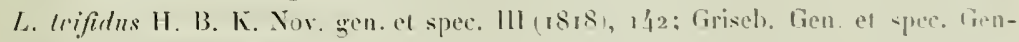
lian., 185 et in DC. Prodr. IN, 7 .

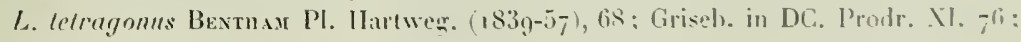
Ilemsley in Biol. Centr.-Am. Bot. II, 34!). 
Andes centrales; cultures, Cafetal la Camelia pres Ingelupolis, dip. Antioquia, alt. $1800 \mathrm{~m}$; plante dépassant I $m$ de hauteur, à lleurs verdittes; Maymo 82, 11 . et lir. IX. - Distrilb. geougr.: Andés du Mexique jusqu'an Pérou.

28\%. Symbolanthus ef. daturoides (Cirıseb.) (ing in Engler-Prantl Nat. Pfl. fam. ハ, 2 (1895), 99 .

Lisianthus daturoides Linseb. Gen. el spec. Gentian. (1839), 177 et in 1) . Prodr. I. 78 .

Indes orientales (de Subia): El Boquerón de Ciuachuni dominant la vallee de Viotia, dẹ. Cundinamarea, alt. $2450 \mathrm{~m}$; arbrissean à lleurs rouges; Mayor 4 , 11. X. - Distril. géogr.: Andes du Pérou.

\section{Apocynaceae.}

288. Plumiera alba L. Spec. $\mu$ l. (1753), 210 ; DC. Prodr. VIII, $39^{2}$; Griseb. Fl. Brit. W.-Ind. Isl., 411.

Antilles; St. Thomas; Mrbre de 4-5 m de lauteur à latex blanc, lleurs blanches, tres odorantes; Mayor 376, 11. 11. V'11. - Distril,. géogr.: Intilles.

${ }_{2} 8_{9}$. Rauwolfia nitida Jaeq. Enum. Pl. Caril, $(1 ; 60), 14$; Grisel,. Fl. Brit. Wr.-Ind. Isl., 407 .

Antilles: San Thomas; arhrissean de 1 m de hauteur; Mayor 269 , ll. 1 1 . VIl. Distrib. géogr. : Intilles.

290. Mandevilla ef. mollissima (H. B. K.) K. Scuumann in Engler-Prantl. Nat. Pfl.-Fam. J, 2 ( $\left.189^{5}\right), 17$.

Echites mollissima H. B. Ki. Nov, gen. el spee. III (1818), 218; DC. Prodr. VIII, 461 .

Exothostemon mollissimum G. Dox Gen. Syst. IV (I838), 82 .

Andes centrales; haies, lisières de forèts aux euvirons du Cafetal La Camelia près Angelopolis, dép. Antioquia, alt. $1800 \mathrm{~m}$; plante grimpante à IJeurs jaunes; Mayor 575 , fl. et fr. VIII. - Distrib. géogr.: Colombie.

\section{Asclepiadaceae.}

291. Asclepias Curassavica L. Spec. pl. (1753), 215 ; DC. Prodr. VII, 566 ; Hemsley in Biol. Centr.-Im. Bot. II, 323; Fournier in Mart. Fl. Brasil. VI, 4, 199.

Andes orientales (de Subia); hords de chemins, Cafetal Nagdalena dans la vallée de Viota, dép. Cundinamarca, alt. $1050 \mathrm{~m}$; plante ligneuse, ne depassant pas $80 \mathrm{~cm}$ de hanteur, à lleur orange. "I'ai rencontré cette plante à la mème altitude dans les $\lambda$ ndes orientales, centrales et occidentales." Mayor ı 5, 11. 26. X. - Distrib. géogr.: Amérique tropicale, subpontané en Asie, Afrique et Australie. 


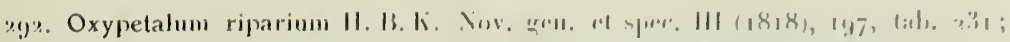

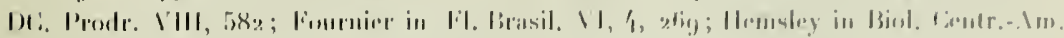
Bu1. 11, 3:3.

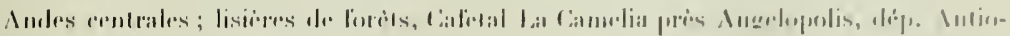

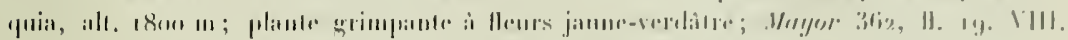

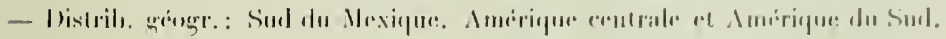

\section{Convolvulaceae.}

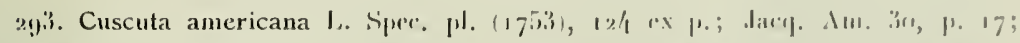

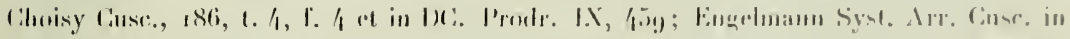

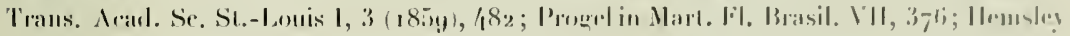
in Biol. Centr.-Am. But. II, 401, 11, 11.5, 113.

Antilles: San Thumas.-Jamä̈рu, lïusstum.

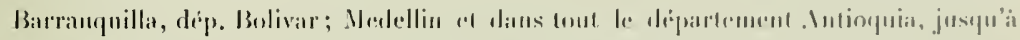

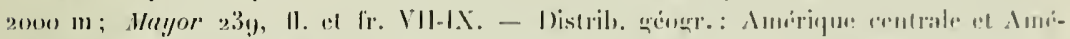
rique infuatoriale, Antilles.

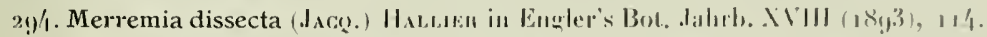

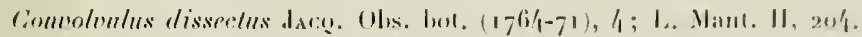

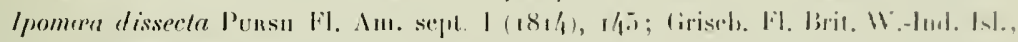
467 - non Willd. Plyylogr. (1794), 5, 1. 2.

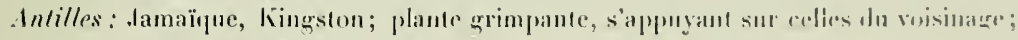

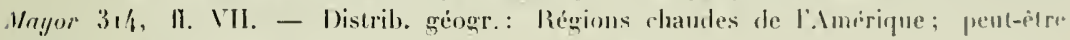
senlement acdimaté dans les tropiepurs de l'Aucien-Monde.

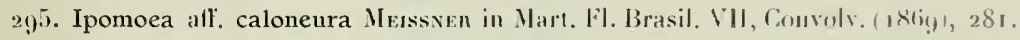

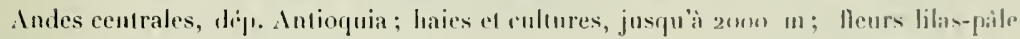

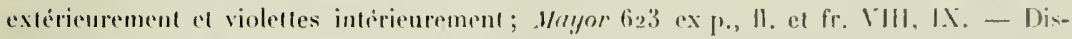
tril, quérgr. (I. culonenra): Brésil.

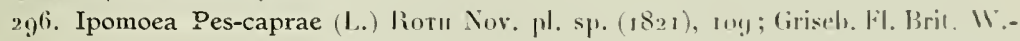
Ind. Isl., 470 .

Conrolvulus Pes-caprae L. Spec pl. (1753), sing.

Intilles: Ilaïti, Cayes; sahle au bord de la mer, plante rampante à lleurs purpurines; Mayor 258, 11. V11. - Distrils. grogr.: Tropiques des dews himisplueres.

297. Ipomoea tiliacea (Wniro.) Chorsy in DC. Prodr. IX (184.i1. 37.5.

Comolvulus tilinceus Wilto. Enum. h. Berol. ( 1809$), 203$.

Ip. fusligiule Swet Ilort. Bril. ed. I (1827), 288; Choisy in DC. Prodr. IS. 380.

Bord du Magdalena à Puerto Wilehes, dep. Sintander, alt. tino m; lleurs purpurines; .1/ayor 256, 11. VIII. - Distril. géogr.: Imérique Iropicale; Iropique's de l'Ineien Monde oì il n'est peut-ètre pas spontané. 


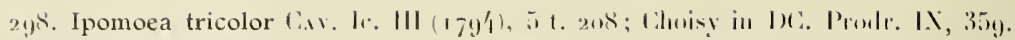
Indes centrales, dep. Antioguia; haies et cultures, alt. 1000-rgoo m; Muyor 623 ex.

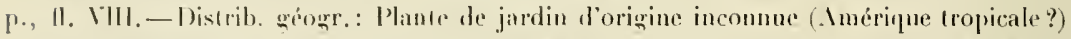

299. Ipomoea umbellata (L.) G. F. W. MEsen Prim. II. Esseq. (I818), 99; Mrissner

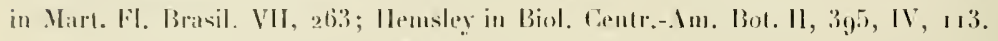

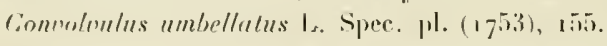

Indes eentrales; lord du Lio Xmaga an-dessous du Catelal La Camelia près Ange-

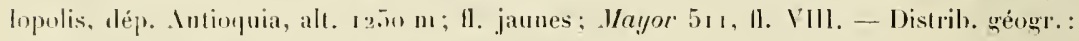
Amérique iquatoriale. Intilles.

300. Ipomoea spec.

Incles centrates, dép. Antioquia; baies el cultures, entre 1400 et $2000 \mathrm{~m}$; Mayor 623 ex p., II. VIII-IX.

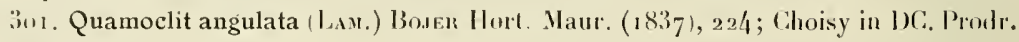
I.X (1845), 336 .

Ipomoer angulalu Lam. III. I (1791), 464 n. 2116 ! '.

Ip. coccinen 1. Sprec. pl. (1753), Ifor ex minore p.

9. phnenicea Cuossy in Mém. Soc. Gienève VI (1833), 4333 el in DC. Prodr. IX, 336.

Ip. hederifolia Meissien in Mart. Fl. Brasil. VII, Convolv. (I869), 2 8 ex p. et 1. 7f, f. I! non L.

Bord du Canca à Puerto de los Polres, Paso de Concordia, dép. Antioquia, alt. 720 ; plante arimpante, lleurs rouges; Ma!yor 622, 11 . et fr. IX; revu le long du chenin le Honda à Bogota priss de Villeta dans les Andes orientales, dép. Cundinamarca, alt. environ goo m. - Distril. géogr.: Amérique, Afrique el Asie équaloriales.

\section{Boraginaceae.}

302. Cordia laxiflora H. B. K. Nov. qen. el spec. IIl (1818), 72 ; DC. Prodr. 1X, 489.

Andes centrales; chemin de Cisneros à Medellin, près du Porce, non loin de Yarumito, dép. Antioquia, alt. $8340 \mathrm{~m}$; arbuste de $2-3 \mathrm{~m}$ de haut, à ll. blanchâtres; Mayjor 379 , Il. et fr. VIIl. - Distrib. géogr. : Colombie.

303. Tournefortia hirsutissima L. Spec. pl. ( 753$)$, 140; D)C. Prodr. 1X, 517 ; Fiesen. in Hart. FI. Brasil. IIII, I, P. 49; Hemşley in Biol. Centr.-An. Bot. II, 373.

Bord du Canca au Paso de Concordia, Puerto de los Pobres, alt. $720 \mathrm{~m}$; arbuste de 2-3 $\mathrm{m}$ de haut., à lleurs hanches; Mayor 343, fl. et fr. IX. - Distrib. géogr.: Mexique, Amérique centrale et Amérique du Sud. Antilles.

:304. Tournefortia volubilis I. Spee. pl. (1753), 140;1)C. Prodr. IX, 523 sens. ampl.; Griseb. FI. Brit. IV.-Ind. Isl., 484. - Distril. géogr.: Antilles. Amérique du Sud.

1 Feht im Index Kewensis. 


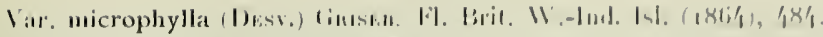

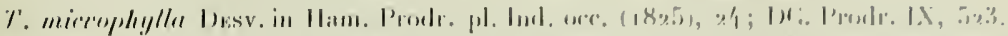

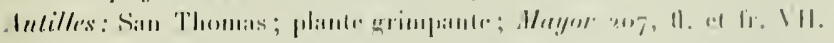

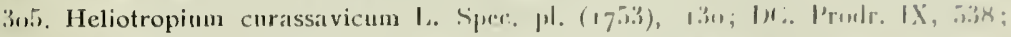

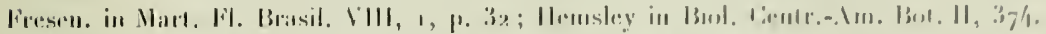

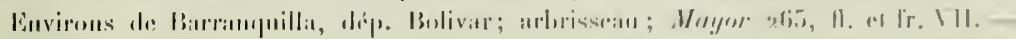

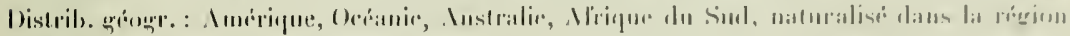
miditerratrónur.

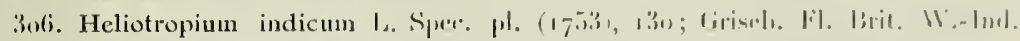

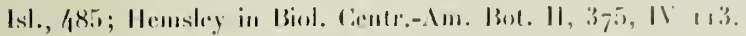

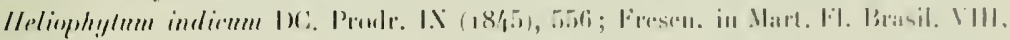
1, 1. 198.

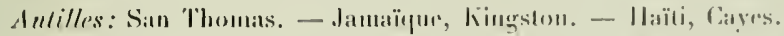

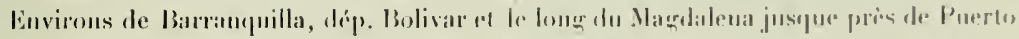

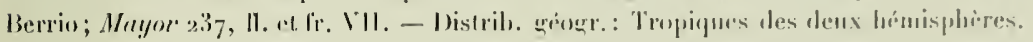

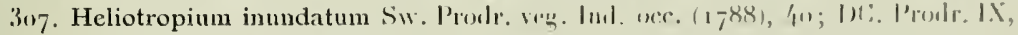
539 ; Hemsley in Biol. Centr.-Am. Bar. II, 37-5, 11, 115)

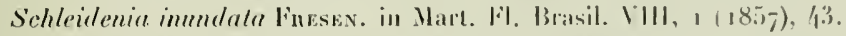

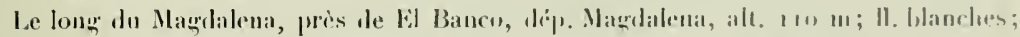

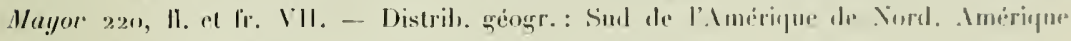
centrale el Améripue du Sud. Antilles.

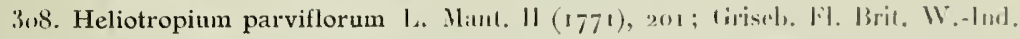
IsI., 1,85.

Meliophytum parviflornm DC. Prodr. IX (18/5), 5is3; Presen. in Nart. Fl. Brasil. VIII, 1, 1. 44.

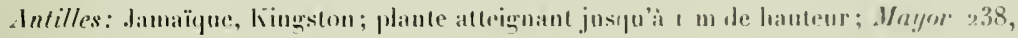

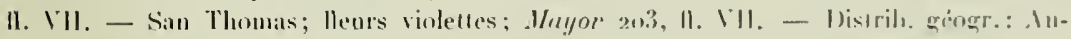
tilles, Mexique, Ameripue du surl.

\section{Verbenaceae.}

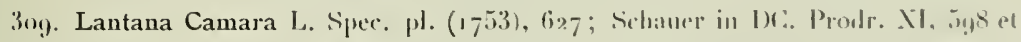

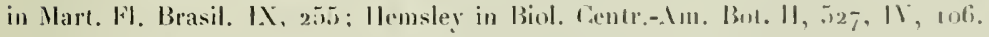

L. aculealu L. Spec. pl. (17.5.3), 627.

Bord du Canca à Puerto de los Pobres. Paso de Concordia dép. . Intioyuia, alt. 720 m: plante atteignant jusıu à 2 m de haut, feuilles se détachant an moinde contact, lleurs

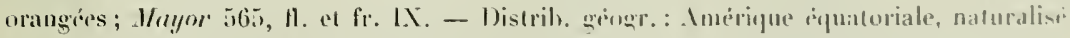
daus les tropiques de l'Ancien-ilnonde.

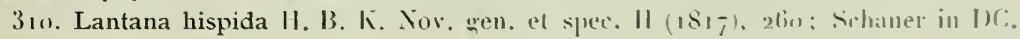

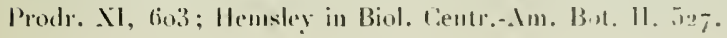


Indes centrales; taillis et forts de l'Mlto Don Elias aturlessus du Calfetal La Lamelia pres Ingelopolis, dép. Intioquiat, alt. $1800-20 n 0 \mathrm{~m}$; Heurs liliss-paile à centre jauneorange, plante dépassant I m, pursant presque alteindre 2 m de lautemr, à lenilles se

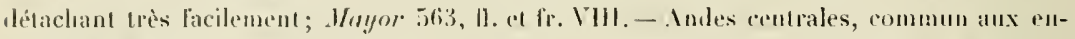

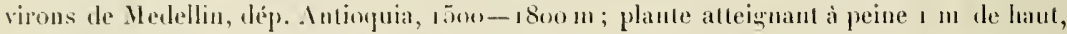
a feuilles aromatipues, se délachant an moindre contact, fleurs violettes; Mayor 562 , 11. et fr. VIII (plantat quasi intermedia inter L. hispidum et L. involucratum L., dillerens a L. hispide typica foliis breviorihus obtusins crenatis brevsisime acuminatis sublus catnescenti-tomentosis; an sprecies propria?).-Distrib. quogr. : Mexique. Costa Rica (etc.?).

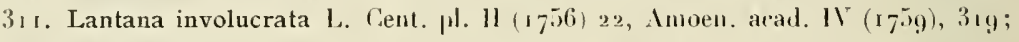
Selaver in DC: Prodr. Xl, 6oz; Grisel. Fl. Brit. W.-Ind. Isl., 49gi.

Antilles: San Thomas; Mayor zoz, H. VII. - Distrib. géogr. : Antilles. Panama.

312. Lantana tiliifolia Cn.x, in Limnaea VII (1832), r22, 1. 7 , f. $\Lambda$; Schaner in DC. Prodr. X1, 600 el in Mart. Fl. Brasil. IX, 257 ; Hemsley in Biol. Centr.-Am. Bot. 11, 528.

Paine du Magdalena à Beltran, prairies arides le long du llewe, dép. Tolima, alt. 26011 ; plante pouvant alleindre 1 in de hauteur, llenrs jaune-orange, feublles el rameanx se detacliant au moindre contact au cours de la dessieation; Mayor 3o, 11. X. - Distrib. géogr. : Amérique centrale et Amérique dı sud.

3ı3. Lantana trifolia L. Spec. pl. (1753), 626 ; Schaver in DC. Prodr. XI, 605 el in Mart. Fl. Brasil. IX, 264; Hemsley in Biol. Centr.-Am. Bot. II, 528.

L. annna L. Spec. pl. $(1,53), 627$.

Paine du Magdalena à Beltran, prairies arides le long du lleuve, dép. Tolima, alt. :60 m; lleurs violet-Jilas, plante ne dépassant pas $80 \mathrm{~cm}$ de hauteur; Mayor 31, 11. et fr. X. - Andes centrales, forèts et lisières de bois aux environs du Cafetal La Camelia près Anggelopolis, dép. Antioguia, alı. $1800 \mathrm{~m}$; lleurs violet-lilas, plante dépassant I m; Moyor 564, fl el fr. VIII. - Distril. péogr. : Amérique centrale el Nord de l'Amérique du Sud. Antilles.

314. Lippia americana L. Spec. pl. (1753), 633 ; Sclatuer in DC. Prodr., II, 579; Hemsley in Biol. Centr.-Am. Bot. I1, 529.

Lippia floritunda H. B. K. Nov, gen. et spec. II (1 $\left.8 \mathrm{I}_{7}\right), 267$.

Bord du Magdalena, non loin de Barranquilla; arbuste de $2-3$ m de hant, à lleurs Llanchitres; Moyor 10, 12, 11. 2. Xl. - Distrib. géogr.: Mexique(?). Panama, Equateur.

31.5. Lippia betulifolia 11. B. K. Nor. gen. el sper. 11 (1817), 264; Schaner in Mart. Fl. Brasil. IX, 2:37 ; Hemsley in Biol. Centr.-Am. Bot. II, 529.

Bord du Maggdalena, près de El Banco, dép. Mağdalena, alt. 18 m ; plante rampante à lleurs jaune-orange; Mayor, 274, fl. et fr. VII. - Distrib. géogr.: Trinidad, lìyane, Nicaraurua, Brésil.

3. 6. Lippia nodiflora (L.) Mranx. N1. Bor.-Am. 11 (1803), 15; Schauer in DC. Prodr. NI, 585 et in Mart. Fl. Brasil. IX, 28; Irisel. FI. Brit. W.-Int. Isl., 499/; Hemsley in Biol. Centr.-.1m. Bot. 11, 5.30, IV, rnti, 113. 


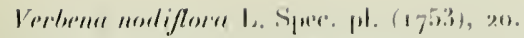

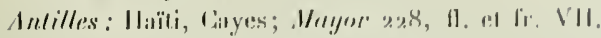

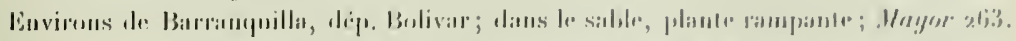

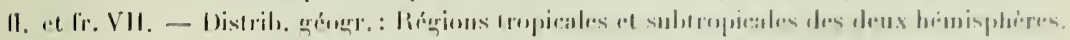

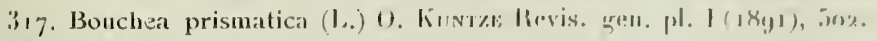

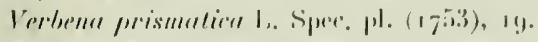

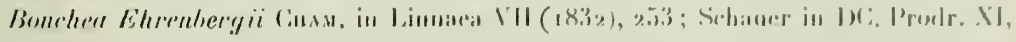

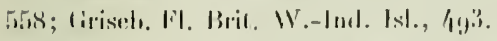

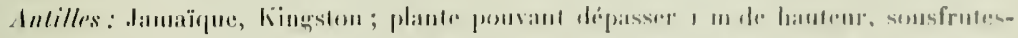

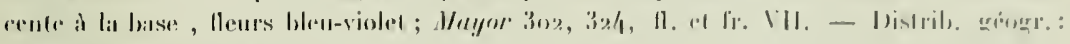

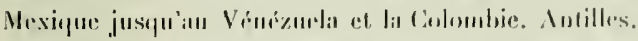

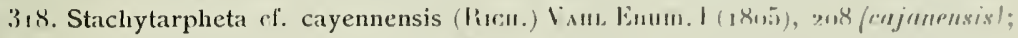

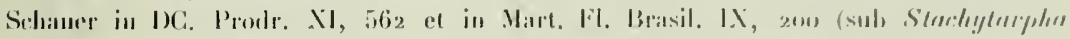

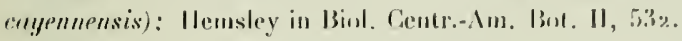

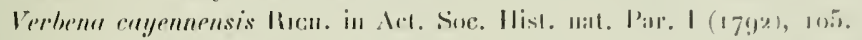

Amles centrales, depe. Antioquia; partoul daus les cultures, les palurates el limus

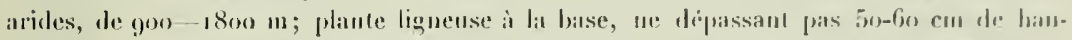

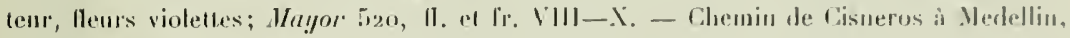

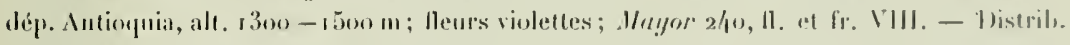
ưoumr.: Amérique ípuatoriale.

319. Priva lappulacea (I..) Pris. Encheir. II (1807), r.3.9.

Yerbena lappulacea L. Spec. pl. (1753), 19.

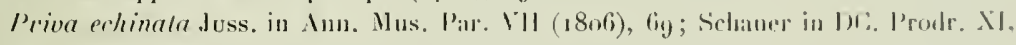
534 ; Grisel). lil. Brit. W.- Ind. Isl., 193.

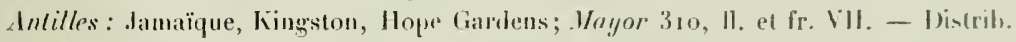
groger. : Mexique jusqu'au Brésil. Mntilles.

320. Clerodendron aculeatum (L.) Cirisel. Fl. Brit. W.-Inrl. Isl. ( 860 ), Eno.

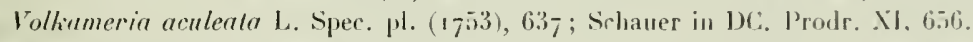

Antilles: Sinn Thomas, près de la mer, plante ne dépassant pas 1 un de hentenr; Matyor ıgo, n. et fr. Vll. - Distril, gângr.: Intilles, tropiegues de l'Amérique de Sud.

\section{Labiatae'.}

3:1. Leonotis nepetifolia (L.) R. Bn. in Aiton Hort. Kew. el. 2, III (1811), 4oy: Benth. in DC. Prodr. NI1, 535; Griseb. Pl. Brit. W.-Int. Isl., 492.

Phlomis nepelaefolin L. Spec. pl. (1753), 586.

Antilles: lamaïque, lïngston, Ilope Gardens; I1. ronge-orange: Vayor 219). 11. VI. - Distrib. géogr.: Tropiques de l'Amérique, de l'Ifrique el de l'Asie.

t Defterminés par M. J. Briquet.

51 
322. Leonurus sibiricus L. Spec. pl. (1753), 584; Benth. in DC. Prodr. X11, 501; Griseb. Fl. Bril. W.-lnd. Ist., 491.

Antilles: Jamaïque, Kingston; Mayor 245, 11. VI1. - Distrib. géogr.: Régions chandes de l'Amérique, de l'Afrique el de l'Asie.

\section{Stachys Mayorii Bur.. spec. nov.}

Herha biennis vel perennis, elatil, ramosa, ramis elongatis laxis sat debilibus, internodiis elongatis, undique laxe pilis patulis praeditis. Folia petiolata; lamina ovata vel ovato-elleptica, apice obtusa vel subobtusa, marginibus infra medium convexioribus regulariter crenatis, basi truncato-subcordata, membranacen, utringue viridia, pilis sparsis undique praedita, nervatione simplici, subtus haud prominula; petiolus lamina brevior, undique dense patule pilosus. Verticillastri multillori (ad 12-15 llori), in spicastris subfoliosis interruptis dispositi, bracteis inferioribus folia reducta subsessilia aemulantibns, cacteris elliptico-lanceolatis denticulatis parvis, summis quam flores breviorilus. Calix sub anthesi campanulatus parrus, subsessilis, pilis patulis longis rigidulis conspersus, lubi ohconici nervis haud prominulis, dentibus lanceolatis tubum subaequantibus apice aristato-spinulosis; calix maturus ample ovatus, dentibus basi late ovato-deltoideis, nervo medio nitido prominulo in aristam spinulosam dentis limbum subaequantem protensis. Corolla minima, calicis dentibus brevior, lilacino-violacea; tubus intus nudus, cylindricus, superne'sensim ampliatus, apice vix incurvus; labrum ovato-oblongum, apice ol,tuso-rolundalum, erectum; labiolum labro longius, dellexo-patens, versus faucem dense pulicrulum, trilobum, lobis lateralibus parvis rotundatis, lobo medio lato, obovato. Stamina et stylus sub labro ascendentia, labrum fere aequantia. Nuculae obovoideae, fuscae, laeves.

Planta ultra $60 \mathrm{~cm}$ alta. Internodia media ad $\mathrm{r} 2 \mathrm{~cm}$ longa. Foliorum lamina ad $4 \times 3 \mathrm{~cm}$ longa; crenarum culmina I $\mathrm{mm}$ alta et $2-4 \mathrm{~mm}$ distantia; petiolus $1-2 \mathrm{~cm}$ longus. Spicastrum a verticillastro infimo messum demum ad $20 \mathrm{~cm}$ longum el ultra, sed etiam brevius, internodiis inter verticillastros $6 \ldots 4 \ldots 3 \ldots 2$ etc. cm longis. Pedicelli vix $1 \mathrm{~mm}$ longi. Calicis tubus sub anthesi $1,2 \mathrm{~mm}$ profundus, dentes $\mathrm{I}, 2 \mathrm{~mm}$ alti; maturitate tubus $\mathrm{I}, 9 \mathrm{~mm}$ longus, dentes fere $2 \mathrm{~mm}$ longi (arista fere $1 \mathrm{~mm}$ longa). Corolla tola ad $3,5 \mathrm{~mm}$ longa, labro $\mathrm{I} \mathrm{mm}$ labiolo $1,5 \mathrm{~mm}$ longis. Nuculae mat. long. $\mathrm{I}, 3 \times \mathrm{r}, \mathrm{I} \mathrm{mm}$.

Espèce de la section Eustachys \& Olisiae voisine des $S$, boliviana Bus. el Lorentzii BRıg., dont elle diffère par les verticillastres multillores, par les dents du calice mûr uvées deltö̈des à la base, à nervure médiane luisante et saillante prolongée en arête spinuleuse longue de près de $1 \mathrm{~mm}$, et par la corolle très petite, plus courte que les dents calicinales.

Andes centrales: chemin de Medellin à Bello, dép. Antioquia, alt. $1500 \mathrm{~m}$; Mayor 405, 11. 4. VIII ; Heurs lilas. - Cultures, Cafetal La Camelia près Angelopolis, dép. Antioquia, alt. 1800 m; Mayor 5o5a, 11. 19. Vll1. - Bord de chemin à Guaca, dép. Antioquia, alt. $1480 \mathrm{~m}$; Mayor $505 \mathrm{~b}$, fl. 29. VIII. Fleurs violet-lilas. 


\section{1 . Silvia cataractarum Bus., spec. nov.}

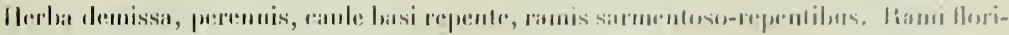

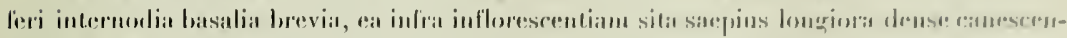

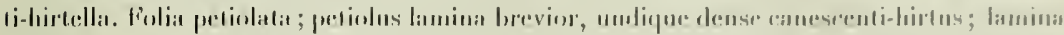

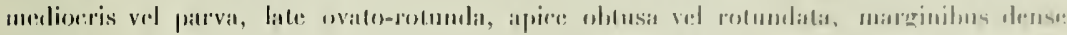

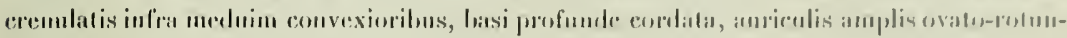

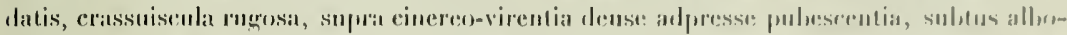

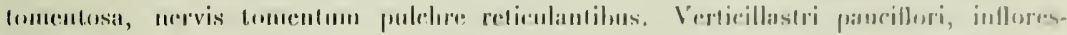

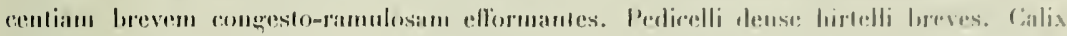

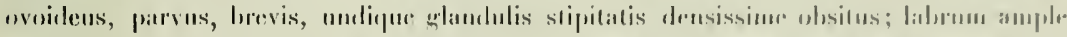

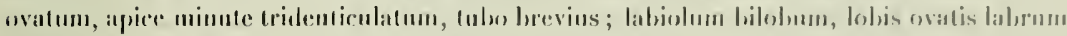

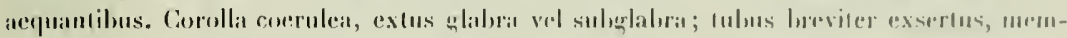

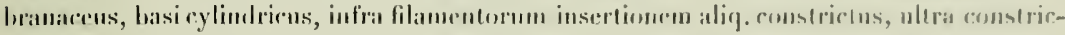
tionem alip. ventrieosus, inlus nulus; labrum subrectum, breve, brevissime biloburn; la-

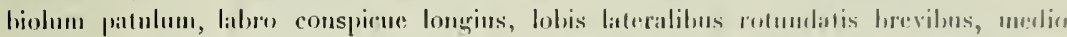

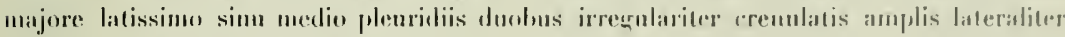

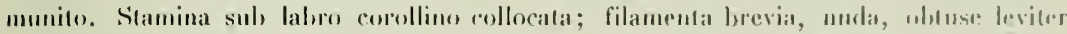
ulara articulationem protensa ; pollinatoria vectiaris anspiene longiora, moda, loculum lanceolatu-lineare beve ferentia; vectiaria unda, hrevia, cochlearibus brevites remiformilas, apice obusis, in ventriculo tuhi corollini collocatis. Siglus e labro corollino leviter exsertus, Glaber, valde inatequaliter bifidns, ramo antico brevissimo aculo, postico cuecurvo elongatro.

Internodia interfoliaria cire. 1,5-3 cm longa. Foliorum pediolus circ. I cmi fongus, lamina superticie $1,5-2 \times 1,8-2 \mathrm{~cm}$, crenis $0,4-0,8 \mathrm{~mm}$ altis et $0,5-2 \mathrm{~mm}$ distandiluns. luflorescentia sub anthesi in specim. nostris circ. $2 \mathrm{~cm}$ alta. Pedicelli vix a muloner. Calicis fulus circ. $2 \mathrm{~mm}$ longus, lahrum o, $8 \mathrm{~mm}$ altum, lahoulum fere $1 \mathrm{~mm}$ lonerum. Corollit calicis os circ. $3 \mathrm{~mm}$ excedens; lubus circ. $3,5 \mathrm{~mm}$ profundus; lahrum $2,5 \mathrm{~mm}$ longum; lahioli $3 \mathrm{~mm}$ longi lobi laterales superficie $1 \times 1 \mathrm{~mm}$, medius $2 \mathrm{~mm}$ longus, sinu inter plenridias circ. o, $5 \mathrm{~mm}$ profundo. Staminum filamenta $1 \mathrm{~mm}$, pollinatoria $2 \mathrm{~mm}$, vectiaria, $8 \mathrm{~mm}$, liculi o,8 mm alti. Stylus $5 \mathrm{~mm}$ longus, ramo antico o,3 mm, fostico $0,8 \mathrm{~mm}$ lonero.

Espèce de la section Calosphace \$rachyanthae, groupe Seorodonieae mais sans rapport étroit avec aucune espréce du groupe, dout efle diffère abondamment par le port, la forme et l'indument des feuilles, le petit calice hérissé de glandes stipitées, ct l'organisation de la corolle et des organes sexuels.

Andes orientales; pris de la chute du Tequendama à l'usine de Charquito, dép. Cunflinamaca, alı. 2300 m: Mayor 6o, HI. 12. X; Henrs blenes.

32.5. Salvia cernua II. B. K. Nov, gen. ol spec. II (1817), 300, tab, 151; Bentlı. in DC. Prodr. NII, 317.

Andes centrales; Paramos du Ruiz, dép. Antinquia, alt. $3500 \mathrm{~m}$; Mayor 137, fl. 5. $\mathbf{X}$; plante pouvant atteindre plus de $2 \mathrm{~m}$ de longeur en sappuvant sur celles du voisinage, fleurs et calices violet-lilas. - Distrib. géogr. : Colombie. 


\section{6. Salvia Mayorii Bho., spec. nov.}

Frutex vel sutfrutex elatus. Rami minnte adpresse et dense pulneroli, cinerei, validi, internodiis mediocribus. Folia petiolata; lanina ovata, apice acuminata, marginilus infra medium convexioribus superficialiter crenato-scrratis, basi rotundato-cordata sinu parum profundo angustissimo, membranacea, supra viridia minute puberula, sublus canescentitomentella, nervationi subsimplici laminam non reticulanti; petiolus in foliis caulinaribus tenuis undique canescenti-tomentellus, lamina brevior, in summis brevissimus. fuflorescontia pramidalis, ramosa, rachi pedicellisque undique glandulis violaceis stipilatis obsitis; verticillastri billori, bracteis caducis. Calix sulıtubulosus, undique glandulis stipitatis violaceis obsitus, labiis multo longior; labrum late ovatum, integrum, apice mucronulatum; labiolum bidentatum, dentibus valde approximatis sinu perangusto separatis, basi dissymetrice ovatis (latere exteriore magis evoluto), in apicem filiformiter protensum abeuntibus. Corolla rubra (unica el ideo analysi superficiali tantum subjicienda) pulclıra exserta, extus subglabra; tubus basi cylindricus tenuissimus, dein antice aliq. ampliatus sed non saccatus, superne angustatus, elongatus; labrum breve, oblongum, breviler bilolum; labiolum labou longius, patulum, trilobum, lobis lateralibus rotundatis, medio obovato bifido. Stamina exserta filamentis nudis, loculis lineari-elongatis, caeterum haud exacte describenda. Stylus exsertus, superne sape duplici pilorum alborum praeditus, valde inaequaliter bifidus, ramo postico valde elongato recurvo, ramo anticu breviter subulato.

Internodia media circ. $4 \mathrm{~cm}$ longa. Foliorum lamina superpicie ad $5 \times 4 \mathrm{~cm}$, dentium culmina circ. $6,5-1 \mathrm{~mm}$ alta et $4 \mathrm{~mm}$ distantia, petiolus in caulinaribus ad $4 \mathrm{~cm}$ longus. Inllorescentia tota circ. $18 \mathrm{~cm}$ alta. Pedicelli circ. 3-4 mm longri. Calicis tubus sub anthesi fere $4 \mathrm{~mm}$ longus labiis ad $1,5 \mathrm{~mm}$ longis maturus in toto ad $6-7 \mathrm{~mm}$ altus. Corolla (unica) $2 \mathrm{~cm}$ longa, tubo $17 \mathrm{~mm}$ alto, labro $3 \mathrm{~mm}$, labiolo $4 \mathrm{~mm}$ longo. Staminum loculi 1,2 $\mathrm{mm}$ longi. Styli ramus posticus $2,2 \mathrm{~mm}$ longus, anticus $0,8 \mathrm{~mm}$ altus.

Espèce de la section Calosphace $\$$ Tubiflorae, apparentée avec les S. striata Benrur. et mollissima Maıт. ет GaL., mais facile à distinguer par les abondantes glandes stipitées violacées qui recouvrent toute l'inflorescence.

Andes orientales: Près de la chute du Tequendama, à l'usine de Charquuito, dép. Cun dinamarca, alt. $2300 \mathrm{~m}$; Mayor 57 , 11. 12. $\mathrm{x}$; fleurs rouges.

327. Salvia petiolaris H. B. K. Nov. gen. et spec. II $(1817), 304$; Benth. in DG. Prodr. XII, 347 .

Andes centrales; cultures, Cafetal La Camelia près Ingelopolis, dép. Antioquia, all. $1800 \mathrm{~m}$; Mayor 543, 11. 30. VIII. - Distrib. géogr.: Colombie.

\section{8 . Salvia spec.}

Andes centrales; Soledad, chemin de Manizales à Honda, dép. Tolima, alt, 2345 m; Mayjor r32, 11. 6. X. Plante à 1l. rougges, dépassant i $\mathrm{m}$ de hauteur, feuilles se délachant au moindre contact, fleurs généralement isolées et appliquées contre la tige à la base des feuilles ou des rameaux. 


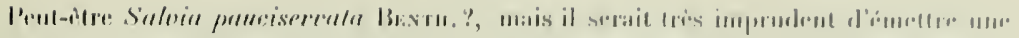

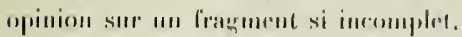

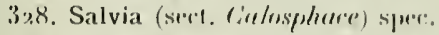

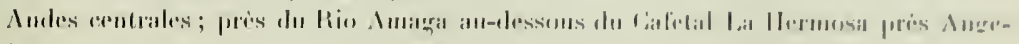

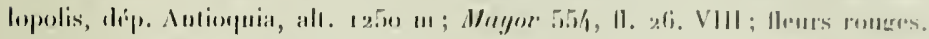

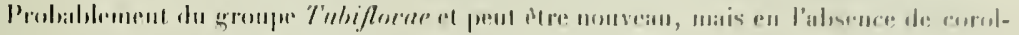
le il n'y a pas de diderminalion sicre pussible.

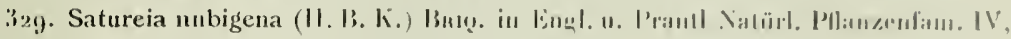
3it $(1896), 3100$.

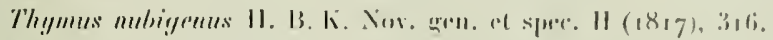

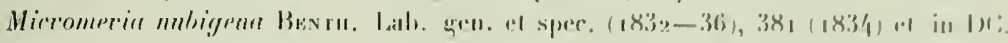
P'roile. XII, 222.

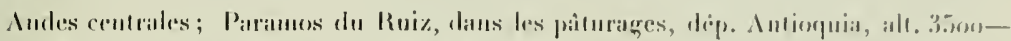

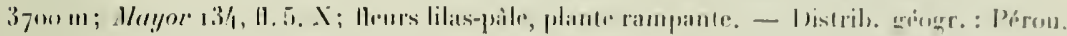

330. Hyptis atrorubens Port. in Amu. Mus. Par. V'll (18uti), ffiti, 1. 27, lier. 3 ;

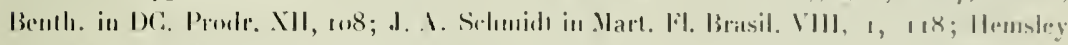
in Biol. Centr.-.1m. Bot. II, ĭ/2.

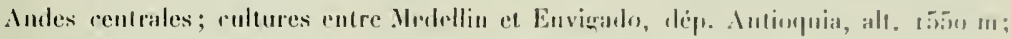

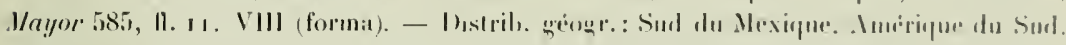
Intilles. Alrique ureilentale tropicale.

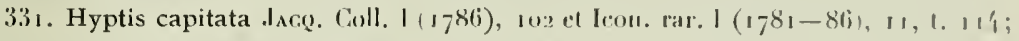

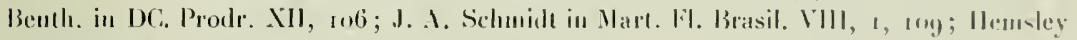
in Biol. Cintr.-Am. Bot. 11, 542.

Clinoporlium copitatum Sw. Prorle. Vew. Ind. ace. (1 788$), 88$.

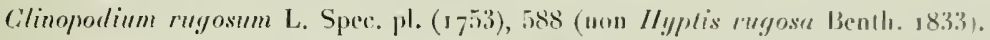

var. vulgaris Bme. in AmI. Cons. bol. Genive II (18ys), 224.

Andes centrales; chemin de Mederlin is Bello, dép. Antioquia, alt. 1550 m; Vayfor

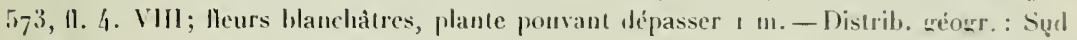

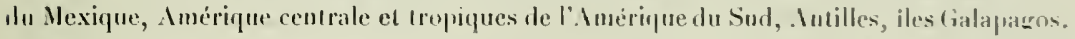

332. Hyptis savannarum lirug. in Aun. Conserv. et tarl. lut. Genève 11 (18gx), 216.

Andes occidentales; collines arides dominant le Cauca entre supia el Filadelfia, dep.

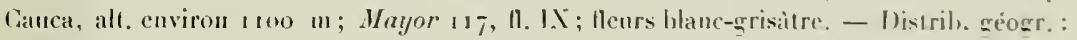
Jusqu’ici senlement an Costa-Rica.

333. Hyptis mutabilis (Rucu.) Brug. in Bull. Merl. Boiss. IT (rsghi), -8s.

Nepeta mutabilis Recu. in Act. Soc. Mist. Nat. Par. (17922), 111.

Var. spicata (Рогт.) Вег. І. с. 788 .

Hyptis spicuta Porr, in Anı. Mus. Par. VIl (1806), 474. 1. 28, f. 2; Benth. in DC. Prodr. XII, 122; J. A. Sclunidı in Mart. Fl. Brasil. VIII, 1, 135 ; Hemsley in Biol. Centr.-Am. Bot. 1I, 544. 
Bord du Cauca. Puerto de los Pobres an Paso de Concordia, dép. Antionuia all. $720 \mathrm{~m}$; Mayor 627, 11. 6. IX; llenrs violettes. - Bord du Magdalena, pris de El Banco, dép. Magdalena, alt. environ $110 \mathrm{~m}$; Mayor 221, 11. 27. VIll. - Distrib. géogr. : Floride. Mexique. Amérique centrale el Amérique tropicale.

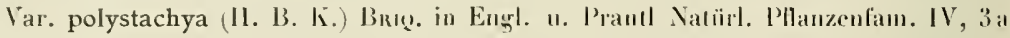
$(1897), 339$.

Ilyptis polystach!ya II. B. K. Nov. gren, el spec. II (1817), 321; Benth, in I)C. Prodls. XII, 121; Hemsley in Biol. Centr.-Am. Bot. 11, 544.

Andes centrales; cultures el Cafetal la Camelia près Anģelopolis, dép. Antionuia, alt. $1800 \mathrm{~m}$; Nayor 624, 11. 19. VHIl. Heurs violeltes. - Environs de Medellin, díp.

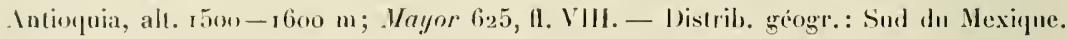
Amérique centrale et Amérique do Sud équatoriale.

334. Hyptis pectinata (L.) Port. in Anm. Mus. Par. VIl (1866). 474, 1. 30; Benll. in DC. Prodr. XII, r27; I. A. Schmidt in Mart. Fl. Brasil. VIII, I, 140; Hemsley in Biol. Centr.-Am. Bot. II, 544 .

Nepela pectinata L. Spec. ph. ad. 2, II (1 763$), 799$.

Indes centrales; commun aux environs de Medellin, dép. Antionuia, alı. 1.5on-_ fon u; Mryor 626, Al. V111. Feurs lilas. - Distrih. géogr.: Mexique. Amérique centrale a. Amerique du Sul. Antilles. Tropiques de l'Afrique du Sul et de l'Alrique occidentale.

335. Marsypianthes Chamaedrys (VAll ) O. Lusrze Rev. gen. plant. II (1891), 524 el III, 259 (Marsypianthus).

Clinopodium Chamaedrys Vaut Symb. III (1794), 77 .

Marsypianthes hyploides MАнт. in Benth. Lab. gen. el spec. (1832-36), 64 (1833) el in DC. Prodr. XII, 84; J. A. Schmide in Mart. Fl. Brasil. VIII, 1, 78 ; Hemsley in Biol. Centr.-An. Bot. I1, 542. - Distrih. géogr.: Sud du Nexique. Amérique centrale. Tropiques de l'Amérique du Sud. Antilles.

Var genuina Brıg. in Amu. Cons. bot. Genève II (1898), 232.

Andes centrales; culures entre Medellin et Euvigado, alt. $1550 \mathrm{~m}$; Mayor 553 , 11. 13. VIII.

\section{Solanaceae.}

336. Physalis turbinata Medikus in Aet. Acarl. Theod.-Palat. IV (1780), 188, 1. 5 f. 2 ; O. E. Schulz in Urban SymL. Antill. VI, 2, P. 145.

Andes centrales; cultures, Cafelal La Camelia près Angelopolis, dép. Autioquia, alt. I $800 \mathrm{~m}$; lleurs jaune-pàle; Mayor 348, H. et fr. VIII. - Distrib. géogr.: Antilles, Curaçao, introduit au Vénézuela.

337. Saracha edulis (Sculecut1).) Tinelung comb. nov.

Jallomata edulis Sculecnto. Ind. sem. h. Hal. (1838), n. 7 ex Linnaea XIII (1839), Lill. $9^{8}$. 


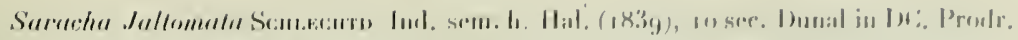

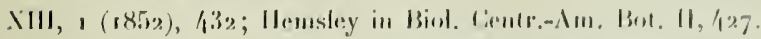

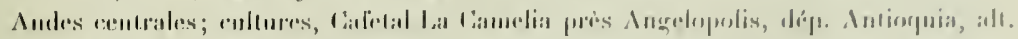

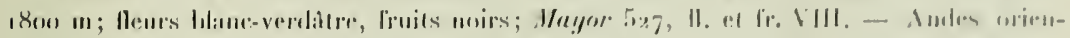

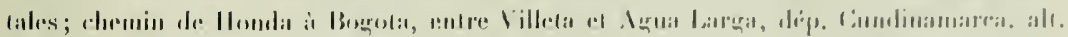

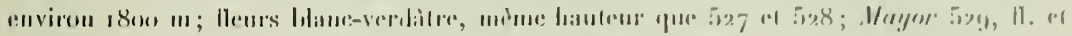

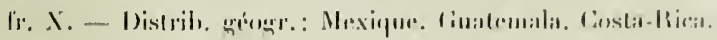

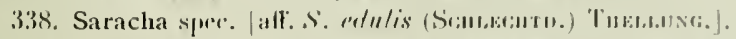

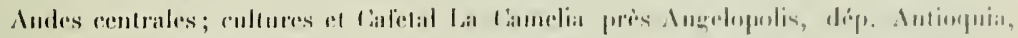

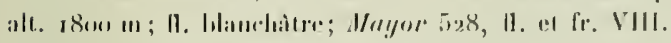

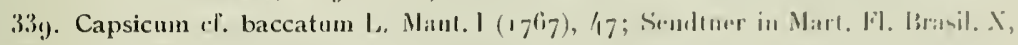

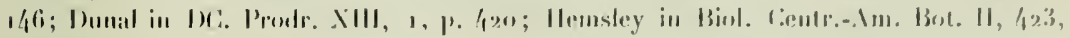
IV, $111 \%$.

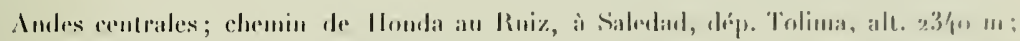

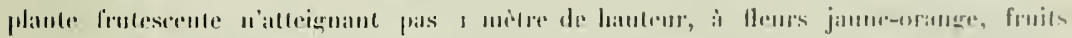

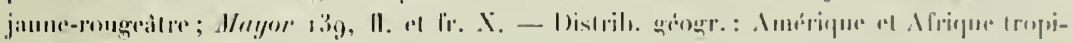
cilles.

340. Capsicum (?) spec.

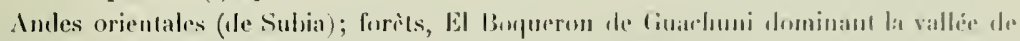
Viota, dêp. Cundinamarca, alı. 2/.5o m; Ilours brunes; Mayor 8, 4, 11. X.

3/11. Brachistus atl. hebephyllus Mens in AmI. and Mag. of Nat. Ilist, new sor. :3, III (1849), 266; 1. DC. Prodr. .111, 1, p. 688.

Nostra planta liffert floribus penlaneris.

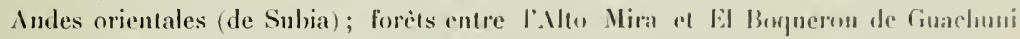
dominant la vallée de Viota, dép. Cundiuamarca, alı. environ $2400 \mathrm{~m}$; Solanée arloréscrute, pouvant dépasser $5 \mathrm{~m}$ te hauleur, à lleurs blanchìtre-violacé; 1/ayor 27, II. el fr. X. - Distrib. géorrr. (B. hebephyllus) : Colombie.

342. Solanum hirtum Vsur. Symb. II (1791), 40 et Ic. pl. Amer. Dec. III, 1. 21 ;

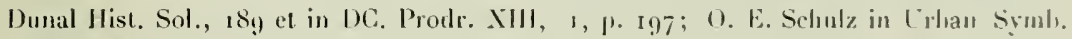
Antill. IV, 2, 1. 217 .

S. flavescens Dunat in Poiret Encycl. Suppl. III (1813), $77^{8}$ el in DC. Prodr. .111, 1, p. 254 .

Plaine du Magdalena, Beltran (au lord du flenve) dans les paiturages arides, dép. Tolima, alt. 260 m; Solanće frutescente, épincuse, à Il. lilas-violet: Mayjor fi, fl, el fr. X. - Distrib. géogr. Antilles. Vénézuéla.

343. Solanum lepidotum H. B. K. Nor. gen. et spec. III (1818), 30; Dunal in DC. Prodr. XIII, I, p. 131 .

Andes centrales; lisières de hois aux environs du Cafetal La Camelia près Ingelopolis, dép. Antioquia, alı. isoo m; arbrisseau de $1-2$ m de haul i fleurs lulanches: Ifuyor 401, 11. VIII. - Distrils. grogrr.: Colombie. 
344. Solanum alf. ovalifolium Huxn. E.r Boxp. ex Dunal Solan. Syn. ( 1816$), 37$ a in DC. Proilr. XIII, I, p. 269.

Andes orientales; chemin de Honda ì Bogota, entre Villeta et Agua Largá, dép. Cumdinamarcal, alt. $1300-1600 \mathrm{~m}$; plante arborescente, dépassant $2 \mathrm{~m}$ de hauteur, à 11. violelles; Mayor 55, 11. ef fr. X. - Distrib. géogr. : Brésil.

345. Solanum torvum Sw. Prodr. veg. Ind. ace. (1788), 47; Dumal llist. Sol., 20.3 ef in DC. Prodr. XIII, 1, p. 260 ; Griseh. Fl. Brit. W.-lnd. Isl., 441; O. E. Sichulz in Unban Symb. Antill. IT, 2, p. 233.

S. indicum L. Spec. pl. (1753), 177 ex p.

S. torvum el sinuatolobatum O. Kuntze Revis. gen. pl. II (1891), 45..

Antilles: Ilaïti. Cayes; plante de 1 in de hauteur, ì lleurs blanches; Mayor 22 g, 11. ef lr. VII. - Distrih. géogr.: Amérique, Afrique et Asie tropicales.

346. Species alfines Solano torvo Sw.

Andes centrales, dép. Antioquia, commun partout entre 1100 et $1700 \mathrm{~m}$; fleurs hanches, plante épineuse pouvant dépasser $2 \mathrm{~m}$ de hauteur; Mayor 520. 11. el fr. VIII, IX. Le long du Cauca à Puerto de los Pobres, Paso de Concordia, dép. Antioquia, alt. $720 \mathrm{~m}$; plante épineuse, dépassant 1 in de hauteur, à fleurs blauches; Mayor $530^{a}$, II. IX.

347 . Solanum spec.

Pied des Andes orientales; entre le Cafetal Buenavista et Viota, dép. Cundiuamarca, alt. environ $800 \mathrm{~m}$; plante dépassant $2 \mathrm{~m}$ de hauteur, fleurs violettes; Mayor 150 , H. X.

348. Browallia americana L. Spec. pl. $(1753), 63$ г.

B. demissa L. Syst. ed. 10, II (1759), 1118; Bot. Mag. 1. 1136!; Bentham in DC. Prodr. X, 197 .

B. elata L. I. c. (1759), I 18 ; Bot. Mag. t. 34 !

Indes centrales; cultures, Cafetal La Camelia près Angelopolis, dép. Antioquia, alt. $1800 \mathrm{~m}$; fleurs violettes; Mayor 549, II. et fr. VIII. - Distril. géogr. : Amérique centrale et Amérique du Sud. Antilles.

349. Browallia speciosa Ноокеr Bot. Mag. LXXII (1847), 1. 4339 !

Forèts, le long du Cauca à Puerto de los Pobres, Paso de Concordia, dép. Antioquia alt. $720 \mathrm{~m}$; fleurs violettes; Mayor 548, H. et fr. IX. - Andes centrales; cultures, Cafetal La Camelia près Angelopolis, dép. Antioquia, alt. $1800 \mathrm{~m}$; Maym 549a fl. et fr. VIII. - Distrib. ģéogr. : Colombie.

\section{Scrophulariaceae.}

350. Calceolaria perfoliata L. F. Suppl. ( 1781 ), 66: Bentlı. in DC. Prodr. X, 211; Kränzlin in Engler's Pfl, reich 28. Ileft. (IV, $257 \mathrm{C})$, Scroph.-Anlirsh.-Calceol., 57.

Andes centrales; Paramos du Ruiz, dép. Antioquia, à partir de $3000 \mathrm{~m}$; Calcéolaire ¿̀ lleurs jaunes, urimpant en s'appuyant sur les plantes voisines el pouvant alor's atteindre 


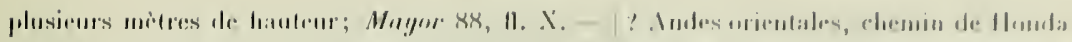

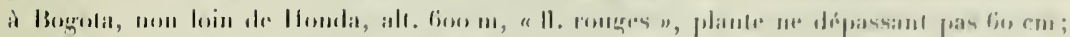

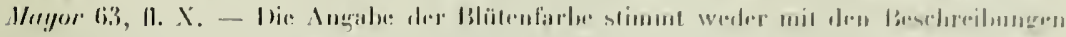

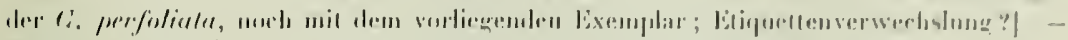

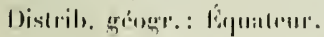

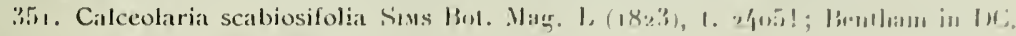

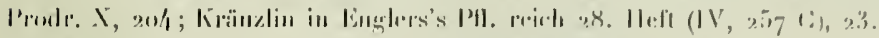

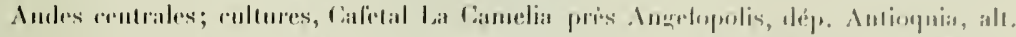

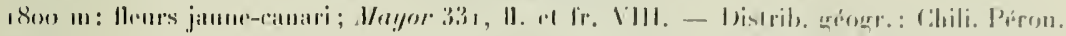
Equaleur.

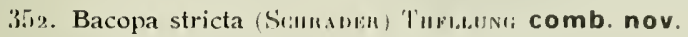

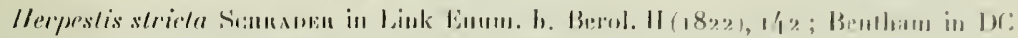

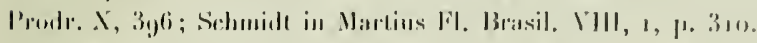

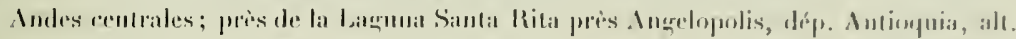

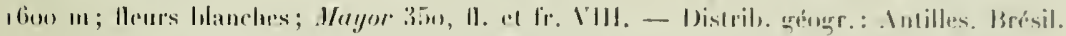

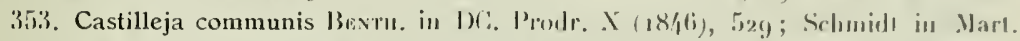

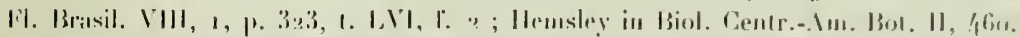

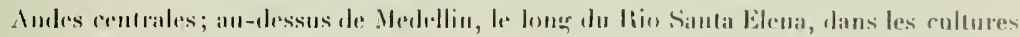

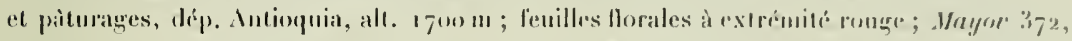

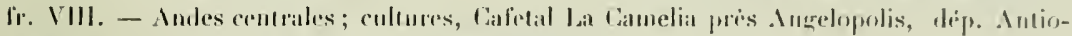

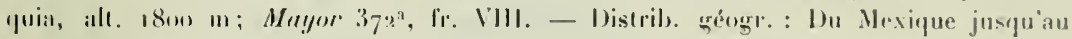
Pirmu in liuguay.

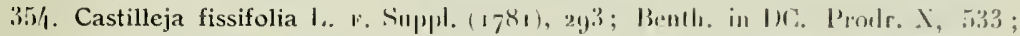
Hermsley in Biol. Lentr.-Am. B3ol. H, 4lio.

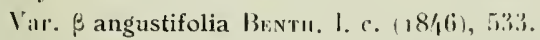

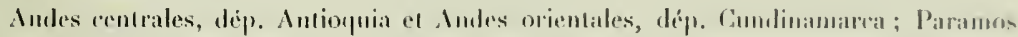

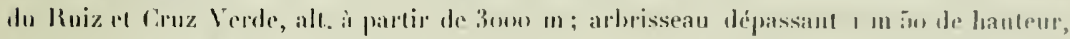

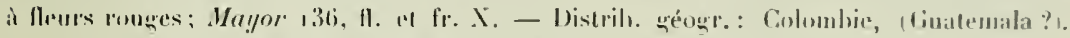

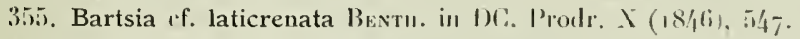

Andes contrales; Paramos du liniz, dipr. Antimpuia, dans les palurares. alt. 3.mo-

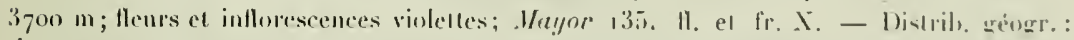
Eifualeur.

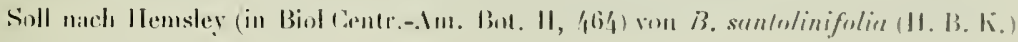
Brantu. niclut verselieden seill.

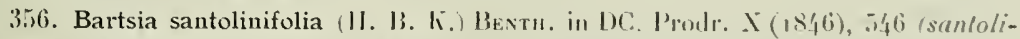
naefolia): Hemstey in Biol. Cantr.-.1m. 13ot. 11. 464.

Euphrasia santolina folia II. B. K. Xux. gen. el spec. 11 (181,) 333, 1. 166!

Ambes orientales; Paramo Cluz Verde au-elessus de Bogrotil, dep. Cumdinamarea, alı. $3000-3500 \mathrm{~m}$; Heurs el infleresecnees violettes: Brtyor 32. fl. el fr. A. - Distrib. griogr. : Région sud du Mexique, Colombie justu ia Pérnu. 


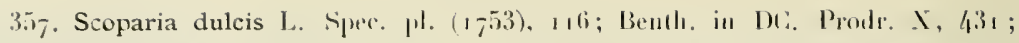
J.-1. Schmidt in Mart. FI. Brasil. VIII, 1, 264; Rol. E. Fries Syst. Uelners. Scoparia in

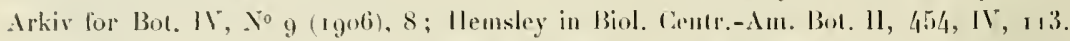

Environs de Barranquilla, dép. Bulivar; Nayor 227 , fl. el fr. Vll. - Distrib. géogr. : Régions tropicales des deux hémisphìres, probablement indigène sentement en Amérique.

\section{Bignoniaceae.}

358. Tecoma triphylla (L.) Mant. ex DC. Prodr. IX (1845), 215 in syu. ad Talebuiam triphyllam.

Bignonia triphylla L. Sprec. pl. ed. 2, II (1 763$)$, 870 (?); Niller Gard. Dict. ed. 8 ( 768$)$, n. $14(?)$; Sprengel Syst. II (1825), 832 teste A. Pyr. DC. I. c.

Tabebuia triphylla A. Pук. DC. Prodr. IX (1845), 214; O. Kuntze Revis. gen. pl. I (1891), 480 .

Tecona (9) Berterii A. Prr. DC. I. c. (1845), 220 ; Grisel. Fl. Brit. W.-Ind. Isl., 220 ; K. Schumann in Engler-l'rantl Natürl. Pll. fam. IV, 3, 238.

Antilles: San Thomas; arbuste de $2-3 \mathrm{~m}$ de lauteur; llenrs lilas-pâle; Mayor 200 , 1l. VII. - Distrib. géogr. : Antilles.

\section{Marlyniaceae.}

35g. Martynia annua L. Spec. pl. (1753), 6ı 8.

Marlynia diandra Gloxin Olss. (1785), 14, t. 1; DC. Prodr. 1X, 253.

Antilles: Haïti, Cayes; bords des chemins; Mayor 259, fr. 17. V11. - Distrib. géogr.: Probablement indigène au Mexique et répandu de là dans diverses parties des régions tropicales des deux hémisplères (Stapl' in Engl. n. Prantl Natürl. Pllanzenfam. N, $3^{\text {b }}$, p. 269 ).

\section{Gesneraceae.}

360. Kohleria spicata (11. B. K.) Oenst. in Vidensk. Selsk. Skr. V, 5 (1858), 101 ;

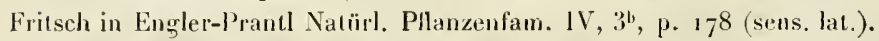

Gesneria spicata H. B. K. Nov. gen. el spec. II (1817), 393, 1. 188 ; DC. Prodr. Vill, 531 .

Isoloma spicatum Decarsve in Rev. Hortic. ser. 3, Il (1848), 465; Hemsley in Biol. Centr.-Am. Bot. 11, 479.

Andes centrales : lisières de forêts anx environs du Cafetal La Camelia près Angelopolis, dép. Antioquia, alı. I800 m.; plante dépassant I $\mathrm{m}$ de haul, à fleurs ronges; Yayor 356, 11. et fr. VIII. - Distrib. géugr.: Andes, du Mexique à l'Équateur. 


\section{Lentibulariaceae.}

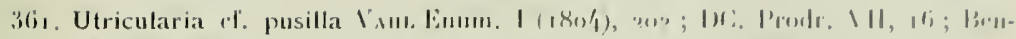
jamin in Matr. N1. Mrasil. $x$,

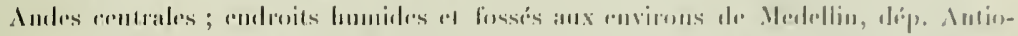

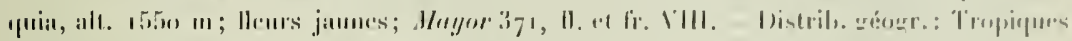

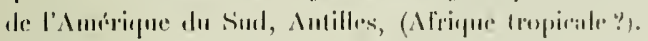

\section{Acanthaceae.}

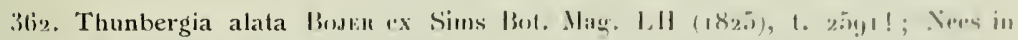

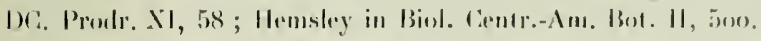

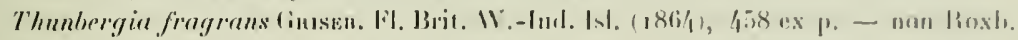

Antilles: Iläili, Cayes. - Inmä̈que, limgston.

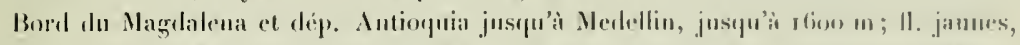

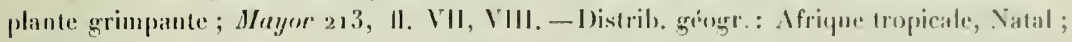
introduit dans les régions chandes des deux liemispluires.

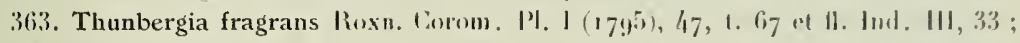
Bot. Marg. 1. 1881!; Ners in 104. Prode. 11, 57; Griseh. lil. Brit. W.-Ind. Is1., 458 ex p.; Burkill in Thiselton-1)yer H. Trop. Afr. Y, 20.

De synonymis vide Burkill I. c. p. 2n.

Antilles: Jamaïque, K̈̈nsston; plante grimpante à lleurs hlanches; Mayor 30 , f. et fr. V11. - Distrib. géogr.: Rrigions tropgicales des deux himispheres : prubahlement indigène en Indo-Malaisie.

364. Blechum Brownei Juss. in Anu. Mus. Jar IX (1807), 270 ; Griseh. Fl. Brit. W.-Int. Is1., 45:3; Hemsley in Biol. Centr.--1m. Bot. II, 5o8, 1V, 106.

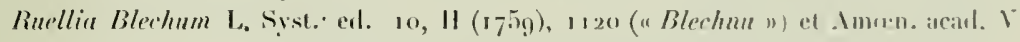
( 1760$)$, for (" P'ug. damaic. Plant., 17.jg)").

Antilles: San Thomas; Nh!yor 246, fr. VII. - Martinique: liort de France : fleurs litas-violet; Mayor ı, Al. Xl.

Andes centrales; cultures et hord des demins aux environs de Medellin. dép.

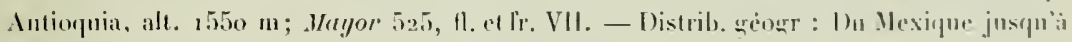
l'É

365. Ruellia spec.

Sect. V. Physirnellia Lindau \& Eglundulosne Lindau in Engler-Prantl Natürl. Plan-

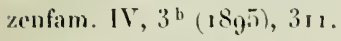

Andes orientales; chemin de ILonda a Boguta, press de Villeda, díp. Cumbinamarca,

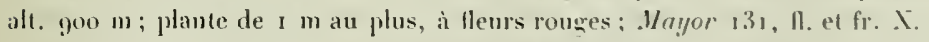

366. Barleria lupulina Lixuley Bot. Rer. . 11111 (18321, 1. 1483! 
: B. monostachya Bosen in Hooker Journ. of Bot. I (1834), 356 .

Antilles: San Tlomas: plante pouvant dépasser $1 \mathrm{~m}$ de hauteur ; Mayor 2y4, fr. Vll. - Distrib. géogr.: Madagascar, Maurice (cultivé); acelimaté el introduit anx Antilles (Sin Thomas).

36-. Andrographis paniculata (Bunм. F.) NeEs in Wallich P. As. rar. II) (1832), 116 et in 1)C. Prodr. NI, 515; Griseh. Fl. Brit. W.-Ind. Isl., 458.

Justicia paniculata Buкм. ғ. Fl. Ind. $(1 ; 68), 9$.

Jamaigue: Kingston; lleurs ponctuées de violel; Mayor 222, 1l. et fr. Vll. - 1)istril). géogr. : Indes, Ceylan, Java; introduit aux Antilles (Jamaïque, Saint-Vincent, Culıa).

368. Justicia of. secunda VAHL Symb. lrot. Il (1791), 7 et Enum. 1, r33; Bot. Magg. 1. 2060 !

Rhytiglossa secunda NeEs in DC. Prodr. XI (1847), 340.

Dianthera secunda Gisısen. in Gül. Abh. Vtll (r857), 246 et Fl. Brit. W.-lud. Isl., 455 ; Hensley in Biol. Centr.-Am. Bot. II, 5rg. - Distrib. géogr. : Antilles, Panama et Guyane jusqu'en Colombie.

Cf. var. intermedia (Nees I. c. [1847, 340 sub Rhytiglossa) Thellung.

Andes centrales; le long d'un ruisseau, entre Filadelfia el Neira, près Manizales, dép. Intioquia, alt. r260 $\mathrm{m}$; à fleur's violettes; Mayor 98 , 13. X. - Distrib. géogr. : Surinam (d'après Nees l. c.).

Iayor $\mathrm{N}^{0} 9^{8}$ unterseheidet sich vom Typus der $J$. secunda nicht nur, wie die Var. intermedia, durch pfriemlich-borstliche kelchzipfel und am Grunde lang allmählich verschmälerte, elliptisch-lanzettliche Laubblätter, sondern auch durch beträchtlich kleinere (20-25 mın lange) Blïten; ob besondere Varietät?

\section{Plantaginaceae.}

369. Plantago tomentosa LaM. I1I. I ( 791 1), 340; Barnéoud Monogr. Plantag., 14; Decaisne in DC. Prouls. XIII, I, p. 725 ; Schunidt in Mart. Fl. Brasil. V1, 4, 1) 172.

Var. glabrescens Schlechtd. ex Sclımidt l. c. $(1878), 172$.

Commun dans les cultures des Andes centrales, dép. Antioquia, jusqu'à $2000 \mathrm{~m}$ d'altitude; Mayjor 574, ll. et lr. V111, IX. - Distrib. géogr. (P. tomentosa): Brésil, Uruguay (etc. ?).

\section{Rubiaceae.}

370. Manettia calycosa Guser. Fl. Brit. W.-Ind. Isl. (1864), 330; K. Scluum. in Mart. FI. Brasil. VI, 6 (1888), 175.

Andes ceutrales; forèts et taillis près du Cafetal La Camelia près Angelupolis, dép. Antioquia, alt. $1800 \mathrm{~m}$; plante grimpante à fleurs rouges; Mayor 355, fl. et fr. 31. Vıll. - Distrib. géogr.: Vénézuela, Antilles (Saint-Domingue). 


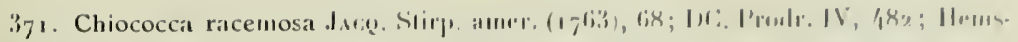

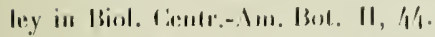

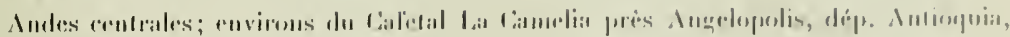

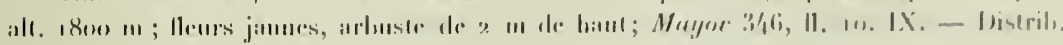

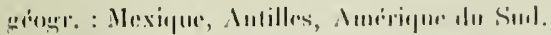

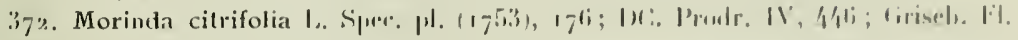
Bril. WV.-Imel. Isl., 3/17.

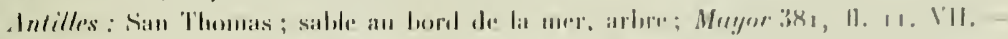

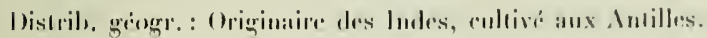

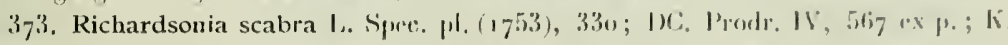

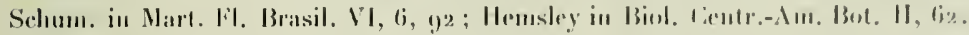

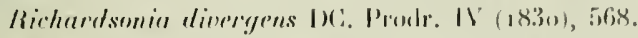

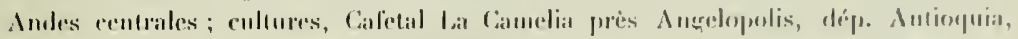

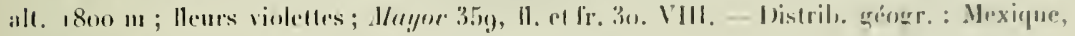
Anérique rentrale, Norrl-Ouest de l’Iméripue du Sul, Antilles.

374. Hemidiodia ocimifolia (Wu, 29 , 1. 73.

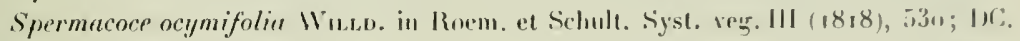
Pruels. IT, 556.

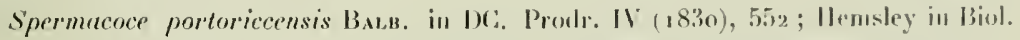
Centr.-Am. Bot. II, tio.

Spermacoce coeruler Pous in I)C. I. c. (1830), 5is.

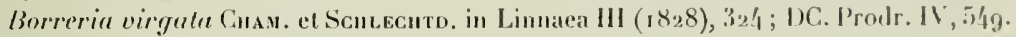

Borreria aspernla DC. I. c. (1830), 5/3.

Spermacoce virgala Henseey in Biol. Centr.-1m. II $(1881-1882)$, 61.

Andes centrales ; hord de hairs et taillis, pres de Graca, dép. Intionuira, alt. 1480 m;

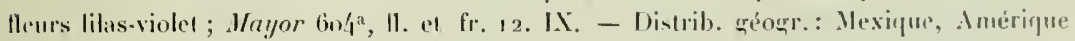
centrale et Amerique du sud, Antilles.

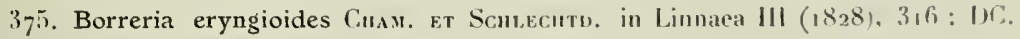
Prodr. IT, 546 ; K. Schum. in Fl. Brasil. II, 6, 47, tah. 74, f. 1.

Borreria diffusa DC. Prodr. II (1836), 544.

Andes centrales; commun dans les cultures: Medellin, Cafetal La Camelia, près Argelopolis, dép. Antioquia; Soledad, dép. Tolima, elc., att. $15.0-2.30 n$ m : Anurs lifenes. plante rampante stolonifère; Mayor 542, 11. et fr. IIII, IX et X. - Distrib. géogr. : Amrrique du Sud.

376. Borreria laevis (Lam.) Grsser. FI. Bril. W.-Ind. Isl. (1864), 349; Dr. Prodr. IN, 5.56 ; K. Schum. in Marl. Fl. Brasil. 17, 6, 43.

Spermacoce laevis Lam. III. gen. I ( 791$), 273$; DC. Prodr. 1V. 556 , Hemsley in Biol. Centr.-Am. Bot. 11, 5q.

Borreria (?) linifolia DC. Prodr. 11 (1830), $5 \overline{1}$. 
B. eapilellala Cham. et Schlechtn, in Linnaea III (1828), 319); DC. I. c., 545.

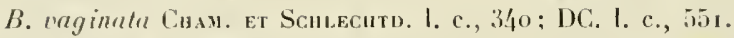

B. tampicana DC. I. c., 544 exp.

B. spluarica DC. I. c., 547 ?

Spermacoce assurgens Rutz et Par. FI. Per. I ( 1798 ), 60; 1)C. I. c, 5.57 ex P.

Spermacore tennior Ноok. in Beech. Voy. (1841), tal, 99; Hensley in Biol. Centr.Im. Bol. II, 60 - non L.

Antilles: lläti, Cayes, près de lit mer; Heurs blanchess Mayor 305, 11. 17. VIl ; Mrryor 218 , fr. 14. 111. - Jamä̈que, Kingston, Hope Gardens.

Bord du Magdalena à Puerto Wilches, dép. Santander, alt. ı $30 \mathrm{~m}$; lleurs blanchìtres; Mayor 267. 11. 29. VIl.; répandu partout daus les Andes centrales et orientales, dép. Intioquia, Tolima et Cundinamarca, depuis le bord du Magdalena jusquı̀ à $2000 \mathrm{~m}$; hleurs violettes; Mayor 6o.3, 1I. VIII, IX et X. - Distril,. géogr.: Régions chandes de l'Amérique. Antilles.

377. Borreria tenella (H. B. K.) Chaм. ет Sichlechto. in Linnaea III (1828), 3 r 7 ; DC Prodr. IV, 547; K. Sclum, in Mart. Fl. Brasil. VI, 6, 55.

Spermacoce tenella 1I. B. K. Nov. gen. et spec. III (18,8), 345.

Borreria suaveolens G. W. W. Mex. Prim. F. Esseg. (1818), 81. Lab. 1; DC. Prodr. IV, 546 .

B. salurejifolia Chan. et Sculecutd. in Linnaea, I. c. 3 г 3 ; DC. Prodr. IV, 546.

B. rubro-stipulala DC. Prodr. IV ( 830$), 546$.

B. strictissima DC. I. c., 547 .

$\dot{B}$. linoides DC. I. c., 548 .

B. Inlescens DC. 1. c., 547.

Spermacoce psyllioides H. B. K. Nov. gen. et spec. III (1818), 346 tab. 278 ; Hemsley in Biol. Centr.-Am. Bot. II, 6o.

B.? psyllioides DC. 1. ¿., 548 ?

B. Haenlieana DC. I. $6 ., 547$ ?

Borreria procera Sculecutd, in Linnaea IX (1835), 593.

Spermacoce Itrentieana II musqey in Biol. Centr.-Am. Bot. If (1881-1882), 59 .

Spermacoce procera Hensuey in Biol. Centr.-An. Bot. II (1881-82), 68.

Borreria verticillata G. F. W. MEY. Prim. Fl. Esseq. (1818), 83; DC. J. c., 54 I.

Spermacoce nerticillata Hemsey in Biol. Centr.-Ain. Bot. Il (188 I-82), 60 ex p.

Audes centrales; forèts, Alto Don Elias près Ingelopolis, dép. Antioquia, alt. $2000 \mathrm{~m}$; Mayor 604, fl. J. IX; lleurs lilas-violet, jante pouvant dépasser i m. - Au-rlessus de Vedellin, cultures et pâturages le long do Rio Santa Elena, dép. Antioquia, alt. I 800 m; Matyor 374, 11. 6. VIJ. - Distrib. gqéogrr.: Mexique. Amérique centrale et Amérique du Sud.

378. Relbunium hypocarpium (L.) Hemsıey in Biol. Centr.-Am. Bot. II (1881-1882), 63; K. Schum. in Mlart. Fl. Brasil. VI, 6, 112. 


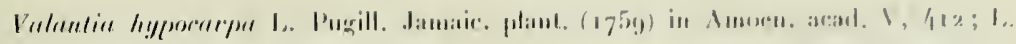

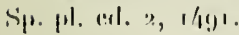

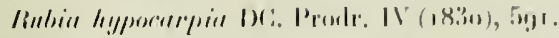

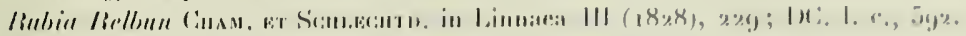

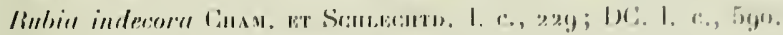

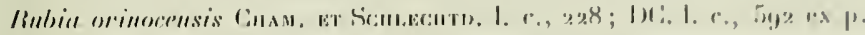

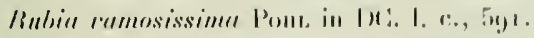

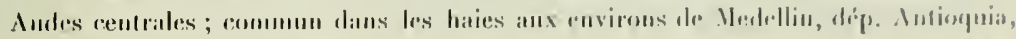

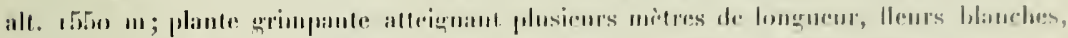

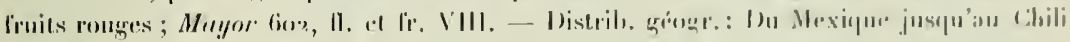
et Argentine.

\section{Cucurbitaceae.}

379. ? Gurania spec.

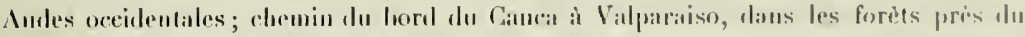

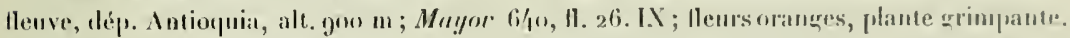

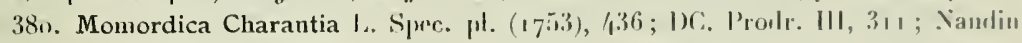

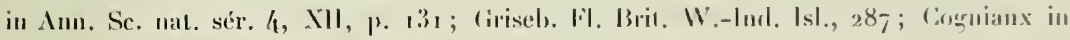
DC. Mon. Plan. HI, 4.36.

Antilles: Ilaïti, Cayes; plante grimpante, à lleurs jaune-verdatte, fruits rouge-

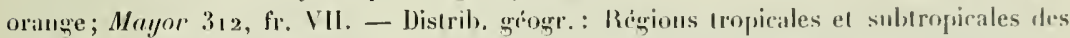
deux hímispheres, probablement seulement introduit en Anérijur.

\section{Campanulaceae.}

38. Centropogon surinamensis (L.) Prest P'roltr. Monogr. Lohel. (1836), 48 n. 1: DC. Prodr. VII, 2 p. 345; Hemsley in Biol. Centr.-.Im. Bot. 11, 264; Kanitz in Мart. Fl. Brasil. VI, 4, 134 et 1. XXXIX!

Labelia surinamensis L. Spec. pl. ed. 2, II (1 -633), 1.320.

Ancles centrales; cultures, Cafetal La Camelia, près Insetopolis, díp. Intioquiat, alt. $1800 \mathrm{~m}$; lleurs rouges; Mayor 8:3, 11. IX. - Distrib. géogr.: I'anama, tropiques de l'Amérigue du Sud, Antilles.

382. Siphocampylus ef, glandulosus I Іоокеr Bol. Mag. LXIII (1847, 1.4331!: Fl. des Serres IV (1843), 1. 401 ! (Planta Mayoriana differt foliis hasi vix corilatis et antheris distinctius exsertis.)

Andes centrales; forèts el lisières de lorèts aux environs du Cafolitl La Camelia prís

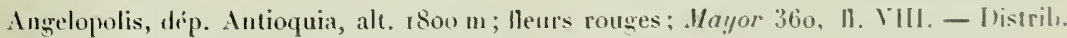
gुéogr. : Colombie (Bogota). 


\section{$-416-$}

383. Siphocampylus of. Mutisianus (II. B. Ki.) G. Dox Gen. Syst. 111 (1834), 703 ; DC. Prodr. VII, 2, P. 402.

Lobelin Mutisiuna II. B. K. Nov. gen. et spec. III ( 18 I8), 308.

Indes centrales; cultures, Cafetal La Camelia près Angelopolis, dép. Antioquia, alt. 1 Sou $\mathrm{m}$; plante pouvaut dépasser $1 \mathrm{~m}$ de hauteur; fleurs verditres extérieurement et Wlanches intérieurement; Mayor 333, 11. VIII. - Distrib. géogr.: Colombie.

384. Lobelia xalapensis H. B. K. Nov. gene et spec. 111 (1818), 315; DC. Prodr. VII, 2, 372; Kanitz in Mart. Fl. Brasil. VI, 4, 139 .

?. L. monticole H. B. K. I. c. $(1818), 316$; DC. I. c., 373 .

L. Cliffortiana Griseb. Fl. Brit. W.-lnd. Isl. (1864), 385 ex p.; IIensere in Biol. Centr.-Am. Bot Il (188I-1882), 266 saltem ex maxima p. - non L.

Andes centrales; cultures, Caletal La Camelia près Anggelopolis, dép. Antioquia, alt. $1800 \mathrm{~m}$; lleurs violetles; Mayor 556, H. et fr. VIII. - Distrib. géogr.: Amérique centrale et tropiques de l'Amérique du Sud, Antilles.

385. Lysipomia muscoides Ноок. in Hook. Lond. Journ. Bot. V1 (1847), 286, t. 9 A!

Var. (?) sepalis minus oltusis, antheris apice et lobis corollae glabris.

Andes centrales; Paramo Cruz Verde au-dessus de Bogota, dép. Cundinanarca, alt. $3000-3500 \mathrm{~m}$; lleurs lilas pàle; Mayor 36, ll. et fr. X. - Distrib. géogrr. : Colombie.

\section{Compositae.}

386. Pacourina edulis Aublet Hist. pl. Guian. II (1775), 800, tab. 316 ; DC. Prodr. V, 14; Baker in Mart. Fl. Brasil. V1, 2, 9 .

Environs de Barranquilla, dép. Bolivar, dans les fossés et endroits marécagenx; plante dépassant I $m$ 5o de liauteur, à fleurs blanches; Mayor 262, fl. 21. VI. Distrib. géogr.: Amérique tropicale.

$\left.387 .{ }^{1}\right)$ Vernonia cinerea (L.) Less. in Linnaea $I V(1829), 291$ et VI (1831), 67.3; DC. Prodr. V, 24 ; Griseb. Fl. Brit. W.-Ind. Isl., 353.

Conyza cinerea L. Spec. pl. ( 753 ), 862.

Vernonia physalifolia (p. 24), abbreviata, leptophylla, Iaxiflora el conyzoides DC. Prodr. V. (1836), 25.

Antilles: Jamaïque, Kingston, Hope Gardens; Mayor 217 , tl. et fr. 14. VII. Distrib. géogr.: Indes. Afrique el Australie tropicales. damaïque.

388. Vernonia rubricaulis II. B. K. P. equinox. II (1809), 66, 1. 99 ; DC. Prodr. V, 46; Baker in Mart. Fl. Brasil. VI, 2, 79; Hensley in Biol. Centr.-Am. Bot. II, 73.

Andes occidentales; collines arides dominant le Cauca entre Supia et Filadeltia, dép. Cauca, alt. environ $1200 \mathrm{~m}$; Mayor 1 16, 1I. 30. IX. Fl. violet-lilas. - Distrib. géogr.: Colombie. Brésil.

1 Les espèces des genres Vernoni:ı, Eupatorium, Baccharis el Liabum ont èté déterminées par M. W. Heering. 


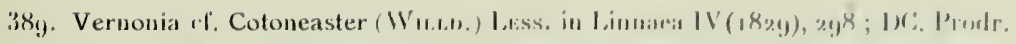
V, /7; Bakire in Miat. II. Brisil. VI, $2,80$.

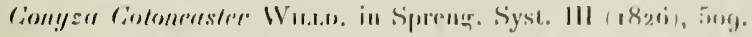

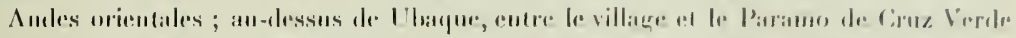

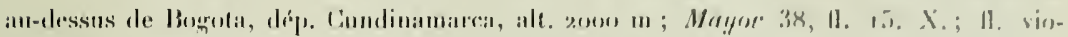

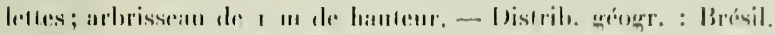

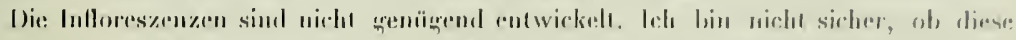

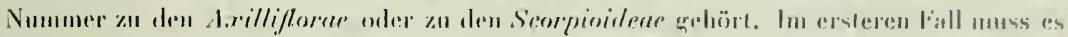

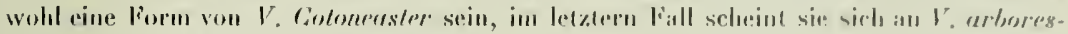
("pts: anzuschliessen.

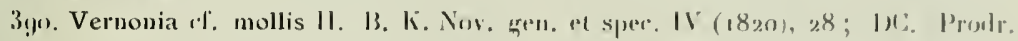
V, १1.

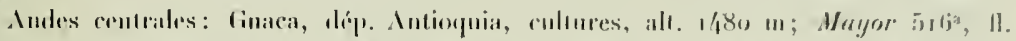

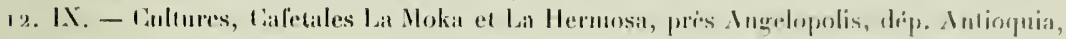

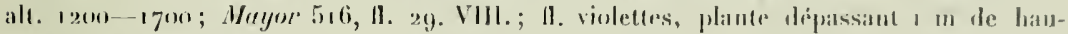
trut. - Distrib. géogre: : Colombie.

Durch die Bbattlorm und den anllälligr grossen rispigen Blätenstand erinuert die Pflanze

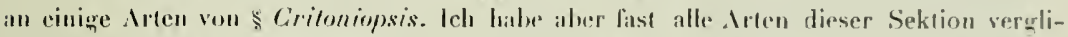
chen, olue tatsächliche Uebereinstimmung gefunden zu hahen. Sie muss daher wohl

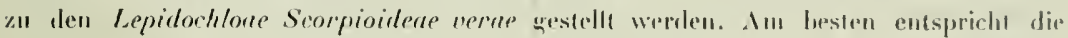
Beschreilung von 1. mollis H. B. K.

3y). Vernonia scabra P'ens. Syu. II (1807), 40, (ex deser.); 1):. Prodr. 1, 3y; Baker in Mart. Fl. Brasil. VI, 2, roo; Ilemsley is Biol. Centr.-Aul. Bot. 11, 74.

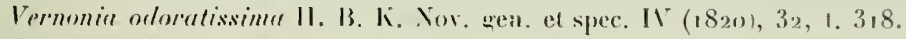

Paine du Magntalma, près de Mariquita, pratrie le long du chemin de fer, dép.

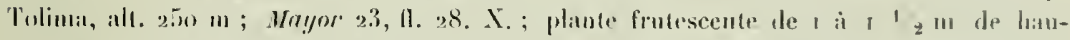
tenr, à llums biamehes. - Distrib. gíger. : Brésil, Sull du Mexique.

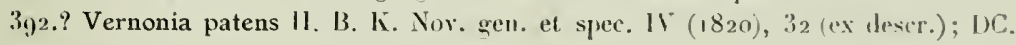
Prodr. $\mathrm{I}, 39$; Hemsley in Biol. Centr.-1m. Bol. 11, 73.

Andes centrales, occidertales et orientales, tép. Intinquia, Tulina el Cundinamarea,

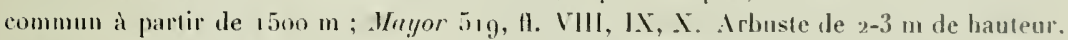
¿ li. blanches. - Distril), zqéogr. : Panama, Amérique du Sud.

Diese Pflanze is der $\mathrm{N}_{2} 3$ (Ternonia sculura Pens.) zwoifellos sehr nahe verwandl. Sie unterscheidet sich durch die Blatfform und die Bethartung. Bei No 23 sind die Blätter verkehrteifürmig, slmmpf, auf der Unterseite dicht kurzharig, bei jog sind die Blälter spitz, deutich gestielt und nur anf den Verven der Linterseite helaart.

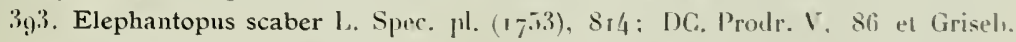

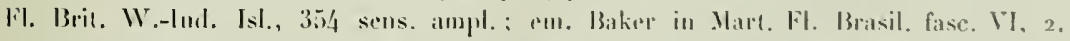

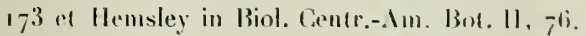

E. Lomentosus L. I. e. $(1753), 814$. 
E. caroliniamus Willo. Spec. pl. III, 3 ( $180 / 4)$, 3390 ; DC. Prodr. I. c., 86; Griseb. 1. c., 355 in textu.

E. mollis II. B. K. Nor. gen. et sprec. 11 (1820), 26; DC. I. c.; Griseb. Fl. Brit. 11.-Ind. Isl., 355.

E. Marlii Guana in Elinh. New. Phil. Journ. 1830, p. 2; 1)C. I. e.

Andes centrates, oceidentales el orientales, thép. Antioquia, Canca el Cundinamarea; assez commun entre 1200 a 1 goom; lleurs libs-pale; Mayor 526, fr. IX-X. - Distrib. géogr.: Régions trupieales des deux hémisphères.

Jlayor's P'lanze seheint am besten mit der Diagnose des von West-Indien und Mexiko bis Pern und Brasilien verbreiteten E. mollis H. R. K. äbercinzustimmen.

394. Ageratum conyzoides L. Spec. pl. (1753), 839; DC. Prodr. V, 108 ; Baker in Mart. FI. Brasil. VI, 2, rg4 ; Hemsley in Biol. Centr.-Am. Bol. II, 8r.

Andes éntrales; chemin de Medellin à Bello, dép. Antioquia, alt. s5.ho m; lieurs violettes, plantes défrissaut I m de haut; Mayor 567, lt. 4. V11. - Commun aux environs de Medellin, dép. Antioquia, alt. $1550 \mathrm{~m}$; lleurs lilas trìs paile, presque blanches, plante ne dipassant pas 1 in de hautenr; Maygor 566, 11. el fr. YIII. - Disltils. grogrr.: Dans toutes les régions tmpicales.

Var. inaequipaleaceum HIEHox. iu Engl. Bol. Jahrlı. XIX (1895), 14.

Andes orientales; praries au hord de la Laguna Pedropalo, près de Tena, dép. Cundinamarea, alt. 2000 $\mathrm{m}$; Heurs violelles; Mayor 69, II. 18. X. - Distrib. géngr. : Colombie.

395. Mikania scandens (L.) Wrus. Spec. pl. I11,3 (1804), 1743; DC. Prorls. V, 199 ; Hemsley in Biol. Centr.-Am. Bot. II, $10 /$; Baker in Mart. Fl. Brasil. V1, 2, 248.

Eupatorium scandens L. Spec. pl. (1753), 836.

Andes eentrales; elremin de Cisneros à Medellin, près dı Poree, dép. Antioquia, alt. $1300 \mathrm{~m}$; lleurs blanches, plante grimpante en s'appuyant sur celles dn voisinage ; Mryor 252, fl. (nondum expansi) VII. - Près dn Poree an pied de la Cordillère de lia Quiebra, chemin de Cisneros à Metellin, dép. Antioquia, alt. $1300 \mathrm{~m}$; Mayor 6.37 , 11. VIII. - Haies et taillis près de El Pollado sur Medellin, dép. Antioquia, alt. 1700 m ; Iayor 636, 11. 84. V111. - Chemin de Medellin à Bello, dép. Antioquia, alt. 1550 m; Mayor 635, fr. VIII. - Distril, grogr. : Régions chaudes des deux hémisphères.

396. Eupatorium ballotifolium H. B. K. Nor. gen. el spee. IV (1820), I21; DC. Prodr. V, r53; Baker in Mart. FI. Brasil. VI, 3, 360.

Conoclinium prasiifolium DC. Prodr. V (1836), 135.

Andes centrales; cultures; Yarumito, ehemin de Cisneros ì Medellin, dép. Antioquia, alt. $1340 \mathrm{~m}$; Mutyor 569 , II. I. VIIl. - Distrib. géogrt. : Brésil.

397. Eupatorium guadalupense Spreng. Syst. III (1826), 414; DC. Prodr. V, 170 ; Baker in Mart. Fl. Brasil. VI, 2, 307.

Eupatorium panicalatum Schnaden ind. sem. Hort. Golting (183\%), 3 ; Hemsley in Biol. Centr.-Am. Bol. 11, gr. 


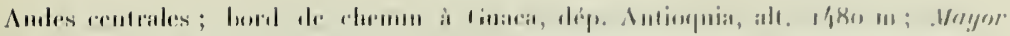

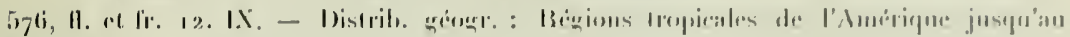
Mexipue. Antilles.

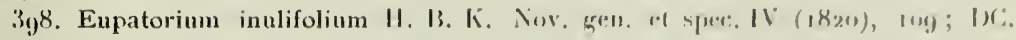
Prorle. V, infi.

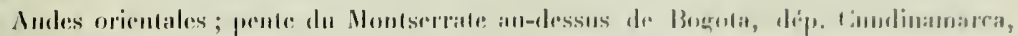

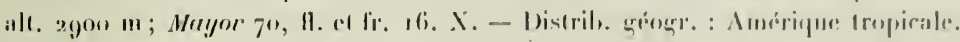

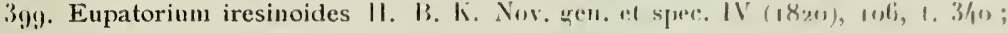

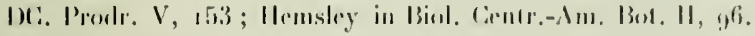

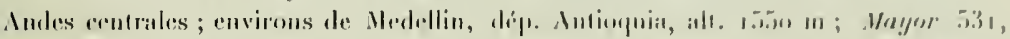

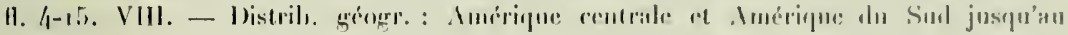
l'éron.

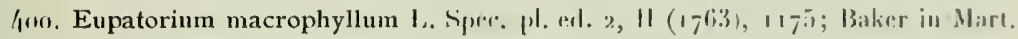

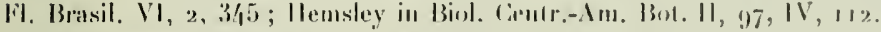

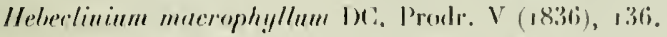

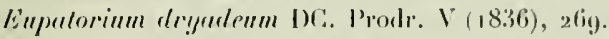

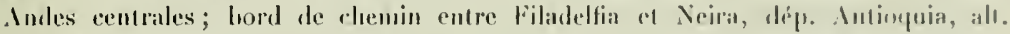

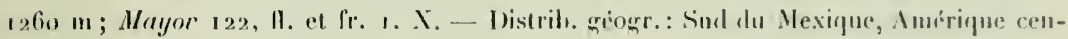
lrale, mopiques de l'Amérique du Suml, Antilles.

401. Eupatorium microphyllum 1. F. Suppl. (1781), 335.)

Conoclinium microphlyllum DC. Prodle. V (1836), 135.

Audes orientales; pente du Montserrate ed Paramo Crouz Vierle, an-ilessus de Bogrota, dép. Cundinannarca, alı. 2700-3500 m; Mayor 75, H. 1/, 15, 16. X. - Mistrilı, géogr.: Colombic.

402. Eupatorium pomaderrifolium 13ExT11. P'. Harlweg $(18399-1857), 199$.

Andes orientales; pente du Montserrate, au-dessuss de Bogota, dep. Cundinamarrat,

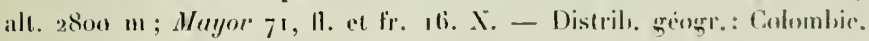

403. Eupatorium pycnocephalum Less. in Limata 17l (1831), 404; I)C. Prodr. I, 1,70; Hemsley in Biol. Centr.-Am. Bot. H, 99.

Audes orientales; an-dessus de Chaupe, coute le village ed le Paramo Cruz lede,

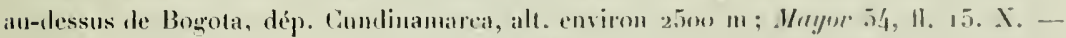
Distrih. géogre: Amérique du Nord, Sul du Mexique.

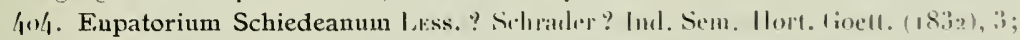

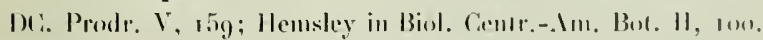

Andes centrales; colline dominant la rive anauche du Perce pres de Merdellin, dép.

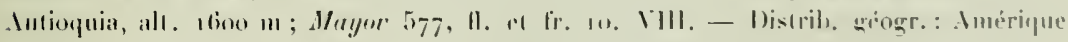
centrale jusiquiu Nord du Mexiqur.

405. Eupatorium stoechadifolium 1. r. Simpl. (1-81), 35i); I)C. Prodr. 17, 14?.

Andes orientales: pres de la chute du Tequendiama, dép. Comdinamarra, alt. 2201 m; Mayor 58, 11. et fr. 12. X. - Distrib. geogr. : Colombir. 
406. Eupatorium Vargasianum DC. Prodr. Y (1836), 155.

Andes centrales; colline au-dessus de Imerica près Medellin, dép. Intioguia, alt. $1700 \mathrm{~m}$; Nayor $39_{2}^{2}$, 1 . et fr. 15. V111. - Distrib. géogr.: Vénizuela.

407. Eupatoriun obscurifolium Hınos. in Engl. Bot. dahrb. XXIX (1900), 9.

Andes orientales; an-dessus de Cbaque, entre le village ef le Paramo Cruz Verde sur Bogota, dép. Cundinamarca, alt. environ $2500 \mathrm{~m}$; Mayor 53, H. 15. X. - Pente du Montserrate au-dessus de Bogota et Paramo Cruz Verde, $2700-3200 \mathrm{~m}$; Mayor 76 , 11. 14, 15. el 16. X. Fleurs blanches. - Distrib. géogr.: Équateur.

408. Eupatorium popayanense Hıkon, in Engl. Bot. Jahrl. XL (Igo8), 37.3.

Andes centrales; taillis au-dessus du Cafetal La Camelia, près Angelopolis, dép. Intioquia ; alt. environ $1600 \mathrm{~m}$; Mayor 64 $\mathrm{s}$, fl. 27 . VIII. - Arbuste de $2 \mathrm{~m}$ de bauteur à lleurs blanc-violacé.

409. Eupatorium tacotanum KLatt in Engl. Bot. Jahrb. VIII (1887), 35.

Andes centrales ; environs de Medellin, Guaca, etc., dép. Antioquia, alt. entre 1300 - $1700 \mathrm{~m}$; Mayor 533, H. VIll et IX. lileurs violettes; arbrisseau dépassant pen I m de hauteur. - Distrib. gréogr. : Colombie.

410. Eupatorium thyrsigerum Hiknon, in Engl. Bot. Jahrb. XXVIII (Igor), 570.

Andes centrales, orientales et occidentales, dép. Antioquia, Cauca, Tolima et Cundinamarca; commun entre 800 et $1600 \mathrm{~m}$; Mayor 582 , fl. VIII, IX, X. Plante à fleurs blen-violacé, ligneuse, formant de petits taillis de $2-3 \mathrm{~m}$ de hauteur. - Distrib. géogr.: Colombie.

411. Eupatorium tequendamense Hıeron. in Engl. Bot. Jahırb. XXIX (1900), 6.

Eupatorium pulchellum Klatt in Engl. Bot. Jahub. VIII (1887), 35 non H. B. K.

Andes orientales : taillis près de la Laguna Pedropalo non loin de Tena, dép. Cundinamarca, alt. $2000 \mathrm{~m}$; Mayor 14 I, 11. 18. X. Arhuste de 1-2 $\mathrm{m}$ de hauteur à fleurs violettes. - Distrib. géogr. : Colombie, Équateur (var.).

412. Eupatorium conyzoides VAuL Symb III (1794), 96; DC. Prodr. V, 143 ; Baker in Mart. Fl. Brasil. VI, 2, 277 ; Griseb. Fl. Brit. W.-Ind. Isl., 358.

Involucri squamae 32 , intimae ad $8 \mathrm{~mm}$ longae, $\mathrm{I} \mathrm{mm}$ latae, extimae $\mathbf{~}, 5 \mathrm{~mm}$ longae, $0,75 \mathrm{~mm}$ latae, trinervatae vel intimae interdum uninervatae, extimae ultra 3 nervos gerentes, omnes \pm acuminatae. Flores 32 . Achaenium 3,5-4 mm longum, nigrescens, costis quinque distincte scabridis instructum. Corolla 5 nm longa, pallide lilacina.

Diese form erinnert sehr an Eupatorium orloratum Vallu, die dieser Art ja auch selı nahe steht und vielfach mit ihr zusammen geworfen ist. Das echte E. odoratum. soll aber weisse Blöten haben. Bei beiden Arten, $E$. odoralum und E. conyzoides, ist in den typischen Formen die Blütenzahl geringer.

Andes centrales, orientales et occidentales, dép. Antioquia, Tolima et Cundinamarca; commun jusqu'à $2000 \mathrm{~m}$; Nayor 544, fl. VIII, IX, X. - Distrib. géogr. (du type): Antilles, Mexique, Amérique centrale. 


\subsection{Eupatorium columbianum Ifr.1แ1: nov spec.}

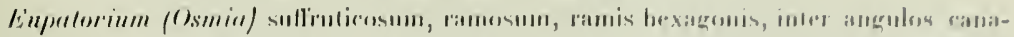

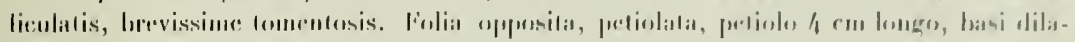

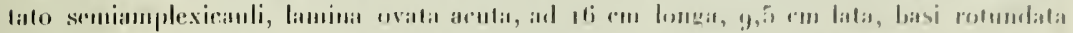

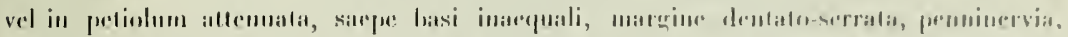

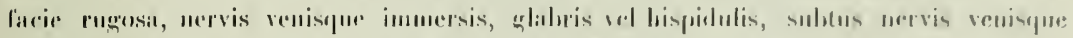

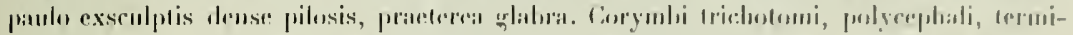

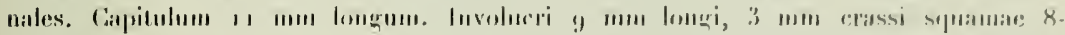

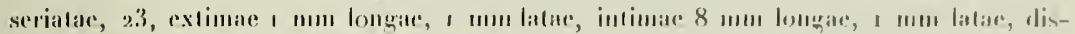

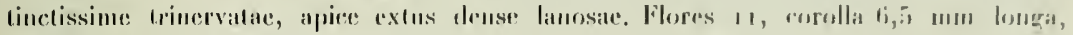
alliela-violacea, ardaenio :" mu longo instructi.

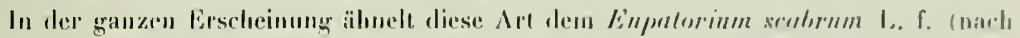

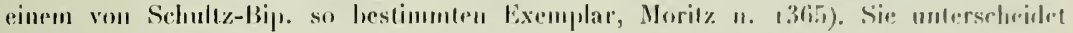

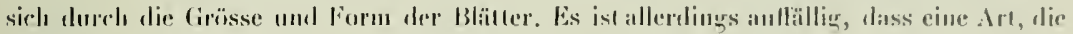

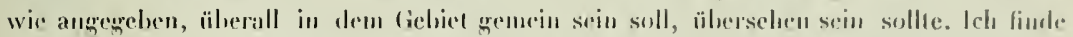
aber keine Art, die mit dieser Pllanz äbereinstimnt.

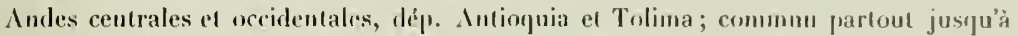
$20 n 0 \mathrm{~m}$; Mnyor 629, II. VIII, IX et X. lileurs blanches un pen violacées ; plante ligueuse à la base et pouvant dépasser $1 \mathrm{~m} .5$ w.

114. Eupatorium spec.

Tota planta glaberrima. Folia opposita, petiolatia, lanina ad $7 \mathrm{~cm}$ longa, $4 \mathrm{~cm}$ lata, basi paulo in petiolum atlenuata, apiec allusiuscula, margine serratu-crenata, triplinervia, venis primaris validioribus, afl tertium laminae conspicuis, demum flexunsis, pulcherrime reticulata.

Capitula 5 mm longa, $3,5 \mathrm{~mm}$ crassa. Involucri squamae 14, dense erlanduloso. punctatae, acutae, apice subciliatae. Flors 17, achaenium 1,5 $\mathrm{mm}$ longum costis verruculosis instructum.

Es passen melurere Diagnosen aniilhernd zu dieser Pflanze, es liisst sich aluer nicht mit Sicherheit entscheiden, wohin sie gehört.

Andes centrales; près de la Laguna au-dessus de Medellin, dép. Antioquia, alt. 2300 m ; Mayor 385, 11. 8. VIII. Arlirisseau de 1 m 5o, à fl. blanches.

415. Eupatorium spec.

Ramus tetragonus. Folia opposita, petiolata, ovata v. ovaln-ohlonga, hasi acula $v$. subcordata, margine crenato-serrata, peliolus subtomentosus, in foliis maximis $1-1,3 \mathrm{~cm}$ longus, lamina 6-8 cm longa, 3-5 cm lata, glabra membranacea. Capilula ihyrsoiden-paniculata. Involucri squamae 20 , pluriseriatae, ad $3 ., 5 \mathrm{~mm}$ longae, margine ciliatae, exteriores uni-, interiores trinervatae. Receptaculum paullo convexum. Flores 24 . Achacnium a mm longum, corolla $3 \mathrm{~mm}$ longa, styli rami suhclavati.

Diese Alt erimert sehr an Ophryosporns, die Intheren haben aher ein grosses lionnecliv, das ron rielen Adern durclizogen ist. 
Indes centrates; Soledal, sur le chemin Fresno, dẹp. Tolima, alt. $2340 \mathrm{~m}$; Mayor 104, 11. 6. X; plante de r m 50 de hauteur, il lleurs blanches.

41(i. Erigeron bonariensis 1. Spec. pl. (1753), 863 (bonariense); (irisch. Fl. Brit. Wr.-lud. Isl., 36i:; Hemsley in Biol. Centr.-An. Bot. II, 123.

Andes orientates (de Subia); Cafetal Argelia dans la valtee de Viota, dép. Cundinamarea, ah. $1880 \mathrm{~m} ; M$ ayor 2.5, fl. 25. X; lleurs htanches. - Distril, géogr. : Sud du Mexique, Antitles, Amérique centrale et Imérique du Sud.

417. Erigeron ef. chinensis .lace. Hort. Schoenbr. III (1798), 30, talı. 303; DC. Prodr. I, zgo; Baker in Mart. Fl. Brasil. VI, 3, 3ı.

Andes orientales (de Subia); Cafelat Mrgetia dans la vallée de Viota, dép. Cundinamarca, alt. $1880 \mathrm{~m}$; lleurs hanches; Mayor 25, 11. 25. X. - Distrib. géngr.: Amérinue centrale el Amérique du Sud.

418. Erigeron 1'. uliginosus Bexrn. Pl. Hartweg. (18:39-57), 204.

Andes centrates; cultures ì Guaca, díp. Antioquia, alt. 1480 m; Erigeron pouvant

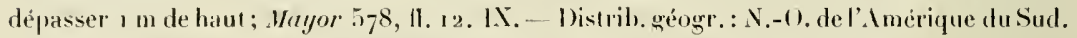

419. Diplostephium Cyparissias WVevo. Chlor. And. I (1855-7), 203.

Andes orientales; pente du Montserrate et Paramo Cruz Verde au-dessus de Bogrota, dép. Cundinamarca, alt. 2700-3500 m; Mayor 145, 11. 14, 15 et 16. X; plante ne dépassant pas 80 con de hauteur. - Distril, géogre. : Colombic

420. Baccharis rhexioides II. B. K. Nov, gen, et spec. IV (1820), 66; DC. Prodr. r., 399 ; Hemsley in Biol. Centr.-Am. Bot. II, ı3ı.

Baccharis trinervis Pens, var. Phexioides Baker in Mart. Fl. Brasil. VI, 3 (1882), 74.

Indes centrales; commun aux environs de Medellin, dép. Aıtioquia, alt. r550 m; Mayor 538, hl el fi. VHII. —Distrib. géogrr. : Du sud du Mexique jusqu'au Pérou el au Brésil.

421. Baccharis anomala DC. Prodr. I (1836), 403; Baker in Mart. FI. Brasil. VI, 3,77, lab. XXY1H.

Subsp. andina HeEruxg ined.

Andes orientates; chemin de Honda à Bogota, près de l'auberge La Sensitiva, dép. Cundinamarea, alt. environ $1800 \mathrm{~m}$; Wayor 110 , H. 9. X. Plante frutescente pouvant atteindre $2 \mathrm{~m}$ de hauteur, à Heur's blanches. - Distrib. géogr. (du type) : Brésil.

422. Baccharis bogotensis II. B. K. Nov. gen. et spec. IV (1820), 61; DC. Prodr. $1,417$.

Andes orientales; pente du Montserrate au-dessus de Bogota, dép. Cundinamarca, alt. 28 o m; Vayor 77 , 11. 16. X. Plante plus ou moins lan prante ou décombante à lleurs violeltes. - Distril). géugr. : Colombie.

423. Baccharis floribunda H. B. K. Nov, gen. et spee. IV (1820), 64; DC. l'rodr. $\checkmark, 403$.

Andes orientales; vallon Angarillo, près de Sibate dans la Sabana de Bogota, dép. Cundinamarca, alt. 2720 ; Nayor 24, I1. 23. X. Arbuste de 1-2 in de hauteur à fleurs blanches, - Vistril, géogr.: Colombie. 


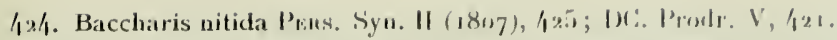

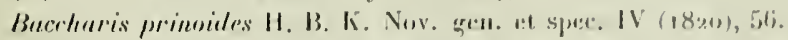

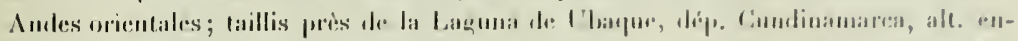

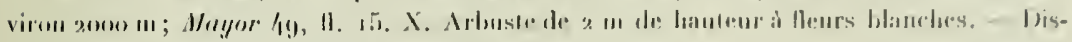

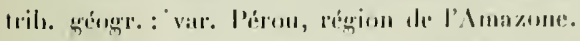

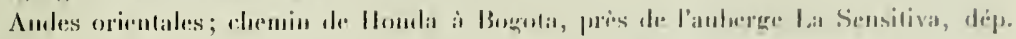

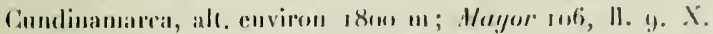

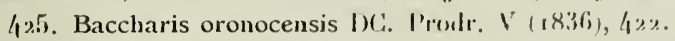

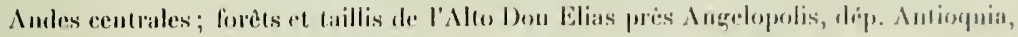

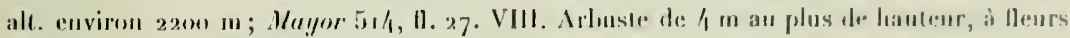
Manches. - Distrilı. géogre. : Pérou.

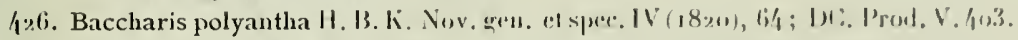

Audes centrales et orientales; cummun un pen partont ì partir de limo-2jon m,

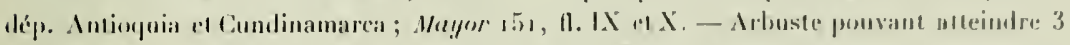

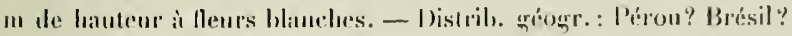

4\%7. Baccharis splendens Iferung in Schrilten Naturw. Ver. Silhleswig-Holst. Xlll (1904), 48 et in Urlau Symh. Antill. V, 2:38, 241".

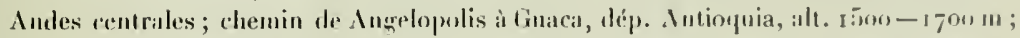

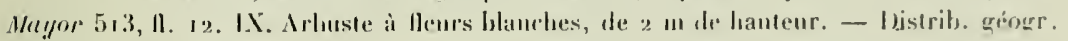
Amerique Centrile.

428. Laestadia rupestris Benrir. Pl. Hartweg. $(1834,57), 203$.

Andes orientales; Paramo linz Verde att-dessus de Bogota, dip. Cundinamarca,

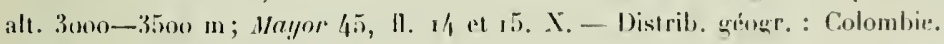

4\%9. Tessaria integrifolia Ruz wr Pav. Proulr. (1794), 112, Mals, 2/1; Baker in Mart. Fl. Brasil. VI, 3, 108 .

Tessurie legitima DC. Prodt. V (1836), 456.

Andes centrales; bord du Porce à Vedellin, lép. Intiuquia, alt. 15ino m: artuste

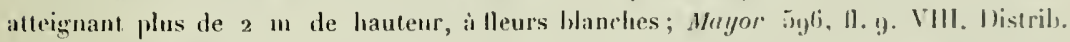
géogrr.: Amériugue du Surl.

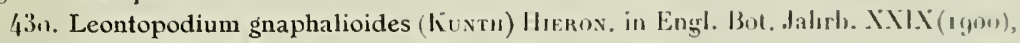
2y) vel spece. alr.

Helichrysum gnaphalioides Kuntu in II. B. К. Nor. gen. et spec. IN (1820), 18, 1. 33u.

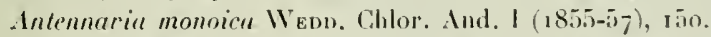

Andes orientales; Paramo de Cruz Verde au-ilessus de Bogota, dép. Cumdinamarea, att.3000-3500 m; Layor 43. 11. 14 et 15. X. - Mème plante constatée entre 3000 et 3700 m au Paramo du Ruiz, lép. Antioquia el Tolima. - Disirib. géoggr.: Indes de l'Amrique du Sud, de la Colombie à la Bolivie el an Pérou.

431. Gnaphalium spicatum Lax. Dicl. II $11-861,757 ;$ DC. Proilr. 11, 232 : Ilemsley in Biol. Centr.-Im. Bot. II, 138.

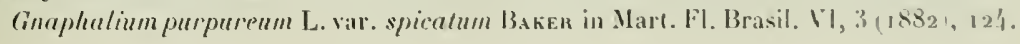


Indes centrales; entre Cisneros et l'auberge de la Quielora au-dessus de Cisneros. chenin de Medellin, dép. Antioquia, alt. $1300 \mathrm{~m}$; Mayor 241, 11. 31. VII. - Andes centrales; cultures, Cafetal La Camelia près Angelopolis, dép. Antioquia, alt. $1800 \mathrm{~m}$; Mnyor 351, 11. 23. VIll. - Andes centrales; Paramos du Ruiz, dép. Antioquia el Tolima, alt. $3000 \mathrm{~m}$; Layor 102, 11. 5. X. - Distrib. géogr.: Texas. Miexique. Amérique centrale et Amérique du Sud.

432. Gnaphalium ef. stachydifolium La». Dict. II (1786), 757 ; DC. Prodr. VI, 233.

Gnaphalium purpurenm L. var. stachydifolium Baḱer in Mart. FI. Brasil. V1, 3 (1882), 125.

Andes centrales; Paramos du Ruiz, dép. Antioquia et Tolima, alt. à partir de 3000 m; Hayor 102, t1.5. I. - Distrib. géogr.: Andes de la Colombie au Pérou.

433. Gnaphalium viscosum II. B. K. Nov. gen. et spee. IV (1820), 82 ; DC. Prodr. 11, 224 ; Klatt in Engl. Bot. Jahrb. VIII, 41; Hemsley in Biol. Centr.-Am. Bot. II, I38.

Andes orientales; pàturages arides, Barro Blanco près de Madrid dans la Savane de Bogota, dép. Cundinamarea, alt. $2640 \mathrm{~m}$; lleurs jaunes ; Mayor 66, 11. 19. X. - Distrib. géogr. : Sud du Mexique.

434. Clibadium surinamense L. Mant. II (177r), 294.

var. asperum (Aublet) BaKEn in Mart. Fl. Brasil. VI, 3 (1882-1884), 152.

Baillieria aspera Aublet Hist. pl. Guian. II (1775), 804, t. 317 .

Trixis aspera Pers. Encheir. II (1807), 491.

Clibadium asperum DC. Prodr. V (1836), 506.

Andes centrales; chemin de Medellin, entre Cisneros et l'auberge de la Quiebra, au-dessus de Cisneros, dép. Antioquia, alt. $1300 \mathrm{~m}$; arbuste de $2 \mathrm{~m}$ à fleurs blanches; Mayor 254, fl. 31. VII. - Andes centrales; environs de Medellin, dép. Antioquia, alt. $1550 \mathrm{~m}$; arbuste de $2-3 \mathrm{~m}$ de hauteur, à fleurs blanches; Nayor 630 , II. V1II. - Andes orientales (de Subia) : Cafetal Argelia dans la vallée de Viota, déj. Cundinanarca, alt. $1880 \mathrm{~m}$; arbuste à tleurs blanches de $2-3 \mathrm{~m}$ de hauteur; Mayor 26, H. 25 . X. - Distrib. géogr.: Tropiques de l'Amérique, du Mexique au Pérou.

435. Espeletia argentea Humb. eт Bonpl. Pl. Aequin. Il (1809), 14, 1. 71; DC. Prodr. $\mathrm{r}, 5 \mathrm{i} 6$.

Andes orientales ; Paramo Gruz Verde au-dessus de Bogota, dép. Cundinamarca, alt. $3000-3500 \mathrm{~m}$; Mayor 62, 11. 14 et 15. X; fleurs jannes, plante pouvant avoir un pied de $2 \mathrm{~m}$ de hauteur. - Distrib, géogr. : Colombie.

Espeletia corymbosa Нunв. ex Bonpl. PI. Aequin. $\mathrm{JI}$ (1809), 16, tab. 72 ; DC. Prodr. $\mathrm{V}, 517$.

Andes orientales: Paramo Cruz Verde an-dessus de Bogota, dép. Cundinamarca, alt. $2700-3500 \mathrm{~m}$; fleurs jaunes, tige pouvant atteindre jusqu'à $1 \mathrm{~m}$ 5o et mème $2 \mathrm{~m}$ de lantenr ; Mayor 37, 11. 14 et 15. X. - Distrilı. géogrt. : Colombie.

437. Espeletia grandiflora Huмв. Eт Bon'ı. Pl. Ne(quin. II (1809), 11, tals. 70; DC. Prodr V, 516 . 


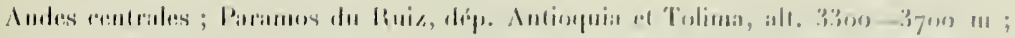

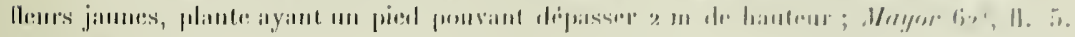

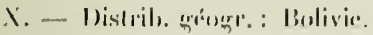

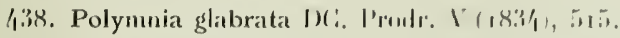

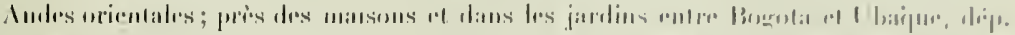

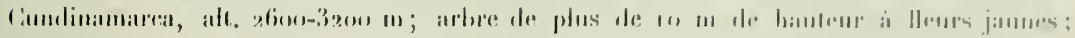

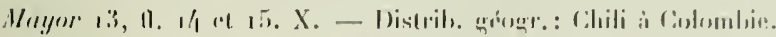

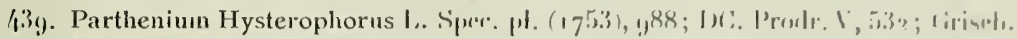

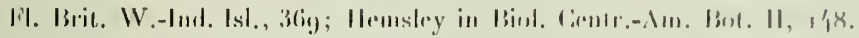

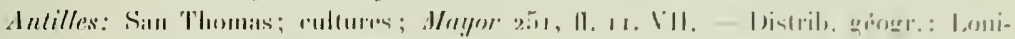
sime me Texas jusqu'on Iromtine. Antilles.

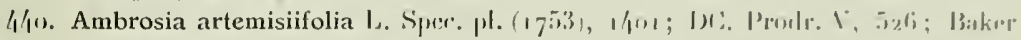

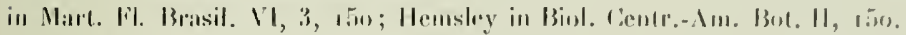

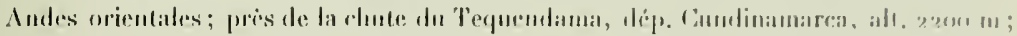

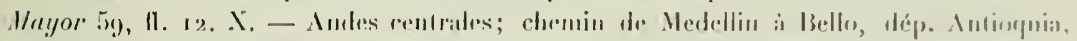

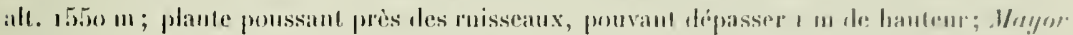

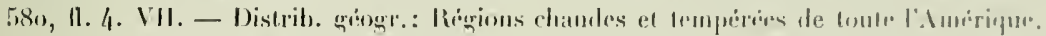

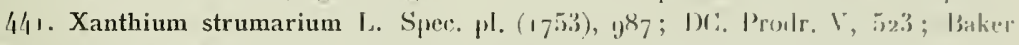
ii Mart. Fl. Brasil. VI, 3, 147.

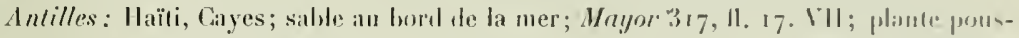
siunt dans le sable au lord te la mer, alleignant an plus a mère de lanteur. - I)istrib. grógre: Cosmopolite (originaire probablement de l'Ancion Monde).

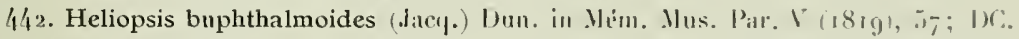
Prodr. V, 5.5o; Ilemstey in Bial. Centr.-Am. Bol. II, risto.

Anthemis buphthalmoides Jace. Hort. Schoenhr. I] (1797), 1. 1.it.

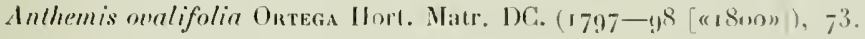

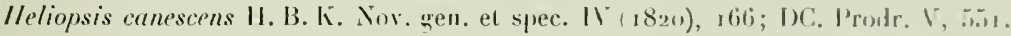
Andrien.xia mexicana DC. Prodr. V (1836), 50̄g.

Andes centrales; cultures, Cafetal La Camelia près Angelopolis, dejp. Antinquia alt. 1800 ; lleurs jaunes; Mayor 586, fl. IIIt a IX. - Andes occidentales : prairies non foin

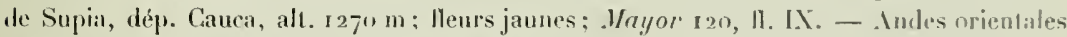
(dr Bogota); Uhayue, sur le sentier de la Laguna, dép. Cundinamarca, alt. 20 m m fleurs jaunes; Vayor 48, I1. 15. X. - Distrit. gregrr. : Mexique. Colombie jusqu'an Pérou.

443. Siegesbeckia orientalis L. Spec, pl. (1753), goo; DC. I'rodr. V. 495 ; Baker in

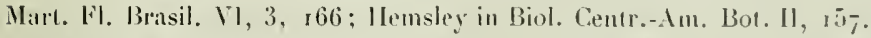

Andes centrales: cullures, Cafelitl La Camelia près Ingelopolis, dep. Antioquia, alt.

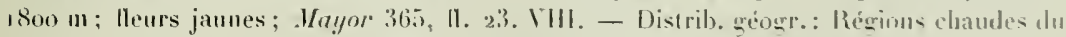
gholie.

444. Eclipta alba (L.) H.ssk. P. jar. rat. (1848), T28: Baker in Mart. H. Mrasid. 11. $3,170$. 
Ferhesinu alba L. Sprece pl. ed. 2, II (1-663), 1272; DC. Prodr. V, 49u.

Eecliptu prectu L. Hant. II (1775), 286; Hemsley in Biol. Centr.-.1u. Bot. II, 158, II, 112,

Bord du Magdalena i P'uerto Wilches, dép. Santinder, alt. $130 \mathrm{~m}$; Heurs blanches; Jaygor 280, 11. 29. V11. - Distrib. queger.: Régions tropicales du golobe.

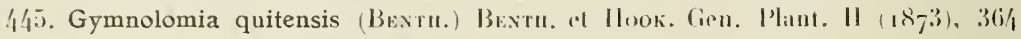
vel spee. aff:

Andrieuxia quitensis BеNти. PI. Harlw. (I839-57), 206.

Andes orientales (de Bogota); au-dessus de Ubaque, entre le village el le Paramo Cruz Verde, dẹp. Cundinamarea, alt. 2000-2ino m; J/nyor 47, II. 15. X; lleurs jannes, plante arborescente, dépassant 3 m de hanteur. - Distrib. géogr.: Équateur.

446. Wedelia carnosa Picı. in Pers. Ench. II (1807), 49n; DC. Proulr. V, 538 ; Criseb. Fl. Brit. W.-Ind. Ist., 371; Hemsley in Biol. Centr.-Am. Bot. II, $17^{\circ}$.

Antilles: llaili, Cayes; lleurs jannes; Mayor 284, 11. 17. V11. - Distril. géogr.: Amérique da sud orientale, Amérique centrale, Antilles.

447. Wedelia frutescens IACo. Stirp. Amer. (1763), 217, 1. 130; DC. Prodr. V, 541; Hemsley in Biol. Centr.-Am. Bot. II, 170.

Antilles; San Thomas; arbrisseau de $1-2 \mathrm{~m}$ ì lleurs jaunes; Hayor 193 , $11 . \mathrm{r}$. VII. - Distrib. géogrr. : Antilles. Vénézuela. Guyane.

448. Wedelia ef. Trichostephia DC. Prodr. V (1836), 540; Baker in Mart. FI. Brasil. VI, 3, I 85 .

Andes centrales; cultures, envirous de Medellin, dép. Antioquia, alt. $1550 \mathrm{~m}$; fleurs jaunes ; Hayor 584, 11. VIII. - Distrib. géogr.: Brésil.

449. Eleutheranthera ruderalis (Sw.) Scuutrz-Bip. in Bol. Zeilg. (1866), 165; Baker in Mart. Fl. Brasil. V1, 3, 209.

Melamporlium ruderale Swantz Fil. Ind. occ. III (1806), 1372; DC. Prodr. I, 521.

Eleutheranthera ovata Port. ex Steudel Nom. ed. 2, I (1840), 549; Hemsley in Biol. Centr.-Am. Bot. II, I 7 I.

Bord du Magdalena à El Banco, dép. Magdalena, alt. 1 o m; fleurs janoes; Mayor 276, 11, 27. VIl. - Distrib. géogr.: Amérique tropicale el Antilles.

450. Melanthera aspera (.JAct.) Steudel Nom. ed. 2, II (1841), 113.

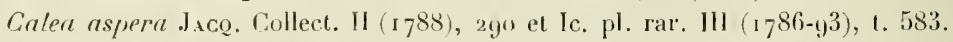

Jelonthera deltoidea Micux. Fl. Bor.-Am. II (1803), 106 not. ("Melannthera"); DC. Prodr. V, 545; Hemsley in Biol. Centr.-Im. Bot. II, $18 \%$.

Andes centrales; cultures entre Medellin et Envigado, dép. Antioquia, alt. 1550 m; lleurs blanches; Mayor 597, I1. et fr. VIII. - Bord de torrents non loin de Neirit sur le chemin de Manizales, dép. Antioquia, alt. $2000 \mathrm{~m}$; Mnıor 121, 11. 1. X. - Distrib. géogr. : Mexique jusqu'au Vénézuela et à l'Équateur. Antilles.

Var. canescens $(O$. Kuntze) Tueluung comb. nov. (Amellus asper y canescens O. Kuntze Revis. I [189I], 306). 


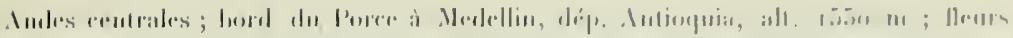

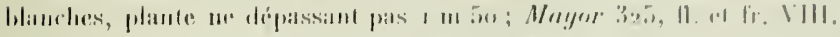

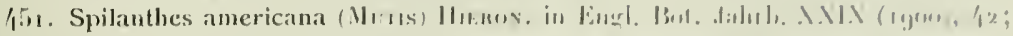

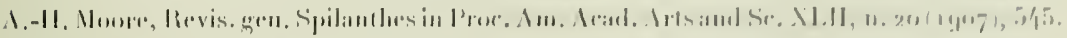

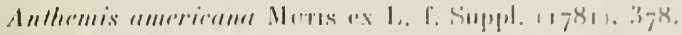

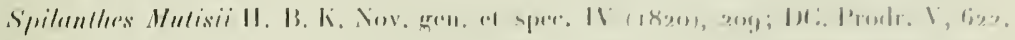

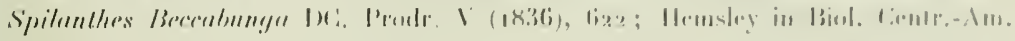
1ion. 11, 19\%

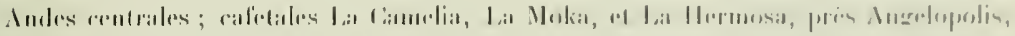

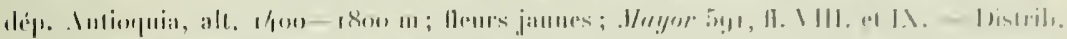

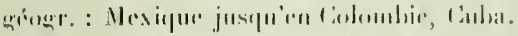

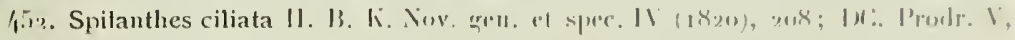
6.21; 1.-11. Moure 1. c., 5.38.

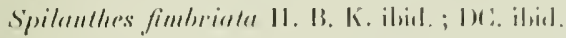

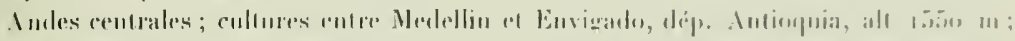

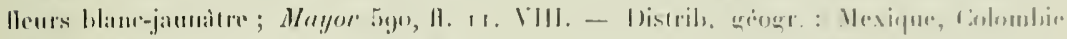
justuniun Pérun, la Bulivie of le Brísil.

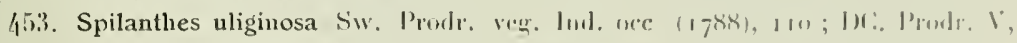

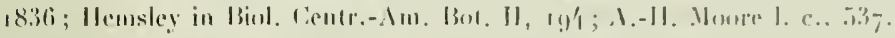

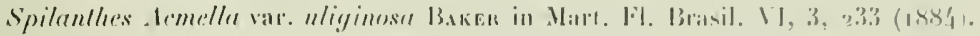

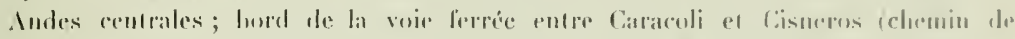

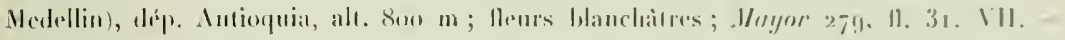

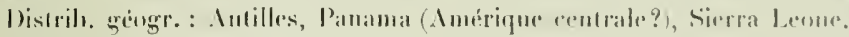

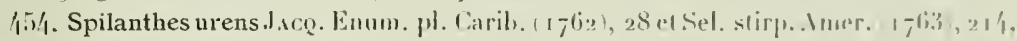

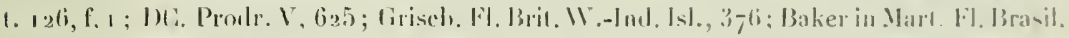
ІІ, 3. $233 ;$;.-11. Howe 1. с., 528.

Antilles: Häti, Cayes; Heurs arrisitres; Matyor 28.5, 11. 17. 111.

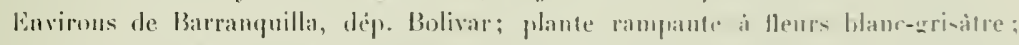

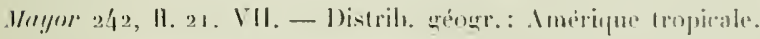

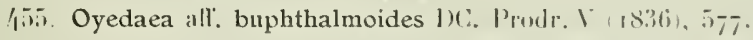

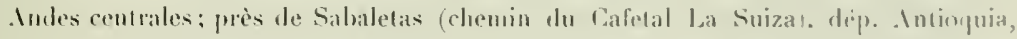
all. environ $1500 \mathrm{~m}$; Heurs jaunes, arlusste de $3-4 \mathrm{~m}$ de latuleur : Mayor 330, 11. 15. IX.

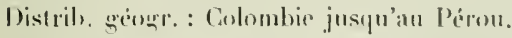

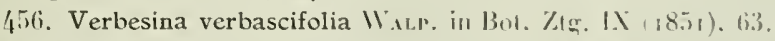

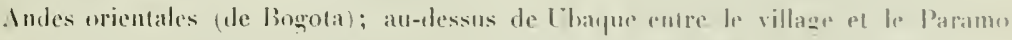

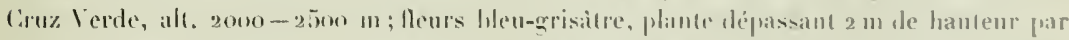
son infloresince; 1/ayor 5o, H. 15. X. - Distrib. giogr.: linizuela.

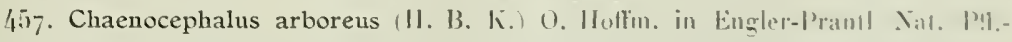
liam. II, $5(1890), 239$.

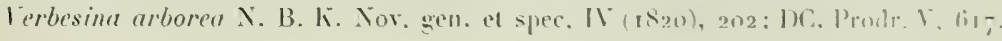




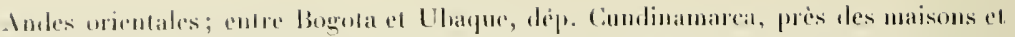
dans les jardins, alt. 2qum-3000 m; arlore i lleurs jaunes, pourant dépasser 10 m de

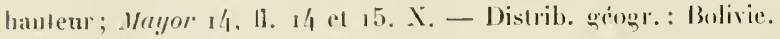

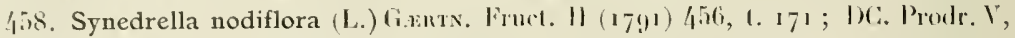

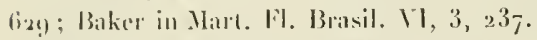

lerbesime nodiflora 1. Amoen. IN (1759), 290\%.

Intilles: damaïque, lingston; hord de chemins, lleurs jannes: Vu!ym zan, fl. id fi. 1个. VII.

Antes reridentales: chemin de Vajparaiso, daus les forèts dominant le Cauca, dóp. Intioguia, all. goo m ; Heurs jaunes, plante plus ou moins rampante ou s'appuyant sur

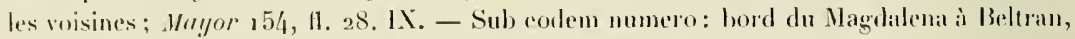
lép. Tolima, alt. 260 m ; 11. 28. X. - Distril. géogr. : Amrique ropicale.

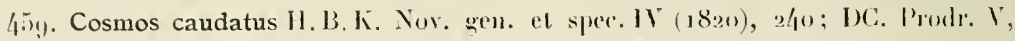
Gofi; Baker in Mtut. Pl. Brasil. VI, 3, 242; Hemsley in Biol. Centr.-Am. Bot. II, 199.

Indes occidentales; prairies aux environs de Supia, dép. Cauca, alt. $1260 \mathrm{~m}$; plante a lleurs rouge-rosé; Mayor r52, 11. el fr. 3o. IX. - Distrib. géogr.: Indiggine aux Xutilles, seulement acclimaté dans toute l'Amérique tropicale.

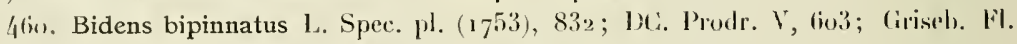
Brit. W.-Lnd. Isl. 373; Baker in Mart. Fl. Brasil. 11, 3, 2/4.

Antilles: Jamaïque, Kingston, Hope Gardens; Heurs jaunatues; Mayor 316, 11. el fr. 14, VII. - Distril, úógr.: Dans les régions chaudes du globe.

461. Bidens pilosus L. Spec. pl. ( 753$)$, 832; DC. Prodr. V, 597 ; Baker iı Mart. FI. Brasil. VI, 3 244; Hemsley in Biol. Centr.-Am. Bot. II, 203, IV, 58.

Andes centrales, dép. Antioquia; commun dans les cultures jusqu’à $2000 \mathrm{~m}$; lleurs Hanches; Mryor 56 , 11. VHI et IX. - Distrib. géogr. : Régions chatudes du globe.

462. Bidens squarrosus H. B. K. Nov. gen. et spec. IV (1820), 238 ; DC. Prodr. V, 599.

Andes orientales (de Bogota); an-dessus de Ubaque, entre le village el le Paramo Cru\% Verte, dép. Cundinamarca, alt. 2000-2500 m; plante arhorescente, arbusle dépassant $3 \mathrm{~m}$ de hauteur, à flenrs jaunes; Nayor 52, 11. 14. et 15. X. - Distrib. géogr.: Vénéznéla.

463. Calea glomerata KLATt in Engl. Bot. Jahrb. VIll (1887), 45.

Andes centrales; très commun partout aux environs de Medellin, dép. Antioquia, a11. $1550 \mathrm{~m}$; lleurs jaunes, arbuste de $3 \mathrm{~m}$ el plus; Mayor 534, 11. VH1. - Distril. gुiogr. : Colombie.

464. Tridax procumbens L. Spec. pl. (1753), g0o; DC. Proulr. V, 679; Hemsley in Biol. Centr.-Am. Bot. II, 208.

Bord du Cauca, Paso de Concordia à Puerto de los Pobres, dép. Antiopuia, alt. $7^{20}$ m; Heurs jaunes, plante rampante; Mayor 338, II. 6. IX. - Distril. géogr.: Mexique, jusqu'au Nord de l'Amérique du Sud. Antilles.

465. Galinsoga caracasana (DC.) Scnultz.-Bip. in Linnaed XXXIY (I865-66), 529 el in Bull. Soc. Bot. Fr, XlI (1865), 8o, 


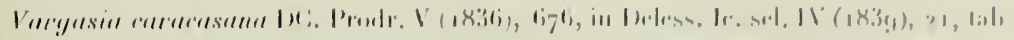
17 a l'rouls. YII, :

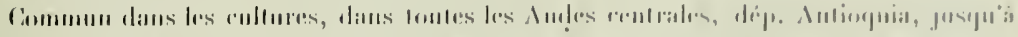

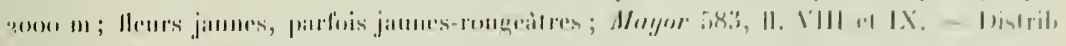

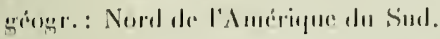

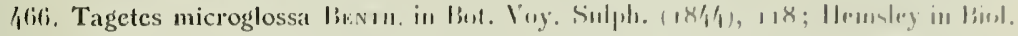

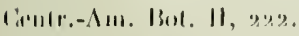

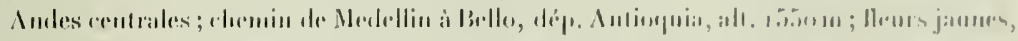

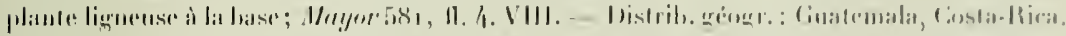

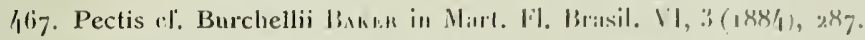

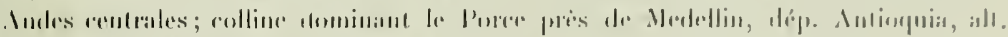

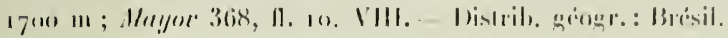

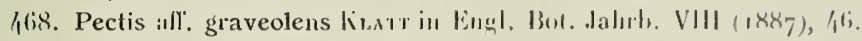

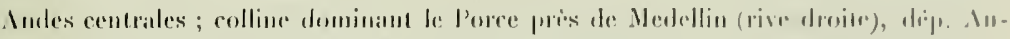

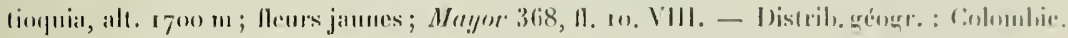

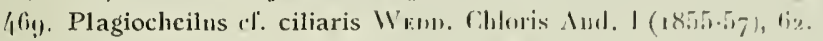

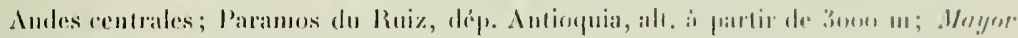
118, 11. 5. .. - 1)istrils, grougr. : Bolivie.

170. Cotula minuta. (1.f.) Sriunz comb. nov.

llippirı mimnlı L. r. Suppl. (1781), 38y.

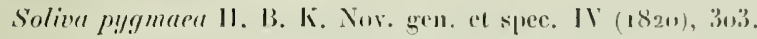

soliva mexiermu DC. P'rodr. V'1 (1837), 1/,3.3.

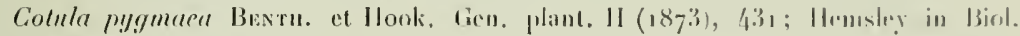
lentr.-Am. Bot. 11, 230 .

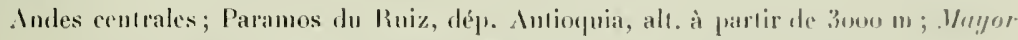
.9o, Il. el fir. / el 5. X. - Distrib. grogr. : Mexique jusou’au P’́rou.

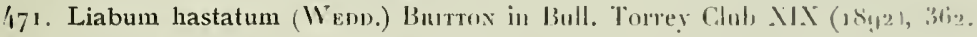

Munnosia hastala WeDb. Chloris Ind. I (1855-57), 211.

Andes centrates et occidentales, dép. Antioquia el Cauca: commun un peu partont i partir de $1700 \mathrm{~m}$ d'altiudr; fleurs jaunes, phane depassant 1 m de lanteur; Huyor

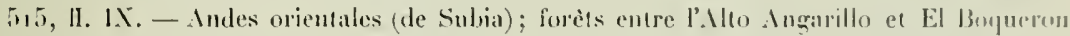
de Guachuni, dominant la vallée de Viota, dép. Cundinamarea, alt. 2300-30on m: Meurs james; plante ligèrement glutineuse, pouvant devenir grimpante el dépasser 2 m: Mlıyor 11, 11. 24. X. - Disırib, géogr.: Bolivie.

472. Liabum cl. igniarium (HuMn. et Hoxpl.) Less. in Linnalea l' (1831), 701.

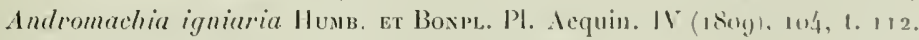

Liabum Bonplundii Cass, in Dict. sc. nat. XITI (1823), 206.

Ardes centrales; forès el lisière de forits, Ato Don Elias sur Ingelopolis, dep. Intioquia, alt. $2100 \mathrm{~m}$; fleurs jaumes, plante pouvant alleindre I m 50 de hauleur: Mayor 536, tl, 24. VIII. - Distrib. géogr.: Amérique centrale el Imérique du Sud. 
473. Liabum cf. nigropilosum Hienox, in Engl. But. dahrb. XXIX (19ou), iy.

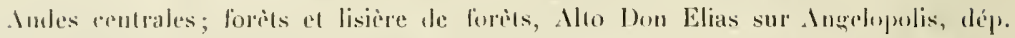

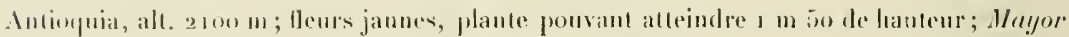
736, t1. 2\%. VIII. - Mistrib. quéor. : Equateur.

474. Liabum ef. vulcanicum KLATt in Engl. Bol. Jahrl. VIII (1887), 47.

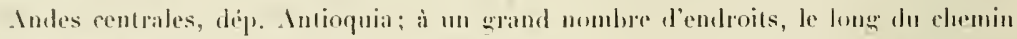
le Manizales a Medellin, an bord des russeaux entre lino el zono m; Heurs jammes,

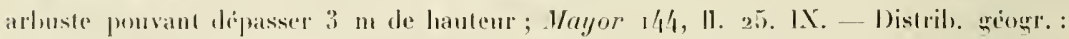
Calombic.

475.) Schistocarpha Hoffmannii O. Kunrze Rev. gell. III, 2 (1898), 170.

Indes centrales; laillis au-dessous du Cafelal La Camelia près Angelopolis, lép. Antioquia, alt. thoo m; lleurs jaunes, arbuste de 2-3 m de haut; Mayor 628, 11 . 26 . VIll. - Distril). géogr.: Bolivie.

4-6i. Erechthites hieraciifolia (1.) Rar. in DC. Prodr. VI. (1837), 29/4; Baker in Mart. II. Brasil. V1, .3, 298 ; Hensley in Biol. Centr.-Am. Bot. II, 234.

Senecio hieracifolius L. Spec. pl. (1753), 866.

Andes centrales; cultures, Cafelal La Camelia près Angelopolis, dép. Autioquia, alı. $1800 \mathrm{~m}$; fleurs jaunes; Mayor 394, 11. 10. I. - Distrib. géogr.: Mexique, Amérique tropicale, Intilles.

477. Erechthites of. valerianifolia (W'OLE) DC. l'rodr. V'I (1837), 295; Baker in Mart. I1. Brasil. VI, 3, 300; llemsley in Biol. Centr.-Am. Bot. 11, 234.

Senecio valerianaefolius WoLF in lnd. Sem. llort. Berol. (1825).

Andes centrates; cultures, Caletal La Camelia près Angelopolis, dép. Antioquia, alt. 1 son $\mathrm{m}$; Heurs lilas; Meyor $36_{7}$, Il. el fr. 10. IX. (f. loliis subintegris). - Distrib. giogr.: Du Mexique méridional jusqu'an Brésil.

478. Emilia sonchifolia (L.) I)C. Prodr. VI (1837), 302; Baker in Mart. lil. Brasil. Y1, 3, 297.

Cucalia sonchifolia L. Spec. pl. (1753), 835.

Andes centrales; environs de Medellin, dép. Antioquia, alt. $15.50 \mathrm{~m}$; lleurs rouges; Mayor 326, 11. 5. VIII. - Distrib. géogr. : Dans toutes les régions tropicales.

179. Senecio crepidifolius DC. Prodr. VI ( 1837$)$, 4 5 .

Andes orientales; Paramo de Cruz Verde, au-dessus de Bogola, dép. Cundinamarea, alt. environ $3000 \mathrm{~m}$; lleurs violettes; Mayor 4r, fl. $14 \mathrm{et} \mathrm{15.} \mathrm{X.} \mathrm{-} \mathrm{Distrib.} \mathrm{grogre:} \mathrm{Pérou.}$

480. Senecio ledifolius (II. B. K.) DC. Prodr. VI (1837), $42 \mathrm{I}$.

Ciacalia ledifolia II. B. K. Nor. gen. et spec. IV (18з0), 162.

Audes centrales; Paramos du Ruiz, dép. Antioquia, alı. 3000-3700 m, arbuste atteiqnant jusıu’à 2 m de hauteur, à lleurs jaune-pâle; Mayor ı33, H. 5. X. - Distril. géogr.: Colombie.

48r. Cf. Lycoseris mexicana (L. f.) Cass. Opuse. phyt. II (1826), $9^{6}$ et 112; Less. in Linnuea V (1830), 256 ; DC. Prodr. VII, 22. 


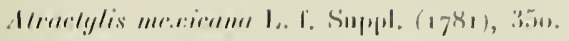

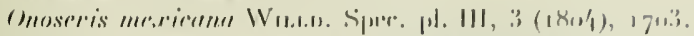

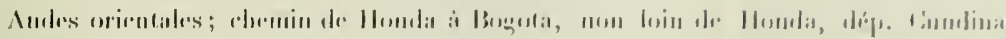

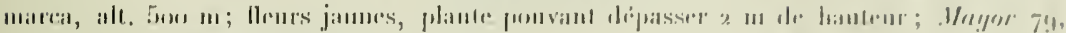

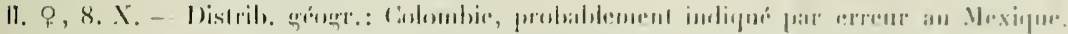

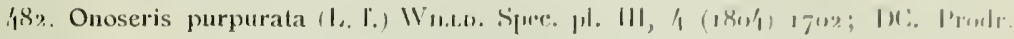
VII, $3 /$.

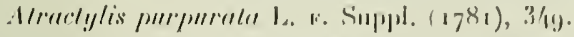

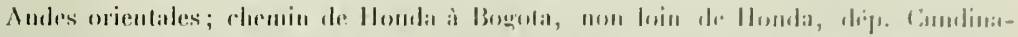

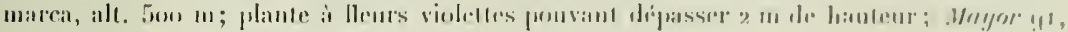
II. 8. X. Distrils. wringre: Cirlombic.

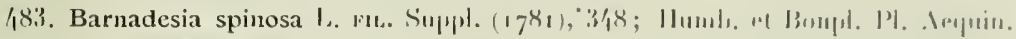

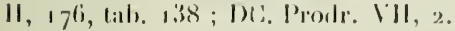

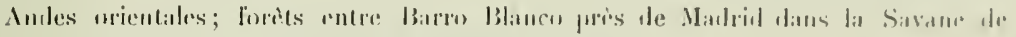

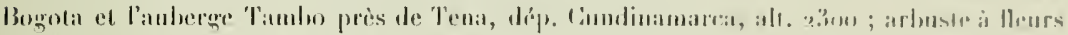

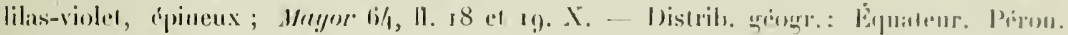
Bolivie. Brósil.

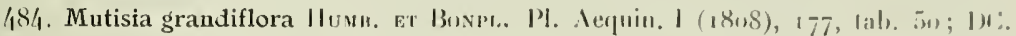
Prodr. YII, 5.

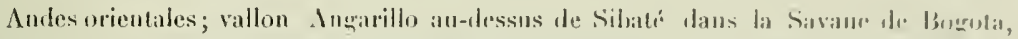

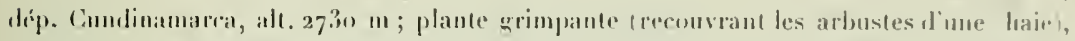

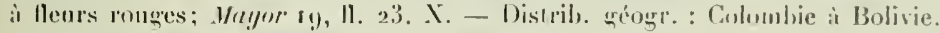

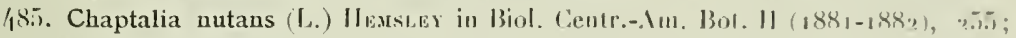
Baker in Mart. Vil. Brasil. V1, 3, 377.

Thissilugo meluns I. Syst. ed. 10, II (17ing), 1214.

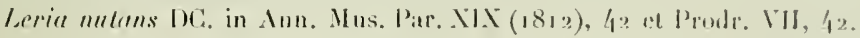

Audes centrales; cultures, Cafmal La Camelia près Angelopolis, dip. Antionguia,

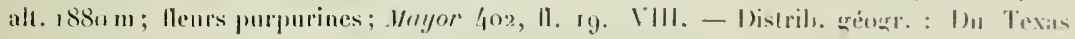
au Bresis na da Bolivie. Intikles. 


\title{
CONTRIBUTION
}

\section{à l'étude des Champignons parasites de Colombie \\ I'III}

\author{
H. et P. SYDOW, de Berlin.
}

Les champignons parasites que M. le Dr Maron a recueillis au cours de son voyage d'exploration scientifique en Colombie, à l'exception des Urédinées, nous ont été remis pour en faire la détermination. Quoique la collection ne comprenne que 42 espices, nous y avons trouvé un genre nouvean el r espèces nouvelles. Les champignons de la Colombie étant encore presque tout à fait incounus, nous croyons que ce petit mémoire serit de quelque intérèt.

\section{Basidiomycetes.}

1. Exobasidium Gaylussaciae P. Hen.s.

Sur les feuilles de Gaultheria anastomosans (L. F.) II. B. K.

Andes centrales (dép. Antioquia); taillis près de la Laguna, au-lessus de Merlellin; alt. environ $2300 \mathrm{~m} .8$ aoùt ( $\mathrm{n}^{\circ} 223$ ).

Les spécimens concordent parfaitement avee les exemplaires sur diverses espèces de Ganltheria du Brésil que Hennings lui-mème a identifiés avec l'exemplaire original sur Goylnssaciu. Les basidies sont cylindriques, $20-25 \mu$ de longuenr sur $2-3 \mu$. de largeur; les spores ont $5-8 \times 11 / 2 \mu$, obtuses aux deux extrémités, cylindriques. L'espèce est voisine

de $E$. Truccinii (Fuck.) Wor, dont elle diffère surtout par la forme des basidies et des spiores. 


\section{Ustilagineae.}

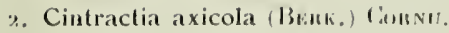

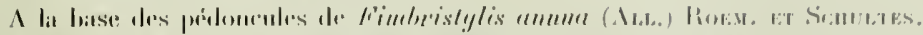

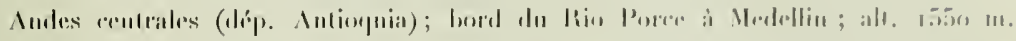

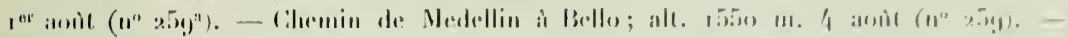

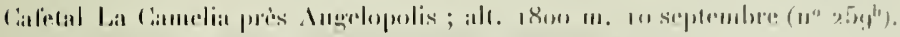

3. Spluacelotheca Hydropiperis (Somus.) D): Bмия.

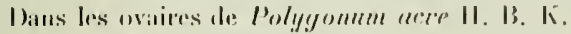

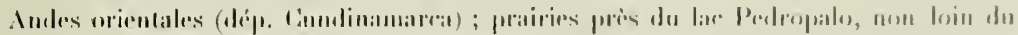

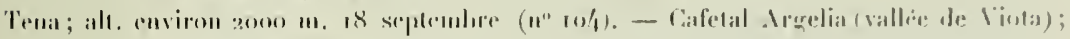
all. 1800111.04 artolime (11" 10/4).

1. Urocystis Anemones (l'Biss.) Mivt.

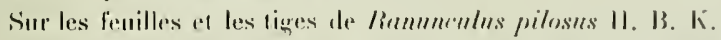

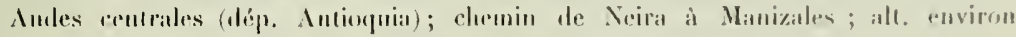

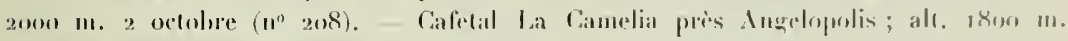
25 a011 (11020 $\left.205^{\circ 1}\right)$.

\section{Phycomycetes.}

\section{Peronospora Borreriae Lafill.}

Sur les lenilles de Borreria eryngioides Canu. гт Scalecutr.

Andes centrales (dép. Antioquia); Cafetal La Lamelia pris Angelopolis; alt. $1700 \mathrm{~m}$.

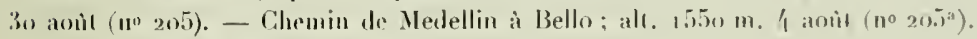

6. Cystopus candidus (Pers.) Lér.

Sur tomtes les parties vertes de Capsella Bursu pastoris (L.) Medrus.

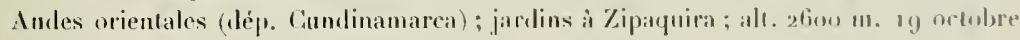
$\left(n^{\circ} 22\right)$.

Sur les feuilles el les tiges de Nusturtium offirimule R. Bu.

Andes orientales (dép. Cumbinamarea) ; jardins i Zipanpuira ; alt. 2 timo m. ryoctolse (11"23).

7. Cystopus brasilieusis SPEg.

Sur les fenilles des . Igeralum con!y Enides $\mathrm{L}$.

Audes rentrales (dip. Antioquia); ehemin de Medellin à Bello; alt. 1.550 m. 4 amò

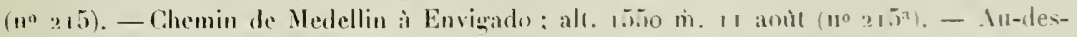
sus de Medellin, le loner du Rio Santa Elena; all. 1700 m. 6 a ant (110 $\left.31.3^{-1}\right)$. - Pàtu-

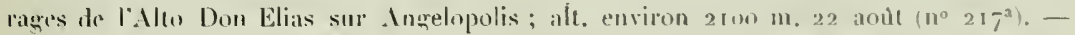

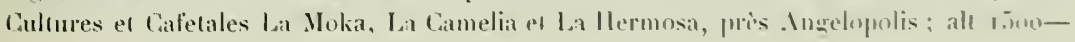


$1800 \mathrm{~m} .3$ aont $\left(\mathrm{n}^{\circ} 215^{\circ}\right)$. - Bord de chemins ì Guaca; alt. $1480 \mathrm{~m} .12$ septembre $\left(1^{0} 215^{11}\right)$.

Sur les fenilles de Eupatorium conyzoides Vaut.

Andes centrales (dép. Antioquia); taillis, liuaca ; alt. 1480 m. 12 septembre $\left(n^{\circ} 325\right)$.

8. Cystopus Bliti (Biv.) de Barr.

Sur les feuilles de Atternanthert polygonoides (L.). R. BR.

Antilles : Jamaïque ; Kingston. Hope Gardens. I/ aoìt ( $\left.n^{\circ} 125\right)$.

Sur les ferilles de liesine spec.

Andes centrales (dép. Antioquia); chemin de Medellin à Bello; alt. $1550 \mathrm{~m} .4$ aout (n 153 ). - Colline au-dessus de America pris Medellin; alt. environ 1700 m. 15 aont $\left(n^{\circ}, 153^{\mathrm{a}}\right)$.

9. Cystopus Portulacae (DC.) LÉv.

Sur les feuilles de Portulaca oleracea L.

Environs de Barranquilla (dép. Bolivar). 2 I-24 aoùt (no 155$)$.

10. Cystopus platensis Speg.

Sur les feuilles de Boerhaavia erecta L.

Environs de Barranquilla (dép. Bolivar). 21 juillet (n 354).

Sur les feuilles de Bocrhaavia coccinea Mhuen f. parcehirsuta Hengert.

Environs de Barranquilla (dép. Bolivar). $21-24$ juillet (10224).

Sur les feuilles de Boerharavia paniculata L. C. Ricı.

Environs de Barranquilla (dép. Bolivar). 21 juillet $\left(n^{\circ} 126\right)$. - Ibidem, $21-24$ juillet $\left(\begin{array}{lll}n^{\circ} & 1 & 22\end{array}\right)$.

11. Cystopus Ipomoeae-panduratae (Scuw.) Stev. Et Sw.

Sur les feuilles de Ipomoea aff. caloneura Meissner.

Andes centrales (dép. Antioquia); cultures el Cafetal Lal Canelia, près Angelopolis; alt. r $800 \mathrm{~m}$. ro septembre $\left(n^{\circ} 291\right)$. - Cultures près de Rio Porce, au pied de la Cordillìre de la Quiebra (chemin de Cisneros à Medellin); alı. environ $1400 \mathrm{~m}$. $\mathrm{I}^{\mathrm{er}}$ aoùt $\left(n^{0} 2 \mathrm{r}^{2}\right)$. - Cultures au-dessous du Cafetal La Hermosa près Angelopolis; alı. 1400 m. 9 septembre $\left(\begin{array}{ll}n^{\circ} & 292\end{array}\right)$.

\section{Ascomycetes.}

\section{Meliola Lantanae Syo. nov. spec.}

Mycelio amphigeno maculas orbiculares vel irregulares $r-3 \mathrm{~mm}$ latas tenues saepe confluentes modice manifestas efficiente, ex hyphis dense intertextis anastomosantibusque subtorulosis obscure fuscis 7-10 $\mu$ crassis composito; hyphopodiis capitatis modice copiosis, plus minus longe stipitatis, totis $20-28 \mu$ longis $9^{-12} \mu$. latis, cellula superiore ovata vel ovalo-globosa; liyphopodiis mucronatis raris, usque $20 \mu$ longis ; setis mycelicis sparsis, rectis, erectis, rigidis, apice obtusis, septatis, usque $450 \mu$ longis, $6-8 \mu$. crassis, inferne 


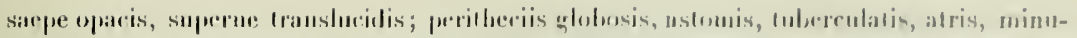

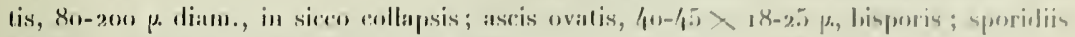

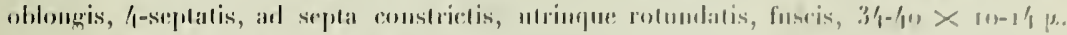

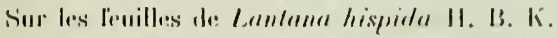

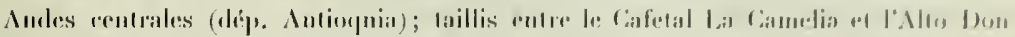

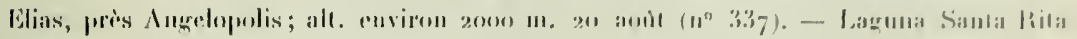

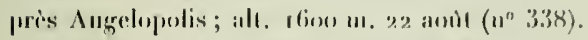

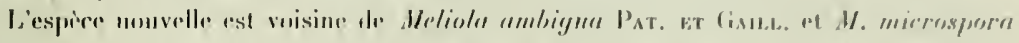

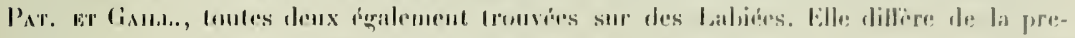

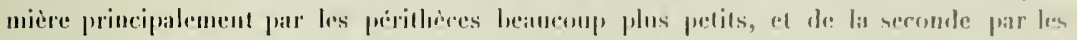
spurielies al les hyphoporlies capilces plus grandes.

13. Mycosphaerella Drymariae Sirm. nov. spec.

Naculis amphiganis, mimtis, rolundatis, $1-2 \mathrm{~mm}$ latis, flavo-l,muneis; perilleciis

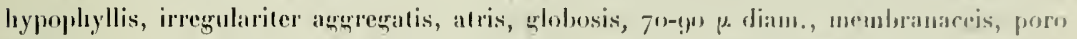

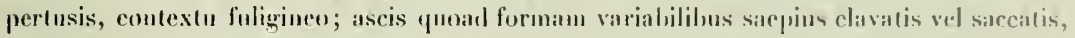
sessilibus vel sulsessilibus, apice rolundatis vel etian allenuntis, $25-10 \times 7-1.30$, nctosporis; sporidiis oblongis vel oldongo-fusoideis, utrindue obusis, mediu sparie 1 -septatis,

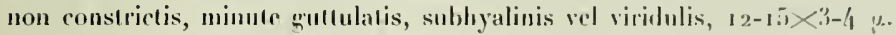

Sur les fenilles vivantes on languissantes de Drymarin cordala (L.) WHLu.

Andes centrales (dép. Antioquia) ; cultures et Cafrual La Camolia prés Anerolopulis; alt. $1800 \mathrm{~m} .28$ aont $\left(\mathrm{n}^{\circ} 260\right)$.

r/. Didymella Penniseti Srd, nov. spec.

Peritheeiis epipliyllis, in greges minutos ellipticos vel parum elongatos usque 1 mm longos digestis, epidermirle diu teetis, tanden vertice rrumpentibus, grobulosis, jo-roo $\mu_{0}$ liam., atris ; aseis clavatis, apice obusis, crasse tunicatis, crassiuscule breviterque nonluloso-stipitatis, 40-60× $\times 10-13 \mu$, octosporis, parce paraphysatis; sporidiis distichis, fusoideis, medio vel circa medium $r-s e p t a t i s, n o n$ constrictis, hyalinis, $18-22 \times 31 / 2-5)$.

Sur les feuilles virantes ou languissintes de l'ennisetum trishuch!ym (H. B. K.) SPrexgf.L.

Andes centrales (dép. Antioquia); cultures el Cafetal La Camelia pris Augelopolis:

alt. 1800, III. 20 aonit $\left(\mathrm{n}^{\circ}, 64\right)$.

15. Phyllachora Crotonis (Cке.) SAcC.

Sur les feuilles de Croton flavens L.

Antilles; San Thomas. I juillet ( $\left.1^{\circ} 114\right)$.

16. Phyllachora peribebuyensis SPEg.

Sur les feuilles de Tibouchina spee.

Andes centrales (dép. Antioquia); environs de Meclellin ; alt. environ 1600 m. 10 aou $\left(n^{\mathrm{ns}} \quad 249\right.$ et 251$)$.

Nous croyons que les exemplaires de la Colomhic appartiennent à la dite espéce, mais les sporidies finissent par se brunir. Il sera done peut-ètre nécessaire de ranger l'espèce sous te genre Anersualdia. 
17. Phyllachora Ambrosiae (B. el C..) Sicc:

sur les lenilles de Ambosiu artemisiifolin $\mathrm{I}$.

Andes centrales (dep. Antionuia); le fong du Rio. Saula Elena sur Medellin; alt. euviron

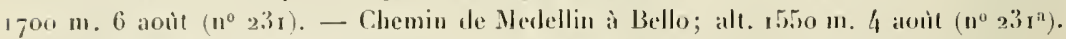

18. Phyllachora Espeletiae Sirn. nov. spec.

Stromatihus epiphyllis, irregulariter sparsis, rotumdatis vel irroularibus, conicopromimulis, ${ }^{-2} \mathrm{~mm}$ latis, atris, opacis, glahris, intus $1-3-$ locularihus ; ascis cylindraceis vel clavalis, apice rotundatis, $65-120 \times 1 / 1-18 \mu$, octosporis; sporicliis late ellipsoideis, utrinque subinde leniter acutiusculis, saepe indequilateralibus, contimuis, hyalinis, $1 / 1-17 \times 8-11 \mu$.

Sur les feuilles de Espeletic corymbosic Humb. el Boupl.

Audes orientales (dép. Cundinamarca); Paramo Cruz Verde, an-dessus de Bogota; al1. 28 su-3300 m. 14-15 actobre $\left(n^{\circ} 31\right)$.

19. Phyllachora perlata SYD. nov. spec.

Stromatibus hypophyllis, hemisphaerico-prominutis, in eppipyllo etiam conspicuis sed non prominentihus, sparsis, soltariss vel hine inde pancis aggrrgatis el subconfluentibus, minulis, rolundatis, $1 / 3^{3} / 4 \mathrm{~mm}$ diam., levihus, ghabris, nitidulis, atcrimis, inus plerumque 1-ran 2-locularilus; ascis cylindraceis, apice ol,tusis, $80-120 \times 11-14 \mu$, octosporis; sporidiis monostichis, late ellipsoideis, continuis, utrinque late rotundatis, hyalinis, $13-16 \times 8-12 \mu$.

Sur les feuilles de Polymnia glabrata DC:

Andes orientales (dép. Cundinamarea); chemin de Bugota à Lbaque, près des maisons et daus les jardius; alt. 2400-3200 m. 14- 5 octobre (1 $\left.1^{\circ} 3 /, 3\right)$.

20. Phyllachora Acaciae P. Henn.

Sur les feuilles de Acacia lorluosa (L.) WILlo.

Antilles; San Thomas; 11 juillet ( $\left.\mathbf{1}^{0} \quad 112\right)$.

Differe un peu du type provenant de l'Équateur frar les stroma un peu plus grands.

21. Phyllachora Eriochloae Speg.

Sur les fenilles de Eriochlon punctula (L.) Hamuton.

Andes centrales (dép. Antiorquia); hord du Rio Porce à Merlellin; alt. $1550 \mathrm{~m}$. 9 aoùt ( $\mathbf{n}^{0}$ 158).

22. Phyllachora paspalicola P. Henn.

Sur les feuilles de Paspalum conjugalum Berg.

Andes centrales (dép. Antioquia); cultures et Cafetal La Camelia, près Angelopolis; alt. $1800 \mathrm{~m} .19$ août $\left(\mathrm{n}^{0}, 65\right)$.

Sur les feuilles de Paspalum compressum (Sw.) Rasp.

Andes centrales (dép. Antioquia) ; bord de la voie ferrée entre Pavas et Cisneros; alt. environ $800 \mathrm{~m} .3_{1}$ juillet ( $\mathrm{n}^{0}$ 143).

Phyllachora Pazschkeana SyD.

Sur les feuilles de Panicum pilosum Sw. 


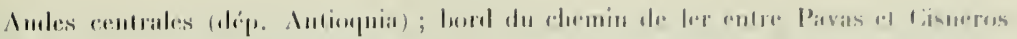

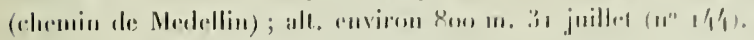

2/. Plyyllachora graminis (Plus.) linek.

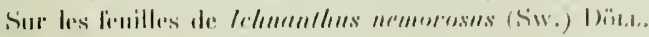

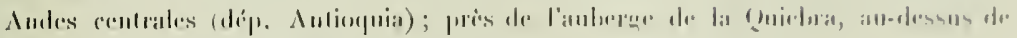

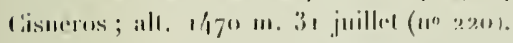

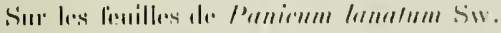

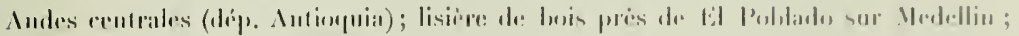

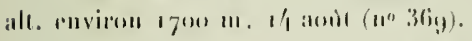

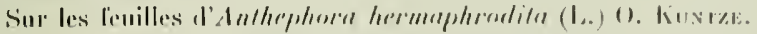

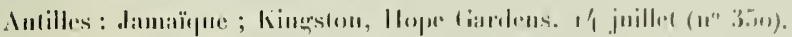

25. Dothidea Anthurii linms. (1) liniss.

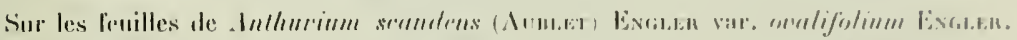

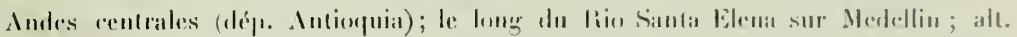
environ 1700 m. li and (11"356i).

26. Montagnella Puiggarii Sirlar.

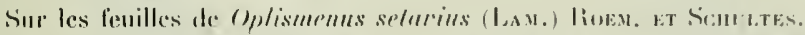

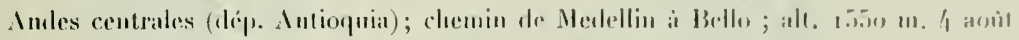
$\left(11^{0} \cdot 321\right)$.

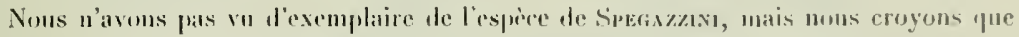

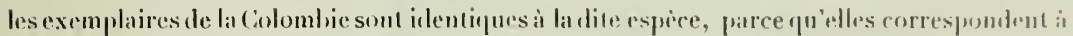

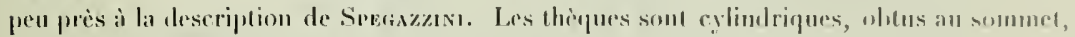

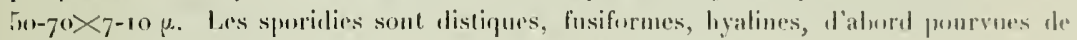

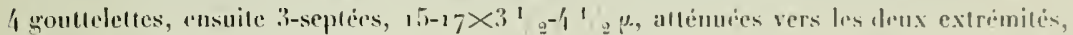

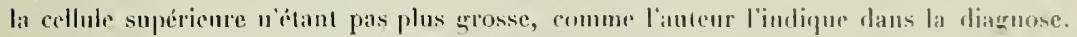

\section{Niptera aureo-tincta Sro. nov. spec.}

Ascomatilus in maculis sordiele fuscis irregularibus $2.8 \mathrm{~mm}$ lalis sacpe conlluentilms aggregratis, epiphyllis, 200-3ow p. diam., ceraceis, sessilibus, primitus elolusuclausis, dein disco plano temuiter marginato amnene anreo-fincto, extus fuscilulis, in sicru sorilide succinen-fuscis el contortis, ghabris, parenchymatice contextis ; ascis cymbacen-clatalis, apjec rotundatis, breviter slipitatis, octosporis, $18-58>8-10 \mu$; sporidiis oblique monostichis usque distichis, ohlongis vel subfusoides, utringue obtusis, medin 1-septatis, non

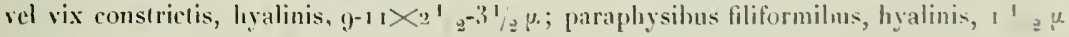
crassis, ad ayricem 2-2 ${ }^{1}$, u crissis.

Sur les feuilles vivantes de Tibonchimn Bomrgermu Cons.

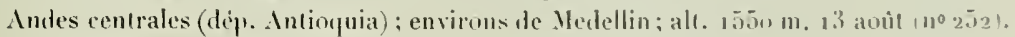

28. Calloria quitensis PAт.

Sur les feuilles de Relbunium hypocnrpinm (L.) Hersi.f.x.

Andes centrales (dep. Antioquia); laaies an-dessus de Medellin, le long du Rio Santa

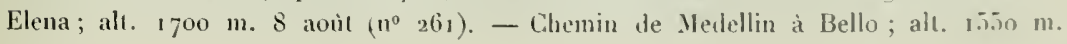


4 aoù $\left(n^{\circ} 261^{3}\right)$. - Haies à Guaca; ah. 1500 m. 12 septembre ( $\left.n^{\circ} 261^{h}\right)$. IIaies Cafetal La Camelia près Ingelopolis; alt. 1800 m. 20 aout $\left(n^{0} 2\left(i_{2}\right)\right.$. - Haies entre Medellin ef Envigado; alt. 1550 m. I 1 aoù $\left(1^{\circ} 2\left(62^{\mathrm{a}}\right)\right.$. - Chemin entre Medellin el America; alt. 1.5ix m. I台 aoùt $\left(\mathrm{n}^{0} 262^{\mathrm{c}}\right)$.

\section{Melanochlamys SrD. nov. gen. (Microthyriacearum).}

Stronal membranaceum, dimiliato-scutatum, microtlyriaceum, atrum, per cuticulam erumpens el subsuperficiale, ex lyphis radiantibus contextum, ambitu fimbriatum. Perithecia hypostromatica, gloluloso-tenticularia, ostiolata, contextu minute tibroso. Asei clavati, octospori, paraphysati. Sporidia transverse pluriseptata, colorala.

29. Melanochlamys leucoptera SrD. nov. spec.

Stromatilus hypophyllis, sparsis, irregularihos, rotundatis vel oblongis, $1 / 2^{-2} \mathrm{~mm}$ longis vel latis, sub cuticula ortis, mox erumpentibus et partim cuticulac laciniis tectis,

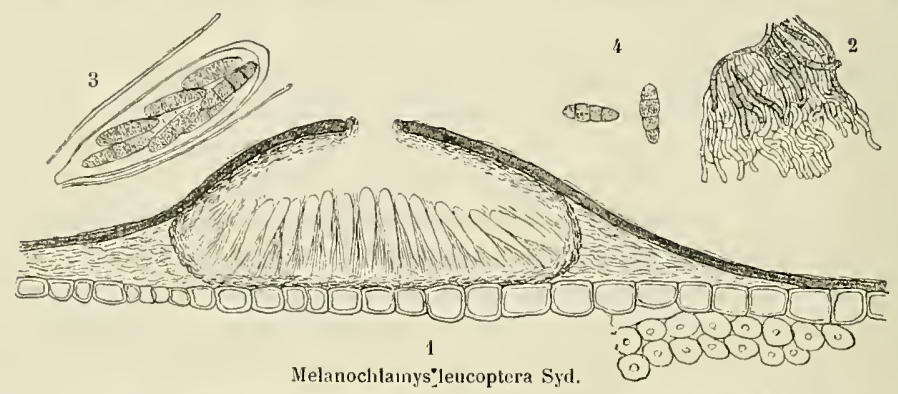

Fig. 1. Section longitudinale au travers d'un bouclier avec périthèce. Gross. $370: 1$. -

Fig. 2. Partie marginale du bouclier vue d'en haul. Gross. $300: 1$. - Fig. 3. Thèque et paraphyses. Gross. 625: 1. Fig. 4. Deux Spores. Gross. 625:1.

sulsuperticialibus, atris, opacis, membranaceis, ex hyphis radiantibus longis $2 \cdot 2 \frac{1}{2} /$. latis Hexnosis vel maeandrice curvatis septatis fuscis contextis, ad ambitum multo tenuioribus albo-membranaceis et fimbriatis; peritheciis $2-10$ in quoque slromate, hypostromaticis, convexis, globuloso-lenticularibus, $80-130 \mu$ diam., contextu dilute l, runneo minute fibroso; ascis clavatis, brevissime stipitatis, apice obtusis, 38-46×9-10 $\mu$, oclosporis, filiformiter paraphysatis; sporidiis distichis, oblongis, utrinque obtusis, 3-septatis, ad septa leniter constrictis, cellula secunda superiore paullo latiore, ex liyalino mox ohscure olivaceobrunneis, $13-16 \times 31 / 2-4 \frac{1}{2}$ u.

Sur les feuilles vivantes ou languissantes d'une Bambusée.

Bord du Magdalena près de El Banco (dép. Magdalena); alt, $110 \mathrm{~m}$. 27 juillet ( $\left.\mathbf{1}^{\circ} 120\right)$.

Le champignon se développe au-dessous de la cuticule qui est bientôt rompue. Il est alors presque superficiel étant seulement recouvert des débris de la cuticule. Le stroma, 


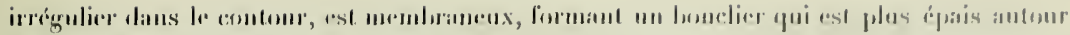

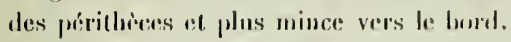

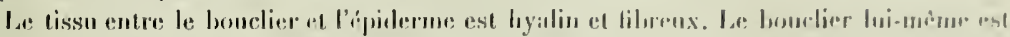

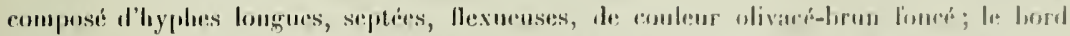

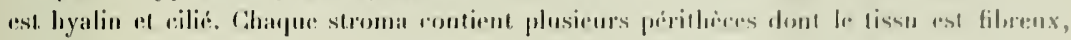
d'uแ lım rlair.

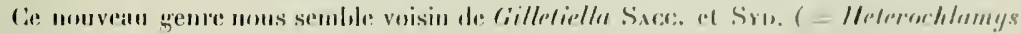

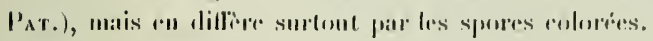

\section{Fungi imperfecti.}

\section{Macrophoma Symbolanthi Sro. nov. spec.}

Pycuiliis hypophyllis vel caulicolis, sparsis, glolsulosis, uspur 350 p. diam., alerrimis, listincte papillatis, in sieco collapsis, opacis, valde prominnlis, contextu sub microsenjin atro-purpure ex cellulis majusculis composito; sporulis oldongo-ellipsod reis, utringure olutu-

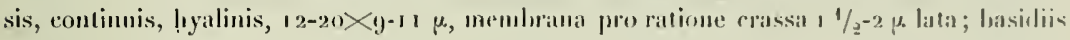
dense stipatis, 10-22 $\mu$. longis, lyalinis.

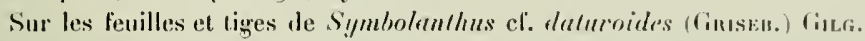

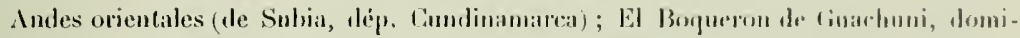
nant la vallée du Viota; alt. $2450 \mathrm{~m} .24$ octulure (no 358 ).

31. Darluca Filum $\left(B_{1}\right.$.) Cinst.

Sur les uredos des feuilles dr /hynchospora cyperoides (Sw.) Mar.

Autilles: Martinique; Fort-de-France. 10 movembre (1" 34/4).

Sur les uredos de Tessarin integrifolia Ruz at Pav.

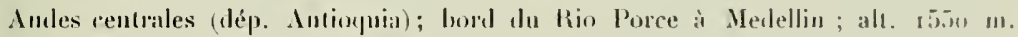
9 anit (n*339).

32. Septoria Balansae Sipeg.

Sur les leuilles de Billens pilosus L.

Andes centrales (dép. Antiongia); Cafetal La Camelia juris Angentupolis; alt. 18 no 11. 28 aoilt (no 340$)$.

33. Septoria inconspicua B. Eт C.

Sur Irs feuilles de Plantago tomenlosa Lam. var. glubrescens Sculecurd.

Andes centrales (dip. Antioquia); culcures entre Medellin et Envigado; alt. $150 \mathrm{~m}$. 11 aoùt $\left(n^{\circ} 225\right)$. - Cultures et Cafetal La Camelia près Ingelopmlis : alt. $180 n$ m. 19) aoùt ( $\left.11^{\circ} 22^{2} 5^{\mathrm{i}}\right)$.

34. Septoria Spigeliae P. HenN.

Sur les fenilles de Spigelia anthelmin L.

Antilles: damaïnue; lingston, Hope Gardens. 14 juillel (no rq1). 
Celle espice, jusqu ici, n’étail connue qu’an Brésil (jardin botanique de Para), où elle se développe sur le mime hòte. Les pycnides sont tris serrées sur lis lace supérieure des fenilles. Les sporules sont filiformes, un peu aiquës aux deux extrémilés, d'abord

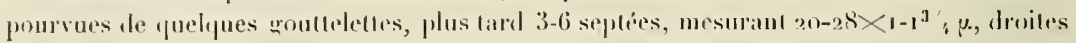
"ul légèrement incurvées.

3.). Septoria albo-maculans Sio.

Sur les feuilles de Eupalorinim pomaderrifolium beNTu.

Andes orientales (dép Cundinamarca) ; pentes du Montserrate int-lessus de Bogota; alt. 2 yoo $\mathbf{m}$. I 6 octohre $\left(\mathbf{n}^{0} 362\right)$.

36. Oidium erysiphoides $F_{R}$.

Sur les feuilles de Galinsoga cararasana (D):). Schubtz. - Bip.

Andes centrales (dép. Antioquia); cultures, Calletal La Camelia pris Angelopolis; all. $1800 \mathrm{~m}$. (110236).

Sur les feuilles de Gymnolomia quilensis (Bentu.) l Bentlı. et llook.

Andes orientales (dép. Cundinamatca); an-dessus de Ubaque entre le village et le Paramo Cruz Verde au-dessus de Bogola ; alı. 2000-2600 m. (10 360).

Sur les fenilles de Tageles microglossa Bentu.

Andes centrales (dép. Antioquia); chemin de Medellin ì Bello; alt. r55o m. 4 août $\left(1^{\circ} \quad 232\right)$.

Sur les feuilles de Desmodium lortnosum (Sw.) DC.

Andes centrales (dép. Antioquia); cultures près du Rio Amaga, sous le Cafetal La Camelia près Angelopolis; alt. environ r $200 \mathrm{~m} .26$ aoùt $\left(\mathrm{n}^{\circ} 268\right)$. - Cultures Cafetal Lil Moka près Angelopolis ; alt. environ 1600 m. 29 auìt ( $\left.\mathbf{n}^{0} 268^{\mathrm{a}}\right)$.

Sur les feuilles de Salvia Mayorii Buo.

Andes orientales (dép. Cundinamarca); Charquito, près de la chute de Tequendama; alt. $2200 \mathrm{~m} .12$ octobre $\left(\right.$ n $\left.^{\circ} 39\right)$.

37. Oidium leucoconium Desn.

Sur les leuilles de rosiers cullive's.

Andes orientales (dép. Cundinamarca); Ubaque, dans les jardins; alı. $2000 \mathrm{~m}$. л 5 octobre $\left(n^{\circ} 36\right)$. - Andes centrales (dép. Antioquia); sur les feujlles d'un rosier échappé de jardin. Environs de Medellin ; alt. $1550 \mathrm{~m}$. 13 aout $\left(n^{0} 255\right)$.

38. Cercospora Líabi Sro. nov. spec.

Caespilulis hypophyllis, in epiphyllo maculas indeterminalas llavidas vel viridulas efficientibus, in comentu lodiorum nilubantibus, dense gregariis el maculas rotundatas 2-4 $\mathrm{mm}$ diam. fusco-brumneas vel olsseure olivaceo-fuscas formantibus ; hyphis lertilibus rectis vel leniter flexuosis, plerumque simplicibus vel rarissime parce ramosis, fuscolorumeis, septatis (articutis $15-25 \mu$. longis), $150-50 \%$. Jongis $3-5 \mu$ crassis ; conidiis cylindraceis vel clavato-cylindraceis, plerumgue ntrinque obtusis vel apice leniter attenuatis, $2-4$ septatis, subhyalinis vel dilutissime olivaceis, $20-44 \times 31 / 2-5 \mu$.

Sur les feuilles de Linbum hostolmm (IVEdo.) Britton. 


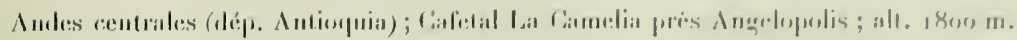

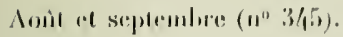

3.). Heterosporium paradoxum Sirn. noy. spec.

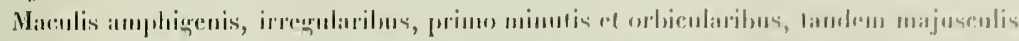

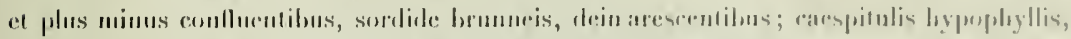

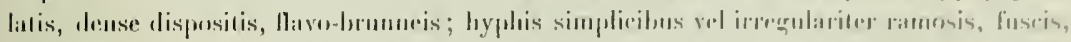

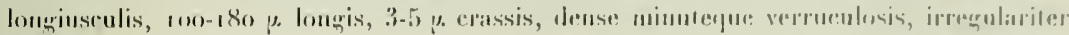

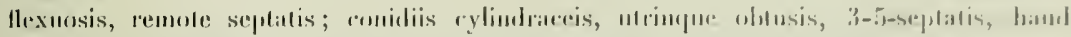

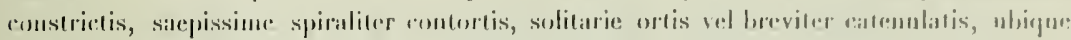

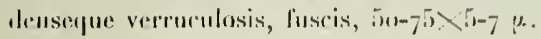

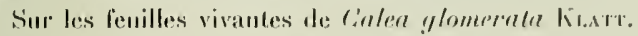

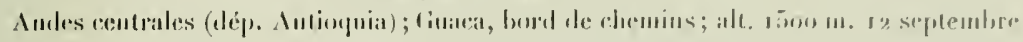
$\left(11^{0} 3 / 1(i)\right.$.

10. Illosporium Mayorii Srn, nov, spec.

Sporodochie in soris Pucciniate parasitantibus, orbicularibus, lenticulari-pulvinalis, minutissimis, 74-125 p. diam., all,is; hyphis tenubus, dense stipatis, hyalinis, 10-2: p.

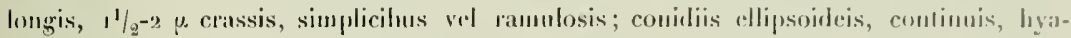
linis, 8-9 $1 / 2 \times 1-$-i $\mu$.

Sur les pustules de Panceinia laterilin Brak. Fт Cunt., sur les feuilles de Borrerin larvis (Lam.) Cimsen.

Audes centrales (dép. Antioyuia); Cafetal La Camolia près Angelupolis ; all. 1800 m. 30 anil (n*3/7).

41. Cerebella Paspali CKL. ет Mass.

Sur les ipis de Paspalum compressum (Sw.) Riss.

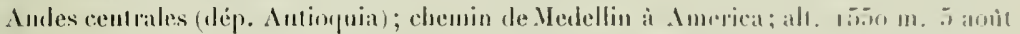
$\left(\begin{array}{ll}11 & 157\end{array}\right)$.

42. Tuberculina persicina (1),тм.) SAcc.

Sur les pustules de Aecidium Lantanae Maron, sur les fenilles de Lantana hispida II. B. K.

Andes centrales (dép. Intionuia); taillis, pente le l'Mlo Don Elias au-dessus du

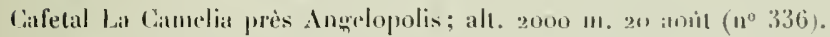




\title{
CONTRIBUTION
}

\section{à l'étude des Urédinées de Colombie}

\author{
P.IR \\ Dr-Méd. Eug. MAYOR
}

La flore mycologique de la Colombie est à l'hcure actuelle à peu près inconnue et l'on ne posside encore que des renseignements très peu nombreux et très confus sur toutes ces vastes régions du nord de l'Amérique du Sud. Pour ce qui concernc plus particulièrement les Urédinćes, les recherches bibliographiques ne mont donné que 6 espèces recueillies jusqu'ici dans toute la Colombie, soit: Uromyces Iledysari-paniculati (Schw.) Farl. sur Desmodium mexicanum (Quindiu, Andes centrales, alt. $2000 \mathrm{~m}$ ) ${ }^{1}, U r$. Euphorbiicola (Вевк. ет Curt.) Tranzsch. sur Euphorbia pilulifera (Colombie), Ur. Gissampelidis Diet. sur Cissampelos spec. (Santa Marra), Puccinia Bombacis Diet. sur Bombax spec. (Santa Marta), P. levis (SAcc. Et Bizz.) P. MagN. sur Manisuris granularis (Colombic) et Uredo Theresiae NEGEn sur Crolalaria anagyroides (Quindiu, Andes centrales, alt. $2000-2400 \mathrm{~m}$ ). Ce sont là les seules indications de Rouilles récoltées en Colombic ou du moins les seules que j'ai trouvées. Dans ces conditions, les espèces que j’ai eu l'occasion de recueillir contibueront à combler quclque peu cettc grande lacune en montrant quc les Urédinées colombiennes sont du plus haut intérêt et mériteraient d'attirer davantage l'attention des savants qui voyagent dans ces contrées.

J'ai recueilli 558 espèces se rattachant à r 3 genres diflérents y compris les Aecidium et Uredo isolés; dans ce nombre, 84 espèces sont nouvelles et parmi les autres, j'en ai

1 Uranyces Hedysari-paniculali et Lredo Theresiae ont été reeueiltis par la Prineesse Tú́nìse DE Baviśre au eours de son voyage dans l'Amérique du sud (Beihelte zum Bol. Centralb., B. xIII, ı903, p. 8, 78 el 79); les 1 atutres espèces sont mentionnées dans Sruow (Mou. Ured. I et II). 


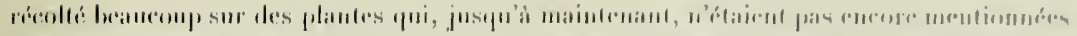

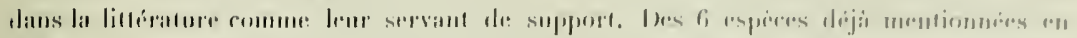

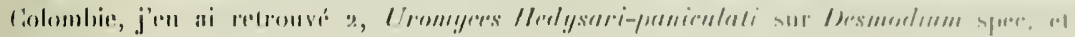

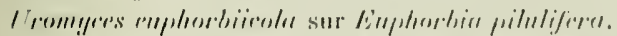

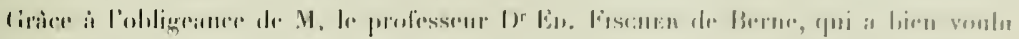

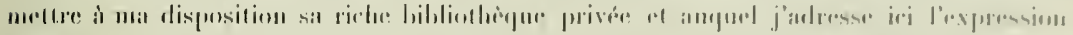

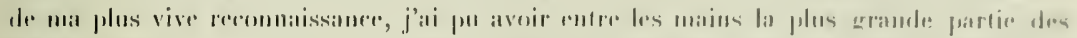

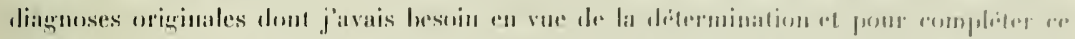

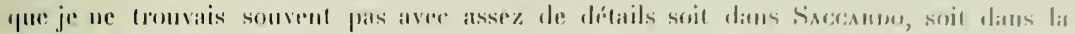

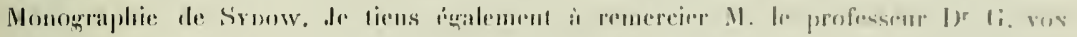

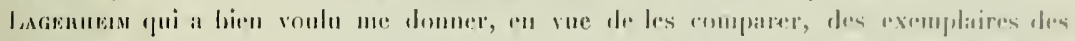

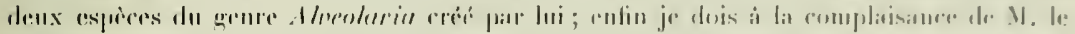

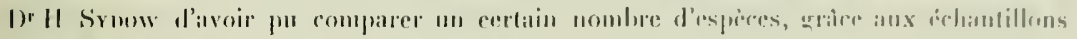
types qu'il a hien vemlu mellere iो ma disposition.

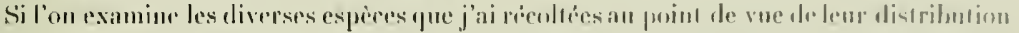

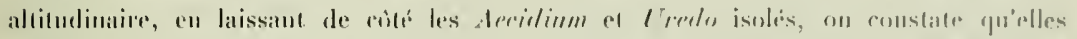

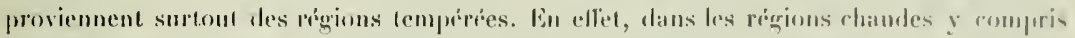

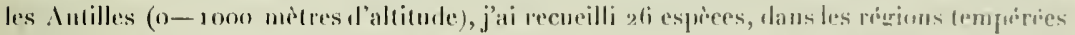

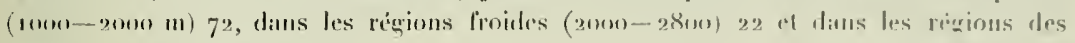

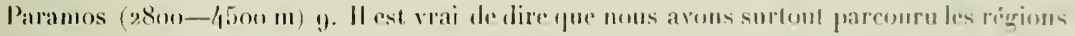
tempéries, ce qui expligue en parlie celle plus grande richesse, cepundant mìne en

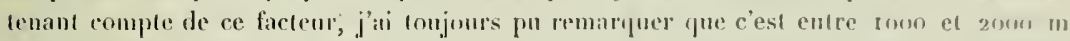

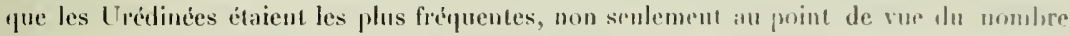

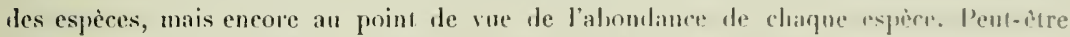
re fait lient-il aux conditions climateriques do res régroms infuitoriales.

Pour a qui eonerne le divelopprement de ces diverses espreses, si mous adoptosis la

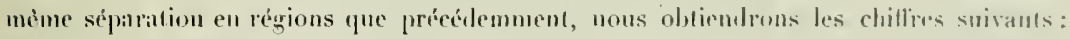
Dans les régions clrandes, j’ai observé 13 espèces dont le developlement est celui de lopplo

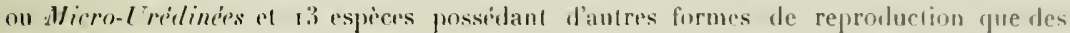

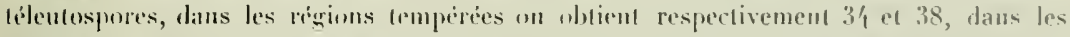

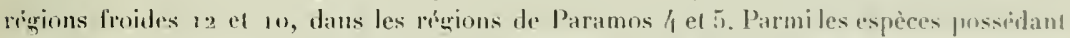
deux ou plusieurs appareils différents de reproduction. les plus mombreuses sont celles du type Ilemi-Urédinées (toules ou la plupall n'élaut trés proballement qure des formes

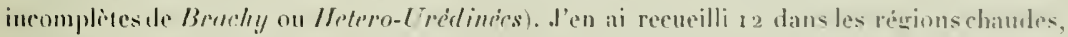
30 dans les régions tempréces, 6 dins les rínons froides el 3 dans les laramos: leespices ayant un antre développement sont, pour les memes régions, au nombre de 1 . 8,4 et 2.

La répartition des espèces d’après les diverses formations végétales est rendue difficile par le fait qu'un certain nombre d'entre elles se tromvent aussi bien dans les cultures que dans les haies ou à la lisière des forits. On remarquera toul dadord que je nai jais 
recueilli une soule Uredince dans la forid vierge, a qui sexplique assez bien lorsqu'on songe combien alle est inextricable. Dans les forcts pen thenses, ou la hade des bricherons a pénélué. j’ai ricolté 5 especes: lans les praries inctiles 10 ; daus les culures ou endroits cultivés 4o; an hord des clemins 22 ; dans les thaies el les laillis, a la lisiere des

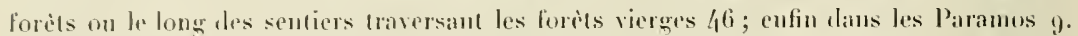

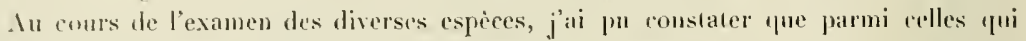

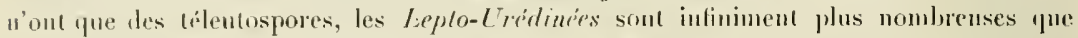

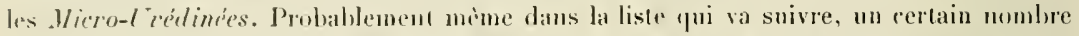

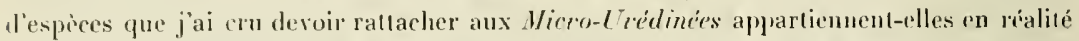
¿̀ des Rouilhes présentant le développement des lepto-L rédinées. Cluez les especes ayant. un dévelıppement autre que celui des Leplo-lićlines, j’ai souvent remarqué dans les préparations un grand nombre de télentospores gernćes on en pleine germination. Si je n'avais pas eu sur les mèmes feuilles el à côté dés anas de tíleutospores soil des ureclos, soit mène des aecilles, j’aurais pu me croire en présence d'une espèce ayant le développement d'um Leptr-Lrédince el penser que les aecidies at uredos appartenaient à me autre espioce. Celte olservation biologique fort intriressante a d’aillenrs déji élé mentionnée par nn certain nombre d'auteurs el trouve ici une nouvelle confirmation. Dans la liste 'jui va suive, on relèvera assez fréquemment cetle renarque vraisemblablement en relation avec les comlitions dans lesquelles se développent ces champignons daus les riggions équatoriales.

An point de rue biologique, j’ai pu faire' une intéressante constatation sur le développement de Cromarlium praelongum Wonter s'attaquant à divers Eupatorium. Cette espèce, en effet, présente sur le mème support phanéroganique des pycuides et des tíleutospores, ce qui, à ma connaissance du moins, n’a encore élé relevé sur aucune espèce de ce genre dont les aecidies se développent sur les Conifères. Il s'agirait donc daus notre cas d'une adaptation très intéressante et d'une nodification du cycle habiluel des Cironartinum. Ce changement si profond serait-il dì an fait que les Conifères font délaut dans tuutes les régions que j’ai parcournes? On serait tenté le le croire el ce serail lá somme tonte une explication tres plausible et en harmonie avec les olservations que j'ai en l'occasion de faire en cours de route.

Avant de donner la liste des espèces que j'ai recueillies en Colombie (y compris quelques-unes récoltées aux Antilles : Jamaïque, llaïli et Martinique), je tiens encore ì exprimer ma reconnaissance à $\mathrm{M}$. le $\mathrm{D}^{\mathrm{r}} \mathrm{W}$. Tranzscuel qui a bien voulu éludier el décrire le parasite de Euphorbil orbiculala (Uromyces Mayorii Tranzscuel). Je désire anssi remercier tout particulièrement M. le Dr P. Dietes, qui s'est chargé si aimalılement de l'étude et de la détermination des Urédinces recneillies sur les fougères [Uredinopsis macrosperma (CKE.) P. MAgN, Uredinopsis Mayoriana Dietel, Milesina Blechni Srw., Melesina Dennstaedtiae Dietel, Milesina columbiensis Dieté el Uredo Nephrolepidis Dietel], 'ainsi que du parasite de Lupinus spec. (Chrisocelis Lupini Lagerm, ét Diet.) Enfin j’exprime encore loute ma gralitude à M. le professeur Dr H. Scunz de Zurich qui, 


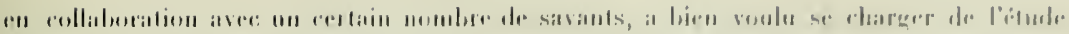

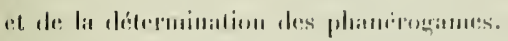

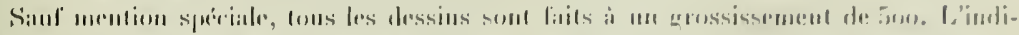

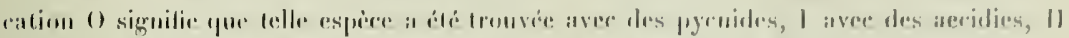
avere des amis d'uredos, 111 aver des amis de télouluspones.

Neuchitul, avril 1,)!.?.

\section{Genre Uromyces Link.}

\section{Uromyces Rynchosporae Ell.}

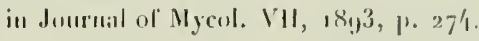

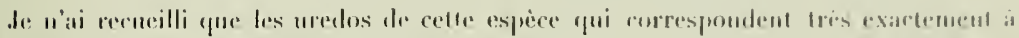

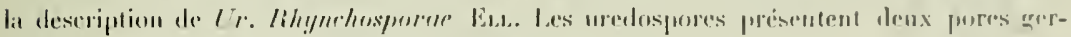

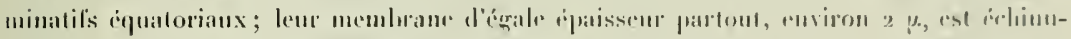

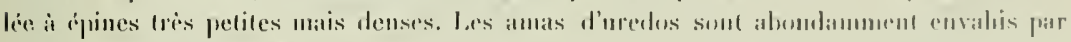
Darlunere filum (Bry.) Gast.

Sur feuilles de Rhynchospora cyperoides (Sw). . Мкт.

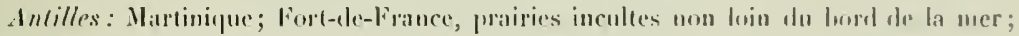
II. I1 novembre (11" 2).

\section{Uromyces antioquiensis spec. nov.}

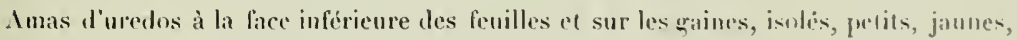
arondis et punctiformes, soit un peu allongés dans le sens de la longueur des fenilles et alors pouvint alleindre à peine $1 \mathrm{~mm}$ de Longueur, grinerilement nombrenx el parfois un pen confluents, ne faisant pas de tache i la surface des fenilles, longtemps recouverts par l'épiderme qui ne se fend que tris tardivement. - Tredospores arrondies, owirles ou oroides-elliptiques, hyalines on subhyalines, $21-2$ f $\mu$ de dianètre on $23-30 \% x$ 1 (i-23 $\mu$; membram mince, 1 y. d'epaisseur envirom, igale partout, finement echimber a épines petites et assez peu denses. La position ef le unmbre des pores grerminatifs nout pu ètre exactement déterminés.

Amas de télètospores ì la face inférieure des fenilles et sur les „raines, grénéralement nombrux mais isolés, pects, grossièrement arronelis et punctiformes ou un pen allongés, atteignant i peine $1 \mathrm{~mm}$ de longueur, pulvérulents, d'un brun-noir, très longtemps recouverts par l'épiderme qui ne se fend que tardivement. - Téleutospores ovoides ou oblon- 
gues ou whlongues-elliptiques, brun-clair, $18-26 \mu \times 12-16 \mu$, presque toujours attínúes à la hase el arrondies à l'extrémiti ou plus ou moins prointues; pore germinatif apical.
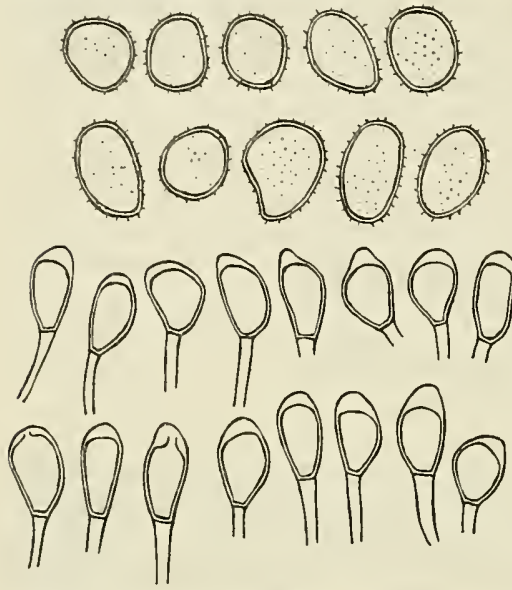

Figr. 1: Uromyces anlioquiensis. - Uredospores el téleutospores. Membrane lisse, mince, environ 1 u, épaissic i l'extrémité où elle peut avoir jusqu'à $5 \mu$ lorsque les spores sont arrondies et jusqu'à 7 \%. et rarement 9 p. quand clles sont poin. tues. Pélicelle persistant, faiblement coloré en jaune brunàtre près de l’insertion, jusqu’à $26 \mu$ de longueur sur 3-5 $\mu$ de largeur.

Soris uredosporiferis hypophyllis, sine maculis, sparsis, minulis. rolundulis et puncliformibus nel oblongis (nix I mm lony.), saepius numerosis sed raro prulo confluenlibus, diu epidermide lectis, tarde fissis, flavis. Uredosporis subglobosis, ovoideis wel moideo-ellipsoirleis, hyalinis nel subhyalinis, 21-2.9 p. dium. vel $23-30 \mu . \times 16-23 \mu ;$ membrana tenui, ca I p. erassa, minute salisque laxe echimulata. Soris telentosporiferis hiypopluyllis, numerosis, sparsis, minutis, rotundulis el puncliformibus, vel paulo oblongis (vix I mm loug.), alro-brumneis, pulvernlentis, din epidernide teelis, dein fissis. Telenlosporis ovoideis, oblongis vel oblongo-ellipsoideis, dilule brunneis, $18-26 \mu \times$ $12-16$ p., basi allenualis, apice rolundalis vel aculiusculis; poro germinativo apicali;

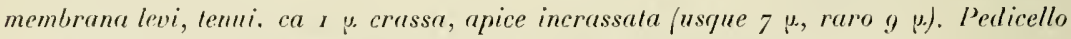
persistenti. in parle superiore flavobrumneolo, inferiore hyalino, usque 26 ". longo, $3-5$ u. lalo.

Sur feuilles de Rhynchospora polyphylla VAnL.

Anrles centrales, dép. Antioquia. Cultures au-dessous du Cafetal Lal Hermosit près Angelopolis, alt. environ $1400 \mathrm{~m}$; 11 et III. 2 septembre $\left(\begin{array}{ll}n^{\circ} & 261\end{array}\right)$.

Cette espèce est voisine de Uromyces Rhynchosporae Elz.; elle s'en distingue par l'aspect des uredos et par les uredospores passablement plus grandes et hyalines ou sublyyalines, ainsi que par la membrane très mince. L'asject des amas de téleutospores est aussi différent; les spores sont sensiblement plus petites et moins larges ; leur épaississement terminal atteint au maximum 5 et 9 y. alors que chez $L r$. Rhynchosporae il atteint 8-ro $\mu$. lorsque les spores sont à sommet arrondi et $10-16 \mu$ lorsqu'il est terminé en pointe. Ces dilférences sensibles et constantes justifient la création de cette nouvelle espèce dont le développement, pour le moment, est celni d'un Hemi-Uromyces. 


\section{Uromyces Scleriae P. Henn.}

ii Ilolw. XXXVIII, 18y, 1, liz.

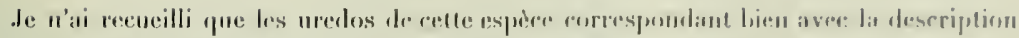

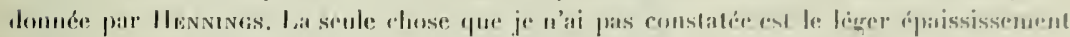

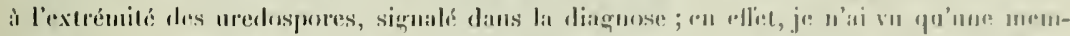

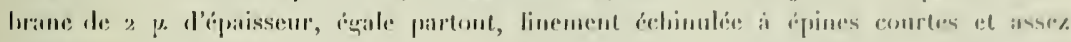

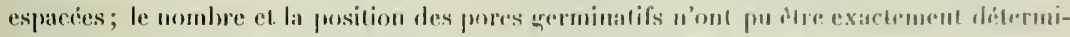

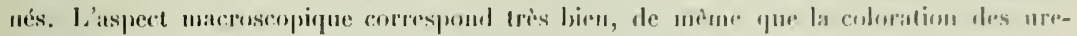

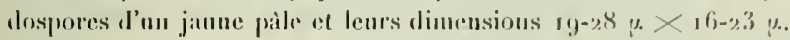

Sur feuilles de Scleria melaleuca Cin for Sicnu:ut.

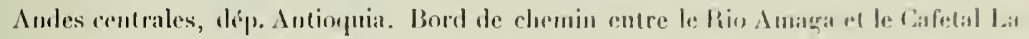
Hermosi pris Angelopolis, all, environ $1400 \mathrm{~m}$; II. Aont al september (110 28/).

\section{Uromyces Spegazzinii (de Toni) Arthur.}

$$
\text { in Bull. Torr. Bol. Cl. (1910) 1. i7.?. }
$$

To nai recueilli que les uredos de cette espece correspondint hien ì lit diagnuse de l'ancien Ureelo Spegazzinii de ToNr.

Sur fenilles de Commelina virginica L.

Antilles: Jamaïgne; lingston; II. 14 et sin juillat (n³ 3bif).

Sur Penilles de Commelina nudiflora 1.

Antilles: Janaïque; lingston; II. 14 at r 5 juillet (n” r fit).

Sur feuilles de Tradescentia multiflora Sw.

Andes centrales, lép. Intioquia. 11. Chemin de Cisneros ì Medellin, près de Yarumito, alt. $1340 \mathrm{~m}$. $1^{\mathrm{er}}$ aonit $\left(\mathrm{n}^{0},-8\right)$. - Cliemin de Merdellin it Bello, alt. $1550 \mathrm{~m} .4$ anut

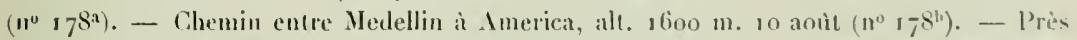

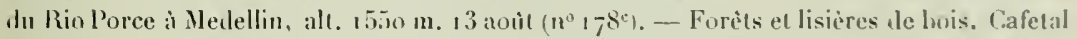
la Camelia près Angelopolis, alt. $1800 \mathrm{~m} .25$ aout $\left(n^{0}{ }_{7} 7^{8}\right)$ - Cultures, Cafetal la Mokil près Angelopolis alt. $1700 \mathrm{~m} .20$ aoilt $\left(\mathrm{n}^{\circ}, 7^{80}\right)$. - Bord de chemin à Giraca, alt. 14800.13 septembre $\left(11^{\circ}, 78^{\circ}\right)$.

Sur les ? supports phanirogramiques, les uredospores ont le minte aspect et les meimes dimensions ; leur membrane est d'egale épaissenr partout, environ 2 u: les spures nnt 2 pores germinatil's equatorianx. 


\section{Uromyces Smilacis spec. nov.}

Anas de téleutospores à lit face inférienre des lenilles, arroulis, petits, $1 / 4-1 / 2$ mm de diamètre, isolés, irrégulièrement disposés, dissíminés on an contratre nombreux ef rapprochés mais non conlluents, d'un hrun foncé ou noirs, nus, pulvérulents, ne fatsant

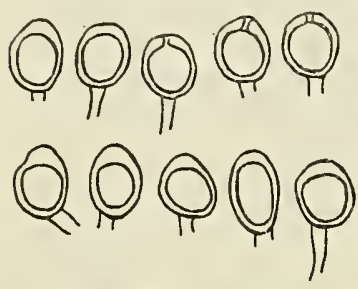

Fig. 2: Uromyces Smilacis. - Téleutospores. pas de taches spéciales à la surface des feuilles. - Télentospores arrondies, ovoiles ou parfois ovalaires, $18-23 \mu . \times 16-$ $19 \mu$, d'un brun foncé, arrondies aux deux extrémités; jore germinalif apical ; membrane lisse, $2.21 / 2 \mu$ d'épaisseur, rentlée ì son extrémité où elle peut atteindre jusqu'à $7 \mu$, souvent l'extrémité de ce rentlement terminal est colorée en brun plus clair. Pédicelle persistant, jusqu’à $45 \mu$ de longueur sur 4-5 $\mu$ de Jargeur, d'un brun pâle ou subliyalin à son extrémité supérieure puis devenant hyalin.

Soris telentosporiferis hypophyllis, minutis, rotundalis

$1 / \mathrm{r}^{-1 / 2}$ mm diam., sparsis vel numerosis et gregariis sed uon confluentibus, atro-brunneis vel atris, nudis, pulverulentis, sine maculis. Telentosporis globosis, subglobosis, ovoideis vel interdam ovatis, $18-2.3 \mu \times 16-19$ p., brunneis vel obscure brunneis, utrinque rotundatis: poro germinativo apicali; membrana levi, $2-21 / 2$. erassa, apice incrassatn usque 7 p., Pedicello persistenti, nsque 45 . longo, $4-5$ u. lato, hyalino-branneolo in parte superiore dein hyalino.

Sur feuilles de Smilax spec.

Andes centrales, dép. Antioquia. Le long de la voie ferrée entre Pnerto Berrio et Caracoli (ligue de Medellin), alt. environ $500 \mathrm{~m}$; III. 31 juillet ( $\left.\mathbf{n}^{\circ} 323\right)$.

Le développement de celte espèce semble être celui d'un Miero-Uromyces, car je n'ai pas vu de spores gernées ou en germination.

\section{Uromyces Phtirusae spec. nov.}

Amas de téleutospores à la face inférieure des fenilles, moins fréquemment à la face supérieure, sur les pétioles et sur les tigges, rarement isolés, presque tonjours réunis en nombre plus ou moins grand pour constituer des taches irrégulièrenent disposíes, le plus sonvent nombreuses et confluentes. Cies taches, sur les feuilles, sont arrondies et mesurent jusqu'à $7 \mathrm{~mm}$ de diamètre (le plus sonvent $3-5 \mathrm{~mm}$ de diamètre); sur les pétioles, sonvent entièrement envahis, les amas sont tous conlluents et forment une sorte de manchon de 1 a 2 cur de longuenr se prolongeant souvent sur la nervure médiane; sur les tiges, les amas sont soit isolís, soit au contraire conlluents et peuvent s'áteudre sur une longua ur de r à $1 \frac{1}{2} \mathrm{~cm}$. Sur les feuilles oì l’infection est de beaucoup la plus considérable. 


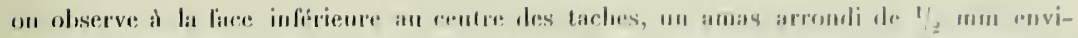

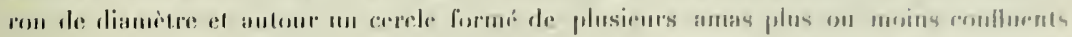

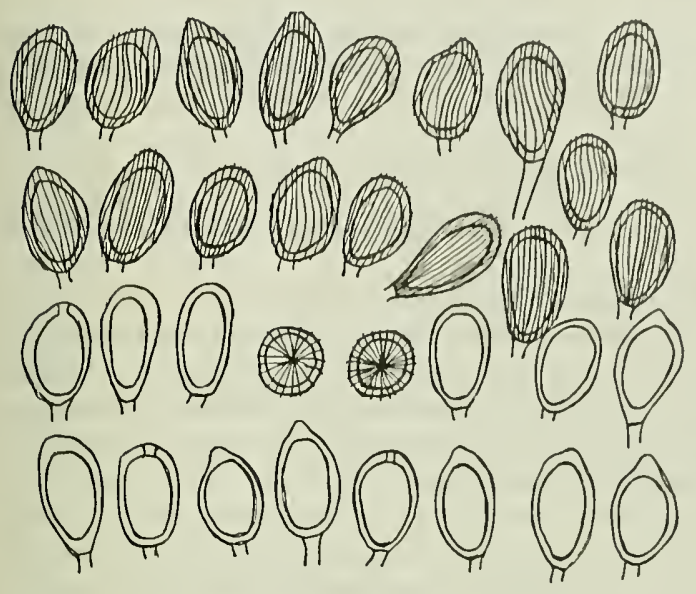

Fig. 3: Uromyces Phtirusae. - Téleulospores. soit arromblis, sonit, la plase

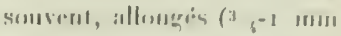

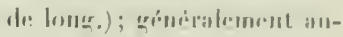

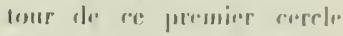

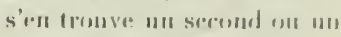
troisicme el parfois misme,

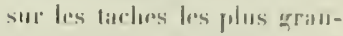

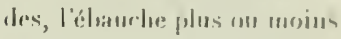
commplète d'un quatriomu ;

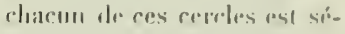
paré ra voisin par un pretir rspace no on voit le lissu da la feuille mortific al colores eu bruu. $A$ la fare supurienre des fenilles on correspundant aux aums de la fare infirieure, on vist des taches d'un brun foucé, formant une cronte par mortification

des tissus oì on remarque assez souvent quelques amas irrégulièrement disposés, pirfois aussi arrangés en cerdes. Les amas sont pulvérulents, conleur cannelle, d’ahurd reconverts par l'épiderme qui se fend de honne heure et leur forme un rehord apais al suréleve. Sur les pétioles el tiges, les amas sont confluents sans prísenter und organisation prarticulière. - Télentospores ovoüdes, oblongues on elliptiques, arrondies à lenr extriunité ou un peu terminćes en pointe, arrondies on parfois un peu atténuées ì la base. d'un jaune un peu brunàtre, $29-38, \ldots \times 16-22 \mu$; pore germinatif apical; membrane épaisse, de $2-3 \mu$, souvent renllée à l'extrémité où elle peut alteindre jusqu'à $7 \mu$; elle présente des stries longitudinales plus on moins nombreuses, sillantes al très visilutes, rarement anastomosées, souvent en forme de spirales. Les stries se voient surtont nettement sur les spores vues d'en haut et prentent un aspeet ladiaire. Pédicelle hyalin, raduc, court, jusqu'ì $19 \mu$ de longueur sur $2-4 \mu$ de largeur.

Sorris teleutosporiferis hypophyllis rurins epiphyllis, petiolicolis vel conlicolis, raro sparsis, fere semper gregariis et confluentibus, macnlis obscure brunneis ruriue magnitudinis insidentibus (in foliis rotundatis usenne $7 \mathrm{~mm}$ dirm.. in peliolis et nerris mesliis foliorum elongatis usque $1-2 \mathrm{~cm}$, in cuulibus usque $11_{2} \mathrm{~cm}$ longis): soris folicolis cirrinuto dispositis (1-4 circulis concentricis\%. rotundatis, ca 1/2 mun diam.. vel snepius oblongis ( $3 / 5^{-1}$ mm long.), puliemulentis, cinnamomeis, plus minusve eonfluentibus. primo epielermide tectis dein mo.r fissis et epridermide crussu cinctis: soris confuentibus sed 
non circinuto dispositis in petiolis cunlibustue. Teleutosporis onoideis. oblongis vel ellipsoideis. apice rotundulis nel aculiusculis, lusi rotundulis vel interdunm allematis, flaro-branneolis, $24-38 \mu \times 16-22 \mu$ : poro germinutiun upicali; membranu 2-3 $\mu$. crassa, suepe sed non semper apice incrussulu usyue 7 u. longitudinaliter striatis, striis plus minusuenumerosis, praeeminentibus, saepe spirneformilus. Pedierllo hyalino, deciduo, usque 19 e longo el $2-4 \mu$ lulo.

Sur feuilles, pétioles el liges de Phtirusa pyrifolia (11. B. K.) Eıcııen.

Andes centrales, dép. Antioquia. Cafelal La Cantelia près Angelopolis, alt. 1800 11 ; 111. 24 aonit (n० 1 (bi)).

Celte espece diffëre de Ur. circumscriplus Neger, par le manque d'aecidies qu'ou Irouve fréquemment autour des amas de téleutospores; les amas de téleutospores n'ont pas cette organisation tres nette en cercles concentriques et ont une autre coloration; les téleutuspores sont à peine épaissies à l'extrémité, leur membrane présente des verrues rangies longitudinalement mais pas les stries nettes, nombreuses et spiralées de notré espicere, en outre, la membrane est plus épaisse $\left(2^{1} / 2^{-4} \mu\right)$. Lr. Urbanianus P. Hens. possède des aecidies; les amas de téleutospores ne sont pas organisés en cercles concentriques et ont une couleur différente; les télentospores sont très sensiblement plus longues et un peu plus étroites, leur membrane n'est qu'à peine épaissie à l'extrémité, n'alteignant pas jusqu'i $7 \mu$ d'épaisseur comme c'est le cas dans notre espèce ; enfin la struclure de la membrane est dilférente, ear au lieu des stries longiludinales et souvent spiralées, la diagnose indique pour les deux Uromyces ci-dessus "verrucis longitudinaliter dispositis dense obsitis». En outre le dessin que donne SYDow de Ur. circumseriplns, espèce très voisine de Ur. Urbunianus (Sydow. Mon. Ured. II, p. 249, Tah. IX, fig. 122), ne correspond en ancune manière à l’inage que donne l'espèce se développant sur Phtirusa pyrifolia, ce que j’ai encore pu confirmer en comparant des échantillons de $U_{r}$ r. circumscriptus sur Loranthus verlicillatus. Le développenent de cette espèce semble ètre celui d'un Micro-Uromyces, car je n'ai pas couslaté la présence de spores germées ou eı germination.

\section{Uromyces Iresines Lagh.}

in Syd. Mon. Ured. II, P. 227.

Les exemplaires recueillis en Colombie correspondent bien avec la description de LagernerM sur Iresine spec. récolté dans l'Ĺquateur.

Amas de téleutospores à la face inférieure des feuilles, réunis en nombre plus on moins considérable pour former des tackes arrondies pouvant atteindre jusqu'a $5 \mathrm{~mm}$ de diamètre, irrégulièrement disposées, isolées ou un peu conlluentes lorsque l'iul'ection est 


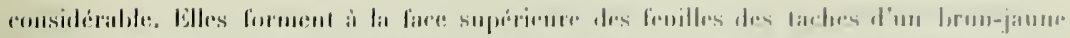

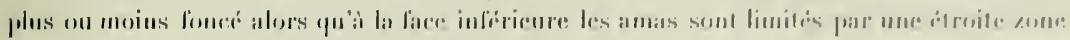

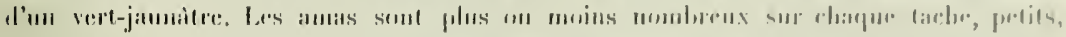

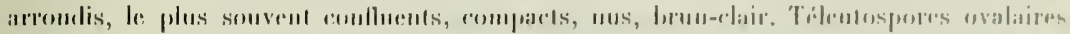

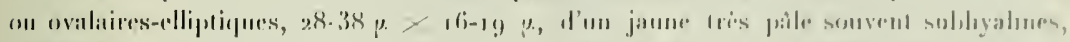

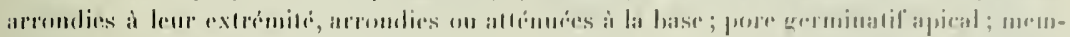

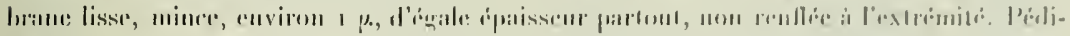

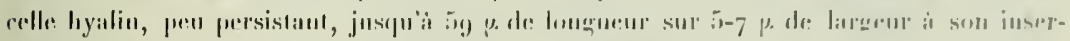

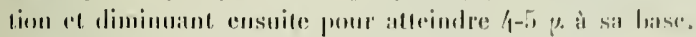

Siur firuilles de: Iresine paniculata (L) 1). liusta..

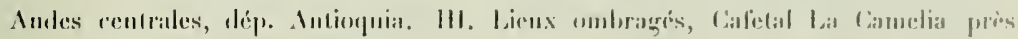

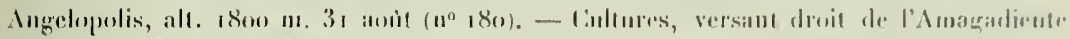

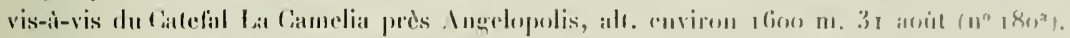

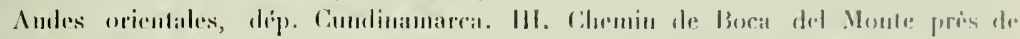

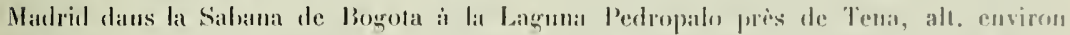

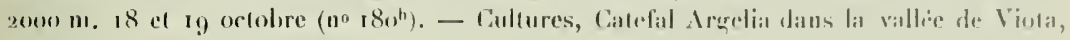

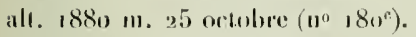

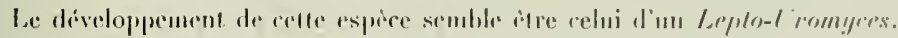

\section{Uromyces Lagerheimii P. Magn.}

iu Ber. Deutsch. Bot. Cies. .11, 18!y, 1, :377.

Amas de téleutospores in ha fare inférienre des feuilles, parfois sur les prefinles el sur les tiges. Sur lesfiulles ils sont réunis en petit nombre prour former des laches arromdies de 1 mm de dianètre, disséminces, isolées el non confluentes, ne faisant ancume lache ì la face supérienre des feuilles, sauf parfois une vague teinte d'un lorun plus ou menins

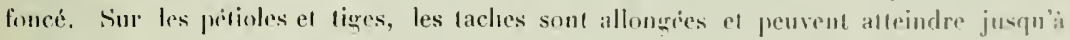
/ mm de lomgueur. Les amas sont petits, arrondis, compacts, souvent plus ou moins conflumls sur les taches, assez longlemps recouverts par l'épiderme, d'un jaune clair. - Teiteulospores elliptiques-allongies, 33-42 $\mu>$ i $4-17 \mu$, hyalines, arrondies on un peu coniques à leur "xlrémili, allémuces a leur hase; pore germinatif apical; membrane lisse, mince, ì peine I $\mu$,

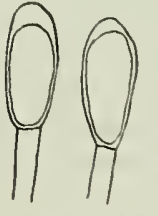

Fig. 1 : Lromyces Lałerheimii. - Téleulospores sur liubus
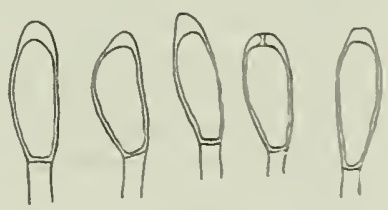

épaissie à son extrémité où elle peul attemble jusıu’i $6 \mu$. Pidicelle hyalin, pen persistant. jusqu'ì $20 \mu$ de longueur sur $\bar{j}-7 \mu$ de largeur à son insertion. - Lredosperes mé- 


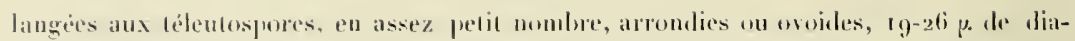
mètre, lỵalines ; memhrane environ 2 p. d'épaisseur, égale partout, échimulo-verrnquense.

Sirr feuilles de Rubus glaucus BentiI.

Andes centraless, déjs. Tolima. Bord de clemin pries de Soledad, alt. conviron $2200 \mathrm{~m}$; 11 el 111.6 actobre $\left(11^{\circ} 101\right)$.

Sur linilles de Rubus spec.

Andes centrales, dép. Antioquia. Taillis près de la Laguna an-dessus de Medelliu, ilt. $2300 \mathrm{~m} ; 11$ et 111.8 aout $\left(\mathrm{n}^{\circ} 30 \mathrm{2}\right)$.

La description ci-dessus correspond avec la diagnose de Magus, mais présente cependant juelques petites diflérences. Les amas de líteutospores ne sont pas isolés et irrégulierement dispersis à la surface des feuilles, mais sont réunis en petit nombre pour former de pelites taches. Les dimensions des téleutuspores correspondentà celles de $\mathrm{Ur}$. Lagerheimii ; seul l'ápraississement terminal alteignant jusqu’a $6 \mu$ sur Rubus glancus semble plus accentué. Ces différences ne me semblent pas suftisantes pour justifier la créalion d'une nouvelle espèce et jusqu'à plus ample inlormé, je ferai rentrer les échantillous colombiens dans $Z r$. Lagerheimii. Celte espèce présente le développement d'un IIemiTromyces dont les táleutospores germent immédiatement, car j’ai olsservé de nombreuses spores germées ou en gुermination.

\section{Uromyces cundinamarcensis spec. nov.}

Amas d'uredos à la face supérieure des feuilles, réunis en petit nombre pour former des taches arrondies ayant en moyenne $\mathrm{I}$ mm de diamètre, sans coloration particulière des tissus foliacés; ces taches sont plus ou moins abondantes, irrégulièrement disposées, isolées et non conflnentes. Les amas, parfois un peu conlluents, sont circulaires ou un peu allongés, petits, organisés en un cercle d'un jaune clair, rapidement nus et entonrés d'un rebord cpidermique assez mince. - Uredospores arrondies ou le plus souvent ovalaires, ovoides ou elliptiques, $23-31 \mu . \times 18-23 \mu$, hyalines ou subliyalines d'un jaune excessivetnent pàle; membrane d'égale épaisseur partoul, 2-3 $\mu$, fortement verruqueuse à verrues grosses el denses. Le nombre et la position des pores germinatifs n’ont pu être exactement déterminés.

Amas de téleutospores à la face inférieure des feuilles, rarement quelques-uns disséminés à la face supérieure, plus ou moins nombreux et abondants, isolés, non confluents, ne faisant pas de taches particulières à la face supérieure des feuilles, irrégulièrement disposés, petits, o,5-1 mın de diamètre, grossièrement arrondis, d'alord recouverts par l'épi- 


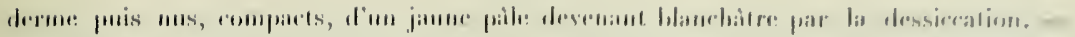

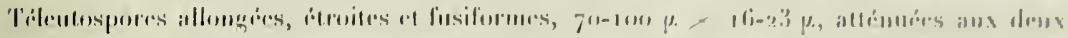

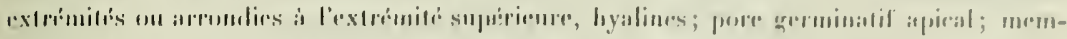

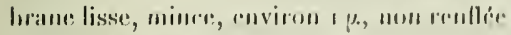

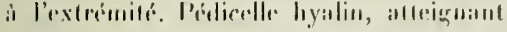

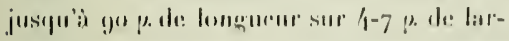

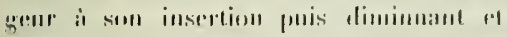

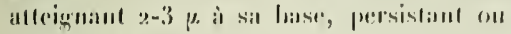
pen pretsistant.

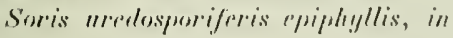

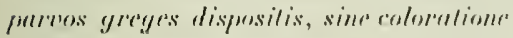

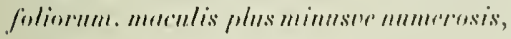

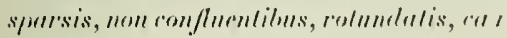
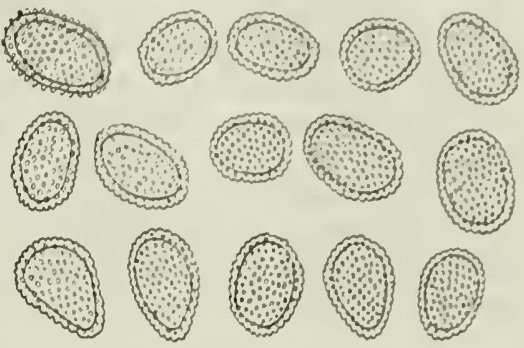

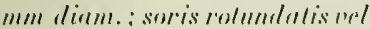
pertum oblong is, cirrinaten dispositis, minutis, inlerdmm pusrume ronfluenlitus, flumidlis, primos lectis drin epralermide cinclis. Utrelosporis subglerbosis wel suepins and is welonoidris rel ellipsoideis, 23-31 u. $\times 18-2.3 \mu$, hyalimis bel sul,-

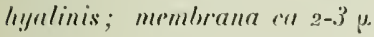
crussen, dense grosseryur verrucosa. Soris telnutosporiferis lyppophyllis raro epiphyllis, plus minusue numerosis, sparsis, sine maculis, minnlis. rolumdalis, o. 5-1 mm diam., mox nurlis, compactis, flavescentibus dein albescentibus. Teleulosporis elongalis, anguslis, fusiformibus, $70-$ $100 \mu \times 16-23 \mu$, hyalinis, ulrinque allennatis vel upice rolundulis: poro germinulivo apicali: membrana levi, lenui, ra I y crassa, apice non inerassata. Pedicello hyalino, persistenti vel parum

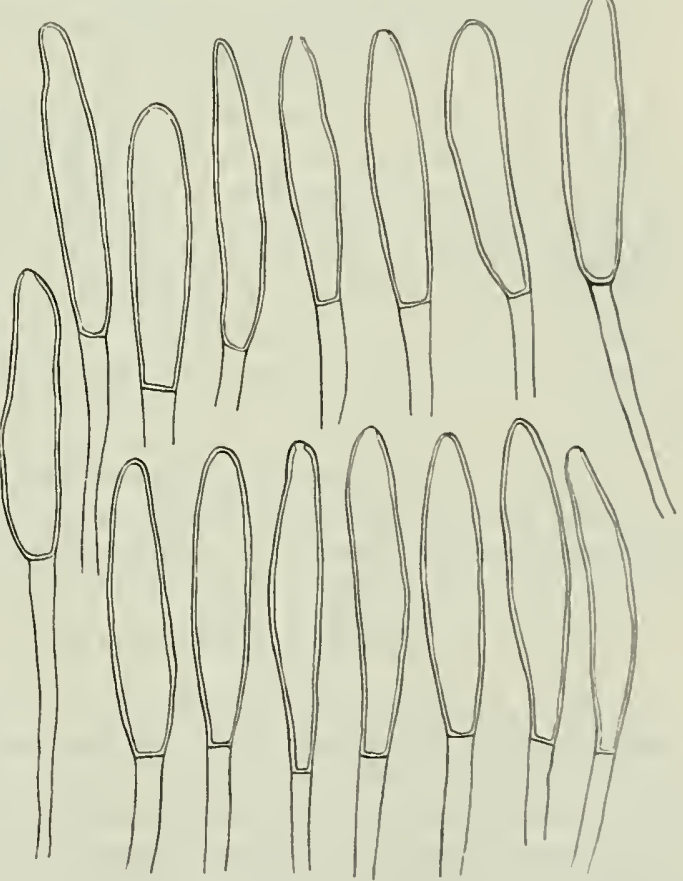

Fig. 5 : Uromyces cundinamarcensis - Lretospores et téleutospores. 
persistemli, nsune go jo. Iongo. 4-j $\mu$ lato in parte superiore deorsum diminuanli el husi $2-3$ y...

Sur feuilles de Rubus peruvianus Fritscu.

Audes orientales, dép. Cundinamarca. Versant oriental du Paramo Cruz Verde audessus de Bogota, alt. environ $3000 \mathrm{~m}$; 11. et 111.14 et 15 octobre ( $\left.\mathrm{n}^{0} \times 05\right)$.

Celte espèce se rapproche de $U r$. Piltierianus 1 ?. Hexn. dont elle se distingue lacilement par ses téleutospores beaucoup plus grandes atteignant el pouvant mème parfois lépasser 100 u de longueur, généralement plus étroites car elles ont en moyenne de $15-19 \mu$. le largeur et assez rarement jusqu'i $23 \mu$; les uredospores différent aussi par leur aspect et surtout par leurs dimensions. Le développenent de celte espèce est celui d'un Hemi-l Tromyces dont les téleutospores germent de suite, ear j'ai rencontré dans les préparations de nombreux téleutospores déjà germés.

\section{Uromyces Loesenerianus (P. Henn.) Syd. \\ in Mon. Ured. 11, 1. 202}

Je n’ai rencontré que les uredos de cette espèce faisant de grosses galles sur les tiges; elles atteignent jusqu'à $31 / 2 \mathrm{~cm}$ de largeur sur $2 \mathrm{~cm}$ d'ápaisseur et attirent de loin l'attention grâce à leur couleur d'un jaune clair produite par la poussière des spores qui se répand sur tonte leur surface; elles sont arrondies, à surface irrégulière ou plus ou moins manelonnée ou crevassée. Les uredospores sont oblongues, ovalaires ou elleptiques d'un jaune très pàle, à membrane épaisse présentant une structure très particulière. On constate en effel des stries longitudinales épaisses, spiralées ou parfois plus ou moins transversales, en nombre plus ou moins grand, fortement proéminentes à la surface. Sur les feuilles je n’ai rencontré ni uredos, ni amas de téleutospores.

\section{Sur tigres de Rubus urticifolius Porn.}

Andes centrales, dép. Antioquia. Taillis près du village de Filadelfia, alt. environ $1500 \mathrm{~m}$; Il. I octobre $\left(11^{0} 107\right)$. - Haies à Nanizales, alt. $2130 \mathrm{~m}$; 11.2 oct. $\left(11^{0} 107^{\mathrm{i}}\right)$.

\section{Uromyces Rubi-urticifolii spec. nov.}

Amas de téleutospores rares et disséminés à la face supérieure des feuilles, très nomhreux à la face inférieure on ils sont réunis en nombre plus ou moins grand pour former des taclies arrondies d'un jaune-brun, débordant largement la zone des amas et pouvant atteindre jusqu'à 1 et $\mathrm{r}, 5 \mathrm{~cm}$ de diamètre. Lorsque l'infection est considérable, ces taches peuvent devenir confluentes, mais le plus souvent elles ont 5-10 mn de diamètre, sont peu nombreuses, isolées et irrégulièrement disposées. Les amas sont surtout le long des petites nervures, petits, arrondis et nombreux, nus de bonne heure, un 


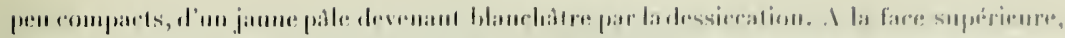

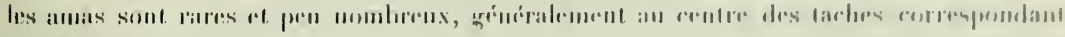

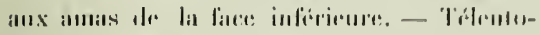

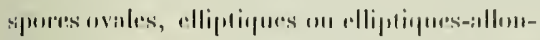

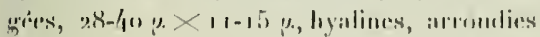

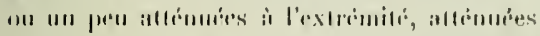

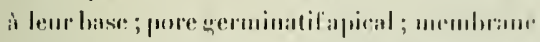

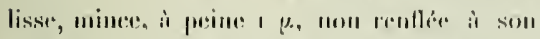

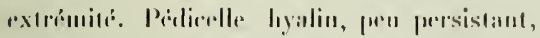

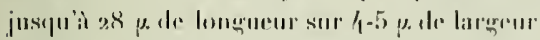
it son insertion.

Soris telentonsoriferis leypoplyyllis, raro eprohyllis, pless mimusere grergarris, macen-

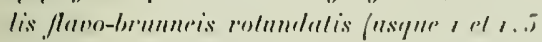
ane dium.) plers minnsne numerosis intepdam confluentilus insidentiluss, prearevipue nernicolis, minntis, rolundelis, numeressis, mon"

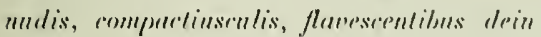
albescrulibus. Trelentospor is ovatis, ellipsoi-

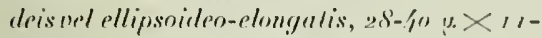
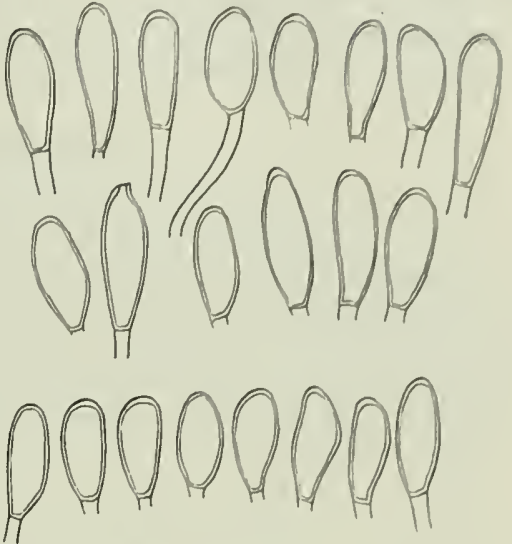

liig. 6: Lromyces Mubi-urticifolii. - Tëleutospureg sur Kubus urlicifolius.

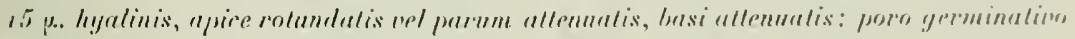

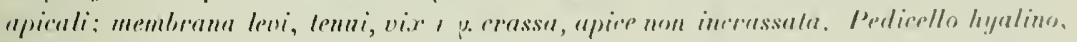

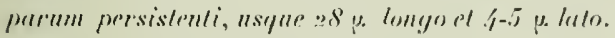

Sur leuilles de Rubus urticifolius Ponn.

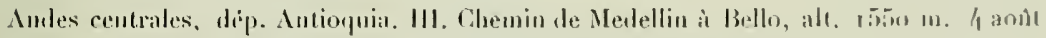

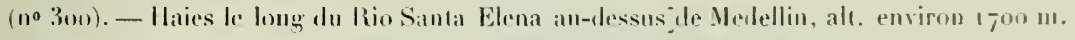
(i aoult $\left(1^{\circ} 300^{\mathrm{a}}\right)$. - Itaies, Cafetal La Camelia pries Ingelupolis, alt. 1800 m. 21 amil ( $\left.1^{\circ} 30.3\right)$. - Chemin de Titiribian borel du Canca, alt. environ $1500 \mathrm{~m} .8$ septembre

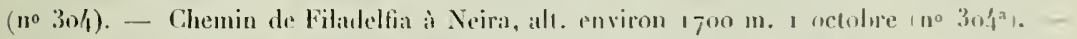
Dép. Tolima, Pres du village de Fresun sur le Chemin de Maripuila, alt. environ rqum m. 9) octobere (11" 30 q $\left.^{\prime \prime}\right)$.

\section{Sur fenilles de Rubus spec.}

Andes rentrales, dip. Antioquia. III. Colline au-dessus de Imerica prés de Medellin. alt. environ $1700 \mathrm{~m}$. 15ituth (no $300^{\mathrm{b}}$ ).

Celte espice se distingue de $T r$. Lnesenerinms (11. Hexs.) Sun. par le fail que les amas petils, nombreux et rapproches sur de grandes laches de 1-1,5 cm de diamétre se

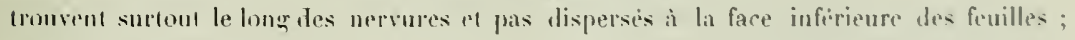

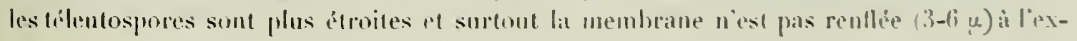


trémité des spores. Elle se rapproche de $T r$. quitensis lagu dout les amas de télentospores sont égalenent surtout sur les nervures de la face inférieure des feuilles, mais ont un autre aspect; elle en differe en outre par la formedes téleutospores el surtout par lenrs limensions beacoup plus petites $(28-40 \mu \times 11-15 \mu$ el jomais $4(1-70 \mu .<1 / 4-15 \mu)$. I. diveloprement de rette espece semble dtre celui d'un Lepto-l'romgres.

\section{Uromyces quitensis Lagh.}

in Bull. Soc. Myc. Frince NI, $1895,1,213$.

Amas d'uredos à la face supérieure des fenilles, quénéralement en petit nombre an centre de taches arronties d'un jaune brun un peu rougeatre pouvant alleindre jusqu'ì $7 \mathrm{~mm}$ de diamitre; ces taches sont en plus ou moins grand nombre, isolées on 1 !n peu conlluentes, irrégulièrement disposées. Les amas sont petits, grossìrenent arroudis, isolés ou rarement un peu confluents, longtemps recouverts par un épiderme épais colort' en jaune brun. - Uredospores arrondies, ovalaires on elliptiques, $21-33 \mu . \times$

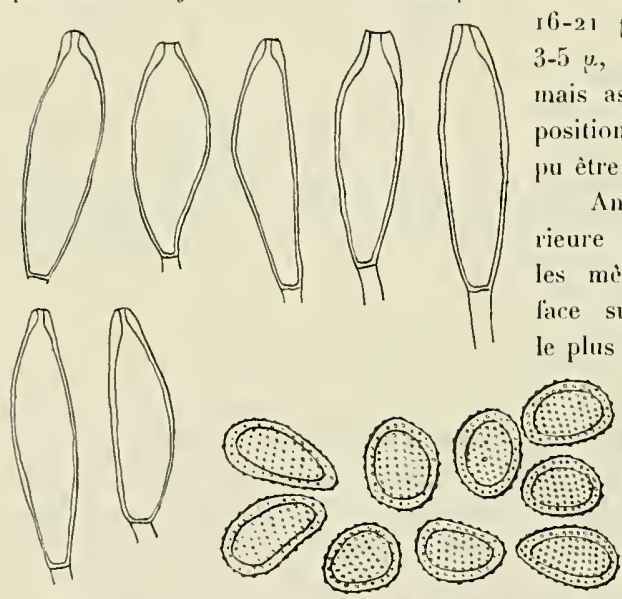

Fig. 7 : Uromyces quitensis. - Uredospores et téleutospores sur Rubus spec. $\left(\mathrm{n}^{0} \mathrm{3} 0 \mathrm{l}^{\circ}\right)$. r6-21 $\mu$, hyalines; membrane épaisse de $3-5$ u, verruqueuse ì verrues assez grosses mais assez peu denses; le nombre et la position des pores germinalifs n'ont pas ètre exactement déterminés.

Amas de téleutospores à la face inféieure des feuilles et généralement sur es mèmes laches que les uredos de la lace supérieure, irrégulièrement disposés, e plus sonvent le long des nervures, isolés ou rapprochés et un pen conlluents; ils sont petits, arrondis, assez longtemps recouverts par l'épiderme puis nus, un peu compacts, d'uu jaune pàle devenant blanchâtre par la dessiccation. - Téleutospores fusiformes, atténuces aux deux extrémités, hyalines, $50-75 \mu \times 18-2 / \mu$; membrane lisse, mince, à peine $1 \mu$, un peu épaisse ì son extrémité (2-3 u.); pore ggerminatil apical. Pédicelte hyalin, peu persistant, jusquà so $\mu$ de longueur sur $4-7$ de largeur à son insertion.

Sur feuilles de Rubus spec.

Andes orientales, dep. Condinamarca. Chemin entre Ubaque et le Paramo Cruz

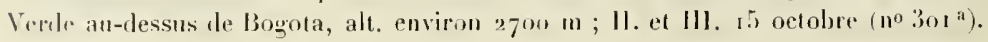


Sur lenilles de: Rubus speer.

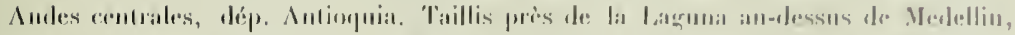

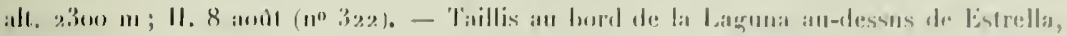
alt. $2500 \mathrm{III}$; II. 18 a010) (100.322").

Siur linilles de: Rubus spec.

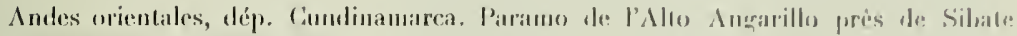

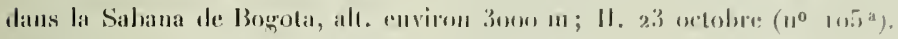

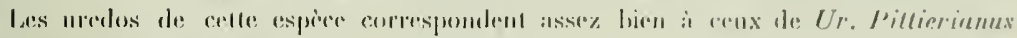

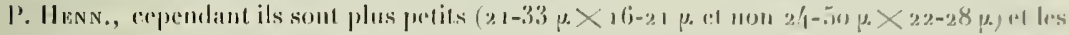

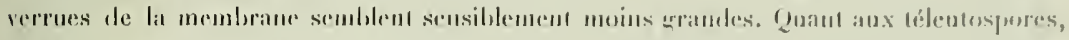

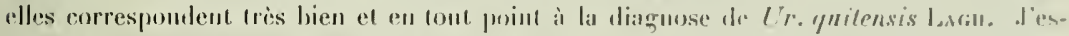

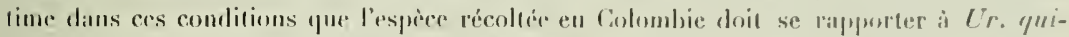
tensis qui anrail le développenent d'un /lemi-l romyers. Les léleutuspores ond dit tries

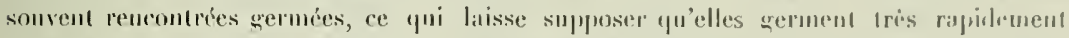
sans périole de repos ou an moins après un très court limps de repus.

Sur les $1^{\circ} .322$ el $322^{a}$, les uredus ont le mème ispect que sur le $n^{\circ} 301^{\text {a }}$ at j'entime qu'on doit les réunir. Sur le $0^{0} 1 w^{2}$, les uredos sont semblables au point de vue microscopique à ceux do $301^{\text {a }}$; par contre, an point de vue macroscopique, ils sont un peu différents daus ce sens quou les rencontre plus souvent ì la face inférienre qu'à la face supérieure des fenilles el presque toujours le long des nervares oú ils sont en grand nombre. Sur les $n^{0} 322,322^{a}$ et $105^{\mathrm{a}}$, je u'ai pas pu observer de téleutospores, mais comme les uredos sont très semblables les uns aux antres, jusqu'à plus ample informé, je le's rimuis à $L r$. quilensis.

\section{Uromyces variabilis spec. nov.}

Lmas d'uredos à la face supérieure des feuilles, rarement à la face inférienre. réunis en nombre plus ou moins considérable pour former des taches arrondies, attei„quant jusqu'à $6 \mathrm{~mm}$ de diamètre, peu nombrenses, isolies, irrigulièrement disprosées, parfois un peu conlluentes. Au centre des taches d'un brun plus ou moins foncé sont les amas irrégulièrement arrondis on un pen allongés, gínéralement contluents, d'abord recouverts par' l'épiderme, puis fendıs, d’un jaune chair devenant hauchâtre par la dessiccation. - Uredospores arrondies, ou le plus souvent ovoïdes, ovales on elliptiques, $21-35 \mu$ (rament jusquì 40 $\mu$ ) $\times 17-24 \mu$, lyalines; membrane environ $2 \mu$, d'érale épaisseur partout, non renllée à l'extrémité, verrutgueuse à verrues assez petites el assez peu denses. La position et le mombre des pores germinatifs n'ont pu stre exactement déterminés. 
Amas de tíleutospores à la face inférieure des ferilles, plus ou moins abondants, irrégutièrenent disposés, isolés, non contluents, petils, punctiformes, compacts, nus de très
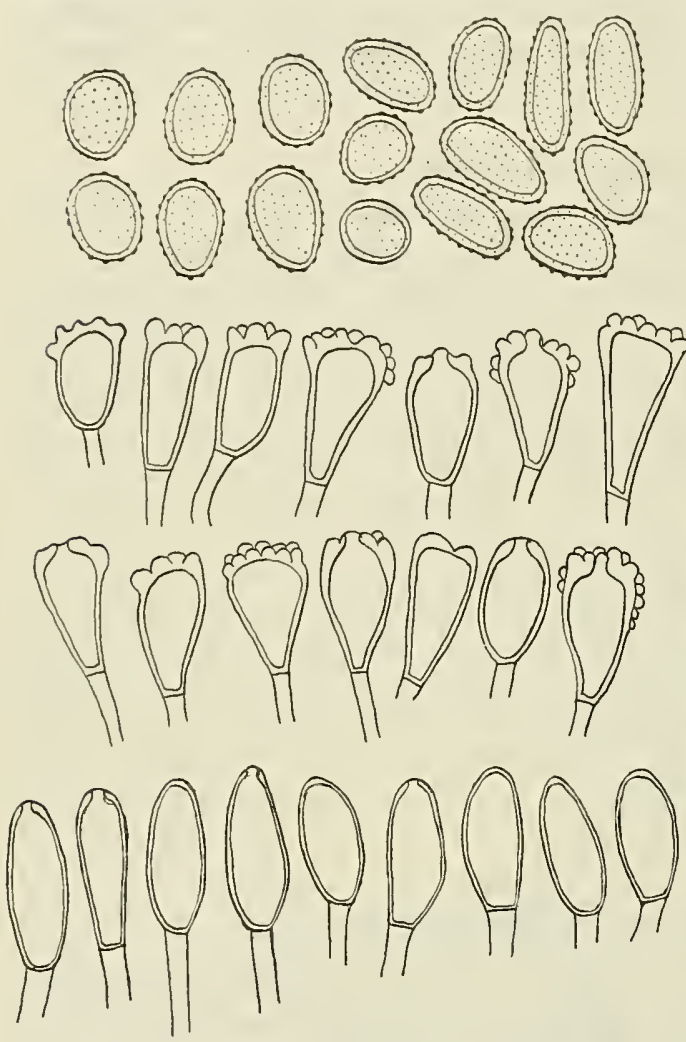

Fig. 8: Uromyces variabilis. - Uredospores et léleutospores (Téleutospores lisses el lobulées à leur extrémilé supérieure). honne leare, ne se manifestunt par aucune tache, gris-jaunàtre ou grisbrunâtre. - Les téleutospores dinns les amas se présentent sous deux aspects très différents qui, i premiere vue, liaisseratient sujposer qu'on est en présence do deux espèces différentes. $1^{\circ}$ Téleutospores oblongues ou elliptiques, $39-50 \mu . \times 1 / 4-20 \mu$. d'un brun paile et souvent subhyalines ou liyalines à la base, arrondies ì leur's deux extrémités, or un peu atténuées à la base; pore germinatif apical; membrane lisse, mince, environ i $\mu$, un peu renflée et encore pas toujours à l'extrémité oì elle ne dépasse pas $3 \mu$. Pédicelle hyalin, persistant, jusqu'à $25 \mu$. de longueur sur 5-7 $\mu$ de largeur à son insertion. $-2^{\circ}$ Téleutospores ovales, pyriformes ou en forme de coin, 35-52 $\mu$ de longueur sur $18-26 \mu$ de largeur ì leur partie supérieure et $12-15 \mu$ dans leur moitié inférieure, d'un brun pâle, atténuées à leur base ou plus rarement arrondies, rarement arrondies à leur extrémité, le plus souvent élargies et plus ou moins tronquées,

présentant des lobulations en nombre variable (jusqu'ì to et davantage, rarement aucune); ces lobulations sont arrondies et atteignent jusqu'à $4 \mu$ de hauteur sur tout autant de largeur; pore germinatifapical; membrane lisse, sauf à son extrémité où elle présente ces lobulations, I $1 / 2^{-2} \mu$ d'épaisseur, renfléc à l'extrémité où elle atteint jusqu'à $7 \mu$. P'édicille hyalin, persistant, jusqu'à $30 \mu$ de longueur sur 5-7 $\mu$ de largeur.

Soris uredosporiferis epiphyllis, raro hypophyllis, gregariis, maculis rotundatis (usque $6 \mathrm{~mm}$ diam.) brunneis vel fuscis sparsis insidentibus; soris in centro macula- 


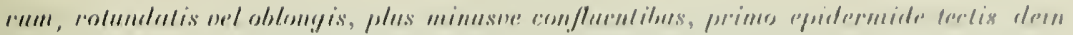

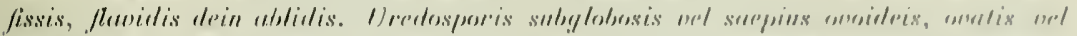

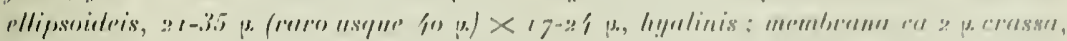

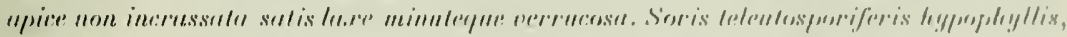

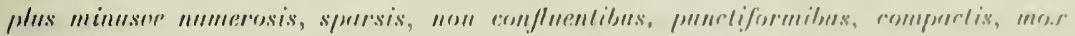

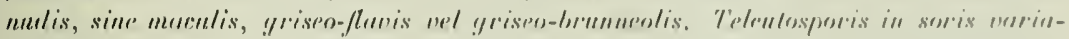

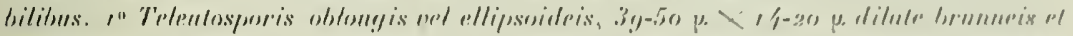

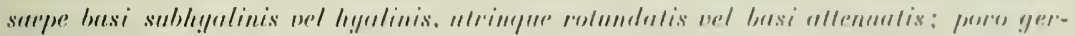

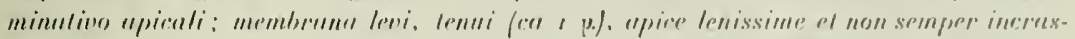

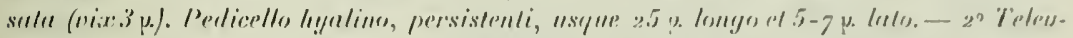

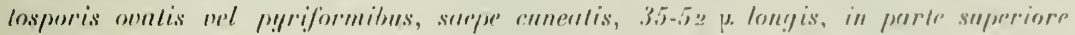

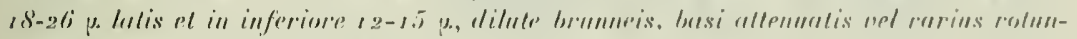

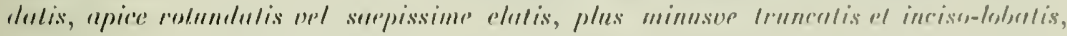

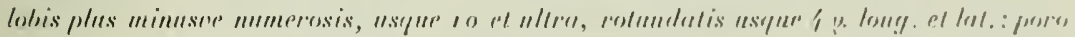

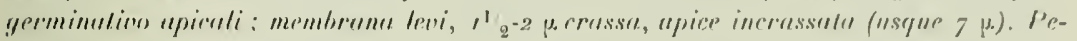
dicello hyalino, persistenti, usqune 3o p. longo el 5 -7 p. lulo.

Sur feuilles de Rubus spec.

Andes orientales, dép. Cundinamarciı. Taillis, pente du Montserrate an-dessus de Bogota, alt. environ $2900 \mathrm{~m}$; II et 111 . 16 octolore (n"301).

Celle esprece est voisine de $/{ }^{\top} r$. Arthuri Sro. dont elle se distingue facilement par f'aspect des uredospores qui sont plus grandes, it membrame mince el irgale partumt sans renflement à l'extrémiĺ. D'après Sinow, les ureduspores rappelleraient celles de $T r$. Loeseneriumns (P. Itens.) Syu., ce qui n'est absolument pas le cas chez notre espèce. Les amas de téleutospores chez Ur. urirubilis sont punctiformes, franchement compacts el de couleur différentr; la présence de ces denx sortes de téleutospores si différentes est très caractéristique et ne se retrouve pas dans la diagnose de Lre Arlhuri. En outre les spores sont passablement plus longues mais moins barges chez les spores lobulies tant dans leur parlie supérieure qu’a lenr partie inférieure. Les deux formes de tilleutospores sont colories en brun pale et ne sont pas hyalines ou subhyalines. Le déseloppenent de celle esprece est celui d'un Ilemi-Lromyces dont les téleutospores germent immidiatement on apré un très court lemps de repos, car j’ai constati la présence de nombrenses spores germées.

\section{Uromyces porcensis spec. nov.}

Amas de téleutospores sur les deux faces des feuilles, assez rares à la face supérieure, formant des taches arrondies de $1-3 \mathrm{~mm}$ de diamire ou un pell allongées for:qu'elles sont sur les mervures, jusifu'à 5 et $f$ mm de longueur: elles sont irrégulièrement disposées, souvent nombreuses mais non confluentes. de couleur brun foncé el entourées 
d'une zone de 2-4 nm d'épraisseur ò̀ le tissu foliacé prend une coloration vert-jaunature ou jaume-brunitre. Les amas toujours plus ou moins confluents oceupent le pourtour des taches, tant à la face inférieure qu’ì la lace supérieure; an centre sont les pycnides en nombe plus on moins considérable, se manifestant sons l'aspect de petits points d'un brun assez foncé, sur les denx faces des fenilles mais surtout sur la supériemre. Ies amas de télentospores sont petits, pulvérulents, grossièrement arrondis ou de beancoup le plus souvent allonges, bruns, d'alhord recouverts par l'épiderme qui éclate de honne heure en leur filisant un rehord d'un brun plus clair que les spores. - Les pyenides, vues en

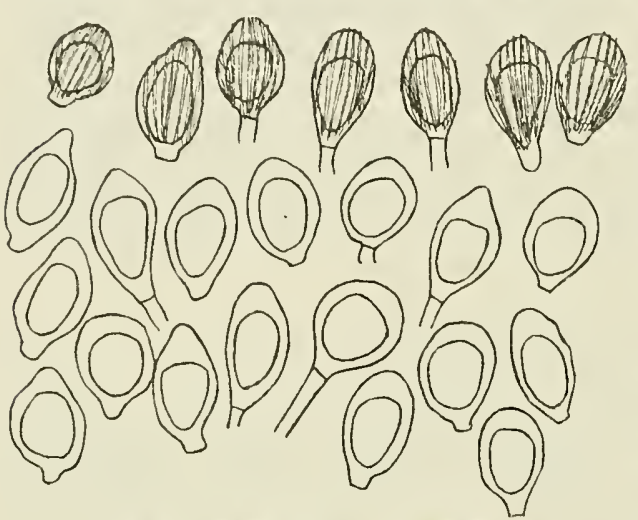

Fig. 9: Uromyces porcensis, - Tèleutospores. coupe, ont une coloration jannebrunàtre. - Téleutospores de forme assez irréguliire, ovoütes, oblongues ou oblongues - clliptiques, le plus souvent brusquement atténucies près de l'insertion du pédicelle, arrondies ou souvent coniques ou un peu pointues à leur extrémité; elles sont de couleur jaune-brunattre, un pen plus fortement colorées à leur extrémité toujours épaissie; elles mesurent $26-42 \mu \times 18-23 \mu$. Le pore germinatif n'a pas puêtre distingué. La membrane est épaisse, $3 \mu$ en moyenne et jusqu'à $5 \mu$, épaissie à l'extrémité où elte peut atteindre jusqu'ì $12 \mu$; elle présente des stries longitudinales épaisses, assez nombreuses, très visibles, proéminant fortement à la surface des spores el s'arrêtant au niveau du rétrécissenent de la base qui est hyalin ou subhyalin. Le pédicelle est caduc, court, jusqu'à i $7 \mu$ de longueur sur 4-6 $\mu$ de largeur, hyalin.

Soris telentosporiferis amphigenis, plernmque hypophyllis, maculis rotundatis ( $1.3 \mathrm{~mm}$ diam.) uel oblongis (nsqne $5-6 \mathrm{~mm}$ longis), obscure brunneis sparsis saepe numerosis sed non confluentibus insidentibus. Soris peripheriae macularum dispositis, minutis, plerumque oblong is, pnlverntentis, plns minusve coufluentibus, primo epidermide brunneola tectis, dein nudis, epidermide cinctis, brmnneis. Pycnidiis plus minnsue numerosis, epiphyllis vel rarius hypophyllis, in centro macularum sitis, minutis, brmmeis, rotundatis. Pycnidiis flavo-brunneis. Teleutosporis ovoideis, oblongis vel oblongoellipsoideis, plernmrne ad basim subito attenuatis, apice rotundatis nel aculiusculis, faun-brannerolis, $26-42 \mu . \times 18-23 \mu$ : membrana crassa, $3 \mu$. et usque $5 \mu$, apice valde incrassata, usque $12 \mu$, longilndinaliter crasse striata. Pedicello decidno, hyalino, brevi, usque $17 \mu$. longo et $4-6 \%$. lato. 


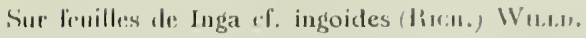

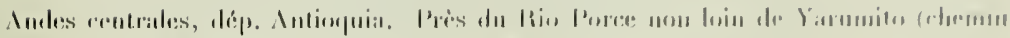

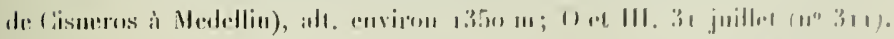

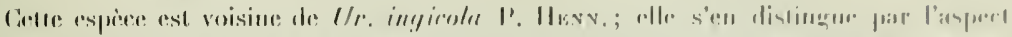

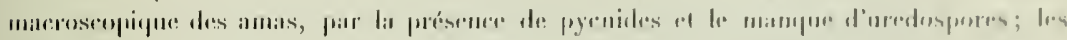

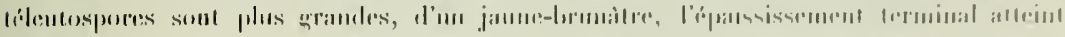

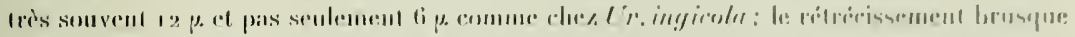

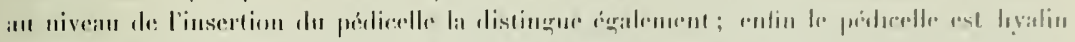

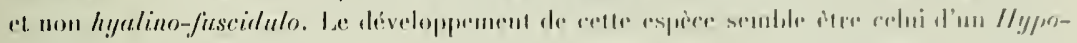
Uromyces.

\section{Uromyces Hedysari-paniculati (Schw.) Farl.}

in Ellis N. Amer. lïgr. $9,187 ! 9,11 " 29$ li.

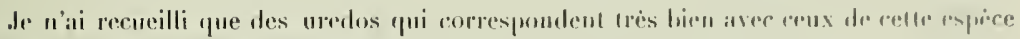
tant mieroseopiquement que macrosespingement.

\section{Sur fenilles de Desmodium spee.}

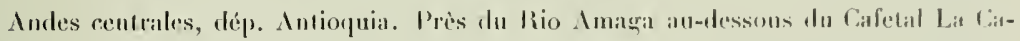
melia près Angedopolis, alt. environ 1250 m; 11,26 aort (n" 270).

\section{Uromyces Dolicholi Arth.}

in Bull. Torr. Bot. Cl. XXxilt, sgot, p. 27.

Je n'ai recueilli que des uredos dont l'aspect macroscopique ef micruscupique correspond hien avec la description de $U r$. Dolicholi. En effer, les amas d'uredos sunt petis, arrondis, dissémines on an contraire très nombrenx et frarfois un peu confheuts. nus dta tris honne heure, brun chair, pulverulents. Les uredospores sont arrondies. 18-2\} $\mu_{\text {de }}$

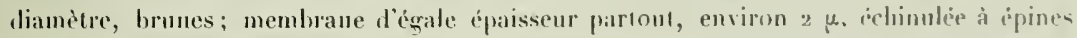
courtes et assez peu denses; pores germinatifs gémiralement 4 équatorianx. Ler amas sour ahomdamment attaqués par Darluea Filum (BN.) Cast., ce qui expliq̣ue peut-ètre pourunoi je n’ai pas rencontré de téleutospores.

Sur feuilles de Rhynchosia of. Iongeracemosa Mart et Gall.

Indes centrales, dép. Antioquia. Chemin de Medellin ì Bello, alt. $1550 \mathrm{~m}: 11.4$ acût $\left(\mathbf{n}^{0} 273\right)$. 


\title{
17. Uromyces appendiculatus (Pers.) Link
}

\author{
in Observ. $11,1816,1.28$.
}

Sur feuilles el tiges de Vigna luteola (daco.) Benru.

Andes centrales, dépre Antioguia. Bord de torrent aux environs de Medellin, all. $15.50 \mathrm{~m} ; 1.10$ antit $\left(11^{\circ} 27^{2}\right.$.)

Les aecidies rencontrées en Colombie sur Vigna luteoln, correspondent assez hien avec celles de Lr r appendicnlalus; malgré quelques différences, il ne ure semble pas justifié, pour le moment, d'en faire une nouvelle espece, des essais d'infection pouvant seuls trancher la question. Les aecidies sont dispersées à la face inférieure des feuilles, souvent en très grant nombre et recouvrent de gुrandes surfaces; elles sont rares à la lace superieure. L’infection se manifeste à la face supérieure des fevilles par de petits points bruns correspondant anx aecidies; en cas de forte atteinte, de grandes surfaces prennent une coloration brun-verdatre criblée de petits points bruns. Les aecidies sont arrondies, $1 / 2 \mathrm{~mm}$ de diamètre généralement, d'un jaune blanchàtre devenant par la suite d'un jaune brun plus on moins foncé; elles présentent un rebord assez épais grossièrement déchiqueté non on peu renversé. Les aecidies se rencontrent aussi très abondamment sur les pétioles et les tiges; elles sont plus grandes, un peu allongées, pouvant mesurer $1 \mathrm{~mm}$ de longueur; leur rebord est très épais et irrégulier, non déchiqueté ni renversé; leur coloration est la même. Aecidiospores plus ou moins régulièrement arrondies I $8-24 \mu$. de dianètre ou ovoïdes-elliptiques, $2 t-27 \mu \times 18-23 \mu$, hyalines; nembrane très mince, à peine $1 \mu$, très finement verruqueuse, à verrues ou granulations très petites, très difficilement visibles et assez denses.

\section{Uromyces Geranii (DC.) Ott et Wartm.}

$$
\text { in Schweiz. Krypt. } 1^{\circ} 401 \text { (1863). }
$$

J'ai recueilli en Colombie des uredos qui semblent concorder très bien avec ceux de $U_{r}$. Geranii. Les amas d'uredos sont à la face inférieure des feuilles, petits, au plus I $\mathrm{mm}$ de diamètre, arrondis, isolés, plus ou moins abondants, faisant à la face supérieure des feuilles de petites taches d'un vert-jaunâtre; its sont brun clair, d'abord recouverts par l'épiderme qui éclate de bonne heure et leur lorme un mince rebord. Les uredospores sont de forme très variable, arrondies, ovoïdes, oblongues ou pyriformes, très souvent un peu incurvées à leur base ou dans leur moitié inférieure, d'un brun clair, $23-30 \mu \times 19-20 \mu$; membrane d'égale épaisseur partout, environ $1 \frac{1}{2} 2^{-2} \mu$, parfois légèrement épaissie au niveau de l'insertion du pédicelle hyalin court et caduc, échinulée à épines très courtes "t assez peu denses. Le nombre et la position des pores germinatils n'ont pu être exactement déterminés. 
Sur fenilles de Geranium mexicaunu II. R. K.

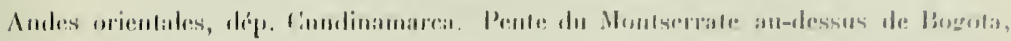

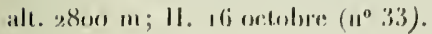

\section{Uromyces euphorbiicola (Berk. et Curt.) Tranzschel \\ in Amuil. Mymul. VIII, p. 8 (1!)ro).}

Sur fruilles dr. Euphorbia pilulifera I.

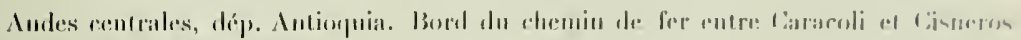

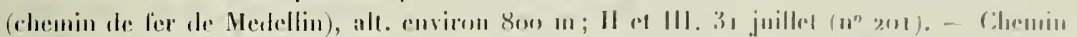

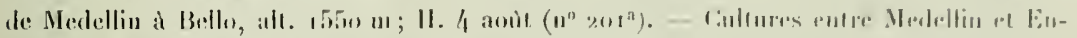

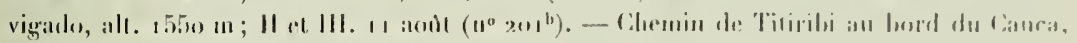
alt. $900-1500,111$; II. 5 singlembre $\left(n^{0} 201^{c}\right)$.

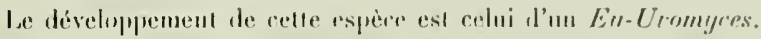

\section{Uromyces Mayorii Tranzschel spec nov.'}

Mycelion totam innonationem infeciente; folies soriferis nommalihus majoriluss. Pycnidris non visis. Soris telentosporiferis h!ypophyllis nel etium pancis opiphyllis, forma (suepe irregulari) el maynitudine valde variis, tolam plerumque superficiem omnimm foliornm (interslum inferioribus p.xclusis) dense tegentibns, epulermiele bullata diu tectis, pulvere telentosporarnm cinnamomeo repletis. Teleutosporis subglobosis vel ovatis, plernmque $18-21, \mathrm{l}$ longis, $15-1, \mu$. lutis, singulis majoribus ustgue $23 \mu$ lnng.,

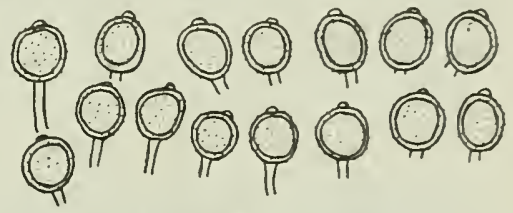

Fig. 10: Lromyces Mayorii. - Téleulospores. 2o $\mu$ latis: episporio dilute brnnneo, ad pormm papilla plerumque conica instructo. nerrnculoso, verruculis parvis, sine ordine sparsis: pedicello fragili. (Typus in Herb. Acalemiae Pelropolitanae.)

Diese nene Art gehört zn den Arton, deren Telrutosporenlager anf einem ganze

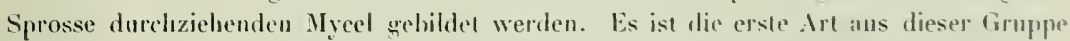
auf Arten der Gallung Euphorbia aus der Soction Anisophyllum. Die auf einjährigen Euphorhien dieser Secrion vorkommenden Arlen hesizen Lecillien und Ľredosporen, welche dem neuen auf einer peremnierenden Art parasilierondem Pilze fehlen. In den Teleutosporen ist Uromyces .Mayorii dem L'rom!yces prominens (DC.) Leiv. Ähnlich.

W. TraNzscinel.

- Espèce itudié par M. le Dr W. Trauzschel, de Saint-Pélicsbourg. 
Sur leuilles de Euphorbia orbiculata. H. B. K.

Andes orientales, dép. Cundinamarca. Paiturages arides à Barro Blaneo près de Madrid dans la Sabanal de Bogrota, alt. 2600 in ; III. 19 vecobre ( $\left.1^{\circ} 50\right)$.

\section{Uromyces Hyperici-frondosi (Schw.) Arth.}

iı Bull. Minnes. Acarl. Nat. Sc. $\mathrm{Xl}$, 3883 , p. 15.

Cette espèce concordc bien arec les exemplaires recueillis en Colombie. Les aecidies se présentent sous le mime aspect ainsi que les aecidiospores dont la membrane est mince, environ 1 .. Les cellules de la péridie se dissocient facilement; vues de face, elles sont finement verrquenses, en coupe elles présentent une paroi externe lisse et une interne assez fortement verruqueuse, toutes deux de $3-4 \mu$ d'apaisseur. Je n'ai pas rencontré d'ur'rdospores. La diagnose indique les amas de téleutospores comme étant d'un brun-noir ou mème noirs. Dans notre cas ils sont simplement d'un brun assez foncé; sauf cela, les caractères microscopiques correspondent très exactement. Le pore germinatif est apical. La membrane est mince, environ I $\mu_{.}$d'épaisseur, renflée très fortement à son extrémité où elle peut atteindre jusqu'à $9 \mu$. Pédicelle peu persistant, jusqu'à $26 \mu$ de longueur, 3-4 $\ldots$ de largeur, brunâtre supérienrement puis hyalin. Le développenent de celte espèce est celui d'un Kata-Uromyces.

Sur feuilles de Hypericum aff. uliginoso H. B. K.

Andes centrales, dép. Antioquia. Pàturages de l'Nlto San Miguel, au haut de la vallée du Porce, alt. $2500 \mathrm{~m}$; I et III. 26 septembre $\left(\mathrm{n}^{\circ} 7^{5}\right)$.

\section{Uromyces Crucheti spec. nov.}

Aecidies sur les deux faces des feuilles, généralement en petit nombre, 4-10, pour former une petite tache arrondie atteignant $1-2 \mathrm{~mm}$ de diamètre et se manifestant sur l'autre face par une coloration brunàtre des tissus; au centre de ces taches se trouvent fréquemment les pycnides en petit nombre, d'un jaune clair, petites, arrondies et à peine proćminentes. Les aecidies sont petites et arrondies, d'un jaune clair, d'abord recouvertes par l'épiderme qui se fend ensuite el forme un rebord irrégulies, non déchiqueté ni renversé. - Aecidiospores alrondies, $2 \mathrm{~J}-28 \mu$ de diamètre, d'un jaune pàle; membrane d'égale épaisseur partout, environ $\mathrm{I} 1 / 2 \mu$, verruqueuse à verrues petites et denses. Cellules de la péridie ne faisant que rarement une suite ininterrompue, le plus souvent se séparant très facilement les unes des autres; elles présentent en coupe une paroj externe lisse et une interne assez fortement verruqueuse, toutes deux d'égale épaisseur, $4-5 \mu$.

Amas de téleutospores à la face inlérieure des feuilles, le plus souvent isolés, mais pouvant aussi être rapprochés et parfois un peu conlluents lorsque l’infection est con- 


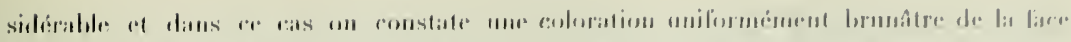

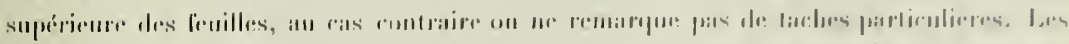

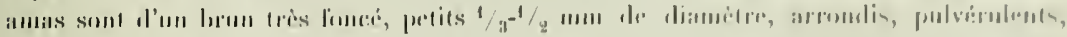

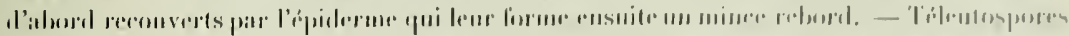

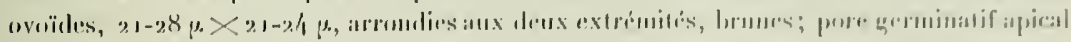

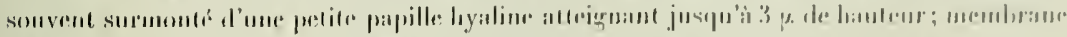

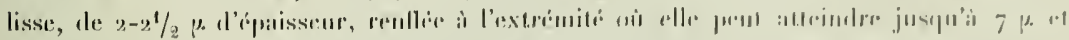

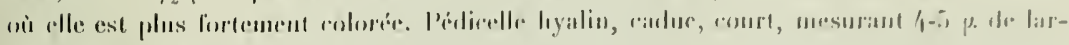
werur iो sirn insertion.

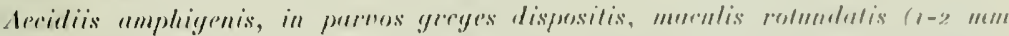

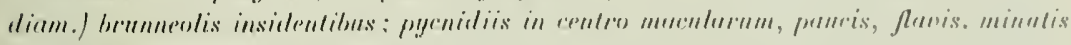
ol rolumbletis; nervilis mimulis, rolundatis, flano-tanreis, primo clansis dein

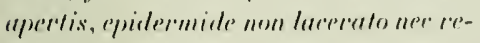

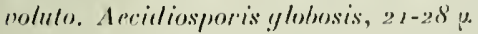

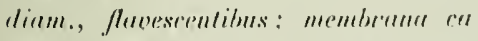

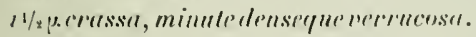
l'eridli cellutis ratus levis inlus mererncosis, 4-5 u. crossis. Sortis teleuslosporiferis hypophyllis, spuesis nel greguriis el intertum purum confluentiluss, surpins sine mornlis, minntis, rolun-

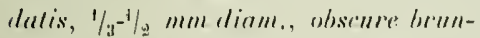
neis, pulvernlentis, primo leatis dein

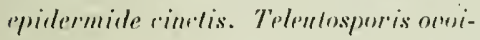
dris, $21-28$ p. $\times 21-2.4$ p., utrinque rolumelatis, brumneis: poro yermiantiono apicali, sarpe papilla hyyalima
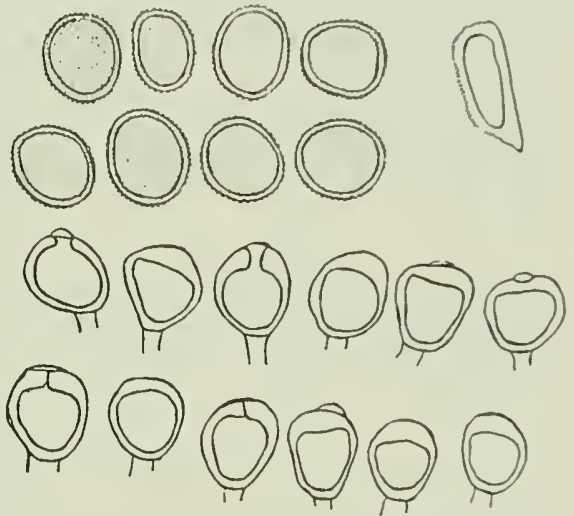

Fir. II: Iromyces Craclieti. - Aeritliospores Ine cellule de la péridie aue en coapu. Téleulospores. (usique.3 $\mu$ allue) instructo; membrana

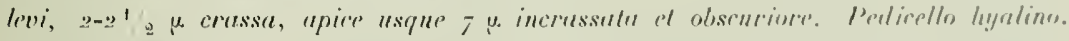
decidno. breevi, \&-5 p. linto.

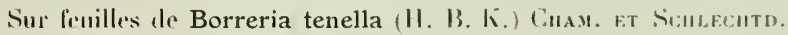

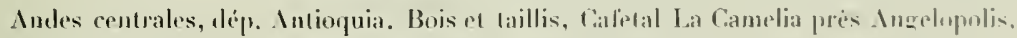

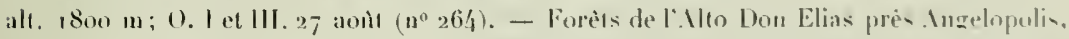

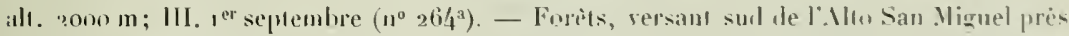

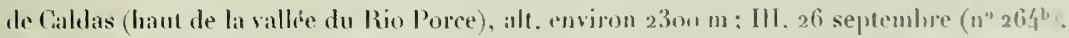

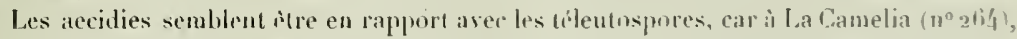
fai recueilli les deux formes, non seulement sur la mème plante, majs curore sur la mème

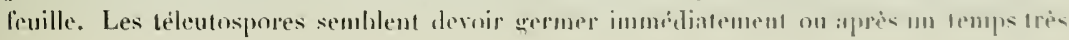


court de repos, car j’ai observé de nombreuses spores déjì germées. Le développenent de cette espece semble donc ètre celui d'un Opsi-l romyces. Cetle espice se distingue de Cr. Borrerize P. HeNs. par ha présence d'aecidies et le manque d'uredos sans compter ¡ue les téleutospores sont très diflérentes et impossibles à confondre. Cette espèce est dédiée à M. le pasteur. Crucnet qui a dé mon guide daus mes átudes mycologiques.

\section{Uromyces Guraniae spec. nov.}

Amas de téleutospores à la face inférieure des feuilles, irrégulièrement disposés, isolés mais souvent rapprochés les uns des autres et un peu confluents, pulvérulents, ne faisant pas de taches à liı face supéricure des feuilles, d'un brun foncé, arrondis, $1-1^{1 / 2} / \mathrm{q}^{\mathrm{m}}$ de diamètre, nus de très bonne heure et présentant assez souvent une ébauche de rebord non continu. - Téleutospores arrondies on ovoïdes, arrondies aux deux extrémités,
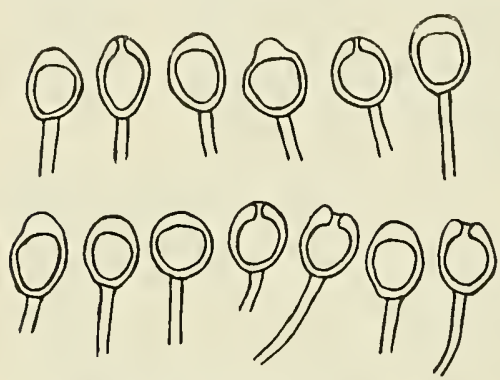

Fig. 12: Uromyces Guraniae. - Téleutospores. parfois un peu coniques à leur extrémité supérieure, $16-24 \mu . \times 15-19 \mu$, de conleur lirun clair, pore germinatif apical; membrane lisse, épaisse, $2-21 / 2 \mu$, rentlée ì son extrémité supérieure oì elle alteint jusqu’à $7 \mu$; comme la membrane, l'épaississement terminal est souvent plus fortement coloré que la cellule, cependant on remarque assez fréquemment des spores on il est au contraire d'un brun très clair ou mème presque sublıyalin. Pédicelle persistant, lıyalin, atteignant jusqu’à $40 \mu$ de longueur sur $3-5 \mu$. de largeur ì son insertion.

Sorts teleutosporiferis hypophyllis, sine maculis, sparsis vel gregariis et parum confuentibus, obscure brunneis, rotundatis $(1-11 / 2 \mathrm{~mm}$ diam.), mox nudis, pulverulentis. Telentosporis globosis vel ovoideis, ntrinque rolundatis vel interdnm apice parum aculinsculis $16-24 \mu \times 15-19 \mu$, dilute brunneis; poro germinativo apicali; membrana crassa, $2-21 / 2 \mu$, apice incrassata (usque $7 \mu$ ) et saepe abscuriore. levi. Pedicello hyulino, persistenti, usque $40 \%$. longo, $3-5 \mu$. lato.

Sur feuilles de Gurania spec.

Andes occidentales, dép. Antioquia. Chemin entre le bord du Cauca et Valparaiso, alt. environ goo m; 111. 26 septembre (no 324).

Andes centrales, dép. Antioquia. Chemin entre Filadelfia et Neira, alt. environ $1700 \mathrm{~m}$; 11I. $1^{\text {er }}$ octobre $\left(\mathrm{n}^{0} 324^{\mathrm{a}}\right)$.

Beaucoup de spores ayant été trouvées déjà germées, lé développement de cette espèce semble ètre celui d'un Leplo-Uromyces. 
24. Uromyces Polymniae (P. Henn.) Diet. et Holw.

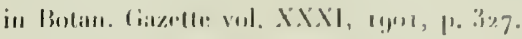

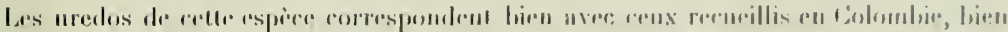

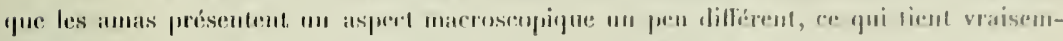

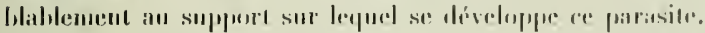

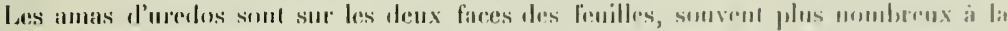

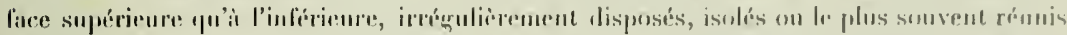

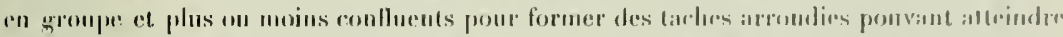

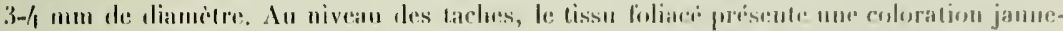

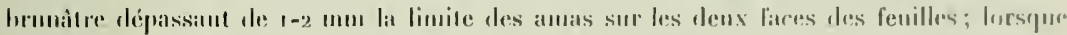

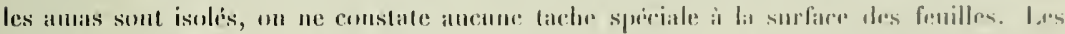

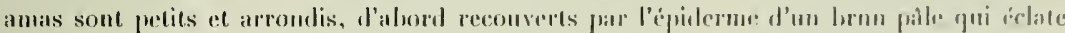

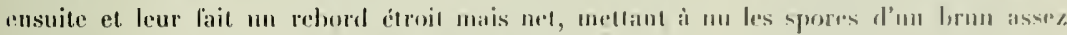

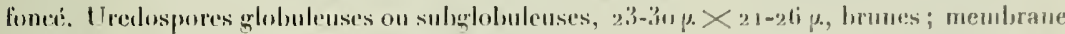

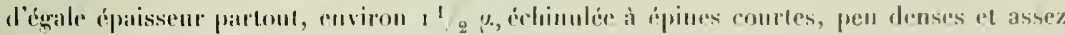
pen visibles; pores germinatilis 2 éguatoriaux.

Sir fenilles de Polymnia glabrata I)C.

Andes otimuales, dép. Cundinamarca. Press des hutles el dans les jardius le loner du eliemin de Bogota it l baque, alt. $2200-3000 \mathrm{~m} ; 11$. 14 et 15 oclohre $\left(\mathrm{n}^{0} 11\right)$.

\section{Uromyces columbianus spec. nov.}

Aecilies a la face inférieure ales feuilles, peu nombreuses, siluées surtout le long des nervures et alors réunies en uroupe pouvant atteindre 5 et $6 \mathrm{~mm}$ de longueur, parfois isolérs on ríunies an nombre de 3 à 4. Elles forment à la face supérieure des feuilles der taches d'un jaune brum tranchant nettement aree le reste de lit fenille. Lescupules sont petites el arrondies, d'un janne clair, d'alord recouvertes par l'épiderme. puis ouvertes et présentant 1 m rebord irrégnlier non on ì peine déchiqueté et non renversé. Aecidiospores arroulies, 14-19 $\mu$. de diamètre, d'un jaune très pàle ou sulhyalines; membranc mince, I $u$, égale partout, verruqueuse à verrues petiles mais denses. Pas de péridie en chaine iniuterrompue, seulement quelques rares cellnles jsolées.

Amas d'uredos snr les deux faces des fenilles mais surtout à linférieure, irrégulièrement disposés, soil disséminés el isolés, soit rapprochés et souveul un peu confluents, formant alors de petites taches arrondies pouvant altcindre $3 \mathrm{~mm}$ de diametre, se manifestant à la face supérieure par une coloration brunàtre des lissus; les amas isolés font eux aussi de petites taches punctiformes à la face supérieure el de mème couleur: les 
anas sont petits, arromdis, brun elair, d'ahorit recomverts par l'épirlerme qui éclate de

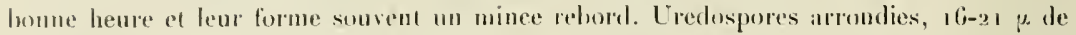

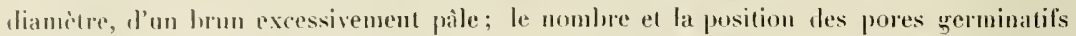

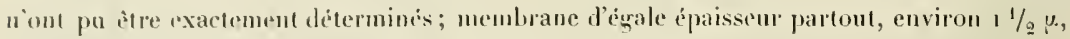
echinule i iphes conrtes at espacées les unes des autres.

Inas de téleutuspores à la face inférieure des fenilles, pulverulents, semblables à cenx des uredos el me s'en dislinguant que par une coloration à peine un peu plus foncée.

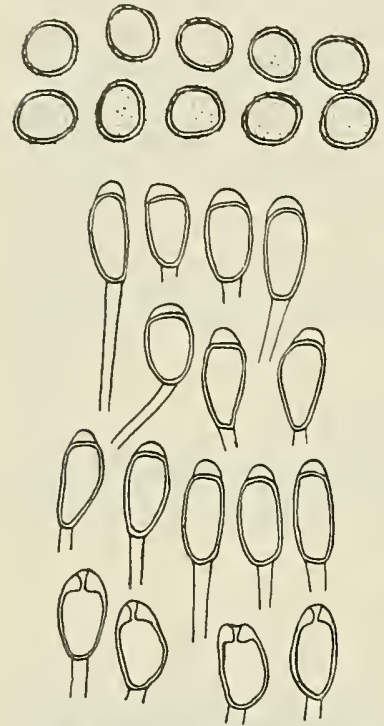

Fig. 13: Uromyces columbianus. Uredospores et téleutospores. Tritentospores ovoüdes, ovalaires ou elliptiques, $21-3.3 \mu$ $\times 1 / 18 \mu$, d'un brun très pàle ou sublyyalines, arrondies à leur extrémité, arrondies ou atténuées à la hase; pore germinatif apical; membrane lisse, mince, environ $1 \frac{1}{2} \mu_{\text {; }}$; les téleutospores sont surmontées d'une papille atteignant jnstju'à $7 \mu$ de hanteur sur $14 \mu$ de largeur, soil de mème coloration que les spores, soit plus foncée, soit parfois subbyaline. Pedicelle hyalin, peu persistant, jusqu’à $35 \mu$. de longueur sur 4-5 $\mu$ de largeur à son insertion.

Aecillis hypophyllis, pancis, saepe nervicolis et gregariis, mnculis flavo-brunneis $5-6 \mathrm{~mm}$ diam. insidentibus, interdum sparsis, minutis, rolundalis, fluvoaureis, primo clansis dein aperlis, margine non vel vix lacerato nec revolnto. Lecidiosporis globosis, 14-19 $\mu$. diam., fluvescentibus vel subhyalinis; membrana tenu. (ca 1 u.), dense minuteque verruculosa. Soris uredosporiferis amphigenis praecipue hypophyllis, sparsis vel parum gregariis el macnlis ca $3 \mathrm{~mm}$ diam. brunneolis insidentibs, minutis, plus minusve rolundatis brunneolis, primo epidermide lectis sed mox nudis. Uredosporis globosis, $16-2$ I $\mu$ diam , pallide brunneolis : membrana $11 / 2 \mu$ crassa, laxe minnteque echinulala. Soris leleutosporiferis hypophyllis, pulverulentis, conformibus, vix obscurioribus. Telentosporis ovoideis, ovalis vel ellipsoideis, $21-33 \mu$. $\times 14-18 \mu$, pallide brunneis vel sublygalinis, apice rolnndatis, basi roluudalis vel ullenuatis: poro germinativo apicali: membrana levi, tenui ca $11 / 2 \mu_{-}$; sporis apice papilla magna (usque $7 \mu$ alla el $14 \mu$ lata) pallide brunneola vel subhyalina instructis. Pedicello hyalino, parum persistenti, nsque 3ij y. longo el 4-5 $\mu$ lato.

Sur feuilles de Melanthera aspera (.JAcQ.) Steudel.

Andes centrales, dép. Antioquia. Cultures entre Medellin et Envigado, alt. 1550 m; II et IfI. 19 aoùt ( $\mathrm{n}^{0}$ 256). - Cultures, Cafetal La Camelia près Angelopolis, alt. I $800 \mathrm{~m}$; I. H et III. 19 aoù $\left(1^{\circ} 29^{3}\right)$. - Cultures au-dessous du Cafetal La Camelia près Angelo 


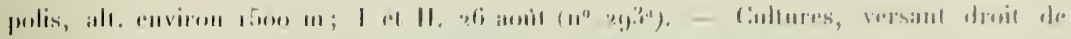

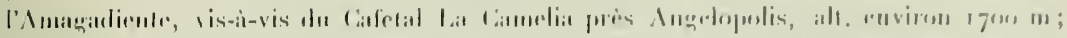

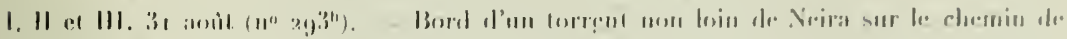

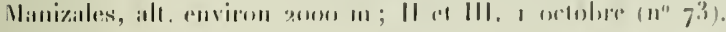

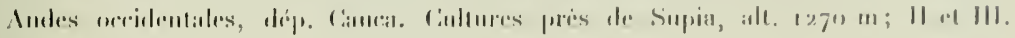
in septembere (110)

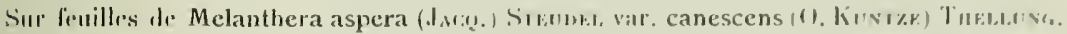

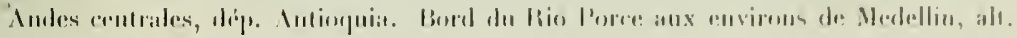

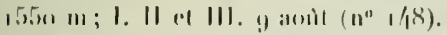

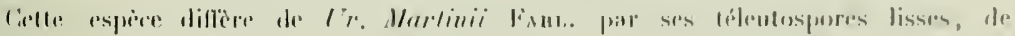

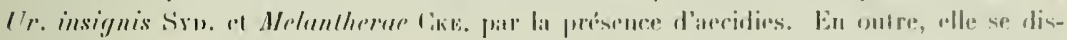

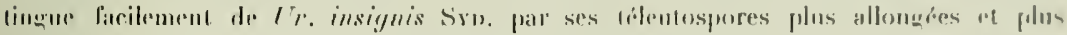

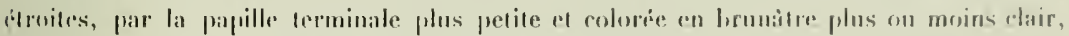

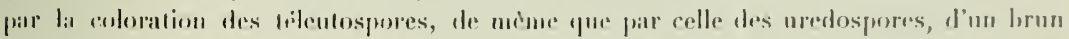

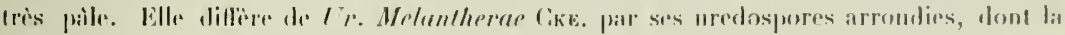

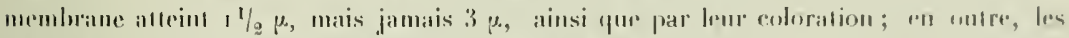

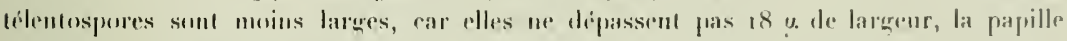
terminale est anssi plus petite a colorée en lirunatre plus on moins clair. Celte esprere

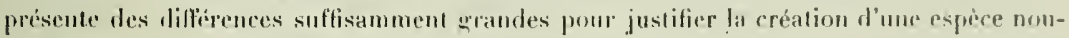
velle. Ides accidies renrontrés lréquomment en rompagnie des uredos el tálentospores el souvent sur la mème fenills semblent bien appartenir à celte espèce at, jusquà plus

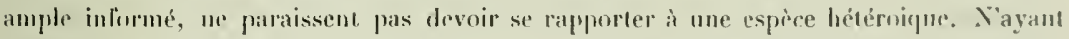

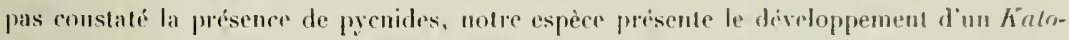
Iromyges: l'examen des télentuspores semblue indiquer qu'elles doivent germer inmérliatement on après un tris court temps de ropos.

\section{Uromyces megalospermus Speg.}

in Fin. Argentini novi vel critici, p. 218 (1899).

La description des uredos de celle espece semblent hien correymudre avec reux remontris an Colombie. Les amas duredos soul sur les deux faces des foulles, mais surtout à l'inférieure, petits, arrontis. dissémines ou ahomdants, mais isolés et non conHuents, d'un hrun fonce, se manifestaul par de petiles taches brunes déhordant les amas, dabord recouverts par l'epiderme qui leur forme ensuite un rehord plus ou moins net.

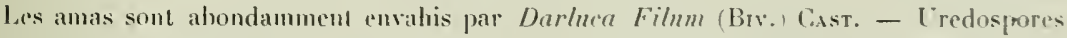
arrondies ou ovoïdes, $19^{-2} 7 \mu$ de diamètre, d'un brun clair; pores germinatifs 2 , équato. riaux: memhrane d'égale épaisseur partout, $2-2 \% \mu$, finement ichinulée à épines courses et assez peu nombreuses. 
Sur feuilles de Tessaria integrifolia Ruz ır P’Av.

Andes centrales, dép. Antioquia. Bord rlu Rio P'orce ì Medelliu, alt. 1550 m. 9 aont (no 254). - Bord de ruisseau non loin de America près de Medtellin, alt. 1600 m. 10 aoǹt $\left(1^{0} 254^{\mathrm{a}}\right)$.

\section{Uromyces Bidentis Lagh. \\ iin Bull. Soc. Mye. France i 895, p 213.}

Les uresdospores nut ane membrane d'égale épaisseur partunt, environ 2 p. et ont 2 pores greminatifs équatorianx. Les télentuspores sont qénéralement colorées en hrou clair à l'épaississement terminalet sur le reste de la spore en janne-brunàtre pâle et de phas en phus pàle à mesure qu'on se rapproclse de la base, qui est le plus souvent hyaline; le pore germinatif est apical. La pridicelle prersistant atteint jusqu’à 70 \% de bongueur sur

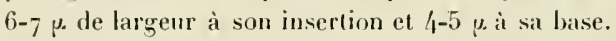

Sur feuilles de Bidens bipinnatus $\mathrm{L}$.

Antilles: Jamaïque, Kingston, I1ope Gardens ; II. 14 juillet ( $\left.{ }^{\circ} 140\right)$.

Sur feuilles de Bidens pilosus $\mathrm{L}$.

Andes centrales, dép. Antioquia. Chemin de Medellin ì Bello, alt. $1550 \mathrm{~m}$; 11.4 aoǹt

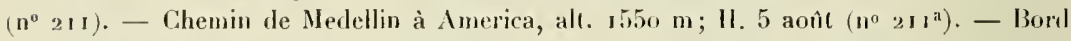
du Porce à Medellin, alt. $1550 \mathrm{~m}$; Il et 111.9 aoùt $\left(\mathrm{n}^{\circ} 2 \mathrm{I}^{\mathrm{b}}\right)$. - Colline au-dessus de America près de Medellin, alc, environ $1700 \mathrm{~m}$; II. 15 aoùt $\left(\mathrm{n}^{\circ} 2 \mathrm{I}^{\circ}\right)$. - Cultures el Cafe-

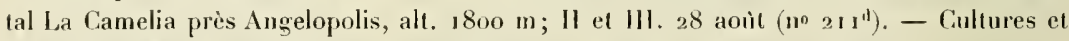
Cafetal La Moka près Anģelopolis, alt. $1700 \mathrm{~m}$; II et III, 29 aonit $\left(\mathrm{n}^{0} 21^{\mathrm{e}}\right)$.

Sur feuilles de Bidens squarrosus II. B. K.

Andes orientales, dép. Cundinamarea. Au-dessus de Ubaque, entre le village of le Paramo Cruz Verde an-dessus de Bogota, alt. $2000-2500 \mathrm{~m}$; 11 et 111,15 octobre $\left(1^{\circ} 42\right)$.

Le développement de celte espèce doit ètre celui d'uı Ilemi-Uromyces, du moins pour le moment. L'examen des téleutospores fait supposer que les spores doivent germer immédiatement ou en tout cas après un temps très court de repos. 


\title{
Genre Puccinia Pers.
}

\author{
28. Puccinia purpurea Cke. \\ in timvillea $V$, r. Iis $\left(1877^{(i)}\right.$.
}

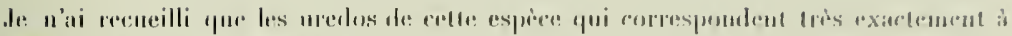

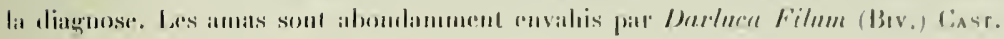

Sur fruilles de Andropogon halepensis (1.) Bmor.

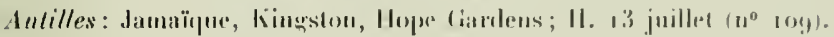

\section{Puccinia substriata Ell. et Barth.}

$$
\text { in Eryuliea } 1897, \text { p. } 17 \text {. }
$$

de n'ai recueilli à la damä̈que que des uredus qui semblent correspondre très bien

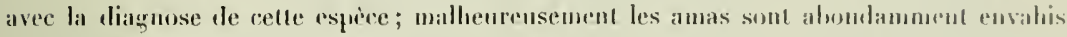
par Darlua Filum (Bıv.) Cast. el je n'ai pu observer la prisence de tálentospores qui auraicul prermis une détermination rigonrense.

Les amas d'urodos som sur les gaines of les deux faces des feuilles, surtuat ì l'inférienre; ils sont petits, le plus sonvent un peu allongris, emviron 1 mun de longueur, irrognlìrement disposés, le plus sumvent isolés, mais pouvant aussi itre nombremx, rapprochés at "n pen confluents, l'un brun rouille, assez longtemps recouverts par l'épiderme coloré en brun clair qui lear forme ensuite le plus somvent un mince relurd. Les fenilles allaquées prennent une coloration brun-jauntre avec un piqqueté plus foncé correspondant anx amas. Uredospores arromlies, woüdes on ovalaires, $21-33 \mu \times 19-24 \mu$, hrunes; pores germinatifs 4 équatoriaux; membrane d'égale épaisseur partout, euviron $1^{1}$ e u., échiunlée à épines courtes et assez denses.

Sur feuilles de Paspalum fimbriatum H. B. K.

Antilles: Jamäque, lïngston, Hope Gardens; 11.14 juillet $\left(11^{\circ} 367\right)$.

\section{Puccinia Paspali Tracy et Earle.}

$$
\text { in Bull. Torr. Bot. CI. } 1895, \text { p. } 174 .
$$

de nai recueilli que les uredos de celle espèce qui correspondent très hien avec la diagnose de $P$. Paspali. Les amas sont sur les deux faces des fruilles, mais surtout ì l'inférieure; ils sont gुénéralement nombreux, allongés dans le sens des feuilles, souvent confluents et alors alteignant et dépassant mème $\mathrm{r}$ cm de longueur. L'infection se 
manifeste par une coloration brune plus ou moins foncée des tissus; lorsqu'elle est considérable, de grandes surfices prennent une coloration d'un brun strié de zones plus linacées correspondaut aux anas. Les amas sont d'un brun-noirâtre, très longtemps recouverts par l'épilerme devenant grisàtre a la fin et ne se l'endant que très tardivenent. Les ureduspores sont arrondies on ovö̈des, $25-30 \mu \times 23-28 \mu$, l'un brun foncé ; la menbrane est d'égale épaisseur partout, $2-3 \mu$, sauf parfois près du pédicelle très court oì elle est un pen plus épaissie, elle est épineuse, à épines assez grandes at assez rapprochées les unes des autres; pores germinatifs 4, équaturianx. Les amas sont aboudamment enviluis par Darluca Filum (Bw.) Cast.

Sur feuilles de Paspalum Fournierianum Ricker var maximum Thelung.

Andes centrales, dép. Antioquia. Cultures, Caletal La Camelia près Angelopolis, alt. $1800 \mathrm{~m}$; II. 19 aoùt (p. 163). - La Primavera près Caldas an hant de la vallée du Rio Porce, alt. $1870 \mathrm{~m}$. 26 septembre $\left(n^{\circ} 71\right)$.

\section{Puccinia Cenchri Diet et Holw. \\ in Botan. Gazette XXIT, ז897, p. 28.}

Les uredospores ont 2 pores germinatifs équatoriaux; la membrane a une épajsseur de $2-3 \mu$, le plus souvent épaissie un peu à la base au niveau de l'insertion du pédicelle très cou't el caduc; elle est échinulée à épines courtes el assez denses. Les deux cellulles des téleutospores sont le plus souvent inégales; la supérieure est généralement plus ou moins arrondie et mesure $20-26 \mu$ de largeur, l’inférieure esl allongée ét plus étroite, $17-194$. Le pore germinatif est apical pour la cellule supérieure, la position de celui de la cellule inférieure n'a pu ètre exactenent détermince. Le pédicelle coloré en brun pâle est caduc, court et mesure $6-9 \mu$. de largeur à son insertion.

\section{Sur feuilles de Cenclırus echinatus L.}

Andes centrales, dép. Antioquia. Chemin de Medellin à Bello, alt. ı5ío m; II et III. 4 aoì (n $n^{\circ}$ 154).

Le développenent le cette espère est celui d'un Ilemi-Purciniu, du moins pour le moment.

\section{Puccinia Maydis Béreng.}

in Atti VI Riun. sc. ital. Milano 1884, P. 475.

Sur feuilles de Zea Mays L.

Andes centrales, dép. Antioquia. Cultures à Yarumito (chemin de Cisneros à Medelliu), alt. $3340 \mathrm{~m}$; II. 1 aoùt $\left(\mathrm{n}^{\circ} 222\right)$. - Cultures au-dlessous du Cafetal Liı Camelia près Angelopolis, alt. environ $1600 \mathrm{~m}$; II. 10 septembre $\left(1^{0} 22^{\mathrm{i}}\right)$. 


\section{Puccinia antioquiensis spec. nov.}

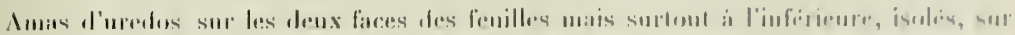

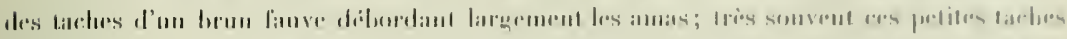

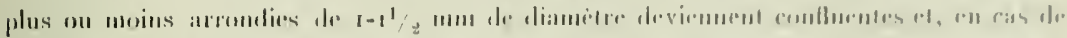

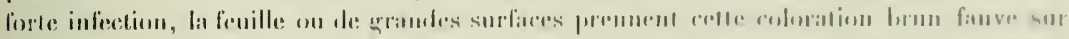

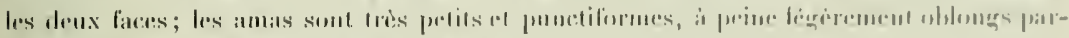

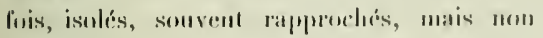

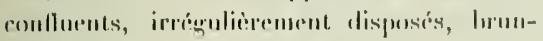

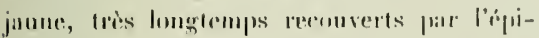
derme qui ne se lend pue lacis lardivement.

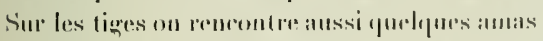

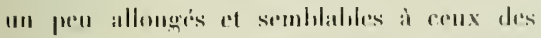

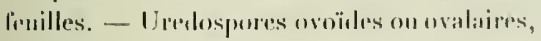
$18-2.3 \mu \times 1 / 1-16$ pe, lyalines on sul,hyalines, l'un jamme rexessivement pille; memblanm

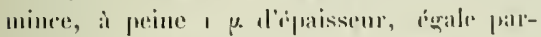

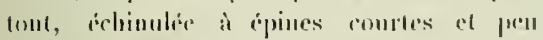
delises.

Amas de tileuluspores sur lins tiges al la face inférienre des fenilles, formant des titelus semblahles a colles des urodos, mais un pen plus foncées. Les amas sont isolex, parfois nombers et rapprombers mais non conflucuts, petits, arrondis mo beancoup plus storvent 111 pen allongris, alleignant $1 / \mathrm{g}$ mm
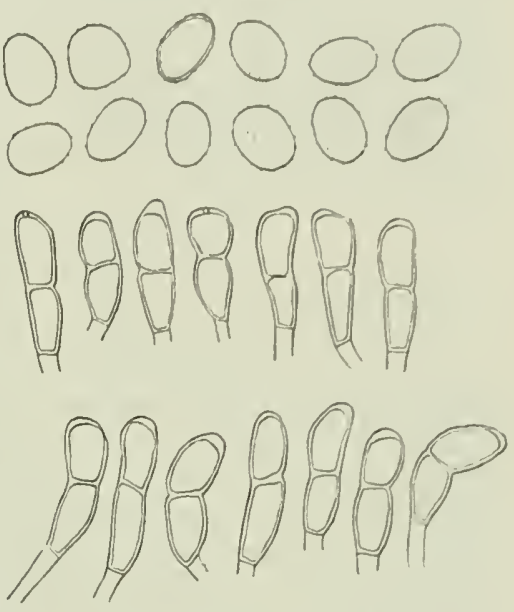

Fig. 14: Puccinia antioquiensis. - Vreduspores el léleulospores al rimement i mm de longuems, d'un hrun

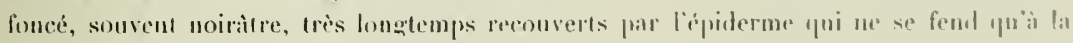

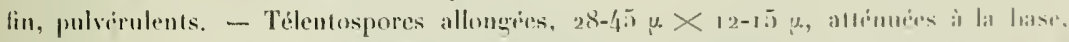
arroudies on tromquées ou parfois un peu coniques it liextrimiri, faiblement étrantien

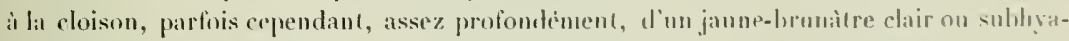

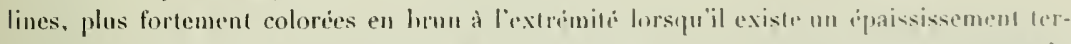

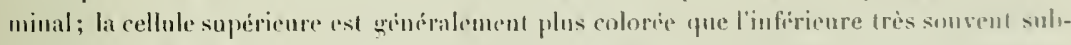
lyyaline on mime hyiline; les denx cellules sont sensiblement de mime forme ed de mème dimension; pore germinatif apical purr la cellule supripteure, relui de la colluh infirientre u'a pu ¿̀re exactement distingue; memhrane lisse, mince, ensiron $1, \mu$, sourent mais pro

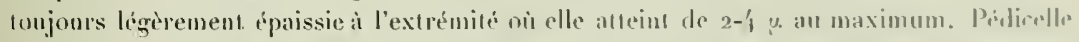

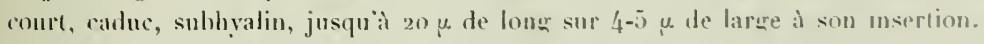

Soris uretosporiferis canticolis uel amphigenis prapripne hypuphyllis, spursis uel numerosis sed non confluentilus, monlis fulvis rolundalis $1-7 \%$ mun dium.) sarperent- 
flnentibus insidentibus, minulis. punctiformibus vel purum oblongis, flavo-brunneolis, diu epidermide lectis. Lredosporis onoideis vel onatis, $18-23 \mu \times 14-16$ u. hyalinis vel hyulino-flavescentibus: membrann tenui ca. t u. crassa, minute laxeque echinulata. Sortis telentosporiferis cunlicolis uel hypophyllis, conformibus, sparsis vel mumerosis sed non confluentibus, minutis, rolundutis nel praecipue oblong is (1 $\mathrm{g}^{-1}$ mu long is), ol,scure brunneis, din epidermile tertis dein fissis, pulvernlentis. Telentosporis elongatis

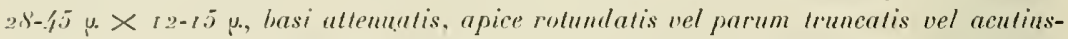
"ulis, medio praecipue leniler constrictis. flavido-pallido-brnnneolis nel sublyyalinis, cellula superiore obscuriore, inferiore saepinss snbhyulina vel interdum hyalina; cellulis sensim paribus: poro germination cellular superioris apicali: membranu tevi, ternui ca. I 4 crassa, apice suepe sed non semper leniter incrassatu (2-4 y.). Pedicello deciduo, subhyulino, brevi usque 20 u. longo et 4-j $\mu$ lato.

\section{Sur liges el feuilles de Cyperus diffusus VAut.}

Indes centrales, dép. Antioquia. Bord de la voie ferrée pris de Pavas (chemin de fer de Hedellin), alt. environ $7^{\circ o} \mathrm{~m}$; II el 111.31 juillet $\left(n^{\circ} 27^{6}\right)$, - Cultures à Guaca, alt. $1480 \mathrm{~m}$; 11 et 111 . I2 $_{2}$ septembre $\left(\mathrm{n}^{\circ} 277\right)$.

Cette espèce est voisine de $P$. subcoronala P. Henn. dont elle se distingue cependant facilement par un certain nombre de caractìres importants. Les téleutospores ne sont jamais denticulées à l'extrémité, mais arrondies, tronquées on un peu coniques; elles ne sont pas d'un jaune-brun mais d'un jaune-brunâtre si pâle qu'elles sont fort sonrent subhyalines, parfois mème liyalines. Les téleutospores ne présentent sourent pas d'épaississement à leur extrémité; quand il existe, il est toujours faible et n'alleint que très rarement $5 \mu$; enfin elles sont sensiblement plus petites, $28-45 \mu$. et uon $35.60 \mu$. Le développement est celui d'un Ilemi-Pucciniu, du moins pour le moment, car il est probable que des recherelıes ultérieures et des essais d'infection montreront qu'on est en présence d'une espèce hétéroique.

\section{Puccinia Marisci spec. nov.}

Anas d'uredos sur les tiges et à la face inférieure des feuilles, le plus souvent ne faisant pas de taches spéciales ou donnant aux tissus foliacés une coloration brunâtre; les amas sont soit arrondis el trìs petits, soit un peu allongés et pouvant atteindre $1 \mathrm{~mm}$ de longueur, ils sont irrégulièrement disposés, disséminés ou, au contraire, nombreux et rapprochés mais non confluents; sur les tiges ils sont peu nombreux et toujours allongés, pouvant un peu dépasser r mm de longueur. Les amas sont d'un brun assez foncé, d'abord recouverts par l'épiderme qui éclate de honne heure et leur forme un rebord d'un brun plus clair. - Uredospores arrondies ou plus souvent ovoüles ou ovales ou ovaleselliptiques, 21-26 $\mu \times 16-19 \mu$, d'un jaune clair; membrane d'égale épaisseur partout, 


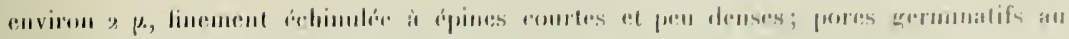

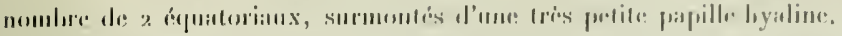

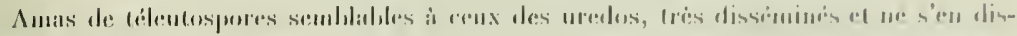

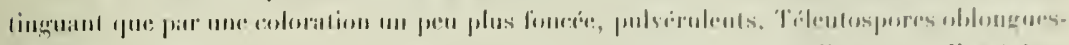

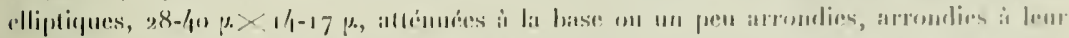

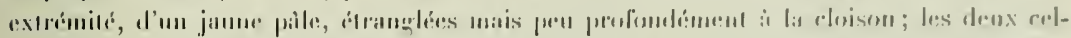

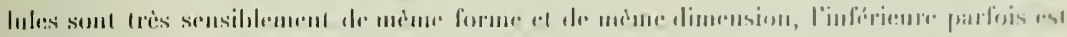

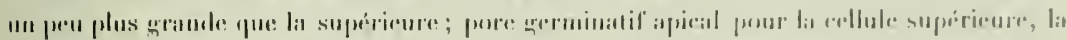

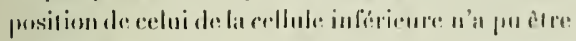

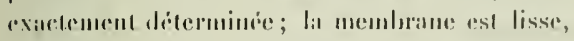

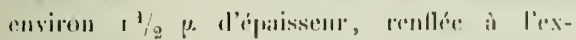
trémits oi elle pent alleimstre jusegu'it $7 \mu$, renflement quénélitement un peu plus colorit que le reste de la spore qui est jimue paile; la collule inleriente est somsent sublyyaline mème liyaline à la base. Pédicelle sublyyaliu, cirluc, jusifu ì $20 \mu$ de longueur sur $5-7$ p de largeur it son insertion.

Soris uredosporiferis canticolis vel hypoplyyllis, marulis nullis nel minulis brummis insidentibus. rotundutis, minutise vel oblongis usqu" I mm longis, sparsis nel numerosis seel non confluentibus, fuscis, primn tectis dein epidermide cinctis. Uredosporis subglohosis lef surpius movideis, ovatis velellipsoideis, $21-26$.

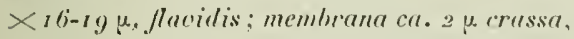
mimule luxerpue echinulata; poris germinativis 2 unuatoriulibus. Soris telentosporifer is conformilus, pulwerulentis, parum ahscurioribus. Teleutosporis oblongo-ellipsoidecis, $28-40 \%$ $\times 11-17$ u, basi atlenuatis, apice polundulis,

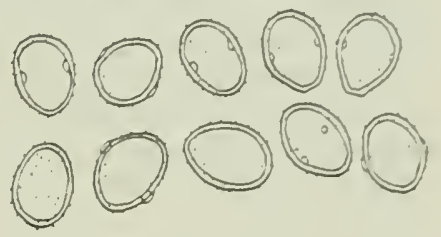

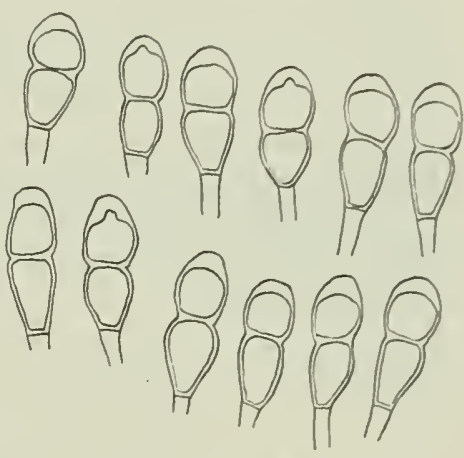

Fig. 15: P'uccinia Marisci. I'redospores el téleutospores.

flunescentibus, medio constrictis : cellulis sensim paribus interdum inforinere majore; poro

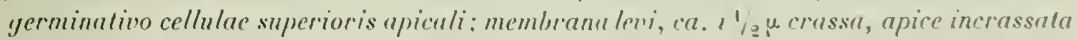
ustue $7 \mu$ et obseuriore coloratu. P'edicello subhyalino, deciduo, usque $20 \mu$ longo el j-7 u. lalo.

Sur (iges el leuilles de Mariscus hermaphroditus (JACQ.) ['rax.

Andes centrales, dép. Antinquiai. Cullures, Cafetal La Moka près Ingelopolis, alt.

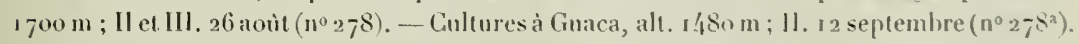

Andes orientales, dép. Cundinamarca. Cultures, Cafetal Magdalena dans la vallée de Viota, alt. $1050 \mathrm{~m}$; II et III. 26 octobre $\left(\mathrm{n}^{0} 2 \mathrm{~g}^{\mathrm{b}}\right)$. 
Sur liges et feuilles de Mariscus flavus Vam..

Dép. Intionuia. Bord du Canca prés du Paso de Concurdia à Pererto de los Polores, alt. $720 \mathrm{~m} ; 11.8$ septembre $\left(\mathrm{n}^{\circ} 283\right)$.

Cente esprece diffìre de I'. antionniensis m. par son aspeed macroseopique, par la dimension at la coloration des uredospores; elle est surtont différente par la forme

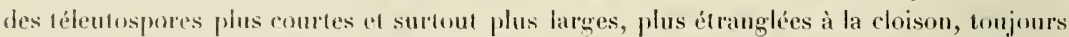
arrondies ou phus ou moins arroudies ì leur extrémité et assez fortement renllée jusqu’̀ $7 \mu$ (che\% P. antioquiensis it s'agit d'un simple petit épaississement n'existant pas d'une uaniere constante); lent coloration est aussi diffirente. Elle se distingue de P. sabcoronata P. Hexs. par ses ureduspores un peu plus petites et plus fortement colorées "n jaune, par ses téleutospores à extrémité tonjours artondie el pas tronquée, conique on surtont denticulé, par ses dimensions plus petiles surtont en longueur, $28-40$ \% et non 35-60 \%, par leur coloration subleyaline ou l'un jame paile et non d'un jaune hron; enfin l'aspect macroscopique des anas d'uredos et de téleutospores est aussi sensiblement différent. Sur Mariscus flavas Vaht, je n'ai recueilli que des uredos ahondanment envahis par Darluca Filum (Buv.) Cast., ce qui leur donne une coloration noiràtre; comme ces amas d'uredos ainsi que les uredospores sont en tout itlenliques ì ce qu'on observe chez Mariscus hermuphrodilus (IACQ.) UBBAN, j'ai fait rentrer le parasite rencontré sur ces leux supports dans la mème espèce, attribuant les quelques dilfirences macroscopiques ¿̀ l'infection surajoutée due an Dar/uca. Le développement de celte espèce est celui d'un Hemi-Puccinia, du moins jusqu'ì ce que des recherches uhérieures el des essais d'infection aient nettement démontré qu'on n'est pas en présence d'uredos et de téleutospores d'une espìce hétéroique.

\section{Puccinia Fimbrystilidis Arth.}

in Bul. Tor. Bot. Club, XXX11 ( ( go6), p. 28.

Amas d'uredos sur les deux faces des feuilles, mais surtout à l'inférieure ainsi que sur les tiges, soil isolés, soit rapprochés et un peu confluents. Ce n'est que lorsque l'infection est abondante que les feuilles prennent une teinte jaunatre, le plus sonvent on ne remarque pas de tache spéciale. Les amas sont un peu allongés sur les ferrilles et mesurent 1 mm de longueur; sur les tiges ils sont plıs longs et atteignent jusqu'à 5 mm ; ils sont assez proéminents par le fait que l'épiderme qui recouvre les amas se gonfle et se distend avant de se fendre tardivement; ils sont brun fauve. - Uredospores arrondies $16-19 \mu$ de diamètre ou ovö̈les ou ovales, $18-22 \mu \times 13-16 \mu$, de couleur jaune, souvent subhyalines et parfois mème hyalines; membrane d'égale épaisseur partout, environ $\mathrm{I}^{1 / 2} \mu$, finement échinulée à épines courtes et assez peu denses; pores germinatifs au nombre de 2 , équatoriaux. 


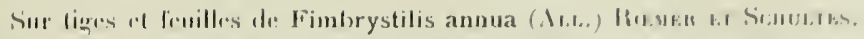

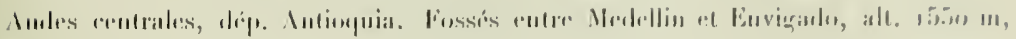
11 insite $(110,258)$.

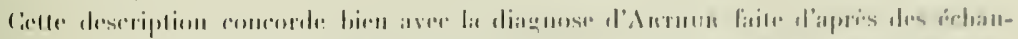

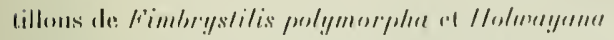

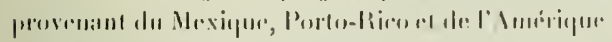

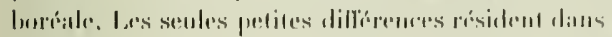

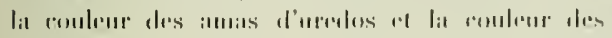

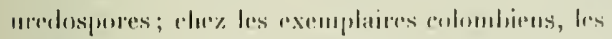

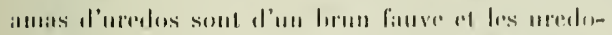

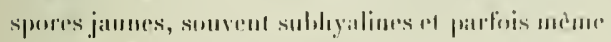

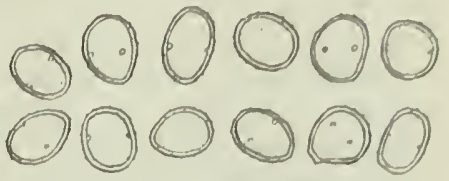

Fig. I6: l'uccinia fimbrystilidia. liedospores sur Fimbryolition innua.

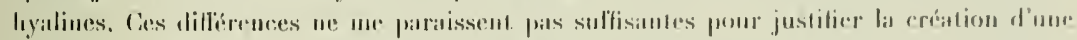

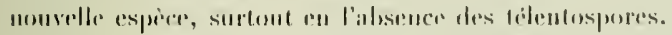

\section{Puccinia Cannae (Wint.) P. Henn.}

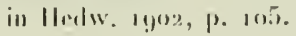

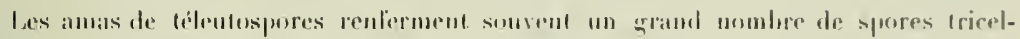

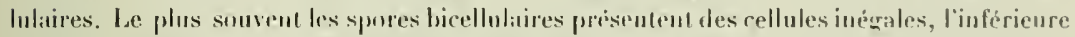

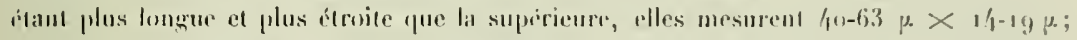
les spores tricellulaires mesurent $50-66 \mu_{0} \times 1 / 4-19 \mu$ et présentent anssi prespue tonjunrs more inigalití entre leurs cellules, les doux supérieures sont très sonsiblement de mème forme ot de mème dimension alors que l'inférieure est plus longrue ex souvent un peu plus étroite. La place exacte des pores rerminatifs na ju ètre déterminée. Le développement stmble ètre celui d'un Hemi-Puccinin.

\section{Sur feuilles de Canna coccinea MrLter.}

Antilles: Jamaïjue; Kingston, Ilope Gardens; II. 14 juillel (nn 116).

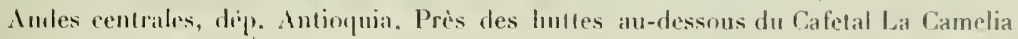
pris Angelopolis, alt. envirum $1600 \mathrm{~m}$; 11 el III. 26 aonil $\left(n^{\circ} 19^{6}\right)$. - Cafetal La Yoka prés Angelopolis, près des hutles, alt. $1700 \mathrm{~m} ; 11$ 11 111.29 aoù $\left(n^{0} 196^{\mathrm{a}}\right)$. - Près des hutles de la rive droite de l'Amagadiente, vis-it-ris du Cafetal $I_{a}$ Camelia pres Angelopolis, alt. curivon $1700 \mathrm{~m} ; 11.31$ anù $\left(\mathrm{n}^{\circ} 19^{6 / 1}\right)$. 


\section{Puccinia Polygoni-amphibii Pers.}

$$
\text { Syn., 1. } 227(1801)
$$

Sur fenilles de Polygonum acre II. B. li.

Intilles: llä̈ti ; Cayes, dans le sable; II. 17 juillet (n" 13 1).

Anders centrales, dép. Antioquia. Cultures, Cafeat La Moka prés Augelopolis, alt. 1 7on m; 11. 24 aonit $\left(n^{\circ}{ }_{168}\right.$. - Cultures, Calfetal La Hermosil près Angelopolis, alt. envirou $1600 \mathrm{~m}$; Il. 2 se

Andes orientales, dip. Condinmarca. Prairies humides aux environs de Madrid dans la Sabana de Bogota, alt. $2600 \mathrm{~m}$; II. 19 octobre ( $\left.\mathbf{n}^{\circ} 60\right)$.

\section{Puccinia macropoda Speg.}

$$
\text { Fg. Arg. Pug. II, no } 34(1887) \text {. }
$$

Je n’ai recueilli que des uredos très caractéristiques avec leur striation presque toujours transversale et très accentuée qui leur donne un aspect des plus particuliers.

\section{Sur feuilles de Iresine spec.}

Andes centrales, dép. Antioquia. Chemin de Santa Barbara à l'auberge El Cairo nou loin du Canca, alt. environ $9^{50} \mathrm{~m}$; II. 26 septembre $\left(\mathrm{n}^{\circ} 7^{8}\right)$.

Andes orientales, dép. Cundinamarca. Forèts entre Boca del Monte près de Madrid dans la Salıana de Bogota et l'auberge de Tambo près de Tena, alt. environ 2000 m ; II. I 8 el ig octobre $\left(n^{\circ} 52\right)$.

\section{Puccinia Bocconiae spec, nov.}

Anas de téleutospores sur les deux faces des feuilles et sur les pétioles, toujours réunis en grand nombre et conlfuents pour former des taches de grandeur très variable soit arrondies, soil allongées el ponvant attcindre ou même dépasser $1 \mathrm{~cm}$ de longueur, en nombre variable, irrégulièrement disposties, souvent nomlıreuses mais très généralement isolées les unes des autres; ces taches semblent avoir une prédilection marquée pour les nervures et surtout les plus grandes, mais on les rencontre aussi fréquemment sur les petites nervures où elles perdent souvent leur organisation allongée ponr devenir arrondies. Du fait de l’invasion des nervures, celles-ci sont élargies, contournées et plus ou moins tordues, déformant souvent considérablement les feuilles; lorsque les amas sont ell dehors des nervares, ils forment des hoursouflements plus ou moins grands, une des 


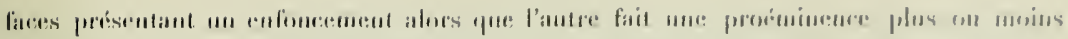

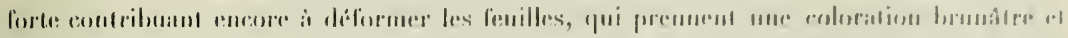

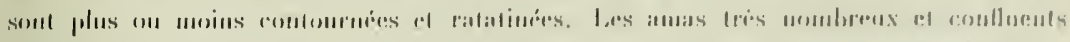

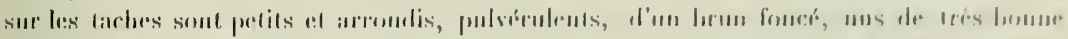

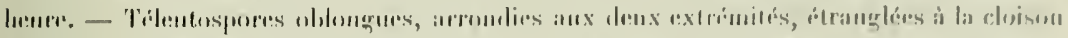

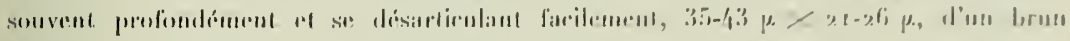

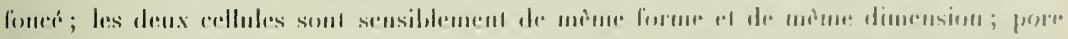

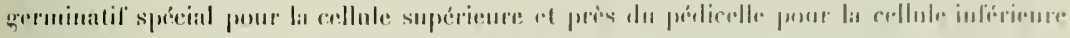

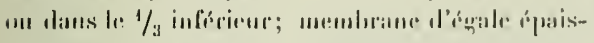

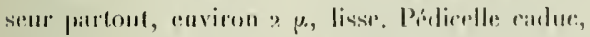

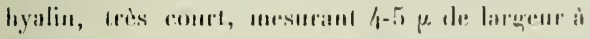
son insertiun.

Soris telentosporiferis amphigurnis ef petiolicolis, sempere gregarios confluentibustume. marnlis

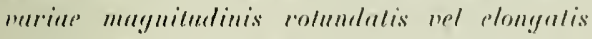

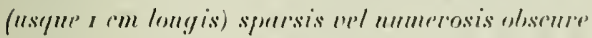
brameis prosecipue arevicolis insidentibus al folits incrassulis deformulisyne redelemlibus: soris mumerosissimis, mimulis, rolumblatis, pulue-
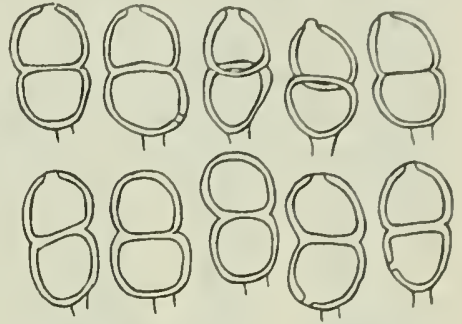

frig. 17: P'uccinia Bocconiae. - Téleutospores.

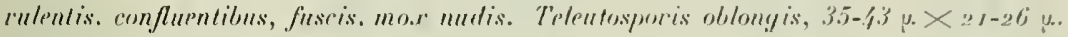

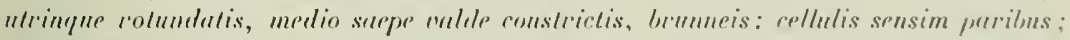

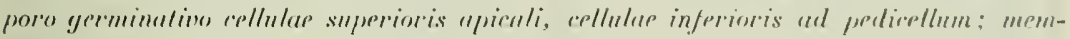

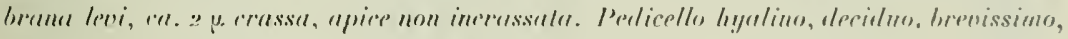
4-., $\mu . \operatorname{lito}$.

\section{Sur pétioles at feuilles de Bocconia frutescens $L$.}

Autes centrales, dép. Antioquia. III. Taillis non loin du Rio Amagra au-dessons du

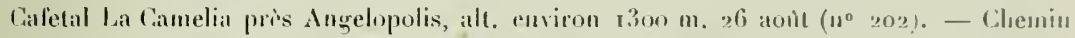
le Simta Barbura an Canca, près de lauberge El Cairo, alt. environ gro m. 2 fi septembre ( $\left.n^{\circ} 202^{2}\right)$.

Le développenent de celte espice semble atre celui l'un Leplo-Paceinia, cepentant il ne m'est pats possible de l'affirmer avec toute cortitude.

\section{Puccinia Pruni-spinosae Pers.}

$$
\text { in Syn., } 11.226(1801) \text {. }
$$

Sur feuilles de Prunus Persica (L.) Stokes.

Andes orientales, dép. Cundinamarcal. Culures, Cafetal Buenavista dans la vallee de Viotia, alt. $1020 \mathrm{~m}$; II. 27 uctolure (no i). 


\section{Puccinia bogotensis spec. nov.}

Amas de téleutospores à la face inférieure des feuilles at sur les pétioles, irréuntièrement disposés, très peu nombrenx; sur les feuilles ils sont arrondis at mesurent $\mathbf{1 - 2}$ mm

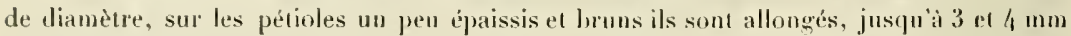

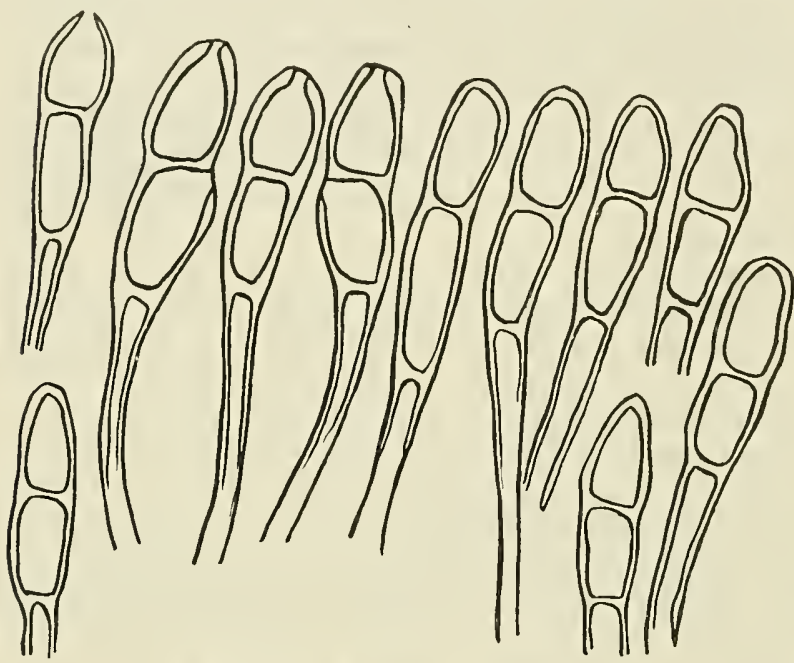

Fig. 18: Puccinia bogolensis. - Téleutospores. de longneur. Sur les feuilles, it la face supérieure el correspondant anx amas, on constate des taches d'un brun un peu violacé contontés diune zone de $r .3 \mathrm{inm}$ oì le tissn foliacé prend une coloration lirun pourpreà l'état frais ; a la face inférieure, autour des amas, on voit le plus somvent une étroite zone colorée en brun chamois. Les amas sonl proéminents alorsqu’a la face sujérieure on constate souvent un petite dépression, ils sont compacts, d'un brmn-jaunàtre, nus de honne henre. - Téleutospres allongées, arrondies on rarement un peu coniques à l'extrémité, atténuées à la base, non étranglées à la cloison ou à peine d'une manière sensible, d'un jaune très pâle, parlois snblyyalines; elles mesurent en moyenne 65-80 $\mu . \times 18-24 \mu$, quelques-unes cependant ne mesurent que $60 \mu \times 24 \mu$, alors que d'autres très grandes atteignent jusqu'à $87 \mu$ de longueur sur $21 \mu$ de largeur; les deux cellulles sont sensillement de même forme et dimension, parfois l'inférieure est un peu plus allongée que la supérieure; pore germinatif apical pour la cellule supérieure, au niveau de la cloison pour la cellule inférienre; la membrane est lisse, d'égale épaisseur partout, environ $1 \frac{1}{2} !_{0}$, non renflée à l'extremití. Pédicelle hyalin, persistant, jusqu' ì $9^{5} \mu$. de longueur sur $11-14 \mu$. de largeur à son insertion et 5 - 10 . à la base (mesurant encore souvent $u$ u. de largeur à $50 \mu$. de l’insertion).

Soris teleutosporiferis folizolis et petiolicolis: in foliis, hypophyllis, sparsis, pauris, rolundalis, $1-2 \mathrm{~mm}$ diam., in petiolis oblongis, usque $3-4 \mathrm{~mm}$ longis. Soris folierrlis in maculis rolundatis, brunner-purpmrascrntibus. compurtis, flum-brumneis, 


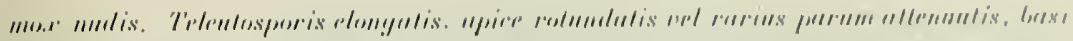

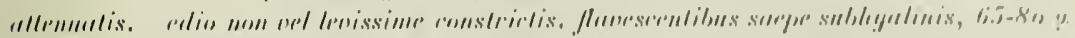
২

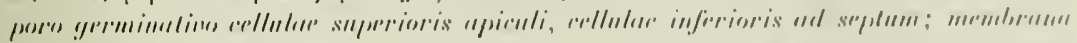

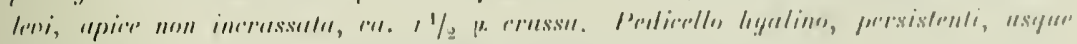

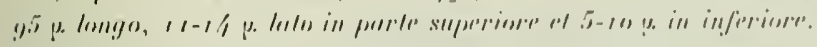

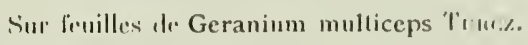

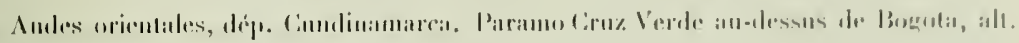

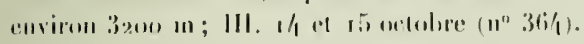

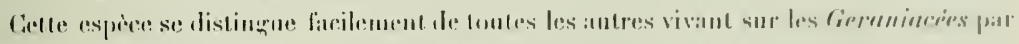

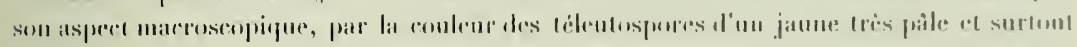

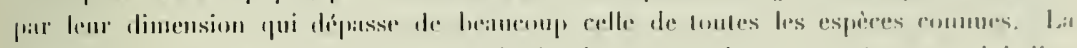

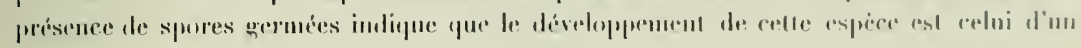
laphlr-l'merimirs.

\section{Puccinia Arechavaletae Speg.}

in liung. Arecul. Puy. IV, 1., 22 (1881).

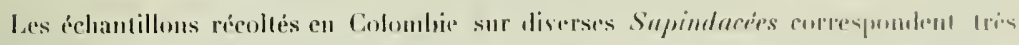

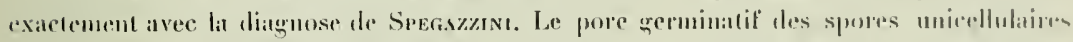
ast aprical et la membrame d'égale épraisseur partoul, z p. Les spores bicellulaires sonl le plus souvent en tris petite quantiti companthivement aux unicellulatres; leurs domx

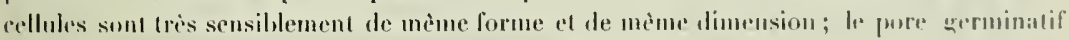

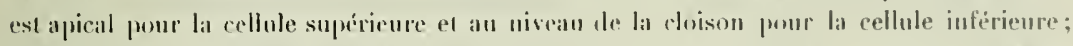

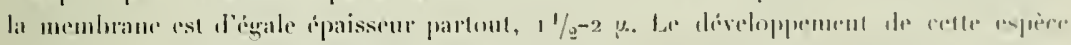
semblite itre celui d'un Leptr-l'ucrinin.

Sur feuill's d'unr. Sapindacée inlélerminix.

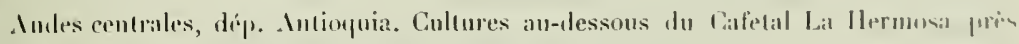

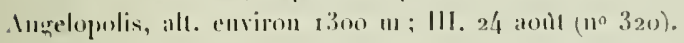

\section{Sur fenilles de Serjania spec.}

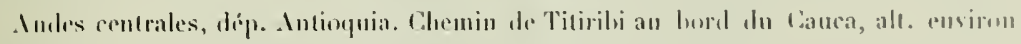
$1200 \mathrm{~m}$; III. S septembre $\left(10^{\circ} 318\right)$.

Sur feuilles d'une Sapindacée indeterminci.

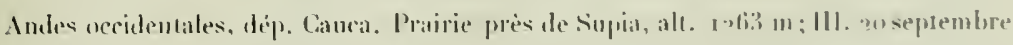
$\left(11^{0} 317\right)$.

6. 
Sur feuilles d'une Sapindacée indéterminée.

Indes orientates, dép. Cundinamarea. Portillo an bord du Rin Bogota, alt. environ $500 \mathrm{~m} .27$ uctolure $\left(12^{\circ} 31 y\right)$.

\section{Puccinia dubia spec. nov.}

Inas de téleutospores à la face inlérieure des leuilles, réunis en petit nombre pour former des taclies arrondies de $1-2 \mathrm{~mm}$ de diamètre, irrégulièrement disposées, disséminćes ou assez abondantes, faisant à la lace supérienre des taches crontenses d’un brun plus ou moins fonce; sur les taches les amas sont conlluents, un peu compacts, longtemps recouverts par l'épiderme de conleur fauve, puis nus al d'un brun-jaune, petits el gros-

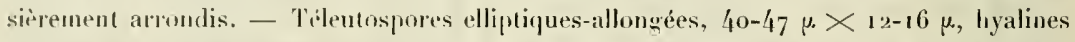
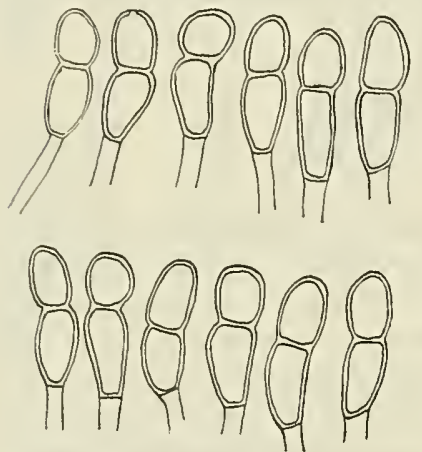

Fig. 19: Puccinia dubia. - Téleutospores. ou subhyalines d'un jaune très paile, armonties à leur extrémití, atténuées à la base, peu étranglées à la cloison; les deux cellules sont le plus souvent de dimensions inégales, l'inférieur étant plus allongréce que la superieure souvent plus ou moins arrondie; pore germinatif apical pour la cellule supéricure, la position de celui de la cellule inférieure n'a p'm ètre exactement déterminée; membrane lisse, mince, environ I $\mu$, d'égale épaisseur partout, non renllée it l'extrémité. Pédicelle hyalin peu persistant, jusyu’ì $30 \mu$ de longueur sur $4-5 \mu$. de larweur.

Soris telentosporiferis hypoplyyllis confluentilns, in parvos greges dispositis, macnlis brunneis rolnulatis ( $1-2 \mathrm{~mm}$ dinm.) sparsis vel satis numerosis sed non conflnentibus insidentibns. compartimsculis. din epidermide fulva tectis, dein nudis, flavo-brunneis, minntis, plns mimusve rotundatis. Trelentosporis ellipsoideo-elongatis, $40-17 \mu \times 12-16 \mu$, hyalinis vel hyalinoflavescentibus, upice rolundatis, basi altenuatis, medio leniter constrictis ; cellula inferiore plerumune majore. cellnla superiore saepe plus minusve rotundata; poro germinativo cellulue superioris apicali; membrann lrvi, temmi ca. I u., upice nou incrassata. Pedirello hyalino, parnm persistenti, usque 30 p. longo et 4-5 p. lato.

Sur feuilles d'une Ampélidacée indéterminée?

Andes centrales, dép. Antioquia. Cultures en dessous du Cafetal Ia Moka près Angelopolis, alt. environ $1600 \mathrm{~m}$; III. 2 septembre ( $\mathrm{n}^{\circ} 3 \mathrm{I} 5$ ).

Le développement de celte espèce semble ètre celui d'un Micro-Puccinia. car je n’ai observé ni spores germées, ni spores en voie de germination. 


\title{
44. Puccinia helerospora Berk. el Curl.
}

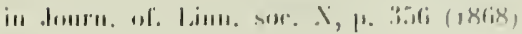

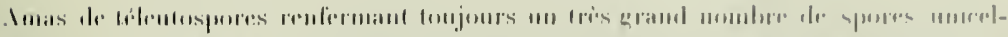

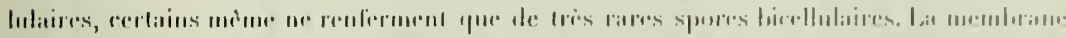

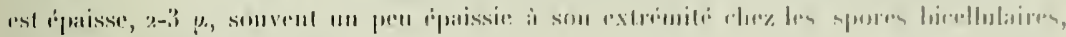
.

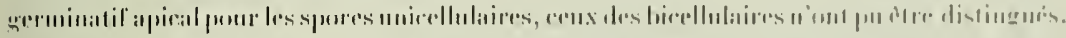

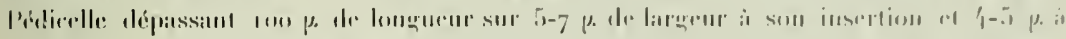

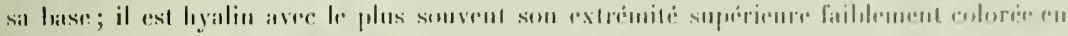

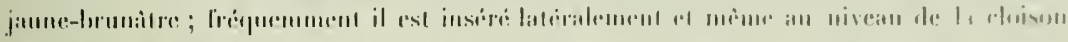

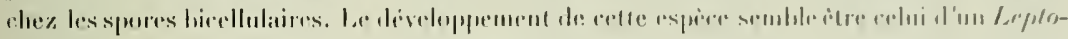
Pucrinin.

Sur leuilles d'un Malvacée indélermince.

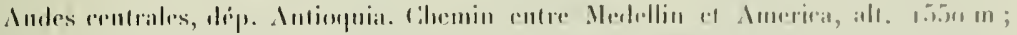
III. 11 :111 $\left(11^{0}: 31 /\right)$.

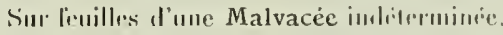

Andes centrates, dép. Antioquia. Chemin de Simbil Batharal an Cauca, non loin de l'anherge El Cairo, alt. envirnm g)o m; 111.28 septembre $\left(1^{n} 7\right.$ (i).

Sirr feuilles de Anoda cristata (1.) Simletiltinu.

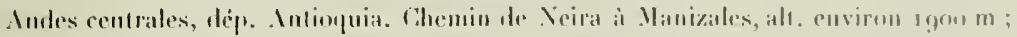
III. 2 coctolire $\left(n^{\circ}\right.$ 90) .

Sur leuilles de Wissadula periplocifolia (L.) P'nESL.

Dép. Tolima. Prairies arides lo long du Magglatena à Beltran, all. 2 tin m: IIf. 28 actolise $(n-16)$.

Sur leuilles de Bastardia viscosa L.) H. B. K.

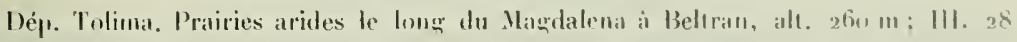
uctolure $\left(11^{\circ}, 5\right)$.

Sur leuilles de Abutilon umbellatum (L.) SwEET.

Dejp. Tolima. Prairies arietes te long du Magdalena it Beflran, all, gho m: III. of aclubre (11" 37$)$. 


\section{Puccinia Malvacearum Mont.}

in liay Ilist. tis. y polit. de Chile VIII, 1. 43 (1852) et Syll., 1. 314 (18.60).

\section{Sur fenilles de Malvastrum coromandelianum (L.) linhcke.}

Indes centrales, dép. Antioquia. Chemin de Meslellin à Bello, alt. 1550 m; 111. fand (11" 240). - Cultures le long du Rio Santa Elena au-dessus de Medellin, all. envirun $1,700 \mathrm{~m}$; III. 6 aoù $\left(\mathrm{n}^{0} 240^{4}\right)$. C Chemin de Medellin à America, alı. $1550 \mathrm{~m} ; 111.10$ ancit

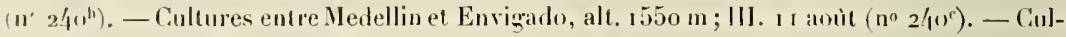

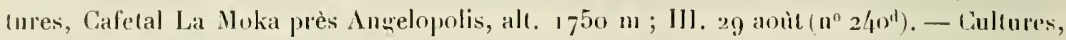
Cafetal La Camelia pres Angelopolis, alt. r800 m; III. 12 septembre $\left(1^{\circ} 240^{\circ}\right)$.

\section{Puccinia Anodae Syd.}

Ilonogr. Ured. I, 1. 475.

Les deux cellules des téleutospores sont très sensiblement de mème forme et de mème dimension, parfois cejendan l’inférieure est un peu plus grande que la supéricure; pore germinatif apical pour la cellule supérieure, immédiatement au-dessous de la cloison pour la cellule inférieure. Pédicelle atteignant jusqu'à $9^{\circ} \mu$. de longueur sur une épaisseur de $5-7 \mu$ à son insertion, 11 peu plus étroil à sa base. La présence de spores germées ou en grermination semble indiquer qu'on est en présence d'un Lepto-Puccinia.

\section{Sur feuilles de Anoda hastata $\mathrm{CAv}$.}

Andes centrales, dép. Intioquia. Ill. Chemins au haut de la ville de Medellin, alt. $1600 \mathrm{~m} .6$ août ( $\left.n^{\circ} 218\right)$. - Bord de chemins à Guaca, alt. 1480 m. 12 septembre $\left(n^{0} 218^{\mathrm{a}}\right)$.

\section{Puccinia Sidae-rhombifoliae spec. nov.}

Amas de téleutospores à la face inférieure des feuilles soi isolés, soit plus sonvent réunis en grompes et confluents pour former des laches arromlies ou grossièremot arrondies, irrégulièrement disposées, souvent un peu confluentes et nombreuses; ces taches mesurent en moyenne $2-3 \mathrm{~m} ı$ de diamètre et peuvent atteintre $5 \mathrm{~mm}$ lorsqu'elles deviennent confluentes. A la face supérieure et correspondant aux amas, on constate des laches d'un brun noir entourées d'une étroite zone colorée en jaune-brun, faisant souvent une petite dépression alors yu'ì la face infériemre, au contraire, les amas sont proćminents el presque toujours entourés d'une étroite zone oì les tissis son colorés en brun fauve. Les amas sont petits, arrondis, à peine $1 / 2 \mathrm{~mm}$ de diamètre, souvent moins, nus, bruns, 


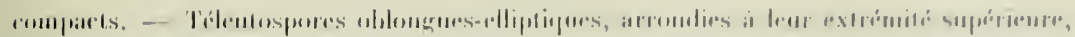

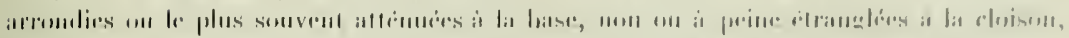

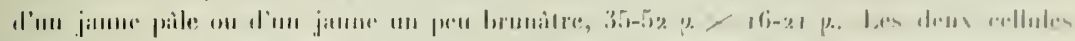

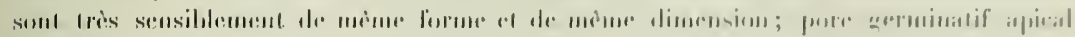

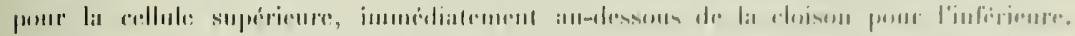

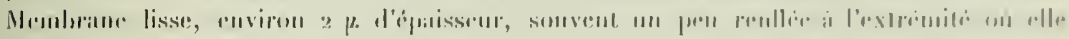

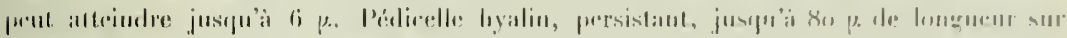

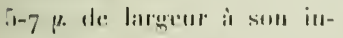

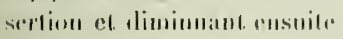

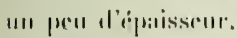

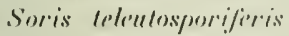

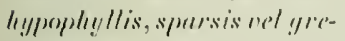
yurvisis ol conflumblibus, murulis rolumblutis, /usquesinm diam.) obsenre hramueis plem ruminue numerosis insidenlibus; sorisminulis, ni, $1 / 2$ mm dium., rotumlatis, mor: nulis, rmmpuctis. fusets. T'pleutosportis oblongo-ellipsoideris, aprice rontundeltis, husi rolumblatis uel stuppius allementis, mediononnelerixconstriclis, flumescentibus vel flawo-pullide bunnrolis, 3ij-

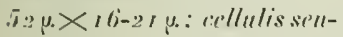
sim puribus, poro germinulivo cellulae supervioris api-

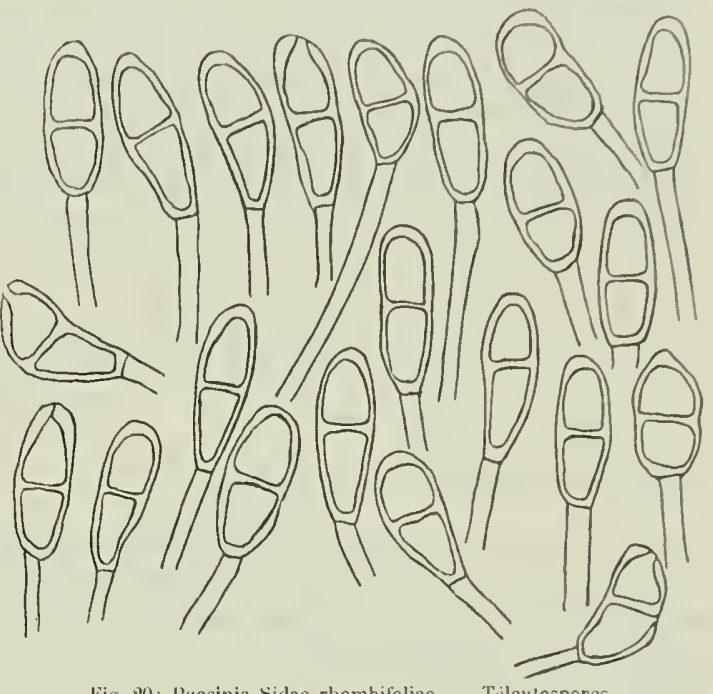

Fig. 20: I'uccinia Sidae-rhombiloliae. - Tileulospores.

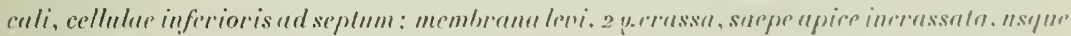

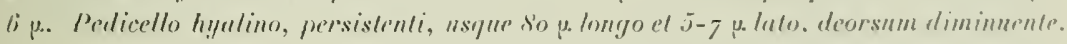

Sur feuilles de Sida rhombifolia $L$.

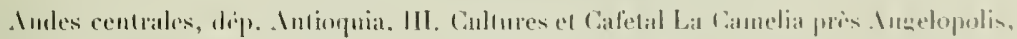

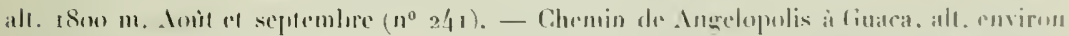

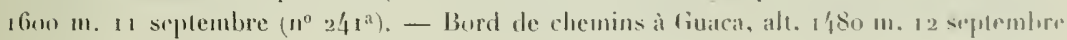
$\left(11^{\circ} 21^{\prime \prime}\right)$.

Indes accidentales, dép. Caunca. III. Clamin de Valparaiso at Supia, alt, envirun tixo m. 2!) septembre $\left(11^{\circ} 241^{\circ}\right)$.

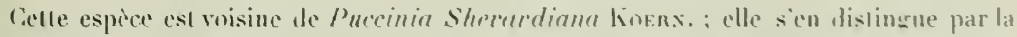
dimension des spores qui atteignent an maximum $52 \mu$ de longuen al jamais bif e et 


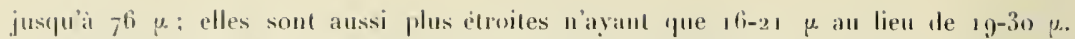

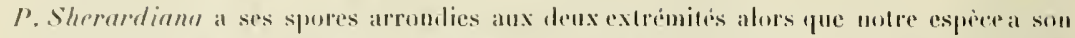
extrémité inférime de beaucoup le plus souvent atlénuce; la coloration des spores est leaturoup plus daire, enfiu le predicelle n'attrint que $80 \mu$ de longueur et pas jusqu'i

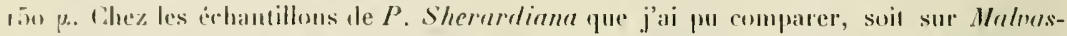

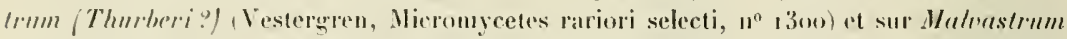
rorcinemm (Sydow, Uredineen, $1^{n}$ 2277), on rencontre bion des spores ayaut la mime longneur que cetle indipuée ci-dessus, mais à coté nombreuses sunt colles qui dépassent in $\mu_{\text {; }}$; eltes sont aussi très sensiblement plus larges, frès grénéralement arrondies à la baso

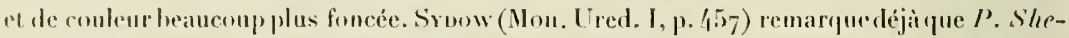
rordiunn forme en quelifue sorte une espece d'allente que l'on mentionne sur des supprts trís diflérents où les féleutospores varient très sensiblement de l'un à l'autre. Me basaul sur les dillérences très netles et constantes mentionnées plus ham, cette espice nouvelle semble se justifier. Le développement est celui l'un Lepto-Puccinio, car j’ai constaté de nombreuses tileutospores germées ou en germination.

\section{Puccinia Hydrocotyles (Link) Cke. in Girevillea IX (1880), p. 14.}

de n'ai recueilli en Colombie que des uredos qui correspondent tris exactement en loul avec la description de $P$. Hydrocotyles.

\section{Sur feuilles de Hydrocotyle umbellata $\mathrm{L}$.}

Andes centrales, dép. Antioquia. Il. Endroits lumiıles entre Medellin et Bello, alt.

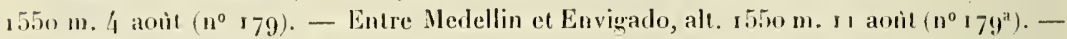

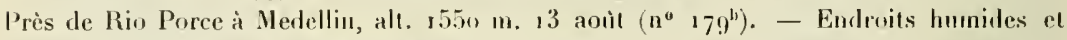
ombragés, Cafetal La liamelia près Inggelopolis, alt. r800 m. 19 aoù ( $\left.11^{\circ} 179^{\prime \prime}\right)$.

Sinr feuilles de Hydrocotyle quinqueloba Ruz et P'avon, var. stella (I'йL) UвваN.

Andes centrales, dép. Antioquia. Versint occilental du Ruiz an commencement des Paramos, alt, environ $3000 \mathrm{~m}$; II. 4 octobre ( $12^{\circ}$ (6) $)$.

Sur leuilles de Hydrocotyle leucocephala linam.

Indes orientales, dép. Cundinamarca. Barro Blanco près de Madrid dans la Sabana de Bogotit, alt. $2600 \mathrm{~m}$; II. 19 octobre $\left(11^{\circ} 9^{\prime}\right)$.

\section{Puccinia ruizensis spec. nov.}

Anas de féleutospores sur les pétioles et les deux faces des fenilles, surtout sur l'inférieure. Les feuilles attaquées prennent une coloration jaunâtre, s'allongent très 


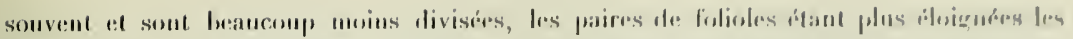

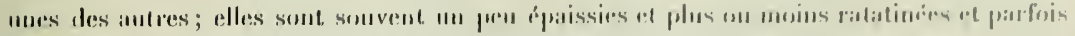

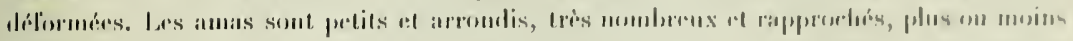

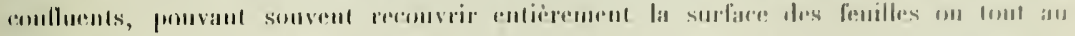

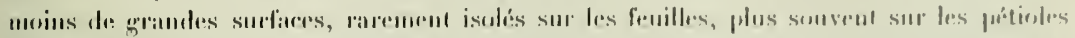

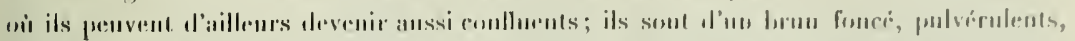

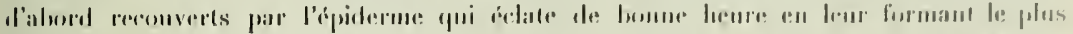

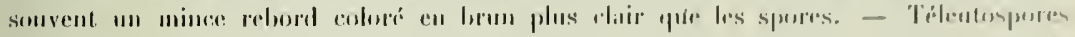

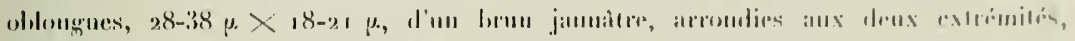
mettement at somvent profondinent flranglies at la cloison, re qui lasorise

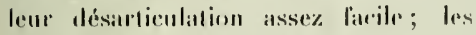
denx rellules sont tries sensiblement de mime forme of de mème dimension;
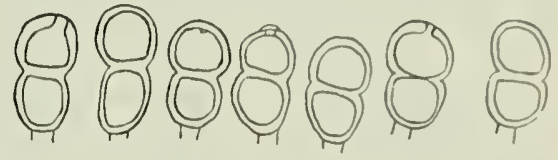
prere germinatif de la cellule suprériemre aprical el partois surmonté d'une très perite papille lyaline, celui de lis cellula infiricure n'a pur itre exactement déterminé; membrane lisse, d'égale épaisseml prarloul, environ $2 \%$, non renllee
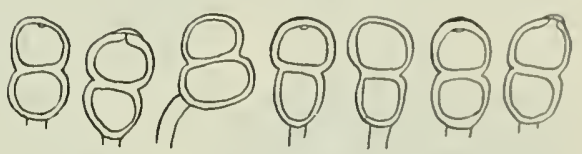

Fig. 21: l'uccinis ruizensis. - Téleutospores.

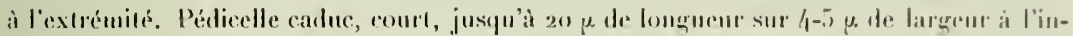
sertion, lyyalin, parfois inséré plus ou moins latéralement.

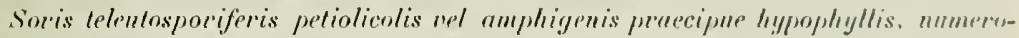
sissimis confluentibnstue, mimulis, rolundalis, fuscis, morn spmsis, puluremlentis,

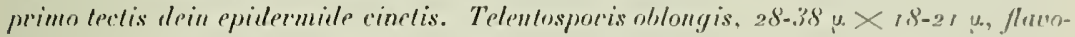

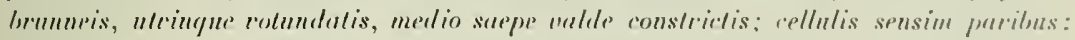

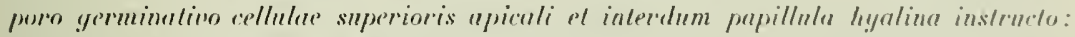

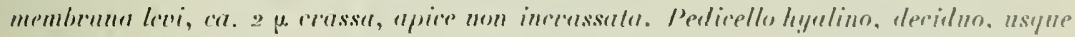
2o y longo el ti-j $\mu$ lato.

Sur pitioles et fenilles de Oreomyrrhris andicola (II, B. K.) Evblucuer.

Anles centrales, dép. Antioquia. Prairies, Paramos du Ruiz, alt. 3̈jou m; III. 5 octurise $\left(n^{\circ} 67\right)$.

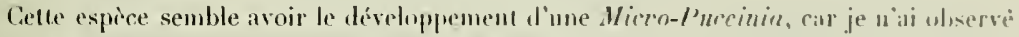
aurune tétentospore germie ou en voie dre germinatim. 
50. Puccinia Ipomoeae-panduratae (Schw.) Syd.

in Mon. Lred. I, p. 32.3.

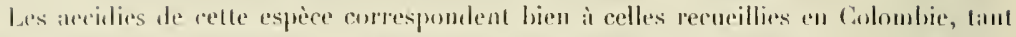

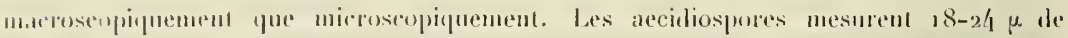

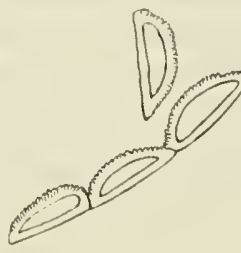

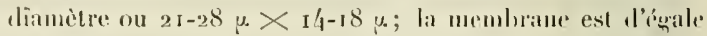
cpaissen partout, $1 \frac{1}{2}-2$ y. linement vermquense à vermes

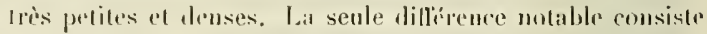
dans la couleur des areidinspreses indiquéc comme janne chair dans la diagnose de I'. Ipomoeae-panduratar, alors que dans les exemplaires de Colombie, les spores sont lyyat lines ou sublyalines d'un janne trìs pâle. Les cellules de la péridie, vues de face, sont fortement verruquenses, 'n coupe elles présentent une paroi externe el lisso de $2-4 \mu$

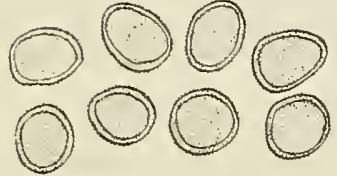

Fig. 22: Puccinia Ipomoeae-panduratae. - Cellules de la péridie vues en coupe et aecidiospores sur lpomoea all. caloneura. d'épaissem et mue interne assez fortement verruquensc de 3-5 $\mu$. d'ípaisseur.

Sur feuilles de Ipomoea all: caloneura Missner.

Andes centrales, dép. Antioquia. I. Chemin de Medellin à Bello, alt. $1550 \mathrm{~m} .4$ aoù $\left(n^{\circ} 289\right)$. Colline au-dessus de America près de Medellin, alt, environ 1700 m. 15 aloit $\left(11^{0} 289^{\mathrm{a}}\right)$. - Cullures au-dessous du Cafetil La Ilermosia près Angelopulis, alt. environ rinoo m. $2 / 4$ aonit $\left(\mathbf{n}^{n} 288\right)$.

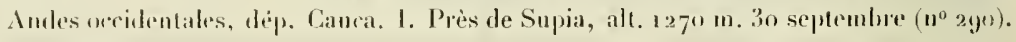

Sur feuiltes de Ipomoea spee.

Andes rentrales, dép. Anlionpria. I. Chemin de Medellin ì Amorian, alt. 1550 in. 5 a

\section{Puccinia Convolvulacearum spec. nov.}

Amas de télentospores à la lace inférieure des fenilles, rarement isolés, de lueanconp le plus souvent réunis en groupe et plus ou moins nombrenx pour former des taclies arromlies de $1-2 \mathrm{~mm}$ de liamètre, irrémulièrement disposées, dissíminces ou, an contrin abondantes et parfois conlluentes, faisant à la face suprérieure des lenilles des laches d’un brun assez foncé. Les anas sont petits, arrondis, parfois un pen confluents, d'un hrun lanve, nus de bonne hemre, mu peu compacts. - Trilentospores allongées, qu-17 p. (et

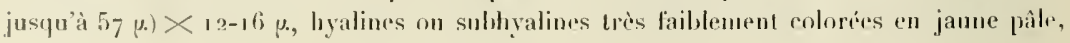




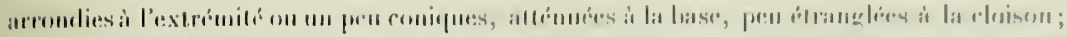

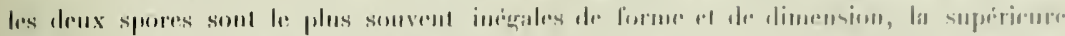

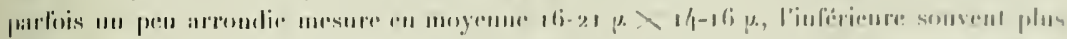

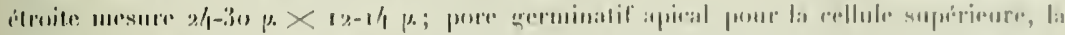

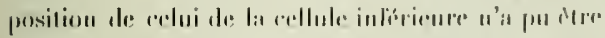

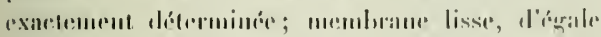

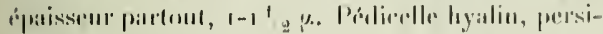

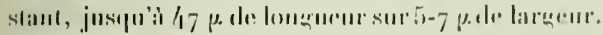

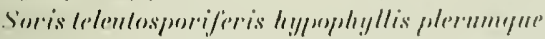
grefgariis, menculis rolmulalis ( $1-2$ mun dium.) brummers plus mimusoe numerosis insidentibus, mimulis, rotundalis, interdmm conflnentiturs, julvis.

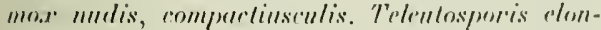

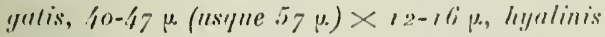

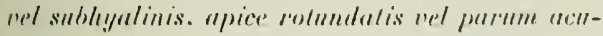
linserulis, basi allemuatis, medio via nel leniter

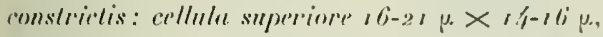

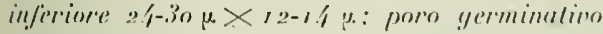

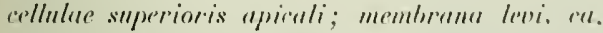

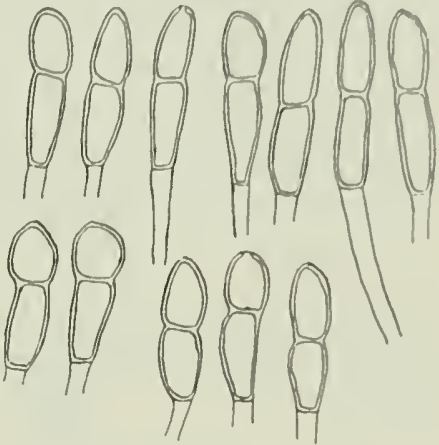

rig. 23: I'uccinia Lonvolualocearum. Telinutuspures.

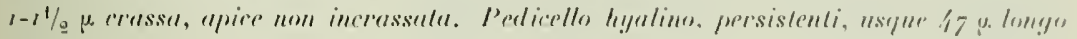

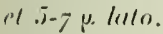

Sur feuilles de Convolvulacées intrilerminées.

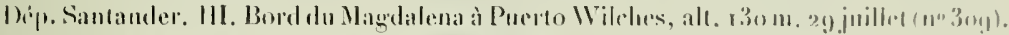

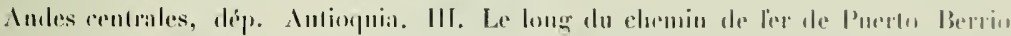

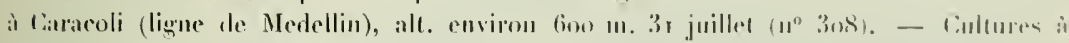

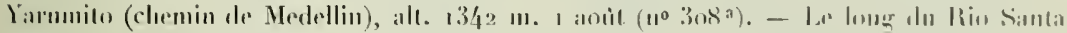

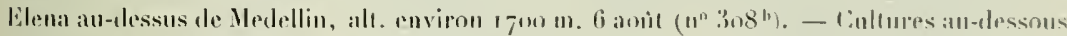

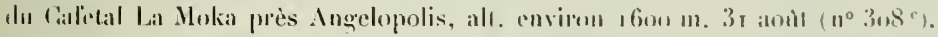

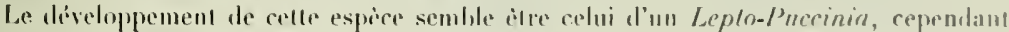

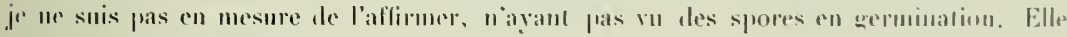

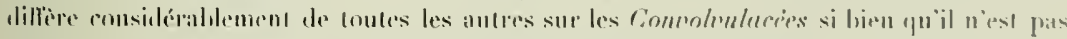

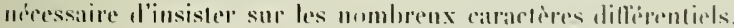

\section{Puccinia Lantanae Farl.}

in Proceed. Americ. Acanl of Arls and Sc. XYIII, 1883, P. 83.

Téleutospores uni ou bicellulaires; dans les amas examines les bicellulitires ont lon-

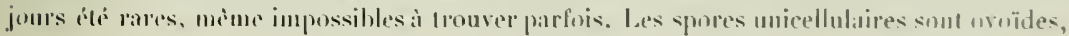
62 
oblongues on elliptiques, arrondies à leur extrémité, arondies ou attémues it la base;

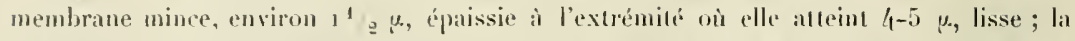
position exacte du pore greminatif n’a ju citre déterminée; elles sont hrunes, un pren phus funcies a la membrane el surtout ì son épaississement terminal. Pédicelle persistant, un

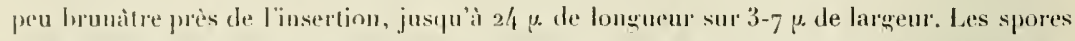
bicellulares sont arrouties aux denx extrémités, peu on ì peine étranghes à la cloism, l'un brun clair. Les drux rellnles sont tris sensiblement de mime forme el de mème dimension, la position rate des pores germinatifs n'a pu dere détermine. Membrane lissé, mince, $1_{2}^{1}{ }_{2}$, égale partout, pas sensiblement épaissir à l'extrémité. P’édicelle lyalin ou un peu brunitre pris de l'insertion, persistant, jusqu'i 40 p. de lenguenr sur 5-7 $\mu$ de largeur it son insertion el 3-4 $\mu$ ì sil base.

Sur fenilles de Lantana hispida H. 13. K.

Andes centrales, dép. Antiotpia. III. Chemin de Merlellin à Bello, alt. 1550 m. 4 aom (1 20 2). - Le long du Rio Santa Elena antessus de Medellin, alt. environ $1700 \mathrm{~m}$. 6 aoùt $\left(11^{\circ} 212^{\mathrm{a}}\right)$.

\section{Sur feuilles de Lantana trifolia $\mathrm{L}$.}

Andes centrales, dép. Antioquia. 111. Lisières de bois, Cafetal La Camelia près Angelopolis, alt. $1800 \mathrm{~m}$. Aon̂t ( $\mathbf{1}^{0}$ 2/4). - Taillis, Cafetal La Moka près Angelıpolis, alt. $1700 \mathrm{~m} .29$ aonิ $\left(n^{\circ} 24^{a}\right)$. - Cultures et taillis sur la rive droile de l'Amagadiente, ı is-à-ris du Cafetal La Camelia près Angelopolis, alt. environ $3700 \mathrm{~m}$. 2 seplembre $\left(24^{\mathrm{b}}\right)$.

Díp. Tolima. III. Bord dı Magdatena, prairies arides le lom du Heuve à Bettran, alt. $260 \mathrm{~m} .28$ octobre $\left(\mathrm{n}^{\circ} 29\right)$.

\section{Sur feuilles de Lantana tiliifolia Cın .}

Díp. Tolima. 111. Bord dn Magdalena, prairies arides le long dn fleuve ì Bultran, alt. $260 \mathrm{~m} .28$ octobre $\left(n^{\circ} 28\right)$.

Le téveloppement de celte espèce semble ètre celui d'un Lepto-Pnccinia, cependant je ne suis pas en mesure de pouvoir l'affirmer.

\section{Puccinia VonGunteni spec. nov.}

Amas d'uredos à la face inférieure des feuilles, irrégulièrement disposés, isolés, palfois nombreux mais non conlluents, très petits, punctiformes, arrondis, nus de bonne lieure et entonrés d'un mince rebord épidermique, d'un brun clair, ne se manifestant par aucune tache, pulvérulents. - Uresdospores arrondies, $211-24 \mu$ de diamètre, d'un lirun clair; membrane d'égale épaisseur partout, $1-1 / \frac{1}{2} \mu$, fincment échinulée à épines courtes et peu denses; pores germinatifs 2 équatoriaux. 


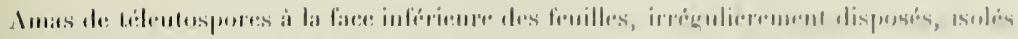

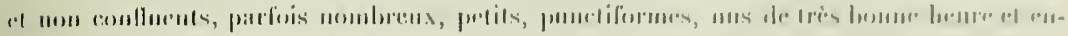

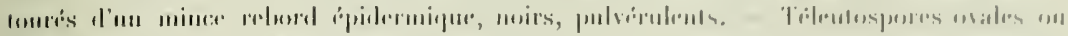

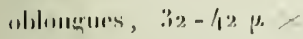
"1-28 pe, mirers on hirmumoir et opraylues it rontplide maturist, arroudires at1x deux rxtrémitris, mun ilrangléces a la cluisem ; less denxcrllulessontsonsildemenl de meste forme et ale mine dimension, dlles IIr so distingment netle-

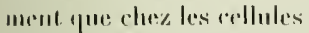

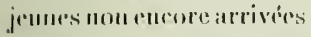
i maturite el colorées en lorun plus ou moins clair; cher les spores it malurifé

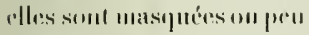
nefles grios sila membrame "parylue, d'un lirun fence ou novire; la position des prors germinalifs 11 'a pu itre exactement déterminé; membrane épaisse, 3-5 $\mu$, ruale partout ef mellement visible seulement surles spores jennes, verruguense à vermes grosises el denses; les sprores sont surmontces d'une Iris petite papille colorise eu lirun paile. Pédicelle persistane, jusquà
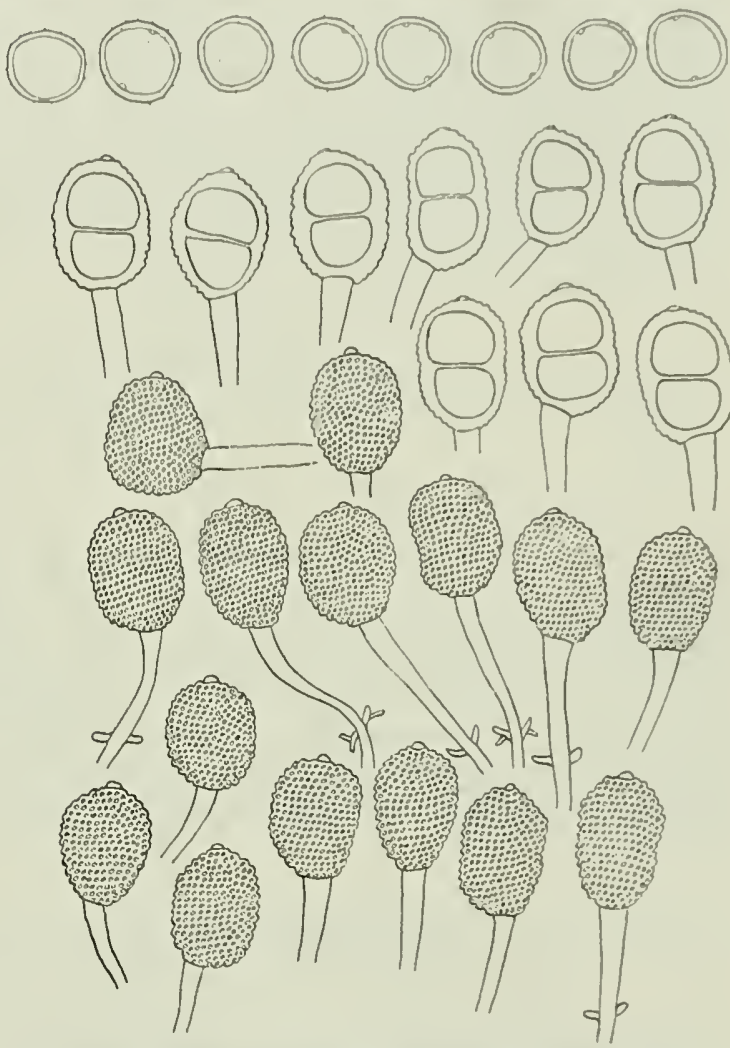

Fig. 24: Puccinia VonGunteni. - L'redospores el le̊leutospores.

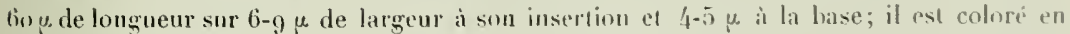
brun dair dans sa partie superieure, coloration yui devieut de plus en plus pille plus bas el enfin il est lyalin dans la 1 go le ${ }^{1}{ }_{3}$ inférieur; dans le liers inférienr on conslate trés sonvent la présence de denx denticulations, parfosis hifurquées, placécs de chaque còte. lyalines, de $4-5 \mu$ de longueur sur $1-2 \mu$ de largenr. Parfois le pédicelle est inséré de còté el mème an niveau de la cloison intercellnbire. 
Sortis uredosporiferis hypuphyllis. syursis nel mumerosis sol non confluentibus, punetiformilus, mo.r nudis el midermide cimetis, brunnestis, sine muculis, pulmernlentis.

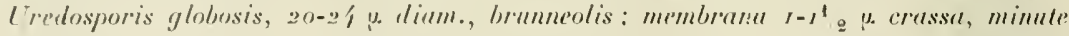

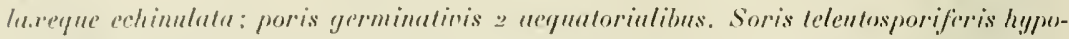

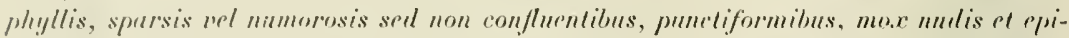

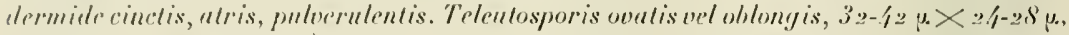
utris uel alro-brunneis, opucis, ulrinque rolundulis, mealin non constrictis, appire pupit-

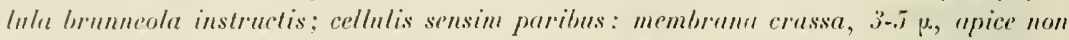
imerassalu, dense grosseque urrucosu. Pedicello persistenti, saepe plus minusue lutera-

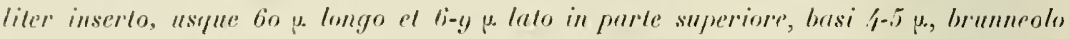
in parte superiore deorsum subluyalino dein hyulino: ad tertium inferum suepe a ramulis

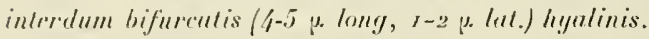

\section{Sur feuilles de Lippia americana $\mathrm{L}$.}

Dép. Bolivar. Bord du Magdalena, non loin de Barranumilla; II. III. 2 usvembre $\left(n^{\circ} 368\right)$.

Celte espece, par l'aspect de ses téleutospores, se rapproche de P'. Lippine Spra., mais s'en distingue facilement par la couleur des amas qui sout d'un brun clair pour les urélos et franchement noirs pour les téleutospores sans mélange d'uredospores; les uredospores sont plus petites et d'un brun clair, non "aureis" comme l'indique la diagnose ; les téleutospores sont beaucoup phis foncées, franchement uoires à complète maturité et opaques, elles sont toujours surmontées d'une très petite pipille brunàtre, la membrane est épaisse, $3-5 \mu$; enfin le pédicelle ne porte que 2 denticulations (du moins je n’en ai pas vu davantage) souvent bifurquées. Le développenent de celte espéce est celui d'un Hemi-Pucciniu. Cette espèce est dédiée à nos compatrintes, les MII. von Gunten auprès desquels nous avons trouvé à Barranquilla la plus cordiale lospitalité el les conseils les plus précieux.

\section{Puccinia leonotidicola P. Henn.}

in Botan. Ergehnisse der Kumene-Sambesi Exped., 1902, p. 3.

Je n'ai pu recueillir que les uredos de cette espèce qui correspondent avec ceux rócoltés dans l'Afrique australe. Leur membrane d'égale épaisseur partoul, environ $2 \mu$, est épineuse à épines courtes el assez peu denses; les pores germinatifs sont au nombre de 5 à 6 , irrógulièrement disposés. Les uredospores sout colorées en brun clair et sont arroudies, 18-23 p. de diamètre.

Sur feuilles de Leonotis nepetifolia (L.) R. Br.

Antilles: Jamaïque, Kingston, Ilope Gardens ; 11.14 juillet $\left(\begin{array}{lll}11^{\circ} & 119\end{array}\right)$. 
55. Puccinia albida Diet, et Neg.

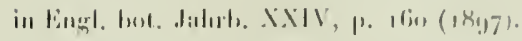

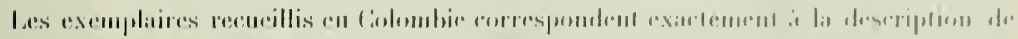

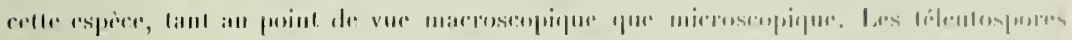

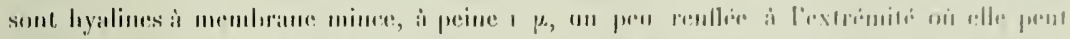

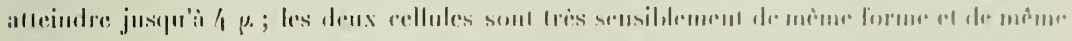

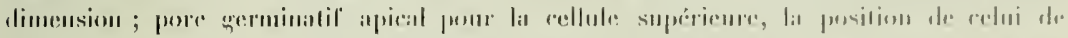

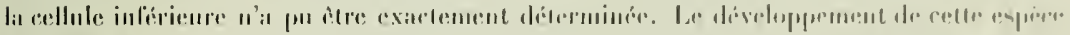

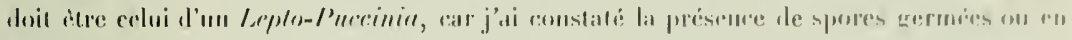
germination.

Sill lenill's de Stachys Mayori IBn!.

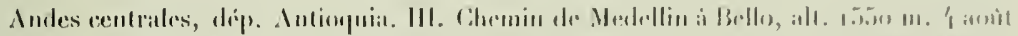

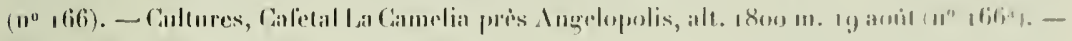

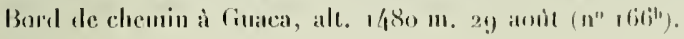

\section{Puccinia paramensis spec. nov.}

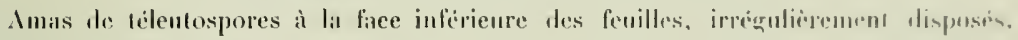
disseminés on assez nombrenx, isolés un parfois conlluents al formant de perlites laches de 1 mm de diamètre. Les lenilles présentent ì la face suprericure de petits puints un de pelites taches d'un jannc-brunitre correspondant aux amas de la face inférieure; en ciss de forte infection, touf on parlic des fenilles prend une coloration janne-brun aves de petites taclies plus foncées correspondant aux amas. Ceux-ci son petits, arroudis, punetiformes, pulvérulents, d'un brun cannelle, d'abond recouverts par l'épiderme qui somvent leur forme ensnite un rebord irrégulicr. Téleutospores ovales ou ohlongnes-ovalaires, $23-28 \mu \times 16-19 \mu$, d'un brun clair parfois
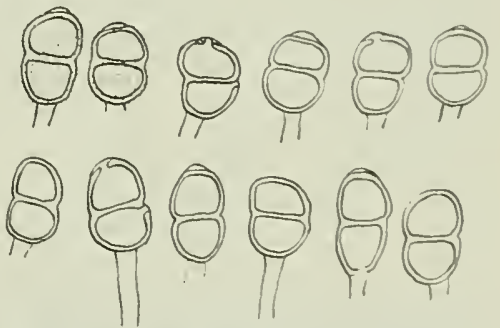

Fig. 25: Puccinia paramensis. - Téleulospores. subliyalines, arrondies aux deux extrémilés, pen éranglées à la cloison; les deux cellules sont très sensiblement de mème forme el de mème dimension; pore germinatif apical pour la cellule supérieure el surmonté d’une petite papille hyaline, immédiatement an-desonus de la cloison pour la cellule inférieure; membrane d'egale épaisseur partout. environ ${ }_{1}{ }_{2}{ }_{2}$., très finement granulo-verruqueuse à gramulations très petites, peu visibles ef assez denses. Pédicelle hyalin, caduc, jusıu à $25 \mu$ de longueur sur $4-5 \mu$ de largeur. 
Soris teleulosporifer is hypophyllis, sparsis vel yreguriis et interdum confluentibus, maculis minulis (car. I mm alirm.) fluwo-brunneolis insidentibus, cinnumomeis, minutis. puncliformibus, pulerulentis, primo tectis dein suepe epidermide cinctis. Telentosporis

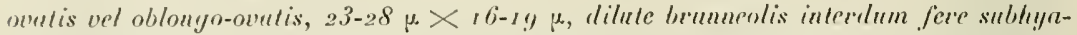
linis, utrinque rotumlatis, medio leniter constrictis: cellullis sensim paribus : poro greminalico cellullae superior is apicali papilla minima et hyalinu instructo, cellulae infervioris

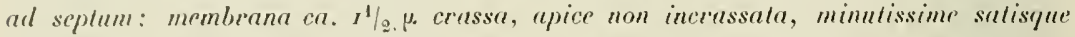
dense gerenulo-verruculosa. Pedicello hyalino, deciduo, usque 25 u. longu et 4-,5 p. lato.

Sur feuilles de Salvia cernua II. B. K.

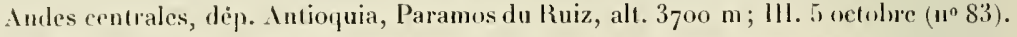

Cette espece se distingue facilement des autres se développant sur le genre Salvin et ne saurait ìtre confondue avec elles; les dimensions des téleutospores suffisent déjì à elles seules à la différencier, car il n'y a que ${ }^{\prime}$. conspersa Diet qui possède des spores aussi petites mais pour le reste bien dilférentes. Le développement de cctte espèce semble ètre celui d'un Miero-l'uccinir, car je n'ai pas pu constater la préscnce de cellules germées ou en roie de grermination.

\section{Puccinia soledadensis spec. nov.}

Amas de téleutospores à la face inférieure des feuilles, réunis en petit nombre pour former des taches arrondies d'environ $1 \mathrm{~mm}$ de diamètre, se manifestant à la face supé-
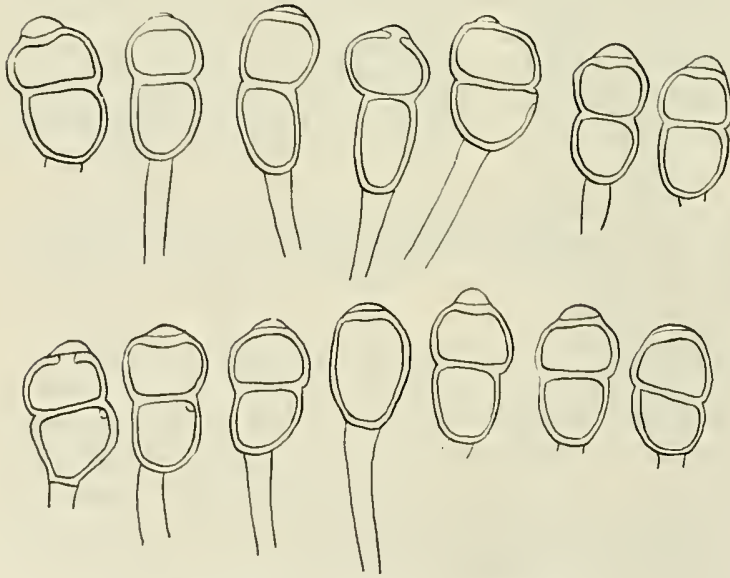

Fig. 26: Puccinia soledadensis. - Téleutospores. rieure des feuilles par de petites taches d'un brun foncé; ces taches sont irrégulièrement disposées, le plus souvent dissiminées, d'autres fois plus ahondantes mais non conHucutes. Les amas sont plus ou moins contluents sur les taches, d'un brun foncé, pulvérulents, d'alord recouverts par l'épiderme qui ensuite leur forme souvent un mince rehord. - Téleutospores oblongues ou oblonguesovalaires, $40-52 \mu . \times 22-$ $29 \mu$, d'un brun clair, 


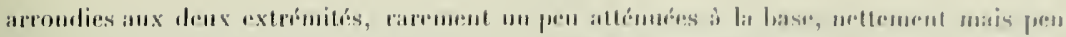

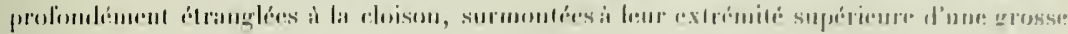

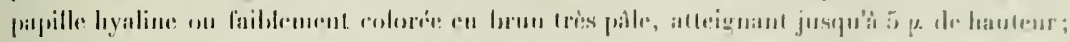

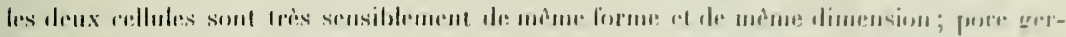

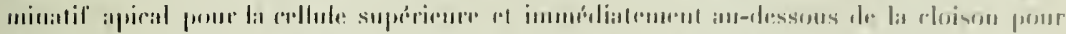

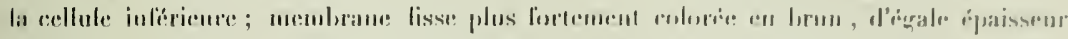

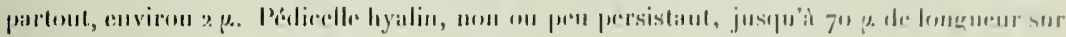

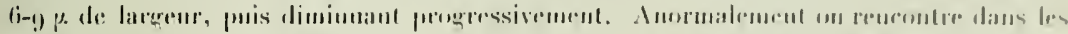

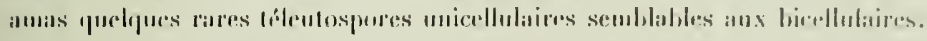

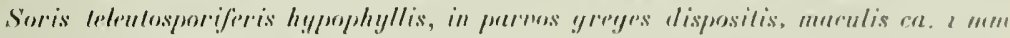

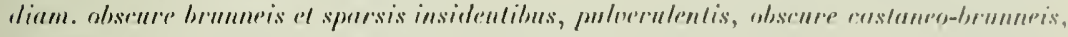

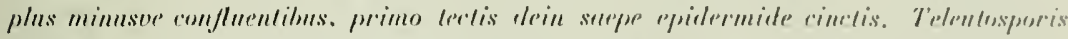

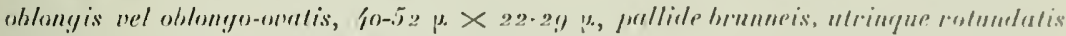

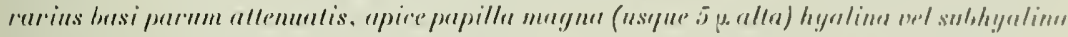

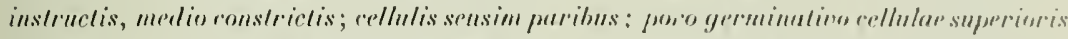

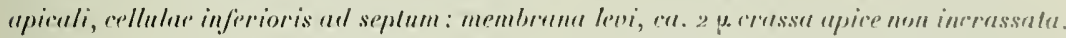

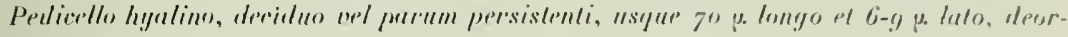
sum diminnemte.

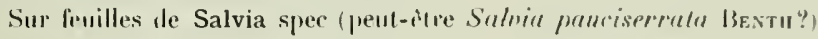

Andes rentrales, drep. 'Tolima. Soledal, sur le clemin de Maripuita, alt. 2345 in; III. (i oclobire $\left(11^{\circ} 79\right)$.

Cirlla aspece se distingue très facilement de toutes les autres si développant sur lan

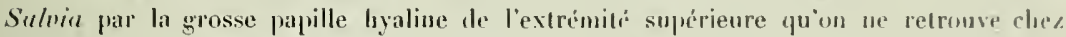

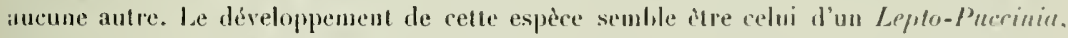
sans yüil soit cependant possilile de l’affirmer.

\section{Puccinia Hyptidis (Curt.) Tracy et Earle.}

\section{iı Bull. Mississippi Agricult. Exper. Stat, XXXIT, 1895, p. 86.}

Je n’ai recueilli en Colombie que lrs uredos de celte espèce qui correspondent exactement i la deseription tant microscopiquement que microscopiquement. Les uredospores sont globuleuses on subglobuleuses, 2 I-26 $\mu$ de diamètre, d'un jaune clair; pores germinatifs au nombre de 2 équatoriaux; membrane d'égale épaissenr partout, environ $2 \mu$, tinement échinulée ì épines conrtes peu visibles el pen denses.

Sur fenilles de Hyptis capitata Jace, var. vulgaris Bвı.

Andes centrales, dép. Intioquia. II. Chemin de Medellin à Bello. alt. 15.50 m. 4 anu

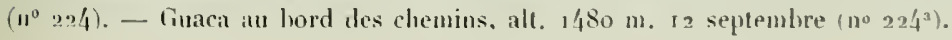




\section{Puccinia Hyptidis-mutabilis spec. nov.}

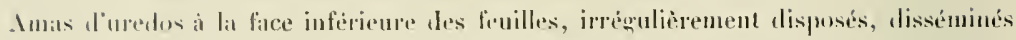
un, an contraire, rapprochés mais isoles el non ou tres sarement un peu conthents, petits,

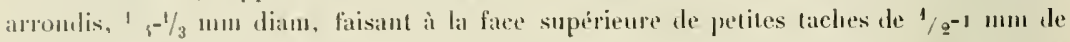

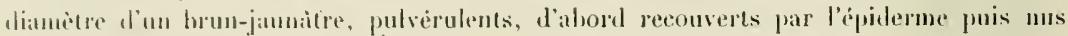
ct le plus sument sans rebord, d'un hrun amelle. - Uredospores arondits, 17-22 $\mu$

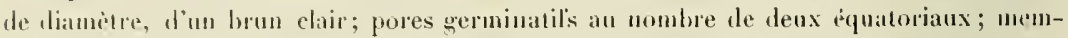

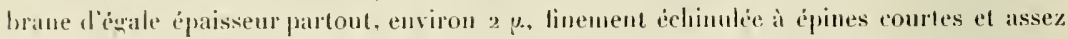
espacées.

Amas de tébentosporess semblables à ceux des uredos, ne s'en distinguant que par ane coloralion un peu plus lincéé, pren nombreux et très dissiminés. Téleutospores ellip-
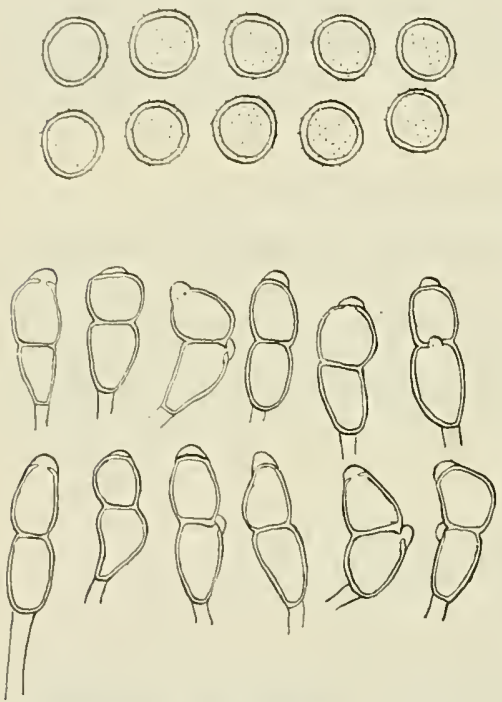

Fı. 27: Puccinia Ilyptidis-mutabilis. - Uredospores et téleutospores.

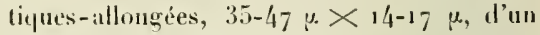
lurun jaune clair (la cellule supérieure quénéralenrent plus fortement colorée que l'inlérieure sourent subliyaline), arrondies au sommet, atténuées a lat base; les deux cellutes sont le plus souvent très sensiblement de mème forme et de mème dimension, partois l'inléricure un peu plus grande; pore germinatif apical pour la cellule supérieure el surmonté d'une papille hyaline pouvant atteindre jusqu’i $5 \mu$ de hauteur, pour la cellule inférieure le pore germinatif est situć immédiatement au-dessous de la cloison et également surmonté d'unt papille hyaline mais plus petite; membrane lisse, mince, environ $I \mu$, d'ígale épaisseur partout. Pédicelle hyalin, non persistant, jusqu'ì $26 \mu$ de longueur sur $5-7 \mu$ de largeur.

Sor is mredosporiferis hypophyllis, sporsis vel numerosis ol gregariis sed non vel ruro confluentibus, minutis, rolundatis, $1 / 4^{-}$ $1 / 3$ mm diam., maculis minulis / $\mathrm{ca} .1 / \mathrm{q}^{-1} \mathrm{~mm}$ dium.) flaun-brunneis insidentilus, pulvern-

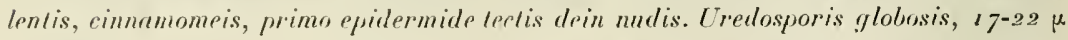
tlirm., dilute branneis; poris germinativis 2 aequutorialibus ; mombrana ca. $2 \mu$ crassa, minule satisque laxe echinulata. Soris telentosporiferis conformibus wix obscurioribus,

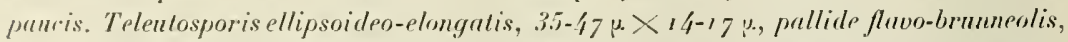
apice rolundulis, busi allenuatis; cellulis sensim parilus inlerelum inferione parmm ma- 


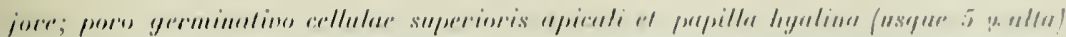

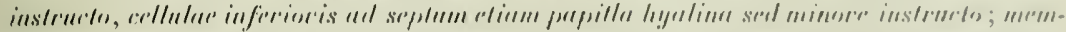

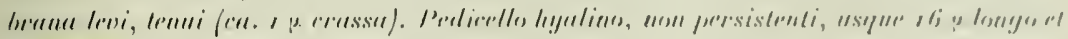
$i_{i \rightarrow 7} \mu$ lulo.

Sur linilles de Hyptis mutabilis (Ra:H.) lime. sar. spicata (Rort.) line.

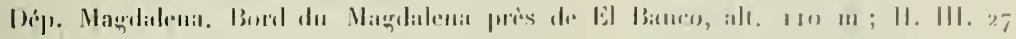
juiller (n"1\%1).

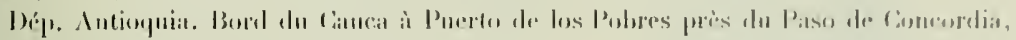

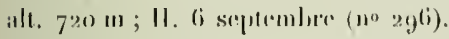

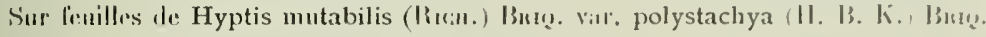

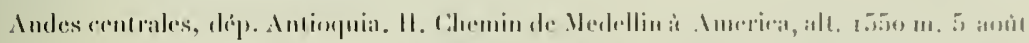

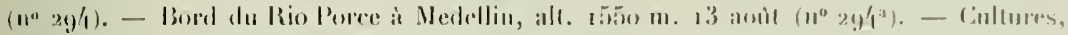

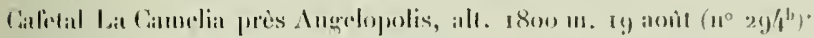

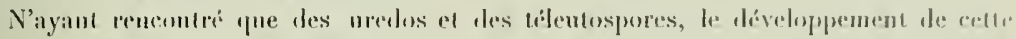

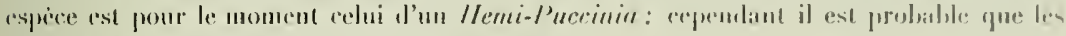

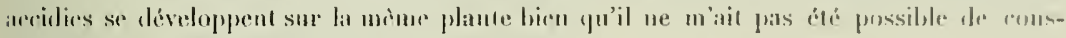

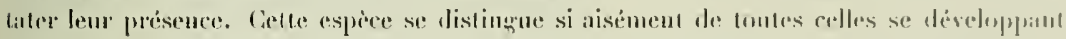

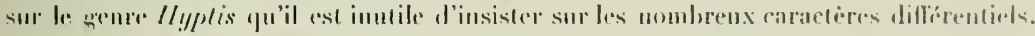

\section{Puccinia medellinensis spec nov.}

Pyenides at la lace suprérieure des feuilles a parfois sur les liges, lomjours an

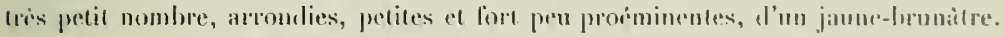

Aecirlies soit à la face supérience des leuilles, soit sur les tiges. Sur les ferrilges elles somt sournt wroupeses en petit nombe pour former de petites taches arrondies de 1-2 mu de diametre ou les cupules sont légerement espacies les unes des autres el se manifestent

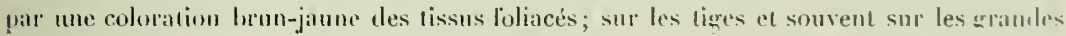

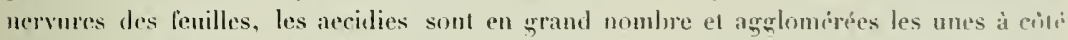

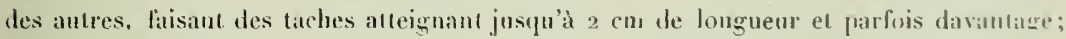
les tigres, de mème que les nervures. sont sousent déformées, épaissies el plus ou moins tordues. Les cupules son petiles, grossierement arrondies, dahorl recouvertes frar un chiderme épais jaune-lumàtre qui éclate ensuite en laissant voir les spores d'un jaune diar; les arcilies ant une ouserture irrégulierement arrondie et ue présentant pas de re-

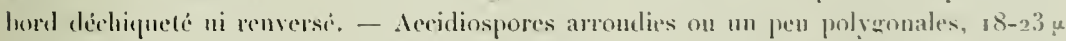
de diamère, d'un janne tres pale ou subhyalines, mene hyalines; membrane d'egale

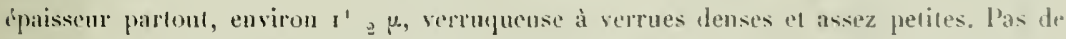
péridie ininterrompue, seulement queleques cellules isoles.

Iunas diuredos ef de titentospores semblables et ne se distinguant pas les uns des 63 
autres; ils sont petits, arrondis, prespue punctiformes, irrégulierement disposés, dissémines ou au contraire ahondants et parforis un peu conlluents quand linfection est très consitirable; ils sont à lit face inférienre des feuilles et se manifestent le plus souvent
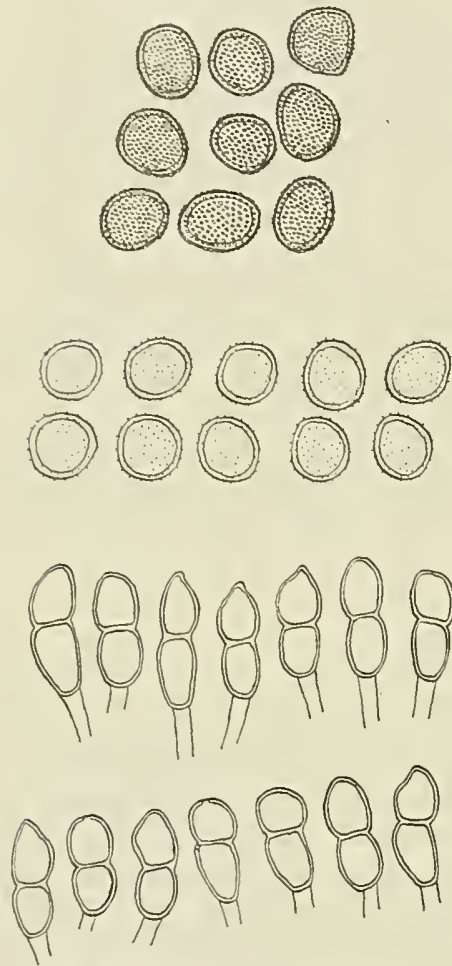

Fig. 28: Puccinia medellinensis. - Aecidiospores, uredospores et téleutospores. far de: tontes petites taches d'un jaune-brunitre; ils sont assez longtemps recouverts par l'épiderme, puis nus, d'un jaune plus ou moins elair, devenant un peu brunitre par la dessiceation. - Uredospores arrondies, 18-2 r p. de diamèlre, d'un jaunelounatre clair; membrane d'rgale épaisseur partout, environ $r^{1} / 2 \mu$, finement échinulée ì épines courtes et assez denses. Le nombre et la position des pores germinatifs n'ont pu dite exactoment léterminés.

Túleutospores olılongues on oblongues-elliptiques, $30-38 \mu \times 14-17 \mu$, hyalines ou subhyalines d'un jaune excessivement paile, arrondies ou un peu pointues ì leur extrémiti, arrondies à la base, nettement mais peu profondément ítronglées à la cloison; les deux cellules sont trìs sensiblement de mème forme et de mème dimension ; pore germinatif apical pour la cellule supérieure et immédiatement au-dessous de la cloison pour la cellule inférieure; membrane lisse, mince, environ $I \mu$, égale partout, non renflée ì l'extrémité. Pédicelle court, jusq̨u’̀̀ 15 u. de longweur sur 4-5 $\mu$ de largeur, liyalin, caduc.

Pycnidiis epiphyllis rarius canticolis, pancis, minutis, rolundatis, flavo-brunneolis. Accidiis epiphyllis vel caulicolis: foliicolis saepe in paruos greges dispositis et maculis rolundatis $1 r-2 \mathrm{~mm}$ diam.) flovo-brunneis insidentibus: in caulibus nervisture, saepe incrassalis et plus minusve deformatis tortisgne numerosis el gregariis, macnlis elongatis (ustue $2 \mathrm{~cm}$ long.) flawolunnneis insidentibns; aecidiis minntis, rolundatis, primo epidermide flavo-brunneoln leclis, dein aperlis, flavidulis, murgine crasso non vel parum laceralo nec revoluto. Aceidiosporis globosis vel prolygoneis, $18-23$ p. diam.. hyalinis vel subliyalinis pallide flavescentibus: membrana ca. $1{ }^{1}$ a 4 . crassa, satis mimule denseque verrncosa. Soris mredosporiferis et telentosporiferis couformilus, minntis, rolundatis, fere punctiformibus, sparsis vel numerosis sed raro parnm confluentibus, maculis minutis flawo-brnmneolis insidentilus.

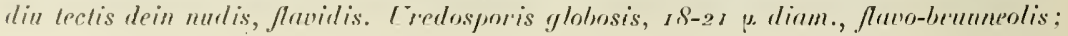




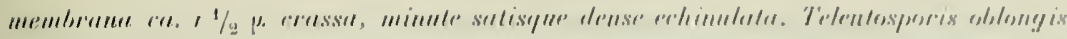

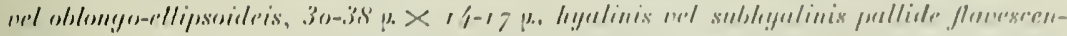

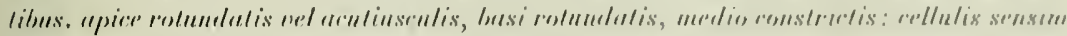

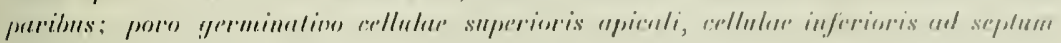

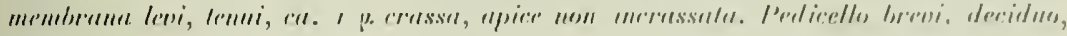

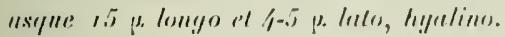

Sur liges of feruilles de: Hyptis pectinata (l..) l'ort.

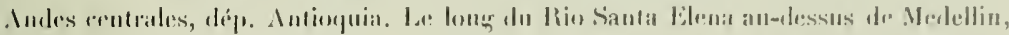

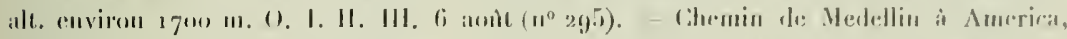

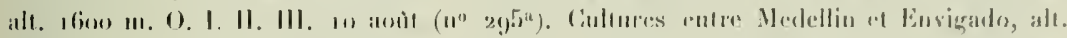

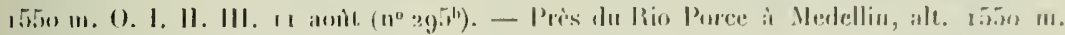

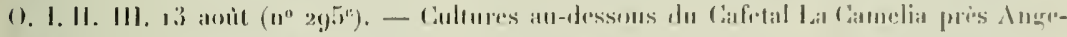

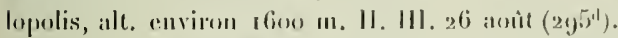

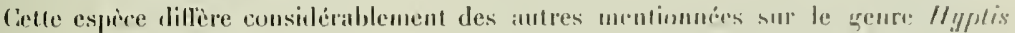

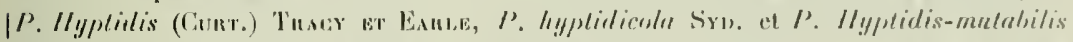

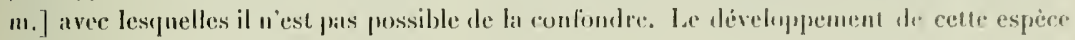
est celui l'un E'u-l'ucciniu.

\section{Puccinia Sarachae spec. nov.}

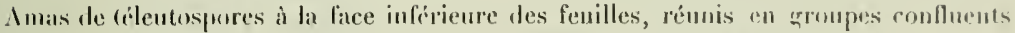
a numbrex pour lormer des taches arrondies prarlois nombreuses et pourant devenir conlluentes, de $2-3$ mun de dianétre en moyenne mais pouvant aussi dépasser 7 mm. I la face superienre el correspondant aux amas, on constate ume coloration chamois ou lirunjaunitre des tissus. A la face inférieure sont les amas conlluents et plus on moins nettrment organisis en cercles concentriques; ils sont petits, arrondis, nus de bonne heure, compacts, d'un brun foncé, alors que les amas lu centre sunt très sonsent grisàtres. Téleutospores ovales on ovales-elliptiques, arrondies aux deux extrénités. non étranglées a la cluson ou à peine sensiblement, jaune clair on d'un jann-lırnnàlre, $23-3 . i \mu . \times 16-21 \mu$; les deux cellules sout très sensiblement de mème forme et de mème dimensionn; pore grerminatif apical pour la cellule supérieure, la position de celui de la cellule iuférieure n’a pu "'tri" détermince exactement; membrane lisse, environ $2 \mu$ d'êpaisseur, renllée à l'extrémité où alle mesure jusqu'à $6 \mu$. Pédicetle hyalin, persistant, jusqu’à $9^{5} \mu$. de longुueur sur 4-6 $\mu$. de largen à son insertion. - On rencontre dans les amas de très nombreuses téleutospores unicellulaires, sourent mème plus nombreuses que les bicellulaires. Elles sont ovoïdes on ovalaires, jaune ou jaune-hrunitre, $21-30 \mu \times 17-19 \mu$. arrondies à leurs deux extrémités ; la membrane de $2 \mu$ environ d'épaisseur est renflée à son extrémité supérieure oǹ elle peut atteindre jusqu’i $\rightarrow \mu$. Pédicelle semblable i celui des spores bicellulaires. 


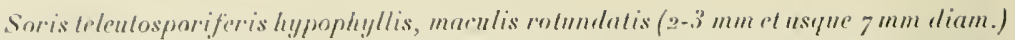
snepe numerosis confluentibustue, flam-brunneis insidentibus, circinuto dispositis, minulis, rolumelatis, confluentibus, mox mulis, compactis, obscure brunneis ef suepe centro grisen-brunneis. Telentosporis onatis nel nouto-ellipsodeleis, mtrinque rotundatis, medio non vel interdum leniler constrictis, fluwis uel flavo-brunneslis,

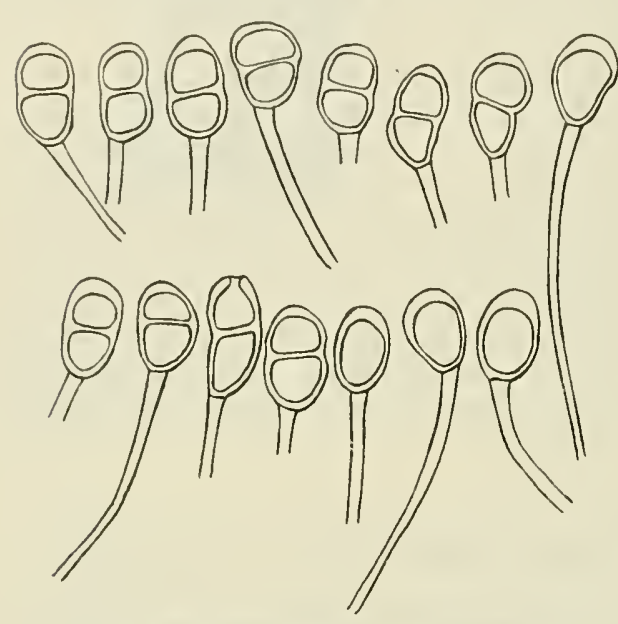

Fì. 29: Puccinia Sarachae. - Téleutospores uni et bicellulaires. $23-35 \mu \times 16-31 \mu$; cellulis sensim paribus; poro germinertiun cellulae superioris apicali; membrana levi, ca. 2 y. crassser, apice usque ti u. inerassata. Pedicello hyulimo, persistenti, "rstgue 9. $\mu$. longo et l-6 p. lato. sporis muiedlularibus. numerosis, snepe numerosissimis moideis nel ovalis, flnvis vel flavobrunneolis, $21-30 \mu \times 17-1$ !) $\mu$, utrinque rotumlatis; mombrana. ca. 2 p. crassu, upice usyue 7 p., incrassata; pedicello ul supra.

\section{Sur leuilles de Saracha edulis (Scilecitto.) Thellung.}

Andes centrales, dép. Antioquia. Cultures, Cafetal La Camelia prés Augelopolis, alt. $1800 \mathrm{~m}$; 111 . 20 aoùt $\left(n^{0} 187\right)$.

Andes orientales, dép. Cundinamarca. Chemin de ftonda à Bogota, entre Villeta ef Agua Larga, alt. environ rgoo 1 ; IIl. 9 octobre ( $n^{0}$ I 89 ). - Cultures, Cafetal Argelia dans la vallée de Viota, alt. I $880 \mathrm{~m}$; III. 25 octobre $\left(n^{\circ} 187^{\mathrm{a}}\right)$.

\section{Sur feuilles de Saracha spec. [aff. S. edulis (Schlegnto.) Tueblung.]}

Indes centrales, dép. Antioquia. Cultures, Cafetal La Camelia près Angreloprolis, alt. I $800 \mathrm{~m} ;$ III. 20 aoùt $\left(\mathrm{n}^{\circ}\right.$ I 88$)$.

Le développement de cette espèce semble ètre celui d'un Lepto-Pnccinir d'après l'aspect des amas et des spores, néanmoins je ne suis pas en mesure de l'affirmer d'une manière certaine; j’ai cependant observé quelques téleutospores déjà gyermées. 


\section{Puccinia Capsici spec. nov}

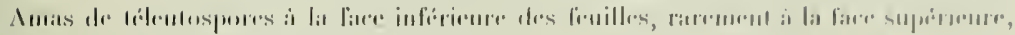

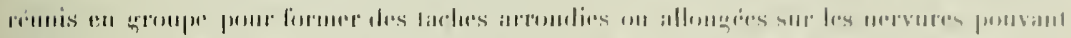

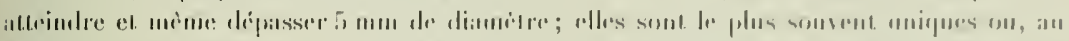

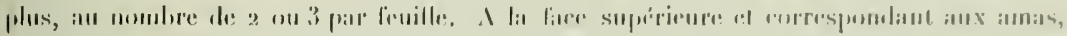

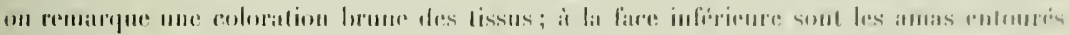
l'une cllovile zanuc lorun linuve; ils suml protits, arromalis, combluents, complatets, mus de: trise loune larore, d'un bron matroun limes. - Talentlospurese covales-elliprliques, $28-35$ p.

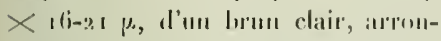
dies anx denx extrémitis, non ćltrangrlós it la cloison; les denx cellules simil de mente forme et de mente dimension; pre gormanatif aprical pour la cellule suprírienre, lat position de crlui de la cellule infirienre n'a puètre exactement délrruinée; memhranr lisse, environ $2 \mu$ d'praisseur, mon ou à peine sensiblement épaissie ì l'ixtrimilé. Pédiectle hyalin, persislaut, jusqu'à $120 \mu$ de longुueur sur
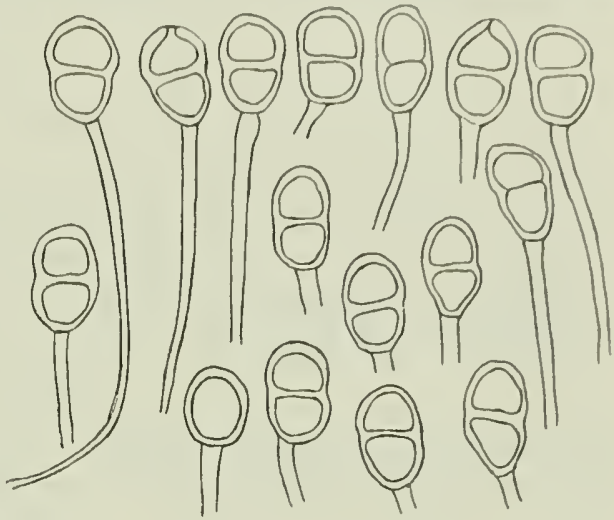

Fig. 30 : l'uccinia tapsici.

T'éleutospores dont une unicellulaire.

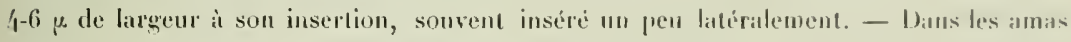

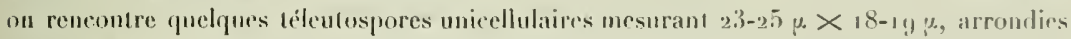
on ovödes, semblibles pour te reste anx spores licellulaires.

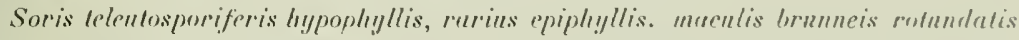
(nsque 5 mm rliam.) mnicis vel pancis insidentibus, mimulis, mumetntis, confuentilurs, compactis, mo.r nudis, obcme custane-brunneis. Telentosporis ouato-ellipsoideis $28-35 \mu>1 t-21 \mu$, dilute brunneis, utrinque rolundatis, medio non constrictis; cellnlis sensim paribns: poro germinalivo cellutae superioris apicali: membrana ea. 2 y. crassan. aprice non rel lenissime increlssalu, levi. Pedicello hyglino, persistenti, usque r 20 y. longo et $4-6 \mu$ luto. Nonnullis sporis ruris unicellntaribus, $23-25 \mu . \lambda 18-19 \mu$. globosis rel ovoideis, caeternm bicellularibus similibus.

Sur feuilles de Capsicum ef. baccatum $L$.

Andes centrales, dép. Tolima. Soledad sur le chemin de Mariquila, alt. 234a m; 111. 6 octobre $\left(n^{0} 84\right)$. 
Celte espece se dislingue de $P$. Suraho m. par l'aspret macroscopique des amas qui sont coufluents mais non disposis en cereles concentripues; ils sont en ontre heancoup moins abondants et ne forment pas de nombrenses taclies; les télentospores sont d'un Iити clair et non jaune ou lorun-janne; la membrane est d'égale ćpaisseur partout, parfois à peinc sensiblement épaissie à l'extrémité; le pédicelle est plus longy; ènfin les spores unicellulaires sont rares el jamais en grande quantití ou ponvant dépasser le nombe des hicellulaires. Ces dillírences constantes dins les anas examinés me semblent justifier la séparation de ces denx espèces. Le développenent parait ètre celui d'un l.epto-P'urcinia, cependant je ne puis l'aftirmer d'une manière absolue.

\section{Puccinia Gonzalezi spec, nov.}

Imas de téleutospores à la lace inférieure des feuilles, rarement et quelpues amas seulement à la face superieure, plus rarement sur les tiges, réunis en nombre plus un

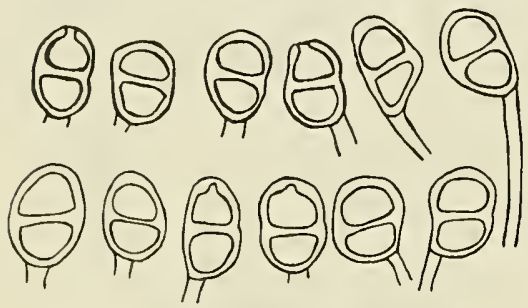

Fig. 31 : Puccinia Gonzalezi. - Téleutospores. moins grand pour former des taclies arrondies ou un peu allongées mesurant jusqu'à 8 et $9 \mathrm{~mm}$ de diamètre, généralement uniques, soit 2 on 3 , rarement davantage. Les l'enilles malades présentent à leur face supérieure et correspondant anx amas une coloration d'un brun plus ou moins foncé ì surface mamelonnée, mamelons très petits correspondant aux amas de la face inféricure. Cenx-ci sont petits, arrondis, punctiformes, pulvérulents, souvent très rapprochés, mais non conlluents, plus fréquemment un peu isolés les uns des autres, laissant apercevoir entre eux le tissu foliacé coloré en jaunebrun; ils forment une très petite proéminence à la surface de la feville, sont longtempss reconverts par l'épiderme coloré en brun-noiràtre qui s'ouvre tardivement sous forme d'un pore irrégulièrement arrondi on un peu allongé. - Téleutospores ovales ou ovaleselliptiques, $25-31$ y. $\times 18-24 \mu$, d'un brun pâle, arrondies aux deux extrémités, non ¿́ranglées à la cloison; les deux cellules sont très sensiblement de mème lorme el de mème dimension; pore germinatif apical pour la cellule supérieure, la position de celui de la cellule inférieure n’a pu ètre exactement déterminée; membrane lisse, épaisse, $2-l_{1} \mu$., souvent très légèrement épaissie à l'extrémitć ou elle atteint $5 \mu$ parfois. Pédicelle caduc, liyalin, atteignant jusqu'a $20 \mu$, rarement $40 \mu$ de longueur sur $4-6 \mu$. de largeur à l'insertion, souvent inséré latéralement. Aucune spore unicellulaire.

Soris telentosporiferis hypophyllis rarins epiphyllis et canlicolis, macnlis rotundatis (1nsque 8-g mm diam.) unicis vel pancis brunneis insidentibus, minutis, punctiformibus, numerosis sed non confluentibus, pulverulentis, epidermide atro-brunnea tectis, tarde 


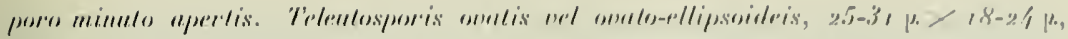

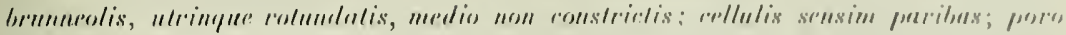

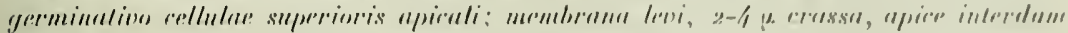

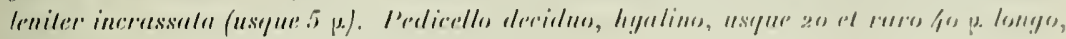

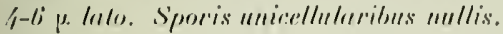

\section{Sur fentlles du. Capsicum spri:}

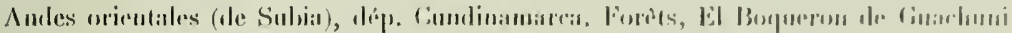

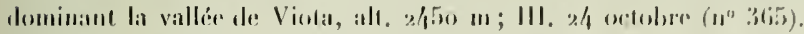

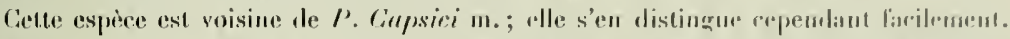

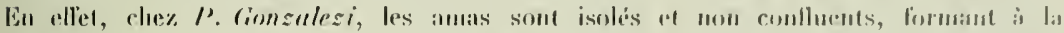

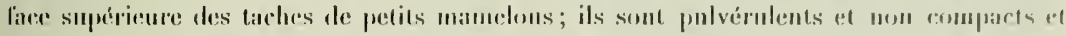

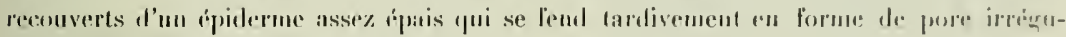
lioment arromeli par lequel sóchappent les spores. l'aspert des télentropores ast asse\%

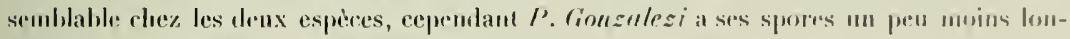

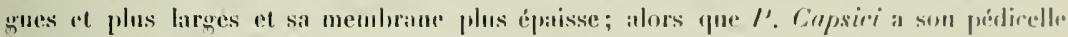
persistant et atteignant jusqu’d t20 p. de longueur, l’. Gomzulezi a un púdicelle casduc et

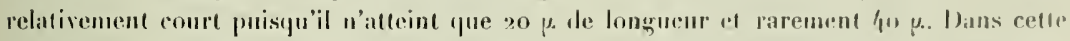

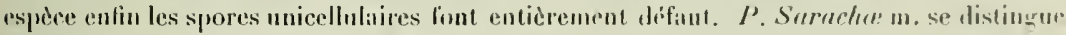
ficilement par la présence de très uombreuses spores unicallulirires, par l'aspect des anas, la dimension et la coloration des spores, l'épaisseur et l'épaississement lerminal de la membrane, l'aspect du pídicelle el d'autres caractères encore. I'apris l'aspect des spores, il semble que le développement de cette espèce doive ètre celui d'un Micio-I'uccinir, il n'est cependant pas possible de l'aftirmer avec toute certitude. Cetle espèce est dédire à M. Enrique Gonzalez de Bugota, qui a en l'obligeance de mous faire visiter les rafotales de la vallée de Viotir.

\section{Puccinia Ortizi spec. nov.}

Amas de tileurospores à la fice inférieure des feuilles, réunis en nombre plus an moins grand pour lormer des taches arrondies, mesurant jusfylì 3 et 4 umm de diamètre", irrégulierement disposées et pen nombreuses, se manifestant ì la face supérieure par une coleration janne-brun. I lit face inférieme sont les amas entonres sonsent d'une étroite zone jannitre; ils sont conlluents, petits et arrondis, diabord rerouterts par l'épiderme, hruns, compacts. - Túleutospores oblongues-elliptiques, arrondies à laur extrémití, un pen arrondies on atténuces ì la base, non ou à peine sensiblement élranglées à la cloison, $25-33 \mu \times 11-15 \mu$, hyalines ou subhyalines d'un jaune excessivement palle; les deux cellules sont très sensiblement de mème forme et de mème dimension, la position des press germinatifis n il pu ètre exactement diferminese: membrane lisse, mince, environ 


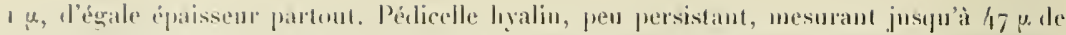
lengueur sur 3-4 e de largenr it son insertion.

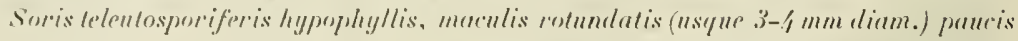

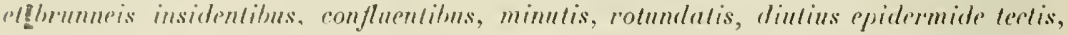

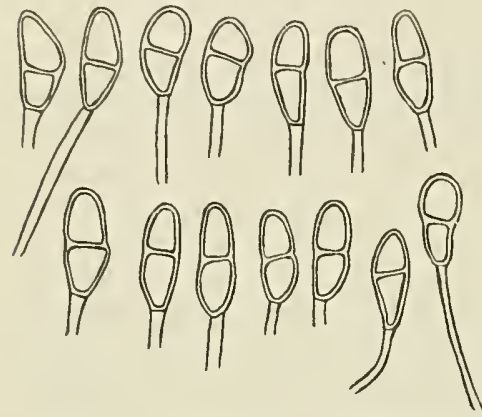

Fïg. 32: Puccinia Ortizi. - Téleutospores. brunneis, compactis. Trelpulosporis oblongoellipsoideis, "priee rotumlatis, bessi pormun rotundatis net allenualis, medion non constrictis,

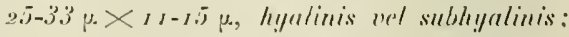
cullulis sensim prribus: memhramu levi, temui ca. I y. crassa, apice non incressisuta. Pealicello hyulino, parmm persistenti, usque 亿7 $\mu$ longo el $3-4$ p. lato.

Sur leuilles de Brachistus all. hebephyllus Miers. Audes orientales (de Subia), dép. Cundiua marca. Forèts entre l'Mleo Nira et El Buqueron de linachuni dominaul la vallác de Violis, alt. euviron $2400 \mathrm{~m}$; III. 24 octolure (n 25.$)$.

L'alsence des spures germées on en voie de germination ferait supposer que le deve-

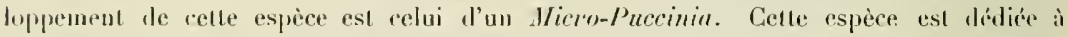
M. G. Ontuz de Bogota qui a en l'obligeance de nous farire visiter les caletales de la région de liota ef qui nous a oflert la plus gracieuse hospitalite dius son Cafelal Magdalena.

\section{Puccinia huallagensis P. Henn.}

in Fungi Amaz. I, P. 158 (Halw. 1go/).

Les échantillons recuejllis en Colombie tiennent à la fois de P. rhuviformis Lagu. et de P. hurallagensis P. Ilexs. En elfet, les amas sont compacts, d'un brun plas ou moins foncé et plus ou moins conlluents; les spores mesurent $30-40 \mu . \times 16-2.3 \mu$, le pédicelle est court ou prut alteirtre jusqu’à $24 \mu$ de longuenr sur $1-7 \mu$. le lingenr el colorí en jaune-brun très clair ou subhyalin; ces caractiores concordent avec la description de I'. hurallagensis. Seule la coloration des téleutospores est dillérente, car Hennings daus sa diagnose indique "episporio brunncon, alors que dans mes rechantillons l'rpispore est d'un jaume-brunatre, "diluste flavo brunneo» comme l'indique la deseription de P'. cluviformis. Les exemplaires colombiens cependant semblent se rapprocluer davintage de P. Iuallagensis puistgue seule la coloration de la membrane est un peu différente, aussi est-ce pour cela que je rattache ì cette espèce ce que j’ai rócolté en Colombie. Comme l'indlique d’ailleurs Hennings, ces deux espèces som très voisines l'une de l'autré, peut-ìtre 


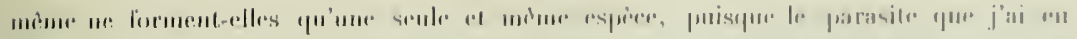

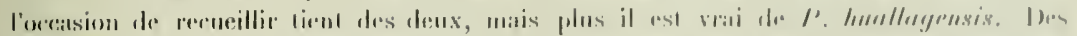

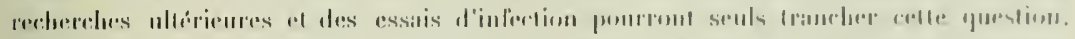

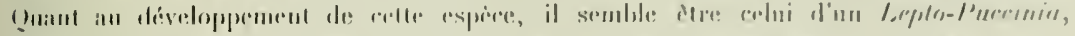

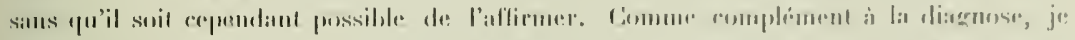

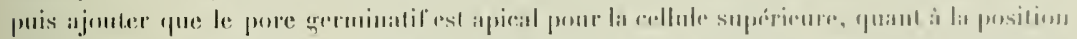

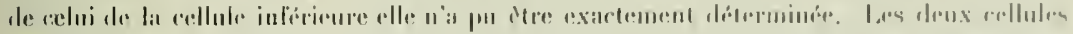

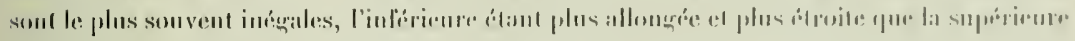

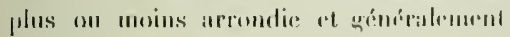

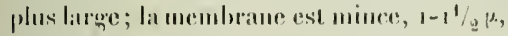

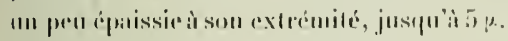

Sinr fenilles de Solanum all, torvum siw.

Audes centrales, dép. Anlinguia. IHI.
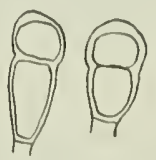
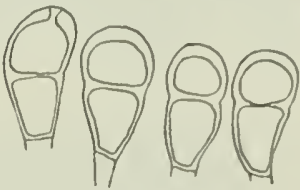

Pig. 333: Puccinis huallagensis. - l'álentuspores.

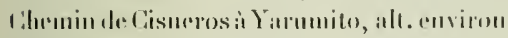

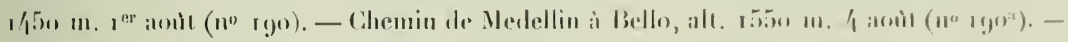

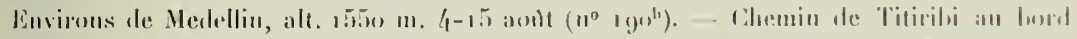

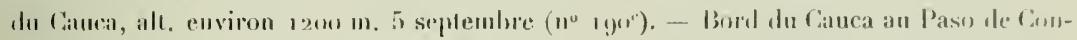

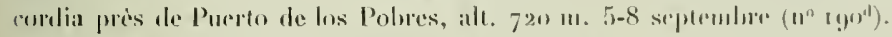

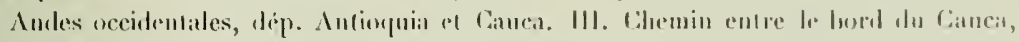

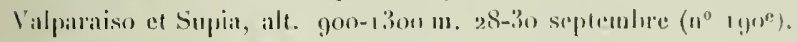

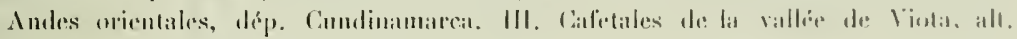

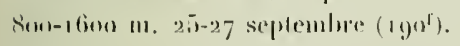

\section{Puccinia solanicola spec. nov.}

Amas de lédentospores à la lace inférience des leubles, rarement sur les pébioles. rimis en plus on moins grand nombre ef ronlluents pour former des taches arrondies

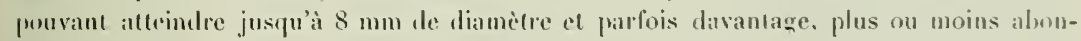
dantes, irrégulierement disposées et isolics. I la fate supúrieure el correspondant anx amils, on coustate une coloration d'un brun phs un moins foncé des tissus entumre diune zone plus claire. Les amas sont plus ou moins cachés an milieu de la forte villositri der lenilles, ils sont nombreux sur chupe tache, petits, arrondis of confluents, d'un brun loncr, compacts. - Téleutospores oblongues, elliptiques ou allongées, 3.7-i6 $6 \times 1-2 . i \mu$.

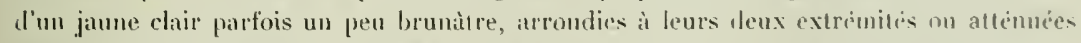
it lit hase, étrangles ì la chison el souvent assez profondement: pore germinatif apical pour la cellule suprérieure, la position de cetui de la cellule inférieure n’a pu èlle exactemen diterminire; les deux cellules sont le plus sourent de forme el de grandeur intigales:

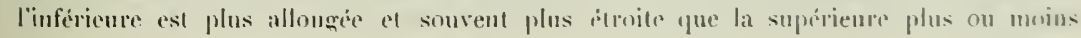


arrondie et plus large; la membrane est lisse, miner, euviron $1 \frac{1}{2} \mu$, renflée à son extrémité où elle alteint jusqu’à $7 \mu$. Pélicelle court, persistant, $q_{-7}-\mu$ de largeur d'un jaune clair. Anormalement de rajes spores à 3 et mème 4 cellules.

Sor is telentosporiforis hypophyllis uel ruro petiolicolis, dense yregariis el confluenlibus, maculis rolundatis (usque \& mm dium. interdum ultra) plus minusur numerosis

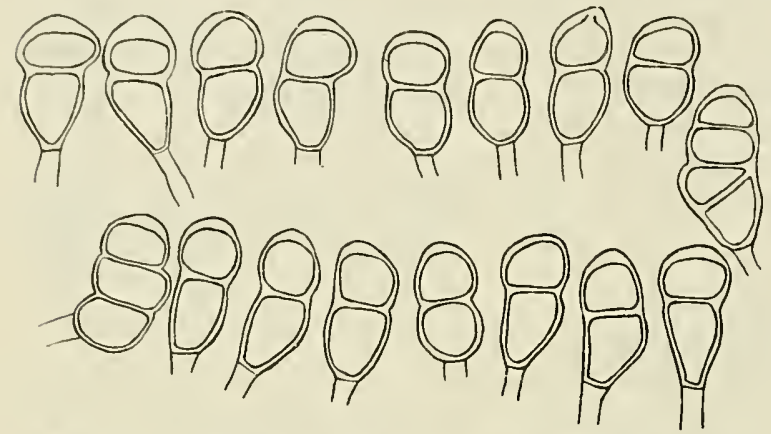

Fig. 34: Puccinia solanicola sur Solanum hirtum. - Téleutospores dunt anormalement une à 3 cellules et une à 4 cellules. sed non confluentibus: obscure lrmmeis insidentilus, minutis, rotundutis, numerosis, compactis, obsrure brunneis. Telentosporis oblongis, ellipsnideis nel elongatis. $3.5-56, \mu>$ $17-25 \mu$, flunidis nel palliale flavido-brinnneolis, utrinque rotundatis vel basiallenuatis, medio interdnm sutis valde ronstrictis : poro germinatiun cellulue superioris apicali; celluln superiore plus minusue rotundatu ot latiore, cellula inferiore longiore et angustiore: membrrma levi, tenui ca. $11 / 2$. crassa, upier incrassala (usque $7 \mu$ ). Pedicello persistenti, brevi, $\ell_{=} 7$ u lato, flawidulo.

Sur feuilles de Solanum aff. ovalifolium Іимв. ет Bonpl.

Andes orientales, dép. Cundinanarca. Chemin de Ilonda it Bogota, près de Villeta, alt. environ goo $\mathrm{m}$; 1II. 9 ortobre ( $\left.\mathrm{n}^{\circ} 46\right)$.

\section{Sur fevilles de Solanum hirtum VAllt.}

Dép. Tolima. Bord du Magdalena, prairies arides le long du fleuve à Beltran, alt. ${ }_{2} 60 \mathrm{~m}$; III. 28 octobre $\left(\mathrm{n}^{\circ} 3\right)$.

\section{Sur feuilles de Solanum spec.}

Andes orientales, dép. Cundinamarca. Bord de chemin entre le Cafetal Buenavista et Viota, alt. environ $650 \mathrm{~m}$; III. 27 octobre ( $\left.\mathbf{n}^{0} 9^{8}\right)$.

Dép. Tolima. Bord du Magdalena, prairies arides ì Beltran, alt. $260 \mathrm{~m}$; IIl. 28 octobre $\left(n^{0} 9^{8^{a}}\right)$.

Cette espice est voisine de $P$. clnviformis Lagll. Elle s'en distingue par ses amas compacts, par ses téleutospores sensiblement plus longues, par lenr couleur d'un jaune clair à peine un peu brunâtre parfois, par leur époississement terminal atteignant le plus souvent $7 \mu$, par leur pédicelle coloré en jaune. Elle se distingue de $P$. huallugensis 


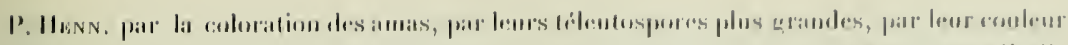

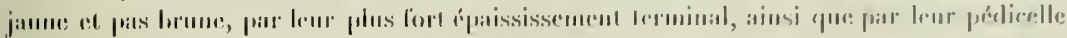

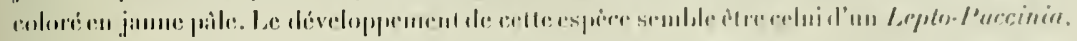

\section{Puccinia Fuhrmanni spec. nov.}

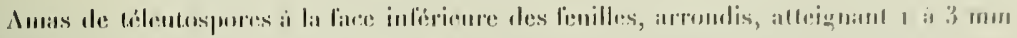

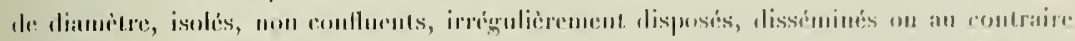

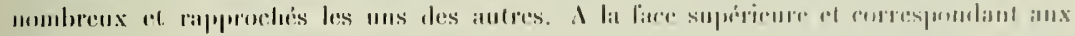

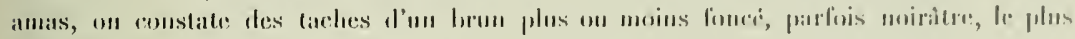

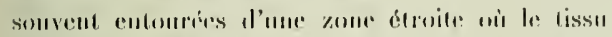
foliake est coloré en jiunne-brun plus ont moins alair. Les antas sont complacels, l'un lormu elair, l'illowl recouverts par l'épilerme puis nuts; its foul une asse\% forte promincme it la surfice des fenilles. - Tébentospores ellipriques ou allongées, $\left.35-17 \mu^{2} \times 1 / 1-19\right)$; la collule supérienre est coloré en jumne clarir, l'inférieure en jaune très pile ou sulshyaline; elles sont aromlies ì leur extremite ef allemues à la batse ; les deux cellubes sont le plus sonvent de mime forme el dimension, cependant, parlois, l'inferieure est un peu plus longue; la posilimu des pores germinatifs n'a pu ètre exactement délermince; membrane lisse, environ I k., l'égale
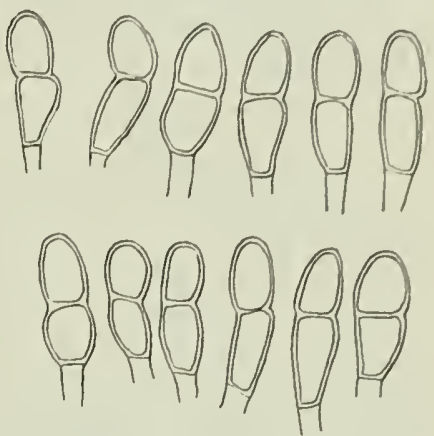

Fig. 35: l'uccinia Fulumatnni. - Téleulospores. ipaisseur partout, non renllée a l'extrémité. Pédicelle lyailin on subluyalin parfois, prersistant, court, 4-7 ? de largeur à son insertion.

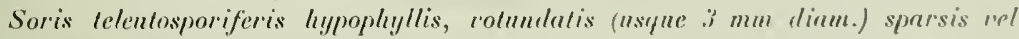
numerosis sed non confluentibus, macnlis rotundatis brunne is insidentibus, compactis dilute brumneis, primo epulermide tectis. mox nudis. Telentosporis ellipsoide is uel elonyalis, 35-47 $\mu \times 1$-19 $\mu$, apiee rolundalis, basi allenuatis; cellula superiore prapcipue flavidu vel flunescenti. inferiore flawescenti vel subhyulina: membrana lovi, tenui /ca. tucrassa), apice non incrassata. Pedicello hyalino uel interdum subhyalino, persistenti. lirevi, я-7 ب. lato.

Sur feuilles de Justicia ef. secunda Vtall. ef, var, intermedia (NeEs) Thellung.

Amles centrales, dep. Antioquia. Le long du Rio Sardina entre liiladelfia et Neira pris Manizales, all. $1260 \mathrm{~m}$; 111. $1^{\mathrm{er}}$ ociobre $\left(1^{\circ} 62\right)$.

Cette espèce se dislingue très facilement des denx autres dejja mentionnées sur le genre Insticiu, soit P. Shiraiana Svo. et P. Thmailesii BERk., avec lesquelles il est impossible de la confondre. Le díveloppement de cette espèce semble ètre celui d'un 


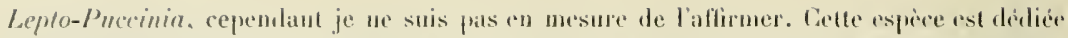
à mon ami, M. le professemr liunnaxs, de Neuchatel, en compagnie dupuel j’ai voyagé en Colombie.

\section{Puccinia lateritia Berk. et Curt.}

Exul. Fy. from the Selwwein. herh., p. 281 (1854).

Les amas de téleutosperes sont compacts; les deux cellutes sont sensiblement de mime forme el de mème dimension ; le pore germinatles est apieal pour la celbule supérieure et immédiatement an-dessons de la cloism pour la cellule inférienre; la membrane a 3-4 p. d'épaisscur, égule putoul, non épaissic à l'extrémité ou pas sensiblement. Le púdicolle sublyyalin mesure jusqu’à jo $\mu$ de longueur sur $4-5 \mu$ à son insertion el $3-3 \mu$ d'śpais-

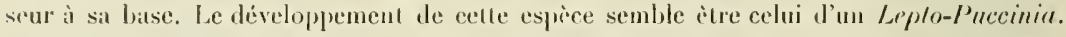

Sur tiges et feuilles de Borrèria laevis (Lam.) timsen.

Allilles: Jamaïque; lïngston, Ilope Gardens; III. 14 juillet (11"118).

Andes entrales, dép. Antioquia. III. Cultures, Yarumito (Chemin de Cisneros i Medellin), alt. $1342 \mathrm{~m}$. $1^{\text {er }}$ aout $\left(1^{0} 263\right)$. - Chemin de Medeltin à Bello, alt. $1550 \mathrm{~m}$. 々 aorit $\left(11^{\circ} 263^{\mathrm{a}}\right)$. - Au-dessus de Medellin, le lomg du Rio Santa Elena, alle environ

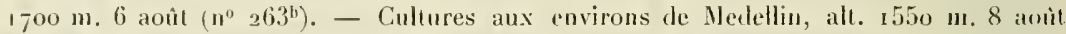
$\left(n^{\circ} 263^{\circ}\right)$. - Cultures le long du Rio Porce près de Medellin, alt. $1550 \mathrm{~m}$. ro itnil $\left(1^{\prime \prime} 263^{\prime \prime}\right)$. Chemin de Medellin à America, alt. environ $1600 \mathrm{~m} .15$ aoùl $\left(n^{\circ} 263^{\prime \prime}\right)$. -

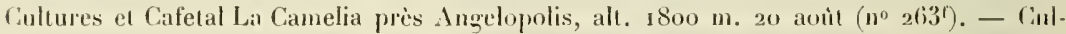
tures de la rive droite de l'Amagadiente, vis-à-vis du Cafetal La Camelia près Angelopolis, ill. $1700 \mathrm{~m} .29$ aon̆ $\left(\mathrm{n}^{\circ} 263^{\prime \prime}\right)$. - Bord de chemin près de Titiribi, alt environ $1700 \mathrm{~m}$. 4 septembre $\left(n^{0} 2^{6} 3^{\mathrm{h}}\right)$. - Chemin de Titiribi au Cauca, alt. environ $1400 \mathrm{~m} .5$ septembre $\left(1^{\circ} 263^{\mathrm{i}}\right)$. - Bord du Cauca, au Paso de Concordia, pris de Puerto de Los Pobres, all. $720 \mathrm{~m} .7$ septembre $\left(n^{\circ} 263^{\mathrm{k}}\right)$. - Cultures et bord de chemins à tinaca, alt. envirou $1500 \mathrm{~m}$. 12 septembre $\left(n^{\circ}{ }_{2} 63^{1}\right)$. - Bord du chemin de fer près de Pavas (chemin de Medellin), alt, environ $600 \mathrm{~m} .31$ juillet $\left(\mathrm{n}^{\circ} 263^{\mathrm{m}}\right)$.

Andes occidentales, dép. Cauca. Chemin de Valparaiso it Supia, alt. pon-130o in; III. 29 el 30 septembre $\left(\mathrm{n}^{\circ} 263^{\prime \prime}\right)$.

\section{Puccinia punctata Link.}

Ols. Mycol. 11, p. 30 in Magaz. naturf. Freunde Berlin (1816).

Sur feuilltes de Relbunium hypocarpium (L) HEMsLEY.

Andes centrates, dép. Antiorguia. Haies le long du Rio Santa Elena au-dessons de Iledellin, alt. environ $1700 \mathrm{~m}$; 11.6 aoùt $\left(\mathrm{H}^{\circ} 262^{11}\right)$. 


\section{Puccinia Becki spec. nov}

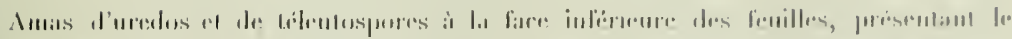

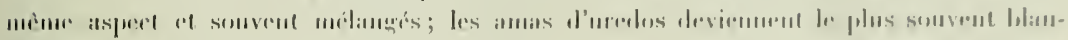

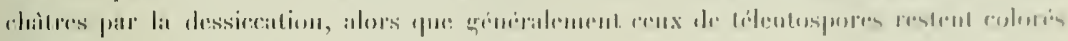

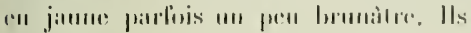

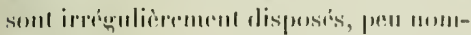

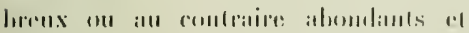

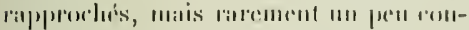

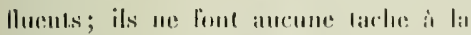
liare superieure des feuilles, some pertits, grossionenent arroudis, pulvorulents,

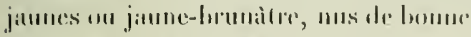

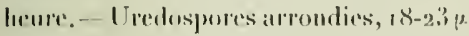

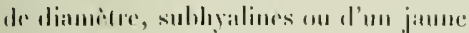

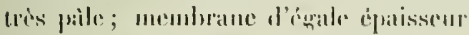
partont, moviron $2 \mu$, érhinulie il spines comates el pru denses. Le mombre dit position des pores germinatits niont pu Atre catetement diternines.

Télentospores de forme alsise vilrialle, oblongues-allongées on allungeres,

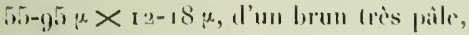
pan dranglíes a la cloison; rarement le's dertx cellules sont de méme lentme et dre mene dimension; les spores sont plus ou moins altinnces el terminios en prointe assez longue et étroile à lrur
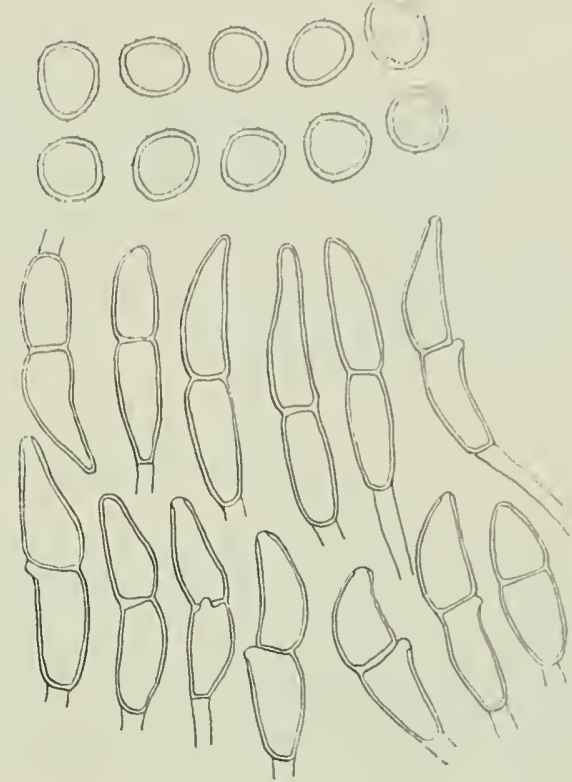

Fig. 36: Puccinia Becki. - U'redospores el tileulospores. exlremisé smperienre, alors qu' ì leur base elfes sont un peu arrondies ou plus souvent altemace; la pointe se fait, woit insensiblenent, soit le plus sourent brusiguenent à partir du milien de la cellule supurieure qui mesme 12-18 $\mu$ de largeur à la eloison el $4-5 \mu$ prés de son extrémité pore serminatif apieal four la celfube supérieure el immédiatenent au-dessous de lat cloison pour la cellule inférieure; membrane lisse, mince, environ 1 \%. d'érale ípaisseur partout. Pidicelle hyalin, caduc, jusiqu’a $38 \mu$ de longueur sur 5-7 $\mu$ de lirgeur it son insertion.

Soris uredosporiferis et telentosporiferis cenformibus, hypophyllis, spensis red unmerosis ef gregariis sed raro parum conflumtibus, sine maculis, minutis, plus.

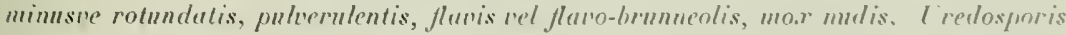
globosis, $18-23$ u diam.. subhyalinis vel hyulino-fluerscentibus; membruna ca. 2 u crassa. 
minmte laxeque echimuluta. Telentosporis variabilibus, oblongo-elongatis vel elongutis, $5.5-9.5 \mu \times 12-18 u$, pullide brunneolis, melin via: vel leniter constrictis. apice fere

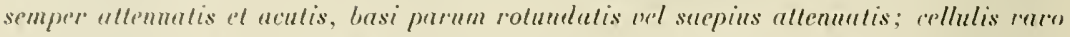
paribus, cellulu superiore plerumque t2-18 u. lato al siplum, apice 1-5 p.; poro germinativo eellalae superioris apicali, cellulue infervoris ad septum; membrana levi, temui, ea. I p. crassa, apice non incrassalu. Pedicello hyalino, deciduo, usque 38 y longo et $j-j \mu \operatorname{lol} w$.

\section{Sur feuilles de Vernonia Cotoneaster (W/LL1) Liss.}

Indes orientales, dép. Cundinamarca. Au-dessus de Uhanjue, rutre le village et le

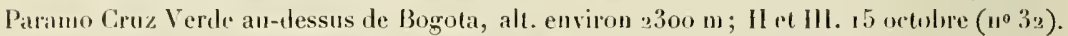

Le développenent de cette espèce semble ètre celui d'un $/ / \mathrm{emi-l}$ 'uceiniu, du moins pour le monent: la présence de nombreuses spores ayant déjà ggermé laisse supposer "jue la germination doil se faire immédiatement ou après un temps trìs cout de repos. Cetle espice est dédiée à M. Robert Beck, notre compatriote, cousul suisss' à Bugota, en hommage te recounaissance pour tout ce gu'il a fait pour nous faciliter toutes choses durant notre séjour à Bogrota el aux environs.

\section{Puccinia Vernoniae-mollis spec. nov.}

Amas t'uredos et de téleutospores présentant le mème aspect el souvent à cóté les uns des autres sur la face inférieure des feuilles, généralement nombreux et parfois répandus sur toutc la surface des feuilles, irrégulièrement disposés, isolés ou rapprochés les uns des autres, mais non ou rarement un peu conlluents; les feuilles allaquées prennent une coloration jaunatre plus ou moins marquée suivant le degré d'infection; souvent les amas de téleutospores prennent une coloration brune qui permet de les tlistinguer les uredos toujours colorés en jaune ou jante-brunàtre. Les amas sont petits, punctiformes, arrondis, très longtemps recouverts par l'épiderme qui ne disparaît que très tardivement. - Urerlospores arrondies, 18-2 I $\mu$ de diamètre ou ovoïdes on ovalaires, $23-28 \mu \times 18-23 \mu$, hyalines ou subhyalines très légèrement colorées en jaune très pâle; membrane mince, à peine I $\mu$ d'épaisseur, échinulée à épines courtes et espacées les unes des autres; la position et le nombre des pores germinatifs n'ont pu ètre exactencnt déterminés. - Téleutospores oblongues ou ovalaires, 3o-38 $\mu \times 1 /$-2 I $\mu$, d'un janne très clair, arrondies à leur extrémité, arrondies on un peu alténuées à la base, pas ou à preine étranglées ì la cloison; les deux cellules sont très sensiblement de mème forme et de mème dimension; pore germinatif apical pour la cellule supérieure, immédiatement an-dessous de la cloison pour la cellule inférieure; nembrane lisse, mince, environ I $\mu$. égale partout, non renflée à l'extrúmité. Pédicelte hyalin, caduc, court, jusqu'à $26 \mu$. de longueur sur 4-5 $\mu$. de largeur à son insertion. 


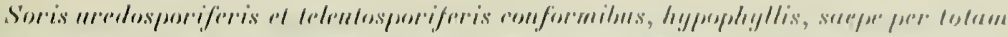

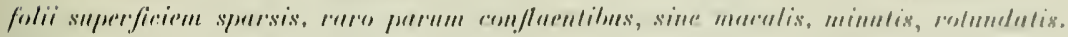

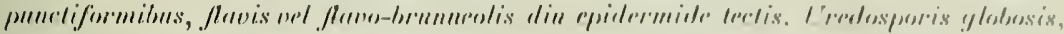

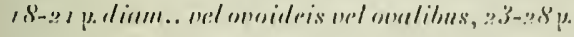

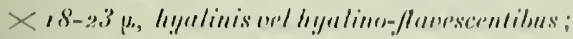

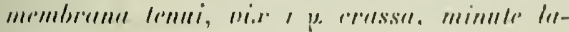

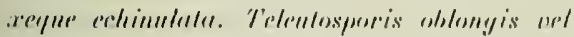

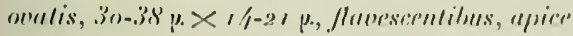

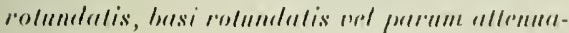

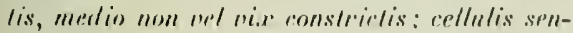

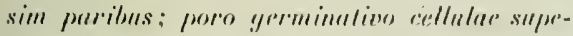
riorris appirali, colluture inferioris ad septum:

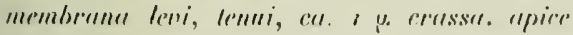

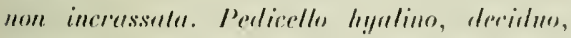

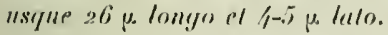

Sitl fenilles de Vernonia ef. mollis II. B. K.

Audes centrales, dép. Antionuia. II a III. Eutre le Rio Amaga et le Cafetal La llermosa prìs Angelopolis, alt. ensiron 1/,00 m. 2/ aont
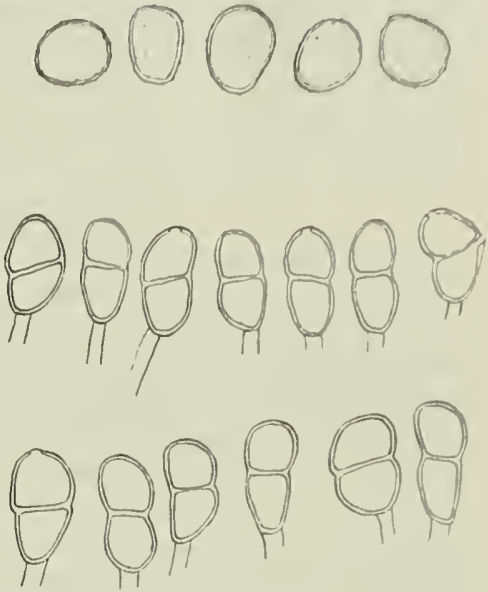

Fig. 37: P'uccinia Vernoniat-moltis. - Ureulospures el tileutospores.

Angrdopolis, dansles cullures, alt. enviromi6onm.

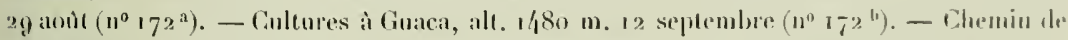

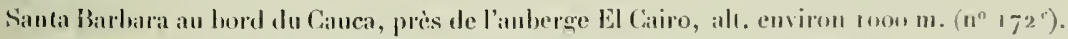

Calle espece, par la dimension de sess spores, se rapprocherait de P. Ternoniue tionw. mais elle en dillère considirablement par toute une sírie de caractires qui ne permettent ancume confinsion. Pour le moment, le déseloppement de celte espice semble dire celui d'un Ilemi-Puecinia dont les tíleutospores semblent devoir girmer apres an temps de repos tris court.

\section{Puccinia rugosa Speg.}

in Fig. Guaranit 1, ז886, p. 52.

Cefle espice correspond très bien avec les échantillons recueillis en Colombie ainsi qu'avec les matériaux de comparaison quw j’ai pu avoir (Rick, fungi anstro-americani $n^{\circ} 338$, Sao Leoprotdo ig̣os).

Sur feuilles de Vernonia patens H. 13. K.

Andes centrales, dép. Intioquia. III. Chromin dr Medellin à Bello, alt. 1.й m. 4 aout (n० 176$)$. - Haies et taillis le long du Rio Santa Elena an-dessus de Medellin, 


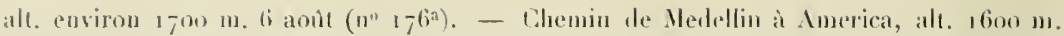

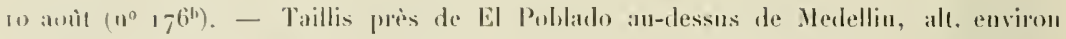

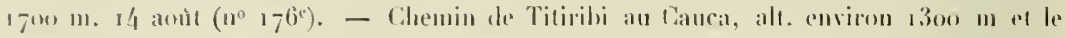

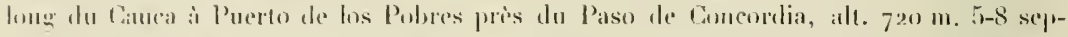

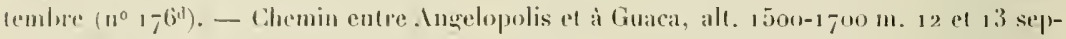
tembline $\left(11^{\circ} 17^{\mathrm{e}}\right)$.

Antes secidentales, dép. Antioquia of Cintea. 111. Chemin entre Valparaiso et Supia or

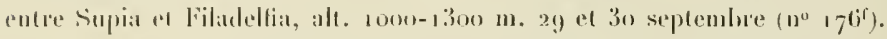

Sur fenilles the Vernonia scabra Pens.

Dép. Tolina. Paine du Magdalena, non loin de Mariejuila, alt. 560 m. 28 octobre ( ${ }^{\circ}$ i 7 ).

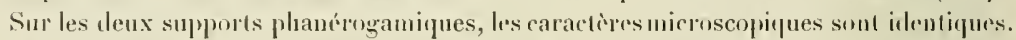
Les deax cellules sont de mime forme el de nòme dimension; le pore greminatif est aprical pour la cethule supérieure, la position de colui de la collule inférienre n'a pur sitre exactement tétermince; la membrane est d'égale épaissenr partout, 2-3 p., non renflée à sul extrémitr; le predicelle hyaliu, caduc ét court, mesure 4-5 $\mu$ de largent à son insertion. N'ayant pas pu constater nettement la présence de spores germées ou en germination, he déveluppement de celle espèce semble être celui d'un Micro-Puccinia. Macroscupiquentent les amas de téleutospores sont assez différents eutre les deux supports. Cihro Vernonia scabra les amas sont réunis en petit nombre pour former de pelites taches mesurant en moyente $2-3 \mathrm{~mm}$ de dianctre. Chez V.patens, les anas sont en beancoup) plus grand nombre et également contluents pour former des taches atteignant jusqu'ì 5 mm de diamétre très souvent conlluentes et alor's déprassant a $\mathrm{cm}$ de longueur surtout sur le rebord des fenilles qui peut ètre plus on moins garni de ces taches conlluentes. Les taches lorment une forte proéminence à la surface des fenilles alors que bien souvent a l'autre face on remarque une dépression netle. Lorsque l'infection est considérable, less ferilles sont arrítées dans leur développentent, elles restent plus petites que les autres et sont plus ou moins ratatinées et crispées. Ces déformations ne se retrument pas che\% I. scabra ou l’iulection est toujours très peu intense.

\section{Puccinia Spegazzinii de Toni \\ in Sacc. Syll. VIl, I. 704 (1888).}

Les deux cellules des téteutospores sont le plus sonvent inégales, la largenr est sensiblement la mème, mais la longueur est différente; la supérienre mesure 18-2.3 $\mu$, l'inlfirieure $23-40 \mu$ de longueur ; pore germinatif apical pour la cellute supérieure, la position exacte de celui de la cellule inférieure n’a pu itre déterminće; nembrane d'égale ćpaissentr partout,ensiron a u, non épaissice à l'extrémité. Pódicelle hyalin el persistant, jusifu'i titi j. te longueur sur 5-7 p. de largen is l'insertion. 
Sur linilles d. Mikania scandens (1.) IVı,1,1).

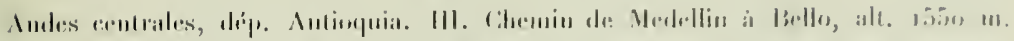

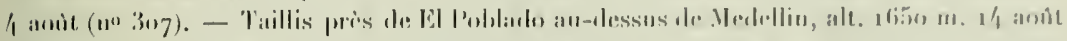

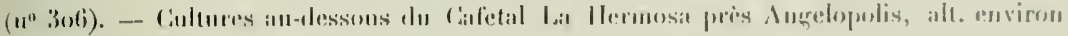
1.

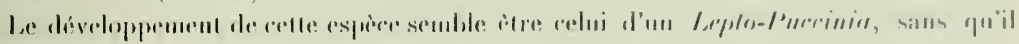

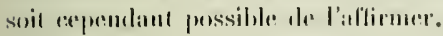

\section{Puccinia Eupatorii Diet.}

iil Indw. $18(9)$, 1. .3\%.

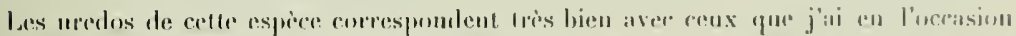

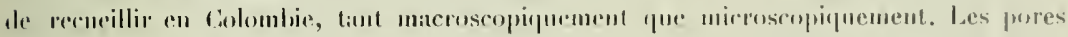

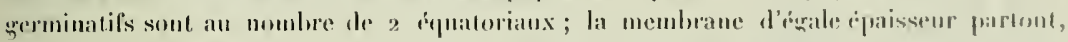

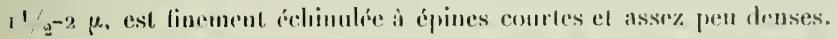

Sur ferilles de Eupatorium ballotifolium 11. B. K.

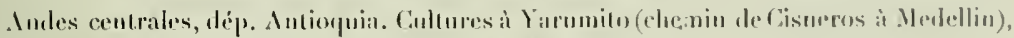

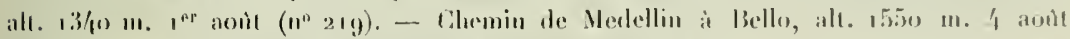

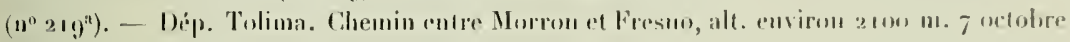
$\left(11^{\circ} \geq 19^{11}\right)$.

\section{Puccinia eupatoriicola spec. nov.}

Amas de lédeutospores it la liace inlérienre des feuilles. réunis en uombre plus ou moins considerable pour former des taches arrondies de ${ }_{2}-3 \mathrm{~mm}$ de diamilre. irrégulièrement disposées, disséminés on an contraire nombrenses mais isolées et non confluentes, faisant souvent à la face supérieure une petitedépression alors qu'elles prómincut plus au moins fortement at la fited inférieure, ne faisant le plus sonvent pas de taches à la face superienre ou parlois on constate une coloration brunatre des tissus. Les amas, nombreux sur les taches, sout conlluents, compacts, arrontis, d'un jamme clair un peu brunitre on d'un fiuve chair, d'ibond recouverts par l'épielerme puis nus. - Tíleutospores allongées, 35-47 $\mu$. $12-15 \mu$, ly̧alines on à peine colorées en jaune très paile, arroudies ou pitrfois un peu coniques ì leur extremite, atlinuces it la base, tres peu útrauglées à lat chison; les deux collules sont sensibloment de mime forme el de meme dimension; pore germinalif apical pour la cellule supérienre, la position de celui de la cellule inférienre n a pu d̀re exactement détermince; membrane lisse. mince, à peine $r u$. non on très preu épaissie à son extrémite ou elle attein au maximum 3 u. Pédicelle 
hyalin. peu persistant. atteignant jusqu’i $20 \mu$ de longuent sur $5-7 \mu$ de largent is sou insertion.

Sorris lelentosporiferis hypophyllis, gregariis, maculis rotundalis (' sparsis wel mumerosis sed uon cunfluentibus fluuo-brunneolis insidentibus, primo epidermille ted is dein nuelis, compuct is, confluentibus, fluno-brunneolis rel fulvis. Teteulosporis

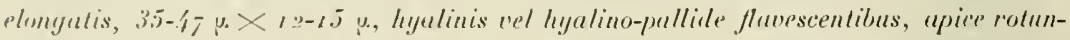
dutis vel ruriuss purnm aculiusculis, busi attenuntis, medio vix vel leniter constrictis;
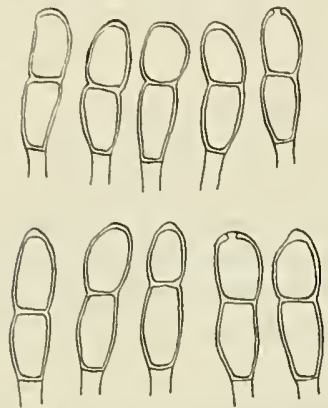

Fič. 3S: Puccinia eupatoríicola sur Eupatorium pycnocephalum. Téleutospores. cellulis sensim puribus: poro germinutiuo cellulue superioris apicali; membranu levi, tenui, vix 1 p. cressa, apice

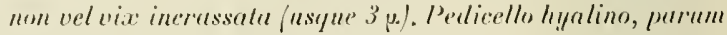
persistenti, usque $20 \mu$ longo et 5-7 p. lato.

\section{Sur leuilles de Eupatorium Schiedeanum Less.}

Andes centrales, dép. Antioquia. Colline sur la rive gauche dı Rio Porce, près de Medellin, alt. $1650 \mathrm{~m}$; 111. го аองิ $\left(\mathbf{n}^{0} 228\right)$.

\section{Sur feuilles de Eupatorinm pycnocephalum Less.}

Andes orientales, dép. Cundinamarca. Au-dessus de Ubaque, pres du Paramo Cruz Verde au-dessus de Bogota, alt. environ $2.000 \mathrm{~m}$; 111. 15 octobre $\left(\mathrm{n}^{0}\right.$ /4).

Cette espèce se distingue très facilement des autres sur le genre Eupatorium par son aspect macroscopique, le manque d'uredos, par ses téleutospores hyalines ou subhyalines, de dimensions différentes el à membrane non on à peine épaissie à l'extrémité. Le développement de celte espèce semble ètre celui d'un Lepto-Pucciniu.

\section{Puccinia Eupatorii-columbiani spec. noy.}

Amas d'uredos à la face inférieure des f'euilles, irrégulièrement disposés, disséminés ou au contraire rapprochés et devenant plus ou moins contluents, ne faisant pas de taches spéciales en cas de faible infection; an cas contraire on constate à la fice supérieure une coloration brune plus ou moins foncée, pouvant mime recouvrir de grandes surfaces des feuilles attarjués abondannent; ils sont petits, arrondis, brun clair, nus de tris bonne heure el souvent entourés d'un nince rehord épidermique. - Uresdospores arrondies, $21-26 \mu$. de diamètre un ovoïdes-ovalaires, $28-30 \mu_{0} \times 18-21 \mu$, d'un brun pàle; membrane d'égale ípaisseur partout, environ $2 \mu$., échinulée à épines courtes el assez espacées; pores germinatifs au nombre de 2 équatoriaux.

Anas de tálentospores semblables à ceux des uretos mais rares, disséminés el non conflnents, à peine de couleur un peu plus funcée, pulvérulents. Téleulospores elliptiques, 


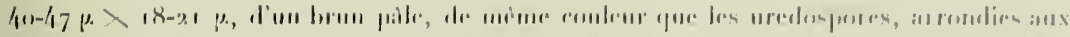

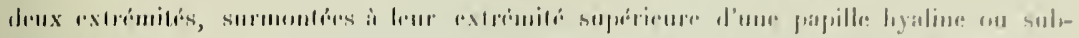

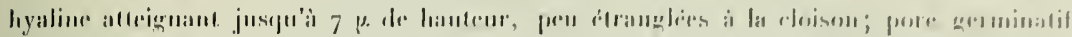

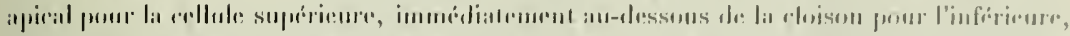

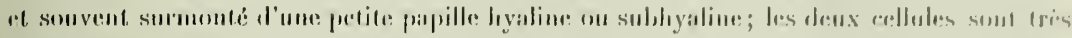

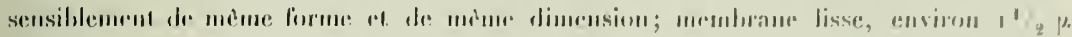

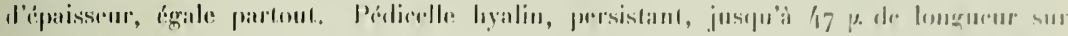

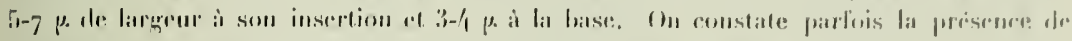

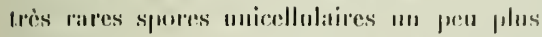

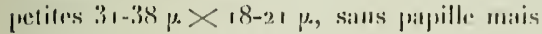
pour le reste somblables ans lienllulaires.

Soris uredospuriferis le!pupluyllis, spur-

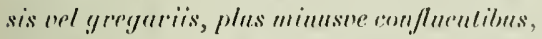
sine muculis nel muculis brumeris plos mi-

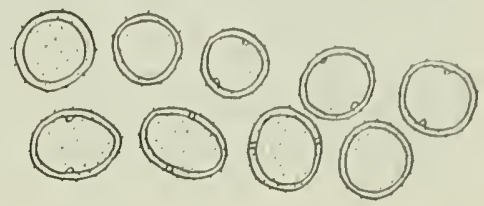
musene maynis insidentilus, mimulis, rolun-

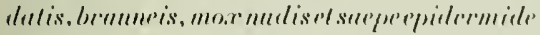
rinclis. Uredosporis ylobosis, $21-26$ p. dium.. nel ovonileis, $2 \delta-30 \mu \times 18-21 \mu$, dilule brunneis; membrana cu. 2 p. crussu, mimule laxprue echinulata; por is yerminutivis a aequuloriulibus. Soris Imlentusporiferis conformilus sed rencioribus, spearsis non confluentibus, uir obsenrioribus, pulverulentis. Telemtosporis allipsoileis, $10-17 \mu . \times 18-21 \mu$, dilute brunneis, ulrinque rolundatis, apire papilla hyjulime vel subluyulina usyme 7 p. alla inslructis, medion leniler constrictis: collulis

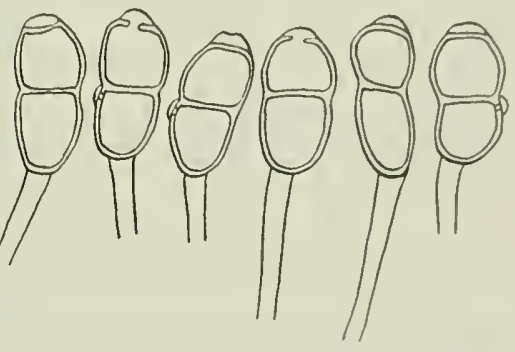

Fig. 39: P'uccinia Eupatori-columbiani. - Erealospores et léleulospores.

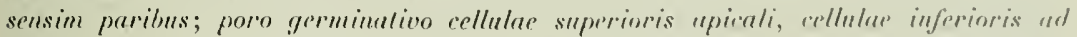

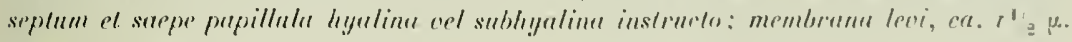

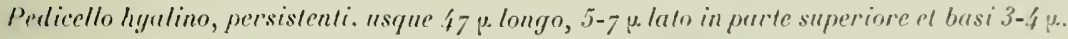

\section{Sur feuilles de Eupatorium columbianum HeErrsi.}

Andes contrales, dép. Antioquia. Chemin de Medellin à America, alt. $1550 \mathrm{~m}$; Il et III. 5 aonit ( $\left.11^{\circ} 29^{8}\right)$. - Taillis près de Guaca, alt. 1480 m: II et 111 . I2 septembre (n) $\left.29^{8 n}\right)$.

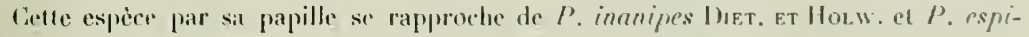
nosarum Dieт. ит Howw. mais elle s'en distingue wès facilement par sa papille beaucoup plus grande, frar la couleur très pàle des uredos et téleutospores ainsi que par leurs formes et leurs dimensions très différentes. Pour le moment le déreloppentent de cetfe espiece est celui d'un /lemi-Puccinia. 


\section{Puccinia tolimensis spec. nov.}

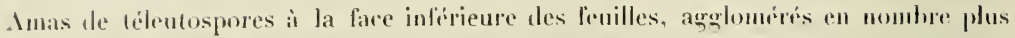
ut moins ronsidéable pour former des taches anrondies atteignant justju à 5 mu de diamètre d’un brun foncó à la face supríreure, un peu plus elair à l'inférieure el déborelaut un peu la zone des amas; ces taches sout irréguliorement disposées, dissćminces, isolées ef freu nombremses. Les amas sint petits, arrondis, confluents, d'un brun marron, compacts, assez longlemps recourerts par l'épiderme. - Télentospores elliptiques-allongées,

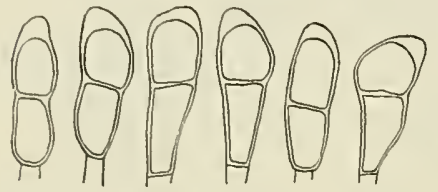
$45-52 \mu . \times 14-19 \mu$, d'un jaune un peu hruntıe, arrondies on $1 n$ peu atténuées à l'extrémité, attimuées ou un peu arrondies parfois à la base, pas ou à peine étrauglées à la cloison; les deux cellules sont sonvent de dimension inégale, l'inférieure étant plus longue que la supérieure; la position des pores gyerminatifs n’a pu ère exactement déterminée;

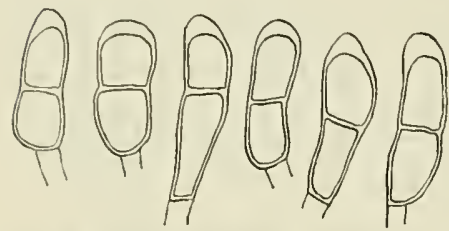

Fig. 40: Puccinia tolimensis. - Tẻleutospores. membrane lisse, mince, environ $1 \mu$, renllée à l'extrémité où elle pent atteindre jusqu'à 8 p. d'épaisseur. Pédicelle hyalin ou subhyalin, eaduc, court, mesurant $4-5$ u. de largeur ì son insertion.

Soris lelentosporiferis hypophyllis, dense gregariis, maculis obscure brunneis rolundatis (nsque $5 \mathrm{~mm}$ aliam.) sparsis insidentibus, minulis. rolundatis, confluentibus, compactis, costaneobrunneis, diutius epidermide tect is. Teleutosporis ellipsoideo-elongalis, 4.5-52 $\mu . \times 14-1$ !) $\mu$, flavo-brunneolis, apice rotundatis vel parum acutiusculis, basi plerumque attenuatis vel rarius rolundatis, medio non vel vix constrictis; cellula inferiore saepius longiore;

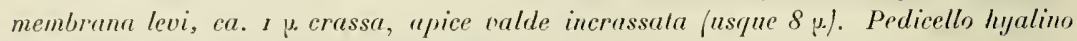
vel subliyalino, decilno, brevi, 4-5 lato.

\section{Sur feuilles de Eupatorium spec.}

Andes centrales, dép. Tolima. Soledad, sur le clemin de Mariquita, alt. 23/15 m; III. 6 octobre ( $\left.n^{\circ} 64\right)$.

Celte espèce se différencie facilement des autres se développant sur le genre Ĺuphtorium par son aspect macroscopique, ses amas compacts et conlluents, par la coloration des téleutospores, leur forme et leur dimension, leur coloration et l'épaississement de la membrane. Bien que je ne puisse l'alfirmer, il semble que le développement de cette espèce doive être celui d'un Leplo-Pnccinia. 


\section{Puccinia doloris Speg.

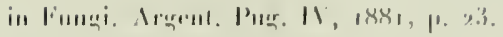

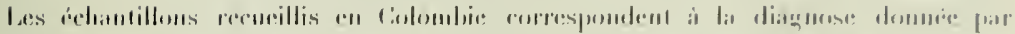

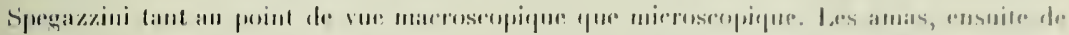

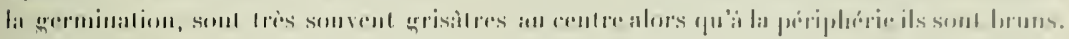

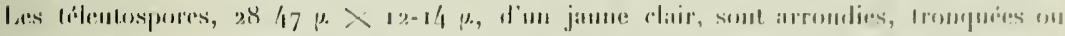

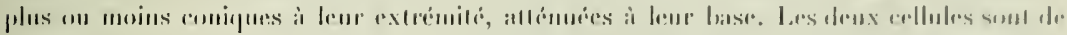

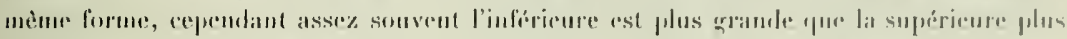

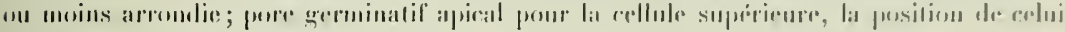

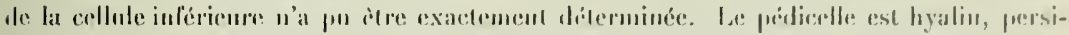

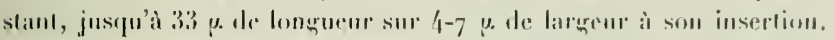

Sur fenilles de Erigeron ti. uliginosus BEENTI.

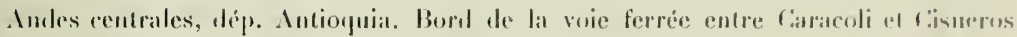

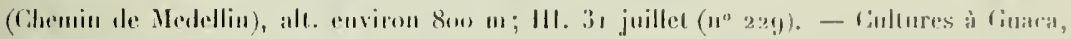

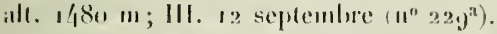

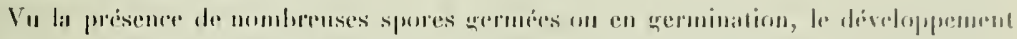
de colle rispice doil ètre celui d'un lepto-l'uccinir.

\section{Puccinia Baccharidis-rhexioidis spec. nov.}

Pyruides sur les deux faces des feuilles, an petil nombre en dispersies coutre les arej-

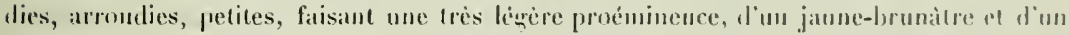
jaune dair vues en coupe.

Aecidies sur les denx faces des feuilles mais surtout ì la face supérienre, réunjes le phus soment en petit nombre prur former de petiles laches arjondies de $1-2 \mathrm{~mm}$ de diat-

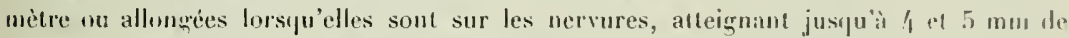
longnueur, irregulièrement disposées, disséminées ou nombreuses mais nou cunfluenter, faisint sur les denx faces des feuilles des laches d'un brun foncé déloriant plus ou monims largement la zone des atecidies. Les aecidies sont petites, arrondies, d'un jaune-lrunàtre, loughtemps recouvertes par l'épiderme qui reclate assez tardivement en formant une unverture irreguliement arrondie, ne presentant pas de rebord dielniquete ni renverse. Accidiospores arrondies, orö̈des on ovalaires, $23-31 \mu \times 18-24 \mu$, d'un jame trics clair. mime hyilines ou subliyilines, membrane d'égale épaisseur partoul. $2-2^{1}$ o po échinulie à épines courtes et peu denses. Pas de péridie nelle, seutement quelques collules isolies.

Amas d'uredos à la fiace iuférieure des feuilles, le plus sument ne faisant pas de taches spéciales sauf lorsqu'ils sont nombreux al alors la face supérieure des fenilles prend 
me vague coloration jannitre unifurme, dissemines ou trìs nombreux, rapprochés el souvent confluents, d'un janme clair mu peu frunatre, petits, arrondis, longtemps recourerts par l'apiderme qui n’édate que tardivement, pulvérulents. - Uredospores ovö̈les 0 pyriformes, $23-28 \mu \times 18-21 \mu$, lyalines on parfois sulhyalines al'un brum excessive-

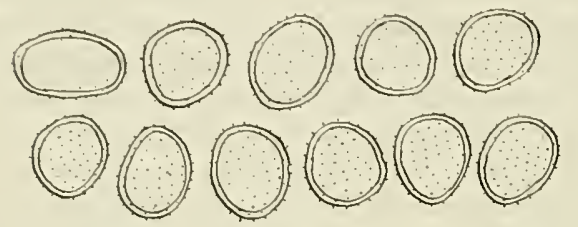
ment pàle; membrane mince, d'égale épaisseur partout, environ r p., íchinulée à épines courtes et peu denses; pures germinatifs au nombre le? équatoriaux.

Amas de téleutospores à la liace inférieure des feuilles, ne faisant pas

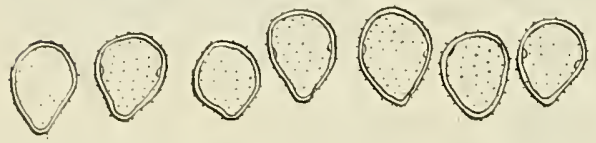
de taches spéciales à la surface des feuilles, dispersés et pen nombremx ou abondants mais le plus souvent isolés, ponvant eependant devenir

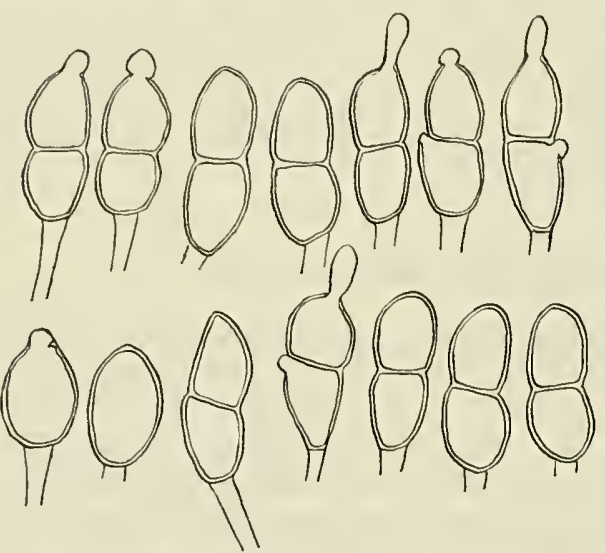

Fig. 41: Puccinja Baccharidis-rhexioidis. - Aecidiosporcs, uredospores et tẻleutospores. aussi un peu conlluents, d'un brunjame, mus de bonme lieure et presque toujours entonrés d'un mince rebord épjdermique; ils sont petits et plus ou moins irrégulièrement arroudis, $1 / 4-1 / 2 \mathrm{~mm}$ de diamètre, pulvérnleuts. - 'l'éleutospores elliptiques ou oblongues-elliptiques, $40-52 \mu . \times 18$ 2 r $\mu$, d'un brun très pâle, presque lıyalines, arrondies à leur extrémité, arrondies on rarement atténuées à la hase, peu étranglées à la cloison; les deux cellules sont sensiblemeut de mème forme et de nèmedimension ; pore germinatif apical pour la cellule sujérieure et immédiatement au-rlessous de la cloison pour la cellule inféricure; membrane lisse, mince, environ $1 \mu$, d'égale épaisseur partout, non resllée à l'extrémité. Pédicelle caduc, hyalin, jusqu'à $25 \mu$. de longueur sur 7-9 $\mu$. de largeur à son insertion. Anormalement quelques spores unicellulaires, $30-35 \mu . \times 20-22, \mu_{-}$, pour le reste semblables anx bicellulaires.

Pycnidiis amphigenis, paucis, mimutis, rotundatis, flavo-brunneolis. Aecidiis antphigenis plerumque epiphyllis, in paruos greges dispositis, maculis rotundatis $1 \mathrm{r}-2 \mathrm{~mm}$ dirm.) vel oblongis (usque 4 et $5 \mathrm{~mm}$ long.) fulvis sparsis vel numerosis sed non confluentibus insidentibus, minutis, rotundatis, flnoo-brumneis, diutius epidermide tectis 


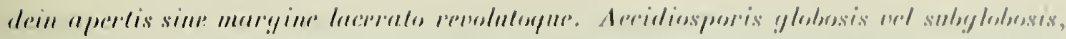

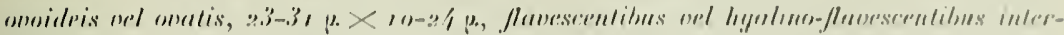

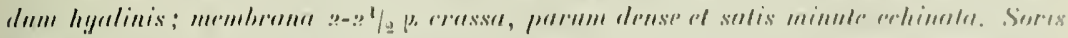

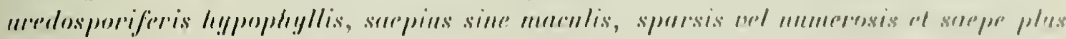

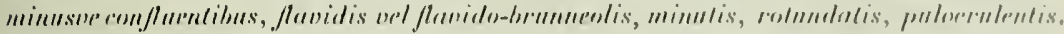

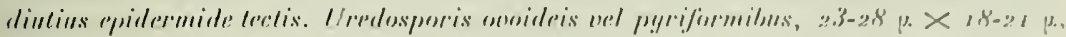

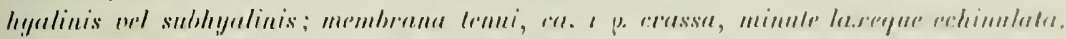

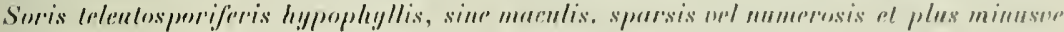

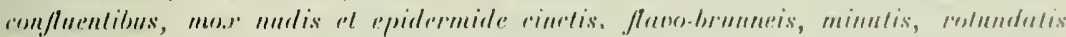

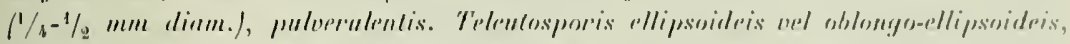

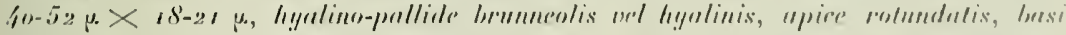

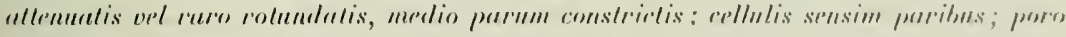

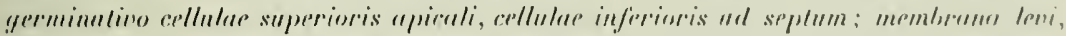

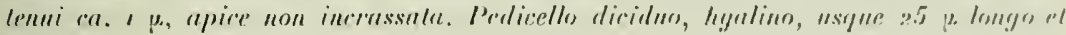
$7-9)$. Into.

Sur lenilles de Baccharis rhexioides. II. I3. K.

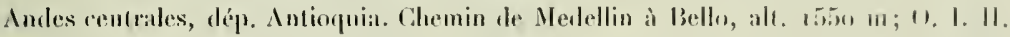

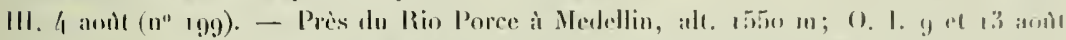

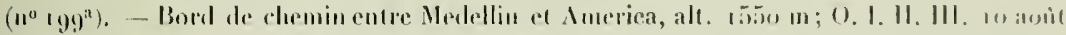

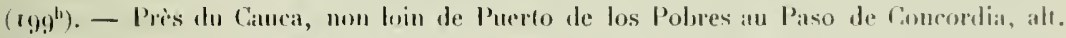
('nviron $800 \mathrm{~m} ;$ (). 1. 6 septimbre $\left(199^{\circ}\right)$.

Colle espice diffire suftisamment tes aulres se développant sur les Burrhuris pour quaucune confusion ne soit possible. Elle presentr en eflet tontes les diverses formes de reproduction, comme P'. peulens Harks. dont elle se distingue aisóment par l'ispect des arcidies ne faisant jamais des tumenrs ainsi que par lin forme, la grandenr ct lil couleur des aecidiospores, uredospores el tíleutospores. Elle se distingue de P. Ifonningsii Dhet. par la présence d'alecidiospores, par ses uredospores plus petiles ed échinulére, par ses télentospores sensiblement plus petites et hyalines ou d'un hrun exressivement paile. I’. Baccharihlis-hirtellae Dat. ет Hosw. n’a pas d'aecidies, a ses télentospores d'un hrun pàle, mais sa membrane est ponctuée el pas lisse; si leur longume est bo mème, par contre la largenr est sensiblement plus petite chez notre esjèce, te pídicelle est plus court el plus

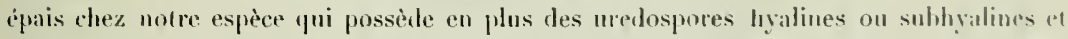

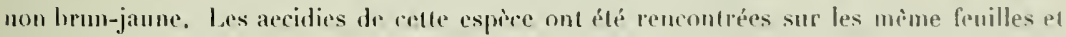
à proximité immédiate des uredos el télentospores: jai olsservi me très qrande quantité de spores germées er surtout en pleine germination. Le développement de celte espèce est celui d'un Eu-Puccinia dont les tédeutospores, rraisemblablement par suite des condilions climatériques, germent très rapidement sans période de repos un aprís une périonte tries courte. 


\section{Puccinia Montserrates spec nov.}

Imas d'ureders a la face inférieura des lenilles, ne faisant pats de tarlies à la lace suprírienre, petits, arrondis, conleur cannelle, isolés, dissémincs el peu abomlants, non anfluents, assez longtemps recouverts par l'épiderme, puis nus, pulvérulents. Amas de tilentospores semblables at ceux des uredos el ne s'on distinguant pas facilement, à peinc peut-ou remarquer une coloration un pen plus foncée. - Uredospores arrondies, $2.3-26 \mu$.

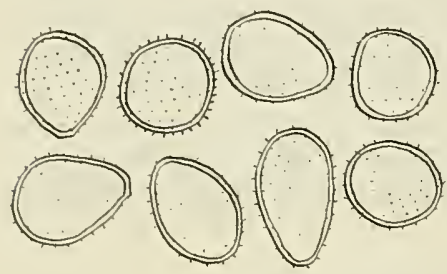
de diamètre ou woödles ou ovalaires, $30-45 \mu \times 23-$ $28 \mu$, subhyalines ou d'un jaune excessivement chair; memblune d'egale ápaisseur partout, enviroun $r^{t} / 2 \mu$, épineuse à épines assez grandes et assez peu denses; la position et le nombre des pores germinatifs n'ont pu itre exactement déterminés. - Téleutospores

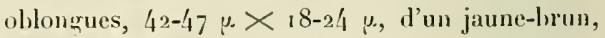
arrondies ì leur extrémité, arrondies on un pen atténuées à la base, pas ou à peine cutanglées à la

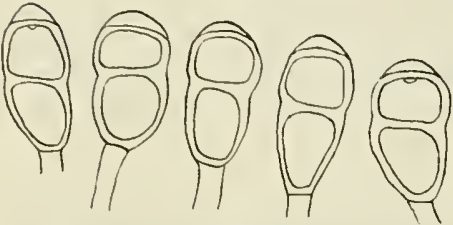

Fig. 42: Puccinia Montserrales - UTrelospores el téleulospores. cloison; les deux cellules sont très sensiblement de mìme forme et de mème dimension; jore gurminatif apical pour la cellule supérienre, la position de celui de la cellule inférieure n'a pu ètre exactement déterminée; membrane lisse, $2-24 / 2 \mu$ d'épaisseur, rentlée à son extrémití où elle peut atteiudre jusqu'à $7 \mu$; ce renllement terminal est le plus souvent coloré en janne-lorun plus clair que le reste de la spore. Pédicelle hyalin, non ou peu persistant, court, mesurant 5-7 $\mu$ de largeur à son iusertion.

Soris uredosporiferis el leleulosporiferis conformibus, sine maculis, mimulis, roInndutis, cinnamomeis, sparsis, paucis, non ronfluentibns, pulverulentis, din epidermide

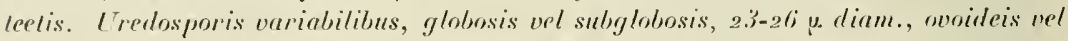

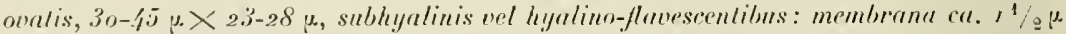
crassa, sulis dense pelinala. Telentosporis oblongis, $42-47 \mu . \times 18-24 \mu$, flawo-brunneis, "pire rolundalis, hasi rolundalis vel allenuatis, medio non nel vix constrirlis: erllulis sensim paribus; poro germinativo cellnlae superioris apicali; membranu levi, $2-.3^{1 / 2} \mu$. crassa, apice incrassalu astue 7 u. Pedicello hyalino, non vel partum persistenti, brevi, j-7 p. lato.

Sur feuilles de Baccharis bogotensis II. B. K.

Andes orientales, dép. Cundinamarca. Pente du Montserrate au-dessus de Bogota, alı. environ $28 \mathrm{su}$ m; 11 et 111.16 octobre $\left(1^{\circ} 56\right)$. 


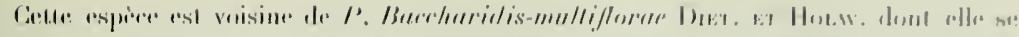

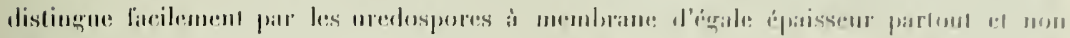

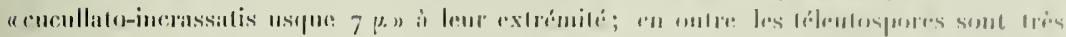

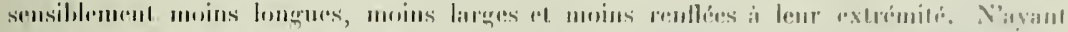

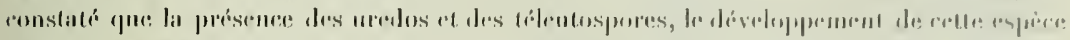

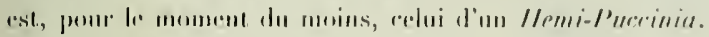

\section{Puccinia caeomatiformis Lagh. \\ in syal. Mın. Iirml. I, I. $2 /$.}

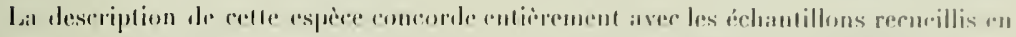

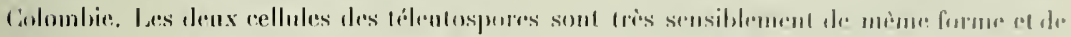

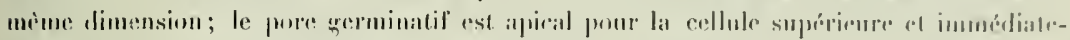

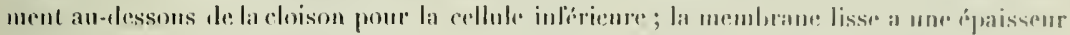

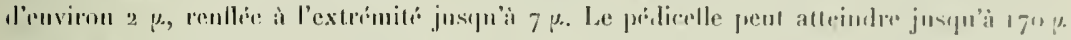

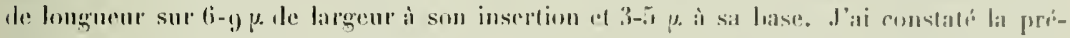
sence de tris rales spores anomalement tricellulirires.

Sur finilles de Baccharis polyantha II. 13. K.

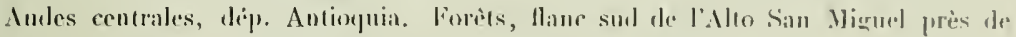

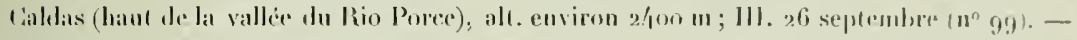

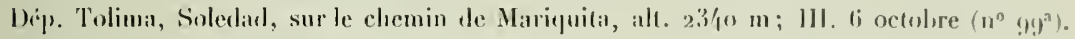

Andes occidentales, dép. Antioguia. Bord de chemin prés de Valpariniso, alt. environ $1 / 100, \ldots 1111.29$ septembre $\left(n^{\circ} 99^{11}\right)$.

Anles orientales, dép. Condinamarca. Taillis près de la chutr du Tequendama. alt. $2200 \mathrm{~m}$; 111. r2 octohre $\left(\mathrm{n}^{\prime \prime} 99^{\circ}\right)$. .- Taillis pres de la Laguni de Ihaque, alt. $2000 \mathrm{~m}$; III. 15 ocholre $\left(11^{\circ} 99^{11}\right)$.

Le développement de celle espèce, vu la présence de spores germies on en germinalim, sembla bien ètre relui d’un Lepto-I'uceiniu.

\section{Puccinia Mayerhansi spec. nov.}

Pyonides it lit face supéricure des fenilles, petites, tris peu proéminentes, en petit nombre, d'un jaune brunatre, simces sul les taches d'un brun plus ou moins funcé formeres par les Cacoma de la face inférieure.

Caroma it la face inférieure des fenilles, arrondis ou un peu oblongrs, isoles ou sourut reunis en peit nombre el plus on moins confluents ponr former les laches arrondies de $1-4 \mathrm{~mm}$ de diametre. A la fice supérieure des feuilles. on constate une coloration brune des tissus pouvan devenir d'un lirun-moir et debordant largenent les amas, colo-

60 
ration quon retrouve it ta fice inlérieme antour des amas. Jes antas sont soit arrondis,

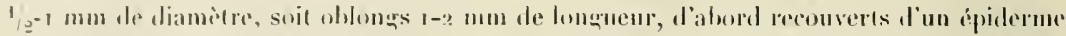
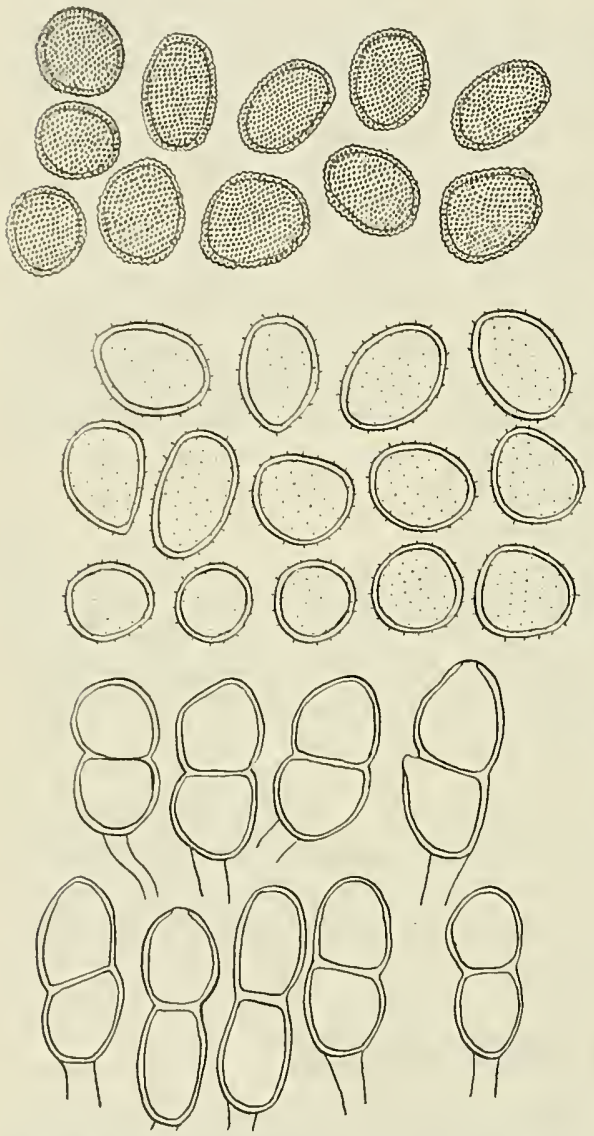

Fig. 43: Puccinia Mayerhansi. - Caeomaspores, uredospores et téleulospores. épais el janne-hrom qui se lend et forme l. plus souvent une fente irrigulière et Épisse entre les levres de laquelle on voit les spores d'un jaunc tris clair. Les spores sonl variables de forme, suit arrondies, $23-28 \mu$. de diamétre, suit ovalaires on elliptiques, $28-35 \mu . \times 23-$ $28 \mu$. hyalines on subliyalines très faiblement coloríes en jaune trìs pâte; membrane d'égate épaisseur partout, emiron $2 \mu$, verroquense, à verrues grosses et ılenses.

Amas d'uredos el de téleutospores très semblables, à peine ceux de télentospores sont-ils un peu plus foncés que ceux d'uredos; ils sont irrógulicrement disposés à la face inférieure des feuilles, dissiminés et peu nombreux ou au contraire abondants et rapprochés les uus des antres, mais non conlhnents ou rarement, se manifestant à la face supurienre par un petit pointillé jannâtre; ils sont petits, punctiformes, d'un jaune elair, louglempss recouver's par l'ápiderme, pulvérulents. - Uretospores trìs variables de forme, soit arrondies, 23-28 $\mu$ de diamitre, soil ovalaires ou elliptiques, $28-38 \mu . \times 23-28 \mu$, liyalines ou faiblement colorées en jaune très pâte; membrane d'égale épaisseur partout, environ $2 \mu$, épineuse ì épines assez grandes et assez peu denses. Lil position et le nombre des pores germinatifs nont po ètre exactement détermines.

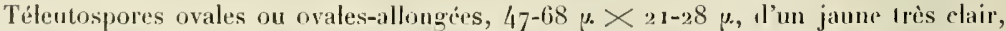
subliyalines ou liyalines quand elles ne sont pas à complète maturité, arrondies aux deux extrimités, dranglíes à lat eloison, souvent assez profondément; les deux spores sont 


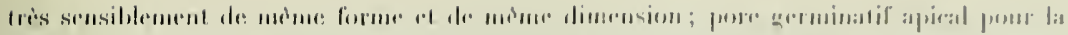

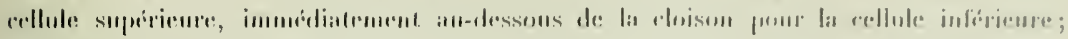

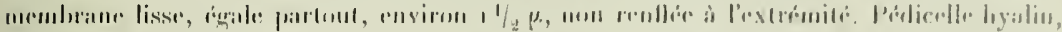

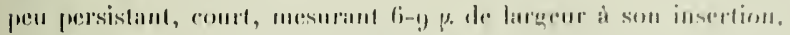

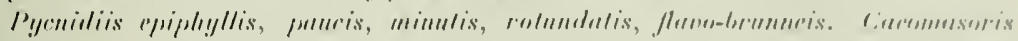

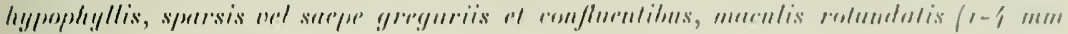

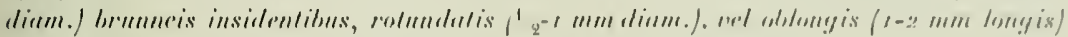

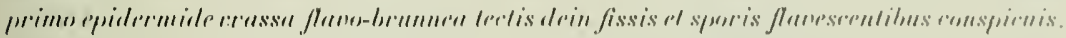

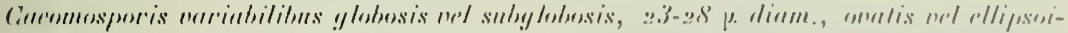

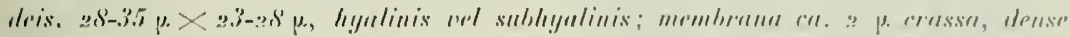

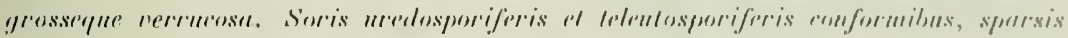

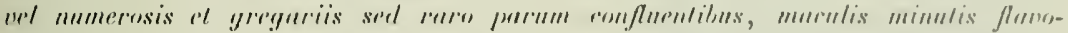

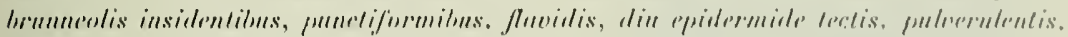

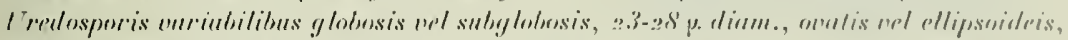

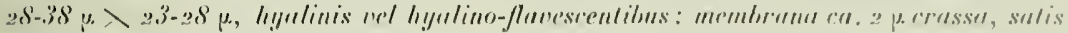

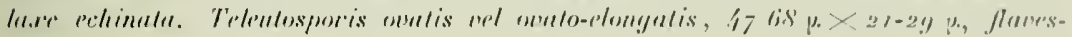

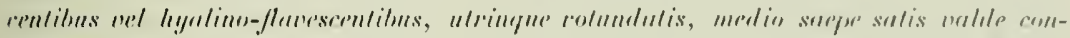

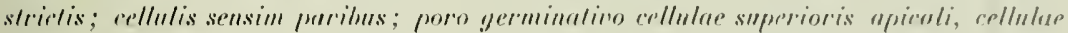

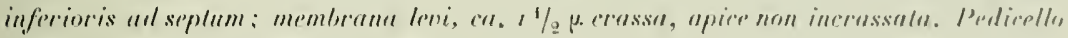
li!fulino, parum persistenli, breni, li-g y. lulo.

Sur fruilles de Baccharis oronocensis 1$)$ :

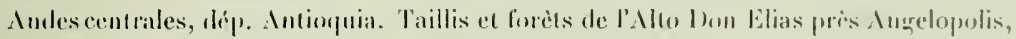
alt. $2100 \mathrm{~m} ;$ (). 1. 11. 111. 27 31011 (110 170).

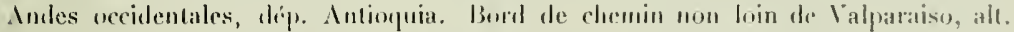

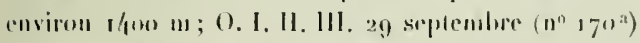

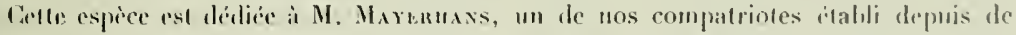

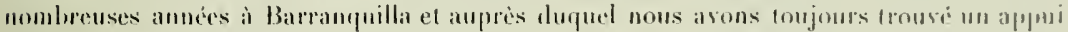

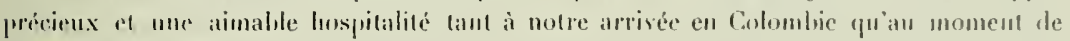
notre alepart.

\section{Puccinia Montoyae spec. nov.}

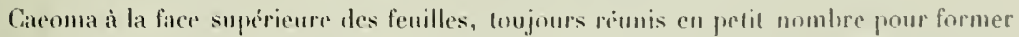
des laches arrondies de $1-3$ mm de diamitre, irrigulicrement disposes, isolies el gentralemont pen nombreuses, donnant te plus souvent i la face inferieure une culoration plus ou moins brun fonci qui deborde largenent les amas el qu'on retrouse à la face superieure. Les amas sont pelits, qrossièrement arrendis, d'about rerouverts d'un ifriderme epais d'un brun fonci ou d'un brun noir qui se fent ensuite irregulierement at entre les lives épaisses du rehord apparaissent les spores d'un jaune tres paile. - Spores arrondice ou 


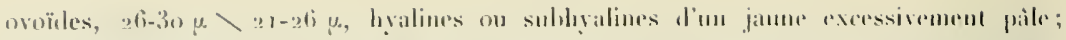

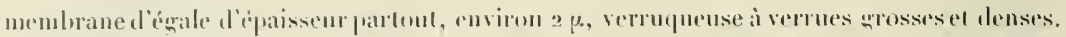

Amas de tributospures a la face inférieme des feuilles, imrgulierement disposés, isoles, dissemines un abondants mais jamais rimnis pour former de pertites taches, ne se manilestant par aucune coloration particuliere des tissus foliates, petits, arrondis, punctiformes, d'un lrun clair, mus, compacts. - Télentespores oblomgues on oblongues-allongrors,

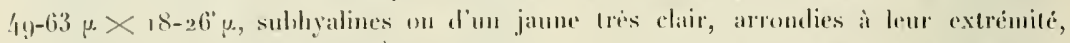

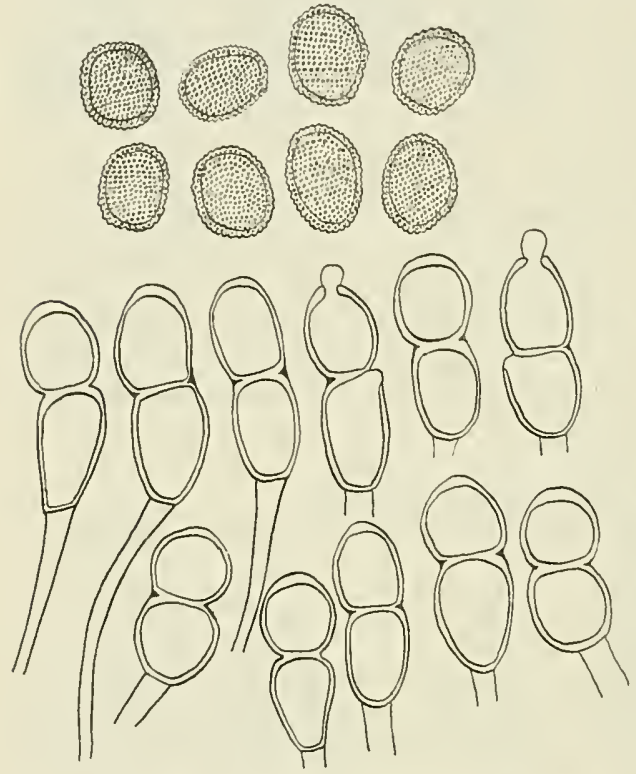

Fig. If: Puccinia Montoyae. - Caeomospores el téleulospores. atrondies, rarenent un peu atténuées à la base, prolombenent élanghes it la cloison el se desarticulaul fiteilement; les deux cellules sont très sensiblement de mime forme it de mème dimension; pore germinatif apical prour la cellule supurienre, inmedialtement au-elessous de la cloisom pour la cellule inférienre; menbrane lisse, environ I 1/2 pal'épaissemr, it peine un peu renfléc à l'extrémité où elle alteint au plus $4 \mu$. Pédicelle hyalin, persistant, jusqu'i $85 \mu$ de longueur sux 7-8 $\mu$. de largeur ì son insertion el diminuant ensuite progressivemenet jusqu’à sa base oì il mesure seulement 3-4 p..

Caeomasoris epiphyllis, semper in parvos greges dispositis, maculis rotundatis ( $1-3 \mathrm{~mm}$ diam.) sparsis plus minusve obscure brunneis insidentibus, minntis, rolundatis, prino epidermide crassa obscure vel utrobrunnen tertis, dein fissis et sporis flavesrentibus conspicuis. Capomasporis globrsis, subglobosis vol ovovideis, $26-30 \mu . 入$ 21-26 y., hyalinis vel hyalino-flavescentibus; membrana ca. 2 p. crassa, dense grosseque verrucosa. Suris telentosporiferis hypophlyllis, paucis, sparsis non confluentibus, sine maculis, minutis, punctiformibus, brumuris, mox nudis, compactis. Teleutosporis ablangy is nel ollongo-elongatis, $4.9-6.3 \mu \times 18 \cdot 26 \mu$ subhyulinis vel ly!gulino-flavescentibus. apice rolundalis, basi rolundatis nel raro parmm attemutis. medio molde constrictis; cellulis sensim paribus: poro germinativo cellulue superioris apicali, cellutae inforioris ad septum: membrana levi, ca. ${ }^{1} \frac{1}{2} \mu$ crassa, apice vir vel leniter incrussatn (usyne $\left.4 \mu.\right)$. Pedi-

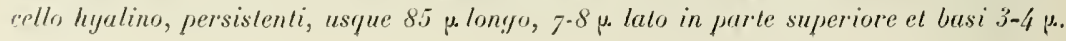


Sur linillen dl. Bacclaris floribunda H. 1:. 4.

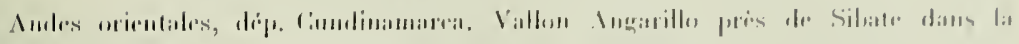

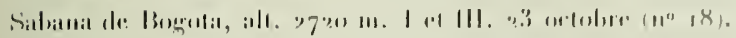

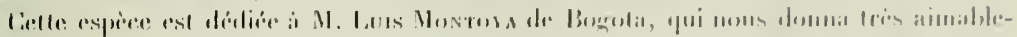

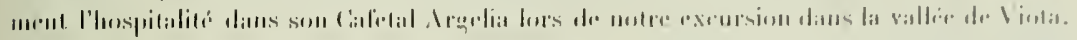

\section{Puccinia Ancizari spec. nov.}

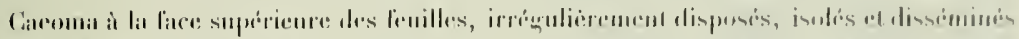

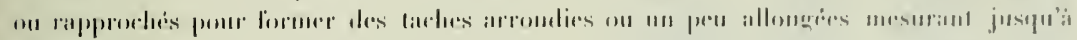

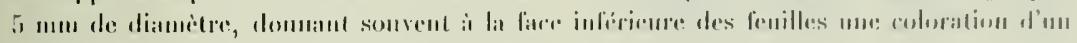

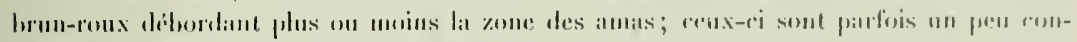

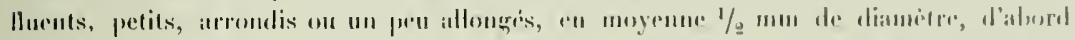

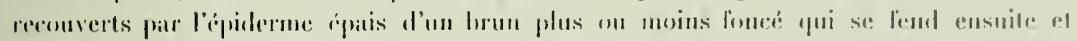

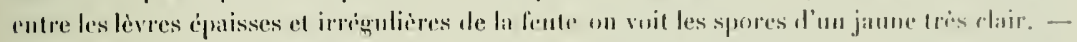

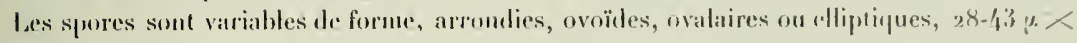

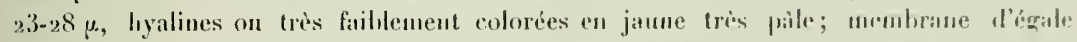
ppasseur partout, environ $2 \mu$, vermuguese, it verrmes assez grosses et denses.

Amas de téleutospores it la lace inférieure des feuilles, irrigutioment disposis,

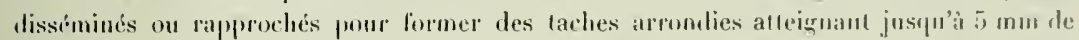

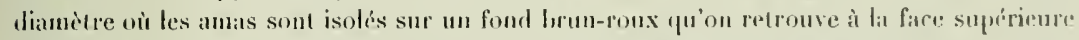
des fenilles, coloration gui diborde plus on moins largement la zume des anas: ils sont tres rarement un peu conllownts, petits, arrondis, prespue punctiformes, d'm jaunp-

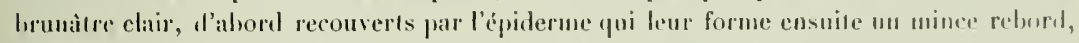

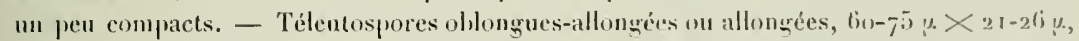

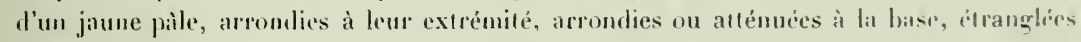
sourent assez profondénent à la cloison; les deux rellules sont très sensiblement de mimr furme aldemime dimension; poregerminatif apical pour la cellule supérieure, inmécliatement an-tessons de la cloison pour la cellule inférienre; memhrane lisse, environ ${ }^{1}$ g y.

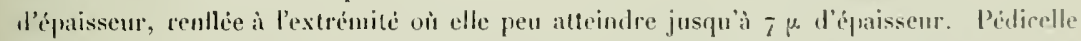
hyalin, persistant, jusqu'i $70 \mu$ de longueur sur $7-9$ y. de largeur ì son insertion, puis diminuant el ayant 4-5 $\mu_{0}$ it sil biase.

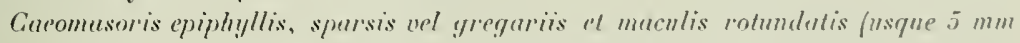
dium.) rufo-brnmeis insidentibus, interdnm parmm conflnentibns. mimulis. rotundutis "el parmm oblongis (1/a mm diam.), prino epjidermide crassa plus minusue obscure

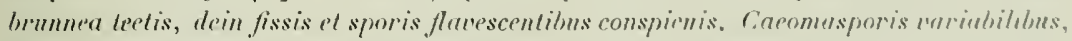

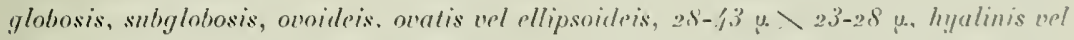

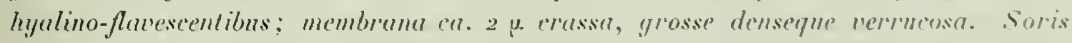
telentosporiferis hypophyllis, spursis uel greguriis sed non wel ruro premum confluentibus. 


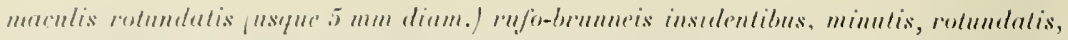

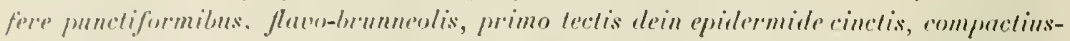

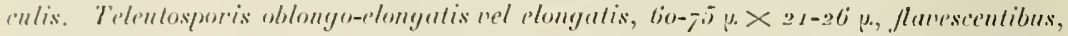

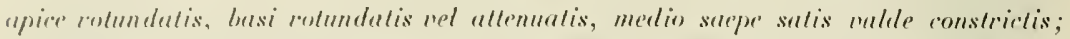
cellulis sensim puribus; poro germinaturo cellulue superioris upiouli, erllulue inferioris

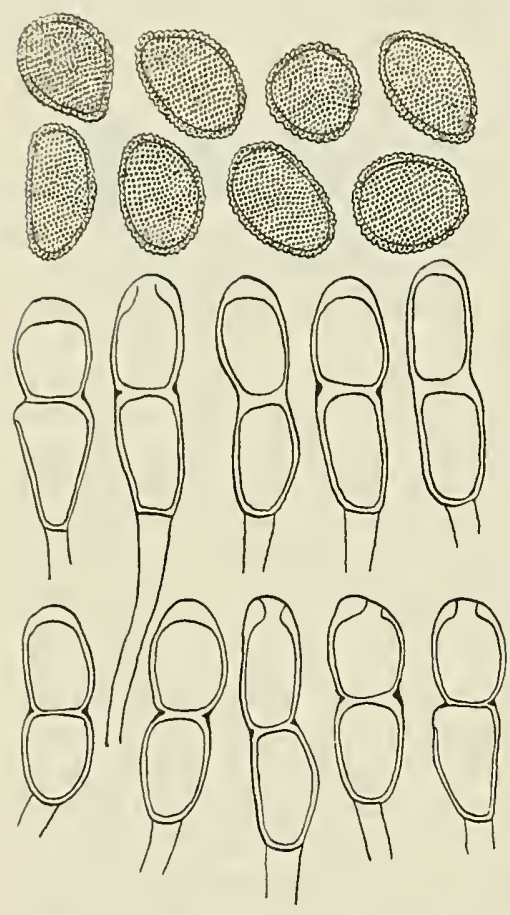

Fig. 45: Puccinia Ancizari. - Gaeomaspores et téleutospores.

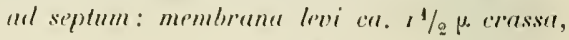
upice useyue 7 p. incressuta. Pedicello hyalino, persistenti, usqume go p. longo, 7-9 p. late in perte superiore ol busi $\{-5$ p.

\section{Sul lenilles de Baccharis nitida Pens.}

Andes centrales, díp. Antioquia. Chemin entre Ingelopolis et Guaca, alt. environ $1550 \mathrm{~m}$; 1. Ir septembre (no 170$)$. - Bord de chemin à (inaca, alı. 1/80 m; 1. 12 septembe $\left(11^{\circ} 170^{\mathrm{a}}\right)$.

Andes orientales, dép. Cumlinamarca. Taillis près de la Laguna de Thaque; alt. $2000 \mathrm{~m}$; l. 15 octobre $\left(n^{\circ} 38\right)$.

\section{Sur feuilles de Baccharis nitida Pens. var.}

Andes orientales, dep. Cumdinamarea. Bord du ehemin entre Villeta el Facataliva dans la Salsana de Bogote, alt. environ $2000 \mathrm{~m}$; I et III. 9 oetobre ( $\left.\mathbf{n}^{\circ} 65\right)$.

Celte espèce est dídice à M. Jonge Ancizan de Bogota, qui contribua qrandement à la réussile de nos excursions aux environs de Bogrota et auprès duquel nous avous trouvé la plus gracicuse hospitalité.

Puccinia Mayerhansi, P. Montoyne el P. Ancizari forment un groupe nettement distinct parmi les Puccinia se développant sur le geme Buccharis el ne sauraint ère confondus avec les autres espèces qui en diffërent considérablement soit par lenrs caractères macroscoprques, soil par leurs raractères microscopiques. Ces trois espèces sont assez voisines les unes des autres, P. Montoyge chant l'intermédiaire entre les deux autres. Eu comparant les téleutospores, on voit que P. Mayprhansi a sa membrane égale partout et ne présentant aucun épraississement à son extrémité; $P$. Ancizari au contraire, présente un fort épaississement de la membrane allant jusqu’à $7 \mu$, quant à $P$. Montoyae, il est intermédiaire par le fait que la membrane est très peu épaissie, parfois mème 


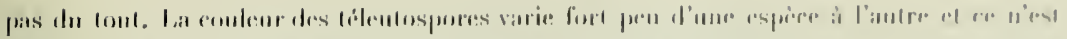

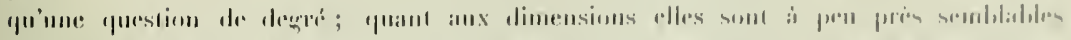

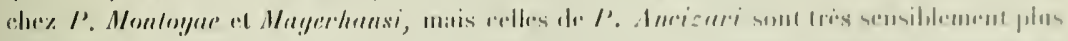

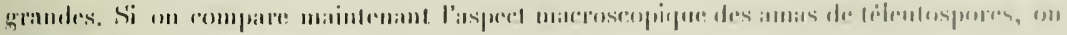

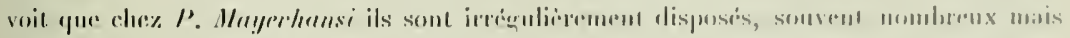

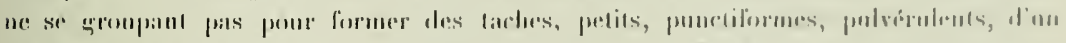

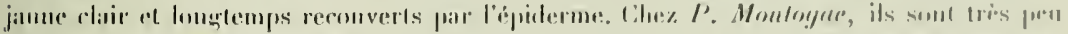

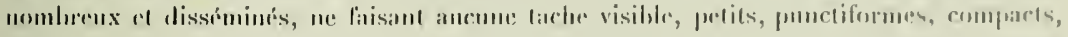

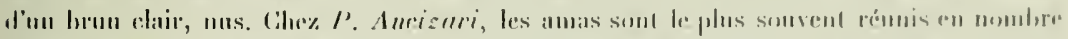

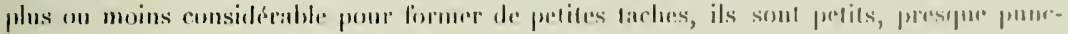

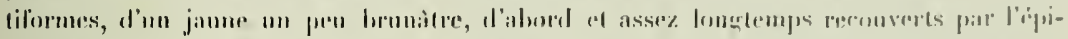

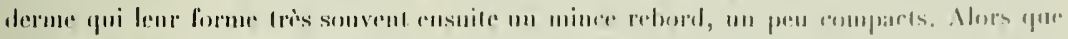

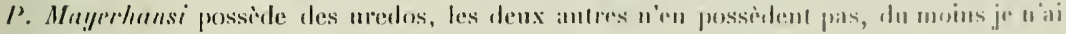

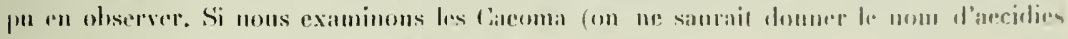

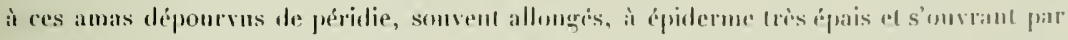

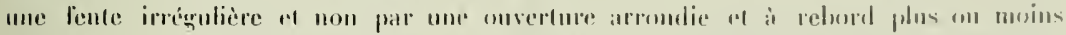

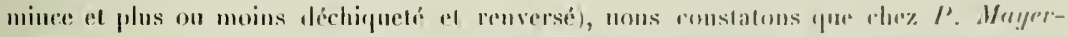

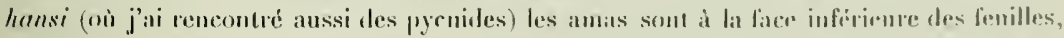

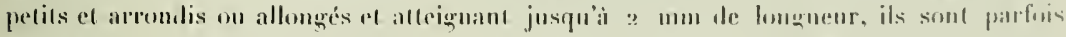

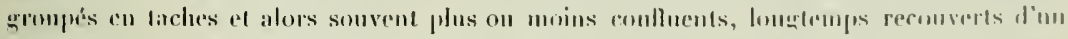

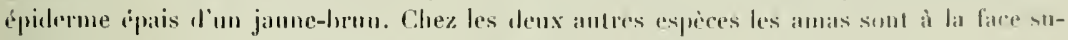

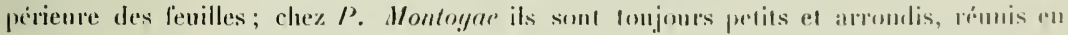

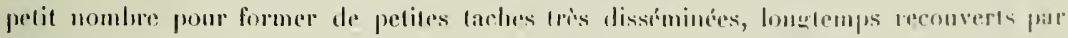

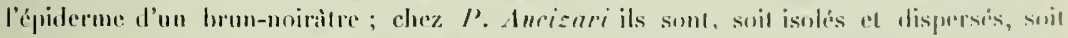

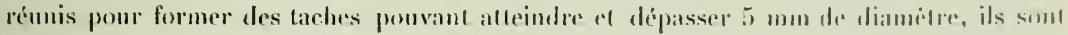

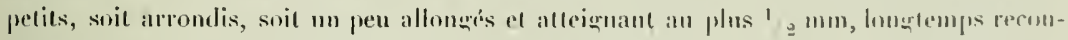

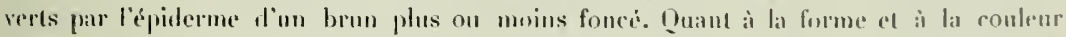
des spores, elles sont sensiblement pareilles dans les trois espèces. Comme on le roit, res trois espreces sont voisines les mes des aulres, mais alles prisentent crpemdint des diftirences morphologiques suffisamment maryués el constantes pour justifier lenr séparalien, que tries vaisemblablement des expériences ultérieures viendront encore confirmer.

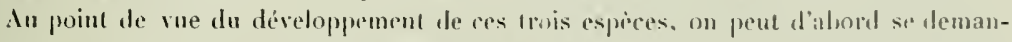

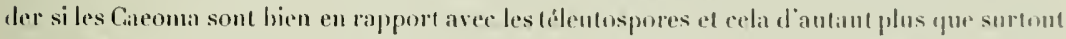

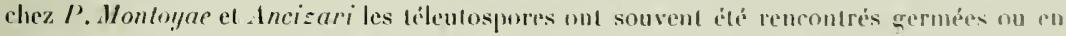
voie de germination. Les Caloma ayan tonjours élé rencontrés sur les mèmes fenille: que les téleutospores et à proximité immédiate, it semble donc logique, pour le moment

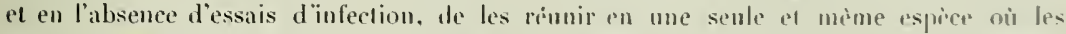
léleutospores germent immédiatement ou an tont cas apris une période de repos exressisp-

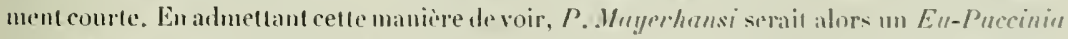

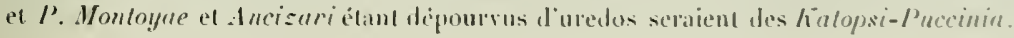




\section{Puccinia Wedeliae spec. nov.}

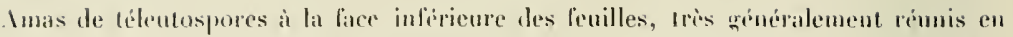
groupe plus ou muins netlement organises en cercles concentriques pour lormer des laches arrondies de 2-3 mm de diamitre, irregulicrentent disposies, somrnt nombremses el ponvant devenir confluentes. I la linee supérieure des fenilles el correspondant aux amas, on constate des lachess d’un jaune-verditre devenant brun foncé frar la dessiceation; celle

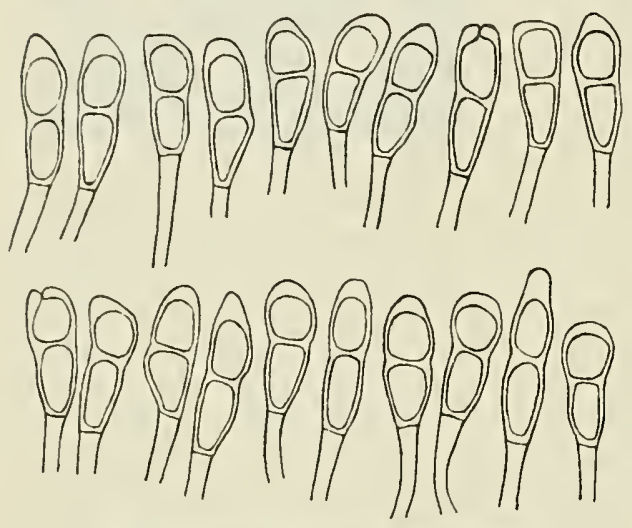

Fig. 46: Puccinia Wedeliae. - Téleulospores. mène coloration se retrouve i la lace inférieure débordant m peu les amas. lorsque l'infection est abomlante ot que les taches devinment comllumtes, de gramdes surlaces des leuilles juennent une coloration d'un jaune-verdàtre. Les amas sont plus on moins confluents sur les taches, plus rarement isules, petits, arromdis el punctiformes, brums, compacts, nus. Téleutospores oblongues - elliptiques ou elliptiques-allongées, d'un jaumebrun clair, parfois presque subliya-

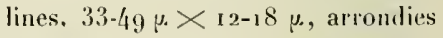
ou plus ou moins coniques à leur extrémité, altinuées à la hase, pas ou très peu étranglées à la cloison; les deux cellules sont presque toujours inégates, linfírieuré étuıt plus longue et sonvent plus étroite que la supérieure généralement plus ou moins arrondie; pore germinatif apical pour la cellule supérieure, la position de celni de la cellule inférieure n’a pu ètre exactement déterminée; membrane lisse, $11 / g^{-2} \mu$ d'épais-

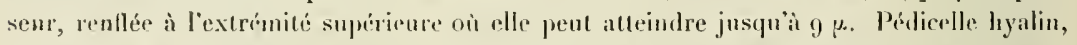
persistant, alteignant jusqu’ì $35 \mu$ de longnemr sur $4-7 \mu$ de largeur à son insertion.

Sortis teleutosporiferis l!ypophyllis, sparsis vel praecipue aggregatis et plus minnsve circinatw dispositis, maculis rotundatis $/ 2-3$ mm dian.) saepe numerosis confluentibustue brume is vel virido-flavo-brunneis insidentilus; soris raro sparsis, surpius plus minusve confluentibus, rotundatis, punctiformibns, fuscis, compactis, undis. Teleutosporis ollongo-ellipsoideis vel ellipsoideo-elongatis, flano-brunneolis interdun fere subhyalinis, 33-4g $\mu \times I_{2-1} \& \mu$, aprice rolundatis vel conicis, basi attenuatis, medio non vel vix constrictis; cellulu superiore plus minusve rolumbuta, inferiore longinre et snepe angustiore; poro yerminativo cellulae superioris apicali : membruna

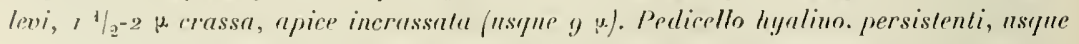
3.5 y. $\operatorname{long} n, 4-7$ u. lato. 
Sirr fruilles ale Wededia Trichostephia lX:

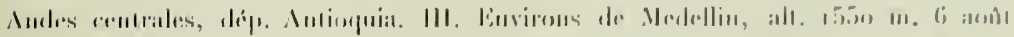

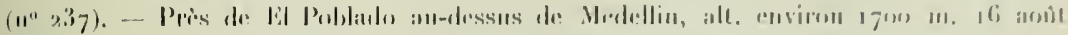

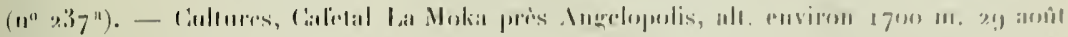

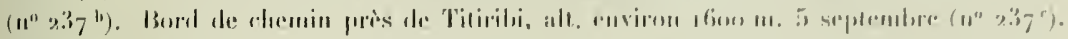

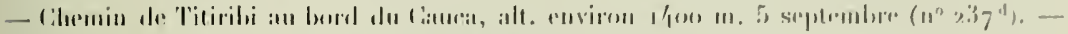

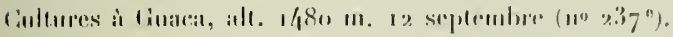

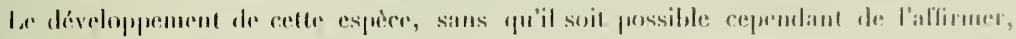

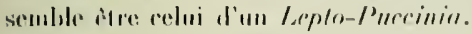

\section{Puccinia Eleutherantherae Diet.}

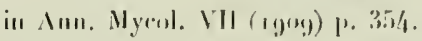

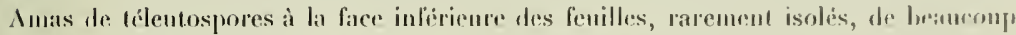

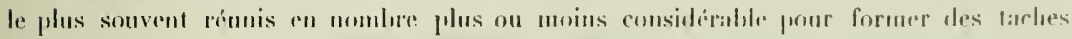

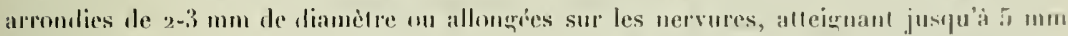
de longuenr. A la face supierienre des fenilles, on comstate an nivean des amas isolés un pointillé bronatre an nivean des amas congroméres des taches d'un brun-fauve dolordant plus ou muins largement la zone des amas et somvent comllumes en cas de forte intertion, $\Lambda$ la lace inféricure les amas sont enteurets d'une etroite zone d'un jaunelorunitre; ils sont petits, arrondis, conlluents, inn pen campacts, d'un brun foncé, mos de bonne henre. - Télentospores ohlonguneselliptiques, 35-47 $\mu>12.18 \mu$, d'un janurelorunitre dair, la celule inférieure gémiralement d'un jaune très pàle ou mème hyaline, arrondies ou tronqués a leur extrimiti, tris rarement un pen coniques, altinuées it ia hase, pen itranglies ì la cloison; les deux rellutes som le plus sonvent te dimrnsions incigales, linferienre citant plus longne el plus eitroite que la supusieure plus on moins arrondie; pore germinatid apuical pour la cellule superrieure, la position de celui de la collule in-
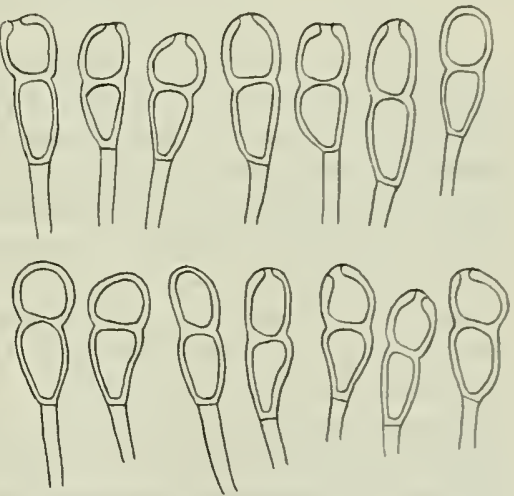

Fì. 47: Puccinia Eleutherantherae. - Téleulospores. firienre n: renflés ì l'extrémité oì elle mesure te plus souvent $3 \mu$. Pédicelle coloré en janne clair

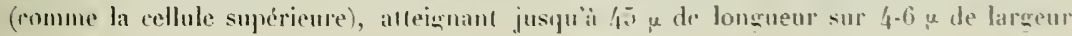
$6_{7}$ 
ì son insertion, persistant. - Mrant observe de nombreuses spures gromécs ou en germination, te déseloppentent de cette espèce doit ètre celui d'un Lepto-Pacrinia.

Sur feuilles de Eleutheranthera ruderalis (Sw.) Scпuıт-Bњ.

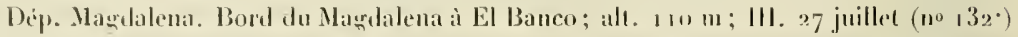

\section{Puccinia Xanthii Schw.}

in Syn. Fung. Carol., p. 73 (1822).

Les deux cellules des tileutospores sont trìs sensiblement de mîme forme et de mème dimension; cependant assez souvent l'inférieure est un peu plus longue et parfonis un peu plus étroite que la supérieure plus ou moins arrundie; pore germinatif apical pour la cellule supériénre, la position de celui de la cellule inférienre n'a pu ètre exactement léterminée. Pédicelle jusqu’à $35 \mu$ de longueur sur $5-7 \mu$ de largeur à son insertion.

\section{Sur feuilles de Xanthium strumarium L.}

Antilles: Ilaïti; Cayes, dans le sahle au bord de la mer; 111.17 juillet ( $n^{\circ} 1 / 2$ ).

\section{Puccinia Bimbergi spec. nov.}

Amas de téleutospores à la face inférieure des feuilles, rarement isolés, de beaveouj le plus souvent réunis en nombre plus ou moins considérable et confluents pour former des taches. Ces taches sont généralement arrondies et penvent alteindre $4-5$ mm do diamètre et parfois jusqu’̀̀ 8 et $9 \mathrm{~mm}$; elles sont irrégulìrement disposćes, soit péu ahondantes "t isolées, soit souvent nombreuses et alors pourant devenir conlluentes; à la face supérieure des feuilles et correspondant anx amas, on constate la présence de taches d'un brun plus ou moins foncé entourées d'une zone étroite d'un jaune-brun; à la face inférieurè, les amas sont entourés d'une étroite zone d'un vert-hrunâtre. Les amas, rarement isolés et toujours conlluents sur les taches, sont compacts, d'un brun-noir, petits et arrondis, nus de très bonne lieure. - Téleutospores oblongues-elliptiques, alténuées à la base, arrondies à leur extrémití ou un pen coniques, peu étranglées à la cloison, d'un

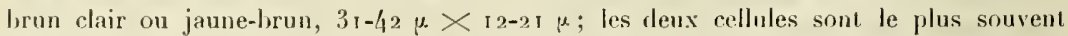
inégales, l’inférieure étant plus longue et plus étroite ( $12-16 \mu$. de largeur) que liı supérieure généralement arrondie et ayant г8-2 г $\mu$ de largeur; pore germinatif apical pour la cellule supérieure, la position de celui de la cellule inférieure n'a pu ètre exactement

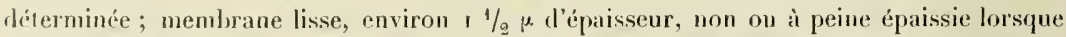
les spores sont à sommet arrondi, présentant nn épaississement alteignant $7 \mu$ lorsque 


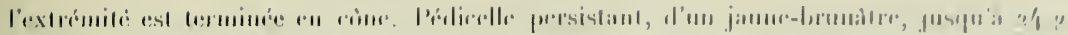

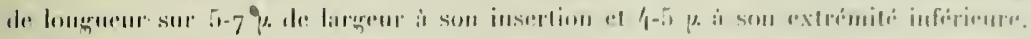

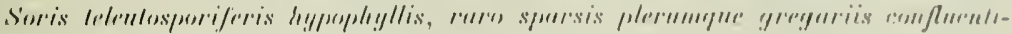

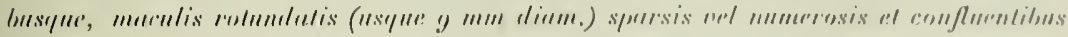

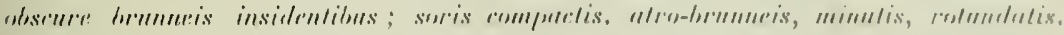

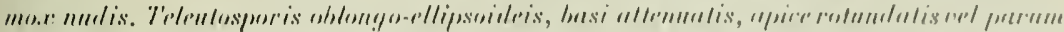

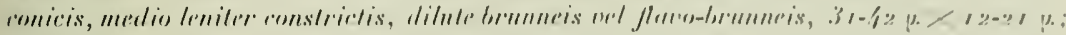

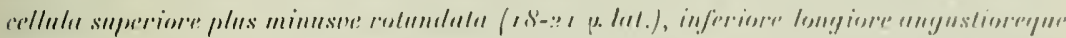

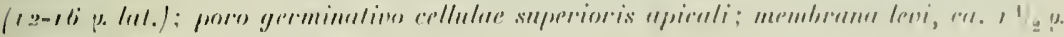

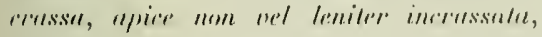

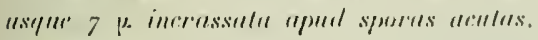

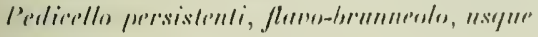

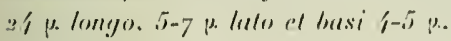

Silr feuilles ar Heliopsis buphthalmoides (Jace.) I Jun.

Andes rentrales, dep. Antionguia. Caul-

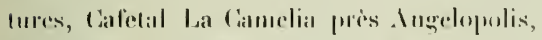

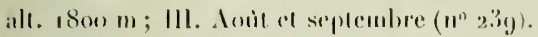

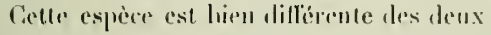
dicrites jusqu'it maintenamt sur le gुenre Ilelingsis et s'on distingne tres facilensent soil prar son aspect macruscopinue, soil patr
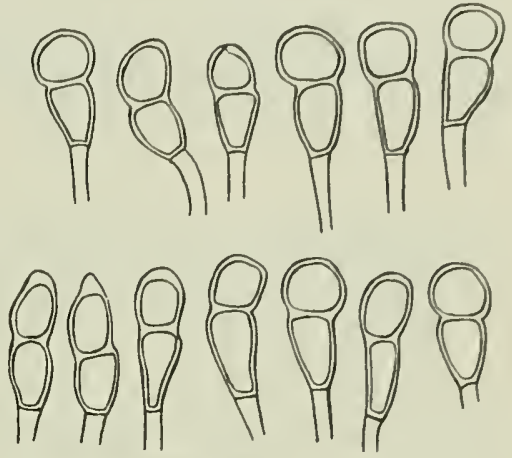

F̈ig. 48: Puccinia Bimbergi. - Tẻleutospores.

lit forme et les dimensions des spores. Le diveteppement doil dre celui d'un Lepto-

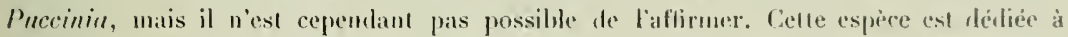

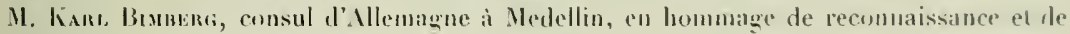
zratitude pour la large hospitalité qu il nous a génireusenent oflerte dans son beau Cafetal Lil Camelia et pour tont ce qu'il a fait en rue de la réussite de notre voyage.

\section{Puccinia spilanthicola spec. nov.}

Amis de tideutospores a la fice inférieure des fevilles, rarement quelques amas à la litce suprériente lorsque l'infection est tres considérable. Les amas sont rarement isoles. de beaucoup le plus sourent, à peu pris turjours, réunis en nombre considérable et conluculs pour former des laches arrondies ponvant alleindre ef mème dipasser is mm de diamilre; ces taches sont irriguliirement disposies, le plus souvent nombreuses el fríguemment conlluentes. A la face supérioure des feuilles al correspondant aux amas. on roit des taches d'un brun-jaunitre; lorsune lunferlon est ahondante, les taches 


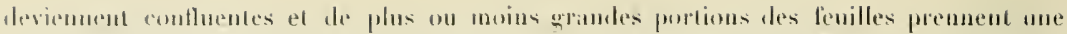

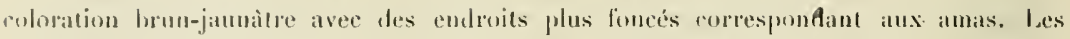
antas sont roulluents sur les taches, petits, punctiformes, ordinatrement disposés plus ou

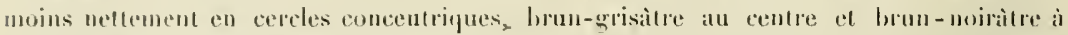
lit piripherie, nus de tres bomne heure, compacts.

Tileutospores uni on hicellulaires, le plus souvent, du moins dans les amas exalmines, les spores unicelluaires sont de beancoup les plus nombreuses, si bien pue les bicellulaires sent plutòt rares. Sprores unicellulaires elliptiques ou allongées, atténtes à

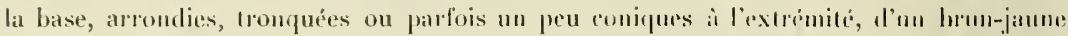

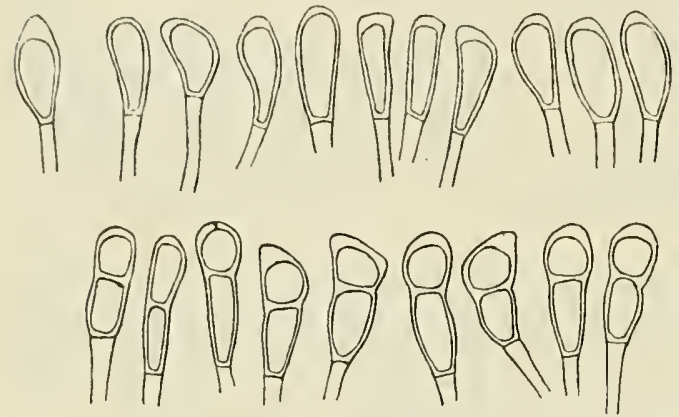

Fig. 49: Puccinia spilanthicola. - Téleutospores uni et bicellulaires. clair, $21-35 \mu \times 11-10 \mu$; lis siluation alu pore germinatif u' it pu être déterminéc exactement ; membranc lisse, mince, rnviron J $1 / 2 \mu$, le plus souvent éprissie ì son extrémité où alle alleint $2-5 \%$; pédicelle liviblement coleré en jaune paile, persistanu, jusqu'it 35 p. ar lomgueur sur 3-4 p. d'épaisseur. Spores birellulaires oblongues-elliptiques ou elliptiques-allongées, arrondies, trompuces ou un pen ennques à leur extrémité, alténuées. à la lase, $30-42 \mu . \times 11-16 \mu$, d'un brun-janne clair, à peine étranglées à la cloison; las deux cellules sont presque toujours inćgales, l'inférieure ćlant plus longue el parfois plus étroite que la supérieure généralement arrondie; pore germinalif apical pour la cellule supérieure, la position de celui de la cellule inférienre u’a pu ètre léterminée exactement; membrane lisse, mince, environ $1^{\prime}{ }_{2} \mu$ d'épaisseur, un peu rentlée à l'extrémité oǹ elle mesure $2-5 \mu$; pédicelle persistant, coloré en jaune pàle, jusqu'à $24 \mu_{0}$ de longrueur sur $3-5 \mu$ de largeur.

Soris lelentosporiferis hypophyllis, ruro spursis, saepissime dense gregariis et confuentibus, maculis rotundalis (usque $5 \mathrm{~mm}$ diam.) plus nuinusve numerosis et sacpe confluentibus fluvo-brunneis insidentibus, circinulo tispositis, confluentibus, minutis, puncliformilus, mox nudis, compactis, brunneis vel obseure brunneis. Teleutusperis uni vel birellularibus, saepissine unicellularibus numerosissimis. Sporis unicellularibus ellipsoideis vel elongatis, basi allenualis, apice rolundatis, trancatis vel parum crmicis, dilute flavo-brunneis, $21-35 \mu \times s_{-16} \mu$; membrann levi, tenui (ca. $11 / 2 \mu$ ) apice incrassaln, 2-5) u. ; pedicello flavescenti, persistenti, nsque 35 u. longo el 3-4 $\mu$. lnto. Sporis bicelluluribus ablongo-ellipsoideis vel ellipsoideo-elongatis, apice rolundalis,

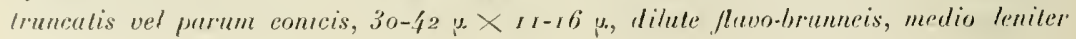




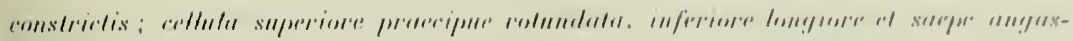

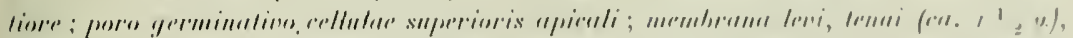

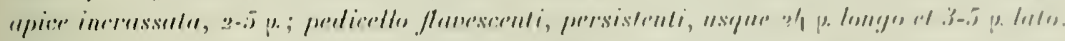

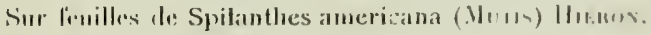

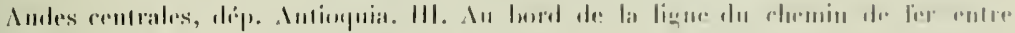

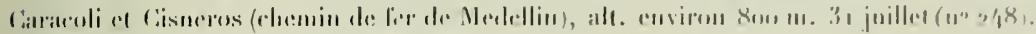

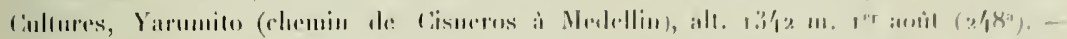

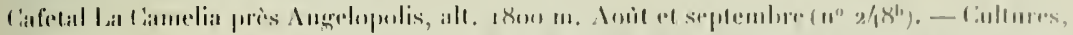

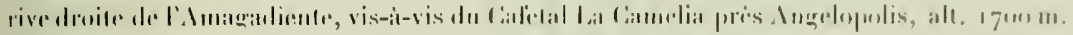

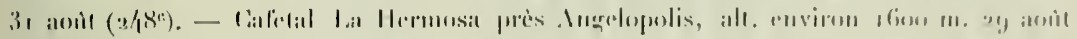

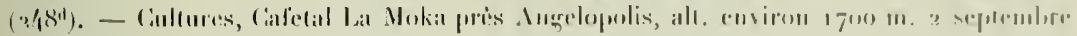
(11" $2 /$ (1") $^{\prime \prime}$.

Sur lenilles d. Spilanthes ciliata H. I3. Ki.

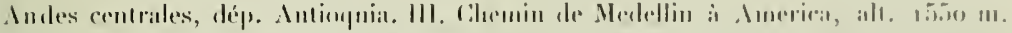

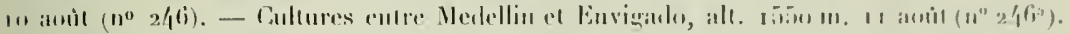

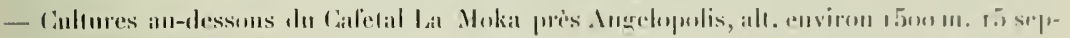

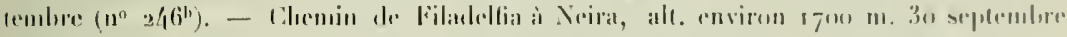
(II" $3 /$ lit $\left.^{\circ}\right)$.

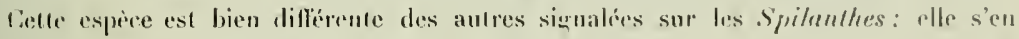

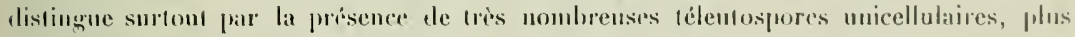

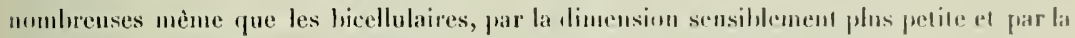
coloration des spores of du péticolle, ainsi que par l'aspect macroscopigur des amas. I.e

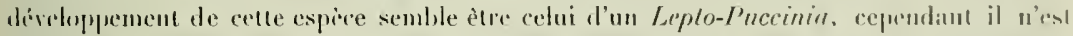

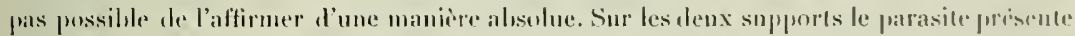

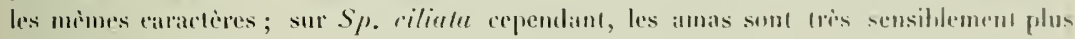

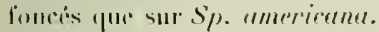

\section{Puccinia Barranquillae spec. nov.}

Imas de chleutospores à la face inférienre des fenilles, arrondis, en movenne i mm de diamire, imigulierement dissemints a la surface cles fenilles, peu nombreux our au

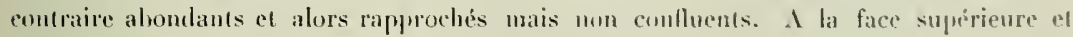
correspondant anx amas, on constate de pelites tacless d'un brun-jiunatre formant mne lingere dipression alors qu’à la face infericure au contraire les amas forment le plus soment me petite prominence; lorsiguils sumt nombrems et rapprochés, les parties enrabies des feuilles prenuent une coloration d'un hrun-fauve. Les anas sont pulverulents.

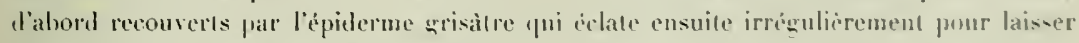

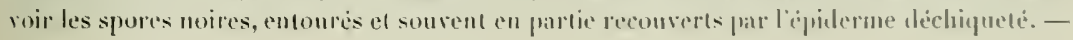




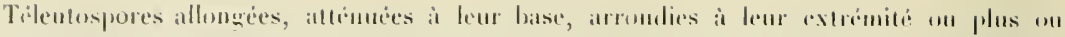

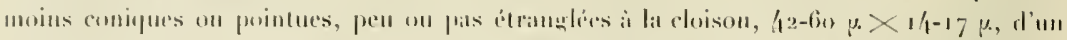

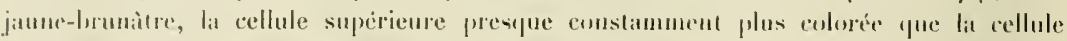
infericure trios souvent sulhyaline; les deox cellules sont le plus souvent dimirales

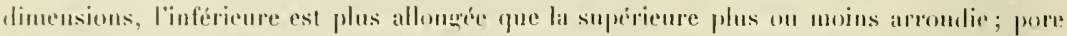

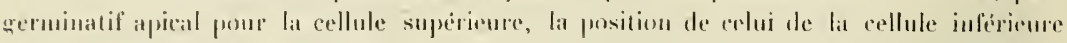

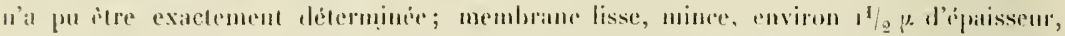
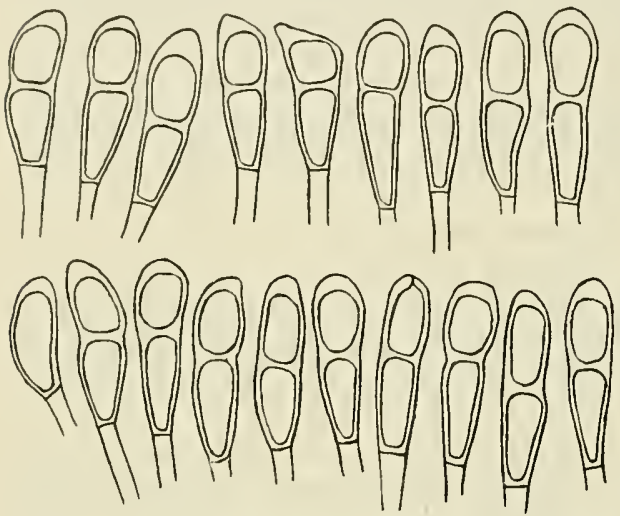

Fig. 50: Puccinia Barranquillae. - Téleutospores; anormalement une spore unicellulaire.

flisse, renllée a l'extrénité uil elle peur

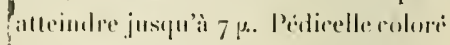
('n jaure-brum, semvent plas fortemont coloré que la cellule supérienre,

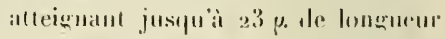
sur 5-7 $\mu$. de largerur à son insertion. persistant.

Soris telentoxporiferis hypopluyllis, rolumblatis, $r$ mm diam., sparsis vel purnm gregarias sed non conflnentilus, muculis fluno-brunneis: uel fuluis insilentibus, pulvernlenlis. primo epidermide grisere tectis, drin mudis, atris. epidermide cinctis vel olus minnsue lectis. Telentosporis elongatis, basi attemulis, apice roundatis vel plus minnsve conicis vel

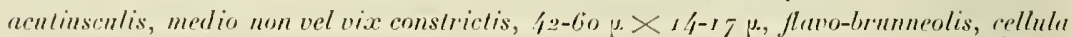
superiore obscuriore, inferiore suepe subluyalina; cellula inferions longiore, superiore plus minusve rolundata: poro germinativo cellulae superioris apicali; membranu levi, ca. $1 \frac{1}{2} \mu$ crassu, upice usque $7 \mu$ incrassala. Pedicello persistenti, flauo-brunneo, us'jue 23 p. longo et $5-7$ p. lalo.

\section{Sur fenilles de Spilanthes urens ince.}

Environs de Barranquilla, dép. Bolivar. Dans le sable non Ioin du Magdalena; III. 21 juillet $\left(n^{\circ} 127\right)$.

Celle espèce diffère de P. Spilanthis P. Henn. el P. africann CKr par l'aspect des amas de téleutospores qui ne sont jamais puntiformes, mais atteignent I mon de diamitre; ils sont pulvérulents et recunverts en partic par un mince biphlerme qui ne disparait que tardivement pour leur former un rebord très net; ils sont franchement noirs, irréqulièrement disposés et janais organisés en cereles concentriques. Lés téleutuspores sont un pen plus longues et un preu plus étroites, d'un jaune-brunatre mais pas "llavidis " ou "dilute bruncis"; le pédicelle n'est ni "fusco » ni " hyalino ", mais coloré en jaune-brun, 


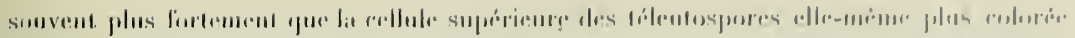

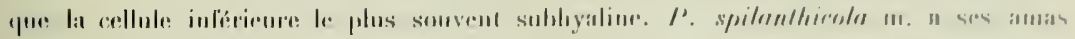

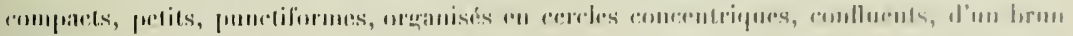

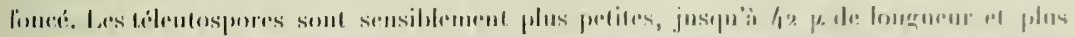

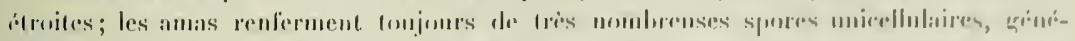

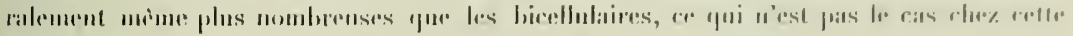

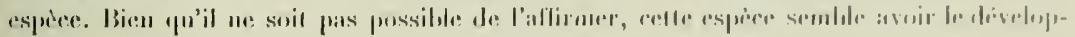
p'ment d'un l,eplo-l'uerinin.

\section{Puccinia Oyedaeae spec. nov.}

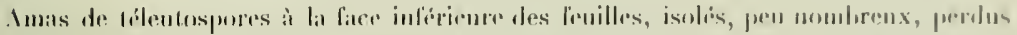

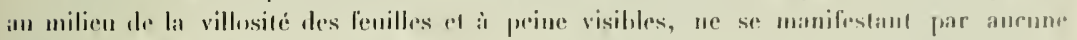

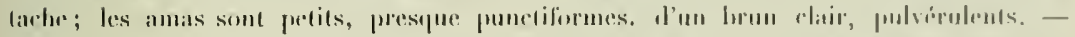

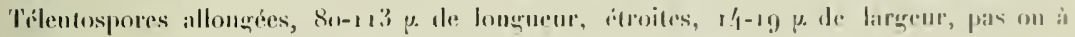

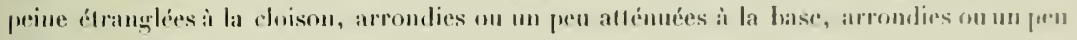
allémures ì l'extrómité; les deux cellules somu le plus souvent de mime lorme ed dre mime dimension ; pore arerminatif apical from la ceflule supricicure, immediatement au-dessums de la cloison pour la cellute inferieure; memhatare lisse, mince, environ ep., fordement ipraissie d'extrimite superieure oi elle alleint $7^{\text {-ro }}$ y. d'paisseur. Eiles sont colorées en janne ¿l l'épaississement fermina! 't en jaune paile sur le reste de la spore?; somvent la cellule supirienre senle prisente cette coloration, l'infíricure chane heaucoup plus pile et

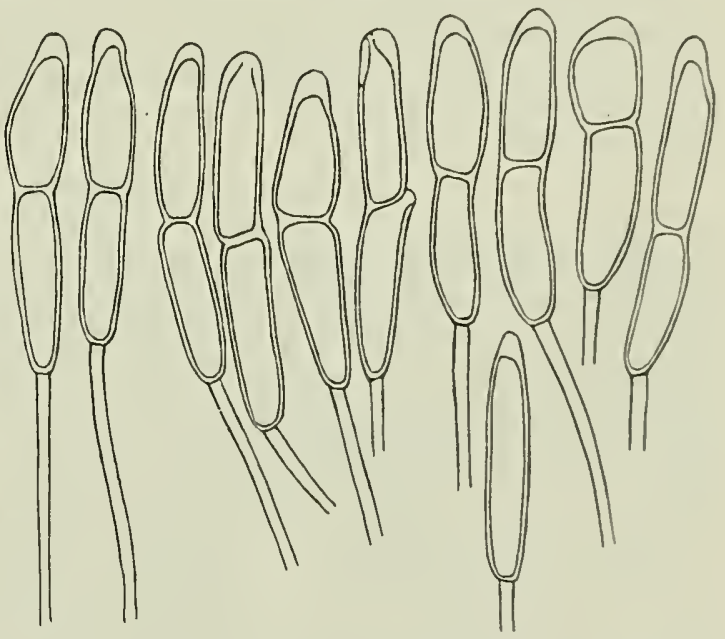

Fig. ป็ : Puccinia Oyedaeae. - Téleulospores dont une uniceltulaire. mime sublyyaline à la base.

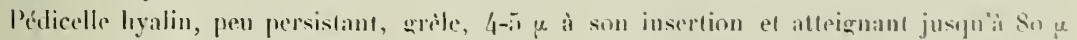

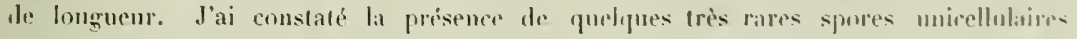
mesurant $\gamma^{\circ} \mu . \times 1$ ! $\mu$. 
Sortis telnutosporiferis hypophyllis, spmesis. prouris, sime monulis, mimulis, fere

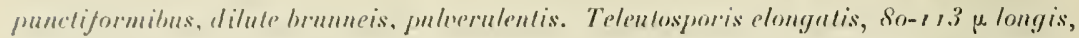

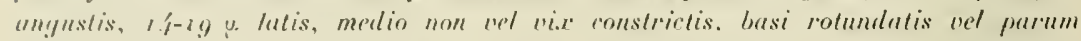
"llemuntis. "upier rotundulis vel parum ullemunlis: cellulis sensim paribus : foro germinutivo rellulae superioris apicali, rellulae inferioris anl septum: memhrana levi, tenni,

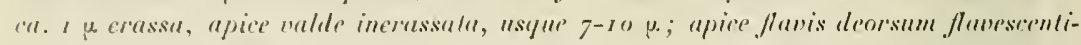

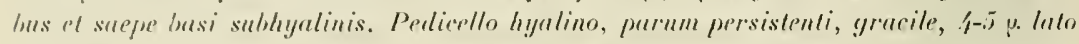

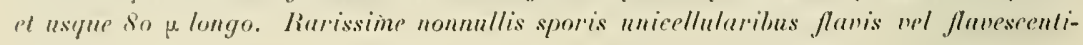
lus $75, \mu \times 1.4 \mu$.

Sur feuilles de Oyedaea alt'. buphthalmoides DC.

Andes centrales, dép. Antioquia. Taillis aux envirous de Sabaletas près de Titiribi, alt. emvion $1600 \mathrm{~m}$; III. I5 septembre ( $n^{\circ}$ i 50 ).

La prisince de nombreuses spores germées fait supposer que le diveloppentent de cette espèce est celui d'un Lepto-Puccinia.

\section{Puccinia cundinamarcensis spec. nov.}

Amas de téleutospores sur les deux faers des fenilles, réunis en nombre plus ou moins grand pour former des taches d'un brun plus ou moins foncé, arrondies, jusqu'ì $5 \mathrm{~mm}$ de diamètre, ou allongées sur les nerrures, jusqu’à $\mathrm{r} \mathrm{cm}$ de longueur, irréguliirrement disposées, isolées et plus ou moins abondantes, formant le plus souvent

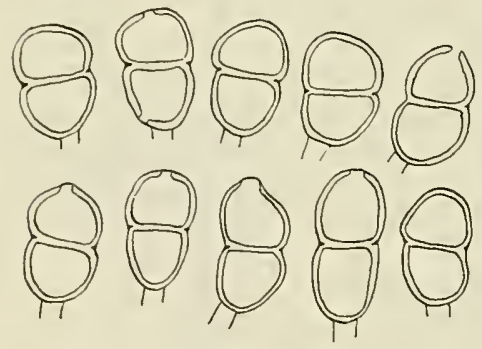

Fig. 52: P'uccinia cundinamarcensis. T'éleutospores. une proéminence nette à la face supérionre et au contraire une petite dépression à la face inférieure. Les amas sont plus on moins conthuents sur les taches, petits, arrondis, bruns, pulvérulents, d'ahord recouverts par l'épilerme qui ćclate de bome heure et leur forme ensuite le plus souvent un mince rebord. - Tílentospores oblongues ou oblongues-elliptiques,

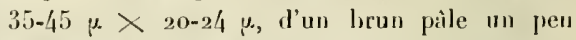
jannittre, arrondies aux deux extrémités, étranglées it la cloison el se désarticulant assez facilement; les deux cellules sont très sensiblement de même forme el de mème dimension; pore grerminatif apical pour la cellule supéricure, près du pédicelle pour la cellul. iuférieure; membrane lisse, d'égale ípaisscrm partout, environ 1 $1 / 2 \mu$. Pédicelle court, mesurant 5-7 y. de large, caduc, lyaliı.

Soris tolentosporiferis amphingenis, maculis brumeis plus mimsue munerosis sed uon confluentilus rolundatis (usyne $5 \mathrm{~mm}$ dimm.) nel elongutis el nervicolis /usque I $\mathrm{cm}$ 


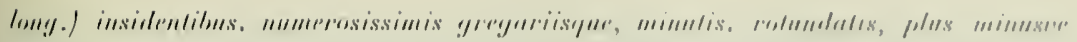

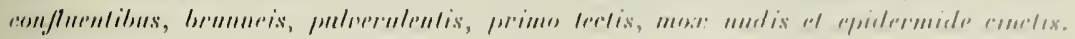

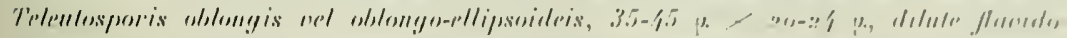

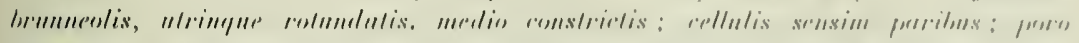

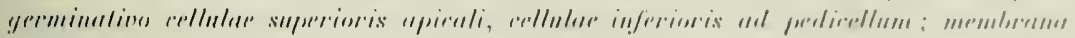

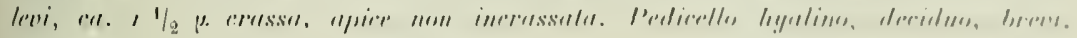
is $\rightarrow$ p. $\ln 10$.

Sur finilhes de Verbesina verbascifolia 11 i.1.

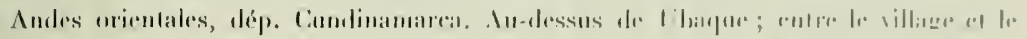

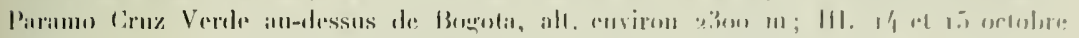
$\left(11^{\circ} /(11)\right.$.

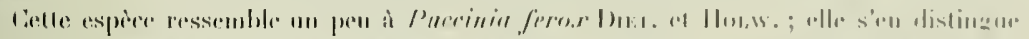

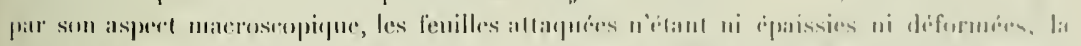

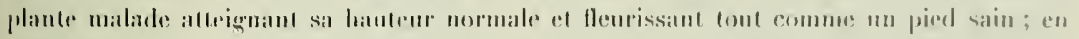

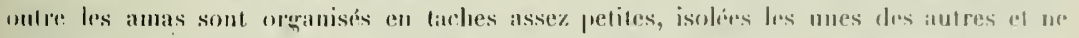

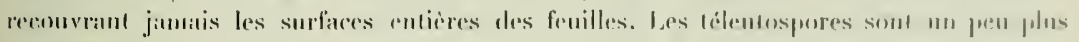

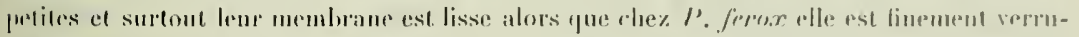

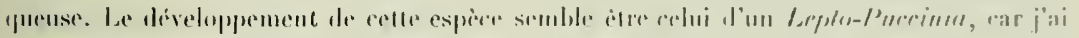
oleservi des spores germios el d'antres on merminitim.

\section{Puccinia Samperi spec. nov.}

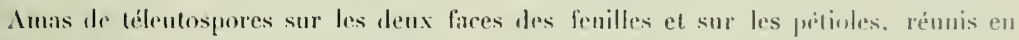
numbre généralement ronsidérable pour former des laches lommes fris somvent conflüutes el mumbreuses. Sur les leuilles, les amas se frourent de préférence sur les nersures la. long desquelles ils son. en tris grand mombre si bion que parforis la nervure midians

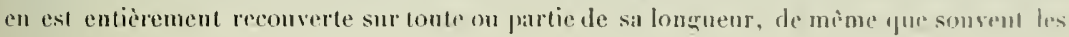

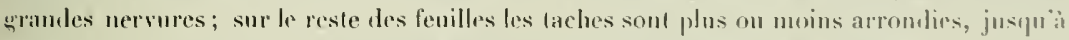

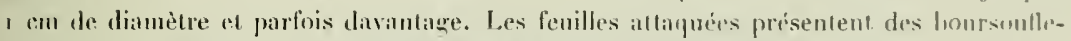

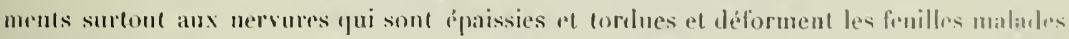

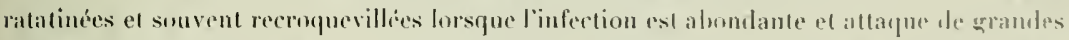
surfices. Sur les pétioles boursoufles el tordus, les amas conflusents fes recuurent sur unc longueur de $2-3 \mathrm{~cm}$ ou davantage et parfuis l'antourent complètement. Les amas sont de couleur brume, pulvérulents, petits, nus de très honne hemr, confluents. fralemospores oblongurs, arrondirs anx denx extremifis, profondement étranglés i la

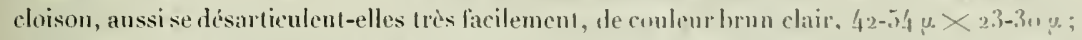
les deux cellules sont très sensiblement de mème forme el de mime diminsion; fure

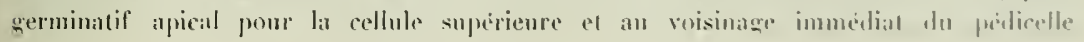


pour la cellule inférienre; la membrane est lisse, d'iggale épaisseur partout, $11 / 0^{-2} \mu$. Púdicelle caduc, hyalin, court, jusquà $47 \mu$ de lonerrexr sur $4-5 \mu$ d'épaisseur ì son insertion.

Sorvis telentosporiferis ampltigenis ef petiolicolis denser gregariis, muculis brunneis magnis numerosis confluentibusque insidentibus, preneripue nevicolis, follin ef petiola incrassatu deformatayne veddentibus: soris fuscis, minnlis, confluentibns, mox mulis.

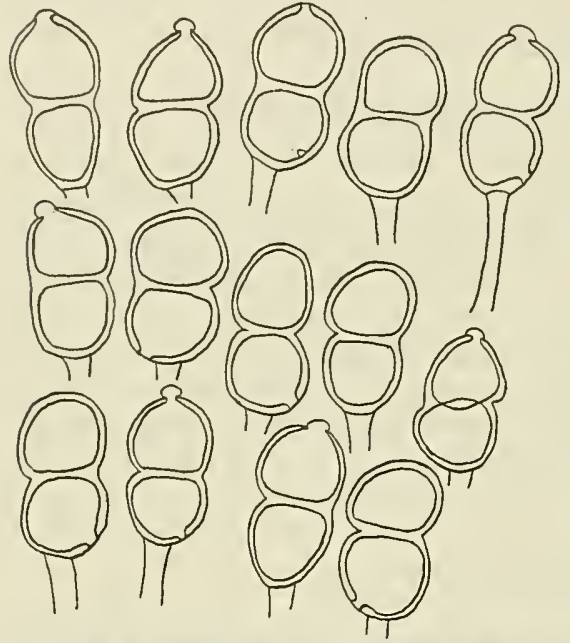

Fig. 53: Puccinia Samperi. - Téleutospores. Telputosporis oblong is, utrinque rolumdatis, medio balde constrictis, pallide brunneis. $42-5.4 \mu \times 233-30 \mu$; cellnllis sensim paribus: poro germinationo celInlare superioris apicati, cellulue inferioris ad pedicellum: membrana lovi $11 / 2-2 \mu$ crassa apice non incrassalu. Pealicello deciduo, hyalino, usgure $47 \%$. longo, 4-5 ب. lato.

Sw linilles et pétioles de Chaenocephalus arboreus (11. B. K.) O. HoFrM.

Andes orientales, dép. Cundinamarca. Chemin de Bogota à Uhaque, près des habitations, alt. 2700-3000 m; 111 . 14 et I5 octobre ( $\left.n^{0}+2\right)$.

Ayant vu des spores gremées ou m germination, il semble que le développement de cette espèce est celui d'un Leplo-Pnceinir. Celte espèce est dédiée à M. J.-M. SAMPER, ingénieur à Bogota, aupres dupuel nous avons trouvé la plus aimable hospitalité el qui a bien voulu nous conduire aux usines électriques dn Charquito ainsi qu’à la célèbre chute du Tequendama.

\section{Puccinia Synedrellae P. Henn.}

in Hedw. 898 , p. 277 .

Les deux cellules des téleutospores sont le plus souvent très sensiblement égales, cependant il arrive assez fréquemment que la cellule inférieure soit un peu plas longue et plus étroite que la supérieure généralement plus on moins arrondie. Pore germinatif apical pour la cellule supérieure et au-dessous de la cluison pour la cellule infírienre. La présence de spores germées laisse supposer que le développement de celle esprice est relui d'un Leplo-Purecinito. 
Sur lenilles de. Synetrella modiflora II.) (isknr.s.

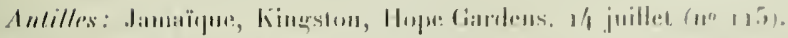

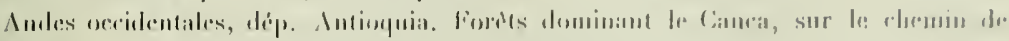

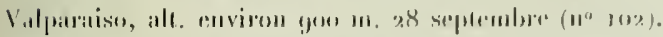

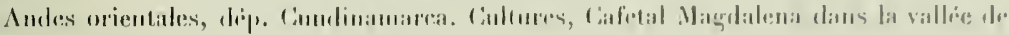

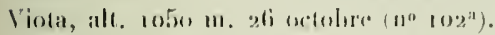

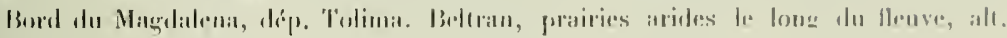

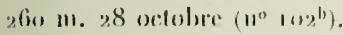

\section{Puccinia tageticola Diet. et Holw.} in Bol. riazette XXIV, 1897 , [3. ati.

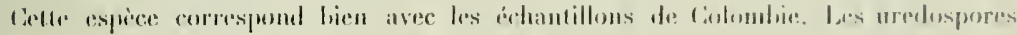

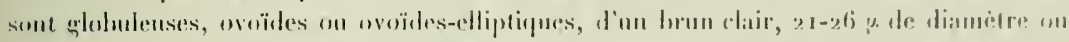

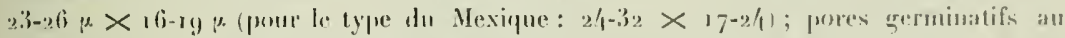

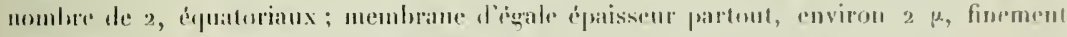

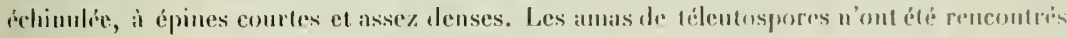

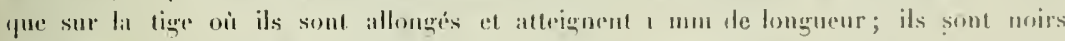

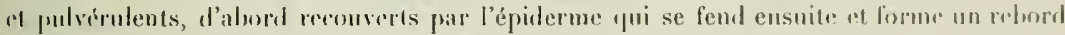

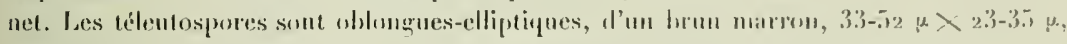
arrondies à leurs drux extrémités, peu étranglées à la cloison. Les denx cellules sont trion sensililement de mène forme el de mème dimension; pore germinatif apical pour lit

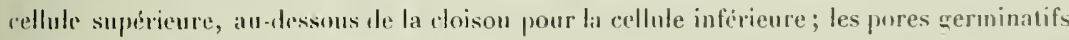

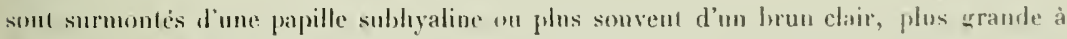
l'extrémifé que sur lo pore querminatif de la cellule inférieure; membrane ipaisse, cuviron

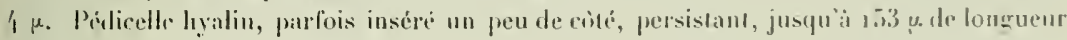
sur $7-9) \mu$ de largeur à son insertion ef $4-5 \mu$ a sia base

Sur les finilles, pétioles el liges de Tagetes microglossa Bexth.

Indes centrales, dép. Intioquia. Chemin de Medellin it Bello, alt. 155o m: II et III. 4 aonit $\left(n^{\circ} 2.33\right)$.

Le dévehplement de celle espéce est, pour le mument, cedui d'un Ilemi-Prnccinia.

\section{Puccinia Liabi spec. nov}

Amas de talentospores à la face inférieure des fenilles, rémnis en plus ou moins grand nombre et confluents pour former des laches dissimines et pen nombrenses généra- 


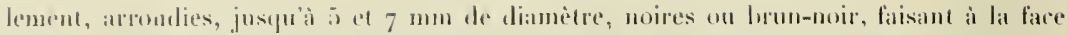
superienre des feulles des taches d'un hrum-jaunatre; les amas sont perts, arroudis,

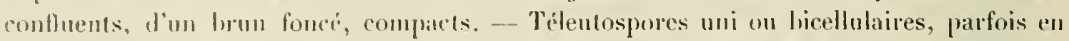

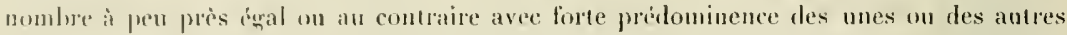
dans clague amas ou meme exclusion presque complite des unes ou des autres. Les spores unicellubares oblongues-elliptiyues, sont arromlies à leur extrémitr et généralement

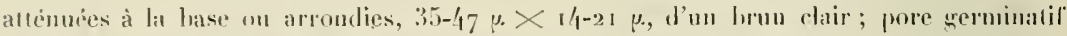

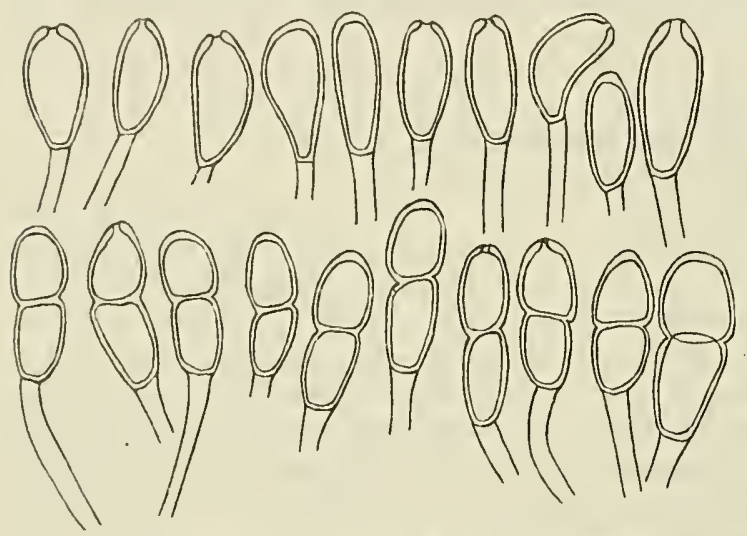

Fig. 5k: Puccinia Liabi, - Téleutospores uni et bicellułaires. aprical; membrane lisse, mince, envilon 1 p, frésentant presque toujours à l'extrémité un léger remflement de $3.4 \mu$; pélicelle subhyalin, persistant, jusquà 30 u rle longueur $\operatorname{sur} 4-5 \mu$ d'épaisseur à son insertion, puis diminuant un peu de largeur. Spores bicallulaires, (b)langues-ellipliques, $40-$ $50 \mu \times 1 / 1-21 \mu$, d'un brun clair, arrondies aux deux extrémités, parfois alténuées ì la base, nettement el souvent profondément

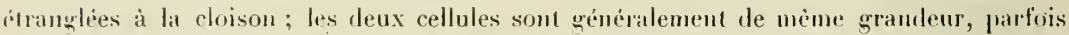
cependant la supérieure est plus petite que l'inféricure; pore germinatif apical pour ha cellute supérieure, au-dessous de la cloison pour l'inférienre; membrane lisse, environ $11 / 2 \mu$ d'épaisseur, un peu épaissie à l'extrémité où elle alteint jusqu’à $4 \mu$; pédicelle subhyalin, persistant, atteignant jusqu'a $47 \%$ de longueur sur $4-7 \%$ de largeur à son insertion puis diminuant un peu d'épaisseur.

Sor is teleutosporiferis hypophyllis, maculis sparsis atris vel atro-brunneis ot rotundutis (usque 5 et $7 \mathrm{~mm}$ dium.) insidentibus; soris minutis, rolundalis, compactis. confluentibus, abscure brunneis. Teleutosporis uni vel bicelluluribns. Sporis unicellulariluss wblongo-ellipsoideis, apice rotundatis, basi rotundalis nel saepins allenurntis,

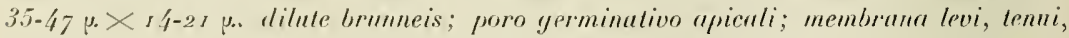

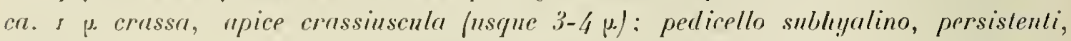

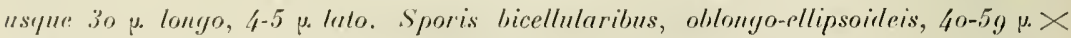

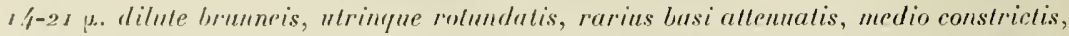
suepe urelde constrictis; cellulis sensim parilus, interdum inferiore paulo majore, poro germinativo cellulae superioris apicali, cellulae inferioris ad septum; membrana levi, 


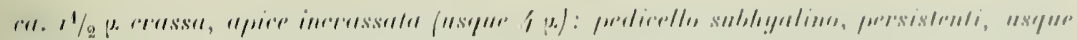

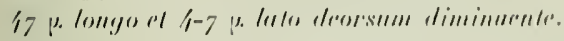

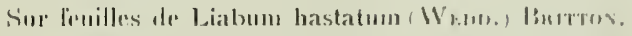

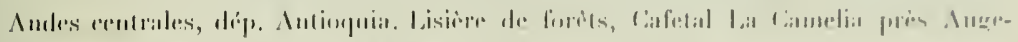

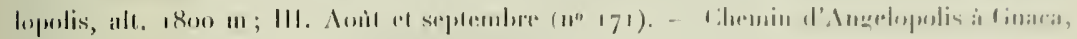

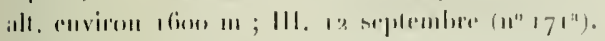

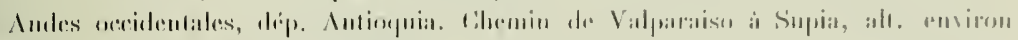

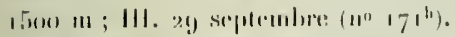

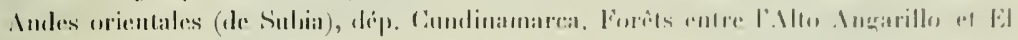

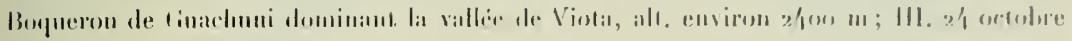
(11"!)

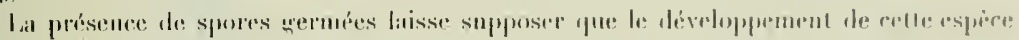

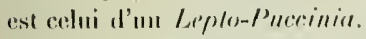

\section{Genre Phragmidium Link.}

\section{Phragmidium disciflorum (Tode) James.}

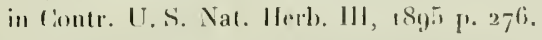

Sur lenilles de Rosiers cultivés.

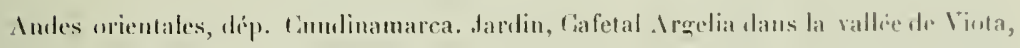
alt. $1880 \mathrm{~m}$; 11.29 octolse $\left(11^{\circ} 7\right)$.

\section{Genre Ravenelia Berk.}

\section{Ravenelia Mimosae-sensitivae P. Henn.}

in Heaw., 13. XXXY (1896), 1'. $24(i$.

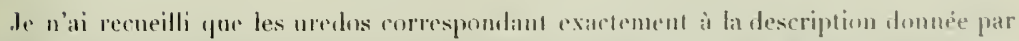

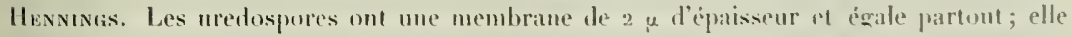

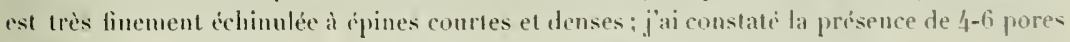
greminatifs irregulièrement simés. Les paraphyses nombreuses sont subhyalines on 


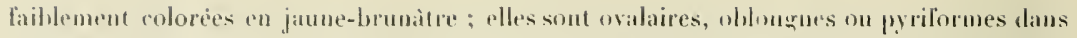
leur prartie supérieure et reullée, mrsurant r2-18 $\mu$ de largeur sur 16-26 $\mu$ de longueur ;

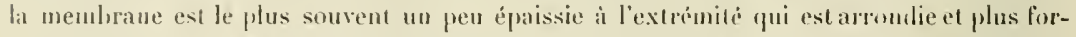
tement colorian; elles sont atténtés it la base et se continuent en un pidicelle hyalin de

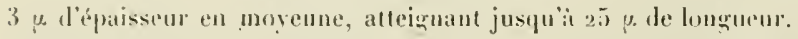

\section{Sur feuilles de Mimosa sensitiva $\mathrm{L}$.}

Andes centrales, dép. Intioquia. II. Haies près du Rio Poree a Yarumito (chemin de Medellin), alt. $1392 \mathrm{~m}$. $1^{\mathrm{er}}$ aou $\left(\mathrm{n}^{0} 174\right)$. - Haies le long du cheniu de Medellin à

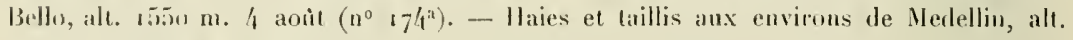
$1550 \mathrm{~m}, 6$ aout (no $\left.174^{11}\right)$.

\section{Genre Chrysocelis Lagerh. et Diet. nov. gen.'}

I'ychidiis globosis vel ovoideis immersis. Ireviliis sine peridin semaimmersis. Telentosporis cylimtraceis sine perlicello sessilibus, non septutis, inter se non conjuntis.

\section{Chrysocelis Lupini Lagerh. et Diet. spec. nov.}

Pycuidiis amphigenis immersis obscure bronneis, usque tho y. allis tro p. latis.

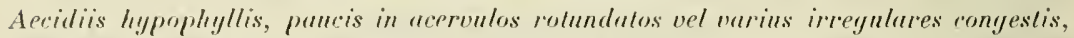
interdum solitarios, epidermide convexn inclusis apice poro rolumdato apertis: psendoperidin carentitus; aecidiosporis subglobosis vel ellipsoideris, rarins oblong is $22-36 ; \mu$.

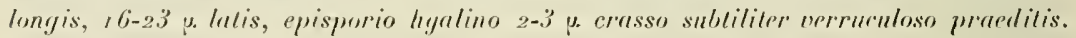
Soris teleutosporiferis nudis mimutis in marulis circuluribus nel irregularibus lute rexponsis el interdum magnum folii partem ocrupantibus dense gregariis anreis, denique pallescentibus; teleutosparis cylindraceis vel chuvatis, membrana tenerrima hyalina lrvi

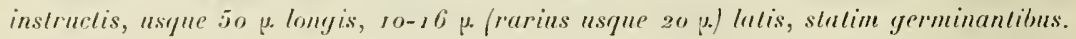

\section{Aư Blältern von Lupinus spre.}

Ostl.-Anderi, lép. Cundinamarca. O. I und III. Parano Ciruz Verde oberlall, Bugota, alt. ca. 3000 m. 14. und 15. Okt. ( $\left.0^{\circ}, 55\right)$. - Z Zischen Agua Larga und Facalativa in

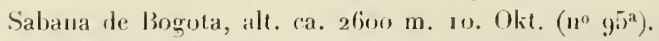

Dieser eigenarlige Pilz ähmelt im Aussehen etwa einem Coleosporinm mil sehr ausgedehuten Sporenlagern. Er grelört aber nicht in die Verwandschaft dieser Gattung,

1 Géare et espèce citudiés par M. te Dr P. Dietel. 


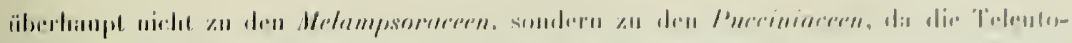

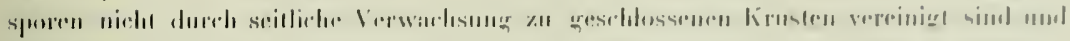

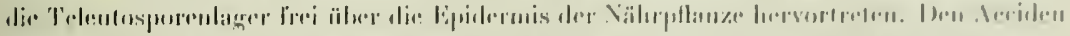

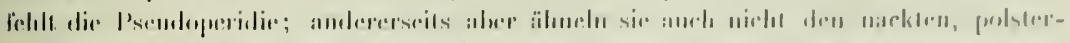

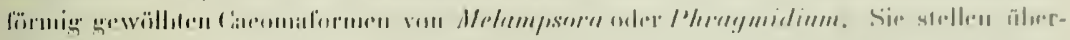

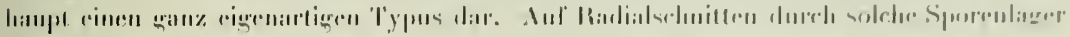

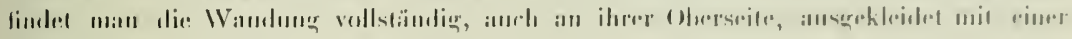

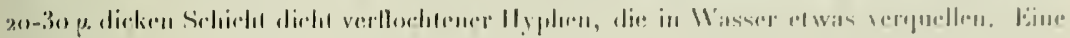

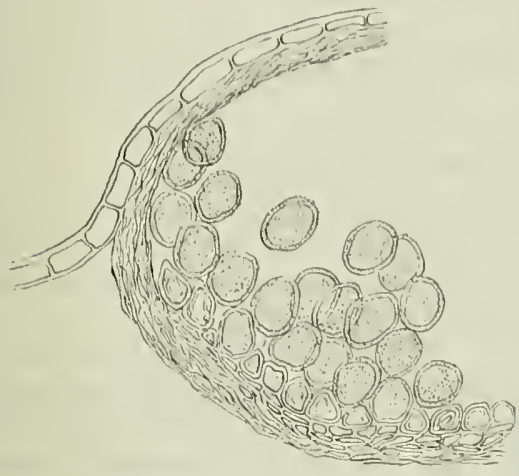

$\boldsymbol{\alpha}$

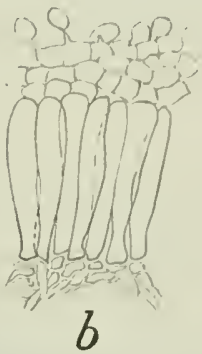

Fig. 55: Chrysocelis Lupini auf Lupinus spec, a) Iurchschnitl durch ein Aecidium. Vergr. $300 \times$. b) Teil eines Telentosporenlagers. Vergr. ca. $500 \times$.

solelue Srhicht ist auch hei lypischen Aecidien ausserhalh der Peridie, soweit dieselle dar Nälıpllanze cingresenkt ist, zu timden. Die Sporen zeigen keine Spur einer keltenformigen Anordmung und der firund rines solehen Lagers ist anch nicht wir bei anderen Aecidien gebildet von einer Schic.l dich stehender aufrechter Hyphen, an deren Enden reihenweise dic Sporen ibgeghliedert werden, sondern man sieft nur ein dichtes Yetzwerk, dessen obere Maschen sich zu Spuren in der Weise umbilden, dass jede Zelle zur villigen Sporengrösse heranreift, ehe eine tarunter befindliche sich anschickt, ihre Iushilung zmr Spore zu beginnen (sielse Fig. 559 ${ }^{\mathrm{a}}$. - Die Telentosporen sind völlig sliellus und keimen sofort mach der Reife sem enerwisch, sodiss die Sporenliger mit einer dichten Schicht sporidienbildender Promycelien bedeckt sind und nugreinte Sporen in mancluen Lagern kaum noch angetrolfen werden (siehe Fig. $55^{b}$ ).

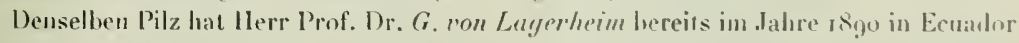
gesammelt und zwar auf Lapinus hirsutus im botanischen Garten von Quito, anf Lupinus mufubilis in Colocollaw bei Quito und auf einer dritten schmalh)ätlerigen, seidenhaarigen Art von Lnpinus, die nicht näher hesimum wurde, an einem nicht spezieller 
bezeicheten Fundorte in der lemperierten Region. An allen drei Othen wurten, wie in

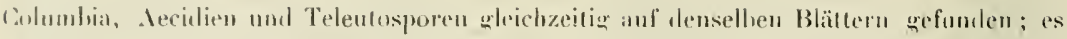

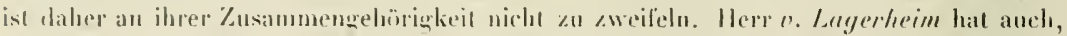

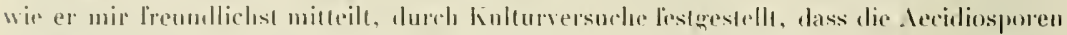

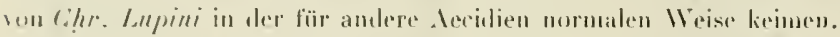

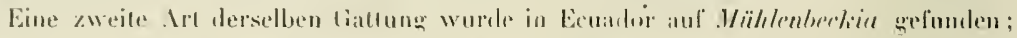
sire wirl an amelerer Stelle heschrieben werden.

\section{Genre Cronartium Fries.}

\section{Cronartium praelongum Winter.}

in Helw. 1887 , p. 24. F. E. $11^{\circ} 3419$.

I'ai recueilli sur un certain nomber d'Eupatorinm un Gronurtinm qui colrespond tris bien à la deseripution de Cr. peraelongum Wavren à quelques pelitrs diffirences pris

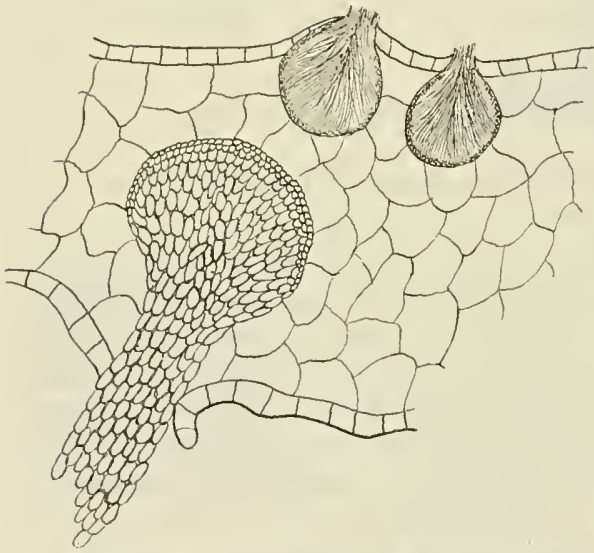

Fis. 56: Cronartium praelongum sur Eupalorium pomaderrifolium, - Pycnides à la face supérieure et columelle téleutosporique à la face inférieure d'une feuille. Gross, environ 80. fui n'ont pas une imporlance fres considcrable: dans ce genre ou les esjuces sont relativement assez polymorplies. C'est ainsi que rarement j'ai pu mesurer iles columelles atteignant $1 \mathrm{~cm}$ de longueur, quant à leur largeur je l'ai tronvie très variable; la diagnose indiұue 5o u, mais j'en ai mesmré alleignam plus du double. Les columelles some souvent en grand nombre el serries les unes contre les autres pour former des taches arrondies de dimension lrès vatriable, de nombre éralemenl variable, souvent conlluentes el alurs, surtout cluz Enpalorimm pomalerrifolimm, pouvant recuuvrir de larges surfaces des leuilles. fes columelles sont filiformes, plus ou moins flrxucuses, d'un jaune-clair pour vant deveniı orangé; par la dessication elles prennent souvent une teinte plus ou moins brune qui n'existe pas à l'état frais. less téleutospores sont elliptiques on oblongues, arromdies anx deux extrémités, hyalims lorsqualelles sont isolées ou d'un janne excessivenent pille lorsyu'elles sont vues agglomérírs 


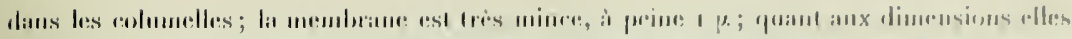

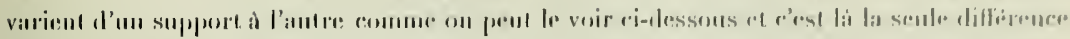

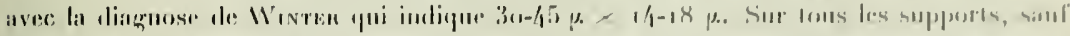

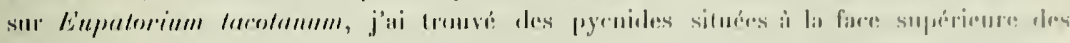

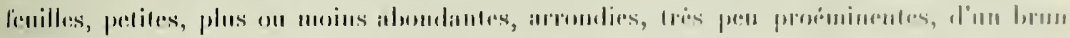

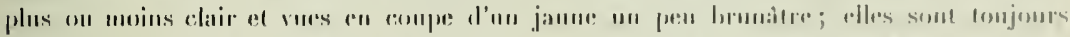

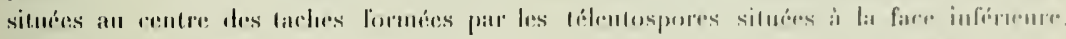

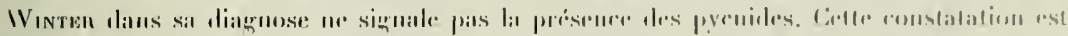

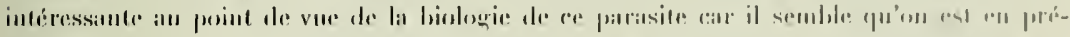

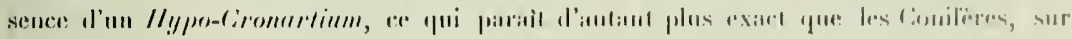

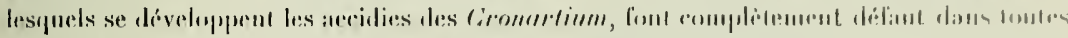

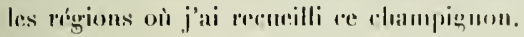

\section{Sur linilli's d. Eupatorium spree.}

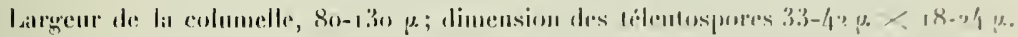

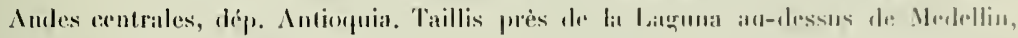

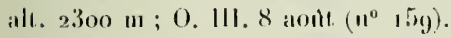

Silr Penilles de Eupatorium tacotanum li.atr.

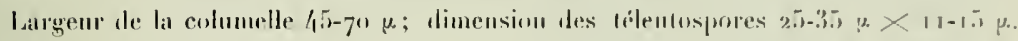
Andes eentrales, dép. Antioquia. Colline dominant le lain Porce prose de Madellin,

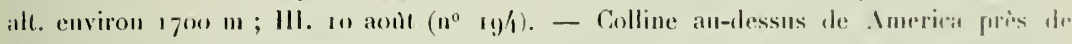

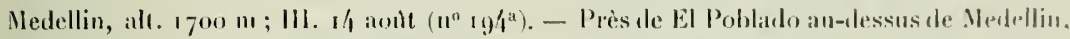

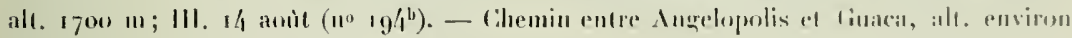

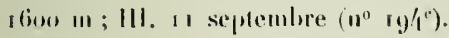

Sur lenilles de Eupatorium conyzoides lislı.

largeur de la columelle, 40-70 $\mu$; dimension des téleutospores $25-33 \mu \times 14-1$ li $\mu$.

Andes centrales, dép. Antioquia. Chemin entre Medellin el Aneriea, alt. 1.in m;

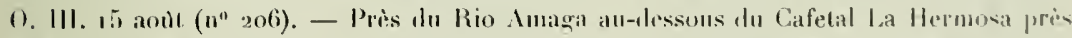

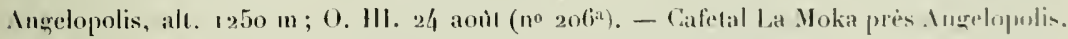
dans les cultures, ait. $1600 \mathrm{~m}$; O. III. 29 aonit $\left(1^{0} 206^{\mathrm{b}}\right)$. - Borel du Caucil is Puerto de los Pobres près du Paso de Concordia, alt. $720 \mathrm{~m}$; 0 . H. 8 seprembre $\left(n 1^{\circ} 206^{\circ}\right)$.

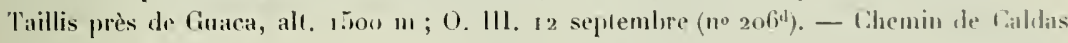

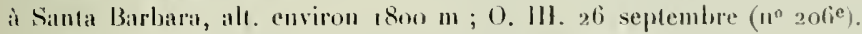

Amles vecidentales, dép. Antioquia el Cauca. Chemin du bord du lauca a lalparaiso

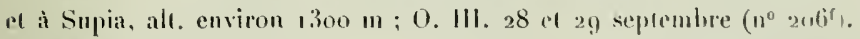

Andes orientales, dép. Cundinamarea. Chemin de Honda à Bogotal, priss de Villeta,

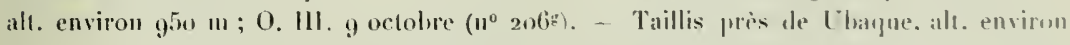

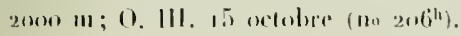


Sur leuilles de Eupatorium thyrsigerum H1ınox.

Largen de la columelle, $25-40 \mu$; dimension des télentospores $25.35 \mu . \times 11-1 / \mu$.

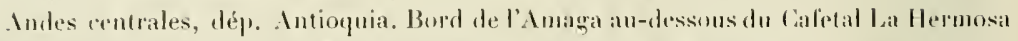

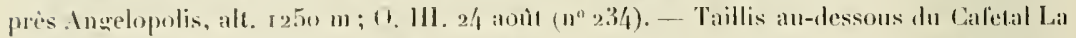

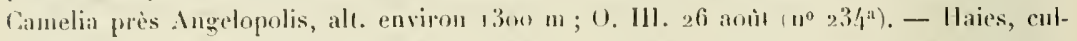
fures sur le llanc droil de l’Amagudiente, ris-à-ris du Cafelal La lamelia près Angrelopolis,

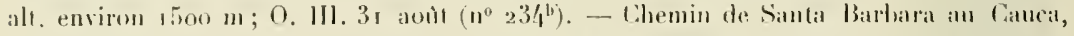

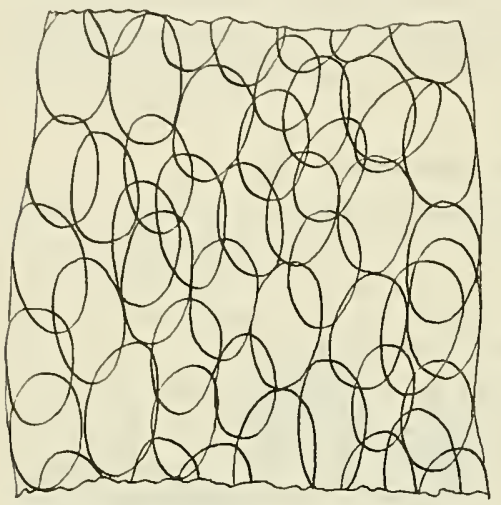

Fig. 57: Cronartium praelongum sur Eupatorium inulifolium. - Fragment d'une columelle. pres de l'auberge al Cariro, alt. environ goo m; O. 111. 2 (i septemlire $\left(n^{\circ} 234^{\circ}\right)$. Dép. Tolima. Chenin entre Morron et Fresmo, als. environ 1800111 ; O. III. 6 octobre $\left(11^{\circ} 2.34^{d}\right)$.

Andes occidentates, dép. Canca. Taillis près de Supia, alt. environ $1300 \mathrm{~m} ; 0.111$. 30 septembre $\left(n^{0} 234^{\mathrm{e}}\right)$.

Andes orientales, dép. Cumdinamarca. Chemin de Honda ì Bomota, près de Villetia, alt. environ $950 \mathrm{~m}$; 0 . 111.9 octobre $\left(\mathrm{n}^{\circ} 234^{\prime}\right)$.

Sur liuilles de Eupatorium pomaderrifolium BENTII.

Largenr de la columelle, $80-1$ in $\mu$; dimension des téleutospores $37-49 \mu$ ○ $>1-26 \mu$.

Indes orientales, dép. Cundinamarais. Taillis, pente du Montserrate au-dessus de Bogota, att. $2800 \mathrm{~m}$; O. III, 16 octohre (n 55$)$. - Bnis près de boca del Monte près de

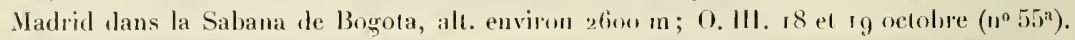
- Taillis an-dessus de Sibate dans la Sabana de Bogota, alt. envison $2700 \mathrm{~m}$; $0.11 \mathrm{l}$. 23 octobre $\left(n^{0} 55^{1}\right)$.

Sur feuilles de Eupatorium inulifolium II. B. K.

Largeur de la columelle 5o-70 $\mu$; dimension des téleutospores $30-40 \mu \times 18-24 \mu$. Indes orientales, dép. Cundinamarca. Taillis, pentu du Montserrate an-dessus d. Bogota, alt. $2800 \mathrm{~m}$; O. III. 16 octobre $\left(\mathrm{n}^{\circ} 54\right)$.

Sur fenilles de Eupatorium tequendamense IIıron.

Largenr de la columelle $70-85 \mu$; diniension des tileutospores $33-42 \mu \times 14-17 \mu$. Anrles orientales, dép. Cundinamarca. Taillis près de la Lagnua Pedropalo mon hoin

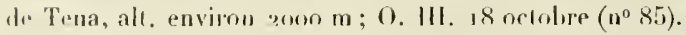




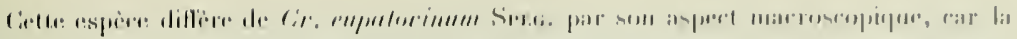

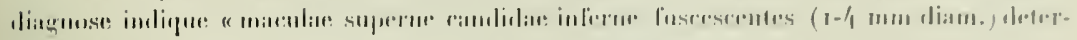

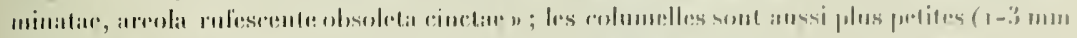

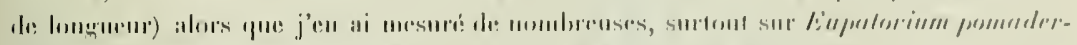

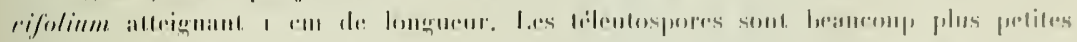

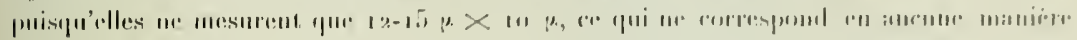

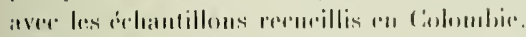

\section{Genre Alveolaria Lagerh.}

\section{Atveolaria Cordiae Lagerh.}

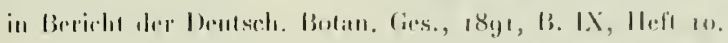

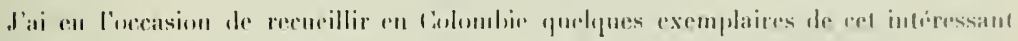

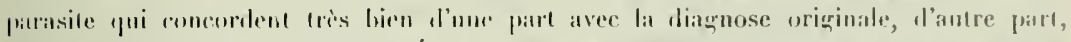

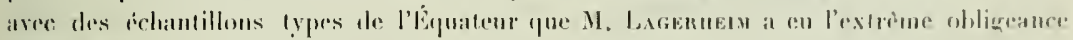

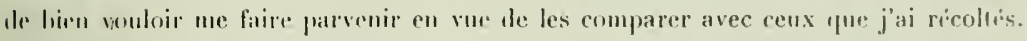

Je n’ai constatí que la présence de léleutospores. Ies amas sont a la facr inférienre

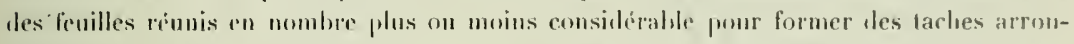

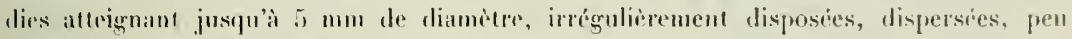
mombreuses, isolies el mun comlluentes; rlles sout d'un lirmu-murrou foncé à la face

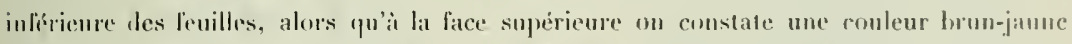
ou hrun-fonce des tissus foliacés. Les amas sont pelits et arromdis d'un brun-marmu, Ires lipprochis souvent lis uns des autres sur les taches mais non conlluents, faisant une

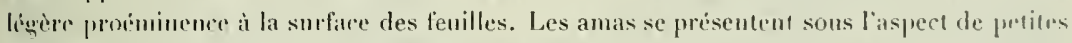

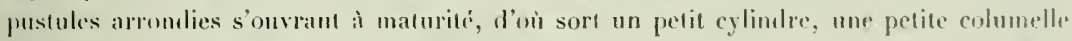

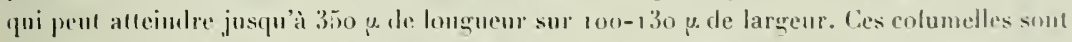

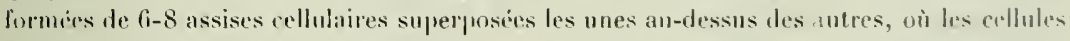
sont fortement ippliquées les unes contre les autres, au nombre de 8-to généralemput en diamctre, mais en beaucoup plus gramel nombre (fo-jo et meme davantage), si nn examine la columelle en conpe horizonale. Géméralement les 3 assises supérienres sont colores en janne, coloration qui va en diminnant d’intensite et à la base des columelles les cellules sont subhyalinas, puis entin hyalines. Les cellules des 3 assises supérieures soml funtes sensiblement de mime dimension, alors quen dessous elles deviennemt de moins "n moins hautes, mais ronservent le phus souvent leur mène largenr. Les cellules

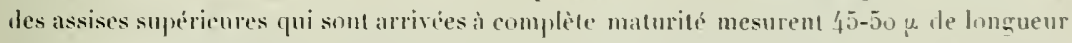
sur $16-21 \mu$ de largeur, chevaluedut julus ou moins les unes smr les autres en largeur. mais 


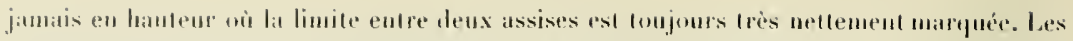
letentospores plus ou moins prismatiques ont leur membrane lisse et mince, environ $1 \mu$.

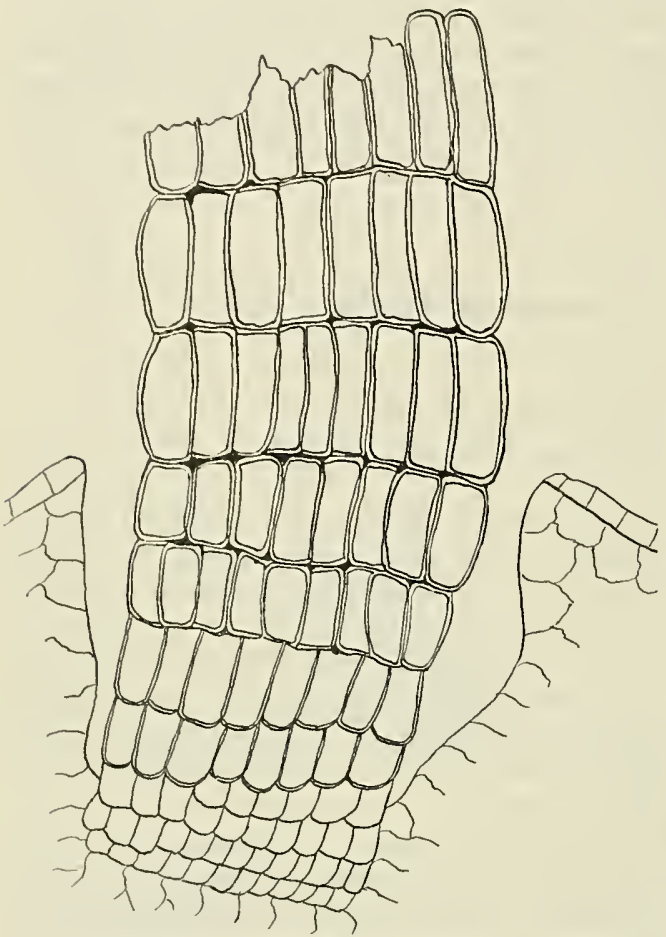

Fig. 58: Alveolaria Cordiae sur Cordia laxiflora. - Columelle.
Sur feuilles de Cordia laxiflora

II. B. K.

Aurles cenurales, dép. Antioquiat. Taillis au bord the chemiu de Cisneros it Medellin, pres de Yarumitu, att. envirom $1.350 \mathrm{~m}$;

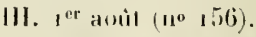

Celte espece a été recueillic prour la première fois en 1890 dans la république dr. I'Équateur par Lagenнам, en septembre el tícembre entre Bahahoyo (prov. del Guayas) el Balsapamba (prov. de los Rios). A mal connaissance du moins, cet intéressant parasile n'a pas été rencontré ailleurs daus l'Amérique dlu sud. D'après ce que j’ai pu observer, il me semble que les téleutospures doivent germer très rapidement. Comme le lait déjà remarquer Lagenneim dans sa descriplion, les assises cellulaires se séparent les unes des autres au fur at à mesure qu'elles arrivent à malurité très vraisen-

hlablement suns l'inlluence de la pression exercée par les promycélium an moment de la germination.

La seconde espece du genre Alveolaria est Alveolaria andina Lagenı. (Bericht. der Deutsch. Butan. Gés., I891, B. IX, Hefi ro). Celte espèce a été recueillie par Lagenneim sur Cordia spece dans la république de l'Équateur en octobre $189^{\circ}$ entre Milegalli et Pongo (prox. de Pichincha) et se distingue très facilement de A. Cordirte. 


\section{Genre Pucciniosira Lagerh.}

\section{Pucciniosira pallidula (Speg.) P Henn (I'. T'rinmfollur Lavinu.)

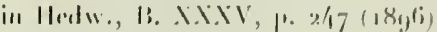

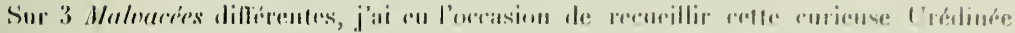

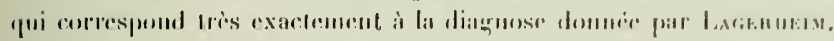

Sur fenilles de Triumfetta Lappula 1.

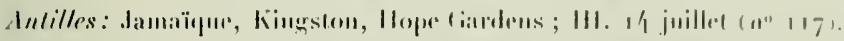

Sur limilles d’une Malvacée indriltrminne.

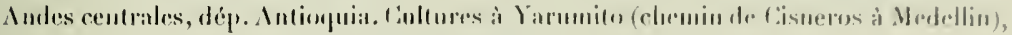

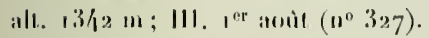

Sur afuilles de Pavonia paniculata lidv.

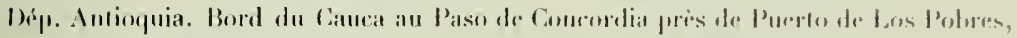

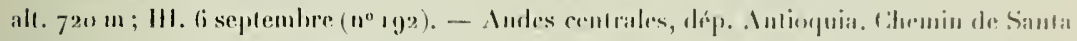

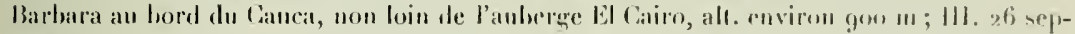

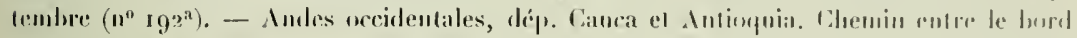

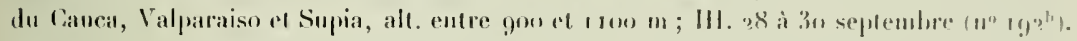

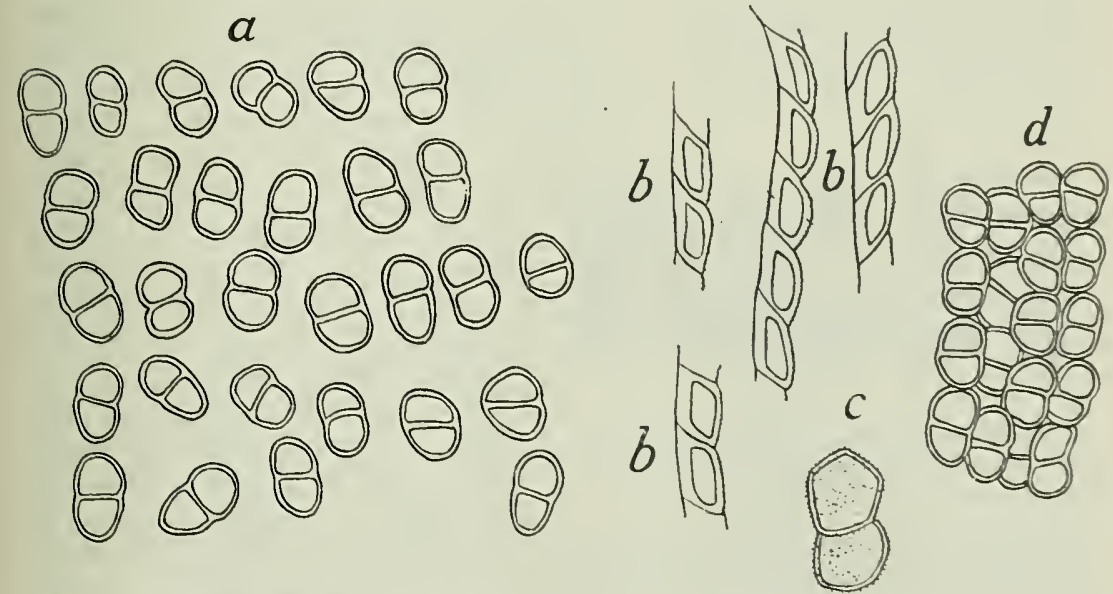

Fig. 59 : Pucciniosira pallidula sur Pavonia paniculata. - a) Téleulospores. b/ Cellules de la péridie vues en coupe c) Cellules de la péridie rues de face. d) spores en chainelles dans un amas. 


\section{Genre Coleosporium Lév.}

\section{Coleosporium Fischeri spec. nov}

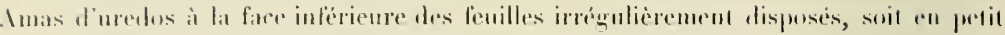

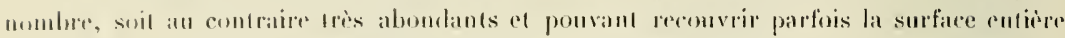

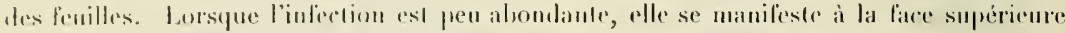

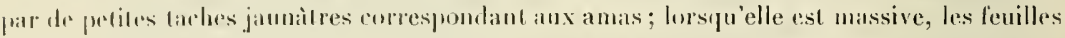
en entier prennent une coloration janne-hrun. Les anas sont pelits, arrondis, isolés on partois un peu conlluents, l'aboral reconverts par l'épiclerme coloré en rouge qui échale

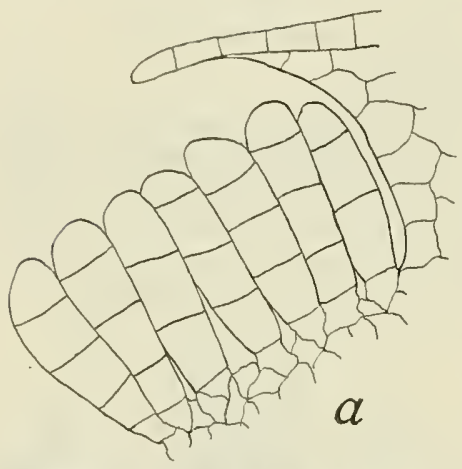

ensuite pum laisser rechapper les spures d'un janne très paìle devenant blanchàlre par la dessiccation. - Treduspores ifrondies on subgholuleuses, $18-24 \mu .>15-21 \mu$, hyalines; membrane d'émale ipaisseur partout, $1-1 \frac{1}{2} \mu$, vermpueuse it virrues assez pretiles el denses. La position a le nombre des pores germinatils nont pru cire exactement délerminés.

Amas de téleutospores a la lace inférieure des fenilles, semblahles à cenx des uredos, mais assiez dissćminés, petits, arrondis, isolés, très 'lonertemps recouverts par l'épiderme coloré en ronge. - Télentospores elliptiques - illongás, $42-55,4014-20 \%$, subliyalines on d'un
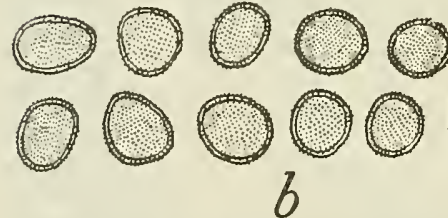

F1g. 60: Coleosporium Fischeri sur Qunmoelit angulati ( Coupe par un amas de téleutospores.

$$
\text { b) Uredospores. }
$$

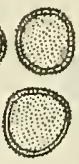
jaunc lrès pàte, arrondies à leur extrómili, un peu atténuces à la base, présentant le pilus souvent 3 cloisons; te contenu des spores est granulenx ; la membrane est mince, lisse el d'égale épritissenr partunt.

Sor is nredosporiferis liypoplyyllis, sparsis nel gregariis, maculis plus minusse magnis fluwis vel flano-brunneis insidenlibus, minulis, rolumlutis, interdum parram confluesulbus, primu epadermide rubenti lectis, dein nulis el sporis flauescentibus consprenis. L redosporis globosis vel subglobosis, $18-24 \mu . \times 15-21 \mu$. liyalinis: membram $1-1_{2}^{1}$ u. crassa, dense el satis minute verrucosa. Soris teleutosporyeris conjormibur, 


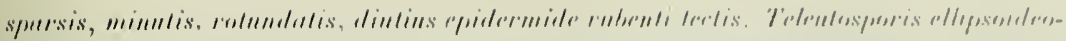

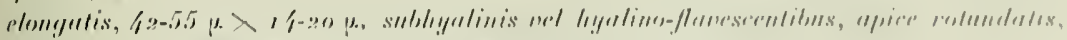

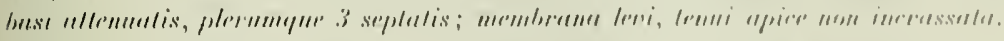

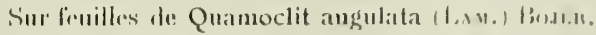

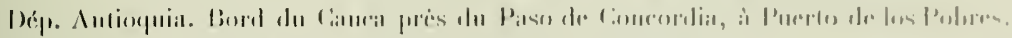

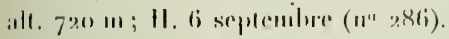

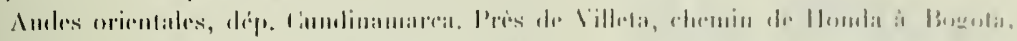

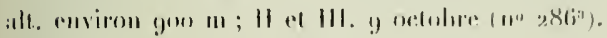

Sur fruilles de Ipomoea all. caloneura Mrtsisik.

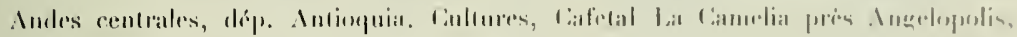

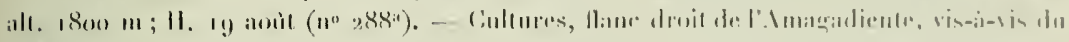

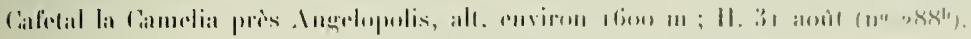

Sur finilles ate Ipomoea spere.

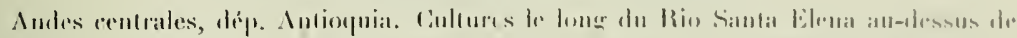

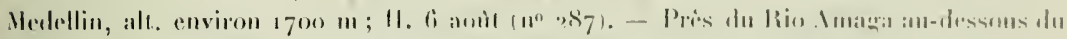

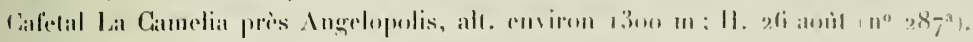

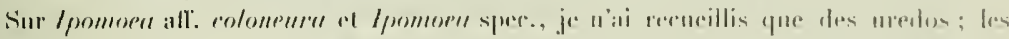

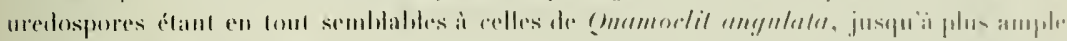

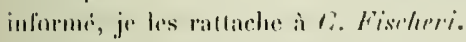

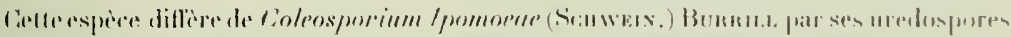

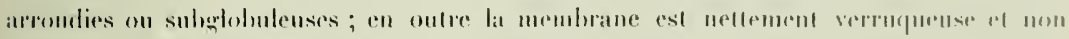

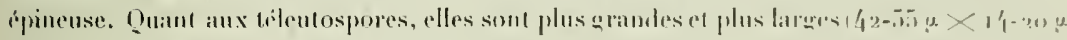

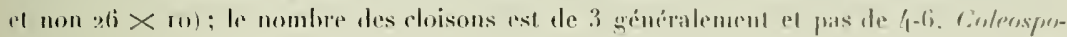

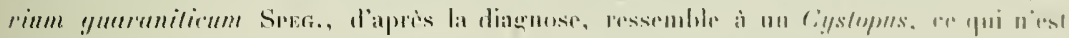

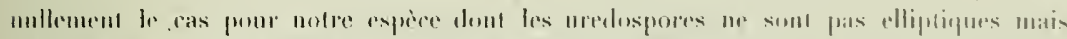

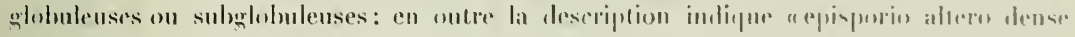

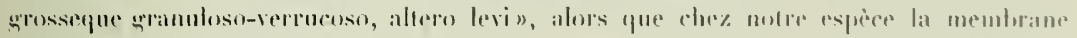

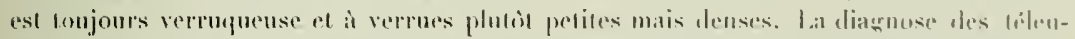

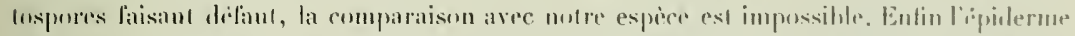

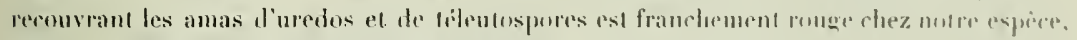
alor's que dans les antres il stmble avoir une leinde moins vive. Ces dillierences me

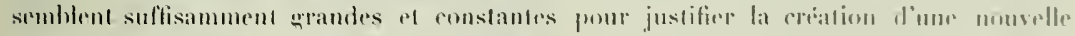

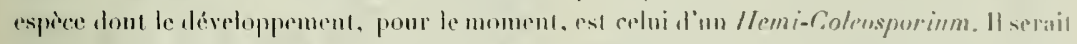

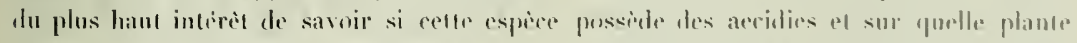

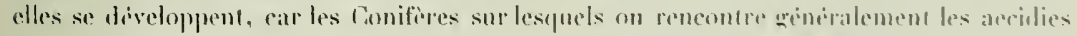

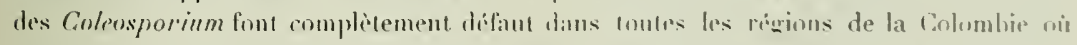

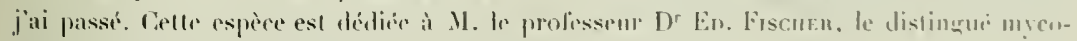
logur do Ploniversiti de Berme. 


\section{Coleosporium Elephantopodis (Schw.) Thüm.}

in Mre. Huiv.

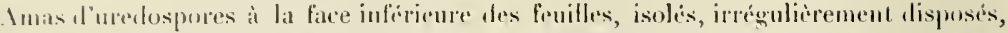

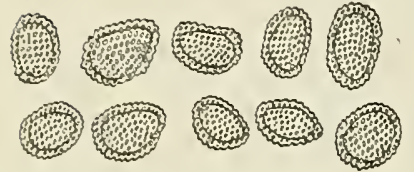

Fig. 6l : Coleosporium Elephantopodis sur Elephantopus scaber. - Uredospores. petils, we formant pas de takele speciale à la face superiente des feuilles, arrondis, non on rarement III pen confluents, an petil nombre on ahondants, dialwit recourerts par l'ipiderme coloré en rouge hrigue, puis nus el mellant i dicousert les spores colories en jaune. Uredospores sulgylobuleuses on elliptiques, $18-26 \mu^{\circ} \times 1$ /4-19 $\mu$, d'un jaune pâle; membran d'igale épaisseur partout, 2-3 p, verruqueuse à vermes wrosses et denses.

\section{Sul feuilles de Elephantopus scaber L.}

Andes centrales, dep. Antioquia. Taillis, tlanc droit de l'Amagadiente, vis-it-vis du Cafelal La Camelia près Ingelopolis, alt. environ r.500 $\mathrm{m} ; 11.31$ aoùt ( $\left.n^{0}, 855\right)$.

Andes riceidentales, dép. Antioyuia. Taillis non loin du Canca, sur le chemin de Valparaiso, alt. environ $1000 \mathrm{~m}$; 11.28 septembre $\left(n^{\circ} \mathrm{r}^{8} 5^{\mathrm{a}}\right)$.

Andes orientales, dép. Cundinamarca. Taillis, Cafetal Magdaleua dans la vallée de Viota, alı. ro5o m; 11. 26 octobre $\left(1^{\prime \prime} 185^{b}\right)$.

Les uredos ci-dessus décrits appartiennent it une espèce du genre Coleosporium el très vraisemblablement à C. Elephantopodis (Scuw.) Tun̈n, bien qu'il ne me soit pas possible de l'altirmer, n'ayan pas trouvé la deseription des uredos de celle espèce.

\section{Coleosporium Eupatorii Arth.}

in Bul. Tor. Bot. Cl. (1906) p. 31; North Amer. Fl. v. VII (rgoz) p. 90.

Amas d'uredos ì la face inférieure des feuilles irrégulierement disponsés, nombreux, isoles on rapprochés et conlluents, se manifestanl a la face supréricure par de pelites taches d'un brun plus on moins foncé souvent confluentes el pouvant en cas de forte inlection recouvrir de grandes surtices des feuilles; les amas sont pelits, arrondis, an maximum $1 / 2 \mathrm{~mm}$ de diamètre,

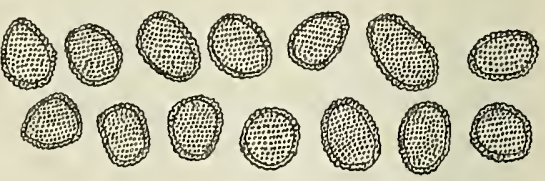

Fig. 62 : Coleosporium Eupatorii. - Uredospores.

d'abord recouverk par l'épiderme coloré en rouge brique qui disparaît de boune lieure en mettant à nu les spores d'un janne très clair devenant blanclies par la dessiccation. 


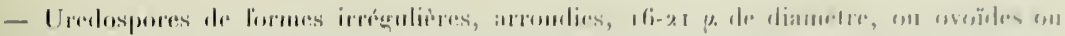

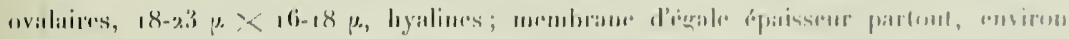

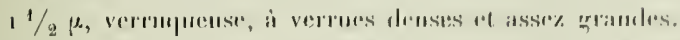

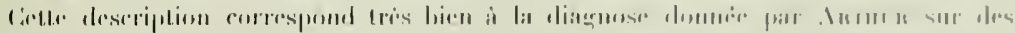

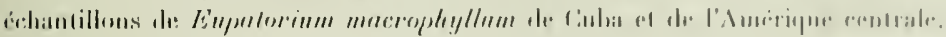

Siur linilles de. Eupatorium macrophyllum I..

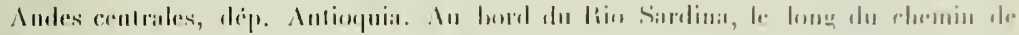

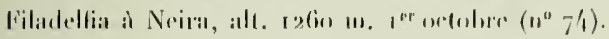

\title{
Genre Uredinopsis P. Magn.
}

\author{
106. Uredinopsis macrosperma (Cke.) P. Magn.' \\ in Ilalwigia N1.111. 1. 12\%.
}

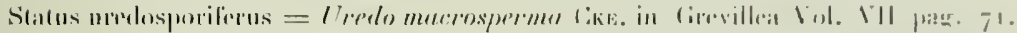

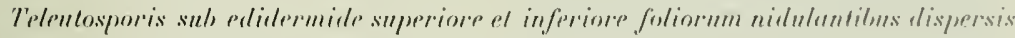

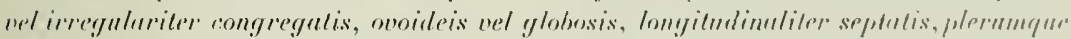

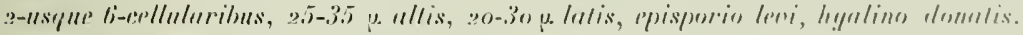

Auf alen Wulelu von Pteridium aquilinum (L.) livux.

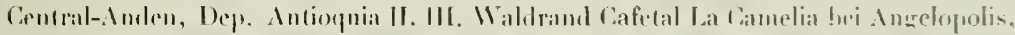

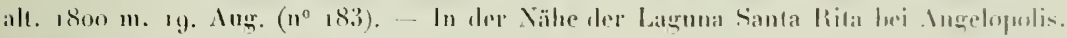

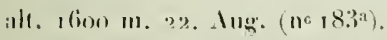

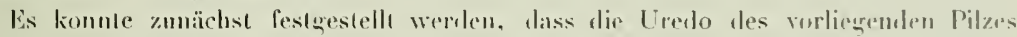

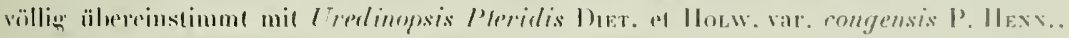

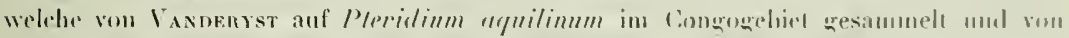

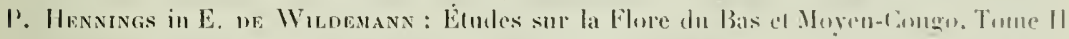
pag. \& folgendermassen hesehriehen woliden ist: "Maculis fuscidulis, rotumlintis ve] elfusis; uredosoris bypophyllis, sparsis vel gregariis, rolundatis, epiclermide fuscielula

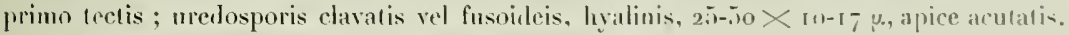

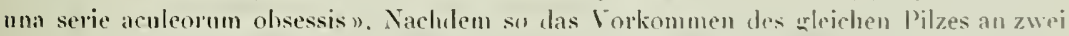

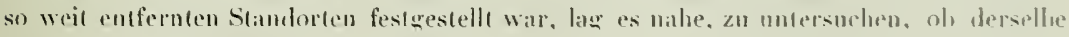

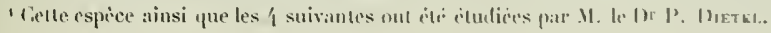

70 
vielleicht mit der schon früher von Cooke ans Natal heschriehenen LTredo macrosperma

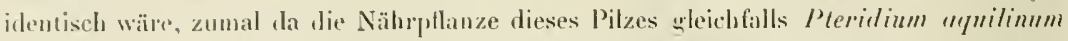
ist. Diese frage zu entscheiden wurde mir durch die Lichenswärdigkeit des Herrn Geh.

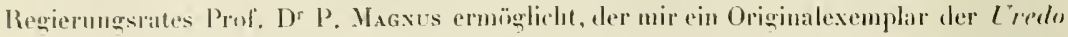
macrospermo zur L'ntersuchung äberliess, wolïr ich ihm aluch an dieser Stelle den verhiullichsten Dank ansspreche. Die Diaqnose der Lredo marosperme lautet nach Saccardo's
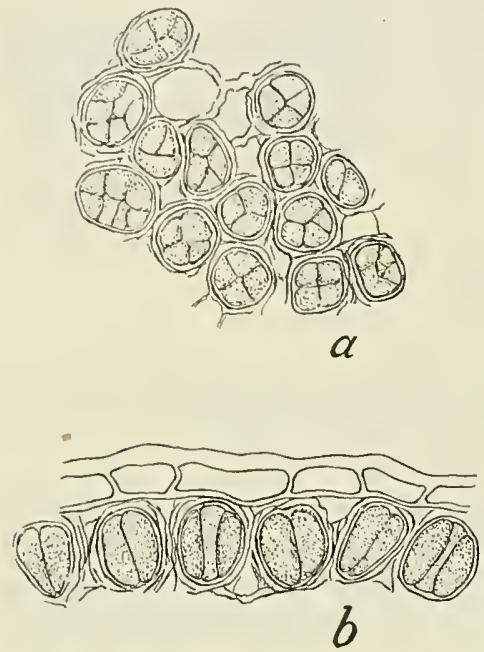

Fig. 63 : Uredinopsis macrosperma. - a) Eine Gruppe von Teleutosporen in der Flächenansicht. b) Durchschnitt durch eine solche Giuppe. Vergr. ca. $300 \times$.

sylloge 111 p. 853 "llypoplylla, sparsa; soris hemisphacricis, aurantiacis, demum pallescenlibus; medosporis sublanceolatis, utrinque whtusis, levilus, $45 \times 16-18 \mu$.$) . Verogleicht$ man diese Beschreibung mit der oben zitierten von P. Hennings, so fällt bei sonstiger Vehereinstimmung die Abweichung in zwei Punkten anf, nämlich dass Cooke die Sporen als beiderseits abgestmmplt und als glatt bezeichnet. Ilierzu ist Folgendes zu bemerken. An den Pilze vom Congo, von dem ich eine Probe untersuchen konnte, und elenso an den Exemplaren aus Columbia ist der Sporenscheitel meist mit einem kurzen, kaum über $3 \mu$ langen, deutlich abgesetzten Spitzclsen oler anch nur mit einer kleinen Warze versehen, seltener ist die Spitze von grö̈sserer Länge, oft ist aber auch weder eine Spitze noch $1 V^{7}$ arze vorhanden. An dem Exemplar aus Natal fand ich in zwei Sporenlagern rlie Sporen von letzterer Beschaflenheit in weit überwiegender Menge, in einew dritten waren sie umgekehrt meist zugespitzt oder mit einem deutlich abgesetzten Spitzchen versehen. Es handelt sich also hier um ein Merkmal, das an ein und demselben Material eine zienlich Variabilität aufweist und zu einer Unterscheidung melırerer Arten keineswegs herechtigt.

Ferner grieht Hennings von den Sporen des Congo-Pilzes an; "una serie aeuleorum obsessis». Der Ausdruck ist hier nicht ganz glücklich gewählt. Es zieht sich nämlich an jeder Spore eine bei der Untersuchung in Wasser meist undeutlich sichtbare Reihe von Warzen von der Basis der Spore über den Scheitel hinweg und auf der anderen Seite zur Basis zurück. Die Warzen sind bisweilen etwas mehr verlängert also kurz stälıchenförmig und durch eine leichter quellbare Substanz unter einander verbunden, sodass eine Struktur zustande kommt wie sie ähnlich von vielen Conileren-Aecidien her bekannt ist. Im ül,ringen sind die Sporen glatl. Eine solche ans Warzen gebildete Leiste laben auch die Exemplare aus Natal. 


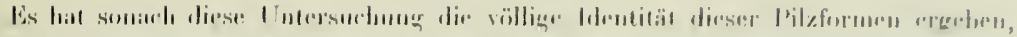

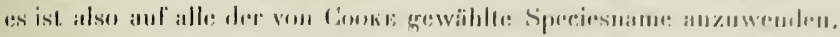

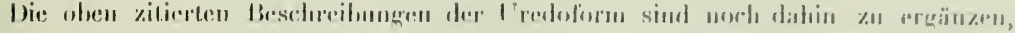

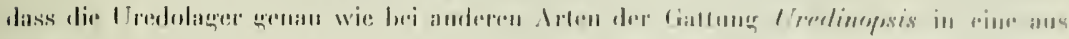

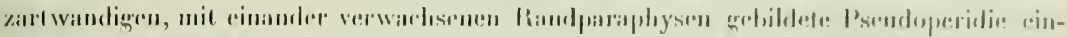
geschlossen siud.

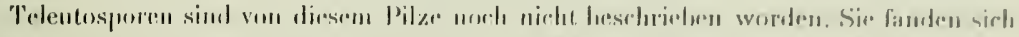

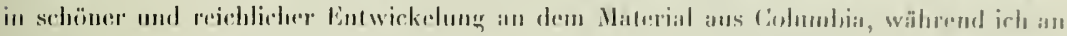

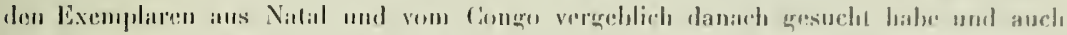

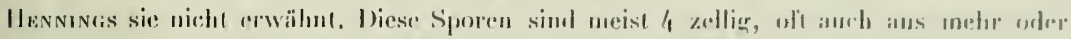

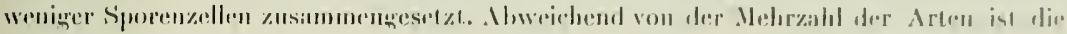

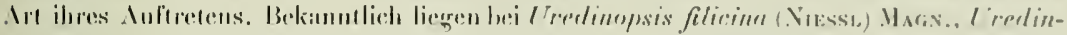

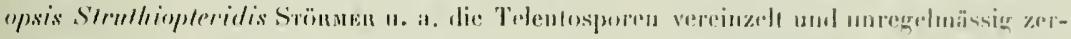

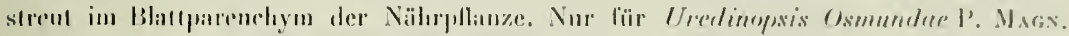

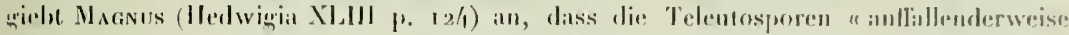

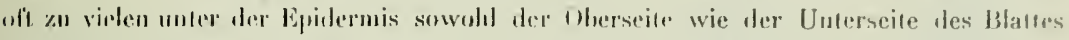

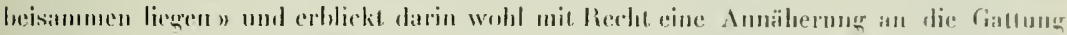

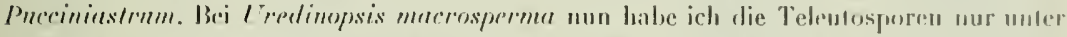

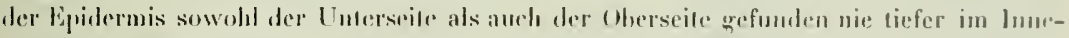

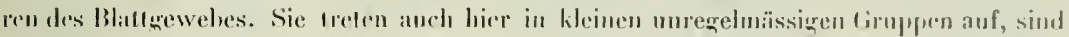

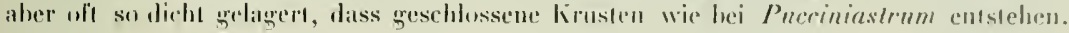

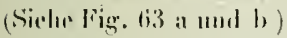

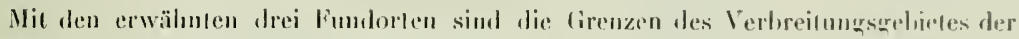

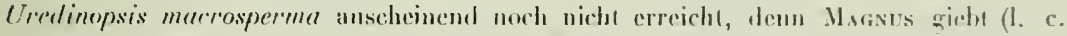

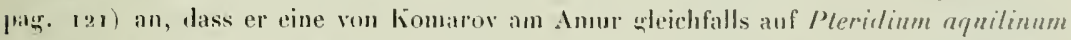
gresimmelte Uredo nicht von Uredo mocrospernut Cke, zu unterscheiden sermochle. Auf dom Adlerlin'n ist ansserdem, smiel mir liekannt ist, mur noch einmal eine lredinee gresammelt worden, nämlich won Luzew in der Provinz Perm im ITralgehiet. Dursh das dankenswerle Entgegenkemmen des Herru Prof. 1)r li. Lasdau wurle es mir ermönlichl, ein im Berliner Botanischen. Museum befindliches Exemplar dieses russischen Pilzes zu untersuclu'n. Dabei stellu sich heraus, dass derselhe nicht zu Lredinopsis mucrospermu, sondern $\%$ der sonst nur aus Californien lekannten / redimopsis /'teridis DIET. el IInLW. gehört, einem Pilze, der durch schlankere, meist laner zugespitzte oder in einen langen Schnabel anstaulemk [redosporen und leilweise grö̈ssere Uredolager von der anderen . Irt sich deutlich unterseheidet.'

An den erwïhnten, so weit von einander entfernt liegrenden mo in ihren kilima so

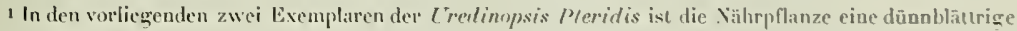

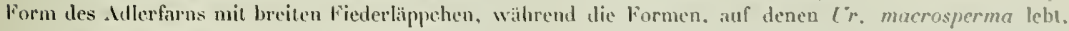
derber sind und schmale Fielerlippeben haben. 


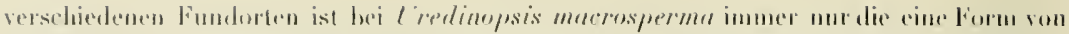

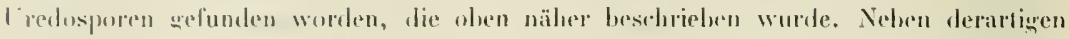
sjoren bilden alere die meisten lisher lekannten Arlen von L redinopsis noch eine zovite,

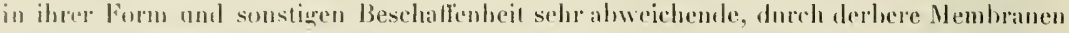

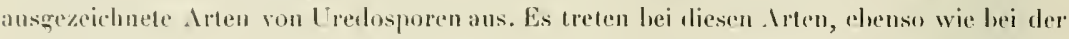

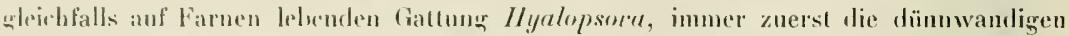
Syeren ant, denen alwer schon nach kürzester Zeit die derbwandigen folgen, sordass in der lingel bride formen zusammen gefunden werden. Wenn also in den rortiegenden Fall immer nur die dünnwanlige Gredn gefunden worde, teilweise sogar in Begleitumg ven Telentospren, so diof man daraus wohl schliessen, dass bei Lerdinopsis macrosperma rinc zweite Credosform äberhaupt nich gebildet wird.

\section{Uredinopsis Mayoriana Dietel spec. nov.}

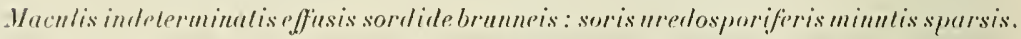
mpidermide din lectis, psendoperidio tenero inchusis: uredosporis ovoideis, clavatis vel oblongis. apice apiculo brevi vel usque 13 p. longu recto vel obtiquo aculatis, episporio hygalino levi, serie singula longiludinali verrucarum purum distincta ornato vestitis, $28-48$ u. $\times 12-20$ u. Telentosporis non visis.

Aul' den Wedeln von Blechnum blechnoides Lag.

Central-Anden, Dep. Antioquia. II. Am Wege von Titiribi nach dem Canca, alt. 8oo-r 500 m. 5. Sept. $\left(n^{\circ} 182\right)$. - Bei dem Gasthause La Quielıra olserhalh Cisneros, am Wege nach Medellin, alt. $1470 \mathrm{~m}$. 3 1 . Juli $\left(\mathbf{n}^{0} 182^{\mathrm{i}}\right)$. - Schatlige Orte bei El Pohlado aberhalh, Medellin, att, $1700 \mathrm{~m}$. 14. $\mathrm{Mng}$. ( $\left.\mathrm{n}^{0} 182^{\mathrm{b}}\right)$.

Die Besebaftenheit der 1 redo dieses Pilzes lässt keinen Zweilel darüber, dass er zur Gallung Tredinopsis gehört. Von der sehr ähnlichen Uredo der Uredinopsis macrosperma nuter'scheidet sie sich hauphächlich dadurch, dass die Spitze auf dem Sporenscheitel

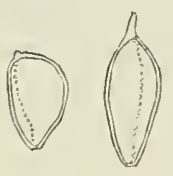
oft stark verlängert ist. Sie gleicht darin der Uredinopsis Strmlhiopterid is SтӧвмеR, mit deren dïnnwandiger Uredo sie überhaupt ganz übereinstimmt. Nan wird aher ans dieser Uebereinstimmung allein nicht olne weiteres auf die Identitäl beider Pilze schliessen dürfen. Anscheinend fehılt auch diesem Pilze aul Blechnum blechnoides wie der Uredinopsis macroFig. 61: Uredinopsis spermu eine derbwandige Uredoform wie sie bei Vredinops is Struthiop-

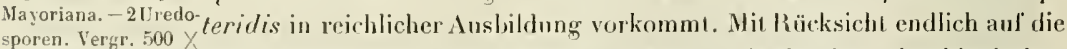
Versehiedenheit der Nährplanzen betrachten wir also ren columbianischen

Pilz als eine von $U_{r}$. Struthiopteridis verschiedene newe Art, die wir uns zu Ehren ihres Eutdeckers als Lr. Mayoriana zu benennen erlauben. 


\title{
Genre Milesina P. Magn.
}

\author{
108. Milesina Blechni Syd. \\ in. Im111. myeol. IIII 1. 㣙1.
}

Anl alin Wirleln von Blechnum occidentale 1. .

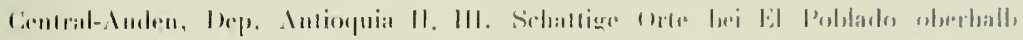

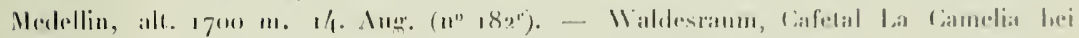

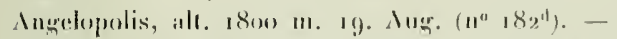

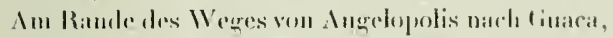
all. 1560-17001 m. 12. Seph. $\left(0^{\circ} 182^{\circ}\right)$.

Osll.-Amlen, D)(p). Comdinamarea I1. III. Am Rande des Weges zwischen dem Paramo lin\% Verde oherhalh, Bugotal und dem Dorle Lhatpue, alt. ea. 2.300 m. 15. Oke. ( $\left.1^{\circ} 182^{\circ}\right)$.

Die Uredo dieses Pilzes stimunt mil derjernigen Arulscher Exemplare and Blechnum Sprexnl I. selır qut überen. Dic Beschaflenheit, Vorteilung nul Girösse der Lredolager, die Beseltaflentreit der Iredoperidie und der l redospren sind bei lociden genin gleich, nur die Stacheln der Credosporenmembran sind an ren columbianischen Exemplaren meist elwas krältiper als an den deutschen.

Von der 'releutosporenform haben H. und l?. Srom, alie diesen Pilz zuerst als eigene Irt aufstellen (. Innales mycol. I pag. 337), ans Manged an greeignetem Material nur eine dürlige Beschreibung gehen können. Es mag daher hier rint atwas auslührlichere Beschreibung und Mbhilelung Platz finden. Dic Teleutosproren wurden an dem colnmhianischen Naterial auf manchen Wéleln in schön Entwicklung beobachtet. Sie treten ausschliesslich in den Zollen der unterseitigen Epidermis ter IV adel anf, wurden aher nie in den Schliesszellen der

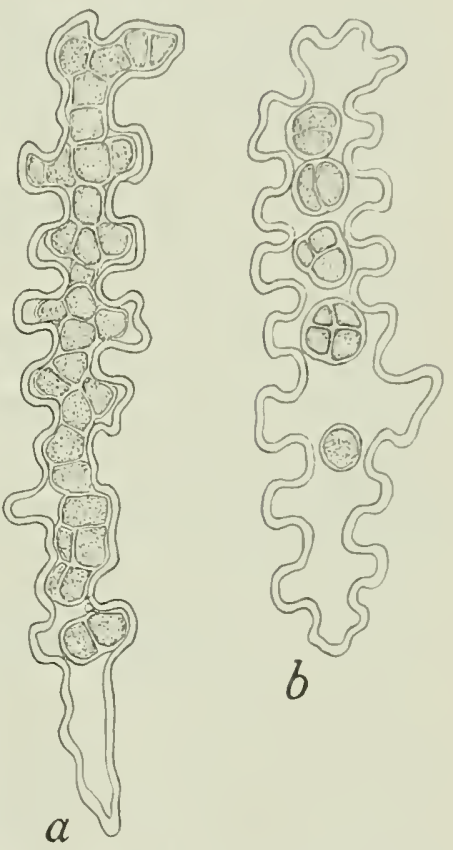

Fig. 65, $a$ und $b$ : Milesina Blechni. - Zwei Epidermiszellen von Blechaum occideatale. Teleutosporen enthattend. Vergr. ca. finu $\times$. Sprattiolfmungen gefunden. Meist sind die von ihnen hefallenen Zellen von den dicht gedrängten, sich gergenseitig ahplatlenden sporen mehr oder weniger vollständig ansgefüllt (vergl. Fig. 65a) und es ist dann wicht sicher zu 


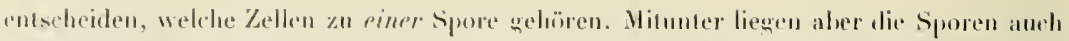
mely vereinzeld in den Wirtszellen (verol. Fig. (6.j) und lassen erkennen, dass sie meist 1- his fzelligr sind. Vielleicht ist die Zahıl der Zellen in einer Spore manchmal auch noch

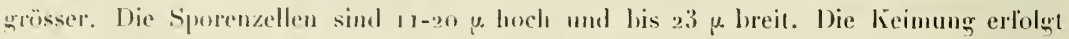
anscheinend erst nach einer längeren linhesperiorle.

Noch eine allgemeine Brumerkung mag hier Platz linden. Das Vorkommen von M/ilesina Blechui, suwic auch ron Lredinopsis macrosperma (s. o.) in ränmlich so weil qetrenuten und in ihrer Flora so selur verschierlenen fiebielen herechtigt mus nicht unr zu dem Schlusse, dass wir es hier mit Arten ron hohem geologischem Nter zu tun haben, sumtern selzt uns anch in len Stand, äher die Entwicklung dieser l'ilze bestimmtere Vermulmugen auszusprechen als es hisher möglich war. Man kronı von den Farnkräuter lawoluenden, den Gallungen Hyalopsora, Liredinopsis nul Vilesina angehörenden Credineen bisher nur Teleutosporen nnd Tredosporen. Nachleu man von einer stathlichen Anzalıl von Arten immer nur diese Sporenformen (in manchen fïllen auch nur eine von heiden) gefumlen lat, darf man es als feststehend ansehen, dass auf larnen eine der Aecidinmgeneration anderes. Uredinemgatmugen entsprechende dritte Sporenform nicht rorkommt. Es blieh also nur die Möglichkeit, diese in Eulwicklungskreis etwa noch lehtende Generation auf anderen Nährpllanzen zn suchen. Die an die genannten drei Genera am nächsten sich anschliessenden Gallumgen Jelampsorella und Pucciniastrum (einschl. Theliopsora und Calyptosporn) enthatten durchweg heteröcische Arten, deren Aecilien aul Abies und Picen leben. Man durfe also die Aecidien der Fasmmedineen auf Abictineen vermuten. Nachdem nun aler zwei dieser Arten mit reichlicher Teleutosporenbildung in Ländern gelunden worden sind, denen die Abietineen völlig lehlen, erschein. aurlı diese phen ausgesprorhene Möglichkejt als ausgeschlossen. Und da lïr rine etwajge Aecidiumform angiosperme. Nährpllanzen wohl nuch weniger in Betracht kommen, ist es härhst wahrscheinlich, dass sich die gunse Entwichlung dieser Farnuredineen auf die Bildung uon Uredro- und Telentosyoren beschränlit.

\section{Milesina Dennstaedtiae Dietel spec. nov.}

Soris uredosporiferis in maculis fuscis vel alrobrmmeis denique arescentibus indeterminatis, hypophyllis, irregulariter aggregatis, interdum pinnmles plane obtegentibus, minutis, oblongis vel punctiformibus, epidermide fuscu vel pullescente, irregulu-

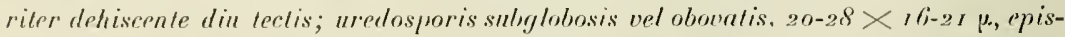
porio tenui hyalino subtiliter echimulato praeditis, psendoperidin tenero inchesis. Tetentosporis adhuc ignotis.

Aul den Wedelı von Dennstaedtia rubiginosa (Kaulf.) Moore.

Central-Anden, Dep. Antioquia II. Waldrande bei Cafetal La Camelia unweit Angelopolis; ait. 1800 m. 20. August ( $\left.1^{\circ} 184\right)$. 


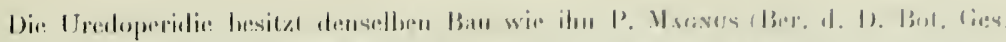

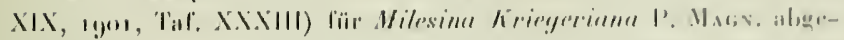

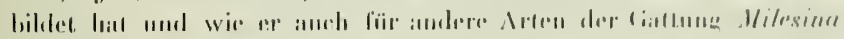

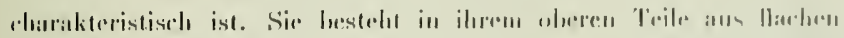

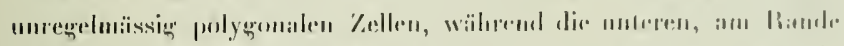

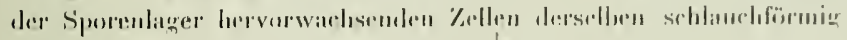

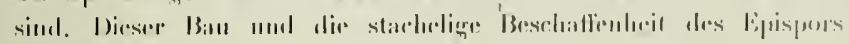

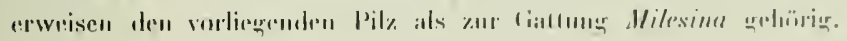

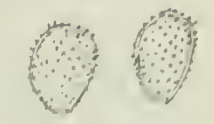

lïg Ii; Milamena JunnMliuduas: 2 lirenifosporin. Virk :AM)

\section{Milesina columbiensis Dietel. spec. nov.}

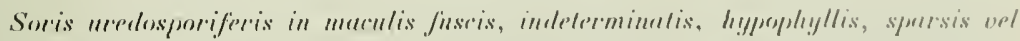

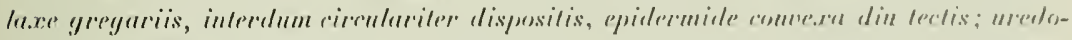

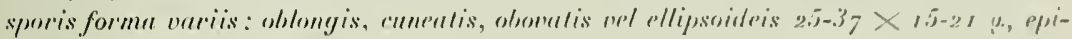

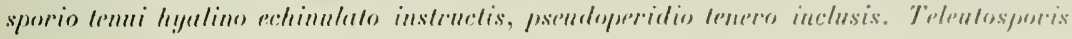
non visis.

Anf den Werlehı von Nephrolepis pendula Risı).

Cenlral-inden, 1)ep. Antioquia. II. Tueluatas am Wege von Angelopolis nach linaca, alt. 1500-1700 m. 12. Sept. $\left(\mathrm{n}^{\circ} 151\right)$.

Das selor spärliche Material dieses Pilzes worde anf meloreran

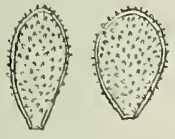

Fig. 67: Milesina columbiensis. - 2 Uredosporen.Vergr. $500 \times$

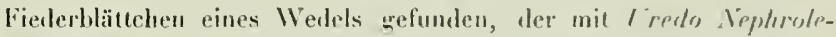
prelis Dreter gesammell worden war. Er ist schon mit der Lupe durch die lange bedeckt bleibenden sporenlager sun l'redo lephrorlepridis DIETEa zu unterscheiden, von der er anch durch die fiestalt der Sporen selbst und die Beschalfenheit ates Epispors der letzteren sich unterscheidet. Die Perilie, die sich am Scheitel nut einem Loche öffuet. hesteht in ihrem oberen Teile aus zarten polygonalen Zellen. IIerdurch, sowie durch die dünne, stachelige, der Keimporen ermanghelnde Membran der Liredosporen ergibt sich auch fïr diesen Pilz mit ziemlicher Gewissheit die Zusehörigkest zur Gattung Milesina.

\section{Aecidium Pers.}

\section{Aecidium Bomareae spec. nov.}

Aecidies sur les deux faces des feuilles et rennies pour former des laches ovalaires atteignant jusqu'à $1 \mathrm{~cm}$ de longueur sur $3-5$ mm de largenr, généralement tròs pen nomhreuses, isolés et irrégulièrement disposées. Les taches se manifestemt par une coloration 


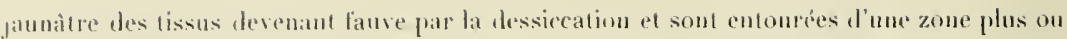

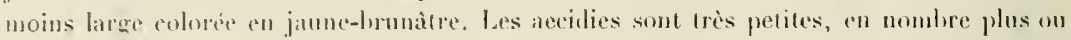

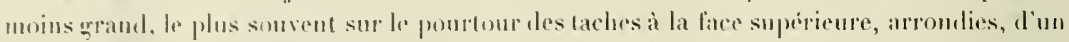

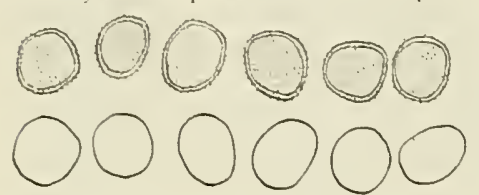

Figr. (6s: Aecidium Bomareae. - Aecidiospores.

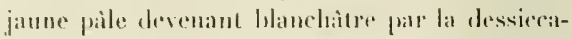
lion, souvraut is maturite par 111 pore itroil el arrondi el me presentant pas de rebord dichiqueté ou renversé. Sur les tiges on rencontre ismalement des groupes d'arecidies présentam le mime asprect que sur les finilles. - Aecilionspores arroulies on un peu polygonales, , $6-2 / 4 \mu$ de dianetre, lyyalines on prarfois sublygalines; membrane d'égale ćpaissenr partont, envi-

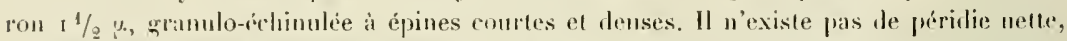
à peine distingue-t-n quelques cellutes isotess et non réunies en une chaine continure.

Aecislies amphigenis, rurins conlicolis, gregariis, maculis usque r cm long. et .3-5 $\mathrm{mm}$

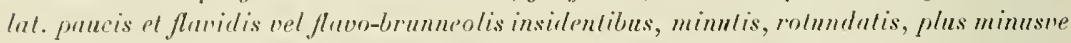
numerosis, flavidis dein albidis, primo dansis dein poro minuto rt rolumlato apertis, sine margine lacerato vel revoluto. Aecidiosporis globosis vel subglolosis nel polygoneis

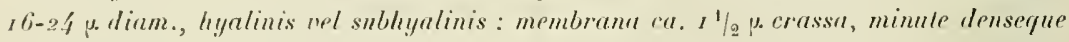
granuloso-echinulatula.

Sur liges el feuilles de Bomarea ri: Caldasii (II. B. K.) WILLD.

Audes orientales (de Subia), dép. Cundinamarca. Forits entre I'Nlon Mira et le Buqueron de Ruachuni dominant la valléte de Viota, alt. $3400 \mathrm{~m}$. 24 octohre $\left(n^{\circ} 13\right)$.

\section{Sur feuilles de Bomarea potacocensis НЕвв.}

Andes orientales (de Subia), dép. Cundinamarca. Forèts entre le Boqueron de cina-

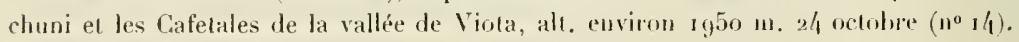

\section{Aecidium Bocconiae spec. nov.}

Aecidies i la face supérieure des lenilles, plus rares it la face inférieure, ne formant pas de tirches prarticulières, le plus souvent très noubreuses et irrégulìrement disposées, isolées, et non réunies en groupes, très rapprochées les unes des antres; elles sont d'un jaune clair, petites, arrondies $1 / 4^{-1 / 2}$ mm de diamètre, s'ouvent largement ef de bonne heure en présentant un mince rebord blanchâtre irrégulier, ni déchiqueté ni ren-

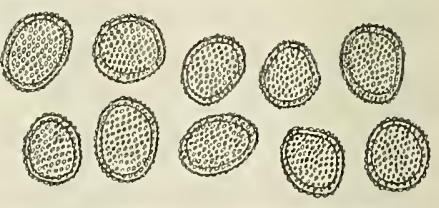

Fig. 69: Aecidium Rocconiae. - Aecidiospores. versé. - Aeciliospores atrondies, $16-23$ p. de diancetre, d'un jaune très pàle presque 


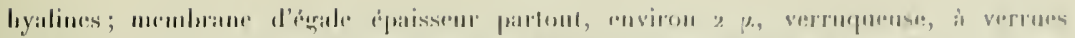

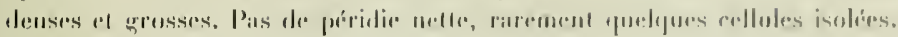

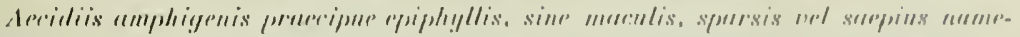

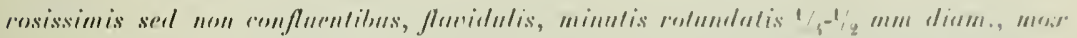

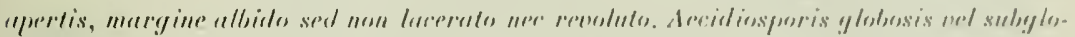

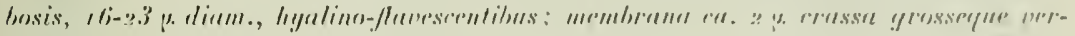
rencesse.

\section{Sur Piuilles de: Bocconia fructescens 1.}

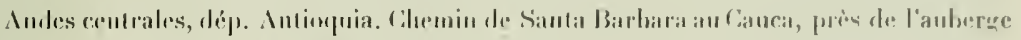

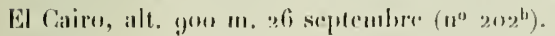

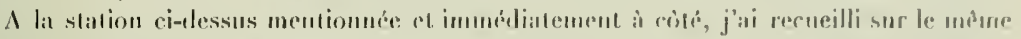

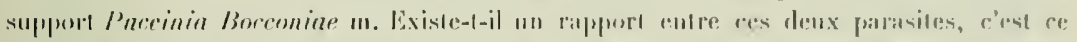

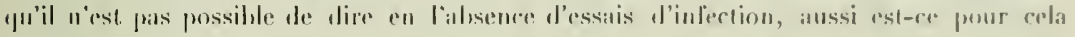

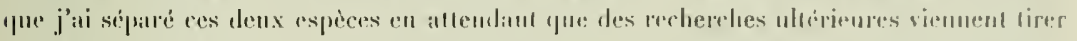
all elatir cerle question.

\section{Aecidium amagense spec. nov.}

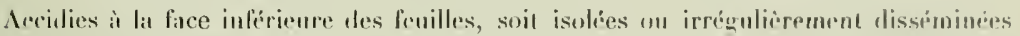

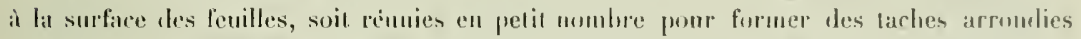
alteignant le plus souvent 3-5 mm de dianelde, freu nombreuses. I la face supirienre el

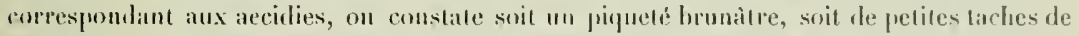

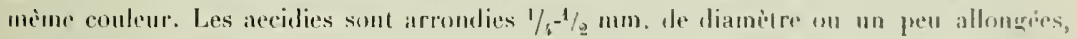
l'un jaune clair (la majorité déji anciennes ou dépourvoes de léurs spores sont colorées en jaune-lorun plus ou moins foncé), sourrant à la maturite el présentant un rebord épais d'un jannc-hlanchàtre on d'un jaun-lırunille, grossierenent el pen profondément incisé, nun dichiqueté ni renversé. On rencontre anssi des aecidies sur les tigeses où elles sont pristées les unes contre les autres el présentent te mème aspert que sur les fenilles.

Arcidiospores arronties on un peu antrulenses, $16-23 \mu$ de diamilre. hyalines; memlirane mince, à peine $1 \mu$, granuleuse à granulations très petiles, peu visibles al esparies. Las arevies me présentent pras de périlie nellement formée, mais seulenent guelyues cellules isolées el non réunies rn une suite ininterrompue.

- lecidiis hypophyllis, sparsis vel gregariis in maculis rolundalis $3-5$ mm dium., mennneis plus minnsur confluentibus. molnurlatis / ${ }_{5^{-1}}$ amm dium.) vel oblongis, flavis dein fluwo-brunneis vel brunneis. primo clausis drin upertis, murgine erasso flauro-allsido wel furo-brunneolo param inciso sed non luerato nee revoluto. Aecidits etian interdum canlicolis, dense gregariis et ronformibus. decriliospuris globosis, wel parum poly!goneis. 16-23 u diam., hyalinis: membrana lemni, vix a u erassa, sublitiler el lare granulosorerruculosa. 
Sur feuilles de Desmodium tortuosum (Sw.) DC.

Indes centrales, dép. Antioquia. Cultures près du Rio Amaga au-dessous du Cafetal La Camelia près Augetopolis, alt. environ $1300 \mathrm{~m} .26$ a $10 \hat{t}\left(\mathrm{n}^{\prime \prime} 267\right)$.

Celte espece diffère de Aecidium Desmodii P. Henn. par la présence de nombreuses atecidies isolies et non toujours réunies en wroupes, par la forme des aecidiospores toujours arrondies, par lenr membrane tris finement granuleuse el non lisse et par le fait qu'elles sout hyalines el pas jaunàtres. Elle dillère aussi des aecidies de Lromyces orbiculuris. Dnet. par le fait que heaucoup sont isolées et non réunies en groupes et par le fait qu'elles sont hyalines et pas jaunitres et plus finement granuleuses.

Ces aecidies ont été rencontrées en compaqnie de Uredo amagensis nu. et sur lis mèmes feuilles, ce qui laisse supposer avec assez de raison que ces deux espèces n'en forment en réalité qu’une seule appartenant très traisemblablement an genre Uromyces.

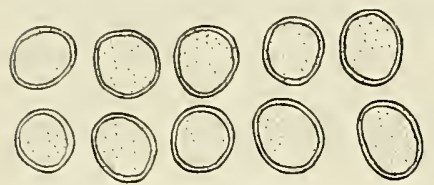

Fig. 70: Aecidium amagense. - Aecidiospores.

Ne pouvant cependant affirmer les rapports existant entre ces aecidies et ces uredos, je les sépare provisoirement en attendant que des expérienees tranchent la question. Si on admet la réunion qui semble la plus logique, les aecidies n'appartiendraient en tout cas pas à Uromyces orbicularis Diet, qui ne possède pas d'uredos et qu'on aurait certainement dì observer puisque j’en ai récolté en très grande quantité; malheureusement je n'ai vu aucune téleutospore, ce qui aurait perınis de lever toutes les hésitations.

.le joins à cette espèce des aecidies rencontrées sur Desmodium cajanifolium (H.B.K.) 1)C. Sur ce support, les aecidies présentent le mème aspect que sur Desmodium tortuosum, elles sont surtout isolées et plus rarement groupées; elles sont de mème forme et de mème dimension; à maturité elles présentent un rebord épais fendu irrégulièrement et non profondément déchiqueté ni renversé; leur coloration est la mème et les vieilles accidies deviennent aussi d'un brun plus ou moins foncé. Quant aux caractères microscopiques, ils sont alssolument pareils à ceux de l'aecidie de D. tortuosum. Je n'ai malheureusement pas vu d'uredos qui auraient permis de poursuivre encore plus loin la ressemblance entre ces deux parasites. Jusqu'à plus ample informé, je réunirai donc ces deux Aecidium. récoltés dans la même région el des expériences uttérieures décideront si ces déductions sont exactes ou non.

Sur feuilles de Desmodium cajanifolium (H. B. K.) DC.

Andes centrales, dép. Antioquia. Cultures, Cafetal La Camelia près Angelopolis, alı. environ $1700 \mathrm{~m} .20$ août $\left(\mathrm{n}^{\circ} 269\right)$. 


\section{Aecidium medellinense spec. nov.}

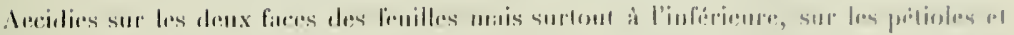

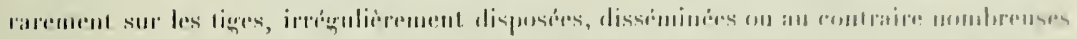

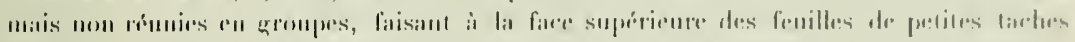

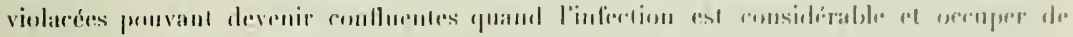

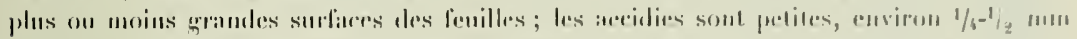

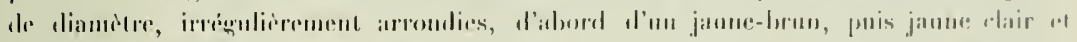

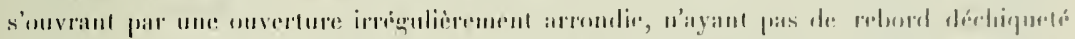

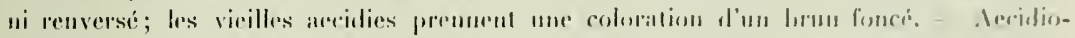

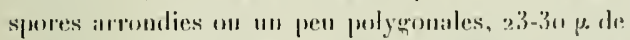

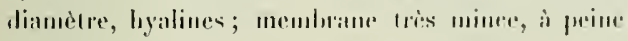
t $\mu$, prespar invisiblement gramuleuse. Pas de peridic mellement formes.

Aecirlis amphigenis plerumque h!pophlyllis, petiolicolis vel ruro cunlicolis, spmersis nel mumeresis sed non yreguriis in marulis, minutis, $1 / \mathrm{s}^{-1 / 2} \mathrm{~mm}$ diam., rolmudatis, maculis snepe confluentilus brun-
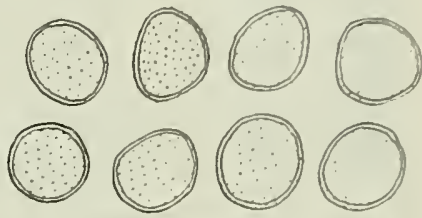

Fig. 71: Aecidium medellinense. - Aecidio pores

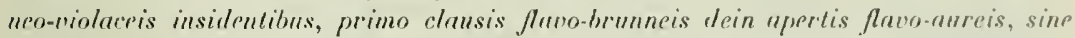

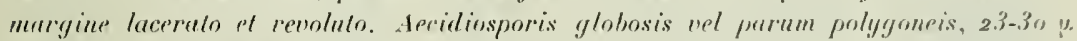

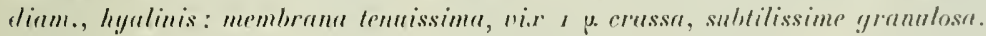

Sur fenilles de Eriosema spec.

Amles centrates, dép. Antioquia. Colline au-dessus de Merlellin, all. environ i gon m. 15 :

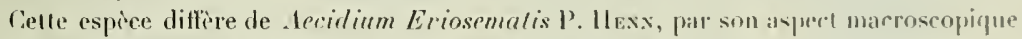
assez different, par ses aecidiospores phos grandes, foujours arrondies el toujours livalines.

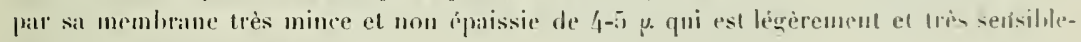
ment mranuleuse et pas lisse.

\section{Aecidium bogotense spec. nov.}

Aecidies réunies en petil nombre (uéneralement 4-ro) it la face inférieure desfeuilles at formant des taches arrondies ou un pen allongées de $1-3$ mm te diamétre et parfois jusıu’à 5 mu de diamètre, irrógulièrement disposties, souvent uniques ou m tous cas jeu nombreuses, isolées, non contluentes. I la face suprerieure des feuilles on constate delatedes d'un brun-purpurin au centre desquelles se trouvent les prenides en petit monlore. petites a arrondies ne faisant qu'une trios légère proéminence. d'un brun clitir à létat 
frais: ces laches sont souvent séparées du tissu sain par une atroite hordure violacíe. I la face inférieure sont les aecidies rarement isolées, presque toujours disposcés en rerefe dont le centre sins apules correspond anx pycuides de la face supérieure; les aecidies se trourcul sur des taches d'un brun-clair parfois un peu purpurin. Les atecilies sont assez rarement arrondies, prestgue toujours un peu allongás ef peuvent atteindre jusqu iो 2 mm de fongueur, d'un jaune-bruntitre ; efles sont d'alsord

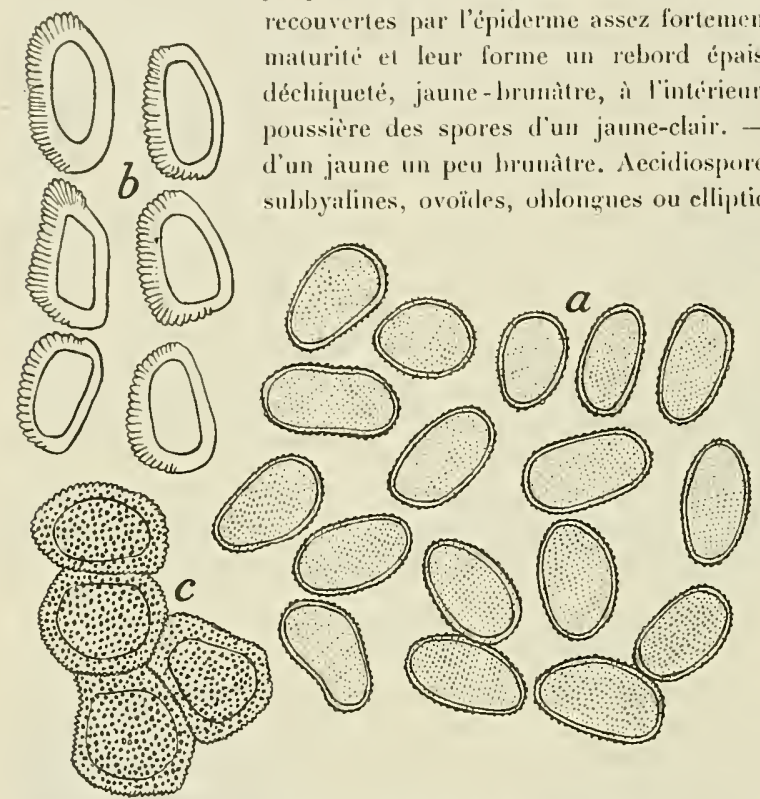

Fig. 72 : Aecidium bogotense, - a) Aecidiospores. b) Cellules de la péridie vues en coupe. c) Cellules de la péridie vues de face. membrane d'égale épaisseur partout, environ $1 / 2 \mu$, verruqueuse à verrues nombreuses et denses, mais assez petites. Les cellules de la péridie vues de face sont polygonales el à membrane fortement verruqueuse ; vues en coupe, elles présentent une paroi externe el lisse de 4-5 $\mu$. d'épaisseur et une interne fortement verruquense de 7-12 \%. d'épaisseur.

Aecidiis paucis $(4-10)$, in parvos greges dispositis, hypophyllis, maculis rolundatis $1-3 \mathrm{~mm}$

diam.) vel oblongis (usque $5 \mathrm{~mm}$ lougis) unicis vel puucis el non confuentibus brunneo-purpurnscentibus insidentibus; aecidiis peripheriae macularum dispositis, oblongis (usque $2 \mathrm{~mm}$ longis) rarius rolundatis, flavo-brunnealis, primo clansis el epidermide crassa tectis, dein fissis, margine crasso non laceralo cinctis et sporis flavidis conspicuis. Pycnidiis epiphyllis, in centro maculurum dispositis, paucis, minntis, rotundatis, flava-brunneolis. Aecidiosporis subhyalinis vel pallide flavescentibus, ovoideis, oblongis vel ellipsoideis, $25-40 \mu \times 19-24 \mu$; membruna ca. $1 / 2 \mu$ crassa, dense et satis minute verrucosa. Peridai cellulis extus levibus et $4-5$ p crassis, intus grosse verrucosis el $7^{-12} 2 \mu$ crassis. 
Sur leuilles de: Geranium nulticeps T'um\%.

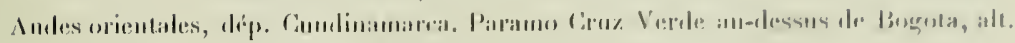

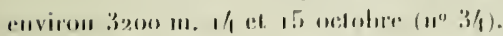

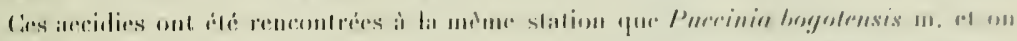

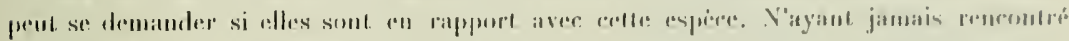

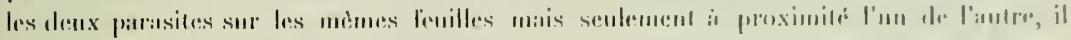

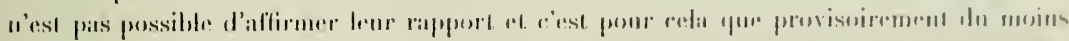

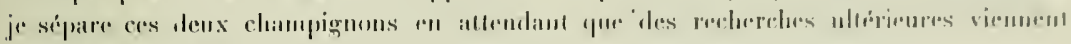
trinchere lis quastiont.

\section{Aecidium Cissi Winter.}

in Hohw. 1884, P. 168.

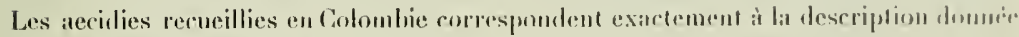
par Winten sur le mème support phanérogamiepur provenant du Brésil, d'un donne rilessutus nne description un peu plus détaillée en me hasaut sur les exemplaires que j'ai ricoltés.

Les aecidies sont it la fice inférienre des fenilles, ranement à la suprórienre; on les rencontre sonvent sur les pétioles et mime sur les tigres. Sur les tiges et pétioles sonvent spaissis et tordus, elles sont runies en nombre très considerable pour former des tachrs allongéeses, atteignant jusqu’à $3 \mathrm{~cm}$ de longuenr; sur les feuilles fes taches sunt arrondirs - 1 mesurent jusıu’à 5 et 6 mu de diamètre; lintspue les aecirlies sont sur les nervures, les taches deviennent allongres et peurent aroir de 7 a $8 \mathrm{~mm}$ de longueur. Ces laches sont irrégulièrement disposées, disséminies, ou au contraire nombreuses et parfois conlluentes; dans ce cas souvent les feuilles sont plus on moins plissées et crispées. A la face supirieure, on constate une coloration brun foncé des tissus correspondint nux accidies, puis un anneau étroit d'un hrun clair au dela duquel on voit une zone
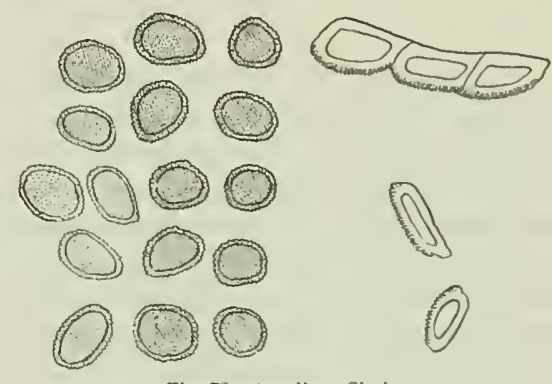

Fig. 73 : Aecidium Cissi.

Aecidiospores et cellules de la péridie vues en coupe. colorie en brum-noir, épaisse de $2 \mathrm{~mm}$ on un peu plus; ì la face inférieure les aecidies sont circonscriles par une zone d'un mème brun-noir et de mème épaisseur. Les aecidies très nombreuses sur chaque lache sont sur un fond d'un brun très foncé; eltes sont te plus souvent très rapprochées les unes des autres; d'abord recouvertes par l'epiderme et d'un jaune-hrum, elles s'ourrent ensuite el 
forment aux spures d'un janne clair un rebord blanchatre déchiqueté el sourent un peu renverse. Les vieilles aecidies deviennent d'un hrun très foncé. Les aecidiospores sont arrondies at un peu polygonales, $14-18 \mu$ de dimètre on ovoüles on ovalaires, $16-21 \mu$. 入 $1-16 \mu$, d'un jaune très charr, subliyalines et mene hyalines; la membrane est d'égale ípaissenr partut, ensiron $2 u$, verruquense à verrues pretiles mais denses. Cellules de la peridie présentant en coupe une paroi externe lisse ot une interne fortement verruqueuse, foutes denx de $3-5$ p d'ipaisseur.

Sur feuilles, pétioles el tiges de Vitis ef. sicyoides (L) Baken / = Gissus sicyoirles L).

Andes centrales, dép. Antioquia. Prés de Yarunito (chemin de Medellin), alt 1342

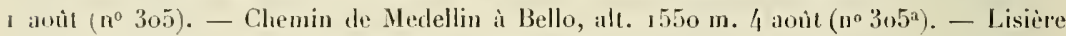
de bois au- lessous du Cafetal La Camelia près Angelopolis, alt. $1300 \mathrm{~m} .26$ aoùt $\left(1^{\circ} 305^{\mathrm{b}}\right)$. Cultures au-dessous du Cafetal La Moka près Angelopolis, alt. I 400 m. 29 aoùt $\left(\mathbf{u}^{\circ} 305^{\mathrm{c}}\right)$. Chemin de Tilirihi au bord du Cauca, alt. environ $1300 \mathrm{~m} .5$ septembre $\left(n^{\circ} 305^{\mathrm{d}}\right)$. - Guaca, alt. 1480 m. 12 septembre (n ${ }^{\circ} 3$ ro). - Bord de chenin à Sabaletas près de Titirili, alt. environ $3500 \mathrm{~m} .13$ septembre $\left(n^{0} 305^{\theta}\right)$.

Sur feuilles, pétioles el tiges de Vitis spec.

Andes orientales, dep. Cundinamarca. Chemin entre Villeta et Agua Larga (chemin de Bogota), alt. environ $1800 \mathrm{~m}$. 9 octobre ( $\left.n^{\circ} 45\right)$.

\section{Aecidium Adenariae spec. nov.}

Aecidies à la face inférieure des feuilles, réunies en nombre plus ou moins grand pour former des taches arrondies atteignant jusqu’à $5 \mathrm{~mm}$ de diamètre ou hien allongées le long des nervures où elles peuvent atteindre jusqu'à $2 \mathrm{~cm}$ de longueur en déformant plus ou moins les nervures qui sont souvent tordues ct épaissies; ces taches sont disséminées, peu nombreuses et isulées, elles se manifestent à la face supérienre par une coloration lirun foncé des tissus, entourée d'une zone de $x-3 \mathrm{~mm}$ de largeur d'un jaune-brun ou brun-roux qui se retrouve à la face inférieure. Les aecidies sont petites, arrondies, d'un jaune clair, d'ahord recouvertes puis s'ouvrant à maturité et présentant un rebord blanchàtre, lécliqqueté el renversé. - Accidiospores arrondies ou un preu ovoüdes, 18-26 $\times$ 18-24 $\mu$, d'un jaune très pàle; membrane d'égale épaisseur partout, environ $2 \mu$, verruqueuse à verrues denses el grosses. Cellules de la péridie fortement verruqueuses vues

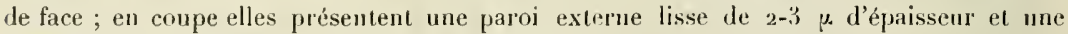
interne fortement verruqueuse de $4-5 \mu$ d'épaisseur.

Aecidiis hypophyllis. maculis rolundatis /nsque $5 \mathrm{~mm}$ diam. vel nervicolis usque $2 \mathrm{~cm}$ longis) sparsis et pancis obscure brumneis saepe circumdatis coloratione flava vel 


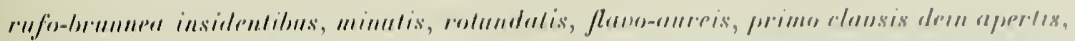

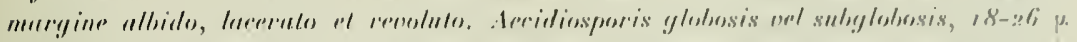

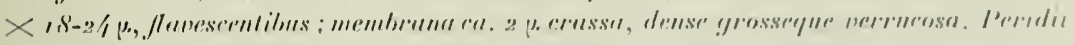

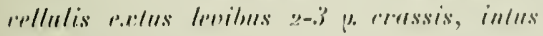
onerencosis, l-5 po.

Sur lenilles de Adenaria floribunta II. B. K. f. purpurata (H. B. K.) Konink:

Andes contrales, dép. Antionguia. Taillis

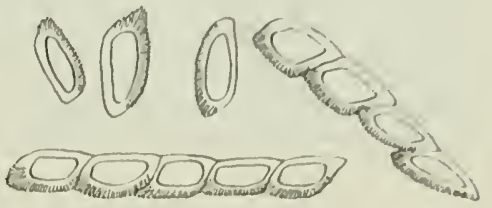
priss de la languna Santa Rita prés Mngelopolis, alt. 1 (6on m. 22 anth (110 175). Taillis, Cafetal Ia Moka près Angelupulis,

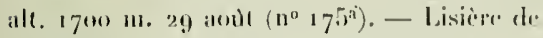
forrit, flane droit do l'Amagadiente, vis-it-vis du Caretal La Camelia pris Nugrelopolis, alt.

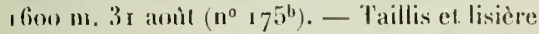
de hois, Cafetal la Camedia pris Angelopolis,

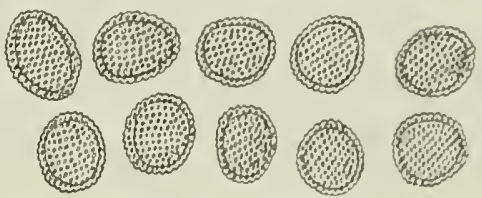

Fig. Th: Aecidium Adenariae. Aecidiospores el cellules de la péridie vaes en coupe. alt. $1800 \mathrm{~m}$. 12 sipptembre $\left(n^{\circ} 3-5^{\mathrm{c}}\right)$.

Andes centrales et occilentales, drip. Antioguia ef Cauca. l'ai ruscontrí fróguemment

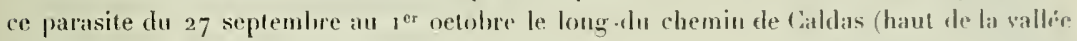
du Porce) au Cauca el à Valparaiso, puis eutre Valparaiso el Supia, Supia el Filarlelfia et entin entre Filadelfia ef Neira mon loin de Manizales, alt. $1260-1800 \mathrm{~m}\left(\mathrm{n}^{\circ} 17^{5 / 2}\right)$.

\section{Aecidium Lantanae spec. noy.}

Aecidies à la face inférieure des feuilles, toujours réunies en sroupes pour former des taches arroudies ou $u n$ pru allongées te dimensions très variables, depuis $2-3 \mathrm{~mm}$ jusqu’à $2 \mathrm{~cm}$ de diamètre; ces taches sont qeénéralement uniques sur les feuilles ou au nombre di 2 à 3, rarement davantage. A la fice supérieure ef correspondant aux amas on constate une tache d'un lorun foncé souvent violacé, entourér le plus souvent d'une étroite zone jaunàtre. $\Lambda$ la face inférienre sont les arcidies gínéralement un peu espacées les unes des autres et peu agglomérées, laissant apercevoir le tissu foliaci altíri et coloré en jaunehrunitre, eoloration qui déborde sourent de $1-3 \mathrm{~mm}$ la zone ou se troureut les cupules. tess aecidies, petites et arrondies, sont d'un janne pàle, l'abord recouvertes par l'épiderme, fuis ouvertes ct présentant un reborl hanehàtre, assez épais, déchiqueté et rensersé. lecidiospores arrondies on polygonales, $\mathrm{t} 6 \mathrm{~b}-2 \mathrm{r}$ u de diamitre on un pen allongées, 18-21 $\mu \times 14-18 \mu$, de conleur jaune pàle ; membrane d'égale épaisseur partout, environ $1 \frac{1}{2} \mu$, finement et assez densément granuleuse. Les cellules de la péridie vues en coupe 


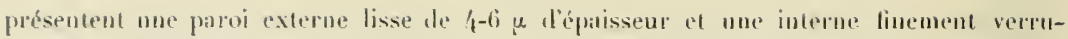
quense de $2-3 \mu$ d'épraisseur

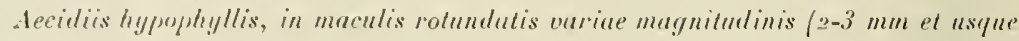
$2 \mathrm{~cm}$ diam.) unicis vel pancis dispositis, super obscure brunneis infra flumo-brunneolis; upcillis purnm greguris, minutis, rolundotis fuvo-unreis, primo clunsis dein upertis, margine albielo, luceruto revolntorpue. Aeciliosporis globosis vel polygoneis, $16-21$ p.

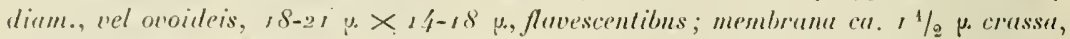
mimnte denseque granulosa. Perielii cellulis extus levibus $4-6$. crussis intus verrucosis $2-3 \mu$.

Siur fenilles de Lantana hispida II. B. K.

Indes centrales, dép. Antioyuia. Taillis et forets de T'Alon Don Elias au-dessus du Casfelal La Camelia près Ingelopolis, alt. coviron $2000 \mathrm{~m} .20$ atoù $\left(\mathrm{n}^{0}, 2,3\right)$.
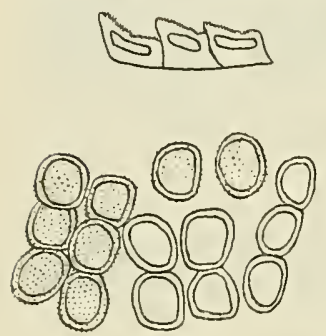

Fig. 75: Aecidium lantanae. Aecidiospores et cellules de la péridie vues en coupe.

Sur le mime support phanéroganijue, j’ai recueilli aux environs de Medellin Puccinia Lantanae FarL. Dès lors la question se pose de savoir si les aecidies ci-rlessus déerites se rapprortent à cette espèce. Aux diflérents endroits ui j’ai recueilli P. Lankanue sur ses divers supports je n'ai jamais remarqué la présence d’accidics el d'autre part à la station où j’ai récolté les Lecidium, je n’ai pas rencontré des télentospores. Il semble lone plus loginue de conclure que l'Aecidimm que je viens de décrire appartient probalbement à mor espèce létérö̈que; il n'est eependaut pats possible de l'affirmer d'une manière absolne, car seuls des expériences et des essais d'iuleetion seront eapables d'élucirler eette question qui doil forcément rester provisoirement en suspens.

\section{Aecidium Stachytarphetae P. Henn.}

in Hedw. 1899, p. 7 1.

Lat description snivante a été faite l'après les exemplaires de Colombie qui correspondent bien à ceux provenant du Brésil. Aecidies à la face inférieure des fenilles, rarement à la face supérienre et sur les liges. Sur les fenilles, les acrilies sont soit isslís, soit plus souvent réunies en petit nombre pour former de petites taches arrondies de 1 à $2 \mathrm{~mm}$ de diamètre, irrégulièrement disposées, souvent nombreuses et parfois un pen confluentes. A la face supérieure, on trouve des cupules isolées sur des taches de couleur brune; sur les tigres, les groupes d'aecidies sont allongés et peuvent alteindre el mème 


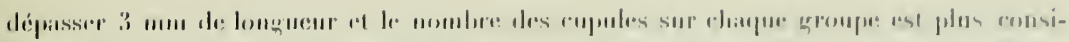

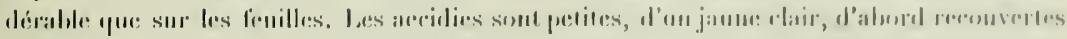

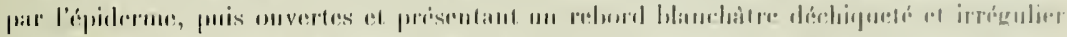

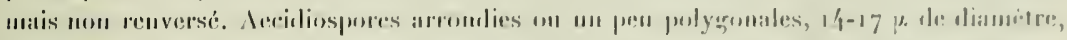

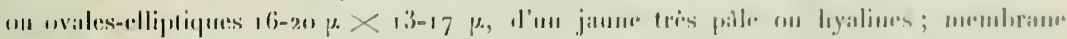

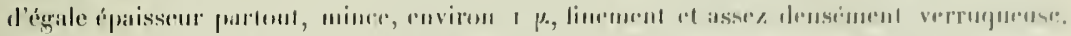

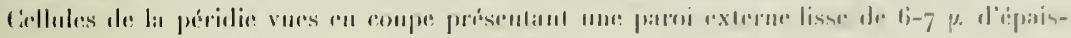

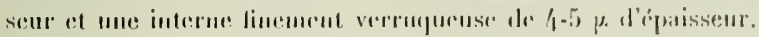

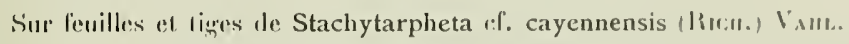

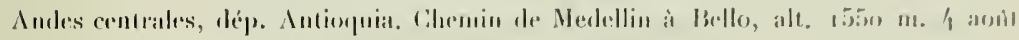

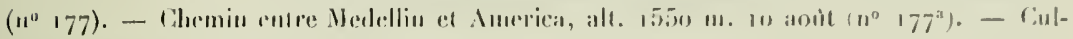

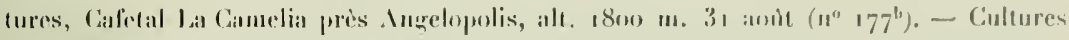
à Giltaca, alt. 1/980 m. 12 septembere $\left(\mathbf{n}^{\circ} 177^{\mathrm{c}}\right)$.

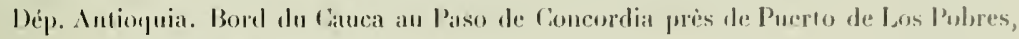
alt. $7^{20} \mathrm{~m} 11.7$ septembre $\left(n^{0} 177^{d}\right)$.

\section{Aecidium Borreriae Pat.}

in Duss. Eum. clamp. Guarlel., Igoi?, p. 7 .

Les aecidies recurillies en Colombie semblent hien correspondre avec la description de Aecidimm Borreriar Pat. La description ci-rlessons a dé fuite daprís les échantillons que jai récoltés.

Pycnides sur les deux faces des feuilles, mais rares ì l'inférieure, souvent tris nombreuses et formant une petite proéminence; rlles sont arrondies, petites, d'un jaune-hrun ì l'etat frais, devenant d'un brun-noiritre par la dessiccation, jaunes vues en coupe. Les aecidies sont ì la face inférieure des fenilles, très rarement quelquesunes ì la face supérieure, irrégulièrement disposées, isolées, dispersées et en petit nombre ou au contraire nombreuses et rapprochées mais non réunies en taches, domnant alor's à toute ou partic des feuilles une coloration d'un jaune-brun; les cupules sont petites, arrondies ou un peu allongées, blanchatres ou
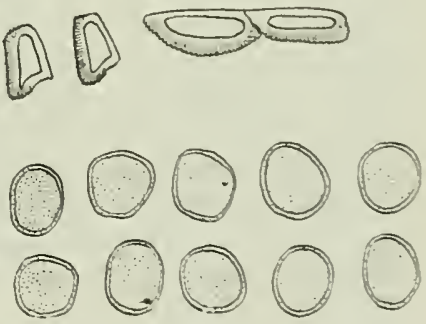

Fig. 76: Aecidium Borreriac. - Aecidiospores et cellules de la péridie rues en coupe. jaune-hlanchàtre, d'ahord recouvertes par l'épiderme, puis ouvertes et présentant un rebord blanchàtre irrégulier et un peu déchiqueté mais non renversé. Les aecidiospores sont arrondies ou un peu polygonales, $16-24 \mu$ de diamètre, subyalines ou d’un jaune très paile; membrane mince, environ $1 \mu$, d'égale épaisseur 


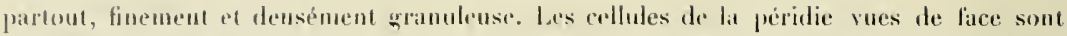
rerrugueuses; vues en eoupe elles présentent une paroi externe lisse de $2-3 \mu$ d'épaissemp et une interne asscz fortement verruquenso de $\{-5 \mu$ d'épaisseur. Les feuilies altaquées IIC sout géníratement pas déformées, ceprendant lorsque l'infection est très considérable et yue les aecidies sont réparties sur de grandes surfaces, surfout sur les jeunes feuilles à l’extrémité des liges, elles s’allongent et deviennent plus étroites que les feuilles normales en mène temps que plus épaisses.

Sur fenilles de Hemidiodia ocimifolia (WuLD.) K. Sç⿰uм.

Audes centrales, dép. Antioqunia. Culures près de Yarumito, alt. $1342 \mathrm{~m}$. $1^{\text {er }}$ aont $\left(u^{\circ} 265\right)$. - Cultures à Fuaca, ah. $1480 \mathrm{~m}, 12$ septembre $\left(\mathrm{n}^{0} 265^{\mathrm{a}}\right)$.

\section{Aecidium Vernoniae-mollis spec. nov.}

Aecidies sur les tiges et les denx faces des feuilles, surtout à la face supéricure, ne faisant pas de taches à la surface des fenilies, irrégulièrenent disposcies, généralement

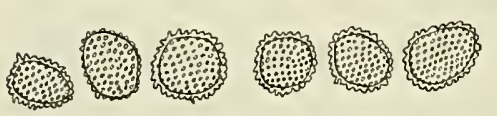

Fig. 77: Aecidium Vernoniae-mollis. - Aecidiospores. peu nombreuses et isolées, arrondies et pelites ou oblongues surtout sur les tiges, d'un jaune très pàle à l'état frais, devenant blanclıàtre par la dessiccation, d'abord recouvertes par l'épiderme jaune clair qui disparait en formant parfois mais pas toujours un très petit rehord irrégulier non déchiqueté ni renversé. Aecidiospores irrégulièrement arrondies ou ovö̈des, i 8-20 $\mu$ de diamèire on 20-24 $\mu$ $\times 18-20 \mu$, hyalines ou subhyalines; membrane mince, environ $1 \mu$, égale partoul, tubercnlo-verruqueuse à verrues grosses, alteignant i $\mu$ de hanteur, très proéminentes et denses. Pas de péridie, du moins on ne constate que la présence de quelques cellules isolées, non réunies en une suite ininterrompue.

decidiis canlicolis vel amphigen is praecipue epiphyllis, sine maculis, sparsis, minutis, rolundatis, vel oblongis, fluvidis, primo clausis drin apertis sine margine lacerato revolutorque. Aecidiosporis globosis, $18-20 \mu$ diam., vel ovoide is, $20-24 \mu . \times 18-20 \mu$, hyalinis vel subhyalinis; membrana tenui, ca. I p. crassa, dense mayneque tuberculuto-verrucosa/verrucis usque, 1 . altis).

Sur tiges el feuilles de Vernonia ef. mollis H. B. K.

Andes centrales, dép. Intioquia. Cultures entre le Rio Amaga et Le Cafetal La Hermosa près Angelopolis, alt. environ $1400 \mathrm{~m} .9$ septembre $\left(n^{\circ}{ }_{1} 72^{d}\right)$. - Cultures, Cafetal La Moka près Angelopolis, alt. environ 1600 m. 29 aout $\left(n^{0}\right.$ I $\left.72^{9}\right)$. 


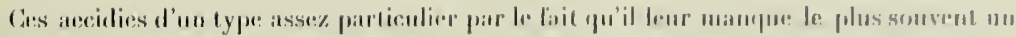

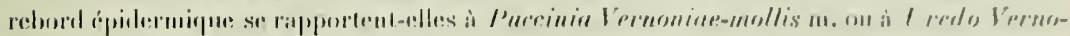

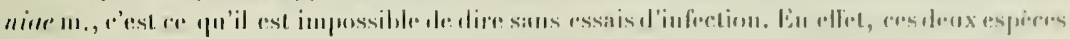

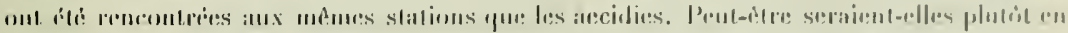

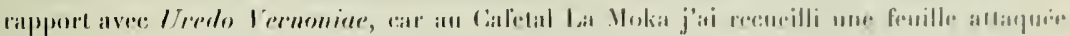

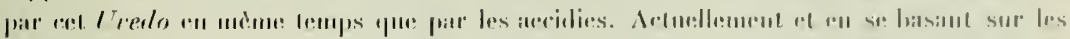

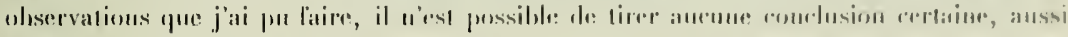

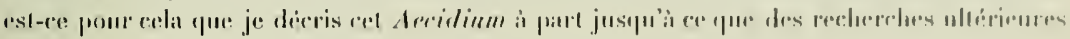
viement edaircir la punestion.

\section{Aecidium paramense spec. nov}

Aecicties sur les lenilles, les pritioles eu les ligres. Sur les lemilles, rolles sumt rares is la

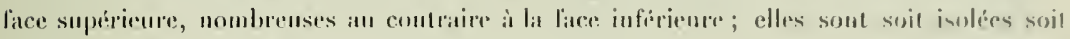
lo plus souvent réunies en numbre plus an moins comsidérable pour linmer de petites tachess de 2 mm en moyenur de diamitre, somvent conlluentes en cas de forto infertion, parfois allongies te loug des nervures at alteignam jusqu'i

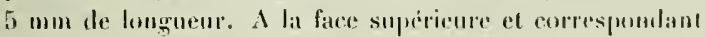
ans aecilies, on constatede petiles taches d'un lorun-moiritre, déboriant plus on moius largement la zone des cupules ce le plus souvent conlluentes avec celles du voisinagr en com-

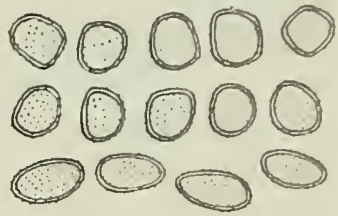

Fig. 78: Aecidium paramense. Aecidiospores. muniquant parlois à de graudes surfaces des leuilles une

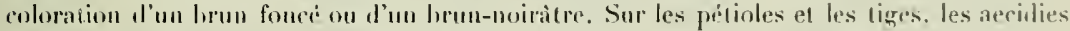
sont riunies en qrand nombre sur des taches noiratres el allorges pousant alteindre I cm de longueur sur 1-2 mm de largeur. Les aecilles sont tris petiles, prostgue puncliformes, aromdies, d'un janne clair, longtemps reconvertes par lípirlerme qui írlate

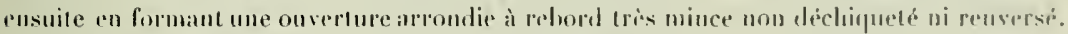
- Aecidiospores soit arroudies on un pen polygonales, 14-19 u de diamedte, soit ovoñdes

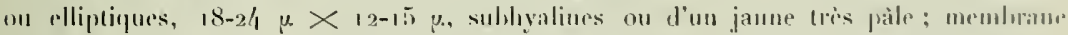

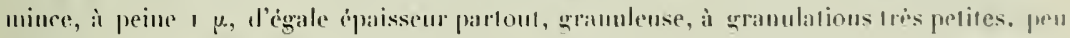
visilld's el assez pen denses. de n'ai pas constalli la présence de piridie nelle mais senlement quelyues rares crllules isolies.

Apciliis folicolis, petiolicolis wel coulicolis. In foliis mern epiphyllis, hyjpoph!yllis mumerosis, sparsis rel saepissime gregarris, maculis minutis (2 um diam.) sacpe onn-

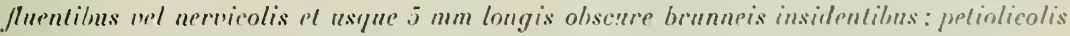

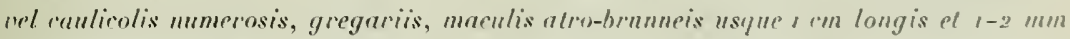
Intis insidentibus: aecidiis minutis, fere punctiformibus, rotundulis, fluvidis, diu clunsis drin upertis, poro mimuto el tenui non lncernto nec revoluto. Aeridiosporis globosis ied 


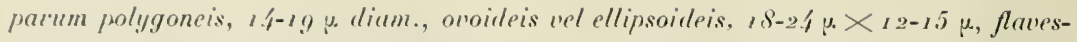
centibus vel subhyalinis: membrana tenui, vix I parassa, granulosa.

Sur tiges, pétioles et feuilles de Eupatorium obscurifolium Hıron.

Audes orientales, dép. Cundinamarca. Versant oriental du Paramo Cruz Verdu audessus de Bogota, alt. environ 2800 m. 15 octobre (no /,3).

\section{Aecidium Spegazzinii de Toni.}

(Aec. australe Speg. in Fung. guaranitici, 1., "1' 154).

Les aecidiospores d'un jaune très pâle ou subhyalines sont arrondies ou un peu polygonales, 14-21 \% de diamètre; membrane $1-1 \%$ p. d'épaisseur, dyale partout, verruqueuse à verrues petites el denses. Cellules de la péridie vues en coupe présentant une paroi esterne et lisse de 4-5 $\mu$ d'épaisseur et une interne finement échinulée de 3-4 $\mu$. d'épaisseur.

Sur les deux faces des feuilles de Erigeron bonariensis $L$.

Andes orientales (de Subia), dép. Cundinamarca. Cultures, Cafetal Argelia dans la vallée de Viota, alt. 1880 m. 25 octobre $\left(n^{0} 19\right)$.

\section{Aecidium Clibadii Syd.}

in Ann. Mycol., 1903, I p. 333.

La description de Sroow correspond exactement avec les échantillons recueillis en Colombie. Les aecidies à la face inférieure des feuilles sont en grand nombre et lorment. des taches arrondies pouvant atteintre et mème dépasser $1 \mathrm{~cm}$ de diamètre sonvent confluentes. Les cupules arrondies sont d'abord recouvertes par l'épiderme, juis s'ouvrent et présentent un rebord blanchâtre déchiqueté et renversé en forme de coupe ; elles sont d'un beau jaune d'or. Les aecidiospores, d'un jaune très pâle ou même hyalines, sont anglueusespolygonales, , I 1 -1 $6 \mu$ de diamètre, verruqueuses à verrues très petites el espacées. Les cellules de la péridie vues de face sont densément et assez longuement échino-verruqueuses, vues en coupe elles présentent une paroi externe et lisse de 5-7 $\mu$ d'épaisseur et me interne de 3-4 $\mu$ fortement échino-verruqueuse.

Sur feuitles de Clibadium surinamense L, var. asperum (АивLET) Baker.

Andes centrales, dép. Antioquia. Au-dessus de Cisneros (chemiu de Medellin), alt. environ r $200 \mathrm{~m}$. 3r juillet ( $\left.\mathrm{n}^{\circ} 131\right)$. - Bord du Rio Porce à Medellin, alt. $1550 \mathrm{~m}$. 9 :10ût 


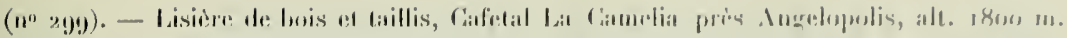

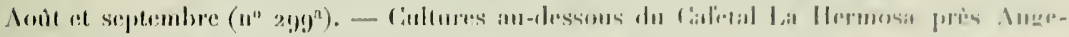

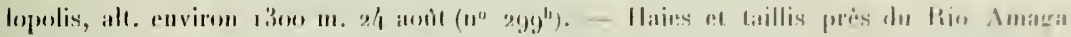

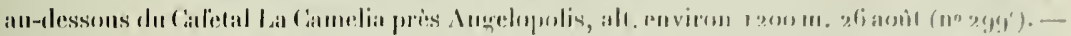

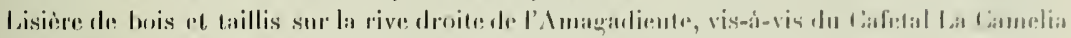

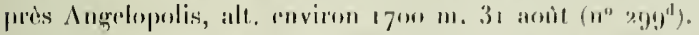

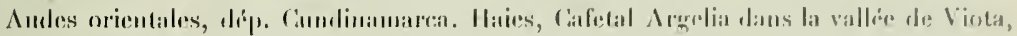
all. 1880111.25 aelobre $\left(11^{\circ} 2 /\right)$.

\section{Aecidium Heliopsidis spec. nov.}

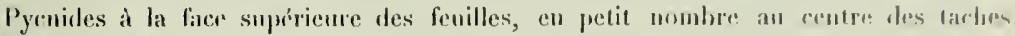

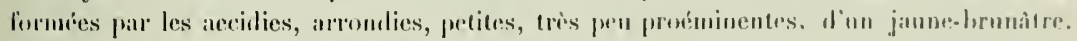

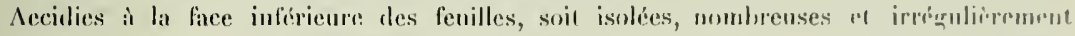
situces a la surface des fenilles, soit réunies en plus ou moins urand nombre frur fromure des taches circulates pouvant atheindre ot meme dipasser 5 mon de diamètre, communiquant ì la face supérienre des lenilles (oin un renconare les pyenides) une coloration al'nu hrun-fanve, en nombre variable, souvent nomloreuses et pouvant devenir confluentes. Les aecidies lorsiqu'clles sont

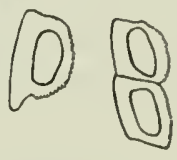
rénnies en taches sont le plus sonvent en pretit mombre et uII peu espacés les uns des antres; elles sont petites, arromdies, d'un janne pite, d'ahord recouvertes par l'epiderme, puis ouvertes et présentent un rebord blanchitre déchiqunté et renversé, laissant voir la poussière des spores d'un jaune rair. - Aecidiospores arrondies on un pen polygonales. r6-21 4 de diamètre, dinn janne trìs paile on mème sublyyalines; membrane d'égale épaissrur partout, mince, envirou i $\mu$, finement verrupueuse, it

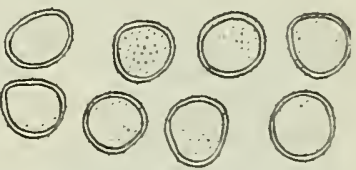

Fig. 79 : Aecidium Heliopsidis. Aecidiospores el cellules de la péridie rues en coupe. verrues petites, peu risihles al assez pen denses. Les cellules de la péridie rues ón coupe présentent une parni externe lisse de 6-7 p d'épraisseur et une interne verruqueuse de $4-5 \mu$ d'épaisseur; ves de face elles sont assez fortemenl verruqueuses.

Pycuidiis epiphyllis, in parvos greges centro masulomm dispmsitis, minnlis, rolundatis, flawo-brunneolis. Aeculius hypophyllis sparsis vel gregariis et macnlis rotundutis (urspue $5 \mathrm{~mm}$ dian.) sparsis vel numerosis confluentilusque brunneis insidentibus. minulis, rotundutis. flawis, primo clansis, dein apertis. murgine albido lacerato recolntogure.

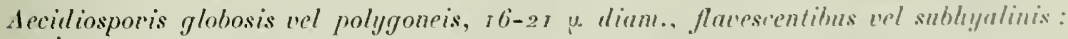

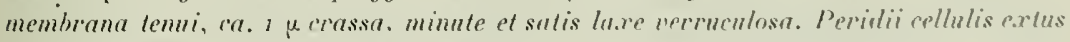
lenibus et $6-7$ u crussis. intus verrucosis et $4-5 \mu$ crassis. 
Sur fenilfes de Heliopsis buphthalmoides (JItce.) Dun.

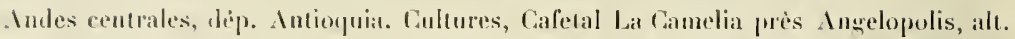

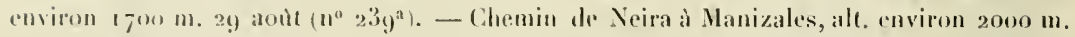
2 actulur $\left(10^{\circ} 82\right)$.

Aules orcidentales, dép. Cauca. Prairies non loiu de Supia, alt. $1270 \mathrm{~m}$. 30 septembre (110 $\left.7^{2}\right)$.

Indes orientales, dép. Cundinamarea. Chemin entre Uhanpe el La Latgua de Ubaque, alt. envion $2000 \mathrm{~m}$. 1 i octolore $\left(1^{\circ} 37\right)$.

Ces arecidies se rapportent-elles ì Purcinia Bimbergi m, c'est ce qu'il est bien difficile de dire en l'alssence dexpériences qui seules lèveraient tous les doutes. Il est vrai de dire qu'au Cafetal La Camelia j’a recueilli ces aecidies sur i ou a feuilles ou se trouvaient aussi quelques amas de téleutospores de P. Bimbergi et ì proximití immérliate de l'Aecidinm; aux autres stations je n’ai jamais rencontré de téleutuspores en compragnic de l'Accidium. Néanmoins le fát d'avoir recueilli sur la même leuille des aecidies el des léleutospores, pose la question de la réunion de Aecidium Heliopsidis et de P'ucciniu Bimbergi en une seule et mème espèce, question qui ne peut ir re encore résolue et ne pourra l'ètre que lorsque des essais d'infection auront pu ètre entrepris.

\section{Aecidium Gymnolomiae spec. nov.}

lecidies sur les deux faces des feuilles; à la face supérieure réunies généralement en
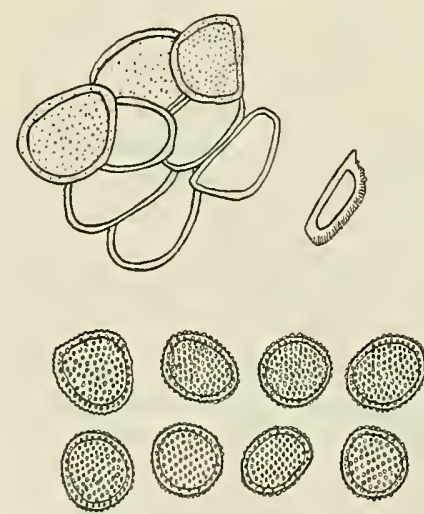

Fig. 80: Aecidium Gymnolomiae. - Aecidiospores et cellules de la péridie vues en coupe el de face petit nombre pour former de petites taches trìs dissíminées, arrondies, de $1-2 \mathrm{~mm}$ de diamètre où le tissu foliacé est brunâtre; à la face inférieure elles présentent le mème aspect ou sont souvent en nombre assez grand le long des nervures sur une longueur de 4-5 $\mathrm{mm}$, parfois mais rarement on en rencontre aussi i la face supérieure sur les nervures. On ne constate pas de déformation sauf souvent aux nervures qui sont un peu éfraissie et parfois un pen tordues. Les aecidies sont petites, arrondies, d'un jaume pâle, d'ahord recouvertes par l'épiderme puis s'ouvrant à maturité et présentant un rebord assez grand, hlanchâtre et dérlinpuetí mais non ou peu renversé. - Aecidiospores arrondies ou un peu ovoïdes, parfois grossicrement polygonales, $2 \tau_{-2} 6 \mu$ de dianètre, d'un jaune très [âle; menibrane d'ígale épaisseur partout, environ $2 \mu$, verruqueuse à verrues nombreuses, denses et assez 


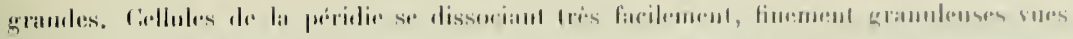

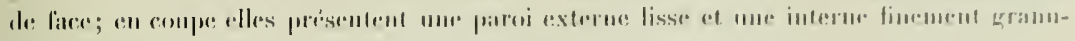

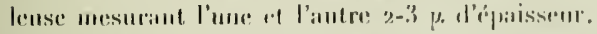

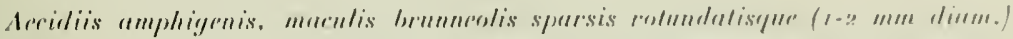

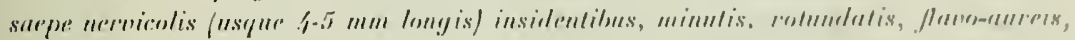

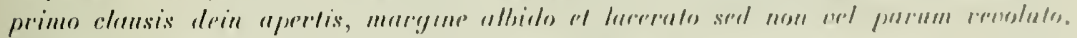

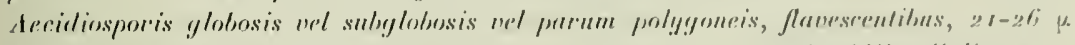

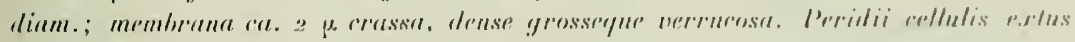
levilus el intus yremulosis, 2-3 p. crassis.

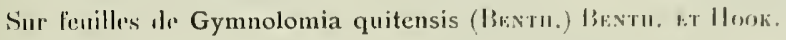

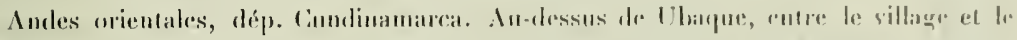

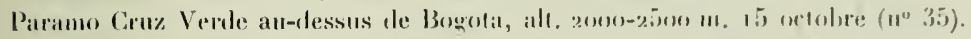

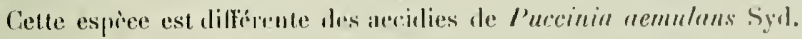

\section{Aecidium Wedeliae Earle.}

in Mulilenhereriiı igor, J. I6.

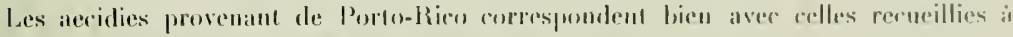
Häti. Les aecidies sont ì la face infériomm des fenilles, parfuis isolies, le plus sumsun groupres en nombre plus ou moins considérable pur former des laches arrondies on un peu allongies mesuraut justu'ì 6 mm de diamètre et parfois dasimlauce, isolées, irrégulièrement disposées et en pretil nombre géméralement. I la face supérieure on constate une coloration janne-brun à l'état frais desenant brun-nuiritre
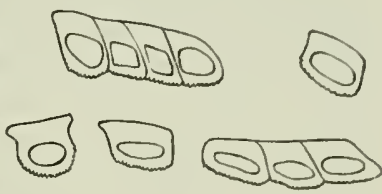
par la dessiccation, tranchant netlement avee le reste de la fenille indemue. A la faec inférieure, les eupules sont le plus souvent un por espacées les unes des autres et entre elles on voit mne coloration brmne des tissils qui déborde les aecidies de 1 à 3 mu. Les a recidies sont pelites, d'un jaune elair; lorsquidles s'ourrent ellis présentent un rebord un pen déchiqueté mais non on rarement renversé. Les aecidiospores sont pretiles, $14-17$ u. de diametre, atrondies ou le plus somvent pulygonales,

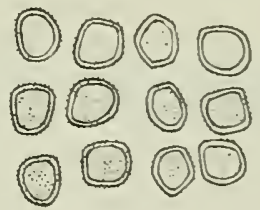

Fig. 81 : Aecidium Wedeliae. - Aecidiospores el cellules de la péridie vues en coupe. d’un janne très pàle; membrane mince, mviron d ${ }^{1} \mu$, tris thement granuleuse. Cellules de la peridie rues en conpe présentant une paroi externe of lisse de 7-9 p. d'épaisseur et une interme rerruquense de 3-5 $\mu$.

\section{Sur feuilles de Wedelia carnosa Rıcн.}

Antilles: Haîti : Cayes, daus le sable prìs de la mer. 17 juillet $\left(n^{\circ} 135\right)$. 


\section{Aecidium Liabi spec. nov.}

Aecidies a la face infiriente des fenilles réunies en nombre plus ou moins considerahle prour former des taches arrondies pouvant alleindre et mone dépasser 1 em de diatmetre, irrénulioment disposies el pen nombrenses. I la face supérieure, on constate gé-
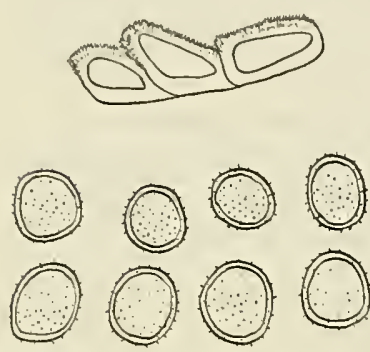

Fig. 82 Aecidium Liabi. - Aecidiospores et cellules de la péridie vues en coupe. niralement une lache d'un bron-noiràtre an centre de langelte sont les pyenides en petit nombre, arrondies et petites, d'un jatune-lorunatre devenant brunes par la dessiceation. Les aeeidies sont petites et arrondies d'un jaune d'or, d'abord recouvertes par l'épiderme qui ensuite se lend ef forme un rebord blanchâtre déchiqueté mais non ou rarement renverse. - Aeeidiospores arrondies on un peu polygonales, 18-24 $\mu$. de diamètre, d'un jaune pale, presque subhyalines; membrane d'égale épaisseur partout, environ $2 \mu$, finement verruqueuse à verrues petites et assez espacées. Les cellules de la péridie vues en coupe présentent une parni externe lisse de $5 \cdot 7 \mu$ d'épaisseur et une interne ćchinulée de 4-6 $\mu$.

Aecidiis hypophyllis, plus minusve dense gregarïs, maculis rotundatis (1 cudiam.) paucis obscure brunneis insidentilus. Pycuidis in parvos greges dispositis, in centro macularum sitis, epipluyllis, minutis, rotundatis, flavo-brunneis dein brunneis. Aecidiis parvis, rotundatis, aurantiacis, primo clansis, dein apertis, margine albido et lacerato sed non vel raro revolnto. Aecidiospor is globosis vel polygoneis, $18-24 \mu$ diam., flavescentibus, fere sublyyalinis: membrana ca. $2 \mu$ crassa, minute laxeque vertucosa. I'eridii cellulis extus levibns et 5-7 $\mu_{0}$ crassis, intus echinulatis et 4-6 $\mu_{.}$crassis.

Sur feuilles de Liabum igniarium (Нunb. ет BonpL.) Less.

Andes centrales, dép. Antioquia. Taillis au sommet de l'Alto Don Elias, alt. $2100 \mathrm{~m}$. 22 aoî̀ $\left(11^{\circ} 197\right)$.

\section{Uredo Pers.}

129. Uredo Nephrolepidis Dietel. spec. nov. '

Maculis iuleterminatis pallidis mox brunneis et arescentibus; soris uredosporifer is hypophyllis, irregulariter dispersis minimis, nudo oculo siugulis vix conspicuis, e parvo

1 Espécc étudice par M. te Dr P. Dietel. 


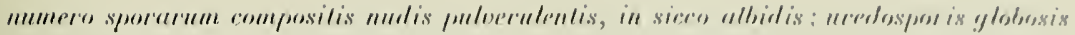

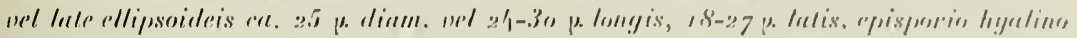

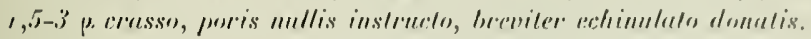

Aul' ren Werlilu sun Nephrolepis pendula liıuнr.

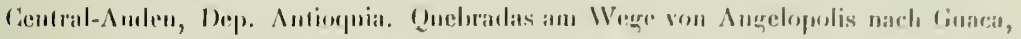

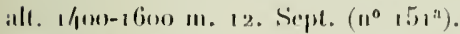

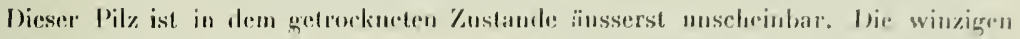

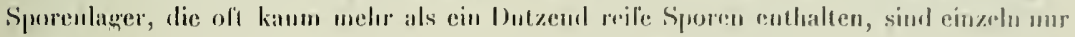
mit der Lupe orkenubar und werden unr dadorch, dass sie oft in grosser Zahl anf einem Fiederhläthen leisammen stehen, mul die abgefallenen Spmen

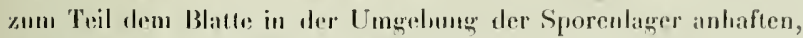
dem hlussen Auge bemerkhar. Die Sproren werden anf einem Ilyphenloindel alugeschürt, das anscheinend immer aus einer Spaltëlfumug hervormegt und keinerlei Vorwöllung des Epidernis verursacht. Ilierdurch unterscheidet sich Uredo Nephrolepidis gan\% wesentlich vou der Uredo von Milesina columbiensis. Eine Peridie ist bei

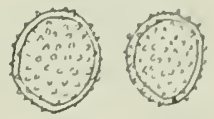

Fig. 83: Úredo Nephrolepidis. - 2 Sporen. Vergr. $500 \times$.

unserem Pilze nicht vorhanden, ebenso keine Paraphysen. Es gehört daher anscheinend diese Pilzlorm in keine der drei auf Furnen hisher bekanut gewordenen fattungen IIy/lopsor"u, Wilesina und ITredinopsis. Die Stachehn der Epispors von Uredo Nephrolepislis sind locker gestellt, krïl'tig, kurz und stumpf, fast warzenförmig, wïhrend sie bei.llilesinu columbiensis dicht stehen umd selur feiu sind.

\section{Uredo Antephorae Syd.}

Ann. Mycol. 1903, p. 22 .

Les uredos recucillis à la Jamaïque correspondent exactenent avec ceux recueillis à Cuba sur le mème support phanérogamique. Comme complément de diagnose, je puis ajouter que la membrane épaisse de 3-5 4 est très tinement et densément granulo-verruqueuse. Les pores germinatifs sont au nombre de 2 ou 3 , équatoriaux lorsqu'ils sont au nombre de 2 .

Sur feuilles de Antephora hermaphrodita (L) O. Kuntze.

Antilles: Jamaïque ; Kingston, Hope Gardens. 14 juillet ( $\left.\mathrm{n}^{\circ} 110\right)$. 


\section{Uredo paspalicola P. Henn.}

in Hedw. XIIT, P. 57.

Les uredos recueillis en Colombie correspundent très hien avec cenx récoltés sur l. mème support par L'LE an Brésil. Les uredosprores sont arrondies, $16-21 \mu$ de diamètre, on ovalaires ou ovales-elliptiques $22-26 \mu . \times 16-19 \mu$, d'un jatune très pàle, subhyalines, parfois mème livalines; membrame d'érale ćpaisseur partout, environ $t^{1 / 2} \mu$, finement échinulée à épines denses el assez grandes. Le nombre al la position des pores germinalifs n'ont pu ètre exactement déterminés.

Sur feuilles de Paspalum conjugatum BEng.

Andes centrales, dép. Antioquia. Bord du Rio Porce aux rnvirons de Medellin, alt. $1550 \mathrm{~m} .13$ aoùt $\left(n^{0} x 65^{\mathrm{a}}\right)$. - Cultures, Cafetal La Camelia près Angelopolis, alt. $1800 \mathrm{~m}$. 19 aoùt $\left(n^{\circ} 165^{\mathrm{b}}\right)$.

\section{Uredo Henningsii Sacc et D. Sacc.}

in Sacc. Syll. XVII, p. $456=$ Uredo Panici P. Henn in Hedw., B. XLIII (1904), Fungi amazonici 1, p. 165.

Sur feuilles de Panicum lanatum Sw.

Andes centrales, dép. Antioquia. Lisière de bois près de El Poblado au-dessus de Medellin, alt. environ 1700 m. 14 aoùt $\left(n^{\circ} 242\right)$.

Ces uredos correspondent très bien avec la description d'Hennings. Les uredospores sont d'un brun clair, subglobuleuses, ovoïdes ou elliptiques, $23-29 \mu \times 17-24 \mu$ (la description originale indique $20-32 \mu \times 18-28 \mu$ ) ; la membrane d'égale épaisseur partout, $2 \mu$., est très finement verruqueuse, à verrues petites, peu visibles et assez pen denses; les pores germinatifs sont au nombre de 2, équatoriaux. Les amas d'uredos sont abondamment envahis par Darluca Filum (Brv.) Cast.

\section{Uredo Cameliae spec. nov.}

Amas d'uredos sur les deux faces des fenilles, petits arrondis on souvent allongés dans le sens des fenilles et atteignant à peine $1 \mathrm{~mm}$ de longueur, isolés ou nombreux et alors un peu conlluents ; lorsque l'infection est considérable, les feuilles deviennent plıs ou muins jaune-brunâtre ; dans les cas légers, on constate seulement à la surface des feuilles de petites stries brunàtres. Les amas sont d'un janne-brun clair [abondamment envahis par Darluca Filum (Brv.) Cast.], longtemps recouverts par l'épiderme qui ne 


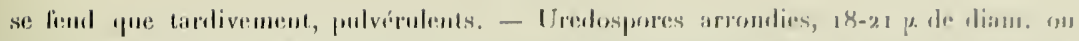

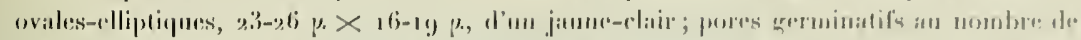

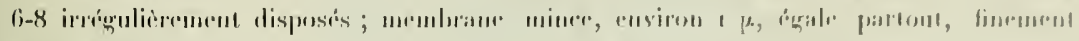

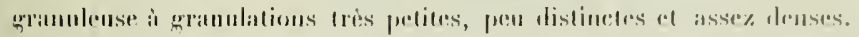

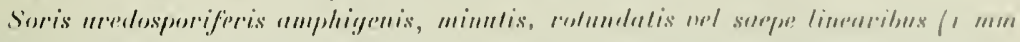

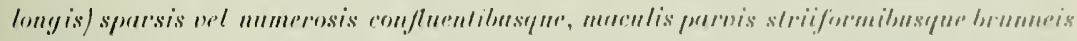

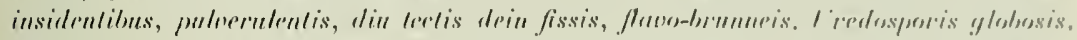

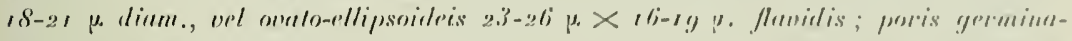

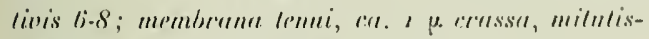
sime el salis dense grammlessu.

Sim feuilles rle Setaria scandens Simnamen.

Aurles rentrales, dép. Antioguia. Cinltures, Cafolit

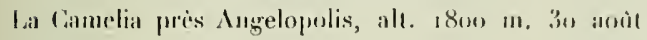
$\left(\begin{array}{lll}\left(11^{0}\right. & 257\end{array}\right)$.

Celte espere dillère des ureslos de firomyess
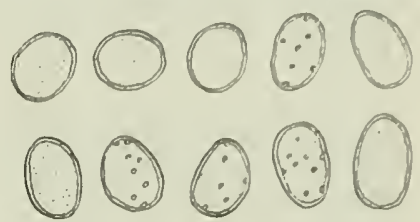

Fig. 81: Uredo Cameliae. - Iredorpores.

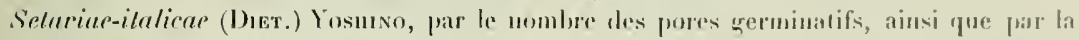
dimension et la coloration des spores. Elle se distingur des ureelos de Pruccinio alra

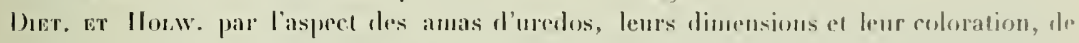
mène que par le nombre des pores gorminatifs. Elle se différencie des uredus do Pluccinio

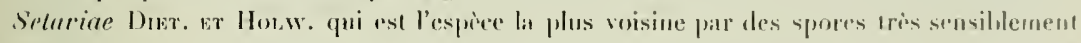
plus pretites el de couleur fauchement jaune; par comle le aumbre des pores germinalifo est lo mème, mais la structure de la membrane semble ètre, ditus uolre espice, rnocore plus finement granuleuse cl surtoul la membrane est mince et pas cpaisse cumme l'iullipur

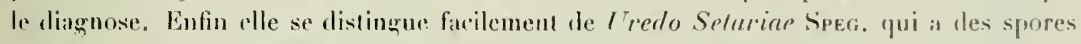

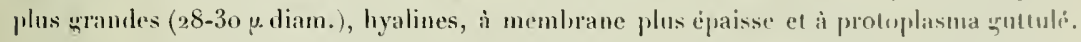

\section{Uredo Torulini P. Henn.} in Hedw. XLIV, p. 5\%.

Les uredos recueillis en Colombic correspondent très exactement ì la liagnus de Ilsanings faite daprès des échantillons sur le mème support phanérogamique provenant du Brésil et récoltés par Ule. Comme compliment à la diagnose, jajouterai yue les pores werminatifs sont au nomhre de deux, équatoriaux; la membrane est l'égale épaisseur partoul, curiron $2 \mu$, finement mais peu densément verruqueuse.

\section{Sur feuilles de Torulinum ferax (L. C. Ricn.) Ĺвв,}

Andes centrales, dép. Antioquia. Bord de la vole ferrée entre Camanli ot Cisuros (chemin de fer de Medellin), alt. ensiron $800 \mathrm{~m}$. 3r juillet ( $n^{\circ} 133$ ). 


\section{Uredo Kyllingiae P. Henn. \\ in Hedw. XXYV. 1896 , p. 256.}

Amas d'uredos sur les tiges et les deux laces des feuilles mais surtout sur la face inférieure formant de petites taches arrondies de $1 / 2^{-1}$ mm débordant un peu les amas et d'un brun clair. Lorsque l'infection est considérable, tout on partic des feuilles prenil une coloration jaune-brun avec des points plus foncés corresjondant aux amas. Les amas sont petits, arrondis, généralement $1 / \mathrm{s}^{-1} \mathrm{e} \mathrm{m}$ de diamètre, ou oblongs et un pen allongés

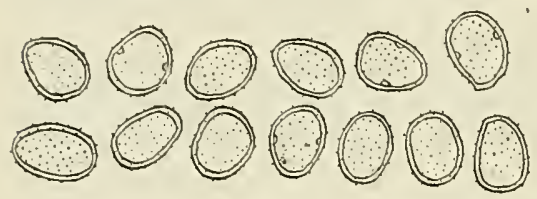

Fig. 85: Uredo Kyllingiae. - Uredospores. dans le sens de la longueur des feuilles, jusqu'à I mm de longueur, isolés ou dispersés ou au contraire nombreux et rapprochés et parfois mais rarement un pen confluents, trìs longtemps recouverts par l'épiderme qui ne se fend que tout à la fin, brun foncé on brun ocre. - Uredospores arrondies ou le plus souvent ovoïdes ou ovalaires, $20-26 \mu . \times 16-19 \mu$, d'un jaune un peu brunàtre, souvent subhyalines et parfois même hyalines; pores germinatifs au nombre de 2 , équatoriaux; membrane d'égale épaisseur partout, environ $2 \mu$, échinulée à épines courtes et peu denscs.

\section{Sur tiges et feuilles de Kyllingia odorata Vall.}

Andes centrales, dép. Antioquia. Chemin de Medellin à Bello, alt. 1550 m. 4 aon̂t $\left(n^{0} 280\right)$.

\section{Sur tiges et feuilles de Kyllingia brevifolia Rotrв.}

Andes centrales, dép. Antioquia. Colline dominant le Rio Porec près de Medellin, aft. environ $1700 \mathrm{~m}$. 10 août $\left(\mathrm{n}^{0} 279\right)$. - Bord de chemins à Guaca, alt. 1480 m. 12 septembre $\left(\mathbf{n}^{\circ} 279^{2}\right)$.

Cette description concorde très exactement avec les échantillons mis à ma disposition par M. Sy dow (Ur. Kyllingine P. Henn. sur Kyllingia odlorata, Martinique, Ieg. Sieber). Il existe cependant une différence entre la diagnose originale de Hennings et les échantillons que j'ai pu examiner, en ce sens que la membrane est indiquée comme étant lisse, alors que tant chez les exemplaires que j'ai recueillis que chez cenx que j’ai comparés, elle est nettement échinulée mais à épines très courtes. 


\section{Uredo superior Arthur.}

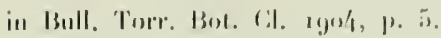

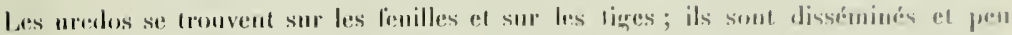

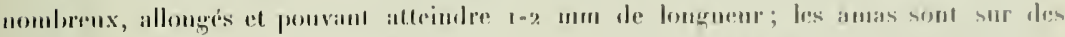

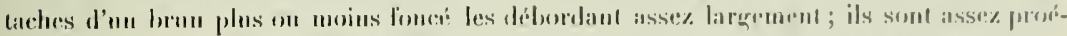

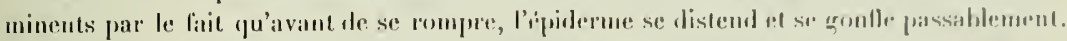

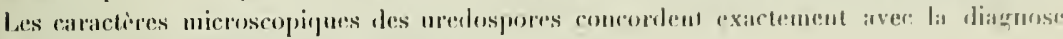
fitite sur des échintillons provenant de Portu-ltico.

Sur liges et feuilles de Fimbrystilis spadicea (I.) Villl.

Antilles: Ilaïli; Cayes, dans le sable an bord de la mer. 17 juilled (In toig).

\section{Uredo Dichromenae Arthur.}

in Bull. Torr. Bot. C.. XXXlll (yob) p. 3ı.

Amas d'uredos sur les liges et il la face inférieure des fenilles, formant sur les deux faces des fenilles des taches d'un hrun fonci, arrondies, débordant largement les amas et mesurant 2-3 mm de diamètre ; lorsque l'infection est considérable, ces taches deviennent sonvent conlluentes et parfois de gramd's surfaces des fenilles prenuent cette coloration Irrun foncé. Giéméralement sur chaque tache, on constate la présence d'un senl amas ou en tout cas d'un très petil nombre; les amas sont arrondis ou un peu allongés, atteignanl à peine $r \mathrm{~mm}$ de longuenr, irrégulièrement disposís, isolt's at dissíninés on nombrenx et rapprochis's mais rarement un peu confluents; ils sont d'un brun foncé ou lrun-noiràtre, très longtemps recourerts par l'épiderme qui ne: se

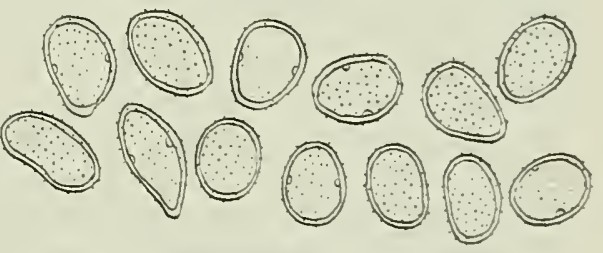

Fig. 86: TTredo Dichromenae. - Uredospores. lénd un peu que très tardivement. Sur les tiges les amas ont le mème aspect, mais ils sont tonjours allongés et très disséminis, prodnisant des taches de mème coloration que sur les fenilles. Les amas duredos sont ahondanment envahis par Durluca Filum (Br.) Cist. - Uredospores ovö̈des ou ovales ou ovales-ellipliques, 20-33 $\mu$. $\times 16-19 \mu$. d'un brun-jaune clair; pores germinatifs an nombre de 2, iquatoriaux; memhrane d'égale éprisseur partout, $2 \mu$, échinulée, à épines conrles, peu risibles et pen denses.

Catte description concorde tris bien avec la diagnose d'.Arthur d'après des échantillons sur Dichromena ciliata et radicans provenint des Antilles et de l'Amérique Centrale. 
Sur tiges et ferilles de Dichromena radicans Cusm. eт Schlecut.

Audes contrales, dép. Antioquia. An-dessus de Cisneros, près de l’auberuge de la Quichra (chemin de Medellin), alt. 1470 m. 3r juillet ( ${ }^{\circ}$ 128). - Bord du Rio Porce

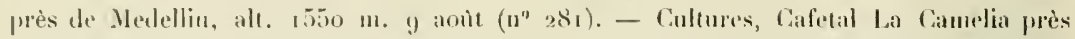

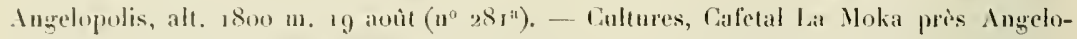
polis, alt. $17^{001}$ m. 29 a and $\left(n^{0} 28^{\mathrm{b}}\right)$.

Sur liges et feuilles de Dichromena polystachys Tunnis.

Andes centrales, dép. Antioquia. Taillis au-dessous du Cafetal la Camelia prìs Inugelopolis, alt. environ 1500 in. 10 septembre $\left(n^{0} 282\right)$.

\title{
138. Uredo Hypoxidis (Bres.) P. Henn.
}

\author{
in Hedw. 190 r, p. $(173)$.
}

Amas d'uredos sur les deux faces des feuilles, souvent très nombreux mais isolés et non conlluents, irrégulièrenent disposés. Au niveau des amas, les tissus foliacés prennent une coloration brune parfois un peu rougeatre débordant les amas et, en cas d'infection considérable, les feuilles sur leurs deux faces sont maculées de taches plus on moins

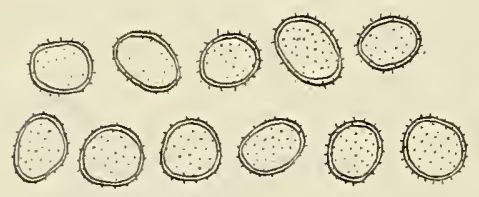

Fig. 87: Uredo Hypoxidis, - Uredospores. grandes el confluentes d'un brun-rougeâtre. Les amas sont petits, arrondis, d'un brum assez clair, très longtemps recouverts par l'épiderme qui n'éclate que tardirement. Uredospores arrondies, 16-19 $\mu$ de diamètre ou ovalaires, 17-23 $\mu$. $\times$ 16-18 $\mu$. d'un jaune-brunâtre; la position et le nombre des pores germinatifs n'ont pu ètre exactentent déterminés; membrane d'égale épaisseur partout, I 1/2-2 $\mu$, échinulée à épines courtes et assez peu denses.

Cette description concorde très bien avec la courte diagnose originale; celte espèce a été rencontrée à São Paulo (Brésil) par Putremans, sur le mème support phanérogamique (Hedw. B. XLI. rgoz, p. ro6i).

\section{Sur feuilles de Hypoxis decumbens L.}

Andes centrales, dép. Antioquia. Cultures, Cafetal La Camelia près Angelopolis, alt. $1800 \mathrm{~m} .19$ aoùt $\left(\mathrm{n}^{\circ} 230\right)$. - Cultures à Guaca, alt. $1480 \mathrm{~m}$. İ septembre $\left(\mathrm{n}^{\circ} 230^{\mathrm{a}}\right)$. 


\section{Uredo Guacae spec. nov.}

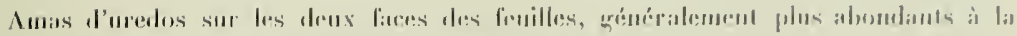

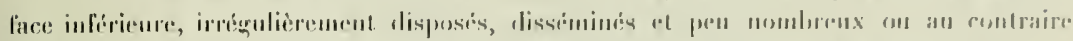

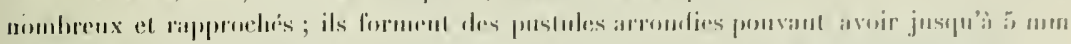

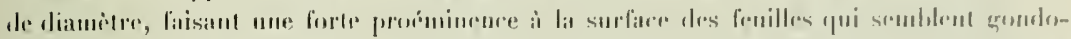

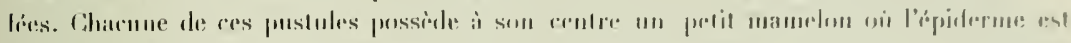

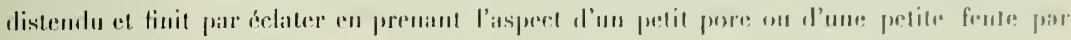

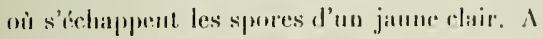
la face opposion a relle ois soml les amas el leur correspomblant, on remaryure des bonrsouflures prespue anssi marquins mais sitns onverture. les leuilles allatuces ne subissent pas de déformation sauf celle produite par les amas eux-mèmes; quand l'unlection est considérable, elles prenuent mur eoloration d'un jounte-brunatle, sinou cetle mème cou-
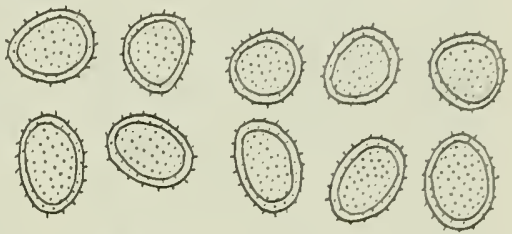

Fig. 8s: Uredo liuacae. - Uredospores.

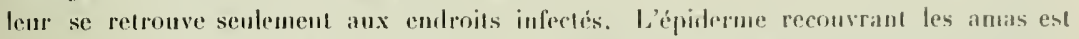
d'un brum-jaune on fauve et le mamelon, januitre il l'itat frais, devient lomatre par la dessiccalion. En cas de forte infection, les amas peuvent un pen confluer, mais alors c'est le pourtour des pustules qui se rejoignent el pas les ouverlures tonjours tres nellement séparées. - Uredospores arrondies, 2.3-26 p. de diamètre on ovilairrs, 23 - $28 \mu \times 19$ $23 \mu$, d'un jaune clair; membrane d'ígale épaisseur partonl, envirm $2-2 \frac{1}{2} \mu$, épineuse à épines assez grandes mais pen denses. Lit position el le nombre des pores germinatifs nout pu itre exaetconent déterminés.

Soris urerlosporiferis amphigenis. praeripne luypophyllis, spursis el pancis nel numerosis el aggregatis sed non confluentilus, rolundatis (ustue ij mm diam.). pustulantibus, flavo-brunneis, in centro pustularum mamillis flavis epidermide lullatn tertis dein fissis, maculis flawn-brumm is wel fulvis insilentibus. L'pedosporis glohosis $23-26$ diam. vel ovatis, $23-28 \mu \times 19-23 \mu$, fluvidis; membrana ca. $2-21 \%$ crassa, salis laxe echinala.

\section{Sur feuilles de Epidendrum spec.}

Andes centrales, dép. Antioquia. Bord de chemin ì Guaca, alt. 1480 m. 12 septembre $\left(n^{\circ}\right.$ ro8).

Celle esperce diftère de Uredo Epilendri P. Hex.s. (sur Epidendrum spec. au Brésil par laspect des anas, par la couleur des uredospores qui sont l'un janne clair mais pas subhyalines ou rarement, par leurs dimensions plus petites, par lippaisseur de la membrane qui est de $2 \mu$ el pas jusqu'à à $\mu$, entio la membrane est meltement épineuse el pas nepisporin sublevi vel minute punctalo-verruculoso ". Elle differe aussi de $U$. Willmactiana P. Hexs- 
et Kiltzang (sur Epidendrum spec. au Mexique) par l'aspect des amas d'uredos; leurs uredospores sout hyaline's el plus graudes et leur membrane alleiut jusqu'à 5 u d'épraisseur.

\section{Uredo Cyathulae spec. nov.}

Amas d'uredos à la lace inférieure des feuilles, rarement guelques-uns à la fice supérieure, isolés ou souvent rénnis en groupes confluents pour former des laches arrondies de $1-2$ mm de diamètre, irrégulièrement disposées el généralement non confluentes. Lorsque les amas sont isolis, ils ne provoquent ancune alteration des tissus; lorsqu'ils sont

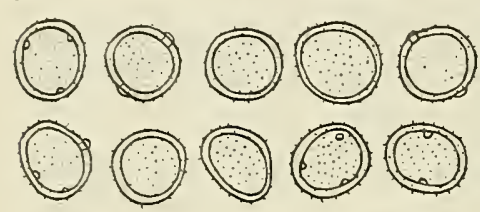

Fig. 89: Uredo Cyathulae. - Uredospores. agglomerés, on voil sur les deux faces une coloration brun-chamois des tissus. Les amas sont petils, arrondis, isolés un conllıents, de couleur caunelle, d'abord recouverts assez longtemps par l'épiderme qui ćclate ensuite en leur formant. souvent un petit rebord, - Uredospores arrondies on un peu ovoïdes, 20-24 $\mu$ de diamètre, d'un jaune-brun pàle ; pores germinatifs 2 équatoriaux parfois au nombre de 3, surmoutés d'une très petite papille hyaline; membranc d'égale épaisseur partout, 2-3 y., échinulée à épines courles et assez peu denses.

Soris uredosporiferis hypophyllis, raro epiphyllis. sparsis et sine muculis vel gregariis confluentibusque et maculis rotundatis $(\mathrm{I}-2 \mathrm{~mm}$ diam.) sparsis flavo-brunneis insidentibus, minutis, rotundatis. diu epidermide tectis dein saepe cinctis, cinnamomeis. Iredosporis globosis vel subglobosis, 20-24 \% diam., dilute flavo-brunneis ; poris germinativis 2 aequatorialibus vel interdum 3 ; membrana $2-3 \mu$ crassa, minute satisque laxe echinulata.

Sur feuille de Cyatula achyranthoides (H. B. K.) Moe.

Andes orientales, dép. Cundinamarca. Chemin de Ilonda à Guaduas, non loin de Honda, alı. environ $700 \mathrm{~m} .8$ octobre $\left(\mathrm{n}^{0} 80\right)$.

\section{Uredo amagensis spec. nov.}

Amas d'uredos sur les deux faces des feuilles, mais surtout à la face inféricure, en nombre variable, souvent très abondants sur toute la surface des feuilles, rapprochés mais non confluents ou très rarement; les amas font de petites taches d'un brun parfois un peu violacé, le plus souvent confluentes, et alors de grandes surfaces des feuilles prennent une coloration brune. Les amas sont petits, punctiformes, longtemps recouverts par l'épiderme brun clair souvent violacé ou rosé, tardivement nus, d'un brun clair et entourés d'un très mince rebord épidermique. - Uredospores arrondies, I6-23 $\mu$ de diamètre, 


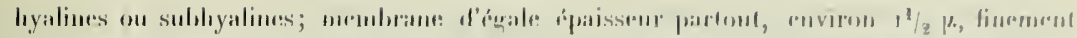

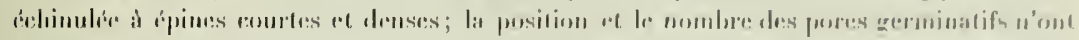

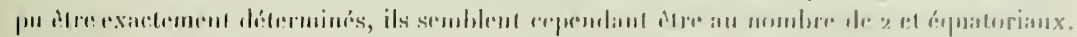

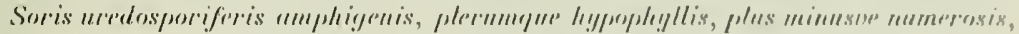
surpere mumeressissimis al grergariis sed non wel ramoro prormum confluentiluss, muculis minutis stuppius confuentitus bremuneis: nel brunueo-violucris insidrutibus, punctiformilus, diu rpislermider brunneola intere-

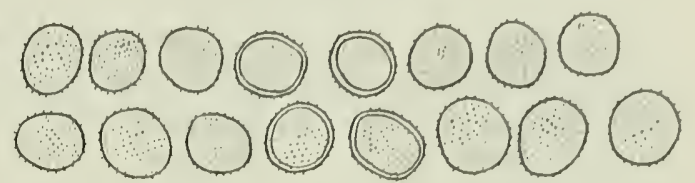

Vig. 90: Urudo itmagensis - Viredospores.

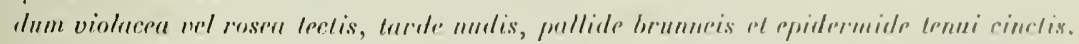

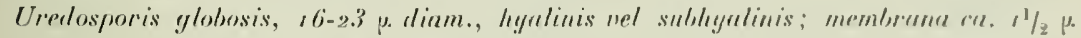
cressser, minule dernseryue echinuletu.

Sur feuilles de Desmodium tortuosum (Sw.) Dr.

Audes centrales, dép. Antiorpuia. Culfures press du lio Amagit au-tlessous du Ciafelal

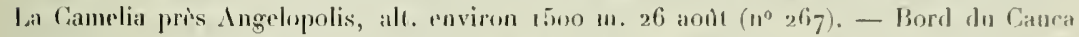

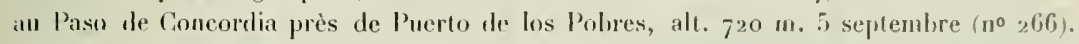

Cette espice differe de Tr. Desmoulii-torluosi P. IIesx. provenant de Porto-lico par de nombreux calactires. En effet l'aspect macroscopique des amis est dilfrent, ils sont très longtemps recouverts par l'épiderme d'un lirun clair souvent vinhacé ou rosé, ils ne sont pas "pulvinato-applanalis » el surtout jamais "patelliformibns». Les uredospores sont arrondies et pas ovoüdes on ohlongues, elles sont hyalines ou subhyalines, mais jamais "llavo-brunneis»; la membrane est tris finement échimulée alors que la liagnose de $U r$. Desmodii-tortuosi indique "pisporio levi, hrunneo». Ces nombreux caractères differentiels me semblent justifier la création d'une espece nouvelle.

\section{Uredo Hymenaeae spec. nov.}

Amas d'uredos à la face inférieure des fenilles, petits, punctiformes, disséminés,

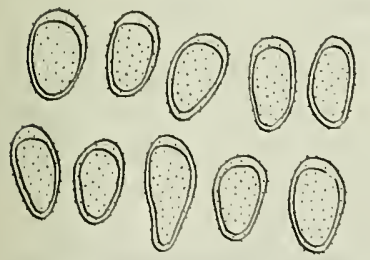

Fig. 91: Uredo Hymenaeae. - Uredospores. isolés, ne faisant pas de taches spéciales sur les feuilles, brun foncé, longremps recouverts par l'épiderme qui ne disparait que tardisement. - Uredospores osalaires, ovoïdes ou elliptiques, $23-30 \mu>14-16 \mu$, d'un brunjaune clair; membrane environ $1 \frac{11}{2} \mu$ d'épaisseur, un peu renflíe à son extrémité où elle atteint 4-5 u, ichinulée, à épines courles et assez espacées. Le nombre et la position des pores germinatifs n'ont pu étre exactement determinés. 
Soris uredosporiferis hypuphyllis, sine maculis, puncliformilues, sparsis non con-

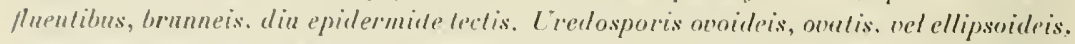

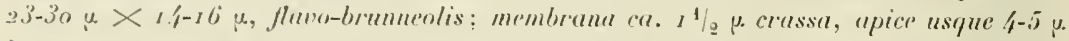
incrassalu, minule satisyne laxe echimuluto.

Sur feuilles tle Hymenaea spee.

Indes centrales, dép. Intioquir. Bord de chemin non loin de Salvaletas près de Titiribi, alt. environ $1500 \mathrm{~m}$. 15 septembre $\left(n^{\circ} 149\right)$ ).

\section{Uredo Aeschynomenis Arth.}

in Botat. Gaz. XXXIX (rgo5) p. 392; Nortlı, Amer. NI. v. VII (Ign'7) p. 104.

Amas d'uredos sur les deux faces des feuilles mais surtout à l'inférieure, isolés et dispersés ou an contraire abondants et rapprochés et souvent un peu confluents, formant alors de petites taches d'un brun-roux atteignant jusqu'à 1 mm de diamètre; les amas
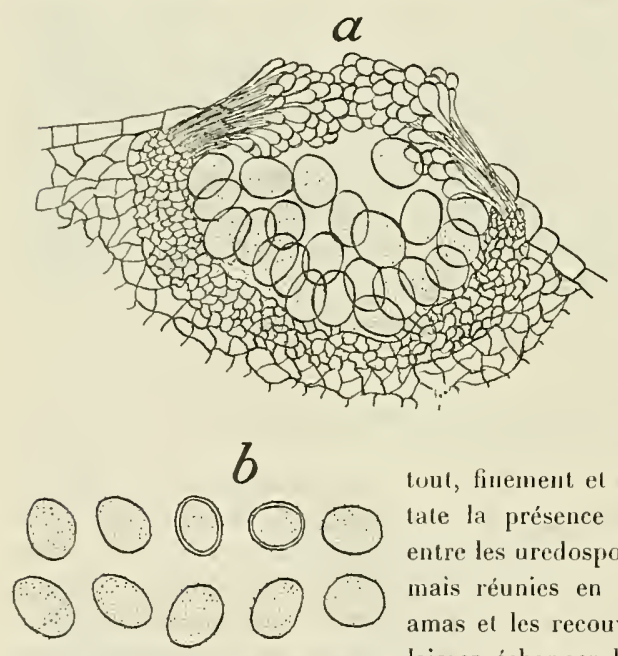

Fig. 92 : Uredo Aeschynomenis sur Aeschynomene americana. - a) Coupe par un amas d'uredo. - b) Uredospores. très souvent groupés en nombro plus ou moins grand et un peu confluents sont d'un brun-ronx, petits et arrondis, longtemps fermés et s'ouvrant tardivement par une sorte de pore central irrégulièrement arrondi et non par une fente. - Uredospores arrondies, $16-19 \mu$, ou ovalaires, $18-26 \mu \times 13-16 \mu$, d'un jaune paile; le nombre et la position des pores germinatifs n'ont pu ètre exactement déterminés; membrane mince, environ I $\mu$, d'égale épaisseur partout, finement et assez densément gramuleuse. On constate la présence de nombreuses paraphyses non pas entre les uredospores et les séparant les unes des autres, mais réunies en nombre considérable au pourtour des amas et les recouvrant; à maturité elles s'écartent pour laisser échapper les spores par une sorte de pore. Ces paraphyses sont d'un jaune pâle, un peu rentlées à leur extrémité en forme de massue (jusqu’à $10 \mu$ de largeur).

Cette description concorde très bien avec la diagnose d'Antnur faite sur des échantillons de Aesehynomene amerieana provenant du Mexique. 
Sur fruilles dr: Aeschynomene sensitiva Sis.

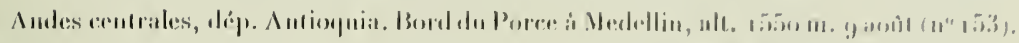

Sul limilles ald Aeschynomene americana I.

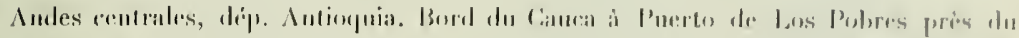

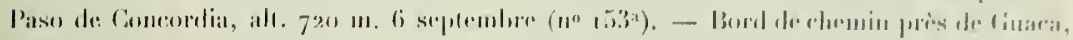

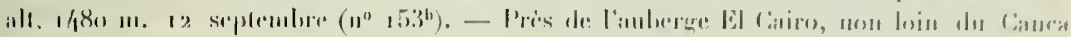

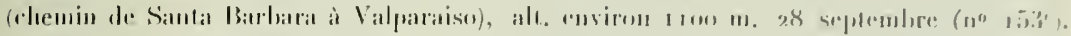

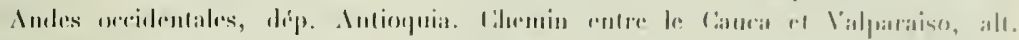

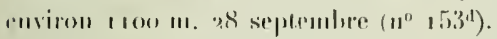

\section{Uredo Teramni spec. nov.}

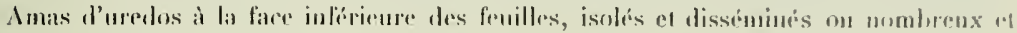

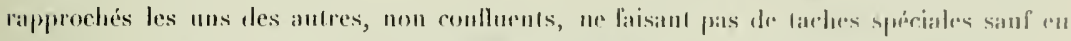
cas de forte infection où on constitte nute roleration

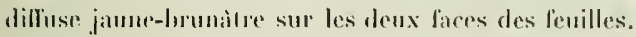
Les amas semt prelits, arromlis, bruns, d'almed recou-

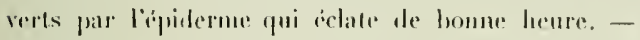
Credospores arrondies, 17-21 y. de diamidre, d'un

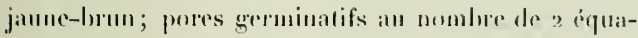
loriaux on 3, recouverls d'une très petite papille
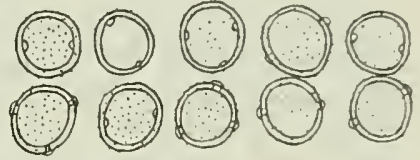

Fig. 93: ['redo Teramni. - Uredospores.

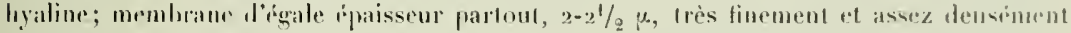
dchimulée à épines tris courles et très pen visibles.

Soris uredosporiferis hypophyllis, sparsis, puncis vol unmerosis, nom monfuentiluns, sine maculis, minutis, mundatis, brunneis, primo ppielermide tectis, drin nulis. Lredosporis globosis, $17-21 \mu$ dirmm., flano-brmuneis: poris germinatinis z afoun-

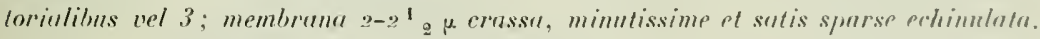

Sur livuilles de Teramnus uncinatus (L) Sw.

Andes centrates, dép. Antioquia. Taillis le long du Rio Porce aux environs de Medellin, alt. $1550 \mathrm{~m}$ m. 6 aout $\left(\mathrm{n}^{0} 274\right)$.

\section{Uredo caucensis spec. nov.}

Amas d'uredos à la face inférieure des feuilles, généralement nombremx, irrigulièrement disposés, isolés ou rarement un peu conllnents, parfois réunis pour former de petites 
taches de 2-3 mm de diamètre prenant à la face supérieure unc coloration brune; les amas sont petits, arrondis, très rapidement nus, d'un brun pìle ou d'un jaune-bruntre. -
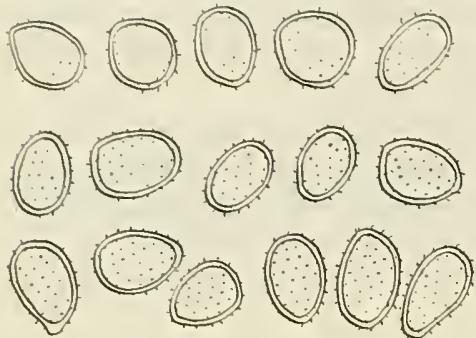

Fig. 97: Uretlo caucensis, - Uredospores. Ureduspores ovoïdes, ovales ou elliptiques, $21-30 \mu \times 16-22 \mu$, de couleur jaune clair sourent subhyalines; membrane d'égale épaisseur partout, environ $1 \%$, épineuse ì épines asse grandes urits peu denses; le nombre et la position des pores germinatifis n'ont pu ètre exactement déterminès.

Soris uredosporiferis hypophyllis, numerosis, sparsis vel gregariis sed raro parmm confluentibus, muculis minutis (usque $2-3 \mathrm{~mm}$ diam.) brunneis insidentibus, rotundatis, minulis, mox madis, pullide vel fluvo-brunneolis. Uredosporis onoideis vel ovatis vel ellipsoideis, $2 \pi-30 \mu \times{ }_{1} 6-22 \mu$, flavidulis vel hyalino-flavescentibns: membrana ca. ' '․ erassa, satis laxe echinatu.

Sur leuilles de Vitis spec.

Andes occidentales, dép. Antioquia. Forèts près du Cauca sur le chemin de Valparaiso, alt. environ $850 \mathrm{~m}, 28$ septembre $\left(\mathrm{n}^{\circ} 9^{\mathrm{I}}\right)$.

\section{Uredo Gossypii Lagerh.}

in Journ. of Myc. $18_{9} 1$, p. 48 .

Cette espèce décrite par Lagerheru sur des échantillons de Gossypinm spec. provenant de l'Équateur, correspond bien avec celle que j’ai eu l'occasion de recueillir en Colombie et je ne constate de différence que dans l'organisation des paraphlıses.

Les amas d'uredos sont sur les deux faces des feuilles, mais surtout à l'inférieure, irrégulièrement disposés, disséminés ou au conIraire très nombreux et rapprochés mais rarement coulluents. Quand l'infection est

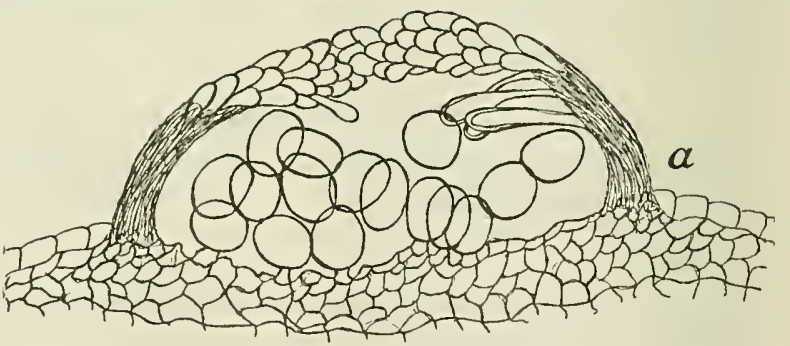
considérable les feuilles entières prennent une coloration jaunâtre piquetée de pointsł̧bruns correspondant aux amas; en cas de faible infection, on constate un nombre plus ou moins 


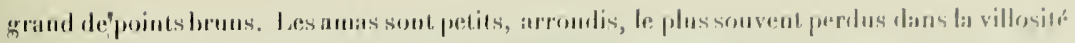

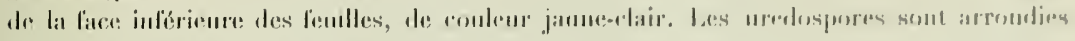
( 18 -2/pedediamilare), ovoüdes on

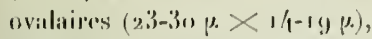
d'un jiune: lries prile, souvent subliyalines; mombrane d'regale épaisseur partout, envirot $\% \mu$, parfois mais ratement un peu épatissic an nivean de l'insertion du pélicelle triss court et rarluc, elle est fípineuse à cipines courtes mais assez denses. 1e nombre ch la position des pores germinalil's nont pu dire exactentent détermines. La diannose de Lagenuв inelique "paraphysi-

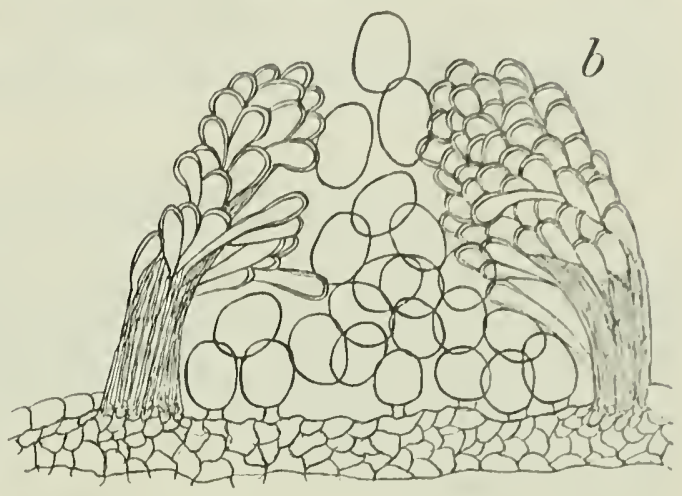
lus clavatis immixtisn; dans les relantillons de Colombie, les paraphyses forment une sorte d'enveloppe aux antas; alles les recouvrent d'ahord et à malurité s'écartent pour laisser échapper les spores: je u'ai pas vu de parapliyses mélangés aux uredospores. Ces parapliyses qui furment me sorte de rehord aux amas d'uredos sont un peu renllés en massue à leur extrímité et atteignent $1 \% \mu$ de largeu'; ìl'extrémité la membraneest un peu ćpaissic, environ $1 \frac{1}{2} \mu$; elles sont decouleur jaune très pàle on sublyyalines.

Sul feuilles de Gossypium ef. religiosum I.

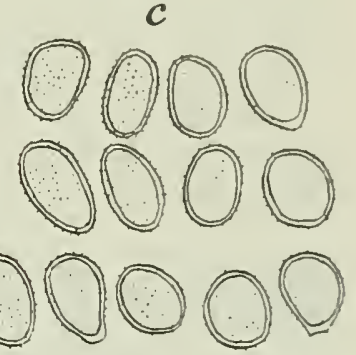

Fig. 95: Uredo Gossypii. - a) et b) coupes

Andes centrales, dep. Antioquia. Cultures au-dessous par un amas diuredo. c) Uredospores.

du Cafetal La Camedia près Angelopolis, alt. emviron 1600 m. 30 aoult $\left(11^{\circ} 2001\right)$. Cultures à Guaca, alt. r.5oo $m$. 1? septembre $\left(11^{0} 200^{2}\right)$.

Sur fenilles de Gossypium spec.

Andes orientales, dép. Cundinamarea. Cultures près de Villeta (cliemin de Honda à Bogota), alt. environ $870 \mathrm{~m} .9$ octobre (n० 63). - Cultures, Cafelal Buenavista dans la vallée de Viota, alt. $1020 \mathrm{~m} .27$ octohre $\left(1^{\circ} 6\right)$. 


\section{Uredo Cupheae P. Henn.}

in $11 e d w .18$ yin, P. 99.

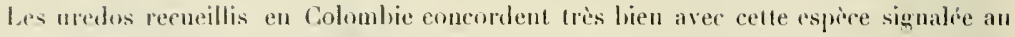
brésil sur Cuphea spece et C. micrantha.

\section{Sur feuilles de Cuphea serpyllifolia II. B. li.}

Andes centrales, dép. Antioquia. Cultures près de Yarumito (chemin de Medellin à Cisneros), alt. environ 1500 n. 1 andut $\left(n^{0} 198\right)$. Chemin de Medellin à Bello, alt.

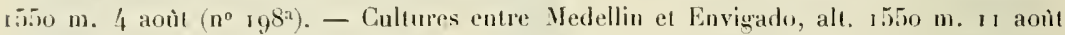
$\left(n^{0} 198^{b}\right)$. - Culures Cafetal La Moka près Angelopolis, alt. environ r 600 m. 29 aotic $\left(11^{\circ} 19^{\circ}\right)$. - Cultures, Cafetal La Camelia et La Hermosa près Angelopolis, alt. 14001800 m. Loùt et septembre (no r $\left.9^{8^{d}}\right)$. - Cultures et burd de chemins ì Guaca, alt. 1480 m. 12 septembre $\left.\left(n^{\circ} 19^{3}\right)^{\mathrm{e}}\right)$.

\section{Uredo Myrciae spec. nov.}

Amas d'uredos à la face inférieure des feniljes, rarement isolés, généralement réunis en groupes pour former des laches plus on moins arrondies mesurant jusquà 5 mun de diamètre, irrégulièrement disposées, sonvent nombreuses et eonfluentes; à la face supé-

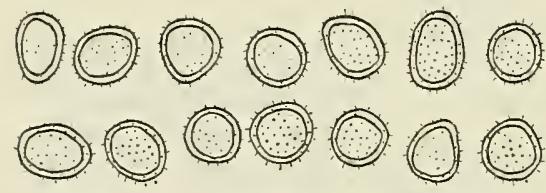

Fig. 96: Uredo Myrciae. - Uredospores. rieure des feuilles et correspondant aux amas, on constate des taches d'un brun foncé souvent un peu rougeàtre entourées d'une zone d'un brun clair. Les amas sont sur un fond brun-fauve qui les déborde le plus souvent; ils sont isolés ou plus souvent conlluents, d'un jaune paille, longtemps recouverts par l'épiderme qui se fend assez tardivement et leur forme un rebord irrégulier. - Uredospores arrondies, $16-19 \mu$ de diamètre ou ovö̈les ou ovoüdes-elliptiques, $18-21 \mu . \times 15-17 \mu$, d'un jaune trìs pâle ou subliyalines, membrane d'égale épaisseur partout, environ $2 \mu$, ćpineuse à épines assez grandes mais pen denses. Le nombre et la position des pores germinatifs n'ont pu ètre exactement cléterminés.

Soris uredosporiferis hypophyllis, gregariis vel raro sparsis, maculis molunlatis (nsque 5 mm diam.) saepe numerosis confluentibusque rufo-brunneis insidentibns, sparsis, sappius conflnentibus, flanulis, dintins tectis, dein epidermide cinctis. Uredosporis globosis, $16-1.9 \mu$. diam. vel ouoideis vel ovoideo-ellipsoideis, $18-21 \mu \times 1.5-17 \mu$, flavesrentibus vel subthyalinis; membrana ca. 2 p.crassa, sutis taxe echinata. 
Sur lenilles de: Myrcia rf. acuminati (11. B. K., 1):

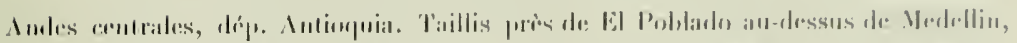

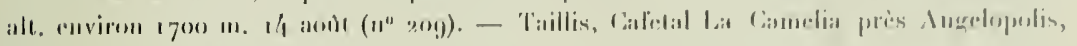

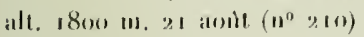

\section{Uredo cundinamarcensis spec. nov.}

Amas d'uredos sur les deux linces rles fonilles mais primripalement à la far inforimare, disséminés el très peu nombreux, ne faisant ancume larlur sur len lissus, iscoles mais mon

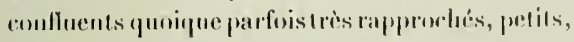
arrondis ou le plus souvent allongés et atleignant 1 mum de longueur, d'un lorun faure, d'abord recouverts par l'épiderme qui śclate à la fiu el leur forme un morl irrégulier d'un lirmn plus clair. - Trerlospores arrondies ou ovoüde's, $21-28 \mu . \times 18-23 \mu$, d'un jaune paile; pores rer-

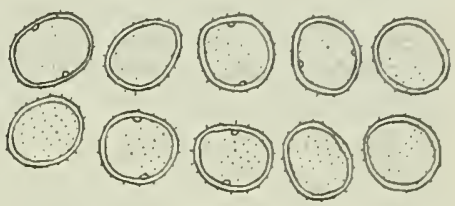

Fig. 97: Uredo cundinamarcensis, - Credospores. minatils an nombre de 2 équatoriaux; memlorane d'égale épaisseur partont, environ $1 / \frac{1}{2}-2 \mu$, finenent fichnolée à épines cosurtes at peu denses.

Soris uredosporiferis amphigenis preferipue hypophyllis, spursis, non romfluentibus, sine maculis, minutis, rotundatis vel sacpins oblongis ol usque 1 mm longis, fulvis, primo tectis dein epilermide cinctis. Urerdosporis ylobos is vel onoide is, $21-28 y .<18-2.3 \mu$., flavidis; poris germinativis 2 aequatorialibus, membrana ca. ${ }^{1} 1 / \mathrm{g}^{-2} \mu$ crosss, mimute laxeque echinulata.

Sur feuilles de Apium ternatum (Wuld.) Thellung var. ranunculifolium (H. В. К.) Thellusi.

Andes urientales, dep. Cumbinamarea. Paramo Cruz Verde an-dessus de Bugua, all. $3400 \mathrm{III}, 14$ et 15 octobre $\left(11^{\circ} 30\right)$.

\section{Uredo Mandevillae spec. nov.}

Amas d'uredos à la face inférieure des feuilles, irrégulièrement disprosés, dissémines ou le plus souvent nombreux et rapprochés mitis non conthents, se manifestant à la face supérieure par un pointillé janne-brunàtre d'autant plus abondant que l'infection est plus intense; ils sont petits et irrondis (à peine $1 / 9$ mu de diamc̀tre), jaunes, nus de très bonne 
heure, pulvérulents. - Lredospores arrondies, ti-1 9 p. de diamètre, diun jaune très paile;

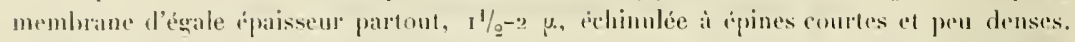

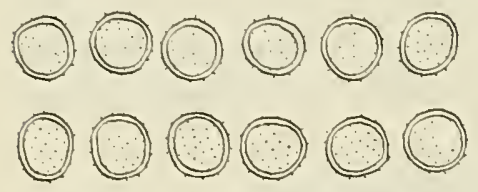

Fig. 98: Uredo Mandevillie. - Uredospores. le nombre et la position des pores germinatifs n'ont pu ètre exactement détermincs.

Sortis uredosporiferis hypophyllis, sparsis vel numerosis el gregariis sed non conflnentibns, maculis mimulis rotundatis flano-lnrmueis insidentibus, minutis, rolundatis (1/2 mm diam.), flavis, mox nudis, pulerernlentis. Uredosporis

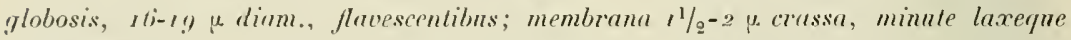
echinulate.

Sur feuilles de Mandevilla ef. mollissima (H. B. K.) K. Schumann.

Andes centrales, dép. Antioquia. Itaies, non loin de Sabaletas près de Titiribi, alt. environ $1500 \mathrm{~m}, 15$ septembre $\left(n^{\circ} 226\right)$.

\section{Uredo Salviarum spec. nov.}

Amas d'uredos à la face inférieure des feuilles, ne donnant pas aux tissus foliacés une coloration particulière, petils, arrondis, alteignant au maximum ${ }_{1 / 2}^{1 / 2 m}$ de diamètre, irrégulièrement disposés, isolés, disséminés ou assez abondants, d’un brun funcé, d’abord recouverts par i'épiderme, puis nus. - Lredospores arrondies, I9-24 $\mu$. de diamètre on plus rarement ovoüdes, $23-26 \mu . \times 19^{-2} 3 \mu$, d'un brun assez clair; membrane d'égale épaisseur partout environ 2 p., très peu visiblement et peu densément granuleuse; pores germinatifs au nombre de 2, équatoriaux.

Soris utedosporiferis hypophyllis, sine maculis, minutis, rotundatis, vix $1 / 2 \mathrm{~mm}$ dium., sparsis interdnm numerosis sed non confluentibus, brunneis vel obscure brunneis, primo epidermide lectis dein nudis. Uredosporis globosis, $19-24 \mu$ dimm. nel rarius
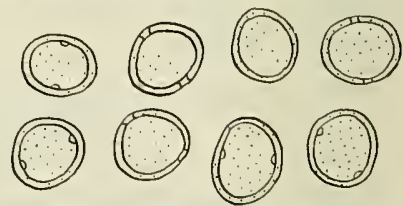

Fig. 99: Uredo Salviarum sur Salvia petiolaris. - Uredospores. ovoideis, $23-26 \mu \times 19-23 \mu$, brnnneis nel dilute brunneis: membrana ca. $2 \mu$. crassa, minutissime el subtilitissime grannlosa; poris germinativis 2 aeqnatoriatibus.

\section{Sur feuilles de Salvia petiolaris H. B. K.}

Andes centrales, dép. Antioquia. Cultures, Cafetal Le Camelia près Angelopolis, alt. $1800 \mathrm{~m}$. Aoùt et septembre $\left(\mathrm{n}^{\circ} 203\right)$. - Dép. Tolima. Près de Soledad, sur le chemin de Mariquita, alt. $2345 \mathrm{~m}$. 6 octobre $\left(\mathrm{n}^{\circ} 203^{\mathrm{a}}\right)$. 
Sur fenilles de Salvia cataractarun lius.

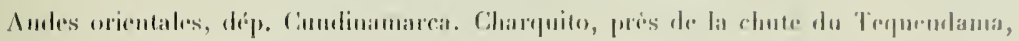
all. 2.300 m. 12 octolure $\left(11^{n / 19}\right)$.

Sur fruilles de: Salvia Mayorii Bume.

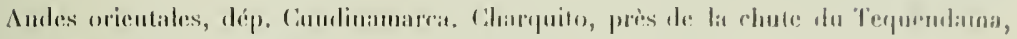
alt. $2300 \mathrm{~m}$. 12 actohe $\left(10^{n} / 7\right)$.

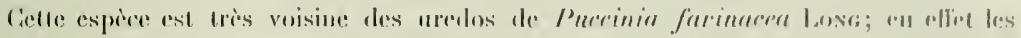

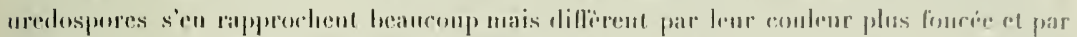

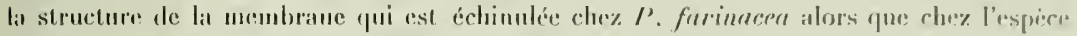
dérite ci-dessus, elle ast tris finement, subtilement ef presine invisiblament gramuleuse.

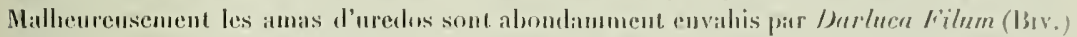

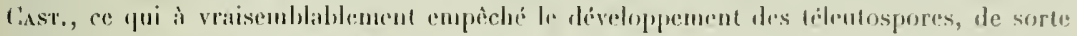
qu’il ne u'a pits été possible de les comprarer avec celles do P’ furinncen. Sur les fenilles de Salvia Mayorii Bug., les uredospores ont le mème aspect microscopique que sur les deux autres supports, seul l'aspect macroscopigue est un peu dillírent. Les urerles sout perdus au milieu de la villosite des feuilles, le plus souveut rénnis en groupe pour former de petiles taches de $1-3 \mathrm{kmm}$ de diamère, d'un brun-jaune; ils sont uns de très bonne heure et la ponssière des spores se répand daus la villusité du voisinage.

\section{Uredo Hyptidis-atrorubentis spec. nov.}

Amas aluredos it la fice inférieure des fenilles petits, arrondis, punctiformes, isoles, dissemincs ou assez nomhreux mals tris rarement conlluents, faisant ì la face superieure dre très petites taches ne dépassant pas 2 mm de diamètre d'un brun plus ou moins foncé qui peut s'étendre à tout ou partie des feuilles en cas de forte infection. A la face inféricure les amas sont sonvent entoures d'une étroile zone brunitre pouvant conlluer avec colles du voisinage en cas de forte infection. Les amas irrégulièrement disposés sont d'un brun asscz foncé, d'aliord recouverts par l'épiderme qui dispalrait ensuite en laissant les spores ì mu. Uredospores arrondies, 2 I-24 $\mu$ de diamelre, brunes;
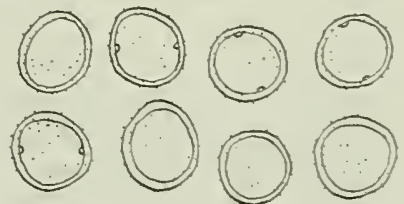

Fig. 100: U'redo Hyptidis-alrorubentis. Uredospores.

menbrane d'égale épaisseur partout, environ $2 \mu$, fonement échinuléc à épines conrtes et assez denses; pores germinatifs au nombre de 2 équatoriaux.

Soris uredosporiferis hypophyllis, minutis, punctiformibus, fuscis, sparsis vel numerosis, maculis mimutis (vix $2 \mathrm{~mm}$ diam.) saepe ennfluentibus brunneis insidentibus, primo epidermide tectis dein nudis. Uredosporis globosis, $21-24$ u diam., brunneis: 
membrana ca. 2 y. crassa, mimule satisque dense eclinulata: poris germinativis 2 aequatorialibus.
\end{abstract}

Sur feuilles de Hyptis atrorubens Port.

Andes centrales, dép. Intioquia, P’ès de l'auberge La Quiehra au-dessus de Cisneros rchemin de Medellin), alt. 1700 m. 31 juillet (n $\left.{ }^{\circ} 38\right)$ - Coltures entre Medellin et Envigado, alt. 1550 m. 11 aorit $\left(n^{0} 238^{a}\right)$. - Cultures, Cafetal La Camelia près Aurelopolis, aht. $18 \mathrm{~cm}$ m. 21 aoit $\left(1 t^{\circ} 238^{\mathrm{b}}\right)$. - Cultures à Cuaca, alt. $1480 \mathrm{~m} .12$ septembre $\left(n^{\circ} 238^{\circ}\right)$.

Cette espece est voisine les uredos de Puccinia Ilyptidis-mutabilis m.; les amas sont cependint d'une brun assez foncé et pas cannelle clair; les uredospores somt plus petites, leur couleur est dithórente, sensiblement plus foncée; entin la membrane est plus fortement el densément échinulée. Je n'ai malheureusement recneilli que des uredos envalis très fréquemment par Darluca Filum (Brv.) Cast et s'étant probablement opposés à la formation des téleutospores. Je crois cependaut les différences assez sensibles entre ces deux uredos pour justifier la création de celte nouvelle espèce jusqu'à ce que la décomverte des téleutospores tranche définitivement la question. Les uredospores de $P$. IIyptidis (Curt.) Tracy et Eakre sont jannes de mème que celles de P'. hyplidicola Syd.; celles de $P$. medellinensis $m$. diffèrent considérablement par leur aspect macroscopique et leur couleur d'un jaune-brunàtre.

\title{
153. Uredo balaensis Syd. \\ in Inn. Mycol. 1903 , ए. 20.
}

Les uredos recueillis correspondent exactement à ceux récoltés dans l'Équateur comme aspect macroseopique et microseopique. Les uredospores présentent 2 pores germinatifs surmontés d’une très petite papille hyaline; la membrane a une épaisseur de $2 \mu$, égale partout, échinuléc à épines courtes et peu denses.

\section{Sur feuilles de Blechum Brownei Juss.}

Antilles: Martinique; Fort-de-France. 10 novembre $\left(\begin{array}{ll}n^{\circ} & r\end{array}\right)$.

Andes centrales, dép. Antioquia. Chemin de Medellin à Bello, alt. $1550 \mathrm{~m}$. / aonit $\left(n^{\circ}\right.$ 18r). - Borrl dn Rio Porce aux environs de Medellin, alt. r55o m. r3 aont ( $\left(n^{0} 18 r^{a}\right)$. - Cultures à Guaca, alt. I $480 \mathrm{~m}$. 12 septembre ( $\left.18 \mathrm{I}^{\mathrm{h}}\right)$.

\section{Uredo Vernoniae spec. nov.}

Amas d'uredos à la face supérieure des feuilles réunis en petit nombre pour former de petites taches arrondies de $1 \mathrm{~mm}$ de diamètre, faisant ì la face inférieure un piqueté lıun-noir ; elles sont irrégulièrement disposées, disséminées ou au contraire très abondantes 


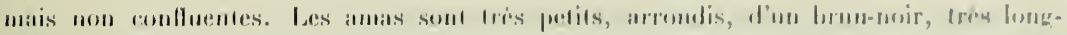

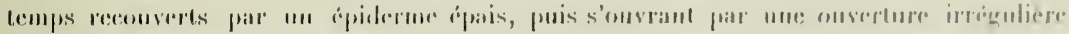

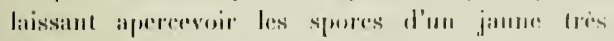
pale puis lolanchatere par la dessictaliom. -

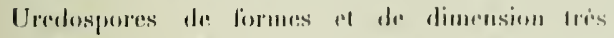

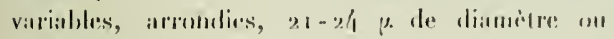

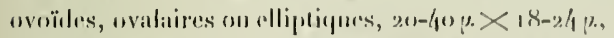

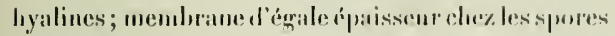

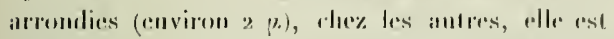

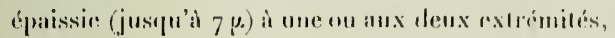

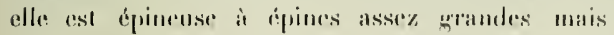

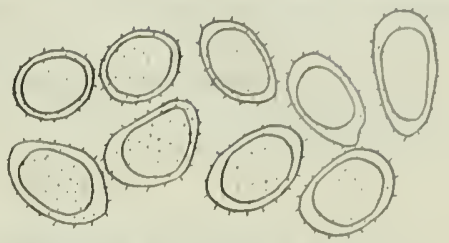

Vig. 101. Uredo Vernonian, - Uredosporen.

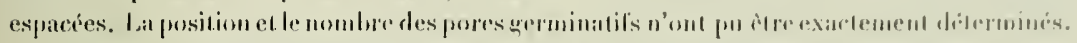

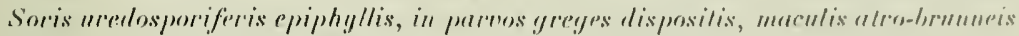
mimulis (ear. I mm diam.) spursis uel mumerosis insidentihus, mimulis, polumblatis, alto-

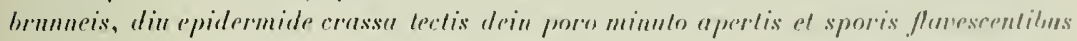

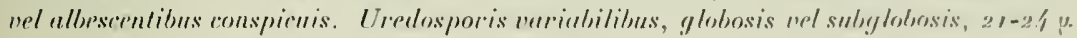

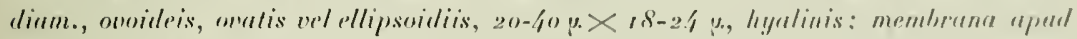
sporus globosus ubique cu. 2 pe crussu, apud ulleras apice vel ulringue usque $i$ y. incrassuta, laxe pchinula.

Sur leuille's de Vernonia of. mollis II. B. K.

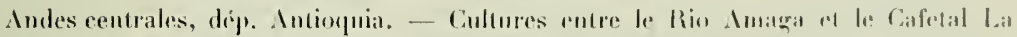

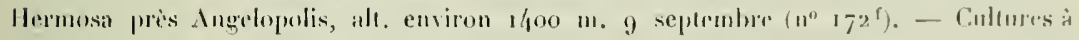
Gilaca, alt. $1480 \mathrm{~m} .12$ septembre $\left(11^{0} 17^{\circ}\right)$.

Ces uredos tant par lrur aspert macroseopique que microscopigue different considerablement de ceux de Puccinia lernoniae-mollis m. el me samraient d̀ confondus avec eux.

\section{Uredo Agerati spec. nov.}

Amas d'uredos à la face inférieure des fenilles, irrézulièrement disposis, soil disieminds et pen nombrenx, soit abondants et rapproches mais nou confluents, ne se manifestant pas
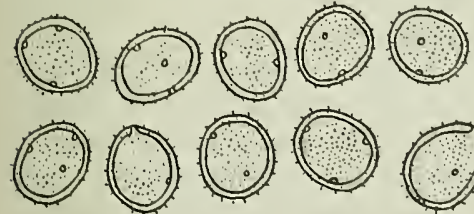

Fig. 102: Uredo Agerali. - Uredospores. par des taches speciales, safu on cas de forte inlection où tout wu partie des fenilles prend une coloration brunatre. Les antas sont pelits, arrondis, it peine $1 / 2$ mon de diamilre, lirun foncr. pumvérulents, d’abord recouverts jar l'épiderme qui idate de hounr heure al leur forme un rebord d'unbrun clair. - Credospores arrondies, ownîdes on ovoüles-clliptiques, 19-26 y. de diamètre. d'un hrun clair; pores geminatifs au nombre de 2 , dipaloriaux plus rarement 3 ; memlirane d'érale épaisscur partout, $2 \mu$, echinulée à épines courtes, peu visibles et denses. 
Soris urealosporriferis hypophyllis, sparsis interdum numerosis el gregariis sed non confluentibus, plerumque sine maculis, minutis, rolundutis $\mathrm{cu}$. 1/2 mm dium., fuscis, primo epidermide bruneola tectis, dein nudis et eppidermide cinctis. pulnerulentis. ITredosporis globosis, ovoideis nel rurius ovoideo-rllipsoideis, 1g-26 $\mu$ diam., dilute brunneis : poris germinulivis 2 aequatoriulibus, rarius 3 ; membrana cu. 2 e erassu minnte denseque echinulata.

Sur feuilles de Ageratum conyzoides L.

Andes centrales, dép. Antioquia. Bord du chemin de fer entre Caracoli el Cisueros (chemin de Medellin), alt. emviron goo m. 31 juillet ( $\left.n^{0} 217\right)$ - Chemin de Medelliı ì Bello, alt. 1550 m. 4 inoùt $\left(1^{0} 217^{\mathrm{il}}\right)$.

Sur fenilles de Ageratum conyzoides L. var. inaequipaleaceum Ilieron.

Audes orientrales, dép. Cundinamarca. Prairies près du lac Pedropalo non loin de Tena (près de Madrid daus la Sabana de Bogota), alt. 2000 m. 18 actohre (no 53).

\section{Uredo Eupatoriorum spec. nov.}

Amas d'uredos à la face inférieure des feuilles, rarement à la face supérieure, irrégulièrement disposés, disséminés ou nombreux et parfois rapprochés pour former de petites taches d'un brun foncé; en cas de forte infection, tout ou partie des feuilles prement

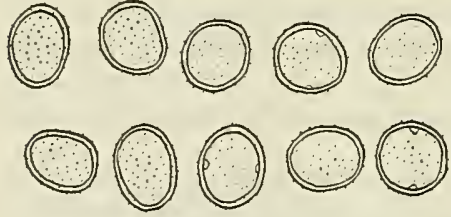

Fig. 103: Uredo Eupatoriorum sur Eupatorium Vargasianum. - Uredospores. cette colocation d'un brun plus ou moins foncé; les amas souvent conlluents sont d'abord recouverts par l'épiderme puis rapidement nus, petits, arrondis, pulvérulents, bruns. Uredospores arrondies ou ovoüdes, $18-25$ u de diamètre, d'un jaune brun ; pores germinatifs au nombre de 2 , équatoriaux; membrane d'égale épaisseur partout, $1 \frac{1}{2}-2 \mu$, échinulée à épines courtes et assez espacées les unes des autres.

Soris uredosporiferis luypophyllis, rarins epiphyllis, sparsis vel mumerosis, greguriis et confluentibus, maculis plus minusve magnis rolundatis obscure brunneis insidentibus, primo epidermide tectis, mox nudis, minutis, rotundatis pulverulentis, brunneis. Uredosporis ylobosis vel ovoideis, ${ }_{18-25} \mathrm{\mu}$ diam., flavo-brunneis; poris germinativis 2 aequatorialibus; membrana $I_{1}^{1 / 2}-2 \mu$ crassa, minute satisque lare echinulata. 
Sur lenilles de Eupatorinm iresinoides 11. 1: K.

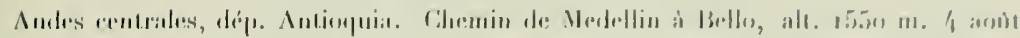

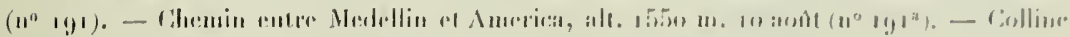

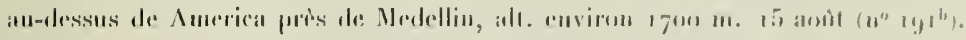

Sur lemilles de. Eupatorim Vargasianum 1):

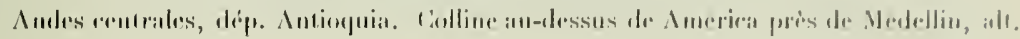

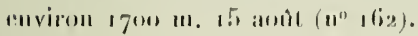

Sur fruilles de Eupatorium guadalupense Simuivi.

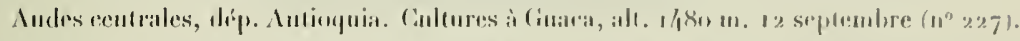

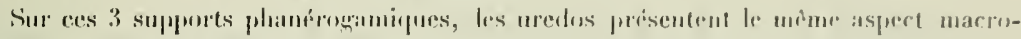

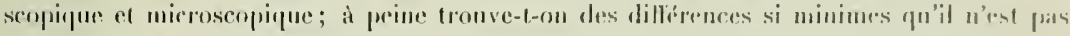

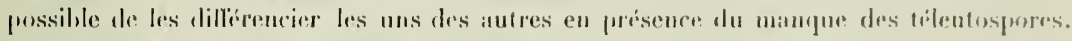

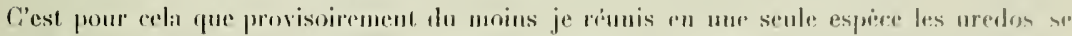

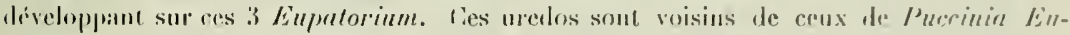

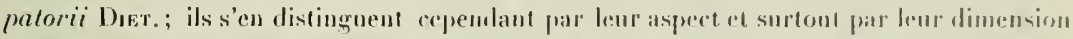
sensiblement plus petite, car chez notre espece les ureslospores attrignent an maximum

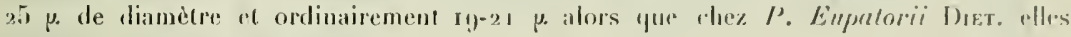
mesurent $25-30 \mu$. de diamètre.

\section{Uredo Baccharidis-anomalae spec. nov.}

Amas d'uredos à la face inférieure des feuilles, rares à la face supérieure, irrignlipirement disposés, petits, punctiformes, dissémines ou nombreux et rapprochés mais isulés ef non confluents, ne se manifestant par aucune coloration des tissus des feuilles, rapirle-

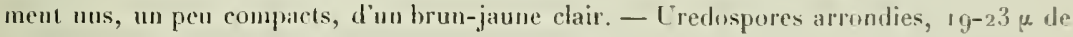
diamitre ou ovoüdes on ovalaires, $23-26 \mu \times 18-2$ I $\mu$, d'un brun chair, hyalines ou subhyalines à l'état jeune; nembrane 2-3 $\mu$ d'épaisseur, échinulée à épines assez petites et peu denses; pore germinatifs 2 équatoriaux. Les uredospores sont portíes sur un pédicelle caduc, hyalin, pouvant atteindre 30 et $40 \mu$ de longueur sur $3-5 \mu$ de largeur.

Soris nredosporiferis hypophyllis, ruro epiphyllis, inordinate instructis, minulis, punctiformibus, sparsis vel numerosis el gregariis sed non con-

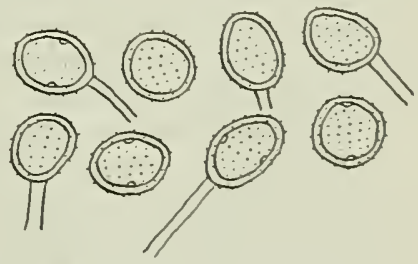

Fig. 101: Uredo Baccharidis-anomalae. Uredospores. fluentibns, sine maculis, mox nudis, compactinsculis. flano-brunneolis. Iredosporis globosis vel subglobosis, $19-23 \mu$ diam., wel onoileis vel onatis $23-26 \mu \times 18-21 \mu$, 
brunneolis, snbhuglinis vel hyalinis: membrana ca. $2-3$ y. crassa laxe minuteque pchimulata: poris germinativis a ueyualorialibus. Pedicello deciduo, hyalino usque 3o el to u. longo. 3-5 y. lato.

Sur feuilles de Baccharis anomala DC:

Andes orientales, dép. Cumbinamarea, Chemin de Honda à Bogrota, près de Villela, alt. environ goo m. 9 octobre ( $11^{\circ} 68$ ).

\section{Uredo Caleae spec. nov.}

Amas d'uredos à la lace supérieure des feuilles, irrégulièrement disposés, disséminis ou nombreux, le plus souvent isolés, parfois aussi un peu confluents, petits, arrondis, en moyenne $1 \mathrm{~mm}$ dian.; les feuilles altaquées présentent surtout à leur face supérieure une

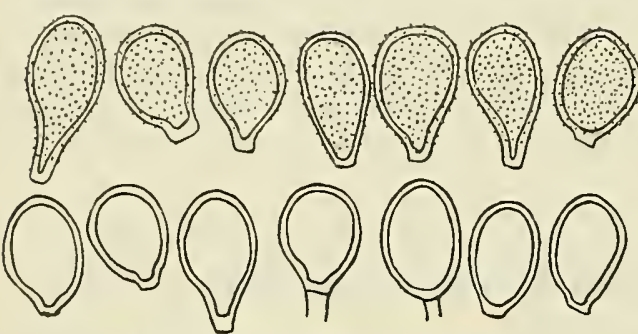

Fig. 105: Uredo Caleae. - Uredospores. coloration brune d'autant plus marquée que l'inlection est plus intense, envahissant parfois la surface presque entière lorsque les amas sont nombreux et rapprochés; les amas sont bruns, d'abord recouverts par l'épiderme qui se fend et leur forme un rebord irrégulier et un peu surélevé. Uredospores ovoïdes, pyriformes ou oblongues, plus rarement subgolobuleuses, d'un brun clair, 33-47 $\mu \times 21-28 \mu$; nembrane d'égale épaisseur partout, $2 \frac{1}{2} \mu$, plus fortement colorée que la cellule, échinulée à épines très courtes el assez denses; à la partie inférieure des spores de forme oblongue (généralement atténuées à la base), on constate le plus souvent que la membrane perd sa coloration brune pour devenir subliyaline ou mème hyaline. Le nombre et la position des pores germinatifs n’ont pu ètre déterminés exactement.

Soris uredosporifer is epiphyllis, sparsis vel numerosis, interdum confluentibus, minulis, rolundatis, ca. $1 \mathrm{~mm}$ diam., maculis brunneis insidentibus, primo epidermirle tectis, dein nualis, brunneis, epidermide cinctis. Uredospor is ovoideis, pyriformibus vel ablon-

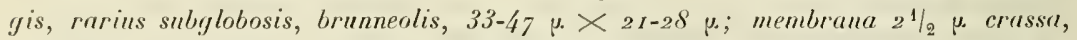
brunnea, minute ot satis dense echinulata; sporis saepissime ad basim allenuatis el hyalinis vel snbhyalinis. 
Sur linillas dr. Calea glomerata kistr.

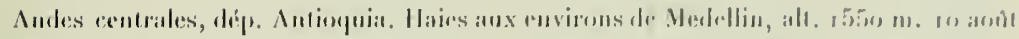

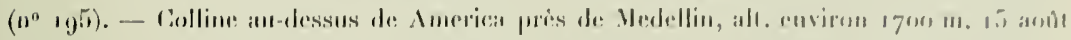

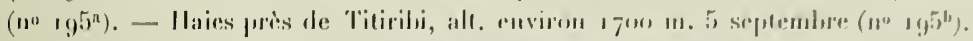

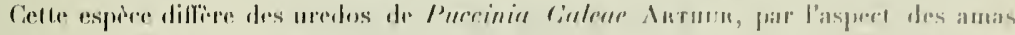

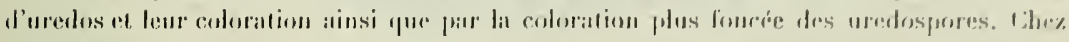

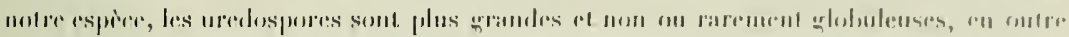

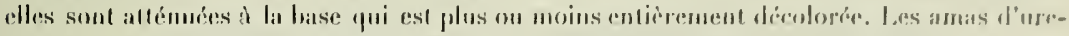
dos sont alondanment envahis par Dorlura Filum (Biv.) Ciss. 


\title{
CLADOCEREN
}

\section{aus den Gebirgen von Kolumbien,}

\author{
hearbeitet ron
}

Dr. TH. STINGELIN (Olten).

(Mit 3r Figuren in Text.)

\section{Einleitung.}

Ueber die Cladocerenfauna von Südamerika ist seit Daday's grosser Publikation, in "Zoologica", Heft 44, wo sämtliche bis zum Jahre $\$ 905$ in diesem Erdleile grefundenen Arten, in Ganzen 130 Species, zusammengestrll sind, wenig Neues bekannl geworden."

"Zu DaDAY's Literaturverzeichnis sind nun noch nachzutragen :

1. Haxsen, H. 1.: Die Cladoceren und Cirripedien der Planktonexped.; in vol. II der Ergehnisse der Planktonexped, der Humboldtstiliung, 1. Ieli, pag. 3-14 (Joinn minu/a n. sp, aus dem Amazonasästuarium), 1899.

2. Poppe und Mruzek: Entomostraken von Süd-Georgien; in: Beihelt zum Jahrb. der Hamburg. wiss. Anstalten, vol. 12, 1895. - (Chydorus sphaericus).

3. Stivgelts, Tu.: Entomostraken gesammelt von Dr. G. Hagmann in Mündungsugebiet des Amazonas; in: Zool. Jahrh. Syst., vol. 20, pag. $575-590$; tab, 20, Fig. 1-12, 1904. (Blieb in Literaturverzeichnis von D.ADs (1905) vergessen, während die neuen Arten in seinem Speciesverzeichnis der südamerikanischen Cladoceren (pag. 227-230), hereits eingetragen sind. - Vergl. auch: Sringeus, Th., in: Znol. Anz., vol. 28, pas. 153-15/; 1904. -

1. Striseln, Tn.: Unser heutiges Wissen üher die Systematik und die geogr. Verbreitung der Clidoceren; in: Comptes rendus du 6 me Congrès international de Zoologie, Berne, rgof.

5. Eкмкм, Svis: Cladoceren aus antarktisehen und subantarktischen Binnengewässern; in: Wiss. Ergelınisse der schwedischen Südpolarexpedition (190ı-rgo:3) unter Leitung von Dr. Otto Nordenskjöld, vol. 5, pag. 1-40; Ig05. - (Neu: Iliocryptus brevidentatus und Alona buliobensis var. subantartica, aus Süd-Georgien und Falklandinseln). 


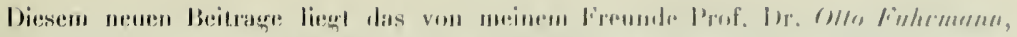

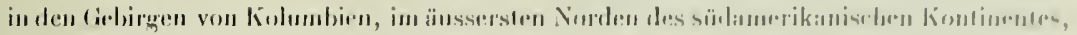

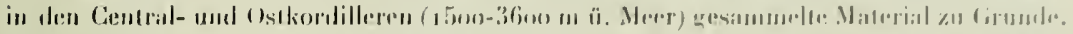

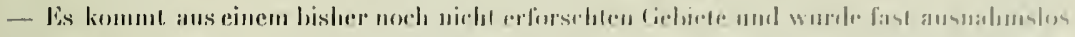

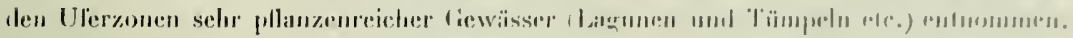

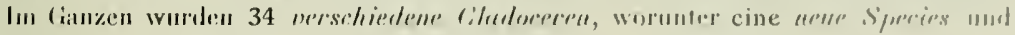

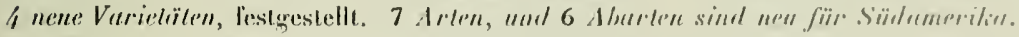

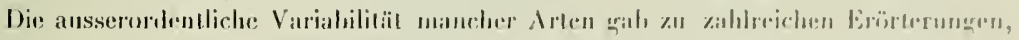
Vergleichen und Bemerkungen Aulass.

\section{Verzeichnis und Charakteristik der Fundorte.}

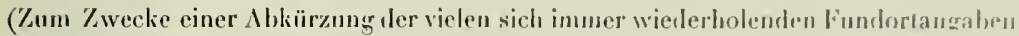
wird in Texte nur auf die Nummern dies's Verzeichnisses verwiesen.)

\section{Centralkordilleren:}

Füinge vom 1.-12. Augrust ! gro.

[F. 1.] Laguna ästl. oberball, Medellin (westl. von Bogota) 2504 m ï. M. 5 Species.

[F. 2.] " " " " " " " $25440 " 5$ Speries.

[F. 3.] Laguna d'Estrella, westl. von Medellin und Bogrola 1779" " " 3 Species.

[F. 4.] " " " " " " " 779 " " " 3 Sipreries.

[F. 5.] Sumpfige Wiese, in geringer Entfermung von [F. 1.] . . 4 Speries.

[F. (i.] Sümpfe, 1/2 Stunde unterhalh Medellin, 157.5 m is. M., an der

Strasse zwischen Medellin und "America" gelegen . . . 4 Species.

[F. 7.] Sümpfe, 1/2 Stunde unterhalh Medellin, $1575 \mathrm{~m}$ ii. M., an der Strasse zwischen Medellin nnd ". Imerica” gelegen . . 4 Sprecies.

[F. 8.] 2 Lagunen am Don Elias, in der Nälıe von Angelopolis, eine Tagreise von Medellin, $2097 \mathrm{~m}$ ̈̈. M. . . . . . . . 3 Species.

6. Stingelin, Th. : Cladoceren aus Paraguay: in: Annates de Biologic lacustre, vol. I, pagr. $181-192$. mil 7 Textlig. - rgot. - (neu: Simocephalirs latirostris n. sp.)

7. Saks, G. O.: Freshwater-Entomostraca from S.uth-Georgia; in: Archiv for Matho og Xilurvidensti.

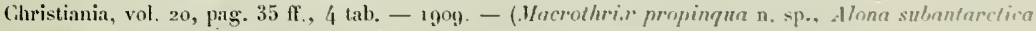

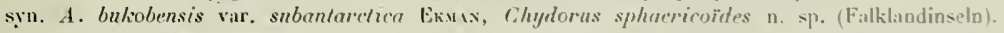

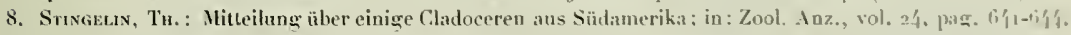
2 Textlig. - rgo9. - Hacrolhrix montana Bune, nov, var, major Strixels alus den kiorlitleren von Mendoza, Argentinien; Lepfodora spec., nehen IJolopedium amazonicum Sirsuendx im . Inazunasïstuarium. 
[F. 9. Sumpf auf dem Don Elias, 2097 m ӥ. .. . . . . . . 2 Species.

F. 10. Wahtsumpt hinker dem Don Elias, 20g7 m ï. M. . . . . Kerine Cladoceren.

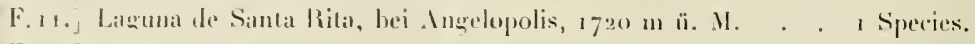

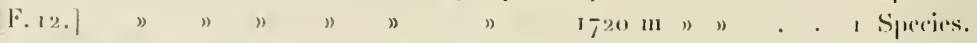

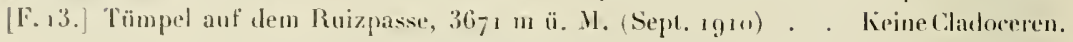

\section{Ostkordilleren:}

Fänge rom 14.-24. Oktober 1910.

[F. 14.] Laguna I bei "Madrid», 2585 m ï. M., zwischen Centralund Osikordilteren, 1/2 Tagreise von Bogota, inf einem Hochplatean ӥbr dem oberen Magdalenenstrombale, äusserst pllanzenreich

[F. г...] lieine Cladoceren.

[F. 16.] Laguna II hei "Madrid", sehr nahe bei [F. 14.] . . . . 6 Species.

[F. 17.] Tümpel I und II, nahe bei [F. 14]. . . . . . . . 7 Species.

[F. 18.] Tümpel III, nahe bei [F. 14.] . . . . . . . . . 8 Species.

F. 19.] Tümpel IV, nahe bei [F. 14.] . . . . . . . . . . 4 Species.

F. 20.] Lagmna "Pedropalo", $2000 \mathrm{~m}$ ü. M.; ein klarer See am Westrande des Hochplateau der Ostkordilleren, eine Tagreise von Bogota, litoral.

Keine Cladoceren.

F.2 . Laguna "Pedropalo» $2000 \mathrm{~m}$ ï. M. ; ein klarer See am Westrande des Hochplateau der Ostkordilleren, eine Tagreise von Bogota, litoral: rein pelagischer Fang . . . . . .

F.2..] Pfïlze am Tequendemafall, $2210 \mathrm{~m}$ ï. M., am Rande der

F. 23.] Laguna "Ulaque» 2 I 2 m ï. M., kleiner Sumpfsee issll von Bogota, eine Tagreise von Rio Meta, hereits im Strongeliete des Orinoco . . . . . . . . . . . . . . 13 Species.

F.24.] Laguna de Gruz Verde, 3026 m ӥ. M., höchster Fundort, iı Stromgeliete des Orinuco

$\therefore$ Species

Keine Clatocereu.

\section{Bemerkung über die Jahreszeiten im Fundgebiete.}

Im Gelsiete von [F. I] his [F, I3] ist Rergenzeit vom April his Nitte Juni. Nitte Juni bis Nilte Angust fällt wenig liegen und nur nachts. Von Milte Angust bis Mitte Novemher folgrt wieder eine liegenzeil; dann von Nitle November bis zum April die Trockenzeit. 


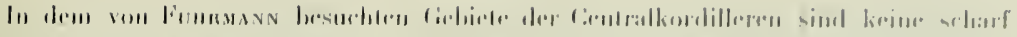

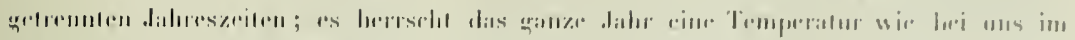
Sipialliöilıling.

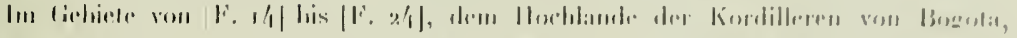

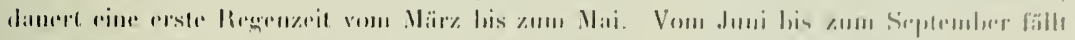

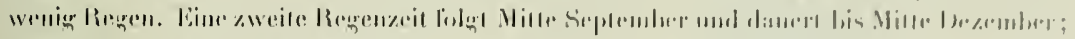

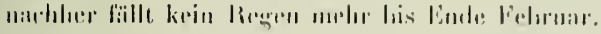

Verzeichnis der Cladoceren aus dem Hochlande von Kolnmbien.

1.- Fundorte:

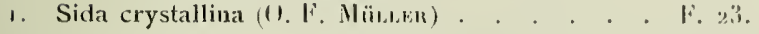

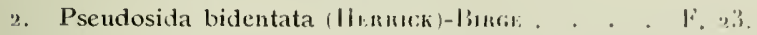

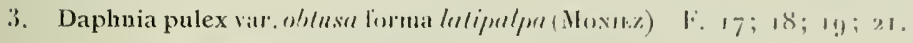

1. " longispina var. guterele lurmin oblusifroms
(ii. (1. Sinis)

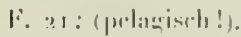

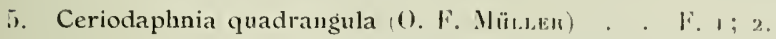

(i. 1) reticulata vas. dubiuliosma silerestrii
(1)aris.)
1. $18 ; 3$.

7. Simocephalus serrulatus (Kinu) und var. influlus.

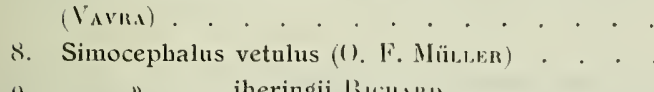

F. 1;2;4;5;11; 21.

().

11. Moina makrophthalma nov. spec.

F. 23.

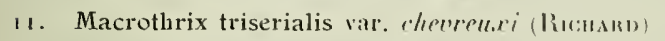

F. $8: 16 ; 17 ; 1 ! 1$.

F. 18.

F. $(i ; 1 / 4$.

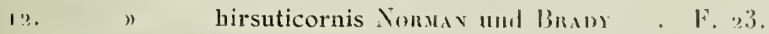

13. Iliocryptus sordidus libirs . . . . . 1:.24.

1/. " "rir. sursi nov. var. . l. 5.

15. " halyi var. longiremis (SAns). . F. F: $8 ; 0 ; 11: 12: 14 ; 17: 18$.

if. Streblocerns serricaudatus Surs . . . . . F. 1; 2; i.

17. Camptocercus australis var. duduyi noy. var. . F. 14.

18. Kurzia latissina (limsz) . . . . . . F. 18: 23.

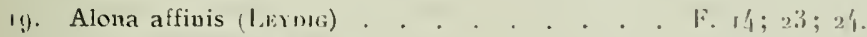

20. " costata (Sims) . . . . . 1. 14.

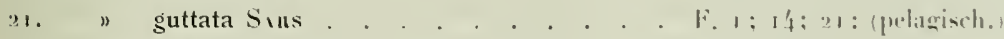

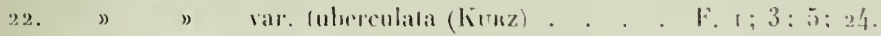

23. " pulchella lixg . . . . . . . F. 17; $18 ; 19$. 
2\%. Alonella excisa (S. Fiscuen) . . . . . . li. 2/.

2.) Pleuroxus similis var. fuhrmnnni nov. var. If. 14; 1 i.

26. Dunhevedia odontoplax Sirss. . . . . If 1/1;16;17.

$27 . \quad$ " var, colombiensis nov. var. li.23.

2k. Chydorus ovalis liukz. . . . . . . . . F. $2 /$.

29. $"$ piger sins . . . . . . . 1.23;24.

31. "I leonardi kixg . . . . . . 1. 16; $17 ; 23 ; 24$.

31. $"$ eurynotus Sins . . . . . F. 3; $6 ; 7 ; 18 ; 23$.

32. " pubescens SAlH. . . . . . $1.6 ; 7 ; 14 ; 16 ; 18$.

33. ") hybridus JADAY . . . . . 1. 17; 33.

34. $"$ flavescens DADAY . . . . . F. F 14;16;17;2.3.

\section{Cladocera-Calyptomera.}

\section{נ. Tribus: Clenopoda.}

1. Familie : Sididae.

Lus Südanerika waren bisher hekanul die Genera: Diaphanosoma, Latonopsis und l'seurlosida (mil Sulgen. Parasida). Nun konımt neu hinzu das Genus Sirla mit der typischen Species :

1. Sida crystallina O. F. MüLıer.

(Fig. 1, 2, 3.)

Bei Lilljeborg, Igor, pa. 18 ; tab. I und 2.

Einigge Exemplare dieser grossen und schönen Clarlocere, die mit Vorliche vegelationsreiche Ufergebiete bewohnt, konnten ans einem, hauptsächlich aus organischem Detritus bestehenden Materiale [F. 23] frei gemacht werden. Die zarten Geschöpfe waren allerlings, flermassen zerdrückt, dass man sie unr an einzelnen Organen wieder erkenmen konnte. Die beistehende Textfigur 1 veranschallicht das Postabdomen, Figur 2 die $\mathrm{Ru}^{-}$ derantenne. Beide zeigen zur Genüge die völliz̧e Uebereinstimmung mit der in :Europa 


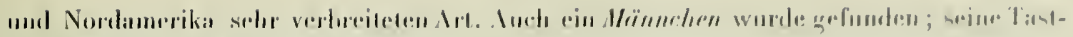
antente ist in lige. is daremestellt.

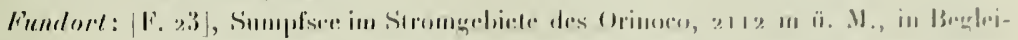
tong von 12 amleren Cladocerenarten.

lieogr. Irerberlung: Cians liuropa, vour Islanel his Italien, sourar in larackischem IVasser. Fernor: : Norilrand von Afrika; Vorder-, IVest-, Centrial-, Ost- und Nordasien bis zuin 71. Graden. Is. Auch verbreitel in

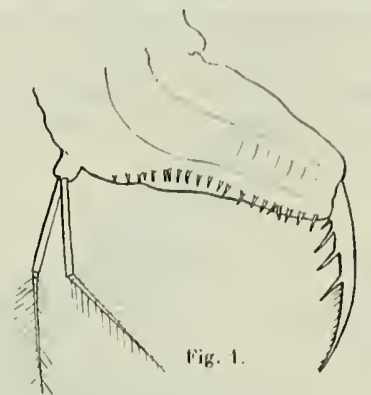

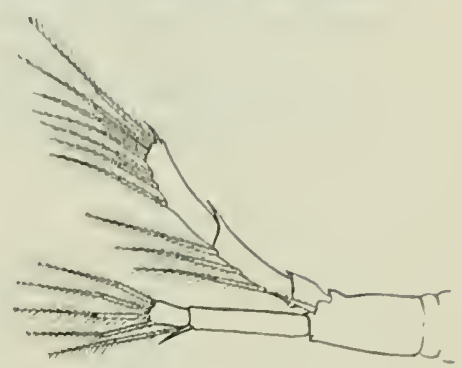

Fig. 2.

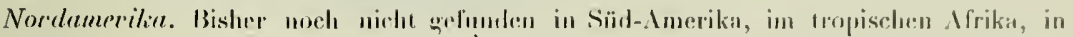

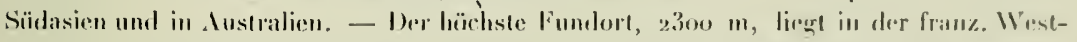
alpen. In den Centrabalpen (Schweis), die schon gründlich untersucht sind, kennt man mur 2 l'undorle (hei 1700 and 1800 m ii. M.). Sida frhlt in

Fig. 3.

der holien Tatra, wude lingegen in Kleinasien, luei $2229 \mathrm{~m}$ ï. M., angetrolfin.

folumbien ist also das ersthekannte. Fundyethet von Sida erystallina innerhally der Tropen; [F. 23], hei 2ut2 in ï. M., der dritthöchste Fundort.

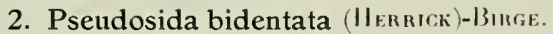

(Fig. 4, 5, 6.)

Brige, E. A., 1910, pg. ror 7-1029; lab. 67, Fig. 1-9.

Zusanmen mil Sida crystullina lebt in der Laguna "Ubaque ". bei $2066 \mathrm{~m}$ ü. Mree. eine viel umstriltene, sehr seltene Spreies, die von Henuck in lahre 188 4 hei Wohile, U. S. A., entdeckl und im Hinweise anf die Bewelnung der Endkrallen des Postabdomens als Psendosida bidentata nov. gen. nov. spee. beschrieben wurde. Späler grlauhte Henuck dieselbe Species wieder gefunden zu haben; sie halle mun aher 3 stall mur 2 grosse Zähne an den Endkraflen. Das veranlassle Hennck (ISSj) den Sipecirsnamen in

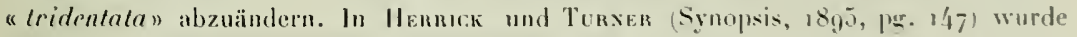
daun die Confusion volständig und ring leider auch in andere Hauptwerte über, wie z. B. in Ricnanu's Revision des Cladocères, etc. Ich hatte nun das frlück, in einen Material aus Paraguay dic dreizähnige Form wieder anfzufinden und habe sie als Psendosidatriden-

* Vergl. Stingeun. Th., 1908, pg. 8. 


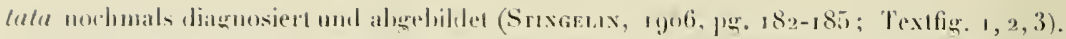

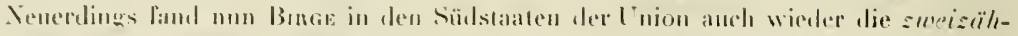

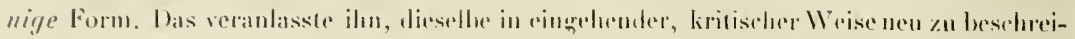

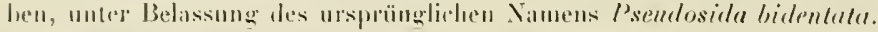

l)iese Irt kann ieh mun anch ans loblumbien molden.

Ëinige chenfalls durch l'llanzen[. 23] ergämælen sich wenigstens in

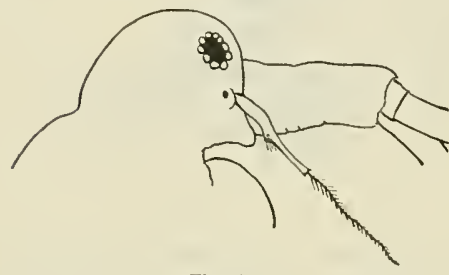

Fig. 1.

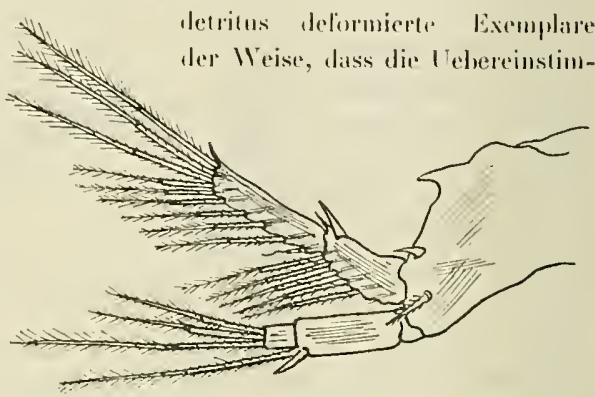

Fig. 5.

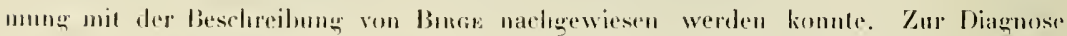
und den leigragelenen figuren habe ich noch folgendes zo lemerken:

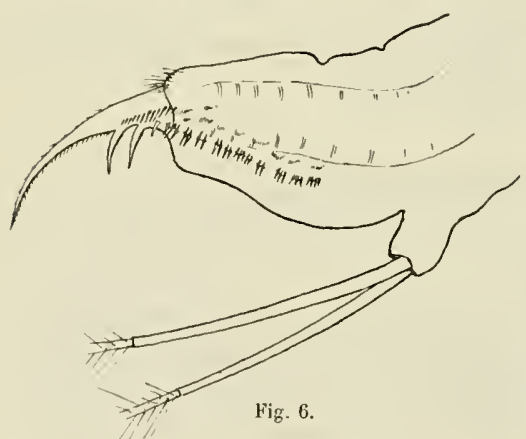

Fig. 4 stelli den kiopf des IVeilxhens mit der 1 . Antenue und dem Basalgliedr der Rulerantenne dar. Sie ist ohne Deckghtas, mil dem Ahlés schen Zeichnumgsapparale entworfen. Es ist recht sehwierig, die äusserst delikaten fieschöple in die richtige: Seitenlage zu liringen. Ol, is mir ganz gecolizekt ist?

In der Mitte zwischen dem stumpfen Rostrum und dem ovalen luge liegt der Pigmentleck (von Burge nichl gुezeichmet); direkt daneben sind die langen Taslanamonen inseriert.

Fig. 5 veransehaulicht dic Ruderantenne. Der Basipodit hat eine elwas verdrelute Lage und ist gequetseht. Unso hesser kummen die heiden Schwimmäste mit ihrer Bewehrung zur. Darstellung. Die Zahl der Schwimuhorsten ist merkwärligerweise bei den Arten dieses Genus sedır verschieden, was aurh

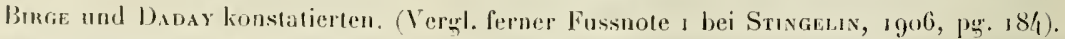
Nach meinen Beobachtungan wechselt ihre Zahıl an proximalen Gliede des längeren, zweighedrigen Astes zwischen 5 und 7 , am distalen Giliede zwischen 9 mol 1 .

Figg. 6, das Postablomen des Weibehens, ist seillich mit Gruplen von Dornen be- 


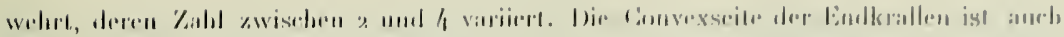

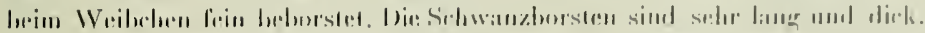

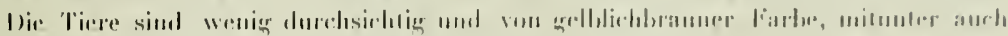

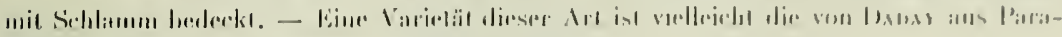

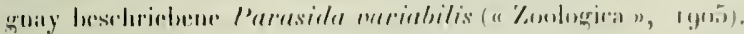

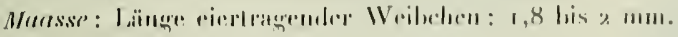

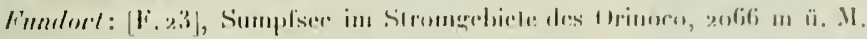

\section{IT. Tribus: Anomopoda}

\section{Familie: Daphnidae}

\section{Daphnia pulex var. obtusa (Kun\%) forma latipalpa (Мณxњ\%):}

(Fing. 7 und 8.)

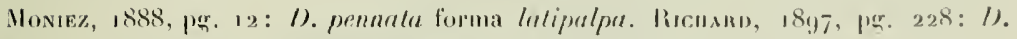

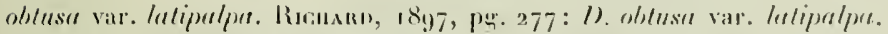

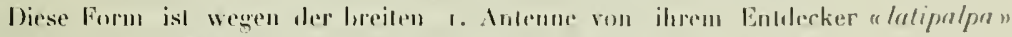
genannt worden, Dieses Merkmal hesilzen aber alle formen der D, ob/ustofiruppe. Interscheidnmasmerkmale der losma latipalpas sind hingegen:

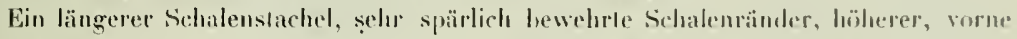

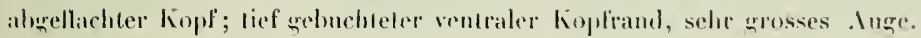

Das sind hei meinen Exemplaren komslante Merkmale mul dadurchunlesscheded sich

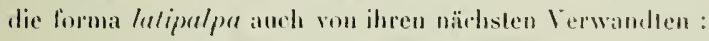

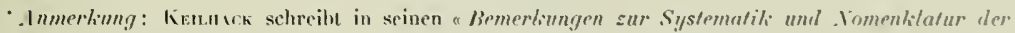

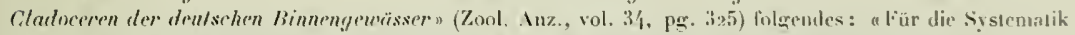

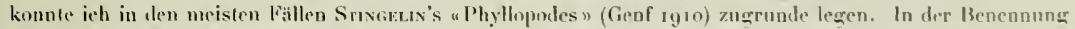

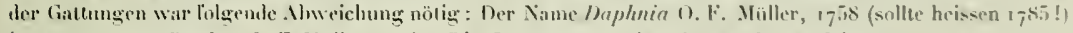

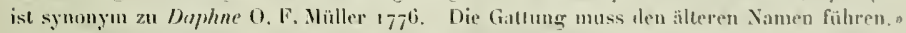

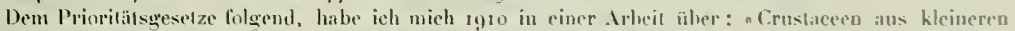
Seen der Unterwaldner. und Bernemilpen w tiesen Vorschliere angeschlossen.

Nun lese ich aber in ten interuationalen Regeln der zool. Nomenklatur: a Man vermeide es in dir

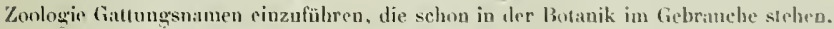

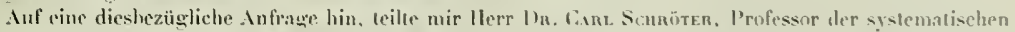

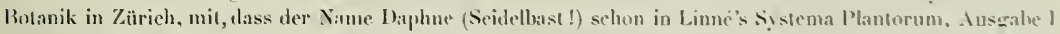

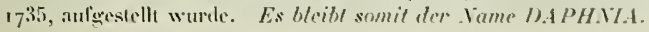




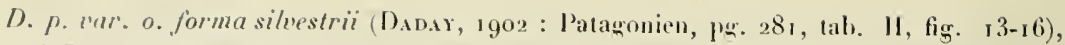

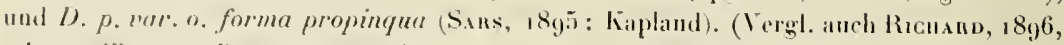
(ab), 21, lïr. 19: D. o. var. propinqua und tig. 12: D. o. ear. latipalpa).

Varialeel sind die Schalenstruktur (Feldermug mehr oder

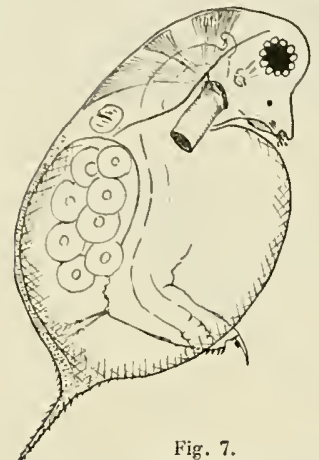
werniger deutlich) und die Richtung des Schalenstachels.

Auch hier ist eine genauere Slizze der kï̈perform (Fir. 7) und des Postablomens (Fig. 8) nicht ïberllüssig.

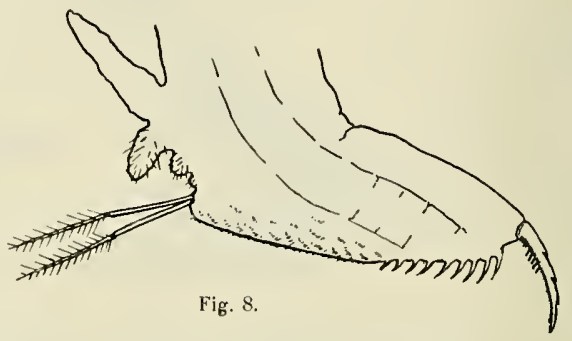

Maasse: Länge eiertragender Weibcheı : 1,26 bis 1,62 mm; Höhe 0,75-0,9 mm; Schalenstachel: o, i 8-o,2 $\mathrm{mm}$.

Fundorte: [F. 17]: nur einige junge Weibchen.

[F. 18$]$ : kleine Formen, mil wenigen Eiern.

[F. 19] : massenhaft, sehr grosse und eierreiche Individuen.

$[F, 21]$ : ein einziges, sehr durchsichtiges, in pelagischen Fange, zusammen mit $D$. longispina... erheutetes Weibehen.

Geogr. V'erbreitung: Azoren (Autor 1). In Südamerika weite Verbreitung : Chile, Argentinien, Patagonien, Uruguay, Brasilien, neu : Kolumbien.

\section{Daphnia longispina var. galeata forma obtusifrons ( $\left.S_{\Lambda \Perp s}\right)$.}

(Fig. 9, 10, und 11.)

SARs 1903 , pg. 169 ; tab. 5, Fig. 2. (D. I. var. jardinii ${ }^{1}$ forma obtusifrons).

Die systematische Stellung dieser ungehelmten Form von D. longispinu (Fig. 9) konnte nur ermittelt werden Dank der Gegenwart von gehelmten Jugendformen, init allen Uebergängुen zur ungehelmten form (Fig. ro und 11 ). Da ein l'igmentfleck vorhan-

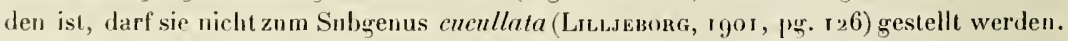

Funtort: Die in [F.21] lebende, pelagische Daphnie, stimmt am besten mit der von

- Der Nane jaudinii Bund ist, wie schon LıLaEnong (19o1, pg. 128) anrät, fallen zu lassen und dureh galeala zu ersetzen. 


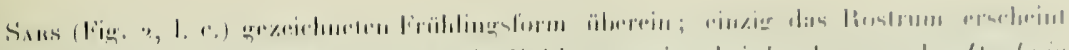

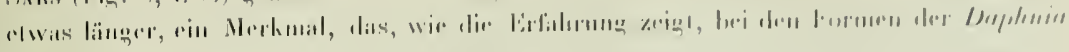

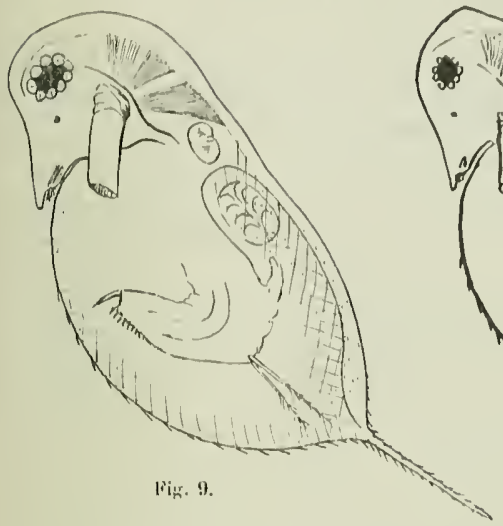

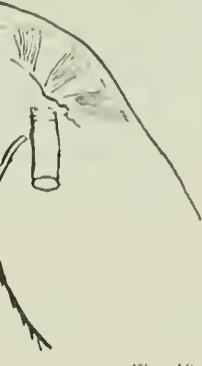

Fig. 10 .

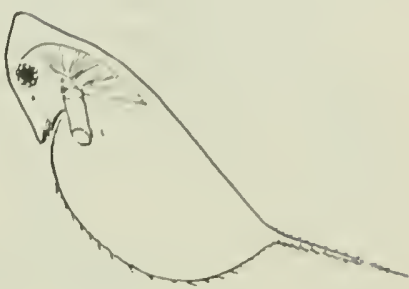

Fig 11

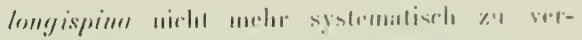
wrilan ist.

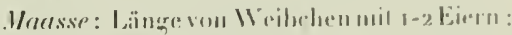

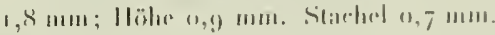

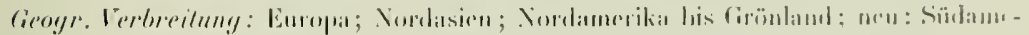
rika; Kulumbirus.

5. Ceriodaphnia quadrangula (1). I*. Miitr., H).

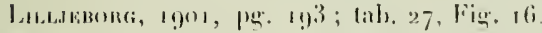

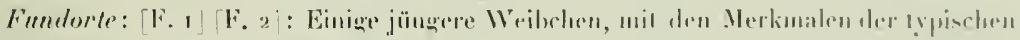
species (kopelbililung! Postithdomen!).

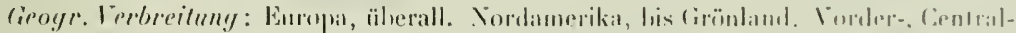

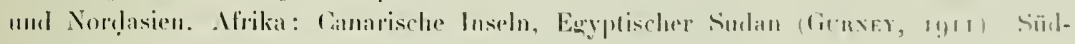
amerika: Patagonien; nen: lonlumbien.

\section{Ceriodaphnia reticulata var. dubia forma silvestrii (1) $\mathrm{MI}$ ).}

(Fig. 1:: und 13.)

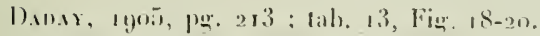

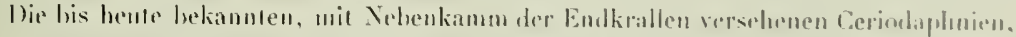

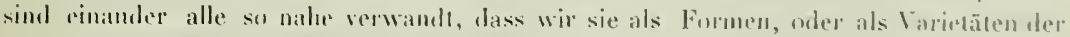

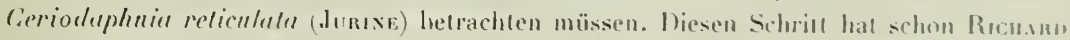

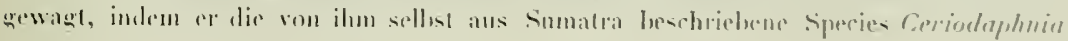




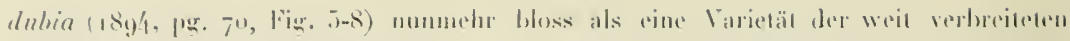

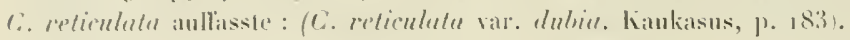

Diese $C$. dubia ist num bekannl ans:

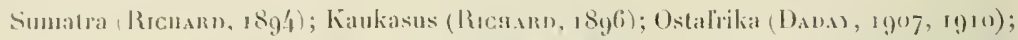

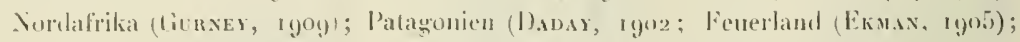
Neuseelant (Sins. 1903).

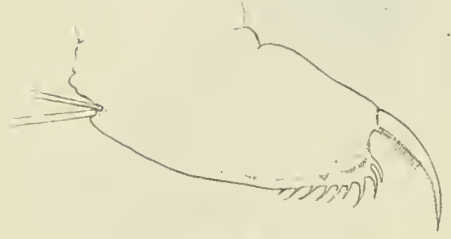

Fig. 12.

Jentisch mit $Q$. dnbiu bezw. C. rediculatu simb lerner:

Cerioduplenia dubue var, acuminata Ekмax (Patagronien, 1900$)$;

" limicola Екмах (I'atagonien, 1906); affinis lallajeborg (Schiveden, Norwegen, Igor) und Varra (kileinasien, 1902);

Ceriodaphnia sublaevis: SArs (Neuseeland, rg̣o4)):

" nalulis Bridu (Natal, 1907);

") richurli Sars (Brasilien, Igor);

1) reliculata var. Richard (Brasilien, I897);

") silvestrii DADAY (Patagonien, 1902 und Paraguay, 1905).

Cerioduphnia reticnlata s. str. ist aus allen Erdteilen, ausgenommen Australien, gemeldet. Von C. subluevis aus Neuseeland sitgl aher der Autor, Sars, sellsw: aselur nahe C. reticuluta!",

So wäre also zur Genüge die kosmopolitische Verbreilnug ater Species Cerciodaphniu reficuluto und ilarer Varietät dubia erwiesen.

Ein gutes Merkmal, woran sich die Formen der Var. dubiu erkennen lassen, fondu sich in der Bewelırung der Endkrallen des Postabdomens (Fig. 12). In der Beschreilung seiner $C$. affinis (rgor : pg. 20.3; tab. 28, Fig. 23) schreilu Lıláborg : "An den Eudkrallen findet sich ausser den gewöhnlichen Härchen, aussen, nahe aı der Basis, eine ziemlich lange Reihe von Stachelchen, welche, obschon schr fein, nur bei stärkerer Vergrösserung merkilıa, jedoch vicl gröber und hïngev als die Härchen sind." In Fig. 13 habe ich die Endkralle von C. reticnlatn und in Fig. 12 diejenige der C. r. var. dubia alogelibildet. - Ferner verweise

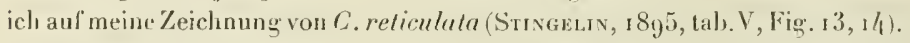

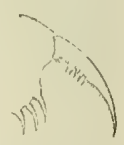

Fig. 1:3.

Wenn wir die gesamte Literatur über die oben anfyeführlen Speciesnamen vergrleichen, so ertennen wir, dass augenfällige Dillerenzen bloss auftreten in Bezug anf die mehr oder weniger deutliche Schalenstruktur und die Schalenrandbewehrumg, sowic die sehr wechselhafte Bchaarung der Seiten tess Postalılomens. (Siärkere, schnächere, oder auch felulende Bewimperung !) Das sind aber keine specifischen .lerkmate.

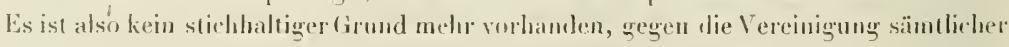




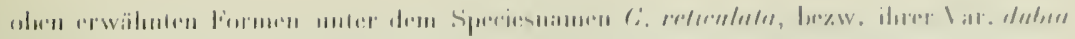
Mirisин.

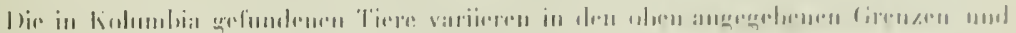

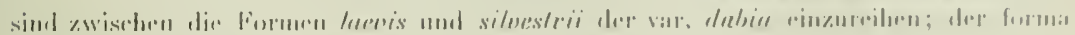

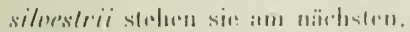

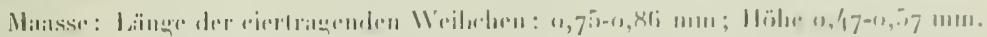

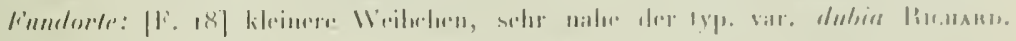

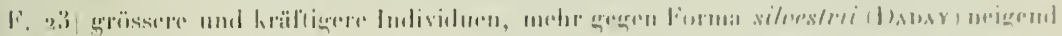

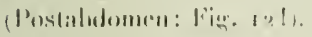

\section{Simocephalus serrulatus (Kris:I.)}

(liigr. 1', 1,i, 11..)

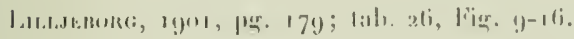

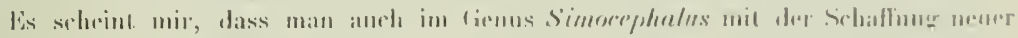

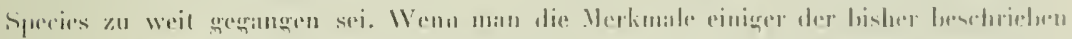

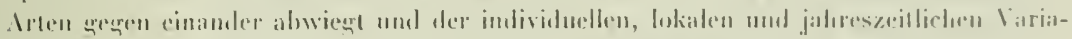

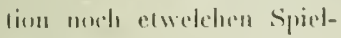

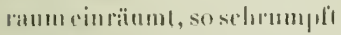

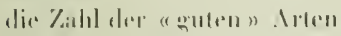
hier elentialls zusammen.

1):as Vorkenmen von typischen Exemplaren ron s. sermblalus (kónis) habe ich im dahrer ryolizum erstenmal aus Süblamerilia (l’araquity) gemeldel und nem hale iclo dieses Tier wioler ans zahlreichen T'ümpeln kinlumtriens erhalten. Ein Vergleich mil milleleuropäisclıem Misterial, ans der Umgehung von

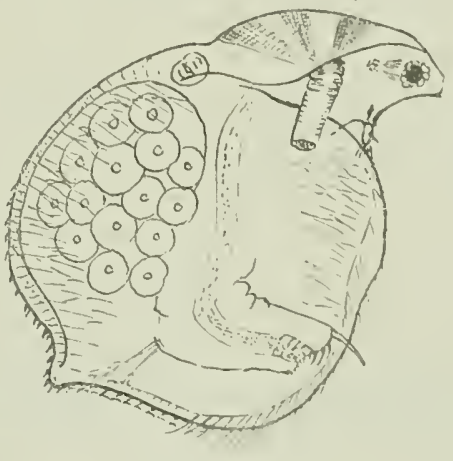

Fig. 11.

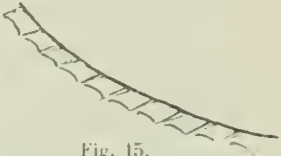

Fig. 15.

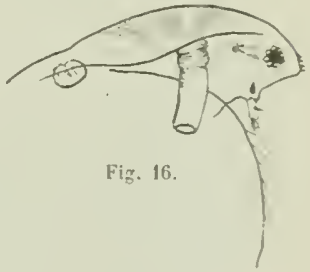

Basel, ergah die vällige Lebereinstimmung mit der Iypischen Art. Es hestelı kein stichhalliges Unterscheidungsmerkmal, das anch nur die Aufstellung einer neuen Varietät rechufertigen wïrde.

Bislur sind ansserdem in südamerika entdeck worden:

1. S. cacicus Moxuz, 1880, Peru: Titicacasee.

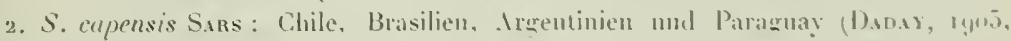
lug. 200, (ith, 13!). 


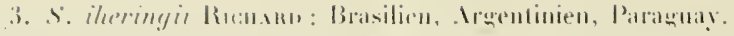

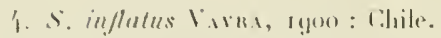

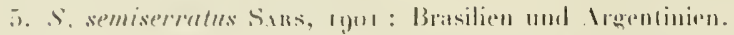

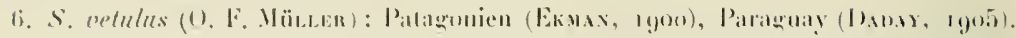

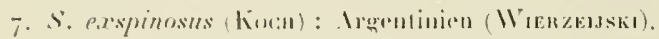

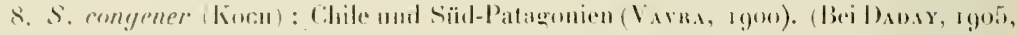

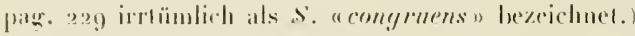

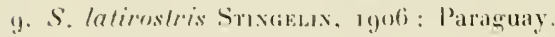

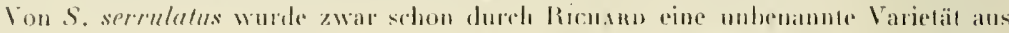

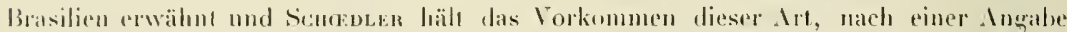
ron F. Mülter aus Destero (Brasilien), fïr wahrscheinlich. (Verogl. Varka, rgoo, ps. r 1). Diese. Angahen sind ron Dans ( worden.

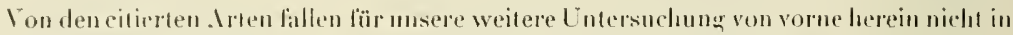
Betratht: S. vetulus: S. ersypinosus (mit var. congener); S. iheringä und S. Intirestris.

Hingregen sind: $S$. capensis. $S$. inflatus, S. semiserratus und s'. caciens mit $S$. serrnhlutus \%u veruteichen.

D.war (rgo5, fag. 2og) fïlnt untre S. capensis als Synonyme aul':

$S$. influtus Vava und $S$. semiserralus Salrs.

Die Synonymie von $S$. copensis Dabay - non Sans - mit $S$. influtus Varra lasse ich gehten. $S$. capensis Sams hingegen unterscheidel sich von $S$. inflatus durch das Fehlen von Dornen an den hinteren Sehalenrändern; aquite smooth, non serrulaten, sagr Sars (verọl. anch Brady, 1907, pag. 179).

In $S$. inflalns haben wir aher eine Form mit extrem liäftiger Bewehrungु dieser hinteren Schalenränter vor uns; während $S$. serrulalus in dieser Bezielıng eine Mitlelstellung einnimm (Fig. 14). In Kolumbiamaterial fanden sich alle lebergänge von kaum sichtbarer, his zu sehr starker Bewehrung. Fig. 15 stellt die Betvehrung der freien hinteren Sehalenränder von Simocephalus serrulatus dar, wie sie bei stärkerer V'ergrösserung sich zeigt. Die Dornen stchen bei dieser Species und allen ihren Varietälen, nicht, wie die meisten Forscher (z. B. VAvra) zeichnen, frei am Schalenrande, sondern scheinen in einen sehr hyalinen, sägearligg gezälnten llautsaum cingefasst zu sein. (Vergl. auch die Fig. hei Stıvgelin, 1 go/: Reise Volz.)

S. semiserralus Sars weicht noch medr al und zejchnet sich u. a. dadurch aus, dass die hinteren Sehalenränder nur eine kurze Strecke weit bedornt sind. Das Postabdomen lesilzl eine grössere Anzahl von Zähnen.

Ich betrachte also $S$. capensis SArs, S. inflatus Vavina und S. semiserralns Sars als gut ansgeprägte Vurieläten von S. serrulatus (Kocui).

In Fig. 16 habe ich den liopf der Var, inflatus aus $[$ F. 1/] abgebildet."

- Eine durch ihre Kopfliorm noch mehr vom Iyp. S. serrolalus abweichende, s, Z, von biusis aus Cordancrika beschriebene .Irt, S. americamus, wurde schon längst als identisch erklint mit $S$. serrulatus. (Vergl. Ilennek und Tenser, Synopsis, 18y.5, pe. 179.) 


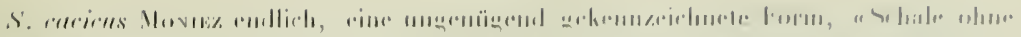

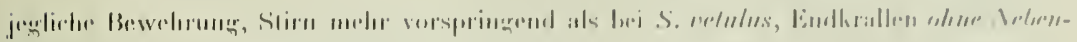

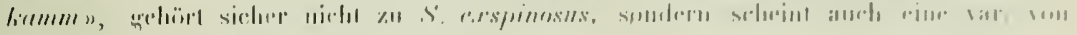
S. sererululus: all spin.

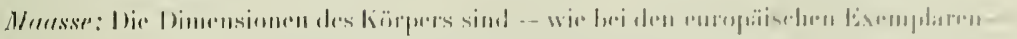

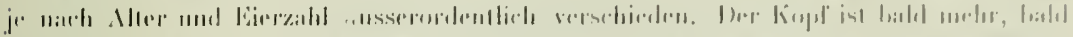

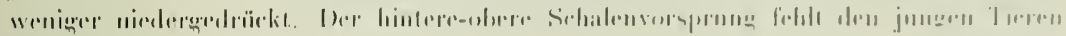

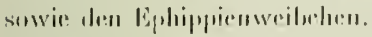

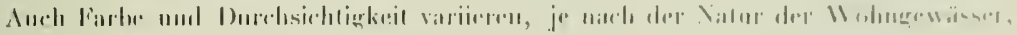
anssonotromlich.

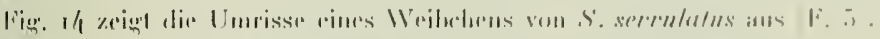

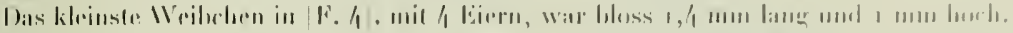

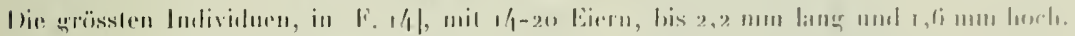

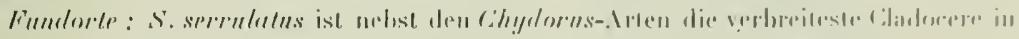

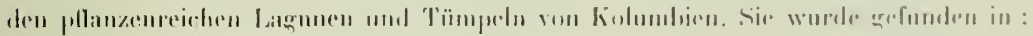

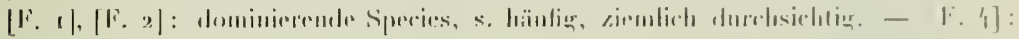

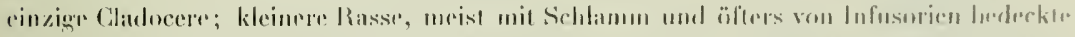

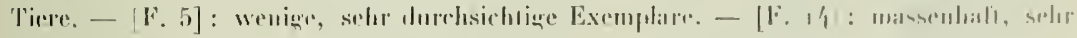

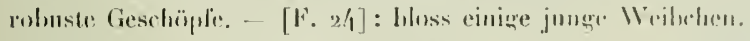

froogr. Terlureilung aler speries:

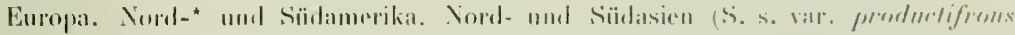

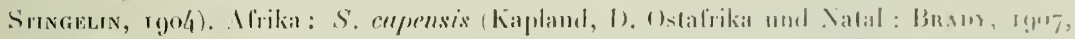

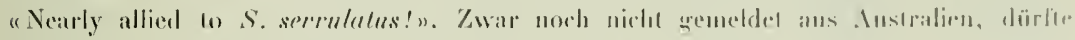

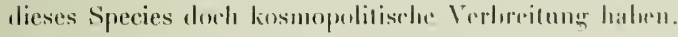

\section{Simocephalus vetulus (1). li. Niit,1:k).}

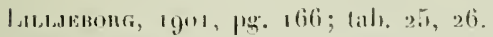

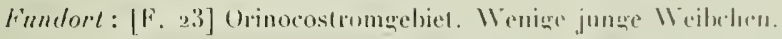

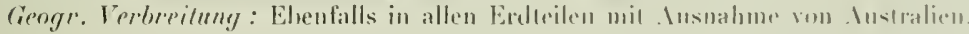

\section{Simocephalus iheringii, fiм:пињ).}

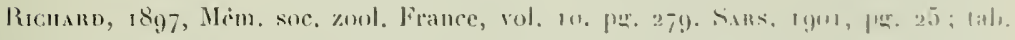
1. Fis. $10-13$.

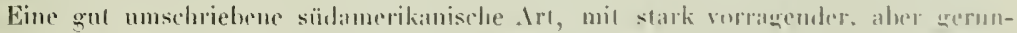
deter Stirn. Dorsaler-hinterer Schathminkel in cinen zweispizigen. Ireiten stachedarlizen liorlsatz verlinngert.

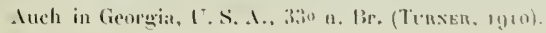




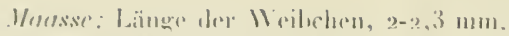

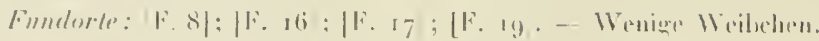

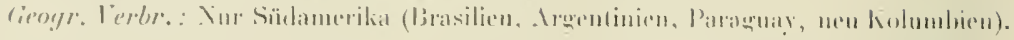

\section{Moina makrophthalma nov. spec.}

Fiv. 17 .

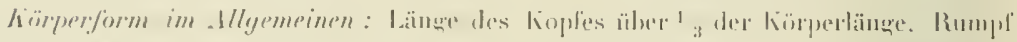

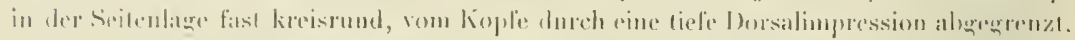

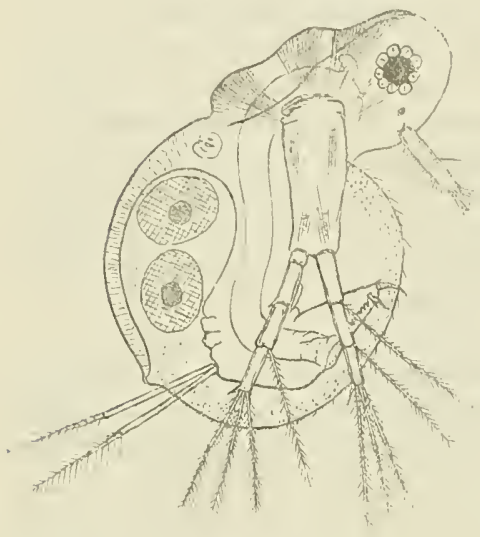

Fig. 17.

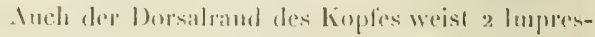

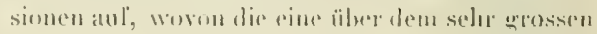
Anee, die amdere zwischen den Lrsprmuge der

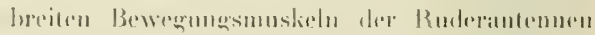
liegl.

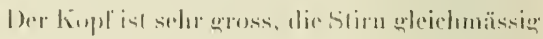

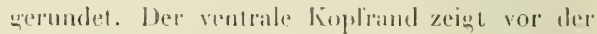
hosertionsstrlle: der Tastantenten keinen Vorsprumg. Die: Tirstantemen, hall, so hag wie der Konfl, eylublrisch bis schwach spindellärmig, tragen in der liblte der Vorderseite dats äbliche Tasthaar und simb anf der llinterseite lang und lein helraart. Dits Ange Jalt eine aussergewöhnliche Grösse; die Pignuentmasse ist von sohr trossen Kristallinsen numelben. Ein winzigrer Pigmentheck liegt in der Mill. zwischen Auge und ler Insertionsstelle der Tastantmuen.

bie Ruderantennen, von mitlerer Stärke, zeigen keinerlej mullälime Bewehrung. Dorsaler Schalenrand und hinterr freie Schalenränder treffen ohne scharf ansgeprägte Winkelbilusng zusammen. Hintere mud ventrale Schalenränler gehen ohne Grenze in gleichmässig hogigen Verlanfe in rinander üher. Ein Saum leinster Härehen, aus dem in grleichmässigen Abständen etwass längere Börstchen hervorragen heglcilet dieselhen. Die Schalenklappen sind mu fein granulier.

Postabdomen: J)asselhe ist ganz von don Sehalenklajpren berleckl. Der distale Teil ist stark kegelförmig verjüngt. Die Endkrallen tragen keinen Veluenkanm und sind and der concaven Sete hoss lein hwinpurt. An der Basis der convexen Seite sitzt ein Burstenbüschel. I uf den äbliehen Gabeldorn, dessen proximaler Zweig blıss hall, so hang ist als der änssere, folgu seitlich noch 5 lxwimperte Zähme.

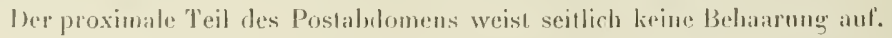

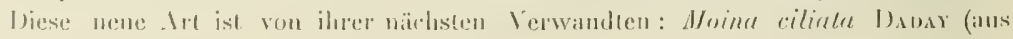




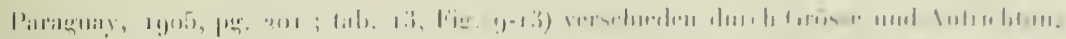

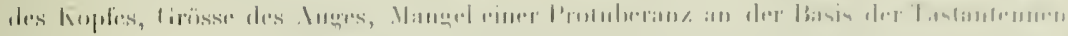

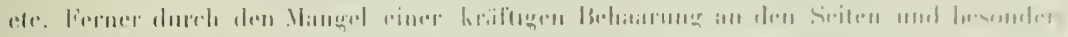

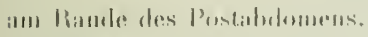

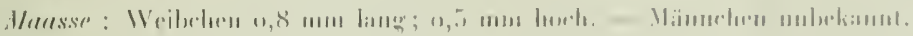

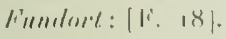

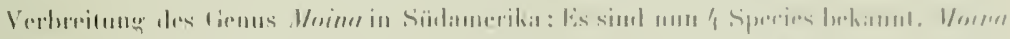

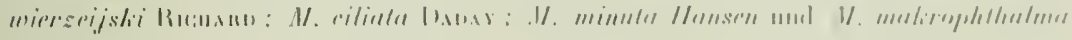
11. sp. Striil.

\section{Familie Lyncodaphnidae}

11. Macrothrix triserialis 13 мm var, chevreuxi liı:ıиюn.

(1ї.е. 18, 1!1.)

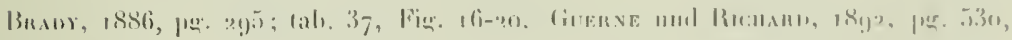

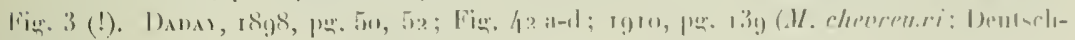
(Istillitik).

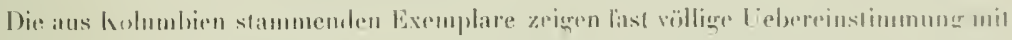

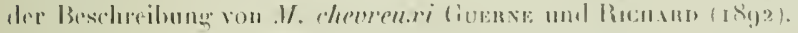

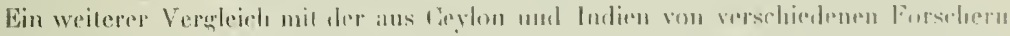

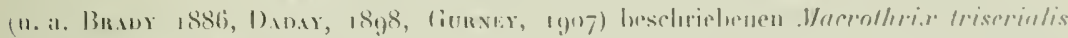

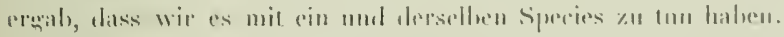

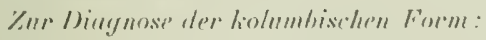

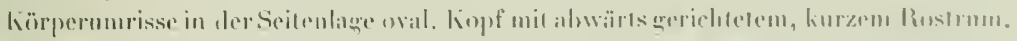

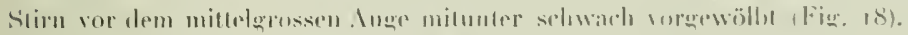

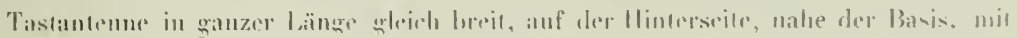

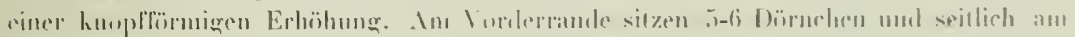

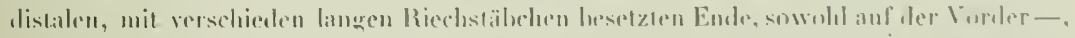

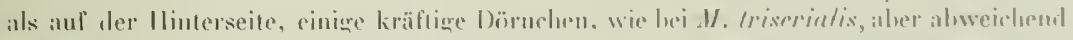

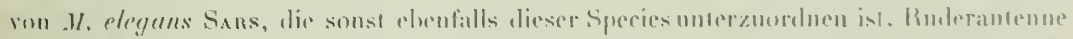

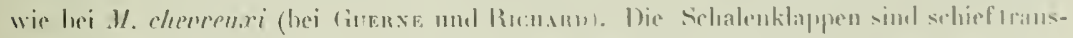

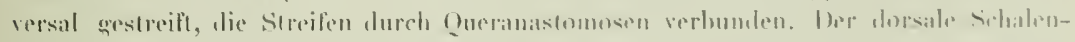

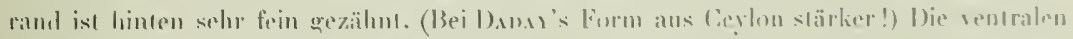

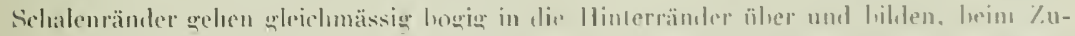

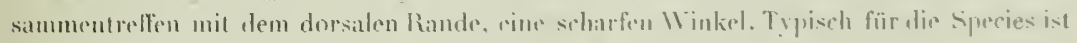

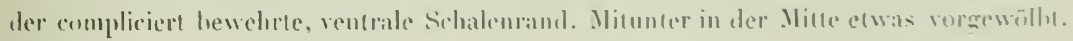

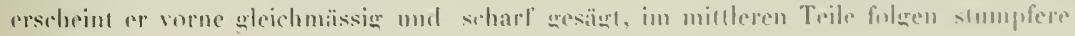




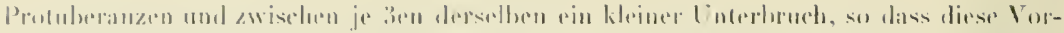

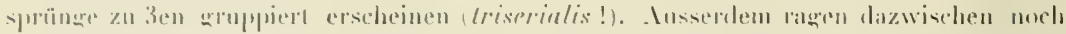
kïrzere und lïngere, krältig hewimprerte, breite Borsten hervor.

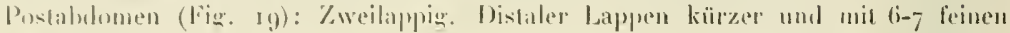

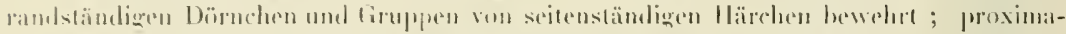

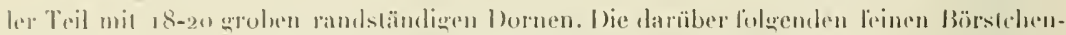

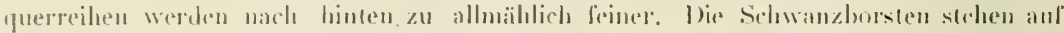

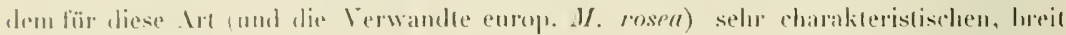
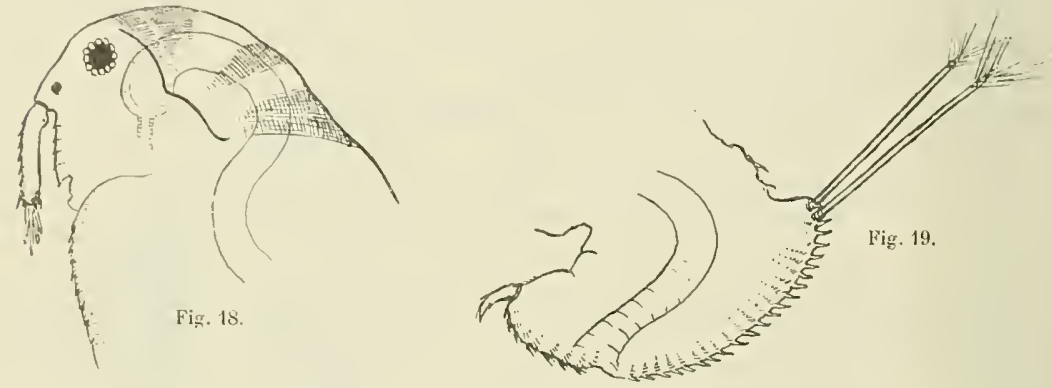

nath hinten rorstehenden Teile des Postabulomens. Ehenfalls sehr chatrakteristisch fïr diese Species isl die lüschelfürmige Anordnung der llarean Ende der Selowimmborsten.

Die Endkrallen endlich, lie äussersl schwer herauszuprïparieren sind, da sie sich mil den zahlarichen Inhängen der hinteren Beinpare stets verwickehn und dureh die Schalen hindurch in keinem Falle sichtbar werden, scheinen grösserer Variabilität unterworlen zu scin. Jeder Forscher zeichnel sie wieder anders. Wie sie bei meinen Tieren ausgehildel sind zeigt ebenfalls Fig. 19. - I las "reigentümliche, schlauchförmige Gebilde» hinter dem tetzlen Beinpaare, das Weltner (1896, Fig. in pg. 19) noch fïr cincen Paral-

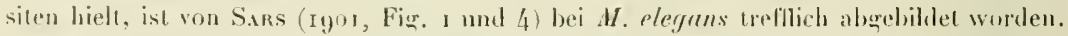

Maasse: Wribehen $0,5,5-0,9^{3} \mathrm{~mm}$ lang und $0,3-0,57 \mathrm{~mm}$ luch. Farbe blassegell, bis bü̈unlich.

Fumelorle: F. 6 selton und [F, 14] häufie. Zwei, bezüglich der firösse elwats von einan-

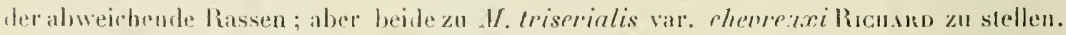

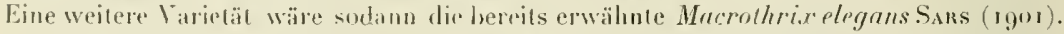

Ciergyr. Verbreitung der Sprecies : Sü̈lasien (Vorderindien und Ceylon, Sumalra, davia,

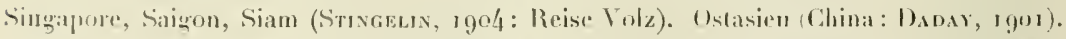

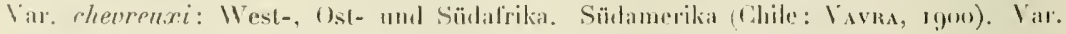

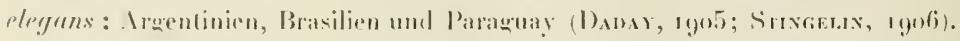




\section{Macrothrix hirsuticornis Vomss. $\cdot 1$ |}

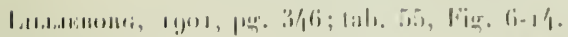

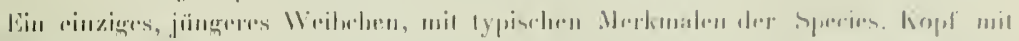

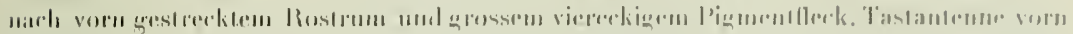

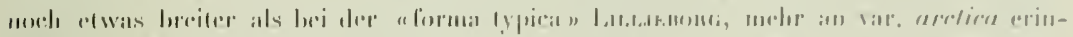

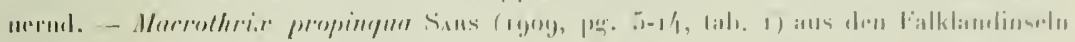

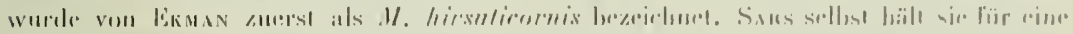

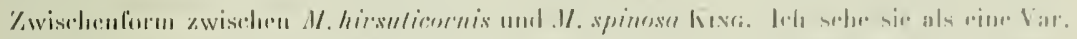

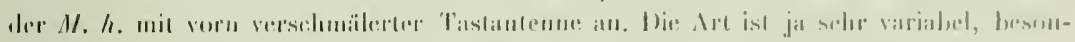

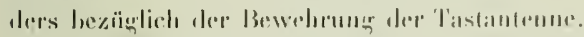

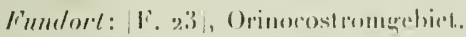

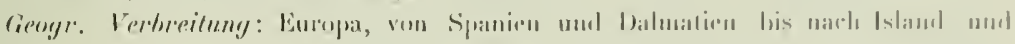

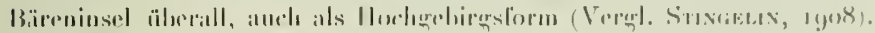

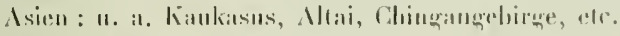

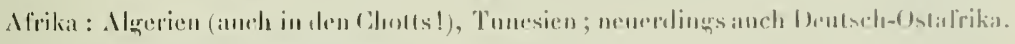

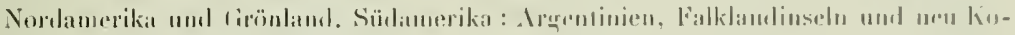

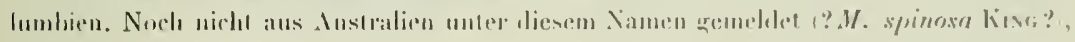

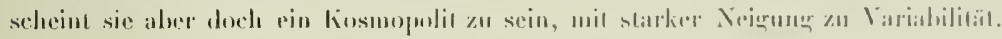

\section{Iliocryptus sordidus Litis.}

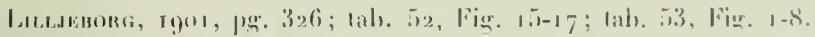

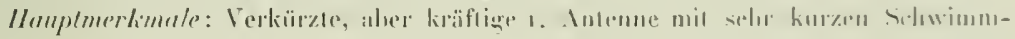

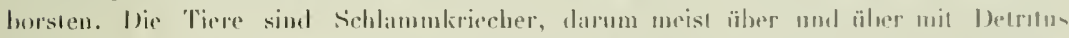

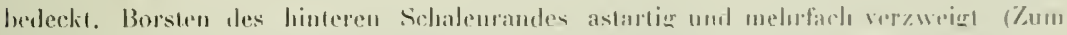

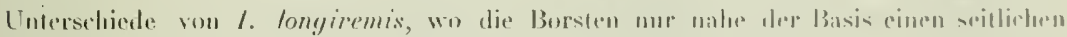
Dorn lragen mul in äbrizen hloss lein hewimperl sind.)

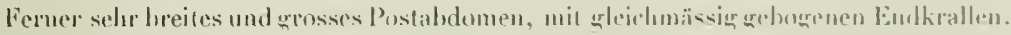

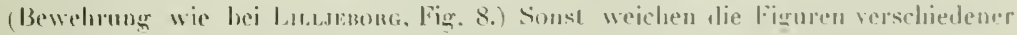

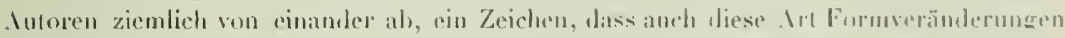

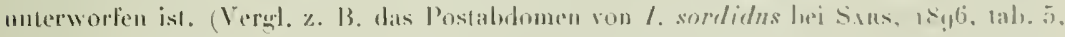
Lig $1-3$, aus Sicher:)

Maasse: Ein Weihchen mil 4 Eirrn: $11,85 \mathrm{~mm}$ ling, $10.6 \mathrm{~mm}$ hoch.

Ein Männchen, o,. m m lang.

Fumlort: [F. 24, Orinocosilomgebiet.

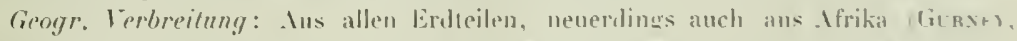

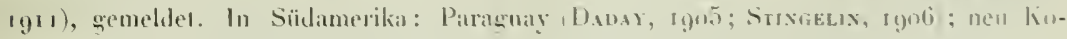
lumbien. 


\section{Iliocryptus sordidus var. sarsi nov. var.}

Sars. Igor, pg. 42; (ab. 7, lïg. I1-13 (I. sordidus!).

Dits in Frage kommende Tier habe ich in einem einzigen, bereits deformierten Exemplare in [F. 5] gefunden. Es ist leider im Laufe der Untersuchmg noch rollents zn Grunde gregangen, so dass es mir unmöglich war, eine genaue Zeichnung des aulfälligsten hörperteiles, des Postaludomens herzustellen. Dasselhe war sehr breit, wie bri $/$. wordidus. Dic Seric der längeren, präanaten Dornen bestand aher aus bedeutend kürzeren Elementen als hei der forma typica. Postanalzähne waren 9 vorlianden.

Ekmax (1905, pg. 5; lab. 1, Fig. 1) und Sars (1909, pg. 14; lab. 2, Jig. 1-7) haben einen lliocryptus brevidentatus beschrieben, mit kürzeren Präanaldornen. Bej liesem ist aber ter proximale Teil des Postabdomens breiter und länger als bei /. sordidus ron Sans (1901) und am Ran le mit ig Zähnen bewehrı.

Ob) das von mir gefundene Tier nun ganz identisch war nit them von Sars beschrichenen, kiamn also leider nicht mehr festgestellı werden.

Immerhin kommt dem I. sordidus Sars (rgor!) mintestens der Wert einer nenen Varietäl zu. Ich bezeichne sie darum nach ihrem Entdecker als I. sordidus var. sarsi.

\section{Iliocryptus halyi var. longiremis (SARS).}

(Fig. 20.)

Sars, I888, pg. 33; tab. 4, Fig. I, 4, 5. (I. longiremis); SARs, rgor, pg. 40; lah. 7 , Fig. I-10. (I. longiremis); Brady, I 886, pg. 95; 1ab. 37, Fig. 6-9).(I. halyi); Daday, 1898 , pg. 48; Fig. 23 a-1. (I. halyi).

Ich habe mich schon 1904 (Reise Volz, pg. 20) für die Vereinigung von I. longiremis und I. halyi ausgeprochen. Nachdem ich nun aher I. longiremis aus eigener Anschanung kennen gelernt habe, kann ich mich nicht entschliessen, nach dem Vorgehen Daday's (Igo5, pg. I9o/191), den Namen, der von SARs in so meisterhafter Weise beschriebenen und alggebildeten /. longiremis unter dem Namen der viel weniger scharf unschriebenen Species I. halyi, eingehen zu lassen, zumal, da sie durch ihre sehr langen Schwimmborsten genügend als Varietät gekennzeichnel ist. Dieser $I$. halyi var. longiremis (SAns) hat in Südamerika eine grosse Verbreitung. In Kolumbien sehr gemein!

Mausse: Die Grössenunterschiede erwachsener Weibchen von verschiedenen Fundorten sind beträchtlich und abhängig von Alter (Weibchen mit melıreren Schalenresten) und Eierzaht.

Länge: $0,5 \bar{y}$ bis 1,1 $8 \mathrm{~mm}$; Höhe: 0,36 bis $0,97 \mathrm{~mm}$. Die grössten Exemplare waren also mehr als doppelt so ling und etwa $3 \mathrm{mal}$ so hoch als die kleinsten. 


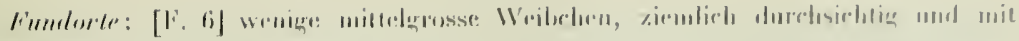

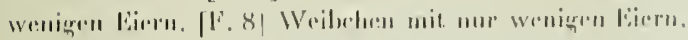

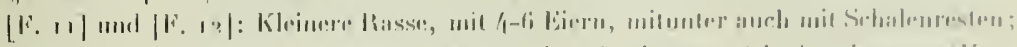

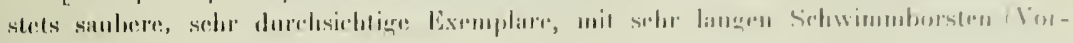
zï̈gliclue Sichwimmer!).

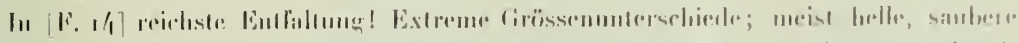

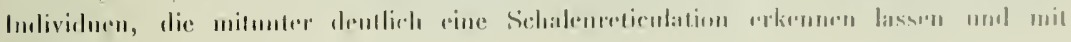
lesomeles langen Sirluwimmborshon auscrerinstel siml. - |li, 18|: grïsste

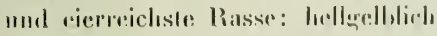
grä̈rlste, mitmoter mil Schlanm luderkbe Tieremit 1/1-20 Subitanciern;

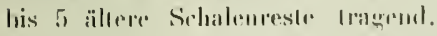

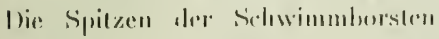
iilertagen elentials den hinteren Schalenrimb um rin Borleutrules.

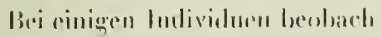
lete ich eine kräfieger. Gimulation

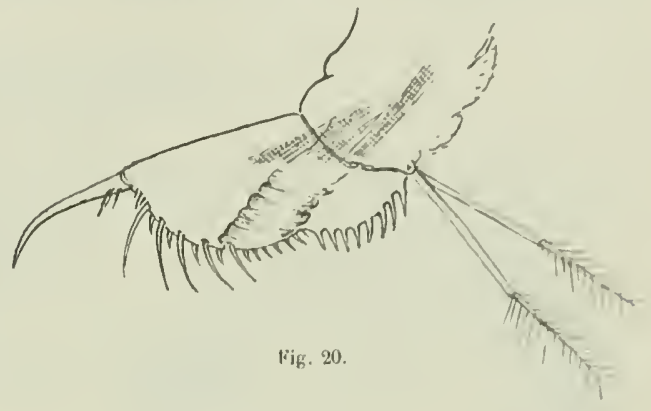
der Selazle, dic cinigremassen an

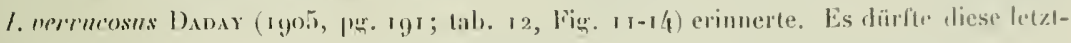
genannte eine individurlle Varietäl von $/$. holyi sein.

Geogr. Verbreitung: Die Species /. halyi scheint ihre grösste Virlıreitung in Sürlasien zu hahen. Unter den Bezeichnnugen /. halyi und /. longiremis * wurde sie aus allen Erifteilen gemeldel, nit Ausnahme von Europa! Dit wird sich wohl noch ein . Aequivalent finden. In Süılamerika: Argentinien, Brasilien, Chile, Paragnay und men Kolumbien.

\section{Streblocerus serricaudatus SARs.}

Lilliserorg igot, tab. 56 ; Fig. I $5-27$.

Vom Genus Streblocerts kemt man mur 2 Arten. Die zweite, St.pygmaeus, ist anch von Sars (Brasilien) beschrieben worden.

Nun kann ich auch das Vorkommen der in Europa und Nordamerika verhreiteren Species S. serricandatus melden. Sie ist grö̈sser als $S$. pygmaens und besizz ein sehr charakteristisch hewehrtes Postahdomen, mil urohen, scharlen Sägezähnen am proxmalen Rande.

Mausse: Weibchen (ohme Eier) waren 0,35 his $0,36 \mathrm{~mm}$ lang und cirea $2 \mathrm{~mm}$ hoch.

Fundorle: [F. 1; [F. 2]; [F. i].

Geogr. Verbreilung: Europa, überall, lis zum äussersten Norden; immerhin sellen!

- Auch Gunser, Igo7: Vorderindien. 


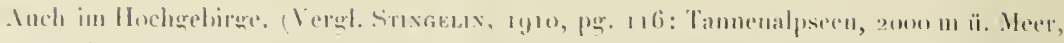
Tïmpel mil reicher Bodenvequation.)

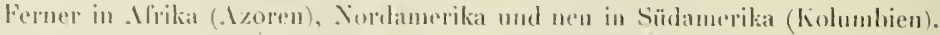

\section{Familie: Chydoridae.}

\section{Camptocercus australis Silks var. dadayi nov. var.}

(Fig. 21, 22 .

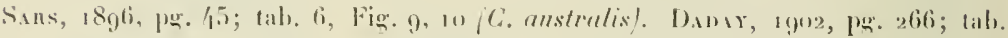

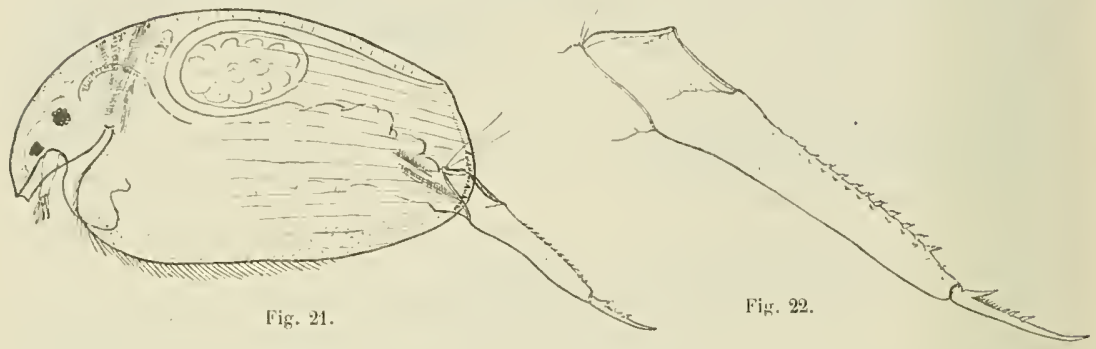

10, Fig. 2, 4 und 1905, pg. 189; lab. 12, Fig. 4 (C. austrulis). Stingebin, 1904, pg. 21 ; 1ab. 2, Figs. 17 (C. australis).

Camplorerens austrulis Surs ist auch eine sehr variahle Species, besonders was den Bau des Kupfes (Rostrum, Kopfkiel), der Schalenränder und des Postabdomens anhetrifft.

Bei SArs $(1896)$ ist z. B. der hintere-untere Schalenwinkel ohne Bewelırung; aher bei den kolumbischen Exemplaren trill eine feine Randhezahnung aul, wie bei Dams (1902) und den von mir aus Südasien (1904) gekennzeichneten Tieren.

Die kolumbischen Exemplare stimmen an besten mit den von Dabar ans Patagonien (1goz) beschriehenen und gezeichneten Tieren üherein. Das Postahdomen hesser noch mit Fig. 4 in tah, r2, Da Day rgo5. Die Endkrallen haben abrer in der Mille der Concavseite 3 statt 2 Dornen, wovon der vorderste ziemlich kräftig und breit ist (Fig. 22).

Der grosse viereckige Pigmentfleck, 3/3 von der Grösse des Anges, liegt genan in der Mitte zwisehen diesem und dem Ende des breit abgestutzten Rostrums.

Da dieses von DaDay und mir beobachtete Tier in rerschiedenen Punkten von der ursprünglich von SARS aus Australien beschriebenen Species ahweichı, und in Südamerika eine grössere Verbreitung aufweist, ist es als südamerikanische Varirtät mit einem lesonderen Vamen zu bolegen. Ich nenne es greziemend C. australis var. dadayi. 


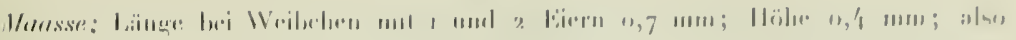

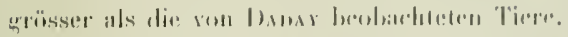

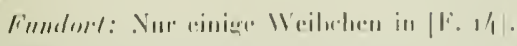

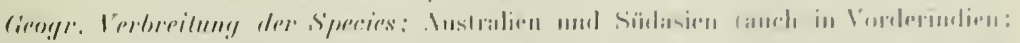

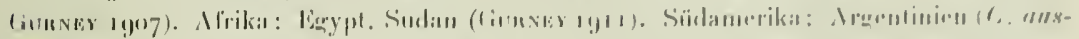

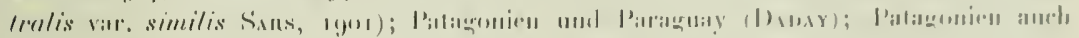

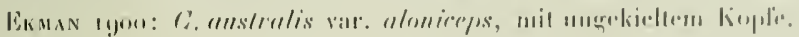

\section{Kurzia latissima fiuн\%"}

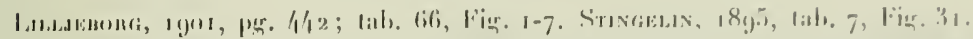

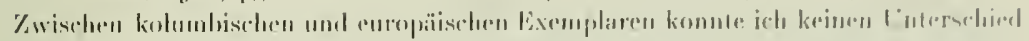

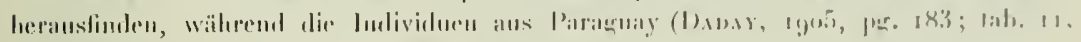

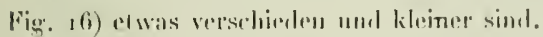

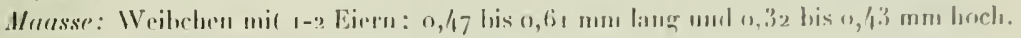

Findorle: [1;. 18] mud [F. 23].

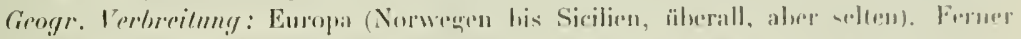

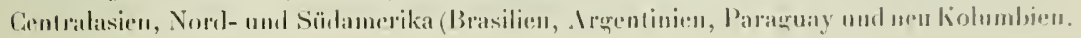

\section{Alona affinis (LEvig).}

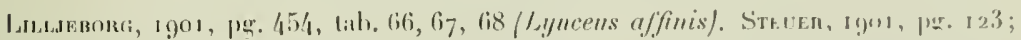

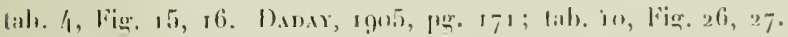

Wie die von SAns aus Brasilien gomelalelon Tiere, weichen anch die kolumbischen

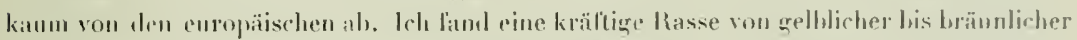

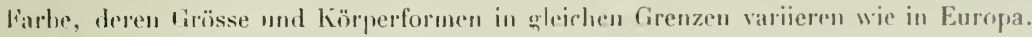

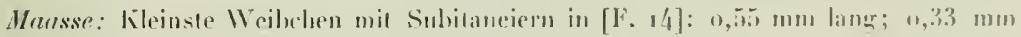

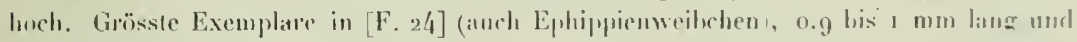
0,54 his $0,6 \mathrm{~mm}$ hoch.

Findorle: [F. 14]; F. 23; F. 24! selur IYisish!

Geogr. Verhreilung: Teherall, mit Iusmalume von Australien, gefument Auch im

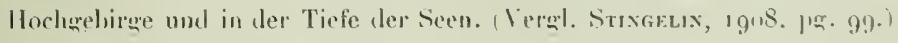

\section{Alona costata SARs.}

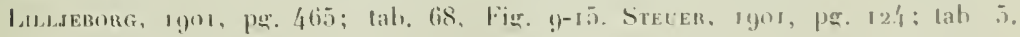
Fig. 17.

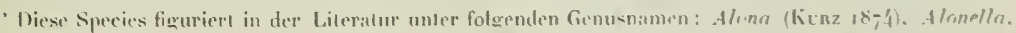

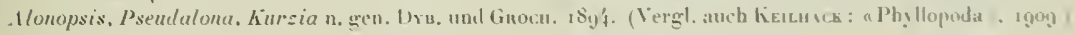


Lianzer llabitus wie bei anopüischen Exemplaren.

Mursse: Liänge 0,52 $\mathrm{mm}$; Höhe $0,32 \mathrm{~mm}$.

Fundort: 19.19.

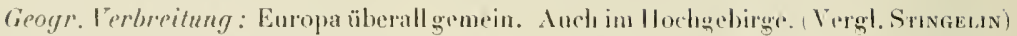
1go8, pg. 101.) Ifrikit (Azoren), Asien (Aralsec, Pamir, China), Nordamerika und Südamerika (Arqentinien, nen: Kolumbien). - Noch nich qemeldet aus Südasien uml dem afrikanischen liontinente, sowie atus Australien.

\section{Alona guttata Sirs.}

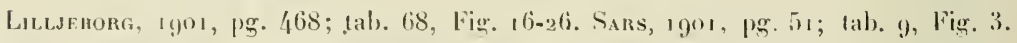

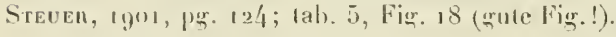

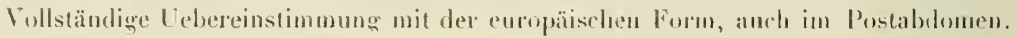
Eine seilliche Reihe von Börstchen war nie vorlanden.

1/nasse: Länge von Weilvelren mit Subitaneirrn $0,3-0,35$ mm; Höhn $0,2-1,24$ mm.

Finndorte: [F. I]; [F. I4]; [F. 2 I]: pelingisch!

Gengr. Verbeitung: Ueherall, ausgenommen Australien (?). Gemeinste Cladocere!

\section{Alona guttata var. tuberculata (livRz).}

(Fig. 23.)

livnz, 1874, tab. 2, Fig. 3.

Wie in andern Ländern, so tritt auch hier in Kolumbien als Begleitform der A. guttota mitunter eine individurlle Varietäl auf, die wie livız zoichnel, den Schalenräudern parallel trufende Reilıen von Höckerehen aufweist.

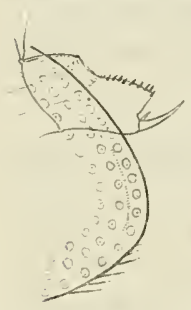

Fig. 23.

Bei einigen Exemplaren waren diese Höckerchen besonters gross (wie übrigens auch lunz sie zeiclnet), hatten aber bisweilen noch saugnapfartige Vertiefungen, genau wie DАDAr bei seiner Alona anodonta (1905. (al. 1 1, Fig. 5, 6) abbildet.

In seiner neuesten, grossen Arbeit (Ostafrika, rgto; pg. 131) stellt Daday diese A. anodonta num zu A. rectangula. lch glaube aber, wie aus seiner Fig. 5 (tab. II, 1905) zu scluliessen ist, dass sie eher bej 1. guttata unterzubringen väre. Einzig die seilliche Bewehrung des Postabutomens ( 1 go5: lab. i r, Fig. 6) könnte noch cinen Zweifel erwecken. Aber Lako (1goo) zeichnet bei seiner val. spinulosa seillich am l'ostabdomen auch Börstchen. (Siehe auch A. guttala var. Stingelin, 1904, Reise Volz, pg. 23.

Maasse: Länge $0,35-0,38 \mathrm{~mm}$.

Fundorle: [F. I] ; [F. : ; [F. 5]; F. 24]. 
23. Alona pulchella lisis.

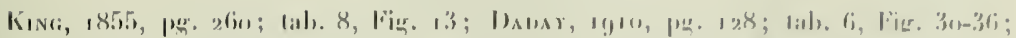

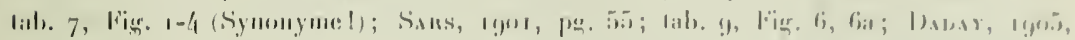

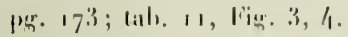

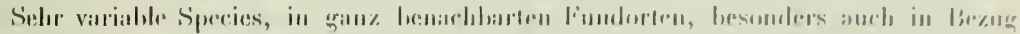

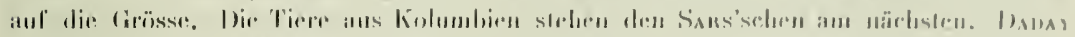

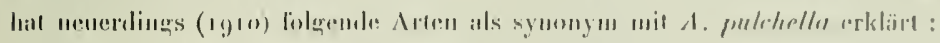

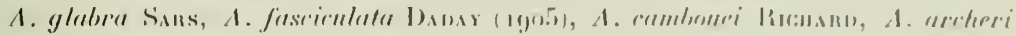
Sins, A. lorevis Sils.

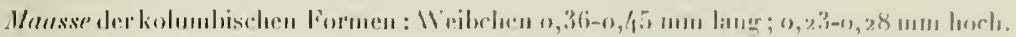

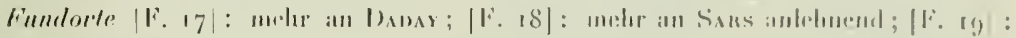
kilciuste liurm.

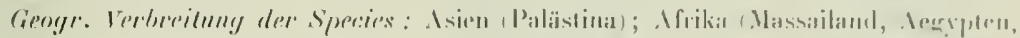

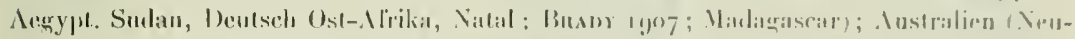

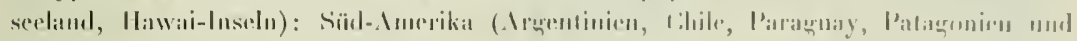
neu: Kinlumhioi).

\section{Alonella excisa (Fisturik).}

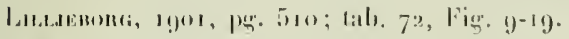

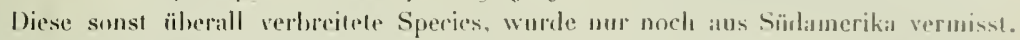

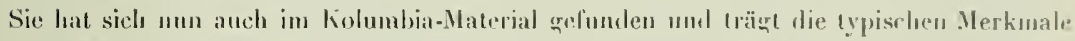

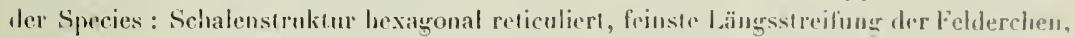
Zacken an der hinteren-unteren Schalenecke, charakteristischer Bau der Pustalmbmens;

- hingegen ist sie elwas kleiner als die empopäiscle Form.

I/ursse : Länge ales Weilıchens 0,32 umm; Mähe 0,2 mm.

Fundort [F. 21/ : Orinocogebiet.

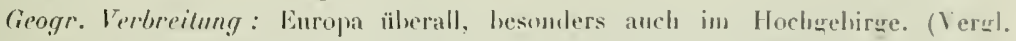

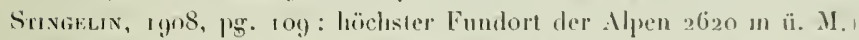

Ferner in Sibirien, Cientratasion, Südasien. Sordann in Ifrika (Azoren, Mansisiland).

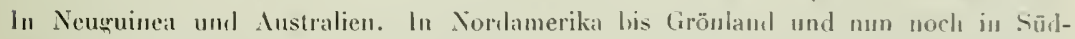
anerika (Kolumbien).

Die nächste Verwandte dieser. Irt in Südamerika ist A. clathrentrla SARs (Igur, Pg. 62; tab. 4, Fig.5). Ich hale sic für cine Varietäl ter A. excisa.

A. excisa ist ulso der verbreitelste liosmopolit! 
25. Pleuroxus similis Vara-SAns var. fuhrmanni nov. var. Fing. $24,25$.

Im Kolumbia-Malerial fand sich auch ein Vertreter des Genus Plenroxus, der dem

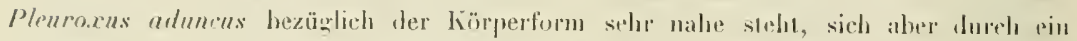
anders geformtes, lïngeres Postablomen unterscheidel.

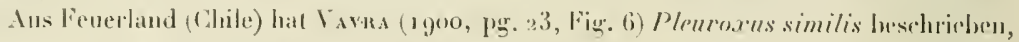

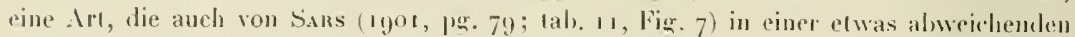
IVeise ans Argentinien wieder beschriehen and algechildet wurde. Nach dem Vergleim meiner Tiere aus Lolumbia mit der Reproduction der Nikrophotongaphe bei Vava

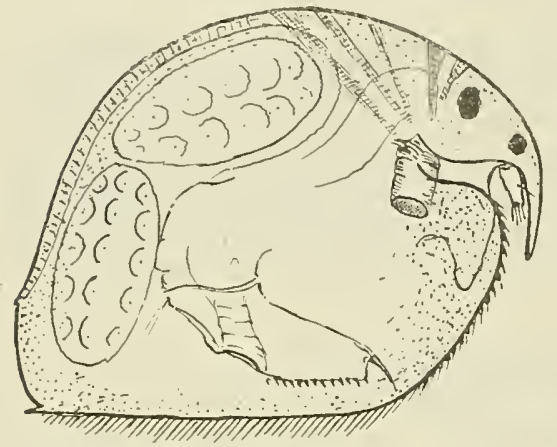

Fig. 24 .

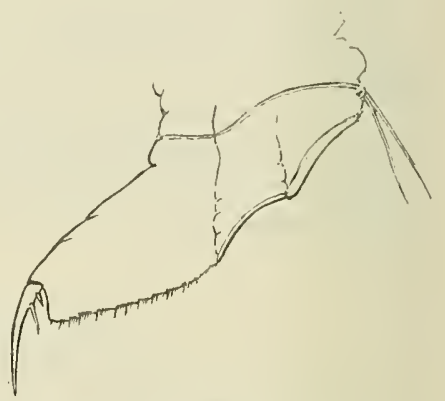

Fig. 25.

(Fig. 6) glaubte ich zuerst eine neue Species vor mir zu haben, dic sich durch viel sürzerr, hintere Schalenränder und ein kürzeres Rostrum, sowie Unterschiede im Ban des Postabromens unterscheidet. Aber die Sars'sche Beschreihung liess mich nirht mehr in Zweifel, dass bloss eine sehr ausgesprochene Varieläı einer in Südamerika wril verbreitelen Art vorliege.

Diagnose des Weibchens : Körper in der Seitenansicht herzförmig. Dorsaler Schatenrand hoch gewölbt, dann plüzlich nach hinten steil gegen die sehr niederen, lanterı Schalenränder abfitlend. Ventrale Schalenränder ganz gerade und dicht mit slark hewimperten Borsten hesetzl. Vorne steigen diese Ränder unter breitem, stumpfem WVinkel gegen die hohen Vorderränder an, die fast parallel lanfen nit dem hinteren Teile der dorsalen Schalenränder. Sie erscheinen bei schwächerer Vergrïssirung qesägl ; lei stärkerer Vergrösserung bemerka man, dass diese Sägezähne sich in feine Borsten aasspitzen (Fig. 24). Die Schalenklappen erscheinen dicht granulierı, mitunter im linteren Teik auch deutlich retikuliert. Aeusserst schwach angedentete, transversale Streifen, die milunter vom vorderen Schalenrande ausgehen, komnte jch nur in einem einzigen fialle wahrnehmen. An der hinteren-unteren Schalenecke sitzen 1-3 winzige Zähnchen. 


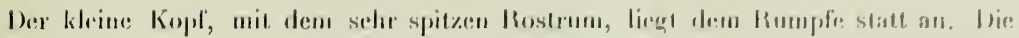

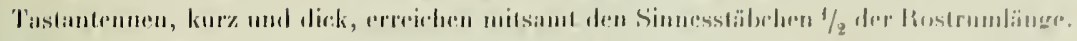

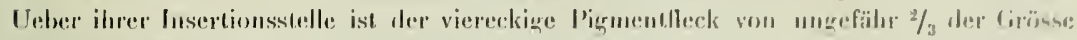
des Angess. Forme des lifprenanhangeses in lïir. $\%$.

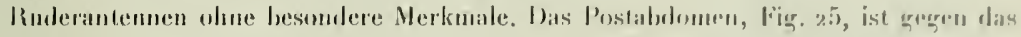

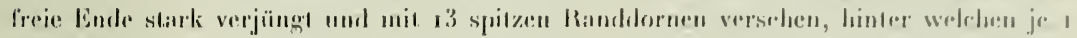

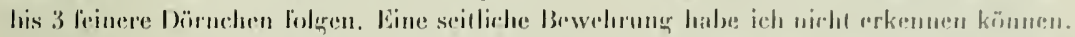

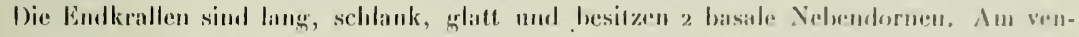

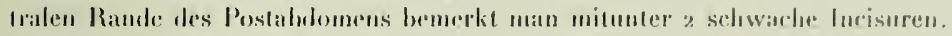

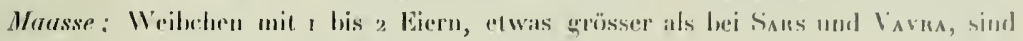
0,515 lis $0,6.3$ mon lang and $0,11-0,18 \mathrm{~mm}$ hoch.

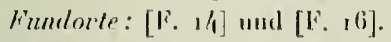

Geogr. Verbrritmug der Art: Nur Südamerika (Argentinien, Chile, Falklandinseln, Patraguay und P'atagonien); neue Virr. in Kolumbien.

\section{Dunhevedia odontoplax SArs.}

Sins, 19or, po. $7^{6}$; tah. 11, Fig. 6 .

Unterscleidet sich von D. crassa lixg (syu. Crepidocercus seliger Bunge; läir. bei Strageun 1895, lab. 8) dureh cinen grossen, scharfen Zitlufortsalz in der Mille der Vorderseite des Lippenhanges und durch ein kräftiger lewelırtes Pustalvlomen. Bà eineın

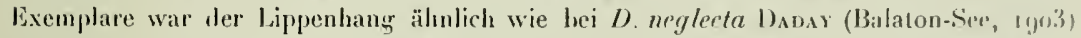

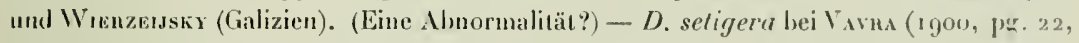
[ïg. 5 aus Chile) ist syn. D. odontoplax!

Marsse: Längre der Weibchen $0,48-0,58 \mathrm{~mm}$; Höhe $0,32-0,4 \mathrm{~mm}$.

Fundorte: [F. 14], [F. 16], [F. 17].

Geogr. Verbreitung: iBrasilien Chile, Paraguay; nen Kolumbien.

\section{Dunhevedia odontoplax var, colombiensis nov. var.}

(Fig. 26 und 27.)

Der Lippenanhang weist über dem grossen, zalunförmigen Fortsatze noch 3 seharfe Incisuren anf (Fig. 27) und am hinteren-unteren Schalenwinliel finden sich 2 Zïline. cin grösserer und ein hleinerer (Fig. 26).

Matsse: $0,5-0,58 \mathrm{~mm}$ lang; $0,36-0,4 \mathrm{~mm}$ hoch.

Fundort: [F.23], Orinocogebiet. 


\section{Bemerkungen zum Genus Chydorus.}

Das Genus Chyylorus ist in den Sümpfen von kolumbia quantitativ und qualitativ an reichsten vertreten; so dass P'rof. Fuhrmann mir änssitle, or habe fast nichts als

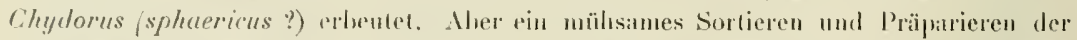
unzïhligen, winzigen heschöpfchtn ergah schliesslich rim Liste von 7 verschiedenen Arten, wortunter liein einziger Ch. sphapricus! Es zeigh sich also ein ähuliches Verdaltun wie in anderen lopischen Gehieten, z. B. in Südasien, von wo ich ( 1 go/) ein umfing-

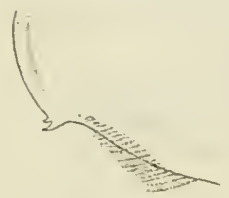

Fig. 26.

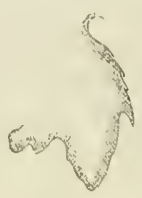

Fig. 27. reiches, durch W. Touz tresammeltes Material, bearbeitete. Diunals schrieb ich: "Vergebens fahndete ich - unter den unzähligen Chydoriden - nach cinem typischen Chydorns sphuericus.) Dieser Salz gilt num also wieder für das Fulurmonn'sche Kolumbianaterial. Auch für das Amazonasgebiel (1go/) kimnte ich diese Art nicht feststellen. - Ich zweille darmu je länger je mehr daran, dass Ch. sphaericus ebenfalls der tropischen fauna angehöre. Die wenigen in der Literatur gemeldeten Vorkommen dïrften vielleicht auf Einschlepprung, oder falsche Bestimmung zurückzuführen sein. Hier einige Angahen:

Sars (19or, Brasilien) meldet u. a. auch den Ch. sph., lä̈lt es aher nicht fïir ausggeschlossen, dass diese Species mit skandinavisclien Wasserpllanzen, welche er in dic Aquarien einsetzte, in denen er, aus getrocknetem Schlamme von Brasilien, südamerikanische Cladoeeren zur Eutwicklung lorachte, ringeschleppt worden sei.

Gunney (rgo7, Vorderindien) citiert (pg. 26) Chyd. sphaericus und schreibt dazu: "a few specimens were taken." DaDas (1g10, oberer Nil): Ch. sph. "Wenige nichl gü

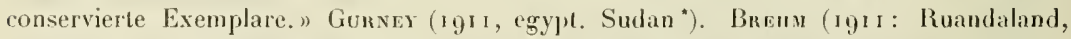
Centralalirika!") hemerkt pg. 168: "Genus Chydorns ist durch den typischen Chydor'us sphaericus, aher auch durch manche mit Ch. sph. frïher vervechselte Art vertreten; bisher war Ch. sph. uur aus Nordafrika bekannt, geht jetzt also weit südlicher. )

Andere Fundorte in Südamerika reichen schon über die Tropen hinans.

DadaY (rgo5) nennt Chyd. sph. aus Paragnay und auch ich habe im Ternetz'schen Material (1go6) ein Exemplar gefnnden. Anderseits wurde cin von Ekman (rgo5) aus den Filklandinseln gemeldeter $C h . s p h$, von SArs (1gog) als neue Art erkannt und als Chy. sphnericoïdes lueschrieben. Sie hat etwelche Aehnlichkeit mit Chy. ovulis. hesizt aber einen kïrzeres Rostrum, kürzeren Lippenaulang u. a. m. - Brady (igo6) meldet Cih. sphaericus aus Neuseeland.

Vie äussert spürlichen Angaben über das Vorliommen non Chyd. sphaericus in tro. dischen Gebieten sind geeignet, die Annahme einer passiven Einschleppnny zn stülzen- 
28. Chydorus ovalis Kuw\%.

(1.ïg. 2x.)

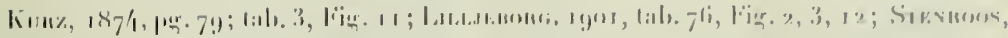

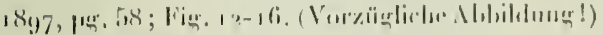

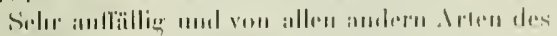

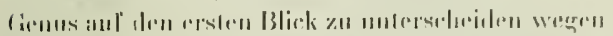

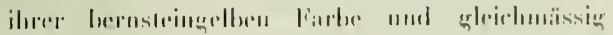

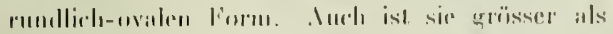

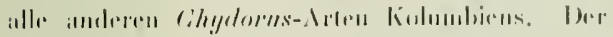

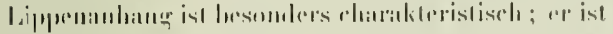

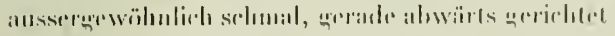

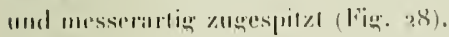

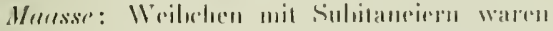

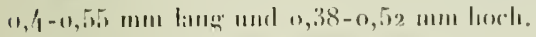

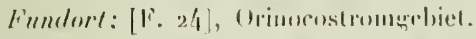

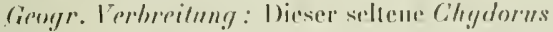
ist bislare an wenigen Orton in Europa gufunden warden, besonders aber in Nordourental

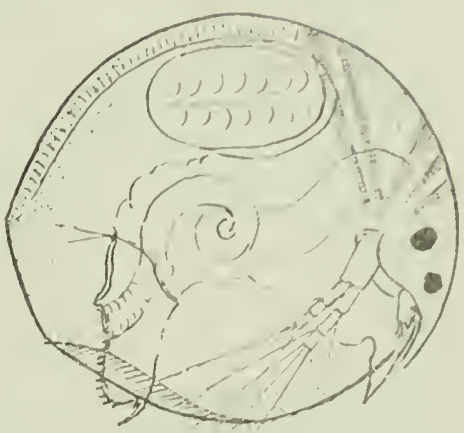

Fir. 29.

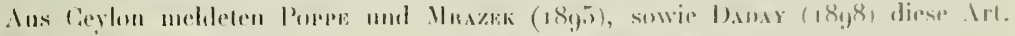
Interessant ist darum anch das Anluelen der typ. Species im Hochlande ven liohmbia.

\section{Chydorus piger Sims.}

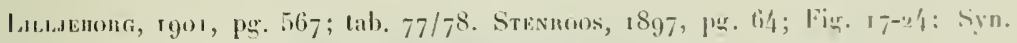

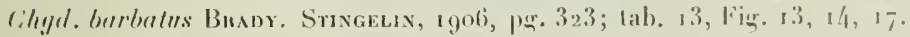

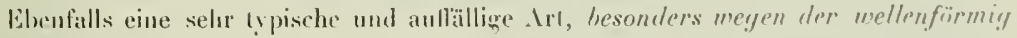
struierten Schale 11. a. m.

Maassp: Länge $0,38-0,45 \mathrm{~mm}$; Häle: $10,34-0,41 \mathrm{~mm}$.

Fintorle: [1..23], [F. 24], Orinocostromgehiet.

Geographische ferbreitung: Diese ebenfalls seltene und solur clatrakterislische Sirecies wurde nur in Lumpa gefunden, Ronssland, Skandinavion, Pommern, England, Frankreich. firol mal selmeiz (vergl. Strngeun, 1908, pre. 12/).

30. Chydorus leonardi kivg.

Fir. 20, 3n.)

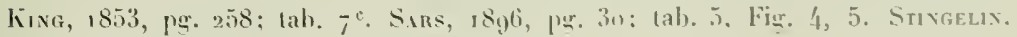
igo4. Singaprore, pg. 33. 
Wahrscheinlich die kleinste Art der Genus und der nächste Verwandte won Gh. sphaericus. Doch ist der Lippenanlang weniger spitz (Fig. 29), das Postabdomen

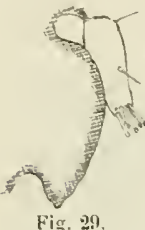

Fig. 29.

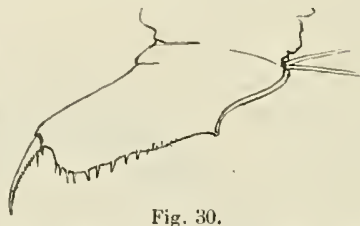

Fig. 30 . (Fig. 3o) relativ schmäler nnd kürzer und olne den typ. winkedartigen, distal vom Auus gelegenen Vorsprung. ( Vergl. Stingivurs, 1904, Reise Volz, tab. 3, Fig. 33.)

Maasse: Erwachsene Weibchen mit 1-2 Eiern waren 0,27-0,29 $\mathrm{mm}$ ling und $0,24-027 \mathrm{~mm}$ hoch.

Fundorte: [F, 16]; [F, 17]; [F, 23]; [F, 24].

Geogr. Terbreitung: Australien, Südasien, Südamerika (Brasilicu, Chile, neu: Kolumbien.

\section{Chydorus eurynotus SArs.}

SARs, I90I, pg. 70 ; tab. II, Fig. 3 .

Körperform schr ähnlich wie bei Ch. sphaericus. Aber Schalenduplikatur des venIralen Schalenrandes vicl breiter. Postabdomen kleiner und schmäler, mit 10-I z Zähnen bewelırt. Lippenanhang nicht zngespitzt, nur eine rundliche Platte. Pigmentleck sehr klein. Farbe hellgelb, Schalen mitunter deutlich und grossmaschig reticuliert.

Maasse: Länge $0,44 \mathrm{~mm}$; Höhc $0,37 \mathrm{~mm}$.

Fundorte: [F. 3]; [F. 6]; [F, 7]; [F, 18]; [F. 23].

Geogr. Verbreitung: Nur Südamerika: Brasilien und neu Kolumbien.

\section{Chydorus pubescens $S_{A R S}$.}

SArs, 1901, pg. 7x; tab. 11 , Fig. 4 .

Körperform selır variabel, bald rund, bald oval, wie bei Chydorus sphaericns. Lippenanhang ähnlich wie bei voriger Species. Hinterer-oberer Schalenwinkel scharl' ausgeprägt.

Ihren Namen hat diese Art von der eigenartigen Bchaarung der Schatenklappen. Dieselbe ist bald mehr, bald weniger stark ausgeprägt. Bei einigen meiner Exemplare erstreckt sie sich über die ganze Schale; die Tiere sind bewehrt wie ein Igel!

Maasse: Länge bis $0,28 \mathrm{~mm}$; Höhe $0,2-0,27 \mathrm{~mm}$.

Fundorte: [F. 6]; [F. 7]; [F. 14]; [F. 16]; [F. I8].

Geogr. Verbreitung: Nur Südamerika : Südbrasilien und Argentinien. Neu Kolumbien. 
33. Chydorus hybridus I Im,

(1iig. 31.)

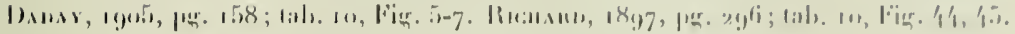

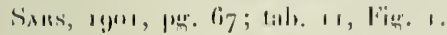

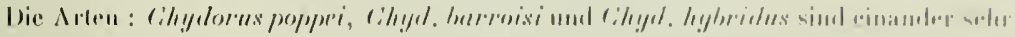

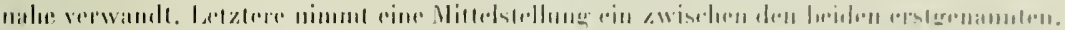

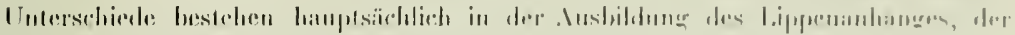

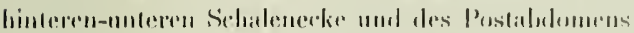

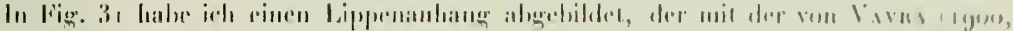

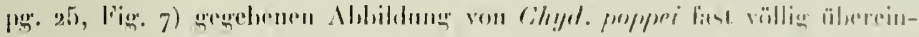

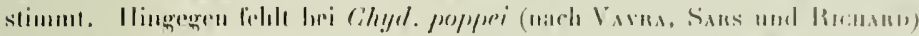

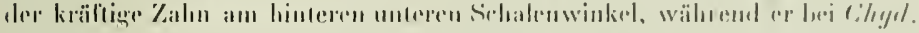

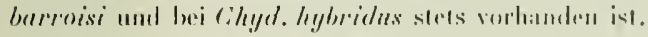

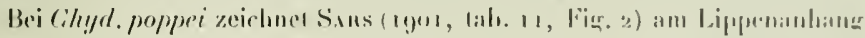

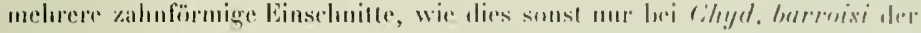
Fill isl.

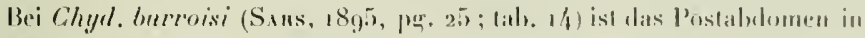

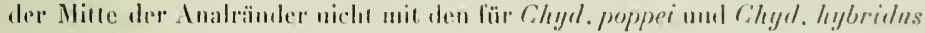

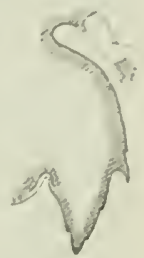

Fig. 31.

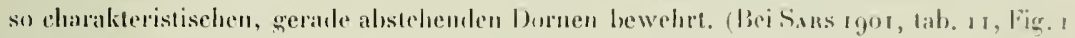
hingegen ist das wieder der Fall.)

Die vou vorderen Schalenrande ausueliemle Transversalstrifung koumt allen 3 Arten zn. Dieses, sowie andere gencinsame Merkmale cinerseils und lie Virlabliliäl der

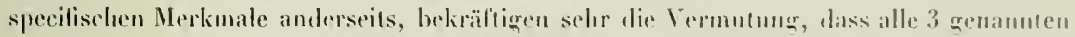
Chydoriden zu einer, auf der ganzen Erde weit verbreiteten Species gehisen.

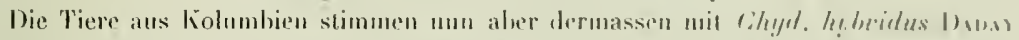
überein, dass ich sie hier noch unter diesem Speciesnimen aulführe.

Writere Nachforschungen sollen entseheiden, oh sic mur als eine sïdamerikantiscle

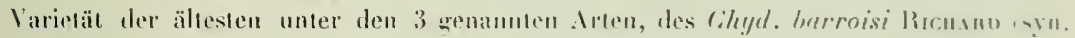
Plenrorrus burroisi, 1894, p. 375, aus P’alästinal, aufzufiasien sei.

Mansse : Länge o,3-0.33 mm; Höhe o, 2\{-0, $26 \mathrm{~mm}$.

Fundorle: $[1.17] ;[\mathrm{F}, 23]$.

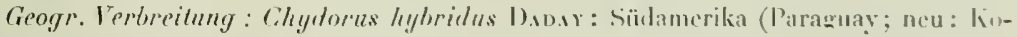
lumbien). Nordamerikix: Wisconsin, Michigan, lunisiana. Texas (nach Burge, r!) ro).

Che poppei Rucuano: Südamerika (Brisilien, Chile, Paraguay), Nordamerika (Lonisiana, Bınge, 1910$)$.

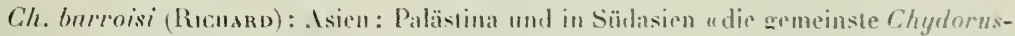
species ". (Fundorte bei Stwgers, 1904, par. 32, 33.)

Afrika: Deulsch-Oslalrikat, Azoren, kaphlankI. 
Anstralien: Tar. Lrevis Sins, ans Veuseedamed.

Vordamerika : Lomisiana, Südamerika : Paraguan, Brasilicn.

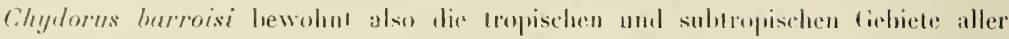
Erituile, scheint alee in hïheren Breiten der gemässigten Zane nicht rorzukommen.

\section{Chydorus flavescens IA1.}

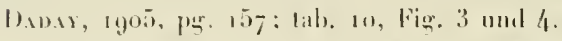

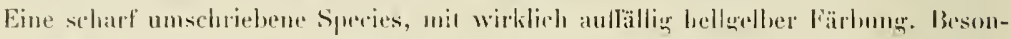
ders charakteristisch ist hier die Bewehrung des Postahdonens. Sihon die Endkrallen

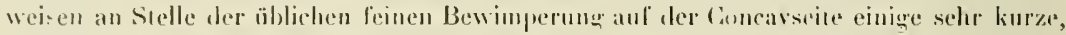
aber dicke Zähnehen auf; dann lolgen auch a basaldornen. Die 3 ersten Standeln an

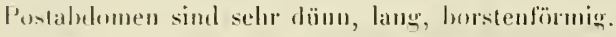

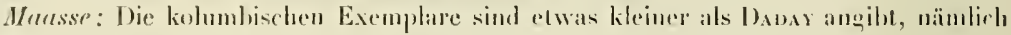
uแ1 $0,31-0,36 \mathrm{~mm}$ lang und $0,25-6,3 \mathrm{~mm}$ hoch. Ein Zwergweihehen, mit einem Ei, wal sograr hloss 1, 22 min lang.

Fundorle: F. 14]; [F, 16]; [F, 17]; [F. 23.

Geogr. Verbreilung: Bisher nur Paraguay; neu: Lohmubien.

\section{Allgemeine Betrachtungen.}

Prof. Fumsaxs's Cadocerenansbeute aus Kolmmbien hat in mancher Beziehung musere lienutnis äher die diesbezügliche Fauna Süılamerikas gefördert.

1. Das Material stamml aus einer bisher noch nicht erforsehten fiegend. Das Fundgrehiet, zwischen $4^{\circ}$ und $7^{\circ}$ nördl. Breite, nahe der miltehnerikaniseluen Landhrücke, 1rägt chwas dazı bei, eine Lücke in unserer Kenntuis über dic quengr. Verhreitumg der Cladoceren in Amerika auszufïllen, da hisher das Gebiet zwischen Brasilien und Texas (also Viltelamerika unil Mexiko) noch nicht untersucht worlen ist. In Auftinden der

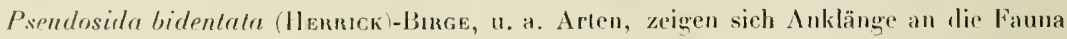
drs schon gut erforschten Unionsgebieles am Golfe von Hexiko.

2. Dats Material stamm lemer aus den liodilleren, also aus dem Hochgebirge, was besonders hervorzuluben ist; denn von den his zum Jibre rgoj (DaDay!) hekannt gewordenen 130 Cladoceren Südamerika's sind fasl alle in den Tieflandsgebieten der Südhemisphäre gesammel worden. Nur ein kleines Material wurde in höheren Lagen erbeutel, 


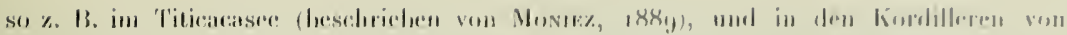

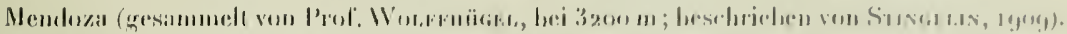

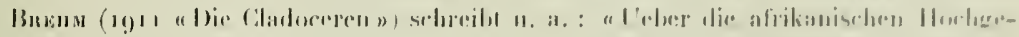

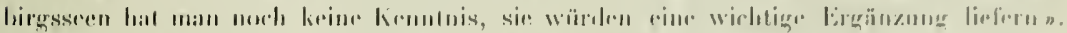

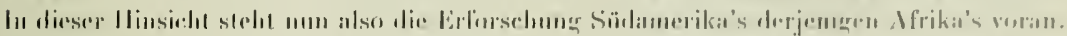

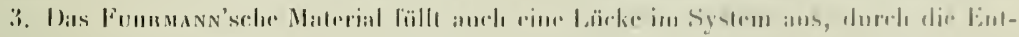

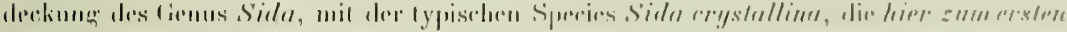

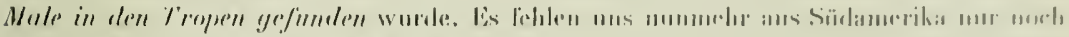

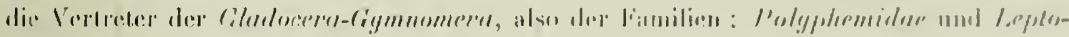

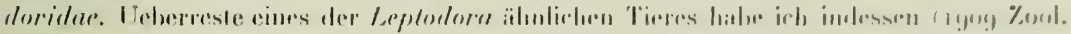

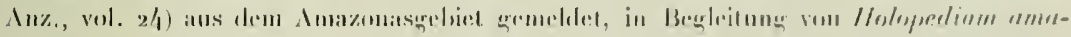

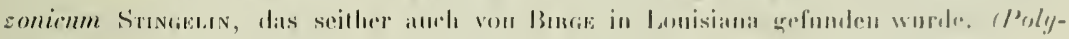

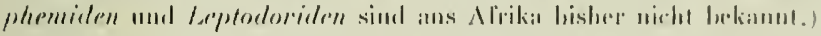

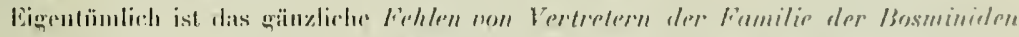

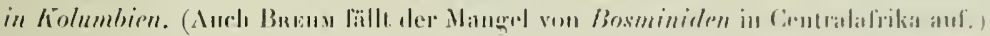

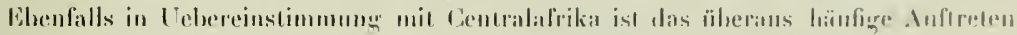

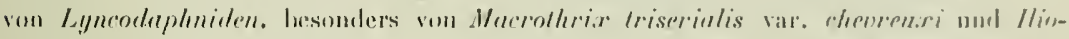

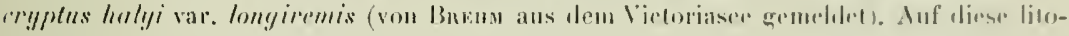

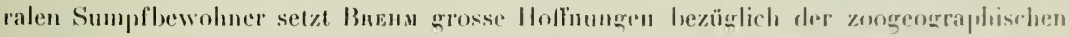

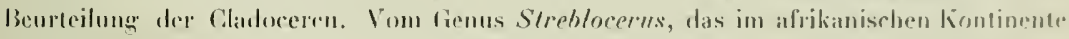

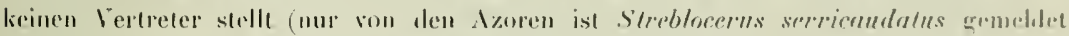

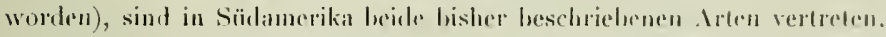

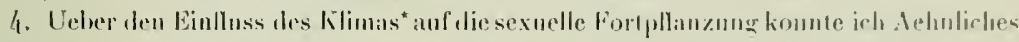

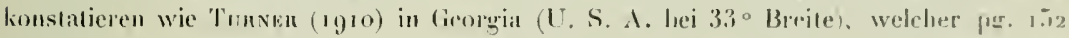
schreibt: "Alt is well known that, in warm climates, clatheera do not furm winteresers" Es fand in warmen Klina Georgias weder Datuereirweilıhen noch Mämohen. Anch aus fiolumbien. dem tande des euvigen Frühlings, lamen mir bloss einige Spuren non

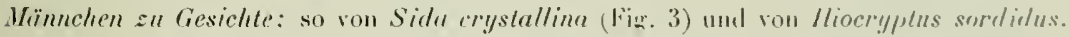
Wintereier traten voreinzelt ant bej Alonn affinis und Simocephalns serrulalus. Fermer fanden sich einige ahgestossene Ephippien ron Hiocryplus (spec.?) und Hacrolhrix (spec.?)

i. Geographische Verbreitung:

a) Leber ${ }_{3}{ }_{3}$ der in Lolumbien erbonteten Chdoceren sind in Sï̈lumerilia endemisch, nämlich :

Cerioduphnia reticulata var. Anbia forma sihestrii (DAD.w).

Simocephatus iheringui licunno.

Moina malirophthalma nov. spec.

lliocryples sordidus var. sarsi nov. var.

Camptocerens australis var. Arduyi nov. var.

Pleuroxus similis var. fuhrmanni nov. var.

- Jahreszeiten rergl. ps. 602. 
Dunhevediu odonloplar. S.aks.

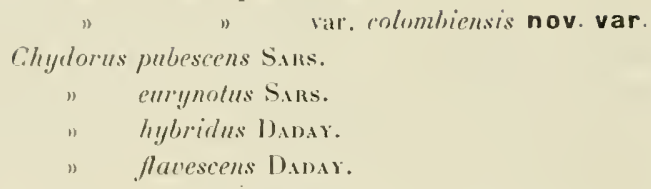

1) ie in Sï̈lanerikia weit verheitute Daphnia pulsx var. oblusa forma latipalpa 1.Moniez) wurde ausserdalh, dieses liontinentes nur noch in den Azoren trefunden. Vielleicht dorthin verschleppt, dürfte sie auch noch als endemische Species ron Südamerikit angesetuen werden. Ilioer!pplus halyi var. longiremis $\mathrm{S}_{\mathbf{A n s}}$ ist auch aus Centralalriki und Vorderindien aemeldet.

1) Inler den in Kolumbien gefundenen Cladoceren konmen in Südamerika am hïufigsten

Daphria pulex var. oblusa forma latipalpa.

Simocephalus serrulatus mit var. inflatus Vavra.

lliocryplus halyi var. longiremis.

Macrolhrix triserialis var. chevreuxi.

Alona affinis.

Alona gnilata.

Dunhevedia odontoplax, sowie besonders die Repräsentanten des Genus Chydorıs.

c) Alus Südamerika waren bisher nicht belannt:

Sida crystallina. (Vorkommen: Europa und Nordasien, bis $75^{\circ} \mathrm{n}$. Br.; noch nicht bekanut aus dem trop. Asien, Afrika und Australien; also nen für die Tropen!) P'serudosida bidentata (Südstaaten der Union; neu für Südamerika, insofern nicht Parasida variabilis DaDAY identisch ist).

Daphnia longispina var. galeatu forma obtusifrons Sans. /Erstmals in den Tropen!)

Streblocerus serricaudatus SARs. (Auch auf den Azoren gefunden!)

Alona guttata var. tuberculata (livnz).

Chydorus onalis (Kunz): Europa. (Auch ans Ceylon gemeldet).

Chydorus piger, (bisher einzig in Europa), erstmals in den Tropen!

Dazu kommen die bereits oben aulgeführten neuen endemischen Arten und Varietäten.

Im Gunzen ist somit die südamerikanisehe Cladocerenkenntnis durch dus Kolumbirmaterial um 12 Tierformen bereichert worden.

Mit den in den Literaturnachträgen (aul' Seite i) seit rgo5 nen binzugqekommenen Arten ist die Liste der südamerikanisctien Cladoceren von 130 auf 150 angestiegen.

Von den 12 nenen südamerikanischen Chudoceren entfallen 6, also die Ilälfle auf die 2 Fundorle im Orinocostromgebiet nämlich:

Sida crystallinu, Pseudosida bidentatn, Alonella exeisa, Chydorus ovalıs, Chydorus piger und Dunhevedia odontoplax var. colombiensis nov. var. 


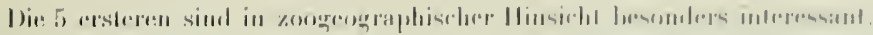

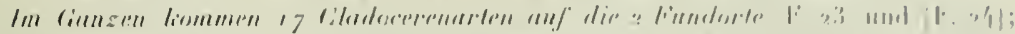

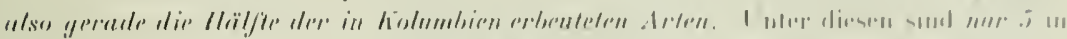

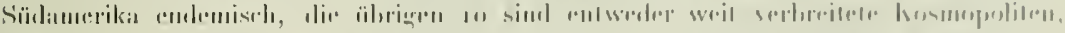

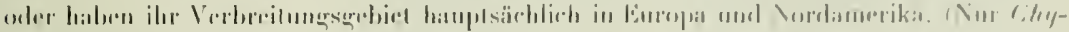

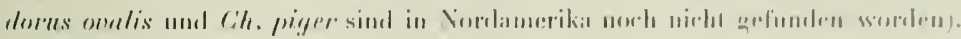

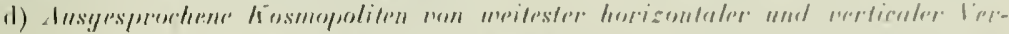

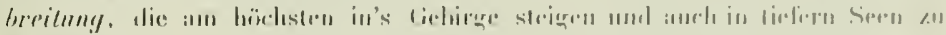
limblen sind":

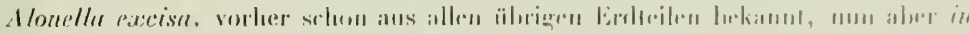

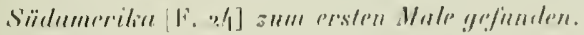

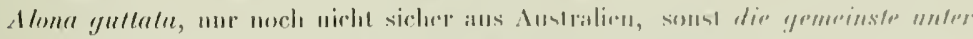

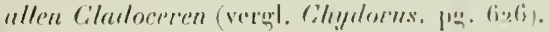

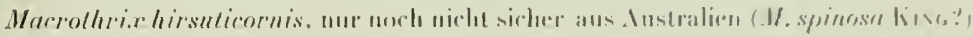

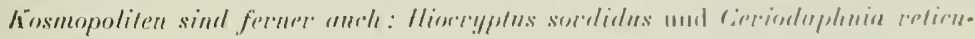

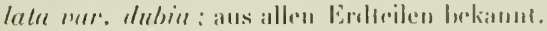

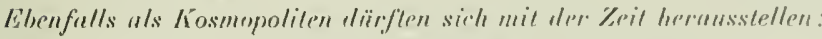

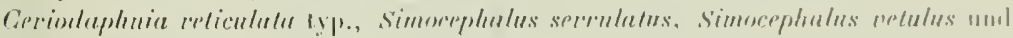

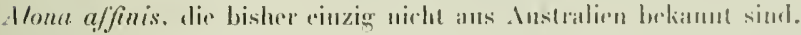

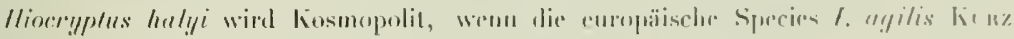

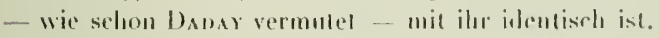

6. Nene Arlen, Varietëten und firmuse.

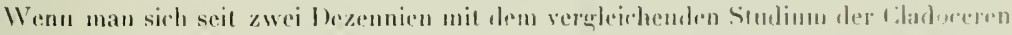

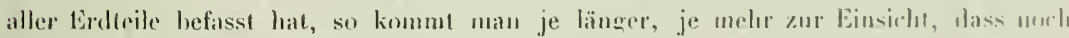

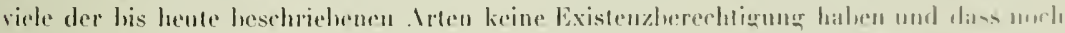

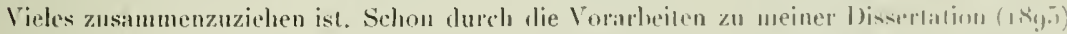

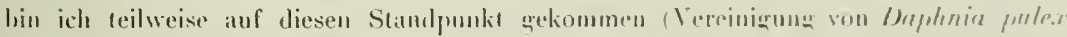

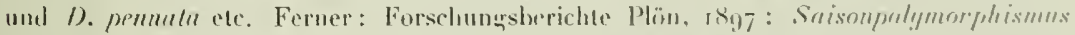

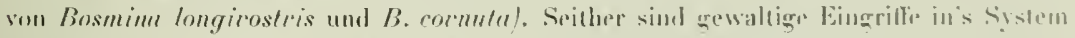
der Cladoceren erfolegt, besonders im Genus Daphnia und Besmime (11, al. durch G. Iis ur k-

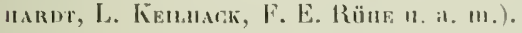

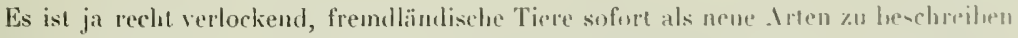
und erfordert lange nicht so viel Mälse; aber die Erfalıungm, die man an den lesser bekannten Clatoceren Europas, mit ihrer oft unlegrenzten Veiguner zur Formwerinderong

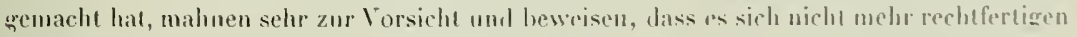

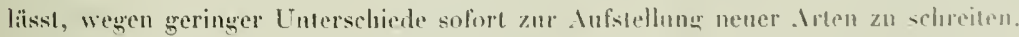

loh habe in dieser Ilinsicht anch in sorlingender. Whei sehr zurückgehallen und

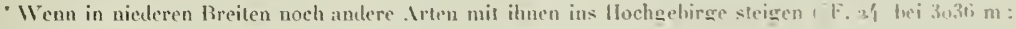

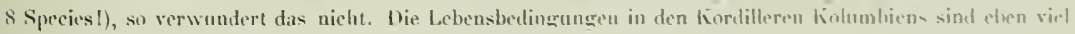
şünstigrere als in den europäisch-asiatischen Hochgebirgen.

So 
neben einer einzigen, sehr eigenartigen Moina, die ich als neue Lrt betrachte, bloss vier newe, endemische Varieläten aufgestellt. Drei anderen, früher als besondere Arten beschriebenen Cladoceren, komm naed unseren heuligen Inschaungen höchstens der Wert ciner neuen "forma» zu.

Vieht im Schaffen nnähliger nener Species darf das Ziel des forschers liegen; denn dadurch wird ein zoogeographisches Verständnis unseres Planeten nicht ersehlossen.

Olten, den 12. April 1,y13. 


\section{Figurenerklärung.}

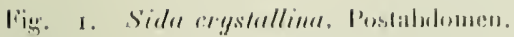

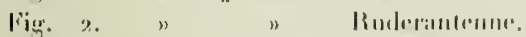

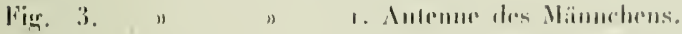

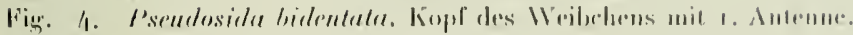

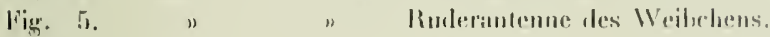

lig. 6. " "20sialulamen " "

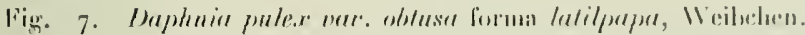

lifi. 8

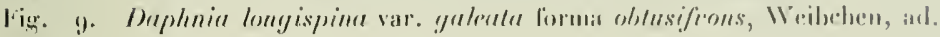

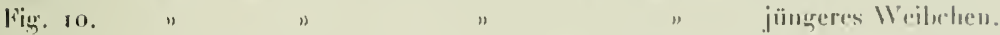

Fig. 11. " " " " " selur jumges "

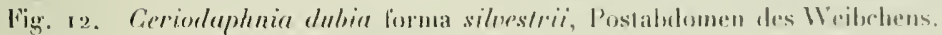

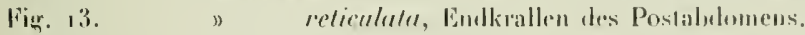

lig. 1/. Simocephalus serrulalus, Weibchen.

lïg. 15. " " Bewehrung de's hinteren Scludenramtes.

Fig. 16.0 " " nar. inflalus, liopl ales lleibhens.

lig. 17. Moina malirophlhalmu nov. spec., Weihehen.

Fig. 18. Macrolhrix triservalis var, chevernri, Kopf des Weilschens.

Fig. ry. " " "'ostahdomen des Wribchens.

Fig. 3o. Ilocryplus halyi var. Iongiremis, Postabiomen des Weibchens.

Fig. 21. Camplocercus anstrulis var. dadayi nov, var., Weibchen.

Fig. $22 . "$ " Postabdomen des Weilichens.

lig. 23. Llona gulla var. Inberculula, hinterer Schalenrand und Postabdomen.

lïg. 24. Meuroxus similis vir. fuhrmanni nov. yar., Weilichen.

Fig. 25.4 " " Postabdomen des Weihchens.

Fig. 26. Dunheredia odontopla.r vall. colombiensis nov. var., Bewehrung der hinterenunteren Scliatenecke.

Figg. 27. Dunhevedia odontopla.x var. colomhiensis, Lippenanhaner.

Fig. 28. Chydorus aualis, Weibchen. (Man beachte Rostrum und Lippenanhang.)

Fig. 29. " leonardi. Lippenanhang.

Fig. 30. " " Postabiomen.

Fig. 3r. y hybridıs, Lippenanhang. 


\section{Literaturnachweis.}

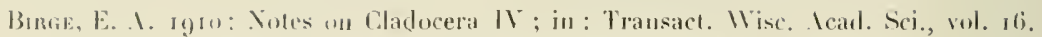
Buny, G. Sr. I886: Votes on Entomosdraca collected lỵ Mr. A. Ilaly in Ceylon; in: Jurren. Linn. Sne. London, vol. rg.

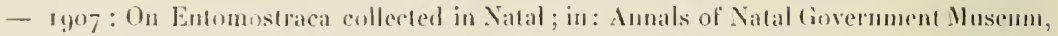
rol. I.

BnEnx, V. 1991 : Dir Lladoceren; in: Wiss. Eregebn. der Dentschen Zentral-Afrika-Exped.

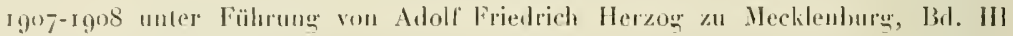
(Klinkharilt, leipzig).

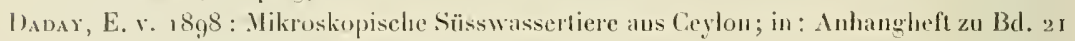
der Termeszetrajzi liäzetek. Budiapest.

- ıgn : Mikroskopiselue Süsswassertiere; in: Zoologische Erurebnisse der 3. asial. Forschungsreise des Lirafen Zichy, Vol. Il (Budapest und Lejpig).

- 1902 : Mikroskopische Sïsswassertiere aus Paragonien; in : Termes. Füzctek, vol. 25.

- rgo3: Miliroskopische Süsswassirliere der Lmgeloung des Balaton ; in: Zool. .lahrb. Sist. vol. 1!)

- rgo5: Untersuchungen äber die Süsswassermikrofauna Paraguay's ; in : "Zoologica », Heft 44 (Stullegart).

- 1910: Die Süsswassermikrofauna Deutsch Ostafrika's; in : "Zoologica ", lleft 5q (Stullurarl).

1910: Beiträ̈re znr Kenutnis der Mikrofauma des Niłs; in: Sitz. ber. Akad. der Wiss. Wien, Math-Nat. Klasse, Bd. I 9 .

Ekran, Sven rgoo: Cladoceren aus Patagonien, gesammelt von der schwed. Exped.; in: Zool. Jahrb. Syst., vol. 14.

- ıgo5: Cladoceren und Cop. ans antarkı. nnd subant. Bimnengewässern; in : Wiss. Ergebnisse der schwed. Südpolarexpedition (rgor-rgo3) unter Leitung von Dr O. NorDENSKJöLD, vol. 5.

fiuenne und Richand 1892: Cladncères et Cop. d'eau douce des environs de Rufisque (Scregal); in: Mém. Soc. Zool. France, vol. 5.

Gunney, R. ryo7: Further notes on indian freshwater-cntomostraca; in: Records of Indian Museum, vol. I.

- igo6: On some freshwater-entomostraca in the collection of the Indian Musenn, Calculta; in: Ionrnal und Proceed. Isiatic Soc. of Bengal. N. Ser., vol. 2.

- 1gog: On the frehwater Crustacea of Algeria und Tunis; in : Journ. R. Micr. Soc. 1909. 


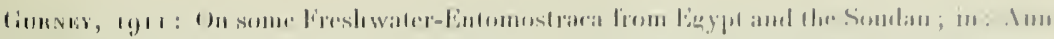
Mitg. Nill. Ilist. Sirr. 8, val. 7.

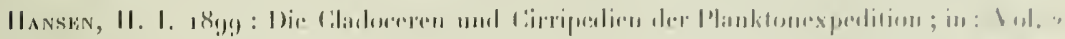

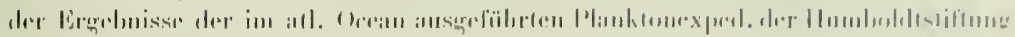
(liinl unul laiplyig).

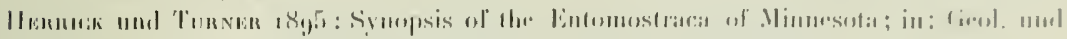

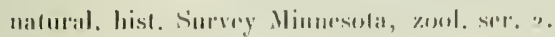

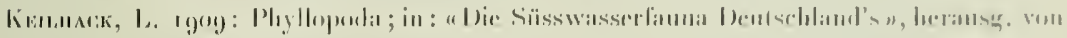
Brituer, Ilelli (1).

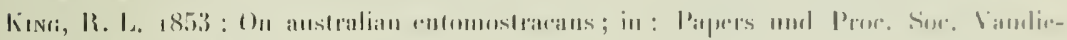
umensiuml, vul. $\%$

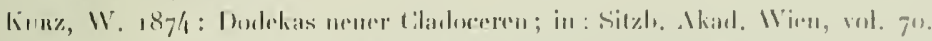

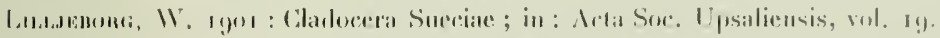

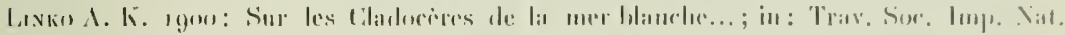
St-Pefreshourey, vol. 30.

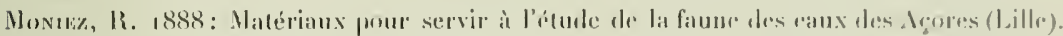

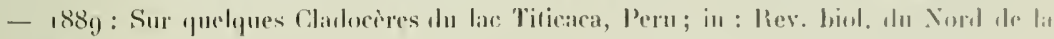
lirance, vol. 1 .

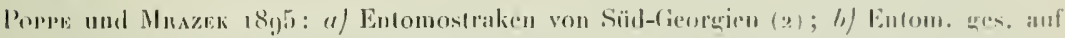
Ceylon (3); in: Beiluefte zum dalırb. der Hamburer. wiss, Instalt, wh. 12.

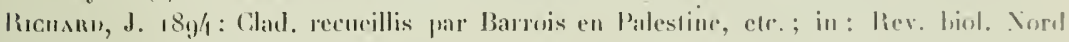
lirance, vol. ti.

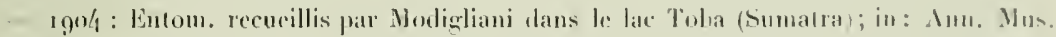
(icnova, wol. 14.

-- I8gy5: Révision des Chadocères 1; in : Inn. Sici. Nat. Sér. 7, vol. 18.

-18960 : " 11 ; in: " " " " $8, "$ "

- 1896: Sur la fanue de quelques lacs du Caucase dapres les récolies do M. Karraisky: in: Bul. Soc. Zool. Franre, vol. 21.

- 1807: Sur quelpues antomostracés d'ean douce des environs de buenus-.lires; in An. Musemm Buenos-lires, vol. 5 .

- 1897: Entomostraces de l'Amérique du Sul; in: Mém. Sor. Zuol. France, vol. In.

Sans, fi. O. 1895: On sume South-1frican Entomostrara; in: Vidensk. selsk. strift. 1. Kilase No 8 .

- 1896 : On Freshwater-Entemostraca frum the neighlonghond of svilney: in : Arch. Natury, Christimia, vol. 8 .

- rgot: Contributions to the knowledge of the breshater-Entom, of Simult-Amerisat: in : Mrch. Naturv. Christianti, rol. 23.

- igo3: On the crustacean fauma of Centralasia ; in : Annuare Mus. St-Petarkl.. vol. s.

- rgon: Freshwater-Entomostraca from South-tieorgia; in : Arch. Naturv. Christiania. vol. 30 . 
Srexmos, K. E. IS9̣j: Zur Kenntuis der Clatocerenfuna ron Russisch-Karelien; in : Icta soc. pro fama et flura fennica, vol. 25.

Steuer, ID. Igou: Die Entomostraken der alten Donau hei Wien; in: Zool. Jahrb. Sist., vol. 15.

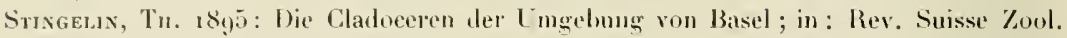
vol. 3.

- 1904: Leleer Entomostracen aus dem Mündungsgebiet des Amazonas; in : Zool. Anz., vol. 28 .

- 1904: Unser heutiges Wissen über die Systematik und lie geogr. Verlur. der Cladoceren; in: Comptes rendus dn $6^{\text {me }}$ Congrès international de Zoologie à Berne.

- гgo4: Entomostraken gresammelt von Dr G. Hagmann im Mündungsgebiet des Amazonas; in : Zool. Jalırb. Syst., vol. 20.

- 1904: Untersuchungen äber die Cladocerenfauna von llinterindien, Sumatra und Jiva (Reise Volz); in : Zool. Jahrb. Syst. vol. 21.

- rgo6 : Cladoceren aus Paraguay ; in: Annales de biol. lacustre, Bruxelles, vol. 1. 1906 : Nene Beiträge zur kemutnis der Cladocerenfauna der Schweiz; in : Rev. Suisse Zool., vol. 14 .

rgo8: Phyllopodes; Catalogue des Invertibrés de la Suisse, herausg. von M. Bedot Yuseum d'histoire nat. de Genève. (II. Lieferung.)

- 1909: Mitteilungen über einige Cladoceren aus Südamerika; in: Zool. Anz., vol. 24 .

- 19ro: Crustaceen aus kleineren Seen der Unterwaldner-und Berneralpen; in: Rev. Suisse Zool., vol. 18.

Tunxer, C. 1910 : Eeologieal Notes on the Cladoeera and Cop. of Iugusta, Georgia ; in : Transact. Aearl. St. Louis, vol. 19 .

VAvra, W. rgoo: Süsswasser-Cladoceren; in : IIamburger Magelhaensisehe Sammelreise V (Mitteilungen Mus. Hamburg).

Weltner, W. 1896 : Die Cladoceren Ost-Afrika's; in : Tierwelt Deutsch-Ostalrika's vol 4.

Zsснокке, F. 1900: Die Tierwelt der Hochgebirgsseen ; in: Neue Denksehr. Sehweiz. Nat. Gies, vol. 37 .

- ıgo8: Die Resultate der zool. Erforseh, hochalp. Wasserbecken seit rgoo; in: Int. Rev. der ges. Hydrol,iol., v. 1. 


\title{
Süsswasser-Ostracoden
}

\section{aus Columbien und Argentinien}

(1)II

\author{
Dr. Gyula MÉHES, Budapest.
}

Die Materialien, welche auf nachfolgenden sieiten bearbeitet sind, stammen von Herm Prof. De. (1. Fumnuan, der die in Cohmbien gesammelien Ostracuden, nelsw

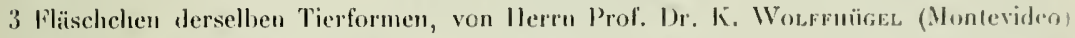
iu der Kurdillere vou Mendoza gesammele, Herru Prof. Dr. E. vos Damus zur Bearbeitum äbergals. Da aber llerr Prof. Dr. Eurien vox Dadar in liolge seiner arossen wissenschafilichen Obliegenheiten das Studium der Ostracoden nicht äbernehumen konnte, ïhortrug er mir gütigst die Arheit, der irh mich nmso freudiger wiclmete, als ich hoffte, liedurch die südamerikanische Fauna mit interessanten Funden zu bereichern.

Die aus Südamerika stammenden Muschelkrelse betreffende Literatur ist in Eutian rox D.1D.1,'s grossem zusammenfassenden Werke (2) leicht übersichtlich zusammengestellt. Um Wiederholungen vorzuhengen, will ich mich nur anf das soeben erwïhntr Werk berufen und von den in der dortselhst auf S.5. 268-269 hefindlichen Tahelle vorkommenden Angaben nur Folgendes lervorheben: Bis zum Erscheinen des Werkes E. v. Daday's (1ge5) waren ans Südamerika 5 1 Ustracolen-irten bekanm, die sich mil den von Danar heschriebenen 8 neuen Arten vermehrlen, so dass die Zahl derselhen sich :uf 59 crhoh. Der grössten Verbreilung arfeus sich die Gallung Eucypris, die durch 29 Arten vertreten war.

Das nene Material, welches mir zur lerfügung stand, stamml aus zwei von einander in wciter Entfernung liegenden Gebieten und zwar der eine Teil desselben aus Columbien. aus der Gegend der Central- und Ost-Kordilleren, wo disselhe von Ilerra Prof, O. Finnmans an folgenlen Fumlorten gesammelt wurile: 
1. Columbien, Centrulliordillere:

ı. Sumpte zwischen Medellin und Amerikil r5.3o u.

\section{Ostiorlillere:}

2. Laguna \}. hei Madrial anl aler Sabana von Bogota s640 m.

3. Laguna 11. " " " " " "

4. Tümpel 3 bei Ligguna 1.

₹. Tümpel 4 "

6. Tïmpel beim Tequendamalisll $2250 \mathrm{~m}$.

7. Layuma Pedropalo $2000 \mathrm{~m}$.

8. Laguna Lobaque $2112 \mathrm{~m}$.

Der andere Teil des Jaterials stammt ans Argentinien, wo denselhen Herr Proliessor K. Wouffnïge an folgemlen Fundorten sammelte:

11. Argentinien, fordillere von Mendoza:

1. Tupungatotal $3200 \mathrm{~m}$.

2. $2500 \mathrm{~m}$.

3. Station Espeyo bei Mendoza.

Das gesammelte Material war für die Untersuchung nichıt sonderlich geeignet, waıs ich dem Umstande zuschreibe, dass das Material nicht seiner natürlichen Eigenschati musprechend konserviert war. Die Sammler haben nämlich das Haterial zuerst in Formalin und dann in Alkohol gelegt, in Folge dessen die Schalen selır beschädig̣t, manche sogar so weich geworden sind, dass man sie während dem Präparieren kaum handhaben konnte; manche giengen sogar während der Präparation zongunde. In Anbetracht dessen, dass ron einer Art manchmal nur wenige Schalen orler nur eine zur Verfügung stehen, ist eine zweckmässige, quute Präparierung hüchst wichtig.

Alle Arten der Ostracoden-Fauna des von mir untersuchten Materiales gehören zur Familie der Cypridae, und zwar ist das Genus Encypris luoch 3, das Genus Strandesin durch 2, das Genus Cypridopsis durch 2 und das Genus Candonn durch 3 Arten vertreten. Von diesen Arten sind Encypris nobilis (G. O. Sans), Eucypris areguensis Dabar, Strandesia bicnspis bicuspis (CLaus) und Strandesia mucronata (G. O. Sans) schon bekanut und zwar aus Südamerika. Ihr Verbreitungsgel,iel wirl durh meine Untersuchungen erweilert. Die übrigen seclıs Arten:

\section{Eucypris wolffhügeli n. sp. \\ Cypridopsis fuhrmanni n. sp. \\ Cypridopsis dadayi $\mathbf{n}$. sp.}

Candona pedropalensis $\mathbf{n}$. $\mathbf{s p}$.

Candona annae n. sp.

Candona columbienensis n. sp.

sind nicht nur lï̈r Südamerika, sondern auch lï̈ die Wissenschaft neu.

Bei meinen Untersudungen habe ich hesombers die linere Struktur der Sidnalen 


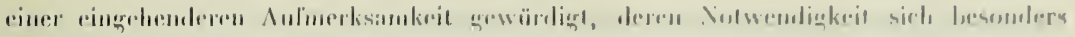

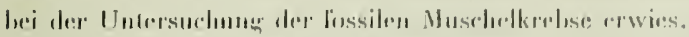

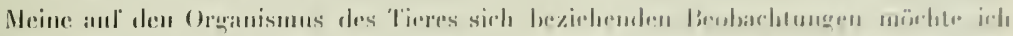

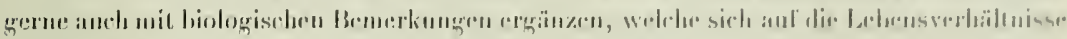

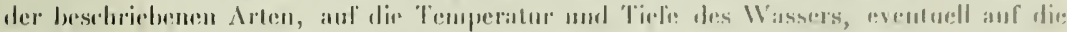

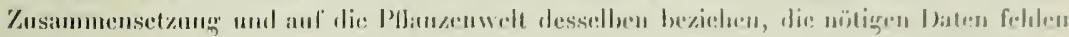
alere leider merlis.

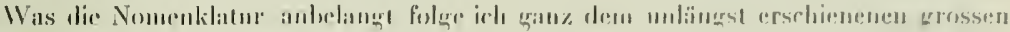

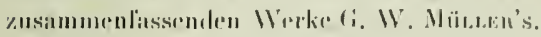

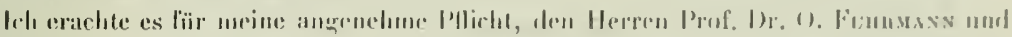

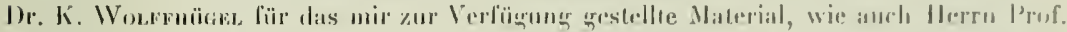

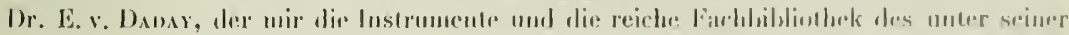

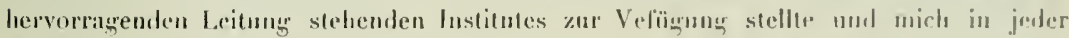
Hinsicht freundichst unterstiotzte, hiermit meinen anfrichtiesten bank auszusprerhn.

Das Material wurde im zoologrisehen Institute des kï̈nigrl. Ling. Josef-I’olytechuikuns aufgearbeitet.

\section{Fam. Cypridae.}

\section{Eucypris nobilis (G. O. SARs).}

Amphycypris nobilis G. O. SARs (7), p. I8. T. IV. Fig. I-12.

Eucypris nobilis DADVY (2), p. 243.

Wie in dem uir behufs Untersuchung zur Verfügung gestellten Materiale vorkommenden weibliclien und jungen Exemplare stimmen vollkommen mit den von G. O. SArs beschriebenen überein. Laut Sars' und DadaY's Untersuchungen ist diese Art bisher aus Argentiuien und aus Paraguay bekann. Ich fand melirere Exemplare dieser Art in dem

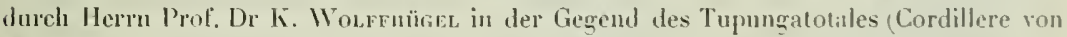
Mendo\% $3200 \mathrm{~m}$ ) an 10. Felr. 1908 gesammelten Materiale.

\section{Eucypris areguensis (D.ı.r).}

Eucypris areguensis Dadis (2), p. 243 . T. XV. Fig. II-13.

Die von mir untersuchte Art unterscheidet sich von der ans Paraguay stammenden und durch D.wox beschriebenen nur in einigen Zügren, die nicht ron Bedeutunır sind. Der Dorsalrand meiner Exemplare ist nämlich nicht so stark gewölbt und der Bauchrand 
ist beinahe grerade, wogegen tetztrer an den Exemplaren desllerrn Prof. Dr. Davay eine auffallende Bucht sehen lässt. Der lintere Schalenrand ist bei meinen Exemplaren stumpf und ghteichmässigr abgerundet. - Von ohen betrachtet sind meine Exemplare nicht kahuförmig, sondern vielmehr gestreckt-oval. Was die Struktur anbelangt, finden wir einen kleinen Unterschied nur hezüglich des Furkalanhanges, indem derselbe bei meinen Exemplaren in seinem ganzen Verlaufe gुleichmässig hreit und grerade ist, wogegen bei den von D.dDaY heschrichenen Exemplaren er sich der Mitte zu ein wenig verjüngt und wellenförmig dahinzieht. Er ähnelt mehr demjenigen der Eucypris anisilsi Dadar, welche Art auch nach Dadar's Insicht der Eucypris areguensis DaDaY sehr nahe steht.

In meinem Material fand ich einige weibliche und junge Exemplare.

Fundolt: Columbien: Sumpf zwischen Medellin und America, i53o m. - Sammlung des Herru Prof. Dr O. Funmaxx.

\section{Eucypris wolffhügeli n. sp.}

Fig. I $a-h$, Fig. $2 a-e$.

Die beiden Schalen unterscheiden sich von einander sowohl in ihrer Form, als auch in ihrer Struktur.

Die rechte Schale (Fig. r $a$ ) ist regelmässig nierenförmig. Ihr Dorsalrand bildet um. die Mitte der Schale einen merklichen Höcker der in den Vorder-und Hinterrand unbemerkbar übergeht. Der Vorderrand ist stumpf und gleiclımässig abgerundet (Fig. I $d$ ), der äussere Rand, der ein wenig niederer ist als der Hinterrand besitzt ziemlich auffallende kleine Kügelchen, welche der Schale einen eigentümlichen Charakter verleihen ; er hat keinen Porenkanalgürtel, die Randborsten entspringen aus kleinen Kügelchen; die Innenlamelle ist ein schmaler Gürtel. Die Verwaclısungslinie der Innenlamelle und des Saumes ist leicht zu unterscheiden (Fig. $1 d$ ). Der Bauchrand ist leicht gebuchtet und verschmilzt so mit dem Vorderrand wie mit dem Hinterrand mittels eines stumpfen, gleichmässigen Bogens. Auch der Hinterrand ist stumpf, gleichmässig abgerundet (Fig. I e) und ist in seiner Struktur derjenigen des Vorderrandes sehr ähnlich, von dem er am meisten darin abweicht, dass sein Schalenrand wie auch seine Innenlamelie einen schmäleren Gürtel darstellt, ferner, dass die Verwachsungslinie nicht so scharf und auch der Ursprung der Randborsten nicht so leicht bemerkbar ist (Fig. I $e$ ).

Die linke Schale hat die Form eines gestreckten Ovals (Fig. I $b$ ). Der Dorsalrand ist leicht, gleiclımässig gewölbt, in der Nähe des Auges bildet er ein kaum bemerkbares Hügelchen und zichıt sich abschüssig zum Vorderrand. Der vordere Saum ist stumpf, gleichmässig abgerundet (Fig. I. $f$ ) ; er besitzt einen breiten Cuticularsaum und cinen wohlentwickelten Porenkanalgürtel. Die Porenkanäle stehen dicht ueben einander und sind einander parallel; - die Innenlamelle hat einen viel breiteren Gürtel, als dies beim rechten Rand der Fall ist. - Der Hinterrand ist um vieles höher als der Vorderrand 


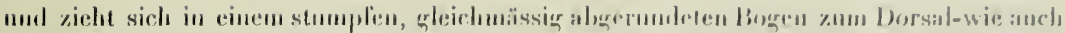

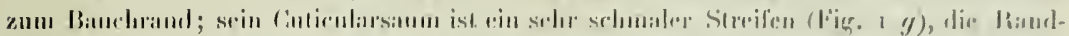

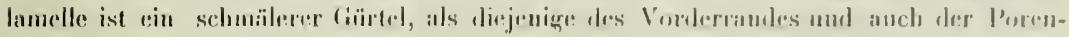
knualgürtel ist sclumiler. bie Poreukanäle lierenen silur zer. strent und sint sisher westrenkt.-Der Verlaul des Banclumudes ist lersellue, wie wir as and ale. rechtenschaletrilfen, diekleinen Kï̈grelelien alser, dir lï̈r den Satum der rechten selisle bezeichnend waren, fellten ganz.

Von oben gesehra hieten die Schalen die firm eines langgestreckten Eies (Fig. ic). D)ic Seitenlinie beschreibt cinen yon linten nach rorne absteigenden Bogen und in der Nïhe des Vorderrandes ist sie kaum hemerkbar ausgebuchtet. Am längsten ist der Durchmesser in der Nähe der Millellinie.

Die Schalemwandung ist sehr dïnn und fein. lhre Oberfläche ist fein granuliert. Die Sehale ist grünlich gelh.

Die zwei vorletzten Glierler des zweiten Antennenpaares (Fig. 2 a) sind zusamulugewachsen. Der äussere distale Gipfel des vorletzten Gliedes trïgt eine äussere kurze, und eine innere lange wolılgezälnehe Klane. Die innere lilaue ist so lang wie die Klave des letzten Gliedes. An der ïusseren Seite erliehen sich unweit
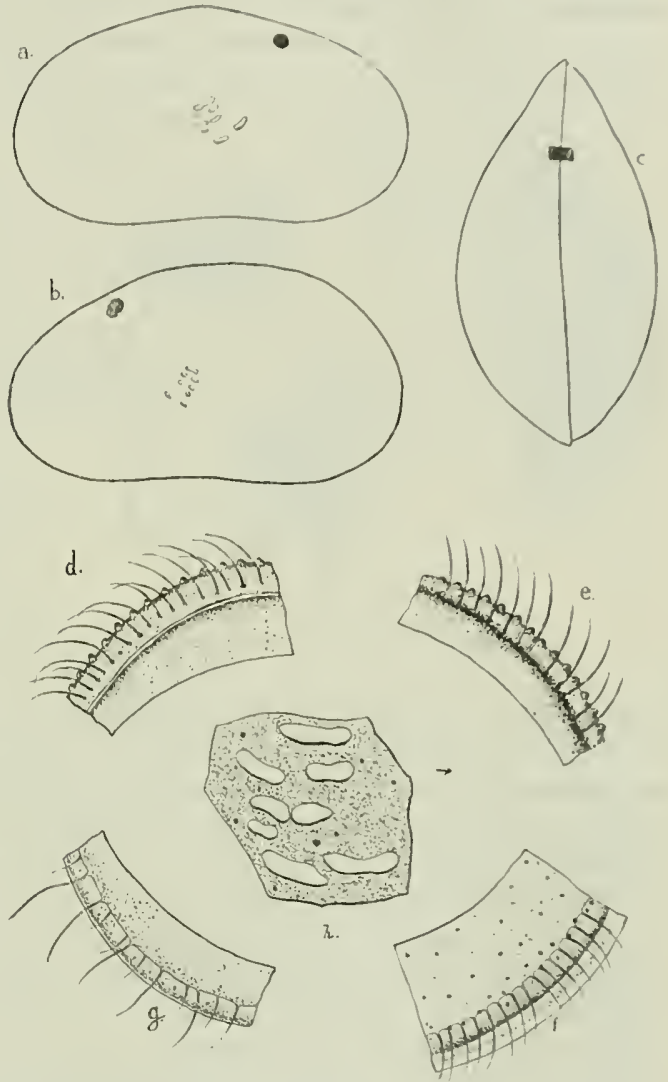

Fig. 1. - Eucymis wollhingeli n. sp. $-a$. Rechle Schale , b. linke Schale $O, c$. Schale von oben gesehen $O, d$. Yorderrand der rechten Schale, $e$. llinterrand der rechlen schale, $f$. Forderrand der linken Schale, $g$. Hinterrand der linken Schale, h. Nuskeleindrûcke.

vom Ursprunge der Klanen zwei Borsten. Der äussere Gipfel des letzten Gliedes Irāgt zwei gleich starke gezähnelte Endkrallen, der junere Giplel ist mit zwei Sinneshorslen und einem Sinnesstäbchen verselien. - Ion den liuderborsten is die aussere kurz, 
und erreicht nicht cinmal die Lïnge des vortetzten Giliedes, dir übrigen fünf dagegen sind Jïnger als die Endkrallen.

Das letate filied des Palpus mandibularis (Figr. a c) ist etwas länger als hreit. Dats vorletzte Glied trïgt ein mit stmmpfer Spitze und mit feinen Härchen reichlich versele-

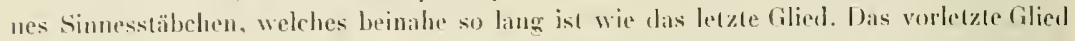
ist in der Hitte mit rinem aus verschieden langen llärchen hestehenden kianze versehen.

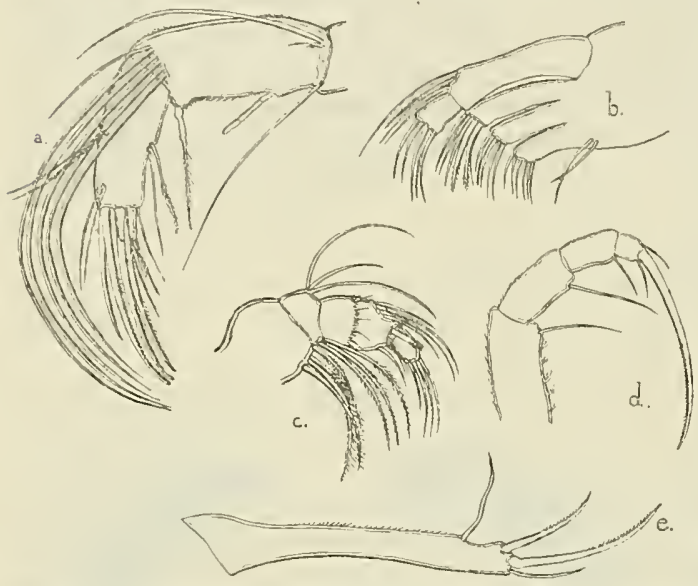

Fig. 2. - Eucypris wolffhügeli n. sp. - $a$. Antenne des 2. Paares $0, b$. Maxille $ᄋ$, c. Mandibulartasler $0, d$. Bein des 1. Paares $Q$, e. Furca

Dasmeite Glied des Palpus maxillaris (lïn. 2 b) ist länger als Jireit, der Unterschied betrïgl aber nicht einmal ein Dritlal der Länge. Aul' dem erston Fliede des Palpus maxilaris erlechen sich vier Borsten, von denen die kleinste stark grefiedert ist. - Von ten aul' dem ersten Kaufortsatz befindlichen Borsten sind zwei sehr stark entwickelt und wollhefiedert.

An der inneren Oberlläche (Fig. $2 d$ ) des ersten Gliedes des ersten Fusses erliehen sich Harbündel; die Endborste ist gut entwickelt. An der Aussenfläche des ersten, zweiten und dritten Gliedes befinden sich feine Härchen. Das zweite Glied trägt eine viel längere Borste, als das erste. Die Endliralte ist sichelförmig und ist länger als die drei letzten Glieder.

Der zweite Fuss stimmt mit der typischen Form üherein.

Der proximale Teil des Furkalanhanges (Fig. $2 e$ ) wird sehr hreit, ist ein wenig gekrümmt und in seinem ganzen Verlaufe heinalse gleich breit; sein vorderer oder unterer Rand ist glatt, der hintere oder obere fein behaart. Die Randhorste entspringt in der Nähe der Seitenkralle und ist ebensolang als letztere. Die Endlorste ist wenig entwickelt; ihre Länge beträgt nicht einmal dic IJälfte der Endkralte. Die Endkralle dagegen ist selır gut entwickelt und ist heinahe zweimal so lang als die Seitenkiralle. Beide Kratlen sind sichelfïrmig und wohlgezähne]t.

Länge: $1.3 \mathrm{~mm}$. Höhe: $0.7 \mathrm{~mm}$. Durchmesser : $0.7 \mathrm{~mm}$.

Fundort: Argentinien, Kordillere von Mendoza 2500 11. Einige Exemplare stammen aus den stehenden Gewässern des Tupungato. - Sammlung des Herru Prof. Dr. K. TVolfäüGer, 6 Febr. Igo8. 


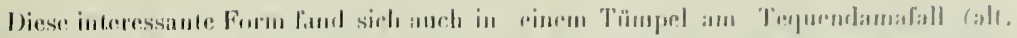

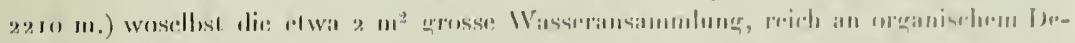

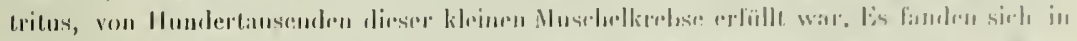

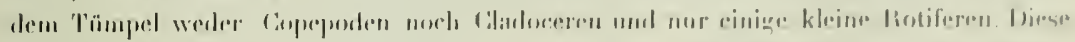

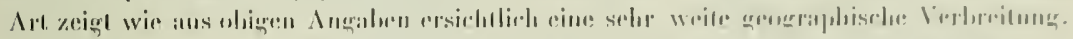

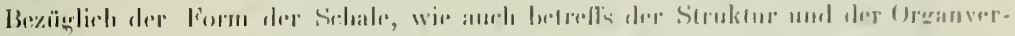

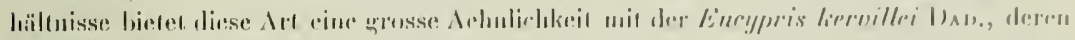

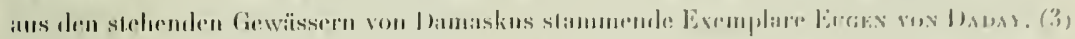

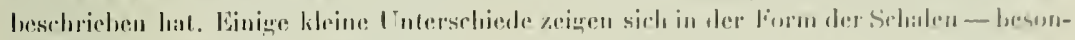

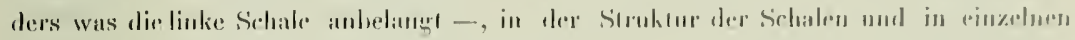
Teilen des Oromismus, nämlich an der zweiten Antrune, an Piolpus maxillaris and am

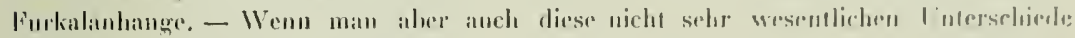

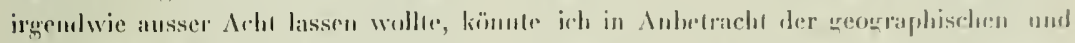

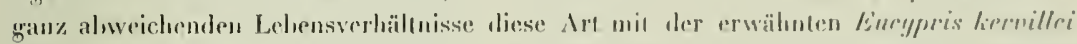

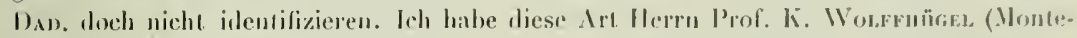
viden) zu Eleren lonamut.

\section{Strandesia bicuspis bicuspis (Chats)}

Acanthocypris bicuspis Cidus.

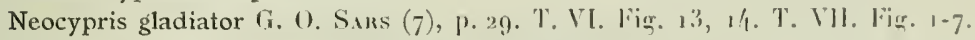

Encypris bicuspis DADAY (2), p. 2/.3.

Strandesia bicuspis bicuspis G. W. Mïı, (i), 1. 187.

Meine Exemplare kann ich mit ded von den bisheriģen Forschern leselurielenen Art vollkoumen identifizieren. Bisher war dieselle aus Argentinien, Brasilien, Venezurla nul aus Parbugy bekannt; zu diesen Fundorten uresellt sich nun auch Columbicn, so dasliedurch sich der lireis dey Verbreitung dieser inferessanten Art ziemlich roweitert.

Das mir zur Verlügung gestellte Material enthielt mehrere. Weihehen und junge Exemplare.

Fundort: Colnmbien. Ostkordillere. Laguna de LTbaque $2112 \mathrm{~m}$. - Sammlung iles Herm Prof. De. O. Fumman.

\section{Strandesia mucronata (f, O. Sirs).}

Neocypris mucronata G. O. SABs (7), p. 36. T. VIII. Fig. 5, 6.

Encypris mucronata Didar (2), 1, 2:8.

Strandesia acanthigera (i. W. MüLt,en (i), p. 188.

Diese interessante und sehr schöne. Irt is hisher ans Brasilien und Paraquay hekannt. bie ans Brasilien stammente hat G. (). Sars, die andere E. V. Dow heschriehen. In 
heiden Gebieten gehören sie zu den seltenen Arten. Von dem Gehiete, auf wehchem der Finndort der von mir untersuchten Exemplare sich befindet, können wir sagen, dass diese Irt in der Ostracoden-fauna des in Rede stehenden fieldietes nur noch in einigen wenigen Exemplaren vorgefunden werden komute, die aber grenügten um mit denjenigen ans Brasilion und Paraguay identitiziert werden zu können.

Fundort wie bei Standesin bicuspis bicnspis (Cuaus).

Im grossen zusammenfassenden Werke $G$. W. Mäller's (6) befindet sich die von G. O. S.ns beschrichene Neocypris mucronata in die Gattung ein Strandesia cingereiht und fülıt den neuen Irtnamen acanthigera. So sehr es auch notwendig ist in Folge derauf der Struktur der Schalenwandung und auf den organischen Verhälnissen des Tieres fussenden Verwandischalt die G. O. Sans'sche Art unter die Strandesin-Arten einzuteilen, - so sehr eutbehrt es einen jeden Grundes dieser Art einen neuen Artnamen zu geben oder dieselbe zu ciner Varietät zu degradieren. Die Strandesiu mucronata (G. O. SArs) belıamptet ihren Platz einer selbstständigen $\lambda \mathrm{r}$, was auch E. v. DaDAr (2) zugibt; ich selbst lin auch der Neinung, dass in Folge des Prioritätsgesetzes der von G. O. Sars gegebene .Tame mucronata als Artname auch weiter beizubelıalten ist; eine Aenderung des Namens ist selbst deshalb nicht begründet, weil das Wort "mucronata" in der Literatur zur Bezeichnung einer Unterart schon in Anspruch genommen ist: Strandesia bicuspis mucronata (ClaUs).

\section{Cypridopsis fuhrmanni n. sp.}

Fig. $3 a-h$. Fig. 4 a-e.

Die Schaten unterscheiden sich in ihrer Form und in ihrer Struktur.

Yon der Seite gresehen ist die rechte Schale (Fig. 3 a) regelmässig nierenförmig. Der Dorsalrand ist in der Mitte erholen bogig, nach vorne sanft absteigend, über den Augen breit gebuchtet, bei der Vereinigung nit dem Vorderrande breit abgerundet, zum IIinterrand ziehıt er stark alıschüssig, in den er unbemerkbar übergeht. Der Vorderrand ist stum pf, gleichmässig abgerundet und höher als der Hinterrand; von innen gesehen (Fig. $3 d$ ) ist der breite Saum nit seinen beiden Gürteln gut sichtbar, innerhalb dessen sich die In nenlamelle befindet, die ebenso breit ist wie der Schalensaum. Der Saum ist von einem dünnen kutikularsaum bedeckt; die Randhorsten sind ziemlich lang und stehen dicht neben einander. Der Vorderrand geht unbemerkbar in den Bauchrand über, welch letzterer in der Mitte gleichmässig ausgebuchtet ist und in einem gleichmässigen Bogen zum Hinterrand zielıt. - Der Hinterrand ist schärfer abgerundet als der Vorderrand; von innen betrachtet unterscheidet er sich rom Vorderraude besonders dadurch, dass sein Kutikularsaum einen viel breiteren Gürtel darstellt, seine Randborsten viel dichter sind, der Schatenrand aber nur einen sehır schmalen Gürtel bildet.

Die linke Schale ist melır oder weniger hoch, nierenförmig (Fig. 3 b). Der Dorsal- 


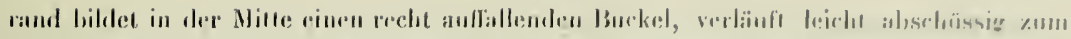

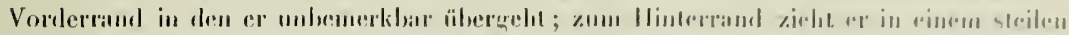

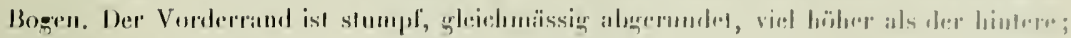

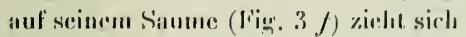

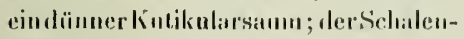
silum ist ein breiter Gïrtel, der alwer schunäler ist als derjenige des Vurterraudes der rechien Sehasls, - die: Innenlamelle hingeren listet cinen doppelt so grossen fiürtel dar als dies bei der rechten Schate der Fall ist. Der Banchanud verläuft leciualı: gerarllinig, indem derselhe nur in der Mill. kaum bemerkbar ausgehuchtet ist. Der Hinterrand ist viel schïrfer aligerundet als der Vordere und inthelirt eines Kutikularsammes (Fig..3 $g$ ); sein Saum ist ein schmaler Gürtel, seine Saumlamelle ist breiter als derjenige der rechten Schale und die Randhorsten sind spärlicher. - Kéene der Schalen besitzt an den Rändern einen Porenkanalgürtel.

Von oben betrachtet (Fig. $3 c$ ) sind die Schalen regelmässig oval. Der hintere Gipfel ist stumpf, gleichmässig abgerundel, der vordere etwas spitzer. Die Seitenlinie bildet einen gleichmässigen Bogen. - Der grösste Durchmesser der Scluale befindet sich in der Mittellinie.

Die Schalen haben eineharte, dicke Wandung, ihre Oberflïche ist mit kleinen Grübchen besäet und ausserdem
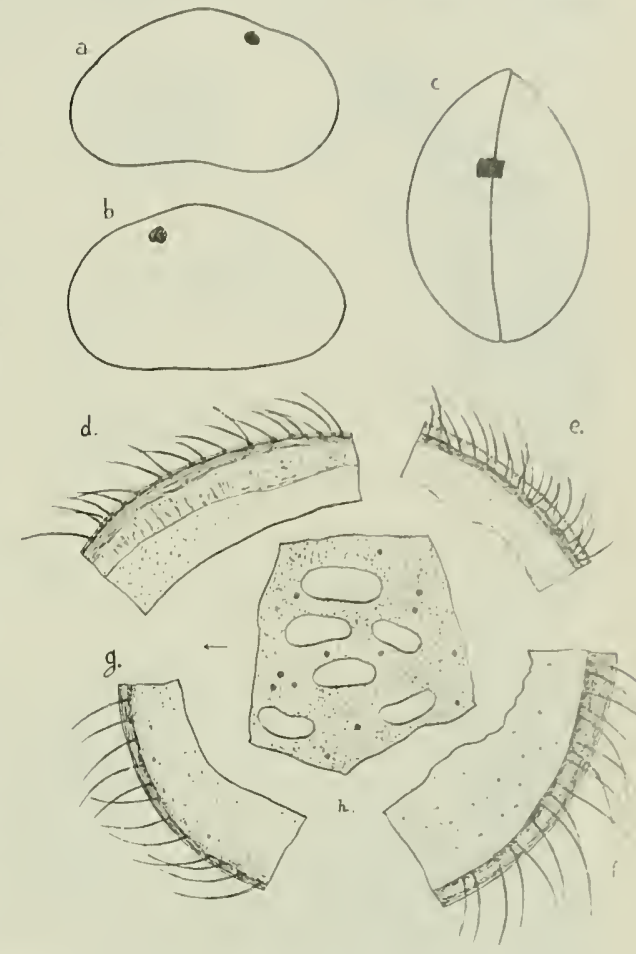

Fig. 3. - Cypridopsis fuhrmanni n. sp. $-a$. Rechte Schale 9. b. linke Schale $O, c$. Schale von oben gesehen 0 , $d$. Vorderrand der rechten Schale, $e$. llinterrand der rechlen Schale, $f$. Forderaud der linken Schale, g. Ilinterrand der linken Schale, h. Muskcleindrücke.

mit verhältnismässig kurzen Borsten zienlich dichı hesetz1. - Die Schalen sind grünlich geth.

Die Muskelabdrücke (Fi . $3 \mathrm{~h}$ ) sind vier an der Zahl, welche in drei übercinander folgende Reihen geordnet sind, und zwar so, dass sich in der rersten und drilten Reilie je ein Muskelabdruck befindet, in der mitteren es aher deren zwei gilu.

Die zwei vorletzten Glieder der zweitrn Intenne (Fier. 4 a) sind lang gestrecht. Der äussere Gipfel des vorletzten Gliedes trägt drei wohlentwickelte Endkrallen, deren äussere 
kurz und grroh gezälunelt ist, die beiden inneren etwas länger, schmäler, so lang wie die

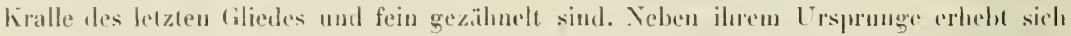
eine Borste, welche becinalıe so lang ist wie die äussere, breite Endkralle. Was letate Glied ist beinalıe doppelı so lang als hreit; sein innerer Gipfel trägt ein fein gezähneltes

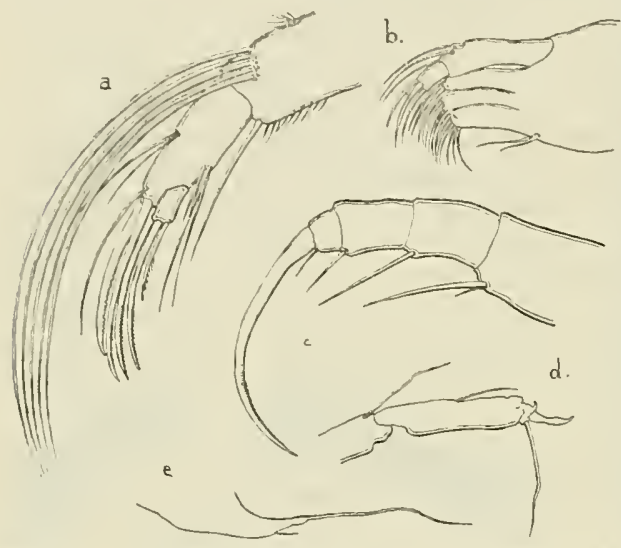

Fig. 4. - Cypridopsis fuhrmanni n. sp. - a. Antenne des 2. Paares $O, b$. Maxille $Q, c$. Bein des 1 . Paares $Q, d$. Bein des 2. Paares $q$, e. Furca $q$.

des lamellenartigen Anhanges ist breit, wird aber immer schmäler, delınt sich am Ende spindelförmig aus und seizt sich in einer gut entwiekelten Geissel fort. Vor der spindelförmigen Ausdehnung befindet sich die Raudborste.

Länge : $0.68 \mathrm{~mm}$. Höhe : $0.4 \mathrm{I} \mathrm{mm}$. Durchmesser : $0.45 \mathrm{~mm}$.

Fundort: Columbien. - Ostkordillere. Laguna de Lbaque $2112 \mathrm{~m}$, Laguna Pedropalo $2000 \mathrm{~m}$, Laguna 1. bei Madrid auf der Sabana von Bogota $2640 \mathrm{~m}$, Laguna II. bei Madrid auf der Sabana von Bogota $2640 \mathrm{~m}$, Tümpel 3. auf der Sabana von Bogota, Tümpel 4. bei Laguna I. Centralkordillere: Sumpf zwisehen Medellin und Amerika $1530 \mathrm{~m}$. - Sammlung des Herro Prof. O. Fuiriann.

Argentinien. - Station Espeyo bei Mendoza in Febr. 19»8. - Sammlung des IIerru Prof. K. WOLfFÜ̈GEL.

Bezüglich der Form und der Struktur der Schale bietet diese Art eine grosse Achnlichkeit mit der aus Süd-Amerika stammenden, von G. O. SARs (7) hesehriebenen Cypridopsis pinguis, ich kann sie aber mit derselben doch nicht identifizieren, weil G. O. SAus keine detaillierte Besehreibung der organischen Verhälınisse lieferte, mir also alle die Charakterzüge, auf Grund deren iel die von mir untersuchte $\Lambda$ rt mit der G. O. SAns'chen eventuell identifizieren hätte können, unbekannt sind.

Ich habe diese Art Herrn Prof. O. Funaraxn zu Ehren benanut. 


\section{Cypridopsis dadayi n. sp.}

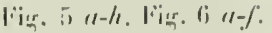

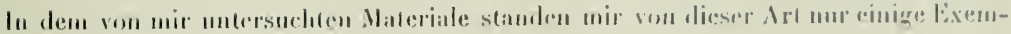
plare zu (ielusle.

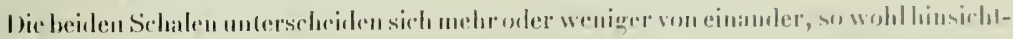
licli ilued form als auch ihrerstrukiur.

Vonder Seite geseloen ist die rechte Schale (lïg. 5 a) länglich nierenlärmig. ber Lorsalrand bilded in der Mille einen merklichen s(umplen Buckel; am lö̈clsten ist er ïber den Xugen, also iun ersten Drillel der Sichale; dem Vorlerrande zu ist er steil alsschüssig, dem hinteren zu sanlier alssteigend. Der Vorderrand ist stumpf, ghleiclimässig abgerundet, etwas niederer als der hintere, ron innen mesehen mit. eimem sclumalem Kutikularsaum (Fig. 5 d); die Grenzlinie des Randes ist verwaschen, die Randborsten stehen in zwei Reihen mit einem kleinen kügrelehen am Ursprunge; sie sind ziemlich lang und stehen sehr dicht nebeneinander. Kein Porenkanalgürtel. Die Innenlamelle ist ein sehr breiter Gürtel. Der Bauchrand ist in der Mitte leicht, gleichmässig gehuchtet und grelı mbemerkbar in die beiden Ränder über. - Der Hiuterrand ist stumpfer abrerundet, als der vordere und bililet mit dem Dorsalrande cincn ziemlich aulfallenden 11 "̈nkel; seinen Saum umgibt ein schmaler liutikularsanm (Fit. 5e); seine Seitenborstenentspringen auf dieselhe Weise, wit diejenigen des Vorderrandes, sie sind aber viel lïnger und spärlicher; die Innenlamelle ist ein sehr schmaler Gürtel.
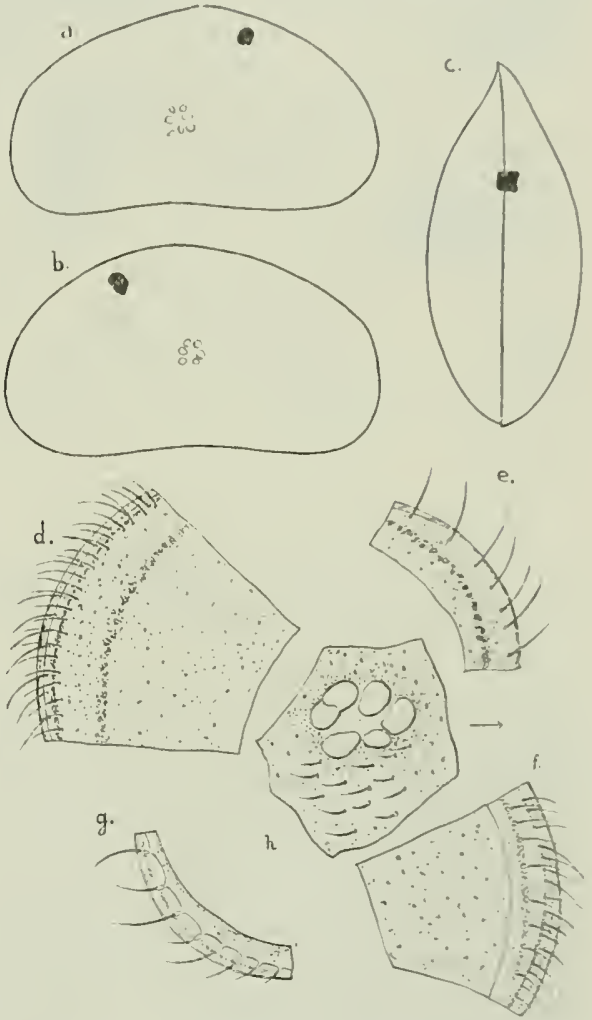

Fig. 5. - C.Mmidopsis dadayi n. sp. - a. Rechte Schale Q. $b$. linke Schale 0 , schale von ohen gesehen 0. . $d$. Vorderrand der rechlen Schale, e. Hinterrand der rechlen Schale. $f$. Vorlerrand der linken Schale. g. llinterrand der linken Sclıale, h. Ilnskieleindrúche. 
Die linke Schule ist unregelmässign nierenförmig (Fig. 5 b). - Der Dorsalrand zieht sich ein wenigg gebogen absteigend zum Vorderrand, in den es unbemerkbar äbergeht. Fon innen betrachtet (Fig. 5 $f$ ) unterseheided sich der Vorderrand der liuken Sehate von demjenigen der rechten Schale darin, dass sein kutikularsaum viel schmäler ist, der Saum einen breiten Gürtel darstellt und leiclst erkenubar ist. Kein Porenkanalgürtel. Die

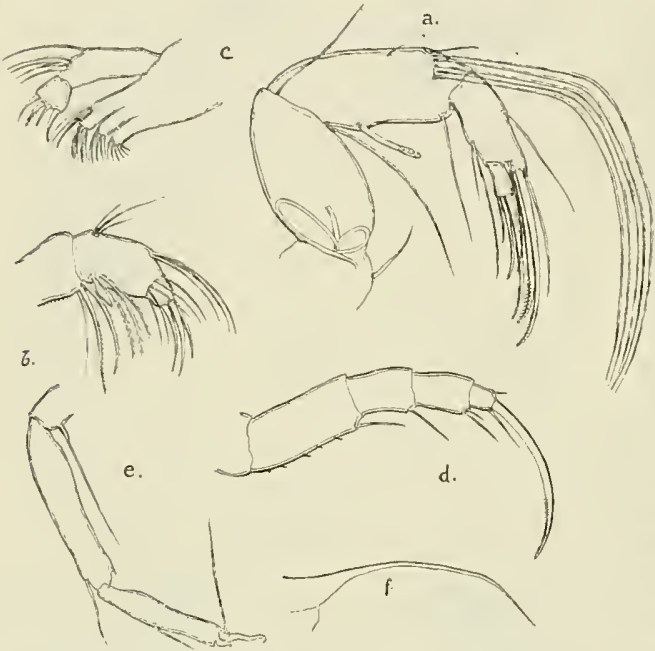

Fig. 6. - Cypridopsis dadayi n. sp. - a. Antenne des 2. Paares $Q$, c. Maxille $0, b$. Mandibulartaster $0, d$. Bein des 1 . Paares $0, c$. Bein des 2. Paares $Q, f$. Furca ${ }^{+}$. Imnenlamelle ist ein sehmaler Gïrtel. Der Bauchrand verläuft chenso wie bei der rechten Schale. - Der Ilinterrand verschmilzt mit dem Banchrande in einem stumpfen, gleichmässigren Bogen und mit dem Dorsalrand bildet er einen stumplen Winkel; von innen gesehen (Fig. 5 g) unterscheidet er sich wesentlich von demjenigen der rechten Scluale, indem er mit einem wohlentwickełten Porenkanalgïrtel versehen ist. In der Nähe des Ursprunges der Poreskanälchen gibt es ampullenförmige Erweiterungen. - Die Porenkanälclıen verlaufen gleichmässig und zu einander parallel.

Von oben geselıen sind die Schalen (Fig. 5 c) kahnförmig. Der hintere Gipfel iststumpf, der vordere stark in eine Spitze zulaufend. Die Seitenlinie zieht sich in einem gleichınässigen Bogen zum vorderen Gipfel, in dessen Nähe sie einen auffallenden Winkel bildet. - Der grösste Durchmesser befindet sich in der Mittellinie.

Die Schalenwandung ist ziemlich hart und dick. Die Oberfläche ist mit feinen kleinen Grübchen besäet und mit ziemlich kurzen, dicken Haaren (Fig. 5 h) dicht bedeckt, welche in der Nälıe der Gipfel und der Ränder an Diclıtigkeit gewinnen. Bei stärkerer Vergrösserung erscheint die Wandung fein granuliert. - Die Schalen sind bräunlich grün.

Die Muskeleindrïcke sind 5-6 an der Zahl (Fig. 5 h), von welchen zwei manchimal einander so nahe liegen, dass sie wie verschmolzen aussehen. Sie bilden einen Kreis.

Die zwei vorletzten Glieder der zweiten Antenne (Fig. $6 a$ ) sind zienulich schmal. Der obere distale Gipfel ist mit zwei wollentwickelten, fein grezïhnelten Endkrallen versehen, von den die äussere nm vieles länger ist als die imere. Neben derselben entspringt eine Borste, die beinahe so lang ist wie die Kralle. Das letzte Glied ist beinahe doppelt 


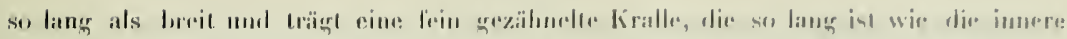

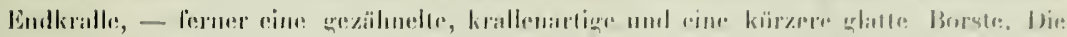

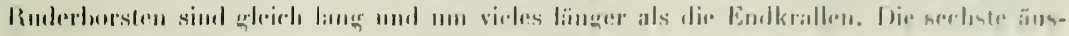

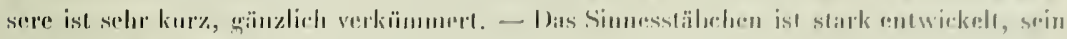

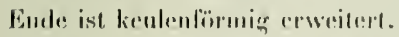

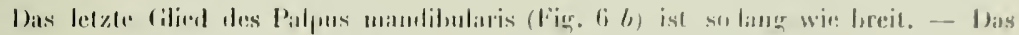

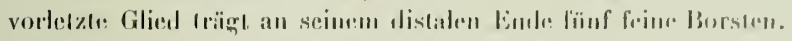

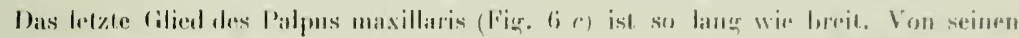

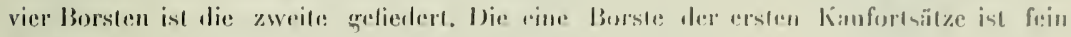
geziilınelt.

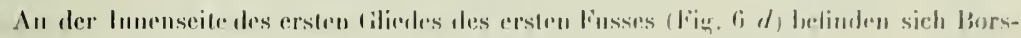

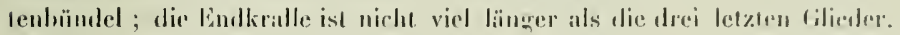

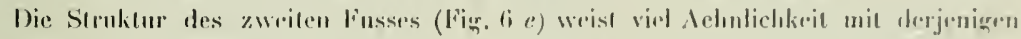
des \%weilen lusses der vorheromend heschriehenen Arl.

Auch der furkalanhang (Fig. 6,f) ist mit demjenigen der Cippridopsis fullrmanni sozasagen identisch, aber bei der Verschuälerung der lamelle finden wir nicht dir charakliristische Enveiterung.

Länge: $0.58 \mathrm{~mm}$. Il̈̈he: $0.32 \mathrm{~mm}$. Murrhmesser: $0.36 \mathrm{~mm}$.

Fundort: Columbien. - Ostiondillere. - T'ümpel 4 luei Lisguna 1, 26/10 m auf der Sibana von Bogota. - Sammluner des lleern Prof. Dr. O. linumsisx.

Ielı habe diese Art Lerron l'rol. L. vox Dabay zu Eliren henanut.

\section{Candona pedropalensis n. sp.}

lig. 7 "-f. Fig. 8 a-h.

Beide Schalen sind in iluer Form mileinander äbereinstimmend, nur in ihrer StrukIIIr Interseheiden sie sich cin wenig von einander.

Von der Seile gesehen ist die rechle Schale (Fig. 7 a) sehr lang gestreckl nieren-

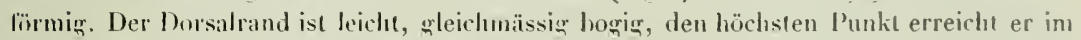
hinteren Dritted der Schale, in den Vorderrand geht er unbemerkhar über und mil dem hinteren bildet er eine sanfi absteigende Linie. Der Vorderrand ist trteichnässig ahgerundet (Fiæ. 7 c), seinem äusscren Saum antlang zirht sich ein dünner Kutikularsaum und er besilzt einten wohlentwickelten Porenkinalgürlel. Im Lrsprungre der Porenkanăle ist ein kleines hï̈gelchen, die kanälehen verlanfen mit einander parallel, sind ghleichmāssiog und stehen ziemlich dicht nehen einander. I) Innenlamelle isl ein schmaler frürtel. Die Struktur des Vorderrandes der linken Schale ist mil derjenigen des Vorderrandes der rechten Schate volfliommen identisch. - Der Banchrand ist leicht ansrebuchtet, bogig: dic Ausbuchtung ist beinahe im vorderen Dritled der Schale am grïssten; der Batchrand verschmilzt unbemerkt mit den Rändern. Der llinterman is etwas höher als der 
vordere, sein Kullkularsaum aber (Fig. $7 d$ ) ist etwas heiter und enthehrt eines Porenkanalgürtels; die Ramborslen sind spärlich, kur\% und dick. Die Innenlamelle ist ein

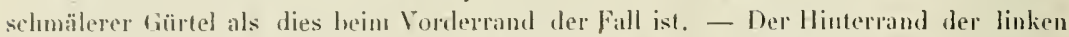
Schale (lig. 7 e) mulerscheidet sich ron demjenigen der rechten Schale darin, dass sein Schalenrand nicht gut entwickelt ist, seine lomenlamelle cin viel hreilerer Gürtel ist, und dass seine Randhorst'n dichter stehen, ferner dünner und länger sind.

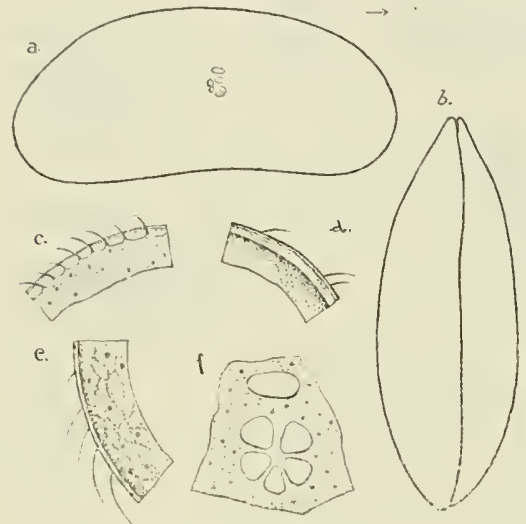

Fig. 7. - Candona pedropalensis n. sp. $-a$. Rechte Schale O, b. Schale von oben gesehen O, $c$. vorderrand der rechten Schale, $d$. Hinterrand der rechten Schale, $e$. Ilinter'rand der linken Schale, f. Muskeleindrücke.

Von olen letrachtet sind dic Schalen (Fig. 7 b) kahuförmig. Der lintere Gipfel ist stumpl, der vordere spitz. Der Verlauf der Seitenlinie ist nicht gleichmässig, indem sie in der Mitte etwas gerade ist. - Der läıgste Durchmesser liegt in der Mittellinie.

Die Schalemwandung ist sehr fein und diinn. Die Oberlläche ist beinalıe nackt, nur mit spärlich stehenden Ilaaren versehen. Auf der Schalenwandung befinden sich ziemlich dicht sehr kleine Grübchen; hei starker Vergrösserung erscheint die Wandung granuliert (Fig. 7 e).

Die Muskeleindrücke (IFig. $7 f$ ) sind sechs an der Zahl, von welchen fünf gleich gross sind und einen Kreis bilden, wogegen der sechste Muskeleindruck über denselhen allein steht und der grösste ist.

Die Struklur der ersten Antenne stimmt mit derjenigen der ersten Antenne der ïlorigen Candona-Arten überein. Die Borsten sind sehr lang gestreckt, die längsten sind sogar länger als die vier letzten Glieder.

Die Länge des letzten Gliedes der zweiten Antenne (Fig. 8 a) beträgt die Hälfte seiner Breite. Das vorletzle Glied trägt drei wohlentwickelte ungezähnelte krallen, von denen zwei gleich lang sind, die äussere aber nur halb so lang als die beiden andern. - In ihrer Nähe erheben sich drei Borsten. - Das Sinnesstäbchen ist lang gestreckt (Fig. 8 b), sein letztes Glied endet slumpf.

Der Palpus mandibularis ist selır stumpf (Fig. $8 \mathrm{c}$ ). Die Länge und die Breite des letzten und des vorletzten Gliedes sind mit einander gleich. Iu der Mlitte des distalen Randes des drilten Gliedes ist eine stark entwickelte Borsle. Auf dem vorletzten Gliede lefindet sich eine starke, glalte Borste.

Das letzte Glied des Palpus maxillaris ist eben so breil wic lang (Fig. $8 d$ ).

Der Taster des Kieferfusses (Fig. 8 e) hat am letzten Gliede drei Borsten, von denen die eine kürzer ist als die übrigren zwei. Die mittlere ist rlie längste. 


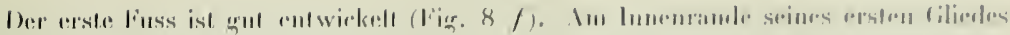

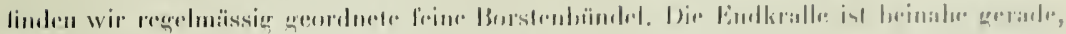

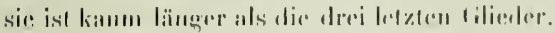

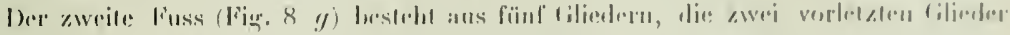
siml alwer mit cinamler verwachsen. Die Länge and die Breite des letelen filiedes sind riutunder gleish. Vinn den Eudbursten ist die eime sehr

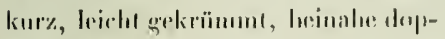
pele so lang, als das lelyte Gilied; dic amlerengweitullorsten sind krallan-

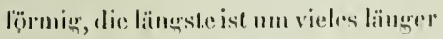
als die drei dedzon Giliedar.

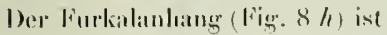
ziemlich kur\%, leicht gekrïmms; scin proximales Ende wird platfenarlign breit und dann nach und nach wieder schmal. -- Sein (therrand lesigal frime Hatre, - Der I reprung der Randlonste lirgl weit von den Endkiallen; sie ist ziemlich liurz, ihre Länge hetrïgt nicht rimmal die Ilälfte der Endkrallen. Die Endborste ist kamm liemerkbar, leinahe ganz rerkümmert. Hingegen sind die Endkrallen sehr grut entwickelt. Sie stehen nahe beisammen und sind beinahe wheich lanor, die untre ist elwas linger als die
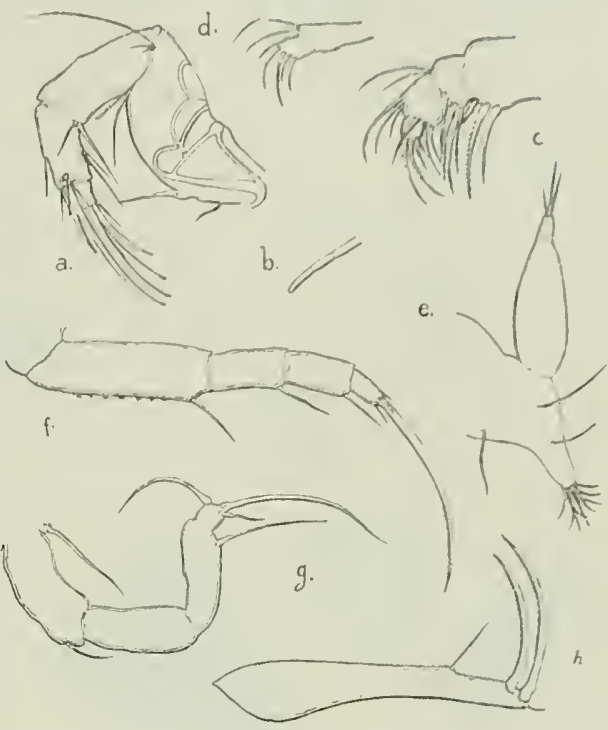

Fig. 8. - Candona pertropalensis n. sp. - $a$. Antenne des 2. Рaares $O, b$. Spiitborsle der 2 . Antenne $O$, c. Palpus mandihularis $ᄋ, d$. Pilpus maxillaris 0 , e. hieferfuss $O$. $f$. liein des 1. Paares $Q, g$. Bein des 2. Paares $O_{\text {, }} h$. Furca ${ }_{T}$. olere; sic sind grobezezihnt.

Länģe: $0.95 \mathrm{~mm}$ Höhe: $6.41 \mathrm{~mm}$ Durchmesser: $0.35 \mathrm{~mm}$.

Findort : Conlumbien. - Ostkordillere. - Laguna Pedropato $2000 \mathrm{~m}$. - Sammlung des Herrn Prof. Dr. O. Funnasix.

\section{Candona annae n. sp.}

Figr. 9 a-f. Fig. 10 a-i. Fig. I1 $a-g$. Fig. 12.

Im Matrrial, welchesmir zur Verlïgung sland. gab es einig̨e Männchen und einige Weibehen.

Männchen (Fig. 9. a-f. Fig. ro a-ı). In ihrer form sind heide Schalen heinalie ghleich und ihre feinere Struktur bielel war keine Linterschiode. 
Von der Seite gresehen ist die rechte Schale (Fig. 9) gestreckt, unregelmässig nierenförmig. Der Dorsalrand besclıreibt beinalse eine horizontale Linie, die aber dem Vorderrand zu ein wenig ahschüssig ist und mit dem Vorterrande einen gut bemerklaren stumplen Winkel bildet; dem Hinterrande zu zeigt sie eine einen etwas aufwärts gerichteten Bogen beschreibende Linie, welche dann absteigend mit dem llinterrande beinahe
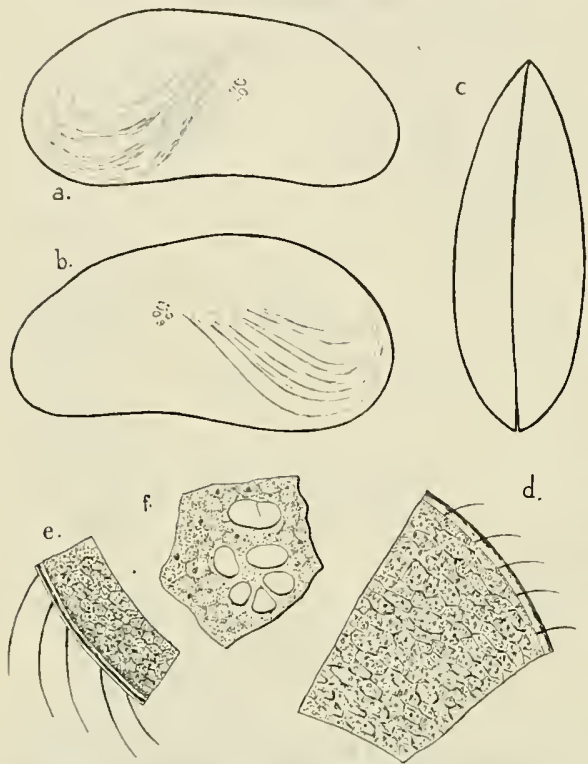

Fig. 9. - Candona annae n. sp. - $a$. Rechte Schale ${ }^{1}, b$. linke Schale $\sigma^{1}, c$. Schale von oben gesehen $d$. Vorderrand der linken Schale, e. Hinlerrand der linken Schale, $f$. Muskeleindrücke.

selımückter Gürtel. Längs des Saumes des Hinterrandes (Fig. $9 e$ ) zielıt sich ein sehr dünner lutikularsaum, dessen Schalensaum ein noch schmälerer Gürtel ist als derjenige des Vorderrandes. Auch existiert lier kein Porenkanalgürtel. Die Randborsten sind sehr lang und dünn. Die Innenlamelle ist ein schmaler Gürtel, dessen Struktur dieselbe ist wie beim vorderen Saume.

Von oben betrachtet sind die Schalen (Fig. 9 c) beinahe regelmässig kahnförmig. Der hintere Saum ist etwas stumpfer abgerundet als der vordere. - Die Seitenlinie beschreibt einen dem vorderen Rand zu alsteigenden Bogen.

Die Schalenwandung isı fein und düm. Auf der Oberlläclte befinden sich nur sehr zerstreut stehende Haare, zwisehen welchen feine, kleine Grübchen sichtbar sind. Die 


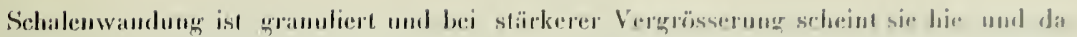
retikuliert zu sein. Furke: gröulicherell.

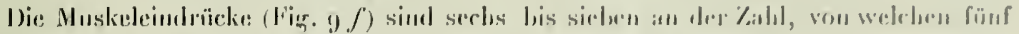

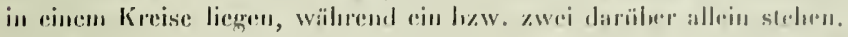

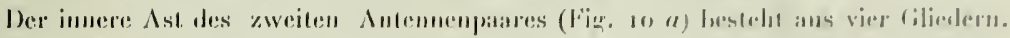

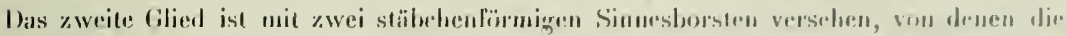

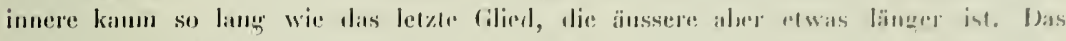

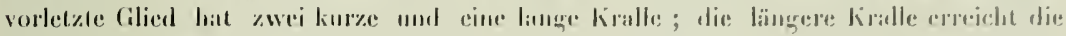
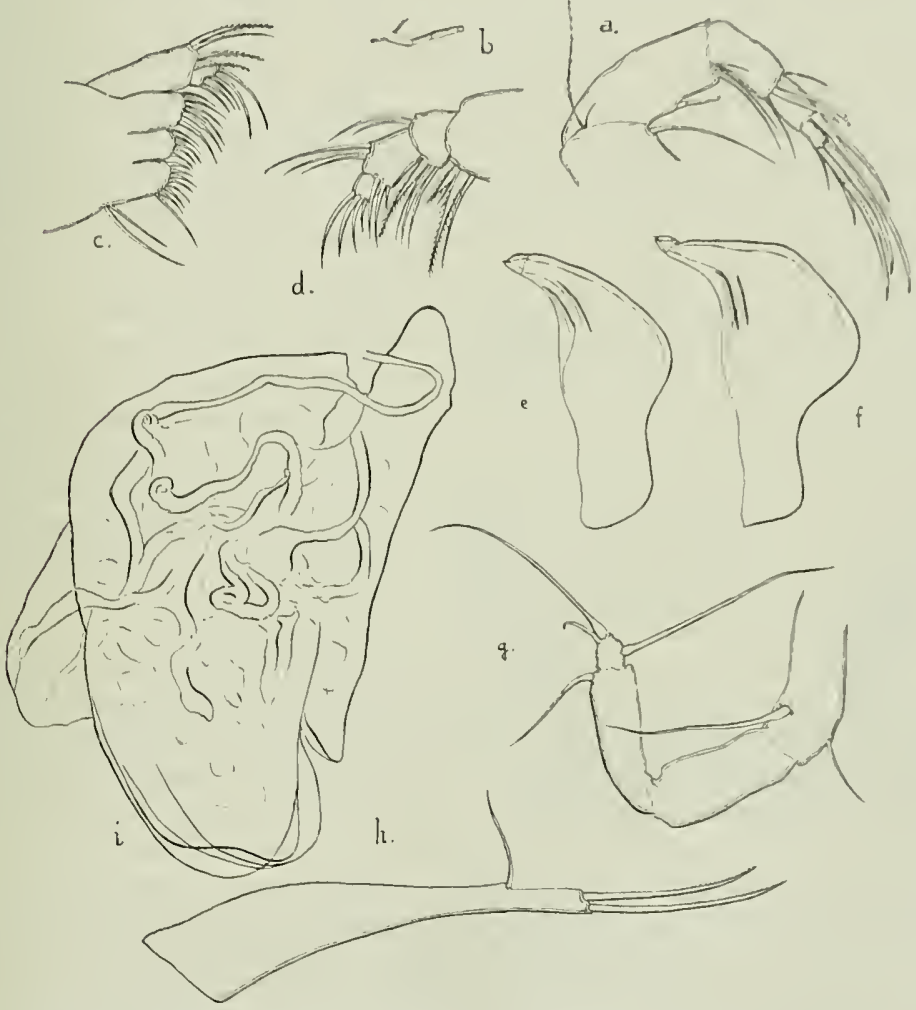

Fig. 10. - Candona annae n. sp. - $a$. Antenne des 2. Paares 4 , b. Spürborsle des 2. An-

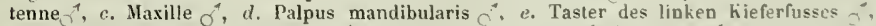
$f$. Taster des rechten Kieferfusses $\sigma^{\prime}, g$. Bein des 2 . Paares $j^{*}, h$. Furca $\sigma^{*}, i$. hopulationsapparat ${ }^{\prime}$. 
liänge der drei letzten Gilieder zusammen. Das letzte Glied ist mit einer längeren und einer kïrzeren Kiralle hewallnet; lie lïngere ist elen so lang wie die Endkralle des vorletzten

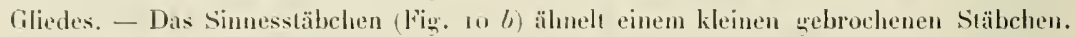

Das letzte Cilied des Palpus mandibularis (lig. lod) ist eben so breil wie lang. Das vorletzte Gilied hat drei Borsten verschiedener Längूe, von den die niltlere die längste ist.

Die Taster der Kieferfüsse sind von einander nicht sehr verschieden. Im allgemeinen sind sie einer breiten Sichel ähnlich. Der Taster des linken lieferfusses (Fig. $10 e$ ) ist seinem vorteren Ende zn verjüngl, an seinem äusseren mitleren Teil bildet er cinen stark hervorragenden Hügel. Der untere, ïussere Rand ist auflallend ausqehuchtet. Der innere Rand beschreilı cine gleichmässig gewellte Linie. - Die an seinem inneren Rande hefindlichen zwei Sinnesdornen sind beiläufig gleich lang. Der Taster des rechten Kieferfusses ist auch sichelförmig, aher breiter als derjenige des linken Kieferfusses. Der Verlauf und lie Struktur seines Innenrandes sind dieselben wie auf der linken Scite, sein Aussenrand aber zeigt einen wesentlichen Unterschied. - Auf dem Aussenrande erheben sich nämlich zwei sehr wohlentwickelte Ilägelchen, von welchen der untere augenfälliger stark erhöht, der obere dagegen viel verschwommener ist. - Die Linie, welche die zwei Hügelchen verbindet, hat einen greraden Verlauf. Unter dem unteren Hügel ist der Aussenrand tief ausgebuchtet, der obere Hïgel nähert sich dem vorderen Teile in einer horızontalen Linie. Das Sinnesorgan des Gijfels der beiden Taster isı kurz, kegelförmigr.

Die beiden Glieder des Palpus maxillaris (Fig. so $c$ ) sind doppelt so lang wie der erste Kaufortsatz. Sein erstes Glied ist mit vier Krallen bewalthet, von denen die längste glatt, die ïbrigen drei fein befiedert sind. Das zweite Glied ist etwas breiter als lang; es besitzt zwei wohlentwickelte und drei kurze Krallen. -- Der erste Kaufortsatz, sowie auch die beiden anderen sind dick, sehr kurz. Er besilzt drei wohlentwickelte zweigliedrige Borsten. Auf dem letzten Fortsatze ist die letzle Borste doppelt so lang als die übrigen und richtet sich nach hinten.

Die Struktur des ersten Fusses hat keine besonderen Eigenschaften.

Der innere Ast des zweiten Fusses (Fig. $10 \mathrm{~g}$ ) ist viergliedrig; die zwei vorletzten Glieder sind zusammengewachsen. Das letzte Glied ist eben so breit wie lang. Die sich

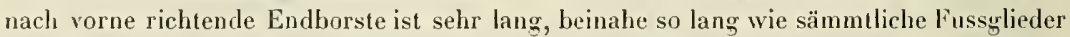
zusammen. Die sich nach hinten richtenden zwei krallenförmigen Borsten sind nicht gleich lang. Die längere ist beinahe so lang wie diejenige, welche sich nach vorne richtet, die kürzere aher ist kaum länger als das letzte Glied.

Der Furkalanhang ist langgestreckt (Hig. 10 h); in seiner proximalen Hälfte breil, plattenförmig, seinem Gipfel zu ungleichmässig verjüngt. Sein leicht gekrümmter oberer Rand ist glatt. Die Randborste entspringt ziculich weit von den Endkrallen und ist halb so lang wie die längere Endkralle. - Die Endkrallen sind selır wohlent wickelt; die äussere ist etwas länger als die innere. Die Endborste fehlt gänzlich, - oder ist kaum bemerkbar.

Die Struktur des Ductus ejaculatorins ist dieselbe wie bei den übrigen Arten der Candona-Gattung. Der Zentralkanal ist von 7 Dornenkrinzen umgeben. 


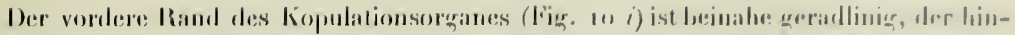

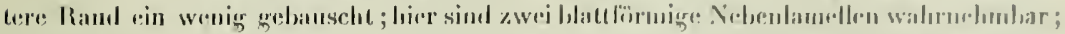

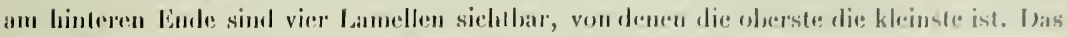
Vas dederens bilalet in seinem Verlanle: melirere Wimlungen und AusluehIIII)en.

Weibrhen (ligg. 11 11-9. Fis. 12). In ihrer l'orm sind die Schalen ähereinstimment, in ihrer Siruklur weichern sie alser von rinander wescmelieh als.

Die: rechte Sichule (liz. It $a$ ) ist von der Sicite gesehen gestreelit nierenrörmigg. Der Dorsalrand ist dem Vorderrande an gerallinig absteigend; in seinem vorderen Drittel bilelet er cinen
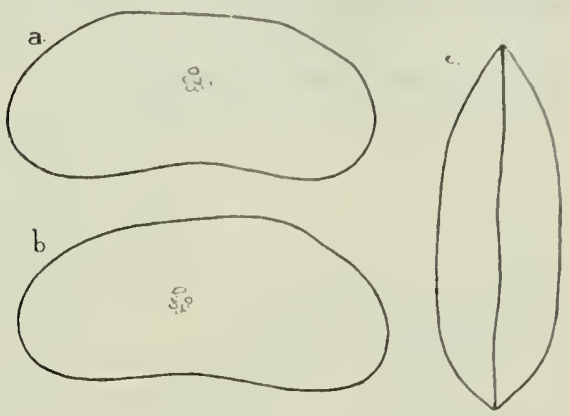
stumpren Winkel und zieht siult absteigend zum Vorderrand mil d'm er einen stumpfen Winkel lilket. Der Vorderrand ist stumpf, gleiehmiissig alggerundet; sein Rand hat einen selir schmalen Kutikularsaum (lig. I $d$ ), sein Schalenrand ist ein selur schmaler Giürel, ein Porenkanalgürtel fehlt; die Seitenborsten stehen dicht nehen einander und sind dünn und lang. - Die Innenlamelle ist ein sehr breiter Gürtel und ist nicht retikuliert wie beim Männchen. Der Vorderrand vereinigt sich in einem Bogren mit dem Bauchrande, der bei läufig in der Nitte ansgebuchtet und unbemerkbar mit dem Hinterrand versclumolzen ist. Der Hinterrand ist stum-
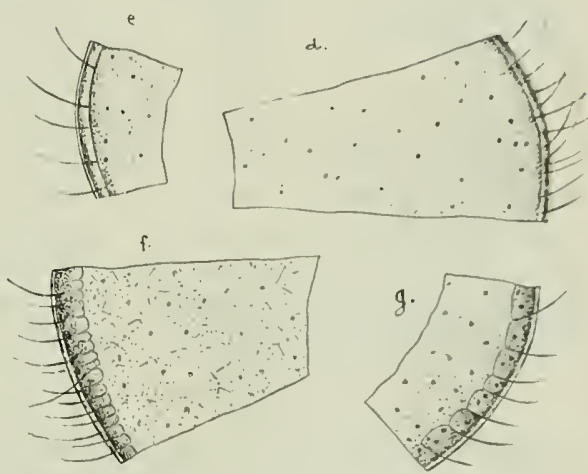

Fig. 11. - Candona annae n. sp. - a. Rechle Schale O b. linke Schale $Q$, c. Schale vou oben gesehen $Q$, d. Vorderrand der rechlen Schale, e. Hinlerrnd der rechten Schale, $f$. Vorderrand der linken Schale. g. Hinterrand der linken Schale.

pfer abgerundet als der vordere und ist

viel höher. - Von innen gesehen (F̈ig. 11 e) zeigt sich der Kutikularsaum, wie auch der etwas breitere Gürtel; ein Porenkanalgürtel fehlt auch hier. Die Randhorsten slehen am Selıalenrand spärlicher als am Vorderrand. Die Innenlamelle ist ein schmaler fiürtel und bildet mit dem Dorsalrande einen stumpfen Winkel.

Die linke Schale (Fig. if b) ist, ron der Scile gresehen, der rechten ähnlich. Der Dorsalrand beschreiht beinalie cinen geraden Bogen, der mit den Vorderrande unbemerklar verschmolzen ist und mit dem hinteren eine kaum wahrnehmbare I usbuchtung bildet. - Der 
Vorderrand (Fig. 1 f $f$ ) ist stumpf, gleichmässig ahgerundet. Der Kutikulargürtel ist breil, der Schalenrand ist ein viel lreiterer Gïrtel als bei der rechlen Schale; ein wohlentwickelter Porenkandlgärtel ist vorlsanden. Die l'orenkanäle stehen dicht neheneinander, verlaten grleichmässiğ, sind einfich und an ilırem Lrsprunge mil kleinen kügrelehen versehen. - Die Inneulamelle ist ein etwas schmälerer Gürtel als bei der rechten Schale. Der Bauchand ist nicht so ausgebuchtet wie hei der rechten Schale, sein Verlauf ist aber derselbe wie dort. Der llintermel ist etwas spitzer abgerundet, als der vordere.

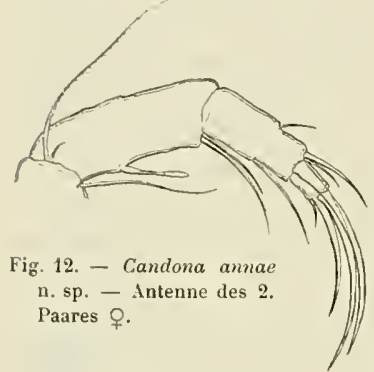
Was seine feinere Struktur anthelangt (Fir. $11 \mathrm{~g}$ ) ist er dem Vorderrand ähulich, aber lie Porenkinälchen steben spärlicher neben cinander und iln Ursprung entbehrt der kieinen Kügelchen. - Die lunenlamelle ist ein schmaler Gürtel.

Von when geselsen sind die Schalen (Fig. 11 c) einem zusammengedrückten Kahıe ähnlich. - Der hintere Rand ist etwas stumpfer als der vordere. - Die Seiteulinien verlaufen cinauder parallel.

Die Zahl und die Anordnung der Muskeleindrücke, sowie die Struklur der Schalenwandurg ist dieselbe wie bei den Männclien.

Am inneren Ast des zweiten Antennenpaares (Fig. 12) sind die zwei vorketzten Glieder zusammengewachsen. Der Gipfel des vordelzten Gliedes trägl eine längere und eine kürzere hralle, sowie auch eine kleine Borste. Auch das letzte Glied ist mit einer längeren und einer kürzeren tiralle versehen. Das Ende des Simnesstähclsens ist lanzenförmig. Die Mandibula, Maxilla, der erste und der zweite Fuss, sowie der Furkalanhang bieten keine besondere Eigentümlichkeiten. Sie sind ganz so wie beim Männchen.

$$
\text { Länge: }\left\{\begin{array} { l l } 
{ 0 } & { 0 . 9 5 \mathrm { mm } , } \\
{ 0 } & { 0 . 9 \mathrm { m } \mathrm { mm } , }
\end{array} \text { Höhe: } \left\{\begin{array} { l } 
{ 0 . 4 4 \mathrm { mm } , } \\
{ 0 . 4 \mathrm { mm } , }
\end{array} \text { Durchmesser : } \left\{\begin{array}{l}
0.33 \mathrm{~mm} . \\
0.3 \mathrm{~mm} .
\end{array}\right.\right.\right.
$$

Fundort : Columbien. - Ostkordillere. - Tümpel 3. auf der Sabana von Bogola ${ }_{2} 640 \mathrm{~m}$. - Sammlung des Prof. Dr. O. Funmunn.

In der Form der Schalen weist das Weibchen der soeben bescliriebenen Art auf eine sehr grosse Verwandtschaft mit der von S. Ekмa (4) beschriebenen Candona longipes hin, von der sie sich aber in ihren Organisationsverhälunissen so sehr unterscheidel, dass wir berechtigt sind dieselbe in die Literatur als eine neue Art einzuführen.

\section{Candona columbienensis $\mathbf{n}$. sp.}

Fig. 13 $a-e$. Fig. $14 a-b$. Fig. $15 a-i$.

Das Material, welches mir zır Verfügung stand, enthielı einige Mäuncheı und einige Weibchen. Die Form und die Struktur der Schalen der leiden Geschlechtsindividuen bieten kaum einen geringen wesentlichen Unterschied. 


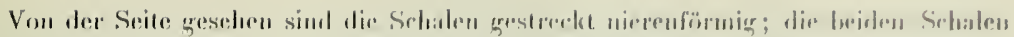

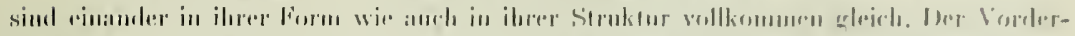

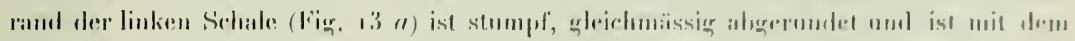

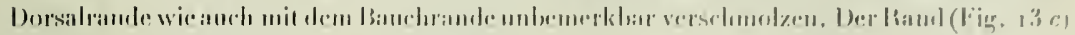

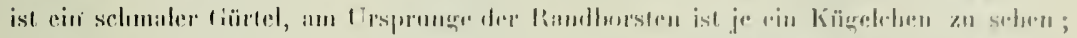

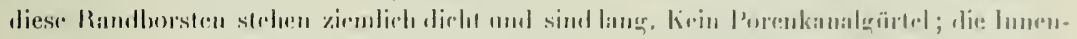

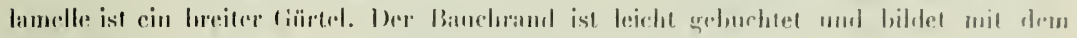
llinferrand einen blwas stumpleren lingen als

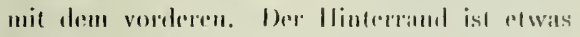

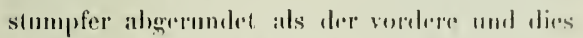
ist die Ursache wroblall, die Sirhale in ihrem linteren Drithe cin wenig höhrep ist als im rorderen. Was die lemere Strukfur des llinter-

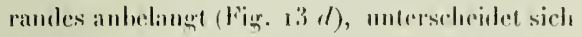
letzterer von dem vorderen nu dariu, dass seine Randlworsten doppelt so langr simd mud viel

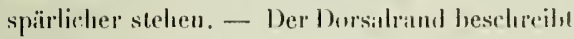
cincen vom Vorderand zum hinteren sich er hehenten Bogen.

Von ohen gesehen sind die Schaten (Firg. г3 b) regelmässig kahulörmig. Der vordere (iiplel ist kaum merklich spitzer als der hinfere. Dic Scitenlinie verläuft in einem gleichmässig ahsteigendrm Bogen dem vorderen Gipfel zu. Der längste Durchmesser befunlet sich beiläufig in der Mitlellinire

Die Wandung der grönlicherelhen Schalc ist

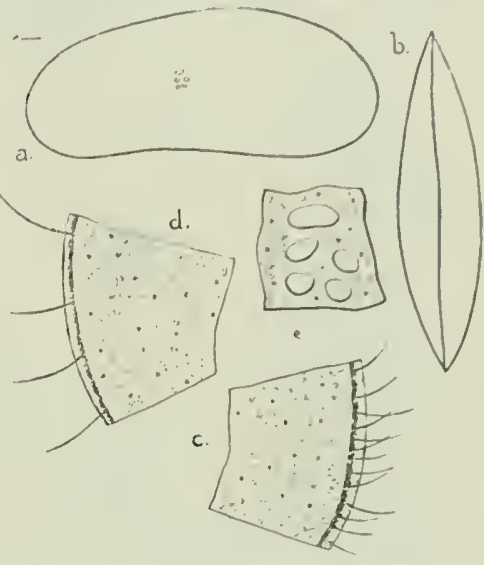

Fig. 13. - Candona columbienensis n. sp. $a$. Linke Schale $0, b$. Schale von oben gesehen $0, c$. Vorderand der rechten Schale, d. Hinterrand der rechlen Schale, e. Muskeleindrücke.

selır düın und frin. Dic Oherflïche der Schale des Männchens ist ein wenig behaart; die Schalemwandung heirler Geschlechter ist mranuliert.

Die Muskeleindrücke (Fig. 13 e), sind fünf his sechs an der Zahl, von denen vier his fünf gleich gross sind und einen Kreis bilden : eiucr, nïmlich der grösste befindel sich horizontal oberhall desselben.

Der innere Ast der zweiten Antenne des Männchens (Fïig. 15 a) hat vier Glieder. Das letzte Glied ist beinahe doppell so lang als lreit. Es I rägt eine wolllentwickelte Liralle, die aher nicht so lang ist wie die zwei Endkrallen des vorletzten Gliedes. Letzteres trägl auch nod eine drille kralle, die aher nicht einmal halh so lang ist wie die zwei amderen. In der Mitfe des zweiten Giliedes hefinden sich zwei stähchenfirmige Sinnesborsten, von den die imnere his zur Mitte des letzten filiedes reicht, die äussere dagegen viel kïrzer ist. Neben der imeren Sinnesborste finden wir noch eine klauenartige Borste, die elwas länger ist als das letzte Glied; der äussere Rand ist mil einer längeren 
und einer kïrzeren Borste versehen. Das Sinnesstäleden der zweitrn Antenne (Fig. 15 b) ist sehr lang gestreckt und stïbchenförmig.

Das letzte Glied des Palpus mandibulars (Firg. 15 d) ist elwas länger als breit. -

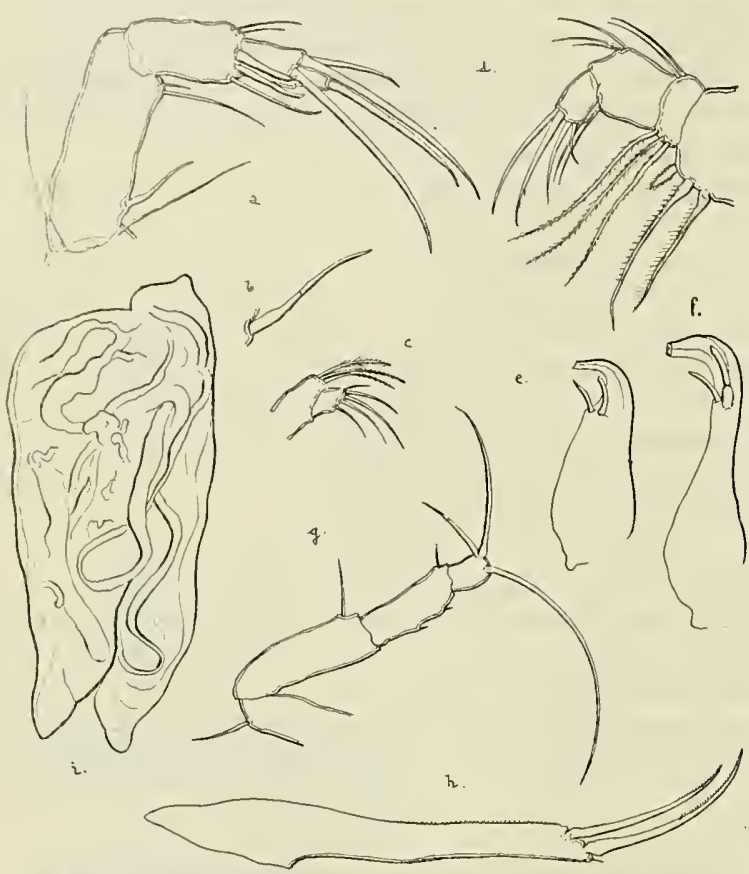

Fig. 15. - Candona columbienensis n. sp. - $a$. Antenne des 2. Paares $b$. Spürborsle der 2. Antenne $c, c$. Palpus maxillaris $\sigma^{7}, d$. Palpus mandibularis $f, e$. Taster des linken Kieferfusses $f, f$. Taster des rechten Kieferfusses $\delta, g$. Bein des 2 . Paares $\delta, h$. Furca $o$, i. Kopulationsapparat 6 .

Spitze. Er besitzl zwei Simneshorsten, von denen die äussere auf einem kleinen Hügel sitzt; der Innenrand verjüngt sich plötzlich in der Gegend der Sinnesborsten und geht sich gleichmässig erhebend in den hinteren Teil über. - Der Taster des linken Kieferfusses (Fig. $15 \mathrm{c}$ ) ist viel dicker, als derjenige des rechten Kieferfusses; sein proximaler Teil ist auch breit lamellenförmig, der distale Teil sichellörnig, aber viel schmäler als der rechte. Während der rechte Taster sich in der Gegend der Sinnesborsten auflallend verjüngt, finden wir bein linken das Entgegengesetzte, inden er am in Rede stehenden Orte dicker wird und ein kleines Hüggelchen bildet, welches die innere Sinnesborste trägt. 


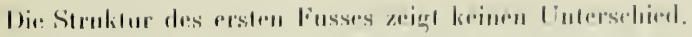

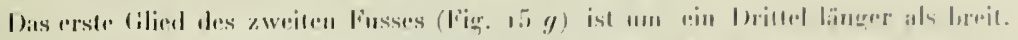

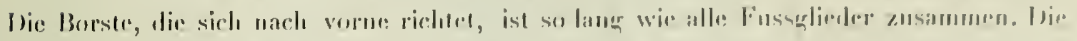

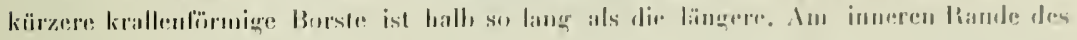

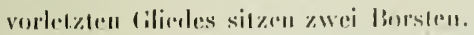

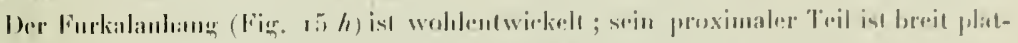

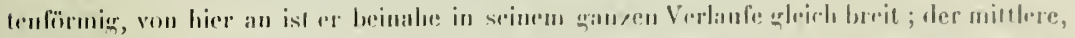

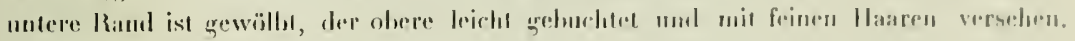

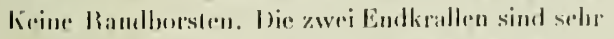

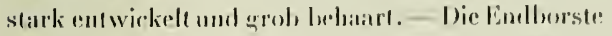

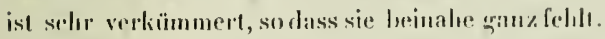

loer Dnclus ejaculatorins stimms mit tem-

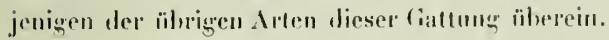

Das Kopulationsorgan (Fig. 15 $i$ ) ist lang gestreckt, der vordere mul der hintere Rand desselhen verlanfen leicht gewellt, sie sind rinander beinahe parallel. - Das proximale Ende ist rtwas breiter als das distale, ticf und aweischeibig. Das $V$ as Deferens lilded in seinem Verlaufe mehrere Schlingen, wodureh Ausbïchtungen entstehen.

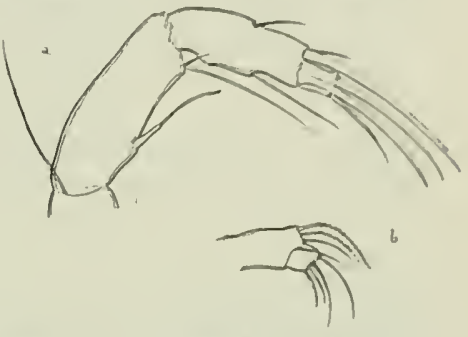

Fig. 14. - Candona columbienensis n. sp. a. Antenne des 2. Pares , b. Palpus maxillaris ?.

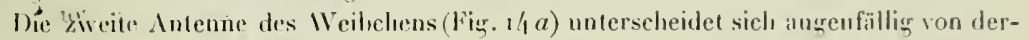
jeniǧn des Männchens. Das letzte Glied ist um ein Driltel länger als lıreit. Es trägr eine läns 'e nnd cine kürzere Kralle; die lïngere ist so langr wie die Eudkralle des vorletzlen Gliedes. Das Sinnesstähchen ist viel länger und entet in der Form eines feinen, dïnnen Stäbcliens.

Das letzte Glied des Palpus marillaris (Fig. 146 ) ist viel hreiter als lang und trägl vier Borsten verschiedener Lïnge.

Die vibrigen Teile der Organisation des Weihchens sind mit denjeniggen des Mănnchens ühereinstimmend.

Länge: $0.88 \mathrm{~mm}$. Höhe: $0.38 \mathrm{~mm}$. Durchmesser: $0.2 \mathrm{~mm}$.

Fundort: Columbien. - Ostliordillere. - Tümpel 3. auf der Sabanat von Bogota, 2640 m. - Sammlung des Herrn Prof. Dr. O. Funвмax.

Die Arten nach Fundorten zusammengestellt:

\section{Columbien.}

Centralkordillere:

Ostkordillere: г. Sumpf zwischen Medellin und Amerika 1530 m. Eucypris arequensis DaDAs, Cypridopsis fuhrmanni n. sp.

2. Laguna I. hei Madrid auf der Sahana ron Bogota 26 fo m. Cypridopsis fuhrmanni n. sp. 
3. Laguna II. bei Madrid auf der Sabana von Bogota $2640 \mathrm{~m}$. Cypridopsis fuhrmanni n. sp.

4. Tümpel 3. auf der Sabana ron Bogota. Cypridopsis fuhrmanni n. sp., Candona annae n. sp., Candona columbienensis n. sp.

5. Tümpel 4. bei Laguna I. Cypridopsis fuhrmanni n. sp., Cypridopsis dadayi n. sp.

6. Tümpel beim Tequendamafall $2210 \mathrm{~m}$. Eucypris wolffhügeli n. sp.

7. Laguna Pedropalo $2000 \mathrm{~m}$. Cypridopsis fuhrmanni n. sp., Candona pedropalensis n. sp.

8. Laguna Ubaque 2 г $2 \mathrm{~m}$. Strandesia bicuspis bicuspis (Cusus), Strandesia mucronala (G. O. Sars). Cypridopsis fultrmanni n. sp.

\section{Argentinien.}

Kordillere von Mendoza: I. Tupungatolal $3200 \mathrm{~m}$. Eucypris nobilis (G. O. SARs).

2. Tupungatotal $2500 \mathrm{~m}$. Eucypris wolffhïgeli n. sp.

3. Station Espeyo bei Mendoza. Cypridopsis fuhrmanni n. sp. 


\section{Literatur.}

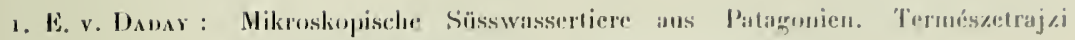
liizetek, Budlapest XXV. 1,jo\%.

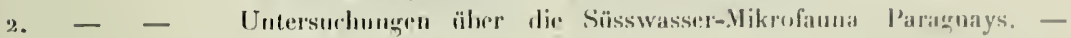
Zoologica, Stutteart, Heli, /4. Igus.

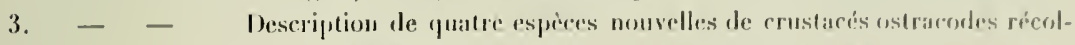
lées par M. Ilenri Giadean de liervillo pendant son voyage en Syrir.-

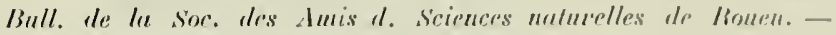
Ronen, 1911, P. 1. Fig. 1-?).

1. S. Eкмам: Ostracoden aus den nordschwedischen Hochgelsirgen. - Vaturw. Untersuchungen des Sarekgrehirges in Schwedisch-l appland. Zoolucrice, Stockliolm, B.I. IV, 1908 , p. 189. lïg. 6-7.

5. A. Kaurann : Cypriden und Darwinuliden der Schweiz. Revne suiswe de Zorologie, Genève, 1 goo.

6. G. W. Mülıen : Crustacea, Ostracoda. - Das Tierreich (Line Zusammenstellung uud Kennzeichnung der rezenten Tierformen). In Anftragn der kinnigl. Preuss. Akademie der Wissenschaften an Berlin. - Berlin, 31. Lief. 1912.

7. G. o. Sans: Contributions to the knowledge of the Freshwater Entomostraca of Sonth America. Part. It. - Mrchiv for Mathematik og Naturvidenskab. B. XXIV. Nr. 1. - Kristiania 1gor, p. 41, T. VIIl. Fig. 13. 14.

8. - - Zoological Results of the Third Tanganyiku Expedition... Report on the Ostracoda. - Procedings of the Zoological Society of London, 1910 .

9. W. Vava : Süsswasser- Ostracoden. - Hamburger Magalhaensische Sammelreise. - Hamburg, 1908. 


\title{
Freilebende Nematoden
}

ron

\author{
Prof. E. v. DADAY, Budapest.
}

Auf Grund der Aufzeichnungen von A. Certes (1889) und E. v. Daday (Igoz u. $1905)$ sind derzeit aus der Fauna Südamerikas 23 Nematodenarten bekannt, deren 2 aus dem Feuerland, eine aus Patagonien und 20 aus Paraguay stammen.

Herr Prof. O. Funksaxs hat im Jahre rgıo, gelegentlich einer wissenschaftlichen Forschungsreise in Columbien aus mehreren verschiedenen Fundorten in Süsswasser freilebende Nematoden gesammelt und latte er die Verbindlichkeit mich zu ersuchen diese Nematodenarten zu bestimmen.

IVährend meiner Untersuchungen gelang es mir in dem mir zu Gehote stehendem Material folgende Arten zu unterselieiden :

\section{Alaimus spec. juv.}

Die Galtung war bisher nur aus Europa bekannt. Das einzige mir zur Verfügung stehende junge Exemplar war nicht näher bestimmbar. Es ist aber zu erwähnen, dass seine Kutikula geringelt war ; ich fand die folgenden Dimensionsverhältnisse : Körperlänge $0,55 \mathrm{~mm}$; Oesophaguslänge $0,1 \mathrm{~mm}$; Schwanzlänge $0,15 \mathrm{~mm}$; der grösste Durchmesser betrug $0,03 \mathrm{~mm}$.

Fundort: Centralkordillere, Sumpf olserhabl America ( $1540 \mathrm{~m}$.).

\section{Ironus longicaudatus de MaN.}

Ironus longicaudatus J. G. DE MAN, 3, P. 7. Tab. 34, Fig. 140.

Die VerhäItnisse der Organisation der mir zur Verfügung stehenden Weibchen stimmen mit denjenigen der von J. G. DE MAN beschriebenen Exemplare vollständig über- 


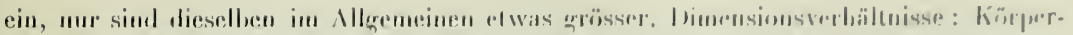

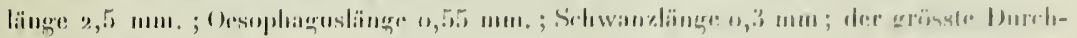
messer betriggt $0,05 \mathrm{~m}$ mm.

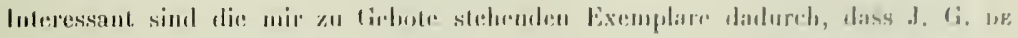

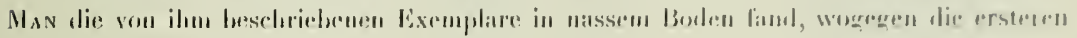
aus cincus Sï̈sswassersumplir her'slimuten.

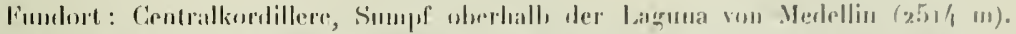

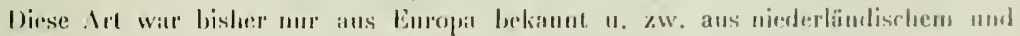
dentschem fiehicte.

\section{Trilobus diversipapillatus (1)ND.)}

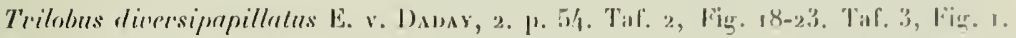

Diese Art war hisher unr ans Paragnaly lokanut, wo P'rof. I. 1). Avistts dieselloe ans zahbreichen (18) Fundorlen sammelte; sir scheint da gewähulich zn sein. Die mir zur Verfügung stehenden Exemplare stimuen genau mil den Exemplinen ans l'araguay äberein. Die Dimensionsverhähthisse sind die folgenden:

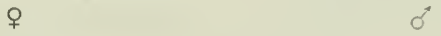

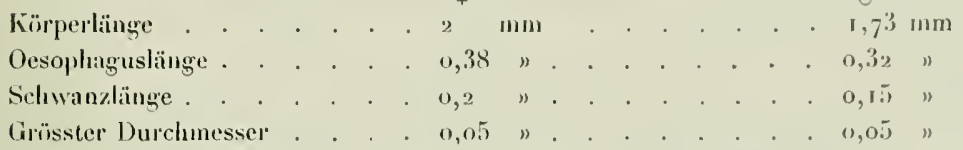

Bezüglich ihrer Dimensionsverhälntisse stchen also die Exemplare aus Columbien imnitten zwischen den kleinsten und gुrössten Paraguay'ischen.

Fundort: Ostkordillere, Tümpel bei Laguna 1. $(2626 \mathrm{~m})$.

\section{Trilobus gracilis Bast.}

Trilobns gracilis J. G. oE MaN, 3, p. 75 , Taf. 2, Fig. 40.

Diese Art kann zu den verbreiteren Arten gerechnet werden, die aus Paraguay schon seit frülier bekiunt war.

Diese Art kam als eine in Columbien gewöhnliche bezeichnet werlen, da ich dieselbe aus folgenden Fundortm kemne: Centralkordillere, 2 Sïmpte auf dem .llo Don Elias, 2097 II; Ostkordillere, Lilguna I. 11. auf der Sabana de Bogota und Tïmpel 3 anf der Sabana de Bogota $(2626 \mathrm{~m}$.).

Aus den soehen erwälnten Fundorten hatte ich zahlreiche Männchen und Weibchen zur Verfü̈ung, während aber der grïsste Teil der Weihchen geschlechtsreif war, kamen unter den Männchen vollkommen seschlechtsieife und vollkonmen entwickelte nicht ror. 
Bezüghlich der Organisation Verhältnisse stimnen diese Exemplare vollkommen mit denjenigen aus Europa üherein. Die Dimensionsverhïlnisse sind die folgenden:

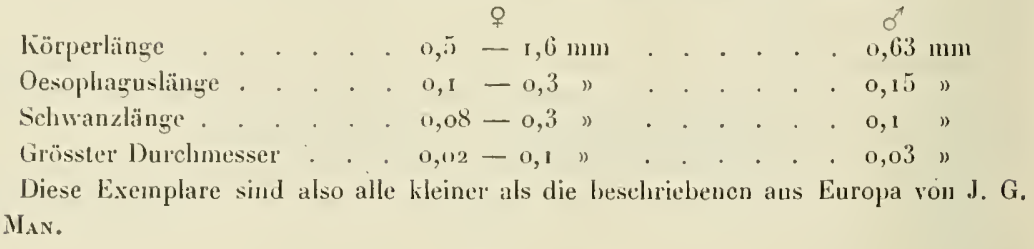

\section{Dorylaimus Carteri Basr.}

Dorylaimus Carteri, J. G. de Man 3, p. 177. Taf. 29. Firg. 122.

Diese Al't war bisher nur aus Europa bekannt; in dem mir zur Verfügung stehenden Material fand ich drei Weibchen, die selbst bezïglich ihrer Dimensionen den von J. G. vE $M_{A x}$ beschriebenen beinalıe gänzlielı gleichkamen.

Kïrperlänge $1,8 \mathrm{~mm}$; Oesophaguslänge $0,4 \mathrm{~mm}$; Schwanzlänge $0,1 \mathrm{~mm}$; grrösster Durchmesser $0,08 \mathrm{~mm}$.

Fundort: Ostkordillere, Tümpel beim Tequendamafall (22 10 m).

\section{Dorylaimus filiformis BAsT.}

Dorylaimus filiformis J. G. DE $\mathrm{M}_{\mathrm{AN}}, 3$, p. 187 , Taf. 32, Fig. 134 .

Man kann diese Art als eine allgemein verbreitete betrachten, indem diesellsc aus Europa und auch aus Afrika bekannt war, aus Südamerika dagegen bisher noch nicht.

Das mir zu Verfügung gestellte Material enthielt nur Weibchen, und zwar ebenso junge wie auch ältere, deren Organisationverhältnisse mit denjenigen der von J. G. de Max beschriebenen gänzlich übereinstimmten. Dimensionsverhältnisse :

Körperlänge ז,8-2,35 mm; Oesophaguslängge $0,38 \mathrm{~mm}$; Schwanzlänge $0,1-0,15 \mathrm{~mm}$; grösster Durchmesser o,o5 $\mathrm{mm}$.

Fundorte: Centralkordillere, Laguna oberhalb Medellin, $2504 \mathrm{~m}$; Sumpf oberhalb der Laguna de Medellin, $2514 \mathrm{~m}$.

\section{Dorylaimus macrolaimus J. G. de MAN.}

Dorylaimus macrolaimus, J. G. de MaN, 3, p. 191, Taf. 33, Fig. 138.

Diese Art war bisher nur aus Europa Jekannt, wo dieselbe ebeuso in nassem Boden, wie auch in stelıenden Gewässern lebt. 


\section{bifi7}

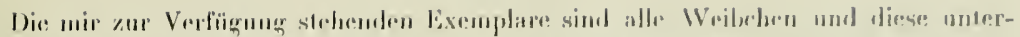

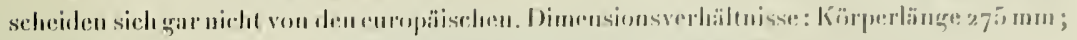

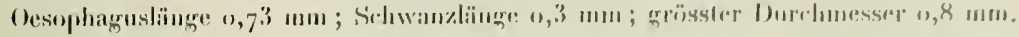

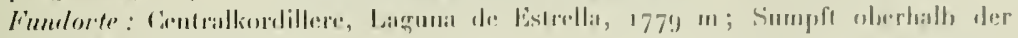
latgunis de Medellin, $2.114 \mathrm{~m}$.

\section{Dorylaimus pusillus $\mid)_{\lambda 1}$.}

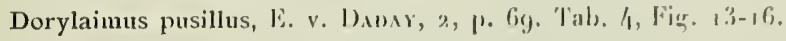

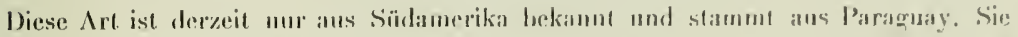

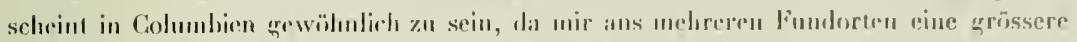

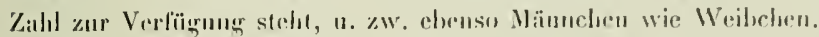

Die Dimensionswerhälnisse der von mir untersuchen Exemplan sind die fofgenden:

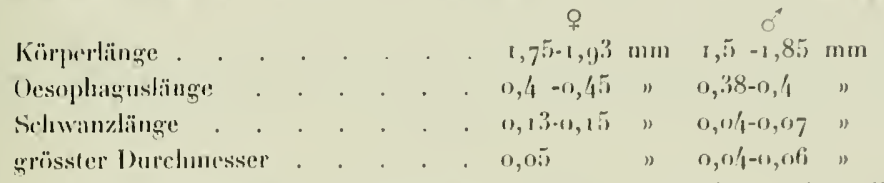

Die Dimensionsverhältnisse Jer Exemplare ans Columbicn erinnern im Allgemeinen an die Paragnaysisclır.

F'undorte: Ostkordillere, latguna auf dem Paramo Cruz Verde, :3o26 un Laguna I anf der Sabaua de Bogota, $2626 \mathrm{~m}$; Centralkordillere, Waldsumpf hinter $\Lambda$ to Don Elias, $2160 \mathrm{~m}$.

Bezï̈licl ihrer geographischen Verbreitung können die angeführten Arten in drei Gruppen geteilt werden, и. zw. :

1. A uch aufunderen Evdteilen lebende, aus Südamerilin früher nicht beliannte Arten: Ironus longicaudatus de Max. Dorylaimus Carleri B.ssr. Dorylaimus faliformis Basr. Dorylaimus macrolaimus de Mas.

Warlusclueinlich kann man auch das junge, nicht hestimmbare Exemplar der Alaimus-Galtung hielser rechnen.

2. Bisher nur ans Südumerika beliannte Arten:

Trilobus diversipapillatus Dad.

Doryluimus pusillus DAD.

3. Anch in anderen Erdtcilen lebendr, ans Südameritia schon frïher betiannte Art: Trilobns gracilis BAst.

Hienach gibt es also unter den von Herr Prof. O. Fun melten Nemutoden-Arten vier solche, die bisher aus Südamerika unbekannt waren, so dass sich hiedurch die Zahl der aus Südamerika bekannten Arten auf 27 erhöht. 


\section{Literatur-Verzeichnis.}

1. Daday E. v. Mikroskopische Sïsswasserthiere aus Paligonien. Term. rajzi. füz 1902, p. 201.

2. " Untersnchungen rïber die Süsswasser-Mikrofanta Paraguays. Zoologica. Iteft. 4'́, 1905 .

3. M.x J. G, de. Die frei in der reinen Erde und in Süsswasser lebenden Nematoden der niederländischen Fauna, 188 . 


\title{
Rhizopodes
}

I'AII

\author{
E. PENARD, Genève.
}

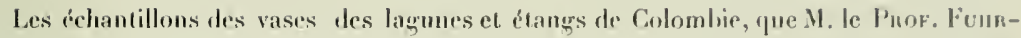
mans a bien voulu me confier pour la recherehe des lihizopodes d'enu donce, ont die rácoltés dans les localités suivantes:

\section{A. Cordillère cenlrale; terrain cristallin.}

Numéros.

1 et 2. Lagune au-dessus de Medelliu, 2504 m. Joù 1910.

3 et 4. Lagunes de Estrella, i 779 m. Sott igro.

5. Etang près de la lagune de Medellin, $2514 \mathrm{~m}$. Loǹt igro.

6. Élang entre Mcdellin et America, I 5400 m. Aont igı.

7. Elang près de America, $1540 \mathrm{~m}$. Lorit 1910.

S et 9. Deux élangs sur l'Alto Don Elias, ca zlig7 m. Aott igro.

10. Ėang dans la forèt derrière l'Alı, Don Elias, ca $2160 \mathrm{~m}$. Aoǹt 1910.

11 et 12. Lagune de Santa Rita, $1720 \mathrm{~m}$. Aoùt 19 10.

r3. Petit élang sur le col du Ruiz, $367 \mathrm{r}$ m. Sept. Ig10.

\section{B. Cordillère orientale; terrain calcaire.}

14. Lagume $n^{\circ} 1$, pres de Madrid, $2626 \mathrm{~m}$., Oclobre 19 ro.

15. $" n^{\circ} 2$,

16. $" \mathrm{n}^{\circ} 3$,

17. Étang $n^{\circ} \mathrm{r}$,

18. $"$ n० 3 .

19. $" n^{\circ} 4$.

$\begin{array}{lll}n & n & n \\ n & n & n \\ n & n & n \\ n & n & n \\ n & n\end{array}$




\section{$-670-$}

20. Lagune de Pedropalo, $2000 \mathrm{~m}$.

23. Flaque d'eau près du Tequenuluna, 22 ro m.

23. Lagune de Uhargue, $2112 \mathrm{~m}$.

2\%. Lagune sur lo versant oriental du Paramo Cruz Verde, 3026 m.

Toutes ces vases, il faut l'ajouter, ont été recueillies daus la zone littorale, de o ì 5o cur. de profondeur.

Voici la listes des espèces observées dans ces différentes stations ${ }^{1}$ :

Bien que ce tableau général, avec ses 34 Rhizopodes, semble au premier abord indiquer une certaine richesse, il faut en rabattre considcrablement de cette première impression.

En réalité, presque toutes les récoltes se sout montrées fort paurres. Dans la station I8, par excmple, il ne s'est rencontré en fait de Rhizopodes qu'une Difllngie indéterminahle, que je n'ai pas cru devoir mentionner au tablcau; et pourtant, c'était là une des récoltes les plus intéressantes pour tout ce qui n'était pas Rhizopodes; on y voyait heaucoup d'algues, de heaux Volvox, des Rotateurs, et en particulier le curieux et rare Nrotops clavulatus ${ }^{2}$ en quantités immenses. Dans la station 7 , on ne trouvait que l'Arcella discoides, une espéce, remarquons - le en passant, qu'on pourrait qualifier te semi-pélagique, par le fait que l'animal aime à grimper sur les plantes aquatiques, ou mème se remplit de bulles de gaz et s'èlève à la surface. En 20, sculement Centropyxis aculeata, un rhizopode généralement très commun; en r 3 et 15 , deux espèces; en 7 et 14, seulement trois, etc.

Beancoup des Rhizopodes mentionnés ne se sont ainsi tronvés que dans un nombre très restreint des stations visitées, très souvent mème dans une seule; et fréquenment aussi, malgré des recherches prolongées, il ne s'est rencontré que deux ou trois individıs, parfois mème un seul, pour témoigner de la présence de l'espèce.

En somme, ce que nous devons constater, e'est une grande pénurie de Rhizopodes dans les localités visitées par M. Funrmann. Faut-il étendre alors cette pénurie à la Colombie tout entière? Rien sans doute, ni la latitude, ni l'altitude, ne nous autorise à le faire. D'après ce que nous savons aujourd'bui, l'Amérique du Sud, des deux còtés de la chaîne des Indes et jusqu'à la Terre de Feu, est aussi riche en Rhizopodes que n’importe quel autre Continent. L'insuccès tiendrait plutòt, me semble-t-il, à l'habitat: toutes ces récoltes proviennent de llaques, d'étangs, de lagunes, qui sont rarement productifs; la richesse, pour les organismes qui nous occupent, c'est dans les marais qu'on la trouve, les marais a iridées et à nénuphars, à renoncules arjuatiques, et dont le fond est recouvert d'un feutrage organisé; ou bien aussi dans les tourbières ì Sphagnum, qui abritent toujours une fiune rhizopodique aussi abondante que variće.

Cependant, parmi les organismes étudiés, quelques-uns se sont montrés intéressants, et il convient de leur consacrer quelques lignes ici.

1 Les numéros en tête de chaque colonne de la liste correspondent à ceux qui viennent d'ètre donnés daus l'énumération des loealités.

2 Déternination due à l'obligeance de M. G. DE BEAvchamp. 


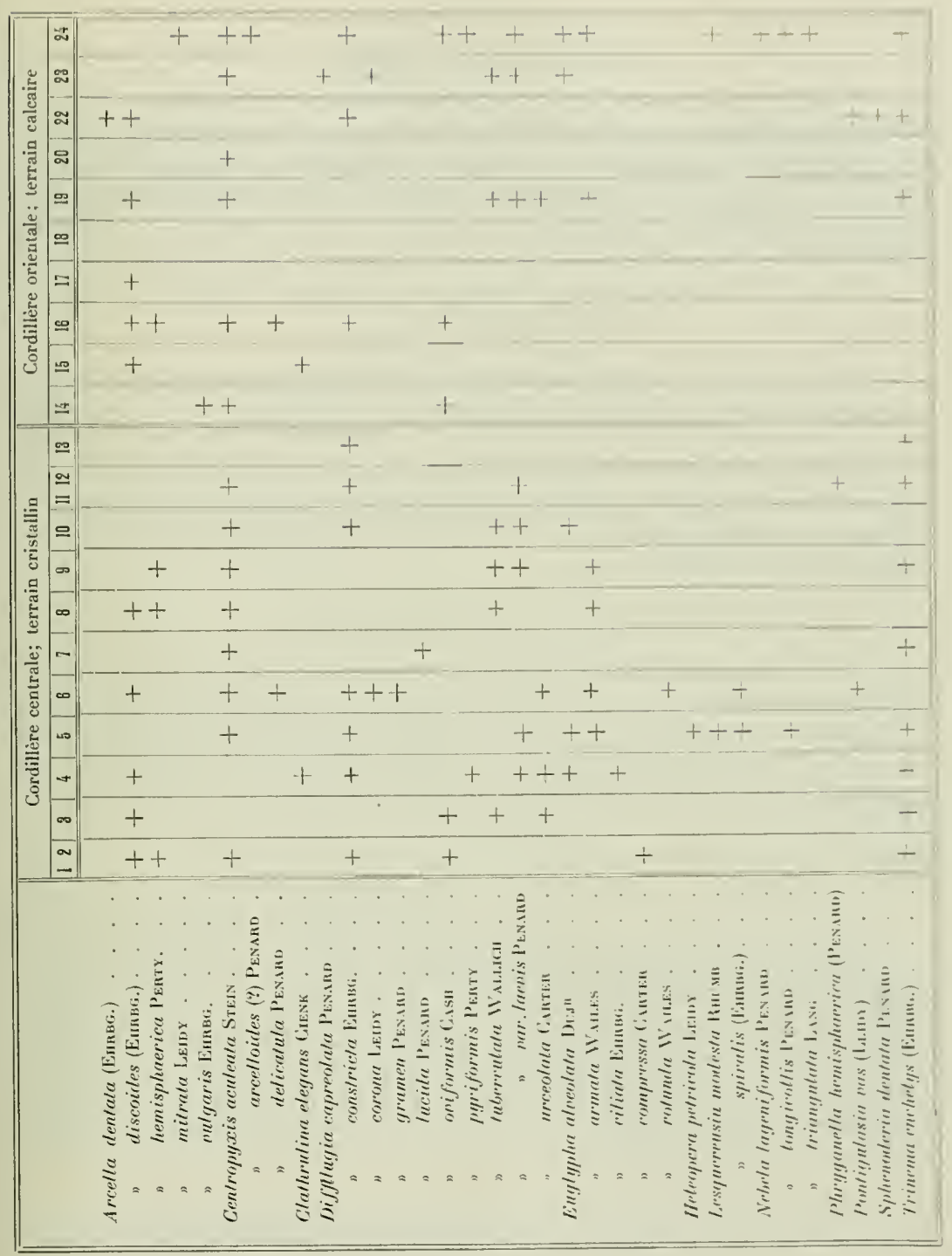




\section{Arcella discoides EHRENHEHG.}

Cette espice, qui comprend tant de variétés diserses, s'est présentée ici encore avec différentes apparences, suivant la localité. Dans la station 15 , on trouvait une forme

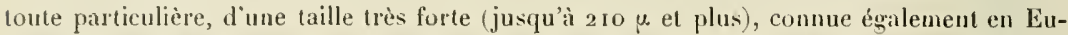
rope oì clle s'est toujours montrée pourvue, non pas des deux noyaux habituels dans le genre Arcella, mais de très petits noyaux extrèmement nombreux, el qui représente peut-è̀re en fait une espèce ì part."

\section{Centropyxis aculeata Stein.}

Ce Rlizopode se rencontre en général sous les formes les plus diverses, ì coquille très variable de taille et mème de forme, pourvue ou non d'épines, ete., et c'est comme très variable également qu'il est apparu dans les collections de M. Funmann. Dans la récolte 20, on trouvait une forme curieuse, qui n'a pas été signalée jusqu'ici, et daus laquelle la coquille était pourvue d'une seule grande épine qu'on aurail pu comparer à un prolongement caudal. Dans la station 23 , se voyait la var. discoides, très grande et très belle, arec ou sans épines.

\section{Clathrulina elegans (CIENk).}

Dans les deux stations où s'est montré cet Héliozoaire, c'était sous la forme d'une variété très petite, à tige fine, et où l'enveloppe ou cage caractéristique sphérique se voyait percée d'ouvertures très nombreuses, rondes, dépourvues de bordure en relief. Cette variété, que d'ailleurs on connail en Europe, pourrait bien représenter un type spécifiquement distinct de la Clathrulina elegans, sensu stricto.

\section{Difflugia corona (LEIDY).}

Cette belle espèce s'est trouvée en abondance dans la station 23 , puis dans la station 6 où l'on pouvait constater un fait très intéressant: les individus - représentés, cela va de soi, par leur seule coquille - se voyaient pour ainsi dire à tons les àges. Entre les exemplaires normanx et adultes, de $170 \mu$ en général, pourvus de leur couronne de larges cornes creuses, et des exemplaires tout petits ( $98 \mu$ et au-rlessous) et sans cornes, on trouvait tous les intermédiaires, individus à l corne, à 2 ou à 3 cornes, etc., el ces prolongements se montraient toujours plus neltement réguliers ì mesure qu'on se rapprochait du type normal de l'adulte.

1 PeNard, Faune rhizopodique, Bassin du Léman, p. 409. - Si je ne me trompe, celtc forme scra décrite trés-procbaincment, par Wines, dans le Liunaean Socity's Journal, sous lc nom de Arcella megastoma. 
Difflugia oviformis (

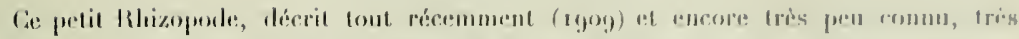

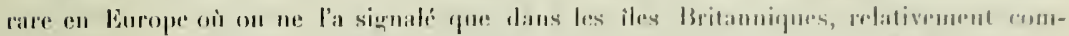

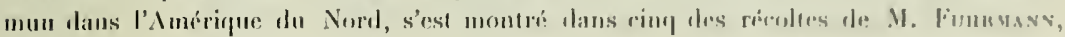

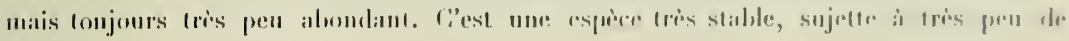

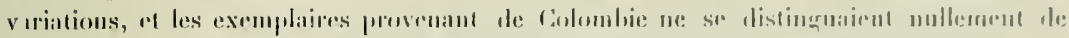

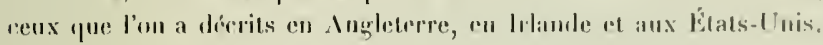

\section{Difflugia tuberculata $\left(W_{M, 1,1}, 11\right)$.}

Cette esprece, git qu'on la troure, se voit lis phupart du temps arcompagne d'un Rlizopote de taille beancoup plus faible, d'une apparence it promiere vae tomte dilli-

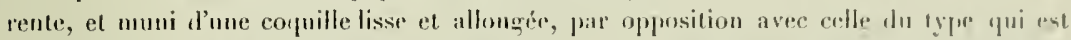

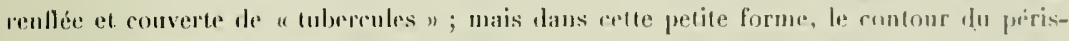
tume, assez curieux en lui-meme, est identique i celui qui caracterise la Diff. Culserenlnta². Il semblerait que ces petits Rhizopoles reprisentent une forme jenus de la grande

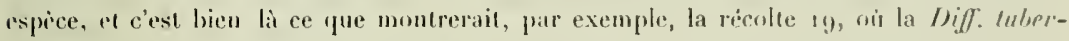
culata revetait une forme un pen spéciale, tress large, presque sphérique, avec absence de la rollerette ou bordure earactéristique du péristome, el oil ces mèmes caractires spuiriaux se relonuaient daus le petit Rhizopode à coquille lisse de la méme station.

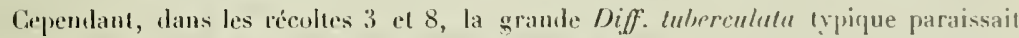
étre seule représentée, a par contre, dans les stations / $, 5,11,1.242 .3$ la pelite forme seule semblait exister ; mais re fait n'a peut-ètre pas la signilication fu'un pourrait ètro tenté de lui attribuer, car les exemplaires trourís ont déten si petit nombre qu'il n'y arail guire de conclusion sérieuse à tirer.

Ajoutons que dans une autre récolte (station 23), la Difflugiu lubercululn s'est montrée belle qu'on ne la jamais indiquée en Europe, d’une taille inorme $2_{2} 4^{5}$ y. en regard des $130 \mu$ que mesure normalement cette espece), et avee conuille totalement dépourvue des "tubercules" on reliefs caractéristiques, comme anssi de toute indication de collerette. La forme du péristome était seule, en fait, à indiquer la Diff. Imberculatu.

Dans les stations 9 , so et 19 , la coquille était presque parfaitement sphérique, mne forme irès exceptionnelle aussi.

t British Frehswater Rhizop. and Helioz. Vol. 11, p. 52.

senard, Faume Rhizopodique, Bassin du Leiman, p. 240.5. 


\section{Nebela triangulata $\left(\mathrm{IANG}_{\mathrm{AN}}\right)^{\prime}$}

Celte jolie petite Nébélide, délicate, très transparente et qui représente suivant toute probabilité un de ces très rares Rhizopodes d'ean douce que l'on pent appeler pélagiques, ut s'est trouvée que dians la récolte 24 , oì d'ailleurs il n'est apparu qu'un seul individı, une coquille vide mais nettement référahle à cette espère par la forme si caractéristique de l'enveloppe.

I Diftlugia triangulata Laxi, Quart. Journ. Micr. Sci. new ser, vol. V. 1865, p. 285. 


\title{
Die Moosfauna Columbiens
}

$\mathrm{V}(1)$

\author{
Dr. FR. HEINIS (Basel)
}

\section{A. Einleitung.}

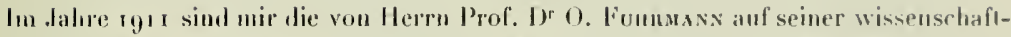
lichen Reise durch Columbien qesammetien Moose zur Infersuchung anf ihre fanna anvertrant worlen. Das Material bestand aus 35 in versehiedemen Teilen Columbiens, speziell in den Cordilleren gesammelten Moosprohen, sowie einem Fläschıchen mit Sichlamm aus ausgedrücktem Sphagnum.

Die Untersuehung des reichlıattigen Materials war bahl vollendet, doch verzügerte sich infolge verschiedener Unstünde die Zus:ummenstellungr der Resultate.

Die Moose waren reich an Rhizoporten und Rolatorien, weniger an Turdiguralen. liotulorien und Tardigraden erwachten nach dem Befenclaten mit Winsier zum grissiru Treil auf. In rinzelnen Moosproben bliehen allerdings zahlreiche Rädertiere zusammengrezogen und konnten weder durch Schüfteln noch durch Druck des Deckinlases zum Letien gebracht werden. Ohne dieser unangenehnen mo oft lästigen Imstand würde sich die Liste der Rotatorien gewiss um melırere interessante Arten vergrössert laben.

Es wirl sich daher bei späteren Reisen empfehlen, ron der jeweilig gresammelten Moosprohe nur einen Teil trocken aufzubewabren und den andern in leichtem Sublimalalkohol otler einem andern geeignet erscheinenden Conservierungsmittel zu conservieren.

Herrn Prof. Dr O. Funnass seri hier für die gütige Ceberlassung des faunistisch wie tiergeographisch recht interessanten Materiales bestens gredankt.

Herr Dr E. Penard in Genf hatte auf Veranlassung ron Herrn Prof. Fennmsx die qrosse Freundlichkeit, die Moose in summarischer Weise auf Rhizopoden zu durchsuclien und mir seine diesbezüghtichen Notizen und Präparate zu cingehenderem Studium und zur Bearbeitung zu überlassen. - Der Liste Pesanos konnte ich im Laufe der Lntersuchung noch einige weitere Formen beifügren. 


\section{B. Verzeichnis der Fundorte.}

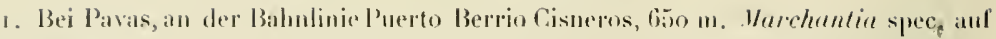
Lateril.

2. Paras, Mastigobryum columbicum Stern. auf Lateril.

3. Oberhalb Ineriea, hei Medellin ca $1560 \mathrm{~m}$., Meteoriopsis petula Sw.

4. Liaguna, oberhall, Dedellin 2504 m. Bryum pycnopyris C. M. mit viel Erde.

5. Litguna, oberhall, Medellin. Moos mit Laul.

6. Laguna, oherbalb Medellin. Plugionhila ovifolia Srems. mil dürrem Laub.

7. Laguna, oberlıalb Mrdellin. Fleclıten mit Erde.

8. Laguna, obeshalb Medellin. Flechten u. Marchantia spee. mit Erde.

9. Laguna, oberhalh, Medellin. Trichostommm novogranatense $\mathbf{n}$. sp.

10. Cafetal Camelia. $1800 \mathrm{~m}$. Taxilejennea auriculata. STEmrit. ant Rinde.

I1. Cafetal Camelia. Flecisten und Erde.

12. Cafetal Camelia. Flechten,Frullania ohumiensis Stepı. mit Erde.

13. Cafetal Camelia. Frullania evolitu Steph., Flechten und Laub.

14. Caletal Camelia. Flechten.

Ii). Cafetal Camelia. Trichostomum Raapii Brorn.

16. Cafetal Camelia. Brachythecium stereopoma (Sipruge).

7. Cafetal Camelia. Leucobryum spec.

18. Bei Angelopolis, in einer Quebrada, ea $1700 \mathrm{~m}$. Plagiochila ILans Meyeri Stepu und Flechten.

19. Titiribi $1580 \mathrm{~m}$. Philonotis tenella C. M., auf Laterit.

20. Titiribi. Philonotis spec.

21. Guaca $4460 \mathrm{~m}$. Squentidium nigricuns Hook.

22. Soledad, $2310 \mathrm{~m}$. Polytrichum aristiftorum Мит.

23. Cannon des Aguacatal, Frullania longicolla L. u. G. u. Taxilejeuner prominnla (Gotrsche).

24. Manizales, Polylrichum aristiflormm Miтr.

25. Manizales, Papilluria appressa (Honssch.).

26. Pass des Ruiz, auf einem Baumstamm 3800 m. Porotrichnm nitidum (II pe.) u. Rucula Sprucei Stepu.

27. Westluang des Ruiz, bei der Mine ITuion $3600 \mathrm{~m}$. Brentelia falcaluta n. sp.

28. Oberhalb Bogota ca $2700 \mathrm{~m}$. Pilopogon gracilis u. Ciampylopus spec.

29. Pass des Boqueron ca $2500 \mathrm{~m}$. Omphalanthus filiformis (Sw.) Nees.

3o. Oberhalb Tambo ea $2000 \mathrm{~m}$. Thuidium spec., Frullanir coalita Stepn.

31. Paramo Cruz Verde. $3500 \mathrm{~m}$. Moose.

32. Bei Lbaque, unterhalb des Paramo $2300 \mathrm{~m}$. Erythrodontium consanguineum, Tortula spec., Campylopus spec. u. Splagnnum. 


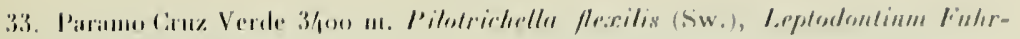
mannii n. spec.

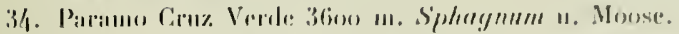

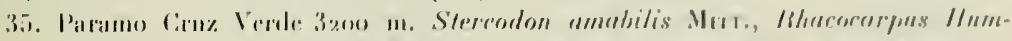

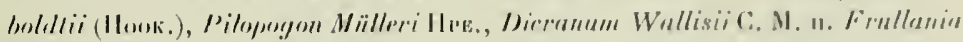
Mellanii sintru.

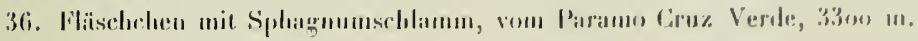

\section{Rhizopoda.}

a) Verzeichnis der beobachteten Arten.

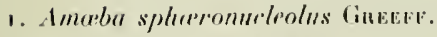

2. 1. Terricolu Eunug.

3. Amphitrema flanum .Іщинен.

1. A. stenostoma Nïssus.

5. Imphizonella violneed Ginvir.

6. Arcella arenaria GizefF.

7. A. velgaris Eimusa.

8. Assulinu muscornum GREEFT.

9. A. seninulum Eumвi.

10. Awerinsewia cyclostoma Scuoutenex.

11. Bullimula indica Penand.

12. Cenlropy:ris aculeata Stein.

13. C. aculeatn uar. discoides Pexanu.

14. C. laevigula Pexasu.

15. Corycio flues Greafr.

16. $C$. penarli Schoutedex.

17. Comythion dubium Taraxfok.

18. C. dubinm var. spicalnm Pexalus.

!!). C. pulchellum Pexarb.

20. Cryplodifflugin oviformis Pexaru.

21. Cyphoderia ampulla (EHвехвевa).

22. Difflugia brevicolla Casir.

23. D. constricla Eurag.

24. D. lucida Penard.

25. D. pyriformis var. bryophila Pexard.

26. D. pyriformis var. bacillifera Pexard. 
37. Diplochlam!gs frayilis D'exams.

28. D. yruberi Pexanb.

29. D. limidla Pename.

3i. D. vestita Penand.

3i. Englypha ulveolatu Dus.

32. E. riliatu Enввg.

33. E. compressi Ciñter.

34. E. cristata Leivs.

35. E. filifera P'enand.

36. E. lavis Perty.

37. E. minor PeNakd.

38. E. strigosa Leidy.

3y. Heleopera petricola LeIDY.

40. $I I$. rosea Penand.

41. 11 soedida Pexard.

42. $I$. sphagni Leidy.

43. II. silvatica Penard.

44. Ilyalosphenia slegans Lesds.

45. $I 1$ papilio Lesur.

46. H. subflava Ciss.

47. Nebela caudala Leidy.

48. N. certesi Penand.

49. N. collaris Leum.

50. N. dentistoma Penaro.

5. $N$. gracilis Penaro.

52. N. lugeniformis Pexaro.

53. $N$ var. cordiformis nov var.

54. N. marliali Certes.

5i). N. militaris Pexard.

56. $\mathrm{Y}$. lincla LEIDY.

57. V. lubulosa PENand.

58. $N$. vas Certes.

5. Parmulina brucei Pexard.

6o. P. cyathus Pexaro.

61. Phrygunella hemisplirerica l'Exann.

62. Plagiopy xis callida PEvaru.

63. Plagiopyxis spex.

61. Placncysta jurassica PExaro.

65. P. spinosa Lenv.

66. Pontigulasia bryophila Penand. 


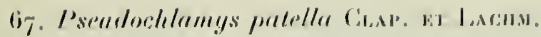

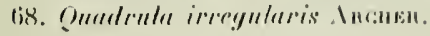

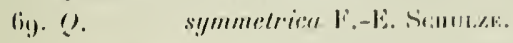

70. Splesnoderin denlutu l'vensur.

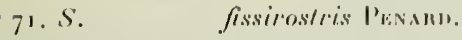

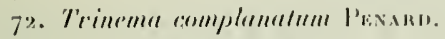

7.3. T. enchelys linums.

7\%. T. lineare levalus.

75. Trigonop!y xis arealu (1,at) ).

\section{b) Bemerkungen $z u$ den einzelnen Arten.}

\section{Amoeba sphaeronucleolus liHEEF.}

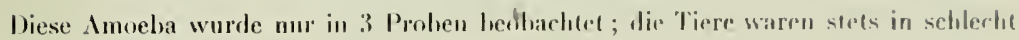
rhattenem Zustande.

\section{Amoeba terricola linkirf.}

In zahlreichen Moosprohen, doch fast immer mit eingeschrumpftor llïlle und aluese-

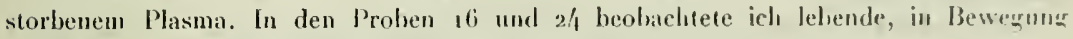
hegriltene Individuen. Penard sah in Probe 31 ein 1 . terrimolo.

\section{Amphitrema flavum Ancuen.}

Ein einziges grosses Individum in Probe 34.

\section{Amphitrema stenostoma NüssLi.}

A. stenostoma ist eine für Sphagnum charakteristische, aber seltene Art. Wenn man sie aber antriff, so ist sie immer in grosser Menge rorhanden. Typisch in 29 und 34.

\section{Amphizonella violacea Greerf.}

Diese Art fand sich nur in Probe 31 von Paramo Cruz Verde aus einer Höhe von $3600 \mathrm{~m}$. Die Tiere waren tot und gelblich gefürbt. Die violette Farhe, welche A. violucen ausgezeichnet war fast ganz verschwunden; mur wenige Exemplare wiesen einen leichten violett gefärbten Anflug aut.

\section{Arcella arenaria Lineeff.}

Arcella arenaria ist eine für die Moose trockener Orte charakieristische und anpassungstïhige Form. 
Fast in allen Proben; jedoch meist nur als leere Schaten. In 15 uml ry lebten einige Tiere, doch ohne die Pseudopodien auzustrecken.

\section{Arcella vulgaris ËH ENHEng.}

Arcella sulgaris lebt als Wasserbewohner nur in den feuchten Laubmoosen uml in Sphagnum, wo sie his zn einem grewissen Grade dic Trockenheitliebende A. arenuria ersetze.

Im untersuchten Material war A. onlgaris nur in Probe 2o. Einige Tiere erreichten eimen Durchmesser von ro8 u.

\section{Assulina muscorum GreffF.}

Dieser kleine, zierliche Rhizopode fehlte fast keiner Prohe. Im Sphugnum vom Paramo Cruz Verde, Probe 34, tral eine elwas grössere Form auf von $4(i-55 \mu$ Länge uml 38-44 Breite von lief dunkelbrauner, chokolade ähnlicher Färbung. Diese Färbung mag vielleicht auf den Einfluss des bewohnten Mediums zurïck zulähren sein.

\section{Assulina seminulum (Ehrenberg) Leidr.}

A. seminulum ist ein Bewolneer der Sphagumpolster, licht aber auch die femchten Yoose der Wälder.

Unter der normalen Form in Probe 3द befand sich die schöne, grosse und scheihenfïrmige, rein sphagnophile Varietät scandinavica Penard.

\section{Awerinzewia cyclostoma (Penand) Schouteden.}

In 15 häufig, in 16 selten. Gehäuse stark violett, amethystfartig bis fast schwarz. Länge der Gehäuse $146 \mu$.

\section{Bullinula indica Penard.}

Diese Art scheint eine grosse Verbreitung zu besitzen. 1906 von Murray im llimalaya aufgefunden und von Penaro (10) beschrieben, ist die Form seither an den verschiedensten Orten und Erdteilen wieder nachgewiesen worden. Мивках meldet sie aus dem Sphagnum von Ecosse und Uganda; Penard aus den meisten Lokalitäten der British Antarclic Expedition (15). IVarles (2r) gibl Fundorte aus Bolivia und Peru an und ich (4) wies sie in den zentralamerikanischen Anden nach.

In der Scliweiz ist Bullinula indica selten. Penard beobachtele sie in Torfmore von La Pile und ich in Sphagnum vom Bölchen im Baslerjura, sowie im Hochmoor von Jungholz (Schwarzwald).

Im untersuchten Material war diese, his vor kurzem noch seltene Art, in verschiedenen Proben aus den Cordilleren Columbiens von $1700 \mathrm{~m}$ bis $3600 \mathrm{~m}$ häufig, meisı 190-2 го $\mu$. 


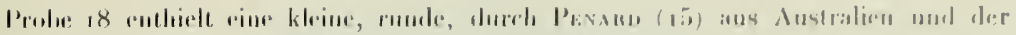

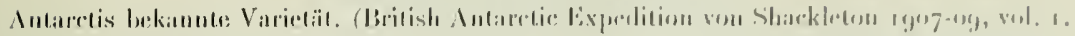
Tillel XXll. ligg. 1.) von liso his 170 p.

\section{Centropyxis aculeata Srrox.}

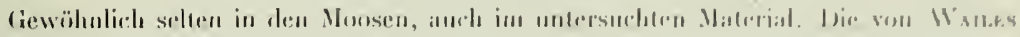

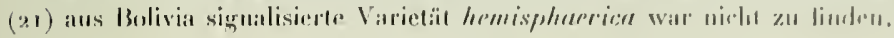

Centropyxis aculeata var, discoides I'li.

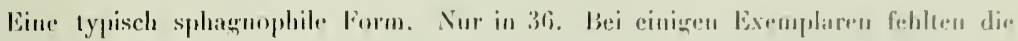
Dornen. Girisse 1 (g)-200 $\mu$.

\section{Centropyxis laevigata I' $1:$.}

Silleos in $16,17,20$.

\section{Corycia flava lintrif.}

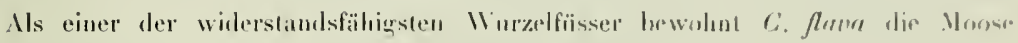

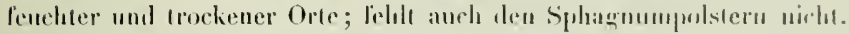

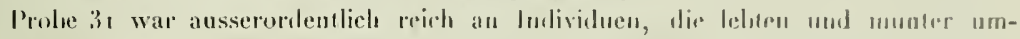
herkirochen.

\section{Corycia penardi Simoutenex.}

Selten, wenige Tiere in Probe 23.

\section{Corythion dubium TARANECK.}

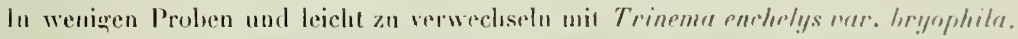

\section{Corythion dubium var. spicatum l'ExARD.}

Diese kleine häbsche Varietät erinnert dureh ihy . Inssehen an eine Euglypha. Der Schalenranl ist mit kleinen, regrelmässig verteilten zugespitzten Dornen vorsehen, dir nicht aus Kiesel, sondern ans Chitin bestelıen.

Penano kennt diese Abart nur aus dem Material der Expedilion Sunckitetos, nämlich von der Insel Stewart, aus Gueensland nud llawaï.

\section{Corythion pulchellum PExard.}

Selten. Mehrere Exemplare dieser kleinen, ovalen Spezies ron 24 u. Länge in Prohe 36.

\section{Cryptodifflugia oviformis PEXARo.}

Selten in 5. Wie Form des Gehäuses ist selır veründerlich. Von der fist runden Form bis zu der vval langgestreckten waren fast alle Lebergänge vertrelen. Länge gewöhnlich 20 u. sii 
Cyphoderia ampulla Eniexreng.

Drei leere Gehäuse von $98 \mu$ Längre im Sphaguumschlamm der Probe 36.

\section{Difflugia (brevicolla CAsu?)}

In Probe 34 eine Form mit grossem kugeligen aus Diatomeen zusammengesetzten Gehäuse von $\mathbf{4 5}$ u, das vielleicht dieser Art angehört. Stets nur leere Schalen.

\section{Difflugia constricta Emrenberg.}

Difflugia constricta bewolnt fast jeden Moosrasen und fehlt selten. Im untersuchten Material in allen Proben mit Ausmabme der ersten. Unter den vielen veränderliclıen Formen dieser Art schienen zwei ziemlich constant aufzutreten, eine habbugelige breite und eine kleine langgestreckte (Penand, Faune rhizopodique, p. 299, Fig. I und Fig. 5). Probe 24 enthielt ferner eine Ir5 $\mu$ grosse Varietäı mit kleiner Mundölfung und braun gefärbtem Gehäuse, sowie 1 oder 2 Dornen.

\section{Difflugia lucida Penakd.}

Diese kleine Spezies bewohnt mit Vorliebe Moosrasen trockener Standorte, doch tritt sie nie häufig auf.

Vereinzelt in $13,15,16,26,29,30,33$.

Difflugia pyriformis var. bryophila Plenard.

Meist leere Schalen in 20, 27, 34.

Difflugia pyriformis var. bacilifera PENARD.

In Probe 34 eine Varietät von r $20 \mu$ Längुe, deren Schale ganz aus Diatomeen bestand.

\section{Diplochlamys fragilis Penard.}

Diplochlamys fragilis ist schwierig mit Sicherheit zu identifizieren, wenn die Tiere tot sind. Einzig in Probe 25 fand ich ein Tier, dessen Zugehörigkeit zn dieser Art unbestritten sein dürfte. Die übrigen Fundorte müssen mit einem Fragezeichen versehen werden.

Diplochlamys fragilis ist bis jetzt durch Penaru (II) bekannt geworden aus der Schweiz, Australien, Neuseeland und Canada.

\section{Diplochlamys gruberi Penard.}

Diese Art bewohnt gerne die trockenen Moose der Bäume. Nur in 26.

Bis jetzt bekannt aus der Schweiz, Centralamerika und Hawaï. 


\section{Diplochlamys timida P'r.NAlır.}

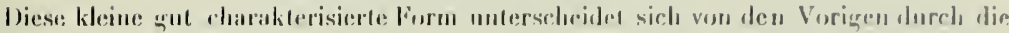

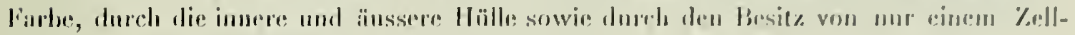
kern voul 3 his 5 p. Inrchmesser.

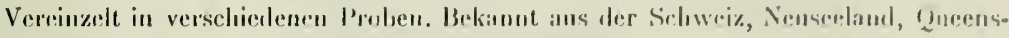
land, Ilawaï, Cianadis nud der distarktis.

\section{Diplochlamys vestita l'Exam.}

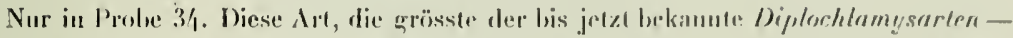

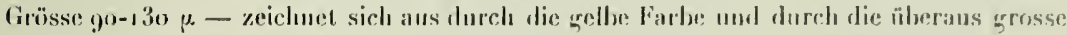
Zahl der lierne sowie dureh die Anwesenheil von kleinen prismalisclen líristallen.

Bekaunt aus der Schweiz, Australien und Vaucouver.

\section{Eugylpha alveolata Dussnux.}

Linglypha aloeolate lebt nur im Moss, sei e's in Laubmoosen oder Splaarnum.

In den Proben 16, 17,30 und 36. An den beiden ersten Fundorten Irat dine kleine Varieläl aul' von $65 \mu$.

\section{Euglypha ciliata Eunexneณg.}

Die Arten der Gallung Euglyphn dürfon, was Individuen- und Artenzalíl aubetrifn, zu der in den Moosen am besten verlretenen Rhizopodengruppe gezälılet werden. lis ist oft recht schwierig, die cinzelnen Arten aus cinander zu laalten, da sie in einander ïber gehen. Speziell ist dies der Fall hei Euglypha ciliata, die in den Moosen immer in zillilreichen Formen vorkommt.

In Probe 36 fand ich eine Form von $80 \mu$ mit vielen starken, unregelmâssig angeordneten ïber die ganze Schale verhreiteten Dornen.

\section{Euglypha compressa Carter.}

Dieser in Sphragnum und Laubmoosen sonst häufige Rhizopode bewolnnte dic Proben 34 und 36. Am letzlen Fundort ausserdem eine kleine Form von $68 \mu$.

\section{Euglypha cristata Lejor.}

Diese im Gegensatz zu den meisten Englypha Arten sehr charakteristische Art bewohnt nur Sphagnum. Proben 26, 29 und 34 .

\section{Euglypha filifera Pexand.}

Dieser kleine, durch lange feine Nadeln ausgezeichnete Rhizopode heobachtete ich nur im Sphagnumschlamm rom Paramo Cruz Verde. Probe 36. Länge $54 \mu$. 
Euglypha laevis l'ErTr.

Die Monse heherbergen immer eme grosse Zahl klejuer Euglyphen, die entweder z.n Euglypha lamis oder E. minor gestellt werden.

E. laevis ist in Funm,x' schen Material nicht selten. Länge $42-48 \mu$.

\section{Euglypha minor Pexind.}

Pexino (6) leschrieh diese kleine, nich üher $36 \mu$ grosse Form ursprïnglich als Varietät ron E. lapvis. Für den Untersehied beidrr Arten ist einzig die Grösse massgebend. Alle Formen unter $40 \mu$ mögen zu E. minor, alle über $40 \mu$ zu E. licevis gerechnet werden. Englypha minor ist in einzelnen Prohen recht häıfig.

\section{Euglypha strigosa LeIDY.}

Von E. ciliala schwer zu trennen, doch crkemntlich an den vielen kurzen Dornen und an der Form nnd Strucktur der Mundplatten. In der Proben 17, 29, 34, 36.

\section{Helopera petricola LEIDI.}

Gewöhnlich findet man von Heleopera petricola mur die leeren Schalen oder encystierte Tiere; die Pseudopodien bekommt man selten zu sehen.

Im Material stets durch eine in den Mossen häufig vorkommende Varietät vertreten, die Penano in der "Faune rhizopodique du bassin du Léman " auf Seite 384, Figur 6 abbildet. Diese kleine Form ist $70-75 \mu$ lang, braunviolet oder lichtrosa gelärbt und immer mit unreggelmässigen Platten bedeckt.

\section{Heleopera rosea PenARD.}

Diese weinrot grefärbte, hülsche Heleopera geniesst weite Verbreitung. In Europa ist sie laäufig, ebenso in den centralamerikanischen Anden. Vertikal kann sie eine bedeutende Ilöhe erreichen. Pevard (10) knnstatierte sie im llimalaya in einer llöhe von 6oon Fuss. Irh kenne die Art aus der Schweiz rom Pascuninersee $2006 \mathrm{~m}$ und rom Nonte Rosa alls $4000 \mathrm{~m}$ sowie vom Lötschen prass $2000 \mathrm{~m}$.

Probe 34 enthielt eine besonders grosse, schöne Form mit runden dachziegelartig über einander gelagerten Platten.

\section{Heleopera sordida l'ENARD.}

Schlecht erhalten in P'rolsen 15, 27 und 34. Bekannt aus der Schweiz, dustralien und Vancouver.

\section{Heleopera sphagni LEIDY.}

Selten. In typischen Exemplaren in 26, 27 und 36. 


\section{Ileleopera silvatica l'visull.}

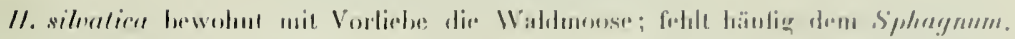

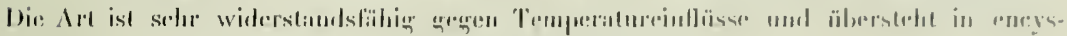
lientom Zastand leiche grösseres Trockenperioden.

Hyalosphenia elegans Liars.

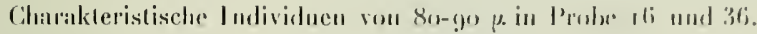

Hyalosphenia papilio Is:ms.

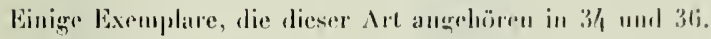

Hyalosphenia subflava Cisiı.

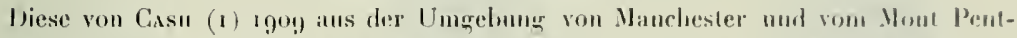

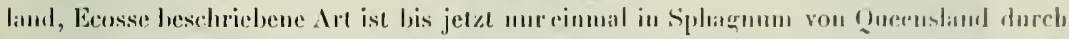
Penand (15) wieder nacherewirsen worden. Das erneute Vorkommen in Columbien is

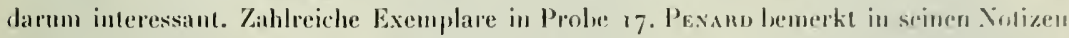

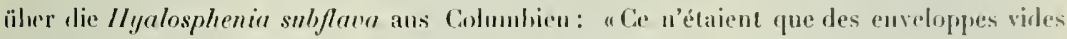
ou renfermant du plasma mort, bien typinge d'ailleurs, mais dépourves du petit "pore" apical dont parle Casu. Au Queensland ce pore manquait aussi, et la figure de Casul luimìne ne l’invoque nullement."

Nebela caudata LEIDY.

Nur einige typische Exemplare von 7 什 $\mu$. Länge in 36 .

Nebela certesi l'exaru.

(Siche Fig. 3.)

Penaru (15) fand diese Form im Material der Shackleton Expedition.

Probe 36 enthielt einige Exemplare von 148 bis $154 \mu$, welche ich nur mit dieser Art illentifizieren konnte.

\section{Nebela collaris Eurenberg.}

Die Arten des Gathng Vebela sind Bewolner der immer fenchten Waldmoose und des Sphagnum. Sie sind an einen gewissen Feuchtigkeitsgehalt gebunden, ohne welchen sie nicht aktir leben können. Die Vebelaarten sind deshalt, Fenchtigkeitsanzeiger. Sehr oft treten sie massenhaft auf. So zählte ich in einem kleinen, auf den Ohjektträger grehrachten Wassertropfen aus Sphagnum rom Bölchen im Schweizerjura über Go Exemplare der Arten $N$. collaris und $N$. lageniformis.

N. collaris ist in Fummaxx' schen Material relatir selten. Probe 5 enthielt eine kleine: Probe 7 und 36 eine grössere llabelluloide Eorm. 
Nebela dentistoma P'ENARD.

Sphagnophil und je nach dem Wohnort in Bezug auf Grösse veränderlich. Mittlere Grösse $78 \mu$.

\section{Nebela gracilis Penand.}

Diese kleine, zierliche Form ist nur bekannt aus der Schweiz, Bolivia und Peru.

Selten in Probe 15.

\section{Nebela lageniformis Penand.}

Nebelı lageniformis ist einer der hänfigsten Rhizopoden, weist aber in der Grösse starke Unterschiede auf. Probe $3_{2}$ enthielt eine eigentümliche Form, welche an der Stelle, wo der IIals des flaschenförmigen Gehäuses sich verengt, stark eingeschnürt war.

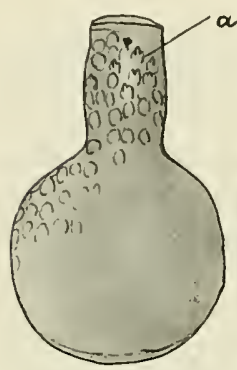

Fig. 1. - Nebelalagenimifors var, cordiformis n. var. Von der Breitseite gesehen. $a$. Mundplatten von Euglypha.
Nebela lageniformis var. cordiformis $\mathbf{n}$. var.

(Fig, 1 u. 2.)

Probe 34 rom Paramo Cruz Verde enthielt neben der gewölnnlichen normalen Form eine eigentümliche, hübsche und grosse Varietät. Der Hals dieser Varietät ist lang, tubusartig und ron dem übrigen Gehäuse scharf abgesetzt. Der untere Teil des Gehäuses erscheint abgerundet und von der Seite geschen herzförmig zugespitzl wie eine Lanze. Länge der Gehäuse I 28 bis $135 \mu$.

Nebela lageniformis var. cordiformis weist einige. Aehulichkeit auf mil Nebela nas, wo der Hals an der Basis ebenfalls eine starke Einschnürung besilzl. Merkwürdig ist auch die Beobachtung, dass N. I. v.

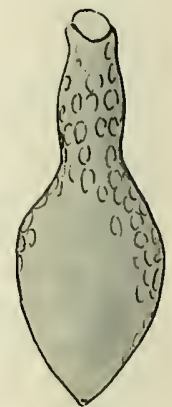

Fig. 2. - Nebela lageniformis var. cordiformis n.var. Von der Schmalseite gesehen. cordiformis gleich wie andere Nebelaarten schadhafte Stellen des Gehäuses mit fremdem Material ausbessert. Oft sieht man auf dem Hals Mundptatten von Euglypha ciliala oder E. strigosa mit der deutlichen Zähnelung.

Die Merkmale der vorliegenden Varietät sind so typische, dass sie jetzt schon zu einer besondern Art erhoben werden könnte.

Vebela lageniformis könnte auch als Grundform von einer Anzahl Arten angesehen werden, von denen var. cordiformis die Mitte und $N$. vas den Endpunkt darstellt.

\section{Nebela martiali Certes.}

(Fig. 3, 4 v. 5.)

Ton Certes (2) i889 am Cap Horn entdeckl, wurde dieser Rhizopode von Penaro (15) kürzlich in Moosen von der pacifischen Insel Macquarie, Neuseeland und Australien wieder gefunden. 
Nobela martiali ist so lypisch, dass sire mil knimer andern Art verwecheselt warden

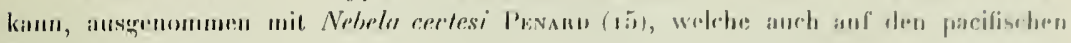
Inseln vorkoumunt.

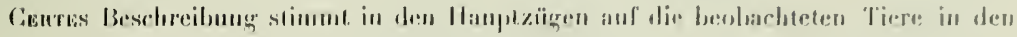
Prolien $26,27,3 / 4$ und 36 .

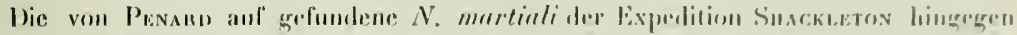

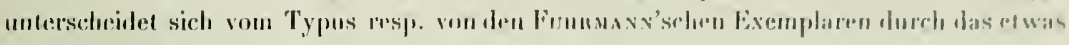

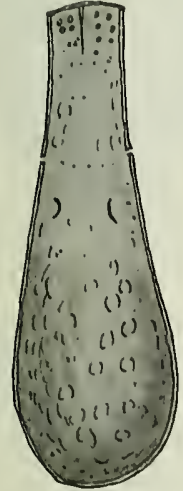

Fig. 3. - Nebela cerlesi Pen. Exp. Fulormann.

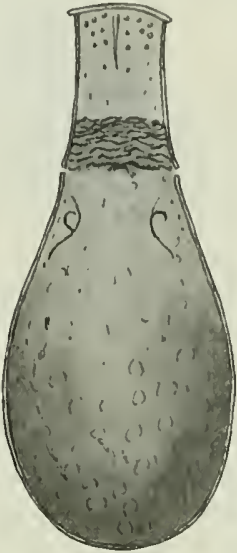

Fig. 4. - Nebela mastiali Certes Exp. Fuhr mann.

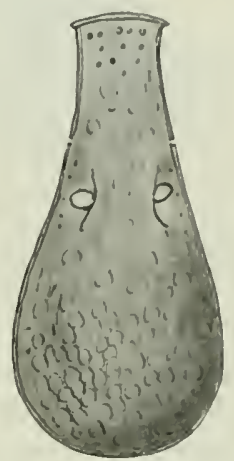

Fig. 5. - Nebelamarlial, Certes Exp. Skack leton. Nach einem Prãparat von PENARD.

grösscre Gehäuse und durch die grösseren seitlichen Oefhunngen; auch hesitz sie am llals keine Längsfurche.

Vebela marliali der Exped. Funrmans hält durch den Besitz einer Längsfurche am IIals und den kieineren seitl. Oellnungen die Mitte zwischen Nebela Certesi Pexaro (I5) und Nobela marliali (Penand non Certes).

Wir haben es also mit drei einander nahestehenden Formen zu tun :

1. Nebela certesi Penaro (Exped. Slackleton p. 241. Tafel 23. Fig. 7), (Exped. Fuhrmann. Probe 36).

2. " martiali Centes (2) Typus, Exped. Fuhrmann).

3. " murtiali Penaro non Certes, Exped. Shackleton, p. 246 , Tafel 23. Figur 9.

Diese drei Formen mögen aus einer ursprünghlichen form durch eine lanısame Entwicklung hervorgegangen und jetzl zu besonderen Arten geworden sein. Für die dritte Form würde sich zu Ehren des Entdeckers der Name Nebeza Pexann empfehlen.

Die Grösse der Furraxix'sehen Exemplare heträgt i 85 bis 195 u. 
Nebela militaris Pr:ım1.

Diese kleine, hühsche Irt bewohnte die Proben 17, 34 und 36. In Probe 17 relatis gross $65 \mu$.

Nebela tincta Leinr.

Nehen Nebela colluris und Vebela lageniformis ein häufiger Rhizopode feuchter Hoose. In columbischen Material allerdings nur in etwa 5 Proben. Nebela tincla variiert in der Grösse sehr. Probe 34 enthielı zwei Varietäten, eine kleine seltenere von 68 p. und cine grössere häufigere von go $\mu$.

\section{Nebela tubulosa Penaro.}

Einige Exemplare dieser grossen Nebela in Probe 36. Läıge $210 \mu$.

Nebela vas Certes.

Das Verbreitungsgebiet von $N$. vas ist auf die südliche Halbkugel beschränkt. Das Vorkommen in Columbien konnte deshalb nicht überrascheu. Selten in den Proben 26, 27,34 und 36. In 26 eine kleine seltenere For'm von $120 \%$. in 34 eine grosse, loreite $210 \mu$. lange Varietäl in encystiertem Zustande.

Das Gehäuse der Nelela vas isı gelblich und aus runden regehnässigen Platten zusanmen gesetzt. Aber oftunals findet man unter den Platten Stücke fremder Herkunlt. So Iraf ich in Probe 36 Gehäuse, deren Hals mit Mundplatten von Euglypha compressa geschmückt waren. Die Zälnnelung dieser Euglyplıaplatten war bei starker Vergrösserung recht gut zu erkennen. Auf welche Art und Weise die Nebela sich die Platten aneignet und sich mit "fremden Federn " schmückt ist schwer zu sagen. Da aber die Arten der Gattung Nebela zu den räuberischen Rhizopoden gehören und carnivor sind, lässt sich rermuten, dass sie die Euglyphen überfatlen und aussaugen, un sich die Mundplatten anzueignen.

Die gleiche Erscheinung ist auch bei den Arten Nebela martiali, Nebela lageniformis $\mathrm{v}$. cordiformis und bei Hyalosphenia cockayni beobachtet worden.

\section{Parmulina brucei Penard.}

(Fig. 6 bis 11.$)$

Penard (14) fand diese Form im Früljahr rgo7 in einer kleinen von Murray übersandten Moosprobe von Gough Island, einer kleinen Inseln im atlantischen Ozean zwischen dem Kap der guten Holfuung und Feuerland. Diese Moosprobe enthielt neben 13 schon bekannten Rhizopoden eine neue der Gattung Corycia nahe stehende Art, Parmulina lirucei.

Das relativ häufige Vorkommen dieser, seither nichı wieder beobachteten Art in Prolse 34 rom Puramo Cruz Verde bei $3000 \mathrm{~m}$ Höhe ist deshalb umso interessanter. 


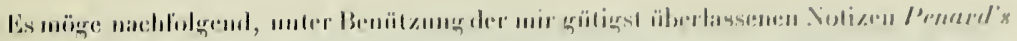

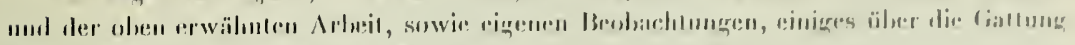

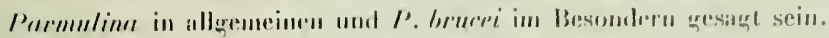

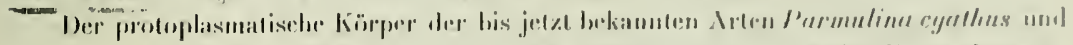

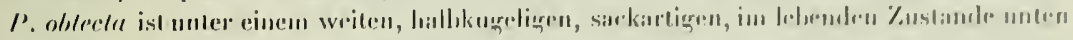

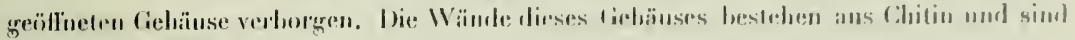

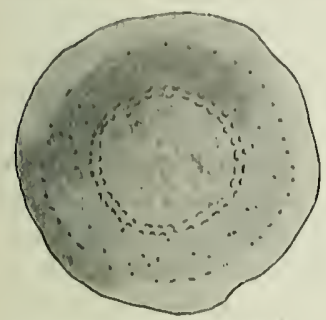

Fig. 6. - Pamulina brucei Penard. Von oben geselien.

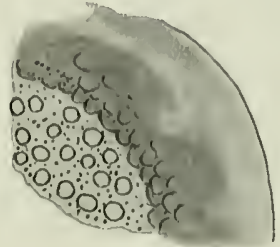

Fig. 7. - Parmulina brurei l'enard. Stark vergrossert's Stük der Stirnfliche.

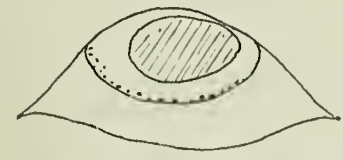

Fig. 9. - Parmulina brucei Penard. lincystiert, von der-Seite nesehen.

(Figuren z. T. nach einer Skizze von Penard.)

besourlers an der Basis äusserst biegsim und meschmeidig. Der Rücken ist rällig bedeckt mit fremden Erd-mul Kieselteilchen, die dem körper fest anhaften. Die breiten Psendopodien entfalten sich selten. Je nach der Art enthält dis Plasma r, selten 2 kuyrelige kerne, ebenso 1 oder 2 kontractile Vakuolen.

Parmulina brucei weicht un in interessunter Weise ron den bis jetzt bekannten Arten ab.

Das gelblich gefärbte, fast durchsichtige Gehäıse dieser Form ist chitinös. (In kochender Schwefdsäture löst es siclı auf.) Die Grehäuse abgestorbener Tiere haben dic Form einer $8_{7}$

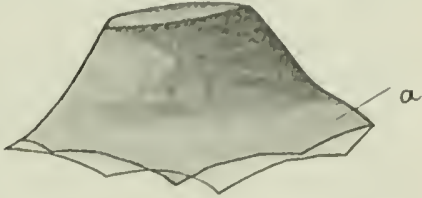

Fig. 8. - I'ermulina brucei Penard. Ticer von iler Seite. a. llizuliger Saum.

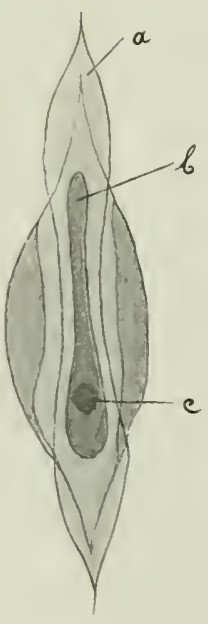

Fig. 10. - Parmulina brucei Penard. Individuum im Begriff. sich spindelformig zusammenzuziehen. a. Saum. b. Plasma. c. liern.

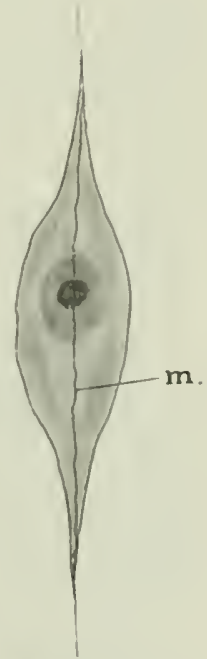

=Fig. 11. '-"Parmulina brucei Penard. Spindelformig zusammencezogenes Tier. Die schüzende Jembran $/ m$ / schliessl das Tier vollstãndig 
scharf abgestutzten Prante oter eines Kegels. Von der Seite gresehen sieht es aus wie ein Lampenschirm, der ohen durch einen soliden Deckel geschlossen ist. Am lebenden Tier verhäh sich die Sache anders. Von der Mundseje aus betrachtet, laufen die Ränder des Schirmes von der Mille an zuesst auscinander, dann gegen einander und spitzen sich zu, so dass eine spindelförmige, schilfchenartige Figur entstelıt.

Auf den ersten Blick ist das Gehäuse glant, hei starker Vergrösserung jedoch erschein! die IIaut stark punktiert, ähnlich wic hei Centropyxis aculeata. Zwischen den punktierten Stellen hemerkt man zahlreiche lece kreistunde Zwischenräume, die sich of berühren. Wahıscheinlich sind dies keine chitinöse Platten, die nach Behandlung mit kochender Schwelelsäure verschwinden, An versehiedenen Stellen der Schale, besonders aber an Rande des Kopfplatte - der ohern Grundlläche der Pyramide - stehen diese Platten dicht gedräng1, fast dachziegelartig beisammen. Diese letztere Erscheinung zeigt sich aber nur unter natürlichen Bedingungen, d. h. wenn sich das Tier in Wasser befundet. In Kanadabalsam ist das Bihd ein ganz anderes. Es erscheint da alles dunkel geädejt und an Stelle der Platten und punktierten Stelien sieht man nur ein Netz dunkelbrauner Flecken.

An der Basis der Pysamide wird die Haut dünn und bjegsan und krïmmt sich gegen das lunere, um das Proloplasma zu schützen. Wenn sich das Tier encystiert, oder wenn es in Ruhe ist, zielsen sich die Ränder wie ein Rirlicule oder Strickbeutel zusammen und verschliessen das Gehäuse hermetisch.

Ueber das Plasma selbst lässt sich nichı viel sagen, da meist nur leere Schalen angeIrotfen wurden. Mauchmal konnten jedoch die Ueberreste des abgestorbenen Plasmas noch nachgewiesen werden. Sehr häufig waren die Tiere encystiert, d. h. sie hatten sich kuggelig in das Gehäuse zurückgezogen und sich durch Ausscheidung einer hyalinen, chitinösen Membran mit einer schützenden Hülle umgeben.

Lässt man die Tiere einige Stunden in Boraxkarmin, so kann man die Anwesenheit eimes kugeligen Kernes nachweisen, der vom weniger stark gefürbten Plasma gut abstichıt.

Die Grösse der Tiere variiert zwischen 140 und $170 \mu$.

Der Untersehied zwischen den Gattungen Corycia und Parmulina beruht darin, dass bei Corycia der dünne, biegsame Teil der Schale stark und breit entwickelı ist, vermöge dessen sich das Tier oft zusammenfaltet und schützt, während bei Parmulina dieser Körperteil nur als dünıer, schmaler Rand erscheint, der bei einem äusseren Reiz das Tier nicht deckt, bis es spindelförmige Gestalı angenommen hat. Dieser dünne schmale Schalenrand besteht auch aus anderem Material ats die Schale sellst, denn er verschwindet rasch bei abgestorbenen Tieren.

Die hier beschriebene P. bracei des Funmanx'schen Materials ist etwas verschieden von derjenigen von Gough lsland, deren Gehäuse - von der Seite betrachtet - aus regehı̈̈ssigen polygonalen Feldern zusammengesetzt erscheint. Vielleicht gehören $P$. brucei von Gough Island und $P$. brucei vom Parano Cruz Verde zwei verschiedenen Arten an, oder die eine kann als spezielle Varietät der andern aufgefasst werden. 


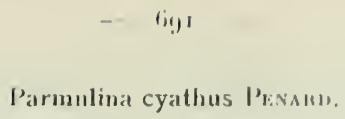

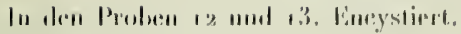

Pliryganella hemisphaterica P'inam.

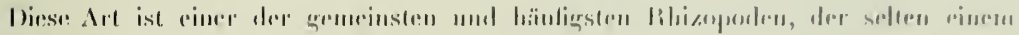
Monstasen lehilt.

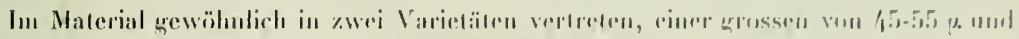
riumer kleinern von 28 lis $40 \%$ p.

\section{Placocysta jurassica l'iммй.}

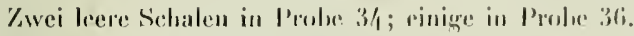

Bekanul aus der Sichweiz (la Pile) und V'ancunver ; rein sphatgnophil.

\section{Placocysta spinosa leEITr.}

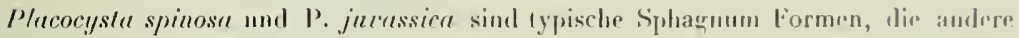
Moose meiden.

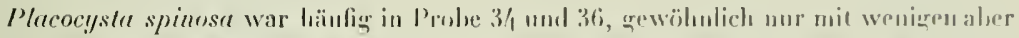
langen Nadeln umb relativ kleinen Mundplatten. In der Grösse ändert die Art slatk. Dor mittlere Grösse betrïgt 125 p..

\section{Plagiopyxis callida P'ENakD.}

Leicht zu verwechseln mit Difflugire constricke. Typischinden Prohen r5, 16, 17, 18. P'robe 36 enthielt eine kleine Form wn $85 \mu$ Durchmesser. Da die Tiere of nicht lebten, komme manchmal nur die Gatlmugsangehörigkeit angegreben werden.

$P$. cullida hewohnt mit Vortiebe die Hymumrasen der Waldräuder.

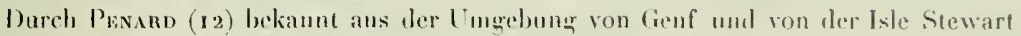
(British Antarct. Exp.). Wantes (21) giht Fumblorte aus Bolivia und Pern an. Ich fand die Arı kürzlich in IJymum vom B̈̈lchen im Baslerjura.

\section{Pontigulasia bryophila P'Exard.}

Nur leere Gehäuse. Probe 36.

\section{Pseudochlamys patella C.n.r. "I L.icms.}

Selten in den Proben ro und $3 \mathrm{r}$.

Quadrula irregularis Ancren.

Q. irregularis ist ein seltener Moosbewohner. Einzig in Probe 20 in lypischen Exemplaren. 
Quadrula symmetrica F. C. ScHulze.

Diese Form ist ein häuliger Bewohner der feuchten Waldmoose and vor allem des Sphagnum.

Im untersuchten Material trat Q. symmetrica in der von Penard (6) 18 go beschriebenen Varietät irregularis anf. Diese Varietät zeichnet sich vornehmlich aus durch die Grösse, die von 120 his $145 \mu$ variiert.

\section{Sphenoderia dentata Penaro.}

Häufig in Laubmoosen und Sphagnum. Probe 34 euthielt eine an Sphenoteria lenta Schlumberger sich anlebnende Varietät ron $7^{3} \mu$.

\section{Sphenoderia fissirostris Penand.}

Einige leere Gehäuse in Probe 18.

\section{Trigonopyxis arcula (LE⿰D)).}

Trigonopyxis arcula (LE1or), systematisch den Gattungen Bullinnla und Centropyxis mahestehend, ist einer des charakteristischen Wurzelfüsser des Sphagnum und der feuchten Laubmoose. Je nach dem Wohnort ändert die Grösse der Schale. In Probe 36 sah ich 2 Formen, eine grosse von $180 \mu$ und eine kleine von kaum $100 \mu$ Durchmesser. In einigen Proben waren die Tiere lebend.

Im übrigen war die Art kürzlich Gegenstand einer eingebenden Arbeit Penaros (13).

\section{Trinema complanatum PENAKD.}

In wenigen Proben selten.

\section{Trinema enchelys Eнrexbeng.}

Der geographischen Verbjeitung dieser Art sind kosmopolitische Grenzen gezogren; sie fehlt fast keinem Moosrasen und erreicht vertikal oft hedeutende Höhen. In den columbischen Cordilleren erreicht sie $3800 \mathrm{~m}$, im Himalaya 6ooo F'uss, aus den Rocky Mountains kennt sie Pexard ans $3000 \mathrm{~m}$ Erhehung. In Hoclialpengebiet der Schweiz fand ich sie häufig. (Oberalp $2028 \mathrm{~m}$, Matterhorn $3800 \mathrm{~m}$, Weissmies $4000 \mathrm{~m}$, Mont Blanc $4000 \mathrm{~m} \mathrm{etc}$ )

Probe 29, 34 und 36 enthielt die grosse Varietät bryophila PENard.

\section{Trinema lineare PENARD.}

Trinema lineare entgeht der geringen Grösse wegen oft leicht der Beobachtung. Hie und da in einzelnen Proben. 


\section{Verbreitung der Rhizopoden in Südamerika}

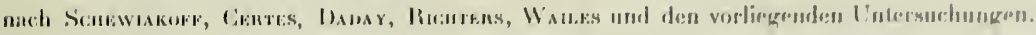

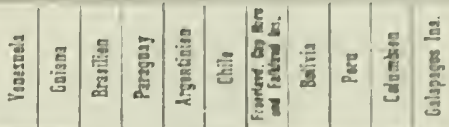

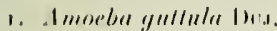

2. "limad. Iud.

3. " protens Rios

4. ” réliose Emennim:

i. $n$ spleareronurloolus finess

(i.) $)$ trrricola Eunus.

7. $)$ nerruroset Eumbri.

8. " villost WALL.

9. Imphilremu flawnm Arcuen

10. "n stenostoma Niissisis

11. Imphizonella violacen Ginerk

13. Ireplla arenaria Ginerap

13. " slellaris Pentr.

14. " discoides Еинав.

15. " marginata Dans

ili. n mitrata Enabi.

17. " rota D.iDAy.

18. " melgaris Ennв;.

19. Assulina muscorum Greers

20. „ seminulum Еиввт.

31. Awerinzemia cyclostoma Schort .

22. Bullinula indica Pessmu

23. Centropyxis aruleata $\mathrm{S}_{\mathrm{TE}}$

24. „ aruleatn v. discoides P'EN.

25. " aruleata $v$. hemispharmion Wanes

26. " laevigata Pex.

27. Cochliopodium bilimbosum Аекнв.

28. D testilum Ircuer

2y. Corycia, flana Gaenf

30. „ penardi Schoutedex

3. Corylhion dubium Taraneck

32. " dubium ve spicatum l'Ex.

33. " pulchellum PEx.

34. Cryptodifflugia oriformis PEN.

35. Difflugia brevicolla Casu.

36. " acuminala Enrвg.

37. " constricta Eumnr.

38. ") corona WALL.

39. " globulosa Dus.

40. " lobostoma Leinx

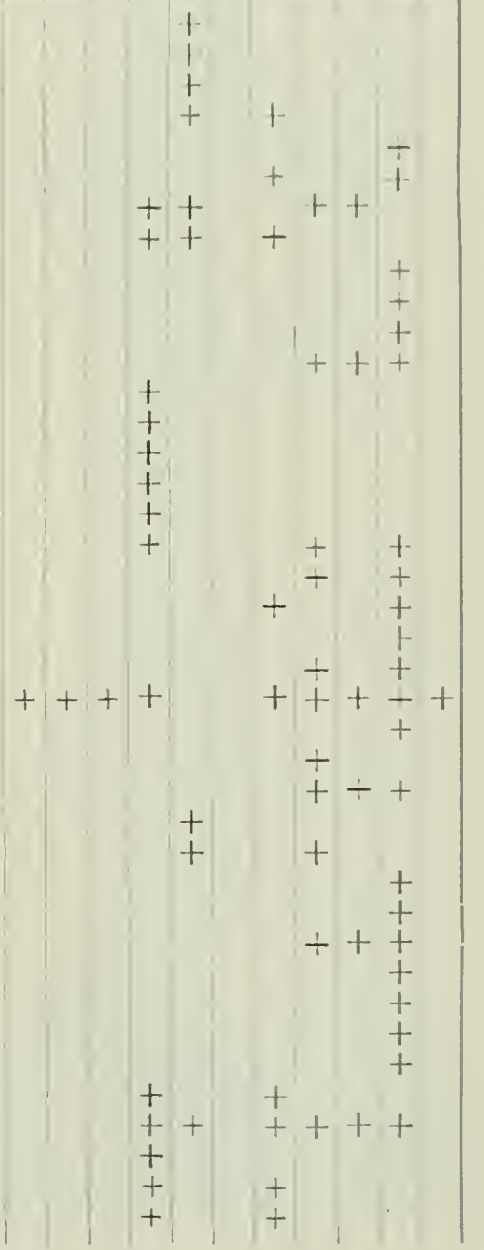




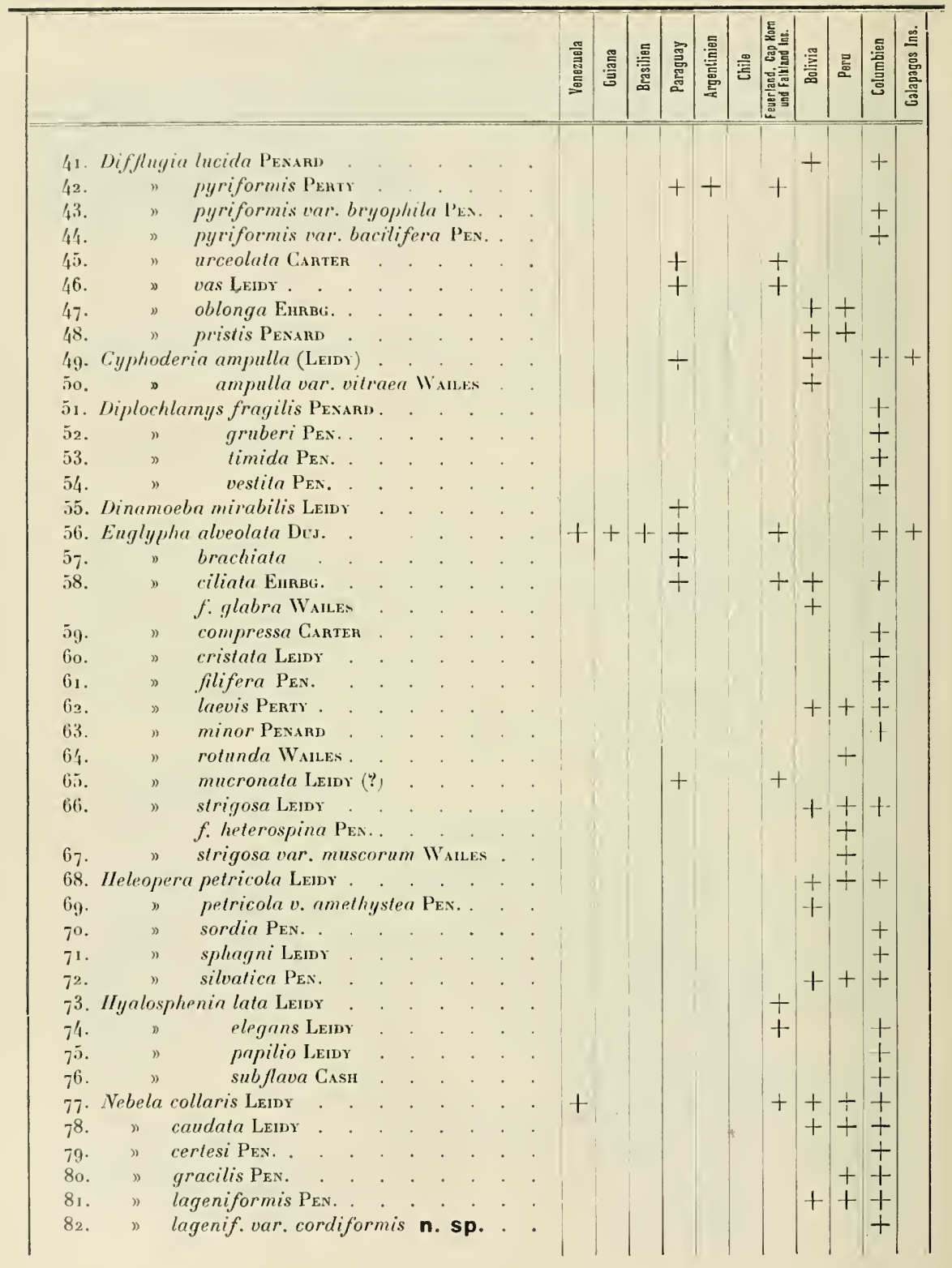




\section{IIIII)}

8.3. Nelole merliali Gontes

84. "militaris.

85. " parmmla WAILIS

8ij. "lincla Lainy .

87. " Inlmlesa PEN.

88. " Tropica Walles.

89. " vas Ciertes

go. Lequerensin spriralis burnw.

gt. Parmulina brucei PeN. .

9:. D cyalluns PEN.

93. Phryganella hemisphaterica l'EN.

9 1. aeropodia llow.

95. Ployiony.ris callidu PEN.

96. Plncocysle jurrassica P'ox.

97. " spinosa Lenw

g'. Pontigulasin bryoshilu PEs:.

99. Psendochlamys palellar C.. et Isacas.

roo. Onadrula irregularis Ircuen

101. " symmelrica Sanuzz:

102. ") symmetrica v. irregularis PEN.

103. Sphenoderia dentata Pen. .

104. " fissiroslris PEN.

105. Psendodifflngin gracilis Scunums.

1o6. Trigonopyxis arcula LeID

107. Trineme complanalum PEN.

ro6. " enchelys Earra. . . . . . . t

10y. " enchelys v. bryophila PEx. .

110. "linerre PEN.

\section{Zweifelhafte Arten:}

Imoeba tentaculata Grubex

Cientropyxis magdnlenae CERTF.

Viebeli Fubrei Centes

Trinema conslricla CEntes = (Trinema enchelys var. bryophila?!

Trinema sanvineli Certes

Vorstehende Tabelle stiitzt sich auf die Zusammenstellung von Schewıкоғғ, ferner auf die Beobachtungen von Certes, Dadir, Richters, Walles und auf lie vorliegenden Ćntersuchungen.

Es wurden nur die sicher beobachteten Arten aufgrenommen. Die Resultate Frexzels. die Argentinien betreffen, sind uиr so weit berücksichtigt worden, als sie Scnewıкоғғ in seine Tabelle aufgenommen hatte. Die Angaben Frexzels sind zudem oft zweifelhaft; anch stand mir nur die kleine Arbeit von Frexzel zur Verfügung, in welcher er blos Gattungsnamen erwähnt, sodass ich seine Beobachtungen nicht auf ihre Riehtigkeit kontrollieren konute. 


\section{Verteilung der Rhizopoden}

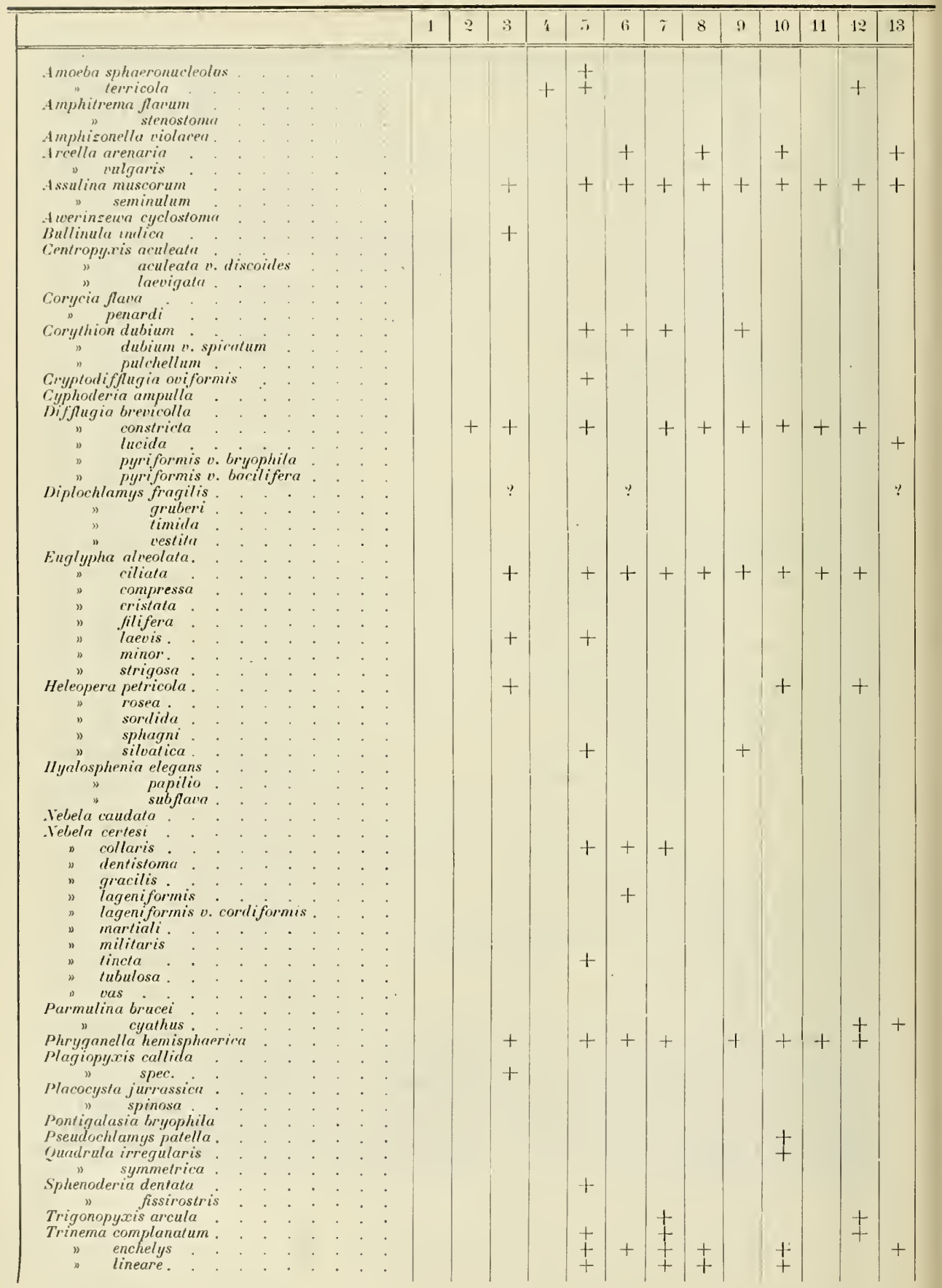




\section{auf die einzelnen Fundorte}

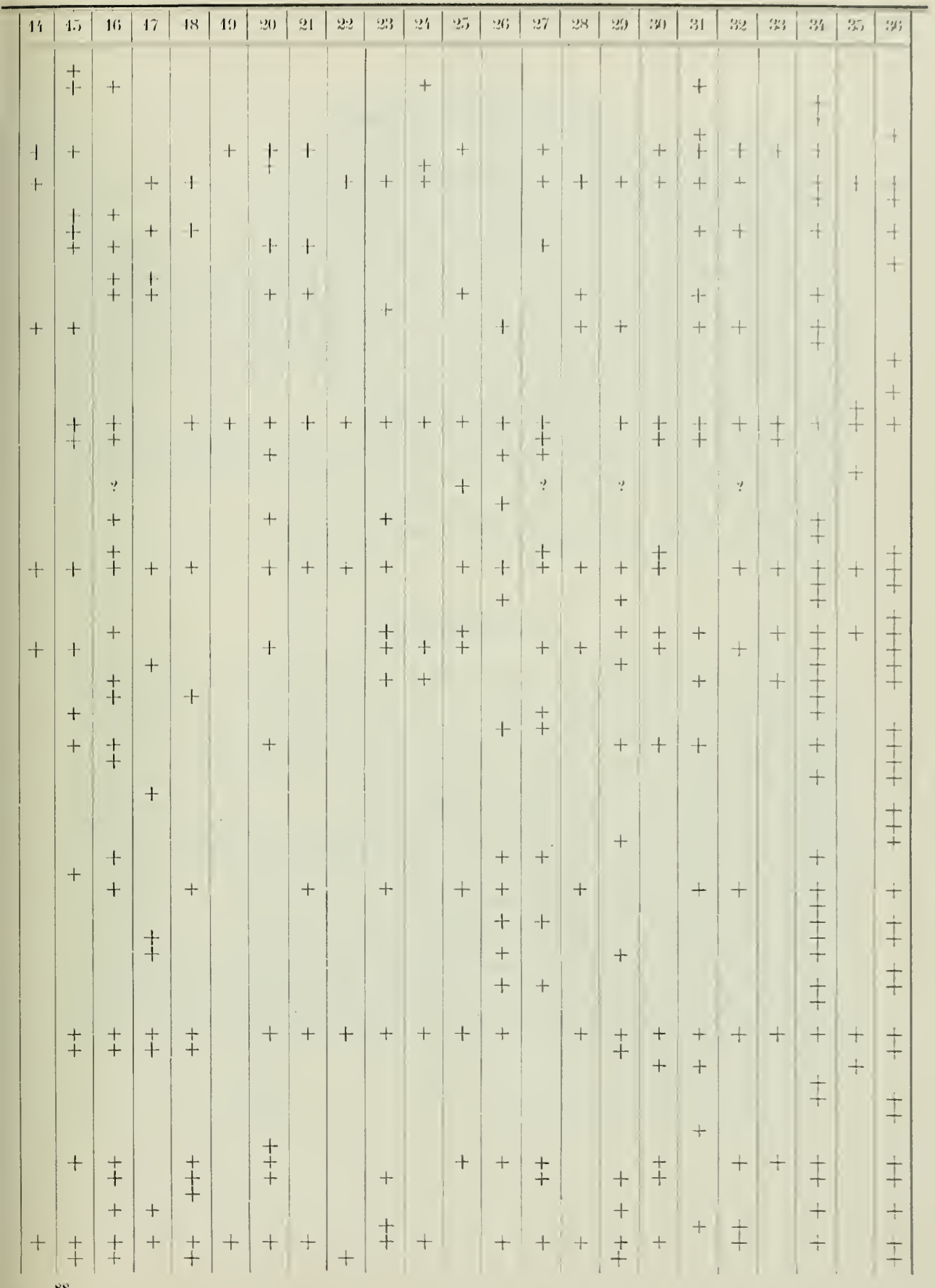




\section{c) Geographische Verbreitung.}

Ausser der Probe I enthielten alle Moosproben Rhizopoden.

Der Kosmopolitismus der Wurzelfïsser ist bekannt. Eunexbeng, Leidy, Schewtakofe und Pexaro haben die grosse Expansion der Rhizopoden nachgewiesen.

Das Material Fon m. xx ist nun in mehrfacher Bezichung interessant: 1. Die überaus weite Verbreitung der Rhizopoden wird anfs nene bestätigt und die Existenz einer besondern Moosfauna nachgewiesen. 2. Der Kosmopolitismus ist nicht ohne Ausnahme. Einige Formen, Nebela vas. Vebela martiali, Nebela certesi, Nebela lageniformis var. cordiformis, Parmulina brucei, sind auf die sülliche Halbkugel beschränkt. 3. Die columbischen Cordilleren werden von bestimmten pazifischen Arten bewohnt /Nebelu martiali, Nebela certesi. Nebela vas, Vebela lageniformis $v$ cordiformis, Purmulinu brucei, Corythion dubium var. spicatum). 4. Einige der unter 2. und 3. genannten Arten können als letzte Ueberreste eines einst grösseren Verbreitungrggebietes angesehen werden. 5. Einige in Europa häıfige Formen (speziell der Gattung Difflugia) fehlen Columbien.

Ueber die Verbreitung der Rhizopoden an den einzelnen Fundorten gibt die Tabelle Aufechluss.

\section{Rotatoria.}

Unsere Kenntuisse über die südamerikanischen Rotatorien waren bis vor kurzem sehr gering. Die von älteren Autoren (Eurenberg 3, 4), Schirada (23), und Zelinka (25) gegebenen Beschreibungen und Abbildungen sind heute unvollständig und ungenügend. Als erster hat Murray in drei kleinen, aber wertvollen Arbeiten in ausgezeichneter Weise die Moosrotatorien verschiedener Teile Südamerikas behandelt. In einer ersten 1907 erselienenen Arbeit ( 11 ) notiert Murray das Vorkommen von i5 Arten und Varietälen aus British Guiana und in zwei kürzlich erschienenen Publikationen ( 17, I8) stellt er die von ihm beobachteten Moosrotatorien aus Argentinien, Chile, Peru, Bolivia und Brasilien zusammen. Aus Brasilien verzeichnet er 32, aus Cihile ro, aus Peru 6, aus Bolivia 33 und aus Argentinien ro Arten.

In der nachfolgenden Darstellung mögen die Ergebnisse über die Untersuchung des von Herrn Prof. Dr O. Funrsaxs in Columbien gesammelten Naterials gegeben werden.

Durch die Gïte des Ilerrn DAvid BRrce erhielt ich einige mir bisher unzugänglicher Schriften, insbesondere seine New classification of the Bdelloid Rotifera, der ich mich im Folgenden anschliesse. 
a) Liste der beobachteten Arten.

\section{Bdelloida.}

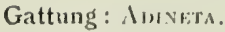

1. Adinete agega bavis.

2. A. gracilis danson.

3. A. oculalı MuNe.

4. 1. barbalu Janson.

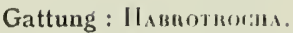

1. Habrotrocha perforala Munmay.

2. 11. perforata aner. americane Мивкау.

3. I1. angusticollis Murray.

4. II. angusticollis var. allenuala Muват.

5. II. mucnluta Мuпнау.

6. H. eremita Munsax.

7. II. ampull" Мunsax.

8. Il. Fulurmanni nov. spec.

9. $I$. constricta Dujarom.

10. 11.

11. H. aspera Buree.

12. 11 tripus Murray.

13. 11 spec.

Gattung: Callidixa.

1. Cullidina papillosa Thoupson.

2. C. mullispinosa Tuonpsox.

3. C. mullispinosa var. crassispinosa Murray.

4. C. mallispinosa var. brevispinose .ोвказ.

5. C. multispinosa, Varietäten.

6. C. Zichendrahti limenters.

7. C. speziosa Мunay.

8. C. ehrenbergi Jassox.

9. C. spec.

Iо. C. spec.

ti. C. spec. 
Gattung: Rotifen.

1. Rotifer vulgaris Sспимк.

2. R. longirostris Jansos.

3. R. quadrangularis nov. spec.

4. R. tardigradus Еивв.

Gattung: Pleuretra.

1. Plenretra humerosa Muray.

2. Pl. alpium Ehrenberg.

3. Pl. triangularis Murnax.

Gattung: PillLodina.

I. Philodina roseola Errenberg.

2. Ph. cilrina Ehrenberg.

3. Ph. vorax Janson.

4. Ph, americana Murray?

Gattung: Млговіа.

1. Mniobia scarlatina Enrenberg.

2. M. russeola Zelinka.

3. M. magna Plate.

4. M. symbiotica ZeLINKA.

5. M. tetraodon Ehrenberg.

\section{Phloïma.}

Gattung: Furcularia.

1. Furcularia forficula Ehrenberg.

\section{Loricata.}

Gattung : Euchlanis.

1. Euchlanis dilatata Eurenberg.

Gattung: Monostyla.

I. Monostyla lunaris Ehrenberg. 


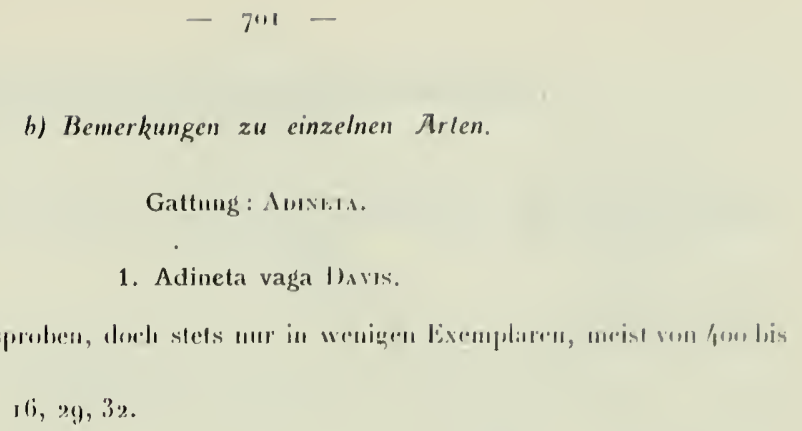

2. Adineta gracilis J Assen,

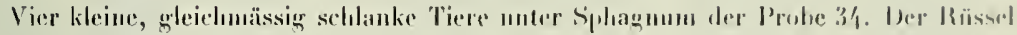

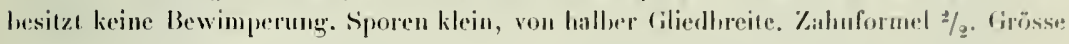
$23 \% \mu$.

\section{Adineta oculata Muxi.}

Ein zu dieser Art an rechnendes Tier in Probe 22. Da Muxes (8) Beschreilung von 1. oculala noch mangelhaft ist, würde es sich lohuen, das Tier einer eingrehemden Betrachtung zu unterzielten.

\section{Adineta barbata I INson.}

Unter Sphagnmm der Probe 29.

\section{Gattung : I AвRotrogha.}

1. Habrotrocha perforata Mııณ 1 .

Die häıfigste Irt, fası in allen Moosproben. Gehäuse von 125-140 $\mu$ Lä̀nge.

2. Habrotrocha perforata var. americana MUnRAY. (I I) (Fig. 12.)

Nehen dem Typus hie und da die kileinere Varietäl americum! mit 106 bis $112 \mu$ langen Gehäusen.

In dem Proben $6,13,14,24,25,27,29$.

3. Habrotrocha angusticollis MURRAY.

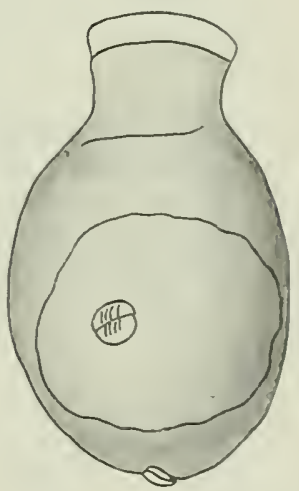

Fig. 12. - Habrotrocha perforata var. americana MtrRas.

Habrolrocha angusticolls ist eine in Europa, Amerika und Indien weit verbreitete gut zu unterscheidende. Art. Typische Gelıäuse in den Prohen: $4,6,15,1617,33,34,35$. 
4. Habrotrocha angusticollis var. attenuata Mинка.

(Fig. 13 bis 16.$)$

Von Murnar (10) im llimalaya enteckt und ron mir (5) auch in den centralamerikanischen Anden nachgewiesen. Das Gehäuse dieser Varietät ist lang, flaschen-

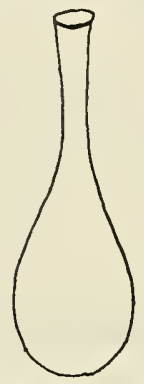

Fig. 13. - Habrotrochangusticollis var. altenuata MIURRAY, Gehãuse.

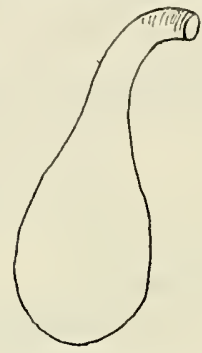

Fig. 14. - 11abrotrocha angusticollis MurRay. Gehäuse mit gekrümmtem Hals.

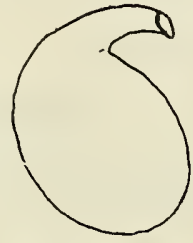

Fig. 15. - Habro. trocha angusticollis Murray. Abnormes Gehäuse.

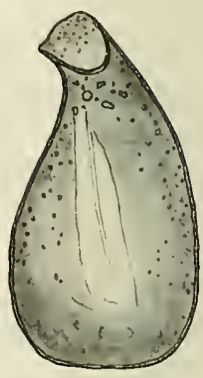

Fig. 16. - Habrotrocha angusticollis Iurray. A mpullenartiges Gehäuse.

förmig ausgezogen. Zwischen dem Typus und der var. allenuala finden zalılreiche Uebergänge statt. Hie und da treten auch Formen mil gebogenem Hils auf. (Verg\}. 5.) In den Proben : 17, 25, 33.

In Probe 29 war die typische form ron angnsticollis dureh eine aullallend kleine Varietät vertreten.

\section{Habrotrocha maculata Munnay.}

Ilabrotrocha maculata ist für Südamerika neu; bisher durch Murnay (15) um aus Canada bekannt.

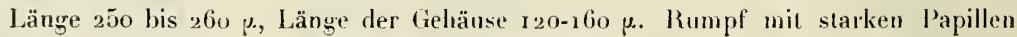
versehen. Räderorgan von mittlerer Grösse. Auf der Seite des Kojfes kleine Mundlappen.

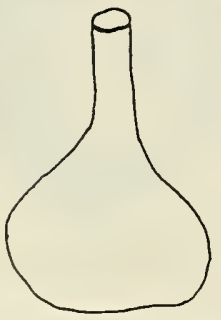

Fig. 17. - Habrotrocha ampulla MURRAY. Gehäuse.
Rüssel kurz. Zähne 4 auf jeder Seite. Murray gibt als Zaluformel 3 , oder $4 / 4$ in jeder Reihe an. Sporen klein, zugespitzl, ohne Zwischenraum. Gehäuse glatt, hellbraun gefärbt. Einige Exemplare in Probe 33.

\section{Habrotrocha eremita BRYCE.}

Wenige typische Tiere in Proben 8, ig.

7. Habrotrocha ampulla MurRay.

(Fig. 17.)

In Probe 26 fand ich ein 160 y. grosses Geluäuse einer Mabrotrocha Art. Das Gehäuse ist flaschenförmig mit breiter Basis ähnlich 


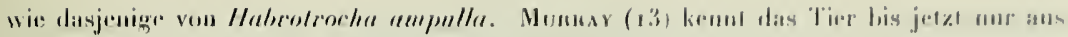

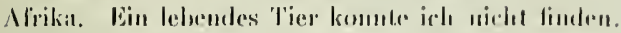

\section{Habrotrocha Fuhrmannii nov. spec.}

(liig. 18 lis 2er.)

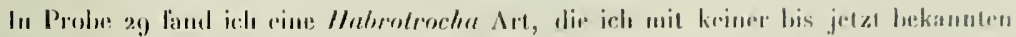

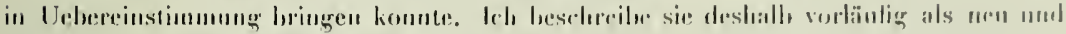
nenue sie zu liluren von lleren Prof, Jor Fumasis in

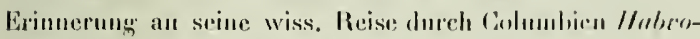
trocha finhermanui nov, sper.

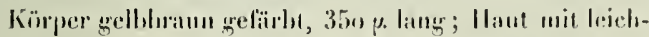
len Längsfallen. Das Räderorginn ist mïssig grensis, fis his 7" $\mu$ hreit. Hals ungelïls lallh so breit wic der Rumpl'.

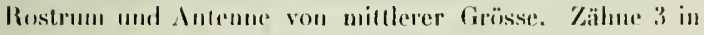
jeder Reihe. Das vortelzte Fussugied rägt einen stumpfen dorsalen Itïeker, Alessen Bedrulung nichıl recht rersichtlich ist; foch mag er vielleicht heim Gchäusehan irgent welche Funktionen ausüben. Sporen ïber tiliedbreite, zugespitzl, etwas nach answärts grebogen mit kurzem Zwischenraum.

Der körper der $/ 1$. fuhrmanai 1 . sp. erinuert an $/ 1$. lalu Buyce, doch sind Räderorgan mil fuss betleutend grösser. Nit //. tridens Mrane hat die vorliegende Art nur die Zahl der Zähne und dic Grösse gemeinsam.

Oh II. fuhrumani n. sp. zu den gehäusehewohnenden Irten gehür, konnte nicht herausgebracht werden, da ith keine tichäuse heobachten konnte. Nber es scheint nicht

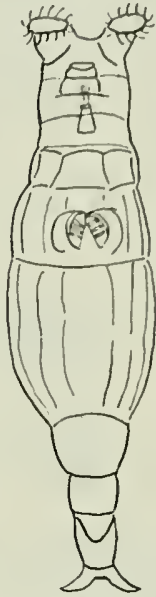

Fig. 18. - Habrotrocha Fuhrnannii $\mathrm{n} . \mathrm{sp}$.

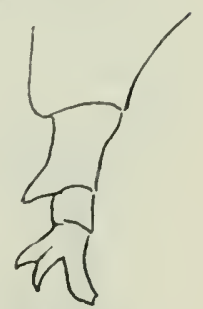

Fig. 19. - I/abrotrocha Fuhr. mannii n. sp. Fuss.

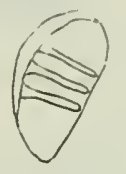

Fig. 20. $-\mathrm{Ha}$ brotrocha Fulirmannii n. sp. Kauapparat. ausgeschlossen, dass auch $/ /$. fuhrmanni gleich einigen antern IIabrotrocha arten wenigstens zeitweilig Schutzerehäuse herstellt. Nach Murn.1Y(13.) whabt Burce, dass wahrscheinlich alle Arten der Gallung Habrolrocha beim Eintritl ungünstiger Lehensbedingungen Schutzģelıäuse erzenģen.

\section{Habrotrocha constricta DUjaRDIN.}

Weit verbreitete Form.

In Proben 9, 15, 18.

10. Habrotrocha lata Brice.

Wenige Exemplare dieser gut bekannten Form in den Proben 24, 2\%. 
11. Habrotrocha aspera BRTCE.

11. aspera ist eine weit vethreitcte Form, die anch Muras (17) schon in Bolivia beobachtete.

In den Proben 16, 34.

12. Habrotrocha tripus Murray.

Kïrper der beobachteten Exemplare schwach gelblich gefärht. Kopf klein mit kleinem Räderorgan von $50 \%$ Breite. H. tripus ist leicht kenntlich an den grossen Zehen. Die

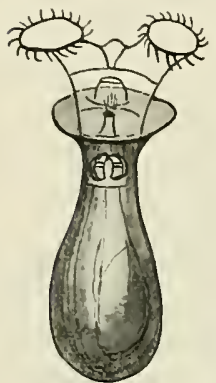

Fig. 21. - Habrotrocha spec, Gehäuse. beiden mittleren werden beim Kiriechen aus und eingezogren, während die dorsale mit den Sporen einen Dreifuss bildet. Sporen spitz auslanfend jund von einander abstehend. Kauapparat mit 2 ¿ Zähnen.

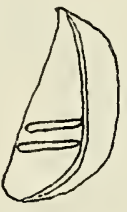

Fig. 22. Habrotrocha spec. Kauapparat.

Nur an zwei Lokatitäten heobachtet. Probe 16,32.

\section{Habrotrocha spec.}

(Fig. 21 und 22.)

Kleine gehäusebewohnende Form mit kurzem Rostrum. Räderorgan von mittlererBreite. Zahnformel $2 / 2$. Gehäuse braun, $145 \mu$ lang, gegen die Oeffuung schüsseloder tellerartig verbreitet.

Keine bis jetzt bekannte Form besitzt ein solches Gehäuse Da ich jedoch den Fuss des Tieres nicht näher studieren konnte und auch nur zwei Exemplare fand, möchte ich vorläufig von einer definitiven Benennumg alssehen. Probe 16.

\section{Gattung : Callidina.}

\section{Callidina papillosa Thом Pson.}

Der Körpes der typischen Form trägt an den letzten Segmenten zahlreiche dorsale, warzenartige Höcker, die in Bezug auf Grösse und Aussehen sehr veränderlich sind. Zahnformel $3 / 3$.

In Probe 23 war eine dem Typus ähnliche, aber nur mit wenigen Papillen versehene Varietät. In den Proben 7 und 23.

\section{2-5. Callidina multispinosa Thом Pson.}

(Fig. 23 bis 27.)

Callidina multispinosa ist eine der veränderlichsten und varitäten reichsten Formen der Gattung Bdelloirla. Verschiedene dieser Varietäten scheinen constant zu sein und 


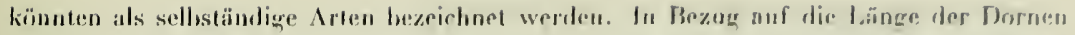

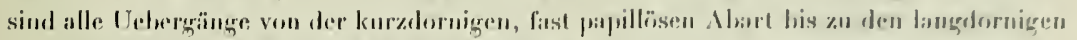

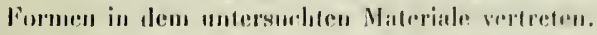

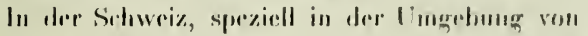

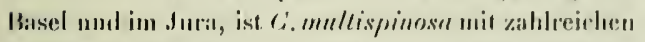
Vurietälen häufign. Ich losfle, dies solowrizeriseluen Varietïten der Species mullisprinosa in rime lesomderon Aplueit näher behambleln zu kïnmen.

Sidun Munnar $(11,13,1 / 1,15)$ ist der formenreichtum von $C$. multispinosn aufigefillen und in eingen Arbeiten bescheribl er verschiedene Variotiaten.

Collieliun multispimosu $\vee$ cresssispinosn MunnuY (II).

Vordere Dormen lang, die an der Rumpliseite breit uml dick. Hant schwarh pippillïs. (Fig. 2.3.) Melurere Tiere in den Proben of und 29.

C. m. v. crassispinosi kommt anch in der limgeblum von Based vor.

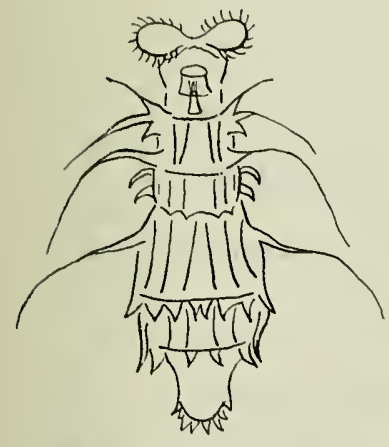

Fig. 25. - Collidina multispinosa lıosison. Varietät.

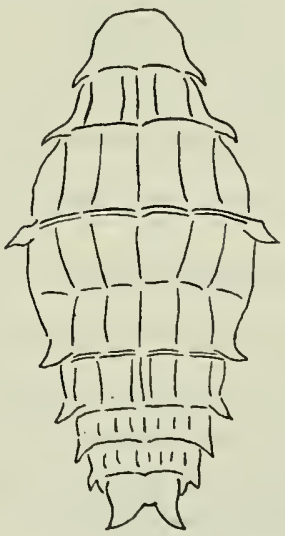

Fig. 24. - Callidina mul. tispinosa Thospsox. Varietit.

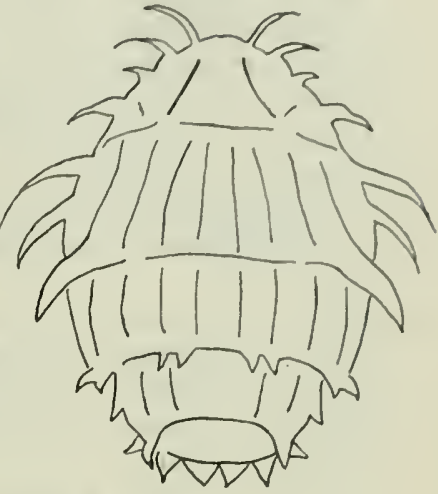

Fig. 23. - Callidina niullispinosa var. crassispinosa Mftray.

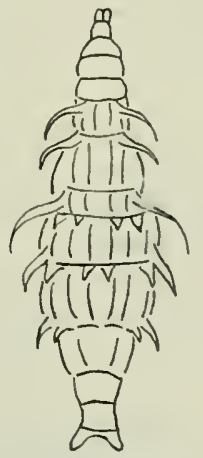

Fig. 26. - Calli. dina multispinosa Thompsox, Varietã1.

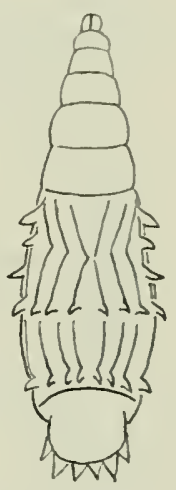

Fig. 27, - Callidina mullispiresa Tuompsox. Varieไầ.

\section{Callidina multispinosa 1 . brevispinosa Murray.}

Von Muraty ( 3 ) zuerst aus dem tropischen Afrika beschrieben. Dornen zurïckgebildet, kurz, fast papillös. Zahnformel ${ }^{?}$.

C. multispinosa $\mathrm{v}$. brevispinosa ist wenig veränderlich und könute gut als selbststïndige Art anfgefasst werden. 
Einige Tiere in den Proben $6,15,16,20$ und 35.

Andere limiptiäten.

1. Vurioläl: Kurzdornigr. Im Rumpf S seitliche breite Dornen. Zälıne 2. (Fì. 24.)

Zwei Exemplare neben dem Typus in Probe 31.

2. Vurietrit: de vier laterale tange in Päden austaufende Dornen. Hinter dem zweiten

Fadten ein und hinter den driten Faden zwei kurze Dornen. An tetzten Rumpfsegment zwei dursale Querreihen ron 8 und 6 Dornen. (Fig. 25.)

Einige Tiere in Probe 34.

3. Vırietüt: Der vorigen Varietät ähnlich mit etwas kürzeren seitlichen Dornen und 2

dorsalen Auerreilien von je 4 Dornen. Längुe 220 y. (Iig. 26.)

In Probe 27 .

4. Irarietät : Gleicht einer von Munnay in den Bdelloid Rot. of South American, Taf. II.

Fig. 8 a abgebildeten kurzdornigen form. (Fig. 27.)

Je zwei Tiere in Prolsen 17 und 19.

5. Varietät: Dornen mit verlneiteter bulbusartiger Basis, sonst wie der Typus.

In Probe 19 und 33.

\section{Callidina zickendrahti Richters.}

Munray (15) unt Rousselet (21) hetrachten diese Art als eine Varietä von Callidima multispinosa.

C. Eickendrahti ist bis jetzt bekannt aus Russland, Deutsehland und Afrika.

In Probe 24.

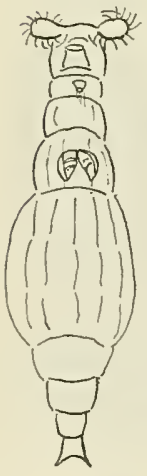

Fig. 28, - Callidina spec.

\section{Callidina speciosa Murnay.}

Kleine Form von $170 \%$. Haut mit zahtreichen Ques- und Längrsfalten.

Bis jetzt bekannt aus British Guiana, Bolivia, und British Columbien.

Einige Tiere in Probe 33, Paramo Cruz Verde aus einer Höhe von $3000 \mathrm{in}$.

8. Callidina ehrenbergi $\mathrm{J}_{\mathrm{A} \text { NSon. }}$

Häufig in den Proben 4, 5, 9, 19, 21, 25, 32. C. ehrenbergi ist weit verbreitet. Bekannt aus Europa, Afrika, Neuseeland, Havaï, Canada.

\section{Callidina spec.}

(Fig. 28, 29, 30.)

Körper getbbraun $340 \%$. Rumpf doppett so breit als der

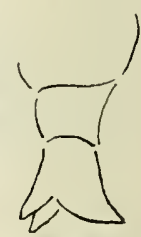

Fig. 29. Callidina spec. Fuss.

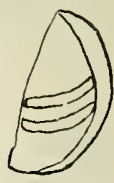

Fig. 30. Callidina spec. Kauapparat.

Hals mit Längsfalten. Rostrum kurz. Breite des Räderorgans $7^{\circ} \mu$. Sporen kurz, zugespitzt mit gebogenem Zwischenraum. Zähne $2 / 2$ auf jeder Seite. 


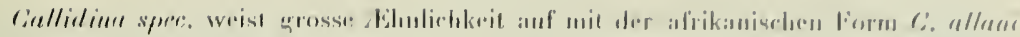

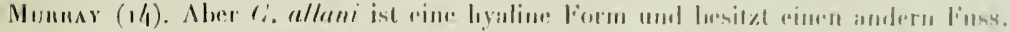

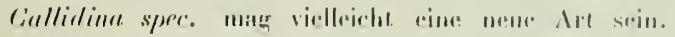

Proben : 21 (28\%).

10. Callidina spec. (liig. :3r.)

In Proble an cine dunkelrol geläilute Ciallielina mit glillem Körpere. Da die Tiere niclı : dem Trockensehlat arwachtru, war rine sichere Bestimmumer nicht möglich. Z:ïlı, $7 / 7$.

11. Callidina spec. (Fiv. 32.)

Nielıterwachtmit $/ 4 Z$ Zülınen. I1 Prohen 11, 15, 2 (i.

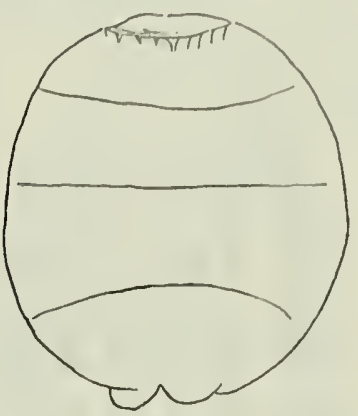

lig. 31. - Callidina spec.

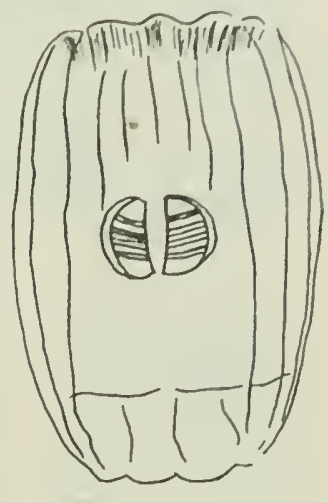

lïg. 32. - Callidina spec.

Gattung : Rotlier.

1. Rotifer vulgaris Sспиякк.

IVenige Tiere unler Sphagnum der Prohe 34.

2. Rotifer longirostris IAxsox.

Vereinzelt in verschiedenen Moosproben-lianapparat stets mil $\%$ Zälinen. lirr̈sse 380 bis $450 \mu$.

Proben: $3,4,9,22$.

3. Rotifer tardigradus Enrexberg.

Nur in Probe 26.

\section{Rotifer quadrangularis nov. spec.}

(tig. 33 his 3.5 .)

Körper dunkelbraun gefärbt; Haut klehrig mit fremden Erdteilchen und verwesemben Moosblättchen, die in Form von vierrekigen Panten den Rumpf bedecken. Vou der dorsalen Seite geselsen erscheinen 6-7 solcher Plattenreihen mit je ti-S Plallen, wornon die milllere jeweilen die grösste ist. Sporen so breil wie der Fuss, zugespilzt mit kleinem Zwischenraum. Rumpf doppelt so breit wie der IJals. Rostrum ron mittlerer Gröse: Augen klein. 
Fuss und Kopf tragen keine Platten. Die Bewegnugen des Tieres sind heim hriechen lingsam.

Länge des Tieres $580-650$.. Räderorgan $80 \mu$. Zahnformel $\%$.

Rotifer yuadrangularis kommt $R$. tardigradus und $R$. longirostris nalıe. Lis fehlen aber bei $R$. tardigradus wie bei $K$. longirostris die regrelmässigen mit frenden Teilchen

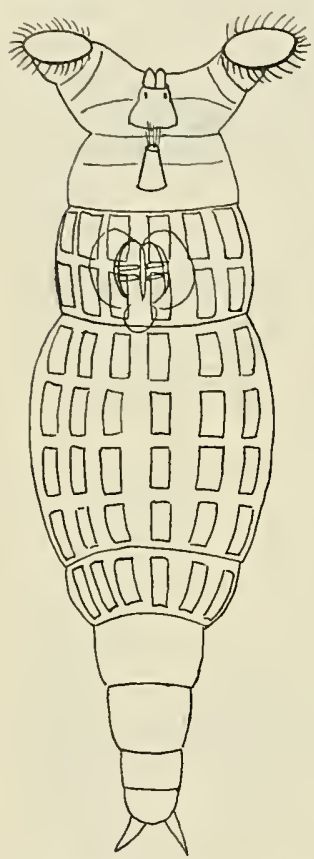

Fig. 33. - Rolifer quadrangularis n. spec. Die Detritusteilchen auf den Platten und am Körper sind weggelassen.

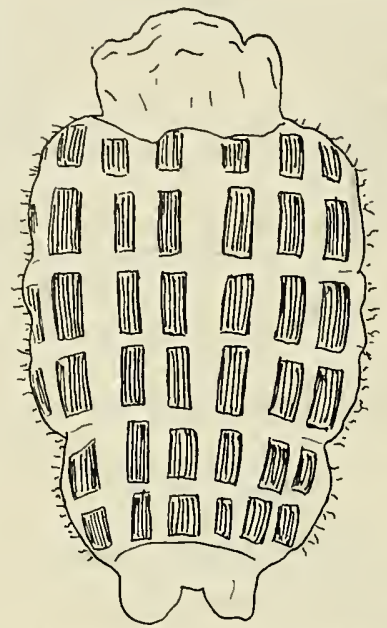

Fig. 34. - Rotifer quadrangularis n. spec. Zusammengezogenes Tier. besetzten Platten des Rumpfes. Anch ergelien sich im Bau des Fusses und des Rüssels Unterschiede, die die Aufstellung einer besondern Art rechtfertigen.

Eine interessante Beolaclıtung konnte ich bei einem Exemplar vou $620 \mu$. Grösse machen. Das Tier war offenbar in Häutung begrilfen und verliess seine Platten hesetzte Hülle, ohne wieder dahin zurückzukehren. Diese Hülle ist wohl eine Art Schutzgehäuse gegen Feinde. Bei eingezogenem fiuss und Räderorgan gleicht $R$. quadrangularis cher einem faulenden, carrierten Moosblätıchen als einem Rotator.

Unter Sphngnum und Hypnum der Probe 29.

\section{Gattung : Pleuretra.}

\section{Pleuretra humerosa Mukiax.}

Diese Art besitzt eine weite Verbreitung. Sie ist bis jetzt bekannt aus England, der Sclwweiz, Afrika, Neuseeland, Kanada, den Fidschi Inseln und Bolivia.

In den Proben 25, 35.

\section{Pleuretra alpium Ehrenberg.}

Bis jetzt bekannt aus Europa, den australischen Alpen, und der Arktis. Murray's (20, p. I67) Bemerkung "It never occurs in dry moss" möchte ich entge- 


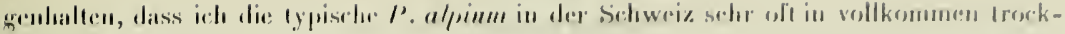
enem Moos andigefurulen habe.

Writge Tiew in Prol» $\% 7$.

\section{Pleuretra 1riangularis Munss.}

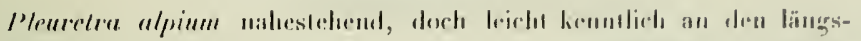

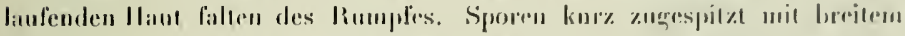

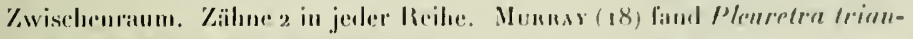
gularis in P'unta Arenas, Chile, Argentinion und Brasilion.

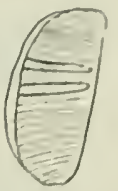

Bis jel\%t un! an!s Sï̈lanterika hekan!ul.

In den Proben 18, \%.

\section{Gattung : l'I11..1mins.}

\section{Philodina roseola lïnкиния.}

In Sphaygum der Prolie 34.

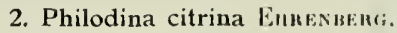

In Sichlamm ansgedrückt aus Spha!ynum.

Prole 36.

\section{Philodina vorax IANsox.}

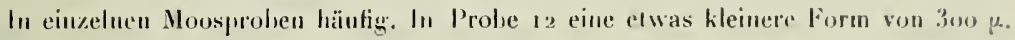
Liinge.

In Proben 17, 20, 3.

\section{Philodina americana MURRAY ?}

In Probe 20 eime kleine weissliche form mit kurzem Rostrum und $2 / 3$ Zähnen.

Da ich un a Exemplar sah, lionnte ich die Art nicht mit sicherheit bestimmen. Bekanut durch Murray (18) aus Argentinien.

In Probe 10

\section{Gattung : MNioms..}

\section{Mniobia scarlatina Enrexiberg.}

In den Proben 15, 17, 30 und 35.

Aus allen Erdteilen bekannt. 


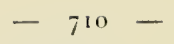

\section{Mniobia russeola Zelinka.}

Vereinzelt in Probe 16; in 20. loüutig.

I/niobia russeola ist bis jetzt bekannt aus Europa, Ifrika, Canada und Hawaï.

\section{Mniobia symbiotica Zelinka.}

In den Proben 16,18 und 35.

Ius allen Erdteilen bekannt.

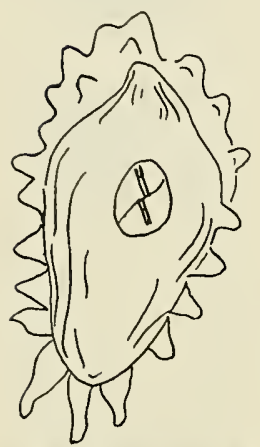

Fig. 36. - Unbekanntes Ei. Fig. 37. - Unbekanntes Ei.

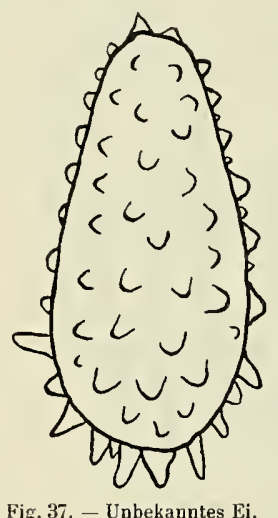

4. Mniobia magna Plate.

Nur in Probe 21.

Bekannt aus Europa, Canada, Bolivia und Neuseeland.

5. Mniobia tetraodon Eurenberg.

In Proben 13 und 26.

Bekannt aus Europa, Afrika, Canada, Neuseeland, Brasilien.

\section{Ei einer unbekannten Art.}

(Fig. 36 und 37.)

In Fig. 37 ist ein unbekanntes $\mathrm{Ei}$ einer Callidina oder Philodinaart abgebildet. Dieses Ei ist länglich oval, $150 \mu$. lang und 75 \%.. loreit und mit langen stumpfen Höckern versehen. Grösse der Höcker bis $50 \mu$. Probe 20.

Fig. 36 stellt ein anderes Ei dar. Länge ohue Dornen 84 p.., mit den Dornen $112 \mu$. Grösste Breite des Eies 53 \%.. Zähne 2/2. Probe 11.

\section{Phloïma.}

\section{Gattung : Furcularia.}

\section{Furcularia forficula Enrenberg.}

Durch Murray (18) aus dem Titicaca See bekannt. In Schlamm aus ausgedrücktem Sphagnum. Probe 36. 


\section{Loricata .}

\section{Gattung!: livillavis.}

1. Euchlanis dilatata Limusum.uri.

Ëu Exemplar iı $2 g$.

$$
\text { Gattung : Movostrit. }
$$

1. Monostyla lunaris Emแ:inturi.

Iu Probe 20.

\section{c) Geographische Verbreitung.}

Die gengraphiselse Verbreitung der Bdelloida ist noch zn mugenïrgend bekannt, um sie vollkommen feststellen zu können. Munksy, Bkyce und Roussezet laben zwar in ansgexeicheten Arbeiten unsere Kenntnisse äber die geogriphische Verbreitung der mooshewohnenden Rotileren erweitert. Aber trotzdem liegen atus vielen tiegrenden nur wenige oder ımgenügende Beobachtungen vor. Jede, auch noch so kleine. Irlseit vervollständight Wiher unser IVissen.

Es ist anzunchmen, dass die Verbreitung einiger bis jetzt nur selten anfurefundener Arten eine bedeutend grössere sein wird; denn die eminente Anpassungsfähigkeit an die hiologischen und ökologischen Verhältnisse (Temperatur, Feuchtigkeit und Trockenheit) sichert den moosbewolnenden Rotatorien weiteste Verbreitung.

Es mögen nachfolgend die bis jetzt in Südamerika (Argentinien, Chile, Bolivia, Peru, Brasilien, Britisels Guiana, Paraguay) bekannten Arten der Ordnung Bdelloidn mit denjenigen aus Columbien zusammengrestellt werden

Von 70 bis jetzt in Südamerika beobachteten Arten der Ordnung Bolelloida sind demnach 35 , also die Hälfte für Columbien nachgewiesen worden.

Neu sind 2 Arten:

1. Habrotrocha fuhrmanni n. sp.

2. Rolifer yuadrangularis $\mathbf{n}$. sp.

Zwei von mir noch nicht benannte Arten dürften ebenfalls neu sein.

Für Columbien resp. für Südamerika neu sind ausserdem :

r. Philodina citrina Eнrвg.

2. Pleuretra alpium EhrBg.

3. Habrotrocha ampulla Munkux.

4. II. maculata Murrax.

5. Callidina sichendrahti Rranters. 


\begin{tabular}{|c|c|c|c|c|c|c|c|c|c|c|}
\hline & Name & & 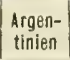 & Chille & Bolivia & Peru & $\begin{array}{c}\text { Brasi- } \\
\text { Ilen }\end{array}$ & Gulana & \begin{tabular}{|c} 
colum- \\
blen
\end{tabular} \mid & $\begin{array}{l}\text { Para- } \\
\text { guay }\end{array}$ \\
\hline 1. & Arlineta baga Duris & . & & & $\therefore$ & & $x$ & $x$ & $\times$ & \\
\hline$\because$. & "gracilis Jusson . . & . & & & $x$ & & & $x$ & $x$ & \\
\hline 3. & barbata Jaxsun . . & . & $\times$ & & $x$ & & & & $x$ & \\
\hline 4. & " deulata Miline . . . & . . & & & & & & & $x$ & \\
\hline $\bar{\jmath}$ & 1) longicornis Mltrray. & . . & & & $x$ & & $x$ & & & \\
\hline 6. & Ilabrotrocha perforata Munus. & & & & $x$ & & $x$ & $x$ & $x$ & \\
\hline$\pi$. & angusticoll is MURn & & & & $x$ & $x$ & $x$ & $\times$ & x & \\
\hline 8. & longiceps Мевлау . & & & & $x$ & & $x$ & & & \\
\hline 9. & consiricta Dus. & . & & & $\times$ & & $\times$ & $x$ & $x$ & \\
\hline 10. & pulchro Mluray & . : : & & & $x$ & & & & & \\
\hline 11. & annulata МекRау . & . & & & $x$ & & & & & \\
\hline 12. & tripus Мснвау. & . & & & $x$ & & & $x$ & $x$ & \\
\hline 13. & crenala Murr.iy & . & & & $x$ & & & & & \\
\hline 14. & aspera BRYcE & . & & & $x$ & & $x$ & & $\times$ & \\
\hline 15. & raudala Murnay. & . & & & & & $\times$ & & & \\
\hline 16. & acornis Мlurray . & . & & & & & $x$ & & & \\
\hline 17. & fusca Murnay . & . & & & & & $x$ & & & \\
\hline 18. & chneala Murniy & . & & & & & x & & & \\
\hline 19. & Iata Bryce . & . & & $\therefore$ & & & & & $x$ & \\
\hline 20. & eremila MLrnity & . & $x$ & & $x$ & & & & $\times$ & \\
\hline 21. & ampulla МบвRмy & . & & & & & & & $\times$ & \\
\hline 22. & maculata MUкRиy. & . & & & & & & & $x$ & \\
\hline 23. & fuhrmanni nov. sp. & . & & & & & & & $x$ & \\
\hline 24. & Callidina habita BRyee . . & . & & & $x$ & & $x$ & $\times$ & & \\
\hline 25. & formosa Мunan. . & . & & & x & & $x$ & & & \\
\hline 26. & plicata BMчce . . & .. & & & $\times$ & $\times$ & $x$ & & & \\
\hline $2 \pi$. & ehrenbergi Janson. . & . & & & & & & $x$ & $\times$. & \\
\hline 28. & punctata MURray . . & . & & & $x$ & & & & & \\
\hline 29. & quadricornifera MILNE & . & & & $x$ & & & $x$ & & \\
\hline 30. & speziosa Murray . . & . & & & $x$ & & & $x$ & $x$ & \\
\hline 31. & microcornis MLRRAY . & . & & & $x$ & & & & & \\
\hline 32. & papillosa Tномson . & . & $\times$ & & & $\times$ & $\therefore$ & & $x$ & \\
\hline 33. & mullispinosa Тномгson & . & $\therefore$ & & $x$ & & $x$ & $x$ & $x$ & \\
\hline 34. & sicliendrahti Rıchters & . & & & & & & & $x$ & \\
\hline 35. & pacifica Muratat. . & . & & & & & $x$ & & & \\
\hline 36. & vesicularis Murn.tr. & $\cdot$ & $\times$ & & & & & & & \\
\hline $3 \pi$. & Rotifer actinnтus EнRвG. . . & $\therefore$ & & & x & & & & & $x$ \\
\hline 38. & "longirostris Jaxson... & . & & & $\times$ & & x & $x$ & $x$ & \\
\hline 39. & "valgaris Sсинмкк. . & . & & $x$ & & & $x$ & & $x$ & $x$ \\
\hline 40. & lardigradus Енввя. . . & . & & & & & $\therefore$ & & $x$ & $x$ \\
\hline 41. & " qaadrangularis n. sp. & . & & & & & & & $x$ & \\
\hline 42. & macroceros Gosse. & . & & & & & $x$ & & & $x$ \\
\hline 43. & 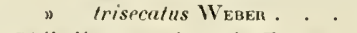 & . & & & & & $x$ & & & \\
\hline 41. & Philodina megalotrocha Eunra. & . & & & & & $x$ & & & \\
\hline 行. & acuticornis MURвау. & . & & & & $x$ & $x$ & & & \\
\hline 46. & nemoralis Bryce. & . & & & & & & & & \\
\hline $1 \%$ & rugosa Вичсе & 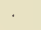 & & & $x$ & & $x$ & & & \\
\hline 48. & 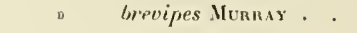 & . & & x & & & $x$ & & & \\
\hline
\end{tabular}




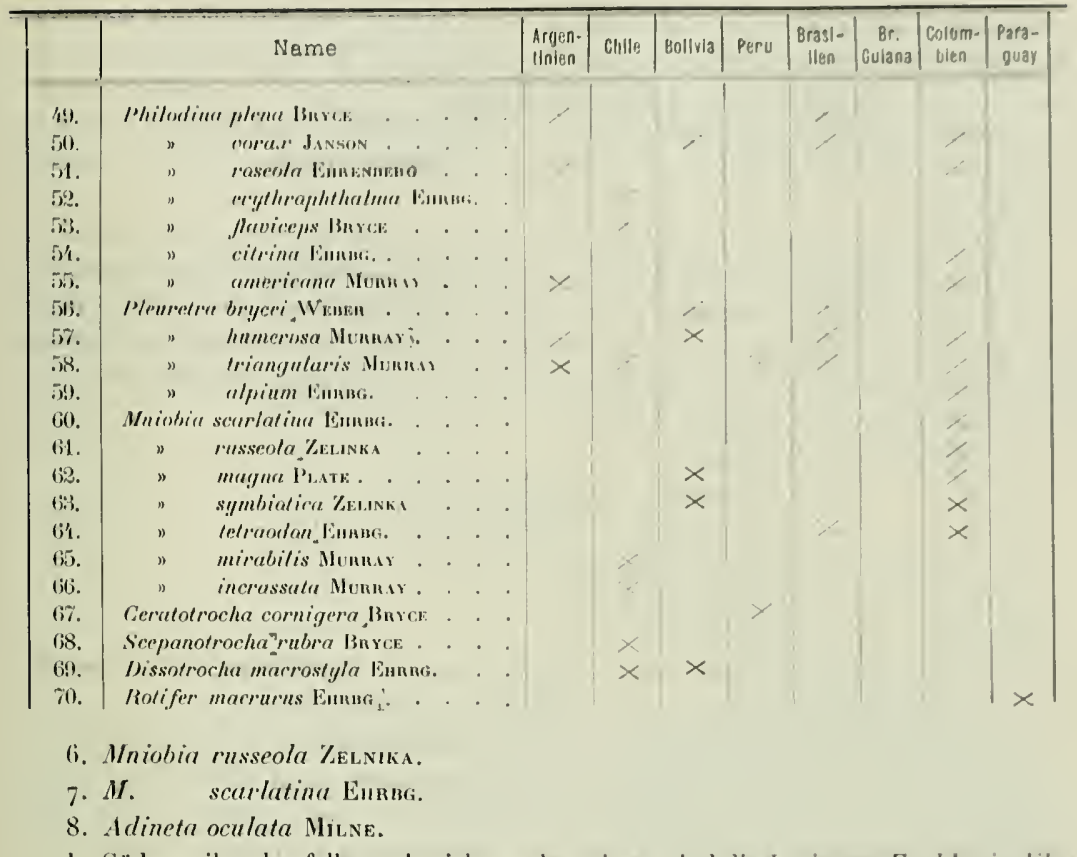

In Südamerika ebenfalls noch nicht uachgewiesen sind die Loricaten Euchlanis dilatata Еивв und Monostyla lunaris Еивв.

Einige Arten scheinen lis jelzt einen geringen Verbreitungshezirk zu besitzen; was besonders bei einigen tropischen und antarktischen Formen der Fall ist.

Auf Südamerika beschränkt sind:

1. IIabrotrocha fuh'manni n. sp.

2. Callidina speciosa Murray.

3. Pleuretra triangularis Murnay.

4. Rotifer quadrangularis $\mathbf{n}$ : $\mathbf{s p}$ :

\section{Tardigrada.}

IIistorisches. Unsere Kenntuisse über die südamerikanischen Tardigraden sind noch sehr gering. PLAтE ( $\mathrm{I} 3$ ) fand in chilenischen Moosen drei Arten, nämlich Macrobiotus intermedius Plate, M. oberhäuseri Dus. nnd Diphasconchilenense Plate. Daday (1) 
verzeichnet in seiner Süsswasser Mikrofauna von Paraguay den Macrobiotus macronyx Dus. Durch die neueren Untersuchungen ron Ricutens und Murnay ist die Zahıl der süd:merikanischen Bärierchen rasch gestiegen. Ricurers $(18,19,20)$ konstatierte in verschiedenen Teilen Südamerikas (Feuterland, Paraguay, Chile) 16 verschiedene Arten und aus Bolivia und Peru gibt Munn.r (11) in einer kürzlich erschienen Arbeit ebenfalls 16 Arten an.

. Ius Centralamerika meldete ieh (3) das Vorkommen von 5 versehielenen Arten.

Ueber die Tardigradenfatuna Columbiens ist ausser ciner kleinen Notiz Rıchters (20) nichts bekannt. Aus den columbischen Cordilleren - aus denen das Meiste von Prof. Fun Max gesammelte Material stammt - sind bis jetzt überhaupt keine Bärtierchen bekannt geworden. Ricurers fand in Hoosen, die bei Honda am obern Magdalenenlluss in Columhien gesimmelt wurden, folgende 6 Formen:

1. Echiniscns smillus Eнrвg.

2. E. novae-seelandiae Ricurers.

3. E. wendli Ricuters.

4. Macrobiotus harmsworthi Murray.

5. M. hufelandi C. Schultze.

6. Diphascon chilenense Platre.

Veitere Benterkungen über das Vorkommen und die Verbreitung der südamerikauischen Tardigraden werden im geogr. Teil dieses Abschnitles folgen.

Die Tardigraden waren im Fuв мaxy'schen Material relativ zahlreich vertreten ; doch enthielt keine Moosprobe viele Tiere. Die Individuenzahl war gewöhnlich sehr gering, so dass oft erst wach stunden-und tagelangem Durchsuchen einer Probe ein Tier aufgefunden werden konnte. Von den 36 mir zur Untersuchung übergebenen Moosproben enthielten 14 gar keine Bärtierchen.

Die meisten Tardigraden erwachten nach dem Befeuchten mit Wasser aus dem Trockenschlaf oder quollen auf, so dass eine Bestimmung möglich war. Die Macrobioten kamen mit wenigen Ausnahmen nach einigem Schütteln des mit Wasser übergossenen Moosdetritus zun Leben; die Echiniscnsarten hingegen quollen wohl auf, blieben aber regungslos.

\section{a) Verzeichnis der beobachteten Arten.}

1. Macrobiolus hufelandi C. Scuultze.

2. ") echinogenitus Richters.

3. " harmsworthi MURRAY.

4. $"$ intermedius Plate.

5. „) oberhäuseri DAx.

6. „ oberhänseri var. granulatus Ricuters.

7. „) arcticus Murray. 


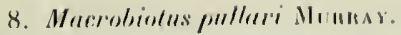

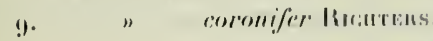

10. " Fuhrmumi nov. spec.

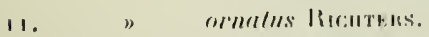

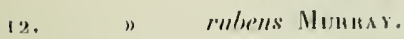

13. 1 spec Ei.

1/1. " spee lii.

15. Diplereseon chilenense l'ute.

16. " seolicum Nersass.

17. Milmesinm tareligradum lis.

18. Echiniscus suillus Emunu.

19. " blume Reriltens.

20. " fischeri lincintries.

$21 . \quad$ spiniger Rucutens.

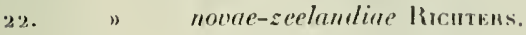

23. " quadrispinosus lin:нтьнs.

2/. " spec.

2\%. " spec.

2i. "spec.

\section{Bemerkungen zu den einzelnen Arten.}

Gattung MAcnomotus.

Macrobiotus hufelandi C. Schulze.

Diese weit verbreitete A't fand ich in verschiedenen l'roben. Probe find is enthiplt typische, schöne hufelandi. Eier ron $80 \mu$ Durchmesser wie sie Ricntens (1 7 ) ans dem Taunıs kemnt und deren Fortsätze umgestülpten Eierbechern oder Likörgläschen gleichen. Jn Probe 32 und 33 waren diese Fortsätze etwas kleiner.

\section{Macrobiotus echinogenitus Ricuters.}

Die Arten der echinogenilus-Gruppe sind lis jetzt nur durch die gleichzeitige Auffindung der Eier resp. der reifen Embryonen sicher von cinander zu unterscheiden. Aus dem früheren formenteichen $U$. echinogenitus hal licuters (2 i) drei Arten abgespalten : W. harmsurorthi, M. areolatus und $M$. echinogenitus.

Macrobiolns echinogenilus Ricutens im engern sinne zeichnel sich aus durch sternfömige Eier, \& hacilli und einem körnchen im schlundknf und hnfelandi kirallen in Mter. Aus den Eiern ausgedrückte Embryonen loben getrennte kiallen, die Anfangs $\mathrm{V}^{\circ}$ förmig sind und später verwachsen wie die Hufelandikrallen. 
I. echinogenitus ist aus allen Erdteilen bekaunt. Im Himalaya steigt die Art bis zu Sooo Fuss: in den Schweizeralpen nach neueren, noch nicht verölfentlichten Untersuchungen im Wallis bis über $4000 \mathrm{~m}$. Höhe.

Ausrewachsene Tiere neben Eiern in Probe 13 und 26.

\section{Macrobiotus harmsworthi MURнג.}

Ausgezeichnet durch 3 bacilli und einem Kiomma im Schlundkopf mit Hufelandikrallen.

Probe 23 neben sternförmigen Eiern von $7^{8} \mu$.

Macrobiotus intermedius PLATE.

Hie und da in verschiedenen Proben.

\section{Macrobiotus oberhäuseri DUJ.}

(Fig. 41.)

Mac, oberhïuseri ist eine'Art ron kosmopolitischer Verbreitung, die oft bedeutende Meereshöhe erreicht. Murray (8) kennt die Art aus dem Himalaya in Moos von Bagh-

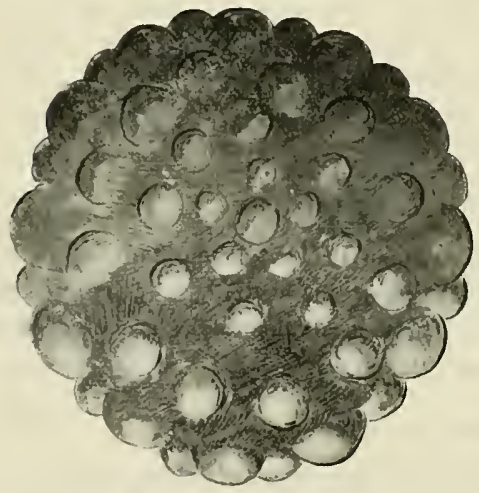

Fig. 41. - Macrobiotus oberhāusert Duj. Ei. ghora 6000 Fuss und von Pelechuco in Bolivia (I I) aus 12,000 Fuss. Ich fand $\boldsymbol{M}$. oberhäuseri in den Hochalpen in verschiedenen Höhen (z. B. Weissmies $4000 \mathrm{~m}$., Val Sorcy $3600 \mathrm{~m}$., Matterhorn $3800 \mathrm{~m}$. etc.).

Die glashellen, himbeerförmigen Eier salı ich in Prohe 30.

\section{Macrobiotus oberhäuseri var granulatus Richters.}

2 Exemplare in Probe 17 ; 1 Exemplar in 27. Körper mit blassrotem Pigment und 7 Querbinden von kleinen Höckern oder Körnern.

Durch |Ricurens (18，2I) bekannt aus Ushuaia auf Feuerland und aus Chile.

\section{Macrobiotus arcticus Munray.}

Der Schlundkopf dieser Art ist leicht oval und weist in jeder Reihe 3 Verdickungen auf : ein Körnchen und 2 Stäbchen, die gleich lang und breit sind. Krallen V-förmig. Eier 70-8o $\mu$ mit stumpfen dornenartigen Fortsätzen umgeben von einer byalinen Haut. Selten in Probe 33. 


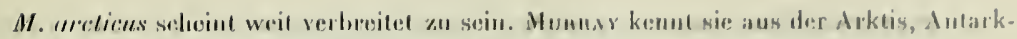
lis, Sclostlunicl, Anstralien, Afrika, Canadis und Bolivia.

\section{Macrobiotus pullari Mเ«њ».}

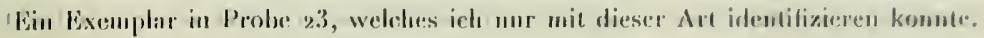

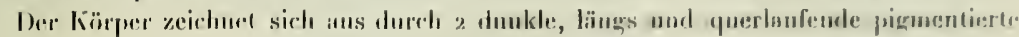

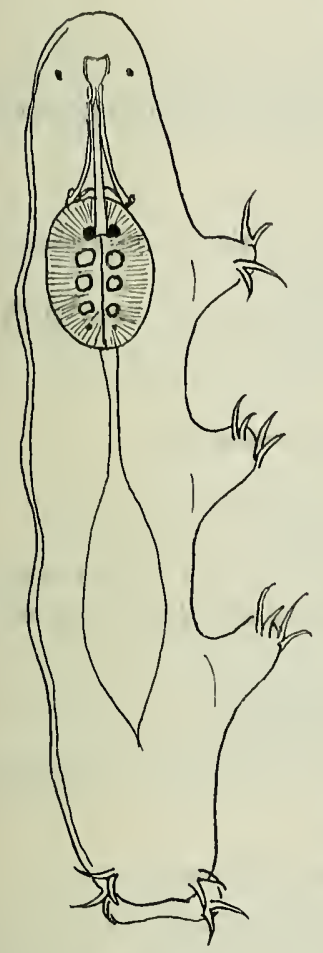

Fig. 38. - Macrobiolus Fuhr. manni n. sp.

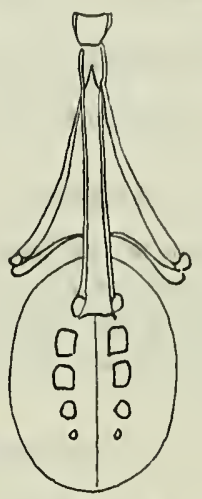

Fig. 39. - Marsobiolus Fuhrmanni n. - sp. Kauapparat.

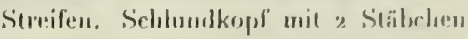

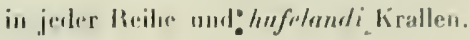

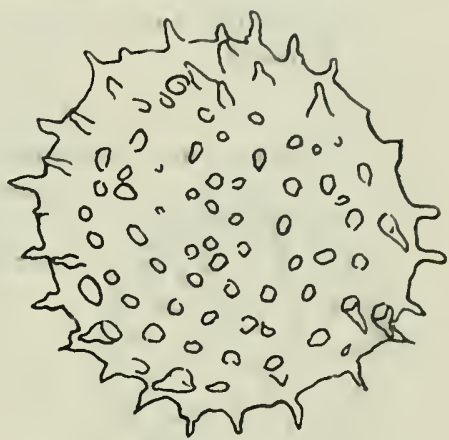

Fig. 10. - Macrobiolus Fuhrmanni n. sp. Fi.

Eier sterufiormigr, echinogenitusartig, jedoch mil kleineren conisch zugespritzten Furkäitzrn.

\section{Macrobiotus coronifer liı:॥tEณS.}

Iels war üluer das Vorkommen dieses päehtigen Tardigraden in Probe 30 erstaun, da er his jetzt uur als Form der quemässignten und kalten Zone bekannt war.

Die beobachteten Tiere waren hellggelb gefärht und 6750. lang. Ein Ei mass $140 \mu$.

Bekannt aus Deutsehland. Schottland, Arktis und der Schweiz (Ungelum von Basel, Rhätikon und Val sorey $3600 \mathrm{~m}$.

\section{Macrobiotus Fuhruanni nov. spec.}

(Fig. 38. bis fo.)

Prolie 6 enthielt einen kleinen Macrobioten, der mir einer newen Al't anzugrehören schien. Ich beschreibe ihn deshalb hier unter allem Vorhehalt als neu und nenne die Art Macrobiotus Fuhrmanni nov. spec. 
Die Grösse dieser kleinen Art schwankt zwischen I 75 und $250 \mu$. Körper hyalin mit 2. Augen und leicht gekrümmten Zähnen und Zahnträger. Schlundkopf oval mil 4 Chitineinlagerungen : Ein Kïrnchen, 3 fast f gleich grosse quadratische Stälıchen. Komma als schwache Punkte angedentet. Krallen leicht V förmig divergierend, Diphasconartig. Das Ei misst $7^{2} \mu$. im Durclımesser und ist mit unregelmässigen Fortsätzen oft von bulbus artiger Basis und zulaufender Spitze versehen.

\section{Macrobiotus ornatus Richrers.}

Diese zierliche, leicht kennhare $\mathrm{Ar}$ ist hekannt aus Neuseeland, Australien, Europa. In Probe 36.

\section{Macrobiotus rubens Murkay.}

lettzellen braun rot gefärbt. Die von mir beobachteten Individuen entsprechen der

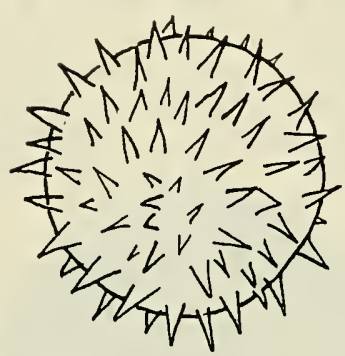

Fig. 42. - Macrobiotus spec.

Murray'schen Beschreibung (8).

Bekannt aus dem Himalaya, 6ono Fuss, Afrika, Centralamerika und Ascension.

Probe 27 .

Unbekannte Macrobiotus Eier.

Macrobiotus spec.

(Fig. 43.)

Probe 29 enthielt ein Ei von $104 \mu$. Länge und $88 \mu$. Breite. Das Ei gehört wahrscheinlich Macrobiotus areolatus an.

\section{Macrobiotus spec.}

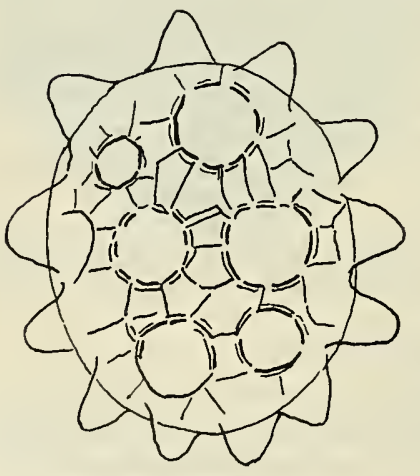

liig. 43. - Macrobiolus spec.
(Fig. 42.)

Kileines $\mathrm{Ei}$ von $58 \mu$. Durchmesser mit spitzen Dornen. Probe $3 \mathrm{I}$.

\section{Gattung : Diphascon.}

Diphascon chilenense Plate.

Von Plate zuerst in chilenischen Moosen heobachtet, geniesst die Art eine ausserordentlich weite Verbreitung. Sie ist ausser Afrika aus allen Erdteilen bekannt. Vertikal steigt Diphascon chilenense im Himalaya bis zu 8000 Fuss; in der Scluweiz am Säntis bis $\mathrm{zu} 2400 \mathrm{~m}$ and in den Columbischen Cordilleren bis zu $3000 \mathrm{~m}$. 
Diphascon scoticum Mищия.

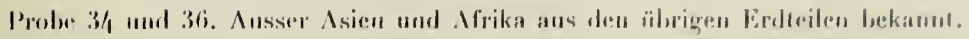

\section{Gattung : Mu.vestum.}

Milnesium tardigradum 1).

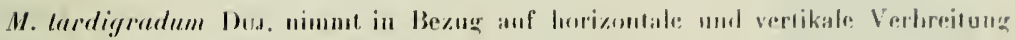
unter den Tardigraden die erste Stolle cin.

In zahlreichen Proben. Gelegre mit (i-!) Eiern.

\section{Gattung : Echunıscius.}

Echiniscus suillus linแHri.

Weit verbreitet. Steigt oft in bedeutende Höhen. Himalaya ?uon fuss, Hochalfwn: IVeissmies $4000 \mathrm{~m}$., Matterhoru $380^{\circ} \mathrm{m}$., Nont-Blane $4.300 \mathrm{~m}$.

Wenige Tiere in den Proben 15, 21, 27 und 32.

\section{Echiniscus blumi Richters.}

Das Verbreitungsggebiet dieser Art liegt in der gemässigten und kalten \%one.

4 Exemplare in Probe 15.

\section{Echiniscus fischeri Rucuters.}

Eine aussehliesslich südamerikanisehe Form. Platten V und VI getrennt mil grober lockerer Körnelung. Laterale Anhängre : a Faden, $c$, $d$ und e kurze Dornen; dorsale Anhängुe : über $c$ und $d$ kurze Dornen.

Bei den beobachten Exemplaren in Probe 33 war der laterale Dorn d der Längste bis $20 \mu$.

\section{Echiniscus spiniger Ricuters.}

Ein präpariertes Tier von $220 \mu$ stimmt mil Ricuters ( 1 4) Beschreibung und Murnar's Mbbildung (10, Tafel 17 . Firg 24) äberein, nur ist der laterale Dorn $b$ länger. Platten $\mathrm{V}$ und $\mathrm{V}$ 'l vereinigt mit kleehlatteinschnit, fein gekörnelt. Viertes Beinpaar mit stumpfdornigger Franse.

Probe 32.

\section{Echiniscus novæ-zeelandiæ Rrchters.}

Bekannt aus Neuseeland und Columbien.

Ein leicht gekörneltes Exemplar eines Echiniscus mit $V$ und VI getrennten Platten schien mir dieser Art anzugehören. Platte Veinpaarig mit a kurzen Dornen.

Prohe 18. 


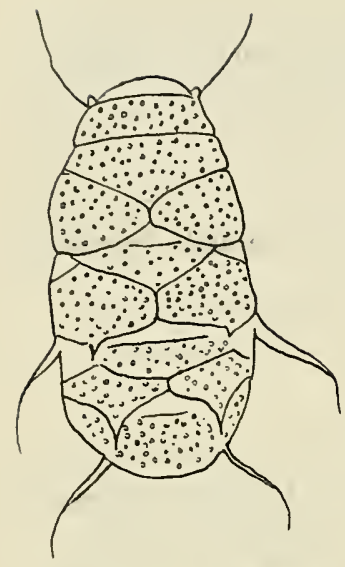

Fig. 4h. - Echiniscus spec.

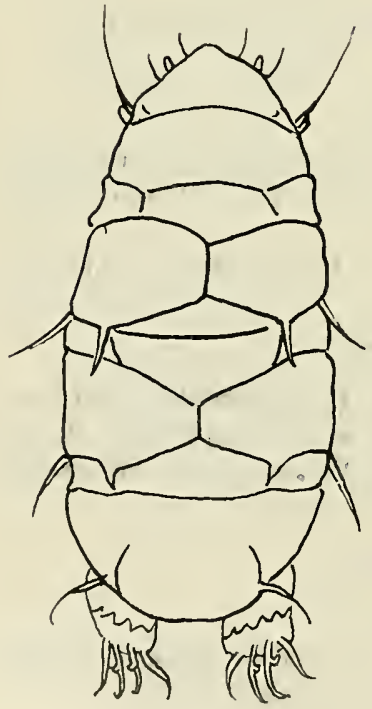

lig. 55. - Echiniscus spec.
Echiniscus quadrispinosus Ricuters.

Häufig in Probe 13 ; vereinzelt in 33.

Bekannt aus Schottland, Deutschland, Schweiz, Himalaya.

\section{Echiniscus spec. \\ (Fig. 45.)}

Platten 10. Y und Y'I vereingt. Laterale Anhänge : "Faden, $c, d, e$ Dornen, Dorsale Anlünge: über $c$ ein langer, kräftiger Dorn, über $d$ je ein kurzer Dorn mil breiter Basis. Platten leicht gekörnelt. Viertes Beinpaar mit Fransen. Innere Krallen mit stark zurïck gekrümmten Hacken.

Probe 29. Das Tier weist einige Aehnlichkeit auf mit einer kanadischen. Form von Murnay (Brilish Antarctic Exn. Tafel 20. Fign. 44).

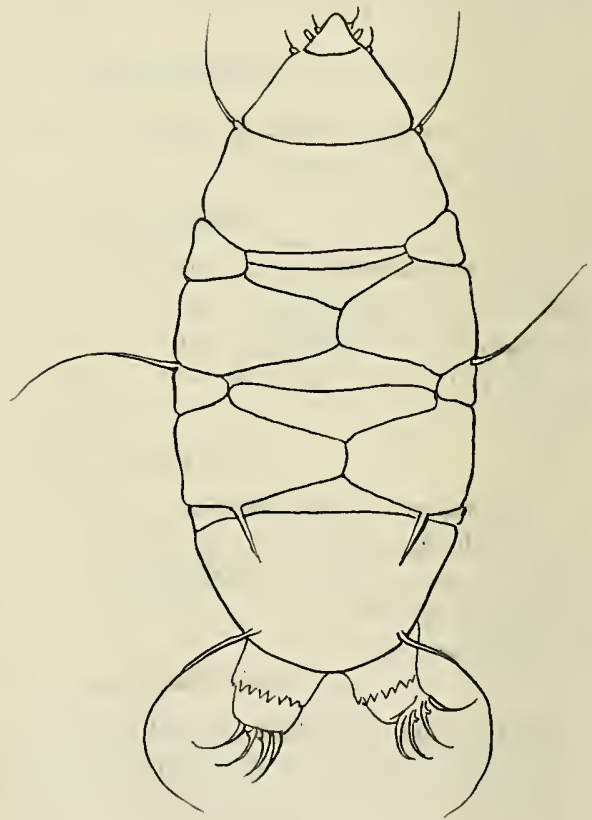

Fig. 46. - Echiniscus spec. 


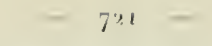

Echiniscus spec.

(Vig. 位)

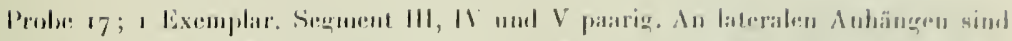

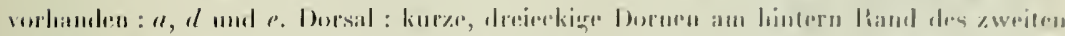

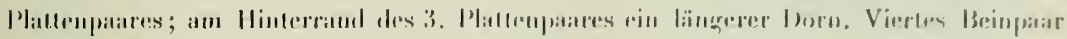

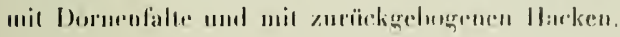

\section{Echiniscus spec.}

livin. (fi.)

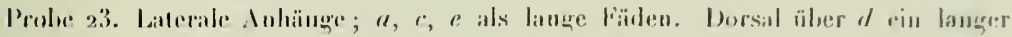
Dorn. Viertes Beingar mis franse mul zuräckgrlugenra llarken.

\section{c) Geographische Verbreilung.}

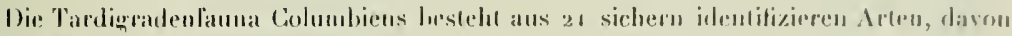

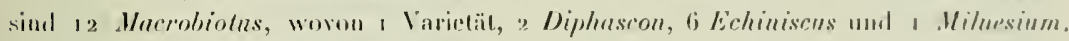
fïr das südamerikaniscle lestand dürlten nen sein :

1. Macrobiohns echinogenitus Rucutтus.

2. M. pullari Mumar.

3. M. coronifer Ruchens.

4. M. Fulumanni nov. spec.

5. M. ornatus Rucureus.

6. Echinisens blomi Rucutens.

7. E. spiniger Ricatens.

8. E. Ynadrispinosus lincuteas.

leberhaupt neu ist cine $\mathrm{Mr}$ :

\section{Macrobiotus Fuhrmanni noy. spec.}

Veber die Verteilung der Bärlierehen in den einzelnen Proben des von Mrn. Prof. Funumang gesammelten Materials gribt die Tahelle Infschluss.

Sïdanerika zählı nach meiner Zusammenstellung 33 versehiedene Tardigraden. Auf diesen hontineut beschränkt sind:

Echiniscus fischeri Ricnters.

Macrobiotus Fuhrmanni nov. spec.

" oberhü̈serivar. gramulahs Rıситевs.

Interessant, wenigstens für Columhien, ist das Vorkommen einiger Mitteleuropäischer und arktischer Arten /Echiniscus blumi, E. quadrispinosus, E. spiniger, Macrobintus ornalus, M. pulluri, M. coronifer). 


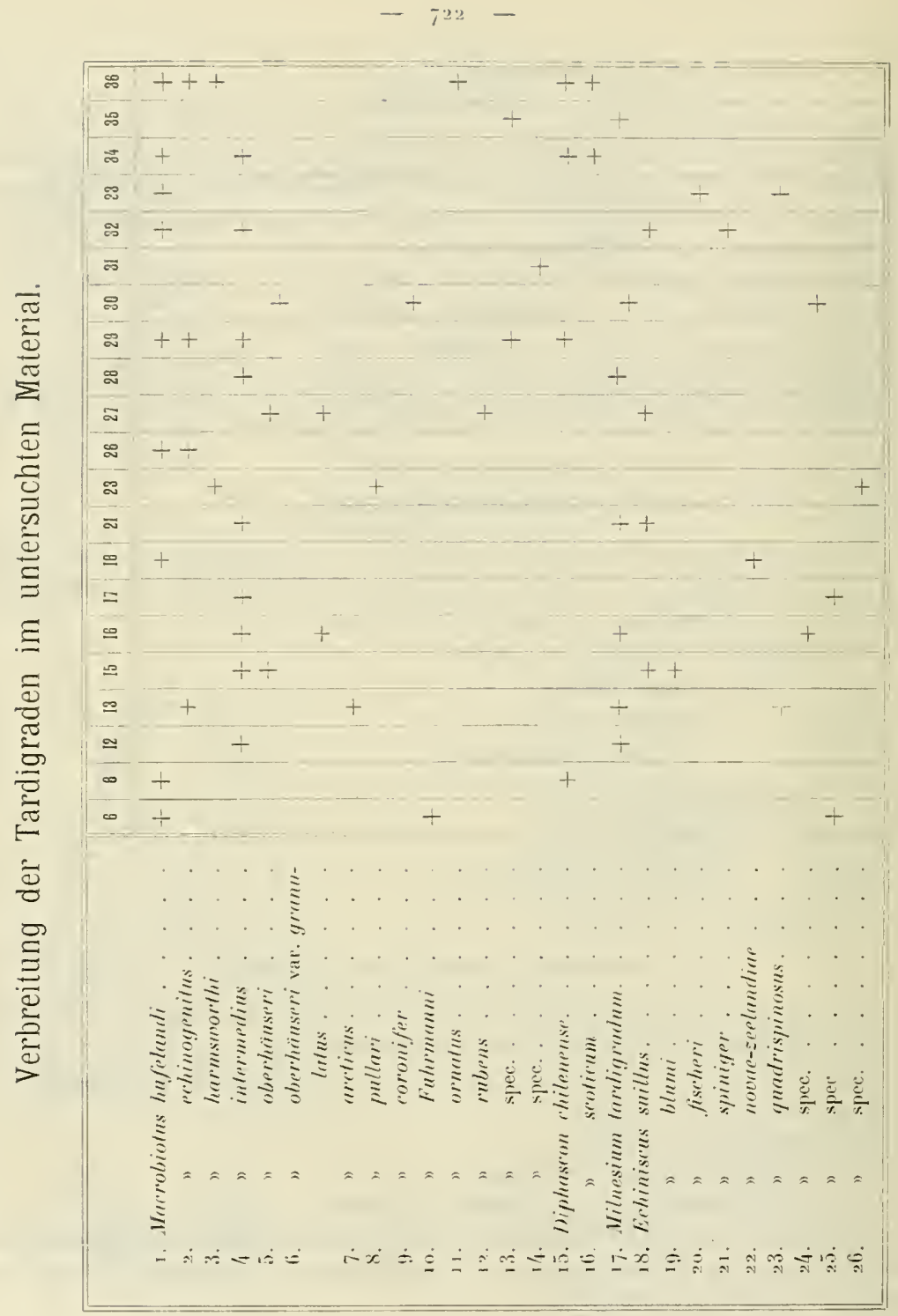


Verbreilung der Tardigraden in Sïdamerika

IV AME

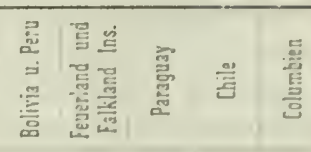

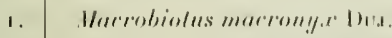

2.

3.

1.

5.

(i.

7 .

s.

!)

111.

11.

$1 \%$

13.

$1 /$.

i.i.

iti.

17.

1 เ่.

I!).

20.

21 .

23.

.3.

21.

n.

$\therefore$ i.

$: 7$.

2ล.

29.

31.

3.

3:?

33.

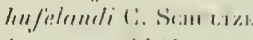

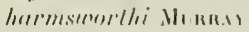

aresulalus Mrвn.tr.

erhimogenilus linomens

intermorlius Peste:

obrerhimseri l)

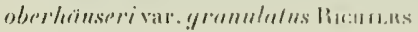

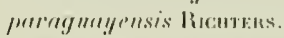

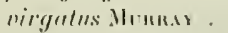

areliams Menasur

acridentulis Mrunus

rubens Muruily

nodosus Miтrus:

luberentalus Puar:

rormifore linatems

pullari Мгенан.

furcerlus Monray.

amdersoni Rucheress

Fuhrmanni nov. spec.

ornalus Ricutens.

Mluesinm lardigradum I).y.

biphascone rhilenense P'asts.

seolicmm Мromis

Erhiniscus suillas Panвo.

uendli Richtels.

bigfromululus Ricnum:

novne-zerlandien Ruatems.

fischeri Runters . .

inlermealims Mинату

hlumi liscutens .

1)udrispinosus lincutras.

spiniger licutens . . .

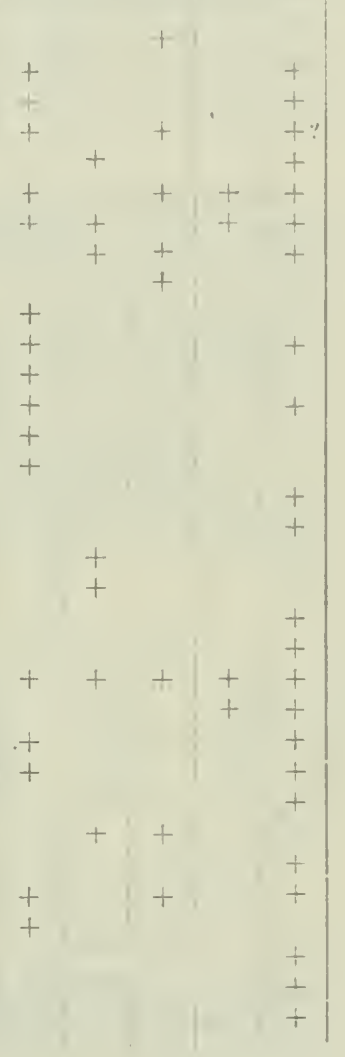




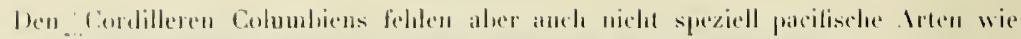
Eehiniscus notur-zeelandiae, und lucrobiolus oberhäuseri vir. granululus.

In Lebrigen verweise ich auf die Tibelle äber die Verhreitung der Tardigraten Südamerikas. In dieser Zusammenstelhng habe ich die durch die verschiedenen antarktischen Expeditionen von den luseln südlich Feuerland (Süd Georgien, Süd Orkney clc.) bekannt rewordenen Tardigraden nicht berïcksichtight.

\section{Andere Moosbewohner.}

\section{Infusoria.}

Den moosbewohnenden Infusorten schenkte ich weiter keine Aulinerksamkeit, doch fiẹ mir in Prohe 20 eine kleine Jebende Vorticelln auf, die als Vorticella picks Eurug. bestimust werden konnte.

\section{Nematoden.}

Fast die meisten Moosproben enthielten Nematoden; doch waren es gewöhnlich juvenile Exemplare. Aus einigen Proben conservierte ich die Tiere und äbergab sie

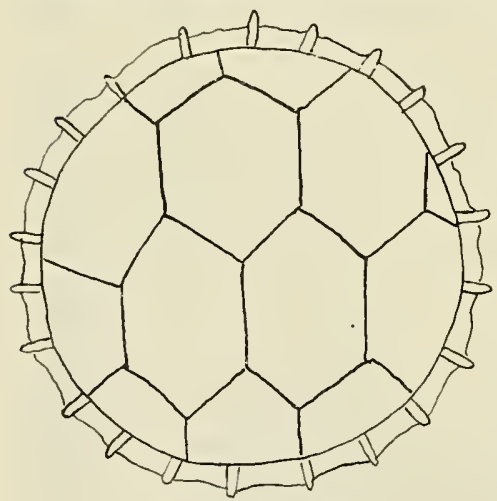

Fig. 47. - Milbenei? Herm cand. phil. R. Menzes, Assistent am zoolog. Institut der Universität Basel, der sich mit den freilebenden Nematoden beschäftigt. Hier nenne ich nur zwei seltenere und anffälligere Arıen :

\section{Bunonema reticulatum Richters.}

Aus Probe 17 montierte ich ein prachtvolles Präparat dieses aus Deutschland, Schotlland und durch miels aus der Schweiz bekannten Tematolen, den licnters in den Verhandluıgen der deutschen zool. Gesellschiaft 1905 beschrieben hat. Das Interessante an dem Tier sind die sedtsamen dorsalen Warzeupaare, welche die Gattum Bunonema charakterisieren. Diese Warzen sind aul' der Rärkenseite dureh zierliche Perlenreilien untercinander verbundeu, in der Weise, dass eine kreuzhandartige Zeichunng zustande kommt.

Plectus otophorus (od, auriculatus?) DE MaN.

Probe 12 enthielt einen Nematoden von $278 \mu$ Länge, der nach Aussage des Herm Mexzer, zu einer dieser beiden durch DE Man bekannten Arten zu stellen sein dürfte. 
3. Milben.

(liiv. 17 )

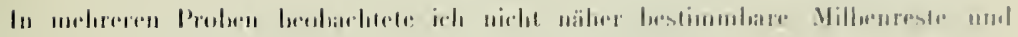
Xymilien.

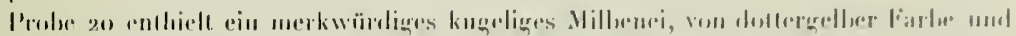

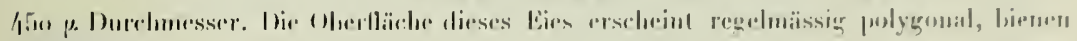

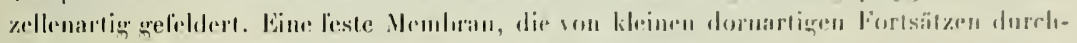

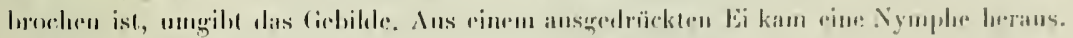

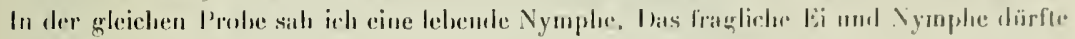
einer Oribatidenert angehören.

\section{Zusammenfassung und Schluss.}

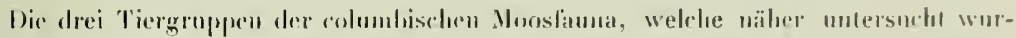

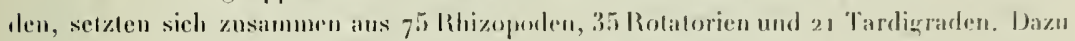

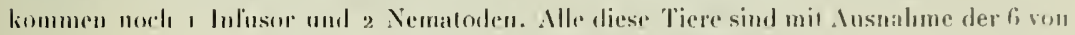

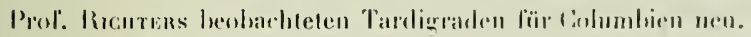

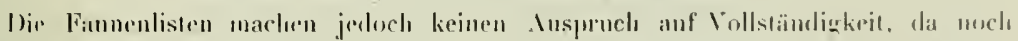

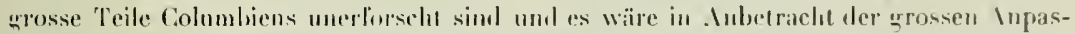
sungsfähigkeil der Mooshewohner nicht äberraschend, wenn die Zahl der drten - speziell ans den Cordilleren - sich hei weiteren Studien verdoppeln wïrde.

\section{Literatur.}

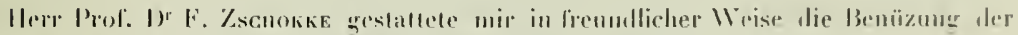
Bihliobhek des zonlogischen Institutes der Universität Basel.

\section{T. Rhizopoda.}

т. Casu, J. and Hopkissox, .. The British Freshwater Rhizopoda and Heliozoa. Printed for the Ra!y. Society. Vol. H. rgog.

2. Centes, A. Mission scientifipue du Cap Horn. Tome VI. Zoologie. r889.

3. Ilemss, F. Systematik und Biologrie der moosbewohnenden Rinizopoden, Rotatorien der Umgehenge von Basel. Atehir. f. Hydrohinhngie nud

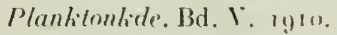

4. "Betragr zur lienntnis der centralamerikanischen Mooslauna. Revur suisse de Zootogie. Vol. rg. rg1r. 


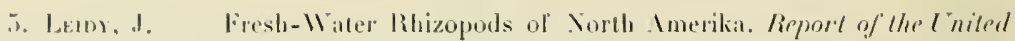
States geological Survey. Vol. 12. Is 79 .

6. Pexano, E. Études sur les Rhizoprodes d'eau donere. Mémoire Soc. Phys. et Hist. Nat. Cietève. Tome 31, 189 s.

$\begin{array}{ll}7 . & \quad 1 \\ 8 . & \quad 1 \\ 9 & \quad 1\end{array}$

Rocky Mountain Rhizopods. American Vaturalist. I 801.

Fanne rhizopodique du hassin du béman. Genèc, $190 \%$

Catalogue des invertébrés de la Suisse : Sarcorlinés. Mhusée d'hist. nal. Genève. $190 \overline{\text {. }}$

10. " On some Rhizopods from the sikkim Ilimalaya, Iourn. R. Micr. Soc. 1907 .

11. "Sur quelques Rhizopodes de mousses. Archiv f. Prolistentiunde. 13d. 17. 1909 .

12. Prann, E. Rhizopodes nouveaux, Reune suisse de Zool. Tome I8. 1!̣to.

13. "Notes sur quelques Sarcodinés. Revup suisse de Zool. Tume 20. IgI 2.

14. "Scolia " Collections. Further note on microscopic life on Gough Island, South Allantic Rhizopoda. Proc. Rony. Phys. Soc. Edinlurgh. Vol. 18. 1912.

15. " Rhizopode d'ean douce. British Antarctir: Exped. rgo7-9. Iol. I. Part. VI. I9I 1 .

16. Liscurbas, F. Fauna der Moosrasen des Ciaussherges und einiger südlicher luseln Deutsche Sïilpolar Exped. 19o1-3. Bd. (). Zool.

17. 1) Moosbewohner. Schwedischr Sïdpolarexpedition. Igor-3. Bd. 6. s

18. " Beitrag zur Kenntnis der Monsfauna Australiens mol der lnseln des pacif. Ozeans. Zool. Juhubïcher. Syst. Bıl. s6. 1908.

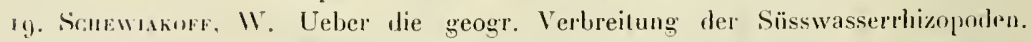
Mèm. Iead. Saint-Pétersbourg. Vlle série. Toune 4 १.

20. Schnuteden, H. Les Rlizopodes testacées d'ean douce, d'après la monographie du prol: S. Awerinzew. Amn. Biologie lacustre. Tome I, 1906.

21. Watles, Li-M. Report on the Rhizoporta. (Notes on the Natural listory of Bolivia and Peru by d. Mennay) Scollish ozfanographical Laboratory Edinburgh. s, r.3.

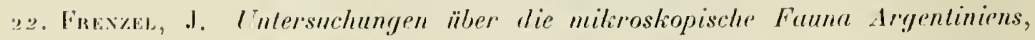
wrrl. Milllg. Arch. f. milir. Anatomie, Bde 38. $18 \mathrm{~g} I$.

23. Fufvzel, I. Intersuchungen über die milroskopische Fanna Argentiniens, 1, Prolozon. Bibliothert soologirn. Heft, 12. 18,2-97 (War mir nicht zugïnglich.) 


\section{Rolatoria.}

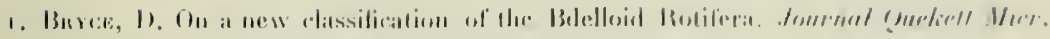
(ilul) 1 !) 111.

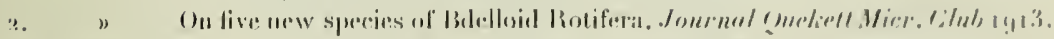

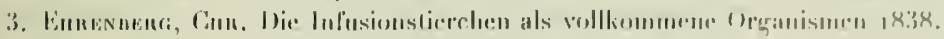

4. Nikrogreologie 185\%.

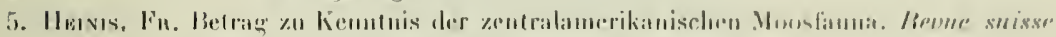
areorlogir. Vol. 1!), 1918.

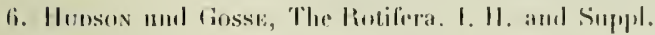

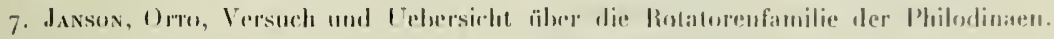

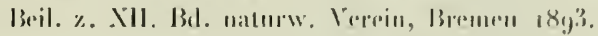

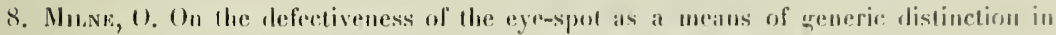

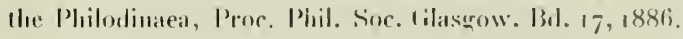

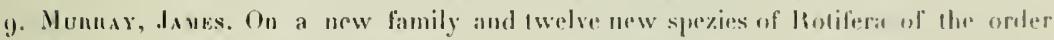

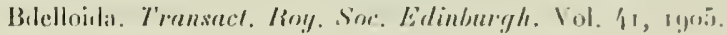

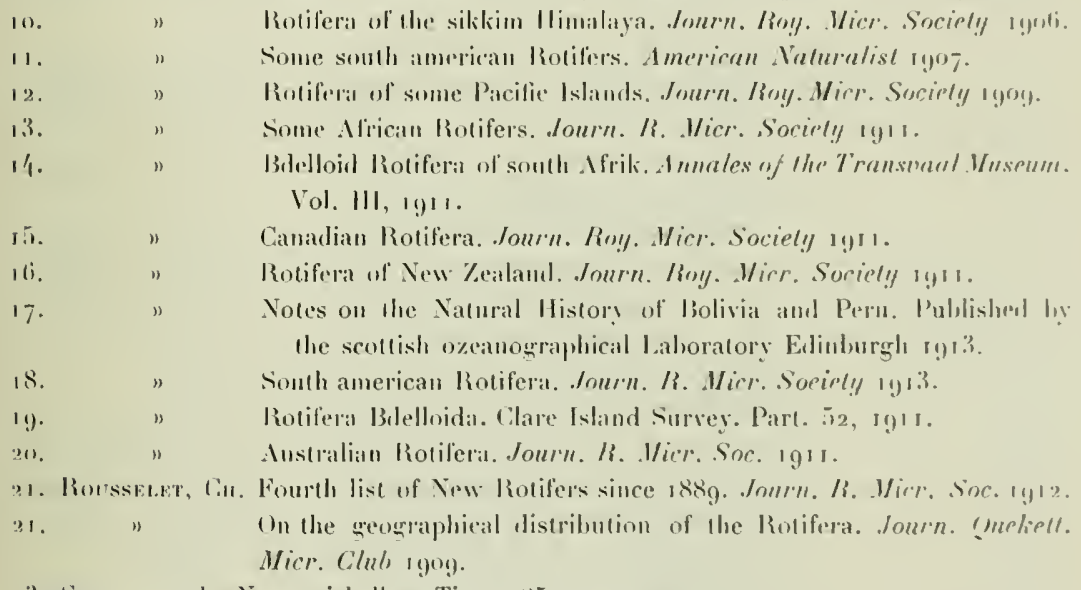

2.3. Scimanoa, L. Neue wirbellose Tiere 1859 .

24. Weber, E,-F, Faune Rotatorienne du hassin du Léman. Revue Suisse de Zonlogie. Bd. I. 1898 .

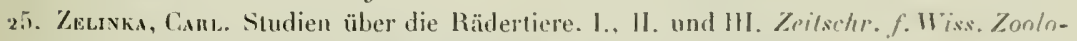
gie. Bd. 44. Bd. 47, Bd. 53.

26. Madar E. Intersuchungen über ,lie Süsswasser-Nlikrofauna Paraguars. Zuologica. Heft $44 \mathrm{Bd}$. 18 , 


\section{Tardigrada.}

1. DADAl, E. von. Untersuelungen über die Siisswasser-Mikrofauna Paragualys. Zoologica. Herausqueben von Chun. Bd. 18. Jeft 4/4. 1905.

2. HEINis, Fis. Rhizoporden, Rolatorien und Tardigraten der l'mgebung von Basel und der ïbrigen Selweiz. Archin f. Mydrobiologie und Plantitonkunde. Bd. V. 1910.

3. " Beilrag zur Kenntnis der zentralamerikanischen Mooslauma. Renne suisse de Zoologie. Bd. 19. 1910.

4. Munray, Jases. The tardigrada of the scottish lochs. Transact. R. Soc. Edinburgh. Bd. 41.1905 .

5. "Tardigrada of the south Orkneys. Transact. R. Sor. Erlinburgh. 13d. 45. 1906.

6. "Scottish Tardiglada. Transact. R. Soc. Edinburgh. Bd. 45. 1907.

7. $\quad$ Iretic Tardigrada. Transact. R. Soc. Edinburgh. Bd. 45.1907.

8. "Some Tardigrada of the Sikkim Himalaya. Journ. R. Micr. Soc. 1907 .

9. 1 Some south African Tardigrada. Jomrn. II. Micr. Soc. 1907.

10. "Tardigrada. Bpitish, antarkt. Experl, rgo7-9. Vol. I. Biologie. Part. V. 1910.

11. Notes on the natural History of'Bolivia and Peru. Scottish ozeangogr. Laboratory Edinburgh. 1913.

12. African Tardigrada. Jourm. R. Micr. Soc. 1913, 1. 136-144.

13. Plite, Luow. Beilräge zur Nalurgeschichte der Tardigraden. Zoolog. Jahrb. Bd. 3. Inatomie 1889 .

14. Ricnters, Fend. Beitr. z. Verbreitung der Tardigraden im südl. Skandinavien und an der mecklenb. Küste. Zoolog. Anzeiger. 1905.

15. Antarklische Tardigraden. Zool. Anzeiger. Bd. 3 r. rgo7.

16. " Die Fauna der Moosrasen des Taussherges und einiger südl. Inseln. Deutsche Südpolarexped. 1901-3. Zoologie. Berlin 1907.

17. B Beitrag zur lienutnis der Moosfauna Australiens und der Inseln des pacit. Ozeans. Zool. Juhrb. Syyst. Bd. 26 . 1908.

18. " Moosbewohner. Wiss. Ergebnisse der schmedischen Südpolar: Experl. $1901-3$. Bd. VI. 1908.

19. "Tardigradenstudien. Ber. Sentenberg. Nat. Ges. Frankfurt a;M. Igog.

20. " Südamerikanische Tardigraden. Zool. Anseiger. Bd. 38. 1911.

21. Moosfauna. Avifauna Spitzbergensis. Herausgegeben von Prof. A. Kienıg. Bonn 1yı 1 . 


\section{Figurenerklärung.}

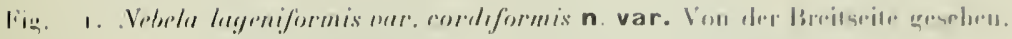

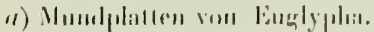

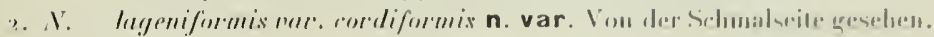

3. V. cerlesi Plavam. lixp. linlurmann.

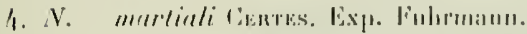

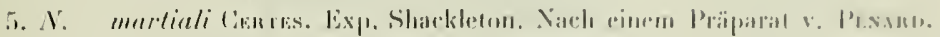

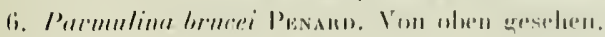

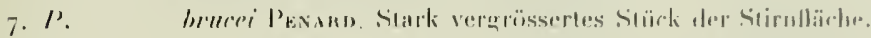

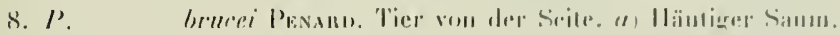

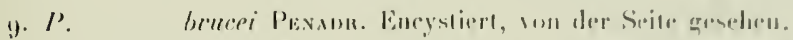

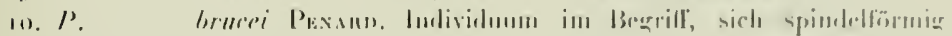

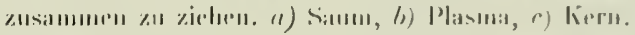

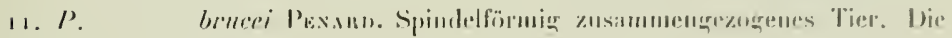

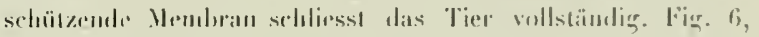
7. 112, Hach P'Esalis.

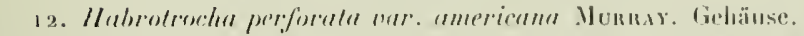

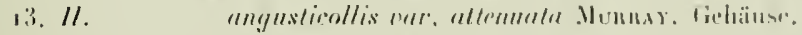

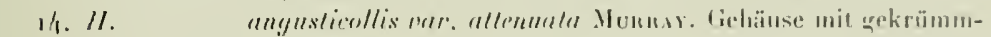
tem Ilals.

15. II. angusticollis Munms. Ahmornes (iehäuse.

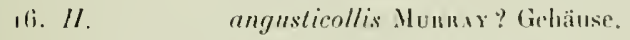

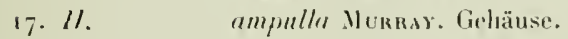

18. II. Fuhmanni nov. spec.

1!). II. Fuhrmanni nov. spec. Seitersansicht des Finsops.

20. II. Fuhrmami nov. spec. Kauaplaral.

3. II.

22. II. sper. Kanaplatral.

23. Callidina multispinosa var. massispinosa Murur.

24. C. mullispinose Thompsox. Vinteläl.

25. C. mullispinosa Thompsox. Varietial.

26. C. multispinosa Thompson. Varielät.

27. C. mullispinose Tumusox. Varieläl.

28. C. spec.

?). C. spec. Fuss.

30. C. spec. Lauapparat.

3. C. sper.

3.2. (.. spec. 
Fin. 33. Rotifer quadrangularis nov. spec. Mie Detrilusteilchen anf den Patten und am lö̈per sind weggelassen.

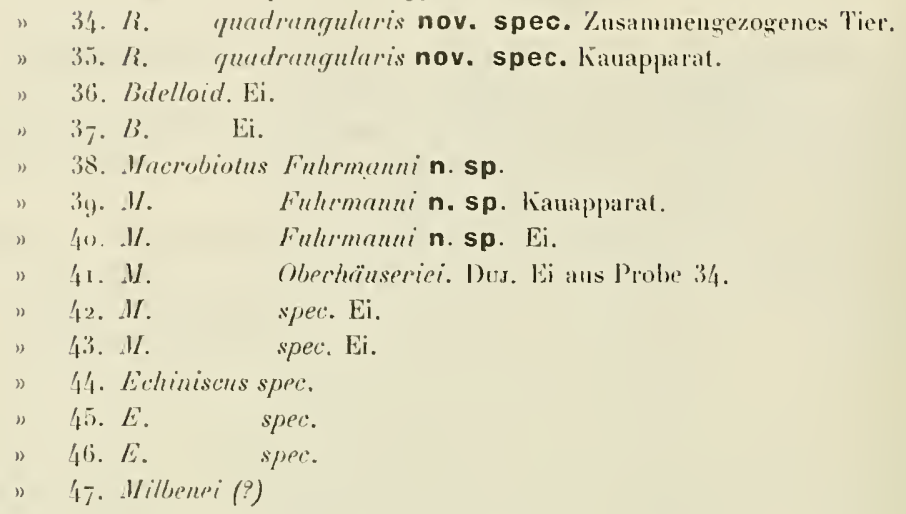




\title{
Hirudinées colombiennes
}

1314

\author{
MAURICE WEBER
}

Assistant at Laboratoire de Zoologic (Neucluatel)

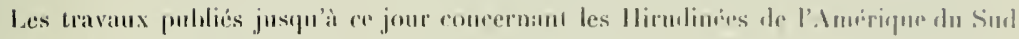
sout reclativement peu nombreux.

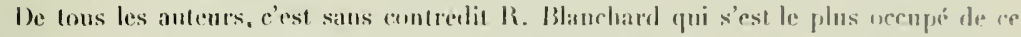

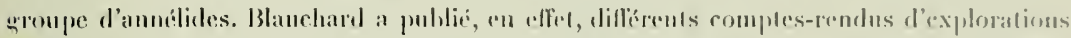
sud-americanes contenant les déterminatiuns des lliruelinces recoltios 11 me suffira de

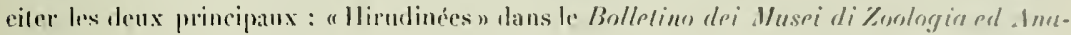

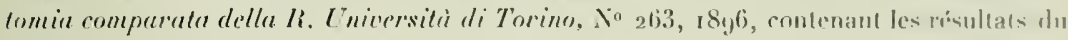

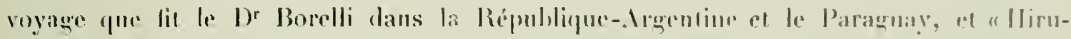

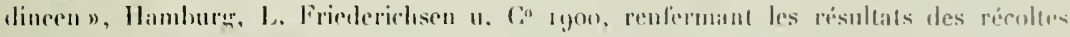

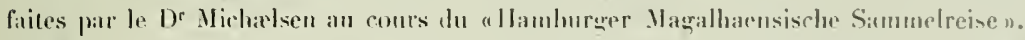

Mais nos connaissances sont loin d’ètre completes eneore au sujel de la fame hiru linénne de l'Amćripue du Sud, d’autant plus que le plus eqramb nombre des esperces connues en dieriles proviennent des còtes ou tont au moins de l'embonchure des lleuses. Dusclques récoltes unt pourtant fité faites à l'intérienr, mais toujours an bord des rivières ou dans les

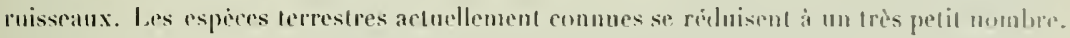

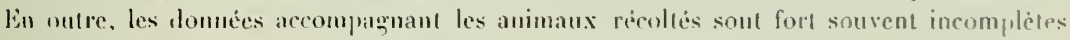
of reudent difficiles les déteminations, sims compter avec les difficultés de la classification provenant de la synonymie, extrèmenent compliquée chez les Ilirulinécs. Malgré le momhre restreint de travanx publicis, la meme ispece est déerite sous 20 on 30 noms diffïrents, el très sourent aussi les types, qui pourraient faciliter grandement le contrüle les déterminations antérientés, n'ont pas été conservés. - Il n’existe, à ma connaissaner du moins, ancun travail trailant spécialement des Hirndinces colombiennes. On trouve ici

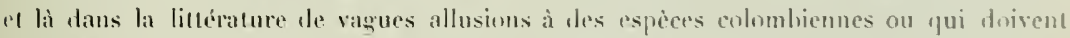
anssi se tronver en Colombic. Itais les quelyues apèces connes proviennent fontes des cites mu dimbouchure des llenves et se retrouvent d'ailleurs un peu partout dans l'Amrique du Sud. Je tiens donc à remercier spécialement M. le Dr Fuhrmann qui a bien 


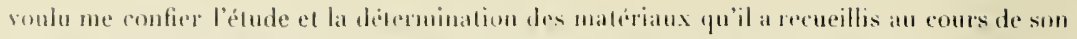
voyage dins res régions el me permeltre de contribuer ainsi it la eommassance de celle partie de la fimure colombionue. La collection du lor linhmann comprend des aspices

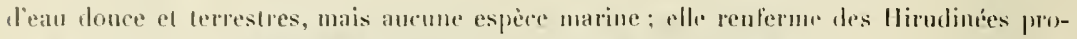
venant de dix stations dillérentes, domt les altiludes varient de $1800 \mathrm{~m}$, a $3800 \mathrm{~m}$. Celle collection comprend an total 1' s esperes, rentrant dans 4 genres. Il y a a respices unuvelles el 1 nouvean genre. Hais ce gui rend surtoul interessantes et précieuses les récoltes

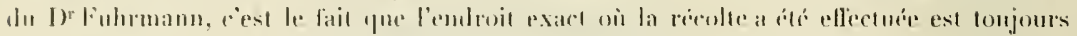

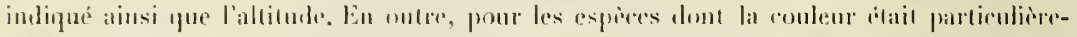

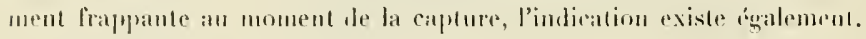

Comme moven de contribe de nos determinations, nous mons summes adressi an

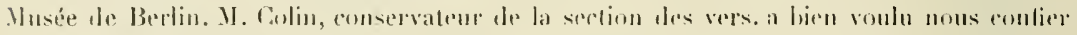

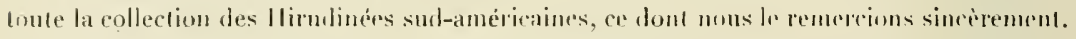

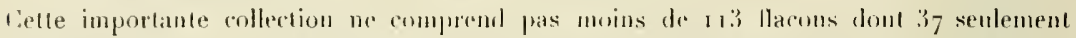

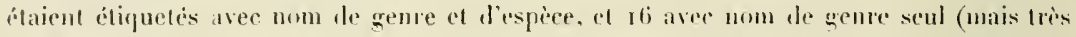
souvent faux). Il en restait done 60 sans autre indication que la provenance. Lílude de res matériaux n'eat pas encore complètement acherée, pourtant elle peruet déjà de faire quelques considérations intéressantes. J'ai été très leureux de constater que la collection entière ne renferme qu'un seul lol colmmbien, et, re qui rst plus intéressant encore, qu'aucun. des espèces de la collection Fuhrmann déterminćes comme nouvelles, ne se retrouve dans la collection de Berlin.

Tous nos remerciements aussi à M. Le directeur du Nusée de Ifambourg qui nous a forl obligeamment envoré en communication la enllection d'llirudinces provenant du voyage du Dr Miedrelsen en Amérique du Sud.

Nous voyons done que, pour le moment da moins, la faune liruclincenne colonbienne occupe une place à part el semble, dre plus, riche en aspeces lerrestres. II n'est pas doutenx que des recherches subséfuentes nous fourniront plus d'une domée intiressante concernant ce groupe.

Voici la liste des Hirudinées sud-américaines actuellement décrites, à laquelle vienuent s'ajouter les dix espèces nourelles de la collection fuhrmann.

\section{Lisle des Hirudinées sud-américaines.}

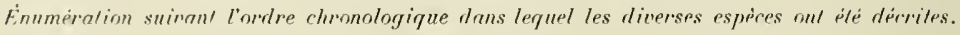

1. Helobdella slagnatis Lixiné, I 758 .

2. Liostomum concincum WVAGLI, 3831 .

3. Liostomum ghilirenii, F. DE FiLIPPI, 184 !̣.

4. Helobdella triserialis Em. Buaxchanu, 1849

5. Mesobdella gemmata Em. Bisxcmand, 1849. 


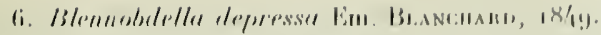

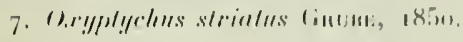

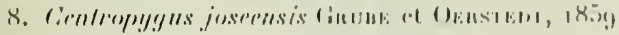

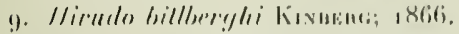

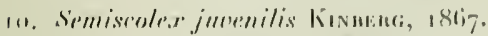

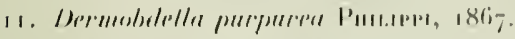

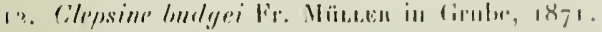

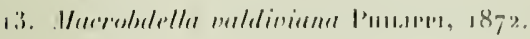

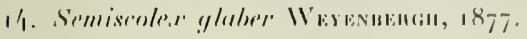

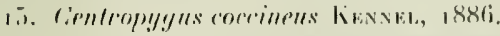

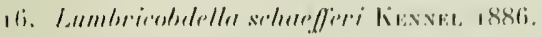

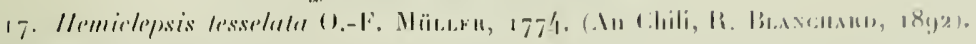

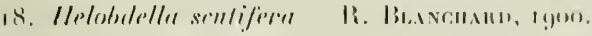

\begin{tabular}{|c|c|c|c|}
\hline$"$ & gr'murnertar & $"$ & 19 \\
\hline$"$ & mirlharesermi & $"$ & \\
\hline$"$ & rhilensis: & $"$ & \\
\hline \multicolumn{2}{|c|}{ Truelueloblellu uns/rulis } & $"$ & \\
\hline \multicolumn{2}{|c|}{ Somisenles merabilis } & $"$ & \\
\hline \multirow{3}{*}{\multicolumn{2}{|c|}{ 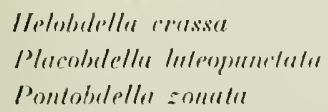 }} & Aratis, & $19 n$ \\
\hline & & $\cdot n$ & \\
\hline & & $"$ & \\
\hline
\end{tabular}

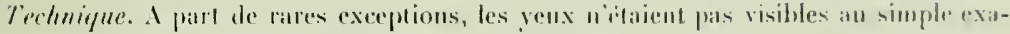

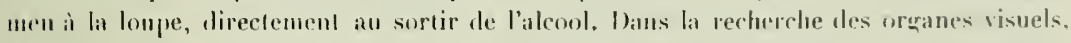

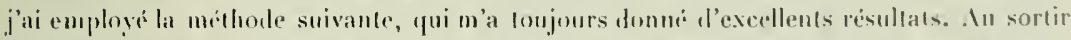

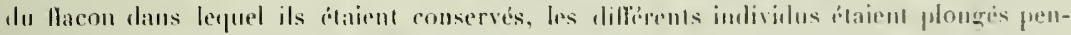

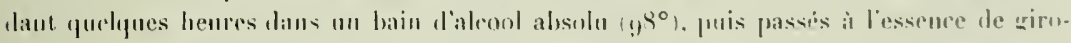

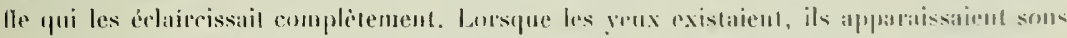

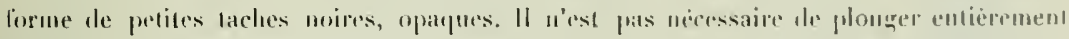

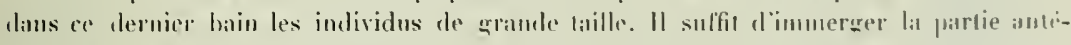
ricule du corps.

\section{Hirudinées de Colombie}

\section{A. Hirudinées aquatiques (d'eau douce).}

Les Hirmdinces aquatiques rapportés de Colombic par le Dr Fuhruamu provienneme le 2 stations: 1. Latgunu Pedropulo (all. 2000 m.) et 2. Rinissean priss de Bora del

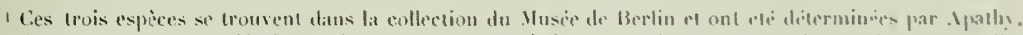

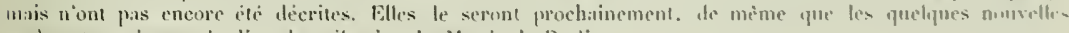
especes trouveres en indiant la collection du Musce de Berlin. 
1/onte, dums la Cordillire orientule, it 2 fon m. d'ull. Elles appartienneut loutes an quente

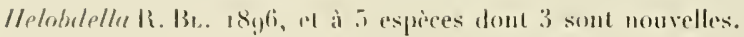

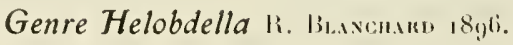

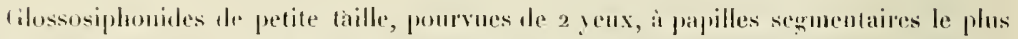

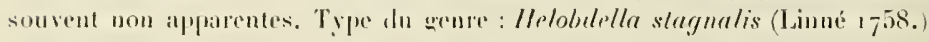

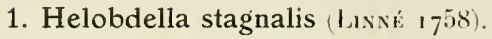

Synonymie: Mirulo staynalis L. 1758 . Quinze exemplaires d'un ruissean près de Bucir del Nonte, dont quelques-mus aver des anl's. Le plas grand excmplaire mesure 1.2 mu. de long et $4,5 \mathrm{~mm}$, de large.

Tous ont la lache dorsale noire bien marquece.

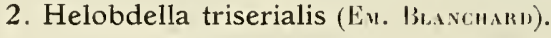

- Synonynie : Glossiphonia Wiserialis Es. BL. 1849. - Clepsine triserialis Gnun 1859 . - Clepsine lineolata Gruвe 1871. - Helobdella lriserialis R. BL. 1896. - Trentering exemplaires de la Laguna P'edropalo dont 3 portent des coufs.

I'ai eu sous les yeux les exemplaires types du Nusée de Hamhourg, provenant de l'expédition du Dr Michielsen dans l'Amérique du Sud.

Par suite de leur long sijonr lans l’alconl, ces individus on complètement perdu leur culoration primitive, et seuls quelques tubercules sont encore frérèrement visibles. Mais, sauf la coloration, tous less caractères extérieurs coüncident.

Certains individus sont presque entièrement bruns à la face dorsale, d'autres présentent plusieurs bandes hrunes séprarées par des raies claires, d'autres entin sont tachetés le brun noir et de blanc jaunàtre. Chez tous, m voit nettement les différentes rangées le tuhercules dorsaux, et chez tous également, la fare ventrale iest de couleur blanc jaunàtre ou grisàtre absulument uniforme.

\section{Helobdella columbiensis n. sp.}

Linq exemplaires d'un ruisseau en dessous de Boca del Monte. Le corps présente muroloration particulièn, se rapprochant de certains exemplaires de Helobrlella lriserialis. La face torsile rst partagée en 33 baudes tongitudinales tris nettes dont 7 jaunatres er (i) intemédiaires gris noiràtue. La bande claire médiane ualteint pas l'extrinité anté- 


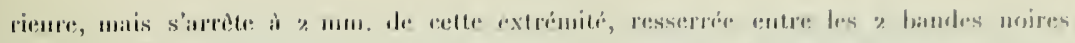

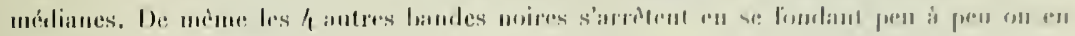

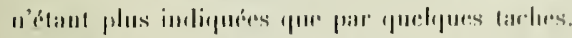

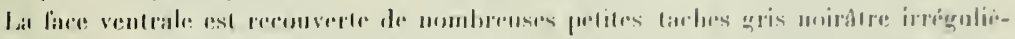

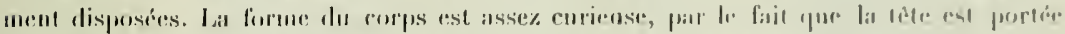

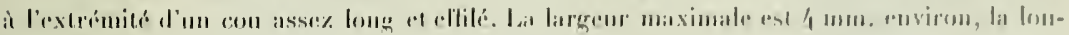

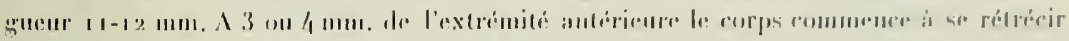

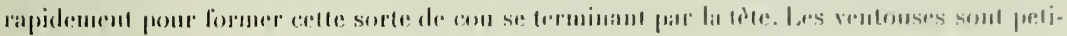

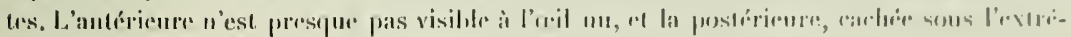

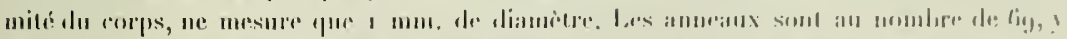

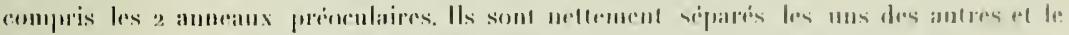

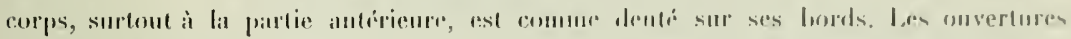

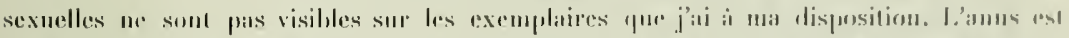

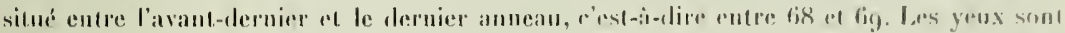

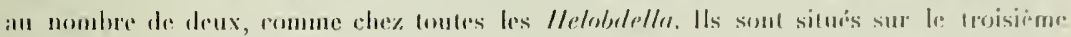

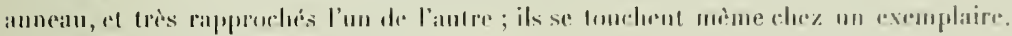

\section{Helobdella fuhrmanni n. sp.}

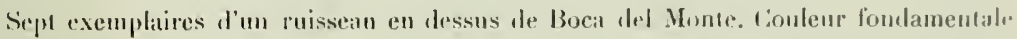
jannàtre aver un hande médiane noire, allant de la ventouse antéricure à lis ventomate postérirure. En outre, de change crite de cette bamle midiane, 1 on 2 traits unirs, lieanconp plus lins, paralleles aux 2 bords, allant anssi d'une extrémité í l'antre, et plus on moins visibles snivant has individus. Ia conlenr jannatre londamentale est presque entiorment eache par de nombrenses taches et par des points très fins qui donnent ansi a tout le corps une coloration grisitre. La face ventrale est d'un gris uniforme, saul quelques points noirs à peine visibles.

Le corps a une forme très caractéristique. Il est en elfet beaucoup plus Large it la partie míliane gu’aux deux extrémitis (fig. 1). La partie antérienro ist plus longue et plus effilée] que la partie postérieure, qui est pourtant lortrment rillécie aussi. La longuenr totale varie de 8 a 11 mm. La largeur maximale est de 3 i 4 mm. tandis que la partic posterieure du corps ne mesureque 11 gmm. et la partie antérieure I mm. à peine (mesures prises sur l'exemplaire le plus (ypique \&̀ $1,5 \mathrm{~mm}$. de chilpue extrémité).

Les rentouses sont circulaires et tris petiles. Lintérieure se distingue í peine à liail nu, la postérieure, entièrement eachír sous l'extrémiti du corps, mesure $1 \mathrm{~mm}$. de diamidre.

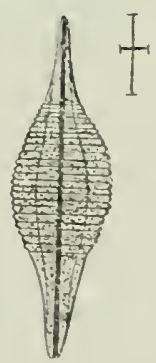

Le nombre des anneamx est de 68, y compris les a anneaux préoculaires. Ces anneaux sont lies netfement sépares les uns des autres et doment au corps, surtout à la partie módiane, l'aspect d'une lame de scie dentic des deux cibés. les dents álant un peu imoussces. 
Les ouvertures sexuelles ne som malhemrensement pas visibles. L'anus est situí entre les anneaux 66 el $t_{7}$.

Les rens sont an nombre de denx, disposés sur le troisieme annean, et methmont siparés l'un de lautre.

Parmi les 7 individus recueillis par le Dr Fulumann, il s'en trouve 2 portant des arufis a la face ventrale, trroupés en une plaque qui orcupe toute la partir médiane du rorps. Lin troisieme exemplaire portitit des jeunes qui se sont malheureusement détaches l'un apress l'autre, par suile du long séjour dans l’alcool.

\section{Helobdella hemispherica n. sp.}

In seul exemplaire de la Laguna Pedropalo.

Le corps du sent exemplaire de cette espèce est de couleur brun foncé uniforme. La firce rentrale est absolument de mème teinte que la face dorsale, et on ne distingue incune tache quelconque, mème sous un fort grossissement.

Cetle hirudinée de petite taille est eurieuse non seulement par sa couleur, mais encore par sa forme globuleuse, presque aussi large que longue. Le corps mesure en elfel 4, $5 \mathrm{~mm}$. de longr sur $4 \mathrm{~mm}$. de large. L’épaisseur est aussi relativement forte, $2 \mathrm{~mm}$. Le corje a done presque exactement la forme d'une demi sphìre, la face ventrate étant aplatic tandis que la face ilorsale est fortement bombée, re yui est dì sans doute à une furte contraclion.

Les ventonses sout naturellement petites. L’antérieure, circulaire et terminale, dépasse un peu en avant. Elle n'est d'ailleurs visible qu'à la loupe. La postérieure, au contraire, est

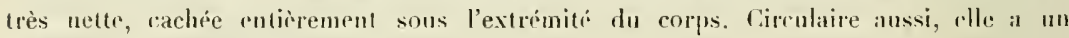
diamètre de $1 \mathrm{~mm}$.

Les anneaux sont très nets, mais très fins. Leur nombre est assez difficite à itablir cxactement à cause de cette forme globuleuse du corps et de la petitesse de l'individu. J'en ai compté 66 , y compris l'anneau préoculaire. Les pores sexuels sont absolument invisibles mème sous le plus fort grossissement.

L'anus par contre, bien visible, est situé dorsalement entre les anmeaux 65 et 60, c'est-à-dire entre l'avant-dernier et le dernier.

Les yeux, au nombre de denx, sont petits mais neltement séparís l'un de l'autre. Ils sont disposès sur le denxième anneau.

\section{B. Hirudinées terrestres.}

Les Ilirudinées terrestres rapportées par le Dr Fuhrmann proviennent des 8 stations suivantes :

Bogota, Cordillères orientales, altiade $2560 \mathrm{~m}$.

Boca del Monte, Cordillices orientales, \# $2500 \mathrm{~m}$. 


\section{$7: i 7$}

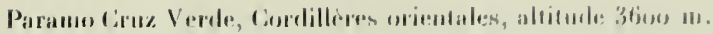

Tambu

Camelia

Pissige du lini\% " " "3800

reill rialish, "

1200111.

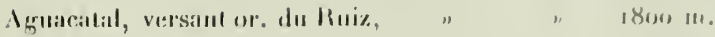

Calcal Suiza pres 'Tilirili, " "

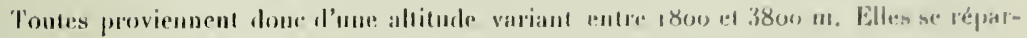
tissinl en 3 genres, dont un unuvent, et g esprices, dont 7 monvelles.

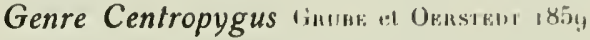

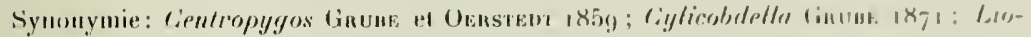

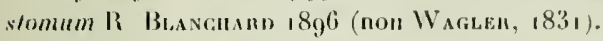

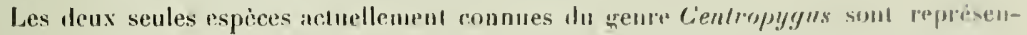
lées dans la collection Fulımann.

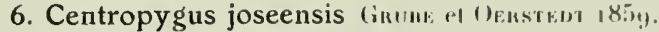

Synonymie: Cientropygos jospensis dir. el Oens' 18ig. Cientrop. jocensis lih. w

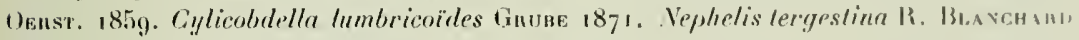
1892 . Liostomum joseense (Grune al Oenst. 185g). R. BL. 1896.

Trois rxemplaires récoltés près de Bogota, dont deux mesurent 89 mul, de long et l. troisiène $50 \mathrm{~mm}$. Les 3 ont ume. largeur maximale de 4-4,5 mm. On ne comblate clie" :ucun une anomalie dans la posilion des ouvertures sexuelles.

\section{Centropygus coccineus Kexsel 1886 .}

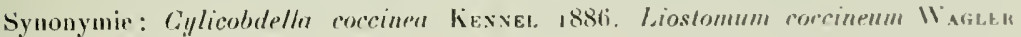
183 i, apud R. BL. 1896 .

Trois exemplaires aussi, récoltés l'un ì l'A guacatal. à $1800 \mathrm{~m}$. d'altitude, un aure an rafetal la Camelia, ì r $800 \mathrm{~m}$., le troisième à la Suiza, à la mème altitude de 1800 m. Ce: 3 exemplaires, d'un beau rouge à l'état vivant, ont perdu leur coloration primilive. La couleur dans l'alcool est maintenant jaune brun assez foncé. Le nombre total des anneaux varie de $\mathrm{I}_{2}$ à 104 , ainsi que l'indique déjà Kexwe dans son travail Lẻebr einig Landblutegel des tropischen America. "Zoologischen Jahrbüchern. Zweiter Bd. 1886. "Chez. l'un des exemplaires les pores sexuels sont aussi sitnés respectivement entre les anneaus 
ventrans 27 et 28 el sm l'anneau 30 . Lil longueur du cosps varie de 27 à 36 mm., la largreur de 3 à 3,5 mum.

Remaryue concernant les denx especes du genre Centropygus. - On trouve les Hirndinées se rallachant au genre Centropygus dans le bois pourri ou dans le sol, vivant absolument conme des vers de terte. Elles s'en distinguent à première vue par leur coulenr ronge opaque et par les ventouses de leurs extrémités. Mais je n'ai pas été peu surpris en consultant les différents traraux concernant ces espèces, de constater qu'au font, elles ue sont parfajtement définies ni l'une ni l'antre. L'une atteignant une longueur le r $145 \mathrm{~mm}$. serait le Centropygns joseensis, l'autre, plus petite (vigue), serait le Centropygus coccineus (nom provenant de sa couleur rouge vif à l'état vivant). Où les cho‘es se gàtent, éest lor'squ'on a affaire à des exemplaires conservés dans l'alcool sans indirittion de la couleur qu'arait l'aninal à l'état vivant. C'est justement le cas pour la plus grande de ces denx Hirudinées $C$. joseensis. Nulle part dans ancune publication, il I'existe une indication de la couleur à l'état vivant. Blaxcuand lui-même avoue, après avoir śtudié une trentaine l'exemplaires provenant dn Musée de Berlin, que malheurensement l'indication de la couleur manque partout. Dạns les deux espèces le nombre des anneaux est le mème, 103 chez joseensis, 102-104 chez coccineus (les nombres penvent d'ailleurs varier dans d'aussi étroites limites). Pas d'yenx, mème position des pores sexuels, unème aspect des anneaux, mène forme des ventouses. Les seules différences d'ordre morphologique seraient done la taille et la conleur, chacun remarquera d'emblée que la différence de taille ne signifie plus rien si les exemplaires comparés sont d'ages différents. La couleur dans l'alcool est à peu près la mème pour les deux espèces. Fort heureusement, II. Funmans a rapporté de Colombie six exemplaires de ce genre Centropygus et pour claque exemplaire il a indiqué la couleur au moment de la capture. Ronge cinabre clair pour trois exemplaires, rouge vif pour les trois autres, de taille plus petite. Nous avons done la preuve indiscutable que la différence de couleur se réduit à une diflérence de unance pouvant parfaitement bien provenir, soit de l'àge, soit des conditions particulières dans lesquelles vivait l'animal. Une simple étude morphologique ne nous permet done pas actuellement de trancher la question en faveur de l'une ou de l'autre des espèces. Il existe très probablement de petites différences anatomiques, si vraiment les espèces sont dillérentes, mais lorsqu'on à affaire à un exemplaire unique ne pouvant par conséquent ètre sacrific pronr une dissection, la déternination exacte est très difficile, sinon impossible.

\section{Blanchardiella nov. gen.}

Ce nouveau gente oceupe une place très voisine du genre Centropygus (Grube el (Erstent $185 y$ ). Les espèces s'y rattachant sont en effet terrestres; en outre, la venLouse antérieure est dépourvue de mâchoires et la forme du corps est souvent très semblable à celle des Centropygus. Mais la création de ce nouvean genre me semble pleine- 


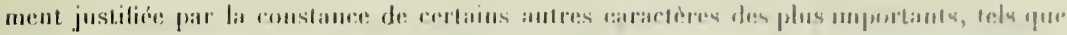

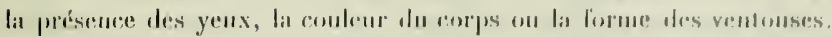

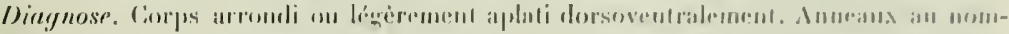

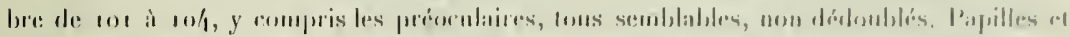

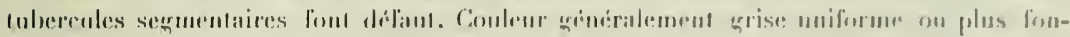

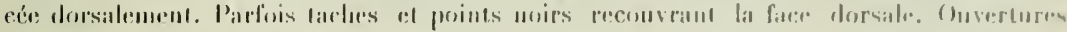

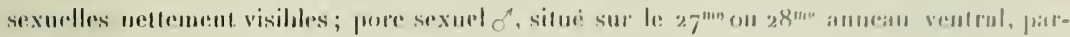

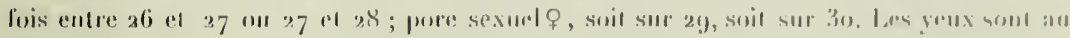

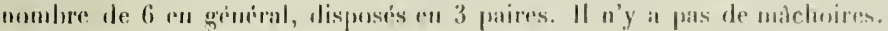

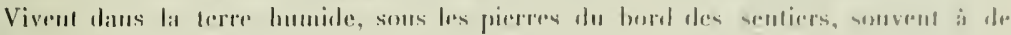
hantes altiludes en ciolombice.

\section{Blanchardiella fuhrmanni n. sp.}

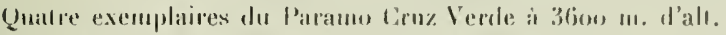

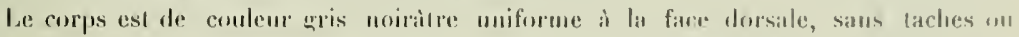
hambes plus claires on plus lonerese. La lace ventrale est d'un gris sale plus rair, mais unilorme également.

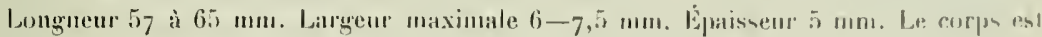
aphati ventralement, fortement hombe dorsalement.

Les ventonses sont très caractéristiques. Lantérieure est très pelite, allongée en forme de cuillìre, longue dr 1,5 mm., larga dr 1 mm. La postérieure, par contre. est énorme, nellement séparée de la face ventrale du romps. I la face dorsile, par contre, la ventouse semble ne pas exister al les sillons séparant les differents anneaux se voient aussi très nellement sur la ventouse, quoiqu'un peu moins accentués. Le corps se termine ainsi par une partie large, il est presque coupé à angles droits, la ventouse étant reclangulaire, vue de la face dorsale ef contractée par l'alcool. La face ventrale est toute différente. La reutouse est nettement séparée du

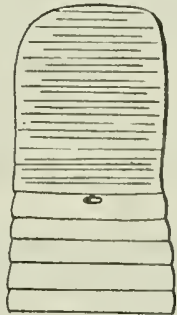

Fig. 2. - Blan. chas diella fuhrmanni nov. sp. Ventouse postérieure (face dorsale).

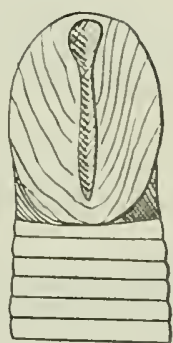

Fig. 3. - B'antchardiella fuhr. manni nor. sp. Ventouse postérieure conlractee (face ventrale).

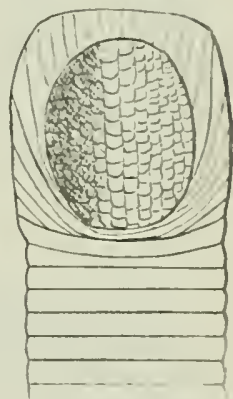

Fig. 4. - Blancharditlla fulvmanninor. sp. Vellouse posle. rieure élalée (face ventrale). corps. Contractée, elle est reclangulaire, un peu arrondie aux deux extrémités et repliée de façon à ne laisser voir qu'une fente longitudinale très étroite. Elle mesure $7-8 \mathrm{~mm}$. de lonqueur. sur $5-6$ de 
largenr. Si on étale les deux bords repliess vers l'intérieur, on obtient alors la ventouse telle qu'elle est lorsque l'animal se fixe à un ohjet. Dans cette position, la ventouse se remarqu' inrsalement déjì, étant plus large que le corps. Vue de la face ventrale, elle représente un carré de 8 mum. de coté environ. Ce carré est formé par un fort repli cutané qui rntoure toute la ventonse comme d'un anneau. L'intérieur est cireulaire et d'aspect pavimenteux. (Fig. 2, 3 et 4.)

l.es anneaux trè distincts sont an nombre de 102 , y compris les deux anneaux préo-
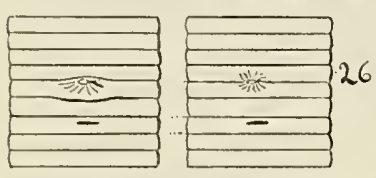

Fig. 5. - Blanchardiella fuhrmanni nov. sp. Partie de la face ventrale monIrant 2 dispositions dn pore sexuel of.

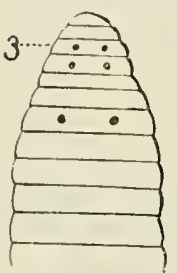

Fig. 6. - Blanchar diella fuhrmanni nov. sp. l'arlie an. térieure (dorsale) avec les yeux. culaires. Ventralement, on en compte $y^{6}$. En outre, la ventouse postérieure est aussi annelée clorsalement, mais les sillons sont moins profonds que sur le corps de l'animal et les deux bords ue sont pas festonnés. On compte 10-12 de ces anneaux, dont plusieurs partagés encore par un sillon plus fin.

Les pores sexuels sont disposés conmue suit : Pore sexuel of sur le $27^{\text {t }}$ anneau ventral, mais très près de l'amean 26 . II se présente sous forme d'un petit orifice entouré d'un bourrelet a cheval sur tes anneaux 26 et 27 ou empiétant seulement'sur l'anneau 26. Plusieurs petites stries convergent vers l'oritice. Le pore sexuel ㅇ est une petite fente située deux anneaux plus en arrière, c'estì-dire au milieu de l'anneau 29. (Fig. 5.)

L'anus est situé dorsalement entre le demier anneau et la ventouse, éest-à-dire entre le $102^{\circ} \mathrm{du}$ corps et le $1^{\mathrm{er}}$ de la ventouse postérieure.

Les yeux, au nombre de 6 , sont disposés par paires, sur les anneaux : 3, 4 et 7 . Its sont bien nettement séparés les uns des autres et assez espacés. (Fig. 6.) Le corps ne présente ni tubercules ni papilles segmentaires permettant de distinguer les différents somites.

\section{Blanchardiella cameliæ n. sp.}

Six exemplaires de la Camelia, à $1800 \mathrm{~m}$. d'altitude.

Corps de couleur' gris jaunâtre, absolument uniforme à la lace ventrale, gris noiràtre à la face dorsale. Aucune tache ni aucune bande ne sont visibles sur l'animal conservé dans l'alcool. Le corps des 6 exemplaires mesure de $30 \mathrm{~mm}$. à $45 \mathrm{~mm}$. Il est large de $2 \mathrm{~mm}$. à $4 \mathrm{~mm}$. à sa partie médiane, se rétrécissant aux deux extrémités. L'épaisseur est de 2 aे $3 \mathrm{~mm}$.

Le rétrécissement de la largeur est surtout bien visible chez le plus grand individu, qui ne mesure plus que $\mathrm{I} \mathrm{mm}$. de large derrière"la ventouse antérieure et $2 \mathrm{~mm}$. devant la postérieure, tandis que dans la partie mediane la largeur est de $4 \mathrm{~mm}$. Les ventouses sont hien visibles, mais l'antérieure est très petite en forme de cuillère. La postérieure, par con- 


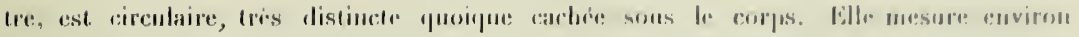
1 , 21111 . di diancìre.

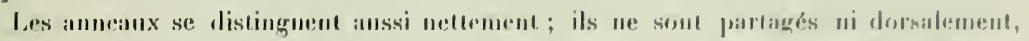

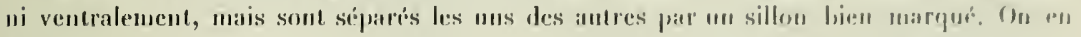
compte 103 dorsalement (y compris toujours les "3 prosulaires) al 99 ventralement. Ancune varialion d'un exemplatire à l'antre. la position des pores sexuels est la suivante: Pore sexuel of sul I.

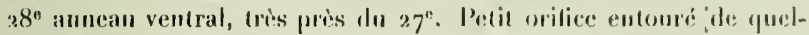
yues legers sillons y ahoutissant. Ouverture sexuelle 우, petite frente sur l'annem 30. (lïg. 7.)

L'anus est dorsal, placé dans le sillon sépatrant las anneaux 101 et 102, c'est-à-dire l'avant-dernier et le deruier. les yeux, enfin, sont an mombe de 6 . Ils sont disposis en 3 pares, nellement séparés ot visibles seulement après íclaircissement ì l'essence de girotle; ils se tronvent sur les anneaux 4, i el 7 . Les deux yenx de la $3^{\text {e }}$ paire sont passablement plus ícartés que ceux de la prenière paice. (Fig. 8.)

Ontre les 6 exemplaires de la Camelia, il s'en tronve encorr 1 de Bogota à $2560 \mathrm{~m}$. d'alt. el 4 de Tambo à 2200 m. Celui de Bogota mesure $39 \mathrm{~mm}$. de long et $3 \mathrm{~mm}$. de large, la couleur gristate de la face dorsale a presque entièrement disparn il le corps est de couleur uniforme gris jannàtre. Tous les autres caractères sont très nettement accusés.

Les 4 exemplaires de Tambo sont de taille un peu plus forts et mesurent de 4t-52 $\mathrm{mm}$. de long et de 3-4 à $\mathrm{mm}$. de large. Face dorsale un peu plus foncée que la face ventrale.

En résumé, les 11 exemplaires prísentent avec une grand. régularité les caractères suivants: 6 yeux sur les anneaux 4,5 et 7 .
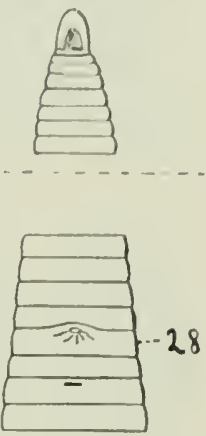

Fig. 7. - Esir. ant ventrale avec pores sexuels (Blanch. camelive) nov. ep.
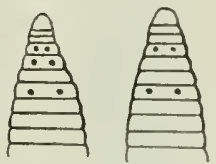

Fig. 8. - Exir. anterieure dorsale. Disposilion des yeur (Bl. camelice) nor. sp ro2 anneaux, anus entre ror ef 102 , ouverture sexuelle of sur es (contre 27), onverture sexuelle ㅇ sur 30 .

Il convient d'ajouter à cette liste? atutres exemplaires provenant: l'un de la Camelia, l'autre de Bogota el qui présentent nellement les caractères de l'espèce, sauf en re qui concerne le nombre des yeux.

Clrez l'exemplaire de la Camelia, on n'en compte en effel que 4 silués sur les anneaux 4 et 7 . Les deux de l'anneau 5 manqueraien

Chez l'exemplaire de !Bogota, les caractères spécitiques présentent de petites variations, qui ne me semblent cependant pas suffisantes pour motiver la création d'une espèce nouvelle. On ${ }_{\perp}$ compte 4 yeux seulement, disposés en 2 paires, mais il ne m'a pas été possible de déterminer leur position exacte par rapport au nombre des anneaux. Les anneaux sout au nombre de 102 (comme pour les 12 exemplaires précédents). L'anus est légère- 
ment déplacé ell avant; il est silué entre les anneaux 101 et to2. Les ouvertures sexuelles de meme sont tontes deux situées un anneau plus en avant, soit sur les ameaux 27 et 29, comme chez B. fuhrmanni. Il convient enfin de signaler un épaississement de la partie antéreure du corps, épaississement qui se fait sentir jusquà l'ameau 35 , et qui donne un aspect particulier au corps de l'animal.

Cet exemplaire dtant unique, il ne m'est pas possible de savoir si certains de ces caractères particuliers sont normaux on simplement accidentels.

\section{Blanchardiella bogotensis $\mathbf{n} . \mathbf{s p}$.}

Sept exemplaires de Bogota, à $2560 \mathrm{~m}$. d'altitude.

Ces 7 exemplaires appartiennent évidemment au mème gaenre que l'espèce précédente, dont ils se distingnent pourtant par les différents caractères suirants qui sont eommuns aux 7 individus examinés.

La forme du corps tout d'abord dilfère passablement. Au lieu d'ètre fortement rétréci it la partie antérieure, il est an contraire assez large, jusque tout près de la ventouse antirieure. A $2 \mathrm{~mm}$. de l'extrémité antérieure, en effet, il mesure encore 2 à $3 \mathrm{~mm}$. de largeur.

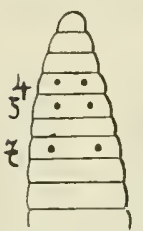

Fig. 9. Blanch. bngotensis nov. :p. Exır. antérievie dorsale montrant la disposition des yeux.

Le nombre des anneaux est aussi différent. Il en existe ro4, très nettement marqués. L'anus est également déplacé, et se trouve entre le $102^{\text {me }}$ et le ro3 ane anneau, c'est à-dire qưil y a encore deux anneaux après l'anus, jusqu'à la ventouse postérieure. Eufin, l'ouverture sexuelle ó au lieu de se présenter sous la forme d'un petit orifice sur l'anneau 28 , est placée au centre d'un bourrelet qui occupe à pen près toute la largeur de ce mème anneau 28 . Chez aucun des 13 exemplaires de l'espèce précédente on ne remarque ce bourrelet (r expl. de $51 \mathrm{~mm}$, 6 expl. de $33-38 \mathrm{~mm}$.). Les caractères communs aux deux espèces sont la coloration plus foncée dorsalement que ventralement, la position des pores sexnels sur les anneaux 28 et 30 et la présence des 6 yeux sur les anneanx 4,5 et 7 . (Fig. 9.)

\section{Blanchardiella paramensis $\mathbf{n} . \mathbf{s p}$.}

13 exemplaires provenant de z stations très élevées, soil 8 dı Paramo Cruz Verde à $3600 \mathrm{~m}$. d'alt., 5 du Ruiz à $3800 \mathrm{~m}$.

Les 8 exemplaires du Paramu Cruz Verde sont extrèmement bien conservés. La coloration de la face dorsale est restée assez intense, et les anneaux sont faciles à compter par suite de l'absence totale de rides ou de plis.

Le corps esı gris uniforme à la face ventrale, coloration qui passe.à la face dorsale pour former dé chaque còté une pelite hande longitudinale de $1-2 \mathrm{~mm}$. de largeur. Le dos 


\section{$7 / 3-$}

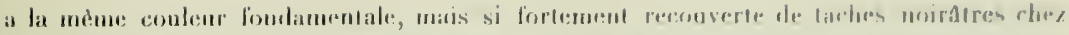
extains exemplaires yu'on n'aperegoit presyum: plus le: grris.

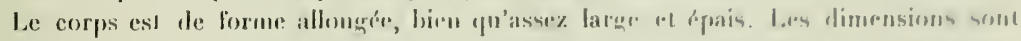
les suivantes:

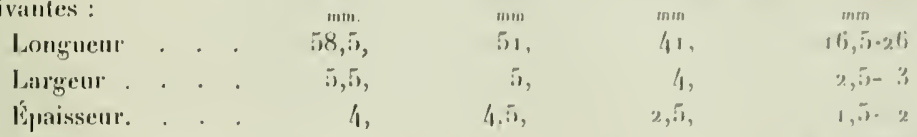

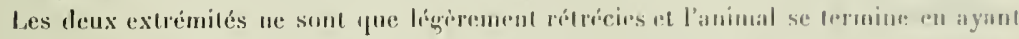

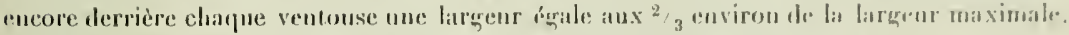

Les ventouses sont plutot pretites si l'on tient comple de lin tiille. assez srande des inelividus les phus dévehoppés. Lat pustérioure est cireulaire, fprolonde, el crensée de nombrenx sillous convergeant verse le fomil del'entonnoir. Dimensions: diamicre 2-2,5, profonfeur 1, ,i- 2,5 (mesures

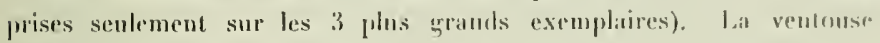
antérieure est petite, en forme do cuillere, nellement séparée du corjes,

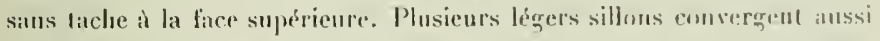
vers le fond de la ventouse qui est forme de 5 anneaux. (fïg. Io.)

Les anneanx au nombre de ro3 sont très nelfement visibles. Hs se comptent facilement sous un failule grossissement. Ancun anneau ne jurte des papilles on des tulercules permetlant de distumencer les différents somites. Ventralement, on comple $9^{8}$ annenux. Les ouvertures sexuelles sont disposes comme suit: Pore sexucl of chez tous les exemplaires entre les ammeaux 27 et 28 . II se présente sous forme diun pelil orifice très pen apparent, mais nettement visible pourlant sur les grands eximplaires. Le pore sexuel of est une pelite lente, situce tantit sur l'annean 29, lankit sur 30.

L'anus est dorsal el s'ourre entre les anneanx 102 el ro3, c'est-à-tire entre te dernier et l'avant-dernier.

Les yeux enfin, all nombre de 6 , som disposis par paires sur les anneaus 5,6 et 9 . (Fig. 11.)

Sur l'un des plus petils exemplaires, on remarque une anomalie dans la disposition des yeux.

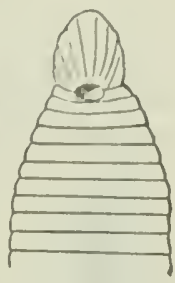

Pig. I10. - Blanch. promamensis nos. sp lixlr. ant. ventrale.

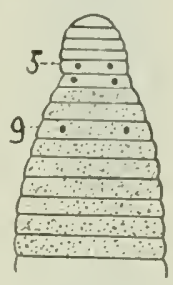

Fig. 11. - Blanch paramensis nov. sp. Extréunilé ant. dorsale mnntrant les yeux.

Au lieu des 6 yeux, on en trouve 7 , disposes comme suit: $1^{\text {re }}$ paire sur le $4^{\text {me }}$ anneau an lieu du $5^{\text {me }} ; 2^{\text {me }}$ paire sur le $6^{\text {me }}$ normilement, entin, 3 yeux sur le $S^{m o}$ anneas dont un a ganche et deux très rapprochés l'un de l'autre à droite. De ce fait, il n'existe plus que 3 anneaux préoculaires. Le nombre tolal est donc réduil à 102 , cl l'anus est silué entre les anneaux ror el 102. Mais l'aspect général de l'animal, sa forme el les différents autres caractères, sont absolument identiques à ceux des 7 antres exemplaires.

Les 5 exemplaires du Ruiz sont assez difficilement déterminables, par suite de leur état de conservation. Ils ont Irès probablement soulfert pendant un certain temps du man- 
que de liquide, l'alcuol s'élait sans doute évapuré. Le corps est très dur el très ride, ce qui reud difficile le dénombrement des anneaux. Je suis arrivé pourtant ì les compter exactement. Chez 4 exemplaires, il en existe ro3, et 102 chez le $5^{\text {me }}$. L'anus est situé che\% 4 exemplaires entre l'avaut-dernier et le dernier anneau, et chez le $5^{\text {mo }}$ qui a 103 anneaux, il existe 2 anneaux encore après l'anus qui se trouve donc entre 101 et $10 \%$. Les pores sexuels ont la mèméposition que chez les 8 exemplaires déerits plus haut, les yeux de mème. En outre, la conleur du corps, quoique un peu alténuée, correspond aussi parfaitement.

\section{Blanchardiella tamboensis n. sp.}

Un exemplaire de Tambo à $2200 \mathrm{~m}$. d'altitude.

C'est l'exemplaire le plus joliment coloré de toute la collection, mais il est malheureusement unique. La face ventrale et les flanes sont jaune-orange vif, tandis que le dos

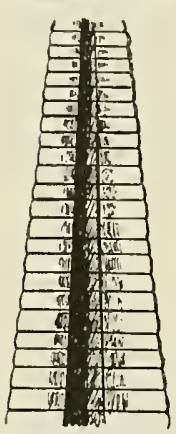

Fig. 12. Blanch. lamboensis nov. sp. Par. lie ant. de la face ventrale montrant la goultière renest parcouru parönne bande médiane du plus bean noir et large de $3 \mathrm{~mm}$. Cette baude noire ne s'atténue pas du tout sur les bords, et ne montre ancune solution de continuité. C'est absolument semblable à un large Irait d'encre de Cline aracé d'une ventouse à l'autre.

Le corps, allongé mais assez large et épais, mesure $54 \mathrm{~mm}$. de longueur, 4,5 de largeur et 2,5 mm. d'épaisseur. La partie antérieure, à partir du $40^{\mathrm{me}}$ anneau environ, se rétrécit assez brusquement jusqu'ì l'extrémité, et le corps ne mesure plus que $2,5 \mathrm{~mm}$. de large à la hautenr des pores sexuels. Les deux bords de cette partie du corps sout comme rabattus sur la face ventrale, ce qui crée une sorte de longue goutlière assez profondeisur le milieu de la face ventrate. (Fig. 12.) Rien de particulier à dire an sujet des ventouses qui sont très peu apparentes. L'antérieure a malheureusement été abìmée au cours des manipulations. Elle est en forme de cuillère. La postérieure, par contre, est circulaire, cachée sous l'extrémité postérieure. Diamètre $2 \mathrm{~mm}$. Les anveaux, an nombre de 102, sont nettement visibles mais peu saillants.

Les pores sexuels disposés entre les anneaux 26 et 27 et sur l'anneau 29 sont assez diffieilement visibles. Petit orifice arrondi comme pore sexuel 07 . Fente étroite comme pore sexuel ㅇ․

L'anus, dorsal, s'ouvre entre l'avant-dernier et le dernier anneau, c'est-à-dire entre 101 et 102 .

Les yeux sont an nombre de 6 , disposés en trois paires sur les anneaux 4.5 el 7 . 


\section{Blanchardiellá octoculata n. sp.}

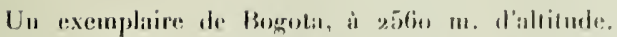

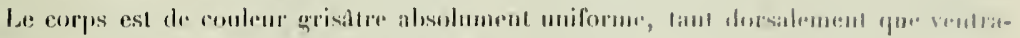
lement; sans ancome taelor mi aurume papille.

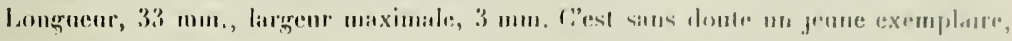

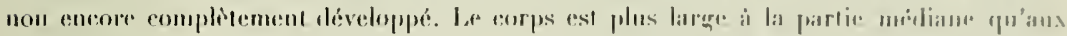

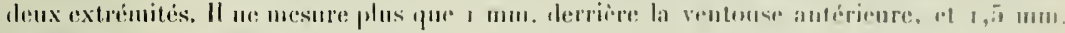
devaut la ventonse postérienre.

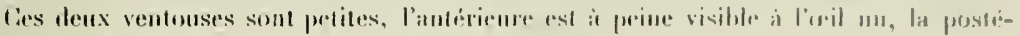
rienre, eirculaire, mesure I mun. de diamilre.

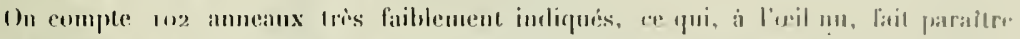

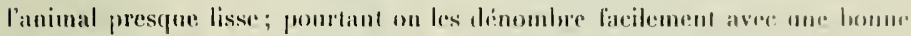

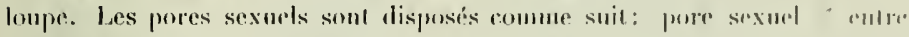

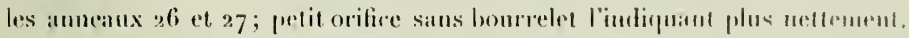
Ouverture sexuelle 0 : lrès fine, lente sm l'amean 2y.

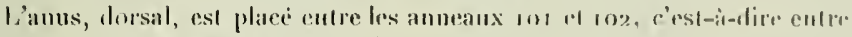
l'avant-rlernier el le dernier.

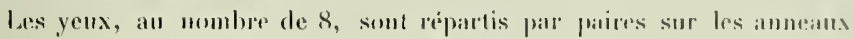

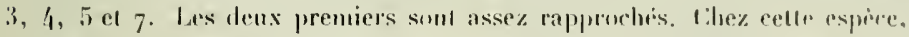

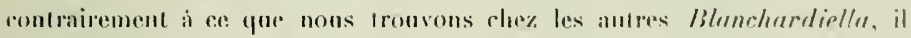

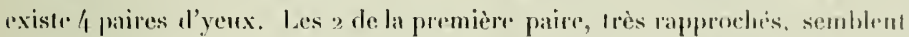

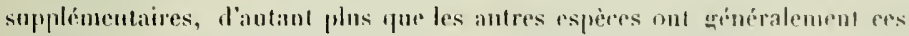

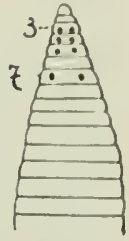

Fig. 13. Blanch. ocioculata n. sps. Partieanl.dorsale aver les yeas

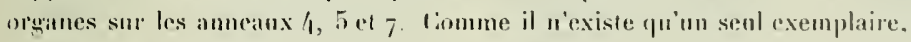

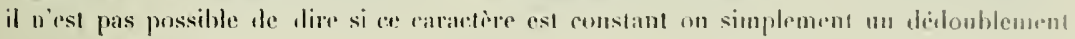
accilentel. (Fig. 13.)

\section{Macrobella columbiensis $\mathbf{n}$. sp.}

I cximplaire do Ruiz, à $3800 \mathrm{nt}$. d'ahilude.

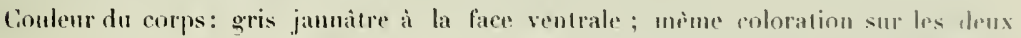
bords de la faec dorsale, et bande midiane pris noir làs nelle, de $5,5 \mathrm{~mm}$. te largenr. Cette bande noiràtre tend à s'effacer pen à peu dans l'alemol. On n'ohserve aneune taelur. ni aucune autre bande.

Cet exemplaire est le plus grand de tonte la collection dillirudines rapponflées de Colombie. II mesure $g^{5}, 5 \mathrm{~mm}$. de loug et $8 \mathrm{~mm}$. de larefe. Le corps, aplati ventralement. légèrement bombé dorsalement, est épais de $4,5 \mathrm{~mm}$.

Lextrémite antérieure, comprenant environ fo auneatox, est assez fortemont rélrecie. Elle ne mesure que 4 ì 5 mm. de largeur. Ce n'esl yn à parlir du f.3me annean dorsal fue a' 
le corps reprend peu à peu sa largeur nurmale ( 8 mm.), qu'ił conservera jusque près de l'extrémití postérieure, légèrenent rélrécie elte aussi.

Les ventouses ne presentent rien de hien particulier; elles sont plutir petites et l'antérieure surtout ne se remarque qu'a peine et mesme 2 um. de long el a mun. de large. lille est en forme de petite cuillere ave des sillons longitudinaux convergeant ver's le fond. La postériente est bien visihle, circulaire, en forme de cloche, dont lonverture mesure 4 mm. de diamedre. La profoudenr ast de 2 mm. Le pourtour de la paroi interne rst strié de lérgers sillons convergeant vers le fond de la cloche d'aspect pavimentenx.

Les anneaux an nombre de tof dorsalement et de roo ventralement se distinguent très bien, mème à l'oeil mu. Ceux de la tète seuls nécessitent l'emploi de la loupe pour

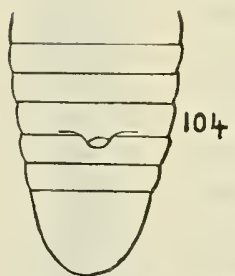

Fiǵ. 14. - Macrobd. columbiensis nov. sp. Position de l'anus.

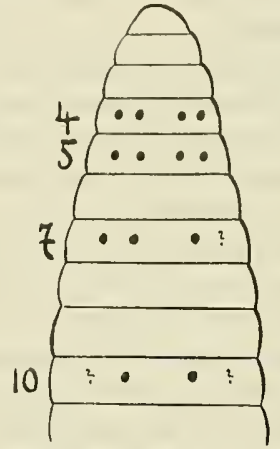

Fig. 15. - Macrobdella columb. n. sp. Schéma montrant la disposition des yeux.

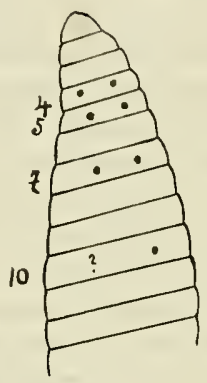

Fig. 16, côté gauche.

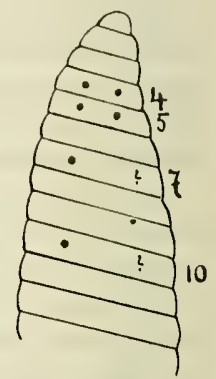

Fig. 17 , côté droit.
Macrobdella colunib. n, sp. Disposition des yeux (vues de côté).

ètre comptés exactement. Ceux des deux extrémités sont entiers et absolument unis. Mais à partir du $45^{\mathrm{me}}$ anneau dorsal el jusqu'au $97^{\mathrm{me}}$, claque antueau est partagé, tant dorsalement que ventralement, en deux parties égales par un léger sillon, à peine visible à l'œil nu.

Les pores sexuels sont bien visibles. Le pore sexucl of est un petit orifice percé sur l'anneau ventral 27 , au sommel d'un bourrelet qui occupe toute la largeur de cet anneau et les deux tiers environ de l'anneau 28.

L'ouverture sexuelle 울 est une petite fente percie sur l'anneau 29 .

L'anus, dorsal, se voit tris nettement à l'œil nu; il est percé sur l'anneau 104, mais la papille qui le porte est recourbée en arrière, de sorte qu'il semble être situé entre ro/ et 1 05 (Fig. 14). Le nombre des yeux est un des caracteres les plus particuliers de cette espèce. 11 en existe en effet r3 visibles, c'est-à-dire à droite 2 paires el 2 yeux isolés : à gauche, 3 paires et 1 ceil isolé (Fig. 15, r6 et 17). Its sont situés sur les anneaux 4, i, 7 et 30 . I] inanque f́videmment un ceil du còtr droit, ce qui explique le nombre impair 


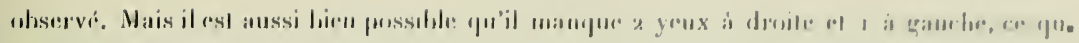

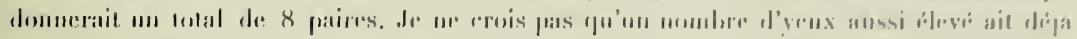

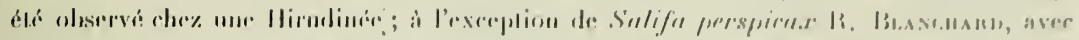

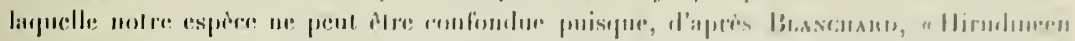

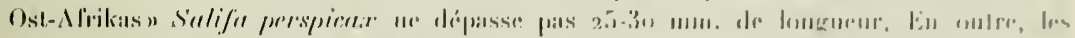

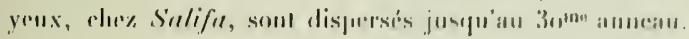

\section{BHBLOORRAPIIE}

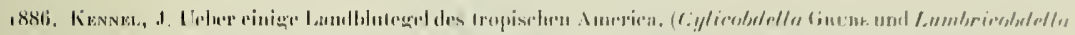

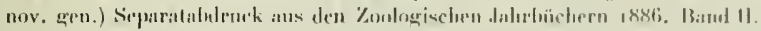

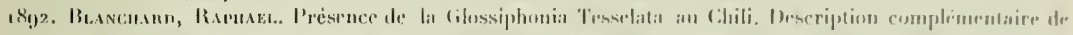

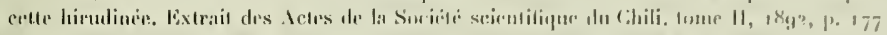

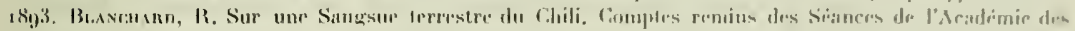
Sciences, fiverier 18 ifi.

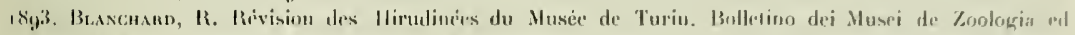
Anatumia rouparala della lR Universita di Torino. No 145 Vol. V1ll, avril $180,3$.

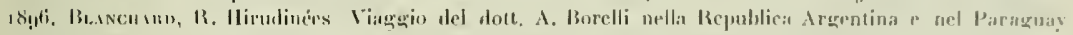
thill. No zli3. Vul. Xl, isgti.

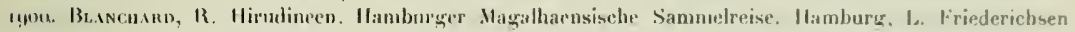
1., (.0, 1900 .

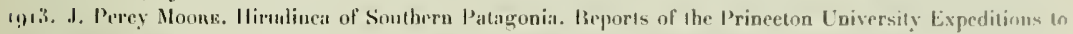
P'atagonia, isgpti-ı \&!̣q. (Jo n'ai malheureusenent pas pu me procurer ce dernier Iravail.) 


\title{
Planaires terrestres de Colombie
}

PAR

\author{
Dr O. FUHRMANN, Neuchâtel. \\ (Avec 3 planches el $3 y$ figures dium te texte.)
}

Le groupe des phanires terrestres est très richement représenté dans la région néotropique. Von Graff, dans sa helle Monographie ', décrit 80 espèces auxquelles n'est venue s'ajouter, depuis, qu'une seule espèce nouvelle? De ces espèces, dont la majorití fut trouvée daus la subrégion brésilienne (56), 3 seulement out été siqnalées en Colonbie, ce sont: Limacopsis terricola Scunarda, Geoplanu olivacea Fr. MüLt. el Geoplana bogolensis GuafF.

Il élait donc à prévoir que les riches matériaux que nous avons rapportés de Colombie contiendraient de nombreuses formes nouvelles, mais nous avons été étonné quand mème de ne trouver, parmi les 23 espèces récoltées, qu'une seute espèce déjà connue.

La région néotropique est caractérisée surtout par les Géoplanides qui y sont le plus richement développées; en effet, 72 espèces sont déjà connues et i 8 nouvelles espèces viennent s'y ajouter. Toutes ces formes rentrent à l'exception d'une seule dans le genre Geoplana. Les petits genres Choeradoplana (4 espècess connues), Polycladus (1 espèce connue) et Geobia (I espèce connue) n'ont pas reçu d'accroissement par l'étude de nos récoltes. Par contre, nous avons trouvé une mouvelle espèce d'un genre appartenant, d'après les conmaissances actuelles, presque exclusivement à la région orientale et qui n’a jamais été observé en Amérique, c’est Pelmuloplana graffi n. sp.

Les Rhynchorlemides, richement représentées en Afrique, dans les lndes et en Australie, ne possèdent que 7 espèces dans l'Amérique dn Sud; nos rerherches viennent y ajouter 4 nouvelles espèces dont uue forme intéressante parce qu'elle appartient à un grenre essentiellement africain (Madagasear), c'est Amblyplana monloyue n. sp. que nous avons Irouvée à $3600 \mathrm{~m}$. dans les Cordillères orientales.

Nos matérianx ont été conservés au sublimé acétique chaud, qui fut versé sur l'animal rampant sur une assiette, sur laquelle il restait le plus souvent collé, ne se

1 1. vos fnaff, Honographie der Turbellarien. II Trielada Terricola (Landplanarien). Leejpzig, 1899.

A. Мвıxмer, Zwei neue Landplanarien. Zoolog. Anz. Bd. 29, 1906, p. 665. 


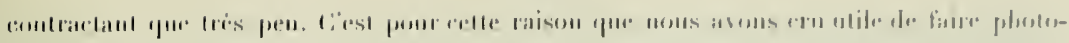

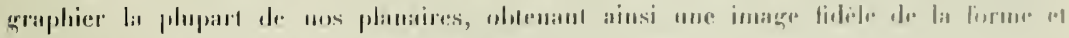
seruvent anssi de lat dispusilion des pigurouls.

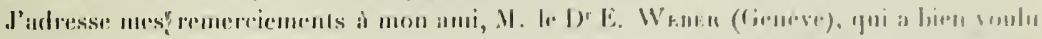

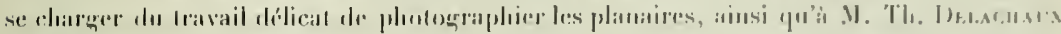

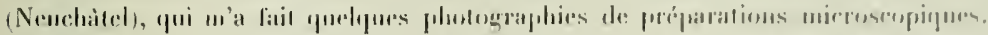

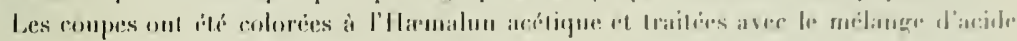

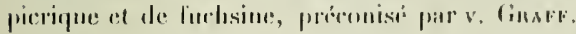

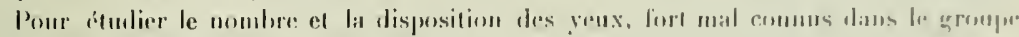

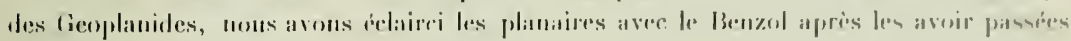
dius l'alcool alsosolu.

\section{Geoplana lin. N1เsten}

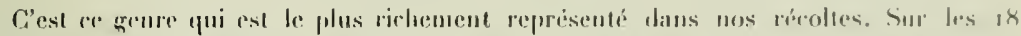

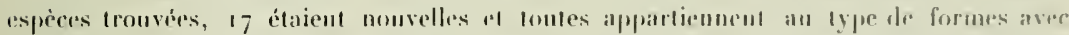

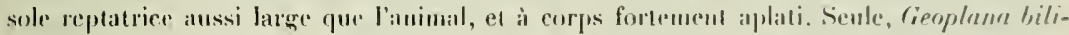

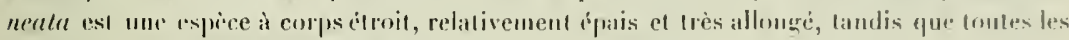

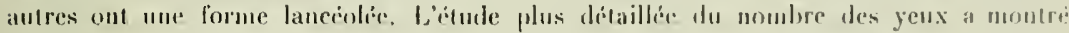
quils som beaucoup plus nombreux quim ne le croit, puisque les formes qui possèdent

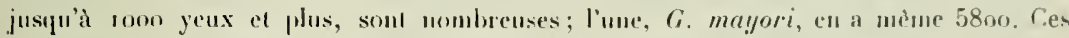

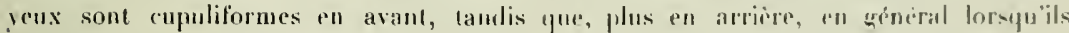
commencent à s'écarter du bord, ils deviennent plus pelits el prennent une furme spéciale (v. Fig. 3 et 6 du texte).

Partout, là bì nous avons pu éfulier Jes arlandes vifellogènes il libal jeune encore,

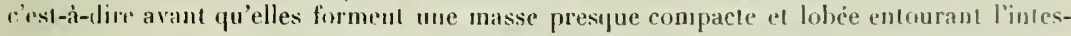
lin, ces goludes génitales se sont montrées réticulés el non pas comme les décrivent les auteurs sous forme de glandes folliculaires ( $v, 1,754)$.

Les testicules, sauf chez une espece, sont lons silués sur le còte dorsal dil tube digestif. Chez G. guncensis, par contre, nous trouvons des lesticules du còté dorsal el du ciré ventral. L'organe copulaterr màle, le plus sonvont très hien léveloppes si montri chez certaines espèces à peine marqué. Mais l'étude du G. anaggensis a momlẻ que, suivant l'ẻlat de contraction de la riche musculature qui enveloppe l'rusemble de l'appareil copulateur. une mème espèce peut aroir un penis rudimentaire on an contraire bien développé (v. Figr. io et I r). Je me demande done si les catégories citahlies par vox Graff dans sa momeraphie. p. 173 el 174 , existent réellement pour ce qui cuncerne le penis indiqué nul ou rudimentaire chez les espèces des groupes 1 el 2. ou si au contraire ces formes, dans un rerlain étal de contraction de leur appareil copulateur, ne présentent pas toutos un pénis bien apparent. 


\section{Geoplana bogotensis GrafF.}

(I). XV. Fig. 1-5.)

Nous avons rapporté de Colombie un riche matériel, se composant de 38 exemplaires de retle espece et provenant les uns de la Sabana de Bogota (alt. 2640 m.), les antres du Paramo Gruz Verde (alt. $3600 \mathrm{~m}$.) el des emvirons de Ulaque (alt. .) on ils ont été récoltés au mois d'uctubre 1910.

Bussox ${ }^{4}$ a décril, d'après les materianx de Bängen récoltés près de Bogota, une variété nowelle $\boldsymbol{r}$. bogolensis, var. bürgeri, mais il nous semble qu'elle n'a pas sa raison d'ètre prarce que cette espèce est assez variahle el nous pourrions avec notre riche matériel créer plusieurs variélés. Les diflérences de grandeur, de forme el de couleur, ainsi que les petites différences anatomiques sont de pen d'importance et peurent s'expliquer en grande parlic par des différences d’ìge, de contraction el de conservation.

Comprant la description el l'excellente figure de vos fraff avec la description de Bussox, je ne vois aucune différence bien marquée. Daus la largeur relative des bandes "laires el foncées et dans leur dématcation plus ou moins nette, ainsi que dans la liorme de l'ensemble du corps, comme dans celle de l'xtrémité antérienre, il y a nécessairement des différences chez ces animaux si contractiles. Mes 38 exemplatires conservés au sublimé acétique cliaud montrent ainsi de multiples petites variantes dont quelques-unes sont représentées dans les photographies de la pl. XV, liz. t-5. te crois done que la variété bürgeri peut ètre supprimée.

A l'état vivant, les plus grands de mes exemplaires élaient longs de 60 à $70 \mathrm{~mm}$. ; conservés, ils présentent une longueur maximale de 54 a $67 \mathrm{~mm}$. avec me largeur de 6 à $7 \mathrm{~mm}$. Graff indique pour son unique exemplaire une longueur de $36 \mathrm{~mm}$. et une largeur de $6 \mathrm{~mm}$.; c'élail sans doute un jeune individu. Bussov donne le chilfre maximal de $45 \mathrm{~mm}$. pour la longueur et $5 \mathrm{~mm}$. pour la largeur.

La coloration de l'animal vivant est pen dilfírente de celle de nos exemplaires conservés. La couleur fondamentale est jaune ocre tandis que les bandes sont d'un brun plus ou moins foncé suivant la densité des cellules pigmentaires. La face ventrale est presque loujours d'un blanc laiteux, très rarement (chez 4 exemplaires) ocre on brun clair, comme dans la figure de Graff (loc. cit.). Quant à la largeur de la bande médiane et celle de la bande nere marginale, nous constatons une assez grande variabilité; tantòt elles sont représentées sous forme de lignes très étroites $(0,25 \mathrm{~mm}$.) tantit plus large atteignant dans certains cas $1,5 \mathrm{~mm}$. pour la ligne médiane, I $\mathrm{mm}$. pour la bande ocre marginale. Les deux bandes brun foncé sont le plus:souvent, mais pas toujour's, bordées et délimitées par une ligne noire, provenant d'une concentration des cellules pigmentaires. Le bord tranchant de l'animal se pri-

1 Bussox, B.. Vpher einige Landplanarien. Silzungster, Akat. Wien, Igo3, vol. 112, p. 37.5-429. 5 tig.. I pl. 


\section{- 7 in -}

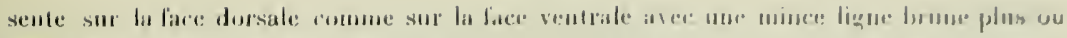

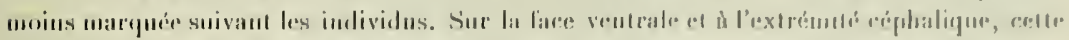

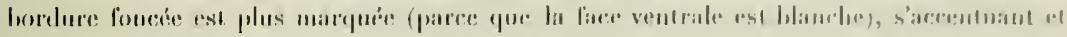

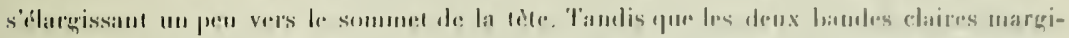

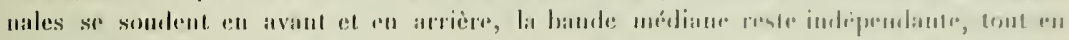

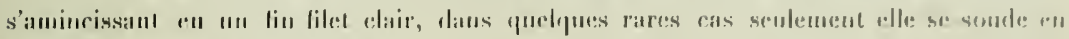
arriere avee la batude: maregiuale.

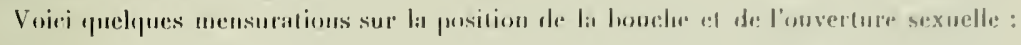

\begin{tabular}{|c|c|}
\hline Longneur do l'nnimal & Largeur \\
\hline mแ1. & $m m$ \\
\hline$i_{7}$ & 7 \\
\hline 5.5 & 7 \\
\hline 55 & ti \\
\hline$\therefore / 1$ & $i$ \\
\hline$\therefore$ & (i \\
\hline 5 & 5 \\
\hline 17 & 6 \\
\hline 16 & $5, \overline{1}$ \\
\hline 4.5 & ij \\
\hline 45 & 5 \\
\hline 35 & 1, i \\
\hline 35 & 4 \\
\hline
\end{tabular}

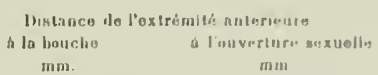

17

47 (ii)

3. 作

.3i 13

$34 \quad$ 1:3

31 1\%

3\% 们

27

$39 \quad 37$

$29 \quad 37$

$27 \quad 37$

$20 \quad 26$

$22 \quad 28$

Les yeux de G. hogotensis seraient, d'nprès Bussox, an nombre de $2 n 0$ à 300 ; si ce nombre était exact, nous devrions faire de nos exemplaires une nouvelle variété parce que nous en avons compté, un à un, de chaque cité, 6ou ì 635 , el il y a donc an moins 1270 yeux chez $G$. bogotensis. Les yeux sont répartis sur tout le pourtour du corps, mais c'esı daus la moitié antérieure jusqu'à la hauleur tu pharynx qu’ils sont le plus nomlireux. Dans la partic céphalique, jusqu'à 2 mm. en arrière de l'extrémité de la lète, les yeux se trouvent en rangée simple; de 2 à $4 \mathrm{~mm}$., ils ne sont pas disposés tris régulièrement en louble rangées; de 4 a $6 \mathrm{~mm}$., en 3 rangées trìs irrégulières; de 6 i 8,5 mm., nous les trouvons au nombre de 4 à 5 dans le sens transversal; plus en arrière (łे 13 num. p. ex.). nous rencontrons jusqu’i 7 yeux en ligne transwersale. Tandis qu'en avant. les yeux se trouvent jusqu’à $0,15-0,19 \mathrm{~mm}$. du hord, à $8 \mathrm{~mm}$. ils se disposent sur une largeur de $0,6 \mathrm{~mm}$. et à $13 \mathrm{~mm}$. de l'extrémité antérieure el sur une zone d'environ 5 à 6 mm. de longुueur, les yeux s'écartent jusqu’à $1-1,2$ mm. du bord. En arrière du pharỵx, les yeux ne se irouvent qu’isolément et à des distances relalivement assez graudes.

L'anatomie de celle espèce a déjà élé étudiéce en détail par Bussox (loc. cil.). L'étude de quelques séries de coupes nous a confirmé l'idé que la variété bürgericrééc par Bessus n'a pas sa raisnn d'ètre et que les différences anatomiques el histologiques signalées par 
l'auteur proviennent des différences d'àge, de conservation ', de contraction ainsi que de la variabilité qui peut se présenter dans certains détails anatomiques.

En effet, nos coupes ont montré que les animaux récoltés par nous possédaient des details anatomiques de l'une et de l'autre des deux formes. En ontre, nous trouvons quelques differences avec la description de Bussox. Ainsi, la unsculature longitudinale chez nos individus est passiblement plus forte et le nombre des fibres dans les faisceaux musculaires est, par place, presque. le donble de celui indiqué par Busson. Les glandes vitellogènes qui enveloppent tout l'intestin ne s'arrètent pas au niveau de l'ovaire, comme: dit l'auteur, mais rous encore au moins à $1 \mathrm{~mm}$. en avant de celui-ei. Les ovaires accessoires ne sont pas au nombre de 6 à 8 , inais nous trouvons sur charpue ovilucte, et à $1,2 \mathrm{~mm}$. en arrière de l'ovaire, un petit ovaire accessoire arec des oufs mùrs et d'autres encore jennes. Contrairement à ce que disent Bussov et Bergendal ${ }^{2}$, cet ovaire accessoire repose directement et ale toute sal lonģteur sur l'épithelium de l'oviducte et les oufs peurent ainsi facilement pénétrer dans celui-ci. Grande est la différence entre les dounées de Busson al les miennes en ce qui concerne le nombre des yeux; en elfet, comme nous l'avons déjà indiqué plus haut, nous avons compté sur des individus passés par l'alcool absolu "t éclaircis an Benzol au moins r 270 yeux, tandis que Busson parle de 200 à 300 , ce qui est évidemment faux et provient sans doute de ce que l'auteur a compté les yeux sur des individus non eiclaircis.

Parasites. Comme Busson, nous avons trouvé dans certains individus, grouprós ensemble en très grand nombre, les grèrarines de forme allongée et amincies aux deux extrémités. Elles étaient placées les unes dans le parenchyme, eutre les ramifications de l'intestin, les autres, dans l'intestin mème, entre les cellules épithéliales de celui-ci.

Plus intíressante est la déconverte de Nématodes se trouvant dans la musculature du pénis et qui se montraient assez nombreux sur une série de coupes. Ce qui est intéressant, c'est le fait que ces Nématodes étaient adultes et que les femelles renfermaient dans leur utérus de nombreux cufs embryonnés ; ils étaient longs de 1,1 mm. avec un diamètre de $0,057 \mathrm{~mm}$. A còté d'enx se tronvaient, plus nombrenses, des larves de Nématodes longues de $0,28 \mathrm{~mm}$, avec un liamedre de $0,012 \mathrm{~mm}$. Sont-ce des jemnes éclos? Jusqu'à maintenant, on n'a trouvé que des larves de Nématodes chez les planair's terrestres. Les planaires étaient donc dans ce cas hòte internédiaire. D'après nos observations, le $G$. bogotensis peut aussi ètre hòte définitif, et l'hòte intermirliaire du Nématote mentionné plus haut est sans doute un mollusque on antre animal qui serl de monrriture aux planaires.

'L'auteur dit p. 419 que les grlandes vitellogènes n'étaient qu'ébauchées che\% $G$. hogrtensis mar. bürgyeri 1.1 que l'état de eonservation de $G$. bogolensis n'éliti pas tris lavorable.

? D. Bergendu, Sludier öfner Turbellarier 11. Land, r8y6. 


\section{Geoplona mayori n. $\mathbf{s p}$.}

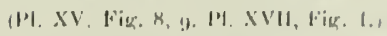

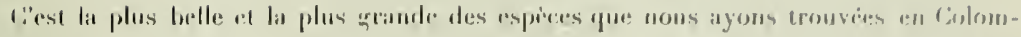

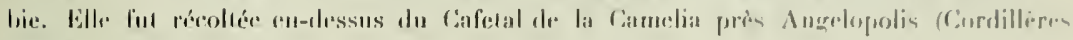
centrales, alt, ruv. Iquo m.).

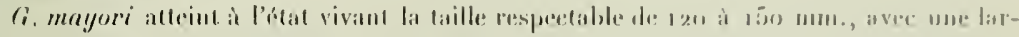

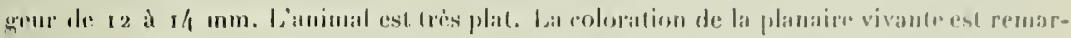

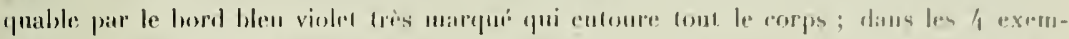

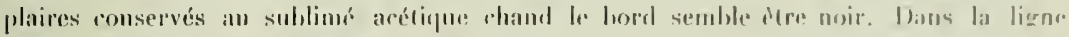

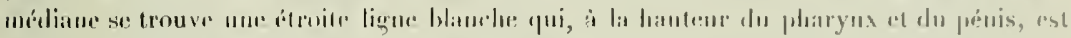

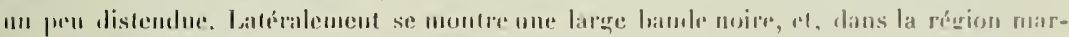

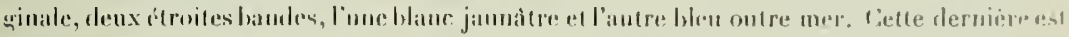

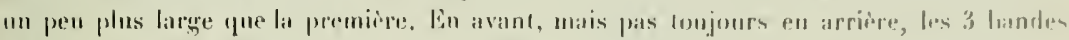
blatrelues se réunissent.

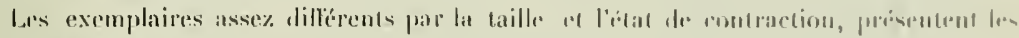
mentres snivantes:

\begin{tabular}{|c|c|}
\hline longнен & Larrgrur \\
\hline 9: $\mathrm{mm}$. & $1 / 4 \quad 11111$. \\
\hline $9^{2} \quad " 1$ & $8,2 \quad "$ \\
\hline $81 "$ & $14,5 \quad "$ \\
\hline$l_{7}$ " & y) \\
\hline
\end{tabular}

\begin{tabular}{|c|c|}
\hline \multicolumn{2}{|c|}{ Distance de lisestrimils anterieur. } \\
\hline$\therefore$ lis houchr & an pore sormel \\
\hline in m. & $7 \because 11111$. \\
\hline liti n & -8 \\
\hline .36 & 6.5 \\
\hline .37 & i1 \\
\hline
\end{tabular}

lat position variahle de la bonche el du pore sexuel proviont sans dunte de lat coul-

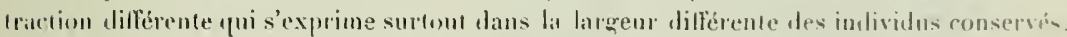

(i. muyori prisente certainement le plus grambl nombre d'yenx de tons lan planatire

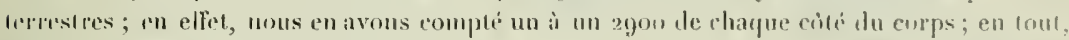
lanimal prote done 5800 yeux. Sur l'exemplaire le 81 mur. de long, mous voyons. jum

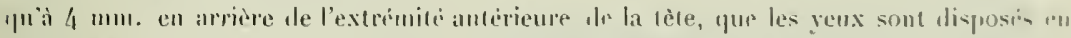

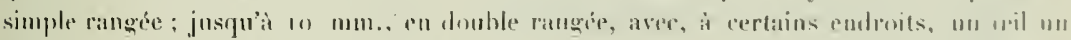

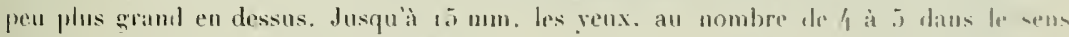

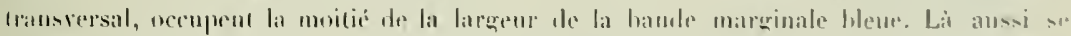

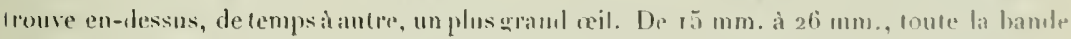

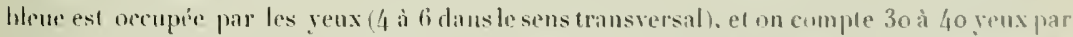

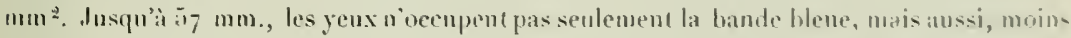
unmbreux il est rai, la moitié latérale le la bande hlanche. De lì jusquäi zo mum.. les peux ne se trourent plus que daus la bande blene, 8 a 10 par $\mathrm{mm}^{2}$. Plus en arriere, ils levinneut rares, mais se rencontrent jusqu'i l'extrímiti postírieure.

Analomie el hislologie. L'épiderme du dos est si fortement lyourri de rhalulites yuion ue voil pas les cellules qui le forme. Le revitement ciliaire nes se wil pas dialinen़i 
tement sur la face dorsale. Les cellules épithéliales ont une hanteur de n,027 mm. Les rhabdites qui remplissent tout l'épiderme appartienuent surtoul an type des rhammites, c'est-i-dire qüils sont filiformes, undulés ou spiralés, et dépassent en longueur la hautrur des cellules épithéliales. Les cellules glandulaires qui forment les rhammites se trouvent en grant, nombre directement sous la musculature cutanée et $y$ forment une couche de cellules tont les produits glandulaires sont fortement colorés par l'Haemalun. Sur la face ventrale, l'épiderme a une hauteur de $0,04 \mathrm{~mm}$. et le revètement ciliaire inesuro 1,, $006 \mathrm{~mm}$. La zone périphlérique de l'épithélium est remplie de petits rhabdies, longs de 0,004 à 0,008 mm. seulement. Les ghandes cyanophiles sonf très nombreuses sur tonte la face rentrale de l'animal, rares sur la face dorsale. La musculature cutanée est l'égale "praisseur du còté dorsal et du cóté ventral. La musculature circulaire el diagornale présente une "épaisseur de $, 0,014$ à 0,018 mur, tandis que les étroits faisceaux musrulaires longitudinaux sont hauts de 0,04 à $0,06 \mathrm{~mm}$. La musculature du parenchyme consiste en filores musculaires relativement grosses; e'est surtout les muscles dorso-ventraux ainsi que les muscles transverses en dessus de l'oviducte, done sur la face ventrale, qui sont très bien diveloppés.

L'intestin est très richement ramitié et montre souvent des anastomoses (v. pl. XVII, fig. 1). Les glandes sexnelles femelles sont bien développées sur l'iudividı que nous

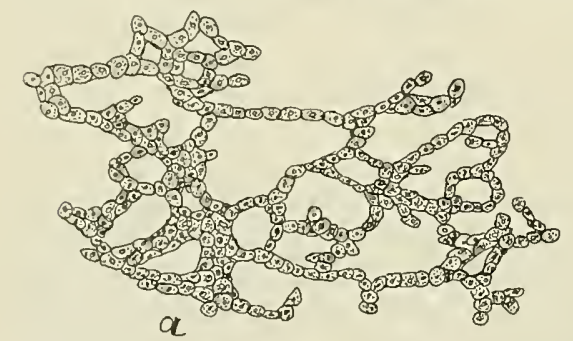

Fig. 1. - G. mayori n. sp. a rẻseau de la glande vitelloçène vu sur une coupe horizonlale (Dessiné avec l'appareil Abbe). b) fragment du réseau.

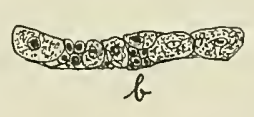
arons étudié. L'ovaire, en forme de massue, long de $0,8 \mathrm{~mm}$., est situé à $6 \mathrm{~mm}$. environ en arrière de l'extrúmití antérieure. Les œufs mesurent jusqu'à 0,05 mu. L'oviducte prend naissance a tu milieu et sur le còté dorsal de l'ovaire. Les glandes vitellogènes qui ne sont pas encore arrivées à leur complète maturifé dans l'exemplaire que nous avons éludié montrent une disposition que je ne vois ni signalée ni figurée dans le magistral ouvrage de von GrafF (loc. cit.) bien que celie disposition ait été observée par moi chez d'autres espèces encore du genre Geoplanu, comme G. bogotensis, $G$. cameliae efc, La glande vitellogìne de F. mayori, qui commence un pen en avant des ovaires et s'étend en tous cas jusqu'à la hautenr de l'appareil copulateur, n'est pas une glande composce de nombrenx follicules glandulaires. Elle se présente comme un réticulın, se montrant ainsi comme une seule glande réticulée avec de multiples conduits déhouclant dans l'ovilucte.

Vox Graff résume les recherches de v. Kenvel, et ses propres études à ce sujet, en disant: 1 . Les glandes vitellogènes, mème à l'état de parfatte maturité, sont toujours composées de follicules isolés qui peuvent ètre parfois réunis par groupes quand ils devien- 


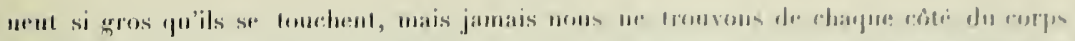

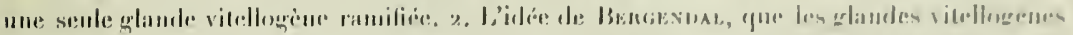

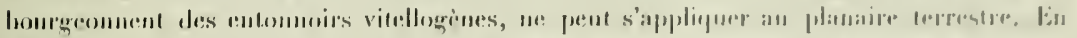

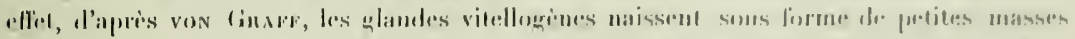

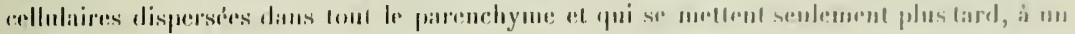

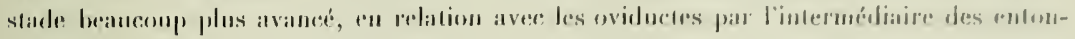
moir's vitelloginnes.

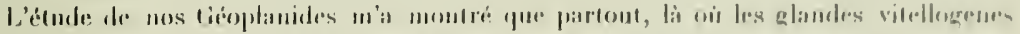

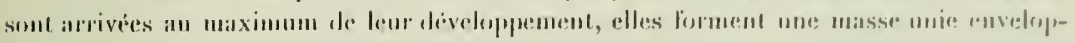

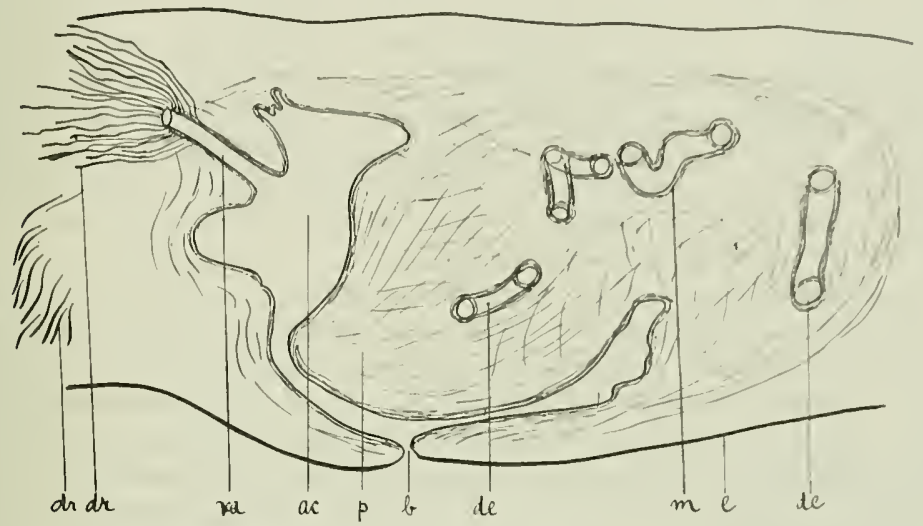

Fig. 2. - G, mayori n. sp. Coupe sagitlale des organes copulateurs, $e$ épiderme, b ouverture sexulle, ac atrium commun, $p$ pénis, de duclus ejaculatorius, $m$ musculature du ductus, de canal déférent, va vagin, $d r$ glandes. (Dessiné avec l'appareil Abbe.)

fant le tuhe digestif el pénétraut mème entre les ramifications de celui-ci. l’our ilucider ta question de savoir si les glandes vilellogènes sont folliculaires ou non, il fautétudier les stades oì la glande n'est pas encore asse\% développée pour que les follicules ou ramifications se touchent. Un fait me semble dejà parter contre la glande vitellogene follirulatice, cirst le nombre relativement petit des entonnoirs vilellogènes qui s'ourrent dans l'oviducle. Comme on ne voil pas de conluil vitellogene simple ou ramitié dans les coupes, les follicules doivent ètre réunis ensemble en très grand nombre pỏur alroulir enfin à l'oviducte. 11 me semble probable que les glandes vitellogenes doivent former un réliculum, par le fait que ces glandes se trouvent souvent 5 à $10 \mathrm{~mm}$. en arant de l'oraire el que d'unjautre côté s'étendent souvent jusqu'à l'extrémité postérieure du corps sans qu'aueun conduit allanı vers l'oviducte ne soil visible sur les coupes. L'élude de séries de coupes farorables à élucider celte question nous a montré que chez $G$. mayori el d'autres formes encore, les glandes vitellogènes forment un réliculum entourant le tuhe digestif el 
envorant des bamitications entre les hranches de celui-ci. Dans ce roticulum, les cellules vitel-

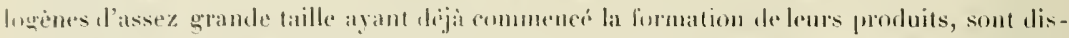
puseses en simple rangé. Elles contiennent assez souvent de petits groupes de collales moins volumineuses dont les noyaux oecuprent une très gramde place, ne latissant que peu de protoplasme. Ce sout sans doute de jennes cellules vitellogines qui doivent agrandir al itumenter le resisan de la glamde vitellogine. Par cette disposition de la glande vilellegène, un nombre relativement petit d'araginations de l'oviducte suflit pour recurillir les prouluits de cette glaude volumineuse qui nous semble ètre unique. En tout cas, nous

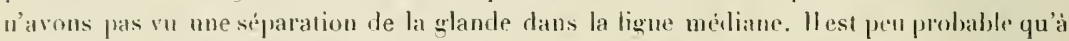
chacun des trios comts conduits vitellogines formes par l'oviducte corresponde un petit riscau vitullogène. L a's coupes horizontales ne montrant toujours que des lragments du réscau, uous n'avons pu ilueider ce print, mais il nous semble qu'il n'y a au fond qu'une glande vitellosène formant un réseau et sur lequel penvent naturellement s'élever des lobes plus on moins nombrenx. L'oviducte ne montre rien de particulier. Les testicules sont situés exclusivement sur le crité dor'sal, en dessus du système dignestil. Lenr diamètre est de 1,28 nm. au maximum; leur nombre ne semble pas très considérable, une trentaine de clıque còté, dans la régrion antérieure du corps.

L'appareil copulateur u'est pas très nettement dèlimité dn parenchyme. L'appareil mâle consiste en un énorme pénis de forme conique, long de $2 \mathrm{~mm}$. et avec une base large de 1,5 mm. Sa paroi n'est pas beaucoup plus musculeuse que le reste de l'atriun génital. Les glandes qui débouchent à sa surface sont trìs nombreuses. Le ductus ejaculatorius, ondulé, est extrèmement musculeux. L’atrium génital, qui u’est divisé pas aucun repli en atrium masculinum et atrium femininum, est presque entierement occupé par le pénis. L'appareil femelle consiste en un court vagin débouchant dans l'atrum sur une espèce de papille. Dans la partie glandulaire du vagin débouchent un nombre énorme de glandes coqnillières qui ne sont pas seulement placées du cóté dorsal, mais anssi en grand nombre sur le côté rentral de l'animal.

.le dédie cette espèce à mon ami et compagnon de voyage $M$. le Dr méd. Eug. MAYOR.

\section{Geoplana cameliae n. sp.}

(P1. XV. tig. 10, 11.)

Lin grand nombre d'exemplaires de cette espece (20) ont été récoltés. Ils furent tronvés au Cafetal La Camelia près Angelopolis, el à Sabaletas près Titiribi cordillères cen(rales, alt. I $400-1800 \mathrm{~m}$.).

Les animanx virants sont longs de 30 is $50 \mathrm{~mm}$. avec une largeur de 2,5 ì $5 \mathrm{~mm}$. La couleur fondamentale du corps de l'animal conservé est d'un jaune ucre plus on moins foncé, masquée par de nombreuses petites taches d'm brun noir qui rouvrent toute la face dorsale, laissant plus ou moins libre une étroite ligne médiane et une zone margi- 


\section{$-7 \%$}

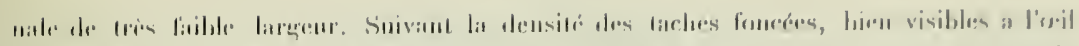

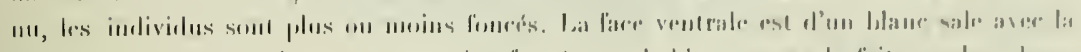

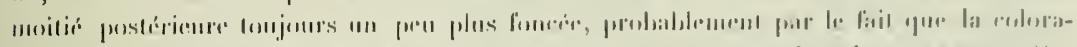

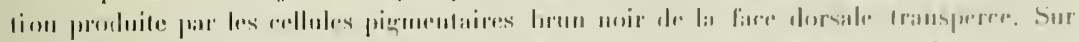

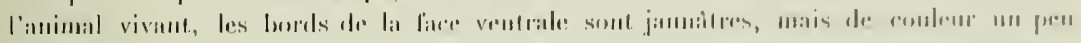

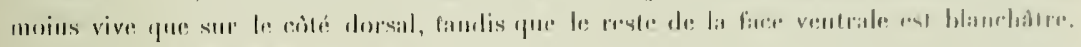

Verici querlyuess mentustratiuns:

\begin{tabular}{|c|c|}
\hline 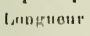 & f.argent \\
\hline เมะ!. & Imm \\
\hline I:" & $?, \bar{i}$ \\
\hline 18 & 1 \\
\hline 23 & 1 \\
\hline i. & i \\
\hline (9) & i \\
\hline 31 & $i$ \\
\hline 38 & 4 \\
\hline 保 & $3, \overline{1}$ \\
\hline 45 & 4 \\
\hline
\end{tabular}

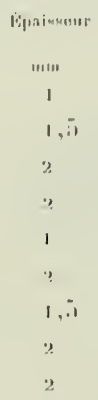

\begin{tabular}{|c|c|}
\hline 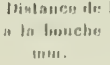 & 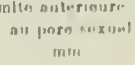 \\
\hline 7 & III \\
\hline III & $1 \because$ \\
\hline 14 & 17 \\
\hline 11 & ix \\
\hline $1 x$ & .3 \\
\hline $1 . \overline{1}$ & 211 \\
\hline 22 & 77 \\
\hline '? & א. \\
\hline 23 & $2 y$ \\
\hline
\end{tabular}

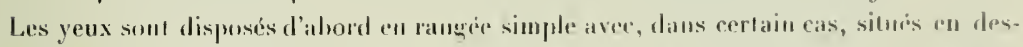

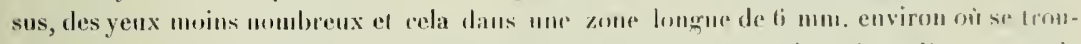
vent de chaqur còté 250 yenx de $0,0.57 \mathrm{~mm}$. de diamèlte. En arrière, jusqu's $11 \mathrm{~mm}$. de l'exfrémilé antérioure, les yeux se dispersent sur une largeur de $2 \mathrm{~mm}$. vers l'interieur at manquent presque complitement sur la ligne marginale claire où ils sont dispusés plus en avant. Les ocelles de crlle région sont plus petils $(0,0) 9^{-0,038} \mathrm{~mm}$.)

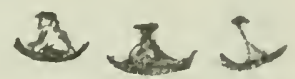

Fig 3. - G. cumeliae n. -p. leux de la région du pharỵox. el leur cupule pigmentaire semble ètre divisée en deux parties inésales relićes entre elles (lïg. 3). Prés du milieu de la longueur du corps de l'animal, les yeux disparaissent ou deviennent très rares.

Analomie et histologie. L'épiderme présente les mèmes dispositions que chez $G$. mayori: sur le dos il est haut de $0,03 \mathrm{~mm}$. el bourré de rhabdites, du type des rhammites ainsi que de gros choudrocystes, beancuup moins nombreux. La musculature sous-épithéliale forme une conchr de $0,018-0,027 \mathrm{~mm}$. A la face venırale, l'épithélium mesure $11,022 \mathrm{~mm}$. et porte un revètement ciliaire de $0,1007 \mathrm{~mm}$. de haut. Les cils vilıratiles du dos nir sont pas bien visibles et semblent mème manquer par places. L'ípiderme de la sole replatrice est assez riche en petits rhabdites longs de 0.003 à $0.005 \mathrm{~mm}$. La musculature de la face ventrale mesure $0,023 \mathrm{~mm}$. De nombreuses glandes cyanophiles débouchent à la surface de tout le corps. De la musculature du parenchyme, seuls les imuscles dorso-rentraux sont bien apparents.

Le pharyux, cylindrique, long de $1,7 \mathrm{~mm}$. avec un diamètre de 0.9 à $1 \mathrm{~mm}$.. es suspendu dans une cavité longue de $3 \mathrm{~mm}$. environ et qui porle louverlure buccale an 
milien. Nous arons compte sur un individu 32 ramifications primaires de l'intestin antérieur et 23 sur les deux branches postérienres du système digestif. Ces ramifieations sont i leur tour fortement divisies.

L'ovaire, silué à 6 ì $7 \mathrm{~mm}$. de l'extrénite antérienre, a une forme ovale. Il est long de o, $4 \mathrm{~mm}$. avec un diamètre de $0,2 \mathrm{~mm}$. Les a al's mùrs mesurent o, of mm. L'ovidncte vient pénétrer da coilé dorsal dans la moitié postérieure de l'ovaire. la glande vitellogène, s'útend de $3 \mathrm{~mm}$. en avant de l'ovaire jusqu’à l'extrémité postérieure; elle est très

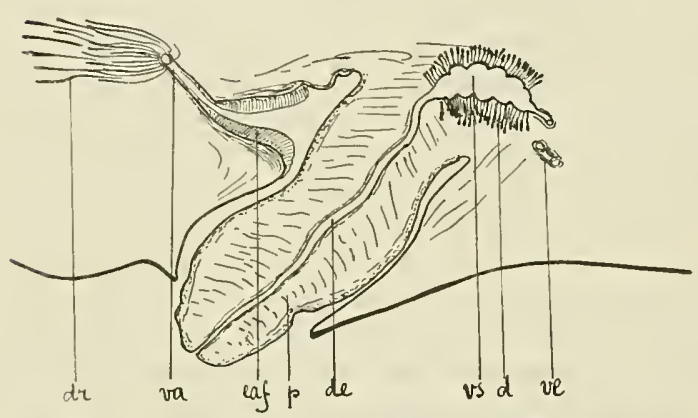

Fig. 4. - G. cameliae n. sp. Coupe sagirtale des organes copulateurs. $p$ pénis, de ductus ejaculatorius, vs vésicule séminale, $d$ ses glandes, ve canal déférent, eaf épillélium de l'atrium femininum, va vagin, $d r$ glandes. (Dessiné avec l'appareil Abbe.)

l'apprareil copulateur. L'enveluppe musculaire le délimite peu nettement du parenchyme. Le pénis, très volumineux, remplit tont l'atrium; il est pen musculenx; de mème que son duclus ejaculatorius. A l'entrée, dans l'organe copulateur, le canal déférent se dilate légèrement sur une longueur de $0,4 \mathrm{~mm}$., formant ainsi une vésicule séminale. Dans cette région dilatée débouchent de très nombrenses glandes granulenses qui se rencontrent, mais beaucoup moins nombreuses, sur le canal éjaunlateur, tapisśs d'un épithélium vibratile. A l'extrémité du pénis, l'épithélium qui le recouve forme de petites papiltes, comme chez $G$. von gunteni, mais beaucoup moins nettement développées.

Le vagin, très court, débouche daus un alrium femininum qui, bien qu'aucun repli ne le sépare de l'atrim commun, se présente quand mème nettement distinct. Il est en effet toujours tapissé d'un épithélium 7 ì 8 fois plus haut que celıi de l'atrim commun et de l'atrium masculinum mesurant $0,12 \mathrm{~mm}$. de haut; en outre, la musculature do relte région est très forte. 


\section{$-750-$ \\ Geoplana tamboensis n. sp. \\ (1). XY. Jik. Hi.)}

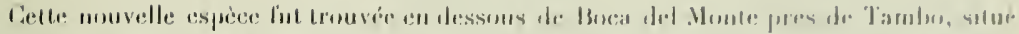

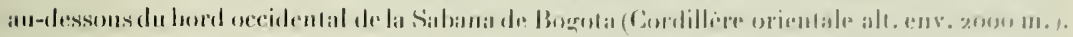

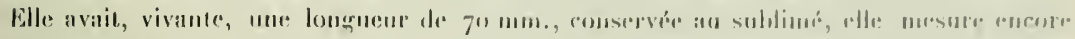

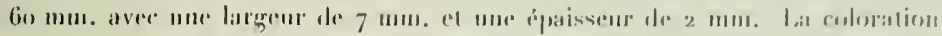

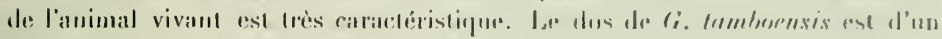

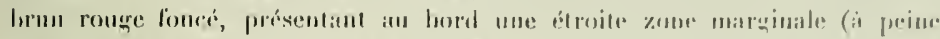

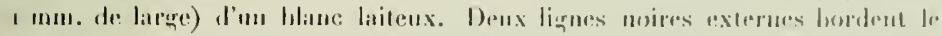

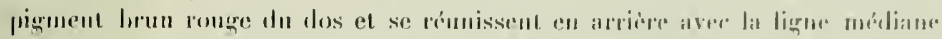

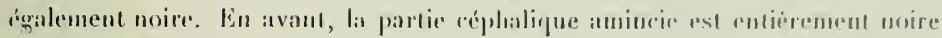

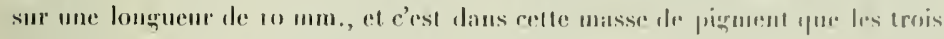

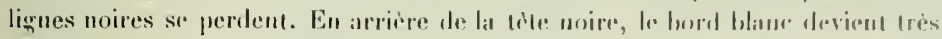

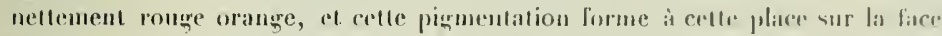
ventrale un vaque ruban tausversal rougeatre en avant dieguel la fier rentralle de la tète est presque ansisi noire que son coti dorsial. La reste de la face ventrale est fum chir et les bords sont blanchilles comme du cotó forsal. L'animal conserve a l's menu's couleurs, senlement le rougr urange est moins apparent el la face ventrale an lieu d'ètre brun clair ust légrientent lorun rougo tuile. Les hords de la fitee ventrale sout d'un jaune blunchàtre sur unc largeur de $1 \mathrm{~mm}$.

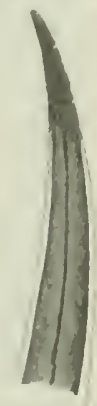

Yig. 5. ri. Iamboensis n. вp. parlie antérieure.

De petits points hiancs (diamitre $0,095-0,11 \mathrm{~mm}$.) dans la pigmentation foncée du dos sont assez visibles. Ils commenceul à apparaitre en arrière de la bordure rouge corangre el s'étendent jusqu'à la hauteur du pore sexuel. Ils sont nombreux, te t 3 à $30 \mathrm{~mm}$. en arrière de liextrémité antérieure du corps. En arrière de cetle région, ils deviennent assez distants les uns des autres. Ces taches minuscules, dont j'ai complé à la loupe environ 3oo de chaque còtí, marquent la place des yeux, mais le nombre réel de ces organes est au moins le double du nombre des taches visibles à la loupe. Les yeux se trousent eu avint, en une rangíe simple, pas très serrée, jusqu' 7 mm. de distance du sommet do la tète. Dans la moitie postérieure de celtr rangée, on remarque en dessus, de temps en tempss (à des distances de 0,3 ì $0,6 \mathrm{~mm}$.), un ail plus gros. De là jusqu'a to mm. en arriere de l'extrémití céphalique, les yeux sont disposís en double rangée. $A$ to $\mathrm{mm}$. commence la courte zone marginale rouge-orange en arrière de laquelle les yenx, limités jusquà maintenant au bord, se disposent aussi dans le piğment foncé dn dos et ront jusqu à $2 \mathrm{~mm}$. du bord. Leur disposition a été décrite plus laut. Tout à fait à l'extremilí postéricure en arricre du pore sexuel, se trouvent encore quelyuses yenx dans la bande marginale claire. mais pas dans le pigment noir.

L'ouverture buccale de $G$. tamboensis se tronve à $40 \mathrm{~mm}$.. le pore sexucl à $50 \mathrm{~mm}$. de l'extrémité antérieure. 


\title{
Geoplana von gunteni n. sp.
}

\author{
(Pl. XV. Fig. 7.)
}

Les trois exemplaires que nous avons trouvés près de Medellin au bord du Porce, daus un trone de saule pourri, sont tous de mème taille et mesuraient $55 \mathrm{~mm}$, le long sur $4 \mathrm{~mm}$. de large. Les animaux conservés mesurent $35 \mathrm{~mm}$. de long et $5 \mathrm{~mm}$, de large. La coloration de l'animal fixé au sublimé acétique est la mème que celle de l'animal virant. La fice dorsale est de couleur histre avee une étroite lignn noire dans la ligur médiane; cette ligne sélargit un pen en dessus de la bourle où se tronve ansi une petite lache fusiforme. Le long de cette lignne, des leux còtés, se trourent, disposées en rangée simple sur les individus vivants, de petites taches grisatres, devenues peu visibles sur les exemplaires conservés. Lal zone marginale montre nue assez large bande grise dans laquelle un remarque en anant de petites taches claires qui renferment les yeux. Cette bande est bordée à l'extérieur d'une très étroite zone de conleur ocre. Au milieu de la longueur du corps jes mesures pour les bandes sout les suivantes: hord ocre large de 1, 1 mu, bande marginale grise large de $0,9 \mathrm{~mm}$., baude ocre $1,6 \mathrm{~mm}$. ef la ligne médiane noire $1,2 \mathrm{~mm}$. Lal face ventrale est gris jaune-clair avec une mince bordure de couleur ocre. La bouche se trouve chez un individu longue de $33 \mathrm{~mm}$. of large de $5 \mathrm{~mm}$. à $21 \mathrm{~mm}$. de l'extrémité antérieure, tandis que le pore sexuel est placé à $25 \mathrm{~mm}$. Les yeux sont irrégulièrement disposés sur te hord, en rangée simple ou double, et cela jusqu'a $6,6 \mathrm{~mm}$. de la pointe de la tète, puis

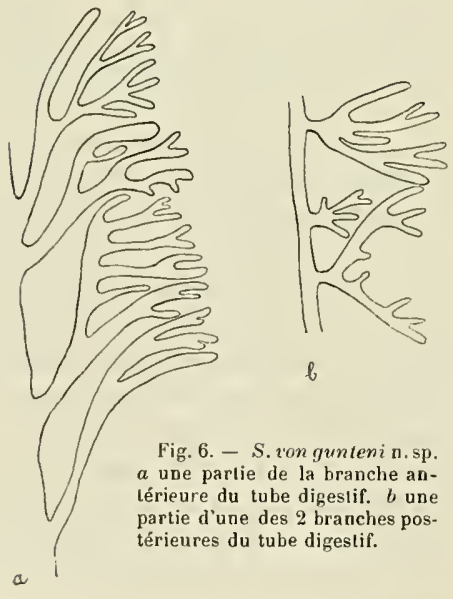
sur $2 \mathrm{~mm}$. de longueur on les (rouve en rangée triple. Dans celte région de o à $7,6 \mathrm{~mm}$, nous avous compté de chaque còtí du corpss 250 yeux, d'un diamètre de 0,025 à $0,057 \mathrm{~mm}$. A partir de là, les organes visuels prennent un aspeet différent (Fig.3) "1 ne mesurent plus que $0,022 \mathrm{~mm}$. En mème temps, ils se dispersent jusqu'à 1,1 à $1,4 \mathrm{~mm}$. du bori et se trouvent en très grand nombre dans la bande marginale grise, et cela jusqu'à la haufen! dı pharynx. Plus en arrière, les yeux sont beancoup moins nombreux, et, près de l'extrémité postéricure, ils sont distants les uns des autres de 0,57 ì $0,-6 \mathrm{~mm}$.

Anatomie et histologie. L'épiderne mesur' $0,018 \mathrm{~mm}$. sur le còté dorsal, o,02 ì $0,028 \mathrm{~mm}$. sur la face ventrale. La musculature a $0,02.3 \mathrm{~mm}$. d'épraisseur sur le dos et o,o4 sur la sole reptatrice. Les cellules épidermiques du dos sont hourrées de rhammites et de chondrocystes, si bien qu'on ne voit pas les cellules elles-mèmes. Les rhabdites de l'épiderme de la face ventrale sont très courts, ils n'ont que 0,004 à $0,008 \mathrm{~mm}$. 


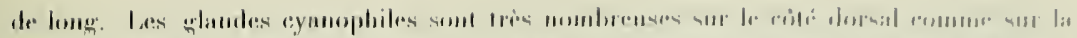

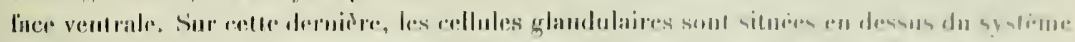

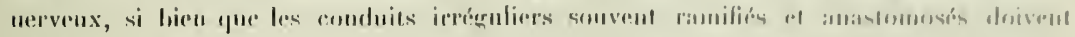

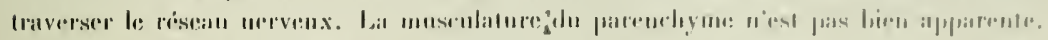

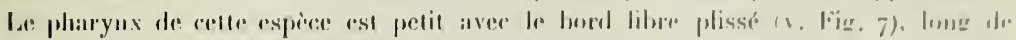

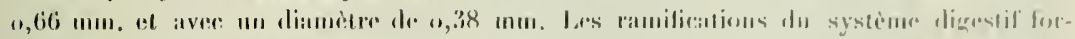

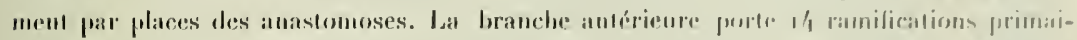

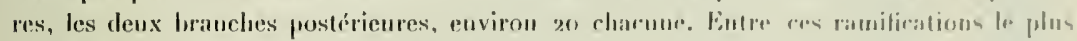

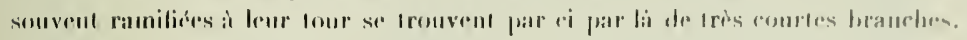

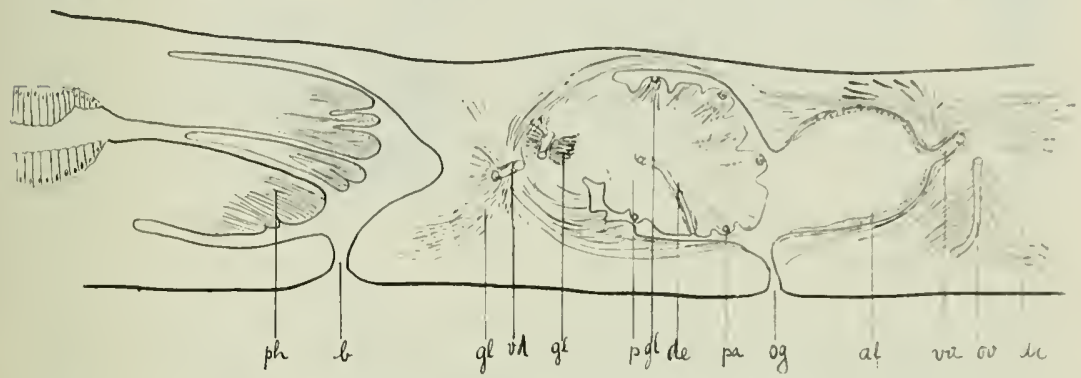

lig. 7. - G. ygn yunleni n. sp. Coupe sagillate el médiane des organes copulateurs. ph pharynx, b bouche. og ouverture génitite, $p$ pénis, pa papille, gl ghlandes de ces papilles et du canaí déférent, de duclus ejaculatorius. "d canal déférent, of atrium femininum, "a vagin, $m$ oviducte. $d r$ glandes du vagin et de l'oviducle. (llessinct avec l'appareil Abbe.)

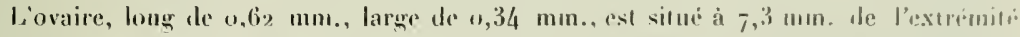
antérieure du corps. Les auts ont un diamètre de 1,44 mm. L'ovilucle prend naisisance latéralement et sur le còti externe de l'ovaire : il est, pis plice. hourré de sperme. Le يrlandes viteltogènes, énormément développées, et plus fortes du citri dorsal que du cril. ventral, vont jusqu'ì 3,8 mu. en avaut de l'ovaire. En arris̀re, les frlandea vilellugine alteignent presque l'extrémité postérirure.

Les testicules ont 110 diamitre de 0,3 at $0,4 \mathrm{~mm}$. of sont silnes sur le criti: dorsil de l'animal, en dessus des glandes vilellogènes. Ils sétendent, au nombe d'environ lim de chaque còtc, jusqu'à la hauteur du plıarsnx. Le canal déférent forme par place un faible réseau. Les organes copulateurs prisentent des dispositions curieuses. Le pénis ent de forme globuleuse et recourert de grosses papilles qui, sur les coupes sagillales (Fig. \$ . uontrent une forme polygonale. Le revètrment épithélial est très curieux. parce yue lerellules sont séparées ì la face exteme les unes des autres el forment ainsi des papilles microscopiques également polygonales (Fig. gel 10). La partie prominentr du protiplasme de ces cellules est modifiée, elle présente une autre structure el une plus fort. aftinité pour les colorants. De très nombreuses glandes débouchent à la surface du pünis (ti 
IFig. 7 grl.). Au milieu des grandes papilles du pénis on remarıue des wales de o, 025 mm. de diamètre el qui montrent an centre une ouverture ou dépression claire de $0,009 \mathrm{~mm}$. de diamèlre (Fig. 10, Fig. 7, et Fig.:8 pa). Je n’ai pu élueider avec cerlilude quelle était la

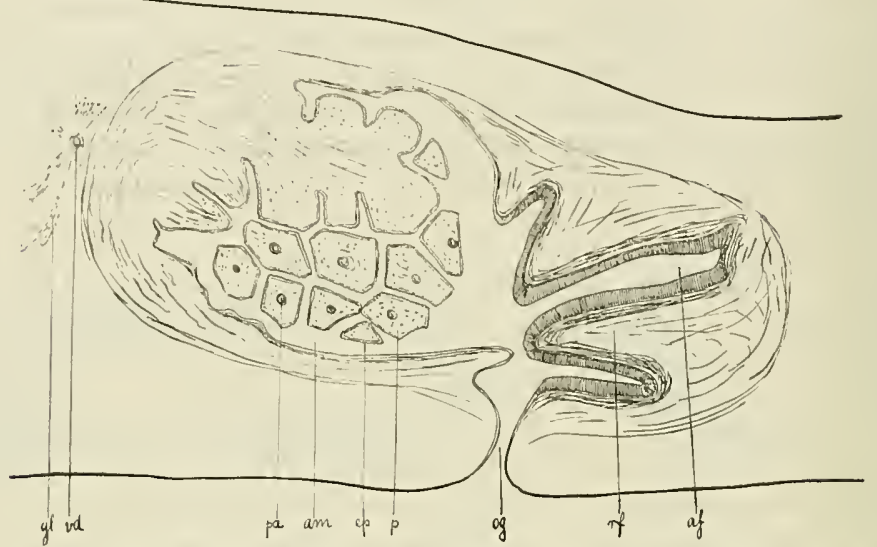

Fig. 8. - G, von'gunteni ฉ. sp. Coupe sagittale des organes copulateurs touchant ta surface du pénis. og ouverture génitale, $y$ grande papille du pénis, pa papille cenlrale, ep epithélium, $v d$ canal déférent. gl glandes de ce canal, am atrium masculinum, af atrium femininum, of replis laléral de l'atrium. (Dessiné avec l'appareil Abbe.)

structure exacte et lęiròle de ces organes qui ont l'air d'ètre de gros sphincters sous lesquels de nombreuses glandes unicellulaires semblent aboutir et peul-ètre déboucher dans l'ouver-

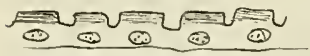

Fig.9. - G. von gunteni n. sp. Coupe sagittalè de î́pithélium du pénis.

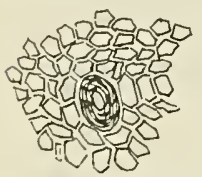

Fig. 10. - G. von yunleni n. sp. Coupe horizontale de l'épithélium du pénis avec une papille ovale (sphincler?)

Nous n'avons récolté en dessus de Ubaque (Cordillères orientales,
'soo m.) que deur exemplaires de cette planaire qui mesurait zo $\mathrm{mm}$. de long sur $2,5 \mathrm{~mm}$.
de largé el i mm. d'épaisseur. La coloration de l'animal est assez caractéristique. I,a zone

Nous n'avons récolté en dessus de Ubaque (Cordillères orientales,
'soo m.) que deur exemplaires de cette planaire qui mesurait zo $\mathrm{mm}$. de long sur $2,5 \mathrm{~mm}$.
de largé el i mm. d'épaisseur. La coloration de l'animal est assez caractéristique. I,a zone

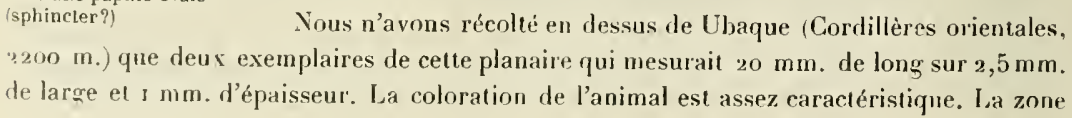

ture centrale. Le canal éjaculateur est peu musculeux. Le canal déférent, près du pénis comme dans le bulbe du pénis, est entouré de nombreuses glandes. L'atrium femininum est très vaste, tapissé d'un épithélium haut de o,048 mm. tandis que dans l'alrium masculinum il ne mesure plus que $0,006 \mathrm{~mm}$. de haut. Un repli assez élevé s'avance à gauche el à droite dans la cavité atriale (Fig. 8 rf.). La musculature de l'atrium femelle est très forte ainsi que celle du vagin qui est entonré de nombreuses glandes. Cette espèce est dédiée à nos compatriotes MM. von Gunten à Barranquilla en hommage de leur aimable hospitalité.

\section{Geoplana ubaquensis $\mathbf{n}$. sp.}




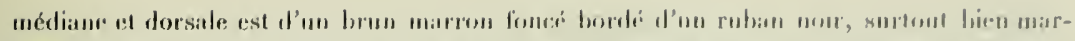

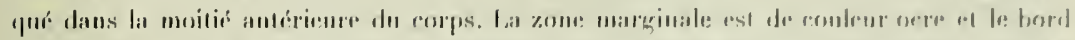

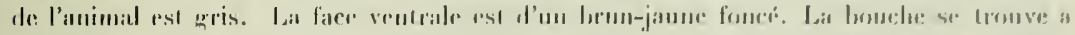

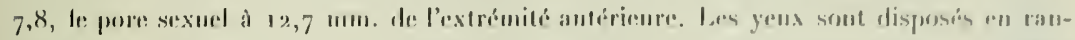

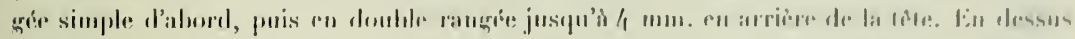

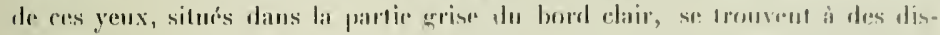

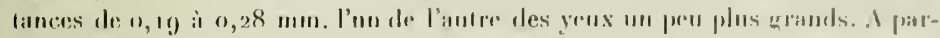

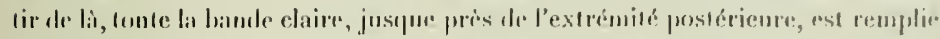

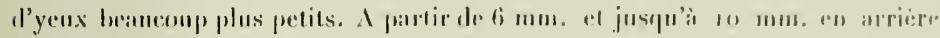

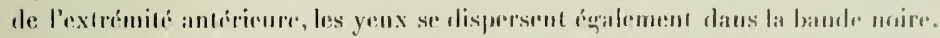

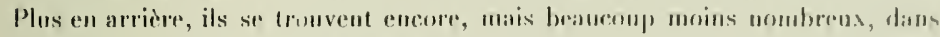
la bante marginale jaume serulement.

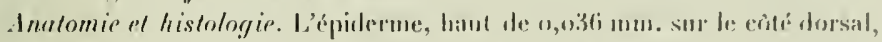

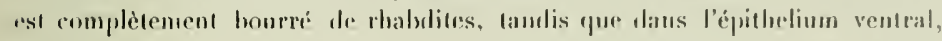
latul de 0,028 mm., les rhabdites ln:acump moins nombreux sunt seulement

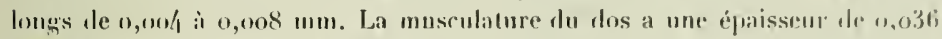

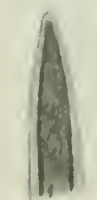
Fig. 11 l'artie anlórieure de i. ula quensis $\mathrm{n}$. sp. IIII. If celle de la face ventrale de $0,030 \mathrm{~mm}$. La musculature dorso-ventrale, formée de tibres entrecroisées, "st triss apparente entre les divertienles de l’utestin. Le pharynx était

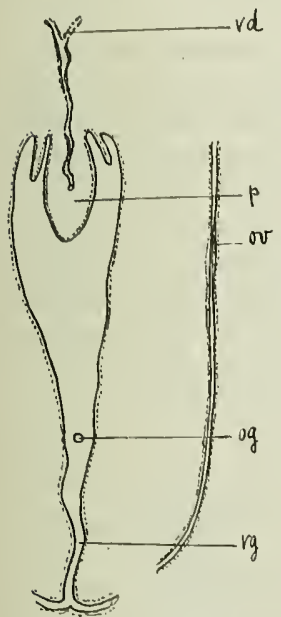

Hig. 12. - G. ubaquensis n. sp. Coupe horizontale par un jeune, individu. ov oviducle, og ouverture génitale. idd canal déférent, $p$ pénis, "g vagin. (Dessiné avec l'appaleil Ahbe). dévaginc el montrait une longueur de 1,57 mm, avee un diançre de $0,6 \mathrm{~mm}$. à sa hase, landis que l'extrémitri libre. dilatéc en forme de cloche, mesurait 1, I mun. Des compes lorizonfales à travers un exemplaire montraient que l'individu n'itait pas complètement mù. Les testicules, très nombremx el situés sur le cobte dorsal, n'avaient pas encore forme de sperme. Chez la plupart, on voyait les uasa efferentia descendre vers le canal déférent silué sur la face ventrale. Les glandes vitellogènes dtaient peu développées. Je n'ai pas vu l'ovaire. La fig. 12 montre les dispositions de lappareil copulateur incomplètement développé.

Parasites. Nons avons vu dans le parenchyme de petites larves de Nématodes.

\section{Geoplana caucaensis $\mathbf{n}$. $\mathbf{s p}$.}

(Pt. XV, Fig. 15. Pl. XV11. Fig. 4.)

Nous arons tromé deux exemplaires de celte espèce au bord de la rive gauche du Canca, au Passo de Concordia (alt. $760 \mathrm{~m}$.). L'animal, long de $25 \mathrm{~mm}$. et large de 3 à $4 \mathrm{~mm}$., a une couleur foudanentale jaune recouverte d'un pigment réticulé brun foncé Irès dense qui ne laisse apparaitre le fond jaune pour l'œil nu. qu'à l'extrémité céphalique de couleur nettement orange. Celle rouleur se voit aussi, mais moins nettement, sur la face ventrale 
We celte régrion du corps. Lanimal parait donc ètre d'un brun foncé assez uniforme sur tnule la face dorsale. Ivec une faible loupe dejà, on remarque que le pigment brun fonci se concentre dans la zone marginale près du bord en une étroite ligne mire. qui se prolonge sur toute ba longuenr de l'animal, mais saus que les lignes des deux rités se rémissent ral avant ou en arrière. La face ventrale esit jamàtre.

Les mesures four, low individus conserves sont les suivantes:

\begin{tabular}{|c|c|c|c|c|}
\hline 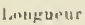 & Largeur & Epaissetur & \multicolumn{2}{|c|}{ Distance de f'extrónuté autérieure } \\
\hline & & & it la bouche & an pore sexuel \\
\hline mm. & mu. & mı. & $\mathrm{min}$. & $\mathrm{mm}$. \\
\hline 2.5 & 3 & 2 & 10 & 10) \\
\hline 18 & 3 & $1, \bar{\dagger}$ & 9 & 13 \\
\hline
\end{tabular}

Fig. 13. -

G. eauca-

ensis n. sp.

v'u du côtè

dorsal, des-

siné d'a-

près l'ani-

mal con-

servé.

Les yeux sont marginamx et en rangte simple jusqu'à 4 mm. en arrière de l'extrémité antérienre. On voit rarement un oeil placé en dessus de la rangée. Lés r2 premiers yeux sont très petits. De 4 mu. à 12 ou à 13 mun, les yeux plus petits sont dispersés dans une étroite zone marginale, mais ne se trouvent plus tout à fait au bord. La richesse en pigment de la face dorsale ne permet pas de les roir nettement.

Anatomir et histologie. Épiderme et musculature cutane sont identiques à cerux de l'espèce précédente.

les nuscles dorso-ventraux et les muscles Iransversaux de la musculature du parenchyme sont très hien développés; ces demiers surtout sur la face ventrale de l'animal. l.e pharynx est relativement petit et presque cylindrique; l'intestin semble peu ramifié.

L'ovaire, de forme ovö̈de, est long de $0,24 \mathrm{~mm}$., large de $0,16 \mathrm{~mm}$. L'oviducte y débouche, rempli de sperme, presque à l'extrémité postérieure et sur le còlé externe de celui-ci. Des glandes vitellogènes enveloppent l'intestin ; elles vont jusqu'à $0,7 \mathrm{~mm}$. en avant de l'ovaire et en arrière jusqu'à la hauteur des organes copulateurs. Sur cette espèce, on voit nettement déboucher dans l'oviducte, en nombre relativement grand, les conduits vitellogìnes très courts. L'oviducte semble dépourvu de musculature. Les con-

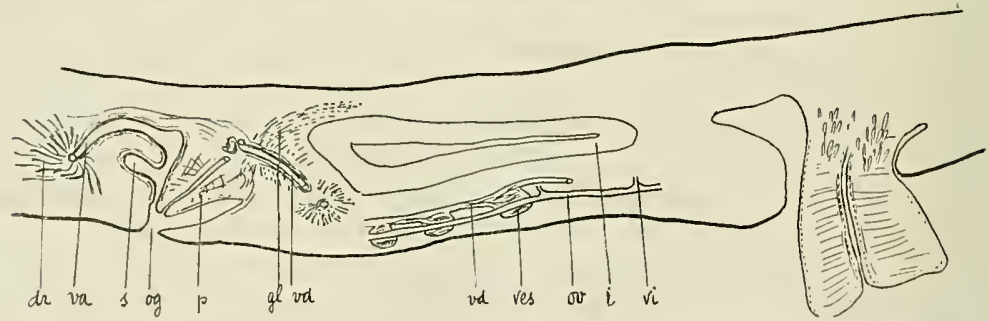

Fig. 14. - G. caucaensis n. 8p. Coupe sagittale el médiane de l'appareil copulaleur. og ouverlure yénitate, $v d$ canal déférent, res vésicule séninale, $g l$ ses glandes, $p$ pénis, ov oviducle, vi conduit vitellogène, $s$ diverlicule de l'atrium femininın. va rag̨in. dr ólande, $i$ intestin. (Dessiné asec l'appareil Ahbe.) 


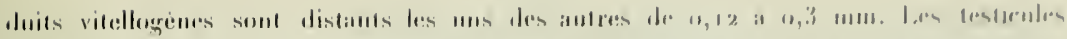

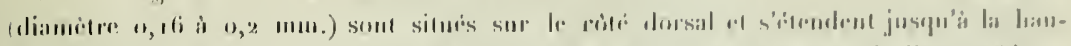

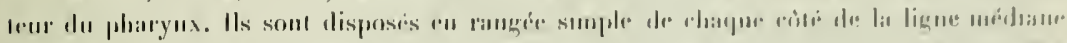

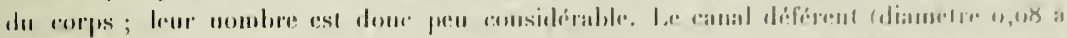

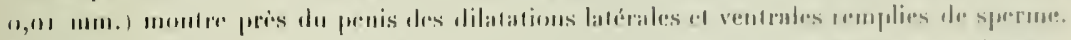

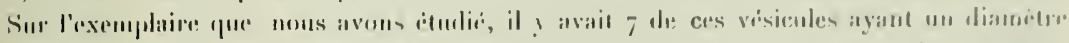

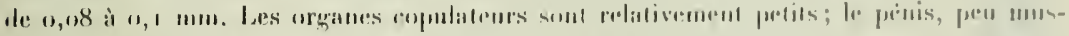

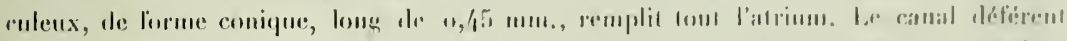

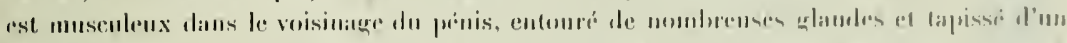

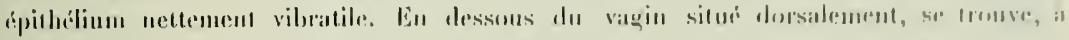

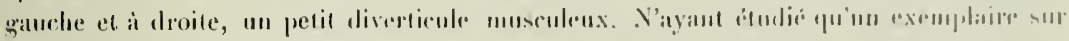

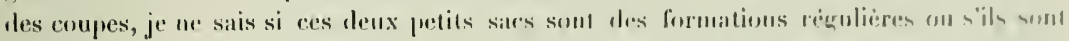

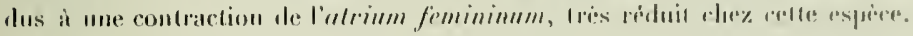

\section{Geoplana columbiana n. sp.}

\section{(1). XI. Fir. If.)}

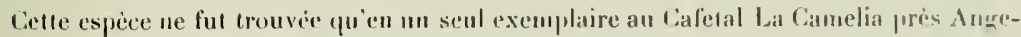
lopolis (Condillères centrales, 1820 m.). L'animal vivaut mesurait $30 \mathrm{~mm}$. ave um largenr maximale, un peu en arrière du milien, de 7 à 8 mm. et ume épaisseur de 1, 8 mm. Le rôtú dorsal de $G$. columbiana était de couleur bistré, avec une lignge ocre clisire au milien, allant jusqu'aux deux exrémitis. Sur te reste du corps, des edellules pigmentaires d'un lorun fonee, produisent un pointille tres fin qui se concentre dans la rigion marginale, en une étroite bande lorun fonce. Celle-ci laisse une très mince bordure, ayant la couleur fondamentale ocre. La face vemrale, tris plane, est jaunàre dans le tiers antérieur.' blanchatre dans les denx autres liers. L'animal conservé an sublimé a bien gardé sa roulent, seule la finer verntrale est uniformément colorée d'un hlane sale; il a un longueur de 29 nin. et une largeur de $6 \mathrm{~mm}$. L'ouverture buccalt est à $16 \mathrm{~mm}$. de l'exiramils antérieure, tandis que l'anverture génitale ell est éfoignée de $20 \mathrm{~mm}$. Les yeux situés sur le bord sont très serrés, jusqu’a 6 , 8 mm., el disposés le plus souvent en deux rangres; de là, jusqu'i 11,5 mu., nous les rnyons se disperser sur le bord et prendre, en meme lemps quails diminuent de taille, anr forme différente. Plus en arrière encore, les yeux devioment rares, mais existent jusqu'à l'extrémité postérieure. Les yeux ont en avant une cupule

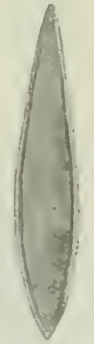

Fig. 15. G. colum bianan.sp. Dessin fail d'après le vivant. pigmentaire à peu près sphérique on ovale, tandisque les yeux de la zone de 7 \& 12 mm., semblent avoir deux petites cupules pigmentaires. l'une un peu plus grande que l'autre, opposées l'une à l'autre el reliées entre elles par un ou plusieurs minces filets de granulations pigmentaires Fig. 19. 


\section{Geoplana bilineata $n$. sp}

Geoplann bilineatu, lrouvé à fuaduas (Cordillères orientales, alt. 1015 m.), probente une forme el un dessin très earactéristiques. Tandis que presque toutes les espèces de

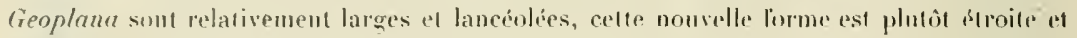
très allungée: sa longneur est de $26 \mathrm{~mm}$., sa largeur ale $3 \mathrm{~mm}$. el son ćpaisseur de I mm. I partir du premier tiers en avant el du dornier einquieme en arriere,

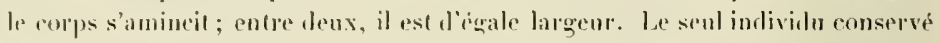
simplement it l'aleool, a une coulem ocre fonce el présente deux handes longitudinales brun fonce, frestue noires, fui ne se runissent ni en avant, ni en arrière. Ces bandes ont la mime largenr que la ligne oere médiane. Sur les

Fig 16. G. bilineaIa n. sp. Porlion dn milieu du

bords, on remarque un zonr de comleur acre qui pusside une largeur un per moindre que les handes noires. La fare ventrale est d'un jaune quisàtre. La houche se trouve a $55 \mathrm{~mm}$, le pore sexuel à $19 \mathrm{~mm}$. de l'extrémils anlérieure. Les yeux jusqu'ì y mm. de l'extrémité antélieure sont en l'angét simple, puis en dessus apparaissent des yeux isolís plıs gros. $15 \mathrm{~mm}$. en arrière de l'extremité antérieure, les yeux, łui jusqu'à maintenant étaient placés dans la bande claire du bord, se répandent aussi jusque daus la partie marginale de la hande hrum foncé où ils se trouvent, il est vrai, en petil nombre. A $7,5 \mathrm{~mm}$. en arrièye de la tète, les yeux deviennent plus petits et plus nombreux. A partir de $13 \mathrm{~mm}$., jusqu'à l'extrémité postérieure, ils sont en moins grand nombre ret se frourent à des distances de 0,2 ì $0,6 \mathrm{~mm}$. les uns des antres.

\section{Geoplana nigrocephala n. sp.}

(PI. NT. Fig. 1:, 13)

Celle belle espece di planaire lut lrouvée près de Bogota (Cordillìres orientales, alt. $2650 \mathrm{~m}$.) et au bord de la Sabana de Bogota, à Boca del Monte (alt. $2400 \mathrm{~m}$.). L'animal vivant itait long de $80 \mathrm{~mm}$. ef large de in mm.; conservé, il ne mesure plus que $56 \mathrm{~mm}$. avec une largeur de $8 \mathrm{~mm}$. et une épaisseur de $2 \mathrm{~mm}$. Le serond exemplaire est long de 6o $\mathrm{mm}$., large de $9 \mathrm{~mm}$. et épais de $2 \mathrm{~mm}$.

La coloration de la face dorsale est très simple, tout le dos. excepté nne étroile zone marginale de $1 \mathrm{~mm}$. lle largeur, est d'm bean noir. Le bord présente une couleur brun olivàtre. En avant, cette bordure se perd si bien, que la tète de l'animal est entièrement noire sur une longueur de 4 a $6 \mathrm{~mm}$. La face ventrale est gris clair, mais en avanı, dans la région céphalique où le côté dorsal est noir, nous voyons que la face ventrale est gris foncé, tandis que lo horal rentral de la lète lancénlée est noir. La couleur de l'animal conservé est noire sur 


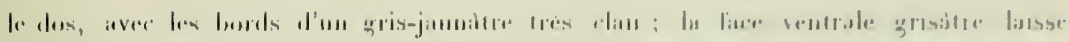

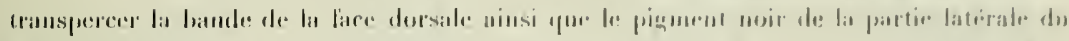

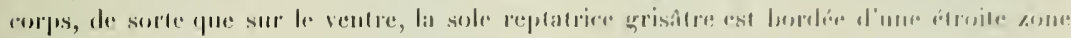

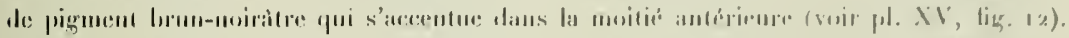

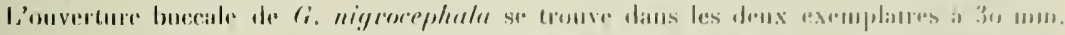

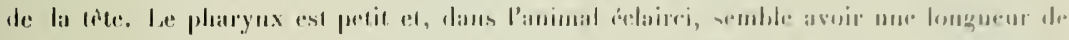

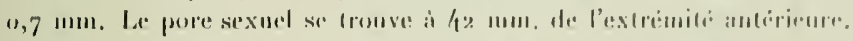

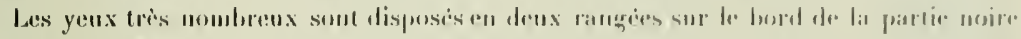

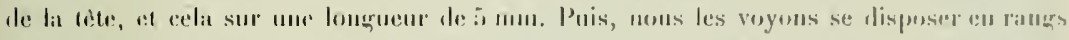

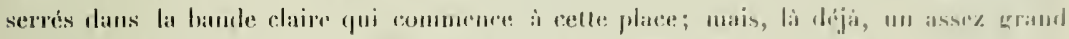

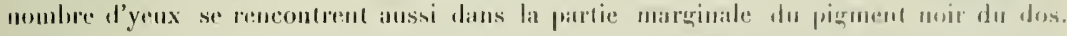

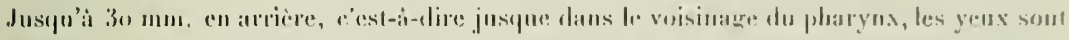

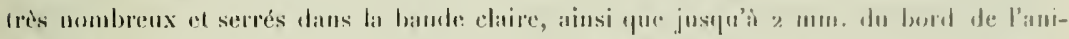

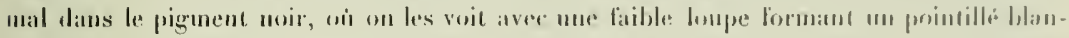

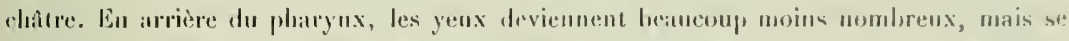

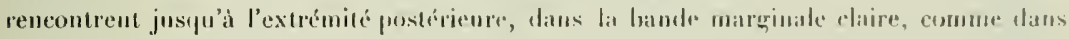
le pigment noir du dos.

\section{Geoplana bimbergi n. sp.}

(P1. XVI. lizig. 17 iे I!!.)

Les donze exemplaires de celte nouvelle espece, trouve dans le Cafetal La Camelia, appartenaut ì M. Bıввng, consul allemand, présentent tous la mème coloration très. compliquée et caractéristique de la riggion eéphalique.

Suivant l'élat de contraction, la forme de ces animax varie beaucoup (PI. . $1 \%$, Fig. 17 à 19). L'animal vivant prisente, à fexception de la tète, une coloration noir velouté avec un bord blane plus ou moius large. L'extrémité antérieure de la tète est blanche sur une longueur d'environ $1 \mathrm{~mm}$, ce qui est surtout visible lorsque la tète se contracte. tietle tache blanche se continue eu unt courte hande médiane de coulenr brume qui se hifurque, de sorte que le tout prent ainsi la forme dime langue de serpent. La partic anterienre de lia tete est complètement noire, ì l'exception de la baude médiane brune. La hande blanche qui entoure tout le corps pinitre en s'effilant dans la partie marginale de la tète de conleur noire, mais s'arrete ì ? à $3 \mathrm{~mm}$. du sommet de la tìte. A la hantenr de la tache midianr el bifurquée. sonvent déjà un peu eu avant, la hande hordubale banchr devient neltement jaune.

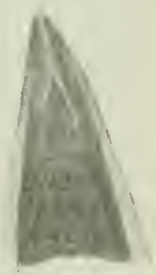

Fig. 18. $-G$. himbergi n sp. Extrétnilé anté. rieure courle. Sur l'aumal conservé, les différents dessins de la tète sont hien visibles, mais te brun

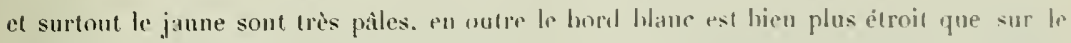
vivant, ì canse de la contraction. 
Voici quelques mensurations:

Longueur
$71 \mathrm{~mm}$.
$68 " 1$
$63 " 1$
$56 " 1$
$48 "$
$45 " 1$
$31 "$
$17 "$

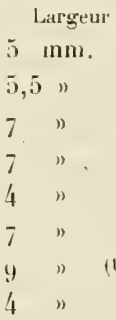

Dislatice de l'extremite anterieure

\begin{tabular}{|c|c|}
\hline it la bouche" & in pore sexuel \\
\hline $46 \mathrm{~mm}$. & $54 \mathrm{sm}$. \\
\hline $44 n$ & i2 \\
\hline 37 & 46 \\
\hline 33 & 411 \\
\hline 30 & 37 \\
\hline$n$ & 33 \\
\hline 32 & 77 \\
\hline 1011 & pas développé. \\
\hline
\end{tabular}

Les yeux sont en asant disposés d'abord en rangée simple puis en rangée double et triple. Iu-dessus d'eux, à des distances plus grandes, se trouvent des yeux plus grands. Jusqu'à $12 \mathrm{~mm}$. en arrière de l'extrénité antérieure, les yeux restent concentrés sur le bord, puis se dispersent, si bien que la zone marginale contenant les yeux qui était jusqu’ł mainte-

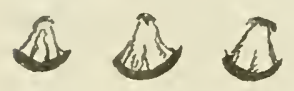

Fig. 19. - Geoplana bintbergi $\mathrm{n} . \mathrm{sp}$. Yenx de la région du pharynx. nant large de $0,19 \mathrm{~mm}$. augmente jusqu'à $0,47 \mathrm{~mm}$. A la hauteur de l'extrémití postérieure de la tache marginale jaune, l's organes visuels entrent également dans le bord du pigment noir et se remarquent là par des points blancs très pelits, visibles seulement à la loupe, et qui se voient jusque près du pharynx. Dans cette région, les yeux pénètrent jusqu'à $1,5 \mathrm{~mm}$. du bord, sur la face dorsale de l'animal. Un peu en avant du pharynx, les points blancs disparaissent mais il y a toujours encore un certain nombre d'yeux. Dans le dernier quart de la planaire, il ne semble plus y avoir d'yeux. En tout, nous avons compt' chez un exemplaire 1300 yeux de chaque còté. Les yeux en arrièré de la région céphalique ont une forme trìs caractéristique, parce qu'elle se présente, sur les individus éclaircis au Benzol, avec une cupule pigmentaire en forme d'écuelle très peu profonde devant laquelle est placé un goros point noir relié à la cupule par de légères traìnées de pigrnent (Fig. 19).

Anatomie et histologie. L'épiderme est d'égale épaisseur des deux còtés de l'animal; il mesure $0,036 \mathrm{~mm}$., les cils vibratiles bien visibles sur la face ventrale seulement ont une longueur de o, $008 \mathrm{~mm}$. l'épiderme du dos est surtout rempli de rhammites, dout les glandes nombreuses forment une couche continue eu dessous de la musculature cutanée. Sous celte couche de cellules, se colorant très vivement, se trouve une couche de glandes cyanophiles. Du côté rentral, l'épiderme ne renferme que de petits rhabdites, longs de o,0oh à $0,008 \mathrm{~mm}$., les glandes cyanophiles sont beaucoup moins nombreuses que du cité dorsal. La musculature cutanéc, formée de fibres circulaires, diagonales et longitudinales, montre une épaisseur de 0,06 à $0,07 \mathrm{~mm}$. Toute cette musculature est traverśe du còté dorsal par les ramifications très nombreuses rles cellules pigmentaires noires. La museulature du parenchyme est peu marquée, seules les fihres musculaires dorso-ventrales sunt très uombreuses et relativement épaisses. 


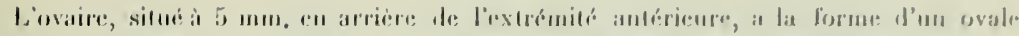

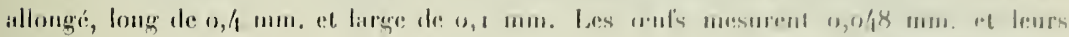

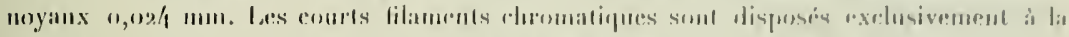

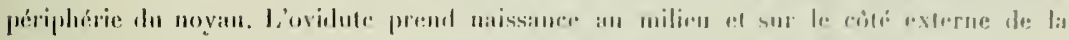

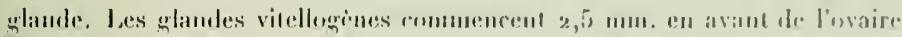

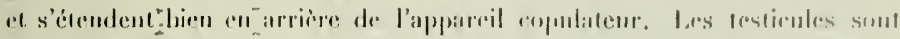
sifus exclusivement du crite dorsil de l'intestin, lene diamidere est do

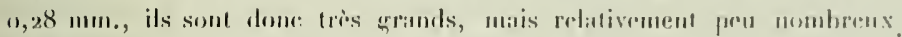
Dians la partie antérieure da corps, jai compté, sur une lonermenr do

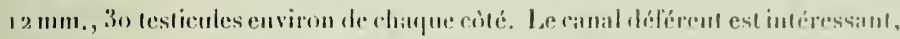

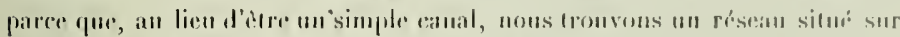

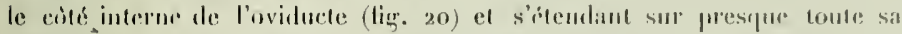
longueur. Près de l'apparril copulateur se présentent de nombreuses dilatations du ranal defferent, qui lonctionnent sans doute comme visienles séminales. A l'approche du prónis, ce camal s'entoure al'une faible musculafure

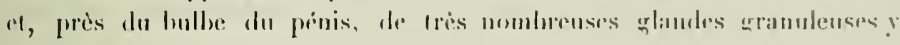
dibouchent.

L'organe copmbatent mile, dans son ensemble, a me lonerume de

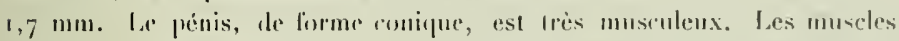

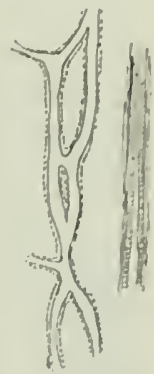

Pig. $20-1$. bimberyen. 8p. Késeau du cam nal défírent; a droite loviducle. rirculaires se rémissent. m laisceanx formant des lamelles qui, par place, sout hatules de $0,06 \mathrm{~mm}$. Le ductus ejaculatorius, fortement contourné, mi musculeux lintrinm feminimum est moins musculenx que le pénis; lo vurin dans lequel débouchent de tris nombrenses ghandes est entoure d'une forte musculature. I I mon. en arriere de l'ulrinm, feminimum se lrouve, du còte dorsal, un volumineux amas, forme de grandes cellules wlandulaires dont les conduils se dirigent vers le ragin.

Paresiles. De nomhrenses'larres dr Nímatodes se trouvent lans le parenchyme.

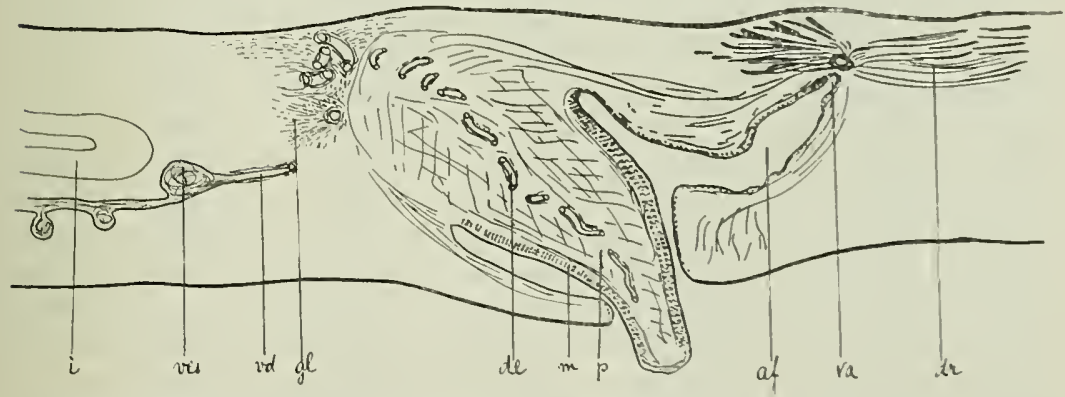

Fig. 21. - G. bimbergi n. sp. Coupe sagittale el médiane de l'appareil copulateur. p pénis, m musculature. de duclus ejaculatorius, $g l$ glandes du canal déférent vd, ves vésicule séminale, af atriun femininum, va vagin. $d r$ glandes, $i$ intestin. (l)essinẻ avec l'appareil Abbe.) 
Cette intéressante espèce est dédiée à M. Karl Bimberg, consul allemand à Mledellin, en lommage de reconnaissance pour sa large lospitalite et les grands services qu’il nous a rendu.

\section{Geoplana becki n. sp.}

(Pl. Xit, Fig. 16. Pl. XVll, Fig. 2 et 5)

Les riches matériaux consistant en 50 exemplaires de toutes tailles furent récoltés par nous dans une Quebrada près de Bogota, à Zipaquira et en dessous de Boca del Honte (Cordillères orientales, alt. 2400 à $3000 \mathrm{~m}$.). Les exemplaires, longs an maximum de

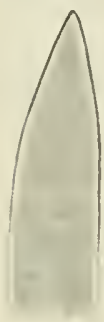

Fig. 22. G. becki n. $\mathrm{sp} . \mathrm{Ex}-$ trémité anlérieure et dorsale. $140 \mathrm{~mm}$. et litrges de $12 \mathrm{~mm}$., avaient tous la mème coloration, plus ou moins foncie seulement. La couleur fondamentale est ocre, reconverte par un rélicuIum très serré de pigment noir, ce qui fail que le dos de l'animal semble brun noir avec de petites taclıes irrégulières de conleur jaune. Un bord clair el étroit, presque invisible dans certains cas, entoure l'animal; il est de couleur ocre. Dans la région céphalique, nous trouvons en dehors de ce bord jaune ocre, une ligne noire très nette el caractéristique pour tous les exemplaires. La face ventrale plane et claire est d'un jaune sale, parfois un peu brunitre par place. La bordure noire de la région céphalique et dorsale se trouve aussi sur la face ventrale de la tète et sur la mène étendue.

Les animaux conservés au sublimé ont la même coloration, mais la légère couche de mucus qui les couvre leur dontue une teinte noir olivàtre et couvre un peu les petites taches claires difficilement visibles; le jaune du bord clair est peu prononcé.

L'espèce a extérieurement une certaine ressemblance avec $G$. amagensis, mais chez cette dernière, les taches jaunes sont beancoup plus grandes et bien visibles.

Voici quelques mensurations prises sur $\mathrm{r} 3$ exemplaires:

Longueur
$\mathrm{mm}$.
88
88
80
80
80
78
75
70
70
50
40

$\begin{array}{cc}\begin{array}{c}\text { Largeur } \\ \mathrm{mm} .\end{array} & \begin{array}{c}\text { Épaisseur } \\ \mathrm{mm} .\end{array} \\ 10 & 2 \\ 9 & 2 \\ 10 & 2 \\ 9 & 2 \\ 10 & 2 \\ 10 & 2 \\ 12 & 2 \\ 8 & 2 \\ 7 & 2 \\ 6,5 & 2 \\ 6 & 2\end{array}$

\begin{tabular}{|c|c|}
\hline \multicolumn{2}{|c|}{ Distance de l'extrémité antérieure } \\
\hline $\begin{array}{c}\text { à la bouche } \\
\text { mm. }\end{array}$ & $\begin{array}{l}\text { au pore sexuel } \\
\text { mm. }\end{array}$ \\
\hline 5.3 & 67 \\
\hline $\bar{\vdots}$ & 65 \\
\hline 45 & 58 \\
\hline 48 & $6_{1}$ \\
\hline 46 & 60 \\
\hline 45 & 58 \\
\hline סט & 6.3 \\
\hline 51 & (ii) \\
\hline $4 \%$ & $5 / 1$ \\
\hline 32 & בצ'3 \\
\hline 28 & .34 \\
\hline
\end{tabular}




\begin{tabular}{|c|c|c|c|c|}
\hline \multirow[b]{2}{*}{$\begin{array}{l}\text { Lunguour } \\
\text { mum. }\end{array}$} & \multirow[b]{2}{*}{$\begin{array}{l}\text { Largent } \\
\text { ІІІн. }\end{array}$} & \multirow[b]{2}{*}{$\begin{array}{c}\text { lepnlmanur } \\
\text { muil. }\end{array}$} & \multicolumn{2}{|c|}{ 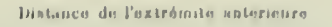 } \\
\hline & & & $\begin{array}{c}\text { a la lonisoliso } \\
\text { mone. }\end{array}$ & $\begin{array}{l}\text { au poren moxespl } \\
\text { mon. }\end{array}$ \\
\hline 211 & $\therefore$ & 1 & $1 \%$ & pas de pure: mexuel. \\
\hline 15 & 2 & 1 & 11 & 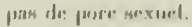 \\
\hline
\end{tabular}

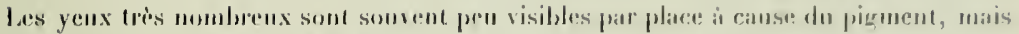

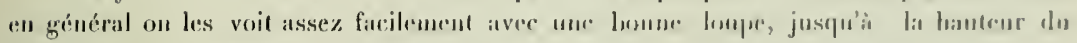

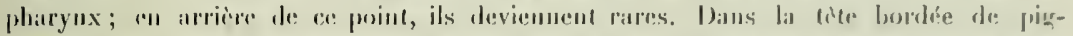

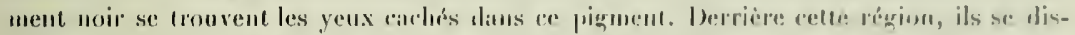

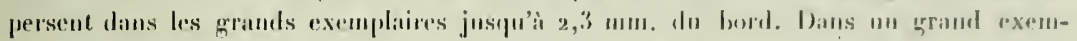

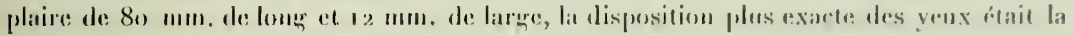

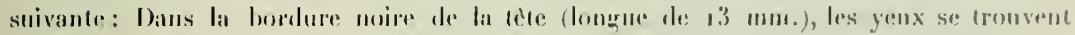

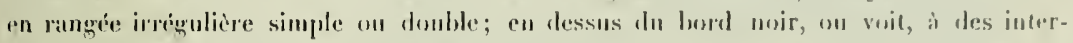
valles de 0,17 i 0,57 mun., des youx plus gramds, d'un diamètre de $1,0,5,7$ inm. Ën

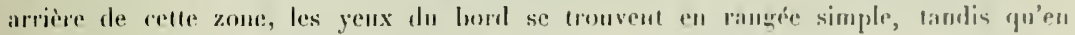

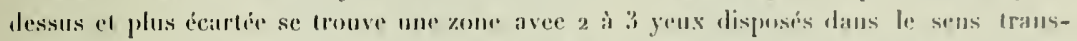

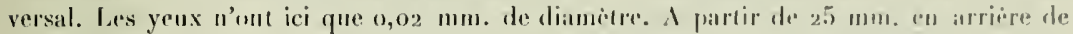

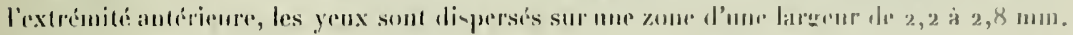
Dans cette région, il n'y a plus d'yeux sur le hord immondial de l'animal un du moins il y en a très pen, à des distances de 0,6 i 0,8 mm. Eu arriere de lia réginu du pharyux ou les yeux sont encore nombreux, ils deviennent rares el on ue compup plus que 6 à 8 yeux

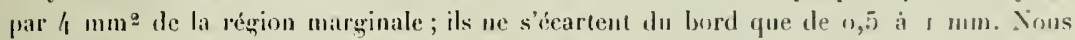
avons compté rhez l’individu an question 7 gy yeux de chaque exité, mas leur nombre est sans doute un peu plus consilérable, paree que bien des yenx doivent íchappes a cause de la pigmentation. En elfel, dius un exemplaire de $87 \mathrm{~mm}$, nous avons complé, dans la rígion antéricure de o à $25 \mathrm{~mm}$. seulement, 660 yeux de chaque cóté. Plus en arrière, bien que les yeux soient encore assez nombreux it jo mm., nous n'arons pu las compter, purr les raisons indiquées plus haut. Somme coute, le nombre des yeux semble ètre variahle chez cette espece, leur disposition par contre est assez constante.

Anatomie et histologie. L'épiderme du eòté dorsal présente une hauteur ale $0,027 \mathrm{~mm}$. et il est rempli de rhammites filiformes longs de 0,036 a $0,045 \mathrm{~mm}$. La gaine musculaire, relativenent failile, ne mesure que $0,048 \mathrm{~mm}$. En tlessous, se trouve une zone de glandes it phammites a laquelle font suite en avant les testicules pris les glandes vitellogènes, énormément dévelopures, puis l'intestin. L'épiderme de la face ventrale est à peine plus haut "t renlerme en faible quantité de petits rhabdites qui mesurent $0,009 \mathrm{~mm}$ au maxinum. Les cils vibratiles, très distincts sur la face ventrale, ont $0,005 \mathrm{~mm}$. de long. Les glandes cyanophiles, trìs nombreuses sur le còté dorsal, sont relativement peu nombreuses sur la face rentrale. La musculature du parenchyme est trés apparente, surtout les muscles dorso-ventraux et une couche de muscles transversiux directement au-dessus de l'intestin

Le pharynx est relativement petit; la cavitédu pharynx sur un exemplaire de $14 \mathrm{~cm}$. est longue de $2 \mathrm{~mm}$., tandis que sur un individu de $18 \mathrm{~cm}$., cette mème cavité mesure 
4 mm. L'ouserture buccale est situce an milien on mu pen en arribe. Cliez un individu, nous avons compté à la branche antérieure de l'inteslin, qo branches secondaires très irrégulièrement ramifiées, tandis quen arrière se trouvent de chaque còté une rrenlaine de diverticules, sur les deux loranches posterieures dn système digestif. Certaines ramifications peurent s'anatomoser (PI. XYII, Fig. 5).

Lovaire est situé à $13 \mathrm{~mm}$. en arrière de l'extrémité antérieure, il est piriforme, longr de $1 \mathrm{~mm}$. el large de $1,23 \mathrm{~mm}$. Sur les coupes horizontales, la glande ovarienne est complètement entourée latéralemeut par les réseaux du système nerveux. Les urufs ont un diamètre de 0,047 mm. avec nu noyau mesurant 0,029 mm. I la périphérie du protoplasme, on roit sur tontes les cellules mùres une simple couche de granulations vitellines.

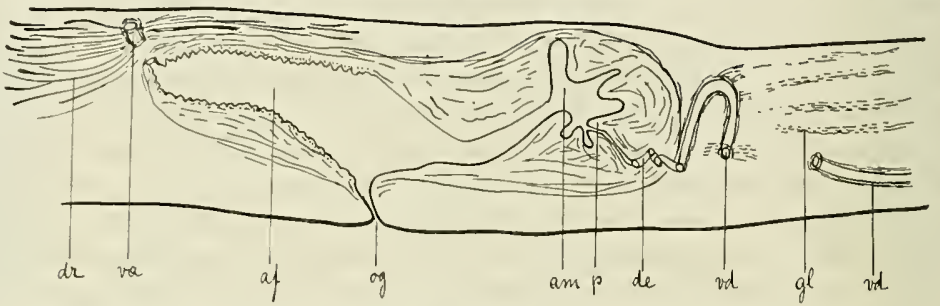

Figr. 23. - G. becti n. sp. Coupe sagittale et mèdiane de lappareil copulateur. og ouverture génitale, am atriuın masculinum, $p$ pénis, de duclus ejaculatorius, $v d$ canal déférent, $g l$ glandes de ce canal, af atriun femininum, va vagin, $d r$ glandes. (Dessıné avec l'appareil Abbe).

L'oviducte, entouré de muscles et rempli de sperme jusqu'ì l'endroit où il débouche dans l'ovare, longe la partie amincie el externe de celui-ci pour s'ourrir an milien et dorsalement dans la glande génitale. Les glandes vitellogènes, très développées, entourent l. tube digestif et pénètrent entre ses ramificalions. Elles commencent $4 \mathrm{~mm}$. en avant de l'ovaire et s'étendent jusqu'ì l'extrémité postérienre.

Les testicules situés dorsalement et serrés les uns contre les autres, sont très nombreux puisqu'il y en a an moins 250 de chapue coite de l'animal. Ils se montrent depuis la hanteur de l'ovaire jusqu'au plarynx. Le diamètre des testicules est de 1,28 mun. Le canal déférent bourré de sperme est entouré, à partir d'une faible distance du pénis, d'une gaine musculaire. Dans cette partie musculeuse dn canal déférent débonchent de tres nombreuses glandes. Ce canal pénète daus lo lublle du pínis depuis le còté ventrat. L'organe copulateur male est très petit; par contre, l'atriun génital màle est long, avec des parois présentaut quelques gros plis daus le voisinage du pénis tandis jue la moitié porale de l'atrium est étroite. Lors de la copulation, les plis du fond de l'atrium serviront sans doute à agrandir le pénis, qui devient alor's, comme dans les autres especes, un organe assez volumineux de forme conique (voir $G$. amagensis p. $77^{5}$ ). L'atrium femininum est sacciforme, à parois finement plissées. Le vagin est court, d'inormes quantités de cellules glandulaires y déhouchent. L'appareil copulateur, enveloppé do 


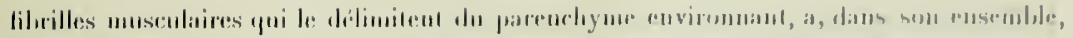

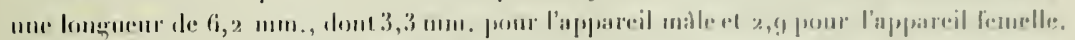

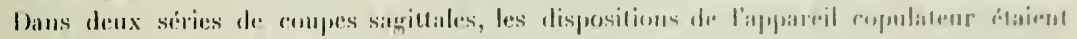
inlenlingurs.

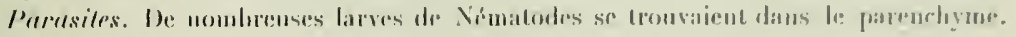

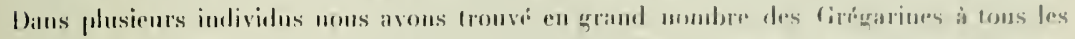

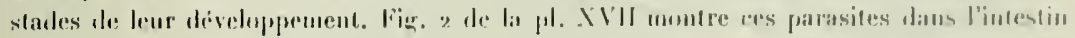

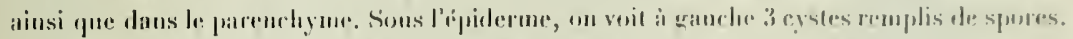

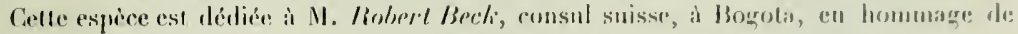

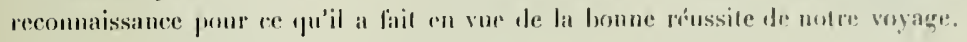

\section{Geoplana amagensis $\mathbf{n} . \mathbf{s p}$.}

(1). XV1. Pig. 23, 2f.)

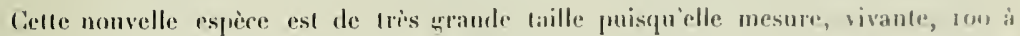
$1.30 \mathrm{~mm}$, avec une largeur de 10 ì $12 \mathrm{~mm}$. Les lres nombromx exemplaires vipment lom des environs du Caldelal Ia Camelia, situé sur les llaues de la vallée du Rio Amaga (Cordillères centrales, alt. 1 (600 à $1800 \mathrm{~m}$.).

La couleur fondamentale de l'animal est jaune ocre el le dos lacheti par des cellules prigmentaires brunes. Les tache's formies sont the grandeur et de forme très irrégulieres. Daus la ligne médiane, mais seulement en dessus de l'énorme pharynx el des organes copulateurs, le pigment brun se concentre le julus somvent en une ligne foncée, se perdant bu avant et allant en arrière presque jusqu'i l'extrémite posterienre. Ia fate ventrale est jaunitre, le bord de la région cophalique sur la lice dorsale comme sur la face ventrale rst borle de noir.

Plusieuts exemplaires montraicnt une partie de lia liare ventrale el de la face dorsale converte de centaines de pretits joints hancs. L'itude a montré que c'itaient des parasites appartenant it une intéressante espere de grégarine. Les points ldancs sont les kystes remplis de spores qui éclatent et se diversent it la surface de l'animal, lantis que de milliers de gregarines se trouvent daus la profondem du parenchyme, inutour du tuhe digestif.

Voici quelques mensurations:

\begin{tabular}{|c|c|c|c|c|}
\hline Longueur & Largeur & Ëpais-eur I & Wistamed & remite auterieure \\
\hline & & & is l:a bouche & au por" sexuel \\
\hline $\mathrm{mm}$. & $m+1$. & mm. & $\min$ & $\because 1 \mathrm{~m}$ \\
\hline 112 & 8 & 3 & (i.) & 81 \\
\hline 90 & 11 & 2 & 38 & li.t. \\
\hline $9^{\prime \prime}$ & 12 & 2 & 4.3 & ii3 \\
\hline 8.3 & 12 & 2 & 4.3 & it \\
\hline 60 & 8 & $1, \overline{1}$ & 37 & pas de pore se'vuel \\
\hline 1) & !) & $1, \overline{1}$ & 22 & pas de puro exuel \\
\hline
\end{tabular}

1 Hans la regrion du pharyox inorme. l"épaisseur de l'animal esl un peo plus urrande. 
Sur un exemplaire de 112 mm., étroil et allongó, nous voyoms les veux d'alord en simple puis en touble et finalement en triple rangée et en rangs serés, si bien que dans les 17 mm. en arriere de l'extrémité antérieure, se troment 466 venx de chaque corté Entre $17 \mathrm{~mm}$. ef $35 \mathrm{~mm}$., les yeux se trousent dispersés sur une zone latérale de 1,9 à $2,3 \mathrm{~mm}$. : nous y avons compte 300 yeux de chaque criti. En arrière, des yeux isoles se rencontrent jusqu’à l'extrémité postéricure. Sur cet exemplaire, il y a an moins r boo yeux.

Chez un individu long de 80 mm., les yeux sont placés jusifu'à 10 mun. en arrière de la pointe de la tète, tout à fail au bord; j’en ai compté 280 de chaque còté! Leur. diamètre est de $0,045 \mathrm{~mm}$, mais une partie n'a que $0,0114 \mathrm{~mm}$. De ro à 3o mm., les reux sont dispersés dans une zone inarginale de 2 mm. environ. Nous n'avons pu en compter que 250 , mais beaucoup sans donte étaient cachés par la pigmentation. Un exemplaire de $45 \mathrm{~mm}$. montrait beaucoup moins d'yeux, ils s'étendaient en grand nombre jusqu’ì $15 \mathrm{~mm}$. en arrière de l'extrémité antérieure, et jusqu'à $6 \mathrm{~mm}$. ils étaient concentrés tout it fait an bord. Le nombre des yeux semble angmenter heaucoup avec la taille.

Nous avons déjà dit plus haut que le pharynx est énorme, sa cavité, chez l'exemplaire long de 1 I $2 \mathrm{~mm}$, est longue de $\mathrm{r} 6 \mathrm{~mm}$. et large de $4 \mathrm{~mm}$. L'ouverture luccale se trouve an milieu de la poche. La fig. 24 de la pl. XVI montre le pharynx dévaginé avec son bord fortement plissé. La branche médiane et antérieure de l'intestin (d'mn exemplaire de $8 \mathrm{~cm}$.) n'a que 45 branches primaires fortement ramiliées.

Anatomie el histologie. L'épiderme du cóté dorsal, haut de 0,028 ì 0,04 mm., est rempli de rhablites et de rhammites. Les glandes à rhabdites forment une couche se colorant en bleu très foncé, sous laguelle s'en trouve une autre formée de nombreuses glandes cyanophiles mélangées à quelques glandes granuleuses se colorant en jaune. La musculature transversale el diagonale a une épaisseur de 0,02 à $0,034 \mathrm{~mm}$. ; les étroits faisceaux longitudinanx, dont les fibres sont peu serrées, mesurent 0,04 à $0,052 \mathrm{~nm}$. Sur le còté ventral, l'épiderme présente très nettement un recouvrement ciliaire hant de o,oo6 à $0,008 \mathrm{~mm}$., qui semble manquer à la face dorsale. La couche épithéliale est haute de 0,024 à $0,032 \mathrm{~mm}$. el dépourvue de rhabdites. La musculature cutanée est un peu moins forte que du cóté dorsal, puisque son épaisseur est de 0,04 à $0,056 \mathrm{~mm}$. Les glandes cyanophiles, très nombreuses du còté ventral, forment en dessus du réseau nerveux une couche continue, leủrs canaux excréteurs passent à travers les mailles dı système nerveux et traversent, très nombreux, l'épiderme. Sur le bord latéral, nous voyons déhoncher de nombreuses glandes granulenses jaunes (coloration van Gieson) rlont les corps cellulaires sont fort áloignés de la surface. La musculature du parenchyme est assez hien développée, les libres rlorso-ventrales sout particulièrement nombreuses. En dessus du système nerveux ventral ainsi que du cóté dorsal du tube digestif, se trouvent de nomlireuses fibres transversales.

L'ovaire, situŕ à $13 \mathrm{~mm}$. en arrière de la tète, a une forme très allontrée, puisqu'il mesure $1 \mathrm{~mm}$. de long et seulement 0 , $18 \mathrm{~mm}$. de large. II est piriforme, la partie élargie lirigée en avant. Dans la région antérieure sẹ trouvent surtout les oufs mûrs avec un 


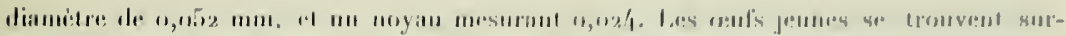

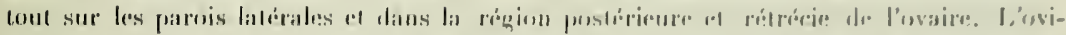

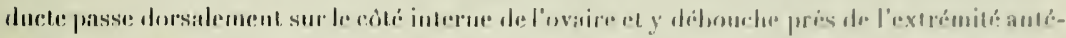

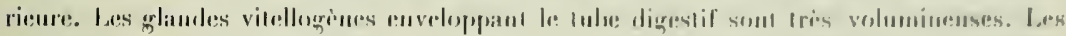

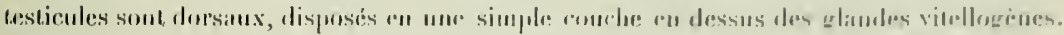

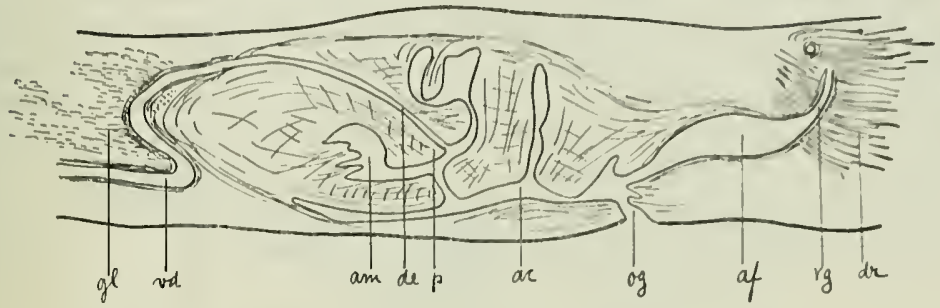

Fig. 24 .

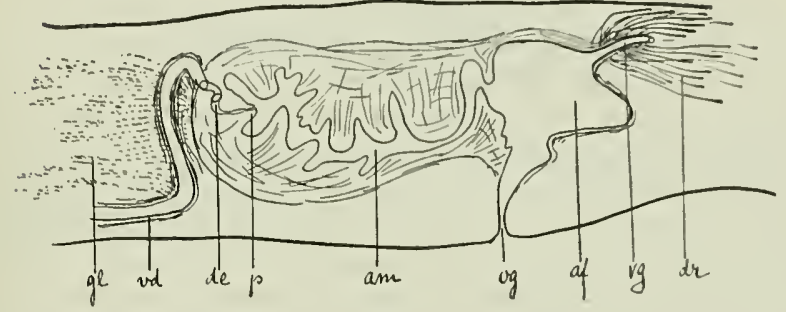

Fig. 25.

Fig 21 et 25. - G amagensis o. sp. Coupe sagituate par l'appareil copulaleur. og ouverture génitale, ac atrium commun, am atrium ma sculinum, $p$ pénis, dle duc. tus ejaculatorius, vil canal déférent, $g l$ glandes, at atriun femininum, vg vagin. dr glandes. (Dessiné arec lappareil Abbe).

Ils laissent libre une étroite zone médiane et sont de forme irrigulieve ayant un diamiatro de 0,28 ì $0,36 \mathrm{~mm}$. Les orranes copulateurs sont très intéressants chez celte espèce, parce que nons avons pu olserver sur deux sciries de coupes les élats dilférents de contraction de ces organes. Ils ont donné des images si complètement différentes pour les organes copulateurs màle el femelle qu'on aurail pu se croire en présence de deux espices dilférentes si l'aspect extérieur de l'animal, ainsi que les particularités histologiques, n'avaient pas été identiques chez les denx individus. Sur l'une des séries de coupes (fig. 24), nous voyons le pénis volumineux el de forme assez parliculière remplir presque complìtement un atrium masculinum, séparé de l'atrium conmun par deux aros plis qui s'élèvent du còté dorsal et rentral de l'atrium. liatrimm masculinum lni-mème est forte- 
ment plissé. Chez l'autre exemplaire, par contre (fig. 25), le pénis est rudimentaire et se presente sous forme d'une petite papille faisant saillic dans un long alrium masculinum, ì parois fortement plisiées. Les deux gros plis que nous avons signalés plus haut n'existent pas sous la mème forme chez le secund individu, mais, vu la riche musculature, rien n'empèche leur formation.

Le canal déférent, en sortant de l'enveloppe musculaire qui entoure l'appareil copulateur, s'entoure d'une forte musculature et les glandes qui y débouchent sont très nombrenses. Plus en avant, pris tu pharynx, le spermiducte montre des dilatations hourrées de sperme. L'alrium femininzm est de lorme allongée chez l'un, très large et court chez l'autre des deux individus. Le vagin est court et comme dans l'alrinm femininnm, il y dibouche de tris nomlreuses glandes.

Parasites. Le parenchyme de cette esprece est très soment hourri de lirigarines; les larres de Nématodes parasites sont aussi assez nombreuses.

\section{Geoplana multipunctata n. sp.}

(I). NIT. Fig. 25, 26.)

Cinte belle espece trouvée pris de Bongota (alt. $2660 \mathrm{~m}$.) ressemble beancoup' à C. carrierei Graff, mais elle est certainement différente par le manque d'une tète coulem rouille, par une coloration différente de la lace ventrale, par une position différente de lat bouche et du pore sexuel et par un arrangement différent des yeux.

L'animal vivant est noir sur la face dorsale, gris brun assez foncé sur sa face ventrale. Celle-ci est bordée d'une étroite bande noire $(0,5-0,7 \mathrm{~mm}$.) qui entoure tout le corps. En arrière de la région céphalique amincie, se trouve, des deux còtés, une zone pointillée en hlane et très apparente, qui s’étend jusqu'à l'extrémité postérieure. Les 9 exemplaires, longs de 12 à $55 \mathrm{~mm}$., conservés an sublimé acétique chaud, sont identiques comme coloration et comme arrangement des points blancs. Deux exemplaires senlement montrent une tète un peu moins foncée que le reste du corps. La coloration correspond à celle de l'animal vivant.

Voici quelques mensurations qui montrent la position de la bouche très en arrière et la distance relativement grande la séparant du pore sexuel:

$\begin{array}{ccc}\text { Longueur } & \text { Largeur } & \text { Epaisseur } \\ \text { inm. } & \text { mm. } & \text { mm. } \\ 55 & 5 & 2 \\ 50 & 4 & 2 \\ 48 & 4 & 2 \\ 46 & 5 & 3 \\ 40 & 4 & 2 \\ 37 & 4 & 2 \\ 30 & 4 & 1\end{array}$

Distance de l'extrémite antérieure
$\begin{array}{cc}\text { it la bouche } & \text { au pore sexuel } \\ \text { mm. } & \text { mn. } \\ 34 & 44 \\ 32 & 40 \\ 33 & 40 \\ 31 & 40 \\ 27 & 34 \\ 25 & 31 \\ 21 & \text { pas dévelople }\end{array}$




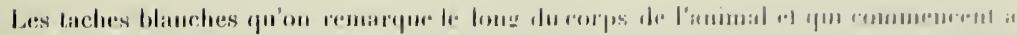

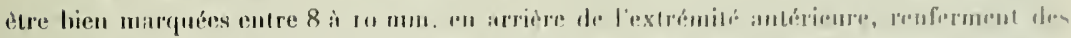

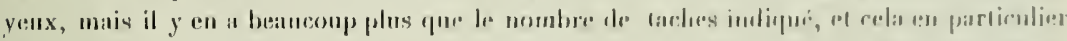

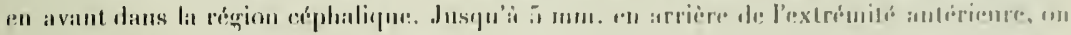

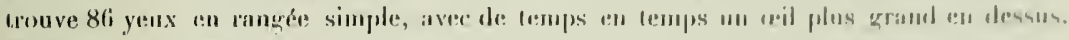

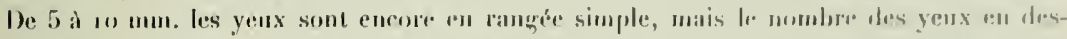

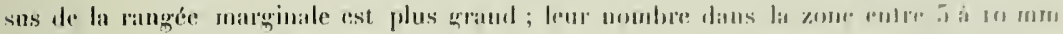

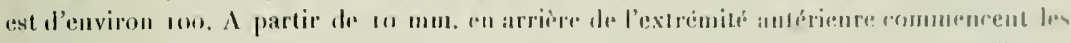

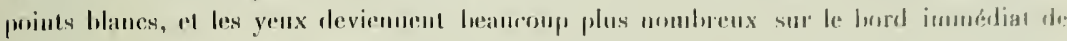

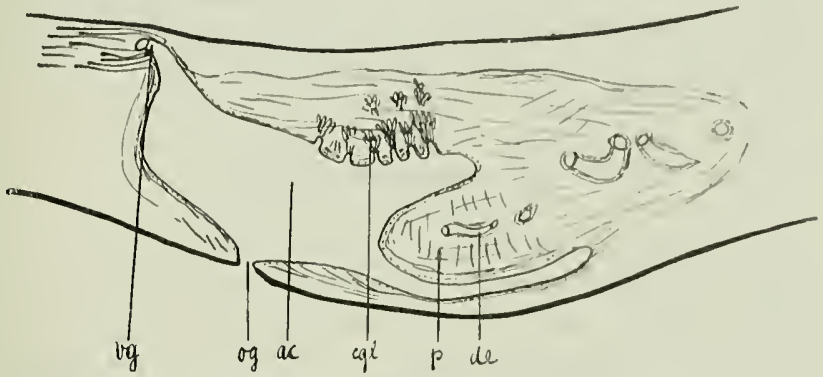

Fig. 26. - G. multipunctata n. sp. Coupe sagittale par l'appareil copulateur. og ouverture génitale, ac atrium commun, p pénis, de duclus ejaculatorius, cgl glandea atriales. ug vagin. (Dessiné avec l'appareil Abbe.)

l'animal et se répandent mais moins serrés jusigu'à 2 mun. du bord. Les taches claires, gui vont jusqu’à l'extrémité postérieure, sont d'aborl d'un diamètre de 1,19 ì 0,11 mom., puis plus en arrière, clles mesurent de 0,19 ì $0,28 \mathrm{~mm}$. Les yeux qu'clles renferment mesurent n,019 à $0,038 \mathrm{~mm}$. Dans les taches blanches de grand liamètre, les yeux ann les plus petits et montrent une cupule pignentire divisée en deux (comme lans la Fig. 19). I, nombre de ces taches, qui sont toujours plus petites el moins visihles it l'ieil 131 sur lo bord immédiat de l'animal que sur le dos, est de 460 de chaque critr, si lien que lo. nombre des yeux est d'environ s3oo au total.

Anatomie el histologie. L'épiderme de la face dorsale de l'animal, haut de 0,029 mu. est rempli de gros rhabdites el de longs rhammites recourbés. I.a musculature cutanís. mesure $0,036 \mathrm{~mm}$. Sur la face ventrale, la hauteur de l'épiderme esl de $0.018 \mathrm{~mm}$. ; contrairement à ce que nous avons trouvé chez les Geoplana étudiés précédemment, les cellules épithéliales renferment en assez grand nombre des rhabdites. longs do $0.0 \mathrm{r} 2 \mathrm{~mm}$. La musculature cutanée de la face ventrale mesure $0,045 \mathrm{~mm}$. d'ipaissenr. Latéralement. la inusculature est plus faible. Celle du parenchyme n'est pas hien apparente. semls lea muscles dorso-ventraux sont hien développés. 
L'uvaire est placé à ro $\mathrm{mm}$. ell arrière de la tète, il est de forme ovale, long de $10,48 \mathrm{~mm}$. et large de $0,28 \mathrm{~mm}$. Les aufs ont un diamètre de $0,048 \mathrm{~mm}$. L'oviducte pénètre depuis le coté dorsal dans la moitic antérieure de lovaire. A son entrée, il était dilaté fortemeut (diamètre $0,14 \mathrm{~mm}$.) par des masses spermatiques formant là une espère de réceptacle séminal. Sur loute sa longueur, il est, comme thez presque tous les Geoplana, cureloppé d'une forte musculature et tapissé d’un ćpithélium vibratile.

Eu arrière de l'ovaire, on voit des vitelloductes courts, nais nombreux, déboucher daus l'oviducte qui a un diamètre de 0,08 mm., y compris la musculature. Les gylandes vitellogèues enveloppant le système digestif se montreut déjà à 5 mon. en avant de l’ovaire et s'étendent jusqu'à l'extrémité postérieure de l'animal. Les testicules, relativement peu nombreux (on n'en voit que 2 on $3 \mathrm{su}$ chaque coupe transversale), sont situés en dessus du tube digestif et ont un diamètre de 0,12 mu. Le vas deferens se trouve situri sur le còté interne de l'oviducte, il est, dans la région lu pharyux, fortement rempli de sperme, si bien qu’il forme des vésicules séminales ("falsche Samenblasen »). Près du pénis, le canal déférent possède une forte musculature et se montre tapissé d’un épithélium vibratile, ce qui est rare chez les Geoplana. Le tube épithèlial du canal séminal mesure ",, $088 \mathrm{~mm}$. avant son entrée dans le bulbe du pénis et $0,18 \mathrm{~mm}$. avec la gaine musculaire. La cavité atriale de l'organe copulateur n'est pas divisée en deux, c'est une vaste cavité dans laquelle est suspendu en avant un pénis de forme conique, dans lequel pénètre un ductus ejacnlatorius fortement ondulé. Sur le còté dorsal de l'atrium, dans l'épithélium qui le tapisse, et en dessus dı pénis, se trouvent des cryptes dans lesquelles débouchent des paquets de glandes unicellulaires. La partie postérieure et femelle de l'atrium semble avoir une plus forte musculature que la rígion antérieure. Le vagin est court et le nombreuses glandes coquillères y débouchent.

Parasites. Nous avons vu dans le parenchyme de nombreux petits Nématodes dont certains renferment des ceufs dans leurs utérus.

\section{Geoplana meyerhansi n. sp.}

(P1. XVI. Fig. 27.)

Geoplana ineyerhansi ressemble beaucoup à l'espicce précédente; nous avous trouvé le seul exemplaire que nous possédons en dessous de Boca del Monte (Cordillères orien(ales, alt. $2400 \mathrm{~m}$.). La coloration de l'animal est assez foncée, presque noire; l'extrémití antérieure, mais surtunt l'extrémité postérienre, sont d'ın brun rougeàtre avec deux taches allongées et étroites de couleur brun clair, en dessus du pénis et du pharynx. Cette dernière se prolonge assez indistinctement jusqu'en avant, sous forme d'une ligue un peu plus claire gue le reste du dos. La face ventrale est d'un jaune verdâtre très clair. Le hord de la sole reptatrice est noir, devenant brun rougeâtre en avant et surtout en arrière.

Comme sur F. multipunctata, il existe de petites taches blanches sur le bord de l'ani- 


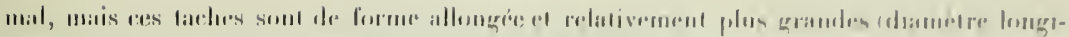

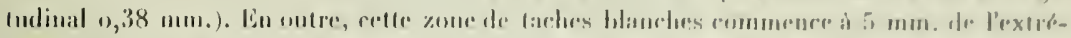

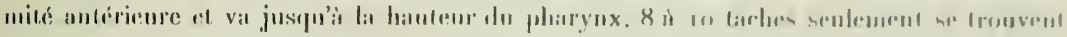
rurcore dans la régiem du prois.

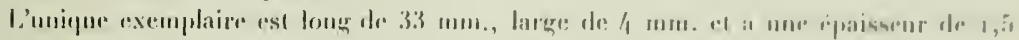

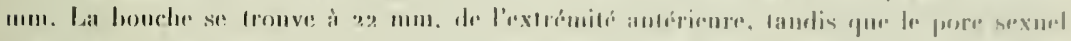
est situr iो 20 mint.

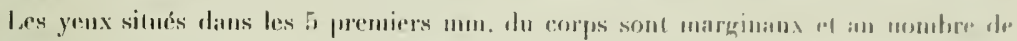

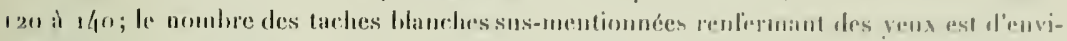

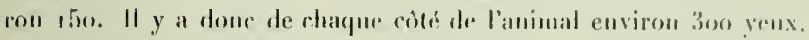

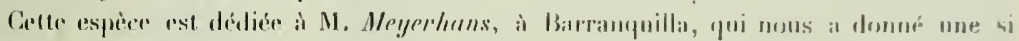

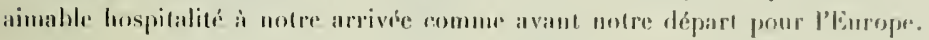

\section{Geoplana ortizi n. sp.}

(IP. XVI. lïm. 20.)

Les trois exemplaires récoltés provienneme du Parano tiruz Verde (Cordillères urienlales, alt. environ 3400 m.). Le phus grand exemplaire mesure, conservé, $67 \mathrm{~mm}$, de long el

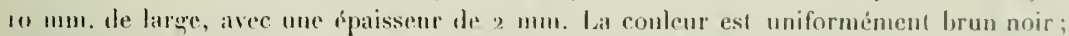
l'animal est recouvert d'un mucus qui hii donne unc feinte olivâtre. L'extrémité anterieuro" est bentére d'une ligne noire. Chez les trois exemplaires un remarque, lorsqu'on les ídaircil au Benzol, des groupes de laches ocellaires des deux crités de la ligne médiane et dans lat rigion moyenur du corps. Cés taclies, d'un diamètro de $1,29 \mathrm{~mm}$, avec le centre datir, mesurant $0,2 \mathrm{~mm}$., sont placies trìs irlégulièrement et sont peut-ètre causies par des parasites enkystés. Lit face ventrale est d'un brun rongeatre dair pl miforme. La pigmentation dn dos transperce sur te bord qui est ainsi, sur une etroite ligne, plas foncé que le reste de la fice ventrale. Les positions de la linuche el du pore sexuel sont les suivantes:

\begin{tabular}{|c|c|c|c|}
\hline \multirow[t]{2}{*}{ Longueur } & \multirow[t]{2}{*}{ Largeur } & \multicolumn{2}{|c|}{ Dislauce de l'extremite anlèrioure } \\
\hline & & a la bouche & au pore sexuel \\
\hline mm. & mm. & $\mathrm{mm}$. & $\mathrm{mm}$. \\
\hline 67 & 10 & 10 & 50 \\
\hline 50 & 7 & 33 & 140 \\
\hline 37 & 6 & 22 & 29 \\
\hline
\end{tabular}

Les yeux du grand exemplaire sont disposés en douhle on triple rangée sur les hords. jusqu'à $11 \mathrm{~mm}$. de l'extrémité antérieure; leur nombre est très considérable. mais ils sont difficiles à compter à cause du pigment. De 11 à $33 \mathrm{~mm}$., les yeux sont dispersés sur une plus large zone marginale. Sur le petit exemplaire, ils sont placés sur le bord de la lète jusqu'à $5 \mathrm{~mm}$. el dispersés, par place, jusqu'à $1,3 \mathrm{~mm}$. du hord, jusqu'à $22 \mathrm{~mm}$. en arrière de l'extrémité antérieure. 
Analume el histologie. L'épiderme est de mène épaissemr sur la lace ventrale et torsale; il mesure $0,032 \mathrm{~mm}$. Les cils vibratiles des cellules épithéliales ventrales sont hauts de o,oos mum. Les rlabdites ef rhammites remplissent complètement l'épidermu' dorsal, tandis que du cotte de la sole reptatrice, les rhalidites sont peu nombrenx et longs de $0,009 \mathrm{~mm}$. au maximun. La musculature est également développée sur les deux faces de l'animal (cipaismetu $11.05 \mathrm{~mm}$.). La museulature du parenchyme, mème less

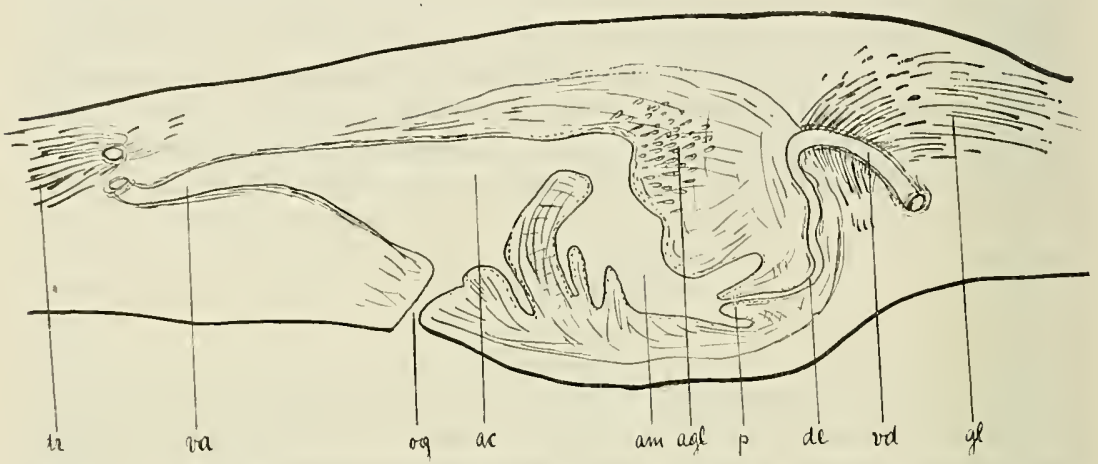

Fig. 27. - G. ortizi n. sp. Coupe sagittale et médiane de l'appareil copulateur. og ouverture sexuelle, ac atrium commun, am atrium màle, $a g l$ glandes alriales, $p$ pénis, de ductus ejaculatorius, $v d$ canal déférent, $g l$ glandes, ra vagin. $d r$ glandes. (Dessiné avec l'appareil Abbe).

fibres dorso-ventrales, sont faiblement développées. La branche antérieure du système gastro-vasculaire porte de chaque côté 26 branches fortement ramifiées.

Les glandes vitellogènes enveloppent tout le systìme digestif, pénètrent entre ses ramifications et s'étendent jusqu’à l'extrémité postérieure. Les testicules, très nombreux. sont situés dorsalement en dessus des glandes vitellogènes, ils mesurent 0,24 à $0,38 \mathrm{~mm}$. Le canal déférent s'élargit en arrière de la cavitẻ du pharynx (diamètre $-0,15 \mathrm{~mm}$.) et à l'approche du pénis il s'entoure d'une musculature et de nombreuses glandes unicellulaires y débouchent. Le pénis se présente sous forme d'une petite papille. La paroi de l'atrium masculinum est plissée; un grand pli ventral le sépare de l'atrium commun. L'atrium femininum se prolonge sous forme d'un còne allongé $(\mathrm{r}, 6 \mathrm{~mm}$.) dans un vagin très court et riche en glandes.

Cetle espèce a été dédiée à M. G. Ortiz-Williamson, de Bogota, qui nous a offert une si charmante hospitalité dans son Cafelal Le Magdalena. 


\section{Geoplana gonzalezi n. sp.}

(1') Xvil lik. 3.)

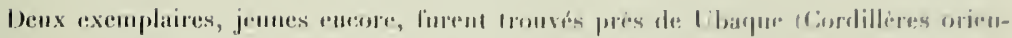

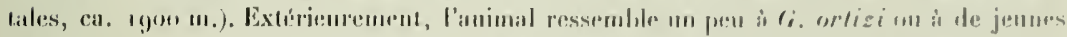

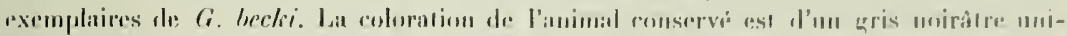

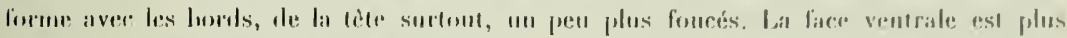

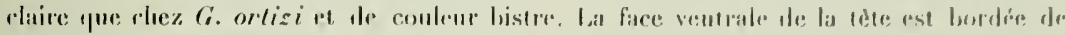

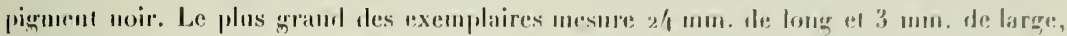

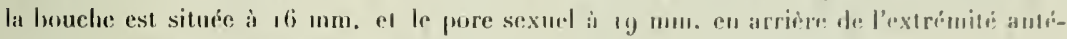
rieme. Le petit exemplaire, long de $17 \mathrm{~mm}$. et large de 2,8 mm., al sen ouverture louceale à 11 mm. ; le pore sexucl u'est pas visible.

Chez le petit exemplaire, les yeux sont disposés en rangre simple, saus yeux plinces au dessus jusqu’ì / mm. ; do lì jusqu'à 10 mum., les yenx uombrenx mais difficiles à compter, sont dispersts sur une bande marginale large de 0,57 inu. Chrz le grand exemplaire, la rangér simple des yeux va jusıju'i $5,3 \mathrm{~mm}$, les yenx dispersés vont jusqu'a 14 mm. en arrière de l'extrímité antérieure.

Analomie el histologie. L'épiderme du dos montre des thammites filiformes recourbés, de quros rhabdites de la hanteur de l'épirlerme $(0,018 \mathrm{~mm}$.) el de pelifs rhabdites, longrs sculement de 0,0018 à $0,0036 \mathrm{~mm}$. Sur la face ventrale, il n'existe daus les cellules épidermiques que de courts rhabdites. La substance intercellulinire, qui se remarque très hien dans les coupes horizontales à travers l'ipiderme, est très abondante et de struture alvéolaire (II. XVII, Fig. 3). La musenlature ne présente rien de particulier. Le tube digestif est rehativement peu ramifié.

L'ovaire se trouve i 2, I mu. en arrière de la tète; comme l’individu est jeune encore, les ccufs ne sont pas mùrs. La glande ovarienne, longue de 0,5 mm., ust très étroite. La glande vitellogène enveloppe le système gastrovasculaire. Les testicules simés sur le còté dorsal de l'animal vont jusqu'à 4 mm. en arrière de l'appareil copulateur, tandis que dans toutes les autres formes étudiées, cest à la hauteur du pharyax qu'ils s'arrètent. L'ouverture génitale, qu'on ne pouvait pas voir sur l'animal entier, se montre sur les coupes à 2,8 mm. en arrière de la bouche. L'appareil copulateur est malheureusement très jeune et n'est pas complètement développé.

Cette espèce a été dédiéc à M. Enrique Gonzalez, de Bogrota, qui nous a accompagné durant to royage par les Cafetales de Vinta.

\section{Geoplana guacensis $n$ sp}

(PI. XVI. Fig. 21, 22.)

Cette espèce fut trouvée aux Salines de Guaca (Cordillères centrales, alt. $1458 \mathrm{~m}$.1. Les 5 expmplaires recueillis sont presque de mèue taille et mesurent au maximum 22 mm. 
de long et $3 \mathrm{~mm}$. de large, avec une épaisseur de z mm. Le dos dont la cunlenr linndamentale est d'un jaune ocre, est reconvert d'un réticnlum trìs serré, brun foncé, ne laissant libre que l'extrémite antérieure et me très etroite ligne sur le hord de l'animal. L'extrémité antirienre présente sur me longueur de 1 ì z mu. une conleur acre légìrement rougeàtw. Lat face ventrale, à l'exception de lextrénité anterieure de coulenr ocre sur a à ? mu., est d'un blanc sale très légèrement hrunàtre.

Les mesures pour la bouche et le pore sexuel sont les suivantes:

\begin{tabular}{|c|c|c|c|}
\hline \multirow{2}{*}{ longueur } & \multirow[t]{2}{*}{ larkenr } & \multicolumn{2}{|c|}{ Distaace de lextrémité antérioure } \\
\hline & & i la bouche & atz pore sexinel \\
\hline mะ1. & wm. & $\mathrm{inm}$ & $\mathrm{mm}$. \\
\hline 22 & 3 & 13 & 19 \\
\hline 30 & 2 & 12 & 16 \\
\hline 20 & 2 & け & 17 \\
\hline 15 & 2 & 9 & 13 \\
\hline
\end{tabular}

Les yeux sont disposés en avant, sur le bord le la tète, dabord en rangée simple, ivee, par ci par là, un ceil en dessus; à pratir de 2,3 nun., ils se groupent irrégulièrement sur 2 à 3 rang's jusqu'à $5 \mathrm{~mm}$. en arrière de l'extrémité antérieure. 11 y a ainsi de chaque còlé go à 120 yeux disposes sur le bord clair de la planaire. Plus en arrière, sur une longueur de $5,7 \mathrm{~mm}$, les yeux s'écartent jusquà $0.7 \mathrm{~mm}$. du boril et sont situés, assez luin les uns des autres, dans les mailles du piğment réticulè de la face dorsale. Nous arons complé dans celte zone 80 à 100 yeux très petits et à cupule pigmentaire ressemblant à celle dessinée dans la Fig. 19.

Anatomie et histologie. L'épiderme de lat lace dorsale, haut de 0,029 mun, renlerme de tries nombreux rhabdites et rhammites, tandis que sur la face ventrale, ou il est haut de $0,023 \mathrm{~mm}$., les rhabdites sont très petits, longs de 0,0018 à $0,0054 \mathrm{~mm}$. Les cils vibratiles, comme chez la plupart des formes précédentes, ne se voient que sur lit face ventrate oì ils sont longs de $0,0054 \mathrm{~mm}$. La musculature cutanée est relativement. lrès forte; sur le dos, elle a une épaisseur de $0,072 \mathrm{~mm}$., landis que sur la face ventrale elle ne mesure que $0,054 \mathrm{~mm}$. Sous celte musculature se trouve un parenchyme très peu dense, dans lequel nous trouvons, du cóté dorsal, les corps cellulaires, des glandes à rhabdites, ainsi que des fibres musculaires obliques, Comme Busson (loc. cit.), uous avons vu des rhammites et des rhabdites dans la même cellule glandulaire. Du còté ventral, cette mème zone est traversée par des filores essentiellement longitudinales, et sur cette zone repose le système nerveux réticulé, dont les mailles sont traversées par de grosses fibres transversales. Entre le systeme nervenx el l'intestin, dans une zone d'une épaisseur de $0.18 \mathrm{~mm}$. environ, se trouvent des glandes cyanophiles et des grandes vitellogènes. Dans la région correspondante de la face dorsale, située entre l'intestin it la couche des glandes à rhabdites, se trouvent, appliquées contre l'intestin, les glandes vitellogènes; plus à l'extérienr, existent de très grosses fibres transversales, longitudinales et obliques, ainsi que des glandes cyanophiles. La musculature dorso-ventrale passant entre les ramificalions du systène digestil est très développée. Lit musculatırc latérale, 


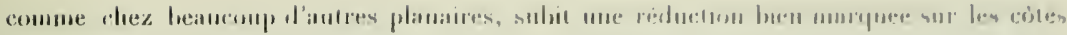
de l'animal.

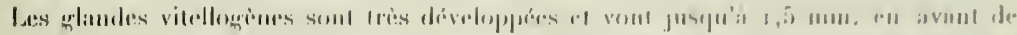

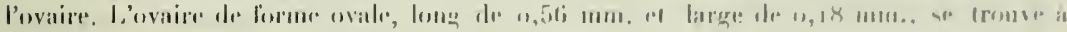

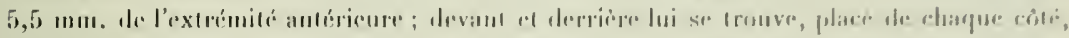

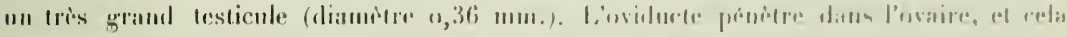

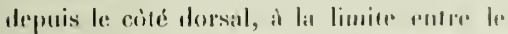

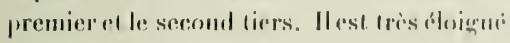
de lat face ventrale "l se louve "pplingur conlre: l'intestin.

G. guncensis est la seule des lineplit_ ninles ripportées par mons yui ail mon seulement des testicules siluts du crite dorsal, mais aussi sur la firer ventrale du lube digestif et mene entre les ranificalions de celui-ci. Nous comptoms de chaque cobri 15 iो 20 lesticules dor'salement placés; me dizaine sont entre less branchess de lintestin, landis que sur la lace ventrale, ils sont hien plus nombreux, plaris des

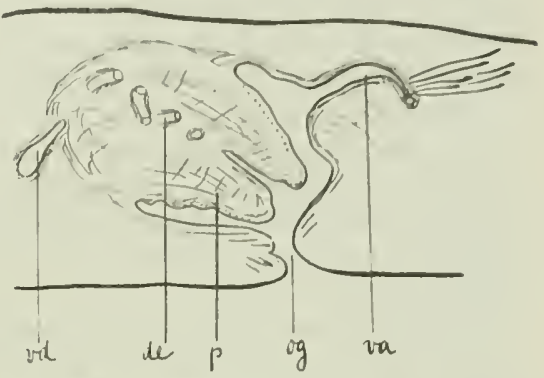

lig. 28. - Gi. gracensis n. sp. Coupe ragillale el médiane de l'appareil copulatenr. og ouverture fénilale, $p$ pinis, de ductus ejaculalurius. on canal défẻrent, va vagin. (Dessiné avec l'appareil Alibe.)

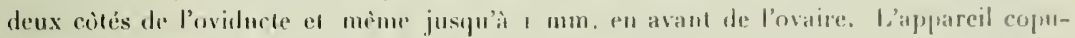
listeur nous semble petil. Le pénis, de forme conique, aussi larese que loms, remplit tout l'atrium dans lequal díbouche du coté dorsal un vagin museuleux. Le ranal ijaculateur

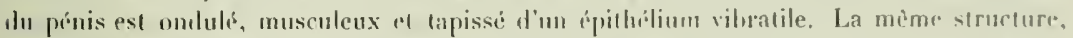
mais avec me musculature plus forle, se présente pour le canal déférent lorsqu'il s’approclıe du pénis.

\section{Pelmatoplana linaff.}

Le sence Pelmatoplana renfermant 14 espices appartient à la region orientale ef éthiopienne. La plupart des espèces ont été trouves à Ceylan el dans les iles de la sionde (Java et Sumatra), 3 espèces proviennent d'. Lfrique ( 2 de Madagascar el i de Togro). Il est done fort intéressant d'avoir decouvert une nourelle espece de ce quenre en Imérique du sud dans les Condillères centrales de la Colombie.

\section{Pelmatoplana graffi $\mathbf{n}$. $\mathbf{s p}$.}

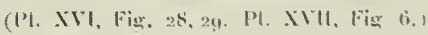

Nous avons trouvi de nombreux exemplaires (20) de celle intéressante espice. au CafeLal La Camelia près Angelopolis et à Guica (Cordillères centrales, alt. $1820 \mathrm{~m}$. et $1480 \mathrm{~m}$.). Lanimal se trourait toujours caché sous des picres ou de viejlles tuiles. En marche. 
le corps de l'animal eat de dianète égal sur tonte sa longueur et presque cylindrique: l'extrémité antérieure et l'extrémité postérieure sont arrondies. Ces deux extrémités du corps, sur une longueur de 1 à 2 mm., sont comme chez Amblyplana coctierlli (Graff. loc. cil. Pl. XIV, lïg. 25), d'un rouge orange, un pen plus foncé en avant yu'en arrière: le reste du corps semble ètre noir avec une ligne blanclie dans la ligne médiane et dorsale. A un examen plus minutieux, nous voyous que des deux coités de la ligne blanche se trouve une étroite bande d'un bẹu noir, puis, ver's l'extérieur. suit une ligne gris clair, de mème largeur, tandis que les flancs de l'animal présentent une large bande marginale d'un noir un pen moins prononcé que les denx lignes médianes. La face ventrale de l'animal présente une étroite sole reptatrice, d'un jaune très clair bordé de deux lignes grises.

La zone marginale de la face ventrale montre la mème couleur fondamentale avec des traces de pigments noirs. L’animal, conservé au sublimé acétique, est recouvert d'une légère couche de mucus brunàtre, mais les dessins restent bien visibles et de mème couleur que sur l'animal vivant, sauf les deux extrémités orange qui deviennent très pâles dans l'alcool.

Comme les ouvertures buccale et sexuelle ne sont pas visibles et que les deux extrémités ont la mème forme, il devient très difficile, sinon impossible, de distinguer ce qui est antérieur ou postérieur.

Gràce à la puissante musculature du parenchyme, les animaux conservés sont presque toujours fortement contractés, et de ce fait, ridés transversalement. Les plus grands exemplaires ont, vivants, une longueur de $7^{0} \mathrm{~mm}$. avec une largeur uniforme de $2 \mathrm{~mm}$. au maximum. Conservés, ils se raccourcissent beaucoup et ont alors jusqu’à $3,5 \mathrm{~mm}$. dev large, avec une sole reptatrice de $r, 2 \mathrm{~mm}$. Le plus long exemplaire conservé mesure $55 \mathrm{~mm}$. avec une largeur de $2,5 \mathrm{~mm}$. et une épaisseur de $2 \mathrm{~mm}$.; comme son petit pharynx cylindrique est dévaginé, nous pouvons déterminer la position de la bouche qui se trouve à $3 \mathrm{r} \mathrm{mm}$. en arrière de l'extrémité céplıalique. La sole reptatrice de cet exemplaire est large de $0,5 \mathrm{~mm}$. Voici encore quelques mesures des bandes du dos : ligne blanche médiane $0,38 \mathrm{~mm}$., lignes noires $0,038 \mathrm{~mm}$, lignes latérales gris clair, $0,3 \mathrm{~mm}$. et bandes marginales $1,3 \mathrm{~mm}$.

Les yeux sont peu nombreux 10 à 16 de claque còté de la tète. Les cupules pignmentaires ont une profondeur de $0,056 \mathrm{~mm}$, avec un diamètre de $0,04 \mathrm{~mm}$.

Anatomie et histologie. L'épiderme de $P$. graffi est haut de $0,016 \mathrm{~mm}$., il est rempli de rhabdites très petits et de rhammites allongés, excepté dans l'étroite sole reptatrice qui occupe, sur l'individu étudié, un quart de la largeur de l'animal. Seul l'épiderme de cette étroite zone porte des cils vibratiles. Les glandes à rlabdites se trouvent sous la musculature cutanée formant une couche continue se colorant vivement. Dans la région de la sole reptatrice, ces glandes disparaissent pour ètre remplacées par de nombreuses glandes granuleuses se colorant en gris-jaune. Ces glandes ne sont pas limitées d la face ventrale, mais se trouvent moins nombreuses tout autour du corps. La musculature cutanée est relativement faible, elle montre une épaisseur de o,or-o,or $8 \mathrm{~mm}$. 


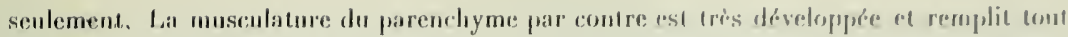

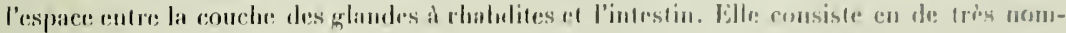

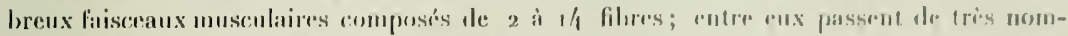

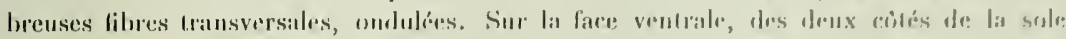
reptatrice, les faisceanx longitudinanx sont particulidement forts, ave un diarnetre de

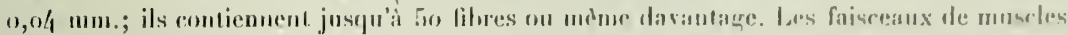
dorso-ventranx sont surtout visibles entre les ranifications du lul, diermalif.

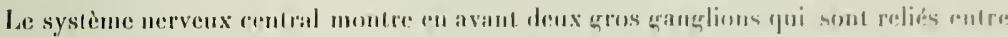
eux par des commissures. Sur les compes transversules, on voil trois de res cumminsurm,

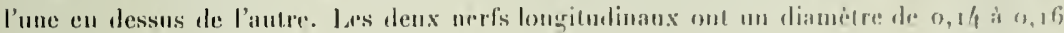

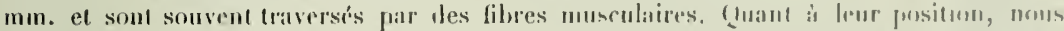

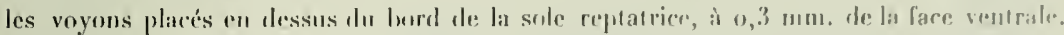
Le pharyux est cyliudriyue, long de $2,2 \mathrm{~mm}$. La ravite du plaryox est un froll plus lon-

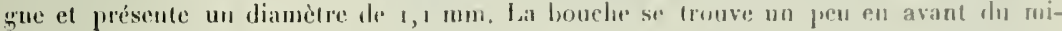
lieu de la poche, it $0,1 \mathrm{~mm}$. de lit base dı pharynx. L'intestin est très fortenent ramifié, puisqu'on trouve en avant 200 ramifications latérales, tandis qu'en arriare on en comple

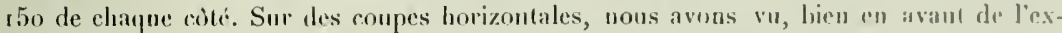
trémité postérienre, une commissure entre les deux branclies postéricures du système gastrovasculaire (P]. XVII. Fïg. 6).

Nous avons coupé les plus grands individus sans pouwoir tronver un exemplaire avec les organes sexuels déveloplés. Nous n'avons pu roir que des ébauches de lestirules qui semblent ètre limités à la face ventrale de l'animal et ne se trouvent que dans la moitié antéricure. Les organes copulateurs ont eté constatés à 1.3 mm, en arrière de l'onverture huceale, mais leur dévetoppement n'étail pas complet. Le pénis, de forme conique, était long de $0,14 \mathrm{~mm}$. Le ductus ejaculatorius est long de $0,32 \mathrm{~mm}$. et se dilite en une petite vésicule séminale à son extrémité; on y roit déloucher les áhanches des deux canaux déféreuts. L'atrium femininum ot le varin semblent ètre longr $(0,7$ mm.) et étroits, ils sont tapissés d'un épithélium très haut.

Parasiles. Le parenchyme pent renfermer des larves de nématodes.

\section{Rhynchodemides.}

\section{Rhynchodemus p. p. Leidy (em. s. GrafF).}

Daus la région néotropique, 5 espèces de Rhynchodemus seulement ont été décrites jusqu’à maintenant tandis qu'en Australie on en connail 36 espèces, en Afrique I 7 et dans la région orientale 24 espèces; nous avons trouvé en Colombie 3 nouvelles espèces bien caractérisées, ce qui montre que ce genre est sans doute beaucoup plus 
richement représeuté qüil ne le semble d'après nos connaissances actuclles; mais ces animaux relativement petits et filiformes ichappent facilement anx chercheurs.

\section{Rhynchodemus samperi n. sp.}

Rh. samperi a été trouvé près de Bogota et près de Zipaquira, sur la Sabana (Cordillères orientales, $2650 \mathrm{~m}$.). Les 6 exemplaires sont très allongés et fusilormes, longs de $20 \mathrm{~mm}$. et larges de $0,8 \mathrm{~mm}$. L'extrémité antérieure s’amincit plus lentement que la région

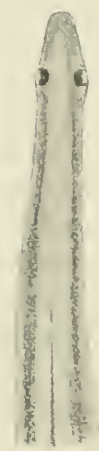

Fig. 29, Rh. samper n. sp. Partie antérieure du corps. caudale et l'animal en marche relève légèrement la tète comme un rostre tactile.

La couleur fondamentale de cette planaire est brun-clair et sur le dos se remarquent trois bandes longitudinales noires. La ligne médiane noire est très étroite, bordée de chaque còté par une étroite zone brune, suivie d'une bande latérale brun-noir relativement large. La zone marginale très étroite est d’un gris-brun assez loncé. La ligne médiane qui va jusqu'ì l'extrémité postérieure s'arrète en avant, à r,5 mm. de l'extrémité céphalique, tandis que la bande latérale noire est continue tout autour de l'animal. La face ventrale est grise et la sole reptatrice large de $0,46 \mathrm{~mm}$. chez un individu de $1 \mathrm{~mm}$. de large. Tout en avant, la face ventrale présente une dépression concave en forme de courte rigole. Sur un individu long de $55 \mathrm{~mm}$., large de $1 \mathrm{~mm}$., l'ouverture buccale se trouve

fiig. 30 . Rh. samperi n. sp. Portion médianede la face dorsale. à $5,7 \mathrm{~mm}$., le pore sexuel à $8,5 \mathrm{~mm}$. Les deux yeux, assez grrands, ont un diamètre de $0,114 \mathrm{~mm}$. et se trowvent à $0,3 \mathrm{~mm}$. de l'extrémité antérieure.

Anatomie et histologie. L'épiderme est de mème épaisseur du còté dorsal et du côté ventral; il mesure 0,009 à 0,0 I I $\mathrm{mm}$., en dehors de la sole replatrice, dépourvue de rhabdites, l'épiderme est hourré de gros rhabdites. Les cils vibratiles ne se trouvent que sur la face ventrale, dans l'étroite zone reptatrice qui, sur nos coupes, a une largeur de $0,45 \mathrm{~mm}$., tandis que le corps est large de $1 \mathrm{~mm}$. Tout autour du corps, les glandes cyanophiles sont nombreuses. La musculature cutance est la plus fortement développée sur le còté latéral, et ventral du corps, surtout pour ce qui concerne les faisceaux de muscles longitudinaux. En elfet, sur le còté dorsal, la musculature a une épaisseur de $0,018 \mathrm{~mm}$, sur le còté latéral 0,027 à o,o3 mm. Dans la région de la sole reptatrice, les faisceaux longitudinaux, hauts de $0,022 \mathrm{~mm}$, sont formés d'une simple série de fibrilles placées les unes en dessus des autres. La musculature du parenchyme est bien développée, surtout les fibres dorsoventrales et transversales. Les branclies latérales du tube digestif sont peu ramifiées. Le pharynx, légèrement conique, est long de $0,7 \mathrm{~mm}$., avec un diamètre de $0,42 \mathrm{~mm}$. à sa base.

Les deux nerfs longitudinaux réunis par des commissures ont un diamètre de o,06$0,08 \mathrm{~mm}$. et se trouvent en dessus de la sole reptatrice. 


\section{$-787-$}

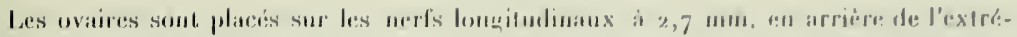

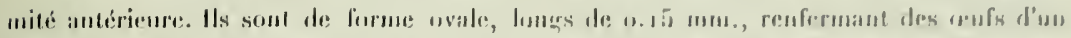

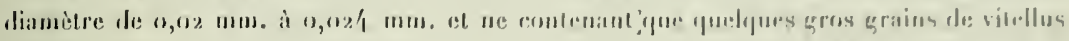

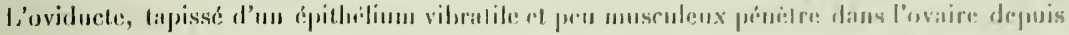

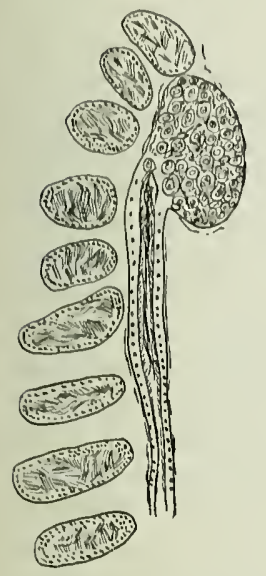

ling. 31. - Rh, samperi в. sp. Coupe liorizontale montrant lovaire et les lesticules placés surle cỏté externe del'oviducte.(Dessiné avec l'appareil $\mathrm{Abbe}$.

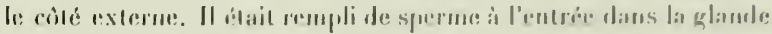

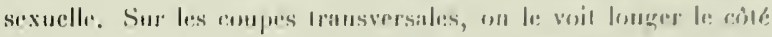

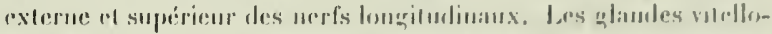

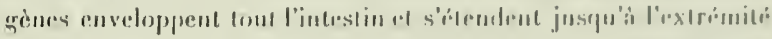

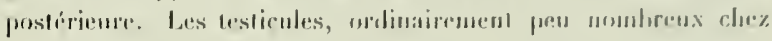

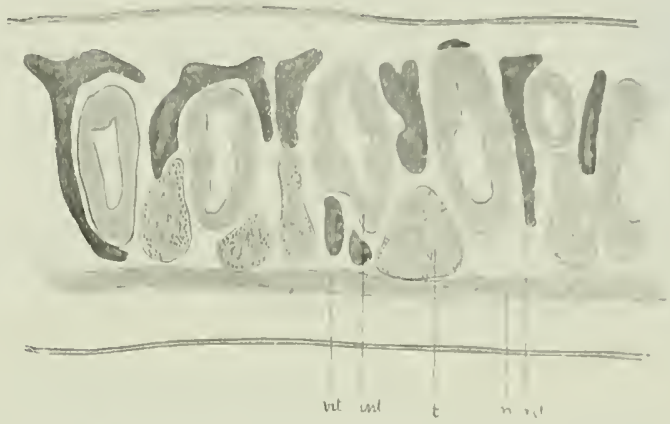

Fig. 33. - Rh. samperi n. sp. Coupe sagittale et latérale, int intestin, $n$ nerf longitudinal, $t$ testıcule, vit glandes vitellogènes. (Dessiné avec l'appareil Abbe).

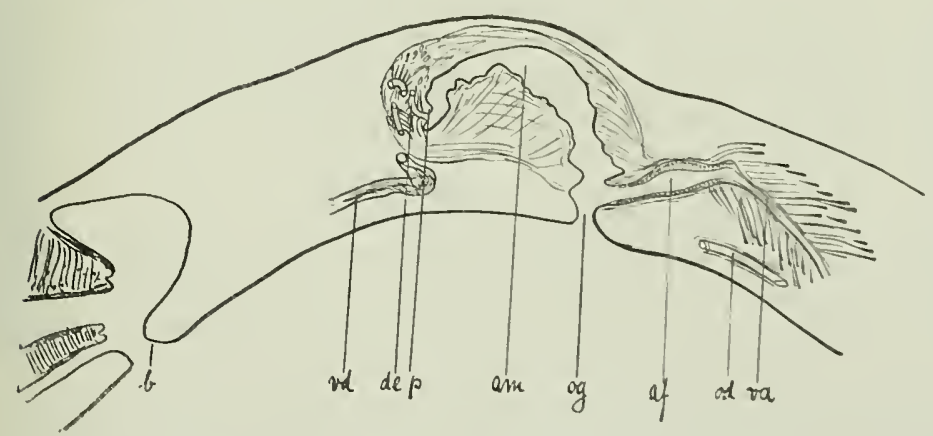

Fig. 32. Rhynchodemus samperi $\mathrm{n}$, sp. Conpe sagittale et médiane. $b$ bouche, og oureriure génitale, aun atrium masculinum, p pénis, de ductus ejaculatorius, vd canal déféreol, af atrium femininum, $v a$ vagin, $0 t$ oviducte. (Dessiné arec l'appareil Abbe.) 
lihynchodemus, puisque le chiffre maximal indiqué par von Graff est 24 paires, sont très nombreux et s'étendent en outre, ce qui est fort rare chez tontes les planaires terrestres, sur toute la longueur de l'animal. En effet, nous trourons en avant de l'ovaire 7 paires de testicules, et nous voyons tont le long du còté externe de l'oviducte des vésicules testiculaires, en rangs serrés el disposées en rangée simple. Il y en a ainsi environ 50 situées ventralement ou entre les branches de l'intestin. Mais ce qui est le plus remarquable, c'est que les testicules se rencontrent encore en arrière de l'appareil copulateur au nombre d'une trentaine de paires. Deux Geoplana $(G$. munda et $G$. cerrulea), ainsi que deux Pelmatoplana ( $P$. sondaica et nasuta) seulement montrent une pareille disposition des glandes sexueltes màles. L'organe copulateur est très semblable à celui de Rhynchodemus vejdovslit. Le pénis est très petit et se présente sous forme d'une simple papille située an fond du long atrium masculinum fort musculeux. Le canal déférent antérieur reçoit de l'extrémité postérieure une branche qui y débouche sous le pénis. Le canal éjaculateur du pénis est ondulé, musculeux et riche en glandes. L'alrium femininum est court, étroit et tapissé d'un épithélium élevé. La musculature de cette région de l'appareil copulateur est faible. Le vagin s'incline obliquement en arrière vers la face ventrale. L'ouverture sexuelle se trouve, sur l'exemplaire mis en coupes, à $2,3 \mathrm{~mm}$. en arrière de la bouche.

Cette espèce est dédiée à M. J.-M. Samper, ingénieur à Bogota, auprès duquel nous avons trouvé une si aimable hospitalité.

\section{Rhynchodemus maculatus n. sp.}

Les trois exemptaires de cette espèce furent trouvés en dessus de Uhaque (Cordillères orientales $2000 \mathrm{~m}$.). L'exemplaire le plus grand mesure, conservé, $30 \mathrm{~mm}$, et présente

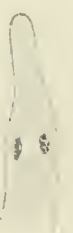

Fig. 34. Rh maculalus n.sp. Extrémité antérieure un diamètre et une épaisseur de $1,5 \mathrm{~mm}$. En avant, juste devant le pharyux, le corps commence à s'amincir lentement et se termine par une région céphalique ayant la forme d'un rostre étroit sur lequel sont placés, à $o, 8 \mathrm{~mm}$. en arrière de la pointe, deux gros yeux de $0,17 \mathrm{~mm}$. de diamètre. Les organes visuels sont d'une grandeur exceptionnelle pour le genre Rhynchodemus, si bien que je me suis demandé si la forme ne rentrait pas dans le genre Plalydesnus; mais la forme générale du corps esı bien celle du genre dans lequel nous plaçons l'animal. L'extrémité postérieure est moins étroite et se termine en une courte pointe. La sole reptatrice occupe environ la moitié de la face ventrale.

L'animal est tacheté de brun-noir, surle dos, les taches sont très serrées et se tonchent, ne laissant que de petits espaces clairs. Sur les flancs et la partie latérale de la face ventrale de l'animal, par contre, les taches étroites, de forme irrégulière et allongée, sont séparées les unes des autres et laissent voir la couleur fondamentale jaunàtre de l'animal. La sole reptatrice est

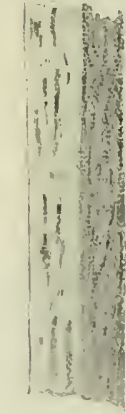

Fig. 35. Rh. niaculalus n.sp. Vue latérate de la région moyenne du corps. 


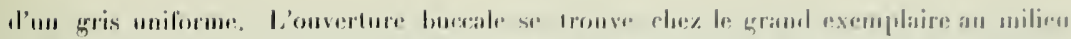

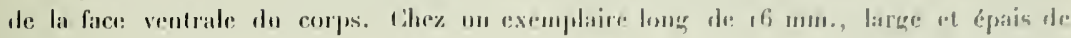

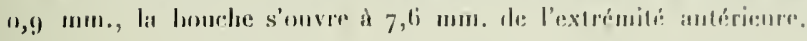

\section{Rhynchodemus cameliae $\mathbf{n}$. sp.}

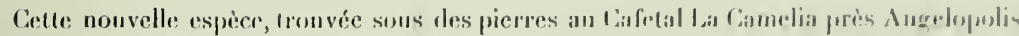

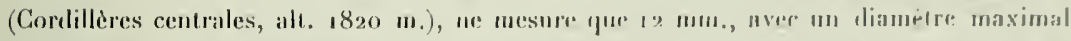

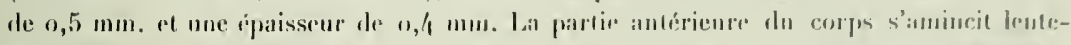
ment et se termine par une pointe en linme de rostre; par contre, liextrémitio posterieure est arrondic el pen anincie. Lal coluration de l'animal ressemblait à celle de Pelmutoplana grofffe, mais sans bi moloration orange des extrémités.

Les deux exemplaires conservés au sublimé se somt à preine rontractés, ils mosurent, en effet, 10 et $11 \mathrm{~mm}$. L'animal montre nne couleur forrtitmentale jam atre al présente sur le dos / bandes longiturlinales d'un brun très foncé, presque noir. La délimitation de ces handes, dont dens sont métianes et les autres marghinales, n'est pas très nelte, mais quand mème

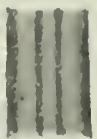

Fig. 3f. Hh. ramelian n. sp. Visedorsale d'un fragment de la rú. gion moyenne du corps. bien marquée. La tète est de couleur claire el tris panve en cellules pigmentaires noires. La face ventrale est grise et présente une sole reptatrice te $0,3 \mathrm{~mm}$., tandis que la largeur de l'animal est de $0,5 \mathrm{~mm}$.

Les yeux, relativement grands, avec un diametre de $0.057 \mathrm{~mm}$, se trouvent che\% l'exemplaire à tète très claire ì $0,5 \mathrm{~mm}$. de l'extrémité antérieure, tandis que chez l'autre exemplaire, lorgane visuel (diamètre $0,04 \mathrm{~mm}$.) est à $0.3 \mathrm{~mm}$. seulement, par lo fuit que l'extrémité céphalique est plus contractée.

La position de l'ouverture buccalı et de l'ouverture sexuelle n'a pu ètre déterminéc que chez l'exemplaire de $1 \mathrm{~mm}$. de long. liouverture lunccale se 1 rouve it $5,9 \mathrm{~mm}$. de l'extrémité antérieure, tandis que le pore sexuel s'ourre à $8,5 \mathrm{~mm}$. L'exemplaire éclairci iu Benzol montrait un petit pharynx cylindrique et un organe copulateur màle, long de $1,4 \mathrm{~mm}$.

\section{Amblyplana v. Graff.}

Von Ginaff a décrit r 3 espèces du genre Amblyplana appartenant presque toutes à la région élhiopienne (Madagascar); 2 espèces seulement ont éte trouvées à Ceslan et une espèce it la Jamaïque'. Depuis la publication de vox Graff, plusieurs espéces ( 7 ) d'Amblyplana ont été décrites provenant d'Afrique et surtout de Madagascar. accentuant

1 Von Graff signale p. 273, sans la nommer, une espèce habilant Barbados el La Guyane, mais dans la partie descriptive de son magistral travail, ainsi que dans le tableau sur la distribution séographique des espèces, il ne cite que l'espèce de la Janaïque dont il ne parle pas à l'endroil indiquẻ plus haul (loc. cil.. p. 273.$)$ 
encore la prédominance de ce genre dans celte zone zoogéographique. Il est donc intéressant de constater sur la erète des Cordillères orientales, à $3600 \mathrm{~m}$, , 1 n nouveau représentant de ce genre.

\section{Amblyplana montoyae n. sp.}

Dans la rosette de feuilles très humides de Paepalanthus columbieusis nous avous trouvé au Paramo Ciuz Virde, à $3622 \mathrm{~m}$. avec des exemplaires de Geoplana bogotensis et

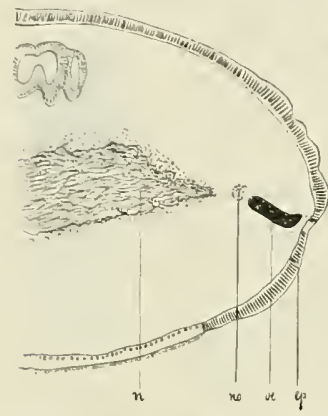

Fig. 37. - A. montoyae n. sp. Coupe sagittale de la têle. $c p$ épiderme rempli de rhabdiles, $n$ système nerveux, no nerf optique, or cupule pigmentaire de l'œit. (Dessiné avec l'appareil Abbe.) des sangsues terrestres (Blanchardiella fuhrmanni n. sp.) deux exemplaires d'une intéressante espèce du genre Amblyplana.

L'animal vivant, long de $40 \mathrm{~mm}$, semble ètre cylindrique comme un Oligocbète, les deux extrémités très arrondies, ressemblant ainsi beaucoup comme forme à Pelmatoplana graffi n. sp. décrit plus haut. Sa coloration est très simple, il est en effet d'un bean noir avec une étroite ligne [médiane blanche qui se perd aux deux extrénités. La face ventrale avec son étroite sole reptatrice est d'un gris noir. L'animal, conservé, a gardé la mème coloration, mais il s'est fortement contracté et ne mesure plus que $20 \mathrm{~mm}$. avec un diamètre de $2 \mathrm{~mm}$. sur toute sa longueur. La ligne blanche a $0,25 \mathrm{~mm}$. de large, tandis que la sole reptatrice mesure $0,5 \mathrm{~mm}$.

Anatomie et histologie. L'épiderme de cette intéressante espèce a une épaisseur de 0,024 à $0,028 \mathrm{~mm}$. Les cils vibratiles, déreloppés seulement du còté ventral, sont très courts el ne mesurent que $0,004 \mathrm{~mm}$. Du còté dorsal et latéral, l'épiderne est rempli de très fins rhammites. La musculature cutanée semble ètre faible, elle ne mesure que $0,027 \mathrm{~mm}$. d'épaisseur, par contre la nusculature du parenchyme est très forle; les muscles longitudinaux du parenchyme sont formés de nombreux faisceaux remplissant le parenchyme, les fibres transversales et dorso-rentrales sont aussi bien développées. Le système nerveux est très développé; le ganglion cérébral a une épaisseur de $0,45 \mathrm{~mm}$. En avant se trouvent deux yeux dont la cupule pigmentaire, de forme cylindrique très allongée, a une longueur de $1,14 \mathrm{~mm}$. avec un diamètre de $0,035 \mathrm{~mm}$. seulement. Le systime digestif, fortement ramifié, présente un pharynx cylindrique long de r,8 $\mathrm{mm}$. La bouche ne se trouve pas à l'extrémité postérieure ou au milieu de la cavité du pharynx, mais à l'extrémité antérieure de celle-ci, e'est-à-dire près de la hase du pharynx. Les ovaires sont à $2 \mathrm{~mm}$. en arrière de l'extrémité antérieure; sur une coupe sagittale, ils ont une hauteur de $0,24 \mathrm{~mm}$. et $0, \mathrm{~s} 6 \mathrm{~mm}$. de long. Leur forme triangulaire est due au fait que leur partie dorsale est resserrée entre deux branches du système digestif. Les glandes vitellogènes qui 


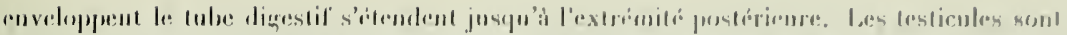

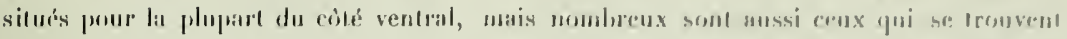

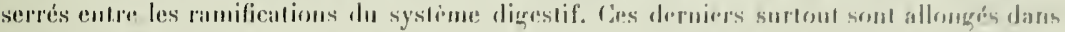

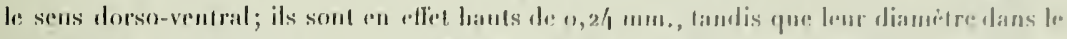

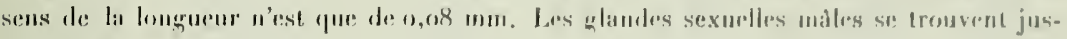

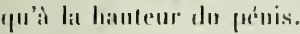

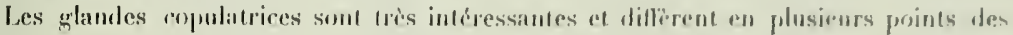

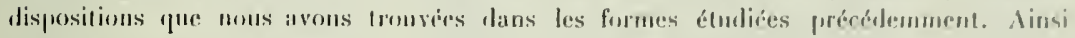
l'apprareil copulateur male, très musculeux, joss'de une vésicule séminale relativement fuorme et fortement rutouré de muscles; en outse, le vagin mentre un durtus génito-intestinalis comme il à été déja trouvi: chez d'autres Amblyplanu.' ailssi que chez Pelmaloplanu.

l.e pore sexuel se trouve it $5,7 \mathrm{~mm}$, de la bouche el it 2,8 $\mathrm{mm}$, de l'extrémitri postérieure. Dans l'alrium masculinum, lapissé d'un épillé-

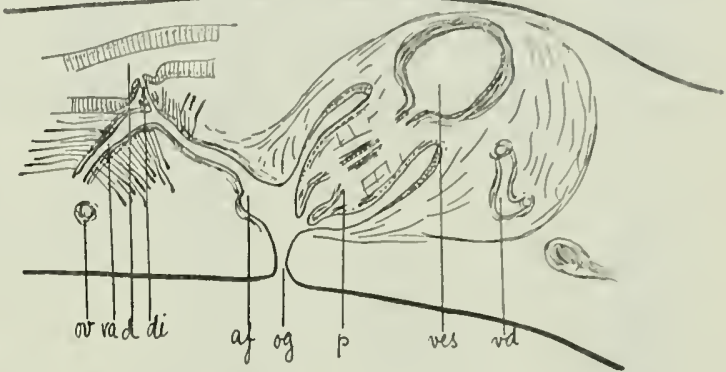

Fig. 38. - A. monloyae n. sp. Coupe sagittale el médiane de l'appareil copulateur. or ouverture génitale, p pénis, ues résicule séminale, id canal déférent, $a f$ atrium femininum, va vagin, ov oviducle, di duclis géniloinlestinalis, $\boldsymbol{d}$ intestin. (Iessiné avec l'appareil dbbe.)

lium très haut, est suspendu le pénis musculeux. Iong de $0,7 \mathrm{~mm}$. et renfermant un large canal éjaculatem, riche en glandes, qui se dilatr dans le bulbe du pénis en une vésicule séminale excesivivement musculeuse, longue de o,j- $\mathrm{mm}$. avec un diamètré de o,4 mm. et lapissće d'un épithéliun plat. Le canal déférent qui ‘n sort es! mnsculemx. aussi longtemps qu'il se trouve encore dans l'enveloppe musculaire de l'appareil copulatrur. Le long de l'oviducte, il présente des dilatations remplies de sperme.

Latrium femininum est petit, le vagin est lapissé d'un épithélium vibratile, le toul euveloppes d'une forte musculature et enfouré de nombreuses glandes. Le vagin mont. vers le cité dorsil el là, dans le voisinage de l'intestin, s'unve un court canal musculeu. qui fait commoniquer le vanin aver le tube digestif'. I celle place, l'épithélimm de l"intestis rest relativement his.

Celte espece est dédiée à M. Louis Montoya, de Buguta, qui nous a conduit dall: notre royagre par les Cafetales de la région de Viota.

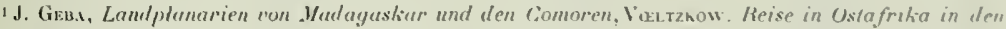
Jerkren $1,003-190 . \overline{3}$. 13.1. 11. 1909.

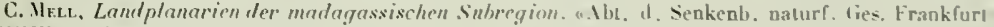
Bd. XIVII, 1903. 


\title{
EXPIICATION DES PLANCHES
}

\author{
PL. XY. \\ Toutes les figures sont reproduites d'apres les photographies des originaux.
}

Fig. 1-5. Cieoplana bogotensis, v. Gnaff. Fig. 1 à 4, vues de la liace dorsale; fig. 5 , vue de la face ventrale 6. G. Immboensis $x$, sp., viue de la faee dorsale.

7. $\quad(i . \quad$ nonisgunteni $\mathrm{x}$. sp., vue de la face dorsale.

8-9. $G$. mayori s. ss. Fig. 8, vue de la face dorsale: fig. 9, vue de la lace ventrale.

10-11. $G$. cameliae x. sp., vue de la face dorsale.

12-13. G. nigrocephala $\times$. SP. Fig. 12, vue de la face dorsale; fig. 13, vue de la face veotrale (légitrement agrandie).

14. G. columbiana N. Sp., vue de la face dorsale (agr. 2 fois).

15. G. $\quad$ cancaensis s. sp., vue de la face dorsale.

\section{PL. XVI.}

Toules les figures sont reproduites d'après des photographies tes originath:

Fig. 16. fieoplana becki x. sp., vue de la face dorsale.

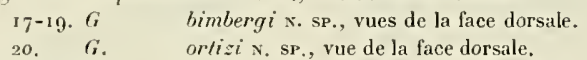

21-22. G. guacensis $\mathrm{x} . \mathrm{sr}$. , vue de la face dorsale.

23-24. $G$. amagensis $x$. sp. Fig. 23 , vue de la face dorsale; fig. 24 , vue de la face ventrale.

$25-26$. G. multipunctata $\times$. SP. Fig. 25 , vue de la face dorsale; fig. 26 , vue de la face ventrale (agr. 2 fois).

27. $\quad(;$ meyerhansi $N$, sP., vue de la face dorsale (agr. 2 fois).

28-29. Pelmutoplana graffi $x$. ss. Fig. 28 , vue de la face dorsalei; fig. 29, vue de la face ventrale.

\section{PL. XVII.}

Toutes les figures sont reproduites d'après des microphotographies.

Fig. 1. Coupe horizontale par l'extrèmité antérieure de Geoplana mayori, montrant les anastomoses du système digestif.

2. Coupe horizontale d'une jeune Geoplana becki par la région du pharynx, montrant des grégarines el des eystes sous épithéliaux de grégarines remplis de spores.

3. Coupe horizontale par l'épiderme de Geoplana gonzalesi montrant la substance interépithéliale.

4. Fragment d'une coupe horizontale par Geoplana caucaensis montraot le réseau nerveux.

5. Coupe horizontale par l'extrémité postérieure d'une jeune Geoplana becki montrant les anastomoses du système digestif.

6. Coupe horizontale par la région postérieure du corps de Pelmatoplana graffi montrant une anastomose entre les deux branches postérieures du tube digestif. 

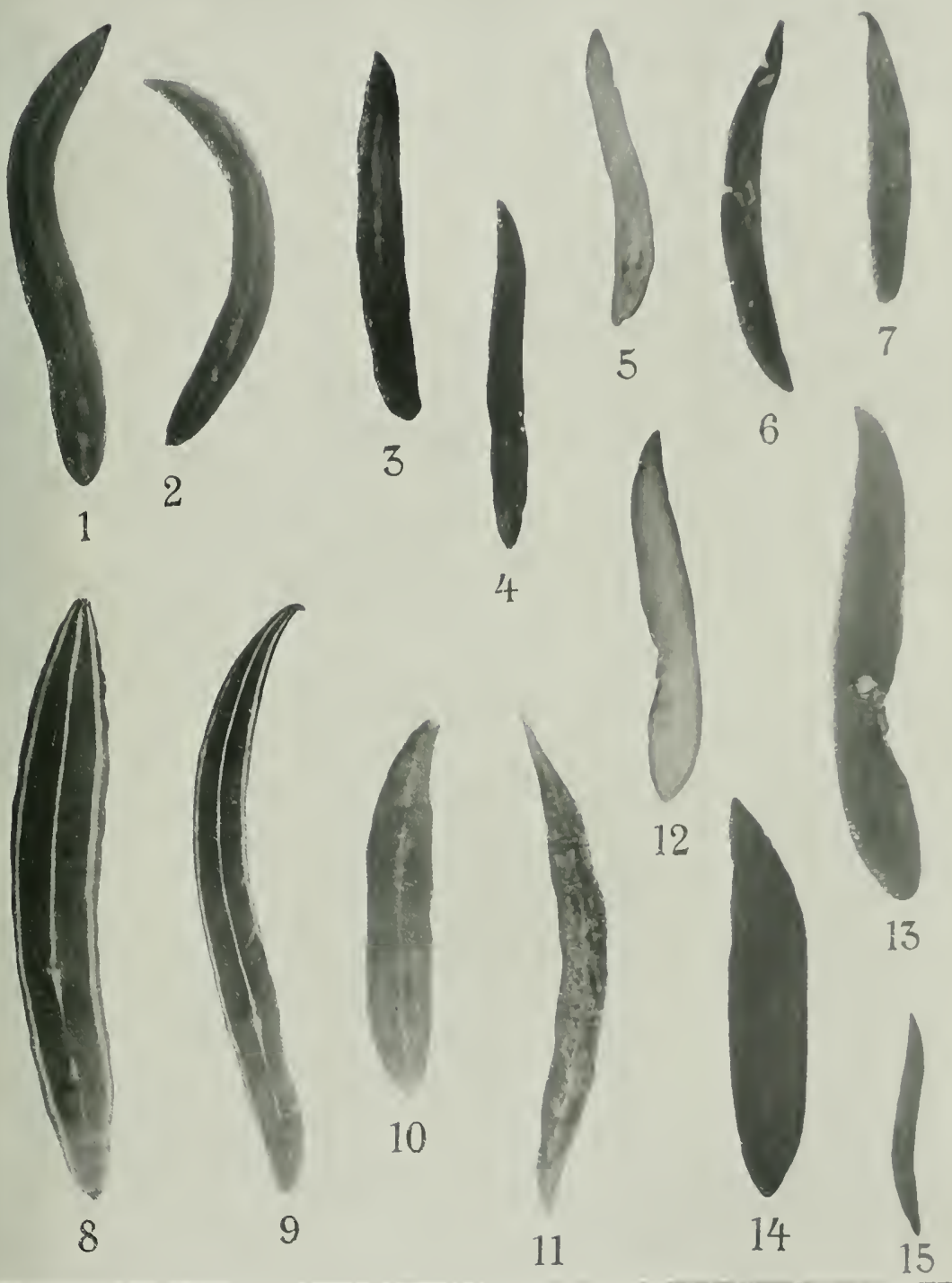



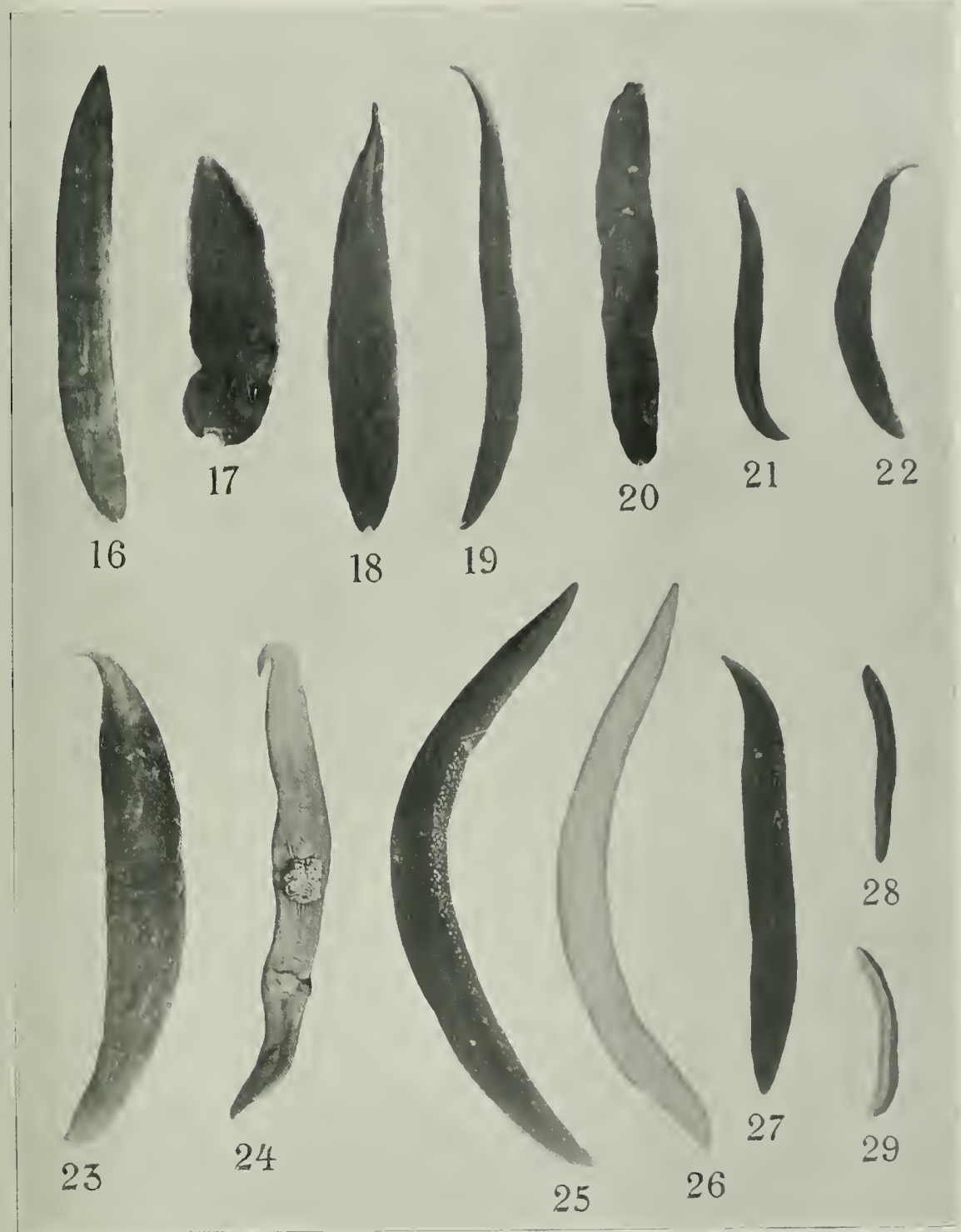




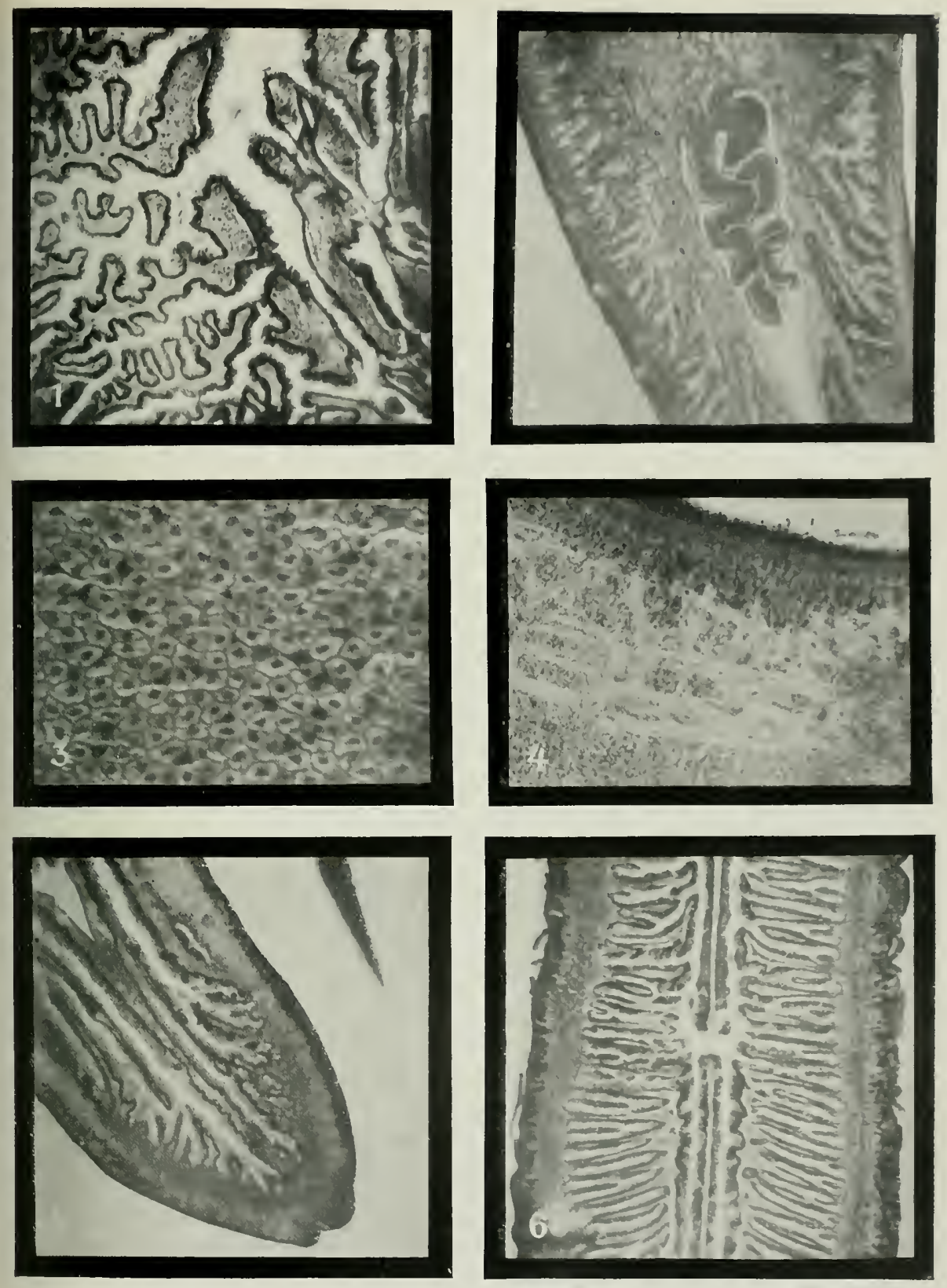



\title{
Turbellariés d'eau douce de Colombie
}

PAN

\author{
$\mathrm{D}^{r}$ O. FUHRMANN
}

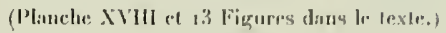

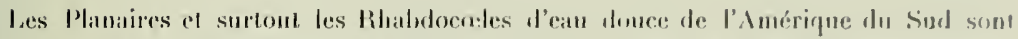
encor fort mal connes; des premieres, uons commaissons 14 especes at des derniers, espices seulement.

Les Rh:Ihdocoles commus sont les cepreces suiviantes:

Mesostoma mutabile Bönnag. Sul des la Terre de linu.

Vorlex incertus Bünma. Sud de la Terre de fieu.

L,es Planaires paludicoles commues comprennenr:

1. Planaria jheringi В̈̈̈ми ' (Brésil).

2. Pl. anrila lenvel ${ }^{2}$ (Trinidad).

3. Pl. fissipara Kenneq ${ }^{2}$ (Trinidad).

4. Pl. festae Boneld ${ }^{3}$ (Ecuadeur).

5. P. festae var, albolineata Borels: (Lcuadeur).

6. P. dimorpha B̈̈нми ${ }^{7}$ (Chili).

7. Pl. similis Bӧıми ${ }^{7}$ (Cliti).

8. Pl. Alubia Bonest ${ }^{4}$ (Argentine et Paraguay).

9. $\mathrm{Pl}$. Alubin var, maculala Bonelu' (Paraguay).

10. $\mathrm{Pl}$ andina Bonelut ${ }^{4}$ (Arigencine).

I. Pl. patagonica Boneldi ${ }^{5}$ (Argentine).

12. Pl. laurentiana Bonelt ${ }^{6}$ (Argentine).

13. Pl. michaelseni B̈̈ung ${ }^{7}$ (Sud de la Terre de Feu).

14. Pl. ambigua Bönsng ${ }^{7}$ (Sud de la Terre de Feu).

I Böнмк. L. P'lanaria jheringi, cine neue Triclade aus Brasilien. Znol. Anz. Bd, X, is87.

SExnec, J. Untersuchungen an neuen Turbellarien. Zoolog. Adhrbücher. Aluh. f. Anat, und Ontog. d. Thirre. Bd. III, 1889 .

3 Bonelt, A. Plinaria d'acqua dolce. Boll. dei Mas di Zoologica el Anat. comp. Torino. Vol. 20 , 19nj.

+ Bonell, A. Planaria d'acqua dolee. Boll. dei Musei di Zool. ed Anal. comparala d. R. Luiversila di Torino. Vol. 10,1895 .

- Bonell, A. Di una nuova Planaria d'acyua dolee della Republica . Argentina. Ibid. Vol XVI, 1901.

6 Bonellı, A. Planaria d'aequa dolce. Ibid. Vol. N11, 1897.

; Вöнm L, Turbellarien: Rhabdveœliden und Trieladen. Hamburger Magahæenisehe Sammelreise. I goz. 100 
I cetle liste viennent s'ajouter 6 espèces de Rhabderedides anosi que 4 mouvelles especes de Planaires paludicoles.

\section{Rhabdocolides.}

Les Rhablocefides semblent ètre assez rares dans les caux staguantes de Colombie. Dans deux pèches, faites dans des mares de l'Nto Don Elias (Cordilieres centrales alt. 2097 m.), nous n'avous trouvé que le Stenostomn agfile Suluman, recueilli pour la premicre fois en Amerigue du Nord, mais constati ryalement depuis en Europe (Suisse et Bohème); celle esprece semble done avoir une aise de répartition très vaste. Stenostomu lencops Dug., qui a cité trouvé en Europe, Arrique orientale el Amérique du Nord et que nous avons découvert daus la mème mare, est dans le même cas. Dans deux lagunes de la Sabana de Bogota pris de Madrid (2580 m.), nons avons rencontré plusieurs exemplaires très Iypiques de Gyratrix hermaphroditus Ennga, espèce qui habite l'Europe et l'Afrique orientate. En Suisse, elle atteint les hautes altitudes de nos Alpes, oir nous la trouvons jusqu'it $2557 \mathrm{~m}$. (Saint-Bernard) el elle descend dans les grandes profondeurs (roo m.) du lac de Neuchitel; cette mème espice se rencontre du reste dans les eaux saumatres et dans l'eau de mer, rien d'étonmant si nous retrouvous cette forme

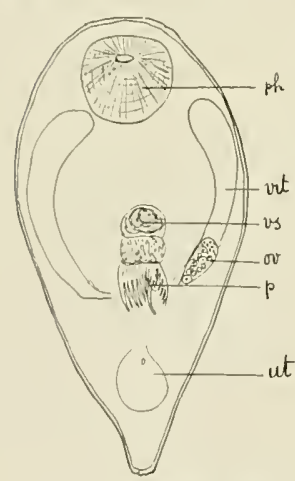

Fis. 1. - Vorlex cumplicatus n. sp. ph pharynx, ov ovaire, vit glandes vitellogènes, ut utérus, vs vésicule séminale, $p$ pénis. (D'après une préparation totale, dessiné avec l'appareil $\mathrm{Able.}$.) ubiquiste sur les hauts plateaux des Andes; Von Gnaff l l'a du reste déjì trouvée en Imérique du Nord.

Outre les espèees précitces, nous avons encore trouvé nue Microstoma spec. formant une chaine de deux individus, et deux nouvelles espèces de Vortex (Vortex complicatus n. sp. [sur la Sabana, près de Madrid] et $V$. quadriden soüdess n. sp. [au Tequendama].

Nous avons amsi trouvé 6 espèces de lihabdocoelides dans les eaux de Colombie.

\section{Vortex complicatus $\mathbf{n}$. sp.}

(Fig. I el 2.)

Plusieurs individus ont élé trouvés dans denx larunes du hant plateau de Bogota près Madrid (alt. 2650 m.). L'animal conserve a $0,7 \mathrm{~mm}$. de long avee $\mathrm{nn}$ diamitte de $0,24 \mathrm{~mm}$. Il présente la lorme typique des Vortex et montre en avant. deux gros yeux de o,otti mm. te diamètre el un pharynx de

IL. v. GnafF. Acuela, Rhabdocoela und Alleocola des Ostens der Vereinighen Staaten von Ameriki. Zeitscbrift f, wiss. Zool. Bd, ICIX, I9I1. 


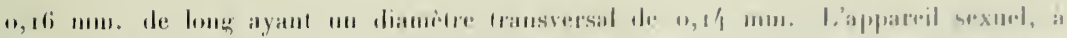

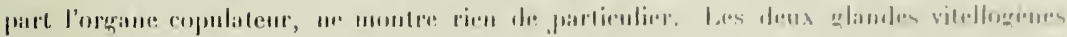

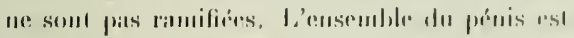

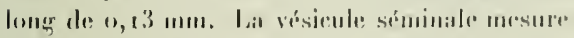

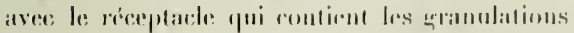

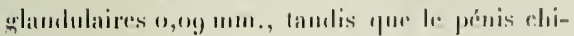

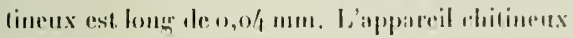

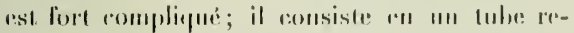

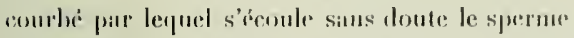
a. qui ast entoure d'opines de dispositious dif-
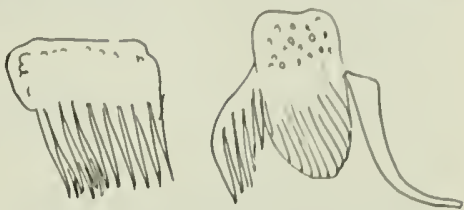

Fig. 2. - Vorter rompliratus. Farlies chulsneuses du pénis dilaréré.

firentes. Les lïg. 1 at montreront mienx

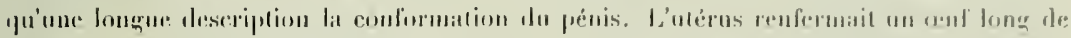

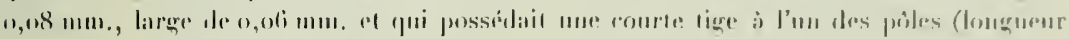
(1, (119!) 11111.$)$.

\section{Vortex quadridensoïdes $\mathbf{n}$. sp.}

(1iin. 3.)

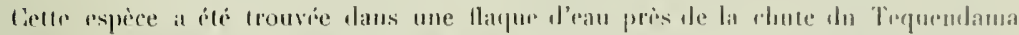

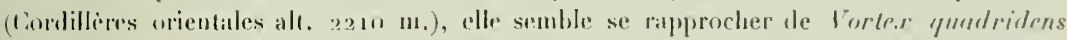

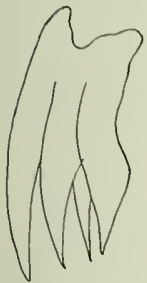

Fig. 3. - Vor(e.t) quadriden. soìtes $\mathrm{n}$. sp. Pénis chitineux.

Böns ${ }^{2}$, provenant de Bukoha silué an lac Victoria, en Afrirpue orientale. Y. quadridensö̈des est long de 1 mu, avee un diamidre de $0,66 \mathrm{~mm}$. la forme extéricure, mènr it lélat conserve, est celle de la plupar des Vortex. Les deux yeux ont un diametre de o,ouf mm. Le plarynx est long de o, 8 mu. L’un des deux iudirulus trousis, portait dius l'utérus un ouf brun long de 1,15 mm., avee un diamètre transiersal de o. 1 mm. L'ouf est lisse el ne montre, à l'opposé de l'espice africaine, aucunt striation longiludinale. Les wlandes vitellogènes ne semblent pas ramifiées, comme elles le sont eliez I. quadridens. L'appareil copulateur chitineux, long de o, $1 \mathrm{~mm}$., est relativement simple, puisqu'il consiste en quatre dents réunies par une bande chitineuse. L'une des dents semble ètre plus ćtroite, tandis que les autres sont larges, mesurant à leur hase $0,018 \mathrm{~mm}$. Le seeond individu était bourré de spores polygonales, d'un sporozoaire semblable à ceux qu'on trouve chez nos Mesostomides d'Europe.

1 Böнми, L. Die Turbellarien Os1-Afrikas. Tierwelt Ostafrikas 4. Bd. 1897. 


\title{
Triclades paludicoles.
}

\author{
Planaria longistriata n. sp.
}

(PI. SVIII. Fig. :; Fig. 1-7 du texte.)

Cette intéressante forme de Planaire a été trouvée dans les Cordillères orientales à deux endroits bien éloignés l'un de l'autre, à la Lagma Ubaque, sur le versant oriental du Paramo Cruz Verde, à une altitude de $2112 \mathrm{~m}$., et sur les rives de la Laguna Pedropalo, située sur le versant occidental de la Sabana de Bogota, it $2000 \mathrm{~m}$. d'altitude. La planaire est longue de $18 \mathrm{~mm}$. au maxinum et large de 2,5 a $3 \mathrm{~mm}$., suivant que lanimal est en marche ou à l'état de repos. Conservée, la planaire se contracte un peu, et nos plus grands exemplaires mesurent 15 à $16 \mathrm{~mm}$. et sont larges de $3 \mathrm{~mm}$. Le corps très aplati montre une tète triangulaire légèrement rétrécie en arrière des auricules; de là, le corps montre le mème diamètre transversal jusque près de l'extrémité postérieure. L'animal agile et rampant très rapidement, a une couleur fondamentale ocre clair, et à l'neil nu, on voit de nombreuses raies longitudinales d'un brun foncé. La face ventrale est claire, sans raies, et ne montre sous le microscope que de rares et très petites taclies pigmentaires brun clair. Celte coloration si particulière caractérise déjà assez hien notre espèce. Sous le microscope, on constate que le pigment est arrangré sur le corps en 8 à 2 bandes longitudinales et parallèles, qui s'anastomosent par places. Près de la tète, leur nombre diminue, el sur la tète mème, on constate que les bandes, surtout sur le bord, se transforment en un réseau pigmentaire. La ligne médiane, les auricules, le contour de la tète et un petit espace à l'extérieur des yeux restent toujours elairs et transparents.

Sur un jeune exemplaire de ro $\mathrm{mm}$. de long et de $\mathrm{r}, 5 \mathrm{~mm}$. de large, les yeux se trouvent à $1 \mathrm{~mm}$. de l'extrémité antérieure, ils sont distants l'un de l'autre de $0,42 \mathrm{~mm}$. et un peu plus éloignés du bord de la tète qui, à cet endroit, est large de $1,7 \mathrm{~mm}$. La plus grande largeur de la tète se trouve un peu en arrière des yeux ( $\mathbf{r}, 8 \mathrm{~mm}$.).Les yeux ont un diamètre longitudinal de $0,16 \mathrm{~mm}$. et possèdent quatre à cinq couches decellules rétiniennes; devant eux se trouve un ganglion optique assez volumineux. Dans ce mème exemplaire, la bouclıe est placée à $5 \mathrm{~mm}$. de l'extrémité postérieure, donc au milieu du corps.

Un exemplaire de $55 \mathrm{~mm}$. de long et $2 \mathrm{~mm}$. de large présentait les mesures suivantes : distanc: entre les deux yeux $0,38 \mathrm{~mm}$., largeur de la tête, 1,7 mm., longueur du pharynx, $2 \mathrm{~mm}$., son diamètre, $0,38 \mathrm{~mm}$.; la bouche est à $7 \mathrm{~mm}$. de l'extrémité postérieure et l'ouverture sexuelle a $1,5 \mathrm{~mm}$. en arrière de la bouche.

Le pharynx est long de $2 \mathrm{~mm}$. et son diamètre ì la base est de $0,6 \mathrm{~mm}$., tandis qu'à l'extrímité distale il n'est que de 0,28 à $0,38 \mathrm{~mm}$. Chez l'exemplaire en question, le 
bord libe prend la forme de dena dojegts probensiles, mais dans d'antres exemplares, la.

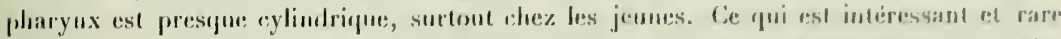

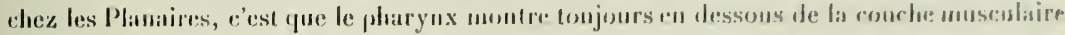

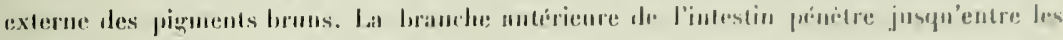
yeux, ses ramilications smot iméźnliomes.

les glandes sexuelles. Liovaire est situé andre lit troisione at la quatriome branche litcriale de l'intestiu,

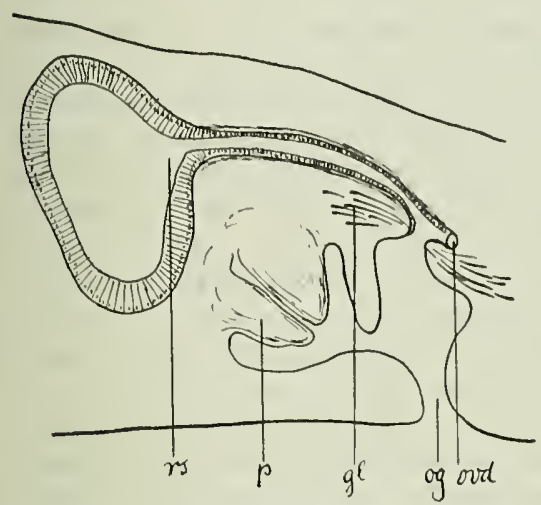

Fig. 4. - Plenaria longistriala n. sp. Canpe sariltale et méliane à travers l'appareıl copuldteur. og onverture génitale, rs réceptacle séminal, ovd oviducle, $g l$ glandes, $p$ pénis. (Tessiné avec l'apparesl thbe.)

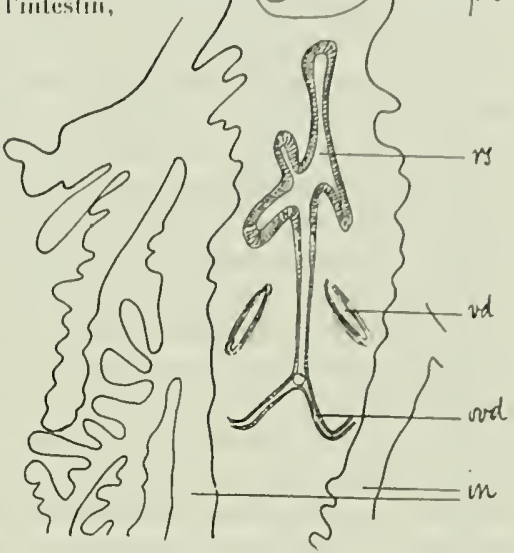

Pig. 5. - Planaria tongislriala n. sp. Coupe hirizontale, ph pharyns, in intestin, rs réceptaclo: séminal, ord oviducte, wé canal déférent. (Wessiné arec l'appareil Abbe.)

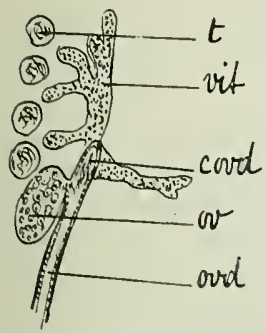

Fig. 6. - Planaria longistriala n. sp. Coupe horizontale. $t$ testicnle, vil glande vitellogène, or ovaire, covd partie préorarienne de l'oviducte remplie de sperme.

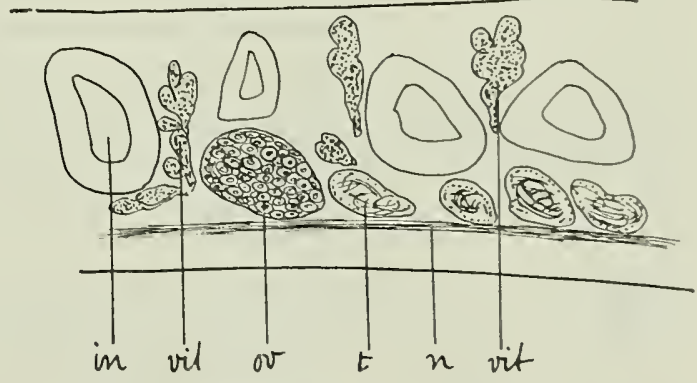

Fig. 7. - Plansiria longistriala n. sp. Coupe sagittale par la région antérieure. in intestin, $n$ nerf longitudinal, vil glande vitellogène. or oraire, $l$ testicule. (Dessiné arec l'appareil Abbe.) 
¿ 3 mm. en arriere de l'extrémite antérieure. Situe rentralement sur les nerfs longiludinaux, il est long de 0,2 mu. Loviducte y pénètre sur le côté externe et présente relte interessante particularite de se prolonger encore un peu en avant de la ghande femelle. Ce prolongrement antérieur est bourré de sperme chez l'exemplaire étudić. De nombreux follicules des glandes vilellogènes s'avancent également un peu en avant de linvaire. Les glandes vitellogenes sont situées surtout sur le cótí dorsal el entre les ramifications de l’intestio. En arriere, on trouve encore leurs lobes it 4 mm. derrière l'entrie des oviductes dans l'alrimm femininum. Le réceptacle sémiual (utérus) présente dans certaines coupes horizontales une forme irrégulière el lobée; dius un autre cas, il montre simplement deux lobes postérieurs. Sa cavite, lonģue d'environ 0,4 mm., est lapissée d’un épithélium très haut $(0,057 \mathrm{~mm}$.) et contient des spermatozoides. Le canal du réceptacle séminal, longr de $0,5 \mathrm{~mm}$., est tapissé d'un ćpithélium vibratile el entomri d'une couche musculare; il débouche dans la partie dorsale de l'alrium feminimum en se réunissant avant avere les oviluctes. Dans celle région de l'appareil lémelle dibouclent de quandes quantites de glandes micellulaires.

Les testicules extrènement noubreux sont situés en rangs serres sur la face ventrale llu planaire. Dans la partie antérienre, les premiers testicules se tronvent à 0,4 mm. con avant de l'ovare el ils s'ctendeu jusquà l'extrémité postérieure du corps. Leur dianèlre est de 0,12 it 1,16 mm.; ils sont de forme circulaire, ovale ou irrégulière. Yous avons comptí sur une coupe horizontale 60 testicules sur $1 \mathrm{~mm}^{2}$ ! le canal délérent s'élargit ì la lianteur du pharyux et présente en arriere de nombreuse's dilatations bourrées de sperme. Les deux canaux séminaux vont jusqu'à la lantenr du pore sexuel al retournent en avant pour déboucher séparément dans le pénis; celte partie récurrente est entourée d'une très forte musculature. Le pénis, trìs musculeux, se préscute sous forme d'un court ròne (long de $0,08 \mathrm{~mm}$.), suspendu dans la cavilé alriale mile. Il n'y a pas de vésicule síminale interne.

\section{Planaria paramensis $\mathbf{n}$. sp.}

(Pl. XVttl. Fig. 3 et 4 ; Fig. 8 et 10 du texte.)

Quelques exemplaires de cetle intéressante espèce nouvelle furent trouvés dans un ruisseau sur le versant oriental du Paramo Cruz Verde (Cordillères orientales alt. $3200 \mathrm{~m}$.).
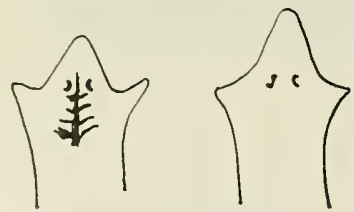

Fig. 8. - Tèle de Planaria paramensis n. sp.

Les plus grauds individus mesuraient, vivants, $20 \mathrm{~mm}$. de long et $2 \mathrm{~mm}$. de large. Ils étaient d'un beau noir sur le dos, el gris noirìtre sur la face ventrale. La tête porte deux tentacules triangulaires presque sans pigment; la région céphalique présente comme les auricules la forme d'un triangle. Les deux yeux sont placés à la base du triangle céphalique et la divisent en trois parties égales. La distance des organes visuels à l'extrémité antérieure 


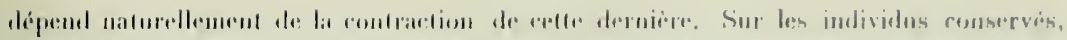

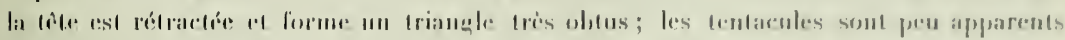

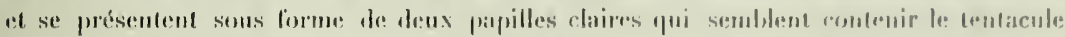

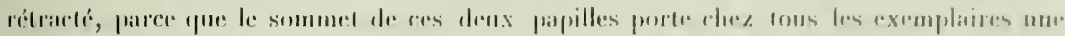
invagination dre larme irrégulièrer.

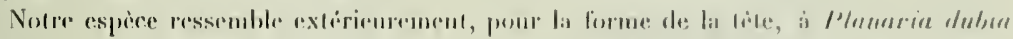

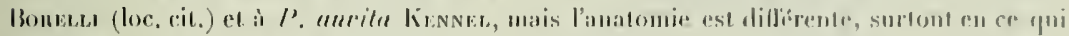

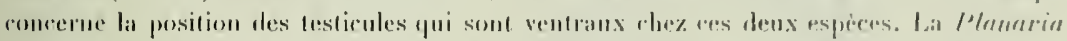

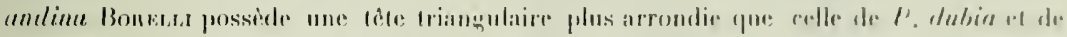

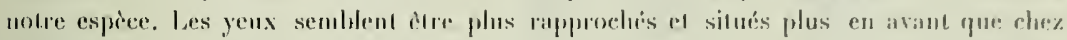

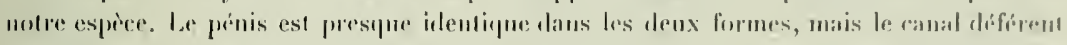

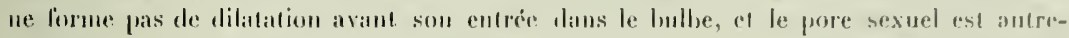

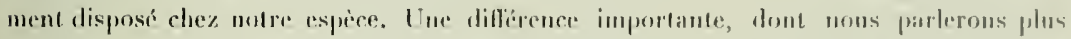
longuenent, comsiste dans le fait que la reproduction ascouelle par division transtersale se lail tont dillíremment chez $1 \%$ purenmestsis.

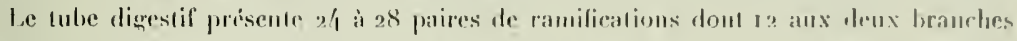

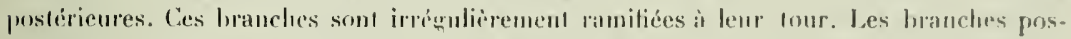
lípieures du systime digestif prisentent sur leme cotti interne de courtes ranifications don l'une on l'antre peut se transformer on me anastomose transversale. I.e pharyox est loner

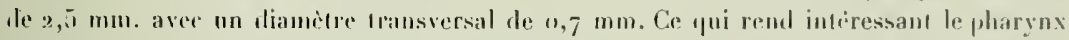
de cette espece, c'est pu'il montre sous la conche musculaire exterme une assez forte pigmertation, :qui se trowail dijà chez l'espice précedentr of so montre égalenent dans les denx antres esperes nourelles que nous ćmbierons. Celle pigmentation semble done èro maractéristique pour toutes nos planaires de Colombie, landis que chez les autres espéces

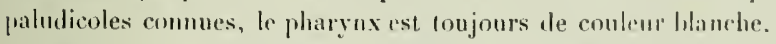

En éluliant des series de coupes horizontales, nous arons ibes liapues du fail qu'en avant du pharyms se trume chez des individus jeunes, comme chez d'antres is uppareil sexpet complitement developpé, un autre plaryux folus ou moins volumineux qui mens indique que cefte espore se reproduit sans anemn doute par segmentilion transiersale. Dams liexemplaire dont nous venons de decrie le systime digestif, le petit pharyns anti-

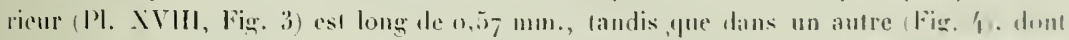

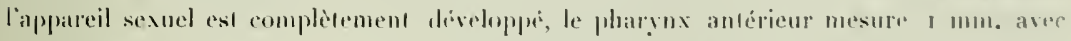
un diamelace de o, aree un diamitre de 0,4 li mum.

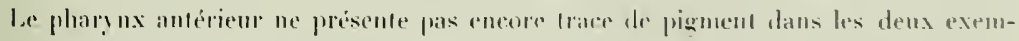

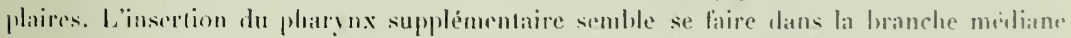

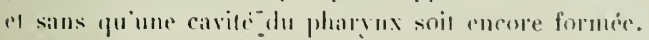

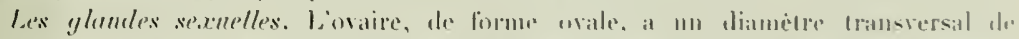

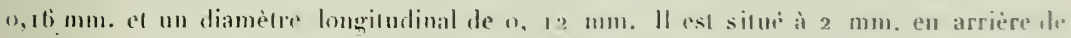
lextrimité anterieure. Les glandes vilellogìnes commencent déjà $0,\{$ mnı. en avant du 
lovaire et s'etendent jusqu ì l'extrémité postérieure. Elles sont situées mutralement, invovant entre les ramifications du tube cligestif de nombreux prolongements qui n'atteiwnent pas la face dorsale du systime digestif. Les oviductes ne présentent rien de parti-

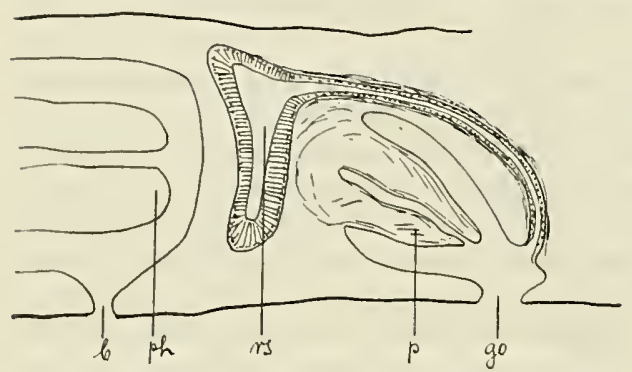

Fig. 9. - Planaria paramensis n. sp. Coupe sagittale el médiane de l'appareil copulaleur. $b$ branche, ph pharynx, go ouverture génitale, $r$ s réceptacle séminal, $p$ pénis. (Dessiné avec l'appareil) Able.) il débouche avec les deux oviductes dans l'atrium. Le réceptacle était rempli de sperme et de produits glandulaires.

Les testicules très nombreux (environ go de chaque còté) ont une position dorsale et se prolongent en s'amincissant entre les ramifications du tube 'digestif. Ainsi sur les coupes sagittales, ils ont la forme d'mne poire allongée. Sur les jcoupes horizontales et dorsales, leur forme est très irrégulière et lobée, le diamètre est de 0,13 à $0,23 \mathrm{~mm}$. Il est intéressant de constater que comme les glandes vitellogènes, les testicules se trouvent au nounbre de 3 ou 4, déjù en avant de l'ovaire; disposition rare chez les especes du genre Planaria.

Tandis que chez les formes sud-américaines $P$. ambigna Böıмг et $P$. michaelseni Böıмı (loc. cit.) les testicules, dorsalement disposés comme dans notre espèce, ne s'étendent que jusqu'it la hauteur du pharynx, ils se rencontrent chez $M$. paramensis jusqu'à l'extrémité postérieure. Le canal rléférent se présente le long le la poche du pharynx sous forme d'un canal fortement ondulé et dilaté. II se prolonge ainsi

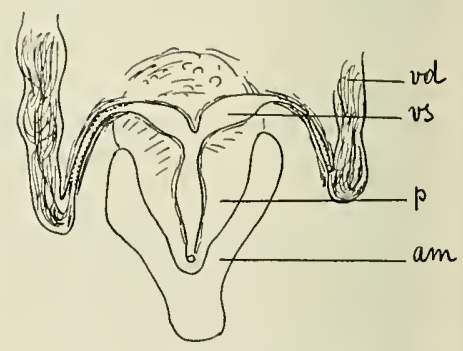

Fig. 10. - Planaria paramensis n. sp. Coupe horizontale. am atrium masculinum pénis, vs vésicule séminale, vd canal déférent. sans musculature et sans revitement épithélial appirent jusqu’au niveau du milieu du pénis. Il se recourbe en avant en angle aigu pour Iléboucher daus le bulbe du pénis. Cette partie du canal déférent est étroite et très fortement musclée, tapissée en outre d'un épithélium cubique. 


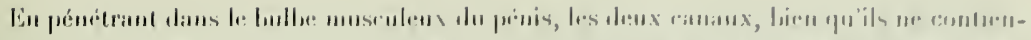

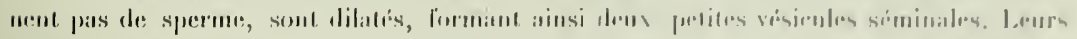

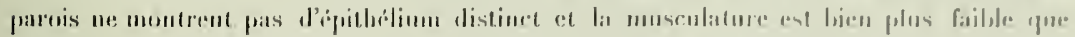

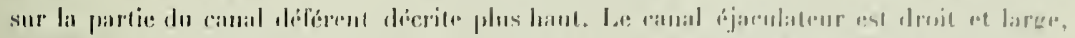

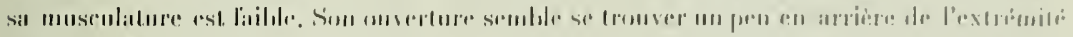

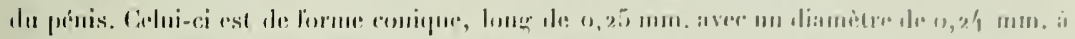

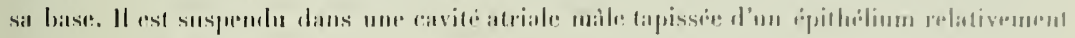

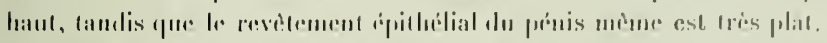

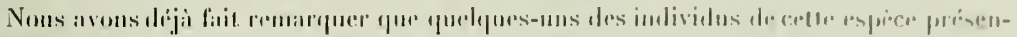

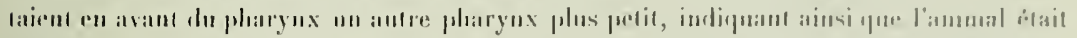

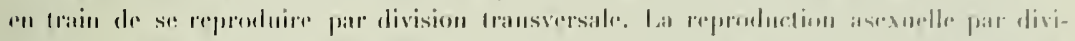

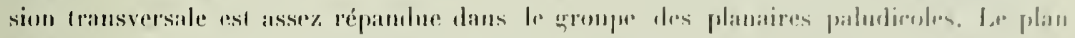

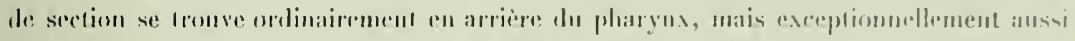

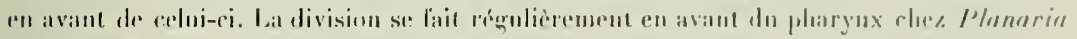

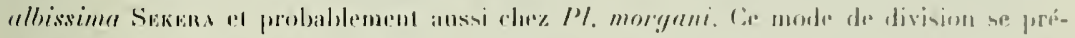

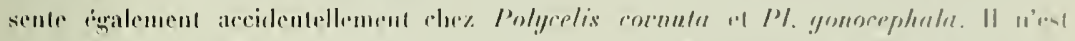

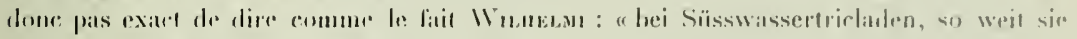

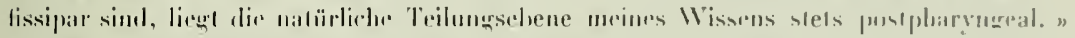

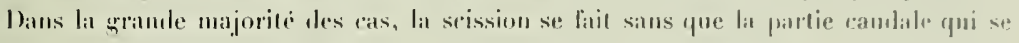

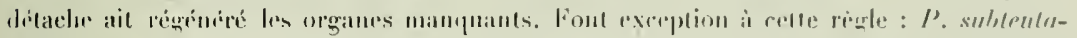

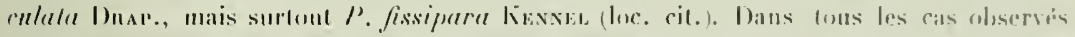

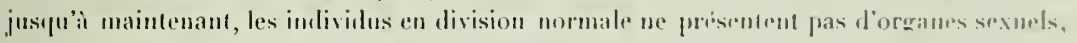
ou renx-ci sont tris incomplitement dévelippres.

L'espece Pl. paramensis, que nous venons de décrire, est intéressante à trois points

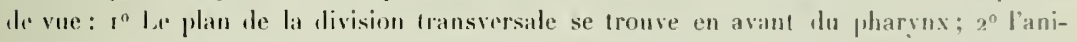
mal, avaut de se diviser, lorme un nouveau pharynx, si hien que les individus en voire de division présentent deux pharyox l'un devant l'autre; 3" la division put se faire pendant que les organes sexuels sont complètement diveloppés, probablement parce qu le plan de division se trouse col arant lu pharynx.

l'existence d'un second pharynx me doil pas ètre considirée comme un phénoméne de polypharyngie; celle affirmation me semble juslifice par le fait que le second pharyin est situé en avant el en dehors de la poelie du pharynx fonctionuant de la planaire; nous avons in oure trouvi un individu chez lequel la parlie postérienre au pharsmx était très courte, imliquant ansi que lindividu en question correspondait a la mostio antéricure d'une planaire qui venait de se diviser el de se rénénérer.

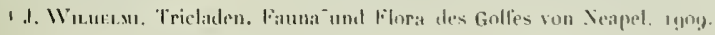




\section{Planaria polyorchis $\mathbf{n}$. sp.}

(Pl. XVIII, Fig. 5 el 7.)

Dans les coupes de plusieurs Pl. paramensis, provenant lu Paramo Cruz Verde, nous arons trouvé une série qui appartient certainement à une autre espèce. L'aspect extirieur de l'animal, sa taille el sa couleur étaient sans doute les mèmes que chez l'espéce précédente.

Nous n'arons pu compter les ramifications du tulse digestif. Le pharynx pigmenté, comme dans les autres espèces, est long de $2,3 \mathrm{~mm}$. avec un diamètre de $0,65 \mathrm{~mm}$.

Glandes sexuelles. L'ovaire est de forme circulaire et a un diamètre de 0,17 mm. Les glandes vitellogènes s'étendent depuis l'ovaire jusqu'à l'extrémití postérieure. Les deus oviductes débouchent séparement dans latrium femininum, el entre eux s'ouvre le canal musculeux du réceptacle sémind rempli de sperme. Le diamère longitudinal du réceptacle séminal de forme ovale est de $0,7 \mathrm{~mm}$. et te diamètre transversal de $0,57 \mathrm{~mm}$. L'épithélium glandulaire est très haut, puisqu'il mesure $0,18 \mathrm{~mm}$.

Les testicules, à l'opposi de ceux de Pl. paramensis, sont situés ventralement des deux còtés des deux nerfs longifudinaux. Ils sont de forme ovale ou circulaire et ont un diamétre de 0,17 à $0,2 \mathrm{~mm}$. On les trouve cléjì un peu en avant de l'ovaire el ils s'étendent en rangs serrés justju’à l'extrémité postérieure. Lecur disposition est la suivaute: en arant du pharynx, sur le còté externe de chaque nerf longitudinal, nous trouvons 50 testicules, et sur le còté interne, 35. Des deux còtés dn pharynx et sur le còté externe du nerf longitudinal seulement, nous avons compté 3o testicules; en arriore du pharynx sur le còté externe des nerfs, nous trouvons 75 testicules, et sur te cilté interne 56 . Nous avons ainsi complé de chaque coté de l'amimal 246 testicules, ce qui fait que $\mathrm{Pl}$. polyorchis possède an moins 500 testicules, cat un certain nombre peuvent nous avoir échappé. Les deux canaux déférents courent sur le còté interne des nerfs longifudinaux, et des deux côtés du pharynx, ils se dilatent comme chez toutes les planaires d'eau douce pour former des vésicules séminales ("falsche Samenblasen »). En pénétrant dans le bulbe du pénis, les canaux déférents se rétrécissent el se montrent tapissés d'un épithélium cubique. Le pénis, de forme conique, est long de $0,25 \mathrm{~mm}$; sa base est large de $0,17 \mathrm{~mm}$. Celle espèce présente une certaine ressemblance anatomique avec $\%$. longistriala $\mathbf{n}$. sp., mais elle en dilfère surtout par la forme du réceptacle séminal qui est toujours fortement lolé chez celle dernière.

\section{Planaria cameliae n. sp.}

(Pl. XVIIt, Figr. 2 el 6 et fig. 1 el 13 du texte.)

Planaria camaliae fut trouvé dans tes ruisseaux près de Medellin, de Guaca et du Cafetal La Camelia (Cordilléres centrales alt. 5540-1820 m.). 


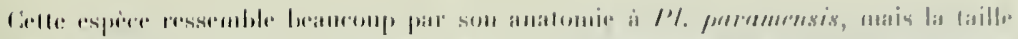

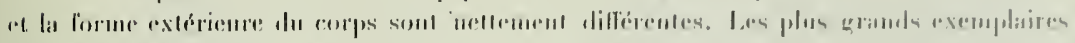

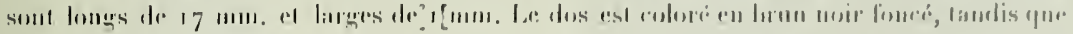

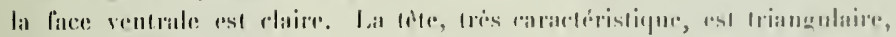

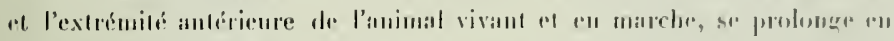

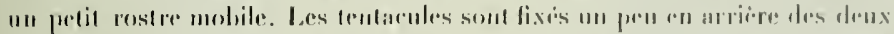

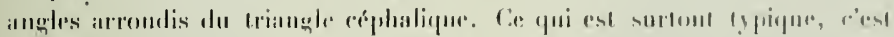

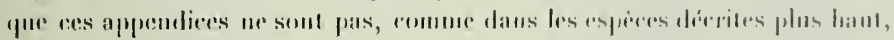

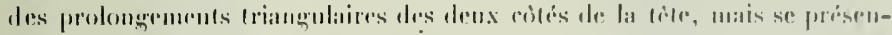

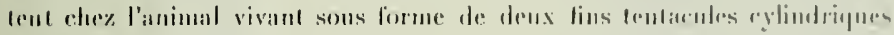

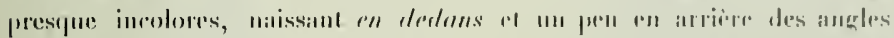

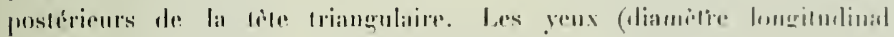

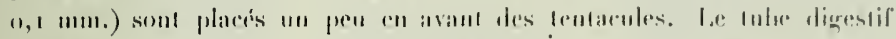

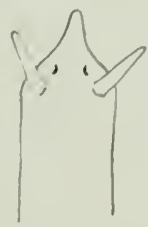

Fik. 11. TMlederlanaria cantriae n. ip.

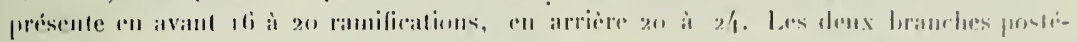

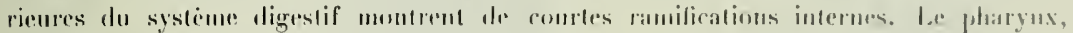

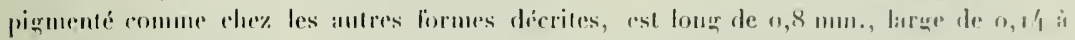
$0,16 \mathrm{~mm}$.

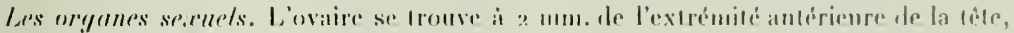

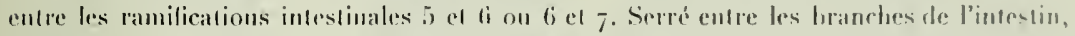

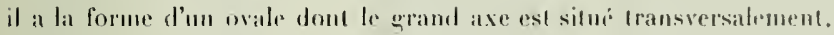

Les cellules couf oul un diametre de $0,02 \%$ mm., lenrs noyanx mesurent

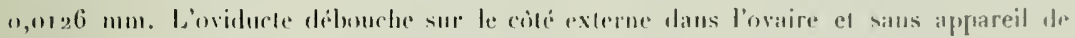

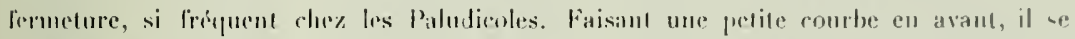

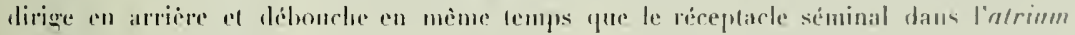
fomininmm.

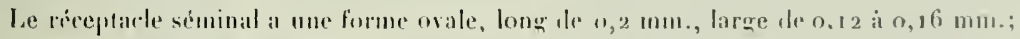

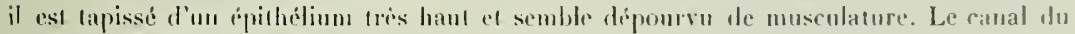
réceptacle (long de $0,25 \mathrm{~mm}$.) par contre, est enveloppe d'une trés forte musculature, si bien yue son diamedre mesure o, o6 $\mathrm{mm}$.

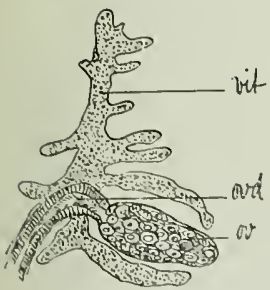

Fizy. 12. - M. cameliae n. sp. Coupe horizontale. ov oraire, vit glande ritello. gène, ovd oviducte.
Les grlandes vilellogenes commenent en avant de lovaire ct lenveloppen presque complidement. Comme les lesticules possident une position dorsale, les glandes vilellngiones sunt

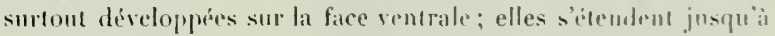
lextrémite postiricure.

Les tristicules sont siluis dursilement el pinetrent entre les ramifications de lintestin. Ils sont placés latéralement et nous en comptons 60 en avant du pharynx, 20 sur le cutti de cet organe et 34 en arrière da pharrax. La planaire a done, mu lout, au moins 232 testicules. I la hautur du platroux, le canal déferent devient plus larere, formant ainsi des vésicules séminales. 


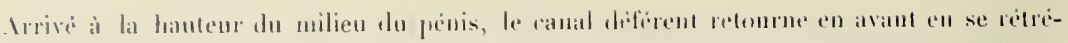
cissant pour déboucher dans le lublue du prosis. Lelte partie ricurrente du vas deferens an entoure doun envelople musculaire qui, contrairement it celle de Pl. paramensis,

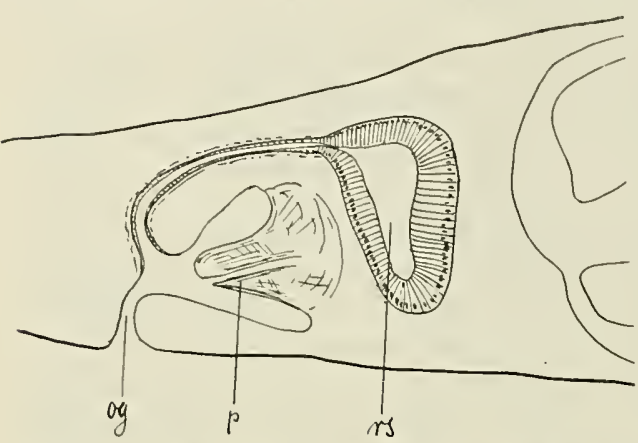

Fig. 13. - Planaria cameliae n. sp. Compe sagrillale de lappareil copulateur. og ouverture génitale, $p$ pénis, $r$ réceptacle séminal. (Dessiné avec l'appareil Abbe). rest wes forle sur les denx branches du canal diferent qui se trouvent dans le lube et automr du canal ajaculatrur dans lequel elles se coulimuent. Ces canaux, it l'uppersi de ce gui se rencontre cliez $P l$. paramensis, sont étroits. Leur revètement ipulhélial est pen appparent, tandis que dans ba parlic ricurente du vas teferens, les cellules épithéliales sont neltement développées. Le pínis est conique el son ouverture semble se Irouver un pen en atriere de soll somuel.

Planarin cameliue se multiplie par division transiersale et son plan de division se trouve en arriere du pharynx.

Parasites. Nous avons trouvé dans le tube digeslif de grus infusoires semblables it cenx qu'on trouve chez nos planaires et que nous avons figure dans un Iravil pl. $X$, Figr. $3^{1}$. Dans les dilatations du canal deférent, nous avons conslaté chez deux exemplaires de nombreuses cellules spliériques assez grandes (diauètre 0,014 , noyan 0,00 / mon.), qu nous croyons ètre des parasites.

\section{EXPLICATION DE LA PLANCHE XVIII}

Toutes les figures sout failes d'apre's des microphotographies que je dois ì $\mathrm{M}$. Th. Delachaux.

Fin. 1. Tète de Planuria longistriata x. sp.

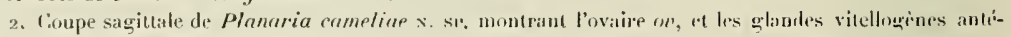
ricure dort, it postćrieures dop.

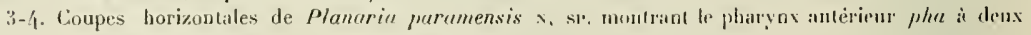
stades dilfirents de son diveloppenent.

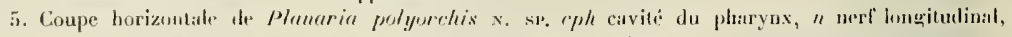
d pénis, tlesticules, tol cand delérent, res réceptacle siminal.

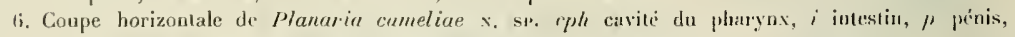
ud canal délërent. nil glandes vitellogènes, res réceptacle sỉminal.

7. Coupe horizontale par l'extrémité postírieure de Plonorin polyorchis x sr. I testicules, " nert' louyitudinal.

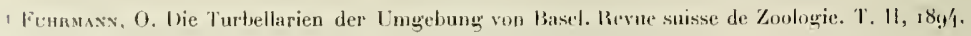




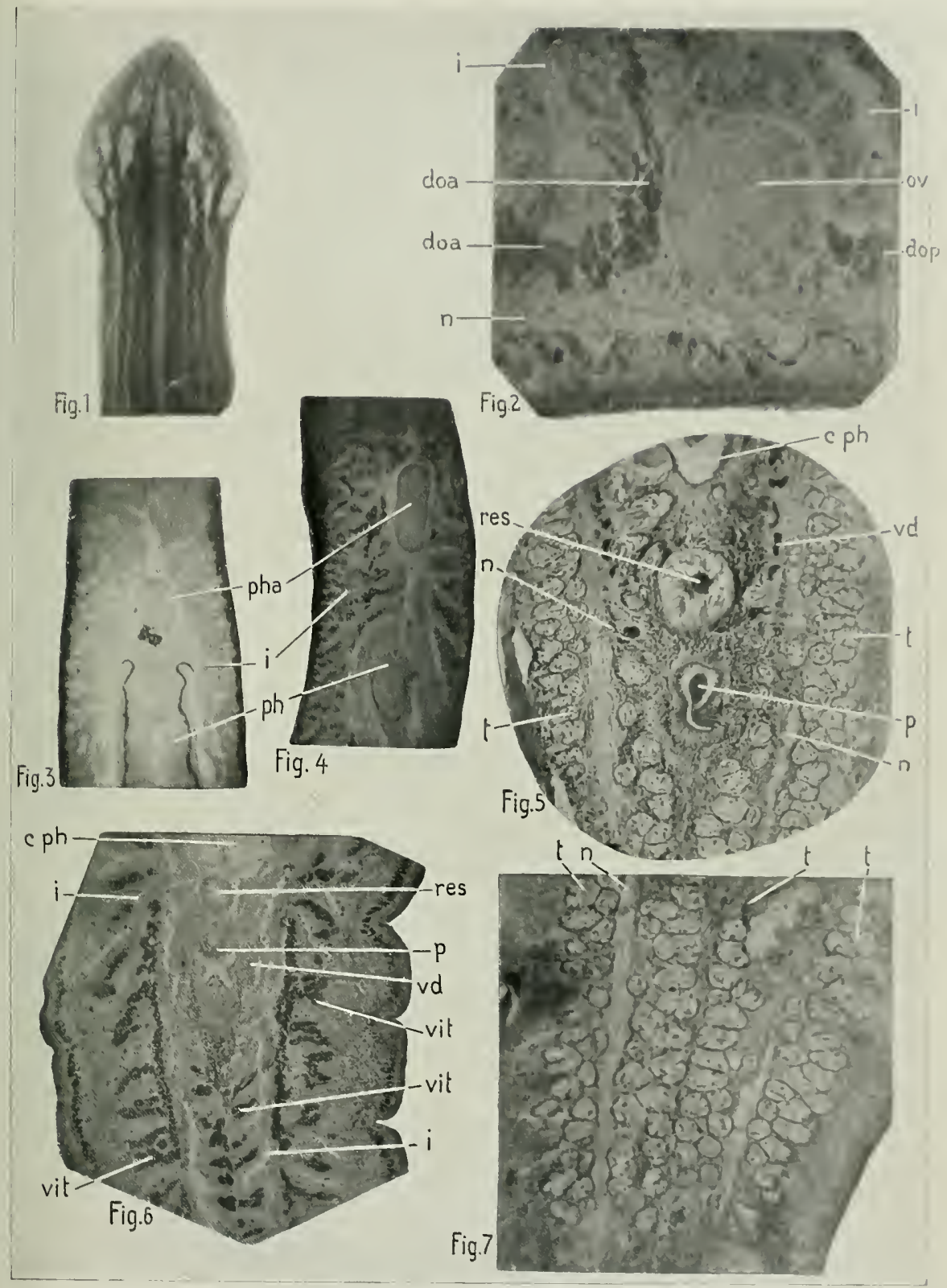





\title{
Oiseaux de Colombie
}

I.A IS I.1:

\author{
Dr E. PIGUE'T \\ Professeur a Neuchatcl.
}

Nous avous pu determine aver exactimde ing esprees dans le matériel rapporte de

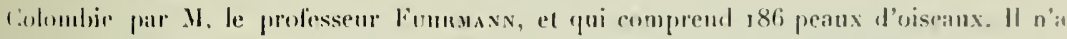

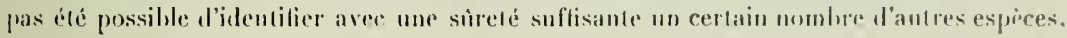
representés par des jemes on par des femelles.

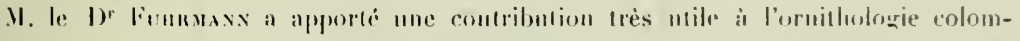

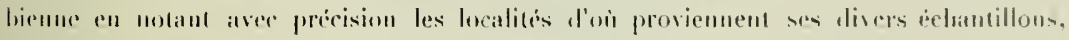

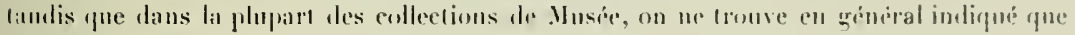
le nom du pilys.

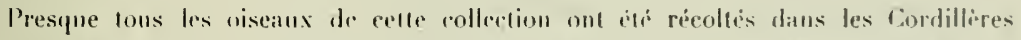
rentrales de Colombie, dins la province d'Antienguia, aux ensirons de Vedellin et d'Inere-

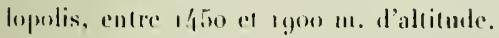

\section{Ord. Galliformes.}

Fam. Cracidae.

Chamaepetes goudoti (Less.) I exemplaire. Angelupolis pres Medellin.

Fam. Odontophoridae.

Odontophorus hyperythrus (iovı.. I exemplaire. Angrelopolis près Medellin. 


\section{Ord. Columbiformes.}

Fam. Peristeridae.

Chamaepelia talpacoti (Tran ef KNır.). 4 exemplaires. Nedellin.

\section{Ord. Charadriiformes.}

Fam. Charadriidae.

Helodromas solitarius (Wusov). I exemplaire. Angelopolis prìs Medelliı.

\section{Ord. Ardeiformes.}

Fam. Ardeidae.

Butorides striata (Lis..). 2 exemplinires. Medellin.

\section{Ord. Cathartidiformes.}

Fam. Cathartidae.

Cathartes aura (I, xx.). I exemplaire. Medelliı.

\section{Ord. Accipitriformes.}

Fam. Falconidae.

Rupornis magnirostris (Gis.). 2 exemplaires. Angelopolis et Medellin.

Cerchneis isabellina (Swans.). I exemplaire. Medellin.

\section{Ord. Psittaciformes.}

Fam. Psittacidae.

Conurus finschi ŚALvin, I exemplaire. Rio Frio près Jerico (Cordillères occirlentales). 


\title{
Ord. Coraciiformes.
}

Fam. Momotidae.

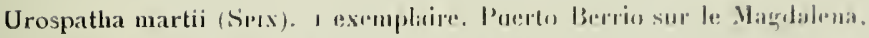

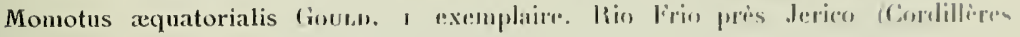
orcillentales).

\section{Fam. Trochilidae.}

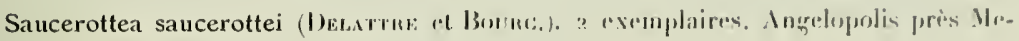
dellin.

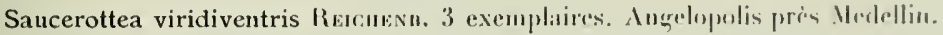

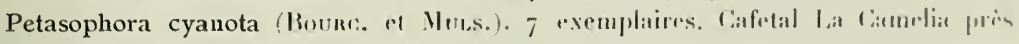
Inerelopolis

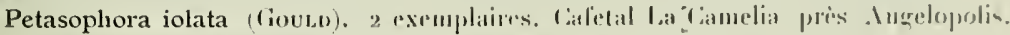

Chrysolampis mosquitus (LinN.). I exemplaire. Medellin.

Helianthea colombiana (LLLsor). I exemplaire. Angropolis pris Medellis.

Heliangelus exortis (FHasen). I exemplair". Angelopolis pris Mrdellit.

\section{Ord. Coccyges.}

\author{
Fam. Cuculidae.
}

Coccyzus pumilus Sracke. I exmplaire. Mealellin.

Piaya cayana (Lixx.). 2 exemplaires. Angelopolis pres Medellin.

Diplopterus naevius (Lıx.). I exemplaire. Mclellin.

Crotophaga ani Lıxs. 4 pxemplaires. Cafetal La Camelia pres. Ingelopulis.

\section{Ord. Piciformes.}

\section{Fam. Picidae.}

Chloronerpes gularis Ilaramt. \& exemplaires. Caletal La Camelia près Ingelopolis. Melanerpes flavigularis Sclater. 2 exemplaires. Angelopolis près Medellin.

Campophilus pollens (BP.). I exemplaire. Medellin. 


\section{$-\sin -$ \\ Ord. Passeriformes.}

Fam. Tyrannidae.

Megarhynchus chrysocephalus (Tsinuou). I exemplitr. Medellin.

Pyrocephalus rubineus (Bopn.). I exemplaire. Medellin.

Tyrannus melancholicus VIent. g exemplaires. Medellin et Cafetal La Camelia prìs Angelopolis.

Muscivora tyrannus (Lisx.). 6 exemplaires. Medelliı.

\section{Fam. Cotingidae.}

Pipreola riefferi (Boiss.). 3 exemplaires. Cafelal La Camelia près Angelopolis.

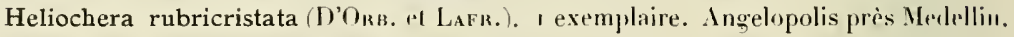

\section{Fam. Turdidae}

Semimerula gigas (linasen). 5 exemplaires. Medellin el Cafelal La Camelia prís Angelopolis.

Fam. Mniotiltidae.

Dendroeca aestiva (Gx.). I exemplaire. Medellin.

Myioborus verticalis (LAFr. el n'Orв.). 5 exmplaires. Cafetal La Camelia pris Ingelopolis.

Myioborus chrysops Sirvis. I exemplaire. Medellin.

\section{Fam. Fringillidae.}

Sporophila gutturalis (Licıт.). 2 exemplaires. Medelliı.

Euethia pusilla (Swarns.). 3 exemplaires. Cafetal La Camelia pris Angelopolis.

Spinus xanthogaster (Du Bus). I exemplaire. Angelopolis près Medellin.

Astragalinus mexicanus (Swans.). 5 exemplaires. Cafetal La Camelia près Augelopolis.

Brachyspiza pileata (BODd.). 4 exemplaires, Cafetal La Camelia près Angelopolis. Atlapetes gutturalis (LAFr.). 2 exemplaires. Cafetal La Camelia près Angelopolis. Buarremon brunneinucha (LAFR.). I exemplaire. Medellin. 


\section{- Xi!! \\ Fam. Cocrebidae.}

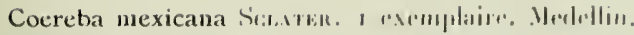

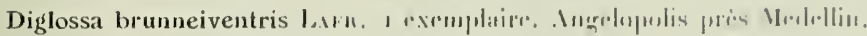

Diglossa personata (limssin). I "vimplaire. Mrollin.

Fain. Tanagridae.

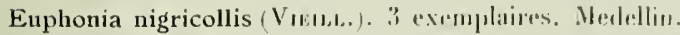

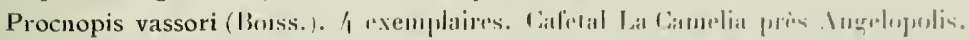

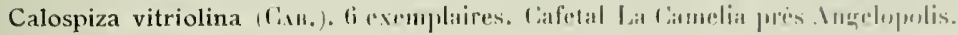

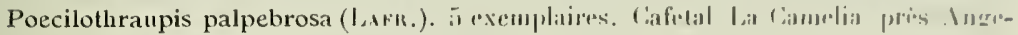
lopuilis.

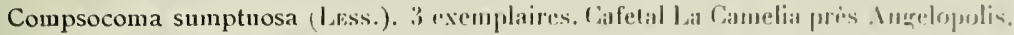

Tanagra cana Swans. \& exemplisires. Caluca pris Tiririlii.

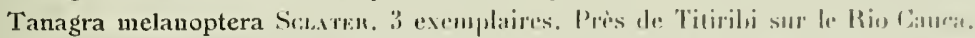

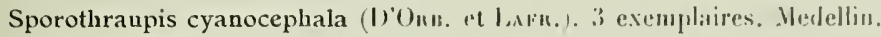

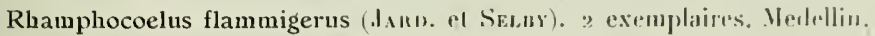

Rhamphocoelus chrysonotus LaFи. 2 exemplaires. Vedellin.

Chlorospingus flavipectus (L.wi,). 7 pxemplaires. Medellir.

\section{Fam. Icleridae.}

Icterus giraudi Cass, ì exemplaires. Caletal Lal Camelia près Augrolupolis.

Hypopyrrhus pyrhypogaster (1): T.ukr.). 4 exemplaires. Cafelil l.it Camelia prè Angelopolis.

\section{Fam. Corvidae.}

Xanthura yncas (Bono.). is ixemplaires. Angelopolis près Medellin. 


\title{
Spinnen der Familien
}

\section{Sparassidae, Lycosidae, Sicariidae und Pholcidae aus Kolumbien}

ION

\author{
EMBRIK STRAND, Berlin.
}

Die von Herrn Prof. Fuhrmann von seiner kolumbischen Reise mitgebrachten Spinneı der Familien Sparassidae, Lycosidae, Sicariidae und Pholcidae werden im Folgenden behandelt; die übrigen Familien seiner Spinnenausbeute werden an anderer Stelle veröffentlicht werden.

\section{Fam. Sparassidae.}

Gen. Olios W $W_{\text {ALCK. }}$

1. Olios helvus (Kers.)

Sparassus helvus Kieyserling, Spinnen Amerikas, Laterigradae, p. 262, 1. 7, f. 144 (1880).

Olios helvus Sinon, Act. Soc." Linn. Bordeaux, 34, p. 300.

Ein unreifes Exemplar von Bodega Central am Magdalena, go m hoch gelegen, dürfte ،lieser . Irt anyelö̈ren. 


\section{Olios sp."}

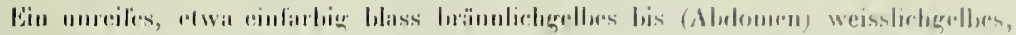

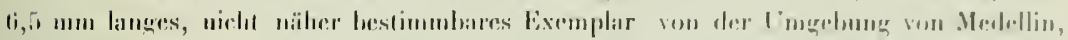
$15 \%$ tio 13.

\section{Olios Fuhrmanni sirusu, n. sp.}

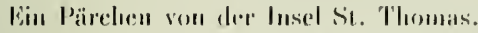

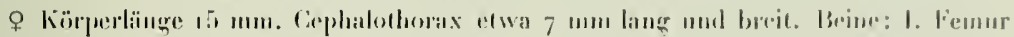

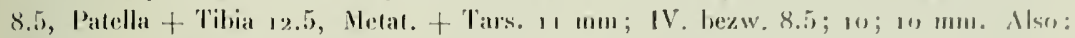
1. 32, IV. $28.5 \mathrm{~mm}$ lang.

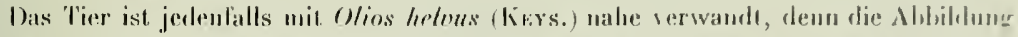

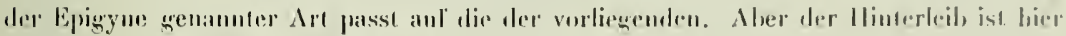
uidu bam gellockt, wohl aluer sind dir Muskelpmule des Räckens schwarz und scharf markierl, die Grïse ist bedeutender (helons wird als 1 m mm lang mit 4 mm langen (cephaholhorix beschrieben), die Metalarsen und l'arsen sind mit grauschwarzer bis schwarzer Scopula versehen, die so anffallend ist, dass kersem,was sie sicher heschriehen hitte, wenu sie hei helous elenso gewesen wäre, Cephalohlıorax ist kürzer als Tilna I,

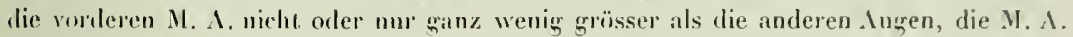
Wre zweiten Reihe sint von den $\$$. $\Lambda$. ein klein weng weiter als unter sich entfernt, die vorderen M. A. erscheinen (in Flïssigkeil Wenigstens) den Clypeusrande ein klein wenig

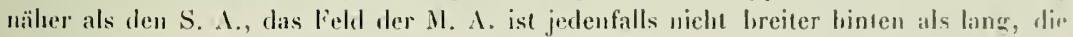
Mandilehn sind nicht kïrzer als die vorderen Patellen.

Das of ist is num laug, Cephotothorax ist 5 mn lang und breil, die Beine I: Femur 11, Patella + Tihia 14.5, Metatarsus + Tarsus 14 mm, 1 hezw. 10,5; 1 i ; r, 5 mm, also: I 39.5, IV 32 mm. Cephalothorax kïrzer auch als Tibia IV. Tarsalglied der Paljen reichlich so lang wie die berilen vorhergehenden Glieder zusammen (bezw. 3.5 und $3 \mathrm{~mm}$ ). Das Tibialglied hat am Ende aussen einen fortsatz, der im Profil wie folgt erselerint: nich vorn und ein wenigr nach oben gerichtet, uach unten konvex gebogen, in der Endhailfte schwarz, in der Basallıälfte rü̈lichgell, gegen die ziemlich scharfe Spitze allınählich verjüngr und reichlich so lang wie die grösste Hïhe des Tibialgliedes. In Dorsalansicht erscheiut er nalıe der Basis gerade, dann aber schwach s-förmiğ gehogren, nit der Spitze gegen das Gilied gerichtet, gegen die Spitze allmählich verjüngt, nach vorn und ein wenigr nach aussen gerichtet, also dem Tarsalgliede nicht anliegend und nur im apicalen Driltel sclswarz.

Cephalothorax und Extremitäten rötlich braungelb; letztere apicalwärı am dunkelsten. an der Basis blass. Tarsalglied der Palpen dunkel. Mandibeln rot. Abłomen röllich liranngelb mit blassem Epigaster. Weder Sternum noch Bauch gezeichnet.

Die vordere Augenreihe leicht recurva gebogen; die .I. A. die grössten aller Augen. 


\section{Gen. Heteropoda LaTn.}

\section{Heteropoda camelia Siтихи n. sp.}

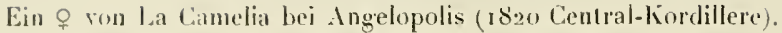

hörperlänge $8 \mathrm{~mm}$. Cephalothorax 3.5 num lang und zwar länger als Tilial I (3 mm) oder IV $(3.5 \mathrm{~mm}), 3 \mathrm{~mm}$ breit. Beine: I Femur 3.5, Patella + Tibia 4.5, Metatarsus + Tarsus $4.3 \mathrm{~mm}$, zusammen also $12.3 \mathrm{~mm}$; $1 \mathrm{~N}^{\circ}$ bezw. 3.5 , 4 und $4.5 \mathrm{~mm}$, also $12 \mathrm{~mm}$.

Iuffillende Borstenbeharung anf dem Clypeus (wie es bei der aus Peru beschriebenen Ilet. meticulosa Sts. der Fall sein soll) ist hier kaum rorhanden, wenn anclu einige Borsten daselbst vorhanden gewesen.

Ilit Het. pumila Kers. jedenfalls nabe verwand, aber Epigyne weicht von der Mtbildung zn urteilen dadurch ah, dass ihr Medianfeld (in Flässigkeit gesehen) länghichrhombenfürmig, am vorderen und hinteren Ende ghleich stark verschmälert und mitten mindestens $1 / 3$ so hreit wie lang erscheint. Insserdem erstreckt das Medianteld sich ganz his zur Spalte und der vor demselben gelegenen Teil des gesamten Genitalfeldes ist ebenso lang wie das Medianfeld, während bei pumila letzleres den Vorderrand der Epigyne zu erreichen scheint. Trocken gesehen erscheint die Grube der Epigyne subtriangulär, 1ach hinten verbreitel, vorn abgestumpft, schliesst aber im Grunde eine secundäre Grube cin, die etwa dieselbe Form wie in Alkohol zeigt. Ein weiterer Untersehied der Epigynen beider Arten (in Alkohol gesehen) ist, dass die Samonhlasen briderseits den Vorderende des Medianleldes gelegen, sowie grösser als bei pumila sind, wo sie eben beiderseits des Hinterendes sich finden.

Cephalothorax und Extremitäten rötlich hraungelh, ersterer mit dunklerer Miltellängslinie und Strahlenstrichen, sowie ebensolchem Seiteurand; un die Iugen tiefschwarze Ringe. Abdomen oben und an den Seiten dunkellsann, leen schwar\% punkitiert nud mit Andeutnng eines helleren Herzstreilens; der Bauch ein wenig heller, das Epigaster hraungelhlich.

Die vorderen M. A. viel kleiner als ihre S. A. und unter sich nu doppelt so weit

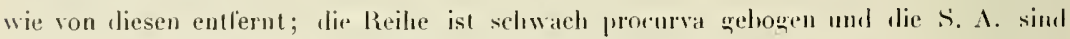
um elwa ihren Durchmesser rom Clypeusrande entlernt. Die Augen der hinteren Reilie sind unter sich um etwa unterch weit entfernt und hiluen rine ganz schwach recurva grebogene Reilie.

\section{Fam. Lycosidae.}

\section{Gen. Tarentula suxw.}

\section{Tarentula Thorelli lisss. 1876 .}

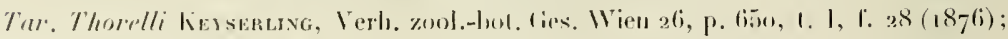

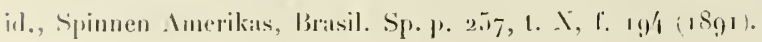




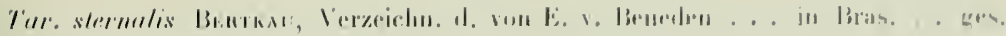
Arachin. 1. 73, 1. II. 1. $2 / 1$ (1880)

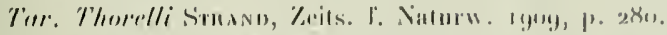

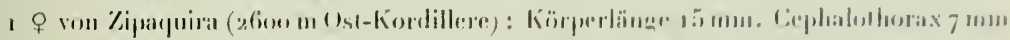

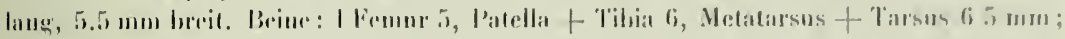

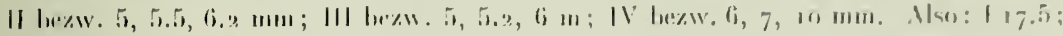
II Ifi.7; III Ili.?; II 2.:

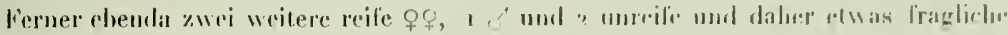

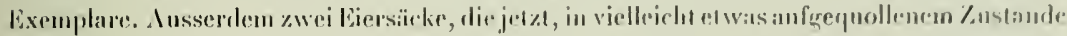

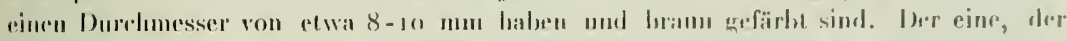

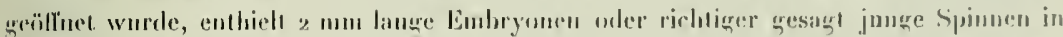

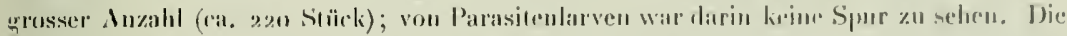

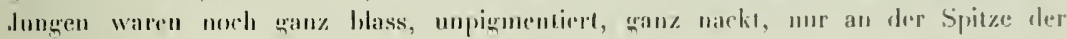

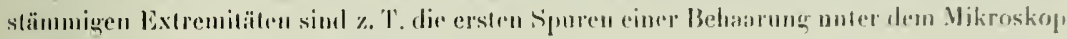

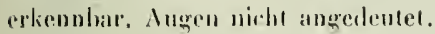

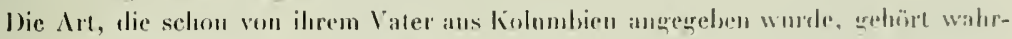
scheinlich zu den länlizeren kolumbischen Sprinuen.

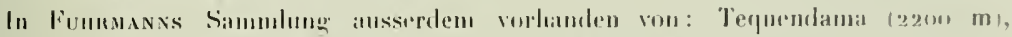

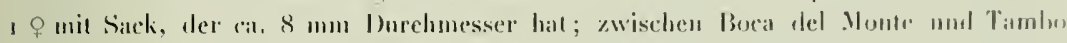

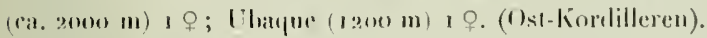

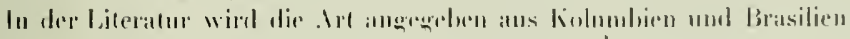

\section{Tarentula medellina Srкs:i, n. sp.}

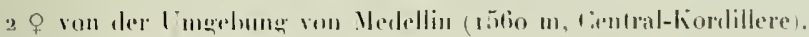

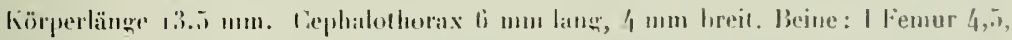

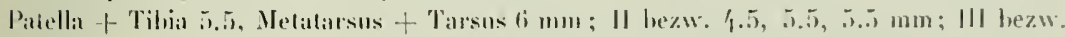

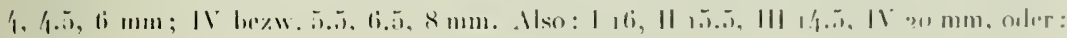
$11,1,11,111$.

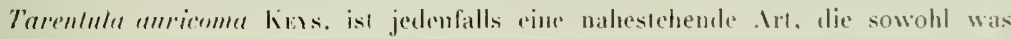

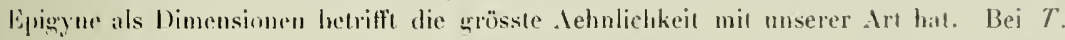

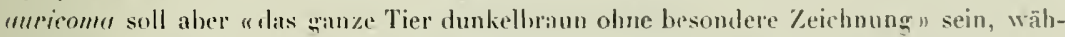
rend hier Gephahohorax mit scharl markierten, hellen Längshinden versehen ist, Sternum

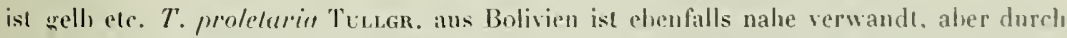
ihre orangerote Behatang der Mandibein und ein wenig abweichende Epigrue zu mintrischeiden.

Letzlere besteh wie gewöhnlich in dieser Galtung aus einem Lings- und einem Oncrseplum. In Flüssignkeil erscheint das Feld rïlich braungetb: die hintere Häfte des lingsseptums und das ganze Querseptum ist braunschwarz umrandel, die vordere Hälfte der Epigrnengrube ist an den Seiten schmal schwarz umrandel. Das Längsseptum 


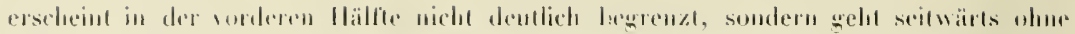
"rhemubare lirenze in die daselhst ziemlich tiefe Epigynengrube äher unl köunte daher als rorn loreiter als hinten anfgelassl werden, wälırend es vorn mit dem Rand der Gmbe

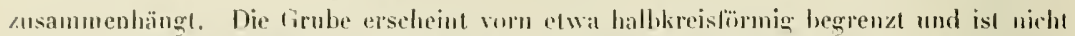
s) hreit wie das Yuerseptum lang ist, last mumerklich procurva gebogen, an der Ansat\%slelle des Längsseptums an schmälsten. Die lirube wird von langen wrissen Randhaaren wilweise ïherragt. Trueken gesehen erscheint die Grube lïnglichuml, lief, mit ziembich scharf abresetztem Scitenrand, der sich hö̈ckerartig in len WVinkel жwischen längs- unel

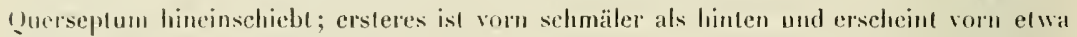
lrislenförmig.

Cephalothorax und Extrentäten bram bis rötlieh braungefi, ersteres mit drei scharf markierten gelben, weiss beharan Längsbinden, von denen die millere vorn zwischen

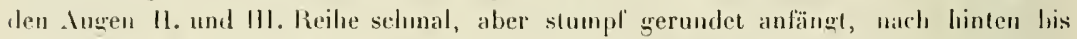
litrz vor der Mittelritze sieh allmählich erweitert, ist dasellsst so beit wie die Spitze dew hinteren Femora und verschmälett sich dann wiederum alluählich gegen den Ilinterrand. Die hellen Seitenbinden sind elwa so breit wir die Nittelbinde, aber olsen und noch melne unlen unregrelmässig begrenzl und durch cine unr wenig schuälere braune, melırlach unterbrochene Binde rom Rande getrenul; auf dem lopfteil nehmen sie aher die ganze Seite ein. Augenfeld schwarz; zwischen den Augen II. Reihe eine ganz schmate, weis. behatate Bindr, die nicht mit der Rückenlänģsbinde zusammenhängt. Mandibeln dunkel rothrann, Stermum und Maxillen bräunlichgelb, Lippenteil dunkler mil schmalem hellem Vorderrand. - Abdomen oben uml in der oheren Hälfie der Seiten schwärzlich mit helleren und rein schwarzen Punkten bestreut, mil einer nur durch die helle Begrenzung markierte dunkle Nittellängshinde, die in den vorderen $4 \mathrm{~mm}$ ihrer Länge last parallelseitig und doppelt so breit wie ilıre hellen Grenzbindm ist, dann aber durch Einbuchtungen der hellen Binden in 4-5 rundliche, mur noch schmal verbundene Flecke eingeteilt wird, mit anderen Worten, die lellen tirenzbinden sind in der hinteren Hällte stark zickzackwellenförmig gekrïmmt. Bauchfeld hellgraulich, vorn zwei kurze dunkle Linien einschliessend, nach hinten verschmälert, von der lraungetblichen unteren Hälfte der Seiten deutlich abgesetzl.

\section{Gen. Lycosa L.ıт.}

\section{Lycosa fastosa Kers. 1877 var. viota Sirasu n. var.}

1 우으 Viota, ca. $1000 \mathrm{~m}$, in Ilen Ost-Kordilleren.

Eprigyne hat die grösste Aehulichkeit mit derjenigen von Pardosa [= Lycosa m] limeli L. lierl. (in: Mission du service géogre de l'armépenr la mesure d'un are de

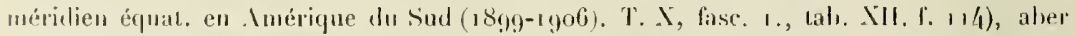
die Medianlängsfurehe ist am Hinterrande breit dreieckig erweitert und die beiden Wülste, 


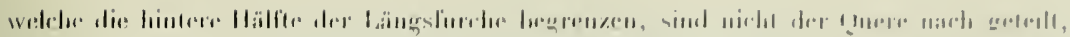

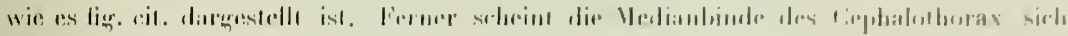

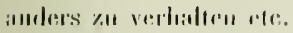

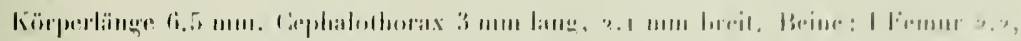

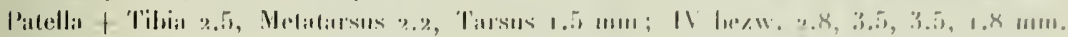
Alsu: I 8.4, IV 11,6 11111.

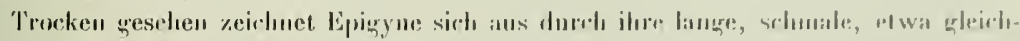

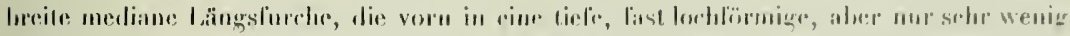

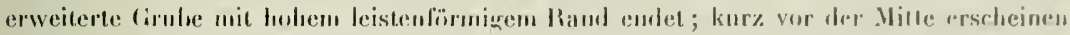

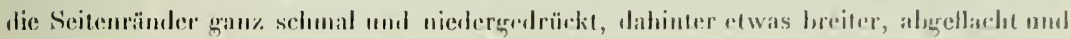

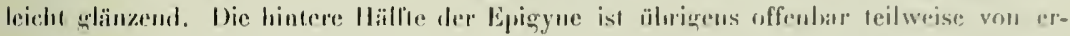

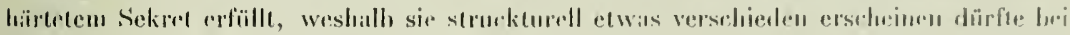

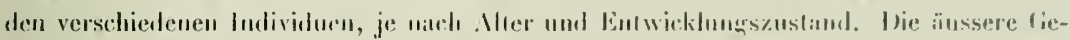

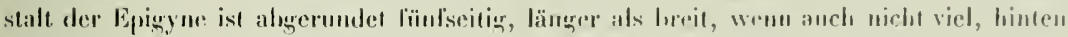
quergeschmilten. Die länge heträgrt last I mu.

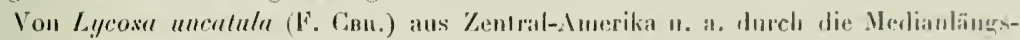
liude des Ceplatothorax zu unterscheiden, indem diese sich hei L. uncatula bis ins Augenfeld hincin erstrecht, wähend sie hier an dem llinterrandr des liopfeilex endret und dasellost bloss awei kleine Sritrnschräghinden, die aul den linpleif hinübrgreifen, entsondet; von der Millelvitze an nach hinten nimmt die Medianlinde an Breite sclınell als. Ferner sollen hei unculula die Beine "pale yellow, nore or less distinclly annulate" sein, während sie hier dınkel, mit mudeullicher hräunlichgelher Ringehng, sind. -

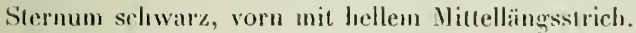

Die Zugehörigheit zur lievsentıses. Irt ist nichut ganz sicher und jedenfalls scheinen hemerlienswerte Variationsunterschiede vorlanden zu sein. Viach liesseutsws Abhildung

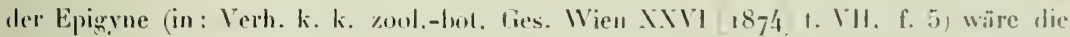
Längstirche vorn zu einer Querfurhe stalt einer runden Grube erweitert, am hintern Ende wäre es umgekehrt und die hintere Hälfte der Furche scheint in einer Einsenkung gelegen zu sein, während daselist Randwïlste der Furche nicht angedeutet sind.

J)ir Iypisch' Lokalitïl der Art ist Bogola (26.5 m).

\section{Lycosa fastosa liess. var.}

2 우 von La Camedia bei Angelopolis, 20 , V111 (18m m, Central-liordillere).

Gehören zu der von hexsencixg beschriebenen helleren Form, bei welcher stermum lraungelb mit einigen unregelmässigen dunkleren Fleckchen ist, die Beine Iraungell, mil dunklerer Ringelung und die Medianlängsbinde des Cephalothorax sich bis zum . Iugenfelde erstreckt. Epigyne ist bei den heiden Exemplaren nicht ganz gleich und stimml nicht ganz weder mit der var. viota noch mit der angenommenen Hauptorm. Fs wiir"

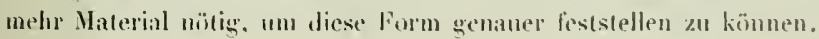




\section{Tarentula pulchella ハis.}

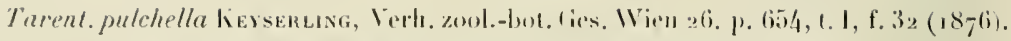

3 ㅇ 1 fon La Camelia bei Angelopolis (t\$20 un Central-kordillere), 20 , VIII. Iusserdem ein unreifes fragliches Exemplar.

O Lörperlänge $9 \mathrm{~mm}$. Cephalothorax \{ mm lang oder = Patella + Tibia $\mathbf{N}=$ Meta(arsus IV. Beine: I Femmr 3, Patella + Tibia 3.5, Melatarsus + Tarsus 3.7 mm; IV bezw. $3.8,4,6 \mathrm{~m}$. Msı: 110.2 ; 11 13.8 $\mathrm{mm}$.

Die vordere Augenreihe ist ein wenig kürzer als die zweite und ganz schwach procurva.

Die hellen Seitenbinden des Cephalothorax sind bei dunkel grefïrbten Exemplaren ziemlich undeutlich und hei den belleren treten sie nur stellenweise eingermassen deutlich lservor. Ueberhaupt stimmen die drei rorliegenden 우우 von La Camelia am besten mit den von Kersenusio beschriebenen dunklen Exemplaren. Wemn aber liersenung dir Beine als "kräftig" bezeichnet, so möchte ich dazu bemerken, dass sie mir vielmelır für eine Tarentula recht dünn, grazil, erscheinen, eigzentlich melı an eine L,ycosa erimernd.

of liörperlänge $5.5 \mathrm{~mm}$. Cephalotorax $3.1 \mathrm{~mm}$ lang. Beine: 1 lemur 2.7, Patella + Tibia 3, Metatarsus + Tarsus $3.7 \mathrm{~mm}$; IV bezw. 3, 3.5, 5 mm. Also : 1 9.4; IV $11.5 \mathrm{~mm}$.

Cephatothorax rorn und an den Seiten einfarligg schwarz, also olne Seiteubinden, dagegen ist die Rückenlängsbinde mindestens so deutlich wie beim . Die Mlctatarsen und Tarsen aller Beine sind bräunlichgelb; die übrigen Glieder der Beine 1-1l sind schwarz, bloss an der Spitze der Tibien ein wenig heller, diese Glieder der Beine III-IV sind braun„relb mit dunkleren Flecken und Ringren an den Femoren. Die Paipen sind schwarz mil bräunlichem Endglied.

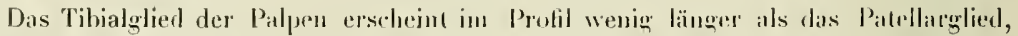
،lick, leicht nach oben komex gुobogen, mitten mindestens su luch wie die grö̈sste llöhe des Tarsalgliedes, sowie an eler Spitze unbewchrt; letzlores ein wenig länger als das Tibialglied, auch mil Bulbus kaum so dick wie diese's, an Ende ziemlich seharl' zugespitzl; im Profil erscheint Bulbus newölht mit einem rundlichen Einschnill nuten in seiner distalen Hälfe und mit seiner Spitze in etwat gleicher Entiernung ron der Spitze mul Basis des Gliedes.

Ferner liegen 2 O Exemplare, darunter ein unreiles von: Vis-à-vis Calamar, ca. 80 mI hweh gelegen, ausserdem ein Pärchen von: Zwisehen Honda und Guaduas (6oo-1000 m Ost-Kordiltere). Diese Exemplare sind selır hell gefärbt, was besonders beim ơ aullallend ist, indem es, abgesehen von den teilweise geschwärzten Vorderbeinen, so hell wie die hellsten $\circ$ ㅇ und wahrscheinlich neugehäutet isı; auch die Kopulationsorgane erseheinen rin venig abweichend, ohne dass ich mich habe ïherzengen können, dass es sich hier $\mathrm{nm}$ eine andere $\mathrm{Irt}$ handelt. 


\section{Tarentula calamarica Sirusur n. sp.}

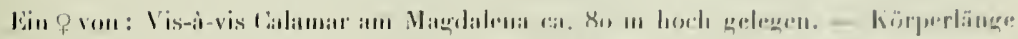

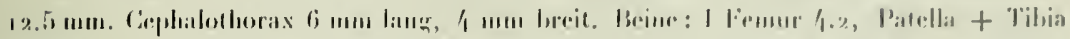

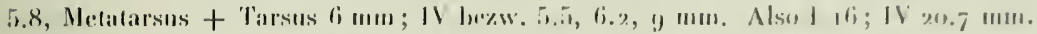

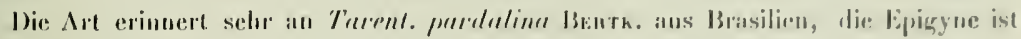

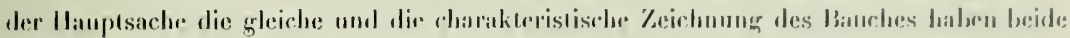

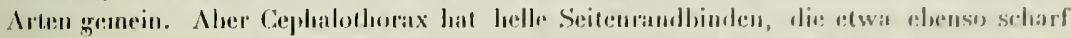

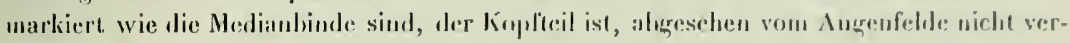
donkelt, Stermun ohme dunklere Miltellingsbinde, der Ablominalrïrken hat hinter dem schwatran, an den Seiten, aher nicht hiuten scharf markiert hellor begrenzten Basallleck

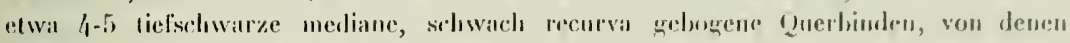

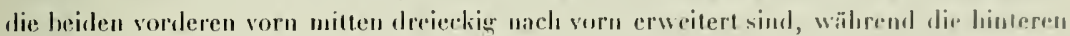
liniensehunal und undentlich siud, an jedem Ende dirser Biuden findel sich ein schwarzer Fleck, der ehenso wie die Bimlen sellost hinten schmal weisslich lregrenzt ist. Mie Sriten des Abdomen simd im Grumde heller, insbesondere nach unten zu, dicht und unregelmässigy mit kleineren und grösseren schwarzen P’unklen und leckchen lespritz. Die hellen Grenzbinden des basalen lileckes des Mhdominalräckens erstrecken sicl weiter nach hiuten als der Fleck und zwar his zur Rückenmitte und die ganze Röcken\%eichunug ist scharf markiert. Die vorderen M. $\Lambda$. sind unter sich ein wenig weiter als von den $S . \Lambda$, entfrrnt. Epigyne weichı, wenn trocken, dadurch ah, dass das Längsseptum vorn fein leistenfïrmig, last linienschmal erscheint, uach hinten allmählich und schwach verheetet, während der Randwulst sich scharf höckerartig in den Winkel zwischen Längs- und guerseptum lineinerstreckl; das Hinterende jedes Seitenramdwulstes scheint in wei Hïckerrhen z.ı ruden, von denen das eine schräg nach innen, das andere schröig nach anssen grerichte isl; in dem Winkel zwischen beiden endet das Querseptum. In lilissigkeit hat allerdings Epigyne mehr Aehnlichkeit mit der von Beıтkau gegehenen Figur, indem das Längsseputum vor der Witte erweitert erscheint, jedoch nicht ganz am Vorderrande, sondern hinter demselhen seine grösste Breit. hat, ferner treten die Randhöcker in Flïssigkeit weniger hervor. Leider gibt Bentкsu uicht an, al) seine thhiddung nach trockner oder in Flïssigkrit gehaltener Epigyne gemacht ist.

Noch nüher als mit $T$. pardalina ist verliegende . Irt mit $T$. pardala Straxd (in Keit. f. Naturw. 1909, p. 280-281) verwand, dïrfte aber dureh die Epigyne, das léehlen eincr dunklen Längshinde anf Sternum, bedeutendere Grösse etc. zu unterscheiden sein. Ferner dürfte die mexikanische $T$. dilatula $F$. Cun. nahe verwandt scin.

\section{Tarentula magdalenensis Straxo n. sp.}

Ein o von Calamar am Magdalena, ca. $80 \mathrm{~m}$ hoch gelegen.

körperlïnge $7 \mathrm{~mm}$. Cephatothorax $3.5 \mathrm{~mm}$ lang, $2.5 \mathrm{~mm}$ breit. Beine: 1 Femur 2.7, แ13 
Patella + Tibia 3, Metalarsus + Tarsus 3.2 mu ; IV lie\%w, 3.2, 4, 5 mm. Mso: 1 8.9.

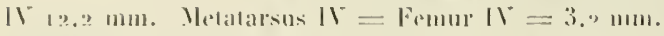

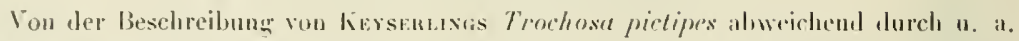
folgrndes: Die fast linienselnuale, aber tiefschwarze Scitenrandhinle ist in Flecken aulيnelöst bezw: ülver die Zwischenräume der Ilüften unterbrochen, die Mandihelı grangelblich (das Exemplar dürfte neugehäutet und daher ungewöhnlich blass sein). Abdonen oben und an den Seiten im Grunde graugelblich mit schwärzlicher, aus Flecken, P’unkten und wenigen kurzen Strichen gebildeter Zeichnung, die erheblich komplizierter ist als sie nach kersenLnos Abbildung zu urteilen bei seiner pictipes ist; länğs der Rückenmitte zicht nieht eine einfarhig schwarze Binde, sondern eine Reihe von nach hinten ollenen Winkelfiguren, zwischen denen wieder runde dunkle Punktllecke sich hefinden und die schwarze Grenzlinde des Herzstreifens ist unregelmässig sowie unterbrochen. - Die vordere Augenreihe ist gerade, die S. A. also nicht wie hei $T r$. pictipes tiefer stehend und sie erseheinen, in Flïssigkeit gesehen, auch nicht weiter von den Angen II. Reihe als von dem Clypeusrande. Die I. Reihe ist kaum länger als die II. Alle Patellen haben vorn und hinten je I Stachel. Die Tibien III-IV haben olsen I. s Stacheln. Epigyne ähnelt zwar derjenigen von $T$. pictipes nach der Ablildung zu urteilen, ist aber doch jedenfalls verschieden. Sie bildet ein kleines, hellbräunliches, hinten quergeschnittenes, sonst werundetes, breiter als langes Feld, das in Flüssigkeil gesehen zwei runde, schwarzbraune, kleine Samentasehen zeigh, die vom Hinterrande des Feldes um ihren Durchmesser, unter sich um mehr als ihren dopjelten Durehmesser entfernt sind, Im Profil arscheint Epigyne als ein leicht gewölbter, hinten etwa senkrecht alıfallender Hügel.

\section{Fam. Sicariidae.}

\section{Gen. Scytodes Latk.}

\section{Scytodes ruizensis Strixp n. sp.}

Ein ㅇ von Pass des Ruiz ( $3700 \mathrm{~m}$ Central-liordillere).

Cephalotorax blass graugelblich mit dunklever (graulsäunlicher) Rïckenseite, einigen unregelmässigen dunklen Snirkellinien an den Seiten und dunklem Clypeus und Augenfeld. Das dunkle Rückenfeld ist an den Seiten zackig-wellenförmig begrenzt, schliesst am hinteren Ende einen hellen Längslleck und wor diesem einen elsensolchen Querfleck ein; von letzterem erstreckt sich jederseits gegen die Seitenaugen eine ganz schmale helle Längshinde, die hinten eine schwarze Längslinie einschliesst und sich vorn fleckförmig erweitert. Mandibeln gelblich mit dunkter Vorderseite. Haxillen und Lippenteil blass grell, letzterer mic dunklerer Basis, Coxen blassgelb mil je 2-3 schwarzen Punktllecken. Sternum 


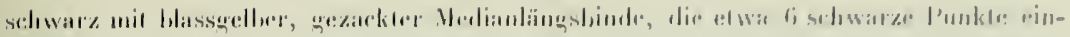

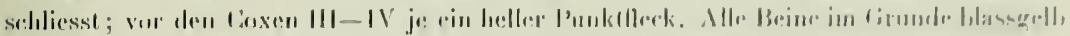

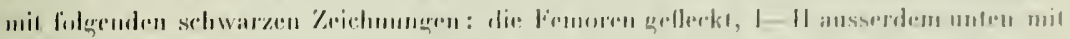

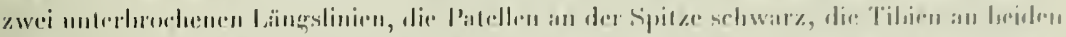

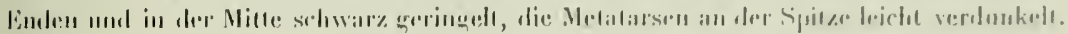

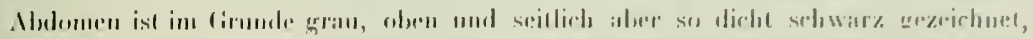

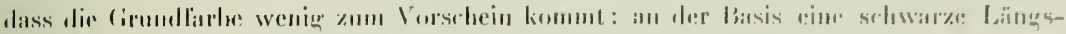

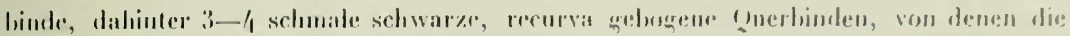

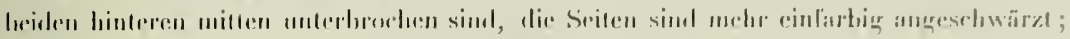

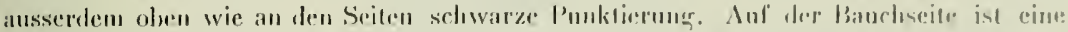

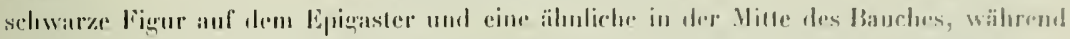

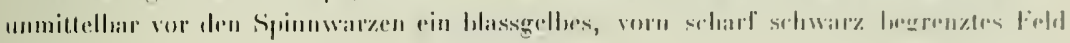
sirli limlel.

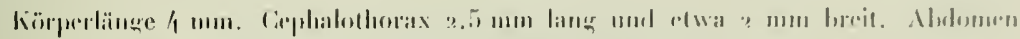

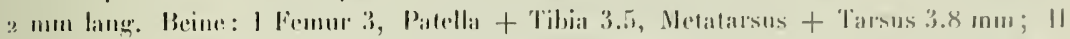

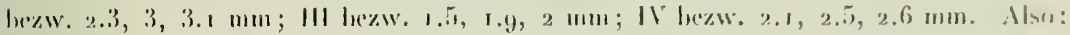
$110.3,118.4,1115.4$, IV 7.2 mm orler: I, II, II, III.

\section{Gen. Loxosceles HEเxњkix mad Lowe.}

\section{Loxosceles pictithorax Sтнки n. sp.}

Ein of von: zwischen Honda und Guaduas (fion-10no $\mathrm{m}$ Ost-Kordilleres. - Fin

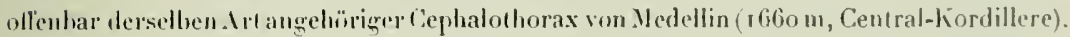

Beine: I Femur 4, Palchla + Tilia 4.5. Metatarsus + Tarsus 5 mm; II $=I$; HI

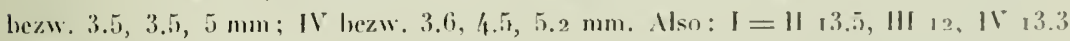
mm. Körperlïnge $8 \mathrm{~mm}$.

Ist sehr charakteristisch durch die Zeichnung des Cephalothorax. - Dieser ist hell rählichbran mit tiefschwarzen linienschmalen Ringen um die Augen, zwei verwischten, schwarzen Linien von den M. A. bis zur Mitlelritze, wo sie zusammenlanfen, bis kurz vor diesem Punk aber parallel verlaufen und zwei rolgellıen Längshlinden, die kurz hinter den S. A. zugespitzl anfangen, sich bis etwa 0.0 mu Breite erweitern, um kurz vor dem Hinterrande wieder schmäler, sowie elwas verwischt und eingekrummt zu werden; der Aussenrand dieser Binden ist zwemal tief dreieckig ausceschnitlen. Mittelritze sclwärzlich. Mandibehn und ihre klanen rot. Lippenteil und Maxillen liraungeblieh, ersterer mit feiner weisser Randlinie, letztere mit weissel dreiechiger spitze. Extremitäten hraungelblich mil olivenfarbigem . Intlug: an den Pałpen ist das Tarsalglied mt, das Tihtialglied schwïcher gerötet. Abdomen ist granhräunlich, dich fein dunkler punkitiert, und spärlicher mit weisslichen Punkiten unregehmässigg besprenkelt, oben mit bis 
zur Dltte reichendem, undeutlich hellerem, fast unmerklich dunkler umrandelem, schualem Herzstreifen; Medianfeld des Bauches ein wenig heller. Spinnwarzen braungelhlich.

Die M. A. sind um fast $2^{1} \frac{1}{2}$ ihres Durchmessers voun Clypeusrande entfernt und erseleinen in Flïssigkeit um die Breite ihres schwarzen Randringes unter sich entfernt. Gerade von vorn gesehen wïrde eine die $\mathbf{M}$. $\Lambda$. oben tangierende Gerade die S. $\Lambda$. mnten berühren. Cephalothorax $3 \mathrm{~mm}$ lang und $2.1 \mathrm{~mm}$ breit.

\section{Fam. Pholcidae.}

\section{Gen. Coryssocnemis six.}

\section{Coryssocnemis Simoni O. Свк. 189 §.}

Cor. Simoni O. P. Cвr., Biol. Centr.-Amer. 1. P. 237 , 1. 31. f. y.

Ein $q$ von Boca del Monte in den Ost-Kordilleren (ca. $2000 \mathrm{~m}$ ). - Die Medianbinde des Cephalothorax ist hinter dem Kopfteile nicht in 3 anfgelöst wie an der Abbildung in Biol. Centr. Amer. Aran. I. tab. 3i. f. 9 dargestellt. 


\section{Die Diplopoden von Columbien}

XIISST

\section{Beiträgen zur Morphologie der Stemmatoiuliden \\ rox}

$D^{r}$ J. CARL,

Assistent am Naturhist Muscum in Genf.

\section{EINLEITUNG.}

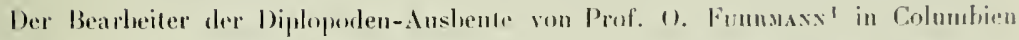

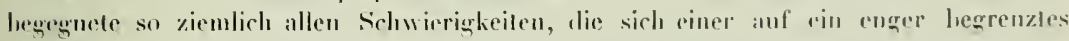

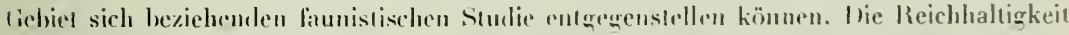
dieser Sammlnug war cinerseils dazn angedan, dem Verfasser die arosson Lü̈cken in der

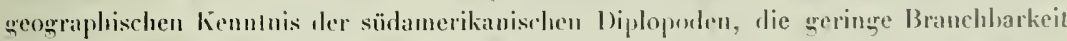
vieler älerer mel and riniger nenerer Aldeiten ïber die Diploporten Columbiens und benachbarler Gebiele und besonders anch den chanlischen Znstaml in der uregenwärtigen Detailsystematik der sülamerikanischen Diplopoden emplinden zu lassen. Andererseits war das Material wiederum nicht grenügend, nm etwa als . Insgangspunki für systematische Revisionen grösseren Styls zu dienen. Ich war also genëtigh. auf der vorhandenen Basis anfzubanen unl un soweil die columbische Finna in Frage komme eine elwas nathirlichere Umgrenzung der Gatlungen zn versuchen. Die libliographischen Vorarbeiten zn meiner Studie fühten mir schon die Schwierigkeit der Identifizierung der Gattungen und Arten in ihrem vollen Lmfang vor Angen. Von den nahezu roo Arten, die

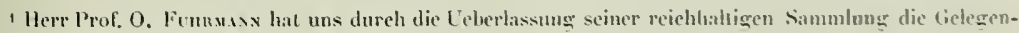
heit zam Studium einer der interessantesten Diplopodenfaunen versehaff. Hiefur. sowie für das unbeschrinkle Entgegenkommen hinsichlich der Iufnalme von Zeichnungeu, verdient er unsern wärmsten Dank. 


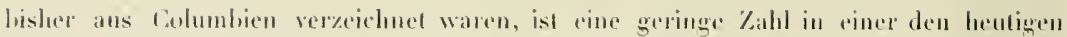
Anforderungen genügenden Weise heschriehen worden. Ein erosser Teil dersellen entfällt auf speziell in Columbien angelegte grö̈ser Simmlungen, die von älteren Autoren nach dem damaligen stand der Diplopodenkumle selı ku\% leschieben wurden. So rei-

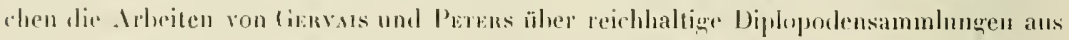
Columbien in die ältere l'eriode zurïck, wo der systematische Wert mehrerer Merkmale, inshesondere der lionopolen, noch nicht erkannt war. und der Gallungshegriff norh sehr weit gefasst worde. Eine Anzahl Ginvas'scher Arten wurten zwar dured

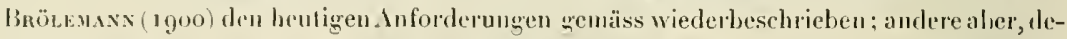
ren Originalexemplare keine genanere Besclıreibung zuliessen, müssen leiler weiter als "Species incertae sedis" in den Arlisten figurieren, solern die Genvass'schen Abrildungen in Castel.yas Reisewerk sie nicht mit einiger Sicherheil wiederzuerkemen erdanhen. Achnlich verhält es sich mit tem von P'ETEss bearbeiteten Material. Wenu auch die Beschreihungen dieses Autors das Charakteristische in den äusseren Formen ziemlich scharl hervorheben, so gुenügen sie meistens nicht, um nahestchende Arten auseinanderhalten und die arenerische Zugehörigkeit der Arten erkennen zu lassen. Ein Teil der Peters'schen Aren is durch Atteas $(1898 / 99)$ und Cook (1898) nach den Typen im Berliner Museum rehabilitiert worden. Leider kam auch einer neueren Arbeit, der ein sehr reichhaltiges Material aus Columbien und Venezuela zu Grunde lag, der Vorwurf zu grosser Kürze in den Beschreihungen und des Mangels von Whildungen nicht erspart bleilsen. Sicvestris Diagnosen der von Bürgen gesammelten Arten sollten wohl von besseren, illustrierten Beschreihungen gefolgt werden; da aber letztere heute, nach 15 Jahren, noch auf sich Warten lassen, kann man wohl hehauplen, dass auch die voläuligen Diagnosen mehr liemmend als fördernd auf den Gang der Forschung gewirki haben.

Abgesehen von Aттемs" "System der Polydesmiden ", in welchem Werk neben nenen anch früher hekannte Arten, zum Teil nach den Typen, sorgfältig heschrielıen werden, brachten erst Brölexaxs's Arbeiten ${ }^{1}$ üher die Diploporlen von Venezuela und Brasilien wieder einen bedeutenden Fortschritt und einen fördernden Zug in die südamerikanische Diplopodenkunde. Von diesen Lehandelt die eine anch Materalien aus dem columbischen Gebiet des Haut-Sarare. Text und Mbbildungen der betrellenden Arten lassen kaum elwas zu wünschen übrig. Hingegen kann man sich von den vielen durch Silvestri aus Ecuador und Bolivia beschriebenen Arten und Genera in den meisten Fällen keine deutliche Vorstellung machen, sei es wegen der zu kurzen Fassung seiner Diagnosen, sei es wegen des Mangels an Mbildungen, sind doch die of sehr komplizierten Formen der Gonopoden nur im Bilde nit der gewünsclıten Schärfe darstellbar. Fïr das nördlich anstossende Gebiet von Centralamerika besitzen wir dagegen äusserst zuverlässige Arbeiten, von denen Pocock's umfassende Monographie der Diplopoden in "Biologia

1 . Iun. Soc, eutom. de lirance vol. 67,1898 ; vol. $71,1902$. Revista do . Nuseo Paulista, vol. V, Igos; vol. VI. 1903. 


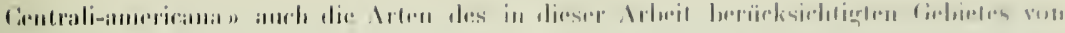

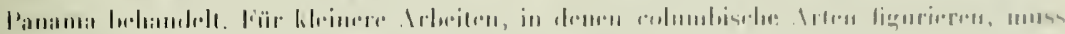

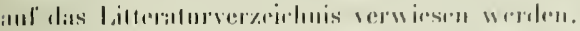

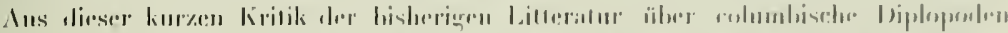

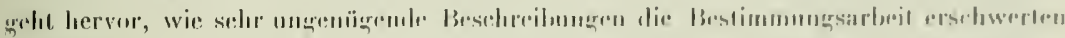

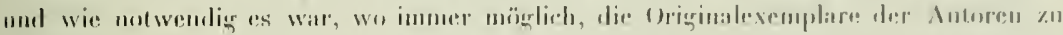

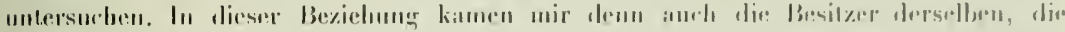

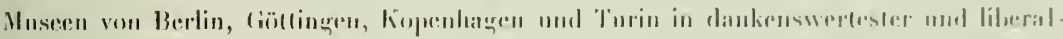

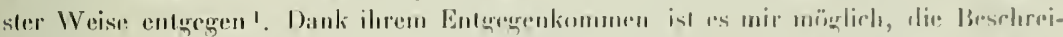

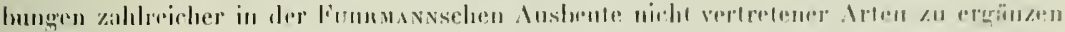

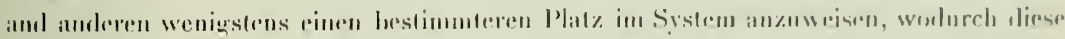

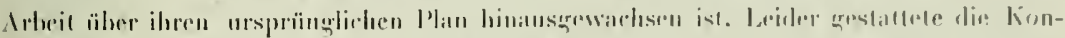

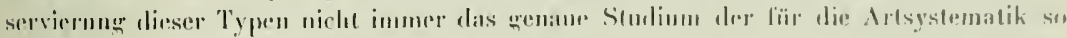

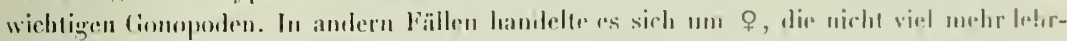

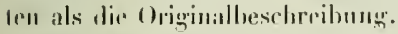

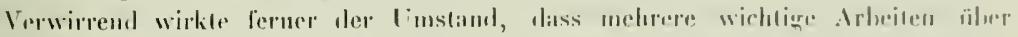

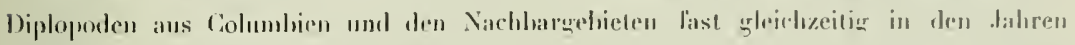
$18, y^{8-1900}$ erselienen sind.

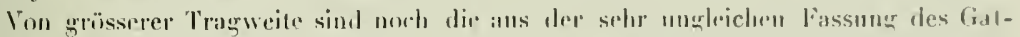

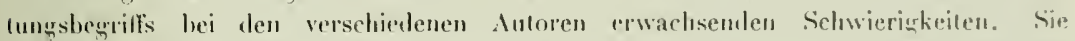

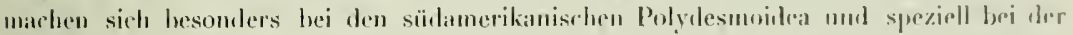

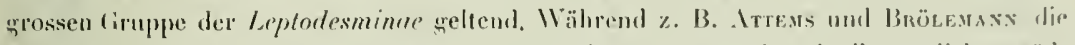

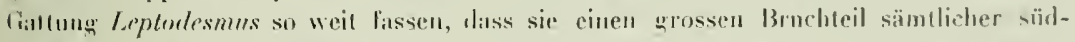

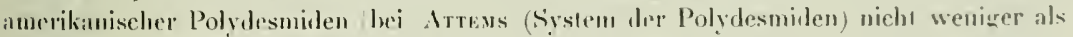

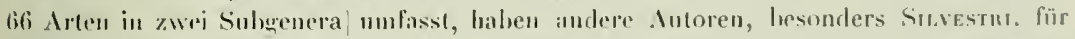

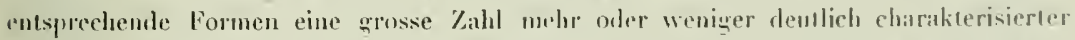

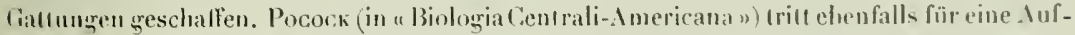
leilum der grossen Gallungen ain. Ohwohl ich b̈herzung hin, dass mur eine allgemeine: Revision aller süt- und centrahmerikanischen Polrolesmiden zn scharf umseluriehenen, rleichwertigen liallungen fïhren kann, mussle ich mich ıloch entschliessen, die allzu

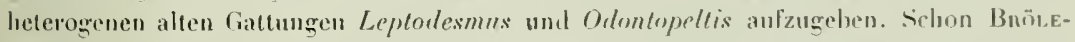
maxx mersehied Areguppen, und die colmmbische Fauna belehrle mich, dass diese

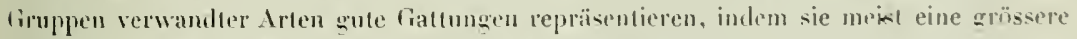
Anzahl gemejusamer. Merkmale in don äusseren Formen, der Skulptur, Beharung und sellıt

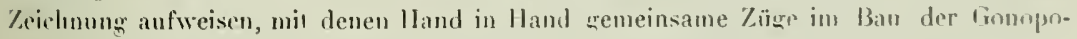

1 Ganz besonders dinkbir lin icla der Direktion des kigl. Zool. Museums in Berlin für die Leplurrlassung vipler Originalex'mplare von PEsens. Dieses wichtige Material ist zun grössten Tecil trocken konserviert.

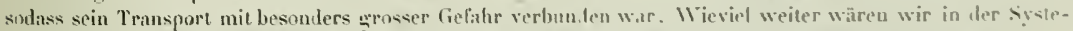

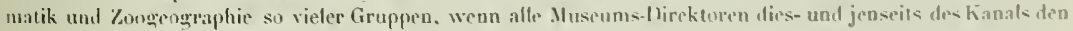
Spezialforselwen in so weitherziger Wrise zu llilfe kimen. 
den erehen, wenn letzere auch häufier unr im besonderen . Iusbau einzelner Teile oder in

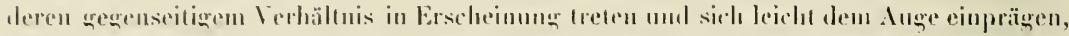

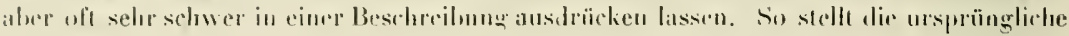

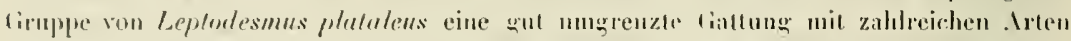
dar (Chondrodesmus Sux. = Dirhubdophallus I'oc.). Auchulie von . Irtems eingezogene, ursprünglich monotypische Gattumg Alocodesmus stw. erweist sich als definierbare Artengruppe, und in ïhnlicher Weise werden alte andern von fröheren Autoren zu Loptodesmus oder Odontopeltis gestellten Arten oder Artgruppen zn Gatlungen erhoben werden, besonders wenn, wie bei den obgenannten Gattmugen, die rerwandten Arten auch cin zusammenhängendes Gehiet bewohnen. Doch solle diese Aufteilung womöglich ron einheitichen Gesichtspmukten aus in einer systematischen Revision vorgenommen werden. Bei dem heutigen systematischen Wirwarr lassen sich immer noch vereinzelte Arten nicht anders als in die alte Collektivgattung Leplodesmus unterlnringen.

Wis die Hauptgruppen des Systems anhetriff, so haben wir in mehreren vortäuligen Yitteilungen' die von VernoefF bis vor kurzem anfrecht erhattenen Ordnungen der Pro-

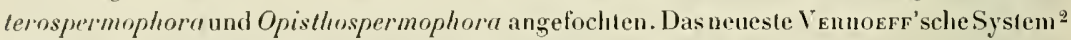
gilut uun diesen Namen einen ganz anderen Inhalt und trägı der natürlichen Verwandtschaft der Gruppen besser Rechnung. Es besteht allerdings ein dringendes Bedïrfnis, den VEnnoefF'schen Ordnungen entsprechende systematische Einheiten zu schallen, da Gruppen wie z. B. den Polydesmiden einer-und twa den Spirostreptiden andererseits offenhar nicht die gleiche Rangstufe gebührt. Doch können wir Vennовғfs System vorläufig nur als einen Versuch betrachten und folgen dem Beispiel Pocock's, indem wir die allgemein anerkannten natürlichen Gruppen der Polydesmiden, Spiroboliden, Spirostreptiden, etc. als hühere Kategorien beibehahen. Indem wir dafür anch nur den unbeslimmten Ausdruck "Gruppe" gebrauchen, möchten wir andeuten, dass wir sie nicht als gleichwertig hetrachten. Das lässt sich einerseits durch die noch fortdanernden Diskussionen übes die Hauptgruppen der Diplopota Proterandria und andererseits durch den vomehmlich faunistischen Clıarakter der vorliegenden Arbeit rechtfertigen.

Die obigen Ausführungen werden gezeigt haben, dass es sich vornehmlich darum handelt, auf Grund der reichen Fumnsaxs'schen Ansbeute die Kenutnis der Diplopoden-Arten Columbiens zu fïrlern, um künftigen Arbeiten eine elwas sicherere Grundlage zu geben, als dicjenige ist, von der wir ausgehen mussten.

Mägen auch spätere Untersuchungen die Lulfassung der Gattungen modifizieren und diese oder jene von uns isls neu lieschriebene Form sich als mit früher ungenügend beschriebenen identisch erweisen, so loffen wir doch, unsere Bemühungen, die weitere Forschung durch klare Darstellung der Arten in Wort und Zeichnung zu unterstützen, won den Spezialforschem auf dem Gehiet der Diplopodeukunde anerkannt zu sehen.

1 Ggl. Diploporlenstudien I und /I, Zoolog. Anzeiger, B1. /2, p. 176,177 und $216 ; 1913$.

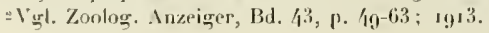




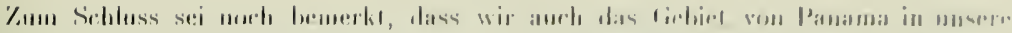

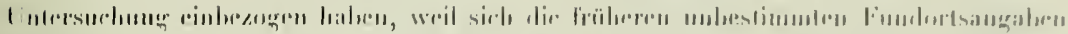

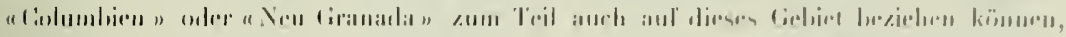

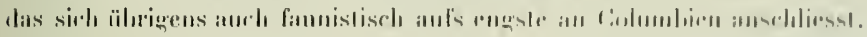

\section{SYSTEMATIK.}

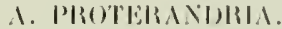

\section{Gruppe Colobognatha.}

\section{Fam. Siphonophoridae.}

\section{Gen. Siphonophora Bпит.}

In der Beschreihumg von S. zehntneri Casm, ist auf das Vorkommen von Simuesgruben anf der oberen äusseren seite dis 5 . und 6. Antemnengliades aufmerksan gemach

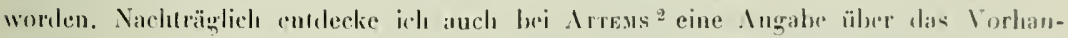
densein von je einem akleinen, ahgregrênzlen ledel von Simneszïpfclsenn auf der laleralen Seite an Ende des 5. und 6. Gliedes (bei S. braneri Atr. und S. Iropiphora Itт.)

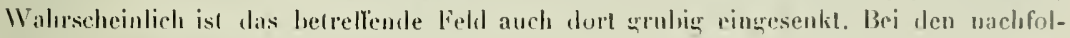
wend heschriehenen drei nenen Arfen ans Columbien handelt es sich elsenfalls un Sinnesgruben, so dass der Besil\% von solchen als cin Gallung'snerkmal angeselien werden kann.

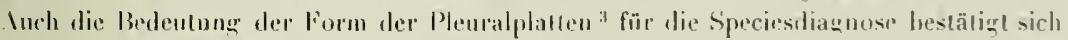
bei den amerikanischen. Irlen wieder; doch muss lrelent werden, dass dieselhe im vordern und hinteren Kärperteil elwas verschieden ist, so dass nur die Pleuralplatten des-

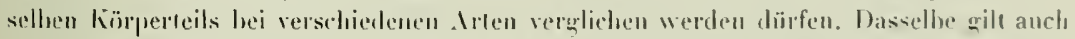

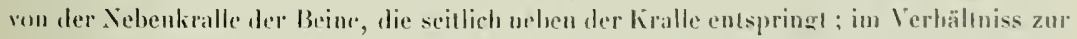
limalle wird sie nach hinten hin immer kïrzer und stellt auf den hintersten Beinen meist mur ein kleines sprizchen dar.

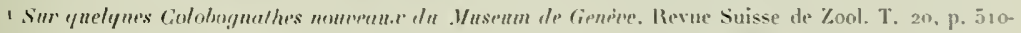
in: Tat, 9. Fig. 7 ; 1912 .

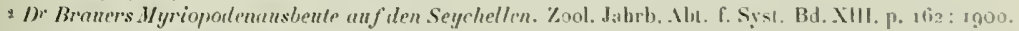

3 In der Beschreibung und Abbitung der Pleuralplatlen von s. zehntneri Cins. (loe. cit. p. 5u, Taf. g. lig. (b) ist ein lrrtum zu beriehtigen: Was dort als Vorderrand der l'lemralplatten bezeichnet worden ist, ist deren Jinterrand. und die Plalten liegen so übereinander, diss der hiulere Teil der voranghehenden jeweils den vorderen Teil der darauffolgenden bedeckl und nicht umgekehrt. In derselhen Beschreilung jsı der. Name s. bilineala l'ET, enm. Bü̈., dureh s. linenta zu ersetzen. 


\section{Siphonophora fuhrmanni n. sp.}

(lïg. 1-8.)

Einfarbig, intensix gells.

Jäığe: $23-35 \mathrm{~mm}$; Breite: $1 \frac{1}{2}-2 \mathrm{~mm}$.

Siegmentzalil: $100-11 \overline{1}$.

Kople (Fig. I) von oben geselnen ror den Antennen deutich verdickt, bis zur Wirzel

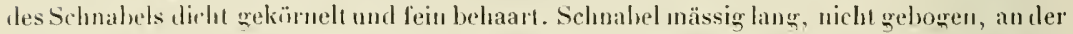
Basis jederseits mit zweilingeren Borsten, biszur Spize mit kïrzeren Borsten beselzt. Inten-

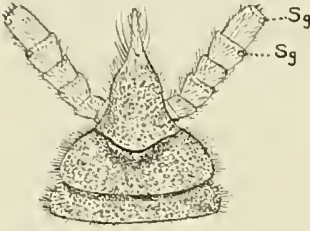

Fig. 1. - Sijhonophora fuhrmanni n. sp. Kopf und die zwei ersten liörperringe. $\mathrm{Sg}$. Sinnesgruben. nen von der Basis an last queichmässig dick, schr sehwach

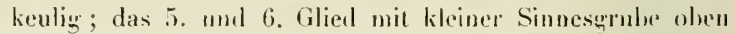
ganz seitlich vor dem Endrand, die Simesstäbclıen kurz, den Raud dor Gimbe kaum überramend; 6. Gilied fast cylindrisch, nicht tonnentömigr; die kleinen Endglieder mit den 4 Sinneskegrelo tief eingesenkt und von oben nicht sichthar, so dass dic Intennen ron oben gerade abgestulzt erschemen. Sie überragen den Rüssel last mil dem granzen 6. Crliede.

Halsschild den liopt seitlich wenig umlassend, in der Mitte ant doppelt so lang als die näclıstfolgenden Segmente; Vorderrand in der tlite seicht eingehuchter und von einer schwachen Depression der Fläche ggefolgt. Halsschild und Metazoniten dicht mit tlachen Körnern besät und dicht, fein und gleichnässig belsorstel; dic Borsten ('utspringen zwischen den hörnern. Freier Prozonitenteil mit ohensolelen, elwas grösseren, thaclien, hellen körnern bedeckt.

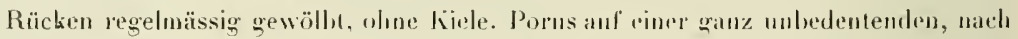
hinten hin elwas dentlicher werdenden Erlebung; auf den vorderen Segmenten (5.-10.) liegt der l'orus in der vorderen, mach hinten zu immer deutlicher in der hinteren Melazonitenhälfte.

Körperende wie bei den ïbrigen Irten.

Pleuralplatten (Fig. 8) wie gewöhulich kurz behaat und llach quekörnelt, etwas breiter als lang, medialwärts vom Hinterrand lier deutlich in flachem Bogen verschmälext, mit ziemlich tief eingebuchletem medialem Rand und geselweiften Vosderrand.

Beine (Fig. 7) mil glatlem Hïfglied, ganz verslecktem Trochanter mnd kleiner Nebenkralle, die auf den Beinen der Körpermilte gerade ist und kaum melı als ein Drittel der Jänge der Kralle erreichı.

Gonopolen des 1. Paares 5-gliedrig, mil umgehogener, grestulzter Endkralle (Fig. (i), der eine liurze dornfürnige Borste des 5. Gliedes gegenübersteht; die Glieder 3 lis 5 traggen auf der Inmenfläche eine breite Rinne und eine dieselbe gegen die übrige Fläche abgrrenzende, mil kurzen Borsten besetzte Leiste, an Lnter- und Oberrand nur je r-2 steife

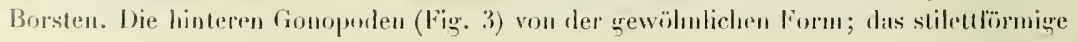




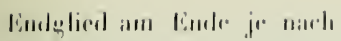

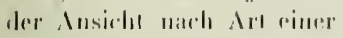

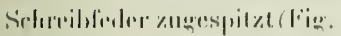

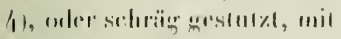

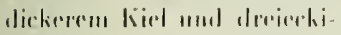

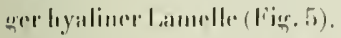

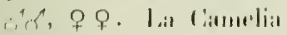
bei Aregelepulis ctentratlombilleren, 1820111.$)$.

Die: Form des liopless und der Antrumen in der Ansicht von oben rimuert all S. rormulu Powi., aus limalemala (Biolegjen Cientrali-imericuna, Chil. at.

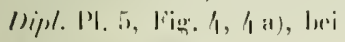

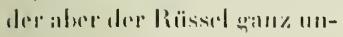

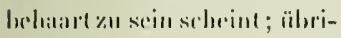
gens ist diese Art nur natel

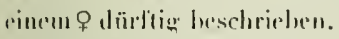
(ian\% underanchlall sind die Besefrreihungen zweice $\mathrm{Al}$ Irnatustoulumbien: S. Interolet

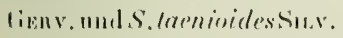

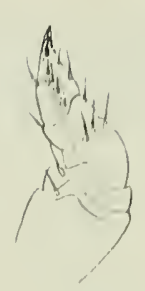

Fin. 2.

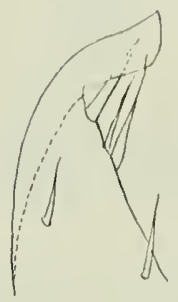

Fir. 6 .

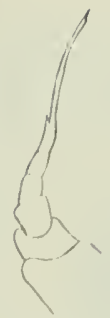

lig. is.

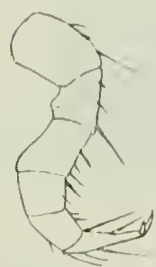

Fig. 7 .
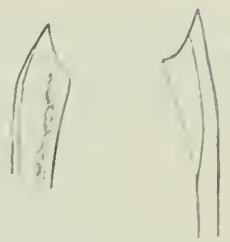

I. ig. 1.

$1 \cdot \mathrm{i} z .5$.

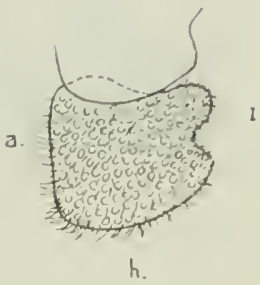

Fig. 8.

$$
\text { Siphonophora fuhmanni n. sp. }
$$

Fiz. 2, Vorderer Gonopode von innen. - Fig. 3. Ilinherer Gonopode. Fig. 4, .. Spitze des linteren lionopoten. - Fig 6. Spilze des vorderen fionopolten. - Fig. 7. Bein der vordesen Korperhälne. - Fig. 8. Pleuralplatle der liorpermilte: a. Aussenrand, i. Medialrand, h. Hinterrand.

\section{Siphonophora columbiana $\mathbf{n}$. sp.}

(Fiщ. (1-1я.)

Schumbigr araugelh, mit einer diffusen dunklen Längsbinde auf ler liückenmilte. Antranen und Brine heller trühugelh.

Länge : $18-27 \mathrm{~mm}$; Breite $1 \frac{1}{2}-2 \frac{1}{2} \mathrm{~mm}$.

Segmenlzahl : $63-7$ i.

Körperformen, Skulptur und Beharung wie bei S. fuhrmanni.

Lopf (Fig. 9) vor den Antennen won oben gesehen nicht merklich verdickl. Intemen endwärts dentliclıer keulig verdickt, mit leicht tonnenfërmigem 6. Glied.

Ilalsichild mit leicht eingebuchtetem seitenrand.

Plemralplatlen (Fig. 1.3) medialwärs, vom Hinterand ber weniger deullich verschmälert, mit wanz schwach cingehuchtetem medialem Rand.

Beine mil dicht granuliertem llültglied und sehr dentliclem Trochanter (Fig. If, in übrigen wie hei s. fuhrmanni.

Conopolen (Figs. 10-12) denjenigen der helzleren . Ir elvenfalk sebr ähnlich, mil fol- 
qenden Lnterschieden: Im vorderen Paar sind sowohl die Inmen- und Aussenlläche als hesonders der Cuterrand des 3. his 5. Gliedes mit viel zahlreicheren, lïngreren und biegsaneren Borsten heselal; die Endkralle ist am Ende störker \%ugerundel. An den linteren Gonopoden endet das 6. Cilied in zwei grebogenen Spitzchen und einer hyalinen

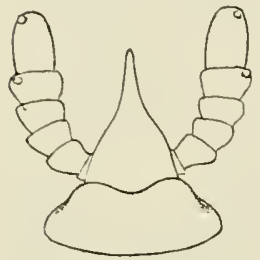

Fig. 9.

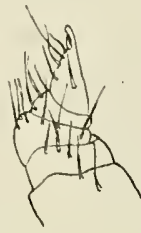

Fig. 10.

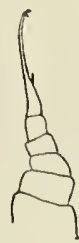

Fig. 11.

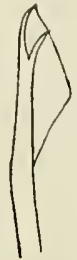

Fig. 12.

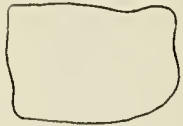

lïg 13.

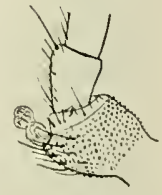

Fig. 14.

Siphonophora columbiana n. sp.

Fig. 9. liopf und Halsschild. - Fig. 10. Vorderer Cionopote. - Fig. 11. Ilinterer Cionopode. - lïg. 12. Hessen Spitze. - Fig. 13. Pleuralplatte der liöpermilte. - Fig. 14. Cirundglieder eines Beines.

Lamelle, die in der Form von derjenigen von $S$. fuhmanni ein wenig abweiclı.

$\checkmark$, 우 우 La Camelia bei Angelopolis (Central-Cordilleren).

Durch den Besitz einer dunklen Räckenhinde erimert diese Art an S. nigrosignatı Silr., von Trinidad (ungenügende Beschreibung), und an S. linerıla Peт. cmmend. Bröt., an letztere auch noch dureh das gekörnelte Ilältglied der Beine. Nher lineala hat nach Brölemaxss Beschreibung und Ablildung wesentlich anders gestaltete vordere Gonopoden.

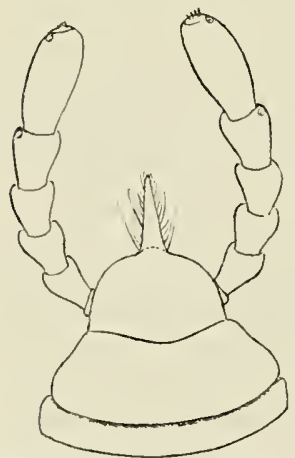

Fig. 15. - Siphonophora grarilicornis n. sp. liopf und die zwei ersten Leibesringe (Behaarung und Spulptur grösstenteils wergetlassen).

\section{Siphonophora gracilicornis sp.n.}

(Fig. 15-23).

Einfarbig, trüligeli.

länge : $25-29 \mathrm{~mm}$. Breite : $1 \frac{3}{4}-2 \mathrm{~mm}$.

Form, Skulptur und Behaarung des hïckens wie bei $S$. fuhrmanni und columbiana, ebenso der l'orus.

Kopf (lïg. 15) stark kugelin, von allen Seiten her plötzlich in den Rässet verschmälerı, dicht glanuliert und gleichmässig fein beborstet; Rüssel clier kurz, die drei ersten Antennenghieder nicht überragend, von der Seite gesehen last gerade, jederseits einzeilig kurz behaart und mit 2 längeren Borsten darunter. Antennen lang und schlank, alle Glieder basalwärıs verschmälert, das 6. Flied deullich tonnenförmig, das 5. und 6. mit je einer kleinen, nicht pigmentierten Sinnesgrulse an der obern äusseren Ecke; das Ende der Antennen erselscint zugerundet, nicht gestutzt. 


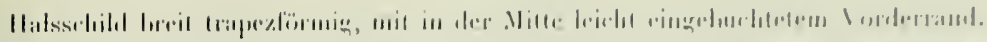

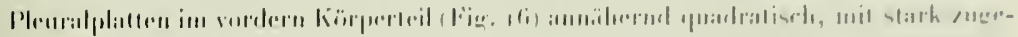

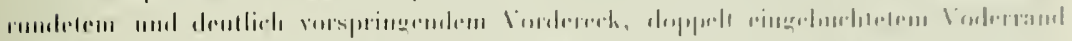

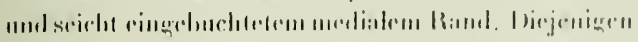

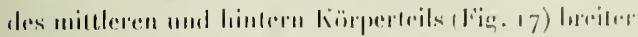

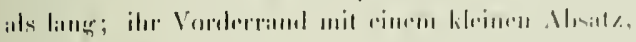

a.

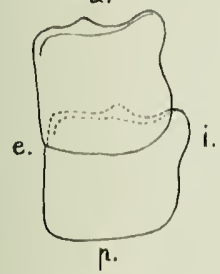

lïir. 11i.

i.

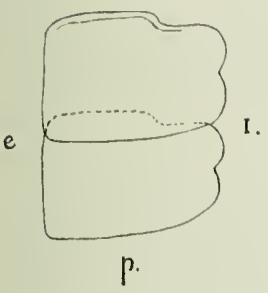

Fir. 17.

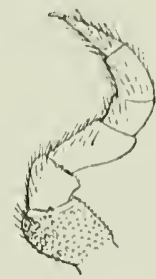

lin. 18.

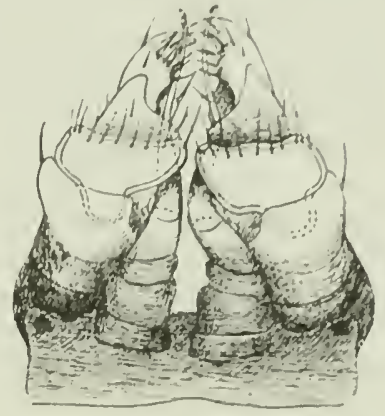

I if. 21 .

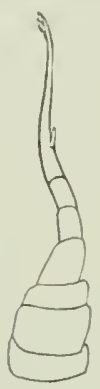

Firg. 22.

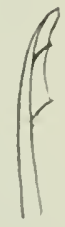

liig 23.

Siphanophora gracilirornis $\mathrm{n}$. sp.

Min. 16. Zwei Pleuralplatten des vordern liorperteils. - Fig. 17. Idem, iles hintern hurperleils; a lorderrand. i medialer Rand, p Ilinterrand, "Aussentand. - Fig. 18 - Bein des 6. Segments. - Fig. 19. Bein eines der hintersten Paare. - Fig. 20. Gonopoden beider Paare von hınten. - Fig. 21. Drei linglieder eines vorderen fronopoden, von vorn. - lig. 22. Hinterer Cionopotle. - Fig. 23. Dessen Spitze.

das Vordereck wenigar dendich oder gar nicht vorspringrend. der mediade liand mit schmälerer, fast winkliger Einbuchtumg.

Gonopoden des vorderen Patares (Fig. 20, 2 r) von drujenigen andrer Arten ziemlich

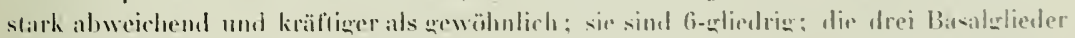

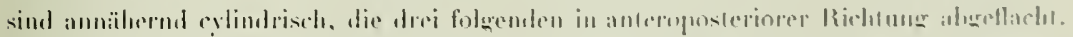
Dis 4. Gitied ist von hinten greschen ein Trapes mil zugerundeten Eckén und doppeti konturierten, chitinisierten Rändern, von denen der Basalrand kuppelformig ins 3. Glied 


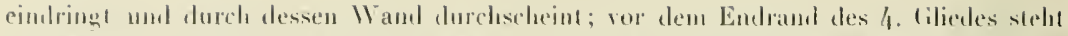

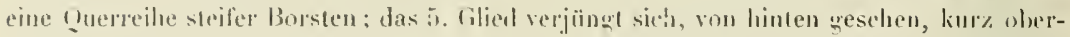

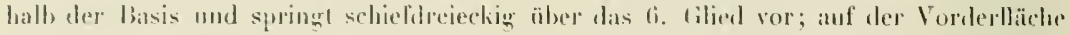

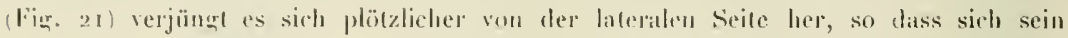

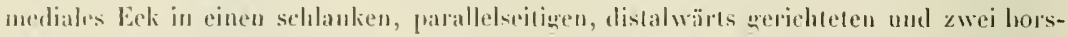
Arnartige Spizen lagenden Pfeiler verlängert, der elwas an den prafemuralen Borsten-

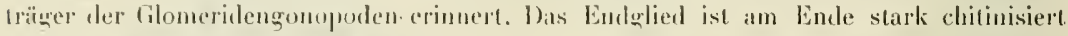
und hakig nach innen umgehogen; aher dieses krallenarlige Ende ist nicht deutlich algesetzl; vor ihm auf der Medialseite tilded das Endglied einen llachen, mit zahlreichen steifen Borsten besetzten Buckel. Auf der Medialsoite ist sehon der Endranl des :3.

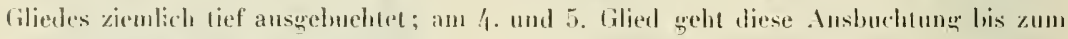
(irunde, so dast einc liefe Rime zwisehen einem vorderen und hinteren medialen Lilppen der betreflenden Gilieder entsleht, in der der hintere Gonopode ghleitet. Hintere (ionopoden (Fig. 22) von gewählieher Form; das Endglied am Ende schwach umgebogen, mit schmaler, durch zwei dünne Chitinstäbchen gestützler hyaliner Lamelle (Fig. 23).

Beine untriscils dichter, ghteichmässiger und kürzer behaart als bei den übrigen Arlen, hesonders die vordern (Fig. 18), ohne längere Apiealborste an den Basalgrliedern;

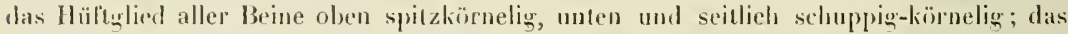
Endelied der Beine der vordern Kïrperbälfte endwärls qradweise verschınälert und ringsum ghtrichü̈ssig dicht hehorstet, ohne die zwei längeren Borsten der Unterseite; erst weiter hinten leginut das Endglied die charakteristische Form und Behatrung anzu-

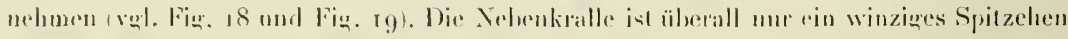
an der Basis der kiralle.

2 Buenavista, Kafeetal bei Viota (Ost-Lordillere).

Vorzäglich charakterisient dureh dic Lorm des Kopfes, der Intennen, der Gonopoden und durcls die Form und Behaarung der Beine. Von allen amerikanisehen Siphonophora-Arten eriunert dirse dureh die Form des kopfes und der Antennen noch am meisten an die primitive Abbildung dieser Teile bei Genvas (184h) für $S$. Inteoln Gisnv. et Goun. Doch lässt sich nicht entscheiden, ob diese Abbildung zuvertässig ist, und weitere Anhaltspunkte für eine hentitizirrung felılen.

\section{Gruppe Stemmatoiuloidea.}

Die Cialtung Stemminlus Geur. (1844) wurde on Pocuck zom Vertreter einer eigenen lamilie erlıohen wod von Conk als Unterordung seiner unhalibaren Ordnung der Monorhelit zugreteilı. In cincer Schrifi betitelt "Stemmatoiulus as an Ordinal Tyge" (Amer.

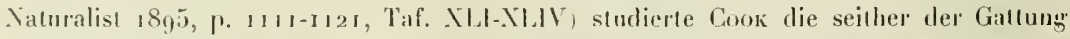
Diopsinlus: Silv. zugewiesenen liberisclen Stemmatoiuliden etwas eingehender und versuchte, die Ciruppe zu harakterisieren. Seine Diagnose ist in manchen Punkten lichtig, 


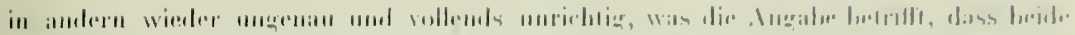

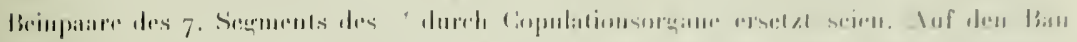

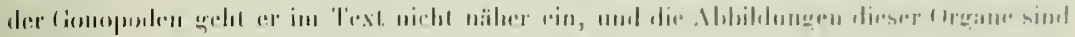

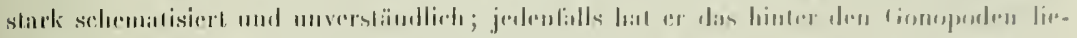

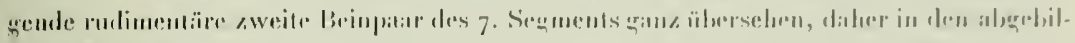

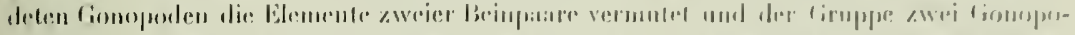

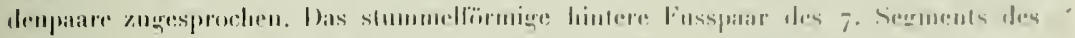

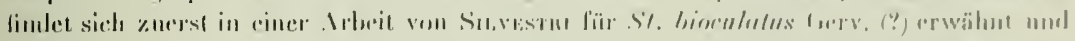

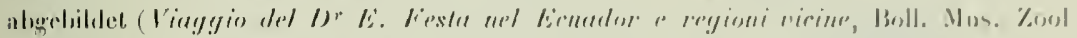

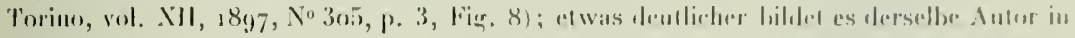

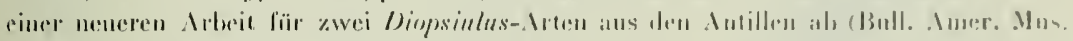

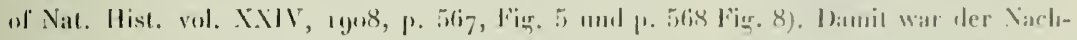

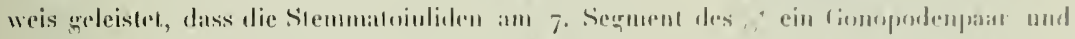

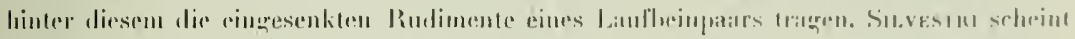

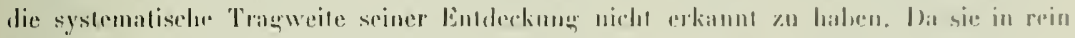

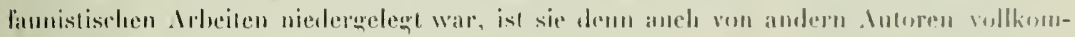

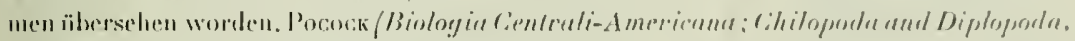

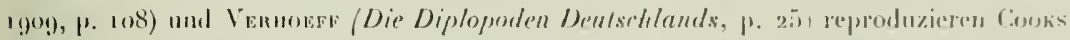

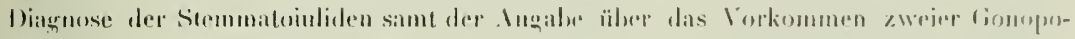
dinplititre.

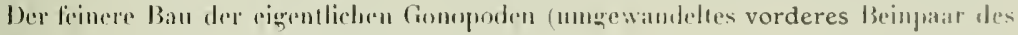
7. Segments) ist his jetzt gïnzlielt unhekannt gehliehen, wenn man von den dïrftigen

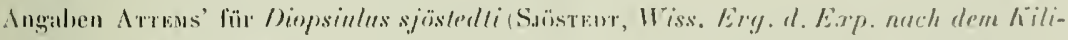

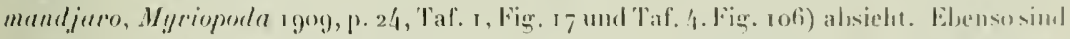

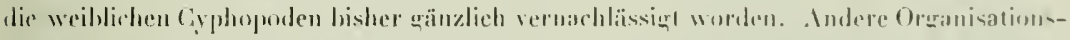

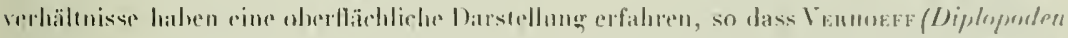

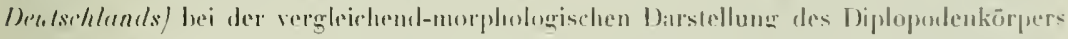

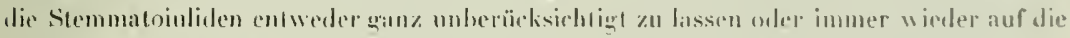

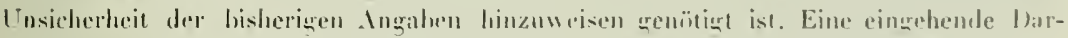

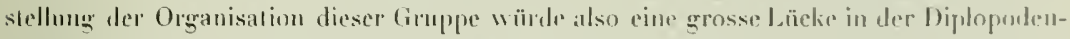

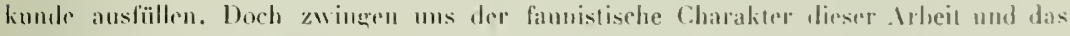

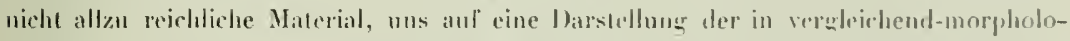
grischer und systematischer IJinsieht wichtigsten Oreanisationsterhällnisse zu heschränkin. Die Unterschiede zwischen den heiden bisher anseinamdergehiltenen batmugen Stemmuloiulus und Diopsinlus sind so gueringrfügig, dass die an Vertretern der ersteren Gallung gremachen Befunde im wesentlichen als fïr die ganze cimppe griltig betrachtel weralen können.

Kopfkapsel. Das Labrum trä̈n in der Laloralbucht 3 Zähne. Supralithralporen fehlen. Dits Sinnesquebiet des Mittellioples ist hinten dureh einen schmalen, liefen, -chrä̈ren

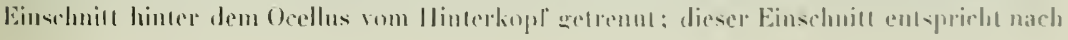




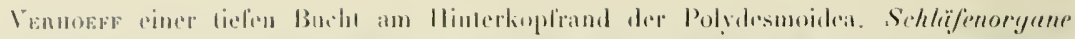

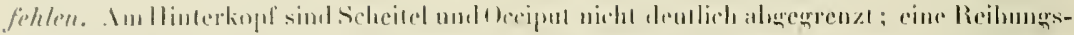

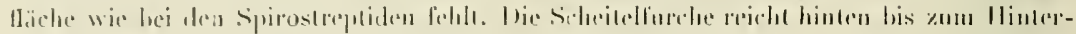

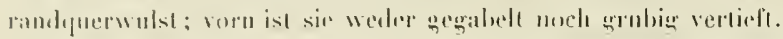

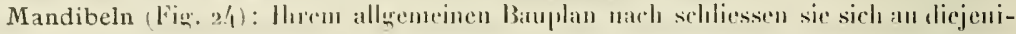
gen der Lisiopelaliden und Ascospromophora an. Besonders gill das für das Lamellen-

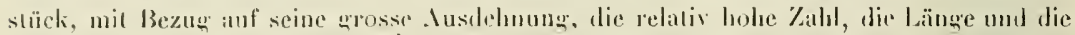

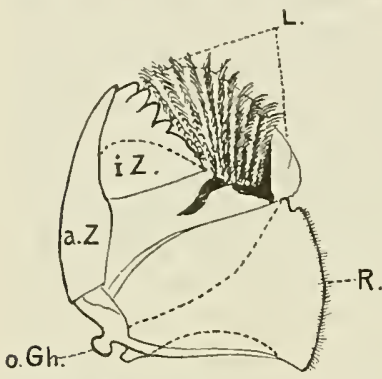

Fig. 24. - Stemmatoiulus major. n. sp. Mandibel von oben; $i \%$. inneres Zahnstück, $a \%$. äusseres Zahnslück. L. Lamellenstäck, otih, oberer GeJenkhöctier, $R$. Reibleiste. ewas rarliäre Anordnung der Lamellen. Die Zailıl der Lamellen beträğ bei Stemmatoinlus ur ; bei Diopsiulus sjöstedli zählte Artess 8 "liammbtälter". As Stützen des Lamellenstücks dienen wie bei Ascospermophora zwei Chitinslürke. Das äussere Zahnstïck is gegen die Basis nicht bauchigerweitert, aber wohl nicht so lire heweglich wie bei den Lysiopetaliden, indem die

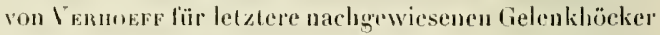
Pchlen. Dafür ist der obere Gelenkböcker des firundstïckes der Mandibel wie bei den Polydesmiden stark vortretend und kugelig zugerundel. Das inucre Zahnslürk weist 4 Zäluse und eine breite niedrige Platle aul'. Jie Reibplatte entspricht keinem der bekanntיo Typen genatu, indem sie weder die "Feile " der Lysiopelaliden, noch die "limnengrube" und die "Reibleisten"

der Polydesmiden aulweist. Ihr Unterrand is glatt; ihr Oherrand dagegen ist fein gekerth und wird, wie bei den luliden, von einer dichten Reihe von Spitzen überragt, dic ganz an diejanigen der "Reihplattenschneide " von Polydesmus erinnern. Im allgemeinen Umriss gleicht diese Reihplatle derjenigen von 1 p folbeclire. Zusammenlissend kann man also die Mandibet der Stemmaloiuliden als einen vermilteluden Typus hinstelten, der in seinen verschiedenen Teilen Beziehungen zu versehiedenen firuppen anfiveist und somit als ein ursprünghlicher, wenigh dillerenzierter grelten kann.

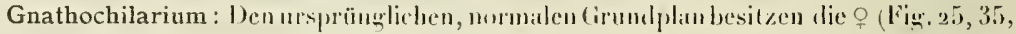
55). In demsellien sind folgende Merkmale liervorzuleben : Das Mentum (Duplomentum YeRULFF) Weist slets rine mehroder weniger licfe, basalwäls scharl umgrenate linngrubr auf. Das Posmentum isl eine selir schmale Duerspange, die ganz onler teilweise vom Vor-

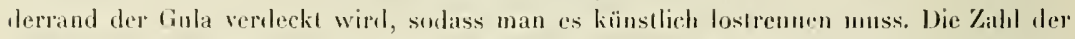

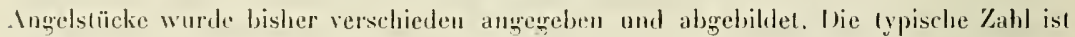
3, die man nach ihrer lage ats imeres, äusseres mol hinteres hezeichnen kamm (Fig. 55 i, a, h). Von diesen inuss das änssere als die eigentliche Cardo aufgefasst werden und \%war aus topographischen und morphologischen Giönden. Es stellı nämlich die plysiologrische Beziehung zwischen Gnathochilariun und Kopfpleuriten her. Meist birn-odur keulenförmigh, hängt es mil sıincon nach anssen und rorn gekehrten Stiel selunigg (Fig. 25, S) 


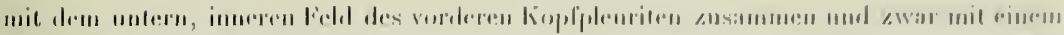

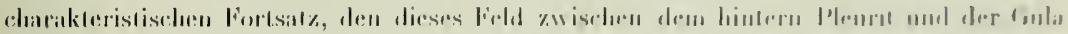

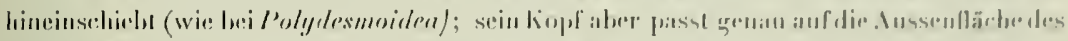

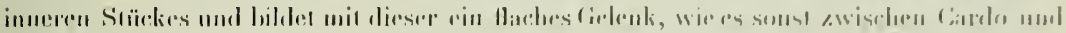

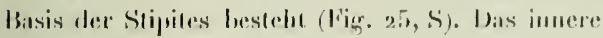

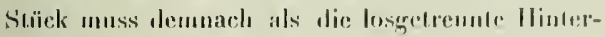

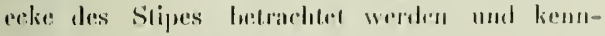

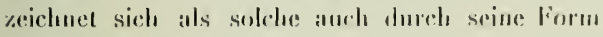
rines mil der Basis nach vorn mol mit der sil\%" nakl hinten grerichteten Dreionks. Mit dem Stipus ist es alurel eine broite Membran verbumlen mad

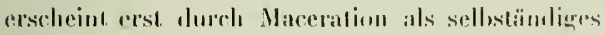
Stëck. Dadureh erklärt sich aurls der limstand, dass bei den Ablvildungen lioülerer Antoren, dir dieses Slürk niclut zeigen, dir Stipites hinten in einen spitzen Winkal versclumilert emeligen (s.

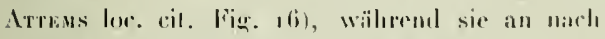
makerierlen J'riiparaten hergestellsen Zeichnumgen

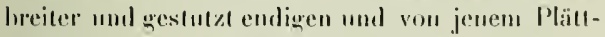
rhen gofolot siml (vol. Sicrestur, Cilassis Diplopodre, vol. 1, Amelome, J. 6o, lïig. 88, und Cook. foc. cit. pl. XLI, Fig. 3). Wie eben zitierte . (bbildung von Suvestri gilut im shema die seschilderten V'erhältuisse richtig an; sie zeigt auch das in Cooks und Artbus' Mblildungen felulende

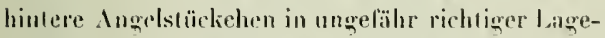
heriehung. Dasselbe stellt ein keines dünnes, elliptisches Päldehen dar, das immer unmillellar vor dem Ende des Postmentum gelegen und ron untenher meist teilweise vom ungebogenen Vor-

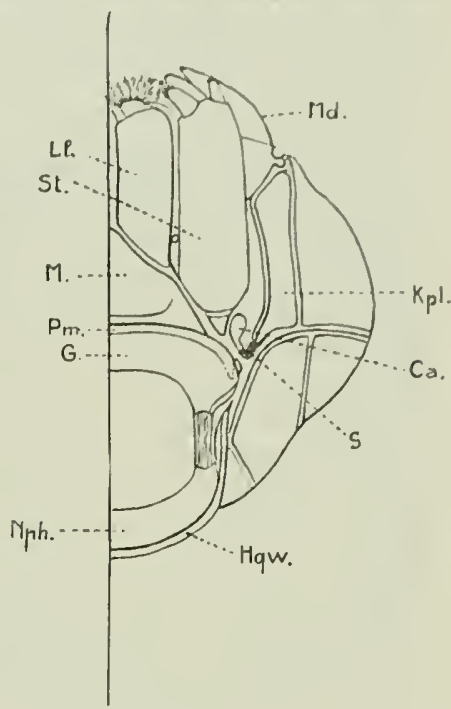

Fis. 25. - Stemmatoiulus fuhrmanni n. sp. Q llälfte der Kopfunterseite, nach Jaceralion. Mil. Mandibel, Kipl. inneres Feld des vordern liopfpleuriten, $\mathrm{Ca}$. Cardo, S. sehnige Verbindung zwischen Cardo und kopfpleurit, Hyw. llintertandquerwulst, Xiph. Nackeophragma. G. Gula, Pin. Postmenturn, M. Mentum: St. Stipes, $L l$. Lamella lingualis.

derrand der Gula verdeckl wird. Ob es den "Noduli» der Vennoeff'schen Nomenklatur entspricht und somit ein selbständig şewordenes Promentum-Ende darstellı oder etwa als ein selar rudimentäres Gula-Plenrit (rgl. Polydesmoriden in VernerF, Diplop. Dentschlands, p. 278) aulzufassen ist, muss noch unentschieden bleiben.

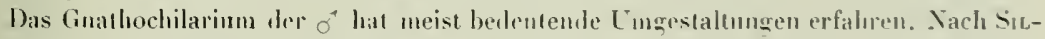
Vestn und Pocock wïrden diese Verschiedenlecilen zwischen a und 9 mur in der Giallung Diopsinlus Sux: anftrelen, zn der auch die von Conok untersuchten Arten rezählt Werden, somit ein generisches Herkmal von Diopsinlns gegeniiluer Stemmatoinlus darstellen. Das ist ein Irrum. Die geschlechtichen Lnterschede im Ban des linathochilariums tinden sich in molor oder weniger starker Ausprägung anch bei Stemmatoinlns unit (10.) 


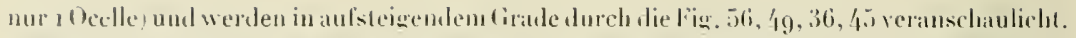

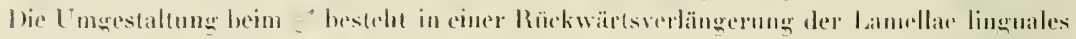
anf kosten des Yentums, das immer stumpler wirl und in der Vitte immer weniger

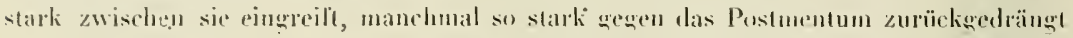
wird, diss seine spitzen . Inssenecken sich loslïsen und als sehmale Plätchen zwischen Stipites und Postmentum zu liegen kommen (Fig. 49), oder dass sich die Lamellae mit ihrer Basis über den distalen Rand des Mentums vorschieben (Fig. 45, 49). Damit ist anch eine Verschiedenheit in der Gestalt des ganzen Organs verbunden, indem der Aussenrand der Stipites und der Lamellen sich wölbt. Die Guda erscheint im Extrem etwas schwäcluer beim $\sigma^{1}$ als beim ${ }^{\circ}$. Bemerkenswert ist die Konstanz in der relativen Lage der P’utzlrüsenmündung in der Rinnc der Stipites bei of und $q$. Diesellse ändert sich natirllich bein ơ mit Bezugr auf die Länge der Lamellae linguales und mit Bezug auf das Mentum, hleibt aber fast dieselbe bei ${ }^{-1}$ und o mit Bezug aul ihre Entfernung von der Basis der Stipites resp. von der Cula. Bej manchen Jrten tritt noch als geschlechliche Ditferenz beim of eine bogige Querstreifung der Lamellae linguates verbunden mil einer arubigen Punlitierung der Stipites hinzu.

Die Antennen haben eine von der gewöhnlichen abwejchende Gliederung. Schon bei schwacher Vergrösserung erscheinen sie kurz hinter dem ı. Gliete leicht geknickt. Bei stärkerer Vergrösserung und besonders nach Macerierung überzeuğt man sich lejcht von der Existenz cines kurzen Zwischengliedes zwischen den ersten und dem grewöhnlich als zweiten gezählten längsten Intennenglied; von letzterem wird es lurch eine typische, dümne, pigment-und borstenlose, sogar etwas eingefaltete Gelenkhaut getrennt. Dieses kleine, bisher bei den Stemmatoiuliden gänzlich übersebıne Zwischenglied ist unlrehorstet und besitzt keine eigene Muskulatur; es stellt also eimen Intennentrochanter dar, wie

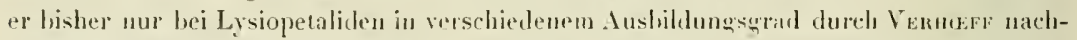
gewiesen war. Streng genommen sind also die Antemen der Stemmatoiuliden g-wiederion, wje diejenigen der Lysiopetaliden. Von allen Ciliedern ist das 3. Trochanter mitgezählt) das längste, die 3 folgenten sind unter sich elwa gleich lang oder von 4. nach dem 6 . lin allmählich etwas kürzer. Das 7. Glied trägl auf der äusseren IHälfte seines Endrandes rine Reilıe von kurzen Sinnesstäbchen, die sich aussen zu einem Büschel verdichtel; anf dem Endrand des 8. Gliedes findet sich ringsum cine solche Reilıe, aber aussen kein Büschel. Das atrophierte 9. Filied trägt \& zweigliedrige Sinneskegel.

An Collum ist die geringe Aushildung der beiden Duplicaturen zu erwälnen. Die Vackentuplicatur ist äusserst einfach, schmal, mit regelmässigem, weder verdicktemn, noch gebuchtetem Hinterranıl und sehr schwach ausgebildeten Collumhöhles ; sie geht seillich ohne weiteres in den etwas einwärts eingeschlagenen Vorderrand der Seitenlappren über. Der für die Lysiopetaliden charakteristische Collumzaplen (vgl. VennwrF, Diplop. Dentschlands, p. 87) fehlt den Stemmatoiuliden.

Wras die Ventralplatten (Sternite) anbetriflt, so ist das wesentliche darüber schon bekannt. Ihre freie Beweglichkeit teitro sie mit denjenigen der Lysiopetaliden und Asco- 


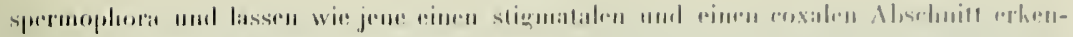

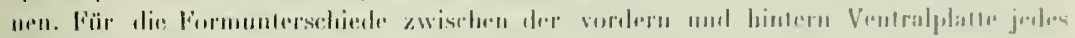

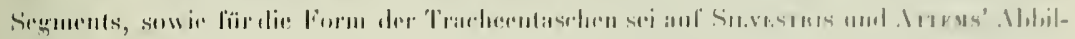
dumen verwirsen.

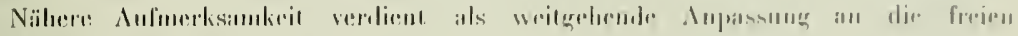

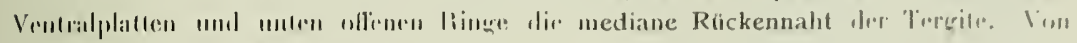

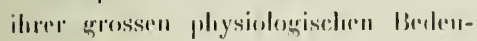
lung lïr die Selowinglugenluswegung der lainge, die den Banch arwilert mud verengert, kann man sich schon Aurch loichten Druck anf slie Seiten des kïrpers mittelst rimer Pincellu. älırzengen. Nowh dendlicher tritt diese liolle aler Nalı hervor, wenn man ihre

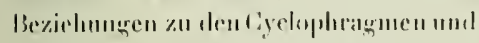

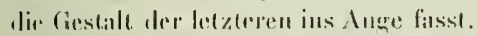

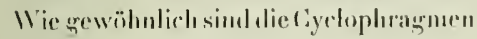
in der vordern linmplregion an stïrksten enlwickelt. Wïhrembl siea alver sonst, sellost hei laysionmalialen (Callipuse, nach Vonutrip), wben am Rä̈cken nicht unterlrochen, somtern nur spritzwinkligr versclumälent siml, simt sie bei Stemmatoinlus: in der Mcelianchene ïberhanpt nicht geschlossen; der lmurnrand der rechlen und der linken Plıragmahälfte vereinigen sielı nich gnegen die Räckenmille hin, somlern setzen sich, jeder lïr sich, in je einen Rand der Nilat forl (Fig. ofi). Damil diese mun nicht anfRn.

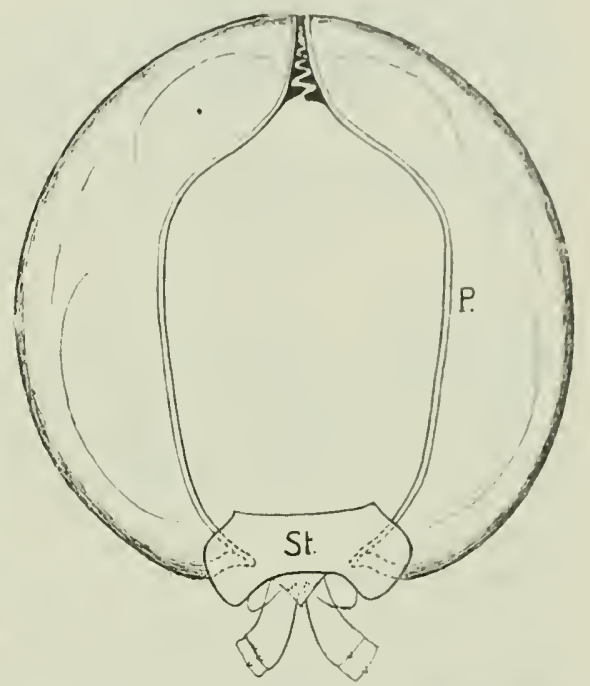

Fig. 26. - Stemmatoiulus major n. sp. - 5. Spermen! von vorn: maceriert. Rn. Rückennahi, P. Plirąma (Cyclophragma, Verh(efF), Sl. Sternil.

klalle, ist sie an ihrem Inrderende, da wo der Tergit in die Plıagmen' ïhergeht. dureh

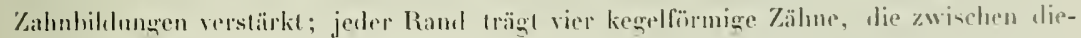
jenigen des gegenübrliegenden Randes eingreilen, mol deren Grösse won rom narh linten ahnimme. Der Innenrand des Phragmas ist wie die Ränder der Naht deutlich wredickt; anf dem Phragma selbst zeichnet sich jederseits eine flache suludorsale mot eine grössere litero-ventrale ovale Grube ab; diese Gruben.entsprechen den Insertiunsflächen der arrossen segumentalen Lä̈nsmuskeln. Die Grenze zwischen Einschielueil des Prozoniten und Plıragma is hauptsïchlich durch die feine Skuptur des ersteren bezeichnel.

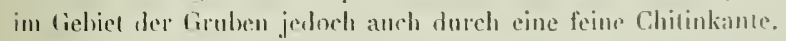

1 Weil sic hier oben vicht zusammenschliesseo, nenne ich sic einlach l'hragmen stan Cyclophragnen. 
Vehenhei hemerkl, ist anch die Lage der Phragmen zu den Pleurotargiten im rordern und hintern Rumpleil verschieden: auf den vordern Segmenten slehen sie nich senkredı zur Längsachse des lï̈r|er's, somlern hilden mit dem chenfalls leich gewälhen Einschieheleil des Prozoniten fust eine regelmässige liugelzone, die unten durch den proximalen Teil der vorelern lentralplatte und dessen breite Flügel vervolständignt wird. Es hamele sich da wiedermm um eine Einrichıng, die auf grössere Beweglichkeit der vordern linge gregeneinander hinzielt.

Beine. Was die Giliederung der Latuflsebe (scliundäre Teilung des Tarsus, slarlie Entwicklung des Trochanters) anhelrillt, so können Coors und Artens' Befunde als fïr

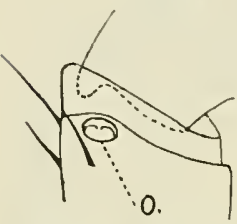

Fig. 27. - Stemmatoiulus majorn. np. Ende der Cosa und Trochanter. O.Hüftöllnung. die ganze Gruppe charakteristisch gelten. Dazu komml eine hisher ähersehene Eigentümlichkeit der Coxa der Laufheine, mit Ausnalıme derjenigen de's 1. und 2. Paares. Nuf der Hinterflärbe der Coxa, näher der Innenseite und hart an dem an dieser Stelle elwas ausgelogenen distalen Rand des Gliedes, weist die Chitinwand cine je nach den Arten etwas grössere oder kleinere, elliptische oder lireisrunde, immer sehr deutliche Oeffnung auf (Fig. 27,0). Es liegt nalse, dieselhe mit einem Coxalorgan in Zusammenhang zı l,ringen, und zwar würde es sich nach der Lage des Porus, dessen Grösse und dem Vorkommen in beiden Geschlechtern nur nm Coxalsäcke landelu lï̈unen. Ausgesestïlpte Coxalsäcke oder deren Umrisse im Innern des Gliedes konnte ich allerdings nie beolachten. Ich vermute daher, es handle sich um eine Reminiscenz von Vorfalıren mit ausstülpharen Coxalsäcken, die in Lanfe der Phylogenese verloren gegangen wären. Vielleichı lïnnen genaue bistologisclı Lntersuchungen dirsen wicl.tigen l'unkt aufklären.

An den leicht metamorphosierten Beinen des 1. mon 2. Paares of und des ersten Beinp:ares of lällt vor allem die grosse lionstanz in der form, Gliederungy (6 gliedrig; Troclanter unterdrückl, Coxa und Praefemur nur durch Naht gelrennt, Tarsus cinfachi) und in den Grössenverhälınissen anf. Wälırend somst geratle die nelamorphosierten boine häufing gute specifische orler generische Merkmale lielern, sind sie hier in erster linie lïr die ganze Gruppe charakteristisch und varicren nach den Arlen nur in ganz nelensäch-

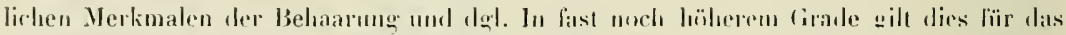

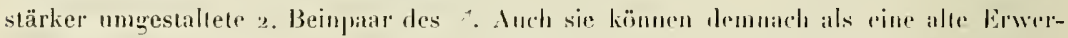

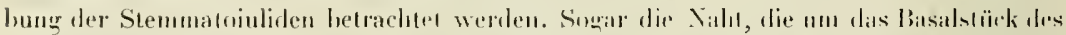

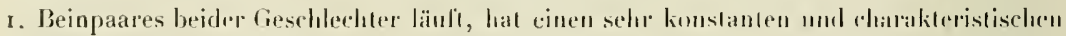

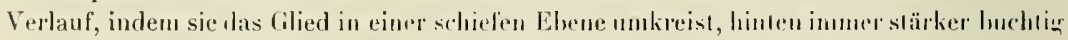
basalwärts vordringend als vorn. Dass sie wirklich die tirnze zweier rers-hmolzener

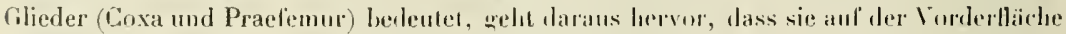

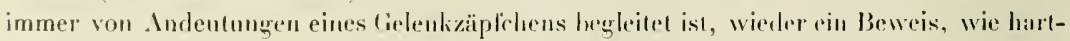

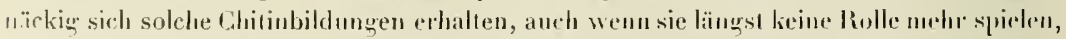
nml in diesen Sinne eine Stütze lär die oben gegelene Deulmug der Hüftülfuungen. 


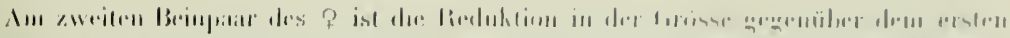

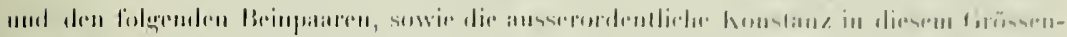

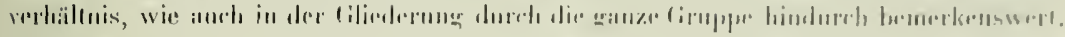

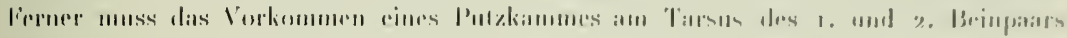

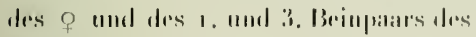
; "rwithul werdert.

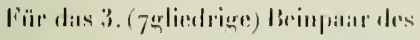
ist die melde coler weniger slark vorgeschriltene Rodulition der kimalle chatrakleristiseh, während in B̈hrigen van allen baulbeimen garads dicjenigent dieses Patares himsichelich der Behorsfunge und der Grössen- mol furmverhälenisse dere einzednen lilieder noch ants rlesten zur Artunterscheidung lurlangezogen werden kïnnen, somit norh in I mwandlung wad Anpassmug begrilleme Extremititen darstellen.

Den liir die ganze Gruple so chatrakteristiselen mpataren Penis leesclureilu Cook als scheindarr zweigliedriw. ATrems aber (bei Diopsinlus sjösletli)

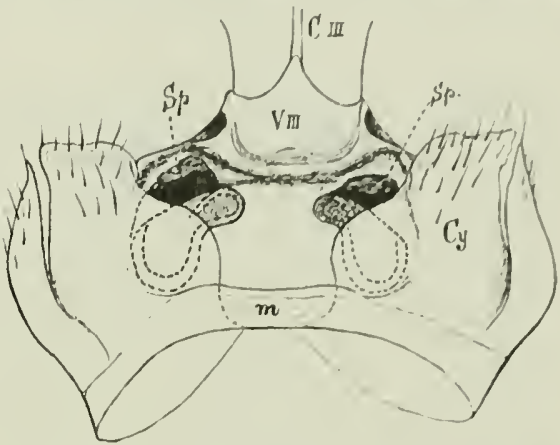

Fig. 28. - Stemmuloixlus majom n. sp. P. Cyjullopulun und Sternit des 3. Peinpazes, von vorn. Cy Cyphopadul ili. Verbindungsmembran der beillen typhopodile (Cypliosternit ?): V III. listaher abschnitt des Sternits; C IIl. Ilofle des 3. Beinpaars; $S p$. Spermaklumpen. lie Receptacula (punktierte kontouren) sind grissteuleils vom medianun l,appen der Cyphopodite verdeckl.

als a einfach, zugespitz, in einer Rähre steckend, die ans ciner erösseren Platle sich erhelu ". Itrtens' Darstellung ist die richlige. Ich fand den Penis hei Stemmatrinlus

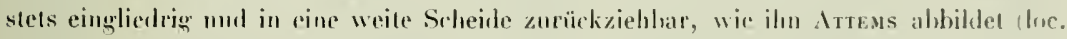
cit. Tal. I, liig. 18).

Die Cyphopoden des 우 (Fig. 28) hängen viel imigger mit dem 3. als mil dem 2. Brin-

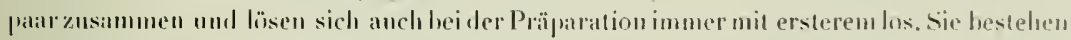
jederseits at cimem einfachen, lief zweiteiligen Iläliglied; die beiden Cyphopodite (Cy,

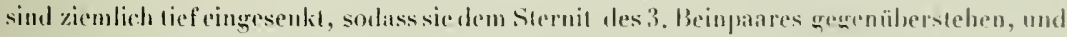
daluer anch nur in ihrem dislalen Teil helorsted; sin liegen ziemlich weil ansoinander mol

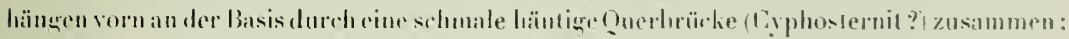
hinten lä̈ıgen sie durd Membran mil dem Stronil des 3. Beingares zusammen, den

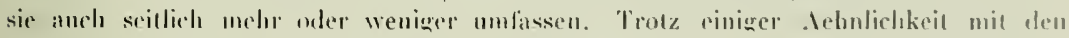
Cyphopoditen der Isensprermophora scheinen sie viol weniger differenzier als jenn. Telogodilreste kunute ich nicht nachweisen; ebensu wenig war es mir möglich, drösige

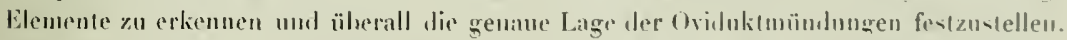

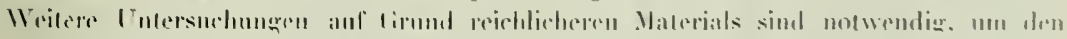

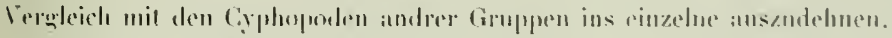

Receptacula. Höchst eigentümliche Inszeichmungen lat das sternit des 3. Beinpaars 


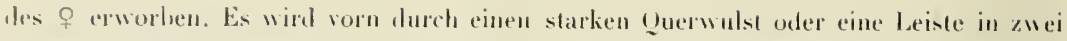
.lıschnitte geteilt, cinen kloinen distalen Abschnilt mit den llüftansälzen und Stigmen

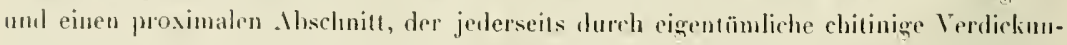

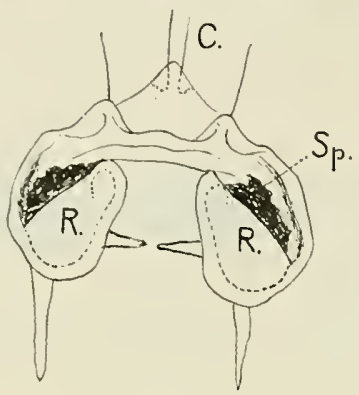

Fig. 29 .

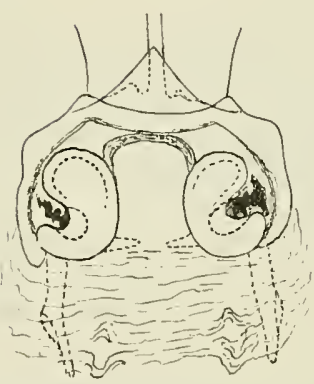

Fig. 31 .

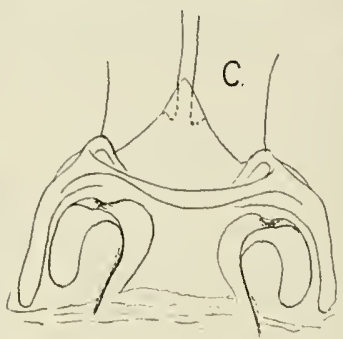

Fig. 30.

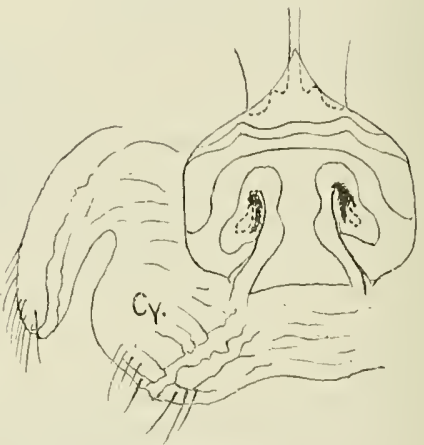

Fig. 32.

Fig. 29. Stemmatoiulus major n. sp. ㅇ. Sternit des 3. Beinpaares mit den Receptacula $(R)$, C. Ilufte, Sp. Spermaklumpen. - Fig. 30. St. fuhmanni n. sp. . Idem. - Fig. 3l. St. hortensis n. sp. ‥ Idem. Darunter die Verbindungsmembran mit den Cyphopoden. - Fig. 32. St. bogutensis n. sp. O. Idem, nebst nach vorn heruntergeklapptem Cyphopodit $(C y$.

gnen und 1 ulstlildungen von gelbbranner Farbe ausgezeichnet ist. Je nach der Art handelt es sich um eine nach aussen oflene Tasche (Fig. 29), eine Hufeisenform (Fig. 30) uner ein ohrmuschelförmiges Gebilıle (Fig. 32) (4c. In allen Fïllen aber begrenzen diese

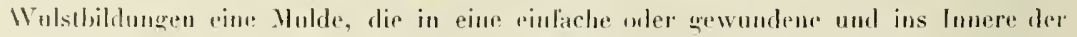

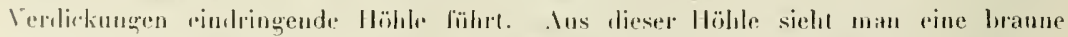
Mass heraustreten, die sehon dem unbewaffneten Auge durch ihıe Färbung aulfällı. Je 


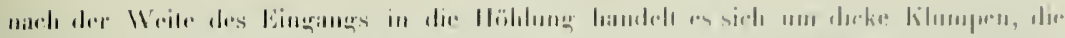

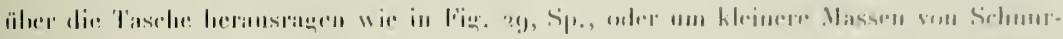

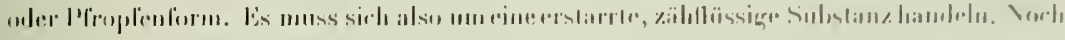

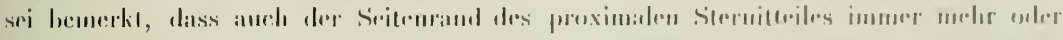

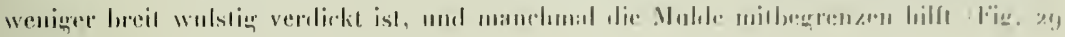
IIIII 31 ).

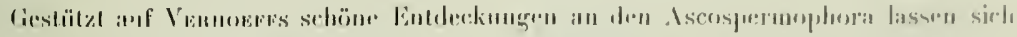

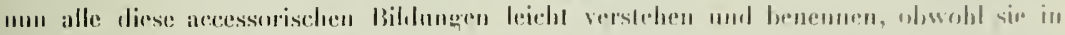

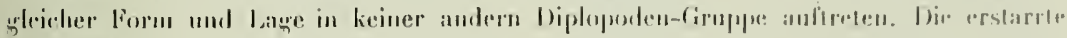

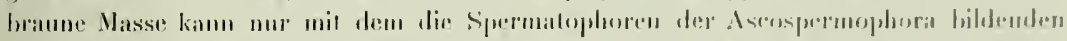

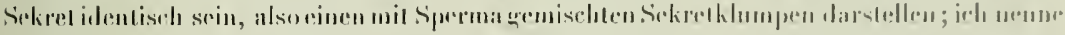

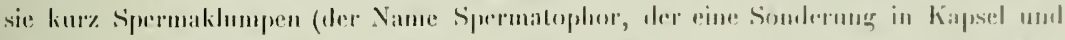

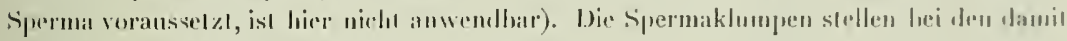

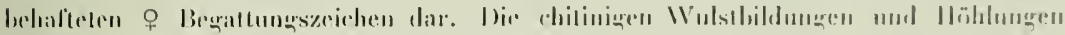

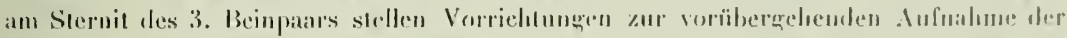

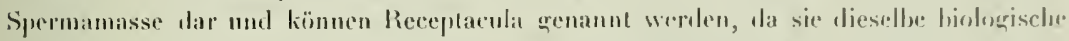

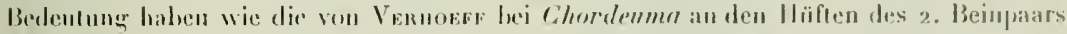

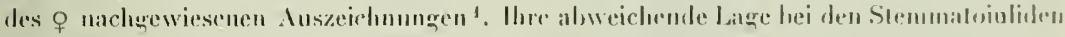

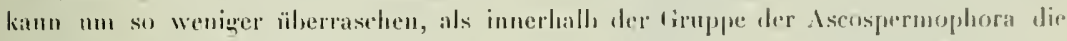

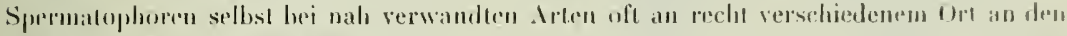

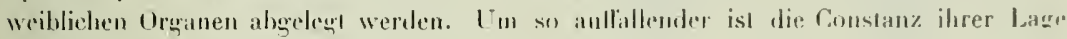
hei den Strommatuiuliden.

So einheilich diese Inpassung bei den Stemmatoinliden im Prinzip ist, so chatak|crislisch und konstant sind ihre I nterschiede lei den einzelnen . Irten. Ein Blick auf

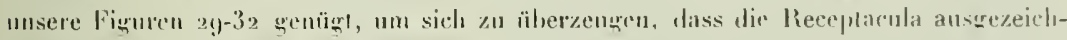

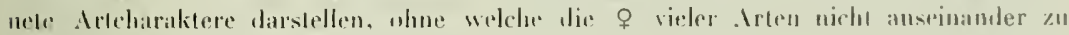
latton wären. Soviel ich his leute meteilen kann, sind sie wach den Iren viel schärfer dillerenzierl als alie Cyphopoden selbst.

Gonopoden. Wie schon eingangs bemerkl, hat das zwejte Beinparar des 7. Segmentes hein "gin\% den Charakion eines atrophierten Laulheinpaars, das nie in Dienste der samenleitung gestanden isl, und dic Gonopoden entsprechen trotz ilures komplizierten

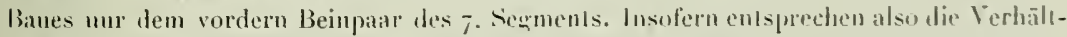
nisse bei den Stemmalondiden tenan den ron mir bei den Rallungen Epinunnolene. Psetulonannolene und Holopodos/replns nachgewiesenen ${ }^{2}$, ohne dass die Unhereinstim-

I In alleriüngster Zeit hat Bıgeen (Rex. Suisse de Zool. T. 21, p. 7oR, Pl. 17, Fig. 15, 1913) bei r.tur-

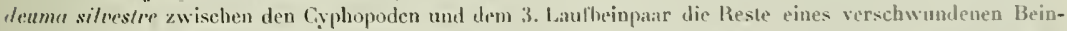

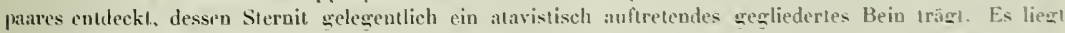
nahe, in den Receptacula der Stemmatoiuliden-o diesem Sternit (Platosternit Broter $=$ Cyphnuternit Ven-

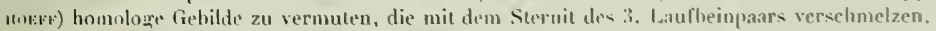

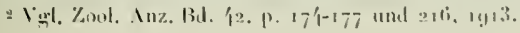


mungr zur Annalame einer engeren Verwandtschaft der Stemmatoinliden mit den genannten Gallungen berechtigte, indem sie sich leicht durch parallele Entwicklung arklären lässl.

Die linnopuden der Stemmatoindiden haben einen sehr typischen und in seinen

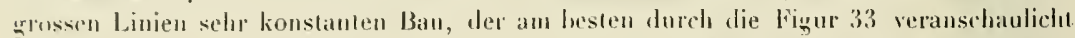

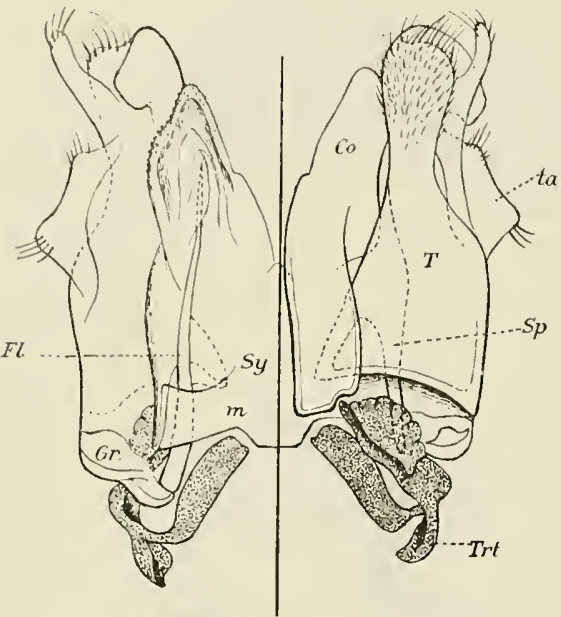

Fig. 33. - Stemmatoiulus fuhrnanni n. sp. T. Gonopoden, rechts von vorn, linlis von hinten geselien. Trt. Tracheentasche, T. Telopodit, $\mathbf{C r}$. dessen Gruadglied, Sp. Sporn des Telopodits, ta. laterale Apophyse des Telopodits(Tarsus?), Fl. Flagellum, Co. Coxit, Sy. Syacoxilplatte, m. deren basale Verbindungsbrücke mit dem Telopodit. wird. Sie bestohen aus einem Paar medialer und je einemn lateralen llachgedrückten Hohlkörprer. Die medialen Stïcke (Co) müssen mit Rücksicht auf ihre Bezichungen unter einander und zum Stülzapparat als medianwïlts verlaterte Coxite hetrachtel werden. Sir sind nur in ihren distalen Teil getronnt; im proximalen Teil sind sic zu einem synowit (Sy) verwachsen, der auf der llinterseite durch eine brcite, schwach chitinisierte, manchmal noch eine mediane Verwardsungsnaht oder Verdikkung antweisomle Platte dargestellt wird, während at der Vorderseite sein pariger ITspoung deullicher hervortritt. Hier sind nämlich die dirken Vorderwände jedes Coxits in der Mille nur durch eine schmale däune Vlembran verhunden. Distałwäls weichen dir Coxite meist lyraförmig auseinander und greifen von der Vorder-aul die Hinterseite der seitlichen Stücke älser; in ilırem parrigen, schwächer chitinisierten Abschnill dienen sic jeder der Führung eines Flagellums, das sic in verschiedener Weise umwickeh oder in eine Rinne anfmehmen.

Die lateralen Ilohlkörper (T) betrachten wil als Telopoditen; sie sind an der Basis innen membranös mit dem Syncoxit verbunden. Auch ibre Wandung ist vorn dick mad stark ehitinisiert, hinten lingegen häutig und elastisch. An ihrer Basis gliedert sich von der vordern Wand ein schmales muschelähnliches queres Gilied (Gr.) ab (Praefemur?), das dureh zwei Chilinspangen grestïtzl ist und an dessen Ende sich das Flagellum (FI.) ansetzt. Das Flagellum lührt eine an der Basis weit ollene, distalwärts zu einem fenen Lianal gesehlossene Rinne, die sich an ihrer Spitze ölnet; es wird, wie schon bemerkı, won den Coxiten geführt. Das Ende der Telopodite ist bei den verschictenen Arten etwas verschieden gestaltet, meist etwas nach hinten übergebogen, der Spitze der Coxite entgegenkommond und häufig eimr Rinne bildend, dir das Ende der Coxite aufnimut und 


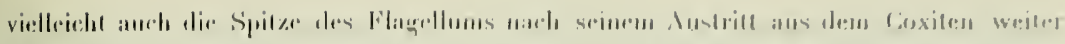

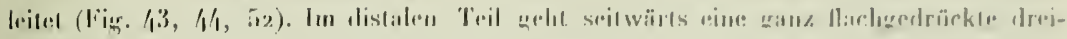

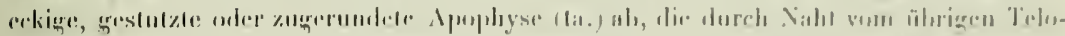

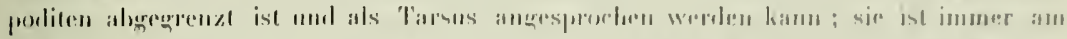

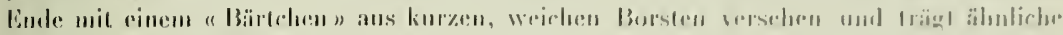

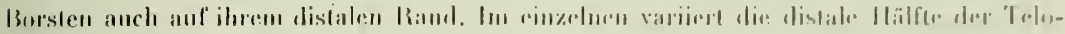

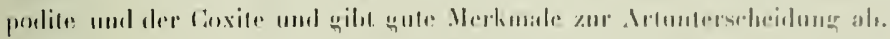

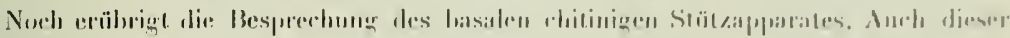

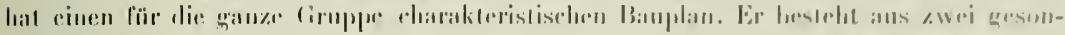

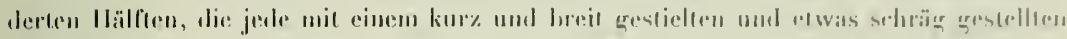

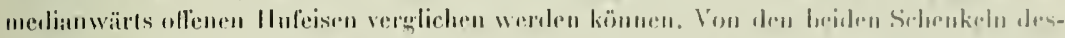

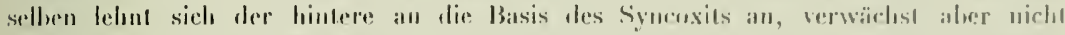

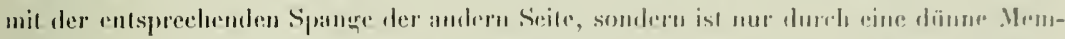

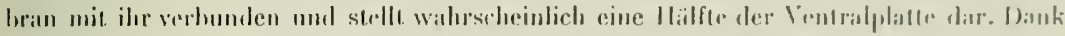

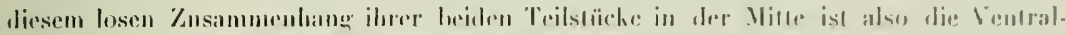

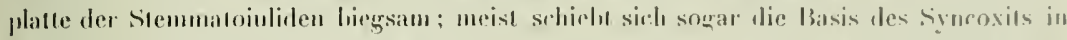

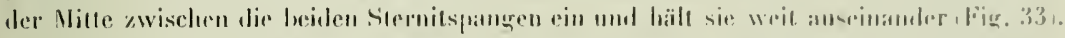

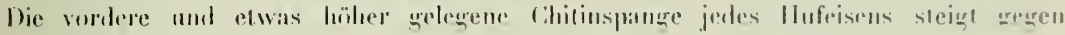

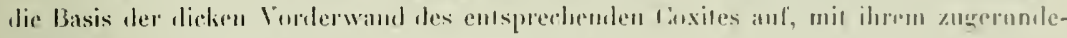

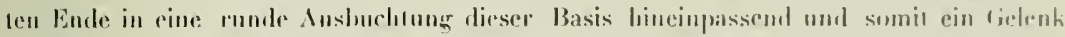

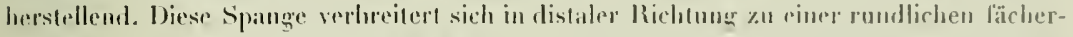

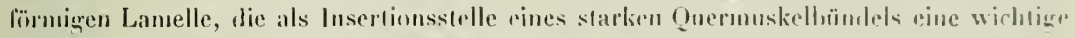
Rolle bei der Funktion des Copulationsorganes spieft. Diese vordere Spange kann man als Fortsatz der Tracheentasche (vielleicht ilu Innenarm) aulfassen. Die eigentliche Tra-

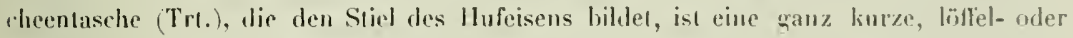
schanlelförmige Lamello; an sie treten slarke Vuskelı heran. Nuch verdient eine Bezic-

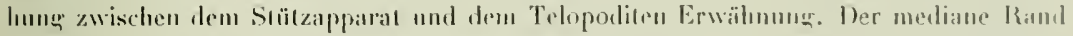
der dicken Vorderwandnng der Telopmodite verlänger sich basalwirls in Form eines Spurns (sp.), der imnen mit dem basalen Teil des Symexits falzirg zusimmonhängl (s. rig. 3.3 rechis) und dessen Ende in den Winkol zu liegen kommt, den die vorilere Spange des Stälzappalrates mit der hinteren und mit der Tracheenlasche lildet.

Dentet schon das Vorhandensein ciner geteillen Ventralplalle mit membranöser Verbindung ibrer beilen Hälften, die Verbindung der lreiden vordern dicken Coxilwänle durch eine delunbare Membran, somie die Lage der Coxite zu den Telopoditen anf eine grosse Beweglichlieil des Orgams hin, so wird dies noch dorell die slarke Entwirklumer der Muskulatur bestätigt. Vor allem ist ein starkes queres Muskelhöndel zu erwähnen. das vom ror der Basis des Organs liegt und jeterseits an der lamellären Verhreiterung der vorderen spange des Stülzapparales inserier. Durch seine Conlaction werden die heiden vordern Spangen gegen cinander gezogen, wodurch das Hufeisen eine Drehang um seine Längsachse anslïhrl, sodass seine hintere Spange sich senkl und die Hinter100 
Wand des Symoxits hasalwills nachegeben lässt. Die modern Spangen schieben ihrerscits die heiden Coxite durch Druek anf die Basis ihrer dicken starren Vorderwand ror. Diese combinierte Brwegung hat zur Folge, dass die beiden Coxite dislalwäls auseinandergehen und anf die IInterseite der Telopodite ïlsergreilen. letzlere mïssen aber riu lestes Widerliger bilden und dürfen die Spreizung der Coxite nicht milmachen. Das kann eincrseits creichl werden, indem gleichzeitig mil der genamuten Drehung des Hufrisens eine Ilebung seines Bogrens stantfuclet, sodass er mun dir Basis der Telopodite anssen stijtal. Eine besonders wichtige Rolle dürfte alher dabei dem als "Sporn " hezeichneten Fortsatz des Telopodilinnenrandes zukommen. Indem er vom Bogen des llufeisens nach vorn und innen gedrängt wird, stellt er eine Sperrvorrichtung dar, die ein Nachgreben der Telopodite verhïlet und deren Lage zu den vorgeschohenen Coxiten so regelt, dass letztere mit ihren Enden dem Telopoditende sich nähern und ilum das Flagellum zur weiteren Führung in dazu bestimmten Rinnen oder zwischen Lamellen übergeben. Den Vorrichtungen, die auf eine wrosse Verschiel,barkeit der Coxite hinzielen, stehen somit solche ga gegen̈hler, die dis Telopodit zu einem Widerlager gestalten. Ist die vorhin präzisierle gegenseilige Lage von Telopoliten und Coxiten hergestellt, so kann das Flagellum in Tätigkeit treten; das Grundghlied des Telopodits, an welehes das Flagellum sich ansetzi und diss als Hebel wirkt, erluält seine Muskeln aus dem Telopoelit. Den starken Quermuskel zwischen den heiden vordern Spangen des Slülzapparates kömnen wir seiner Wrirkung gentäss als . Ilductor bezeichnen. Seine Antagonisten sind starke Muskeln, lie in die Coxite eindringen und durch ihre Contraktion dieselben ans dem grespannten in den Ruhezustand zurückführen; ich nenne sie Retraktoren.

Hiermit ist der Bau der Gonopoden von Stemmuloinlus und teren Mechanismus in den wichtigsten Zügen aufgeklärt; doch hleibn die Homologie einzeluer Teile noch etwas zweifelhaft. L'eber die Vorgänge bei der Aufuahme des Spermas durch die Gonopoden und seine Tebertragung anf die weiblichen Vulven können wir noch keine Anskunlt geben. Ehenso bleibl die Frage nach der IJerkunft des die Spermaklumpen lildenden Sekrets noch unbeantwortet; eine Coxaldrïse komnten wir bisher in den Gonopoden niclı nachweisen.

Tnsere obige Darstellung des Gonopodenbaues ron Stemmaloiultus gilt für die ghanze Gruppe der Stemmatoiuliden; demn in dieser oder jener der von Cook, Suvestra und I ттемs gegebenen Abbildungen der Gonopoden von Diopsiulus lassen sich dieselben Teile (mit Ausnahme des ganz ausser Achı gelassenen Stützapprarates) und in denselben Lagebeziehungen wieder erkennen. Aтtens fand bei $D$. sjöstedli ebenfalls zwei Par von ungegliederten Anbängen, nämlich zwei "mehr lateral ingeordnete» Hälften, mit je einem Flagellum, die auch in ilırer äussern Form ganz denjenigen von Stemmatoiulus grleichen, und lerner zwei innere " ungefähr lyraförmig gebogene " Stücke. Die basaleu Teile sind ihm allerdings ganz entgangen; denn was er als "eine grosse Ventralplatle" bezeichnet und in Fig. 1 o6 abbildet, ist die Syncoxitplatte. Ferner ist seine Beschreihung dahin zu berichtigen, dass das Flagellum nichı "solid" sondern von einem Kanal 


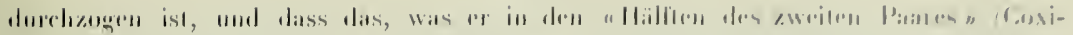

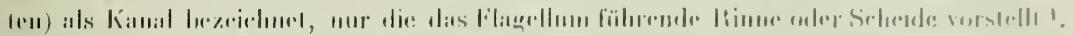

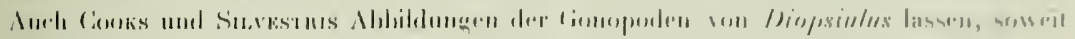

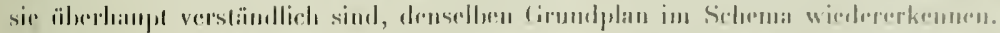

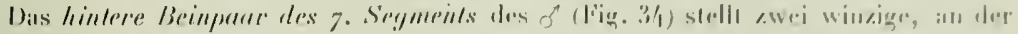

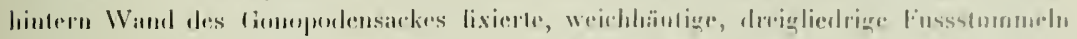

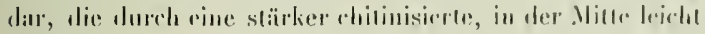

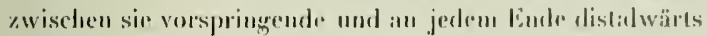

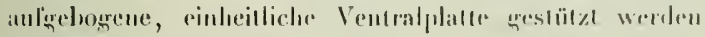

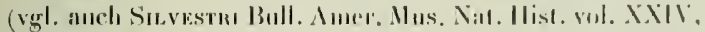

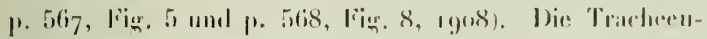

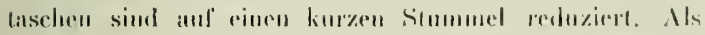
Gomoporlen können diese Rudimente nich lexeichnel werlen; nichls lerechligl zur Amnahme, dass sic jomals im Dienst der Copulation grestimben halden. Ilare Ciestalt ist

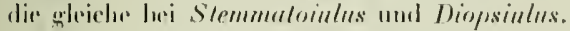

Zur Charaliteristik arer wanzen limpe gehört anch

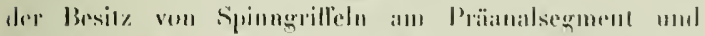
die (nath Vonusw) damit \%usimmenhängende Verjün-

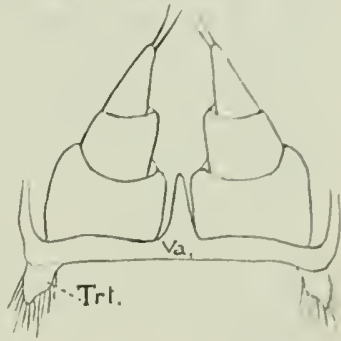

Fig. 31. - Sienimalriulus futormanni n. sp. ơ. Illinteres lieinpaar des 7. Segments. Trt.Trarlieentasche. lia V'en!ralplatle.

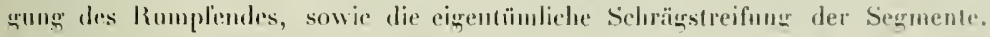

liewisse andere Merkmale hingegen, die der ganzen Gruppe zngescluriehen wnrden, limmmen mur gुewissen Arten zu. So serhält es sieh mit der Queruaht, deren Fehlen nicht

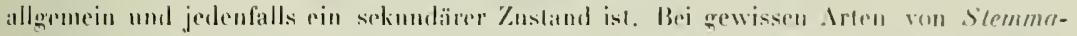

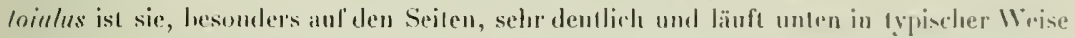

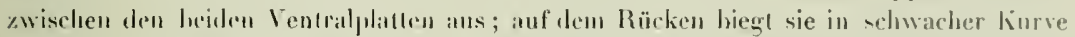
tach rorn, sodass sie bei gestreckter Lawe des Tieres meist versteckt ist. Das Saftloch liegt linter der (Guerfurche, also auf dem Metazoniten. Ehenso ist eine liefre lierthe seitlich an Hinterand der Metazoniten, die als trenze zwischen Tergit und l'lenril betraclıtet werkn könnte, kein durchgreifentes Merkmal. Sie felılı bei den Arten mil schwachen selorighurchen und fast ghatlem Hinterramb der Metazoniten.

Aus dieser Darstellum ergibt sich, dass die Sitcmmatojulielen mit Räcksicht auf die

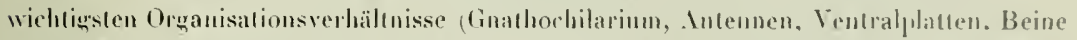

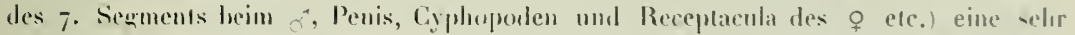
scharl charakbrisierte, in sich ahgeschlossme Gruppe hilden. In manchen Merkmalen hahen sir primilive Verhälnisse bewahrl, wie im Besilz eines . Intemenfrochanters, freier

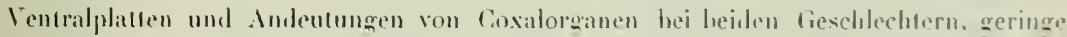
Inzahl der Ocellen ( oder 2 ); in anderer Beziehung wieder hahen sie von urspronghlichen

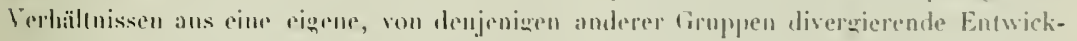

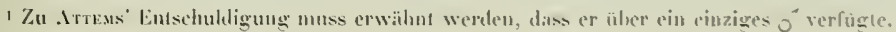




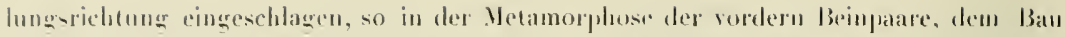
der Gonopoden, den . Imszerichnungen des 3. Sternits der o, der Mnpassung an die freien Sternite dureb Ausbildung einer dorsilen Dediannaht und oben untorbrochener Pluragmen, der lerschiedenheit der vordern und hintern Sternite, der sexuellen Versehiedenheit im Ban des Guathochilarimms, der Giliedernng der Laufbeine, der Skulptur des linge. Eine dritte liategorie von Organen endlich weist gleichzeitig Bezielmngen zum Typus verschiedener heute lehender Gruppen anf, in einem Merlimal mehr an die eime, in einem anderu melı an die andere wemalunend (Manditsein).

In der gesamten Organisation aher komm einc stannenswerte Einheillichkeit des Grundplans zum . Musdruck, die jeelen körperteil sulort als zu einem Vertreter diescr liruppe gehöriog erhenuen und für die. Irlunterscheidung nur kiverien zweiter und driller Ordmung ährie lässt. Die ausserordendich hohe Zahl ron Giruppenuerkmalen und ilare sehr scharfe . Iusprägung machen diese klejne tiruppe zu viner der natürlichsten und orjgrinelkten im ganzen Diplopodensystem und zwingen uns, ihs trolz ihres gुeringren I'mfangs einen holen systematischen Rang (etwa den ghejehen wir den Ascospermophora) einzuI'äแงเnen.

Berücksichtigt man noch ihre weite geographische Verbreitung (Anden, Venezucla, Antillen, tropisches Ifrika, Ceylon, Neu-Guinea) so kann man in ihr un einen ganz alten, selır tief rom Stamm der P'roterandria ahgehenden und hald an die Grenze seiner Evolulionsfähigkeit gelanğten Seitenast erkennen.

\section{Gen. Stemmatoiulus Genv.}

Wie selion bemerkl, stimmen dir beiden bisher untesschiedenen ballungen StemmotIninlus und Diopsinlus in den wesentlichen Verkmalen ïberein und kömntrn nur noch Inreh die Zahl der Ucellen untersehieden werten ( bei Stemmatoinlus, 2 bei Diopsinlus), wis ein sehr zweifelhaftes generisehes Merkmal darsteli, um so mehr als die beilen Arterruppen auch geographisch nicht streng geschieden sind, inden die Antillen wie Mrika Irten mit zwei Ocellen besitzen, Columbien dagegen Arten mil acelle. Die Giatlung Diopsinlns Sis: muss daluer wieder in Stemmatoinlus aufgehen.

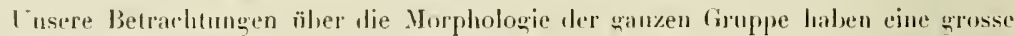
Inzahl ron Jerkmalen ergesten, die als alte Erwerbungen äusserst konstant sind und

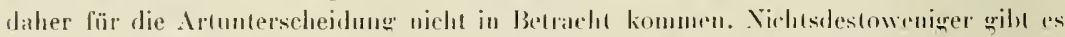
einige sehr zuvertässige Irtmerkmale, die hier nochmals in der Rangordnung ilares Werles zusammengestellt wreden mö̈gen :

1. Die Form des distalen Trils der Gonopoden-Coxite und Teloporlite der a.

2. Die Form des Receptacula an Sternit des 3. Beinpares der o.

3. Der Bau des Finathochilarinms beim a resp. dessen 1 mgestallung im Vergleith zı jenen des 우.

1. Die Formen und die Beborstung des.3. Beingkares hein ơ. (Vgh. Anmerkung p. 851). 


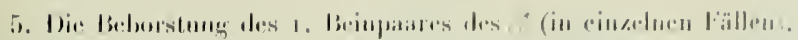

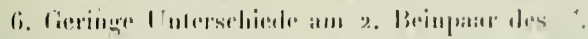

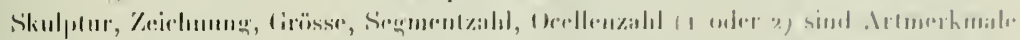

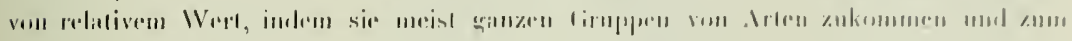

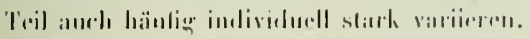

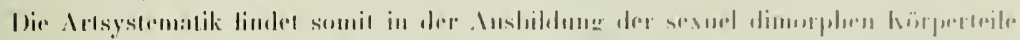

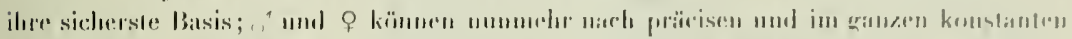

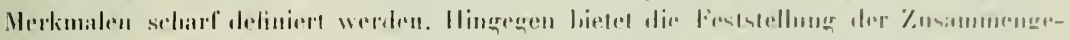

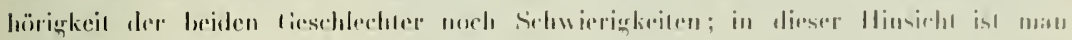

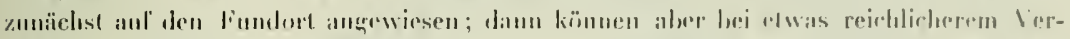

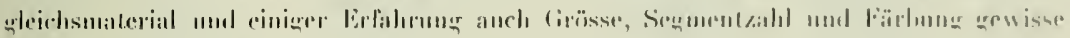

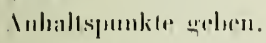

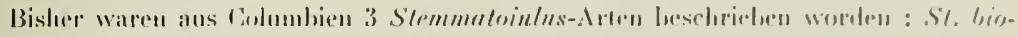

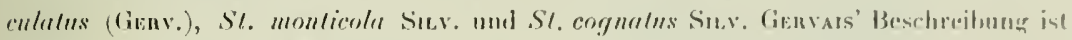

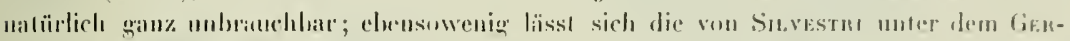

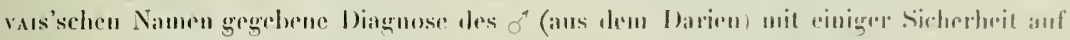

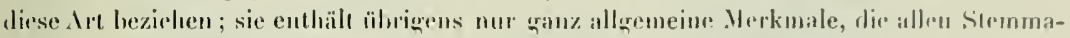

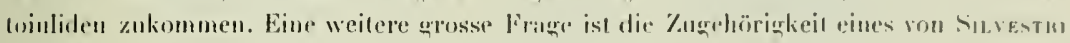

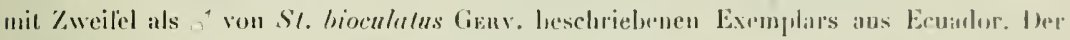

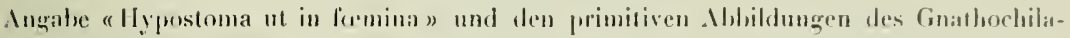

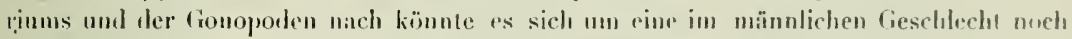
wenig differenzierte $\mathbf{~ r t}, \mathbf{m}$ eine Verwande unseres St. majori bandedn; allein in riner andern Arbert (Classis: Diplopoda, vol. 1, Anatome p. (iti, Fig. 104; 19031, bildel

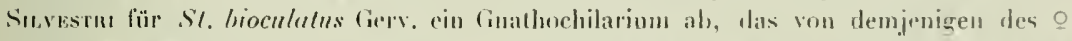

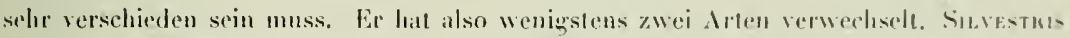
kurze Diagnosen von St. monlicolı und cognalus sind vollends ganz unliranchbar und zum Teil sicher auch lalsch, so z. B. hinsichulich der Ingalue für s\% coynalns ' : "l'erles. scrundi paris biarticulatin.

\section{Stemmatoiulus hortensis $\mathbf{n} . \mathbf{s p}$.}

(liiv. 31. 35-4i.)

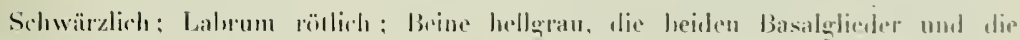

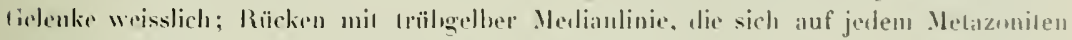

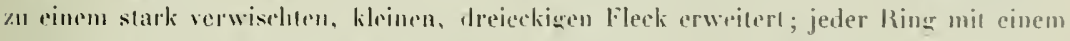

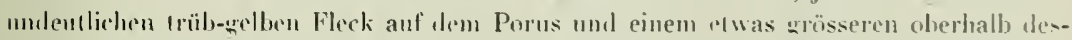

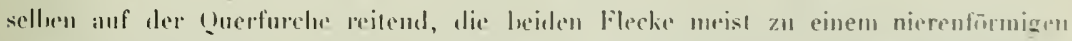

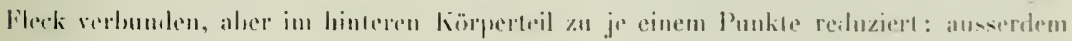

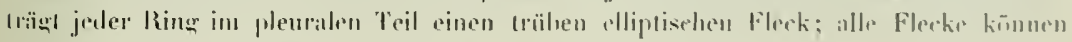
dureh branne Mamoricrong stark verdiostert sein. 


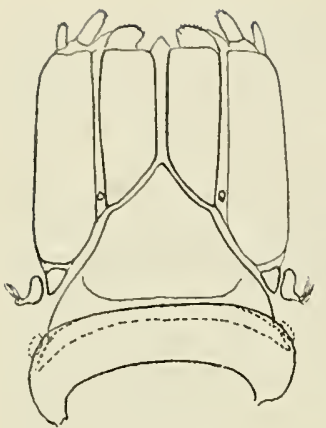

Fig. 35.

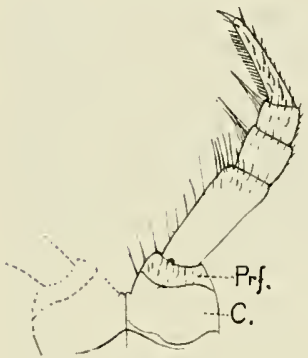

ling. 39.

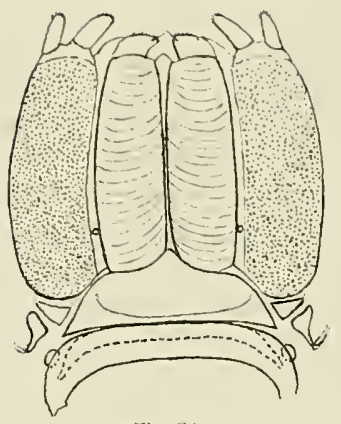

Fig. 36.
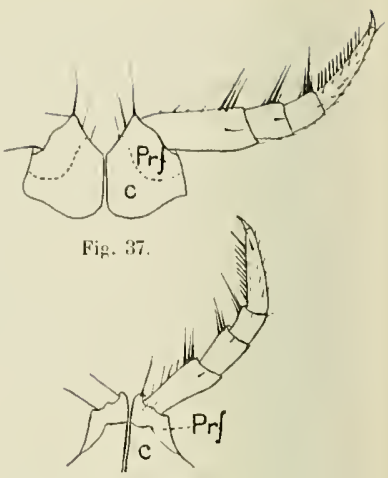

Fig. 38.

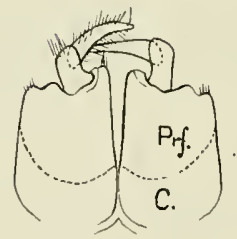

Fig. 40.

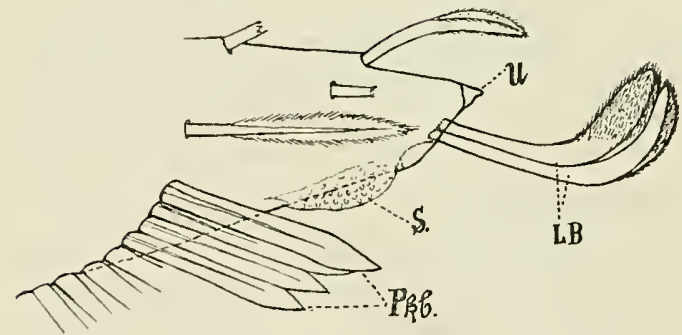

Fin. 42.

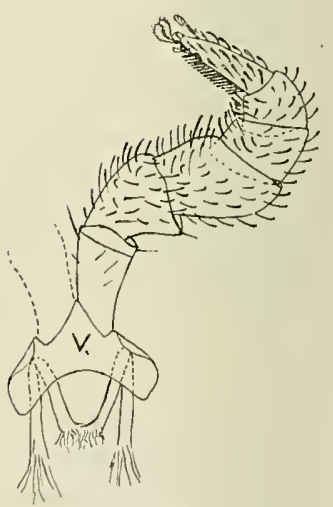

Fig. 11.

Stemmateiulus hortensis n. sp.

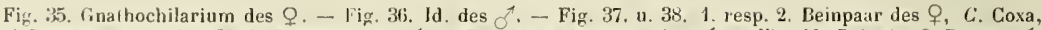
I'rf. Praefemur. - Fig. 39. 1. Beinpaar des א. - Fig. 40. 2. Beinpaar des $\sigma^{-1}$ - Fig. 41. Bein des 3. Paares V. Sternit. - Fig. 42. Endteil des Tarsus eines Beines des 3. Paares, $\vec{A}, I$. Kralle, IJB. Löltelborsten, S. Ilaftheule, l'kh. die vier lotzten Poisten des Putzkammes. 


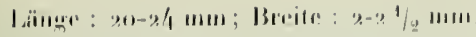

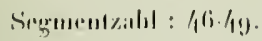

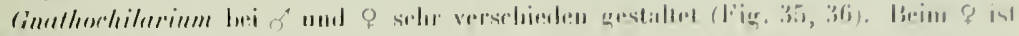

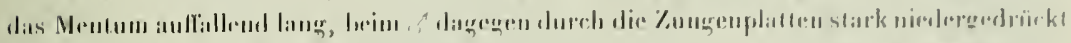

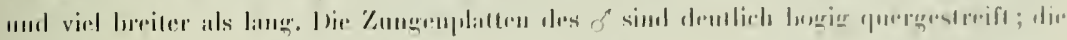

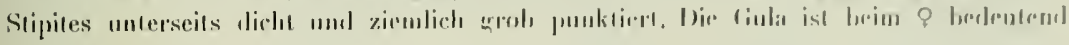
lureiter als beim of.

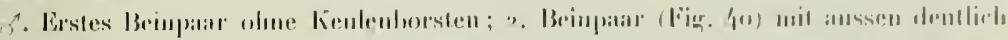

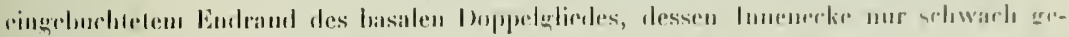

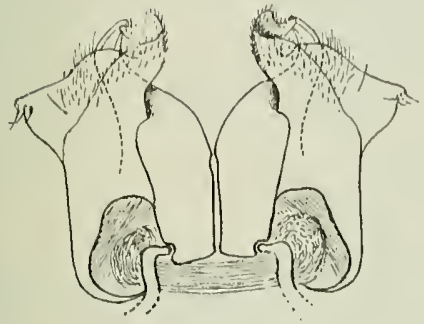

Fig. 43 .

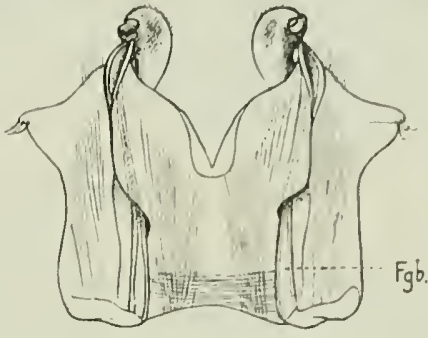

Pìg. is

Stemmatuiulus hortensis n. sp.

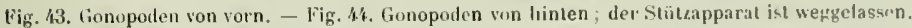
Fgh. Flagellum.

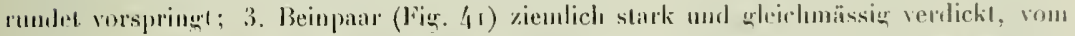
Prafenur an mit verbreiterten, fiedrig hewimperten Bolstrn besetyl; der Tiasus mil nut

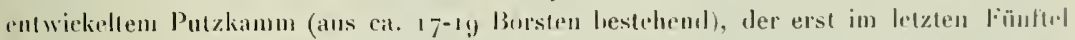

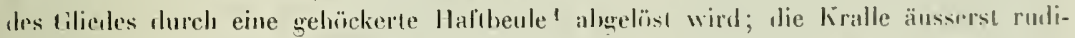
mentiir, ein ganz kleines Chithhöcker, darunter 2 errosse, löffelfürmigne, mil Ausnahme ihr's Stieles diclut bewimperte Borsten (Fig. 42).

Die Gonopoden (Fig. 4.3 und 44) sind selır einfach trestaltet. Dir Coxite nehmen das Flagellum zwischen zwei Lamellen anf, die sich am Ende lippenfürmigr ïlıen: mil ilurer Spitze treten sic zn dem nach hinten äbergebogenen, chenfalls einfachen Ente des felopodits und goleiten wahrscheinlich in die von diesem grehildele linne oder feiten wenigstens das Flagellum sicluer in dieselbe hinein. Die laterale Ipophyse der 't'elopodite ist ein breites Dreieck mit leicht seschwungenen Seiten. Inı Stiotzapparat fällı die ausgesprochene Gelenkverbindung zwischen der vordem Spantre des Hufeisen: und der änssern basalen Ecke des Coxils besonders stark in die . Iugen.

1 Nachträglich konnte ich feststellen, dass dieses Getrilde nicht konstant auftritt und eher als erstarrtes Sekret, denu als Chitinbildung erschcinı. Auch liel miv davor, unterhalb der Insertion der apicalen Löffelborsten, eine Einmuldungr auf, in deren Grund cine Drissta aszumënden seheint: vielleicht hesteht eine Beziehung zwischen dieser Vertiefung und der "Haftben'en. 


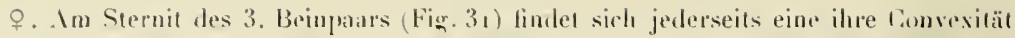
medianwärts kehrende, nicrenförmige Verdickungु; zwischen dem wulstigen Seitenrand des Sternits und der Coneavitat der "Nieren befoudet sich eine Mulde, die sich noch als kleiner Blimback unter der Verdickung fortsetzt; die beiden nierenförmigen Receptacula sind distal noch durch einen vom gुewöhnlichen Guerwulst dieses Sternits nnabhängigen hügelförmigen Wulst verbunden. Das Stronit selhst ist durch seine eckigen lmrisse ansgezeichnet.

Praeanalsegment mil o spingrrilleln.

Der Itinterrand aller Ringूe entsprechend der Furelıung sägezïhnigg, im vorderu und mittleren Kärperteil nur anf den Seiten, im hintern Körperteil immer höher gegen den Rürken hinauf.

- ㅇ. La Camelia, Katfeeptlanzumg hei Angelopolis, 18 mo m.

2 우 우 Puerto de los Pobres, am Caucat; 1 우 Jirardot am Milgdalenat, $250 \mathrm{~m}$.

\section{Stemmatoiulus debilis $\mathbf{n}$. sp.}

(Fig. 15-18).

6. Färbung mul Inlinge der Zeichnng wie hei der vorhergehenden Art; aber der unaze Kopf lıell, die medianc Rückenlinic segmentweise zn deutlicheren Flecken verbreiter, dir sublorsalen Fleckenreihen sehr undeutlich und die lö̈perseiten sind weiter

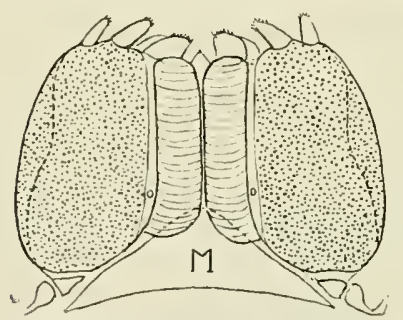

Fig. 45.-Stemmatoiulus debilisn. sp. 4 . linathochilarium von unten; Gula und t'ostmentum weggelassen. M. Nentum. aufwärts, his kurz unterhalb des Porus, anfigelıllı.

Skulptur etwas schwächer als bei hortensis und der Hinterrand der Rịgge daher fast glatt, ungezälınt.

Viel kleiner und dunner als S. hortensis (Länge niclıt genaı messbar).

Breite: $11 / 4 \mathrm{~mm}$.

Segmentzahl : 48 .

Gnathochilarium (0) (Fig. 45) stark moditizietl: Die Stipites sehr loreit, anssen ziemlich stark germudet, unterseits dicht grob punktiert; Zungenplatten hogia gestreift, hasalwärts verlängrevt und an der Basis über das gerundete Ende des Mentums geschoben; letzteres daher noch dreirckigg und nicht autfällig reduziert; Angelstücke normal.

1. Beinpaar ohne spezifische Eigentümlichkeiten. Zweites Beinpaar (Fig. 46) mit schwachem Basalcylinder, dessen Endrand innen nur schwach gerundel rorspringl und nuг 2 Borsten Irägt. 3. Beinpaar (Fig. 47) mit auffallend stark verdicktem Praefemur und Femur, die 2 folgenden Glieder normal; der Tarsus relativ lang und dänn, mit kurzen, nur etwa $7_{-10}$ Borsten zählendem P’ulzkamm, lı̈̈kerlörmiger, winziger Kralle und daneben zwei verhreiterten hewimperten Borsten; im übrigen trägt das 3. Beinpaar nur gewöhnliche, unbewimperte Spitzhorsten. 


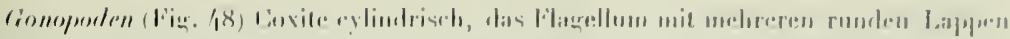

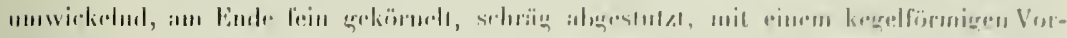

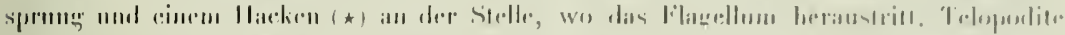

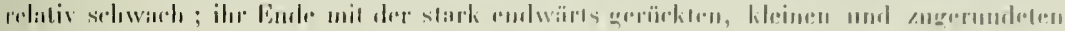

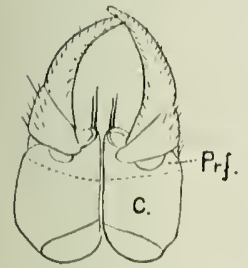

Nig. 4ti.

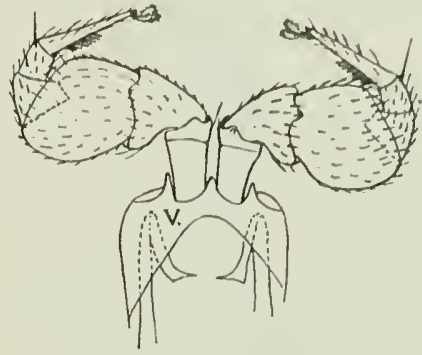

liig. 47.

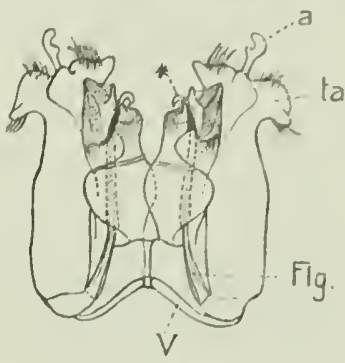

Fig. 48.

Stemmatoiulus debilis n. 8 p. $\%$

Fig. 46. Zweites Beinpaar von hinten. - Fig. 47. Uriltes Beinpaar von vorn, V. Slernit. - Fig. L8. (jonopoden von hinten, $v$. hintere Stange des Stützapparates (Sternit?).

Apophyse (ta) eine Art Doppelkopf hildend; zwisehen den beiden höpfen rigg eine eigren(iimliche, schmale, am Ende zweihöckerige Apophyse (a) vor, an der sich müglicherweise: im aktiven Zustand das Coxil miltels des Häkehens (*) festhlammell.

Pricanalseqment mil 6 kurzen dicken Spiungrilfelı.

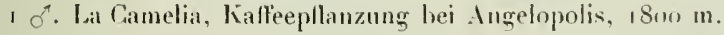

\section{Stemmatoiulus bogotensis $\mathbf{n}$. sp.}

$$
\text { (Fig. 32, 49-5í) }
$$

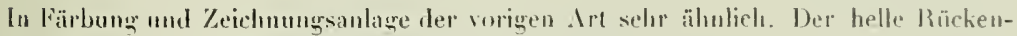
streil segmentweise nach hinton verbreitert unt nach vorn zugespitzt: die beiden suldorsalen Fleckenreihen sehwach hervortretend, aus kleinen Flecken bestehend, ron denen der äussere jeweils iu die helle Fïrbung der Seiten aufgeht; an letzteren steigh anf dem Prozonit ein graner Streifen etwas tiefer bauchwärts herunter. Beine dunkelgran.

Länge : $15-20$ mm. Bretite: $2-2 \% \mathrm{~mm}$.

Segrmentzaht: 44-48 $\mathrm{mm}$.

Der Körper ist beim o $\mathrm{im}$ Bereich des Collums, des 2. und 3. Soyments stark verlickt.

Der Hinterand der Ringe ist erst gegen das Hinterende des körpers etwas deutlicher gezïhnt. Praeanalscgment mit 6 Spinngriffeln.

Gnathochilarimm des o von der gewöhnlichen form: dasjenige des of (Fig. 49 mil llachdreieckigem Mentum, üher welches die Basis der Zungenplatten leicht ühergreift. 
Zungenplatten nich gestreift, Stipites nicht punktient. Zwiselıen den äusseren Zungenplatten und der Gula liegt cin taches Plätichen, dis entweder den vordern Angelstück entsprich oder das durch die Anselehnung der Zungenplatten abgetrennte Ansseneck des Ventums vorstell. Das Postmentum (o) in ciner nach imen gerichteten Spitze endigend.

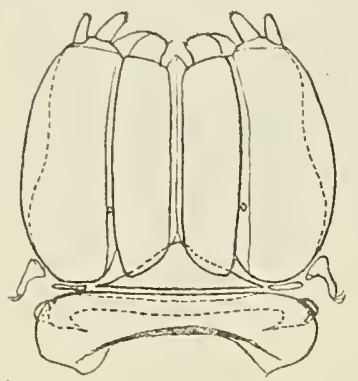

Fig. 4.4.

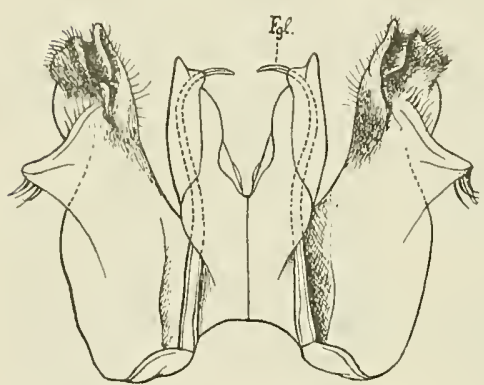

Fig. 52.

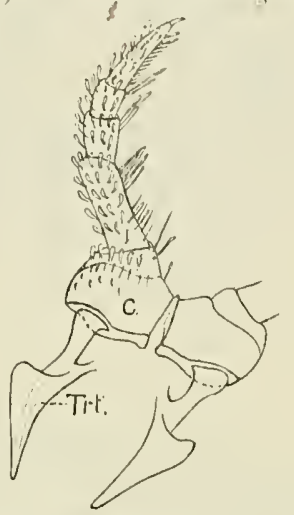

Fig. 50 .

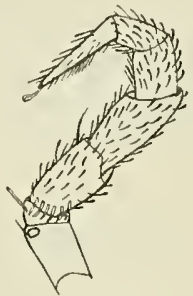

Fig. 53.

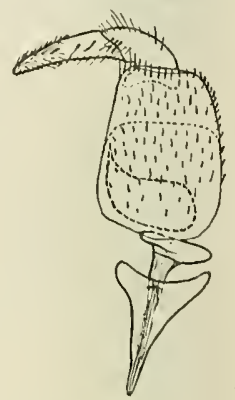

Firs. 51.

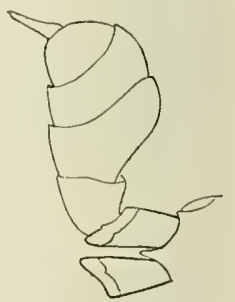

Fig. 54.

Stenmatoiulus bogotensis n. sp. of.

Fig. 19. Gnathochilarum von unten. - Fig. 50. Bein des 1. Paares von vorn. - Fig. 51. Bein des 2. Paares von vorn. - Fig. 52. Gonopoden von hinten (Stiatzapparat weggelassen), Fgl. Spitze des Flagellums. - Fig. 53. Bein des 3. Paares. - Fig. 54. Anormales Bein des 3. Paares (Beborstung weggelassen).

Das ı. Beinpaar des of (Fig. 5o) trïgt auf der Vorderlläche alter Glieder, mit Ausnahme der Häfte, zahlreiche, kurzogesticlte, löffelförmige Borsten mit fein bewimpertem

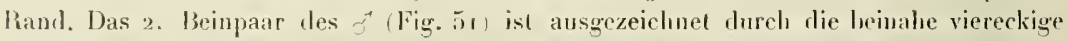
Gestalı des im distalen Teil stark von vorn nach hinten komprimierten hasalen Doppelglieds, dessen gleichnässig schwachgebuchteten, inuen und aussen etwas rundlich vorspringenden Endrand morl dessen zimolich dichten Besatz von kurzen verbreiterten Borsten. 


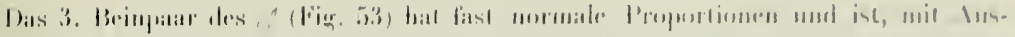

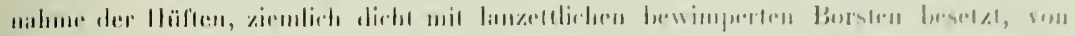

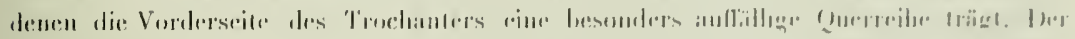

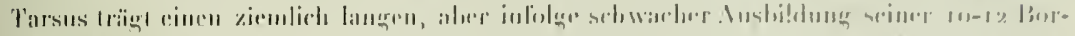

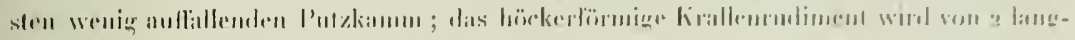

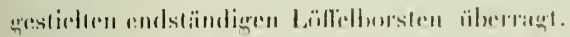

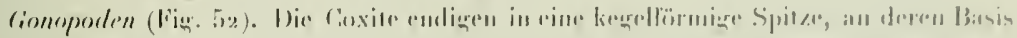

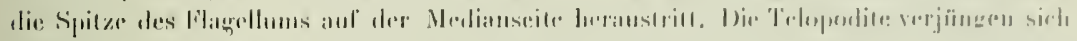

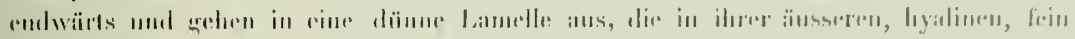

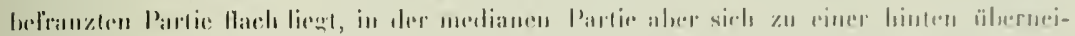

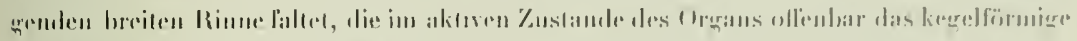

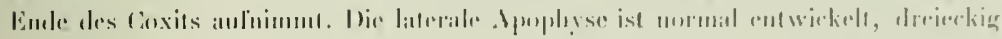

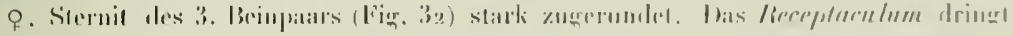

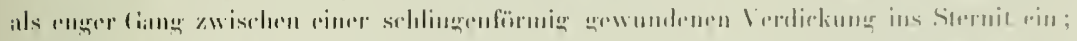

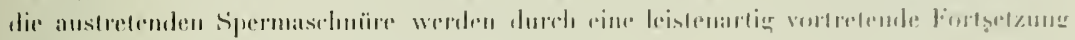

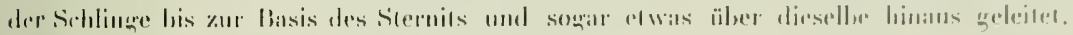

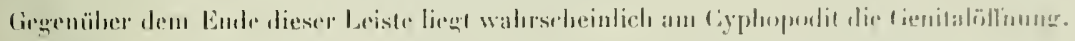
$\therefore$, IBogutal, a(im m.

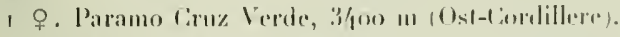

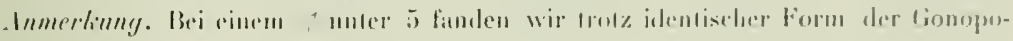

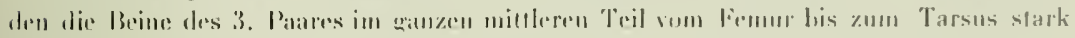

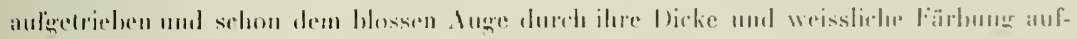

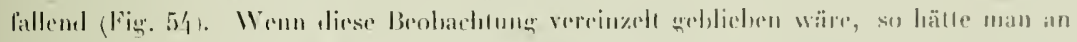

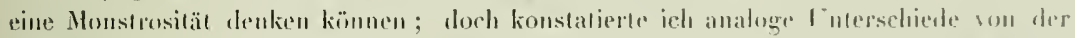

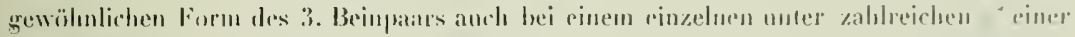

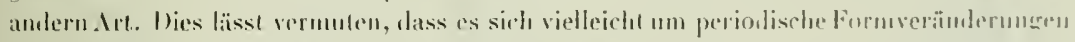

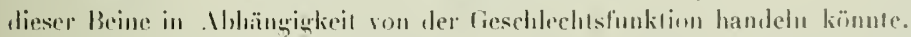

\section{Stemmatoiulus major $n . s p$.}

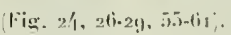

Weniger fleckig als die ülnigen Arlen, indem der läirken von ciner brèten dunklen Längshonde eingenommen ist, die nur won einer sehr feinen, Lellen Medianlinie durchzagen wird. Die Sciten sind weit hinaul grcichmässig aufgehell. gelb ader gelblrann, aher meist mil einem rom Rëcken mehr oder weniger weit hemntersteigenden, diffus dunklerem Streifen anf jedem Ring. Eine subdorsale Fleckenrilue is zwar angedentel, tritl aher nur sehr sehwath hersor, weil die filecken mil der vorderen hedlen Zone der Seifen zusammenhängen und diesethe bis zum Porus hinauf verlängern; erst im hintern körperteil wird die dunkle dorsale Zone breiter und schliesst eine undeutliche 


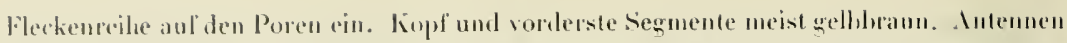

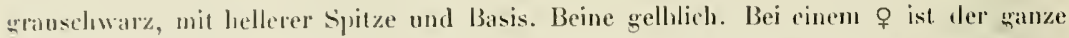
lïrper sint dem liopf grauschwar, mit je einem bellen Pünktchen vor jedem Porus und weisslichen Beinen.

Grösser als die übrigen columbischen Arten. Längुe: 35-40 mm. Breite: 3-31 „2 $\mathrm{mm}$.

Segmentzahlıl: 50-52.

Das Vorderende des kïrpers is anch beim of nicht verdickt.

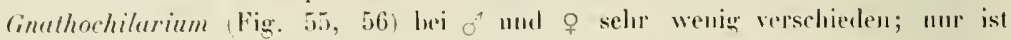
dasjenige des ơ etwas breiter, mil relativ breiteren stipites und im Verhältnis zu den Zungenplatten kürzerem and stumpferem Mentum. Diese Irt hezeidhet somit den Infang in der Ungestaltung des männlichen Ginathochilariuns.

Am. 1. Beimpar des $\sigma^{-1}\left(F_{g} .57\right)$ ist die vordere und obere Fläche vom Eude des

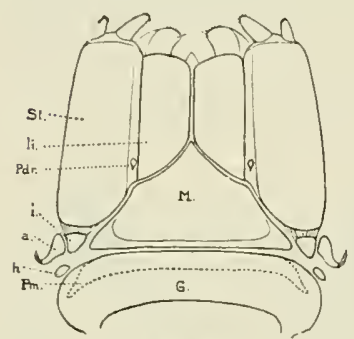

Fig. 55

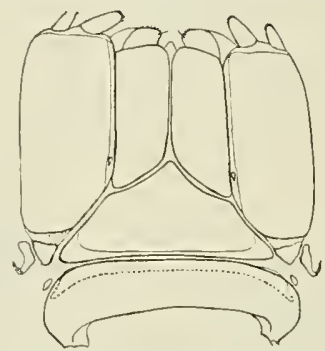

Fig. 5f.

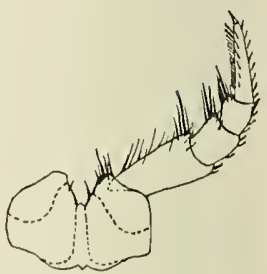

$1 \mathrm{ijh} .37$.

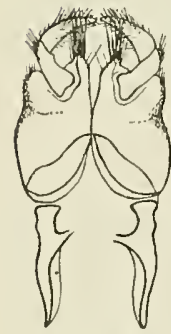

Fig. 58 .

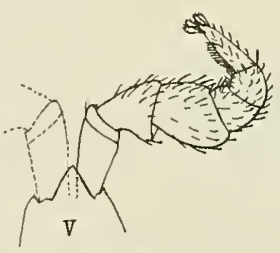

Fig. 59.

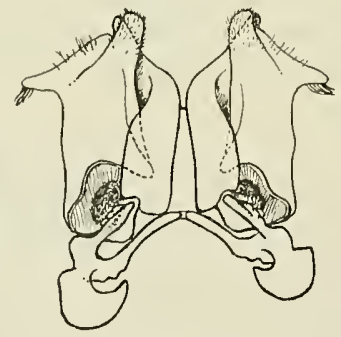

Fig. (io.

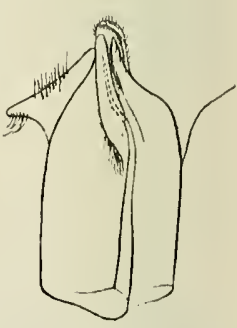

Jig. 61 .

Stemmatriulus major" n. sp.

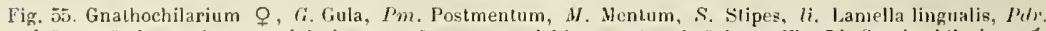
Putzdrüsenmündung, $i ., a$. und h, inneres, ausseres und linteres ingelstiick. - Fig. 5li. Ginathochilarium ${ }^{\circ}$ Fig. 57. Erstes Beinpaar von hinten. - Fig. 78. 7weites Beinpaar ron hinten. - Fig. 59. Bein des dritten Paares $0^{7}$. - Fig. 60. Gonopoden von vorn, mit dem Stützapparat. - Fig. 61. Ein tionopode oline Stiitzapparat von hinten. 


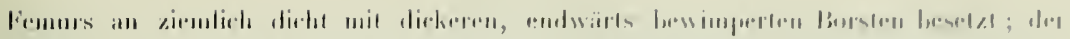

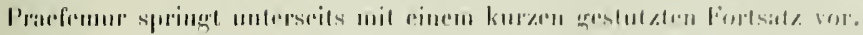

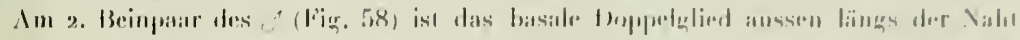

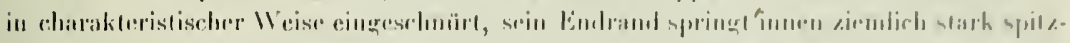

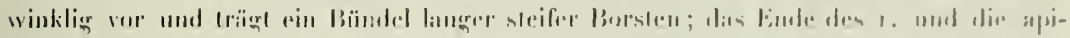

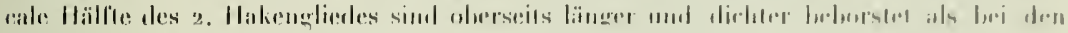
ïlurigen columbiseluen Arlen.

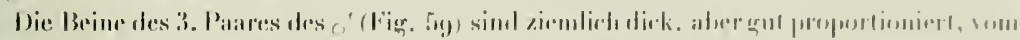

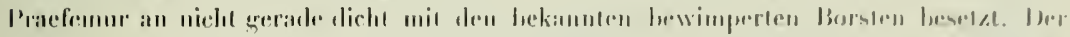

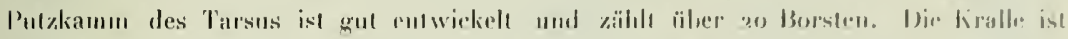

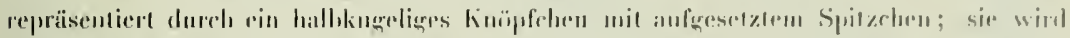

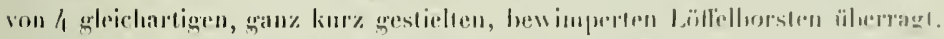

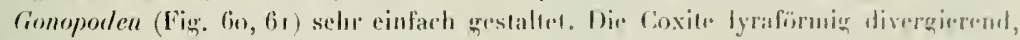

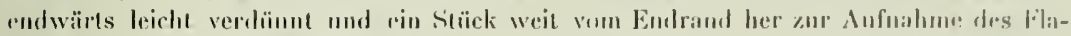

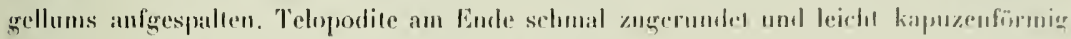
üher das Ende der Coxitr nach histon öbergebogen.

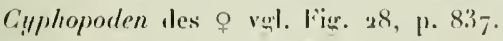

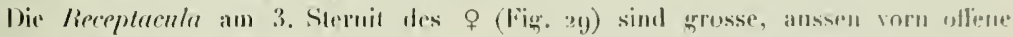

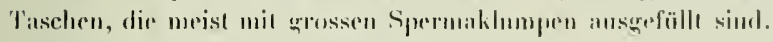

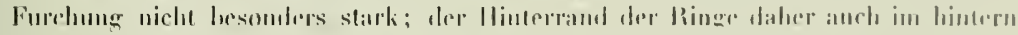

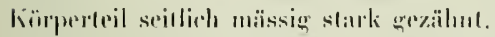

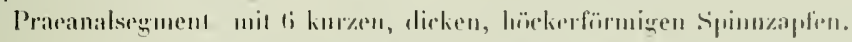

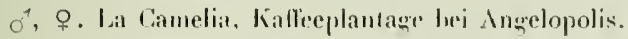

Unter den columbischen Stemmatoinlas-Arten ist dir vorliegrende schon änsserfich

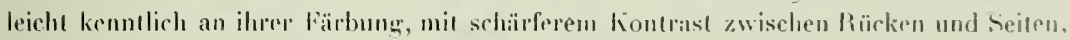
an iltree bedeutenderen Grïsse und höheren Segmentzahl.

Morphologisch ancist sir sich als cine der am weniegsten writ difterenzierten, mit Räcksicht auf die ganz geringen sexuellen Differenzen im Gnathochilarum, die einfache Gestalt der Gonopoden und die primitive Form der weiblichen Receptacula.

\section{Stemmatoiulus fuhrmanni n. sp.}

(Fig. 2.5, 30, 33. 3\%, 62-64).

Die Färbung ist last genau wie bei St. horlensio, mu ist die dorsale gelbe Merlianlinie elwas sehärfer und kaum theckig verbriter, und siud die sciten etwas heller.

Länge : 22-25 $\mathrm{mm}$. Breile : ${ }^{1}{ }^{\mathrm{g}}$ bis $2 \mathrm{~mm}$.

Segmentzahl: 47-5o.

Vorderende des lï̈pers bein schwach verilidkl.

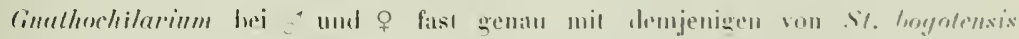
(Figr. 25 und /9) ïhereinstimmend, somil heim chedeutend umgestalee. 


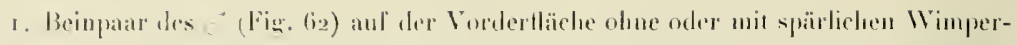
lorsten; der Tarsus mit zwrireihigem P’utzlatmm.

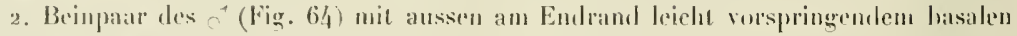
toppelylied, das immen apical mehrere feine, lange Borsten trägt.

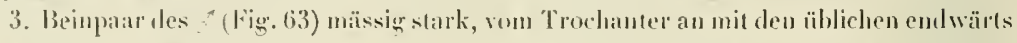
fiedrig bewimpren Borsten lesetzt; der Tarsus mit gut entwickelten Putzkanm ron 'twa 1' Borsten; Kralle versehwmuden his aul' ein winziges, nur bei sehr starker Ver-

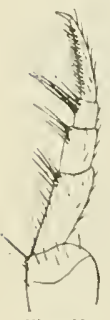

Fig. 62.

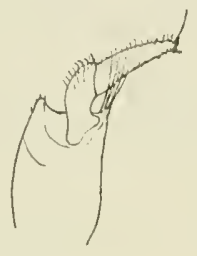

Fis. 63.

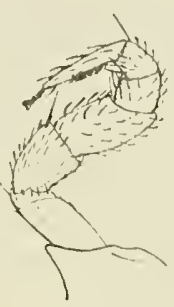

Fig. 61

Stemmaloiulus fulmanin. sp. 5 .

Fig. 62-6i. Bein des 1., 2, und 3. Paares. urösserung nachweisbares Ilëkerchen; an Tarsusende inserieren a schlanke langerestielte Löflelborsten.

Gonoporlen (1ij.y. 33). Die Cuxile sind leicht comprimierte, an Ende schräg gestulzte Cylinder, die das Flagellıun einwicknlı. Die Tropodite versclımälern sich lıalsarlig hinter der Mitte und verbreitern sich dann wieder zu ciner rundlichen Platte, die sich in ihrem medialen Teil hinten in eine sagillal zu ihr gestefte, nach hinten liermutergehogene Lamelle auszielı, welch letztere mit einer leicht hakig nach inmen gokrümmten Apophyse rine hreite Rinne

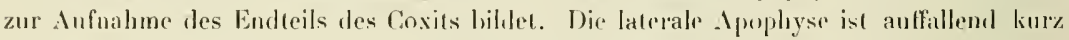
und lreit, trapezförmiğ, mit sanft ugehuchtetem Aussenrand. Der basale Tril der Gonopoden ist schon in der Einleitung zur Gruppe beschrielen worden.

Die Receplacula am 3. Sternit des o (Fig. 30) sind dargestellt durch eine innere Hölılung, die von ciner basalwärts otfenen hufeisenförmigen Verdickung begrenzl tvirl, deren änsserer Schnkel kïrzer und am Ende zugerundet ist, während fler innere als schräge Leiste die Vorderllïche des Sternits ïherragl und sich his zu dessen Basis fortsetzt. Der ganze Seitenrand des Sternits ist wulstig verdickt.

Praeanalsegment mit 6 Spinnzapfen.

Scluäge furchung der linge wie bei den ührigen Arten; lingegen treten neben den Schrägfurchen, namentlich auf dem Rücken, noch kurze seichte Längsstreifen oder kiritzeln and.

s, ㅇ. Tambo, am Westhang der Sabana von Bogota, ca. zoon m.

1 ㅇ․ Bogola, 2600 $\mathrm{m}$.

Wie bei der naluerwandten Art St. hogotensis, so fand sich auch hier unter elwa 10 - eince, bei welehen die Beine des.3. Pate's auflatleml stark verdickt sind und zwar in ganz ähnlicher Weise wie bei St. bogotensis (val. Fig. 5\%). Die Conoporlen und das 2. Brinpaar sind ganz normal gestalter; lingegen trägl das 1 . Beinjaar vorder- mol wherseits viel zahılreichere und stärkere Wimperborsten als gewöhnlich, elwa so wie bei 


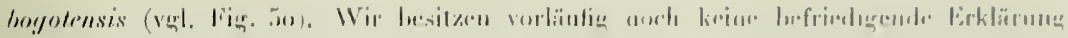

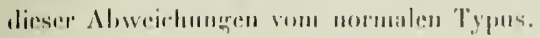

\section{Gruppe Nannolenoidea.}

\section{Fam. Nannolenidae.}

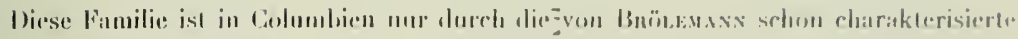

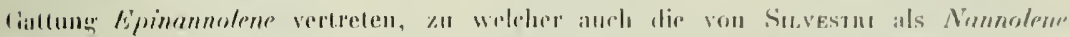

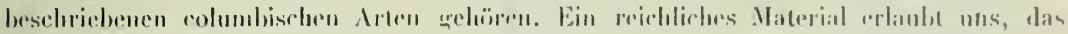

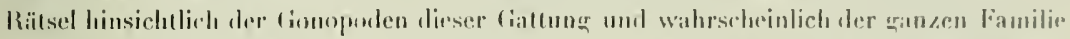

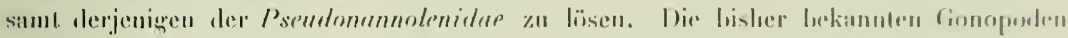

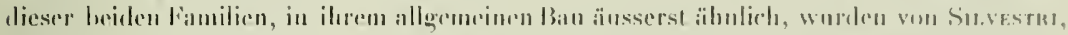

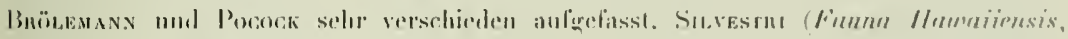

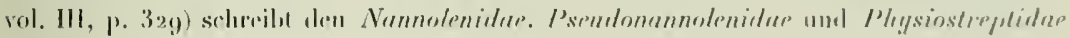
nur cin fonoporlenpar zn, whe zu bestimmen, welehem Beinpant des 7 . Secrmentes

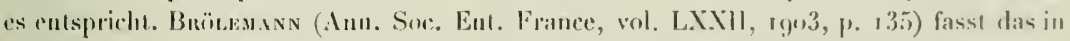

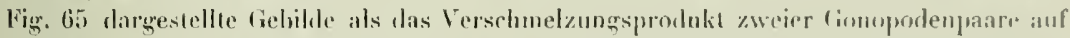
und glanbe nach Analogie mit den Spirostreptiden in dem die Samenrinne fülarenlen

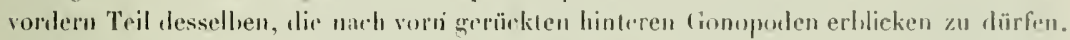
Pocock hingegen vermutel, es handle sich nur un cin cinfarhes fionoporlenpar und zwar um das hinfere Parar des 7. Sermentes, während das vordere Paar unterdrück wïre. Beide letzteren Interpretationen sind nurichtig. Die lis jotzl heliannten Grunopulen ron Pseudonannolene und Epinannolene stellen ein cinfaches Gronopodenpraur

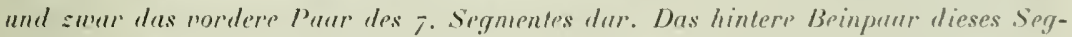

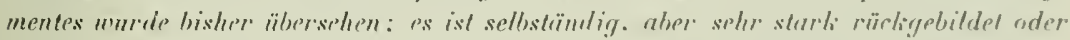

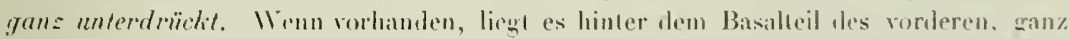

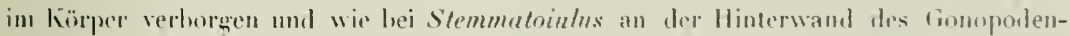
sackes. Bei Epinamolene fuhrmanni, wo ich es zuerst an einem durch Macerieruner in Kalitange erlangten Prïparat enteckle, hestehen die hinteren Beine des 7 . Serments (Fig. 66) ans einem dreighindrigen Stummel, der anf einer Wagrechten Chitin-

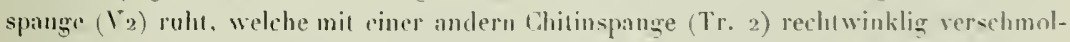

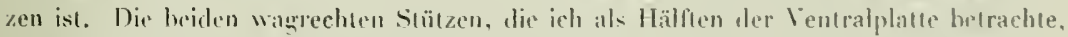
lıängen in der Nlille dureh eine Yembran zusammen. Der ganze Stïlyapparat ist relativ gnts ausgehildet und demjenizen der Gonoponlen sehr ähnlich.

Bei ciner Art des Gattung Psemlonumoleme. aus Brasilien, fand ich dieses hintere Beinpar wieder und zwar in noch rulimentärerer Form. indem hier nur ure chitincese 


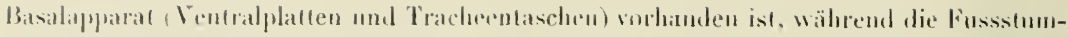

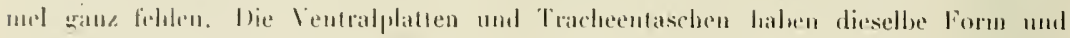

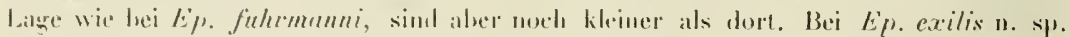
rndlich konnte ich es äberhaupt nicht nachweisen; wahrscheinlich ist is hei den meisten Cannoleniden und Psendonanoleniden ganz verschwumlen.

Sowolıl bei Epinannolene ats bei Psendonamolene handelt es sich also, anch wo Rudimente cines hinteren Pares nicht mehr nachweisbar sind, um ein einfaches Beinpaar,

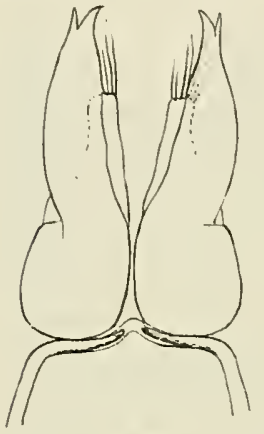

Fig. 65 . das als Conopoden funktioniert, und zwar um das vordere. Diese grosse Lehereinstimmung zwischen den lieiden Generiı

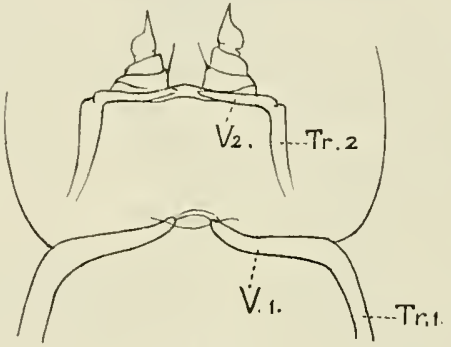

Fig. 66.

Epinannolene fuhrmanni n. sp. o. $^{\text {. }}$

Fig. 65. Gonopoden von vorn. - Fig. 66. Rudimentäres hinteres Beinpaar des 7 . Segments mit Ventralplatte ( $Y$ \%.) und Tracheentaschen $(T r$. 2.), auf die basale Partie der Gonopoden projeziert, um die Grössenverhâltnisse und Lagebeziehungen zu zeigen; 1 . 1. nnd $T r .1$. Ventralplatte und Tracheentasche ier Gonopoden.

Berechtigung einer Familie Nannolenidae bleibt daher bis zul hesseren Kenntuis der Gattung Vannolene zweifelhaft. Falls letztere den Cambalidae angehört, wohin I Trems sie grestellt hat, so inuss Epinamolene entschieden von diesen abgelrennt und je nach der taxomomischen Wertschätzung des Gnathochilariums den Psendonumnolenidue zugerechnet oder zum Typus einer eigenen Familie gemarh werten. Mit letzleren zusammen bildet sie pin äusserst wichliges Glied im System. Tachulem festgestellt ist, dass die die Samenleitung austïlırenden (ionopoden den vordern Beinpaal des 8. Seaments entsprechen, und dass das hintere Par entweder ganz verschwunden oder in Rudimenten vorhanden ist, die es als ein eingesenktes und atrophiertes Laufbeinparar erkennen lassen, können diese beiden Gattungen nicht wie bisher zo den Opisthospermophor gezählt werden.

Obgleich Vemoeff in seinem neuesten systematischen Versuch den Begritfen ProLerospermophora und Opisthospermophorn einen vom frülseren wesentlich verschiedenen Sinn und Inhalt gilı, bemöht er sich doch, für die Gruppen der letzteren Ordnung die Opisthospermie theorelisch nachzuweisen. Trok ihrer vielfachen Beziehungen zu den 


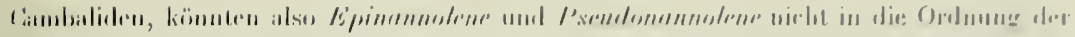

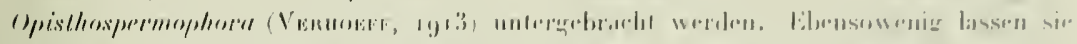

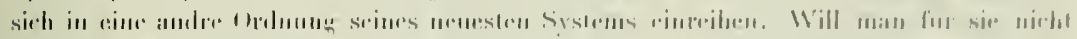

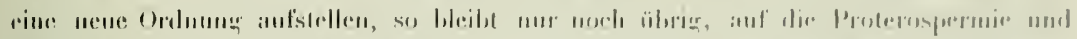

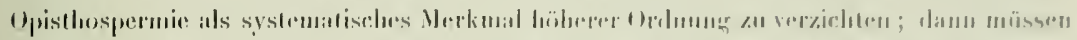

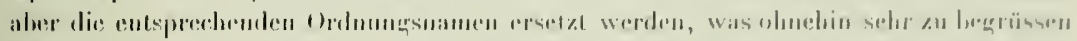

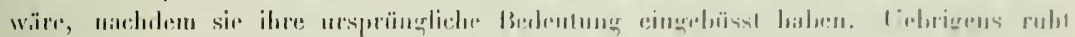

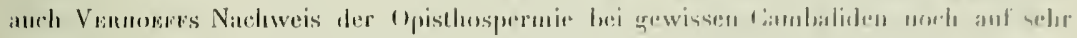
schovachun Pïssen.

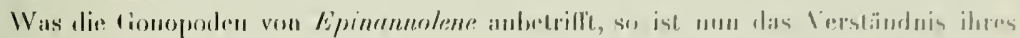

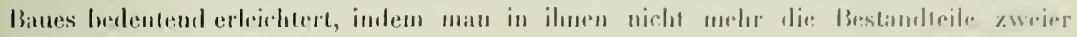

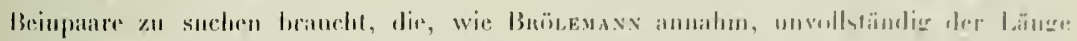

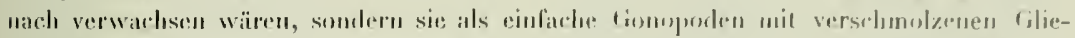

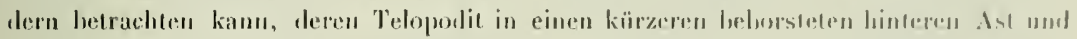

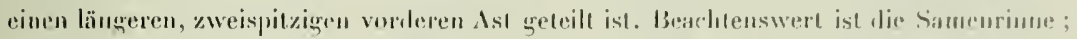

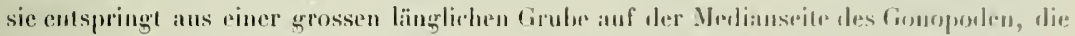

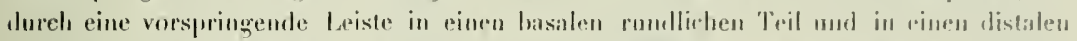

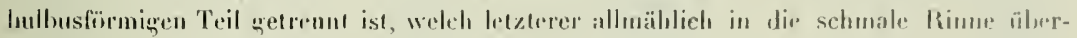

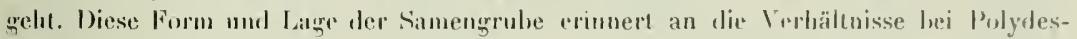

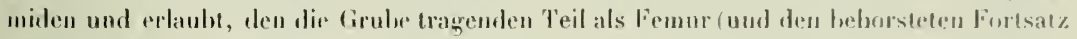
als Schenkelfortsatz) anzusprechen; der vordere zweiästige Ludlappen wäre demnaclı der

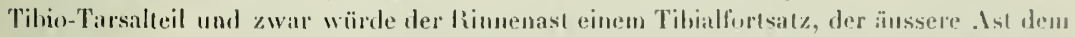

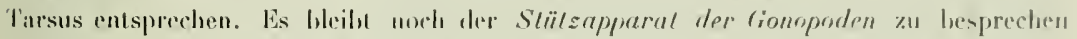

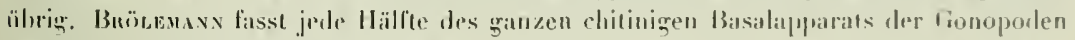
von Epinannolene als Tracheentasche und mu die kleine mediane Viembran als die Ventralplath auf. Auch in dieser Hinsicht ist das rudimentäre hintere Beinparar des 7 . Segments von Ep. finhrmanni o sehr instrukliv, indem bei ihm die beislen Schenkel jeder Spange noth ihre urspringliche rechtwinklige stellung zu cinander bewahrt haben und ihre Verschmelzung am Winkel noch sehr gut angedeutel ist. Narh Inalngie mil diesen

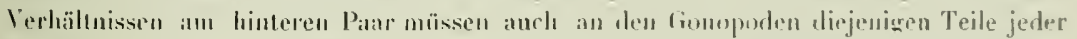
Syange, die siclı an die Basis der (ionoporlen aulegen, als I älften der Ventralplatle angesehen werden. Ein. Verschmelzung der letzteren mit den Tracheentaschen zu einem Stück ist von Itтемs fïr viele Cambaliden nachewiesen. Derselbe futor konstatierte neuerdingrs eine nur membranëse mediane Verbimdung der mil den Tracheentaschen verschmolzenen VirnIralplattenhälfen bei den hinteren Gonnpoden der Cambalide Dinncambala ingens . Iтт. (Founa Südwest-Australiens, BI. III. S. rg2. Fig. 721 .

In allen diesen Verhühussen sind die Gonopouten der Epinannolene-.Irten sehr ein-

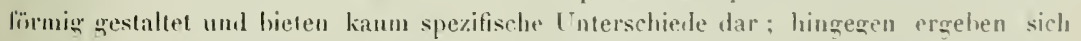

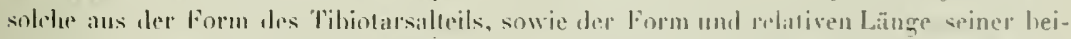

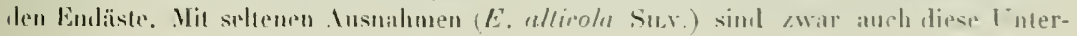


schiede sehr gering und whe \%eirhmungen kaum darstellhar, erweisen sich aber dafïr als selur konstint.

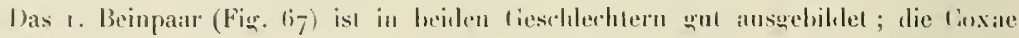
sind mit der Ventralplatte zu einem Loxosternit versehmolzen, dessen vorderer hasaler laand stärker verdickt und chitinisiert ist. Beim ragt das 2. Glied rorn mil rinem grossen Lappen hasalwärts über den distalen Rand des Coxosternits herunter, wie hei vielen Cambaliden.

Das 2. Beinpair (Fig. 68) ist ebenfalls 6gliedrig, mil stärker gestreckten, median getrenuten, aber basalwärts ohne scharfe Grenze in die Ventralplatte iibergehenden IIült-

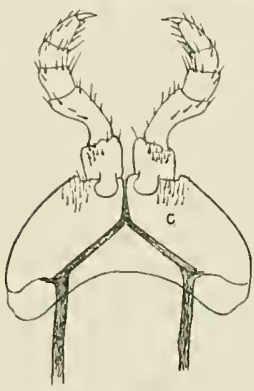

Fig. 67.

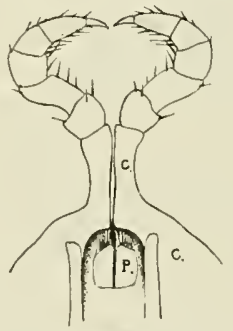

Fig. 68.

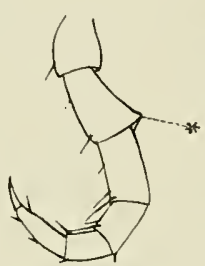

Fig. 69.

Fig. 67. Epinannolene fuhmanni n. sp. $\sigma^{4}, 1$. Beinpaar von vorn, C. Coxa.Fig. 68. Id. 2. Beinpaar von hinten, P. Penis. - Fig. 69. E. exilis n. sp. $q$, Bein der voruern Körperhätfte, bei $\star$ firstartige Erhöhung des Praefemurs. seite der hasalen Platte liegen die Penes, in der Medianlinie durch eine Naht getrennte Platten mit heborstetem und von einem hyalinen Saum überragten Endrand. Ueber den Bauderweiblichen Cyphopoden konnte ich nicht die gewünschte Klarheit erlangen; jedenfalls sind sie sehr schwach entwickelt. Die folgenden lieine sind ehenfalls bgliedrig; der Trochanter ist rudimentär und versteckt. Eine Eigentümlichkeit bietet das 2. Glied (Prafenur) dar; es ist oben endwärts etwas firstartig erhöht und ragt am Ende als stumpfer Höcker (Fig. 69*) über die Basis des 3. Gliedes vor. Coxalorgane fehılen. Die Glieder tragen unterseits nur 1-3 Borsten; das 4. und 5. Glied der Beine des vorderen Körperteils, nii Ausnahme der vordersten, sind beim $\sigma^{-}$mit am Ende lanzedlich verhreiterten liorsten versehen, gewöhnlich in geringerer Zah, ausnahmsweise ( $E$. alticola) zahılreicher ; einzelne dieser Borsten können sich auch an Ende des 3. Gliedles vorfinden.

Die Antennen sind überall kurz.

Das Inalsegment ist auch selır gleichartig geform.

Die Quernaht ist hald glatt, bald mehr oder weniger deutlich punktiert.

Der Halsschild ist seitlich meist hreit und vorn stark gerundet, selten stärker verschımälert ( $E$. fuhrmanni n. sp.). 


\section{- xing \\ Epinannolene fuhrmanni n. sp. \\ (like. (bi-fir, 7', 71,)}

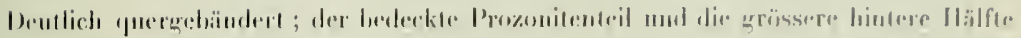

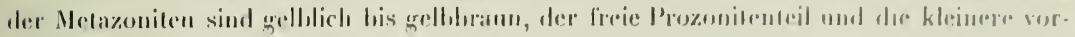

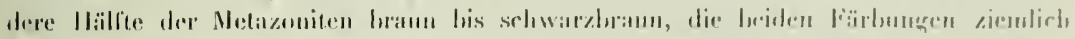

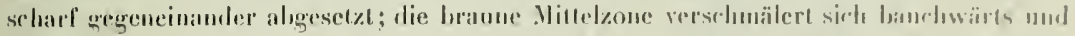

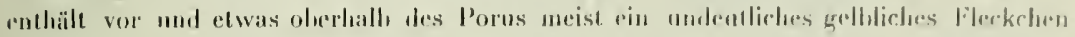

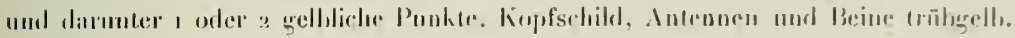

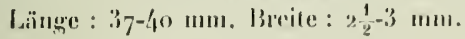

Segmentzalıl : 49-56.

Kürper am Hintrende kaun merklich verjüngt; der liopl und das lablum dirker als aler lïirper.

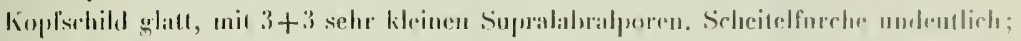

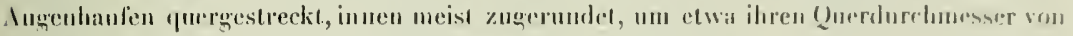

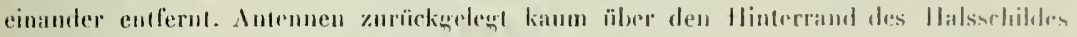
hinaustagend; ihr 3 . Glied etwas linger als das aweite.

Ifalssehilal ziculich weit lurmuterstoigend, seitlich stärker verschuälert als bei den ährigen Arten und ganz kurz symetrisch zugerundet, mil einer brciteren, lieferen Furche längs des Vorderrandes und 2 oder 3 sehr varialolen Cohrägfurehen auf der filehr.

Prozoniten in eingeschachrolten Teil mit sehr deutlichen, punktierten Ringfurchen. lireier Prozonitenteil und Melazoniten glall; letzleve mil Ansmalune der vordersien nur

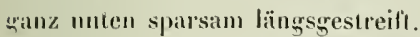

Quernaht ringsum als schmale, scharfe furche ausgebihlet, nich punktiert.

Safilöcher auf dem 5 . Segment beginnend, ziemlich weit ron der Quernaht, ctwan vor der Mille der Merazoniten und auf der Grenze zwischen der braunen und der acllylichen zone gelegen.

Ventralplatten nicht gestreift.

Die Beine des ơ tragen in der vorlern körperhälfte eine geringe Zahl (je 3-4) modificierter Borsten auf der I nterseite des 3., 4. und 5. Gliedes.

Analschuppe flach gehogen.

Die Gonopoden (Fig. 65, 70,71 ) sind endwärs almählich verschmälert und enden in zwei kurze spilzen; won diesen ist die äussere dornfömig, gerade: die innere ist stumpfer, etwas medianwïrts ungebogen und auf der Vedianseite mil einer stumpfdreickigen kleinen Lamelle versehen; ihrem medianen Rand enthang lïuft eine schmale sradlinige saumlamelte. Das lintere Beinpaar des 7 . Segmentes fïg. 66) ist in sehr rudimentïrem Zustand erhalton, jedes Bein stellt einen dreigliedrigen Stummel dar. dessen erstes Gilied auf der medialen Ecke eine Borste trägt und dessen 3. Glied in cine 


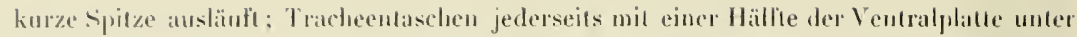
rechtem Winkel verschmolaen, die bejelen Häliten der Ventralplatte in der Milte dureh einc Memblun verhumden.

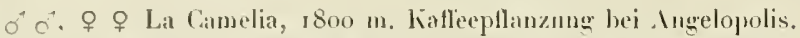

Bemerkenswert ist, dass bei einem of von kikeiner Statur $(22 \mathrm{~mm}$.) und mit nur 4.5 Segmenten, wovon die / letzlen lusslos sind, die Gonopoden bereits vollkommen entwirkelt und auch die modifieierten Borsten an der Lnterseite des 3.-5. Gliedes der Beine

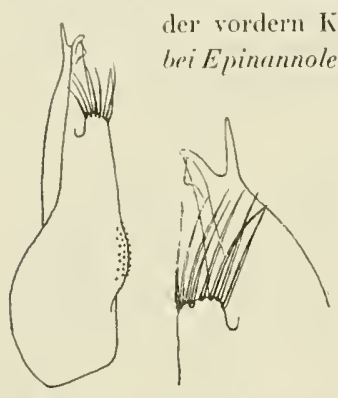

Fig. 71.
Fig. 70 .
Epinannolene fuhmanni n.sp. $\sigma^{\top}$. Fig. 71. Dessen Endteil, stäkervergrussert.

achslum eintrill. Ob dieses eingeschobene Siladium nu in böheren Lagen anftrilt und eine Verlangsammng des Wachstums infolge des Klimas vorliegt, muss erst dis Sludium von Epinannolene- Arten aus lieferen Lagen darLuin. Brölemann (Rev. Mus. Paulisla, V, Igo1, S. 106-114) hat eine solche Wirkung des Klimas verschiedener llïhenlagen auf die Entwicklung der tropischen Diplopoden angenommen und die von ilum enteckten unreifen Stadien von Spirostreptus und Rhinocricus hinsichllich der Irsachen mil den in lö̈seren Lagen auftretenden Schaltstadien der pralaparktischen Juloidea in Parallele gebrachı. Mir scheint diesis frage mol nicht spmulareif. Dic Beohachung eines dem ohigen von Epinannolene heschrichenrn sollkommen vergleichbaren Stadiums lwi riner RhinocricusArt (K/. monilicornis Poc. ?) aus Haïli, lässt miclı rermuten, dass diese Ausbildunr der Gonopoden (wenigstens des I. Paares) vorvollendetem Körperwachstum hei tropisehen Diphlıpolen eine viel allgemeinere und von äusseren Verhälınissen unabhängige Erscheinung sei.

Inser Stadium ist den von BrüLemanx beobachteten nicht alssolut vergleichbar, insofern bei jenen die Gonopoden nicht vollstüudig ansgebildel waren; man könnte es aber als ein noch weiter vorgerücktes Jugendstadium hetrachten oder aber die frühere morpholıgische Geschlechlsreife darauf zurüekführen, dass hier nur das vordere Gonopodenpar zur Ausbildung kommı, welclses anch bei Rhinocricus asper Bı̈̈. dem hinteren vorauseilt.

\section{Epinannolene exilis n. sp.}

(lig. $6 y, 71-7$ i.)

Färbung sehr variabel; meist l, leichgell, mit bräunlichgelben Vetazoniten und zwe undeutlichen seillichen längsreihen bräunlicher fileckichen, wovou eine auf Porenhöhe, die andre weiter unten, kurz oberhalb der Beinansätze. Manche Exemplare sind fiss rinlärbig schwarzbraun. Kopfscbild, Beine und Antennen immer tueller orler dunkler trühgelb.

länge: $15-20 \mathrm{~mm}$. Breite: $1 \mathrm{~mm}$. 


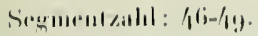

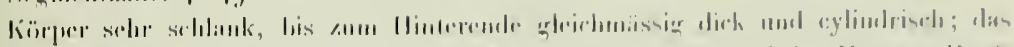

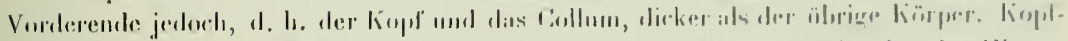

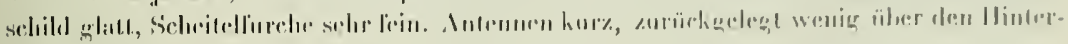

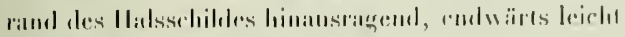

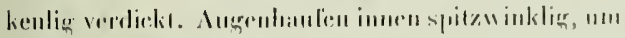

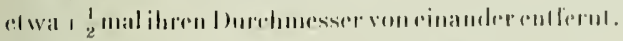

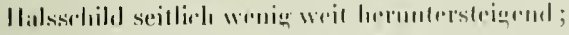

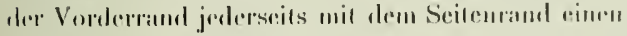

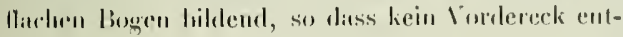

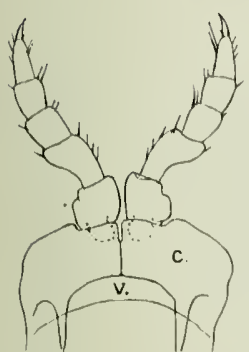

Fig. 71 .

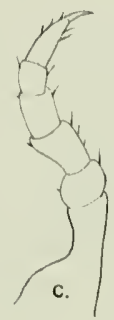

Fig. 72

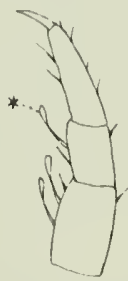

Fing. 73

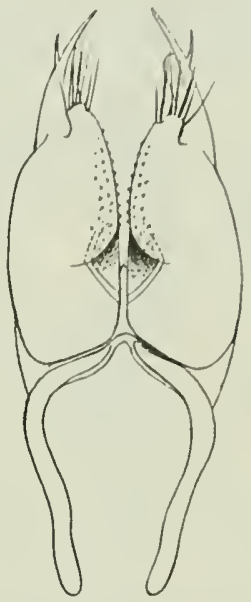

Fig. $i$.

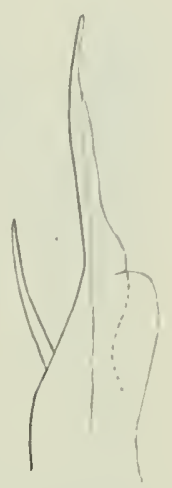

liig. is.

lipinannotene exilis n. sp. - "

Fig. 71. Beine des 1. Paares von hinten. - Fig.72. Bein des 2. Paares. - lïg. 73. Bein des.5. Paares, Endglieder, * spatelfürmige Borste. - Fig. 7h. fionopoden von hinten. - Fif.75. - Endleil eines Gonopoden, vielstärker vergr.

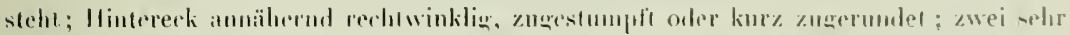
schwach aulsteigende Furrleut.

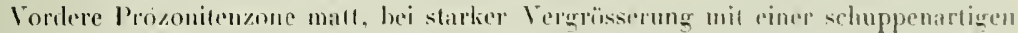
Shulptur, die dureh Anastomosirrung vicler feiner Ringfurelsen entsteht; der ganze unber-

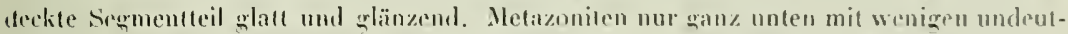
lichen Längsstreifen; nur auf den vordersten Sermenten reicht die streifung weiler dorsalwäts hinanf und sind die Streilen zahlreichur und dentlicher. Ouernaht ringsum gleichmässig stark, zienlich groh punktiert, deutlicher hervortretend als die sermenterenzen; die Metazoniten etwas höher als die Prozoniten. Saftlöcher relativ gross, anf dem 5. Segment beginnent, olverhalb der Mille der hörperscilen, entfernt von der Onernaht, etwas vor der Mitte des Metazoniten weleren.

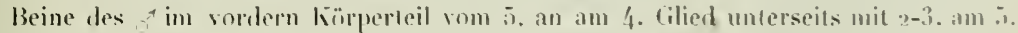

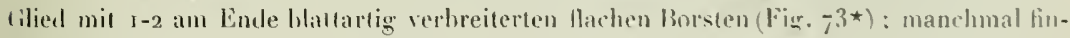
det sich eine solche anch am Eule des 3. Gliedes. 


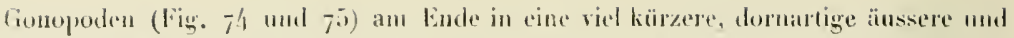
eine längere innere Spitze geteilı; letztere medialwärts his liurz vor den Ende von einer sehmalen, hyalinen Lamelle gresäumt und efwas weiter basalwärts eine breitere, gerumete Lamelle (ragent. Dis zweite Beinpar des 7 . Segments ist ginz versehwunden.

$\therefore$ 두우 Merlellin, 1 tion $m$.

An nitchsten ist diese Art mit L'. licormis BnöL. ', ans lostariea, verwandt, ist aber brdeutend kleiner als diese und hat an den Gonopoden einc im Verhälnis zur äussern

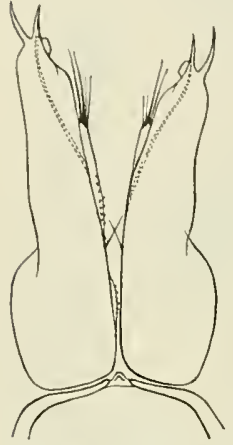

Fig. 76. - Epintennolene Lifasciata (Sitv.). Gonopoden von vorn (Originalex.). viel längere innere terninale Spize; letzteres unterscheidet sie auch ron E. bifusciala SiLr, deren (ionopoden im allgemeinen eine gestrecktere Form halien.

\section{Epinannolene bifasciata (SHA.).}

(Fis. $7^{6)}$.

Die Gonopoden dieser Art (Fig. 76 ) zeichnen sich aus durch ihre gestreckte Gestalt und ilıre vom Basaldrittel his kurz vor dem Uebergang in die beiden dornartigen. Aestchen annähernd parallelen Ränder; von den beiden Enddornen ist der ïussere etwas länger als der innere; an der Basis des letzteren springt merlialwärts eine kteine trapezoidale Lamelle vor. Die Art steht E. bicornis BröL., von Costarica, und E. exilis n. sp. sehr nahe.

1 \& Argelia, Kalfepllanzung hei Viota, $1600 \mathrm{~m}$. Silvestets Exemplare stammten vom Alto M. Sibaté, $2800 \mathrm{~m}$, ron P’aranco, 3300 in., und Bogota.

\section{Epinannolene alticola (StLv.).}

(Fig. $\left.77,7^{8}\right)$.

Durch die Gonopoden und Beine des weicht diese Art von alten ïlırigen bisher bekannten Epinannolene-Arten viel stärker ab als letztere unter sich. Die Zahıl der modificierten Borsten an der Unterseite der Beinglieder 4 und 5 ist nämlich vieł grösser als sonst (Fig. 78); es sind ihrer je 10-15 vorhanden. An den Gonopoden (Fig. 77) ist der die Sameurinne führende innere Endast ansserordentlich lang und durch die Samenrinne der Länge nach in ein äusseres, chitinisiertes, sclımales Band und einen inneren, punktierten, membranïsen Saum geteilt, welch letzterer als wurmförmiger Fortsatz das Eude des ersteren ïberragt; der äussere Endast ist viel kürzer als der innere, aber immer noclı bedeutend länger als bei anderen Arten und dornförmig.

Paranco, 3300 11.; Alto M. Sibati, $2800 \mathrm{~m}$. ; Tequendama (Silvestri).

In ter Sammlung Fenusuas nicht vertreten.

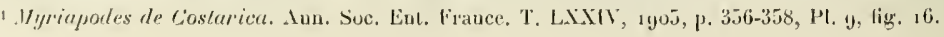




\section{Epinannolene nigrita n. sp}

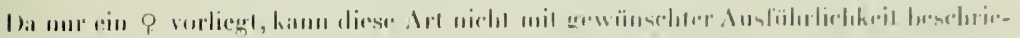
linen werdin.

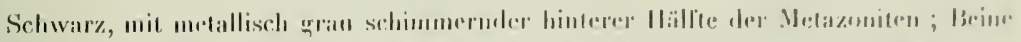

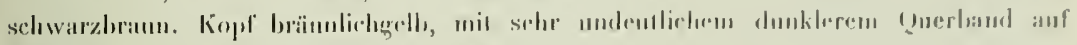
dem Sicheiled. Antennen hleiclegell, Malssehilal mil gellilichem Vorderrand.

Lïnge (niclıt grenan messhar) : ca. 2o mu.

Breite: I mm. Segmentzahl : 19.

Kople und IIalsschild verelickt.

lioptsehila rumzelign, mit merlorochemer Querfurclar zwischen den Unterrïmbru der Antemnengruben. q Suprabalualporen. Anyenturafen mirhl schmars pigmentiert, rerhï̈mmert, indem

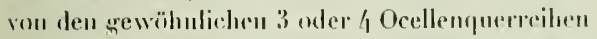
nur die oberste: mit starker Vergrössermug noch nachweisbar ist; sic zählt 5 selı flache grell,liche Deellen, die von aussen nach inmen an tirösse ahnehmen; ron der nädisten Querreihe ist nur die äusserste Ocelle nachwrishar. Antennen endwärts dendlich kenlien, kurz, nacl hioten zurousk-

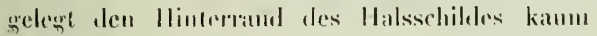
ïlurragend.

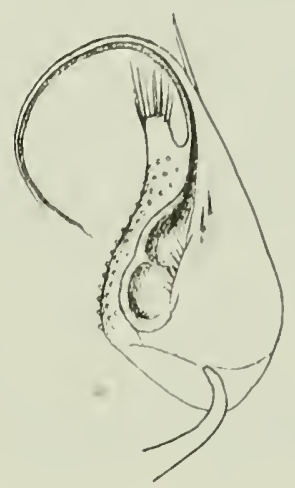

Figr. 77 .

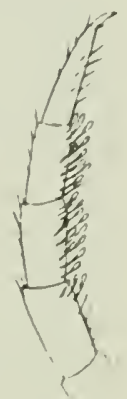

Fig. 78 ,

Epinumolene alticola (Silv.) (Hriginalexemplar l.̈ig. 77. Tionopode von der Medianseite. Fig. 78. Bein des M. Segments $\approx$, distale filieder

Halsschild seitlich sehr wenig schmöler als inf dem Rïcken; del Vorderrand gehr in regelmässiger Rundung in den leich sclirïg nach vorn aulsteigenden langen Scitentand ïber; llintereck rechtwinklig zugestumpft; parallel zum Seitenrand laulen zwei breite, gerade linrehen.

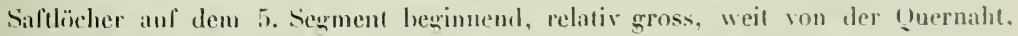
kurs vor der Mille der Metizoniten gelegen. Segmente glatl und glänzend; die Streifung der Metazoniten wie grewöhnlich stark reduzier'.

Quernaht ringsum scharf und deutlich punktiert, besonders seitlich unterhalls der Safthicher.

. Inalsegment und Beine ohme Besonderheiten.

r q. Nlo San Miefuel, somo m. Contral-Cordillere. 


\section{Gruppe Spirostreptoidea.}

\section{Fam. Spirostreptidae.}

In seiner Bearheitung ter Diplopoden Central-Amerikas' hat P'ocock die in der generischen Vomenklatur der amerikanischen Spirostreptiden herrschende Verwirmon teilweise aulghehoben und gezeigh, welchen BröLEvaxvschen Lnterqattungen die von Savesти eingeführten Galtungsnamen entsprechen. Letzteren muss leider die P'rioritäl vor den viel besser hegrïndeten und dureh viełe Abhildungen erlänterten Brö́tesaxsschen Vamen zuerkannt werden. Wie weiterhin qezeigt werden soll, betrachte ich übrigens alle diese Vamen nur als provisorische Bezeichnungen für Gruppen verwandter Arten. Die Spirostreptiden-Ansheute in Columbien ist zu gering, un uns eine Pröfung einiger ron Pocock nicht weiter interpretierten Silyestrusehen Gattungen zu gestatten. Wir mïssen uns begnügen, das Verhältnis zweier in Columbien vertretenen und bei Pocock nicht erwähnten Gattungen darzustellen. Isoporostreptus SiLv. ${ }^{2}$, von dessen Typus I. villicola Sisv. wir die Cionopoden untersuchen konnten (Fig. 81), weist genau denselben Bau der hintern Gonopoden auf wie Epistreplus (z. B. E. ehlersi Silv., Fig. 82) und fïllı mit dieser Galtung zusammen; denn die übrigen von Silvestrı angregebenen Merkmale haben keinen generischen Werl. Vanostreplus Silv. ${ }^{3}$ soll sich von Archispirostreptus dadurch unterscheiden, dass die hintern Gonopoden rinästig sind. Allein bei $N$. incertelinealus Sisw. (Originalexemplar) geht von dem die Samenrinne führenden Stamm vor der Biezung der Rinne das Rudinent eines zwriten Astes ab, den Silvestu ïhersehen hat. Ein prinzipieller linterschied besteht also zwischen Archispirostreptns und Nanostreptus nicht und ebenso dülte Plusioporns Sus. nur ein Glied in der Redulitionsreihe des Coxaldornes darstellen. Dem Bau der vorderen und hinteren Gonoporlen nach stelıt ïbrigens $N$. incertefineutus SiLv. gewissen von BröLEMand zu Gymnostreptus gestellten Irten, z. B. Spirostreptus (Gymnostreptus) perfidus BröL. ' so nahe, dass cine Verteilung dieser Arten auf verschiedene Gattungen und selbst Untergattungen ganz ungerechtfertigt erscheint. Es kann also der Grad der Ausbildung des vor der Biegung der Samenrinne rom hintern Gonopoden abzweigenden Astes d. h. des Coxaldorns, resp. sein Fehlen, nicht zur Aufstellung von Gattungen oder Untergattungen verwendet werden. All die genannten Gruppenbezeichnungen, sowir Cladostreptus BröL. (das nicht, wie Pocock annimmt, Synonym mit Epistreptus Silv. ist) beziehen sich auf Spirostreptiden mit dünn auslaufendem Telopodit der hintern Gonopoden, deren Coxaldorn gut ausgebildet, verkïrzt oder ganz qeschwunden ist.

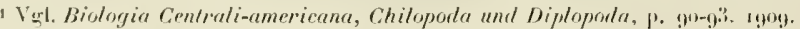

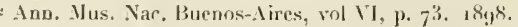

Jlyid., p. 7'i

SRrv. Musea Paulista vol, V., P. VJII, tig. 184, 185. 1901.
} 


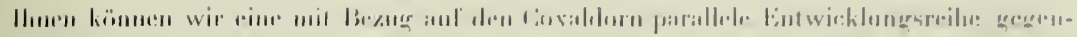

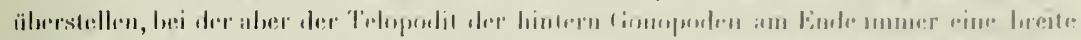

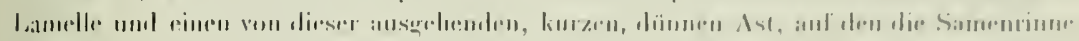

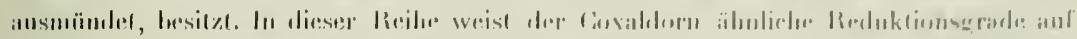

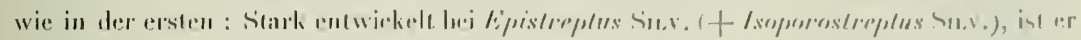

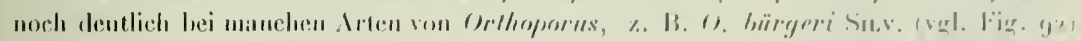

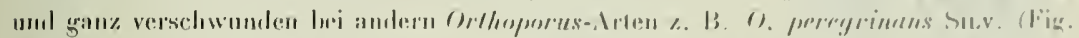

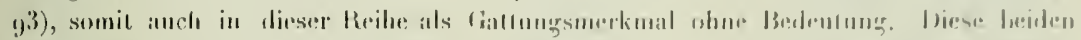

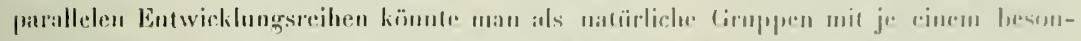

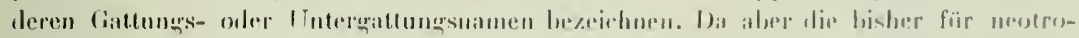

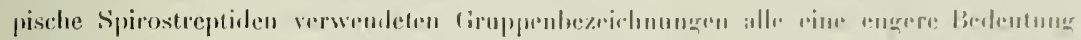

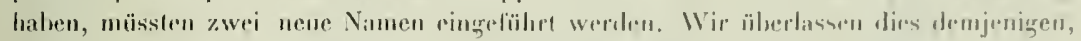

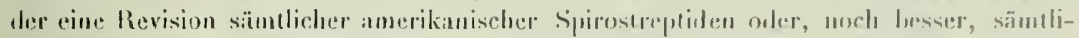
cher Spirostreptidon üherhaupl vormehmen kann, und begnïgen mo damit, auf ein uatürlicheres Einteilungsprinzip hingewiesen zu haben.

Um die Nomonklatur nicht noch komplizierter an grestalten, lwhalton wir fïr die

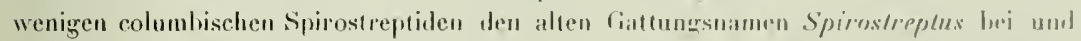

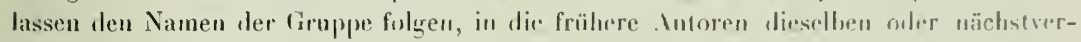
witudte $\Lambda$ iten eingereiht halken, ohne damit letztere als natürliche Gattungen oder l'utergatlungen anerkennen an wollen. Den Namen Jsoporostreplus hingegen lassen wir als Synonym mit Epistreptus gränzlich fallen.

\section{Spirostreptus (Epistreptus) ruralis n. sp.}

(1“ï. 79,80 ).

Fïrbung schwazbraun, mit heller braunen his gelbbraussen Prozoniten und oft rolem Minterrand der Metazoniten; Beine und Antennen gelb bis rothraun. I eber die Metazo-

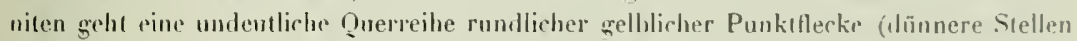
in iler Chitinwand).

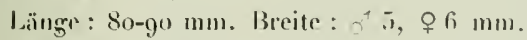

Siegmentzahl : 55-58.

Kopfschild rom mehr oder weniger stark serunzelt: Scheitel glatt, mit feiner Scheitelfurche. Antenmen kurz, zurïckgeleğt beim ơ wenigr, beim of kaum ïher den Hinterrand des Ilalsschildes hinauslagend. Augenhaufen schmal, innen zugespitzı, um etwas melir als ihr Querdurchmesser ron einander entfernt.

Halsschildseitenlappen vorn etwas bauchwärts eingedrückt, fast rechteckigr ; beim o mil etwas schärferem, fast rechtwinkligem Vorder- und zugestumpftem Hintereck, beim o mit etwas stärker zugerundeten Ecken, in heiden Geschlechtern mit 3 scharfen Schrägfurchen, deren oberste beim of fast gुerade, heim o mehr oder weniger S-förmig greschwungen ist.

10!) 
Prozoniten im bedeckten Teil mit ziemlich regelmässigen feinen Ringfurchen, die nach linten zu allmählich an Dichte abnehmen; in freien Teil denllich lén lederartig.

Metazoniten vorn noch fein lederartig, im übrigen fast vollkommen glatt, seitlich ziemlich scharf gestreift his etwas unterhalb des Porus herauf und zwar schräg und

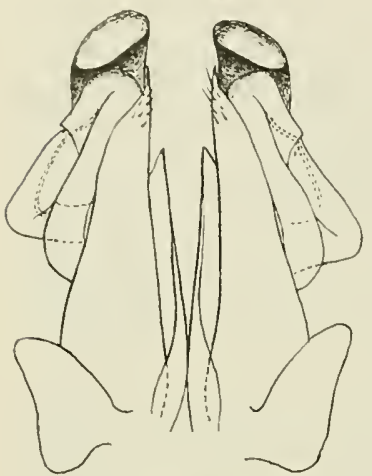

Fig. 79. dicht bauchwärıs, längs und weitläufiger rïckenwärts. Die Metazoniten sind elwas höher als die Prozoniten.

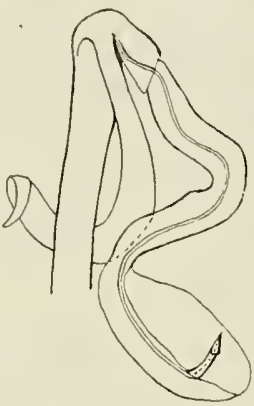

Fig. 80 .

Spirostreptus (Epistreptus! ruralis n. sp. o7.

Fig. 79. Gonopoden von vorn. - Fig. 80. Hinterer Gonopode.

Quernaht ringsum scharf und durch kur'ze IRippchen in ziemlich regelmässigen Abstäuden abgeteilt, vor dem Porus gerade, nicht ausgeloggen, hingegen auf dem Rücken äusserst seicht nach hinten ausgebogen.

Ventralplatten sehr fein, dicht und etwas verworren gestreift.

Analsegment oben in der Hitte nur schwach ausgezogen und stumpfwinklig zugerundet. Analklappen mil hohen, abgesetzten, stark rorspringenden, wulstigen Rändern, die aussen von einer hreiten, ziemlich scharf begrenzten Rinne begleitet sind.

Analschuppe rom ventralen Ringteil des Analsegments nicht abgegrenzt, nur durch einen sehr stumpfen winkligen Vorsprung am Hinterrand des letzteren angedeutet.

Beine mit nur je einem feinen subapicalen Börstchen am 1.-5. Glied und wenigen Borsten am Endglied; oberhalb der Kiralle ein längeres und ein kürzeres Dornbörstchen. Beim of trägt das 5. Glied aller Beine in seiner distalen Hälfte ein Polster; in schwächerer Aushildung findet sich ein solches auch am Ende des 4. Gliedes.

Gonopoden des vorderen Paares (Fir. 79) mit spitz endendem vorderem Blatt und am Ende zugerundetem und nach vorn übergeschlagenen Hinterblatt. Hintere Gonopoden (Fig. 80) mit langem, subcylindrischem, am Ende umgebogenem Coxaldorn und ziemlich scharf umgeknicktem, am Ende in eine elliptische Lamelle und einen Tibialfortsatz geteiltem Telopoditen.

Eundorte : La Camelia, $1800 \mathrm{~m}$., liaffeepllanzung.

Am Magdalena bei Jirardot, $250 \mathrm{~m}$.

Puerto de los Pobres, am Cauca.

Dem Bau der Gonopoden nach ist diese Art sehr nahe verwandt mit Isoporostreptus villicola Silv. und Epistreptus ehlersi Silv.; die kleinen Unterschiede ergeben sich aus dem Vergleich der Fig. 79, 80 mil Fig. 81 und 82. Von E. ehlersi unterscheidet sie sich schon durch den Mangel groher Skulptur auf den Metazoniten; I. villicola Sisv. (Origi- 


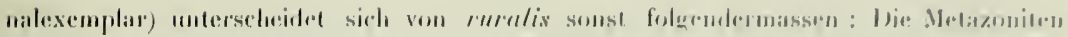

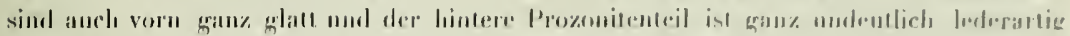
skuptiert; die Queruaht ist vor dem J'ortus schwath ansene-

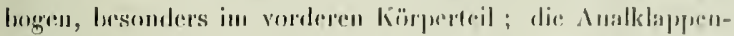
räuder springen viel schwiteluer vor', sind wenigen scharl

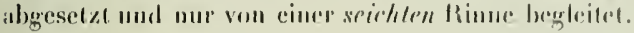

\section{Spirostreptus (Epistreptus) ehlersi Sinv.}

(liig. 8\%.)

Diese Art ist sehr lejeht aut der slarken Skulpur zu erkemnen: Die Prozoniten tragen in Ixoleckten Tril zathloviche lriue lingrlurelien, deren drei hintersten elwas schärfior sind und weiter anseinanderstehen als die zilnrigen; zwischen der letaten Ringlurele und der Qurrnalut sind sie fein und dicht

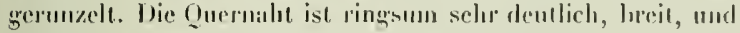
dichter gerijpt als hei der vorhergahenden Art. Dis: Matiszoniten lagen in Dorsalteil eine diehte und zienulich grobe Skulptur, die durch Combination von unregelmässiger, net\%-

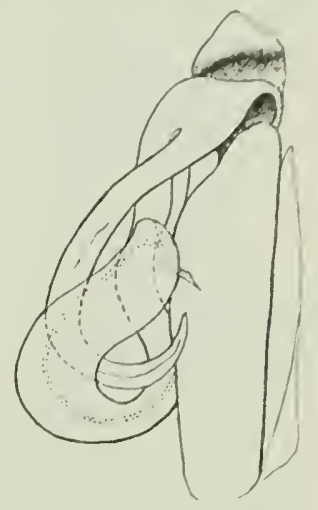

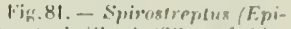
slreplus) villecola (Sils.) Linkes Gomopodenpaar von vorn (1)riginalexemplar).

förmign anastomosierendes Läugssunzelung und Punklierunğ zustande kommt. (Bci

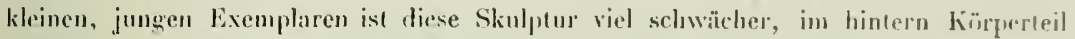
meist nur cine weilläufige Punkierung, in vordern körpertril schon ähulicher derjenien

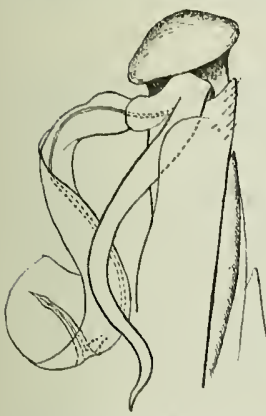

Fig. 82. - Spirostreptus (Epistreptus) ehlersi (Silv.). Linkes Gonopodenpaar von vorn. der erwachsenen, aber feiner und weniger verworren, mit Vorwiegen der Punktierungr). Die Seiten der Metazoniten siml lis zum Porus hinauf telativ dicht und scharf längssestreift: uherhalh des Porus verkürzen sich die Streifen rasch und verlioren sich in der liunzelung. Die l'oren liegrn ganz nahe an der (1unnalıt auf einem Jlachen Höckerchen. Das Inalswament lıat dieselbe Slutpenr wie die Metazoniten; sein Ventralteil ist mil . Iusnahue des distalen Driltels scharf quergefurcht, mit fast geradem Jintertand. Eine Analschuppe ist niclıt ahgegrenzl. Die .Inalkilppen sind feiner skuptiert, mit enlasten, ziemlich dicken, ahgeselzten, vorspringenden und aussen ron einer Rinne beqleiteten Endrändern.

An den Beinen des o Iragen das 4. und 5. Glied in der distalen Itälfte ein Polsler, das auch uoch anf ilen letzten Beinen deutlich ist.

Dic Ventrapplatten sind fast glatt und äusserst fein und undeutlich quergestreift.

Die Gonopoden (Fig. 82 ) sind denjenigen ron $S$. (Epistreptus) ruralis 10. sp. und 
villicula sim. (Fig. si sehr ähnlich; an den vordern is das mediale Eek des vordern Blattes weniger spitz als hei ersterer, aber spitzer als bei letzterer Art, das Ende des hinteren Blattes etwas unregelmässig zugerundet und nach vorn ühergeworfen, von vorn geselien einem sehief gestellten P'ilzhut uicht unähnlich; an den hintern Gonopoden ist der Coxaklorn relativ noch länger und weniger handartig tlach, der Telopodit dagegen relativ kïrzer, mit kürzerer, breiterer Endlanelle.

Fundorte: Buenarista, Cafetal bei Viota.

Guadua.

Suvestms Exemplare stammten ron Mine Purnio und Honda.

Monstrosität' : Ein ơ vou Buenavista weist eine eigentümliche Misubildung an den Segmenten 28 und 29 auf. Iuf der Rüekenmilte sind beide Segmente normal; seitlich ist das 28 . Segment rechts normal, links aber verbreitert und his zum Porus hinanf in zwei vollständige Somiten mit je einem Pro- und Netazoniten geteilt. Diese Assymetrie wird dadurch ausgeglichen, dass das $2 y$. Segment auf der rechten Seite in derselben IVeise verbreitert und bis oberlalb des Porus geteilt ist, so dass jedes fast \& 1/2 vollständige Somiten repräsentiert. Dementsprechend finden wir auch :) Ventralplatten und 6 Piar nornal entwickelter Beine, sodass die Ahnormität schliesslich keine Störung in der allgemeinen Symetrie des Tieres hervorlıringt. Eine ähnliche, aber auf mehrere Segmente siclı erstreckende Ergänzung von Ahnormitäten hat auch Bıölemaxs beim Chilopoden IFimuntarium gabrielis heohachtet.

\section{Spirostreptus (Epistreptus) heterothyreus Kinscin.}

(Fig. 83, 8\%.)

o Länge: $105 \mathrm{~mm}$; Breite: $6 \mathrm{~mm}$.

Skulptur last genau wie bei $S$. (Épistreplus) ruralis n. sp.. ebenso die Merkmale des lioples, die Form des Halsschildes, des Aualsegments, die Form und Beborstung der Beinr und ihre Polster. Doch ist der Ilalssehild vorn seitlich nichı bauchwärts eingeIrückt; die olnerste Furche der Seitenlappen ist stärkrr treschwungen; die Onernahı ist breiter, weniger tief und üher dem Rücken elwas weniger dicht qerippt; die ziemlich stark vorspringenden, wulstigen Analklappenränder sind aussen ımr von einer seichten, undeutlich begrenzten Rinne begleitet, etwa wie bei villicola Sisv.

Die Antennen des of erreichen nicht den llintermand des 5. Segments, wie liarsin es angibt, sundern, längs der Mitte der Seiten zurückgelegl, höchstens den Vorderrand des 3. Segmentes, sind also wenig länger als hei ruralis.

Wie bei ruralis und ehlersi (und villicola?) ist der Hinterrand des 7. Segments hinten jederseits zu einem ohrförmigen Gebilde aufgeworfen, aher in der Mitte breit unterl,rochen.

1 Vgt. unsere Nitteilung in: Arch. d. Sc. phys. et nat. T. XXXVI, 11. 279: 1913. 


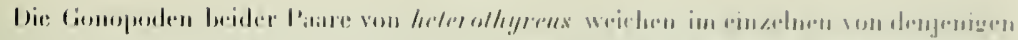

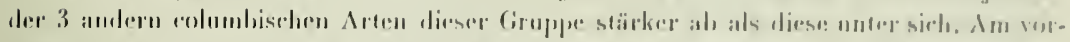

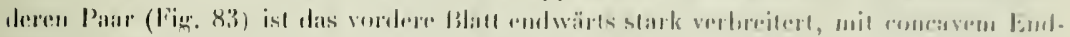

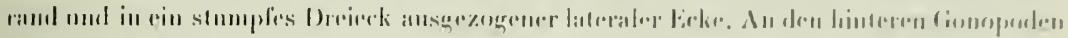

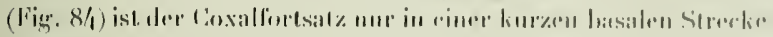
biamlförmigg und d:an!

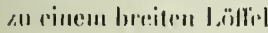
arweitert; or ist relalir kiirzer its leei den nïchsten Verwanden; der Telopolit ist elenfills andfillend lureit IImI leselireily rine Spriale vor dem I eluer-

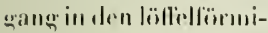
gen Enderil.

Inmerkinng. Ausser len zwei männli-

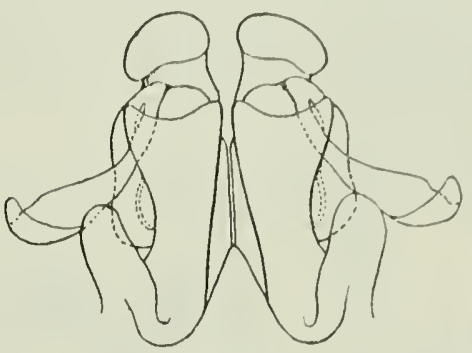

Fig. 83 .

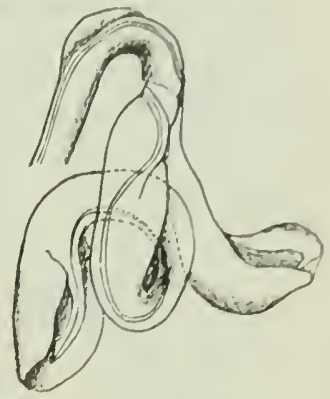

fig. 81 .

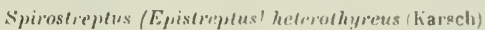

Fig. 83. Gomopoden von vorn. - Fig. Sh llinlerer fionopod.

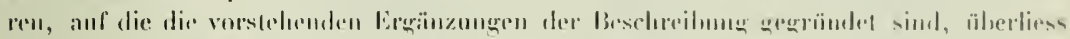

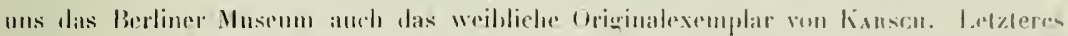

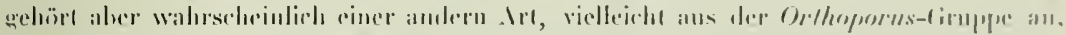

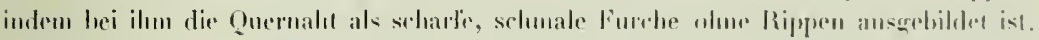

\section{Spirostreptus (Nanostreptus) inconstans n. sp.}

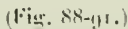

Färloung selu variabel, granz selıarzloaun oder dunkel kastanienbrann mit gुrangellen Prozoniten, manchmal mit Simren einer helleren dorsalen Längshinde. Antennen dunkellıraun. Beine geth oder gelbhraun.

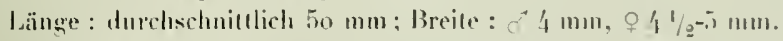

Segmentzahl : 56-60.

liopfschild ghtall und ghänzend, mit 4 Suprabahralporen : Scheitel elsenfalls sehr stalt, ohme oder mit äusserst leiner Milfelfurche. Intemnen ziemlich schlank, zurüchgeleg beim F den Hinterrand des 3. Segments erreichend, lxim o wenig kürzer. Ingenhaufen innen spitzinklig, un efwa $1 \%$ mal ihr Querdurchmesser von einander entfernt.

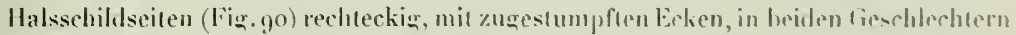

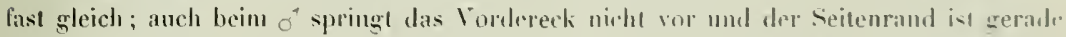
(im Gegensatz zu . I. incetelineutns Sux., lïg. 8-1. Die Fläche trïgt ausser der Rand- 
furche mur eine vollständige Furche und zwischen beiden am Hinterand manchmal noch eime oder zwei ganz kurze Furelsen.

Prozonites im hedeckten Teil mit sehr dicht stehenden, aber ganz feinen, undeutlichen Ringfurchen, im freien Teil, wie ancls die Metazoniten, ghatt und schwach glänzend.

Die seitliclse Streifung der Mrtazoniten reicht auf den vorderen fast his zum Porus linauf; weiter nach hinten wird sie immer feiner und hört in einigem Abstand vom Porus auf; alser die Vorderenden der Streifen setzen sich als Punkte längs der Quernaht bis oberhalb des Porus fort und rerschwinden erst in der Rückenmitte. Metazoniten höher als die Prozoniten.

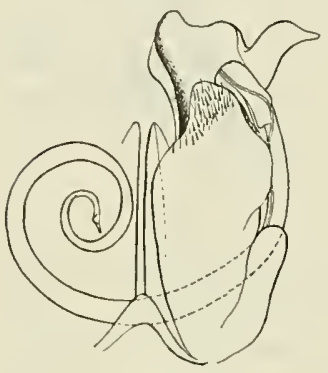

Fig. 85 .

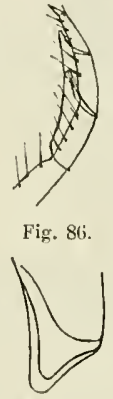

Fig. 87

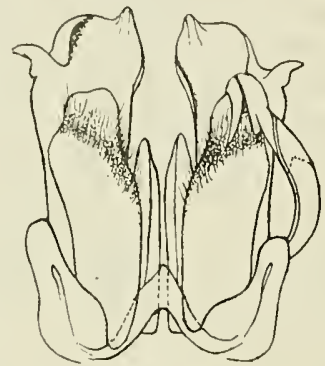

Fig. 88 .

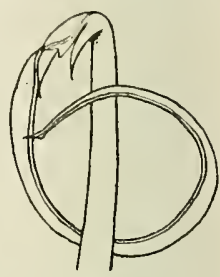

Fig. 89 .

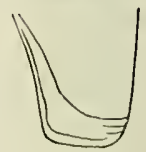

Fig. 90 .

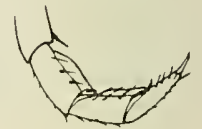

Fig. 91 .

Fig. 85. Spirostreptus (Nanostreptus) incertelinealus Silv. (Originalex.) 1 . Rechles Gonopodenpaar von vorn. - Fig. 86. Id., distale Beinglieder. - Fig. 87. Id., Ilals. schildseitenlappen. - Fig. 88. Spir. (Nanostreplus) inconstans n. sp. of, Gonopoden von vorn. - Fig. 89. Id, Hinterer Gonopode. - Fig. 90. Id., Halsschildseitenlappen. Fig. 91. Distale Beinglieder.

Quernaht ringsum scharf, vor dem P’orus nicht ausgebogen. Porus sehr klein, nicht erhöht, etwas unterhalb der hatben Körperhöhı, elwa auf dem ersten Drittel der Metazoniten gelegen.

Preanalsegment dorsal in ein kurzes Dreieck mit ziemlich scharfem Winkel und meist eingebogenen Schenkeln vorspringend; der Vorsprung an der Basis durch eine mehr oder weniger tiefe Furche abgegrenzt und mit Andeutung eines stumpfen Yittelkiels.

Analklappen mit von der Seite gesehen stark gehogenen, von oben gesehen stark vorspringenden, aber weder ivulstig verdickton noch aussen deutlich abgesetzten Endrändern.

Analschuppe rom Ringteil des Segments durch eine Furche alogesetzl, dreieckig.

Ventralplatten mit wenig zalıtreichen, scharfen Querfurchen.

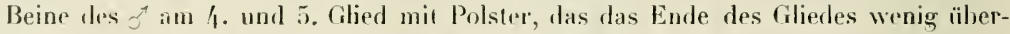
ragt (Fig. y1) und an den letzlen Beinen last verschwindel.

Gonopoden (Fig. 88) denen von $N$. incertelineatus Stur. (Jïg. 85) älunlich, abes am 


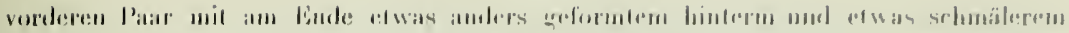

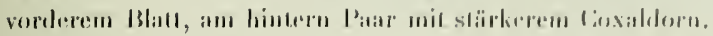

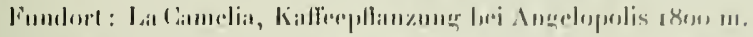

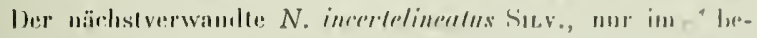

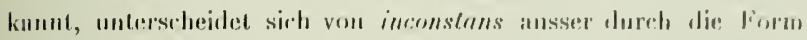

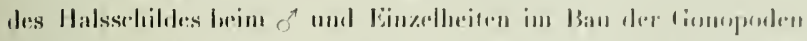

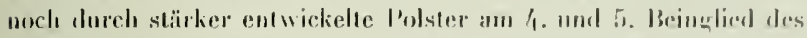

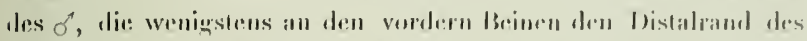
liliedes weit äberragen (ligg. S(i), fermer durch schwächere l’unk-

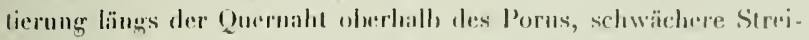
lung der Metazonitenseiten und schlinkeren Kïrpur. Jie of da beiden dran dïrlten selowierio anseinanderzulablen sein.

\section{Spirostreptus (Orthoporus) alticola sius.}

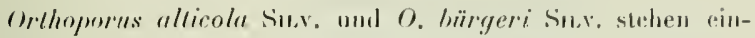
anter ansserordmulich nalue und sind wahrsthriulich our "xtreme Formen riner mol dersillen dil.

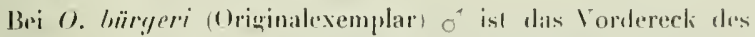
Halsschildes stärker schomal-lappen lämig vorgezogen als hei r). alli-

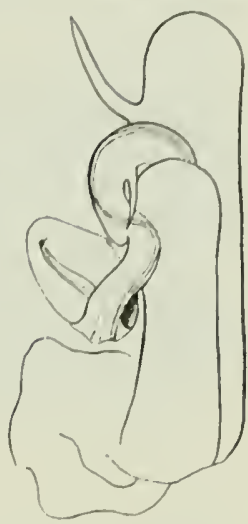

Fif. 92. - Sirirostrey. lus (Orlhuporus) bürferi Silv. Linkea fionopodenpaar von vorn. (rorizinalexemplar).

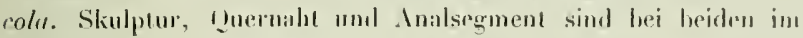

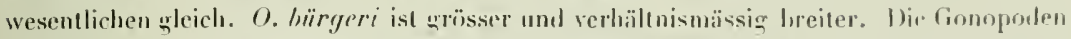
(Fig. (92) sind tast identisch gehaul; bei allicola ist das hinter. Blatt der vordern liono-

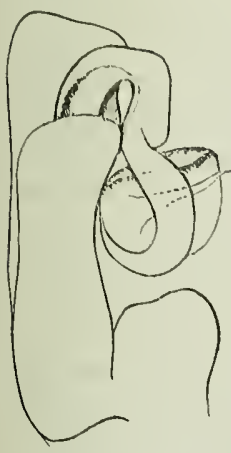

Fig. 93. - spirostreptus (Orthoporus' peregrinans Silv. ${ }^{*}$ Rechtes Gonopodenpaar von vorn (1) riginalexemplar). poden ctwas weniger gestreckl und relaliv breiter und der kurze spiessförnige Coxaldorn der hinteren Cionopoden ist moch stärke reduziert als bei bürgeri (Suvestro hat ihu bei beilen . Irten ïherselenen).

Insere tixemplare schliessen sich der firïse wach oher (1) allicoll an, ebenso fïr die form der Halsschililseiten. Dir Cionopoden bieten Uebergänge zn $O$. bürgeri dar. Bei manchen Exemplaren ist eine äusserst seichte, breitc Einschnïrung über die Milte jedes Somiten bemerkbar, die den hintersten Teil des Prozoniten und das vordere Dritlel des Metazoniten einnimmt, wodurch der Metazonit hinten etwas höher als der Prozonit erscheint. Die Skulplur ist ziemlich variabel, indem bei manchen Exemplaren dir Längskritzelmug, bei andern die Punktiermug üherwiegt.

Fundorte: Argelia, Kaffeetal $1600 \mathrm{~m}$ bei Viota Tambo, ca. $2000 \mathrm{~m}$ am Westhang der Sabana von Bogota.

Silvestris Exemplar stamme von Lia Linion Chingali. 1501)-2400 m. 


\section{$-8 ; 2-$ \\ Spirostreptus (Orthoporus) peregrinans Sis. \\ (liig. !...3.)}

Die tonopoden (Fig. 93, Uriginalexemplar) sind von denjenigen der beiden vorgenannten Arten durch die Form der beiden Bläıter des vorderen Paires, wie auch durch das eränzliche Fehlen des Coxaldorns am hinteren Para deutlich verschieden.

Einige of der Funkmov'schen Ausbeute entsprechen nach Grösse, Färbung und Skulptur am besten dem Originalexemplar $\left(\sigma^{+}\right)$dieser Art. Duch darf nicht verschwiegen Werden, dass die Zuteilung der of zu einer del Arten O. peregrinans Sılv, O. allicola SILv. und $O$. bürgeri SILv. äusserst schwierig und etwas willkürlich isı, insofern durchgreifende spezifische Unterschiede bei den 우 nicht zu bestehen scheinen.

Fundlorte: LaCamelia, Kálleepllanzung, $1800 \mathrm{~m}$; zwischen Fresno und Mariquita, $400 \mathrm{~m}$.

Silvestris Exemplare stammten von Villavicencio.

\section{Gruppe Spiroboloidea.}

\section{Fam. Euspirobolidea.}

\section{Gen. Microspirobolus SiLv.}

Wir weisen diesel Fattung zwei Spiroholiden zu, die nach den äussern Körperformen, nach Skulptur und Zeichnung den von Sıvestru mit diesem Gattungsnamen belegten Arten jedenfalls sehr nahe stehen. Allerding's ist die Gattung Microspirobolus sehr oberflächlich beschrieben, weil die fronopoden des typischen Mr, M. pulcluellus Sitr., aus Venezuela, weder genügend beschrieben noch abgebildel sind; da auch die beschreihungen zweier anderer Arten, aus den Antillen, (1/. insularis Sicv. und M. marmoralus SiLv.), nichı in allen Punkten mit der Gathungsdiagnose übereinstimmen und hinsichtlich der Gonopoden auch keine vollständige Iulklärung hringen, Lleilst die liattung Nicrospirobolns und die Zugehörigkeit unserer 2 Srten zu ilı noch etwas problematisch. Aus diesem Grunde erscheint es uns anch nicht ratsam, ohne genaue Kenntnis der Silvestrischen Arien eine neue Beschreibung der Gattung zu entwerlen. Welche Gefahr ein derartiges Vorgehen hälte, zeigl das Beispiel von Spirobolellus, dessen ausführliche Neubesehreilung durch Itтexs auf Grund einer neuen Art gar nicht auf die typischen Arten passt 4 .

Wir begnügen uos daher mit einer ausführlichen Beschreibung der beiden neuen Arten. Von diesen zeigt $M$. mayori in der Form des Endteils der linteren Conopoden 


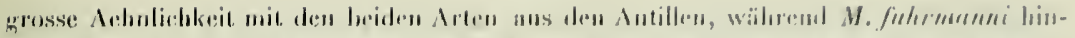

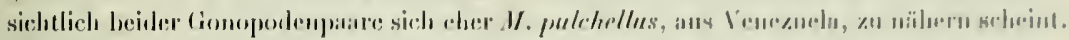

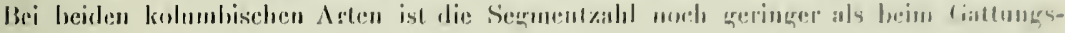
typus N\%. pulchellirs.

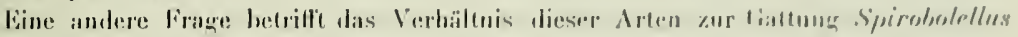

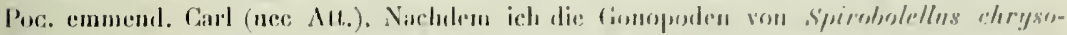

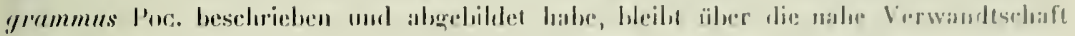

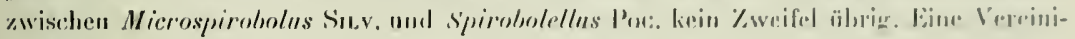

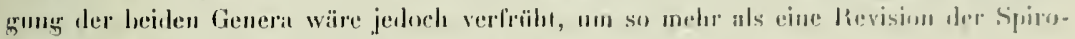

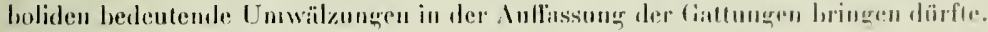

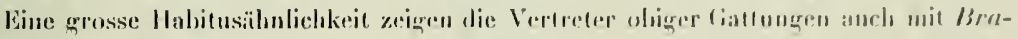

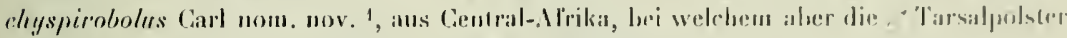
und anders grestaltete Gonopoden haben.

\section{Microspirobolus mayori n. sp.}

(Fïg. (9i-9)

lärbung: Die kleinere untere Hällte der Lörperseiten heller orler dunkler gellı; darüber ein breites, schwarzes Längshand mit unregelmässigem, auf den Prozoniten etwas dorsalwärts vorspringendem oberem Rand; längrs der Räickenmilte ein loreites, ans quer gestreckten Flecken gelibldetes schwarzes Band, das von der lateralen Binde jeder-eits durch eine zickzack- oder treppenförmige, schmälece, gुelbe Längrsbinde tretrennt ist: letztere kann bei stïkerer Ausdelunung der schwarzen Binden in lilerkelien zerfallen, je zwei auf jedem Segmente jederseits, wovon eines mehr medianwärts auf dem Prozoniten und eines schräg dahinter auf dem Metazoniten. Inalsegment schwarz, mit je einem hellen Fleck jederseits am Yorderrand und heller oder dunkler grelben Inalklappen. Halsschild meist breit dunkel gesäumt, mit dunklem Mittelfleck und jederseits davon aufgehellt oder fein brann marmoriert. Liopf rorn meist gelblich, hinter den Intennen ganz dunkel oder mit dunklem, vorn zweispitzigem Scheitelfleck. Antennen und Beine weisslich bis hraungelb.

Länge: $17 \mathrm{~mm}$; Breite : $2 \mathrm{~mm}$.

Segmentzalıl : 33-35.

liopfschild glatt, mit 4+4 Supralahralporen, wovon die beiden äusseren einaniler selur geniluert, und kurzer Medianfurche; Augenhaufen innen winkelig, um etwa zwejmal ihr Querdurchmesser ron einander entfernt. Antenmen sehr kurz, in eine breite Rinne der liopfseiten zurücklegbar.

Halssehild seitlich etwa auf die Ilälfte der Länge seiner dorsalen Vedianlinie ver-

1 Für Microspirobolus a'qualorialis Cart und domesticus Cart (Rev. Suisse de Zool. T. 17, S. 354. - 19og), da der Gallungsname .Microspirobolus schon vergeben war. 
schmillert, so weit heruntersteigend wie das 2. Segment and unten ganz schwach bauchwïrts eingekrimmt Seitenlappen selır flacl ggermndet his fast grerade gestutzt, mit zugestumpften Ecken, schwach concavem Vorder- und geradem Ilinterrand und scharfer Randfurche längs Vorder- und Seitenrand.

Segmente glatt und gुlänzend. Prozoniten im bedeckten Teil olme Ringfurchen, auf der Grenze zwischen dem bedeckten und dem freien Teil mit einer Querreihe sehr kulzer, kommaförmiger Striclie, in freien Teil bis elwas unterhalb des Pores heranf weitläufig mit vorn aufgehogenen Sircifen heselzt. Quernaht ringsum scharl und punkliert. Metazoniten sehr wenig höher als die Prozoniten, ganz glatt, nur ganz unten ober-

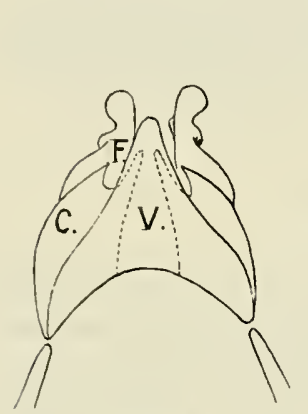

Fig. 9'.

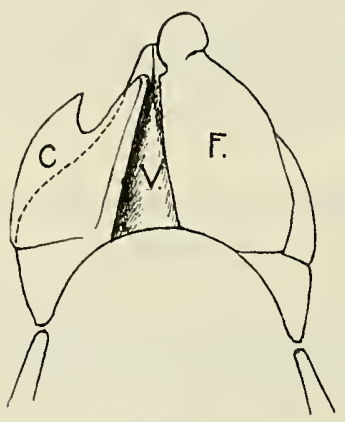

Fig. 95. halb der Beine mil 2-4 Längsfurchen. Saftlöcher sehr klein, etwas oherhall, der Mitte der liörperseiten, fast in der Mitte der Metazoniten gelegen.

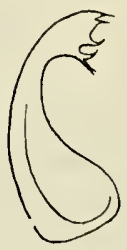

Fig. 96 .

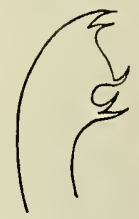

Fig. 97.

Microspirobolus mayori n. sp.

Fig. 9'. Gonopoden von vorn. - Fig. 95. Gonopoden von hinten, links ist das Femoroid weggenommen. V. Ventralplatle, C. Coxoid, F. Femoroid. - Fig. 96. Hinterer Gonopode. - Fig. 97. Dessen Ende, stärker vergr.

Ptceanalsegment glatt, dorsal regelmässig vorgezogen; der Vorsprung mit stumpfer Spilze das obere Ende der Analklappen ganz wenig dacharlig überragend. Klappen gुleichmässig gewölht, direkt zusammenschliessend, olıne vorspringenden freien Rand.

Ventralplatten dicht quergestreift.

Beine selır kurz und schwach, nur mit der subapicalen Borste an jedem der Glieder 1-5 und meist 2 Börstehen auf der Unterseite von Glied 6, bein of ohne Tarsalpolster und ohne Apophysen an den Hüften der vorderen Paare.

Gonopoden des vordern Pares (Fig. 94 und 95): Die Ventralplatte ist dreieckig, mit stumpfer Spitze, geschwungenen Seiten und bogig verlaufender Basis; ihre Hinterlläche bildet eine kegelförmige mediane Verdickung, die die beiderseitigen Coxoide und Femoroide anseinanderhält. An den relativ kleinen Cosoiden ist der Endrand tief eingebuchtel, so dass ein kïrzerer, spitzer, von vorn sichıbarer äusserer Zipfel und ein längerer, stumpfer medianer Fortsatz entsteht; letzterer ist vorn durch die Ventralplatte verdeckt und lehnt sich mit seinem medialen Rand an deren kegelförmige hintere Verdickung. 


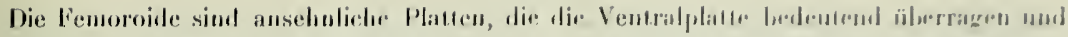

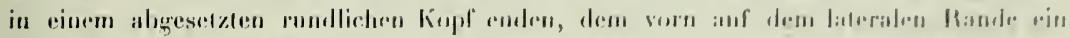

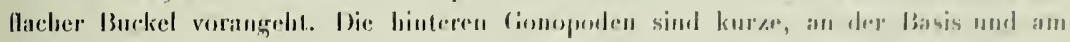

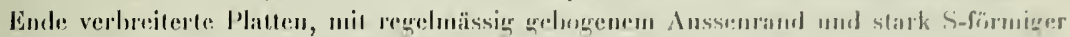

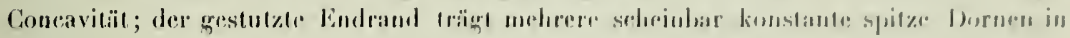

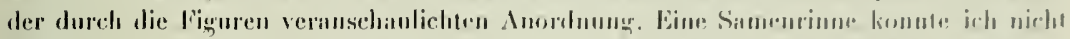

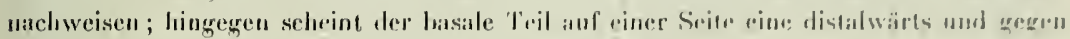
die Concavilät hin offenr, scichte Ë̈nsenkung darzıbleten, die viellejcht anr Aufnalıne des Spermas dient.

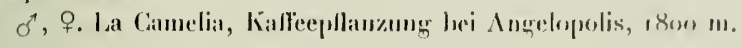

\section{Microspirobolus fuhrmanni n. sp.}

(Fiig. $9^{8-100 .)}$

Der vorigen Art nach Grösse, Färlung, Skulptur und ätsseren formen selie ähnlich, aber an folgenden Merkmalen leicht von ihr an unterschudiden:

Die selıwaren und gelben Längshinden siml regelmässiger ; die heiden gellıen Dorsalbiulen sind hreiter, die schwauze dorsale Nittelbiule selunäler, aus lïngsgestreckten oder subquadratischen stall quergestreckten flecken liestrhend.

Halsselild seillich stärker verschmälert und meist stärlier zugerundel; die näclıstlolgenden Metazoniten, hesonders der 2. leim $\sigma^{7}$, anf den siden herunter wulstartig verdickt. Die Bogenstreifen aul' den Seiton des freien Prozonilenteils sind rerkürzl und rascher dorsalwärts gebogen. Der vorspringeme Teil des Analsegments ist jederseits

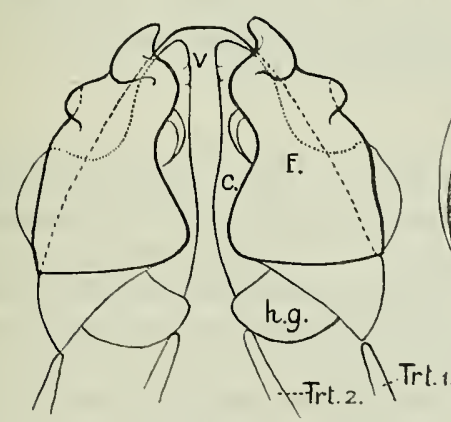

Fig. 98.

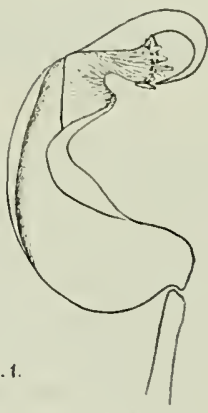

Fig. 9?

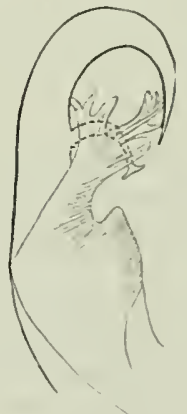

Fig. 100

Microspirobolus fuhmanni n. sp. 6

Fig. 98. Gonopoden von hinten. V. Ventralplatle, C. Coxoid, F. Femoroid, h. g. Basis des hinlern Gonopoden. Trt. I und Trt. 2 Tracheentaschen des vordern resp. hintern Gonopodenpaares. - Fig. 99. 1linterer Gonopode. Fig. 100. Dessen Endleil, stärker vergr. 
eingeluchtet und üherragt selır deutlich die Analklappen, ein schanfelförmiges, von der Seite gesehen verdicktes Schwänzchen bildend.

Die wichtigsten Unterscheidungsmerkmale liefern die Gonopoden. Am vordern Paar (Fig. $9^{8}$ ) ist dic Ventralplatte ein grosses Drejeck mit convexen Seiten und abgrestutzter Spitze; die Coxoide sind am Endrand (punktierte Linie) weniger tief gehuchtet als bei mayori, so dass aussen cine breite "Selulter ", aher kein spitzer Zipfel cutstelıt, dafür ist der mediale Teil breiter und länger, fast so weit vorragent wie die Ventralplatte und ganz hinter dieser versteckt. An den Femoroiden sind der Buckel und das kopfförmige Eude noch stärker ausgeprägt als hei mayori. Die linteren Gonopoden (Fig. 99 u. 10o) weichen von denjenigen der bisher darauf hin geprüften Microspirobolus-Arten bedeuteml ab; jeder ist eine gebogene Platte, die an Eude in eine stark sichelförmig gekrümmte Spitze ausgeht und an der Basis dieser Sichel, auf ler Concavseite, cin gekrümmtes Aestchen mit plattenartig verbreitertem Ende trägt, über welches eine sehr zarte fingerartign geteilte Lamelle sich herlegt; basalwärts von dieser Lamelle findet sich noch ein stumpfer Vorsprung. Auch hier ist der Basalteil der einen Fläclıe llaclı schalign vertieft und setzt sich in eine durch Ueberschlagen der Ränder gebildete breite Bahn fort, die vielleicht die Rolle der fehlenden Samenrinne übernommen hat.

6, juss. La Camelia, Kaffeepflanzung bei Angelopolis, 1800 m. I ot. Argelia, liatfeepflanzung, $1600 \mathrm{~m}$.

\section{Rhinocricus brevipes n. sp.}

(Fig. 101, 102.)

Färbung: Prozoniten graubraun, Metazoniten schwarzbraun mit gelbbraunem Hinterrand; anf den Seiten beide Somithälften heller und fast gleichfarbig; Analsegment sammt Klappen einfarbig grauschwarz; Kopf hräunlich gelb mit einem undeutlichen dunkleren $\mathrm{X}$-förmigen Fleck auf der Scheitelmitte; Antennen und Beine bleich gelb.

Länge: $30 \mathrm{~mm}$. Breite : $3-3 \frac{1}{2} \mathrm{~mm}$.

Segmentzallal: 4 I oder 42 .

Kopfschild glatt, mit deutliclıer Medianfurche, die fast mit der ebenfalls deutliehen Scheitelfurche zusanmenhängt; 2 +2 Labralporen. Augenflecke stark zugerundet, um mehr als das Dreifache ihres Querdurchmessers von einander entfermt. Antennen kurz und dick, zurückgelegt kaum über den Hinterrand des Halsschildes reichend; ihre Glieder deutlich komprimiert; Glied 3, 4 und 5 fast doppelt so breit wie lang; letztes Glied mil zahlreichen Sinneszapfen (Polyrhabdi Bröl.).

Hialsschild mit stark zugerundeten Scitenlappen, dic cine ganz kurze Vorderrandfurche tragen.

Prozoniten im eingeschachtelten und im freien Teil glatt, nur ganz unten oberhalb der Veatralplatten aüsserst fein und dicht schräggefurcht. Scobina bis etwa zum 25. Segment nachweisbar, kleine dreieckige Grübchen. Netazoniten glatt, ganz unten erst längs- 


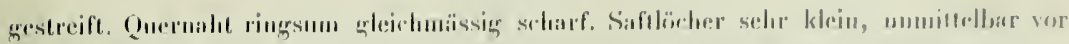

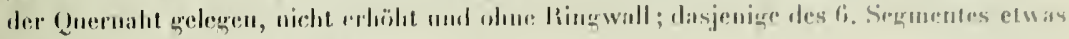
liefer gelegen als die folependen.

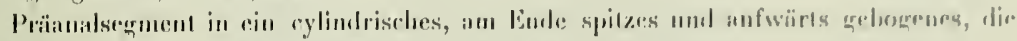

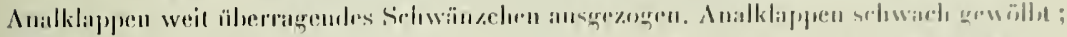

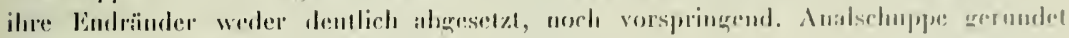
dreicekig.

Ventralplittron setharf und regelmässig fueregestreift.

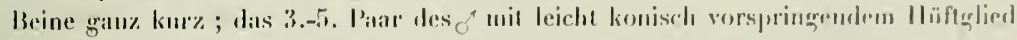

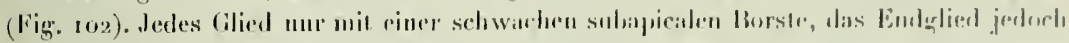
unit 2-3 solchen Borsten nut heint of mulerseits zon einem unlentichen Tarsalpolster vordickt.

Vordere fomopuden (lïgr. 101 ) mit grosserer, dreieckiger, am Eudr zugestumpfter Ventralplatte, schmal nud spitz ansgerogenen Coxoiden und etwas kürzeren, schrïg grestulzten mod aussen eingebuchtelen Femoroiden. Ilintere Gonopoden mit einem hinter der Mitte des zwriten (iliedes auf dessen Vorderseite alggehenden, die Sintenrinne fülırenden $\lambda$ st und lamellär verthreitetrm, am Ende durch rine tiefe runde Einhuch-

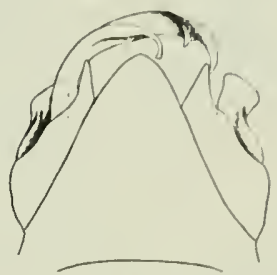

fiig. 101.

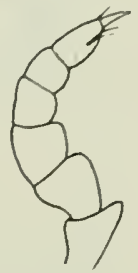

Fig. 102 .

Rhimocricus brevipes n. sp.

Fìr. 101. Cinnopoden von vorn. - Fig. Itz. Bein des 3. Panres. lung in zwei Zïhne geteitlem Tarsilalsschnilte.

107,1 q. La Camelia, liafeepllanzung bei Angelozrolis, $1860 \mathrm{~m}$.

\section{Rhinocricus semiplumbeus $n$. sp.}

(Fig. 103, 104.)

In mehreren Merkmalen mit $R$. brevipes ühereinstimmend: Kopfsehild, form und Entfernung der Augentlecken, Autrnnen, Praeanalsegment sammt Schwänzchen, Klappen und Analschuppe wie bei letzterer Art. Sie unterscheidet sich von ihr in folgenden Punkien :

Pärlungr: Prozonilen, Kopl', Malsschilil mil Ausnahme eines feinen Randsaumes, sowie das Praeanalsegment sind bleigrau; die Prozoniten sind auf den Seiten etwas heller als anf dem Rücken; das Schwänzchen ist unterseits und an der spitze aufrehelit. Mchazoniten auf dem Rüeken dunkder bleigrau, mit feinem, im vordern hörperteil leich welligem, hellem Ilinterandsanm; unterseits einer vom Porus schräg nach olven verlaufenden scharfen Grenzlinie sind die Metazoniten granz gelblich. Antennen hellgrau. mit weisslichen Giedenden und ehensolehem Endghlied. Beine weisslich.

Gestalt gedrungener als bei $R$. brevipes. Länge : 30 1mm. ; Breite : 4 mm. 
Segmentzahl : 40.

IIalsschild aut den Seiten noch weniger verschmälent und stärker zugerundel als bei li. brevipes.

Quernain ringsum deutlich, furchenartig, aher feiner als hei R. brevipes.

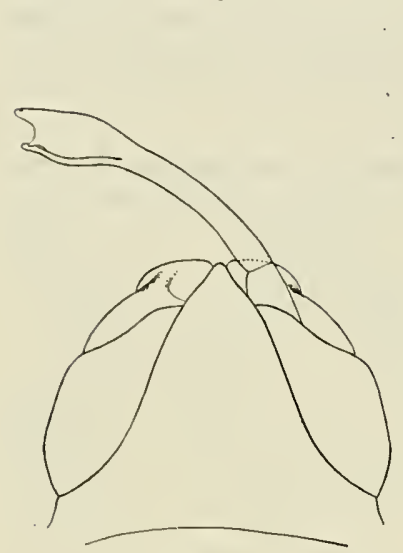

Fig. 103.

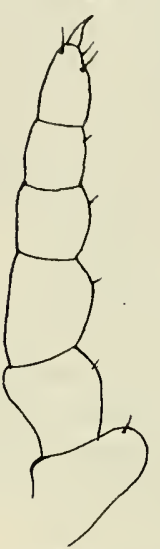

Fig. 104.

Rhinocricus semiplumbeus n. sp.

Fig. 103. Gonopoden von vorn. - Fig. 104. Bein des 3. Paares, in gleicher Vergr. wie Fig. 102.

Endplatte dicht anliegend und so weit distalwärts reichend wie diese (Fig. 103).

I 6 . Puerto de los Pobres, an Cauca-Fluss.

\section{Rhinocricus bürgeri Sıw.}

(Fig. 105.)

Diese Art, von der uns Fragmente des Originalexemplars vorlagen, gleicht nach denäusseren Körperformen den Rhinocricus semiplumbens n. sp. Die hinteren Gonopoden sind ebenfalls nach dem Typus derjenigen der beiden vorangehenden Arten geluut; an den vorderen Gonopoden aber ist die Ventralplatte zungenförnig, am Ende ziemlich breil gestutzt und ganz seicht eingebuchtet; die Coxoide halten in der Form die Mitte zwischen den kurzen breiten Coxoiden

Die saftlöcher liegen anf der Quernaht sellsst, in einer Art Nische derselben, indem die Furche hinten m den l’orus herumläuft.

Beine bedeutend tïnger als bei brevipes, in Verhältnis zur Körpergrösse schlank; die Hüliglieder des 3.-5. Paares beim o melır knoplförmig als konisch vorspringend (Fig. 104).

Vordere Gonopoden breiter, mit spitzerer, auf den Seiten stärker geschwungener Ventralplatte, medianwärts nicht vorgezogenen, das Ende der Femoroide und der Ventralplatte nicht erreichenden Coxoiden. Hintere Gonopoden am Ende platlig erweitert und am Endrand schwächer eingebuchtet; der die Samenrinne führende Ası dem Innenrand der 


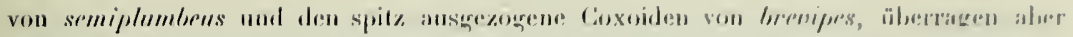
ebenso wie die Femoroide deutlich das Einde der Ventealplattr.

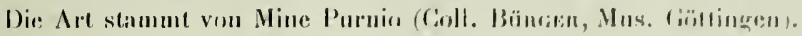

\section{Rhinocricus fundipudens (Kisssin).}

(lïus. Iolii).

Das Originalexemplar sellst konuten wir nicht muter-

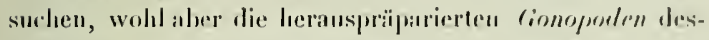

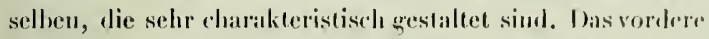
Paar ist sehr Inreit; Ventralphille schon vor der Mille stark verschmälert, ihre mediale Verlänzrerung znogenfïrmier, mit etwas augespitztem Eule; Coxoide kur\% und breit, ihr Endrand fast quergerichtet, zwei llache Buckel bildend, das mediane Eek in eine seharfe, das Eude der Ventralplante nicht erreichende Spitze ausgezogen. Femoroile schräır vorgestreckt, von vorn und hinten komprimierl, mit srrossem stumpfem Aussenzalın, am Ende zurerundet. Die hinteren Gonopoden verbreitern sich am Ende zu einem tiefen Löffel, aus dem der schlanke, zugespitzte Tibialfortsatz mit der Samenrinue heraustritt.

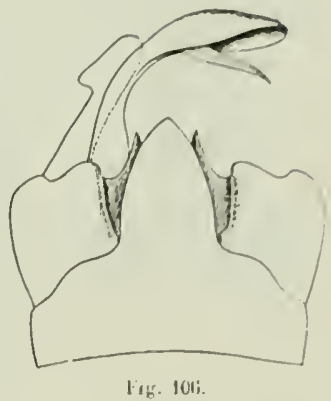

Rhinocricus fundipudens Karsch. C (Originalexemplar). fionopoden von roin. Ilechls ist das Femoroid und der hinleve fio. nopode weggelassen

\section{Rhinocricus instabilis n. sp.}

(Fig. $107,108$.

Quergebändert ; der freie Prozonitenteil ganz schwarz, die Metazoniten ganz rot oder rot mit braunem Hinterrand; der eingeschachtelte Teil der Prozoniten gelhlich; Ilalsschild schwarzbraun mit breitem rotem Rand ; Kopf hraun, vorn und längs der Nitte his zwischen dell Augen herauf rot; Praeanalsegment sammt Klappen und Analschuppe rot; Beine grünlich grelb.

ơ Länge : roo $\mathrm{mm}$; Breite $9 \% \mathrm{~mm}$. O Linge: So, Breite : $9 \mathrm{~mm}$.

Segmentzahl : 41 .

Kopfschild glatt, mit feiner, zwischen den Antennen unterbrochener Medianfurche und $2+2$ Supralabralporen. Augentlecke aussen zugermndet, immen fast srerarle abgeschnitten, um etwa $21 / 2$ mal ilır Querdurchmesser von einander entfernt. Antennen zurïchgelegt den Hinterrand des Halsschildes leicjıt überragend: letztes Gilied mit zahlreichen, dicht stehenden Sinneszapfen (Polyrhabdi Bröl.).

Halsschild soweit herunterragend wie das 2. Segment: die Seitenlappen von hinten her zngerundet, mit fast geradem Vorder-und convexem llinterand, auf der Fläche mit ganz feiner Vorderrandsfurche und mit einigen (3-5) schrägen Längsfurchen vor dem Hinterrand. 
Prozoniten in bedeckten Teil dicht mit feinen, vieifacls anastomosierenden Ringfurchen besetzt, in freien Teil seitlich mit vielen feinen, mehr oder weniger geschlängelten und vorn läng einer grlatten Linie aufwärtsqebogenen Schrägfuschen; rückenwärts liegen diese Streifen etwats weitschichtiger und werden oberhalb des Porus zu Fragmenten von Querstreifen oder bilden mil den entsprechenden der andern Körperseite unregetmässige unterbrochene Bogen; in einiger Entfermung vol der Quesnaht und paralell zu

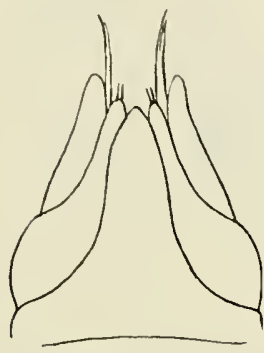

Fig. 107.

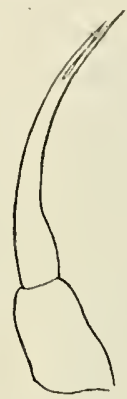

Fig. 108.
Rhinocricus instabilis n. sp. $\sigma^{+}$

Fig. 107. Gonopoden von vorn. - Fig. 108. linterer Gonopode.

dieser trägt der lä̈ckenteil dess Prozoniten eine etwas deutlichere und reggelmässigere feine Querfurclie.

Scobina klein, halbmondförmig, nur halh so breit als ihr Abstand, nach dem liörperende hin sehr allmählich kleiner werdend und als Punkte noch auf dem 36. Segmest nachweisbar.

Quernaht ringsum tief und scharl, direkt unterhalb des Porus eine ganz schwache Ausbiegung nach rückwärts zeigend.

Saftlöcher direkt vor der Quernaht, etwas oberhalb der halben Körperhöhe, dasjenige des 6. Segments etwas tiefer als die folgenden in der kleinen Ausbiegung der Quernaht. Eine gerade Furche liegt linter jedem Porus auf dem Metazoniten; sie findet sich in der entsprechenden Höhe auch auf clen porenlosen Segmenten 2-5 und ist sogar aul dem Halsschild noch angedeutet.

Metazoniten kaum höher als die Prozoniten, ringsum längsgestreift; hauchwärts sind die Furchen dichter, genau längsgerichtet und erreichen des Hinterrand des Metazoniten; auf dem Rücken sind sie etwas weitläufiger, leicht nach vorn und oben gerichtet und erreichen den Hinterrand des Metazoniten nicht; letzterer zeigt keine Spur von Ausbuchtung oberhalb der Scobina.

Pracanalsegment sammt Klappen chagriniert ; Schwänzchen spitz, die Analklappen deutlich überragend (๘) oder bedeckend (o). Letztere schwaclı gewölbt, mit schwach abgesetzten, wenig vorspringeuden Rändern. Analschuppe dreieckig, mit zugerundeter Spitze.

Ventralplatten scharf quergestreift. Das 7 . Segment des $\%$ hinter dem Gonopodensack in eine scharfe, in der Mitte ziemlich tiel eingeschnittene lippe aufgeworfen.

Beine eher lang; heim of länger und dicker als beim o, mit nur schwach stumpfdreichig vosspringendem Hüftglied der vordern Paare, jedes der Glicder 1.5 mit der gewöhnlichen subapicalen Borste, das Endglied (die letzten 7 oder 8 Paare ausgenommen) mit deutlichem Tarsalpolster und einer Borste jederseits an dessen distalem Ende.

Gonopoden des vorderen Paares (Fig. 107) mit schmaler, lang ausgezogener Ventralplatte und elsenfalls in die Länge gestreckten Coxoiden und Femoroiden ; erstere überragen meist ein wenig die Ventralplatte und tragen an ihsem zugestumpten Ende 2-3 cha- 


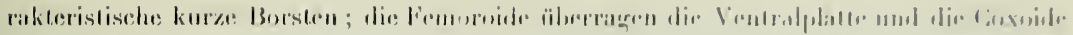

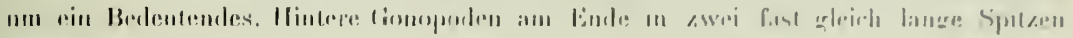

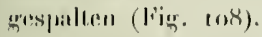

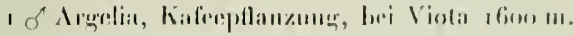

1 아 Homlat-finaturins.

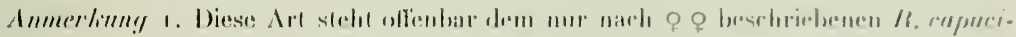

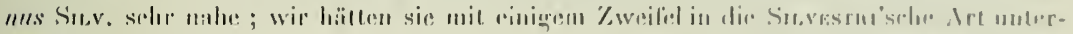

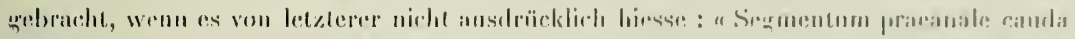

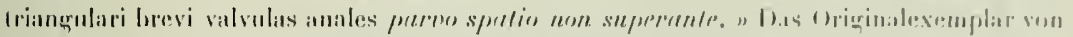

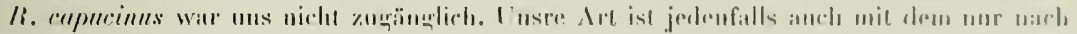
rinem of beschriebenen Rh. costulalus (Porial) nishe serwande.

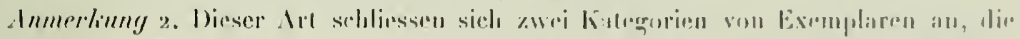

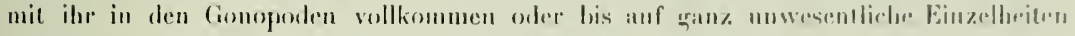

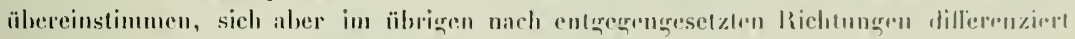

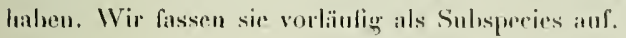

\section{Subspec. adolescens n. subsp.}

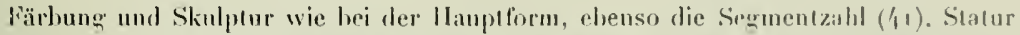
viel kleiner : Länge fo mm., Breite $61 / 2-7 \mathrm{~mm}$. Das a that diesellen fionopolen wie die Ilanpllorm, aher es lehlen ihm, trotz der notmalen Seqmentzahl und Beinzahl dir sekundïren Sexmaleharaktere : Die Bein sind weder lïnter noch stärker als bei den of das llältglied der vorderen Beine springt unterseits gar nicht vor, las Enderlied weist keine Andeutung vom Tarsalpolster auf. Wenn es sich demuach auch nicht um Schalunännchen handeln kann, so darf man diese Tiere vielleicht doch als eine auf' einem letzlen Entwicklungsstadium der Hauptform stehen gebliebene und fixierte systemalische Einheil betrachten.

6', ㅇ Tambo, $2000 \mathrm{~m}$. (Coll. Fuhruasv).

2 $ᄋ$ Bogota (Berliner Museum).

,

2. Sulspec. valens n. subsp.

Bedlentend qrösser und krälligger als die llauptform.

Lïnge : 11 it-1 $40 \mathrm{~mm}$. Breile : $11^{1 / 2-13} \mathrm{~mm}$.

Sewmentzahl : 亿1-脌.

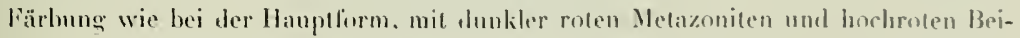
nen (q aus Columbieu) oder nur der Hinterrand ire. Melitzoniten rot und dip Beine Epellnrot (Exemplate aus Eruador; verfärbt ?)

Streifung der Prozoniten anf dem Räcken verwischt, die zur (buernaht parallele (Guerfurche aber stirker, im Extrem die verwisthe Quernaht anf dem Rä̈ken ersetzend 0 ans Colmmbien) und in diesem fall rorne und hinten von piner gerunzelten zone lnegleifel. 
Streilung der Metazoniten verschieden ausgebildet, bald wie bei der Ilauptlorm, bald viel stärker, so dass die Zwischenräume zwischen den breiten Furchen als stumple Kiele erscheinen (ㅇ aus Columbien).

Gonopoden wie für die Hauptform abgebildet (Fïg. 107, 108); die Tarsalpolster des ơ stark ausgebildet.

1 ㅇ. Zwischen Firesno und Mariquita, $400 \mathrm{~m}$. (Coll. Funraass.)

Die hichergehörıgen of des Berliner Museums stammen sämmlich von Sta. Inez, in Ecuidor (leg. HaExscu).

Bemerkenswert ist, dass die zwerghafte Subsp. adolescens die höchsten, die grosse Subsp. valens niedrige und die mittelgrosse typische form mittlere ITöheulagen bewohnt.

Die Subsp. valens ist möglicherweise mit dem sehr älulich sculptierten Rh. insculptus (Porat) (Aun. Soc. Ent. Belg. T. XXXH, 1888), aus Ecuador, identisch; doch fehlt jede Angabe üher die Gonopoden des letztern.

\section{Gruppe Polydesmoidea.}

In der Einleitung haben wir anf die grossen Schwierigkeiten hingewiesen, welche sich vorläufig einer scharfen Abgrenzung der Gattungen bei den sïdanerikanischen Polydesmoidea entgegenstellen, und den hier eingenommenen Standpunkt zu begründen versucht. Die Ansichten gehen fast noch weiter auseinander, wenn es sich darum handelt, die Polydesmoidea in Familien abzuteilen, so dass jeder Autor sozusagen seinen eigenen WVeg gegangen ist. Da die columbischen Polydesmiden einen zu geringen Bruch-

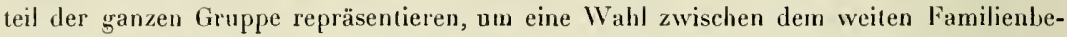
grilf im AtTexs'schen und dem sehr engen Familienbegriff im Cook'schen System zu treffen, so sehen wir von einer Einteilung in Familien ab und stellen nochmals die Darstellung der Arten als Hauptzweck dieser vormehmlich fannistischen Arbeit hin.

Die henlige Verwirnng nnd der Mangel an leitenden Gesichtspunkten im Polydesmiden-System hat vor allem seinen Grund darin, dass verscliedene Autoren auf Grund der Kenntnis einzelner kleiner Faunen voreilig zur Synthese übergegangen sind und Systeme geschaffen haben, denen altzuoft die Basis, nämlich gute Artbeschreilsungen, abgeht. Nur induktive systematische Revisionen grösseren Styls kömnen hierin Wandel schaffen.

\section{Gen. Sirongylosoma Вriт.}

\section{Strongylosoma pulvillatum Aтr.}

Der einzige erwähnenswerte Unterschied zwischen den Gonopoden unserer Exemplare und der Atreasschen Abbildung dieser Organe hesteht in der Form der Coxa. 


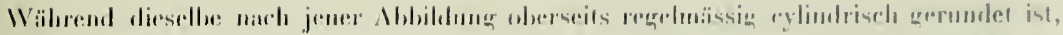

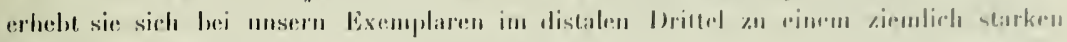

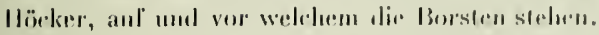

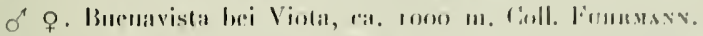

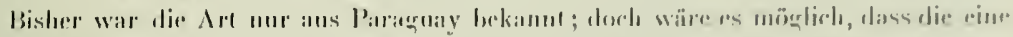

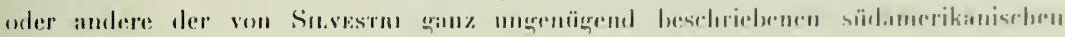

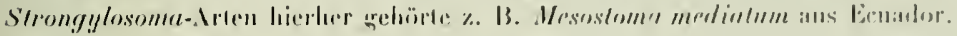

\section{Strongylosoma glabrum l'ı1:ks.}

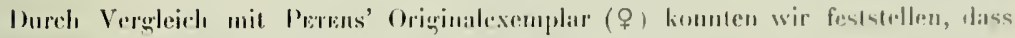

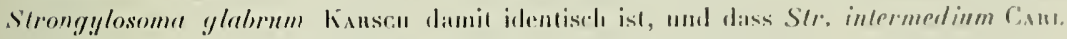

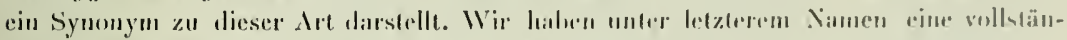
digre Beschreibung sowie Mbildungen der Cimopodon gegereben. '

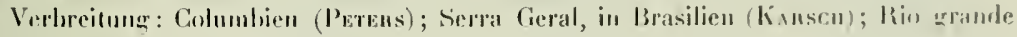
do Sul (Cisms).

\section{Gen. Leptodesmus Sisssum:}

Solange man sich nicht auf den Typus der Gattumg Leplodesmus Sowss. geejnigt

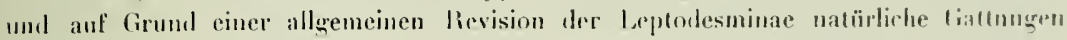
umgrenzt hat, wird das Genus Leplodesmus eine heterogene Sammolgruppe bleihen. Wählt man als Typus der Gattung mit Pocock den L. carnens SAuss. und ancerkennt die vou mir unter diesem Namen heschrielenen of und o wenigstens als Cotypen oder ïherhaupt als unit L. carneus Sauss. identisch, so wïrde die Gattung Leplodesmns jedenfalls

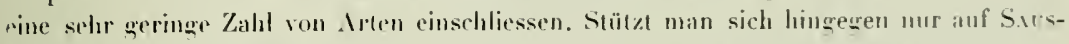
sumbs beschreilung eines unreifen $\sigma$, so ist min auf die äusseren Formen angewirsen mul crst recht un eine einigermasseu scharfe Mhgrenzung der Gattung verlexen.

Wir fechmen vorläutig zu Leplorlesmus diejenigen Arten, die wir nicht in bereits davon abgetrennte Genera oder in newe natürliche Artengruppen unterbringen können.

\section{Leptodesmus areatus Sıル.}

(tiig. 10 in.)

Die Prïlung des Originalexemplars (o) erlauht uns, die Beschreibung in einigen Punkien zu ergä̈nzen.

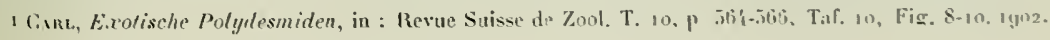


Antennen und Beine hraunschwarz, das 1. und 2. Beinghed dunkel rothraun.

Ilalsschild nit in dro Nlitle änsserst flachem, gegen die Seiten hin aber stark zurückgebogenem Vorderrant, der mit den geraden schrägen Scitenteilen des Hinterrands cin dentliches Eck bildet.

Kiele, mit Ausnahme der \& letzten, vorn und hinten zugerundet, rom r5. Segment an hinten zarkig ansgezogen. Ilinterrand der hiele nit 1 oder 2 sehr schwachen Verdickungren des Randsaumes. Porenbeule hinten znģ⿻rundet und plötzlich abgehrochen,

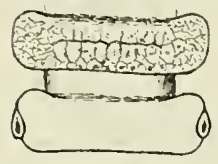

Fig. 109.

Leptodesmus arealus Silv. $Q$

Zwei mittlere Segmente; im hinteren ist die Shulptur weggelassen. a'st vom 15. Sewment an his zum llintereck rejchend, vorn zugespitzt, aber lemoch vom Randwulst abgesetzt, erst auf den letzlen Kïelen allmählich in diesen verjüngl.

Metazoniten (Fig. 10!) oben richt netzig runzelig, mit schwacher, meist zickzacklörmiger Querfurche, von der nach vorne einige Längsfurchen abgehen und hinter welcher zunächst eine Querreihe grüsserer und sodann eine Reihe kleinerer Felder folgen. Einige Felder, besonders der hinteren Reihe, zeigen Andeutungen eines stumpfen IJöckerchens. Seiten der Mletazoniten im vorderen Kö̈perteil undeutlich gekörnelt, im hinteren glatı; Pleuralhöcker bis zum г7. Segment nachweisbar, auf den vordern Segmenten gut entwickel, kegellörmig.

Ventralplatten mit je cinem glatten llöckerchen neben jedem Bein.

Zweites Gilied der Beine unterseits am Endrand in ein Spitzchen vorspringend.

Möglicherweise qehört auch diese Art in das Genus Chondrodesmus und wäre dann an der sehr deutlichen polygsonalen Felderung der Metazoniten und an der starken Abrundung der Kiele zu erkennen. Die Metazoniten sind anf unserer Figur in Verhältnis zur Breite etwas zu lang dargestellt.

\section{Leptodesmus augustus n. sp.}

(Fig. 110-112.)

Sehr hülssch quergebändert. Die allggemeine kärbung des Körpers, Kojfes, der Antennen und Beine ist schmutziggelb; die Prozoniten sind in ihrem ganzen freien Teil dorsat dunkler, seitlich etwas heller kirschrot und ventral wenigstens gegen den Hinterrand hin ebenfalls kirschrot; aul' dem liäcken greift die rote Färbung mit einem schmalen Streifen auf den Torderrand der Metazoniten über. Der ganze Scheitel hinter den Intennen und der Hinterkopf sind elienfalls ron einem grossen kirschroten lileck eingenommen.

Länge : $50-55 \mathrm{~mm}$; Breite am 10 . Metazonit : o $^{-1} 7 \mathrm{~mm}$, $ᄋ 8 \mathrm{~mm}$.

Körper ziemlich schlank, an beiden Euden nur wenig verschmälert. Rücken mässigg gewälls, heim of etwas stärker als beim $ᄋ$.

Metazoniten ganz glatt und glänzend, ohne Querfurche. 


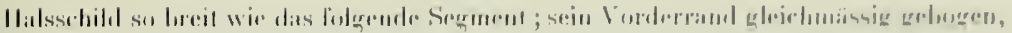

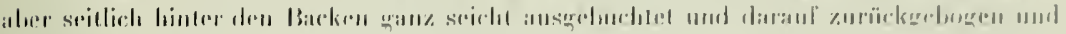

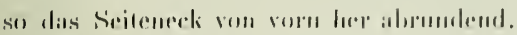

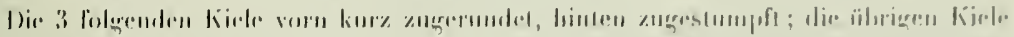

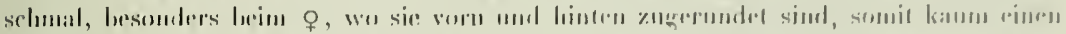

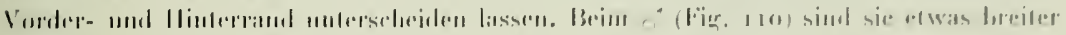

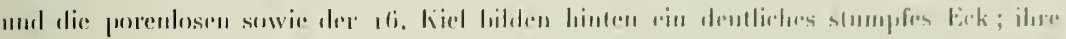

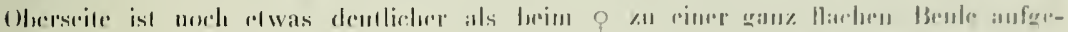

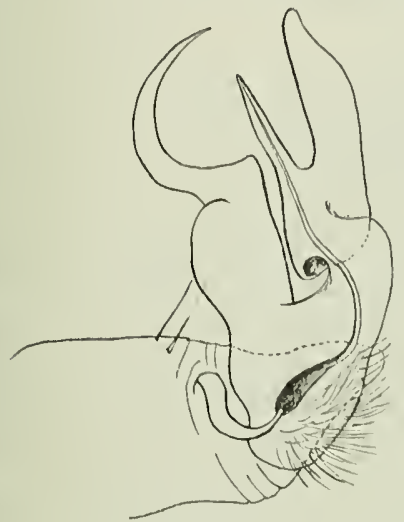

Fig. 111 .

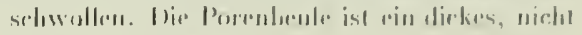

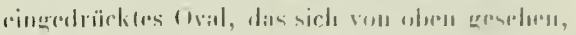

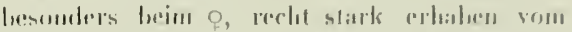

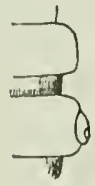

Fig. 110.

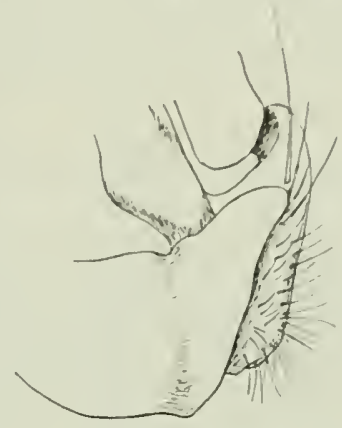

Fig. 112.

Leptodesmus augusfus $\mathrm{n}$. sp.

lïg. 110. Rechte Hillte des 11. und 12. Segments of.-Fig. 111. Linker Gonopode, von innen. Fig. II2. Rechtel Gonopode, Coxa und 'Telopoditbasis von aussen.

Kielrand abhebt und heiderseits gut gegen den Randwulst ahgegrenzt ist; del Porus ist gerade nach aussen gerichtol. Erst die 3 letzten kiele lilden ein zackiges llintereck. in welches sich die Porenbenle auszicht.

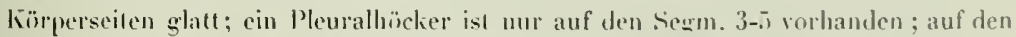
folgenden fethlt sogar eine heulige Iuftreibung an dessen Stelle.

Ventralplatten sehr glatt, nicht quergeteilt, ohne Hicker.

Beine mil natklen milleren Gliederu. nur mit der Subapicalhorste versehenen Basalgliedern und eher spärlich kurz beborsteten Endgrliederu. Diejenienen des o ohne sexuelle Anszeichmungen. Tarsus etwas länger als die zwei vorhergehenden Glieder zusammengenommen.

Analschuppe dreieckig; Schwänzchen konisch ausgezngen; beide mil winziggen Borstenhöckern.

Gomopoden von sehr charakteristischer frorm (Fig. 11, 112). Die Coxa enthehur auf 
der lunenseite rines Zapfeus; aussen ragt sie mit einem grossen, cndwärts verschmälerten und zngestumplten Lappen über den femur vor. Am Telopodit liegt der Schenkelfortsal\% vor dem Tibialteil; er steigt zunächst als zientich hreite Plalte gerade auf und geht dann mit scharfem huie in eine schmale, spitze sichel über. Der Tibialteil ist kurz oherhalb der Basis halsartig verschmälert und hat an dieser Stelle eine sehr kurze Drehung um $180^{\circ}$ um seine Längsachse erfahren; dann erweiten er sich wieder und teilt sich in einen vorderen, spiessförmigen Ast mit der Samenrinne und einen hinteren, lamellären, etwas klingrenförmigen Ist.

$\sigma^{1} \sigma^{-1}$, qo. La Camelia, Kaffeepllanzung bei $1800 \mathrm{~m}$.

\section{Gen. Chondrodesmus siıx.}

Syn. Dirhabulophallıs. Pөсоск, Biologia Centrali-Americana, Chilop. and Diplopoda, p. 161. 1909 .

Die Art, für welche SiLvestru (1897) den Gatlungsnamen Chondrodesmus einfülırte, gehört nach der Gestaltung der Gonopoden zur Gruppe des Leptodesmus plataleus Kinscu, für welche Pocock später den Gattungsnamen Dirhabdophallıs schuf. Der Sinvestusehe Name hat somit die Priorität, wenngleich Pococks Name bezeichnender und die von ihm an mehreren Arten abgeleitete Diagnose genauer ist.

Dieser Gattung gehören ausser den neuen Arten der Funnansschen Ausbeute folgende früher aus Columbien verzeichnete Arten mit ihren Originalbenennungen au :

Polydesmus pustulosus Gers.

Polydesmus (Oxyurus) plalaleus Karscu.

Leptodesnus plataleus flaviporus BuöL.

Leptodesmus goudoli ATtems.

Polydesmus (Strongylosoma, Sectio Oxyurus) chloropus Perens.

Polydesmus (Oxyurus) acanthurus PETEus.

Polydesmus Frauenfeldianus Humb, u. Sauss.

Für die 2 letzleren Arten sind wir allerdings auf die äusseren liormen angewiesen. Von chloropus Peters und acanthurus Pвт. hahen wir die Originalexemplare untersuchen können und versuchen darnach die Beschreibung zu vervollständigen.

Die Gattung ist auch in Ecuador, Venezuela und (mit 5 Arten) in Central-Amerika vertreten. Hingegen glaube ich L. carinovatus Atrexs, aus dem brasilianischen Staate Manaos, weģen der Gonopoden nichı hieher rechnen zu sollen. 


\section{$-8 x_{7}-$ \\ Chondrodesmus chloropus ( I'ET, $^{\prime}$ \\ (1'iz. 113,11 亿).}

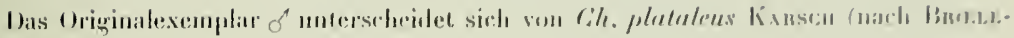
manns Beschreibumg) Polgendormassin :

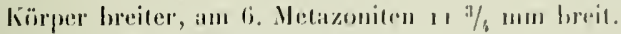

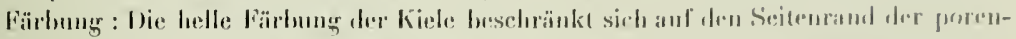

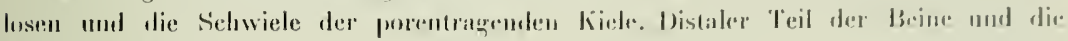
Antenurn gethgrïn.

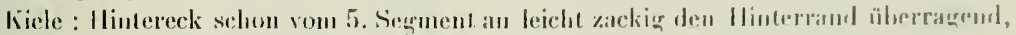

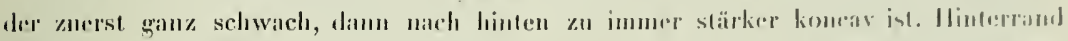

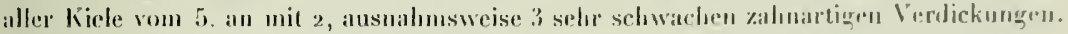

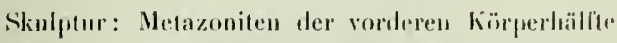
whe spuren einer Querfurche, dicht tederantiog zpermuzelt, hesonders anl den liehn; Spuren einer writmaschigen polygonalen Felderung anf dem Rücken, vereinzelte Körner auf dem baisalen Teil der Kielı: Metazoniten der hintern körperhälfte mit selnwachen Andeutungen einer Querfurche, mehr dicht granuliert als lederartig gerumzelt, in der lintern llällte mit Syuren zweier Querreihen von kleincren polygonilen Fetdern und zweier Tuberkelquerreihen. Manchmal vor der selwwachen Querfurche Spuren einer vordern Tuberkelreihe oder eines sehr flachen Querwulstes.

Die kegelförmige Warze oberhalb jedes vordern Beines recht gross und bis zum ${ }_{7} 7$. Segm. gut entwickilt (Bei plataleus spricht Buelemaxix ron einer "petite verrue conique, mousse").

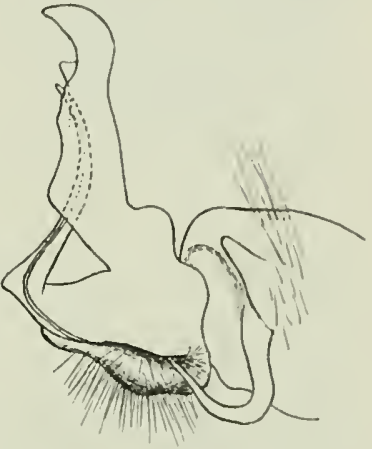

Fig. 113

Chondrodesmus chloropus (Pel.) Gonopode, von innen.

Ventralplatten des 8.-I7. Segments mit je cinem stumpfen, nach hinten gerichteten liegel nehen jedem Beinpaar; diejenige des 7. Segments mit je cinem solchen nehen dem hintern Beinpar.

Beine nur anf dem letzten Glied und besonders oherseits dicht kurz beborstet.

Die Gonopoden (Fig. r r3) sind denjenigen von Ch.plataleus (Kanscu) zwar āhulich, unterscheiden sich aber von diesen durch schmäleren d. h. ghleichmässiger hreiten und mit einer stumpfen auf der Anssenfläche angesetzten Zacke ror dem subapicalen . Iusschnill des Innenrandes versebenen Schenkelfortsatz.

P'etens' Originalexemplar stammt ron Bogola. 


\section{Chondrodesmus acanthurus (PET.)}

(Fig. $11 \overline{i-116) .}$

Wï erüazen die Origrinalheschreibung durch Vergleich des Originalexemplars (o) unil demjenigen von Ch. chloropus (Рет.) ó.

$$
\text { Cb. chloropus (PET.) } \ddot{b} \text {. }
$$

Körper breiter.

Metazoniten mit Sparen von polygonater Fehlerung.

Kiele (Fig. 114) breit, etwa so breil wie lang.

Hinterrand schon vom $\overline{5}$, Kiel an leicht concav (linölchen selır selıwach).

Porenbenle vorn unnerklich in den Randsanm übergehend.

Kegelförmige Höcker wenigstens an den hintern Ventratplatten sehr deutlich.

Borstenwirzchen an den Seiten des Sehwänzchens sehr schwaeh entwiekelt.

Schwänzchen vom hasalen Borstenwärzchenpaar an stark verjüngt.

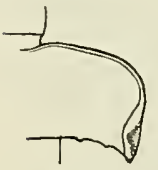

Fig. 114.

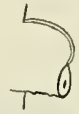

Fig. 115

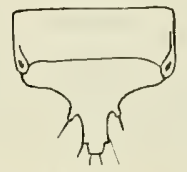

Fig. 116.
Ch. acanthurus (PEr.)

Körper' schlanker unl stärker gewöllt.

Metazoniten ohne Spuren van potygonaler lielderung.

Kiele sebmal, bedeutend linger als breit.

Hinlerwal bis zum 17. Segment gerade (vom 4,-18. mit I oder 2 kinötchen).

Porenbeule vom 5,-16. Segment kürzer ; ihr Vorderende abgesetzl dureh cine schwache Ein. knickung des Seitenrandes des kieles (Fig. 115).

Kegellörmige Höcker der Ventralplatten niedriger und stumpter, undentlieh.

Borstenwärzetren an den Seiten des Schwänzehens, besonders das basale Par, stark entwickelt (Fig. 116 ).

Sehwänzchen in ausgezogenen Teil fast cylindriseh, am Ende stumpf.

\section{Ch. acanthurus stammt von Veragua} (Panama).

Die von Attems (Syst. d. Polyd. I, p. 378 ) als acanthurus beschrieben 우 우 scheinen eher chloropus anzugehöreı.

Fig. 114. Chondrodesmus chloropus (Pet.). Rechter Kiel des 10. Segments, vergr. $4 \times 1$. Fig. 115. Ch. acanthurus (Pet.) Rechter Kiel des 10. Segments, vergr. $4 \times$ I. - Fig. 116. Id. 19 u. 20 . Segment, $4 \times 1$.

\section{Chondrodesmus riparius $\mathbf{n} . \mathbf{s p}$.}

(Fig. 117).

Rïcken dunkelrotbraun, die Prozonilen fast schwarzbraun, die Metazoniten in der Hitte gegen den Hinterrand hin melır oder weniger stark dilfus aufgehellt. Das llintereck der Kiele von etwas hinter der Milte des Seiten-zur Basis des Hinterrandes trübgelblichweiss, aber nicht scharf gregen die übrige Fürbung abgeschnilten, ebrnso eine schmale hintere Querzone auf den Seiten des Halsschildes und auf den 3 folgenden Kielen. Kopf mit den Autennen und Bauchteil der Prozoniten kirschrol. Beine im vordern Körperteil stärker, im hintern Körperteil viel schwächer lleischrot getönt.

Länge: 48-52 mm.; Breite des 10. Melazoniten: $9^{1 / 2^{-10}} \mathrm{~mm}$.

Körper nur ganz vorn und ganz linten schwach verschnälert. 


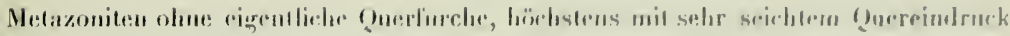

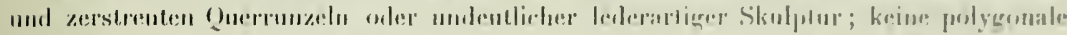

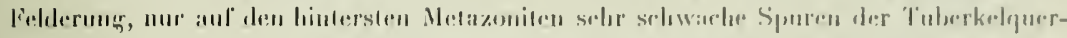

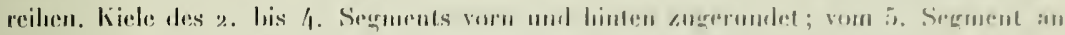

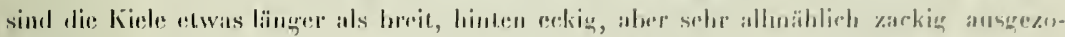

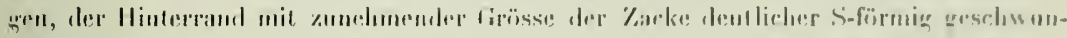

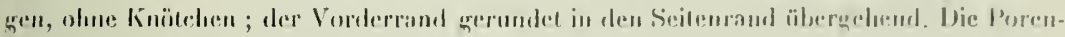
beule mässign loreil, in keimer. Weise vom vor-

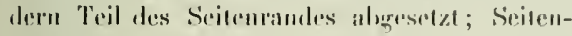
ratud also gilatl.

Peren bis zum 1/1... Segment mit ziemlich spitzem hreitem Hërker olurhall, der Vorderlıйlteı.

Ventralplatten nackt; diejenigen des 4. monl 5. Segments dureh eine hreite liruzlurche in A ziemlich gleichartige mude lläcker geteilt, die folgenten mil sehr Machem Hï̈ker nelien jorlem Beinpaar.

Analseluppe dreieckig, mil einem winzigen Borsteuhörkerchen jederseits vor der Spitze.

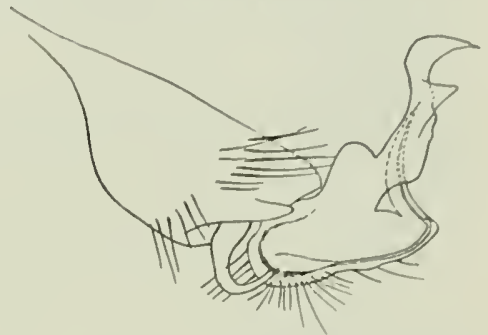

Fig. 117.

Chondrodesums riparius n. sp. of tionopode, von innen.

Schwänzchen konisch atusưogen, jederseits unit 2 qanz kleinen Borstemwärzchen.

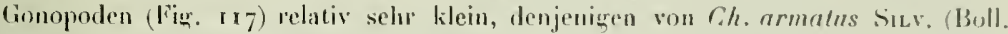
Mus. Torino. vol. XII, No $315, \mathrm{p}, 13$, Fïg. $37,18_{97}$ ), aus Ecualor, selır ähnlich, mit ganz schmalem Schenkelfortsatz, der am Ende in eine spitze Sichel ausgeht und davor anf der Innenseite einc breite dreieckige Zacke trïgt; der Tilialfortsatz ist spitz und ganz schwach gelogen.

3 of, Bodega Central, am Magdalena, 5o m. iils. M.

Trotz der fast vollkommenen lilentität im Bau der Gonopoden sind Ch, riparius n. sp. und Ch. armatus Subv, sehr leicht anseinamlerzuhalten. Ch. armalns (Origginalexemplar!) unterscheidet sich ron unsrer columbischen Art folgendermassen:

1. Durch gुrössere Ausdehnung der hellen Färlung anf den Kielen, dic auch vorn his zum basalen Drittel weisslich sind.

2. Durch dichte, grobkörnige Skulptur der Metazoniten.

3. Durch breitere Kicle, die ungefähr $\mathrm{r}_{1 / 2} \mathrm{mal}$ so lang wie breit sind, und deren llinterrand incist ein Kin̈̈chen oder Zähnchen tränt.

4. Durch eine breite und selır flache Porenbenle. die nicht als Verdickung des übrigens sehr feinen Seitenrandwulstes erscheint, und vor welcher der Seitenrand ganz Hach ausgebuchtet ist.

5. Durch starke, spitze, dornförmige Höcker der Ventralplatten. 
6. Durch die Hachen, nicht durch Kreuzfurche alogeteilten Ventralplatten des 4. und 5 . Segments.

\section{Chondrodesmus convexus n. sp.}

(Fig. 118$)$.

Rücken schwarz; beim o tragen die Metazoniten einen schmalen roten Hinterrandsaum und dic Kiele sind an Seitenrand gegen das Hintereck hin schmal gelblich; beim $q$ ist die gelbliche. Iufhellung auf die Porenbeulen beschränkt, der vordere Teil der Prozoniten trägt in der Räckenmitte einen verwischten roten Streif. Körperseiten tief rotbrann bis schwarzbraun; Bauch schmutzig gelbhraun, mit verwischtem rotbraunem Fleck aul' den Prozoniten. Kopf schwarzbraun mit rülichem Vorderrand. Autennen und Beine rotbraun, an der Basis heller, distalwärts dunkler, mit helleren Gelenken.

Länge : o 50, o $58 \mathrm{~mm}$; Breite am 10. Metazonit: $\sigma^{1} 7 \frac{1}{2}$, $ᄋ 10 \mathrm{~mm}$.

Körper vorn kaum merklich, hinten erst vom 17 . Segment an verschmälert.

Halsschild chagriniert und mit isolierten Körnchen, die etwas zahlreicher hinter der Witte des Dorsalteils stehen; hinter dem Vorderrand ein breiter, seichter Quereindruck; die Seitenlappen stark verschmäler ; ihr Vorderrand erst ganz aussen zur Abrundung der Ecke stärker zurückgebogen, sonst llach.

Rïcken ziemliclı stark gewölbt, besonders beim $q$, sodass die Kiele niedrig angesetzt erscheinen und dentlich nach aussen abfallen.

Die Kiele nehmen von vorn nach hinten gleichmässig an Breite ab und sind beim $\sigma^{1}$ vom $9 .$, beim o schon vom 5 . an in zunehmendem Grade länger als breit; Vorderrand regelmässig zugerundet in den Seitenrand übergehend, der beim $q$ etwas deutlicher convex ist als beim . Hintereck annähernd rechtwinklig, nicht zackig, erst vom 17. Segment an in eine Zacke verlängert; dementsprechend ist der Hinterrand bis zum 17 . Segment horizontal, dann schräg nach hinten gerichtet, aber nicht concav; er trägt $1-3$ (meist 2) zahnartige Knnötchen. Die Porenbeule ist kurz, eiförmig, vorn zugespitzt, nicht allmählich in den Seitenrandwulst verjüngt und auf' manchen Kielen auch durch eine sehr schwache Kerbe von ihm getrennt. Die 3 vordersten Kiele sind beim ơ fast rechteckig, beim o etwas stärker zugerundet.

Metazoniten ohne Querfurche, grob chagriniert, mit Andeutungen einer unregelmässigen Felderung; gegen die Kiele hin wird die Skulptur gröher, gegen den Vorderrand der Metazoniten dagegen schwächer; auf den hintersten Metazoniten geht die Chagrinierung in eine dichte, flache Körnelung in unregelmässigen Querreihen üher.

Prozoniten glatt und matt, während die Metazoniten, besonders beim ơ, stark glän zen .

Ventrajplatten glatt und glänzend, beim $q$ ohne llöcker, beim $\sigma^{\uparrow}$ mit je 4 Höckern, wovon die hintern deutlicher und ziemlich spitz sind.

Seiten der Metazoniten fein chagriniert oder schräg gerunzelt, besonders im vordern Körperteil ; bis etwa zum 16. Segment mit Beule und Höcker oberhalb der Vorderhüften. 


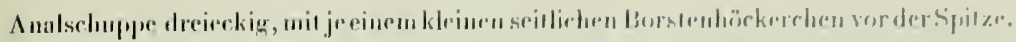

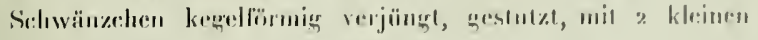
Borstenhörckerchen anf jeder Secile.

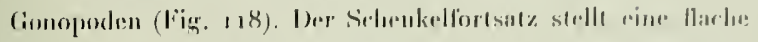

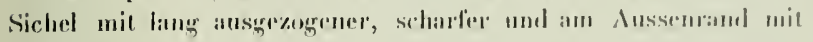

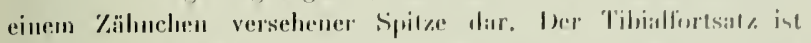

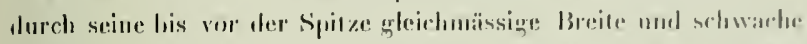

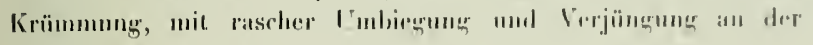
Spitze, ansgezeichnet.

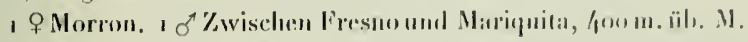

Vorlegende Art ist leseht kenntlich an der Wällung des Räckens, der Skulptur, den erst am Körpereule zackig ausgezourenen Kielen, der fäilumur els.

Das o zeigl anf rem 5. Segment rine kloine Monslousitiil, indem die Porenbeule und das Saftorh auf dem linken Kiel gut entwickelt sind, auf dem rechten aber fehlen.

\section{Chondrosdemus pustulosus (Genv.)}

(lig. I1 1 -120).

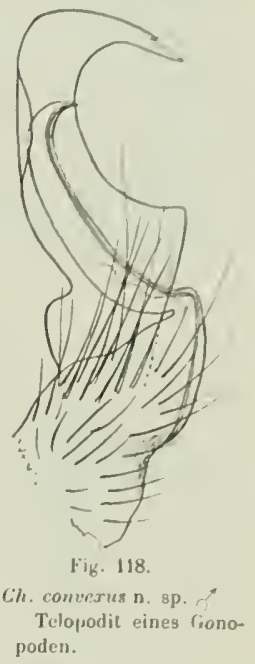

Rücken, Körperseiten, Analsegment, Kopf, Antemen und die Beine mit Iusnahme dur Hüften schwarz. Bauch mit den Ventralplatten uml Hïften heller ohler dunkler rotbrann. Kiele ausserhalb einer Linie, die uach aussen gebogen von der Basis des Hinterrandes gegen die Mitle des Vorderrandes zieht, oberseits und unterseits schwefelyell, stark mit der sclıwarzen körperfärbung kontrastierend, ehenso die Seitenlappen des IJalsschildes und das Ende des Schwänzchens.

Lïnge : of ca. 55, 우 ca. $60 \mathrm{~mm}$; Breite am 10. Melazoniten : of 11 , 우 $12 \mathrm{~mm}$. lörper an Vorder- und Ilinterende leicht verjüngt. Rücken hein ơ ganz schwach grewölh, mit horizontalen kielen, beim $q$ ziemlich stark convex, mil deutich ahfallenden kielen.

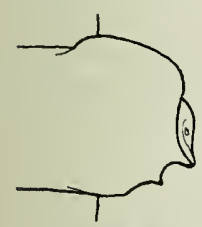

lig. 119.

Ch. pustulosus (Gerv.) 10. Metazonit, rechte Utälfte. liopf glatt.

Ilałsschild breit, mit breitem Quereindruck hinter dem Vorderrand; letzterer Hach gebogen, erst ganz seitlich plötzlich umgehogen und mit dem Ilinterrand ein ziemlich scharfes Hintereck hildenu. Oberfläche dichı aber schwach chagriniert.

Metazoniten chagriniert und zwar vorn schwächer, hinten stärter. mit schwacher Andeutung ciner Wuerfurche, hintel weicher zwei Querreihen llacher, durch unregelmässige längsfurchen getrennter Körnchen aufireten; die Basis der kiele ist meist dichter gerunzelı und mit zerstreuten grösseren Körnern besetzl. 
Die Kïele des 2. und 3. Segments sind vorn zngerundel; hinten bilden sie ein zienlich scharfes rechwinliges Eck; am liel des 4. Seqments ist der Hlinterramb schon deutlich convex mud das llintereck schräg nach aussen vorspringend. Dic folgenden kiele, rom 5.-15. (Fig. 119), sind beim ot elwas loreiter als lang, bein of ewa so breit wie lang und bei beiden äusserst charakteristisch greformu. Das Vordereck ist zugerundet und der Seitenrand gholl, aber etwis nach anssen geschweift und vor des Porenbeule ganz seicht eingedrüclit. Der Hinterrand ist meln oder weniger stark convex nnd gegen aussen hin deullich nach vorn gezogen, auf diese Weise den Seitenrand verkürzend; äberdies trägt er im äusseren Drittel einen scharfen Zahn und ist zwischen

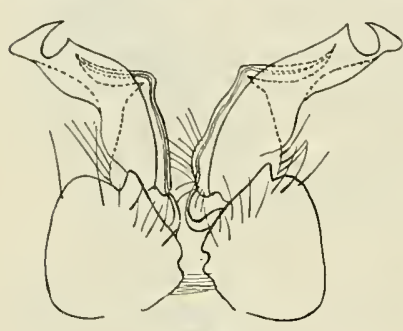

Fig. $\{20$.

Chondr. pustulosus (Gerv.) $\sigma^{\pi}$ Gonopoden, von vorn. diesem und dem Hintereck rundlich ausgebuchtet, wodurch das Hintereck zahnartig wird und schräg nach aussen vorspringt. Eist auf dem i 7. und 18. Segment ist der kiel hinten zackig ausgezogen und überragt den hier leicht concaven, aber immer noth a oder 2 scharfe Zälne tragenden IFinterrand. Auch in der proximalen Hälfte trägt der Kielhinterrand noch $\Lambda$ ndeutungen eines oder zweier Zälnchen, ist aber zwischen diesen gar nicht oder kaum merklich eingebuchtet. Die Porenbeule nimmt den grössten Teil des Seitenrandes ein; sie ist breit und sehr llach, breit eingedrückt, yorn nicht scharf abgeselzt und hinten in das spitze Ilintereck des Kieles endigend.

Körperseiten glatt, bis zum 17. Segment mit einem recht starken kegelförmigen Höcker oberhalb der Vorderhüften.

Ventralplatten glatt, mit je einem ziemlich spitzen Höcker neben jedem Bein.

Femur der vorderen Beinpaare des of (his zum 12. Paar), uuterseits nahe der Basis beulig verdickt und dahinter ganz leicht coneav, die verdickte Stelle durch etwas hellere Färbung hervortretend.

Analschuppe dreieckig, mil je einem winzigen subapicalen Borstenhöckerchen.

Schwänzchen konisch ausgezogen, mit je z lateralen, stufig vorspringeuden Borstenhöckern.

Gonopoden (Fig. 120) mit ganz schwach und gleichmässig gebogenem, allmählich zugespitztem Tibialfortsatz; der Schenkelfortsatz ist his kurz vor dem Ende breit und vorn glattrandig, dann aber scharf, schmal und sehr lief bogig ausgeschnitten und mit einem vogelkopfälınlichen Lajpen endend.

6, \& La Camelia, Kafleepllanzung bei Angelopolis $1800 \mathrm{~mm}$.

Diese Art besitzt den Gonopodentypus der Chondrodesmus-Arten, weicht alyer von den bisher bekannten Arten dieser Gruppe durch die aussergewöhnliche Form der Kiele mit ihrem gezähnten, gebuchteten und im ganzen doch convexen Hinterrand, verkürzten Seitenrand, schräg vorspringendes Hintereck u. s, w. in hohem Masse ab. Doch handelt 


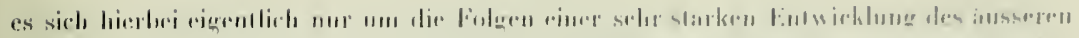

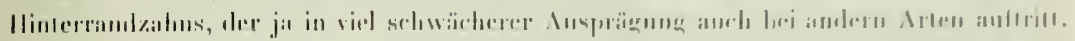

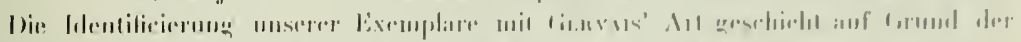

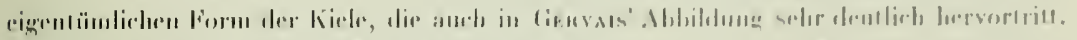

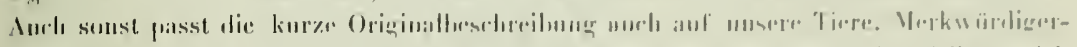

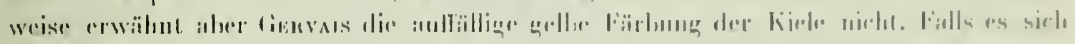

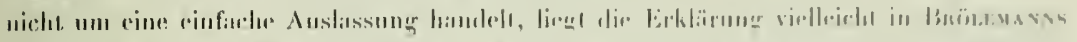

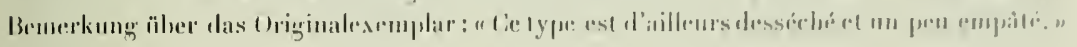

\section{Chondrodesmus nobilis n. sp.}

(liig. 121).

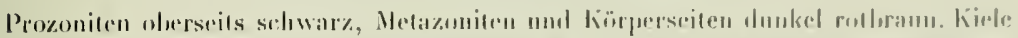

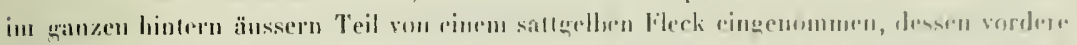

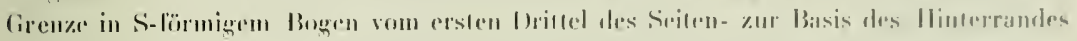

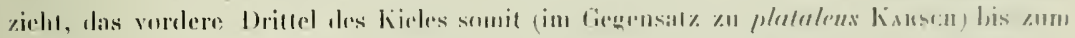

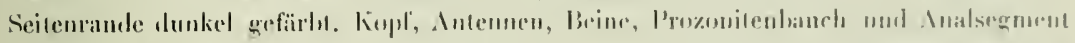

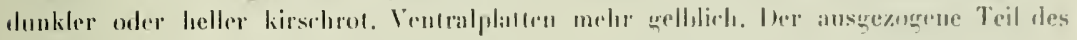
Sehwïnzchens gelh.

Länge : $45-18$ mm. Breite am 11. . Metazoniten : $9 \mathrm{~mm}$.

Räcken schwach gewölls.

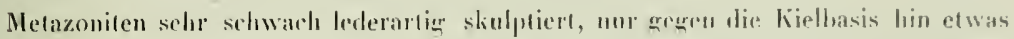
deuticher unt hier meist mit cinigen gerstrenten lï̈nchen; in der hintern hörperhälfte

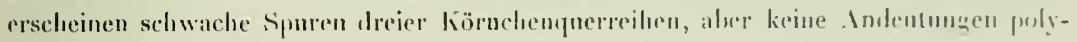
wonaler Fehlerung.

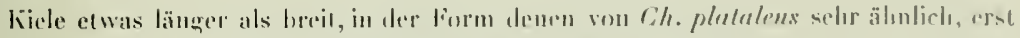

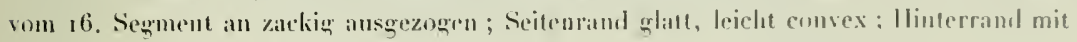
cinm, sclten zwei, ganz sclwachen kin̈tchn; l'orenhenle

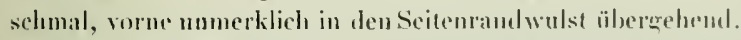

Siten der Metazoniten matt, fein lederarlig skulptiert his last glatl. Pleuralhöcker olserhalb der Vorderhüfen gut answebillet, his zum i6. Serment nachweishar.

Ventralplatten mis je cinem dentichen Höcker nohen jedem Bein.

Analschuppe dreieckig; Schwinzchen konisch gुestulzt; beide mil ganz kleinen Borstenhöckern.

Beine: Der Endrand des 3. Glicdes (Prefemurs) muterseils in der Mitte deullich lö̈kerig rorspringend: Ier Femur der vorleren Beinpane $\left(\sigma^{-1}\right)$ unterseits mit einem Streifen von tran flachen, runden Höckerchen, die wie anfgeklebr erscheinen.

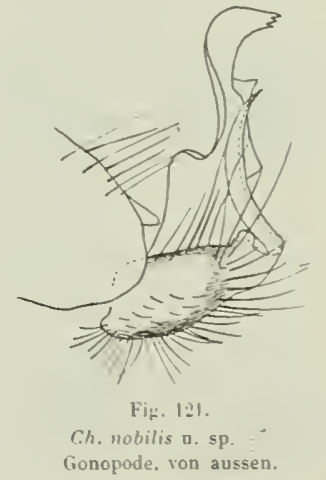


Die Gonopoden (Fig. 121) wohl unterschieden ron denen von platalens (Karscii) und flaviporus (BröL.), aber fast identisch mit denjenigen von Ch, chloropus PET.

25 . Barranquilla am Mandalena. Meereshöhe.

Durch die Form der Kicle und der P'orenbeule und die Skulptur der Metazoniten nähert sich diese . Irt Ch. plataleus, flariporns und chloropus, unterscheidet sich aber von allen durch die geringere Grösse, die kleinere resp. grössere Ausdehnung der gelben Firbe auf den kielen und ron den beiden ersteren auch deutlich durch die Gonopoden. thre spezifische Unablıängigkeit von chloropus bleibt noch etwas zweifelhaft.

\section{Chondrodesmus carbonarius n. sp.}

(Fig. 122.)

우. Oberseite tief schwarz. Kopf mit den Antennen, Ventralplatten und Beine selır dunkel rotbraun.

Länge $60 \mathrm{~mm}$; Breite am 10 . Metazoniten : $11 \mathrm{~mm}$.

Rücken ziemlich stark gewölbt, mit leicht heruntersteigenden Kielen, etwa wie beim 우 von comexus.

liopf glatt und glänzend, nackt.

Halsschild dicht und gleichmässig granuliert; sein Vorderrand in der Mitte gleichmässig flach gebogen, aber seitlich gerade und schräg nach hinten gerichtet, mit den ebenfalls fast geraden und schräg nach vorn gerichteten Seitenteilen des Hinterrandes ein spitzwinkliges, zugestumpftes Eck bildend.

Prozoniten glatt, matt.

Metazoniten sehr dicht granuliert, auf den Kielen jedoch etwas spärlicher, mit zerstreuten etwas grösseren liörnern, die jedoch nirgends als deutliche Querreihen hervortreten; die Körnelung wird rom Vorder- nach dem Ilinterrand des Mletazoniten zu deut-

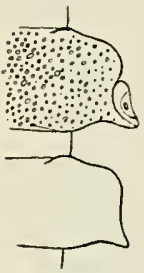

Fig. 122.

Ch. carbonarius n. sp. $Q$

Rechle Iälfte des 10 . und 11 . Segments; Granulierung des 11. Met. weggelassen. lich gröber.

Kiele des 2.-4. Segments stark heruntergebogren und deutlich nach vorn gezogen, mit zugerundetem Vorder- und zienlich scharfem Hintereck. Die übrigen Kiele (Fig. 122) sind eher schmal, nach aussen hiı kürzer als an der Basis, indem der Vorderrand von der Basis an etwas schrägr nach hinten verläuft und der Hinterrand umgekehrt leicht konvex und etwas nach vorn gerichtet ist. Das Vordereck ist kurz zugerundet; das Hintereck springt ziemlich spitz schıäg nach aussen vor, inden sowohl der Seitenrand wie der Hinterrand in seiner Nälse leicht geschweift sind. Die Porenbeule ist ziemlich kurz und breit, binten das Hintereck bildend, vorne zugestumpft und überdies_ noch durch eine schwache, schrägre Kerbe vom vordern Teil des Seitenrandes alggesetzt. Vom 15. Segment an springt das IIintereck zackig über den Ilinterrand vor und 


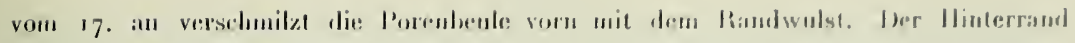

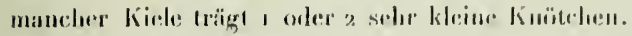

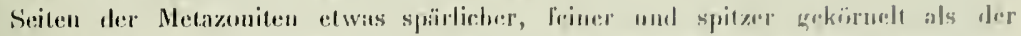

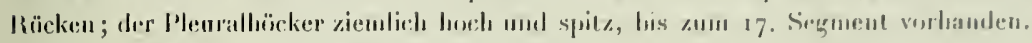

Ventralphitlen mit den gुewöhulichen \& lläckern.

Beine und Analsigment whe Besonderheiten.

1 9, Argelia, Kialleepllanzang leci Vinta, 1 (imm m.

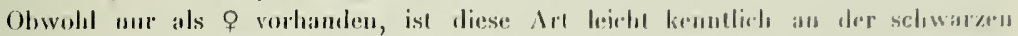

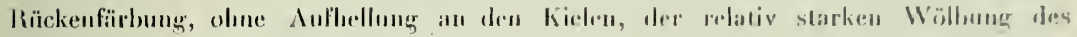

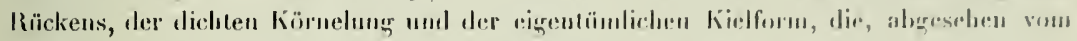

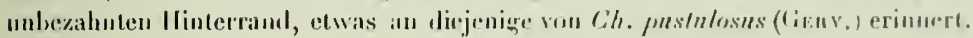

\section{Chondrodesmus attemsi n. nov.}

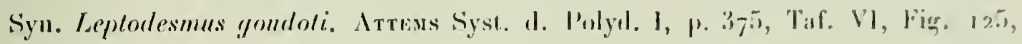
126,1898 .

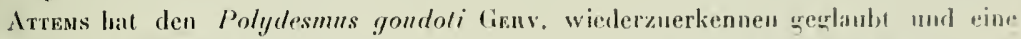

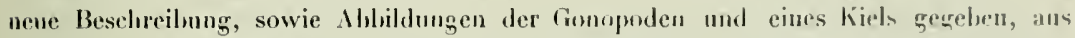
denen hervorgeht, dass der Autor eine Chomdrodesmus-Art vor sich gehalut lat und zwar rinen sehr vahen Verwanden von Ch. platalens (Kinscu).

Da nun aber BröLrmaxx (rgoo) den Polydesmux gondoli im (1riginalexemplar untersacht und der Gallung Aphelidesmus zngewiesen hat, so muss Artems' Art eimen neuen Namen erbalten. Teher die Selbständigkeit dieser form kam ich nicht rutscheiden.

\section{Chondrodesmus dorsovittatus n. sp.}

Rücken schwarzbraun, mit einer ziemlich breiten Irübgelben Mittellinte rom Vorderrand des Halsschildes his zum Schwänzchen. Kiele von der Mitte nach aussen trübgelb aufgehellt. Bauch, Seiten der Metazoniten, Beine und Antennen trübrelb; Kopf rotbraun, nach vorn hin gelblich. Auf den Seiten der Prozoniten geht die dunkle Rückenlärbung allmählich in die hellere Färhung des Bauclies über.

Länge : $55 \mathrm{~mm}$. ; Breite am 10 . Metazonil : $9 \mathrm{~mm}$.

Räcken ziemlich stark und gleichmässig gewölb, mit in gleichem Grade beruntergebogenen kijelen.

Halsschild seitlich stark verschmälert, mit zugestumpftem Seiteneck; Vorderrand hiuter den Backen äusserst seicht ausgebuchtel; Hinterrand auf den Sciten schräg und gerade; die Fläche lederartig gerunzelt, mit zerstrenten kleinen körnchen. die in der Milte etwas zahlreicher sind. 
Metazoniten lederartig gerunzelt und zwar gregen die Kiele und den Iluterrand hin deutlich gröber als vorne, mit kaum nemnenswerten Spuren polygunaler Felderung und aner Querlurche; die Tuberkelreihen sind nur anf den vordern und hintern durch eine schwache hörnelung angedentet. Das ry). Seggnent ist fast vothommen ghatt, sein Metazonit rom Prozoniten nur durch eine schwache Nahtlinie abgegrenzt.

liele des 2.-4. Segments mit breiter zugerundeten Vorder- und kurz zugerundetem oder nur zugrestumpftem Hinteresk. Die folgenden kicle rom 5. an ganz regreluässig an Breite abnehmend, im Mittel etwas länger als hreit; ihr Vorderand in immer breiterem Bogen in den etwas convexen Seitenrand äbergehend, der bis zum 15. Kiel mit dem fast geraden Ilinterrand ein stumplwinklige's, unscharfes Hintereck hitdet. Erst auf dem 17 . und 18. Kiel ist das Hintereck zackig ausgezogen ; auf dem 19. Segm. ist der ganze Kiel nur noeb durch die Porenbeule daryestellt. Iom 4. Kiel an ist der Hinterrand an 2 (selten an 1 oder 3 Stellen) deutlich knotig verdickt. Die Porenbeule ist klein, vom zugespitzt und vom Seitenrandwulst alggegrenzt, hinten stumpfer und das IIntereck bildend.

Metazonitenseiten glatt; ein eigentlicher Pleuralhöcker fehtt; die entsprechende Beule ist auf Ien vordern Segmenten etwas kantig, weiter hinten mehr flach kegelfïrmig.

Ventralplatten ohne Höcker.

Analschuppe dreieckig, mit scharter Spilze und davor 2 kleinen Borstenhöckerchen. Sclıwänzehen olıne Besonderlieiten.

1 Q. Buenavista, Kalfeepllanzumg bei Viota, rooo m. üb. M.

Schon dureh die Rïckenlängshinde von allen ïbrigen Chondrodesmus-Arten unterschieden.

\section{Gen. Alocodesmus SiLv.}

Die Untersuchung mehrerer Arten und der Vergleich mit dem Originatexemplar der typischen Art, A. angustatus SiLv, hat ergeben, dass es sich un eine natürliche Artengruppe handelt. AtтEMs vereinigh sie mit vielen andern Arten zu einer sehr beterogenen Gruppe unter dem Namen Odontopeltis Poc. Nachdem nun Pocock selbst (Biologia Centrali-americana, Diplop., p. 168 u. 169 . г909) nachgewiesen hat, dass Odontopeltis den preoccupierten Galtungsnamen Rhacophorus (Typus : R. conspersus Penty) ersetzen soltte und dass keine der von Atress und ihm selbst bis dahin als Odontopeltis bezeichneten Arten hierher gehört, muss anch die hetreffende Gruppe von Atrems in ihre Elemente zerfallen, wovon eines eben die Gallung Alocodesmus Sulv. repräsentiert.

Dieselbe ist hauptsächlich durch die Form der Kiele, die Skulptur der Metazoniten und den Typus der Gronopoden charakterisiert. In den meist kleinen Kielen (Fig. 126) verschmelzen immer Vorder- und Seitenrand zu einem flachen, glatten Bogen, der nie gezähnt, sehr undeutlich oder gar nicht gesäumt und niemals wulstig verdickt ist, trotz- 


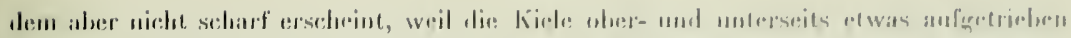

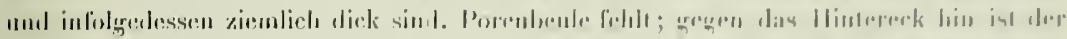

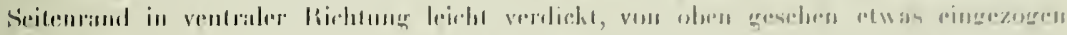

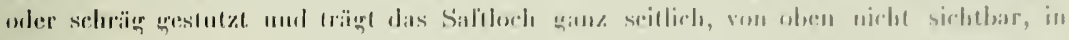

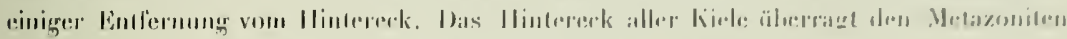

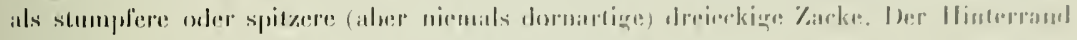

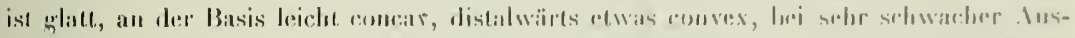

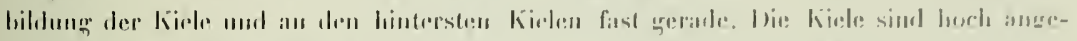

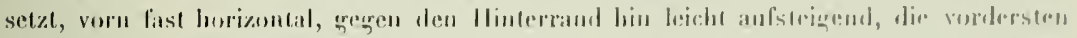
tuml hintersten meist retwas steiler an ligerichtet.

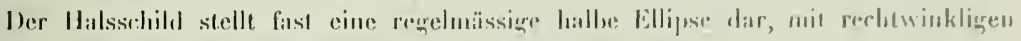

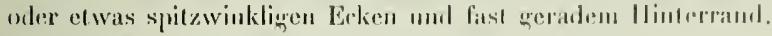

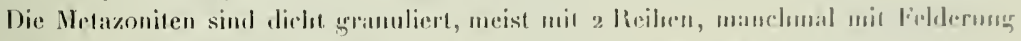
combinierter etwas grösserer hämer in der bintern Ilälfte. Metatzoniten i-18 mit mels oder weniger dentlicher tuerfurehe.

Ventralplatlen etwa aweimal so hreil wie linge, lanter der kiörpermilte mit je einem

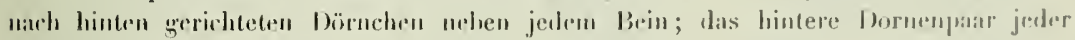
Platle länger als das vordere.

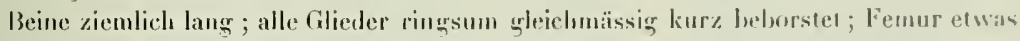
längrer als der Tarsus. Beine des of ohne Tarsalpolster oder Bürsten; dir vorderen Parre olme llöcker.

Schwänzehen dreieckig-konisch.

Gonopoden : Coxa olne Zapfen und ohne Lappen an distilen Aussenrand. Telopolit gerade aufsteigend, mit meist undeutlieher ofler fehlender Grenze zwischen Fiemur und Tibia, tief gespalten, die beiden Spaltäste am Ende sellıer unch eimmal geteilt, oder wenigstens derjenige, der dem Schenkelfortsalz entspricht.

Sichere Vertreter dieser Gattung keumen wir vorläufig nur aus Columbien und Venezuela.

Näclistverwandt scheint die columbische Gattung Centroguster Атт. zu sein.

\section{Alocodesmus angustatus SILY.}

(Fig. 123.)

Suvestur gab für diese Art keinen Fundort an und Attexs vermutete, sie stamme aus Ecuador. Die Originalexemplare des Turiner Musenms tragen aber die Etiquette: Punta Sabana (Darien).

Sirvestras Mbildung der Gonopolen stellt den Telopoditen zu schlank und seine Aeste zu kurz dar. Der Schenkelfortsatz $\pm 13$

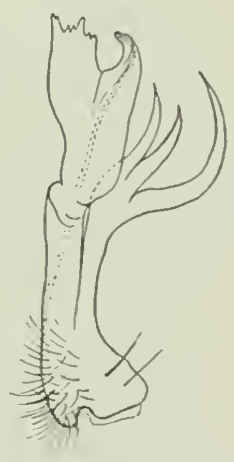

Fig. 123.

Al. angustarus (Silv.) of Telopodit eines Gono. poden, von aussen. 
(Fig. 123) teilt sich in 3 schlanke Aeste, wovon der längste sichelförmig gegen die Tibia hin grekrümnt ist, während die heiden anderı unter sich fast gleich und schwächer gekrümmt sind. Tibia in der Mitte etwas eingeschnürt, dann lamellär verbreitert und am Ende in eine gestutzte, an Ende gezähnte Platte und einen ilı hackig entgegengekrümmten schwächeren fortsatz mit der Samenrinne gespalten.

\section{Alocodesmus serenus SiLv.}

(Fig. 124-125.)

Wir habeı das Originalexemplar aus dem Göttinger Museum untersucht.

Diese Art hat mittelmässig entwickelte Kiele, die grösser sind als bei angustatus

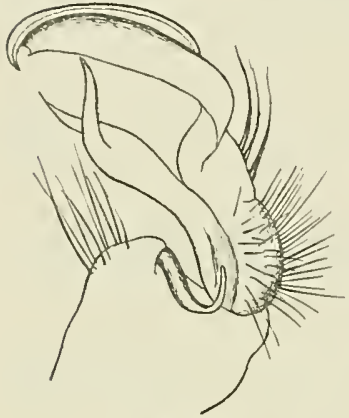

Fig. 124.

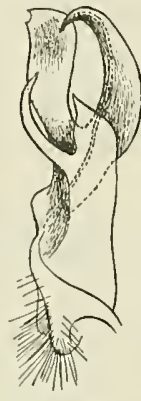

Fig. 125.

Alocodesmus serenus Silv. (Originalexemplar).

Fig. 123. Gonopode, von innen. - Fig. 125. Telopodit, von oben. und bei denen der durch den Vorder- und Seitenrand gebildete Bogen an den mittleren Kielen stärker gekrümmt ist als in Fig. I 26 für $A$. solitarius abgebildet und erst hinter der Körpermitte so flach wird wie in dieser Figur. Ferner ist A. serenus ausgezeichnet durch die selır schwache Ausbildung der Dörnchen an den Ventralplatten, deren vorderes Paar kaum sichtbar ist.

An den Gonopoden (Fig. 124, 125 ) ist der Sclıenkelfortsatz viel kürzer als der andere Spaltast des Telopoditen und zweiästig; die Tibia teilt sich in zwei Platten, von denen die die Samenrinne führende am Ende etwas hakig umgekrüımt ist, während die andere annähernd rechteckig und an dem Inneneck bogig ausgeschnitten ist. Uebrigens ist die Form aller 4 Aeste je nach der Seite, von welcher man sie betrachtet, recht verschieden.

Fundort: Orocué (Silvestri).

\section{Alocodesmus solitarius SiLv.}

(Fig. 1 26.)

Unterscheidet sich äusserlich von $A$. serenus durch sclıwächere Körnelung der Metazoniten, an denen nur die hintere Tuberkelquerreilie angedeutet ist, durch kleinere Kiele mit schwach gebogenem Vorder-Seitenrand (Fig. I26), sehr schwache Metazonitenquerfurche

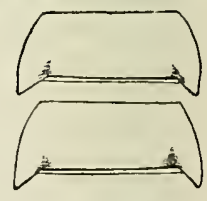

Fig. 126.

Alocodesmus solitavius Silv.

(Originalex. $\sigma^{\top}$ )

10. und 11. Metazonit im IImriss. 


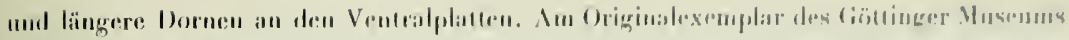
waren dis: Gompromlen ansgerissen.

[imulent: Villavicene:io (Sit,vesmi).

\section{Alocodesmus intermedius $\mathbf{n}$. sp.}

(iviz. 1\%7-1\%g.)

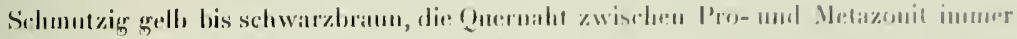

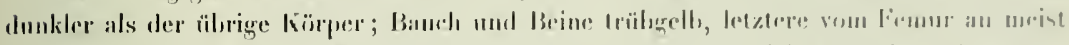

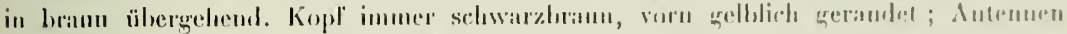
hellbaun. Bei granz dunklen Exempharen sind dir I lintereckn der liele, hesonders der porentragenten, andfgehellt.

Linge: of $30 \mathrm{~mm}$. ㅇ $33 \mathrm{~mm}$. ; Breile: of $33 / 4$, ㅇ $4 \mathrm{~mm}$.

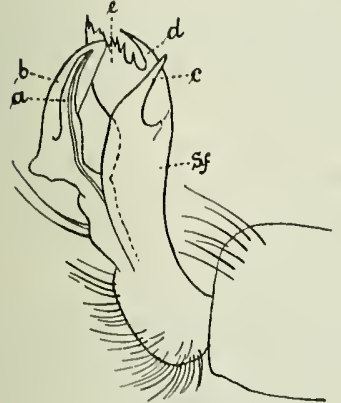

Fig. 127.

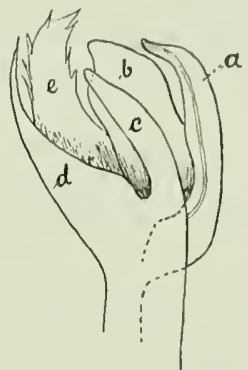

Fig. 128.

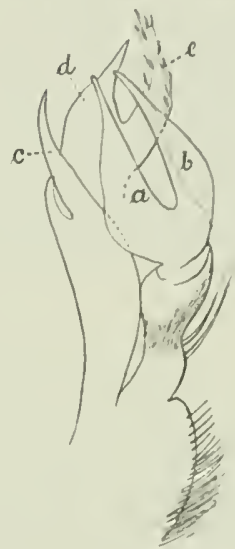

Fig. 129.

Alocodesmus intermedius n. sp. $\sigma$

Fig. 127. Gonopode, von aussen.- Fig. 128. Ende des Telopodils, schräg von oben.- Fig. 129. Telopodil, von unten.

Ilalsschild halbelliptiseh, mit nahezu rechtwiukligen Eeken und geradem Hinterrand; die Oherfläche in der Mitte fast glatı, sonst dicht llach granuliert, mil etwas grösseren Kü̈nern in «wei unregelmässigen Querreilen vor dem Hinterrand.

Körper hinten stark verschmälert, rorn im Bereich des 3. und 4. Segnments leicht halsartig versehmälert, weil die betrelfenden hiele etwas stärker aufsteiģen als die übrignen.

Die Metazoniten mit diehter feiner Granulierung und daneben zwei sehwach hervortretenden Querreihen etwas grösserer Granula hinter der wenig deutlichen Querfurehe, ohue Felderung. Die lï̈rnelung nimmt vom vordern nach dem hintern lïrperteil gleichmässig an Deutlichkeit ab. Prozoniten fein chagriniert: Seiten der Metazoniten in der untern Hälfte vor der Körpermitte fein granuliert: Pleuralkiel oder -höcker fehlen. 
Kiefe mässıg entwickelt, die vordern fïnl' hei ơ und o leicht anfsteigend, die übrigen fist horizontal: Vorder- und Seitenrand der miltleren liele lidden zusammen einen regelmïssigen Bogen mil etwas stälierer lirümmung als in Fig. r26; diss Ilintereck chas stumpfer als in dieser frigur. Beim o sind die kiele bedeutend schmäler als beim ơ, hinten selus schwach zackig und ganz stumpf, mit dusnalıne der drei hintersten Kiele, die in heiden Geschlechtern zu gerade nach hinten gerichteten, sjuitzen Zacken rednziert sind.

Dotnen der hinteren Ventralplatten gut ausgehitlet; diejenigen des hiulern Paares am ito. und 7 . Segment recht lang und sedr spitz. Vordere Ventralplatten und Beine des ô ohne sexuelle Auszeichnumgen.

Gonopoden (Fig. 127-I 29). Von den beiden S S raltästen des Telopoditen spaltet sich der tibiate nach der charakteristischen miltleren Einschnürung in zwei annähernd gleich lange Aeste, von denen der äussere etwas schmälere (a) die Samenrinne lïhrt, während der innere (b) eine hreite, schräg gestutzte Lamelle bildet; der Schenkelforlsatz (Sf) endet in zwei spitze Leste (c und d) und eine etwas längere Lamelle mit spitz gezähnten Rändern (e).

o. . Guadua, Nagdalena, Buenavista.

Die Exemplare ron Magdalena zeichnen sich aus durch ilıe durchgehends dunklere Färbung, diejenigen von Buenavista durch ihre auffallend kleine Statur. Ein reifes of aus letzterer Lokalität ist nur $19 \mathrm{~mm}$. lang und $21 / 2 \mathrm{mmn}$. breit.

\section{Alocodesmus alatus n. sp.}

(Fig. 130).

Trübgelb bis schokoladebraun, mit Andeutung eines dunklen Streifens längs der Rückenmitte. Bauch und Beine strolıgelb bis bräunlichgelb, letztere distalwärts nicht verdunkelt. Bei den dunklen Exemplaren ist die äussere Kielhälfte gelblich anfgehellt. liopf ganz schwärzlich oder wenigstens oberhalb der Antennen verdunkelt; Antennen heller oder dunkler gelb mit dunklerem 7 . Giliede.

Länge : 31-34 mm. ; Breite: $0^{1} 5 \mathrm{~mm}$., 우 $5 \frac{1}{2} \mathrm{~mm}$.

Körper vor dem 5. Segment plötzlich schmäler, aber vom 4. Segment nach dem Halsschild hin doch wieder allmählich verbreiterl, somit etwas halsartig eingezorgen zwischen dem 2. und 5. Segment, am Hinterende weniger stark versclınälert als bei den übrigen Arten.

Kopf hinten und auf den Backen fein gekörnelt, sonst glatt und glänzend. Antennen zurückgelegt den Hinterrand des 4. Segments erreichend.

Halsschild beim o mit annähernd rechtwinkligen, beim ot mit schon deutlich spitzwinkligen Ecken.

Charakteristisch ist die starke Entwicklung der Kiede, hesonders heim ot. Beim o sind sie zwar breiter als sonst, mit etwas convexerem, aber doch ziemlich gleichnässig gekrümmtem Vorder-Scitenrand. Beim of aber sind sie melır llügelförmig, fast zuveimal 


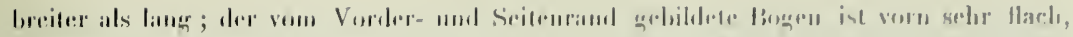

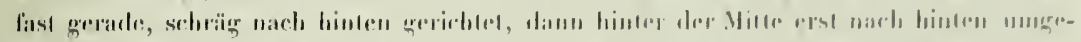

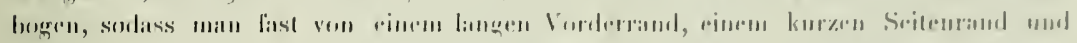

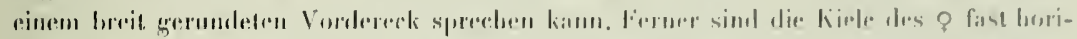

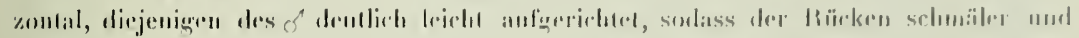

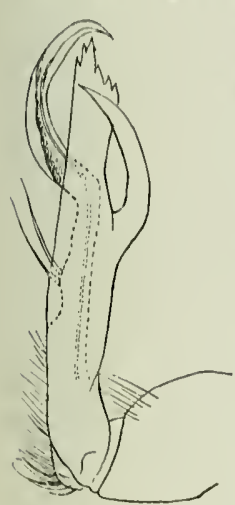

Fig. 130.

11. alalus n. sp. of Cionopode, von aussen.

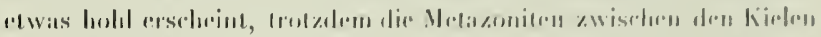

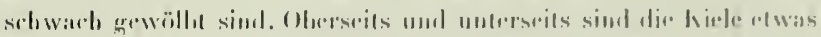

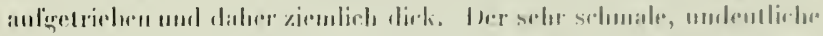

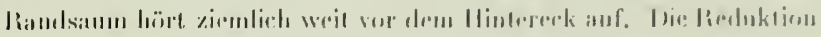

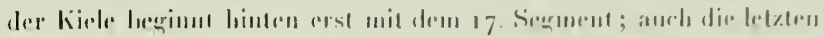

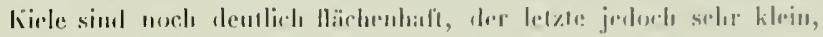
draicelisg.

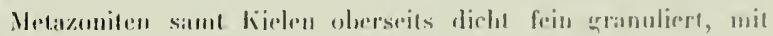

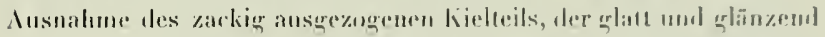

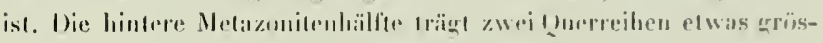

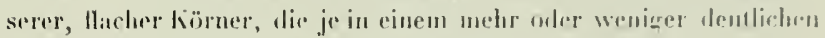

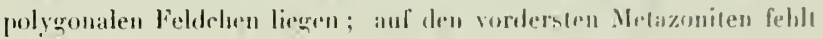
dir Felderung; dalïr ist die hintere lïnereihe elwas stirker unl nälıer an den Hinterrant gerïckt. Metazoniten $5-17$ mil dentlicher, efwas winkliger Wurfurche.

Seiten der Melazoniten glall. P'rozoniten chawriniert.

Ventralplatten des 14.-17. Segments mit je 4 dentlichen, spitzen, dornarligen Hö̈kern; die vorderen des of ohme Furtsälze, die fo.

chas eingesenlit.

Die Häften der Beinpaate 4-7 elwas kngelig aufgetriehen; sonst laben die Beine keine Eigentïmlichlieiten.

Gonopoden (Fig. 130) sehr schlank, in situ his zum Vorderrand ter lentralplatte des 6. Segments reichend. Telopodit gerade ; der tihiale Spaltast schmal, einfarh, mugeteilt, hinter der Mitte geliniet und dann sichelfürmig gelirümmt; der andere Spaltast Schenkellortsatz) zweiteilig.

of, . . Unterhalb Bodega central.

\section{Gen. Heteropellis $\mathbf{n}$ gen.}

Sehr mahe verwandt mit Alocodesmus und in den meisten Nerkmalen mit dieser Fautung übereinstimmend, aber namenlich dureh die Form des Halsschildes, der vorderen Kiele und dic Skulptur der Metazoniten unterschieden.

Am Ialsschild ist der Vorderrand in der Mllte sehr Ilach, gegen die Seiten hin stärker gebogen und geht damn in einen kurzen, gुeraden (ó) oder sogar (o) etwas sehräg 
nach innen gerichteten Seitenrand über. Vordere Kiele grerade abstehend und annähernd rechteckig, anssen etwas länger als an der Basis, mit stmmpfen Ecken und etwas nach hinten convergierenden Seitenrändern, lamellär, hinten nicht zackig ausgezogen. Die folgenden liele rom 5. an werden immer dieker und kleiner; der Vorderrand versehmilzt mil dem Seitenrand zu einem immer Hacheren Bogen; der Hinterrand bleibt aber zunächst gerade, sodass die mittleren Kiele fast schiefe liegel darstellen, die den Metazoniten hinten nicht oder kaum überragen und die anf den entsprechenden Segmenten den Porus ganz aussen am schräg gestulzten Hintereck tragen. Erst die 4 letzten Kiele sind schmäler und spitzer und ragen als Zacken ïber den Netazonitenhinterrand hinaus. Beim o sind die rorderen Kiele wie beim of geformt; die mittleren ebenso, nur kleiner, fast dicken Leisten zu vergleichen, mit sehr kurzem Hinterrand; an den porentragenden ist das Hintereck als rundes glattes Knöpfehen abgesetzt, auf dem der Porus liegt.

Metazoniten ohne Querfurche, ohne Felderung und ohne Querreihen grösserer Körner oder Tuberkel.

Gonopoden nach dem Typus derjenigen von Alocodesmus gebaut, aber der Femur sehr deutlich gegen die Tibia abgegliedert.

Ventralplatte des 4. und 5. Segments beim of und mehrere der vorderen Beine mit sekundären Sexualcharakteren.

\section{Heteropeltis luctuosus n. sp.}

(Fig. $\mathbf{3} 3 \mathbf{I}-133$.

Schwarzbraun; die äussere Hälfte der vorderen und die hintere IIälfte der übrigen Kíele gelblich. Bauch, Beine und Antennen rolbraun.

Länge: $38-45 \mathrm{~mm}$; Breite: $0^{7} 4 \frac{1}{2}$, ㅇ $5 \mathrm{~mm}$.

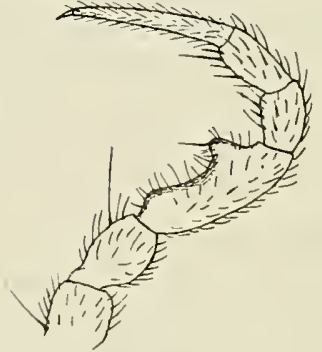

Fig. 131.

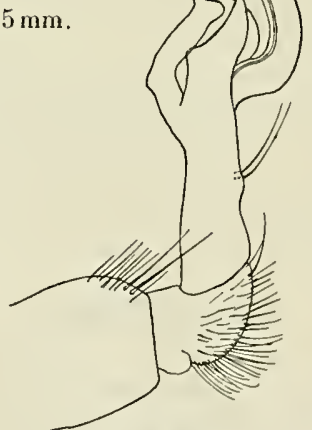

Fig. 132

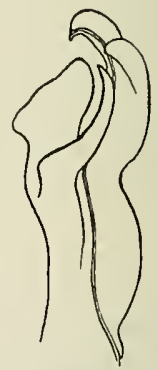

Fig. 133.

Heteropeltis luctuosus n. sp. of

Fig. 131. Bein des 6. Paares. - Fig. 132. Gonopode, von aussen. - Fig. 133. Distaler Teil des Telopodits, schräg von unten und innen. 


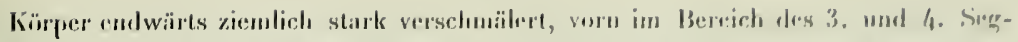

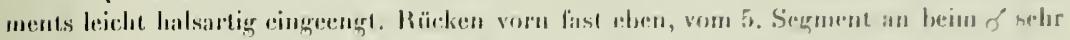
selivinch, heim of etwas deutlicher gewöllts.

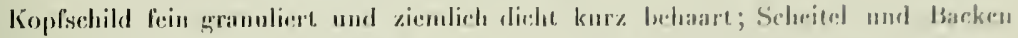

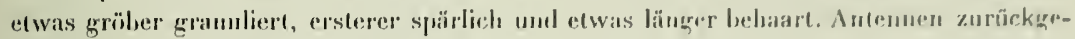
legt bis zum 5. Sexment reiclunul.

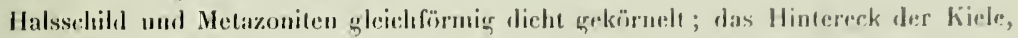
besonders der porentragendes, jedtoch glate und glïnzend; die liranulation wird vom

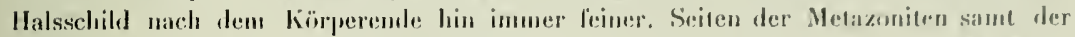
Unterlläche mul dem sehe slumpfon Aussenrand ler Kiele dielat frin granuliert. Eis I'leuralkiel ist nur auf den vordersten Segmenten durch spitzre kïrnelung angedentet.

Prozoniten sehr fein chagrinier, malt.

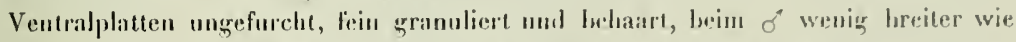
lang, bein of fast zweinal so breit wie lang; von g. Segment an trïgt jude ein sular spitzes Höckrrdien neben jedem Bein. Beim on ist diejenige des 6. Segments hinton tief muldenlïrmigg eingesenk1; diejenigen des 1. und 5 . Serments tragen je a dicke tläckrr zwisclien den Beinen des 3, resp. /. Paares.

Analschuppe gerundet-dreieckig.

Beine des 4.-6. Paates beim ơ mit verdicktem und etwas gekrümmtem liemur, der unterseits an der Basis stmmpf vorspringt unl hinter der Mitte einen stumpfen Hl̈̈ker oder Zapfen Irägt (Fig. 1.31). Die Coxae des 6. und noch dentlicher diejenigen des 7 . Beinpraars springen unten in einen Höcker vor.

Gonoporten (Fig. 132, 133): Die Tilia teilt sich in zwei sichelfürmige Aeste; der Sclienkelfortsatz ist etwas küızer, in einen schmalen, am Ende zugespitzten und einen breiten, plattenförmigen, schräg gुestutzten Ast gespalten.

ơ, 우 Cinmelia, Kaffeepflanzungr.

\section{Gen. Amphipeltis n. gen.}

Ich sehe miclı genötigt, für Polydesmus (Rhachidonorpha) nodosus Peters nacl Untersuchung des Originalexemplars einen neuen Gattungsnamen einzufülıren. Wie ich früher zeigte (Revue Suisse de Znologie, T. XI, p. 553-556, rgo3), gुehürt Rhachidomorpha Sauss. zu einer Gruppe von Gattungen, die des Hüfthörnchens entbehren und die ich Rhachidesminae 1 nannte. Wahrscheinlich ist diese Gruppe auf Centralamerika beschränkt; jedenfalls gehört keine der von Atrexs und Brøelenaxis unter dem Gattungssnamen Rhachidomorpha beschriebenen Arten ans Brasilien in diese Gattung und in diese Gruppe, ebensowenig nodosus PET.

1 Igit. auch Pocock, Biol. Centrali-Americana, Chil. a. Dipl., p. 170, 371, 174. Igog. 
Amphipellis ist nach dem Ban der Gonopoden nächstrerwandt mit Alocodesmus Sulv, Ileteropeltis 11. geru. Ind Batodesmus Cook, unterscheided sich aber von diesen äusserlich durch die zweilapplige form mehrerer liele (vgl. Arbeschreihung) und die unbewehrten Ventralplatten, von Alocodesmus ausserdem durch die gleichmässige Granulierung des Halsschilites und der Metazoniten und, wie anch von Batodesmus, durch die Lage des Porus auf einem Knoplf. Letzteres Merkmal teilı die Gattung mil IVeteropeltis, bei welchem aber die Coxa der Gonopoden sehr dertlich gegen die Tibia alıgegrenzt ist. . Hlen vier Gattungen Jehlen Tarsalpolster an den Beinen der of.

Der folgenden Artheschreibung liegt das Originalexemplar zu Grunde.

\section{Amphipeltis nodosus (PET.)}

(Fig. г $34-139)$.

Kopf fein granuliert, mit Schcitelfurche. Antennen? (ahgrefallen).

Halsschild so breit wie der Kopf, llach, nur die abgerundeten Vorderecken heruntergebogen, gegen die Hinterecken hin leicht aufsteigend. Vorderrand schwach gebogen. Scitenrand fast gerade, mit 4 sehr stumpfen, knotigen Verdickungen, deren letzte das Hintereck bildet, das etwas kleiner ist als ein Rechter. Hinterrand annähernd gerade. Oberseite fein granulicrt und ausserdem noch mit einigen stärkern Kï̈neren. Ueber die Hitte ein seichter Längseindruck und in demselben eine feine Furche.

Körper zwischen Pro- und Metazoniten deutlich eingeschnürt.

Prozoniten sehr fein dicht granuliert, die Quernaht jedoch glatt.

Metazoniten oberseits dicht und zicmlich spitz granuliert, auf den Kielen gröber als im Rückenteil. Seiten der Metazoniten mit Ausnahme der glatten Unterseite der Kiele grannliert und zwar etwas feiner und spärlicher als der Metazonitcurücken.

Rücken flach. Nlle Kicle, besonders gegen das Hintereck hin, leicht aufstcigend. Der 2., 3. und 4. Kiel viereckig, anssen länger als an der Basis, mit zugestumpftem Vordereck und leicht gewelltem bis stumpr höckerzähnigem Seitenrand.

Die folgenden Kiele kürzer als der Metazonitenrücken, schmäler als lang; 5.-8. resp. ro. Kiel durch einen Einschnitt des Seitenrandes zweilappig; der vordere Lappen meist durch vorragende spitze Körner höckerzähnigr; der hintere Lappen endet auf Segm. 5, 7,9 , ro in cinem runden glatten wcissen Knopf, auf dem ganz nach aussen gerichtel der Porus lieğ. Auf den folgenden Kielen verkïrzt sich der vordere Lappen immer niehr, sodass nur der hintere (mit dem Knopf auf den porentragenden Scgmenten) den Seitenrand äberragl; gleichzeitig wird das Vordereck immer stumpfwinkliger, sodass die Kiele etwa vom r 4. an annähernd dreieckig sind. Die drei hintersten sind in spitze schmale aufsteigende Zacken ausgुezogen.

Porus auf dem 5. 7.9. го. 12. 13. 15. 16. 17. 18. (19. ?) Kiele.

Ventralplatten etwas breiter als lang, wie die Seiten der Metazoniten granuliert, 


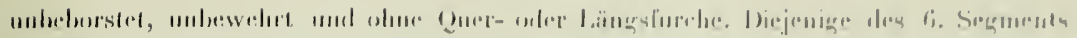

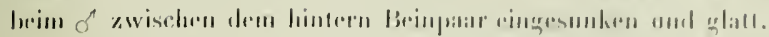

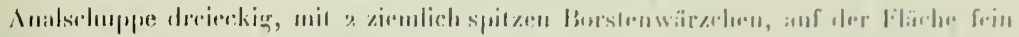

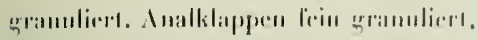

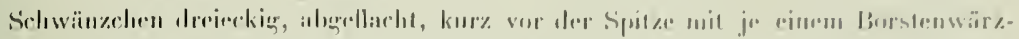

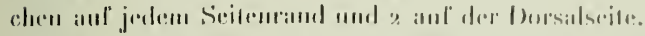

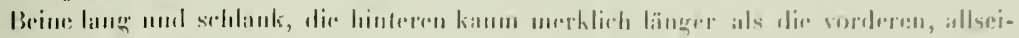

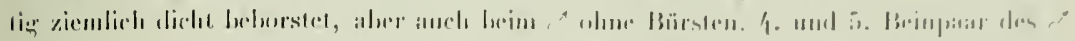

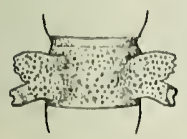

Nig. 134 .

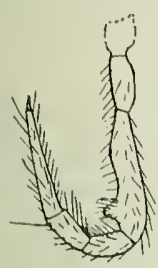

Fig. 136

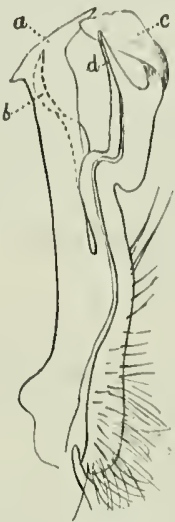

Fin. 137

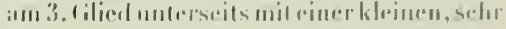

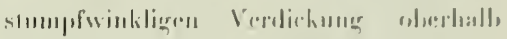

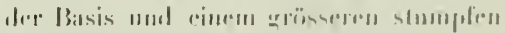

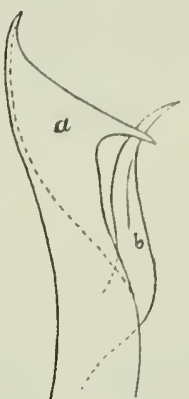

Fig. 1:8.

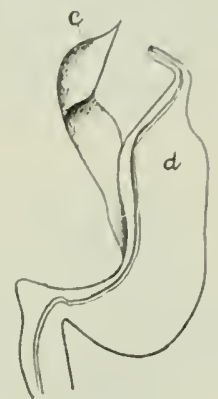

Fig. 1339

Amphipellis nodosus (Pet.) $\sigma^{4}$

Fig. 134. 7. Segment. - Fig. 135. 13. Metazonit, linksseitig. - Fig. 136. Bein des 4. Paares, - Fig. 137. Telopodit eines Gonopoden. - Fig. 138. Dessen äusserer Spaltası, von aussen. - Fig. 139. Innerer Spaltast.

Höcker nahe dem Ende des Gliedes.

Gounpoden (Fig. 137) schlank, gerade. Haifte? (abgelorochen'. Schenkel und Endteil zu einem einzigen Stück verwachsen, der bis ïler die Mitle lerunter gespalten ist Die iussere Spaltualle ist gerade und teilt sich wieder in eine loreite, schräer abgestuzte Lametle $(a)$ mit spitz ausgezogenen Ecken und in einen schlankin, zngespitzlen, geschwungenen Forlsatz (b). Die andere Spalthällte ist gecknickt und galselt sich in zwei einander

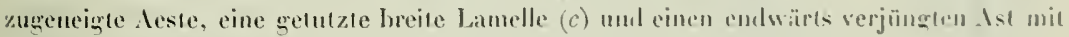
der Samestrinne $(d)$.

Ns Fundort ist nur a Neu-Giranda "angergeben. 


\section{Gen. Batodesmus Cook.}

Соок lat für "Rhachidomorpha alutacea PErens " die Gattung Batodesmus gegründet. Die Segmentzahl 19, an geleimten Originalexemplar gezählt, ist offenbar falsch, indem die im äbrigen mit alutacea so nahe verwandte neue Art der Funrmannschen Sammlung 20 Segmente zähılt. Elienso hezweifelt Artems mit Reclıt die Richtigkeit der von Cook gegebenen Porenformel 5, 9, 11, 14, 16. Ich konnte überhaupt weder bein Originalexemplar ron alutacea noch bei der neuen Art Poren naclweisen. Walsrscheinlich sind diese duch vortanden aber sehr klein und infolge der Granulation der Kiele nicht sichthar. Das auffälligste Merkmal der Gattung wären in diesem Falle die sehr langen, rückwärts gerichteten Doruen der hintersten Ventralplatten.

\section{Batodesmus alutaceus (Peters).}

(Fig. 140-142.)

Wir ergänzen die Beschreibung dieser Art nach dem Originalexemplar.

Kopf dicht fein granuliert, gegen den Vorderrand des Kopfschildes hin glatt. Scheitelfurche seicht. Antennen schlank, zurückgelegt bis zum 4. Metazoniten reichend, nicht keulig, nur das 6. Glied endwärts leicht verdickt; das 3., 4., 5. und 6. Glied unter sich gleich lang, das 2. Glied sehr wenig länger.

Halsschild wie bei Amphipeltis nodosus (Рет.); die vordersten Kiele ebenfalls wie bei

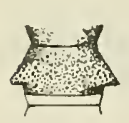

Fig. 140.

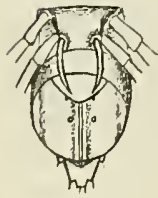

Fig. 141.

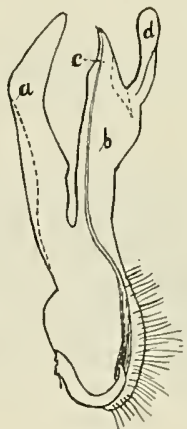

Fig. 142.

Batodesmus alutaceus (Pet.) o

Fig. 140. 10. Segment, $4 \times 1$. - Fig. 141. Die drei letzten Segmente, von unten, $5 \times 1$. - Fig. 142. Telopodit eines Gonopoden. dieser Art, mit etwas stärker löckerzähnigem Seitenrand. Vom 7. Kïjel an verkürzt sich der Vorderrand immer mehr und das Vordereck wird stumpfwinklig, so dass die Kiele 9-16 dreieckig erscheinen; ihr Hinterrand ist gerade und steht senkrecht zur Längsachse des Körpers (Fig. 140). Die drei hintersten Kiele sind deutlicher aufgerichtet und als spitze Zacken nach hinten gezogen.

Rücken zwischen den Kielen kaum merklich gewölbt. Metazoniten dicht und ziemlich grob gekörnelt, bedeutend gröber auf den Kielen als auf dem Rücken ; gegen das Körperende hin wird die Körnelung immer feiner. Querfurche fehlend oder kaum angedeutet, aber jeder Metazonit mit einer sehr feinen, glatten Linie längs der Rückenmitle. Prozoniten infolge einer sehr feinen Granulierung matt. Seiten der Metazoniten bis zur Kielbasis hinauf fein granuliert.

Schwänzchen abgeflacht, dreieckig, mit je einem 


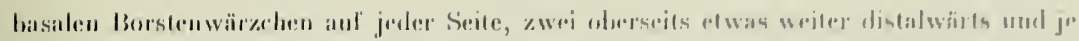

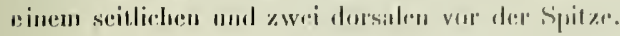

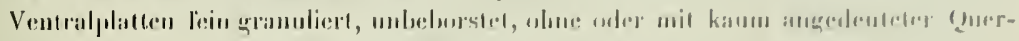

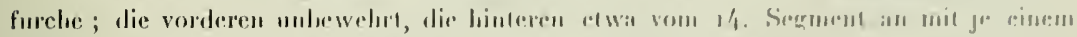

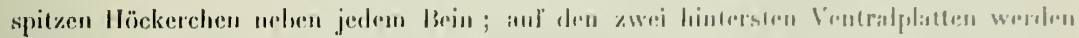

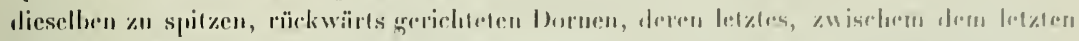

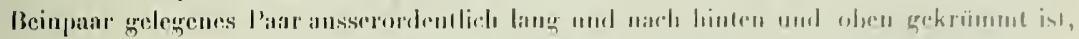

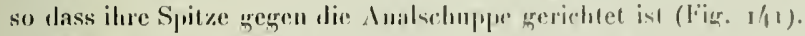

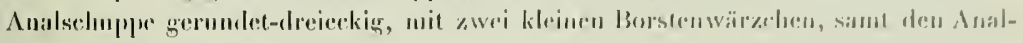
klappen friu lederartig skulpuirt.

Beine ziemlich schlank, dis hinteren wenigr länger als die vorderen; die distalen

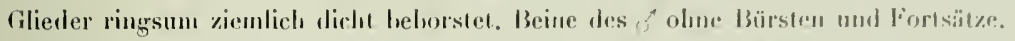

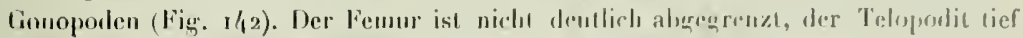
gespalten, mit cinem schräg gestutzlen, einfachen änsseren Spraltist (a) und rimen grengabelten inneren Spaltast (b), dessen kürzerer spitzdreickign Zweig $c$ dis Sammrinue führt, während der Zweig $d$ eine gerundete Lamelle darstellt.

Bogota (Petens).

\section{Batodesmus acceptus n. sp.}

(Fig. 143.)

Färbung oberseits exdbram, Ventralplatten grelblichbraun, Antennen schwarzhraun. Beine bis über die Mitte des dritten Gliedes liellgelb, von da distalwärts rothraun.

Länge : $25 \mathrm{~mm}$. Breite cines Metazoniten: $3 \frac{1}{2} \mathrm{~mm}$.

kopf, Halsschild, vordere und hinterste lïele, Skujptur der Metazoniten und Prozoniten, Schwänzchen, Beine und Ventralplatten wie bei $B$. alutacens. Von dieser Art bauptsächlich unterschieden in der form der mittleren liele und der Gonopoden.

Die milleren Kiele vom 9*-16. sind nicht dreieckig, sondem haben wie die vorderen einen wohl ahgeselzten, glatten Vorderrand und einen etwas schräg nach aussen grerichteten, unregुelmässig zackigen Seitenrand, dazu stumpfes Vordereck und spitzwinkliges llintereck. Der llinterrand ist etwas stärker schräg nach hinten gerichtet als der Vorderrand. Der Seitenrand mancher kiele hat einen etwas tieferen mittleren Einschnit, wodurch er undeutlich zweilappig wird.

Gonopoden (Fig. 143) in gleicher Weise gespalien wie hei $B$. alntaceus, aber in der Form der einzchnen leste verschieden. Der Gabelast $c$ ist schlanker, gesclwwingen und

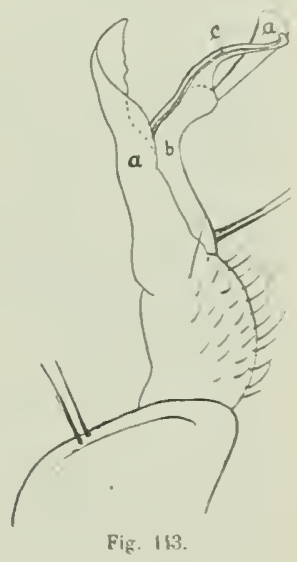

Bacodesmus acceptus n. sp. o Gonopode, von aussen. 
an Einde leichit hackig nmgehogen, der Ast d melı kenlenlörnig, Spaltast a am Ende nicht stark schräg vorgezoren, sontern aussen gerundet, innen spitz.

I O’. Guaduas.

\section{Gen. Melanodesmus $\mathbf{n}$. gen.}

20 Segmente.

Antemnen ziemlich schlank, endwärts kaum merklich verdickt.

Halsschilel so hreit wie der folgrende Rückenschild, fast horizontal, mit spitzwinkligem Seitcoleck.

Rëcken flach. Metazoniten mil Querfurche.

Kiele hoch angeselzt, breiter als lang, fast horizontal, beinahe rechteckig und vom 5. an leicht nach hinten gezogen, mit ganz schwach vorspringendem, erst vom 16. Segment an in eine Zacke ausgezogenem Ilintereck; Seitenrand glinl und scharf, ohne Wulst oder Beule; Vorder- und Hinterrand fein gezähnelı; Vordereck zugerundet.

Saftlïcher auf den Segmenten 5, 7, 9, 16, 12, 13, 15-19, im hintern Drittel, nicht weit rom Seitenrand des Kiels, aussen an Vorderende einer sehr stumpfen zum Hintereck ziehenden kleinen Falte; das Saftoch ist sehr klein, nach aussen gerichtet und von oben kaum sichtbar.

Seiten des Körpers ohne Pleuralkiel oder Pleuralhïeker.

Ventralplatten viel breiter als lang (beim o $2 \frac{1}{2}$, beim o gut 3 mal so breit wie lang), nicht dureh Furchen geteilt.

Beine mässign lanz; Coxa und Praefemur oberseits mit hellen Chitinwärzchen, die distalwärls je ein Börstchen tragen. Praefemur unterseits am Apicalrand mil $2-3$ konischen, hellen Dornen; Femur deutlich lä̈rer als der Tarsus. Beine des of olıne Tarsalpolster, alser mit Auszeichnungen an der Coxa und am Femur mehrerer vorderer Pare. Analschuppe grerundel.

Schwänzchen llach, bis kurz vor dem Ende wenig verschmälert, dann absatzweise verschmälert und mil einem gestutzlen Miltelstïckchen endend.

Gonopoden ähnlich denjenigen vieler Alocodesmus-Arten. Coxa olıne Zapfen oder Lappen; Telopodit ohne freien Schenkelfortsatz, erst weit hinter der Vilte in mehrere kurze Aeste geteilt.

Die Form der Kiele, die Lage des Porus und die Form des Selwwänzchens sind lür diese vielleicht monolype Gattung sehr charakteristisch, ehenso die Chitiuwärzchen und Dornen an Coxa und l'raefemur. In gewissem Sinne nimml sie eine Mittelstellung zwischen den Leptodesminen und Platyrrhachinen rin und nähert sich Platyrrhacus in der Form der liel, der Lage des Porus und der Form des Schwänzchens. 


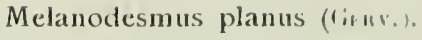

(1.ik. 1\}彳-151).

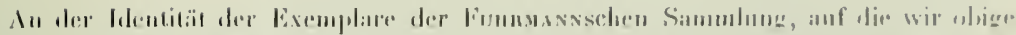

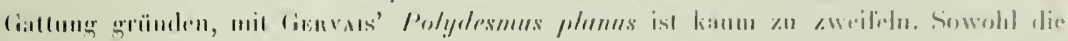

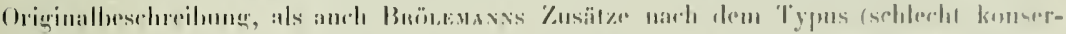

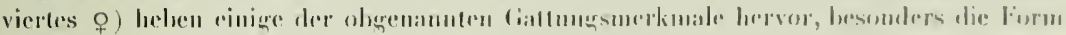

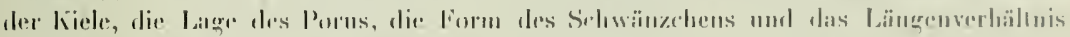

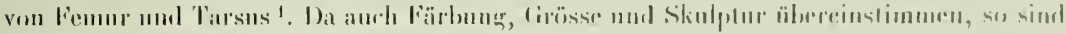

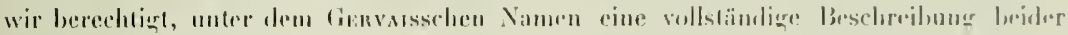
Geschlerliter zu gehrul.

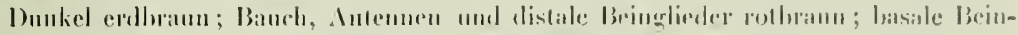

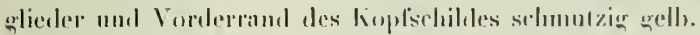

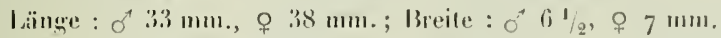

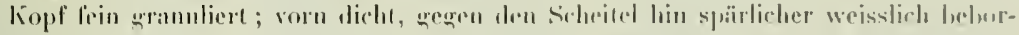

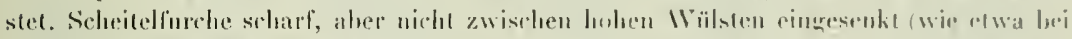

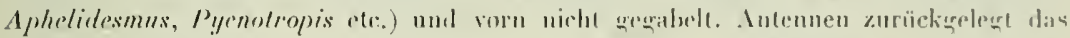

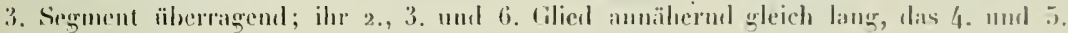
ctwas kïrzer.

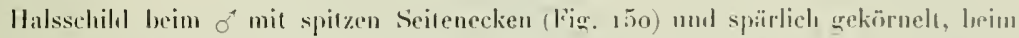
o mit (infolge stärkerer Umbiegung des Vorderrandes) stumpferen Serfenecken umb ilentlich fein gekïmelt.

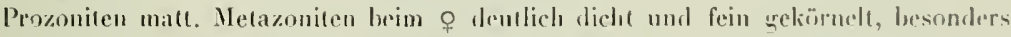
anf den kielen; beim on ist die Kïrnelung vifl selwächer, anf dem liücken kaum wahrnehmbar; hei of und o tragen die Metazoniten vom \{. an eine elwas zickathfurmign, ziemlich scharfe Querfurche, ron der Längsfurchen nach hinten abgelien, wodurch eine schwache Felderung entsteht, sowie eine feine mediane Längsfurche.

Vordere liele (2-1) leicht nach vorn wezogen, kürzer als die folgenden, mil convexem, glattem Vorderrand und ebenfalls ghallem Hinterrand. In ten folgenden hielen ist hë̈ slarlier Vergrösserung lee Vorderrand ziemlich regelnässig slumpf gazähuelı, der llinterrand dagegen gekerbe und die runden lierhzälane wiederum für sich stumpf grzälnnelı.

Seiten der Metazoniten ziemlich spitz welïrnelt, dichter im vordern körpertriltel, immer spärlicher gegen das kïrperende hin. Auch diese kïrncluner ist heim o elwas stärlier als beim o".

Schwinzchen, Analkiaplen und Inalschuppe ebenlalls fein gekïrnell: letzlere fast halbkreisförmiw, jederseits hinter der Mitte mit ziemlich grossem Borstenhëcker.

Ventralplatten mit selur zerstrenten, je ein winziges Härchen tragenden kïrnchen;

I Brö́enssx uannle diese Gilieder damals Tibia resp. 3. Tarsenglied. 
der schmale Itinterrandstreifen des Metazoniten hinter jeder Ventriplatte ist dicht rekiortlen. Beim sind die Ventralplatten des 5. und 6. Segments in der Mltte ctwas beulig aufgetrieben und mit einem Wäızchen versehen; neben jedem Bein tragen sie ein Höckerchen. Die übrigen Ventralptatten tragen keine Höcker.

Beine kurz behorstet, die 2 basalen Gilieder sparsam, die 3 folgenden etwas dieliter; der Tarsus ziemlich dicht beborstet; übes der Kralle findet sich ein Büschel feinerer Borsten. Am 2. und 3. Beinpaar des o (Fig. 144, 145) springt die Coxa in einen starken Kegel vor, am 3. und 4. Paar (Fig. 145, 146) ist der Fenur rerdickt und springt unterseits in einen starken liegel vor und der l'ostfemur des 4. Paares trïgt unterseits einen kürzeren

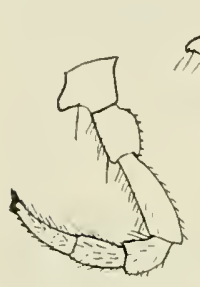

Pig. 144

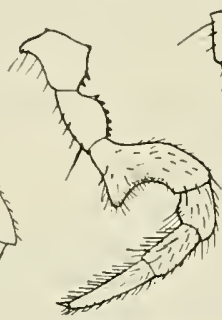

Fig. 145.

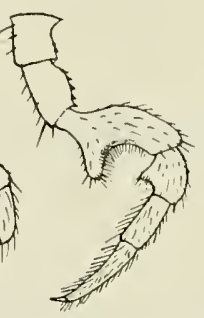

Fig. 146.

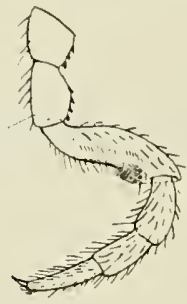

Fig. 147.

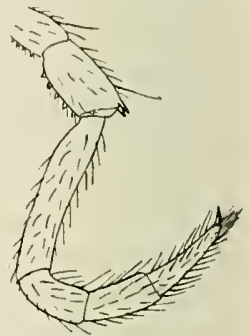

Fig. 148.

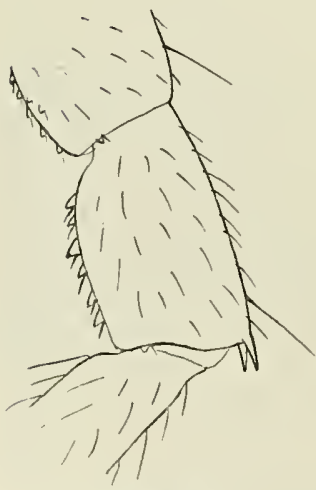

lig. 149.
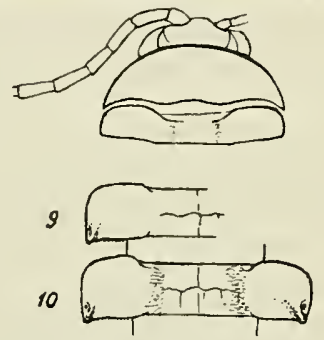

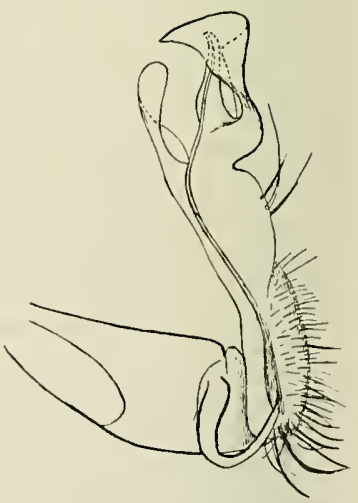

Fig. 151.

Melanodesmus planus (Gerv.) o

Fig. 144 bis 148 o Bein des 2., 3., 4. 5. und 21. Paares. - Fig. 149. Basalglieder des letzteren, stärker vergr. Pig. 150. Liopf, Halsschild, Segm. 9, 10, 17-20, 4-fach vergr. - Fig. 151. Gonopode von innen. 


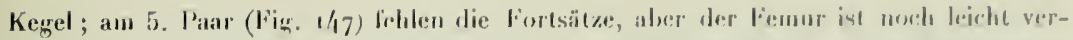

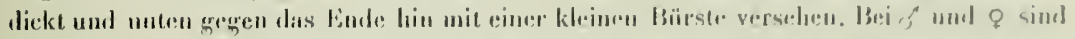

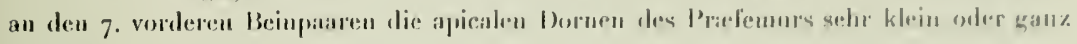
unterilrïckt.

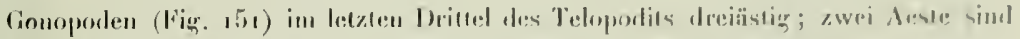

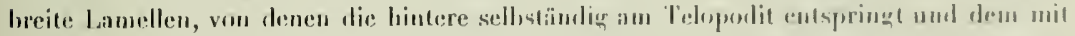

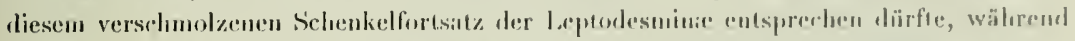

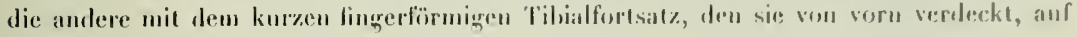
gemeinsinuer basis entspringt und den Tarsus dirstellt.

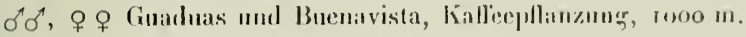

Unter den Erwachsenen findet man meben den schwarkhramen auch manserefürlute, hell brïnnlichgelhe Exemplare.

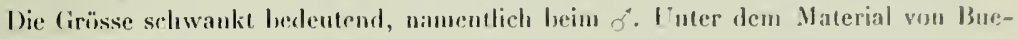
navista finden sich zwei of von nur $2 / 4$ resp. 26 mm. Iäninge.

liin junges of mit ig Srgmenten, vom grleichen Fundort, zeigt interssante Jugendmerkmale : Die Kiele sind schmäler und hatren alle, seltsis dic vorderen, ein dentliches, noch durch ein Zähnchen verschärftes Vordererk, fast greraden, etwas unebenen Sritenrand, mit Andeutung von stumpfen Zähuchun; der llinterrani ist auch an den vorilersten kielen fein gekerbt.

\section{Gen. Trichomorpha SiLv.}

Die Untersuchung des Originalexemplars der typischen Art, Tr. elegans Srux., aus Ecuador, veranlasst mich, dieser Gittung riur qanze Anzahl von columbischen Arten zızuweisen, von denen sich einige cür an den Typus anschliessen, während andere wiederum im äusseren Mahitus zicmlich stark von ihm alweichen, sodass dic Gattung, wir ich sie hier auffasse, auf den ersten Blick einen lieterogenen Eindruck macht. Sobali man sie aber nach irgend einem Merkmal weiter zu zerlegen sucht, so ergeben sich Gruppen, die ehen nur dieses Merkmal ausschliesslich für sich haben und andere wichtigere Merkmale, besonders den Bauplan der Gonopoden, die Form des Halsschildes, das Vorkommen von feinen kurzen Borsten auf dem llalsschild, den Metazoniten und dem Kielseitenrand, den hohen Ansatz der Kiele, das zackige Hintereck aller Kïele, die Lage des Porus u. s. w. mit anderen Gruppen teilen würden.

Andere Merkmale sind sehr variabel und bewirken die grossen Untersehiede im äusseren Habitus, ohne dass sie in einigermassen stabilen Kombinationen auftreten würden. Die äussere Ungleichheit ist in erster Linie durch den ungleichen Ausbildungsgrad der Kiele bewirkt, indem diese bald sehr schmal und oberseits kaum rom Rücken abgegrenzt, hald breiter und dann oberseits durch eigene schwache beulige Wölbung rom Alachen Rücken abstechen. Die Beborstung der Metazoniten besteht entweder in 2 Querreihen mit unr 2-4 Borsten, in 2 oder 3 Querreihen mit zahlreicheren (6-ro) Bürstchen oder 
ist endlich dicht und unregelmässiger, mit eined diehten Querreihe elwas längerer Börstchen am Ilinteraul. Dem ersteren Behorstungstypus entspreclen meist glatte Metazoniten, nit scharfeg Querfurche und einer feinen Längsfurche vor dersellen, hächstens noch mit Andeutung von Beulen hinter der Guerfurelie. Bei dichter Beborstung entspringen die Borsten meist auf je einem Körnchen, die hei andern . Irten zu Ilöckern mul, indem sich diese in die Lünge strecken, zu Lä̈gswülstehen oder Felderchen werden. Die Guerfurche der Metazoniten ist hei den skulpturlosen Arten meist scharf, selten rerwischt; bei den gehö̈kerten Arten mehr orter weniger durch die Skulptur verdeckt.

Dingnose der Gallnng: Kleine his mittelgrosse Formen mit 20 Rumpfsegmenten. hopfschild rorn dicht kurz beborstet; Scheitel mit zerstreuten etwas längeren Borsten und deullicher Scheitelfurche. Antenuen ziemlich lang, zuräckgelegt his zum 4. oder 5. Metazoniten reichend, endwärts leicht keuligy; das 6 . Glied wenig oder kanı kürzer als das 5. ; das 2. 3. und 4. annähernd gleich lang und wenigg länger als die zwei folgenden Glieder. IIalsschild mit annähernd halbkreisförmigem, in der Nitte llacher, seitlich stärker qebogenem Vorderrand, scharfen, rechtwinkligen oder leicht spilzwinkligen, nach hinten gerichteten Ecken und in der Mitte sowie jederseits seicht eingebuchtetem Hinterrand; der Halsschild ist so breil wie der folgende Räckenschild und trägl auf der Fläche wenigstens drei Reihen von Börstchen und am Rande seitlich 3 Bör'stchen in je einem Kierbzähısclıeı.

Rücken schwach gewölbt. Zweiter Kiel in derselben Höhe mit den übrigren. Kiele hoch angesetzl, die vordersten immer gut entwickelt, dann je nach den Arten melır oder weniger rasch verschmälert, die hintersten immer sehr schmal, meist alle etwas nach hinten gezogen. Auf den vordersten geht der Vorderrand noch mit einer Rundung in den Seitenrand über und die Grenze wird durch einen deutichen Zahn bezeichnet; uach linten zu bildet der Vorderrand mil dem Seitenrand einen immer flacheren Bogen und zuletzt fast eine gerade Linie, der Zahn wird immer sclıwächer und rückt immer weites nach hinten; ein oder zwei kleinere, je ein Börstchen tragende Kerbzähnchen des Seitenrandes werden ebenfalls nach hinten zu schwächer oder verschwinden gänzlich, abes das Börstchen bleibt. Der Seitenrand ist schmal wulstig gesäumt, der Randsaum im linteren Teil leicht spindelfürmig verdickt und trägt hier auf den Segmenten 5, 7, 9, ro, 12, 13, 15-rg halbseitlich den Porus. Ilintereck der Kiele imner zackig, manchmal schon von den vordersten an, jedenfalls auf den hintersten immer sehr spitz, dornförmigg; Hinterrand der Kiele resp. Innenrand der Zacke häufig mit spitzen Chitinzähnchen. Oberfläche bei geringer Eutwicklung der Kiele der Rückenwölbung folgend, bei stärkerer Ausbildung der Kiele für sich leicht beuligg gewölbt.

Hetazuniten glatt, mit scharfer, in der Mitte etwas winklign nach voru vorspringenter Querfurche und davor mit einer feinen medianen Längsfurche oder mit Beulen hinter der Querfurche oder fein gekörnelt oder dichıt gehı̈ckert. Sie sind entweder dicht mit kurzen hellen Börstchen, die auf je einem Höcker orler Körnchen stehen, oder nur mit 2 oder 3 Querreihen von je 2-6 Bïrstchen, the leicht abfallen, besetzt. 
Yueruaht ghlatt.

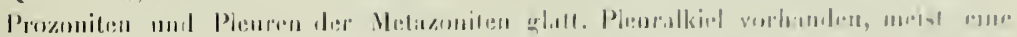

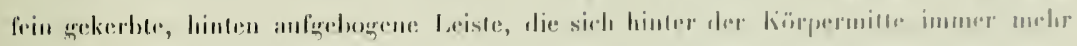
von vorn lue verkï\%.

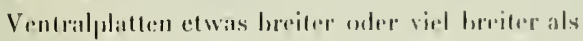

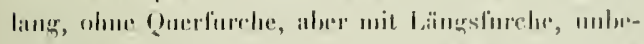

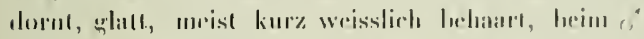

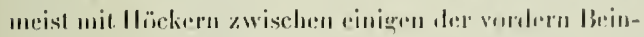
piane (1. uml (i.).

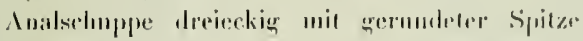
onler parablulisel.

Schwänzchen kurz, konisel, mit 2 (yurreihon

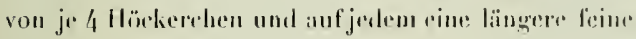
Borste.

Brine ziemlich schlank, ringsim behaare; lis vorderen bein of verdickt, mit meist stark contwickeltem Tarsalpolster (Furlsaly der Tibia unter dem Tarsus) und kurzem Tarsus, der mit der Abnahme des Polsters nach hinten zu sich verlïngert, alur imuser kïrzer ist als der Femur. Fenur des 7 . Beinparars wer melarerer vorderer Brimpare des of meist merlifiziert.

Cionopoden: Coxa kurz und stark, cylindrisch, olen mit starkem, niederliegendem, Borsten tragrendem Zapfen, anssen mit rundem Lappen die verbreiterte Basis I des Telopoditen rerdeckend, der sich somit schräg an seine Innenfläche anlegt. Telopodit meist

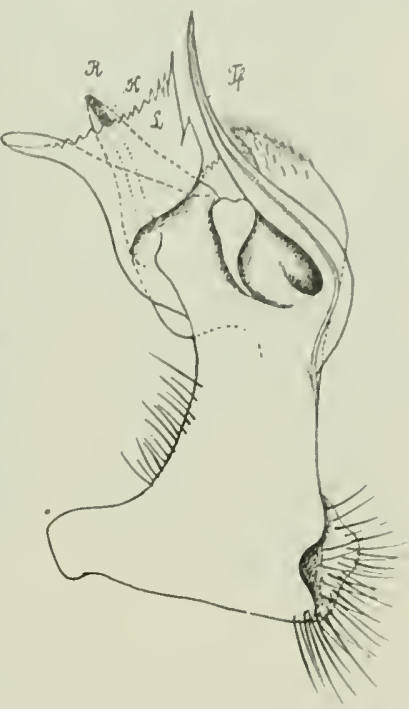

Fig. 152.

Trichomorpha elegans Sils. of (Originalex.) Telopodit eines Gonopoden. undeutlich quergegliedert, die Grenze zwischen Femur und Tilia meist nur durch die Behaarung und die Verbreiterung des licmurs, seltener durch

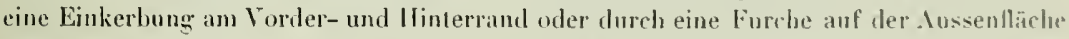
angezeigt; er teilt sich in 2 oder mehrerc Aeste, von denen der die Samenrime führende Tibialfortsatz immer geisselförmigg zugespitzt ist, Während ein Vehenist einc Rinnt zu seiner lählung aufweist oder haubenatig üherwewälbt ist unl eine kurze scheicle für den Tibialfortsatz bildet.

1 Die sehr charakleristische quere Verbreiterung der Femurbasis nnd ilor sehieler .Insalz an der Indenfliche der Coxa treten nur bei Ansieht von oben, unten oder in schräger . Insichl hervor an deullichslen nach Abtrennuog der Coxa. 


\section{$-9 \times 4-$}

Lusser dem Typus, T. elegans SiLv.' aus Ecuador, und den neuen Arten aus Columbien gehören dieser Galtung noch folgende columbische Arten mit ihrer Oriminalbenennung in :

Polydesmus (Oxyurus) sculptus PEт.

Polydesmus (Oxynrus) serridens PEт. Hach dem Originalexemplar.

Polydesnus (Oxyurus) mucronatus PEt, nach Atrears' Beschreihung und Abbildung.

Ferner gehört hierher Leptolesmus folium Bract., von der Cocos-Insel, zwischen Costarica und den Galapagos (Brölemanx, Myriapodes recueillis ì l'Isla de Cocos par M. le Prof. P. Biolley, Ann. Soc. Ent. France, vol. IXXIl, 19o3, p. 139-142, PI. I, Fig. I3-18). Letzlere Arl, in der schon Brocemaxn den Typus einer eigenen Gruppe sah, ist ausgezeichnel durch relativ starke Ansbildung der Kiele und sehr einfachen Telopodit der Gonopoden. Dem äusseren Habilus nach schliesst sie sich jedenfalls $T$. virgata, venusta und propinqua n. sp. sehr eng an. Mit Ausnahme einer insularen Art, hewohnen also sämtliche bestimmt hierher gehörige Arten das Andengebiet von Columbien und Ecuador.

Manche Arten erinnern durch die äusseren Formen und die vorderen Beine des $\sigma$ ziemlich stark an die monotypische Gattung Phylactophallus Poc. (Biologia centr. amer., Dipl. and Ghil. p. ז66, 167, Tab. XIII, Fig. 3-3 h.), die jedoch anders gebante Gonopoden aufweist.

\section{Trichomorpha virgata n. sp.}

(Fig. 153 -156.)

Schwarz oder rolbraun; I. Antennenglied, Labralrand, Beine und Ventralplatten hell. Beine meist weisslich im basalen, mehr oder weniger stark gebräunt in distalen Teil. Metazonilen mit sehr variabler Zeichnung, meist schwarz mit weisslichen Kielen

${ }^{1}$ lch benütze die Gelegenheit, um die Beschreibung dieser Art nach den Originalexemplaren zu crgänzen :

Metazoniten dicht mit borstentragenden IJöckerchen in 6-7 unregelmässigen Querreihen besetzt, etwas gewölht; Querfurche infolge der Höcker undeutlich. Kicle 2-4 schon länger als breit und hinten spitzzackig, aber der Vorder-und Seitenrand noch abgesetzt. Folgende Kiele immer schmäler und hinten spitzer, ohne Grenze zwischen Vorder- und Seitenrand; Hinterrand ohne Zähne ; Oherseite mit denselben Höckern wie der Rücken.

Seiten des Körpers glatt; Pleuralkiel bis zum 15. Segment nachweisbar, auf den vorderen eine fein gezähnelte Leiste, die sich weiterhin in 2 Zäckehen teilt.

Ventralplatten beim $\sigma$ fast so lang wie breit, beim $ᄋ$ etwas brciter als lang; bein $\sigma^{7}$ mit zwei Höckern zwischen dem 6. Beinpaar.

Bcine des o mit kurzem Tarsalpolster bis zum 11. Paar; die vorderen ohne Höcker am Femur; Praefemur oben nur leicht verdickt, unten ohne apicalen Dorn oder Höcker; Tarsus auch an den hinteren Beinen viel kürzer als der Femur, kaum länger als die Tihia.

Telopodit der Gopopoden (Fig. I52) gedrungen, breit, hinter der Mitte init 3 lamellären Aesten und dem geisselförmigen Tibialfortsatz (Tf.) Letzterer gleitet zwvischen der gezähnelten Lamclle (L) und dem flachen Kegel (K) längs einer Rinne (R) dieses letzteren. 


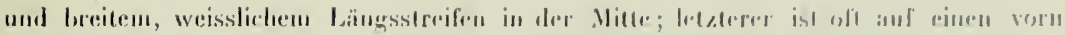

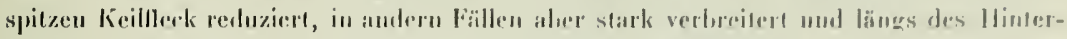

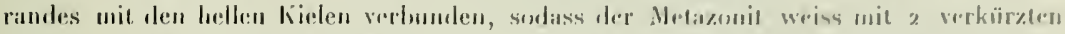

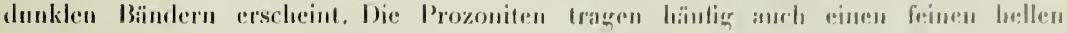

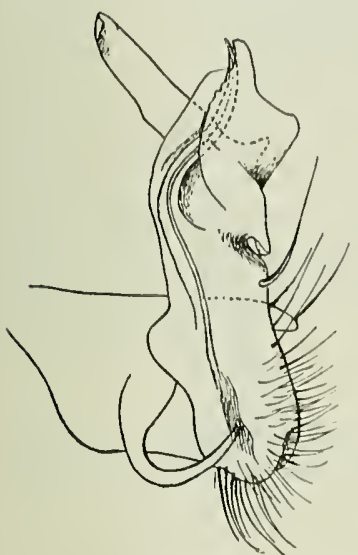

Fig. 153.

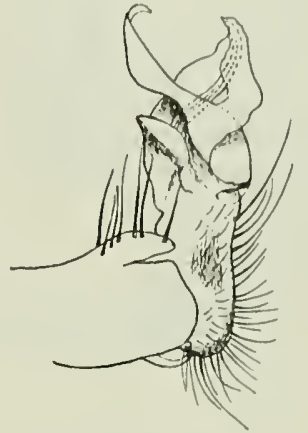

Fig. 154

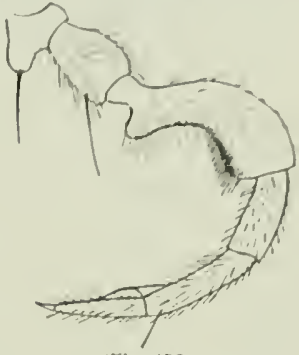

IFig. 15\%.

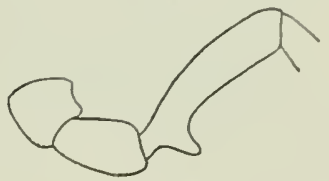

Fig. $15 i$.

Trichomorpha virgata n. sp. $\sigma^{4}$

Fig. 153. Gonopode, von innen. - Fig. 154. Fonopode, von aussen. - Fig. 15ī. Basale Glieder eines Beins des 6. Paares. - Fig. 156. Bein des 7. Paares.

Medianstreifen. Körperseiten schwarz. Unausgefärhte, ganz weissliche Exemplare, sowie solche, bei denen das Schwarz durch helleres oder dunkleres Rotbrann erselzt ist, sind bäufig ; letzlere Fïrhung besitzen alle unreifen Exemplare.

Länge : $20 \mathrm{~mm}$, Breite: ô $2 \mathrm{~mm}$, o 2 ' $\mathrm{mm}$.

Körper hinten schon vom 15 . Segment an deutlich verschmälert.

Rücken schwach srewölht. Kiele hoch angesetzl, beim of qut auscrebildel und leicht aufsteigend, beim o elwas schmäler, wodurch die Metazoniten breiter und stärker qewölh erscheinen. Die Kiele des ô sind oherseits deutlicls beulig aufgewälht; die Beule verstreicht gregen den Seitenrand und Vorderrand, setzt sich aber nach dem Hintereck hin fort. Zacke des Hinterecks sehr spitz und schon vom 2. Kïel an den Hinterrand des Metazoniten überragend; kielhinterrand rom 6 . Segment an mit einem, späterhin mit zwei winzigen Chitinzähnchen. lierhzähnchen des Seitenrandes sehr klein und beim o hinter der Körpermitte kaum wahrnehmbar.

Metazoniten glalt und glänzend, beim ơ mit scharfer, beim of mit seichter Querfurche und sehr feiner Längsfurche, ohne körner oder Beulen, vor und hinter der Querfurche mit je einer Querreihe ron 4 hellen Börstchen. 
Seiten des hörpers glatt : Pleuralkiel eine fein grezälnnelte beiste, die ron vorn leer rerkïrzl nuch auf dem 17. Seqment sichthar ist.

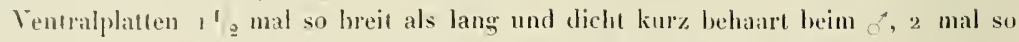
breit als lang und fast nackt beim o ; beim ot mit zwei sehr stumplen Ilöckern zwischen dem 6. und zwei divergierenden Zäpfehen zwischen dem 4. Beinpar.

Beine des of nur lis zum 7. Pair mit Tarsalpolster versehen. Am 6. Beiupaar o (Fïg. 155) Irägt der Femur unterseits nahe der Basis einen kumischen Höcker; am 7. Paar (Fig. 156) ist der Femur stärker gekrümmt, verdickt, unterseits mit stumpfem Auswucls an der Basis und einer feinen Bürste im distalen Teil und die Coxa springt in einen stumpfen, eine starke Borste Iragenden hegel vor.

Gonopoden (Fi2. 153, 154): Zapfen der Coxa oberseits mit zahlreichen Borsten; die haubenlörmige Lamelle des Telopodits, die den Tibiallirtsalz leitel, trägt auf der Aussenseite einen schlanken, körperwärts gerichteten Fortsatz. Sonst ähnelt der Telopodit sehr demjenigen von Tr. folinm (BRöL.).

6, of La Camelia bei Angelopolis.

6, 우 lirardot am Magdalena.

Die Exemplare der letzteren Lokalität repräsentieren eine melanistische Varietät mit ganz oder fast ganz schwarzen Metazoniten; bei einem Exemplar sind auch die Kiele nur teilweise und ganz schwach aufgehellt.

\section{Trichomorpha venusta $\mathbf{n}$. sp.}

(Fig. $157-159$ )

Tiefschwarz, şlänzend; die Spitze der Kielzacken lıell ; Vorderrand des Kopfschildes, erstes Antennenglied und basale Beinglieder gelblich; Antennen und distale Beinglieder braun. Bauch rotbraun bis schwarz. Ventralplatten trülıgell, bis rotbraun.

Länge : $17 \mathrm{~mm}$; Breite: $2 \mathrm{~mm}$.

Kïrper hinten erst rom 17. Segment an schwach verschmälert.

Antennen stärker keulig als bei den übrigen Arten, mit deutlicher verdicktem 6 . Glied.

Halsschild mit in eine kurze, spitze Zacke vorspringenden Hinterecken.

Rücken zwischen den hoch angesetzten, fast horizontalen Kielen schwach gewö̈lbt. Kiele gut ausgebildet, die vorderen breiter als lang, die mittleren etwa so breit wie langr, die hinteren allmälılich verschmälert, alle von 2. an mit stark vorspringender Hintereckszacke. Der Vorderrand schwach gebogen, schräg nach hinten gerichtet und lis hinter der lï̈rpermitte durch ein deulliches Zähnchen vom Seitenrand ahgegrenzl, die zwei anderen Kerbzälnchen des Seitenrandes dagegen sehr schwach ausgebildet; Hinterrand auf den Kielen 2-5 glatt, auf den Kielen 6-ı mit zwei, auf den folgrenden lijelen his zum 18. mit 3-5 Zähnchen. Der 19. Kiel ist fast auf die spitze Zacke redu- 


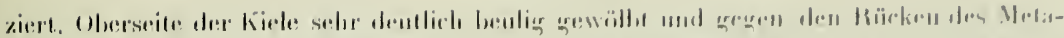

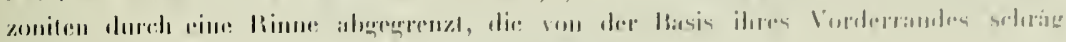

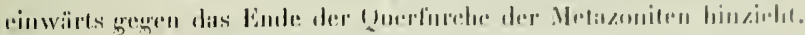

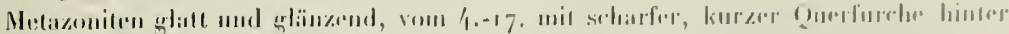

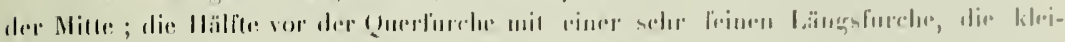

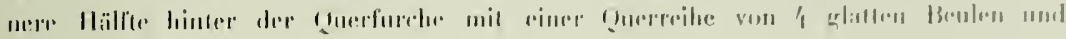

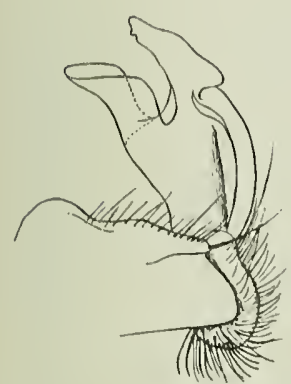

vig. 157 .

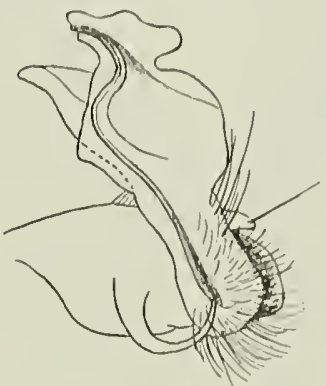

Fig. $1 \bar{j} 8$.

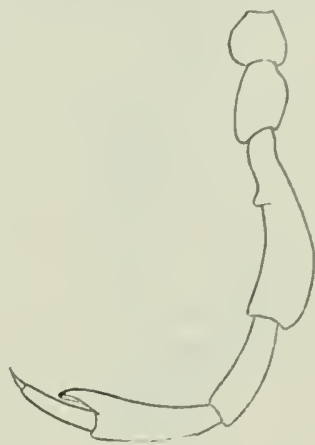

lig. 159

Trichomamha remuste n. sp. o

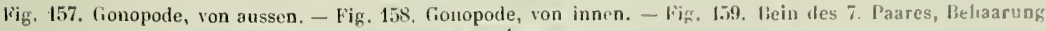
weggelassen.

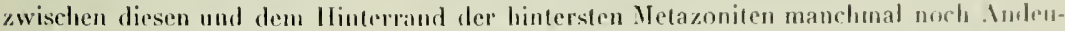

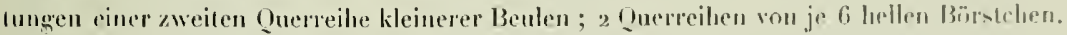

Ventralplatten nur ${ }^{1}{ }^{\prime}, 3$ mal breiter als lang, grlatl, eqtïnzend und mulsehatart, gewölbt, mit sehr seichter Längsfurche, zwischen dem 4. und 6. Beinpaar (־) mil je zwei Hïekerchen.

Beine des o mit Tarsalpulster his zum g. Beinpaar. Femur des 7 . Briuplars (Fir. r59) unterseits mit kleinem hasalem llärker, endwärts wenigy verlicki mul nur gुinz schwach gekrümmt.

Gonopoden (Fig. 157 , r58). (Herrand der Coxa und des Zapfens mit zalulreichen Borstrn, eine stäkere Borste an Ende des Zapfens. Telopodil breil, komprimiert. in zwei

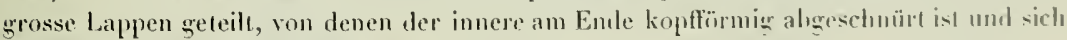
medianwärts über den Tibialfortsatz überwöllıt.

36 . Zwischen Tambo und Bocea del Monte. 


\section{Trichomorpha propinqua n. sp.}

(Fig. $160-162$.)

Sehr nah verwandt mit $T$. tenusta und dieser in der Färbung und dem Aushildungsgrad der Kiele, sowic durch die glatten, nackten, schmalen Ventralplatten selır ähnlich. Aber die Beine sind auch im distalen Teil weisslich. Auf den Metazoniten sind

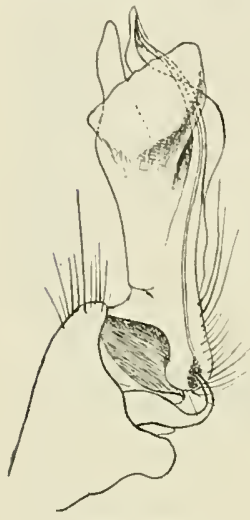

Fig. 160. die Beulen hinter der Querfurche nur schwach angedentet. Der

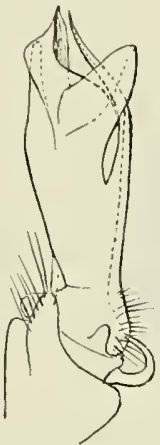

Fig. 161.

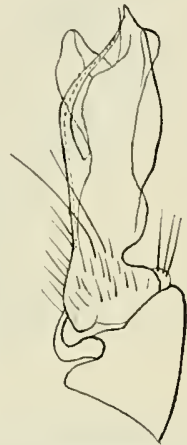

Fig. 162.

Trichomorpha propinqua n. sp.

Fig. 160 bis 162. Ein Gonopode in verschiedenen Ansichlen.

Pleuralkiel ist bis zım 18 . Segment nachweishar. Die Ventralplatte des 5. Segments des $\sigma^{1}$ trägrt auch zwischen dem 5. Beinpaar zwei Hökker und die Höcker zwischen dem 6. Beinpar sind anffallend gross. Der Pracfemur der Beine des ơ, mit Ansnahme der hintersten Paare, springt unterseits am Apicalrand mit einem Höckerchen vor.

Gestalt etwas grösser. Länge : $\sigma^{\uparrow} 21$, ○ $23 \mathrm{~mm}$. ; Breite: of, 우 $3 \mathrm{~mm}$.

Gonopoden (Fig. I60-

I62). Der Telopodit trägt ausser dem Tibialfortsatz noch drei Aeste, einen schräg gestutzten, schildförmigen, einen kapuzenförmigen und einen schmäleren, fingerförmigen Ast. Die Coxa ist viel schwächer entwickelt als bei $T$. venusta.

Beim $q$ sind die Kiele ebenso gut entwickelt wie beim $\sigma^{-1}$ und ebenfalls horizontal; der Seitenrand ist hinter dem sehr deutlichen vorderen Kerbzahn ganz sanft eingebuchtet. Nach Form, Lage und Grösse der liete ist diese Art sehr ähnlich Tr. folium (BröL.) (Ann. Soc. Ent. France vol. LXXII, ı go3, Pl. I, F゙̈g. ı3). Beim $q$ sind die Beulen hinter der Querfurche der Metazoniten ganz verwischt.

i $\sigma^{1}$, i $q$. La Camelia bei Angelopolis.

\section{Trichomorpha annulipes n. sp.}

(Fig. 163-165.)

Kopf, Rücken und Seiten schwarz; Kiele vorn und seitlich breit weisslich umzogen; Antennen braun, mit hellem Basalglied; Bauch braun; Coxa und Praefemur der Beine 


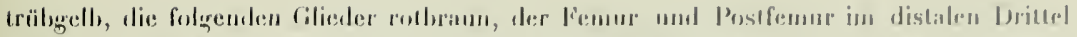

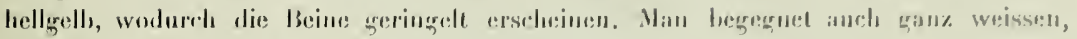
unausereliubten Vixemplaren.

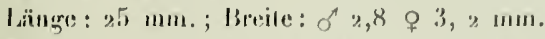

Rücken schwah gewölln; Körper vorn am hreitesten, hintron vonn 17. Segment ass versehinillert.

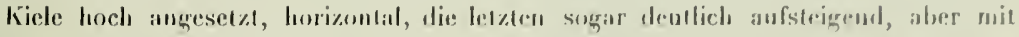

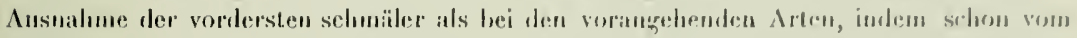

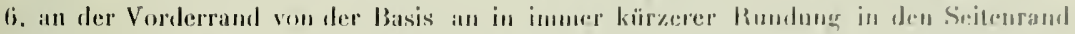

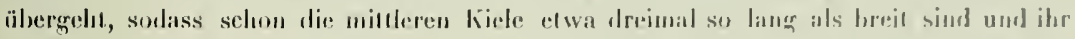

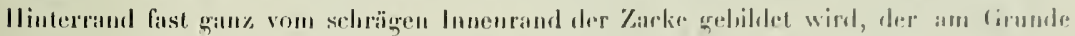

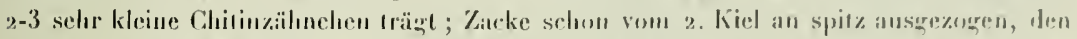

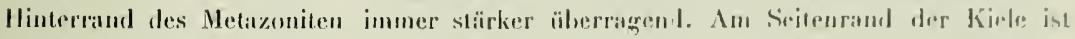

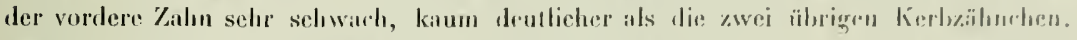
Entsprechend der geringen Breite sinel die Kible oberseits anch nur sehr schwach, die: linteren ïberhaupt nicht beuligr gewölbt, daher auch weniger dentlich vom liäcken der Metazoniten ahgegrenzt, der dadurelt breiter erscheint.

Metazoniten malı, 4-17 mit feiner Querfurche und selıs feiner Längsfurche, hintrer der Querfurche durch schwache Längsfurchen in 6-8 undeutliche Felıler geteilt. Bärstrhen in drei Querreihen von je 8-io.

Seiten des Körpers matt und ghatt; Pleuralkiel leistenfürmig, bis zum 17. Segrnen vorhanden, auf den vorderen Segmenten ziemlich spitz gekörnelt.

Ventralplatten bei of und of sehr kurz und fein weisslich behaart, bein of etwa

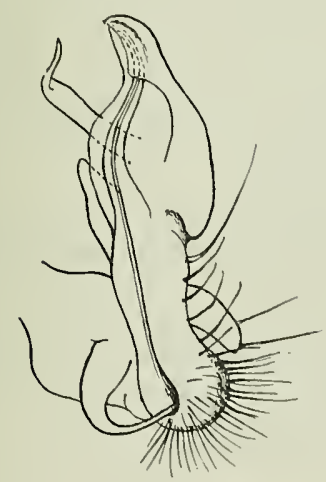

Fig. 163 .

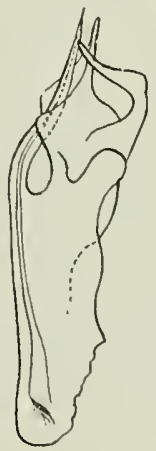

Fig. 16

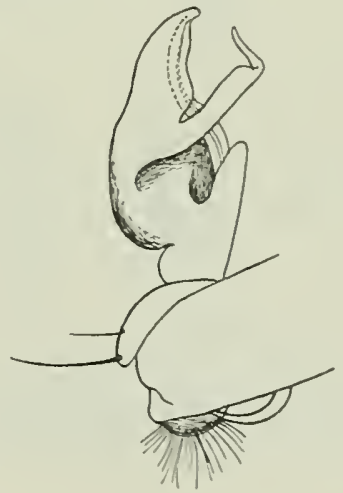

Fig. 165 .

Trichomorpha annulipes $\mathrm{n} . \mathrm{sp} . \sigma^{7}$

lïg. 163. Gonopode, von innen, - Fig. 161. Telopodit, von rorn. - Fig. 165. Gonopode, von aussen. 
$2 m a$, heim of gut 3 mal breiter als lang. Beim of stehen zwischen dem f. Beinpan 2 von vorn und hinten komprimierte, divergierende Zäpfehen, zwischen dem 5. Beinpatr 2 ganz kleine und zwiselsen dem 6. Beinpar awei grössere stumple Hëcker.

An den Beinen des o reicht das Tarsalpolster bis zum 11 . Beinparar ; der lemur des 2. und 3. Beinpaar's ist verdickt und unterseits in der Mitte mit einem IJöctier versehen; der Femur des 6. und 7. Pares ist endwärts rerilickt, gekrinmmt und unterseits oberhalb der Basis mit einem ziemlich langen zapfenfïmigen . Auswuchs versehen.

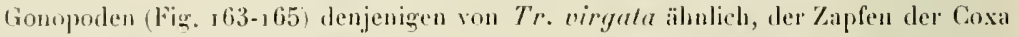
jedoch nur mit 2 Borsten versehen, der Telopodit von aussen und innen gesehen endwärts schmäler und mehr helmförmig, der rückwärts gerichtete fortsatz seiner medianen fläche in der Mitte fast rechtwinklig greknickt.

ot, ㅇ. La Camelia bei Augrelopolis.

\section{Trichomorpha debilitata n. sp.}

(Fig. 166,167$)$

$\sigma^{1}$. In Färlung und Formen der Tr. annulipes selır ähnlich, aber folgenderweise unterschieden :

Gestalt kleiner. Länge : $18 \mathrm{~mm}$; Breite : $2 \mathrm{~mm}$.

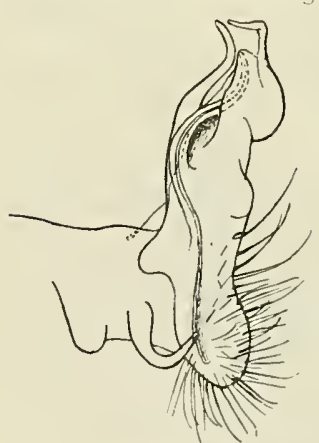

Fig. 166.

Kiele fast his zur Basis weisslich; Beine nicht geringelt, im basalen Teil weisslich, distalwärts bräunlich. Netazoniten ohne Längssfurchen hinter der Querfurche. Ventralplatten fast nackt, diejenigen des 5. und 6. Segments olıne llöcker. Von

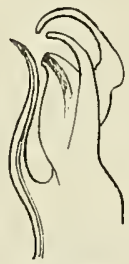

Fig. 167.

Trichomorpha debililala n. sp. $\sigma^{-1}$

Fig. 166. Gonopode, von innen. - Fig. 167. Ende des Telopodits, von rorn; der Tibialfortsatz ist aus der Fübrungsrinne herausgetreten. den vorderen Beinpaaren des $\sigma$ ist uur das 7 . deutlich modifiziert; sein Femur ist unterseits in der Hitte ausgehöhlı und springl apicalwärts davon höckerig vor. Das Tarsalpolster reicht nur lis zum 8. Beinpaar.

Gonopoden (Fig. ı66): Der Telopodit trägt ausser dem Tibialfortsatz und der densellen fülurenden "Haube» noch zwei schlankere hakige Aeste, deren einer an der Basis, der andere auf dem convexen Rand der letzleren entspringt.

I 8 . La Camelia bei Angelopolis. 


\section{- $9 \times 1-$ \\ Trichomorpha hirsuta n. sp. \\ (lijg. liks).}

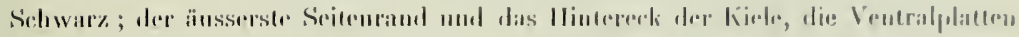

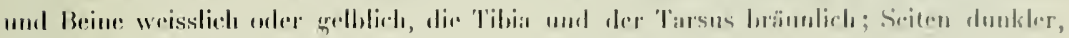
Bituch hellie rolloranu.

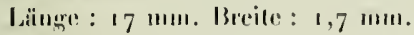

Körper hinten erst vom 18. Segment an verschmiilert, stark mlïnzend, hesombers die Prozuniten.

Riïcken deutlich gewöllıt.

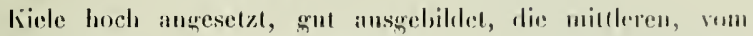
5.-16., wenig verschualerl, etwa lall, so loreit wie lang, alle mit sehr spitzer Zacke, solüig convexem Vorderamd und deutlichem Zälunchen zwischen diesem und dem Ścitenand. Ilinterand concav, olue Zähnelıen. Oberseite der Kiele nicht dentich rom Rörckentril des Mrtazoniten ahgegrenzt.

Metazoniten rom 5.-18. mit seichler Querfurche, ohne Längsfurclie, sant der Oberseite der liele ziemlich dicht mit weissen Bïrstelen in verworrenen Querreilen beselzt; jodes IB̈̈stchen strht

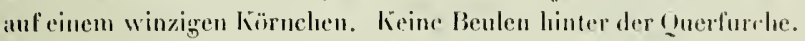

P'leuralkiel nur bis zom g. Segment denlich, gezälnele.

Ventralphatten fast zweimal lneiter als lang, ziemlich dicht kurz weisslich behaart; diejenigen des 5. und 6. Segments des 6

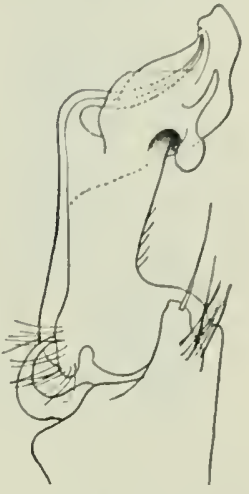

Fig. 168.

Trichomorpha hirsula n. sil. $\delta$ Gionopoile. oline Höcker.

Vordere Beine des o olue Fortsiilze oder Ilöcker, das Tarsalpolster nur bis zum 7. Beinpaar reichemd.

Gunopoden (Figु. 168) : Zapfen der Coxa mil einer tiruppe von Borsten an der Basis unt einer stärkeren apicalen Borste. Telopendit hinter der Nitte getrilt in einen eher knren Tibialfortsatz und eine denselben führemle hreite, tauhenförmige lamelle, deren Aussenlläche nahe der Basis einen hammerförmigen fortsatz trägt.

lo. Agracialil.

Diese Art ist ausser durelt die Gonoporlen noch durch die schwache Iushiludung der sekuntären Geselılechtsmerkmale und durelı die dichtere Behorstung der Vetazoniten charakterisiert. Durch letztere und den damit verbundenen Beginn einer Körnelung leites sie zu den Arten über, die sich engrer an ten Typus $T$. elegans anschliessen, wïhreml die breiteren liele und die schlankeren Beine des o sie mil den vorangehenden Arten verhinden. 


\title{
Trichomorpha pilosella $\mathbf{n} . \mathbf{s p}$.
}

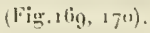

Das eincigre Exemplar isl wahrscheinliels nicht ansgefïrbe es ist trühweisslich, mit rothraunem liopf und leieht gebräunten vordersten Seagmenten.

Länge : 18 mm.; Breile : 1,8 mm.

In der Aushildung und Form der Kiele, der charakteristisehen Bahorstung der Meta-

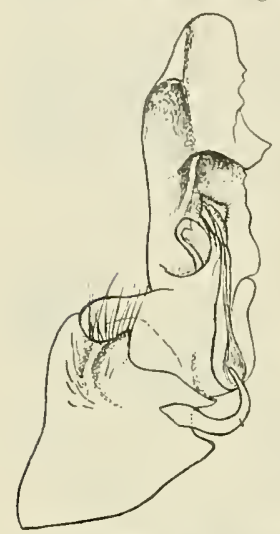

Fig. 169. zoniten und in den Ventralplatten stimml diese Irt mit Tr. hirsula überein; doeh trïgt der llinterrand der miltleren Kiele 1-2 kleine Chitinzälnnehen.

Die vorderen Beine des ot sind stäker verdickt, mil olerseits rundlich aufgetriebenem Prafemur; das Tarsalpolster ist stark entwickelt, his zum 16 . Beinpatar ausgebildet, auf den vor-

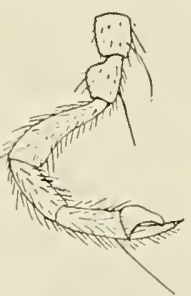

Fig. 170 .

Trichomorpha pilosella n. sp. $\vec{\sigma}$ Fig. 169. Gonopode, von oben innen. Fig. 170. Bein des 8. Paares. dersten Beinen fast so langr wie der Tarsus (Fig. 170). Im 7. Beinpar ist der Femur kur\% und dick, gekrïmml und unterseits ausgehöhlt, vor und hinter des Aushöhlung germulet vorspringend.

Die Gonopoden (Fig. s6g) sind selar verschieden von denjenigen von hirsutu und weichen in Telopodil zienlich stark rom nomalen Typus ab. Der Coxalzapfen ist am Ende zugrespitzl, reichlich lieborstet. Der Femur ist aussen sehr deutlich von der Tibia quer alogegrenzi und an der Basis stark verbreitert. Die Tilia stell eine gerade anfstrebende, anf der Medianseite in zackig», muschelfürmige Nischen begrenzende Leisten vorspringende: Lamelle, mit zugerundetem Ende und unregelmässigem Iunenrand dar. An ihrer Basis löst sich ein kurzer angedrückter Ast al, der sich am Ende in rin viereckiges Schildchen mit kurz bewimperten Rändern verbreitert; dieses Aestchen bildet eine unvollständige Scheide für den ebenfalls tief an der Basis der Tibia entspringenden, sehwachen und kurzen Tibialfortsatz.

I 0 . Merlellin am Ufer des Porce, $1600 \mathrm{~m}$.

\section{Trichomorpha sculpta (PET.).}

(Fig. $171 \cdot 174)$.

Zwei Exemplare der Funruxssehen Ausbeute stimmen bis auf rinen sehr geringen Unterschied an 7. Beinpaar des rollkommen mit l'Etens' Orighinal überein und können, weil besser eshalten, der Besclureilumg zu Grunde gelegl werden. 
Mell kitstamienhiman, Mroiur geblilieh.

Lïnge : 18 mm-; limeite: 1,8 mm.

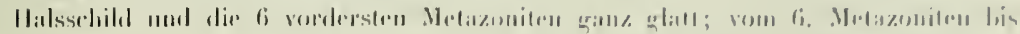

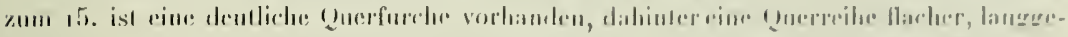

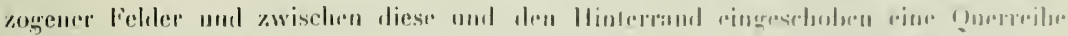

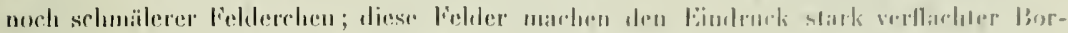

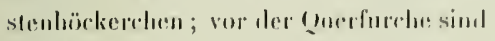

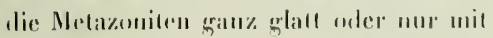

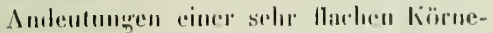

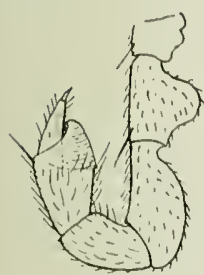

liig. 171.

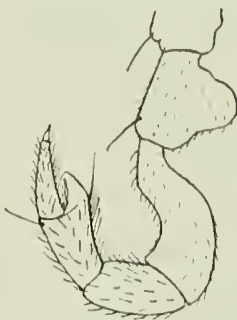

Fig. 172 .

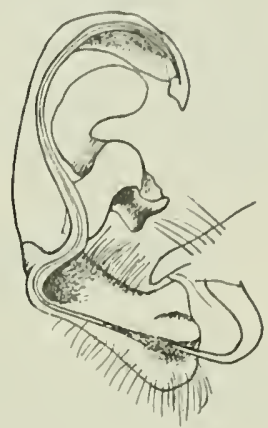

Fig. 173.

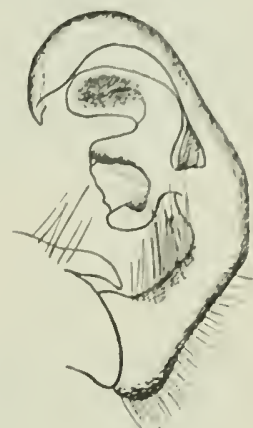

Fig. 174

Trichomorpha si'ulpla (Pet.) •

Fig. 17t. Bein des 2. Paares. - Fig. 172. Rein des 7. Paares (Originalexemplar). - Fig. 173. Cionopode, von innen. - Fig. 17\%. Cionopode, von aussen.

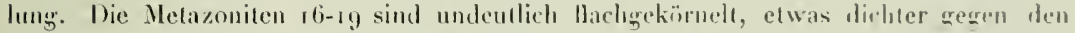
Hinterand hin. Die Bürstchen der Metazoniten sind äusserst fein, auf den vordersten Metazoniten etwas länger und in zwei Querreilıen, weiter binten etwas dichter und unregelmässiger angुeordnet.

Kiele die Wölbung des Räckens fortsetzend, mit Ausnahme der vordersten schmal, mit kur\%em Vorderrand, der zunächst grerumdet, dann immer flacher in den Seitenrand ïberachl und im letzten kïrperdriltel mit letzlerem nur eine sehr selwach gebogene

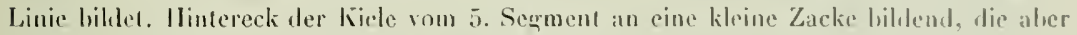
selır allmählich länger wird und erse auf den letzlen lielen etwas bedentender ïber den

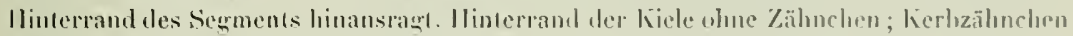
des Seitenrandes sehr kein, rom 14. Segment an ist auch das vordere gaïnzlich verschworaden.

Pleuralkiel ein feines, scharfes Leistchen, dessen linterer Tril his zmon IR. Sirment

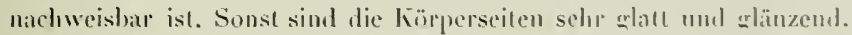

Ventralplatten des o fast quadralisch, glall und uackl, zwischen den 3. Beinpar

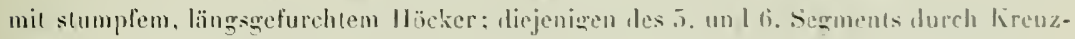
furrhe in 4 kinötchen geteilt. 
Beine des of eler kurz und dick, besonders die vorderen, mit oberseits bucketig rerdicktem Priefermu (1̈̈g. 171, 172). Polster slark ausgebiletet, bis zum 15. Brinpaar gut entwikelt, dann plötzlich quanz fehlend. Beim Origginalexemplar ist der Femur des 7 . Beinjaar's unterseits ausgehöhlt (l゙̈. 172).

Gonopoden (Fig. 173, 174): Die Coxa trägt an der Basis des Zapfens mehrere Borsten. Am Telopodit sind Femur und Tibia verschmolzen; der Teloporlit ist im ersten Drittel gerade und subcrlindrisch, danu stumpfwinklig geknickt, endwärls lameltär und stark sichelfürmign gebogen; an der Knickung geht auf der Nedianseite der lange, der Sichel folgende Tibialfortsatz ab, während aussen auf einem kurzen Stiel ein komplizierter, gewundener, zweiarmiger, lappiger Fortsatz nach hinten rorspringt.

2 ot. Bogola (Coll. Funnany). Petens' Exemplare stammten ebenfalls von Bogrola.

\section{Trichomorpha nitida $\mathbf{n}$. sp.}

(Fig. $175-180)$.

Kopf samt den Intennen und die Metazoniten kastanienbraun; Prozoniten schwarzbraun. Bauch und Beine trübgrelblich.

Länge: $\sigma^{1} 15 \mathrm{~mm}$, 우 $18 \mathrm{~mm}$. Breite: o $2 \mathrm{~mm}$, 우 $2 \frac{1}{2} \mathrm{~mm}$.

Körper selır glatt und glänzend, hinten erst rom 18. Segment an versclımälert.

Rücken deutlich und gleichmässig gewölbt, etwas stärker beim o a als beim ơ. Metazoniten oberseits vollkommen glatt, die mittleren mit einer sehr seichten und feinen, in der Nitte häufig ganz verwischten Querfurche; Börstehen in 2 Querreihen von je 4 und 2. Kiele oberseits im gुleichen Sinn wie der Rücken sehwach gewölbt, mässig stark ausgebildet, die mittleren kaum halb so breit wie lang. Hintereck in eine kurze, ziemlich breite Zacke ausgezogen, die erst auf den hinteren Segmenten spitzer wird und den Metazonitenhinterrand bedeutender überragt. Hinterrand der Kiele flach concav, olıne Zälıne; Seitenrand auf den I 2 vorderen Kielen mit 3, weiterhin mit 2 winzigen Kerbzälınclıen und Börstchen.

Seiten der Metazoniten glatt; Plenraikiel von vorn her verkürzt his zum 17 . oder 18. Kiel nachweisbar.

Ventralplatten beim of mehr als 2 mal, beim of etwa $11 / 2$ mal so breit wie lang, glatl und nackt, beim ot mit je 2 runden Höckern zwischen dem 4. und 6. Beinpaar.

Beine mässig dick, die hinteren länger als die vorderen; die vorderen aber beim o merklich dicker, mit oberseits mässig stark buckelig aufgetriebenem Prafemur; unterseits springt der Prafemur aller Beine des of apical in einen rundlichen linopf vor (Fig. 175-178). Tarsalpolster gut entwickelt, nach hinten sehr allmählich schwäeher werdend und erst etwa vom 25. Beinpaar an gänzlich fehlend.

Gonopoden (Fig. 179 und 180). Der Coxalzapfen trägt an der Basis 3 starke Borsten und ausserdem eine subapicale Borste. Am gerade aufsteigenden Telopodit ist die 


$$
-\quad 1 \%
$$

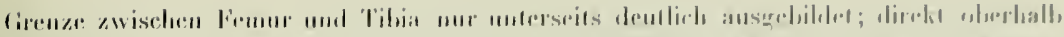

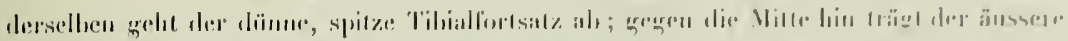

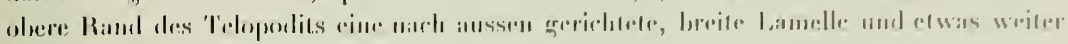

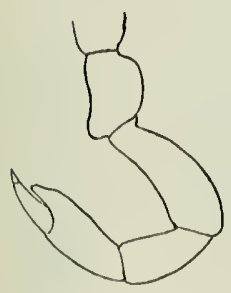

livis. 17is.

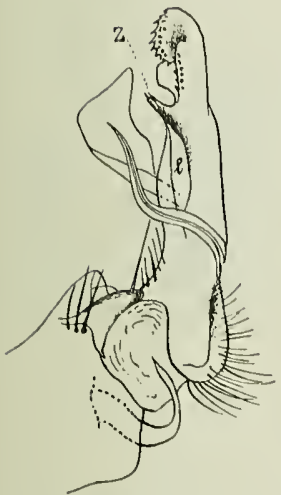

Fig. 179.

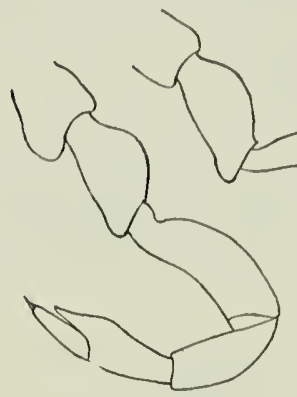

Fig. 176.

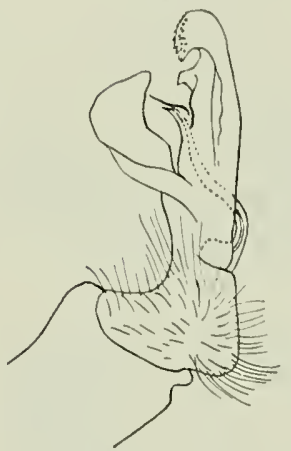

Fig. 180.

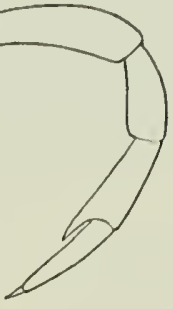

vik. 177.

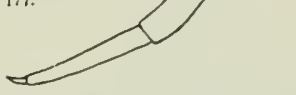

Fig. 178.

Trichomorpha nilida n. sp. 1

Fir. 175-178. Beine deg 2., 5., 19. und 27. Paares (liehaarung weggelassend - lïg. 179. Gonopode, von innen oben. - Fig. 180. Fionopode, sclirïg von unlen aussen.

distalwärts eine zweizïlınige Zacke $(Z)$, die siclı basalwärıs in eine nach innen umgeschlagrene, schmale Lamelle (I) fortsetzl, hinter welcher der Tibialfortsatz gleilet (in Fig. 179 ist der Tibialfortsitz aus seiner na-

lïrlichen Lage in dieser Scheide herausgerissen, in Fig. 180 ist sein nalürlicher Terlauf durch die punklierten Contonren angezeigl); vor dem Ende springt der äussere Rand noch in ein kleines Trapez vor: das Ende des Teloporlits ist lakigh nach aussen und obrn mmgebogen und mil Spitzchen beselzt.

$\sigma^{1}$, O. La Camelia, hei Angelopolis. 


\section{Trichomorpha denticulata n. sp.}

(tig. 18,183$)$.

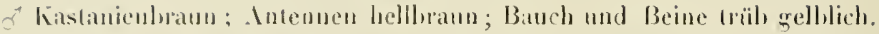

Lïlnge : $18 \mathrm{~mm}$ : Breite : $1,8 \mathrm{~mm}$.

lïrper uhlatt und glämzend, linten arst rom 17. Semment an verschmälert.

Rä̈cken der Vetazoniten sehr schwach gूewälst, ganz grlall, ohne Skulptur, mit mur 4 Bïrstelien in der vordern und 2-4 in der hintern Ouerreile, rom 5.-гf. mit sehr feiner Ouerfurche, ohne längsfurche. Wiele fast horizontal und oberseits vom Rücles nicht deutlich alogegrenat; gnt entwickelt, die vortersten list so breit wie lang,

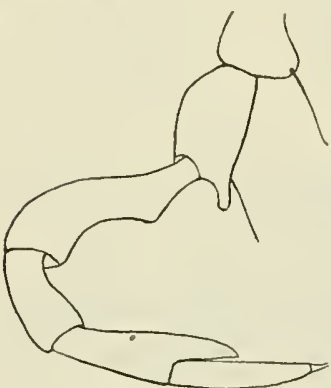

Fig. 181 .

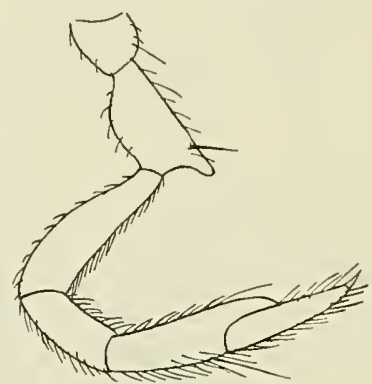

Fig. 182.

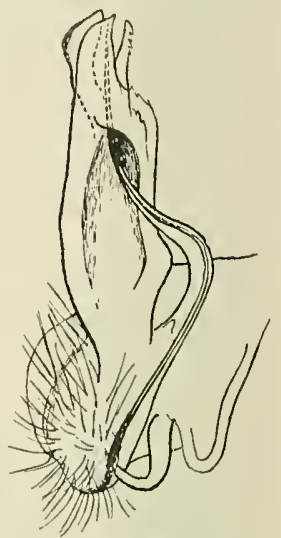

Fig. 183.

Trichomorpha denticulata $\mathbf{n}$. sp. ol

Fig. 181. Bein des 7. Paares (Behaarung wie in Fig. 182), - Fig. 182. Bein des 8. Paares. - Fig. 183. Gonopode, von innen.

die miltleren etwa $2 / 3$ so breit wie lang, mit flach convexem Vorder- und flach concavem, ziemlich langem Hinterrand, der vom 5 . Kïel an zmıächst $1-2$, dann 3 und auf den Kielen der hintern Kö̈perhälfte 4-6 spitze Chitinzähnehen trägl. Am Scitenrand ist das vordere Kierbzähnchen Lis zum 16. Kiel deutlich. Das llintereck bildel rine spitze Zacke, die den flinterrand des Helazoniten dentlich ïherragr, aber bis zum 16 . selır allüilılich lïnger und erst auf dem r8. und 19 . Kiel dornförmign wird.

Plenralkiel cin gezackles Leistchen, das hinter der hörpermilte rasth von vornher sich verkïr\%t.

Ventralplatten des fat fast zweimal so hreit wie lang, sehr spärlich und kurz beharart, zwischen dem 4. und 6 . Beinjaiar mit je zwei ziemlich lohen, quer zugeschärften lläckern.

Beine des ot hinten kaum merklich verlïngert und die vorderen nicht atulfillend dicker; der Prafemur springt unterseits an Ende in einen ziemlich langen, slumpf 


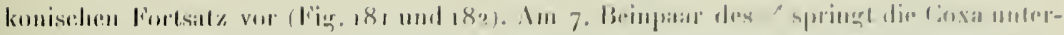

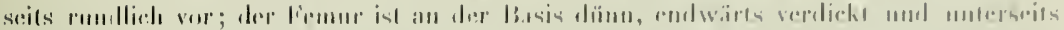

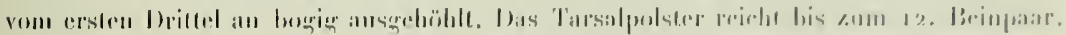

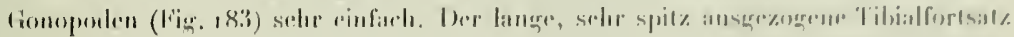

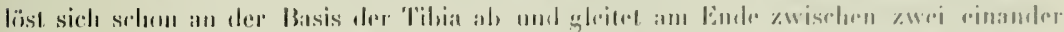

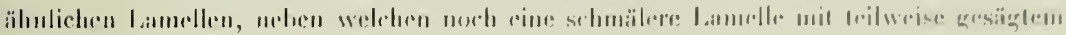
(H)rerand stche

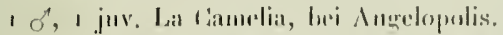

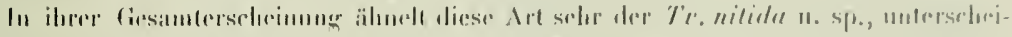

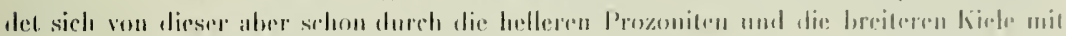

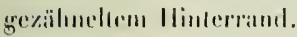

\section{Trichomorpha gracilis $\mathbf{n} . \mathbf{s p}$.}

(lig. $181-187$ ).

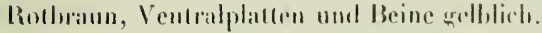

Länge : $13 \mathrm{~mm}$; Breite : 1 ,/ $\mathrm{mm}$.

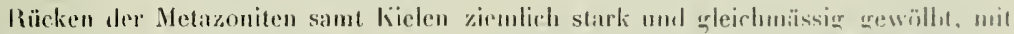

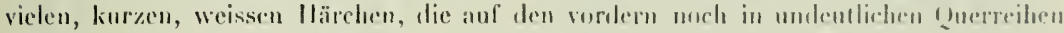

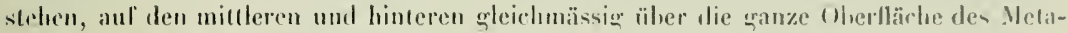

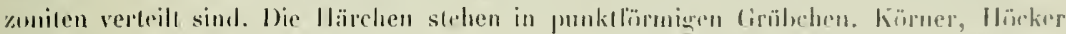

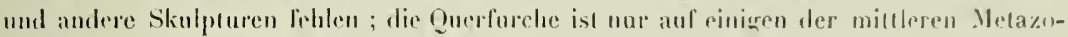
nitrn sehr schwach angedeutel; eine Längshirche lichlı.

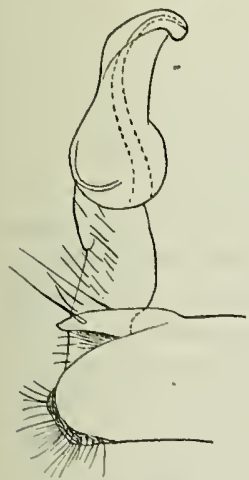

Fig. $18 \%$

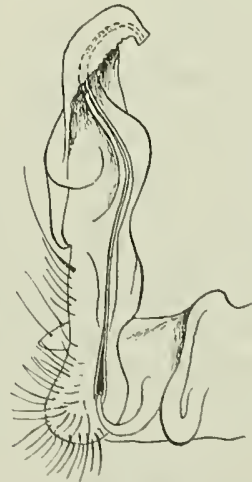

Fig. 185.

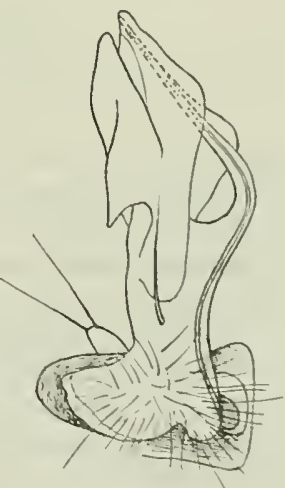

Fig. 186 .

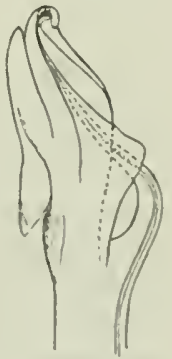

pig. Isi.

Trichomorpha gracilis n. sp. $\varnothing^{4}$

Fig. 181. Cionopode, von aussen. - Fig. 185. Gonopode, von inmen. - Fir. 186. Gonopode, von unlen. Fig. 187. Jistaler Teil des Telopodits, von oben. 
Liele schmal, oberseits in keiner Weise rom Metazonitentücken abgegrenzt und Iessen Wölloung fortsetzend; Vorderrand nur durch die nach hinten immer flacher serundete Schulter der hiele dargestellt; von den kierbzilunchen des Scitenrandes ist nur das vordere und nur auf den vordersten kielen deutlich; das Hintereck zielı sich in cine kurze, spitze Zacke ans, die leicht einwärts gekriummt ist und den Hinterrand des Metazoniten äherragi, aber nach dem lïrperente lin wengy an Länge zunimmt. Der kutze, coneave Hinterand der K̈̈ele trïgt keine Zähnchen.

Prozoniten und Seiten stärker onlïnzend als der Metazonitentüeken. Pleuralkiel nur anif den 3 vosderston Segmenten ausgebildet.

Ventralplatten des ot kaum breiter als lang, spärlich kurz behaart, mit je 2 llöekerchen zwischen dem 3. und 4. Beinpaar, am 5, und 6. Segment durch eine lireuzfurche abgeteilt.

Beine des ô nach hinten kaun merklich verlängert; das Tarsalpolster selır allmählich abnehmend und nur den 3 letzten Beinparen ganz fehlend. Praefemur oberseits etwas buckelig verdickt. 7. Beinpaar des of ohne Auszeichnungen.

Gonopoden(Fig. 181-r87). Zapfen der Coxa nur mil 2 langen Borsten versehen. Telopodit gerade anfsteigend, ohne deutliche Quergłiederung, ungefähı in der Mitte den schlanken, spitzen Tiłialfortsalz abgebend, der von einer helmartig nach oben gebogenen Lamelle gefülırt wird. Ton oben und unten gesehen erscheint ausser den zwei diese Scheide bildenden Lame̊llenblättchen noch ein mit ihnen breit zusammenhängender Lappen, der mit einem kurzen Dreieck basalwärts vorspringt (Fig. 186, 187).

$10^{-1}$. La Camelia bei Angelopolis.

\section{Trichomorpha reducta $\mathbf{n}$. sp.}

(Fi心r. I88, เ89)

Dunkel kastanienbraun, Liopf und Antennen rotbraun ; Beine gelbbraun.

Länge : $10 \mathrm{~mm}$. Breite : $\mathrm{r}, 2 \mathrm{~mm}$.

Rücken leichı gewölbt. Metazoniten matt, rom 5.-17. mit Querfurche und längsfurche vor dersellsen, durch stumpfe, etwas kielartig verlängerte Höcker skulptierı, die auf den vorderen Segmenten in 3, dann in 5-7 verworrenen Querreihen stelen und je ein kurzes, feines Bürstehen tragen. Skulptur und Behaarung dehnen sich anch auf die Olserseite der Kiele aus. Kiele hoeh angesetzt, die vorderen gut entwickelt, dann ganz allmählich verschmälert; die drei letzten fast auf den Scitenrandwulst und die Zacke beschränkı. Das llintereck aller lïiele von 2. an in eine spitze, lange Zacke ausgezogen, die den Ilinterrand der Metazonten weit ülerragl; der kurze concave Ilinterrand der hïele olıne Zähnchen; Kerlyz̈hnchen des Seitenrandes sebr schwach entwickelt.

Seiten des Körpers matt; Pleuralkiel eine feine, gekerbte Leiste, deren hinterer Teil bis zum i6. Segment sichtbar ist. 


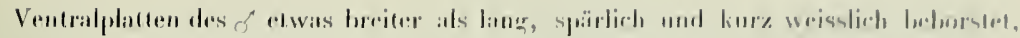

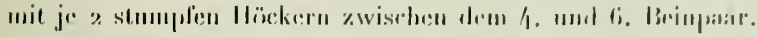

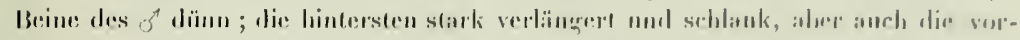

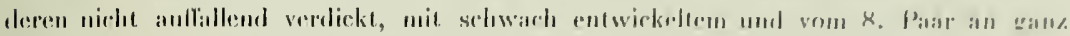

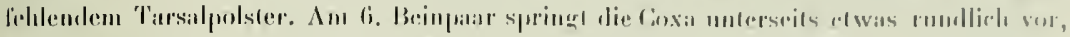
somst sind dic Beine des fi. und 7. Patares

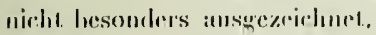

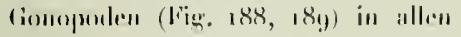
Trilen schwach entwiekelt. Her Zappen

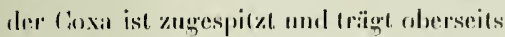
nur starke Borsten. Ber Telopordic ist last gerade, ohne irgend welche lirenze zwisehen femur und Tilgia und teilt sich erst im letaten Drittel. Von srinen droi Arsten ist der innere cine cndwïrts etwas schïssitlörmig verloreiterte Lamelle, Jer äussere (in rundlieher schilal mit riner Lriste, längs welehrer der 3. Ast, aler relatir kuma und dicke: Tibiallortsatz, grleiter.

I ${ }^{1}$. La Camelia, bei Angelopolis.

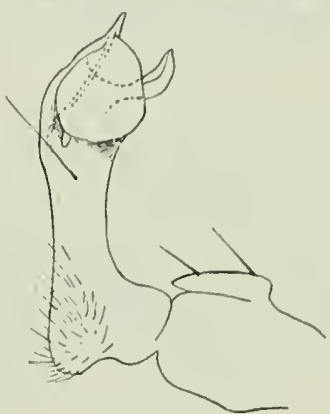

Fig. 188.

Trichomorpha relucta n. ap.

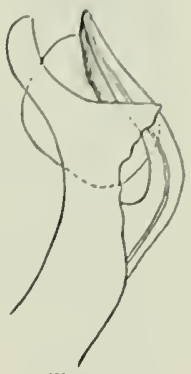

Fiv. 183 .

Fig. 188. Gonopode, von aussen; Jer Telopodit ist nach aussen gedrickl. - Fig. 189. Ende des Telopodits, stärker vergr., von inncn.

\section{Trichomorpha serridens (PET.).}

(Fig. $1 ! n)-t(\xi 33)$

Wir geben nach dem Originalexemplar of einige Ergänzungeu zur Beschreibung. Ilalssehild glatt, lein und kurz beborstel.

Räcken ziemlich stark convex. Prozoniten selar glatt und glänzend; Mrcazoniten ven einem Kielrand zum andern dicht flach granuliert, wie fein gefelelert; auf den hintrren Melazonten sind diese Felderchen pwas in die Länge gezogen. Ansserdem sind die Metazoniten dicht mit kurzen, sehr feincn, hellen Bïrstehen besetzt; anf dem tg. ist die: Beborstung stärker, besonders am Ilinterrand. Querfurche ganz von der Skulptur verdeckt.

Kiele schwach entwickelt, die Wölhung des Röckens fortsetzend: beim 2. und 3. ist noch ein Vordereck angedeutet; anf den folgenden lielen verbindet ein regelmässiger Bogen die Basis der liele mit dem Seitenrand; aber schon rom so. Wiel an bestelat fast kein Vorderrand und der Seitenrand der Kiele geht fast direkt von der Quernaht aus, "twas schräg nach aussen verlaufend. Hintercek der vorderen hiele eine ganz kurze Zacke bildend, dann immer länger und spitzer ansgezogen und zuletzt einen sehr spitz'n, leicht einwärts gekrümmten Dorn bildend, der innen an der Basis 2-3 spitze Zähıclene trägt. (Fig. 190).

117 
Ventralplatten bedeutend lreiter als lang.

Vordere Beine des deutlich veredickt; vom 1. zum 6. Par ist der Femur endwäls stark verbecitert und unterseits ror dem Ende beulig aufgetrichen (Figr. 191); am 7 . ist er unterseits gekrömmt und oberhalb der Basis mit einem etwas knopllörmigr

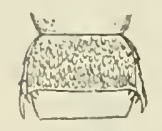

Wig. 190.

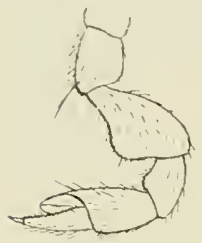

[ïig. 191.

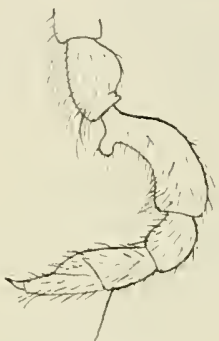

Fig. 192.

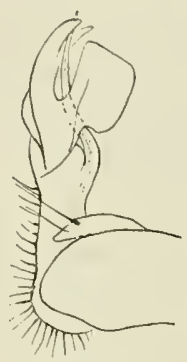

Fig. 19:3.

Trichomorpha servidens (Pet.) of rriginalex.

Fig. 190. 16. Segment. - Fig. 191. Jein des 3. Paares, - 1'ig. 192. Bein des 7. Paares. - Fiss. 193. fionopode, ron aussen.

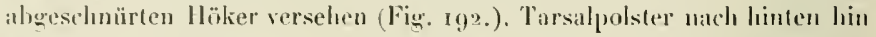
sehr allmälhlich verkürzt und nuch an 4. Beinpaiar nachweishar.

Gonopoden (lï̈. 19.3). Coxalzaly fen mit 2 langen Borsten. Telopodit ohne deutliche Nlogrenzung vou Tilia und Femur, hinter der Mitte eine breite, schaufelrörmige Lamelle nach oben und aussen abgebend, dimn in eine schwach sichelförmig gekriümmte und gegallelte Lannelle endend, die den schlanken, elwa in der Mlitte der Telopodillänge entspringemden Tilvialfortsatz leitet. Bogolit (PEтens).

\section{Gen. Trachelodesmus Рет.}

\section{Trachelodesmus constrictus Peters.}

Wir rervollständigen die Arbesclıreibung nach dem Originalexemplar von Petens (q) und nehmen in dieselhe bei Unkemntnis der übrigen Arten des Genus auch einige vermutliche Gattungsmerkmale anf:

Körper stark gewölht, beinahe cylindrisch, im Bereich des 1.-5. Segments halsartign einģeschnï̈t.

Kopf trlatt. auf dem liopfschilde mit zerstrenten steifen Borsten. Scheitel mit sclarler Mittelfurche. Antennen dünn, zurüchgelegt nur bis zum 2. Metazoniten reichend.

Halsschild schmäler als der liopf, mit kleinen, stumpfen, etwas leralogedrüekten Seitenlappen. Vorderrand schwach gebogen, in einiger Entfernung desselben eine Querrihe:

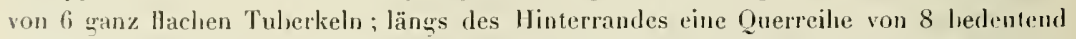
höluern Tuberkeln, die jederseits elwals nach vorn umbiegt. Zwischen den Tuberkelquerreihen ist die filïche des IIalsschildes schwach gekïrnelt. 2. Metazonit sehr kurz, init 


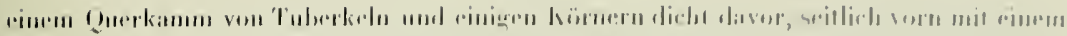

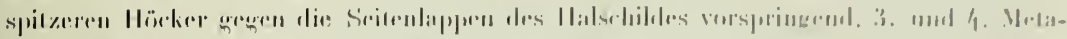

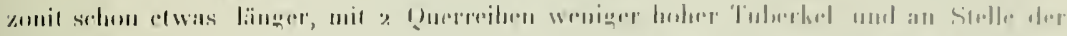

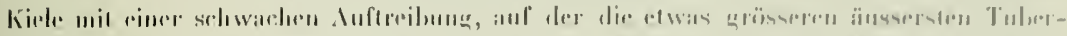

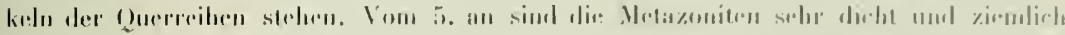

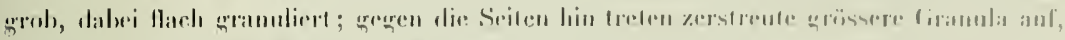

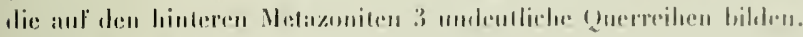

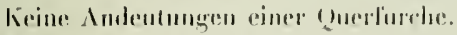

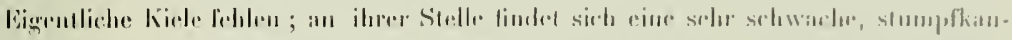

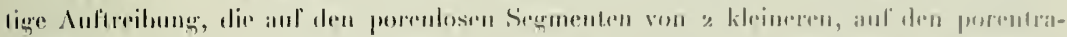

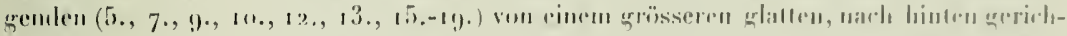

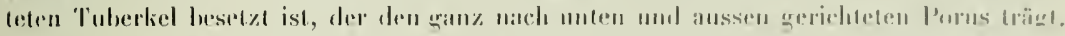

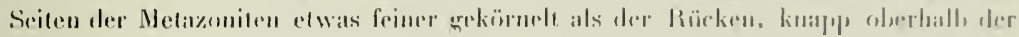

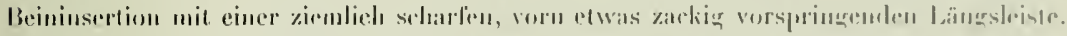

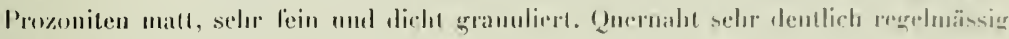
lïugrsugestreili.

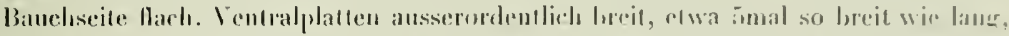

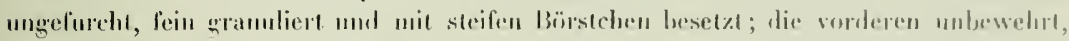

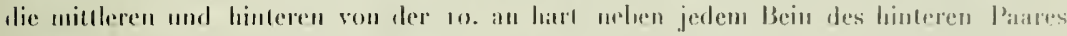
mil rinem spitzen, median- mul rüekwärts gerichleten Dorn.

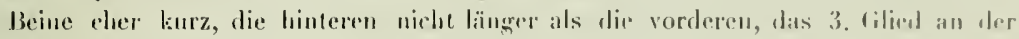

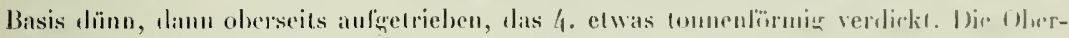

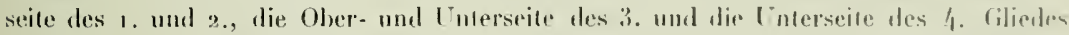
"lielıt mit runden hellen Kärnern lorsetzt. Die Borsten dieser Gilieder entapringen zurschern,

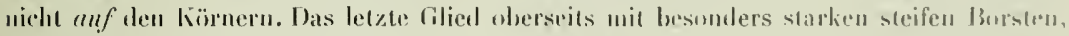
die sich gegen das Ende des Gliedes zusammendrängen. lialle selı lilein, lakig grekrinuml.

Schwïnzchen Hach, endwirts verschmïlert, gestutz, mit je einem winzigen bursten-

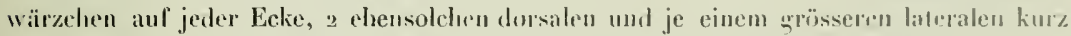
vor dem Ende und je 2 kleinen dorsalen jedrersils nalue der Basis.

Analschuppe breit trapezfirmign, mit z lanģen Borsten anf kleinen Wärzohen.

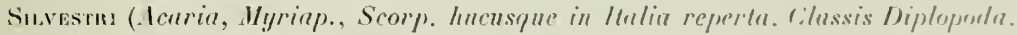

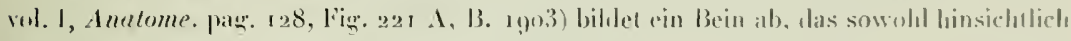
der Form als der Granulation, der Beborstung und der Kleinheit dro kiralle alle Besonder-

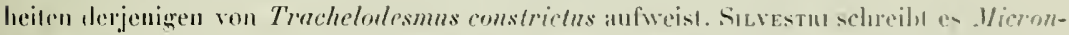

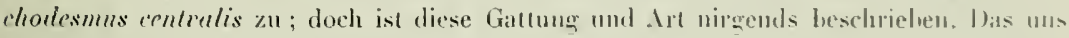

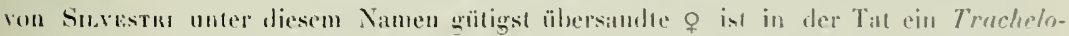

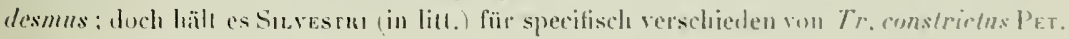




\title{
Gen. Pycnolropis n. gen.
}

\author{
Syn. Euryurus atut. in part.
}

Die Gatlung Éuryurus C. Ki: war urspünglich für eine Art aus Süd-Carolina, E. erythropygus Bnот. (= maculatus C. K., curolinensis Sauss.) auffrestellt worilen. Spätre wurden ihr von Peters auf Grund der Form des Sehwänzchens und des lichwolstes verschiedene Arten aus Columbien zugeteilt. Dann wurde sie durch eine Art aus Minnesola (E. evides Botcs.) bereichert, der Arten aus dem tropischen Südamerika folgten. Atтемs, in seinem System der Polydesmiden, nimmt die Galtung in diesem Umfange an, leschreibt sie aber nach zwei neuen Arten.

Schon die geographische Verbreitung, die sich auf die südlichen Vereinigten Staaten unt das tropische besonders andine Südamerika, mit Ueberspringung Central-Amerikas, erstreckt hätle, musste angesichts der sehr verschiedenen Diplopodenfauna Nortund Südamerikas Zweifel an der Natürlichlieit dieser Gruppierung aufkommen lassen.

Die von Atrens zu Enryurus gestellten Arten gehören in der Tat drei verschiedenen Galtungen an :

Der Gattung Euryurns verbleibt die typische Art: E. erythropygus Brot, und vielleicht noch der ganz oberllächlich beschriebene E. evides BoLc..

Die südamerikimischen Arten aber gehören z. T. in die Gattung Aphelidesmus BRöL. und z. T. in die neue Gattung Pycnotropis, als deren Typus "Euryurus taenian" PEters gelten kann. In dieselbe Gruppe von Gattungen gehören auch Amplinus AтT. (= Pachyurus aut. part.) und Polylepiscus Poc.

Diese im Habitus ziemlich ähnlichen Gatlungen lassen sich schon folgendermassen unterscheiden :

r. Kiele länger als die Metazoniten; ihr Vorder- und llinterrand an der Basis geschultert: Euryurus C. K.

1. 1 . Kiele nicht längुer als die Metazoniten.

2. Rücken der Netazoniten stark skulptiert, mit vollständigen Querreihen von beuligen Feldern oder Hückern. Ventralplatten 8-r 7 subquadratisch.

3. Analschuppe mil geradem oder concavem Endrand; llintereck der Kiele nicht dornartig: Amplinus גтт.

3, 3. Analscluppe gerundet; Hintereck der Kiele oder wenigstens einiger der hinteren in einen einwärts gekrümmten Dorn ausgezogen: Polylepiscus Poc.

2. 2. Rücken der Metazoniten ganz glatl, oder schwach lederartig, mit grober Feldernng auf den lü̈ckenseiten. Ventralplatten schmal, fast doppelt so lang wie breit. 


$$
-\quad \text { tii: }
$$

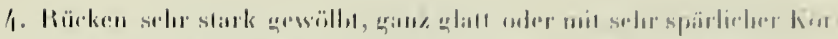

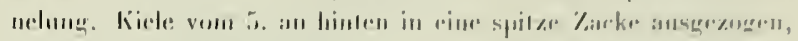

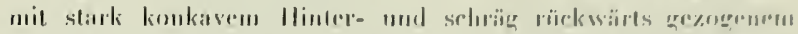

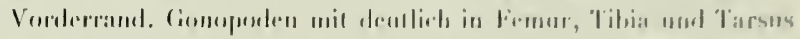

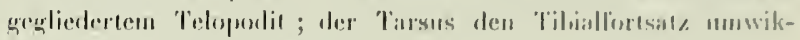
kelual: Aphelidesmus Briil.

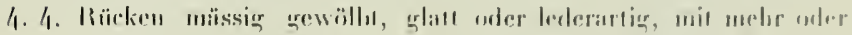

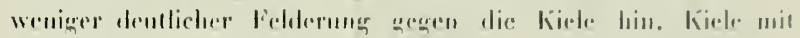

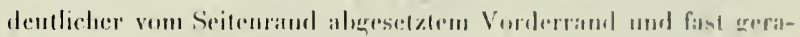

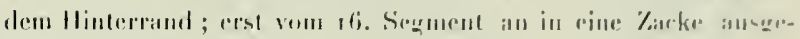

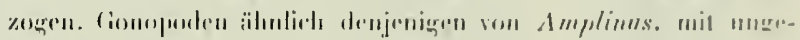

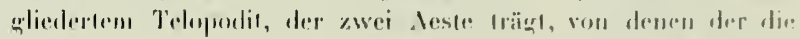

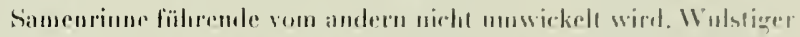

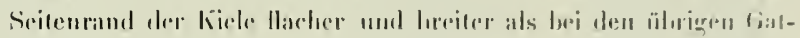

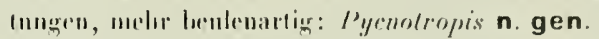

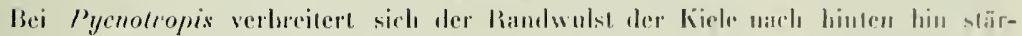

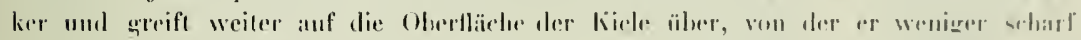

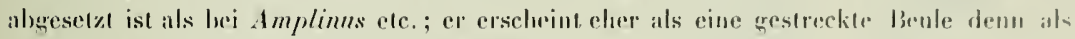

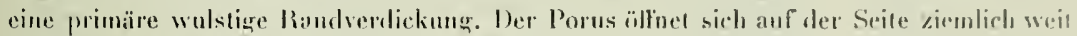

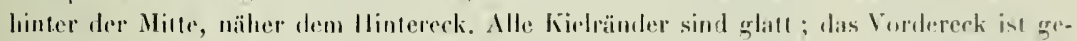

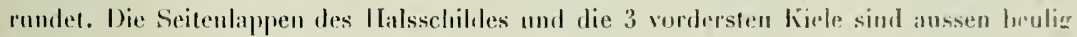

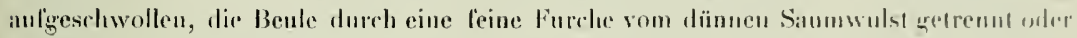
hinten his zum liand reiclsend.

/u P'ycnotroprs qehören l'olgente columbische Arten mit der Griginalhezeichnuner: Polydesmus polygonalus Genv.

Polydesmus (Enryurus) tuenia Petras.

Euryurus flavocurinatus Silv.

Enryurus melanosligma Sux.

Ferner gehört hieher Euryurus Devillei (Sır.), aus Ecuator.

\section{Pycnotropis polygonatus (Genr.)}

(liig igi)

Das einzige Exemplar der Fumnaxschen Aushente, I ct, stimmt gut mit Gervass' Beselıreibung und BnöLexaxxs Zusätzen zu derselben äberein, mit Ausnabme einiger kleiner Unterschiede in der Färbung und Skufptur, die vielleicht mehr scheinbar als wirklich sind.

Fïrlung oberseits schwarzbrann, auf den Sciten rotbrann; der grössere äıssere Teil der liele und die Seitenlappen des Halsschildes gelh. Schwänzchen endwärts bräunlich. Kiopf kistanienbraun; Antennen robraun, mit dunklerem 6. und 7 . Gliede. Ventralplatten und Beine schmutzig gelbbraun. 
Sicheitedfurche vorn nicht gregahelt.

Ilalsschila so breit wie del folgende Metazonit, anf dem Rö̈cken ghat, anf den Sieicenlippen mil . Indeutungen unregednässiger Fehler; Scifenlappen etwas nach vorn gezogen, unt dentlich concavem Vorder- und convexem Ilinterrand. Metazoniten Iederartig skulpticrt, schwächer in der Hitte, viel dichter und etwas grö̈her auf den Seiten des

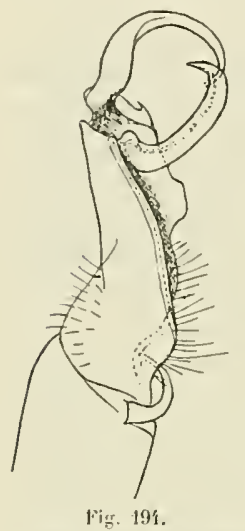

Pycnotropis polygonatus (Gerv.) $0^{+}$ Gonopode, von vorn.

Rïckens; in der Nitte, finden sich Spuren zweier durch Furchen abgegrenzter Felderreihen, die nach aussen hin immer deutlicher werden.

Kiele der Kürpermitte fast so breit wie lang.

Die Seiten der Metazoniten bis znm 8. Segment auf der ganzen Fiälie granuliert, dem Hinterrand nach gröber und rlichter; vom 8. Seqment an bleibt nur ein dichter Streifen grosser kïmer am Hinterrand übrig, die oben auf der Kiehuterseite zu seharfen spiszen werden.

Ventralplatte tes 4 . Segments am Vorderrand mit 2 vorwärts gerichteten IJöckern, diejenige des 5 . Segments mit zwei höheren kegelförmignen Höckern nebrn dem vordern und awei elwas kleineren neben dem hintern Beinpar, diejenige des 6. Segments nur vorne gehöckert, hinten breiter und muldenfürmig. Die den hö̈ckertragenden Ventra!plattenhälften entsprcehenden Beine des 3.-6. J'aares tragen an llüfıglied unterseits vorn einen deutlichen Ilöcker zresade gregenüber demjenigen der Ventralplatte. Vielleicht sind diese Ilïckerbildungen an den vordern Ventralphatten und Beinhüften nur dem ó eigen; sie fehlen den zwei folgenden Arten.

Die Beine des of sind aulfillend stark im Vergleich zu den zwei andern Arten und ahweichend von diesen beborstet: Die Oberseite ist selı schwach und spärlich behorstet; die Unterseite aber trägt cinen dichteren Besatz von kurzen, dicken und stumpfen Borsten auf dem 1. und 2. Gliede und von feineren längeren Spitzborsten auf den übrigen (iliedern.

Schwäuzchen ziemlich stark zugerundet, auch die Seitenrïnder deutlich convex.

Die Gonoporlen (Fig.194) des fiumusxschen Exemplars entsprechen im ganzeu der von Brölemanx gegehenen Beschreihung und dessen Abbildungen. Wir gehen dennoch eine Zeidınng, um den Vergleich mit denjenigen der beiden Galtungsgenossen zo crleichtern.

1 J. Morron. (Coll. Jivuruans.)

Yon Genvars' Originalexemplar ist der genauere Fundort in Columbien nicht bekannt.

Bü̈lemax, der die Type untersuchte, slefte diese Art merkwürdigerweise zu Plalyrrhacus, von wetcher Gathung sie schon durch die Porenbeule unterschieden ist. Allerdings bezeichnet er sie als rin Zwischenglied von Platyrehacus zu Aphelidesmus. Das gilt wun eben in gewissem Grade von der ganzen Galtung Pycnotropis : doch steht sie entschieden Aphelidesmus phylogenetisch näher als Plalyrrhacus. 


\section{- \\ Pycnotropis taenia |'li.)

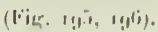

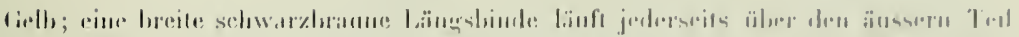

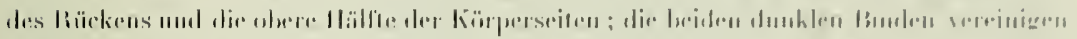

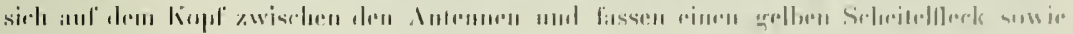

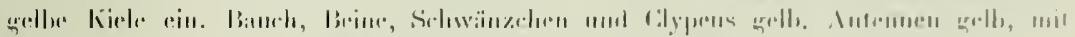

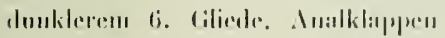
lnatur odere schwar\%.

Silleitelfurche vorn s:an\% liur\%

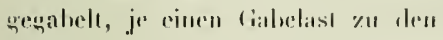

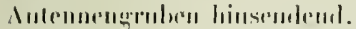

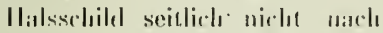
vorl grengen, symelrisch verschmiilert, zogermulet, mit scliwirlt rumvexem Vorder- und fiss gerarlinu Ilinterramb der Seitenlappen.

Rë̈lien schwächere grewölh als lno $I^{\prime}$. polygonofus, wie dort skulptiert, mit elwas weniger dewdichere lieklermug.

licke der lï̈rpermitte deuslich lïuger als breil.

Seiten der Mlatazoniten bis hinter

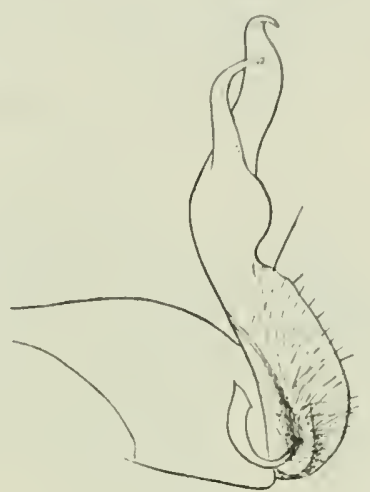

liig. 195.

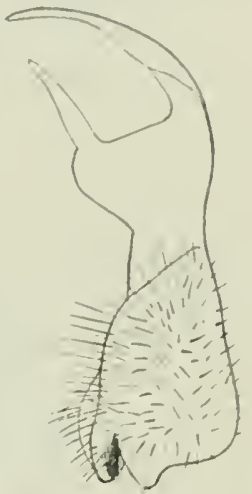

FIg. 196.

Pycnolropis lasnia (Pel.)

Pig. 19.5. Lionopode, von innen. - Fig. ISK;. Telopparlit, von varn. der kïrpermitte ziemlich dicht gra-

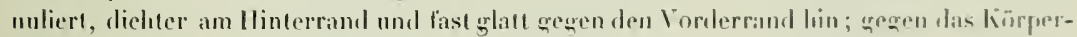
ende verschwindel die Grannlation der Seiten allmählich von vorn nach hinten und felılt anf den hintersten 2 oder 3 Sesmenten selbst an Ilinterand.

Vordere Ventralplatlen bei of und o, sowie die Hüften der vorderen Brinc ulun die bei polyyonatus emïlmten Ilïcker.

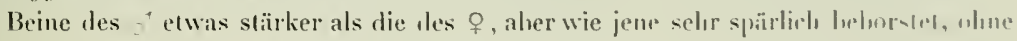
die dichtere Behorstung der Unterseite von P. polyggmalus.

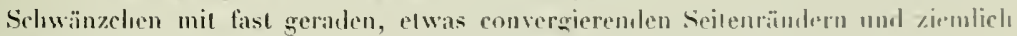
stark grerundetem Endrand.

Conopoden ragi. Fig. 195. 196.

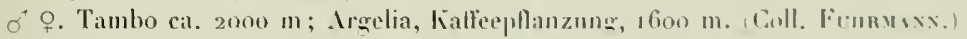

Petfons' Exemplare stammten von Bogota.

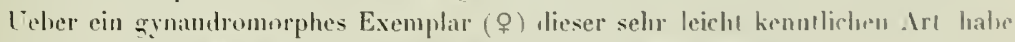

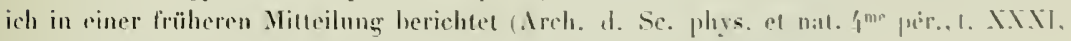
p. 56... 1911). 


\section{Var. melanostigma Sus.}

Der Vergleich des Originatexemplars von Euryurus melanostigma Sisv. mil P. Inenia (РЕT.) ergah ihre rollkommene Uebereinstimmung hinsichtich der Formmerkmale. melanostigma ist nur eine Farbenvarietät vom $P$. Lnenia, bei weleher die briden dunklen längshinden stark unterbrochen und nur noch durch je eine Reihe ron Prozonillheckin unl eimn fleck anf dem Halsschild reprïsentiert sint.

ı O Montererlondo, Bellavista (SiLvestm; coll. Büngen).

\section{Pycnotropis flavocarinatus (Suv.)}

(Fig. 197.)

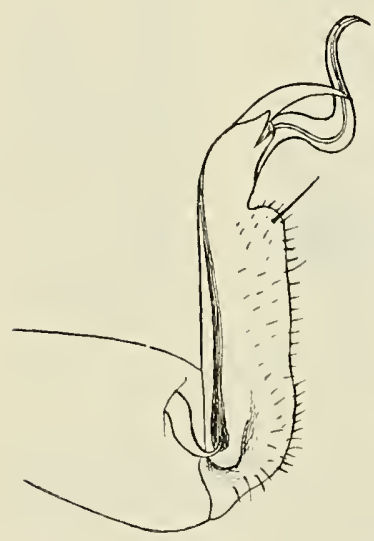

Fig. 197.

Pymotropis flucocarinatus (Silv.) tionoporle, rou innen.

Von den beiden vorigen Arten leicht zu unterscheiden durch seine dorsale Querbänderung (Prozoniten und Yorderrand der Metazoniten sclwarzbraun, der übrige Teil der Metazoniten hellrotbraun), seinen schwächer gewölbten, porzellanartig glatten Rücken mit schwacher Felderung an der lielbasis, ungekörnelte Metazonitenseiten, schrägeren Seitenrand der Kiele, fast gerade Seitenränder und flacher gerundeten Endrand des Schwänzchens.

Die Grösse, Form der Halsschildseitenlappen, höckerlose vordere Ventralplatten und Hüften, Fehlen besonderer Beborstung auf der Unterseite der Beine des $\sigma$ hat sie mit P. taenia gemein.

Hingegen ist die Scheitelfurche, wie bei $P$. polygonatus, rorn nicht gegabelt.

Gonopoden wie in Fig. 197 nach einem Colypus abgebildet. of, \&, Villaricencio, $1000 \mathrm{~m}$; Monteredondo (Silvestri, Coll. Bürger).

Gen. Aphelidesmus Ввöц.

Aul Vertreter dieser Gattung bezichen sich folgende Namen columbischer Arten :

Polydesmus dealbalus Gerv.

1) roulini Gerv. 


\subsection{7}

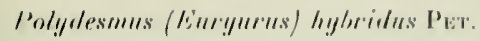

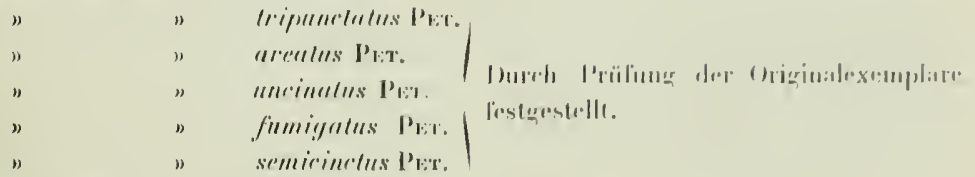

Aphelidesmess hermenphrortilus Isnör.

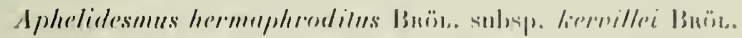

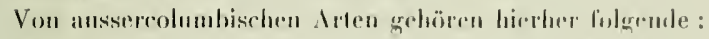

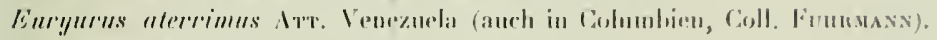

Euryurns glaph!yress Aтт. ${ }^{1}$ Costarica.

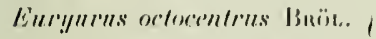

" olongulns Buös. | Brasilianischer Staat Manaos, millerer Amazonas."

T'raehelorhachis rivicola Sirv. ${ }^{3}$ licuatulor.

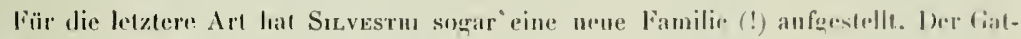
tumgsname: Trachelorhachis ist im gleichen Jahre pulbizierl worden wio Aplefidesmus.

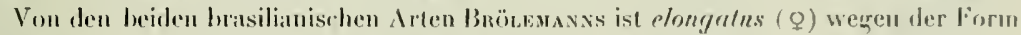

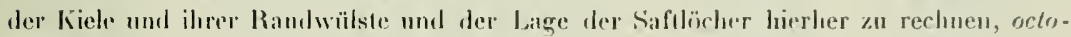
centrus $\left(\sigma^{\prime}\right)$ auch wegen dere form der Gomopoden.

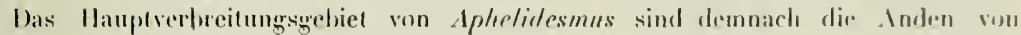
Columbien und Ecuator, von wo Anslïuler his nach Costarica, Venezurla und lief nach Brasilien vordriugen.

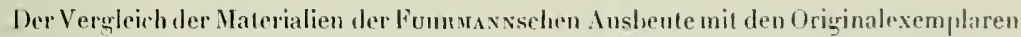
der Petensschen Arten und den meist guten neueren Beschreibungen und Abbildungen fler übrigen Arten crgiht, dass Aphelidesmus eine scharf definierte Gathung darslellt, deren Gonopoden sehr typisch gelaut und nach den Irten sehr wenig differenziert sind, somit ein ausgezeichnctes Gatlungs-, aher ein sehr wenig hrauchbares Artmerkmal abgehen. Der Vergleicls der vorhandenen Ahbildungen der Gonopoden untereinander und mit den mir zur Verfügung stelıenden Materialien ergibt ihre fast rollkommene Identität hei den verschiedenen Arten. Dic kleinen Unterschiede könnten ehenso wohl auf individuelle Varialion wie auf verschiedene Lage im Präparat beruhen, indem eine kleine Verlagerung des Objokts hei diesen gredrehten und l'ortsätze aussendenden Gebilden grleich eine merkliche Aenderung in den Limrissen und Lagebeziehungen der cinzelnen Teile erzeugt.

Wie hinsichtlich der Conopoden, so ist auch in Bezne anf die äusseren Formen der Gatlungslypus stark ausgeprägl und die Difterewzierung nach Arten dafür um so geringer und ausserdem für viele Merkmale durch zahlreiche Zwischenstufen noch undeullicher

1 Vert. Arukss, syst. der Polyelesmiden. 11. p. 27s-279. rsug.

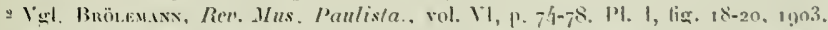

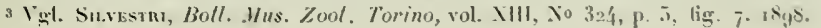


qemacht. Prïlt man ein reichliches Material, so gelingt es allerdings, Individuengruppen zo bilen, die den Eindruck gesonderter Arten hervorluringen. Man begegnet aber wrossen Schwierigkeiten, um die teringen, meist anf ein Mchr oder Weniger hernhenten Unterschiede durelı Beselireihungen oder Zeichnungen fasshar zu machen. Dies trifft namentich zu lïr die mehr ofler weniger tiefe Lage ter liele, ihre Breite, die Entwicklung der l'oreubenle, dir Rumbung des Schwänzchens, die Form der Analschupler

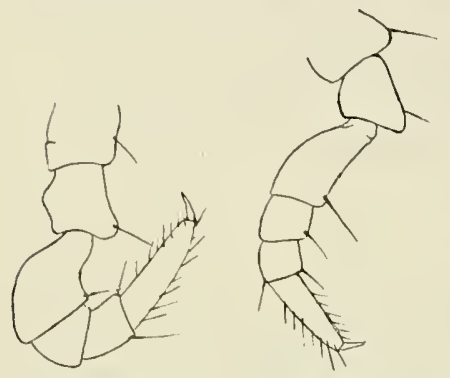

Fig. 198.

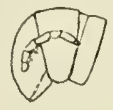

Fig. 200.

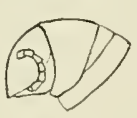

Fig. 201.

Firg. 198. Aphelid. hybridus (Pet.) (1) (19inalex., Bein des 8. Paares. - Fig. 199. Jd. Bein des 24. Paares. - Fig. 200. Fd.. Kopf und die zwei ersten Segmente.

Fig. 201. Aph. semicinctus (Pet.) of juv. Originalex., liopf und die zwei ersten Segmente. (slärlier gormudel oder fast dreieckig), Länge der Antennen, lïrnelung der lï̈pperseiten ı. s. w. Ewas deutlicher und unvermittelter sind die Interschicke in der fiorm des IIilsschildes und der vorderen liele. Manche kïrperteile wörden wrnigstens eine Sonderung der Arten in zwei Gruppen erlauben; so ist die Kante, die jeder Ouadrant einer Ventralplatte neben der entsprechenden Beinhïfte bildet, bald einfach, bald wiceler in zwei Höcker geteilt, sodass damn jede Ventralplatte in ganzen 8 Höcker trïgt. Die Ventralplatte des 4. Segments trägt beim of zwischen dem 3. Beimpant eut weder zwei getrennte, zitzenlïrmige Ilöeker oder einen umparen, am Ende zweispritzigen oder auch slumpfen IJ̈̈eker. Die bisherigen Beschreibungen sind aber viel zu wenig cinlässig, um anf firuml solch minutiöser Mlerkmale eine Beurleilung der betrellenden "Arten" zu gestatten und beziclicn sich ïlserdies manchmal nur aut das 우, oder sellost auf junge Exemplare.

Sehliesslich sei noch der Färbung gedacht. Inf den ersten Blick ist man geneigt, der Fleckung, Guerbänderung, sowie der zwischen grauweiss und tiefschwarz ändernden Grundfärlung spezifischen Wert beizumessen. boch trilft man andrerseits unter morphologisch identischen ausgewachsenen lndivituen so verschiedenartige Färbungen an, dass man an dem absoluten Wert dieses Nerkmales irre wird (vgl, unter A. hermaphroditus BnöL. und A. aterrimas AтT.). Ünter den Begrifl ter Zeichnung fällt auch die lï̈ manche Arten (A. trentus Per.) erwälnte polygonale Felderung der Metazoniten, insofern sie nicht durch Furchen, sondern durch feine, durchscheinende, helle Linien hestimmt wird. Auch sie dürtte kein sehr zurerlässiges Merkmal abgeben, indem sie bei der von uns als $A$. hermaphrodilus Brör. gerdenteten Irt bei jungen Tieren his zum Stadium mit 19 Segmenten sehr deutlich ist, bei den ausgewachsenen aber fast immer gänzlich fehlt.

Aus diesen vergleichenden Betrachtungen lässı sich der Schluss ziehen, dass wir es hier mil einer noch in vollem Flusse befindlichen, in reger Artbildung und Ausbreitung 


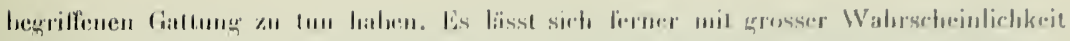

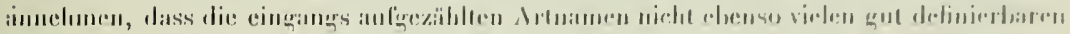

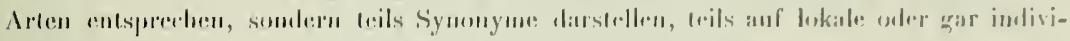

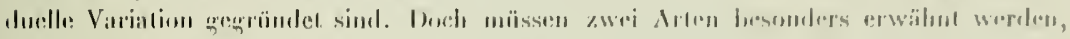

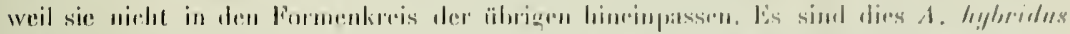

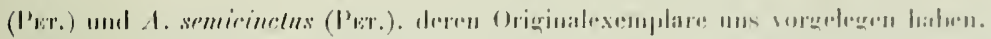

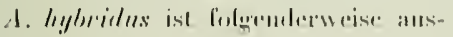

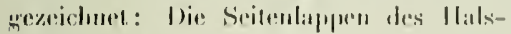

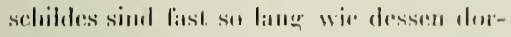

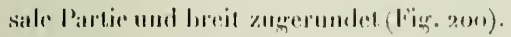

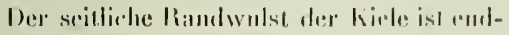
wiirls gatlo leichl verdiekt, kitam stärker

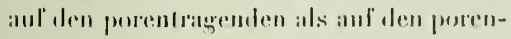

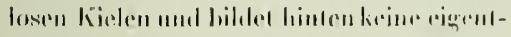

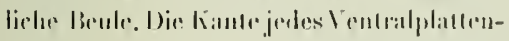

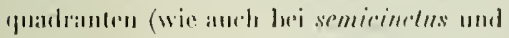

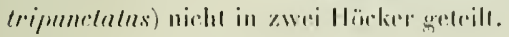
Venlralplalle des f. Siegments des olue sprilze lläcker, von жwe selumalen längswïlsten gevildet. Diss zwrite tilied der Beine (Practimur) springt nntriseits an Emde dentlich stumpl vor; die beine simb aullatlend kur\% und alick (Fig. 19!s, ryg). Die Analschuppe ist nichl germulet oder list dreierkig, sondern trapezlämiz. tiestalt selar klein $(8 \times 2 m m)$.

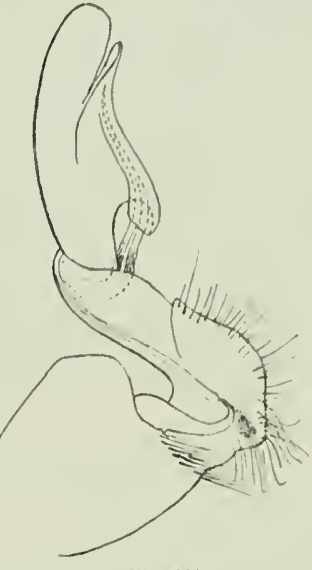

Fir. $20^{2}$.

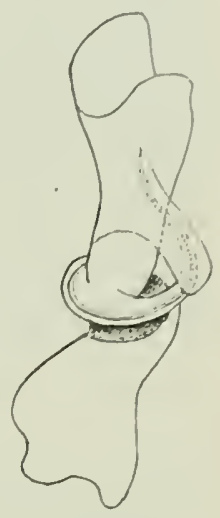

Fig. $20: 3$.

Aphelitesmus trijutretalus (l'el.) of Originalex. Fig. 202. Gionopode, von innen. - Fig. 203. Telopodil, ion vorn und aussen.

1. semicinctus (o juv.) hat lolgende Eigentümlichkerilen: Seitun des Ilalsochildes

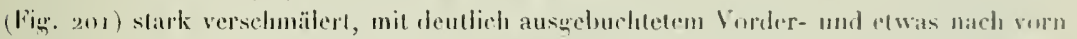

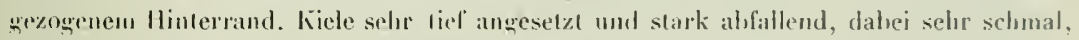

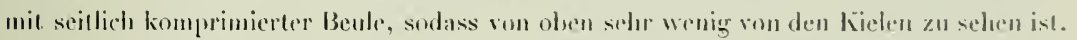

Die Gunoproden von hybridns, Iripunclatus und uncinulus (Originalexemplare) sind kitum vou einander zu unterseheiden. (Fìn. 202, 203.)

Die 4 Exemplare ron A. uncinalns (PET, ), die uns das Berliner Museum zusilndte. siml vällig identisch mil den Originalen von A. tripmetalus. Doch vermule ich. dass es

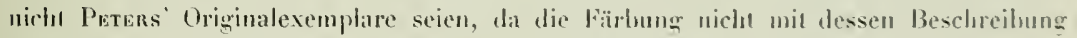
ühereinstimmt, und PErens mur ein crwähnt. Unter diesen Slücken bietet ein eine Monstrosität dar, indem das 8 . rechle Litufhein vollkommen unterilrïckl und das Searment an der betrellenden sitelle rollkommen glall ist.

Vonden Exemplaren der Funzuxsehen Aushente glanden wir die moisten 3 hes hriebenen Aren zuweisen zu sollen, da deren Beschreibungen auf sie passen und Veuhe- 
schreibungen doch nicht irgendwie scharlie spezifische Intersehiede wïrden hervortreten lassen. Lür ein Exemplar sind wir jedoch ggenötign, eine neue An aufzustellen.

\section{Aphelidesmus aterrimus (}

Zwei ot und ein 9 sind wanz tiefschwarz; hei cincm dritten of ist dic Zacke der liele dunkelrothaun wie die Ventralplatten, und die proximalen Beinglieder und die Metazoniten tragen Spuren eines rotbraunen Nittellecks.

Bei einem ․ das den Formen nach hierher gehı̈rt, sind die Seiten des Halsschilıles, die vorderen Kiele und die Beule der äbrigen Kiele trübgelb; der schmutzig braungelbe Rückentleck dehnt sich vom 3. Segment an quer üher den ganzen Metazoniten aus, auf deı Seiten in rauchbraun übergehend, sodass nur der Vorder- und Hinterrand der Metazonilen wie die Prozoniten sehwarz bleiben. Vielleicht gehört hierlıer auch A. fumigalıs (Peteıs).

Bei alerrimus (gedeutete Stücke) ist die Seitenkante jedes Quadranten der V́entralplatten in 2 Ilöcker geteilt; beim $\sigma^{1}$ sind die Höcker des vorderen Parares der Ventralplatte 4 zu einem stumpfen, gefurchten Höcker verschmolzen.

30,1 q Cafetal Buenavista, i $q$ Fresno-Mariquita (Coll. Funuman).

\section{Aphelidesmus hermaphroditus BRöL.}

Die Färbung dieser Art ist äusserst variabel. Man kann wenigstens 3 Fïrbungeı unterscheiden, deren Träger aber häufig rom gleichen Fundort stammen.

1. Trüb weisse Exemplare, mit kaum sichtbarem Kiellleck.

2. Exemplare mit rotbraunem Rücken und Seiten und deutlichem, lellgelloen Kiellleck, entsprechend Bröı, manss Beschreilung; oder der vordere Teil der Metazoniten ist in verschiedenem Grade tiefer braun als der hintere und die Prozoniten.

3. Rücken und Körperseiten tiefschwarz, der Kielfleck durch Kontrast sehr stark hervortretend und fast reinweiss erseheinend; Schwänzehen weiss.

Die dritte Kategorie ist unter den ausgewachsenen Exemplaren die lıäufigste; zwischen ihr und der zweiten gibe es Uebergänge. Die jungen gehören fast alle der zweiten Kategorie oder Uebergängen von dieser zur ersten an; sie tragen wie schon erwähnt eine durch feine Linien begrenzte Felderung, nämlich eine Querreihe kleinerer Felder auf dem hinteren Prozonitenteil und zwei Querreihen gुrösserer anf den Metazoniten; die Felderung ist auch bei einem erwachsenen Exemplar der I. Kategorie sichtbar.

A. hermaphroditus scheint in Columbien die häufigste Aphelidesmus-Art und einer der häufigsten Diplopoden überhaupt zu sein.

Zahlreiche $\sigma^{7}$, q und juvs. von: Camelia, $1800 \mathrm{~m}$; Medellin $1600 \mathrm{~m}$; Puerta de los Pobres am Cauca-Fluss; Hagdalena bei Girardol, $250 \mathrm{~m}, 27$. Oktober.

Eine Etiquette trägt dic Bemerkung: "Diese Diplopoden riechen stark naclı Cyankali.» 


\section{-9 , \\ Aphelidesmus semicinctus P'tr. \\ (l"ïg., $2 n 1)$.}

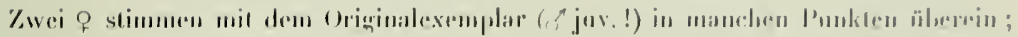

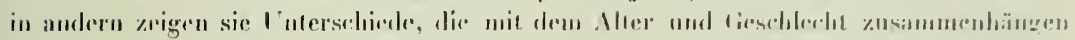

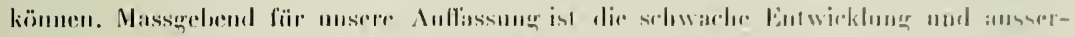

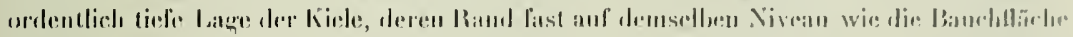

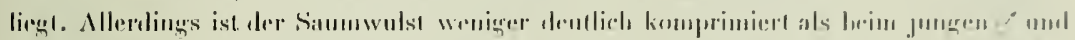

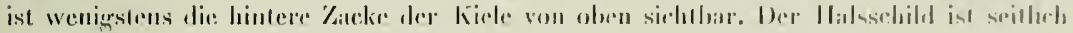

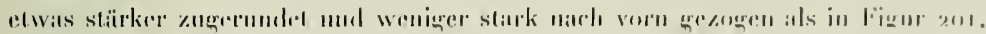

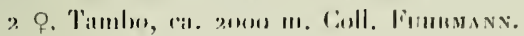

\section{Aphelidesmus ambiguus n. sp.}

(liig. \%).

Schwar\%, mit leicht brannot aulgeheltem Ilintererk der lïele; Banch umd Autommen rothrauı; Beine gelblich.

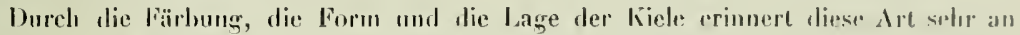

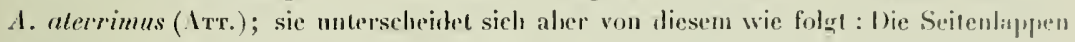
des llalsschildes sind nur wenig, elwa $u m 1 / 3$, kïrzer als die Räekenlinie und breit zugerundet. Dic liele des 2.-Я. Segmentes sind vorn zugerundel, ohne Zälnnchen am Vordereck. Der Saumwulst der lieke ist auf den porentragenden kaum lireiter als anf den porenlosen und nach hinten sehr wenig verdickt, nicht benlenartig wie bei A. alemimus. Die Kante jedes Quadranten der Ventralplatien ist nicht oder nur sehr mondentich in zwei Hëckerchen abgeteilt.

Antennen und Beine sind kürzer und dicker, an ersteren sind das 2.-5. Glied kaum lïnger als loreit.

Dis Schwänzchen ist in der Mitte des Endrandes viel deullicher ansgeduchtet als bei aterrimus und allen ïlorigen Arten.

An den Gonopoden (Fig. 204) ist der Tarsalteil redhälnismässig bedeutend kürzer als bei aterrimus, etwa wie bei hermaphroditus; seine beiden Lamellen, besonders die äussere, sind endwärts breiter als bej letzterem und allen übrigen mir in dieser Beziehung bekamnten Arten.

$10^{7}$. Catetal Buenavista hei Viota. Coll. Funnmans.

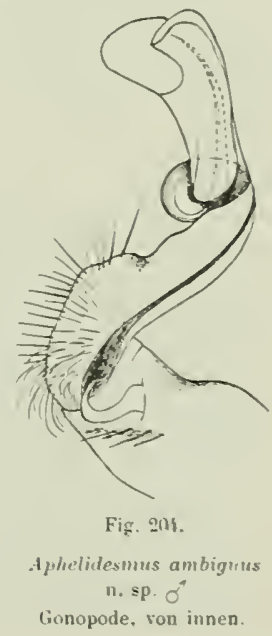


Gen. Plusioporodesmus Sux.

Atтeus hal die nahen Beziehungen dieser Gatlung zu Plalyrrhacus mit Rächsieht auf die äusseren Formen richlig rekannt. In der tiestalt der Antennen, der Form und Liröse des Halsschildes, der Skulplur der Metazoniten, Form der Kiele, Linge des Porus and Form des Schwänzchens stimmen die beiden Gathngen äberein. In anderer Bexiehumg aber nïhert sich Plusioporodesmus melır den Leplorlesminue, so im Besilz von sekundären Sexualcharakteren in Form von Answächsen an manchen der vorderen Beinpainre des und besonders in der Form der Gonopoden, deren Telopodit tief zweiteilig ist.

Cianz eigenartig und wohl von generischem Wert sind gewisse Nerkmale am Kopt". Die Antemnen sind einander an ter Basis stark trenähert; äher ihnen ist der Scheitel bei o und q etwas vorgezogen und trïgt einen nach oben gerichteten, schanfelförmigen . Iulsalz, der sehr an denjenigen gewisser Käfer (Coprinae, Aphodienue) erinnert, aher in beilen Geschlechtern gleich stark entwickelt ist. Ausserden trïgt der kopf jederseits nalu dem Seitenrande auf ter Höhe der Antennen eine holw konische IVurze.

lorenformel: 5, 7-19. Der Porus is wie hei Plalyrrhacus von einem ringlïrmigen Wall umgelien.

Ventraphlatten zwei $\left(\sigma^{-1}\right.$ ) bis drei mal (o ) breiter als lang, weder quer- noch lïngsgeteilt, mil stark concavem llinterrand.

Plenralkiel durch je eine Warze oherhalb jedes Beines repräsentiert.

Analschuppe gerundet-dreieckig.

Sowolt ihre vermittelnde Stellung, als ihre eigene Dilferenzicrung sprechen für ein ziemlich holıes Alter dieser Gatung:

\section{Plusioporodesmus bellicosus SILV.}

(Fitr. 205, 206)

Sitvestrus Diatgnose ist ziemlich scharf, bezicht sicht aber nur auf das ơ, und bedarf einiger Zusälze, ausser den schon oben für die Gallung gegebenen.

Q. Länge: $36 \mathrm{~mm}$; Breite: $6 \mathrm{~mm}$.

Kopf samt den Backen fein grranuliert, mit zwei Querreihen etwas grösserer Körnchen vorn auf dem kiopfschild. Scheitelaufsatz vorn längsgefurch und oben schwach zweilappig.

Die Granulation der Hetazoniten ist sehr dicht und gleichmässig; nur anf den drei letzten treten Querreilien etwas grösserer Körner hervor. Die Kiele des 2.-4. Segmints sind ziemlich stark nach vorn gezogen, mit spitzwinkligem, aber zugestumpltem Vordereck, selır stumpfivinkligem Hintereck und schräg convexem Seitenrand. Die beiden folgenden Kiele leiten zur Form derjenigen des milleren Körperteils äber, die fast recht- 


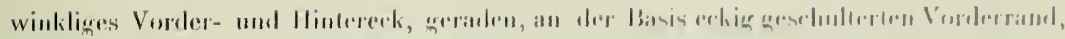

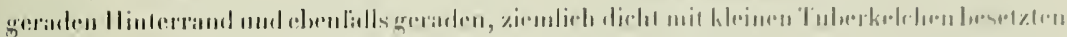

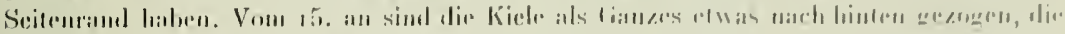

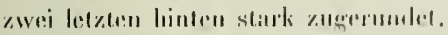

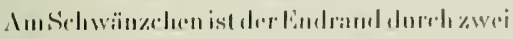

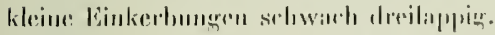

P'rozoniten lingsum lisin rolateriniert.

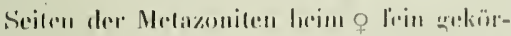

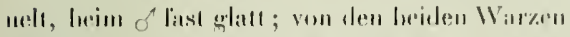

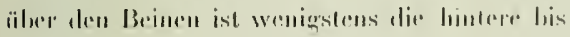

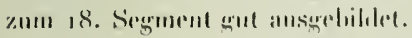

Ventralplatten unlwharl, mil zes'stentru

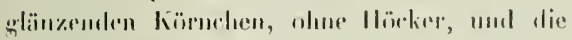
vorderen de's of olue forlsill ze.

Beine ringsum ziemlich dicht kur luh hitarl; Femur lïnger als der T'al'sus. Am 3. 1und 1.

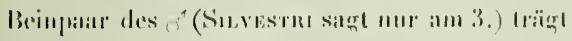
der lemur unterseits dinen kurzen, konischen, stumplint duswuclss.

Analsclumpe umel Kilappen gramuliert.

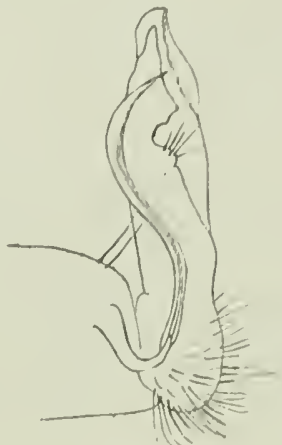

Fig. 20);

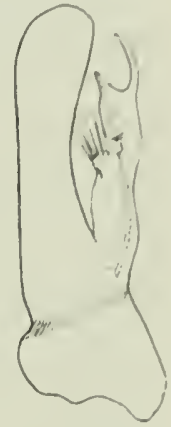

lik. 24 Wi.

$$
\begin{aligned}
& \text { Plusiuponofesmus hellurosus sils } \\
& \text { Irifinalex. } \\
& \text { Fis. 205. fionopode von innen. lif. Lix; }
\end{aligned}
$$

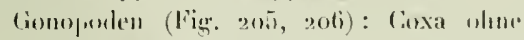

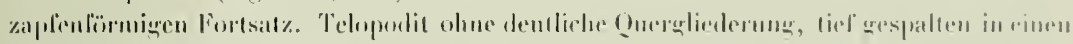

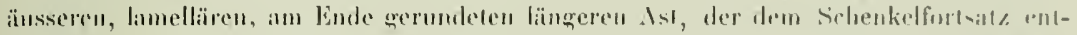

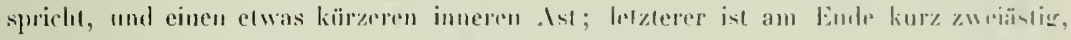

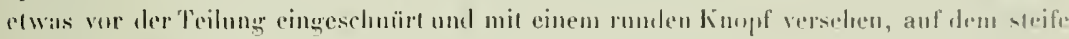
Borsten stehen.

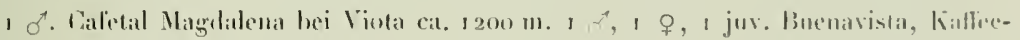
pllanzung,

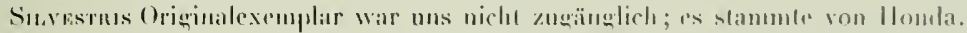

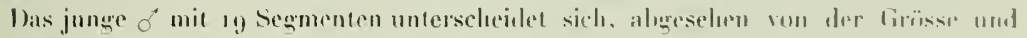

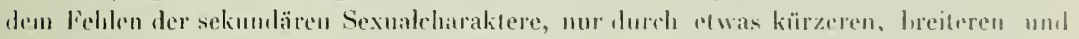
uben nicht ringeschnistenen seheilelfortsatz.

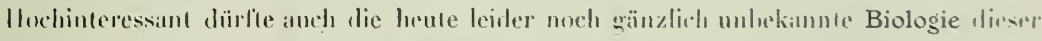

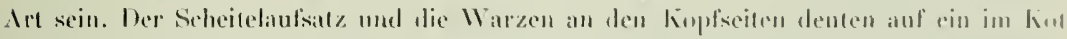

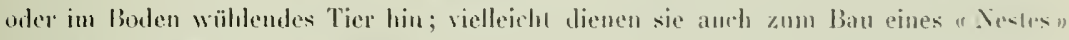
resp. cince Kinpsel für die Eiahlage. 


\section{Gen. Cryplogonodesmus Sisv.}

Durch den Artnamen des Typus ( $C$. clavidives Surv.) mehr als dureh dic Diagnose verinlasst, untersuchte ich das Originalexemplar von Sicvestm, aus Venezuela, den äusseren Formen nach. Sowcit ich ohne Zerghlierlernng desselleen urteilen kann, goehüren diesem Genus mehrere Arten dei Funmaxsschen Jusbeute an. Manche derselben sind nur durch 1 oder 2 Exemplare vertreten und wïrden keine gleichwertigen, ausführlichen Beschreiloungen gestatten. Ich ziche es daher vor, zunächst die gemeinsamen Mcrkmale zusanmenzustellen, dann die unterscheidenden äusseren Merlimale der Arten in Schlüsselform anzugeben und schliesslich jede $\lambda \mathrm{rt}$ kur\% getrennt zu hehandeln.

Gestalt sehr klein. 20 Segmente. Körper vor dem 5. Segment schmäler, hinten vom 17. Segment an konisch versclmälert. Kopf fein und kurz beborstet. Antennen meist schr lang und etwas keulig, gleichmässig kurz behaart, daneben mit je einer langen Sinneshorste auf dem 5. und 6., zwei solchen auf dem 4. Glied und einer kürzeren anf tem 7. Glied; das 5. und 6. Glied endwärts aussen mit kurzen nicht zahlreichen Sinnesstähchen. Halssehild schmäler als der Kopf und als der 2. Metazonit, vorn regelmässig gebugen, mit zugestumpften Ecken und in der Mitte leicht eingebuchteten Hinterrand. Der 2. Metazonit nebst Kielen länger als die 2 folgenden, wie diese und der Halsschild leicht grewölbt. Die folgenden Metazoniten ganz flach, mit horizontalen Kielen. Pro- und Metazoniten tragen eine dichte zellig-körnige Skulptur, die Metazoniten danełen eine kurze Qnerfurche, eine Längsfurche, sowie Andeutungen einer Polydesmus-artigen Felderune und vor allem 3 Querreilien sehr charakteristischer, meist stift- oder leicht keulenförmiger Borsten, von denen im allgemeinen die vier der vordern Reihe länger sind als die ührigen. Auf den hintersten Metazoniten aber sind die 6 Borsten der hintersten Rieilıe die länğsten und stehen auf je einem den Hinterrand des Metazoniten überragenden Höcker. Ich fand immer in der ersten Reihe 4 Borsten, in der zweiten 6, wovon je eine ziemlich weit aussen auf dem kiele, und in der 3. Reihe ehenfalls 6 Borsten, diese in regelmässigen Ahständen. ' Der Halsschild trägt ebenfalls 3 Querreihen von Borsten.

Der dorsale Ilinterrand der Metazoniten ist geschwungen, in der Mitte leicht eingebuchtet, jederseits je nach den Arten mehr oder weniger convex und gegen den kiel hin nach vorn gezogen.

hiicle länger als breit, mit convexem, schmal gesïunitem Vorderrand, bogig oder wiuklig concavem Hinterrand und mehr oder weniger deutlich zackigem, an den vorklersten jedoch meist stumpfwinkligen IJintereck. Die Zacke wird nach hinten lin immer länger und schmäler und stellt auf dem 19. Segment fast allein den Kiel dar. ${ }^{2}$ Der Seitenrand

1 Diese Borsten fallen sehr leieht ah, daher wahrseheinlieh dic abweichenden Zahlen in SiLvestrıs Diagnose ( 1898 , p. 6o).

2 Silvestrus Angabe, dass das 19 . Segment kiellas sei, trifft nicht z1. 


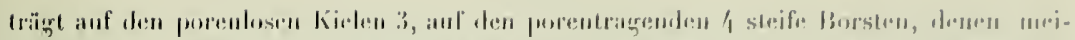

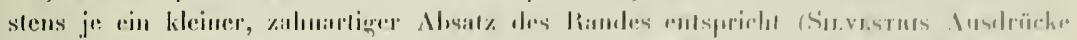

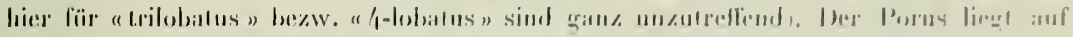

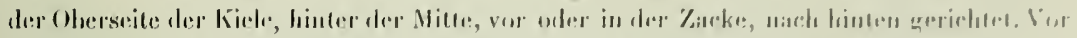

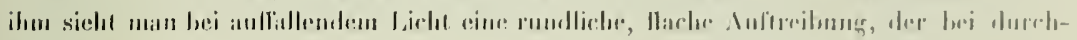

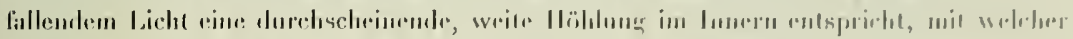
der l'urus kommuniziert.

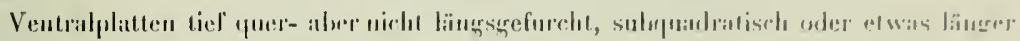

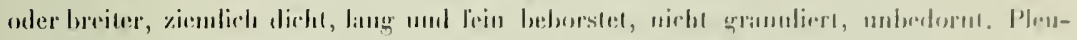

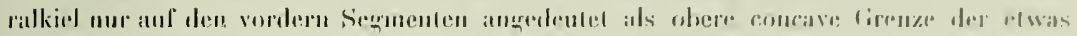

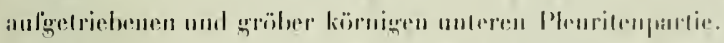

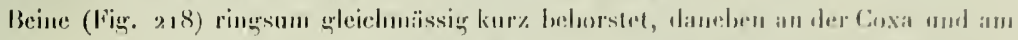

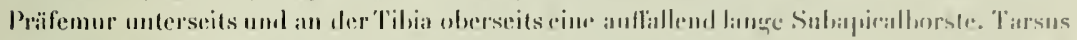

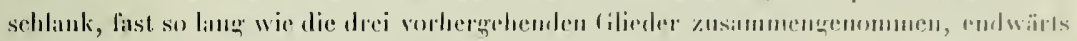

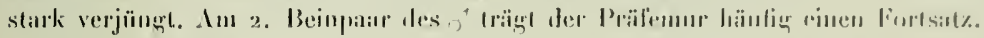

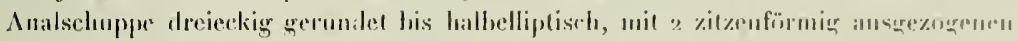
Borstenlä̈ckeru.

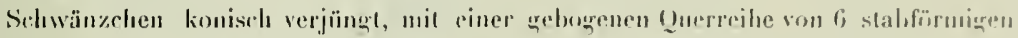

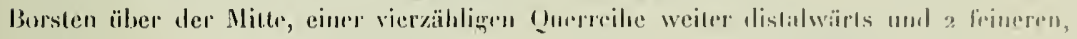
spitzen Borsten an gestutzlen linte.

Gonopoden mit stark entwickelter Coxa, die den Telopoliten vou ansien umd vorn

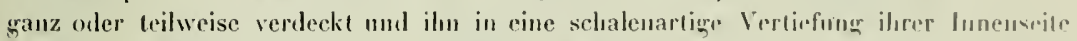
anfuimmt; die beiden Coxae hängen in der Mediane zusilumen. Fomur schief gestell, trompetenförmigg. Tibiatarsus von einem Itarhen llanptteil mit ter Samenrinue uml von

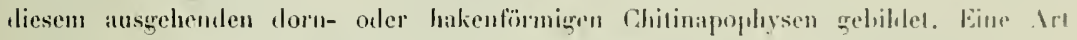

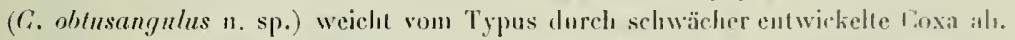

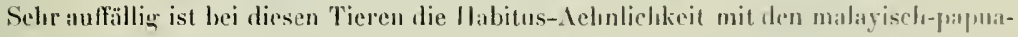

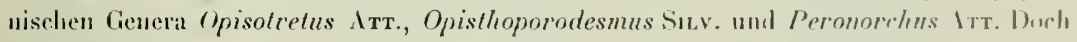
beweist schon der ganz verseluidene Bau der Gonopolen, dass es sich hoss um lionvergrenzerscheinungen handelt. Peronorchns hat anch geringere semmentzalıl.

Was dic systematische Stelluug dieser Galtung und ilıres nächsten Vepwandten, Brachycerodesmus und Fuhrmanuodesmus anbelangl, so lasse ich sie vorläulieg unlestimmt. Sie lassen sich weder in die Itreus'sehe Familie der Sphaeriodesmiden, Suhfim. P'yrgodesminae, wohin Irtess Cryptogonodesmus provisorisch stelt, noch sonst in eine

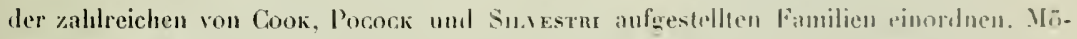

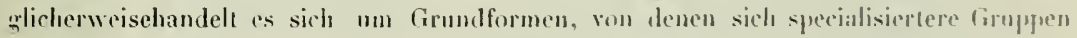
ableiten bassen. 


\section{$-91^{i}-$ \\ lebersicht der columbischen Arten.}

1. Intennen lang und schlank (l̈̈̈. 213,219$)$, zuröckgrelegt das 5. Segment äherragend. Ventralplatten des o last viereckig wer cowas breiter als lang, mit selumbiler Querfurcles.

2. Nitllere Kiele wenier länger als breit, rom 5. an mit spitzwinklig ausgrefogenem Ilintereck; Porus ziemlich weit ror dem Hintereck. Kielscifenrand mit3, resp. 4 deutlichen zaluartigen Absätzen, entsprechend ler Insertion der Borsten (Fig. 2077). Präfemur des 2. Beinpalars des of unterseits mit starkem Fortsatz, der eine dichte Bürste ans strifen, feinen Borsten trïgt.

3. Sattloch auf den porentragenden Kielen $5,7,9,10,12,13 \mathrm{an}$ der Basis der llintereckszacke. Borsten der 2. und 3. Ruihe niclıt stiftförmigg, kurz und spitz. Fortsatz des P'räfenurs des 2. Beinpaars of länger als der Femur. Ventralplatte des 7 . Segments mit einem schlinken, luakigen Fortsatz dicht nehen jeder Ilüfte des 8. Beinpairs (Fig. 208). Scheitel olne dentliche Aultreibung. Gonopoden rgl. Fin. 2 to: C. fuhrmanni n. sp.

3. 3. Saftloch anf den betr. Kielen ziemlich weit vor der Basis der Zacke, die elwas kürzer ist. Borsten der 2. und 3. Reihe stiftförmig, ziemlich lang. Fortsalz des Präfemurs des 2. Beinpaars o viel kürzer als der Femur. Ventralplatte des 7. Segments of olne Fortsätze. Scheitel beim ot oberhalb der Antennen zu einem lreiten, llachen, rundlichen knopf aufgetrieben, der glatt und unbehiat ist. Gonopoden vgl. Fig. 214 : G. anyulifer (P'⿺r.).

2. 2. Kiele vom 5. an (Fig. 2ı9) bedeutend länger als breit, mit Ausnahme der letzten hinten mit kurzer stumpfer Zacke; Saftloch nahe dem Ilintereck; Nielseitentand ohne zahnarlige Absätze an den Insertionsstellen der Borsten. ${ }^{1}$ Präfemur des 2. Beinpaars of ohne Fortsat\%. Gonopoden vgl. Fig. 221, 222: G. obtusangulus n. sp.

1. 1. Antennen (Fig. 223) kürzer und dicker, zurückgelegt kaum über łas 3. Segment hinausragend. Ventralplatten des of deullich länger als breit, durch eine breite Querfurclse abgeteilt.

Borsten der Metazoniten autfallend lang. Hintereckszacke der Kiele kurz und stumpf, auf den porentrigenden Kielen zwischen der 3. Borste und der Eckloorste schräg gestutzt, das Saftloch dieser Abstutzung genälıert und gegen die sellue hin sich öfnend: C. brevicornis n. sp. 


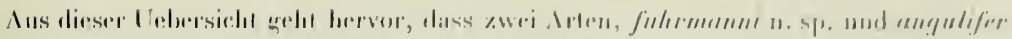

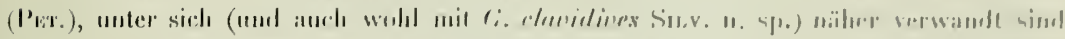

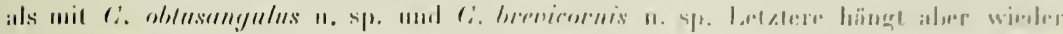

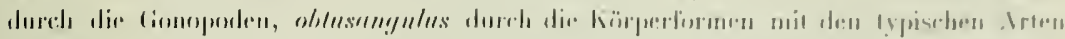

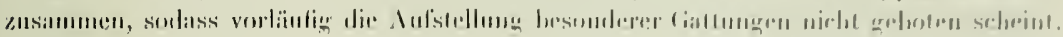

\section{Cryptogonodesmus fuhrmanni $n$. sp. \\ (lii). \%7\%(1).}

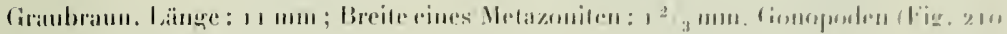

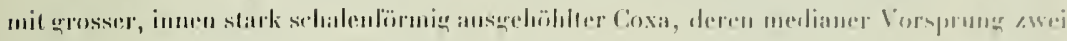

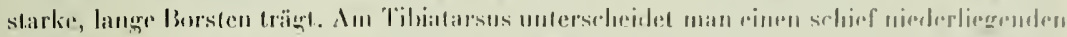

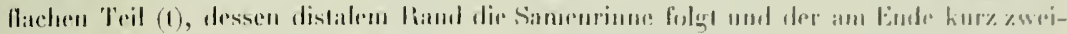

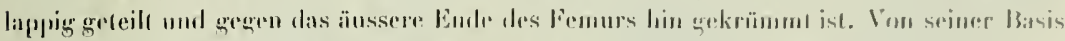

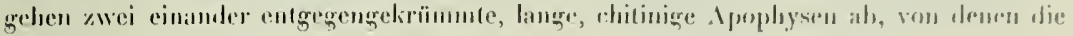

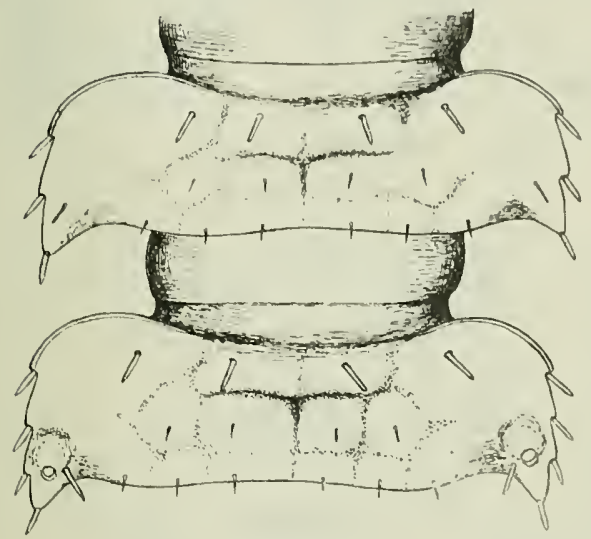

Pig. 907 .

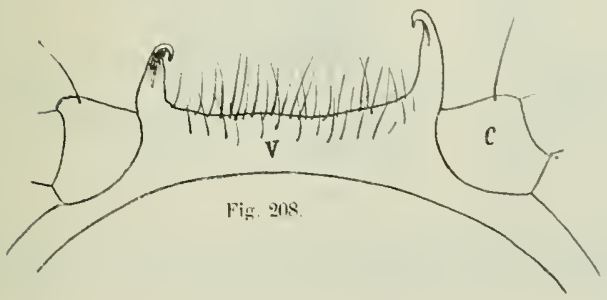

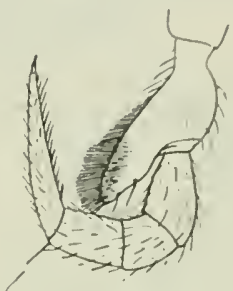

Fig. :0!!.

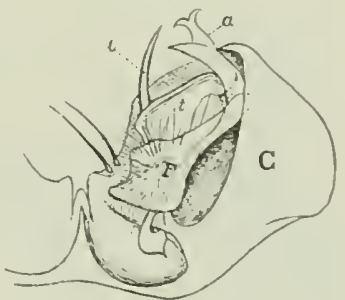

Fig. 210.

Cryprogonodesmus fuhrmanni n. sp. $0^{-}$

Fig. 207. 8. und 4. Segment. sehr stark verg. - Fig. ous. Ventralplatle (V) des 7. Segm., von hinlen: C. Coxa des 8. Lauftreinpares. - Fig. 2003. Bein des 2. Paares. - Fig. ㄴ.10. Gonopode, son linten, C. Coxa, F. Femnr, t, Tibia. i und a Apophysen der Tibia. 
innere (i) einfach, dornförmig, zugespitzt ist, die äussere stärkere (a) aber am Ende sich grabelt in eine einfache kurze und in eine ankerformige Zacke; der Apophyse a kommt rom Endteil der Tibia noch ein kurzer Dorn entgegen (in der Fign punktiert).

Der Fortsatz am Präfemur des 2. Beinpaars of (f̈iqg. 209) unterscheidet sich von demjenigen von $C$. angulifer ausser durch seine Grösse noch durel elwas spitzere Form und slïkere steife Borsten.

1, ‥ Tambo, ca. $2000 \mathrm{~m}$.
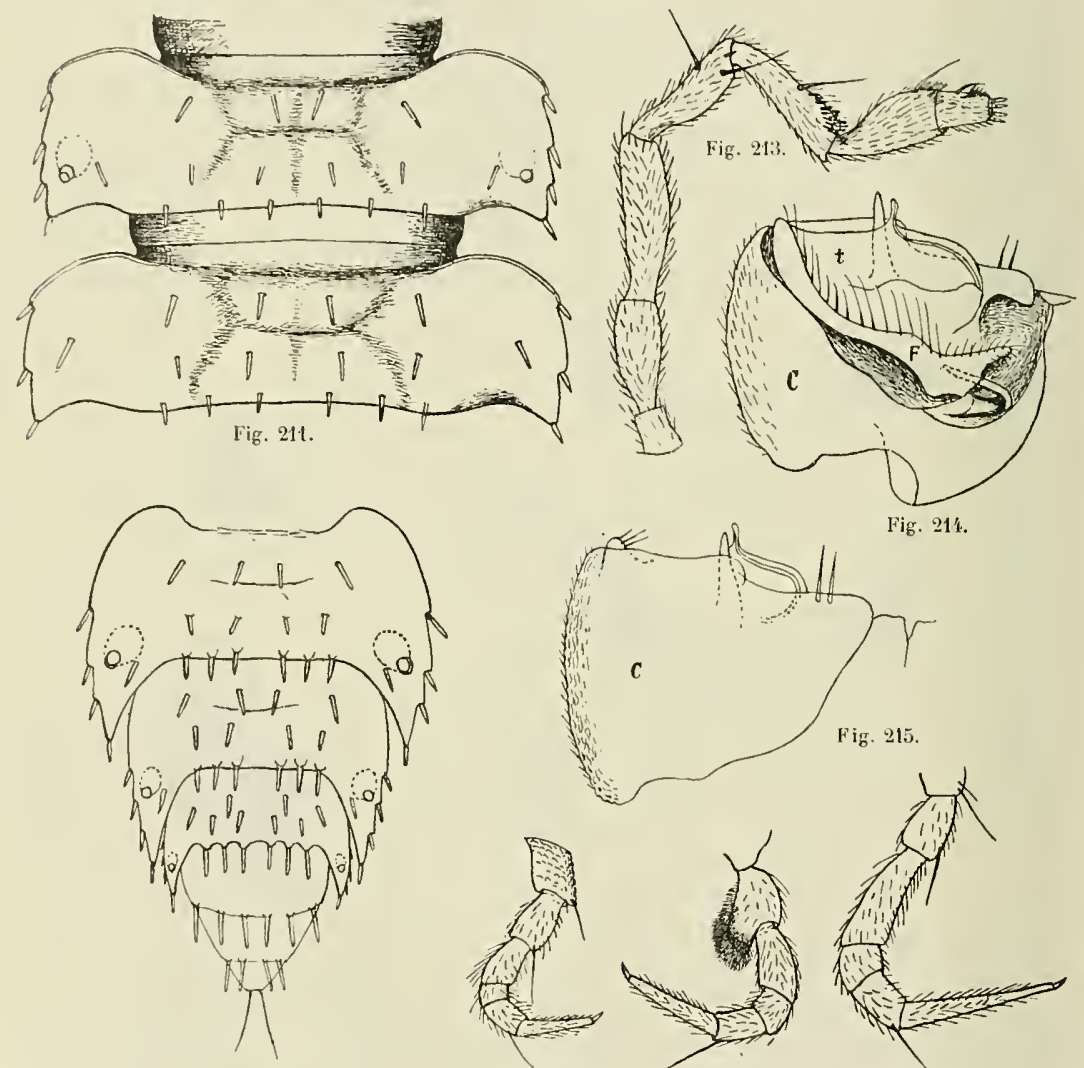

Fig. 212.

Fig. 216.

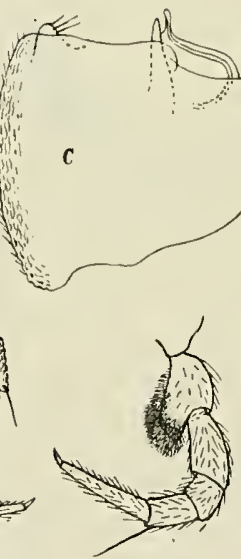

Fig. 217.

Fig. 211.

Cryplogonodesmus angulifer (1'et.) $\sigma$

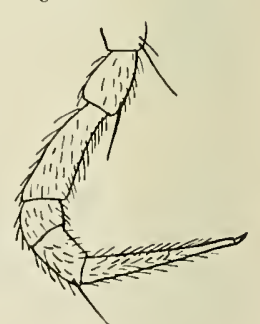

Fig. 218.

Fì. 211. 8. und 9. Segment, sehr slark vergr. - Fig. 212. 17.-20. Segm. - Fïg. 213. Antenne. - Fig. 214. Gonopode, von hinten. - Fig. 215. Cionopode, von vorn. - Fig. 216, 217 und 218. Bein des 1., 2. und 8. Paares. 


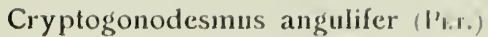

(liig. $21,-2, x)$

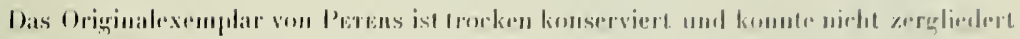

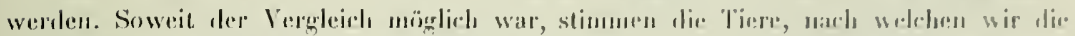

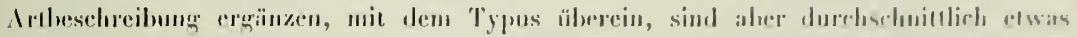

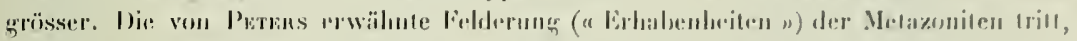

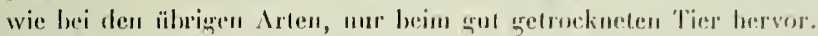

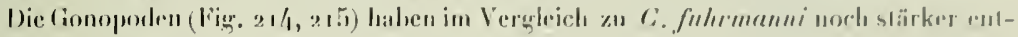

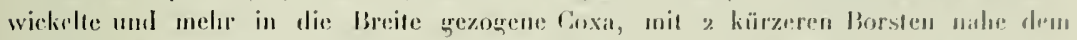

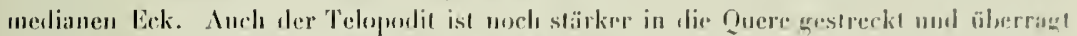

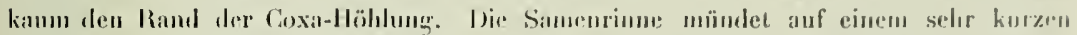

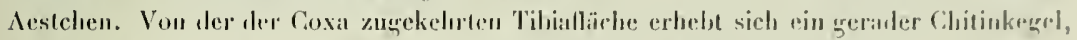
der den distilen Teloporlitrand elsenfalls sehr wrotg üherragl.

ơ, 오. La Camelia, Kalfeepllanzung bei Angelopolis, 1800 m.

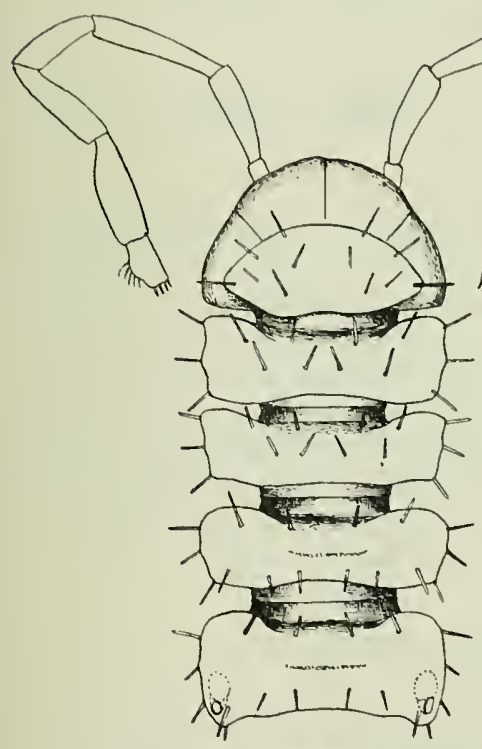

Fig. 219.
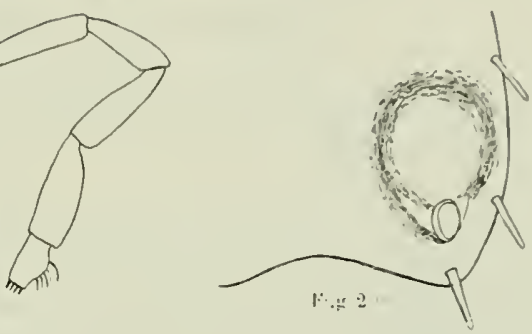

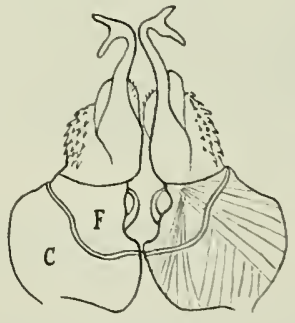

Fig. 221.

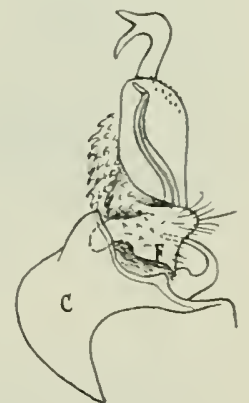

Hig. 202.

Cryptogonodesmus obtusangulus $\mathrm{n} . \mathrm{sp} . \sigma^{\circ}$

Fig. 219. liopf und die 5 vordersten Segmente. - Fig. 22. llintereche eines Kieles des 9. Segmentes. Fig. 221. Gonopoden, von vorn. - Fig. 222. Ein Gonopode, von hinten. 


\section{Cryptogonodesmus obtusangulus n. sp.}

(Fir. $219 \cdot 222)$.

Färbung bräunlich, mit gुelhlichen Beinen.

Länge: $8 \mathrm{~mm}$; Breite : $0,8 \mathrm{~mm}$.

Die Gonopoden (Fig. 22I, 222) dieser Art weichen vom Typus durch viel sehwächere Entwicklung der Coxa und stärkere Ausbildung des Femurs ab. Die Coxa deckt von ausseı nur die Basis des Femurs; der ganze Telopodit ist anfgerichtet; der Femur ist schmïler, setzt sich aber aussen und vorn längs der Tibia in einen dicken, lleischigen, mit basalwïrts gerichteten Chitinhaken bedeckten Teil fort; die Tibia ist gerundet-rechteckig; von ihrer Hinterfläche löst sich schon nahe der Basis ein dünner Ast mit der Samenrinne ab; vorn erhebt sich von der Basis der Tibia ein sie weit überragender, schlanker, am Ende hakig nach aussen umgebogener und gegabelter Fortsatz. Mïglicherweise ergeben spätere Untersuchungen die generische Selbständigkeit dieser Art.

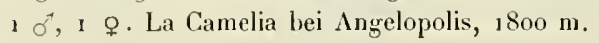

\section{Cryptogonodesmus brevicornis $\mathbf{n} . \mathbf{s p}$.}

(Fig. 223-227.)

Die Sonderstellung dieser Art hinsichtlich der äusseren Formen ergibt sich aus der analytischen Uebersicht.

Länge: $10 \mathrm{~mm}$; Breite: $1 \mathrm{~mm}$.

Gonopoden (Fig. 226, 227) von dem für die zwei ersten Arten charakteristischen Bau. Die grosse Coxa ist aber unregelmässiger; man kann an ilır einen breiten basalen Teil (C) erkennen, dessen Distalrand eine lange Reihe von Borsten trägt und einen schmäleren distalen Teil ( $\mathrm{C}_{1}$ ), der mantelartig den Telopodit von aussen einhöllt und zwei stärkere Borsten trägt. Die Tibia ist ähnlich wie bei $C$. oblısangulus eine llache Lamelle mit gerundeten Ecken; sie wird von der Samenrinne durchzogren, die erst am Ende auf ein selbständiges Aestchen übertritt; von den beiden Chituapophysen ist die eine ein langer, geschwungener Dorn und inseriert an der Basis der Tibia, die andere ist regelmïssiger gebogen, zweizackigg und weiter distal auf der Fläche der Tibia inseriert.

10 Alto San Miquel.

\section{Gen. Brachycerodesmus n. gen.}

Sehr nahe verwant mitCryptogonodesmus, mit folgenden unterscheidenden Mrrkmalen.

Antennen viel kürzer und infolge Verdickung des 5:, 6. und 7. Gliedes stärker keulizr; die Sinnesstifte des 5 . und 6 . Gliedes viel zahlreicher und auf ein schärfer umgrenztes Feld besclıränkt. 


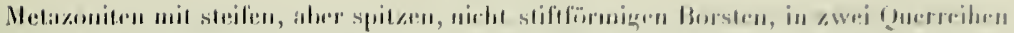

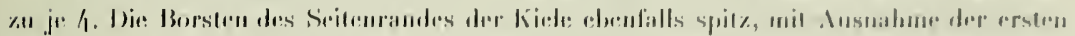

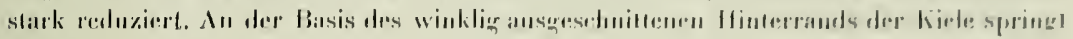

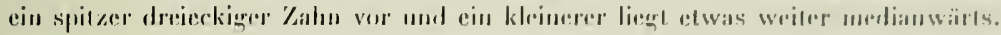

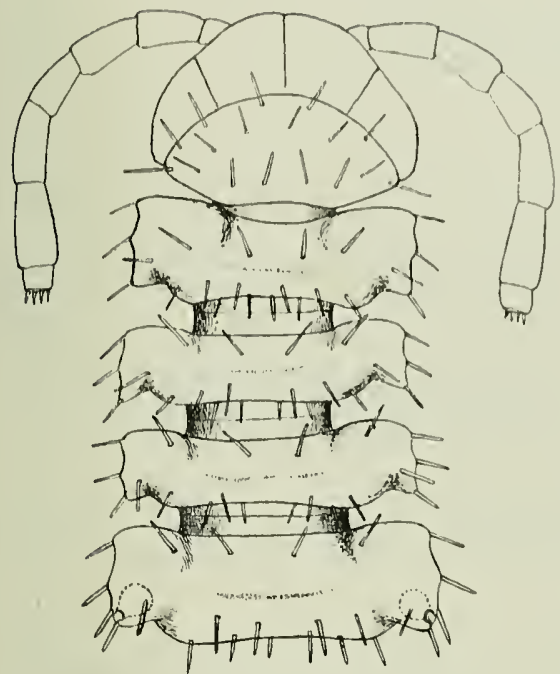

Fig. 22:3.

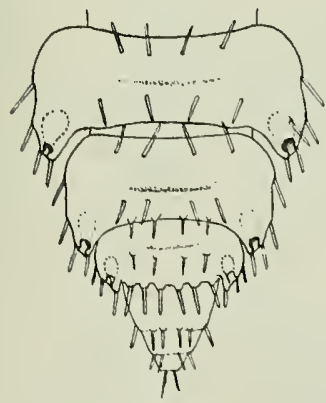

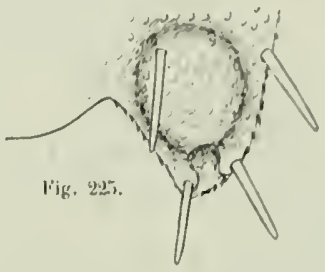
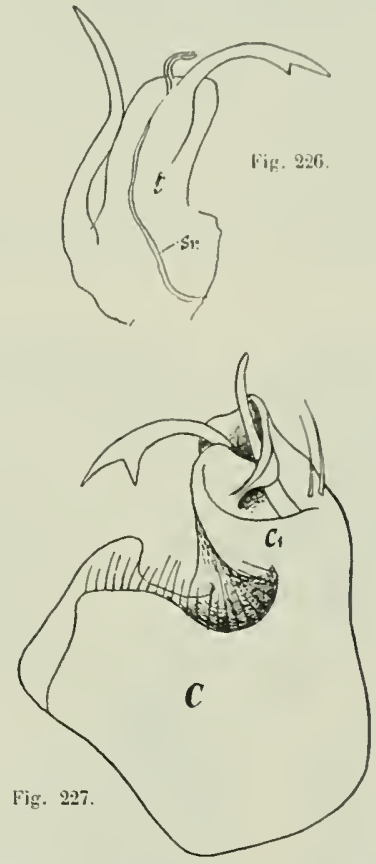

Fig. 2:i.

Crytogonodesmus brevicornis $\mathbf{n}$. sp. ठ์

Fis. 223. Kopf und die 5 vordersten Segmente (Behaarung des Kopfes und der Antennen wegtelassen.) Fig. 22:' 17. -20. Segment. - Fig. 225. Ilinterecke des I2. Kieles. - Fig. 226. Tibia eines Gonoporlen (t mil ihren Apophysen. herauspräpariert, sr. Samenrinne. - Fig. 22:. Gonopode, C und Cl basaler und distaler Abselanitt der Coxa. 
Alles ührige, besonders auch die Gonopoden, wie bei den Lypischen Cryployonodesmus, mit welehen man diese Alt vereingen könnte, wenn letztere fialtung nich schon elwas heterogen wäre.

\section{Brachycerodesmus petersi n. sp. \\ (Fir. ans-23k.)}

Färbung hläulichgrau.

Länge : $8 \mathrm{~mm}$; Breite : $1 \mathrm{~mm}$.

lï̈per vorn kaum merklich verschmälert, hinten erst vom t8. Segment an. Räcken leichl convex.

Kopf dicht mit knrzen feinen IIärchen besetzt. Antennen (Fig. 228) zurärkgrelegt das 3. Segment niclıt ïberragend.

Ialssehild ror'n regehnässig gerunded; der Ilinterrand Fast geradlinig, in der Mitte ganz seicht eingebuchtel; die Fläche mit 3 Reihen langer, spitzer Borsten.

Prozoniten mit körneliger, Metazoniten mit zelliger Skulptur. Dic kurze Querfurchr der Metazoniten gilt an jedem Ende cinen Ast nach vorn und einen nach hinten ab. I) Borsten sind spitz und stehen in zwei Querreihen von je 4, wovon die beiden hinteren, äusseren auf dem Kiel nahe der Hintereckszacke. Kiele bedentend länger als breit, mit zugerundetem, eine feine Zähnelung aufweisendem Vordereck und spilzzackigen Hinter-

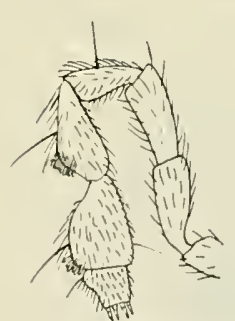

Fig. 228 .

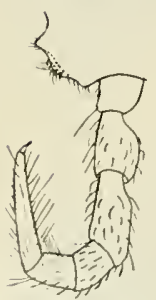

Fig. 233.

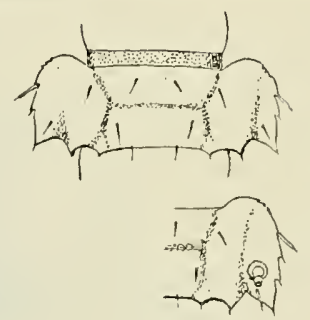

Fig. 229.

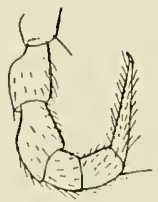

Fig. 230.

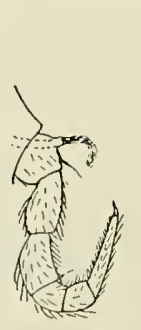

Fig. 231 .

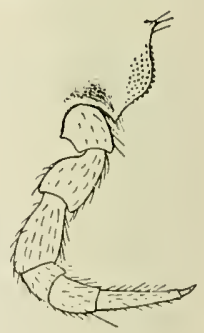

Fig. 232.

$$
\text { Brachycerodesinus pelersi n. sp. } \sigma
$$

Fig. 228. Antenne. - Fig. 229. 11. Segment und rechte llïlite des 12. Metazoniten. - lis. 230-233. Bein des 1., 2., 3. nnd 4. Beinpaares, letatere mil der Ventralplatte. - Fig. 234. Gonopode, von linten; C. Coxa, F. Femur, t. Tibia mit dem Tibialfortsat\% (If) und den Apophysen ap und $x$. 


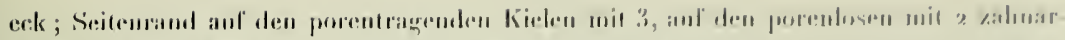

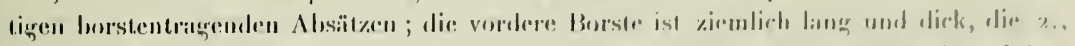

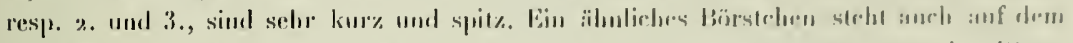

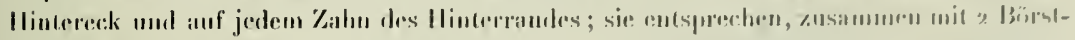

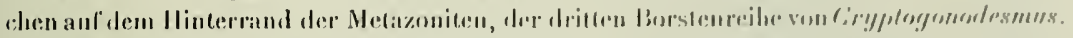

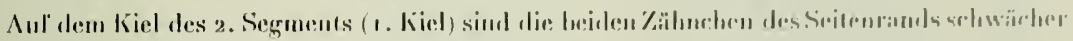

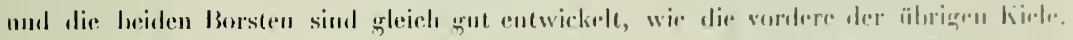

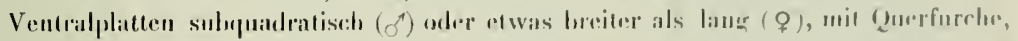

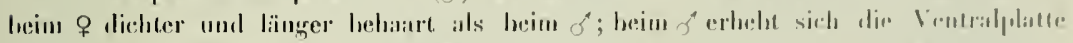

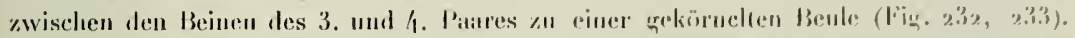

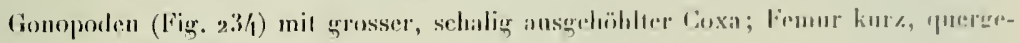

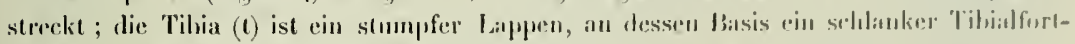

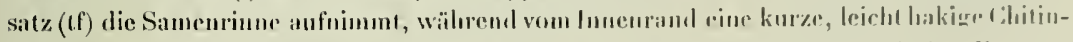

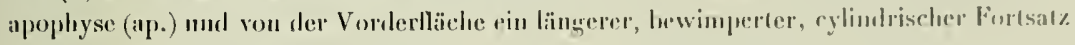
(X) algehen.

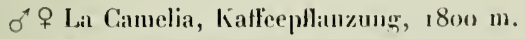

of Medellin, im Ufer des Porce, ifion 11.

\section{Gen. Gyrophallus n. gen.}

Den äısseren Formen nach vollkommen mit Cryptogonordesmus, namentich Gi. olitusangulus und brevicornis äbereinstimmend, aher dureh die ungleiche Sirmentzahl of 19, 920 Segmente - , den Gonopodenhan und die knrzen Antenut'n verschieden.

Gowopoden in der Ruhelage schrïg nach hinten gerichtet, weil die Coxa hauptsüchlich vor't und aussen verdickt ist und sich rorn in einen langen Fortsil\% anszieht; hinten ist die Coxa nicht schalenartig ansgehöhlt. Telopodit gut entwickelt; der kleine l'emur ist anf die Hinterfläche gedrängt, die Tibia ist gestreckt und teilt sich in melırere einfache oder selhst wieder gespaltene Aeste.

Die Antennen reichen nur bis zum 4. Segment wie bei Brachycerodesmus, sind aher dieker als jene, mit gedrungenerem 2. und 4. unt gleichmässiger verdicktem 5 . und fo. Glied.

\section{Gyrophallus imitans n. sp.}

(Fig. 235-23n).

Die äusseren Körperformen, die Grösse, sowie die Behorstung del Metazoniten stimmen so gut mit Cryplogonodesmus brevicornis überein, dass die Fig. 223 und 22ł fast unveründer für diese Art gelten können. Doch sinl die Antennen (Fig. 235) elwas ardrun- 
sener und in distalen Teil dicker. Das ơ unterscheidet sich durch den Besitz von nur 19) Segmenten und den Bau der Gomopoden (Fig. 237-239). An tetzteren ist die Coxa (C) aussen und vorn kugelig aufgetrichen und verlïngert sich vorn in einen langen Fortsatz (Cf),

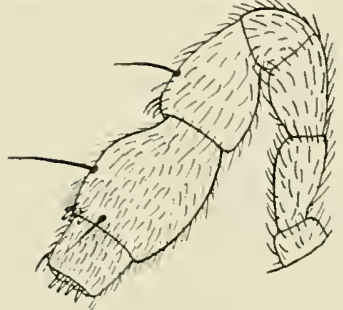

Fig. 235.

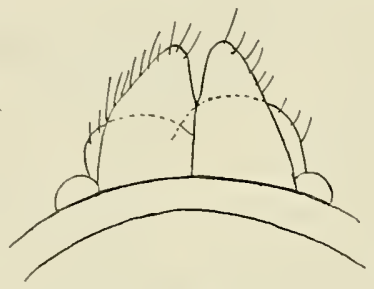

Fig. 236.

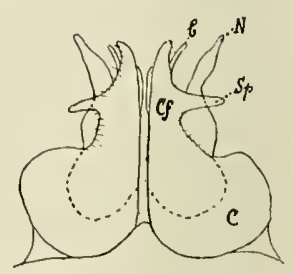

Fig. 237.

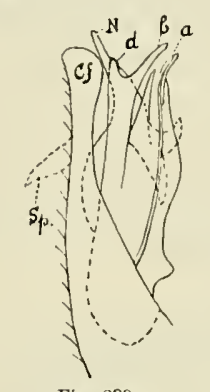

Fig. 239.

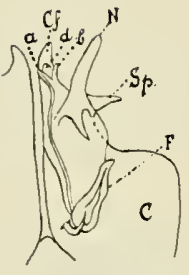

Fig. 238.

Gyrophallus imilans n. sp.

Fig. 235. Antenne des $\sigma^{1}-$ Fig. 236. Vulven des 우 - Fig. 237. Gooopoden, von vorn, - Fig. 238. Gonopode, von hinten. Fig. 239. Telopodit eines Gonopoden, nebst Coxalfortsatz, von innen. Für die Bedeulung der Buchstaben vergl. den Text.

der den Telopoditen von vorn teilweise verdeckt und nach aussen hinten einen starken Sporn (Sp) abgibt. Der kleine Femur ist ganz auf die Hinterfläche gedrängt (Fig. 238 F.) und sehr schräg gestellt; der übrige Telopodit ist sehr kompliziert gestaltet; mann kann an ihm zunächst zwei Hauptteile unterscheiden : einen fingerförmigen Zweig (N), der an der Basis zwei Zacken trägt und einen etwas kürzeren Teil, der sich selbst wieder spaltet in einen geraden Ast mit den Zweigen $b$ und $d$ und einen stumpfen Ast, dem die Samenrinne folgt, um an dessem Ende auf einen kurzen Tentakel $a$ überzutreten.

Das 우 besitzt ziemlich stark entwickelte, vorragende Vulven, die es auch schon in situ von den 9 von $C$. brevicornis zu unterscheiden erlauben; es sind zwei von vorn und hinten flach gedrückte, stumpfe Kegel, die sich median bis kurz vor dem Ende berühren und am freien Rand behaart sind (Fig. 236).

Länge : $7 \mathrm{~mm}$; Breite : $0,8 \mathrm{~mm}$.

Färbung bräunlich, mit hellen Beinen.

I $\sigma^{\prime}$, I 우. La Camelia, Kalfeepllanzung. 


\section{- \\ Gyrophallus simillimus n. sp. \\ (liig. $\%(1)$.}

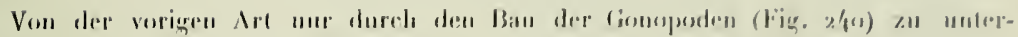

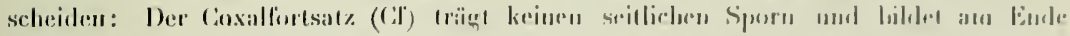

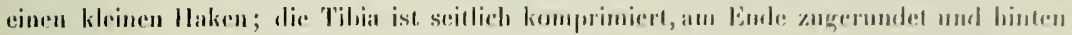

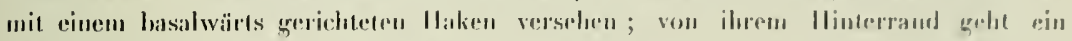

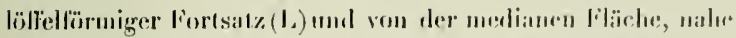
den Ende, ein kur\%er, dünned Tibialfortsats (Tf) ab, muf den

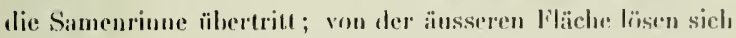
nahe der Basis und groen die Mitle lin je din schlanker Ast

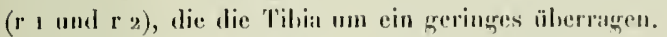

I 6 . Ia Camelia, Kallecpllanzung. 1 6on m.

\section{Gyrophallus funiculus ('⿺r.).}

Die Untersuchung des Originalexemplares grestattete mur die leststellung, dass die Art nach dem äusseren Ilabitus und dem Bauplan der rïckwärts grerichteten Gonoporlen in diese Gattung gehört. Der Teloporlit der Gonopoden seheint noch melir Aeste aufzuweisen als bei den zwei neuen Arten.

Bogota (Prtens).

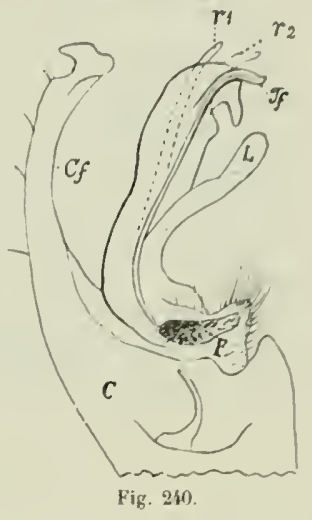

Gyrophallus simillimus n. sp Gonopode, von innen.

\section{Gen. Fubrmannodesmus n. gen.}

20 Rumpfsegmente.

Antemen lang und schlank, etwas kolhig, indem das 5. Gilied endwärts und das 6. verelickt sind; das 2. und 3 . Glied sind die längsten.

Halsschild habelliptisch, schmäler als der Kiopf mit.den Backen.

Das Vorderende des Rumpfes biklet eine Art Hals, indem die Metazoniten 2-4 etwa so breit wie der Kop̣f sind, während der 5. Metazonit plötzlich breiter wird. worauf sich die Metazoniten bis zum 16. allmählich granz leicht verbreitern, sodass die Körperform etwas an Icosidesmus erinnert. Diese halsartige Verschmälerung der vordern segmente ist beim o plötzlicher und daher deutlicher als beim $ᄋ$.

Rücken samt den kielen ganz schwach gewölbt.

Kiele länger als breit, vorn gerundet, hinten rom 4. an in eine breite Zacke ausgezogen. Prozoniten kurz; die Kiele daher ziemlich eng aneinander schliessend. 
Porus anf den Segmenten 5, 7.9, 10, 12, 13, 15-18, anf der Oberseite der Kiele, etwis ron dem llintereck gelegen, klein und nach hinten gerichtet, aher in eine ziemlich qurosse, durchscheinende, runde Höhlung fülırend.

Melazoniten mit drei Querreilien sehr kurzer Börstchen und durch seichte Furchen alogenrenzten, ganz flachbeuligen Feldern.

Präanalscugnent in ein kưzes, konisches Schwänzchen ausgezogen.

Beine mässig langु, un erseits bein ô mit Chithhöckern; Tarsus viel länger als der Femur.

Ventralplatten bein of etwas lïnger als breit, beim o deutlich breiter als lang, tief yuergerteils.

Gonoporlen mit grossem 11 üfgglied, das aussen stark kugelig aufgetrieben ist und eine lange, hakig nach aussen gebogene, cylindrische Apophyse trägt. Femur schräg gestell, trichterförmig ; Tibia lreit, lamellär, mit kurzem Tibialfortsatz.

Pleuralkiel auf den vordersten Segmenten als stumpfe, Schwalbennest-ïlnliche, fein gekïrnelte Leiste ausgelsildet.

Durch die :̈usseren Formen, dic Felderung und das Prinzip des Beborstung erweist sich diese Gattung als verwandt mit Cryptogonodesmus SiLv., Brachycerodesmus n. gen. und Gyrophallus ı. gen., von denen sie sich jedoch durch die Gestalt der Gonoporlen, die Chitintuberkehı an den Beinen des ơ die schwachen, spitzen Borsten der Metazoniten und die stärkere Verschıälerung des vordersten Körperteils unterscheidet.

\section{Fuhrmannodesmus lividus $\mathbf{n}$. sp.}

(Fig. $24 \mathrm{I}-245$.)

Einfurbig schmutzig gelb, mit etwas helleren Ventralplatten und Beinen.

Länge: $13 \mathrm{~mm}$. Breite: 3. Segment or $1 \frac{1}{2}$, o $13 / 4 \mathrm{~mm} ; 15$. Segment of $2 \mathrm{~mm}$, 우 $2^{1 / 3} \mathrm{~mm}$.

liopf glatt und glänzend, zerstreut kurz behaart, mit sehr feiner Sclzeitelfurche. An den Antennen (Fig. 24r), die zurückgelegt bis zum 3. (q) resp. 4. Segment (б) reichen, sind die Sinnesstäbchen aussen am apicalen Ende des 5 . und 6 . Gliedes anffallend klein, wenig zahlreich und liegen nicht auf einem deutlich umgrenzten Feld.

IJalsschild glalt, mit 3 Querreilıen kurzer Borsten; Ecken zugerundet.

Metazoniten glalt und etwas glänzend, mit kurzer mittlerer Querfurche, die an jedem Ende unter stumpfem Winkel einen Schenkel nach vorn und einen anderen nach hinten abgibt, ausserdem mit einer schwäclıeren Querfurche vor dem Hinterrand, feiner mittlerer Längsfurche und schwächeren Furchen auf den Kielen. Die Felder zwischen diesen Furchen sind etwas beulig aufgetrieben, am deutlichsten die beiden, welche die Basis der Kiele einnehmen (Fig. 242).

Der Seitenrand der Kiele ist selır sclımal wulstig verdickt und trägt auf den porentragenden Kielen 3, auf deı porenlosen Kielen z Börstchen, sowie ein Börstchen auf dem llintereck. 


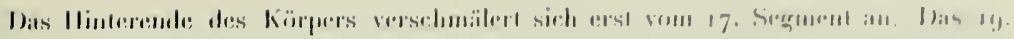

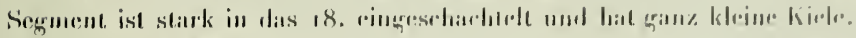

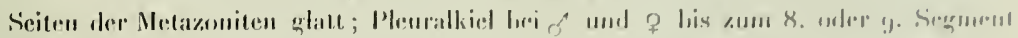
nachweishall.

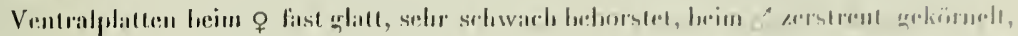

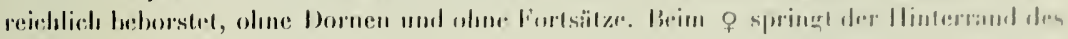

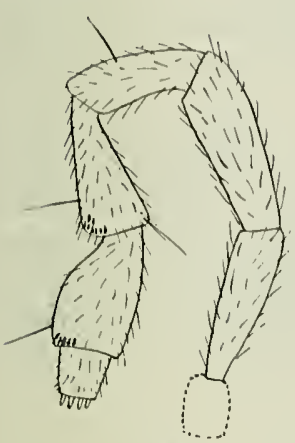

Fig. 2il.

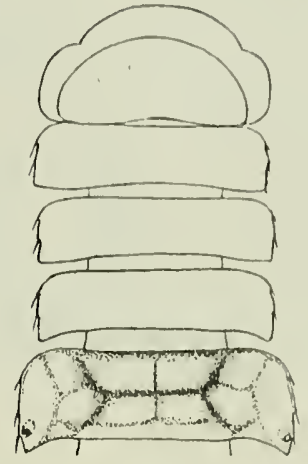

Fig. 242 .

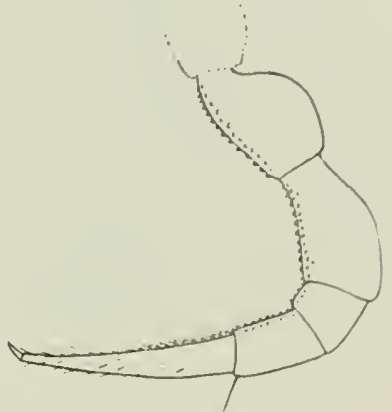

Fig. 243.

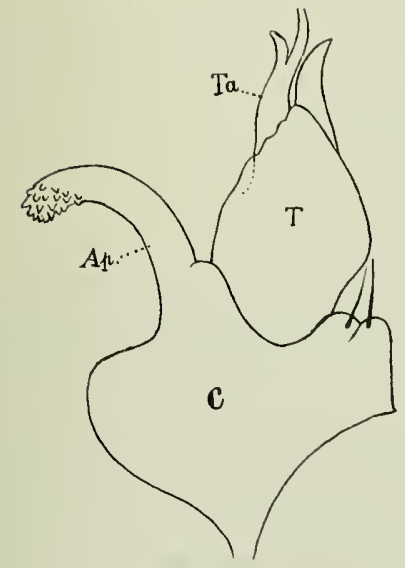

Fig. 24 .

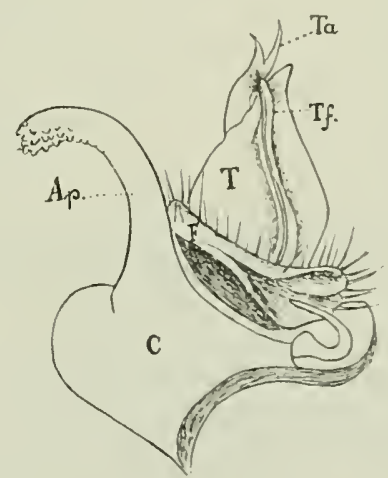

Fig. 245.

Fuhrmannodesmus lividus n. sp. $\sigma$

Fig. 211. Antenne. - Fig. 242. Kopf, ohne die Antennen, und dic 5 erslen segmente (Teborstung nur auf dem Ilalsschıld, Felderung nur auf dem 5 . Metazoniten eingezeichnet). - Fig. 23 . Bein der vorlern hirperhalne. Fig. 24. Gonopode, von vorn. - Fif. 245. Gonopode, von hinten: C. Coxa, Ap. Coxalapophyse. F. Femur. T. Tibia, Tf. Tibialfortsatz, Ta. Tarsus. 
2. Segments seharf vor und ist hinter den Vulven jederseits rundlich sinuiert, sodass eine Bucht in der Form eines thachen $1 \mathrm{~W}$ entsteht.

Analschuppe trapezförmig.

Beine des $q$ auf allen Gliedern ringsum gleichmässig beborstet; dicjenigen des $\sigma$ (Fig. 243), namentlich die vorderen, im basaleu T'eil etwas verdickt; die Glieder r-5 oherseits nackt odmr sehr spärlich kurz heborstet, unterseits mit dichten Reiheu heller Chitinhöekerchen; nach hinten zu wird die Beborstung etwas deutlicher und die Zahıl der Chitinhöckerchen auf der I'nterseite kleiner; der Tarsus ist dichter heborstet und auf den vorderen Beineu unterseits in der Basalhälfte ebenfalls mit kleinen Chitinwärzclen versehen, von welchen je ein liegendes Börstchen ausgeht.

Gonopoden (Fig. 244, 245): Dic lreite, kurze Coxa trägt innen am Endrand 2 runde Höcker mit je einer Borste; aussen ist sie hılbkugelig gewölbt und geht dann in eine cylindrische, hakig nach aussen gehogene Apoplyse (Ap) aus, dic an Ende mit vielen Chitintuberkeln besetzt ist. Der schräge, trompetenförmige Fenur (F) ist ganz auf die Hinterfläche gedrängt. Die Tibia (T) ist eine unregelmässig dreieckige Platte, von deren Filäche sich ein kurzer, cylindrischer, allseitig fein beborsteter Tibialfortsatz (Tf) ablöst; sie wird von einem zweiziıkigen Chitingebilde (Ta) überragt, das als Tarsus angesehen werden kann.

$10^{1}, 1$ ․ Paramo Cruz Verde, $3400 \mathrm{~m}$.

\section{Gen, Cryptodesmus Рет.}

\section{Cryptodesmus alatus Pet.}

(Fig. 246, 247).

Vir behalten für diese Art den Gattungsnamen Cryptodesmus PET. bei, an Stelle des von Соок dafür eingeführten Namens Chonodesmus, indem kein Grund vorliegt, als Typus der Gattung Cryptodesmus PEт eher C. olfersi Budt. als C.alalus PEт, zu wählen.

Die Exemplare der Funrmansschen Sammlung stimmen in den äussern Formen mit Peters' Originalexemplar $\left(\sigma^{1}\right)$ vollkommen überein. Wie bei letzterem ragt der Praefemur des 7. Beinpaars des of unterseits am Ende in einen apicalen Dorn vor. Das Originalexemplar ist getrocknet und gespicsst, sodass die Gonopoden nicht herauspräpariert werden konnten; sowejt sie am Tier zu seheu sind, stimmen sie mit denjenigen des ơ der Sammlung Funrmann (Fig. 246, 247) überein.

Die llüften sind gross und dick, mit stark gebuchtetem Endrand; der Femur springt vorne stark vor; der übrige Telopodit ist ein gestreckter, ron rorn nach hinten flach 


$$
-\quad 9.19
$$

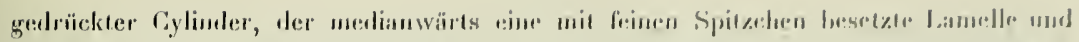

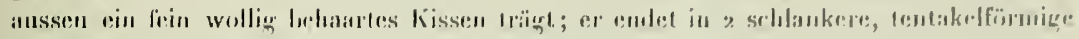

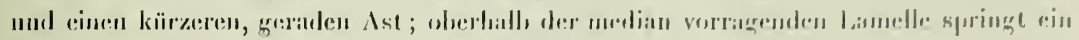

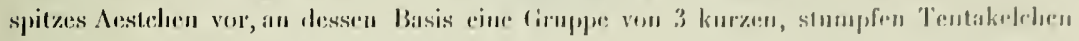
liegt, wovon einer dle Sinnenrinue anlinimmt.

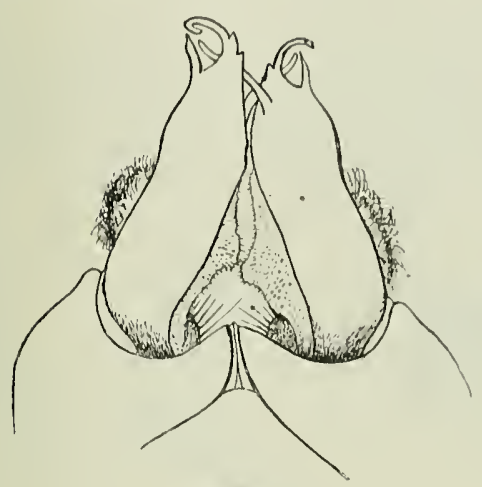

Fig. 246.

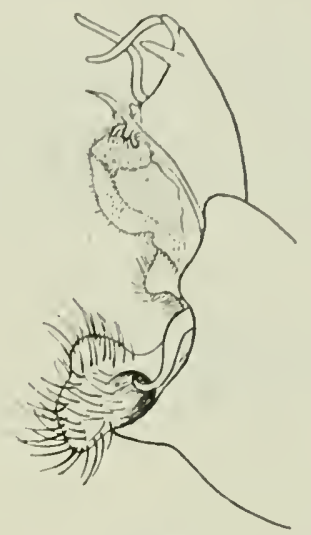

Fig. 217.

Cryptodesmus alalus Pet. ot

Fig. 246. Gonopoden, von vorn. - Fig. 127. Gonopode, von innen.

\section{Gen. Calymmodesmus n. gen.}

Nahe verwandt mit Lophodesmus P'oc. und Treseolobns Itr.

20 Rumplsegmente.

Form des Halsschildes, Wölbung und Höckerung des Rückens älınlich wie hei den genamnten zwei Gatungen.

Porus auf den Segmenten 5, 7, 9, 10, 12, 13, 15, 16, auf einem schräg nach aussen geneigten, gestutzten Kiegel, der nicht als Lappen den Kielseitenrand iiberragt.

Kiele breiter, kïrzer und flacher, am Seitenrand wenigger tief und etwas regelmāssiger gelappt als bei Lophodesmus; ihr IJinterrand mit zwei selır schrägen Einschnitten. Pracanalsegment breit, schaufelförmig, fünflappig, ron oben sichtbar (etwas weniger deutlich als in Fig. 254 unter dem Deckglas gezeichnet).

Gonopoden von denjenigen von Lophodesmus durch schwächere Iusbildung der Hüften und viel stärkere Entwicklung des Telopodits sehr deutlich verschieden; letzterer aussen von der IIüte nicht verdeckt. 


\section{Calymmodesmus andinus $\mathbf{n} . \mathbf{s p}$.}

(Fiu. $2.48-257$ )

Fïrbung weisslich; die Metazoniten schmutzig gell,

Länge : $7-9$ mm.; Breite : $11 \mathrm{q}^{-2} \mathrm{~mm}$.

Scheitel mit einigen kleinen Tuberkeln in der Nitte und zwei unterbrochenen Längswülsten, die rom Inuenrand der Antennenbasis divergierend nach oben ziehen. Antennen (lïg. 25o) hinter der Vitte spindelförmig verdickt; das 5. Glied ist das längste und dickste; 5. 6. und 7. Glied tragen aussen ein subapicales Feld mit Sinnesstäbchen und davor je eine Sinnesborste; im übrigen sind die Antennenglieder ganz kurz beborstet.

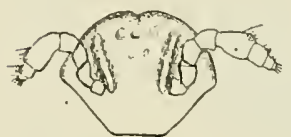

Fig. 248 .

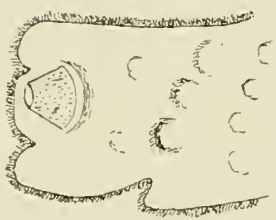

Fig. 252 .

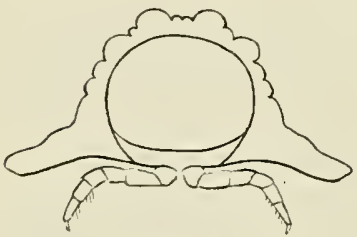

Fig. 25.5

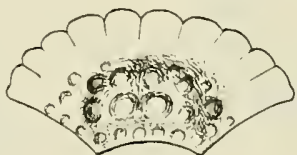

Fig. $2 / 9$.

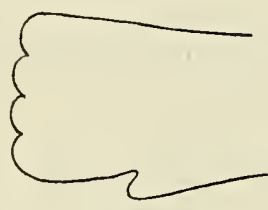

Fig. 253.

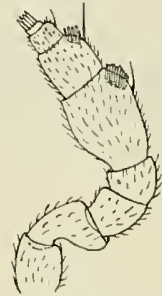

Fig. 250.

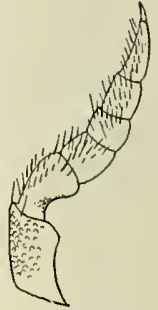

Fig. 251.

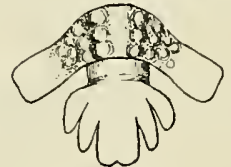

Fig. 254.

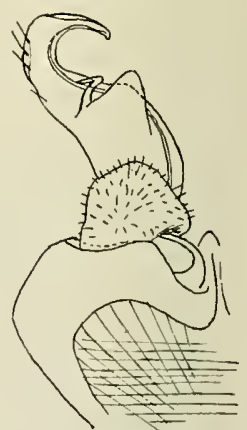

Fig. 257.

Fig. 256

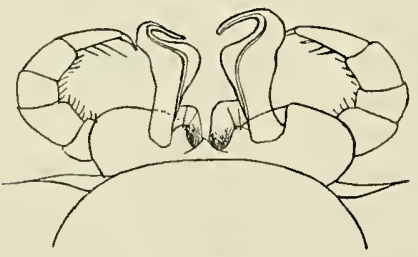

Calymmodesmus andinus n. sp. $\varnothing$

Fig. 248. Kopf, von vom. - Fig. 249. Halsschild. - Fig. 250. Antenne. - Fig. 251. Bein des 1. Paares. Fir. 252. Kiel des 5. Segments. - Fig. 2533. Kiel des 6. Segments - Fig. 254. Körperende, von oben. - Fig. 255. 2. Segment von vorn. - Fig. 25f. Gonopoden und 8. Laufbeinpaar, von vorn. - Fig. 257. Gonopode, stärker vergrössert, von hinlen. 


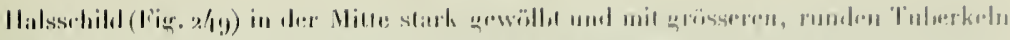

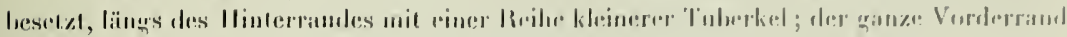

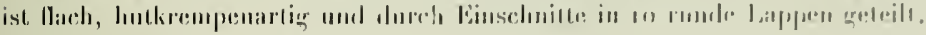

Prozoniten dicht gekërmelı.

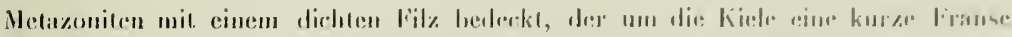

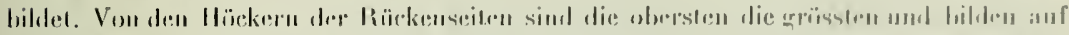

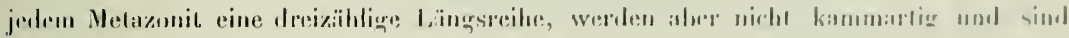

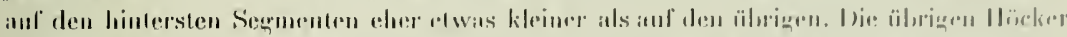

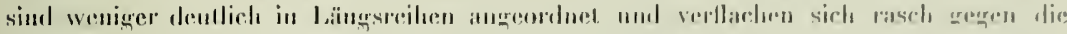

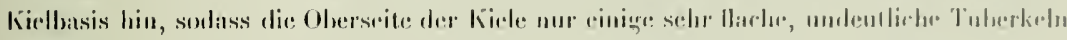
trïgt.

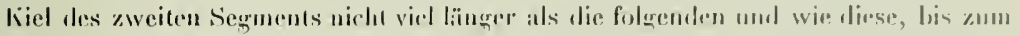

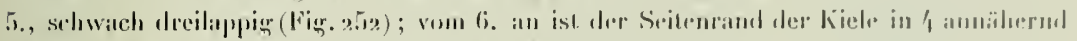

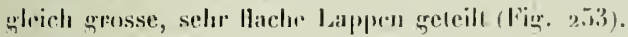

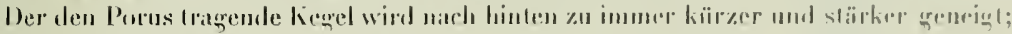

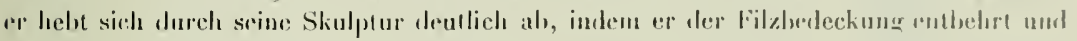
stalt lessen fein punktiert ist.

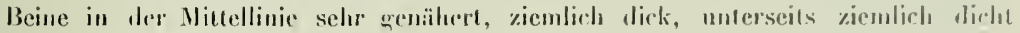

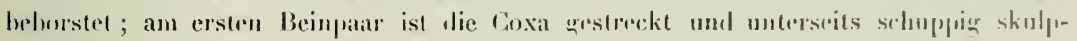
liirt (lïg. sin).

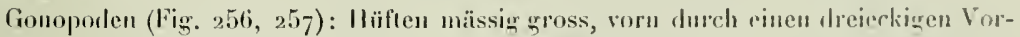
spromer der Ventrablatte getrennt, stark gerundet, aussen nicht lappen- oder zapfenformigr

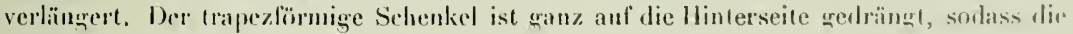
Tilia ron rom grsehen direkt aus der Hählung der Coxa zu entspringren scheint; die Tilhia ist von vorn nach hinten etwas alggellicht, in der Vilte ctwas bauchig medianwirts verbreitert und dann stark lakig nach innen umgebogen; die simenrinne mündet ans Ende dieses Itakens; auf der Ilinterllïete trïgt die Tibia in der Vitte eine stumplfkegrelige Apophlyse und daneben ein sehlankes, winkligr geknicktes Aestehen, das vielleicht dem Tiursus mispricht.

ơ 우. Puerto de los Pobres, am Canci-Filuss.

Gen. Oniscodesmus lient. el lioun.

Cook hat diese Gattung in drei geteilt: Oniscodesmus. Lignydesmus und Detodesmus : doch scheinen uns die ron ihm angegehenen Unterschiede nicht grenerischen Wert zu hesitzen. 


\section{$-9^{6: 3}-$ \\ Oniscodesmus fuhrmanni n. sp.}

(Fis. 25s)

Vorliegende Art wärde in die Cruppe Lignydesmus gelören und dürfte dem $O$. r'ubriceps Per. sehr nahestehen. Wie hei diesem stehen die Poren ant deutliehen T'uberkehn; anch sonst stimmen die äusseren. formen mit den von Соок nach dem Originalexemplar (q) qegebenen Abbildungen (Proc. U. S. Nat. Mus, vol. XXI, P. XXX, Fig 2o-2/. $18,8)$ qut überein, lassen aber wenigstens folgende Lnterschiede erkennen : Bei $O$. fuhr-

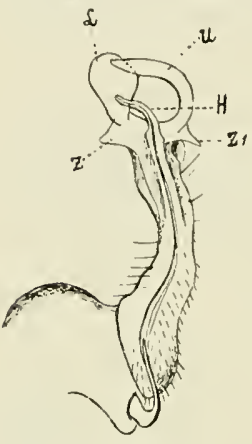

Fig. 258.

O. Rutrmanni n. sp. $\sigma^{1}$ Gonopote, von innen. manni ist der Ialsschild stärker skulptiert, indem die Fläclıe dureh Furchen in undeutliche Felder oder Hache Beulen qeteilt ist; der Vorderrandwulst zerfällt in einen längeren mittleren und je einen lï̈zeren seillichen Absehnitl; letztere sind wieder dureh einen Einsehnitt in zwei Höeker geteilt. Die scharfe Leiste, welche die Krämpe des zweiten Segments hinten lewrenzt, ist oben in der Rückenmilte nicht eingeschnitten, somtern cher etwas stärker nach hinten iöhergehogen. Auf allen Sismenten erscheint die Guernaht im Profil viel schärfer und tielier und die ihr vorhangehende Leiste der Prozoniten ebenfalts schürfer als in Cooks Ablildung $2 e$.

Färbung dunkel olivenhraun; Banch, Beine und Analklappen getblichweiss; Kopl' und die basale Ilälfte der Autennen Heischrot; die distalen Antennenghliesler olivengrrün.

länge ca. $12 \mathrm{~mm}$; Brcite $5 \mathrm{~mm}$.

Am 3. Beinpaar des ot ist der Femur elwas verdickl, wie es Bä̈lemans lïr seinen $O$. rubriceps abbildet.

Gonopoden (Fig.. 258) von den durch Cook und Bü̈lemann abgebildeten Gonopoden anderer Arten dieser Gatlung sehr deutlich verschieden. Häfte oberseits rundlich aufgetrieben. Telopodit schlank, nicht deutlich gegliedert, an der Basis spärlich mit kurzen steifen Spitzhorsten besetzt, im tetzten Drittel dreiästig : Ein kurzer tentakelförmiger $A s t$ (II) nimmt die Samenrinne auf; der hintere $\Lambda$ st (U) ist schmal und sichelförmiğ, der vordere (L) birnförmig, lamellär; die beiden letzteren Neste tragen an ihrer Basis je eine Zacke $\left(Z\right.$ und $\left.Z_{1}\right)$.

I $\sigma^{\prime}$, 1 q. Bocea del Monte, Tambo, ca. $2000 \mathrm{~m}$.

Brölemanv (1898) hat die Gonopoden einer Oniscorlesmus-Art aus Columbien (HautSarare) abgebildet, die er $O$. rubriceps PEt. nennt; jene Organe sind von den ehen heschriebenen deutlich versehieden, obwohl auch dreiästig. Da BröLemans nichts üher die Poren sagt, ist es sehr wohl möglich, dass er nicht die Art von Perens vor sich hatte.

Andererseits hat Bröı.enann fïr O. altrantinchs Prr., ans Venezuela, Gonopoden ahgebilhes, die nicht ganz der ron Conk (loc. cit. PI. XXX, Fig. I a) nael dem Original- 


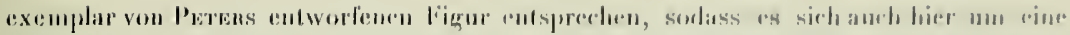

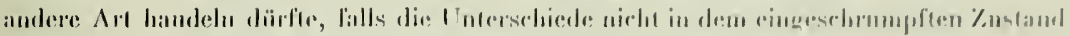

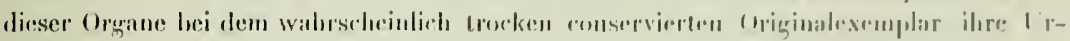
sache halden.

\section{Gen. Trigonoslylus Іиӥн.}

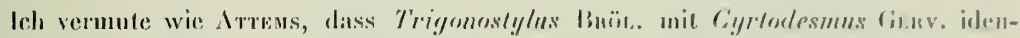

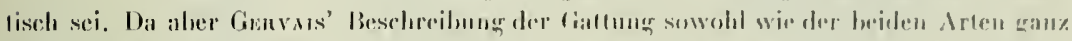

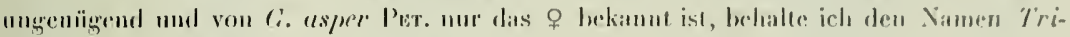

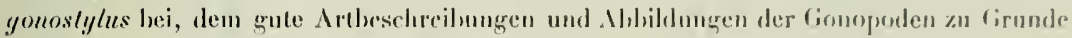

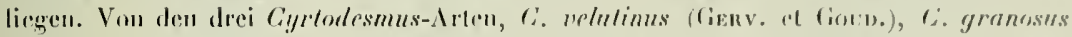

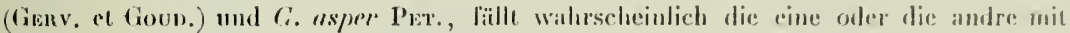
einer Bü̈bmans'schen oder mit riner der nachlolgend heschrichenen Trigronos/y/nsArten zиsammen.

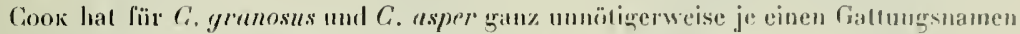
eingefülurt: Oncodesmus und Cy/loryrlus, die beisle in die Synonymie von Cyrlodesmus gुchören.

In zoogengraphischer Jlinsicht ist vor allem die Tatsache wichtig, dass die columhischen Anden sichere Gallungsgenossen der venezuelischen Trigonostylus-Arten aufwoisen und dass diese Gallung auch in Ecuador vorkommt; denn Cygrtodesmus tomenlosus Sisv., Oncodesmus feslue Sruv., und Oncodesmus lacininlus Sux. (Boll. Mus. Turino, vol. XIII, No 324 . 1898 ) quehren mzweifelhaft daher und scheinen. nach den allerdings sehr anspruchslosen Mbhildungen der Gonopoden zu urteilen, sogar sehr nahe mil $T$. niger u. sp. rerwandt.

\section{Trigonostylus niger $\mathbf{n}$. $\mathbf{s p}$.}

(Fig. $.5(y-2)$

6. Schwarz; Batuch, Beinc, der Kopllschild mit den Backen mol die spitze der Antennen trübweiss: Prozoniten in eingeseholvenen Teil weisslich, in freien Teil selır dunkel, mil zwei hellen Flecken aul dem Rä̈cken und hellem dorsalen Miltelstrich.

Länge: $17 \mathrm{~mm}$ : Breile: $31 \% \mathrm{~mm}$.

In den äusseren Formen finde ich wonig nenuensworle Enterschiede mil Brintemanss Bescheibung und Abhildungen von $T$. spinosus aus Venezuela (Anu. Soc. Eul. France, T. 67, p. 27 r-273. PI. 23 , Fig. 39-45; 1898). Doch arscheinen die Kiele im Onerschnill elwas steiler abfallend, weiter herunterreichend und dabei etwas weniger stark gebogen als in Bü̈Lmans lïgur 42, sodass an ihrer Basis auch keine so deutliche breile Lïngsinue entsteht. 


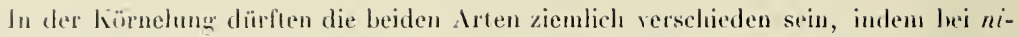
ger die Körner, auch die grössten, nie spitz werden. Halsschild selır dichl, relativ fein und wanz gleichuässign gekörnelt, ehenso der folgende Metazonit in der Itachen Rückenmille und auf den fast senkrecht absteigenden, ohen leicht eingedrückten, grossen Seiten-

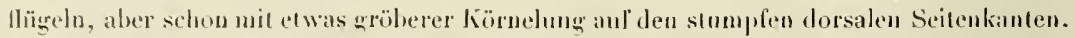
. Iuf den folgenden Hetazoniten werden die Granula weniger zahlreich aber viel grösser,

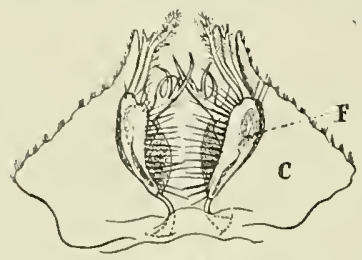

Fig. 2.5.\%.

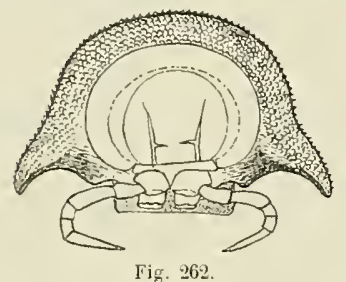

T)igonostylus niger n. sp. of

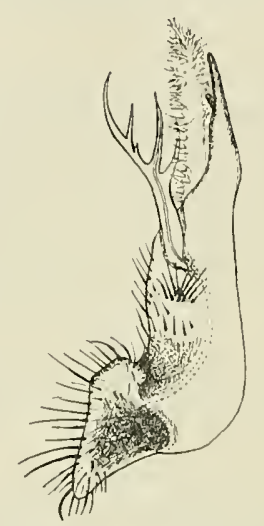

Iig. 260.

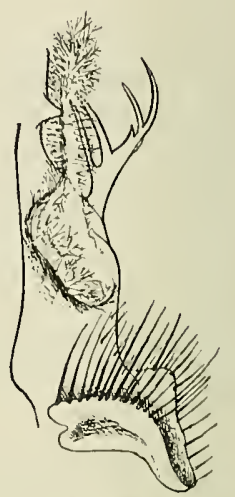

Fig. 261.

Fig. 259. Gonopoder, in silu, von hinten. - Fig. 260. Telopodit, von vorn. - Fig. 261. Telopodit, von hinten. - Fig. 262. Zweiles Segmenl, von vorn.

Inelır papillenfürmig, besonders im oberen Teil der Räckenseiten ; sie sind in drei unregelmässigen Guerreihen angeordnel, von denen die vorderste die kleinsten Körner hat. Auf der Oberseite der Kiele isı die Körnelung viel andeutlicher, kleiner und llacher. Die stäkeren Körner des Rückens bilden keine Längsreihen wie bei T. spinosus BröL.

Der Ilalsschild und die Metazoniten sind wie von einem dichten Filz äherzogen; ditnchen trägt jedes Körnchen ein sehr kurzes Börstchen; trotzdem erscheint der Körper selbst bei ziemlich starker Lupenvergrösserung unbehant.

Der Seitenrand der Kiele 6-16 ist deutlich, wemn auch stump dreilapjig.

Gonopoden (Fig. $259-361$ ) nach dem Typus derjenigen von T. spinosus Brïı. und arassisetis Bü̈L. gebaut. Die Hürte springt anch hier aussen fast so weit vor wie der Telopodit (Fig. 259) und trägt aussen kleine Hardü̈schelchen Selır charakteristisch ist die Giestalt der Telopoditäste : Der Tibialfortsalz ist hirschgeweihartig verästelt; von den 4 längeren Zinken führt die zweite die Samenrinne; der andere $\Lambda$ st (Tarsus) spitzt sich kegelförnigg zu und trägt vor dem Ende einen stumpfen kurzen Seitenkegel; von der Mitte des 


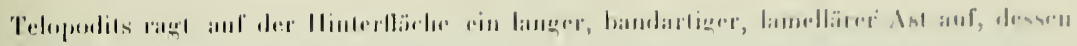

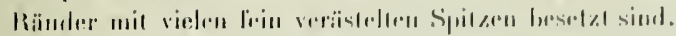

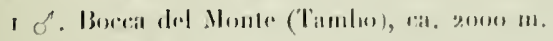

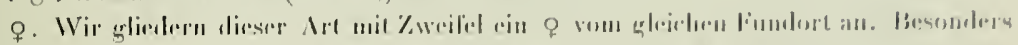

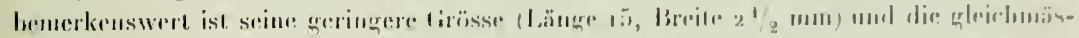

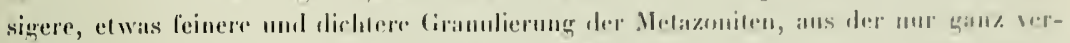

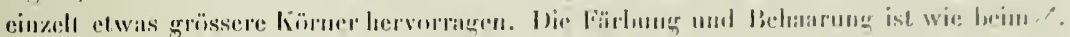

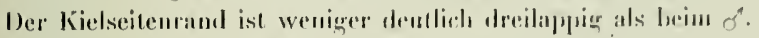

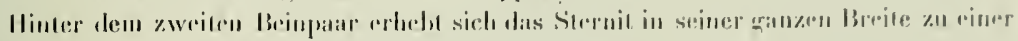

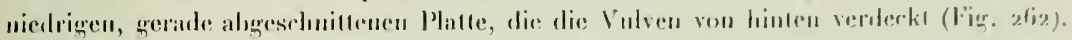

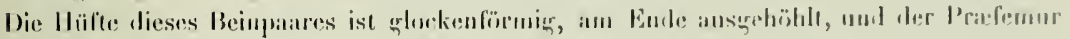
scelat sich excentrisch anf ihrem Ilinterramblan.

\section{Trigonostylus hirsutus $n$. sp.}

O. Schwarzhraun ; Prozoniten ungelleckl; Bauch rolloraun; Beine, Analklappren, liopfsehild und Backen gelblichweiss.

Linge: $20 \mathrm{~mm}$. Breile: /1/2 $131 \mathrm{~m}$.

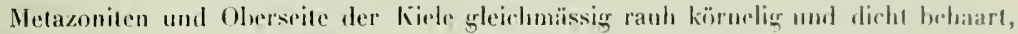
indem jedes Kom eine an ter Basis ziemlich dicke und steile, gregen die feine Sfritze hin liegsime Borste trägt. Die Behararumg lällı schon dem unlwwalliseten Auge auf und verleiht dem Tiere ein etwas raupenälunliches Aussehen. Der Ilalsschihl und der Rücken des 2. Segments sind viel kürzer beborstet, sodass die Körnehng deulliehre hervortrilt.

Seilenflügel des 2. Segments tief ausgehöhlt, wodureh die kinnte, die sie mit dem Rürkenteil bilden, viel schärfer wird als bei $T$. niger. Die hiele fallen wenigar stark alo als hei dieser Art und sind daher an der Basis stärker vom Rä̈cken alygesetzl; der Seitenrand ist, besonders an den mittleren kiclen, viel deutlicher dreilapping als bei niyer. Der llinterrand des Sternits des zweiten Segments erhebt sich zu einer queren Platle genau wie hei niger (Galtungsmerkmal?).

1 o Cimelia, lialfeepllanzung, $1800 \mathrm{~m}$.

Durch ihre Behaarung erinner dirse Art sehr an T. erossiselis Brïl.. aus Venezuela; derlt ist letzterer $\left(\sigma^{-1}\right)$ kleiner und trägl Querreihen dickerer Borsten. Die Entscheidung äher ihren Verwandisehaftsgrad kann jedoch erst das o von hirsutus loringen.

\section{Trigonostylus ammonites $\mathbf{n} . \mathbf{s p}$.}

Schwarzbraun : Bauch, Beine, liopfschild und Antennen weisslich; Prozoniten ungellecki.

Länge : $10 \mathrm{~mm}$., Breite : $11 / 2 \mathrm{~mm}$. 
In eingerollten Zustand erinnert der Körper sehr an gewisse Ammoniten, indem er seitlich stark komprimiert und oben längs der liäckenmittr anf den Metazoniten Ineit canalienliert ist: anch sind die Metazoniten ganz kurz und ragen als hobe Querwälste, den "Rippen » der Ammoniten vergleichbar, im Profil weit üler die Prozoniten vor.

Die Seitenllügel des 2. Segments sind fast senkrecht und kaum merklich ausgehöhlt und bilden mit dem Rücken eine redıtwinlige, stumpfe Kante; das ganze Segment ist dicht sranuliert. Scheitel und Halssehild ebenfalls dicht gekörnelt, letzterer mit einer Tuberkelquerreihe Jängs des Vordermundes. Der 3. Netazonit ist auch noch ziemlich gleiehmässig gekörnelt. Yom 4. Segment an ist die Rückenmitte der Metazoniten leicht concar und glatl; aber jederseits von ihr beginnt eine Querreihe von 5 rnnden Tuberkeln, die bis über die Nlitte der Seiten heruntersteigt und sich manchmal in eine dichtere Reihe von Körnclıen fortsetzt, ror und hinter welcher noch je eine Querreihe von liörnchen steht. Vor dem obersten, wrössten Tuberkel jeder Querreihe liegt noch ein isolierter Tuberkel.

Die Kiele sind schwächer entwickelt als bei den vorhergehenden Arten, wenig breiter als lang, mit undeutlich dreilappigem Seitenrand und flaclı grekörnelter Oberlläche.

Prozoniten dicht und fein gekürnelt.

I † Camelia, Kalfeepflanzung, $1800 \mathrm{~m}$.

Diese kleine Art mag dem T. spinosus BröL. gleichen, hat aher einen stärker komprimierten Kö̈rper und runde, nicht spitze Tuberkehn, die nur eine unvollständige, statt zwejer vollstïndiger Querreihen bilden; auch scheinen die Hetazoniten noch stärker wulstartigr erhöht zu sein.

\section{B. OPISTHANDRIA}

\section{Fam. Glomeridesmidae.}

\section{Gen. Glomeridesmus GЕณ.}

\section{Glomeridesmus porcellus Genv. et Grovd.}

Die Exemplare der Funksмschen Sammlung zeigen keine nennenswerten Ahweichungen von der Besehreilung, die BröLEмıx unter oligem Namen nach Exemplaren aus Venezuela (Colonie Tovar) gegeben lat. Die lirage, oh Bröremaxss Identilizierungr richtig ist, bleibt allerdings noch unentschieden.

of ㅇ. La Canelia, Katteepllanzung bei $1800 \mathrm{~m}$.

Eine weitere Art findet sich anf St. Vincent (Antillen) und eine andere in Equador.

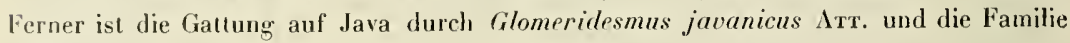
auf Sumatra und Ceylon durch je eine besondere Gattung vertreten. 


\title{
III. VERZEICHNIS DER DIPLOPODEN VON COLUMBIEN
}

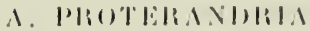

\section{Colobognatha.}

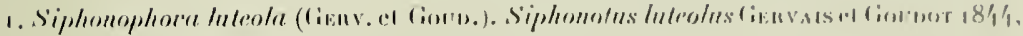

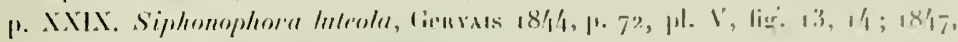
1. $209 ; 1859$, 12. (28). - folmulien.

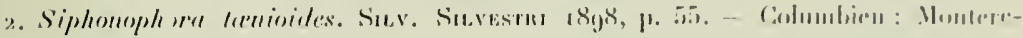
dondu, Buenavista (SHivestur).

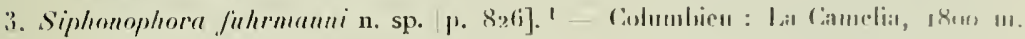
(Goll. Funimans).

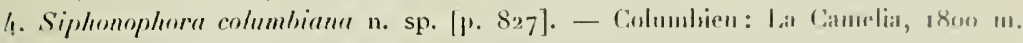
(Coll. Funtsinn).

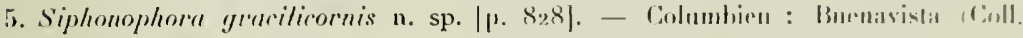

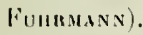

\section{Stemmatoiuloidea.}

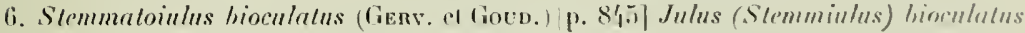

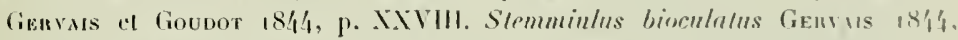

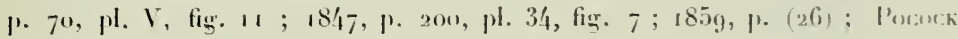
1909 , p. 108 . ? Stemmalniulus bioculalus Silvestur 1896, p. $2 ; 1897,1$. 2.

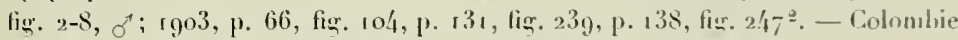
(Gervas et Goudot). "Nouvelle Grenade, régions lemprérés" (Grantus t8.ig). ? Ecuador (Silvestur). ? Darien, Punta Sabana (Susestri).

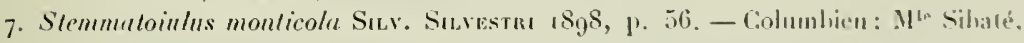
2700 m. (Siliestru).

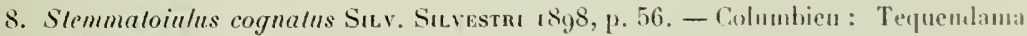
(SULETRI).

1 Mid Secitenzahl in eckiger Klammer hinler den Arlnamen lezieht sieh auf diese Abbeit.

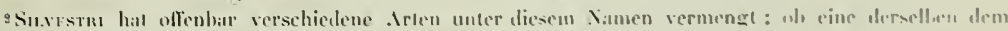

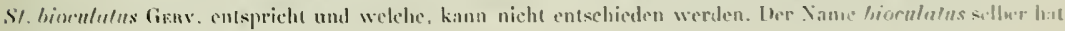
heute nur moch eine historische Bedentung. 
9. Stemmatoinlus hortensis n. sp. p. 845]. - Columbien: La Camelia, 1800 m.;

Puerto de los Polnes; Magdalena bei Girardot (Coll. Funnaxs).

10. Stenmatoialus debilis n. sp. [p. 848]. - Columbien: La Camelia, 1800 m. (Coll. Funmoxis).

11. Stemmutoinlus loggotensis n. sp. [p. 849]. - Columbien: Bugota, 2600 m.; Paramo Cruz Verde, 3/\%00 m. (Coll. Fummaxi).

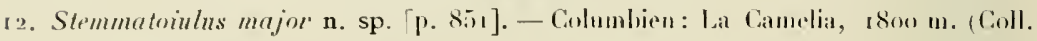
funrmaxx).

13. Stemmatoiulus fuhrmanni n. sp. [p. 85.3]. - Columbien: Tambo, c:1. 2oon m.; Bogota, $2600 \mathrm{~m}$. (Coll. Funвmans).

\section{Nannolenoidea.}

14. Epinannolene fuhrmanni n. sp. [p. 859]. - Columbien: La Camelia, $1800 \mathrm{~m}$. (Coll. Funumsur).

15. Epinannolene exilis n. sp. [p. 860]. - Columbien: Medellin, 1600 m. (Coll. Funuaxy).

16. Epinannolene bifasciata (SıLv.) [p. 862]. Nannolene, bifasciala Suvestm 18g8,

p. 7 x. - Columbien : Mte Sibaté, 2800. ; Paranco, 3300 m.; Bogola (Silvestai)

Argelia, i60o m. (Coll. Funmaxx).

17. Epinannolene alticola (Silv.) [p. 862]. Nannolene allicola Silvestri 18998, p. 69 .

-Columbien: Paranco, $3300 \mathrm{~m}$. ; M Sibaté, $2800 \mathrm{~m}$. ; Tequendama (Siltestmi).

18. Epinannolene major (Sruv.). Nannolene major Silvestri i8g8, p. 69. - Columbien: Consuela (Honda), $1800 \mathrm{~m}$. (Silvestra).

19. Epinunnolene fasciolata (Suv.). Nannolene fasciolata SiLvestur r897 a, p. 355. "Colombie " (SiLvestm).

20. Epinannolene nigrita n. sp. [p. 863]. - Columbien: Alto San Miquel, $2000 \mathrm{~m}$. (Coll. Fundany).

\section{Spirostreptoidea.}

2I. Spirostreptus (Epistreptus) ruralis n. sp. [p. 865]. - Columbien: La Camelia, $1800 \mathrm{~m}$.; Girardot am Magdalena; Puerto de los Pobres (Coll. Funnmann).

22. Spirostreptus (Epistreptus) villicola (Sicr.) [p. 866]. Isoporostreptus villicola Silvestri r 898 p. 73 . - Columbien: Villavicenzio, 1000 m. (Silvestri).

23. Spirostreptus (Epistreplns) ehlersi (SiLv.) [1. 867]. Epistreplus ehlersi SiLvestn? 1898, p. 74. - Columbien: Mine Purnio, Honda (Sulvestru); Buenavista; Guadua (Coll. Fumrmans). 


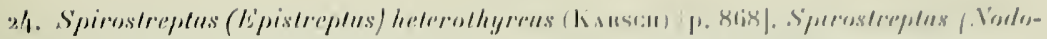

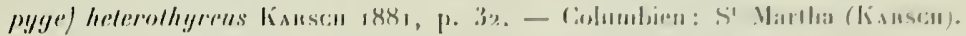

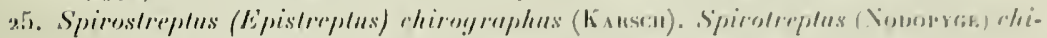

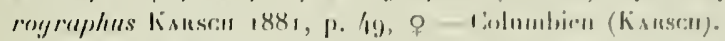

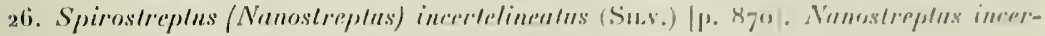

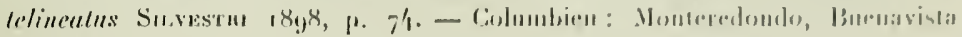
(SHLvistur).

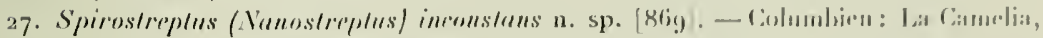
$1800 \mathrm{~m}$. (Coll. Finmsima).

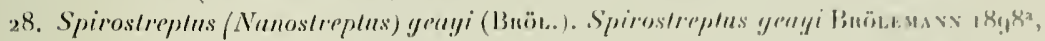

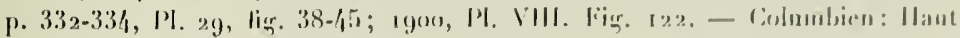

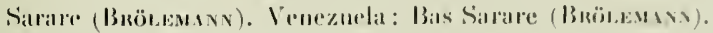

29). Spirostreptus (Orthoporus) chiriquensis (Poc.). Orthopmerts chiripnensis Iocuck 1909, p. 97, T'ab. VIII, fïg. 2. - P'anama ('ocock).

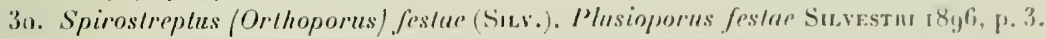

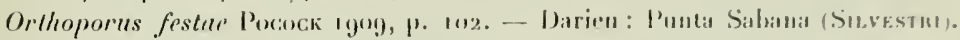

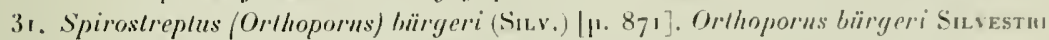
ı 8 g, 1. 71. - Coluubien: Mine Purnio (Silvestri).

32. Spirostreptus /Orthoporus) allicola (SiLy.) [1. 871]. Orthoportus allicala Silvesz ut

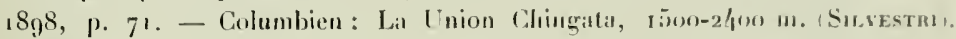

Argelia r6oo m., Sabana von Bogrola, ca. $2000 \mathrm{~m}$. (Coll. Fumusxs).

33. Spirostreptus (Orthoporus) peregrinans (Suv.) p. 872. Orthoporus peregrinans

Sulvestn 1898 , p. 70. - Columbien: Villavicencio (Smestm); La Camelia, $1800 \mathrm{~m}$.; Fresno-Mariquila $400 \mathrm{~m}$. (Coll. Funkmx).

34. Spirostreplus (Orthoporns) variegalus (Sur.). Orthoporus variegalus Silvestm 1898, p. 72. ㅇ․ - Columbieu : Pacho ; Susa (Silvestri).

35. Spirostreplus consobrinus Humb. et Sauss. Humbent el Saussune 187o, p. 174 ; Saussune el Humbert 1872 , p. 68, Pl. 11I, fig. 5. 9. - "La Colombie".

36. Spirostreptus trisulcalus ${ }^{1}$ Didar. Daday i 889, p. 127. o. - Panama (Dsony).

\section{Spiroboloidea.}

37. Microspirobolns mayori n. sp. [p. 873].-Columbien: La Camelia, isoo m. (Coll. Funmasix).

38. Microspirobolus fuhrmanni n. sp. [p. 87.5]. - Columbien : La Camelia, r8oo m. ; Argelia, $1600 \mathrm{~m}$. (Coll. Funrmuxs).

1 Dieser Name ist schon vergeben (vgl. C.. L. Kocn, Die .Jyriaporlen etc. Bd. II, S. 43. r \$63); doch glaubieh ihn nicht durch einen neuen ersetzen zu sollev, weil Dinıs Beschreibung des o olnnehin kaum crlauben wird, die Art wiederzuerkennen. 


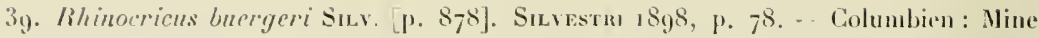
Purnio Silvestra).

40. Rhinocricus capucinus Susv. Silvestra 18ys, p. 78 . - Columbien: Sibaté-Fusagusagu, $2000 \mathrm{in}$. (Sictestu).

41. Rhinocricns instabilis n. sp. [p. $8_{79}$. - Columbien: Argelia, 1600 m.; HondaGuaduas (Coll. Funm.xi).

Subsp. adolescens n. subsp. [1. 881]. Columbien: Tamlo, 2000 m. (Cull. Funrmans). Bogrota (Zool. Museum Berlin).

Subsp. valens n. subsp. [p. 881]. - Columbien: licesno-Mlariquita, 400 m. (Coll. Funnuxy). Eeuador: Sta-Jnez (Kool. Mus. Berlin).

42. Khinocricus brevipes n. sp. [1. 8,6]. - Columbien: La Camelia, 8000 m. (Coll. Fетимыту).

43. Rhinocricus semiplumbeus n. sp. [p. 877]. - Columbien: Puerto de los Pobres (Coll. Fuнмixis).

44. Rhinocricus fundipudens (K.rRsciI) [P. 879. Spirobolus (Rhinocricus) fundipudens Kanscir i 88 г, p. 78. - Columbien: Sti-Martha (K.rnseri).

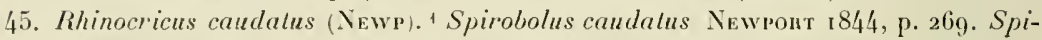
robolus (Rhinocricus) luetus Karsce $188 \mathbf{1}$, p. 70 ; Ponat 1888 , p. 234. Rhinocricus caudalus Brölemaxx ı 8y8, p. 298. PI. 27, fig. 142-149, - Columbien, Venezuela, Brit. Guyana (Kanscit). Venezuela (Brölenaxs). Brasilien (Porat). ? Ternate (Kinsen).

46. Rhinocricus newporli (Genv.). Julus newporli Gervais 1847, p. 182 ; 1859, p. (I9) Pl. IV, Fig. I. Rhinocricus neuporli Brölemaxx igoo, p. i 8 , Pl. VII, Fig. 9-102. - Columbien (Gervais).

47. Rhinocricus roseus (Genv.) Julis roseus Genvals I8/7, p. I8ı, pl. 34, Fig. 9; เ 859 , p. (г9) pl. IV, Fig. 3. Rhinocricus roseus Brölemann igoo, p. i 8 . Columbien (Gervals).

48. Rhinocricus costulalus (Porat). Spirobolus costulatus Ponat i876, p. 31. - Columbien: Bogota (Porat).

49. Rhinocricus crassicornis (Humn. et Sauss.). Spirobollts crassicornis Humbert et Saussure i 870 , p. I77; Saussure et IIumbert 1872, p. 82, pl. 4, fig. 17. "Nouvelle Grenade" (Humbert et Saussure).

5o. Rhinocricus acutus (Humb. el Sauss.). Spirobolus aculus Humbert et Saussure 1870 , p. г 76 ; Saussure el Humbert 1872, p. 79 , pl. IV, Fig. i6. - "Nouvelle Grenade" (Iumbert el Saussure).

\footnotetext{
1 Kunscus Typen von laelus aus Cacaras, sowie Exemplare des Berliner zool. Museums von Garacas und Puerto Cábello gehören den Gonopoden nach zur subsp. montana BuöL. (Bıölesıxv loc. cit. Fig. 1/46-149), die demnach sub ip. laelı K̈.ısci heissen muss. Kinscus Exemplare aus Columbien habe ich nicht prüfen können. Bolluwsss Angabe, dass Rhinocricus arboreus (Suuss.) mit Rh. caurlatus (Newr.) synonym sei, ist irrig. Rh, arboreus (St. Thoma, Coll. Funnsuss) hat anders geformte Gonopoden.
} 


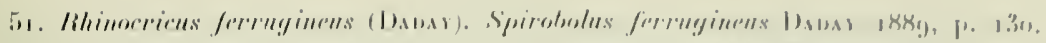

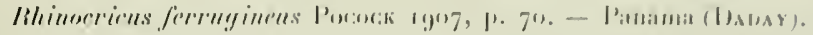

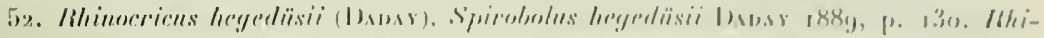

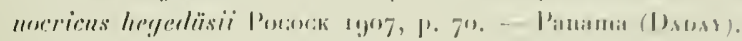

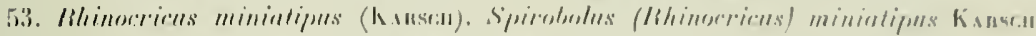

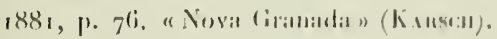

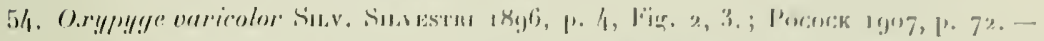

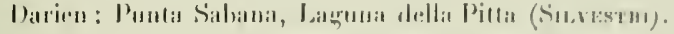

\section{VT. Polydesmoidea.}

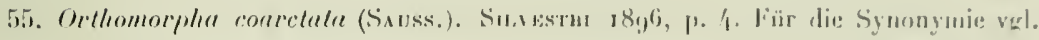

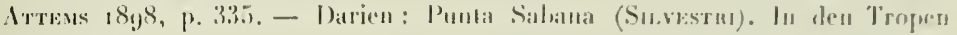
weil rerlireitel.

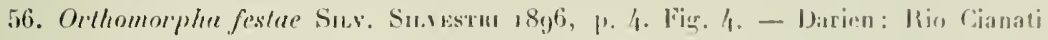
(Sитести).

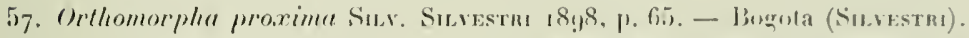

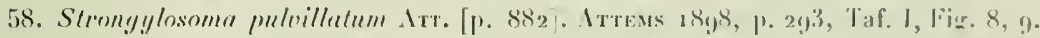
- Columbien: Burnavista, ca.

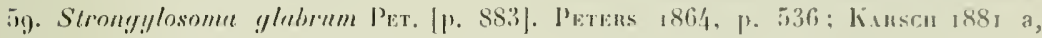

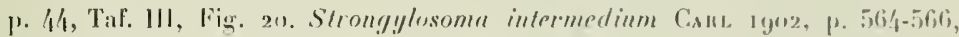

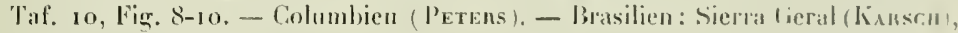
lionciande do Sul (Cirro).

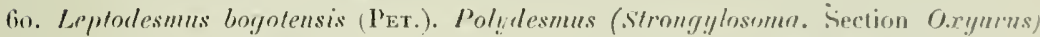

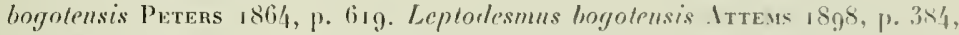
Taf. VII, lïg. 14q, 1 б̆o. - Columbien : Bugula (Peters).

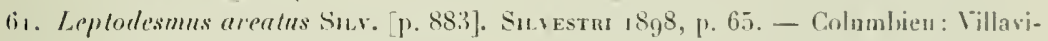
rencio $1000 \mathrm{~m}$. (SiLvestm).

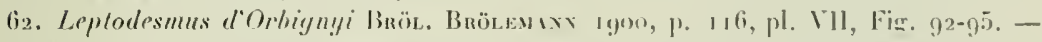
"Colombie " (Brö̈.Emixy).

63. Leplodesmms angmstus n. sp. p. 884. - Columbien: La Camelia, ison m. IColl. Fitrutix).

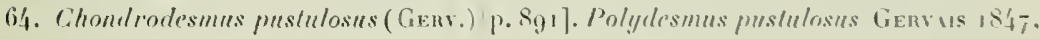

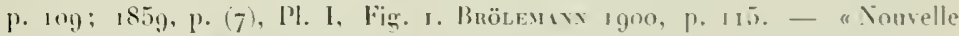
Gronaden (Gemvis).

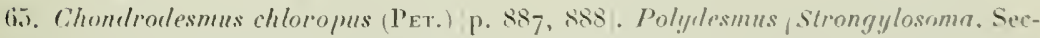

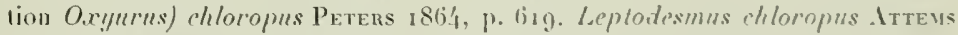

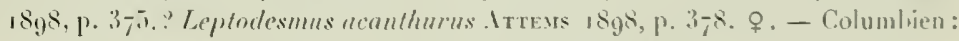
Bogola (l'etens). ? Venezuela (.ITteus ISgs. p. 3-8). 
66. Chondrodesmus acanthurns (PEr.) (P. 888. Polydesmus (Oxyurus) acanthurus Peters 1864, p. 532. - Lamima: Verigua (Peters).

67. Chondrodesmus, franenfeldianus (Husr. el Siuss.). Polydesmus Franenfeldiumus Ilumbert el Saussure 1870, p. 172. Polydesmus (Oxyurus) Frauenfeldiamis

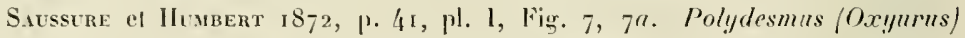
Frauenfeldianus Karscn 188 i a, p.44. ? Leptodesmus Franenfeldianus Sicvestri 1 1896 , p. 5. Leptorlesmns Frauenfeldianus Itтемs 1898 , p. 379. - "Nouvelle Grenaden (Humbert el Siussune). Sla. Martha, Nova Gramada (Kanscir). ? Darien: Punla Sabana, Rio Cinali, Rio Lima (Silvestri).

68. Chondrodesmus platalens (K.nscu). Polydesmus (Oxyurus) plataleus Karsci г 88 i $a$, p. 40, Taf. III, Fig. г 4. Leplodesmus plutaleus BröLemaxn ı898, p. 290 , pl. XXY, Fig. 108-113; Brölemux 1900 , p. 92. - Columbien: Sla. Martha (Brölemaxx igoo). - Venezuela: Puerlo Cabello (Karsci), San Estelan (BröleMAXN 1898).

69. Chondrodesmus flaviporus BnöL. Leptodesmus plataleus subsp. flaviporus BrïLemanx i 898 a, p. 328,329 , pl. 29, Fig. 30-33. - Columbien : Haut Sarare (BröLeMIXY).

7o. Chondrodesmus riparins n. sp. [p. 8887. - Columbien : Bodega central, am Mamdalena (Coll. Fuiruaix).

7r. Chondrodesmus comvexus n. sp. [p. 89o]. - Columbien : Morron; Fresno-Mariquita (Coll. Funmux).

72. Chondrodesmus nobilis n. sp. p. $89^{3}$ ]. - Columbien : Baranquilla (Coll. FurrMans).

73. Chondrodesmus carbonarius n. sp. [p. 894]. - Columbien : Argelia, tooo m. Coll. Funriain).

74. Chondrodesmus dorsovittatus n. sp. [p. 895]. - Columlien : Buenavista (Coll. Funumxe).

75. Chondrodesmus attemsi nom. nov. [p. 895]. Leptodesmus gondoti Aттемs 1898 , p. 375 , Taf. VI, Fig. 125 , I26. - Columbien: Baranquilla. Venezuela: Puerto Cabello (A Ttems).

76. Alocodesmus angustalus Sinv. [p. 897]. Silvestri i 896 , p. 5, Fig. 5. Leptodesmus

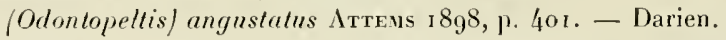

77. Alocodesmus serenus Silv. [p. 898]. Silvestri i 898, p. 57. Leptodesmus (Ollonlopeltis) serenus Attens i 899 , p. 428 . - Columbien : Orocué (Silvestri).

: Die Zugebörigkeit der Exemplare aus dem Darien zu dieser Art ist sehr zweifelhaft. Die zwei $q$ des Turiner Mfuseums zeigen folgende Unterschiede mit H. und S. Besclıreibung: Die gelbe Färbung ist auf den porentragenden und auf den porenlosen Kielen gleich ausgedehnt. Es sind Spuren eines gelben medianen Rüekenstreifens vorhanden. An Yordereck der vorderen Kiele findet sich kein Zähnehen; der Hinterrand der Kiele trägt zwei Knötchen oder Zähnchen; der Sejtenrand der porentragenden Kiele ist vor der Beule leicht eingebuchtet. Der Rüeken ist ziemlich stark gewölht. 


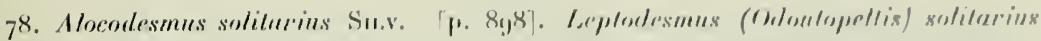

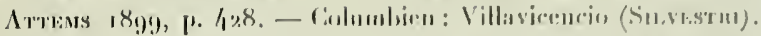

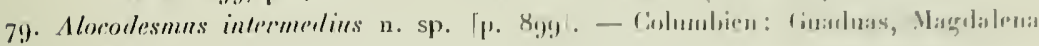
(Coill. Fimumavo).

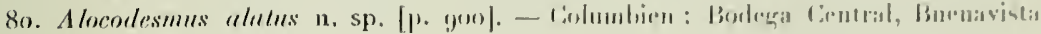
(Cisll. Vinแmans).

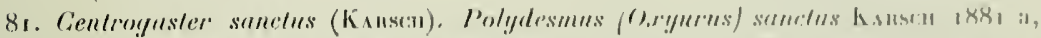

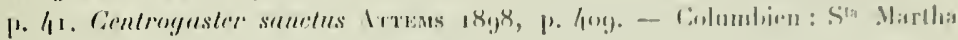
(Kinscir).

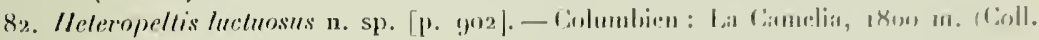
funmans).

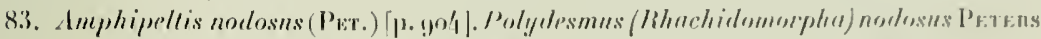

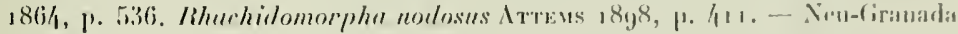
(Petrus).

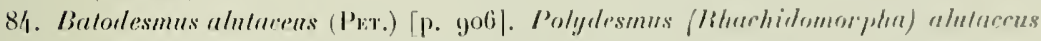

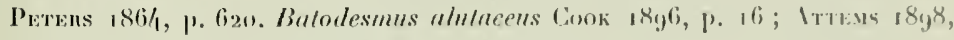
P. \{13. - Columbirn: Bogola (P'Etens).

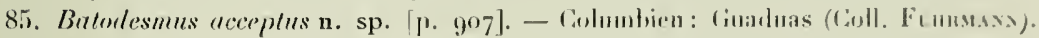

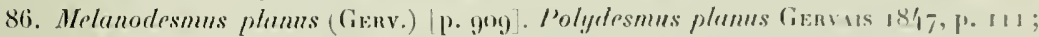

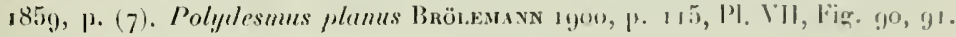
- "Nonvelle Grenade" (Genvas). Columbien: Gumbas, Buenavisla (Coll. funrmaxy)..

87. Trichomorpha virgata n. sp. [1. 914]. - Columbicn: La Camelia; Cirardot a. Magdalena (Coll. Fumnuxix).

88. Trichomorpha venusta n. sp. [p. 9:6]. Columbien: Tambo, Boca del Wonte (Coll. Funnusivi).

8g. Trichomorpha propinuua n. sp. [p. !) 18]. - Columbien: La Camelia, thoo m. (Coll. Fummixx).

9o. Trictomorpha amnlipes n. sp. [p. 918]-Columbien: La Camelia, 1800 m. (Coll. Funnusu).

91. Trichomorphn dehilitata n. sp. [1, 920]. - Colunbien: La Canelia, $1800 \mathrm{~m}$. (Coll. Fummaxx).

92. Trichomorpha hirsuta n. sp. [p. 921]. - Columbien: Iguacala\} (foll. Fommum). 93. Trichomorpha pilosella n. sp. [p. 922]. C Colnubirn: Merlellin (Coll. Funnmu). 94. Trichomorpla sculptu (Рет.) [1. 922]. Polyilesmus /Oryums) sculplus Peters 1864, p. 620. Leptodesmus sculplus Itтемs 1898 , p. 37.5.-Columbien: Bogota (Peters ; Coll. Funrwav).

95. Trichomorpha nitida n. sp. [p. 924]. - Columbien: La Camelia (Coll. Funnum). 96. Trichomorpha denticulata n. sp. [p. 926. - Columbien: La Camelia (Coll. Fенвмахx). 
97. Trichomorpha gracilis n. sp. [1. 927]. - Columbien : La Camelia. (Coll. Funusix).

98. Trichomorpha reducla n. sp. [1.928]. - Columbien: La Camelia (Coll. Funnunx).

99. Trichomorphu servidens (PET.) [P. 929]. Polydesmus (O.xynus) serriden. Petens 1864, p. 619. Leptodesmus serridens Iтtens 1898, p. 377. - Columbien : Bogola (Peters).

10o. Trichomorpha mueronaln.(Pex.). Polydesmus mucronalns Peters i 864, p. (i2z. Leptodesmus (Odontopelis) mucronatus ATtems ı 898 , p. 402, Taf. VII, Fig. I 46 . - Columbien: Bogota (Peters).

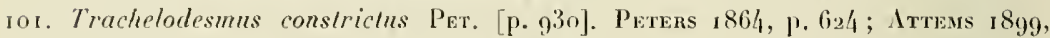
p. 253. - Columbien : Bogota (Peters).

102. Trachelodesmus (?) geayi (Bröц.) Leplodesmus Geayji BröLemun i $898^{\text {a }}$, p. 326-

328, PI. 28/29, Fig. 17-27. 7rachelodesmus Geayi Аттммs 1899, P. 253. Columbien: IIaut Sarare (BröLemurs).

ıo3. Pycholropis polygonalus (Gerv.) [p.933]. Polydesmus polygonatus Gervas i 847, p. го ; г 859, 1). (8), Pl. I, Fig. 3. Polyalesmus (Enryums) polygonalus Peters I864, P. 141 . Euryurus polygonalus Aтtems 1899, p. 280 . Plalyrohacus polygonalus Brölemixv 1900 , p. r1 li, PI. VII, lïg. 85-89. - Columbien (Gervais, Peters), Morron (Coll. Funruaxy).

104. Pycnotropis taenia (Рет.) [P. 935]. Polydesmus (Euryurus) taenia Péters 1864, p. 626. Polydesmus (Euryurus) taenia Karsci $1881^{a}$ p. 44, 45, Taf. III, Fig. 29. Euryurus taenia Atтems r 899, p. 280. - Columbien : Bogola (Peters, hinscir); Tambo, Argelia (Coll. Funrmans).

Var. melanostigma SiLv. [p. 936]. Euryarus melanostigma SiLvestri I 898, p. 68. - Columbien : Monte Redondo, Bellavista (Silvestri).

ı05. Pycnolropis flavocarinalns Silv. [р. 936]. Euryurus flavocarinatus Sulvestm г 898 , p. 68 - Columbien: Villavicencio, Monteredondo (Silvestri).

106. Aphelidesmus aterrimus (Aтт.) [p. 940]. Euryurus alerrimus Aтtens i899, p. 278 , Taf. VII, Fig. I62. - Columbien : Fresno-Mariquita (Coll. Funnanx). Venezuela ( $\Lambda$ TTEMs).

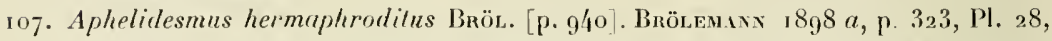
Fig. 4-i 6. - Colombie : Haut-Sarare (BröLemunv) ; Puerto de los Polıres, Girardot (Coll. Funrmaxy). Venezuela : Bas-Sarare (Bröleminx).

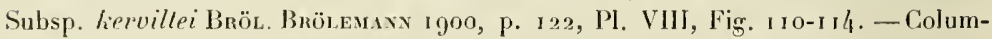
bien: Bogota (Brölemixs).

108. A phelidesmns ambignas n. sp. [p. 9411.-Columbien: Buenavista (Coll. Funnuaxy). rog. Aphelidesmus dealbutus (Genv.). Polydesmus dealbatus Genvars i847, p. iго ; 1859, p. (8), PI. I, lïig. 2. Polydesmus (Euryurus) dealbalus Peters 1864, 1. 54 I.

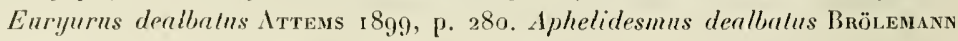
1900, p. ir 6. - Columbien (Gervais, Peters). 


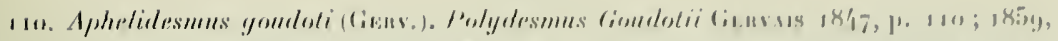

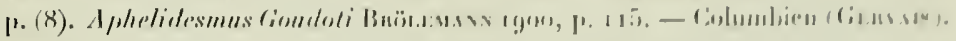

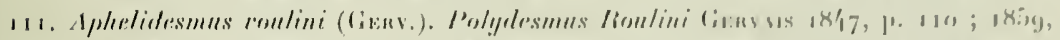

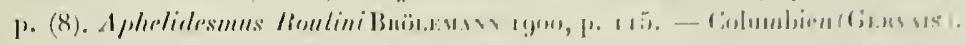

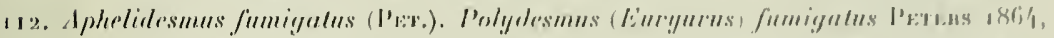

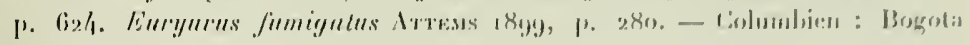
(PETEus).

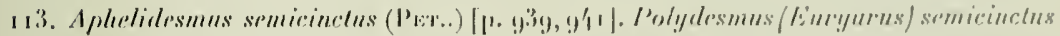

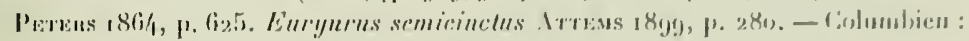

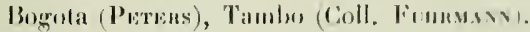

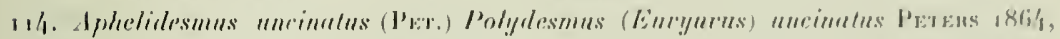

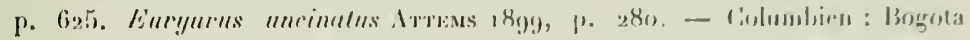
(PETwh).

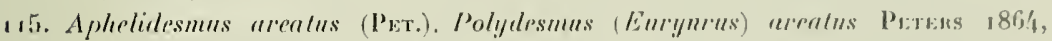

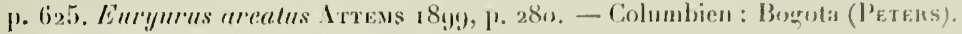

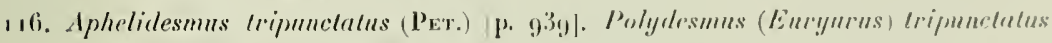

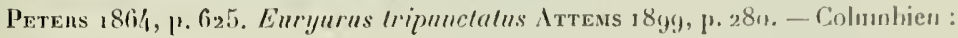
Bogotil (PETERs).

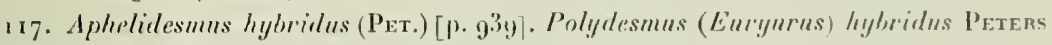
1864, p. 626. Enryurus hybridus Atress 1899, [1. 280. - Columbien : Bogota (Petens).

118. Plalyrrhacus dunali (Gerv.). Polydesmns Dumalii Gerwus 1847, p. Ing; 1859 , p. (7). Polydesmus (Stenonia) Dunalii Petens r 864, P. 543. Plalyprharus Dınali Brölemaxy rgoo, p. 113, P. VII, fig. 83-84. - Columbien (Gerrais, Peters).

119. Platyrohacus clathratus (Genv.). Polydesmus cluthralus Gervas 1847, p. 108; 1859 P. (7), PI. I, fig. 4. Polydesmus (Stenonia) clathralus Peters 1864 , p. 543. Plalymhacus clalhratus Atrems 1899, p. 346 ; Bä̈lenswi 1900 , p. 113. - Columbien : (Gervais, Peters, Ittems).

120. Platyrrhacus fimbrialus (Рет.). Polydesmus (Stenonia) fimbrialus Petens 1864. p. 543 ; S.ussune el Hunbert 1872 , p. 28 . Plalyrrluchs fimbriulus Ittems 1899, p. 347. Tirodesmus fimbrialus Pocock 1909, p. 146. - Pinama : Veragua (Peters, Itтems).

121. Plalyrrhacus ologona (Sux.). Arcidesmus ologona Silvesrri isg8, p. 67. Plalyrrhacus ologona Itrems r899, p. 330. - Columbien: Villavicencio (Sunestri). 122. Plusioporollesmus bellicosus Sulv. [1.942]. Sulestri 1898. 1. 64; Ittens 1899 . p. 354. - Columbien : Honda (SiLvestur); Buenavista (Coll. Fummivy).

123. Cryplogonodesmus angulifer (Рет.) [p. 946, 949] Polydesmus angulifer Peters 1864, p. 623. - Columbien : Bogola (Peters); La Canelia (Coll. Frhruaxi). 
I24. Cryplogonalesmus fulrmunni n. sp. [P. 946, 947]. - Columbien : Tambo (Coll. F(n)uim).

125. Cryptugonodesmus oblusungulus n. sp. [P. g.\%o) - Columbien : La Camelia (Coll. Futruisis).

126. Cryployonodesmus trevicornis n. sp. [p. 950]. - Columbien : Mto San Miquel (Coll. Finruiny).

127. Brachycerodesmus petersi n. sp. [1. 952]. - Columbien : La Camelia, Medellin (Coll. Funmuxi).

128. Gyrophallus finniculus (Рet.) P. (95). Polydesmus funiculus Petens 1864, p. 623. - Colnmbien : Bogola (Peters).

129. Gyrophallus imilans n. sp. [p. 953]. - Columbien : La Camelia (Coll. Funranan). 330. Ciyrophallus simillimus n. sp. [p. y55]. - Columbien : La Camelia (Coll. Funnaxs). 13ı. Fuhrmannodesmus lividus n. sp. [p. 956]. - Columbien : Paramo Cruz Verde, $3400 \mathrm{~m}$. (Coll. Funruaxi).

132. Cryplodesmus alalus (PET.) [P. 958]. Polydesmus (Ciryptodesmus) alalus Peters 1864, p. 621, part. Chonodesmus alatus Соок 1896 a, p. 23 ; 1911, 1. 468469 , Fig. 7-10. Cryplodesmus alalns Aттемs 1899 , p. 366. - Columbien : Bogota (Peters ; Coll. Funrmane).

133. Stictodesmus creper Соок. Соок $1896 a$, p. 20 ; 1911, р. 461. Fig. 5; Аттемs 1899, p. 363. Polydesmus (Cryptodesmus) alalus Peters i869, p. 621, part. - Columbieu : Bogota (Peters, Соok).

134. Calymmodesmus andinus n. sp. [p. 960]. - Columbien : Puerto de los Pobres (Coll. Fuhruans).

135. Oniscodesmus oniscinus (Gerv. et Goud.) Polydesmus oniscinus Gervals el Goudot 1844, p. XXVIII. Oniscodesnus oniscinus Gervais ı 844, p. 64, Pl. 5, Fig. 7-9; 1847, p. 9o, Pl. 44, Fig. 4; 1859, p. (4); Aтtems 1899, p. 384, Taf. XV, Fig. $357-359$; Cook 1898 , p. 454, Pl. XXIX, Fig. I $a$, s $b$. - Columbien (Gervais el Goudot).

136. Oniscodesmus rabriceps Pet. Peters 1864, p. 6I 7; Brölemann 1898a, p. 329, Pl. 29, Fig. 34-37; Aттемs 1899, p. 384. Lignydesmus rubriceps Соок I898, p. 456, Pl. XXX, fig. $2 a-2 f$ - Columbien : Bogota (Pexers) ; Haut-Sarare (Brölemañ).

137. Oniscodesmus micrurus Соок. Соок 1898 , p. 455, Pl. XXIX, Fig. 2 a-2 li. - Columbien : Bogota (Соoк).

138. Oniscodesmus fuhrmanni n. sp. [p. $\left.9^{62}\right]$. - Columbien : Llora del Nonte, Tambo, $2000 \mathrm{~m}$. (Coll. Funzusis).

139. Cyrtodesmus velntinus (Gerv. et Goud.) Polydesmus velntinus Gervais et Goudot 1844, P. XXVIII; Gervals I 844, p. 65, Pl. 5, Fig. гo. Cygrlodesmus velutinus Gervais 1847 , P. $9^{3}$, P. 44, Fig. 5 ; 1859 , p. (5); Cook 1898 , p. 458, Pl. XXIX, Fig. 3 a-36; Atrems 1899, p. 380. - Columbien (Gervais und Goudot). 


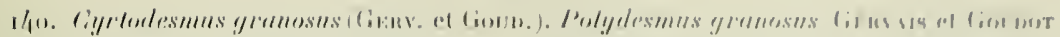

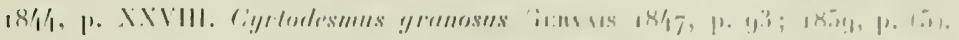

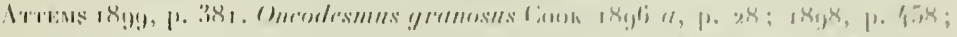

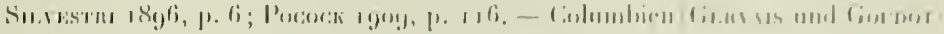

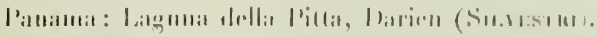

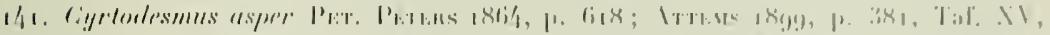

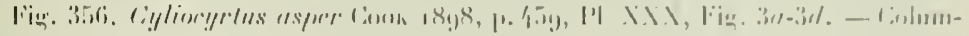
bicu: Bugula (I'ritriss).

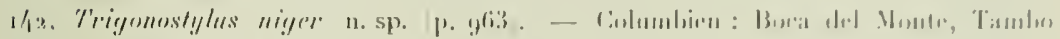

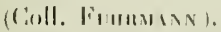

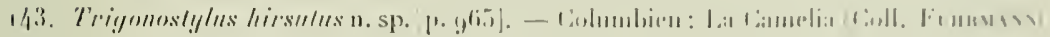

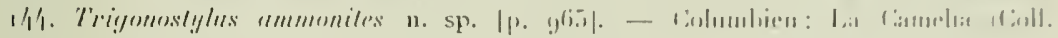

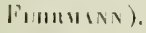

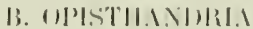

\section{Glomeridesmidae.}

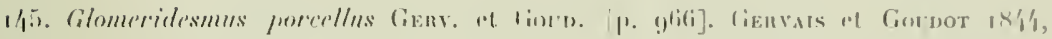

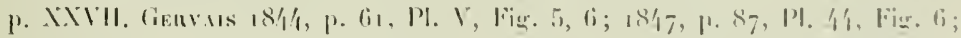

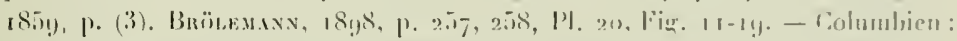

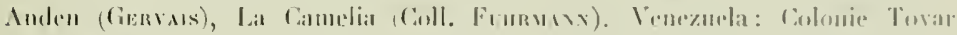
(Виёцвмих).

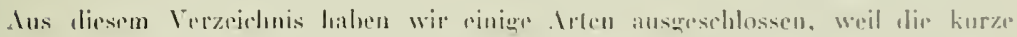

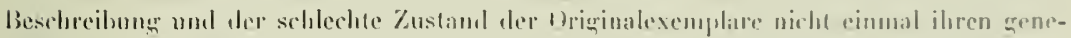
risehen Platz im lientigen System zu hestimmen rolaulwa, die Vimen sumit ad arla an lexen simal. Es simd dies:

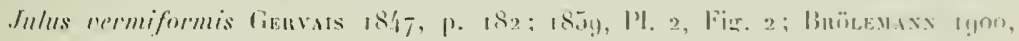
[1. II!).

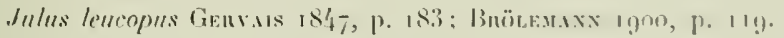

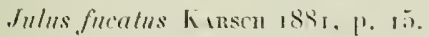

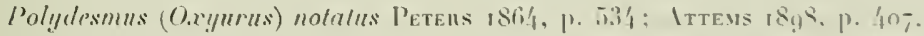

Wegren zu unsicherer Bestimmung stroichn wir aus der Liste der columbischen

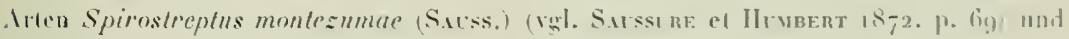

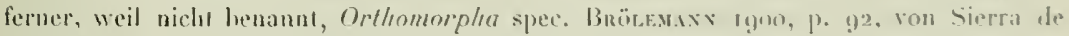
Santit Marta.

123 


\section{FAUNISTISCHE BETRACHTUNGEN.}

Im Hinblick auf die in der Einleitung hervorgheholene Unollständighkeit der fannistischen Durchforschung Südamerikas einerseits und den unlertiggen Zustand der Diplopoden-Systematik andererseits, mag es gewagt erseheinen, an das Studium der Fanna eines kleineren und dazn nicht nach allen Seiten hin natürlich begrenzten Gebjetes faunistische Betrachlungen anzuknäpfen. In der Tat wäle eine ins einzehe gehende Darstellung der Fannengeschichte Columbiens und ein eingehenderVergheich mit den Nachbarländern heute noch unmöglich. Zieht man aber grössere Gebiete heran und unterwirft man als Spezialforscher zunächst die vorhandenen faunistischen Dokumente einer groben kritischen Sichtung, so drängen sich doch einige Fragen von allgemeinerem interesse deutlich grenug. auf, um cine Erörterung zu verdienen. Die sich daraus ergebenden Schlussfolgerungen hahen natürtich einen mehr oder weniger hypothetischen Charakter; sie werden aber auch nicht als unumstössliche Tatsichen himgegehen nnd sollen nur eirer Periode analytischer Forschung auf ganz bestimmtem Spezialgebiet zum Abschluss dienen und andererseits durch Fragestellung und Ilinweis auf die emptindlichsten Lücken in unserm Wissen die Ziele lïr künftige Forschung angeben.

\section{Charakter der columbischen Diplopodenfauna.}

Schon das Verzeichnis der columbischen Diplopodenarten beansprucht nur als Ausgangspunkt für vollständigere Arbeiten einen gewissen Wert. In quantilativer Hinsichl gilut es sicher noch kein annähernd richtiges Bill von der Diplopodenfauna der nördlichen Anden. Infolge ganz ungenügender oder nur auf o gegründeter Beschreilıngen figurieren wohl eine ganze Anzahl Arten unter zwei oder mehr Namen ; das dïrfte besonders in den Galtungen Siplonopliora, Stemmatoiulus, Epinannolene, Rhinocricus und Aphelidesmus zutreffen. A ach mag diese oder jene der alten Cyrlodesmus-Arten muter dem Gallungsnamen Trigonosty/us wieder beschriehen worden sein. Selbst die Untersuchung der Originalexemplare gestattet nicht immer die Lösung dieser Synonymiefragen, teils infolge schlechter Konservierung der Typen, teils weil man verschiedene Geschlechter und Altersstadien zu vergleichen genöligh ist. Aus diesen Gründen wird die Zahl der wirklichen heute bekannten columbischen $\backslash$ rten nicht unbedeutend hinter den 145 Namen unseres Verzeichnisses zurüickbleiben. Dagegen wird diese Reduktion ohne Zweifel durch künltige Sammeltätigkeit sehr raseh aulgewogen sein. Dafür spricht der Unstand, dass Prof. Funruax auch in Gegenden, wo vor ihm schon Bürger, Goudot u. a. gesammelt hatten, bedeutend mehr neue als schon bekannte Arten aulfand und dass ein elwas längerer Aufenthalt an einer günstigen Sammelstation, wie z. B. La Camelia bei Angelopolis, in eiser entsprechend grösseren Artenzalıl zum Ausdruck kommt. Ferner darf man die 


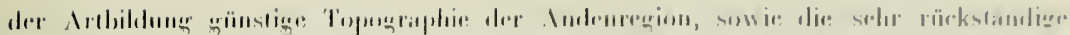

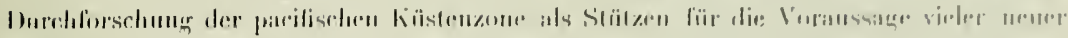

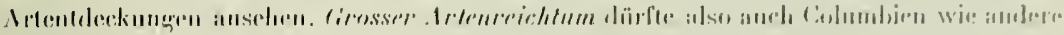

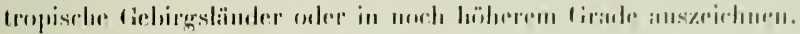

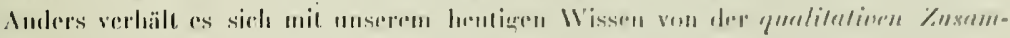

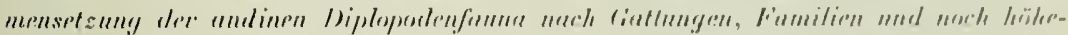

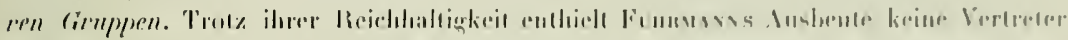

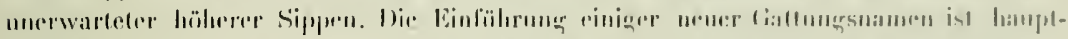

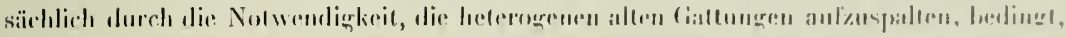

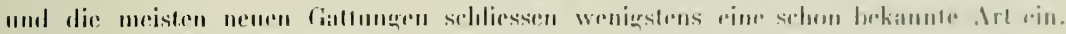

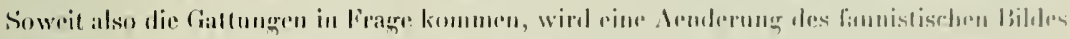

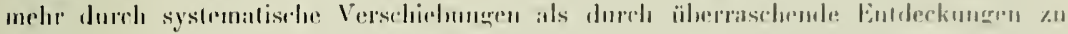

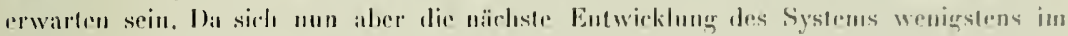

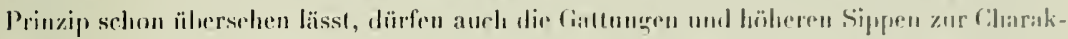

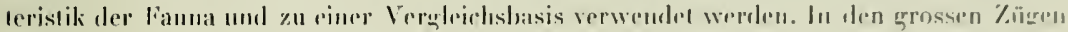
ilıred Zusammensetzung kam also die Diploporleulauna Columbiens als ziemlich ent brkaum quilten.

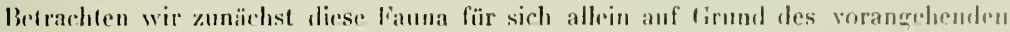
Verzeirlunisses, so fällt vor allem die geringe Zahl höhere Sippen in Vereleich zur Arten-

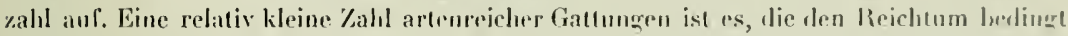

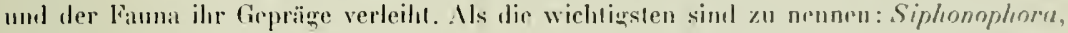
Strmmatoinlus, Epinamolene, Spirostreplus, Rhinoericus, Chomdrodesmus, Alowrodesmus, Trichomorpha, Pycnotropis, Aphelidesmus, Plalyrrhacus, Criplplogonortesmus, Cigrtodesmus elc. Datgegen sind monotype Gatungen in deutlicher Minderzahl und selaliessen sich zum Teil eno an einander oder an eine der eben wenannten artenreichen faulumgen, deren versprengte Elemente sie aufuelumen (Centrogaster, IJeternpeltis. Amphipeltis, Balodrsmus, Fuhrnannodesnuss). Andere strhen walischeinlich unter sich in Synmymicverhïlnis (Trigonosly/us = Cyrlodesmus ?). Eine efwas isoliertu stollumer nehmen nur die beiden monotypen Gallungen Melunorlesmus und Phrsioporodesmus ein ; sie mögen rorläufig, wenigstens in systematischem Sinn, als Rolikf hetrachlet werden.

Von häheren Sippen (Familien, Ordunngen) hexilzl Columbirn keine für sich allsin.

Es handelt siuh also im wesentlirhen 1 me eine Tiemelt, in welcher die niederen Sippen reich enlfaltet, die höheren verhïlmismüssig wenig zahliphih werteden sind und der Relilitcharaliter dic Ausnahme bildet. Daraus lïsst sich auf eine relaliv junge. lureh rasche Differensier'ang entstandene Fauna schliessen, was wirderum in Einklang mit der jungen Erhebung der Inden auf einem alten Festland und ilurer der Irthildung günstigen Gliederung steht.

Für ein junges Nter einiger der charakteristischsten nordandinen Gattungen spricht hesonders ilır melurseitiger Zusammenhang, der eine scharfe Charakterisik ausserordentlich erschwert. In solch engem Verwandischaftsverhältnis stehen zueinander die 


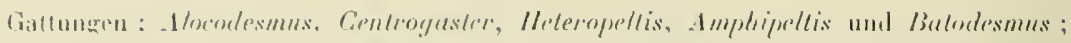

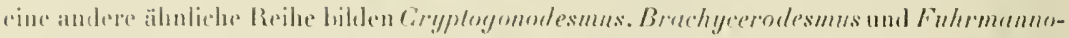
desmus. Sir bezeichuen gheichsam den Lebergang von weit vorgeselurillener Art- zu

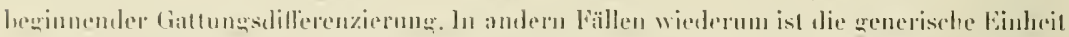

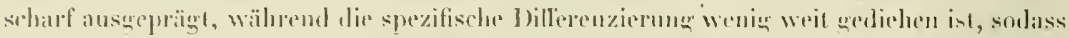

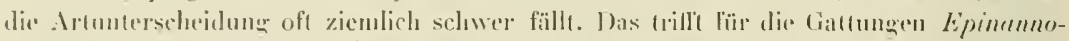

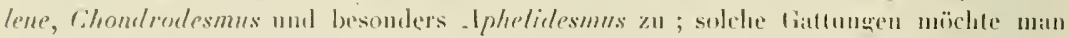

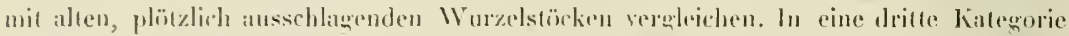

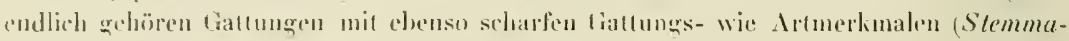

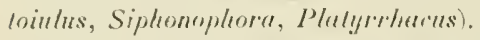

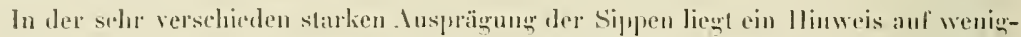
stens zwei verschieten alte Tirerschichten, einer älteren, die zun Teil unter nenen Verhïltnissmo wieder anfzublülıen leginnt und einer stärkeren jüngeren Tiersthichı, die sich lis zum Genus an Ort und Stelle unter den heutigan ähulichen Verhälnissen herausdifferenzicrt hat. Es crhebt sich nun die Frage, ob diese Successionen auch in ten Verbreitungsarealen der Sijpgen und damit zusammenhängend in den faunistischen Bezielungen Colunbiens zu den Nachbargelieten zum Ausdruck kommen.

fierate in tler vergleichenden liaunistik mathen sich der Mangel systematischer Revisionen und die grossen Lüeken in unserer hisherigen Fannenkemutuis am stärksten fühll ar" ; sie zwingen uns, vielfach ron Namen abzusehen und an ihre Stelle unsere eigene Aulfassumg der Sippen zu setzen und andererseits den Vergleich auf grössere, lesser durchforschte fielbiete zu beschiänken.

\section{Artareale.}

Da es sich nicht um ein natüllich abgegrenztes fiebiet handelt und wir von einer exakten Kenntnis der Artareale noch weit entfernt sind, wäre es zweeklos, den Artendemismus in Zalılen oder Proportionen ausdrücken zu wollen. Glükklicherweise liegen uns neuere Arbeiten mit guten Artbeschreibungen über die Diplopodenfaunen von Brasilien, Venezuela, Chili und Centralamerika vor. Sie lassen wenigstens die allgemeine Tatsache erkennen, dass die andine Diplopodenfauna auflillend wenige weit verbreitete Arten anfweist. Dazı gehören nur drei Arten unseres Verzeichnisses: lihinocricus caurlulıs Newr. (Columbien, Venezuela, Britisch Guayana, Brasilien), Strongylosomu pulvillatum Aтt. (Columbien, Paraguay) und Strong!ylosoma glubrum Pet. (Columbien, SüdostBrasilien). Wahrseheinlich handelt es sich un drei alte Arten, die noelı vielerorts in Südanerika sich funden werden und ilır grosses Areal durch Wanderung erworlsen hahen. Bemerkenswert ist, dass diese Jrei Arten weit verbreiteten Gatlungen mit disjunkten Areal angehören. Für Strongylosoma insbesondere sind einige grosse Artareale und grosse Anpassungsfäliggkeil bekannt [St. pallipes (OL.), St. italicum Latzes, St. gue- 


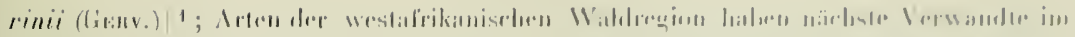

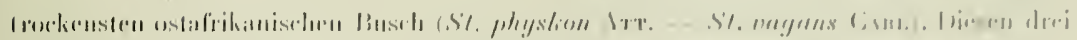

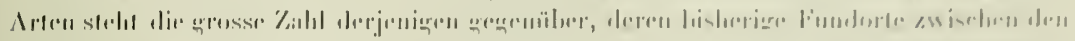

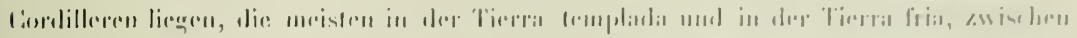

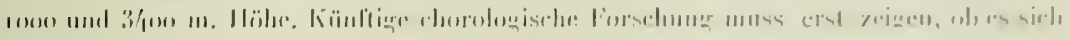

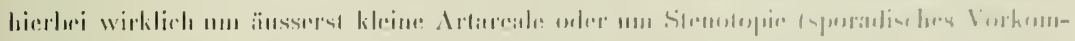

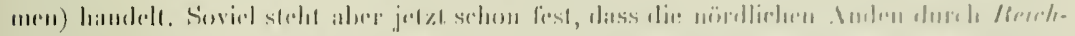

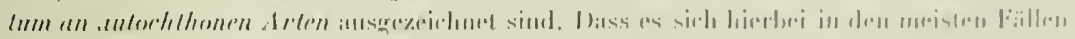

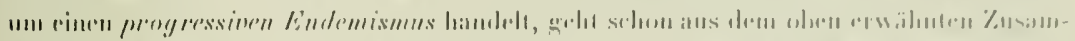

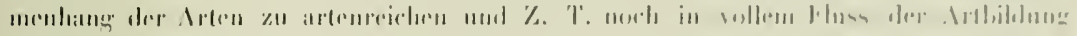
lediullichen riallumegen herour.

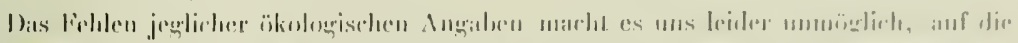

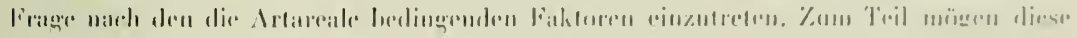

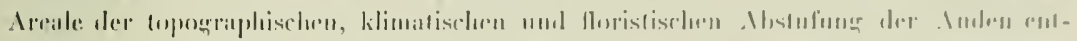

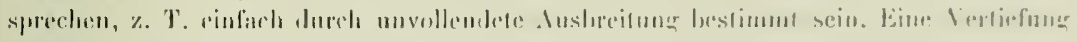

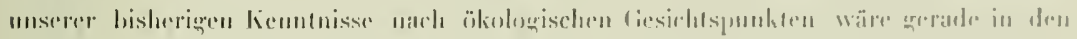

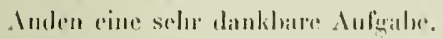

\section{Gattumgsareale.}

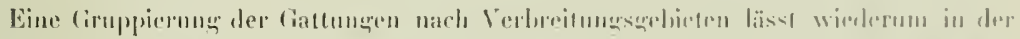

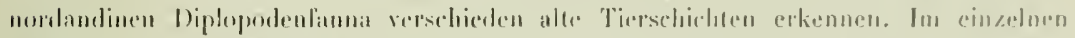

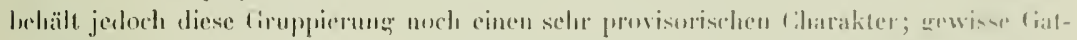

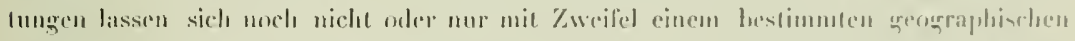

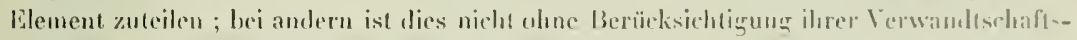
rerhiilnisse möglich. Wir unterscheiden:

\section{Andines Element.}

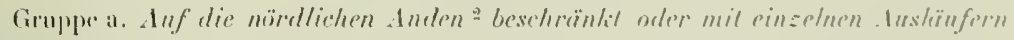

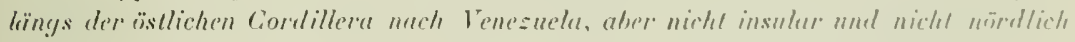
ron Penrumu:

Alocorlesmus: Columbirn, Tenesuela.

theteropellis

$\left.\begin{array}{l}\text { Imphipellis } \\ \text { Balodesmus }\end{array}\right\}$ columbion.

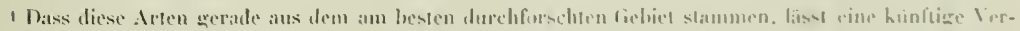

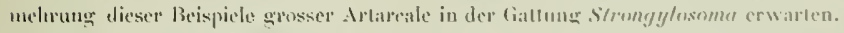

s Wir bezeichnen als uördliche Anden die Cordilleren von Colmmbien und Eenador olue bestimuse Grenze nach Süden hin. 
Trendeledesmus: Columbien, Venezueda.

Pycnotropis : Columbien, Ecuador.

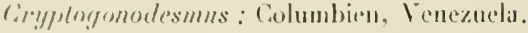

Brorelugecrodes:mus

(igyron)lwallus

Columbicu.

Fuhrmamnodesmus

Sliclodesmus: Columbien, Vinezuch.

Onisconlesmus: Columbien. Veneznela.

Trigonostylus: Columbien, Ecuiulur, Vemenuela.

Velunulesmus: Columbien.

Plusioporortesmms : Columbien.

In dieser Gruppe sind zweifellos zwei rersedieden alte Tierschichten enthalten. Aus systematischen Gründen (s. S. 980) sind die meisten dieser lienera als progressine, andere als lionserenalive Endemiten der nördlichen Auden zu lutrachten. Eine genatue Seheidungr der heiden Séhichten ist beute noch nicht durehführbar.

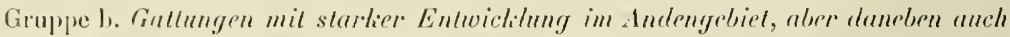
in Centrat-1merilit, oder anf den -Intillen oter anf der Cocos-Insel vertreten:

Chondrodesmus : Ecuador, Columbien, Venezuela, Costarica und Mexico.

Trichomorpha : Ecuador, Columbien, Cocos-Insel.

1phelidesmus: Columbien, Ecuador, Venezuela, Costarica, Brasilicn.

Epinumnolene: Ecnador, Columbien, Costarica, Cocos-lusel (.Intillen?). '

Microspirobolus: Columbien, Venezucla, Antillen.

Diese Gruppe entepricht dem Alter nach wahrscheinlich der älteren Schicht (tionservalive Endemiten) der Gruppe a. Man könnte sie auch als "altandines» Element und die äbrigen Gattungen der Gruppe a als "jungandines» Element hezeichnen.

\section{B. Transoceanisches Element.}

Siphonophora: Columbien, Ecuador, Venezucla, Antillen, Central-Amerika, NeuCaledonien, Neu-Seeland, Neu-Guined, Celebes, Sunda-luseln, Ceylon, Seychellen (fehlt Arrika und Madagascar). ${ }^{2}$

Wahrseheinlich, ugchören zu Epinunolene auch zwei von Pocock (Journ. Linnean Suc, Zoology,

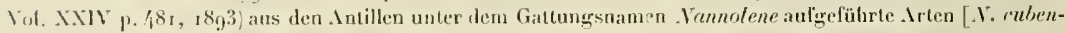

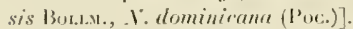

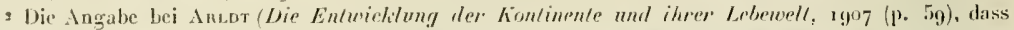
Siphonophore auf Madagasear vorkonme, bezicht'sich offenhar auf den Nachweis dieser Gattung aul den Seychellen. Wer Intersehied ist jedoch wichtig, indem nehrere in der indoitustralischen liegion weitverbreitete sipjen westwärts bis zu den seychellen reichen, aber auf Madagasear fehlen (z. B. Phyllium unter den Phasmiden). 


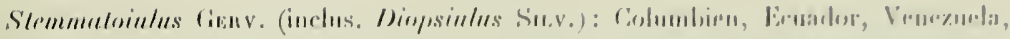

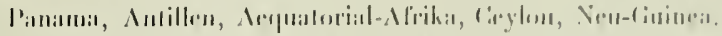

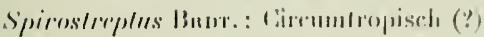

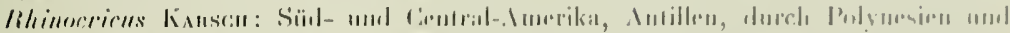

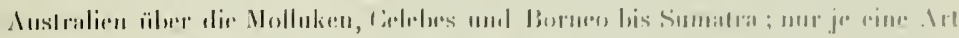

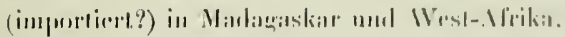

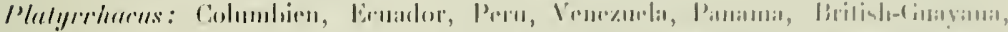

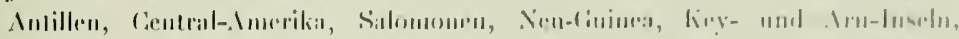

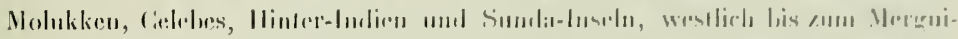

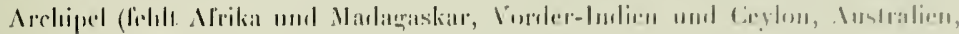

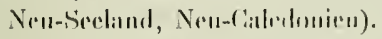

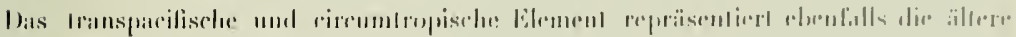
Tierselichlı.

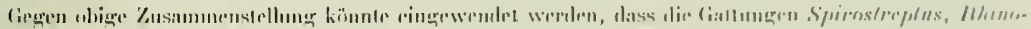

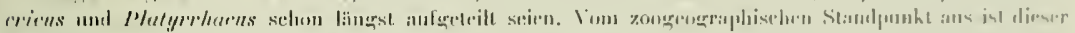

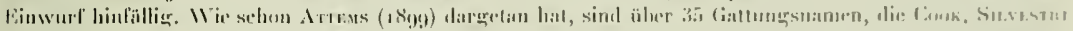

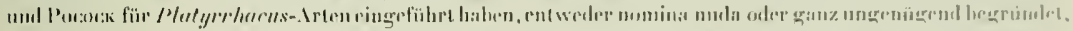

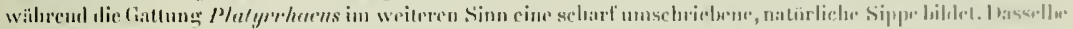

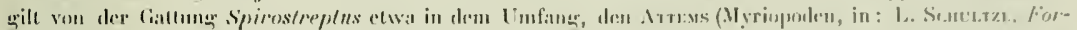

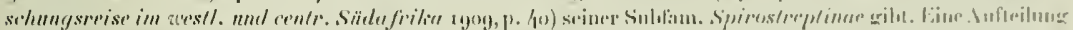

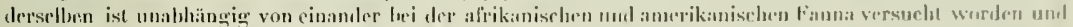

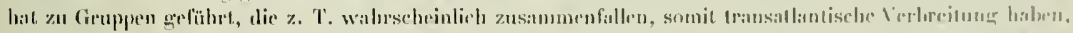

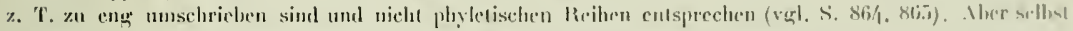

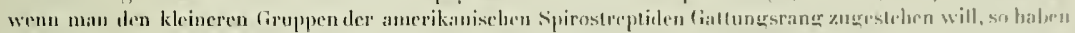

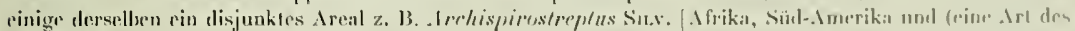

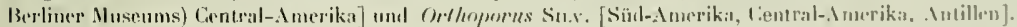

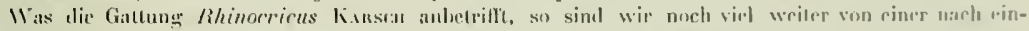

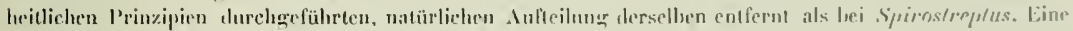

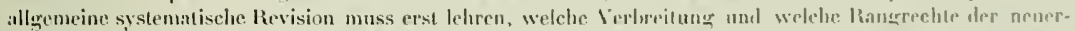

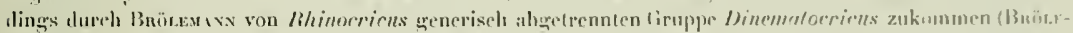

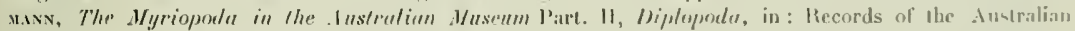
Musptum, vol. $x$, No $\left.6,19^{1} 3\right)$.

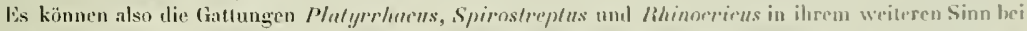
zoogeographisehen Betrachtungen Verweotung linden, wenn es sieh un zeillich und ärllich ent fernte fansuitische Bivichungen hantelt.

\section{Vergleich mit den Faunen benachbarter Gebiete.}

Inden Kappiteln üher Art-und Gallungsareale Ireten sclun einige posilive Bezichungen der Diplopodenfauna Colımbiens zu jener der Nachlargelhele hervor. Der Vergeterch nach Gehelen soll namentlich auch die negaliven Charaklere dieser fanna zum. Iusiruck bringen und anf die erdgesehichliche Grundlage der heuligen Tierverbreilung hinwoisen. 
Di. Diplopordenfiunal ron Ezuador schliesst sich, sow al heute bekannt, eng an die

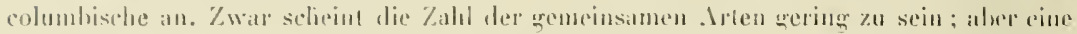

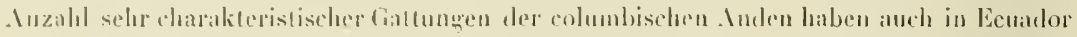

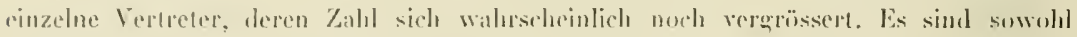

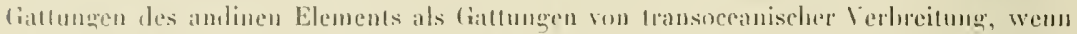

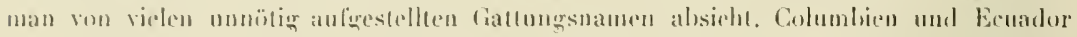

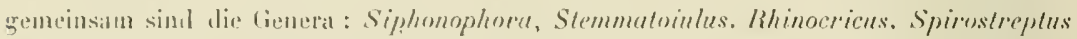

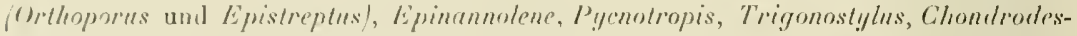

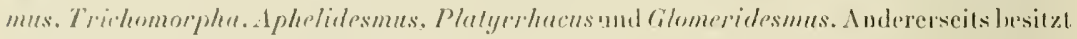
licuador in den beiden monolypen lialtungen Physiostreptus Sus. und Iloloporlostreptus C.rro cine interessunte Sippe (Familie?), die bis lieule ans Columbien nicht bekannt geworden ist. Dat sie systematisch eine Miltelstelhung zwischen Sprostrepliden und Epinamoleniclen einnimmt, kann man sic als Restanz auffassen. Die ebenlalls monotype loblydes-

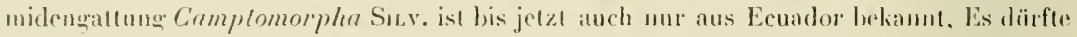
also auch Eeualor seine konservaliven Eutemiten besitzen.

Die Anlen ron Peru sind mit Bezug auf ilure Jiplopodenfauna noch viel zu wenig erforscht, als dass man ihre Beziehungen zu Ecuador und Columbien darzostellen versuchte.

Hingegen muss auf das von jenem der nordamlinen recht abweichemle firpräge der Diplopodenfauna von Chile hingrewiesen werden, in welcher cinmal das Teherwiegen der in den nördlichen Andeu selı sclıwach vertretenen Strongylosominen äber die leptodesminen, sodann das Auftreten einger dem tropischen Andengebiel ganz fremder, höluerer Gruppen, wie Iseospermophora, Cambaliden (Dimerogonus), Pauropoden umd PselafHognathen aulfallen. Antererseits fehlen Chile gerade die charakteristischen nordandinen (iallungen, sowic die Colobognalhen und Stemmatoiuliden.' Besonders bemerkenswert sind die deulichen Beziehungen der Diplopodenlauna Chiles zu jener von Neu-Seclaul (Dimerogonus, verwandte Polydesmiden- und Clordenmiden-Genera), wie sie weder die nordandine noclı die ïbrige südamerikanische Diplopodenfauna aufweist. Wo der Uebergang der nordandinen in die chilenisehe Fauna statufindel, ol er allmählich sith vollzieht, inwieweit die Unterschiede aul" äkologische Verhältnisse beruhen oder ggenhistorische firïule haben, das sind alles noch olfene liragen.

Nach Nordosten hin klingt die andine Founa allmählich aus, sodass Venezuela zu Columbien etwa in temselhen Verhälnisse stelıt wie Ecuador, indem es mit den columlischen Anden einge Jiten und melirere charakteristische Gathungen geneinsim hat (vgl. Fallungsareale). Orographische und lyydrographische Verhältnisse scheincu in dieser Richtung hin der Ausbreitung der andinen Sippen besonders g̈̈̈nstig zu sein; der Verlant der Cordilleren von Meride ist nicht oluse Einlluss auf die Tierverlyreitung gebliehen. Einzelne Giallungen (Siphonophora, Stemmatouilns, Microspirabolus, Glomeridesmus, Plalyrrharus) scheinen sogar der alın Fortsetzung dieses Ambenzweiges ïher den Antillen-

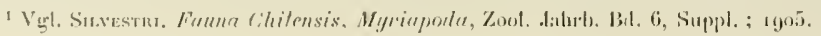




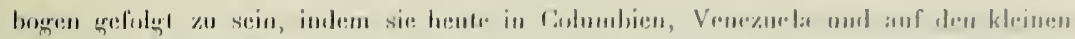

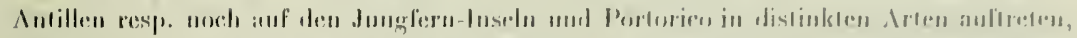

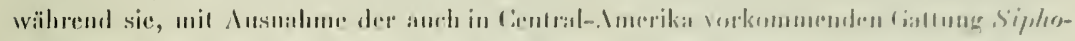

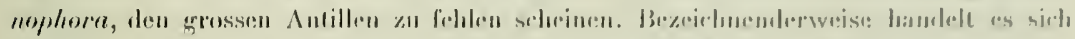

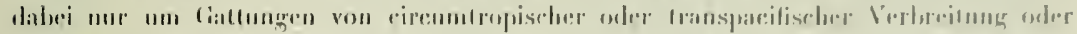

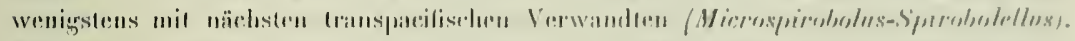

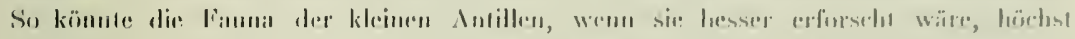

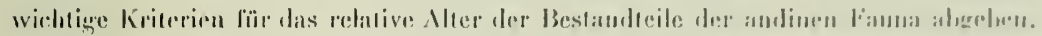

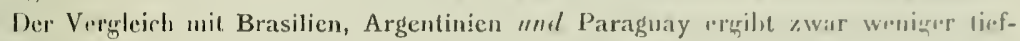

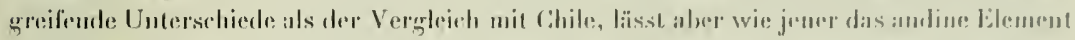

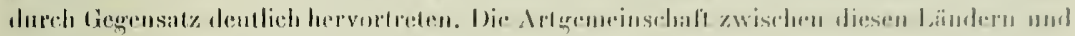

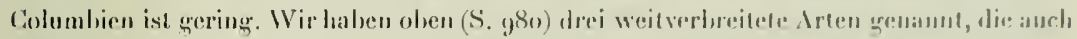

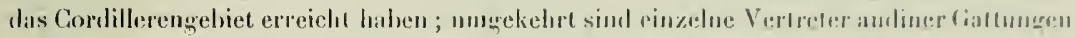

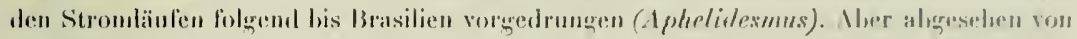

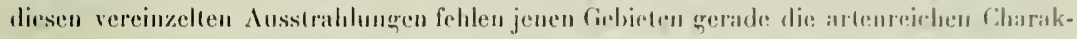
tergenera Columbiens. Untrer den gut heschriehenen drten aus Brasilien fanden wir kroue, lie in jene Gatlungen hätte aulgenommen werden kïmnen. Die systematische Bereiniznng wird die vielen Leptodesmus- und Odontopeltis- Aeten Brasiliens und der Darlubarländer auf zahltreichere lattungen verteilen, die vielleicht Representativ-Sippren zu columbisctun Gartungen darstellen und auf ältere lanunengemeinschaft himweisen; cincer dersellen wird

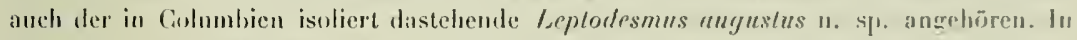
lwomerkenswerter Weise ist die nordindine Gallung Epinamnolene in den Thetlïndern durch l'seadonannolene ersetzt. Ciegenüber der Abwesenheit autuchthuner StrongylusnmaArten in Columbien ist die reiclue Vertretung dieser tiatung in Brasilien und Arangunien

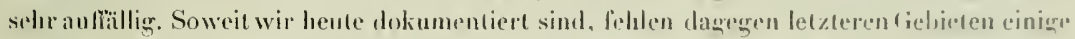
in den Cordilleren von Eeuador und Columbien, Veneznela und trilweise anch in fentralAmerika und den Antillen vertretene Sippen. Dazu gehören in rrster Linie die ganze Gruppe der Stemmatoiuliden, sodann die Gillungen Siphonophora. Plalyprhacus, Amplinns und Polylepiscus; die erstere ist cireumtropiseh vertreitel, die beiden letzteren crattungen aus Pern, Eeuador, Venezuela und Central-Lmerika bekannt, haben in Polylepis Boces. (Pachynras ant. jart.), von den Salomonen lis Borneo verheiled, nathr Iransparifische Verwanden, mit denen sic his vor kurzen generisch vereinigl waren;

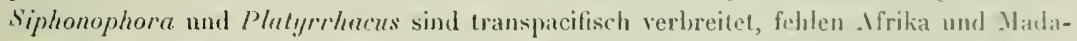
gaskar, Wahturscheinlich auch Vorderindien. Wenn sich das Fehten dieser alten Gathugen in Brasilien und Argentinien auch nicht ganz hestäligen sollte, so sint sie jedenfals in diesen Gehieten sehr schwach vertreten und lassen so wenigstens cinen gewissen conservaliven Zug in der Fauna der nördlichen Anden und hiser Ahzweigungen schärfer hervortreten. Vielleicht darf man aber noch weiter gyehen und in der heutigen Verlsreitung dieser alten Gallungen eine Stälze für eine transpazifische Landverbindung, sowic für den Einfluss eines älteren Andensystems anf die heutige Tierverbreitung in Amerika erhlicken. 124 
Besonders wertrolle Aufschlüsse mit Bezug anf die geogenen Faktoren der Tierverbreitung und die zoogeographische Bedeutung der Diplopoden ergibt ein Vergleich der Diplopodenfauna Süd-Amerikas mit derjenigen Central- und Nord-Amerikas. Vor ro Jahren roch hätte dieser Verghleich, auf rein statistischer Basis, zu ganz andern Schlüssen geführt als heute. Der dimalige Stand des Systems liess vornehulich Analogien zwischen diesen Faunen hervortreten: Die grosse Gattung Leptodesmus unter den Pulydesmoidea sollte sich von Argrentinien bis zum Pacifisehen Ocean und bis zu den Antillen unı Florida erstrecken; Rhachidomorpha soltse in Mexico und Brasilien sogar dureh grleiche Arten vertreten sein, Euryurus die südlichen Vereinigten Staten und die Cordilleren von Colnmbien und Ecuador bewolınen u. s. w. Von dieser vermeintlichen grossen Faunenubereinstimmung hat die neueste Entwicklung des Systems sehr wenig übrig gelissen. Leptodesmus ist heute mur noch ein Sammelbegriff; das Zurückgelien auf die Typen in partiellen Revisionen hat grezeight, dass unter diesem Namen nicht ur viele distinkte Gattungen, sondern sogar natürliche monophyletisehe Gattungsgruppen mit einheitlichem Areal (z. B. die Rhachidesminae CanL) vereinigt wurden. Rhachidomorpha ist zu einer kleinen, auf Jexico beschränkten Gattung geworten. Euryurus haben wir in dieser Arbeit (vgl. S. $9^{32}$ ) dureh Abtrennung der andinen Arten auf einen natürlichen Unfang und beschränktes Wohngebiet zurückgefülırt. Durch diese bestimıntere Fassung der Sippen, die leider für Süd-Amerika noch lange uicht vollständig durchgeführt ist, erscheint das Verlıältnis zwischen den süd-, central- und nordamerikanischen Faunen in einem wesentlich anderen Lichte.

Als erste wichtige Tatsache ist liervorzuheben, dass wir heute keine einzige Diploporlenart lienuen, deren Areal von Süd-Amerika aus nach Central-Amerilia ïbergreift. Die beiden Faunen sind den Arten nach durchwegs verschieden; ein recenter Austauseh über Panama ${ }^{1}$ hat also nicht stattgefunden. Höehstens könnte in der alten Gattung Siphonophora noch diese oder jene der ganz ungenïgend bekannten Arten (o) aus Guatemala mit einer columbischen Art identisch sein; daun kann es sich aber auch um eine langlebige Art, Zeuge einer älteren Verbiudung, handeln.

Ueberblicken wir die Gattungsareale, so konstatieren wir, dass alle columbischen Gattungen des andinen Elements der Gruppe $a$ (jungandin) in Central-Amerika fehlen, währen von der kJeineren Gruppe $b$ dieses Elements (altandin) zwei Gattungen (Epinannotene und Aphelidesmus) bis Costarica reichen, eine dritte (Chondrodesmus) wenigstens mit einer Art bis Mexico vordringt, die zwei andern (Trichomorpha und Microspirobolus) wohl auf Inseln, aber nicht in Central-Amerika nachgewiesen sind. Nur ein ganz geringer Bruchteil der Gattungen des andinen Elements ist sonit südlich und nördlich von Panama verbreitet. Anders verhält es sich mit dem eireumtropischen resp. transpazifisclien Element der nordandinen Fauna (s. Gattungsareale B). Mit Ausnalıme von Glomeridesmus,

1 Panama selbst müssen wir bei diesem Vergleich als neutrales Gebiet betrachten; es ist übrigens noch sehr wenig erforseht. 


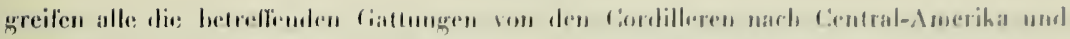

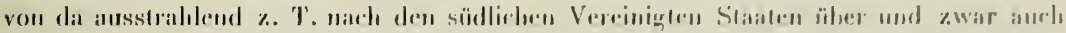

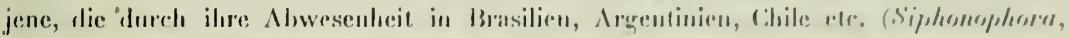

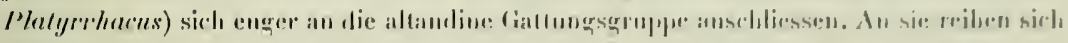

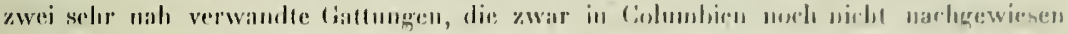

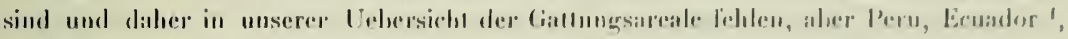

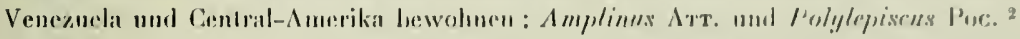

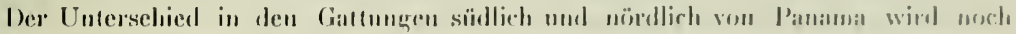

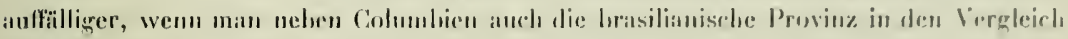
mit Contral-Amerika einbezieht, da in Brasilien gewisse undaudin-contralannerikanisclu

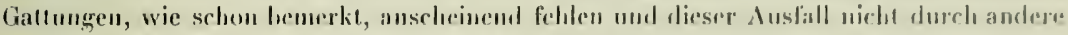

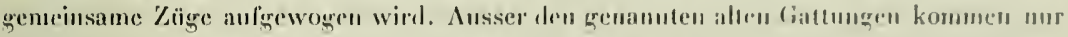

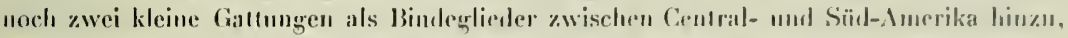

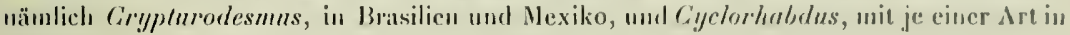
Veneznela und Guatemala ; fïr ein höheres Nlter dieser beilen Gattungen dïrfte die geringe Artenzahl und die Lntfermung der Teilareale sprechun. Soweit die Artheschrejhungen ein Lrteil erlauben, gehört auch keine der lorasilianischen Arten der Collektivsippe "Leptodesmns" in irgend eine centralamerikanisclie Gattung. Wie gregenüher dar columbschen, so unterscheiden sich ferner die Doplopodenfaunen von Brasilien, Argentinien und P'araguay auch gegenüber der centualamerikanisclsen durch den Besitz vun zahlreichen Strongy/osoma- und Psendonannolene-Arıen, deren Central-Amerika gänzlich zu entheluren scheint.

Diese Ausführungen zeigen, dass bei den Diplopoden uit Bezug anl' die Arten und anf die jüngeren Gattungen zwischen Süd- und Central-Amerikit eine ausgesprochenr linu. nengrenze besteht und dass mu die Geneinschaft einer geringen Zahl älterer Gattungen anf einen weit zurïcklirgenden Faunenaustausch liuweist, an welchem die Andenregion stïrker beteiligt war als die brasilianische Provinz. Dass die gemeinsamen Züge zwischen beiden Teilen des Continents wirklich anf eine alte längere Landrerbindung linweisen und nicht etwa blos auf grössere lixpansionsfähigkeit der alten gegenül,er den jüngeren Gallungen heruhen, geht aus folgenden Tatsachen hervor: 1) Erstens sind melırere der betreffienden Gattungen auch insular in sellständigen Arten verhreitel; 2. grehïren cinige derselben, z. B. Siphonophora, nach ilrem lïrperbau und ihren hygrophilen Gewolunheiten sicher zu den Diplopoden mit der geringsten Wanderungsan̈higkeil; 3. ist in keinem Fall auch Artgemeinschaft festgestelli worden.

Von den Gattungen zu den bölseren sippen fortschreitend, von deren cinhritlicher Auffassung und Umgrenzuny wir leider noch weit entferne sind, verwischt sich die Grenz" zwischen Säd- und Central-Amerika immer mehr und kommt die Stammerwandtschaft

1 Eine neue Art von Polylepiscus werden wir nächstens ans Sta. Inez, in Ecuador, beschreilven.

2 Für die transpazifischen Beziehungen dieser beiten Gattungeo s. oben, S. g\$s. 


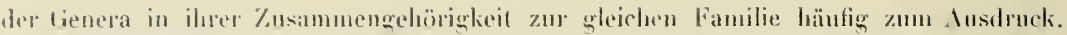
Wie alie hente nuch gemeinsamen alten transoceanischen liallungen, so spricht auch die

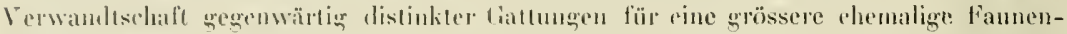
uemeinselatit. Inshesondere ist es der grosse neotropische Stamm der Leplodesminae Atr. (Familie Chelodesmidae 1'oc: ), der zwischen der Famal Sïd-und Central-Imerikas vermit-

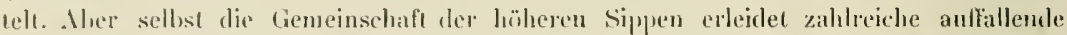
Ansmalmen. Fon Süden ausuehend sei nur daran erinnert, dass die alte Gruple der Stemmutointoiden nördlich ron Panama noch nicht nachgewiesen ist.

Noch anllälliger werlen die Lnterschiede sellsst in den höheren Sipjen, wenn man als Ausgangspunkt für den Verghleich die Fauna Central-Amerikas wählt, wie wir sie dureh zahlheiche neuere Arheiten und namentlich durch Pococss Nonographie in der "Biologia centrali-amerienna " kennen. Die Fanilie der Sphaerioulesmiden (südliche Stanten der Enion, Central-Amerika, Antillen) rejcht südwärts bis Costarica. Die kleine Fanilie der Peridontodesmiden (einzige Gallung: Peridontodesmus, mit zwei Arten in Mlexiko und einer Art in Cuatemala) ist auf Central-Amerika beschränkt. In der schon genaunten, mit Süıl-Amerika gemeinsamen Vanilie der Chelodesmiden hat Central-Amerika eine höchst charakteristische eigene Subfamilie mit etwa to Gatlungen ausgebildet, die ilre Hanptentwicklung in Mexico hat, aber auch noch in Costarica vertreten ist; wir haben sie als Rhachidesminae hezeichnet und sind für ihren monoplyyletischen Ursprung eingretreten.' Die Sulsfanilie der Xystorlesminae Poc. lıat ilıre Sürlgrenze in Guatemala, mnd die in Central-Amerika, hesonders in Mexico und Guatemala, noch stark vertretene Familie der Platydesmidue (Gattungr Plutydesmus) reichı anch nicht weiler südlich als Costarica. Endlich sind die Paraiuliden mit der Gattung Paraiulus südwärts lis Guatemala vorgedrnngen. Diese Namen mögen genügen, um den grossen Unterschied in der Zusammensetzung aler central-und der südamerikanischen Diplopodenfauna und ihre zicmlich scharfe Ahgrenzung im Gebiet von Panama zu veranschaulichen. In rein statistischer Betrachtungsweise durlten wir sie auch zu diesem Zwecke aneinanderreilsen und einander wleichstellen. Wenden wir aber die analytische Nethode anf die centralamerikanische Fauna an, so ergibt sich, dass die eben genannten südlich von Panama fehlemlen Sijpen auf ganz verschiedene Weise zu dieser grossen zoogeographischen Bedeutung gelangt sind. Die Sphacriodesmiden und Peridontodesmiden haben sonst nirgends näelıste Verwande; nach ihrem kleinen Areal und jhrer geringen Diflerenziernng zu urteilen, könneı es alte Sippen sein, die ihre Entwicklung in Mexilio und den südlichen Vereiuigten Staaten mögen durchlaufen haben. Anders die Rhachidesminae; sie befinden sich entschieden in progressiver Entwicklung and, da sie auf den Leptodesminenstamm znrïckgehen, illustrieren sie die selhständige Weiterentwicklung der alten neotropischen Tierschicht in Central-Amerika. An sie schliessen sich als weiteres Zweig desselben Stammes

1 Vght. Carr, Revision ameril. Polydesmiden, in : Rev. Suisse de Zoologie, T. 11, p. 553. I9o3. 


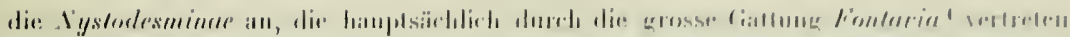

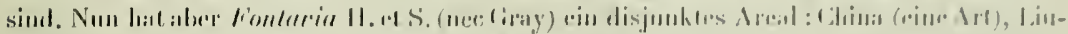

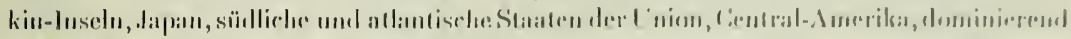

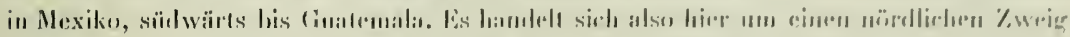

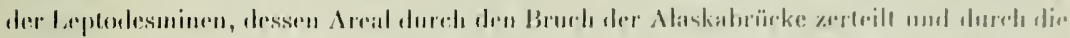

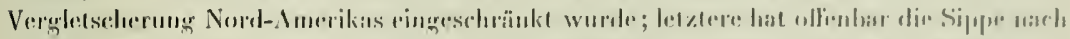

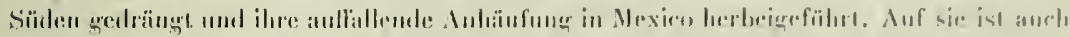

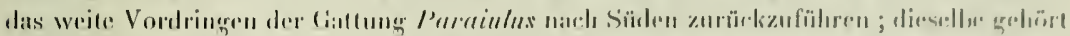

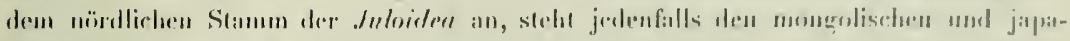

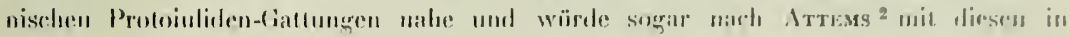

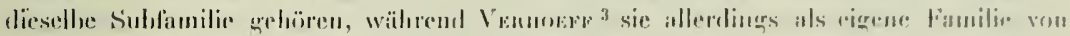

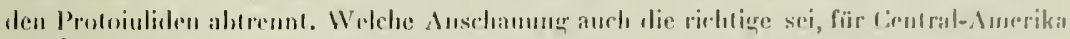

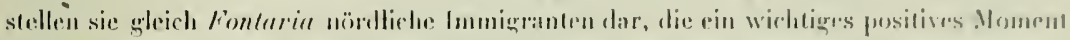
in die ecutral-amerikanische fauna gegenüher der südamerikanischen hineintragen. Isei

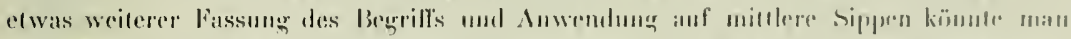
heide Gallungen dem arkfofertiären Element der Pflanzengengraphen assimilieren. Vur

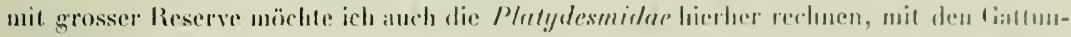

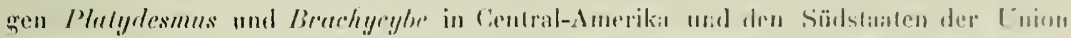

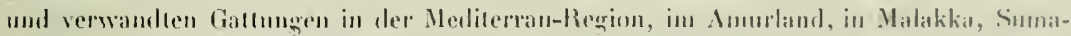

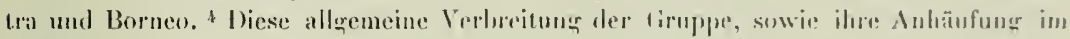
südlichen Nord-Amerika, in Mexiko und tiuatemala, macht idure nördliche Ilorkunft sedar

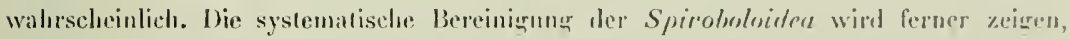
inwieweit die im Vergleich zu Südamerika reichere mul manuigfaltigre Vertsetung dieser

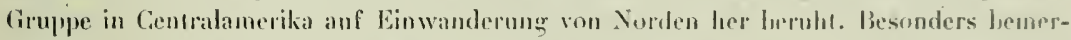
kenswert ist in dieserllinsicht die kleine, originelle, auf Mexicu und Guatemala lesshränkte Gruppe, die Pocock in der "Biologia Contrali-anericana "irlümlich zor liatlung Spirnbolellns rechnet. Solle sie nähere Verwandlschaftsbeziehungrn zum Clsinesischen Zweier „ler Spiroholiden aulweisen? Sichere Eumanderer von Norden lier sind lie zwei einziren

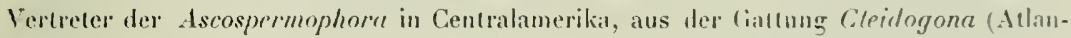
lische Staten der Lnion, Mexien, Guademala); wrwandte Gallungen findet man in der Union, in Siebenbürgen und im tiebict der Seealpen. "

Noch sei eines aulfälligen Znges der crntral-amerikanischen Dipoplorlenfauna gedaclı ;

1 Von der Gattung Fontaria in weiteren Sinn sind verschiedene Artgruppen als besondere Gattungen oder Untergallungen abgetrenut worden. Abgesehen davon, dass diese Aufteilung noch vielfacla der Begründung bedarf und der Rang dieser Gruppen noch versehieden heurteilt wird, ist fontaria in sinne von Siussure u. llumbert hinreichend scharf und nalürlich nmgrenzl, um in zoogeographischen liragen als Sipl." beibehalten zu werden.

9. Arliv för Zoologi. Bd. 5, No 3. p. 30, igog.

s Zool. Ans. Bd. AXXIII, p. 535, 19ı.

4 Vil. Cinr, in: Rev. Suisse de Zool. rol. 20, p. 514-518, 1912.

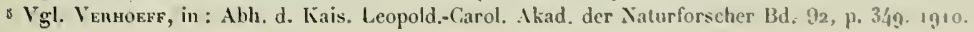


das ist ihr Reichtum an Arten nicht nur, sondern auch an Gattungen, Subfanilien und Familien, der le'sonders für die ggeologisclı jugendlichen Gebiete südlich von Mexiko nur in einer starken Zuwanderung bereits dilferenzierter Gatlungen aus benachbarten Gebieten eine Erklärung findet. Als primäre oder sekundäre Entwicklungrggebiete kommen einmal die alte nordamerikanische Festlandmasse und ilıre mexikanische Halbinsel, sodann der süılamerikanische liontinent und besonders das nördliclıe Andengehiet und dessen alte Verbindung mit Nord-Amerika in Betracht; über die Rolle der Antillen kann man heute noch sehr wenig Bestimmtes aussagen.

Zusammenfassend lässt sich also über das Verhälunis von Central-Amerika zu SüdAmeritia linsichtlich der Diplopodenbevölkerung etwa folgendes feststellen: Gemeinsam sind beiden Gebieten alte circumtropische oder wenigstens transpazilische Gattungen; ein Teil derselben kommt aber iı Süd-Amerika nur der nördlichen Andenregion zu, dic ausserdem noch einen Teil der alt-andinen Galtungen wenigstens mit dem südlichen CentralAmerika (Costarica) gemeinsam hat. Alle süd-amerikanischen Gattungen jüngeren Geprägres fehlen nördlich von Panama. Central- und Süd-Amerika haben keine einzige DiplopodenArt gremeinsan. Die Unterschiede erstrecken sich auch auf höhere Sippen und zwar zu Gunsten Central-Amerikas, das mehrere der charakteristischsten Familien und Subfamilien seiner Fauna durch Einwanderung von Norden her erhielt. Diese Inmigranten sind entweder rein nearktische Gruppeu oder rückgewanderte Dillerenzierungsprodukte neotropischer Nordwanderer der alten Verbindung. Sie haben ihr heutiges Verbreitungszentrum im Süden der Union, in Mexiko und Guatemala und nur vereinzelte Vertreter in Costarica, fehlen aber südlich von Panama. Bezeichnend für ihre unmittelbare Herkunft ist ihr staffelförmiges Erlöschen gegen Süden hin, wobei der Süden von Guatemala für die meisten, Panama für den Rest die Südgrenze bildet. Ihre Südwanderung, die den grossen Reichıum selbst der jungen Teile Ceutral-Amerikas mitbedingıt, hängt offenbar mit der Verarlelscherung Nord-Amerikas zusammen. Ein recenter Austausch der Fauna über das heutige Panama ist nicht zu konstatieren. Die gemeinsamen Züge sind also einer älteren Lundverbindung, die unterscheidenden Bestandteile beider Faunen einer langen Trennung und der Bedeutungslosigheit der heutigen Verbindung beider Kontinenthälften für den Ausgleich suzuschreiben.

Die Fauna des eigentlichen Nord-Amerika hat mit derjenigen Süd-Amerikas nur indirekte Analogien durch Vermittung Central-Amerikas, daneben aber ihren eigenen Charakter, auf den wir hier nicht näher eingehen können.

Indem die alten Bezielıungen Central-Amerikas zu Süd-Amerika das Andengebiet in stärkerem Grade betreffen als das ïbrige Süd-Amerika (vgl. S. ${ }^{8} 7$ ), lassen sie auf eine westliche Lage der alten Landverbindung und zugleich auf eine gewisse Sellständigkeit -des nordwestlichen Südamerika zur Zeit jener Verbindung schliessen ; für letztere spricht auch der Nachweis eines alt-andinen Faunen-Elements.

Die obigen Verbreitungstatsachen lassen sich ohne Mühe mit den Ergebnissen der Geologie und den Resultaten der vergleichenden Faunistik anderer Tiergruppen in 


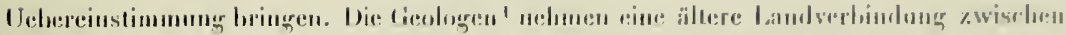

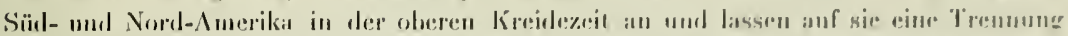

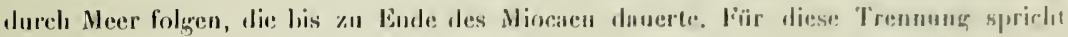

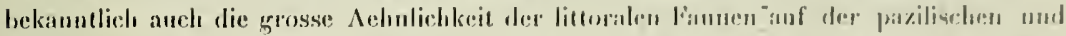

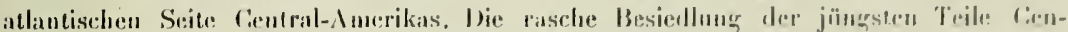

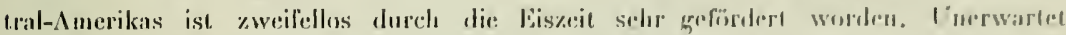

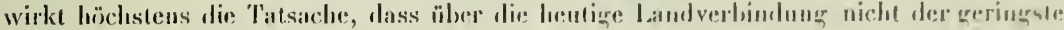

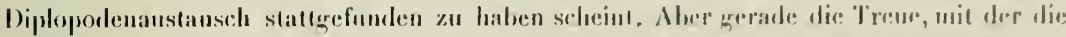

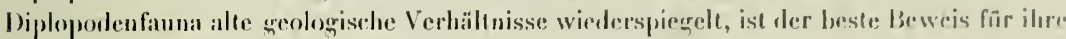

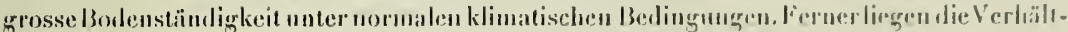

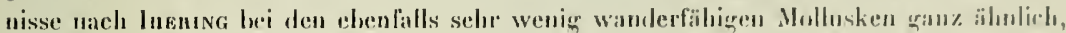
und endlich handelt es sich in denjenigen Fillen, wo ein starker Ansgleich staltgefonden hat, meistenteils un Tiergruppen von grossem aktivem oder passivem Verloreilungsvermïgen. Bin weiterer Faktor, des fïr die Scheidun der Bodenfannen seit dem. Mincaen sehr in

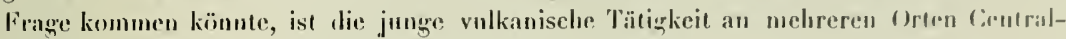
Amerikas. Detailliertere Üutersuchungen werden erst zeigen, welche Rolle dir Eruptirnurn und deren oekologische Folwen als Sehranke für langsam wanternde Bodentiere grespielı haben mögen.

Zum Schlusse sei noch dirauf anfmerksam gremacht, dass in Sïd-Amerikis dir oft hetonte gegenwärtige Sellsstïndigkeit der andinen Diplopodenfauna mit Bezug auf diu: jüngeren niederen Sippen in orographischen Verlältnissen eine hinreichende Erklärung findet, während für die im alt-andinen Element und in der Verbreitung einiger transpitzifischer Galtungen zum \usdruck kommende ältere Selbständigkeit vielleicht anch die ehemalige Amazonas-Bucht und die ihr entgegenkommende La Plata-Bacht verantwortlich gremacht werden können. Die lienntnis der Diplopodenfauna Guayanas und ihr Vergrleich mit derjenigen Brasiliens und Columbiens könnte einiges Licht anf diese Frage werfen.

Indem wir diese Thesen, Suggestionen und Probleme weiterer faunistisclier und systematischer Forschung zur Prüfung vorlegen, möchten wir nochmals anf die grosse Bedeutung der Diplopoden als palaeogeographische Dokumente hingewiesen hahen. "Sie sind geeignet, uns noch heutigen Tages faunistische Verhältnisse zu beurkunden, die bri der übrigen Tierwelt mehr oder wenizer stark verwischt oder überhaupt nicht mrlur erkennbar sind " (VERnOEFF).

\footnotetext{
1 Ich stütze mich auf AnLd, Die Entwielilung der Fonlinente und ihrer Lebewelt (1907).
} 


\section{TERZEICHNIS DER LITTERATUR ÜBER COLUMBISCHE DIPLOPODEN.}

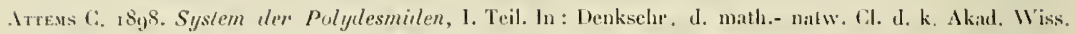

Wien, Bd. LAVII, S. 221-182, Til', 1-XI.

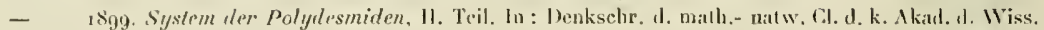
Wien, Bu. LXVill, S. $25 t-436$, Tal. Xil-XVill.

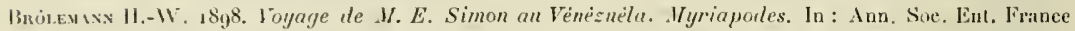
vol. LXVII, [1. 2/11-313, Pl. 20-27.

I898 a). Myriapodes du Haut el Bas Sarare. In: Ann. Soc. Ent. France vol. IxVII, p. 3 г $4-336, \mathrm{Pl} .28,20$.

- 19oo. Myriapodes d'Jmérique. In: Mem. Soc. Zool. de Franee, T. XIII, 1. 8y-131, PI. VI-I’lll.

Canı J. 1902. Exotische Polyelesmidert. In: Revue Suisse de Zool. T. 10, S. 563-679, Taf. $10-12$.

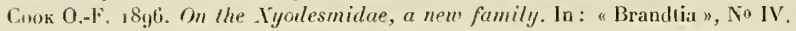

- $\quad 1896$ a). Cryptodesmus and ils allies ln: "Brandtia ", No V.

- ${ }_{1} 898$. Imerican Onisroid Diplopoda of the order Merocheta. In : Proc. U. St. Nat. Mus. vol. XX1, p. 451-468, PI. XXIX-XXXIl.

1911. New tropical Millipeds of the oreler Merochela, with an example of linetili evolution. In : Proc. U. St. Nat. Museum vol. 40, P. $451-473$, Pl. 60.

D.10. E. 1889 . Myriopoda extranea Hasaei nationalis hungarici. In: Ternesz. Füzetek, vol. ג11, P. 115-156, Tab. IV, V.

Genvis P. 1844. Etudes sur les Myriapodes. In: Ann. Sc, nat. (3e sèr.) Zoologie, vol. II, p. 51-80, pl. 5 , fig. I-Ig.

- 1847. Myriapoles. In: W.ıckevaen, Hist. nat. des Insectes aptères. T. IV, p. 1-333, pl. 37.

- 1859. Myriaporles (el Scorpions). In: F. de Castelisu, Animaux nouv. ou rares ree. pendant l'expéd. dans les parties centr. de l'Amérique du Sud, ete. T. 3,39 p., 6 Pl.

Gervis P. et Govdot J. 1844. Description des Myriapoles rec. pur J. Goulot en Colombie. In: Ann. Soe. Ent. France ( $2^{e}$ série). T. II. Bull. entom. p. XXVil-XXIX.

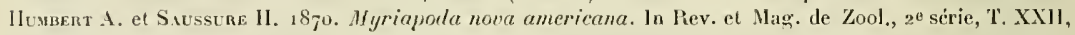
p. $172-177$.

Kunscu F. 1881. Teue Juliden des Berliner Museums als Prodromus einer Juliden- Honographie. In: Zeitschr, I d. «res. Nilurwiss. Bd. LJV, S. 1-79.

- 1881 a). Zum Studium der Myriapoda Palydesmirt. In : Areh. f. Naturg. Bd. 47, S. 36-48, Taf. 111.

Tewpont 1844. A list of species of Myriopoda, Order Chilognatha, contuined in the cabinets of the Brit Huseum etc. In : Ann. a Mag. ol Nat. Hist. (ser. 1). T. NIll, p. 263-27o.

PETERS W. 1861. Uebersich der im Kgl. soolog. Wuseum befindlichen Mlyriopoden aus der Familie der Polydesmi. In : Monatsler. d. kgl. Akad. d. Wiss. Berlin, 1861, S. 520-55i und (Nachtrig) S. 617-627.

Pососк R. J. 1805-1910. Chilopoda and Diplopoda. In: Biologia Centrali-Americana, 217 P., 15 PI. Ponst C. 0. 1876. Om uagra exolistia Myriapoder. In: Bih. Hill. k. Sv. Vel. Akitd. Ilaull. Bd 4, No 7 , p. $3-38$.

- Dieses Ver\%eichnis enthält nur diejenige Litteratur, auf welche im Verzeichnis der Columbischen Diplopoden Bezng genommen wurde; die übrige Litteratur ist, soweit nölig, im Text angeführt. 


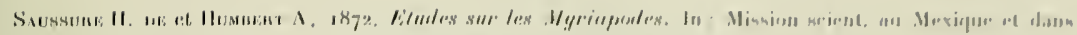

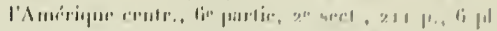

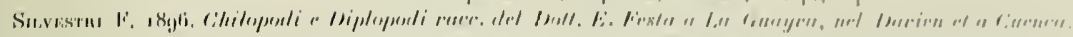

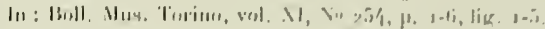

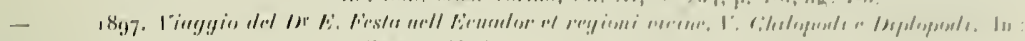

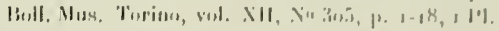

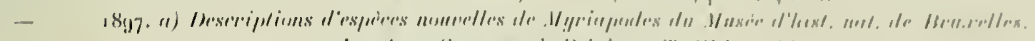

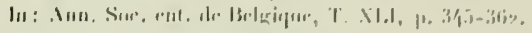

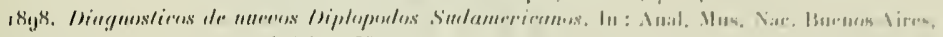
vil. $11,1,53,3=7 ! 1$.

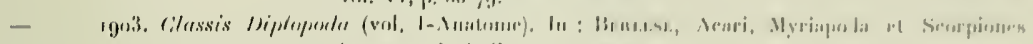

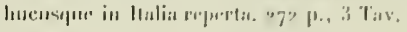




\title{
BEITRAGE
}

\section{$Z U$ R \\ Laubmoosflora von Columbien}

\author{
Dr E. IRMSCHER, Berlin-Steglitz
}

(Mit Taf. XIX und XX.)

\begin{abstract}
Die im folgenden behandelten Bryophyten wurden von Herm Dr Eug. Mayok auf einer Forschungsreise durcli Columbien gesammelt und mir freundlichst zur Bearbeitungr äberlassen. Die Bestimmeng der Lebermoose verdanke ich Ilerrn Stepuns und die der Torfmoose Ilerrn WArssorf, dem Monographen der Gattung Sphagnum, während Herr Prof. Brotnenus die Güte gehabt hat, die Laubmooshestimmungen zu revidieren. Genannten IIerren sei auch an dieser Stelle für ihre Benühungen herzlichst gedankı. Der systematischen Anorduung ist die Bearbeitung der Bryophyten in Engler-Prantu, Natïrliche Pflanzenfamilien zu Grunde gelegt.
\end{abstract}

\section{Hepaticae}

\section{Fam. Marchantiaceae.}

Marchantia (l.) Ravel.

1. Marchantia discoidea STEP11.

Central-Anden, Dep. Antioquia, Wald bei der Laguna gegenüber von Medellin nm ${ }_{2} 300 \mathrm{~m}$, auf Erde (1. $57-8$. VIJI). 
2. Marchantia colunbica Sín.s.

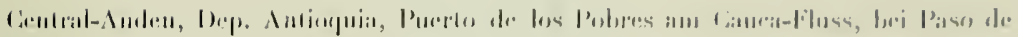

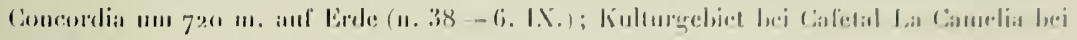

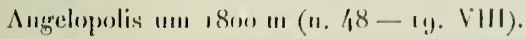

3. Marchantia spec.

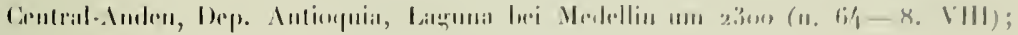

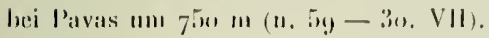

\section{Fam. Jungermanniaceae akrogynae.}

\section{Plagiochila (1)и.) Simucr.}

\section{Plagiochila Hans Meyeri S'TEPll.}

Central-Anten, Dep. Antionuia. Bri Angelopolis um 17m m. (11, $7^{2}-12$. IX).

5. Plagiochila ovifolia Sreptu.

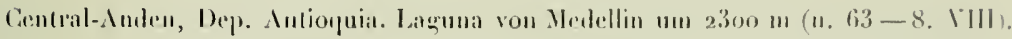

6. Plagiochila oblongo-trigona STElll.

Ost-Anden, Dep. Cundinamarca. Paramo Cruz Verde oberhalb Bogrola, um 3300 in (n. $87 f-14 . x)$.

7 Plagiochila ovato-obconica SterII.

Central-Auden, Dep. Antioquia. Wälder oherbalb ron Cafelal La Camelia lrei Ingelopolis $11112100 \mathrm{~m}$ (11. $52 d-27$. VIII. 19(0).

\section{Mastigobryum Xies.}

\section{Mastigobryum columbicum Steriı.}

Ost-Imen, Dep. Cundinamarca. Boqueron de linachuni ïher dem Tal voi Viola IIII 2 40o m (11.83a-24. X).

Central--Indeu, Dep. Intioquia. Bei Pavas nm -ĭo m in. 60. - 3n. VII. 


\section{Radula Nisis.}

9. Radula Sprucei Sirpu.

Central-.Inden, Dep. Antioquia. Paramos de Ruiz um 3700 m (11. 8ob. - 5. .)).

\section{Taxilejeunea spucs.}

10. Taxilejeunea auriculata S'repu.

Central-Inden, Dep. Antioquial. Bei Tiliribi un 1900 m (n. 66- 29). VIII).

11. Taxilejeunea prominula Goтtscue.

Central-Auden, Dep. Tolima. Aguacatal um 2500 แn (n. $77 a-5 . \mathrm{X}$ ).

\section{Omphalanthus Lindenb. et Nees.}

12. Omphalanthus filiformis (Sw.) NeEs.

Ost-.Inden, Dep. Cundinamarca. Baqueron de Guachuni über dem Tal von Viola um $2400 \mathrm{~m}$ (n. 83 b. $-24 . \mathrm{X})$.

\section{Frullania Raddr.}

13. Frullania coalita

Central-Anden, Dep. Antioquia. Bei Titiribi um 1800 m (n. 68 -4. IX). Ost-Anden, Dep. Cundinamarca. Tambo bei Tena um rgou m (n. $84 b-18 . \mathrm{X})$.

\section{Frullania okanniensis StePH.}

Central-Amlen, Dep. Antioquia. Bei Titiribi um $1900 \mathrm{~m}(\mathrm{n} .67-4.1 \mathrm{X})$.

15. Frullania gibbosa Nees.

Central-Inden, Dep. Antioquia. Wiesen in der Nähe von El Poblado lei Medellin, uแn $1700 \mathrm{~m}$. Auf Graniblöckeı (n. $56 c-14$. VIII. 1910). 
16. Frullania longicolla $1 .$, it $\mathrm{f}$.

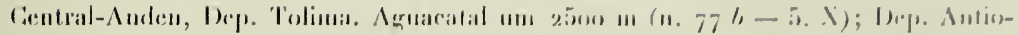

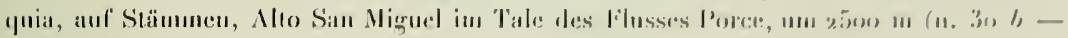
2(i. IX).

17. Frullania riojaneirensis Rimn.

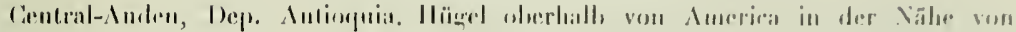

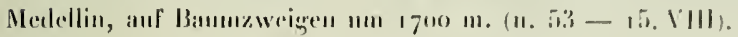

18. Frullania Mathanii S'rrin.

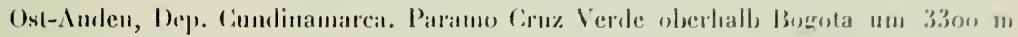
(i. $87 c-14 . \mathrm{N})$.

Central-Auden, Dep. Antioquia. An Banmstämmen in der . Vähe der Lagnua oherball,

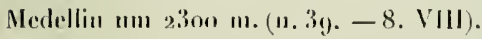

19. Frullania Lechleri Strip..

Central-Anden, Dep. Aulioquia. Alto San Miguel in Tal des lilusses Porre un $2.000 \mathrm{~m}$. An Baumstämmen (n. 32, $-26.1 \mathrm{X})$.

\section{Musci}

\section{Fam. Sphagnaceae.}

\section{Sphagnum (DuL.) Ennu.}

1. Sphagnum medium Limer.

Ost-Anden, Dep. Cundinamarca. Paramo Cruz Verde oherhalh Bogota um 3 fon m an fenchten Stellen (n. $26 a-14 . \mathrm{X}$ ).

2. Sphagnum Lehmannii Warsst, var. aequiporosum Warxst. nov. var.

Folia ramulina utraque superficie multi-et aequiporusa.

Ost-Anden, Dep. Cundinanarca. Paramo Cruz Verde, wherhall Bogota an feuchten Stellen (n. $26 c-14 . \mathrm{X})$. 


\section{Fam. Dicranaceae.}

\section{Ceratodon 13n11.}

3. Ceratodon venezuelensis L. MüLL.

Dit-Anden von Subia, Dep. Cundinamarca. Boqueron de Guachuni üher den Tal ron Víola $\mathrm{um}$ 2quo m., anf Erde (n. 2-2\}. X).

\section{Ceratodon purpureus (I.) BuD.}

Central-Anden, Dep. Antioquia. P'aramo de Ruiz um 3600 m., auf Erde (n. 々 - 5 . I), gemeinsam mil Bryum argentenm L. v. lanatum (P. Beauv.) Br. cun.

\section{Dicranella Scmis.}

\section{Dicranella macrocarpa Brotн. et Irusciser nov. spec.}

Diocca; dense vel laxius caespitosa vel singularis, rigida, viridis vel luteo-viridis, non nitilit. Cantis $4-5 \mathrm{~mm}$ longus, erectus, strictus, basi radiculosus, densiuscule foliatus, simplex vel superne innovationibus brevibus instructus. Folia sicca erecto-appressa, superiora paulum secunda, lıumida omnia secunda, non decurrentia, inferiora 1,5-2 mm longa, oblongo-lanceolata, superiora 2-2, $6 \mathrm{~mm}$ longa, e basi obovata subito latiuscule lanceolata, apice obtusiuscula et minute denticulata rel acuta, marginibus excepta parte inferiore revolutis integerrimis, nervo crasso medio $0,05-0,07 \mathrm{~mm}$ lato infra summum apicem evanido instructa, cellulis laevibus laminalibus mediis breviter rectangularibus saepe subquadratis i 2-1 $8 \%$ longis, inferioribus longe rectangularibus triplo longioribus. Bractere perichaetii foliis superioribus similes, paulum longius acuminatae ; seta excepta c.1psula 10-12 mm longa, sicca flexuosula, tenuis, laevis, lutea ; theca erecta, asymmetrica, ovalis, 1-1,2 $\mathrm{mm}$ longa, collo brevi et angusto instructa, estrumosa, deopereulata sicca sub ore constricta, haud plicatula, castanea; annulus $45 \mu$ latus ; peristomii dentes circ. $0,33 \mathrm{~mm}$ longi, rufescentes in crura dua rarissime tria $2 / 3$ longitudinis metientia divisa, extus inferiore parte indivisa lamellis 7-8 longitudinaliter punctulato-striolatis, cruribus pallidis superne filiformibus transversim papilloso-striolatis instructi, intus linea mediana llexuosa el tralıcculis 5-6 crassiusculis margine papillosis ; spori i 5 p., nuinutissime papillosi ; operculum o,7-0,8 mm longum, e basi brevi conica longe oblique subulatum (Tah. XIX, Figr. 1-y).

Centrol-Anden, Dep. Antioquia. An der Eisenhahn von Medellin zwischen Caracoli und Cisneros um $800 \mathrm{~m}$, auf Erde (n. 33九 - 31. VII, mit jungen und alten Früchten, zwischen einer Riccia wachsend). 


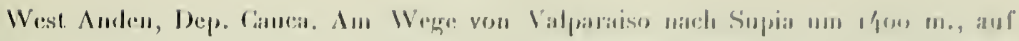
Lirile (11, 16-29. IX, 19101).

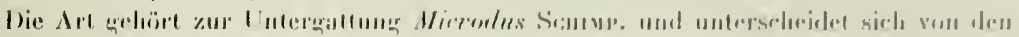

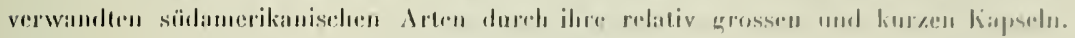

\section{Dicranella Mayorii limun. el Iıмsintil nov. spec.}

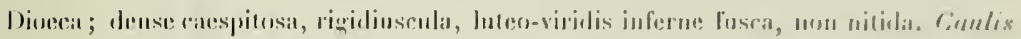

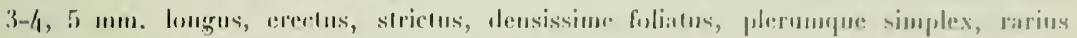

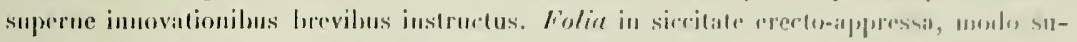

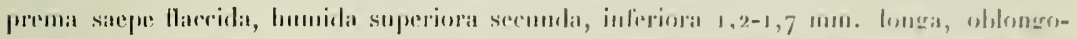

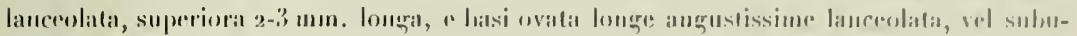

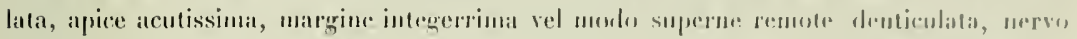

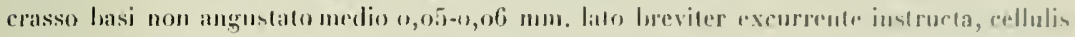

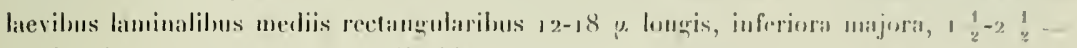

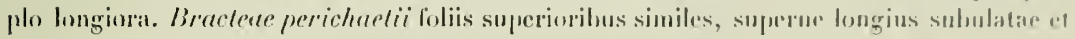

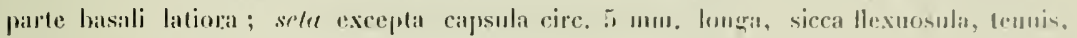
lacvis, fusca ; thece sicea paulum inclinata, inarpualis, asymmetrica, orilicio oblipuo ins-

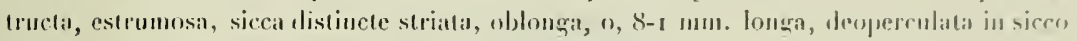
sul, ore paulum constricta, castanea ; peristomii dentes circ, 1, 22 mum. Iongi, modo infuna hasi rufescmess, reliqua parte hyalini, in crura dua 23 longhudinis melientia divisi, extus parte indivisa lamellis $5-6$ minutissime vix conspicue longitudinaliter strulatis obsiti, intus linea media valde llexuosa el traheculis /-j) eroso-papillosis instructi; sprori

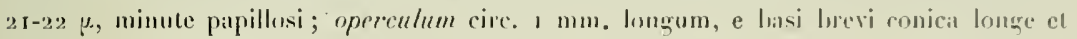
paulum oblique subulatum.

Central-Audeu, Dep. Antinquia, Alen San Mirum, im oberen Trile des Tiales des lilusses Porce um 2500 m., auf Eide (I. 14 - 26. I. ).

\section{Dicranum Henw.}

\section{Dicranum Wallisii C. M[ïll.}

Ost-Anden, Dep. Cundinamarca. Paramo Cruz Verde un $30 n 0$ m. (11. 8; $a-14 . \mathrm{X})$.

\section{Campylopus Bnun.}

8. Campylopus porphyreodictyon L. MüLL.

Central-Anden, Dep. Antioquia. Wälder hei Cafetal La Camelia hei Ingedopolis um 1800 m., an Baumstämmen (n. 36 und $47-2.1 X)$, chenda (n. 4 I -21 . VIII), ebenda 
um $2000 \mathrm{~m}$. in Gesellschaft ron Isopteryginm tenerum, Lepidopilum sprucei und Plugiochila ovato-obconica SrepH. (11. $52 b-27$. V111).

\section{Pilopogon Briv.}

\section{Pilopogon gracilis BณD.}

Ceutral-.Inden, Dep. Intioquia. Paramo de Ruiz um 3700 m., auf Lrde (u. 3-5. X); ügel, oberhall America bei Medellin um 1700 m. (n. $51 b-15$. VIII).

Ost-Inden, Dep. Cundinamarca. Paramo Cruz Verde oberhalb Bogota um 30oo3500 m. (u. $8-15 . \mathrm{X}$, n. $87 b-$ r5. X); hei Bogota um 2700 m. (n. $82-16 . \mathrm{X}$ ).

\section{Pilopogon Mülleri (Hamp.) Brotr.}

Ost-Anden, Dep. Cundinamarca. Paramo Cruz Verde oberhalb Bogota um $3200 \mathrm{n}$. (11. $87 e-15 . \mathrm{X})$.

\section{Fam. Leucobryaceae.}

Leucobryum. Il Aur.

11. Leucobryum spec.

Central-Anden, Dep. Antioquia. Bei Titiribi um 1900 m. (n. $71-4.1 X)$.

\section{Fam. Pottiaceae.}

\section{Trichostomum lleDw.}

\section{Trichostomum Raapii Brotu.}

Central-Anden, Dep. Antioquia. Bei Titiribi un 1900 m. (n. $69-4$. IX).

13. Trichostomum novo-granatense Brotu. et Irmscher nov. spec.

Gracilis, densiuscule caespitosa, rigidiuscula, inferne brunnca, superue viridis vel glauco-viridis. Canlis 8-14 $\mathrm{mm}$. longus, erectus, vix radiculosus, densiucule foliatus, plus minusve ramosus. Folia inferiora minora, superiora conferta, sicca complicata incurvohamata suprema crispula, lumida e basi erecto-patente leniter sursum curvata vel distincte reflexa, longiuscule lineali-lingulata, $2-2,7 \mathrm{~mm}$. longa, apice subito acuninata, nervo breviter excedente mucronata, basi non decurrentia, margine incurvo integerrima, nervo crassiusculo medio $65-75 \mu$. diametro metiente excurrente instructa, cellulis quadra- 


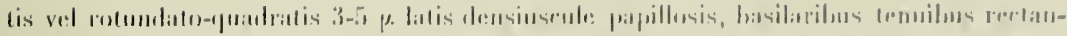

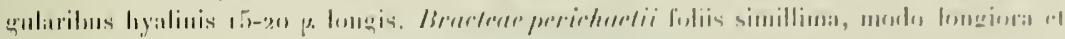

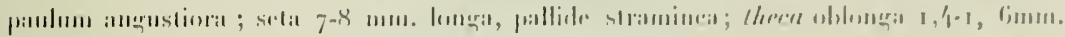

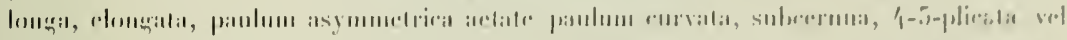

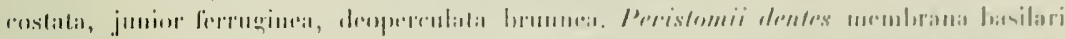

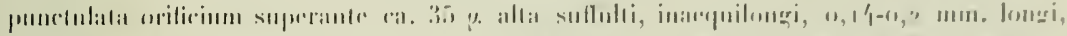

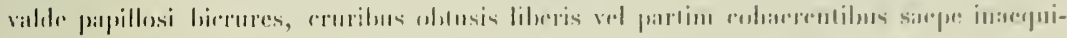

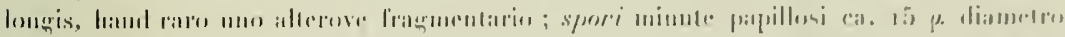

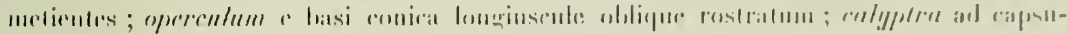

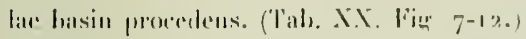

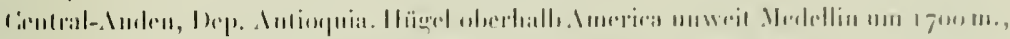

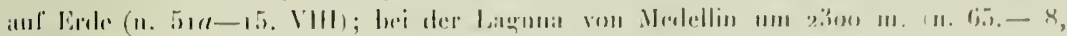
(III).

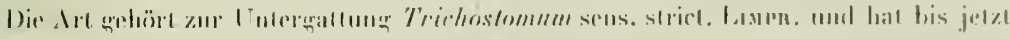

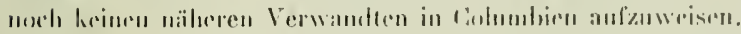

\section{Leptodontium (IL.M!.).}

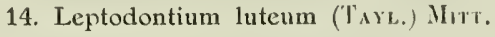

Ost-amlen, Dep. Cundinamareat. Mhlänge des Montserrate olurhall, Bogota um $2860 \mathrm{~m}$, anf Erde (11. $236-16 ., 1)$.

\section{Lcptodoutium Fuhrmannii Bnotu. d lnuschen nov. spec.}

Dioica; gracilis, laxe caespitosa, inferne mubesens, superne alro-virilis. Caulis usinue at $5 \mathrm{~cm}$. longus, suberectus rel arcuito-iscrndens, vix randiculosus, laxe foliosus, inferue modo nervis relictis obsitus, satepe simplex. Folion non nitida, sicca crispata, nom appressa, patentia, humida a basi clecto-patuntial, non refleva, carinato-conciva, non decurrentia,

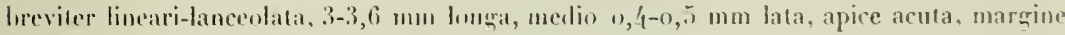

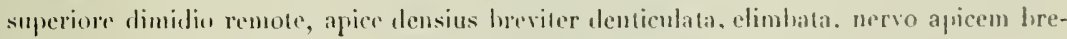
vem acutum formante dorso laxe papilloso instructa, cellulis superiorilus roundatoquadratis minute verrucosis 6-1) p. dianedro medientibus, basilarihms rectangularibus hyalinis phuripapillosis, 2 - $-30 \mu$ longis, infumis hevihus longioribus, marginalihus yuam interiores minorilus. Caterai ignotit.

Ost-Anden, Dep. Cundinamarca. In der Nähe der Schluche von Tequendama um

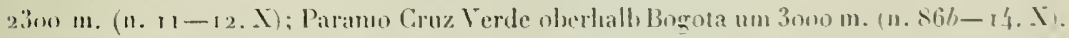

Die Pllanzen von beiden Standorten sind välig identisch und stellen eine von allen bokannten soldr abweichende. Irt dar.

126 


\title{
Barbula Heww.
}

16. Barbula apiculata $1 \mathrm{~A} M \mathrm{r}$.

Ost-Inden, Dep. Candinamarea. Weg nach dem Paramo Cows Verde obrihalh Bogola um $28(6)$ m, aut Erde (n. $28-14$. et 15, X).

\section{Tortula Her,}

17. Tortula spec. (Sect. Syntrichia [BRID.] HARTM.)

Dit die Bläter bis auf die Rippen zerstört siml, war eine nähere Bestimmung Immö̈glich.

Ost-Anden, Dep. Cundinamarea. Uhaque $4 m 2000 \mathrm{~m}$ (17. 85a-r5. X).

\section{Fam. Orthotrichaceae.}

\author{
Zygodon Hook, et Tart.
}

18. Zygodon subdenticulatus НАMP.

Central-.Inden, Dep. Antioquia. Alto San Mignel im oberen Teil des Tales des Flusses Porce um s500 m., an Baumistämmen (n. 31-26. IX).

\section{Macromitrium $\mathrm{BR}$.}

19. Macromitrium spec.

Central-Anden, Dep. Antioquia. Nto San Niguel, im olseren Teil des Talesdes Flusses Porce um 2500 m., an Baumstimmen (n. 30-26. 1X).

20. Macromitrium spec.

Central-Anden, Dep. Antioquia. Unweit der Laguna von Medellin, an Baumstümmen mm $2300 \mathrm{~m}$. (11. 40-8. I'll1). 


\title{
$-11, .3-$ \\ Fam. Splachnaceae.
}

\author{
Tayloria How.
}

21. Tayloria Mayorii limitl. "l lıмstur:s nov. spec.

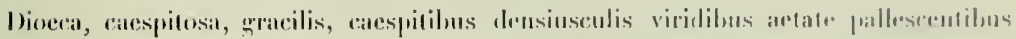

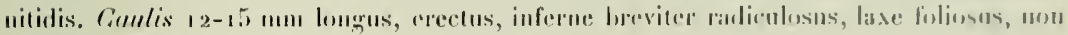

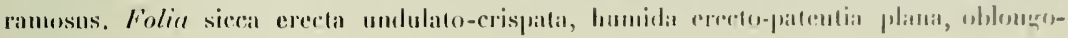

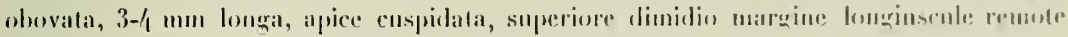

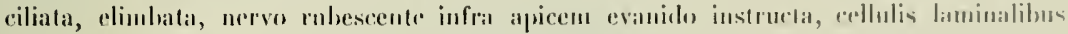

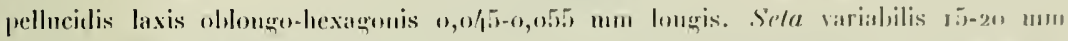

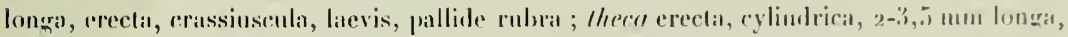
$0,5-0,8 \mathrm{~mm}$ lata, olivacea, lasi subito in collum brevissimum contracta ; peristomiom

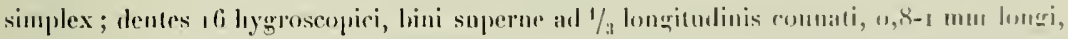

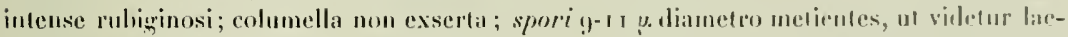
ves ; operentum cire. I mm longum ex basi hrevi conico hreviter strictn-erecto-rostralum, apice obusinsculum ; calyplea r, is mu longa, conica, basi loreviter laciniata, inferme pilis longiusenlis pluricellularilus spansin, superne lorevoribus vel brevissimis densissine olssita. (Tals. NIX. Fïg. 10-15.)

Ost-Anden von Sulsia, 1)ep. Cundinamarea. Bal Bupueron de Guatehmi, äber alem Tal

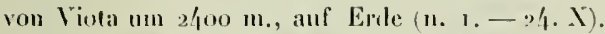

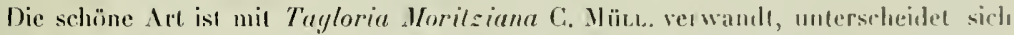
jecloch sofort durch die riber doppelt so lange Seta und die länger walzenförmige Theca.

\section{Fam. Funariaceae.}

\section{Funaria scunen.}

22. Funaria calvescens SimWdegn.

Central-Anden, Dep. Antioquia. Culturgebiet bei Cafetal La Camelia bei Intelopolis IIm 1800 m., auf Erde (II. 44-28. VIII). 


\section{Fam. Bryaceae.}

Mielichhoferia llonscu.

23. Mielichhoferia spec.

Wegen ganz zerstörten Peristomen mulustimmbar.

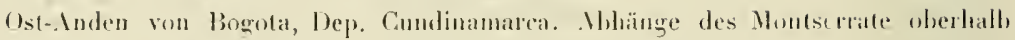
Bogota um 2800 m, auf Eide (1). 21 und $25-16$. X).

\section{Bryum I)HL.}

\section{Bryum Mayorii Buот. el lямsник nov. spec.}

Dioica ; laxe caespitosa, rigida lutescens, Havo-virens. Canlis erectus stricus brevissimus $1, \bar{j}$ mm longus, basi radiculosus, densiuscute foliosus, innovationilus multo longiorilus gracilibus siceis incurvatis $6-10$ mm longis obtusis instructus. Caudiculormu fortilium folia inaequalia, sicca arcte imbricata, lrumida erecto-patentia, breviter lanceolati, 0,7-1,2 $\mathrm{mm}$ longa apice sensim acuminata el nervo excedente aristata, margine subintegra vel superne sparsissime, remote ac breviter denticulata, laud limbatit, basi non decurentia, nervo medio 25-30 y. lato breviter excurrente, cellulis superiorihus et mediis

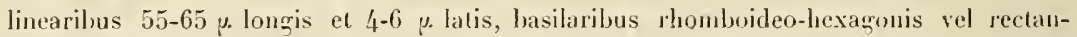

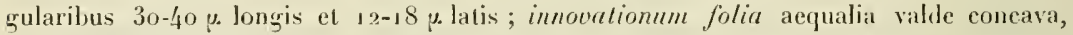
ollongo-ovata, г,0-1,2 mm longa, cellulis superioribus et mediis brevioribus et latioribus. Seta \3-16 mm longa, tenuis, sicca llexwosa, pupurea ; theea subhorizontaliter patens ovalis vel late obovata, collo theca paulum breviore et vix angustiore, laevis, sicco sub ore haud constricta, demum brunnea; peristomium duplex, exostomii dentes $0,63 \mathrm{~mm}$ longi et medio $0,009 \mathrm{~mm}$ lati, Jyaline limbati, superne sulssubito angustati el apice subulati, papillosi, lamellis $40-45$ valde approximatis sulfulti, fusei; endostomii lyyalini minutissime papillosi corona hasilaris ultra medium dentium producta, jocessus carniati 5-6 perforati, cilia terna, lene evoluta, processibus aequilonga, longe appendiculata; spori g- 0 . latilaevissimi ; operculum majusculum cupulatum mamilhatum nitidum ferrugineum. (Tab. XI, Fig. 1-6.)

Central-Auden, Dep. Antioquia. Alto San Miguel am Ende des Tiales des lilusses Porce um $2500 \mathrm{~m}$, aul Erde (n. $15-26.1 \mathrm{X})$.

Die ausgezeichnete, neue Art gehört zur Untersect. Enbryum un zwar zur Gruppe Alpiniformia hivdo, von der bis jetzt noch kein Vertreter aus Columbien bekann war. 
25. Bryum bulbillosum Yari.

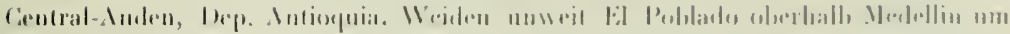

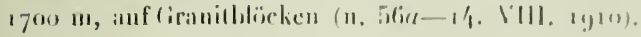

26. Bryum argenteum L. var lanatum (1', Brirvo) Bur.

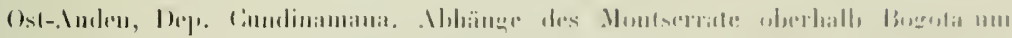

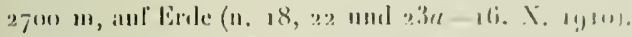

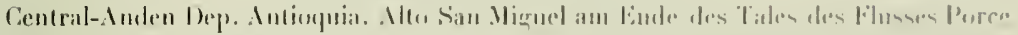

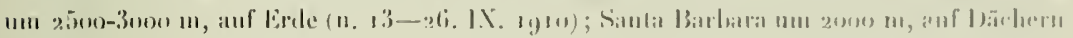
(11. 29-2) IX. 1911).

27. Bryum pycnopyxis 1 :. Mïı...

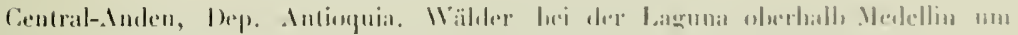

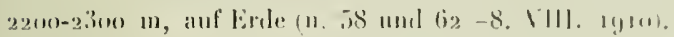

\section{Fam. Bartramiaceae.}

\section{Bartramia 11 เıw.}

28. Bartramia dilatata Bum. (口 lıмs:ms nov. spec.

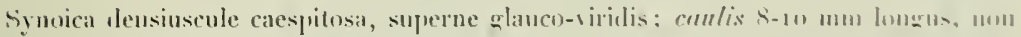

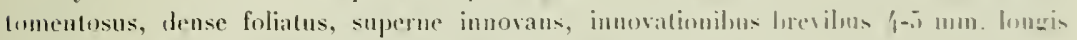
erectis ; folin sicea erecto-appressa, paulum flexuosula, lounida palcntia paulum secumda, e hasi hyalina superne dilatata subito lanceolata, 3-3., mum lonea, nervo excedente lireviter aristala, marminilus siccis incurvis parte laminali luta longimdine densiuscule serrata, Lasi non deeurrentia; nervo usque ad apicem a lamina distinctu in aristam lorevem serrattam producta, medio 6e-jo y. lato, cellulis basilarilus vaginam furmantilus layalinis linea-

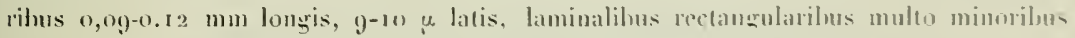

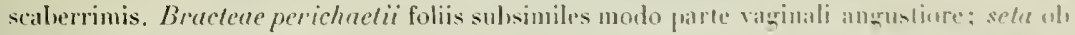

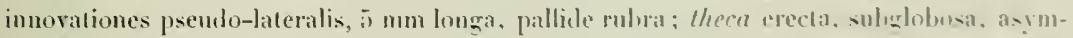

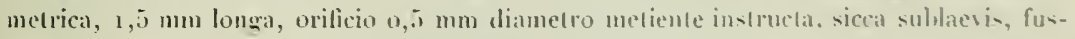
cidula; peristominm nt viletur duplex valde destructum.

Ost-Anden, Dep. Cundinamarea. Paramo Cruz Verde oherhalh, Bogotam 37om m, anf Erde (n. $9-1$ i. X). 
29. Bartramia fragilifolia C. Müıь.

Ost-1uden, Dep. Cundinamarca. Abhang des Montserate oherhalb Bogota um $2800 \mathrm{~m}$, , auf Erile (I) 17,20 und $24-16 . \mathrm{X}$ ).

\section{Philonotis Bки1.}

30. Philonotis tenella C. MüLt.

Central-Aulen, Dep. Antioquia. Bei Tiliribi un ugoo m. (11. 73 und $74-4.1 \mathrm{X}$ ).

\section{Breulelia sims.}

31. Brentelia sphagneticola Bнотн. et Irmscurk nov. spec.

Dionea, inter spluagni caules solitaria, gracilis, inferne fusco-viridis, superne luteoviridis. Canlis ad $5 \mathrm{~cm}$. longus, subercetus, llexuosus, elongatus, parce radiculosus, densissime foliatus, ramis plus minusve tenuibus brevibus irregulariter saepe subfasciculatim instructus, apice oblusus. Folia densissime conferta, sicca erecto-appressa vix secunda, humida paulum secunda, non decurrentia, sicca longitudinaliter profunde plicata, e basi late ovata concava plicata breviter lanceolata anguste acuminata et nervo excerlente aristata margine revoluta superne ad $\% / 3$ longitudinis leviter et remote, apicem versus argutius denticulata, nervo tenui, medio $28-32 \mu$. diametro metiente breviter excurrente instructa, cellulis elongatis superioribus linealibus $25-30 \mu$ longis et $3-5 \mu$ latis irrequlariter papillosis, basilaribus longioribus marginem et basim versus plns minusve l'errugineis sparsin papillosis $50-60 \%$ longis, alaribus numerosis fuscescentilus abbreviatis oblongis vel rectangularibus $40-45 \mu$ longis et $15-18 \mu$ latis. Caetera ignota.

Ost-Anden, Dep. Cundinamarea. Paramo Cruz Verde oberhalb Bogota um 340o m. (11. $26 b-14 . \mathrm{N})$.

Die Stengel dieser Art fand ich cinzeln in den Rasen der oben genanuten Sphagna wachsend.

\section{Breutelia falcatula Brotn, el InssGnen nov. spec.}

Diveca, rolusta, laxe caespitosa, inferne fusea superne luteo-viridis. Caulis erectus $3-6 \mathrm{~cm}$ longus crassitudine valde variabilis, sparsim ralieulosus densissime foliatus pseudodichotome ramosus, apice obtusus. Folia densissime conferta sicca longitudinaliter anguste plicata, sicca et lumida secunda apicibus plus minusve flexuosa, non decurrentia, e basi $2 \mathrm{~mm}$ lala orula sensim falcalo-lanceslata, longitudine valde diversa, 3,5-7 mm 


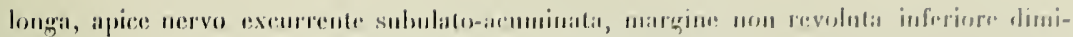

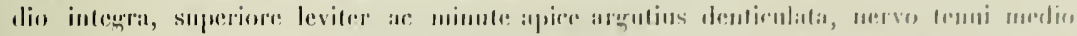

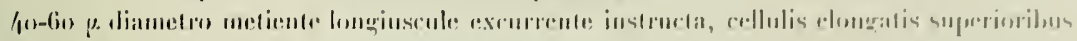

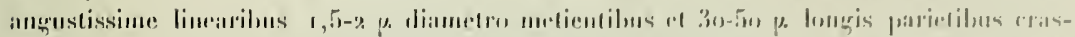

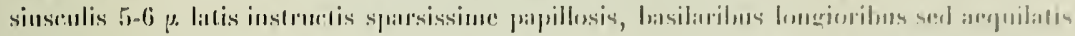

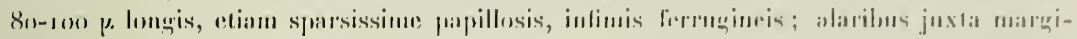

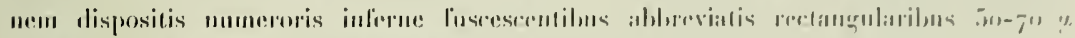

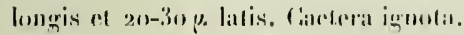

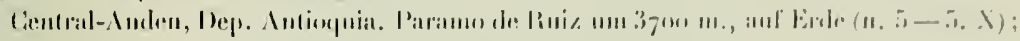

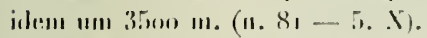

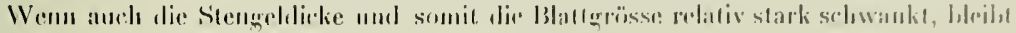

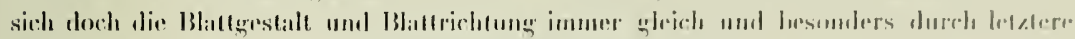

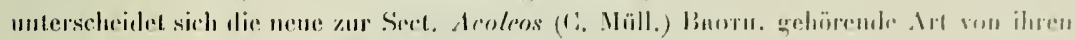
Verwamlaen anf den erstin Blirk.

\section{Fam. Polytrichaceae}

\section{Catharinea limnu.}

33. Catharinea polycarpa C. MïLs.

Central-Anden, Dep. Antioquia. Cafetal la Camelia bei Angelopolis, auf Culturland um 1800 m. (11. 37 b- 19. VIII).

Polylrichadelphus (Г. Мïll.) Мıтт.

34. Polytrichadelphus Triana (IشмP.) Mitt.

Central-Anden, Dep. Antioquia. Alto San Miguel am Eurle des Tales des Flusses Porce, III $2500 \mathrm{~m}$., auf Erde (n. 12-26. IX).

\section{Pogonatum P'ALIs.}

\section{Pogonatum neglectum II.w1י.}

Central-Anden, Dep. Antioquia. Mlo San Mliquel an Ende des Tales des fusses Porce um 2500 m., inl Erde (1) $10-26.1 \mathrm{X}$ ). 


\section{Polylrichum DıL.}

36. Polytriclum aristiflorum Mıтt.

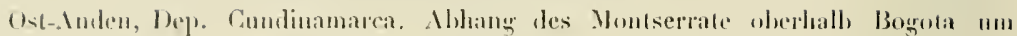
2 soo m, anf Erike (n. 19-16. X).

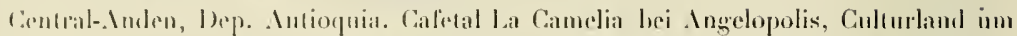

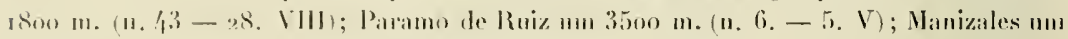

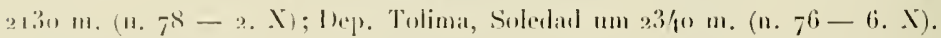

\section{Fam. Hedwigiaceae.}

\section{Rhacocarpus Linds.}

37. Rhacocarpus Humboldtii (Hnok.) LıND13.

Ost-Inden, Dep. Cundinamarca. Paramo Crnz Verde oberhalb Bogota um 3500 m., auf Erde (n. $7-14 . \mathrm{X})$.

\section{Fam. Lepyrodontaceae.}

\section{Lepyrodon HАм.}

38. Lepyrodon tomentosus (Ноюk.) Miтt.

Central-Anden, Dep. Antioquia. Pitramo de Ruiz 1 m 3500 m. an Bammstäumen (11. $27-5 . \mathrm{X}$ ).

\section{Fam. Neckeraceae.}

Squamidium (C. Мӥць.) Виотн.

39. Squamidium nigricans (1оoк.) Bвоти.

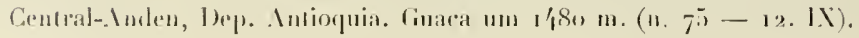




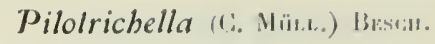

40. Pilotrichella flexilis (Sw.) Bum

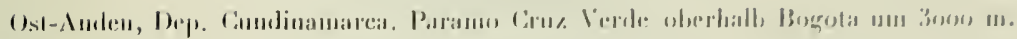
(II. $86 a-1 / . \lambda)$.

\section{Papillaria (1:. Mïiı...) c., Mïı...}

41. Papillaria appressa (Ilumsion.) lakis.

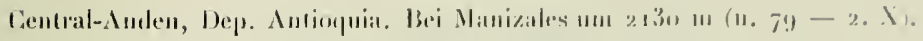

\section{Meleoriopsis litist:H.}

42. Meteoriopsis patula (Si.) Burom.

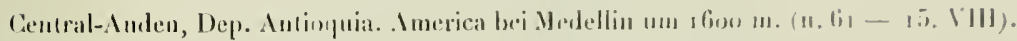

\section{Phyllogonium Вин.}

43. Phyllogonium fulgens (Niw.) IBur).

Central-Anden, Dep. Antioguia. Wäleler hei Cafelal La Camelia hei Angelopolis um เ8m แ1, aแแ Baแmustämmen (11. 35- 27. VIII).

\section{Porolrichum (Bud.) Bryol. dav.}

44. Porotrichum nitidum (HАMP.) NıтT.

Contral-Anden, Dep. Antioquia. Paramo de Ruiz um 3700 m. (n. 80" - 5. X).

\section{Fam. Entodontaceae.}

\section{Erythrodontium 11 AMP.}

45. Erythrodontium longisetum (Honk.) P.ی.

Central-Anden, Dep. Antioquia. Weiden hei El Pobludo wherlath Mealellin um 1 700 m., an Baumstämmen ( 11.55 et $56 a-14$, VIII).

46. Erythrodontium consanguineum (IlıM.) PAR.

Ost-Anden, Dep. Cundinamarca. Bei (Thanne mu 2000 m. (11. $85 b-15 . \mathrm{X}$ ).

127 


\section{Fam. Hookeriaceae.}

Lepidopilum Bno.

47. Lepidopilum Sprucei Mıтт.

Central-Inden, Dep. Intioquia. Wälder oberhalb Cafetal La Camelia bei Angelopolis um 2000 m., an Baumstïmmen (n. $52 c-27$. 「'II).

\section{Fam. Rhacopilaceae.}

\section{Rhacopilum PaLIS.}

48. Rhacopilum tomentosum (Sw.) Bnid.

Central-Inden, Dep. Antioquia. Wälder bei Cafetal La Camelia bei Angelopolis un $1800 \mathrm{~m}$., an Bäumen (n. $54-2 . \mathrm{IX})$.

\section{Fam. Leskeaceae.}

Thuidium Bryol. eur.

49. Thuidium delicatulum (L.) Mitr?

Ost-Anden, Dep. Cundinamarea. Tambo bei Tena um 2000 m. (n. $84 a-$ ı 8 . X).

\section{Fam. Hypnaceae.}

Stereodon (Brid.) MitT.

50. Stereodon amabilis (Mrtт.) Brotn.

Ost-Anden, Dep. Cundinamarea. Paramo Cruz Verde oberlablb Bogota um 3200 m. (n. $87 d-14 . \mathrm{X})$. 


\section{- 1111- \\ Tsoplerygium Mn.}

51. Isopterygium tencrum (Siv.) Mıı.

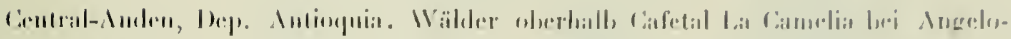

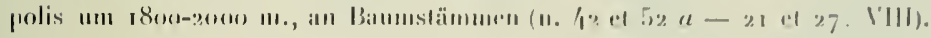

\section{Fam. Sematophyllaceae.}

Rhaphidostegium (Ви, кин.) ๓Е Хит.

52. Rhaphidostegium loxense (Iouk.) IAki.

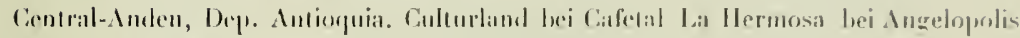

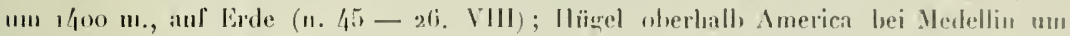
т $700 \mathrm{~m}$., an Bammstämmen (11. 5.3 a- 15. VIII).

\section{Fam. Brachytheciaceae.}

\section{Brachythecium Br. EUR.}

53. Brachythecium stereopoma (SPRUC.) IAEG.

War bisher noch nicht aus Columbien bekannt.

Central-Anden, Dep. Antiognia. Bei Titiribi um rgoo m. (n. 7o - 4. IX).

\section{Rhynchostegium BrYol. EUR.}

54. Rhynchostegium scariosum (T.YL.) JIEG.

Central-Inden, Dep. Antinguia. Wälder oleethalb Cafetal La Camelia bei Ingelopolis um $2000 \mathrm{~m}$., an Bäumen (n. '99-23. VIII). 


\section{$-$ \\ ERKLARUNG DER TAFELN.}

\section{TAFEL NIX.}

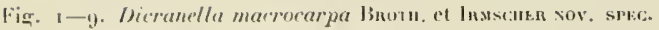

1. Habilus of in troekenem Zustande.

2. Deserl, in feuchtem Zustande.

3. Haube $15 / 1$.

亿. Jingrere Kinpsel $1.5,1$.

5. Reife kingsel ti) ',

6. Jeristom 130/1, links zwei Zähne von der Aussenseite, rechts einer von der Innenscite.

7. Stengelblätter $201 / 1$.

8. Jaminazellen aus der Blattmilte 5tio; 1 .

9. Laminazellen vom Blatlgrunde $5($ iu $/ 1$

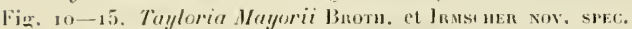

10. Habitus 3, in feuchtem Zustande.

11. Haube 22 '.

12. Kinpel $7 / 1$.

13. a. Zwei oben verhundene l'eristomzihue 38,1 .

b. Zwei Felder von der Aussenseite eines Zahnes $1.50 / 1$.

c. Lin Feld van der lnnenseite desselben $15 \% / 1$.

14. Stengelblitter $10 / 1$.

15. Blaltspitze $80 / 1$.

\section{TAFEL XY.}

Fï. !-6. Brymm Mayorii Broth. et Inuschen nov. shec.
1. Habitus $6 / 1$.
2. Reife Kiapsel $12 / 1$.
4. Blätter der sterilen Triebe 30/1.
5. Blätter der fertilen Tricbe $3 \% / 1$.
6. Zellen aus der Mitle cines Blatles des fertilen Sprosses 250/1.

3. Peristom $75 / 1$ mit zwei Zälnen von der Aussen- und einem von der Innenseite.

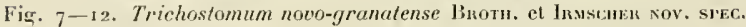

7. Habitus $6 / 1$.

8. Haube $35 / 1$.

9. Reife Ḱapsel $15 / 1$.

10. Peristom $160 / 1$.

11. Drei Stengelblitter 16, je eins von der Spitze, Mitte und Basis eines fertilen Sposses.

12. Jaminazellen aus der Blattmitte. 
PI.ANCHE XIX,

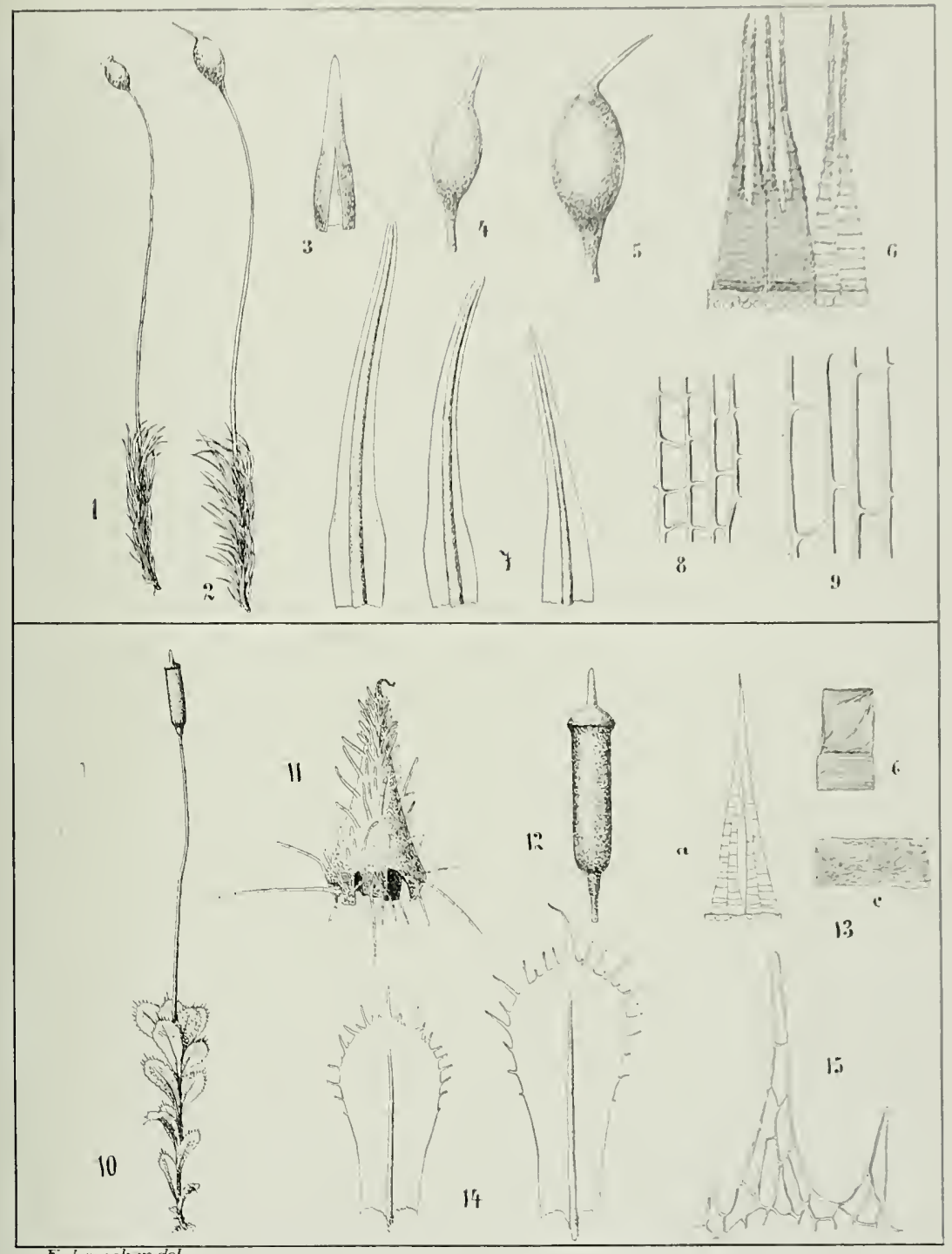

E. Irmscher del 

PLANCHE XX.

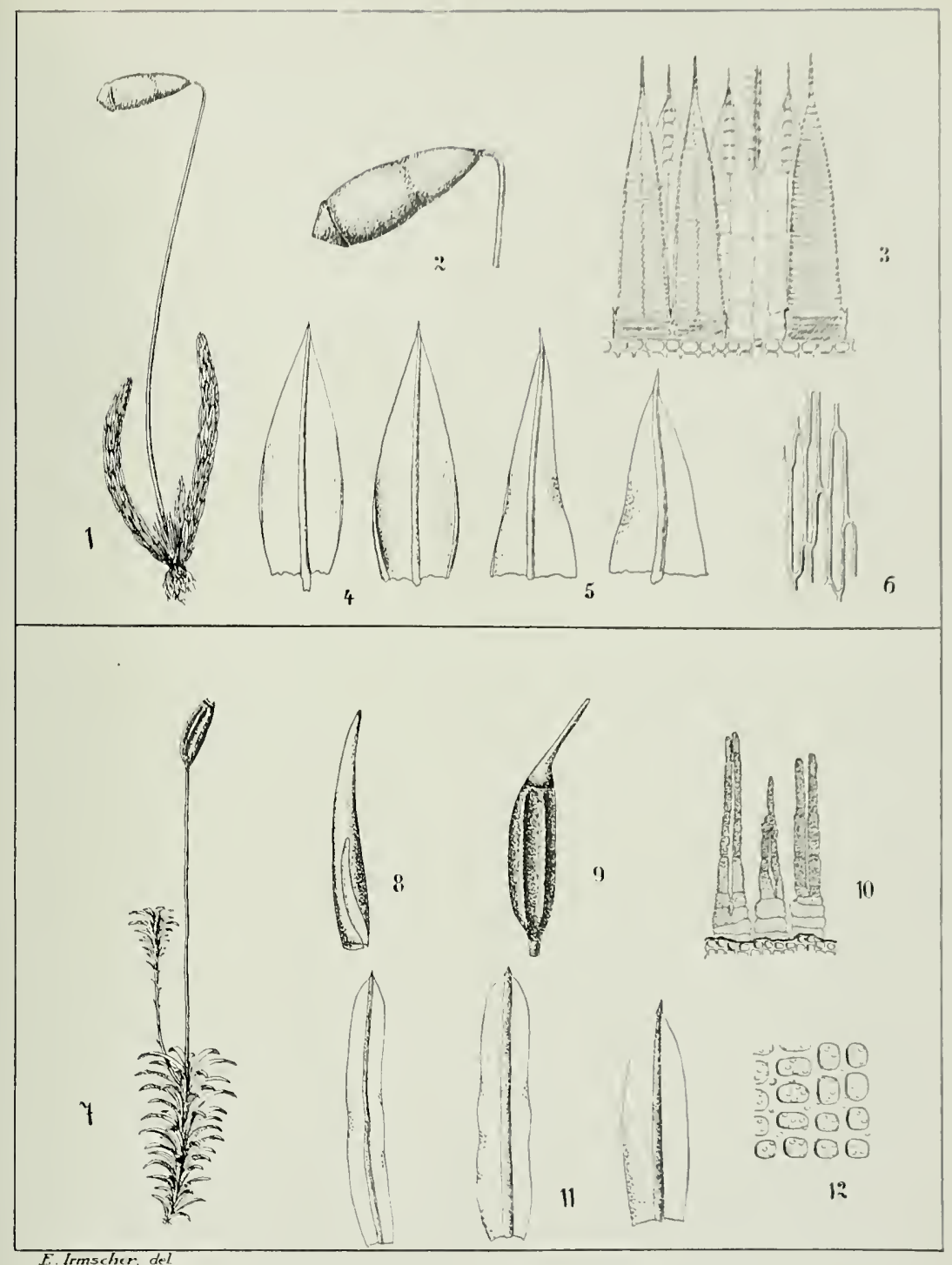





\title{
A CON'TRIBUTION
}

11) 1111

\section{knowledge of the Freshwater Alga of Columbia \\ 11)}

\author{
G. S. West, M. A., D. Sc., F. L. S., \\ Professor of Botany in the University of Birmingham.
}

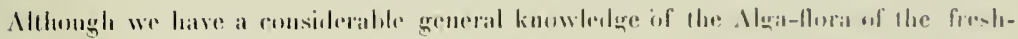

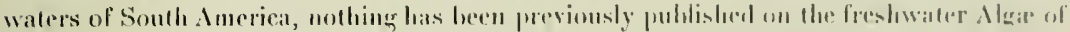
Columbia: The collections mate by Dr. Maron in his Scientifie Experlition of agen lo the Columbian Andes have therefore proved of great interest. There were in all twentylour lubes of algal material collected at altitules varying from 1550 lo 3600 inelres. They were as follows:

$\mathrm{N}^{\mathrm{s}} 1$ and 2. Laiguna above Medellin, Departunent Antioquia, Lentrat Indes. Altit. $2300 \mathrm{~m}$.

Nos 3 and 4. Laguna above Estrella near Medellin, 1)ep. Antionuia, Central dudes. Alit. $2500 \mathrm{~m}$.

No 5. Bog near the Laguna aluse Medellin, Dep. Antiogniai, Central Andes. Altit. $2300 \mathrm{~m}$.

N" 6. Ditches between Merlellin and Imerica, Dep. Antioquia, Central Indes. Mtit. $1550 \mathrm{~m}$.

No 7. Ditch above America and near Medellin, Dep. Antioquia, Central Inder. Mltil. $1850 \mathrm{~m}$.

Jos 8 and 9. Pool upon the Alto Don Elias near Angelopolis, Dep. Antioquia. Central Andes. Nhit. 2 Ioo m.

No ro. Pool on the last slope of the Alto Don Elias near Angrelopolis, Dep. Antioquia, Central Andes. Altit. $2100 \mathrm{~m}$.

Nos is and 12. Laguna Santa Rita near Angelopolis, Dep. Antioquia, Central Indes. Altit, I600 m. 
Vo 13. Ditch, Cot du Riviz, Dep. Antionuia, Central Andes. Altit. $3700 \mathrm{~m}$.

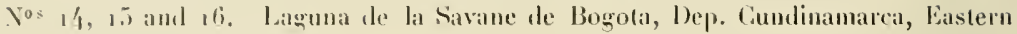
Aules. Nlit. $2580-2600 \mathrm{~m}$.

No: 17,18 and 19). Ditches near the Lagmal de la Sivane de Bogolal, Dep. Cundinamarea, Eastern Indes. Mtit. 2580-2600 m.

X̃o 20. Lalgana Pedropalo, near Tena, Mej. Cundinamarea, Eastern Audes. Mltit. ahout $2000 \mathrm{~m}$.

Yo 21. Pankton-collection from La suna Pedropalo, near Tena, Dep. Cundinamarca, Eastern .Indes. Altit. about 2000 m.

No 22. Ditch above the slope of Tequendama, Dep. Cundinamarca. Eastern Andes. Altit. $2210 \mathrm{~m}$.

No 23. Lilguna de Uhaque, Dep. Cundinamarca, Eastern Andes. Allit. $2066 \mathrm{~m}$.

Xं 24. Laguna de Paramo Cruz Verde ahose Bogota, Dep. Cundinamarca, Eastern Aules. Ntit. $2700 \mathrm{~m}$.

The most inpurtant previous publications on South American freshwater Algie are thuse of Nonnstedt, Börgesex, Bonge and Mönus on Ngae from Brazil, Bonge on Mlgar from Bolivia, Patraguay, Uruguay and Argentina (including Patigonia), Lageruem on the Mega of Ecuador, Racibonski on some Desmide from British Guiana, and O. Mülén on Diatoms from Sumb Patagonia. Varions uther records of South American freshwater Nlear have also appleared in sundry publications dealing with tropical Nlege, and quite a number in Wrtrock, Yordstevt and Lagernem's "Ngate Exsiccalae".

The collections from the Columbian Andes lave yielded altogether 31 i species, of which nearly half are Desmides, as may be seen from the following table.

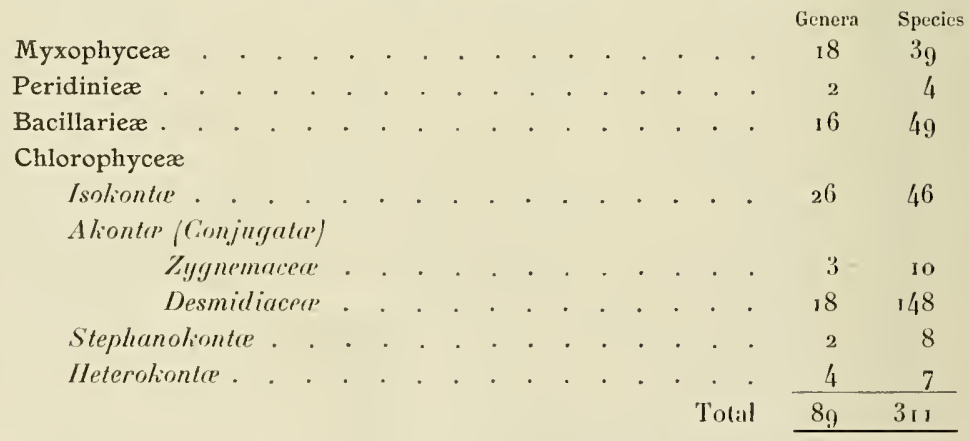

Of the above, 24 species (and also i varieties) are here descrihed for the first lime as new to science.

As the author has mentioned in many previous publications the Desmidiacen is par excellence the family of freshwater Algie which shows definite geographical peculiarities, 


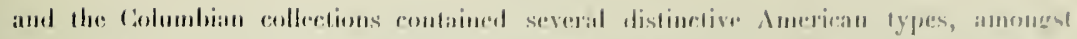

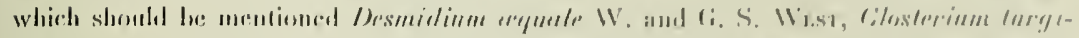

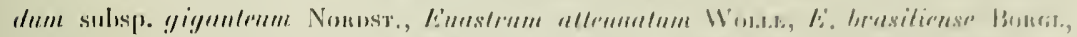

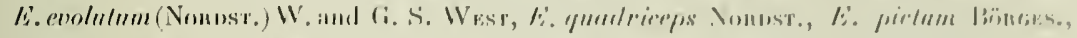

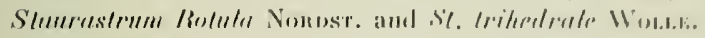

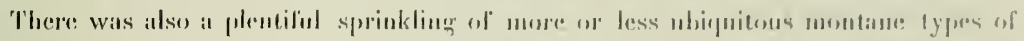

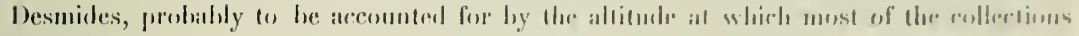
ivere made.

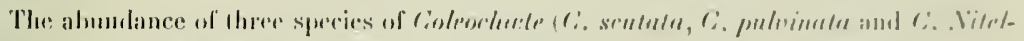

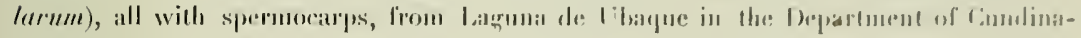
mareat, is worthy of special mention.

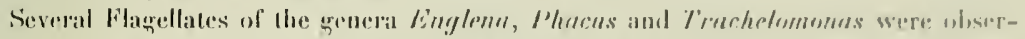
ved in the coltections, fun they were nen satisfacturily determined.

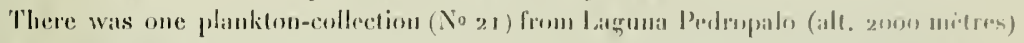

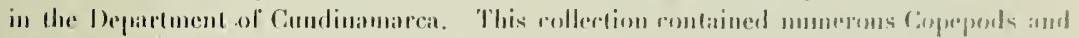

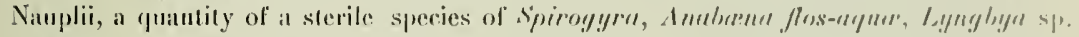

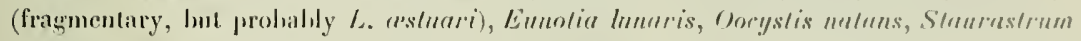
puradoxum vill. longipes and s\%. leplocludum val, elequns.

\section{Myхорһусеæ.}

\section{Family Chroococcacex.}

I. Myxobactron hirudiformis G. S. West in Ann, Sontl Ifrican Mus. IX, IgI2. p. $63,1.2$, f. $54-60 .-A n t i o f u i a: ~ n^{04} 1$ and 2.

This Algat las only previously heen seen from $\$$. W. Ifrica. and $2 /$.

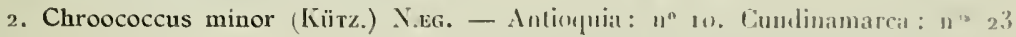

3. Chroococcus minutus (hürz.) N.Eg. - Antioquia: $n^{0} 3$.

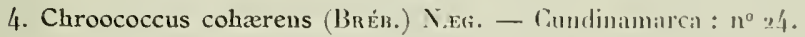

5. Chroococcus turgidus (Kïтz.) N.Eg. - Cundinamarcal : $1^{0.5} 23$ and 24.

6. Chroococcus macrococcus (Küтz.) Ranexu. - Cundinamarra : $1^{0} 24$.

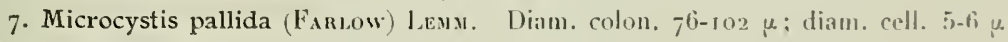
- Cundinamarca: $n^{0 \mathrm{~s}} 1$ 亿 and 23.

8. Aphanothece microscopica X.e.t. - Antioquia : $n^{0} 7$. Cundinamarca : $n^{0} 2.3$.

9. Aphanothece saxicola N.EG. - Cundinamirca: $1^{0} 2$.

10. Merismopedia glauca (Eиrexв.) Neg. - Cundinamarca: $n^{\circ} 24$. 


\section{Family Oscillatoriacex.}

11. Oscillatoria amphibia AG. - Antioquia : $\mathrm{n}^{\mathrm{0s}} 1,2,5,6$ and 13.

12. Oscillatoria chlorina Kü̈zz, - Cumdinamarca: 10 "19.

13. Oscillatoria formosa Bonr. - Intioquia $\Perp^{\circ} 6$.

14. Oscillatoria limosa $A G$. - Antioquia $n^{0} 6$.

15. Oscillatoria splendida tinex. - Cundinamare a: $\Perp^{\circ}$ I9.

The extremities of the tilaments were much altenuated and capitate.

16. Oscillatoria tenuis $\Lambda_{6}$. - Antioquia : $1^{08}$ I and 2. Cundinamarca : $n^{0 \mathrm{~s}} \mathbf{1 6}, 22$, and 24 .

Var. tergestina (Küтz.) Rabenu. - Antioquia: $n^{0} 13$.

17. Phormidium fragile (Menegu.) Gon. - Antioquia $n^{0} 10$.

18. Phormidium tenue (Menegu.) Gon. - Cundinamarca: $\mathrm{n}^{0 .} 14$ and 17 .

19. Lyngbya bipunctata Leмx. - Antioquia: $n^{\text {os }} 1$ and 2 ; crass. fil. I $\mu$.

20. Lyngbya putealis Moxt. - Intioquia: $n^{\circ}$ 4. Crass. fil. $9 \mu$; crass. trich. $6-8 \mu$.

21. Lyngbya major Menegil. - Antioquia: $n^{\circ}$ 6. Crass, fil. $19-20 \mu$; crass. 1rich. $14,5 \mu$.

22. Lyngbya sp. ad L. æstuarum Liermax accedens; crass. fil. $27 \mu$; crass. trich. $22 \mu$. Cundinamarca: $\mathrm{n}^{0} 21$ (plankion).

Only a few fragmentary filaments of this species were observed, and its exact idenlification was therefore uncertain.

\section{Family Noslocacex.}

23. Nostoc paludosum Küтz. - Antioquia: $n^{0}$ 10. Cundinamarca : $n^{0} 24$.

24. Anabæna flos-aquæ (Lyngr.) Bréв. - Cundinamarca: $n^{0} 21$ (plankton).

Several sterile species of Anabcena were observer from Antioquia ( ${ }^{\circ s}$ I and 2 ) and Cundinamarca $\left(\mathrm{n}^{0} 24\right)$, but they were too fragmentary for certain identification.

25. Cylindrospermum minimum sp. nov.

C. filis in stagnis natantibus, non in strato aggregatis; trichomatibus pallide arrugineis, brevibus, subrectis vel leviter curvatis; cellulis cylindricis, diametro $11 / 2-2-p l o ~ l o n-$ gioribus, polis rotundato-truncalis; heterocystis parvis, ellipsoideis vel ovoideis ; sporis angustis et cylindrico-ololongis, episporio glabro.

Crass. cell. 1,8-2 ; crass. heterocyst. $2-2,2 \mu$; long. heterocyst. 2,5-2,7 $\mu$; long. spor. $7,5-10 \mu$; lat. spor. 3,3-3,7 $\mu_{0}$; long. tot. trich. (ut visis) $50-64 \mu$. (Pl. XX'l, fig. 1-3).

Antiornia : Laguna above Estrella near Medellin, Central-Andes; altit. $2300 \mathrm{~m} . \mathrm{n}^{\circ} 3$.

This minute Cylindrospermum is the smallest of all the known species of the genus, and was observed in quantity floating freely among other $\Lambda$ lgae. It is distinguished from 


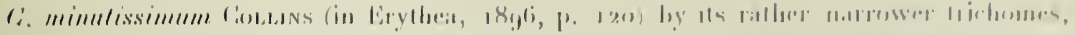

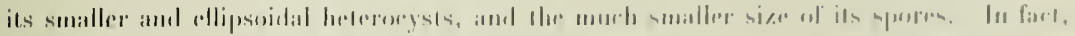

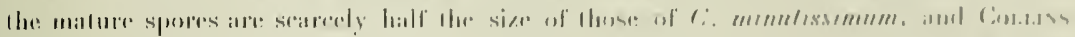

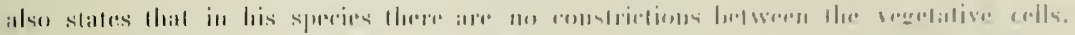

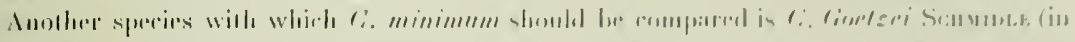

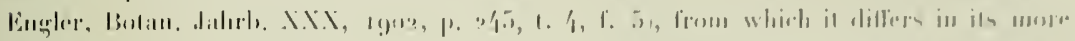

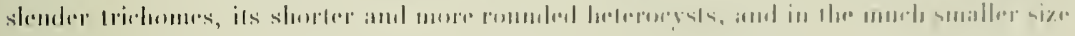
ofl ils sporms.

sfi. Cylindrospermum majus liïı furmis mimer.

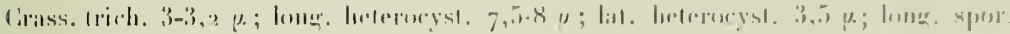

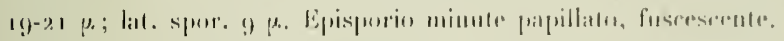

Cimmlimamareas: $11^{189} 1$ 亿

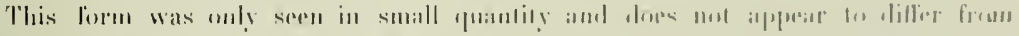
6. mujus rexerent in ils slighlly smallel sim.

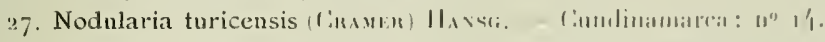

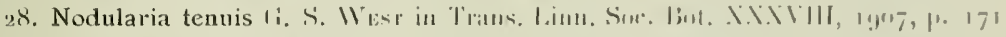

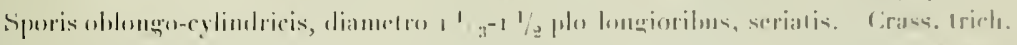

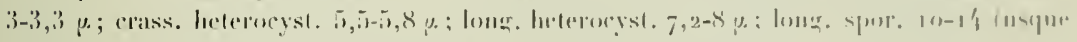

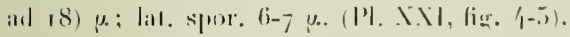

Cimulinamar'a: $0^{\prime \prime} 17$.

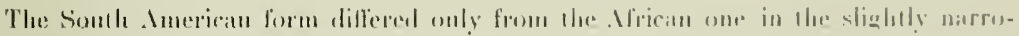

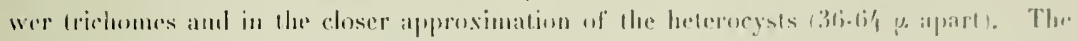
spures were not observed from ifricil.

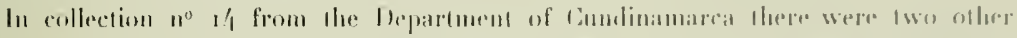

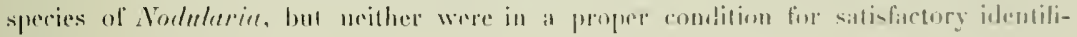
eillioli.

\section{Family Microchrtacex.}

\section{2!). Microchate crassa sp. nov.}

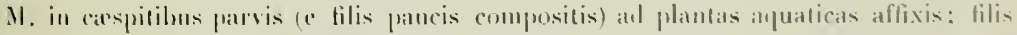

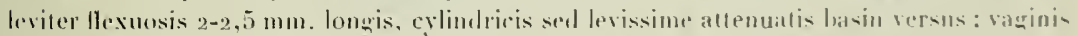

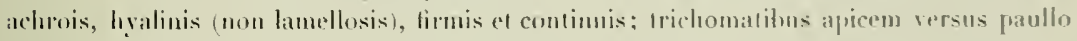

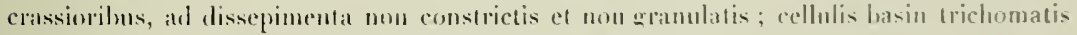

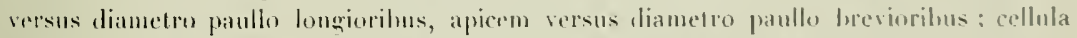
apicali depresso-conica; helerocystis plerumque hasalihus, globosis.

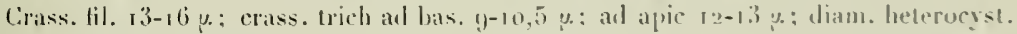
bisial. $9-10,5 \mu$. (Texl-fig. I).

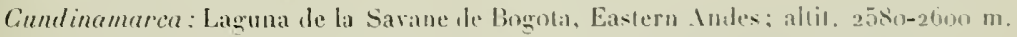
11) 14.

128 
This . Igra formed small tufts consisting of from seven to twelve filaments attached 61) the leaves and stems of aqualic macrophytes. The filaments are rather rigrid and

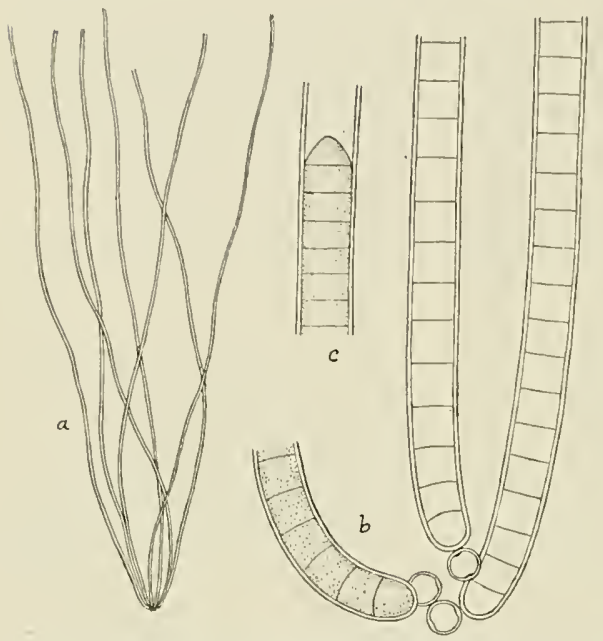

Fig. 1. - Microchate crassa sp. nov.

$a$, tufl of filaments, $\times 40 ; b$, bases of three filaments, $\times 500$; $c$, apex of filament, $>500$. lairly straight, allhough quently undulated from base to ipex, and (la base of each filament is a little decumberat.

It stands nearest to $M$. robnsklu Setchell and Gindoxer (. Igata of N. W. Ameriea, Eniv. Calit. Publ. Bot. Igo3, J. Igf), from which it ditlers in the smaller tufts of shorter and narrower filaments, which are wider at the base than at the apex. Moreover, so far as could he ohserved even the sheaths of the oldest filaments were not lamellose.

M. crassa mightı also be compatred with 1 . calotrichoides Haxsg., a species in which the filaments are much more densely aggregated and the trichomes considerably narrower. The latter are also attenuated at the apices and sometimes piliferous, a character which at once distinguishes it from I. crassa.

\section{Family Scytonemacex.}

3o. Tolypothrix lanata Wartunns. - Cundinamarca: $n^{0} 23$.

31. Scytonema crispum (AG.) Bonver. - Cundinamarca : $n^{0} 20$.

\section{Family Stigonemaceæ.}

32. Hapalosiphon hibernicus W. and G. S. West. - Antioquia : $n^{\circ} 4$. Cundinamarca : $n^{0} 24$.

33. Hapalosiphon intricatus W. and G. S. West. - Cundinamarca : $\|^{0} 24$.

34. Stigonema ocellatum (Dillw.) Thuret. - Cundinamarca : $n^{0} 24$. 


\section{Family Rivulariaceie.}

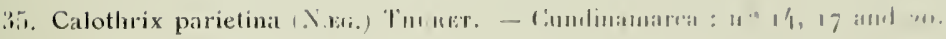

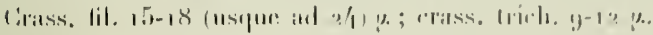

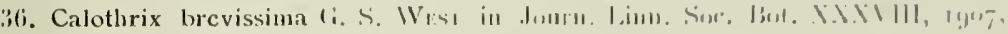
1.. $1811,1,11,1.8$.

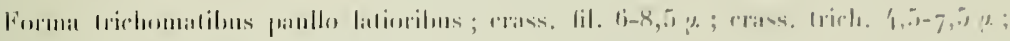

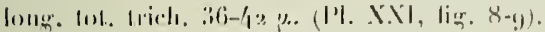

Cimulinamiurea : $3^{\prime \prime} 14$.

37. Calothrix columbiana sp. nov.

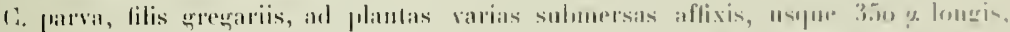

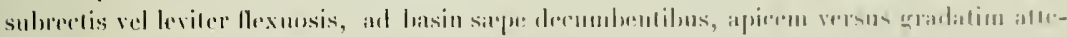

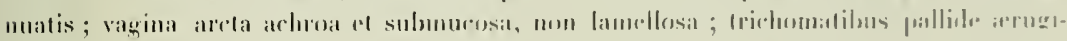

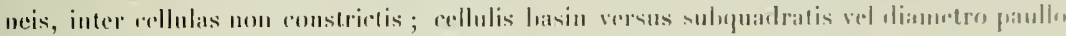

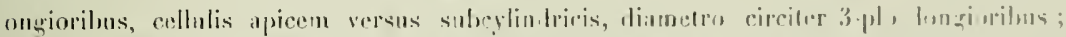

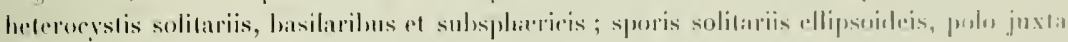

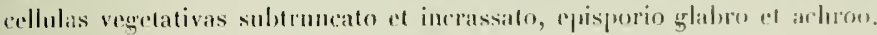

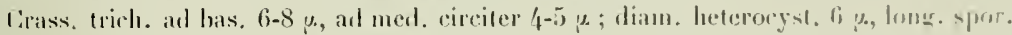

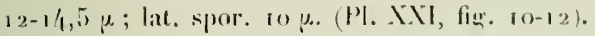

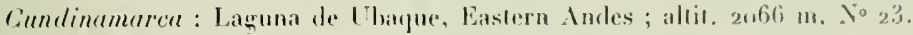

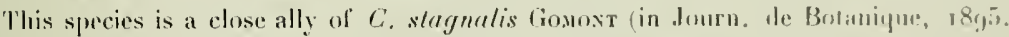
p. $1 ! 7$, cum ligr.), hut dilfers in its shorter filaments, its solitary heterocysts, its cylindrical cells with colire absence of iutercellular coustrictions, and in its shorter and differeul.! shaped spores.

38. Calothrix sp. ad C. stagnalem accelens.

Crass. lrich, ad bas. $6,8-8 \mu$; diam. helerocyst. 6,5-7 \%. Tunclinamarca : $11^{\circ} 14$.

Very litule of this species was seen. It is epiphytic on various aqualic macropleyes. From $C$. slagnalis it differs in its sulitary lueperests and (in the few specimens oberred) in the ahsenec of spores.

3y. Calothrix clavata sp. noy.

C. minula, lilis solilaris vel sulererariis. at plantas submersas ppiphrticis, nsque roo e longis, subrectis vel leviter llexuosis, at basin iullatis, supra hasin subiler allema-

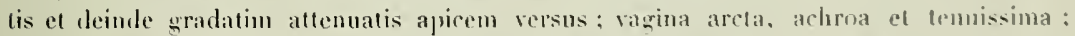
trichomatihus pallide arugincis, inter cellulas latiores hasales loviter cunstrictis : cellulis ad hasin hrevilus el discoideis, in parte superiori cyliudricis cum diamelro 2-3 plo longioribus ; heterocystis solitaris, hasilaribus et hemisphitricis.

Crass. fil. ad has. $7 \mu$; crass. trich. ad has. $55,5 u$ : crass. trich, ad med. $2, j u$. (ग. XXI, fir. (j-7). 
Cundinamarer : Laguna de la Silvane de Bogota, Eastern Andes ; altit, $2580-2600 \mathrm{~m}$. $x=14$.

This tur species is characterized by its very short filaments which are conspicunously clavale at the bise. It might be compared with C. Kawraistigi Scundoe (Agen ans den Hochseen des Kaucisus, $1897, P .9$ ), but differs in its very much shorter filaments which do not liorm a stratum.

\section{Peridinieæ.}

\section{Family Peridiniacex.}

40. Glenodinium uliginosum Schllusg. - Antioquia : $n^{0} 4$.

亿1. Peridinium inconspicuum Lems. - Antioquia : $\mathbf{n}^{\circ}$ то. Cundinamarca : $n^{\circ} 24$.

12. Peridinium pusillum (Penaro) Lem. - Intioquia: $1^{\circ \mathrm{s}} 1,2$ and 3.

43. Peridinium Willei Hutrf,-Kiss. - Antioquia : $\mathrm{n}^{\mathrm{s}} \mathbf{1}, 2$ and 3

\section{Bacillarieæ.}

\section{Family Melosiracex.}

44. Melosira varians $A G,-$ Antioquia: $n^{\circ} 6$.

\section{Family Tabellariacex.}

45. Tabellaria flocculosa (Rorı) Kïrz. - Cundinamarca : $\mathbf{n}^{0} 23$.

\section{Family Fragilariaceæ.}

46. Synedra radians (Kurz.) Grus. - Cundiramarca: $n^{0} 19$.

47. Asterionella formosa Hass. - Cundinamiarca : $n^{\circ} 24$.

\section{Family Eunotiacex.}

48. Eunotia lunaris (Emrexis.) Grun. - Antioquia : $n^{08} 6$ and ro. Cundinamarca : $\mathrm{n}^{\circ .5} 14,16,18$ and $2 \mathrm{I}$.

49. Eunotia triodon EnkENB. - Antioquia : $1^{0} 5$.

5o. Eunotia robusta Ratrs var. octodon. - Cundinamarca : $1^{\circ} 24$.

51. Eunotia prærupta Eurevr. var. bidens (IV. Sn.) Grun. - Cundinamarca : $n^{0} 22$.

52. Eunotia major (IV. S.s.) RaвеNII. - Antioquia: $n^{\circ} 5$. 


\section{$=$ nown \\ Family Achnanlhacere.}

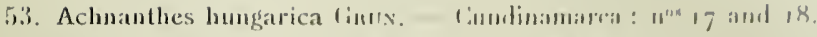

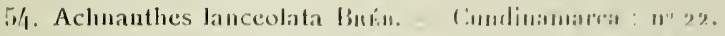

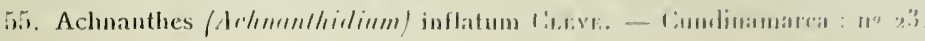

\section{Family Naviculacex.}

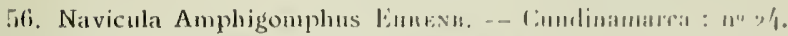

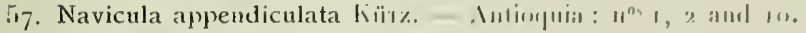

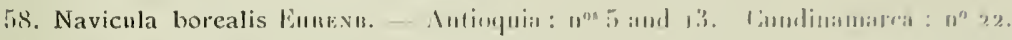

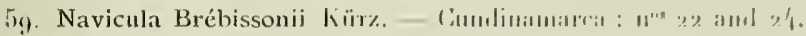

Var. subproducta VAN Imarrik. - Mutimptia : $1^{\circ} \mathrm{x}$.

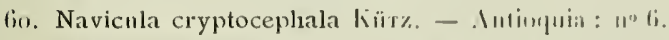

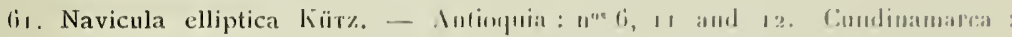
$11^{0} 2 \%$

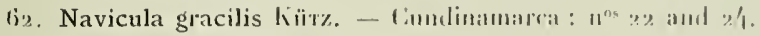

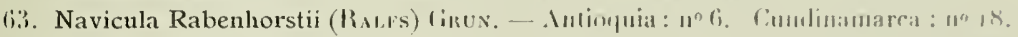

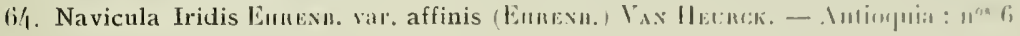
and 13.

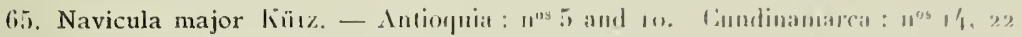
and 23.3.

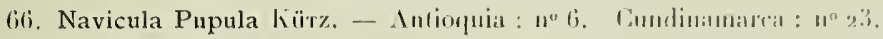

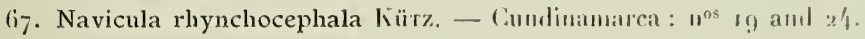

68. Navicula stauroptera Girux. - Cimdinamalcal : $1^{\text {ns }} 2.3$ and 2 亿.

Var. parva (Eumenu.) Van Heunck. - Cundimamarca : " $^{\mathrm{n}} 22$.

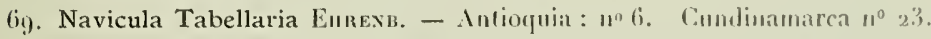

$7^{\circ}$. Navicula viridis Kï̈rz. - Antioquia : $n^{0=} 5,6,8$ and 13 . Cundinamarca : $n^{0} 17$.

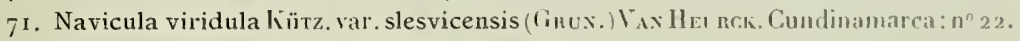

72. Stauroneis anceps Eивехв, - Antioquia: 1 $^{\mathrm{n}} 6$.

73. Vanheurckia rhomboides (Enrexb.) Вив́в. - Cundinamarca: no 24.

Var. saxonica (Rabenu.) G. S. Weșt, 1897 . - Antioquia: $\|^{\circ 5}$ 1, 2 and Ho. Cundinalmarcal : $11^{\circ} 24$.

Some very large forms (long. vals. usifum 120 whe we observed from the liat-menliomed locality (Liguna du Paramo Cruz Verde above Bogota).

\section{Family Gomphonemacex.}

74. Gomphonema Augur Emnexв. - Antiopuia : $10^{\circ}$ ti.

In all the specimens observed the valves were intlated al the sides; long. vals. $33-36 \mu$. ; lat. valv. $13,5-14.5 \mu$. 
75. Gomphonema parvulnm lï̈тz. - Cundinamarca: $n^{\circ} 18$.

76. Gomphonema intricatum Küтz. - Intioquia : $\mathbf{n}^{0} 6$. Cundinamarca : $n^{0} 18$.

77. Gomphonema olivaceum Kï̈rz. var. tenellum (Kürz.) C.cere. - Antioquia : $1^{\text {os }} 6$ and $s$.

78. Gomphonema gracile Euress. - Intioquia: $n^{\text {vs }} 5,7$ and 8. Cundinamarca: $11^{05} 18$ and 24 .

\section{Family Cocconemacex.}

79. Cocconema gracile (Rabexit.) G. S. West. - Antioquia : $n^{05}$ I and 2. Cundinamarca: $\mathrm{n}^{0} 23$.

8o. Cocconema leve (N.玉g.) G. S. West. - Cundinam irca: $11^{0 s} 22$ and 23.

SI. Cocconema turgidum (GrEg.) G. S. WEST. - Cundinamarca : ${ }^{\ominus} 19$.

82. Cocconema cuspidatum (Kü̈z.) G. S. WEst. - Cundinamarca : $1^{\circ} 22$.

83. Epithemia turgida (Eниехв.) Kürz. - Cundinamarca : $n^{\circ} 23$.

84. Epithemia Argus lï̈тz. var. amphicephala Grun. - Cundinamarca : $11^{\circ} 23$.

85. Rhopalodia gibberula (Еипехв.) O. Mült. var. producta (Grun.) O. Mält. Cundinamarca: $n^{\circ} 23$.

\section{Family Nitzschiacex.}

86. Nitzschia linearis (Ag.) WV. Sm. var. tenuis Grun. - Antioquia: $1^{\circ} 6$.

87. Nitzschia subtilis Grux. var. paleacea (Grun.) VAx Неurck. - Antioquia: $n^{\text {os }} 3$. Cundinamarca: $n^{\circ} 24$.

48. Nitzschia Palea (Kü̈rz.) IV. Sm. - Antioquia: $n^{\text {os }}$ I, 2, 6 and 7 . Cundinamarca : $n^{\text {os }} 18$ and 22 .

Var. tenuirostris $V_{\text {an }}$ Heurck. - Cundinamarea: $n^{0} 22$.

Var. debilis Van Heurck. - Antioquia: $n^{o s} 1,2$ and 6 . Cundinamarca: $n^{0} \mathbf{I} 8$.

89. Nitzschia Sigma IV. Sul. - Anlioquia: $\|^{0} 5$.

9o. Nitzschia curvula (Em, exв.) W. Sm. - Cundinamarca: $n^{0} 24$.

gr. Hantzschia Amphioxys (Eırexb.) Grun. - Antioquia: u $^{\circ}$. Cundinamarca : $n^{0.5} \quad 18$ and 22.

\section{Family Surirellacex.}

92. Surirella plana G. S. WVesr in Journ. Linn. Soc. Bot. XXXVIll, 1907, p. 165, t. 8, f. 5. - Cundinamarca: $u^{\circ} 24$.

Long. valv. $86-89 \mu$; lat. valr. $29-36 \mu$; costis $3 \frac{1}{2}-4$ in $10 \mu$. 


\section{$111 \%$ \\ Chlorophycea.}

\section{Division I. ISOKON'T'王.}

\section{Family Volvocacex.}

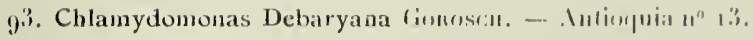

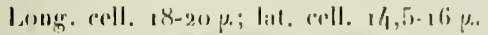

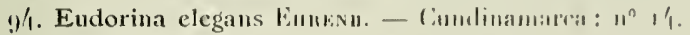

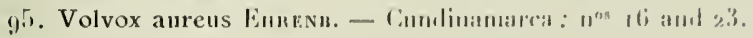

\section{Family Palmellacex.}

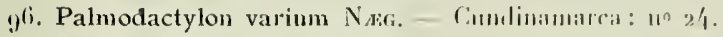

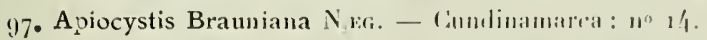

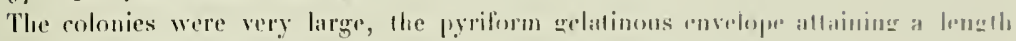
ol" $290 \mu$; diam. cell. 8-12 $\mu$.

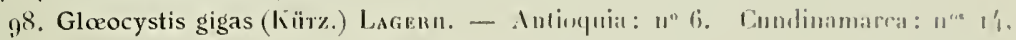
19 and 23 .

\section{Family Prolococcacx.}

99. Protococcus fuscatus sp. nov.

P. parvis et aquaticis, epiphyticis ad algas filamentosas majures; cellulis anerulariglobosis, plerumque 2, 4, 8, 16, 32 vel 64 in finniliis consocialis, arl memhranam alger filamentosar arcte arlherente; chromatophora singula parietali, mingua el lobata, siue pyrenoide; membrana cellularum firma el fuscata. Multiplicatio cellularum vegetativarum divisione in duas directiones altemante.

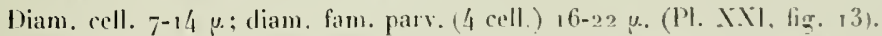

Cundinamarca: Altaclied to QEdogonium sp.. Laguna de la Savane de Bogota, Lastern Indes; altit. $2580-2600 \mathrm{~m}$., $\mathrm{n}^{n}$ 14. Mllached to 1 Edogoninm falunlosnm var. colmmbianum and $G$ s. taphrospornm, Laguma de thaque. Eastern Indes: altit. 2ntif m. $1 n^{\circ} 23$.

The epiphytic habit of Prolococcus fuscalus is truly remarkialle. In all cases the host was a species of Eilogonium and the lareer families of 32 or 64 cells formed a compact stratum of one layer in thickness. The atlacliment to the wall of the GEdogonimm is so firm that it must be due to some definite secreted suhstance. The most 
conspicunus feature of Prolococtus fusculus is the colon of the cell-walls. They are of a dull diry hrown, and when several calls are seen in mass, as al the edge of an Gidogonimm-fibment they appear very dark lirown or almost black.

In size $P$. fusculus is similar to P. mirilis $1=$ Plenrococens vulyuris auct.; Plentococechs Vägelii Chodar), hut the species is at once distinguished by its habit and hy the dull buwn cell-watls.

Wille has recently shown (eft. Nyt Magazin for Naturvidensk. Christiania, I!)r3,

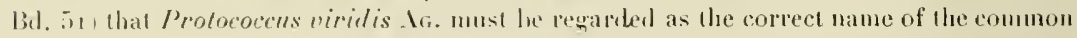
Alga so long placed as "Pleurocorcuss vulguris"

100. Trochiscia reticularis (Renscu.) Haxsi, - Intioquia: $n^{\circ} 4$.

\section{Family Autosporacex.}

101. Oocystis elliptica IV. and G. S. W Wst. - Cundinamarca : $11^{06} 14$ and 23 .

102. Oocystis parva W. and I. S. Wesr. - Cundinamarca : ${ }^{\circ} 23$.

103. Oocystis natans (LEm».) Wille. - Cundinamarca: $n^{0} 21$ (plankton). Long. cell. $18 \mu$; lal. 12 $\mu$.

104. Nephrocytium lunatum W. West. - Cundinamarca: $n^{0} 23$.

105. Eremosphæra viridis De Bakr. - Cundinamarca: $1^{0} 24$. Diam. cell. 142-156 $\mu$.

106. Tetraëdron enorme (Ralfs) Haxsg. - Intioquia: $n^{o s}{ }_{1}$ and 2 . Diam. cell. sine spin. 12-16 $\mu$, cum spin. 2 I-27 $\mu$.

107. Tetraëdron bifurcum (WhleE) Ligeri. - Intioquia: $n^{\circ} 4$. Diam. cell. cum sprill. $29-34$ u.

This species las a wide distribution in both the easiern and western tropics.

108. Ankistrodesmus falcatus (CokDA) Rales. - Antioquia: $n^{\circ} 4$.

Var, acicularis (A. Br.) G. S. West, - Cundinamarca : $n^{0} 14$.

109. Ankistrodesmus sp. Cellulie lanceolatie, 2 vel 4 in tegumento mucoso aggregatie, polis acutis; chromatophora cum pyrenoide singulo. Long. cell. 20-21 p.; lat. $3,5-4,3 \mu$.

Cundinamarca: $n^{0} 23$.

Only two colonies of this Alga were observed. It is probalsly a new species, but it is essential that more specimens should be examined.

\section{10 . Ankistrodesmus Mayori sp. nov.}

1. minutissimis, inter alias algas libere natantibus; cellulis solitariis, angustis, polos acutissimos versus gradatim attenuatis, valdissime spiraliter contortis, anfractibus proxissimis duolus ; chromatophora pallide viride, pyreuoidibus nullis.

Lat. cell. $0,9-1,3 \mu$; diam. anfract. $5,5-7,5 \mu$; anfract. inter se distantibus $2-2,8 \mu$. (PI. XXl, fig. 22-2:3).

Cinndinamarca: Laguna de Ulaque, Eastern Andes; altit. $2066 \mathrm{~m} . \mathrm{n}^{0} 23$. 


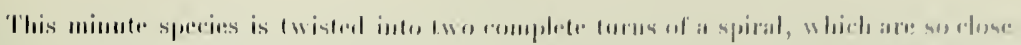

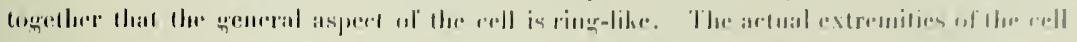

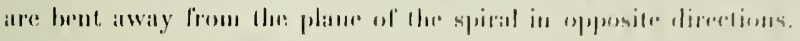

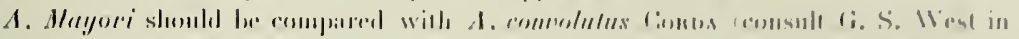

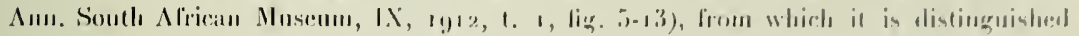

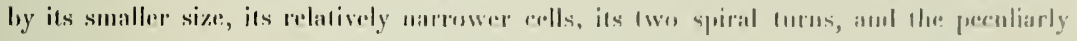
comparet way in which the spiral is lwistorl.

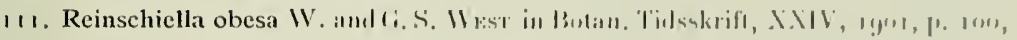
1. 4, 1. $53,5 \%$.

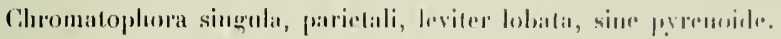

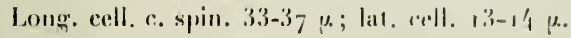

Comdinamarca : $11^{\circ} 14$.

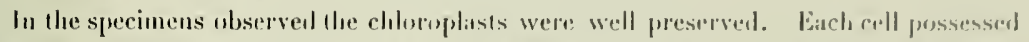

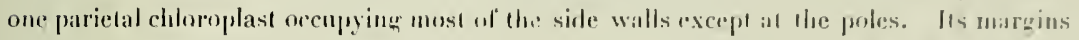

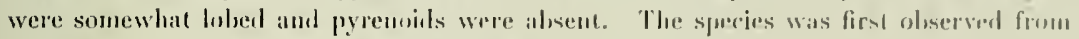
the island of kuh Chang in the Gult of Siam.

There is no doubt that the organism described as Keinschiella siumensis 11 . and G. S. West., /. c. p. 99, 1. 4, f. 52 [from the same locality in the East] is an encysted state of one of the Peridinieie.

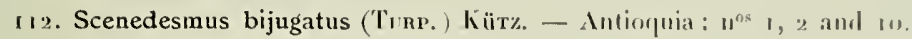

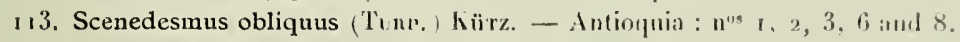

114. Scenedesmus denticulatus L.ageur. var. linearis IIxss. - Intiupuia: $\|^{\circ 3} 6$ and 8. Cundinamarea: $n^{\circ} 23$.

Var, lunatus W. and G. S. West. - Antioquia : no 6.

115. Scenedesmus quadricauda (Tunp.) Bréb. - Inlioquia: no 7 . Cundinamarea : 1014 .

Var. maximus W. and G. S. West. - Cundinamarca : no 24.

Var. rectangularis var. nov.

Conobiis e cellulis 2 vel 4 formatis, compactis, a latere visis plermunge curvalis: cellulis rectangularibus, lateribus rectis, polis leviter convexis; spinis ad angulos exteriores cellularum terminalium brevibus et incurvatis et sape cum spinis additionibus breviorilus al cellutas ullas irregulariter dispositis.

Long. cell. 1/4-21 $\mu$; lat. cell. 6-10 y. (P. XXI, lig. 14-21).

Antioquia: Laguna Santa Rita near Ingelopolis, Central Indes; altit. Itooo m. Nos $I 1$ and 12 .

This variety occured in great quantity from the abure-mentiuned locality. So other deseribed variety of Scen. quadricanda possesses cells of the same shape as Ihose of rar. rectangularis. In outline they remind one of the cells of Scen. perforalus Less., lut in other respects the colonies are quite different.

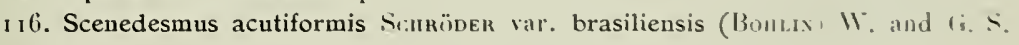




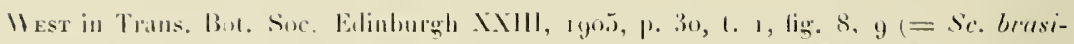

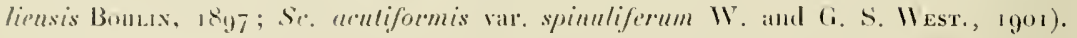
- Intioquia: $n^{\circ} 3$.

17. Coelastrum sphæricum N.Eti. - Antioquia: : n" 6.

118. Colastrum cambricum Incuen. (=C. pulchrnm Schumbe.) - Antioquia: 110 4. Cundiuamarca: $11^{\prime 2} 3$.

In ail the colonies observed the cells wer 4-angled. The largest colonies were $108 \mu$. in diameter with cells up to $28 \%$ in diameter.

19. Sorastrum spinulosum X.EG. - Antioguia : $n^{\circ} \overline{5}$

\section{Family Chaetopeltidacex.}

120. Chætosphæridium Pringsheimii KLLenanv. - Antioguia: $1^{\circ}$ 10. Cundinamarea: n 14 .

\section{Family Hydrodiclyaceæ.}

I2I. Pediastrum Tetras (Enrenb.) Ralfs. - Cundinamarea: $\mathrm{n}^{0}{ }_{2} 3$.

122. Pediastrum sp. (= P. biradialum Ralrs, Brit. Desm. r848, 1. 3 r, f, $3 a$ et $b$ ). - Cundinamarea : $n^{0} 24$.

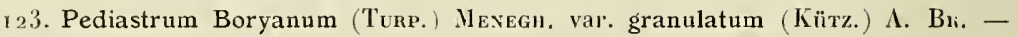
Antioquia: no 5 .

124. Pediastrum duplex Meren var. clathratum A. BR. - Antioquia: $n^{0} 6$.

\section{Family Ulotrichacex.}

125. Geminella mutabilis (BRÉB. ) Wille (= Hormospora mulabilis BréB.). - Antioquia : 1705.

126. Geminella ordinata (IV. and G. S. West.) nov. comb. (= /lormospora ordinalu W. and G. S. West in Journ. Bol. Sept. 1898, p. 330).

Long. cell. 8-r $2,5 \mu$; last. cell. $5-6$ u. - Cundinamareal: $n^{\circ} 24$.

127. Geminella irregularis WILLE. - Cundinamarca: no 24.

Long. cell. $5-7 \mu$; lat. cell. го-г $2 \mu$.

I 28. Ulothrix subtilis Küтz. - Cundinamarca: $n^{03}$ r 8 and 22.

129. Ulothrix tenuissima Kür\%. in Flora, XVI, 1833, p. 518 ; Ilazen in Bull. Torr. Bot. Club, X1, no 2, 1902, p. 149, 1. 20, fig. 5, 6.

Forma filis crassioribus, usque $30 \mu$. lian.; long. cell. 16 - $8 \mu$. ; chromatophora cum pyrenoide singulo.

Antioquia: no 6.

Very lew filaments of this Mga were observed, but they agreed with Clothrix 


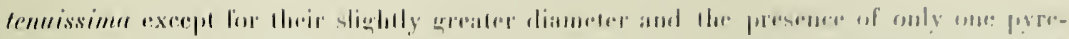

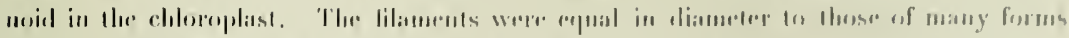

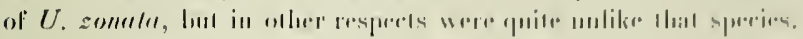

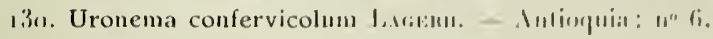

\section{Family Microsporacex.}

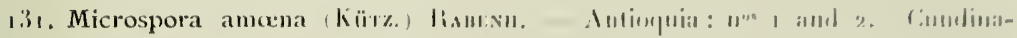
matra: $11^{\circ} 2 / 1$.

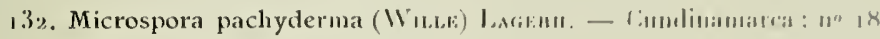

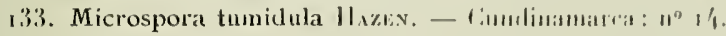

\section{Family Microthamniacex.}

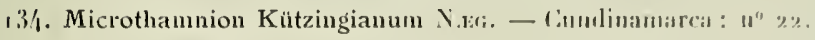

\section{Family Aphanochaetacex.}

135. Aphanochate repens $\mathrm{A}$. BH. - Cumblimamirca : $\mathrm{n}^{0} 1 /$.

\section{Family Coleochaetacex.}

136. Coleochæe scutata Bréb. - Cumlinamarca : "1" 2:3 : ahmulant on varims aquatir macrophytes. Many of the specimens will spermocarps.

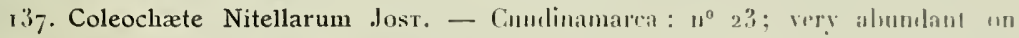
Nitella sp., and mostly with spermocar'ps.

138. Coleochæte pulvinata 1 . BR. - Cundinamara : $n^{0} 23$; alumdant on various aquatic macrophytes and also around the tips of the leaf-segments of Vilelle sp. Mamy. specimens with spermocarps.

\section{Division II. AKONTÆ \\ Family Zygnemacer.}

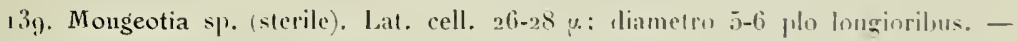
Cundinamarcal : $n^{0} \mathbf{i}$.

141. Mougeotia recurva (HAss.) De Toxs. - Intioquia: $1^{\circ}$ I. Lill, cell. veget. 13-r/4 $\mu_{\text {; }}$; diam. snor. $33 \mu$.

1/1 Mougeotia (Gonatonema) Mayori sp. nov.

I. (G.) cellulis vegetativis vilde elongatis, diametro circiter $18-21$-plo longhuribus. chromatophora cum prenoidibus $11-14$ in serie subiregulare: aplanosporis oblique 
ellipticis, maruine uno convexo, margine altero vatde convexo, polis subtrmneatis; membrana sporarum suberassa, luteola el dense punctala.

Lal. cell. veget. 13-15 $\mu$; long. aplanospor. 34-38 $\mu$; lat, aplanospor. 24-26 $\mu$. ( PI. XXI, fig. 24.)

Antioquia: Laguna above Estella near Medellin, Central Andes; attit. $2500 \mathrm{~m} . \mathrm{n}^{\circ} 4$.

This species seems well characterized by the great length of its vegretative cells, the numerous pyrenoids in the chloroplast, and the shape of the aplanospores. The chloroplast only occupies about three-quarters of the length of the regetative cell and the pyrenoids are arranged in an irregular series. The wall ol the mature aplanospore is fairly thick, of a yellow or yellowish brown colour, and finely punctate.

142. Mougeotia (Gonatonema) tenerrima sp. nov.

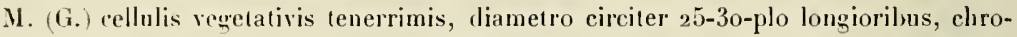
matophora cum prenoidibus 6 in serie singulo; aplanosporis ellipticis vel leviter oblique ellipticis, diametro circiter duplo longioribus, polis leviter productis et sulmamillatis, membrana glabra.

Lat. cell. reget. $4,5 \mu$; long. aplanospor. $24-25 \mu$, lat. 12-13 $\mu$. (PI. XXI, fig. 25.) Antioqniu: Laguna above Medellin, Central Andes; altit. $2300 \mathrm{~m}$. Nos 1 and 2.

This Alga should be compared with Mongeotia (Gonatonema) Boodlei (W. and G. S. West) Coluses (cfr. W. and G. S. West in Trans. Roy. Micr. Soe. 1897, p. 476; Ann. Bol. NII, 1898 , 1. 4, f. 1-9), from which it differs in its narrower and proportionately longer cells, and in the shape of the aplanospores. The latter are relatively narrower and possess submamillate polar thickenings.

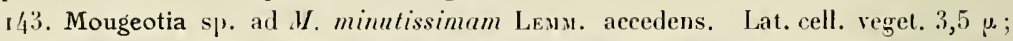
long. cell. 54-58 $\mu$; chromatophora cum pytenoidibus 5-6; sporis non visis. - Antioquia: $n^{0}$ so.

144. Zygnema sp. (sterile). Crass. cell. veget. I6,5-19 $\mu$; inter cellulas leviter constrictum. - Antioquia : $n^{\circ} 4$.

145. Zygnema sp. (sterile). Crass. cell. veget. $22-23 \mu .-$ Antioquia : $n^{0 s} 1$ and 2.

146. Zygnema ericetorum (Küтz.) Haxsg. - Antioquia: $n^{\text {os }} 1$ and 2.

147. Spirogyra decimina (МӥLь.) Кӥтz. forma tropica G. S. West in Journ. Linn. Soc. Bot. XXXVIII, sgo7, p. 106. S. decimina forma W. and G. S. West in Botan. Tidsskrift, X.IIV, 1901 , р. 16 I.

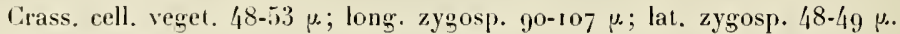

Antioquia : " $"$ " 8 .

This form agreed in all respects with the $\lambda$ siatic and $\Lambda$ frican specimens previously described.

148. Spirogyra splendida spec. nov.

Sp. maxima, cellulis vegelativis diametro $11 / 3-2-p l o$ longioribus, membrana $4 \mu$ crassa, extremitatibus non replicatis ; chromatophoris $5-6$ (plerumque 6) dense aggregatis, latis cum marginibus irregulariter asperis, pyrenoidibus magnis subconferte ordinatis, anfrac- 


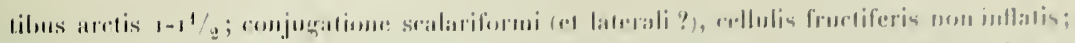

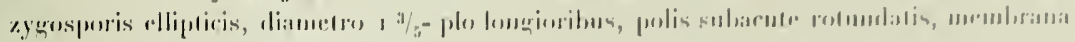

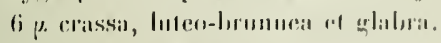

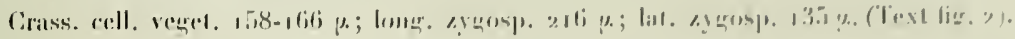

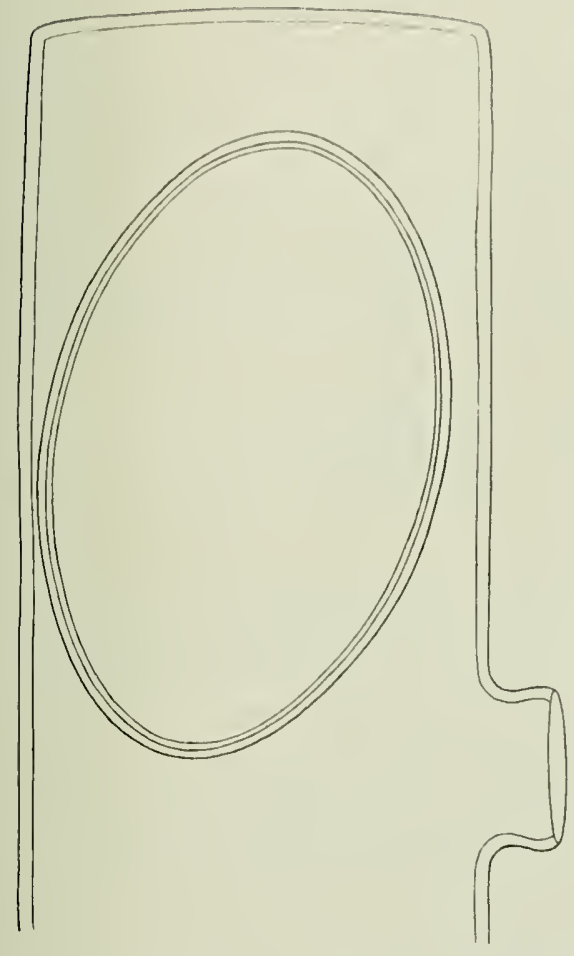

A

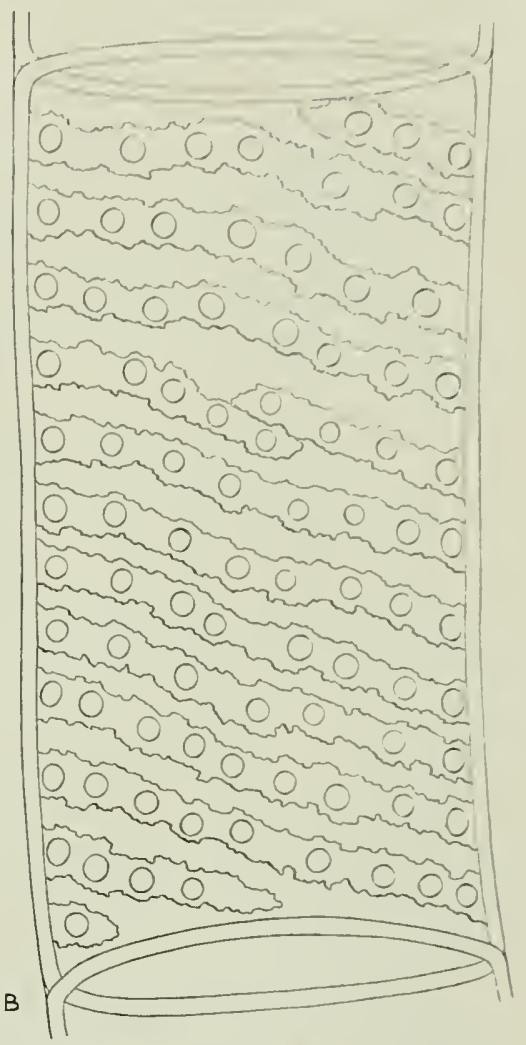

B

Fig. 2. - Spirogyra splendida sp. nov, $a$, vegelative cell; $b$, gamelangium with zycospore. $\times 400$.

Candinamarca: Laguna de C'baque, Easterm Andes: allit. 2066 m. \०23.

This large species occurred along with Gidegonimm, fubulostum var. colmmbianum and GE. laphrospornm among a small species of Nitella. The only known species of the same size is $S_{p}$. polylacniala $S_{\text {Thasb. from which }} S_{p}$. splendida is easily dislinguished 
lyy its lewer chloroplists, which are not so straight, and hy the proportionately larger zygosproses. The latter are elliptic, with somewhat pointed poles, whereas those of Sp. polytueniala are much more rounded and not infreguenly spherical.

Other species of Spirongra, all of which were sterile, were olsserved from Antiongua: $u^{05} 6$ and 7 ; and Candinamarca: $1^{0 \mathrm{~s}} 14,15,16,19,20$ and 24.

\section{Family Desmidiacex.}

1/9.9. Gonatozygon monotænium De Banx. - Antioyuiz: $n^{05} 1,2$ and 6.

Var. pilosellum Nordsr. - Antioquia: $n^{0 \leqslant} 1$ and 2.

ıว̆. Gonatozygon pilosum Wolte. - Antioquia: $n^{\circ}$ 4.

151. Cylindrocystis Brébissonii Menegu. - Antioquia : $n^{05}$ I and 2.

1.52. Netrium Digitus (Ennexb.) Itzıgs. and Rotue. (= Penimm lamellosum Küтz.; P. naviginm Turner; P. elegans Bernaro). - Antioquia: $n^{o s} 3,4$ and 5 . Cundinamarea : $n^{0 s} 23$ and 24 .

Var. constrictum $\mathbb{W}$. and G. S. West. - Antioquia: $n^{0} 3$.

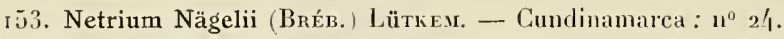

154. Penium Cylindrus (Ehrexb.) Bríb. - Cundinamarca : $n^{0} 24$.

155. Closterium abruptum W. W Est. - Cundinamarca : $n^{0} 24$.

156. Closterium angustatuın Küтz. - Antioquia: $n^{0} 3$.

1:7. Closterium columbianum spec. nov.

Cl. submedioere, cellulis diametro $6 \frac{1}{3}$-plo longioribus, sulbrectis, leviter attenuatis polos versus, dorso leviter convexo, ventre recto, polis crassis et subtruncatis ; membrana lutea vel fuscescente, valde costata, costis visis 7 , juxta apices punctata; chromatophoris .......?

Long. 208 u.; lat. $33 \mu$; lat. apie. $18 \mu$. (PI. XXIII, fig. 59).

Antioquin: Laguna alove Estrella near Medellin, Central-Andes; altit. 2500 m. No 4.

Only empty cells of this species were seen, in consequence of which no statement can be made with regard to the nature of the chloroplasts. The general proportions of the cell, along with its straightness and the few strong costae, afford characters which are quite diagnostic.

In general outline this species bears much resemblance to the Desmicl described from Singapore as Cl. Legumen W. and G. S. West (in Journ. Linn. Soc. Bot. XXXIII, 1897 , ए. 158, , . 8, f. $5-7$, , but the latter has a thin and perfectly smooth cell-wall.

158. Closterium didymotocum Con $\mathrm{A}$. - Cundinamarca : $\mathbf{n}^{\circ} 24$.

ı59. Closterium excavatum Borge in Bih. till K. Sv. Vel.-Akad. Handl. Bd. 27, Afil. 11I, $1^{0}$ Io, p. I9, t. 2, f. $7-9$.

Long. 155-19' $\mu_{0}$; lat. $27^{-29}$ u.

Antiorjuia: $n^{0} 7$. 


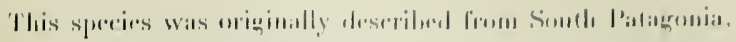

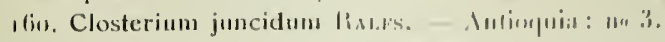

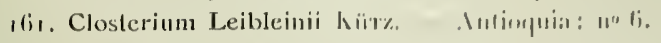

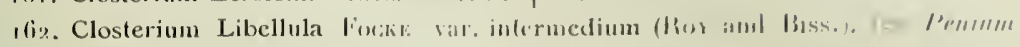

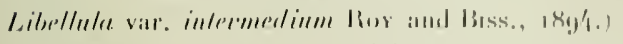

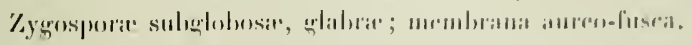

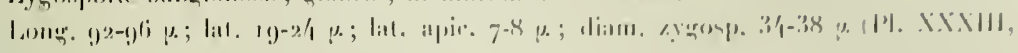

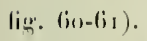

Anlionuia: $110 /$.

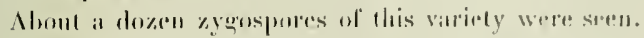

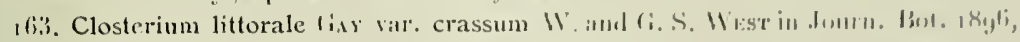
р. 378,1 , $3(1,1,18.18$.

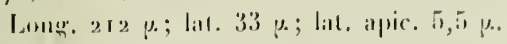

Mutionfuia: " $^{\circ}$.

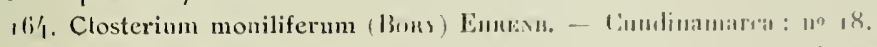

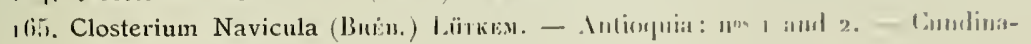
IIIIrea: No 24 .

166. Closterium parvulum N.Ee. - Antimpuia : $n^{0 \mathrm{n}} 11,11 \mathrm{nml} 1 \%$

Vil. angustum W, and fi, S. Wrst.

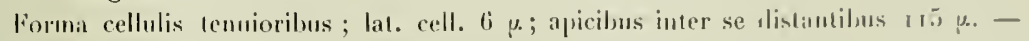
Cundinamareal: $11^{\circ} 23$.

Var.? (P. X.XIII, fig. 58).

Cellulis minus curvatis, polos versus phos minusve subiter altenuatis, polis rotundatis. Lat. or p.; apricibus inter sh distantibus 132 $_{2} \mu$.

Cundinamarca: 11024 .

Each chloroplast possessed three pyrenoids and the apical locellus contained from Iwo to three gypsum graudes. Only one specimen of this form was olserved and it is guite probabl. lhat it should be referred elsewhere.

I(i). Closterium prælongum Вrí., forma brevior WI. Mest. - Iutioquia: no 6.

ı 68. Closterium Pritchardianum Aвсиеи. - Antioquia: no 6.

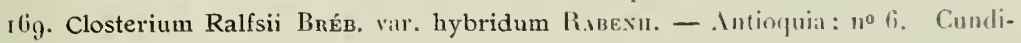
namarca : $n^{\circ} 24$.

Long. $504 \mu$; lat. $52 \mu$; lal. apic. $8, \bar{i}-9 \mu$.

170. Closterium regulare Bú́ı. - Cundiuanalca : $\|^{\circ} 2$.

171. Closterium setaceum Enıеxв. - Cumdinamarea: 1" 23.

172. Closterium tumidum Jonxsox. - Antioquia: $n^{05} 7$ in 18.

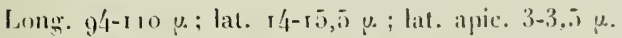

173. Closterium turgidum Eunexb. - Intioguia: $n^{\text {ns }} 6$ and 7.

L.ons. $750 \%$ : lat. $7^{2} \mu$.

Var. giganteum Nonost. 


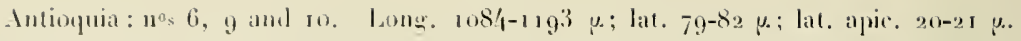

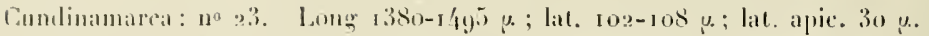

This variely of Cil. turghilum is une of the latroest linown besmids and is applarently contined to South Imericis. It was lirst deseribed from Brazil, but has since heen found in Bolivil, Paraguay and Ecuador. It was abundant in Laguna de l Tbaque, Cundinamalea (no 23), and the specimens were exceptionally the.

174. Closterium UIna locke.,- Cundinmmarca : $n^{0} 24$.

17.j. Pleurotænium eugeneum ( Гnx.) W. and G. S. West, Monogr'. Brit. Desm. I, 190\%, P. 202 .

Forma cellulis paullo angustioribus ; semicellulis ad basin 4-undulatis, ad apicem tuberculis 16 (9 risis).

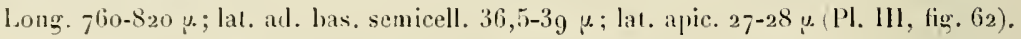

Cundinamarca: ॥ $^{\circ} 3$.

I 7 6. Pleurotænium Trabecula (Еurenb.) Neg. - Cundinamarca: 11022.

17. Pleurotænium maximum (Reissau) Luxd. - Antioquia: no fi. Cundinamarca: no 14 .

Long. $920 \mu$; lat. bas. inllat. semicell. $53 \mu$; lat. med. semicell. $48 \mu$.

i 78 . Euastrum attenuatum Wolle, i88 г Desm. U. S. I884, P. I03, t. 26, f. I 7 ; W. and G. S. West, char. emend. in Trans. Linn. Soc. Bot. ser. 2, V, 1896, p. 243, t. 14, f. 20-21. E. Hastingsii Wolle, Desm. U. S. new edit. I892, p. 113, 1. 42, f. 16, I7. E. pectinalum Bréb var. porrectum Borge. in Bih. till K. Sr. Vet. Akad.

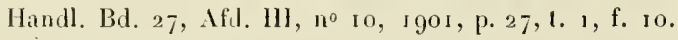

Intioquia : no 5 .

This characteristic Desmid was frequent among $E$. evolutum, $E$. quadriceps, $E$. pictum, etc. It is a very distinctive American type. It has no near relationship to $E$. pectinatum, having a polar lobe which is almost unique in the whole genus (cfr. W. and G. S. WEst, l. c.).

179. Euastrum binale (Turp.) Enrenb. forma Gutwinskii Scumde. - Antioquia: $n^{0} 5$. Cundinamarca: $n^{0} 24$.

Var. subelobatum W. West. - Intioquia : no 6 .

180. Euastrum brasiliense Bonge in Arkiv för Botanik utgifr. af k. Sv. Vet.-Akad. I, I go3, P. I I 2, 1. 5, f. I.

Forma minor.

Long. $54 \mu$; lat. 29 !. ; lat. loh. polar. I $7 \mu$; lat. isthm. so $\mu$; crass. $22 \mu$. (Pl. XXII, fig. 37 ). Cundinamarca: 1024 .

This species is very closely allied to E. ansatum Ralfs, but differs in the relatively more massive lower half of the semicell, and in the shorter and wider polar lobe. The protuberances on the front of the semicell are very similar, but the one immediately above the isthmus is somewhat more prominent and the two upper ones less prominent in E. brasiliense than in E. ansatum. 
181. Euastrum columbiammm spec nov.

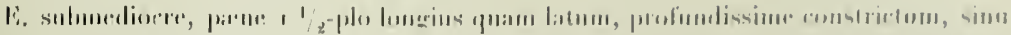

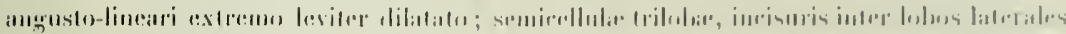

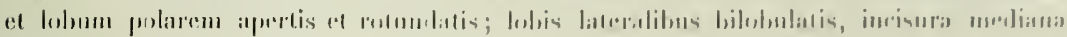

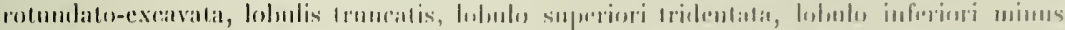

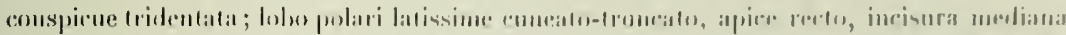

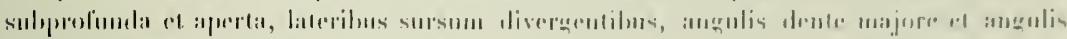

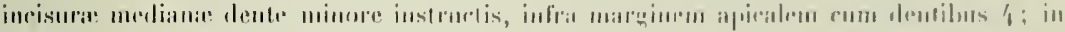

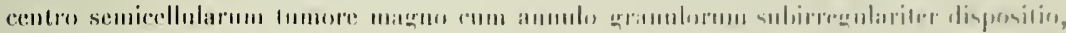

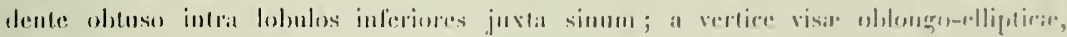

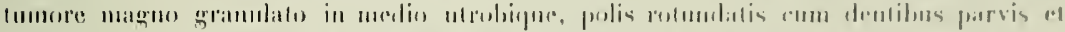

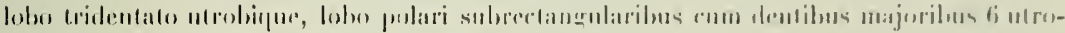

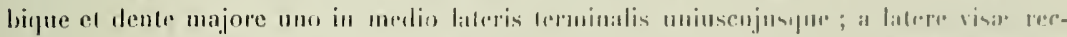

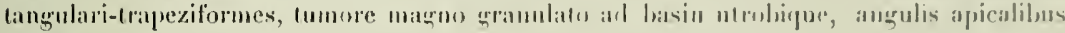
dentatis, apice recto.

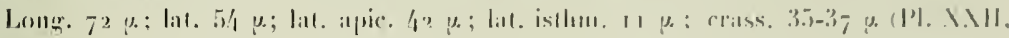
lig. 34).

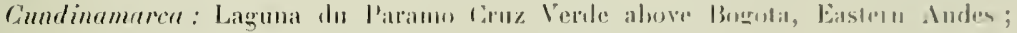
altit. $2700 \mathrm{~m}$. N 2 .

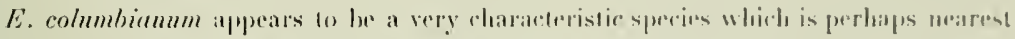

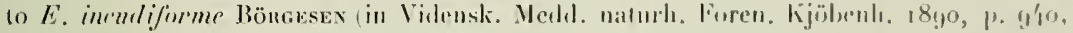
1. 3, f. 22). It differs, however, in the nature of its andral protuberanes, in the divided

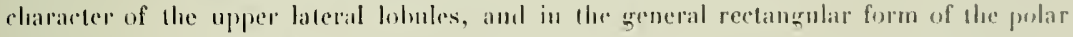
lobe (as seen in vertical riew).

The lower lateral lobules of $E$. columbianum are cnlire, whereas the upper ones are divided into two subtruncate lobnles (vide vertical view). The polin lobe, which is rectangular in vertical view, in fringed all round with large teeth, dilfering in this respect from any of the allied species.

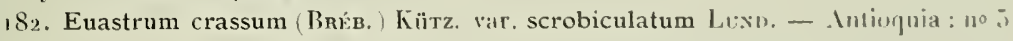
(a)undant).

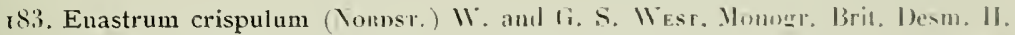

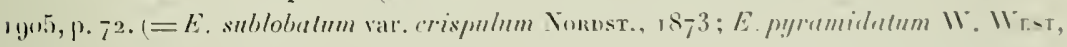
$18(92)$.

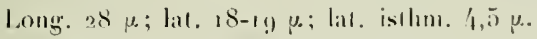

Antionulat: $n^{\circ} 5$ (abmulant). Cumlinamara: : $11^{n}, 2$.

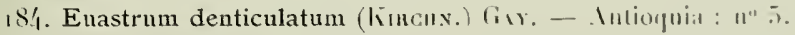

18.5. Enastrum elegaus (Вивъ.) Kїтz.

Forma angulis basalibus semicellularum $u$ in E. fis.o W. and G. S. West, ceteris u in E. alegante typico.

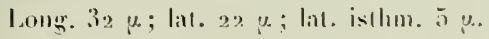

130 
Cumdinamarca : $10^{n} 23$ (frequent).

The main feature of this form lies in the dilatation of the hwer part of the semicells immediately ahove the basal anghes; there is also a slight thiskening of the cell- wall al the apex of the dilatation.

186. Euastrum evolutum(Nondst.) W. and (i.S. West. - Intienuia : no 5 (frequent).

I87. Euastrum inerme Luxd. - Antioquial: 110 5.

188. Euastrum insulare (Wirrk.) Ror. - Cundinamara: 1024.

18 . Euastrum personatum W. and G. S. West vall. columbianum var. nov.

Var. angulis lobulorm lateralium inferiorum spina mimula suberedis prodeditis; in centro semicellularum scrobiculis nullis; granulis intra margines latcrales carentibus.

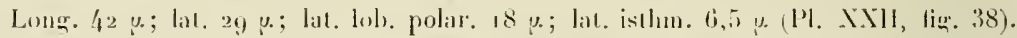

Antiogniu: In ditches between Medellin and America, Central Amdes; allit. r55o m. No 6 .

The type form of this species is known from Central Africa, Madigascar and Ceylon. 190. Euastrum pictum Börgesex in Vidensk. Medd. naturl. Foren. Kjöbenhavn, I 890, 1. 9.39, 1. 3, f. 19.

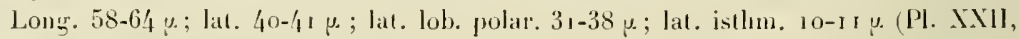
fig. $35-36$ ).

Antioquia: : $n^{\circ} 5$.

The specimens agreed very well with Böngesex's original description and figure. They were a little smalter and there was a trivial difference in the basal angles of the semicells, which were constantly (even if only slightly) bilobulate, each lobule heing emarginate.

191. Euastrum pinnatum Ral.fs. - Antioquia: $1^{\text {os }} 3,4$ (very ibundant) and 5. Cundinamarca : $n^{0} 24$.

I92. Euastrum quadriceps Nondst. in Vidensk. Medd, naturh. Foren. Kjöbenhavn, 1870 , p. 2 I6, t. 2, f. 5 .

Long. I I $2-120 \mu$; lat. $58-64 \mu_{\text {. }}$; lat. lob. polar. $24,5-26 \mu$; lat. isthm. 17-19,5 ; ; crass. $33-36 \mu$. (PI. XXII, fig. 40).

Antioquia: no 5 (frequent).

This species was first pescribed from Brazil, and the Columbian specimens were quite typical. The three basal protuberances of each senicell were especially well marked and the general rectangular character of the vertical view was as pronounced its in the Brazilian form.

The specimen figrured by Bonge (in Arkiv för Botanik ulgifr. K゙. Sv. Vet.-Akad. Bal. 1, rgu3, 1. 4, f. 21) I'rom Paraguay is by no means typical in rertical view, hemg clliplic rather than rectangular.

103. Euastrum sublobatum BRér. forma minor.

Long. If $\mu$; lat. $11,5 \mu$; lat. apic. $11 \mu$; lat. isthm. $2,5 \mu$; crass. $9,5 \mu .,-$ Intioquia : nก 


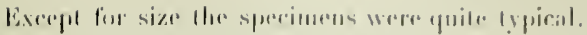

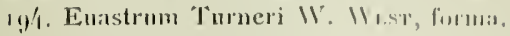

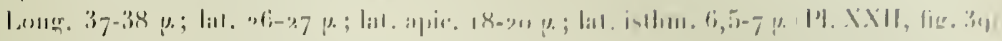

Inliugunia: 11 "1.

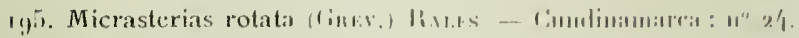

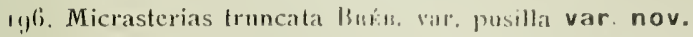

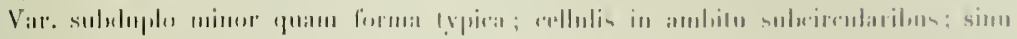

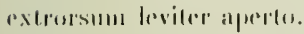

ا. lic. $1: 2-13)$.

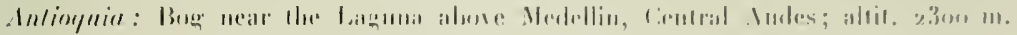
Nin (almumlinul).

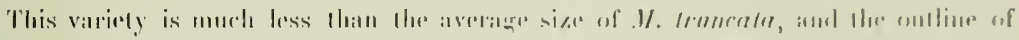

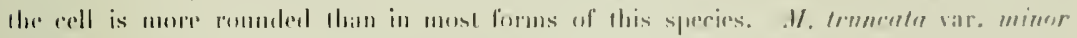

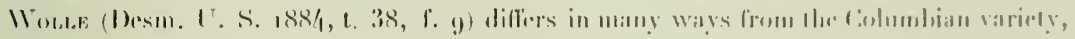

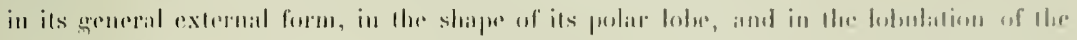
linteral linders.

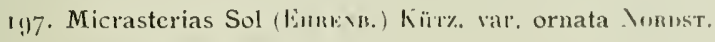

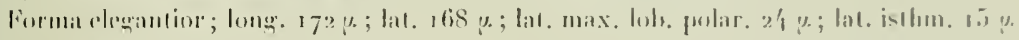

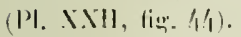

C.mulinamatral: $11^{\circ}, 23$.

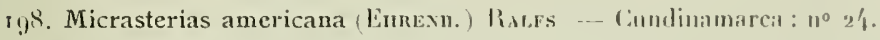

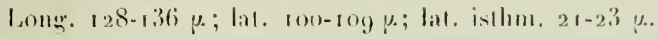

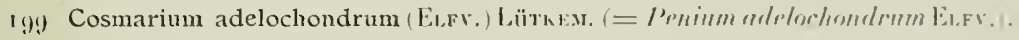

- Artionuia : $1^{10<} 1,2$ and 5 .

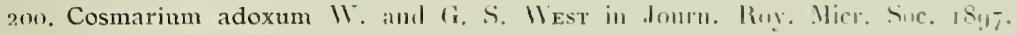
1. 478, 1. 7, f. 24.

Vir. denticulatum var. nov.

lar. sinu anguslo-lineari and ixtremum non ampliato; angulis basilibus rofundotruncalis semicellularm am denticulis minutissimis $1-3$ irregulariter ordinalie, anculis apicalibus cum denticulis minulissimis $\mathbf{1 - 2}$.

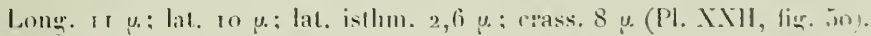

Intioquie : Iagmuni above Medellin, Central Indes; allit. $2300 \mathrm{~m}$. Xos 1 and 2.

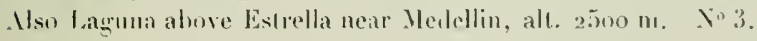

This liny Cosmarium dilfers from lyjical C. aloxum in ils linear sims and in the presence of the excedingly minnte amb very delicate denticntations. The rentral papilla of the semicedls is also a lille smatler. In eperal oulline it is very similar lo C. grome-

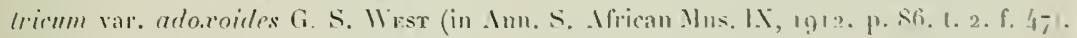

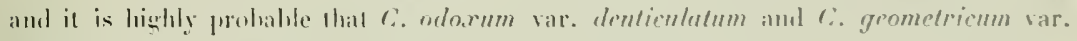

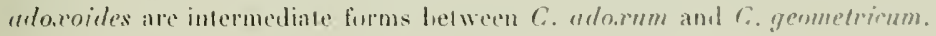




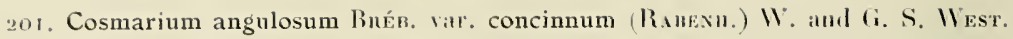
- Cumdinamarea: $11^{0} 23$.

202. Cosmarium antioquieuse sp. nov.

C. minutissimum, circiler 1/6-plo longius fuam latum, modice constrictum, sinu valde aperto et rotumblato; isthmo elougato; semicellular olyeniformes, apice concavo el ghatro, matreine rotundato laterali unoquonue (et palte parsa apicis) cum granulis con-

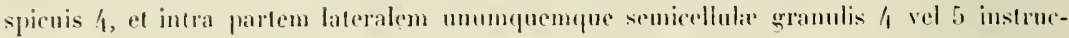
tae : celhula a latere vise oblongate, vix constrictar, patte superiori semicellube gramulate; it rertice visa oblongar, lateribus rectis, polis rotundatis et conspicue gramulatis.

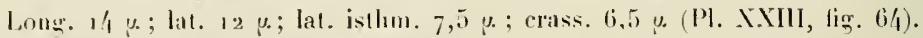

Intiognia : Laguna above Nedellin, Central Andes; altit. $2300 \mathrm{~m}$. Nos 1 and 2 .

This minute species should be carefully compared will C. Novae Semline Wure, and its var. sibericum BoLdt, from holh of which it is distinguished ly the more rounded lateral angles of the semicells, which are furnished will bluntly rombled granules (not acute denticulations), by the absence of the central papitla of the semicells, and hy the oblong vertical vinw with parallel sirles.

203. Cosmarium bacillare Lüткем. (= Penimm inconspicum W. and G. S. WEST). - Intioquia: $n^{\circ} 5$.

Long. I $5,5 \mu$; lal. 4,7 $\mu$.

204. Cosmarium bireme Nordst. - Cundinamarca : $\mathrm{n}^{\circ} 23$.

Loog. 1о $\mu$; lat. 10,5 $\mu$; lit. isthm. $2 \mu$; crass. (c. papill.) $7 \mu$.

205. Cosmarium Blyttii Wille. - Antioquia: $n^{0} 5$.

206. Cosmarium Clepsydra Nordst. (=C. Bicurdiu Reinscu $)$. - Antiouguia : $n^{\circ} 5$ (frequeul).

207. Cosmarium columbianum sp. nov.

C. sulparvum, circiter $1 \frac{1}{5}$-plo longius quam latum, profunde constrictum, sinu angusto-lineari exllemo levissime ampliato; semicellula pyramidato-trapeziformes, angulis inferioribus rotundatis, lateribus in parte-superiori tevissime concavis, in parte inferiori Iriundulatis, angulis superioribus paullo rolunlatis et vix emarginatis, apice reclo vel levissime convexo et biundulato, intra angulum inferiorem unumquemque granulis 4 vel 5 , et infra apicem serie transversa granulorum 4 (granulis binis in medio majoribus), in centro semicellularum leviter incrassalo; a vertice visie elliplica, polis leviter 5-undulatis et cum granulis pancis intra polos, lateribus leviter tumidis et incrassatis ; semicellulir a latere visar sulgglobosic.

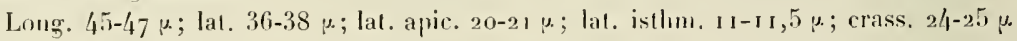
(PI. XXIII, fig. 68-69).

Cinndinamarca: Laguna de Lbaque, Eastern Andes; altit. $2066 \mathrm{~m} . \mathrm{N}_{2}^{0} 3$.

This species was frequent amongst large numbers of $C$. Qnadrum. The form of the semicells and the nature of the granulation are quile distinclive. In generaloutward 


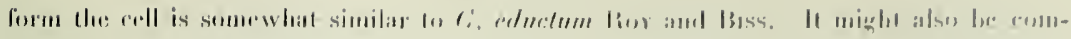

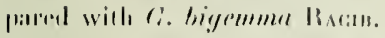

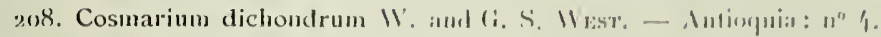
20y. Cosmarium distichoides sp. nov.

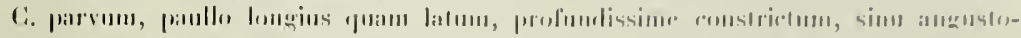

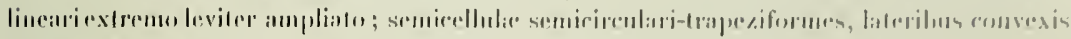

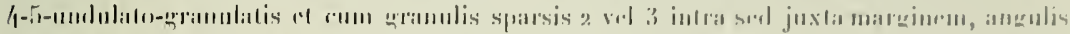

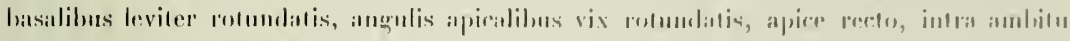

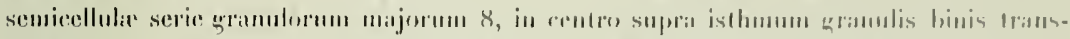

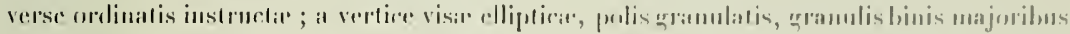

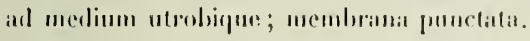

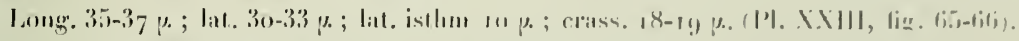

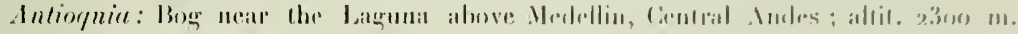

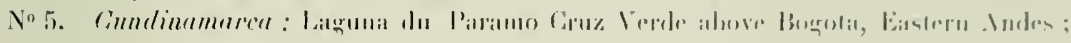
allit. $2700 \mathrm{~m}, \quad \mathrm{~N}^{\mathrm{n}} 2 \%$.

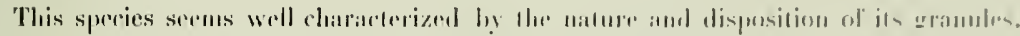

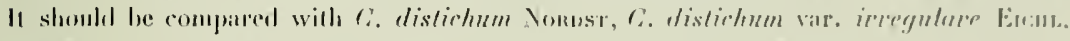

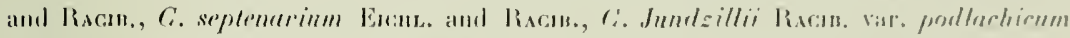

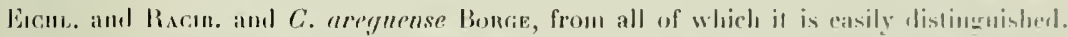

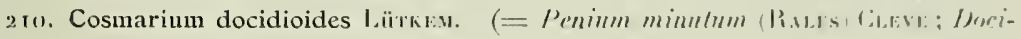
dimm minulum Rasfs). - Antiuquia : $\|^{0.2}$ 1, 2 and i.

\section{Cosmarium floriferum sp. nov.}

C. parrum, tam longum quam latum, profunde constrictum, simm angustr-lintari

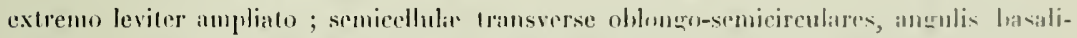
lus bate rolumdatis, parte superioni infra apierm marginis lateralis uniuscujusgue lesiter retusa, angulis superiorihus leviter moludatis, apice recto; membrana verrocusil, vermcis multe depressis cum matginilous minute gramulatis, verrucis granulatis y al marerinem lateralem unumpuempue, \& ad apicem, g intrit marginem semirellular, el serie singula

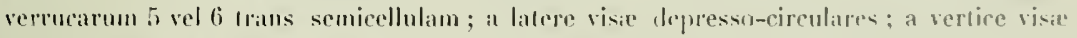
elliplica, polis late rotundatis, lateribus cum tumore lato utrobique.

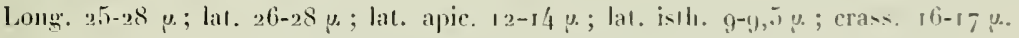
(P. A.XIII, fig. $70-71$ ).

Antioquia: Laguna above Medellin, Central Andes; alıit. 2300 m. Xis 1 and 2.

This pretly little Cosmarimm should be compared wilh C. ornalum R.u.fs forma

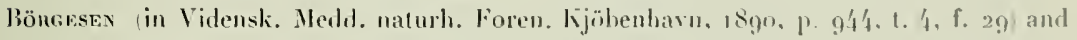

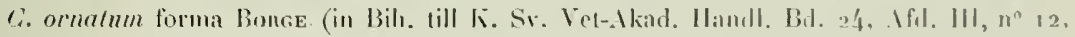
1899, 1. 23, t. 1, f. 26 ). Wthough in the outline of the cell $A$. florifermm clisely resembles $C$. ornatum, it is considerably smaller than any form of the latter species and the framulation is of a totally ditterent character. The gramules are lhemsoties much mase mimute and are arranged in qromps of from 4 to 6 at the margins of greatly llatrened 
warts. Moreover, some of these wats or vermea are arranged right across the front of the semicell, a disposition of markings which is never olserved in any form of $C$. ornutum. C. floriferum might also be compared with the various liorms of $C$. ordinatum (Börgesex) W. and G. S. West.

212. Cosmarium globosum Butxu. - Cundinaniarca : $\mathbf{n}^{0} 24$.

213. Cosmarium humile (G.1.) Nondsr. - Antioguia : $n^{0} 6$.

214. Cosmarium impressulum Elfv. - Intioquia : $n^{o s} 1,2$ and 5 . Cundimarca : 11" 23.

215. Cosmarium læve Ranenn. - Cundinamarca : $n^{0} 14$.

216. Cosmarium Lundellii Det.P. - Cundinamarca : n 32 . Long. $77 \mu$; lat. 58 -

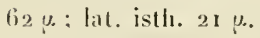

217. Cosmarium Mayori sp. nov.

C. subparvum, tam longum quam latum, profunde constrictum, sinn angusto-lineari extremo leviter ampliato ; semicellula transverse oblongo-trapeziformes, apice subrecto et ghabro, lateribus leviter convexis, verruca conica prope sed supra angulum inferioren unumgremque, et verruca conica singula in medio marginis lateralis uniuscujusque, angulis superioribus minutissime productis et acutis, cum serie singula vervearum rotundatarum 6 juxta sed infra apicem, et seriebus subcurvatis duobus granulorum trans mediun semicellule ; scrobiculis minutis inter granula; a vertice vise elliptica, polis verruca conica singula instructis, serie verrucarum rolundatarum 6 juxta sed intra marginem lateralem unumquemque; semicellulie a latere vise ohovatie, apice leviter convexo, parte superiori marginis lateralis uniuscujusque triverrucosa. Pyrenoidibus linis.

long. $37-38 \mu$; lat. $36-37 \mu$; lat. isthm. I0-J I $\mu$; crass. 22-24 $\mu$. (PI. XXIII, fig. 67). Cundinamarca : Laguma de Ubaque, Estern Andes; altil. $2066 \mathrm{~m}$. $\mathrm{N}^{0} 23$.

This species was rather infrequent among large numbers of C. Ouadrum. Its characters are so distinctive that it is not necessary to compare it closely with any other.

2 I 8. Cosmarium minimum W. and G. S. W West. - Antioquia : $1^{0} 5$. Long. 9-9,5 $\mu$;

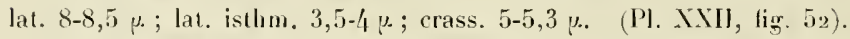

219. Cosmarium moniliforme (TLRP.) Ralfs. - Antioquia : $\mathbf{n}^{08} 5$ and 10.

220. Cosmarium nitidulum De Not. forma minima.

Forma cellulis mule minoribus, profundissime constrictis.

Long. $13 \mu$; lat. $10 \mu$; lat. isthm. 1,8 $\mu$; crass. $6,5 \mu$.

Antioquia : $n^{\circ} 5$.

221. Cosmarium obtusatum Schumbe. - Antioquia : $\mathrm{n}^{\circ} 5$.

Only one specimen was observed and it was decidedly smaller than the average for this species. Long. $46 \mu$; lat. $40 \mu$. ; lat. isthm. 12-5 p..

222. Cosmarium ornatum RaLFs. - Cundinamarca: $n^{0} 24$.

223. Cosmarium propinquum sp. nov.

C. parrum, circiter $2 \frac{1}{3}$-plo longius quam latum, subprofunde constrictum, sinu lineari extremo ampliato; semicellula longitudinaliter oblongo-rectangulares, angulis 


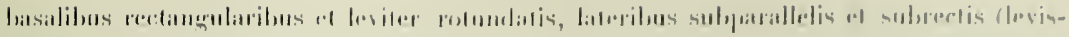

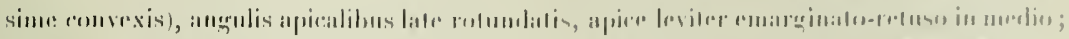

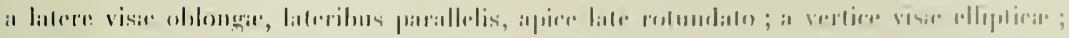

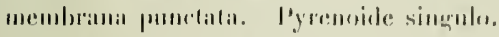

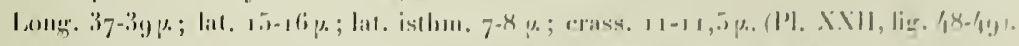

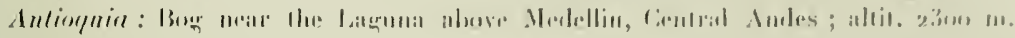
No5.

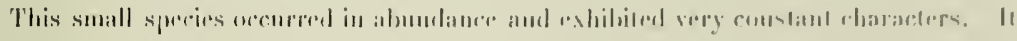

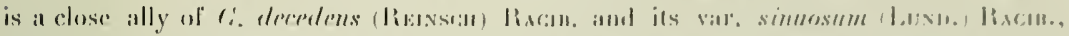

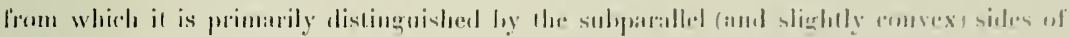

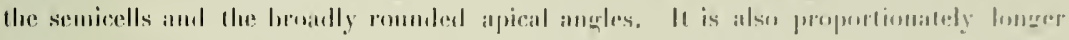

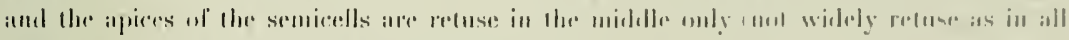

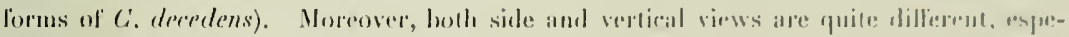
cially lle latter, in which there is no trace of the sulumanillate polles su characteristic of Ci. dererelens.

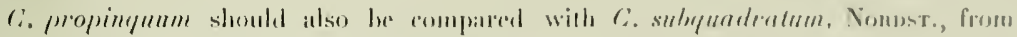

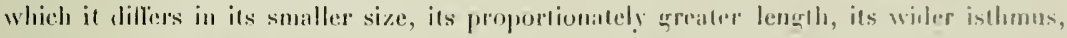
the enarginateretuse apices of the stmienlls, and in the form of the side view.

22/. Cosmarium pseudamcenum WHL.F. - Anlimpuia : n"6 3, 4 (ahmondant and 5.

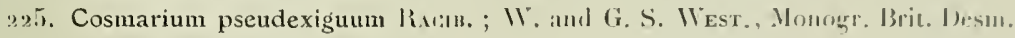
III, 1908, p. 6is, T. 70, f. $25,26$.

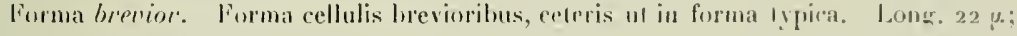
lat. 1.i $\mu$; lat. isthm, $3 \mu$.

Cumdinamarea : $n^{0} 24$.

As in other forms of this species the isthmus was exceedingly narrow. C. psenderigunm appears to be one of the most deeply ennstricted species of the grenus.

226. Cosmarium pseudoconnatum Nonest. - Antioquia : $\mathbf{1}^{\circ} 5$.

227. Cosmarium pseudonitidulum Nondst. - Mulioquia : $n^{\circ} 5$.

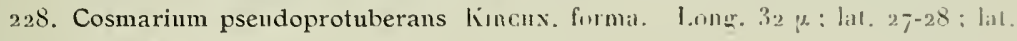
istlım. $8 \mu$. ; crass. $19 \mu$.

Cundinamarea : $n^{0} 23$.

220. Cosmarium pseudopyramidatum Laxn. - Anlioquia: no

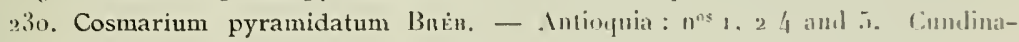
mareal : $n^{0} 24$.

23. Cosmarium Quadrum Lixo. - Cundinamarea : $n^{\circ} 23$.

This species occured in great abumlance. .ll the specimens were rither small, lunt not quite small enongh to be placed under var. mimus Nondst.

Long. $57-64 \mu$; lat. $48-53 \mu$; lat. isthm. 18-20 $\mu$ : crass. $26-27 \mu$.

232. Cosmarium Regnellii Wille. - Cundinamarea : $n^{\circ} 23$.

233. Cosmarium Reginesi Ressscu. - Antioquia: u $^{05}$ 1, 2 am! 5. 
Var. montanum Scimule. - Anliuguia: mo 1 and 2.

234. Cosmarium repandum Nondst. Corma minor W. and R. S. West ( $=$ C. odontoplenrum lios and Bıss.). - Inliounia: no 4 .

235. Cosmarium retusiforme (WILLE) liurw. forma abscissa (SCHMDLE) Borge. Antioquia: $n^{\text {os }} 1$ anl 2. Cundiuamarca: 11023.

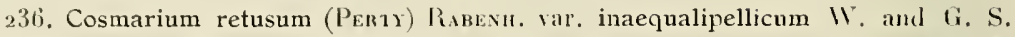
West. Ionogr. Brit. Desul. III, 1gos, p. $267=$ C. inneguralipellirmm W. and G. S.

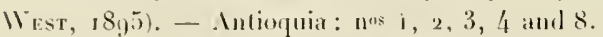

23. . Cosmarium subrquale sp. nov.

C. submediocre, circiter , ${ }^{\mathrm{q}} \mathrm{p}$ to longius quam latum, profundissiuse constrictum, sinu angusto-lineari ad extremum subampliato; semicellula triangulares, base recta, angulis inferiorilus late roundatis el in parte superiori cum undulo vix conspicuo, lateribus concaris, angulo appicali late rolundato el ad apicen cum membrana incrassata; in centro semicellularum tumoribus parvis tribus, lumore uno juxta istlmum et fumoribus hinis superioribus hortzontaliter dispositis ; a latere vise ovato-pyramidata, angulis basalibus rotundatis, lateribus cum tumore depresso et parvo infra medium, apice late rotumlato; a vertice visie elliptice, polis rotundatis, tumoribus parvis tribus utrobique; membrana punctata, punctis ad angulos semicellularum majoribus. Pyrenoidibus biuis.

Long. $64 \mu$; lat. $39 \mu$; lat. ajpic. $14 \mu$; lat. isllm. $13 \mu$; crass. $28 \mu$. (PI. XXIII, fig. 63 ).

Antioquia: In ditches between Medellin and America, Central Andes; altit. r55o m. No 6 .

This sprecies is a close ally of $C$. aequale Tunner (in K. Sr. Vet. Alad. Handl. Bd. $\mathrm{XXY}, n^{0} 5,189^{3}$, p. 6\%, 1. I , f. $3 \mathrm{r}$ ), but is distinguished by its larger size, its proportionately longer cells, its three central tumours (which cause the side and vertical views to be entirely different), and by its conspicuously punctate cell-wall. Borge lits recorded C. aequale from Argentina (cfr. Arkiv för Botanik utgifv. K. Sv. Vet.-Akad. Bd. VI, rgo6, P. 7 c. fig.) and he descrilses and figures the semicells as having a chloroplast with one central pyrenoid. In $C$. snbaequale there are two pyrenoids in each semicell.

238. Cosmarium subarctoum (Lagern.) Racib.; W. and. G. S. West, Monogr. Bril. Desm. III, г9o8, p. 3 , 1. 68, f. 6.8.

Var. minutissimum var. nov.

Cellular minulissima', semicellular, ad isthmum plus minusve tortie.

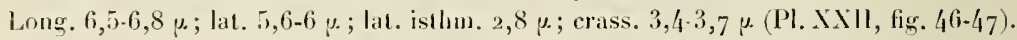
Antioquire: Laguna above Medellin, Central-indes; altit. $2300 \mathrm{~m} . \mathrm{n}^{0 \mathrm{~s}} 1$ and 2.

This variety is one of the very smallest of known Desmids. It is about one-1hird the size of typical C. subarctoum, but is otherwise in no way different fiom that species, the cells of which, as in this Columbian variety, are often slightly twisted at the isthmus. Among other minutespecies of Cosmarium should be mentioned C. suevicum Kincunen 


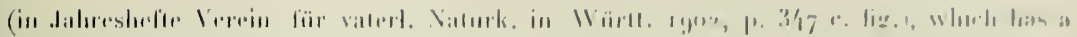

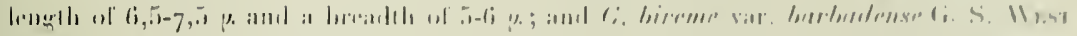

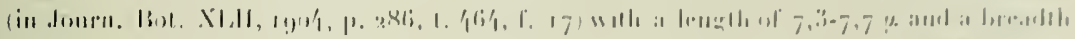

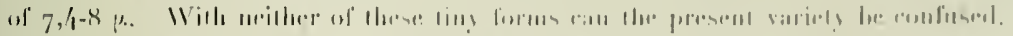

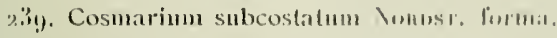

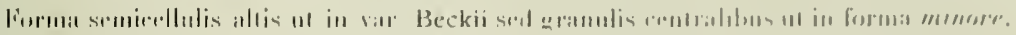

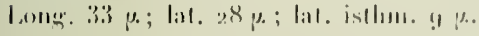

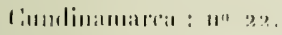

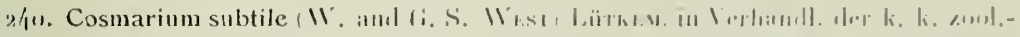

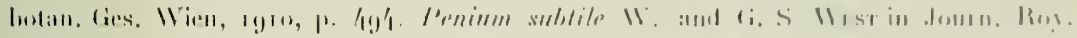

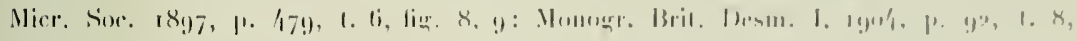
f. $27-99$.

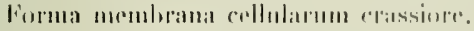

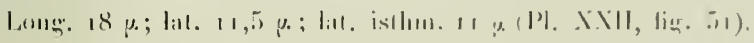

Ciumlinamarca: $11^{0} 2 \%$.

:\{1. Cosmarium subtilissimum spec. nov.

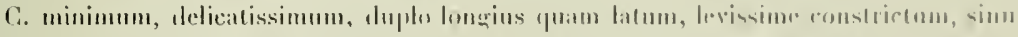

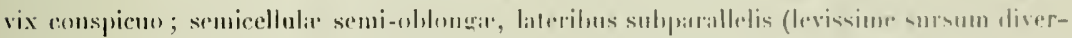

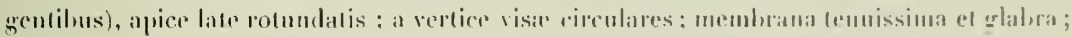

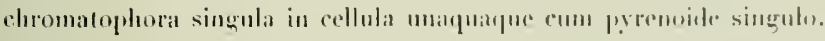

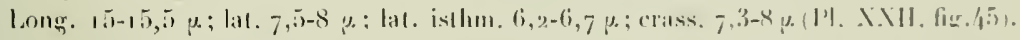

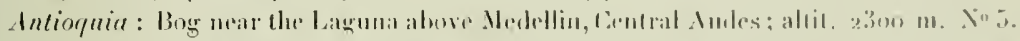

This speries should be rompared wilh C: perminutum uob. (= Ciglindrougstis minu-

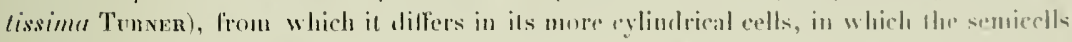
are slightly willer at the apex than the base, and in the single chloroplant (with one cerstral pyrenoid) in each cell. The cell-wall is atso much more delicale.

2/2. Cosmarium subtriordinatum W. and (i. S. Wist. - Inliuinial: $1^{04}$ I ilnd 2.

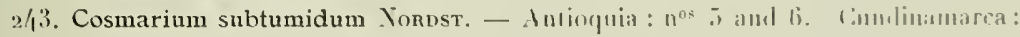
$11^{\text {as }} 1 / 4$ :

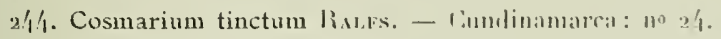

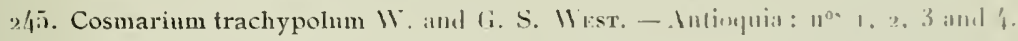

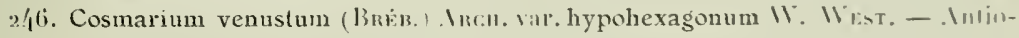
yuia: $11^{\circ} \overline{1}$.

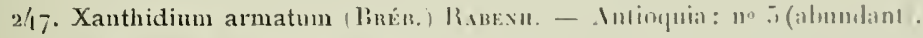

2/48. Xanthidium Mayori spec. nov.

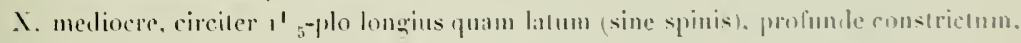
simu lineari extrorsum ampliato; semicellulat transierse oblongo-hexagouar, laterihns inferioribus el superioribus leviter convexis, apper recto, angulis lateralibus ef apicalihu spinis subulatis leviter curvalis hins instruclis, etian spinis simbililus in medin mascrinmm lateralum superiorum ef in medio apicis; in contro semicellularum vertucis lonis trans-

131 
verse dispositis, el cum anmulo serobiculormu minutorum 9-10 cirea rerrucam unumquemeque: a vertice visie subellipticie, polis traneatis, ad angulum unumpuempue spina subulata leviter curvata pattlo divergente, lateribus eomsexis, rermeis rotumblis binis ad medium utrobique, serie subirregulariter disposita spinarum 4 intra marginem lateralem unumyuemque; membrana delicate punctulata.

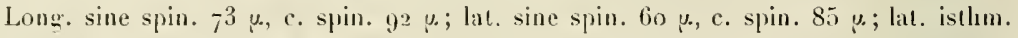
21 y. ; crass. 1? y. (Pl. X.III, fig. 41).

Cundinamarca : Latguna de Llbague, Eastern Andes; altit. $2066 \mathrm{~m}$. No 23.

In this species there are seven pairs of spines on each semicell, one pair at each of lhe lateral and apieal angles, one pair in the mishlle of the apex, and one pair in the middle of each upper lateral margin.

The general outline of the call resembles that of $X$. antilopaenm (Bnśв.) Kärz., from which X. Mayori differs in the three additional pairs of spines and in the presence of the binate central vernuca.

249. Arthrodesmus Incus (Bréb.) Hass. forma minor W. and G. S. Wesr. Antioguia: "10 ${ }^{\text {s }}$ and 2 .

250. Arthrodesmus controversus W. and G. S. West. - Antioquial : no 8.

25i. Arthrodesmus convergens Eunexb. - Antioquia: no 5.

252. Arthrodesmus bifidus BréB. - Antioquia: no 5 .

253. Staurastrum antioquiense spec. nov.

S. minulissimum, eirciter tam longum quam latum (cum processibus), profunde constrictum, sinu valde aperto ad extremum acuminato; semicellula transverse elliptica, polis in processus brevissimos submamillatos bispinatos horizontaliter dispositos productis, ad apicem convexum processibus brevissimis submamillatis bispinulatis 3 predita ; a vertice visæ sexangulares, lateribus concavis, angulis rotundato-mamillatis et bispinatis, intra sed juxta margines processibus brevissimis bispinulatis 3 ; membrana tenuissima el glabra.

Long. sine proc. э $3,5 \mu$, c. proc. I $7,5 \mu$; lat. (c. proc.) I6-i $7,5 \mu$; lat. isthm. $5,3 \mu$. (P. XXI, figr. 29).

Antioquia: Laguna above Medellin, Central Andes; altit. $2300 \mathrm{~m}$. Nos $\mathrm{I}$ and 2.

This minute Staurastrum resembles in its lront view some of the smaller forms of St. furcalum Enrexb., luut is much less. The vertical view is at once distinctive, since it is 6-angular, with six equal mamillate processes in the lower whorl and only three apical ones, one of the latter occuring just within each alternate concave side.

254 . Staurastrum arcuatum Nonost.

Forma semicellulis robustioribus, angulis crassiorilus; isthmo latiori. Long. sine spin. $28 \mu$; lat. c. spin. $46 \mu$; lat. isthm. $12 \mu .-$ Antioquia : $n^{0 s} 1$ and 2 .

255. Staurastrum brachiatum Racfs. - Intioquia: $n^{\text {"s }}$ I and 2.

256. Staurastrum brevispinum BRÉB, Yar, inerme WILLE.

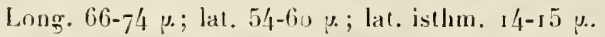

Cundinamarca : $n^{\circ} 24$ (frequent). 


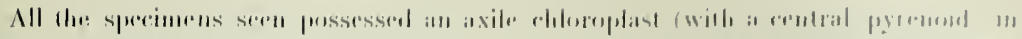

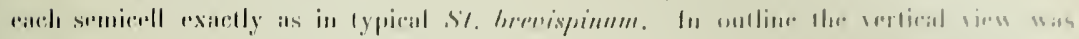

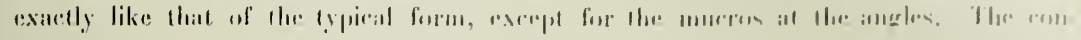

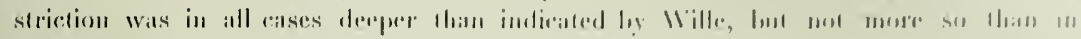
the lypical firm.

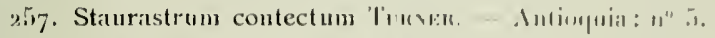

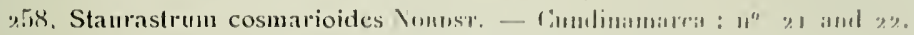

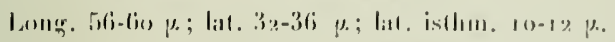

ang. Staurastrum cuspidatum linim. vir. columbianum var. nov.

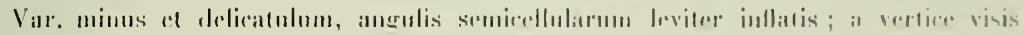
laterilus concaviurilus.

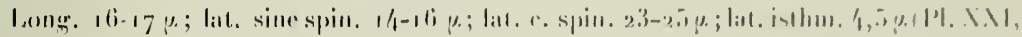
lig. 28).

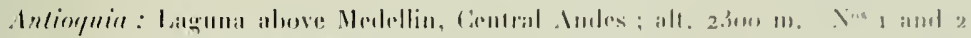

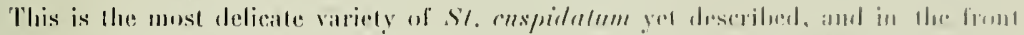

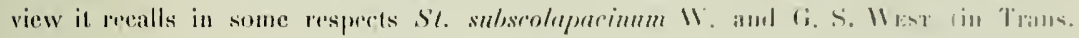

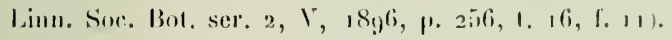

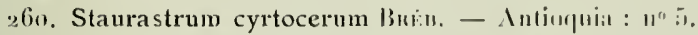

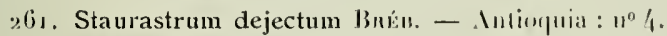

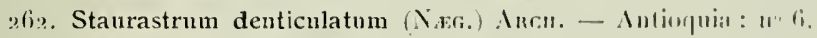

203. Staurastrum Dickiei Risks vir. minutum var. nov.

Var. mimulum, cellulis pufundissine constrictis.

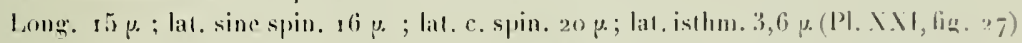

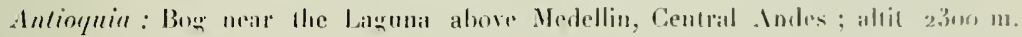
No 5.

A smatl form of this species was described by Scomune (in Desterr. Imtan. Zeit-

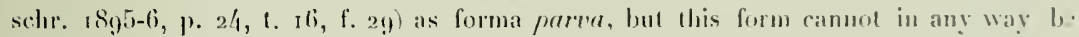
confused with var. minntum, and its wide istlumus and prenliar vertical view matio it donlutul whether it is really a form of $5 \%$ Dichici.

lt is a noteworthy fict that the lareest forms of $S$. Diclici also urcur in America. the North Ameriean specimens of St. Dieliei var. maximum W. and I. S. II Esx attai-

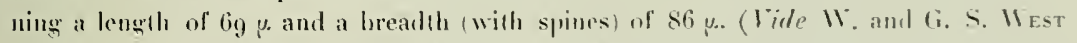

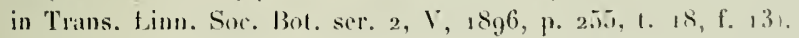

264. Staurastrum dilatatum Eurexu - Intioquia : $n^{0} 3$. Condinamarea : $n^{\prime \prime} 2$.

265. Staurastrum distentum WoLle, 1882; Desm. U. S. 185\%. P. 149. 1. 41, f. 15.

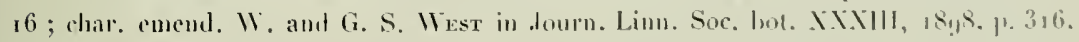
figr. xylogr. is $d-f$.

Var, columbianum var. nov.

Var. circiter lam fongum quam latum, spina simplice parra aul hasin processum uniusenjusque utrobique. 


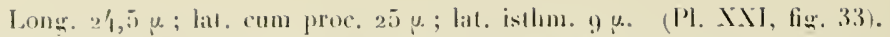

Antiognier: Bog near the Laguna above Mealedin, Central Andes; altit. $2300 \mathrm{~m}$. No:

This variety shoult he comprated with St. sulpolymorphum Bonse, described from Brazil in 1go3. Il seens scarcely possible to renard Bonge's species as other than a form of St. distenlum.

266. Staurastrum gemelliparum \oknst, lorma minot. Long. cum pror. $20 \mu$; lat. cum proc. 18 . - Intioquia: $: 11^{0 *} 1$ and 2.

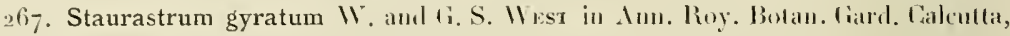
VI, 1907. 1. 219, t. 15, f. 27.

Var, divergens var, nov.

Var. corpore semicellularum paullo minnre ; precessilms validiorilms el crassioribus.

Long. sine proc. $8 \mu$, cum proc. $18-19 \mu$; lit. sine proce cire. $7,5-8 \mu$, cum proc. $23-26 \mu$; lat. isthm. 4 \%. (PI. MN1, tig. 30).

Cinndinamarca: Laghua de Claqur, Eastern Andes: altit. $2066 \mathrm{~m}, \mathrm{~N}_{2} 3$.

268. Staurastrum hirsutum (Еıпехв.) B ве́в - Cundinamarca: ॥"2/.

26y. Staurastrum illusum spec. nov.

St. minutum, paullo latius quam longum, profundissime constrictum, sinu acutangulo el leviter aperto ; semicellula transverse alliptico-oblongir, dorso convexiori quam ventro, angulis lateralibus late rotundatis; a vertice visie triangulares, angulis rotundalis, lateribus valde concavis ; membrana tenuissima el punctata.

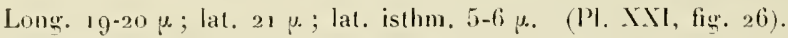

Antioquia: Laquna above Estrella near Medellin, Central Andes; altit. $2500 \mathrm{~m}$.

No3 (alundant).

It is only after careful deliberation lhat I renture to describe hlis Desmid as a new species. Its allies are St. mulicum Bris. and St. laneeolatum Arcu., but there is litle doubt that it would he quite wrong 10 refer it to either of those species. It is much more delicate than $S t$. mutium, will more depressed semicells, will narrower angles in the vertical view, and a very distinchly punctate cell-wall. From St. Lanceolulnm var. compressum it differs in the rounded lateral angles of the semicells, in the more concave sides of the vertical view, and in the punctate cell-wall.

270. Staurastrum inconspicuum Yordst. - Cundinamarrit: $\mathrm{n}^{\circ} 2 /$.

271. Staurastrum leptocladum \onoss. forma africanum (i. S. 11 Esr in Jonrn. Lim. Soc. Bol. XXYY 111,1907, 1. 129, 1. 6, f. 12.

Semicellula a vertice visie corprore rhomboides-rotumdato. Long. \{0-42 $\mu$; lat. sine proc. rirc. $20-21 \mu, \mathrm{cmm}$ proc. $136-1 / 8, \mu$; lat. has, semicell. $10-10,5 \mu$; lat. istlum. $7 \mu$; crass. 17 p. - Cundinamarca: $n^{\circ}$ 2.3.

Except for the rlomboidal shape of the borly of the semicells ans seen in vertical virw the specimens were identical in all respects with those originally described l'mom Nyasa and Victoria Nyanza. 
Vur. elegans var. nov.

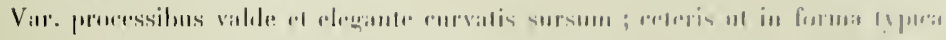

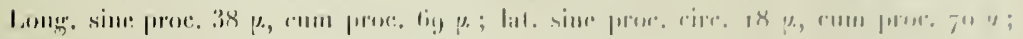

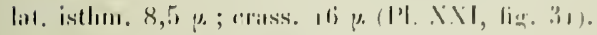

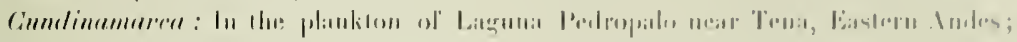
illil 20010 III. N" Ni.

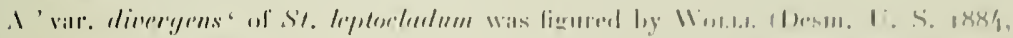

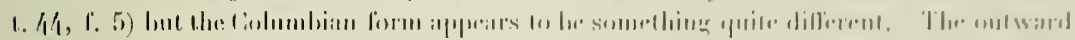

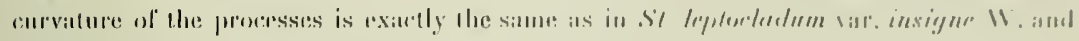
i. S. Wist.

\section{Staurastrum Mayori spec. nov.}

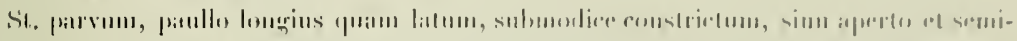

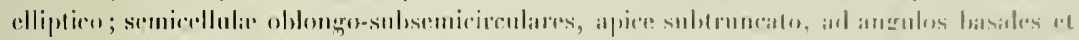

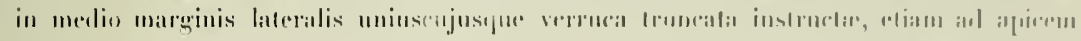

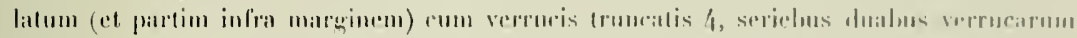

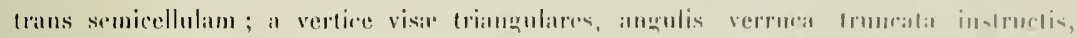

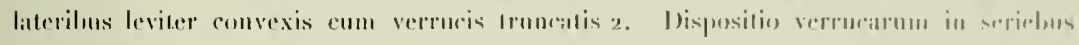

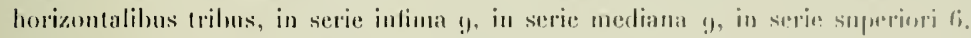

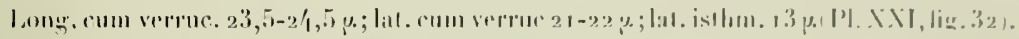

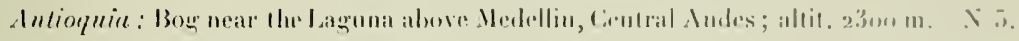

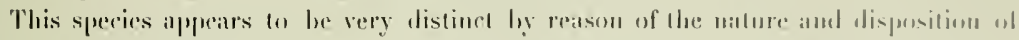

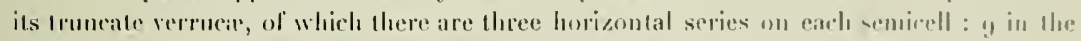
basal series, g in the median spries, lut moly fi in the upper or aprical serices.

In the oulline of the cell s\%. Mayori resembles the Vew \%ealand St. dersuosum

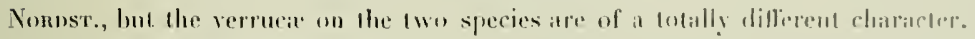

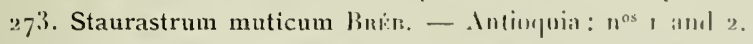

271. Staurastrum O'Mearii Arcmen, - Intioquia: 1 $^{0} 3$.

$27 \%$. Staurastrum orbiculare R.u.Fs. - Antiuquial : $n " \pi$

Var. denticulatum \onvsr. - Intioupia : $n^{\circ}$ q.

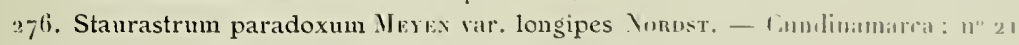
(planklon).

377. Staurastrum pterosporum Loxv. - Intioquial : 11053 a aml it.

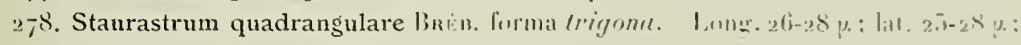
lat. is(lim, $8-() \mu$.

Intionpuia : $n^{\prime \prime} 5$. and 2 .

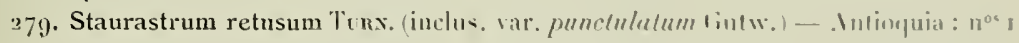

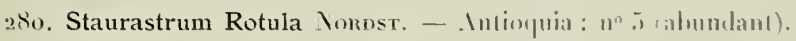

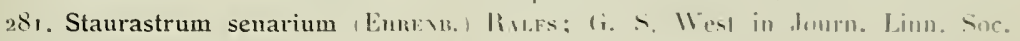
Bot. IXXIX, ıgog, 1. 68, 1. 6, 1. 13. - Intiopuia: 11" 
28. Staurastrnm spicatum W. and G. S. Wrsi in dourn. Bol. XXXIll, 189.5,

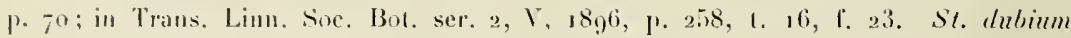
Eicnt. and Gutw., I8g4 (non St. Anbinm W. West, 1890 ).

forma spinis ad anenulos superiores semicellularm brevioribus ef spinis ad angulos inferiores longioriluss.

long. sine spin. $22 \mu$, cmu spin. $29 \mu$; lat. sine spin. $24 \mu$, cum spin. 3o-3 r $\mu$; lat. istlum. $7 \mu$. - Anlionuia : $11^{* 3} 3$.

383. Staurastrum tetracerum Racrs. - Intioquia: $n^{\circ: 3,4}$ and 5.

28\%. Staurastrum trihedrale WoLle, 1883 ; Desm. U. S. 1884, 1. 123 , 1. 40, fig. 12, 13 ; char. emend. W. and G. S. West. in Trans. Linn. Soc. Bot ser. 2,1 , 1896, p. 610, 1. 16, f. 29 .

Long. $47 \mu$; lat. $33 \mu$; lat. isthm. $12 \mu$.

Antimpuia: $n^{0} 5$ (fréquent). Cundinamarcas: $n^{0} 24$.

285. Sphærozosma granulatum Ror and Biss. -- Antioquia : $n^{\circ 8} 1$ and 2.

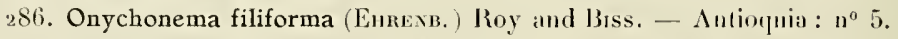

287. Spondylosium tetragonum W. West in Journ. Linn. Soc. Bot. XXIX, 1892, ए. $115,1.19$, f. 2 .

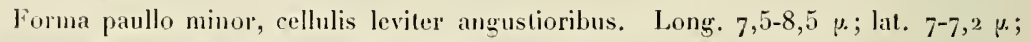

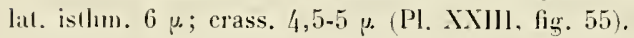

liorma trigona; cellulis a vertice visis triangularibus, angulis rotundatis, lateribus

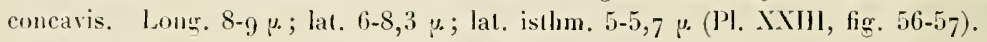

Cundinamarca: $11^{0} 24$ (both forms frequent).

lt would appear that Spondylosium Treubii Bensard (in Bull. Dép. de l'Agric. lades-Yéerl. 19o9, P. 2 I, 1. 1, f. 16) is only a form of $S$ p. tetragonum.

288. Spondylosium ossiculorum spec. nov.

$\mathrm{S}$. parrum, filis non tortis, siue vagina mucosa; cellule cireiter $1 / 3$-plo longius quam latum, subprofunde constrictum, sinu valde aperto et semicirculari; semicellulir subellipticie, apice late convexo, serje singulo punctorum (= pororum) transmediom semicellulie uniusenjuspue ; semicellulie a vertice visa late ellipticie, a latere visie depressosubcirculares.

Long. cell. $12-13,5 \mu$; lat. $9,5-10,3 \mu$; lat. isthm. $5-5,5 \mu$; crass. $7-8 \mu$. (PI. XX111, fig. 54).

Antiorguia: Laguna ahove Estrella near Nedellin, Central Audes; altit. $2500 \mathrm{~m}$. No 3 (freyuent).

This is apparently a very distinet species. The single row of conspicuous punctir across the middle of each semicell really represents a transverse row of large pores in the cell-wall.

289. Hyalotheca dissiliens (Sм.) Brв́в. - Antioquia: $n^{\text {os }}$ 1, 2, 3, 4 and 5. Cundinamarca : $11^{08} 22$ and 24 .

Larga specinens of forma tridentula occurred from $\mathrm{n}^{\circ} 3$, and the specimens from $11^{\circ} 5$ were all very small. 


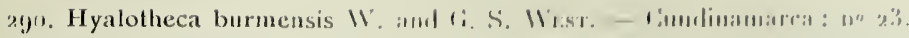

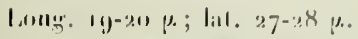

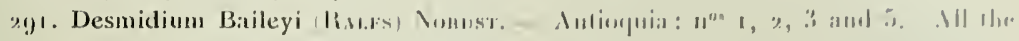

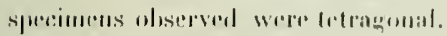

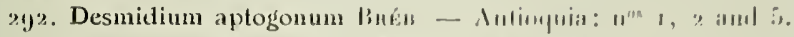

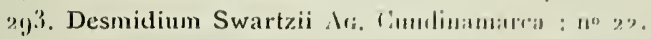

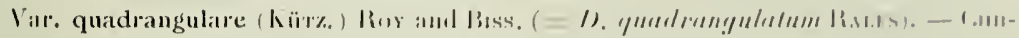

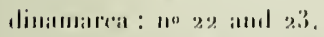

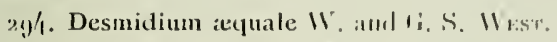

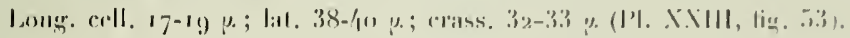

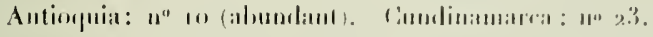

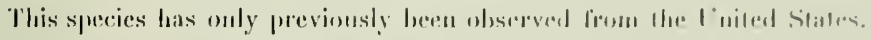

2g\%. Desmidium cylindricum limes. - limulinaman

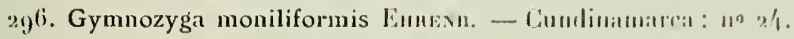

\section{Division III. STEPHANOKONTÆ}

\section{Family Edogoniacex}

297. Edogonium Borisianum (LE CL.) Wittr.

Cirass. cell. veget. $17-17,5 \mu$; altit. 4-i) plo major ;

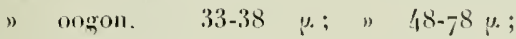

") oospor. $32-36$ p. " $4-63 \mu$.

Antioquia : no 9. Cundinamarca : $n^{\circ} 23$.

The form observed was rather more slender than the arerage for this species. The oogonia were solitary or up ro four seriate.

298. Edogonium undulatum (Bпе́в.) A. BR. - Cundinamiıra: no 14.

299. Edogonium plusiosporum Wittr.

Forma oosporis paullo minoribus oogonis minus complentibus.

Crass. cell. reget. 12-13 $u_{0}$; altit. 3- 4-plo major;

" oogon. $28 \mu$; $) \quad 38 \mu$ :

"nospor. $25 \mu_{0} ; 11 \quad 25 \mu$.

Coundinamarea : $n^{\circ} 16$.

30o. Edogonimn tapeinosporum Miтrr. forma ongonia hinis.

Carass. cell. veget. $3,5-5 y$; altit. $31 / 2$ li-plo major:

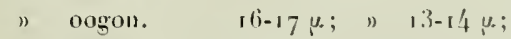

" oospor. 13-14 u.; " 12 u. (Text-tig. 3.1).

Anlioquia : no 10. 
3or. Edogonium inconspicuum IInv.

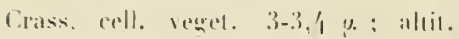
\{-i-plo majerr:

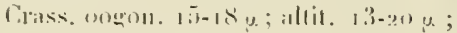

3) 00spror. 14-17\%; $1010,5-120$. Text-fig. :3 B and C).

Antimpuia: $n^{\circ} 9$ (abmulame).

The lilaments were mostly slort and racle will one nognome. They were thickly allawhed 10 a tarke sprecies of spirongyer.

3rz. Elogonium fabulosum IInx var. columbianum var. nov.

Var. cellulis vegetativis tenuioribus, diamelon plerumpue j-(j-plo longiorihus :

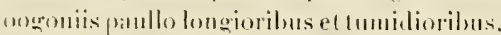

Crass. cell. veget. 56-70 pe ; altit.

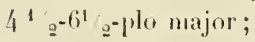

Crass. oogon. $9^{8-100 \mu}$; altil. 163. $174 \%$;

Crass. oospror. 8 i-84 p.; allit. г $2 /$ - 28 u. (Text-fig. 3 D).

Cundinamarca : Laguna de L Hampe, Eastern Andes; altit. $2066 \mathrm{~m}$. No 23 (common amongst Vitella sp.).

Originally described from the Natlo Grosso province of Brazil (cfr. Hirn in Actil Soc. Szi. Fenuica, XXVll, $1^{\circ} \mathrm{I}$, 1900, P. 114, 1. 11, fix. 59), (E. fubulosum is the laresest of all known species of the genus. The Columbian specimens belour
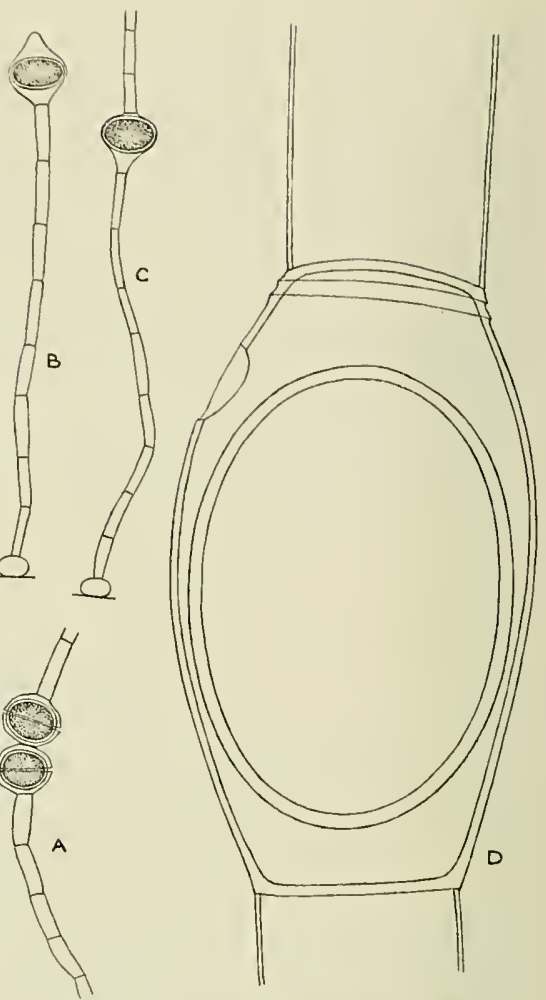

Fir. 3. - A, OEdogonium lapeinosporum Wittr.

$\mathrm{B}$ and $\mathrm{C}, \boldsymbol{E}$. inconspicuum Hirn.

D, E. fabulosum Hirn var columbiamem var. nov. $\mathrm{All} \times 500$. 10 a distinct variety characterized by the more slender filaments, with proportionately longer cells, and the more tumid oogonia with more ellipsiril oospores.

Another variety of this species - var. maximum (Wr. and (i. S. Wesr) IIns - is known limm lioh Chang in the Gulf of Siam.

3.3. Edogonium taphrosporum Yondst. and IImx in Hirn. l. c., 1900, 1. 1.33, 1. 16, f. y1.

Criss cell. veget. I $y^{-2} 2 \mu$; atlit. 8-12-plo mi:jul ;

"

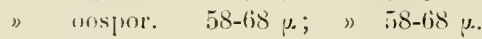


Cumblimamarma : $11^{\circ} 93$.

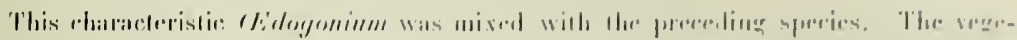

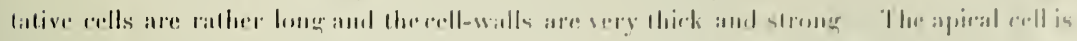

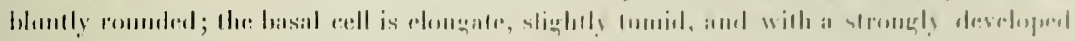
dlise: of allardument.

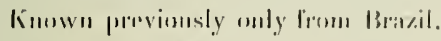

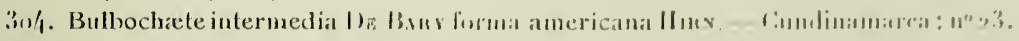

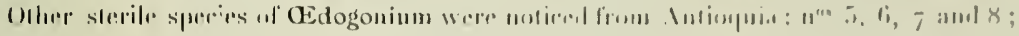

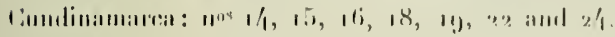

\section{Division IV. HETEROKON'T' A}

\section{Family Botryococcacex.}

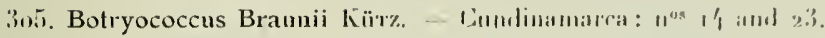

\section{Family Ophiocytiacex.}

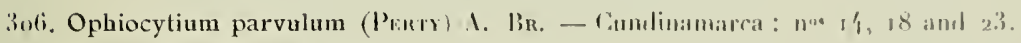
iunl $1 !)$.

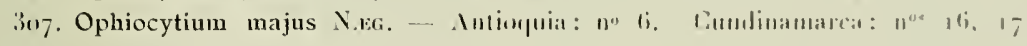

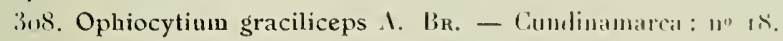

Long. cell. "1sigue $350, \mu$; long. stip. 8-11 $\mu$.

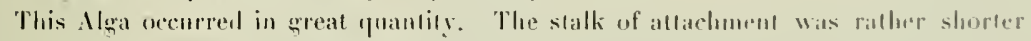
llan usual, lua pussesseal a well-marked hasal dise.

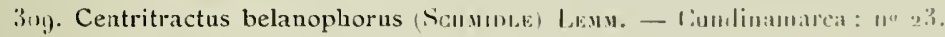

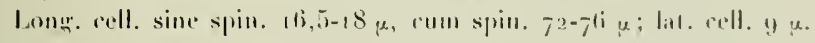

\section{Family Tribonemacex}

310. Tribonema bombycina $($.

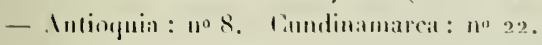

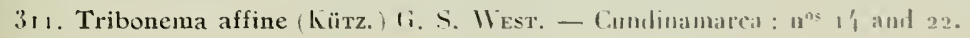
132 


\section{EXPLANATION OF PLATES}

$"$, $u^{\prime}=$ cells trom the front view (at fronte visit).

$b=$ endls froun the end view (a vertice visit). $c=$ cells from the side view (a latere visia).

$d=$ semicells from the basal view (a basi visa).

\section{Plate XXI.}

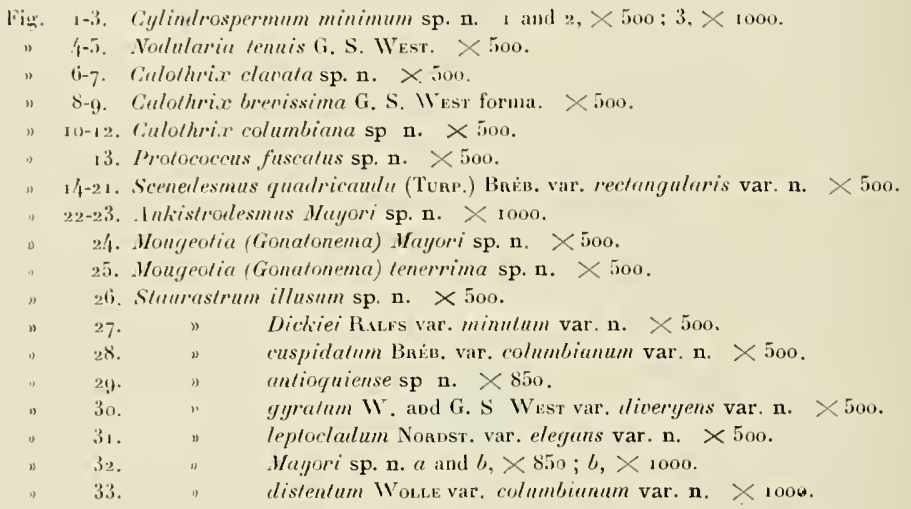

\section{Plate XNil.}

Fig. 34. Enustrum columbianum sp. n. $\times 500$.

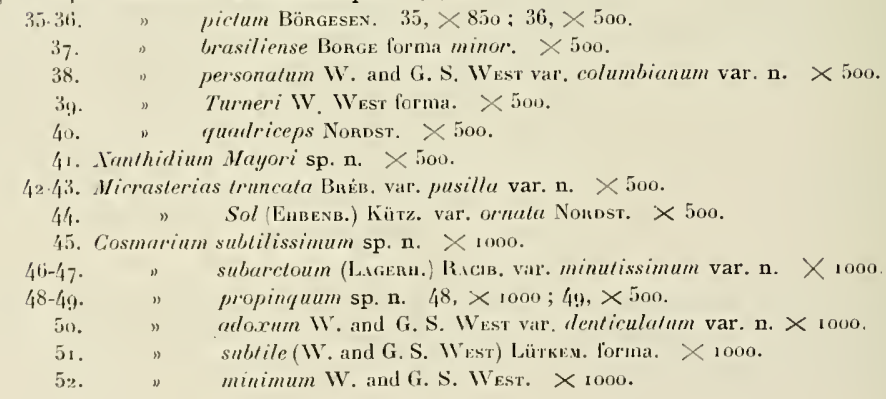




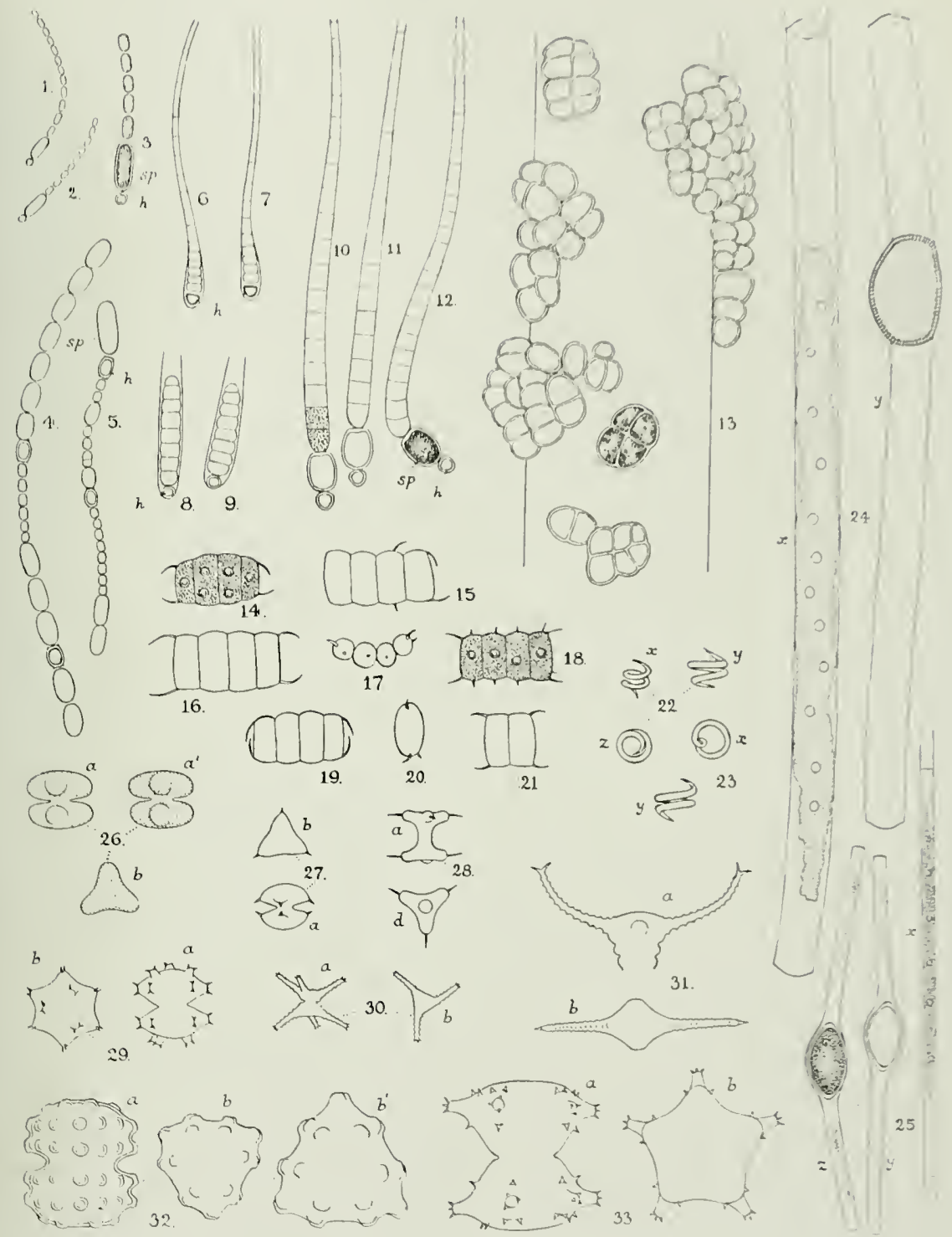

is West ad nat. del 



\section{PLANCHE XXII}

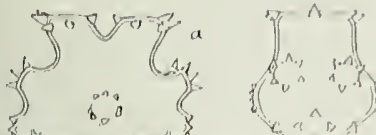

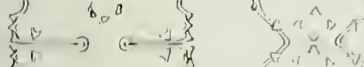

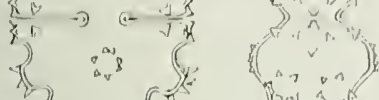

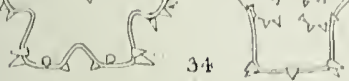

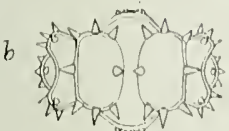
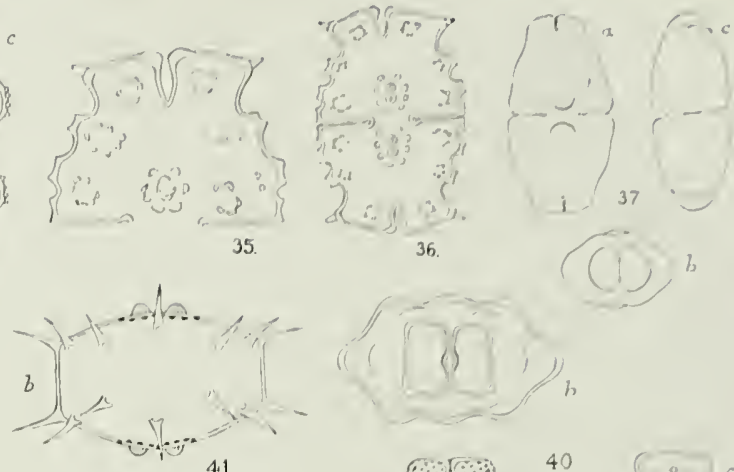

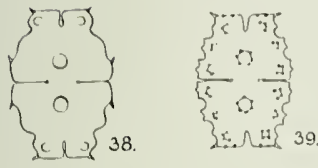

$$
36 .
$$
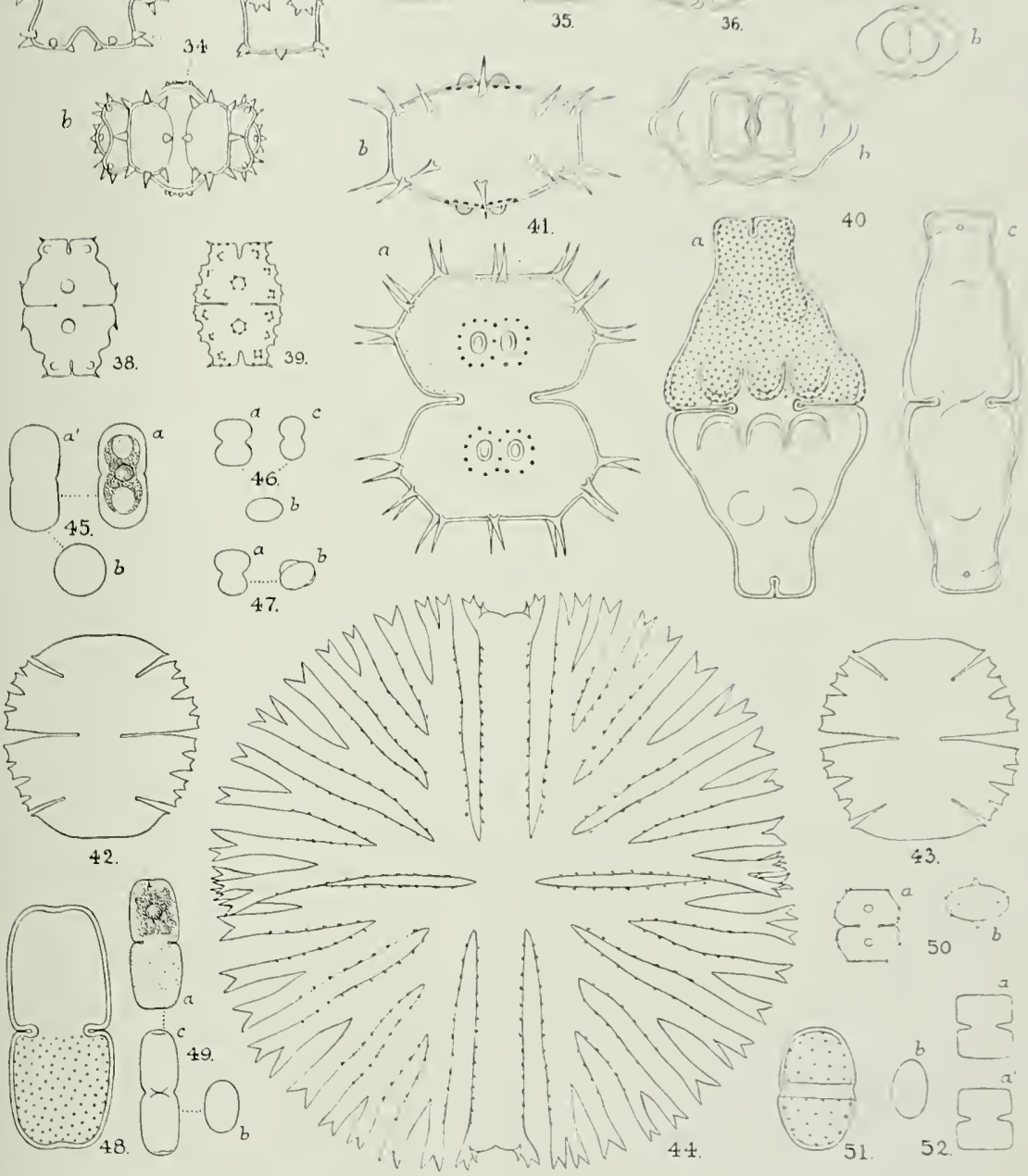

G.S.TVest a.t mat. dal. 


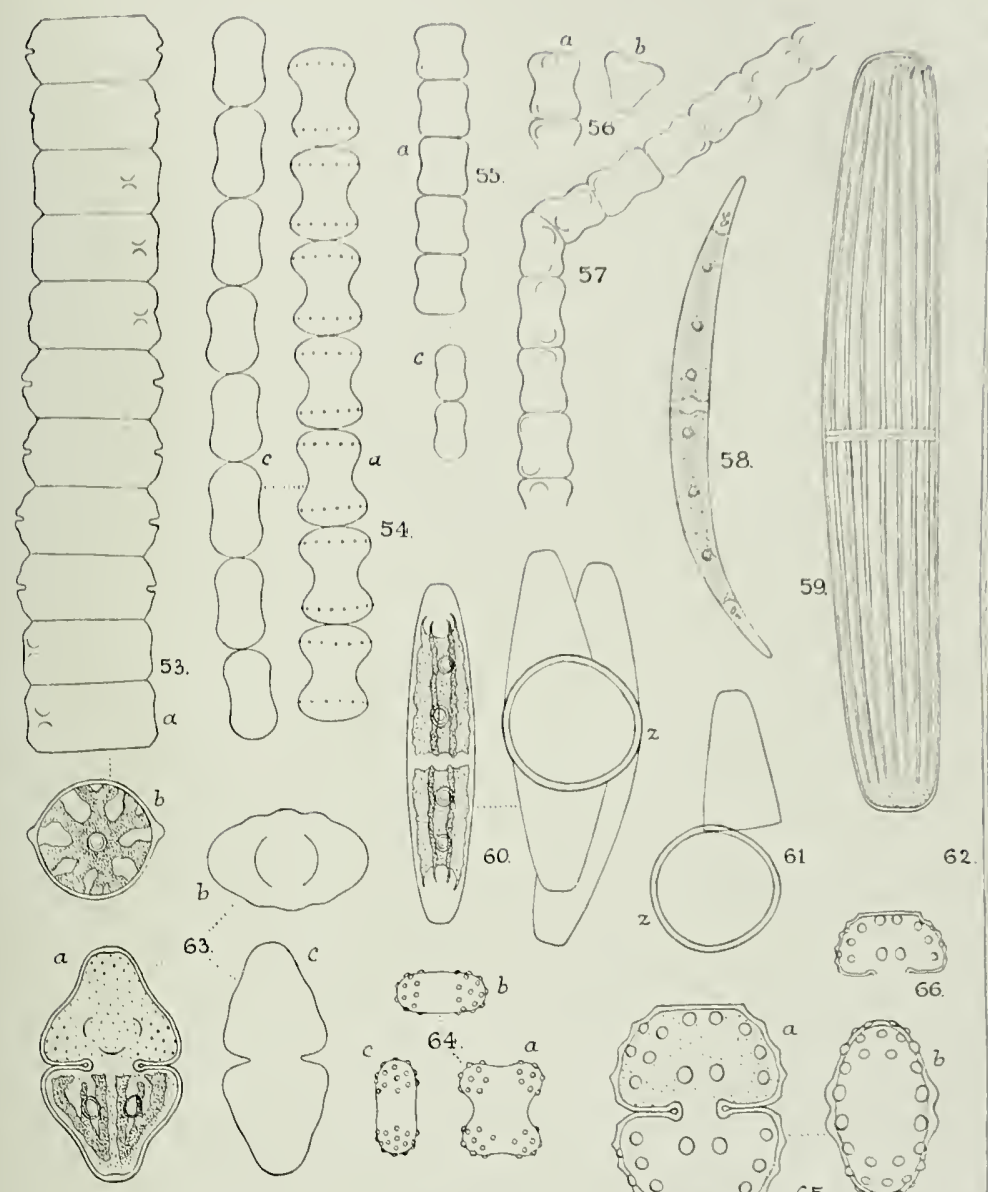

63
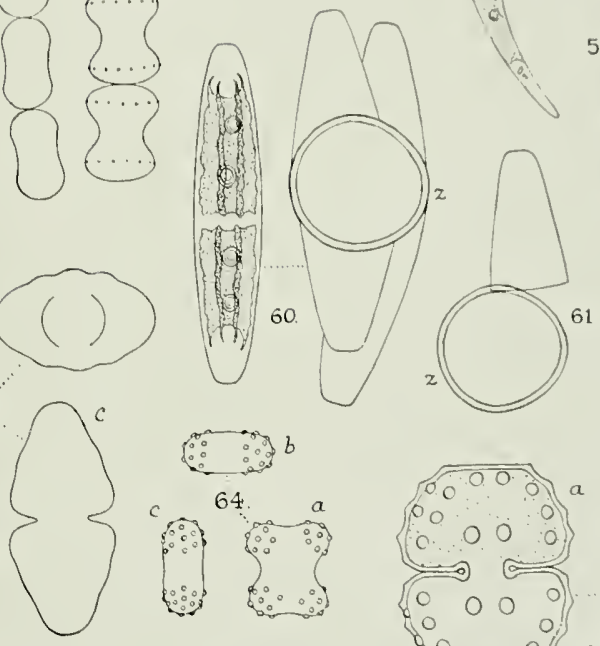

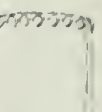
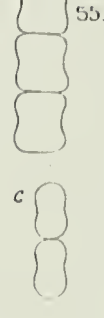

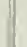

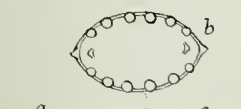

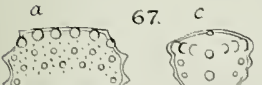

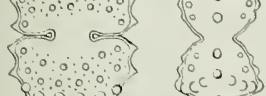

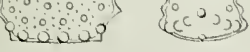

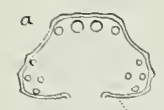

$\left[\begin{array}{cc}6000 \\ 60 & 0.0 \\ 0 & 000\end{array}\right]$

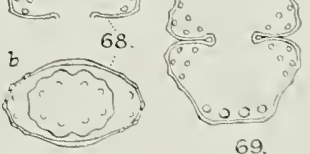

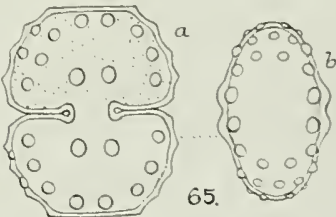

G S. Tiest ad nal. del. 



\section{I',Al, IXIII.}

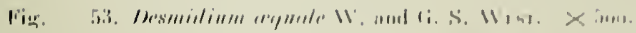

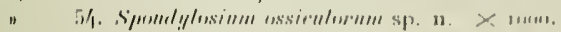

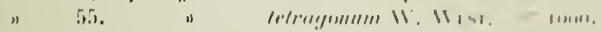

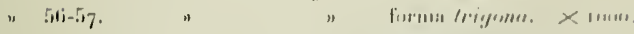

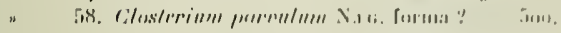

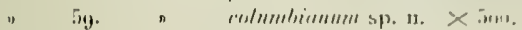

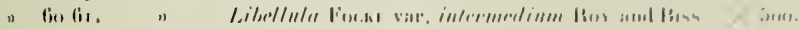

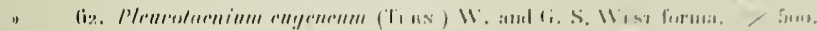

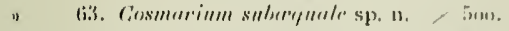

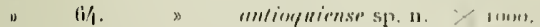

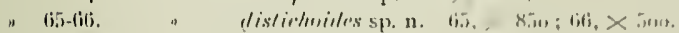

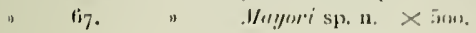

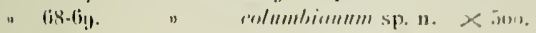

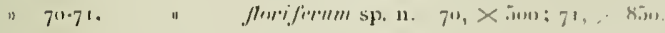




\section{LISTE}

1)ES

\section{Acquisitions nouvelles pour la science.}

An cours de notre royage, nous avons pu l'occasion de recueillir 1279 espreces rigntales et 647 espreses animales différentes dont la plus grande partie n'a pas encore été mentionnée jusquici en Colombie. Ces riches matcriaux ont dounc lien à 32 travaux scientifiques at de ces ćludes, il résulte que 160 espèces vígétales et 185 espéces animales sont nonvelles pour la science. Nous donnons ci-tessous la liste des variétés, espèces et genres nouveaux et renvoyons pour les descriptions détaillées aux différents travaux.

\section{PLANTES}

\section{Algues d'eau douce.}

I. Gylindrospermum minimum (i. S. WVesr. - Andes centr. (p. 1016).

2. Microchaete crassa G. S. West. - Aules orient. (p. 1017).

3. Calothrix columbiana G. S. West. - Andes orieut. (p. 1019).

4. Calothrix clavata G. S. West. - Andes orient. (P. 10г9).

5. Protococens finseatus G. S. West. - Andes orient. (p. 1023).

6. Anliestrodesmus Mayori G. S. West. - Anles orient. (p. 102/)).

7. Scenedesmus quadricanda (Tиве.) Вив́в. var. Iectanguluris G. S. West. - Mndes centr. (p. ro25).

8. Mongeotia Naygri G. S. West. - Andes centr. (p. 1027).

9. Mongeotin tenerrima G. S. West. - Andes centr. (p. 1028). 


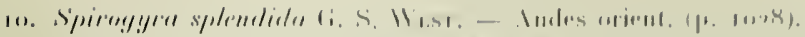

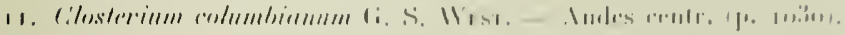

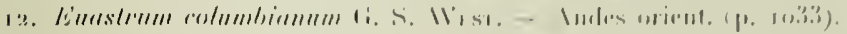

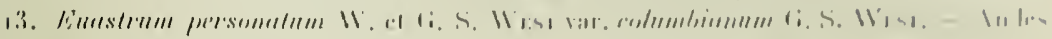
renlle. (11, 11:3/).

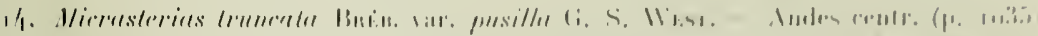

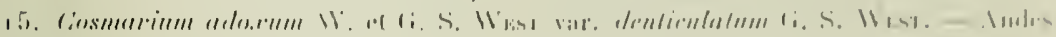
(2)

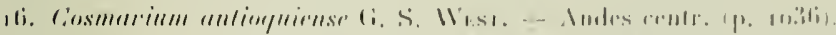

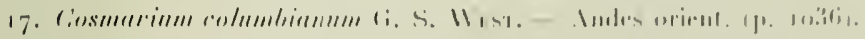

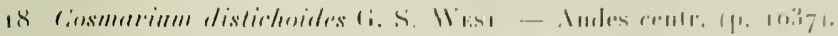

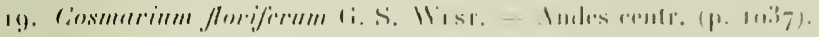

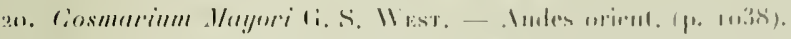

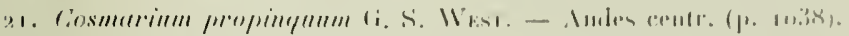

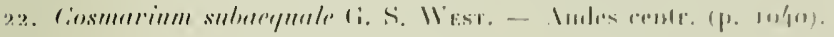

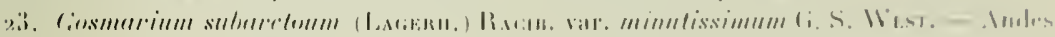
renler. (p). 10/0).

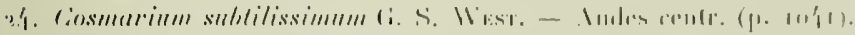

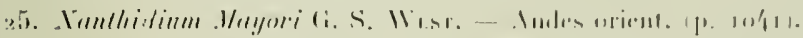

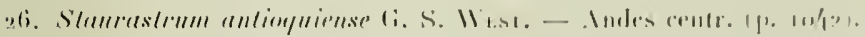

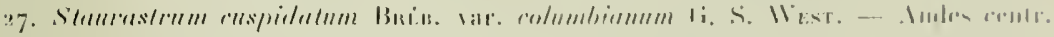
(11. 11:3).

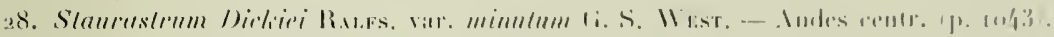

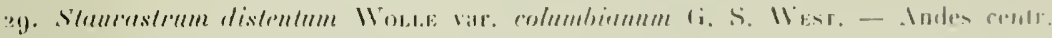
(j). 10,3$)$.

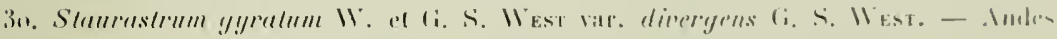
orient. (p. 104!).

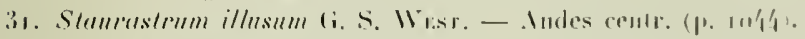

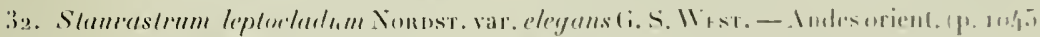

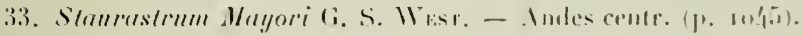

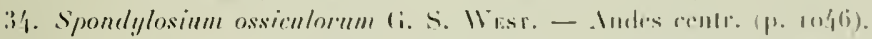

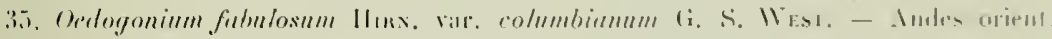
(p. 10,8$)$.

\section{Champignons.}

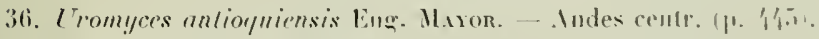

37. Iromyces Smilacis Eun. Mnor. - Indes rentr. (p. 44.

38. Cromyces Phlirusae Eug. Mayon. - Indes centr. (p. 4isi.

39. Lromyces cundinamarepnsis bug. Mnon. - Amles mient. 1) 4.i2).

fo. Tromyces Rubi-urlicifolii Eug. Miron. - Audes cen(r. (1) fô). 


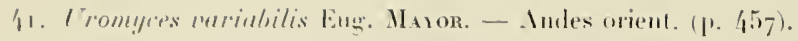

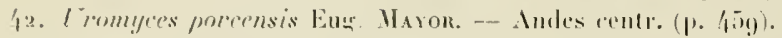

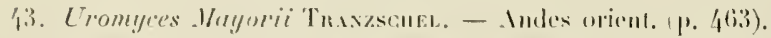

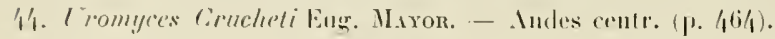

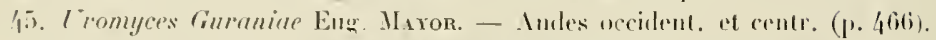

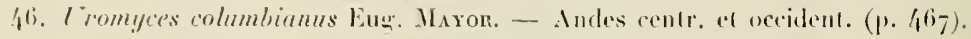

47. Pucciniu antioquiensis Eng. Maror. -... Andes rencr. (p. 473).

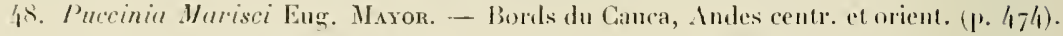

4.9. Paccinia Boceoniue Eus. Maxor. - Andes cenlr. (J. 478).

5o. Puecinia bongotensis Eugr. Maror. - Andes orient. (p. 480).

51. J'uceinia dubia Eug. Maror. - Andes centr. (p. 182).

72. Pnceinia Sidae-rhombifoline Eng. Wayor. - Andes centr. el occeident. (1. 484).

53. Pueciniu ruizensis Eng. Maxur. - Indes cen(r. (p. 486).

54. Puccinia Convoleulacerarnm Eug. Masor.-Bord du Magdalena el Andescentr.(p.488).

5.5. Pucciniu Ton Ciunteni Eng. Mayor. - Bord du Magdalena (p. 490).

56. Pucciniu paranensis Eugr. Maxor. - Andes cenfr. (p. 493).

57. Pucciniu solededensis Eng. Maxor. - Indes centr. (p. /91).

58. P'nreinia Myplidis-mutabilis Eng. M Myor. - Bord du Magdalena el du Canca, Mndes centr. (p. $\left.49^{6}\right)$.

5.g. Puccinia malellinensis Eug. Muxor. - Andes centr. (p. 497).

dio. Puccinin Sarachae Eng. Maxor. - Andes centr. el orient. (p. 499).

6r. Puccinir Gapsici Eug. Maxor. - Andes centr. (p. 5or).

62. Puccinia Gonzalezi Eug. Maxor. - Mules orient. (p. 502).

1i3. Puceinia Orlizi Eug. Mayor. - Andes orient. (p. 5o3).

64. Puccinia solanicola Eng. Mayor. - Bord du Magdatena et Andes orient. (p. 505).

65. Pnecinit Futermanni Eug. Mayon. - Amles centr. (p. 507).

(60. P'nceinia Beclia Eug. Mayor. - Amdes mient. (ן. 5og).

(i). Puccinia Veroniae-mollis Eng. Maxor. - Andes centr. (p. 510).

68. Puccinin enpatoriócolu Eug. Mayon. - Antes centr. el orimt. (р. 513).

lig. Puccinia Eupatorii-colmmbiani Eug. Maxor. - Andes centr. (p. 514).

70. Puccinia lolimensis Eug. Mayon. - Andes centr. (p. Sr6).

71. Pnccinia Baccharidis-rhexioidis Euy. Maxor. - Andes rentr. (p. 5 7 7).

72. Puccinia Montserrates Eug. Maxor. - Andes orient. (P. 520).

73. P’ucciniu Manjerhansi Eug. MAxor. - Andes centr. et occident. (1. 521).

74. Pnccinin Montoyue Eug. Maxor. - Andes orient. (p. 523).

75. Puccinia Aucizari Eug. Maxon. - Indes ceutr. el orient. (p. 525).

76. Puccinia Wedetiae Eugr. Mayor. - Andes contr. (p. 528).

77. Puccinia Bimbergi Eug. Maron. - Andes centr. (p. 530).

78. Puccinia spilanthicola Eug. Mayon. - Andes centr. (p. 531).

79. Puccinia Barranquillae Eug. Mayon. - Barrinquilla (p. 533). 


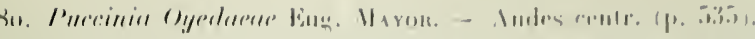

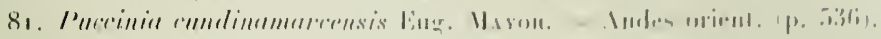

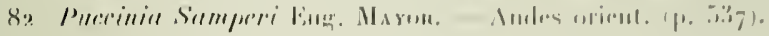

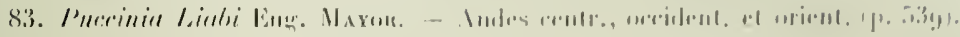

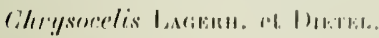

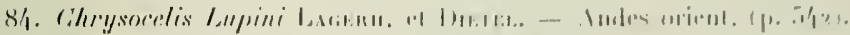

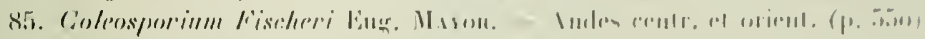

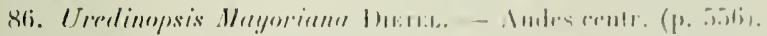

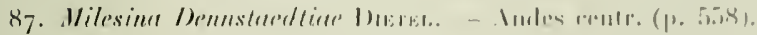

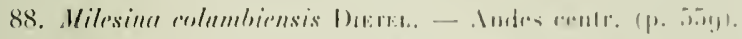

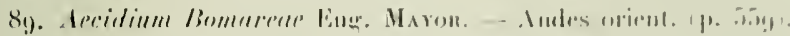

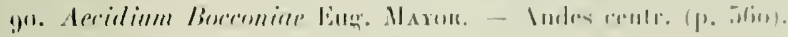

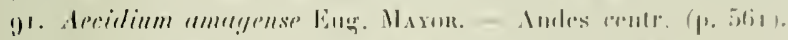

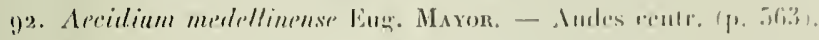

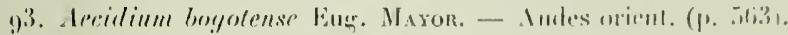

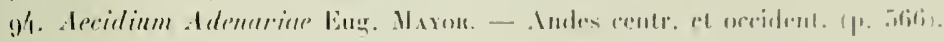

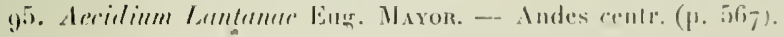

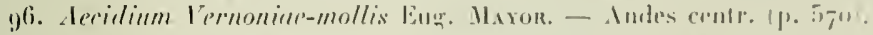

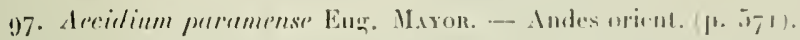

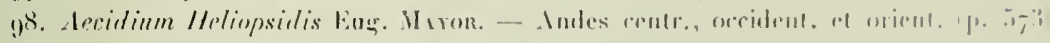

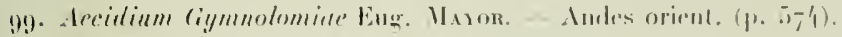

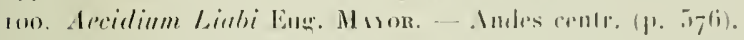

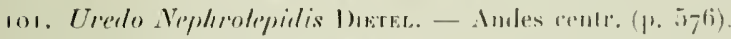

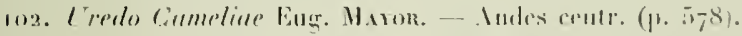

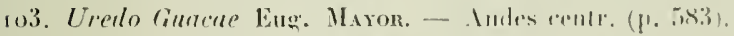

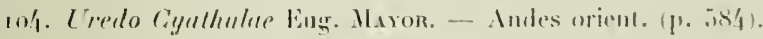

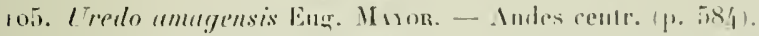

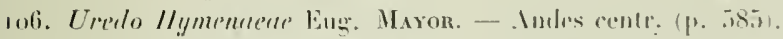

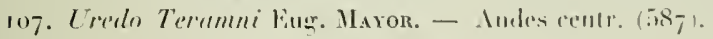

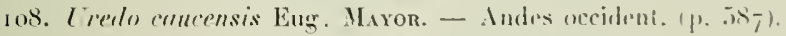

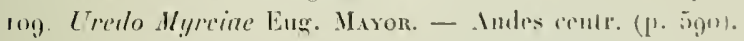

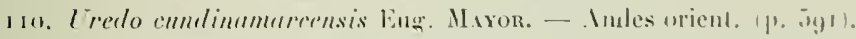

11. Uredo Mandenillar Eng. Maron. - Andes rentr. (p. En)1).

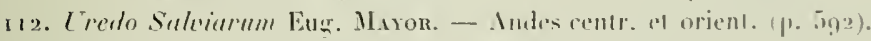

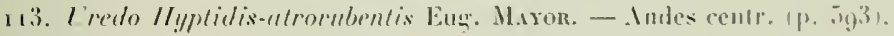

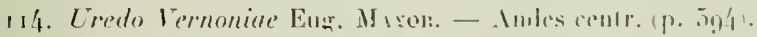

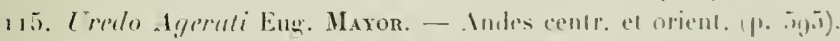

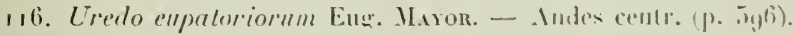

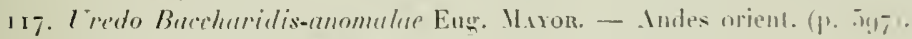

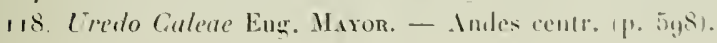


1ro. Metiola Lanlunue Sinow. - Indes rentr. (p. 439).

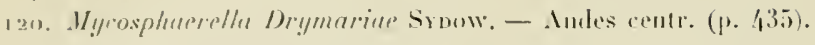

121. Dielymella Penniseti Sritow. - Andes centr. (p. 4335?.

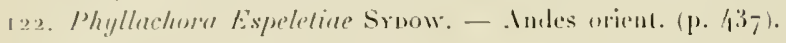

123. Phylluehorn perhutu sirnow. - Andes orient. (1. 437).

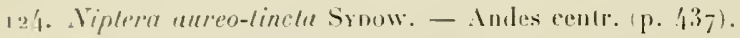

Melunochlnm!s sirwow.

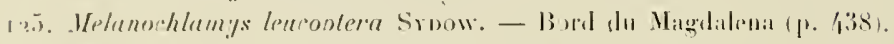

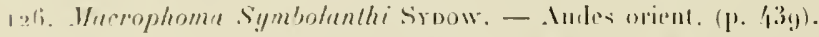

127. Cerecospora Lintsi sroow. - Andes rentr. (p. 440).

128. Helerosporium puradoxum Sivow. - Andes centr. (p. 4/1).

1?0). Illesporium Mayorii syow. - Andes centr. (p. 441).

\section{Lichens.}

130. Leciden (Binlora) Ma!yori Lisdau. - Indes centr. (P. 58).

\section{Bryophytes.}

131. Sphagnum Letmannii Warnst. var. aequiporosum Wansst. - Audesorient. (p. 997). 13.3. Dierunella mucrocarpu Brotu. el Inssinen. - Andes centr. (p. 998).

133. Dicranella Ma!jorii Buorn. et Irмscuer. - Andes centr. (1. 999).

134. Trirhostomum nouo-granalense Bвotн. el lnuscuen. - Andes centr. (p. roon). 1.3.i Leptodonlium Fuhrmannii Brot?. et Iruscuer. - Andes orient. (p. 1001).

136. Thylorin Mayorii Brotn. el lnascnen. - Andes orient. (p. 16o3).

137. Bryum Mayorii Brorn. el Inuscuen. - Mndes centr. (p. row/).

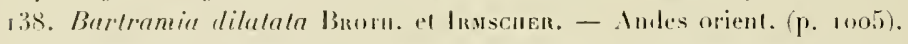

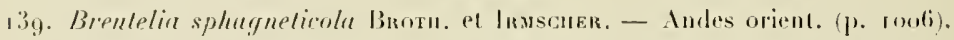

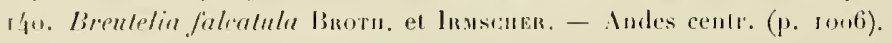

\section{Ptéridophytes.}

141. A/sophilu corimea Rosenstock. - Andes accident. (p. 34 el 5o).

142. Doryopteris Maygoris Rosenstock. - Andes centr. (1). 37 el 51 ).

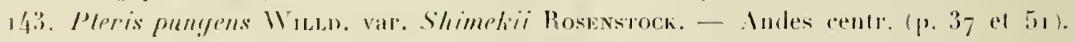

14年. Diphlezinm Mayoris Rosenstock. - Dudes centr. (p. qu el i2).

19.i. Diplazium angelopolitunum Rosesstock. - Indes antr. (p. 4o el 52).

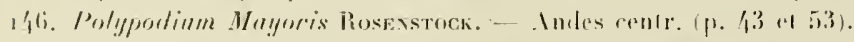

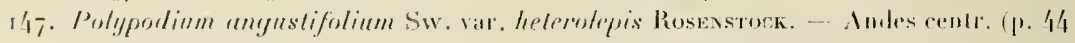
(4) 54 . 


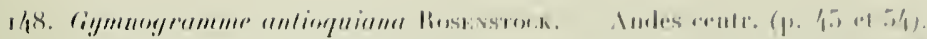

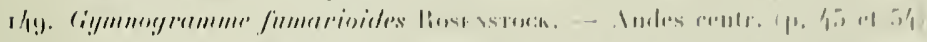

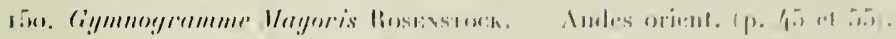

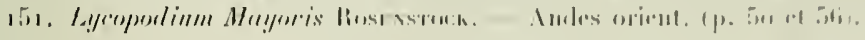

\section{Planérogames.}

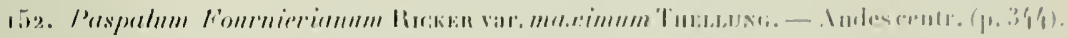

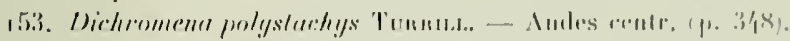

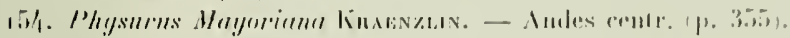

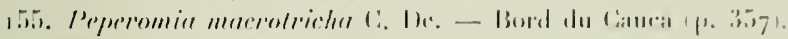

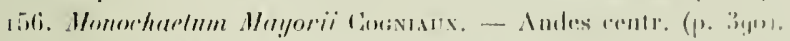

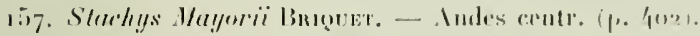

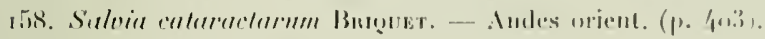

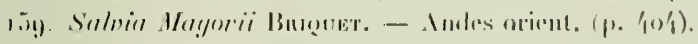

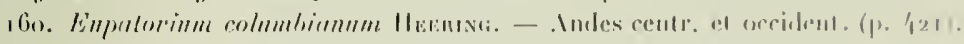

\section{ANIMAUX}

\section{Protozoaires.}

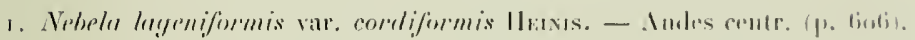

\section{Rotifères.}

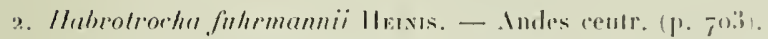

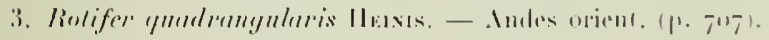

\section{Turbellaires.}

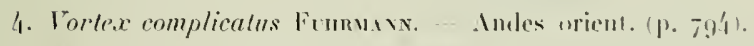

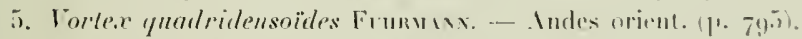

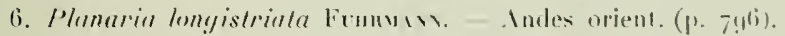

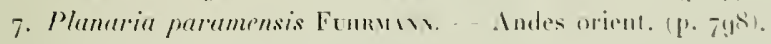

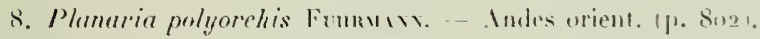

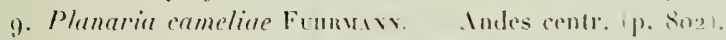

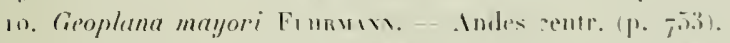

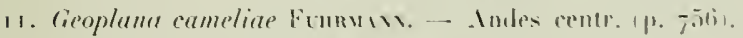

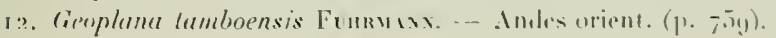
133 
13. Geoplumu won gunteni finmusx. Andes centr. (p. 760$)$.

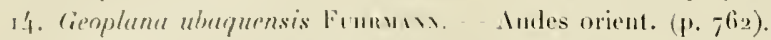

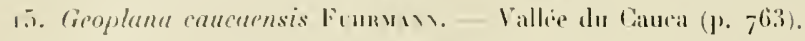

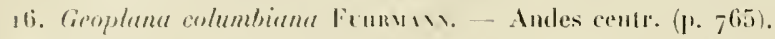

17. Cienpluna bilineala Fипитх. - Indes orient. (p. 766).

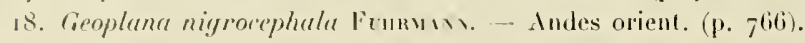

1!). Coropluna bimbergi Funuman. -... Andes centr. (p. $\left.76_{7}\right)$.

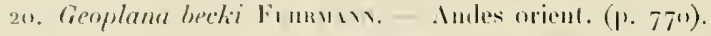

3. Copoplanu amayensis Fumunas. - Andes centr. (p. 773).

22. Cieroplanu multipunctula Funum. - Andes orient. (p. 776 ).

23. Ceopluna meyerhansi Fumum. - Andes orient. (p. 778).

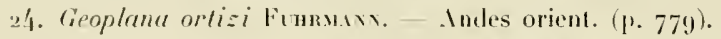

25. Geopluna gonzalezi Fumun. - Indes orient. (1. 78is).

26. Geoplana guacensis Fimmux. - Andes centr. (p. 781 ).

27. Pelmatoplunu graffi Fimmux. - Andes centr. (1. 783).

28. Khynehodemus sumperi Fenumix. - Andes orient. (1) 786).

29. Rhynchodemus maculatus. Fummux. - Andes orient. (1) 788).

3o. Rhynchodemus cameline Fumm, - Andes centr. (p. $\left.78_{9}\right)$.

31. Amblyplana montoyate Finusax. - Andes orient. (1. 790).

\section{Oligochètes.}

32. Henler columbiumu Manaelsex. - Andes centr. (1. 211).

33. Dichngaster medellina Mrchaecsen. - Andes cenlr. (1. 215).

34. Periscolex fuhrmanni Micmaelsen. - Andes orient. (P. 218).

35. Periscolex vialis Micunelsen. - Audes orient. (1).221).

36. Rhinodrilus (Thamnodrilus) cameliae Macnabsen. - Andes centr. (p. 224).

37. Rhinodrilus (Thamnodrilus) bicolor Mrcuaelsen. - Andes centr. (j. 230 ).

38. Andiodrihus mizanus Micuaelsen. - Andes centr. (1. 2/66).

\section{Hirudinées.}

39. Melobdella columbiensis WenEn. - Andes orient. (p. 734).

40. Helobdelln finhrmanni Wевев. - Andes orient. (1. 735).

11. Helobdella hemispherica Wrвws. - Andes orient. (p. 736).

Blanchardiella WeBER.

(p. 738$)$.

42. Blanchardiella fuhrnamni W Ener. - Andes orient. (p. 739 ).

43. Blanchardiella cameliae WEren. - Andes centr. (p. 740).

44. Blanchardiella bogotensis WeBвn. - Andes orient. (1. 7/2).

4.5. Blanchardiella puramensis WEnzn. Audes orient. (p. 742). 
(1)ing -

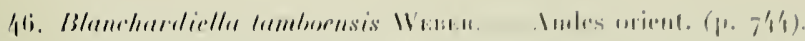

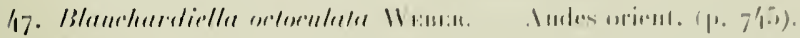

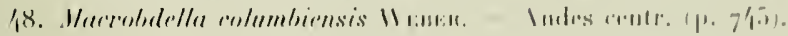

\section{Gastropodes.}

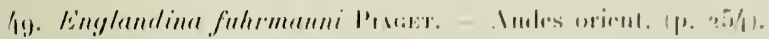

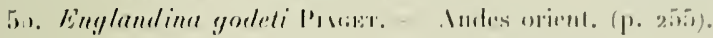

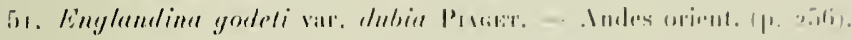

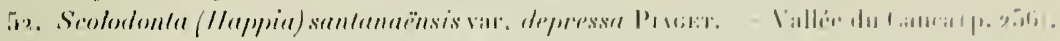

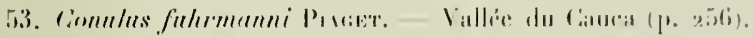

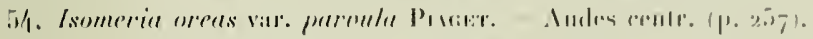

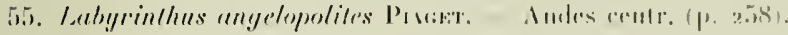

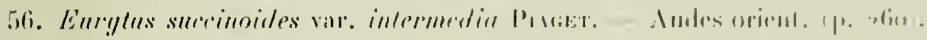

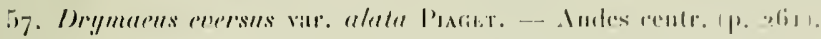

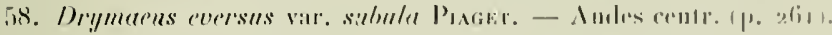

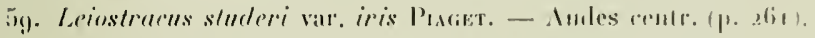

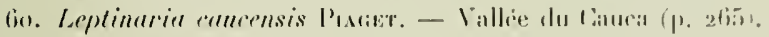

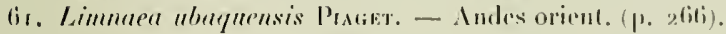

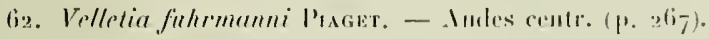

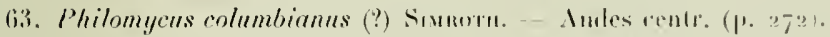

(i/4. Vaginnla nesiotis Sinnorm. - Jimbiäca (p. 297).

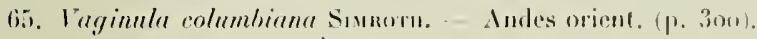

ti6. Tagumba cordillerae Sismoru. - Indes oricnt. (p. 30.3).

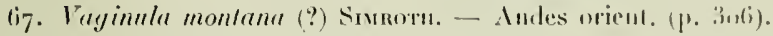

(is. Vayimela allicola (?) Sivnotu. - Andes orient. (p. 3os).

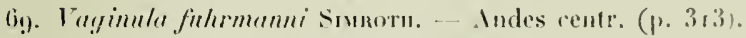

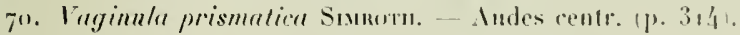

71. Vaginula minuta simrotur. - Andes cente. (p. 318).

72. Vraginula rufescrns Sivurutu. - Aules centr. 1p. 329).

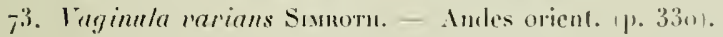

\section{Daphnies.}

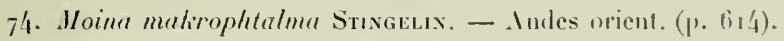

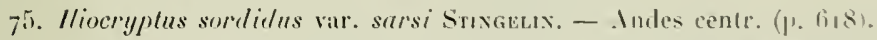

76. Camplocercus australis Sars var, dada!ji Stixgelix. - Mules orient. (p. (j201).

77. Pleuroxns similis vas. fuhrmanni Srugeus. - Andes orient. (p. 624).

78. Dunheredia odontoplax var. colombiensis Strxgeus. - Indes orient. 1). 62.5. 


\section{Ostracodes.}

79. Eurypris wolphägyrli Menes. - Ande's orient. (p. 6133.

So. Ciypridopsis Juhrmanni Ménes. - Andes orient. (1) 69,(i).

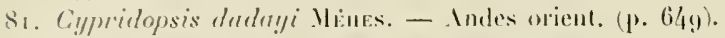

S.e. Camdonu pedropalensis Méuss. - Indes arient. (p. (6ia).

83. Candona annae Vúnes. - Andes orient. (p. 653).

\$я. Cundona columbienensis Méues. - Aurles orient. (p. 658).

\section{Copépodes.}

8.7. Diuplomus colmmbiensis Tubinaud. - Andes orient. (1) 161).

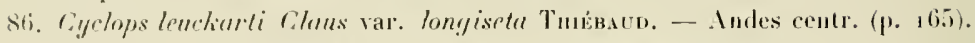

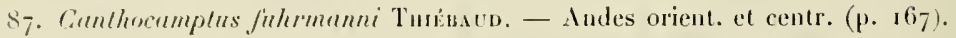

\section{Isopodes.}

88. Sphueroniscus frontalis Richardsox, - Indes orient. (p. 31).

\section{Crabes d'eau douce.}

89. Psendolhelphusen dispur Zimaer. - Amdes orient. (p. 2).

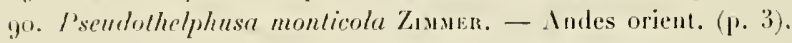

9). Eprilabocera fuhrmanni Zimser. - Andes centr. (1). 6).

\section{Onychophores.}

92. Peripalus bimbergi Fumum. -- Andes orient. et centr. (p. 177).

9.3. 'Peripulus mullipodes Fumusx. - Andes centr. (p, 184).

9\%. Peripalus bonvieri Fumunx. - Andes orient. (p. I86).

\section{Chilopodes.}

95. Nenportia fulmimunni Ribaut. - Andes centr. (p. 72 ).

96. Scolopendra arthrorhabulöles Rubaur. - Andes orient. (p. $7^{6}$ ).

97. Ribaulia fuhrmanni Ribaur. - Andes centr. (p. 79).

\section{Diplopodes.}

98. Siphonophorn fuhrmanni C.us. - Andes centr. (p. 826).

99. Siphonophora columbirma C.sis. - Andes centr. (p. 827).

ıoo. Siphonophora gracilicornis Cirn. - Andes orient. (p. 828). 
w1il

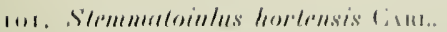

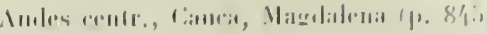

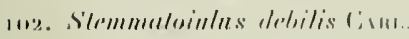

lurles andr. $\left.(1,8)_{1} x\right)$.

Murkes arient. 1p. 819!).

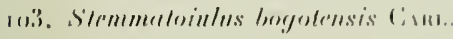

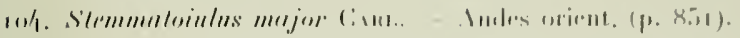

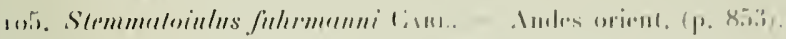

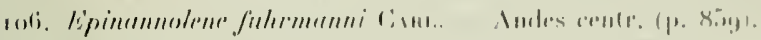

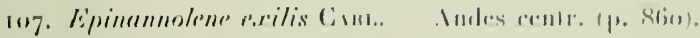

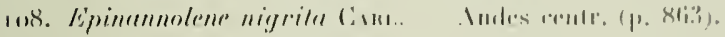

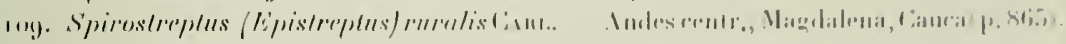

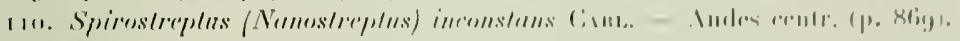

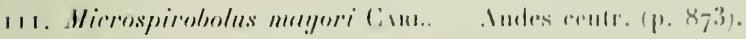

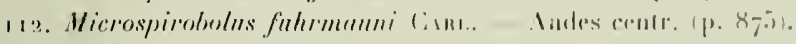

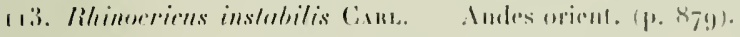

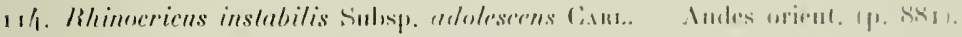

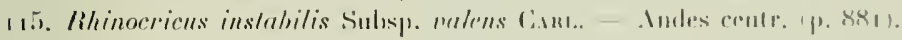

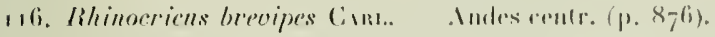

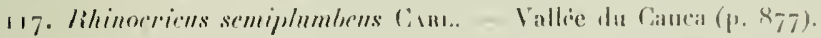

18 . Leplodesmus anyustus Ginı. Indes centr. (1). 8891).

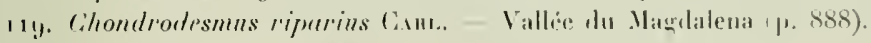

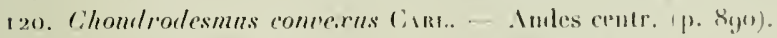

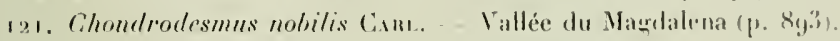

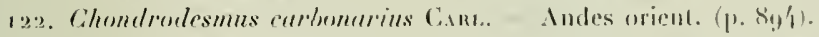

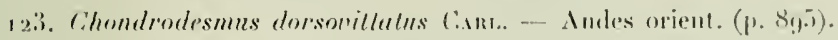

12/. Alocodesmus intermedius Cina...- Imles orient. (p. Bgy)\%.

125. Alucodesmms alutus Cins. - Magdalenat, Indes orient. (p. gum).

Heleropellis Canu.

126. Ileteropellis Ineluosus Cinu. - Indes centr. (p. go2).

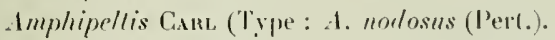

г27. Balodesmus acceptus Cirk..-- Indes orient. (p. go-).

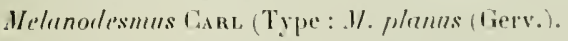

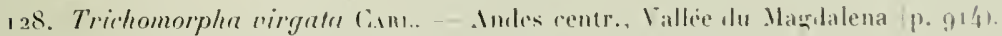

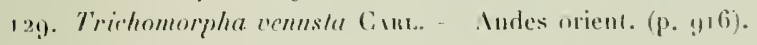

13o. Trichomorpha propinqua Cint. - Andes crmlr. (p. 918).

131. Trichomorpha unmulipes Cinz.. -- Intes centr. (p. 918).

13. I richomorpha debilitala C.anL. - Indes rentr. (p. 920)

133. Trichomorphn hirsulu C.nL. - Indes centr. (p. 921).

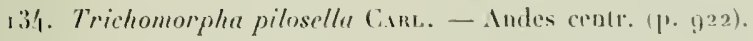

135. Trichomorpha nilida Lisu.. - Andes centr. (p. 924).

136. Trichomorpha denticulala C.enc. - Andes cenlr. (p. ga(i).

137. Trichomonha gracilis C.anL. - Andes centr. (p. 127). 


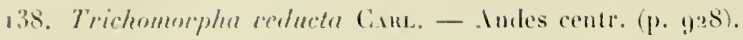

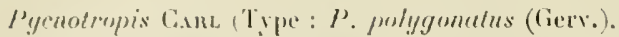

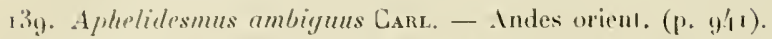

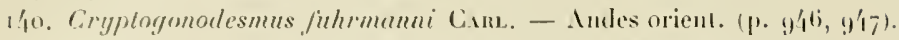

141. Cryployonolesmus oblnsunguhs Cimu. - Andes centr. (p. 950).

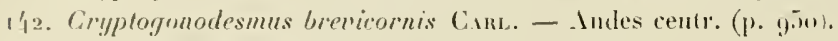
Brachycerodesmus GanL.

19.3. Brachycerodesmus peterwi Cinu. - Indes centr. (p. g5̃a). Gypopleallus Cans.

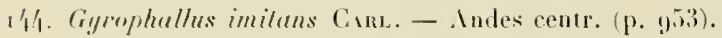

195. Gygrophallus simillimus Cirnd. - Indes centr. (p. 95i).

Fuhrmunnodesmus Caus.

196. Fuhrmannolesmus lividus C.rnu. - Indes orient. (p. yiti).

Calymmodesmus C.un.

197. Calymmodesmus andinus Ciru. - Vallée du Canca (p. !) (io).

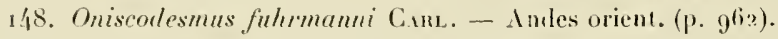

14!). Trigonostylus niger CirL. - Andes orient. (1. y63).

150. Trigonostylus hirsutus C.unu. - Andes centr. (p. 965).

151. Trigonostylus anmoniles CanL. - Andes centr. (1) y(65).

\section{Scorpions.}

152. Tilyes fuhrmanni Kinepelix. - Andes centr. (p. 17).

153. Tityus parvulus Kir.epelix. - Andes centr. (p. 19).

154. Chactas reliculalus Kirepeurs. -- Indes centr. (p. 25).

\section{Opilionides.}

155. Cignoru culcur-rpicalis Rawer. - Andes orient. (P. 1/11).

156. Pararhancus marmoralus Rawer. - Andes orient. (P. 142).

157. Metarhaucus reliculatus Rawen. - Andes orient. (p. 1/5).

158. Metarhancus albilineatus hewen. - Indes orient (p. 147). Melaphareus Ritewen.

159. Melaphareus albimanum liewer. - Indes centr. (p. 1/9).

Camelianus líwer.

560. Cumelianus fuhrmanni litewen. - Andes orient. (p. 152).

16r. Cranaus culcar Riewer. - Audes centr. (p. 153).

Slygnomma Rewer.

162. Stygnonma fuhrmanni REwer. - Indes centr. (p 156 ). 


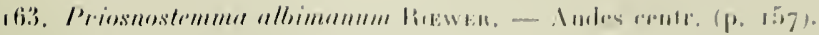

Tamborions liswatse.

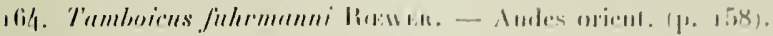

\section{Araignées.}

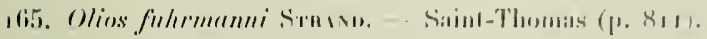

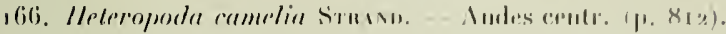

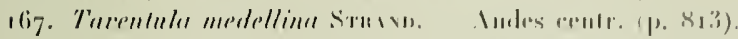

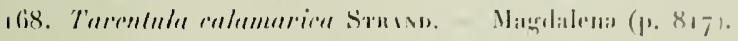

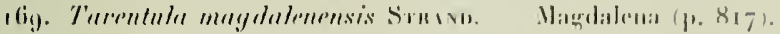

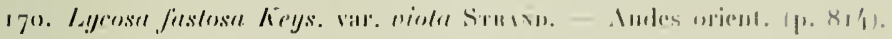

171. Seyfodes rnizensis S'тыnd, - Andes centr. (1. 818).

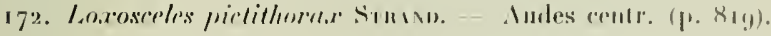

\section{Hydrachnides.}

173. Eyluis columbrimsis Waston. - Andes orient. (p. 193).

17h. Limnessiu, fuhrmamni Watren. - Nndes orient. (11. 197).

175. Arrhrmurns fuhrmanni Witter. - Mudes orient. (1. 19g).

\section{Tardigrades.}

176. M/acrobiolus fuhrmunni Ileaxis. - Andes contr. (p) 717).

\section{Fourmis.}

177. Alla mesonotulis var. fuhrmanni Fones. - Andes cents. (j). In).

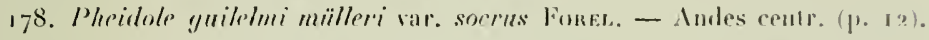

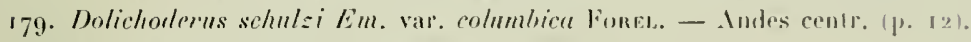

18o. Rhizomyrma fuhrmanni l'Ones. - Andes centr. (1) 12).

\section{Amphibiens.}

181. Mylodes, fuhrmanni Peracca. - Indes orient. (p. 104). 182. IIyla fuhrmunni Penacia. - Imles centr. (1). 108).

\section{Reptiles.}

183. Liophis psendocobella Peracci. - Indes centr. ( 1 . 99). 184. Atrachus fuhrmunni Pen. Acra. - Indes arient. (p. rno). 185. Atruins uremeri Penarca. - Indes orient. (p. 102). 


\section{Mesures bypsométriques en Colombie}

RIIIUUTES PAR

\section{E. LE GRAND ROY}

Professeur à l'Université de Neuchâtel.

M. Fulurmann a hien voulu me confier le soin de calculer les altitudes mesurées par lui au cours de son voyage en Colombie. Avant de résumer les résultats olıtemus, je dois donner quelques indications relatives au mode d'observation et à la technique du calcul.

Les observations ont été faites à l'aide de quatre instruments:

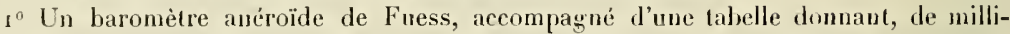
mètre en millimètre de pression, la hauteur brute à $\sigma^{\circ}$, avec l'indication de la correction correspondaute pour cliaque degré de température.

$2^{\circ}$ In luaromètre anérö̈de, systène Goldschmidt, avec des tables donuant:

a) de $10^{\mathrm{mm}}$ en $10^{\mathrm{mm}}$, la hauteur du baromètre à mercure correspondant à la lecture de l'iustrument;

b) de $2^{\circ}$ en $2^{\circ}$, la correction instrumentale de température;

c) les hauteurs brutes ì $0^{\circ}$ correspondant aux pressions de $10^{\mathrm{mm}}$ en $10^{\mathrm{mm}}$;

d) le froteur thermique, proportionnel à la température moyenue entre celles des deux stations supérieure el inférieure, par lequel il faut multiplier la diflérence de latuteur brnte pour avoir le résultat cherché, en tenant compte de la dilatation tle l'air.

$3^{\circ}$ Un thermomètre hypsométrique de liuess, controlé par la "Plıysikalische Reichsanstalt " de Berlin, et gradué en millimìtres de manière à donner, par une simple lecture, la pression atmosphérique. Cet instrument était destiné spécialement à contrôler les résultats fournis par les deux précédents.

$4^{\circ}$ Un thermomitre-fronde de Fuess, destiné à donner la température de l'air.

te baromitre Goldschmidt s'est admirablement comporté pendant tout le voyage, et 


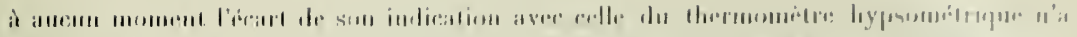

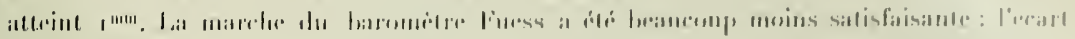

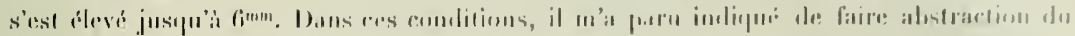

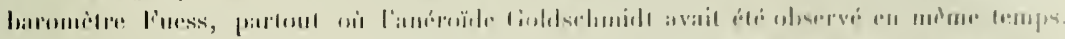

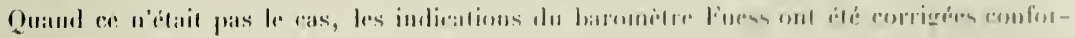

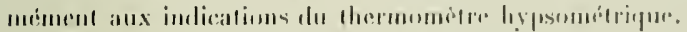

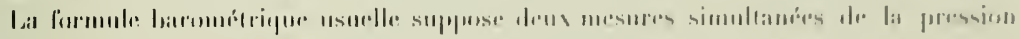

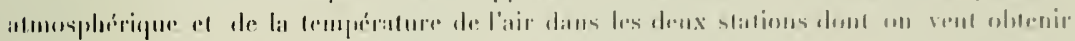

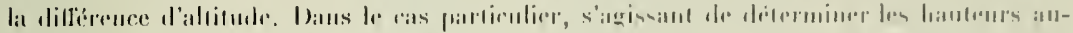

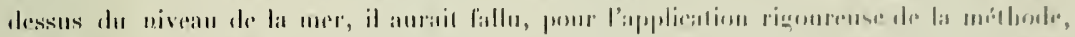

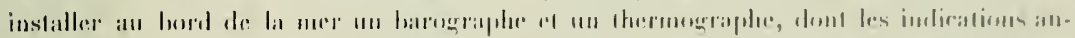

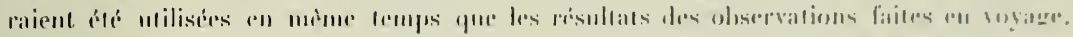

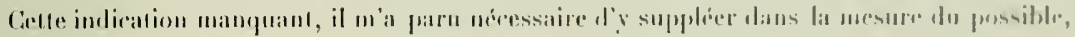

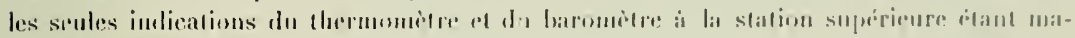

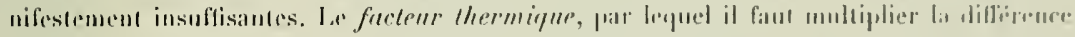

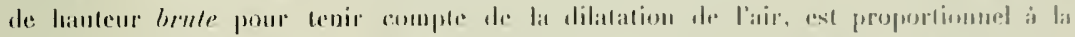

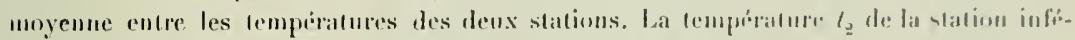
rieure (en l'espece de bord de la mer) manquant, j’ai estimé utile de la calculer à l'a ido de la

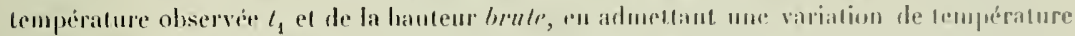

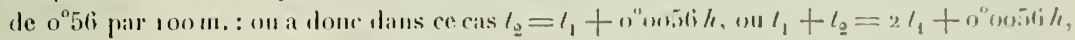

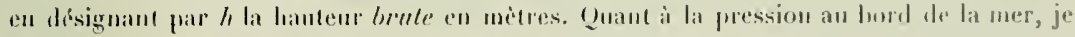

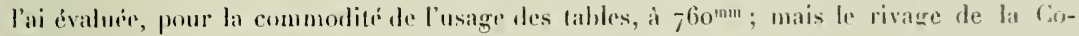

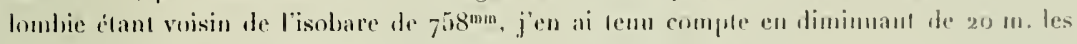

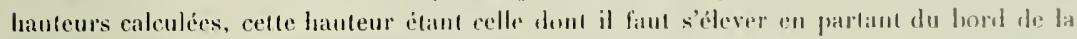
mes pour voir la pression diminuer de $2^{\mathrm{mm}}$.

Le mode d'observation ne comportant pas une grande précision dans les résultats, je n’ai pas cru devoir tenir compte de la variation de la gravité avec la latiturle, le facteur correspondant étant toujours très roisin de liunilé.

de donne ci-dessous deux exemples de mes calculs.

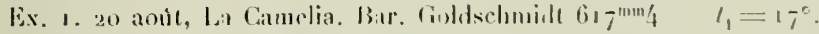

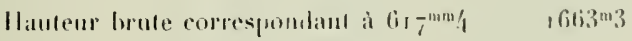

$$
\begin{aligned}
& 2 l_{1} \\
& 0100,36 \times 1663,3=99^{\circ} \\
& t_{1}+t_{2}=4.3^{\circ}
\end{aligned}
$$

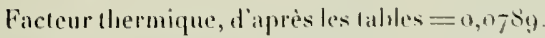

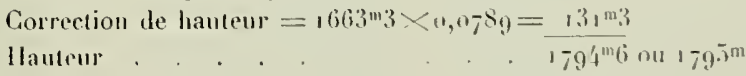

Correction constiute.

Hauteur cherchée.

$$
\frac{-20}{177^{201}}
$$




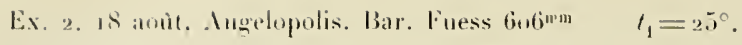

Ilanteur hrute correspontant à $606^{\mathrm{mm}} \quad 18: 7^{\mathrm{m}}$

Correction pun ro d'après lable $6 \mathrm{~m}_{-}$.

$$
\begin{aligned}
& 2 t_{1}=50^{\circ} \\
& 0^{\circ} 10.76 \times 1837=10^{\circ} \\
& t_{1}+t_{2}=60^{\circ} \quad \frac{t_{1}+t_{2}}{2}=31^{\circ}
\end{aligned}
$$

Correction de hanteur $=6^{\mathrm{m}} 7 \times 3 \%=\frac{201^{\mathrm{m}}}{20.38^{\mathrm{m}}}$

Correction d'apris Hypsomitre. $\quad \frac{-13}{2025^{\mathrm{m}}}$

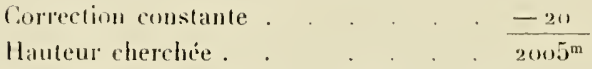

Voici maintenant le tableau des résultats obtenus :

Dans ce tablean, F signifie baromìre Fuess;

$$
\text { G " " Goldschmidt. }
$$

Le nombre qui accompagne chaque tettre est celui des mesures dont le résultat a été

\begin{tabular}{|c|c|c|c|c|}
\hline & & & Mètres & \\
\hline Magangué & . & . & 4.3 & $(c$ \\
\hline El Banco. & . & 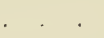 & 53 & \\
\hline Rejiloe. & 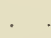 & . & $9^{2}$ & \\
\hline Cañabetal. & & & 142 & \\
\hline Puerto Wilches* & & & 105 & \\
\hline Puerto Berrio* & . & & 143 & \\
\hline Ialena* & & & 158 & \\
\hline fristallina & . & . & 316 & \\
\hline Palestina & 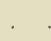 & 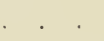 & 540 & \\
\hline Pavas & . & . & 653 & \\
\hline San Raphaël & & 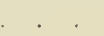 & $6 \mathrm{o} 3$ & \\
\hline Caracoli & & 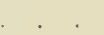 & 612 & \\
\hline S. Juan & & & 846 & \\
\hline La Quichra & & & 1584 & \\
\hline Yarum & & & 1308 & (1) \\
\hline ledellin*. & & & 1515 & \\
\hline au-dess & & Medel & 2504 & \\
\hline Estrel & & & 1506 & ( F \\
\hline $\begin{array}{l}\text { Lagruna de Estl } \\
\text { Paso de l'Alto R }\end{array}$ & & & $\begin{array}{l}1779 \\
2874\end{array}$ & $(\mathrm{~F})$ \\
\hline
\end{tabular}
deduit. L’ordre adopté est celui de l'itinéraire suivi par M. Fuhrmann.

Les localités marquées d'une * sont celles dont l'altitude avait déjà été déterminée par d'autres explorateurs.

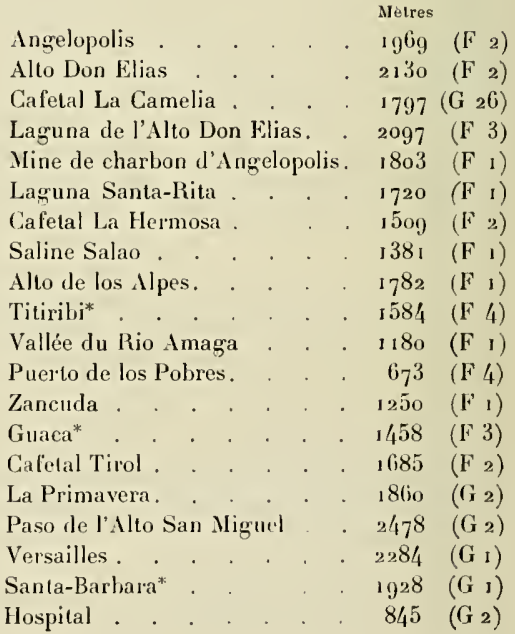




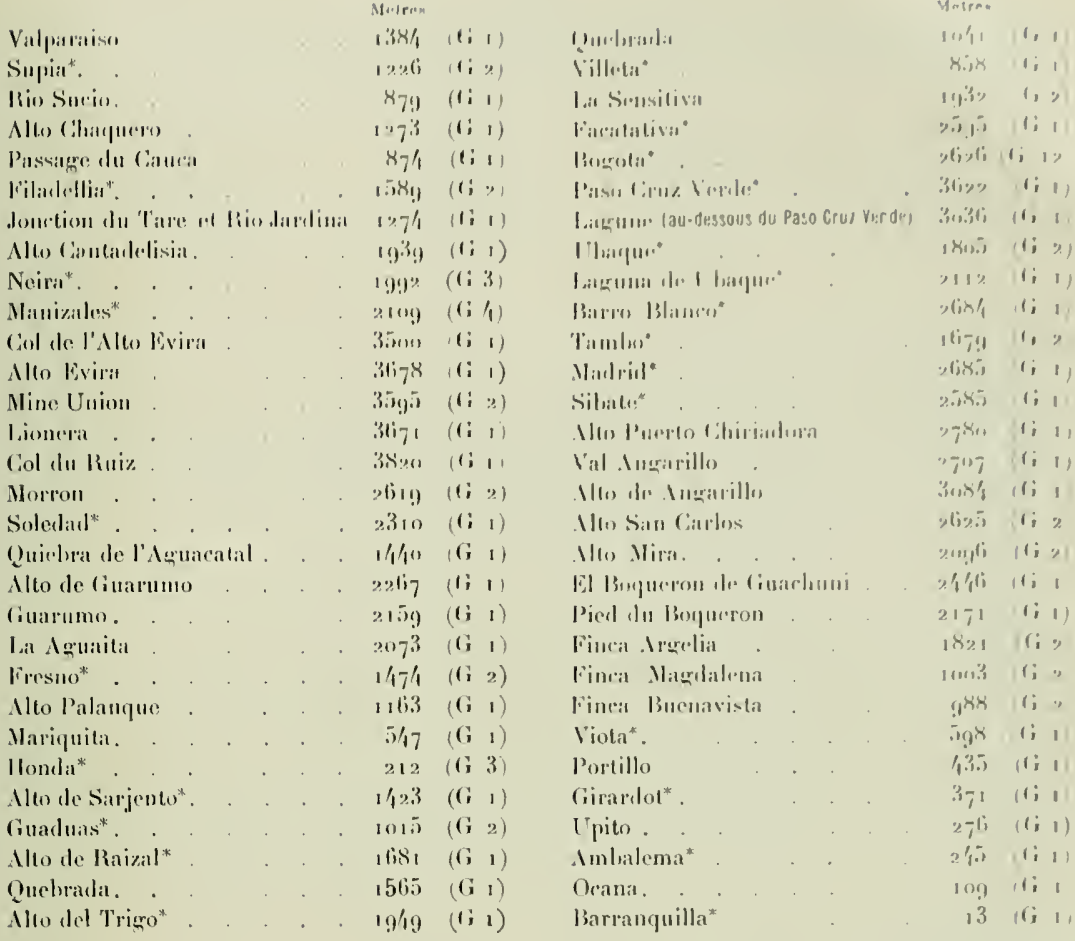

Les explorateurs qui ont lait, arant M. Fubrmam. des déteminations d'altitudes en Colombie sont:

\section{Exploratgurs}

Restrepo.

Boussingault

Mosqueria

Corlazzi .

Lievano .

Reiss et Stiihel.

Rancos

Hellner .

Espinosa.

Nallarino

\section{Dates du voyage Instruments}

179亿-ร ho?

18.20-1 הi2

$183.2-1850$

$1849-18.99$

$$
18(i 3)
$$

$1868-18(4)$ Hypsomerte

$$
\text { 1872 }
$$

$1812-1884$

$18-4-18-8$ IIysometre
Explorateurs

sambez .

Indrice

Pereira

Cisneros.

Faulhaber

White

Pena.

Schenk.

\begin{tabular}{|c|c|}
\hline ates ¿u vorace & Instrumetil \\
\hline $18 x+i-1900$ & Iniroîle \\
\hline $18-7-18-6$ & .) \\
\hline 1890 & 9 \\
\hline 1878 & ? \\
\hline Intis & Inerroüle \\
\hline ? & Barometre \\
\hline ה:הומ & I Iniroilde \\
\hline ? & D \\
\hline אה & Barometre \\
\hline
\end{tabular}

Sleinlseil. 
l'indique ci-ilessons les valent's comparatives des altiludes obtenues. Dans ce tablean, la significalion des aldreviations est lit suivante:

\author{
1 - Iutrece \\ B = Bonssingault \\ $\mathrm{Ci}=$ Cisneres \\ $\mathrm{Co}_{0}=$ Codazzi \\ $\mathrm{E}=$ Espinosa
}

$$
\begin{aligned}
& \mathrm{Fa}=\text { Faulhaber } \\
& F u=F u \text { runamı } \\
& \mathrm{H}^{\mathrm{r}}=\text { Hettner } \\
& \mathrm{L}=\text { Lievano } \\
& y_{: i}=\text { Mallarino }
\end{aligned}
$$

\begin{tabular}{|c|c|c|c|c|c|c|c|c|c|c|c|c|c|c|c|c|}
\hline nerto 1 & & & & 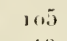 & fia & $9^{6}$. & & & & & & & & & & \\
\hline Puerto Ber & rio. & & $F_{u}$ & 14.3 & $\mathrm{Ci}$ & 128 & & & & & & & & & & 35 \\
\hline a. & & & Fy & 158 & $\mathrm{Ci}$ & $1 / 14$. & & & & & & & & & & 51 \\
\hline & & & 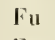 & 1515 & Co & 1541 & Re & $\mathrm{I} / 49 \mathrm{fi}^{\mathrm{i}}$ & 13 & 1547 & $\mathrm{Ci}$ & $1 / 80$ & c & 148 & & 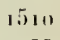 \\
\hline sti & & & & 17 & io & 1730. & & & & & & . & & & & $75:$ \\
\hline (2) & & & & & Co & 1580 & Sic & 1580 & & & & & & & & \\
\hline uaca & & & & $1 / 4$ & o & 1420. & . & & & & 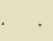 & . & & & & \\
\hline arbar: & d & & & & & 1820 & & & & & . & & & & & \\
\hline 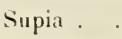 & & & & & o & 1220 & B & 1225 & te & 1230 & . & . & & & & \\
\hline & & & & & $c$ & I 590 . & & & & 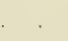 & & & & & & \\
\hline & & & & & o & $194^{\prime}$ & $\mathrm{Sc}$ & 1994 & & & & & & & & \\
\hline les. & & & 1 & & Co & 2140 & RS & 2135 & $r$ & 2217 & $\mathrm{Pn}$ & $207^{5}$ & $\mathrm{Sc}$ & 1 & & \\
\hline & & & & & & & & & & & & & & & & 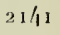 \\
\hline & & & & 2310 & Pn & $22 / 46$. & . & & & & & . & & & & 7 \\
\hline & & & & 1474 & $\mathrm{He}$ & 1340 & Pn & 1.582 & & & & & & . & & 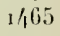 \\
\hline & & & Fu & 212 & Co & 210 & $B$ & 208 & Mo & 219 & $\mathrm{~L}$ & $19^{5}$ & Pis & 26 & & \\
\hline & & & & 2 & $\mathrm{Ci}$ & 199 & & & & & & & & & & \\
\hline ins & & & $\mathrm{Fu}$ & 1015 & Co & 1029 & B & 1022 & Yo & 1008 & L & $97^{6}$ & Ris & $10:$ & 36 & \\
\hline & & & $\mathrm{s}$ & 1 & $\mathrm{Sc}$ & 1020. & & & & & . & & & 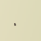 & & 0 \\
\hline lto & zal. & & $\mathrm{Fu}$ & 1681 & $\mathrm{Sc}$ & 1730. & . & & . & & & & . & . & & $70 \%$ \\
\hline It & go. & & Fu & 194 & Sc & 1920. & & & & & & $\cdot$ & & & & 3 \\
\hline & & & $F_{11}$ & 858 & Co & 839 & B & $833_{9}$ & Mo & $79^{\mathrm{I}}$ & RS & 8,3 & $\Lambda$ & $8:$ & 3 & \\
\hline & & & $\mathrm{S}_{c}$ & & & & & & & & & & & & & \\
\hline & & & $\mathrm{Fu}$ & $2 i$ & $\mathrm{Co}$ & ti3o & 0 & & & & $A$ & $7^{\circ}$ & & & & $i 1$ \\
\hline & & & & 20 & Co & 2641 & 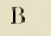 & o & & 2644 & L & 2634 & is & & & \\
\hline aso Cruz & Ver & & $\mathrm{Fu}:$ & 3622 & St & 3560 & Ile & 3520 & & & & . & . & . & & 56 \\
\hline baque & & & $\mathrm{Fu}_{\mathrm{u}}$ & 1805 & He & 1851 & $\mathrm{Se}$ & 1850 & & & & & & & & 33. \\
\hline $\mathrm{ag}$ & Ubart & & $\mathrm{Fu}$ & 2112 & $\mathrm{He}$ & 2100 . & 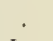 & & & & & . & & & & 106 \\
\hline$n$ & & & $\mathrm{Fu}$ & $26 i 84$ & Mo & 2740 & $\mathrm{~L}$ & 27 & $\mathrm{Sc}$ & 26,40 & & . & . & & & 7.1 \\
\hline & & & $\mathrm{Fu}$ & 1679 & $\mathrm{Sc}$ & ifitio. & & & & & & . & & & & $3_{70}$ \\
\hline & & & $\mathrm{Fu}$ & 258.5 & Co : & 2591 & L & $265 / 4$ & He & 2570 & & & . & & & fior \\
\hline & & & $\mathrm{Fu}$ & 2.58 & $\mathrm{He}$ & 2570 . & & . & & & & . & & & & 578 \\
\hline & & & F & 5 & E & 6 & : & & & & & & & & & 21 \\
\hline & & & F & $37 \mathrm{r}$ & Co & $3:$ & L & & & & & . & & & & 340 \\
\hline & & & F & 24.5 & Ii & 236 & $C i$ & 23 & & 23 & & & & & & 330 \\
\hline arranquil & & & $\mathrm{Fu}$ & 13 & RS & 1. & r. & & & & & & & & & \\
\hline
\end{tabular}

$$
\begin{aligned}
& \text { Mo }=\text { Mosquera } \\
& \mathrm{Pr}=\text { Pereira } \\
& \mathrm{Pn}=\text { Pena } \\
& \mathrm{Ra}=\text { Rancos } \\
& \mathrm{RS}=\text { Reiss et Stübel }
\end{aligned}
$$

$$
\begin{aligned}
& \text { Re = Restrejo } \\
& \mathrm{A}=\text { Sauchez } \\
& \mathrm{Sr}=\text { Sihenk } \\
& \mathrm{St}=\text { Steinheil } \\
& \mathrm{W}=\text { White }
\end{aligned}
$$




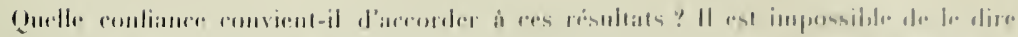

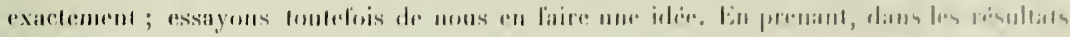

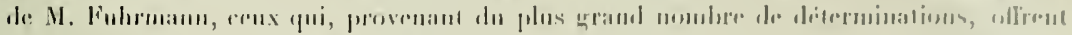

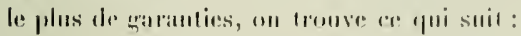

\begin{tabular}{|c|c|c|c|}
\hline & $\begin{array}{c}\text { Nombro } \\
\text { do dotserminations }\end{array}$ & $\begin{array}{l}\text { Emeur mojunn } \\
\text { d'une telormination }\end{array}$ & $\begin{array}{l}\text { Lireur mojenos } \\
\text { di la mojemst }\end{array}$ \\
\hline Merdellin & \% & $=1 x^{\prime \prime 11}$ & 土. $3^{m+}$ \\
\hline Lia Cimelia & ןl, & $\pm 2 . i^{\prime \prime}: 5$ & $\pm \sigma^{m_{0}}$ \\
\hline liogotat. & $1: 3$ & t $33^{4 n_{1}}$ & $\left.-1=y^{m \cdot m}\right)$ \\
\hline
\end{tabular}

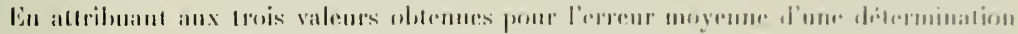

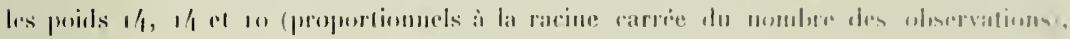

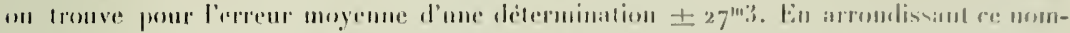

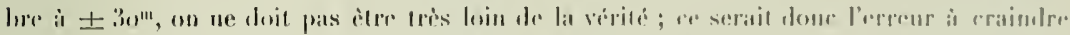

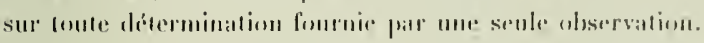

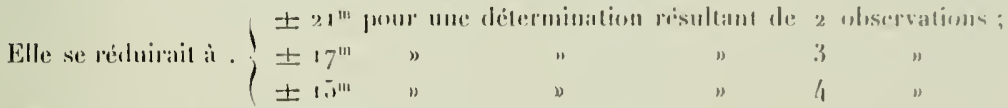

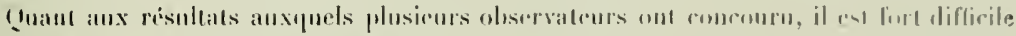

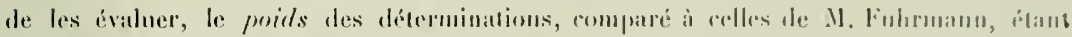

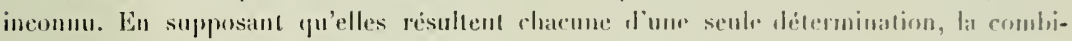
naison aver celles de M. Fuldrumn domedail les résultals consiennis ri-dessous.

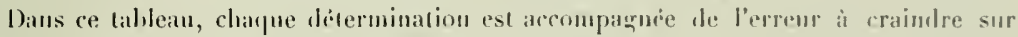

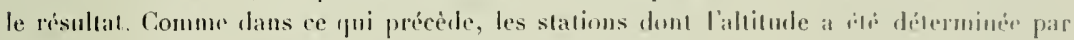
plusieurs ohservarleurs son lésignés par une astérisque.

\begin{tabular}{|c|c|c|c|c|c|c|}
\hline & & & & Meitres & & M.ires \\
\hline Magangue & . & & . & $43 \pm ?$ & Estrelli* & $17,55 \pm 20$ \\
\hline El Baturo. & 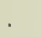 & & & $53 t ?$ & Lagnua de Estrella & $179 \pm \pm 30$ \\
\hline Rejiloe. & 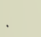 & & & $9^{\prime \prime}$ 上 ? & Paso de li Ito Romeral & $2 x-1=30$ \\
\hline Ciañabetal. & . & . & . & $1 / 2 \pm 30$ & Antrelopolis & $19 \operatorname{lig} \pm 20$ \\
\hline Puerto Wilehe & $e x^{*}$ & , & & $100 \pm 20$ & Ito Don Elias & $2130+20$ \\
\hline Puerto Berrio* & & & & $135 \pm 20$ & Caletal La Camelia & $17 ! 1 \pm 5$ \\
\hline Malena* . & . & & & $151 \pm 20$ & Laguna de l'Alto Don Elias. & $20 ! 17 \pm 15$ \\
\hline Cristallinat. & . & & . & $310 \pm 30$ & Mine de chartion al'Angelopolis. & $140,3 \pm 30$ \\
\hline Palestina . & . & & & $540 \pm 30$ & Laguna Sauta-litit & $1730 \pm 30$ \\
\hline San Raphatil & . & . & . & 1603130 & Cal'etal La Hermosa & Sion \pm 20 \\
\hline Caracoli & . & & . & $6 r_{2} \pm 30$ & Saline Salao & $1.3 \mathrm{Ni}_{1} \pm 30$ \\
\hline S. Iuan & . & & . & $86 \pm 30$ & Ilto de los Ilpes. & $1-x_{2} \pm 30$ \\
\hline La (Uichra & 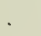 & . & 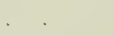 & $1084+30$ & Titiribi & $1.51 \pm 15$ \\
\hline Yarumito. & . & . & . & $1308 \pm 30$ & Vallée du Rio .Imaga & 11 soo +30 \\
\hline Medellin* ${ }^{*}$. & & & & $1510 \pm 10$ & Puertor de los Pobres. & $6 i-3 \pm 1.5$ \\
\hline Lagnima au-1le: & $\operatorname{sinus}$ & de & Mealellin & . $2504 \pm 30$ & Zaneuda & $12 . \overline{1} 0 \pm 3$ \\
\hline
\end{tabular}




\begin{tabular}{|c|c|c|c|c|c|c|}
\hline & & & & & & MLittes \\
\hline & 143915 & Giuaduas* & & $1016 \pm 10$ \\
\hline \multicolumn{3}{|l|}{$\begin{array}{l}\text { Cuata } \\
\text { Cafetal Tirot }\end{array}$} & $168 . \pm 20$ & Alto de Raizal. & & 1705 上 \\
\hline & $1860 \pm 20$ & Quelurada & & $1565 \pm 30$ \\
\hline \multicolumn{3}{|c|}{ Påo de l'.1/to San Nignel } & $247^{8} \pm 20$ & Alto del Trigo. & & 1935 上 20 \\
\hline \multicolumn{3}{|l|}{ Versiailles. } & $2284 \pm 30$ & Quehradi & & $10 / 11 \pm 30$ \\
\hline \multicolumn{3}{|l|}{ Santa-Barlbata* } & $187 / 420$ & Villeta*. & & 8411 \\
\hline \multicolumn{3}{|l|}{ llospital } & $845 \pm 20$ & La Sensitiva & . & 193.12 \\
\hline \multicolumn{3}{|l|}{ Valparaiso. } & $1384 \pm$ & Fiealativa* & & $261 / 15$ \\
\hline \multicolumn{3}{|l|}{ Supia*. } & $1225 \pm 15$ & Bogola* & . & $2633 \pm$ \\
\hline \multicolumn{3}{|l|}{ Rio-Sucio. } & $879+34$ & Paso Cruz Verde & & 3567 上 \\
\hline \multicolumn{3}{|l|}{ Nlto Chapuero. } & $127^{3} \pm 3 n$ & Lagune (au-dessous du Paso Cru & uz Verde) & $3026 \pm$ \\
\hline \multicolumn{3}{|l|}{ Passage ilu Canca } & $814 \pm 30$ & L'baque* & & $1835 \div 15$ \\
\hline \multicolumn{3}{|l|}{ Fibulellia*. } & $1590 \pm 20$ & Laguma de lhaque* & & $2100 \pm$ \\
\hline \multicolumn{4}{|c|}{ Jonction lu Tare et du Rio } & Barro Blaneo*. & & $2711 \pm$ \\
\hline Iardina. . & - & & $1274 \pm 30$ & Tamba* & . & $1670 \pm$ \\
\hline Alto Cantadelecia. & & & $1939 \pm 30$ & Matrid* & 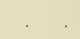 & $2(i 00) 上$ \\
\hline Neira* . . & & & $1958 \pm 15$ & Sillate*. & . & $2578 \pm$ \\
\hline Manizales*. & & & $2141 \pm 10$ & Alto Puerto Chiriadora & . & $2780 \pm$ \\
\hline Col de l'Alto Evira & & & $3500 \pm 30$ & Val Ingarillo & . & $2707 \pm 30$ \\
\hline Nlto Evira . & & & $3678 \pm 3 n$ & Alto de Angarillo & . & $3084 \pm$ \\
\hline Mine Ĺnion & & & 350.520 & Alto San Carros & . & $2625 \pm$ \\
\hline Lionera. . & . & . & $3671 \pm 30$ & Nlo Mira & . & $20 g^{6}: 1$ \\
\hline Col du Ruis & . & & 3820 च 30 & El Boqueron de Guachuni & . & $2 / 140 \pm 30$ \\
\hline Morron & & & $2010 \pm 20$ & Pied du Boqueron & . & 2171 上 30 \\
\hline Soledarl* & & & $277^{8} \pm 20$ & Finca Argelia. & 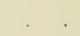 & 1821 上 20 \\
\hline Quichra de l'Iguacat & & & $1440 \pm 30$ & Finca Magdalena & . & $1003 \cdot \underline{1}$ \\
\hline Itto de Guarumo. & . & & $2267 \pm 30$ & Finca Buenavisla. & 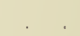 & $988 \pm$ \\
\hline Guarumo & & & $215 \pm 30$ & Viola* . . . & & $626 \pm$ \\
\hline La Aguaita & . & & $2073 \pm 30$ & Portillo & & $435 \pm$ \\
\hline Fresno*. & 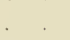 & & $1465 \pm 15$ & Girardot* & . & $340 \pm 20$ \\
\hline Alto Palanque & . & & $103 \pm 30$ & Upito. & . & $276 \pm 30$ \\
\hline Mariquita. & • & & $547 \pm 30$ & Ambalema* & . & $234 \pm 15$ \\
\hline Honda*. & & & $207 \pm 10$ & Ocana & & $109 \pm 30$ \\
\hline Alto de Sargento. & & & $1423 \pm 30$ & Baranquilla* & . & 10 \\
\hline
\end{tabular}

Dans ce tableau, les valeurs des erreurs à craindre sur chaque détermination ont été arrondies el remplacées par le muliple de 5 le plus rapproché. 


\title{
Poteries anciennes de la Colombie
}

\author{
par M. 'I'h. DELACHAUX.
}

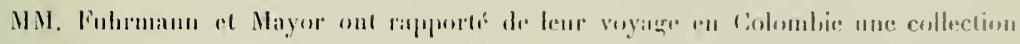

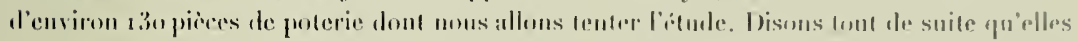

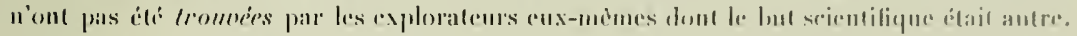

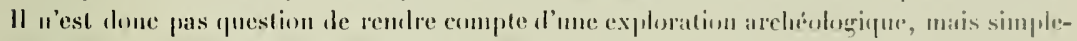

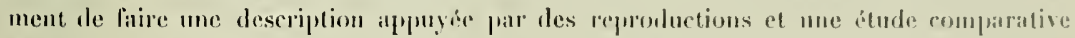
des pieces ave des produits similaires existant dans des collections on les musées ainsi

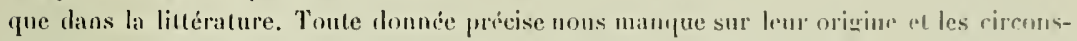
tances dans lesquelles elles ont été découvert's. Nous savons seulement que les explorateurs les ont aequises is Merleflin, d’un jeune Indien qui disail les avoir regues de son frire; celui-ci les amrait recueillies dans fa régrion du Cauca en-ilessus de Minizales.

An premier coup d'exil jeté sur l'ensemble de ces poteries, nous sommes frappes prar leur aspect hizarre de bibelots rares et curieux; involontiarement, nous cherchuns une analogie el notre esprit se porte aux gargouilles des cathédrales gothiques: il nous semble avoir devant nous, en miniature, leur faune grouillante de vie. Cies formes sont pleines d'imprévu, l’invention en est si féconde, les mouvements dénotent une obsersation de la nalure si intense en mime temps qu'une liberté d'interprítation dicorative d'une si complète liberté que nous avons limpression de nous tronver en face de l'reuve d'un urant artiste. La technique libre el pleine de franchise ajoute encore à celle impression, el puisque l'authenticité de ces objets a été mise en doute, disons lout de suitr que leur qualite artistique ne nous semble pas atre la moindre preuve le leur valeur, avec d'autres sur lesquelles nous reviendrons plus loin.

La maliere première est une aruile de couleur noire tirant sur le lorun fonch. Fille contient une forte proportion d'un sable assez grossier ef de paillelles de miera jonant le ròle de "dégraissant". Le mica donne l’impression d'un semis de pailletles d'or. La surface extérieure est plus ou moins lisse el lustrée, comserte de fines cratuelures.

1 Comme on le verra plus hin, cette indication correspond parfaitement avec celles de nos sources de comparaison. 
Le fusonnuge de ces poteries a dì àtre des plus simples: elles ont été modelées à la main, comme toules les poteries anciemnes de l'Améripue du Sud, qui n'a pasconnu l'emploi du tont. Les pieces les plus importantes sont faites de plusieurs parties lappurtés, soudées les unesin anx antes. Les ornements colles sont noyes de bathotine et lont bien rorps avee la piece. Cela frappe surtout dans la fagon dout sont fixés les bras des persomnges dont les altaches ne sont jamais sèches. Pent-ètre la pièce entière était-elle enduite it l'álat frais d'un engube de hi mème terre diponrve de sable, ce que semblent indiguer las crapuelures superficielles.

La surface lustrée d'un hrm-noir tirant au brun plus clair dans certaines piices, a dì être obtenue par polissage de la pirce à l'état cru, au moyeu de pierres. Cette technique était répandue à un moment oủ les émaux et les vernis étaient inconnus.

L'asprect de hibelots que revètent la plupart de ces poteries a déjà éti signalé. Il est certain qu'elles n'ont point été faites pour des usages domestiques; ce ne sont pas des ustensiles de ménage. Étaient-elles consacrées aux usages d'un culte des morts? faisairnt-elles lohjet dune industrie? lenrs images avaient-elles me signification şmbolique on religrieuse? Iutant de questions que nous posons sans avoir la clef pour les résoutre. Les connaissances sur les civilisations primitives de l'Amérique du Sud sont bien fragmentaires et les conjectures que nous pourrions lasarder risqueraient hien d’ètre fantaisistes. Nons savons seulement que ce sont les anciennes sépultures indiennes qui fournissent tous les oljets d'or et de terre euite, et gu’ils donnent lieu à une exploitation systématique souvent rémunératrice pur les "guaqueros", surtout dans les contrées facilement accessibles et roisines de la mer. Nous pouvons admettre que nos poteries ont rraisemblablement été extraites de pareilles sépultures (Anango, catalogue. - Anthropological papers, Amer. Mus. of Nat. Ilist. New-York, rol. II, part. III).

Les sources d'inspiration de ces poteries sont presque exclusivement famistiques; la flore est à peu près absente ou ne joue qu'un rôle secondaire. Ce sont les ètres vivants et mouvants qui intéressent nos arlistes; ils ont su les observer dans leurs monvements les plus caractéristiqus. Leur fantaisie est allée plus loin encore. Comme l'artiste du moyen àge, ils ont évougé tonte une fame d’imagination aussi vivante que la vraie et parfois singulierement troublante $\left(n^{\circ} 46,47,48\right.$ et 124$)$.

Les végétaux sont représentés par un fruil (maïs?) $\left(n^{0} 21\right)$ el par des sortés de disques dans lespuels nous croyons reconnaitre des feuilles de nénuphars avec leurs bords lingèrement deutelis, et servant de support à des crapauds on des salamandres ( $n^{n 8}$, , 3, 4, 5 et 6 ).

Des objets ustzels divers ont cité le point de clépart de cerlaines formes; ainsi quelques calebasses, des corbeilles, ainsi qu'une marmite sur quatre pierls.

Les vases proprement dits, c'est-a-dire n'imitant aucun antre objet, sont peu nombremx dans cette collection. Doit-on en attribuer la raison an fait d'un triage des "gnaqueros" attachant plus de prix aux figurines qu'aux simples vases? Nous ne pouvons le savoir; mais il est plus probable, à en juger l'après d'autres collections, que les figurines sont rellement en polus grand nombre. Les quelques pieces de ce genre que nous avons ici 


\section{$-117.3-$}

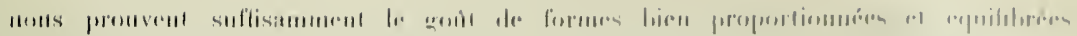

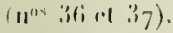

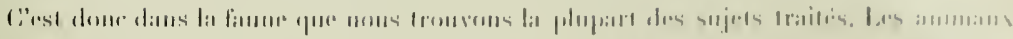

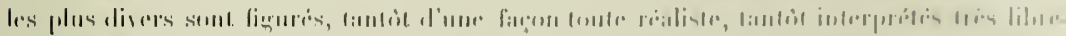

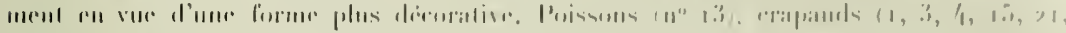

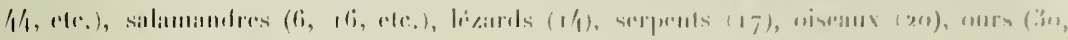

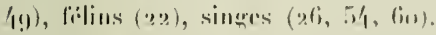

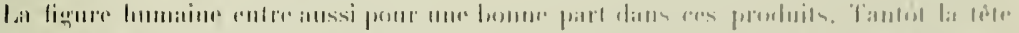

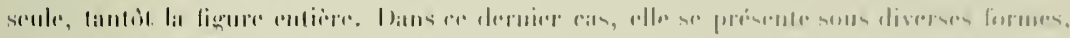

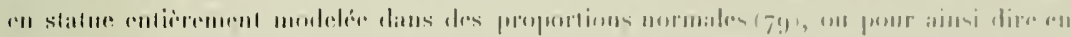

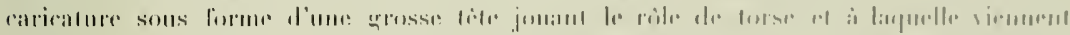

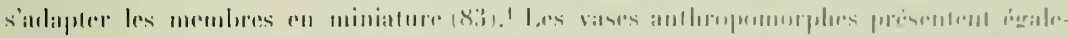

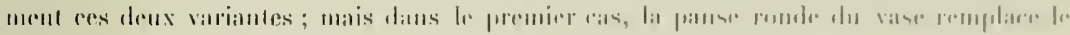

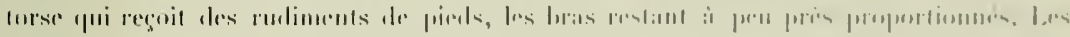

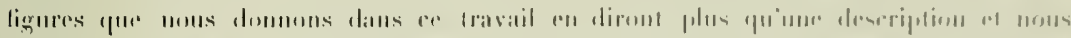

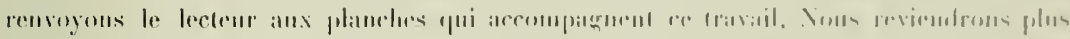

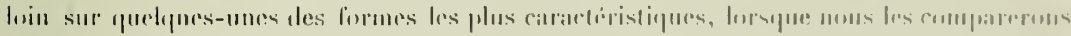
ì celless ale lat collection Irirren.

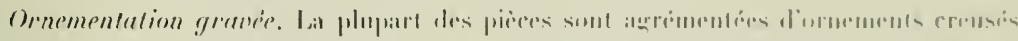

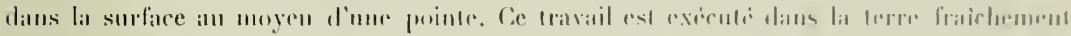

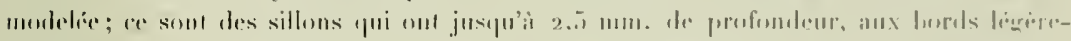

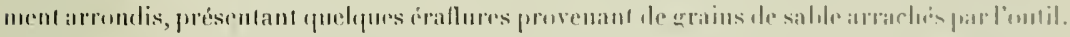

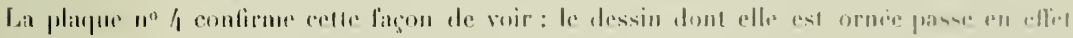

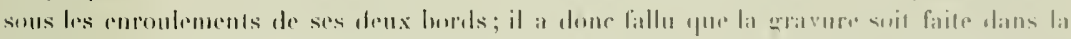

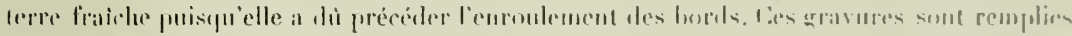

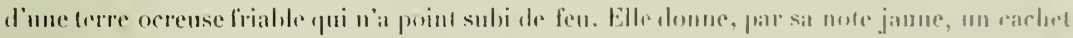

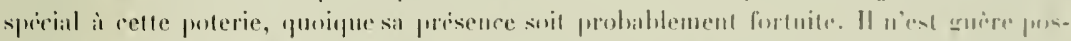

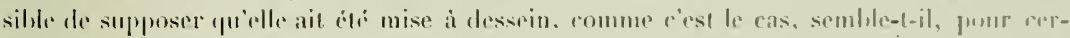

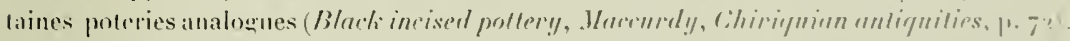

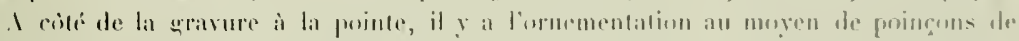

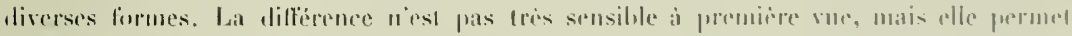

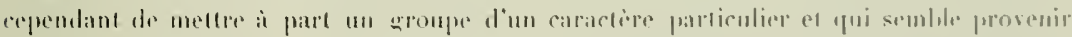
d'inn atelier spreial.

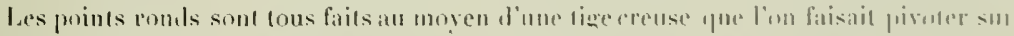

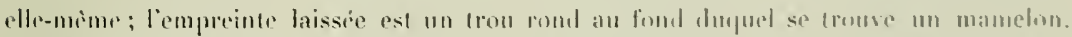

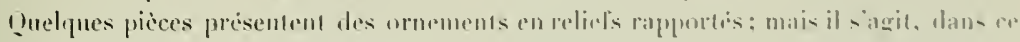

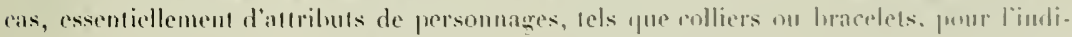

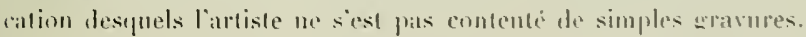

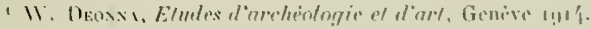


Limnementalion wrave est à première vue grométrique, e’est-ih-dire parair itre crée

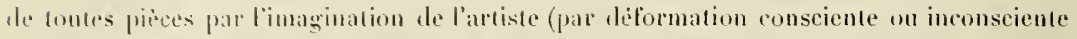
de motifs primilivement naturalistes un par copie de molifs dérivés directement daulres lwholiegues). Capendant if faut se convaincre, après examen, pue ces ornements gravis dirivent directement d'une interpretation naturaliste. Il suffit d'étulier les figurations l'animanx dont les qravures, foin d’èdre arbitraires, représentent bien un aspect décrminé des teguments de changur espece.

L'ornement le plus yppique esi fourni par la ligne dorsale des animaux dont le premier rudiment consiste en me série de points. The série de plus en plus compliquée dérive de ce premier schéma augued riennent d’abord s'ajonter une ligne parallicle de charpue coité (fig. 1) l. Celui-ci se complique d'une double rangie de baitonnets inclinés on perpendieulaires, placés à l'extérient des lignes précédentes; ces bâtonnets représentent les coiles ou les plis de la peau (fig. 2 et 3). Si le lessin s'élend encore davantage pour rejoindre le flane de l'animal comme dans le $n^{\circ} 28$, nous anrons une triple rangée de points entre des lignes parallèles séparées par des batonnets (figr. 4).

Il existe plusieurs variantes de ce schéma : l'm des éléments est tantòt doublé on lien manque tout à fait, selon le caractère particulier de l'animal ou la place disponible jumr lat gravure. Ainsi la série de points peut manquer, il reste alors les deux lignes mílianes m les crites $\left(n^{0} 9^{5}\right.$, fig. 5$)$, ou bien la série de points est double el séparée par une ligne médiane $\left(n^{\circ} 9^{6}\right.$, fig. 7 ). Les rangées de points penvent encore s'écarter et laisser an centre une baude nue $\left(n^{\circ} 35\right.$, fig. 6).

Dans la plupart des eas, ees dessins commencent et s'arrètent sans modifications, c'est-it-dire le motil est coupt sans autre aux deux bouts. D'antres fois, il se modifie soit dans la nuque, soil dans la croupe pour se plier aux formes de l'animal.

Nous trowvons ainsi en arrière de la tète un épanouissement de la ligne médiane lêl que le montre la fig. 19 (n (n) $^{\circ} 48$ et 49 ), ou encore une bifurcation de la bande de l'échine dans la fig. 20 ( $n^{\circ}$ 64). Lorsque le dessin est formé de deux bandes parallèles, celles-ci s'écartent simplement comme sur la fig. $21\left(n^{0} 120\right)$.

Un motif ornemental tris employé est celui consistant en lignes parallèles marquant les plis transversaux de la peau de certaius animaux tels que les salamandres (fig. 10 el $\mathbf{1}$, $n^{0 s} 7$ el 6$)$. Ces bandes transiersales sont parfois agrémentées de points marquant les pustules comme dans les fig. 13 el $14\left(\mathrm{n}^{\circ}\right.$, ro el 33). Si les lignes se croisent à intervalles ígax, nous ohtenons le carrelage des $n^{05} .33$ et ro3 (fig. 15) dont les alvéoles sont sonvent unes; ou bien, dans beaucoup de cas, meublíes d'un point dans chacme d'elles $\left(\mathbf{n}^{0} 2 \mathrm{r}\right)$, fig. 17). Wans le $1^{\circ}$ io (fig. I6), ce n’est que la rangée médiane qui est ornée de points tandis que les autres carrés restent libres. Le $n^{0} 2$ nous fournit un dessin de ce grenre dont les lignes sont obliques par rapport à l'axe de l'animal (fig. 18). Le serpent

1 Les figures mentionnées iei sont celles de la planehe XXXIII et les nos sont eeux que les poteries portent sur les planclies. 


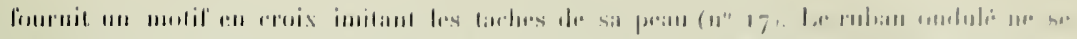

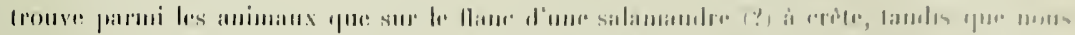

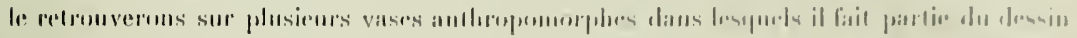

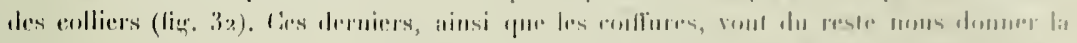

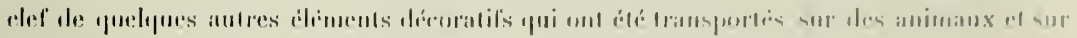
l'auluess oljets.

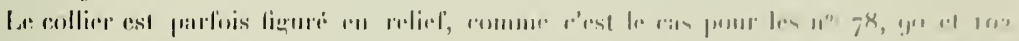

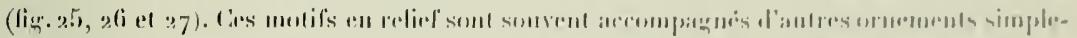

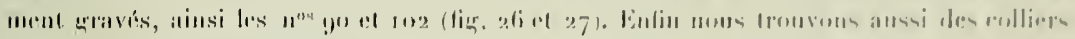

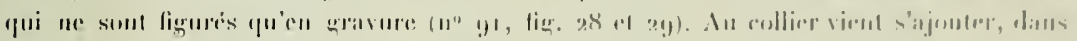

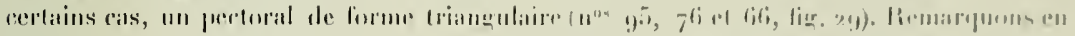

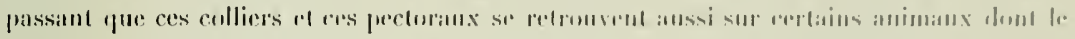

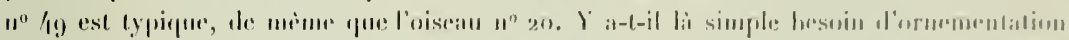

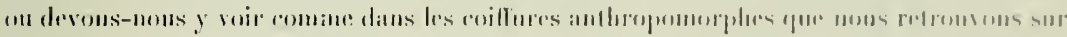

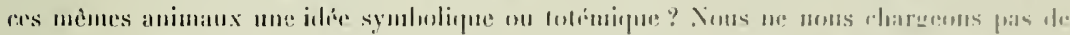

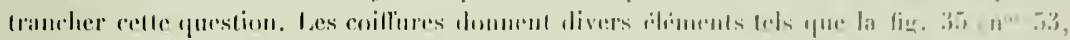

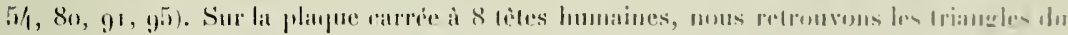

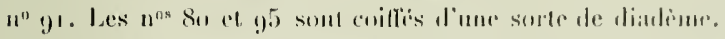

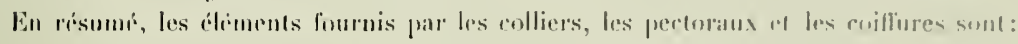

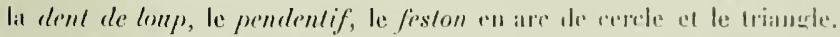

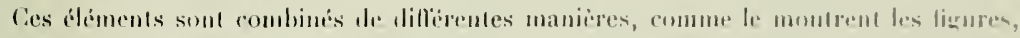

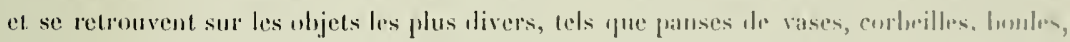

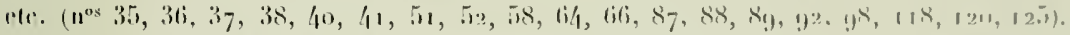

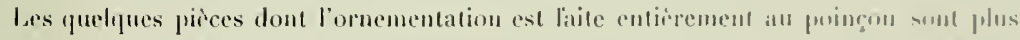

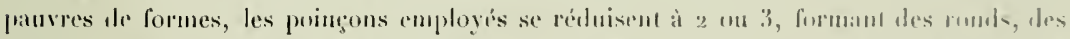

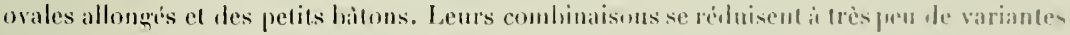
(fig. 22, 23 el 2 f. Nos roti et roz).

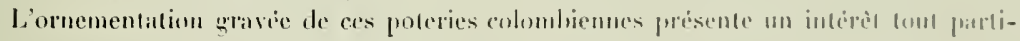
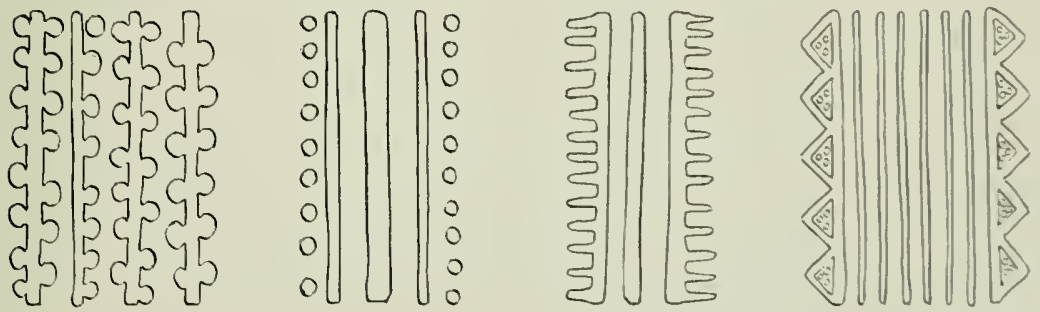

culier par le fail que nous la trowons in silu sur la representation des animanx qui l'a suggérée. l'lusieurs auteurs ont signale des ornements zommorples yu bils ant releves sur 


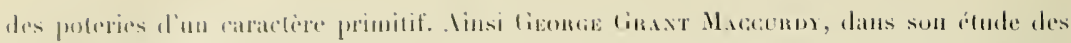

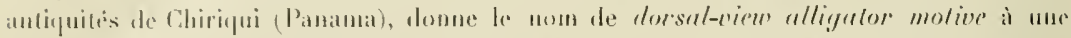

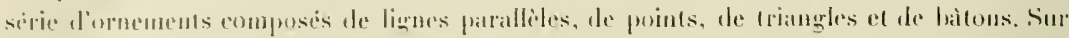

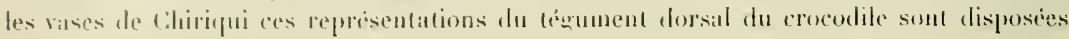

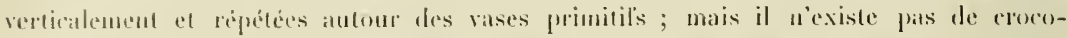

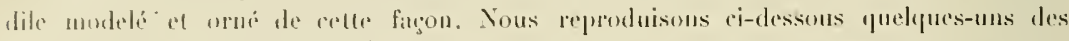

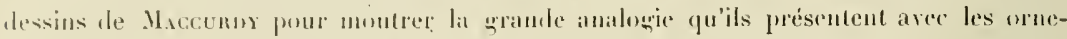
ments dorsanx de divers de mos batraciens ed reptiles. Nous sommes loin de vouloir
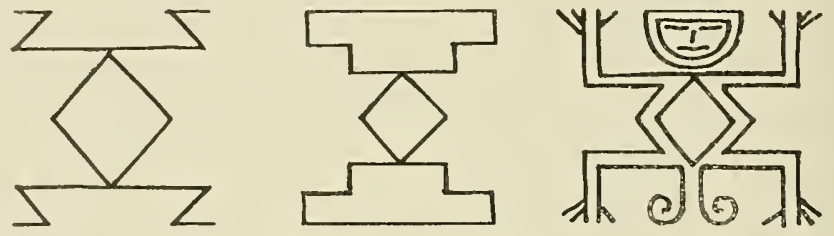

prétendre qu'à l'origine des poteries de Chiriqui devrait correspondre un stade oì cest ornencuts se seraient trouves sur des figurations plastiques telles que les nòtres; res interprobations ornementales ont lout sussi bien pu etre fittes directement sur la panse des vases. Le cas de nos poteries est d'antant plus intéressant pour l'étude de la grenèse de l'ornement. Elles le sont encore à un autre point de vue. C'est parmi elles que nous trowons la représentation naturaliste d'un motif ornemental très répandu dans l'Améri'que du Surl, (Ecuador, Venezuela, Guyanes, etc.), ì savoir le crapand, qénéralement sur un disque. Le Dr Rovet, assistant au Museum d'llistoire naturelle de Paris, explorateur de l'Ecuator, crul voir l'origine de certains disques métalliques à motif de crapaud ou grenouille dans ces platjues dont nous lui avions communiqué la photographie. Cet ornement présente tous les stades intermédiares entre la grenonille on le crapaud et l'homme et n'est souvent plus qu'un ornement purement géométrique (figures ci-dessus) méconnaissable si nons n’en possédions la série complite de ses transformations.

Nous avous cherché à identifier nos poteries avec des produits similaires de divers musées el avec des descriptions el des figures d'ourrages speciaux sur li Colombie. $\Lambda$ notre étomement, n'arons-nous trouvé que peu de chose dans la littérature et moins encore dans les musées.

Sur la contrée très limitće qui nous occupe, nous n’avons trouré que les trois travaux suivants :

$1^{\circ}$ E. Riestrepo Tinado, Ensingo elmografico y arqueologico de la Provinciu de los Cuimbayas en el Nrevo reino de Crranada (Bogola, 18y2).

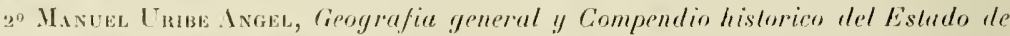
Antionnia en Colombin (Paris, 1885).

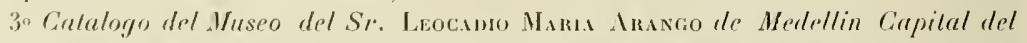
Departamento de Antiogria en la liepablica de Golombia (Nedellin, 1go5). 


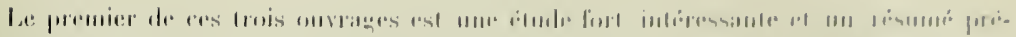

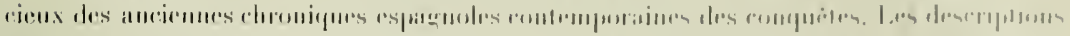

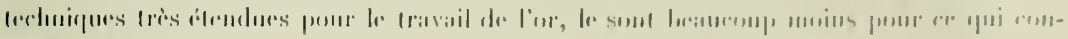

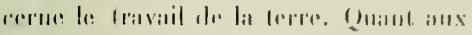

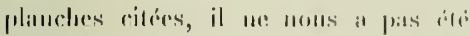

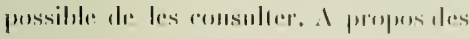

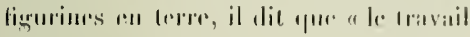

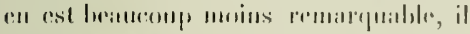

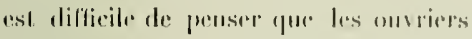

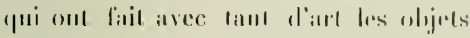
r'll or, aicut mis si pen the soin is celtes

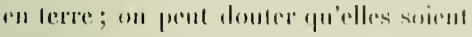

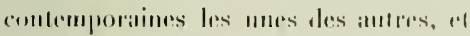

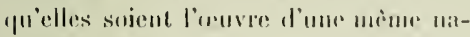
limo..." Mals romme il dil plus lom

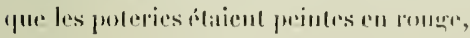

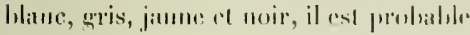

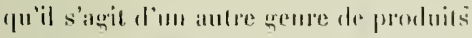
fue colui qui mous ocenpe.

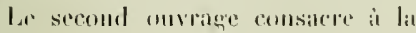
cómmique un pelil chapitre, ou il ast die

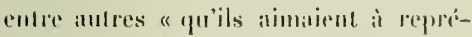
senter sur lours vases, meubles ed bijoux des figures de grenonilles, serpents, crucorliles, lízarids, elce, el il est it remarpuer que ces ohjets ressemblent forlement ì des produits de meme genre de's auciens legproms que lon roil dins les musiés"

Pitr contre le troisione de res ouvariges a prour nous une gramule importimce. C'est an effed to seul dills lequel nous lom rions des poteries sembliahles aux notres, el la valeur de l'ouvrige rst considirablement angmenté prar la fitil que MM. Fulumant el Mayor

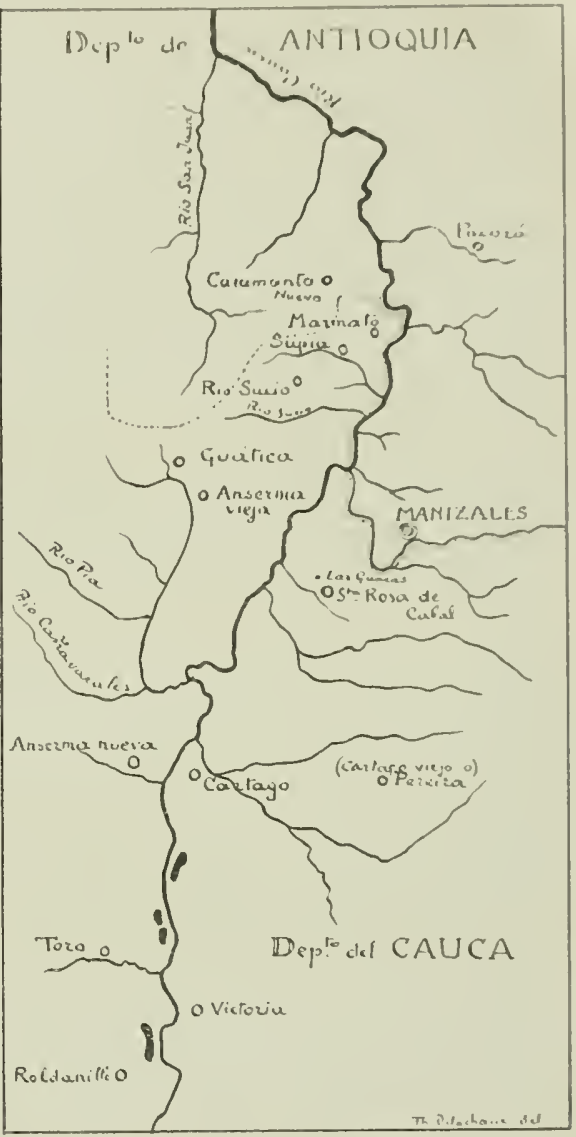

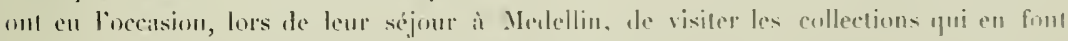

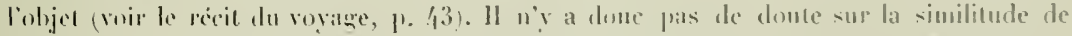

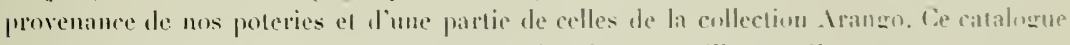

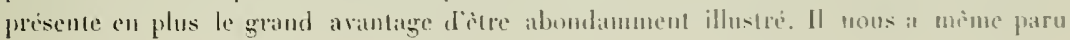




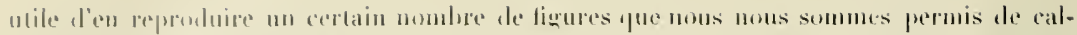

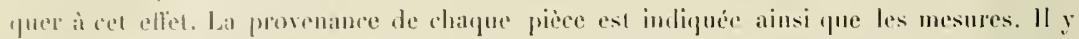

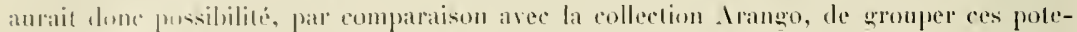
ries selon erelans lypes caracteristiques de mime physionomie, de meme ornementation

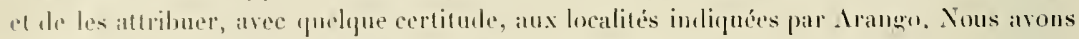
fait un essai dabord avee les dessins du calahogue ef mous atsons remargue quén etfet certaines formes ypirjues provenaient d'une meme localité ou du moins de localités très roisines. Vous pourons done supjoser perm les pieces de la collection buhrmann et Mayor les mèmes liens de provenance en procédant par analogic.

Tuntes les localités cites par Arango pour ses poteries se trouvent à proximité du rio Concu dans un rayon rebativenent gestreint à l'ouest de Manizales. La pelite carte que mous arons tressée en nous servant de plusieurs cartes de la contrée (p. 1077) est incomplete prare que beancoup de noms indiqués par Arango sont de petites localités qui ne se lrouvent sur aucune carte, on lien sont connues sous des noms différents; mais elle ext ln moins sulfisinte pour nous laire une ide de la distritution géographique de ces pronduits ceramiques.

Vuci maintenant quelgues rajprochements : la lig. 1 r62 du calalogue Arango

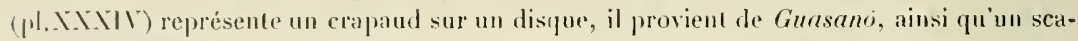
rabee igalement sur un disque. Nous pourons en rapproclies les $n^{\text {ss }} 1,2,3,4,5,6$ et 7 ale la collection fuhn'mann. Deux serpents enroules (fig. 149:3) de la collection $\mathrm{A}$. proviennent

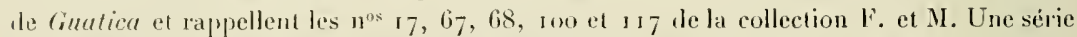
culinctéristique el celle des vases irréguliers et hizarres: collection $\Lambda$. fig. $127^{6}, 1262$,

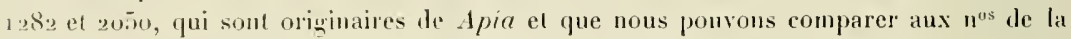

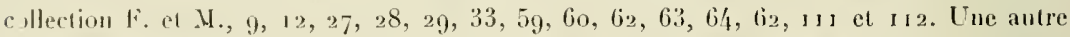
sirie caractéristique est celle d'animaux assis ou accrompis. Dans la collection $A$. ce sont les fig. ro72, 1 134, 1185,1376 , toutes de Guasano; dans la collection F. et M. ce sont les $n^{05}$ 45 à 51,85 et 124 . Les deux petits ours de la collection $\Lambda$. fig. 1299 et provenant de Sruturrio sont bien parents des $n^{0 s} 30$ et 49 de notre collection. Diverses figurines zoomorphes représentant des poissons, des crapauds, des lézards, des oiseaux, des singes, des pantheres, des animanx, faluuleux mime ont dé trousés it Benaleazar, a Apia el surloul a Ciuasano. Nous en avons de beaux representants dans les nos 13 , 14, 15, 16, 18, 19, 11 el 22.

Par contre la collection Fuhrmann el Mayor contient une série hien représentée qui parait ette rare dans la collection . Irango, eiest celle des figurines et des vases anthropomorplies. Dans le catalognue $\lambda$ rango nous ne voyons zunère que la fig. 2195 provenant de Trutumi qui puisse nous rippeler les nitres, ainsi que les fig. 2200, 2201 el 2205 de

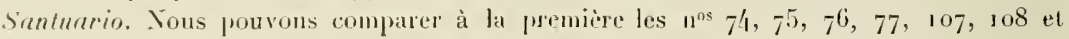
126 , el aux suivantes les $u^{05} 102$ el 103 . La série 74 , 75 , ele., se distingue du reste par un lustre plus brillant el plus poli, la sravure en est sobre et rare.

Ces quelques exemples que nous ne voulons pas continuer nous suffisent pour mon- 


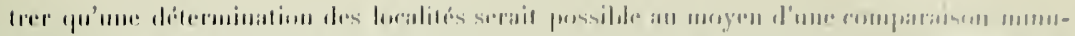

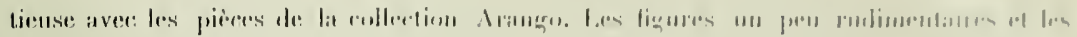

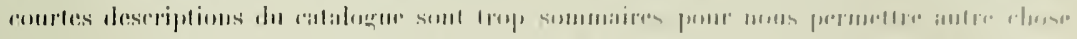

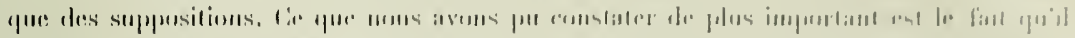

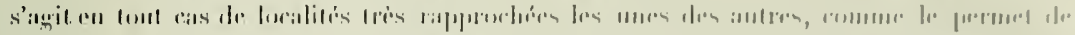

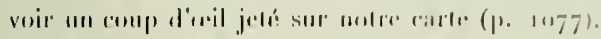

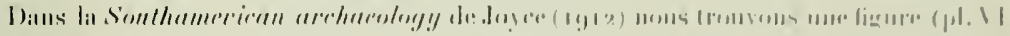

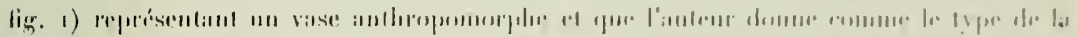

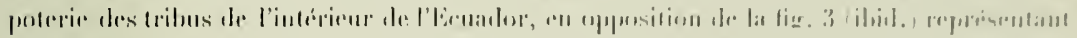

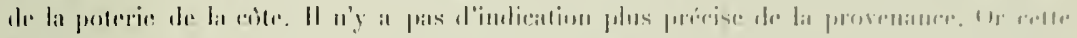

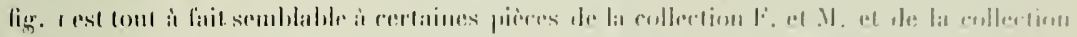

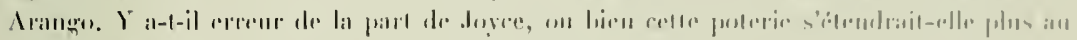

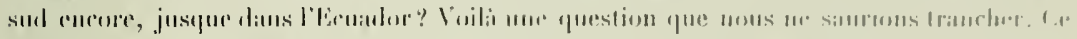

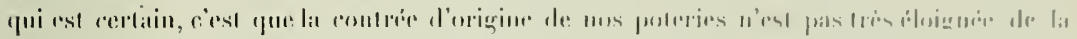

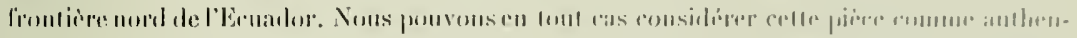

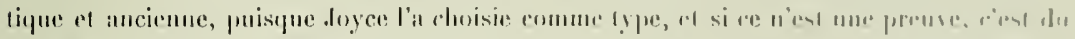

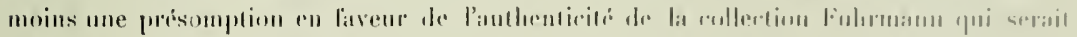

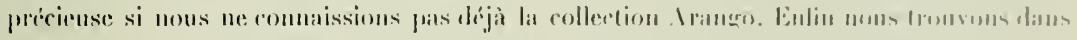

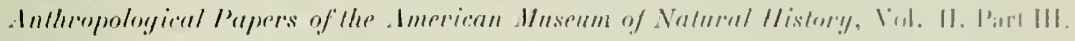

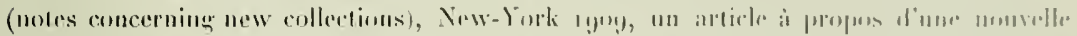

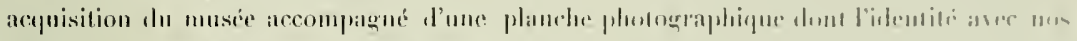
poleries me pent laisser subsister andun dumle.

Voici ce pue alit reet atlicle:

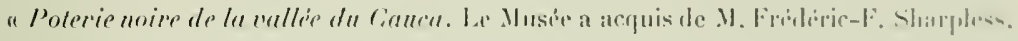

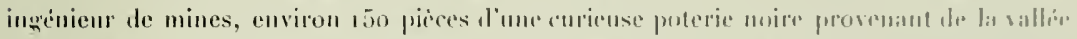

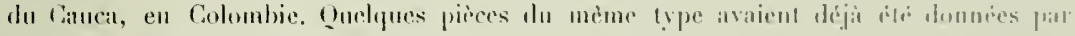

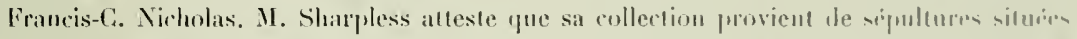
entre les villes de Ouinchia et de Papyal, contrev dans laquelle d. momblemx rimeliopes

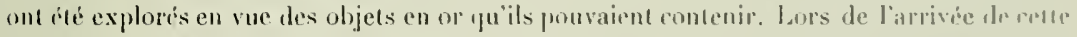

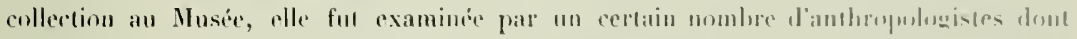

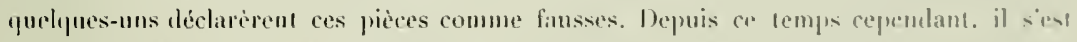

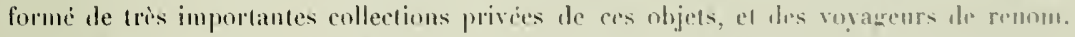

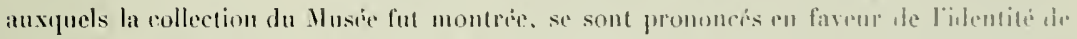

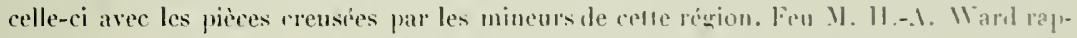
porfa de Culombie m pelit lot de ces mrmes puleries avee mo atteslation de leur anti-

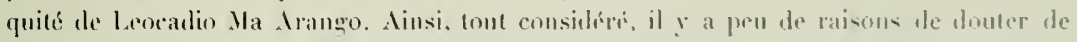
l'aullenticile de celle collection. "

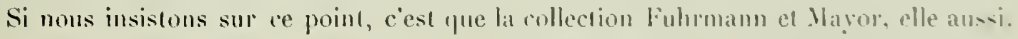

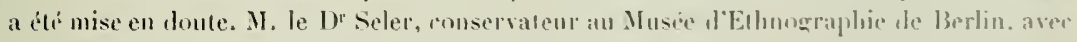

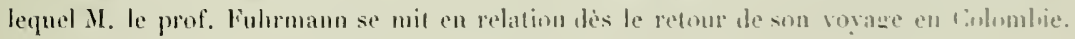




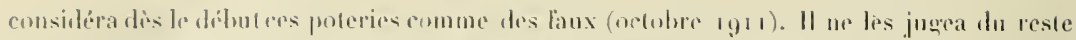

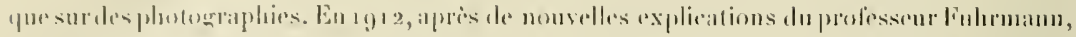

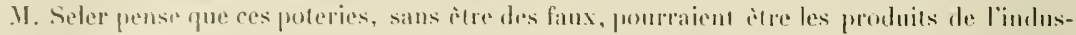

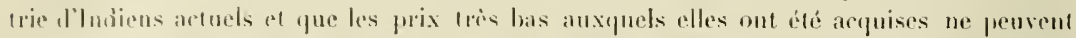

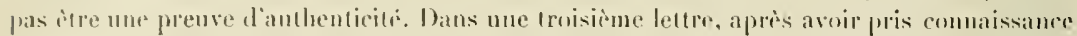

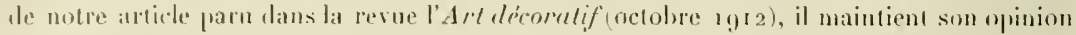

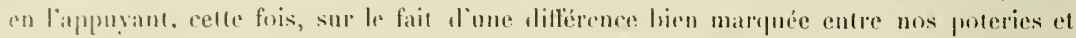

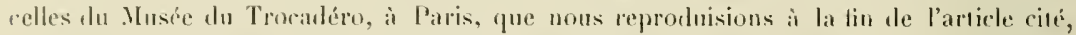
diffrence qui lui parat dérisive en farrur de la faussefé des premières. Or, les proteries dh Trocadero proviennen l'une antre contrée, quoique voisine de la mitre; elles sunt le produit d'une antre civilisalion: celle des Chiluchas. Dans la collection fulumann, Irois

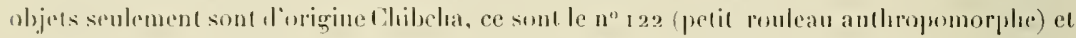
les deux prondentifs en or de la Planche XXXill. Dans le ratalogue Arango, nous trouvons

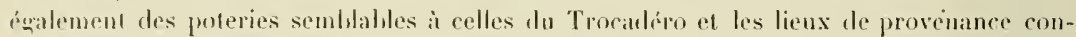
cordent en tout point avec les indications dn catalngue du Trocadéro. Du reste, il mons semble peu probalsle qu'un lromme tel que M. L. Arango ait colfretionmé durant prés d'un demi sirele des laux, lui pui se trouve sur place el dans les meilleures conditions possililes pour réunir des objets authentiques. Nous n'avons donc pas de raisons, pas polus pue le Musie de New-lork, de douter de la valenr des poteries qui nus occupent.

l'attribution de nos poteries à l'une des civilisations connues de res rontrées n'est pas chose aiséc et nous allons essayer d'éclaircir autant qu'il sera possible relle question. Disons tout de suite que nous ne pourons faire que de simples hypolhèses, les connaissances que nous avons de ces pays étant fort rudimentaires.

La contrée yui fournit ces poleries (voir carte [1. 1177) étail habitíe fors de la conquète espagnole par les omimbayras. Le centre de celte région est Carlhago. Leurs voisins, i l'Esi, élatenl les Chibchrs qui luabitaient le haut plateau de Bogrola. Un troisième groupe de tribus occupait la région d'Antioquia, et un quatrième groupe se tromvait a Popajan. Les degrés de civilisation de ces groupes étaient forl dillérents. Les Chibchas l'emportaient guant a lorganisation politique, tandis que les Guimbayas leur étaient supérienrs dans les produits artistiques, el tout spécialement ceux de la céramique et ceux du travail des métanx. Mais la question se complique par le fait que nous ne pouvons admettre, comme auteurs de nos poleries, des ouvriers de la culture que dénotent leurs travanx en or. Nous arons vu déjà que leur poterie stait dillírente de celle qui nous occupe et qu'elle rtait peinte de coulenrs diverses (p. 222). Dans leurs figurines ils employaient frópucmment le sifflet, dont nous n'avons dans notre collection aucun exemple. M. S. Iloyos, dans la préface du calalogue de la collection Arango, se range à l'opinion de E. Restrepo Turado yne nous venons de citer et pense que ces proteries noires ont dì appartenir à une civilisittion disparue déja lors de la conquète espagnole. Or, nous savons que le peuple des (nimbayas a conquis le territoire qu’il occupait lor's de l'arrivée des Espagnols el qu'il itait arrivé dans la virllée du Cauca el de la Vieja conduit jar mo chef et quil mit le 


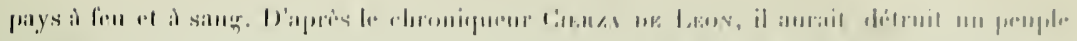

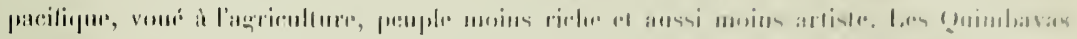

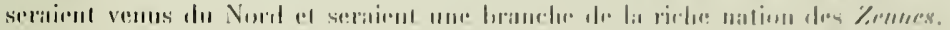

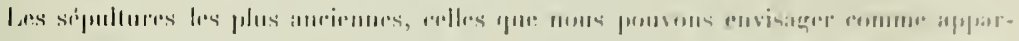

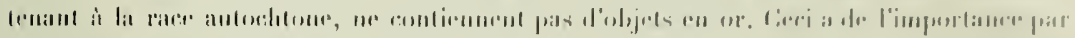

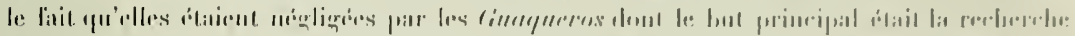

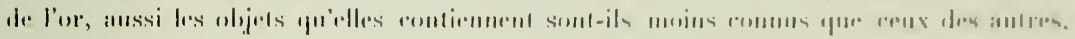

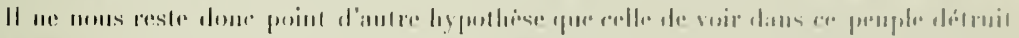

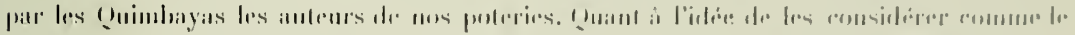

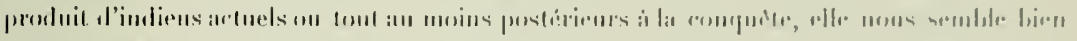

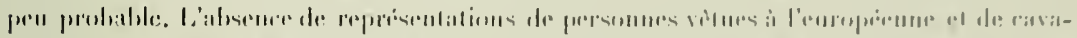

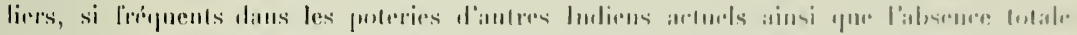

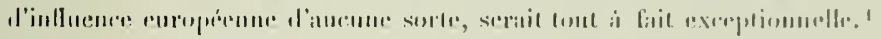

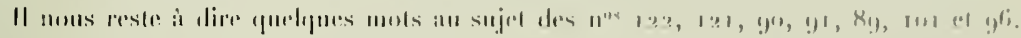

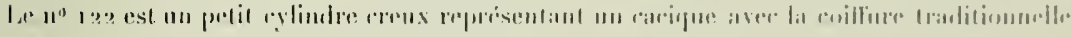

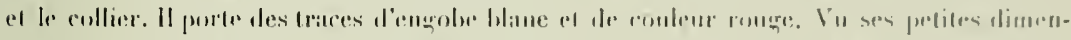

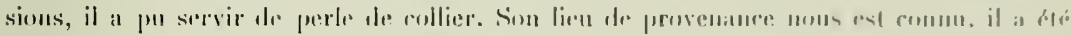

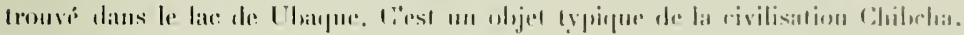

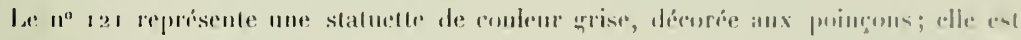

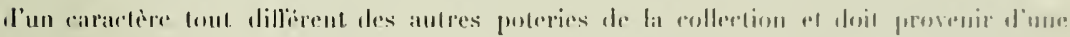

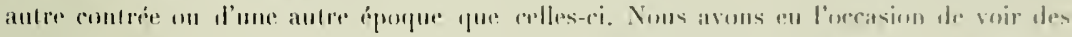

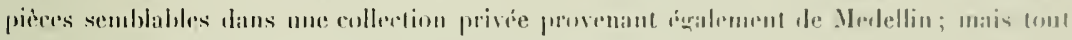

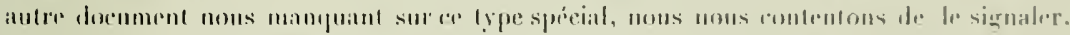

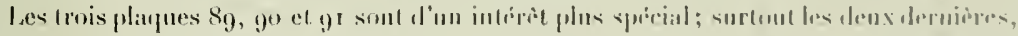

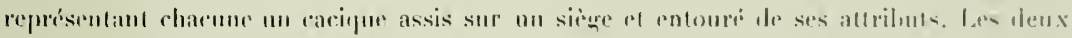

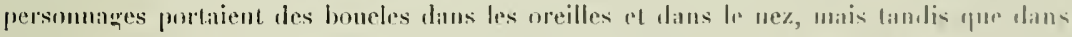

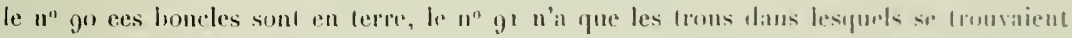

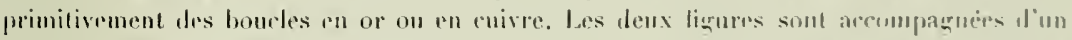

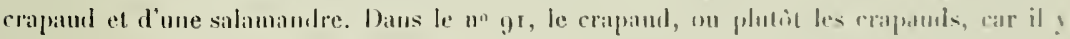

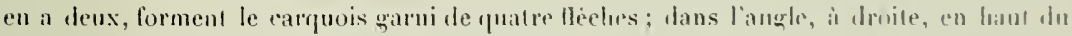

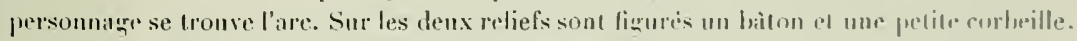

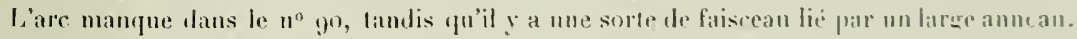
lïnlication des genonx dius le no gr an moyen de deux probuberances sur le milien des jamles est eurieuse. Les coillures sont différentes, druite dans le un go el en demi-cercle

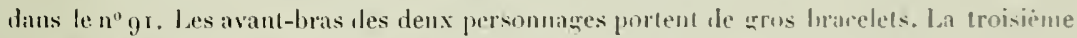

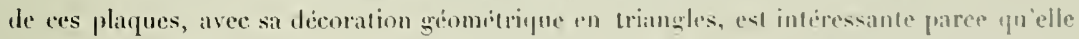
porte 8 tètes de cacigues tout à fail stylisies, que l'on a de la prine it deconvir au premier

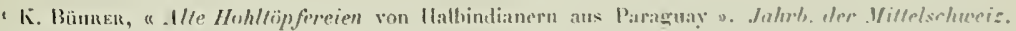
Geograph.-Commercipllen Ges. Aaran, Bel. 11. Issis. 


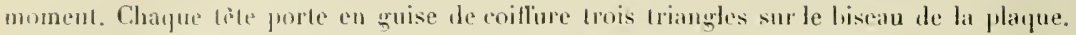
(Gualle pouvail ètre la destination de ces plaques? Dans fous les cas, il semble qu'elles

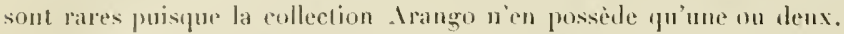

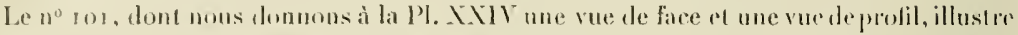
bien sn colé curioux de l'imagination des auteurs de ces poteries. C'est un curienx enchevetrement d'utres humains el de crapauds, où les bras des premiers sont formés par les jambes de's seconds. In crapand alssis sur te col du vase qu’il entoure de ses palles postérieures,

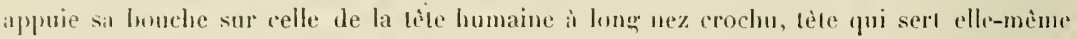
de chapean iो la figme qui se trouve sur l'autre face. Les patles aulérieures du crapaud se hilinquent sul les épanles et forment de chaque crité les hras des personnages. Charque ćprate est i son tour transformée en maspue humain. Les pieds des deux figures el les sexes sortent d'un cerele qui entoure la panse du vise à mi-hautrur. Le loul donne nne sillouetle hizarre quoique bien équilibrée.

Le n" 96 mérite anssi d'ètre signalé (pl. XXXI). H rappelle d'une façon étrange le diable de Notre Dame de Paris, avec sa tète soutenue par ses deux mains. Ciest la seule figure humaine dans layuelle on pourrait trouver une indication de barlue, puoinue cela pourrait stre igalement un menton exagéré dans la mème proportion que le nez! La barlue el la moustache seraient, d’après certains auteurs, le signe évilent et indéniable d'une influence européenne. Lé fail que celte figure est dépourvue de moustache nous fail pencher vers la seconde opinion.

Les deux pendentil's en or représentant un homme of une femme sont de l'orfivrerie

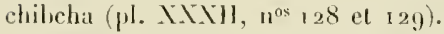

Celte étude n'a d'iutre prétention que de présenter un type de poterie resté presque

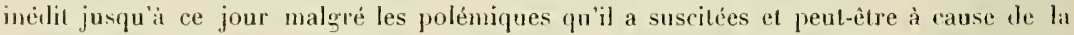
méliance qu'il a rencontrée chez la plupart des conservateurs de musées. Nous espúrons, en publiant ces figures et ces commentaires, susciter de nonveanx travaux el de nouvelles éludes qui pouront donner la clef du probleme. Il se trouvera bien un jour un savant compétent pour faire des fonilles systématipues sur place. Alors seulement - el en cela nous sommes d'accord avec M. Seler - nous saurons avec certilude à quoi nous en tenir sur l'àge de ces produits d'un art si étrange.

lemercions en terminant $\mathrm{S}$. A. la princesse Élisabeth de Bavière qui a hien voulu nous prèter, par l'intermédiaire de M. le prof. Fuhrmann, plusienrs les ouvrages consullés, en particulier le catalogue Arango; puis M. le I)r Seler, conservateur au Musée ellınographique de Berlin, Ml. le Dr Vernean, conservateur du Nusée de Trocadéro à Paris, Ipui nous a facilité l'élude des poteries de ce musée, el entin M. le professeur $\Lambda$. van Liennep à Neuchàtel, Hont les conseils at les indications bibliographiques nous ont été de la plus grande utilité.

P. S. - Ge travail biail sous presse lors du for Congres internalional d'Ethologie el d'Ethnographie qui vient d'avoir lieu à Neuchatel. Les poteries dont il vient d'ètre 


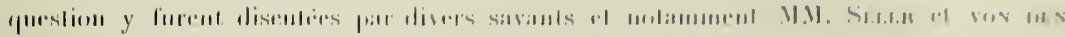

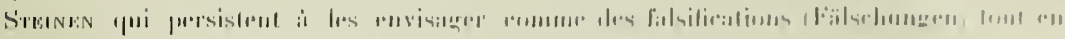

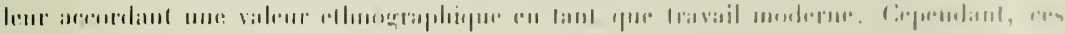

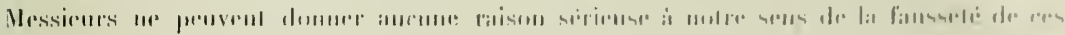

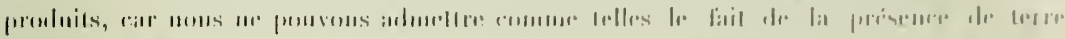

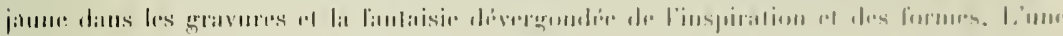

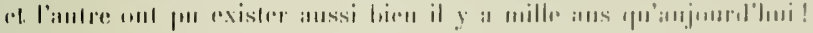

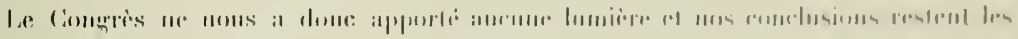
mirities.

1\%. 1).

\section{JIIIIIOCIRAIIII}

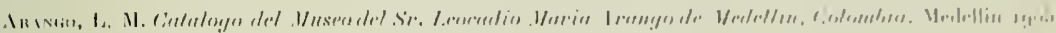

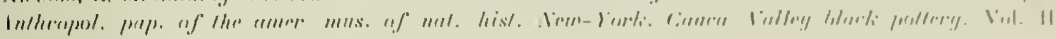
I':

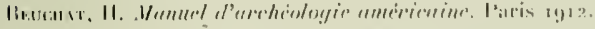

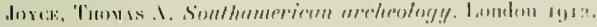

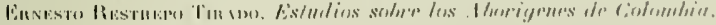

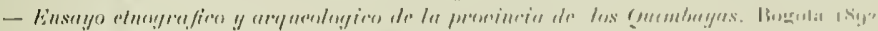

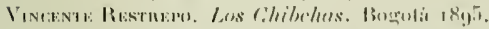

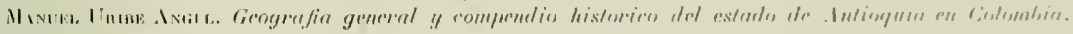
Pilris 188.5.

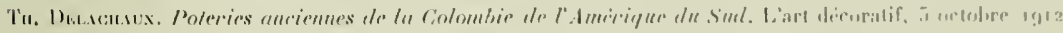
P'iris.

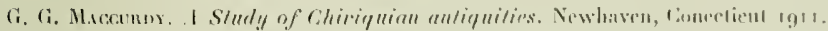

\section{EXPLICATION DES PLANCHES}

\section{Poteries de la Collection Fuhrmann.}

\section{P... I.TI,}

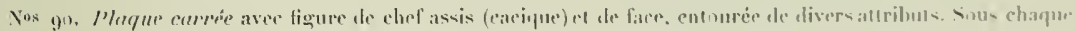

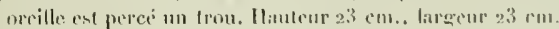

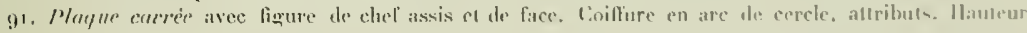
$23 \mathrm{~cm}$., largenr $23 \mathrm{~cm}$.

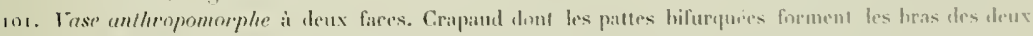

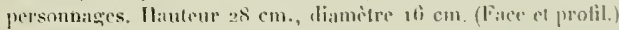

\section{PL. XXI:}

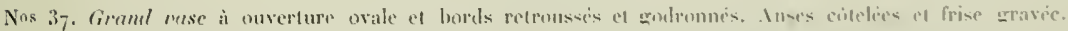

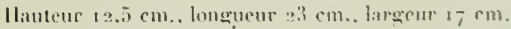

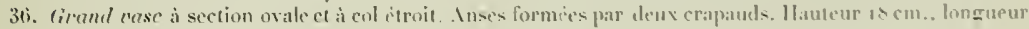
$22 \mathrm{~cm}$, largeur $17 \mathrm{~cm}$. 


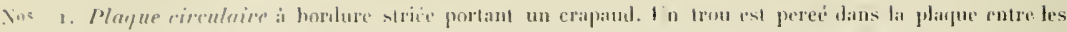

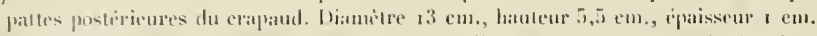

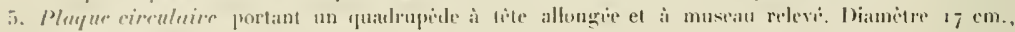
haulesur ti $\mathrm{cm}$.

6. Plaque treculaire portant une silamandre. Diamitre 1't $\mathrm{em}$. hatuteur $3 \mathrm{~cm}$.

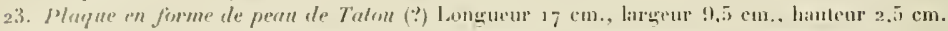

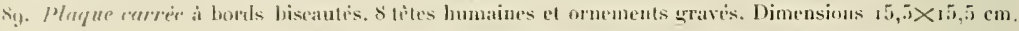

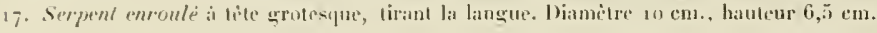

\section{PL. XXYT.}

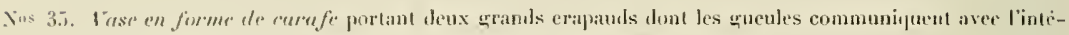
ricur du vise. Ilatueur is $\mathrm{cm}$, dianetre I' cm., longueur $24 \mathrm{~cm}$.

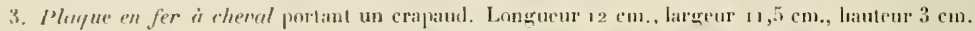

\{. Plaque ripralaire i deux coltes opposis replies en-dessus et supportant les pattes antirieures d'un erapand donl la lite émerge a l'un des houts. Longucur bli en., largeur a cm., hanteur

16. Sulamandre courlie en 5 . Longueur $18 \mathrm{~cm}$, largeur $11 \mathrm{~cm}$., hauleur $2 \mathrm{~cm}$.

18. Animal felulenter a deux paltes et ì queue recourbee sur le dos. Longueur 14 cm., largeur 8 em., hatuteur $7 \mathrm{em}$.

19). Inimal a tite de filin (?) ; fortes stries transversales sur le dos. Longurur 14 cm., largene 8 cm., hatuleur $10,5 \mathrm{em}$.

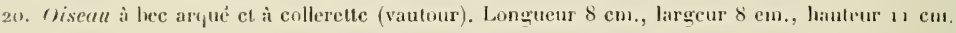

\section{PL. XXVII,}

Xos 78 . Figurine humame i broucles dans le nez et les oreilles Collier en relicf. Aueune ouverture. Ilauteur $13,5 \mathrm{~cm}$.

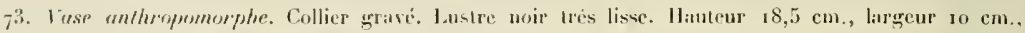
di:tuètre de lonverture $2,8 \mathrm{~cm}$.

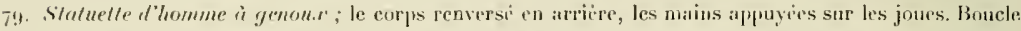

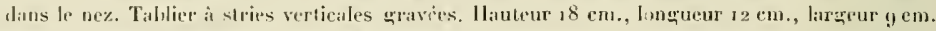

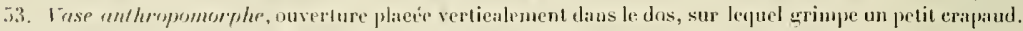
Hinteur $11, \overline{5} \mathrm{em}$. . litegeur $9,5 \mathrm{~cm}$, longueur $8.5 \mathrm{~cm}$.

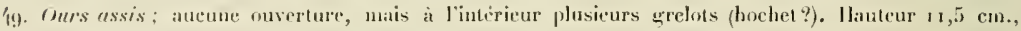
largener $8 \mathrm{cms}$

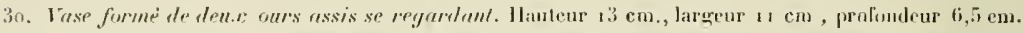

22. Fase en forme de félin tenant son ventre entre ses pattes. Hauteur 11 cu., longueur $13 \mathrm{~cm}$.

r22. Pelil cylimile representint un personnage avec collirr. Traces de couleur blanche el rougc. Provenanee : lac Lthaque (. Irt ehibeha).

17. Irase coomorphe. Animal à long cou: ouverture dans le dos, la queuc sem d'anse. llatuleur $12 \mathrm{em}$, longueur i3 em., largeur 8 eni.

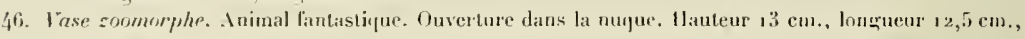
diametre $8 \mathrm{~cm}$.

85. Figurine. Diable on singo (?) accroupi. IIauteur $14 \mathrm{~cm}$.

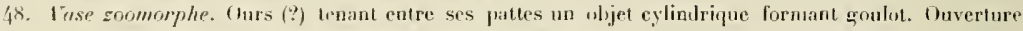
$6 \mathrm{~mm}$ Hateur $12 \mathrm{~cm}$, longueur g $\mathrm{cm}$, largeur g $\mathrm{en}$.

\section{PL. XXVIII.}

Yos 72. Horheten forme de lite humaine avee loncle dans le nez. Grelots et petit trou dans le fond. Longueur $11,5 \mathrm{~cm}$, litrgeur $8 \mathrm{~cm}$, hauteur $7,5 \mathrm{~cm}$.

7.5. Tese anthropomorghe à deux ouvertures. Ilauteur $18 \mathrm{~cm}$., Jargeur $12 \mathrm{~cm}$, ouvertures $2,5 \mathrm{ct} 3,5 \mathrm{~cm}$. 


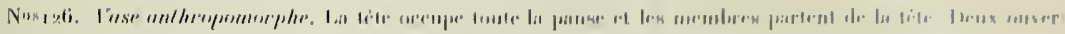

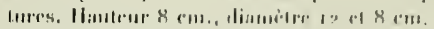

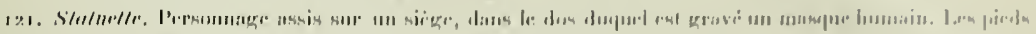

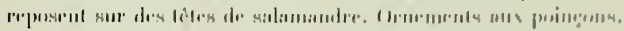

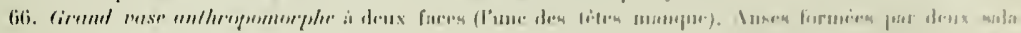

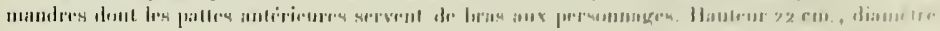
18 :111.

\section{1'. IIII.}

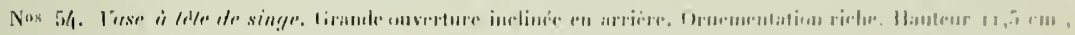

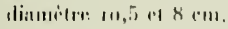

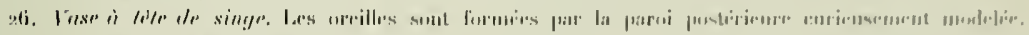

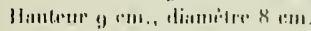

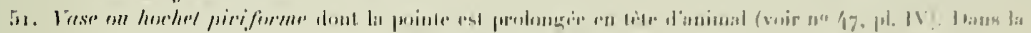

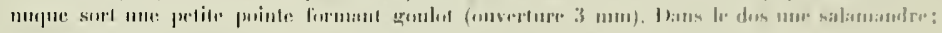

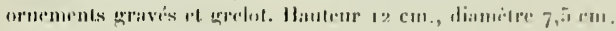

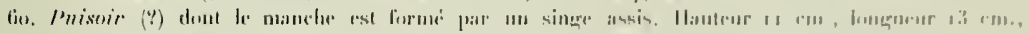
limpour 7 in.

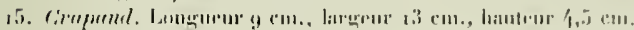

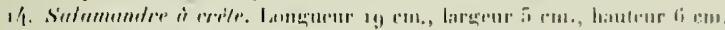

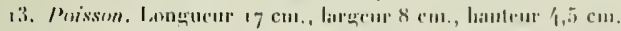

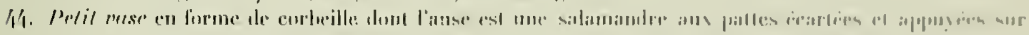

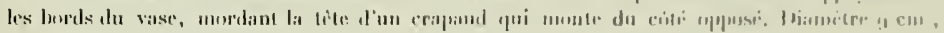
hatutrur $7 \mathrm{~cm}$.

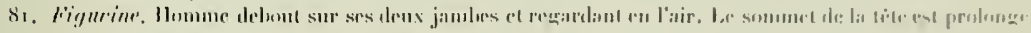
en puinte strice. Ilantenr 7,5 ent.

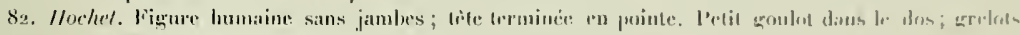
Hauteur $13 \mathrm{~cm}$., diametre $7,5 \mathrm{~cm}$.

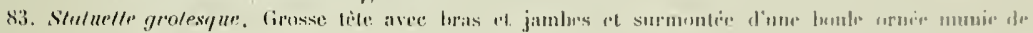

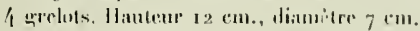

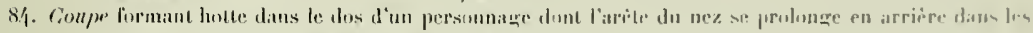
bords le la coupe. Haut:ur g, i em., longueur i2 em., diamedre 7 cm.

\section{P. XXX.}

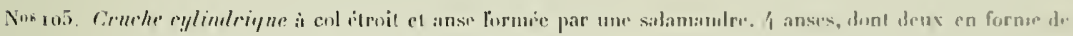

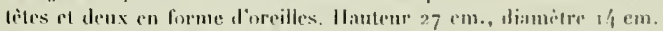

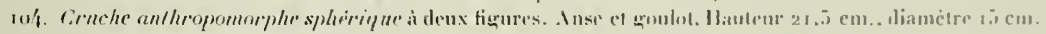

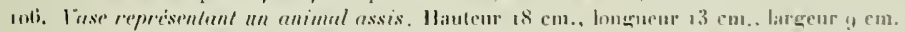

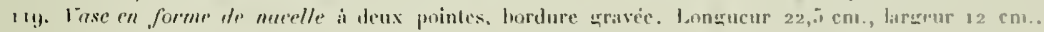
hanteur $8 \mathrm{~cm}$. (auverlure $5 \times 12 \mathrm{~cm}$.).

102. Iisse anthropomerpher. Boucles dans le noz et les oreilles el cullier festonne en relief. Hanteur $31 \mathrm{~cm}$. , diamètre $17 \mathrm{~cm}$.

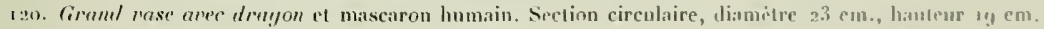
103. Tase unthropomorphe. Fenme avec collier en forme de salamandre pendant entre lex seins.

\section{PL. NiNi.}

Nos bo. Pevile eoupe snpporlice por quulre pieds sur un anneau, representant peut-itre une marmite (ò) Hantcur $6 \mathrm{~cm}$. diamétre sujeriem $6 \mathrm{~cm}$., diamitre inferieur $11 \mathrm{~cm}$.

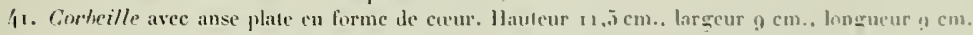

40. Corbeille yuadrangulaire à anse. Hauteur $8 \mathrm{~cm}$. diametre $0.5 \mathrm{~cm}$. 


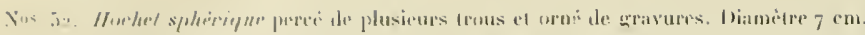

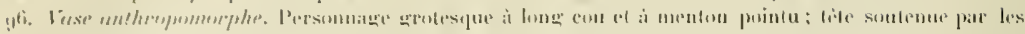

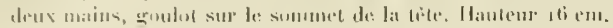

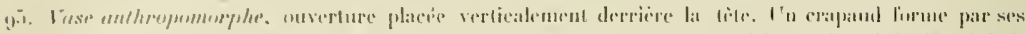

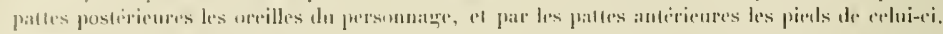
Hanteru เ 1 , .i cm.

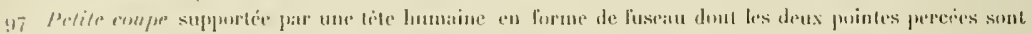

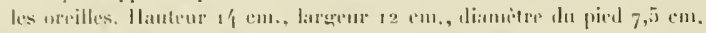

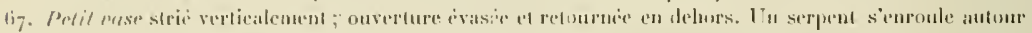

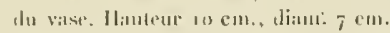

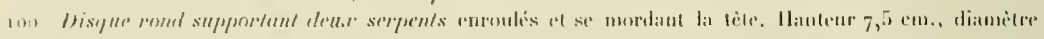

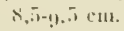

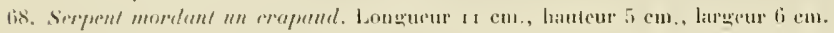

\section{P., XXXII.}

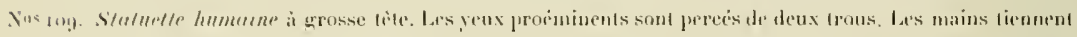

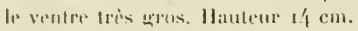

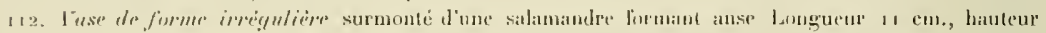

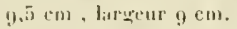

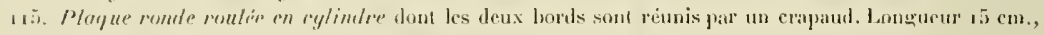
larenour 7 em... hateur $7,5 \mathrm{~cm}$.

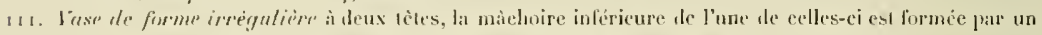
crapaud. Longuenr $14, \overline{5} \mathrm{~cm}$, hautem $12 \mathrm{~cm}$, largeur $10, \overline{\mathrm{cm}}$.

107. Iase anthropomorphe (lype du no $7 \bar{i}$, pl. V) portant sur la tite nne corbeille (?) à auses percies d'un trous. Haulcur 13,5 en., latram $11,5 \mathrm{~cm}$.

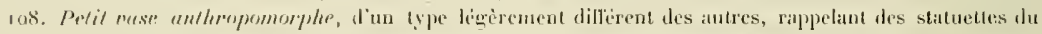
Musie du Trociuléro (eoll. Clablianjon) et provenant de Manizales et de thio de (mor) (Caucai).

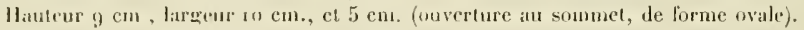

110. Stutuplle (lype du no $81, \mathrm{pl}$. VI). Hauteur $8 \mathrm{~cm}$.

117. Serpent arnè de pints. Hatuleur $7 \mathrm{~cm}$, lirgeur $11 \times 8 \mathrm{~cm}$.

118. Horehel spherigne i ornemenls gravés et à grelols. liamètre $8,5 \mathrm{~cm}$.

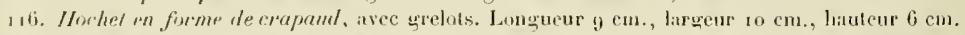

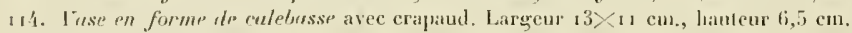

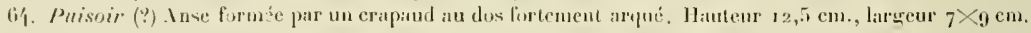

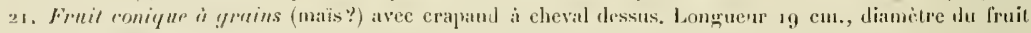
6 cm., hatuleur 11 cul.

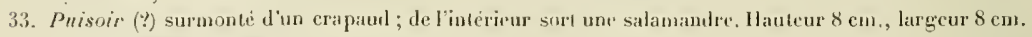
protondeur in ent.

$8_{7}$ Gylintre creux á bordures gravées Longueur 1/,5 cm., diametre exterieur 5,5 cm., intriricur 4 em. rzí et rag. Deux pententifs en or, art Chibcha.

\section{PL. XXXIII.}

\section{Schémas des gravures, explications dans le texte (p. 1076).}

\section{PL, XXXIV.}

Figures calquées sur les planches du catalogue de la collection L. M. Arango à Medellin.

(Mesures en centintires.)

1058. XXi, Hauteur $7 \frac{1}{2}$, lareneur 17. Cañiveral.

1072. XX1. Hauleur $141 / 2$. Guasano.

1134. XX1. Hauteur 1 r $1 / \%$, Guasauo. 


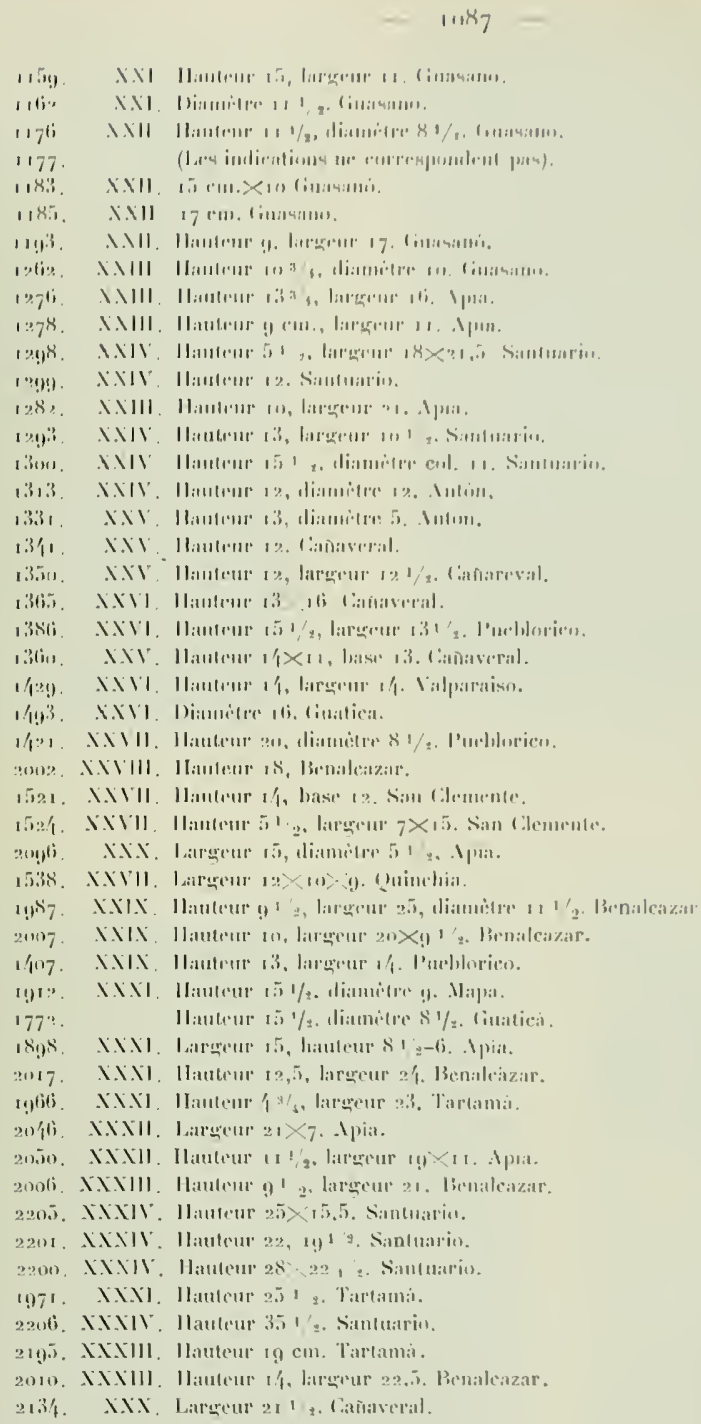





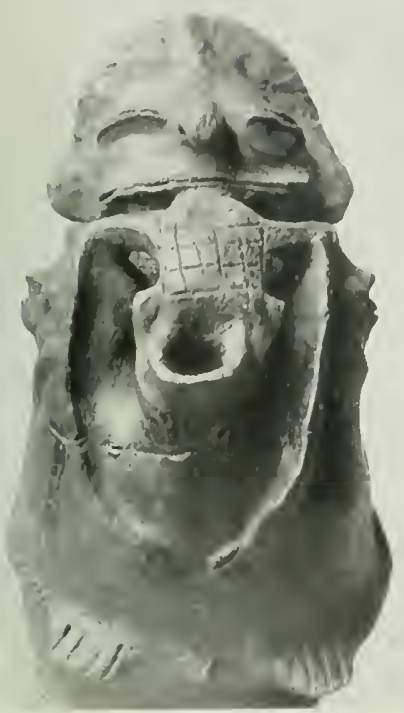

101

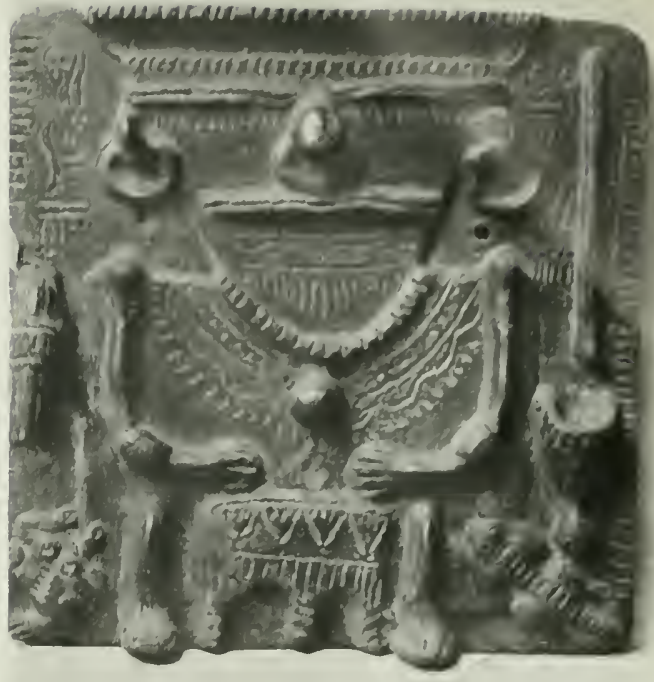

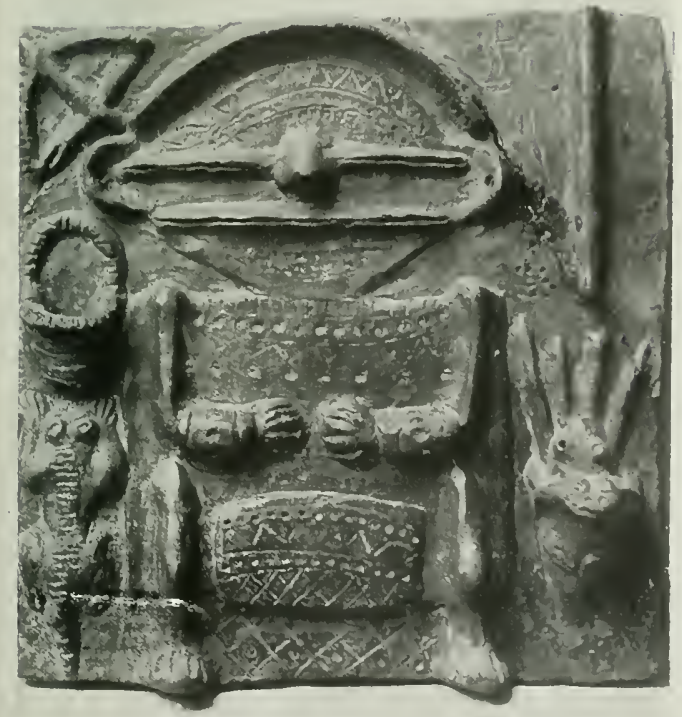

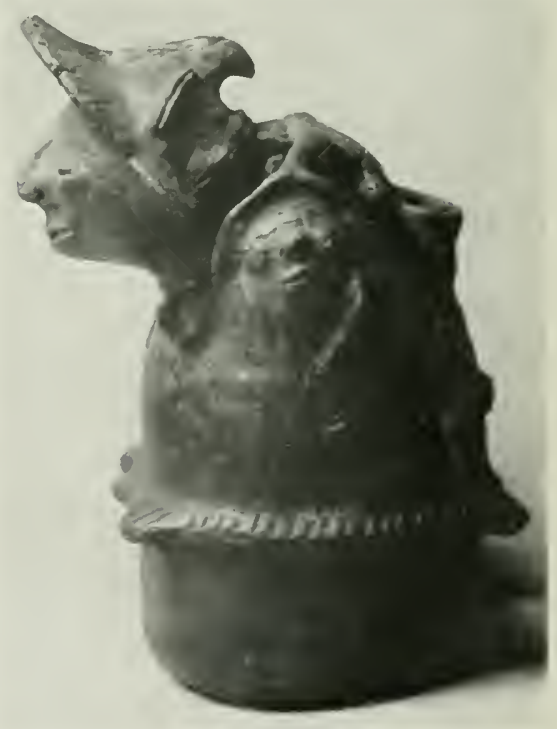

101 


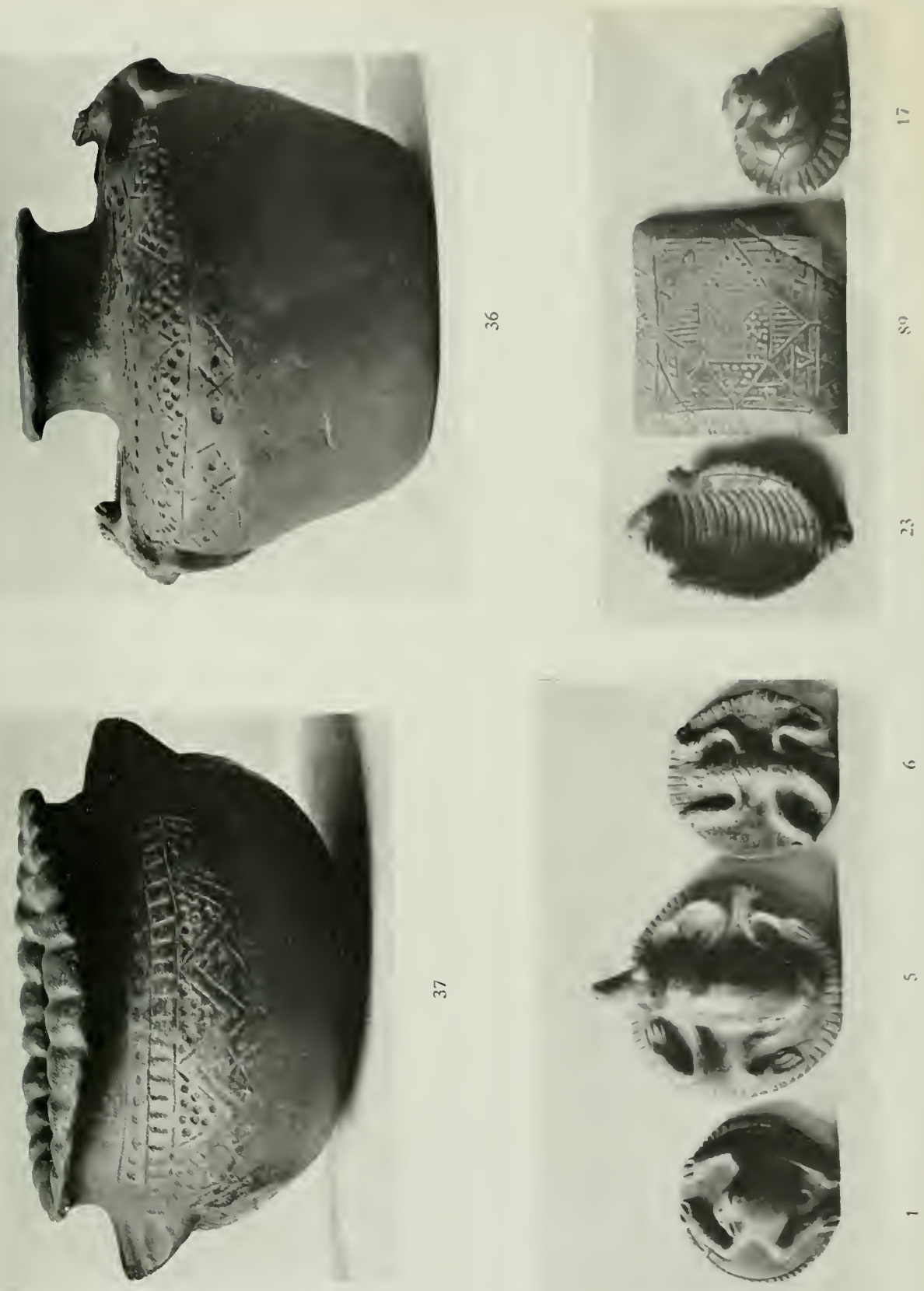



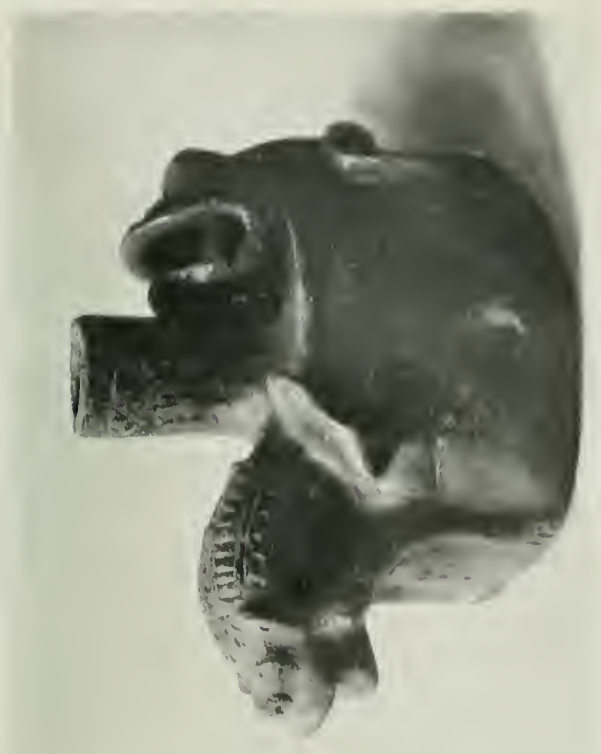

m
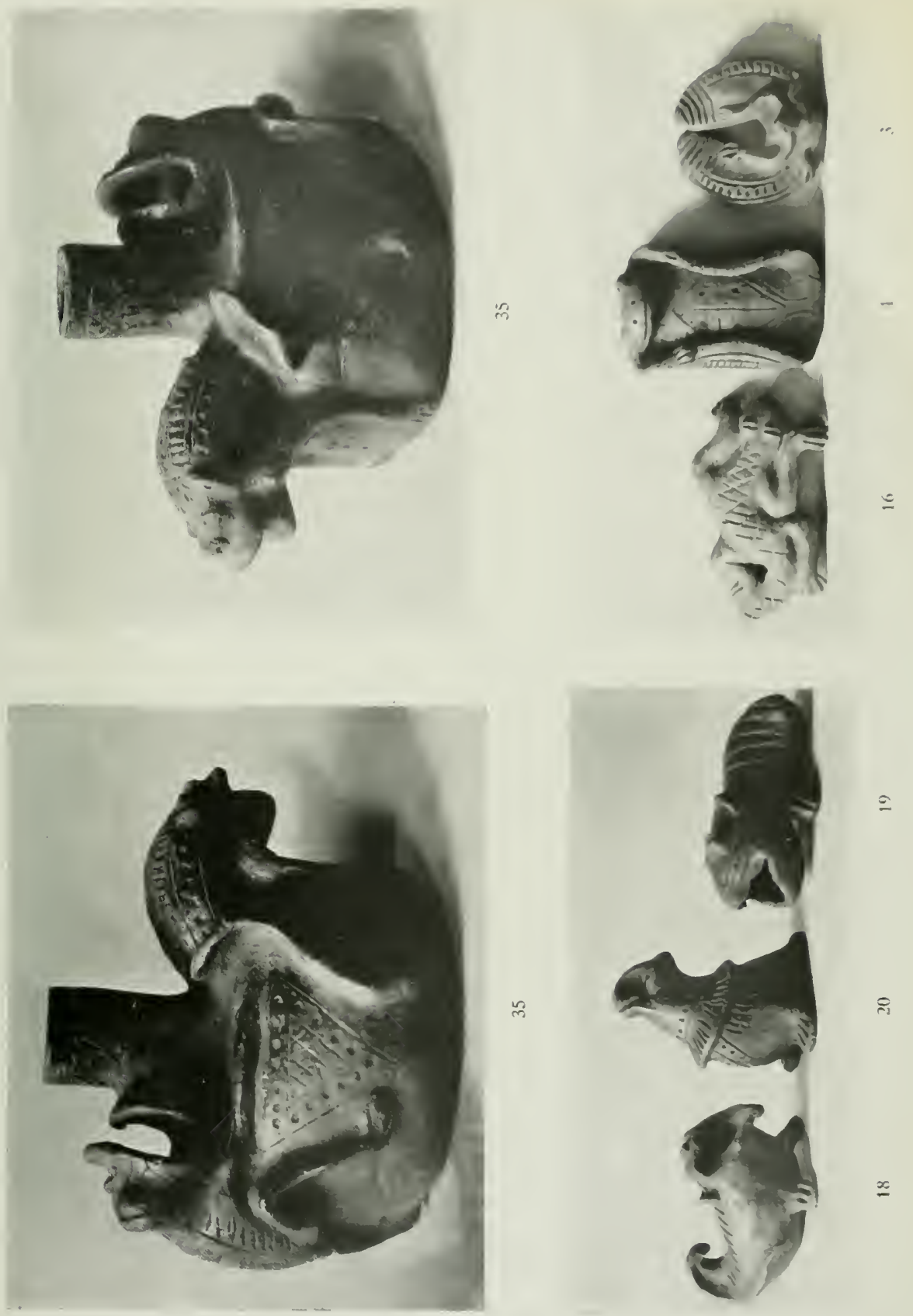

$\ddot{m}$

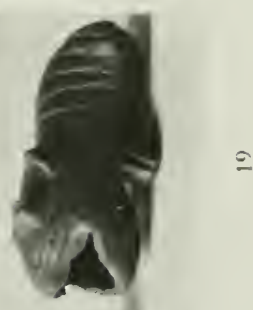



PLANCHE XXVII,
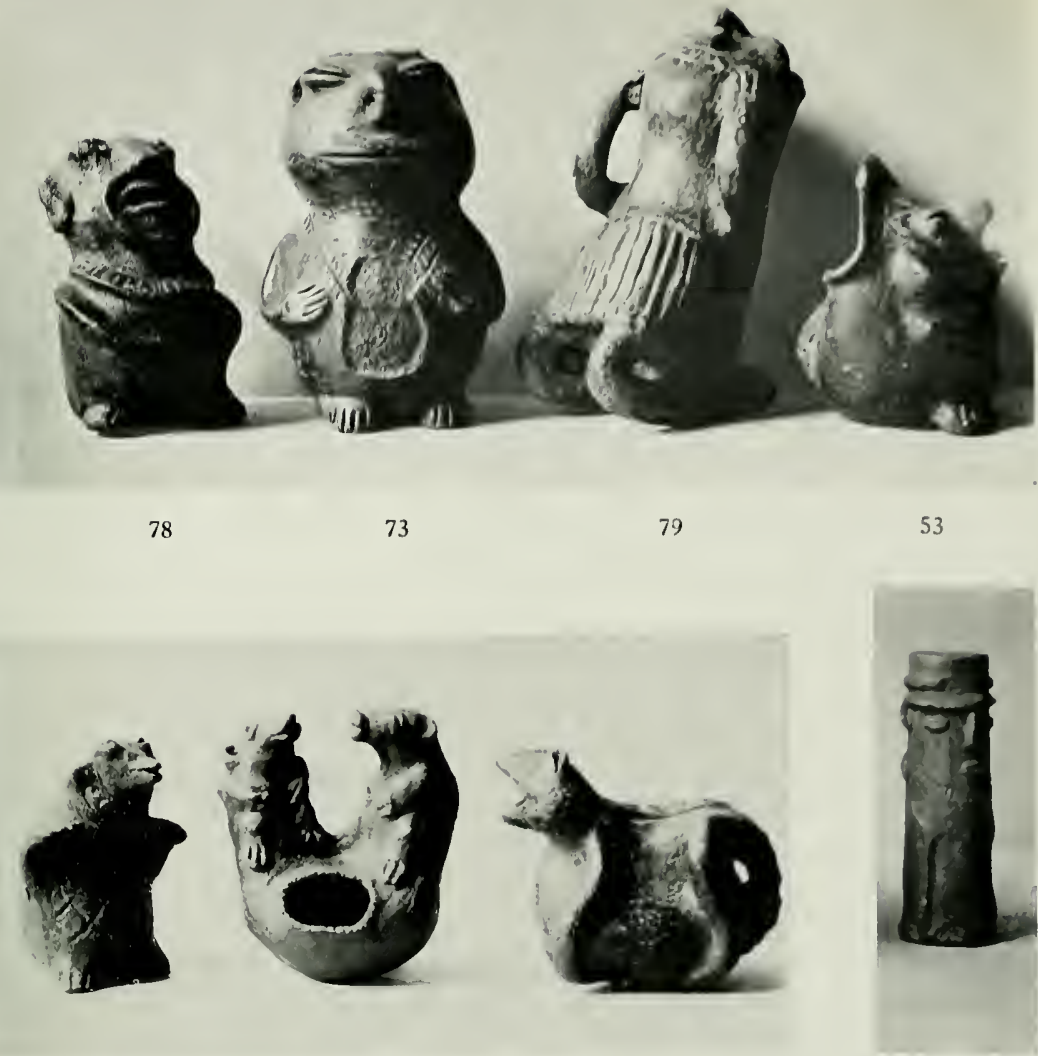

49

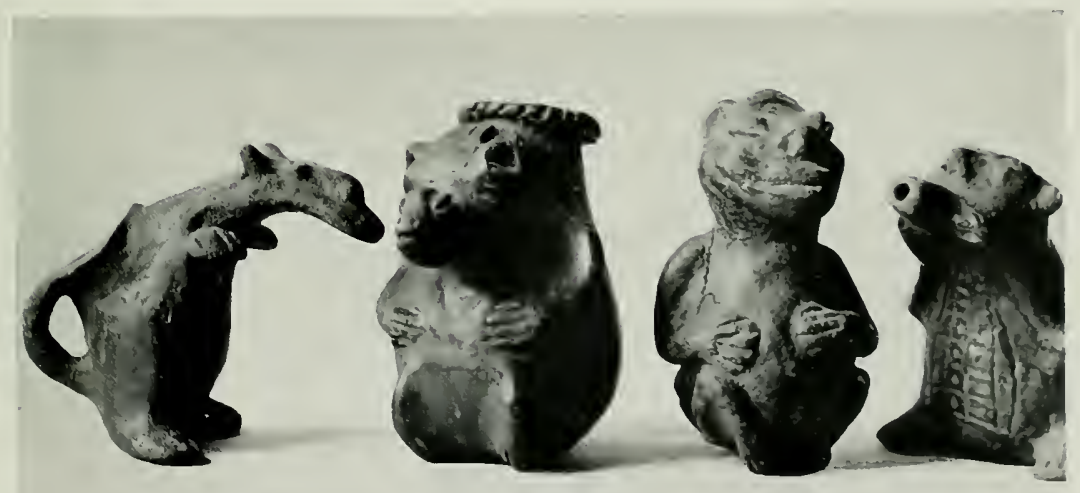





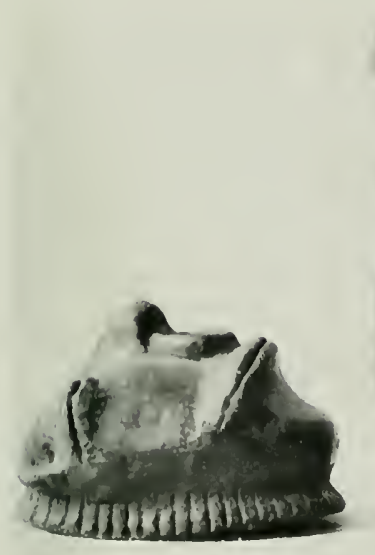

72

121

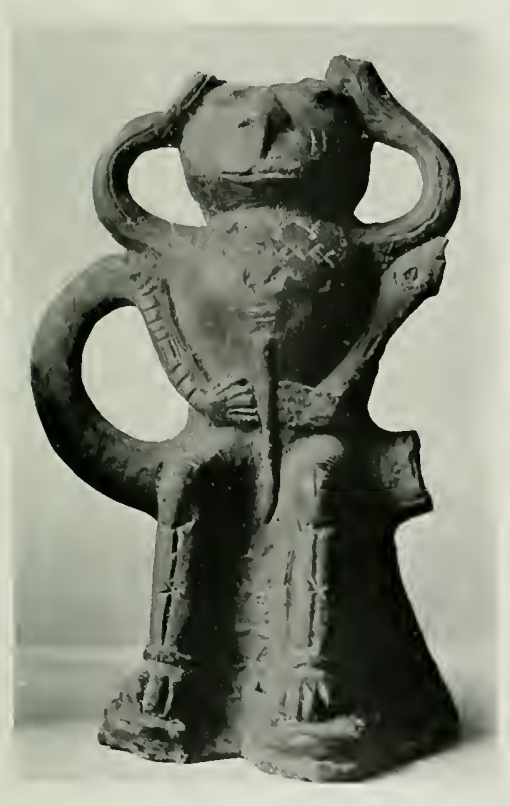

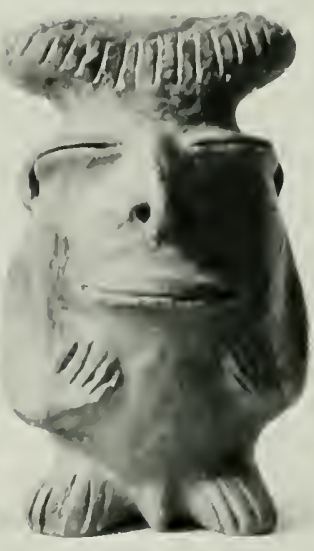

75

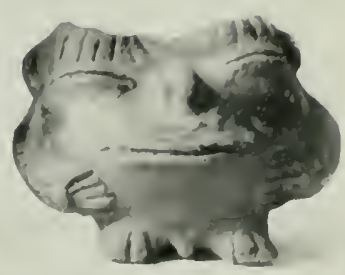

126

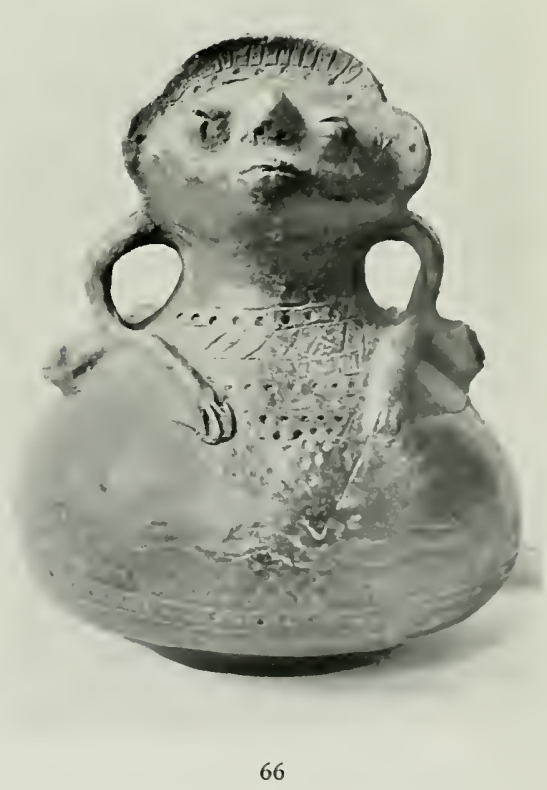





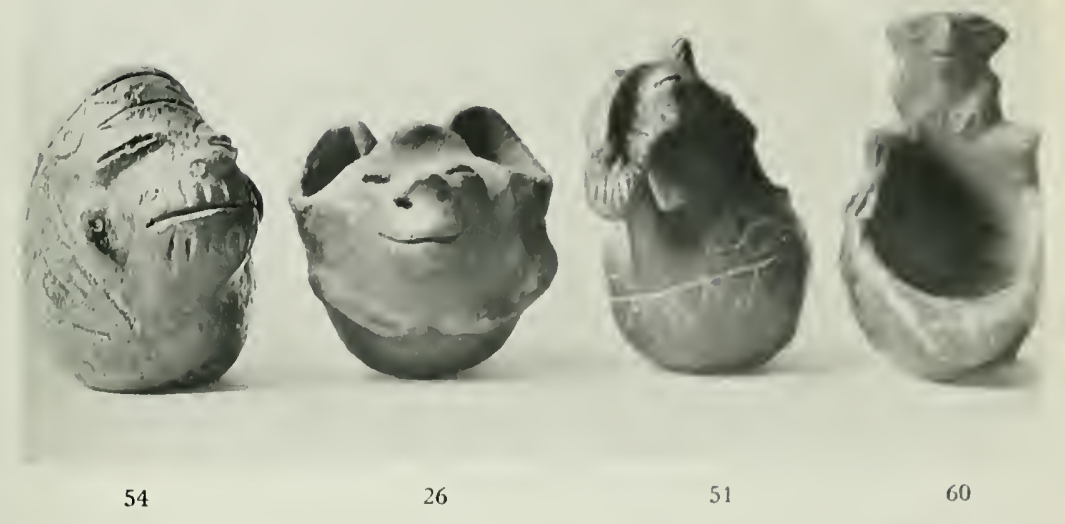

15

14

44

13

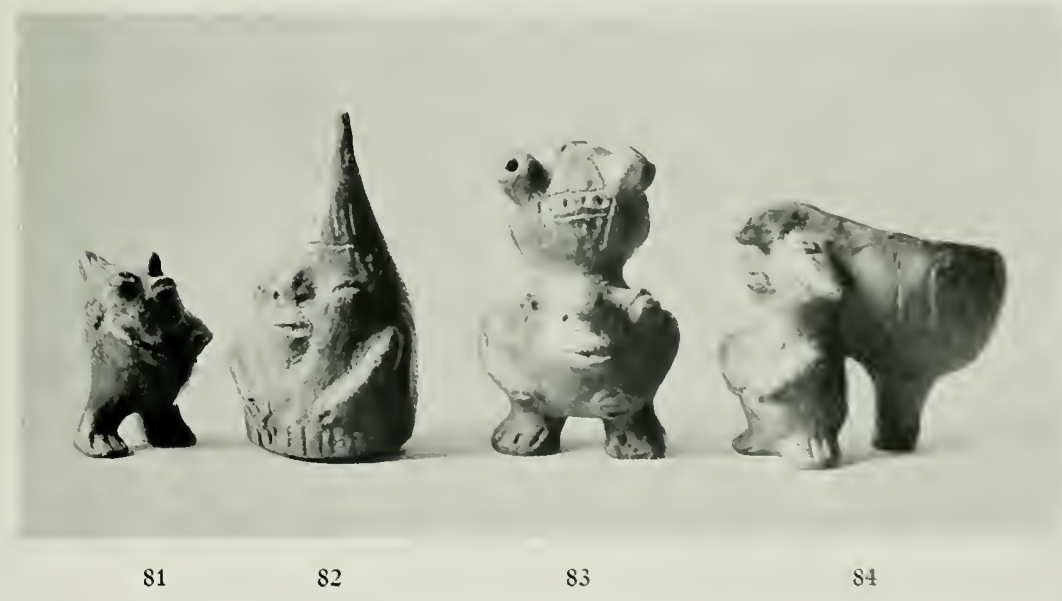




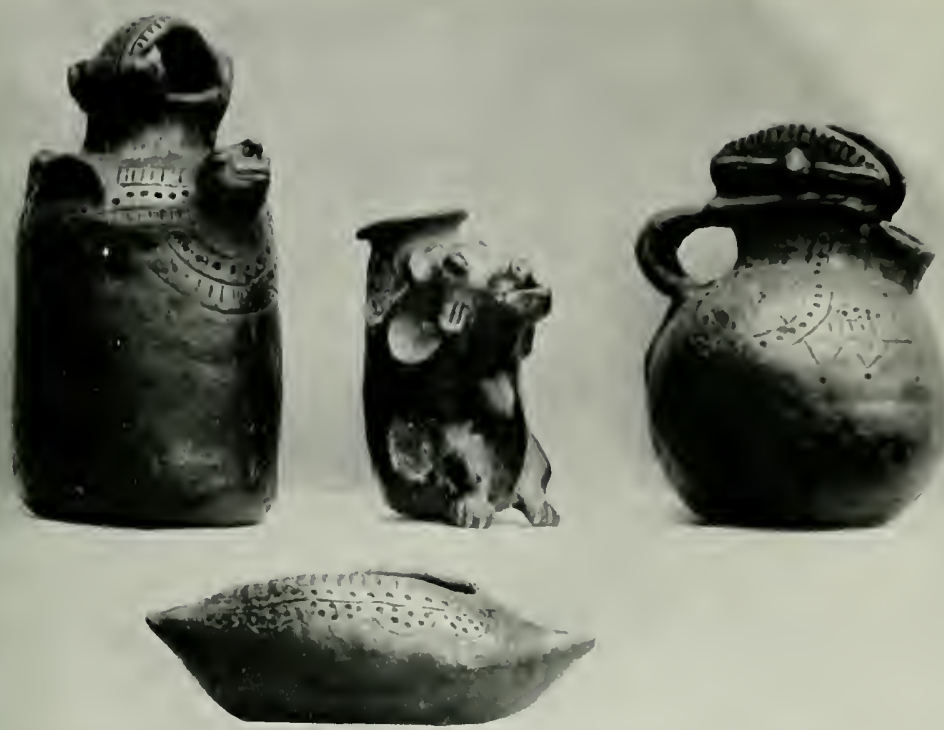

105

106

119

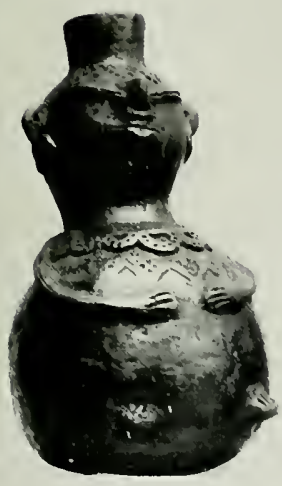

102

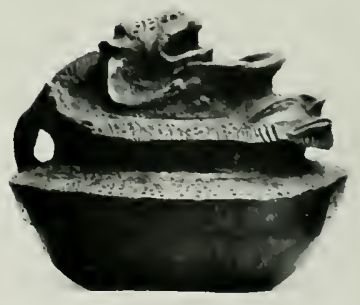

120

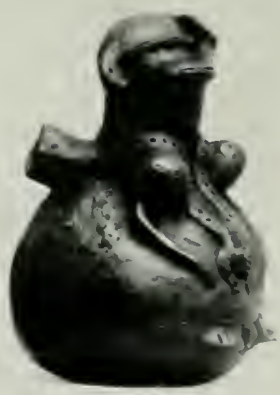

103 



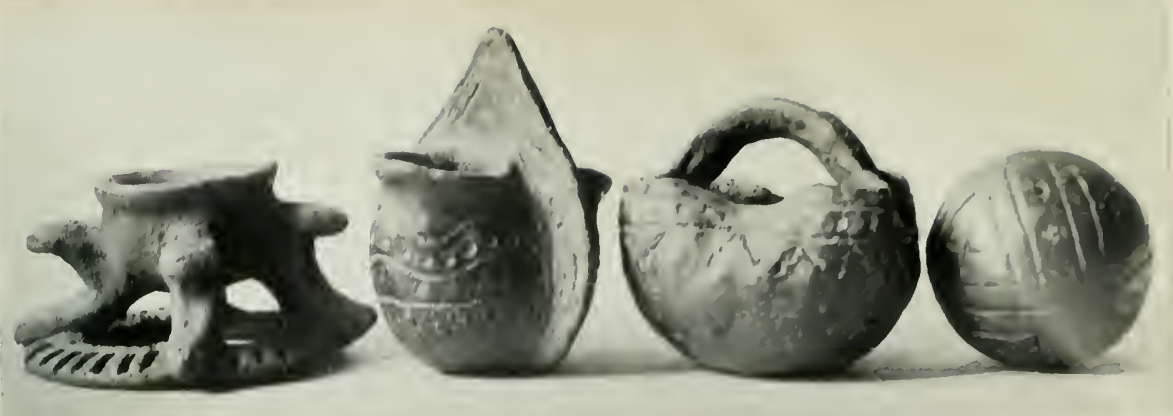

69

41

40

52
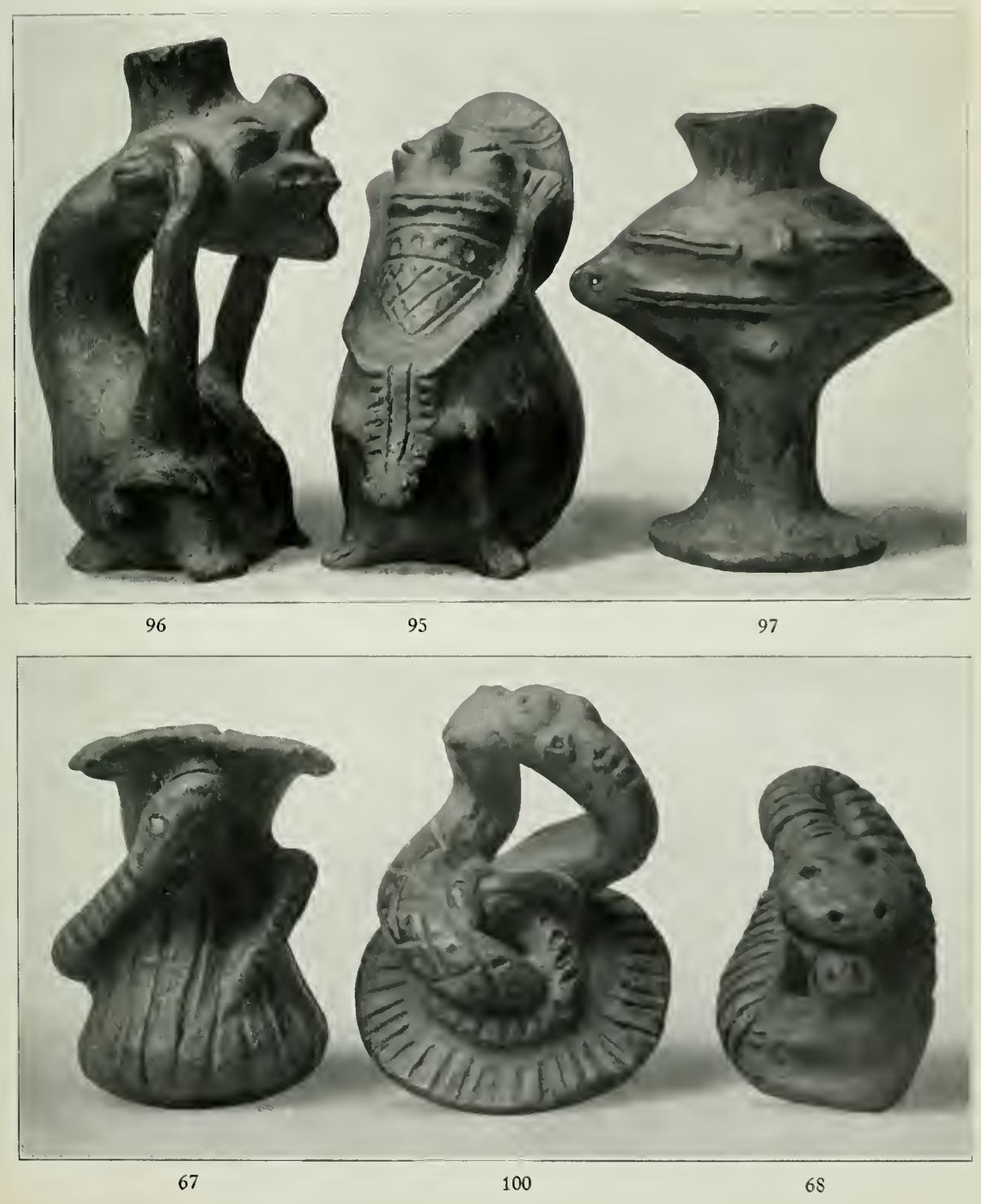

PLANCHE XXXII.

109

112

115

111

107
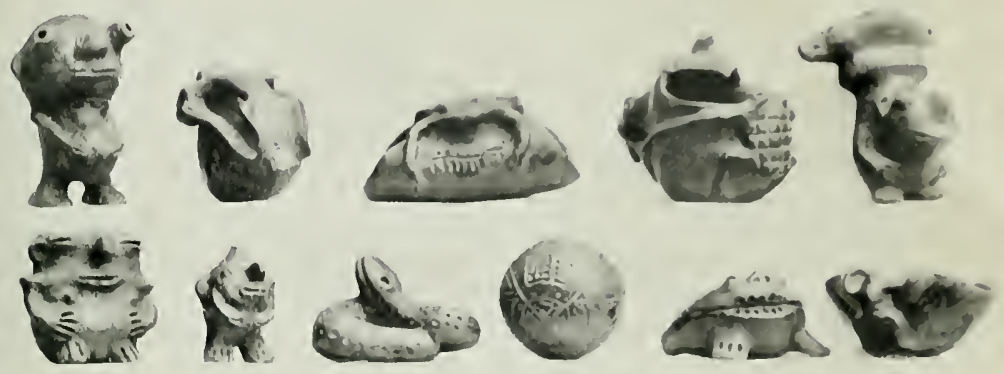

108 110

117

118

116

114

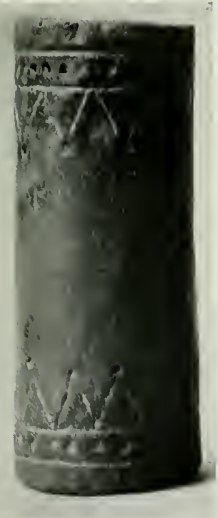

87

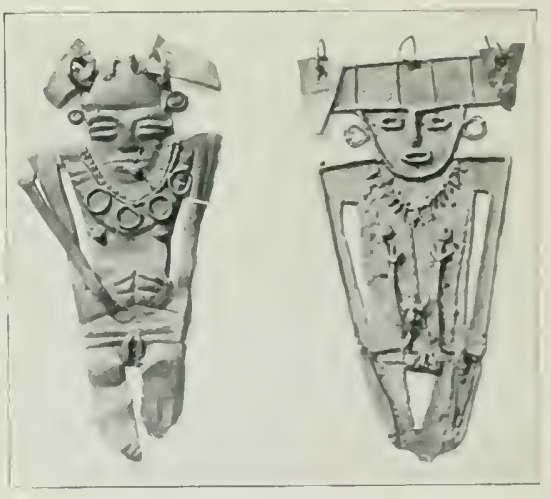

128

129 



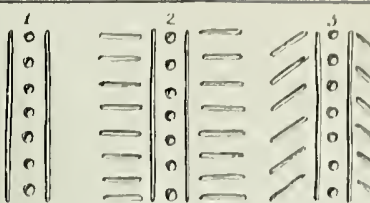

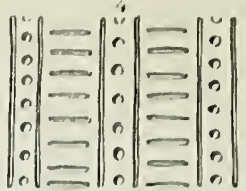

$=$

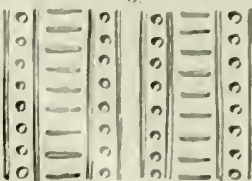

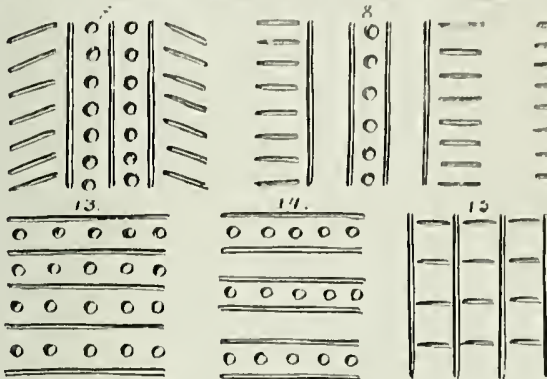

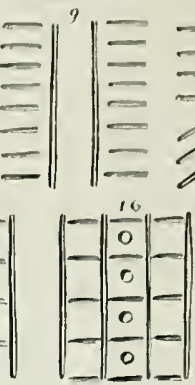

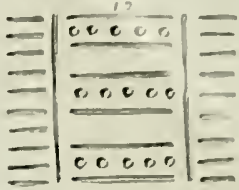

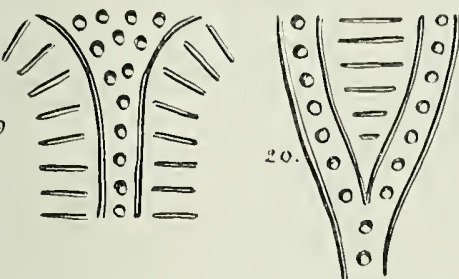
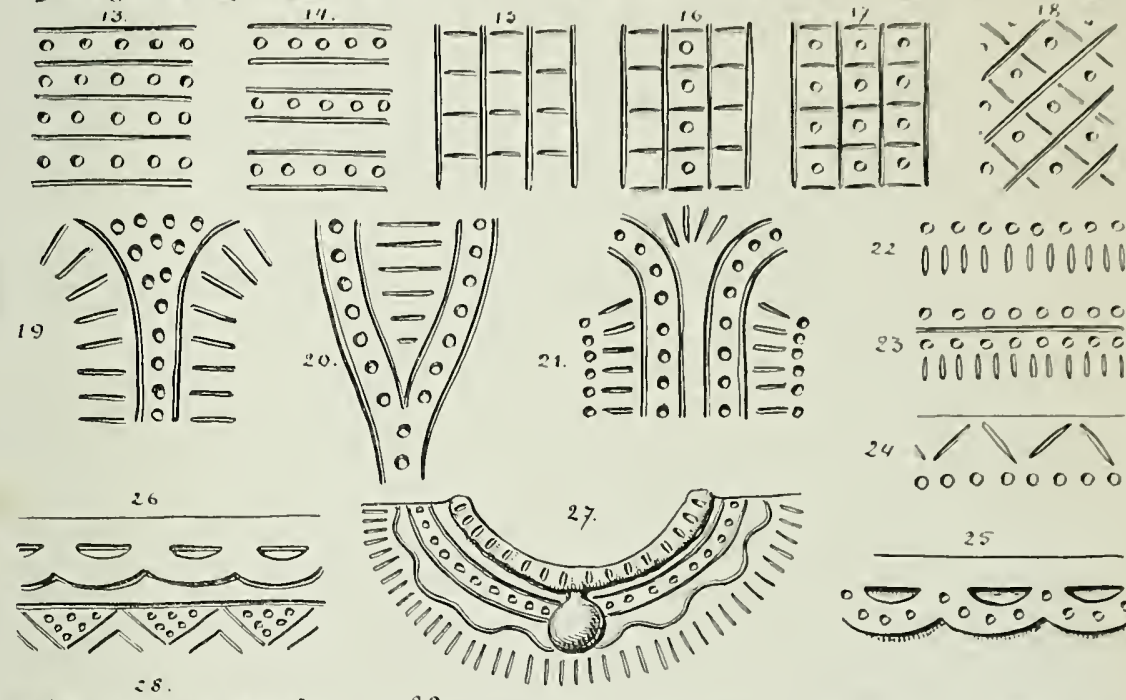

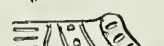

三l:

3.)

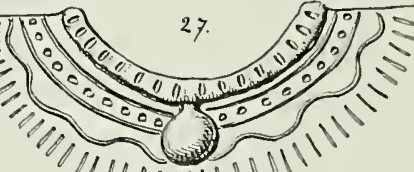

11111111111111
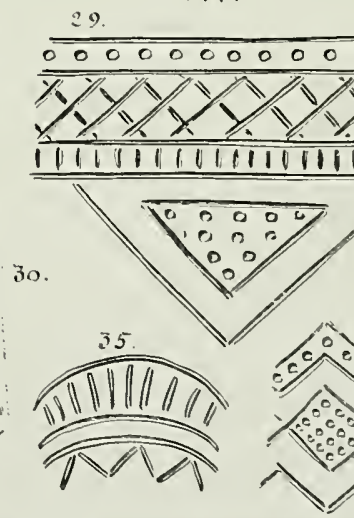

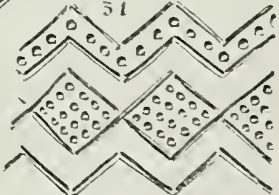

2200000000000

$23 \frac{00000000}{00000000}$ 000100000001

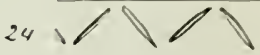
00000000

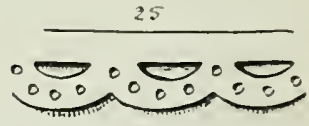

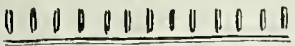

00000000

V// $/ / / /$

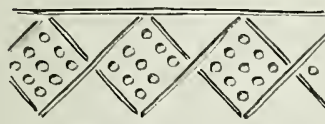

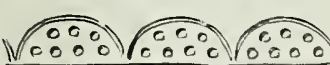

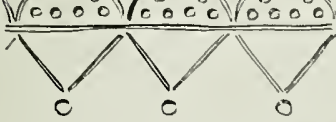

0
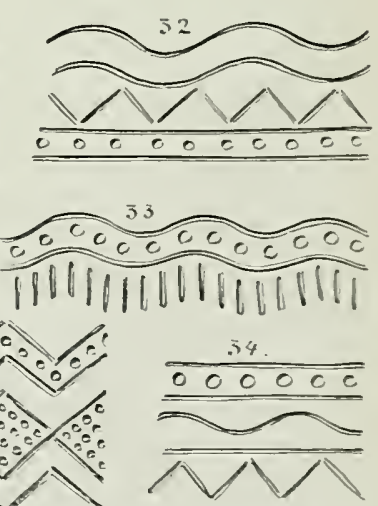


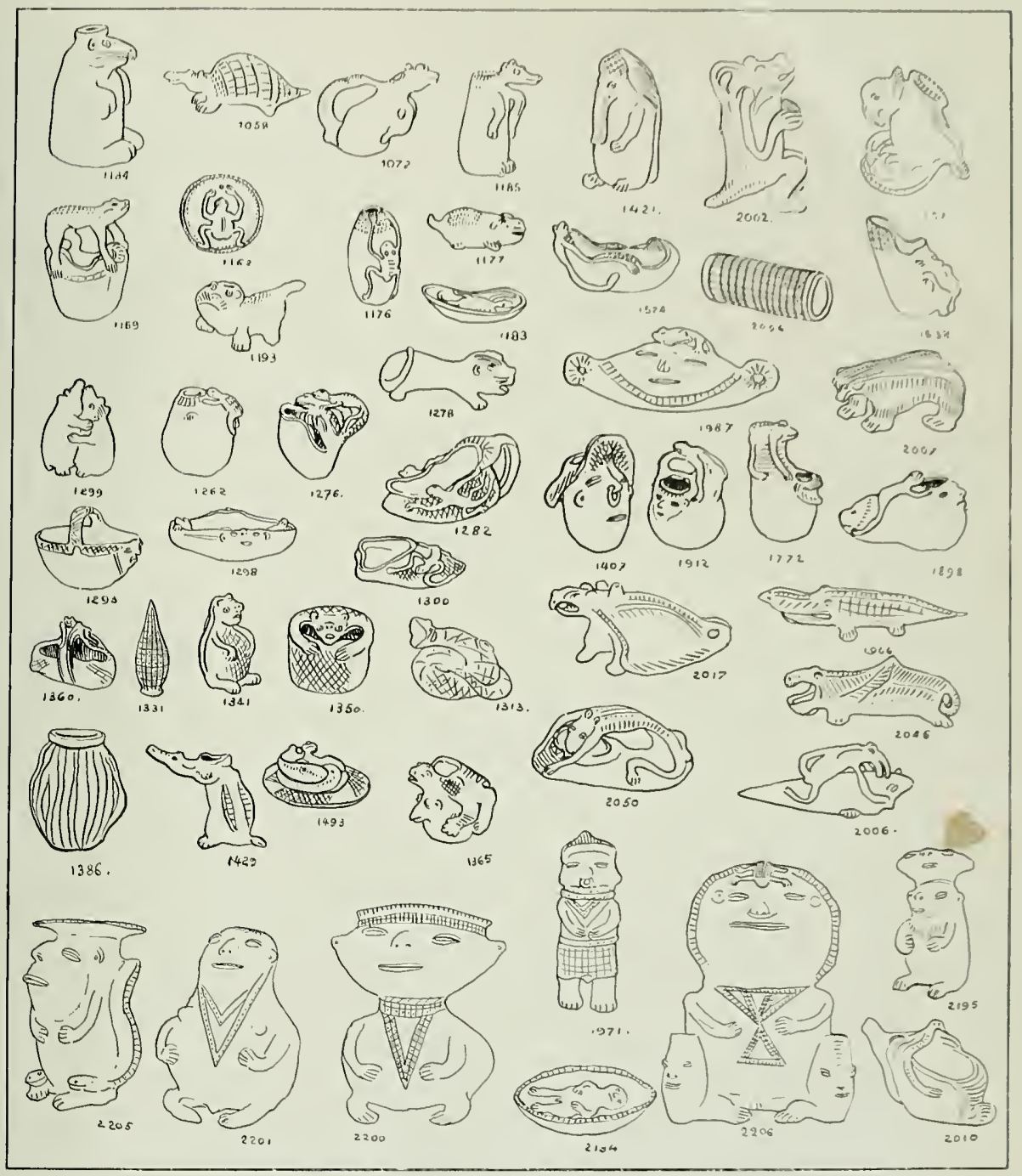

Calques tirés du Catalogue de la Collection L.-M. Arango. 



\section{TABLE DES IATHERLS}

AVANT'PRIMUS'

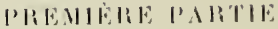

QURLgUES MOIS EN GOLOMIBHE.

\section{TIAVAIX SCIENTIEI!IES}

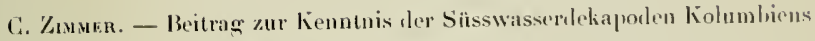

A. Fonel. - Guelques foumis de Colombie

Karl Kropeus, - Beitrag zur lienntnis der Skorpione und Pedipalpen Columbirms

E. Rosensrock. - Contribution a l'edude des Périslophytes de Colombie

G. LaNdud, - Beitrag zur Kenntnis der Flechten von Columbien

I1. Rizaut. - Contribution à l'éturle des Chiloporles ale Colombic

M.-A. Pernaca. - Reptiles el Batraciens de Colombie.

O. Funnusn. - Le frenre Thyphlonectes.

C.-F. Rewror. - Beitrag zur lienntnis der Weherknechte liohmbiens.

M. 'Tüвaun. - Copépodes de Colombie ed des Cordilleres de Mondoza.

(). Fumusx. - Quelques nouveaux Péripates américaius

C. Walter, - Hyidracarina de Colombie

IV. Micurdersen. - Die Oligochieten Columbias

dean Praget. - Ouelques Mollusques de Colombie.

11. Sunotu. - Beirag zur Kenntnis der Niacklschnecken Columbiens angleich eine Leliensicht iiber die neotropische Nicktschnecken Fanna üherhanpt

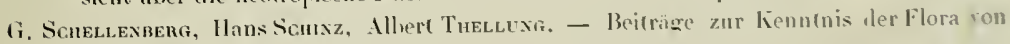
Kolumbien und Vestmelien 
H. et P. Srdow. - Contrihution à l'étule des champignous parasites de Colombie . . 43.

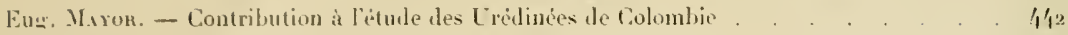

Th. Stragers, - Clindoceren ans den Gebiruen von liolumbien. . . . . . . . . fion

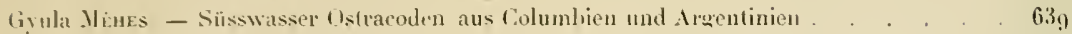

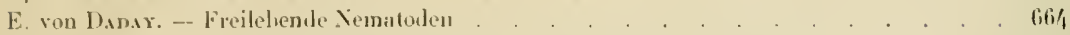

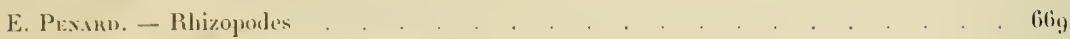

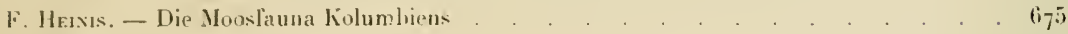

Il. Weber. - Hirulinées colombiennes. . . . . . . . . . . . . . . . . . 731

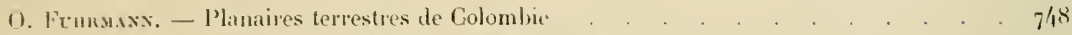

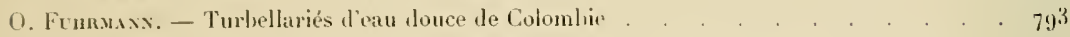

E. Phicet. - Oiseaux de Colomlic. . . . . . . . . . . . . . . 8oí

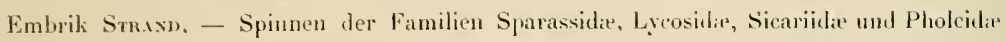

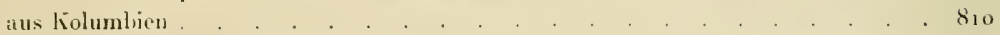

๖. Cinz. - Die Diploparen von Columbien nelst Beitrïgen zur Morphologie der Stemmatoinliden . . . . . . . . . . . . . . . . . . . . . . . 8 8

E. Iruscuer, - Beitrige zur Laubmoosflora von Lolumbien. . . . . . . . . . . . . 99/4

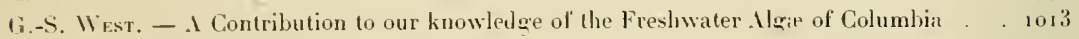

Liste des acquisitions nouvelles pour la science . . . . . . . . . . . . . . . . . . . . 10j̃

E. LeGrindior, - Mesures hypsométriques de Colombie . . . . . . . . . . 1 oti/4

Th. Delacuarx, - Poteries anciemes de la Colomlic. . . . . . . . . . . . . 107 
Printed in France 


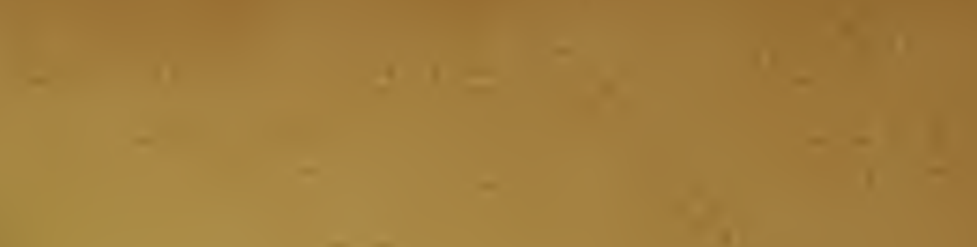

. 

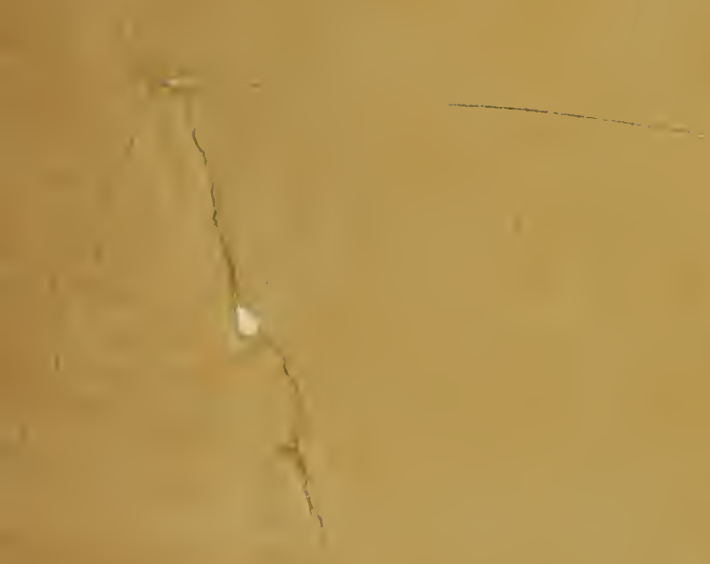




OH121, F84 1914

mann, 0 . Voyage d exploration scient gen 
